DOE/EIA-0437(94)/2

\title{
Financial Statistics of Major U.S. Publicly Owned Electric Utilities
} 1994

December 1995
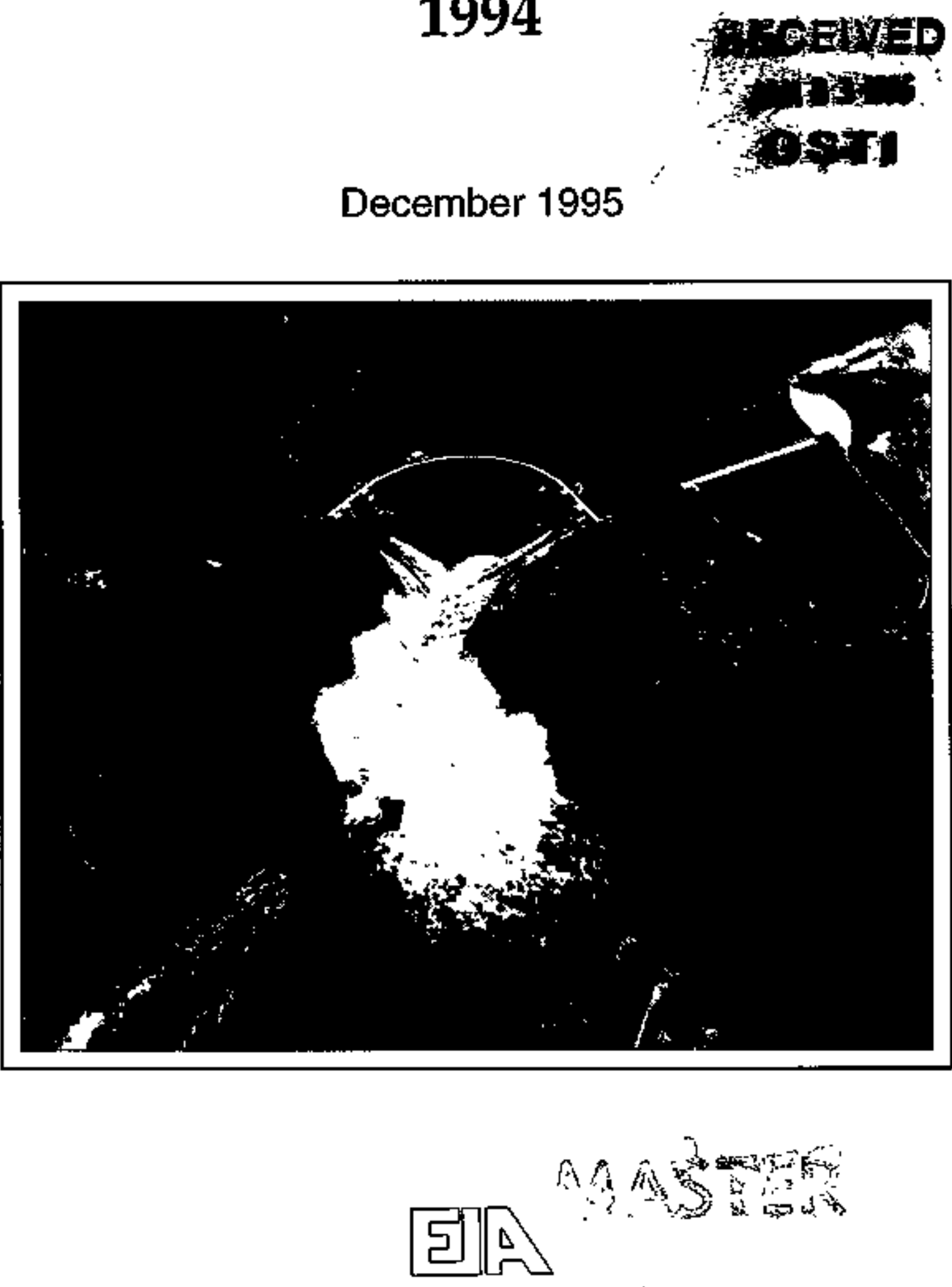

Energy information Adminlstration 
This publication and other Energy Information Administration (EIA) publications may be purchased from the Superintendent of Documents, U.S. Government Printing Offico.

Telephone orders may be directed to:

Superiotendent of Dacuments

U.S. Government Printing Office

Main Order Desk

(202) $512-1800$

PAX: (202) $512-2250$

8 a.m. to $4: 30$ p.m., eastern time, M-F

All mail orders should be directed to:

U.S. Govemment Printing Office

P.O. Box 371954

Pittsburgh, PA 15250-7954

Complimentary subscriptions and single isșues are available to certain groups of subscribers, such as public and acadente jibraries, Federal, State, local and foreign goverintents, EIA survey respondents, and the media. For further information and for answers to questions on energy statistics, please contact EIA's National Energy Information Center. Address, telephone numbers, and hours are as follows:

National Energy Infonnation Center, EI-23!

Energy Information Administration

Forrestal Bujlding, Room 1F-048

Washington, DC 20585

(202) $586-8800$

(202) 586.0727 (FAX)

TTY: For people who are deaf or hard

of hearing: (202) 586-1181

9 a.m. to $S$ p.m., estern time, M-F

Internet Addresses:

E-mail: infoctr@eia,doe.gov

World Wide Web Site: http:/sww.eia,doc.gov

Gopher Site: gopher//gopher.eja.doe.gov

FTP Site: ftp://tp.eja.doe.gov

Cover Photo:

The Boundary Dam, a hydroelectric plant, is Ioczted in Pend Oreille Connty, State of Washington, and owned by the City of Seattle. 


\title{
Financlal Statistics of Major U.S. Publicly Owned Electric Utilities 1994
}

\section{December 1995}

\author{
Energy Information Administration \\ Otilice of Coal, Nuclear, Electic and Aitemate Fuefs \\ U.S. Department of Energy \\ Washington, DC 20585
}

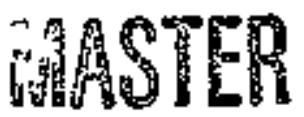

DISTRIBUTION OF THIS DOCUMEYY IS UNLLHATEO

This raport was prepared by tha Enargy Information Adminiatration, the independert statiofical and andhylcer egancy within the Depertmem of Energy. The information conlained herein should nol be construed as edvocating or refiacting any policy posttion of the Depertment of Enaroy or any other nmiantralinn 


\section{Contacts}

The Financial SIatistics of Major U.S. Publicily Onmed Evectric Utthles is prepared annually by the Coal and Electits Data and Renewables Division; Office of Coal, Nuclear, Electric and Altemate Fuels (CNEAF); Energy Information Admitristration (BLA); U.S. Department of Energy (DOE).

General information regarding the contents of this publication may be directed to:

National Energy Information Center $(202 / 586-8800)$

Intertet E-Mail: INFOCTR EIA.DOE.GOV

General information about the data appearing in this publication may be directed to:

Howard L, Walton

Director, Coal and Electric Data and Rentewables Division

(202/426.1223) or Fax (202/426-1308)

Internet E-Mail: HWALTON@EIA.DOE.GOV
Questions and comments may be directed to:

Roger L. Secquety

Project Manager

$(202 / 426-1160)$ or $\mathrm{Fax}(202 / 426-1308)$

Internet E-Mail: RSACQUET EIA.DOEGOV

Specific information about the data contained in the FORM EIA 412 may be directed to:

Charlene Harris-Russell

Survey Statistician

(202/426-1163) or Fax (202/426-1308)

Internet E-Mail: CHARRISR G EIA.DOE.GOV

Historial data may be obtained from:

Charlene Harris-Russell

Strvey Statistician

(202/426-1163) or Fex (202/426.1308)

Intemet E-Mait; CHARRISR EIA.DOE.GOV

\section{Quality}

You are entieled to quality products and quality service. We ask your help in ensuring that this report meets the highest standards for qualty. If you bave any comments or sugsestions about this publication, please contact Roger L. Sacquety on (202) 426-1160 or FAX (202) 426-1308.

For general inquiries about energy data, please contact the National Energy Information Center on (202) 586.8800, internet users may contact them at this address: INFOCTR EIA.DOE.GOV 


\section{Tables}

Page

1. Selected Electric Utility Data by Ownership, 1994

2. Selected Data for Major U.S. Publicly Owned and Federal Electris Utilities Compared to All U.S. Publicly Owned and Federal Electric Utilities, 1994

3. Ten Largest U.S. Publicly Owped Generator Electric Utilities Ranked by Megawatthour Sales to Ultimate Consumers, 1994

4. Ten Largese U.S. Publicly Owned Generator Electric Utilities Ranked by Megawatthour Sales for Resale, 1994

5. Composite Statement of Income for Major U.S. Publicly Owned Generator Electric Utilities, 1990-1994

6. Composite Balance Sbeet for Major U.S. Publicly Owned Genterator Electric Utilities at End of Period, 1990-1994

7. Composite Financial Indicators for Major U.S. Publicly Owped Gencrator Electric Utilities, 1990-1994

8. Electric Operation and Maintenance Expenses for Major U.S. Publicly Owned Generator Electric Utilities, $1990 \cdot 1994$

9. Electric Utility Plant for Major U.S. Publicly Owned Generator Electric Utïlities at End of Period, 1990-1994

10. Number of Consumers, Sales, and Operating Revenue for Major U.S. Publicly Owned Generator Electric Wtilities, 1990-1994

11. Electric Energy Account for Major U.S. Publicly Owned Generator Electric Utilities, 1990-1994

12. Ten Largest Ư.S. Publicly Owned Nongenerator Electric Utiltties Ranked by Megawatthour Sales to Ultiutate Consumers, 1994

13. Ten Largest U.S. Publicly Owned Nongenerator Electric Utilities Ranked by Megawatthour Sales for Resale 1994

t4. Composite Statement of Income for Major U.S. Publicly Owned Nongenerator Electric Utilities, 1990-1994

15. Composite Balance Sheet for Major U.S. Publicly Owned Nongenerator Electric Utilities at End of Period, 1990-1994

16. Composite Financial Indicators for Major U.S. Publicly Owned Nongenerator Electric Utilities, 1990-1994

17. Electric Operation and Maintenance Expenses for Major U.S. Publicly Owned Nongenerator Electric Uttlities, 1990-1994

18. Electric Utility Plant for Major U.S. Publicly Owned Nongenerator Electric Utilities at End of Period, 1990-1994

19. Namber of Consumers, Sales, and Operating Revenue for Major U.S. Publicly Owned Nongenerator Electric Utilities, 1990-1994

20. Electric Energy Account for Major U.S. Publicly Owned Nongenerator Electric Utilities, $1990-1994$

21. Statement of Income by Major U.S. Publtely Owned Electrte Utitity Within State, 1994

22. Belance Sheet by Mnjor U.S. Publicly Owned Electric Utility Within State at End of Period, 1994

23. Electric Operation and Maintenence Expenses by Major U.S. Publicly Owned Electric Utility Within State, 1994

24. Electric Utiltty Plant by Major U.S. Publijly Owned Electric Utility Within State at End of Period, 1994

25. Number of Consumers, Sales, and Operating Revenue by Major U.S. Publicty Owned Electric Utility Within State, 1994

26. Electric Energy Account by Major U.S. Publicly Owned Ejectric Utility Within State, 1994

27. Statement of Incoms by U.S. Federal Electrte Utitity, 1994

28. Balance Sheet by U.S. Federal Electric Utility on September 30, 1994

29. Electric Operation and Maintenance Expenses by U.S. Federal Electric Utility, 1994

30. Electric Utility Plant by U.S. Federal Electric Utility on September 30, 1994

31. Number of Consumers, Sales, and Operating Revenue by U.S. Federal Electric Utitity, 1994

32. Electric Energy Acconunt by U.S. Federal.Electric Utility, 1994

A1. Composite Statement of Income for the U.S. Cooperative Borrowers, 1990-1994

A2. Composite Balance Sheet for the U.S. Cooperative Borrowers on December 31, 1990-1994

A3. Electric Operation and Maistenance Expenses for the U.S. Cooperative Borrowers, 1990-1994

A4. Number of Consumers, Sales, and Operating Revenue for the U.S. Conperative Dlstributor Borrowers, 1990-1994

B1. Major U.S. Publicly Owned Electric Utilities Added to and Deleted from the Form EIA-412, 1990.1994

B2. Mijor U.S. Publicly Owned Electric Utilities by Fiscal Year and Generator/Nongenterator Statıs from the Form EIA-412, 1994 
B3. Major U.S. Publicly Owned Electric Utilities by State and Generator/Nongenerator Status, 1994

B4. Major U.S. Publicly Owned Electric Utilities That Submitted the Form EIA-412, 1994

C1. Ten Largest U.S. Publidy Owned Generator Electric Utilities Ranked by Megawathour Sales to Ultimate Consumers with Financial Year Ending on June 30, 1994

C2. Ten Largest U.S. Publicly Owned Generator Electric Utilities Ranked by Meqawatthour Sales for Resale with Financial Year Ending on June 30, 1994

C3. Composite Statenent of Income for MAjor U.S. Publicly Owned Generator Electric Utilities with Financial Year Ending on June 30, 1990-1994

C4. Composite Balance Sheet for Major U.S. Publicly Owned Generator Electric Utilities with Financial Year Ending on Jane 30 at End of Period, 1990-1994

C5. Composite Financial Indicators for Major U.S. Publicly Owued Genterator Electric Utilities with Fmancial Year Ending on June 30, 1990-1994

C6. Electric Operation and Maintenance Expenses for Major U.S. Publicly Owned Generator Electric Utilities with Fuancial Year Ending on Jure 30, 1990-1994

C7. Electric Utility Plant for Major U.S. Publicly Owned Generator Electric Utilities with Financial Year Ending on June 30 at End of Pertod, $1990-1994$

CB. Number of Consumers, Sales, and Operating Revenue for Major U.S. Publicly Owned Generator Electric Utilities with Financial Year Euding on Junte 30, 1990-1994

C9. Electric Energy Account for Major U.S. Publicly Owned Generator Electric Utilities with Financial Year Ending on June 30, 1990-1994

C10. Ten Largest U.S. Publicly Owned Generator Electrio Utilities Ranked by Megawatthour Sales to Ultionate Consumers with Financial Year Ending on December 31, 1994

C11. Ten Largest U.S. Publicly Owned Generator Electric Utilities Ranked by Megawatthour Sales for Resale with Financial Year Ending on December 31, 1994

C12. Composite Statement of Income for Major U.S. Publicly Owned Generator Electric Utilities with Financial Year Ending on December 31, 1990-1994

C13. Composite Balance Sheet for Major U.S. Publtcly Owned Generator Electric Utilities with Financial Year Ending on December 31 at End of Period, 1990-1994

C14. Composite Financial Indicators for Major U.S. Publicly Owned Generator Electric Utilities with Financial Year Ending on December 31, 1990-1994

C15. Electric Operation and Maintenance Expenses for Major U.S. Publicly Owned Generator Electric Utilities with Finarcia: Year Ending on December 31, 1990-1994

Cl6. Electric Utility Plant for Mijor U.S. Publicly Owaed Generator Electric Utilities with Financial Year Ending on December 31 at End of Period, 1990-1994

C17. Number of Consumers, Sales, and Operating Revenue for Major U.S. Poblicly Owned Generator Electric Utilities with Financial Year Ending on December 31, 1990-1994

C18. Electric Energy Account for Major U.S. Publicly Owned Generator Electric Utilities with Financial Year Ending on December 31, 1990-1994

C19. Ten Largest U.S. Publicly Owmed Nongenerator Electric Utilities Ranked by Megawatthous Sales to Ultimate Consumers with Furancial Year Ending on June 30, 1994

C20. U.S. Publicly Owned Nongenerator Electric Utilities Ranked by Megawatthour Sales for Resale with Financial Year Ending on June 30, 1994

C21. Composite Statement of Income for Major U.S. Publicly Owned Nongenerator Electric Utilities with Finaricial Year Ending on June 30, 1990-1994

C22. Conposite Balance Sheet for Major U.S. Publicly Owned Nongenerator Electric Utilities with Financiat Year Ending on June 30 at End of Period, 1990.1994

C23. Composite Financial Indicators for Major U.S. Publicly Owned Nongenerator Electric Utilities with Finencial Year Ending on June 30, 1990-1994

C24. Electric Operation and Maintenance Expenses for Major U.S. Publicly Owned Nongenerator Electric Utilities with Financial Year Ending on June 30, 3990-1994

C25. Electric Utility Plant for Major U.S. Publicly Owned Nongenerator Electric Utilities with Financial Year Enting on Jute 30 at End of Period, 1990-1994

C26. Number of Consumers, Sales, and Operating Reventue for Major U.S. Publicly Owmed Nongenerator Electric Utilitie with Financlat Year Ending on June 30, 1990 -1994

C27. Electric Energy Account for Major U.S. Publicly Owned Nongenerator Electric Utilities with Financial Year Bnding on June 30, 1990-1994

C28. Ten I argest U.S. Publicly Owaed Nongenerator Electsic Utilities Ranked by Megawatthour Sales to Ultimate Consumers with Financial Year Ending on December 31, 1994

C29. Ten Largest U.S. Publicly Owned Nongenerator Electric Utilities Ranked by Megawatthour Sales for Resale with Firancial Year Ending on December 31, 1994

C30. Composite Statement of Income for Major U.S. Publicly Owned Nongenerator Electric Utilities with Fintancial Year Ending on December 31, 1990-1994

C31. Composite Balance Sheet for Major U.S. Publicly Owned Nongenerator Electric Utilttes with Financial Year Ending on December 31 at End of Period, 1990-1994

C32. Composite Financial Indicators for Major U.S. Publicly Owned Nongenerator Electric Utilities with Financial Year Ending on December 31, 1990-1994 
C33. Electric Operation and Maintenance Expenses for Major U.S. Publicly Owned Nongenterator Electric Utilities with Financial Year Encing on December 31, 1990-1994

C34. Electric Utility Piant for Major U.S. Publicly Owned Nongenerator Electric Utilities with Financial Year Ending on December 31 at End of Period, 1990-1994

C35. Number of Consumers, Sales, and Operating Revenue for Major U.S. Publicly Owned Nongenerator Ekctric Utilities with Financial Year Ending on December 31, 1990-1994

C36. Electric Energy Account for Major U.S. Publicly Owned Nongenerator Electric Utilities with Financial Year Ending on December 31, 1990-1994

C37. Twenty Largest U.S. Publicly Owned Electric Utilities Ranked by Megawatthour Sales to Ultimate Consumers for All Respondents, 1994

C38. Twenty Largest U.S. Publiciy Owned Electric Utiłities Ranked by Megawatthour Sales for Resale for A]] Respondents, 1994

C39. Twenty Largest U.S. Publicly Owned Electric Utilities Ranked by Electric Utility Revenues for All Respondents, 1994

C40. Twenty Largest U.S. Publicly Owned Electric Utilities Ranked by Purchase Power Expenses for All Respondents, 1994

C41. Twenty Largest U.S. Publicly Owaed Electrto Utitities Ranked by Electric Utility PJant for All Respondents, 1994

C42. Twenty Largest U.S. Publicly Owned Electric Utilities Ranked by Construction Work in Progress for Al! Respondents, 1994

C43. Composite Statement of Income for Major U.S. Publicly Owned Electric Utilities for All Respondents, 1990-1994

C44. Composite Balance Shect for Major U.S. Publicly Owned Electric Utilities for All Respondents at End of Period, 1990-1994

C45. Composite Financial Indicators for Major U.S. Pablicly Owned Electric Utilities for All Respondents, $1990 \cdot 1994$

C46. Electric Operation and Matntenance Experises for Major U.S. Publicly Owned Electric Utilities for All Respondents, 1990-1994

C47. Electric Utility Plant for Major U.S. Publicly Owaed Electric Utilities for All Respondents at Enx of Period, 1990-1994

C48. Number of Consumers, Sales, and Operating Reventue for Major U.S. Publicly Owned Electric Utilites for All Respondents, 1990-1994

C49. Electric Energy Account for Major U.S. Publicly Owned Electric Utilities for All Respondents, 1990-1994

CS0. Comparison of the Electric Energy Account for Major U.S. Publicly Owned Electric Utilities for All Respondents, 1990-1994

D1. State Agency Authority to Regulate Rate of U.S. Publicly Owned Electric Utilities, 1994

\section{IIIustrations}

1. Total Electric Utility Plant per Dollar of Revenue, 1990-1994

2. Long-Term Dett, Constraction Work In Process, and Nuclear Fuel for TVA, 1990-1994

3. The Department of Energy's Five Power Marketing Administrations Service Areas, 1994

4. Revemue Applied Chart for APA, 1990-1994

5. Total Revenue and Expenses for BPA, 1990-1994

6. Debt Service Coverage Ratio for SEPA, 1990-1994

7. Financial Performance for SWPA, 1990-1994

8. Electric Sales and Revenue for Western Area Power Administration

B1. Principal Basiness Office of the Major U.S. Publicly Owred Electric Utilities, 1994 


\section{Introduction}

\section{About Thls Publlation}

The [994 edition of the Finoncial Statistiss of Mogor U.S. Publlciy Owned Electric Untlites publication pre sents 5 years (1990 througt 1994) of summary finan. cial data and current year detailed financial duta on the major ptulicly owned electric utilities. The objective of the publication is to provide Federal and State goveruments, industry, and the general public with current and historical dafa that can be used for policymaking and decisionmaking purposes related to publicly owned electrie ntility issues.

Generator (Tables 3 through 11) and nongenerator (Tables 12 through 20) summaries are presented in this publication. Five years of summary finmeial data are provided (Tables 5 through 11 and 14 through 20). Summaries of generators for fiscal years ending Jume 30 and December 31, nongenerators for fiscal years ending June 30 and December 31, and summaries of all respondents are provided in Appendix C.

The composite tahles present aggregates of income statement and balance sheet data, as well as financial indicators. Composite tables also display electric operation and ansintenance experses, electric utillity plant, number of consumers, sales of electricity, and operating revenue, and electric eneroy account data.

The primary source of publicly owned financial data is the Form BIA-412, "Aumal Report of Poblic Electric Utilities." Public electric utilities file this survey on a fiscal year, rather than a calendar year basis, in conformance with their recordkeeping practices. In previous (1990 and prior) editions of this publication, data were agferegated by the two most commonly reported fiscal years, June 30 and December 31 . This omitted approximately 20 percent of the respondents who operate on fiscal years ending in other months.

Accordingly, the EIA undettook a review of the Form EIA 412 submissions to dettermine if alternative classiffeations of publicly owned electric utilties would permit the inclasion of all respondents. The study also focused on understanding the differences in financial characteristics between electric utilities whose fiscal years end June 30 and December 31. The review indicated that financial indicators differ most according to whether or not a publicly owned electric utitity generates electricity. Therefore, the main body of the report provides summary information in generator/nongenerator classifications.

\section{History}

As the result of the Federal Power Act of 1935, the Federal Power Commission (FPC), which was the ptedecessor to the Federal Energy Regulatory Commission (FERC), began collecting financial statistics for investor-owned electric utilities in 1938. In 1946, the FPC started collecting financial statisties on publicly owned electric atilities. The Energy Information Adurinistration (EIA) apon its establishment in October 1977 took over the responsibility of gathering and publishing the financial statistics from the FERC. In 1982, the EIA combined the contents of two publications containing financial statistics of investorowaed (private) and publicly owned electric atilities into a single volume, the Financial Statistics of Selected Electric Utilities . In 1991, the publication titles were changed to the Fhancial Shatistics of Mofor InvestorOwned Electric Utilities and the Financial Statistiss of Mafor Publicty Owned Electric Utilities . In 1992, the publication titles were further changed to the Financlal Stotistics of Major U.S. Investor-Owwed Electric Uhilities and the Financial Statistics of Major U.S. Publicly Owned Electric Unilties .

Currently, the Financial Stotistics of Mojor U.S. PubLlely Owned Electric Uhlities pablication is prepared by the Electric Operating and Financial Data Branch; Coal and Electric Data and Renewables Diviston; Office of Coal, Nuclear, Electric and Alternate Fuels; EIA; U.S. Department of Energy. The format was designed to be used by a variety of private, electric power industry, and government users. The publication contents and format have evolved over the years to better serve the needs and requirements of the targeted audience.

\section{About The Industry}

The U.S. electric power industry is a combination of electric ntilities (investor-owned, publicly owned, cooperatives, and Federal) and nonutility power producers. Investor-owned electric utilities account for over three-fourths of the sales of electricity and revenue in the industry. Historically, the investorowned electric utilities served the large consolidated markets and operated in all States except Nebraska Hawait is the only State in which all electricity is supplied by investor-owned electric utilities.

Publicly owned electric utilities are nomprofit operations that have been eskablished to serve their com. munities and nearoy consumers at cost. The publicly owned electric utilities in this poblication include municipals, pablic power distriets, State authorities, irrigation districts, and other State orgautzations. Publicly owned electric utilities are exempt from taxes 
and can obtain new financing at lower rates than investor-owned electric utilities.

The publicly owned electric utilities are divided into generators and nongenerators (In contrast, virtually all investor-owned electric utilities own and operate generatting capscity). Generators are those electric utilities that own/operate geacrating capacity to supply some or all of their consumer needs. However, some generators supplement their demand by purchasing power. The nongenerators do not prodnce electric power for end use and rely exclusively on purchasing power. Their primary fonction is to transmit and distribute electricity to their consumers. The nongenerators comprise over half of the total number of major publicly owned electric utilities.

Cooperative electric utilities are owned by their members and are established to provide electricity to those members. The Rural Utilities Service (prior to the Rural Electrification Admtnistration), U.S. Department of Agriculture, was established nnder the Rural Electrification Act of 1936 with the purpose to extend electric service to small rural communities (usually under 1,500 consumers) and farms where it was more expensive to provide service. The National Raral Utilities Cooperative Finance Corporation, the Federal Financing Bank, and the Bank for Cooperatives are the most important sources of debt financing for cooperatives. Cooperative borrowers (855 of 939 in 1994 total cooperatives) currently operate in 46 stetes. Financial data for the cooperative bortowers are found in the Statistical Report, Rural Electric Borrowers published by the Rural Utitties Service of the U.S. Department of Agriculture. Summary tables for the cooperative borrowers are provided in Appendix A.

Federal electric utilities are also presented in this pubfication and include the five Federal power maketing adninistrations, the Tennessee Valley Authority, the U.S. Arriy Corps of Engineers, and the U.S. Bureat of Indian Affairs. The five Federal power marketing administrations ane the Alaska Power Adintnistration, the Bonneville Power Administration, the Southeastern-Power Administration, the Southwestern Power Administration, and the Western Area Power Administration. Electric power produced by Feteral electric utilities is generated primarily by water resources. This power, which is not produced for proint, is primarily wholesaled to other electric utilities rather than being distributed to ultimate consumers. As required by law, publicly owned and cooperative electric utilities are given preference in the purchase of this less expensive power produced by the Federal eleatric utilities.

\section{Data Users}

The Financial Statistics of Major U.S. Publisy Omed Electric Utitities publication provides information about the financial resuits from operations of publicly owned electric utilities for use by government, industry, electric utilities, financial organizations and educational institutions in entergy planning. In the private sector, the readers of this publication are researchers and analysts associated with the financial markets, the policymaking and decisionmaking; members of electric utility companies, and economic development organizations. Other organizations that may be interested in the data presented in this publication fnclude mannfacturers of electric powwer equipment and marketing organizations. In the public sector, the readers of this publication include analysts, researchers, statisticians, and ottier professtonals engaged in regulatory, policy, and program activities. These individuals are generally associated with the Congress, other legislative bodies, State public service commisstons, universities, and pational strategic planning organizations.

\section{Sources and Coverage}

Publicly owaed electric utilities are required to submit the Form EIA-412 when the generation, trensmission, or distribution of electricity, for the two previous years, results in one of the following :

- 120,000 megawatthours of sales to altimate consumers.

- 120,000 megawatthours of sales for resale.

These criteria are based on data reported on the Form ELA-861, "Alunual Electric Utility Report." This survey is submitted by all electric utilities in the United States, its territories, and Pnerto Rico. Appendtx B contains a list of the major publicly owned electric utilities that submitted Form EIA-412 data for 1994.

Many of the publicly owned electric utilities are selfregulated while some fall under the jurisdiction of State pablic service commissions as shown in Appendix D. Because of the absence of required reporting to a spectific regulatory body, the accounting practices and policies of publicly owned electric utilities vary considerably. Many use the FERC Uniform System of Accounts or variations of this and other accounting systeas. The composite sta. tistics provided in this publication most be viewed with an approprtate degree of caution.

The Form EIA 412 is used to collect detailed annual accounting, financial, and other operating charactor. istios of publicly owned electric utiltties for publication in EIA reports In 1994, 503 major publicly owned electric utilities sabmitted data to the EIA. Atthough calendar year reporting of data is preferred, electric utilities are given the option of reporting data on a fiscal year basis. This option is permitted in order to minimize respondent burden in preparing the data. When reporting by fiscal year, electric utilities must report operational data for a 12-month period and 
show consistency in fiscal periods and accounting practices.

\section{Industry Proffle}

i

Selected electric utility data for 1994 are compiled from the Form EIA-861 for the total universe of alectric utilities. In 1994, there were 3,204 investorowned, publicly owned, Federal, and cooperative eleetric ntilities (Table 1).

Key facts concerning sales and revenues in 1994 are as follows:

- The 250 investor-owned electric utilities (7.8 percent of all electric utiltttes) accounted for 78.8 percent of all revenues from sales of electricity to ultimate consumers and 41.3 percent of all revenues from sales for resale.

- The 2,005 publicly owned electric utilities (62.6 percent of all electric utilities) accounted for 12.7 percent of all revenues from sales to ultimate con- sumers and 18.8 percent of all revenues from sales for resalt

- The 939 cooperative electric atilities (29.3 percent of all electric utilities) accoounted for 7.9 percent. of all revenues from sales to ultimato consumers and 23.9 percent of all reventues from sales for resale.

- The 10 Federal electric ntilities accounted for 0.6 percent of all revenues from sales to ultimate con. sumers and 15.9 percent of all revenues from sales for resale.

- The average ultimate consumers revenue per kilowathour ranged from 2.8 to 7.1 cents depending on the type of electric utility. The overall average was 6.9 cents.

- The average sales for resale revenue per kilowatthour ranged from 3.5 to 4.0 cents, depending on the type of electric utility. The overall average was 3.7 cents.

Table 1. Salected Electrle Utility Data by Ownership, 1994

\begin{tabular}{|c|c|c|c|c|c|}
\hline \multirow[b]{2}{*}{$\mathrm{man}$} & \multicolumn{5}{|c|}{ Type of Elockis Uulity } \\
\hline & Itw日estorownind & Publiky Owinad & Copopdititivit & Fadartiot & Tolal' \\
\hline 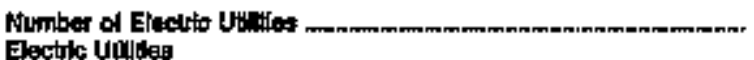 & 250 & 2,005 & 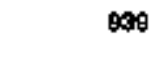 & 10 & 3,204 \\
\hline 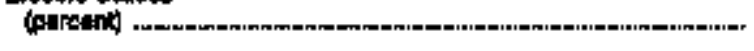 & 7.8 & 6.6 & 295 & Q.3 & 100.0 \\
\hline 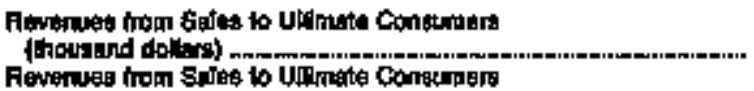 & 159,700,8ge & $25,690,956$ & $16,012,006$ & $1,290,516$ & 202705,069 \\
\hline 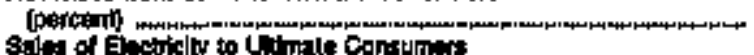 & $7 a, 8$ & 12.7 & 7.8 & $\mathbf{D B}$ & 1000 \\
\hline 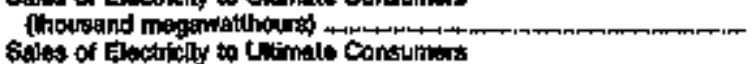 & $2,297,683$ & $4 \mathbf{2 1 , 0 4 2}$ & 228,555 & 46,708 & $2,594,500$ \\
\hline 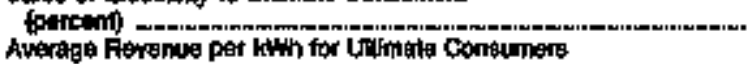 & 76.3 & 14.4 & 7.8 & 1.6 & 100.0 \\
\hline 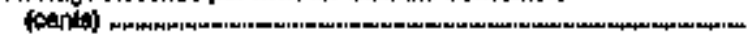 & $7+1$ & $\mathbf{E . 1}$ & 7.0 & 2.0 & 6.9 \\
\hline 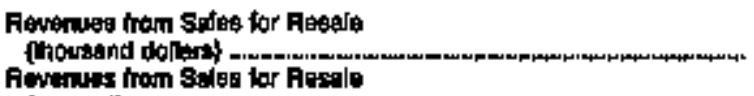 & $17,977,096$ & G,18B,000 & $10,404, \mathrm{gg} 9$ & $6,009,090$ & $49,499,765$ \\
\hline 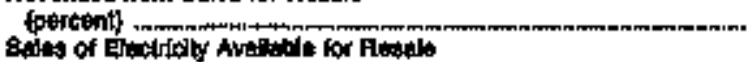 & 41.3 & 18.9 & 20.9 & 15.8 & 1000 \\
\hline 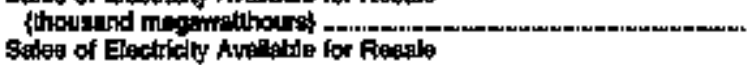 & 517,128 & $21+, 968$ & 257,449 & 108,782 & $1, \tan 3,85$ \\
\hline 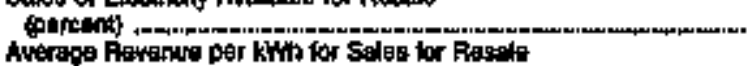 & 49.6 & 17.9 & 21.7 & 16.8 & 1000 \\
\hline 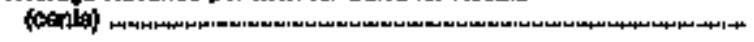 & 3.5 & as & 4.0 & $\mathbf{3 . 5}$ & 3.7 \\
\hline
\end{tabular}

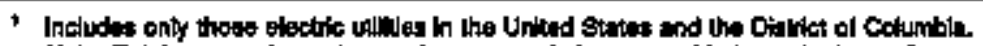

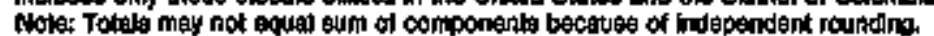

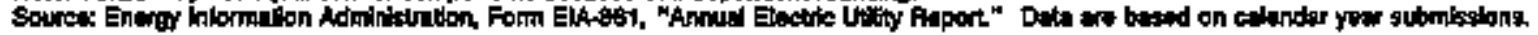


This publication will concentrate on selected operational data for 303 of the 2,005 publicly owned electric utilities and for 8 of the 10 Federal electric utilities in the United States. Table 2 compares these utilities with the total values reported by all pablicly owned and Federal electric utilities on the Form ELA-861.

In 1994, the 503 major publicly owned electric otilities in this publication accounted for 87.8 percent of the revenues from sales to ultimate consumers and 99.7 percent of the revenues from sales for resale of ail publicly owned electric utilities (Table 2). The eipht Federal electric utilities in this publication cover the entire Fedioral segment.

This publication contains summary and detailed data for $\$ 03$ major publicly owed electric utilities (Tables 3 through 26). Also, included are summary and desailed data for the eight Federal electric utilities (Tables 27 through 32).

Appendix A tables contain 5 years of sumbary statistics on U.S. rural electric cooperative borrowers (Tables A1 throush A4).

Appendix B contains a list of the mafor U.S publicly owned electric atility respondents. The major U.S. publicly owned electric utilities added and deleted for 1990 through 1994 are listed (Table B1). The number of generator/nongenerator responilents for Jume 30, for December 31, and for the "other" fiscal years are provided (Table B2). The total nuaber of respondents by State ard generating status of the respondents are also provided (Table B3). The name, State, finenclal reporting date, and geptrating status of the respond. ents are also provided (Table B4),

Appendix $\mathbf{C}$ contasins stmmary statistics for generating and nongenerating major U.S. publicly owed electric utilities for the fiscal year periods ending June 30 and December 31, as well as for all respondents (Tables $\mathrm{C1}$ through $\mathrm{CsO}$ ).

Appendix D contains a list of the State agencies which bave regulatory oversight of publtaly owned electric utilities.

Appendix E contains all Technical Notes for the publication. The key sections are Sources of Data, Quality of Data, Formulas and Calculations, and General Information.

The Glossary defines common terms used in the publication.

Table 2. Selected Data for Major U.s. Publlofy Owned and Federal leptrle Utllties Compared to All U.S. Publiely Omned and Federal Eleotrio Vtilltien, 1994

\begin{tabular}{|c|c|c|}
\hline $\ln$ & Putioby Owmed & Fedoral' \\
\hline 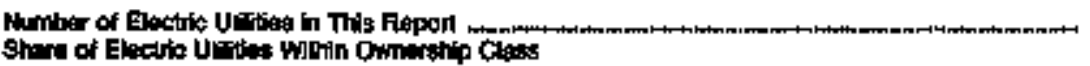 & 503 & 日 \\
\hline 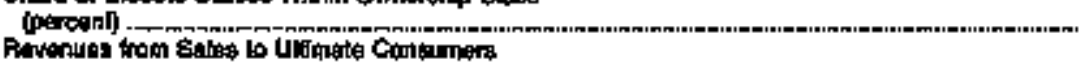 & 25.1 & 80.0 \\
\hline (thousand dollary & $20,570,790$ & 1,29070 \\
\hline 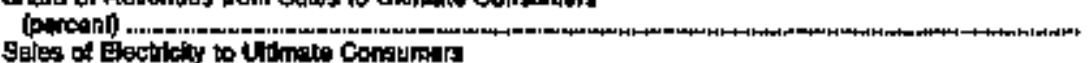 & 67,8 & 100.0 \\
\hline 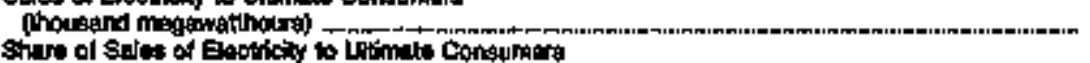 & 373,744 & 49,702 \\
\hline 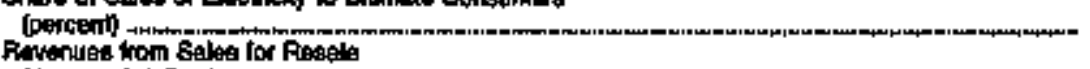 & 8B8 & 300.0 \\
\hline 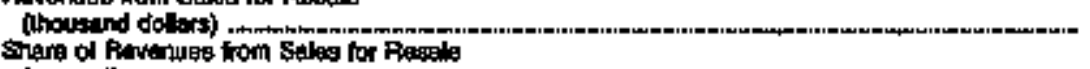 & $8,165,065$ & $6,029,000$ \\
\hline 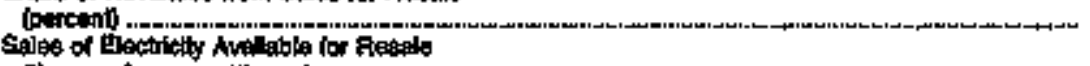 & 80.7 & 9000 \\
\hline 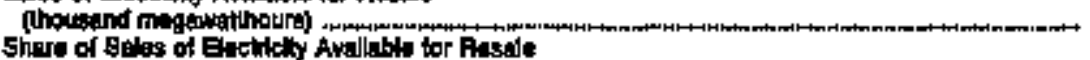 & 211,395 & 160,762 \\
\hline 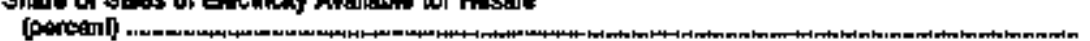 & 90.7 & 1000 \\
\hline
\end{tabular}

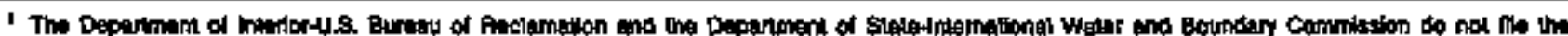

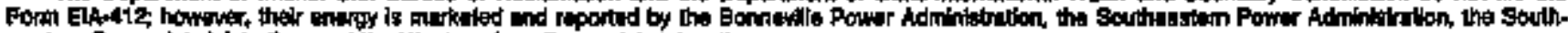

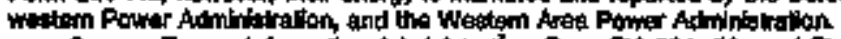

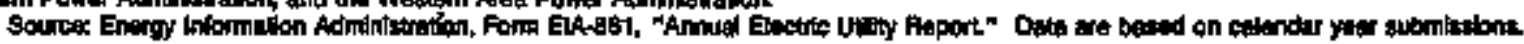




\section{Summary Statistics of Major U.S. Publicly Owned Electric Utilities}




\section{Factors Affecting Major U.S. Publicly Owned Electric Utilities During 1994}

\section{Overview}

Summary firancial statistics are provided for major U.S. publicly owned electric utilities. These statistics include data for 503 electric utilities for 1994; 495 electric utilities for 1993; 483 electric utilities for 1992; 470 electric utilities for 1991; and 467 ilectric utilities for 1990 . Over the five years summarized in this report, a net 36 publicly owned electric utilities have been added as Form EI-412 respondents. Currently, these additional respondents represent 7.2 percent of the 1994 total respondents base, but have a small inupact on overall reported publicly owned electric utility investments.

Economic Context. The economy continued to expand in 1994 at an impresive rate of 4.0 percent. The expansion in the cconomy was accompanied by a reduction in unemployment from 6.7 percent in January to 5.4 percent by the end of the year. Employment in manufacturing recorded its largest inctease since 1987. The budget deffeit declined $\mathbf{5 2}$ bitlion from the previous year as increased Federal receipts offset the increase in Federal outlays. The Califoraig earthquake in January had a negative impact on corporate profits; however, profits rebounded sufficiently that by the end of the third quarter, they were up $\mathbf{5 . 6}$ percent on a cumulative annualized basis. Real disposable income was up 4.3 percent for the year."

Weather. Vartations in weather can contribute significantly to megawatthour sales from year-to-year as well as within the same year. Heating and cooling degree days are a standard measure of the impact of weather on the various sectors of the economy. The first quarter of 1994 was characterized by severe cold, particnlarly in the East and portions of the South. However, the nation overall experienced milder weather throughout the the rest of the year countering the effects of the first quarter. A commonly used jadex of energy consumption is based on degree days. For instance, heating degree days indicate how many degrees the mean temperature fill below 65 degrees for the day. Cooling degree days indicate how many degrees the mean temperature rose above 69 degrees for the day. Heating degree days were 10.1 percent below normal as opposed to 5.2 percent above normal for 1993. The number of cooling degree days were 3.3 percent above normal compared with 4.3 percent above noxmal the previous year.'

Infiation and Intrest Rates. The rate of inflation in 1994, as measured by the Consumer Price Index of all items (CPI-U), continued at historically low levels, averaging 2.7 percent for the year.' Spot prices for faels delivered to all electrite utilities were down 3.4 percent for coal, but up 4.0 percent for petroleum. Interruptible natural gas prices were down more impressive 15.4 percent."

I Council of Economic Advigors, Econamic Report of the President. (Washinaton, DC, Februtry 1995),

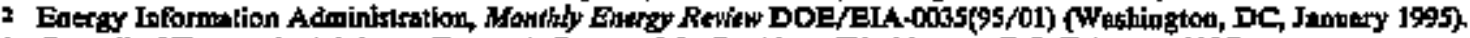

3 Council of Economic Advisort, Ecostmic Report of the Frestedent, (Wathington, DC, February 1995).

- Enexoy Information Administration, Elecric Power Ansud J994 Volame I DOE/EIA-034B(94/1) (Washington, DC, Jvily 1995). 
Federal Reserve Board Actions. The reductions it the unemployment rates along with the minimal slack in labor and capacity utilization rates led many economists to raise concern regarding pocential increases in wage and price inflation. To forestall inflation, the Federal Reserve raised interest rates in early Fetmary 1994 and five subsequent times during the year. These Federal Reserve actions were to reduce the tisks of inflation, having seen a significant picknp in inflation at the early stages of production and increases in non-oil import prices.

The torerease in the Federal funds rate was expected to flatten the yield curve significantly. Instead, yields on long-term bonds imcreased from a low of 5.78 in October 1993 to a high of 8.16 in early November 1994 before easing somewhat to 7.89 by the end of the year. Rising interest rates would be expected to bave a chilling inpact on the refinancing activities of electric utilities. "

\section{Generator Eloctric Uthities versus Nongenerator Electric Uhithes}

The next section of the publication discusses generator and nongenerator electric utilities separately. The two groups are distinct because of operational differences resulting in significantly different financial profiles. For example, significant plant production expenses would not exist for nongenerator electric utilities because existing production plant expenses are miandy ntaintenance costs for stand by plents. It should be noted that both generator and nongenerator elec. tric ubilities report according to varying fiscal years that are determined by their political lncalities.
Becouse nongenerator electric utilities purchase all their power needs, they have less plant investment than generator electric utilities do per dollar of revenue generated. In 1994, generator electtic utilities showed \$3.84 of electric utility plant per dollar of electric uttlity operating revenue, compared with $\$ 1.04$ for nongenerator electric utilities.

Operation and maintenance (OtM) expenses represent very different costs between the two groups of elec. tric utilities. Purchase power expenses, which comprise the majority of nongenerators' $\mathrm{O}$ \&M expenses, contitin all the associated costs for the generating plants from which the power was purchesed, including depreciation. This causes nongenerators' O\&M expenses to appear higher thar generators' O\&M expenses on a mills per kilowatthour basis. In 1994, nongenerators' O\&M expenses were 88.7 percent of revenues and depreciation was only 3.4 percent. For generators, depreciation of plant is shown directly, since all or some of their generating needs are met by their own plants. Generstors OsM expenses represented only 65.1 percent of revenues, but depreciation was 11.1 percent of revenues.

Financing is also defferent for the two groups. Generator electric utilities, with their larger plant investments per dollar of revenue, have more debt per dollar of revenue than nongenerator electric utilities. The large amount of debt creates greater interest expense. Interest expense represented 18.6 percent of revenues in $\$ 994$ for the generators versus just 1.4 percent of revenues for the nongenerators (Tables 7 and 16). 
Figure 1. Total Electric Utility Plant per Dolkar of Rovenue, 1990-1994

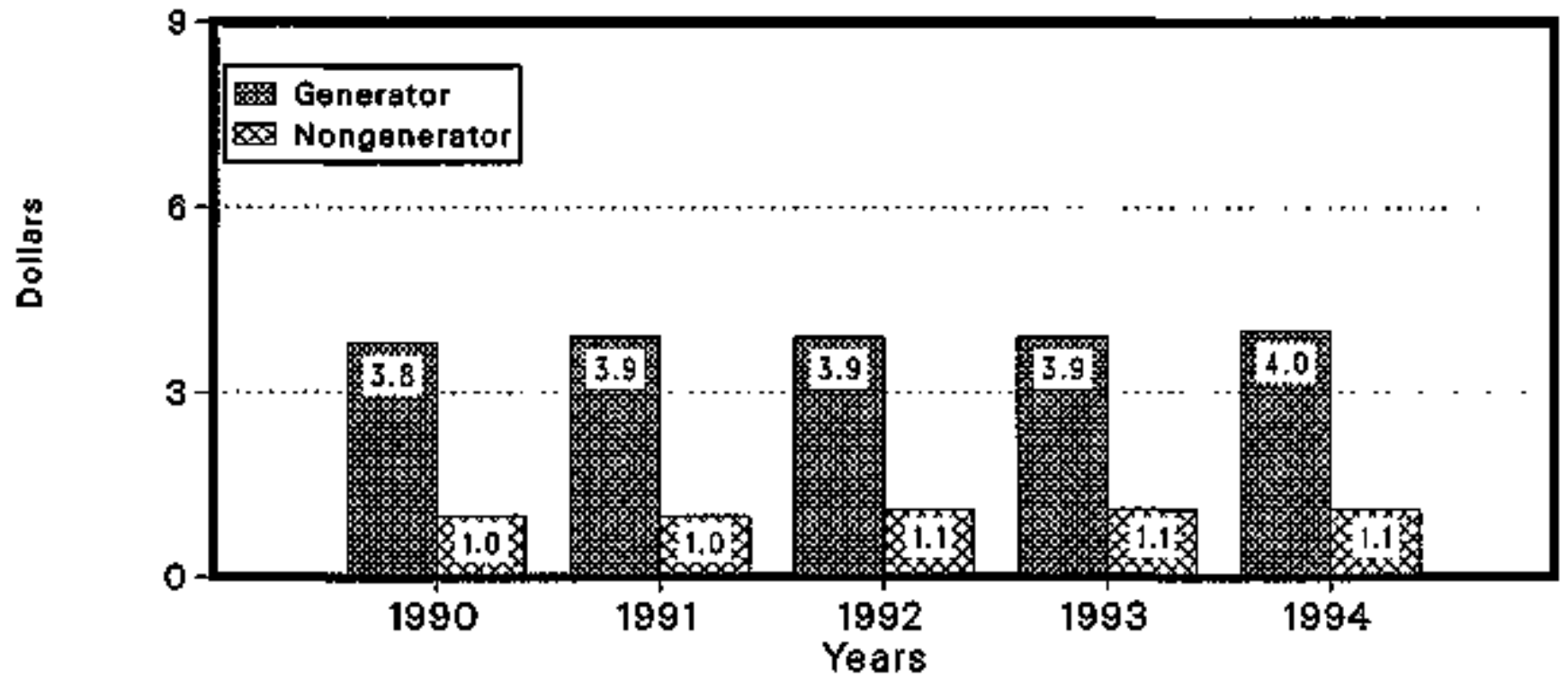

Note: Summary dato are provided fn Tables 7 and 16.

Source: Energy Information Administration, Form ElA-412, "Annual Report of Public Electric Utilities." 


\section{Financial Performance for Generator Electric Utillities}

Financial statistical summaries are provided for major publicty owned generator etectric utilities which include 227 electric utilities for 1994; 226 electric utilities for 1993; 225 electric ntilities for 1992; 218 electric utilities for 1991; and 216 electric utilities for 1990. New respondents and electric utilities no longer reporting from the previous years are listed in Appendix $\mathrm{B}$.

\section{Highlights of Generator Financial Performance}

Increased sales and revenues combined with modest growth in operating expenses to yield a 6.0-percent increase in electrte operating income After accounting for changes in other income and deductions, net income grew 33,4 percent over the prior year (note that 1993 was an off-year for this segment with net income down 30.5 percent below 1992 levels), Key indicators of the generator electric utilities financial performance were:

- Electric revenues were up 3.3 percent on the basis of a 2.8-percent increase in retail sales and a 2.4-percent increase in sales for resale.

- Electric operation and maintenance expenses were up 2.7 percent, but on a per kilowatthour sold basis remained unchanged at 34.3 mills in a row.

- Interest expente continued its downward trend in 1994, dropping for the third year.

- Ansets increased a modest $\$ 1.9$ bitlion in 1994, well below the $\$ 5.4$ billion increase recorded in 1993.

- Investments in distribution plant increased the most in electric plant, up $\$ 1.1$ billion.?

\section{Income Statement}

The Composite Statement of Income for major pub. licly owned generator electric utilities for the years 1990 to 1934 is presented tin Table 5. Net fincome of $\$ 0.9$ billion for generator electric utilities was ap a substantial 33.4 percent from the previous year.

Revenues. Generator electric utlities reventes were up 3.3 percent to $\$ 23.3$ billion in 1994; increased sales were the major contributing factor to incressed revenues. In 1994, wholesale sales grew less than retail sales, but wholesale revenues stew faster than retai] revenues.

Electric Utillty Operating Eypenren. Total electric utility operating expenses of $\$ 18.6$ billion were up 2.7 percent over the previous year, and the largest morease in expenses was in operation expenses, up \$0.3 billion to $\$ 13.6$ billion in 1994. Operation expenses accounted for 72.8 percent of the total elec. tric utility operating expenses. The second largest contributor was depreciation expense, which accounted for 13.9 percent of totel electric utility operating expenses (up \$0.1 billion or 6.1 percent over the prior year). Maintenance expenses were next in contribution to total electric utility operating expenses, accounting for 8.5 percent of the total (up a modest 1.2 percent from the prior year). Tax and tax equivaients were up 0.9 percent in 1994 from 1993 and accounted for 4.1 percent of the total electric utility operating expenses in 1994. ?

Production Bxpenses. Production expenses were \$11.5 billion in 1994, up 20 percent over the prior year (Table 8). Production expenses represented 76.0 percent of total operations and mintenaze expenses and declined on a mills per kilowatthour basis 0.6 percent (26.1 mills per kilowatthours sold in 1994).

At $\$ 5.6$ billion in 1994, purchased power represents the largest production expenise. Historically, despite self generation, generating publicly owned electric utilities have spent less than 50 percent of totel production expenses on purchased power. Purchesed power experises were up 5.4 percent over the previous year.

In 1994, steam penerating expenses were the second largest production expense, $\$ 4.0$ billion, representing 35.0 percent of total expenses. Steam production expenseg were down 1.6 percent from the prior year. Nuclear power production expenses of $\$ 1.3$ billion were also down, off 1.0 percent from the prior year's value, and represented 11.2 percent of total production expenses in 1994.

Hydraulic, other power generntion, and other production expenses accounted for the remaining $\$ 0.5$ billion of total power production experses. Comblined these production expenses accounted for only 4.8 percent of the total production expenses.

Fuel expenses in 1994 were $\$ 3.4$ billion, down 1.5 percent from the previous year, and represented 29.4 percent of total production expenses. This was down from 30.4 percent of total production expesises in 1993 and ytelded to increased purchased power expense.

Transamission and Distribution Expenses. After increasing 7.0 percent in 1993, transmission and distribution expenses wete ap a modest 2.5 percont in 1994. Transmission expenses of \$0.7 billion were up 3.3 percent over the prior year, while distribution experses of 50.8 billton were up 1.8 percent. On a mills per kilowatthour sold basis, both transmission and distribution expenses remained unchanged at $\mathbf{1 . 6}$ and 1.9 , respectively.

Electric Utility Income. Rovenues increased 50.7 billion, whils expenses increased $\$ 0.5$ billion and provided an increase of $\$ 0.3$ billion in electric utillty operating income. A decline in other electric income of $\$ 0.2$ billion accomparied by a $\$ 0.1$ billion decline in other electric deductions, thereby reducing the increase in electric utility income to So.1 billion. Electric utility ircome was up $\$ 0.1$ billion to $\$ 5.7$ bitlion in 1994, a 2.5-percent increase. 
Interest Expense. Interest expense was $\$ 4.3$ bilion in 1994, down 2.3 percent from $\$ 4.4$ billion in 1993. Debt outstanding as reported on the balance sheet increased a mere $\$ 0.7$ billion compared with the $\$ 4.2$ billion increase between 1992 and 1993.

Net Incame. The positive effect of the reduction in interest expense meationed above was directly offiset by an increase in other income deductions which yielded modest $\$ 0.1$ billion increase to $\$ 1,0$ billion for income before extraordinary items. However, the 50.1 billion increase amounted to a rtse of 15.4 percent.

Extraordinary income was up 10.9 percent while extraordinary deductions were off 29.0 percent. Instead of reducing income $\$ 0.2$ billion, as was the case in 1993, these extraordinary items combined to reduce income by only $\$ 0.1$ billion in 1994. As such in 1994, net income was up 33.4 percent to $\$ 0.9$ billion. ?

\section{Balance Sheet}

The Composite Balance Sheet for publicly owned generator electric utiltites revesled a 1.7 -percent increase in agsets for the year (Table 6).

Assebs and Other Dehits. Increases in total assets were significantly off prior year's values, adding only $\$ 1.9$ billion in value. This 1994 increase in essets contrasts with the 55.4 bition added in 1993. Increases in net electric utilty plant (inciuding net nuclear fuel) represented 56.7 percent of the increase in assets, adding $\$ 1.1$ billion. Increases in total other property and investments accokinted for 25.1 percent of the increase tn total assets or $\$ 0.5$ billion. In 1993, the increase in total other property and invertments was 42.1 percent of additions during the year or $\$ 2.3$ billion. Other changes in asset accounts included:

- Constnction work in progress (CWIP) increased to $\$ 4.2$ billion in 1994 , up $\$ 0.5$ billion over the $\$ 3.8$ billion figure for 1993 (note difference does not add dne to rounding).

- Changes in miscelleneous current and axcrned assets dominated the increase in total current and accrued assets. Miscelleneous accounts represented $\$ 0.3$ billion of the $\$ 0.4$ billion increase in current and accrued assets.

- Deferred debits increased $\mathbf{5 2 . 0}$ billion between 1992 and 1993, contributing 36.7 percent of the increase in total assets. In contrast, deferred tebits fell So.1 billion to $\$ 13.9$ billion by the end of 1994.

Electric Utitity Plant. Electric utility plent in service increased 4.1 percent to $\$ 83.8$ billion in 1994 (Table 9). Including adjustments, titility plant thoreased to $\$ 85.3$ billion (Table 6). Noteable changes in the elec. tric utility plant accounts included:

- Increases in total prodinction plant represented 26.0 percent of the change in total electric plant in service, up $\$ 0.9$ billtion. While steam production plant remains the largest component of production plant at \$24.3 billion, other production provided the greatest increase in 1994, up $\$ 0.6$ billion or 34.1 percent over the prior year. Other production plant only accounted for $\$ 2.4$ bittion out of the total production plant of $\$ 53.3$ billion at the end of 1994. While essentially unchanged from the prior year, nnclear plant investments of $\$ 18.8$ billion accounted for 22.4 percent of the total electric plant in service. (Publicly owned generator electric utilities have significant nuclear plant investment exposure.) Production plant accoumts for 63.6 percent of the total electric plant in service

- Increases in distribution plant was signtficant, accounting for $\$ 1.1$ billton or 31.9 percent of the increase in totat assets By the end of 1994, distribution plant accounted for 18.2 percent of tota] electric plant ín service.

- Transmission plant changed little during 1994, increasing a modest $\$ 0.3$ billion and represented 11.1 percent of total electric plant in service.

- General plant showed a significant 20.3-percent increase to $\$ 5.5$ billion in 1994, adding $\$ 0.9$ billion, which was 27.9 percent of the toted increase in electric plant in service. However. general plant remamed at 6.6 percent of total slectrite plant in service.

Liabilities and Other Credits. Increases in proprietary capital domingted the changes on the liabilities side of the balance sheet, accounting for $\mathbf{5 1 . 2}$ percent of the $\$ 1.9$ billion increase. Increases in retatued carnings added $\$ 0.9$ biltion of the $\$ 1.0$ billion of additional proprietary capital at year"s end. Proprictary capital increased from 23.6 percent in 1993 to 24.2 percent in 1994 of total capitalization (proprietary capital plus long-term debt). Other significant changes in llability and other credit accounts included:

- Long-term debt increased $\$ 0.6$ billion, or 0.8 percent to $\$ 76.8$ billion in 1994. Advances from municipalities and other increased $\$ 1.2$ billton, but was offset by a so.5 billion increase in the dednction from the unamortized discount on longterm debt. Increases in long-term debt accounted for 33.4 percent of the increase in total liabilities and other cretits.

- Miscellaneous current and acormed liabilities accounted for most (\$0.2 billion) of the 50.3 billion in cotal current and accrued liabilittes. Clanges in current liabilities represented 16.5 percent of the change in total liabilities and other credits.

- Increases in total other noncurrent liabilities of \$o.1 billion wete offset by a reduction in total deferted credits of \$0.I billian. 
Consumers, Sales, and Revenue

The information in this section is based on the data reported on the Form EIA-86l.

Sales Growth. Sales to ultimate consumers of the major publicly owned generator electric utilities grew 2,8 percent in 1994, a modest improvement over the 2.3-percent increase in sales between 1992 and 1993 (Table 10). The sales increases were lead by a 8.1-percent toncrease in sales to industrial or large consumers. Industrial sales represented 32.4 percent of total ales to ultimate consumers in 1994, up from 30.8 percent in 1993. Of the 6.5 million megawatthours increase in sales to altimate consumers, 5.8 million megawatthours (88.8 percent) was due to the increase in industrial seles.

Sales to commercial cansumers posted a 2.7-percent decline from the 1993 level and dropped from 29.5 pertent of total sales to vilimate corsumers in 1993 to 27.9 percent in 1994. Residential sales were up a modest 2.2 percent in 1994 versus the 4.4-percent increase in sales experienced in 1993.

Average Revenure (Repenues Divided by Sales). Average revenues from sales to ultimate consumers remained essentially unchanged between 1993 and 1994, inereasing a very modest 0.1 percent to 62.5 mills per kikowatthour. However, residential and industrial consumers provided tocreases in average revenues of 1.5 percent and 2.0 percent, respectively. The average revenue provided by residential consumers in 1994 was 70.7 mills per kilowatthour verstu 69.6 mills per kilowatthour in 1993. The average revenue provided by industrial consumers in 1994 was 48.0 mills per kilowatthour versus 47.1 mills per kilowatthour in 1993.

The increases in average revenue in $y$ the the residential and industrial sectors were offset by a reduction in average revenue provided by commercial consumers which declined 1.4 percent to 67.1 mills per kilowatthour.

Average revenue per consumer per month from the commercial consumers declined 4.4 percent from $\$ 394.05$ per month in 1993 to $\$ 375.25$ per month in 1994.

Residential and industrial consumers' monthly bills increased 2.1 percent and 5.7 percent, respectively. The average revenue monthly provided by residential consumers was 558.71 in 1994 compared with 557.51 in 1993. In 1994, average revenue provided by indas. trial consumers increased $\$ 309.80$ to $\$ \$, 704,16$. their montbly bitls of $55,704.16$.

Sales for Resale. Sales for resale were up 2.4 percent in 1994, reaching 46.0 percent of total electricity sales. The share of total electricity sales provided by sales for resale declined marginally in 1994 (off 0.1 percent from the 46.1-percent level in 1993). The share of revenues represented by sales for resale was 34.7 percent in 1994 compared to 34.4 percent in 1993 (an increase of 4.1 percent to $\$ 7.9$ billion). Average revenues from sales for resale increased 1.6 percent to 38.8 mills per kilowatthour, up from 38.2 mills per kilowatthour in 1993. ?

\section{Generation and Purchased Power.}

In 1994, total net energy generated and received increased 2.0 percent, which corresponded closely with the increase in sales volume (Table 11). Net geaeration as a percent of the total net exergy required continued to decline it 1994, dropping to 65.8 percent. The corresponding figures for 1993 and 1992 were 66.9 percent and 67.3 percent, respectively.

Net hydroelectric generation (oonventional hydroelectric generation and net hydro-ptumped strorage) declined 9.9 percent from the prior year, reducing its proportion of total purchased power and aet generation (i.e, total supply) to 14.0 percent. Steam generation increased a very modest 1.3 percent in 1994, accounting for 39.6 percent of the total supply. Nuclear generation rebounded with a 9.3-percent increase. Nuclear generation accounted for 11.6 percent of total supply in 1994, up from 10.7 percent in 1993.

Purchased power continues to play an ever increasing role in the supply mix of publicly owned generator electric utilities. In 1994, porchased power represented 34.2 percent of the supply mix and purchases from electric atilities dominated the power purchases, accounting for $\$ 9.2$ percent of power purchases.

In 1994, steam power production expenses wero 22.2 mills pet kjowatthour generated, down 2.9 percent. from 22.9 mills per kilowatthour in 1993. Despite the 9.4-percent decline from the prior year, nuclear power production expenses were 24.3 mills per killowatthour genetated. For the third year, nuciear power pro. duction expenses per kilowatthour generated exceeded steam power production expenses. On the other band, purchased power expenses were up a marginal 0.5 percent to 35.9 mills per kilowatthour. 
Table 3. Ten Largest U.S. Publity Onined Cenarator Electile Utildiea Ranked by Megawathour 8stes to Ulitmato Consumars, 1994

\begin{tabular}{|c|c|c|c|}
\hline 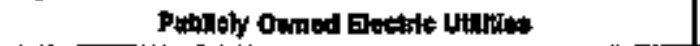 & fintin & Amolint & Paronat \\
\hline Los Anpoles Chy of & Conthomia & 20,40000 & B.67 \\
\hline Salk Fuar Froj Ag I A P Dist & Ateant & $16,058,298$ & 6.77 \\
\hline Powit Authority of State of NY & Nmw Yok & $18,212,015$ & 6.67 \\
\hline San Anionin Purle Saryce Bd. & Texes & $13,007,034$ & 509 \\
\hline Seettis Cony of & Weopingten & 8,074,039 & 8.74 \\
\hline Jactromille Electule Aush m-... & Folda & $8,017,018$ & 3.72 \\
\hline 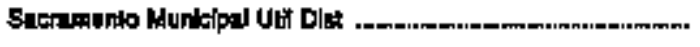 & Collontia & $8,459,156$ & 8.57 \\
\hline Soun Curina Put Sin Auth. & South Carolhal & $7,423,490$ & 3.13 \\
\hline Augtin Chy of & Towes & $7,305,134$ & 3.08 \\
\hline 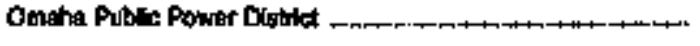 & Notraciea & $7,060,940$ & 2.88 \\
\hline Subtoted & & $110,677,399$ & 40.68 \\
\hline
\end{tabular}

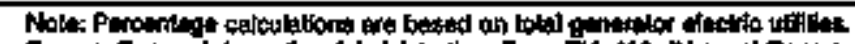

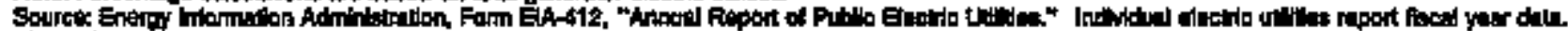

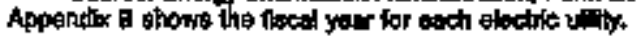

Table 4. Ten Largeat U.S. Publialy Owned Generater Electric Utilties Ranked by Megewatthour sales for Rowale, 1894

\begin{tabular}{|c|c|c|c|}
\hline 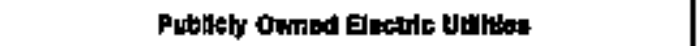 & stits & Ampount & Punsemt \\
\hline Power Authority al Sialo of WY & Now York & $2,320,954$ & 128t \\
\hline 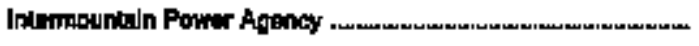 & Whath & $12,191,294$ & 607 \\
\hline 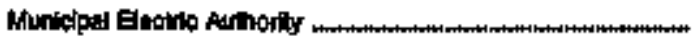 & Goorita & $0,880,403$ & 4.92 \\
\hline 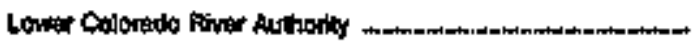 & Tewer & $0,444,885$ & 4.70 \\
\hline 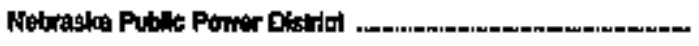 & Nabrivica & $0,248,498$ & 400 \\
\hline Worth Corolha Athn Powar Mary. & North Caroin: & a,050,752 & 4,30 \\
\hline PUD No 1 of Chelen Coumty & Wostingeton & $7,600,135$ & 3.76 \\
\hline 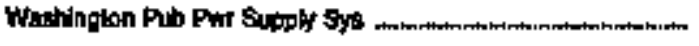 & Whatington & 7,948588 & 3.88 \\
\hline 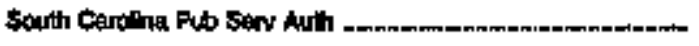 & South Gerolinn & $7,301,068$ & $\mathbf{s} . \mathbf{8}$ \\
\hline North Curoling Eastam M P A - & North Cerpilin: & , $0,8=0,517$ & 3.17 \\
\hline Subtetal & & $103,274,374$ & 51,41 \\
\hline
\end{tabular}

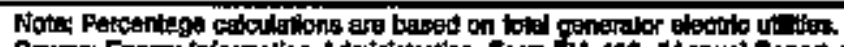

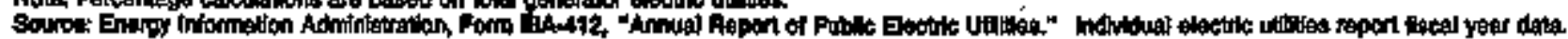

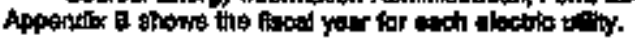


Table 5. Composite Statement of Income for Major U.S. Publlely Owned Generator Eluckic Utultes; 1990-1994 (Thousand Dollars)

\begin{tabular}{|c|c|c|c|c|c|}
\hline Inn & $1 \$ 94$ & 1988 & tsoe & 1981 & 1890 \\
\hline Eluttrk Uutivy Operiding Revenases & $2,260,6980$ & $22,521,047$ & $21,060,340$ & $21,002,670$ & $20,470,37 t$ \\
\hline 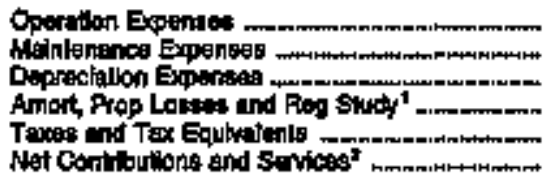 & $\begin{array}{r}13,577,616 \\
1,5,64,444 \\
2,571,4,23 \\
120,197 \\
760,069 \\
=\end{array}$ & $\begin{array}{r}18,241,567 \\
1,505,293 \\
2,441,507 \\
164,172 \\
769,205 \\
-\end{array}$ & $\begin{array}{r}12,527,435 \\
1,054,792 \\
2,285,897 \\
131,472 \\
691,140 \\
=\end{array}$ & $\begin{array}{r}12,155,075 \\
1,40,295 \\
2,300,5 \times 12 \\
595,719 \\
399,300\end{array}$ & $\begin{array}{r}11,048,084 \\
1,457,769 \\
2,075,589 \\
550,042 \\
431,180\end{array}$ \\
\hline 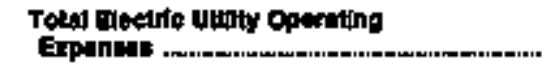 & $18, \$ 40,697$ & $18,162,164$ & $17,190,647$ & $18,9: 8,921$ & $16,160,700$ \\
\hline 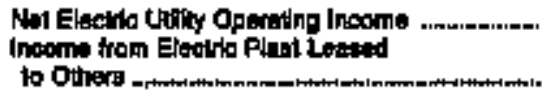 & $\begin{array}{r}4,817,940 \\
\sin , 242\end{array}$ & $\begin{array}{r}4,350,683 \\
20,575\end{array}$ & $\begin{array}{r}4,495,703 \\
15,129\end{array}$ & $\begin{array}{r}4,185,949 \\
5,948\end{array}$ & $\begin{array}{r}4,009,671 \\
11,330\end{array}$ \\
\hline 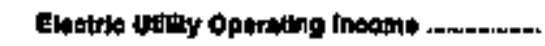 & 4,548,240 & 4,3as;,2, & 4,510,8s: & $4,20-1,921$ & $4,021,001$ \\
\hline 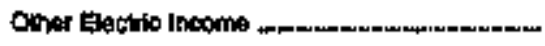 & $1,237,067$ & $1,455,994$ & $1,630,48 d$ & $1, \mathrm{Eog}, 198$ & $1,736,107$ \\
\hline 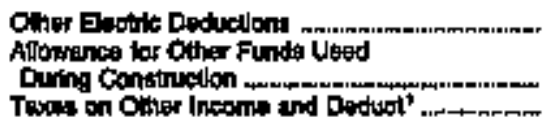 & $\begin{array}{r}139969 \\
7,872 \\
\$ 9,890\end{array}$ & $\begin{array}{l}262,774 \\
28,476 \\
25,751\end{array}$ & $\begin{array}{l}205,472 \\
24,183 \\
24,390\end{array}$ & $\begin{array}{r}123,345 \\
71,026 \\
=\end{array}$ & $\begin{array}{r}- \\
123,28+2 \\
-\end{array}$ \\
\hline 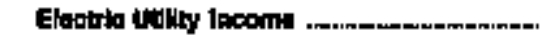 & $6,710,020$ & $5,670,392$ & $0,124,6 * 0$ & $6,030,710$ & $6,078,390$ \\
\hline 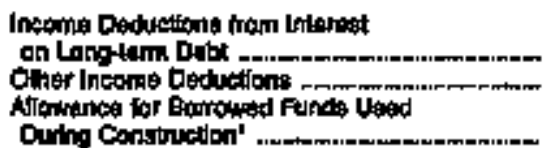 & $\begin{array}{r}4,392,293 \\
387,497 \\
-38,462\end{array}$ & $\begin{array}{r}4,433,067 \\
291,065 \\
-40,010\end{array}$ & $\begin{array}{r}4,757,583 \\
313,694 \\
-46,719\end{array}$ & $\begin{array}{r}4,776,003 \\
400,706\end{array}$ & $\begin{array}{r}4,608,114 \\
401,022\end{array}$ \\
\hline 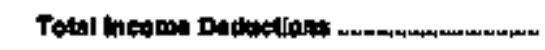 & $4,684,141$ & $4,692,0025$ & $3,025, \pi x=9$ & $5,205,795$ & $5,004,0 \mathrm{~g}, \mathrm{~s}$ \\
\hline 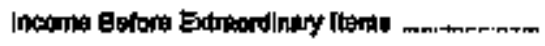 & $1,055,779$ & 697,369 & 1,039, , & ass,911 & $\mathbf{0 1 4 , 4 5 5}$ \\
\hline Exulondinay tincome ............ & $\pi, 340$ & eg,767 & 111,230 & 89,400 & 136,602 \\
\hline Extracodineny Daductions & 201,551 & 2030,04 & $\cos 8,514$ & 164,574 & 245,650 \\
\hline Hot theolwe & 911,589 & 993,142 & 196, & restat & 706,407 \\
\hline
\end{tabular}

Drin reparing intalad in 1900

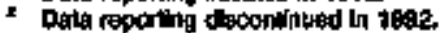

- Dali nol millob.

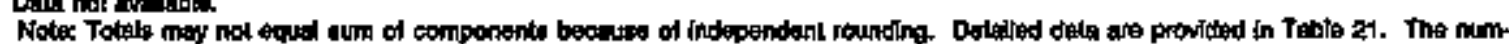

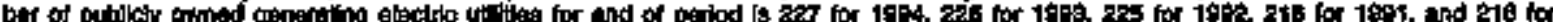

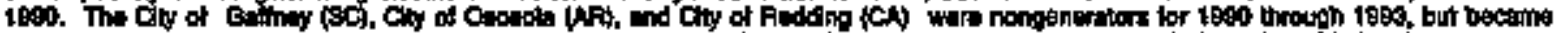

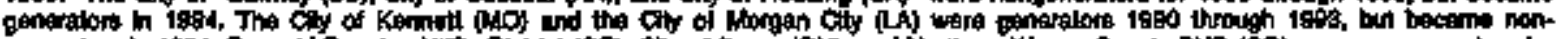

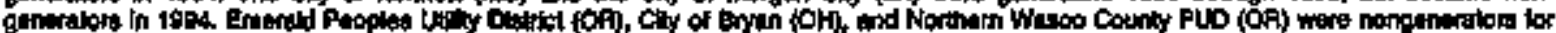

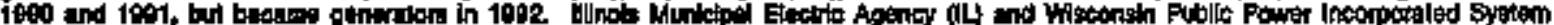

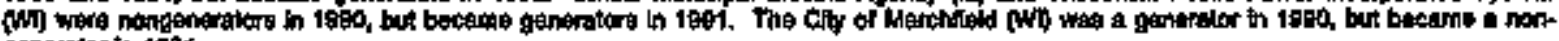
contator th 198x.

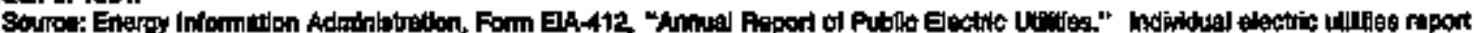

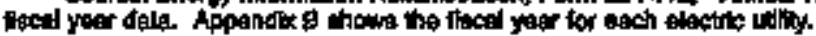


Table 6. Composite Balence Sheet for Mejor U.S. Publely Owned Generator

Electrle Utilites at End of Period, 1900-1994

(Thousand Dollars)

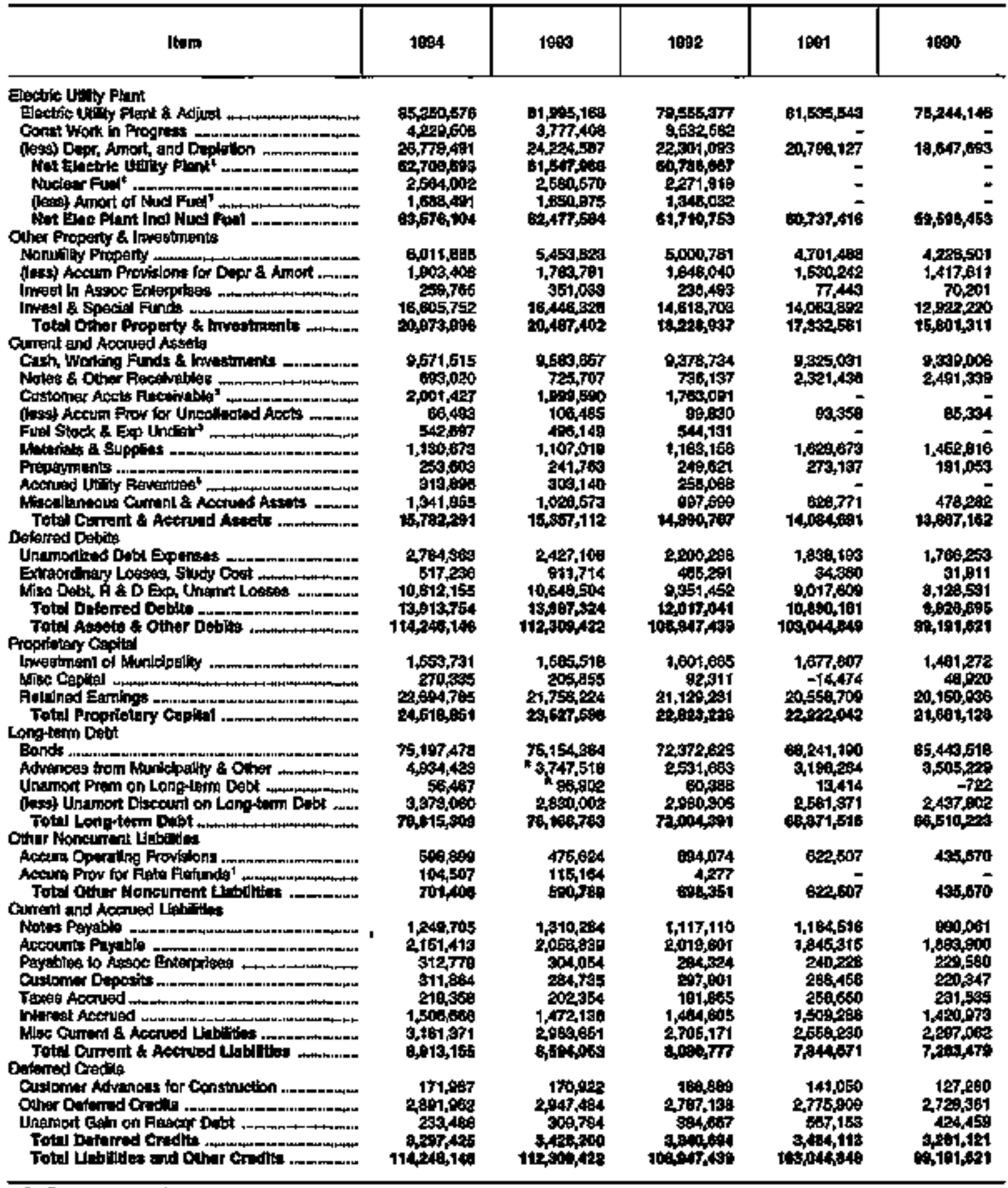

1 Dato raporting initistod in 19982 .

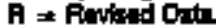

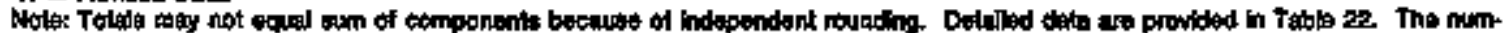

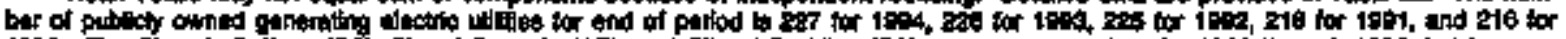

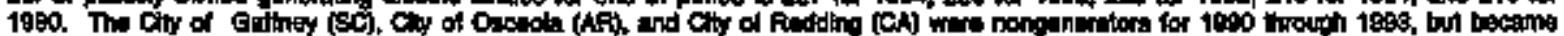

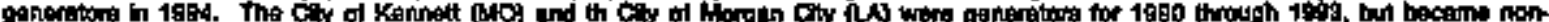

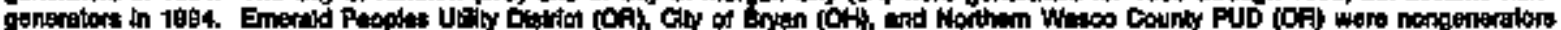

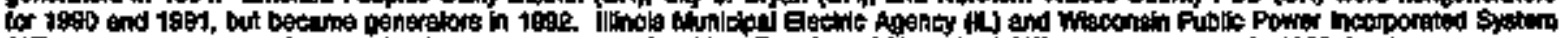

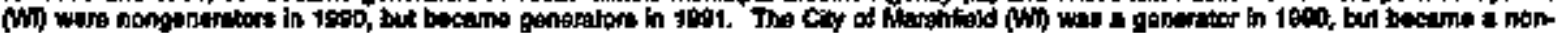
Derrighor h 1091.

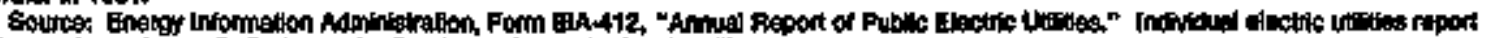

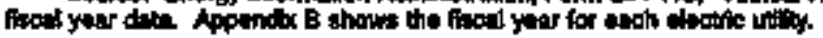


Table 7. Composite Fnanctal Indikstors for Mejor U.S. Publlcly Owned Generator Electric Uthlties, 1990-1994

\begin{tabular}{|c|c|c|c|c|c|}
\hline Hom & 2094 & 1000 & 1902 & $\mathbf{1 0 9 1}$ & סמק1 \\
\hline Total Eactro Urilty Flamt par Doller of Rewanua & 4.0 & 3.. & 20 & 3,9 & 3.6 \\
\hline 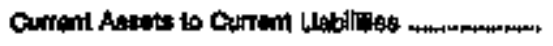 & 1.8 & 1.8 & 19 & 1.8 & 1.8 \\
\hline 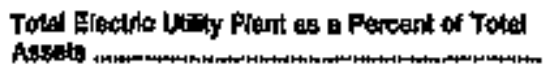 & 80.4 & 76.7 & 79.8 & 79.3 & 78.8 \\
\hline 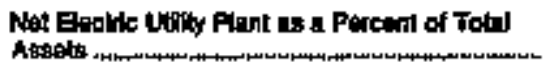 & 55.5 & BS.6 & क7.7 & 59.9 & 80.1 \\
\hline 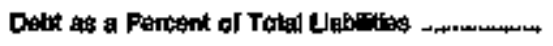 & 75.0 & 765 & 74.9 & 74,4 & 74.4 \\
\hline 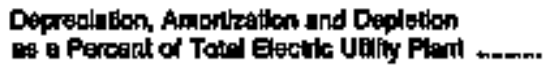 & 30.8 & 29.3 & 27.7 & 25.5 & 23.0 \\
\hline 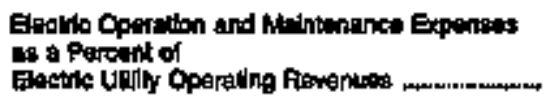 & esp & B5. 7 & 650 & 64,5 & 65.5 \\
\hline 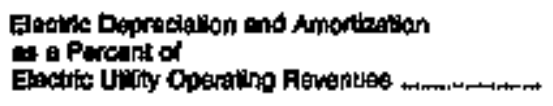 & 11.1 & 10.6 & 105 & 70,9 & 10.1 \\
\hline 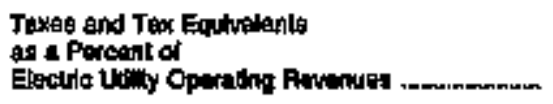 & 3.3 & 3.4 & 3.1 & 28 & e.7 \\
\hline 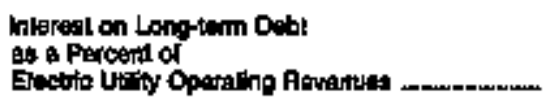 & 18.8 & 18.7 & 21.0 & 28 & 220 \\
\hline 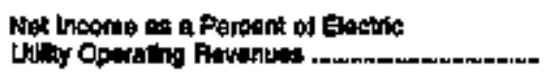 & 3.8 & $\mathbf{a 0}$ & 4.6 & 20 & 3.4 \\
\hline 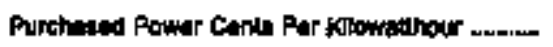 & 3.8 & a.6 & $\mathbf{s . 7}$ & a.s & 3.0 \\
\hline 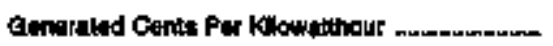 & 1.0 & 1.0 & 19 & 1.8 & 1.8 \\
\hline 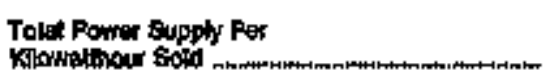 & 2,6 & 2.8 & 28 & 26 & $\mathbf{2 5}$ \\
\hline
\end{tabular}

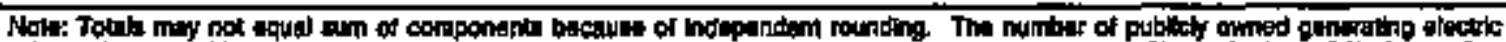

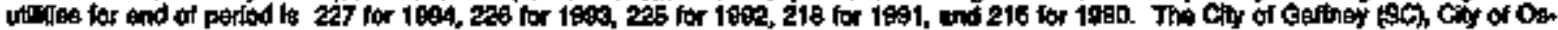

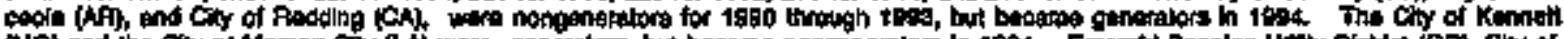

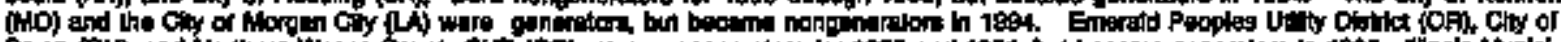

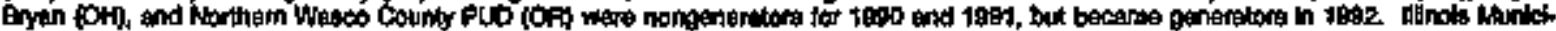

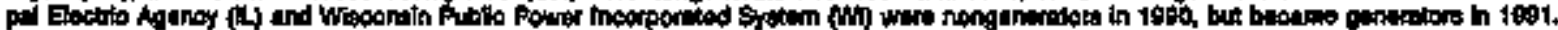

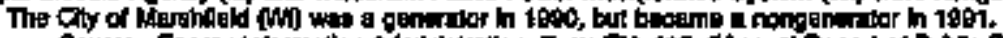

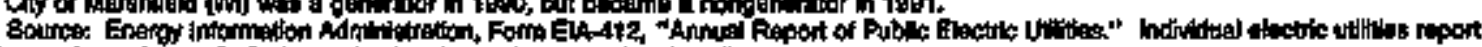

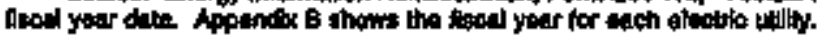


Table 8. Electrle Operatlon and Maintenanoe Expenses for Major U.S.

Publichy Owned Cenerator Electric Utilities, t990-1994

(Thousand Dollars)

\begin{tabular}{|c|c|c|c|c|c|}
\hline nean & 1094 & 1990 & 1962 & two1 & 1900 \\
\hline \multicolumn{6}{|l|}{ Protuotion Expentes } \\
\hline 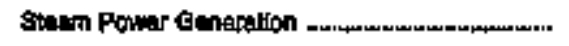 & $4,0 \times 37,582$ & $4,104,890$ & a,781,983 & 9689,320 & $3,741,390$ \\
\hline 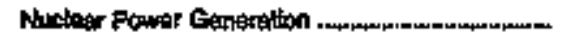 & $1,2=1,932$ & 1,a04,end & $1,319,44$ & $1,247,5,87$ & $1,730,495$ \\
\hline 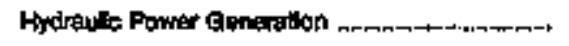 & 242794 & 241,456 & 244,143 & 2059 & 204,495 \\
\hline 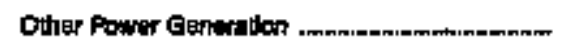 & 177,422 & 178,469 & 178,250 & 167,133 & $1 \infty 6,314$ \\
\hline 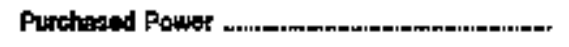 & $5,839,380$ & $0,950,945$ & $8,926,948$ & $5,0 \sin , 489$ & $8,100,250$ \\
\hline Other Production Expenses & 140,427 & 127581 & 72,589 & $\sin 20$ & 108,441 \\
\hline 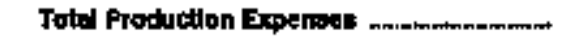 & $11,580,527$ & $11,300,186$ & $10,769,351$ & $10,446,466$ & to 100934 \\
\hline Thankmksion Expenses & 710,745 & 637,049 & 04,503 & $\$ 02,062$ & 500,408 \\
\hline 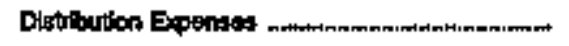 & eeases & 212,470 & 767 , & 700,869 & 661,494 \\
\hline Customer Acoounte Expanses . . & 318,794 & at4, s\$d & 200209 & 290,008 & 278,814 \\
\hline 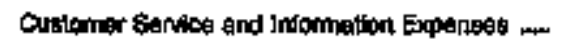 & $104,10 t$ & 84,009 & el, 731 & 73,019 & 60,597 \\
\hline 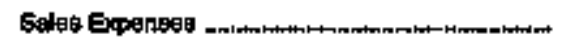 & 22,436 & 17,214 & 17,645 & $18,0 \pi 7$ & 18,006 \\
\hline Adinhlesinthe and General Expenased ........... & $1,852,0 \times 5$ & $1,573,006$ & $1,492,411$ & $1,483,060$ & $1,349,426$ \\
\hline 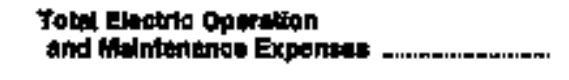 & $15,163,549$ & $14,400,800$ & $14,0,2,2+3$ & $13,601,370$ & 13 atos, 870 \\
\hline \multicolumn{6}{|l|}{ Fual Exponates In Opayation } \\
\hline 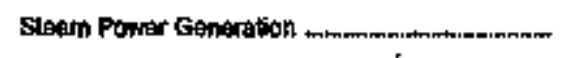 & $2,970,6098$ & $3,008,075$ & $2,733,588$ & $2,634,840$ & $2,894,5604$ \\
\hline 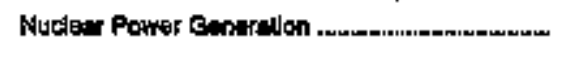 & 313903 & 289,445 & 308,042 & 345,206 & 242,290 \\
\hline 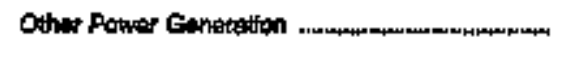 & 104,200 & 100,404 & ax, aes & 02,111 & 113,090 \\
\hline \multicolumn{6}{|l|}{ Numbar af teo bapt Emplayous } \\
\hline Fegilar Fullome' & 59,073 & 68603 & 90,435 & * & - \\
\hline 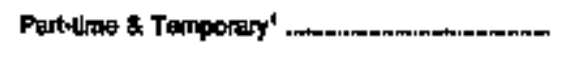 & 2687 & 2,810 & 2,012 & $=$ & 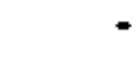 \\
\hline 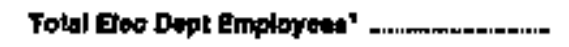 & $51, \pm 40$ & 61,211 & 64,244 & - & · \\
\hline
\end{tabular}

1 Doter raporting intiogted in 1992.

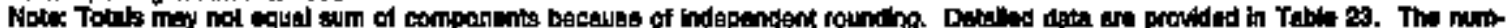

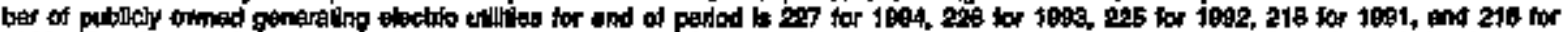

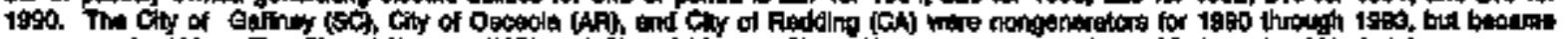

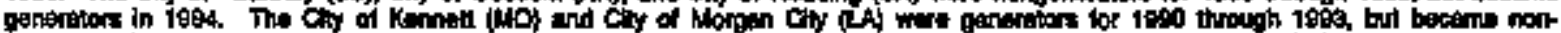

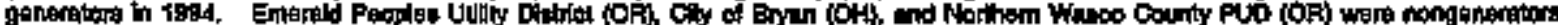

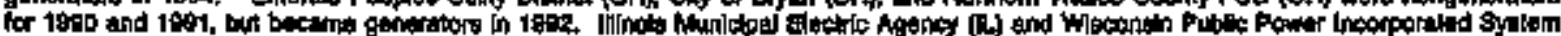

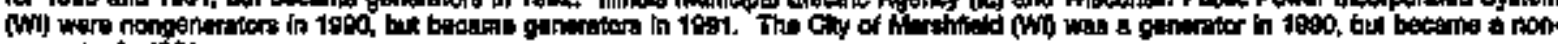
osneratur in 1891.

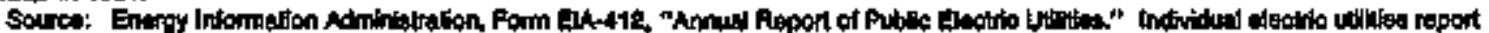

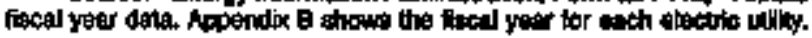


Table 9. Electric Utllity Plant for Major U.S. Publlely Owned Generator Electrio Uttitles at End of Pericd, 1990-1994 (Thousand Dollars)

\begin{tabular}{|c|c|c|c|c|c|}
\hline Iner & 1894 & $10 \% 3$ & $\operatorname{teg}$ & 199 & 1090 \\
\hline \multicolumn{6}{|l|}{ Eteotrto finnt in bention } \\
\hline Irlunglols Plank -..... & sog,1ts & $\mathbf{3 4 1 , 3 8 7}$ & 204,168 & sesiong & S10,464 \\
\hline \multicolumn{6}{|l|}{ Froduction Plaral } \\
\hline 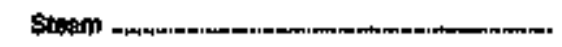 & $24,267,405$ & $24,160,408$ & $23,340,000$ & $20,488,450$ & $21,2+1,438$ \\
\hline Nuclest & $16,796,140$ & $18,014,910$ & $18,743,463$ & $19,440,492$ & to, \\
\hline 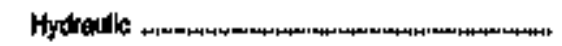 & $7,020,702$ & $7,0052,845$ & $7,491,451$ & 6.075,077 & $0,857,541$ \\
\hline Ohertom & $2,480,094$ & $1,016,249$ & $1,860,094$ & $1,657,195$ & $1,501,000$ \\
\hline 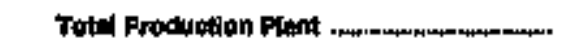 & $6,3,00,42 \pi$ & An,45s,ats & $51,440,0 m$ & Sh,451,044 & 49640,749 \\
\hline 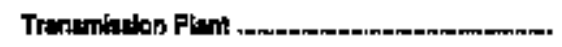 & $0,200,468$ & $8,020,689$ & $0,749,20$ & $8,480,104$ & $7,847,445$ \\
\hline 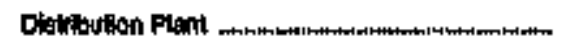 & 15,254909 & $14,222,657$ & $18,482,089$ & 12,508,918 & $91,676,398$ \\
\hline Ganerat Plank ........... & $6,602,910$ & $4,56,602$ & $4,143,705$ & 4,073, sess & $9,700,404$ \\
\hline Total Electrle Plant in sorikes. & ps,ata, & $\operatorname{coph1,002}$ & $70,112,304$ & $15,97,171$ & $72,272,60$ \\
\hline 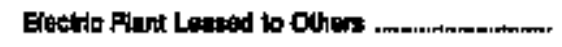 & 15,545 & $16,7 \mathrm{B1}$ & 67,560 & ces,948 & 482,946 \\
\hline Corntonuction Work ln Proposes - Eleotio ......... & $4,200,500$ & $3,77,408$ & $3,60,5,502$ & $3,900,155$ & $3,988,231$ \\
\hline 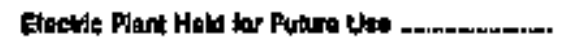 & 302,587 & 321,707 & 305,505 & cas,7ss & $80,00 \%$ \\
\hline 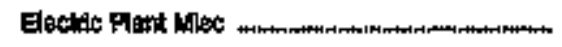 & $1,112,45,5$ & $1,164,00,5$ & 1,00980000 & 458,483 & 731,424 \\
\hline 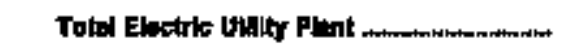 & ADag,des & $05,772,57$ & 69,067,0so & 01605:543 & $79,244,148$ \\
\hline $\begin{array}{l}\text { Aocumulated Proviston for } \\
\text { Deprecialon end Amortiention }\end{array}$ & $26,770,491$ & $24,224,537$ & $22,301,000$ & $20,798,127$ & $18,647,080$ \\
\hline 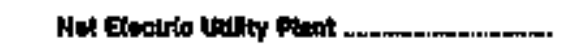 & $\Delta, 70,500$ & $61,607,90.5$ & caprasats? & en,rat,dte & Sheatans \\
\hline
\end{tabular}

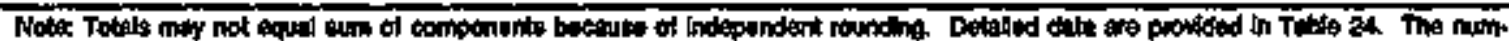

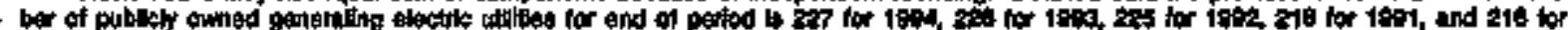

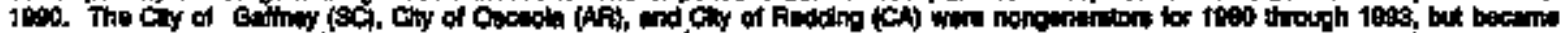

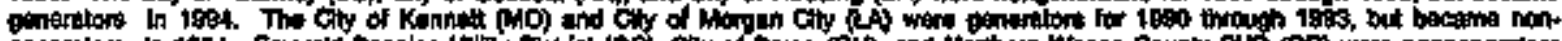

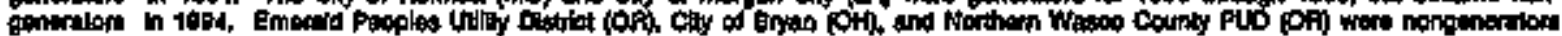

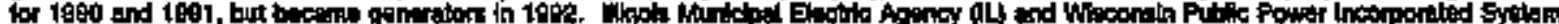

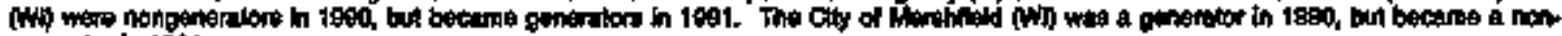

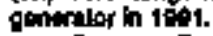

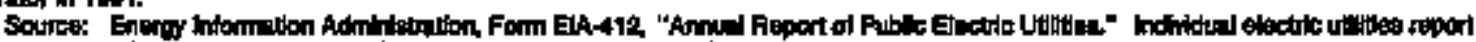

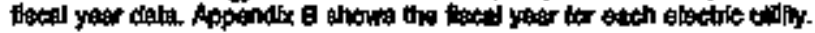

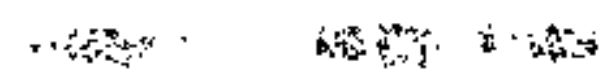


Table 19. Mumber of Consumers, Sales, and Operaling Revenue for Hajor

U.S. Publiply Owned Generator Eloctrjc Utllitles, 1990-1994

\begin{tabular}{|c|c|c|c|c|c|}
\hline um & 1094 & 1909 & 1000 & 1091 & 1990 \\
\hline \multicolumn{6}{|l|}{ Number of Coniumers } \\
\hline 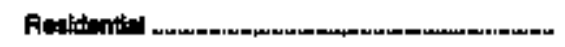 & $7,814,061$ & $7,499,340$ & $7,300,050$ & $7,320,039$ & $7,165,764$ \\
\hline Commated or Simel .......... & 902,375 & 9a5,25: & Dr, $7 \mathrm{ses}$ & e04,004 & era,six \\
\hline Integtisil br Large ... & 54,198 & $\mathrm{B1}, \mathbf{g B g}$ & $\mathbf{s 0 , 4 6 5}$ & 45.202 & 50, Beg \\
\hline 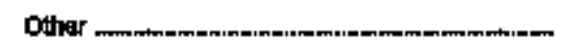 & OA, 654 & 92,901 & 160,000 & 162,875 & 184,051 \\
\hline Tolv Vlumate Coneumers & $0,760,168$ & $8,6 * 9,47 t$ & 0,5e6,909 & $0,422,748$ & $0,264,245$ \\
\hline \multicolumn{6}{|l|}{ salies for the Year (inegawatthentro) } \\
\hline 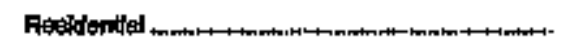 & $75,009,840$ & $74,262,952$ & $71,318,205$ & $77,667,965$ & $70,070,774$ \\
\hline 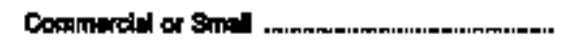 & $68,553,738$ & $68,401,408$ & $60,801,045$ & $66,283,703$ & $65,302,407$ \\
\hline 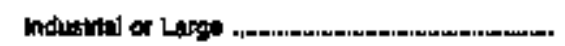 & $7,301,089$ & $71,517,038$ & $70,40,218$ & g8,50,982 & $67,376,604$ \\
\hline Other & $10,727,719$ & $17,904,844$ & $17,977,295$ & $17,648,085$ & $17,370,120$ \\
\hline 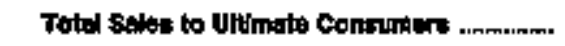 & $280,403,391$ & $231,976,907$ & $229,760,019$ & $228,445,101$ & $220,139,160$ \\
\hline Sales for Ros:als ..1-... & $200,428,731$ & $196,850,138$ & $184,259,848$ & $183,601,5282$ & $184,856,069$ \\
\hline 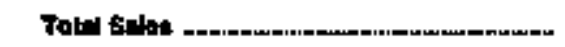 & $441,020,122$ & $430,027,045$ & 411,0\%,6as & $406,616,450$ & $404,072 \times 24$ \\
\hline \multicolumn{6}{|l|}{ Oopralling Rorempuse lor the Year } \\
\hline Residentifal & $6,363,914$ & $5,108,490$ & $4,605,099$ & $4,759,672$ & $4,675,479$ \\
\hline Commercial or Small & $4,486,500$ & $4,058,859$ & 4,494,10B & $4,244,200$ & $4,200,416$ \\
\hline Industroal ot Lange & $3,700,714$ & $3,365,369$ & $3,248,997$ & $3,1 \pm 7,161$ & $3,014,459$ \\
\hline 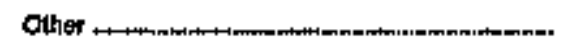 & 1,358,861 & t,270,002 & $1,242,028$ & $7,106,045$ & $1,742,670$ \\
\hline Totel Roweruves kem sabes to & $14,695,188$ & $44,472,590$ & $13,605,158$ & 18,726,174 & $13,127,990$ \\
\hline Sulos for Fiosale ... & $7,802,094$ & $7,502,938$ & $7,246,170$ & $6,995,157$ & $7,061,730$ \\
\hline 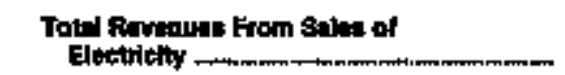 & $2,700,110$ & $22,014,928$ & $21,061,20$ & $20,221,326$ & $20,170,060$ \\
\hline
\end{tabular}

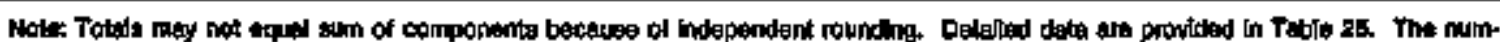

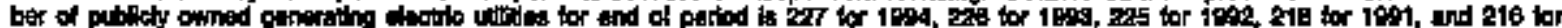

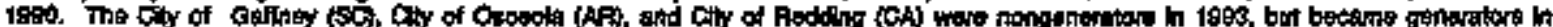

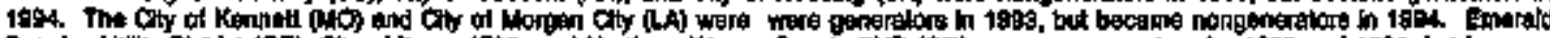

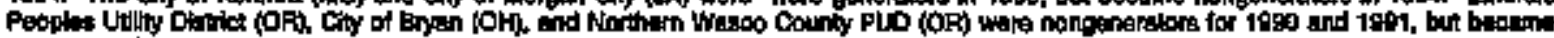

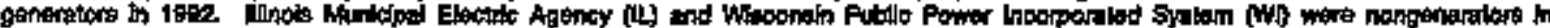

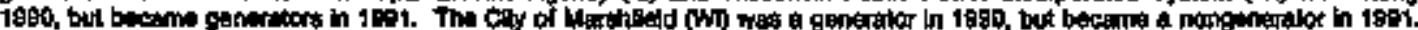
sione.

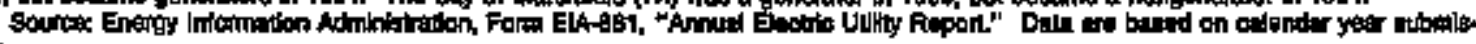


Tabie 11. Electric Energy Account for Major U.8. Publicly Owned Cenerator Electric Utilities, 1990-1994

(Megawatthours)

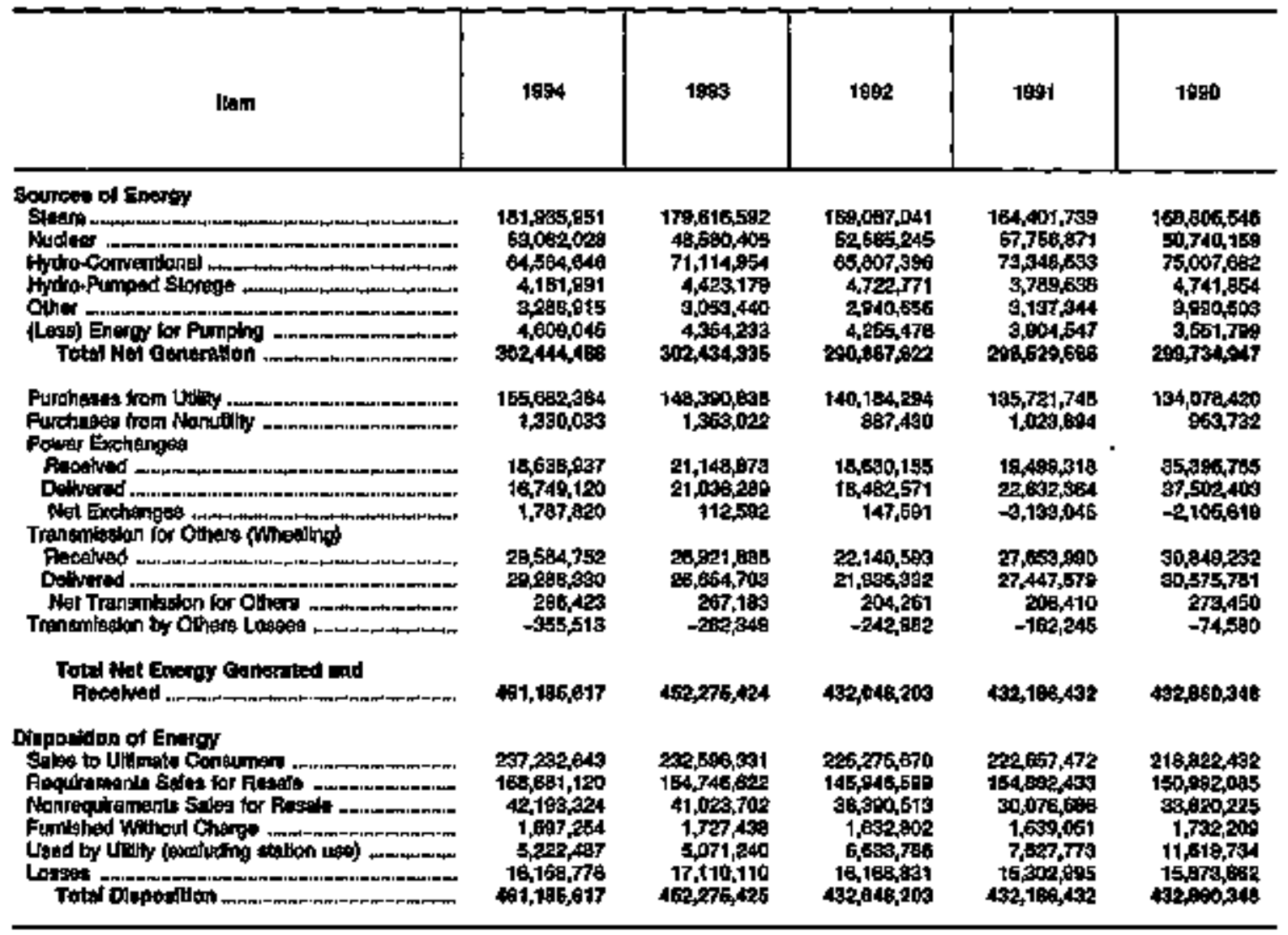

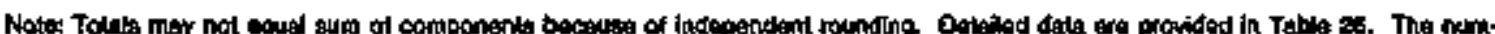

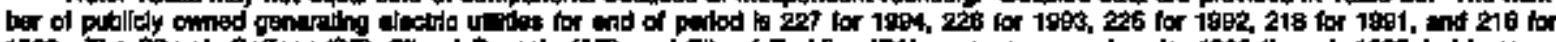

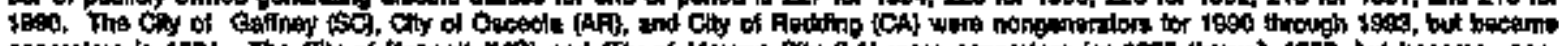

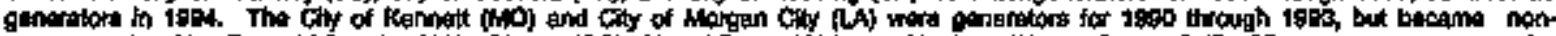

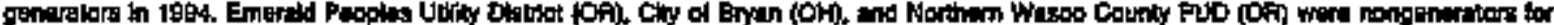

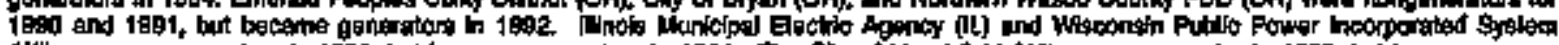

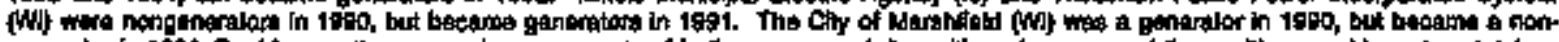

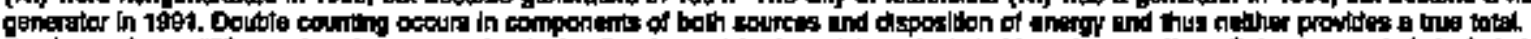

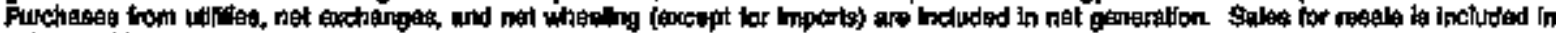

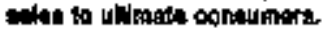

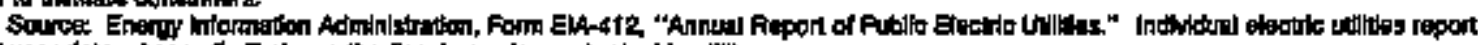

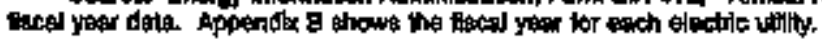




\section{Financial Performance for Nongenerator Electric Utilities}

Finaricial statistical summaries are provided for major publicly owned aongenerator electrid atllities which include 276 electric utilities for 1994; 269 electric utilithes for 1993; 258 electrle utilities for 1992; 252 electric utilities for 1991; and 251 electric utilities for 1990. New respondents and electric utilities no longer reporting from the previous pears are listed in Appendix 1 .

\section{Hilghlghts of Nongenerator Flnandal Performanco}

Despite total electrio atility operating costs increasizg faster than revenues in 1994, the publicly owned nongenerator electric utilities net income was up 1.6 percent. Key factors in the financial performance of the nongenerator electric utilities were:

- Revenues were up 6.3 percent driven, in a large part, by a 5.6-percent increase in sales to the ulttmate consumers.

- Purchased power costs per kilowatthour sold increased 1.6 percent and represented 77.2 percent of the total costs to consumers (up from 76, 4 percent in 1993).

- Expenses increased 7.1 percent, depressing electric utility operation income (down 6.8 percent for the year ending 1994).

- Debt outstanding and interest expenses declined $\$ 0.2$ ballion and $\$ 0.1$ billion of 6.0 percent and 5.1 percent, respectively.

\section{Income statement}

The Composite Statement of Income for major publicly owned nongenerator electric atilities for the years 1990 to 1994 is presented (Table 14). Net income of $\$ 0.4$ billion for nougenterator electric utillties inched up 1.6 percent over the prior year. Income before extraordinary items was off 4,2 percent to $\$ 0,4$ billion in 1994

Revenues Nongenerator electric utilities revenues showed an increase of 6.3 percent to $\$ 8.0$ billion in 1994. Increased sales were a major contributing factor to increased reveanes. Revenues from sales to ultimate consumers increased by $\$ 0.4$ billion in 1994 .

Electric Utillty Operating Expenses. Total electric utility opernting expenses of 57.6 billion were up 7.1 percent over the previous year. The largest doflar increase was in operation experses (Up 6.7 percent or $\$ 0.4$ billion in 1994). Operation expenses necounted for 90.6 percent of total electric utility expenses. The second largest contributor was depreciation expense, which accounted for 3.6 percent of total electric utility operating expense and was up 6.3 percent over the prior year. Maintenance expeniss accounted for
3.1 percent of the total and were up 13.0 percent over the previous year. Tax and tax equivalents were up 15.1 percent in 1994. These tax expenses accounted for 2.7 percent of total electric utility operating expenses in 1994.

Production Dxpenses. Production expenses were up 7.3 percent over the prior year, accounting for $\$ 6.2$ billion of expenses (Table 17). Purchased power expenses represented virtually all of production expenses, which averaged 43.2 mills per kilowatthour sold (Table 19), up 5.9 percent from the prior year.

Trantinission and Ditribution Expenses. Transmission expenses accontuted for only 0.3 mills per kilowatthour sold, ap 0.2 percent in 1994. However, on a total dollar basis, transmission expenses were up 5.9 percent, (accounting for less than $\$ 0.3$ billion). Distribution expenses accounted for 2.9 milts per kilowatthonr sold or $\$ 0.4$ billion dollars of operation and motntentance expease and were up 6.9 percent in dollar terms and 1.2 percent in terms of mills per kilowatthour $801 d$ in 1994.

Electric Utility Income. With revenues increasing less than total electric operating expenses, net electric utility operating income was down 6.8 percent to 50.4 billion in 1994, while other electric income contributed marginally more to the bottom line in 1994 for nongenerator electric utilities. Electric utility income was off 5.8 percent to 50.5 billion in 1994, down from $\$ 0.6$ billion in 1993 .

Interest Expense. Nongenerator electric utilities reduced their debt by 90.2 billion for the year ending 1994, whille interest expenses went down 5.1 percent, which amounted to $\$ 0.1$ billion in 1994.

Net Income Low isterest expenses, reduced income deductions, and contributions from net extraordinary items turned around the 5.8-percent reduction in electric atility imcome to produce an increase of 1.6 percent in net income. Net income of $\$ 0.4$ billion in 1994 was up for the fourth year in a row.

\section{Balance Sheet}

The Composite Balance Sheet for publicly owned nongenerator electric ntilities increased a modest 2.0 percent in 1994 (Table 15).

Assets and Other Debits. Increases in electric utility plant contributed the only significant gain on the asset side of the balance sheet in 1994, increasing 5.6 percent on a gross basis and 4.3 percent on a net basis. Total assets and other debits amounted to $\$ 10.3$ billion in 1994, up from \$10.1 billion in 1993 .

Electric Utifity Plaut. Electric utility plant in service increased 5.8 percent to $\$ 8.4$ billiton in 1994 (Table 18). Distribution plant investment was primarily responsible, incressing 6.6 percent from $\$ 5.9$ batlion in 1993 to $\$ 6.3$ billion in 1994 . Distribution plant represented 74.9 percent of tosal utility electric plant in service for the nongenerator electric utilities. Other noteable changes in asset and deblt accounts include: 
- Net electrio plant inchuding muclear fuel represented $\$ 5.5$ bilition or $\$ 3.4$ percent of total in 1994, up from $\$ 2,2$ percent is 1993 .

- Total other property and investments declined from 18.9 percent to 18.5 percent of total, ending the year at $\$ 1.9$ billion.

- Total current and accrued assets of \$2.5 billion, declined from 24.7 percent of total in 1993 to 24.3 percent in 1994.

Labilities and Other Credits. The most sigzificant increase in liabilities and other credits was a 5.0-percent increase in total proprietary capital. This account represents the equity that the nongenerator electric utilities have in electric operations. In 1994, the equity fraction of total capitaltzation (assomed here to be defined as the sum of total ptoprietary capital and total long-term debt) increased to 69.8 percent, compared with 67.4 percent in 1993. This ratio represents one of the most distinguishing differ* ences between the generator and nongenerator electric utilitites. For the generacor electric utilities, this equity ratio was 24.2 percent in 1994. Other significant changes in liabilities and other credits included:

- Long-term debt at year-end decreased from $\$ 2.9$ billion in 1993 to $\$ 2.7$ billion in 1994, a 6.0-percent decrease.

- Total proprietary capital increased $\$ 0.3$ billion to \$6.3 bitllton in 1994.

- Total capitalization represented 87.4 percent of tatal liabilities and other credits in 1994, dowa from 87.9 percent in 1993.

- Current and accrued liabilíties at 10.7 percent of cotal represented the onily other stguificant element of total liabilities and other crediss.

\section{Consumers, Sales, and Revenue}

The information in this section is based upon the Form EIA-861.

Sales Growth, Sales to ultimate consumers of the publicly owned nongenerator electric utilities grew 5.6 porcent in 1994, an increase over the 4.5 percent sales growth between 1992 and 1993 (Table 19). Commer. cial sales increased at a 4.7-percent rate. Residential sales were up $\$ .2$ percent, while industrial sales expanded the most, increasing at a 6.5 -percent rate.

The vatiance in growth rates across the sectors slightly shifted the relative sector mix of sales to ultimate consumers and proved to be anotber area where nongenerator electric utilities varied significantly from generator electric utilities. The conmercial share of total sales to ultimate cotrsumers of nongenerator etectric utilities accourted for only 17.1 percent. In the case of gemerator electric utilities, commercial sales accounted for $\mathbf{2 7 . 9}$ percent of total sales (a tigure paraliel with that of the investor-owned segment of the electric power industry).

Average Revenue (Revenues Divited by Sales). While average revenue from residential consomers increased a modest 2.0 percent in 1994, industrial and commer. cial sectors produced less average revenue in 1994 than they produced in 1993, a differentece of 2.0 percent and 0.1 percent, respectively. Residential consumers paid on average 61.8 mills per kilowatthour for electricity in 1994, while commercial consumers paid 65.3 mills per kilowatthour and industrial consumers paid 48.3 mills per kilowatthoxir.

Consumption per consumer in the residential sector was up 2.9 percent. Commercial consumption per consumer was onchanged, while industriai consumption per constimer fell a marginal 0.3 percent in 1994. The average monthly bill paid by residential, commercial and industrial consumers amounted to \$67.57, \$232.95, and $\$ 4,492.59$, respectively. The residential monthly bill increased 5.0 percent, while the commercial and industrial monthly bath declined 0.1 percent and 2.0 percent, respectively.

Resale sales increased 7.3 percent from 1993 to 1994. Sales for resale accounted for 5.6 percent of the total nongenerator electric utility seles of electricity in 1994. Whthout any significant generating resources of their own, sales for resale in the nongenerator segment are not very significant to the overall sales and revenaces of these entities. In 1994, sales for resale reveaues accounted for $\$ 0.3$ billion dollars or 3.3 percent of total revenues from the sale of electricity.

Total revemues were up 5.7 percent for the year (Table 19). Increased sales volume resulted in incressed revenues in 1994. Average revenues rembined unchanged at 55.4 minlls per kilowatthour sold.?

\section{Purchased Power}

In 1994, purchased power from electric utilities and nonutilities increased 5.8 percent to 150.0 million megawatthours. Purchased power acconnted for $\mathbf{4 3 . 1}$ mitls per kilowatthour sold of the total average revenue of 55.8 mills per kilowarthour, or 77.2 percent of the costs to the consumer. 
Table 12 Ten Largest U.S. Publloly Owned Nongenerator Electrlo Utilites Rankad by Megawatthour Sales to Ultimate Consumers, 1994

\begin{tabular}{|c|c|c|c|}
\hline 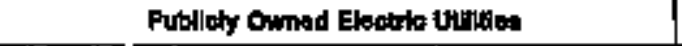 & Stato & Amount & Pereent \\
\hline 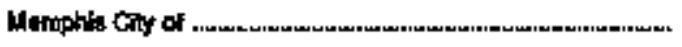 & Temestese & $52,097,393$ & 800 \\
\hline 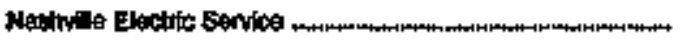 & Tentapese & 10,64:,616 & 7.68 \\
\hline 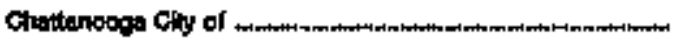 & Tennegege & $6,471,670$ & 4.05 \\
\hline 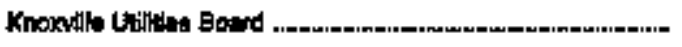 & Temensen & $4,889,480$ & 3.81 \\
\hline Humbritia Ciny of & Arebeame & $3,7=0,05$ & 2.01 \\
\hline FUO No 1 of Clark County & Weatingtom & $3,4: 1,167$ & 2.50 \\
\hline Jolanaon Caly Chy of _ _mom-.... & Tennagses & $1,817,468$ & 1.20 \\
\hline Decatur Chy ol ..... & Alobuma & $1,422,424$ & 1,06 \\
\hline 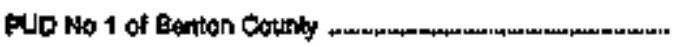 & Wastingtan & $1,395,290$ & 1.00 \\
\hline 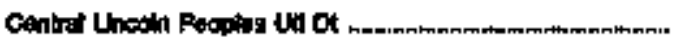 & oregon & $t, 348,363$ & .69 \\
\hline Sebloted ....t. & & $48,128,432$ & 34.16 \\
\hline
\end{tabular}

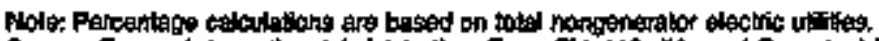

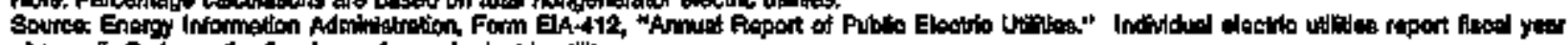

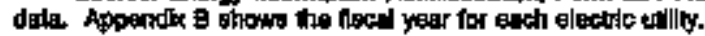

Table 13. Ten Largest U.S. Publicly Ownod Nongenerator Electric Utitities Ranked by Megawatthour Sales for Resale, 1994

\begin{tabular}{|c|c|c|c|}
\hline Publicty Ounes Eectric Utinks. & State & Amoint & Pweceant: \\
\hline 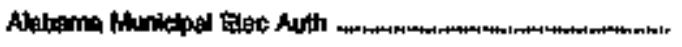 & Alebsera & $2,410,059$ & 30.22 \\
\hline 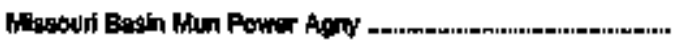 & South Dentoks & $1,898,120$ & 20.74 \\
\hline 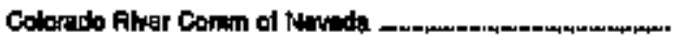 & Mhrads & 905,152 & 1207 \\
\hline 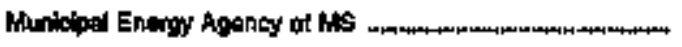 & Mesposipal & exp?egs & 10017 \\
\hline 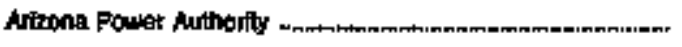 & Artzonn & 760,507 & 600 \\
\hline 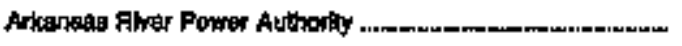 & Colorado & 2162,000 & 3.69 \\
\hline 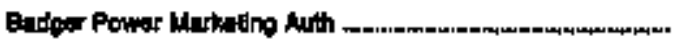 & Whatonglat & astapo & 335 \\
\hline 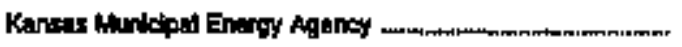 & Kenats & 204,240 & 9.31 \\
\hline 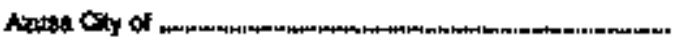 & Cariforito & 120,130 & 1.50 \\
\hline 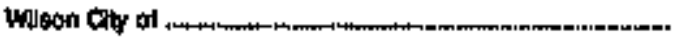 & Norith Cenoling & 68,697 & .70 \\
\hline Btblotal & . & $7,879,123$ & 96.48 \\
\hline
\end{tabular}

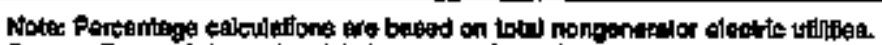

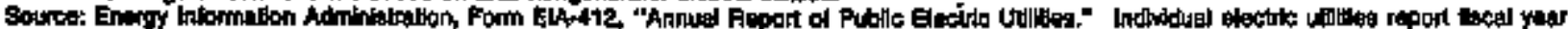

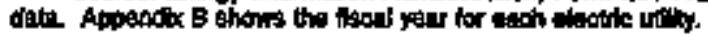


Tabie 14. Composite Statement of income for Major U.S. Publicly Owned Nonginerator Electric Uthilies, 1900-1994 (Thousand Dolars)

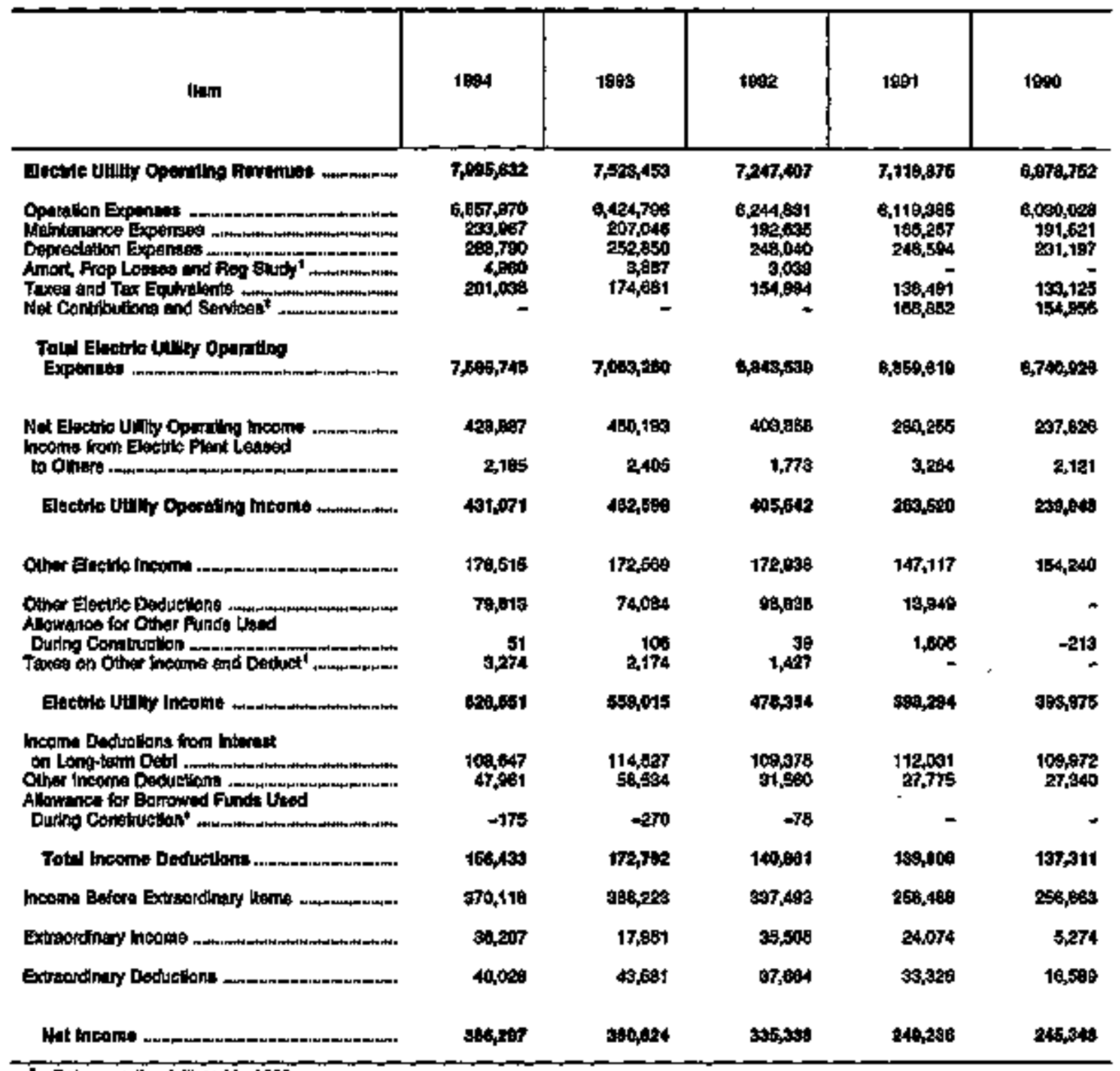

Dite repoting initioled in 1982

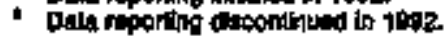

- Date nat ripitible.

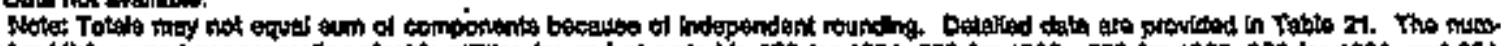

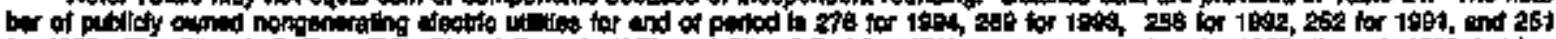

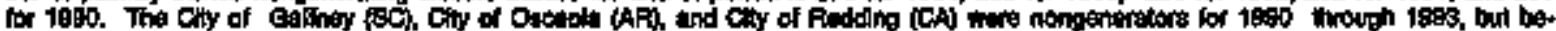

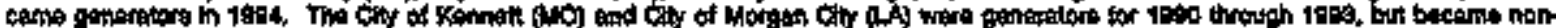

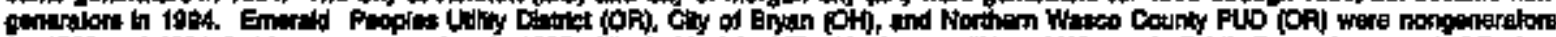

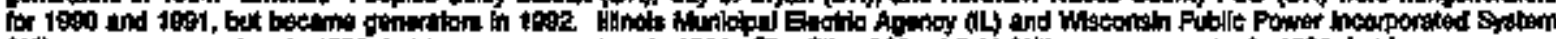

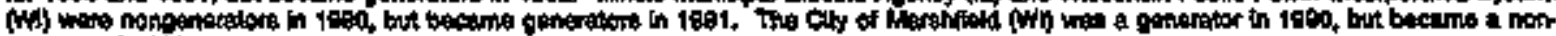
comarator h teol.

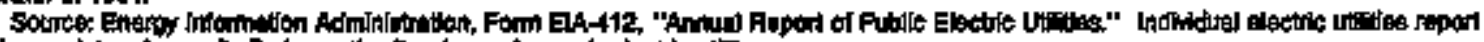

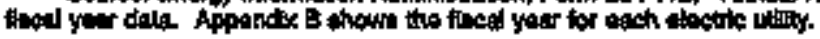


Table 15. Composite Balance Sheet for Major U.S. Publidy Owned Nongenerator Electric Utilites at End of Period, 1890-1994

(Thousand Dollars)

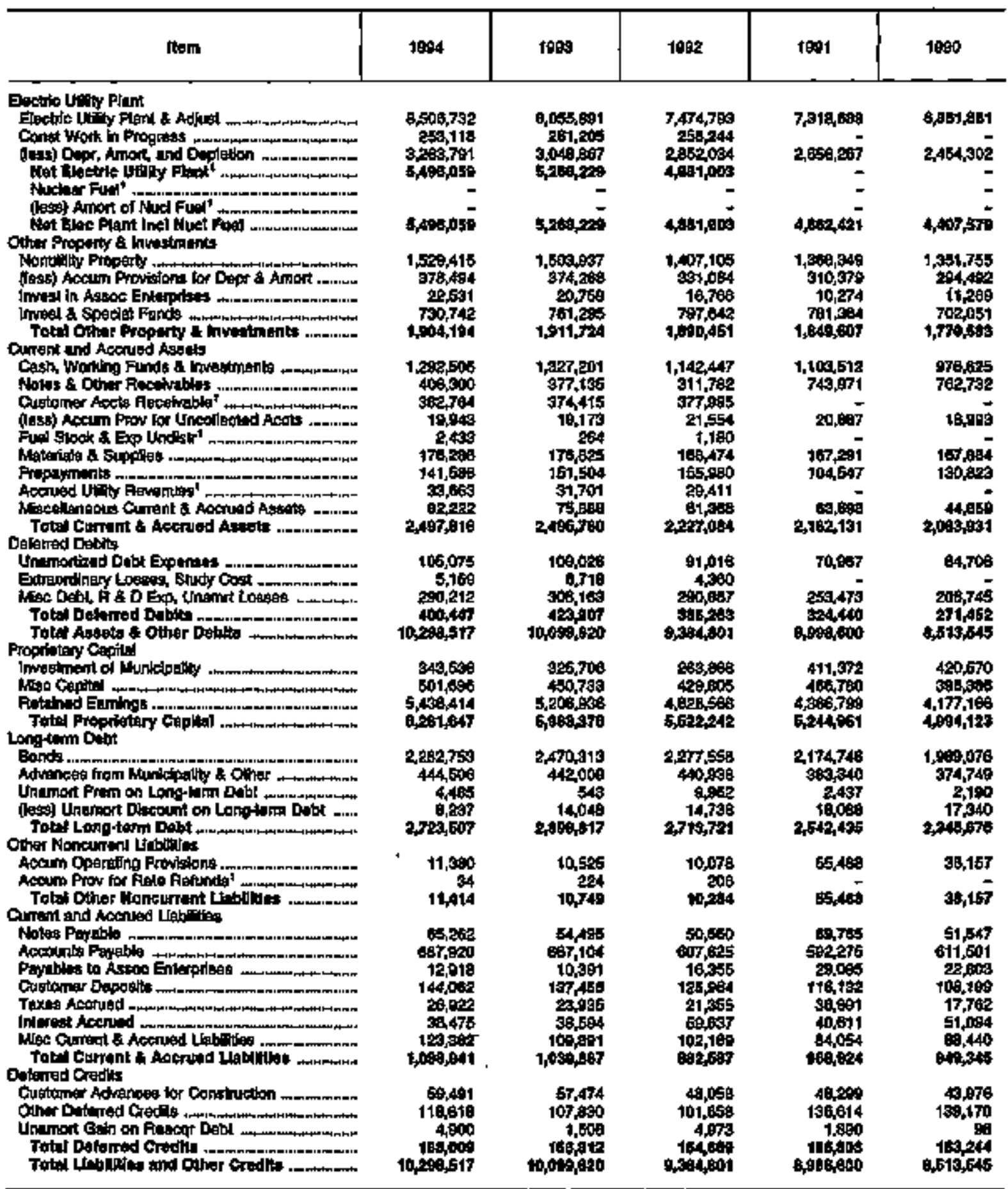

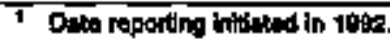

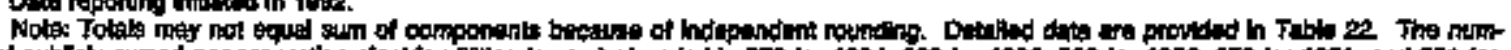

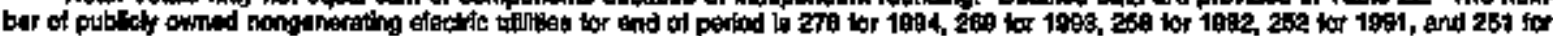

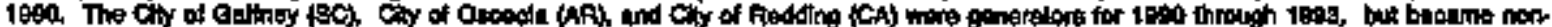

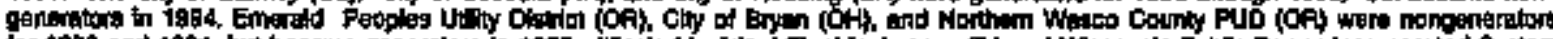

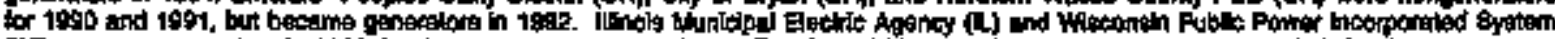

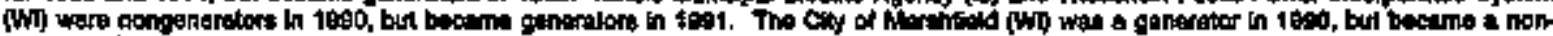
ganerention is 1991 .

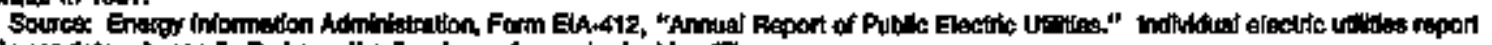

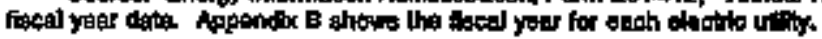


Table 16. Composite Financlal Indicatiors for Major U.8. Publioly Owned Nongenerator Electirtc Utuitus, 1980-1994

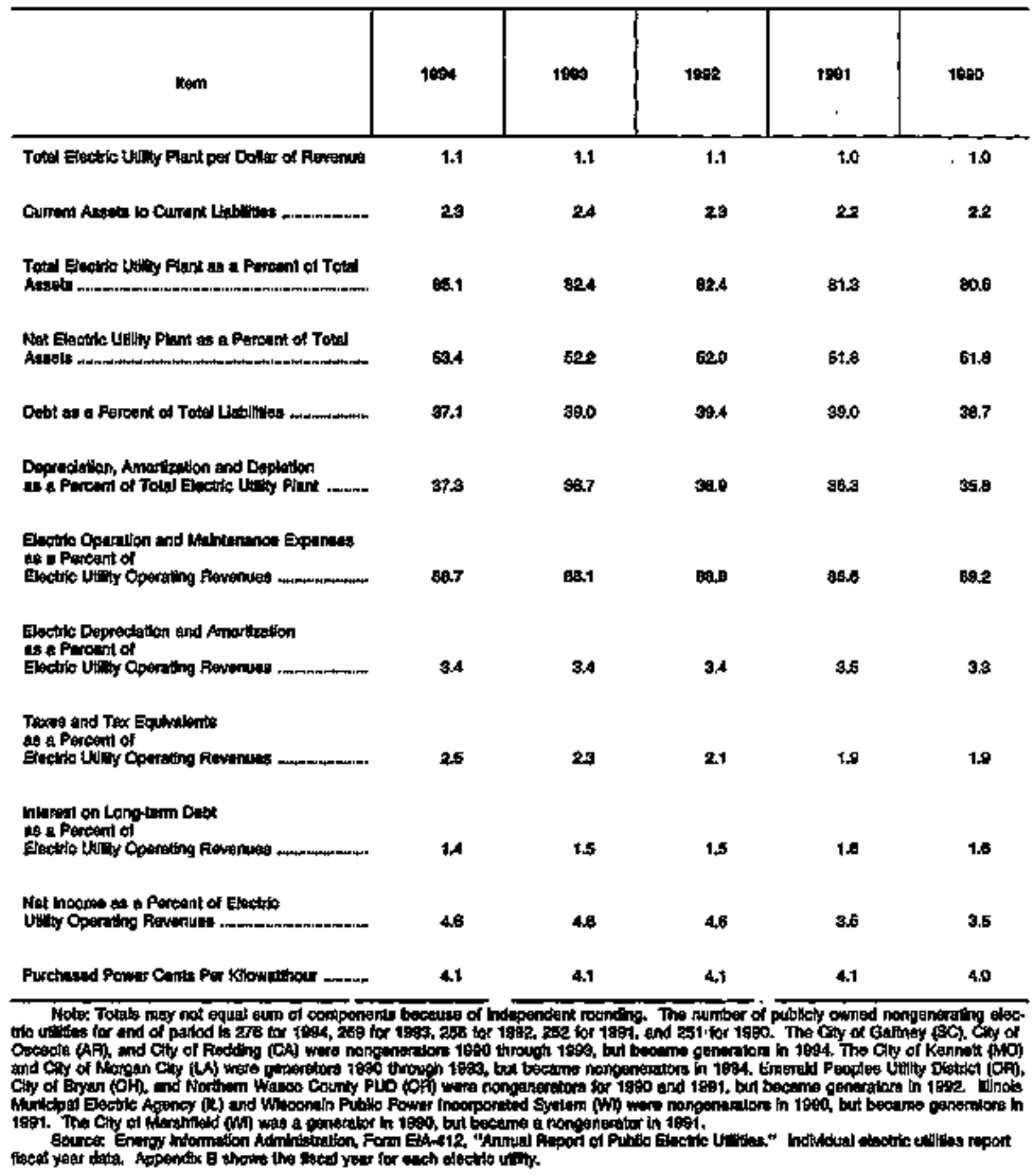


Table 17. Elactrle Operation and Maintenance Expenses for Major U.S. Pubilc|y Owned Nongenerator Electric Utnlties, 1990-1994 (Thoussand Dollars)

\begin{tabular}{|c|c|c|c|c|c|}
\hline sem & 1964 & 1998 & to992 & 1909 & 1980 \\
\hline \multicolumn{6}{|l|}{ Prockuption Expertas } \\
\hline 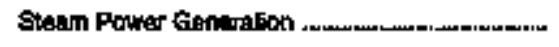 & 289 & asp & 416 & 544 & 280 \\
\hline 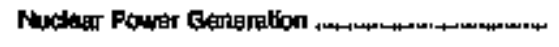 & - & - & - & - & - \\
\hline Hydraulac Power Genaration & 23 & 02 & 18 & 7 & 17 \\
\hline Other Power Genertion . & 1,600 & 1,249 & 622 & 97 & 105 \\
\hline Purchased Powde - & $6,169,491$ & $5,748,727$ & $\mathbf{s , 6 0 6 , 8 7 t}$ & $\$, 5 t 1,000$ & $5,436,710$ \\
\hline Other Production Expenpea & 14,405 & 13,288 & 7,098 & ra,zTt & 49,520 \\
\hline 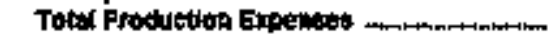 & $6,165,709$ & $5,741,722$ & $5,617,919$ & $5,500,624$ & $5,403,597$ \\
\hline Transmiseign Expenges & 44,274 & 41,796 & 49,128 & 37,107 & 97,600 \\
\hline 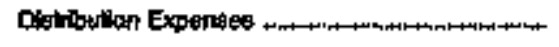 & 413,250 & $\$ 69,962$ & 357,9985 & 329,810 & 298,647 \\
\hline 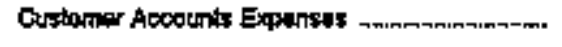 & 719,019 & 117,363 & 109,198 & 700,469 & 701,715 \\
\hline Ostromer Sartco and Information Expenses .... & 16,841 & 17,108 & 15,629 & TE,7/3 & 14,123 \\
\hline 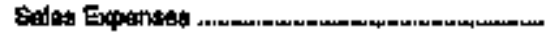 & 9,545 & 6,704 & 11,546 & 11,5B7 & 11,289 \\
\hline 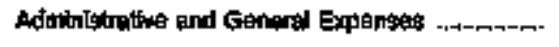 & 302,604 & $298,15 t$ & 291,054 & 284,327 & 275,073 \\
\hline 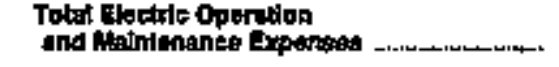 & $7,091,8987$ & $6, a 51,820$ & $0,647,658$ & $6,30,6582$ & $6,221,6 \times 9$ \\
\hline
\end{tabular}

Fued Gxpitnoes in Oparalen

Stopm Powe Bonwalon

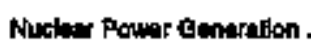

Cther Power Eonertilion

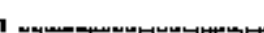

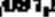

ass1, 800

201,609

Mumbar of Eteo Dapt Employest:

\begin{tabular}{|c|c|c|c|c|c|}
\hline 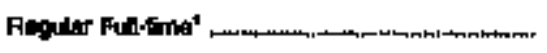 & 14,850 & 14,712 & 14,450 & - & - \\
\hline Part-fme \& Temporary' & 实宊 & 1,031 & 1,054 & - & - \\
\hline Totol Gec Dupt Employees' , & 15,200 & $\mathbf{L , 7 4 8}$ & 15,514 & - & - \\
\hline
\end{tabular}

- Detre reporting intition in 1998.

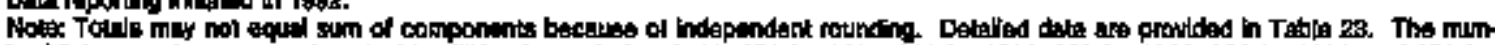

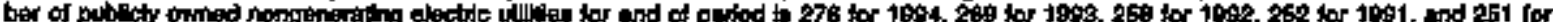

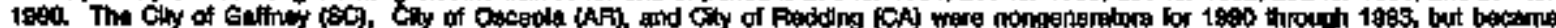

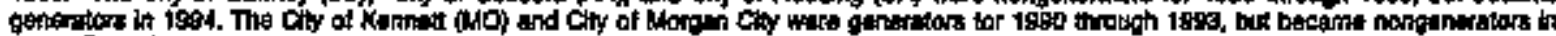

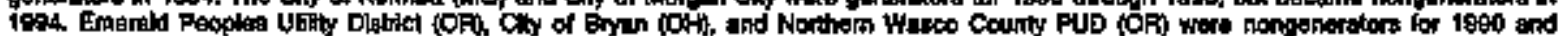

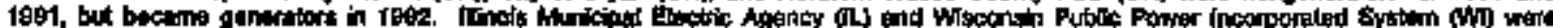

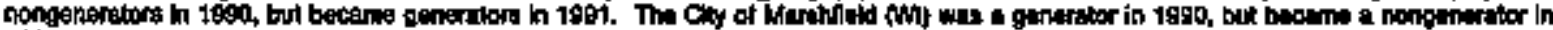
$1 \mathrm{cor}$.

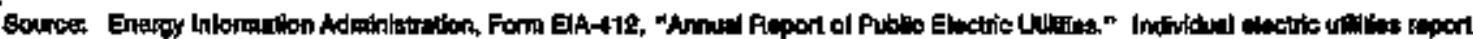

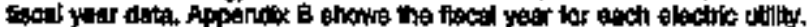


Table 18. Electric Utility Plant for Major U.S. Publicly Owned Nongenerator Elactric Utilities at End of Perlod, 1990-1994

(Thousand Dollars)

\begin{tabular}{|c|c|c|c|c|c|}
\hline $\tan$ & $19 \mathrm{PH}$ & 1003 & $19 \% 2$ & 1091 & 1090 \\
\hline \multicolumn{6}{|l|}{ Ehotide Phad th Aarvios } \\
\hline Intengivita Plant & 1b,ans & 10,505 & 10549 & 8,2ap: & 7,621 \\
\hline \multicolumn{6}{|l|}{ Prodtciton Plemi } \\
\hline 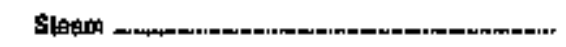 & 70,789 & 98,781 & 60,727 & $6 a, 068$ & 27,215 \\
\hline 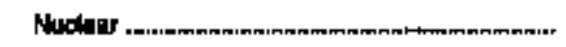 & $=$ & - & - & - & - \\
\hline Fodicalite & 15,346 & 16,334 & 15,334 & 15,334 & 15,354 \\
\hline Other & 35,502 & 27,002 & 10,904 & 10,164 & 10,607 \\
\hline Total Prodiketiont Plank & 130,62: & 112,17 & 104,045 & toe, & 91,168 \\
\hline Trandrission Mant w.... & 的, 132 & B28, 184 & 602713 & $589,80 \mathrm{OB}$ & 501,160 \\
\hline Distribution Pient & 1,313,989 & $5,020,094$ & $5,364,092$ & $5,192,372$ & $4,004,220$ \\
\hline 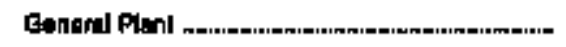 & 1,205,605 & $1,268,857$ & $9,312,189$ & $1,147,474$ & $1,076,042$ \\
\hline Total tefoptrie piant in Servica .. & a,aspas & $7,900,40 \%$ & $7,384,399$ & $7,040,005$ & $6,561,006$ \\
\hline Electic Flant Leased to Othere & 745 & 704 & 615 & 自鹤 & 706 \\
\hline Confluvotion Work in Propress - Elsoive nmmer. & 259,118 & 281,205 & 258,244 & 210,000 & 213,900 \\
\hline 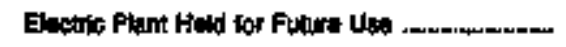 & 11,060 & 18,2899 & 16074 & 19,680 & $11,39 t$ \\
\hline Electric Plant Mage w. & 69,710 & 70,042 & $7 \$, 722$ & 5a.635 & B5,837 \\
\hline 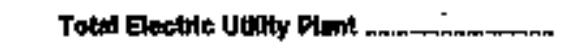 & $0,769,060$ & $6,317,006$ & $7,735,037$ & $7,318,469$ & 6,091,081 \\
\hline 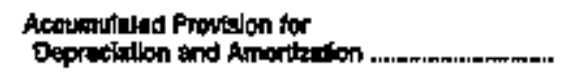 & $3,200,791$ & $3,048,887$ & $2,85,034$ & $2,458,287$ & $2,45,3002$ \\
\hline 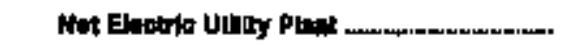 & $5,400,050$ & E,280,209 & $4,041,0 a 3$ & $4,880,421$ & 4,alp,ars \\
\hline
\end{tabular}

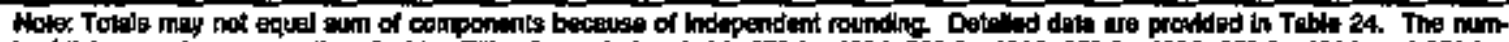

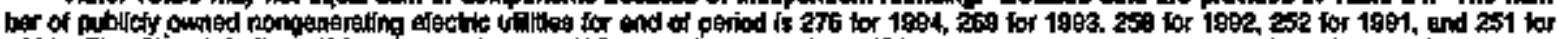

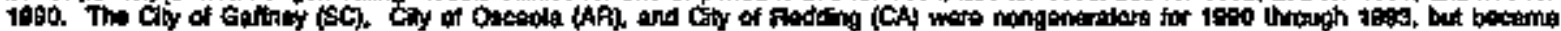

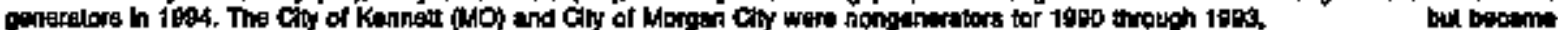

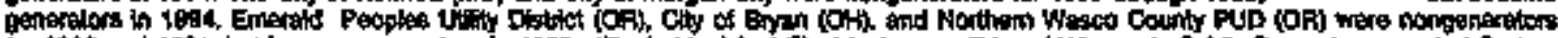

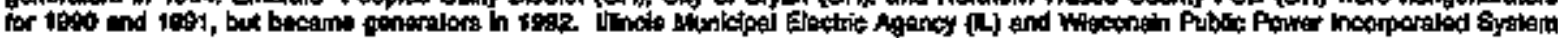

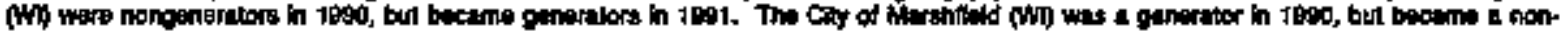
Daneretor in J591.

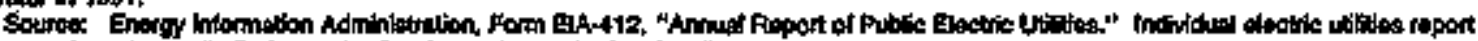

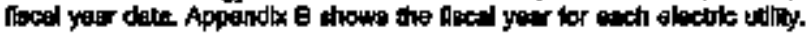


Table 19. Number of Consumert, Sales, and Optrating Revente for Major U.S. Publicly Owned Nongenerator Electrlo Utilities, 1990-1994

\begin{tabular}{|c|c|c|c|c|c|}
\hline Hom & $19 \% 4$ & texs & 1908 & 1691 & 1990 \\
\hline \multicolumn{6}{|l|}{ Mumber of Consumar } \\
\hline 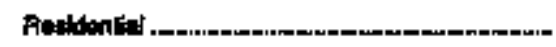 & $3,914,442$ & 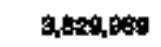 & $3,705,575$ & $9,8,24,017$ & $3,558,400$ \\
\hline 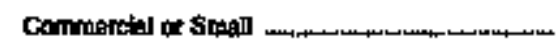 & 541,723 & 517,511 & 488,250 & 509,917 & 498,asB \\
\hline Industrigl or Lerge tint & 51,956 & 46,9000 & 45,597 & andeg & 31,854 \\
\hline Other & 64,642 & 60,040 & 97,097 & 103,377 & 99,040 \\
\hline 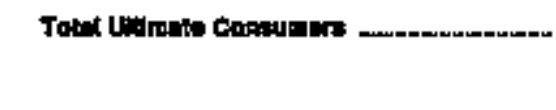 & $\begin{array}{c}4,672,663 \\
.\end{array}$ & 4,484,198 & $4,357,349$ & $4,261,940$ & $4,181,551$ \\
\hline \multicolumn{6}{|l|}{ 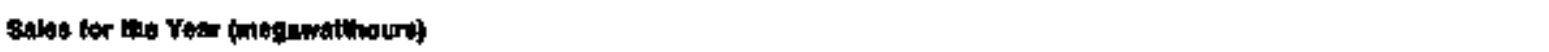 } \\
\hline Plesldentiola & $61,347,298$ & $48,900,402$ & $48,308,852$ & $46,800,67$ & $45,347,849$ \\
\hline Commerciel of Sinel . & $23,179,716$ & $2,121,772$ & $21,615,955$ & $20,0187,619$ & $25,78 B, 440$ \\
\hline Indugrial or Lestoge & $57,975,600$ & 54,A4, 202 & $51,468,656$ & $44,683,894$ & $40,948,454$ \\
\hline 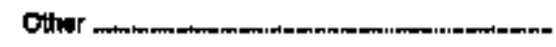 & $2,764,024$ & $2,869,490$ & 2,9389800 & $3,146,600$ & $3,055,644$ \\
\hline Told seles to Uhimate Constmere ....... & 13 aso,psts & $128,046,1044$ & $122,613,423$ & $121,497,476$ & $118,120,4: 1$ \\
\hline 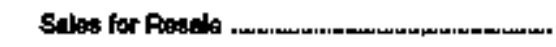 & $7,8009,8200$ & 7,AeB,ory & $7,500,098$ & $7,2186,781$ & $10,767,467$ \\
\hline Totel Gales & $143,218,763$ & $135,976,036$ & $130,000,0208$ & $128,926,266$ & $129,697,649$ \\
\hline \multicolumn{6}{|l|}{ 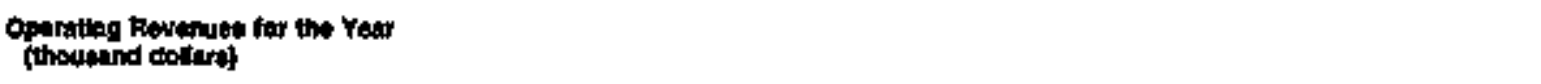 } \\
\hline 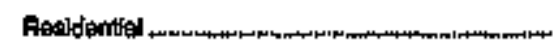 & $3,174,212$ & $2,850,704$ & $2,785,9018$ & $2,752,710$ & $2,850,045$ \\
\hline 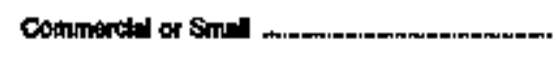 & $1,514,359$ & $1,449,420$ & $1,412,300$ & $1,600,250$ & $1,508,682$ \\
\hline 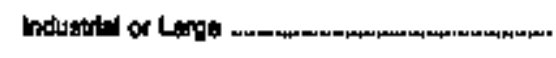 & $2,001,005$ & $2,675,104$ & $3,500,989$ & $2,156,005$ & $2,160,794$ \\
\hline Other & 188,089 & 192,112 & $t \in 9,780$ & 106,760 & 190,697 \\
\hline Toth Ravmuse from sala to & $7,056,400$ & $7,242,490$ & $0,041,997$ & 6910:18. & 0,509,489 \\
\hline Srtes for Rould -... & 283,032 & 248,614 & zad,Bth & 228,888 & 345818 \\
\hline 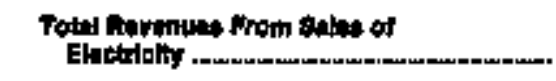 & $7,000,040$ & 7, waspoil4 & $7,174,060$ & $7,0 \mathrm{da}, \mathbf{2 0 1}$ & B, 014300 \\
\hline
\end{tabular}

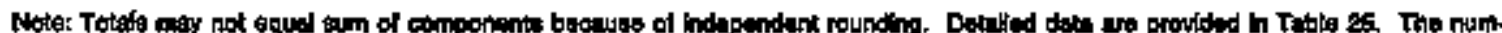

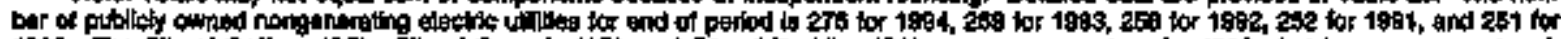

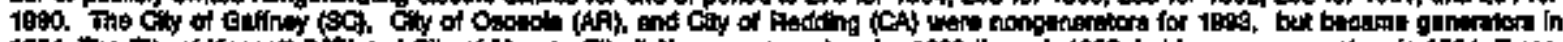

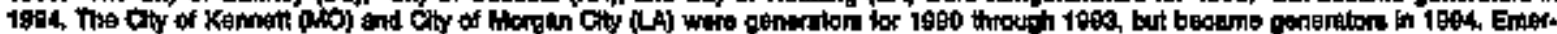

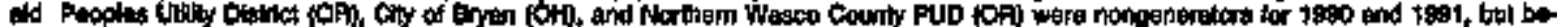

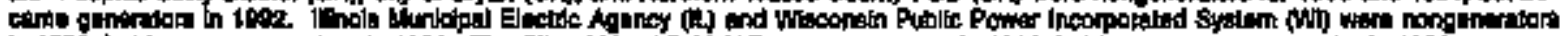

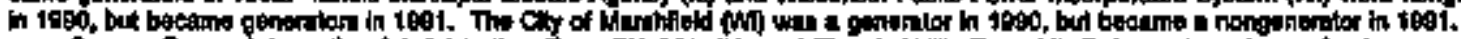
sion.

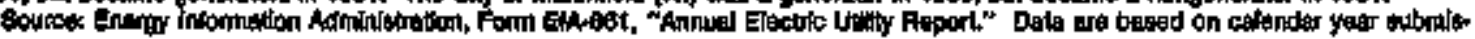


Table 20. Electrio Energy Account for Major U.S. Publiely Owned Nongenerator Electric Utilitiea, 1990-1994

(Megawatthours)

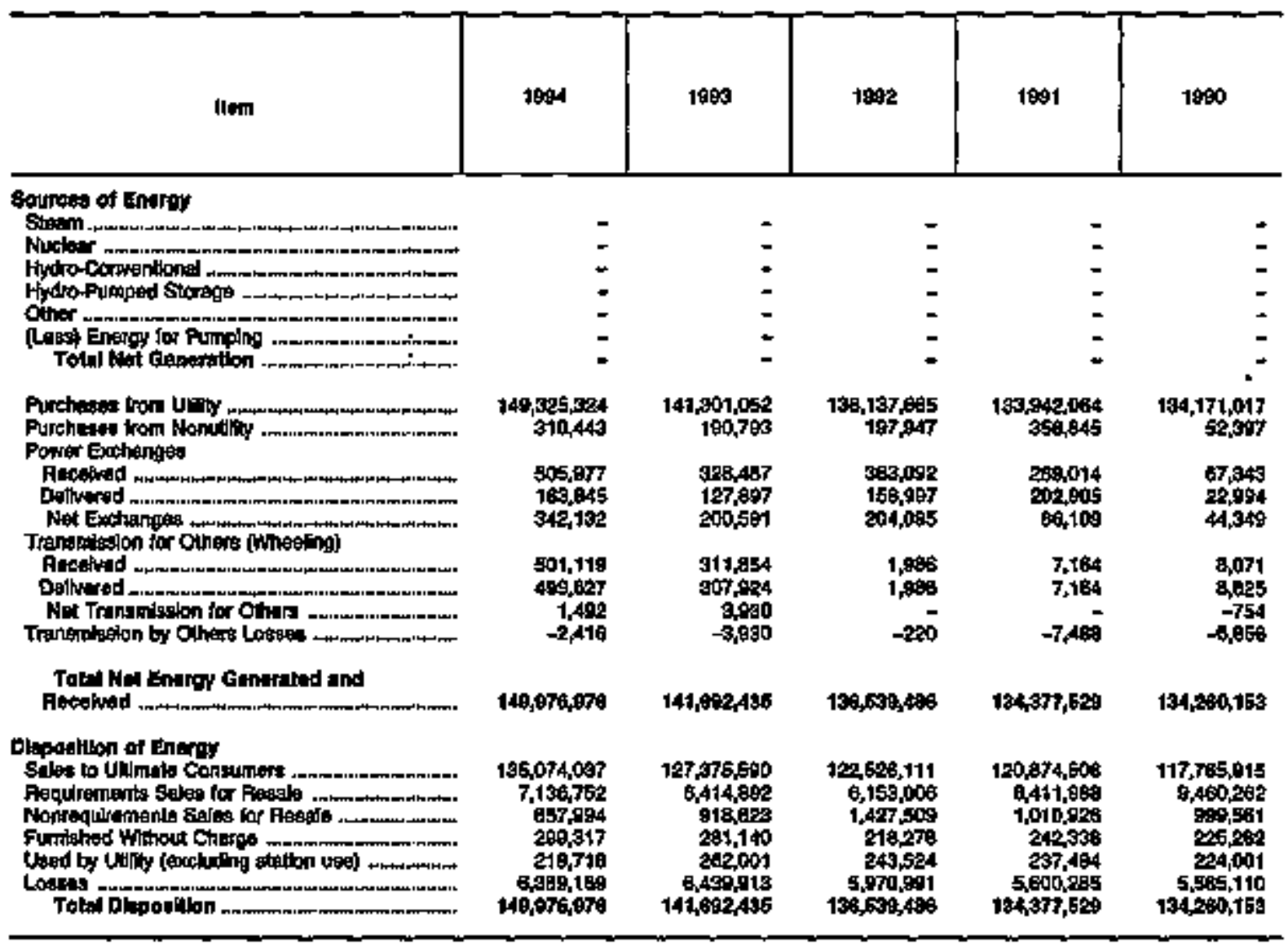

- Dato nol equaleblat

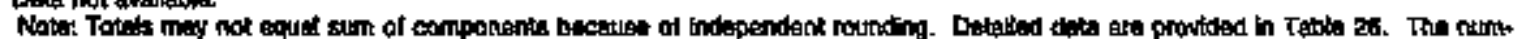

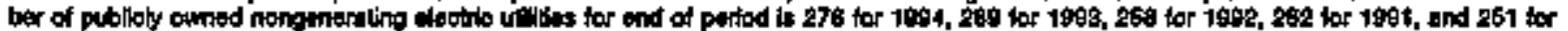

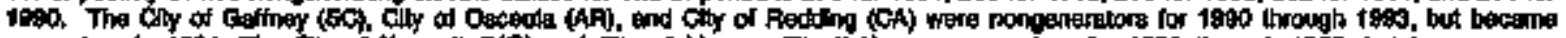

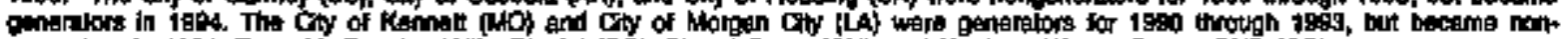

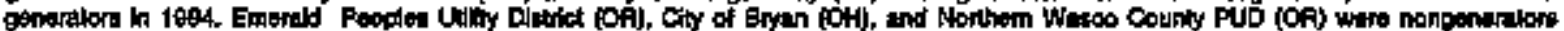

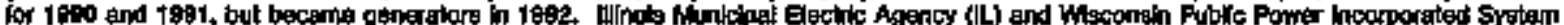

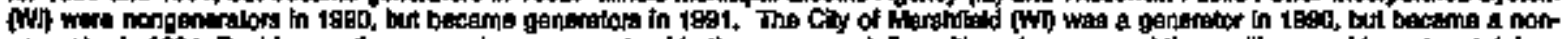

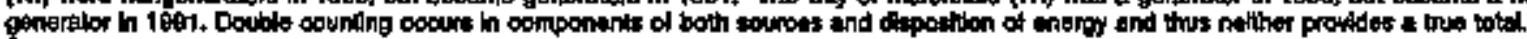

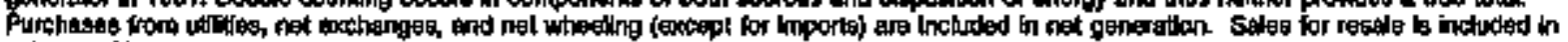

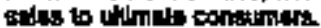

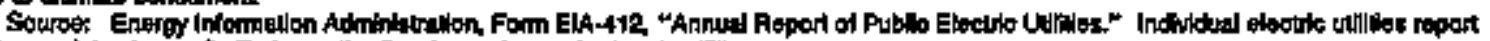

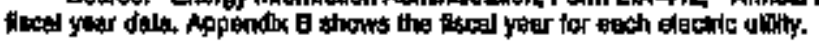





\section{Detailed Statistics of Major U.S. Publicly Owned Electric Utilities}


Table 21. Statement of Income by Major U.S. Publiely Omned Eleotrio Utity Within State, 1994

(Thousand Dollars)

\begin{tabular}{|c|c|c|c|c|c|c|}
\hline Itam & 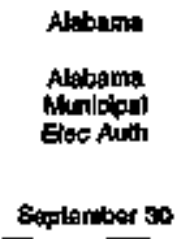 & 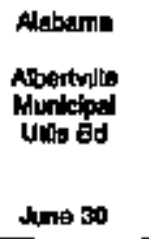 & $\begin{array}{l}\text { Almbana } \\
\text { Andulusida } \\
\text { City of } \\
\text { \$aptemaber } 30\end{array}$ & 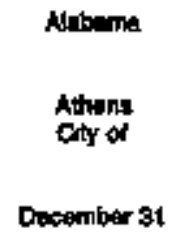 & 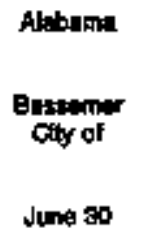 & 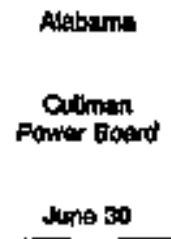 \\
\hline 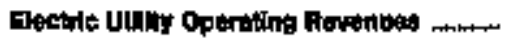 & ses,opio & 21, tos & 14,699 & 36,962 & 18,462 & 16:9aB \\
\hline 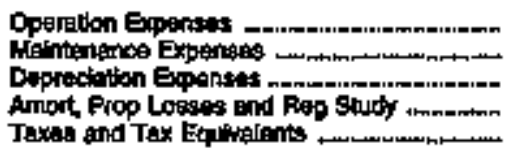 & $\begin{array}{r}77,342 \\
0 \\
245 \\
0 \\
1,000\end{array}$ & $\begin{array}{r}18,509 \\
500 \\
1005 \\
0 \\
906\end{array}$ & $\begin{array}{r}12,007 \\
195 \\
913 \\
0 \\
2,691\end{array}$ & $\begin{array}{r}33,780 \\
727 \\
1,190 \\
6 \\
805\end{array}$ & $\begin{array}{r}16,491 \\
625 \\
645 \\
0 \\
601\end{array}$ & $\begin{array}{r}15,704 \\
340 \\
401 \\
0 \\
287\end{array}$ \\
\hline 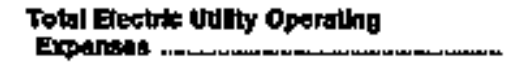 & Toper & 20,9s: & 15,7ra & $98,7 \pi$ & 18,600 & 15,771 \\
\hline 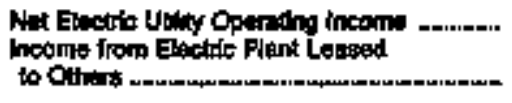 & $+9,479$ & 10 & -870 & $\begin{array}{r}1,873 \\
0\end{array}$ & $\begin{array}{r}-211 \\
0\end{array}$ & $\begin{array}{r}127 \\
0\end{array}$ \\
\hline 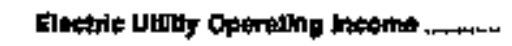 & 19,479 & 110 & $\rightarrow 78$ & 1,153 & -211 & $1 \%$ \\
\hline 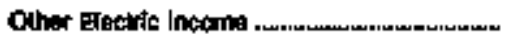 & 4,207 & 244 & $\cdot 71$ & 787 & 290 & 187 \\
\hline 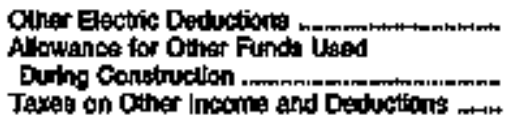 & $\begin{array}{r}12,302 \\
0 \\
0\end{array}$ & $\begin{array}{l}2 \\
4\end{array}$ & $\begin{array}{l}0 \\
0\end{array}$ & $\begin{array}{l}0 \\
0 \\
0\end{array}$ & $\begin{array}{l}0 \\
0 \\
0\end{array}$ & $\begin{array}{l}1 \\
0 \\
0\end{array}$ \\
\hline 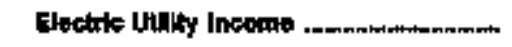 & 11,304 & 352 & -609 & 2,940 & 10 & 313 \\
\hline 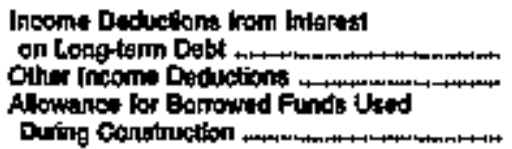 & $\begin{array}{r}11,365 \\
0 \\
0\end{array}$ & 9 & $\begin{array}{l}0 \\
0\end{array}$ & $\begin{array}{r}1,887 \\
19 \\
0\end{array}$ & $\begin{array}{r}150 \\
40 \\
0\end{array}$ & $\begin{array}{r}151 \\
5 \\
0\end{array}$ \\
\hline 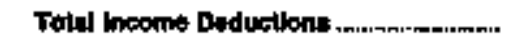 & 11,385 & 1 & o & 1,288 & 189 & 156 \\
\hline 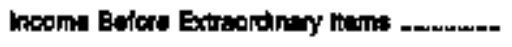 & 19 & 951 & -8008 & 1,954 & -174 & 168 \\
\hline 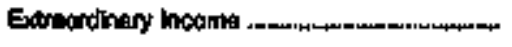 & 0 & 0 & 0 & 23 & 日7 & -88 \\
\hline 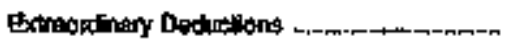 & a & 0 & 0 & 0 & 0 & $\mathbf{0}$ \\
\hline 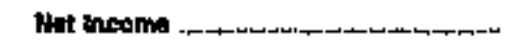 & 19 & 351 & -6009 & 1,375 & -9 & 5 \\
\hline
\end{tabular}

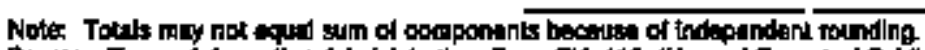

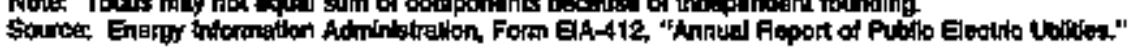


Table 21. Statement of income by Major U.S. Publlefy Owned Electrie Utilly Within State, 1994 (Conthured)

(Thousand Dollars)

\begin{tabular}{|c|c|c|c|c|c|c|}
\hline Ilem & 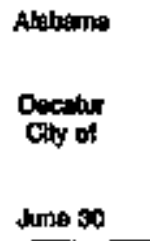 & $\begin{array}{l}\text { Alabeme } \\
\text { Dothan } \\
\text { Oty of } \\
\text { Septemben } 30\end{array}$ & $\begin{array}{l}\text { Alobano } \\
\text { Flopence } \\
\text { Cily of } \\
\text { June too }\end{array}$ & 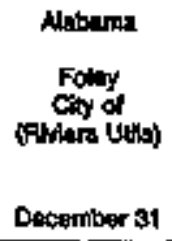 & 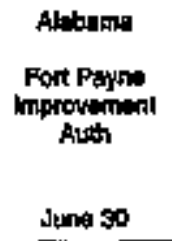 & 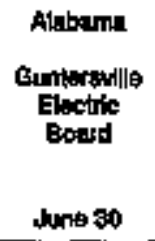 \\
\hline Elotrlo vallty Operating Rowemuse ...m..... & 61,569 & sa,63it & 61,502 & 35,007 & 17,200 & $12 ; 216$ \\
\hline 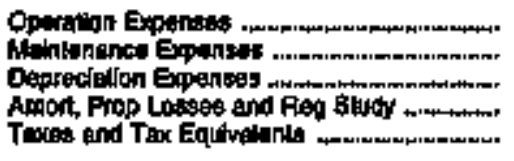 & $\begin{array}{r}58,387 \\
729 \\
1,279 \\
39 \\
1,048\end{array}$ & $\begin{array}{r}42,093 \\
734 \\
2,407 \\
0 \\
0\end{array}$ & $\begin{array}{r}5,031 \\
1,000 \\
2,274 \\
6 \\
2,005\end{array}$ & $\begin{array}{r}20,255 \\
658 \\
2,036 \\
0 \\
2,028\end{array}$ & $\begin{array}{r}15339 \\
407 \\
349 \\
2 \\
314\end{array}$ & $\begin{array}{r}11,092 \\
269 \\
271 \\
0 \\
230\end{array}$ \\
\hline 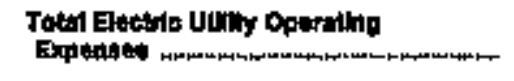 & $61, A 73$ & 45,2024 & 5,147 & 31,497 & 16,405 & 11,979 \\
\hline 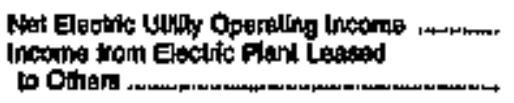 & 96 & $\begin{array}{r}9,416 \\
0\end{array}$ & 2,2555 & $\begin{array}{r}3.110 \\
0\end{array}$ & $\begin{array}{r}754 \\
0\end{array}$ & $\begin{array}{r}337 \\
0\end{array}$ \\
\hline Eleotrte tollty Oparating Ineosne n...... & 86 & 9,416 & 2,365 & $\$, 110$ & 754 & 357 \\
\hline 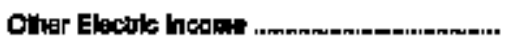 & 486 & 0 & 1,184 & 689 & 283 & $18 \mathrm{e}$ \\
\hline 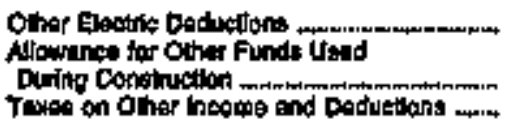 & $\begin{array}{l}0 \\
0 \\
0\end{array}$ & 0 & $\begin{array}{l}0 \\
0\end{array}$ & $\begin{array}{l}0 \\
0 \\
0\end{array}$ & $\begin{array}{l}0 \\
0 \\
0\end{array}$ & 0 \\
\hline 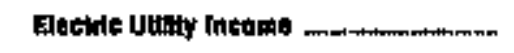 & 692 & 9,416 & 3539 & 3,791 & 1,0037 & 609 \\
\hline 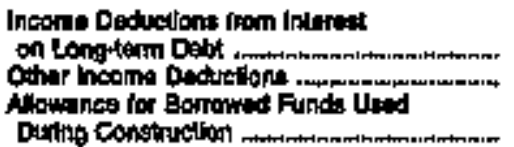 & $\begin{array}{l}0 \\
0 \\
0\end{array}$ & $\begin{array}{l}0 \\
0 \\
0\end{array}$ & $\begin{array}{r}359 \\
15 \\
0\end{array}$ & $\begin{array}{r}810 \\
20 \\
0\end{array}$ & $\begin{array}{r}277 \\
46 \\
0\end{array}$ & $\begin{array}{r}24 \\
0\end{array}$ \\
\hline Tatev Ineome Deductione & 0 & 0 & $\mathbf{3 7 9}$ & $\mathbf{\omega 1}$ & ags & 25 \\
\hline 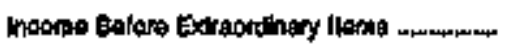 & 592 & 9,416 & 3,185 & 2,901 & 715 & 491 \\
\hline 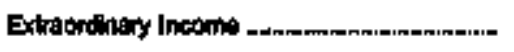 & 0 & 0 & $\mathbf{0}$ & 0 & 0 & 0 \\
\hline Axhoptinary Depductions & 0 & $\mathbf{0}$ & 115 & o & 0 & 0 \\
\hline 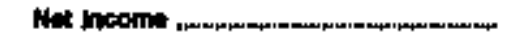 & $\operatorname{sen}$ & 0,416 & 3048 & 2,961 & 715 & 401 \\
\hline
\end{tabular}

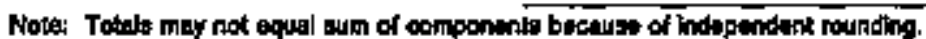

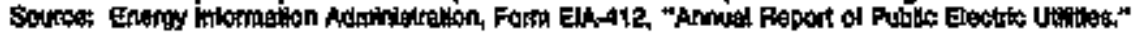


Table 21. Statement of Income by Majpr U.S. Publicty Owned Electric Utility Whin State, 1994 (Continuad)

(Thousand Dollars)

\begin{tabular}{|c|c|c|c|c|c|c|}
\hline Item & 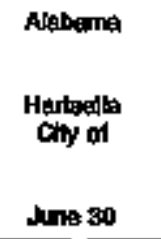 & 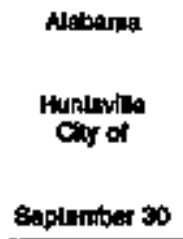 & 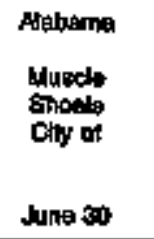 & 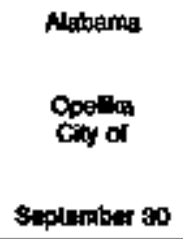 & 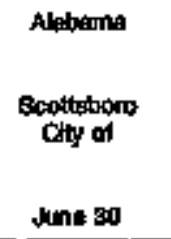 & 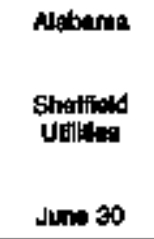 \\
\hline 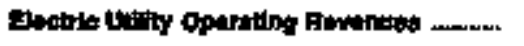 & 7,399 & 197005 & 11,486 & x;ses & 17,159 & 26,105 \\
\hline 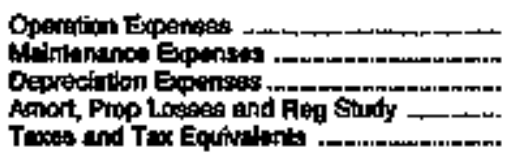 & $\begin{array}{r}6,695 \\
281 \\
177 \\
0 \\
98\end{array}$ & $\begin{array}{r}179,650 \\
3,319 \\
5,050 \\
0 \\
5,159\end{array}$ & $\begin{array}{r}10,181 \\
344 \\
476 \\
0 \\
000\end{array}$ & $\begin{array}{r}14,769 \\
464 \\
602 \\
0 \\
0\end{array}$ & $\begin{array}{r}15.477 \\
625 \\
474 \\
0 \\
320\end{array}$ & $\begin{array}{r}21,074 \\
1,068 \\
1,076 \\
21 \\
701\end{array}$ \\
\hline 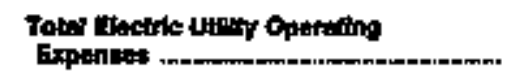 & 7, tept & 108,170 & 11,349 & 16,0058 & 17496 & $24,73:$ \\
\hline 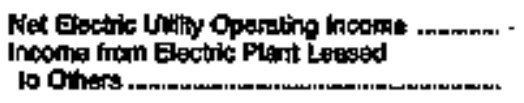 & $\begin{array}{r}195 \\
0\end{array}$ & 3,069 & 137 & $\begin{array}{r}1,113 \\
0\end{array}$ & D60 & 306 \\
\hline Eectric utiltty Oparathit meorne & 195 & 3,400 & \$37 & $\$, 113$ & $\mathbf{5 8 6}$ & 30 \\
\hline Omer Eactis boonse & as & 4,060 & 147 & 1,501 & 267 & 346 \\
\hline 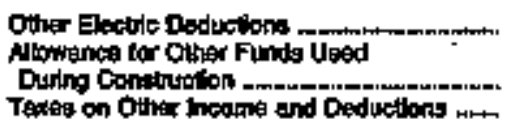 & $\begin{array}{l}0 \\
0 \\
0\end{array}$ & $\begin{array}{l}0 \\
0 \\
0\end{array}$ & $\begin{array}{r}26 \\
0 \\
0\end{array}$ & $\begin{array}{r}160 \\
0\end{array}$ & $\begin{array}{l}0 \\
0 \\
0\end{array}$ & 20 \\
\hline 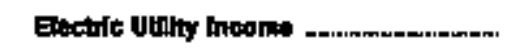 & 280 & 0,635 & 250 & 2,651 & \$14 & 60 \\
\hline 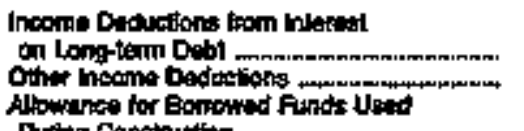 & 10 & $\mathbf{4 2 0}$ & sis & 2,230 & 32 & 118 \\
\hline 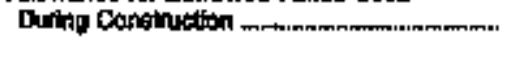 & $\mathbf{0}$ & 0 & 0 & $\mathbf{0}$ & 0 & 0 \\
\hline 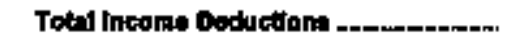 & 12 & Mit & 62 & 2,461 & 302 & 120 \\
\hline 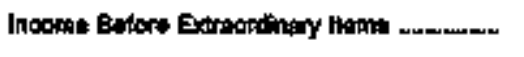 & 200 & 7,504 & 198 & 19 & 513 & 700 \\
\hline Expoominary Intome & 0 & $\mathbf{0}$ & 0 & 0 & 0 & 0 \\
\hline 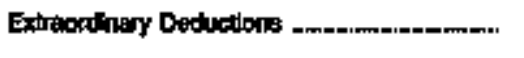 & 0 & 0 & 0 & 9 & 0 & 0 \\
\hline Not labomt nom & 20 & 7,594 & 19.9 & 10 & Ets & 70 \\
\hline
\end{tabular}

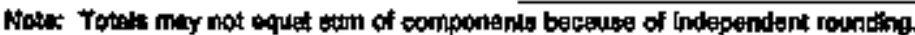

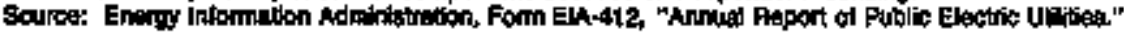


Table 21. Statement of Income by Major U.S. Publicly Owmed Eectrie Utllty Within state, 1994 (Continued)

(Thousand Dollars)

\begin{tabular}{|c|c|c|c|c|c|c|}
\hline Ilem & 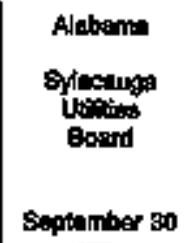 & $\begin{array}{l}\text { Alnteme } \\
\text { Troy } \\
\text { Chy of } \\
\text { Seprember od }\end{array}$ & $\begin{array}{l}\text { Allobuma } \\
\text { Tuskenger } \\
\text { Ciny of } \\
\text { Suptember so }\end{array}$ & 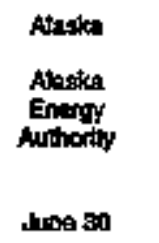 & 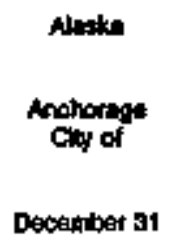 & $\begin{array}{l}\text { Alaste } \\
\text { Faltinlus } \\
\text { Chy of } \\
\text { December } 31\end{array}$ \\
\hline 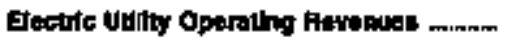 & 11,5 & 12,252 & B, & 25, 134 & 6,00 & $\mathbf{m a t}$ \\
\hline 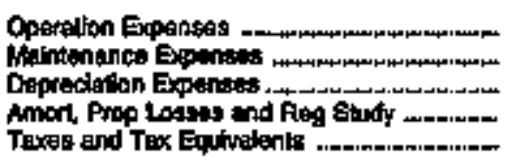 & $\begin{array}{r}8,150 \\
228 \\
451 \\
0 \\
0\end{array}$ & $\begin{array}{r}8,6009 \\
114 \\
0 \\
0 \\
3,561\end{array}$ & $\begin{array}{r}7,794 \\
0 \\
270 \\
0 \\
246\end{array}$ & $\begin{array}{r}4,600 \\
1,024 \\
23,013 \\
0 \\
0\end{array}$ & $\begin{array}{r}36,532 \\
3,720 \\
9,345 \\
512 \\
1,881\end{array}$ & $\begin{array}{r}11,156 \\
350 \\
1,674 \\
0 \\
090\end{array}$ \\
\hline 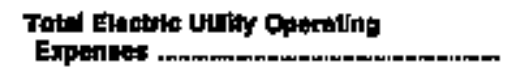 & 0,0368 & 12,644 & B,s00 & 26,637 & 52,200 & 14,150 \\
\hline 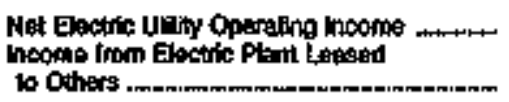 & $\begin{array}{r}2,727 \\
0\end{array}$ & $\begin{array}{r}-298 \\
0\end{array}$ & 274 & $\begin{array}{r}-5000 \\
0\end{array}$ & $\begin{array}{r}15,9099 \\
0\end{array}$ & $\begin{array}{r}2.111 \\
0\end{array}$ \\
\hline 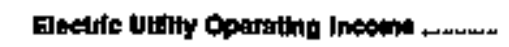 & 2,727 & -202 & 274 & -503 & 15,1009 & 2,111 \\
\hline Other Electic hecomie & 0 & 200 & 8 & 4,2012 & 2,519 & 100 \\
\hline 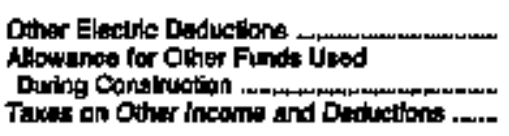 & $\begin{array}{r}1,015 \\
0 \\
0\end{array}$ & $\begin{array}{l}0 \\
0 \\
0\end{array}$ & $\begin{array}{l}0 \\
0 \\
0\end{array}$ & $\begin{array}{r}0 \\
0 \\
0\end{array}$ & $\begin{array}{l}0 \\
0 \\
0\end{array}$ & $\begin{array}{l}0 \\
9 \\
0\end{array}$ \\
\hline Eloutric Uinky inoobit & 1,712 & $\rightarrow$ & $\operatorname{ses}$ & 2000 & 1E,sta & 2,200 \\
\hline 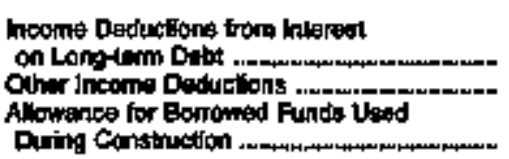 & $\begin{array}{r}501 \\
0\end{array}$ & $\begin{array}{r}511 \\
771 \\
0\end{array}$ & $\begin{array}{r}401 \\
0 \\
0\end{array}$ & $\begin{array}{r}22,015 \\
0 \\
0\end{array}$ & $\begin{array}{r}1,789 \\
2579 \\
0\end{array}$ & $\begin{array}{r}1,+180 \\
0 \\
0\end{array}$ \\
\hline 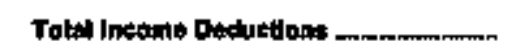 & 659 & 1,262 & 401 & 22,225 & 14,689 & $\$, 160$ \\
\hline 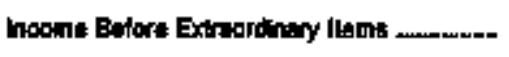 & 1.165 & $-1,201$ & -83 & $-19,095$ & 3,767 & 1,030 \\
\hline 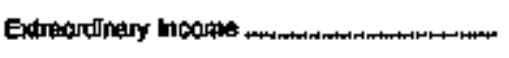 & 0 & $\mathbf{0}$ & $\circ$ & 0 & 0 & 0 \\
\hline Extraodinery Doductlons n...m.m.m. & 0 & 0 & 0 & 0 & $\mathbf{0}$ & 0 \\
\hline 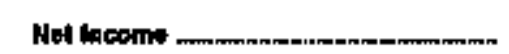 & 1,161 & $-1,201$ & -3 & $-19,885$ & $\$, 767$ & 1,000 \\
\hline
\end{tabular}

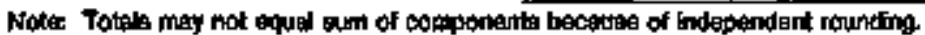

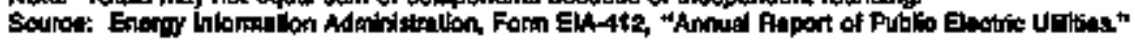


Table 21. Statement of Income by Major U.S. Publkly Owmed Electric Utility Within State, 1994 (Continued) (Thousand Dollars)

\begin{tabular}{|c|c|c|c|c|c|c|}
\hline then & 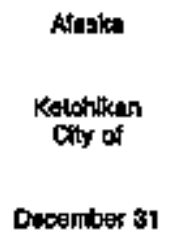 & 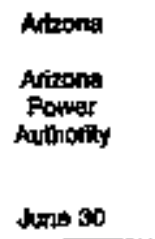 & 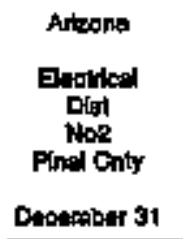 & $\begin{array}{l}\text { Atizionia } \\
\text { Ciny of } \\
\text { June } 30\end{array}$ & 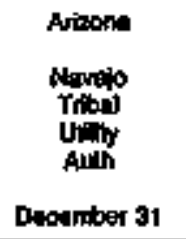 & 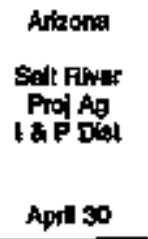 \\
\hline 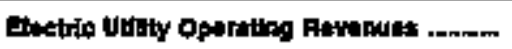 & $12,7 \sqrt{7}$ & 19,894 & Q,011 & 22,t的 & 36,442 & $1,342,397$ \\
\hline 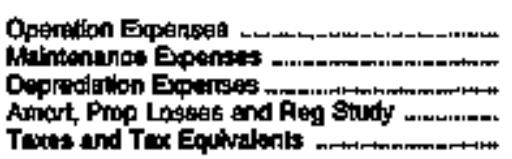 & $\begin{array}{r}7,973 \\
0651 \\
+, 554 \\
0 \\
305\end{array}$ & $\begin{array}{r}19,568 \\
0 \\
72 \\
0 \\
0\end{array}$ & $\begin{array}{r}6,497 \\
652 \\
605 \\
0 \\
0\end{array}$ & $\begin{array}{r}15,165 \\
2,0902 \\
1,316 \\
-2,571 \\
0\end{array}$ & $\begin{array}{r}27,808 \\
914 \\
4,069 \\
0 \\
0\end{array}$ & $\begin{array}{r}51,740 \\
101,577 \\
160,549 \\
7,003 \\
100,347\end{array}$ \\
\hline Tot: Electile Utthy Opersilng & 20,602 & 18,6009 & 7,644 & t5ess & 32,610 & $1,000,700$ \\
\hline 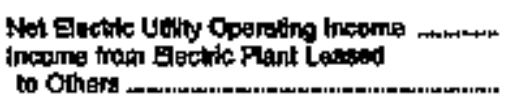 & 20404 & 758 & 407 & $\begin{array}{r}6,202 \\
0\end{array}$ & $\begin{array}{r}2,032 \\
0\end{array}$ & $\begin{array}{r}321,627 \\
213\end{array}$ \\
\hline 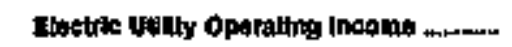 & 2044 & 768 & 467 & 6,202 & 2,852 & 321,945 \\
\hline Other Enctife Insont & 3504 & 3,749 & $\uparrow 41$ & s14 & 451 & 14,225 \\
\hline 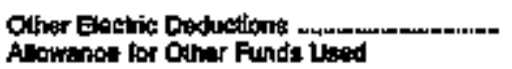 & $\mathbf{0}$ & 0 & 0 & 0 & 579 & 182 \\
\hline 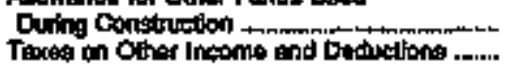 & 0 & $\stackrel{0}{0}$ & 0 & 0 & $\stackrel{0}{0}$ & 0 \\
\hline 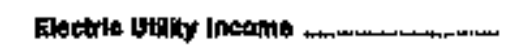 & 2,300 & 4,6as & 608 & 6,516 & 2,70s & 395, \\
\hline 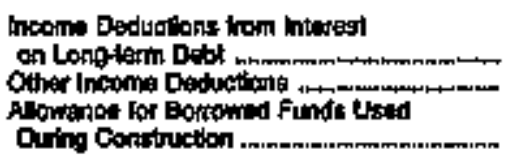 & $\begin{array}{r}470 \\
10 \\
0\end{array}$ & $\begin{array}{r}4,598 \\
64 \\
0\end{array}$ & $\begin{array}{l}0 \\
0 \\
0\end{array}$ & $\begin{array}{r}127 \\
0 \\
0\end{array}$ & $\begin{array}{r}1,047 \\
38 \\
-145\end{array}$ & $\begin{array}{r}213,429 \\
16,370 \\
-6,152\end{array}$ \\
\hline 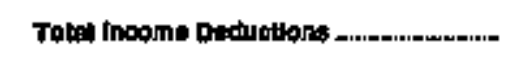 & 480 & 4,57 & 0 & 127 & 93 & 221,659 \\
\hline 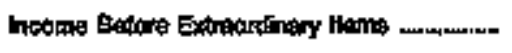 & 1,000 & -71 & 608 & 6,389 & 1,770 & 114,230 \\
\hline Extroonthary Income nnm & 100 & n & $\mathbf{5 1 B}$ & $\mathbf{0}$ & 0 & o \\
\hline Extrapinary Deduclions: & 0 & 0 & 0 & 0 & 0 & 0 \\
\hline Wht Inoome & 2,017 & -71 & 1,424 & 4,989 & 1,770 & $114,9 \% 0$ \\
\hline
\end{tabular}

Note: Totelg mey not equad aum of componente becaluse of indapendent nounding

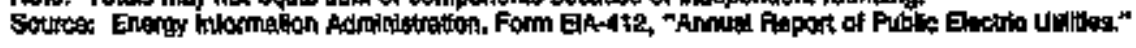


Table 21. Statement of Ineome by Major U.8. Publicly Owned Electric Utitity Within state, 1994 (Continued)

(Thousand Dollars)

\begin{tabular}{|c|c|c|c|c|c|c|}
\hline Item & 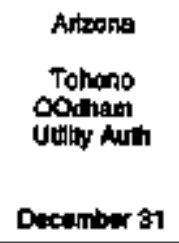 & $\begin{array}{l}\text { Axtensas } \\
\text { Elonton } \\
\text { Cty of } \\
\text { Ductraber } 31\end{array}$ & 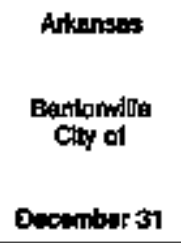 & 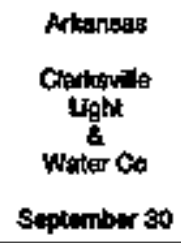 & 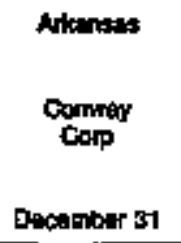 & $\begin{array}{l}\text { Arkensas } \\
\text { Hope } \\
\text { City of } \\
\text { Decamber } 31\end{array}$ \\
\hline 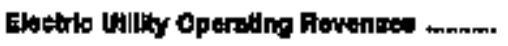 & 7,607 & 14,514 & 9,13: & 10,000 & 25,094 & 11,602 \\
\hline 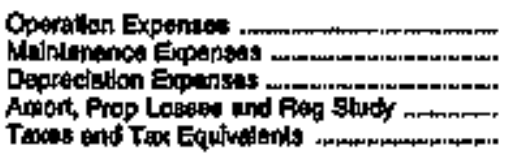 & $\begin{array}{r}6,912 \\
180 \\
298 \\
0 \\
0\end{array}$ & $\begin{array}{r}0,007 \\
200 \\
200 \\
602 \\
742\end{array}$ & $\begin{array}{r}7,486 \\
91 \\
287 \\
0 \\
675\end{array}$ & $\begin{array}{r}6.985 \\
270 \\
475 \\
0 \\
360\end{array}$ & $\begin{array}{r}18,694 \\
902 \\
2,406 \\
0 \\
549\end{array}$ & $\begin{array}{r}7,692 \\
701 \\
412 \\
4 \\
43\end{array}$ \\
\hline Totu1 Eleotrio Utily Openolag & 7,375 & 11,801 & 8,5099 & $7, s 0 ?$ & 22544 & 6.898 \\
\hline 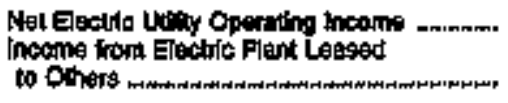 & 202 & 3,013 & $\operatorname{ses}$ & $\begin{array}{r}2,707 \\
0\end{array}$ & $\begin{array}{r}4,450 \\
0\end{array}$ & 2,704 \\
\hline 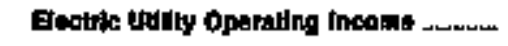 & 232 & $\mathbf{3}, \mathbf{0} 1 \mathbf{3}$ & $5 * 3$ & 2,107 & $4,4 \leq 0$ & $2,76 d$ \\
\hline Ohar Electrif Incoster & 58 & $48 B$ & $\mathbf{g}$ & 120 & $\pi 6$ & 0 \\
\hline 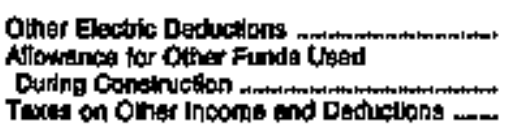 & $\begin{array}{l}0 \\
0 \\
0\end{array}$ & $\begin{array}{l}0 \\
0\end{array}$ & $\begin{array}{l}0 \\
0 \\
0\end{array}$ & $\begin{array}{l}0 \\
0 \\
0\end{array}$ & $\begin{array}{l}7 \\
0 \\
0\end{array}$ & $\begin{array}{l}5 \\
0 \\
0\end{array}$ \\
\hline 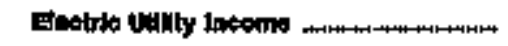 & 200 & 3,47 & $\operatorname{sos}$ & $29 \mathrm{~m}$ & 5,149 & 2,700 \\
\hline 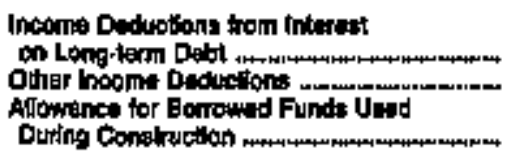 & $\begin{array}{r}218 \\
0 \\
0\end{array}$ & $\stackrel{9}{9}$ & $\underset{0}{115}$ & $\begin{array}{l}\infty \\
0\end{array}$ & $\begin{array}{r}1,494 \\
29 \\
0\end{array}$ & $\begin{array}{r}0 \\
528 \\
0\end{array}$ \\
\hline 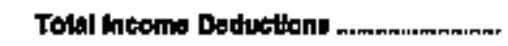 & 226 & 0 & 116 & 69 & 1,513 & ees \\
\hline 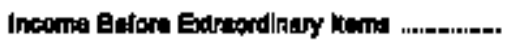 & 86 & 3,471 & 407 & 2,768 & $3,6 \mathbf{s}$ & 2,165 \\
\hline 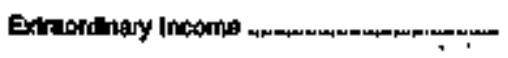 & 0 & 0 & D & 0 & 0 & 0 \\
\hline Exiraondinary Doductions ...nmmnnmmnemmm & 0 & 0 & $\mathbf{0}$ & 0 & $\mathbf{0}$ & 0 \\
\hline 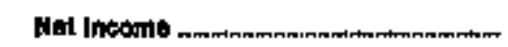 & 65 & 3,471 & 167 & 2,758 & 3,639 & 2,165 \\
\hline
\end{tabular}

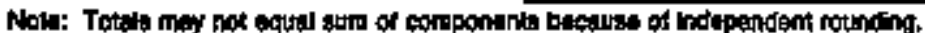

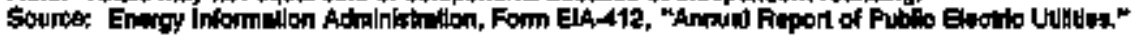


Tabie 21. Statement of income by Major U.S. Publicly Owned Electric Utlity Within State, 1994 (Continued)

(Thousand Dollars)

\begin{tabular}{|c|c|c|c|c|c|c|}
\hline Itom & $\begin{array}{l}\text { Antarses } \\
\text { Jonesbors } \\
\text { City of } \\
\text { December } 3 x\end{array}$ & $\begin{array}{l}\text { Arkgnsas } \\
\text { North } \\
\text { thiles } \\
\text { Fook } \\
\text { Chy of } \\
\text { Decriber } 31\end{array}$ & 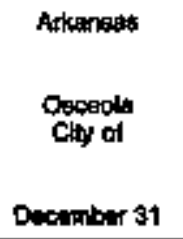 & 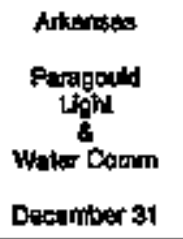 & $\begin{array}{l}\text { Atkansas } \\
\text { STrim } \\
\text { Sprtingt } \\
\text { Gity of } \\
\text { Docember st }\end{array}$ & $\begin{array}{c}\text { Avkenates } \\
\text { Weat } \\
\text { Nomphts } \\
\text { Coty of } \\
\text { Deccenter } 31\end{array}$ \\
\hline 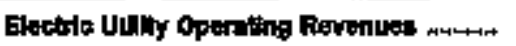 & $97,09 t$ & 90,090 & 9,104 & 12417 & 7,002 & 20,940 \\
\hline 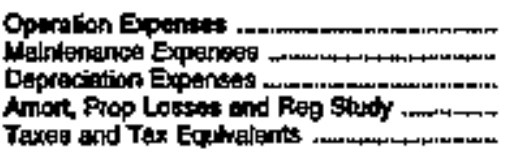 & $\begin{array}{r}20,047 \\
1,457 \\
5,659 \\
0 \\
734\end{array}$ & $\begin{array}{r}34,498 \\
1,841 \\
3,863 \\
0 \\
537\end{array}$ & $\begin{array}{r}7,208 \\
100 \\
491 \\
0 \\
0\end{array}$ & $\begin{array}{r}0.454 \\
798 \\
897 \\
0 \\
0\end{array}$ & $\begin{array}{r}7,150 \\
0 \\
195 \\
0 \\
0\end{array}$ & $\begin{array}{r}12,638 \\
398 \\
1,986 \\
0 \\
784\end{array}$ \\
\hline 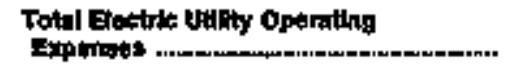 & so,osts & 40,989 & 7,697 & 11,14 & 7,344 & 16,728 \\
\hline 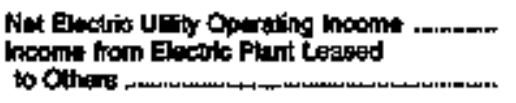 & $\begin{array}{r}6,185 \\
0\end{array}$ & $\begin{array}{r}19,831 \\
0\end{array}$ & $\begin{array}{r}1,345 \\
0\end{array}$ & $\begin{array}{r}1,273 \\
0\end{array}$ & eg: & 5.226 \\
\hline 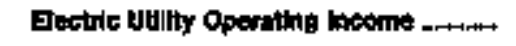 & 6,165 & 18, *a1 & 1,396 & 1,273 & 638 & 5,206 \\
\hline 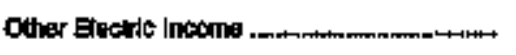 & 1,011 & 3,588 & 0 & 300 & 1,834 & $\mathbf{0}$ \\
\hline 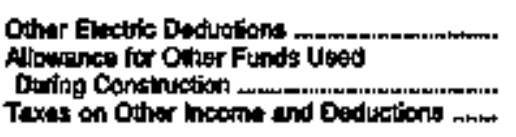 & $\begin{array}{l}0 \\
0 \\
0\end{array}$ & $\begin{array}{r}12,100 \\
0 \\
0\end{array}$ & $\begin{array}{l}0 \\
0 \\
0\end{array}$ & 0 & $\begin{array}{l}0 \\
0 \\
0\end{array}$ & $\begin{array}{r}9,459 \\
0 \\
0\end{array}$ \\
\hline enctfit Utifly heome ...-.................. & 7,176 & $11,3 \$ 7$ & 1,346 & 1,593 & 2,171 & 2,569 \\
\hline 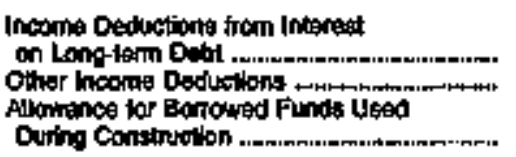 & $\begin{array}{r}2,738 \\
195 \\
0\end{array}$ & $\begin{array}{r}9.801 \\
0 \\
0\end{array}$ & $\begin{array}{r}280 \\
0 \\
0\end{array}$ & $\begin{array}{r}467 \\
81 \\
0\end{array}$ & $\begin{array}{l}- \\
0 \\
0 \\
0\end{array}$ & $\begin{array}{r}1307 \\
144 \\
0\end{array}$ \\
\hline 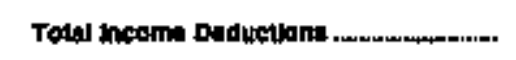 & 2,878 & 9,601 & 200 & 500 & 0 & $\mathbf{1}, \mathbf{5 i t}$ \\
\hline Inforna Belore Exdrawdinary ltemg & 4,308 & 1,505 & 1,1 t6 & 1,005 & 2,171 & 1,117 \\
\hline Extriotdinay heome & D & 0 & o & 0 & 0 & 0 \\
\hline Extrondinay Dedugtions . , & 0 & 0 & o & $\mathbf{0}$ & o & 0 \\
\hline 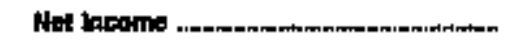 & 4,500 & 1,596 & 1,110 & 1,066 & 2,171 & 1,117 \\
\hline
\end{tabular}

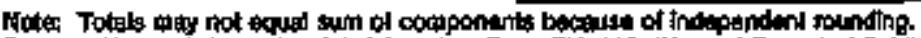

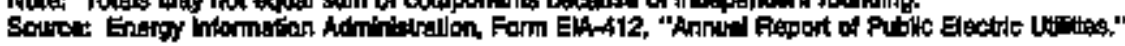


Table 21. Statement of Income by Major U.S. Publicly Owned Electrie Utity Within State, 1994 (Continued)

(Thousand Dollars)

\begin{tabular}{|c|c|c|c|c|c|c|}
\hline Hem & $\begin{array}{l}\text { Gaifunda } \\
\text { Alamedia } \\
\text { Chy of } \\
\text { Jung } 90\end{array}$ & 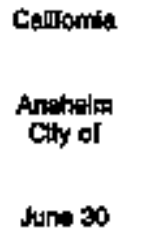 & $\begin{array}{l}\text { Cesterria } \\
\text { Arusa } \\
\text { city of } \\
\text { Jurn so }\end{array}$ & $\begin{array}{l}\text { Calofomk } \\
\text { Bamank } \\
\text { Cliny of } \\
\text { Juna so }\end{array}$ & 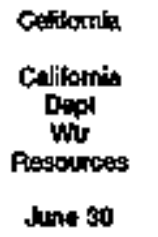 & 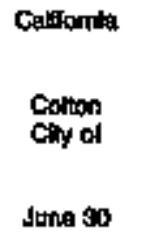 \\
\hline 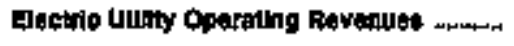 & 44,205 & 201,52t & 56919 & gac,2as & 125,095 & 18,109 \\
\hline 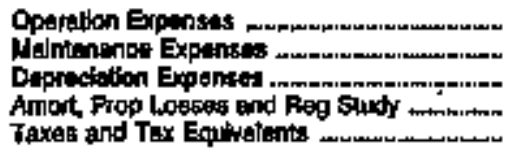 & $\begin{array}{r}35,491 \\
299 \\
1,842 \\
0 \\
316\end{array}$ & $\begin{array}{r}r 3,335 \\
6,791 \\
13,017 \\
1,119 \\
0\end{array}$ & $\begin{array}{r}14,664 \\
1,491 \\
428 \\
0 \\
1,682\end{array}$ & $\begin{array}{r}74,991 \\
4,342 \\
4,713 \\
10 \\
5,762\end{array}$ & $\begin{array}{r}68,158 \\
0 \\
22,014 \\
0 \\
2,112\end{array}$ & $\begin{array}{r}15,425 \\
502 \\
586 \\
0 \\
1,410\end{array}$ \\
\hline 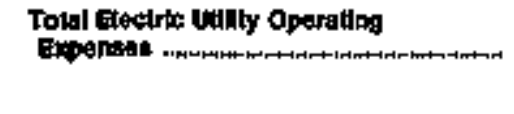 & 39,597 & 195,152 & $18,4 \mathrm{ab}$ & 69,709 & 92,292 & 17,986 \\
\hline 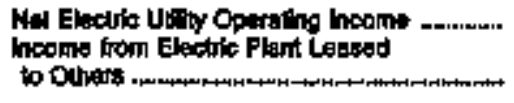 & $\begin{array}{r}5,817 \\
0\end{array}$ & 38,380 & 378 & 2527 & $\begin{array}{r}39,701 \\
0\end{array}$ & 1,178 \\
\hline Eectile Utulty Oparathg lneome .... & 5,677 & 36,369 & 376 & 2,627 & 46,701 & 6,173 \\
\hline Other Gitotida Inocm & $\cos$ & B,012 & r,OFt & 1,625 & 7,045 & 78 \\
\hline 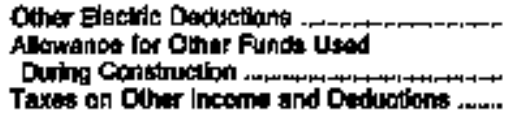 & $\begin{array}{l}0 \\
0\end{array}$ & $\begin{array}{l}0 \\
0\end{array}$ & $\ddot{0}$ & 0 & $\begin{array}{l}0 \\
0\end{array}$ & $\begin{array}{r}190 \\
0 \\
0\end{array}$ \\
\hline 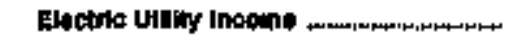 & 6,500 & 44,451 & 1,490 & 4,150 & d3,745 & 1,099 \\
\hline 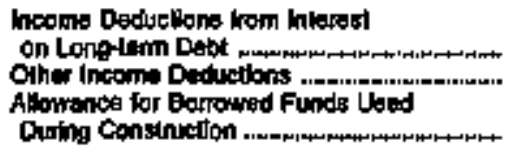 & $\begin{array}{r}663 \\
-15 \\
0\end{array}$ & $\begin{array}{r}89,4285 \\
0 \\
0\end{array}$ & $\stackrel{0}{0}$ & $\begin{array}{r}1,929 \\
0 \\
0\end{array}$ & $\begin{array}{r}60,128 \\
0 \\
0\end{array}$ & $\begin{array}{l}42 \\
0\end{array}$ \\
\hline 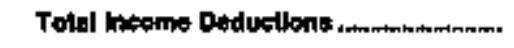 & 867 & 23,4as & 0 & $1, \Delta \dot{x}^{3}$ & 60,120 & 12 \\
\hline 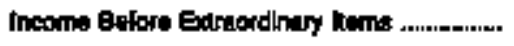 & 5,742 & 24,005 & 1,490 & 2020 & $-16,382$ & 1,017 \\
\hline 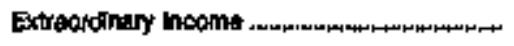 & 0 & o & 4,240 & 0 & 0 & 0 \\
\hline Extraordinary Dedtritons . & $\mathbf{0}$ & 0 & 0 & 0 & 0 & 0 \\
\hline 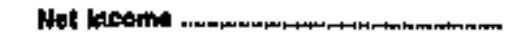 & 5,742 & 21,005 & 6,070 & 2,20 & $-18,48 ?$ & 1,017 \\
\hline
\end{tabular}

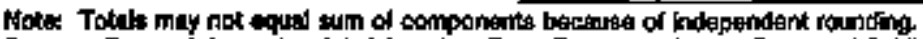

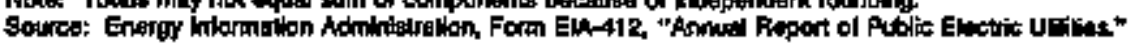


Table 21. Statement of Income by Major U.S. Publicly Ownod Eloctric Utility Within State, 1994 (Continued)

(Thousand Dollars)

\begin{tabular}{|c|c|c|c|c|c|c|}
\hline Ittrin & 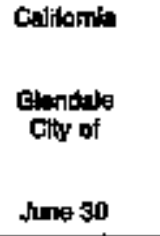 & 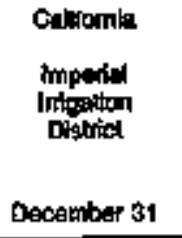 & $\begin{array}{l}\text { Callomba } \\
\text { Kinge Fiver } \\
\text { Constivition } \\
\text { Dist } \\
\text { Jure } 30\end{array}$ & 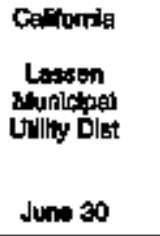 & $\begin{array}{l}\text { Celfiomia } \\
\text { Lod } \\
\text { Cily of } \\
\text { Jure } \$ 0\end{array}$ & $\begin{array}{l}\text { Calromia } \\
\text { Los Angeles } \\
\text { City of } \\
\text { Juna } 30\end{array}$ \\
\hline 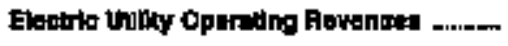 & 06,002 & 200,609 & 11,987 & 14,358 & $36,7: 0$ & $1,0033,445$ \\
\hline 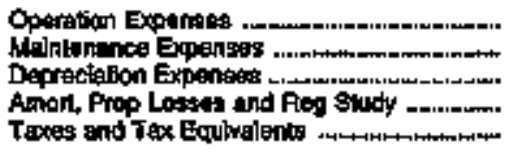 & $\begin{array}{r}69,901 \\
4,005 \\
8,056 \\
0 \\
0\end{array}$ & $\begin{array}{r}134,609 \\
11,974 \\
17,048 \\
0 \\
497\end{array}$ & $\begin{array}{r}4,159 \\
679 \\
1,620 \\
152 \\
0\end{array}$ & $\begin{array}{r}10,518 \\
402 \\
748 \\
0 \\
0\end{array}$ & $\begin{array}{r}29,448 \\
1,419 \\
476 \\
0 \\
0\end{array}$ & $\begin{array}{r}1,310,000 \\
151,600 \\
191,000 \\
17,50 \\
17,507\end{array}$ \\
\hline 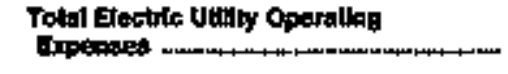 & 4,504 & 165,227 & 0,482 & 11,669 & 81,361 & 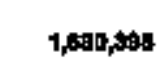 \\
\hline 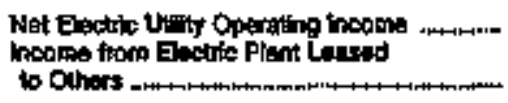 & $\begin{array}{r}12,170 \\
0\end{array}$ & $\begin{array}{r}37,462 \\
0\end{array}$ & 5,405 & $\begin{array}{r}2,700 \\
0\end{array}$ & a,440 & $\begin{array}{r}25 ; 947 \\
0\end{array}$ \\
\hline 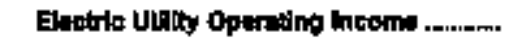 & 12,178 & $\mathbf{3 7 , 4 5 2}$ & 5,465 & 2,700 & 3,495 & 258,947 \\
\hline 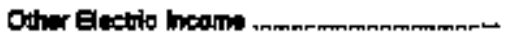 & 3,0es & 4,171 & 357 & $1 B 9$ & 0 & 1899 \\
\hline 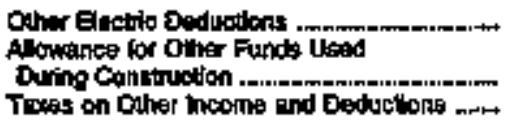 & $\begin{array}{r}9,800 \\
0 \\
0\end{array}$ & $\begin{array}{l}9 \\
0\end{array}$ & $\begin{array}{l}0 \\
0 \\
0\end{array}$ & $\begin{array}{l}\mathbf{0} \\
\mathbf{0} \\
\mathbf{0}\end{array}$ & $\begin{array}{r}3,413 \\
0 \\
0\end{array}$ & $\begin{array}{l}0 \\
0 \\
0\end{array}$ \\
\hline Eeorite Uulhy Income n.mmmnm & 6,019 & $41,4 s 0$ & s,ang & 2,1000 & 78 & 271,869 \\
\hline 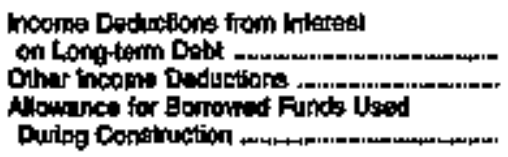 & $\begin{array}{r}1,200 \\
0 \\
0\end{array}$ & $\begin{array}{r}10,285 \\
0 \\
0\end{array}$ & $\begin{array}{r}4,183 \\
1,697 \\
0\end{array}$ & $\begin{array}{r}1,097 \\
-1007 \\
0\end{array}$ & $\begin{array}{r}0 \\
68 \\
0\end{array}$ & $\begin{array}{r}180,802 \\
0 \\
-7,980\end{array}$ \\
\hline 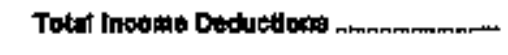 & t,20: & 10,245 & 5,300 & 1,818 & 998 & 162,812 \\
\hline Income Baloke Edrabrdinary Hems ....--...-.. & 4,610 & 31,346 & -50 & 1,061 & -56 & 69,354 \\
\hline 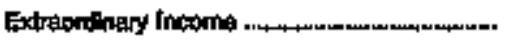 & 0 & 0 & 0 & 0 & 0 & 0 \\
\hline 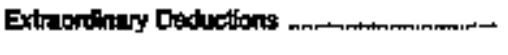 & - & $\mathbf{0}$ & 0 & 0 & $\theta$ & 20,045 \\
\hline Net Inturedé & ס1,010 & 31,349 & -5 & 1,051 & 685 & 0,300 \\
\hline
\end{tabular}

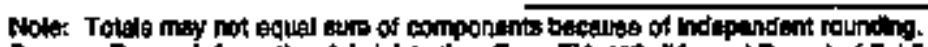

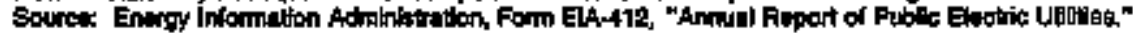


Table 21. Statement of income by Major U.S. Publichy Owned Electric Utility Whinin State, 1994 (Contlnued)

(Thousanti Dollars)

\begin{tabular}{|c|c|c|c|c|c|c|}
\hline in & 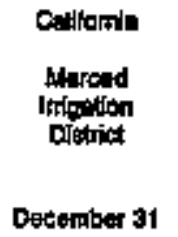 & $\begin{array}{l}\text { Colfomia } \\
\text { Metropoliten } \\
\text { water } \\
\text { Dositiol } \\
\text { Juna } \$ 0\end{array}$ & 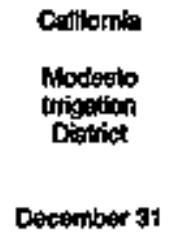 & 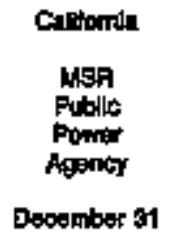 & $\begin{array}{l}\text { Collomia } \\
\text { Northiem } \\
\text { Calfoin'a } \\
\text { Power Agny } \\
\text { Jums } 30\end{array}$ & 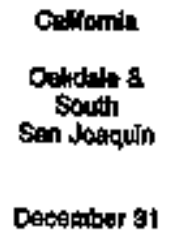 \\
\hline 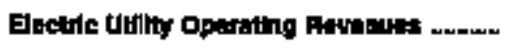 & $3,6.05$ & 13,705 & 130,095 & 6:-ans & 104834 & $5, \mathrm{Bas}$ \\
\hline 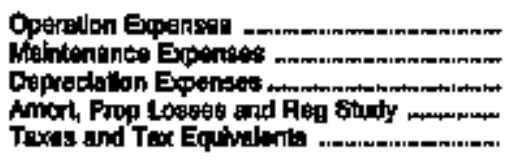 & $\begin{array}{r}812 \\
7637 \\
683 \\
9 \\
484\end{array}$ & $\begin{array}{r}1,281 \\
0 \\
2,002 \\
0 \\
0\end{array}$ & $\begin{array}{r}101,567 \\
7,454 \\
9,184 \\
0 \\
0\end{array}$ & $\begin{array}{r}4,288 \\
2,290 \\
8,394 \\
9 \\
021\end{array}$ & $\begin{array}{r}66,189 \\
5,879 \\
30,859 \\
0 \\
0\end{array}$ & $\begin{array}{r}1,600 \\
327 \\
804 \\
0 \\
0\end{array}$ \\
\hline 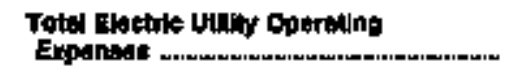 & $3,4: 5$ & $3,3 \%$ & 118, 18: & stiptos & 180,05 & 2,00 \\
\hline 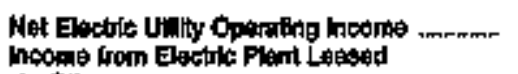 & 169 & 10.442 & 11,813 & 13,213 & $5+1,380$ & 2,045 \\
\hline 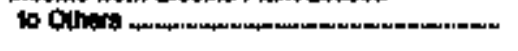 & $\mathbf{0}$ & $\mathbf{0}$ & 0 & 0 & 0 & a \\
\hline 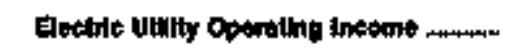 & 160 & 10,48 & 11, 영 & 13218 & E19Pa & 3,045 \\
\hline 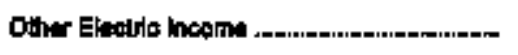 & $\mathbf{0}$ & $\mathbf{0}$ & 2,839 & 4,403 & 49,622 & 1,077 \\
\hline 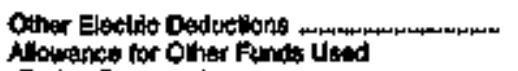 & 125 & $\mathbf{0}$ & stas & 0 & $\mathbf{0}$ & 658 \\
\hline 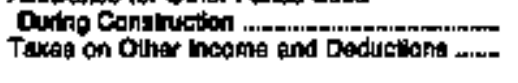 & 0 & 0 & $\begin{array}{l}\mathbf{9} \\
\mathbf{0}\end{array}$ & $\begin{array}{l}0 \\
0\end{array}$ & $\begin{array}{l}\mathbf{0} \\
\mathbf{0}\end{array}$ & 0 \\
\hline 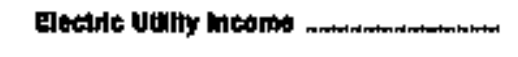 & 46 & 10,44 & 14,427 & 17,676 & $\operatorname{lop}=21$ & 3,204 \\
\hline 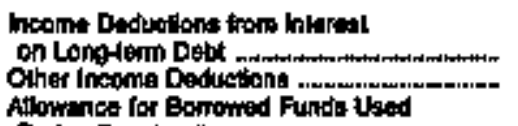 & 80 & $\mathbf{0}$ & 16,895 & 1,2018 & $\begin{array}{r}79,409 \\
\text { B, } 480\end{array}$ & $\begin{array}{l}\mathbf{0} \\
\mathbf{0}\end{array}$ \\
\hline 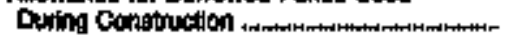 & 0 & $\mathbf{0}$ & 0 & 0 & 0 & 7) \\
\hline Fotel Incone Deduotlons .............. & Dess & $\mathbf{0}$ & 17,000 & 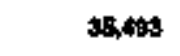 & $60_{1} 108$ & $\mathbf{0}$ \\
\hline Incema Befiore Extraortinary lams ... & -794 & 10,442 & $-3,28 t$ & $-17,817$ & 14,518 & 3,284 \\
\hline 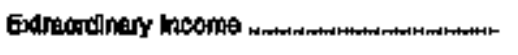 & 0 & $\mathbf{0}$ & 0 & 0 & 0 & 0 \\
\hline Edruordinay Daductions nmmmmmonm- & 0 & $\mathbf{0}$ & 0 & 0 & 0 & 20 \\
\hline 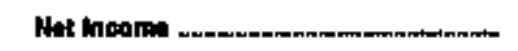 & $-7 a 4$ & 10,48 & $-\$, 261$ & $-\mathbf{t r} \mathbf{0 t z}$ & 14518 & 3.241 \\
\hline
\end{tabular}

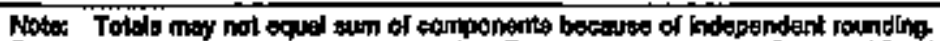

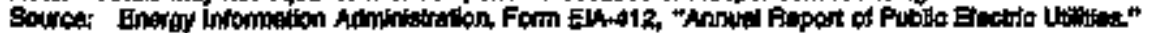


Table 21. Statement of income by Major U.S. Publicly Owned Electric Utility Whin State, 1994 (Continued)

(Thousand Dollars)

\begin{tabular}{|c|c|c|c|c|c|c|}
\hline Ilom & 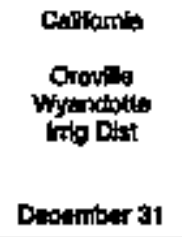 & $\begin{array}{l}\text { Celomia } \\
\text { Pelo Allo } \\
\text { Chy of } \\
\text { June } 80\end{array}$ & $\begin{array}{l}\text { Galiornia } \\
\text { Pandina } \\
\text { Chy of } \\
\text { June } 30\end{array}$ & 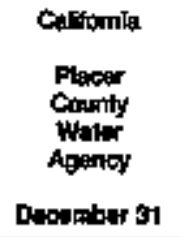 & $\begin{array}{l}\text { Califomb } \\
\text { Ridoting } \\
\text { City of } \\
\text { June so }\end{array}$ & $\begin{array}{l}\text { Caltomba } \\
\text { Piver:ide } \\
\text { Goty of } \\
\text { thene } 30\end{array}$ \\
\hline 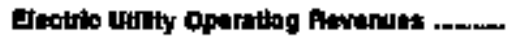 & 7,111 & sopes: & vepa45 & a,oss & $5, \pi r$ & 161,200 \\
\hline 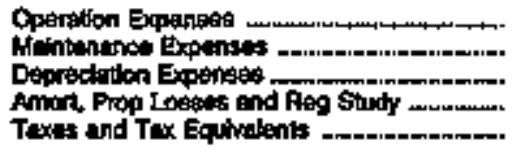 & $\begin{array}{r}1,762 \\
574 \\
1,619 \\
0 \\
0\end{array}$ & $\begin{array}{r}30,492 \\
6,736 \\
3,469 \\
0 \\
9,514\end{array}$ & $\begin{array}{r}60,951 \\
5,490 \\
6,339 \\
0 \\
0\end{array}$ & $\begin{array}{r}1,799 \\
1,642 \\
1,656 \\
0 \\
0\end{array}$ & $\begin{array}{r}45,109 \\
1,280 \\
6,229 \\
0 \\
0\end{array}$ & $\begin{array}{r}119,630 \\
6,697 \\
8,609 \\
0 \\
0\end{array}$ \\
\hline Totel tenetric Ufilly Oparting & 1,065 & 68, 908 & 92,021 & 4leger & 51,912 & 135,091 \\
\hline 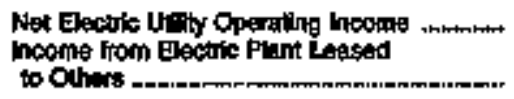 & $\begin{array}{r}3,157 \\
0\end{array}$ & $\begin{array}{r}-12782 \\
0\end{array}$ & $\begin{array}{r}0,424 \\
0\end{array}$ & $\begin{array}{r}3,641 \\
0\end{array}$ & $\begin{array}{r}568 \\
0\end{array}$ & 20,200 \\
\hline 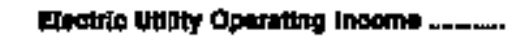 & 3,157 & $-12, \mathrm{rtg}_{2}$ & 9,424 & $3, \mathbf{8 4 1}$ & $\$ 56$ & 28,200 \\
\hline Othar Exatric hoons & $\mathbf{s 0}$ & $3,2 \pi 7$ & 2,945 & 48 & 2,103 & 0,891 \\
\hline 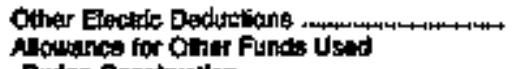 & 0 & a.ta1 & ง & $\mathbf{M 4}$ & 1,303 & 16,071 \\
\hline 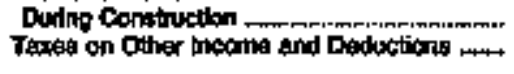 & $\stackrel{0}{0}$ & $\begin{array}{l}0 \\
0\end{array}$ & $\stackrel{0}{20}$ & 0 & $\stackrel{0}{\varphi}$ & $\stackrel{0}{0}$ \\
\hline 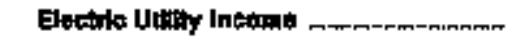 & 3,107 & $-17,686$ & 12,340 & 3,653 & 1,305 & 17,610 \\
\hline 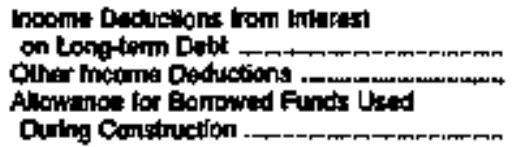 & $\begin{array}{r}2,318 \\
11 \\
0\end{array}$ & $\begin{array}{l}0 \\
0\end{array}$ & 4,484 & 2,413 & $\begin{array}{r}4,146 \\
0 \\
0\end{array}$ & $\begin{array}{r}t 1,380 \\
0 \\
0\end{array}$ \\
\hline Toted income Deduotlons: ...-_-_-_---- & 2,200 & $\mathbf{0}$ & 4,494 & 2,413 & $4,14 B$ & 11,343 \\
\hline 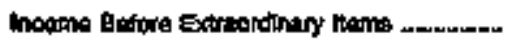 & 850 & $-17,696$ & 7, B65 & 1,240 & $-2,794$ & $5,8,8$ \\
\hline 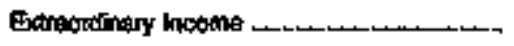 & 147 & 0 & $4,5: 9$ & $\mathbf{n}$ & a & 0 \\
\hline Extrondhory Destuctions . & $\mathbf{0}$ & o & 0 & $\mathbf{0}$ & 0 & o \\
\hline Het heome ... & 1,005 & $-17,636$ & 12,398 & 1,240 & $-2,721$ & s.605 \\
\hline
\end{tabular}

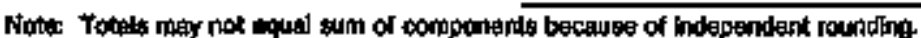

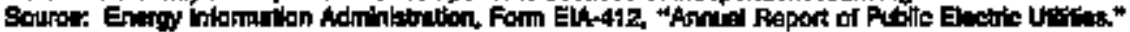


Tabfe 21. Statement of Income by Major US. Publicly Owned Electric Utilty Within State, 1994 (Continued)

(Thousand Dollars)

\begin{tabular}{|c|c|c|c|c|c|c|}
\hline Item & 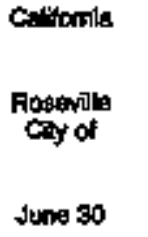 & 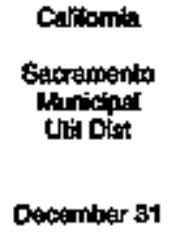 & 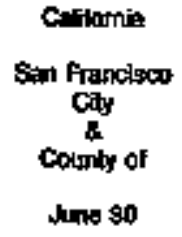 & $\begin{array}{l}\text { Calfomin } \\
\text { Eenta } \\
\text { Care } \\
\text { Ciny of } \\
\text { June so }\end{array}$ & $\begin{array}{l}\text { Cullomia } \\
\text { soulh:m } \\
\text { Caidom: } \\
\text { P P } \\
\text { A } \\
\text { ande } 30\end{array}$ & 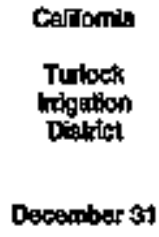 \\
\hline Elnotile Utily Operating Ravronuan .-.... & $\$ 1,560$ & 644,542 & T6,5so & 171004s & 214,430 & 112,180 \\
\hline 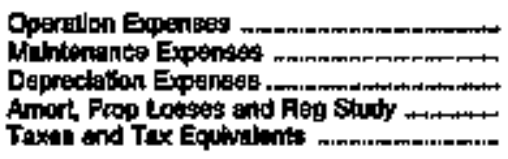 & $\begin{array}{r}31,007 \\
6,502 \\
2,200 \\
0 \\
2,546\end{array}$ & $\begin{array}{r}401,897 \\
25,461 \\
40,770 \\
0,836 \\
141\end{array}$ & $\begin{array}{r}84,306 \\
3,058 \\
6,771 \\
0 \\
975\end{array}$ & $\begin{array}{r}145,399 \\
6,271 \\
6,902 \\
0 \\
9,101\end{array}$ & $\begin{array}{r}60,350 \\
17,002 \\
64,611 \\
0 \\
0\end{array}$ & $\begin{array}{r}00,086 \\
9,568 \\
7,590 \\
0 \\
0\end{array}$ \\
\hline 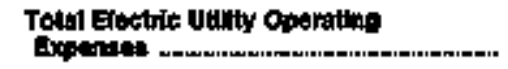 & 4pipa & 568,291 & 67,7 t2 & 167,760. & 181,906 & 91,000 \\
\hline 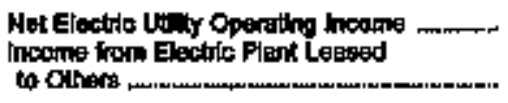 & 190 & $\begin{array}{r}107,051 \\
0\end{array}$ & 8,978 & 3,290 & 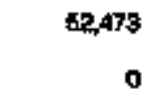 & 21,187 \\
\hline Electlo Uilky Operoting lneoma & 186 & wor,est & ents & 3,209 & 52,478 & 21,167 \\
\hline 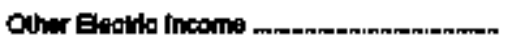 & 7,018 & 39,130 & 14,904 & 24,609 & 36,931 & $-1,160$ \\
\hline 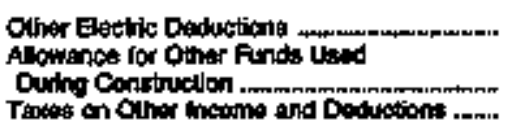 & $\begin{array}{l}0 \\
0 \\
0\end{array}$ & $\begin{array}{r}0 \\
216 \\
0\end{array}$ & $\begin{array}{l}0 \\
0\end{array}$ & $\begin{array}{r}1,484 \\
0 \\
0\end{array}$ & $\begin{array}{r}0 \\
0 \\
11,683\end{array}$ & 0 \\
\hline 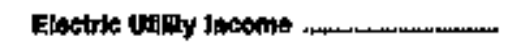 & 7,204 & 145,405 & 28,3077 & 26,455 & $\boldsymbol{m , 7 4 1}$ & Fo, od: \\
\hline 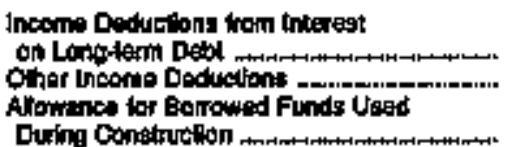 & $\begin{aligned} 556 \\
0\end{aligned}$ & $\begin{array}{r}138,691 \\
7,971 \\
-2,168\end{array}$ & a & $\begin{array}{r}11,254 \\
30 \\
0\end{array}$ & $\begin{array}{r}176,100 \\
0 \\
0\end{array}$ & $\begin{array}{r}5,418 \\
0 \\
0\end{array}$ \\
\hline Totnl uxcome Dedustlons ............. & $5 \div 6$ & 144,434 & $\mathbf{3}$ & 11,284 & 178,100 & 0,410 \\
\hline 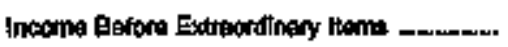 & 6,000 & $1, \$ 71$ & $23,3,8$ & 15,211 & $-98,300$ & 10,500 \\
\hline Extreordintery hocotie & 0 & an,ches & 1,441 & $\mathbf{0}$ & $\mathbf{0}$ & D \\
\hline Extrecodinary Daduations . & 100 & 0 & 38,338 & o & $\mathbf{0}$ & 4,929 \\
\hline 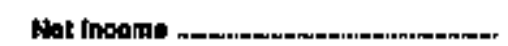 & 5,000 & 22,000 & $-13,5 d r$ & 16,211 & $-89, \sin$ & 5,070 \\
\hline
\end{tabular}

Note: Tolals may nol equal aum of companents because of lndependent rouncling

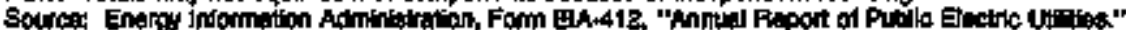


Tabie 21. Statement of Ineome by VIajor US. Publicly Owmed Electric Utility Within State, 1994 (Continuted) (Thousand Dollers)

\begin{tabular}{|c|c|c|c|c|c|c|}
\hline Itom & $\begin{array}{l}\text { Cantemin } \\
\text { Vemon } \\
\text { chy of } \\
\text { June } 90\end{array}$ & 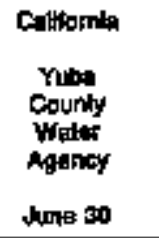 & 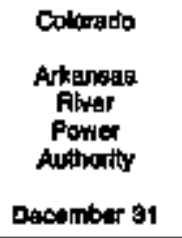 & 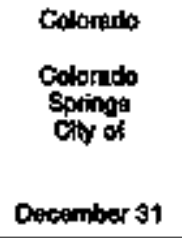 & $\begin{array}{l}\text { Coltuatio } \\
\text { Fort Collints } \\
\text { Ciny 여 } \\
\text { Decomber is }\end{array}$ & $\begin{array}{l}\text { Colonedo } \\
\text { Ford thorgun } \\
\text { Chy of } \\
\text { December } 31\end{array}$ \\
\hline 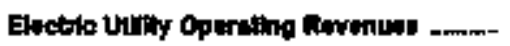 & 65,679 & 11, ans & 10,dts & 170,6:2 & $48,5 \% 4$ & 6,595 \\
\hline 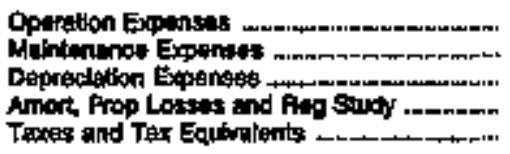 & $\begin{array}{r}42,142 \\
3,607 \\
3,908 \\
1,02 \\
1,622\end{array}$ & $\begin{array}{r}2,586 \\
254 \\
2,444 \\
107 \\
0\end{array}$ & $\begin{array}{r}10,250 \\
0 \\
0 \\
0 \\
0\end{array}$ & $\begin{array}{r}91,829 \\
15,063 \\
25,074 \\
0 \\
11,147\end{array}$ & $\begin{array}{r}40,007 \\
671 \\
3,675 \\
0 \\
2,637\end{array}$ & $\begin{array}{r}4,674 \\
396 \\
277 \\
0 \\
900\end{array}$ \\
\hline 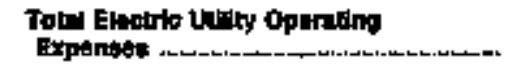 & 51,935 & 6,602 & *0,258 & 142,607 & 46,991 & 6,259 \\
\hline 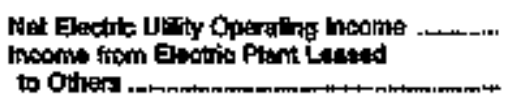 & $\begin{array}{r}4,541 \\
0\end{array}$ & $\begin{array}{r}3,244 \\
3\end{array}$ & $\begin{array}{r}162 \\
0\end{array}$ & $\begin{array}{r}27,976 \\
0\end{array}$ & $\begin{array}{r}-396 \\
0\end{array}$ & 358 \\
\hline Electro vtulty Oporathig lneome nnmm. & $4 ; 841$ & 6,247 & 102 & 27,975 & $-8+6$ & 399 \\
\hline 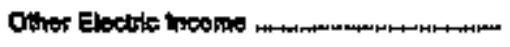 & 30,005 & 䄈 & six & O,B\$4 & 2022 & 119 \\
\hline 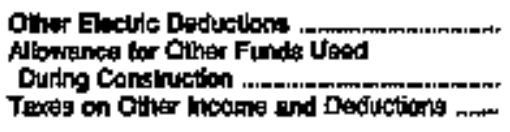 & $\begin{array}{r}250 \\
0 \\
0\end{array}$ & $\stackrel{0}{0}$ & $\begin{array}{l}0 \\
0 \\
0\end{array}$ & $\begin{array}{r}0 \\
57 a \\
0\end{array}$ & $\begin{array}{l}0 \\
0 \\
0\end{array}$ & $\begin{array}{l}0 \\
0 \\
0\end{array}$ \\
\hline Eloctro titllty lacome nom & $38, \tan$ & 6,572 & 65 & as, 20: & 1,628 & 455 \\
\hline 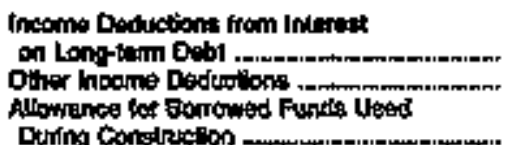 & $\begin{array}{r}0 \\
4,746 \\
0\end{array}$ & $\frac{4,292}{77}$ & $\begin{array}{l}\mathbf{0} \\
\mathbf{0}\end{array}$ & $\begin{array}{r}274 \\
-6,078\end{array}$ & $\stackrel{0}{0}$ & o \\
\hline 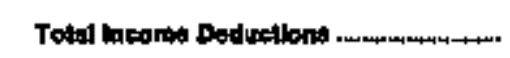 & 4,748 & 4,900 & $\mathbf{0}$ & 28,59t5 & 0 & a \\
\hline 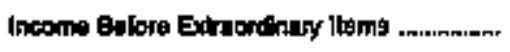 & $\mathbf{3 5 , 4 4 4}$ & 2,009 & $6 \pi 9$ & 12,650 & 1,898 & 455 \\
\hline Extracollinary income & 0 & 0 & a & 0 & 0 & 0 \\
\hline 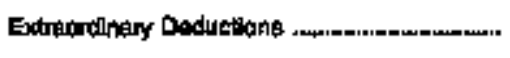 & 0 & 0 & a & $\theta, 816$ & 0 & 0 \\
\hline 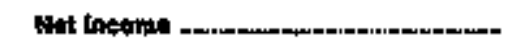 & 33,444 & 2,003 & GT3 & 2,935 & 1,406 & 458 \\
\hline
\end{tabular}

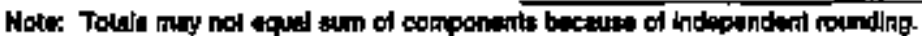

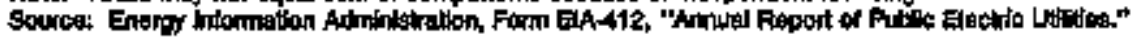


Table 21. Statement of Income by Major U.S. Publicty Owned Electric Utilty Within State, 1994 (Continued)

(Thousand Dollars)

\begin{tabular}{|c|c|c|c|c|c|c|}
\hline Ihm & $\begin{array}{l}\text { Cofortado } \\
\text { Longmont } \\
\text { City of } \\
\text { Deceamber } 31\end{array}$ & $\begin{array}{l}\text { Colorado } \\
\text { Lowedend } \\
\text { City of } \\
\text { Decentuer } 31\end{array}$ & 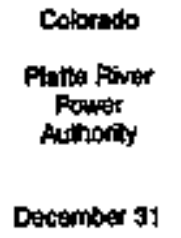 & $\begin{array}{l}\text { Conneotiont } \\
\text { Connoclloul } \\
\text { Nun } \\
\text { Elet } \\
\text { Enpy Coop } \\
\text { Decentuer } 31\end{array}$ & $\begin{array}{l}\text { Commoticul } \\
\text { Crolon } \\
\text { City of } \\
\text { June } 30\end{array}$ & $\begin{array}{l}\text { Connectioun } \\
\text { Nonmich } \\
\text { Gity of } \\
\text { June } 30\end{array}$ \\
\hline Electric Udily Operabing Revanus ....... & 25,0100 & $\mathbf{2 1 , 0 0 4}$ & 137,468 & en,4s: & 45,352 & 25,145 \\
\hline 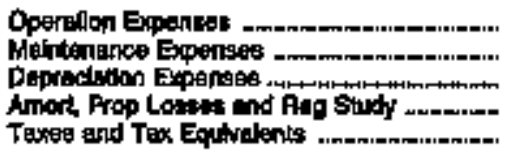 & $\begin{array}{r}21,169 \\
677 \\
1,115 \\
0 \\
1,412\end{array}$ & $\begin{array}{r}14,650 \\
638 \\
1,390 \\
0 \\
1,314\end{array}$ & $\begin{array}{r}58,876 \\
10,065 \\
21,9844 \\
8,986 \\
0\end{array}$ & $\begin{array}{r}62,729 \\
374 \\
1,761 \\
37 \\
62\end{array}$ & $\begin{array}{r}39,987 \\
657 \\
1.291 \\
0 \\
2,110\end{array}$ & $\begin{array}{r}23,059 \\
691 \\
977 \\
0 \\
1,376\end{array}$ \\
\hline 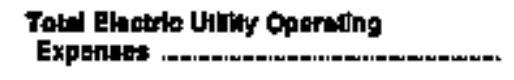 & $\mathbf{2 4 , 3 6 9}$ & tol, 192 & 0,769 & 64,095 & 43,275 & 24,242 \\
\hline 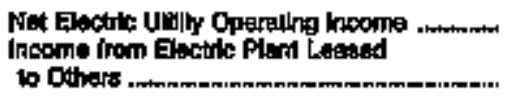 & $\begin{array}{r}-494 \\
0\end{array}$ & $\begin{array}{r}9,712 \\
0\end{array}$ & $\begin{array}{r}37,706 \\
0\end{array}$ & $\begin{array}{r}\$, 475 \\
0\end{array}$ & 2,116 & $\begin{array}{l}-97 \\
641\end{array}$ \\
\hline Electile Utlity Operating lneome & -404 & $\mathbf{3 , 7 1 2}$ & 37,760 & S,ats & 2,116 & 545 \\
\hline 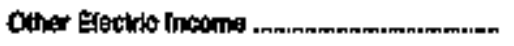 & 475 & 894 & 10,451 & 4,560 & 354 & 72 \\
\hline 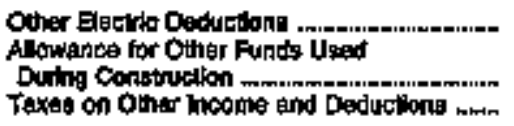 & 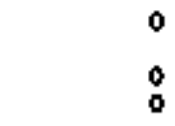 & $\begin{array}{r}1,602 \\
0 \\
0\end{array}$ & $\begin{array}{l}0 \\
0 \\
0\end{array}$ & 0 & $\begin{array}{r}1,002 \\
0 \\
0\end{array}$ & $\begin{array}{l}0 \\
0 \\
0\end{array}$ \\
\hline 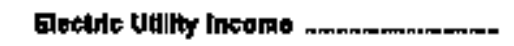 & $-\theta$ & 3,090 & 18,189 & to, 135 & 1,25 & 617 \\
\hline 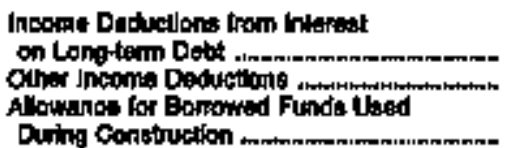 & $\begin{array}{l}0 \\
0\end{array}$ & $\begin{array}{r}632 \\
0\end{array}$ & $\begin{array}{r}32,1195 \\
5,452\end{array}$ & 9,421 & $\begin{array}{r}470 \\
70\end{array}$ & $2 \pi$ \\
\hline 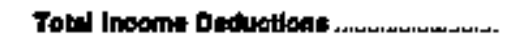 & 0 & $\$ 2$ & 37,638 & $9, \mathbf{1 2 1}$ & sag & 20 \\
\hline 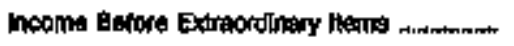 & -9 & 2,551 & 10,581 & $\mathbf{7 1 9}$ & ase & 354 \\
\hline Extreordnary heopop & 0 & 0 & 0 & 0 & 0 & 0 \\
\hline 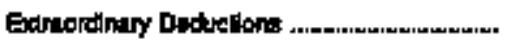 & 0 & 0 & 0 & $\mathbf{0}$ & $\mathbf{0}$ & 0 \\
\hline 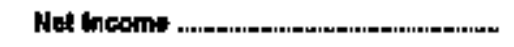 & -6 & 2,601 & 10,521 & 713 & 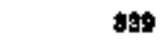 & 354 \\
\hline
\end{tabular}

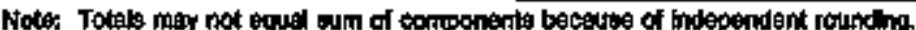

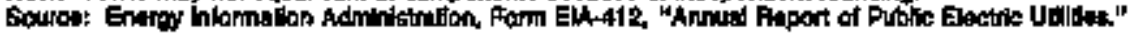


Table 21. Statement of Income by Major U.S. Publicly Ownod Electric Utility Whin state, 1994 (Continued)

(Thousand Dollars)

\begin{tabular}{|c|c|c|c|c|c|c|}
\hline Ikm & 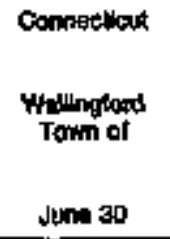 & $\begin{array}{l}\text { Deslawara } \\
\text { Dower } \\
\text { Cay of } \\
\text { June no }\end{array}$ & 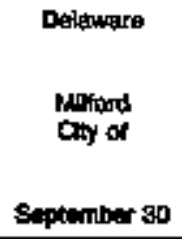 & 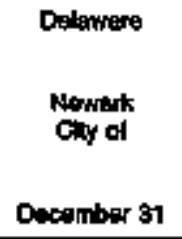 & $\begin{array}{l}\text { Flocida } \\
\text { Bertom } \\
\text { Coly of } \\
\text { Septembar so }\end{array}$ & 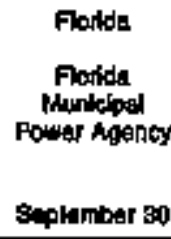 \\
\hline 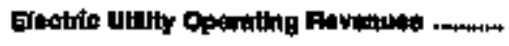 & 90,753 & 46,697 & $11,1+10$ & 21,005 & $20 ; 344$ & 195,949 \\
\hline 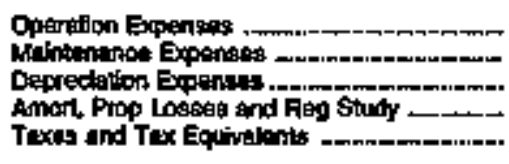 & $\begin{array}{r}36,359 \\
1,659 \\
1,313 \\
0 \\
1,068\end{array}$ & $\begin{array}{r}31,679 \\
0 \\
2,667 \\
0 \\
1,061\end{array}$ & $\begin{array}{r}9,197 \\
427 \\
308 \\
0 \\
368\end{array}$ & $\begin{array}{r}15,399 \\
\$ B 1 \\
491 \\
0 \\
0\end{array}$ & $\begin{array}{r}16,143 \\
0 \\
35 \% \\
0 \\
0\end{array}$ & $\begin{array}{r}114,327 \\
6,435 \\
10,146 \\
0 \\
0\end{array}$ \\
\hline $\begin{array}{l}\text { Totel Elastric Utony Oparading } \\
\text { Expentes: }\end{array}$ & 41,219 & 36,390 & 0,234 & 16,026 & $\tan 49 \theta$ & 130,900 \\
\hline 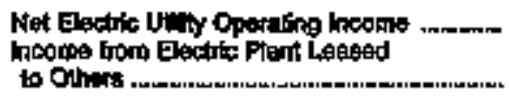 & -467 & 11,290 & $\begin{array}{r}1,876 \\
0\end{array}$ & $\begin{array}{r}6,070 \\
0\end{array}$ & 5044 & 34,700 \\
\hline 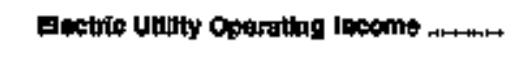 & -47 & 11,290 & 1,075 & 5,070 & 5,144 & 98,790 \\
\hline Other घectilic masine & 499 & $5+0$ & $\mathbf{3 6 2}$ & 0 & 218 & 17,200 \\
\hline 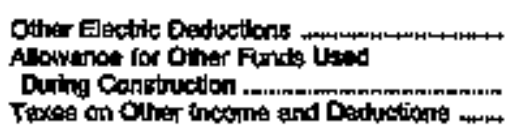 & $\begin{array}{r}1,580 \\
0 \\
0\end{array}$ & $\begin{array}{l}0 \\
0 \\
0\end{array}$ & $\begin{array}{l}0 \\
0 \\
0\end{array}$ & $\begin{array}{l}0 \\
0 \\
0\end{array}$ & $\begin{array}{l}0 \\
0 \\
0\end{array}$ & $\begin{array}{l}0 \\
0 \\
0\end{array}$ \\
\hline 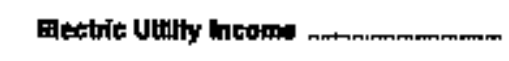 & $-1,001$ & 11,800 & 2,36 & 5,070 & 6,082 & 62,079 \\
\hline 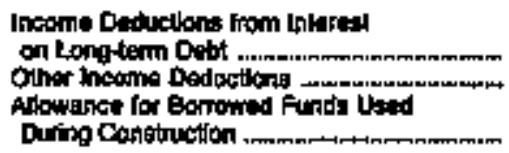 & $\begin{array}{r}35 \\
37 \\
0\end{array}$ & $\begin{array}{r}2015 \\
79 \\
0\end{array}$ & $\begin{array}{r}0 \\
1,766 \\
0\end{array}$ & o & $\begin{array}{l}0 \\
0 \\
0\end{array}$ & $\begin{array}{r}30,120 \\
15,1=0 \\
0\end{array}$ \\
\hline 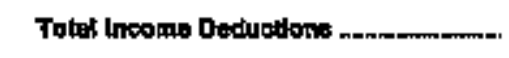 & $\mathbf{7 2}$ & 2,004 & $1,7 \mathrm{tes}$ & o & $\mathbf{0}$ & 62,078 \\
\hline Inoome Bslore Exraordinary liwns nnmrem- & $-1,679$ & $\mathrm{D.700}$ & अa & 5,070 & 6.080 & o \\
\hline Expontinay Ineorde & o & 0 & 42 & a & $5,2,02$ & D \\
\hline 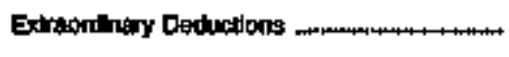 & a & 3,184 & 253 & 0 & 4,720 & 0 \\
\hline Hat locompt & $-1,79$ & 0,595 & $\$ 39$ & 5,070 & 6,544 & 0 \\
\hline
\end{tabular}

Note: Totals may nok equal stum of componense bocaunt od indapendent rounfing.

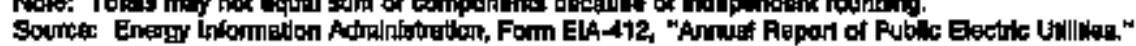


Table 21. Statement of Income by Major U.S. Publicly Owned Electric Utility Within State, 1994 (Continused)

(Thoustand Dollars)

\begin{tabular}{|c|c|c|c|c|c|c|}
\hline tem & 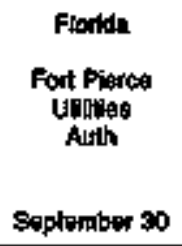 & 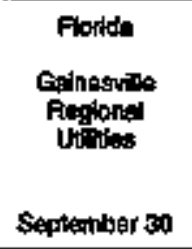 & 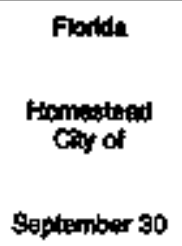 & 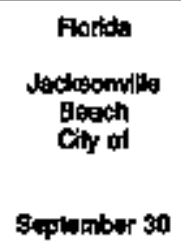 & 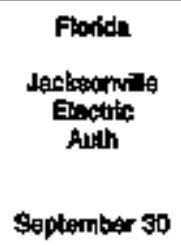 & $\begin{array}{l}\text { Fonds } \\
\text { Koy Wegt } \\
\text { City of } \\
\text { Septomber } 30\end{array}$ \\
\hline 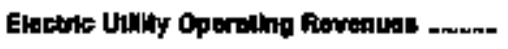 & 41,150 & 134,548 & 15,450 & 40,351 & B98,231 & $B 1,071$ \\
\hline 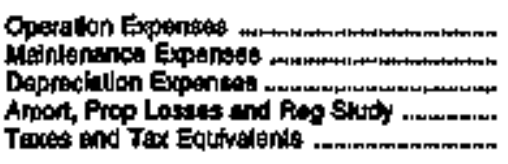 & $\begin{array}{r}27,690 \\
1,769 \\
3,07 \% \\
1,076\end{array}$ & $\begin{array}{r}57,558 \\
10,029 \\
14,298 \\
0 \\
13,167\end{array}$ & $\begin{array}{r}17,707 \\
5,606 \\
1,629 \\
0 \\
1,129\end{array}$ & $\begin{array}{r}32,650 \\
565 \\
2,346 \\
0 \\
0\end{array}$ & $\begin{array}{r}393,418 \\
39,346 \\
78,491 \\
0 \\
15,618\end{array}$ & $\begin{array}{r}33,337 \\
3,936 \\
4,989 \\
1,316\end{array}$ \\
\hline 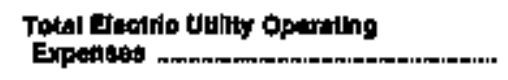 & 34512 & 96,017 & $25,6=9$ & 35,267 & 490,603 & $43, \sqrt{37}$ \\
\hline 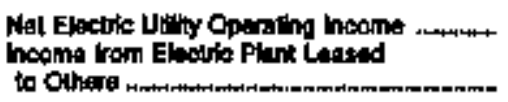 & 6,8388 & $\begin{array}{r}19,529 \\
0\end{array}$ & $\begin{array}{r}-8,570 \\
0\end{array}$ & 5064 & $\begin{array}{r}171,398 \\
0\end{array}$ & $\begin{array}{r}0,294 \\
0\end{array}$ \\
\hline Ehelito Unlty Opereiting heome & 6,089 & 90,620 & $-6,976$ & B,ood & 171,368 & $B, 2=4$ \\
\hline 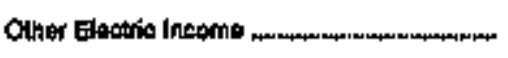 & 609 & $\mathbf{5}, 970$ & e,p1s & 1,447 & 101,202 & $\operatorname{ses}$ \\
\hline 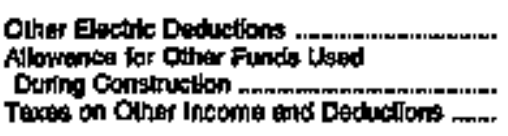 & $\begin{array}{l}0 \\
0 \\
0\end{array}$ & $\begin{array}{l}0 \\
0 \\
0\end{array}$ & 0 & $\begin{array}{r}3,602 \\
002\end{array}$ & $\begin{array}{l}0 \\
0 \\
0\end{array}$ & $\begin{array}{l}0 \\
0 \\
0\end{array}$ \\
\hline 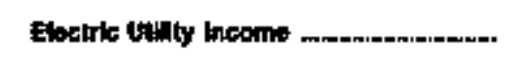 & 7,547 & 25,490 & 40 & 2,536 & 272,670 & 0,217 \\
\hline 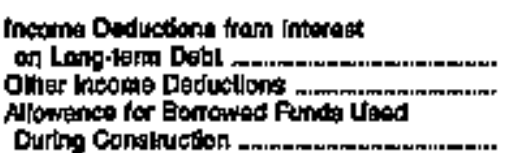 & $\begin{array}{r}2,778 \\
2,820 \\
0\end{array}$ & $\begin{array}{r}17,376 \\
0 \\
0\end{array}$ & ${ }_{0}^{434}$ & $\begin{array}{r}4,458 \\
0\end{array}$ & $\begin{array}{r}170, \operatorname{seg} 9 \\
20,890 \\
-1,340\end{array}$ & $\begin{array}{r}8,054 \\
347\end{array}$ \\
\hline 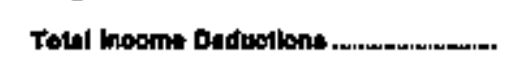 & 6.905 & 17,375 & 40 & 4ABS & 100,495 & B,452 \\
\hline 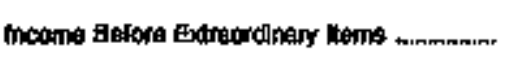 & 1,042 & 8,123 & 12 & $-1,920$ & EA,0aA & 885 \\
\hline 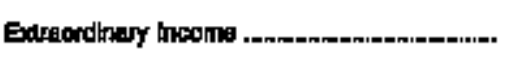 & $\mathbf{0}$ & 0 & o & 0 & 6 & 0 \\
\hline 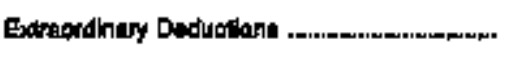 & 0 & 0 & 0 & D & 0 & 0 \\
\hline Hot Inooint & 1,042 & a,123 & 12 & $-1,000$ & 03,004 & ges \\
\hline
\end{tabular}

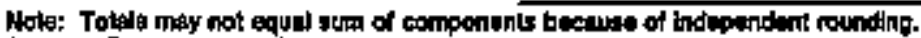

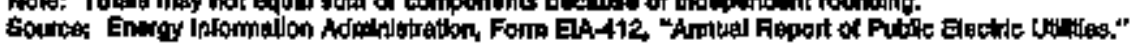


Table 2t. Statement of Income by Major U.S. Publicly Owned Eloctric Utility Within State, 1894 (Continued)

(Thousand Dollars)

\begin{tabular}{|c|c|c|c|c|c|c|}
\hline tham & 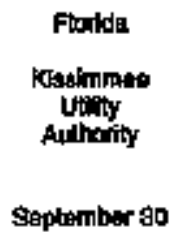 & $\begin{array}{l}\text { Forita } \\
\text { Lake Wonth } \\
\text { Cly of }\end{array}$ & $\begin{array}{l}\text { Florida } \\
\text { Lekpeland } \\
\text { City of } \\
\text { Septeninber } 30\end{array}$ & 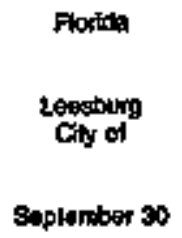 & 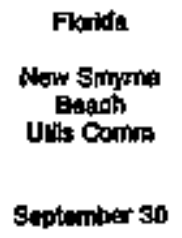 & 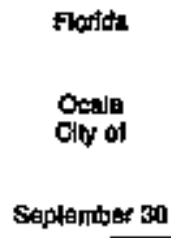 \\
\hline 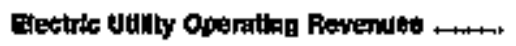 & 65,608 & 3406 & $16 \%, 035$ & 27, B-41 & 24352 & 74,476 \\
\hline 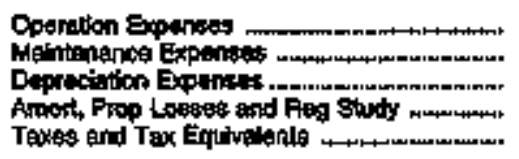 & $\begin{array}{r}41,670 \\
3,797 \\
7,000 \\
2,000 \\
39\end{array}$ & $\begin{array}{r}21,96 \\
1,372 \\
2,353 \\
0,302\end{array}$ & $\begin{array}{r}77,002 \\
16,142 \\
18,178 \\
0 \\
0\end{array}$ & $\begin{array}{r}10,861 \\
1,410 \\
1,772 \\
136 \\
700\end{array}$ & $\begin{array}{r}18,506 \\
654 \\
1,892 \\
31 \\
1,486\end{array}$ & $\begin{array}{r}49,856 \\
2375 \\
2980 \\
4,981 \\
1,881\end{array}$ \\
\hline 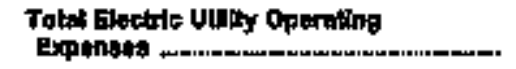 & 56,7405 & 20,809 & 111,342 & 22,708 & 22,3419 & 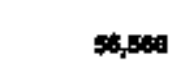 \\
\hline 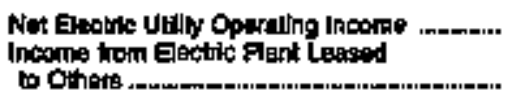 & 0 & 3,702 & $\begin{array}{r}45,694 \\
0\end{array}$ & 4,858 & 2,0 & $\begin{array}{r}17,000 \\
0\end{array}$ \\
\hline 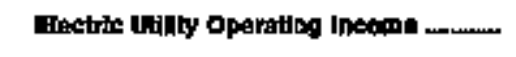 & 9,913 & a,pon & 16809 & 4,650 & 2,038 & 17,909 \\
\hline Other Elactite monmb & 4,167 & 1,016 & 23,231 & 691 & 455 & 1,258 \\
\hline 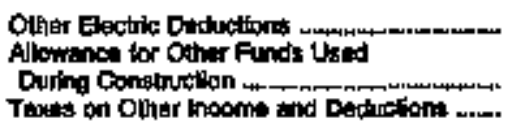 & $\begin{array}{l}0 \\
0 \\
0\end{array}$ & 0 & $\begin{array}{r}11,347 \\
0 \\
0\end{array}$ & $\begin{array}{r}3.402 \\
0 \\
0\end{array}$ & $\begin{array}{r}71 \\
0 \\
0\end{array}$ & $\begin{array}{l}0 \\
0 \\
0\end{array}$ \\
\hline Efoetrit Uy lly meems . & n,0.08 & s,ats & 67,570 & 2,335 & 2,417 & 18,164 \\
\hline 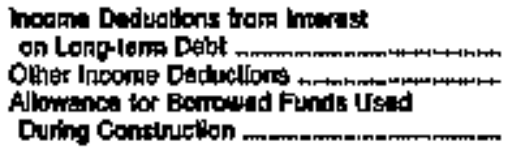 & $\begin{array}{r}6,543 \\
t, 4,99 \\
0\end{array}$ & $\begin{array}{r}2,110 \\
0 \\
0\end{array}$ & $\begin{array}{r}2,8002 \\
1,501 \\
0\end{array}$ & $\begin{array}{r}1,100 \\
0 \\
0\end{array}$ & $\begin{array}{r}1,619 \\
111 \\
0\end{array}$ & $\begin{array}{r}1,179 \\
0 \\
0\end{array}$ \\
\hline Total heome Deduetens ............... & 6,068 & $\mathbf{2 , 1 1 0}$ & 20,363 & 1,100 & 1,7300 & 1,179 \\
\hline 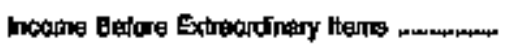 & 6,014 & 3,208 & $\mathbf{3 2 , 2 1 9}$ & 1,236 & $\operatorname{sen}$ & 17,984 \\
\hline 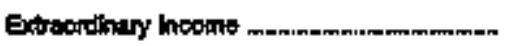 & 0 & 0 & 0 & D & o & 0 \\
\hline 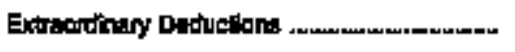 & 0 & 0 & $\mathbf{0}$ & 0 & $\mathbf{0}$ & $\theta$ \\
\hline 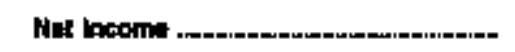 & 0,014 & 8,206 & 32,215 & 1,295 & $\operatorname{ser}$ & $\mathbf{3 7 , 9 9 4}$ \\
\hline
\end{tabular}

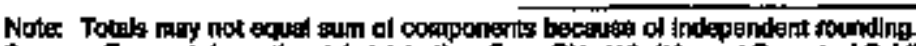

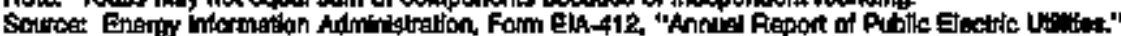


Table 21. Statement of tneome by Mejor US, Fublicly Owned Electric Utility Whin State, 1904 (Continured) (Thousand Dollars)

\begin{tabular}{|c|c|c|c|c|c|c|}
\hline Item & $\begin{array}{l}\text { Fonda } \\
\text { OHanda } \\
\text { Utives } \\
\text { Comm } \\
\text { Seplember ;0 }\end{array}$ & $\begin{array}{l}\text { Fondin } \\
\text { Culney } \\
\text { City of } \\
\text { September } 30\end{array}$ & $\begin{array}{c}\text { Fiorida } \\
\text { Pheody Greek } \\
\text { Improvement } \\
\text { Oid } \\
\text { Eeptember so }\end{array}$ & $\begin{array}{l}\text { Forida } \\
\text { st Clout } \\
\text { Ciny of } \\
\text { Septentuer } 30\end{array}$ & $\begin{array}{l}\text { Floikd } \\
\text { Tallahassase } \\
\text { City of } \\
\text { September so }\end{array}$ & $\begin{array}{l}\text { Florida } \\
\text { Vero } \\
\text { Boach } \\
\text { Ghy of } \\
\text { Seplemiber } 30\end{array}$ \\
\hline Etedrfo Utbity Operating Aovanuse ...r.... & 301,800 & $9,5,7$ & 56,685 & 2,709 & 171,204 & 44,402 \\
\hline 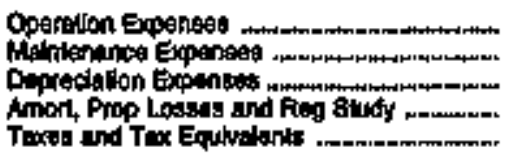 & $\begin{array}{r}145,429 \\
20,025 \\
34,911 \\
115 \\
17,221\end{array}$ & $\begin{array}{r}5,979 \\
420 \\
182 \\
0 \\
147\end{array}$ & $\begin{array}{r}39,658 \\
4,974 \\
4,315 \\
1,054\end{array}$ & $\begin{array}{r}74,740 \\
497 \\
3,050 \\
0 \\
576\end{array}$ & $\begin{array}{r}105,518 \\
3,749 \\
11,9=0 \\
175 \\
0\end{array}$ & $\begin{array}{r}29,097 \\
2,752 \\
4,194 \\
0 \\
103\end{array}$ \\
\hline 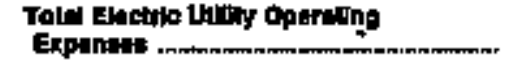 & 221,601 & 4,742 & $6 t, 000$ & 18,210 & 121,762 & 35,009 \\
\hline 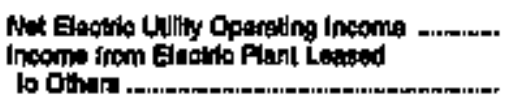 & $\begin{array}{r}80,200 \\
0\end{array}$ & $\begin{array}{r}2,205 \\
0\end{array}$ & 5,686 & $\begin{array}{r}4,529 \\
0\end{array}$ & $\begin{array}{r}49,491 \\
0\end{array}$ & 9,408 \\
\hline 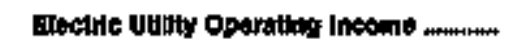 & $60,4 \times 9$ & 3,905 & Apses & 459 & 45,491 & 9,405 \\
\hline 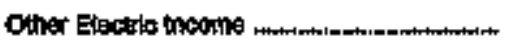 & 27,034 & 149 & 0 & 262 & 7,911 & 1,730 \\
\hline 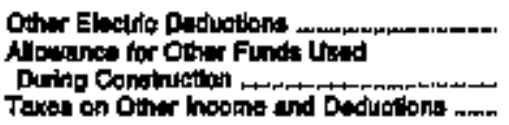 & $\begin{array}{r}15,291 \\
0 \\
0\end{array}$ & $\begin{array}{l}12 \\
0 \\
0\end{array}$ & $\begin{array}{l}1 \\
0 \\
0\end{array}$ & $\begin{array}{l}0 \\
0 \\
0\end{array}$ & $\begin{array}{r}310 \\
0 \\
0\end{array}$ & 0 \\
\hline 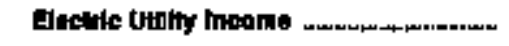 & gaz, 135 & 2;041 & 5,800 & 4,70 & 6,002 & 11,19 \\
\hline 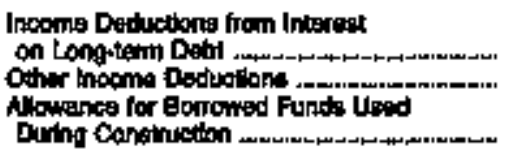 & $\begin{array}{r}68,755 \\
10,282 \\
0\end{array}$ & $\begin{array}{l}0 \\
0 \\
0\end{array}$ & $\begin{array}{r}7,516 \\
04 \\
0\end{array}$ & $\begin{array}{r}1,800 \\
0 \\
0\end{array}$ & $\begin{array}{r}3,697 \\
30,760 \\
-3,570\end{array}$ & $\begin{array}{r}5,819 \\
3,069 \\
0\end{array}$ \\
\hline Toted Ineone Doduttione & 70 nas & $\mathbf{0}$ & 7,000 & 1,069 & 4:408 & 9,7r2 \\
\hline 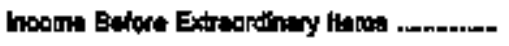 & 13,009 & 2,041 & -2084 & 3,122 & 14,600 & 2,867 \\
\hline 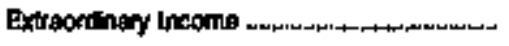 & 0 & $\mathbf{0}$ & a & o & 0 & 0 \\
\hline 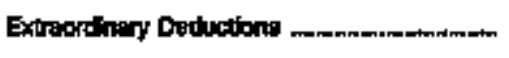 & 0 & 0 & 0 & a & 0 & o \\
\hline 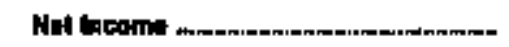 & $\mathbf{x}, 000$ & 2,801 & $-2,884$ & 3,122 & 14,000 & 2,087 \\
\hline
\end{tabular}

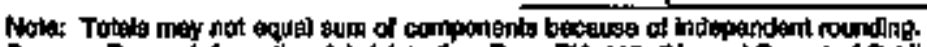

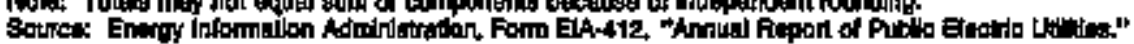


Table 21. Statement of Income by Major U.S. Publiefy Owned Electrte Utility Whtin State, 1994 (Continued) (Thousand Dollars)

\begin{tabular}{|c|c|c|c|c|c|c|}
\hline tiem & 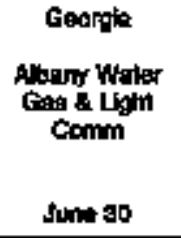 & 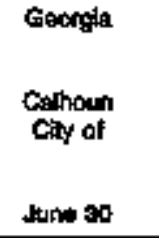 & $\begin{array}{l}\text { Geoposa } \\
\text { Curtersillo } \\
\text { Dity of } \\
\text { Jum } 30\end{array}$ & $\begin{array}{l}\text { Geongia } \\
\text { Caloge } \\
\text { Pat Chy of } \\
\text { Nos } 30\end{array}$ & $\begin{array}{l}\text { Brongh } \\
\text { Covingion } \\
\text { City of } \\
\text { Decamber \$1 }\end{array}$ & 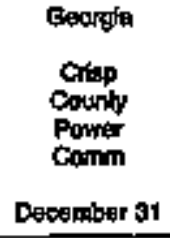 \\
\hline 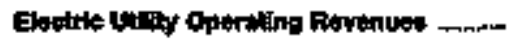 & 58,54 & $19,0 \% 5$ & 27,240 & 17,525 & 16,179 & 7,794 \\
\hline 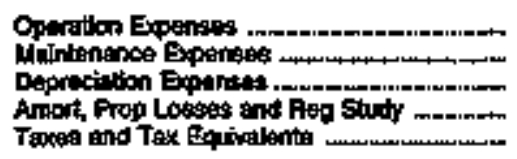 & $\begin{array}{r}5,058 \\
1,720 \\
1,260 \\
0 \\
0\end{array}$ & $\begin{array}{r}76,030 \\
178 \\
291 \\
0 \\
0\end{array}$ & $\begin{array}{r}2,030 \\
118 \\
3 \$ 7 \\
0 \\
1,255\end{array}$ & $\begin{array}{r}17,0098 \\
212 \\
290 \\
0 \\
0\end{array}$ & $\begin{array}{r}12,544 \\
198 \\
6 \\
0 \\
991\end{array}$ & $\begin{array}{r}13,650 \\
585 \\
1,978 \\
0 \\
786\end{array}$ \\
\hline 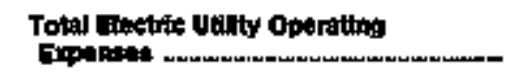 & 53,52: & $16,40 \%$ & 28,739 & 77,530 & - 13,421 & 1,950 \\
\hline 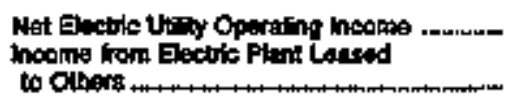 & $\begin{array}{r}4,828 \\
0\end{array}$ & $\begin{array}{r}2,540 \\
0\end{array}$ & $\begin{array}{r}3,502 \\
0\end{array}$ & $\begin{array}{r}-5 \\
0\end{array}$ & 2,757 & $\begin{array}{r}1,413 \\
0\end{array}$ \\
\hline 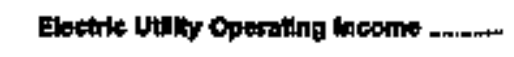 & 4,606 & 2,59 & 3,502 & -5 & 2,767 & 1,413 \\
\hline 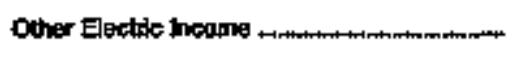 & 2,026 & 55 & 134 & $\$ 3$ & 360 & 386 \\
\hline 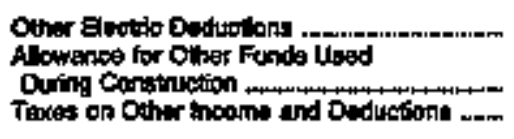 & $\begin{array}{l}0 \\
0 \\
0\end{array}$ & $\begin{array}{l}0 \\
0 \\
0\end{array}$ & $\begin{array}{r}3,900 \\
0 \\
0\end{array}$ & $\begin{array}{r}474 \\
0\end{array}$ & $\begin{array}{l}0 \\
0 \\
0\end{array}$ & $\begin{array}{r}0 \\
0 \\
0\end{array}$ \\
\hline Eletrle Utiby Inepras & 8,651 & 2,508 & -184 & 494 & 3,108 & 1,741 \\
\hline 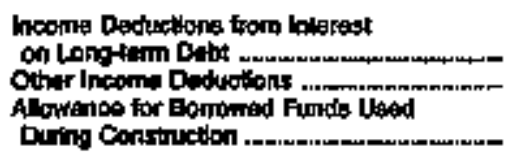 & $\stackrel{0}{90}$ & $\begin{array}{r}441 \\
2,914 \\
0\end{array}$ & $\begin{array}{l}0 \\
0 \\
0\end{array}$ & $\begin{array}{l}0 \\
0 \\
0\end{array}$ & $\begin{array}{r}15 \\
0 \\
0\end{array}$ & $\begin{array}{r}0 \\
288 \\
0\end{array}$ \\
\hline 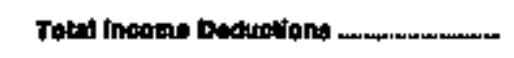 & 30 & 3,354 & 0 & o & 15 & 298 \\
\hline 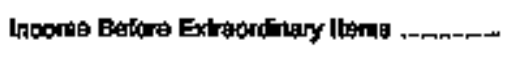 & 6,020 & -757 & -164 & 494 & 3,092 & 1,474 \\
\hline 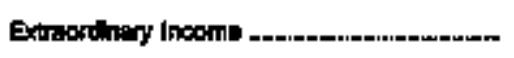 & 0 & 7,696 & $\mathbf{0}$ & o & 0 & 0 \\
\hline Extraontinary Deductions: & 0 & 5,408 & 0 & 0 & 0 & 0 \\
\hline 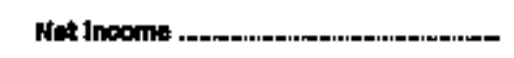 & 6,602 & 1,505 & -184 & 494 & 3,002 & 1,474 \\
\hline
\end{tabular}

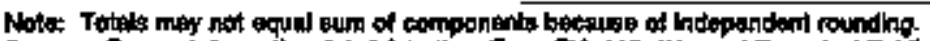

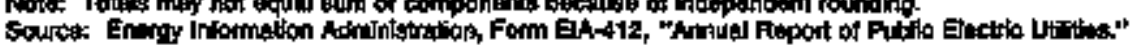


Table 21. Statement of Income by Major U.S. Publicly Owned Electrio Utillizy Within State, 1994 (Continuted) (Thousand Dollars)

\begin{tabular}{|c|c|c|c|c|c|c|}
\hline bem & 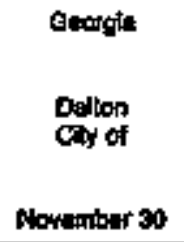 & $\begin{array}{l}\text { Georgin } \\
\text { Doundag } \\
\text { Cing of } \\
\text { Jund } 30\end{array}$ & 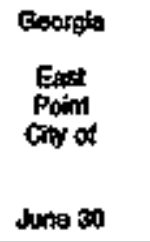 & 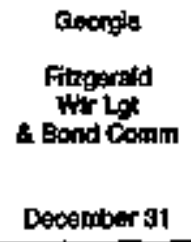 & 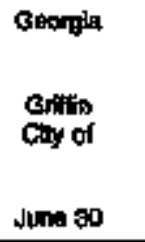 & $\begin{array}{l}\text { Coorga } \\
\text { L Grange } \\
\text { Oty of } \\
\text { June } 30\end{array}$ \\
\hline 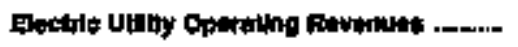 & 4,708 & 1468 & 22,244 & 11,456 & 24,023 & 29,060 \\
\hline 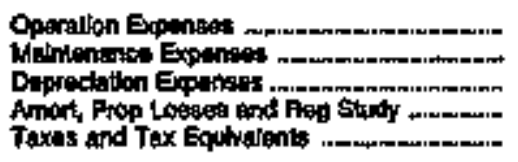 & $\begin{array}{r}27,422 \\
6,963 \\
5,196 \\
140\end{array}$ & $\begin{array}{r}11,696 \\
242 \\
168 \\
0 \\
2,209\end{array}$ & $\begin{array}{r}17,470 \\
160 \\
667 \\
0 \\
0\end{array}$ & $\begin{array}{r}8,364 \\
637 \\
251 \\
0 \\
0\end{array}$ & $\begin{array}{r}18,127 \\
140 \\
390 \\
0 \\
0\end{array}$ & $\begin{array}{r}22,199 \\
0 \\
203 \\
0 \\
0\end{array}$ \\
\hline Total Elastrole villy Operiting & 32,721 & 14,346 & 10,340 & 90,260 & 12,5 & 22,701 \\
\hline 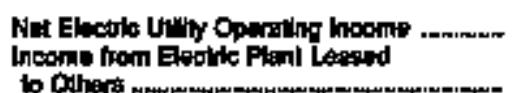 & 7,042 & 97 & $\begin{array}{r}0,804 \\
0\end{array}$ & $\begin{array}{r}1,206 \\
0\end{array}$ & $\begin{array}{r}4,428 \\
0\end{array}$ & $\begin{array}{r}6,587 \\
0\end{array}$ \\
\hline 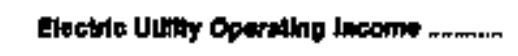 & 6,470 & 97 & 1,and & 1,200 & 4,4s: & 6,357 \\
\hline Othar Electhe hoome & 18,711 & 240 & a & 829 & 28 & 0 \\
\hline 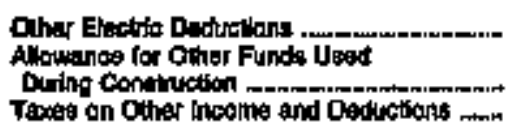 & $\begin{array}{l}0 \\
0 \\
0\end{array}$ & 0 & $\begin{array}{l}0 \\
0 \\
0\end{array}$ & $\begin{array}{l}0 \\
0 \\
0\end{array}$ & $\begin{array}{l}0 \\
0 \\
0\end{array}$ & $\begin{array}{l}0 \\
0 \\
0\end{array}$ \\
\hline 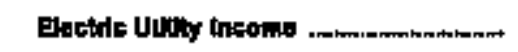 & 27,190 & $\$ 36$ & 9804 & 1,795 & 5,064 & 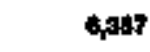 \\
\hline 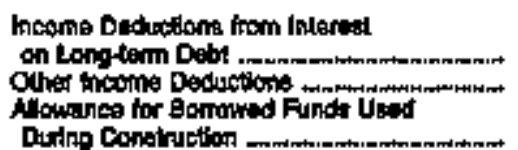 & $\begin{array}{r}6,081 \\
0 \\
0\end{array}$ & $\begin{array}{l}0 \\
0 \\
0\end{array}$ & $\begin{array}{l}0 \\
0 \\
0\end{array}$ & $\begin{array}{r}308 \\
0 \\
0\end{array}$ & $\begin{array}{l}0 \\
0 \\
0\end{array}$ & $\begin{array}{l}0 \\
0 \\
0\end{array}$ \\
\hline Totus Inveme Dodvetlona ................... & 6,081 & 6 & 0 & 300 & 0 & 0 \\
\hline Incorta Belore Edraordinery Leme & 21,100 & $\$ 38$ & $\mathbf{3}, \mathbf{0 0 4}$ & 1,480 & 6,004 & 6,387 \\
\hline Extraordinary income ... & 0 & 0 & 0 & 0 & 0 & 0 \\
\hline 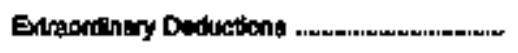 & 0 & 0 & o & $\mathbf{0}$ & 0 & o \\
\hline Not Ineome & 21,100 & 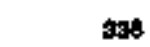 & s,eod & 1,493 & 5,004 & 6,367 \\
\hline
\end{tabular}

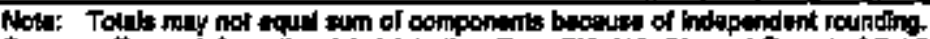

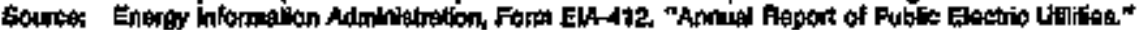


Table 2t. Statement of Income by Major U.S. Publioly Owned Eleotric Utillty Within State, 1994 (Conthuod)

(Thousand Dollars)

\begin{tabular}{|c|c|c|c|c|c|c|}
\hline Hem & 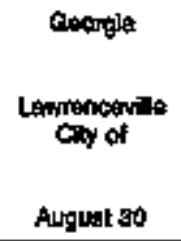 & $\begin{array}{l}\text { Seorgata } \\
\text { Netiolte } \\
\text { Chy of } \\
\text { Jure } 30\end{array}$ & $\begin{array}{l}\text { Georata } \\
\text { Wovitifia } \\
\text { Cip of } \\
\text { September so }\end{array}$ & 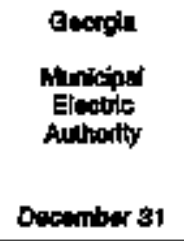 & 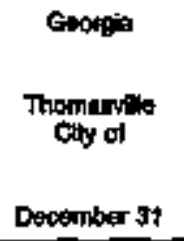 & $\begin{array}{l}\text { ldaho } \\
\text { foldho } \\
\text { Fils } \\
\text { ctity of } \\
\text { Septentaber } 30\end{array}$ \\
\hline Enotrle titiky Opereting furvinues ........ & 15,195 & 71,400 & 19,973 & $40, \pi 1$ & $26,26 \pi$ & 35,344 \\
\hline 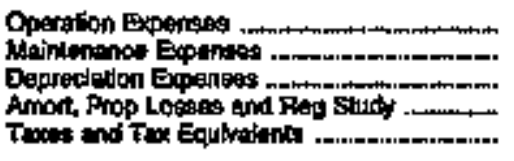 & $\begin{array}{r}13.243 \\
7 \\
441 \\
0 \\
0\end{array}$ & $\begin{array}{r}51.873 \\
0 \\
1,607 \\
0 \\
0\end{array}$ & $\begin{array}{r}10,419 \\
0 \\
220 \\
0 \\
0\end{array}$ & $\begin{array}{r}160,243 \\
40,394 \\
6 \times,+60 \\
28,919 \\
2711\end{array}$ & $\begin{array}{r}22,394 \\
676 \\
613 \\
0 \\
1,003\end{array}$ & $\begin{array}{r}19,760 \\
2,200 \\
3,527 \\
0 \\
2,274\end{array}$ \\
\hline Tolal beotric ufdly Opanabing & 18,600 & 58390 & $+0,630$ & 825,460 & 24,796 & 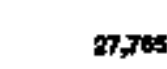 \\
\hline 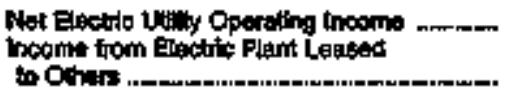 & $\begin{array}{r}1, \sin 2 \\
0\end{array}$ & $\begin{array}{r}18,026 \\
0\end{array}$ & $\begin{array}{r}1,304 \\
0\end{array}$ & $\begin{array}{r}\$ 59,319 \\
0\end{array}$ & $\begin{array}{r}7,517 \\
0\end{array}$ & 7,576 \\
\hline 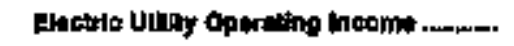 & $1, \mathbf{s}$ on & 10,0028 & 1,534 & 150,301 & 1,B17 & 7,576 \\
\hline Othe Exotic itwoms & 6 & 0 & 46 & $41,8=0$ & $\mathbf{s g}$ & 2000 \\
\hline 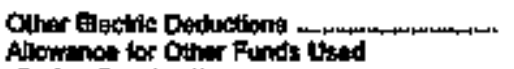 & 1,709 & 9 & $\mathbf{0}$ & 6 & As & 1,40 \\
\hline 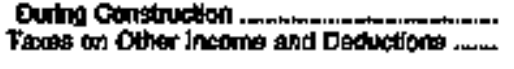 & 0 & 0 & $\begin{array}{l}0 \\
0\end{array}$ & $\begin{array}{r}0 \\
459\end{array}$ & $\begin{array}{l}0 \\
0\end{array}$ & $\begin{array}{l}0 \\
0\end{array}$ \\
\hline 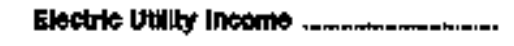 & 258 & 18,026 & 1.378 & 200,713 & 1,506 & a, \\
\hline 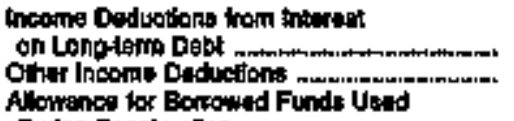 & 0 & 0 & $\begin{array}{r}0 \\
1,447\end{array}$ & $\begin{array}{l}209,860 \\
-46,500\end{array}$ & $\begin{array}{l}0 \\
1\end{array}$ & $\begin{array}{l}7,894 \\
-211\end{array}$ \\
\hline 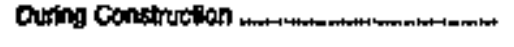 & 0 & 0 & 0 & 1,189 & 0 & 0 \\
\hline Totol Ineome Deduclions & $\mathbf{0}$ & 0 & $1,4 \mathbf{A 7}$ & 191,770 & 1 & 7,760 \\
\hline 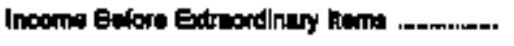 & -256 & 18,028 & -69 & 6,940 & 1,504 & 873 \\
\hline Extedortingly hoama & 0 & 0 & 0 & o & 0 & 0 \\
\hline Extrabrothery Deductions ، & 0 & 0 & $\mathbf{0}$ & 0 & 0 & 0 \\
\hline Nat Ineome - & -246 & 10,025 & $\rightarrow$ & 5949 & 1400 & 673 \\
\hline
\end{tabular}

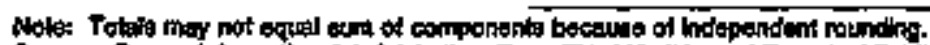

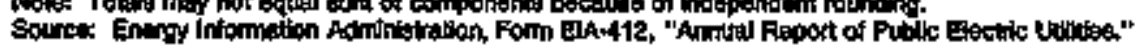


Table 21. Stalement of income by Major U.S. Publiely Owned Electric Uthlity Within State, 1994 (Continued)

(Thousand Dollars)

\begin{tabular}{|c|c|c|c|c|c|c|}
\hline llam & $\begin{array}{l}\text { Drinois } \\
\text { Bataria } \\
\text { City of } \\
\text { Decomber } 34\end{array}$ & $\begin{array}{l}\text { linolo } \\
\text { Cignewa } \\
\text { chy of } \\
\text { kpil sal }\end{array}$ & 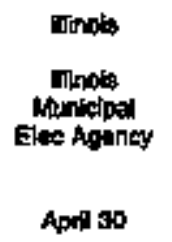 & 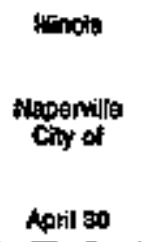 & 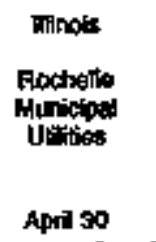 & $\begin{array}{l}\text { nlincit } \\
\text { Springleid } \\
\text { cily ot } \\
\text { Fobruany } 20\end{array}$ \\
\hline 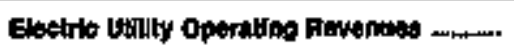 & 15,245 & insers & $60,00 t$ & 58,268 & 12,670 & 98390 \\
\hline 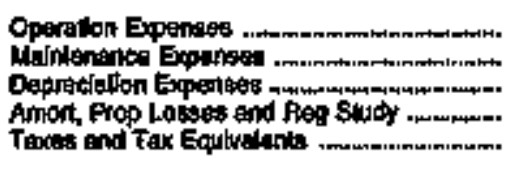 & $\begin{array}{r}t+590 \\
7,50 \\
2,809 \\
0 \\
0\end{array}$ & $\begin{array}{r}7.905 \\
599 \\
605 \\
0 \\
405\end{array}$ & $\begin{array}{r}5 \times, 41 \\
449 \\
3,067 \\
0 \\
0\end{array}$ & $\begin{array}{r}41,769 \\
765 \\
3,552 \\
0 \\
0\end{array}$ & $\begin{array}{r}0,205 \\
1,2000 \\
009 \\
121\end{array}$ & $\begin{array}{r}49,857 \\
15813 \\
12,481 \\
87 \\
3,931\end{array}$ \\
\hline 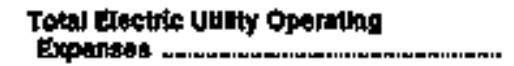 & 16,163 & 9,954 & $67,0,7$ & 46,056 & $\cos 5$ & 51,049 \\
\hline 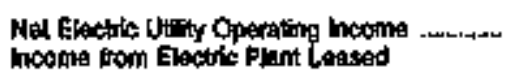 & -37 & 930 & 7,074 & 7,207 & 1,977 & 15,440 \\
\hline D Whera & $\mathbf{0}$ & ) & 0 & $\mathbf{0}$ & 0 & $\mathbf{0}$ \\
\hline 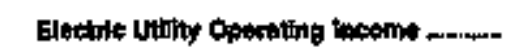 & $-m$ & 的s & $\mathbf{7 , 6 7 4}$ & 7,207 & 1,977 & 16,440 \\
\hline 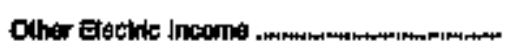 & 397 & 498 & 1,600 & 2039 & 158 & 2005 \\
\hline 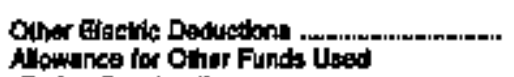 & 0 & 61 & $\mathbf{0}$ & 0 & 0 & 0 \\
\hline 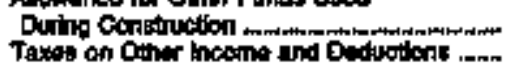 & 0 & $\mathbf{0}$ & 0 & $\mathbf{0}$ & $\begin{array}{l}0 \\
0\end{array}$ & $\stackrel{0}{0}$ \\
\hline 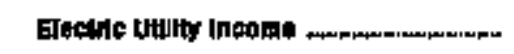 & $s 4$ & 1,976 & Q475 & 9,647 & 2,189 & 19,405 \\
\hline 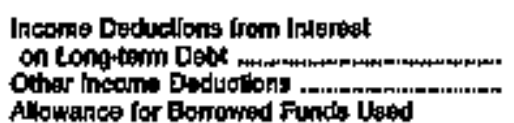 & 0 & 70 & 7,390 & $1,+129$ & 84 & 6.412 \\
\hline 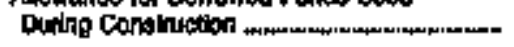 & $\mathbf{0}$ & $\mathbf{0}$ & 0 & $\mathbf{0}$ & $\mathbf{0}$ & 0 \\
\hline 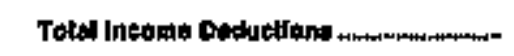 & 6 & Bs & to,tora & 1,125 & 910 & 6,649 \\
\hline 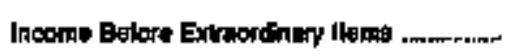 & 349 & 1,291 & 1,442 & 6,717 & 1,500 & 11,790 \\
\hline Exiraoninary incoms & , e & 0 & 436 & $\mathbf{0}$ & $\mathbf{0}$ & m77 \\
\hline Extreordinary Deductiong & 60 & $\mathbf{0}$ & 0 & 305 & $\mathbf{0}$ & 0 \\
\hline Wht Ineoplo - & 398 & $1,2,91$ & 1,976 & 8,418 & 1,500 & 12,779 \\
\hline
\end{tabular}

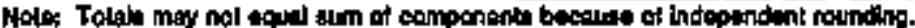

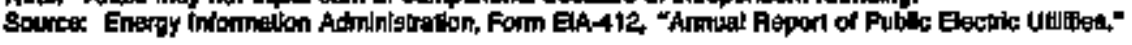


Table 21. Statement of Income by Major U.S. Publicly Owned Electric Utilly Within State, 1994 (Continued) (Thousand Dollars)

\begin{tabular}{|c|c|c|c|c|c|c|}
\hline them & 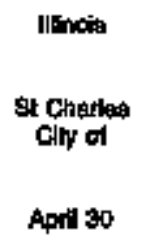 & $\begin{array}{l}\text { Initine } \\
\text { Anderaph } \\
\text { Ciny of } \\
\text { Decanter } 31\end{array}$ & $\begin{array}{l}\text { Indtand } \\
\text { Mubut } \\
\text { Ciny of } \\
\text { December \$ }\end{array}$ & $\begin{array}{l}\text { anciand } \\
\text { Eviften } \\
\text { Chy of } \\
\text { Decormber } 31\end{array}$ & 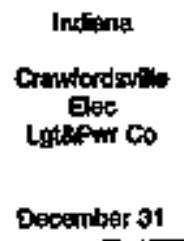 & 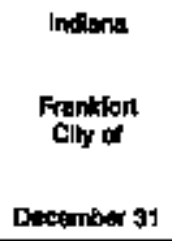 \\
\hline 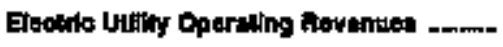 & 26,410 & 34,72 & 16,061 & 8,650 & $21, \Delta 66$ & $14, a 14$ \\
\hline 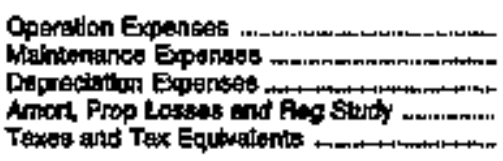 & $\begin{array}{r}17,129 \\
4,900 \\
848 \\
0 \\
0\end{array}$ & $\begin{array}{r}92,585 \\
1,197 \\
1,642 \\
0 \\
204\end{array}$ & $\begin{array}{r}14,617 \\
750 \\
407 \\
0 \\
107\end{array}$ & $\begin{array}{r}7.985 \\
434 \\
209 \\
0 \\
155\end{array}$ & $\begin{array}{r}17,355 \\
1,219 \\
1,091 \\
21 \\
134\end{array}$ & $\begin{array}{r}\$ 3,217 \\
206 \\
6 \times 3 \\
0 \\
241\end{array}$ \\
\hline 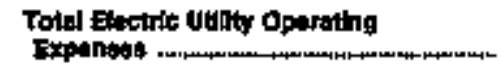 & 22,946 & 35,298 & 16,071 & Fiags & 20,171 & tatה17 \\
\hline 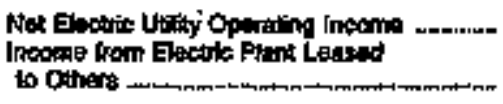 & $\begin{array}{r}2,424 \\
0\end{array}$ & $\begin{array}{r}-1,689 \\
0\end{array}$ & $\begin{array}{r}850 \\
0\end{array}$ & $\begin{array}{r}-275 \\
0\end{array}$ & $\begin{array}{r}1,705 \\
0\end{array}$ & 7e7 \\
\hline 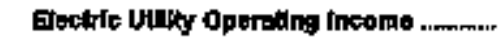 & 2,424 & $-1,469$ & 850 & -276 & $1,7 t 6$ & ret \\
\hline Other Elective Incomp & 946 & 101 & s.t & 163 & 250 & 207 \\
\hline 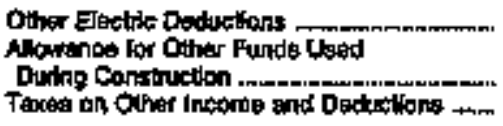 & $\stackrel{0}{0}$ & a & $\begin{array}{l}0 \\
0 \\
0\end{array}$ & $\begin{array}{l}0 \\
0 \\
0\end{array}$ & $\begin{array}{l}30 \\
0 \\
0\end{array}$ & a \\
\hline 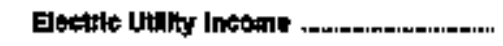 & 3,37rz & $-1,4 \pi T$ & 1,171 & -112 & $1,5 \mathrm{se}$ & 974 \\
\hline 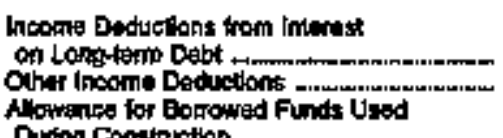 & $\stackrel{0}{0}$ & $\begin{array}{l}53 \\
24\end{array}$ & 80 & o & $\begin{array}{l}450 \\
271\end{array}$ & 0 \\
\hline Dirting Construction - & 0 & 0 & 0 & o & 0 & $\mathbf{0}$ \\
\hline 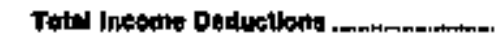 & 0 & $\pi$ & 40 & - & 72 & 0 \\
\hline 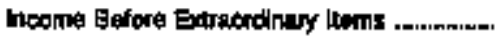 & 3,972 & $-1,855$ & $1,0 B 2$ & -112 & 1,260 & 974 \\
\hline 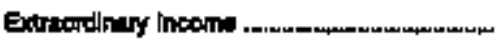 & 0 & 0 & 0 & - & 0 & 0 \\
\hline 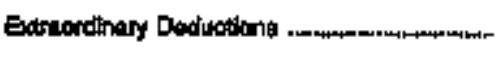 & 0 & 0 & 0 & o & 0 & 0 \\
\hline Not Invome & 3,375 & $-1, \$ 886$ & 1,002 & -112 & 1,200 & 974 \\
\hline
\end{tabular}

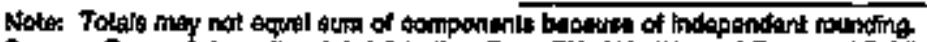

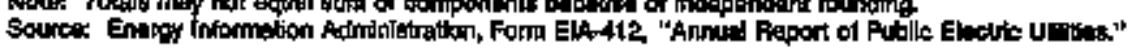


Tabje 21. Statement of Income by Major U.S. Publicly Owned Electrie Utility Within State, 1994 (Continued) (Thousand Dollars)

\begin{tabular}{|c|c|c|c|c|c|c|}
\hline Ilam & 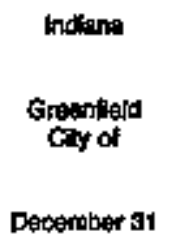 & $\begin{array}{c}\text { motang } \\
\text { molane } \\
\text { nimiclpal } \\
\text { Powar Agingy } \\
\text { Dacember } 31\end{array}$ & $\begin{array}{l}\text { Incilana } \\
\text { Jasper } \\
\text { city of } \\
\text { Dectember } 31\end{array}$ & 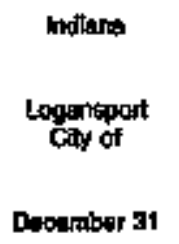 & 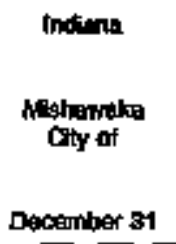 & $\begin{array}{l}\text { Indlang } \\
\text { Pers: } \\
\text { Chy of } \\
\text { Dectamber } 51\end{array}$ \\
\hline 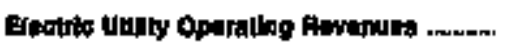 & 8,606 & 158,971 & 15,909 & 17, 6 -1 & 27,090 & wats \\
\hline 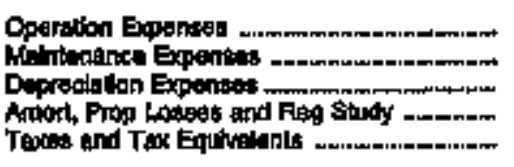 & $\begin{array}{r}7340 \\
671 \\
240 \\
0 \\
0\end{array}$ & $\begin{array}{r}118,670 \\
2,000 \\
11,086 \\
14 \\
1,085\end{array}$ & $\begin{array}{r}12455 \\
4701 \\
200 \\
0 \\
290\end{array}$ & $\begin{array}{r}12,84 t \\
1,249 \\
1,494 \\
0 \\
387\end{array}$ & $\begin{array}{r}2 \times, 302 \\
508 \\
1,098 \\
0 \\
449\end{array}$ & $\begin{array}{r}7,746 \\
411 \\
924 \\
0 \\
400\end{array}$ \\
\hline 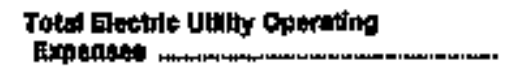 & 6,251 & 130,85: & 13.436 & 14,94 & 25,440 & 0,50 \\
\hline 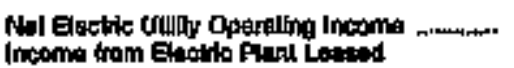 & a54 & 24,012 & 2,758 & $t, 672$ & 2.547 & gns \\
\hline 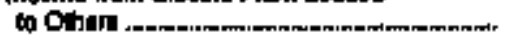 & 0 & 0 & $\mathbf{0}$ & 0 & 0 & $\mathbf{0}$ \\
\hline 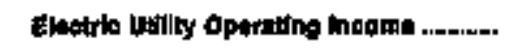 & 954 & 24012 & 2,190 & $1,4+2$ & $2, \mathbf{s} 4 \mathbf{3}$ & $\cos$ \\
\hline 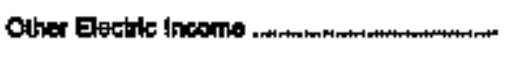 & 101 & 6,250 & 187 & fos & $\sin$ & $\pi$ \\
\hline 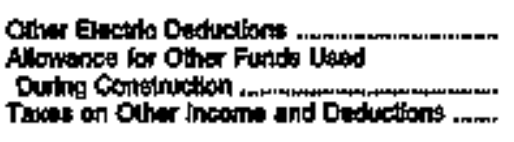 & 0 & 0 & $\begin{array}{l}0 \\
0 \\
0\end{array}$ & $\begin{array}{l}0 \\
0 \\
0\end{array}$ & 0 & $\begin{array}{r}0 \\
0 \\
240\end{array}$ \\
\hline 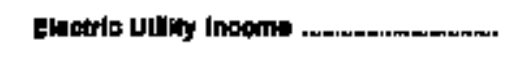 & 455 & $\$ 1,156$ & 2,350 & $2+28$ & $3,0+2$ & 760 \\
\hline 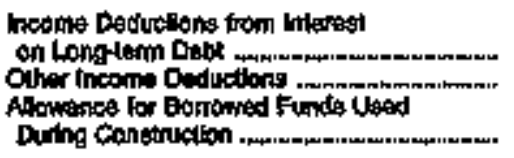 & $\begin{array}{r}120 \\
0 \\
0\end{array}$ & $\begin{array}{r}23,495 \\
4,757 \\
-237\end{array}$ & $\begin{array}{r}494 \\
8 \\
0\end{array}$ & $\begin{array}{r}\text { ero } \\
0 \\
0\end{array}$ & $\begin{array}{l}40 \\
62 \\
0\end{array}$ & $\begin{array}{r}1 \\
0\end{array}$ \\
\hline 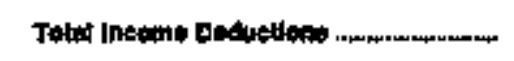 & 124 & 20,000 & $\mathbf{s p a}$ & 670 & 110 & 12: \\
\hline 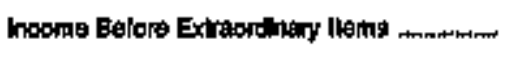 & 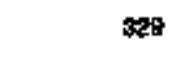 & 3.451 & 8,847 & 1,254 & 2,842 & 640 \\
\hline Exirabrinty Inoome non & 0 & $0,6 \infty 60$ & $\mathbf{0}$ & 0 & $\mathbf{0}$ & 0 \\
\hline 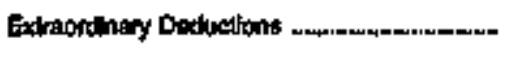 & 0 & o & 136 & $\mathbf{0}$ & $\mathbf{0}$ & $\mathbf{0}$ \\
\hline 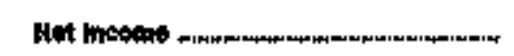 & 37 & stat & 1,712 & $\$, 254$ & 2942 & B.40 \\
\hline
\end{tabular}

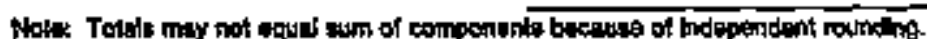

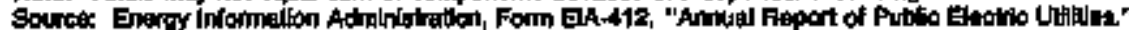


Table 21. Statement of Income by Major U.S. Publicly Owned Electric Utility Within State, 1994 (Continued) (Thousand Dollars)

\begin{tabular}{|c|c|c|c|c|c|c|}
\hline Item & 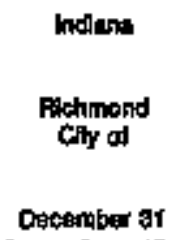 & $\begin{array}{l}\text { Indlante } \\
\text { Wrastingion } \\
\text { Crty of }\end{array}$ & $\begin{array}{l}\text { lowa } \\
\text { Amas } \\
\text { City of } \\
\text { Junte } 30\end{array}$ & $\begin{array}{l}\text { lona } \\
\text { Codar } \\
\text { Fonls } \\
\text { Caty of } \\
\text { Decombert } 31\end{array}$ & 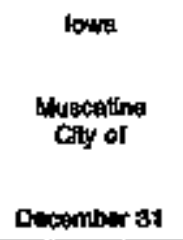 & $\begin{array}{l}\text { bowa } \\
\text { Palla } \\
\text { Caty of } \\
\text { Deompabs } 31\end{array}$ \\
\hline 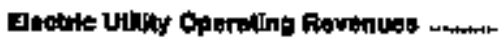 & 42,599 & 7,894 & 21,090 & 18957 & 42,009 & 6,711 \\
\hline 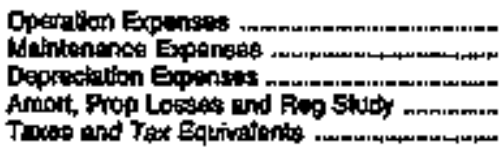 & $\begin{array}{r}32,131 \\
2,000 \\
2,981 \\
0 \\
3,770\end{array}$ & $\begin{array}{r}7,412 \\
195 \\
308 \\
0 \\
200\end{array}$ & $\begin{array}{r}14,387 \\
0 \\
3,606 \\
0 \\
804\end{array}$ & $\begin{array}{r}7,678 \\
t, 583 \\
2,160 \\
73 \\
510\end{array}$ & $\begin{array}{r}25,767 \\
5,795 \\
0,647 \\
0 \\
105\end{array}$ & $\begin{array}{r}0,504 \\
1,289 \\
0 \\
0 \\
0\end{array}$ \\
\hline $\begin{array}{l}\text { Total Factric Utibty Operating } \\
\text { Expouses - }\end{array}$ & as,ges & 0,199 & $14, \pi Y$ & P2804 & 41,316 & s,rra \\
\hline 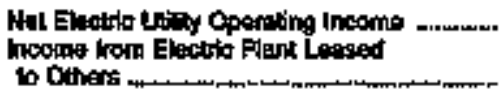 & $\begin{array}{r}2,709 \\
0\end{array}$ & -908 & 2,270 & $1, \sin$ & $\begin{array}{r}1,6980 \\
0\end{array}$ & $\begin{array}{r}-1,062 \\
0\end{array}$ \\
\hline 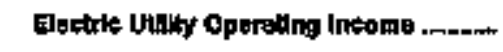 & 2,701 & -300 & 2,200 & 1,352 & 1,659 & $-1,092$ \\
\hline 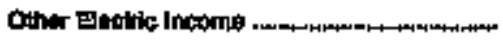 & gat & 24 & 01 & a42 & 6,685 & 1,000 \\
\hline 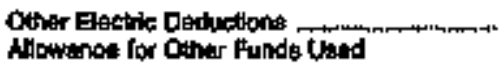 & 92 & $\mathbf{0}$ & 0 & 25 & 0 & a \\
\hline 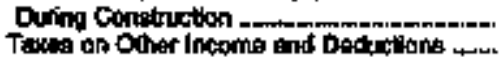 & $\begin{aligned} 0 \\
428\end{aligned}$ & $\stackrel{0}{0}$ & 9 & 0 & $\stackrel{0}{0}$ & 0 \\
\hline 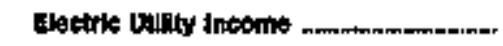 & 3,027 & $-\$ 11$ & $s, 200$ & 2,170 & to, ins & $-\mathbf{2}$ \\
\hline 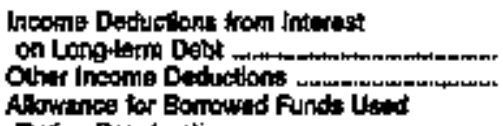 & $\stackrel{0}{0}$ & o & 1,698 & $\begin{array}{r}114 \\
4\end{array}$ & 12,660 & 14a \\
\hline During Construction & $\mathbf{0}$ & $\mathbf{0}$ & v & d & 0 & o \\
\hline 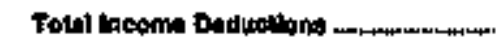 & 0 & 0 & 1,698 & 119 & 12,050 & 469 \\
\hline 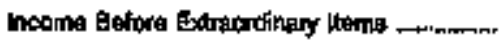 & 3,021 & -341 & $1, \mathrm{kgs}$ & 2,051 & -2477 & -471 \\
\hline 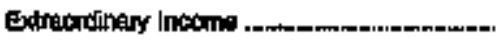 & o & 0 & 0 & o & $\mathbf{0}$ & o \\
\hline Exthordinury Deduotions . & 0 & 0 & 46 & 0 & 0 & o \\
\hline 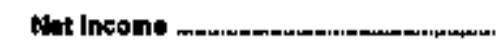 & 3,021 & $-\$ 41$ & 1,540 & 2,061 & $-2,477$ & -471 \\
\hline
\end{tabular}

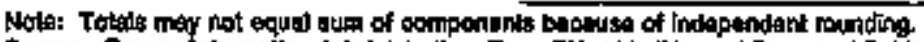

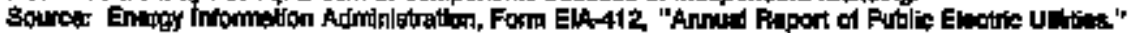


Table 21. Statement of lncome by Major U.S. Publichy Owned Electrle Utility Within State, 1994 (Continued)

(Thousand Dollars)

\begin{tabular}{|c|c|c|c|c|c|c|}
\hline Man & $\begin{array}{l}\text { Kontas } \\
\text { Chonde } \\
\text { Cily of } \\
\text { Dooumber } 31\end{array}$ & 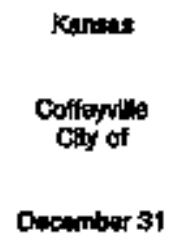 & $\begin{array}{l}\text { Kartas } \\
\text { Corden } \\
\text { Cly Cly of } \\
\text { Dopember } 31\end{array}$ & $\begin{array}{l}\text { Kancas } \\
\text { Kenses } \\
\text { City City of } \\
\text { Dobember } 31\end{array}$ & 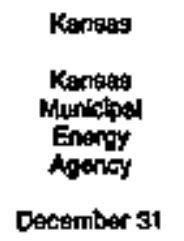 & 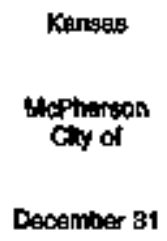 \\
\hline Dectric Uthlty Opesating Revanuet retrime & 5,094 & 11,387 & 12,489 & 119,027 & $B, 7: 3$ & $19,76 t$ \\
\hline 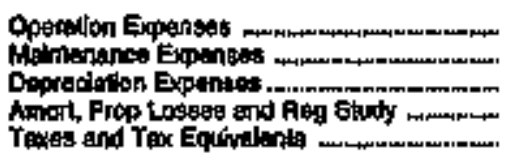 & $\begin{array}{r}5,001 \\
7,470 \\
0 \\
0 \\
0\end{array}$ & $\begin{array}{r}0,657 \\
1,016 \\
1,447 \\
050\end{array}$ & $\begin{array}{r}10,855 \\
0 \\
0 \\
0 \\
0\end{array}$ & $\begin{array}{r}73,119 \\
17,909 \\
17,601 \\
6909 \\
2,201\end{array}$ & $\begin{array}{r}9,609 \\
0 \\
190 \\
1,034 \\
30\end{array}$ & $\begin{array}{r}15,592 \\
989 \\
1,725 \\
0 \\
0\end{array}$ \\
\hline 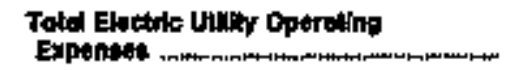 & 0,51 & 11,570 & 11,494 & 111,732 & 10,052 & 18,268 \\
\hline 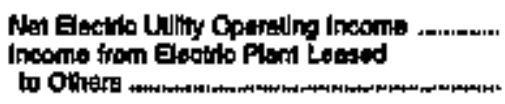 & $\begin{array}{r}2,393 \\
0\end{array}$ & $\begin{array}{r}-182 \\
0\end{array}$ & 98 & $\begin{array}{r}7,695 \\
0\end{array}$ & $\begin{array}{r}-2.214 \\
0\end{array}$ & $\begin{array}{r}1,493 \\
0\end{array}$ \\
\hline 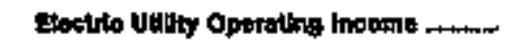 & 2,293 & $-1 \mathrm{eq}$ & tho & $t, \infty 65$ & $-2,214$ & 0,493 \\
\hline Other Eloctio hoome & 141 & $\infty$ & $\boldsymbol{2 7}$ & 4,150 & 3,219 & 1,294 \\
\hline 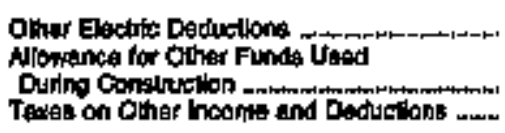 & $\begin{array}{r}700 \\
0\end{array}$ & $\begin{array}{r}47 \\
0\end{array}$ & $\stackrel{0}{0}$ & $\stackrel{0}{0}$ & $\begin{array}{l}0 \\
0 \\
0\end{array}$ & 780 \\
\hline 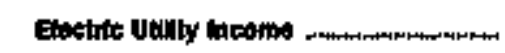 & 1,774 & $-\infty$ & 1,020 & 11,045 & $t, 004$ & 2,000 \\
\hline 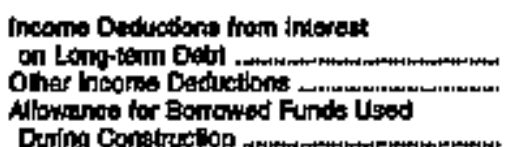 & 1,340 & 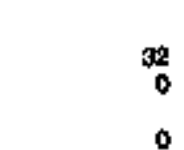 & 325 & $\begin{array}{r}11 \text { ines } \\
0\end{array}$ & $\begin{array}{r}810 \\
+37 \\
0\end{array}$ & 071 \\
\hline Totri incemn Deductions . . & 1,346 & 38 & 225 & 11,064 & wa & $\boldsymbol{m 1}$ \\
\hline Incame Galore Extracedtinary Lems & $\$ 20$ & $-\sin \theta$ & 698 & -119 & 48 & $9,1 \times 5$ \\
\hline 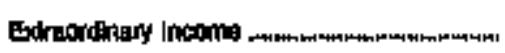 & 0 & $4,5 \times 32$ & 0 & 0 & 0 & 。 \\
\hline Exaraordinary Dodwotions ... & 0 & $\operatorname{ascos}$ & 0 & 0 & $\mathbf{0}$ & 0 \\
\hline 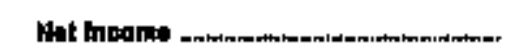 & 420 & 902 & $\sin$ & -190 & 40 & 1,137 \\
\hline
\end{tabular}

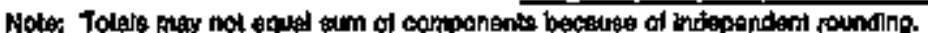

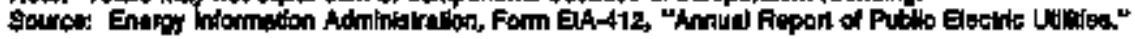


Table 21. Statement of income by Major U.S. Publichy Owned Electric Utilty Whin State, 1994 (Contlnued)

(Thousand Dollars)

\begin{tabular}{|c|c|c|c|c|c|c|}
\hline liam & $\begin{array}{l}\text { Konteas } \\
\text { Yinfield } \\
\text { Cony of } \\
\text { Decentuber } 31\end{array}$ & $\begin{array}{l}\text { Kentukty } \\
\text { Bowling } \\
\text { Criben } \\
\text { Gity of } \\
\text { Jene so }\end{array}$ & 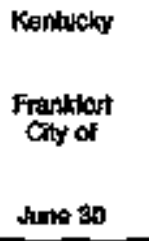 & $\begin{array}{l}\text { Kamitucky } \\
\text { Franlidin } \\
\text { Caty of } \\
\text { Jane to }\end{array}$ & 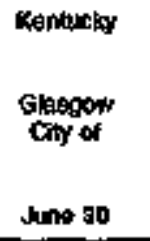 & $\begin{array}{l}\text { Kamukisy } \\
\text { Henderson } \\
\text { Cayy } \\
\text { U6try Comn } \\
\text { Hay } 31\end{array}$ \\
\hline 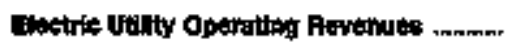 & testo & sesesi & 24,326 & 9,599 & wo,4t & 25,157 \\
\hline 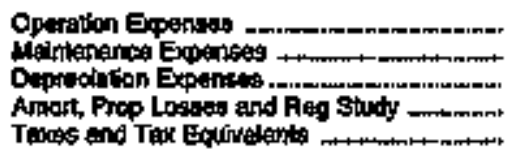 & $\begin{array}{r}10,413 \\
0 \\
827 \\
0 \\
0\end{array}$ & $\begin{array}{r}3,024 \\
1,075 \\
1,391 \\
0 \\
1,509\end{array}$ & $\begin{array}{r}21.043 \\
849 \\
650 \\
0 \\
79\end{array}$ & $\begin{array}{r}0.655 \\
759 \\
139 \\
0 \\
351\end{array}$ & $\begin{array}{r}14500 \\
258 \\
501 \\
7 \\
187\end{array}$ & $\begin{array}{r}13,291 \\
4,913 \\
4,386 \\
0 \\
0\end{array}$ \\
\hline 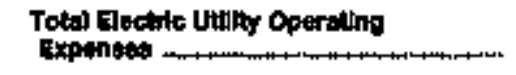 & 11,200 & 37,074 & 23,580 & 9,97 & 15,555 & 22,582 \\
\hline 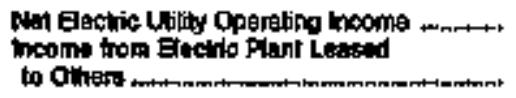 & 1,410 & $\begin{array}{r}1,758 \\
0\end{array}$ & 0 & 302 & 485 & 2.575 \\
\hline Electrio vatity aporating lncoms ......... & 1,010 & 1,758 & 600 & 302 & 495 & 2,676 \\
\hline 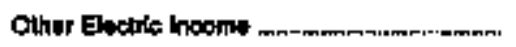 & 116 & 587 & 7,096 & 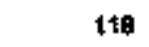 & 225 & 1,071 \\
\hline 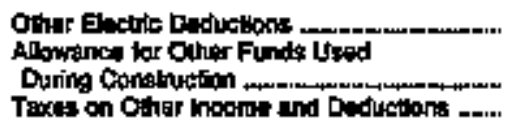 & $\begin{array}{r}68 \\
0 \\
808\end{array}$ & $\stackrel{0}{0}$ & $\begin{array}{r}0,195 \\
0 \\
0\end{array}$ & $\begin{array}{l}0 \\
0 \\
0\end{array}$ & 2 & $\begin{array}{l}0 \\
0 \\
0\end{array}$ \\
\hline 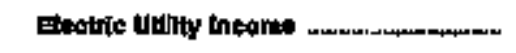 & 569 & 2,343 & 2,200 & 420 & 451 & 2,945 \\
\hline 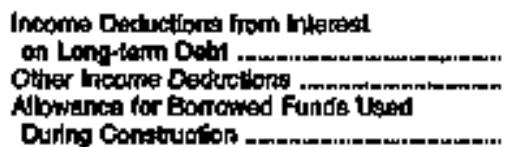 & 821 & 404 & 204 & o & $\begin{array}{r}262 \\
38 \\
0\end{array}$ & 2,181 \\
\hline 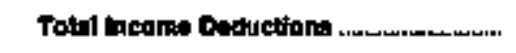 & 321 & 645 & 264 & 9 & sopo & 2,131 \\
\hline 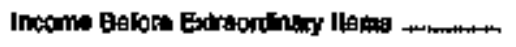 & 207 & 1,608 & 2,002 & 411 & 151 & 1,515 \\
\hline 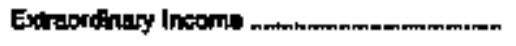 & 0 & 0 & 0 & 0 & 0 & 0 \\
\hline Extrsordingy Deductions & 0 & 0 & 0 & 0 & 0 & 0 \\
\hline 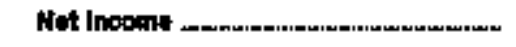 & 267 & $1,004:$ & 2,0902 & 411 & 151 & 1,518 \\
\hline
\end{tabular}

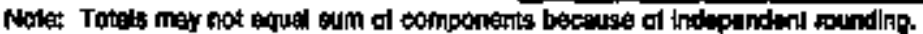

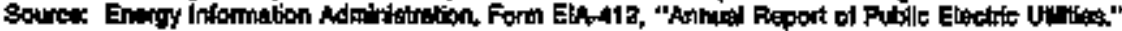


Table 21. Statement of Inceme by Major U.S. Publcly Owned Electric Utity Whin State, 1994 (Conthued)

(Thoussand Dollars)

\begin{tabular}{|c|c|c|c|c|c|c|}
\hline Inn & 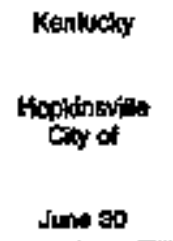 & 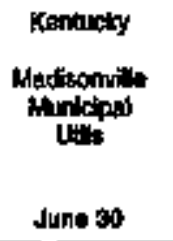 & 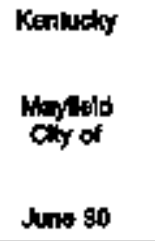 & $\begin{array}{l}\text { Kentucky } \\
\text { Muntey } \\
\text { City of } \\
\text { Jung } 30\end{array}$ & $\begin{array}{l}\text { Kentudisy } \\
\text { Oneneboro } \\
\text { City of } \\
\text { Maysi }\end{array}$ & 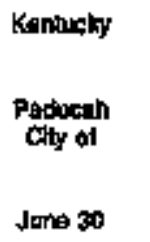 \\
\hline Elootrle villy Oparalling Revenurs .......- & 21,424 & 13,311 & 5,939 & 12 mpr & 49,288 & 32,316 \\
\hline 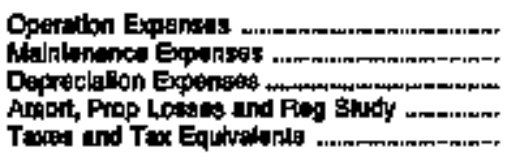 & $\begin{array}{r}18,620 \\
574 \\
470 \\
0 \\
729\end{array}$ & $\begin{array}{r}9,156 \\
650 \\
247 \\
0 \\
0\end{array}$ & $\begin{array}{r}7,995 \\
413 \\
177 \\
0 \\
373\end{array}$ & $\begin{array}{r}11,502 \\
394 \\
297 \\
0 \\
492\end{array}$ & $\begin{array}{r}29,991 \\
5,504 \\
4,734 \\
0 \\
0\end{array}$ & $\begin{array}{r}2,709 \\
978 \\
1,497 \\
0 \\
t, 413\end{array}$ \\
\hline 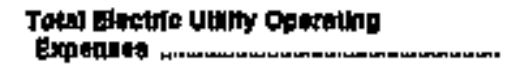 & $\mathbf{2 1 , 4 0 2}$ & $10,0,53$ & 6,789 & 12,675 & 40,090 & at; 581 \\
\hline 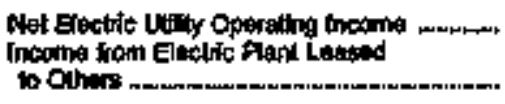 & 2 & $\begin{array}{r}3,258 \\
0\end{array}$ & $\begin{array}{r}141 \\
0\end{array}$ & -88 & 0 & $\begin{array}{r}-245 \\
0\end{array}$ \\
\hline 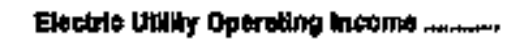 & 22 & 3,260 & 141 & $-\infty$ & 9,203 & -245 \\
\hline Oryor Eleotho Income & 685 & 59 & $s$ & 110 & 4,178 & 548 \\
\hline 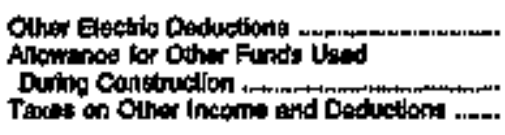 & $\begin{array}{l}0 \\
\text { 0 } \\
0\end{array}$ & $\begin{array}{l}0 \\
0 \\
0\end{array}$ & $\begin{array}{l}0 \\
0 \\
0\end{array}$ & 0 & $\begin{array}{r}3,193 \\
0 \\
0\end{array}$ & $\stackrel{0}{0}$ \\
\hline 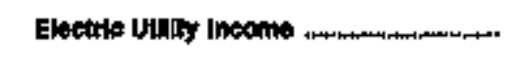 & Ex? & $3,3+18$ & $\mathbf{2 0 0}$ & 2 & 10,2021 & 290 \\
\hline 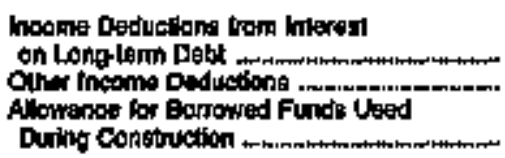 & $\begin{array}{r}187 \\
15 \\
0\end{array}$ & $\begin{array}{r}0 \\
3,403 \\
0\end{array}$ & $\begin{array}{l}0 \\
0\end{array}$ & $\begin{array}{l}0 \\
9\end{array}$ & $\begin{array}{r}4,754 \\
0 \\
0\end{array}$ & $\begin{array}{r}275 \\
27\end{array}$ \\
\hline Totol ineome Dodurdione n... & 168 & 8,4:\$ & s & 9 & 4,754 & 300 \\
\hline 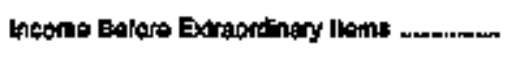 & 434 & -160 & 192 & 13 & 5,487 & -4 \\
\hline 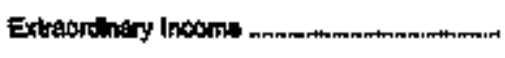 & $\mathbf{0}$ & 0 & 0 & a & 0 & 0 \\
\hline 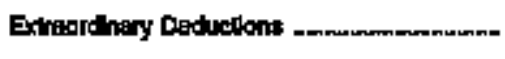 & $\mathbf{0}$ & 4 & 0 & 0 & 0 & 0 \\
\hline Not Inoome & 434 & -160 & t92 & 13 & 5,467 & -4 \\
\hline
\end{tabular}

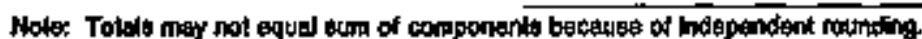

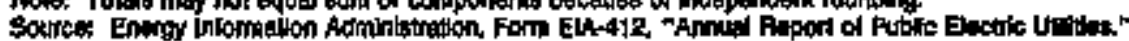


Tabfe 21. Statement of Inoome by Major U.S. Publycly Owned Electric Utuly Within State, 1994 (Continuted)

(Thousand Dollars)

\begin{tabular}{|c|c|c|c|c|c|c|}
\hline ttom & 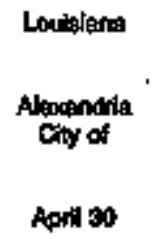 & 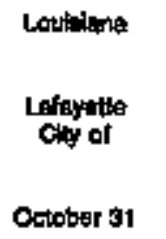 & 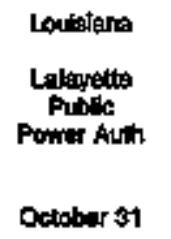 & 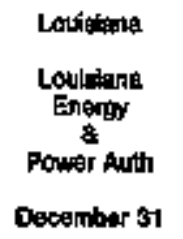 & $\begin{array}{l}\text { Loufolan } \\
\text { City Cory of } \\
\text { Ducentuen at }\end{array}$ & $\begin{array}{l}\text { Loulsian: } \\
\text { Malchitocthes } \\
\text { Cly of } \\
\text { May } 31\end{array}$ \\
\hline Elovoto Utidy Oparating Revanuea ........ & 41,535 & 100,004 & 45:psis & $68,64 f$ & to,kry & 14,671 \\
\hline 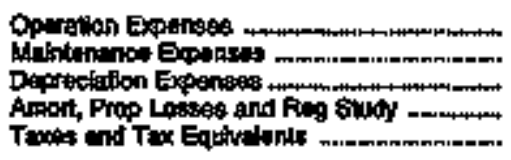 & $\begin{array}{r}27,7,0,0 \\
t, 0,0 \\
2,134\end{array}$ & $\begin{array}{r}70,3 \times 3 \\
3,070 \\
5,465 \\
5,39 \\
7,765\end{array}$ & $\begin{array}{r}38,651 \\
\$, 742 \\
4,316 \\
0 \\
0\end{array}$ & $\begin{array}{r}\operatorname{sen}, 0001 \\
0,001 \\
2,067 \\
1,067\end{array}$ & $\begin{array}{r}8.084 \\
104 \\
690 \\
0 \\
0\end{array}$ & $\begin{array}{r}12, \mathrm{BS} 7 \\
0 \\
050 \\
0 \\
0\end{array}$ \\
\hline 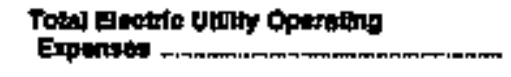 & 92,692 & 98,695 & 39,710 & 56,650 & 0,067 & 13,707 \\
\hline 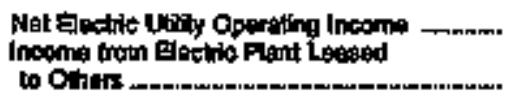 & $\begin{array}{r}8,97 t \\
0\end{array}$ & $\begin{array}{r}16,899 \\
0\end{array}$ & $\begin{array}{r}8,684 \\
0\end{array}$ & $\begin{array}{r}0,091 \\
0\end{array}$ & $\begin{array}{r}1,560 \\
0\end{array}$ & 8\$4 \\
\hline 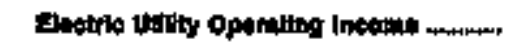 & B,971 & 15,689 & 6,694 & 6,981 & 1,559 & 694 \\
\hline 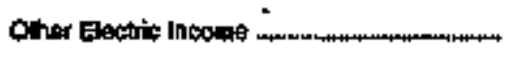 & 1,517 & 2,130 & 213 & 1,680 & 34 & D \\
\hline 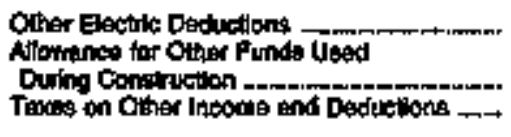 & $\begin{array}{r}2,120 \\
0\end{array}$ & $\begin{array}{l}0 \\
0 \\
0\end{array}$ & $\begin{array}{l}0 \\
0 \\
0\end{array}$ & $\begin{array}{l}0 \\
0 \\
0\end{array}$ & $\begin{array}{l}0 \\
0 \\
0\end{array}$ & $\begin{array}{l}0 \\
0 \\
0\end{array}$ \\
\hline Elestrk Vulity lecome . & 7,620 & 10,026 & 0,897 & 9,815 & 1,56 & $\$ 64$ \\
\hline 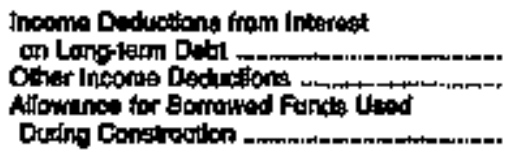 & $\begin{array}{r}2,607 \\
2,7 \% 6 \\
0\end{array}$ & $\begin{array}{r}1,876 \\
569 \\
0\end{array}$ & $\begin{array}{r}8,723 \\
1,790 \\
0\end{array}$ & $\begin{array}{r}0.200 \\
0 \\
0\end{array}$ & $\begin{array}{r}328 \\
0 \\
0\end{array}$ & $\begin{array}{l}0 \\
0 \\
0\end{array}$ \\
\hline Total hroene badwotione & 5,458 & 2,484 & In,ast & Q, 200 & ans & $\mathbf{0}$ \\
\hline Inoome Batore Extraordinary llama & 2,168 & 15,501 & $-1,117$ & 405 & 1.261 & 894 \\
\hline Extrendinary monom & 0 & o & 0 & o & 0 & D \\
\hline 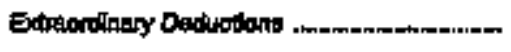 & 1,090 & a & 0 & $\mathbf{0}$ & 0 & 0 \\
\hline 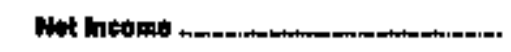 & mo & 15,50t & $-1,147$ & 405 & 1,251 & set \\
\hline
\end{tabular}

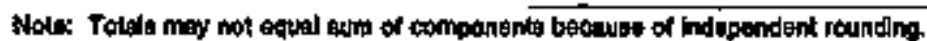

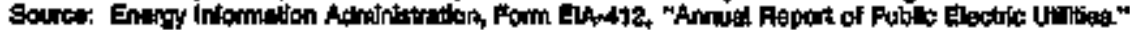


Table 21. Statement of theome by Major U.S. Publicly Owned Electric Utility Wilhin State, 1994 (Continuted) (Thousand Dollars)

\begin{tabular}{|c|c|c|c|c|c|c|}
\hline llom & $\begin{array}{l}\text { Loutining } \\
\text { Putston } \\
\text { Coty of } \\
\text { Septemine } 50\end{array}$ & 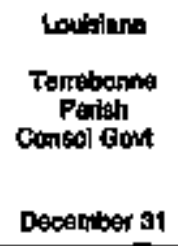 & 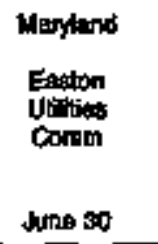 & 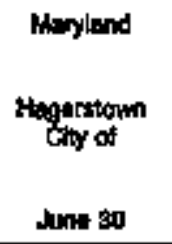 & 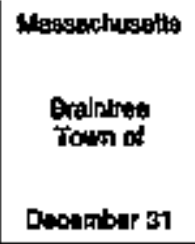 & 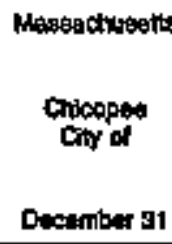 \\
\hline 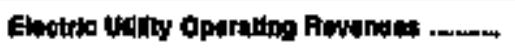 & 12,358 & 10,003 & 14,097 & $17+730$ & soje053 & 79,998 \\
\hline 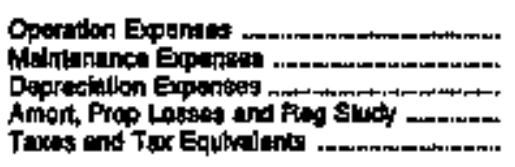 & $\begin{array}{r}0,989 \\
416 \\
816 \\
0 \\
0\end{array}$ & $\begin{array}{r}13,07 \\
1,295 \\
1, \$ d 8 \\
0 \\
0\end{array}$ & $\begin{array}{r}9,659 \\
845 \\
1,250 \\
0 \\
40\end{array}$ & $\begin{array}{r}14,690 \\
205 \\
730 \\
463 \\
206\end{array}$ & $\begin{array}{r}24,228 \\
3,704 \\
1,935 \\
0 \\
0\end{array}$ & $\begin{array}{r}21,782 \\
1,948 \\
2,981 \\
0 \\
478\end{array}$ \\
\hline 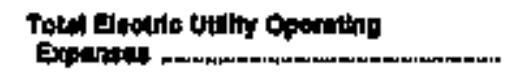 & 10,200 & 15,934 & 12,203 & 16,624 & 29945 & 25,601 \\
\hline 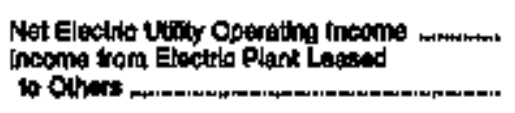 & $\begin{array}{r}2.159 \\
0\end{array}$ & $\begin{array}{r}2,140 \\
0\end{array}$ & $\begin{array}{r}1, \text { 宜的 } \\
0 \\
0\end{array}$ & $\begin{array}{r}714 \\
0\end{array}$ & $\begin{array}{r}707 \\
0\end{array}$ & $\begin{array}{r}3,891 \\
0\end{array}$ \\
\hline 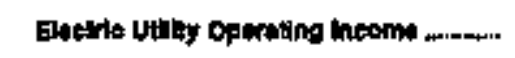 & 2,16: & 2,140 & 1):3 & 714 & 707 & 3,591 \\
\hline Oaher Eleotio fneomo .... & 209 & 687 & 128 & 188 & 241 & 2,480 \\
\hline 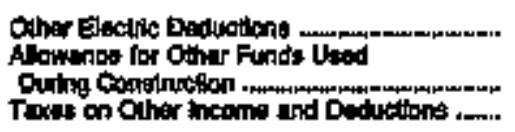 & 0 & $\begin{array}{r}260 \\
0 \\
0\end{array}$ & $\begin{array}{r}0 \\
0 \\
0\end{array}$ & $\begin{array}{l}0 \\
0 \\
0\end{array}$ & $\begin{array}{l}0 \\
0 \\
0\end{array}$ & 440 \\
\hline 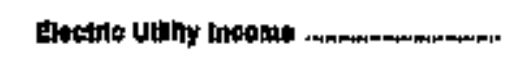 & 204 & 2,84 & 2,011 & 000 & 940 & 5,400 \\
\hline 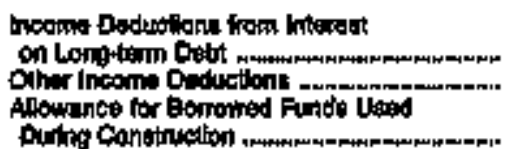 & $\begin{array}{r}100 \\
1,048 \\
0\end{array}$ & $\begin{array}{r}850 \\
50 \\
0\end{array}$ & $\begin{array}{r}2,12 \\
0 \\
0\end{array}$ & $\begin{array}{r}76 \\
0 \\
0\end{array}$ & $\begin{array}{r}0 \\
08 \\
0\end{array}$ & $\begin{array}{r}2,005 \\
128\end{array}$ \\
\hline 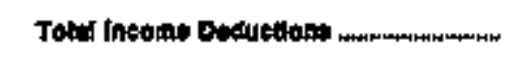 & 1,$2 ; 10$ & $\infty+2$ & $7 a s$ & 75 & $\mathbf{8 6}$ & 2,215 \\
\hline 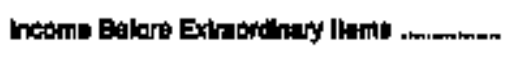 & 1,145 & 1,028 & 1,228 & 629 & 889 & 3,191 \\
\hline 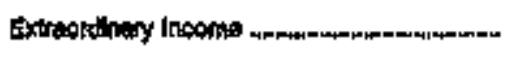 & 0 & $\mathbf{0}$ & 0 & 0 & 0 & 0 \\
\hline Extraordinany Deductions & 0 & 0 & 0 & 0 & $\mathbf{a}$ & 0 \\
\hline 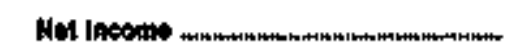 & 1,14:5 & 148 & 1,2ass & 14 & otz2 & 4,191 \\
\hline
\end{tabular}

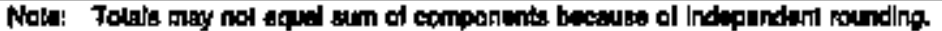

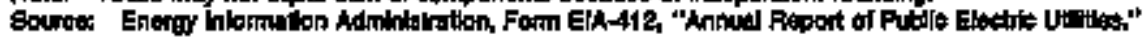


Table 21. Statement of Ineone by Major U.8. Publichy Owned Electrle Utiny Whing State, 1904 (Contitured) (Thousand Dollars)

\begin{tabular}{|c|c|c|c|c|c|c|}
\hline mem & 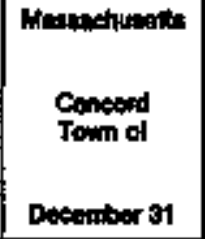 & 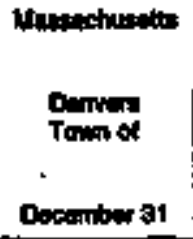 & 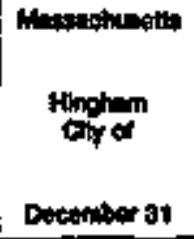 & 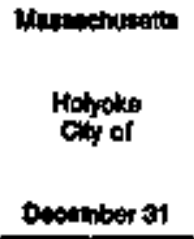 & 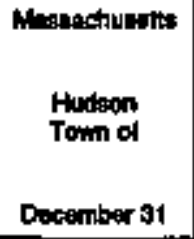 & 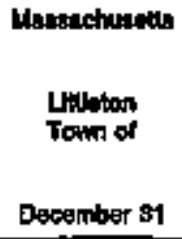 \\
\hline 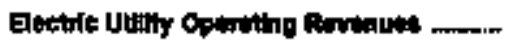 & $12,7+7$ & 20s40 & Lasts & 2000 & 27,128 & 18,411 \\
\hline 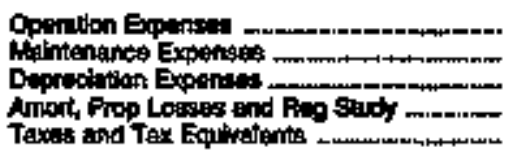 & $\begin{array}{r}10,188 \\
182 \\
404 \\
0 \\
0\end{array}$ & $\begin{array}{r}27,730 \\
840 \\
0 \\
0 \\
0\end{array}$ & $\begin{array}{r}11988 \\
308 \\
617 \\
0 \\
0\end{array}$ & $\begin{array}{r}02,000 \\
1,241 \\
1,448 \\
0 \\
0\end{array}$ & $\begin{array}{r}24069 \\
588 \\
600 \\
0 \\
217\end{array}$ & $\begin{array}{r}14,699 \\
370 \\
307 \\
0 \\
0\end{array}$ \\
\hline 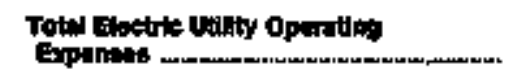 & thots & thos & toga4 & 20,0\%5 & 20,273 & 16,306 \\
\hline 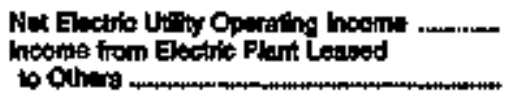 & $1,0+\infty$ & 4. & 0 & 1,200 & b5s & $\begin{array}{r}1,015 \\
0\end{array}$ \\
\hline 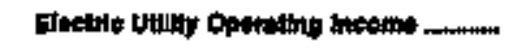 & ins & 4: & aㅏ & 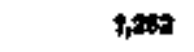 & 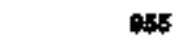 & 1,016 \\
\hline 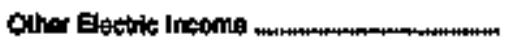 & 720 & ets & -4 & 180 & $\mathbf{5 5 9}$ & 142 \\
\hline 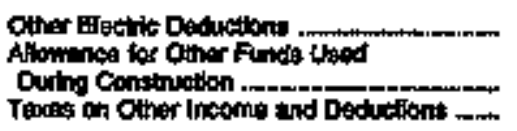 & $\begin{array}{l}0 \\
0 \\
0\end{array}$ & 0 & 0 & 0 & $\begin{array}{l}0 \\
0 \\
0\end{array}$ & $\begin{array}{l}0 \\
0 \\
0\end{array}$ \\
\hline Eletwo uth Incoms . . & 20 & 4048 & 14 & 1,140 & 1,:\$1 & $1, \boldsymbol{M r}$ \\
\hline 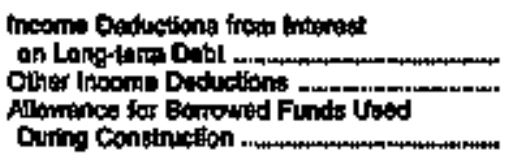 & $\underset{10}{121}$ & $\begin{array}{l}\frac{4}{0} \\
0\end{array}$ & $\begin{array}{r}29 \\
0\end{array}$ & $\begin{array}{r}267 \\
140 \\
0\end{array}$ & $\begin{array}{l}0 \\
0 \\
0\end{array}$ & $\begin{array}{l}5 \\
2 \\
0\end{array}$ \\
\hline 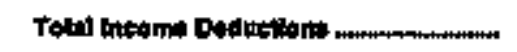 & \$1 & as & 30 & 4at & 0 & 7 \\
\hline 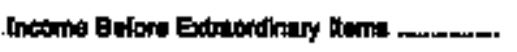 & $2 \infty$ & 1,010 & 禹 & 1,007 & 1,213 & 1,400 \\
\hline Extrordinary incoms & 0 & 0 & 0 & 0 & $\mathbf{a}, 54$ & 143 \\
\hline 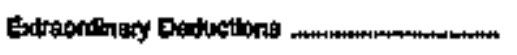 & 185 & o & 0 & 0 & 0 & 160 \\
\hline Het theopat & 24:472 & 100 & $\mathbf{s e d}$ & 1,007 & 4759 & 1,095 \\
\hline
\end{tabular}

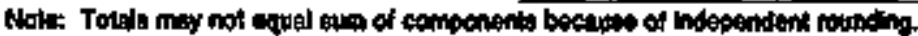

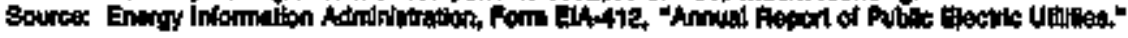


Table 21. Statement of mcome by Major U.S. Publicly Owned Electrte Uthlity Whin State, 1994 (Continued) (Thousend Dollars)

\begin{tabular}{|c|c|c|c|c|c|c|}
\hline hara & 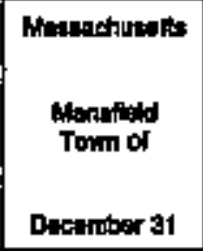 & 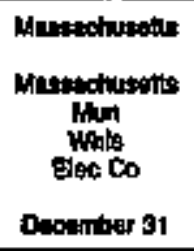 & 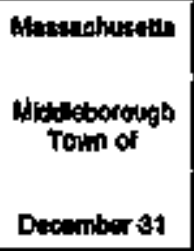 & 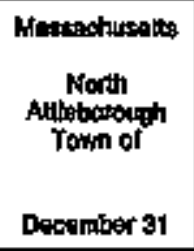 & $\begin{array}{l}\text { Massachuselta } \\
\text { Normood } \\
\text { Ciny of } \\
\text { Jung } 30\end{array}$ & 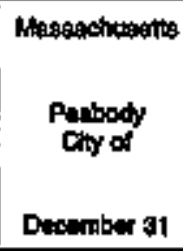 \\
\hline 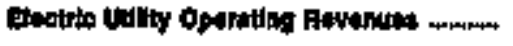 & 17,941 & 2019,001 & $17 / 499$ & 17,049 & 20,100 & 37,196 \\
\hline 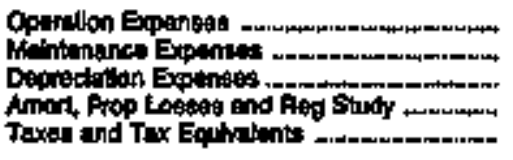 & $\begin{array}{r}16,268 \\
0 \\
408 \\
0 \\
180\end{array}$ & $\begin{array}{r}111,619 \\
0,604 \\
4,474 \\
0 \\
6,271\end{array}$ & $\begin{array}{r}18,549 \\
7 \% 7 \\
169 \\
0 \\
216\end{array}$ & $\begin{array}{r}13,779 \\
549 \\
747 \\
0 \\
208\end{array}$ & $\begin{array}{r}29,014 \\
600 \\
1,000 \\
0 \\
0\end{array}$ & $\begin{array}{r}91,354 \\
490 \\
1,788 \\
248 \\
0\end{array}$ \\
\hline 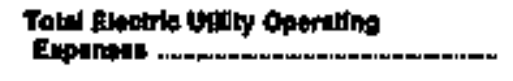 & 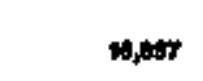 & $17 \sin ^{2}$ & $*, 751$ & $18 ; 271$ & $24,0=0$ & 34,a16 \\
\hline 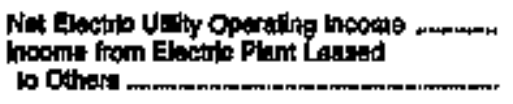 & $\mathbf{2 0 3}$ & $\begin{array}{r}\infty 0,810 \\
0\end{array}$ & 675 & $\begin{array}{r}1,72 \\
0\end{array}$ & $\begin{array}{r}2,451 \\
0\end{array}$ & 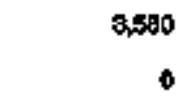 \\
\hline 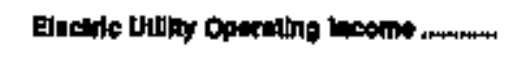 & 903 & wh, & Wrs & $1, \pi 7$ & 2,451 & 3,5000 \\
\hline Other Euctio Income ............nm & 130 & 11,180 & 133 & $\pi 7$ & 9 & 354 \\
\hline 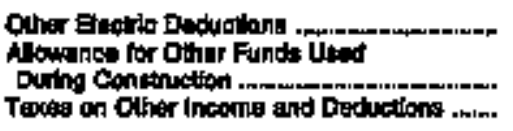 & $\begin{array}{l}0 \\
0 \\
0\end{array}$ & $\begin{array}{r}0 \\
0\end{array}$ & $\begin{array}{l}0 \\
0\end{array}$ & $\begin{array}{r}914 \\
0 \\
0\end{array}$ & $\begin{array}{l}0 \\
0 \\
0\end{array}$ & 0 \\
\hline Ehetile Utiny Inogme & 1,113 & 72,0 & aus & 2,198 & 2,400 & 2,909 \\
\hline 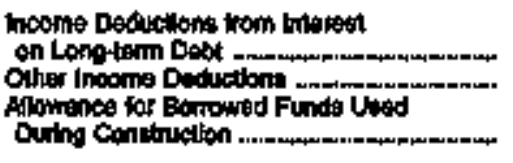 & a & 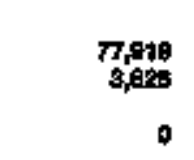 & $\begin{array}{r}9 \\
105 \\
0\end{array}$ & $\begin{array}{r}85 \\
18 \\
0\end{array}$ & $\begin{array}{r}0 \\
148 \\
0\end{array}$ & $\begin{array}{r}1,221 \\
19 \\
0\end{array}$ \\
\hline Total leseme Deducllent: & 12 & $\mathbf{8 1 , 6 4 6}$ & 105 & 264 & 148 & 1,210 \\
\hline 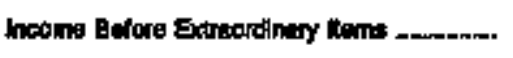 & 1.501 & $-4,454$ & ros & 1,881 & 2,354 & $2 \sin$ \\
\hline Extruordinany heome ...re-...- & o & 5,454 & o & 0 & 0 & 0 \\
\hline 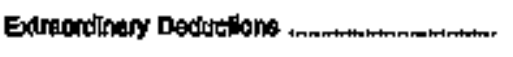 & 0 & 0 & 0 & 0 & 0 & 0 \\
\hline 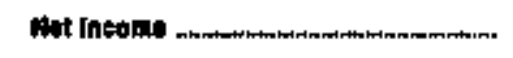 & 1,100 & 0 & 705 & $1, \$ 8 t$ & 2314 & 2600 \\
\hline
\end{tabular}

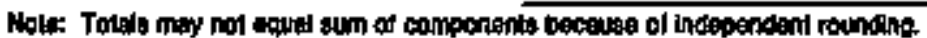

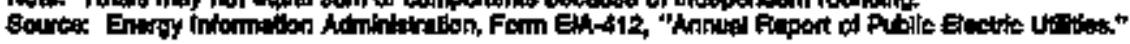


Table 21. Statement of Income by Major U.S. Publicly Owned Electric Utility Within state, 1994 (Continued)

(Thousend Doliars)

\begin{tabular}{|c|c|c|c|c|c|c|}
\hline Ilom & 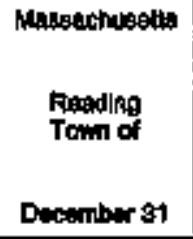 & 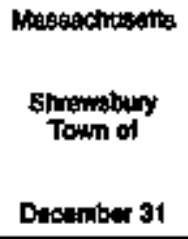 & $\begin{array}{l}\text { Magsachuesulis } \\
\text { Trumion } \\
\text { Chy of } \\
\text { Decombar } 81\end{array}$ & 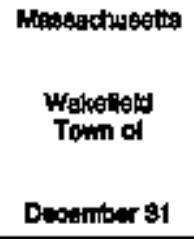 & 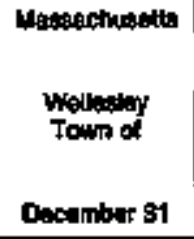 & 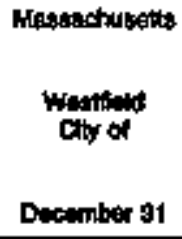 \\
\hline Eleotro toulty Oparating Rovanues & 91,609 & 20,040 & 38442 & 15974 & 16,055 & ats, \\
\hline 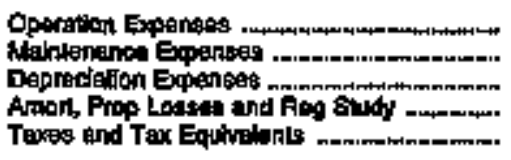 & $\begin{array}{r}46,009 \\
750 \\
1,049 \\
0 \\
489\end{array}$ & $\begin{array}{r}17,7 a 3 \\
609 \\
603 \\
0 \\
0\end{array}$ & $\begin{array}{r}25,469 \\
3.96 \\
3,377 \\
0 \\
2980\end{array}$ & $\begin{array}{r}18,904 \\
450 \\
658 \\
0 \\
213\end{array}$ & $\begin{array}{r}12,588 \\
741 \\
74 \\
0 \\
0\end{array}$ & $\begin{array}{r}27,708 \\
709 \\
69 \\
69\end{array}$ \\
\hline Total Elotso Ually Operoth & 47,246 & 18,072 & 85,560 & 15,109 & 14,200 & 30,742 \\
\hline 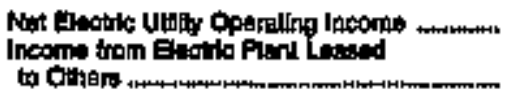 & $\begin{array}{r}4,391 \\
0\end{array}$ & ere & $\begin{array}{r}3,204 \\
0\end{array}$ & $\begin{array}{r}73 \\
0\end{array}$ & $\begin{array}{r}2,447 \\
0\end{array}$ & 003 \\
\hline 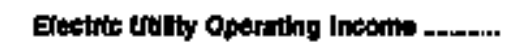 & 4,301 & 由rs & s,ant & $m$ & 2,467 & ous \\
\hline Other Elactule heobate & $\cos$ & 65d & 387 & 68 & -40 & 851 \\
\hline 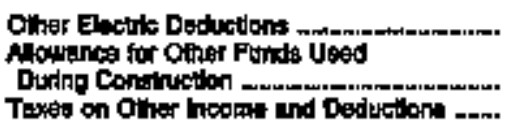 & $\begin{array}{l}0 \\
0 \\
0\end{array}$ & $\begin{array}{l}0 \\
0 \\
0\end{array}$ & $\begin{array}{l}0 \\
0 \\
0\end{array}$ & $\begin{array}{r}34 \\
0\end{array}$ & $\begin{array}{l}0 \\
0 \\
0\end{array}$ & 284 \\
\hline 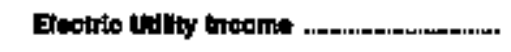 & s,0pg & 1,400 & 30,1 & 605 & $2,40 ?$ & 1,2000 \\
\hline 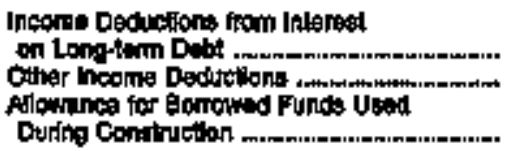 & $\begin{array}{r}298 \\
46 \\
0\end{array}$ & $\begin{array}{c}11 \\
10 \\
0\end{array}$ & $\begin{array}{r}7,303 \\
14 \\
0\end{array}$ & $\begin{array}{r}0 \\
95 \\
0\end{array}$ & $\begin{array}{l}30 \\
00 \\
0\end{array}$ & $\begin{array}{r}21 \\
0\end{array}$ \\
\hline 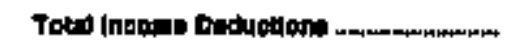 & 303 & $\mathbf{3 0}$ & 1,317 & 35 & $\mathbf{8 *}$ & 29 \\
\hline 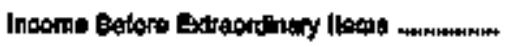 & 4,724 & 1,000 & 2,384 & 470 & 2,354 & oss \\
\hline 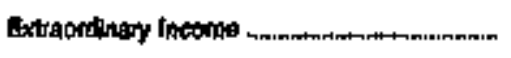 & 0 & 0 & 0 & 0 & 0 & 0 \\
\hline Extraordhary Doductions .-..... & 0 & 0 & 0 & 0 & 0 & . \\
\hline 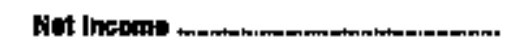 & 4,724 & top & 2,394 & 40 & $2+84$ & 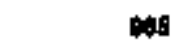 \\
\hline
\end{tabular}

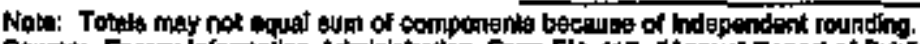

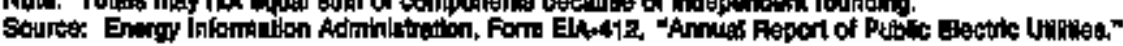


Table 21. Statement of Income by Major U.S. Publkly Owned Electric Utilty Whin State, 1984 (Contimued)

(Thousend Dollar's)

\begin{tabular}{|c|c|c|c|c|c|c|}
\hline Inem & $\begin{array}{l}\text { Mlothigan } \\
\text { City City or } \\
\text { Jum } 30\end{array}$ & 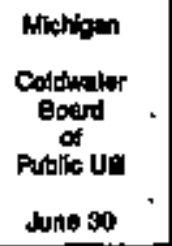 & $\begin{array}{l}\text { Whotigan } \\
\text { Oetreit } \\
\text { City of } \\
\text { June so }\end{array}$ & $\begin{array}{l}\text { Mreshipin } \\
\text { Grand Howen } \\
\text { City of } \\
\text { June } 30\end{array}$ & 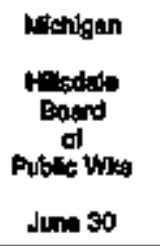 & $\begin{array}{l}\text { Winehigan } \\
\text { Holind } \\
\text { City of } \\
\text { June so }\end{array}$ \\
\hline 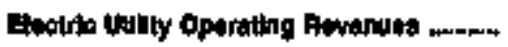 & $1+, 90$ & 11,00 & xis,onts & 21,569 & 9254 & 10,491 \\
\hline 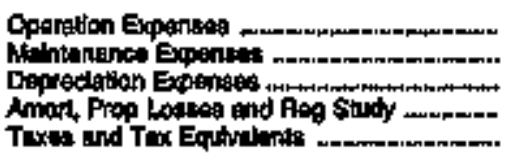 & $\begin{array}{r}13,384 \\
700 \\
1,600 \\
0 \\
426\end{array}$ & $\begin{array}{r}0,504 \\
241 \\
405 \\
0 \\
071\end{array}$ & $\begin{array}{r}41,796 \\
11,195 \\
5,237 \\
0 \\
0\end{array}$ & $\begin{array}{r}11,071 \\
3007 \\
0 \\
0\end{array}$ & $\begin{array}{r}7,301 \\
480 \\
494 \\
6 \\
205\end{array}$ & $\begin{array}{r}27,028 \\
2000 \\
4,766 \\
1,30\end{array}$ \\
\hline 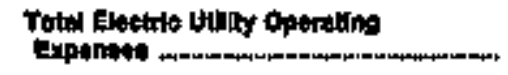 & 10,163 & 10,001 & S4,800 & 19,060 & $9 ;$ & 35,254 \\
\hline 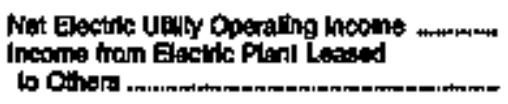 & $\begin{array}{r}2,8690 \\
0\end{array}$ & $2+18$ & 19065 & 0 & $\begin{array}{r}712 \\
0\end{array}$ & 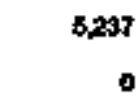 \\
\hline 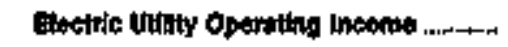 & 2,690 & 219 & to,655 & 0,809 & 712 & 6,237 \\
\hline 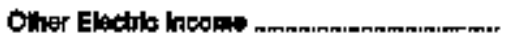 & 1,028 & 240 & 0 & 854 & 277 & 1,409 \\
\hline 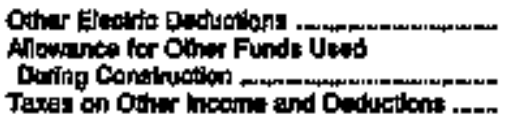 & 0 & $\begin{array}{l}0 \\
0 \\
0\end{array}$ & $\begin{array}{r}1,217 \\
0 \\
0\end{array}$ & 9 & 4 & $\begin{array}{l}0 \\
0 \\
0\end{array}$ \\
\hline 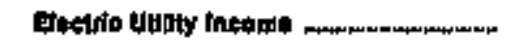 & 3,294 & 494 & T/Aas & 0.54 & 995 & 6940 \\
\hline 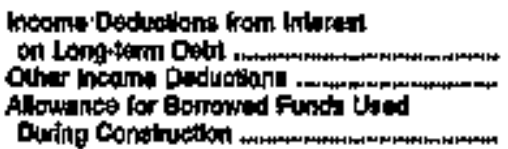 & $\begin{array}{r}1,610 \\
0 \\
0\end{array}$ & $\begin{array}{l}6 \\
0 \\
0\end{array}$ & $\begin{array}{r}6,000 \\
0 \\
0\end{array}$ & $\begin{array}{r}0,360 \\
2 \\
0\end{array}$ & $\begin{array}{l}0 \\
0 \\
0\end{array}$ & $\begin{array}{r}2,160 \\
0 \\
0\end{array}$ \\
\hline 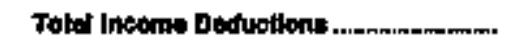 & 1,810 & est & 6,000 & s,300 & 0 & $\mathbf{2 , 1} \mathbf{1}: \mathbf{B}$ \\
\hline 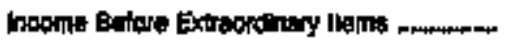 & 1,695 & 401 & 11,978 & 15 & 933 & 4,409 \\
\hline 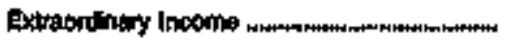 & $\mathbf{0}$ & 0 & 0 & 0 & 0 & 0 \\
\hline 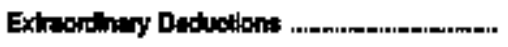 & $\$ 07$ & 0 & 0 & 0 & 0 & 0 \\
\hline Het lneomn ... & 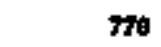 & 401 & 11sira & ats & 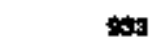 & 4,adp \\
\hline
\end{tabular}

thole: Totals may not equal eum of components becauce of indjoendent roundina

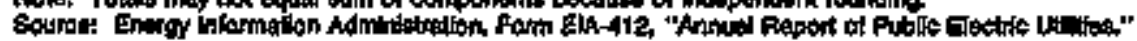


Tabie 21. Statement of knoome by Major U.S. Publieiy Owned Eleotric Utlly Within State, 1994 (Continued) (Thousand Dollars)

\begin{tabular}{|c|c|c|c|c|c|c|}
\hline Item: & $\begin{array}{l}\text { Mlianipen } \\
\text { Loning } \\
\text { Coty of } \\
\text { June so }\end{array}$ & $\begin{array}{l}\text { Nichions } \\
\text { Mapquette } \\
\text { City of } \\
\text { Jung } \mathbf{6 0}\end{array}$ & $\begin{array}{l}\text { Mlohigun } \\
\text { Michtigen } \\
\text { Pubio } \\
\text { Pomer Abency } \\
\text { Decenter } 11\end{array}$ & 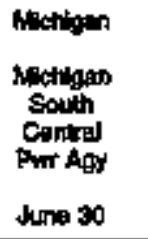 & $\begin{array}{l}\text { Mllotilgen } \\
\text { Sturg: } \\
\text { Chly of } \\
\text { September } 30\end{array}$ & 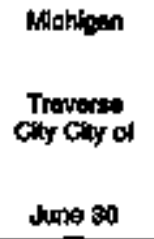 \\
\hline 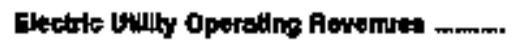 & $100,4: 5$ & 17,760 & tos, ons & 2,781 & 13,294 & 13,762 \\
\hline 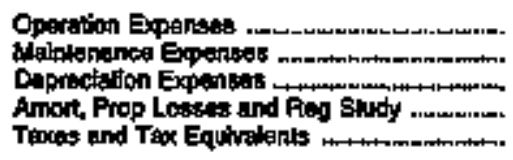 & $\begin{array}{r}104,974 \\
8,127 \\
11,904 \\
0 \\
0\end{array}$ & $\begin{array}{r}11,212 \\
1,346 \\
3,177 \\
1,400\end{array}$ & $\begin{array}{r}66,935 \\
3,190 \\
18,625 \\
4,372 \\
409\end{array}$ & $\begin{array}{r}15,200 \\
1,112 \\
2,160 \\
0 \\
40\end{array}$ & $\begin{array}{r}9,493 \\
390 \\
999 \\
0 \\
690\end{array}$ & $\begin{array}{r}0,711 \\
1,604 \\
837 \\
908\end{array}$ \\
\hline 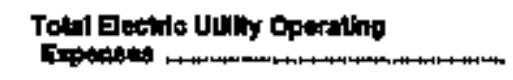 & 124,995 & 17,197 & 44,901 & 18,000 & 11,702 & 12,744 \\
\hline 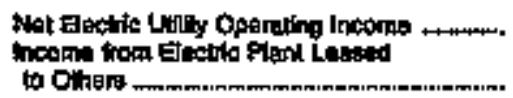 & $\begin{array}{r}5,502 \\
0\end{array}$ & 0 & $\begin{array}{r}18,104 \\
0\end{array}$ & $\begin{array}{r}3793 \\
0\end{array}$ & 1,002 & $\begin{array}{r}1,018 \\
0\end{array}$ \\
\hline Elootrlo Vitity Oparatho Inoome n...... & 5,502 & 609 & 15,104 & 3,790 & 1,932 & 1,018 \\
\hline 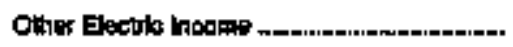 & 1,208 & $\mathbf{s}$ & 5,557 & 2,07 & 798 & $2 \mathrm{ax}$ \\
\hline 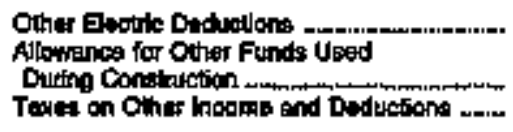 & 0 & $\begin{array}{l}0 \\
0 \\
0\end{array}$ & $\begin{array}{l}0 \\
0 \\
0\end{array}$ & $\begin{array}{l}0 \\
0 \\
0\end{array}$ & 0 & $\stackrel{0}{0}$ \\
\hline topetric udility theolmb & 7,409 & 1,516 & 23,401 & 6,780 & 2,350 & 1,311 \\
\hline 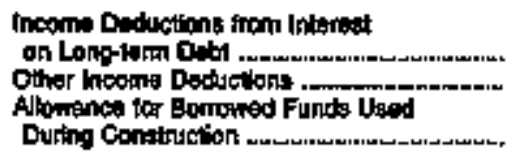 & $\begin{array}{r}\operatorname{sen}_{x \in 3} \\
0\end{array}$ & $\begin{array}{r}2,054 \\
88 \\
0\end{array}$ & $\begin{array}{r}24,010 \\
-605 \\
0\end{array}$ & $\begin{array}{r}5,780 \\
700 \\
0\end{array}$ & $\begin{array}{r}42 x \\
0 \\
0\end{array}$ & $\begin{array}{l}0 \\
4\end{array}$ \\
\hline 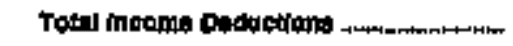 & t,125 & 2,142 & 23,405 & 6,601 & 42 & 4 \\
\hline Intomp Before Edtagrdinuy Hents ......... & 6,, 348 & $-\infty$ & st & 270 & 1,000 & 1,307 \\
\hline 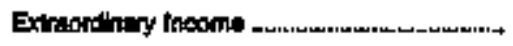 & 0 & (1) & 0 & 0 & 0 & 0 \\
\hline Extrabithery Diduetians & o & 1,034 & $\mathbf{0}$ & 0 & 1,690 & $\mathbf{0}$ \\
\hline Malt lnogme & $6, \$ \mathbf{8}$ & $-1,018$ & Es & 279 & 29 & 1,397 \\
\hline
\end{tabular}

Nola: Totsls may not equel sum of tompinenga becaurag of Independent rounding

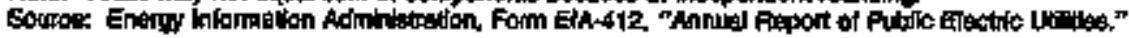


Tabie 21. Statement of Income by Major U.S. Publicly Owned Electric Utility Whithin State, 1994 (Continued)

(Thousand Dollars)

\begin{tabular}{|c|c|c|c|c|c|c|}
\hline ltem & 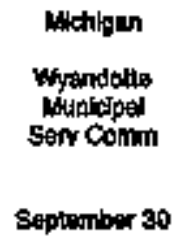 & 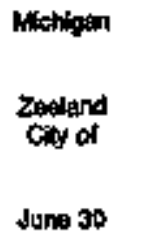 & 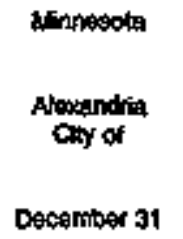 & 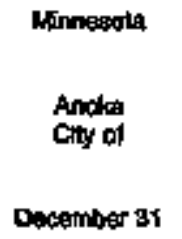 & 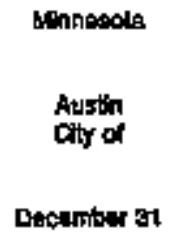 & $\begin{array}{l}\text { Minnosedt } \\
\text { Eralnard } \\
\text { City of } \\
\text { Oucamisem } 31\end{array}$ \\
\hline 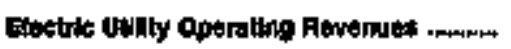 & $t 2,145$ & 0,519 & 8,008 & $12 \pi$ & T.,011 & 7,160 \\
\hline 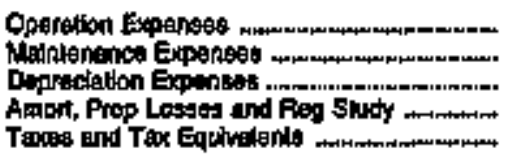 & $\begin{array}{r}14,700 \\
6800 \\
2301 \\
0 \\
0\end{array}$ & $\begin{array}{r}0,470 \\
150 \\
643 \\
0 \\
0\end{array}$ & $\begin{array}{r}6,906 \\
367 \\
4 \$ 0 \\
0 \\
404\end{array}$ & $\begin{array}{r}10,146 \\
171 \\
518 \\
0 \\
0\end{array}$ & $\begin{array}{r}20,040 \\
8909 \\
730 \\
0 \\
9\end{array}$ & $\begin{array}{r}6,514 \\
68 \\
379 \\
0 \\
0\end{array}$ \\
\hline $\begin{array}{l}\text { Tounl Electito Utilhy Operathg } \\
\text { Expentes }\end{array}$ & $\begin{array}{c}17,604 \\
.\end{array}$ & 7,209 & 0,247 & wo,kess & 21,659 & 9,600 \\
\hline 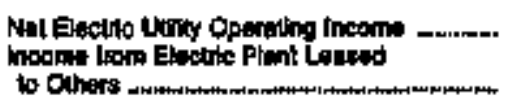 & $\begin{array}{r}1,486 \\
0\end{array}$ & $\begin{array}{r}1,251 \\
0\end{array}$ & $\begin{array}{r}-154 \\
0\end{array}$ & $\begin{array}{r}1,942 \\
0\end{array}$ & $\begin{array}{r}-3,776 \\
4,710\end{array}$ & $\begin{array}{r}194 \\
0\end{array}$ \\
\hline 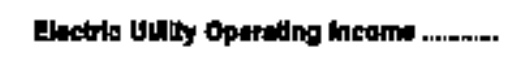 & 1,485 & 1,251 & -154 & 1,942 & 93 & 194 \\
\hline 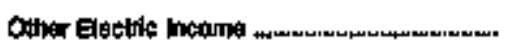 & B.282 & 226 & 300 & 0 & 254 & 211 \\
\hline 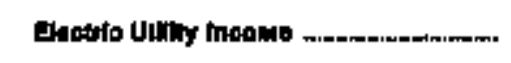 & 7,608 & 1,191 & 149 & tro & $-1,748$ & 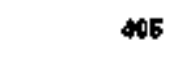 \\
\hline 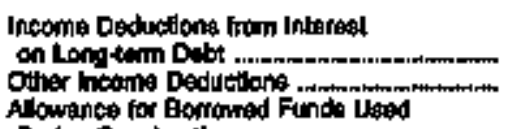 & 1.811 & o & 0 & o & 0 & 0 \\
\hline 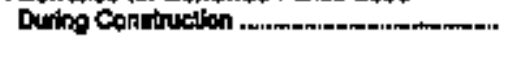 & $\mathbf{0}$ & 0 & 0 & 0 & 0 & 0 \\
\hline 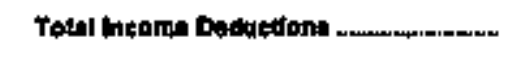 & 20023 & $\mathbf{0}$ & 4 & \% & 4 & 0 \\
\hline Income Belore Extraordhary Itemen & 5590 & 1,181 & 145 & 976 & $-1,750$ & 405 \\
\hline Edreodinary tncome ....-. & 0 & 0 & 0 & 0 & 0 & 0 \\
\hline 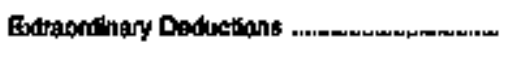 & 0 & $\mathbf{0}$ & 68 & a & 0 & 0 \\
\hline Hat Inequme & S,840 & 1,191 & 70 & 976 & $-1,7=0$ & 405 \\
\hline
\end{tabular}

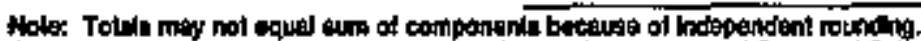

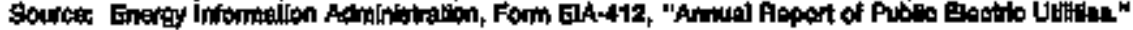


Table 21. Statement of mcome by Mojor L.8. Publioly Owned Electric Utally Within State, 1994 (Contlnued) (Thousand Dollars)

\begin{tabular}{|c|c|c|c|c|c|c|}
\hline Itern & 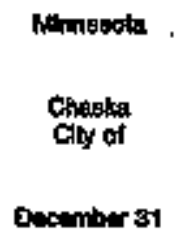 & 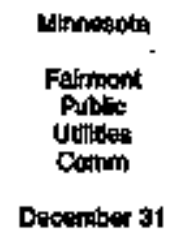 & 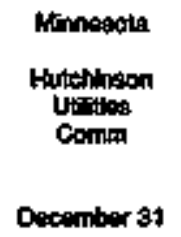 & $\begin{array}{l}\text { Annosote } \\
\text { Mlarthat } \\
\text { Chy of } \\
\text { Desomber } 31\end{array}$ & $\begin{array}{l}\text { Minnisole } \\
\text { Moomond } \\
\text { City of } \\
\text { Dopamber } 85\end{array}$ & 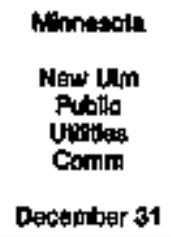 \\
\hline 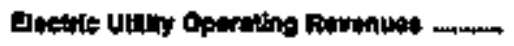 & 9,44 & a,ess & 10 1016 & $12 ; 194$ & 13,287 & 10.979 \\
\hline 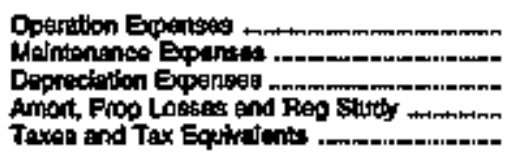 & $\begin{array}{r}7,605 \\
0 \\
389 \\
0 \\
0\end{array}$ & $\begin{array}{r}8504 \\
007 \\
5 e 5 \\
0 \\
0\end{array}$ & 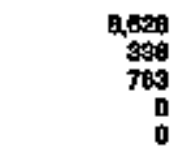 & $\begin{array}{r}11,202 \\
0 \\
072 \\
0 \\
451\end{array}$ & $\begin{array}{r}8,690 \\
448 \\
823 \\
0 \\
2,851\end{array}$ & $\begin{array}{r}7,214 \\
002 \\
750 \\
0 \\
519\end{array}$ \\
\hline Total miectro unity Opanattig & 7904 & 10,634 & 0,740 & theas & 18,720 & 9,119 \\
\hline 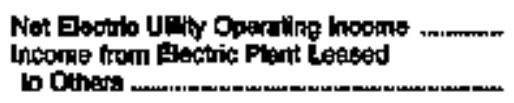 & $\begin{array}{r}1,461 \\
0\end{array}$ & $\begin{array}{r}-2,000 \\
0\end{array}$ & $\begin{array}{r}1+167 \\
0\end{array}$ & $\begin{array}{r}-384 \\
276\end{array}$ & $\begin{array}{r}-452 \\
5\end{array}$ & 1,20 \\
\hline 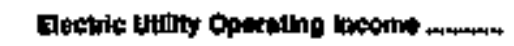 & $t, 451$ & $-2,009$ & 1,167 & -8 & $-3+8$ & 1,206 \\
\hline 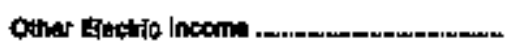 & 179 & $3,0 \leq 5$ & 104 & ges & 369 & 971 \\
\hline 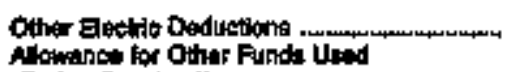 & 0 & sas & o & 0 & 0 & 4 \\
\hline 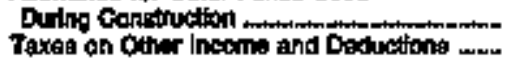 & 1,000 & $\stackrel{9}{0}$ & $\stackrel{0}{0}$ & 262 & $\begin{array}{l}\mathbf{0} \\
\mathbf{0}\end{array}$ & 0 \\
\hline Electors Utity Ineouth & 928 & $\$ 70$ & 1,351 & 900 & -100 & 1,600 \\
\hline 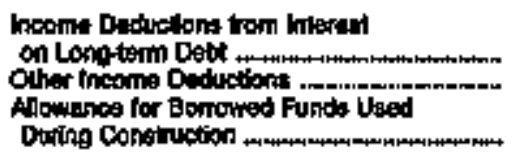 & $\begin{array}{r}100 \\
0\end{array}$ & $\begin{array}{r}177 \\
403 \\
0\end{array}$ & $\begin{array}{r}8698 \\
17 \\
0\end{array}$ & $\begin{array}{l}0 \\
0 \\
0\end{array}$ & $\begin{array}{r}203 \\
0\end{array}$ & $\begin{array}{r}172 \\
0 \\
0\end{array}$ \\
\hline 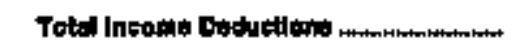 & 103 & 660 & 996 & a & 401 & $\mathbf{m}$ \\
\hline 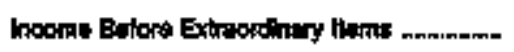 & 62 & -290 & 005 & 890 & .431 & 1,494 \\
\hline Extrantinny Incomi & 0 & 0 & 0 & 0 & a & 0 \\
\hline 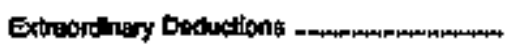 & 0 & 0 & 0 & 0 & $\mathbf{0}$ & 0 \\
\hline 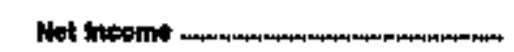 & 60 & $\infty$ & ens & טוs & $-\infty t$ & 1,401 \\
\hline
\end{tabular}

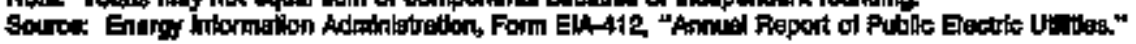


Table 21. Statement of Inwome by Major U.S. Publlcly Owned Eleotric Utility Whin Stato, t994 (Continued)

(Thousend Dollars)

\begin{tabular}{|c|c|c|c|c|c|c|}
\hline them & 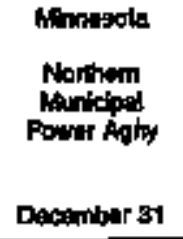 & $\begin{array}{l}\text { Minhinesute } \\
\text { Ometonate } \\
\text { City of } \\
\text { December at }\end{array}$ & 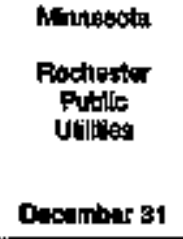 & 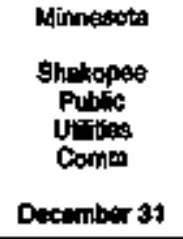 & 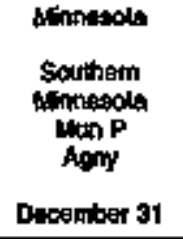 & 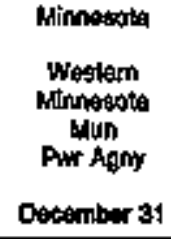 \\
\hline 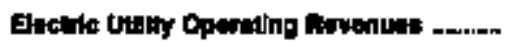 & 39,530 & 18597 & $737 x$ & 4017 & 145,905 & 43,184 \\
\hline 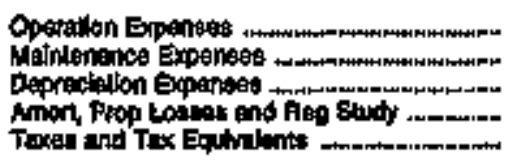 & $\begin{array}{r}11,000 \\
3,545 \\
5,005 \\
0 \\
0\end{array}$ & $\begin{array}{r}18,041 \\
1,216 \\
980 \\
0 \\
0\end{array}$ & $\begin{array}{r}6,708 \\
2,443 \\
2,168 \\
\text { of } \\
0,40\end{array}$ & $\begin{array}{r}609 \\
404 \\
172 \\
08 \\
478\end{array}$ & $\begin{array}{r}52,960 \\
4,091 \\
7,966 \\
0 \\
7,689\end{array}$ & $\begin{array}{r}18,911 \\
3,709 \\
4,840 \\
0 \\
1,351\end{array}$ \\
\hline 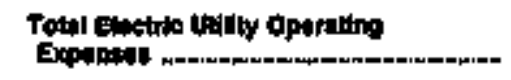 & $19,6 \oplus 0$ & 18,246 & 71,015 & 7,717 & 72,570 & 20,500 \\
\hline 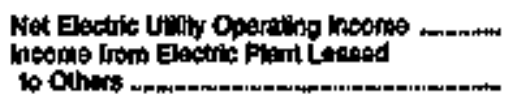 & $\begin{array}{r}18096 \\
0\end{array}$ & $\begin{array}{r}358 \\
0\end{array}$ & $\begin{array}{r}1,000 \\
0\end{array}$ & 60 & $\begin{array}{r}43,335 \\
0\end{array}$ & 14,000 \\
\hline Dipettit Uinty Opantipg Ineome & tostose & 352 & 1,006 & eno & 4,35s & 14,903 \\
\hline Other Electio meame & . 2,074 & 301 & 184 & $24 \theta$ & 7,411 & 3,180 \\
\hline 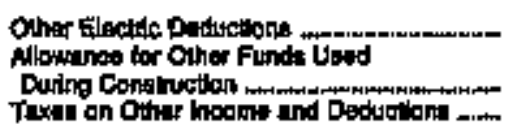 & $\begin{array}{l}0 \\
0 \\
0\end{array}$ & $\begin{array}{r}562 \\
0\end{array}$ & $\begin{array}{r}46 \\
0 \\
0\end{array}$ & $\begin{array}{l}0 \\
0 \\
0\end{array}$ & $\begin{array}{l}0 \\
0 \\
0\end{array}$ & 0 \\
\hline 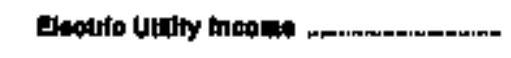 & 20007 & 170 & 2,345 & 的 & 80,746 & 18,173 \\
\hline 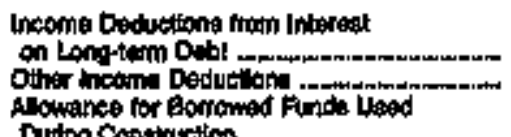 & 20,070 & $\begin{array}{r}391 \\
0\end{array}$ & o1 & 204 & $\begin{array}{r}40,519 \\
6,0069 \\
-1,50\end{array}$ & $\begin{array}{r}18,178 \\
0 \\
0\end{array}$ \\
\hline 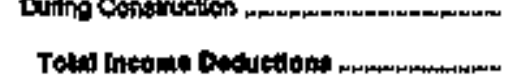 & $\begin{array}{r}0 \\
70,850\end{array}$ & sa1 & $\mathbf{0}$ & 204 & 45,452 & 18,178 \\
\hline 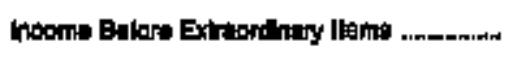 & 0 & -210 & 2,300 & 646 & $6,2,4$ & 0 \\
\hline 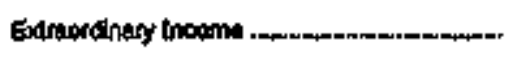 & 0 & 0 & 090 & 0 & 4 & 0 \\
\hline 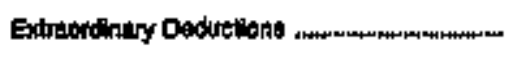 & 0 & 0 & 0 & 0 & 0 & D \\
\hline 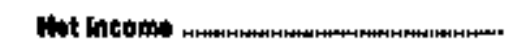 & 0 & -240 & 1,853 & 645 & s,y4 & 4 \\
\hline
\end{tabular}

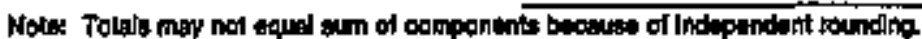

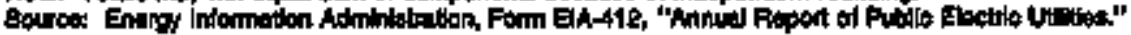


Table 21. Statement of hcome by Major U.8. Publiely Owned Electric Utilly Whin State, 1994 (Coninued) (Thousand Dollars)

\begin{tabular}{|c|c|c|c|c|c|c|}
\hline $\operatorname{Imm}$ & 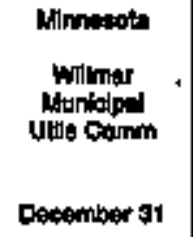 & $\begin{array}{l}\text { Monnewate } \\
\text { Worthington } \\
\text { City of } \\
\text { Eacamber } 31\end{array}$ & 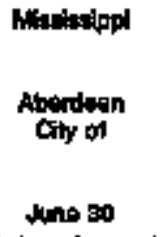 & 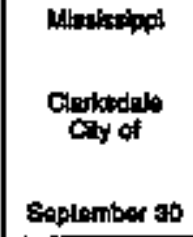 & 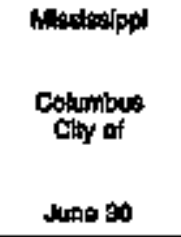 & 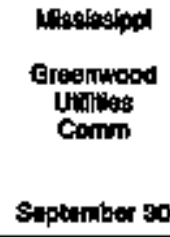 \\
\hline 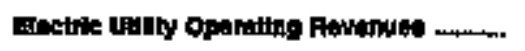 & 11,0020 & 7,497 & 8,160 & Mantin & nequs & 16,000 \\
\hline 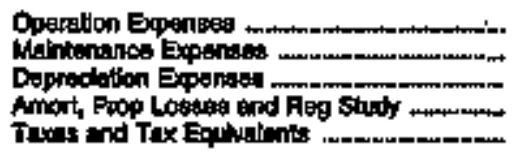 & $\begin{array}{r}7,605 \\
571 \\
013 \\
0 \\
0\end{array}$ & $\begin{array}{r}5,060 \\
102 \\
385 \\
0 \\
0\end{array}$ & $\begin{array}{r}7,758 \\
138 \\
185 \\
0 \\
274\end{array}$ & $\begin{array}{r}11,469 \\
438 \\
889 \\
0 \\
0\end{array}$ & $\begin{array}{r}22,310 \\
729 \\
609 \\
0 \\
6,174\end{array}$ & $\begin{array}{r}12,407 \\
747 \\
760 \\
0 \\
0\end{array}$ \\
\hline 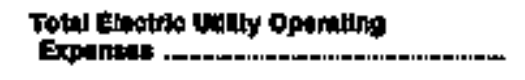 & 905 & 8,480 & s, sas & 12,489 & 24,728 & 14,000 \\
\hline 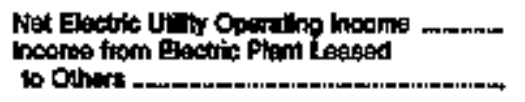 & $\begin{array}{r}2, \text {, } 01 \\
0\end{array}$ & 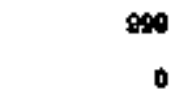 & $\begin{array}{r}-117 \\
0\end{array}$ & $\begin{array}{r}1,869 \\
0\end{array}$ & $\begin{array}{r}-1,284 \\
0\end{array}$ & 2,690 \\
\hline Dectste Utilny Operating theorne & ano1 & $m$ & -17 & 1,0509 & . - -1,201 & 2,000 \\
\hline Other Electlo heoins & 由75 & 15 & 127 & 20 & $\sec$ & 589 \\
\hline 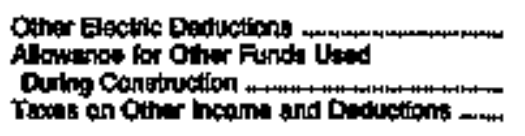 & $\begin{array}{l}0 \\
0 \\
0\end{array}$ & $\begin{array}{l}0 \\
0 \\
0\end{array}$ & $\begin{array}{l}14 \\
0 \\
0\end{array}$ & $\begin{array}{l}\mathbf{3} \\
\mathbf{0} \\
\mathbf{0}\end{array}$ & $\begin{array}{l}5 \\
0 \\
0\end{array}$ & $\begin{array}{r}1,370 \\
0 \\
0\end{array}$ \\
\hline 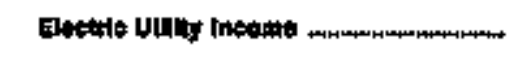 & 3,850 & 1,157 & -5 & 2,109 & $\rightarrow 4$ & 1,971 \\
\hline 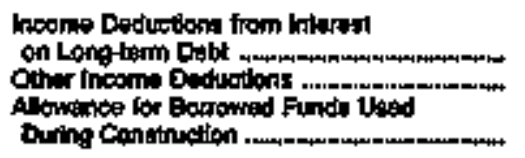 & $\begin{array}{r}764 \\
0\end{array}$ & $\begin{array}{l}0 \\
0 \\
0\end{array}$ & $\begin{array}{l}0 \\
0 \\
0\end{array}$ & $\begin{array}{r}\text { t51 } \\
0 \\
0\end{array}$ & $\begin{array}{r}0 \\
16 \\
0\end{array}$ & $\begin{array}{r}12 \\
0 \\
0\end{array}$ \\
\hline 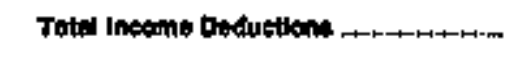 & 613 & a & 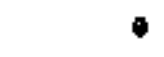 & 150 & 18 & นง \\
\hline 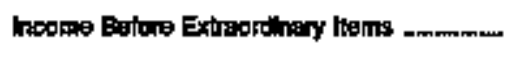 & 2, & 1,167 & -6 & 1,944 & -931 & 1,058 \\
\hline 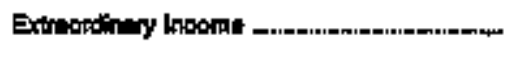 & 0 & D & $\mathbf{0}$ & $1,1+8$ & 0 & 0 \\
\hline 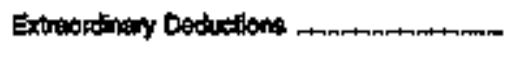 & $\mathbf{0}$ & $\mathbf{0}$ & 0 & 1,549 & 0 & 0 \\
\hline 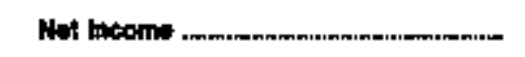 & 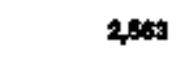 & 1,187 & -8 & 1,669 & -031 & 1,960 \\
\hline
\end{tabular}

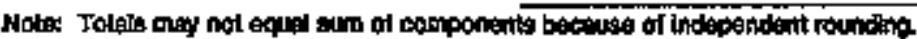

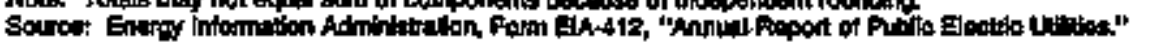


Tabie 2t. Statement of Ineone by Injer US, Publchy Owned Etectric Utilty Within State, 1984 (Continulad)

(Thousand Dollara)

\begin{tabular}{|c|c|c|c|c|c|c|}
\hline ment & 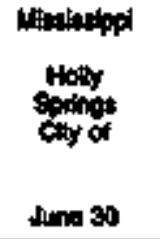 & 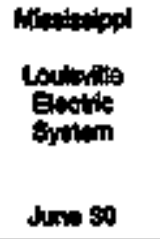 & 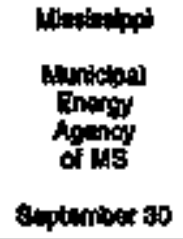 & 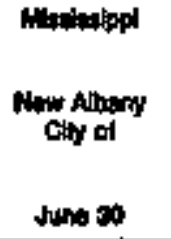 & 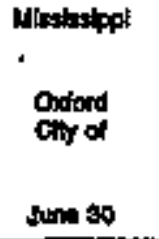 & $\begin{array}{l}\text { Mastisalpol } \\
\text { Soundite } \\
\text { Gity of } \\
\text { Jute } 30\end{array}$ \\
\hline 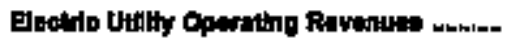 & ntrat & 1:41 & semri & 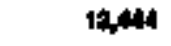 & $\Delta, 00$ & 17,16 \\
\hline 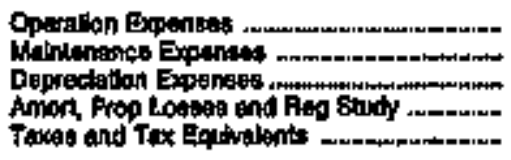 & $\begin{array}{r}10,508 \\
405 \\
508 \\
694\end{array}$ & $\begin{array}{r}7,024 \\
170 \\
208 \\
0 \\
216\end{array}$ & $\begin{array}{r}30,03 \\
n \\
n \\
29 \\
0\end{array}$ & 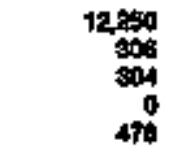 & $\begin{array}{r}7,640 \\
216 \\
169 \\
0 \\
\$ 40\end{array}$ & $\begin{array}{r}15,378 \\
311 \\
349 \\
11 \\
100\end{array}$ \\
\hline 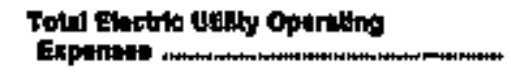 & 11,44 & ats & sopers & 13,90 & 0940 & 18649 \\
\hline 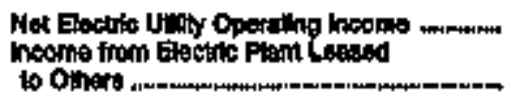 & 0 & 278 & $\begin{array}{r}-16 s \\
0\end{array}$ & $\begin{array}{r}100 \\
0\end{array}$ & $\begin{array}{r}-486 \\
0\end{array}$ & 0 \\
\hline 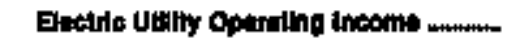 & ext & 278 & -111 & 103 & -400 & 320 \\
\hline 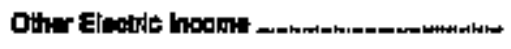 & $\mathbf{s 2}$ & 105 & 140 & 248 & 178 & 195 \\
\hline 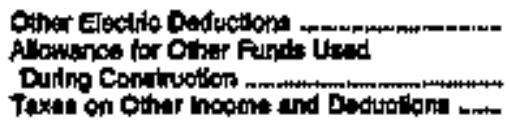 & $\begin{array}{l}18 \\
0 \\
8\end{array}$ & $\begin{array}{l}11 \\
0 \\
0\end{array}$ & : & 0 & 8 & $\begin{array}{l}11 \\
0\end{array}$ \\
\hline 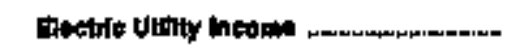 & 938 & sro & 24 & at: & -352 & 497 \\
\hline 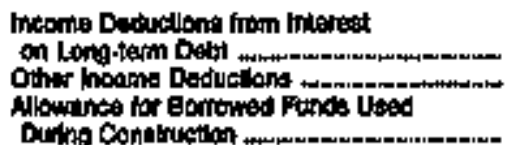 & 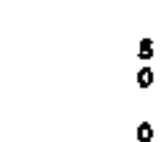 & 0 & o & $\begin{array}{l}10 \\
10 \\
0\end{array}$ & $\begin{array}{r}0 \\
16\end{array}$ & $\begin{array}{r}-11 \\
40 \\
0\end{array}$ \\
\hline 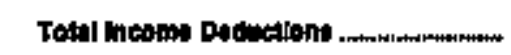 & 5 & $\mathbf{0}$ & 0 & 5 & 15 & 2 \\
\hline 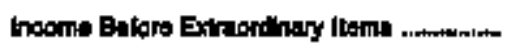 & exp & \$70 & 24 & sest & -347 & 408 \\
\hline 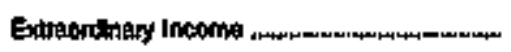 & 0 & 0 & 0 & 0 & 0 & 0 \\
\hline Extabordirary Dedurtion & 0 & 0 & 0 & 0 & -46 & 0 \\
\hline What Inodite - & $9 \pi$ & 370 & 24 & \$as & -8002 & 46 \\
\hline
\end{tabular}

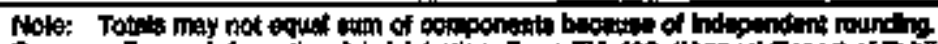

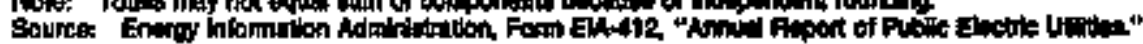


Table 2t. Statement of Income by Major U.S. Publicly Owned Electric Utility Within State, 1994 (Continued)

(Thousand Dollars)

\begin{tabular}{|c|c|c|c|c|c|c|}
\hline Iman & $\begin{array}{l}\text { Mhatsilpgh } \\
\text { Trpolo } \\
\text { Gity of } \\
\text { Jinta so }\end{array}$ & $\begin{array}{l}\text { Wost } \\
\text { Point } \\
\text { Cing of } \\
\text { June so }\end{array}$ & $\begin{array}{l}\text { Misootiti } \\
\text { Certhage } \\
\text { Chy of } \\
\text { Jum to }\end{array}$ & $\begin{array}{l}\text { Mlesoui } \\
\text { Cylumbia } \\
\text { Ciny of } \\
\text { Seplentar so }\end{array}$ & 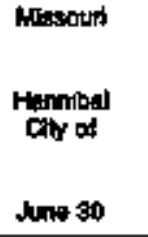 & $\begin{array}{l}\text { Mlasour } \\
\text { Indepindenos } \\
\text { Othy of } \\
\text { Juthe } 30\end{array}$ \\
\hline 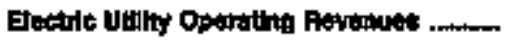 & 32,021 & 20090 & 0,242 & 4h,202 & $\mathbf{w}, 444$ & 69,605 \\
\hline 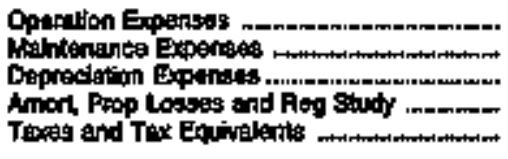 & 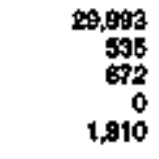 & $\begin{array}{r}0,670 \\
290 \\
211 \\
5 \\
579\end{array}$ & $\begin{array}{r}8,125 \\
395 \\
475 \\
0 \\
0\end{array}$ & $\begin{array}{r}34,304 \\
2,725 \\
3,352 \\
0 \\
4,2009\end{array}$ & $\begin{array}{r}8,605 \\
497 \\
348 \\
0 \\
424\end{array}$ & $\begin{array}{r}34,391 \\
6,801 \\
5,314 \\
0 \\
6,809\end{array}$ \\
\hline Total Elootrk lallky Opersting & \$3,111 & 9,892 & E, & 44879 & 0,904 & 61,604 \\
\hline 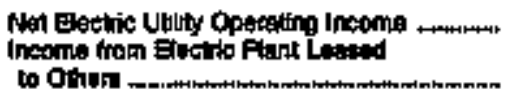 & -250 & $\begin{array}{r}242 \\
0\end{array}$ & 244 & 4,e13 & $\begin{array}{r}579 \\
0\end{array}$ & $\begin{array}{r}5,001 \\
0\end{array}$ \\
\hline Ecotro tedlty Oparating Inooms .......... & -290 & 242 & 24 & 4,615 & sto & 5,001 \\
\hline Othef Elactic Ireorat & sst & 68 & $\$$ & 3,584 & $3 \pi 1$ & 2,119 \\
\hline 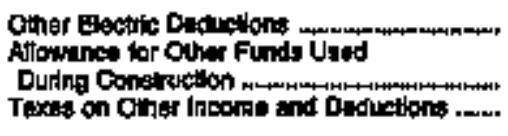 & 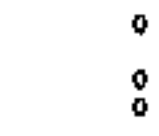 & $\begin{array}{l}1 \\
0 \\
0\end{array}$ & $\begin{array}{l}0 \\
0 \\
0\end{array}$ & $\begin{array}{r}218 \\
0\end{array}$ & $\begin{array}{l}0 \\
0 \\
0\end{array}$ & $\begin{array}{l}0 \\
0 \\
0\end{array}$ \\
\hline 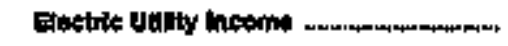 & 241 & 20 & str & $7,0.84$ & 860 & 7,120 \\
\hline 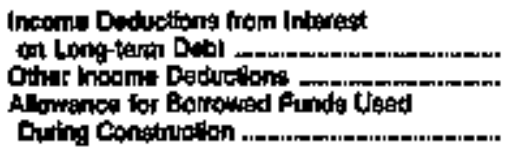 & $\stackrel{0}{0}$ & $\begin{array}{r}31 \\
1 \\
0\end{array}$ & $\begin{array}{l}70 \\
5\end{array}$ & $\begin{array}{r}2004 \\
20\end{array}$ & $\begin{array}{l}0 \\
0 \\
0\end{array}$ & $\begin{array}{r}2,750 \\
0 \times 0 \\
0\end{array}$ \\
\hline Totol 1teone Dedictione & 0 & $\mathbf{3 2}$ & $\boldsymbol{H}$ & $2,3 \oplus 8$ & 0 & 7,998 \\
\hline 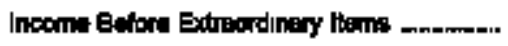 & 241 & 204 & 200 & 5,906 & 890 & 4,131 \\
\hline Extracrodinaty moora & o & 0 & 0 & o & - & 0 \\
\hline Extroudiney Dediefions & o & 0 & 0 & 0 & 0 & 0 \\
\hline 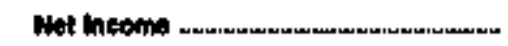 & 241 & 244 & 260 & 5,586 & Bop & 4,191 \\
\hline
\end{tabular}

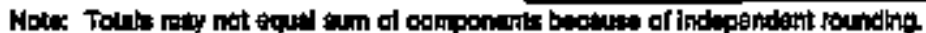

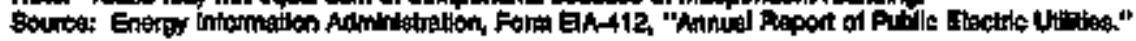


Table 21. Statement of Income by Hejor U.S. Publicly Owned Electrle UtDity Whin State, 1994 (Canknued)

(Thousand Do:tars)

\begin{tabular}{|c|c|c|c|c|c|c|}
\hline ltem & $\begin{array}{l}\text { Miscoun } \\
\text { Kennel } \\
\text { city of } \\
\text { Juna } 30\end{array}$ & $\begin{array}{l}\text { Mtasoun } \\
\text { Kanood } \\
\text { Othy of }\end{array}$ & $\begin{array}{l}\text { Hotheori } \\
\text { Letranon } \\
\text { Cly of } \\
\text { Octution } 31\end{array}$ & 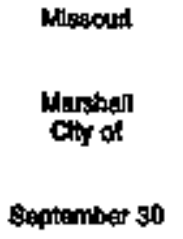 & $\begin{array}{l}\text { Mogond } \\
\text { Monet } \\
\text { City of } \\
\text { March } 39\end{array}$ & $\begin{array}{l}\text { Mistophni } \\
\text { Paplar } \\
\text { Chy of } \\
\text { Decenaber a1 }\end{array}$ \\
\hline 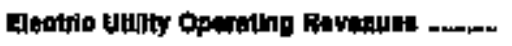 & $4,7 \mathrm{da}$ & 12,163 & seos & 0,836 & \$,13: & 19,711 \\
\hline 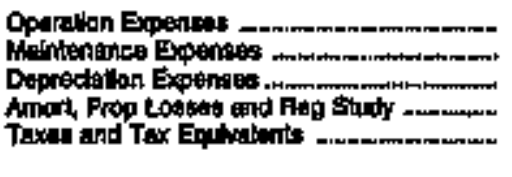 & $\begin{array}{r}4,000 \\
248 \\
535 \\
0 \\
00\end{array}$ & $\begin{array}{r}6,40 \\
677 \\
170 \\
0 \\
0\end{array}$ & $\begin{array}{r}8,060 \\
0 \\
0 \\
0\end{array}$ & $\begin{array}{r}4,720 \\
1,406 \\
1,457 \\
0 \\
0\end{array}$ & $\begin{array}{r}6,167 \\
0 \\
200 \\
0 \\
0 \\
0\end{array}$ & $\begin{array}{r}8052 \\
634 \\
740 \\
0 \\
0\end{array}$ \\
\hline 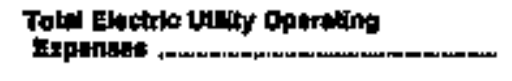 & 4,894 & 9,284 & thes0 & 7,599 & 6,366 & 9,47 \\
\hline 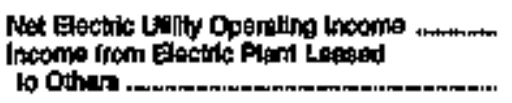 & $\begin{array}{r}-88 \\
198\end{array}$ & 2,800 & $\begin{array}{r}1,158 \\
15\end{array}$ & 2,044 & $\begin{array}{r}1,767 \\
6\end{array}$ & $\begin{array}{r}1,285 \\
0\end{array}$ \\
\hline 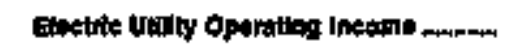 & st & 2,066 & 1,168 & 2,044 & 1,778 & 1,285 \\
\hline 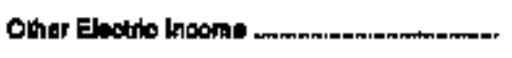 & 0 & 167 & 2as & 30 & $\mathbf{0}$ & 84 \\
\hline 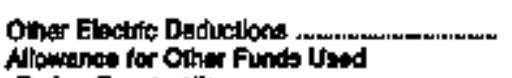 & 0 & $\theta$ & 659 & 870 & 0 & $\mathbf{0}$ \\
\hline 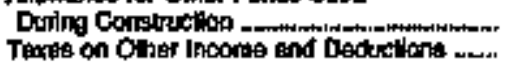 & $\stackrel{0}{0}$ & $\stackrel{0}{0}$ & $\begin{array}{l}0 \\
0\end{array}$ & $\stackrel{0}{0}$ & $\begin{array}{l}\mathbf{0} \\
\mathbf{0}\end{array}$ & $\begin{array}{l}0 \\
0\end{array}$ \\
\hline 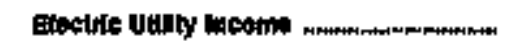 & ss & 3,020 & $\mathbf{4}$ & 1,603 & 1,778 & 1,600 \\
\hline 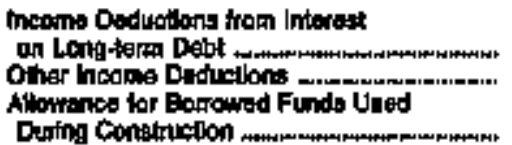 & $\stackrel{0}{0}$ & 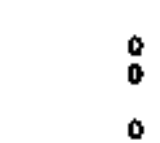 & 244 & $\begin{array}{r}109 \\
30 \\
0\end{array}$ & $\stackrel{0}{8}$ & $\begin{array}{l}0 \\
0 \\
0\end{array}$ \\
\hline 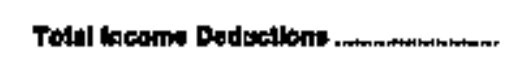 & $\mathbf{0}$ & 0 & 40 & $13 \%$ & 10 & $\mathbf{0}$ \\
\hline 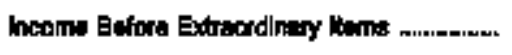 & ம9 & 3,028 & 409 & 1,354 & $1, \operatorname{BEx}$ & 1,901 \\
\hline 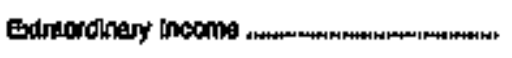 & 0 & 0 & -200 & 0 & 0 & $\mathbf{0}$ \\
\hline 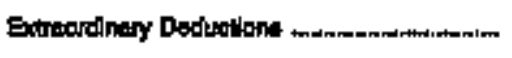 & 0 & 2,968 & 0 & 0 & 0 & 0 \\
\hline Ned beome & $\theta$ & 200 & 180 & 1,394 & 1,000 & 1,000 \\
\hline
\end{tabular}

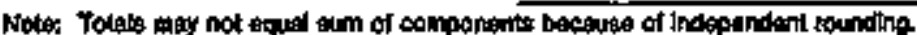

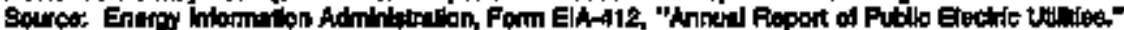


Table 21. Statement of Inconne by Major U.S. Publicly Owned Electric Utility Whith State, 1994 (Continued)

(Thousand Dollars)

\begin{tabular}{|c|c|c|c|c|c|c|}
\hline Ithe & $\begin{array}{l}\text { Missouri } \\
\text { Colly of } \\
\text { September so }\end{array}$ & $\begin{array}{l}\text { Mlatouit } \\
\text { Skeskon } \\
\text { Cyty of } \\
\text { Magy } 31\end{array}$ & 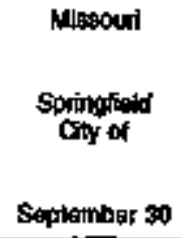 & 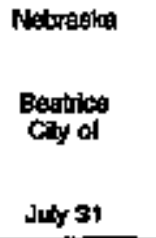 & 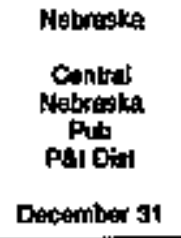 & 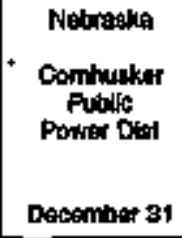 \\
\hline 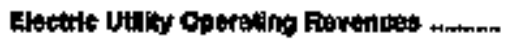 & 11,560 & 62667 & 107,760 & 7,090 & 10,2065 & 10,072 \\
\hline 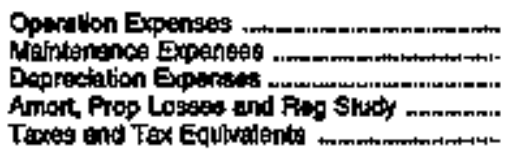 & $\begin{array}{r}0,546 \\
354 \\
40 \% \\
9 \\
607\end{array}$ & $\begin{array}{r}19,419 \\
4,797 \\
2,869 \\
0 \\
0\end{array}$ & $\begin{array}{r}01,4060 \\
74,600 \\
12,029 \\
0 \\
3,2,10\end{array}$ & $\begin{array}{r}6000 \\
0 \\
479 \\
0 \\
0\end{array}$ & $\begin{array}{r}6,442 \\
2,154 \\
2,731 \\
0 \\
8\end{array}$ & $\begin{array}{r}7,754 \\
471 \\
055 \\
0 \\
1\end{array}$ \\
\hline 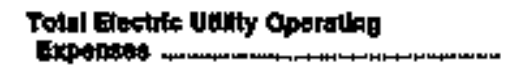 & 10,908 & 37,095 & 20,867 & 6,599 & 11,335 & 9,191 \\
\hline 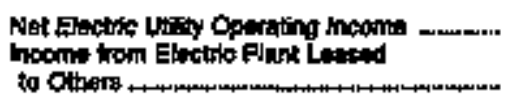 & $\begin{array}{r}672 \\
0\end{array}$ & $\begin{array}{r}19,472 \\
0\end{array}$ & $\begin{array}{r}15,418 \\
6,269\end{array}$ & $\begin{array}{r}651 \\
0\end{array}$ & $\begin{array}{r}-1,0899 \\
a 9\end{array}$ & Bar \\
\hline 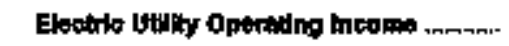 & 672 & 15,472 & 21,702 & 61 & $-1,000$ & 690 \\
\hline Oather Electile Imatrma & 236 & 2,499 & 16,470 & 133 & B94 & 295 \\
\hline 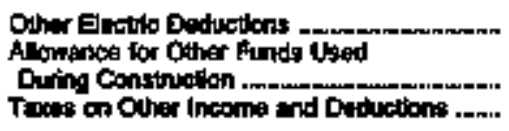 & 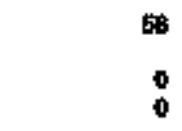 & $\begin{array}{l}0 \\
0 \\
0\end{array}$ & $\begin{array}{r}0 \\
1,680 \\
0\end{array}$ & $\begin{array}{r}271 \\
0 \\
0\end{array}$ & $\begin{array}{l}0 \\
0 \\
0\end{array}$ & $\begin{array}{l}0 \\
0 \\
0\end{array}$ \\
\hline 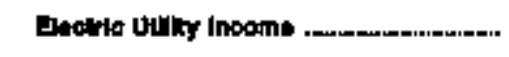 & s51 & 17,972 & $41, \mathrm{E} 65$ & 418 & -407 & 1,105 \\
\hline 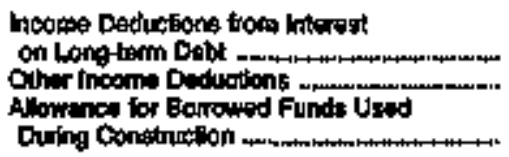 & $\begin{array}{l}0 \\
0 \\
0\end{array}$ & $\begin{array}{r}13,694 \\
262 \\
0\end{array}$ & $\begin{array}{r}9675 \\
721 \\
-190\end{array}$ & $\begin{array}{l}0 \\
0 \\
0\end{array}$ & $\begin{array}{r}100 \\
1300\end{array}$ & $\begin{array}{r}505 \\
-160 \\
0\end{array}$ \\
\hline 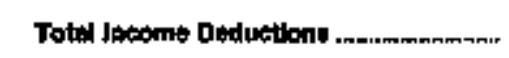 & 0 & 13,046 & 9,408 & 0 & 1,375 & 425 \\
\hline 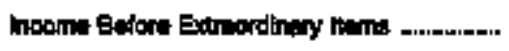 & 851 & 4,028 & 31,969 & 413 & $-1,762$ & 701 \\
\hline 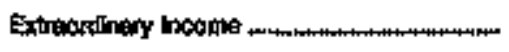 & 0 & 0 & 0 & 0 & 1,3991 & 0 \\
\hline 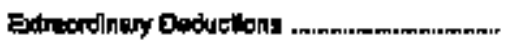 & 0 & 0 & 0 & 0 & 0 & o \\
\hline 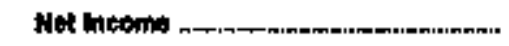 & 851 & 4,026 & $\$ 1,450$ & 4* & -391 & 765 \\
\hline
\end{tabular}

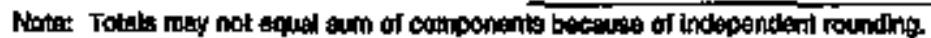

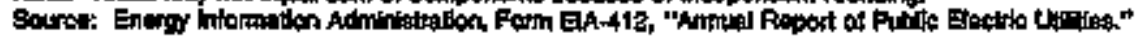


Table 21. Statement of Income by Major U.S. Publichy Owned Electric Utilty Within State, 1994 (Conlinued)

(Thoussand Doilars)

\begin{tabular}{|c|c|c|c|c|c|c|}
\hline man & 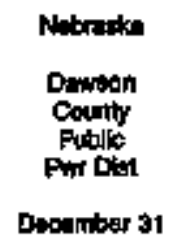 & $\begin{array}{l}\text { Notbralkat } \\
\text { Fremont } \\
\text { Ctty of } \\
\text { Juty } 31\end{array}$ & $\begin{array}{l}\text { Nebrasta } \\
\text { Cirand lodind } \\
\text { Cry of } \\
\text { Jubl } 31\end{array}$ & $\begin{array}{l}\text { Nobritica } \\
\text { Hatings } \\
\text { Chly of } \\
\text { December } 3 t\end{array}$ & $\begin{array}{l}\text { Mebraske } \\
\text { Lrooln } \\
\text { Eloctio } \\
\text { Syritem } \\
\text { Deosmber } 31\end{array}$ & 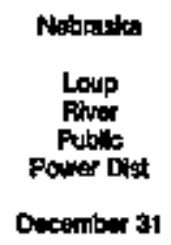 \\
\hline 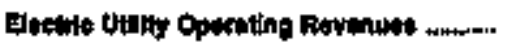 & 15,870 & 14,060 & 28,003 & 18,018 & 130,417 & 39,122 \\
\hline 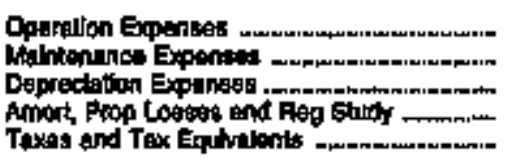 & $\begin{array}{r}11,115 \\
551 \\
1,206 \\
0 \\
165\end{array}$ & $\begin{array}{r}0,289 \\
1,400 \\
2,322 \\
0 \\
1,357\end{array}$ & $\begin{array}{r}11,000 \\
1,602 \\
5,006 \\
100 \\
607\end{array}$ & $\begin{array}{r}0,495 \\
1,280 \\
2,400 \\
0 \\
081\end{array}$ & $\begin{array}{r}6,1,408 \\
6,568 \\
12,267 \\
647 \\
8,448\end{array}$ & $\begin{array}{r}32,041 \\
1,504 \\
1,308 \\
0 \\
2,250\end{array}$ \\
\hline Total Flatric vally Operatind & $18,0,000$ & 198425 & 20,454 & 12,916 & $100, \pi 4$ & $\mathbf{3 7 , 0 7 8}$ \\
\hline 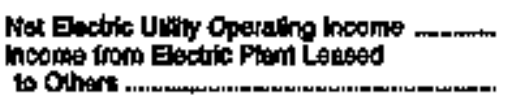 & 2,000 & $\begin{array}{r}735 \\
0\end{array}$ & $\begin{array}{r}6,769 \\
0\end{array}$ & 2,102 & 20,044 & $\begin{array}{r}2,048 \\
0\end{array}$ \\
\hline 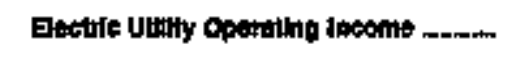 & 2030 & $7 * 5$ & 6,769 & 2,100 & 20,644 & 2,046 \\
\hline Other Electrie hoome n- & 389 & 1,600 & 244 & 3,000 & 2,394 & $\$ 86$ \\
\hline 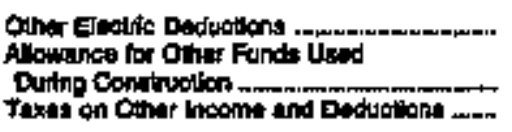 & 0 & $\begin{array}{l}70 \\
0 \\
0\end{array}$ & $\begin{array}{r}25 \\
0 \\
0\end{array}$ & $\begin{array}{l}0 \\
0 \\
0\end{array}$ & $\begin{array}{l}0 \\
0 \\
0\end{array}$ & $\begin{array}{l}0 \\
0 \\
0\end{array}$ \\
\hline 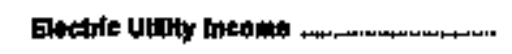 & 3,200 & 2,480 & $7,6.07$ & 5,150 & 23,027 & atsos \\
\hline 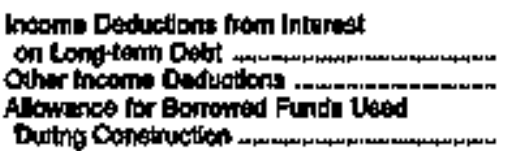 & $\begin{array}{r}260 \\
0\end{array}$ & $\begin{array}{r}041 \\
10 \\
0\end{array}$ & $\begin{array}{r}2,378 \\
108 \\
0\end{array}$ & $\begin{array}{r}3,600 \\
0 \\
0\end{array}$ & $\begin{array}{r}14,477 \\
2,097 \\
0\end{array}$ & $\begin{array}{r}0 \\
29 \\
0\end{array}$ \\
\hline 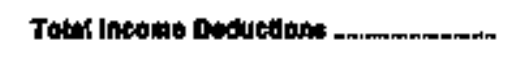 & 307 & कs & 244 & anden & to:534 & $m$ \\
\hline 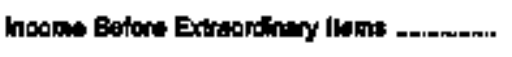 & 2000 & 1,675 & 5,103 & 1,570 & 6,498 & 2,900 \\
\hline 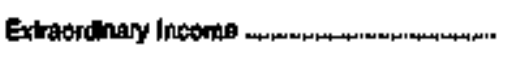 & 0 & o & 0 & $\mathbf{0}$ & 0 & 0 \\
\hline 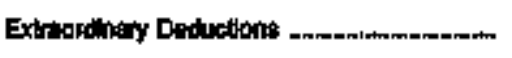 & 0 & 0 & 0 & o & o & D \\
\hline Not Ineome & 20092 & 1,676 & 5,108 & 1,850 & $\sin$ & $2+\infty$ \\
\hline
\end{tabular}

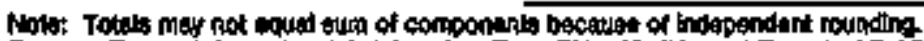

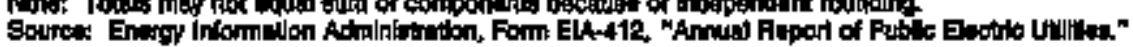


Table 21. Statement of Income by lajor U.S Publiely Owned Electrie Utiliy Within Stats, 1994 (Continued)

(Thousand Doilars)

\begin{tabular}{|c|c|c|c|c|c|c|}
\hline nem & 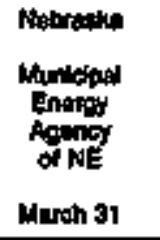 & 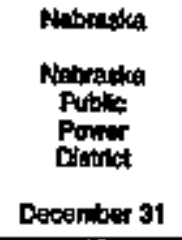 & 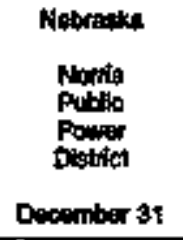 & $\begin{array}{l}\text { Nebotata } \\
\text { North } \\
\text { Platta } \\
\text { Ciny of } \\
\text { Juk } 31\end{array}$ & 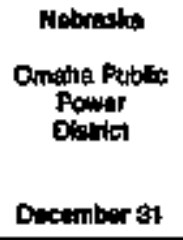 & 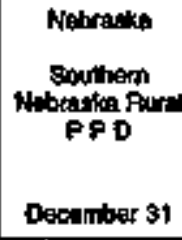 \\
\hline 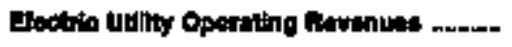 & 136: & 6t:ars & $2,1 * 9$ & 10,675 & ADasec & 20,040 \\
\hline 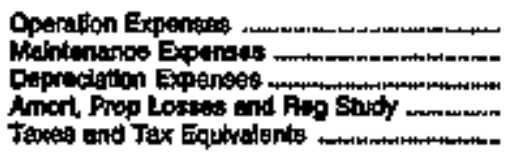 & $\begin{array}{r}29,110 \\
0 \\
1,281 \\
0 \\
0\end{array}$ & $\begin{array}{r}27,509 \\
61,016 \\
95,900 \\
8,168 \\
6,600\end{array}$ & $\begin{array}{r}15,750 \\
1,200 \\
1,0000 \\
0 \\
100\end{array}$ & $\begin{array}{r}\text { B,732 } \\
373 \\
465 \\
00\end{array}$ & $\begin{array}{r}196,279 \\
38,9515 \\
64,004 \\
0 \\
15,616\end{array}$ & $\begin{array}{r}17,647 \\
1,111 \\
2,309 \\
0 \\
129\end{array}$ \\
\hline 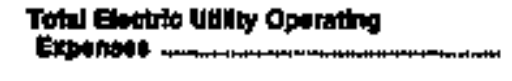 & ant & aratest & 18,409 & 19,465 & 815,\$16 & $2 t \operatorname{sen}$ \\
\hline 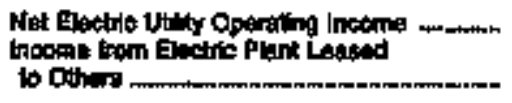 & $\begin{array}{r}1,961 \\
0\end{array}$ & 0 & 8 & $\begin{array}{r}390 \\
0\end{array}$ & $\begin{array}{r}96,761 \\
0\end{array}$ & $\begin{array}{r}1,617 \\
0\end{array}$ \\
\hline 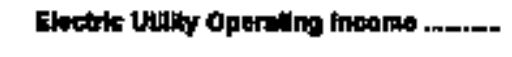 & 1,401 & enpops: & 3,200 & $\operatorname{sos}$ & as; 7 st & 1,017 \\
\hline Othor Eegtic Incorse & 292 & 16,104 & 480 & 131 & $16,12 \pi$ & 0 \\
\hline 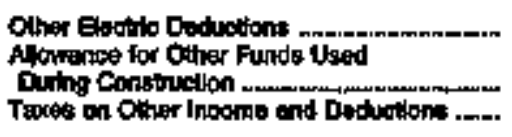 & $\begin{array}{l}0 \\
0 \\
0\end{array}$ & $\begin{array}{r}497 \\
1.574\end{array}$ & $\begin{array}{l}0 \\
0 \\
0\end{array}$ & $\begin{array}{l}0 \\
0 \\
0\end{array}$ & $\begin{array}{r}0 \\
1,401 \\
0\end{array}$ & $\begin{array}{l}0 \\
0 \\
0\end{array}$ \\
\hline 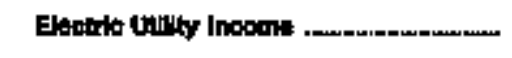 & $2 y+4$ & 110,190 & 0,700 & 591 & 110,300 & 1,017 \\
\hline 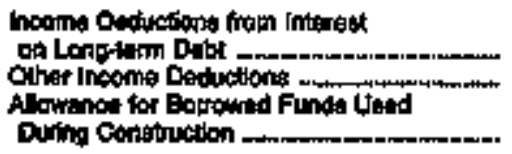 & $\begin{array}{r}3,004 \\
0 \\
0\end{array}$ & $\begin{array}{r}74,188 \\
30,539 \\
0\end{array}$ & $\begin{array}{r}1,100 \\
06 \\
0\end{array}$ & $\begin{array}{l}0 \\
0 \\
0\end{array}$ & $\begin{array}{r}58,921 \\
8,206 \\
-3,401\end{array}$ & $\begin{array}{l}0 \\
0 \\
0\end{array}$ \\
\hline 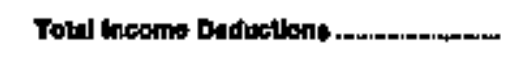 & sold & 104,ros: & 1,104 & e & stritis & $\mathbf{0}$ \\
\hline 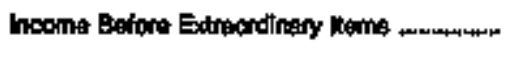 & +701 & 8,495 & 2,569 & 621 & 52,115 & 1,817 \\
\hline Extrectalnery incomn & 0 & 0 & $\mathbf{0}$ & 0 & 0 & $\operatorname{seg}$ \\
\hline 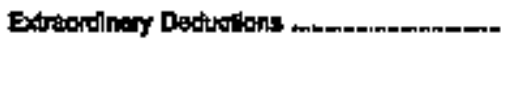 & 0 & t & 0 & 0 & D & - \\
\hline 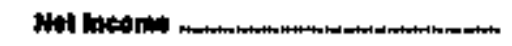 & $-\mathbf{m}$ & 0,4ats & 4, & Bat & 8 si1s: & 2417 \\
\hline
\end{tabular}

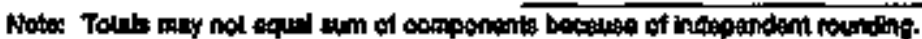

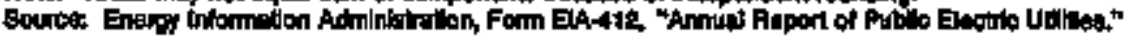


Tabte 21. Statement of heome by Major U.S. Publicly Owned Elootris Utilty Whin State, 1994 (Continued)

(Thousand Dollar's)

\begin{tabular}{|c|c|c|c|c|c|c|}
\hline$n \rightarrow m$ & $\begin{array}{l}\text { Alovada } \\
\text { Colonedo } \\
\text { Fiver } \\
\text { Comm } \\
\text { of Nimgda } \\
\text { whe } 30\end{array}$ & 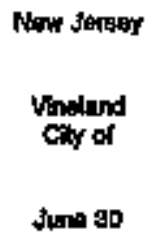 & $\begin{array}{l}\text { Now Mondco } \\
\text { Fanmington } \\
\text { City of } \\
\text { June so }\end{array}$ & $\begin{array}{l}\text { Now Mexico } \\
\text { Collep } \\
\text { Shof of }\end{array}$ & $\begin{array}{l}\text { Mew Mextco } \\
\text { Los Namos } \\
\text { County } \\
\text { Juni \$o }\end{array}$ & 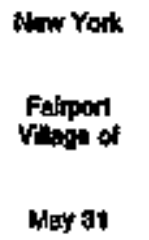 \\
\hline 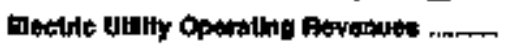 & 31,694 & Q:894 & 43,600 & 19,222 & 80,891 & 11,630 \\
\hline 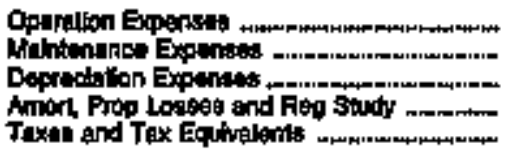 & $\begin{array}{r}95,504 \\
0 \\
120 \\
0\end{array}$ & $\begin{array}{r}30,600 \\
1,911 \\
1,621 \\
0 \\
506\end{array}$ & $\begin{array}{r}7,109 \\
2,7,85 \\
4,471 \\
0 \\
2,985\end{array}$ & $\begin{array}{r}10,980 \\
160 \\
349 \\
0 \\
649\end{array}$ & $\begin{array}{r}1,675 \\
1,264 \\
2,210 \\
272 \\
6,44\end{array}$ & $\begin{array}{r}0,197 \\
26 t \\
875 \\
0 \\
\$ 08\end{array}$ \\
\hline 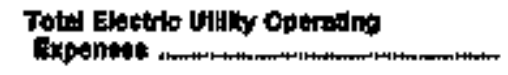 & 31,694 & 34,762 & 26,288 & 12,097 & 20,002 & 10,06 \\
\hline 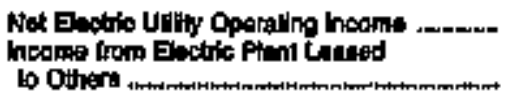 & 0 & $\begin{array}{r}7,130 \\
0\end{array}$ & $\begin{array}{r}17,2+12 \\
0\end{array}$ & $\begin{array}{r}1,154 \\
0\end{array}$ & 7,800 & 16 \\
\hline 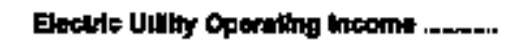 & 6 & 7,132 & 17,212 & 1,164 & 7,000 & 713 \\
\hline 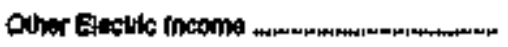 & $\$$ & s96 & 1,717 & 41 & 1,160 & $\infty$ \\
\hline 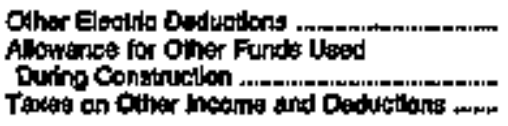 & 0 & $\stackrel{0}{0}$ & 0 & $\begin{array}{r}698 \\
0\end{array}$ & $\begin{array}{l}6 \\
0 \\
0\end{array}$ & $\begin{array}{l}7 \\
0 \\
0\end{array}$ \\
\hline 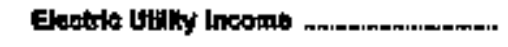 & 63 & 6,760 & 14,026 & 60 & Q,0:51 & mo \\
\hline 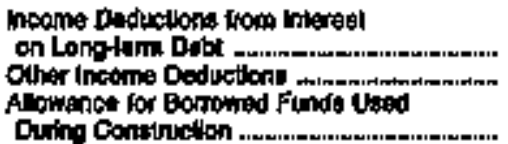 & $\begin{array}{l}0 \\
0\end{array}$ & $\begin{array}{l}281 \\
\text { t07 }\end{array}$ & $\begin{array}{r}10,858 \\
457\end{array}$ & $\begin{array}{l}0 \\
0\end{array}$ & $\begin{array}{r}8,109 \\
376\end{array}$ & $\begin{array}{r}75 \\
6 \\
0\end{array}$ \\
\hline Toted IDComb Dinductionte & 0 & 367 & 11 A10 & 0 & 6,404 & 01 \\
\hline 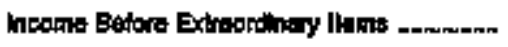 & 69 & 0,881 & 7,618 & $\operatorname{sos}$ & $59 \%$ & $6 \%$ \\
\hline Extrecrd|nary heorta & $\mathbf{0}$ & 0 & 0 & 0 & 0 & 0 \\
\hline Extrectintisy Deductlons & o & 0 & 0 & o & 0 & $\mathbf{0}$ \\
\hline Nat hicemo & 63 & 6,381 & 7,6t: & 60 & $6 \%$ & 64 \\
\hline
\end{tabular}

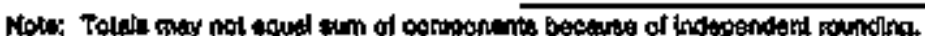

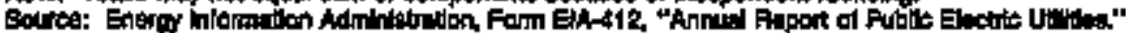


Table 21. Staternent of Income by Major U.S. Publlely Owned Eleotrito Vtilty Within State, 1994 (Continued)

(Thousand Dollers)

\begin{tabular}{|c|c|c|c|c|c|c|}
\hline them & 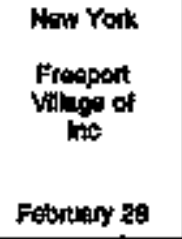 & $\begin{array}{l}\text { Now Yor } \\
\text { Jamentorm } \\
\text { Chty of } \\
\text { December at }\end{array}$ & $\begin{array}{l}\text { Now York } \\
\text { Leso Ptadd } \\
\text { Vintepo int } \\
\text {.Jaty } 31\end{array}$ & 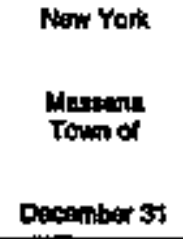 & 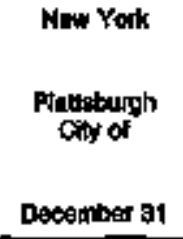 & 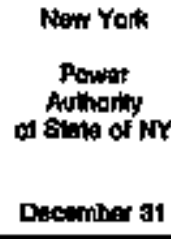 \\
\hline 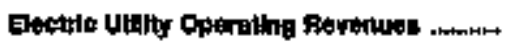 & 14,208 & 20,08 & sens & 2000 & $11,0 v$ & $1, A 86,95$ \\
\hline 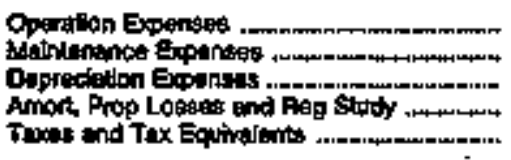 & $\begin{array}{r}10,679 \\
1,079 \\
1069 \\
0 \\
1,005\end{array}$ & $\begin{array}{r}13,129 \\
1,341 \\
2,205 \\
0 \\
1,405\end{array}$ & $\begin{array}{r}3,802 \\
9 \\
280 \\
0 \\
40\end{array}$ & $\begin{array}{r}3,127 \\
170 \\
412 \\
\text { ast } \\
0\end{array}$ & $\begin{array}{r}7,698 \\
390 \\
640 \\
0 \\
60\end{array}$ & $\begin{array}{r}993,966 \\
135,789 \\
174,232 \\
0 \\
0\end{array}$ \\
\hline $\begin{array}{l}\text { Tolal tobetric Ublaty opanatho } \\
\text { Expendes }\end{array}$ & 14,200 & 20,170 & 3,609 & $2,4,46$ & alpot & $1,904,450$ \\
\hline 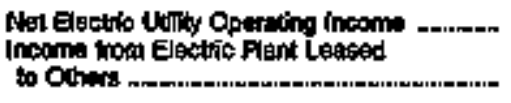 & $\begin{array}{r}-\mathbf{2 1} \\
9\end{array}$ & $\begin{array}{r}2,782 \\
0\end{array}$ & 268 & 2076 & 2,025 & $\begin{array}{r}19 t, 667 \\
1,166\end{array}$ \\
\hline 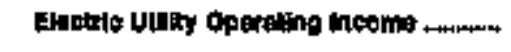 & -12 & 2,748 & 209 & 2,075 & 2,0025 & 132,439 \\
\hline 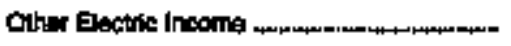 & 182 & 44 & 12 & 81 & 67 & Q64,A7T \\
\hline 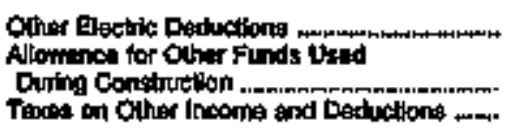 & $\begin{array}{l}0 \\
0 \\
0\end{array}$ & $\begin{array}{l}11 \\
0 \\
0\end{array}$ & $\begin{array}{l}0 \\
0 \\
0\end{array}$ & $\begin{array}{r}0 \\
2 \pi\end{array}$ & $\begin{array}{l}0 \\
0 \\
0\end{array}$ & $\begin{array}{l}0 \\
0 \\
0\end{array}$ \\
\hline 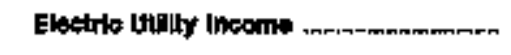 & 160 & 2,015 & 275 & 1,870 & 2,112 & 214,360 \\
\hline 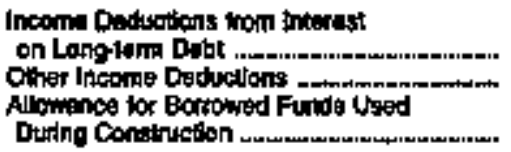 & $\begin{array}{c}121 \\
30\end{array}$ & $\begin{array}{r}1,077 \\
0 \\
0\end{array}$ & $\begin{array}{r}158 \\
60 \\
0\end{array}$ & $\begin{array}{r}581 \\
0 \\
0\end{array}$ & $\begin{array}{r}629 \\
8 \\
0\end{array}$ & $\begin{array}{r}198,45 t \\
10,418 \\
0\end{array}$ \\
\hline Total ineome Deduetione & 100 & 1,077 & ans & 509 & $+\infty$ & 205070 \\
\hline Income Eefore Extreordinay thems .......... & 20 & 1,798 & $\theta$ & 1,280 & 1,500 & 5,409 \\
\hline 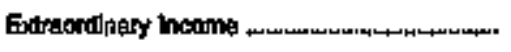 & 0 & 0 & 0 & 0 & 0 & 0 \\
\hline 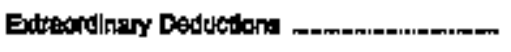 & 0 & 0 & 0 & 0 & 0 & 0 \\
\hline Not Ineosed & 20 & 1,731 & 6 & $1,20 \%$ & toseo & 5,400 \\
\hline
\end{tabular}

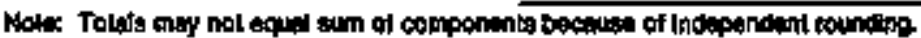

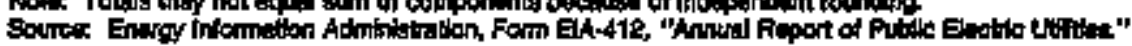


Table 21. Statement of Income by Haijor U.S. Publicly Owned Electric Utility Within State, 1994 (Continused)

(Thousand Dollers)

\begin{tabular}{|c|c|c|c|c|c|c|}
\hline then & 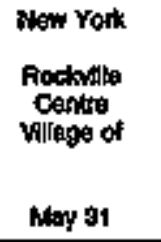 & 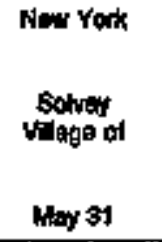 & 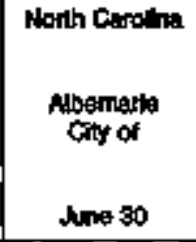 & $\begin{array}{l}\text { North Caredinn } \\
\text { Coneard } \\
\text { City of } \\
\text { Jane so }\end{array}$ & $\begin{array}{l}\text { North Coloting } \\
\text { Eingabein } \\
\text { City City of } \\
\text { Jung so }\end{array}$ & 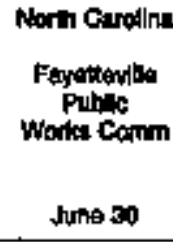 \\
\hline 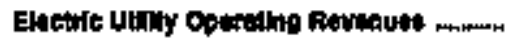 & $\mathbf{m , 0 5 T}$ & 3,:04 & $\operatorname{tas} 344$ & 20,416 & 21,970 & 121,031 \\
\hline 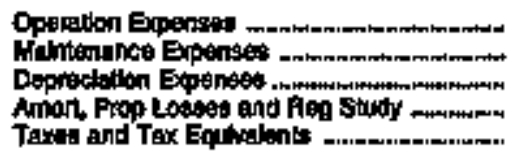 & $\begin{array}{r}7,901 \\
0 \\
708 \\
0 \\
1,30 t\end{array}$ & $\begin{array}{r}3,+30 \\
141 \\
200 \\
0 \\
\$ 10\end{array}$ & $\begin{array}{r}17,047 \\
292 \\
648 \\
0 \\
0\end{array}$ & $\begin{array}{r}20,409 \\
3,408 \\
1,2030 \\
0 \\
0\end{array}$ & $\begin{array}{r}80,300 \\
642 \\
914 \\
0 \\
48\end{array}$ & $\begin{array}{r}1047 \\
5,840 \\
0,068 \\
959 \\
20,877\end{array}$ \\
\hline 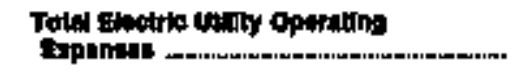 & to,055 & 3,862 & 7,765 & $25,12,3$ & 22,294 & 12600 \\
\hline 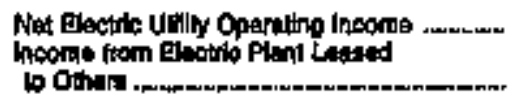 & 592 & 142 & 50 & 3,290 & $\begin{array}{r}-124 \\
0\end{array}$ & $\begin{array}{r}-5,1699 \\
0\end{array}$ \\
\hline Exetrio Uadty Opanting Inseme & fat & 142 & 570 & 3,200 & -424 & $-4,169$ \\
\hline Othat Electide hoteme & 2028 & 12 & 86 & 60 & 170 & 1,460 \\
\hline 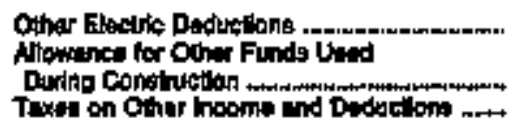 & $\begin{array}{l}0 \\
0\end{array}$ & 0 & $\begin{array}{l}0 \\
0 \\
0\end{array}$ & $\begin{array}{l}\circ \\
0 \\
0\end{array}$ & $\begin{array}{r}382 \\
0 \\
0\end{array}$ & 0 \\
\hline 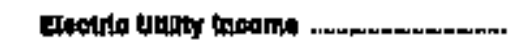 & 604 & 164 & 665 & 3,000 & -98 & $-3,0: 0$ \\
\hline 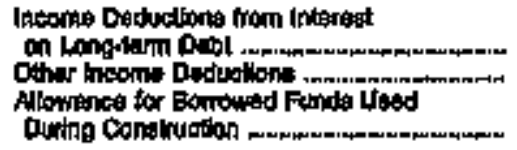 & $\begin{array}{r}709 \\
257 \\
-438\end{array}$ & 180 & $\begin{array}{r}0 \\
1,178 \\
0\end{array}$ & $\begin{array}{r}363 \\
\operatorname{arcos} \\
0\end{array}$ & $\begin{array}{l}0 \\
0 \\
0\end{array}$ & $\begin{array}{r}3,40 \\
0\end{array}$ \\
\hline 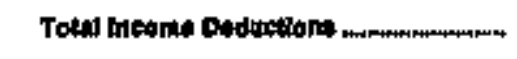 & $\$ 34$ & 180 & 1,178 & 3,456 & 0 & 2,894 \\
\hline 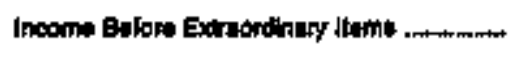 & 271 & 4 & -518 & ses & -060 & $-7, \sin$ \\
\hline 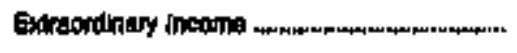 & 0 & 0 & o & 0 & o & 0 \\
\hline Extraordinary Dedivelionse . & 0 & 0 & 0 & 0 & 0 & 0 \\
\hline Set Incorro & $\mathbf{3 r 1}$ & 4 & $-8+16$ & sas & -868 & $-7,392$ \\
\hline
\end{tabular}

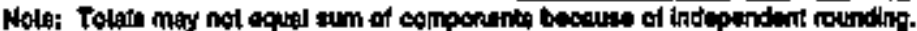

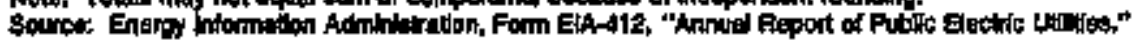


Table 21. Statement of Incomb by Major U.S. Publicly Owmed Electric Utilty Within state, 1994 (Continued) (Thousary Dollars)

\begin{tabular}{|c|c|c|c|c|c|c|}
\hline Itam & $\begin{array}{l}\text { North Curolna } \\
\text { Forest Chy } \\
\text { Town of } \\
\text { June } 30\end{array}$ & $\begin{array}{l}\text { North Cerollina } \\
\text { Castonit } \\
\text { Cly of } \\
\text { June } 30\end{array}$ & 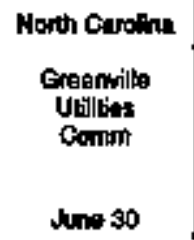 & $\begin{array}{l}\text { North Corolind } \\
\text { High } \\
\text { Point } \\
\text { Towl } \\
\text { of } \\
\text { Juno } 30\end{array}$ & $\begin{array}{l}\text { North Geroine } \\
\text { Kinsion } \\
\text { City of } \\
\text { Juns so }\end{array}$ & $\begin{array}{l}\text { North Garoilne } \\
\text { Lexinglon } \\
\text { Chty of } \\
\text { June an }\end{array}$ \\
\hline 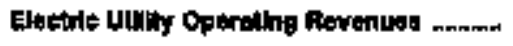 & 0,654 & $44,+60$ & stose & $0 ;, 20 s$ & $\mathbf{3 7 , 1 5 t}$ & 36 st14 \\
\hline 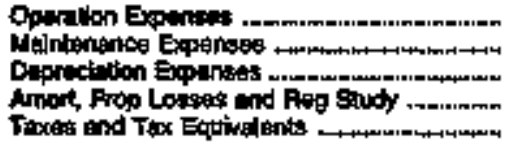 & $\begin{array}{r}6,706 \\
118 \\
0 \\
0\end{array}$ & $\begin{array}{r}32,6+6 \\
1,067 \\
1,202 \\
0 \\
0\end{array}$ & $\begin{array}{r}6,139 \\
2,209 \\
3,020 \\
0 \\
2,605\end{array}$ & $\begin{array}{r}50,184 \\
4,179 \\
899 \\
0 \\
0\end{array}$ & $\begin{array}{r}32,855 \\
59 \\
0 \\
200\end{array}$ & $\begin{array}{r}20248 \\
117 \\
764 \\
0 \\
016\end{array}$ \\
\hline 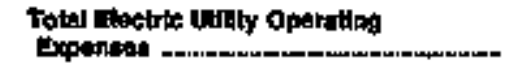 & 6981 & 34,944 & 24,669 & 55,308 & 84,960 & $\mathbf{3 0 , 9 4 3}$ \\
\hline 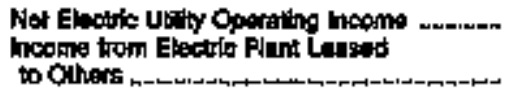 & $\begin{array}{r}1.000 \\
0\end{array}$ & $\begin{array}{r}0,255 \\
0\end{array}$ & $\begin{array}{r}1, \log 30 \\
0\end{array}$ & 9,902 & $\begin{array}{r}2,795 \\
0\end{array}$ & $\begin{array}{r}4,371 \\
0\end{array}$ \\
\hline Eloetric uanty Operating Incomb ... & 1,000 & 9,295 & 1,8003 & g,gov & 2,795 & 4,371 \\
\hline 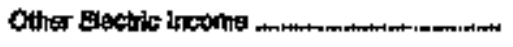 & 350 & 182 & 723 & 400 & 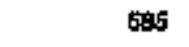 & 1,048 \\
\hline $\begin{array}{l}\text { Olher Eertio Deductions } \\
\text { Alowance for Othar Funts Used }\end{array}$ & a & 0 & 0 & 6,651 & 0 & 3,480 \\
\hline 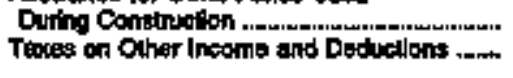 & $\stackrel{0}{0}$ & $\stackrel{0}{0}$ & $\stackrel{0}{0}$ & 0 & $\mathbf{0}$ & g \\
\hline 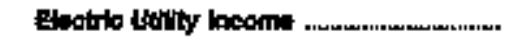 & 1,059 & $9,4 \pi$ & $2,5,4$ & $4, a 7$ & 35800 & 1,954 \\
\hline 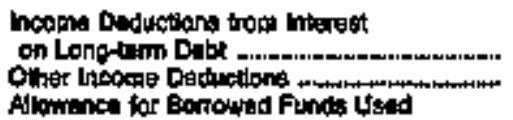 & $\begin{array}{l}0 \\
0\end{array}$ & 925 & 128 & $\underset{0}{9 B}$ & 20 & $\begin{array}{r}15 \\
0\end{array}$ \\
\hline 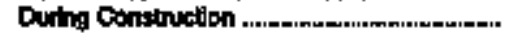 & 0 & .0 & 0 & 0 & $\mathbf{0}$ & 0 \\
\hline Tolal hoomm Diduotions & 0 & \%: & 128 & 36 & 235 & 18 \\
\hline Meamo Before Extratudinary Hems & 1,859 & 6,482 & 2,397 & 4,000 & 3,745 & 1,236 \\
\hline 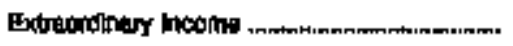 & 0 & 0 & 0 & 0 & $\mathbf{0}$ & 0 \\
\hline 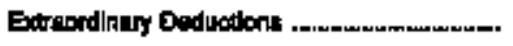 & 0 & $\mathbf{0}$ & 0 & 0 & D & 0 \\
\hline 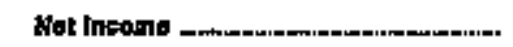 & 1,480 & 0,492 & 2,507 & 4,000 & 3,146 & $t, 0$ \\
\hline
\end{tabular}

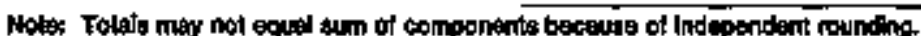

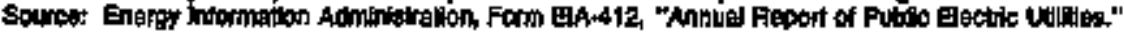


Tabje 21. Statement of Income by Mejor U.S. Publicly Owned Electirle Veility Within State, 1994 (Continued)

(Thousand Dollars)

\begin{tabular}{|c|c|c|c|c|c|c|}
\hline Bem & 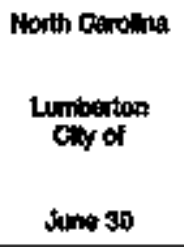 & 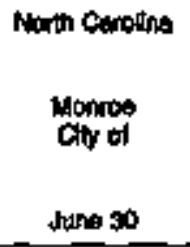 & 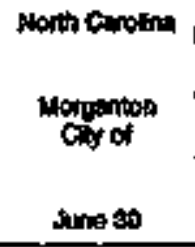 & $\begin{array}{l}\text { Nopth Corotins } \\
\text { June sos }\end{array}$ & 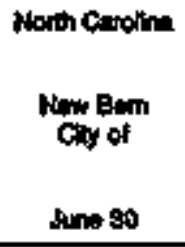 & $\begin{array}{l}\text { Nopth Carding } \\
\text { Non Fiver } \\
\text { Power Co } \\
\text { Deomiter } 31\end{array}$ \\
\hline 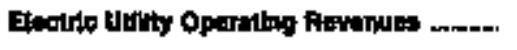 & 22,620 & 27346 & 18,976 & 7,56 & 1950: & 11,700 \\
\hline 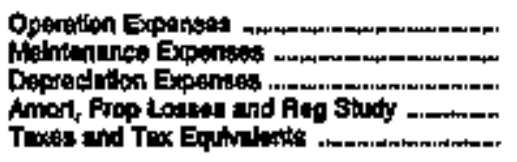 & $\begin{array}{r}21,6=6 \\
106 \\
469 \\
0 \\
0\end{array}$ & $\begin{array}{r}20,574 \\
0 \\
702 \\
0 \\
0\end{array}$ & $\begin{array}{r}16,172 \\
0 \\
404 \\
0 \\
0\end{array}$ & $\begin{array}{r}6,260 \\
100 \\
212 \\
0 \\
54\end{array}$ & $\begin{array}{r}31,204 \\
0 \\
0,52 \\
0 \\
0\end{array}$ & $\begin{array}{r}\text { B.8t4 } \\
460 \\
\text { 319 } \\
0 \\
370\end{array}$ \\
\hline 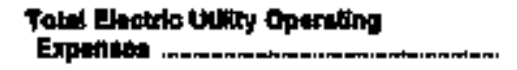 & 2900 & 24255 & torst & 14 & sepuss & te, tho \\
\hline 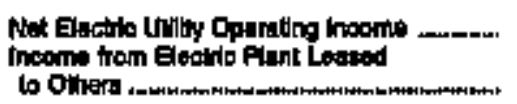 & $\begin{array}{r}508 \\
0\end{array}$ & $\begin{array}{r}3,070 \\
0\end{array}$ & 20000 & 40 & $\begin{array}{r}3280 \\
0\end{array}$ & $\begin{array}{r}1,811 \\
0\end{array}$ \\
\hline Eletrfo tually Operating Inoome n...m. & Eos & 3,070 & $2, \%$ & 04: & 2,200 & 1,841 \\
\hline 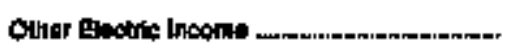 & e28 & 1,015 & 200 & 145 & 148 & 144 \\
\hline 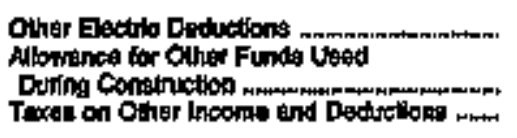 & $\begin{array}{r}1,700 \\
0 \\
0\end{array}$ & 0 & $\begin{array}{l}0 \\
0 \\
0\end{array}$ & $\stackrel{0}{0}$ & $\begin{array}{l}0 \\
0 \\
0\end{array}$ & $\mathbf{0}$ \\
\hline Eloctin Utilly moemm & -80 & 40.1: & 2,400 & ces & 34:0 & 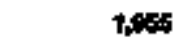 \\
\hline 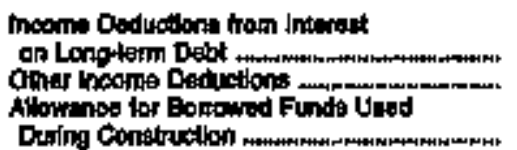 & $\stackrel{2}{8}$ & $\stackrel{4}{0}$ & $\begin{array}{r}0 \\
2,880 \\
0\end{array}$ & : & 56 & o \\
\hline Todnl Ineome Doduotions . & 10 & 4 & 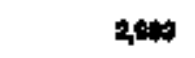 & 0 & $\mathbf{B}$ & 0 \\
\hline meana Befora Extrtardnary liems .-.-.-.. & -38 & 4,091 & $<24$ & $\infty$ & $3,3 r 1$ & 1,005 \\
\hline 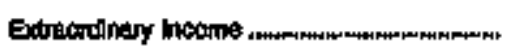 & D & 0 & 0 & 0 & 0 & 0 \\
\hline 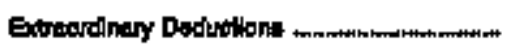 & a & 0 & 0 & 0 & 0 & 0 \\
\hline Hat theorin naw & $-4 n$ & $4,0+4$ & w & ses & s,s7t & nets \\
\hline
\end{tabular}

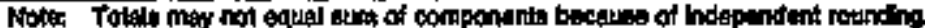

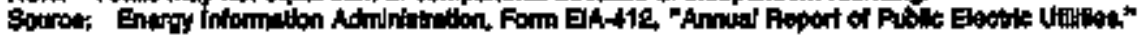


Table 21. Statement of Income by Major U.S. Publlely Owned Electrle Utllity Witin Stato, 1994 (Continued)

(Thoustand Dollars)

\begin{tabular}{|c|c|c|c|c|c|c|}
\hline Hem & 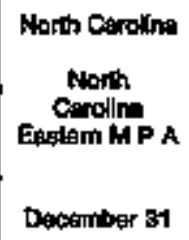 & 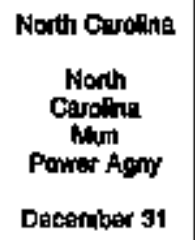 & $\begin{array}{l}\text { North Corollna } \\
\text { Pocky Nount } \\
\text { Chty of } \\
\text { Jurne so }\end{array}$ & $\begin{array}{l}\text { North Couplin } \\
\text { Sholby } \\
\text { Cxty of } \\
\text { Jum so }\end{array}$ & 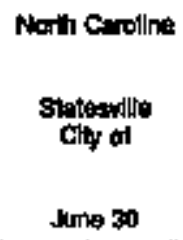 & $\begin{array}{l}\text { North Carolint } \\
\text { Troworo } \\
\text { Junne } 30\end{array}$ \\
\hline 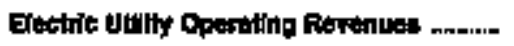 & 460,023 & 6\$0,095 & 60,679 & 1294s & 25,087 & 21,600 \\
\hline 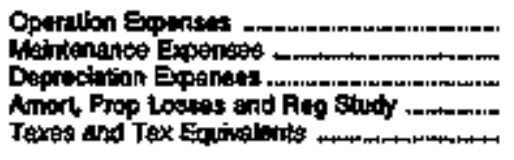 & $\begin{array}{r}238,179 \\
47,168 \\
47,278 \\
0 \\
17.608\end{array}$ & $\begin{array}{r}267,898 \\
36,290 \\
44,685 \\
0 \\
19,284\end{array}$ & $\begin{array}{r}87,629 \\
0 \\
8+2 \\
0 \\
0\end{array}$ & $\begin{array}{r}0,058 \\
614 \\
267 \\
0 \\
0\end{array}$ & $\begin{array}{r}2004 \\
0 \\
540 \\
0 \\
0\end{array}$ & $\begin{array}{r}19,689 \\
0 \\
517 \\
0 \\
0\end{array}$ \\
\hline 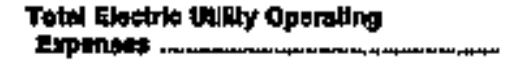 & 314,217 & 297965 & 50,895 & 11,139 & $29,50 d$ & 20sat \\
\hline 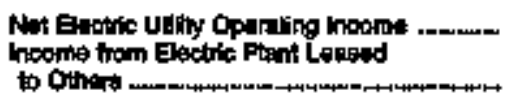 & $\begin{array}{r}142,808 \\
0\end{array}$ & $\begin{array}{r}212990 \\
0\end{array}$ & $\begin{array}{r}4,044 \\
. \quad 0\end{array}$ & $\begin{array}{r}1,805 \\
0\end{array}$ & $\begin{array}{r}2,589 \\
0\end{array}$ & 1,594 \\
\hline 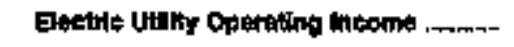 & 142,805 & 212,930 & 4001 & 1,806 & 2,539 & 1.,624 \\
\hline OWer Electic thatma & 109,350 & $-47, \operatorname{sad}$ & 91 & 118 & 2006 & 200 \\
\hline 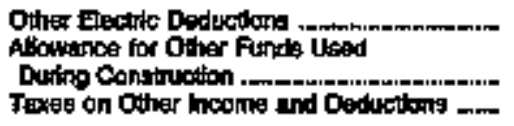 & $\begin{array}{l}0 \\
0 \\
0\end{array}$ & $\begin{array}{l}0 \\
0 \\
0\end{array}$ & $\begin{array}{l}0 \\
0 \\
0\end{array}$ & $\begin{array}{l}0 \\
0 \\
0\end{array}$ & $\begin{array}{r}121 \\
0 \\
0\end{array}$ & $\begin{array}{r}1,167 \\
0\end{array}$ \\
\hline 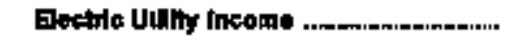 & 262,158 & 164,956 & 4,195 & 1,925 & 2,070 & bots \\
\hline 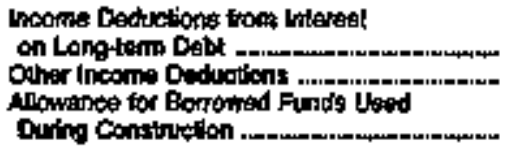 & $\begin{array}{r}217,807 \\
34,240 \\
0\end{array}$ & 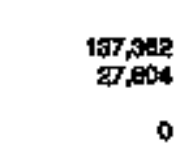 & $\begin{array}{r}72 \\
5,690 \\
0\end{array}$ & $\begin{array}{l}\mathbf{B} \\
\mathbf{2} \\
\mathbf{0}\end{array}$ & $\begin{array}{r}0 \\
2,761 \\
0\end{array}$ & $\begin{array}{l}0 \\
0 \\
0\end{array}$ \\
\hline Towet ineams Deduetkonte & 2052,156 & 164998 & 5801 & 10 & 2,761 & $\mathbf{0}$ \\
\hline 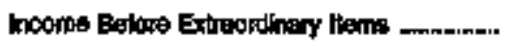 & 0 & 0 & $-1,529$ & 1,913 & -6 & 60 \\
\hline Extrodthery lnoorpe & 0 & 0 & 0 & 0 & 0 & o \\
\hline 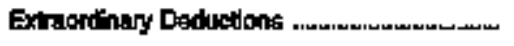 & $\mathbf{0}$ & 9 & 0 & $\mathbf{0}$ & $\mathbf{0}$ & 0 \\
\hline 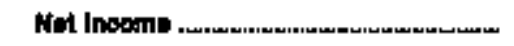 & $\mathbf{0}$ & $\mathbf{0}$ & $-1,5028$ & 1,613 & -9 & 6.5. \\
\hline
\end{tabular}

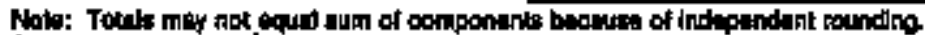

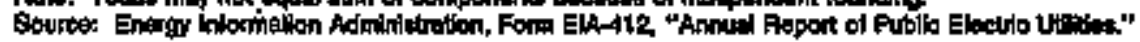


Table 21. Statement of Income by Major U.S. Publloly Owned Electrte Utillty Within State, 1994 (Continued)

(Thousand Dollars)

\begin{tabular}{|c|c|c|c|c|c|c|}
\hline Ilomt & 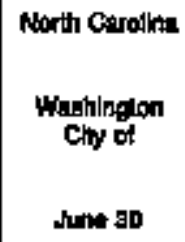 & $\begin{array}{l}\text { North Cercinge } \\
\text { Witeon } \\
\text { Chy of } \\
\text { June so }\end{array}$ & $\begin{array}{c}\text { Ohlo } \\
\text { Amoditan } \\
\text { Otio hor } \\
\text { Cecomber } 31\end{array}$ & 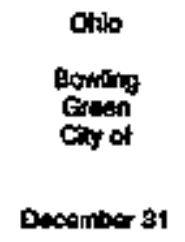 & $\begin{array}{l}\text { Ohb } \\
\text { Enyan } \\
\text { City of } \\
\text { Docemaber st }\end{array}$ & $\begin{array}{l}\text { Otils } \\
\text { Cellna } \\
\text { Ciky of } \\
\text { Decomiter 31 }\end{array}$ \\
\hline 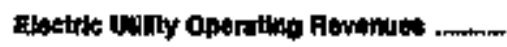 & $22 ; 270$ & $\exp 247$ & tos\$324 & 17,624 & 10,052 & 7,707 \\
\hline 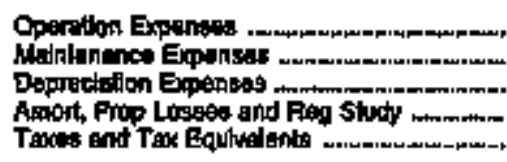 & $\begin{array}{r}18,703 \\
1,596 \\
940 \\
0 \\
1,0 \% 0\end{array}$ & $\begin{array}{r}74,308 \\
1,051 \\
1,690 \\
0 \\
0\end{array}$ & $\begin{array}{r}125,985 \\
8,9481 \\
3,2097 \\
648 \\
7,695\end{array}$ & $\begin{array}{r}15,464 \\
819 \\
480 \\
0 \\
0\end{array}$ & $\begin{array}{r}9,070 \\
0 \\
206 \\
0 \\
0\end{array}$ & $\begin{array}{r}6,059 \\
546 \\
0 \\
0 \\
0\end{array}$ \\
\hline 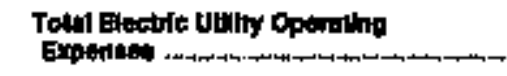 & 22,35: & Th,Be1 & t48,768 & 16,713 & 9,354 & 7,2005 \\
\hline 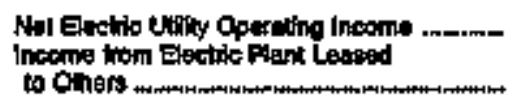 & $\begin{array}{r}-\$ 0 \\
0\end{array}$ & $\begin{array}{r}3,2000 \\
0\end{array}$ & $\begin{array}{r}6,558 \\
0\end{array}$ & 어1 & 697 & 902 \\
\hline Eloctsk Wallty Operatiag Intomb & -40 & 3,260 & 9.556 & e1t & 697 & $\operatorname{sog}$ \\
\hline Other Eective Incont - & 658 & 1,045 & 9,072 & 841 & 100 & 9 \\
\hline 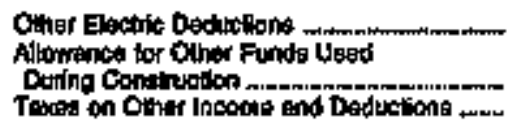 & $\begin{array}{l}0 \\
0 \\
0\end{array}$ & $\begin{array}{l}0 \\
0 \\
0 \\
0\end{array}$ & $\begin{array}{l}0 \\
0 \\
0\end{array}$ & $\begin{array}{l}0 \\
0 \\
0\end{array}$ & $\begin{array}{l}0 \\
0 \\
0\end{array}$ & $\begin{array}{l}0 \\
0 \\
0\end{array}$ \\
\hline Etactile volity luteons & $6 \omega$ & 4.811 & 7,030 & $t, 66 t$ & 886 & et \\
\hline 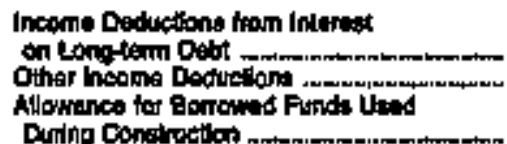 & 250 & $\begin{array}{l}11 \\
872\end{array}$ & 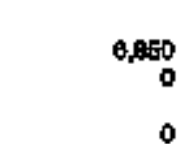 & \$9 & 27 & $\begin{array}{r}0 \\
1,487 \\
0\end{array}$ \\
\hline 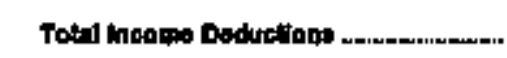 & 280 & 802 & 5,050 & 71 & $\mathbf{2 7}$ & 1,ABr \\
\hline Income batape Extraondinary llema & 296 & 3,429 & 780 & 1,481 & ass & -796 \\
\hline Extraordary Inconth . & 0 & $\mathbf{0}$ & 0 & o & 0 & 0 \\
\hline 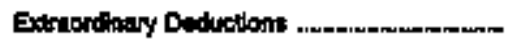 & $\theta$ & $\mathbf{0}$ & 0 & $\mathbf{0}$ & 24 & 0 \\
\hline Not Incoine & 2005 & 3,469 & $7 a p$ & 1,4:01 & UTs & 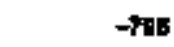 \\
\hline
\end{tabular}

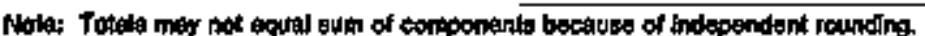

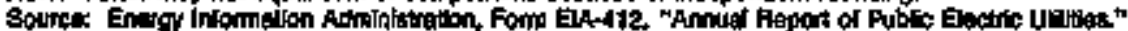


Table 21. Stetement of Income by Mtjor US. Publicly Owned Electric Utility Whthin State, 1994 (Continued) (Thousand Dollara)

\begin{tabular}{|c|c|c|c|c|c|c|}
\hline km & 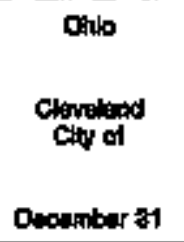 & $\begin{array}{l}\text { Ohlo } \\
\text { Chyde } \\
\text { Chy of } \\
\text { Dacomber } 31\end{array}$ & $\begin{array}{l}\text { Otdo } \\
\text { Columburs } \\
\text { City of } \\
\text { Decomber } 31\end{array}$ & $\begin{array}{c}\text { Ohio } \\
\text { Cuptroga } \\
\text { fadis } \\
\text { City of }\end{array}$ & $\begin{array}{l}\text { Ohis } \\
\text { Dover } \\
\text { Cly of } \\
\text { Decomber } 31\end{array}$ & $\begin{array}{l}\text { Oplo } \\
\text { Hamitar } \\
\text { Cty of }\end{array}$ \\
\hline 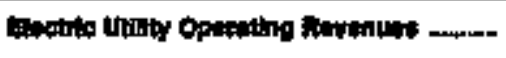 & $70,50$. & sels & 3a, $4 \mathbf{3 2}$ & tengs & 9,809 & 42,652 \\
\hline 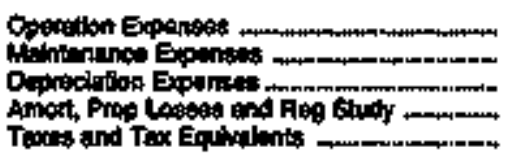 & $\begin{array}{r}40,2000 \\
14,005 \\
4,610 \\
0 \\
0\end{array}$ & $\begin{array}{r}4,970 \\
0 \\
0 \\
0 \\
0\end{array}$ & $\begin{array}{r}25,279 \\
0,181 \\
2,484 \\
0 \\
0\end{array}$ & $\begin{array}{r}18,702 \\
5 \\
583 \\
0 \\
0\end{array}$ & $\begin{array}{r}7,091 \\
1,580 \\
0 \\
0 \\
0\end{array}$ & $\begin{array}{r}22,404 \\
3,209 \\
6,491 \\
6 \\
0\end{array}$ \\
\hline 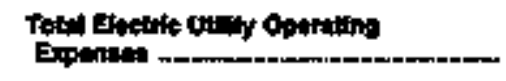 & $-0,0,00$ & 4,070 & $\$ 0,654$ & 17ats & 9,694 & $32,16 t$ \\
\hline 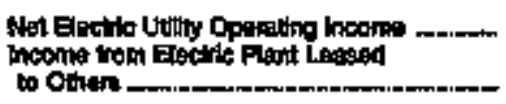 & $\begin{array}{r}11,476 \\
0\end{array}$ & $\begin{array}{r}1,778 \\
0\end{array}$ & $\begin{array}{r}4,4 \pi \\
18,500\end{array}$ & $\begin{array}{r}2,161 \\
0\end{array}$ & $\begin{array}{r}1,271 \\
0\end{array}$ & $\begin{array}{r}10,399 \\
0\end{array}$ \\
\hline 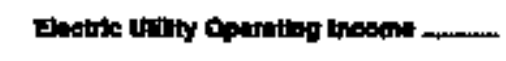 & 11,476 & $1, \pi 7$ & 17,900 & 2,1:1 & 1,271 & w,sins \\
\hline Other Eletito Incorre & $1, \mathrm{Bas}$ & 41 & 924 & 0 & 49 & 2,208 \\
\hline 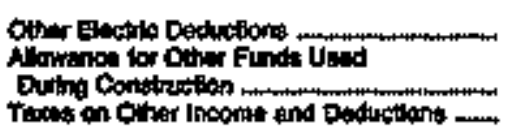 & $\begin{array}{l}0 \\
0 \\
0\end{array}$ & 6 & $\begin{array}{l}0 \\
0 \\
0\end{array}$ & : & 0 & $\begin{array}{l}0 \\
0 \\
0\end{array}$ \\
\hline 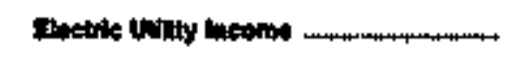 & 10,410 & $1,7,40$ & 18,910 & 2,154 & $t, 500$ & 12,690 \\
\hline 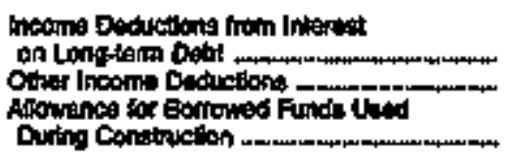 & $\begin{array}{r}1,451 \\
3,041 \\
0\end{array}$ & $\begin{array}{r}790 \\
0 \\
0\end{array}$ & $\begin{array}{r}10,45 \\
0 \\
0\end{array}$ & $\begin{array}{r}205 \\
0 \\
0\end{array}$ & $\begin{array}{r}281 \\
0 \\
0\end{array}$ & $\begin{array}{r}12,917 \\
0 \\
0\end{array}$ \\
\hline Total lasems Dedsetion & 401 & 70 & 10,465 & 245 & 281 & 12,817 \\
\hline 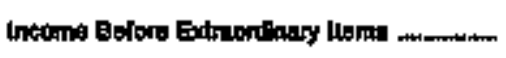 & $\theta, 0$ & gess & B.ASG & 1,889 & $1,0 \times 9$ & -218 \\
\hline 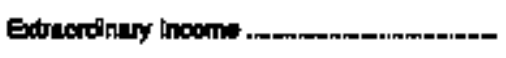 & 0 & 0 & $\mathbf{0}$ & 0 & 0 & $\mathbf{0}$ \\
\hline 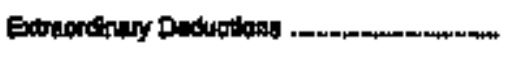 & 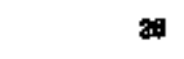 & 0 & 0 & 0 & 0 & a \\
\hline Ant Inoome. & 101 & 96 & 0,406 & 1,010 & 1,408 & $-\mathbf{2 1 0}$ \\
\hline
\end{tabular}

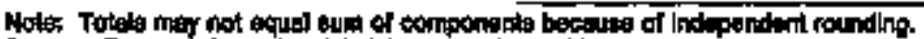

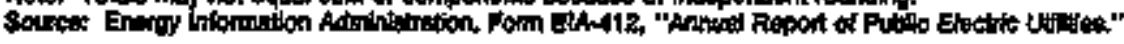


Table 21. Statement of Inceme by Major U.S. Publiely Owned Electric Utility Whin State, 1994 (Continued) (Thousand Dollars)

\begin{tabular}{|c|c|c|c|c|c|c|}
\hline Hen & $\begin{array}{c}\text { Otilo } \\
\text { Nepalaon } \\
\text { Criny of } \\
\text { Dacamber } 81\end{array}$ & $\begin{array}{l}\text { Ohbs } \\
\text { Niby of } \\
\text { Detember at }\end{array}$ & 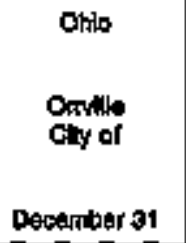 & 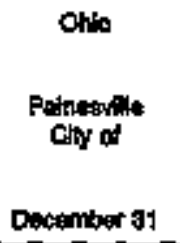 & $\begin{array}{l}\text { Cho } \\
\text { Chy of } \\
\text { Docember } 31\end{array}$ & $\begin{array}{l}\text { Orio } \\
\text { st Marys } \\
\text { Cly of }\end{array}$ \\
\hline Enotrle Uulty Opecuing Rovenuse n...-. & 8,469 & 16958 & 10,039 & 13,860 & 15,643 & 7,468 \\
\hline 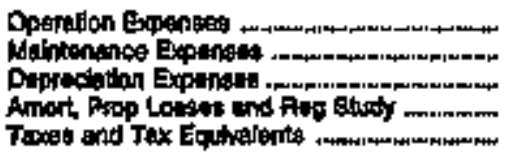 & $\begin{array}{r}8,498 \\
0 \\
0 \\
0 \\
0\end{array}$ & $\begin{array}{r}15806 \\
0 \\
0 \\
0 \\
0\end{array}$ & $\begin{array}{r}10,291 \\
23,392 \\
1,517 \\
0 \\
0\end{array}$ & $\begin{array}{r}11,005 \\
0 \\
1,504 \\
0 \\
0\end{array}$ & $\begin{array}{r}10,995 \\
1,928 \\
898 \\
0 \\
0\end{array}$ & $\begin{array}{r}5.850 \\
521 \\
429 \\
0 \\
0\end{array}$ \\
\hline Tolal Elootro Utilly Oparallnd & 40. & 1E, otos & 14,130 & 12,708 & 43,307 & 6,804 \\
\hline 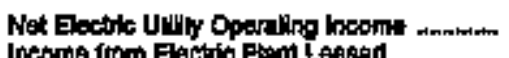 & $\rightarrow 1$ & 1,171 & 1,907 & 1,114 & 2956 & $\$ 54$ \\
\hline 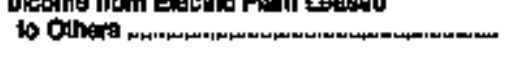 & 161 & . 0 & 0 & 0 & 0 & $\mathbf{0}$ \\
\hline 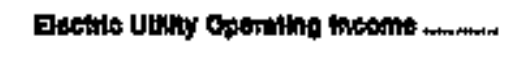 & 110 & 1,171 & 1,:017 & 1,114 & 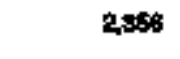 & 864 \\
\hline 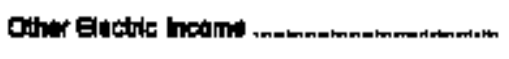 & 0 & 32 & 485 & -197 & 210 & 178 \\
\hline 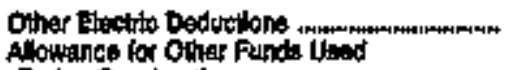 & 0 & 0 & 1,494 & 0 & 240 & 10 \\
\hline 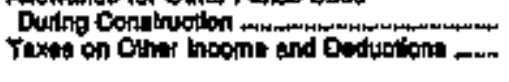 & 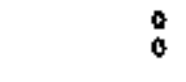 & 0 & 0 & 0 & $\begin{array}{l}0 \\
0\end{array}$ & $\begin{array}{l}0 \\
0\end{array}$ \\
\hline 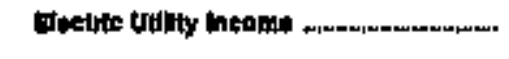 & $1+0$ & 1,200 & 968 & 977 & 2,329 & 620 \\
\hline 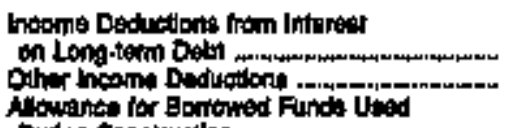 & $\stackrel{0}{0}$ & $\begin{array}{l}0 \\
0\end{array}$ & $\stackrel{0}{0}$ & 423 & 50 & $\begin{array}{r}307 \\
0\end{array}$ \\
\hline 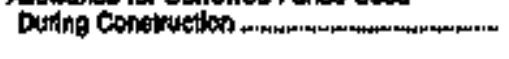 & 0 & 0 & o & 0 & 0 & 0 \\
\hline Total hramb Daddidanta & 0 & 0 & 0 & 430 & ses & $\$ \$ 7$ \\
\hline 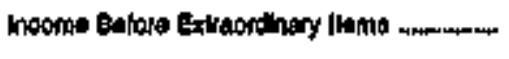 & 110 & 1,200 & 9日es & 649 & 1,701 & 454 \\
\hline 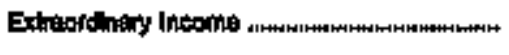 & 0 & $\mathbf{0}$ & 0 & $s$ & 0 & - \\
\hline 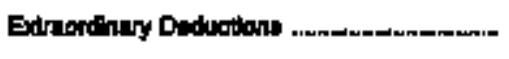 & 0 & 0 & 0 & $\theta$ & D & 0 \\
\hline 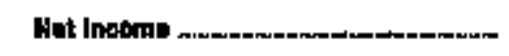 & 10 & 1,200 & 988 & 494 & 1,701 & 454 \\
\hline
\end{tabular}

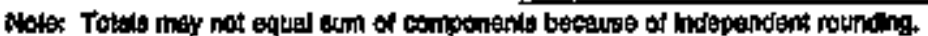

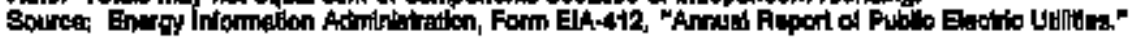


Table 21, Statement of Income by Mafor U.S. Publicly Owned Electolo Utlliby Whiln State, 1994 (Continued)

(Thousand Dollars)

\begin{tabular}{|c|c|c|c|c|c|c|}
\hline Itara & $\begin{array}{c}\text { Ohin } \\
\text { Wodinardh } \\
\text { Chy of }\end{array}$ & $\begin{array}{l}\text { Ohito } \\
\text { Whapenote } \\
\text { Ciey of } \\
\text { Decomber st }\end{array}$ & $\begin{array}{l}\text { Onis } \\
\text { Whestervila } \\
\text { Cry of } \\
\text { Deoumber or }\end{array}$ & 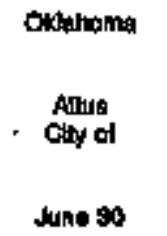 & $\begin{array}{l}\text { Oddahome } \\
\text { Clamemore } \\
\text { Chy of } \\
\text { Juna } 90\end{array}$ & $\begin{array}{l}\text { Oklehoma } \\
\text { Dunoson } \\
\text { City ol } \\
\text { June } 30\end{array}$ \\
\hline 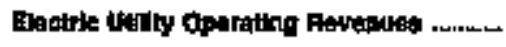 & 11,680 & 1,221 & *,274 & 10,174 & 12,725 & Q.481 \\
\hline 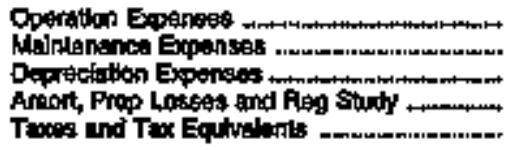 & $\begin{array}{r}11,116 \\
0 \\
3 \% 6 \\
0 \\
0\end{array}$ & $\begin{array}{r}5,516 \\
307 \\
0 \\
0 \\
0\end{array}$ & $\begin{array}{r}11,432 \\
2,190 \\
6,96 \\
21 \\
0\end{array}$ & $\begin{array}{r}0.051 \\
35 \\
443 \\
0 \\
0\end{array}$ & $\begin{array}{r}7,702 \\
t, 033 \\
0 \\
0 \\
0\end{array}$ & 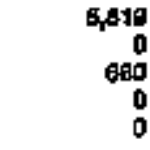 \\
\hline Toted Electof Utithy Oparading & 11,452 & 7,246 & 14007 & 6,589 & 8015 & 6,469 \\
\hline 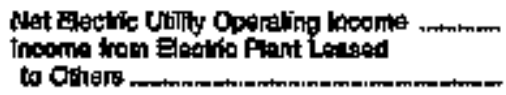 & $\begin{array}{r}410 \\
0\end{array}$ & $\begin{array}{r}-24 \\
0\end{array}$ & $\begin{array}{r}3,767 \\
0\end{array}$ & $\begin{array}{r}1,056 \\
0\end{array}$ & $\begin{array}{r}3,81 t \\
0\end{array}$ & $\begin{array}{r}2,185 \\
0\end{array}$ \\
\hline 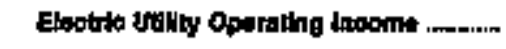 & 416 & $-\infty$ & $\mathbf{s y r}$ & $1,0 \% 8$ & $s, p+1$ & $2, \mathbf{1 0 9}$ \\
\hline 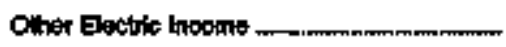 & 204 & $\mathbf{0}$ & 0 & 160 & 0 & 420 \\
\hline 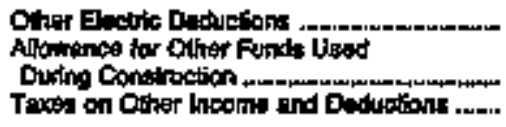 & $\stackrel{0}{0}$ & $\begin{array}{l}0 \\
0 \\
0\end{array}$ & $\begin{array}{l}0 \\
0\end{array}$ & $\stackrel{0}{0}$ & $\stackrel{0}{0}$ & $\begin{array}{l}0 \\
0 \\
0\end{array}$ \\
\hline 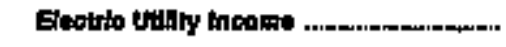 & 60 & -24 & $2,7 \pi 78$ & 1,796 & 3,p11 & 3,605 \\
\hline 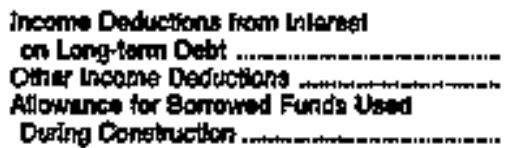 & $\begin{array}{l}0 \\
0\end{array}$ & $\begin{array}{l}0 \\
0 \\
0\end{array}$ & $\begin{array}{l}0 \\
0\end{array}$ & $\begin{array}{l}0 \\
0\end{array}$ & $\stackrel{0}{0}$ & $\begin{array}{l}0 \\
0\end{array}$ \\
\hline Total Mrome Doduetlans & o & 0 & 0 & 0 & 0 & 0 \\
\hline Income Baton Extraphtinany llaphs & 620 & -24 & 3,707 & 7,706 & 3,011 & 2,605 \\
\hline 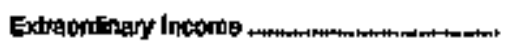 & 0 & 0 & $\mathbf{0}$ & 0 & 0 & 0 \\
\hline 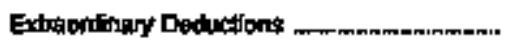 & 0 & 0 & o & $1,48 s$ & o & 0 \\
\hline Not Inoxme & 620 & -24 & 3,707 & $\mathbf{0 0 2}$ & 3011 & 2,00s \\
\hline
\end{tabular}

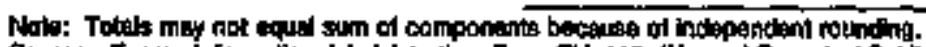

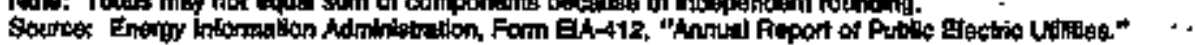


Tebie 21. Stateinent of Ineome by Major U.8. Publiely Owned Electric Utilly Within state, 1994 (Continuwd)

(Thousand Dollars)

\begin{tabular}{|c|c|c|c|c|c|c|}
\hline Itam & 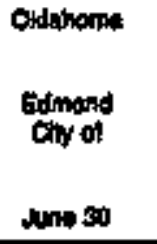 & 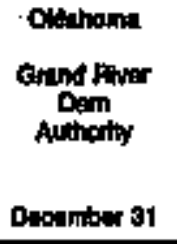 & $\begin{array}{l}\text { Coditiome } \\
\text { Comy of } \\
\text { Jane } 30\end{array}$ & 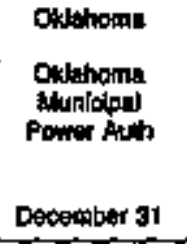 & 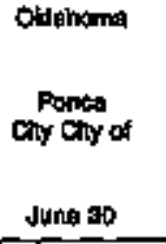 & 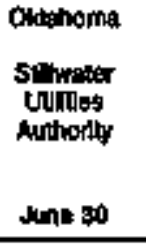 \\
\hline 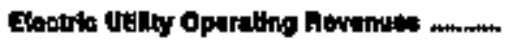 & $\operatorname{sinsen}$ & 105,gist & 7,212 & 7,274 & 21,697 & 22,733 \\
\hline 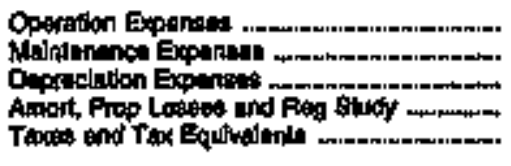 & $\begin{array}{r}24,205 \\
1,160 \\
1,+51 \\
0 \\
0\end{array}$ & $\begin{array}{r}73,799 \\
10,742 \\
28,748 \\
0 \\
0\end{array}$ & $\begin{array}{r}5,260 \\
848 \\
178 \\
0 \\
1,049\end{array}$ & $\begin{array}{r}50,648 \\
4,485 \\
4,845 \\
0 \\
1,209\end{array}$ & $\begin{array}{r}19,816 \\
2,200 \\
747 \\
0 \\
0\end{array}$ & $\begin{array}{r}+1,494 \\
1,210 \\
t, 360 \\
0 \\
2,010\end{array}$ \\
\hline 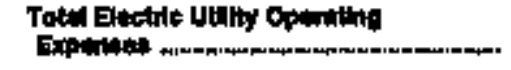 & 26,642 & 111278 & enta & $56,+106$ & 16,568 & 36,980 \\
\hline 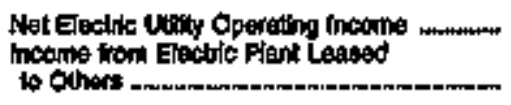 & 27700 & 64,078 & 209 & $\begin{array}{r}13,166 \\
0\end{array}$ & 4,959 & $\begin{array}{r}2,759 \\
0\end{array}$ \\
\hline Electro vildy Operating incempin & 2,700 & 4,006 & 200 & 13,169 & 4,9014 & $2,7=9$ \\
\hline 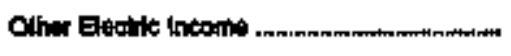 & 1,202 & 16534 & 105 & $3,5,72$ & 235 & 645 \\
\hline 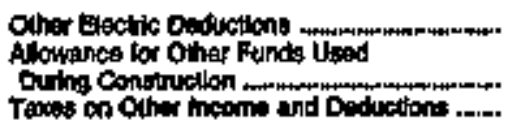 & $\begin{array}{r}0 \\
0 \\
0\end{array}$ & 0 & $\begin{array}{l}0 \\
0 \\
0\end{array}$ & $\begin{array}{l}0 \\
0 \\
0\end{array}$ & $\begin{array}{r}3,995 \\
0 \\
0\end{array}$ & $\begin{array}{l}0 \\
0 \\
0\end{array}$ \\
\hline 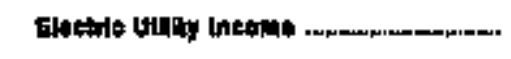 & 102 & mosto & $\$ 4$ & 16,740 & 1,2144 & $2,30 \%$ \\
\hline 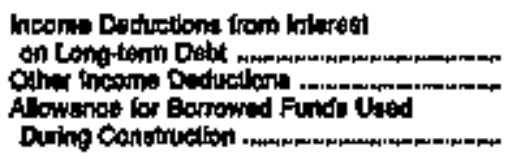 & $\begin{array}{r}1 \% 1 \\
0 \\
0\end{array}$ & $\begin{array}{r}61,507 \\
14,573 \\
0\end{array}$ & $\begin{array}{l}0 \\
0 \\
0\end{array}$ & $\begin{array}{r}21,084 \\
460 \\
0\end{array}$ & $\begin{array}{l}0 \\
0 \\
0\end{array}$ & $\begin{array}{l}0 \\
0 \\
0\end{array}$ \\
\hline 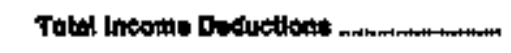 & 121 & $\pi, 40$ & $\theta$ & 22,102 & 0 & 0 \\
\hline 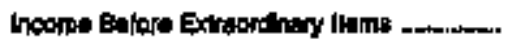 & 81 & $-5,569$ & 434 & $-5,360$ & 1,284 & 3,397 \\
\hline Eximatidhany lintomb & a & 6887 & 0 & 6.671 & 0 & o \\
\hline 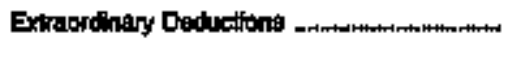 & $\mathbf{0}$ & $\mathbf{0}$ & 0 & 0 & 0 & o \\
\hline Not Inctme .... & 61 & 1,370 & 45 & t,\$0s & 1,284 & 3,597 \\
\hline
\end{tabular}

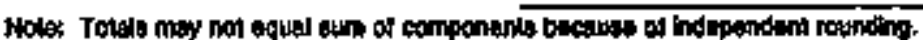

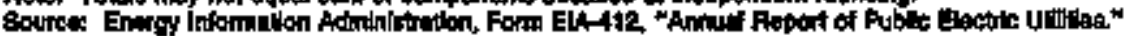


Table 21. Statement of Income by Major U.S. Publichy Owned Electric Utility Winin State, 1894 (Continued)

(Thousand Dollars)

\begin{tabular}{|c|c|c|c|c|c|c|}
\hline $\operatorname{ltam}$ & $\begin{array}{l}\text { Oregan } \\
\text { Alhkend } \\
\text { Clly of } \\
\text { Wults ap }\end{array}$ & 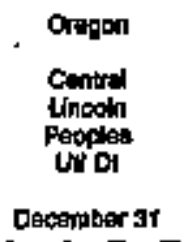 & $\begin{array}{l}\text { Orepon } \\
\text { Cievederie } \\
\text { Pagples } \\
\text { utit bied } \\
\text { Decenter } 31\end{array}$ & 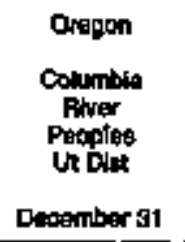 & 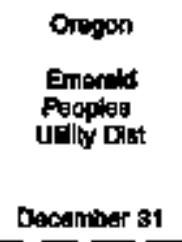 & $\begin{array}{l}\text { Cregon } \\
\text { Eugene } \\
\text { Coly of } \\
\text { Ducember St }\end{array}$ \\
\hline 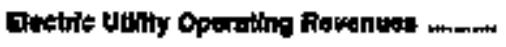 & 6sar & 58,900 & 20,000 & 12,771 & 2475 & $1+1,5.92$ \\
\hline 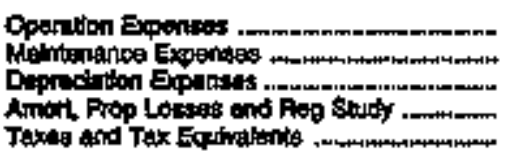 & $\begin{array}{r}6,893 \\
459 \\
0 \\
75 \\
824\end{array}$ & $\begin{array}{r}48,188 \\
1,717 \\
8,501 \\
0 \\
1,096\end{array}$ & $\begin{array}{r}24,441 \\
463 \\
350 \\
0 \\
136\end{array}$ & $\begin{array}{l}0,639 \\
458 \\
480 \\
225 \\
171\end{array}$ & $\begin{array}{r}12,699 \\
640 \\
2057 \\
679 \\
429\end{array}$ & $\begin{array}{r}88,408 \\
4,479 \\
8,090 \\
7,614\end{array}$ \\
\hline 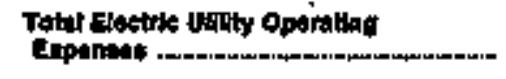 & 7,800 & 50,295 & $25,80 t$ & 11,570 & 18,700 & $16 \operatorname{set}, 6$ \\
\hline 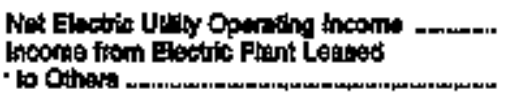 & $\begin{array}{r}782 \\
0\end{array}$ & $\begin{array}{r}\$, 654 \\
0\end{array}$ & 6 & $\begin{array}{r}1,000 \\
0\end{array}$ & 4,050 & $\begin{array}{r}\$, 675 \\
0\end{array}$ \\
\hline 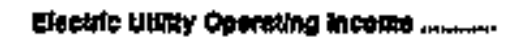 & 782 & 3,654 & 876 & 1,001 & 4014 & 1,875 \\
\hline 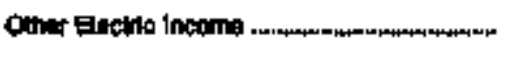 & D & $\mathbf{5 0 1}$ & 169 & 493 & 834 & 4,054 \\
\hline 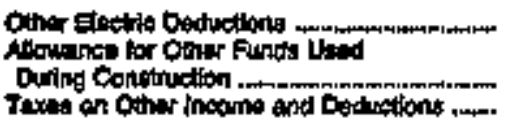 & $\begin{array}{l}0 \\
0 \\
0\end{array}$ & $\begin{array}{l}0 \\
0 \\
0\end{array}$ & $\begin{array}{l}0 \\
0 \\
0\end{array}$ & $\begin{array}{r}0 \\
0 \\
83\end{array}$ & $\begin{array}{l}0 \\
0 \\
0\end{array}$ & $\begin{array}{r}358 \\
58 \\
6\end{array}$ \\
\hline 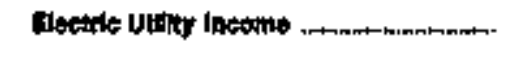 & 792 & 4,215 & sin & 2,005 & 6,07a & 5,482 \\
\hline 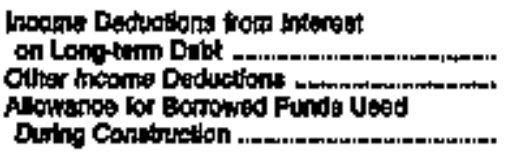 & 9 & कto & 0 & $\begin{array}{r}3,188 \\
108 \\
0\end{array}$ & $\begin{array}{r}4,110 \\
800 \\
0\end{array}$ & $\begin{array}{r}4,007 \\
5,992 \\
-48\end{array}$ \\
\hline 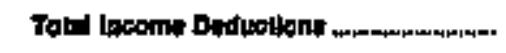 & 0 & 60 & 0 & 1,2098 & $46 r a$ & Ta,00: \\
\hline 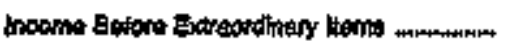 & 702 & 3,970 & 884 & 018 & 1,000 & $-5,404$ \\
\hline 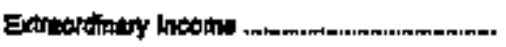 & 0 & 0 & 0 & 0 & 0 & 0 \\
\hline Extreardhary Datroglonil & 0 & $0^{\circ}$ & 0 & 0 & 9 & 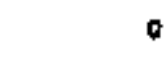 \\
\hline 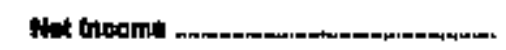 & $7 \% 2$ & 3,856 & as4 & 519 & 1,000 & $-5,404$ \\
\hline
\end{tabular}

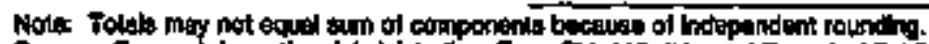

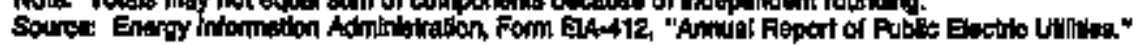


Table 21. Statement of Income by Major U.S. Publlety Owhed Electric Uthiny Within state, 1994 (Conthuret) (Thousand Dollars)

\begin{tabular}{|c|c|c|c|c|c|c|}
\hline then & $\begin{array}{l}\text { Oreopr } \\
\text { Foregk forpow } \\
\text { chy of } \\
\text { Jung } 30\end{array}$ & $\begin{array}{l}\text { Oregon } \\
\text { Dondingullo of } \\
\text { June ato }\end{array}$ & 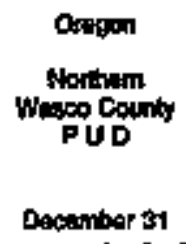 & 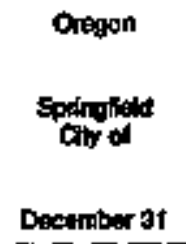 & 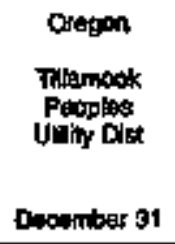 & 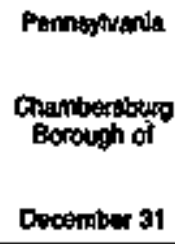 \\
\hline 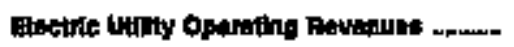 & rod & $\mathbf{2 1}, \mathbf{4 0}$ & 12,618 & MAPT & 17,002 & 11,041 \\
\hline 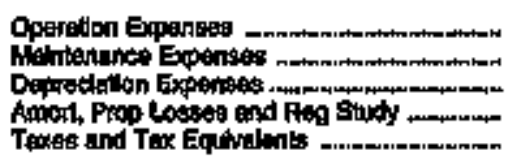 & $\begin{array}{r}6,475 \\
327 \\
413\end{array}$ & $\begin{array}{r}20,516 \\
0 \\
098 \\
0 \\
1.040\end{array}$ & $\begin{array}{r}0,095 \\
500 \\
1,021 \\
0 \\
\text { ins }\end{array}$ & $\begin{array}{r}25,650 \\
1,009 \\
1,09 \\
1,391 \\
1,331\end{array}$ & $\begin{array}{r}14,093 \\
1,101 \\
1,112 \\
41 \\
627\end{array}$ & $\begin{array}{r}10,701 \\
357 \\
827 \\
0 \\
0\end{array}$ \\
\hline Totat Electils InTRy Oparting & 7,911 & 21,212 & 11,0350 & 20,10t & $T 0,034$ & 11, 488 \\
\hline 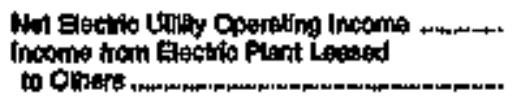 & $\begin{array}{r}\text { s77 } \\
0\end{array}$ & 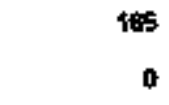 & $\begin{array}{r}t, 517 \\
0\end{array}$ & 2,300 & 908 & $\begin{array}{r}-\$ 27 \\
0\end{array}$ \\
\hline 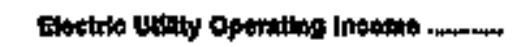 & st7 & 165 & 1,517 & 2,909 & 998 & -127 \\
\hline Other Eletile Income & 2 & $r 8$ & $+B 1$ & 160 & 445 & 30 \\
\hline 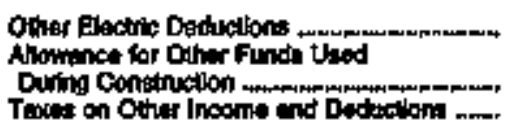 & $\stackrel{9}{0}$ & $\begin{array}{l}0 \\
0 \\
0\end{array}$ & $\begin{array}{l}0 \\
0\end{array}$ & $\begin{array}{r}0 \\
0 \\
0\end{array}$ & $\begin{array}{l}0 \\
0 \\
0\end{array}$ & $\begin{array}{r}0 \\
0\end{array}$ \\
\hline 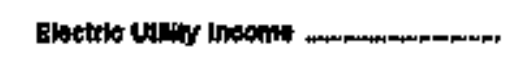 & 360 & 698 & 1,697 & 2,508 & 1,46 & -4 \\
\hline 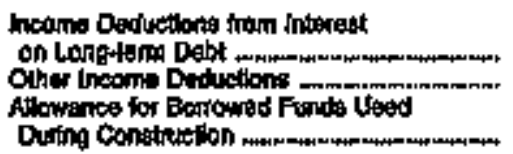 & $\frac{0}{34}$ & $\stackrel{0}{107}$ & $\begin{array}{r}1,607 \\
0\end{array}$ & $\begin{array}{l}69 \\
71 \\
0\end{array}$ & $\begin{array}{r}689 \\
14 \\
-30\end{array}$ & $\begin{array}{l}0 \\
0 \\
0\end{array}$ \\
\hline Totel inesme Deductiont & $\mathbf{4}$ & $10 t$ & 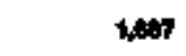 & $\omega$ & 45 & $\theta$ \\
\hline 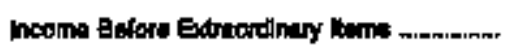 & 395 & 798 & 10 & 2,489 & 781 & -340 \\
\hline Extrapdinany lnoome & 0 & 0 & 0 & o & 0 & 0 \\
\hline 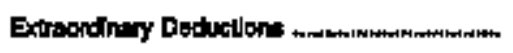 & 0 & 0 & o & 0 & o & 0 \\
\hline Net lacorme & 348 & 795 & 10 & 20300 & 7et & -240 \\
\hline
\end{tabular}

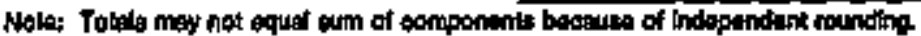

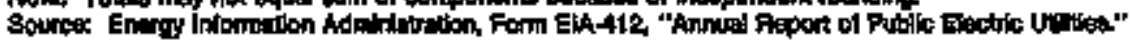


Table 21. Statement of Inoome by Major U.S. Publichy Owned Electric Uthity Whin State, 1994 (Contimued) (Thousand Dollars)

\begin{tabular}{|c|c|c|c|c|c|c|}
\hline Hem & 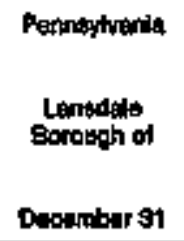 & $\begin{array}{l}\text { South Corolin } \\
\text { Cunden } \\
\text { Chy of } \\
\text { turs } 30\end{array}$ & 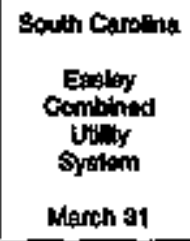 & 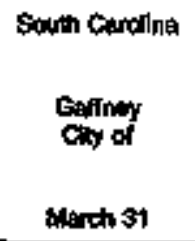 & 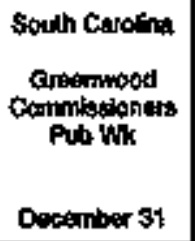 & $\begin{array}{c}\text { South Garolline } \\
\text { Greer } \\
\text { Comm } \\
\text { of } \\
\text { Putite Wotha } \\
\text { Docember } 31\end{array}$ \\
\hline 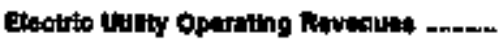 & 10,404 & 12,100 & 146005 & 13,200? & 15,846 & 10;6At \\
\hline 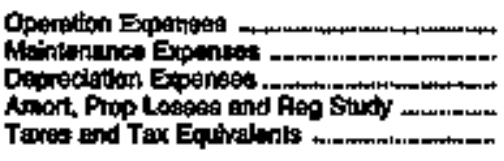 & $\begin{array}{r}7,761 \\
0 \\
377 \\
0 \\
0\end{array}$ & $\begin{array}{r}4,390 \\
0 \\
403 \\
0 \\
0\end{array}$ & $\begin{array}{r}+2,069 \\
5 \pi 7 \\
49 \\
0 \\
0\end{array}$ & $\begin{array}{r}8,711 \\
61 \\
682 \\
0 \\
0\end{array}$ & $\begin{array}{r}12,867 \\
0 \\
524 \\
0 \\
0\end{array}$ & $\begin{array}{r}9,230 \\
0 \\
510 \\
0 \\
0\end{array}$ \\
\hline Total Enctso Utility Opereting & 0,189 & 9,735 & 19,185 & to,das & 12,791 & 0,740 \\
\hline 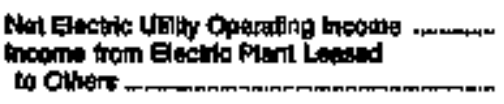 & $\begin{array}{r}2,355 \\
0\end{array}$ & 2,407 & 1,470 & $\begin{array}{r}2,778 \\
0\end{array}$ & 1,065 & 0 \\
\hline Enctive Ually Oparatho Inoome & 2,\$ss & 2407 & 1,670 & 2736 & 1,055 & 601 \\
\hline Ootser Eactile lroome .....mm & 1,007 & 1,300 & 200 & 158 & 1998 & 1,225 \\
\hline 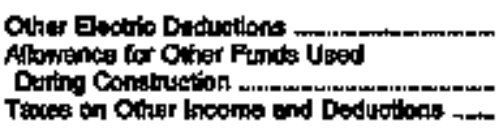 & o & $\stackrel{0}{0}$ & $\begin{array}{r}169 \\
0 \\
0\end{array}$ & $\begin{array}{r}250 \\
0 \\
0\end{array}$ & $\begin{array}{r}109 \\
0\end{array}$ & $\begin{array}{l}0 \\
0 \\
0\end{array}$ \\
\hline 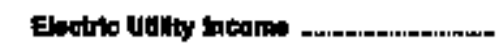 & 1,362 & \$,798 & 1,515 & 2,677 & 1,004 & 2,128 \\
\hline 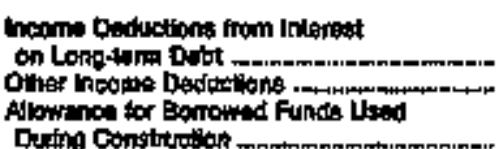 & $\frac{406}{37}$ & 280 & $\begin{array}{r}172 \\
720 \\
0\end{array}$ & $\begin{array}{l}0 \\
0\end{array}$ & $\begin{array}{l}0 \\
0 \\
0\end{array}$ & 100 \\
\hline Tolal hnconis Deduction: & $5 \otimes$ & 200 & 200 & $\mathbf{0}$ & 0 & 1,009 \\
\hline 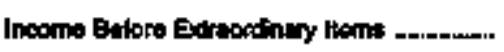 & 2,009 & s,478 & $\$ 15$ & 2,637 & $1,0 B 4$ & 1,032 \\
\hline Bdraontinary incoms & D & COB & 0 & 0 & 0 & $\mathbf{0}$ \\
\hline 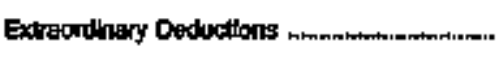 & 0 & 2,72 & 0 & 0 & 0 & 0 \\
\hline Aint lheotion & 2018 & $t$ & s16 & $\mathbf{2 , 6 7 7}$ & $1,0: 4$ & 1,082 \\
\hline
\end{tabular}

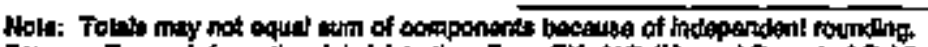

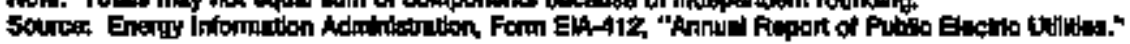


Table 21. Btatement of Income by Major U.S. Publicly Omed Elactric Utllity Whin State, 1994 (Continued) (Thousend Dollars)

\begin{tabular}{|c|c|c|c|c|c|c|}
\hline IHA & 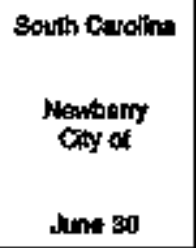 & $\begin{array}{l}\text { South Cerdina } \\
\text { Orungubur } \\
\text { Ciny of } \\
\text { Sopienber } 30\end{array}$ & 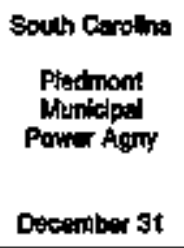 & $\begin{array}{l}\text { South Coroine } \\
\text { Pock Hill } \\
\text { City of } \\
\text { Decuritow } 31\end{array}$ & $\begin{array}{l}\text { Soudh Carotina } \\
\text { Sentera } \\
\text { City of } \\
\text { June sot }\end{array}$ & 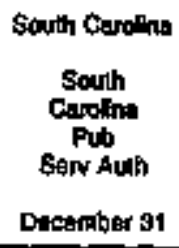 \\
\hline Elettro vally Operaling Hovemues . & 8,610 & 24,7ss & 10,67 & 40,003 & 12,860 & 608,230 \\
\hline 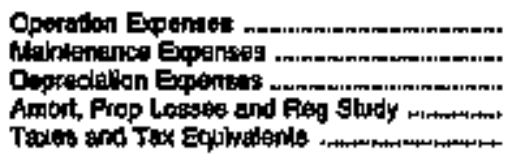 & $\begin{array}{r}8,609 \\
0 \\
201 \\
0 \\
0\end{array}$ & $\begin{array}{r}31,499 \\
0 \\
1,25 \\
0 \\
0\end{array}$ & $\begin{array}{r}95,052 \\
12,429 \\
20,549 \\
0 \\
4,385\end{array}$ & $\begin{array}{r}36,004 \\
2,396 \\
1,004 \\
0 \\
0\end{array}$ & $\begin{array}{r}1,306 \\
1,221 \\
732 \\
0 \\
0\end{array}$ & $\begin{array}{r}325,047 \\
52,429 \\
80,097 \\
0 \\
2,238\end{array}$ \\
\hline 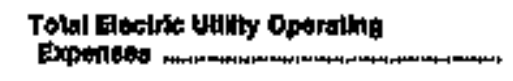 & s,125 & 32,748 & 122,414 & 30,304 & 10,269 & 459,707 \\
\hline 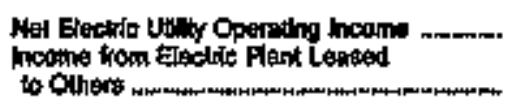 & $\begin{array}{r}760 \\
0\end{array}$ & 6 & $\begin{array}{r}39,269 \\
0\end{array}$ & $\begin{array}{r}9,779 \\
0\end{array}$ & 2,299 & $\begin{array}{r}145,493 \\
0\end{array}$ \\
\hline 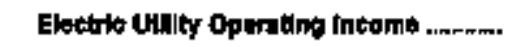 & 760 & 6,002 & 89,260 & E,TH & 2,2009 & 145,433 \\
\hline 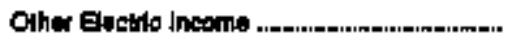 & 160 & 349 & 5,202 & 4 4t9 & 0 & 18,319 \\
\hline 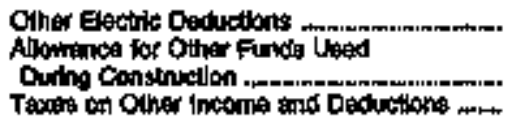 & $\begin{array}{r}69 \\
0 \\
0\end{array}$ & 0 & $\begin{array}{r}-30,420 \\
0 \\
0\end{array}$ & $\begin{array}{r}8,749 \\
0 \\
0\end{array}$ & $\begin{array}{r}2,519 \\
0 \\
0\end{array}$ & $\begin{array}{l}0 \\
0 \\
0\end{array}$ \\
\hline 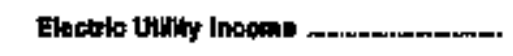 & 461 & Q342 & 108,915 & 1,448 & -20 & 100,762 \\
\hline 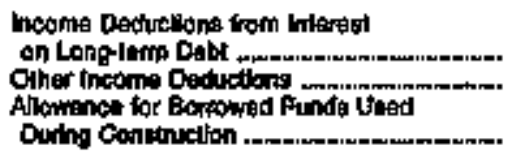 & $\begin{array}{r}136 \\
0 \\
0\end{array}$ & $\begin{array}{r}241 \\
0\end{array}$ & $\begin{array}{r}60,810 \\
20,410 \\
0\end{array}$ & $\begin{array}{r}60 \\
0 \\
0\end{array}$ & $\begin{array}{l}0 \\
0 \\
0\end{array}$ & $\begin{array}{r}117,970 \\
10,4,33\end{array}$ \\
\hline Totd mesme beftudions & 120 & 241 & 107 ne2: & $\$ 28$ & 0 & 128,408 \\
\hline 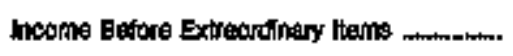 & 725 & 6,101 & $-3,711$ & 922 & -20 & 95,349 \\
\hline Extranthary heome & 0 & 0 & 0 & 0 & a & 0 \\
\hline 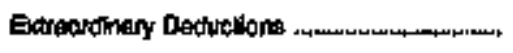 & 155 & 0 & o & 0 & o & 0 \\
\hline Hel meemp & 669 & 5,101 & $-3,111$ & 92 & -200 & 38,410 \\
\hline
\end{tabular}

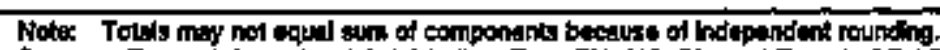

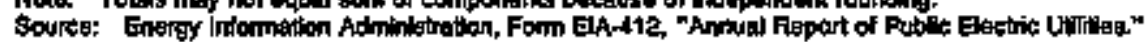


Teble 21. Statemint of Income by Major U.S. Publicty Ownted Electrte Utilty Whthin State, 1994 (Contlinued) (Thousand Dollars)

\begin{tabular}{|c|c|c|c|c|c|c|}
\hline them & 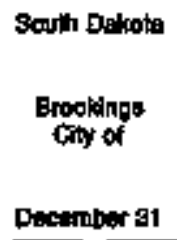 & $\begin{array}{l}\text { South Drikold } \\
\text { Hourtand } \\
\text { Contoumers } \\
\text { Power Dist } \\
\text { Decomber } 31\end{array}$ & 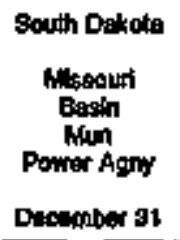 & $\begin{array}{l}\text { Soth Doteola } \\
\text { Plome } \\
\text { Clly of } \\
\text { Dooember } 31\end{array}$ & 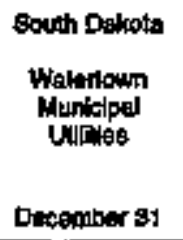 & 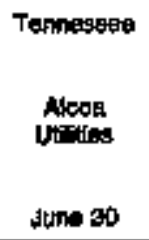 \\
\hline 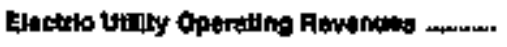 & 6,015 & $11,44 t$ & 58,022 & 6,954 & B,431 & 23,005 \\
\hline 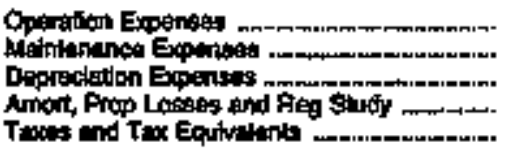 & $\begin{array}{r}6.698 \\
7 \% \\
6 \% 9 \\
2 \\
28\end{array}$ & $\begin{array}{r}7,892 \\
1,076 \\
131 \\
346\end{array}$ & $\begin{array}{r}57,227 \\
0 \\
76 \\
0 \\
24\end{array}$ & $\begin{array}{r}4,400 \\
49 \\
292 \\
0 \\
0\end{array}$ & $\begin{array}{r}6,955 \\
697 \\
834 \\
0 \\
0\end{array}$ & $\begin{array}{r}20,760 \\
1,050 \\
0 \\
100\end{array}$ \\
\hline 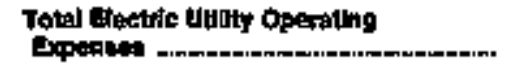 & $7,4 \geq 0$ & 9,447 & 57,327 & 4,741 & HAs & 24,002 \\
\hline 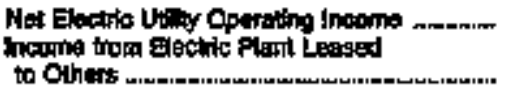 & 6 & $\begin{array}{r}1,004 \\
0\end{array}$ & $\begin{array}{r}606 \\
0\end{array}$ & 2 & 69 & 618 \\
\hline 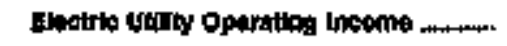 & $\$ 95$ & 1,994 & 695 & 2,213 & 66 & 613 \\
\hline Oliser Gectro Ineorns & 92 & 2,019 & 7,067 & -236 & 213 & 498 \\
\hline 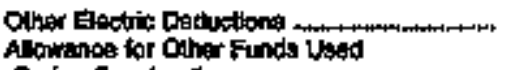 & 0 & 0 & 0 & 1,800 & 89 & 0 \\
\hline 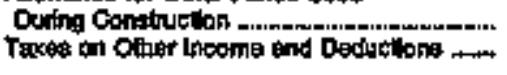 & $\stackrel{0}{0}$ & $\stackrel{0}{0}$ & $\stackrel{0}{0}$ & o & 0 & 0 \\
\hline Eleftro birity lnoome & 68 & 4,012 & 1,789 & 177 & 1S: & 1,050 \\
\hline 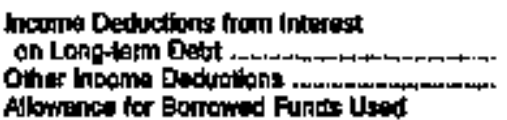 & o & $\begin{array}{l}3,835 \\
-201\end{array}$ & $\begin{array}{l}0 \\
0\end{array}$ & $\begin{array}{l}0 \\
0\end{array}$ & $\stackrel{0}{0}$ & 166 \\
\hline During Construtetion _- & o & a & 0 & $\mathbf{0}$ & 0 & 0 \\
\hline 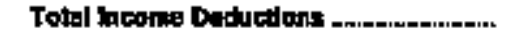 & $\mathbf{0}$ & 3,734 & 9 & Q & 30 & 782 \\
\hline 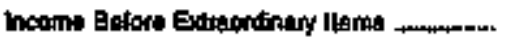 & 688 & 270 & 1,748 & 177 & -194 & aso \\
\hline 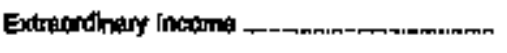 & 0 & 0 & 0 & o & 0 & 0 \\
\hline 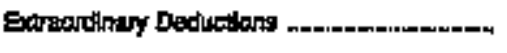 & 0 & 0 & 0 & - & 0 & 1 \\
\hline 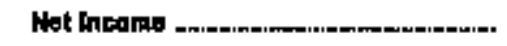 & 698 & 270 & 1,762 & 17 & -190 & 80 \\
\hline
\end{tabular}

Hols: Tolsts may not equal surp of componenis becalise of hependant munding

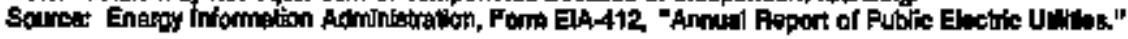


Table 21. Statement of income by Mejor US. Pubilcly Owned Electric Uillty Whith State, 1894 (Continued)

(Thousand Dollars)

\begin{tabular}{|c|c|c|c|c|c|c|}
\hline Ilem & 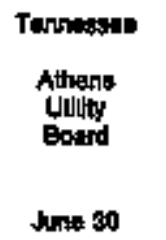 & $\begin{array}{l}\text { Tennessed } \\
\text { Eanton } \\
\text { Counity } \\
\text { Jung ad }\end{array}$ & 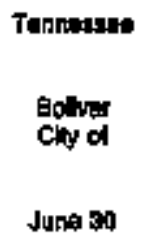 & $\begin{array}{l}\text { Tennespese } \\
\text { enistod } \\
\text { Chy of } \\
\text { Junte } 30\end{array}$ & $\begin{array}{l}\text { Tannesides } \\
\text { Onownosits } \\
\text { Ciny of } \\
\text { June } 30\end{array}$ & $\begin{array}{l}\text { Temnessian } \\
\text { Contol } \\
\text { County } \\
\text { Juns } 30\end{array}$ \\
\hline 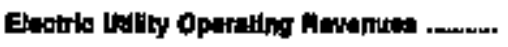 & 26,280 & $\mathbf{2} \mathbf{6} \mathbf{6 1 3}$ & 12,606 & 41,680 & 8,707 & 21,175 \\
\hline 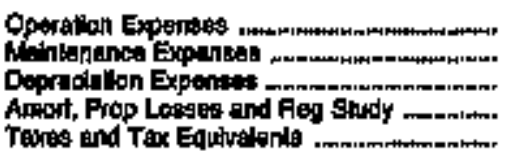 & $\begin{array}{r}23,734 \\
605 \\
588 \\
2 \\
408\end{array}$ & $\begin{array}{r}17,029 \\
76 B \\
45: \\
0 \\
303\end{array}$ & $\begin{array}{r}11,409 \\
467 \\
468 \\
0 \\
206\end{array}$ & $\begin{array}{r}37,052 \\
1,588 \\
1,190 \\
0 \\
951\end{array}$ & $\begin{array}{r}0,219 \\
74 \\
100 \\
37 \\
165\end{array}$ & $\begin{array}{r}16,089 \\
1,090 \\
\text { es1 } \\
-8 \\
300\end{array}$ \\
\hline 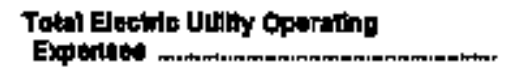 & 26,517 & 12,070 & 12,667 & 40,772 & 2,695 & 21,144 \\
\hline 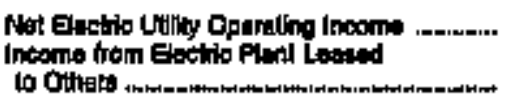 & $\begin{array}{r}743 \\
0\end{array}$ & $\begin{array}{l}35 \\
0\end{array}$ & 20 & $\begin{array}{r}848 \\
0\end{array}$ & $\begin{array}{r}21 \\
0\end{array}$ & at \\
\hline 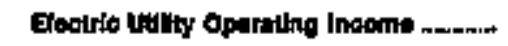 & 743 & 35: & 200 & ast & $2 \mathbf{2}$ & $\mathbf{3 2}$ \\
\hline 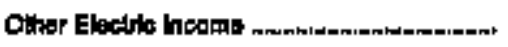 & 240 & 200 & 173 & 1,048 & 128 & 271 \\
\hline 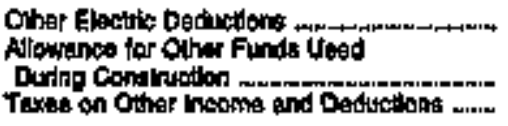 & $\begin{array}{l}15 \\
0 \\
0\end{array}$ & g & $\begin{array}{l}0 \\
0\end{array}$ & $\begin{array}{l}0 \\
0 \\
0\end{array}$ & $\begin{array}{l}0 \\
0 \\
0\end{array}$ & 0 \\
\hline 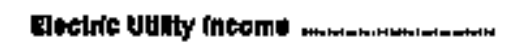 & ev7 & 264 & 412 & 2,458 & 147 & 302 \\
\hline 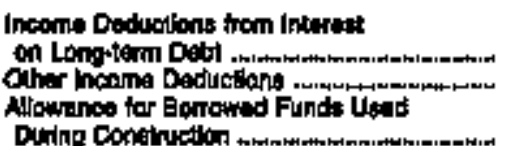 & 0 & 40 & 142 & $\stackrel{0}{17}$ & 39 & $\begin{array}{r}62 \\
3 \\
0\end{array}$ \\
\hline Total Ineome Datuotion: & b & 44 & 145 & $\pi$ & $\mathbf{s}$ & 4 \\
\hline 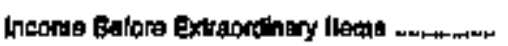 & 0.7 & 224 & 267 & 2,438 & 109 & 297 \\
\hline Extraordintry Income _-_. & 0 & o & 0 & 0 & 0 & 0 \\
\hline 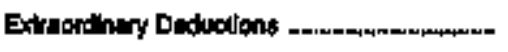 & 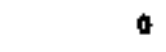 & 0 & 0 & (6) & 0 & 41 \\
\hline Net lnoomi & 907 & 20 & 307 & 3,499 & 100 & 198 \\
\hline
\end{tabular}

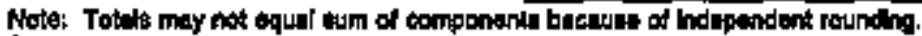

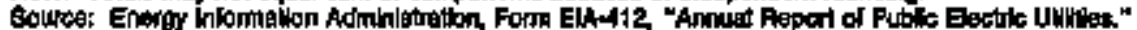


Table 21. Statement of Income by Major U.S. Pubilcly Owned Electric Utility Whtth State, 1994 (Continued) (Thousand Dollars)

\begin{tabular}{|c|c|c|c|c|c|c|}
\hline IFem & $\begin{array}{c}\text { Tannianos } \\
\text { Chatienooge } \\
\text { City af } \\
\text { June } 30\end{array}$ & 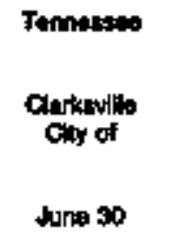 & $\begin{array}{l}\text { Tennewas: } \\
\text { Canvalund } \\
\text { City of } \\
\text { ane and }\end{array}$ & $\begin{array}{l}\text { Tonnestive } \\
\text { Cunton } \\
\text { City of } \\
\text { June } 30\end{array}$ & $\begin{array}{l}\text { Tonnesses } \\
\text { Codumbio } \\
\text { Coty of } \\
\text { Jupe so }\end{array}$ & $\begin{array}{l}\text { Tennosises } \\
\text { Cookevine } \\
\text { Caty of } \\
\text { Juna } \$ 0\end{array}$ \\
\hline 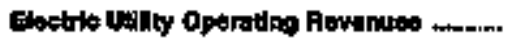 & 295,664 & 19,730 & 47,981 & 34,890 & $28,+36$ & 2542 \\
\hline 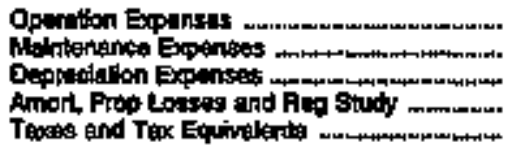 & $\begin{array}{r}268,053 \\
9,600 \\
7,992 \\
7,004\end{array}$ & $\begin{array}{l}4,080 \\
1,430 \\
1,092 \\
1,587 \\
690\end{array}$ & $\begin{array}{r}4,691 \\
+, 255 \\
1,345 \\
177 \\
947\end{array}$ & $\begin{array}{r}31,001 \\
1,148 \\
1,123 \\
0 \\
004\end{array}$ & $\begin{array}{r}26,687 \\
80,5 \\
87 \\
0 \\
514\end{array}$ & $\begin{array}{r}23,240 \\
501 \\
509 \\
712 \\
454\end{array}$ \\
\hline 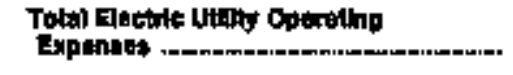 & 200,50 & 48,028 & 40,380 & $34=0$ & 27,042 & 24,467 \\
\hline 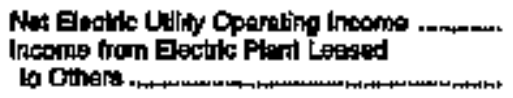 & 4,118 & $\begin{array}{r}701 \\
0\end{array}$ & $\begin{array}{r}1,828 \\
0\end{array}$ & s7s & 190 & $\begin{array}{r}466 \\
0\end{array}$ \\
\hline 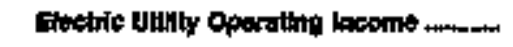 & 5,176 & 701 & 1,028 & 675 & 180 & 458 \\
\hline 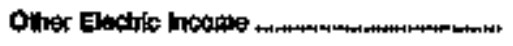 & $\mathbf{3 , 1 3 3}$ & $1,1 \pi$ & 499 & 464 & 384 & $2 \pi$ \\
\hline 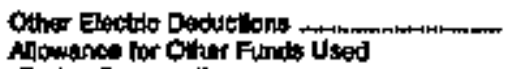 & $\mathbf{0}$ & 2 & 0 & 6 & 1 & 0 \\
\hline 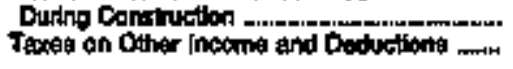 & $\begin{array}{l}0 \\
0\end{array}$ & $\stackrel{0}{0}$ & $\stackrel{0}{0}$ & $\stackrel{0}{0}$ & $\stackrel{0}{0}$ & 0 \\
\hline 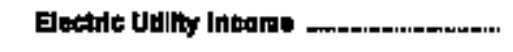 & $8,26.8$ & $1, \mathbf{A 7 7}$ & 2,t1s: & 1,164 & 673 & 732 \\
\hline 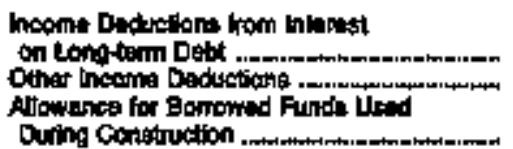 & 20 & $\begin{array}{l}461 \\
50\end{array}$ & $\frac{0}{0}$ & 77 & $\begin{array}{r}41 \\
29 \\
0\end{array}$ & $\begin{array}{r}80 \\
18 \\
0\end{array}$ \\
\hline Total Ineons Doductions & 204 & E90 & ه & $\pi$ & e4 & 16 \\
\hline 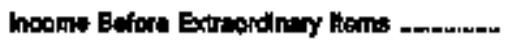 & $7, \$ 6$ & 1,597 & $2,00 \%$ & 1,657 & $\operatorname{sos}$ & 696 \\
\hline 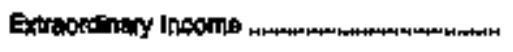 & 0 & 0 & 0 & o & - & o \\
\hline Extreordintry Doductions & 874 & 492 & 168 & 0 & 0 & 0 \\
\hline 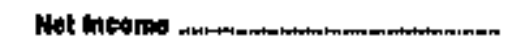 & 7,112 & es: & 1,012 & 1,077 & 600 & 606 \\
\hline
\end{tabular}

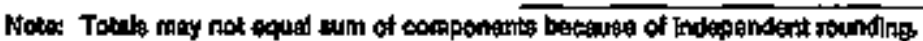

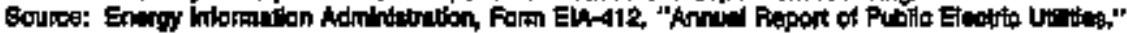


Table 21. Statement of Income by Mejor U.S. Publicly Owned Electric Ltillity Whithin State, 1994 (Continuad)

(Thousand Dollars)

\begin{tabular}{|c|c|c|c|c|c|c|}
\hline Itam & $\begin{array}{l}\text { Tennepeses } \\
\text { Coninglon } \\
\text { City of } \\
\text { June } 30\end{array}$ & $\begin{array}{l}\text { Tenthoses } \\
\text { Onytun } \\
\text { Ciny of } \\
\text { June } 30\end{array}$ & $\begin{array}{l}\text { Tonnegeded } \\
\text { Dickeon } \\
\text { Ciby of } \\
\text { June so }\end{array}$ & 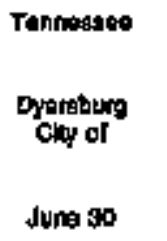 & 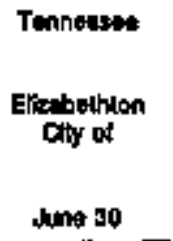 & $\begin{array}{l}\text { Tennosses } \\
\text { Enwin } \\
\text { Town of } \\
\text { Jim sp }\end{array}$ \\
\hline 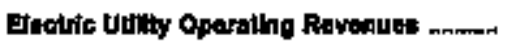 & to,, 918 & 10,496 & 34,075 & 29,624 & at,3t7 & 10,bet \\
\hline 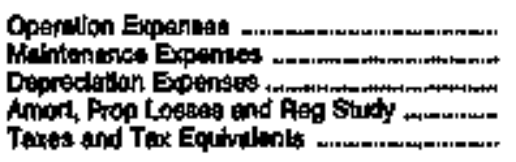 & $\begin{array}{r}0,792 \\
159 \\
215 \\
182 \\
201\end{array}$ & $\begin{array}{r}9.726 \\
242 \\
249 \\
0 \\
219\end{array}$ & $\begin{array}{r}29,375 \\
1,380 \\
1,057 \\
0 \\
5,55\end{array}$ & $\begin{array}{r}28,100 \\
745 \\
636 \\
0 \\
654\end{array}$ & $\begin{array}{r}24.957 \\
868 \\
746 \\
0 \\
715\end{array}$ & $\begin{array}{r}9,854 \\
207 \\
249 \\
0 \\
194\end{array}$ \\
\hline 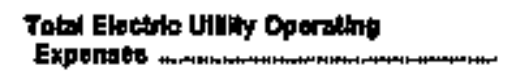 & tor,son & 10,4st: & 32,340 & 20,43 & 27,996 & 10,054 \\
\hline 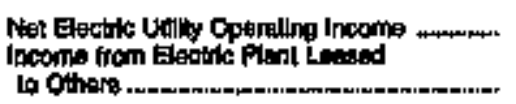 & $\begin{array}{r}378 \\
0\end{array}$ & 0 & $\begin{array}{r}\$, 735 \\
0\end{array}$ & $\begin{array}{r}1,391 \\
0\end{array}$ & $\begin{array}{r}1,001 \\
0\end{array}$ & 257 \\
\hline 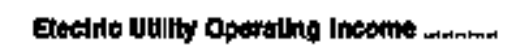 & 378 & $5 \times$ & 1,735 & 1,391 & 1,081 & 207 \\
\hline Obur Elactite heorne & ag5 & 112 & 552 & 685 & 290 & 216 \\
\hline 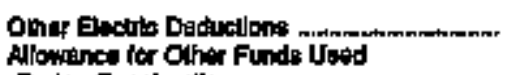 & 4 & $\circ$ & o & 6 & $\mathbf{6}$ & 0 \\
\hline 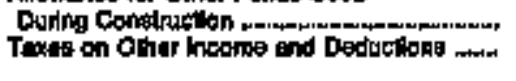 & $\stackrel{\circ}{0}$ & a & $\begin{array}{l}0 \\
0\end{array}$ & $\stackrel{9}{0}$ & $\stackrel{0}{0}$ & $\stackrel{0}{0}$ \\
\hline 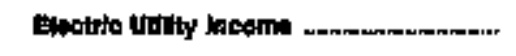 & 760 & $\operatorname{sen}$ & 2,207 & 1,950 & 1,571 & 404 \\
\hline 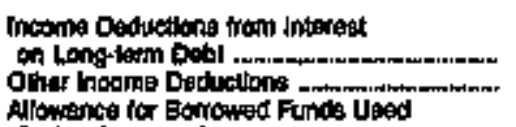 & $\begin{array}{r}41 \\
2\end{array}$ & $\begin{array}{l}0 \\
0\end{array}$ & $\begin{array}{r}709 \\
40\end{array}$ & $\begin{aligned} 412 \\
39\end{aligned}$ & $\begin{array}{r}0 \\
64\end{array}$ & 9 \\
\hline 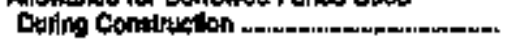 & 0 & 0 & 0 & 9 & o & 0 \\
\hline 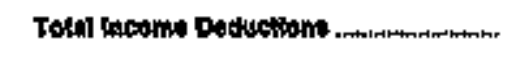 & 48 & $\mathbf{0}$ & 765 & 415 & 64 & 7 \\
\hline 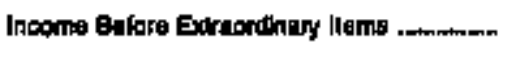 & 716 & 08 & 1,594 & 1,524 & 1,317 & 47 \\
\hline Extroxdingy Incama & 0 & 0 & o & 0 & 0 & 0 \\
\hline 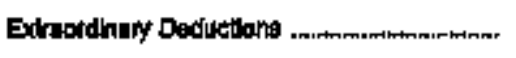 & 0 & 0 & o & 378 & $\mathbf{0}$ & 0 \\
\hline Wot Inoonto - & 716 & 062 & 1402 & 1,16 & 1,317 & 47 \\
\hline
\end{tabular}

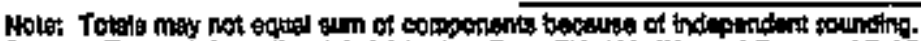

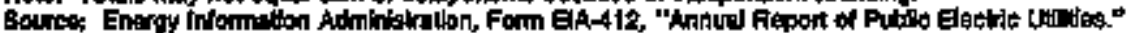


Table 21. Statement of encome by Major U.S. Publleły Owned Electrle Utilly , Within State, 1994 (Continued)

(Thousand Dollars)

\begin{tabular}{|c|c|c|c|c|c|c|}
\hline I $\mathbf{k m}$ & 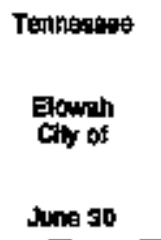 & 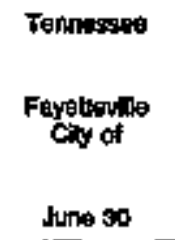 & 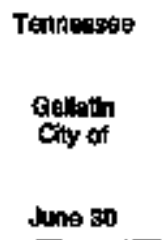 & $\begin{array}{l}\text { Tennogese } \\
\text { Crenoring } \\
\text { Ciny of } \\
\text { Juma ao }\end{array}$ & $\begin{array}{l}\text { Temintosea } \\
\text { Honimint } \\
\text { City of } \\
\text { Jne } 30\end{array}$ & $\begin{array}{l}\text { Tennessea } \\
\text { Hunjuboidt } \\
\text { Coy of } \\
\text { June } 00\end{array}$ \\
\hline 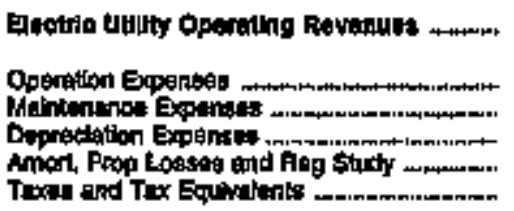 & $\begin{array}{r}7,407 \\
6,068 \\
009 \\
170 \\
0 \\
287\end{array}$ & $\begin{array}{r}21,627 \\
10,670 \\
589 \\
689 \\
0 \\
505\end{array}$ & $\begin{array}{r}22951 \\
21515 \\
410 \\
410 \\
41 \\
310\end{array}$ & $\begin{array}{r}46,250 \\
4,, 636 \\
1,414 \\
1,301 \\
0 \\
8 \% 7\end{array}$ & $\begin{array}{r}17,487 \\
14,641 \\
710 \\
678 \\
0 \\
248\end{array}$ & $\begin{array}{r}10,900 \\
10,530 \\
221 \\
224 \\
79 \\
790\end{array}$ \\
\hline 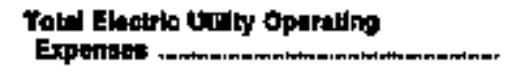 & 7,468 & 20,8羊1 & 22,726 & 40,470 & $16,17 *$ & 11,22 \\
\hline 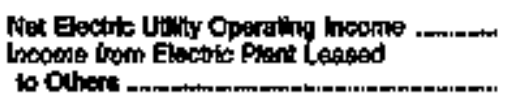 & $\begin{array}{r}-28 \\
0\end{array}$ & $\begin{array}{r}1,200 \\
0\end{array}$ & 208 & $\begin{array}{r}-242 \\
0\end{array}$ & $\begin{array}{r}1,250 \\
0\end{array}$ & -320 \\
\hline 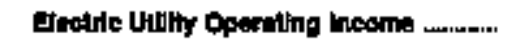 & -28 & 1,200 & 228 & $-n 42$ & $1,2: 0$ & -800 \\
\hline 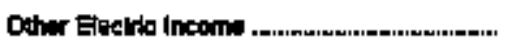 & $\$ 21$ & s21 & 38 & 1.150 & 401 & 288 \\
\hline 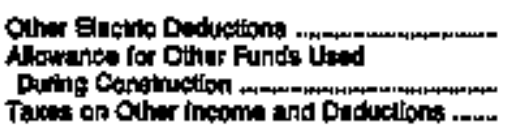 & a & $\begin{array}{l}14 \\
0\end{array}$ & 0 & 21 & $\begin{array}{l}7 \\
0 \\
0\end{array}$ & $\begin{array}{l}0 \\
9\end{array}$ \\
\hline 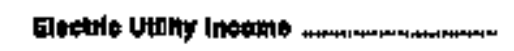 & 91 & $1,7+18$ & mi & 900 & 18.69 & -58 \\
\hline 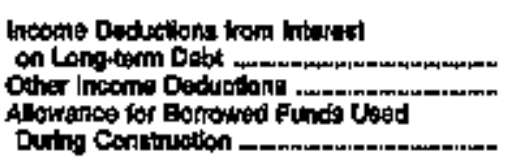 & $\begin{array}{r}17 \\
0 \\
0\end{array}$ & $\begin{array}{r}309 \\
17 \\
0\end{array}$ & 0 & $\begin{array}{l}\mathbf{0} \\
\mathbf{0} \\
0\end{array}$ & $\begin{array}{l}\mathbf{3 5} \\
\mathbf{2 1} \\
0\end{array}$ & $\begin{array}{l}2 \\
0 \\
0\end{array}$ \\
\hline 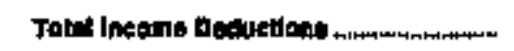 & 17 & 379 & 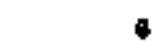 & $\mathbf{0}$ & 58 & 2 \\
\hline 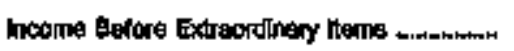 & 75 & 1,304 & 685 & 800 & 1,697 & - \\
\hline 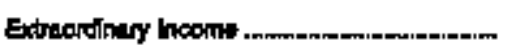 & 0 & $\mathbf{0}$ & 0 & 0 & 0 & $\theta$ \\
\hline Extraddinay Derdintons & $\mathbf{0}$ & 456 & 0 & $\mathbf{0}$ & 0 & 0 \\
\hline 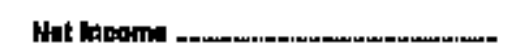 & $\pi$ & gr: & $\mathrm{ms}$ & ged & 1,607 & -40 \\
\hline
\end{tabular}

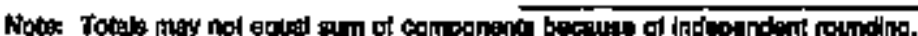

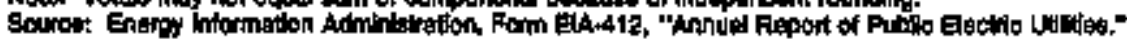


Table 21. Statement of Income by Hafor U.S. Publichy Omned Electric Uitity Within State, 1994 (Continued)

(Thousand Dollars)

\begin{tabular}{|c|c|c|c|c|c|c|}
\hline I由) & 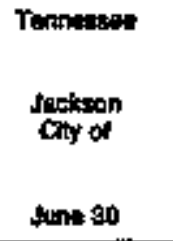 & $\begin{array}{l}\text { Tamosting } \\
\text { Johutson } \\
\text { Oxty City of } \\
\text { Juno so }\end{array}$ & 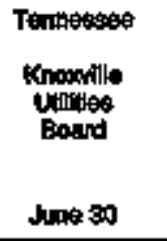 & 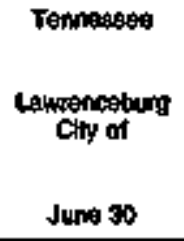 & 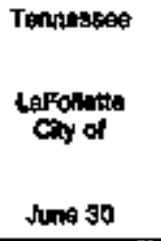 & $\begin{array}{l}\text { Tanneatses } \\
\text { Lebonon } \\
\text { Ciny of } \\
\text { Junp } 30\end{array}$ \\
\hline Electrio Utitly Oparabing Rewanuss ........ & 62,014 & 65,634 & 258,954 & 25,0mat & 20,045 & 18, \\
\hline 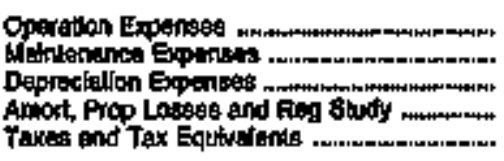 & $\begin{array}{r}58,948 \\
1,257 \\
20045 \\
65 \\
1,413\end{array}$ & $\begin{array}{r}78,004 \\
2,510 \\
1,770 \\
1,346\end{array}$ & $\begin{array}{r}239,649 \\
7,6093 \\
9,980 \\
0 \\
0,573\end{array}$ & $\begin{array}{r}22,608 \\
724 \\
704 \\
0 \\
503\end{array}$ & $\begin{array}{r}18.375 \\
855 \\
774 \\
0 \\
470\end{array}$ & $\begin{array}{r}17,126 \\
516 \\
367 \\
17 \\
328\end{array}$ \\
\hline 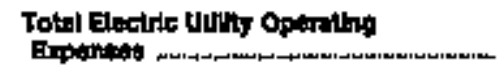 & 6,16 & 61690 & 261,706 & 24,592 & 20,575 & 19,3603 \\
\hline 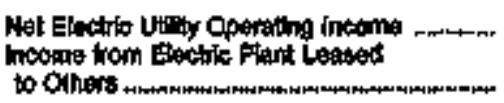 & 843 & $\begin{array}{r}4,144 \\
0\end{array}$ & $\begin{array}{r}7,170 \\
0\end{array}$ & $\begin{array}{r}494 \\
0\end{array}$ & -529 & 163 \\
\hline Electle Ulthy Operating lacorne ........ & 840 & 4,144 & 7,179 & 494 & $-\infty$ & 153 \\
\hline Oher Elaciro Income . . & 780 & 9: & 3,355 & 473 & 494 & 111 \\
\hline 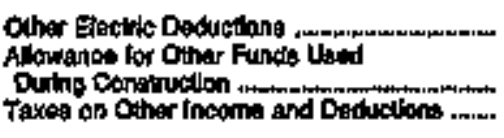 & 1 & $\stackrel{0}{0}$ & 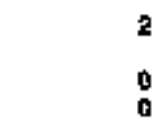 & 0 & $\begin{array}{l}0 \\
0 \\
0\end{array}$ & $\begin{array}{r}108 \\
0 \\
5\end{array}$ \\
\hline Electilc Vitility Ineopile & $t, 0.98$ & s,00:s & 145qz & ang & $\infty 5$ & 181 \\
\hline 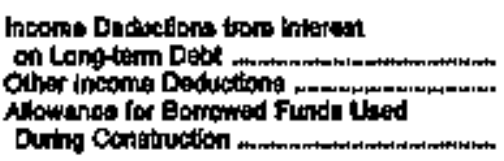 & $\begin{array}{r}647 \\
21 \\
0\end{array}$ & $\stackrel{0}{a}$ & $\begin{array}{r}1, \text { pro } \\
200 \\
0\end{array}$ & $\begin{array}{r}13 \\
0 \\
0\end{array}$ & $\begin{array}{r}197 \\
27 \\
0\end{array}$ & $\begin{array}{l}0 \\
0 \\
0\end{array}$ \\
\hline 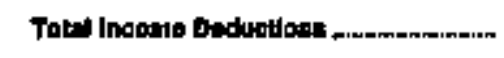 & 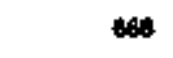 & $\mathbf{3 1}$ & 2,269 & 13 & 20 & 0 \\
\hline 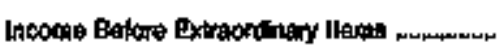 & 968 & s,os & e,kitat & 889 & -200 & $16 t$ \\
\hline 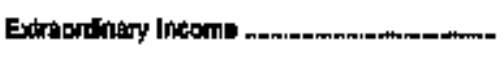 & 0 & a & - & o & c & o \\
\hline Extraprinary Daductions & 0 & 0 & e,b19 & 0 & 0 & 0 \\
\hline Mat Inopomp & 806 & 5,053 & $1,0 \%$ & $\sin$ & -2.00 & 181 \\
\hline
\end{tabular}

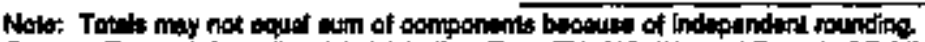

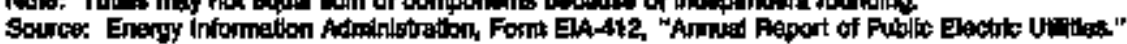


Table 21. Statement of Income by Malor US. Publtely Owned Electrle Utilty Within State, 1994 (Continued)

(Thousand Dollars)

\begin{tabular}{|c|c|c|c|c|c|c|}
\hline $\operatorname{lam}$ & $\begin{array}{l}\text { Tonnossise } \\
\text { Lendr } \\
\text { Chty Chy of } \\
\text { June } 30\end{array}$ & 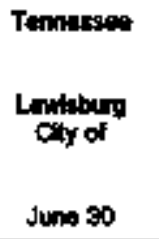 & 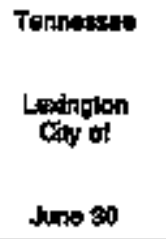 & 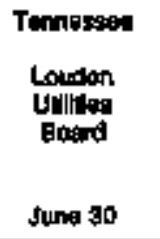 & 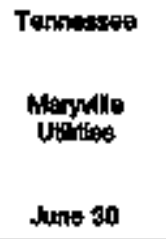 & 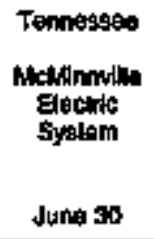 \\
\hline 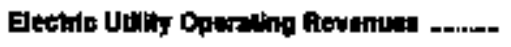 & 61,05 & t446es & 20,604 & 14053 & 27,207 & 12,253 \\
\hline 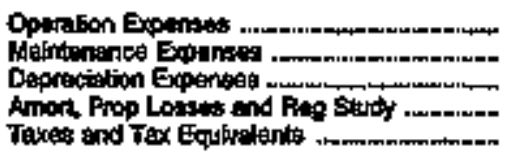 & $\begin{array}{r}5,7,65 \\
1,621 \\
1,851 \\
0 \\
1,269\end{array}$ & $\begin{array}{r}13,174 \\
206 \\
3 \$ 1 \\
41 \\
201\end{array}$ & $\begin{array}{r}20585 \\
766 \\
729 \\
0 \\
496\end{array}$ & $\begin{array}{r}12,34 \\
412 \\
360 \\
0 \\
346\end{array}$ & $\begin{array}{r}21,909 \\
704 \\
857 \\
4 \\
506\end{array}$ & $\begin{array}{r}11,098 \\
327 \\
407 \\
84 \\
262\end{array}$ \\
\hline $\begin{array}{l}\text { Total Electric Wedly Operating } \\
\text { Expentest }\end{array}$ & 56,007 & 14,003 & 22,536 & $\mathbf{1 0}, \mathbf{4 0 1}$ & 27,349 & 12,176 \\
\hline 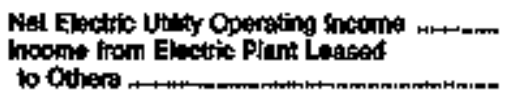 & $\begin{array}{r}3,647 \\
0\end{array}$ & 497 & $\begin{array}{r}556 \\
0\end{array}$ & 50 & -42 & $\pi$ \\
\hline Elocts Lunty Opanting Inoone & $\mathbf{3 , 6 4 7}$ & ast & 550 & 602 & -42 & $m$ \\
\hline 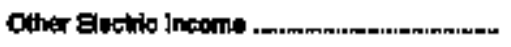 & 1,080 & 184 & 300 & 608 & 398 & 2020 \\
\hline 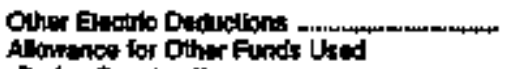 & 1 & 4 & 0 & 69 & 0 & 1 \\
\hline 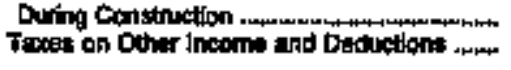 & $\begin{array}{l}0 \\
0\end{array}$ & $\stackrel{0}{0}$ & $\stackrel{0}{0}$ & $\stackrel{0}{0}$ & $\stackrel{0}{0}$ & c \\
\hline 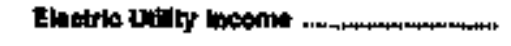 & 4,797 & 917 & 956 & 1,072 & 358 & 20 \\
\hline 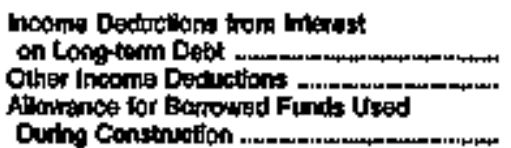 & $\begin{array}{r}1,365 \\
58 \\
0\end{array}$ & $\begin{array}{r}30 \\
4 \\
0\end{array}$ & $\begin{array}{l}0 \\
0\end{array}$ & $\begin{array}{r}305 \\
108 \\
0\end{array}$ & $\begin{array}{r}70 \\
6 \\
0\end{array}$ & $\underset{0}{20}$ \\
\hline Totel Inceme Deduetiona & 1,417 & 33 & a & 601 & 76 & $\boldsymbol{z 2}$ \\
\hline 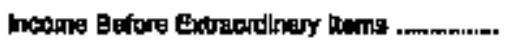 & 3,310 & 609 & $\mathbf{9 E B}$ & 571 & 281 & 276 \\
\hline 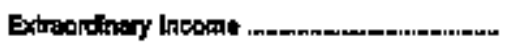 & 0 & 0 & o & 0 & 0 & o \\
\hline Extrendinary Defuctions & $\mathbf{0}$ & 0 & 0 & 369 & - & t \\
\hline Hat heomm & $\$ 3,310$ & 69 & 969 & 198 & 281 & 276 \\
\hline
\end{tabular}

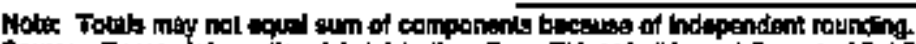

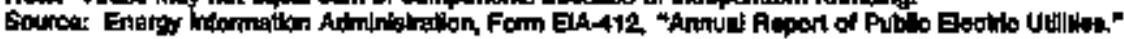


Table 21. Statement of Income by Major U.S. Pubilcly Owned Electric Utilly Whith State, 1994 (Continued)

(Thousend Dollers)

\begin{tabular}{|c|c|c|c|c|c|c|}
\hline in & $\begin{array}{l}\text { Temnoses } \\
\text { Memonio } \\
\text { Cty of } \\
\text { Junb } 30\end{array}$ & $\begin{array}{l}\text { Tennespese } \\
\text { City of } \\
\text { June } 30\end{array}$ & $\begin{array}{l}\text { Tannus:es: } \\
\text { Morigtawn } \\
\text { City of } \\
\text { Juno } 30\end{array}$ & 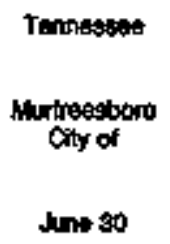 & 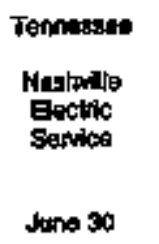 & $\begin{array}{l}\text { Tennessos: } \\
\text { Honpost } \\
\text { Oxy of } \\
\text { June so }\end{array}$ \\
\hline 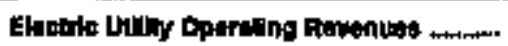 & втв, & 12,104 & 34,590 & $4, x y$ & ET1,, 50 & 23,403 \\
\hline 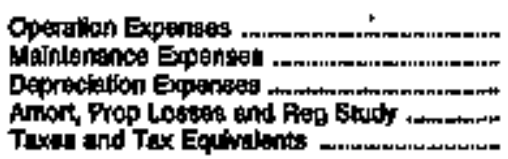 & $\begin{array}{r}601,900 \\
33,297 \\
10,129 \\
320 \\
21,490\end{array}$ & $\begin{array}{r}11,147 \\
397 \\
296 \\
0 \\
200\end{array}$ & $\begin{array}{r}30,857 \\
801 \\
809 \\
270 \\
601\end{array}$ & $\begin{array}{r}41,641 \\
609 \\
1,130 \\
150 \\
1,099\end{array}$ & $\begin{array}{r}511,170 \\
78,710 \\
78,106 \\
12,157\end{array}$ & $\begin{array}{r}20.741 \\
604 \\
638 \\
0 \\
603\end{array}$ \\
\hline 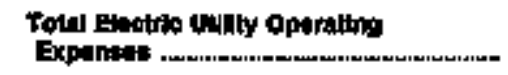 & 678,146 & 12,034 & $20,50 \%$ & 44,585 & $\operatorname{sen} 231$ & 22, \\
\hline 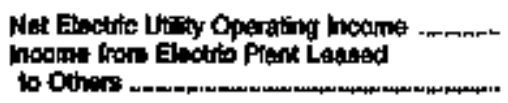 & $\begin{array}{r}2,500 \\
0\end{array}$ & $\begin{array}{r}30 \\
0\end{array}$ & Ea1 & $\begin{array}{r}t, 638 \\
0\end{array}$ & $\begin{array}{r}11.337 \\
0\end{array}$ & $\$ 98$ \\
\hline 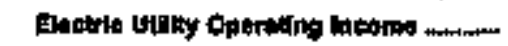 & 2,509 & 70 & $\$ 1$ & 1,693 & 11,357 & \$o \\
\hline Ohine Electilc Income & as,2s5 & 203 & 449 & 790 & 10,254 & $\$ 21$ \\
\hline 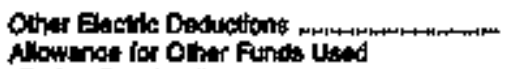 & 452 & 1 & 6 & 19 & $\mathbf{0}$ & 7 \\
\hline 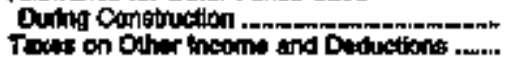 & $\begin{array}{l}0 \\
0\end{array}$ & $\stackrel{0}{0}$ & $\stackrel{0}{6}$ & $\stackrel{0}{0}$ & 0 & $\stackrel{0}{0}$ \\
\hline 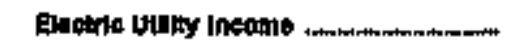 & 85,357 & 272 & 1,899 & 2,404 & 21 mat & 2,051 \\
\hline 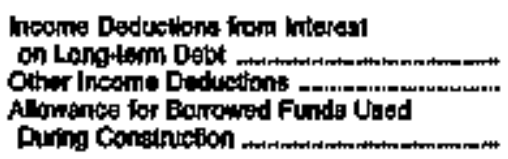 & $\begin{array}{r}\text { 15,27a } \\
\text { es6 } \\
0\end{array}$ & $\begin{array}{l}0 \\
0 \\
0\end{array}$ & $\begin{array}{r}3 \\
45\end{array}$ & $\begin{array}{r}239 \\
5 \\
0\end{array}$ & $\begin{array}{r}11,687 \\
886\end{array}$ & $\begin{array}{l}301 \\
19 \\
0\end{array}$ \\
\hline Total Meoms Dedurlont ... & 16,944 & $\mathbf{0}$ & 铂 & 204 & 12,578 & $3 t$ \\
\hline Incoune Beford Extrexd|nary keme ......... & 10,410 & $\mathbf{2 7 2}$ & 1,345 & 2,180 & 9,010 & 732 \\
\hline Edramalunary heomes & $\mathbf{0}$ & o & 0 & 0 & 0 & o \\
\hline 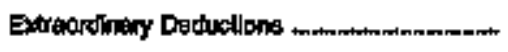 & 7,860 & 0 & 0 & 0 & 0 & 0 \\
\hline Nat meong & 11,460 & 272 & 1,846 & 2,120 & 2,018 & 732 \\
\hline
\end{tabular}

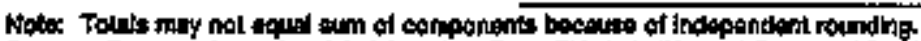

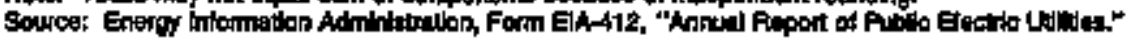


Table 21. Statement of Income by Ifejor U.S. Publiely Owned Electrie Utithy Withln State, 1994 (Conthuted) (Thousand Dollars)

\begin{tabular}{|c|c|c|c|c|c|c|}
\hline $\ln$ & $\begin{array}{l}\text { Temeses } \\
\text { Oak Ploge } \\
\text { Gay of } \\
\text { tun so }\end{array}$ & $\begin{array}{l}\text { Tennespee } \\
\text { Paris } \\
\text { Chy of } \\
\text { June an }\end{array}$ & $\begin{array}{l}\text { Ternespes } \\
\text { Pudand } \\
\text { Gay of } \\
\text { June so }\end{array}$ & 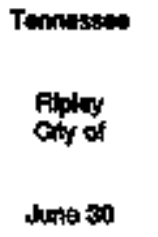 & $\begin{array}{l}\text { Tanniasase } \\
\text { Podkmood } \\
\text { Chy of } \\
\text { Junn so }\end{array}$ & $\begin{array}{l}\text { Tannosses } \\
\text { Sowis } \\
\text { Counity } \\
\text { Erextio } \\
\text { Syatem } \\
\text { June ad }\end{array}$ \\
\hline 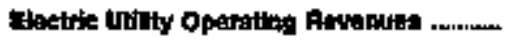 & $25,0,7$ & raptora & 2400 & 12,285 & 18,627 & 52,762 \\
\hline 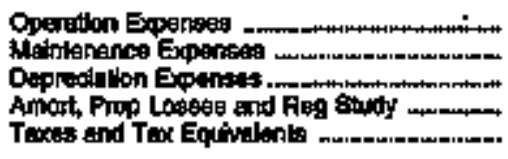 & $\begin{array}{r}22,727 \\
047 \\
754 \\
14 \\
625\end{array}$ & $\begin{array}{r}21,487 \\
642 \\
830 \\
0 \\
477\end{array}$ & $\begin{array}{r}18,291 \\
540 \\
694 \\
0 \\
650\end{array}$ & $\begin{array}{r}11,877 \\
245 \\
208 \\
81 \\
207\end{array}$ & $\begin{array}{r}14,244 \\
490 \\
450 \\
20 \\
430\end{array}$ & $\begin{array}{r}46,008 \\
1,207 \\
1,090 \\
31 \\
913\end{array}$ \\
\hline 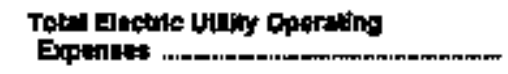 & 25,003 & 23396 & 21,058 & 12,alde & 15,600 & 50014 \\
\hline 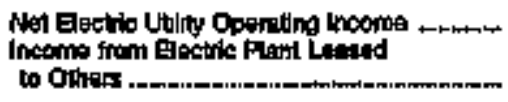 & $\cos$ & 912 & $\begin{array}{r}\text { B44 } \\
0\end{array}$ & $-\infty \times 3$ & 866 & 2,740 \\
\hline 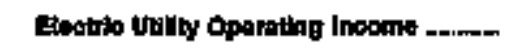 & $6: 89$ & 112 & 644 & $-9: 8$ & 698 & 3,74 \\
\hline Ohar Eextio hoomt _... & 310 & 367 & 234 & SDA & 200 & Q2n \\
\hline 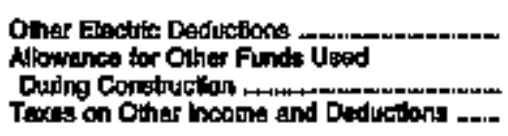 & : & D & $\begin{array}{l}7 \\
0 \\
0\end{array}$ & $\begin{array}{l}0 \\
0 \\
0\end{array}$ & $\begin{array}{r}11 \\
0 \\
0\end{array}$ & $\begin{array}{l}0 \\
0 \\
0\end{array}$ \\
\hline 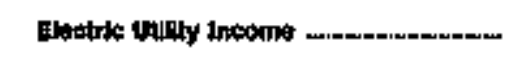 & 1,279 & $4 \pi$ & 1,072 & 0 & 1,104 & $8,7 \%$ \\
\hline 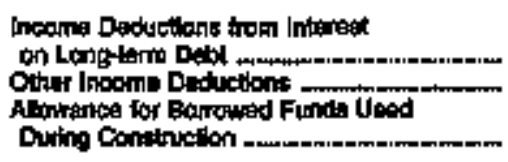 & $\begin{array}{r}302 \\
6 \\
0\end{array}$ & $\begin{array}{r}5600 \\
3 \\
0\end{array}$ & $\begin{array}{r}228 \\
2 \\
0\end{array}$ & $\begin{array}{l}0 \\
0 \\
0\end{array}$ & $\begin{array}{r}25 \\
0\end{array}$ & $\begin{array}{r}117 \\
98 \\
0\end{array}$ \\
\hline 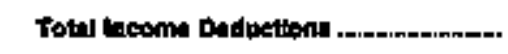 & $\mathbf{3 0 6}$ & $1 *$ & 230 & 0 & 23 & 215 \\
\hline 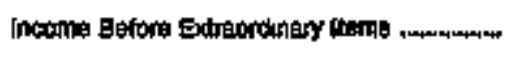 & 964 & 319 & 943 & 0 & 1,080 & a,358 \\
\hline Extracodinary inoome & 0 & 0 & 0 & v & 0 & 0 \\
\hline 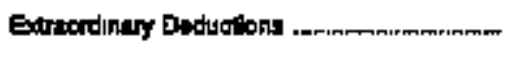 & 0 & 0 & 0 & 0 & 0 & 0 \\
\hline 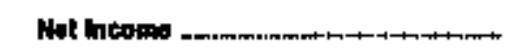 & 604 & 913 & ans & 0 & 1,000 & $\$, 356$ \\
\hline
\end{tabular}

Notes Tolars moy not eqpos aum of componems because of independent rounthy.

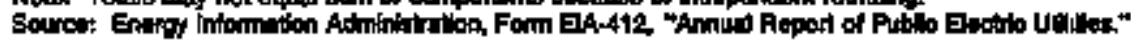


Table 21. Statement of Income by Mejor U.S. Publlcly Owned Electric Utility Whith State, 1994 (Continued)

(Thousand Dollars)

\begin{tabular}{|c|c|c|c|c|c|c|}
\hline tiem & 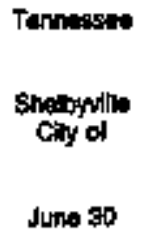 & $\begin{array}{l}\text { Tenriossen } \\
\text { Springliedd } \\
\text { Cily of } \\
\text { Jurpe } 30\end{array}$ & 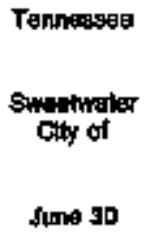 & 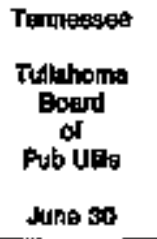 & $\begin{array}{l}\text { Termestete } \\
\text { Unton } \\
\text { City Gity of } \\
\text { June so }\end{array}$ & 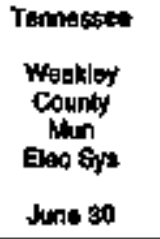 \\
\hline 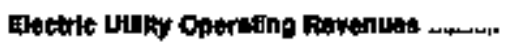 & 17,124 & 11,091 & 10,694 & 14,686 & 15,000 & nt,200, \\
\hline 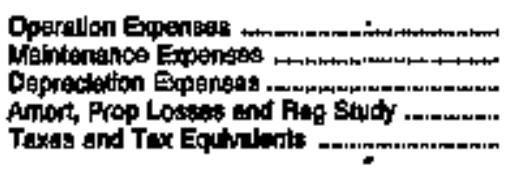 & $\begin{array}{r}15,958 \\
298 \\
399 \\
394 \\
394\end{array}$ & $\begin{array}{r}1,772 \\
1802 \\
304 \\
89 \\
249\end{array}$ & $\begin{array}{r}0,253 \\
276 \\
394 \\
0 \\
222\end{array}$ & $\begin{array}{r}13,376 \\
483 \\
429 \\
12 \\
271\end{array}$ & $\begin{array}{r}14,419 \\
228 \\
355 \\
14 \\
269\end{array}$ & $\begin{array}{r}23,734 \\
495 \\
974 \\
0 \\
620\end{array}$ \\
\hline $\begin{array}{l}\text { Total Elobtrk lafuly Operaing } \\
\text { Expanus: }\end{array}$ & 17,053 & 10,863 & $\mathbf{1 0 , 1 4 5}$ & $\cdot 14500$ & \&5,275 & 25,609 \\
\hline 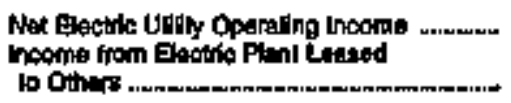 & 71 & $\begin{array}{r}1,000 \\
0\end{array}$ & 5 & $\begin{array}{r}175 \\
0\end{array}$ & $\begin{array}{r}-273 \\
0\end{array}$ & 673 \\
\hline Eectro tujuly Oparatieg Income & $\mathbf{n}$ & 1,000: & ssg & 175 & -279 & s73 \\
\hline 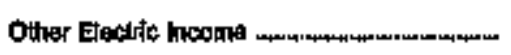 & 215 & $\pi 09$ & 245 & 270 & $\$ 0$ & 42 \\
\hline 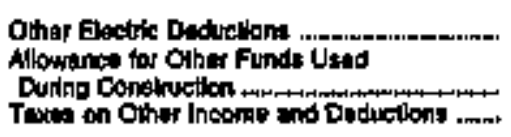 & $\begin{array}{l}0 \\
0 \\
0\end{array}$ & 0 & $\begin{array}{l}0 \\
0 \\
0\end{array}$ & $\stackrel{0}{0}$ & 0 & 0 \\
\hline 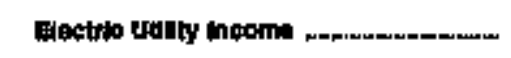 & 296 & $1,2,07$ & $7 \div 9$ & 490 & -5 & $\operatorname{0g} 6$ \\
\hline 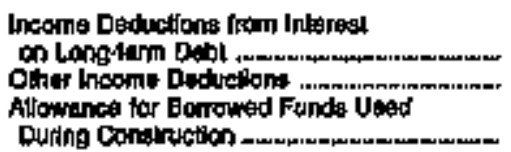 & $\begin{array}{r}0 \\
18 \\
0\end{array}$ & $\begin{array}{r}64 \\
-8 \\
0\end{array}$ & 4 & $\begin{array}{r}115 \\
2 \\
0\end{array}$ & $\begin{array}{l}0 \\
0\end{array}$ & $\begin{array}{r}0 \\
12 \\
0\end{array}$ \\
\hline 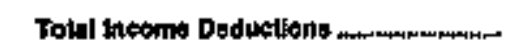 & 16 & $\mathbf{s s}$ & 4 & t17 & 0 & 12 \\
\hline 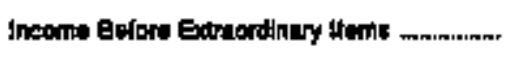 & 258 & 1,151 & 749 & 328 & -6 & 997 \\
\hline 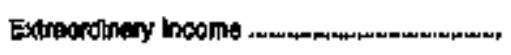 & 0 & 0 & 0 & o & 0 & 0 \\
\hline 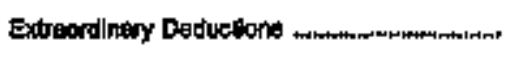 & 0 & 23 & 0 & 0 & 0 & 0 \\
\hline Nok bucoma . . & 20 & $1,+2=0$ & 740 & 923 & -5 & 967 \\
\hline
\end{tabular}

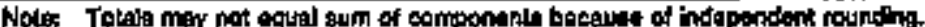

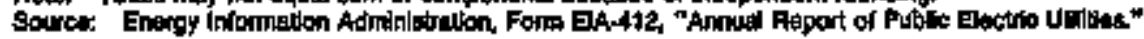


Tabie 21. Statement of Income by Hajor U.S. Publicly Owned Electric Utility Within State, t994 (Continued) (Thousand Dollars)

\begin{tabular}{|c|c|c|c|c|c|c|}
\hline im & $\begin{array}{l}\text { Twout } \\
\text { Austin } \\
\text { City of } \\
\text { September } 30\end{array}$ & $\begin{array}{l}\text { Toxas } \\
\text { Brontann } \\
\text { Crty of } \\
\text { Suphembt ao }\end{array}$ & 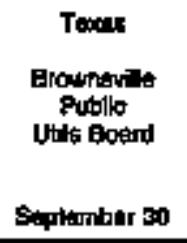 & $\begin{array}{l}\text { Toxat } \\
\text { Eryan } \\
\text { Cty of } \\
\text { Soplomber } 30\end{array}$ & $\begin{array}{l}\text { Touse } \\
\text { Collegs } \\
\text { Station } \\
\text { Cry of } \\
\text { September an }\end{array}$ & 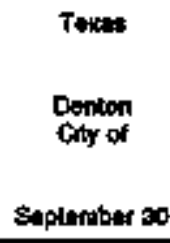 \\
\hline 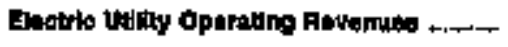 & 405,510 & 12,492 & $4,7 \leq 4$ & 73,791 & $\$ \$ \$ \$ 21$ & 65,002 \\
\hline 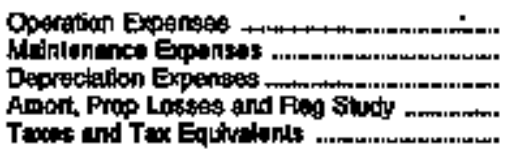 & $\begin{array}{r}249,943 \\
7,955 \\
00,961 \\
0 \\
0\end{array}$ & $\begin{array}{r}10,396 \\
6 \% 9 \\
244 \\
0 \\
619\end{array}$ & $\begin{array}{r}27,000 \\
2,951 \\
3,676 \\
9 \\
960\end{array}$ & $\begin{array}{r}50,146 \\
2,144 \\
4,145 \\
0 \\
3,600\end{array}$ & $\begin{array}{r}26916 \\
920 \\
840 \\
0 \\
3,116\end{array}$ & $\begin{array}{r}50,159 \\
1,810 \\
3,720 \\
0 \\
2,340\end{array}$ \\
\hline 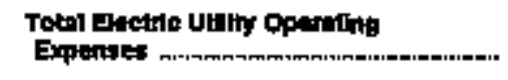 & 350,740 & 11,030 & 38,907 & 98,094 & 30,767 & 69,0030 \\
\hline 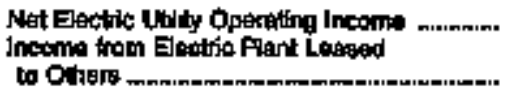 & $\begin{array}{r}138,970 \\
0\end{array}$ & 499 & $\begin{array}{r}10,847 \\
0\end{array}$ & 5,726 & $\begin{array}{r}3,024 \\
0\end{array}$ & 7,069 \\
\hline 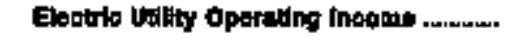 & 135,970 & 400 & 10,947 & 8,726 & 3,024 & 7,005 \\
\hline Other Evotio InCorft & 14,000 & 19 & 24,236 & $1,40\}$ & 906 & 2,602 \\
\hline 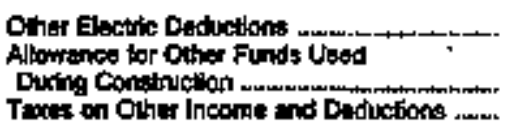 & $\begin{array}{r}355 \\
0 \\
0\end{array}$ & $\begin{array}{l}0 \\
0 \\
0\end{array}$ & $\begin{array}{r}5,071 \\
0 \\
0\end{array}$ & $\begin{array}{r}1,795 \\
0 \\
0\end{array}$ & $\begin{array}{r}1.106 \\
0 \\
0\end{array}$ & $\begin{array}{r}718 \\
0 \\
0\end{array}$ \\
\hline 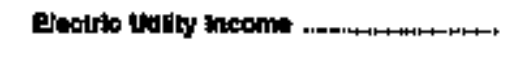 & 151,440 & 512 & 34,012 & 5,429 & 2,84 & 9000 \\
\hline 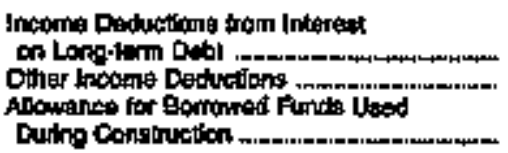 & $\begin{array}{r}129,311 \\
14,406 \\
0\end{array}$ & $\begin{array}{r}42 \\
0 \\
0\end{array}$ & $\begin{array}{r}7,089 \\
2,053 \\
0\end{array}$ & $\begin{array}{l}0 \\
0 \\
0\end{array}$ & $\begin{array}{r}055 \\
86 \\
0\end{array}$ & $\begin{array}{r}1,470 \\
49 \\
0\end{array}$ \\
\hline 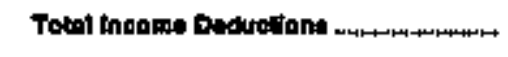 & 137,799 & 49 & 29,734 & 0 & 720 & 1,8:5: \\
\hline Income Befote Extraondiary llemis memmm & 13,641 & 470 & $4,2,77$ & 5,429 & 2,104 & 7,504 \\
\hline Extraordinary Incorne & 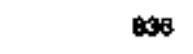 & 0 & 0 & 0 & 0 & 0 \\
\hline 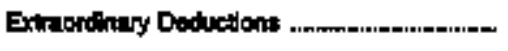 & 0 & B & 0 & 2,800 & 0 & 0 \\
\hline n & 14,677 & Ats & $A, 277$ & 2,505 & 2,40 & 7,504 \\
\hline
\end{tabular}

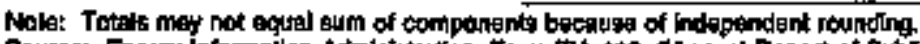

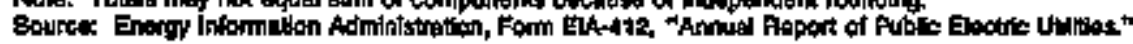


Table 21. Statement of Income by Major U.S. Publlaty Omned Electric Utilty Within Stato, 1894 (Comtinued)

(Thousand Dollars)

\begin{tabular}{|c|c|c|c|c|c|c|}
\hline ltam & $\begin{array}{c}\text { Texpla } \\
\text { Foresal:e } \\
\text { Ciny of } \\
\text { Oaceinter } 31\end{array}$ & $\begin{array}{l}\text { Texas } \\
\text { crefland } \\
\text { Eity of } \\
\text { September } 30\end{array}$ & 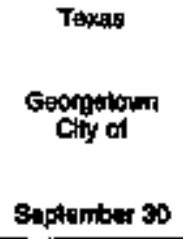 & 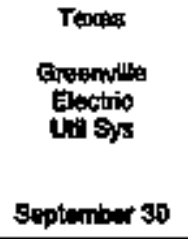 & $\begin{array}{l}\text { Texes } \\
\text { Kernite } \\
\text { Publos } \\
\text { Utilyy } \\
\text { Eoend } \\
\text { September } 30\end{array}$ & 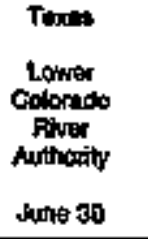 \\
\hline 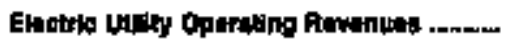 & 10,200 & 160,154 & 12,161 & $30,4: 2$ & 22,731 & 367,029 \\
\hline 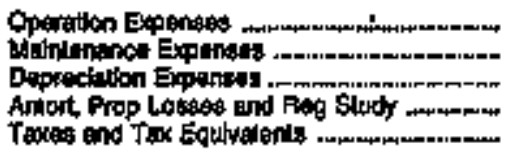 & $\begin{array}{r}0.047 \\
294 \\
609 \\
0 \\
0\end{array}$ & $\begin{array}{r}117,904 \\
10,989 \\
6,674 \\
0 \\
6,097\end{array}$ & $\begin{array}{r}9,273 \\
194 \\
272 \\
0 \\
258\end{array}$ & $\begin{array}{r}23,285 \\
1,731 \\
1,689 \\
0 \\
1,181\end{array}$ & $\begin{array}{r}17,860 \\
\text { 915 } \\
6 \% 0 \\
165 \\
19\end{array}$ & $\begin{array}{r}205,507 \\
33,532 \\
30,993 \\
0 \\
0\end{array}$ \\
\hline Todnl Electrite Udilly Operating & a,9rs & 141,697 & 9,602 & 27936 & 1.,014 & 2:3,032 \\
\hline 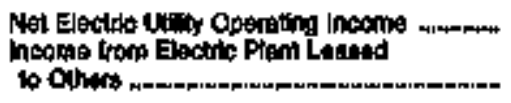 & $\begin{array}{r}1,021 \\
0\end{array}$ & 8,467 & $2 \pi 60$ & $\begin{array}{r}2,645 \\
0\end{array}$ & $\begin{array}{r}2,917 \\
0\end{array}$ & $\begin{array}{r}109,907 \\
0\end{array}$ \\
\hline 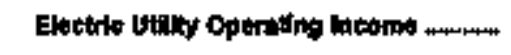 & 1,221 & $\mathbf{B}, \mathbf{4 6 7}$ & $2,15 \%$ & 2,648 & 2,917 & 103,907 \\
\hline Olher Eloglito tincomo & 402 & 5,988 & 201 & $\mathbf{4 1 2}$ & 652 & 3,907 \\
\hline 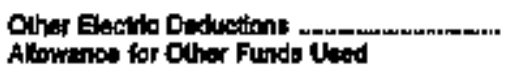 & 0 & 0 & 0 & $\mathbf{0}$ & 0 & 41,108 \\
\hline 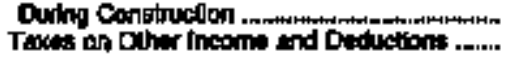 & $\stackrel{0}{0}$ & 0 & $\stackrel{\circ}{0}$ & 0 & $\begin{array}{r}10 \\
0\end{array}$ & $\begin{array}{l}0 \\
0\end{array}$ \\
\hline 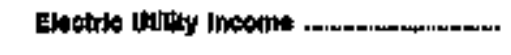 & $t, 0$ & 0,890 & 2,390 & 3,9698 & 3,467 & 66,707 \\
\hline 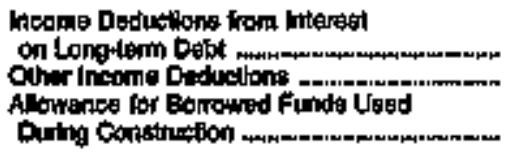 & $\begin{array}{l}20 \\
0\end{array}$ & $\begin{array}{r}1,3+7 \\
3,0,09 \\
0\end{array}$ & $\begin{array}{r}3 \\
0\end{array}$ & $\begin{array}{r}941 \\
410 \\
0\end{array}$ & $\begin{array}{r}2007 \\
0 \\
0\end{array}$ & $\begin{array}{r}73,279 \\
-6,686 \\
0\end{array}$ \\
\hline 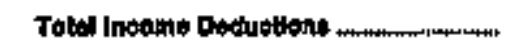 & 29 & 4067 & B,21t & 1500 & 2,007 & Bits:57 \\
\hline 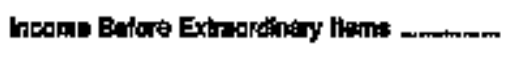 & 1,327 & $5 A 52$ & $-2,051$ & 1,720 & 1,400 & 230 \\
\hline 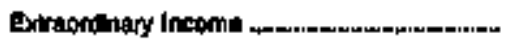 & 0 & $\mathbf{0}$ & 0 & 0 & 0 & 0 \\
\hline 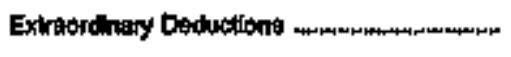 & 只 & 0 & 0 & 0 & 0 & 0 \\
\hline 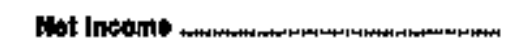 & 1,327 & 8,450 & $-2,0=1$ & 1,728 & 1,A00 & 200 \\
\hline
\end{tabular}

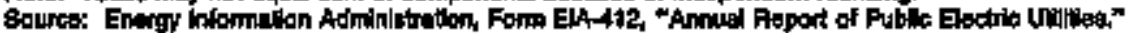


Table 2t. Statement of Income by Lajor U.S. Publledy Owhed Electric Utulity Within State, 1994 (Continued)

(Thousand Dollars)

\begin{tabular}{|c|c|c|c|c|c|c|}
\hline them & $\begin{array}{l}\text { Tonosis } \\
\text { Lubbock } \\
\text { Ciny of } \\
\text { Suptumber } 30\end{array}$ & $\begin{array}{l}\text { Texal } \\
\text { New Eramfels } \\
\text { Cry of } \\
\text { Jut } 31\end{array}$ & 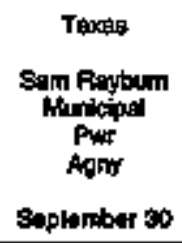 & 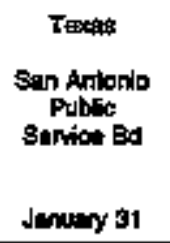 & 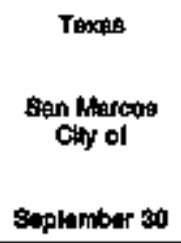 & $\begin{array}{l}\text { Texass } \\
\text { Segin } \\
\text { Chy of }\end{array}$ \\
\hline 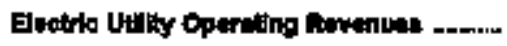 & 54,50 & 3rass & 30,000 & 756,124 & $21,4: 9$ & 12,40: \\
\hline 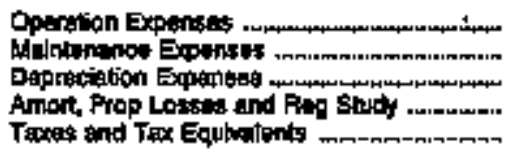 & $\begin{array}{r}40,934 \\
792 \\
4052 \\
0 \\
0\end{array}$ & $\begin{array}{r}32,184 \\
7,44 \\
1,088 \\
0 \\
1,342\end{array}$ & $\begin{array}{r}15,320 \\
2,806 \\
4,640 \\
0 \\
0\end{array}$ & $\begin{array}{r}291,576 \\
63,400 \\
194,076 \\
0 \\
93,051\end{array}$ & $\begin{array}{r}16,494 \\
760 \\
469 \\
0 \\
1,960\end{array}$ & $\begin{array}{r}8,741 \\
163 \\
191 \\
0 \\
0\end{array}$ \\
\hline Tolal Eterific Uilly Oparallag & 45,767 & 35,008 & 22,794 & 602,983 & $18,39 R$ & 8,095 \\
\hline 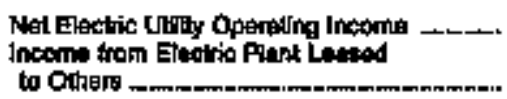 & $\begin{array}{r}8,742 \\
0\end{array}$ & $\begin{array}{r}2,509 \\
977\end{array}$ & $\begin{array}{r}10,245 \\
0\end{array}$ & $\begin{array}{r}17 \$, 191 \\
1,013\end{array}$ & $\begin{array}{r}2,101 \\
0\end{array}$ & $\begin{array}{r}3,323 \\
0\end{array}$ \\
\hline Eleptro Utilly Oparating Insone .......... & 4,742 & 3,486 & 10,245 & 174,944 & 2,101 & $3,4,25$ \\
\hline 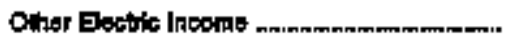 & 3,070 & 844 & 10,700 & $26, m$ & $6+40$ & 117 \\
\hline 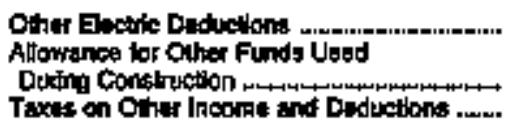 & $\begin{array}{r}0 \\
0 \\
8,210\end{array}$ & 0 & $\begin{array}{l}0 \\
0 \\
0\end{array}$ & $\begin{array}{r}1,252 \\
0 \\
17,115\end{array}$ & $\begin{array}{l}0 \\
0 \\
0\end{array}$ & $\begin{array}{l}0 \\
0\end{array}$ \\
\hline 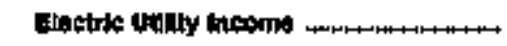 & 5602 & 4,120 & 21,085 & 192,354 & 2,649 & 0,4\$1 \\
\hline 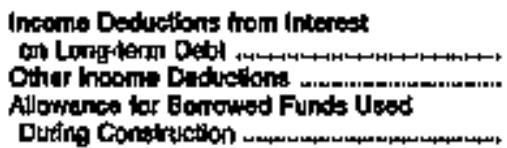 & 2,955 & 412 & $\begin{array}{r}15,048 \\
5,057 \\
0\end{array}$ & $\begin{array}{r}140,156 \\
39,608 \\
\$, 072\end{array}$ & $\begin{array}{r}915 \\
0 \\
0\end{array}$ & $\begin{array}{l}0 \\
0\end{array}$ \\
\hline 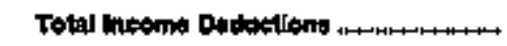 & 2,356 & 412 & 20,206 & 178,717 & 916 & 0 \\
\hline Incorne Before Extreordanay thems ...m.m.m. & 3,246 & 3,712 & ses & a,607 & 1,734 & 3,441 \\
\hline 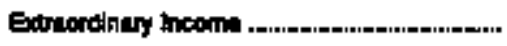 & 0 & 0 & 0 & 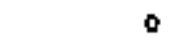 & 0 & 0 \\
\hline Extraonsinary Dodtrtiang & 0 & 0 & 0 & 0 & 0 & $\mathbf{0}$ \\
\hline 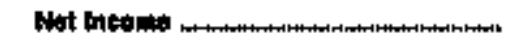 & s,at6 & 3,710 & $\theta$ & $\mathbf{3 , 6 0 7}$ & 1,74 & 2,441 \\
\hline
\end{tabular}

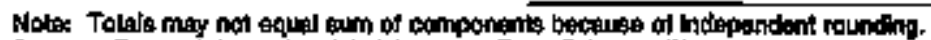

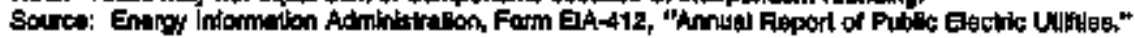


Table 21. Statement of Income by Major U.S. Publlety Owned Eloctric Utlity Within State, 1994 (Continued)

(Thousand Dollars)

\begin{tabular}{|c|c|c|c|c|c|c|}
\hline Inen & 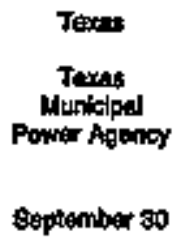 & 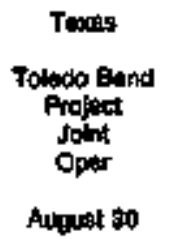 & 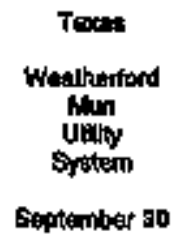 & $\begin{array}{c}\text { Unth } \\
\text { Bounitul } \\
\text { Cty ctyy of } \\
\text { June so }\end{array}$ & $\begin{array}{l}\text { Utih } \\
\text { Inimmountin } \\
\text { Power Agency } \\
\text { Jus at }\end{array}$ & $\begin{array}{l}\text { Utah } \\
\text { Lngan } \\
\text { Cly of } \\
\text { June } 30\end{array}$ \\
\hline 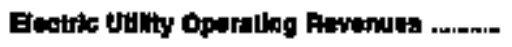 & me,ots & a,204 & $14,5 \%$ & 12,307 & 057,240 & 1:8987 \\
\hline 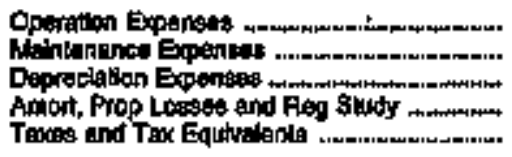 & $\begin{array}{r}7,119 \\
0,849 \\
19,497 \\
0 \\
0\end{array}$ & $\begin{array}{r}6,182 \\
0 \\
724 \\
0 \\
0\end{array}$ & $\begin{array}{r}0,189 \\
754 \\
609 \\
0 \\
731\end{array}$ & $\begin{array}{r}7,783 \\
388 \\
1,144 \\
0 \\
0\end{array}$ & $\begin{array}{r}2: 1,255 \\
7,396 \\
74,498 \\
0 \\
34,729\end{array}$ & $\begin{array}{r}11,402 \\
510 \\
983 \\
0 \\
152\end{array}$ \\
\hline 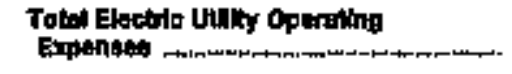 & $\operatorname{ton}, 2535$ & E, & 11,176 & 8,35 & 3ts, 412 & 12,856 \\
\hline 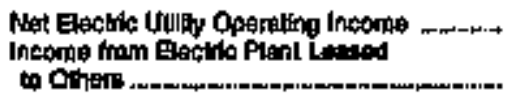 & $\begin{array}{r}78,764 \\
0\end{array}$ & $\begin{array}{r}-2680 \\
0\end{array}$ & $\begin{array}{r}\mathbf{3 , 3 9 4} \\
\mathbf{0}\end{array}$ & 3,002 & $\begin{array}{r}280,828 \\
0\end{array}$ & saga \\
\hline 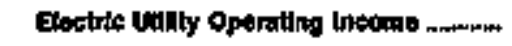 & 76,754 & $-4,000$ & 8;94 & a,oan & 2aBapas & 3,680 \\
\hline Other Eestic hooms & 13,180 & 0 & 200 & 184 & 50,701 & 215 \\
\hline $\begin{array}{l}\text { Other Electic Deductions } \\
\text { Altowance for Other Funds loed }\end{array}$ & 0 & o & 0 & 2,120 & 0 & $\mathbf{0}$ \\
\hline 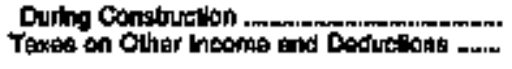 & $\stackrel{0}{g}$ & $\stackrel{0}{0}$ & $\stackrel{0}{0}$ & $\stackrel{0}{\circ}$ & $\begin{array}{l}\mathbf{0} \\
\mathbf{0}\end{array}$ & $\begin{array}{l}\mathbf{0} \\
\mathbf{0}\end{array}$ \\
\hline 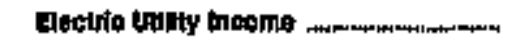 & 11,934 & $-2,400$ & $\mathbf{3}, 541$ & 1,119 & 397,619 & 4,035 \\
\hline 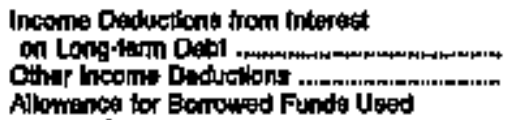 & $\begin{array}{r}75,791 \\
8,164\end{array}$ & $\begin{array}{r}2,207 \\
0\end{array}$ & $\begin{array}{r}168 \\
0\end{array}$ & 0 & $\begin{array}{l}3,55,287 \\
-17,848\end{array}$ & $\begin{array}{r}707 \\
0\end{array}$ \\
\hline 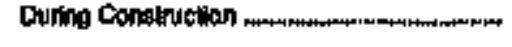 & 0 & o & 0 & 0 & 0 & d \\
\hline Total Inteomo Dadelstions & 04,955 & 2,207 & 148 & 0 & 347,019 & 707 \\
\hline 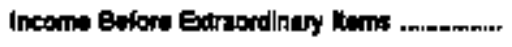 & 3,070 & $-4,600$ & 3,372 & 1,119 & 0 & 3,929 \\
\hline Edraonthary theoma & 0 & $\theta$ & 0 & ( & 0 & $\mathbf{0}$ \\
\hline 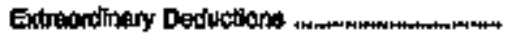 & 0 & 0 & 0 & 0 & D & 0 \\
\hline 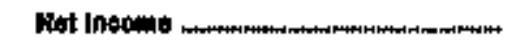 & *,970 & -46099 & 3,372 & 1,119 & 6 & 3439 \\
\hline
\end{tabular}

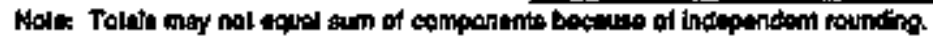

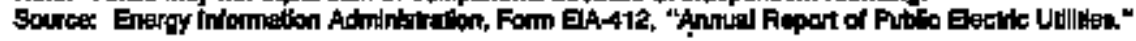


Table 21. Statement of income by Mijor U.S. Publichy Owned Electric Utillty Within state, 1994 (Continued) (Thousand Dollars)

\begin{tabular}{|c|c|c|c|c|c|c|}
\hline Ifent & $\begin{array}{l}\text { Utah } \\
\text { Muray } \\
\text { City of } \\
\text { Jine as }\end{array}$ & $\begin{array}{l}\text { Ulah } \\
\text { Provo } \\
\text { Cly Corp } \\
\text { June so }\end{array}$ & $\begin{array}{l}\text { Uthih } \\
\text { St Eeorg } \\
\text { Cof of } \\
\text { tun so }\end{array}$ & 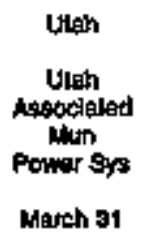 & 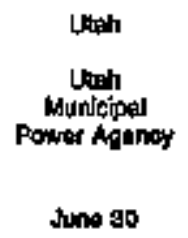 & 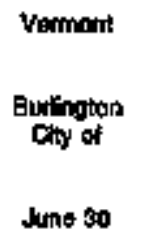 \\
\hline Elactrk Willy Oparabing Fovemues & t:547 & ss,549 & 11,953 & 37,819 & 31,265 & 36,462 \\
\hline 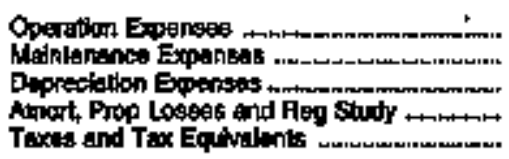 & $\begin{array}{r}12,040 \\
758 \\
1,698 \\
0 \\
1,571\end{array}$ & $\begin{array}{r}25,284 \\
0 \\
3,542 \\
0 \\
0\end{array}$ & $\begin{array}{r}14,630 \\
0 \\
1,106 \\
0 \\
1,469\end{array}$ & $\begin{array}{r}28,700 \\
721 \\
2656 \\
0 \\
756\end{array}$ & $\begin{array}{r}18,027 \\
7,050 \\
678 \\
0 \\
139\end{array}$ & $\begin{array}{r}23,743 \\
1,705 \\
875 \\
2,500 \\
1,449\end{array}$ \\
\hline 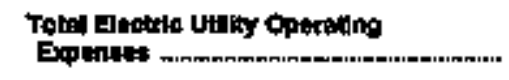 & 18,568 & (2) & 17,206 & 30,743 & 27,607 & $30,2: 2$ \\
\hline 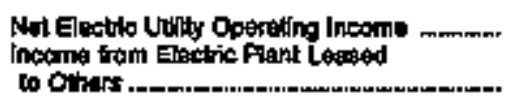 & $\begin{array}{r}1,684 \\
0\end{array}$ & $\begin{array}{r}4,722 \\
0\end{array}$ & $\begin{array}{r}1,748 \\
0\end{array}$ & $\begin{array}{r}7,0 \pi 7 \\
0\end{array}$ & $\begin{array}{r}3,578 \\
0\end{array}$ & 6,40t \\
\hline 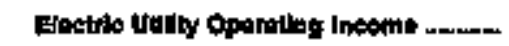 & 1,694 & 4,722 & 1,749 & 7,ort & a,ka & 1, 40 t \\
\hline Ohef Eactic moome & $7 \%$ & 1,248 & 798 & 4,059 & 017 & 1,398 \\
\hline 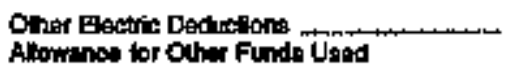 & 0 & $\mathbf{n}$ & D & 0 & 0 & 140 \\
\hline 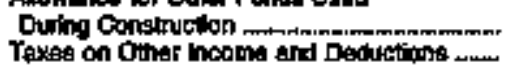 & $\stackrel{0}{0}$ & 0 & $\stackrel{0}{0}$ & $\stackrel{0}{0}$ & $\begin{array}{l}0 \\
\mathbf{a}\end{array}$ & $\stackrel{0}{0}$ \\
\hline Electric Utilty hitomp & 2,400 & 6,570 & 2,540 & 11,185 & 4,395 & $\$ 698$ \\
\hline 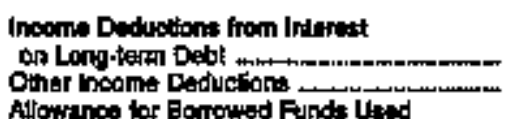 & 691 & 3,207 & $\stackrel{0}{9}$ & $\begin{array}{r}7,350 \\
0\end{array}$ & $\begin{array}{r}3,027 \\
145\end{array}$ & 4,960 \\
\hline Deming Constration & 0 & 0 & 0 & 0 & 0 & 0 \\
\hline 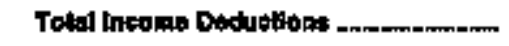 & 601 & 3,270 & 0 & 7,380 & 3,171 & 7,009 \\
\hline Ineome Balore Extrasd lary Items ...-_e....- & 1, Bas & 2,681 & 2,548 & 3,776 & 1,229 & 2,510 \\
\hline 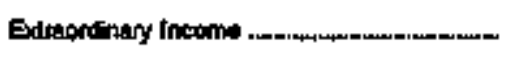 & 0 & 0 & 0 & 0 & 0 & 0 \\
\hline 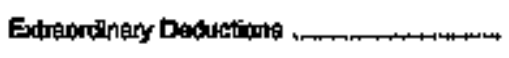 & 0 & 4,000 & 0 & $3 \pi 6$ & 8,458 & 0 \\
\hline Mat heope & 1,019 & $-1,300$ & 2,5,59: & 0 & $-4,2,51$ & 2,519 \\
\hline
\end{tabular}

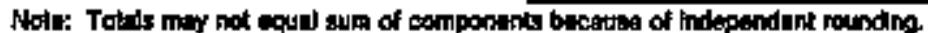

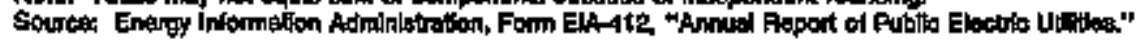


Table 21. Statement of Jncome by Major U.S. Publidy Owned Electrte Utilty Whith State, 1994 (Continued) (Thousand Dollars)

\begin{tabular}{|c|c|c|c|c|c|c|}
\hline $\operatorname{lnm}$ & $\begin{array}{l}\text { Vermont } \\
\text { Vommont } \\
\text { Putic } \\
\text { Puwr } \\
\text { Supply Aulh } \\
\text { December at }\end{array}$ & $\begin{array}{l}\text { Wigloila } \\
\text { Bedionte } \\
\text { City of } \\
\text { Juna } 30\end{array}$ & 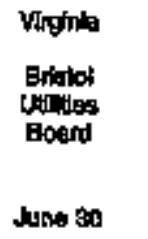 & 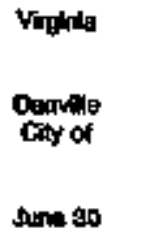 & 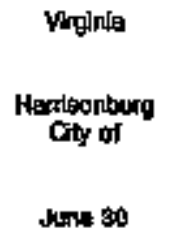 & $\begin{array}{l}\text { Weghla } \\
\text { Mangages } \\
\text { Coly of } \\
\text { Junt ob }\end{array}$ \\
\hline 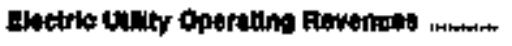 & Pos1 & 11,934 & 2,112 & 4ante & 32,219 & 18,416 \\
\hline 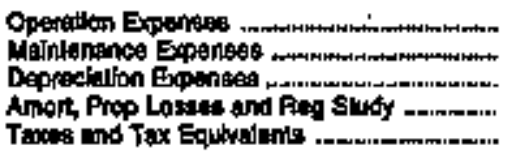 & $\begin{array}{r}5.373 \\
157 \\
255 \\
0 \\
241\end{array}$ & $\begin{array}{r}8,628 \\
197 \\
512 \\
0 \\
0\end{array}$ & $\begin{array}{r}23,875 \\
652 \\
602 \\
0 \\
504\end{array}$ & $\begin{array}{r}33,610 \\
1,300 \\
1,438 \\
0 \\
0\end{array}$ & $\begin{array}{r}24,997 \\
4,60 \\
1,424 \\
184 \\
182\end{array}$ & $\begin{array}{r}16,446 \\
452 \\
1,347 \\
0 \\
441\end{array}$ \\
\hline 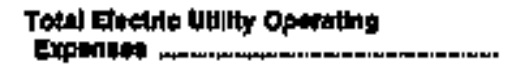 & B,627 & $\mathbf{2 0 3}$ & $\mathbf{2 5 , 7 2 4}$ & 38,040 & 27,228 & 17,800 \\
\hline 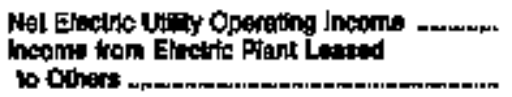 & $\begin{array}{r}2007 \\
0\end{array}$ & $\begin{array}{r}2.497 \\
0\end{array}$ & $\begin{array}{r}1,3886 \\
0\end{array}$ & $\begin{array}{r}10,293 \\
\text { 息 }\end{array}$ & $\begin{array}{r}4,500 \\
0\end{array}$ & 731 \\
\hline 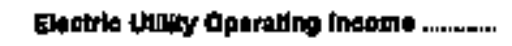 & 2000 & $2, \Delta 67$ & 1, at: & $\operatorname{ton,374}$ & 400 & 71 \\
\hline 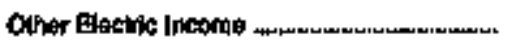 & 410 & 170 & $\mathbf{5 0 4}$ & 158 & 130 & 1,058 \\
\hline 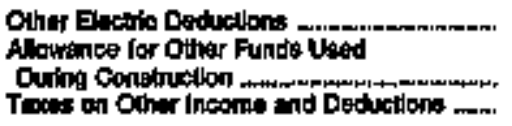 & $\begin{array}{l}0 \\
0 \\
0\end{array}$ & $\stackrel{0}{0}$ & $\begin{array}{l}0 \\
0 \\
0\end{array}$ & $\begin{array}{r}6,855 \\
0 \\
0\end{array}$ & $\begin{array}{l}0 \\
0 \\
0\end{array}$ & $\begin{array}{l}0 \\
0 \\
0\end{array}$ \\
\hline 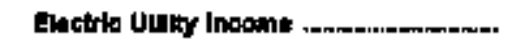 & 2,418 & 2,076 & $1, A 82$ & 3,072 & 5,131 & $t_{\boldsymbol{H}} \boldsymbol{r}$ \\
\hline 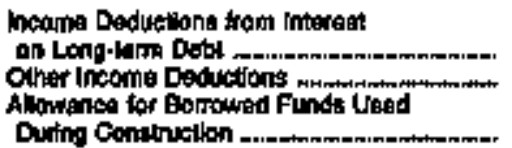 & $\begin{array}{r}2,103 \\
709 \\
0\end{array}$ & $\begin{array}{r}1,396 \\
1,295 \\
0\end{array}$ & $\begin{array}{r}0 \\
41 \\
0\end{array}$ & $\begin{array}{r}\text { g6 } \\
0 \\
0\end{array}$ & $\begin{array}{r}200 \\
0 \\
0\end{array}$ & $\begin{array}{r}569 \\
0 \\
0\end{array}$ \\
\hline 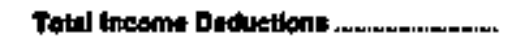 & 2,819 & 2,6a: & at & $\$ s$ & 200 & 650 \\
\hline 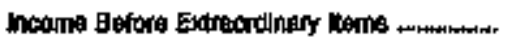 & -386 & -9 & $1,8 \mathrm{B1}$ & 9,579 & 4,502 & 1,219 \\
\hline Extreordiney lneome & 0 & $\mathbf{0}$ & 0 & 0 & 0 & 0 \\
\hline Extradudinary Daductions ..... & 0 & o & 0 & 150 & 0 & 0 \\
\hline Nal heomp & -396 & -8 & $1,0: 01$ & 3,4 ars & 4,42 & 1,219 \\
\hline
\end{tabular}

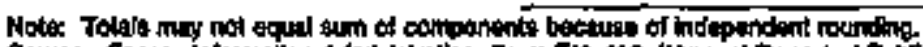

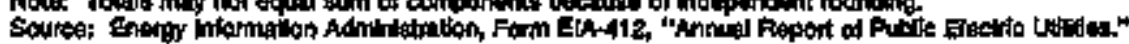


Table 21. Statemont of Inconse by Major U.S. Publichy Owned Electric Utilly Within State, 1994 (Conlthued)

(Thousand Dollars)

\begin{tabular}{|c|c|c|c|c|c|c|}
\hline Nem & 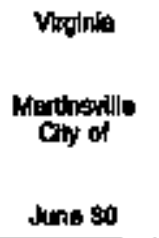 & $\begin{array}{l}\text { Vhoinda } \\
\text { figutiond } \\
\text { Cry of } \\
\text { Juna so }\end{array}$ & $\begin{array}{l}\text { Vingivia } \\
\text { Satem } \\
\text { Culy of } \\
\text { hune so }\end{array}$ & 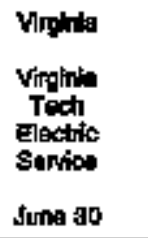 & $\begin{array}{l}\text { Whinhriton } \\
\text { Contrilla } \\
\text { Cuty of } \\
\text { December at }\end{array}$ & $\begin{array}{l}\text { Weshunoton } \\
\text { Elangtory } \\
\text { Cocisy of }\end{array}$ \\
\hline 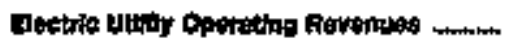 & 11,264 & +3907 & 17,686 & $t+5,54$ & 6,096 & 7,412 \\
\hline 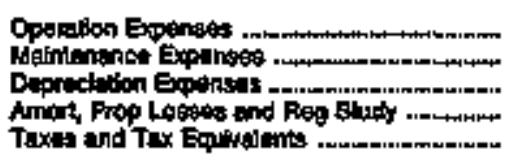 & $\begin{array}{r}6,357 \\
407 \\
754 \\
0 \\
51\end{array}$ & $\begin{array}{r}11,202 \\
602 \\
60 \\
0 \\
12\end{array}$ & $\begin{array}{r}14522 \\
170 \\
784 \\
0 \\
985\end{array}$ & $\begin{array}{r}10,386 \\
800 \\
0 \\
0 \\
250\end{array}$ & $\begin{array}{r}7,474 \\
458 \\
478 \\
3 \\
784\end{array}$ & $\begin{array}{r}5,448 \\
304 \\
400 \\
0 \\
705\end{array}$ \\
\hline 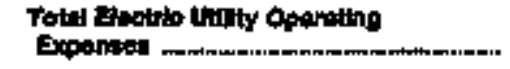 & 0,499 & 12719 & $\mathbf{2 6 , 4 5 8}$ & 11,207 & a,196 & 6,467 \\
\hline 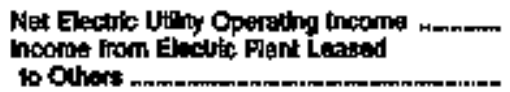 & $\begin{array}{r}1.006 \\
0\end{array}$ & $\begin{array}{r}1,193 \\
0\end{array}$ & $\begin{array}{r}1,263 \\
0\end{array}$ & 27 & $\begin{array}{r}-289 \\
0\end{array}$ & $\begin{array}{r}559 \\
0\end{array}$ \\
\hline 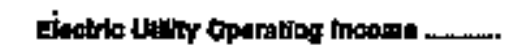 & 1,ats & 1,193 & 1,250 & $\mathbf{m}$ & -209 & 558 \\
\hline 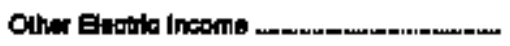 & 0 & $\operatorname{seg}$ & 104 & 76 & 652 & 181 \\
\hline 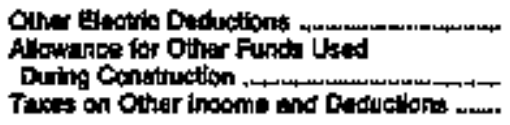 & $\begin{array}{r}\$, 795 \\
0 \\
0\end{array}$ & $\begin{array}{r}1.746 \\
0 \\
0\end{array}$ & $\begin{array}{l}0 \\
0 \\
0\end{array}$ & 0 & $\begin{array}{l}0 \\
0 \\
0\end{array}$ & $\begin{array}{r}67 \\
0 \\
46\end{array}$ \\
\hline 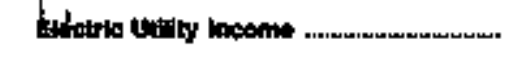 & -71 & -180 & 1,447 & 35 & sts & 626 \\
\hline 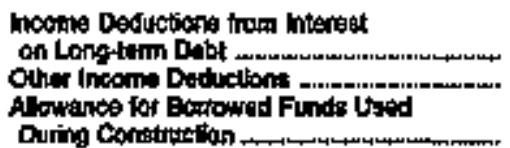 & $\begin{array}{l}0 \\
0 \\
0\end{array}$ & $\begin{array}{r}207 \\
0 \\
0\end{array}$ & $\begin{array}{r}61 \\
0 \\
0\end{array}$ & $\begin{array}{c}162 \\
165\end{array}$ & $\begin{array}{r}208 \\
7 \\
0\end{array}$ & $\begin{array}{r}10 \\
1 \\
0\end{array}$ \\
\hline 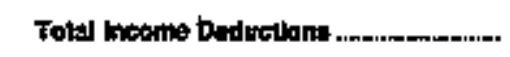 & 0 & 202 & 961 & $2 \pi$ & 286 & 10 \\
\hline 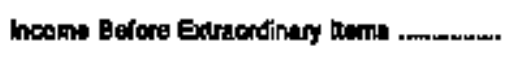 & -71 & -419 & 796 & 76 & 78 & 684 \\
\hline 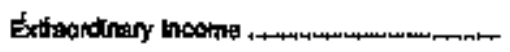 & 0 & 0 & $\mathbf{0}$ & o & 0 & 0 \\
\hline 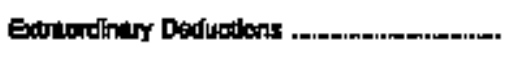 & 0 & $\mathbf{0}$ & $\mathbf{0}$ & 0 & 0 & 0 \\
\hline 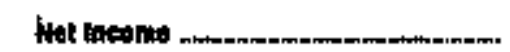 & $-r$ & -413 & 796 & 75 & 74 & 54 \\
\hline
\end{tabular}

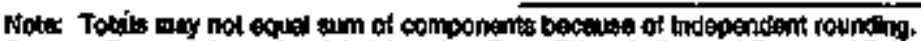

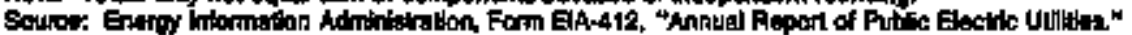


Table 21. Statement of income by Major U.S. Publidy Owned Electrtc Ut!luty Winin State, 1994 (Continued)

(Thousand Dollars)

\begin{tabular}{|c|c|c|c|c|c|c|}
\hline ham & $\begin{array}{l}\text { Whatilfoisn } \\
\text { Port Angules } \\
\text { Clty of } \\
\text { Dosembor } 31\end{array}$ & $\begin{array}{l}\text { Wealhinotor } \\
\text { Pud No } 1 \\
\text { of } \\
\text { Bonlon } \\
\text { Courity } \\
\text { Dowomber } \$ 1\end{array}$ & $\begin{array}{l}\text { Wrohinglon } \\
\text { pup ris } 1 \\
\text { of } \\
\text { Cheten } \\
\text { County } \\
\text { Doowiber } 31\end{array}$ & 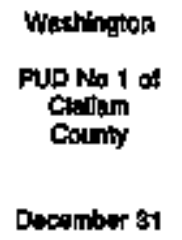 & 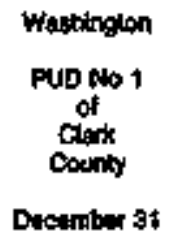 & $\begin{array}{l}\text { Westinintom } \\
\text { Fuo No } 1 \text { of } \\
\text { Cointry } \\
\text { Cointy } \\
\text { Decomber } 31\end{array}$ \\
\hline 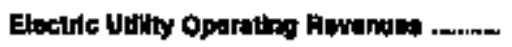 & $\mathbf{2 3 , 2 0 0 0}$ & 由h, 000 s & 739049 & 24,100 & 941,345 & 140,928 \\
\hline 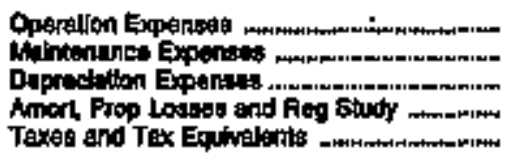 & $\begin{array}{r}19,217 \\
1,216 \\
696 \\
0 \\
2,264\end{array}$ & $\begin{array}{r}4,695 \\
2,057 \\
3,955 \\
0 \\
6,717\end{array}$ & $\begin{array}{r}63,825 \\
10,807 \\
11,006 \\
113 \\
5,335\end{array}$ & $\begin{array}{r}19,507 \\
1,242 \\
1,600 \\
000\end{array}$ & $\begin{array}{r}16,172 \\
2085 \\
0,024 \\
557 \\
8,641\end{array}$ & $\begin{array}{r}123,640 \\
1,732 \\
3,515 \\
72 \\
0,885\end{array}$ \\
\hline Tolel Eloctrke tawlty Oparation & 23,39s & 67,124 & 96,971 & 22,701 & 159,800 & $139,1+2$ \\
\hline 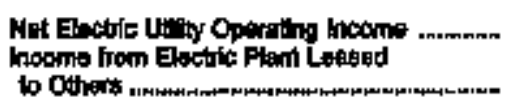 & $\begin{array}{r}-1 \dot{8} 4 \\
0\end{array}$ & $\begin{array}{r}3,900 \\
0\end{array}$ & $\begin{array}{r}4,978 \\
0\end{array}$ & $\begin{array}{r}1,081 \\
0\end{array}$ & $\begin{array}{r}1,715 \\
0\end{array}$ & $\begin{array}{r}4,510 \\
0\end{array}$ \\
\hline Enotid Uulky Opereting hoom .......m. & -184 & 2,800 & d3,97: & $t, \pm 61$ & 1,745 & 4,810 \\
\hline 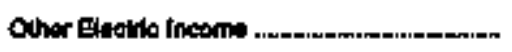 & 219 & 000 & $4,0,02$ & 300 & -68 & $\$$ \\
\hline 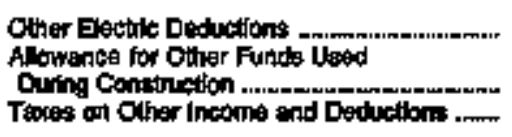 & $\begin{array}{l}0 \\
0 \\
0\end{array}$ & $\begin{array}{l}0 \\
0 \\
0\end{array}$ & $\begin{array}{r}624 \\
0 \\
0\end{array}$ & $\begin{array}{r}0 \\
517\end{array}$ & $\begin{array}{l}0 \\
0 \\
0\end{array}$ & $\begin{array}{r}656 \\
0 \\
0\end{array}$ \\
\hline Eluotrlo toíliky Inoome & 3 & 4,502 & $\$ 7, \pi 78$ & 1,70: & 1,69: & 4,475 \\
\hline 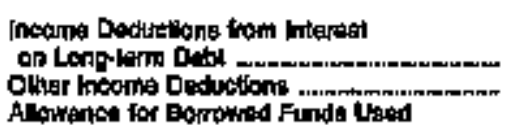 & $\begin{aligned} 138 \\
69\end{aligned}$ & $\begin{array}{r}2,746 \\
125\end{array}$ & $\begin{array}{r}42,792 \\
1,013\end{array}$ & $\underset{10}{508}$ & $\underset{0}{\text { Spat }}$ & $\begin{array}{r}108 \\
2\end{array}$ \\
\hline 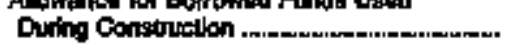 & 0 & 0 & 0 & 0 & 0 & 0 \\
\hline Total beome Daduollont , & 296 & 2,972 & $43,90 \%$ & 528 & :ped & tos \\
\hline Inecine Betord Extreardinery Hens ........m. & -169 & 2,029 & 3,971 & 1.240 & $-1,163$ & 4,708 \\
\hline 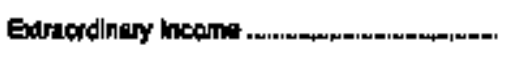 & 0 & 4,493 & o & $\mathbf{0}$ & 9,412 & 0 \\
\hline 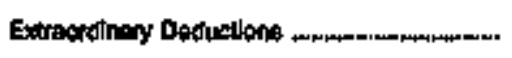 & 0 & 0 & 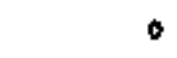 & 0 & 0 & 0 \\
\hline 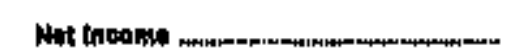 & -169 & 4003 & ant & $1,2,10$ & 6,240 & $4,7 \mathrm{ats}$ \\
\hline
\end{tabular}

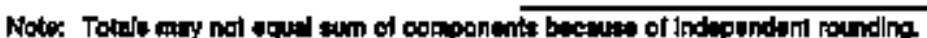

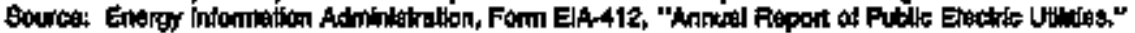


Tabje 21. Statement of Income by Lijor U.s, Publidy Owned Electric Utilly Whin State, 1994 (Continued) (Thouseand Dollars)

\begin{tabular}{|c|c|c|c|c|c|c|}
\hline Aam & $\begin{array}{l}\text { Wheninglon } \\
\text { Puld Ho } 1 \text { of } \\
\text { Dougles } \\
\text { County } \\
\text { Dosemper } 31\end{array}$ & 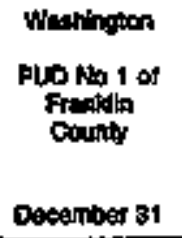 & 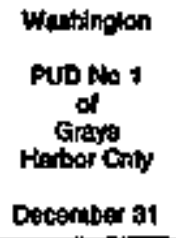 & $\begin{array}{l}\text { Wathingtan } \\
\text { PUbNo } 1 \text { of } \\
\text { Countwy } \\
\text { December } 91\end{array}$ & 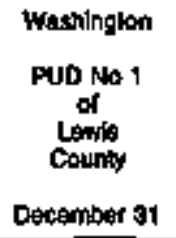 & $\begin{array}{l}\text { Wistinglon } \\
\text { PuD No } 1 \text { of } \\
\text { Olanogin } \\
\text { Coumby }\end{array}$ \\
\hline lectike vility Operation Rovenuee & stow & 27,401 & 58698 & $+2,974$ & 30,608 & 15,659 \\
\hline 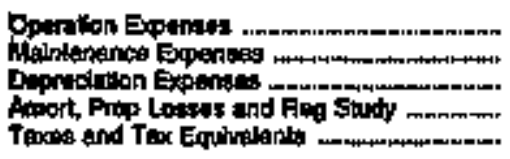 & $\begin{array}{r}18,244 \\
9,018 \\
4,338 \\
0 \\
1,060\end{array}$ & $\begin{array}{r}20,689 \\
738 \\
1,255 \\
0 \\
1,96\end{array}$ & $\begin{array}{r}42,369 \\
5,064 \\
3,240 \\
3,000\end{array}$ & $\begin{array}{r}0,307 \\
567 \\
08 \\
0\end{array}$ & $\begin{array}{r}23,252 \\
1,413 \\
92 \\
0 \\
1,681\end{array}$ & $\begin{array}{r}13,604 \\
697 \\
1,659 \\
29 \\
1,567\end{array}$ \\
\hline 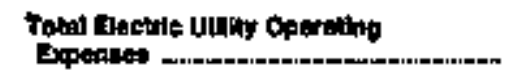 & 20,489 & 24,01 & 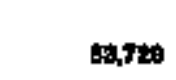 & 11,7tar & 26,437 & 17,000 \\
\hline 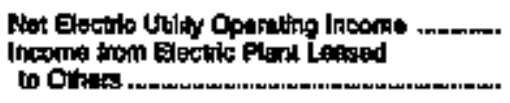 & $\begin{array}{r}11,400 \\
0\end{array}$ & 28009 & 2,894 & $\begin{array}{r}1,160 \\
0\end{array}$ & $\begin{array}{r}4,17 \\
0\end{array}$ & $\begin{array}{r}-1,849 \\
0\end{array}$ \\
\hline 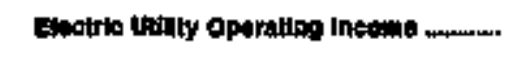 & $11, a g 0$ & 2000 & 2,044 & 1,193 & 4,171 & $-1,549$ \\
\hline Other Enctits incoms & 2034 & r11 & 3,410 & 210 & 940 & as4 \\
\hline 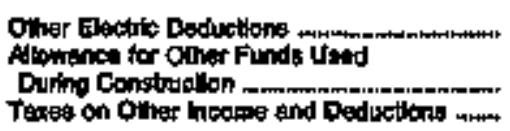 & $\begin{array}{l}10 \\
0 \\
0\end{array}$ & $\begin{array}{l}41 \\
0 \\
0\end{array}$ & $\begin{array}{l}3 \\
0 \\
0\end{array}$ & $\begin{array}{l}0 \\
0 \\
0\end{array}$ & $\begin{array}{l}0 \\
0 \\
0\end{array}$ & $\begin{array}{r}39 \\
0 \\
0\end{array}$ \\
\hline 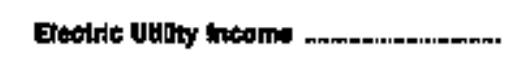 & 10,674 & 3,470 & $6,2 \div 0$ & 1,403 & 6,t11 & $-1,262$ \\
\hline 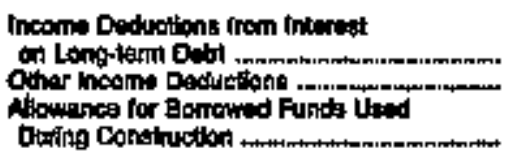 & $\begin{array}{r}8,941 \\
014 \\
0\end{array}$ & $\begin{array}{r}1,740 \\
1.2 \\
0\end{array}$ & $\begin{array}{r}35 \\
0.580\end{array}$ & $\begin{array}{r}592 \\
0\end{array}$ & $\begin{array}{l}0 \\
0 \\
0\end{array}$ & $\begin{array}{l}4 \\
0 \\
0\end{array}$ \\
\hline 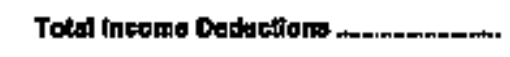 & topest & 1,10 & 8,514 & 635 & 0 & 4 \\
\hline Ihoome Belare Edraordrary thema ............ & 2,000 & 1,679 & 2845 & 76 & 6,111 & $-1,258$ \\
\hline 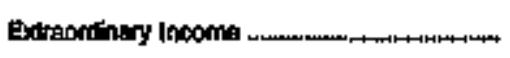 & 200 & $\mathbf{D}$ & 3nas & $\operatorname{sed}$ & $\mathbf{2 , 1 3 8}$ & 602 \\
\hline 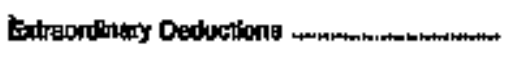 & 0 & 0 & 0 & 1) & 0 & 112 \\
\hline What Inogint & 3,140 & 1,69 & 6,549 & 1093 & 7,950 & -76 \\
\hline
\end{tabular}

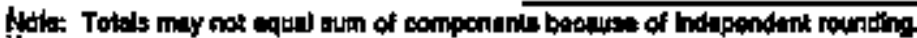

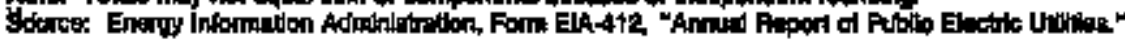


Table 21. Statement of Income by Major U.S. Publicly Owned Electric Utility Within State, 1994 (Continued)

(Thousand Dollars)

\begin{tabular}{|c|c|c|c|c|c|c|}
\hline IIem & 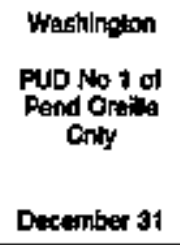 & $\begin{array}{l}\text { Weshingtor } \\
\text { PUD No } 1 \text { of } \\
\text { Snmthomlath } \\
\text { Courty } \\
\text { Deoumber } 31\end{array}$ & $\begin{array}{l}\text { Wrachington } \\
\text { Pug two t of } \\
\text { Whaloom } \\
\text { County } \\
\text { Dosember } 31\end{array}$ & $\begin{array}{l}\text { Wastington } \\
\text { Pud No } 2 \\
\text { of } \\
\text { Erant } \\
\text { County } \\
\text { Decamber o1 }\end{array}$ & $\begin{array}{l}\text { Weastinglon } \\
\text { PuD flo } 2 \text { ol } \\
\text { Pactite } \\
\text { Codinly } \\
\text { Ducamber } 31\end{array}$ & 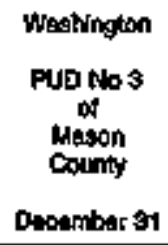 \\
\hline Eleciffo Ubilty Oparatiag Aevenues .... & $23,0+9$ & 000,376 & 4,018 & 94017 & 13,769 & 2,781 \\
\hline 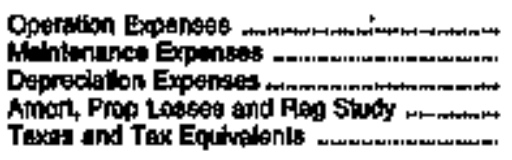 & $\begin{array}{r}17,340 \\
1,285 \\
1,003 \\
1,402\end{array}$ & $\begin{array}{r}222,945 \\
13,970 \\
21,000 \\
10,009\end{array}$ & $\begin{array}{r}45+59 \\
28 \\
16 \\
0 \\
0\end{array}$ & $\begin{array}{r}34,742 \\
20,850 \\
14,499 \\
0 \\
5,724\end{array}$ & $\begin{array}{r}9.850 \\
677 \\
t, 019 \\
9 \\
640\end{array}$ & $\begin{array}{r}12,680 \\
1,751 \\
2,180 \\
1,000\end{array}$ \\
\hline Total Elettrle UAllyy Opereting & 21,040 & 260,87 & 4,357 & 75.814 & 2,195 & 20,674 \\
\hline 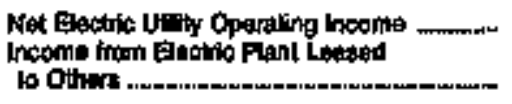 & 2,050 & $\begin{array}{r}58,49 \theta \\
0\end{array}$ & $\begin{array}{r}-470 \\
0\end{array}$ & $\begin{array}{r}10,200 \\
0\end{array}$ & $\begin{array}{r}1,573 \\
0\end{array}$ & 887 \\
\hline 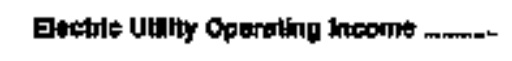 & 2,0503 & 39,498 & -470 & 18,202 & 1,973 & 687 \\
\hline 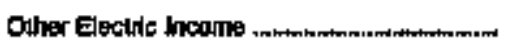 & 439 & 10,579 & 81 & 7,014 & nes & $\$ 69$ \\
\hline 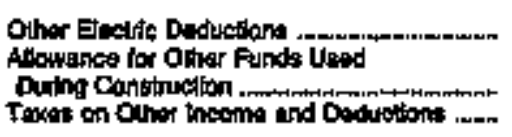 & $\stackrel{0}{0}$ & $\begin{array}{r}0 \\
1.742 \\
0\end{array}$ & $\begin{array}{r}28 \\
246\end{array}$ & $\begin{array}{l}0 \\
0 \\
0\end{array}$ & $\begin{array}{r}673 \\
091\end{array}$ & $\begin{array}{l}0 \\
0 \\
0\end{array}$ \\
\hline 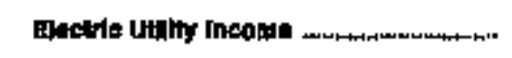 & 2,491 & 51,320 & -645 & 26,116 & 1,532 & $1,4=9$ \\
\hline 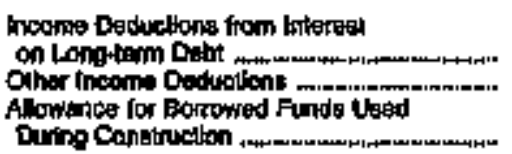 & $\begin{array}{l}272 \\
122 \\
0\end{array}$ & $\begin{array}{r}32,095 \\
8,000 \\
0\end{array}$ & $\begin{array}{l}0 \\
0 \\
0\end{array}$ & $\begin{array}{r}21,169 \\
706 \\
0\end{array}$ & $\begin{array}{r}310 \\
0 \\
0\end{array}$ & $\begin{array}{r}1.047 \\
37 \\
0\end{array}$ \\
\hline 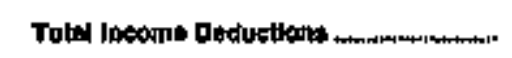 & 894 & 390045 & $\mathbf{0}$ & $21,19=9$ & 910 & 1,094 \\
\hline 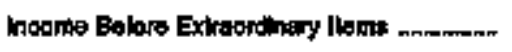 & 2,005 & 12,776 & -648 & 4,159 & 1,222 & 395 \\
\hline 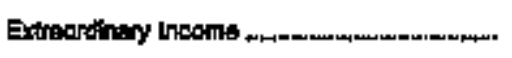 & $\mathbf{0}$ & 0 & 0 & $\mathbf{0}$ & 8002 & 659 \\
\hline Extranthany Deductions , & 0 & $\mathbf{0}$ & 11 & 0 & $\mathbf{0}$ & 0 \\
\hline Net Inctome & 2,097 & 12,775 & $-\infty 6$ & 4,156 & 2,024 & 1,245 \\
\hline
\end{tabular}

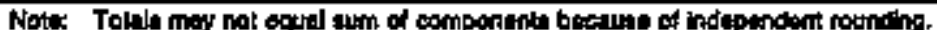

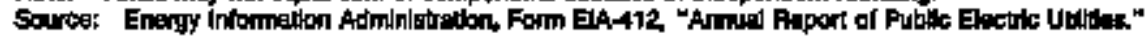


Table 21. Statement of Income by Major U.S. Publichy Owned Electric Utilty Whin State, 1994 (Continued)

(Thousand Dollars)

\begin{tabular}{|c|c|c|c|c|c|c|}
\hline Item & 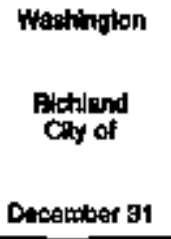 & $\begin{array}{l}\text { Wurpinaton } \\
\text { seatule } \\
\text { City of } \\
\text { December } 3 t\end{array}$ & $\begin{array}{l}\text { Washlugton } \\
\text { Teromen } \\
\text { Chy of } \\
\text { Documber } 31\end{array}$ & 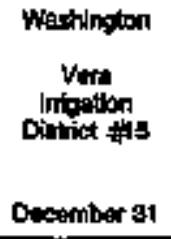 & $\begin{array}{l}\text { Wastintition } \\
\text { Weshinglon } \\
\text { Pub } \\
\text { Pwir } \\
\text { Supply spa } \\
\text { Jun } 80\end{array}$ & 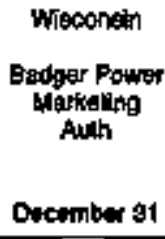 \\
\hline 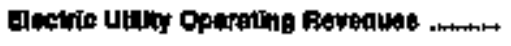 & 26,699 & 392,001 & 200,097 & 7,393 & $564, \pi T 6$ & 10,550 \\
\hline 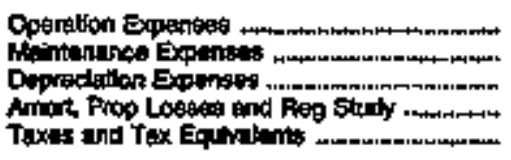 & $\begin{array}{r}21,314 \\
628 \\
1,077 \\
0 \\
2,909\end{array}$ & $\begin{array}{r}240,808 \\
20,834 \\
36,347 \\
9 \\
40,911\end{array}$ & $\begin{array}{r}122,760 \\
18,078 \\
18,209 \\
5194 \\
22,171\end{array}$ & $\begin{array}{r}6,018 \\
300 \\
497 \\
0 \\
284\end{array}$ & $\begin{array}{r}169,149 \\
53,284 \\
112,304 \\
427 \\
3,018\end{array}$ & $\begin{array}{r}8509 \\
27 \\
156 \\
39 \\
133\end{array}$ \\
\hline 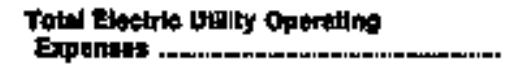 & 28,017 & 307,695 & $103 ; 002$ & 7,040 & 302,160 & D659 \\
\hline 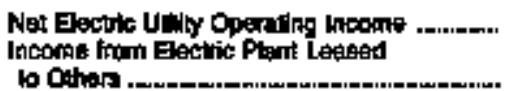 & Brs & $\begin{array}{r}26,108 \\
0\end{array}$ & 22,0005 & $\begin{array}{r}290 \\
0\end{array}$ & $\begin{array}{r}250967 \\
0\end{array}$ & 6et \\
\hline Eletirk Utitity Opereing neome & B79 & $15,10 \times 3$ & $2, \mathrm{pes}$ & $3=0$ & 252,sin & $\infty$ \\
\hline Oaher Electris ineone & 626 & 8,712 & $\mathbf{3 , 3 6 4}$ & 18 & $21,00.5$ & 0 \\
\hline 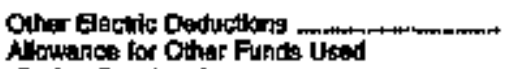 & 0 & 241 & 000 & 10 & o & o \\
\hline 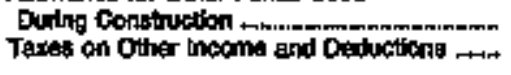 & $\stackrel{0}{0}$ & 0 & $\stackrel{0}{0}$ & $\stackrel{0}{0}$ & $\stackrel{0}{0}$ & $\stackrel{0}{0}$ \\
\hline Dectio UBily Insome & 1,600 & $\$ 4574$ & 26,460 & 47 & 274,692 & 691 \\
\hline 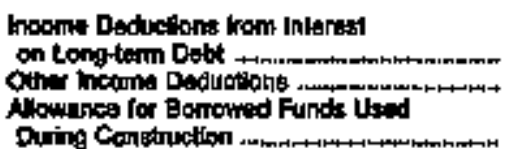 & $\begin{array}{r}060 \\
491 \\
0\end{array}$ & $\begin{array}{r}33,424 \\
4,699 \\
-3,910\end{array}$ & $\begin{array}{r}24,506 \\
1,6000 \\
-3,1009\end{array}$ & 13Q & $\begin{array}{r}16,571 \\
5,844 \\
0\end{array}$ & $\begin{array}{r}395 \\
122 \\
0\end{array}$ \\
\hline 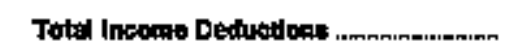 & 1,144 & 34305 & 23,057 & \$6 & 171,414 & $\$ 07$ \\
\hline 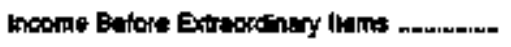 & E8 & a7x & 2,500 & 396 & 102,200 & 294 \\
\hline 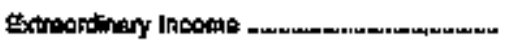 & 0 & 0 & 0 & 0 & o & o \\
\hline 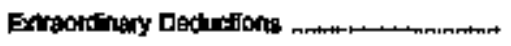 & 0 & 0 & 0 & D & 102,269 & o \\
\hline Hat bosma & 6 & 271 & 2,398 & 235 & o & 239 \\
\hline
\end{tabular}

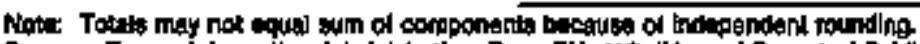

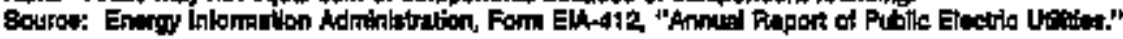


Table 27. Statement of Income by Major US. Publlcly Owned Eleotrte Utulity Within State, 1894 (Continued)

(Thougand Dollars)

\begin{tabular}{|c|c|c|c|c|c|c|}
\hline $\operatorname{lom}$ & 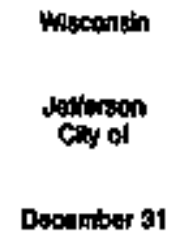 & 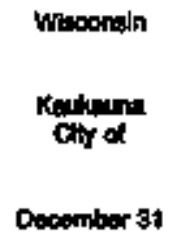 & 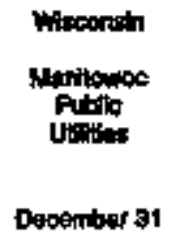 & 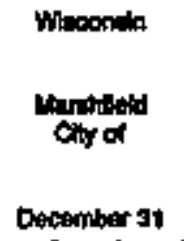 & $\begin{array}{l}\text { Moscotaln } \\
\text { Menatio } \\
\text { City of } \\
\text { Decombar } 31\end{array}$ & 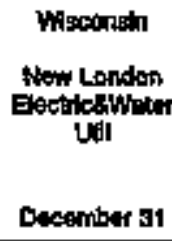 \\
\hline 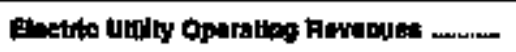 & 6,698 & 20,045 & 25,070 & 13,902 & 20,50s & 7,917 \\
\hline 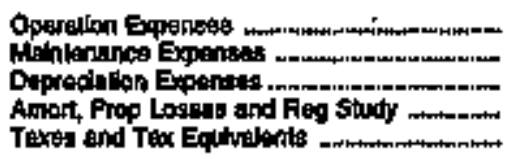 & $\begin{array}{r}869 \\
67 \\
250 \\
0 \\
205\end{array}$ & $\begin{array}{r}10,5 \mathrm{sich} \\
605 \\
1,005 \\
0 \\
0\end{array}$ & $\begin{array}{r}17,436 \\
1,404 \\
2,091 \\
1,607\end{array}$ & $\begin{array}{r}10,750 \\
356 \\
612 \\
5 \\
656\end{array}$ & $\begin{array}{r}20,441 \\
897 \\
756 \\
18 \\
740\end{array}$ & $\begin{array}{r}6,94 \\
234 \\
0 \\
280\end{array}$ \\
\hline Totw Ehatid Uuly Opernelng & $6, t 5$ & 20,704 & $2,5,50: 5$ & 12,45 & $2 ; 880$ & 7,489 \\
\hline 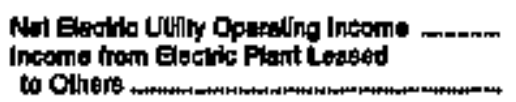 & 608 & $\begin{array}{r}1,691 \\
0\end{array}$ & $\begin{array}{r}2,998 \\
0\end{array}$ & $\begin{array}{r}1,519 \\
0\end{array}$ & $\begin{array}{r}625 \\
0\end{array}$ & 450 \\
\hline 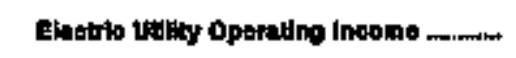 & s\$6 & 1,601 & 2,935 & 1513 & tos: & 480 \\
\hline Other Deostio Inoork6 _.. & 148 & 36 & 618 & 的 & 187 & 130 \\
\hline 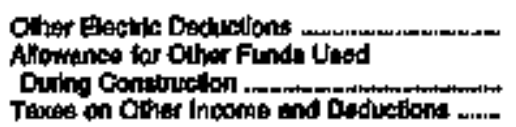 & $\begin{array}{l}0 \\
0 \\
0\end{array}$ & $\begin{array}{r}0 \\
150\end{array}$ & $\begin{array}{r}86 \\
0 \\
0\end{array}$ & 24 & $\begin{array}{r}40 \\
0 \\
0\end{array}$ & $\begin{array}{l}\mathbf{D} \\
\mathbf{0} \\
\mathbf{0}\end{array}$ \\
\hline 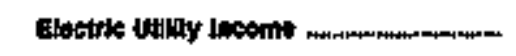 & ris & 1,0009 & 2,619 & 1904 & 73 & sq0 \\
\hline 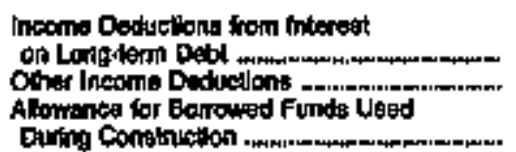 & $\begin{array}{r}398 \\
0 \\
0\end{array}$ & 1,257 & $\begin{array}{r}1,465 \\
120 \\
0\end{array}$ & $\begin{array}{r}494 \\
5\end{array}$ & 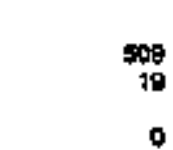 & $\begin{array}{l}\mathbf{0} \\
\mathbf{0} \\
\mathbf{0}\end{array}$ \\
\hline Tolal inteome Dadtellent & ast: & 1267 & 1,578 & $4 m$ & 5 & D \\
\hline 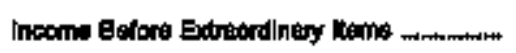 & 379 & \pm 2 & 5,89 & 021 & 245 & 580 \\
\hline 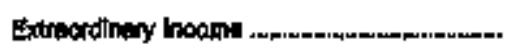 & 0 & 0 & 0 & - & 0 & 0 \\
\hline 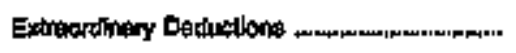 & 0 & 0 & 0 & 0 & 0 & o \\
\hline 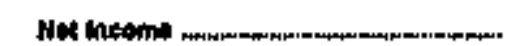 & $\mathbf{3 7 s}$ & 662 & 1,880 & mi & 245 & 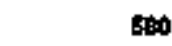 \\
\hline
\end{tabular}

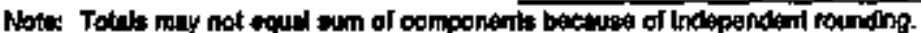

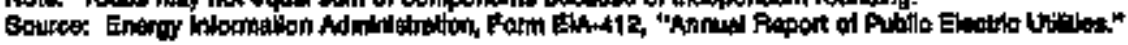


Table 21. Statement of Ineome by Major U.S. Publledy Owned Electric Utilty With'n słate, 1994 (Continued) (Thousand Dollars)

\begin{tabular}{|c|c|c|c|c|c|c|}
\hline them & $\begin{array}{l}\text { Whoonsin } \\
\text { Oconomowoc } \\
\text { City of } \\
\text { Daceonber } 3 t\end{array}$ & 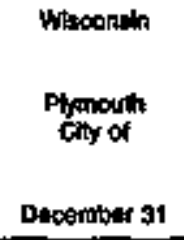 & 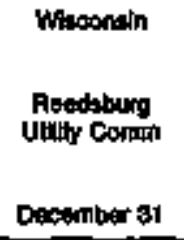 & 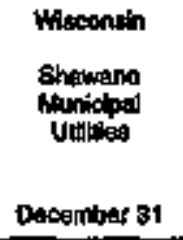 & 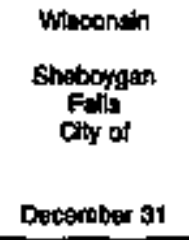 & 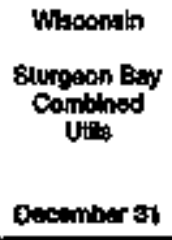 \\
\hline 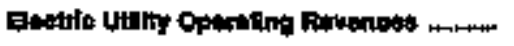 & 9,056 & 7,600 & $7,7 \pi 7$ & a,0t1 & 7,476 & 7,000 \\
\hline 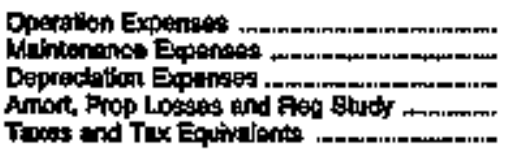 & $\begin{array}{r}7,061 \\
185 \\
473 \\
32 \\
400\end{array}$ & $\begin{array}{r}6,165 \\
168 \\
438 \\
0 \\
272\end{array}$ & $\begin{array}{r}6,928 \\
140 \\
503 \\
2 \\
24\end{array}$ & $\begin{array}{r}7,509 \\
7 a \\
318 \\
0 \\
175\end{array}$ & $\begin{array}{r}6099 \\
0 \\
240 \\
0 \\
165\end{array}$ & $\begin{array}{r}5,782 \\
195 \\
661 \\
0 \\
100\end{array}$ \\
\hline Toinl atestric uniny Oparatian & 0,160 & $7,0.41$ & 7,028 & 6,168 & 7,095 & s,041 \\
\hline 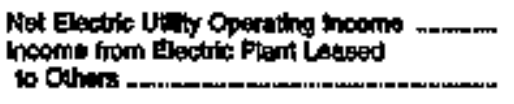 & 876 & 486 & 251 & 496 & 376 & 689 \\
\hline 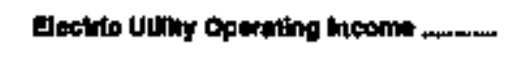 & $\mathbf{s i n}$ & 465 & 301 & 1949 & 376 & $a t$ \\
\hline 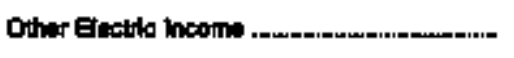 & 134 & 104 & 905 & 1967 & 0 & 98 \\
\hline 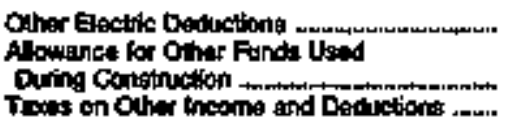 & 0 & $\begin{array}{r}28 \\
0 \\
0\end{array}$ & $\begin{array}{l}0 \\
0 \\
0\end{array}$ & $\begin{array}{r}97 \\
9\end{array}$ & 0 & 0 \\
\hline Eantels laility Ipecome & 1,012 & $6 \%$ & 366 & 1,280 & 376 & 746 \\
\hline 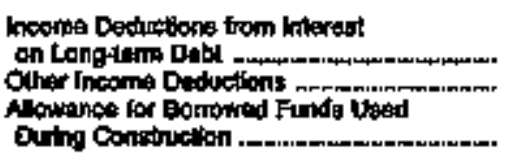 & $\begin{array}{r}119 \\
4 \\
0\end{array}$ & $\begin{array}{r}17 \\
29 \\
0\end{array}$ & $\begin{array}{r}258 \\
148 \\
0\end{array}$ & $\begin{array}{r}119 \\
70 \\
0\end{array}$ & $\begin{array}{l}0 \\
0 \\
0\end{array}$ & $\begin{array}{r}\text { \%9 } \\
\phi \\
0\end{array}$ \\
\hline Tolw Inoome Bedustions & 124 & 40 & 406 & 189 & 0 & 489 \\
\hline 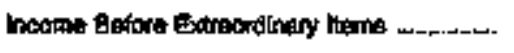 & 688 & 500 & -80 & 1,001 & 378 & 277 \\
\hline 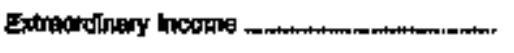 & 0 & o & o & $\mathbf{0}$ & 0 & 0 \\
\hline 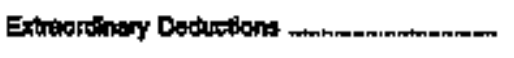 & $\mathbf{0}$ & o & 0 & 6 & 0 & b \\
\hline 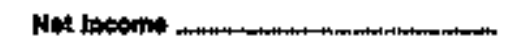 & 800 & $\operatorname{sos}$ & $-\infty$ & 1,013 & 376 & $m$ \\
\hline
\end{tabular}

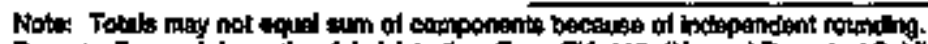

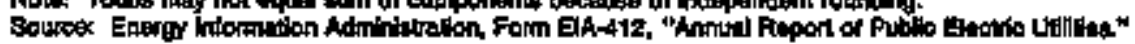


Table 21. Statement of income by Major U.S. Publicly Owned Electile titlity Within State, 1994 (Continued)

(Thousand Dollars)

\begin{tabular}{|c|c|c|c|c|c|}
\hline ham & 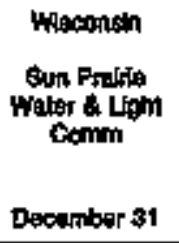 & 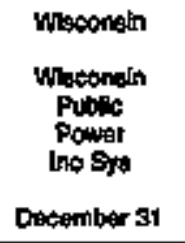 & 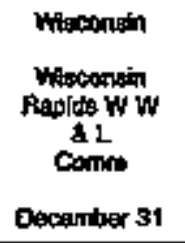 & $\begin{array}{l}\text { Whouming } \\
\text { clipotte } \\
\text { Cry of } \\
\text { Jume so }\end{array}$ & $\begin{array}{l}\text { Whoming } \\
\text { Whoming } \\
\text { Pownof Agenty } \\
\text { Degember } 91\end{array}$ \\
\hline 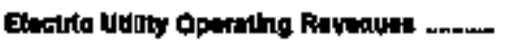 & $7, \infty$, & t13,169 & 10,169 & $\mathbf{7 0 , 2 , 1 8}$ & 5,764 \\
\hline 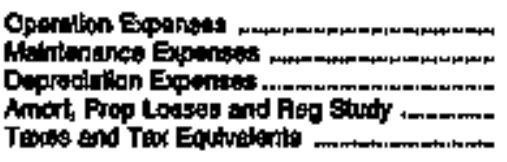 & $\begin{array}{r}0,413 \\
159 \\
408 \\
0 \\
302\end{array}$ & $\begin{array}{l}96,542 \\
1,195 \\
3,004 \\
1,436 \\
2,025\end{array}$ & $\begin{array}{r}7+B 70 \\
309 \\
600 \\
090\end{array}$ & $\begin{array}{r}8,958 \\
0 \\
805 \\
33 \\
45\end{array}$ & $\begin{array}{r}3,100 \\
390 \\
609 \\
0 \\
107\end{array}$ \\
\hline 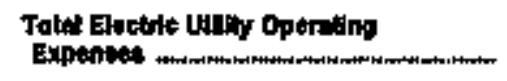 & $7,2 \pi 7$ & ios,071 & 9,375 & 8,051 & 4,879 \\
\hline 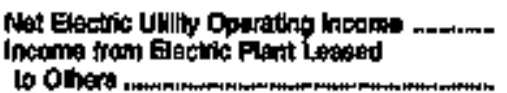 & 100 & $\begin{array}{r}8,281 \\
0\end{array}$ & 791 & $\begin{array}{r}345 \\
0\end{array}$ & $\begin{array}{r}1,381 \\
0\end{array}$ \\
\hline 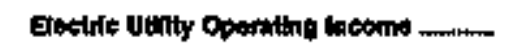 & 40 & $0,2,4$ & 79t & 345 & 1,361 \\
\hline 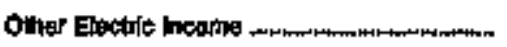 & 0 & $7,6,5$ & 220 & $4 B 7$ & 390 \\
\hline 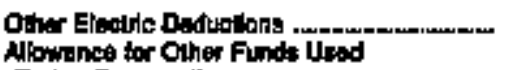 & 0 & 8 & ת & 0 & D \\
\hline 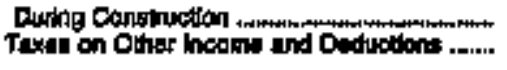 & $\begin{array}{l}0 \\
0\end{array}$ & $\stackrel{0}{0}$ & $\stackrel{0}{0}$ & $\stackrel{9}{6}$ & $\stackrel{9}{0}$ \\
\hline Eectric Utility tineape & 48: & $15,7 s$ & \% & 751 & 1,774 \\
\hline 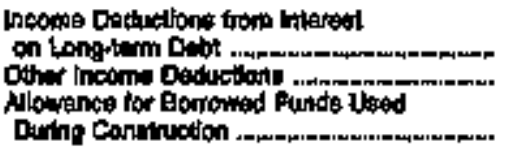 & $\begin{array}{l}\text { 0 } \\
0\end{array}$ & $\begin{array}{r}9,283 \\
3,286 \\
0\end{array}$ & $\begin{array}{r}11 \\
4 \\
0\end{array}$ & $\begin{array}{r}180 \\
0 \\
0\end{array}$ & $\begin{array}{r}1,121 \\
73 \\
0\end{array}$ \\
\hline 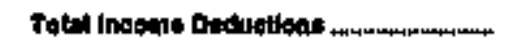 & 0 & 2,648 & 15 & 180 & 1,184 \\
\hline 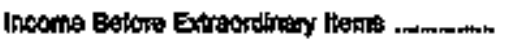 & 483 & 3,249 & 982 & 592 & 580 \\
\hline Extrand nuy Income & o & 0 & 0 & v & 0 \\
\hline 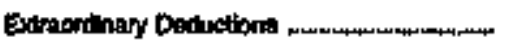 & $\mathbf{0}$ & 0 & $\mathbf{0}$ & 0 & D \\
\hline 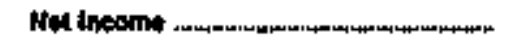 & 499 & 7,249 & $\operatorname{sen}$ & 692 & 50 \\
\hline
\end{tabular}


Table 22. Balance sheet by Mojor U.S. Publicly Owned Electric Utility Whthin State at End of Period, 1994

(Thousand Dollars)

\begin{tabular}{|c|c|c|c|c|c|c|}
\hline Ilam & 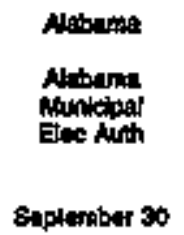 & 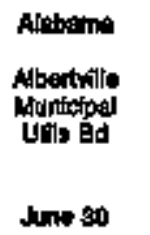 & $\begin{array}{l}\text { Altbanta } \\
\text { Andelugita } \\
\text { City of } \\
\text { Suplantor } 30\end{array}$ & $\begin{array}{l}\text { Alabande } \\
\text { Athent } \\
\text { Chy of } \\
\text { Decomber } 31\end{array}$ & $\begin{array}{l}\text { Alubang } \\
\text { Beseganer } \\
\text { Ciny of } \\
\text { June } 30\end{array}$ & $\begin{array}{l}\text { Alabama } \\
\text { Cownom Bound } \\
\text { Junn } 30\end{array}$ \\
\hline 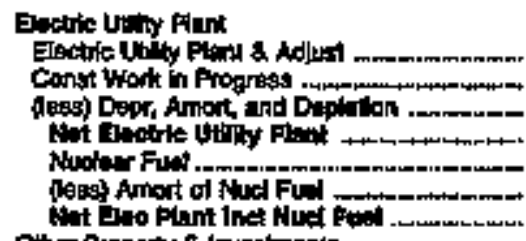 & $\begin{array}{l}0 \\
0 \\
0 \\
0 \\
0 \\
0 \\
0\end{array}$ & 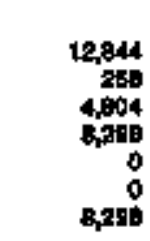 & $\begin{array}{r}3,642 \\
0 \\
1,2,25 \\
2,416 \\
0 \\
0 \\
2,416\end{array}$ & $\begin{array}{r}42,058 \\
151 \\
14,400 \\
7,930 \\
0 \\
0 \\
7,940\end{array}$ & $\begin{array}{r}2 n, 236 \\
554 \\
9,047 \\
11,744 \\
0 \\
0 \\
11,744\end{array}$ & $\begin{array}{r}11,050 \\
1,000 \\
5,547 \\
7,411 \\
0 \\
0 \\
7,4+1\end{array}$ \\
\hline 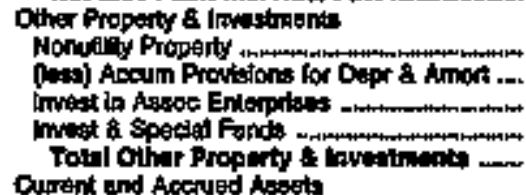 & $\begin{array}{r}3,089 \\
300 \\
0 \\
25,294 \\
20,008\end{array}$ & $\begin{array}{r}0 \\
0 \\
0 \\
18 \\
16\end{array}$ & $\begin{array}{r}11,034 \\
2,006 \\
2,391 \\
397 \\
12,007\end{array}$ & $\begin{array}{r}0 \\
0 \\
0 \\
6,905 \\
0,3,85\end{array}$ & $\begin{array}{r}0 \\
0 \\
0 \\
75 \\
75\end{array}$ & $\begin{array}{r}0 \\
0 \\
400 \\
400\end{array}$ \\
\hline 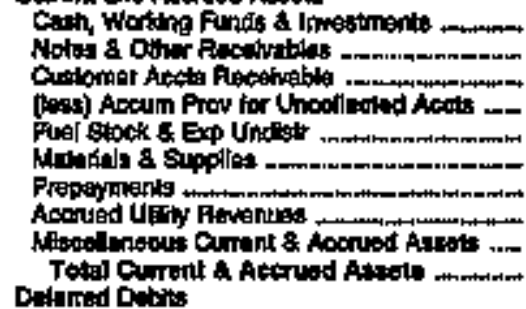 & $\begin{array}{r}0,110 \\
0 \\
0,703 \\
0 \\
0 \\
081 \\
04,390 \\
0 \\
111,603\end{array}$ & $\begin{array}{r}3005 \\
1,714 \\
0 \\
0 \\
0 \\
168 \\
20 \\
0 \\
27 \\
4981\end{array}$ & $\begin{array}{r}424 \\
9 \\
1,247 \\
0 \\
0 \\
109 \\
40 \\
0 \\
0 \\
1,07\end{array}$ & $\begin{array}{r}7,401 \\
2,090 \\
0 \\
0 \\
0 \\
385 \\
265 \\
0 \\
63 \\
6,102\end{array}$ & $\begin{array}{r}260 \\
3,493 \\
0 \\
0 \\
0 \\
204 \\
200 \\
0 \\
04 \\
04000\end{array}$ & $\begin{array}{r}1,732 \\
2,762 \\
0 \\
0 \\
0 \\
300 \\
24 \\
0 \\
31 \\
4,34\end{array}$ \\
\hline 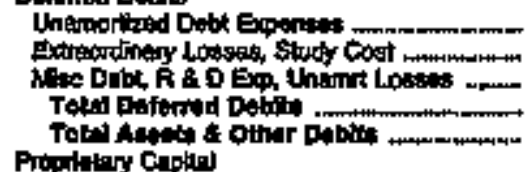 & $\begin{array}{r}13,897 \\
0 \\
49,481 \\
67,268 \\
107,193\end{array}$ & $\begin{array}{r}0 \\
0 \\
1,115 \\
1,1 \leqslant 5 \\
1, \$ 61\end{array}$ & $\begin{array}{r}7 \\
0 \\
0 \\
7 \\
7\end{array}$ & $\begin{array}{r}392 \\
0 \\
725 \\
1,054 \\
40,431\end{array}$ & $\begin{array}{r}12 \\
0 \\
1,831 \\
1,943 \\
17,781\end{array}$ & $\begin{array}{r}117 \\
0 \\
850 \\
19,100\end{array}$ \\
\hline 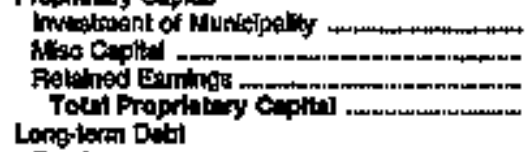 & $\begin{array}{r}0 \\
6 \\
689 \\
698\end{array}$ & $\begin{array}{r}0 \\
10,440 \\
0,400\end{array}$ & $\begin{array}{r}6,480 \\
4,49 \\
5,487 \\
10,049\end{array}$ & $\begin{array}{r}0 \\
0 \\
18,845 \\
58,945\end{array}$ & $\begin{array}{r}0 \\
0 \\
50920 \\
10320\end{array}$ & $\begin{array}{r}0 \\
0 \\
0,5897 \\
6,5 \leqslant 7\end{array}$ \\
\hline 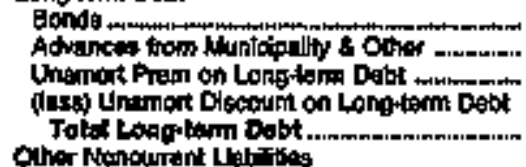 & $\begin{array}{r}169,720 \\
0 \\
0 \\
1,457 \\
10,006\end{array}$ & $\begin{array}{r}0 \\
1,123 \\
0 \\
0 \\
1,125\end{array}$ & $\begin{array}{r}4,340 \\
0 \\
0 \\
0 \\
4,440\end{array}$ & $\begin{array}{r}15,010 \\
749 \\
0 \\
0 \\
10,6=5\end{array}$ & $\begin{array}{r}2,160 \\
1,549 \\
-19 \\
0 \\
8,5200\end{array}$ & $\begin{array}{r}3,116 \\
680 \\
0 \\
0 \\
0,116\end{array}$ \\
\hline 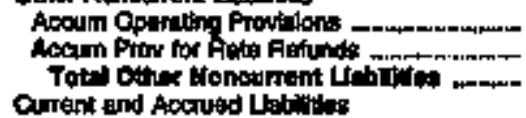 & $\begin{array}{l}0 \\
0 \\
0\end{array}$ & $\begin{array}{l}0 \\
0 \\
0\end{array}$ & $\begin{array}{l}0 \\
0 \\
0\end{array}$ & $\begin{array}{l}0 \\
0 \\
0\end{array}$ & $\begin{array}{l}0 \\
0 \\
0\end{array}$ & $\begin{array}{l}0 \\
0 \\
0\end{array}$ \\
\hline 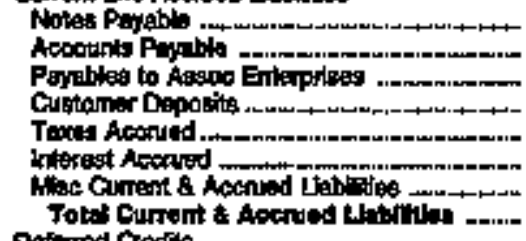 & $\begin{array}{r}0 \\
7,456 \\
0 \\
0 \\
0 \\
894 \\
20 \\
7,379\end{array}$ & $\begin{array}{r}0 \\
1,958 \\
0 \\
468 \\
0 \\
0 \\
379 \\
2,798\end{array}$ & $\begin{array}{r}0 \\
1,000 \\
0 \\
340 \\
70 \\
7 t \\
0 \\
1,540\end{array}$ & $\begin{array}{r}0 \\
3,340 \\
0 \\
1,121 \\
0 \\
114 \\
349 \\
4,920\end{array}$ & $\begin{array}{r}0 \\
2,020 \\
0 \\
1,068 \\
0 \\
18 \\
292 \\
3,982\end{array}$ & $\begin{array}{r}0 \\
1,908 \\
0 \\
970 \\
17 \\
598 \\
197 \\
2,911\end{array}$ \\
\hline 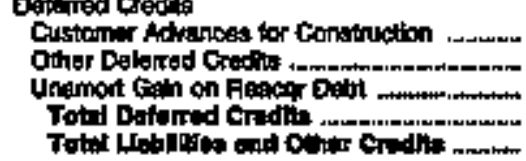 & $\begin{array}{r}0 \\
0 \\
0 \\
0 \\
0\end{array}$ & $\begin{array}{r}0 \\
0 \\
0 \\
0 \\
0 \times 54\end{array}$ & $\begin{array}{r}0 \\
0 \\
0 \\
0 \\
0\end{array}$ & $\begin{array}{r}3 \\
3 \\
0 \\
3 \\
0\end{array}$ & $\begin{array}{r}0 \\
0 \\
0 \\
0 \\
17,781\end{array}$ & $\begin{array}{r}0 \\
11 \\
0 \\
11 \\
15,+10 \%\end{array}$ \\
\hline
\end{tabular}

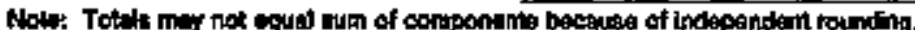

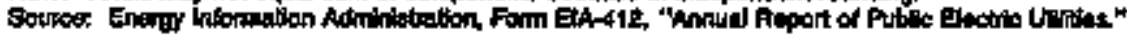


Table 22. Balance Sheet by Major U.S. Publichy Owned Electric Utility With'n state at End of Perlod, 1994 (Continued)

(Thousend Doltars)

\begin{tabular}{|c|c|c|c|c|c|c|}
\hline Hem & 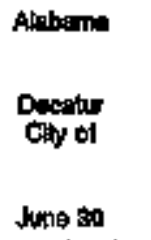 & $\begin{array}{l}\text { Alabang } \\
\text { Dothen } \\
\text { Fity of } \\
\text { Septeminer } 30\end{array}$ & $\begin{array}{l}\text { Alabaing } \\
\text { Florence } \\
\text { Clty of } \\
\text { June } 30\end{array}$ & 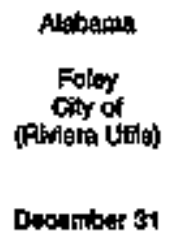 & $\begin{array}{l}\text { Alabenat } \\
\text { Fort Fayme } \\
\text { Alsth } \\
\text { June } 30\end{array}$ & 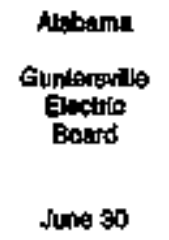 \\
\hline 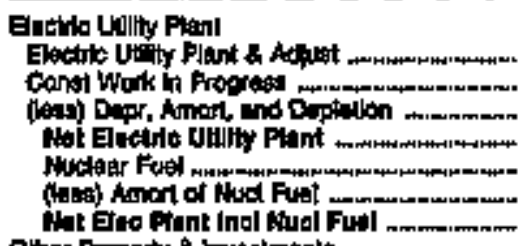 & 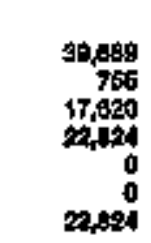 & $\begin{array}{r}5,678 \\
0 \\
24,125 \\
34,745 \\
0 \\
0 \\
34,748\end{array}$ & $\begin{array}{r}74,244 \\
1,344 \\
31,470 \\
44,150 \\
0 \\
0 \\
44,160\end{array}$ & $\begin{array}{r}54,658 \\
2,965 \\
18,085 \\
38,547 \\
0 \\
0 \\
38,497\end{array}$ & $\begin{array}{r}12,764 \\
5,60 \\
4,491 \\
8,301 \\
6 \\
0 \\
0,01\end{array}$ & $\begin{array}{r}9,007 \\
678 \\
4,128 \\
5,017 \\
0 \\
0 \\
6,017\end{array}$ \\
\hline 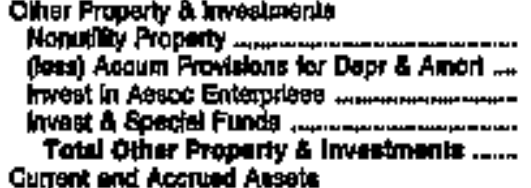 & $\begin{array}{l}3 \\
0 \\
0 \\
0 \\
0 \\
3\end{array}$ & $\begin{array}{l}0 \\
0 \\
0 \\
0 \\
0\end{array}$ & $\begin{array}{r}0 \\
0 \\
0 \\
375 \\
375\end{array}$ & 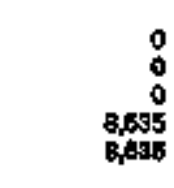 & $\begin{array}{r}0 \\
0 \\
0 \\
304 \\
304\end{array}$ & $\begin{array}{r}0 \\
0 \\
10 \\
19\end{array}$ \\
\hline 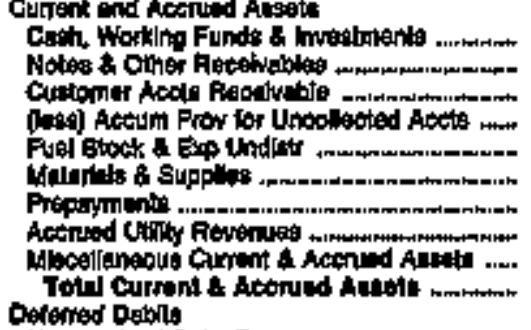 & $\begin{array}{r}5,168 \\
6,469 \\
0 \\
0 \\
0 \\
549 \\
29 \\
0 \\
0 \\
12,201\end{array}$ & $\begin{array}{r}8,870 \\
90 \\
3,447 \\
0 \\
0 \\
188 \\
0 \\
0 \\
37 \\
12,402\end{array}$ & $\begin{array}{r}1,159 \\
7,516 \\
0 \\
0 \\
0 \\
1,591 \\
39 \\
0 \\
196 \\
10,400\end{array}$ & 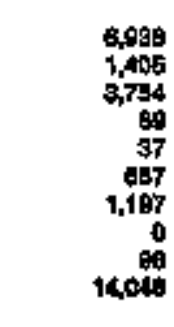 & $\begin{array}{r}2,0002 \\
1,717 \\
0 \\
0 \\
0 \\
150 \\
40 \\
0 \\
51 \\
4,054\end{array}$ & $\begin{array}{r}1,145 \\
1,004 \\
0 \\
0 \\
0 \\
198 \\
49 \\
0 \\
32 \\
2,396\end{array}$ \\
\hline 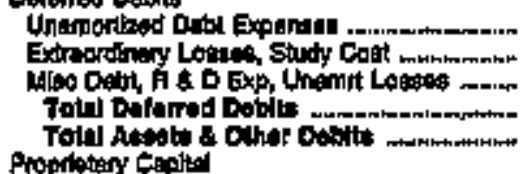 & $\begin{array}{r}0 \\
1,017 \\
1,017 \\
30,040\end{array}$ & $\begin{array}{r}0 \\
0 \\
0 \\
07,200\end{array}$ & $\begin{array}{r}0 \\
2,611 \\
3,615 \\
07,640\end{array}$ & $\begin{array}{r}179 \\
0 \\
0 \\
179 \\
61,99\end{array}$ & $\begin{array}{r}14 k \\
1,917 \\
7,00 \\
14,778\end{array}$ & $\begin{array}{r}17 \\
0 \\
056 \\
675 \\
6974\end{array}$ \\
\hline 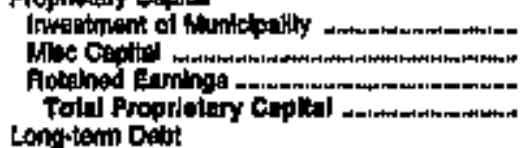 & $\begin{array}{r}0 \\
31,370 \\
31,370\end{array}$ & $\begin{array}{r}0 \\
30,605 \\
39,505\end{array}$ & $\begin{array}{r}0 \\
44,750 \\
44,749\end{array}$ & $\begin{array}{r}0 \\
0 \\
45,390 \\
4,960\end{array}$ & $\begin{array}{r}0 \\
0 \\
\sin 201\end{array}$ & $\begin{array}{r}0 \\
0 \\
0,398 \\
0,926\end{array}$ \\
\hline 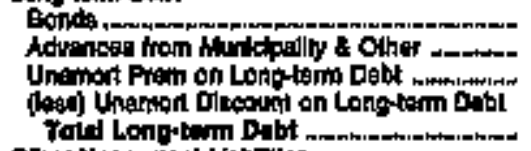 & $\begin{array}{r}0 \\
303 \\
0 \\
0\end{array}$ & $\begin{array}{l}0 \\
0 \\
\text { n } \\
0 \\
0\end{array}$ & $\begin{array}{r}179 \\
2,609 \\
0 \\
0 \\
2,996\end{array}$ & $\begin{array}{r}10,399 \\
0 \\
0 \\
0 \\
14,899\end{array}$ & $\begin{array}{r}4,917 \\
505 \\
0 \\
0 \\
5,8+12\end{array}$ & $\begin{array}{r}375 \\
679 \\
0 \\
0 \\
1,040\end{array}$ \\
\hline 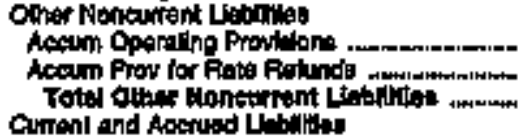 & $\begin{array}{l}0 \\
0 \\
0\end{array}$ & $\begin{array}{l}0 \\
0 \\
0\end{array}$ & $\begin{array}{l}0 \\
0 \\
0\end{array}$ & $\begin{array}{r}288 \\
0 \\
268\end{array}$ & $\begin{array}{l}0 \\
0 \\
0\end{array}$ & $\begin{array}{l}0 \\
0 \\
0\end{array}$ \\
\hline 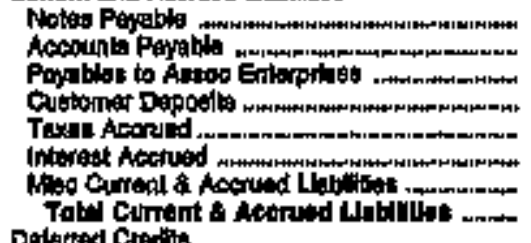 & $\begin{array}{r}0 \\
4,89 \\
0 \\
0 \\
0 \\
0 \\
517 \\
5204\end{array}$ & $\begin{array}{r}0 \\
9,5,21 \\
0 \\
2,940 \\
14 \\
1,921 \\
7,904\end{array}$ & $\begin{array}{r}0 \\
5,609 \\
0 \\
3,984 \\
0 \\
0 \\
994 \\
7,951\end{array}$ & $\begin{array}{r}2780 \\
0 \\
1,400 \\
468 \\
47 \\
11 \\
0,700\end{array}$ & $\begin{array}{r}0 \\
1,654 \\
0 \\
471 \\
0 \\
40 \\
2,08 \\
2,374\end{array}$ & $\begin{array}{r}0 \\
851 \\
0 \\
286 \\
0 \\
0 \\
96 \\
1,900\end{array}$ \\
\hline 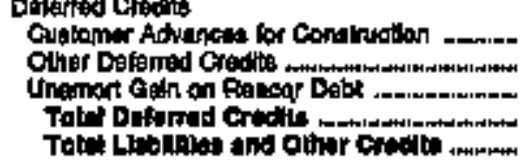 & $\begin{array}{r}0 \\
0 \\
0 \\
\sin \end{array}$ & $\begin{array}{r}0 \\
0 \\
0 \\
0 \\
0\end{array}$ & $\begin{array}{r}0 \\
0 \\
0 \\
5 \\
57+546\end{array}$ & $\begin{array}{r}0 \\
109 \\
0 \\
100 \\
1,300\end{array}$ & $\begin{array}{r}0 \\
t \\
0 \\
14,778\end{array}$ & $\begin{array}{r}0 \\
0 \\
0 \\
0 \\
0,074\end{array}$ \\
\hline
\end{tabular}

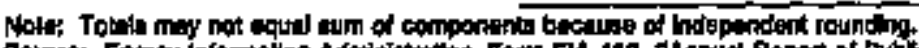

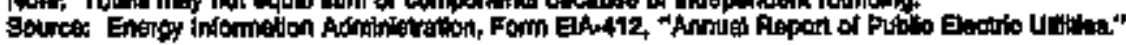


Table 22. Balance Sheet by Major U.S. Publicty Omed Elactric Utility Within State at End of Period, 1994 (Continued) (Thousand Dollars)

\begin{tabular}{|c|c|c|c|c|c|c|}
\hline Hem & $\begin{array}{l}\text { Aliabina } \\
\text { Hetwollo } \\
\text { City of } \\
\text { June so }\end{array}$ & 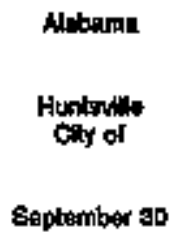 & $\begin{array}{l}\text { Anbeme } \\
\text { Nuscts } \\
\text { Shots } \\
\text { Chy of } \\
\text { June so }\end{array}$ & 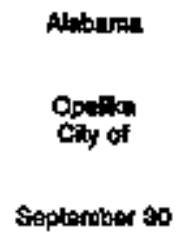 & 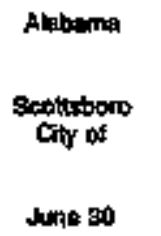 & 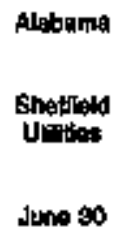 \\
\hline 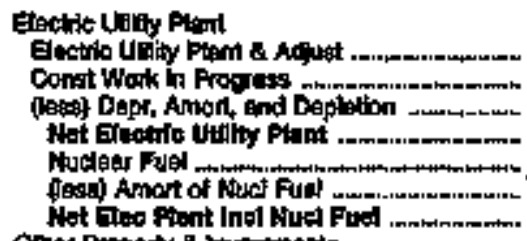 & $\begin{array}{r}5,214 \\
6,271 \\
2,949 \\
0 \\
0 \\
2,949\end{array}$ & $\begin{array}{r}160,771 \\
6,300 \\
63,371 \\
101,706 \\
0 \\
0 \\
101,780\end{array}$ & $\begin{array}{r}13,740 \\
910 \\
4,569 \\
+0,060 \\
0 \\
0 \\
0,0100\end{array}$ & $\begin{array}{r}18,980 \\
378 \\
10,447 \\
0,689 \\
0 \\
6 \\
0,659\end{array}$ & $\begin{array}{r}14,844 \\
1,38 \\
5,658 \\
0,524 \\
0 \\
0 \\
0,527\end{array}$ & $\begin{array}{r}3,309 \\
1,334 \\
14,604 \\
19,629 \\
0 \\
0 \\
19,829\end{array}$ \\
\hline 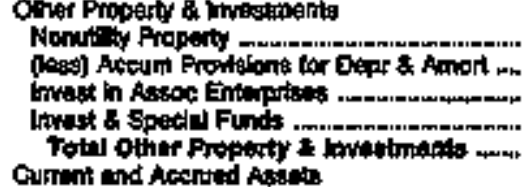 & $\begin{array}{r}0 \\
0 \\
0 \\
105 \\
705\end{array}$ & $\begin{array}{r}0 \\
0 \\
0 \\
21,480 \\
21,430\end{array}$ & $\begin{array}{r}0 \\
0 \\
148 \\
148\end{array}$ & $\begin{array}{r}0 \\
94 \\
815 \\
809\end{array}$ & $\begin{array}{r}0 \\
0 \\
0 \\
098 \\
096\end{array}$ & $\begin{array}{r}160 \\
0 \\
0 \\
2130 \\
2,800\end{array}$ \\
\hline 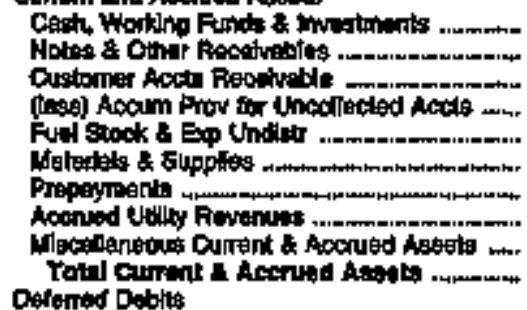 & $\begin{array}{r}212 \\
928 \\
0 \\
0 \\
0 \\
134 \\
6 \\
0 \\
15 \\
1,297\end{array}$ & $\begin{array}{r}25,697 \\
2,728 \\
0 \\
0 \\
0 \\
3,401 \\
52 \\
0 \\
574 \\
39,499\end{array}$ & $\begin{array}{r}62 \\
1,208 \\
0 \\
0 \\
0 \\
201 \\
108 \\
0 \\
30 \\
2,241\end{array}$ & 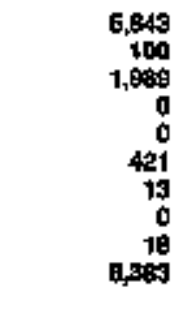 & $\begin{array}{r}1,161 \\
1,607 \\
0 \\
0 \\
0 \\
144 \\
20 \\
0 \\
64 \\
3,045\end{array}$ & $\begin{array}{r}1,209 \\
2,859 \\
0 \\
0 \\
0 \\
740 \\
170 \\
0 \\
66 \\
5,107\end{array}$ \\
\hline 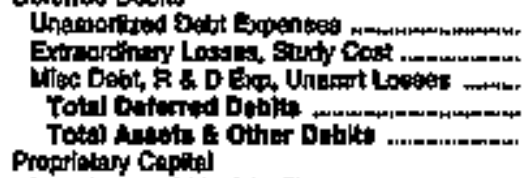 & $\begin{array}{r}1 \\
40 \\
494 \\
4,430\end{array}$ & $\begin{array}{r}212 \\
1,304 \\
1,916 \\
1,4,460\end{array}$ & $\begin{array}{r}30 \\
0 \\
678 \\
706 \\
13,098\end{array}$ & $\begin{array}{r}79 \\
0 \\
0 \\
79 \\
70,200\end{array}$ & $\begin{array}{r}83 \\
0 \\
1,428 \\
1,51 \\
14, \pi 5\end{array}$ & $\begin{array}{r}14 \\
1,824 \\
1,036 \\
20,070\end{array}$ \\
\hline 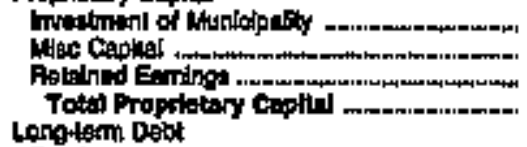 & $\begin{array}{r}0 \\
3,708 \\
3,720\end{array}$ & $\begin{array}{r}0 \\
0 \\
120,044 \\
\operatorname{tag} ; 644\end{array}$ & $\begin{array}{r}0 \\
9,775 \\
9, \pi 75\end{array}$ & $\begin{array}{r}0 \\
10,000 \\
10,900\end{array}$ & $\begin{array}{r}6 \\
0,907 \\
0,007\end{array}$ & $\begin{array}{r}0 \\
21,996 \\
21,9=0\end{array}$ \\
\hline 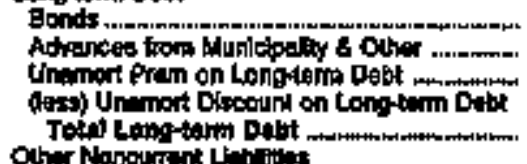 & $\begin{array}{r}20 \\
37 \\
0 \\
0 \\
467\end{array}$ & $\begin{array}{r}8,000 \\
285 \\
0 \\
0 \\
1,70 ;\end{array}$ & $\begin{array}{r}\text { nro } \\
0 \\
0 \\
0\end{array}$ & $\begin{array}{r}3,398 \\
1,087 \\
0 \\
0 \\
4,400\end{array}$ & $\begin{array}{r}2,940 \\
1,456 \\
376 \\
6 \\
4,760\end{array}$ & $\begin{array}{r}1,6065 \\
1,0 \mathrm{Bg} \\
0 \\
3,80 \mathrm{il}\end{array}$ \\
\hline 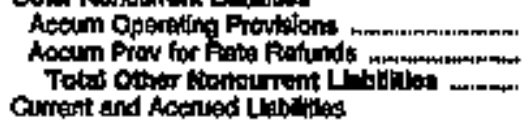 & $\begin{array}{l}0 \\
0 \\
0\end{array}$ & $\begin{array}{l}0 \\
0 \\
0\end{array}$ & $\begin{array}{l}0 \\
0 \\
0\end{array}$ & $\begin{array}{l}0 \\
0 \\
0\end{array}$ & $\begin{array}{l}0 \\
0 \\
0\end{array}$ & $\begin{array}{l}0 \\
0 \\
0\end{array}$ \\
\hline 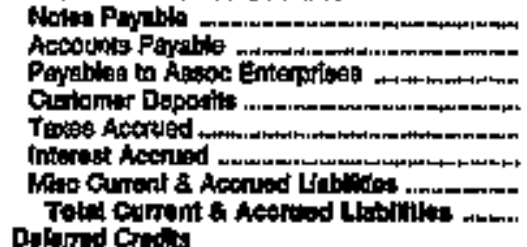 & $\begin{array}{r}0 \\
018 \\
0 \\
0 \\
0 \\
3 \\
8 \\
8 \\
0\end{array}$ & $\begin{array}{r}0 \\
18,947 \\
0 \\
10,454 \\
0 \\
38 \\
1,642 \\
28,478\end{array}$ & $\begin{array}{r}0 \\
1.30 \\
0 \\
416 \\
0 \\
14 \\
65 \\
1,71 \%\end{array}$ & $\begin{array}{r}490 \\
+479 \\
275 \\
559 \\
9 \\
97 \\
112 \\
2904\end{array}$ & $\begin{array}{r}0 \\
2,424 \\
0 \\
410 \\
24 \\
4 \\
244 \\
3,+\infty\end{array}$ & $\begin{array}{r}0 \\
2597 \\
0 \\
641 \\
97 \\
17 \\
445 \\
3,670\end{array}$ \\
\hline 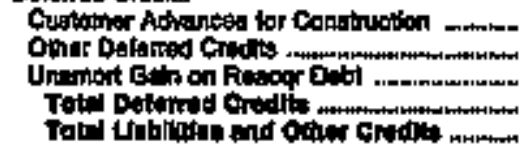 & $\begin{array}{r}0 \\
0 \\
0 \\
0 \\
040\end{array}$ & $\begin{array}{r}0 \\
0 \\
608 \\
104428\end{array}$ & $\begin{array}{r}0 \\
0 \\
0 \\
0 \\
130060\end{array}$ & $\begin{array}{r}0 \\
0 \\
0 \\
0 \\
7900\end{array}$ & $\begin{array}{r}0 \\
0 \\
0 \\
0 \\
14,79\end{array}$ & $\begin{array}{r}0 \\
0 \\
0 \\
0 \\
29,070\end{array}$ \\
\hline
\end{tabular}

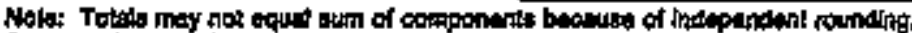

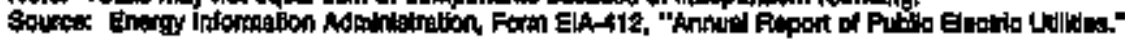


Table 22. Balance Sheet by Major U.9. Pubilely Owned Electric Utility Within State at End of Pertod, 1994 (Continued)

(Thousand Dollars)

\begin{tabular}{|c|c|c|c|c|c|c|}
\hline Itam & 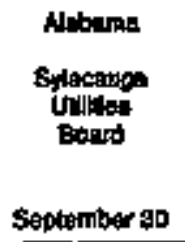 & 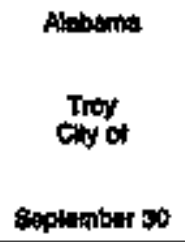 & 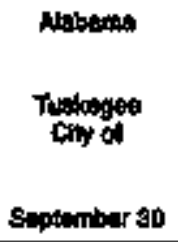 & 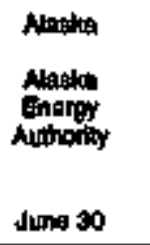 & 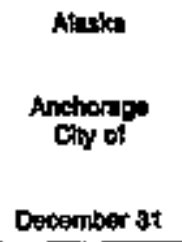 & $\begin{array}{l}\text { Alasks: } \\
\text { Falturkt } \\
\text { Chy of } \\
\text { Decamber } 31\end{array}$ \\
\hline 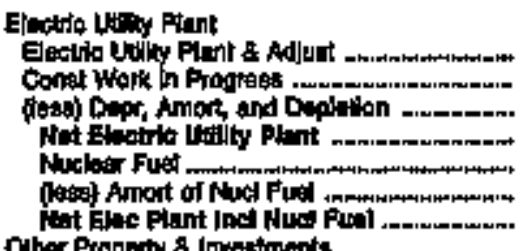 & $\begin{array}{r}10,454 \\
0 \\
6,270 \\
4,150 \\
0 \\
0,165\end{array}$ & 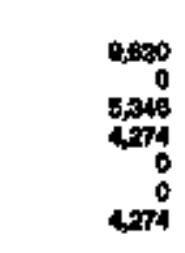 & 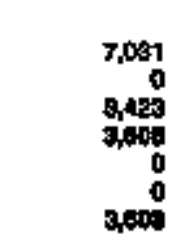 & 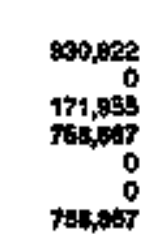 & $\begin{array}{r}262,493 \\
6,441 \\
117,844 \\
160,071 \\
0 \\
0 \\
160,071\end{array}$ & $\begin{array}{r}48009 \\
300 \\
29,128 \\
20,040 \\
0 \\
20,044\end{array}$ \\
\hline 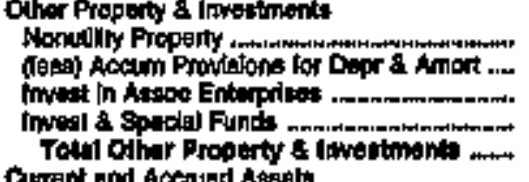 & $\begin{array}{r}0 \\
0 \\
0 \\
4,7 t 4 \\
4,714\end{array}$ & $\begin{array}{r}0 \\
0 \\
0 \\
1+40 \\
1+40\end{array}$ & $\begin{array}{l}0 \\
0 \\
0 \\
0 \\
0 \\
0\end{array}$ & $\begin{array}{l}0 \\
0 \\
0 \\
0 \\
0\end{array}$ & $\begin{array}{r}0 \\
0 \\
0 \\
\operatorname{sos}, 259\end{array}$ & $\begin{array}{r}277,035 \\
137912 \\
0 \\
0 \\
12 B, 128\end{array}$ \\
\hline 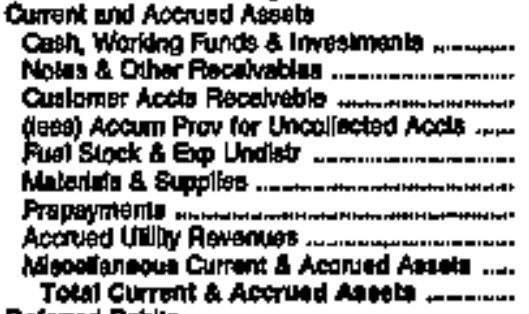 & $\begin{array}{r}306 \\
0 \\
1,1+7 \\
0 \\
0 \\
245 \\
0 \\
0 \\
0 \\
1,300\end{array}$ & $\begin{array}{r}314 \\
0 \\
2,179 \\
0 \\
0 \\
195 \\
10 \\
0 \\
0\end{array}$ & $\begin{array}{r}1,240 \\
210 \\
3,082 \\
0 \\
0 \\
79 \\
0 \\
0 \\
0 \\
0\end{array}$ & 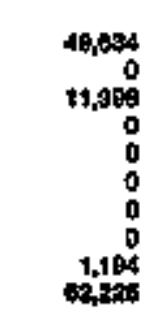 & 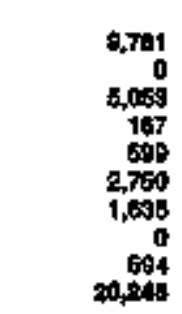 & 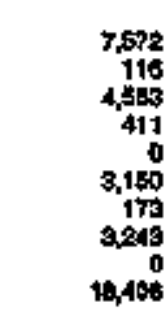 \\
\hline 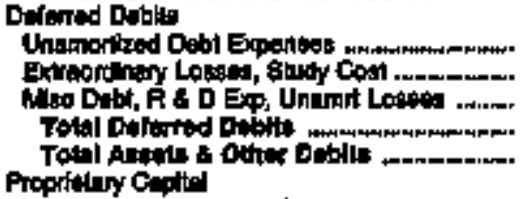 & $\begin{array}{r}0 \\
0 \\
0 \\
0 \\
0\end{array}$ & $\begin{array}{r}170 \\
0 \\
0 \\
170 \\
\operatorname{ting}\end{array}$ & $\begin{array}{r}108 \\
0 \\
0\end{array}$ & $\begin{array}{l}0 \\
0 \\
0 \\
0 \\
0\end{array}$ & $\begin{array}{r}2,311 \\
0 \\
31,720 \\
34,051 \\
0+7,03:\end{array}$ & $\begin{array}{r}0 \\
0 \\
0 \\
0 \\
177,502\end{array}$ \\
\hline 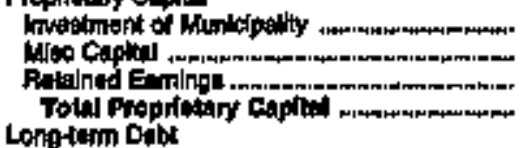 & $\begin{array}{r}0 \\
0,40 \\
7,0.010\end{array}$ & $\begin{array}{r}0 \\
0 \\
64\end{array}$ & $\begin{array}{r}4,516 \\
0 \\
1,954 \\
\text { s,ot: }\end{array}$ & $\begin{array}{r}610,801 \\
-569,807 \\
45,197\end{array}$ & $\begin{array}{r}9 \\
0 \\
48,885 \\
16,105\end{array}$ & $\begin{array}{r}6,765 \\
63,175 \\
29,780 \\
101,691\end{array}$ \\
\hline 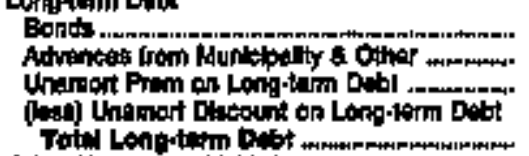 & $\begin{array}{r}2,723 \\
0 \\
0 \\
0 \\
8,723\end{array}$ & $\begin{array}{r}7,340 \\
0 \\
0 \\
t, 186 \\
7,176\end{array}$ & $\begin{array}{r}409 \\
0 \\
0 \\
0 \\
405\end{array}$ & 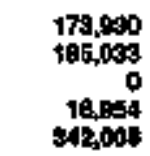 & $\begin{array}{r}1 B 2,485 \\
0 \\
4,384 \\
7,909 \\
178,091\end{array}$ & $\begin{array}{r}48,490 \\
0 \\
-71 \\
0 \\
40,46\end{array}$ \\
\hline 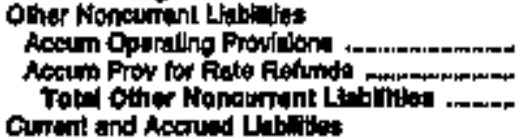 & $\begin{array}{l}0 \\
0 \\
0\end{array}$ & $\begin{array}{l}0 \\
0 \\
0\end{array}$ & $\begin{array}{l}0 \\
0 \\
0\end{array}$ & $\begin{array}{l}0 \\
0\end{array}$ & $\begin{array}{r}1,185 \\
0 \\
1,105\end{array}$ & $\begin{array}{r}10,628 \\
0 \\
10,689\end{array}$ \\
\hline 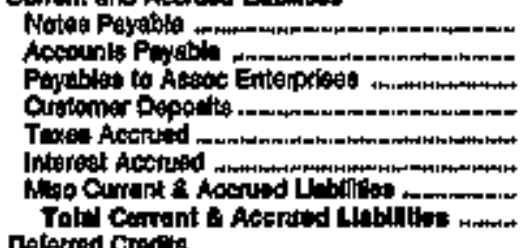 & $\begin{array}{r}148 \\
340 \\
17 \\
17 \\
0 \\
102 \\
0 \\
m\end{array}$ & $\begin{array}{r}24 \\
862 \\
0 \\
206 \\
11 \\
41 \\
141 \\
1,300\end{array}$ & 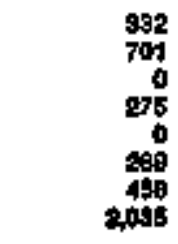 & $\begin{array}{r}2,000 \\
1,200 \\
1,240 \\
0 \\
0 \\
10,101 \\
1,00 \\
2,001\end{array}$ & $\begin{array}{r}0 \\
3,906 \\
0 \\
1,120 \\
0 \\
098 \\
1,020 \\
7,705\end{array}$ & $\begin{array}{r}3,765 \\
2,099 \\
0 \\
800 \\
0 \\
1,000 \\
7,500 \\
1,000\end{array}$ \\
\hline 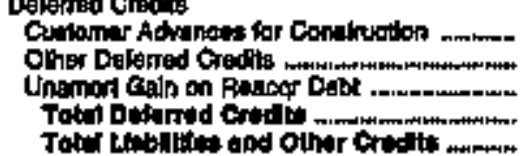 & $\begin{array}{r}0 \\
0 \\
0 \\
0 \\
0\end{array}$ & $\begin{array}{r}0 \\
0 \\
0 \\
0 \\
0\end{array}$ & $\begin{array}{r}0 \\
0 \\
0 \\
0 \\
0\end{array}$ & $\begin{array}{r}0 \\
0 \\
0 \\
0 \\
0\end{array}$ & $\begin{array}{r}347 \\
697 \\
0 \\
1,094 \\
237,038\end{array}$ & $\begin{array}{r}0 \\
0 \\
0 \\
0\end{array}$ \\
\hline
\end{tabular}

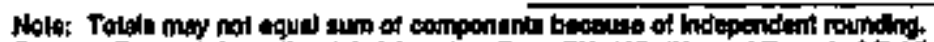

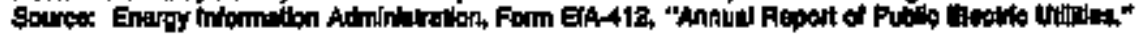


Table 22. Belence Sheet by Mojor U.S. Publlely Owned Electrle Utlity Wtitin State at End of Perlod, 1994 (Continued)

(Thotssand Donlars)

\begin{tabular}{|c|c|c|c|c|c|c|}
\hline Ihm & $\begin{array}{l}\text { Aloska } \\
\text { Kottehiman } \\
\text { City of } \\
\text { Deosniber } \$ 1\end{array}$ & 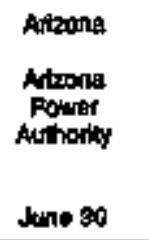 & $\begin{array}{l}\text { Arizona } \\
\text { Electiked } \\
\text { Dist } \\
\text { Hot } \\
\text { Pinal Cinty } \\
\text { Deonmber } 31\end{array}$ & 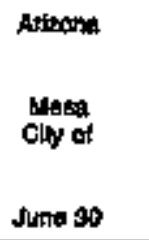 & 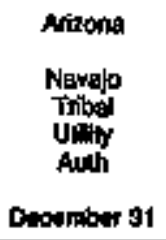 & 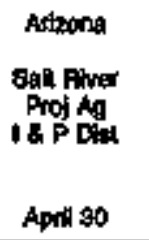 \\
\hline 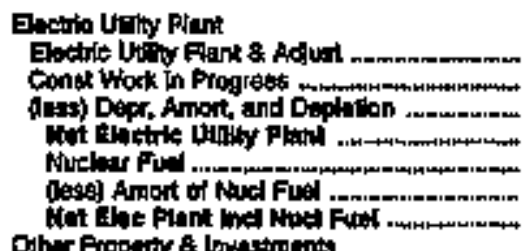 & $\begin{array}{r}46,732 \\
4,201 \\
21,164 \\
29,779 \\
0 \\
0 \\
0 \\
29779\end{array}$ & $\begin{array}{r}1,150 \\
5 \\
718 \\
40 \\
0 \\
0 \\
140\end{array}$ & $\begin{array}{r}16,161 \\
0 \\
0,610 \\
0,651 \\
0 \\
0 \\
0,0 \% 1\end{array}$ & $\begin{array}{r}61,020 \\
4,125 \\
13,104 \\
42,050 \\
0 \\
0 \\
12,000\end{array}$ & $\begin{array}{r}111,327 \\
4,446 \\
46,347 \\
75,439 \\
0 \\
75,498\end{array}$ & 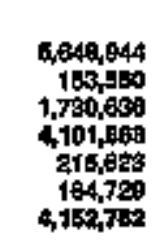 \\
\hline 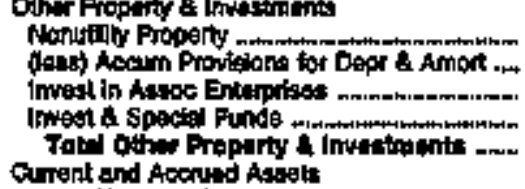 & $\begin{array}{r}0 \\
0 \\
10,728 \\
10,340\end{array}$ & $\begin{array}{r}0 \\
0 \\
0 \\
3,720 \\
3,7 \% 0\end{array}$ & 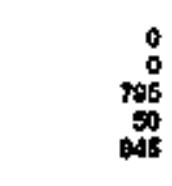 & 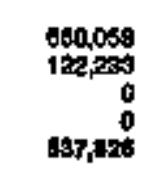 & $\begin{array}{r}673 \\
418 \\
1,905 \\
0 \\
2,000\end{array}$ & $\begin{array}{r}6,251 \\
1,005 \\
10,260 \\
252,424 \\
324,040\end{array}$ \\
\hline 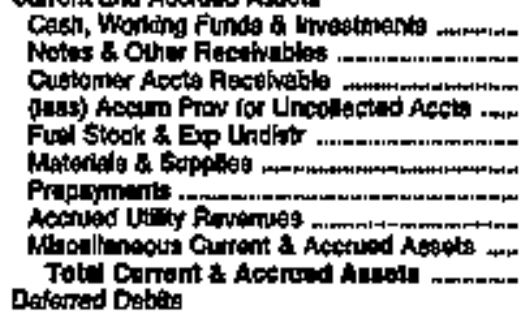 & $\begin{array}{r}7,600 \\
2,574 \\
744 \\
190 \\
0 \\
1330 \\
281 \\
0 \\
0 \\
12805\end{array}$ & $\begin{array}{r}27,707 \\
0 \\
2,068 \\
0 \\
0 \\
0 \\
2,203 \\
0 \\
288 \\
20,315\end{array}$ & 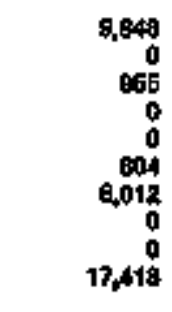 & 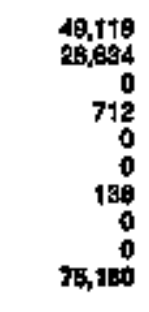 & $\begin{array}{r}2,006 \\
502 \\
4,606 \\
470 \\
0 \\
1,504 \\
78 \\
010 \\
0 \\
9,366\end{array}$ & 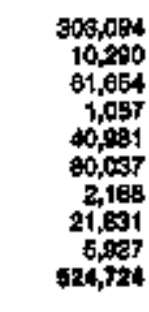 \\
\hline 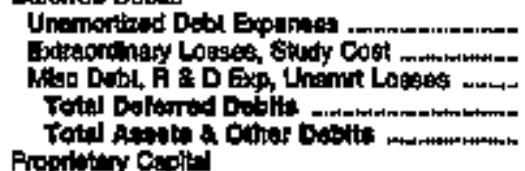 & $\begin{array}{r}900 \\
0 \\
04041 \\
090\end{array}$ & $\begin{array}{r}84,618 \\
0 \\
64,640 \\
07,0092\end{array}$ & $\begin{array}{r}0 \\
0 \\
0 \\
0 \\
0 \\
\mathbf{2}, \mathbf{B} 1 \mathbf{4}\end{array}$ & $\begin{array}{r}314 \\
0 \\
10,989 \\
11,90 \% \\
908,360\end{array}$ & $\begin{array}{r}0 \\
3,0097 \\
0,087 \\
0,0,20\end{array}$ & 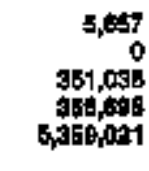 \\
\hline 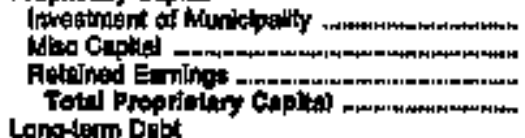 & $\begin{array}{r}\stackrel{0}{0} \\
28,609 \\
2909\end{array}$ & $\begin{array}{r}0 \\
9 \\
5,615 \\
5,624\end{array}$ & $\begin{array}{r}0 \\
0 \\
27,051 \\
27,051\end{array}$ & $\begin{array}{r}80,345 \\
204,285 \\
78,185 \\
964,900\end{array}$ & $\begin{array}{r}0 \\
37,054 \\
19,313 \\
86,067\end{array}$ & $\begin{array}{r}0 \\
1,204,002 \\
1,20,00 \%\end{array}$ \\
\hline 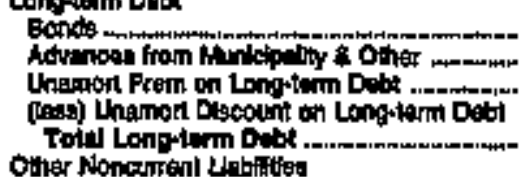 & $\begin{array}{r}23,120 \\
0 \\
0 \\
0 \\
20,190\end{array}$ & $\begin{array}{r}01,410 \\
0 \\
0 \\
0,791 \\
70,219\end{array}$ & $\begin{array}{l}0 \\
0 \\
5 \\
0 \\
6\end{array}$ & $\begin{array}{r}283,498 \\
\$, 406 \\
191 \\
0 \\
295,001\end{array}$ & $\begin{array}{r}0 \\
20,031 \\
0 \\
0 \\
20,031\end{array}$ & $\begin{array}{r}3,3,5,608 \\
376,009 \\
117,407 \\
3,97,209\end{array}$ \\
\hline 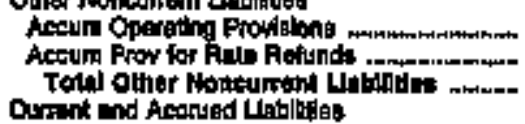 & $\begin{array}{l}0 \\
0 \\
0\end{array}$ & $\begin{array}{l}0 \\
0 \\
0\end{array}$ & $\begin{array}{l}0 \\
0 \\
0\end{array}$ & $\begin{array}{l}0 \\
0 \\
0\end{array}$ & $\begin{array}{l}0 \\
0 \\
0\end{array}$ & $\begin{array}{r}63,805 \\
09,001\end{array}$ \\
\hline 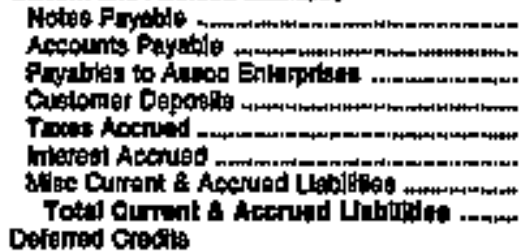 & $\begin{array}{r}0 \\
1,712 \\
0 \\
044 \\
0 \\
09 \\
0 \\
0 \\
2,040\end{array}$ & 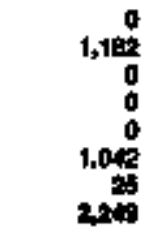 & $\begin{array}{r}0 \\
302 \\
0 \\
505 \\
0 \\
92 \\
0 \\
758\end{array}$ & $\begin{array}{r}18,040 \\
1,545 \\
1,420 \\
4,000 \\
0 \\
6,090 \\
3,400 \\
34605\end{array}$ & $\begin{array}{r}1,890 \\
2,732 \\
0 \\
64 \\
0 \\
0 \\
1,768 \\
6,947\end{array}$ & $\begin{array}{r}0 \\
90,105 \\
0 \\
42,451 \\
73,445 \\
64,650 \\
120,397 \\
291,107\end{array}$ \\
\hline 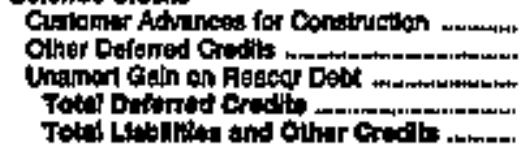 & $\begin{array}{r}0 \\
0 \\
0 \\
0 \\
040-11\end{array}$ & $\begin{array}{r}0 \\
0 \\
0 \\
0 \\
0\end{array}$ & $\begin{array}{r}0 \\
0 \\
0 \\
3\end{array}$ & $\begin{array}{r}0 \\
0 \\
0 \\
0\end{array}$ & $\begin{array}{r}711 \\
3,673 \\
0 \\
9,394 \\
90,298\end{array}$ & $\begin{array}{r}0,050 \\
37,050 \\
0 \\
46,717 \\
5,349,091\end{array}$ \\
\hline
\end{tabular}

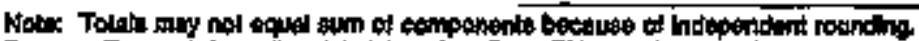

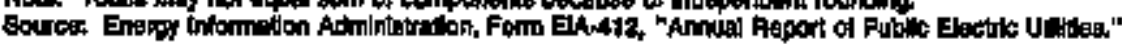


Table 22. Balance Sheet by Major U.S. Publioly Owned Electrio Utitlity Wthin State at End of Perlod, 1994 (Continued)

(Thousand Dollars)

\begin{tabular}{|c|c|c|c|c|c|c|}
\hline He⿻ & 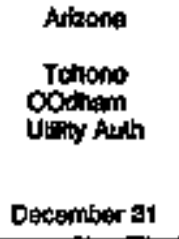 & $\begin{array}{l}\text { Akenzas } \\
\text { Benton } \\
\text { Chy of } \\
\text { Deonmbar } 31\end{array}$ & 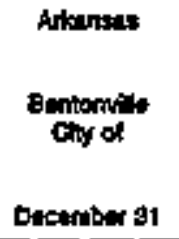 & 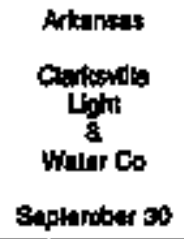 & 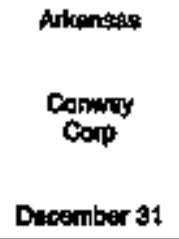 & $\begin{array}{l}\text { Arreming } \\
\text { Hope } \\
\text { Decenger of } 31\end{array}$ \\
\hline 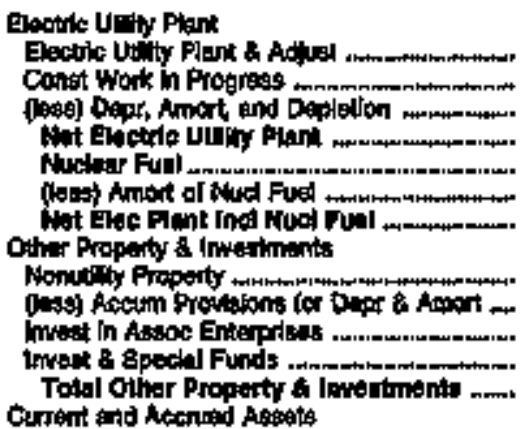 & $\begin{array}{r}9,950 \\
198 \\
2,816 \\
7,057 \\
0 \\
0 \\
7,067\end{array}$ & $\begin{array}{r}7,08 \\
0 \\
5,511 \\
2,154 \\
0 \\
0 \\
2,154\end{array}$ & $\begin{array}{r}48,431 \\
0 \\
90,253 \\
80,170 \\
0 \\
0 \\
30,770\end{array}$ & $\begin{array}{r}12,691 \\
15 \\
9,518 \\
9,389 \\
0 \\
0 \\
4,399 \\
28,074 \\
4,421 \\
6 \\
4,147 \\
24,007\end{array}$ & $\begin{array}{r}96,770 \\
290 \\
26,296 \\
41,702 \\
0 \\
0 \\
41,702 \\
400 \\
0 \\
0 \\
17,547 \\
16,1000\end{array}$ & 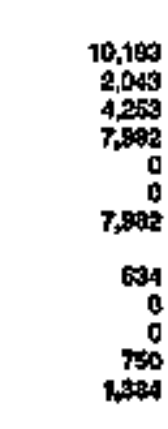 \\
\hline 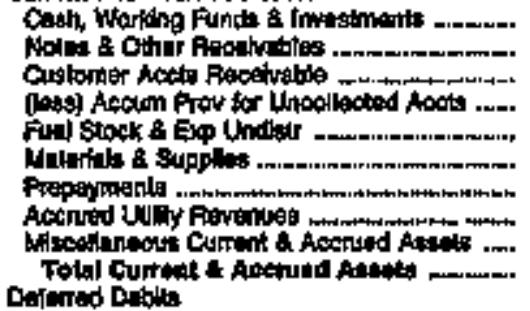 & $\begin{array}{r}575 \\
145 \\
1,014 \\
0 \\
0 \\
200 \\
37 \\
0 \\
1 \\
1,572\end{array}$ & $\begin{array}{r}709 \\
0 \\
1,584 \\
0 \\
0 \\
195 \\
100 \\
0 \\
2 \\
2,018\end{array}$ & $\begin{array}{r}1,172 \\
1+206 \\
714 \\
0 \\
0 \\
590 \\
0 \\
050 \\
0 \\
4,84\end{array}$ & $\begin{array}{r}2,051 \\
54 \\
1,217 \\
0 \\
0 \\
684 \\
103 \\
509 \\
0 \\
1,828\end{array}$ & $\begin{array}{r}759 \\
70,5 \\
1,690 \\
109 \\
650 \\
1,519 \\
108 \\
0 \\
698 \\
6404\end{array}$ & 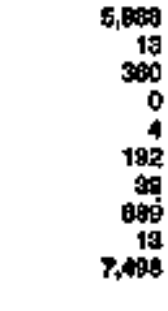 \\
\hline 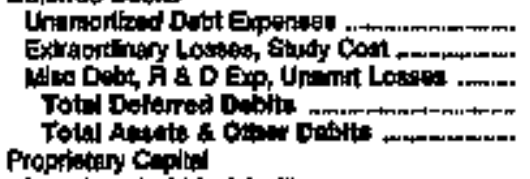 & $\begin{array}{r}0 \\
0 \\
107 \\
\text { imp } \\
900\end{array}$ & $\begin{array}{r}0 \\
0 \\
0 \\
0 \\
7,076\end{array}$ & $\begin{array}{r}509 \\
0 \\
0 \\
0,104\end{array}$ & $\begin{array}{r}105 \\
0 \\
0 \\
205 \\
42,765\end{array}$ & $\begin{array}{r}07 \\
0 \\
598 \\
67,740\end{array}$ & $\begin{array}{r}119 \\
0 \\
040 \\
952 \\
+7917\end{array}$ \\
\hline 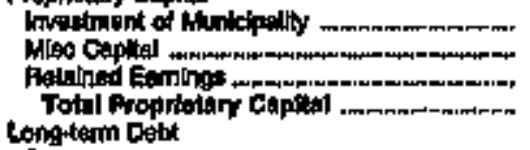 & $\begin{array}{r}0 \\
0 \\
4,136 \\
4,136\end{array}$ & $\begin{array}{r}0 \\
6 \\
6,014 \\
9,014\end{array}$ & $\begin{array}{r}7,302 \\
0 \\
20,647 \\
27,949\end{array}$ & $\begin{array}{r}0 \\
10,489 \\
t 6,069 \\
20,427\end{array}$ & $\begin{array}{r}179 \\
2,002 \\
97,299 \\
9,460\end{array}$ & $\begin{array}{r}0 \\
0 \\
10,078 \\
0,107\end{array}$ \\
\hline 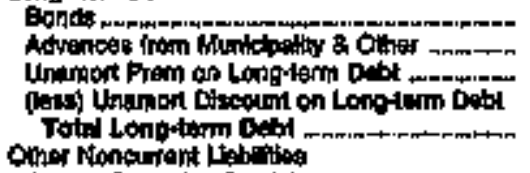 & $\begin{array}{r}407 \\
0 \\
0 \\
0,577\end{array}$ & $\begin{array}{l}0 \\
0 \\
0 \\
0 \\
0 \\
0\end{array}$ & $\begin{array}{r}9,480 \\
10,489 \\
0 \\
0 \\
19,979\end{array}$ & $\begin{array}{r}12,354 \\
0 \\
0 \\
210 \\
12,140\end{array}$ & $\begin{array}{r}25,625 \\
0 \\
0 \\
972 \\
25,459\end{array}$ & $\begin{array}{r}5,480 \\
0 \\
0 \\
283 \\
5,139\end{array}$ \\
\hline 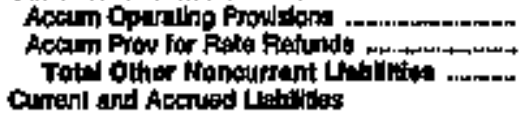 & $\begin{array}{l}0 \\
0 \\
0\end{array}$ & $\begin{array}{l}0 \\
0 \\
0 \\
0\end{array}$ & $\begin{array}{l}0 \\
0 \\
0\end{array}$ & $\begin{array}{l}0 \\
0 \\
0\end{array}$ & $\begin{array}{l}0 \\
0 \\
0\end{array}$ & $\begin{array}{r}402 \\
0 \\
+192\end{array}$ \\
\hline 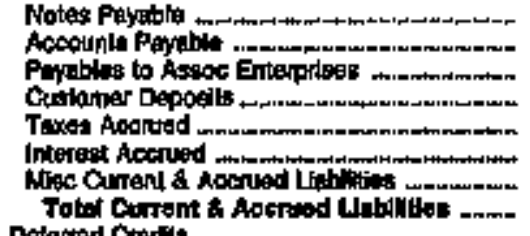 & $\begin{array}{r}0 \\
658 \\
0 \\
8 \\
0 \\
0 \\
74 \\
60\end{array}$ & $\begin{array}{r}0 \\
680 \\
0 \\
384 \\
t 2 \\
0 \\
4 \\
1,062\end{array}$ & $\begin{array}{r}0 \\
1,673 \\
24 \\
27 \\
68 \\
70 \\
140 \\
200\end{array}$ & $\begin{array}{r}0 \\
816 \\
0 \\
231 \\
0 \\
187 \\
840 \\
2906\end{array}$ & $\begin{array}{r}0 \\
1,304 \\
0 \\
411 \\
0 \\
600 \\
0 \\
2,035\end{array}$ & $\begin{array}{r}671 \\
0 \\
0 \\
417 \\
0 \\
225 \\
0 \\
1,308\end{array}$ \\
\hline 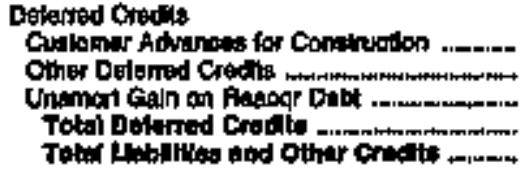 & $\begin{array}{r}0 \\
4 \\
0 \\
40 \\
405\end{array}$ & $\begin{array}{r}0 \\
0 \\
0 \\
0 \\
7,0 ; 6\end{array}$ & $\begin{array}{r}0 \\
0 \\
0 \\
0 \\
0\end{array}$ & $\begin{array}{r}0 \\
0 \\
0 \\
0 \\
0\end{array}$ & $\begin{array}{r}0 \\
486 \\
489 \\
47,742\end{array}$ & $\begin{array}{r}0 \\
0 \\
0 \\
0 \\
\operatorname{tr}\end{array}$ \\
\hline
\end{tabular}

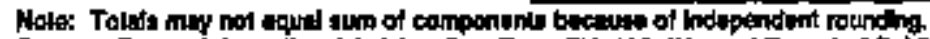

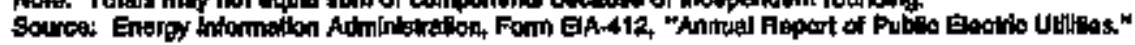


Table 22. Ealance sheet by Major U.s. Publlely Owned Electric Utilty Within state at End of Pertod, 1994 (Continued) (Thousand Dotlars)

\begin{tabular}{|c|c|c|c|c|c|c|}
\hline Viem & $\begin{array}{l}\text { Arkaneas } \\
\text { Jonimbors } \\
\text { Clty of } \\
\text { Dectimber at }\end{array}$ & 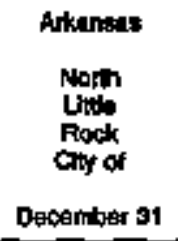 & $\begin{array}{l}\text { Arkensals } \\
\text { Orceola } \\
\text { City of } \\
\text { Decemper } 31\end{array}$ & 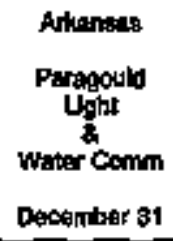 & 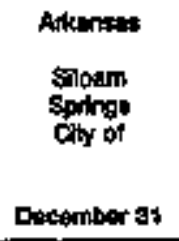 & 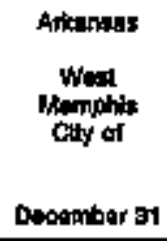 \\
\hline 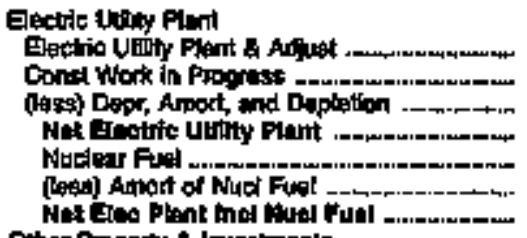 & $\begin{array}{r}141,809 \\
363 \\
65,074 \\
76 ;, 962 \\
0 \\
0 \\
76,9462\end{array}$ & $\begin{array}{r}151,612 \\
675 \\
34,400 \\
117,707 \\
0 \\
117,707\end{array}$ & $\begin{array}{r}12,783 \\
0 \\
6,1582 \\
11,381 \\
0 \\
0 \\
11,381\end{array}$ & $\begin{array}{r}27,155 \\
0 \\
9,738 \\
17,416 \\
0 \\
0 \\
17,418\end{array}$ & $\begin{array}{r}5,102 \\
1,502 \\
3,2006 \\
4,410 \\
0 \\
0 \\
4,418\end{array}$ & $\begin{array}{r}29,400 \\
0 \\
19,391 \\
16,010 \\
0 \\
0 \\
16,010\end{array}$ \\
\hline 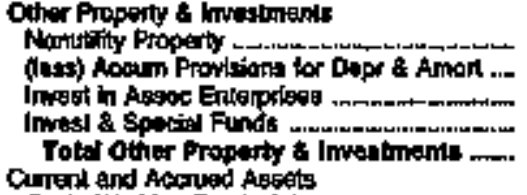 & $\begin{array}{r}357 \\
0 \\
18,713 \\
5,776 \\
212,256\end{array}$ & $\begin{array}{r}0 \\
0 \\
07,028 \\
37,0,0\end{array}$ & $\begin{array}{r}0 \\
0 \\
0 \\
3,028 \\
1026\end{array}$ & $\begin{array}{l}0 \\
0 \\
0 \\
0 \\
0\end{array}$ & $\begin{array}{l}0 \\
0 \\
0 \\
0 \\
0\end{array}$ & $\begin{array}{r}29,460 \\
17,040 \\
0 \\
11,400\end{array}$ \\
\hline 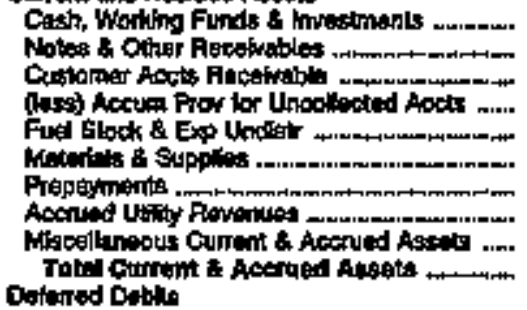 & $\begin{array}{r}18,159 \\
0 \\
2,785 \\
116 \\
1,724 \\
1,830 \\
546 \\
684 \\
100 \\
15,570\end{array}$ & $\begin{array}{r}11,401 \\
1,500 \\
5,306 \\
202 \\
0 \\
731 \\
200 \\
0 \\
19,045 \\
0\end{array}$ & $\begin{array}{r}77 \\
0 \\
749 \\
36 \\
149 \\
398 \\
27 \\
0 \\
9,46 \\
2,143\end{array}$ & $\begin{array}{r}3,498 \\
629 \\
055 \\
0 \\
0 \\
559 \\
21 \\
0 \\
0 \\
5,050\end{array}$ & $\begin{array}{r}1,697 \\
-7 \\
1,065 \\
0 \\
0 \\
0 \\
89 \\
07 \\
3,790\end{array}$ & $\begin{array}{r}24,750 \\
1,037 \\
1,700 \\
160 \\
3,45 \\
670 \\
100 \\
500 \\
0 \\
29,400\end{array}$ \\
\hline 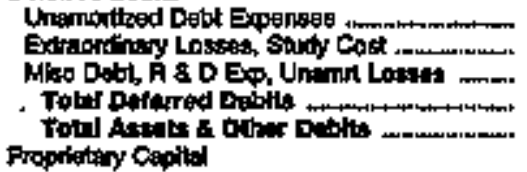 & $\begin{array}{r}657 \\
0 \\
0 \\
057 \\
+25,487\end{array}$ & $\begin{array}{r}2, \theta 21 \\
0 \\
0 \\
2,02 t \\
176,702\end{array}$ & $\begin{array}{r}102 \\
0 \\
0 \\
200 \\
15,054\end{array}$ & $\begin{array}{r}1,609 \\
0 \\
0 \\
1,699 \\
24,600\end{array}$ & $\begin{array}{r}0 \\
0 \\
0 \\
7,600\end{array}$ & $\begin{array}{r}860 \\
0 \\
1 \\
56,600\end{array}$ \\
\hline 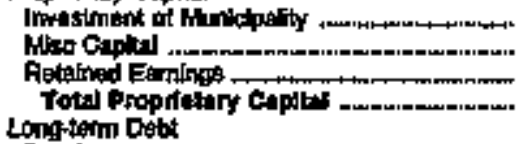 & $\begin{array}{r}0 \\
234 \\
66,434 \\
60,694\end{array}$ & $\begin{array}{r}0 \\
16,747 \\
15,747\end{array}$ & $\begin{array}{r}1,308 \\
11,108 \\
12,414\end{array}$ & $\begin{array}{r}0 \\
0 \\
25,305 \\
25,305\end{array}$ & $\begin{array}{r}0 \\
0 \\
6,107 \\
6,107\end{array}$ & $\begin{array}{r}2,746 \\
0 \\
32,051 \\
34,707\end{array}$ \\
\hline 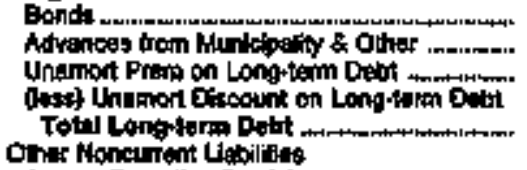 & $\begin{array}{r}45,135 \\
2,85 \\
0 \\
450 \\
47,704\end{array}$ & $\begin{array}{r}152,120 \\
0 \\
0 \\
0 \\
152,120\end{array}$ & $\begin{array}{r}3,005 \\
2,40 \\
0 \\
0 \\
3,045\end{array}$ & $\begin{array}{r}0,125 \\
0 \\
0 \\
0 \\
0,125\end{array}$ & $\begin{array}{l}0 \\
0 \\
0 \\
0 \\
0\end{array}$ & $\begin{array}{r}20,000 \\
0 \\
0 \\
024 \\
19,075\end{array}$ \\
\hline 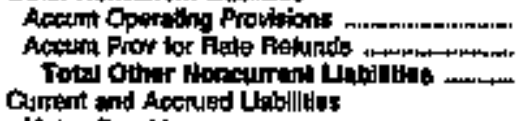 & $\begin{array}{r}\arg \\
0 \\
\cos \end{array}$ & $\begin{array}{l}0 \\
0 \\
0\end{array}$ & $\begin{array}{l}0 \\
0 \\
0\end{array}$ & $\begin{array}{l}0 \\
0 \\
0\end{array}$ & $\begin{array}{l}0 \\
0 \\
0\end{array}$ & \\
\hline 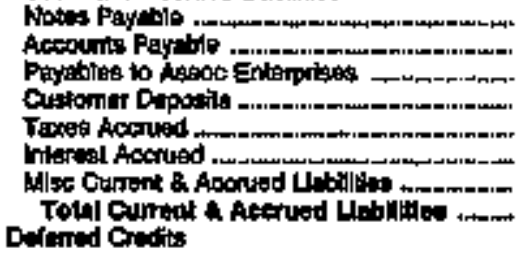 & $\begin{array}{r}3,201 \\
7,205 \\
0 \\
461 \\
73 \\
224 \\
249 \\
11,472\end{array}$ & $\begin{array}{r}0 \\
3,110 \\
0 \\
0 \\
0 \\
4,809 \\
810 \\
0,055\end{array}$ & $\begin{array}{r}0 \\
88 \\
27 \\
163 \\
17 \\
101 \\
0 \\
305\end{array}$ & $\begin{array}{r}0 \\
620 \\
0 \\
107 \\
0 \\
547 \\
21 \\
905\end{array}$ & $\begin{array}{r}0 \\
1,160 \\
51 \\
179 \\
70 \\
0 \\
42 \\
1,499\end{array}$ & $\begin{array}{r}0 \\
397 \\
165 \\
671 \\
0 \\
953 \\
910 \\
2,735\end{array}$ \\
\hline 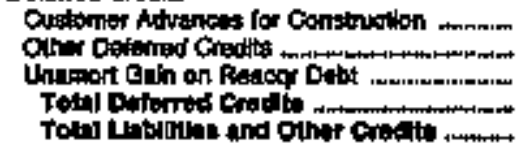 & $\begin{array}{r}0 \\
0 \\
0 \\
0 \\
125,997\end{array}$ & $\begin{array}{r}0 \\
0 \\
0 \\
0\end{array}$ & $\begin{array}{r}0 \\
0 \\
0 \\
0 \\
10,864\end{array}$ & $\begin{array}{r}0 \\
-10, \pi \pm 4 \\
-10,70 \\
24,600\end{array}$ & $\begin{array}{r}0 \\
0 \\
0 \\
0 \\
7,600\end{array}$ & $\begin{array}{r}0 \\
0 \\
0 \\
0 \\
0\end{array}$ \\
\hline
\end{tabular}

Noter Tolgts may nol equal swa ol components becalue of indapendent nounding

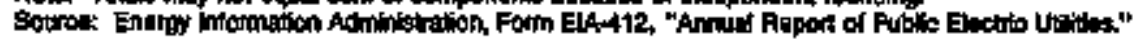


Table 22. Estance Sheet by Major U.S. Publlely Owned Electric Utulty Within State at End of Period, 1994 (Continued)

(Thousand Dollers)

\begin{tabular}{|c|c|c|c|c|c|c|}
\hline inem & $\begin{array}{l}\text { Galfomide } \\
\text { Afandedta } \\
\text { Cing of } \\
\text { Jure } 30\end{array}$ & $\begin{array}{l}\text { Coplinemis } \\
\text { Anghain } \\
\text { Chy of } \\
\text { June } 90\end{array}$ & $\begin{array}{l}\text { Carfotinia } \\
\text { Chase of } \\
\text { June so }\end{array}$ & $\begin{array}{l}\text { Caltionia } \\
\text { Burbent } \\
\text { tity of } \\
\text { June } 30\end{array}$ & 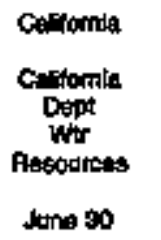 & $\begin{array}{l}\text { Callorifia } \\
\text { Collon } \\
\text { City of } \\
\text { Juns on }\end{array}$ \\
\hline 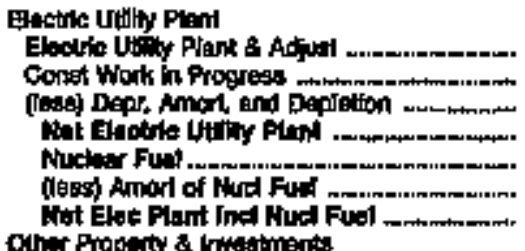 & $\begin{array}{r}47,510 \\
0 \\
13,370 \\
34,140 \\
0 \\
0 \\
34,140\end{array}$ & $\begin{array}{r}49,606 \\
20,687 \\
120,671 \\
396,8021 \\
40,291 \\
38,192 \\
400,020\end{array}$ & $\begin{array}{r}14,730 \\
0 \\
4,835 \\
9,000 \\
0 \\
0 \\
0,900\end{array}$ & $\begin{array}{r}168,098 \\
16,779 \\
86,245 \\
18,672 \\
0 \\
0 \\
86,572\end{array}$ & 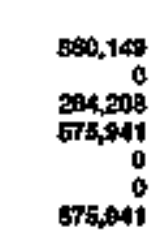 & $\begin{array}{r}13,505 \\
50 \\
5,951 \\
7,94 \\
0 \\
7,984\end{array}$ \\
\hline 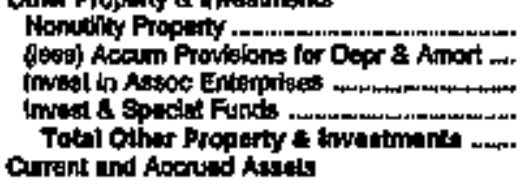 & $\begin{array}{r}0 \\
0 \\
0 \\
17,181 \\
17,181\end{array}$ & $\begin{array}{l}0 \\
0 \\
0 \\
0 \\
0\end{array}$ & $\begin{array}{r}0 \\
0,030 \\
0,0 \\
0,0\end{array}$ & $\begin{array}{l}0 \\
0 \\
0 \\
0 \\
0\end{array}$ & $\begin{array}{r}0 \\
0 \\
0 \\
70,572 \\
70,5 r 2\end{array}$ & $\begin{array}{l}0 \\
0 \\
0 \\
0 \\
0\end{array}$ \\
\hline 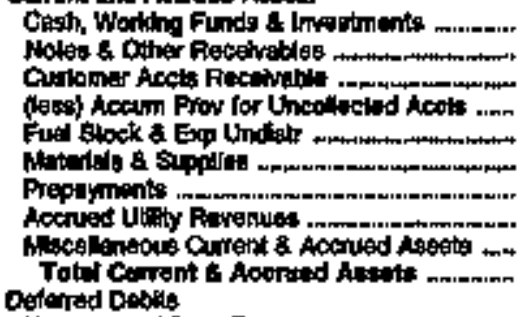 & 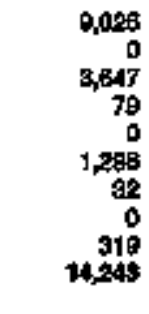 & $\begin{array}{r}205,240 \\
0 \\
24,189 \\
0 \\
0 \\
9,858 \\
1,840 \\
0 \\
2,779 \\
267,711\end{array}$ & $\begin{array}{r}15,747 \\
1,679 \\
2,072 \\
0 \\
0 \\
386 \\
0 \\
0 \\
0 \\
79,774\end{array}$ & $\begin{array}{r}20,002 \\
943 \\
14,200 \\
0 \\
0 \\
4,049 \\
2,341 \\
0 \\
0 \\
42,405\end{array}$ & $\begin{array}{r}204,8989 \\
12,809 \\
0 \\
0 \\
0 \\
4,891 \\
0 \\
0 \\
0 \\
20,68 \%\end{array}$ & $\begin{array}{r}0 \\
8,468 \\
1,111 \\
0 \\
0 \\
1,510 \\
0 \\
1,979 \\
3,024 \\
15,770\end{array}$ \\
\hline 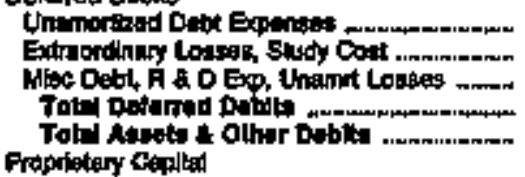 & $\begin{array}{r}100 \\
-246 \\
-149 \\
68,415\end{array}$ & $\begin{array}{r}28,909 \\
0 \\
679 \\
27,91 \\
69,152\end{array}$ & $\begin{array}{r}0 \\
0 \\
0 \\
0 \\
0,518\end{array}$ & $\begin{array}{r}562 \\
0 \\
0 \\
131,560\end{array}$ & $\begin{array}{r}0 \\
0 \\
270,692 \\
279,592 \\
1,140,672\end{array}$ & $\begin{array}{r}0 \\
0 \\
0 \\
0 \\
2 s, 73 \%\end{array}$ \\
\hline 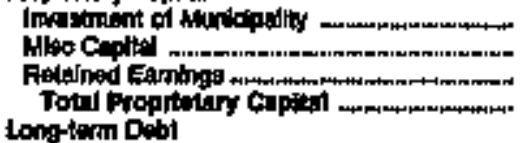 & $\begin{array}{r}0 \\
11,747 \\
41,076 \\
58,007\end{array}$ & $\begin{array}{r}14,699 \\
139,009 \\
198,099\end{array}$ & $\begin{array}{r}0 \\
041 \\
36,604 \\
36,145\end{array}$ & $\begin{array}{r}6,228 \\
69,273 \\
74,008\end{array}$ & $\begin{array}{r}36,676 \\
0 \\
-27,388 \\
8,288\end{array}$ & $\begin{array}{r}0 \\
0 \\
19,180 \\
19,160\end{array}$ \\
\hline 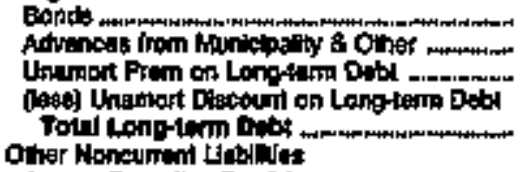 & $\begin{array}{r}0 \\
2,600 \\
0 \\
0 \\
0,600\end{array}$ & $\begin{array}{r}330,721 \\
5,586 \\
0 \\
0,967 \\
393,350\end{array}$ & $\begin{array}{r}0 \\
138 \\
0 \\
0 \\
135\end{array}$ & $\begin{array}{r}44,215 \\
0 \\
0 \\
160 \\
44006\end{array}$ & $\begin{array}{r}670,716 \\
0 \\
0 \\
20,017 \\
050,090\end{array}$ & $\begin{array}{r}60 \\
0 \\
0 \\
0 \\
600\end{array}$ \\
\hline 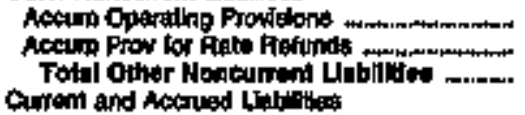 & $\begin{array}{l}0 \\
0 \\
0\end{array}$ & $\begin{array}{l}0 \\
0 \\
0\end{array}$ & $\begin{array}{l}0 \\
0 \\
0\end{array}$ & $\begin{array}{l}0 \\
0 \\
0\end{array}$ & $\begin{array}{r}80,087 \\
0 \\
80,097\end{array}$ & $\begin{array}{l}0 \\
0 \\
0\end{array}$ \\
\hline 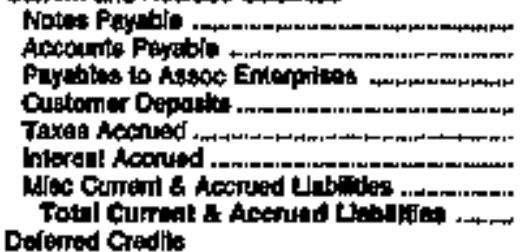 & $\begin{array}{r}0 \\
802 \\
-9 \\
210 \\
0 \\
46 \\
1,774 \\
2,84\end{array}$ & $\begin{array}{r}38,496 \\
1,106 \\
0 \\
4,587 \\
0 \\
4,970 \\
12,386 \\
195,457\end{array}$ & $\begin{array}{r}0 \\
1,001 \\
0 \\
1,150 \\
0 \\
0 \\
0 \\
0 \\
0,01\end{array}$ & $\begin{array}{r}0 \\
8,890 \\
3,455 \\
589 \\
0 \\
209 \\
13000\end{array}$ & $\begin{array}{r}2,065 \\
-20,5 \% 5 \\
0 \\
0 \\
0 \\
7,574 \\
21,547 \\
11,594\end{array}$ & $\begin{array}{r}600 \\
305 \\
702 \\
19 \\
0 \\
2,209 \\
0 \\
8922\end{array}$ \\
\hline 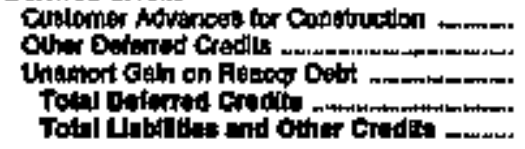 & $\begin{array}{r}0 \\
0 \\
0 \\
080 \\
0,415\end{array}$ & $\begin{array}{r}28,250 \\
15,3104 \\
0 \\
40,450 \\
605,152\end{array}$ & $\begin{array}{r}0 \\
0 \\
0 \\
0 \\
\text { sas, }\end{array}$ & $\begin{array}{r}0 \\
0 \\
0 \\
0 \\
0\end{array}$ & 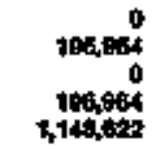 & $\begin{array}{r}0 \\
0 \\
0 \\
0 \\
0\end{array}$ \\
\hline
\end{tabular}

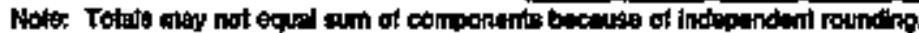

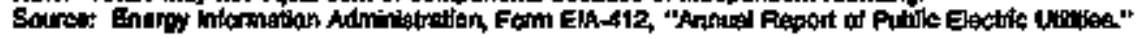


Table 22. Balance Sheet by Majpr U.S. Publioly Owned Electric Litlity Whithin State at End of Porlod, 1994 (Continued) (Thousand Dollars)

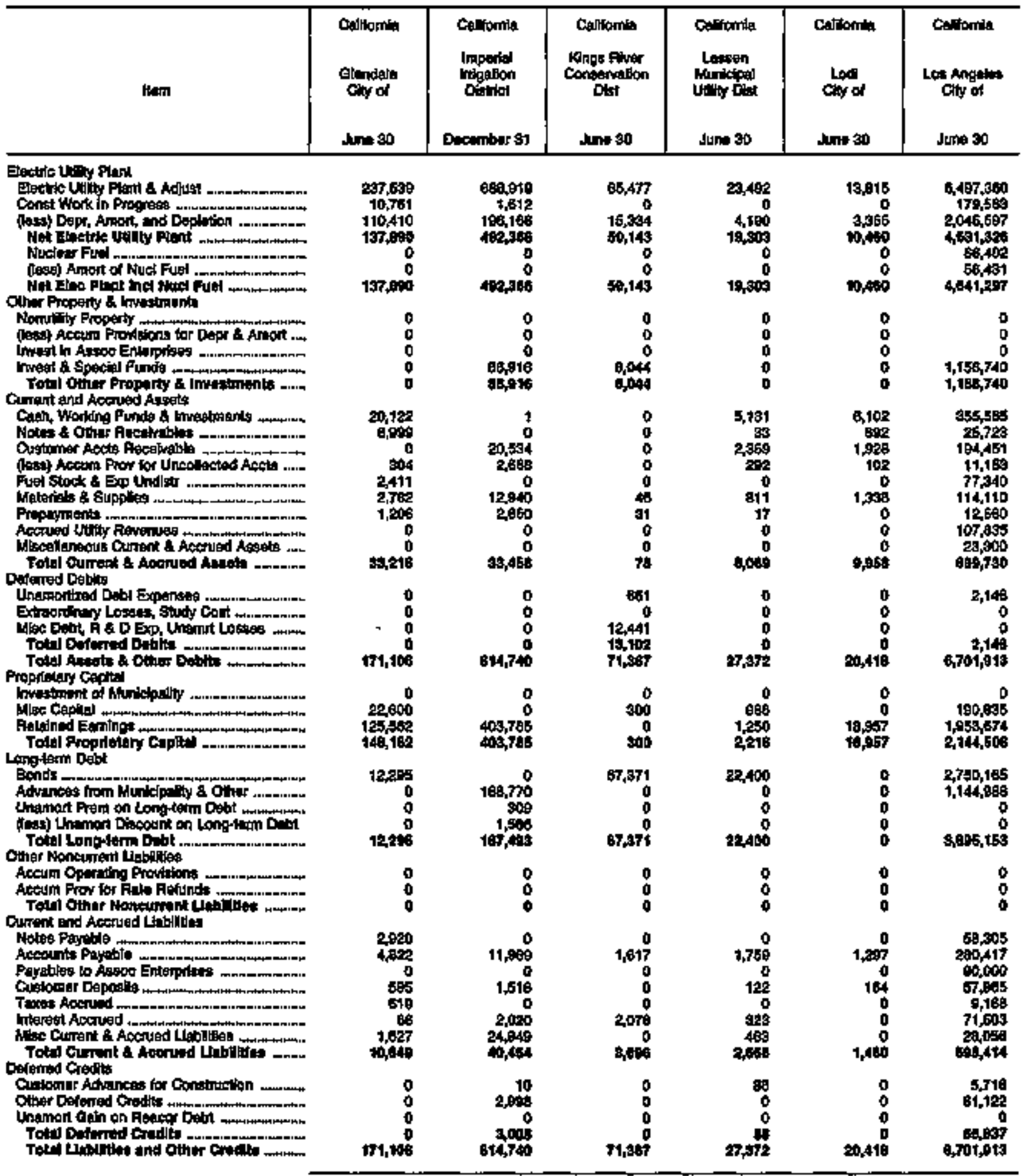

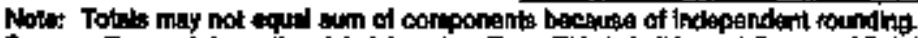

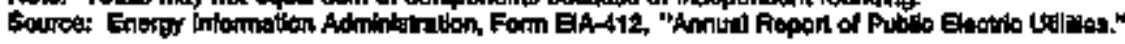


Table 22. Balance Sheat by Major U.S. Publlely Owned Electric Utility Within State at End of Period, 1994 (Continued)

(Thousand Dollars)

\begin{tabular}{|c|c|c|c|c|c|c|}
\hline |lerr| & 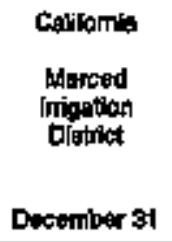 & 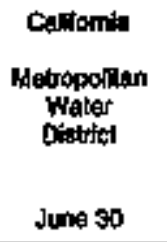 & 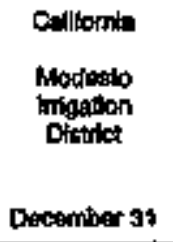 & $\begin{array}{l}\text { Cilfomla } \\
\text { Msp } \\
\text { Publit } \\
\text { Power } \\
\text { Aoungy } \\
\text { Decanaber } 31\end{array}$ & 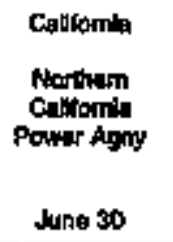 & $\begin{array}{l}\text { Callowida } \\
\text { Oakdeld } 8 \\
\text { Sounth } \\
\text { Son Jowquin } \\
\text { Decomber } 31\end{array}$ \\
\hline 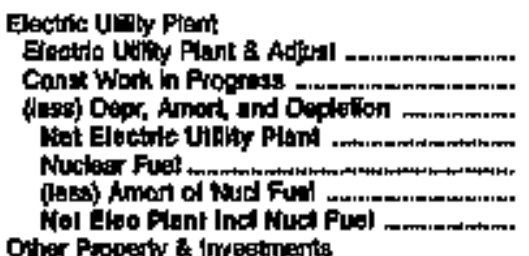 & $\begin{array}{r}54,938 \\
0 \\
22,7+8 \\
32,219 \\
0 \\
0 \\
32,210\end{array}$ & $\begin{array}{r}103,123 \\
22,014 \\
22,119 \\
109,024 \\
0 \\
0 \\
109,024\end{array}$ & 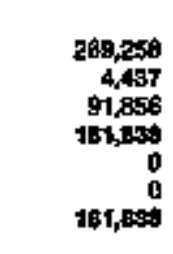 & $\begin{array}{r}275,002 \\
47,090 \\
79,638 \\
243,304 \\
0 \\
0 \\
243,904\end{array}$ & $\begin{array}{r}9 t 5,581 \\
54,4100 \\
262,546 \\
737,445 \\
0 \\
0 \\
737,445\end{array}$ & $\begin{array}{r}60,545 \\
344 \\
23,581 \\
3,927 \\
0 \\
37,327\end{array}$ \\
\hline 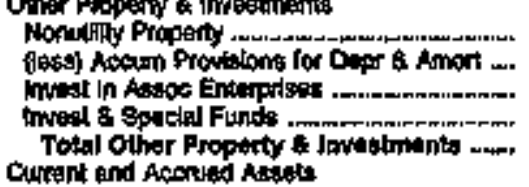 & 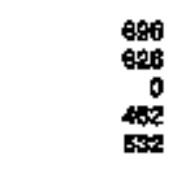 & $\begin{array}{r}5,251,506 \\
1,641,061 \\
0 \\
7,79,797 \\
4,397,971\end{array}$ & $\begin{array}{r}0 \\
0 \\
-23,259 \\
111,457 \\
69,204\end{array}$ & $\begin{array}{r}15,983 \\
0 \\
0 \\
123,676 \\
139,059\end{array}$ & $\begin{array}{r}\text { 0 } \\
0 \\
0 \\
649,049 \\
640,040\end{array}$ & $\begin{array}{l}0 \\
0 \\
0 \\
0\end{array}$ \\
\hline 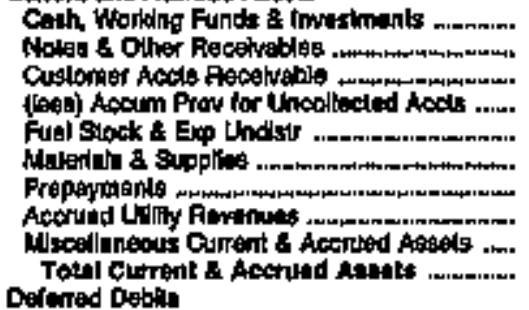 & $\begin{array}{r}198 \\
22,005 \\
0 \\
0 \\
0 \\
0 \\
109 \\
0 \\
1,597 \\
21,290\end{array}$ & $\begin{array}{r}516,657 \\
46,340 \\
119,955 \\
0 \\
427 \\
18,251 \\
0 \\
0 \\
0 \\
696,930\end{array}$ & $\begin{array}{r}90,1398 \\
3,869 \\
9,046 \\
0 \\
2,77 \\
2,847 \\
5,29 \\
0 \\
4,102 \\
110,599\end{array}$ & $\begin{array}{r}27,225 \\
3,698 \\
0 \\
0 \\
1,320 \\
1,096 \\
330 \\
0 \\
1,543 \\
35,120\end{array}$ & $\begin{array}{r}30,651 \\
70 \\
1,497 \\
0 \\
0 \\
3,754 \\
506 \\
0 \\
9,941 \\
49,800\end{array}$ & $\begin{array}{r}18,350 \\
1,070 \\
0 \\
0 \\
0 \\
0 \\
148 \\
0 \\
178 \\
1,746\end{array}$ \\
\hline 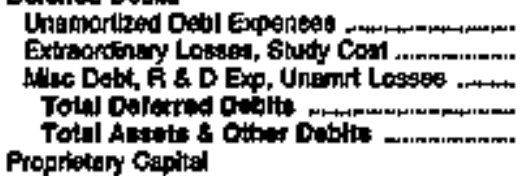 & $\begin{array}{r}0 \\
0 \\
0 \\
0 \\
0\end{array}$ & $\begin{array}{r}4,763 \\
0 \\
218,120 \\
278,663 \\
5,420,008\end{array}$ & $\begin{array}{r}4,090 \\
0 \\
0 \\
4,090 \\
594,721\end{array}$ & $\begin{array}{r}10,431 \\
0 \\
0 \\
10,431 \\
427,502\end{array}$ & $\begin{array}{r}22,860 \\
0 \\
402,009 \\
42,942 \\
1,0,5,005\end{array}$ & $\begin{array}{r}0 \\
0 \\
0 \\
0 \\
57,073\end{array}$ \\
\hline 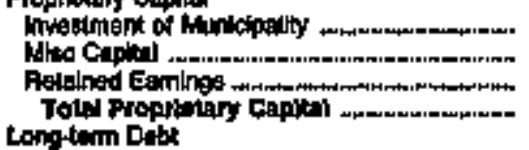 & $\begin{array}{r}10,819 \\
0 \\
-1,0 ; 0 \\
9,164\end{array}$ & $\begin{array}{r}0 \\
0 \\
2,800,595 \\
2,801,500\end{array}$ & $\begin{array}{r}0 \\
0 \\
100,498 \\
100,436\end{array}$ & $\begin{array}{r}0 \\
0 \\
-20,0,002 \\
-200,042\end{array}$ & $\begin{array}{r}0 \\
0 \\
15,205 \\
15,265\end{array}$ & $\begin{array}{r}0 \\
05,690 \\
55,650\end{array}$ \\
\hline 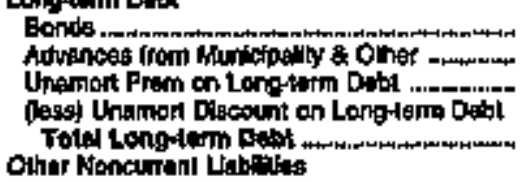 & $\begin{array}{r}21,610 \\
0 \\
0 \\
0 \\
21,810\end{array}$ & $\begin{array}{r}2,039,925 \\
189,770 \\
4,783 \\
37,736 \\
2,196,746\end{array}$ & $\begin{array}{r}58,620 \\
208,939 \\
0 \\
10,204 \\
269647\end{array}$ & $\begin{array}{r}4,4736 \\
0 \\
0 \\
34,460 \\
612,949\end{array}$ & $\begin{array}{r}1,746,075 \\
0 \\
2,703 \\
59,981 \\
1,000,002\end{array}$ & $\begin{array}{r}0 \\
700 \\
0 \\
0 \\
703\end{array}$ \\
\hline 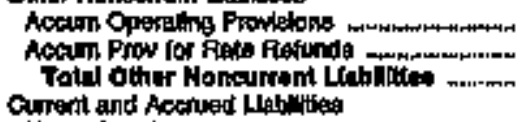 & $\begin{array}{r}347 \\
0 \\
347\end{array}$ & $\begin{array}{l}0 \\
0 \\
0\end{array}$ & $\begin{array}{r}5,109 \\
0 \\
5,10\end{array}$ & $\begin{array}{r}12,800 \\
0 \\
12,000\end{array}$ & 0 & $\begin{array}{l}0 \\
0 \\
0\end{array}$ \\
\hline 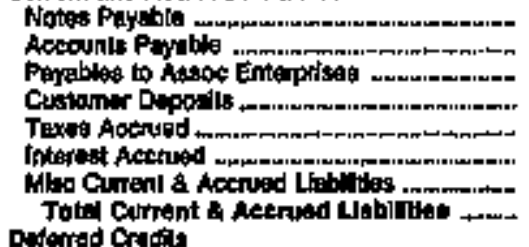 & $\begin{array}{r}0 \\
1,192 \\
408 \\
0 \\
1 \\
413 \\
0 \\
2,013\end{array}$ & $\begin{array}{r}0 \\
356,102 \\
0 \\
19,709 \\
0 \\
46,760 \\
0 \\
42,465\end{array}$ & $\begin{array}{r}0 \\
12,901 \\
0 \\
285 \\
18 \\
4,081 \\
1,289 \\
10,514\end{array}$ & $\begin{array}{r}0 \\
4,499 \\
0 \\
0 \\
0 \\
20,496 \\
5,189 \\
30,915\end{array}$ & $\begin{array}{r}0 \\
16,677 \\
198 \\
0 \\
28 \\
51,190 \\
67,058\end{array}$ & $\begin{array}{r}0 \\
217 \\
0 \\
0 \\
0 \\
0 \\
524 \\
740\end{array}$ \\
\hline 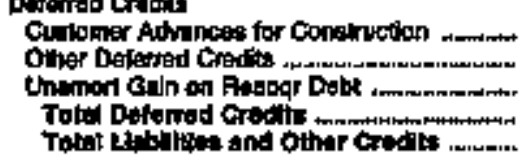 & $\begin{array}{r}0 \\
28,911 \\
0 \\
23,9 t 1 \\
97,044\end{array}$ & $\begin{array}{r}0 \\
0 \\
0 \\
0 \\
0,40,909\end{array}$ & $\begin{array}{r}157 \\
2,950 \\
3,0 \\
384,721\end{array}$ & $\begin{array}{r}0 \\
0 \\
0 \\
0 \\
427,992\end{array}$ & $\begin{array}{r}\$, 922 \\
78,058 \\
0 \\
81,990 \\
1,058,005\end{array}$ & $\begin{array}{r}0 \\
0 \\
0 \\
0 \\
67,070\end{array}$ \\
\hline
\end{tabular}

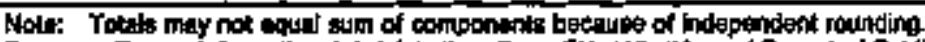

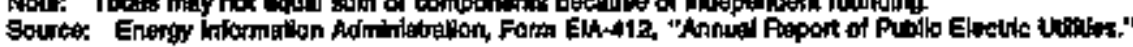


Table 22. Balance Sheet by Major U.S. Publicly Owned Electric Utilly Within State at End of Perlod, 1994 (Thousand Dollars)

\begin{tabular}{|c|c|c|c|c|c|c|}
\hline Ikem & 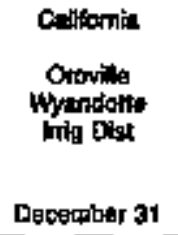 & $\begin{array}{l}\text { Gablomia } \\
\text { Palo Allo } \\
\text { CHy of } \\
\text { Jurig on }\end{array}$ & $\begin{array}{l}\text { Caltionla } \\
\text { Patediona } \\
\text { Ciny of } \\
\text { Jume } \$ 0\end{array}$ & 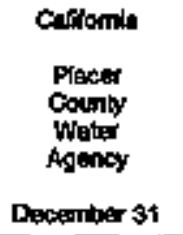 & $\begin{array}{l}\text { Coiffornta } \\
\text { Fiodeling } \\
\text { Chy of } \\
\text { June so }\end{array}$ & $\begin{array}{l}\text { Corliomian } \\
\text { Riverelda } \\
\text { Clly of } \\
\text { June } 30\end{array}$ \\
\hline 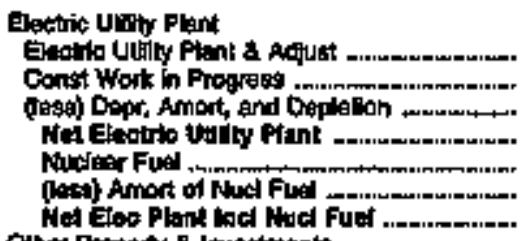 & $\begin{array}{r}29,477 \\
762 \\
37,705 \\
47,524 \\
0 \\
0 \\
47,524\end{array}$ & $\begin{array}{r}115,034 \\
+0,047 \\
45,010 \\
10,071 \\
0 \\
0 \\
=0,071\end{array}$ & $\begin{array}{r}295,800 \\
13,340 \\
111,774 \\
137,355 \\
0 \\
0 \\
137,385\end{array}$ & $\begin{array}{r}17,455 \\
189 \\
42,970 \\
74,674 \\
0 \\
0 \\
74,674\end{array}$ & $\begin{array}{r}135,495 \\
45,084 \\
43,925 \\
137,549 \\
0 \\
0 \\
137,698\end{array}$ & $\begin{array}{r}284,487 \\
25,600 \\
103,224 \\
208,969 \\
5,135 \\
1,260 \\
210,920\end{array}$ \\
\hline 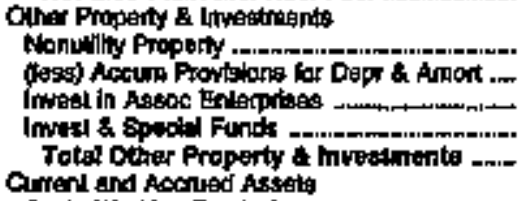 & $\begin{array}{l}0 \\
0 \\
0 \\
0\end{array}$ & $\begin{array}{l}\mathbf{0} \\
\mathbf{0} \\
\mathbf{0} \\
\mathbf{0} \\
\mathbf{0}\end{array}$ & $\begin{array}{l}0 \\
0 \\
0 \\
0 \\
0\end{array}$ & $\begin{array}{r}0 \\
0 \\
0 \\
1,205 \\
1,226\end{array}$ & $\begin{array}{r}0 \\
0 \\
19 \\
38,056 \\
38,075\end{array}$ & $\begin{array}{r}0 \\
0 \\
0 \\
20,720\end{array}$ \\
\hline 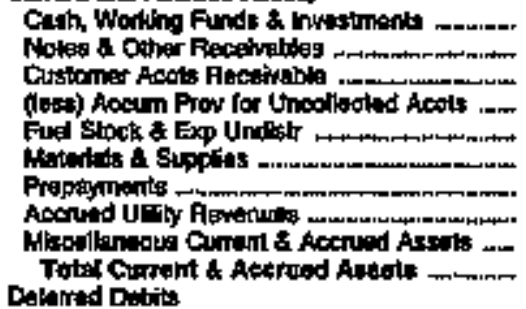 & $\begin{array}{r}4,688 \\
120 \\
0 \\
0 \\
0 \\
0 \\
64 \\
0 \\
0 \\
4,842\end{array}$ & $\begin{array}{r}51,302 \\
7,740 \\
0 \\
244 \\
0 \\
0 \\
0 \\
0 \\
0 \\
66,818\end{array}$ & $\begin{array}{r}52,7 \mathrm{F2} \\
0 \\
14,224 \\
397 \\
3,506 \\
3,761 \\
4,307 \\
0 \\
0 \\
79,244\end{array}$ & $\begin{array}{r}1,779 \\
0 \\
56 \\
0 \\
0 \\
0 \\
305 \\
0 \\
14 \\
2,184\end{array}$ & $\begin{array}{r}20,169 \\
9,007 \\
3,615 \\
01 \\
0 \\
4,429 \\
0 \\
2,290 \\
2,292 \\
39,928\end{array}$ & $\begin{array}{r}07,085 \\
0 \\
21,472 \\
1,484 \\
0 \\
509 \\
4,260 \\
0 \\
1,349 \\
124,042\end{array}$ \\
\hline 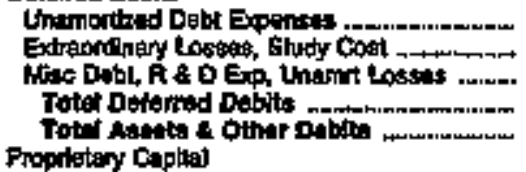 & $\begin{array}{r}0 \\
0 \\
0 \\
0 \\
52,367\end{array}$ & $\begin{array}{r}0 \\
0 \\
0 \\
0 \\
0\end{array}$ & $\begin{array}{r}0 \\
0 \\
0 \\
0 \\
0 \\
215,008\end{array}$ & $\begin{array}{r}0 \\
0 \\
0 \\
0 \\
\operatorname{rag}, 090\end{array}$ & $\begin{array}{r}2,598 \\
9,390 \\
5,098 \\
2+8,436\end{array}$ & $\begin{array}{r}2,087 \\
0 \\
504 \\
2,591 \\
360,189\end{array}$ \\
\hline 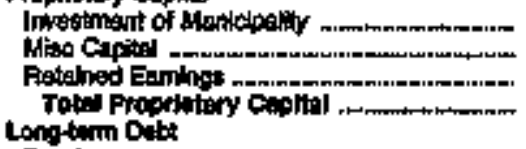 & $\begin{array}{r}0 \\
0 \\
3,009 \\
3,999\end{array}$ & $\begin{array}{r}0 \\
17,180 \\
118,350 \\
136,460\end{array}$ & $\begin{array}{r}0 \\
0 \\
128,300 \\
128,360\end{array}$ & $\begin{array}{r}0 \\
0 \\
10,891 \\
10,891\end{array}$ & $\begin{array}{l}0 \\
24,947 \\
33,080 \\
68,012\end{array}$ & $\begin{array}{r}0 \\
37,898 \\
65,648 \\
100,466\end{array}$ \\
\hline 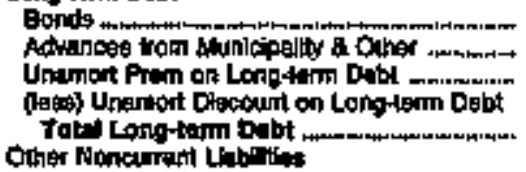 & $\begin{array}{r}4,446 \\
0 \\
2,516 \\
1,128 \\
45,9098\end{array}$ & $\begin{array}{l}0 \\
0 \\
0 \\
0 \\
0 \\
0\end{array}$ & $\begin{array}{r}74,305 \\
0 \\
0 \\
0 \\
74,705\end{array}$ & $\begin{array}{r}450 \\
430 \\
0 \\
03,123\end{array}$ & $\begin{array}{r}148,6662 \\
4,072 \\
0 \\
486 \\
151,626\end{array}$ & $\begin{array}{r}188,606 \\
72 \\
0 \\
3,696 \\
184,712\end{array}$ \\
\hline 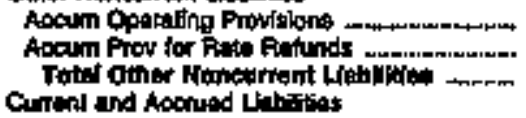 & $\begin{array}{l}0 \\
0 \\
0\end{array}$ & $\begin{array}{r}806 \\
006\end{array}$ & $\begin{array}{l}0 \\
0 \\
0\end{array}$ & $\begin{array}{r}168 \\
0 \\
158\end{array}$ & $\begin{array}{l}0 \\
0 \\
0\end{array}$ & $\begin{array}{l}0 \\
0 \\
0\end{array}$ \\
\hline 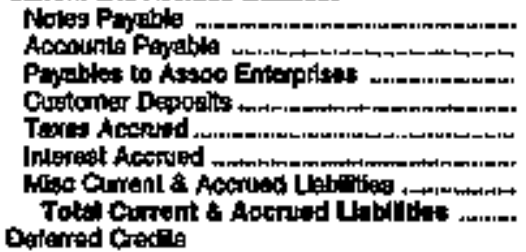 & $\begin{array}{r}07 \\
0 \\
0 \\
0 \\
1,074 \\
1,850 \\
2,585\end{array}$ & $\begin{array}{r}0 \\
2,076 \\
0 \\
100 \\
0 \\
0 \\
244 \\
2,400\end{array}$ & $\begin{array}{r}0 \\
4,008 \\
0 \\
1,918 \\
0 \\
1,798 \\
5,209 \\
12,924\end{array}$ & $\begin{array}{r}1,080 \\
1,060 \\
27 \\
0 \\
0 \\
1,178 \\
906 \\
3,017\end{array}$ & $\begin{array}{r}0 \\
0,390 \\
0 \\
0 \\
0 \\
1,016 \\
2,397 \\
8,748\end{array}$ & $\begin{array}{r}0 \\
5,015 \\
0 \\
2,018 \\
0 \\
2,014 \\
20,349 \\
31,415\end{array}$ \\
\hline 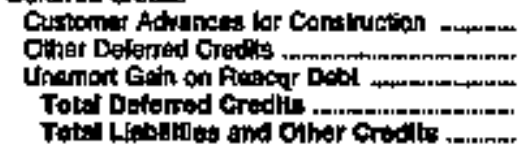 & $\begin{array}{r}0 \\
0 \\
0 \\
0 \\
52,397\end{array}$ & $\begin{array}{r}0 \\
0 \\
0 \\
0 \\
126,869\end{array}$ & $\begin{array}{r}0 \\
0 \\
0 \\
0 \\
215,000\end{array}$ & $\begin{array}{r}0 \\
0 \\
0 \\
0 \\
70,062\end{array}$ & $\begin{array}{r}50 \\
0 \\
0 \\
50 \\
218,40\end{array}$ & $\begin{array}{r}48,074 \\
0 \\
48,074 \\
386,100\end{array}$ \\
\hline
\end{tabular}

Not: Tot:s may not equal sum of compenents becaulse of independent raunding

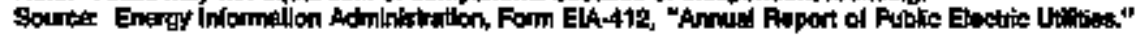


Table 22. Bakance sheet by Hajor U.S. Publicly Owned Electric Utility Within state at End of Period, 1994

(Thousand Dollars)

\begin{tabular}{|c|c|c|c|c|c|c|}
\hline Nen & 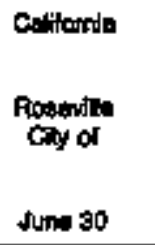 & $\begin{array}{l}\text { Cuttomia } \\
\text { Sactamento } \\
\text { Hinicipal } \\
\text { Ull Digt } \\
\text { Oecamber s1 }\end{array}$ & 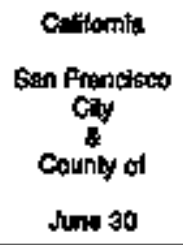 & 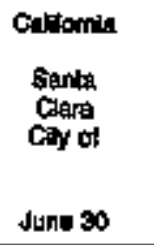 & 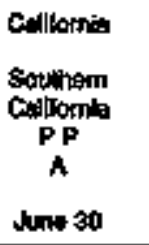 & 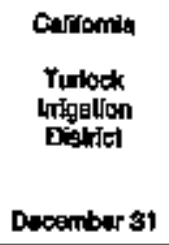 \\
\hline 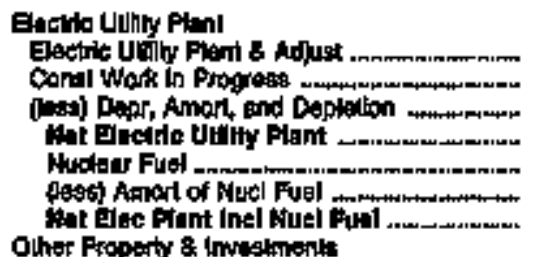 & $\begin{array}{r}61,305 \\
606 \\
13,3608 \\
66,545 \\
0 \\
0 \\
06,645\end{array}$ & 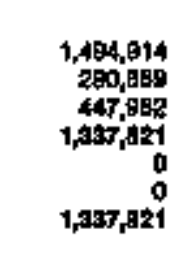 & $\begin{array}{r}446,745 \\
9,505 \\
199,341 \\
26 f, 911 \\
0 \\
0 \\
26 x, 911\end{array}$ & $\begin{array}{r}207,701 \\
3,521 \\
59,429 \\
301,794 \\
0 \\
0 \\
001,724\end{array}$ & $\begin{array}{r}1,511,271 \\
102,4015 \\
354,003 \\
1,2,59,073 \\
29,448 \\
13,900 \\
1,274,391\end{array}$ & $\begin{array}{r}222,499 \\
5,667 \\
70,659 \\
157,819 \\
0 \\
0 \\
157,819\end{array}$ \\
\hline 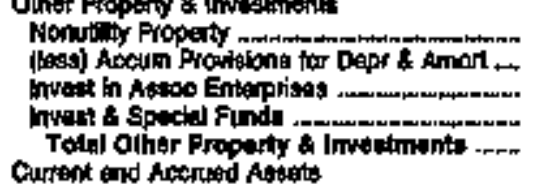 & $\begin{array}{r}0 \\
0 \\
0 \\
1,510 \\
1,610\end{array}$ & $\begin{array}{r}0 \\
0 \\
127,712 \\
311,244 \\
40,057\end{array}$ & $\begin{array}{r}410 \\
0 \\
0 \\
0 \\
410\end{array}$ & $\begin{array}{r}0 \\
0 \\
30,896 \\
5,000 \\
35,969\end{array}$ & $\begin{array}{l}0 \\
0 \\
0 \\
0 \\
0\end{array}$ & $\begin{array}{r}25,440 \\
0 \\
0 \\
49,540 \\
60,4 \% 8\end{array}$ \\
\hline 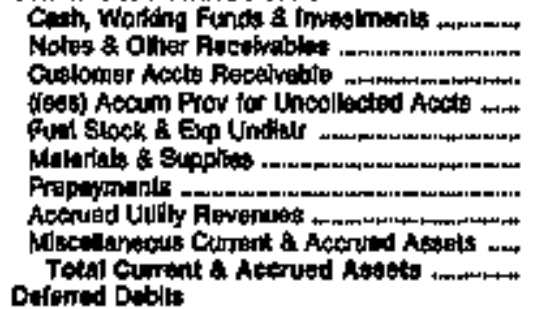 & $\begin{array}{r}15,911 \\
805 \\
0 \\
0 \\
0 \\
2,309 \\
5,979 \\
9,359 \\
0 \\
31,391\end{array}$ & 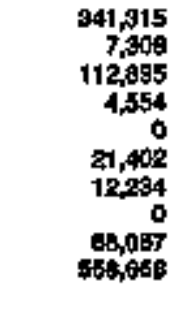 & $\begin{array}{r}30,230 \\
267 \\
5,396 \\
0 \\
0 \\
1,992 \\
2 \\
0 \\
0 \\
37,896\end{array}$ & $\begin{array}{r}199,743 \\
4,084 \\
19,875 \\
29 \\
0 \\
2,987 \\
0 \\
0 \\
9,978 \\
221,807\end{array}$ & $\begin{array}{r}1,245,959 \\
0 \\
6,707 \\
0 \\
0 \\
15,30 \% \\
42,107 \\
0 \\
305,5,968 \\
1,703,577\end{array}$ & $\begin{array}{r}30,197 \\
590 \\
20,770 \\
401 \\
0 \\
1,963 \\
1,472 \\
0 \\
44,692\end{array}$ \\
\hline 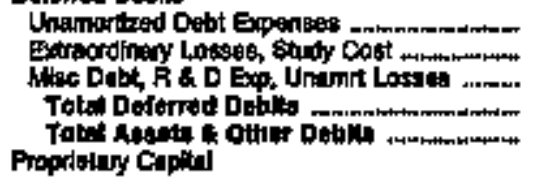 & $\begin{array}{r}207 \\
0 \\
22 \\
220 \\
90,675\end{array}$ & $\begin{array}{r}36,059 \\
0 \\
1,005,409 \\
1,040,411 \\
3,375,847\end{array}$ & $\begin{array}{r}0 \\
0 \\
0 \\
0 \\
0\end{array}$ & $\begin{array}{r}0 \\
0 \\
0 \\
0 \\
459,590\end{array}$ & $\begin{array}{r}453,078 \\
0 \\
0 \\
460,078 \\
2,130,884\end{array}$ & $\begin{array}{r}2,748 \\
0 \\
12,951 \\
22,596 \\
293,997\end{array}$ \\
\hline 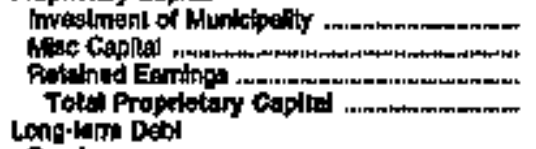 & $\begin{array}{r}0 \\
0 \\
95,044 \\
03024\end{array}$ & $\begin{array}{r}0 \\
-12,208 \\
227,782 \\
27,5,54\end{array}$ & $\begin{array}{r}0 \\
44,132 \\
247,897 \\
21,584\end{array}$ & $\begin{array}{r}644 \\
4 \\
205,048 \\
205,991\end{array}$ & $\begin{array}{l}0 \\
0 \\
0 \\
0\end{array}$ & 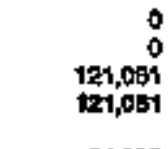 \\
\hline 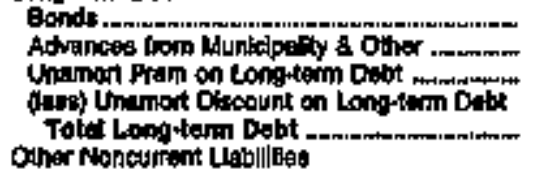 & $\begin{array}{r}8,705 \\
0 \\
0 \\
0 \\
8,706\end{array}$ & $\begin{array}{r}2,213,310 \\
17,026 \\
0 \\
39,574 \\
2,1 \%, 701\end{array}$ & $\begin{array}{r}0 \\
1,479 \\
0 \\
0 \\
1,476\end{array}$ & $\begin{array}{r}239,909 \\
0 \\
5 \\
5,914 \\
205,994\end{array}$ & $\begin{array}{r}3,607,065 \\
0 \\
0 \\
329,024 \\
3,270,04 t\end{array}$ & $\begin{array}{r}64,003 \\
63,475 \\
0 \\
4,278 \\
143,182\end{array}$ \\
\hline 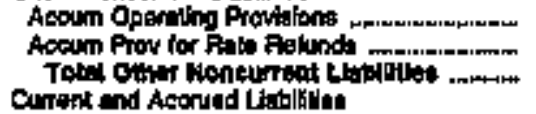 & $\begin{array}{r}692 \\
0 \\
692\end{array}$ & $\begin{array}{r}7,257 \\
0 \\
7,207\end{array}$ & $\begin{array}{l}0 \\
0 \\
0\end{array}$ & $\begin{array}{l}0 \\
0 \\
0\end{array}$ & $\begin{array}{l}0 \\
0 \\
0\end{array}$ & $\begin{array}{r}0 \\
-605 \\
-805\end{array}$ \\
\hline 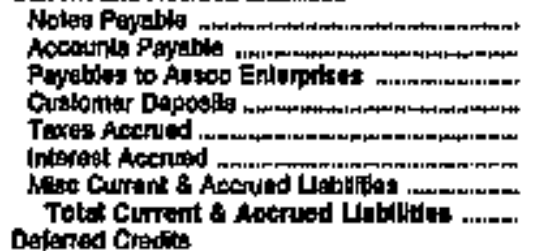 & $\begin{array}{r}0 \\
959 \\
0 \\
250 \\
0 \\
220 \\
1,724\end{array}$ & $\begin{array}{r}196,191 \\
113,360 \\
0 \\
7,8060 \\
4,890 \\
35,891 \\
99,840 \\
455,201\end{array}$ & $\begin{array}{r}0 \\
5,327 \\
0 \\
189 \\
0 \\
0 \\
1,557 \\
7,074\end{array}$ & $\begin{array}{r}2,800 \\
10,601 \\
0 \\
0 \\
0 \\
5,440 \\
0 \\
10,005\end{array}$ & $\begin{array}{r}0 \\
14,037 \\
0 \\
0 \\
0 \\
84,988 \\
59,120 \\
152,940\end{array}$ & $\begin{array}{r}4,405 \\
9,006 \\
0 \\
289 \\
0 \\
3,050 \\
6,040 \\
24,550\end{array}$ \\
\hline 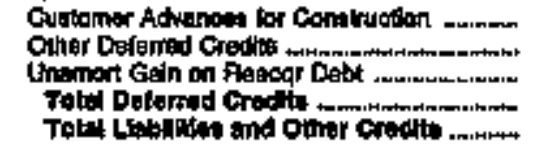 & $\begin{array}{r}0 \\
5,603 \\
0 \\
9,693 \\
99,695\end{array}$ & $\begin{array}{r}5,447 \\
404,866 \\
20,760 \\
191,094 \\
3,375,697\end{array}$ & $\begin{array}{r}110 \\
55 \\
0 \\
774 \\
300,266\end{array}$ & $\begin{array}{r}0 \\
0 \\
0 \\
0 \\
000\end{array}$ & $\begin{array}{r}0 \\
0 \\
0 \\
0\end{array}$ & $\begin{array}{r}1,049 \\
6,109 \\
0 \\
6,2000 \\
293,997\end{array}$ \\
\hline
\end{tabular}

Now: Tobals moy not equal awm of componenta bectute of indapendink rounding.

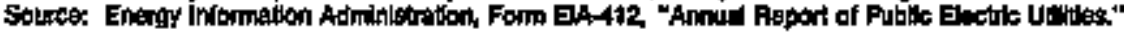


Table 22 Balanee sheet by Major U.S. Publlcly Owned Electric Utifity Within State at End of Period, 1994 (Thousand Dollars)

\begin{tabular}{|c|c|c|c|c|c|c|}
\hline Item & $\begin{array}{l}\text { Cerfomia } \\
\text { Yernon } \\
\text { Ciny of } \\
\text { June } 30\end{array}$ & 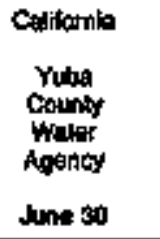 & 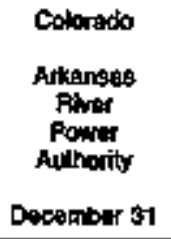 & $\begin{array}{l}\text { Coloruda } \\
\text { Celokato } \\
\text { Spring: } \\
\text { oty of } \\
\text { Decomber } 31\end{array}$ & $\begin{array}{l}\text { Colbrado } \\
\text { Font Colins } \\
\text { Gity of } \\
\text { Dacomber } 31\end{array}$ & $\begin{array}{l}\text { Colomide } \\
\text { Fon Wornen } \\
\text { City of } \\
\text { December } 3 t\end{array}$ \\
\hline 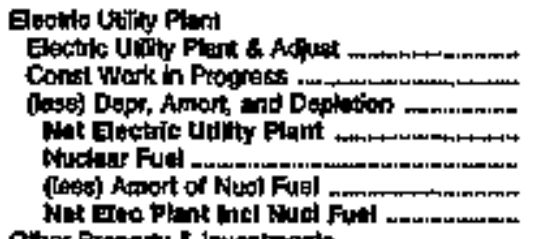 & $\begin{array}{r}71,904 \\
0,919 \\
2,342 \\
5+560 \\
0 \\
0 \\
54,500\end{array}$ & $\begin{array}{r}190,007 \\
5 \\
54,886 \\
144,141 \\
0 \\
0 \\
144,141\end{array}$ & $\begin{array}{r}2,710 \\
0 \\
360 \\
2,360 \\
0 \\
0 \\
2,960\end{array}$ & $\begin{array}{r}606,038 \\
5,458 \\
166,402 \\
599,515 \\
0 \\
0 \\
039,515\end{array}$ & $\begin{array}{r}5,203 \\
5,225 \\
89,318 \\
5,140 \\
0 \\
0 \\
54,142\end{array}$ & $\begin{array}{r}10,005 \\
434 \\
4018 \\
6,472 \\
0 \\
0 \\
0,472\end{array}$ \\
\hline 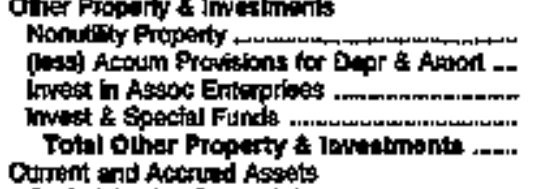 & $\begin{array}{r}489 \\
0 \\
0 \\
97,687 \\
96,769\end{array}$ & $\begin{array}{r}5 y \\
107 \\
0 \\
49,718 \\
44,+57\end{array}$ & $\begin{array}{r}287 \\
101 \\
0 \\
1,050 \\
2,135\end{array}$ & $\begin{array}{r}0 \\
0 \\
676 \\
128,785 \\
120,3 \times 2\end{array}$ & $\begin{array}{l}0 \\
0 \\
0 \\
0 \\
0 \\
0\end{array}$ & $\begin{array}{l}0 \\
0 \\
0 \\
0 \\
0\end{array}$ \\
\hline 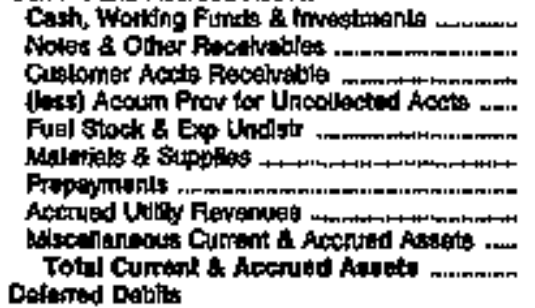 & 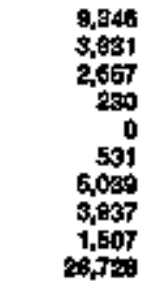 & $\begin{array}{r}751 \\
219 \\
0 \\
0 \\
0 \\
0 \\
021 \\
0 \\
0 \\
1,+\infty 5\end{array}$ & $\begin{array}{r}3,252 \\
0 \\
010 \\
0 \\
0 \\
33 \\
130 \\
0 \\
0 \\
4,030\end{array}$ & $\begin{array}{r}32,137 \\
305 \\
18,685 \\
973 \\
0 \\
12,382 \\
568 \\
0 \\
984 \\
66,028\end{array}$ & $\begin{array}{r}15,001 \\
0 \\
6,579 \\
160 \\
0 \\
2,599 \\
0 \\
0 \\
200 \\
24,187\end{array}$ & $\begin{array}{r}174 \\
0 \\
000 \\
5 \\
0 \\
398 \\
58 \\
0 \\
0 \\
1,+56\end{array}$ \\
\hline 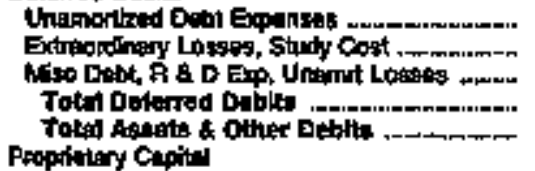 & $\begin{array}{r}0 \\
0 \\
0 \\
0 \\
m e, 45 ?\end{array}$ & $\begin{array}{r}1,528 \\
0 \\
0 \\
1,529 \\
190,691\end{array}$ & $\begin{array}{r}68 \\
0 \\
0 \\
69 \\
0,919\end{array}$ & $\begin{array}{r}6,183 \\
0 \\
658 \\
6, a 15 \\
740,720\end{array}$ & $\begin{array}{r}0 \\
0 \\
0 \\
0 \\
70,309\end{array}$ & $\begin{array}{r}0 \\
0 \\
0 \\
7,690\end{array}$ \\
\hline 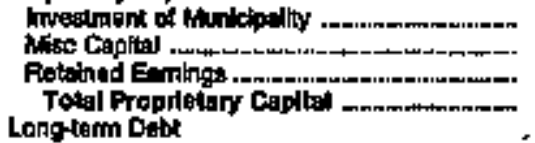 & $\begin{array}{r}0 \\
0 \\
160,843 \\
180,043\end{array}$ & $\begin{array}{r}0 \\
0 \\
60,371 \\
00,371\end{array}$ & $\begin{array}{r}0 \\
0 \\
4,674 \\
4974\end{array}$ & $\begin{array}{r}0 \\
455 \\
212,655 \\
220,111\end{array}$ & $\begin{array}{r}28,405 \\
0 \\
47,452 \\
76,436\end{array}$ & $\begin{array}{r}0,116 \\
0 \\
0 \\
0,118\end{array}$ \\
\hline 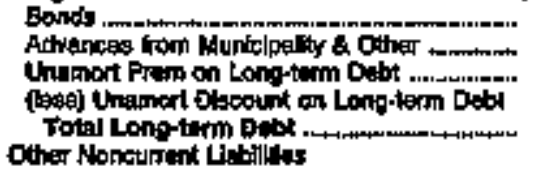 & $\begin{array}{r}0 \\
3,489 \\
0 \\
0 \\
3,468\end{array}$ & $\begin{array}{r}105,131 \\
1,980 \\
0 \\
0 \\
107,051\end{array}$ & $\begin{array}{r}2,895 \\
0 \\
0 \\
6,839\end{array}$ & $\begin{array}{r}311,35 s \\
3,999 \\
0 \\
0 \\
310,392\end{array}$ & $\begin{array}{l}0 \\
0 \\
0 \\
0 \\
0\end{array}$ & $\begin{array}{l}0 \\
0 \\
0 \\
0 \\
0\end{array}$ \\
\hline 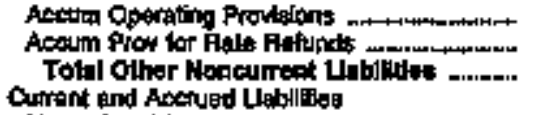 & $\begin{array}{l}0 \\
0 \\
0\end{array}$ & $\begin{array}{l}0 \\
0 \\
0\end{array}$ & $\begin{array}{l}0 \\
0 \\
0\end{array}$ & $\begin{array}{r}2,134 \\
130 \\
2,764\end{array}$ & $\begin{array}{l}0 \\
0 \\
0\end{array}$ & $\begin{array}{l}0 \\
0 \\
0\end{array}$ \\
\hline 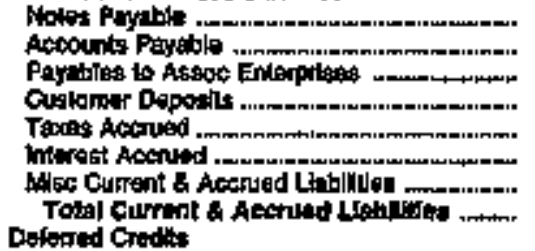 & $\begin{array}{r}0 \\
4,08 \\
688 \\
254 \\
607 \\
361 \\
104 \\
6,726\end{array}$ & $\begin{array}{r}0 \\
2,609 \\
0 \\
0 \\
0 \\
3,000 \\
0 \\
0,009\end{array}$ & $\begin{array}{r}0 \\
1,060 \\
0 \\
0 \\
0 \\
19 \\
28 \\
1,212\end{array}$ & $\begin{array}{r}0 \\
15,248 \\
0 \\
439 \\
0 \\
1,986 \\
8,1,38 \\
25,800\end{array}$ & $\begin{array}{r}0 \\
3,671 \\
0 \\
0 \\
0 \\
0 \\
207 \\
3,873\end{array}$ & $\begin{array}{r}0 \\
0 \\
0 \\
90 \\
0 \\
0 \\
6 \\
05\end{array}$ \\
\hline 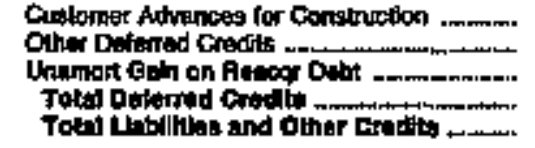 & $\begin{array}{r}0 \\
0 \\
0 \\
0 \\
\text { motat }\end{array}$ & $\begin{array}{r}17,000 \\
17,060 \\
190,001\end{array}$ & $\begin{array}{r}0 \\
0 \\
0 \\
0 \\
0 \\
0,9+9\end{array}$ & $\begin{array}{r}2, \mathrm{Bg60} \\
\mathbf{4 3 6} \\
170,660 \\
174,194 \\
790,720\end{array}$ & $\begin{array}{r}0 \\
0 \\
70,390\end{array}$ & $\begin{array}{r}1,420 \\
0 \\
0 \\
1,420 \\
7,030\end{array}$ \\
\hline
\end{tabular}

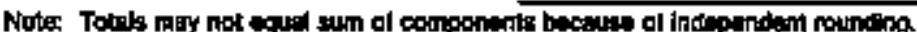

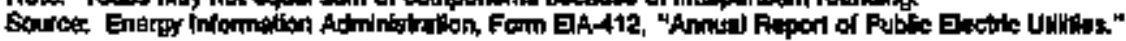


Table 22. Balance Sheet by Major U.S. Publiely Owned Electrle Utillty Whin State at End of Perlod, 1994

(Thousand Dollars)

\begin{tabular}{|c|c|c|c|c|c|c|}
\hline Ilem & $\begin{array}{l}\text { Colorado } \\
\text { Lopgraont } \\
\text { Ciny of } \\
\text { Deombor is }\end{array}$ & 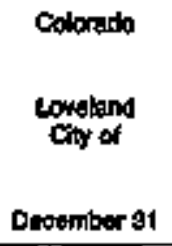 & $\begin{array}{l}\text { Colorado } \\
\text { Pinto Piver } \\
\text { Powise } \\
\text { Authotity } \\
\text { Decamber } 31\end{array}$ & 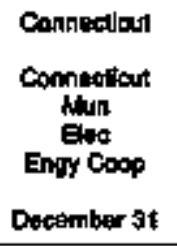 & $\begin{array}{l}\text { Commecticut } \\
\text { Groton } \\
\text { Ciny of } \\
\text { June so }\end{array}$ & $\begin{array}{l}\text { Condiaticul } \\
\text { Wonwith } \\
\text { Coty of } \\
\text { June an }\end{array}$ \\
\hline 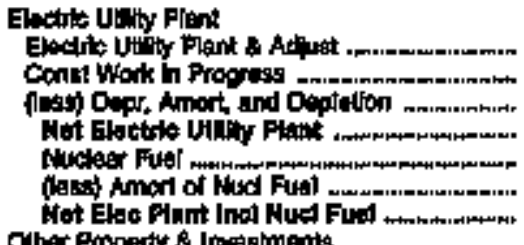 & $\begin{array}{r}30,826 \\
0 \\
15,748 \\
29,776 \\
0 \\
0 \\
20,776\end{array}$ & $\begin{array}{r}46,969 \\
605 \\
11,0022 \\
35,0534 \\
0 \\
0 \\
35,534\end{array}$ & $\begin{array}{r}768,511 \\
6,158 \\
246,384 \\
621,303 \\
0 \\
0 \\
521,903\end{array}$ & $\begin{array}{r}54,811 \\
1,9 \\
14,280 \\
40,390 \\
4,143 \\
3,419 \\
41,121\end{array}$ & $\begin{array}{r}25,124 \\
0 \\
15,839 \\
10,646 \\
0 \\
0 \\
10,645\end{array}$ & $\begin{array}{r}27,202 \\
6,641 \\
16,974 \\
16,786 \\
0 \\
0 \\
16,788\end{array}$ \\
\hline 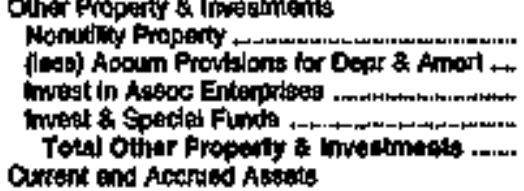 & $\begin{array}{l}0 \\
0 \\
0 \\
0 \\
0\end{array}$ & $\begin{array}{r}0 \\
0 \\
600 \\
4,673 \\
5,278\end{array}$ & $\begin{array}{r}0 \\
0 \\
0 \\
+900,204 \\
190,294\end{array}$ & $\begin{array}{r}0 \\
0 \\
0 \\
29,458 \\
29,469\end{array}$ & $\begin{array}{l}0 \\
0 \\
0 \\
0 \\
0\end{array}$ & $\begin{array}{r}0 \\
0 \\
0 \\
395 \\
996\end{array}$ \\
\hline 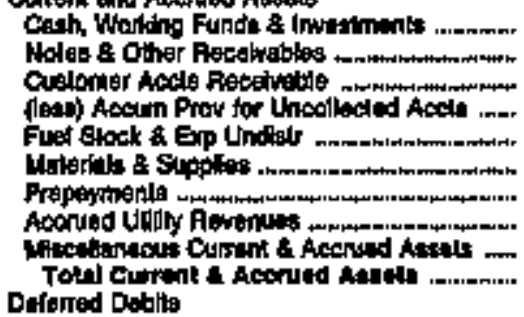 & $\begin{array}{r}6,857 \\
14 \\
4,770 \\
01 \\
0 \\
0 \\
0 \\
0 \\
710 \\
10,029\end{array}$ & $\begin{array}{r}8,500 \\
0 \\
1,172 \\
17 \\
0 \\
850 \\
4 \\
0 \\
10,748\end{array}$ & $\begin{array}{r}10,118 \\
167 \\
12,602 \\
6 \\
4,409 \\
8,207 \\
400 \\
0 \\
3,694 \\
4,070\end{array}$ & 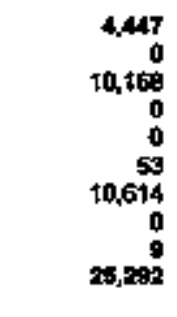 & $\begin{array}{r}11,205 \\
0 \\
9,397 \\
0 \\
0 \\
618 \\
4 \\
900 \\
795 \\
0,900\end{array}$ & $\begin{array}{r}4,070 \\
2,779 \\
3,559 \\
850 \\
0 \\
250 \\
71 \\
0 \\
-204 \\
9,060\end{array}$ \\
\hline 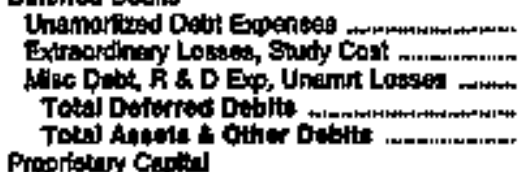 & $\begin{array}{r}0 \\
0 \\
0 \\
0 \\
0\end{array}$ & $\begin{array}{r}58 \\
0 \\
0 \\
51,008\end{array}$ & $\begin{array}{r}6,845 \\
245 \\
72,696 \\
70,677 \\
1039,943\end{array}$ & $\begin{array}{r}2,204 \\
00 \\
60,689 \\
66,687 \\
151,759\end{array}$ & $\begin{array}{r}0 \\
0 \\
397 \\
397\end{array}$ & $\begin{array}{r}0 \\
0 \\
0 \\
0 \\
06,471\end{array}$ \\
\hline 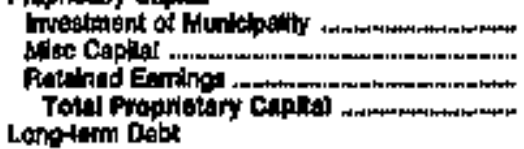 & $\begin{array}{r}10,3609 \\
0 \\
20,609 \\
91,160\end{array}$ & $\begin{array}{r}0 \\
0 \\
41,241 \\
41,241\end{array}$ & $\begin{array}{r}0 \\
356 \\
211,067 \\
211,483\end{array}$ & $\begin{array}{r}800 \\
0 \\
4,206 \\
6,012\end{array}$ & $\begin{array}{r}0 \\
0 \\
10,691 \\
10,561\end{array}$ & $\begin{array}{r}0 \\
0 \\
14,676 \\
14,476\end{array}$ \\
\hline 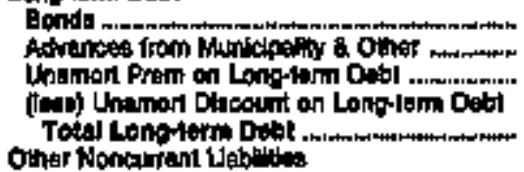 & $\begin{array}{r}0 \\
69 \\
0 \\
0 \\
0\end{array}$ & $\begin{array}{r}4,273 \\
760 \\
0 \\
0 \\
5,093\end{array}$ & $\begin{array}{r}599,245 \\
41,16 ? \\
0 \\
11,267 \\
B 13,145\end{array}$ & $\begin{array}{r}110,005 \\
0 \\
0 \\
1,054 \\
118,401\end{array}$ & $\begin{array}{r}6578 \\
0 \\
0 \\
0 \\
6,578\end{array}$ & $\begin{array}{r}384 \\
6,632 \\
0 \\
0 \\
6,080\end{array}$ \\
\hline 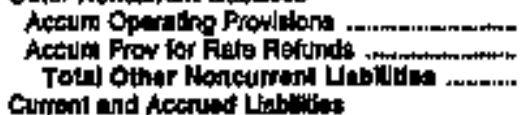 & $\begin{array}{l}0 \\
0 \\
0\end{array}$ & $\begin{array}{l}0 \\
0 \\
0\end{array}$ & $\begin{array}{r}5,74 \\
0 \\
5,749\end{array}$ & $\begin{array}{l}0 \\
0 \\
0\end{array}$ & $\begin{array}{l}0 \\
0 \\
0\end{array}$ & $\begin{array}{r}208 \\
0 \\
00\end{array}$ \\
\hline 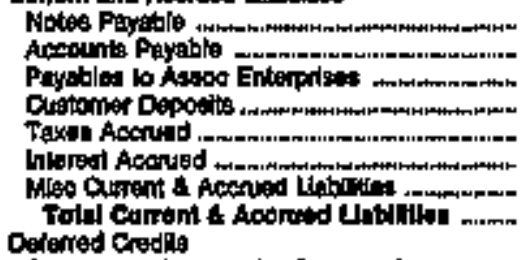 & $\begin{array}{r}0 \\
1,502 \\
0 \\
477 \\
72 \\
0 \\
414 \\
2,656\end{array}$ & $\begin{array}{r}402 \\
1,451 \\
0 \\
205 \\
0 \\
169 \\
241 \\
2,447\end{array}$ & $\begin{array}{r}0 \\
4,300 \\
0 \\
0 \\
0 \\
2,028 \\
079 \\
0,146\end{array}$ & $\begin{array}{r}2,160 \\
1,200 \\
1,492 \\
0 \\
159 \\
3,400 \\
169 \\
13,001\end{array}$ & $\begin{array}{r}0 \\
5,685 \\
0 \\
3,198 \\
428 \\
47 \\
1,377 \\
0,7,712\end{array}$ & $\begin{array}{r}0 \\
0.286 \\
0 \\
249 \\
274 \\
0 \\
-29 \\
3,745\end{array}$ \\
\hline 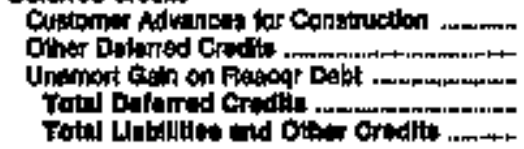 & $\begin{array}{r}0 \\
0 \\
0 \\
0 \\
30,800\end{array}$ & $\begin{array}{r}367 \\
2,415 \\
0 \\
2,767 \\
51,003\end{array}$ & $\begin{array}{r}0 \\
087 \\
0 \\
397\end{array}$ & $\begin{array}{r}0 \\
18,740 \\
0 \\
16,749 \\
161,750\end{array}$ & $\begin{array}{r}0 \\
0 \\
0 \\
0 \\
27,971\end{array}$ & $\begin{array}{r}1,247 \\
0 \\
0 \\
1,247 \\
26,671\end{array}$ \\
\hline
\end{tabular}

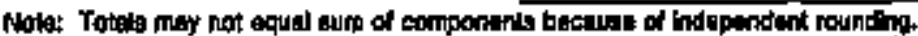

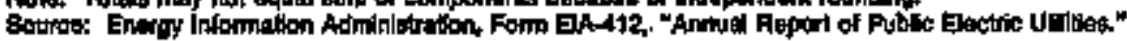


Table 22. Balance Sheet by Mojor U.S. Publloly Owned Electric Utillity Whith State at End of Pertod, 1994 (Thousand Dollars)

\begin{tabular}{|c|c|c|c|c|c|c|}
\hline dent & $\begin{array}{l}\text { Comtuneticul } \\
\text { Tom of } \\
\text { Tun } 30\end{array}$ & $\begin{array}{l}\text { Dedentine } \\
\text { Oenuer } \\
\text { June of }\end{array}$ & 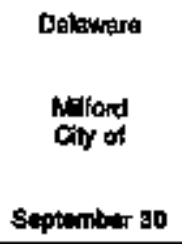 & 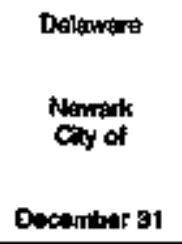 & $\begin{array}{l}\text { Flarida } \\
\text { Cidy of } \\
\text { Seppotimber go }\end{array}$ & 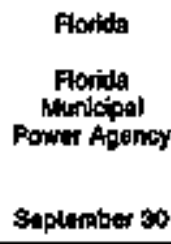 \\
\hline 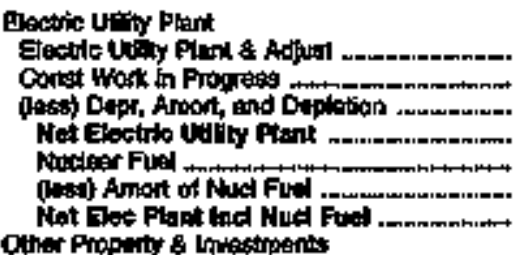 & $\begin{array}{r}44,278 \\
\$, 205 \\
25,579 \\
21,0002 \\
0 \\
0 \\
21,902\end{array}$ & $\begin{array}{r}63,500 \\
0 \\
32,856 \\
63,684 \\
0 \\
0 \\
63,584\end{array}$ & $\begin{array}{r}7,089 \\
0 \\
4,168 \\
2,415 \\
0 \\
0 \\
2,916\end{array}$ & $\begin{array}{l}0 \\
0 \\
0 \\
0 \\
0 \\
0 \\
0\end{array}$ & $\begin{array}{r}11,650 \\
0 \\
5,206 \\
6,4 \% 3 \\
0 \\
0 \\
0,438\end{array}$ & 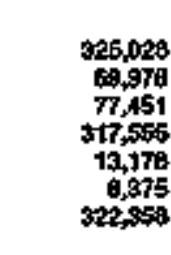 \\
\hline 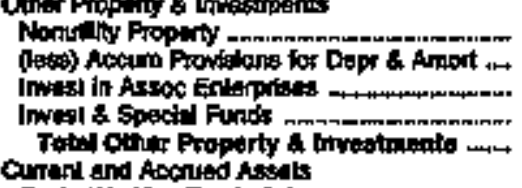 & $\begin{array}{l}0 \\
0 \\
0 \\
0 \\
0\end{array}$ & $\begin{array}{r}0 \\
0 \\
0 \\
17,219 \\
17,210\end{array}$ & $\begin{array}{l}0 \\
0 \\
0 \\
0 \\
0\end{array}$ & $\begin{array}{l}0 \\
0 \\
0 \\
0 \\
0\end{array}$ & $\begin{array}{r}0 \\
9 \\
0 \\
6,701 \\
5,701\end{array}$ & $\begin{array}{r}0 \\
0 \\
0 \\
t 07,768 \\
107,769\end{array}$ \\
\hline 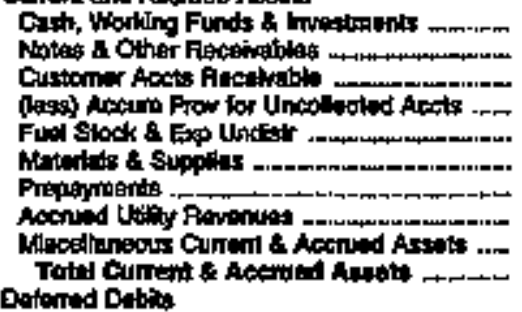 & $\begin{array}{r}11,892 \\
0 \\
4,399 \\
111 \\
40 \\
708 \\
6 \\
0 \\
343 \\
17,907\end{array}$ & $\begin{array}{r}319 \\
1,146 \\
3,645 \\
3 \\
279 \\
2,247 \\
0 \\
0 \\
0 \\
7,004\end{array}$ & $\begin{array}{r}4,321 \\
0 \\
1,298 \\
0 \\
0 \\
1,013 \\
0 \\
0 \\
0 \\
0,027\end{array}$ & $\begin{array}{l}0 \\
0 \\
0 \\
0 \\
0 \\
0 \\
0 \\
0 \\
0 \\
0 \\
0\end{array}$ & $\begin{array}{r}687 \\
2,287 \\
-200 \\
0 \\
907 \\
0 \\
0 \\
0 \\
0 \\
3,681\end{array}$ & $\begin{array}{r}49,729 \\
1,030 \\
15,051 \\
0 \\
064 \\
0 \\
1,742 \\
0 \\
0 \\
66,215\end{array}$ \\
\hline 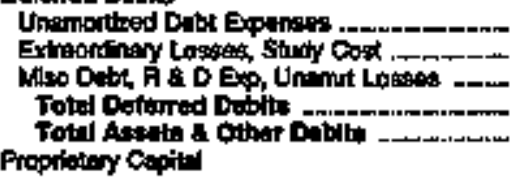 & $\begin{array}{r}0 \\
0 \\
0 \\
0 \\
\$ 9,709\end{array}$ & $\begin{array}{r}0 \\
0 \\
0 \\
0 \\
\text { aB, } 417\end{array}$ & $\begin{array}{r}0 \\
0 \\
0 \\
0 \\
0\end{array}$ & $\begin{array}{l}0 \\
0 \\
0 \\
0 \\
0\end{array}$ & $\begin{array}{r}0 \\
0 \\
0 \\
0\end{array}$ & $\begin{array}{r}9,8300 \\
0 \\
221,271 \\
251,041 \\
726,362\end{array}$ \\
\hline 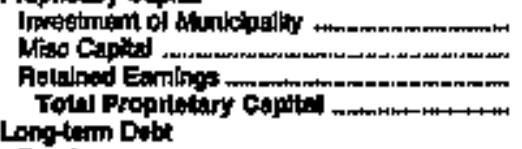 & $\begin{array}{r}0 \\
0 \\
30,490 \\
30,410\end{array}$ & $\begin{array}{r}0 \\
0 \\
44,161 \\
44,161\end{array}$ & $\begin{array}{r}0 \\
0 \\
a, 495 \\
0,495\end{array}$ & $\begin{array}{l}0 \\
\mathbf{0} \\
\mathbf{0} \\
\mathbf{0}\end{array}$ & $\begin{array}{r}27 \\
0 \\
12,094 \\
13,0+1\end{array}$ & $\begin{array}{l}0 \\
0 \\
0 \\
0\end{array}$ \\
\hline 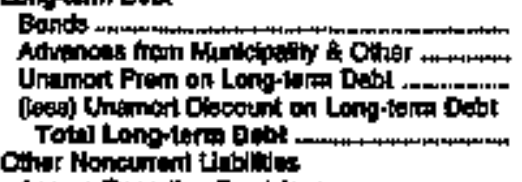 & $\begin{array}{r}640 \\
0 \\
1 \\
0 \\
041\end{array}$ & $\begin{array}{r}31,393 \\
0 \\
0 \\
0 \\
31,318\end{array}$ & $\begin{array}{l}0 \\
0 \\
0 \\
0 \\
0 \\
0\end{array}$ & $\begin{array}{l}0 \\
0 \\
0 \\
0 \\
0\end{array}$ & $\begin{array}{l}0 \\
0 \\
0 \\
0 \\
0\end{array}$ & $\begin{array}{r}671,046 \\
17,069 \\
0 \\
28,500 \\
642,594\end{array}$ \\
\hline 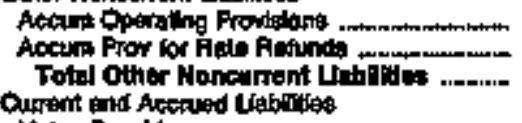 & $\begin{array}{l}0 \\
0 \\
0\end{array}$ & $\begin{array}{r}0,152 \\
0 \\
9,152\end{array}$ & $\begin{array}{l}0 \\
0 \\
0\end{array}$ & $\begin{array}{l}0 \\
0 \\
0\end{array}$ & $\begin{array}{l}0 \\
0 \\
0\end{array}$ & $\begin{array}{l}0 \\
0 \\
0\end{array}$ \\
\hline 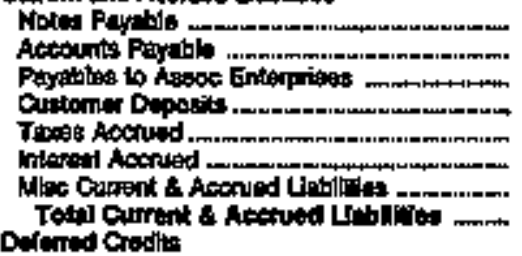 & $\begin{array}{r}0 \\
6,684 \\
0 \\
1,205 \\
480 \\
700 \\
641 \\
0,000\end{array}$ & $\begin{array}{r}0 \\
1,954 \\
0 \\
505 \\
0 \\
7,007 \\
205 \\
3,761\end{array}$ & $\begin{array}{r}0 \\
798 \\
0 \\
130 \\
0 \\
0 \\
350 \\
0\end{array}$ & $\begin{array}{l}0 \\
0 \\
0 \\
0 \\
0 \\
0 \\
0 \\
0\end{array}$ & $\begin{array}{r}1 \\
1,152 \\
0 \\
0 \\
191 \\
0 \\
707 \\
2,864\end{array}$ & $\begin{array}{r}10,975 \\
31,050 \\
0 \\
0 \\
11,234 \\
7,350 \\
165 \\
01,394\end{array}$ \\
\hline 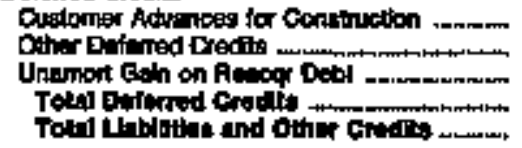 & $\begin{array}{r}66 \\
750 \\
0 \\
218 \\
38,900\end{array}$ & $\begin{array}{r}0 \\
0 \\
0 \\
0\end{array}$ & $\begin{array}{r}0 \\
6 \\
0 \\
98 \\
98\end{array}$ & $\begin{array}{l}0 \\
0 \\
0 \\
0\end{array}$ & $\begin{array}{r}0 \\
0 \\
0 \\
15,0 \%\end{array}$ & $\begin{array}{r}0 \\
2,484 \\
2,49 \\
2,49\end{array}$ \\
\hline
\end{tabular}

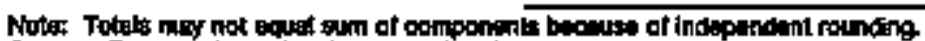

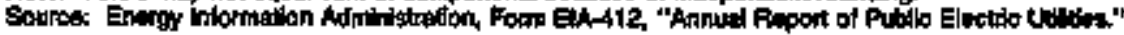


Table 22. Balance Sheet by Major U.S. Publldy Owned Electric Utllity Whtthin state at End of Portod, 1994

(Thousand Dollars)

\begin{tabular}{|c|c|c|c|c|c|c|}
\hline bem & 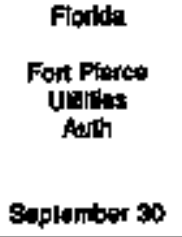 & 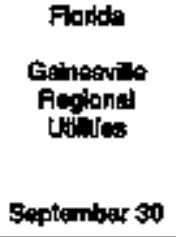 & $\begin{array}{l}\text { Fiondd } \\
\text { Homesiled } \\
\text { Chy of } \\
\text { Soptomber } 30\end{array}$ & 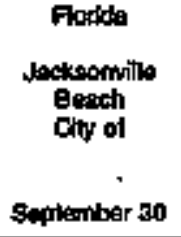 & $\begin{array}{l}\text { Fionda } \\
\text { Jackosonvile } \\
\text { Electitc } \\
\text { Auth } \\
\text { Septomiber \$0 }\end{array}$ & $\begin{array}{l}\text { Florids } \\
\text { Key Weat } \\
\text { Cly of } \\
\text { September } 30\end{array}$ \\
\hline 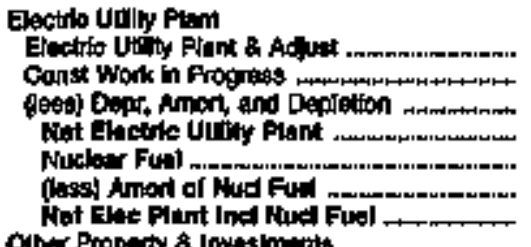 & $\begin{array}{r}110,547 \\
1,504 \\
45,840 \\
68,404 \\
0 \\
0 \\
06,490\end{array}$ & $\begin{array}{r}421,402 \\
34,095 \\
144,554 \\
310,063 \\
6,096 \\
4,2235 \\
311,752\end{array}$ & $\begin{array}{r}43,160 \\
0 \\
19,236 \\
23,92, \\
0 \\
21,02\end{array}$ & $\begin{array}{r}74,552 \\
2,400 \\
21,687 \\
65,072 \\
0 \\
0 \\
0,072\end{array}$ & $\begin{array}{r}2,871,798 \\
39,642 \\
650,794 \\
2,278,649 \\
0 \\
0 \\
2,279,648\end{array}$ & $\begin{array}{r}159,406 \\
13,905 \\
60,718 \\
100,634 \\
0 \\
0 \\
\cos , 934\end{array}$ \\
\hline 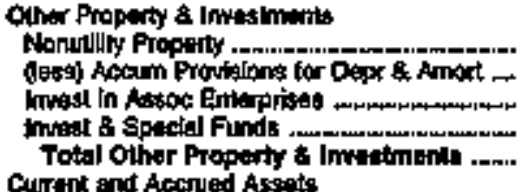 & $\begin{array}{r}0 \\
0 \\
0 \\
15,605 \\
15,605\end{array}$ & $\begin{array}{l}0 \\
0 \\
0 \\
0 \\
0\end{array}$ & $\begin{array}{l}0 \\
0 \\
0 \\
0 \\
0\end{array}$ & $\begin{array}{r}0 \\
0 \\
0 \\
21,714 \\
21,514\end{array}$ & 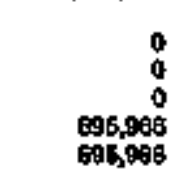 & $\begin{array}{r}0 \\
0 \\
0 \\
20,328 \\
20,326\end{array}$ \\
\hline 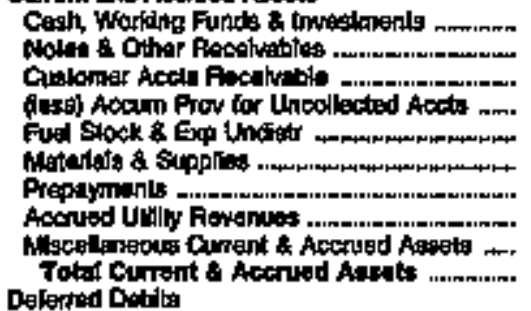 & $\begin{array}{r}9,649 \\
31 \\
2,658 \\
34 \\
0 \\
4,7,11 \\
4,760 \\
2,760 \\
352 \\
19,489\end{array}$ & $\begin{array}{r}113,157 \\
6,023 \\
8,703 \\
458 \\
5,900 \\
4,758 \\
0 \\
7,722 \\
182 \\
145,971\end{array}$ & 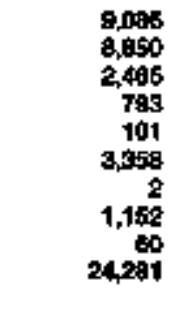 & $\begin{array}{r}7,015 \\
0 \\
5,014 \\
181 \\
0 \\
1,130 \\
0 \\
0 \\
0 \\
19,500\end{array}$ & $\begin{array}{r}169,707 \\
7,396 \\
00,524 \\
1,913 \\
32,023 \\
40,648 \\
58 \\
0 \\
7,180 \\
95,014\end{array}$ & $\begin{array}{r}4,074 \\
68 \\
4,510 \\
t 10 \\
1,926 \\
2,640 \\
276 \\
0 \\
0 \\
2,708\end{array}$ \\
\hline 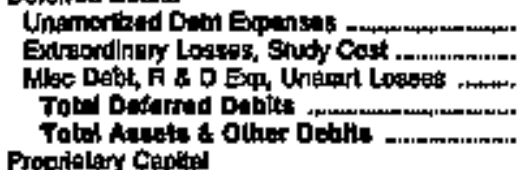 & $\begin{array}{r}981 \\
334 \\
581 \\
1,946 \\
\times 03,979\end{array}$ & $\begin{array}{r}2,766 \\
0 \\
41,782 \\
47,587 \\
605,251\end{array}$ & $\begin{array}{r}0 \\
0 \\
0 \\
0 \\
49,205\end{array}$ & $\begin{array}{r}945 \\
0 \\
0 \\
946 \\
91,100\end{array}$ & $\begin{array}{r}30,106 \\
\mathrm{a,463} \\
35,774 \\
302,429 \\
3,704,654\end{array}$ & $\begin{array}{r}3,868 \\
9 \\
0 \\
3,096 \\
140,031\end{array}$ \\
\hline 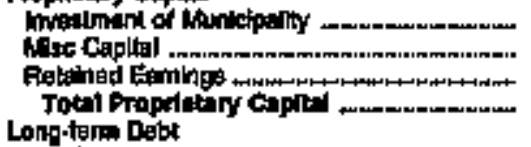 & $\begin{array}{r}0 \\
0 \\
30,298 \\
39,204\end{array}$ & $\begin{array}{r}0 \\
168,494 \\
109,494\end{array}$ & $\begin{array}{r}3,951 \\
0 \\
30,192 \\
34,143\end{array}$ & $\begin{array}{r}5 \\
5,656 \\
12,767 \\
16,606\end{array}$ & $\begin{array}{r}0 \\
0 \\
611,748 \\
611,746\end{array}$ & $\begin{array}{r}0 \\
0 \\
14,758 \\
14,766\end{array}$ \\
\hline 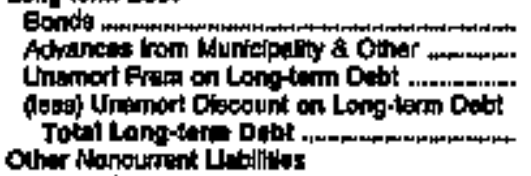 & $\begin{array}{r}5,954 \\
0 \\
0 \\
0 \\
50,154\end{array}$ & $\begin{array}{r}245,309 \\
50,017 \\
0 \\
4,408 \\
290,983\end{array}$ & $\begin{array}{r}0 \\
7,402 \\
0 \\
0 \\
7,402\end{array}$ & $\begin{array}{r}61,847 \\
0 \\
n \\
0 \\
61,847\end{array}$ & $\begin{array}{r}2,673,547 \\
8,269 \\
0 \\
59,095 \\
2,0,7,671\end{array}$ & $\begin{array}{r}117,290 \\
0 \\
0 \\
0 \\
117,206\end{array}$ \\
\hline 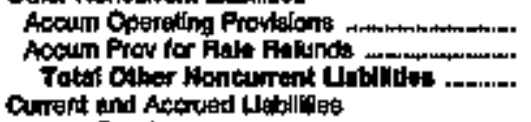 & $\begin{array}{r}1,456 \\
0 \\
1,468\end{array}$ & 0 & $\begin{array}{l}0 \\
0 \\
0\end{array}$ & $\begin{array}{l}0 \\
0 \\
0\end{array}$ & $\begin{array}{r}199,609 \\
199,698\end{array}$ & \\
\hline 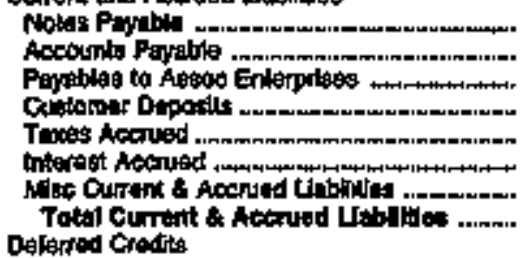 & $\begin{array}{r}1,810 \\
4,235 \\
0 \\
2,567 \\
551 \\
1,500 \\
10,174\end{array}$ & $\begin{array}{r}0 \\
6,022 \\
0 \\
3,794 \\
-79 \\
7,601 \\
24,203 \\
41,631\end{array}$ & $\begin{array}{r}0 \\
4,439 \\
0 \\
1,401 \\
0 \\
021 \\
0 \\
0,600\end{array}$ & $\begin{array}{r}0 \\
3,250 \\
0 \\
1,940 \\
0 \\
1,087 \\
3,725 \\
10,05\end{array}$ & $\begin{array}{r}0 \\
39,984 \\
3,765 \\
15,957 \\
1,791 \\
60,650 \\
20,190 \\
100,30 \%\end{array}$ & $\begin{array}{r}0 \\
325 \\
0 \\
3,587 \\
153 \\
688 \\
1,029 \\
505\end{array}$ \\
\hline 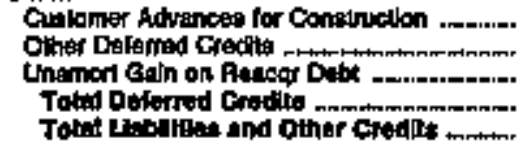 & $\begin{array}{r}0 \\
0 \\
0 \\
0 \\
0,0,9\end{array}$ & $\begin{array}{r}3,202 \\
3,202 \\
50,251\end{array}$ & $\begin{array}{r}0 \\
0 \\
0 \\
0 \\
40,205\end{array}$ & $\begin{array}{r}0 \\
0 \\
0 \\
0 \\
9\end{array}$ & $\begin{array}{r}0 \\
17,020 \\
17,00 \\
3,704,654\end{array}$ & $\begin{array}{r}0 \\
121 \\
0 \\
121 \\
\text { twosi }\end{array}$ \\
\hline
\end{tabular}

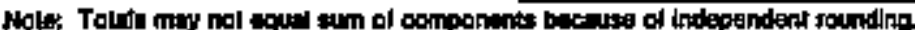

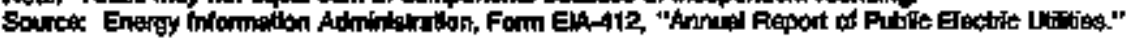


Table 22. Ealance Sheet by Major U.S. Publlcly Owned Electrio Utility Within State at End of Patod, 1994 (Thousand Dollars)

\begin{tabular}{|c|c|c|c|c|c|c|}
\hline Rem & $\begin{array}{l}\text { Forifta } \\
\text { Kossinmes } \\
\text { Utility } \\
\text { Authofily } \\
\text { Septumber } 30\end{array}$ & $\begin{array}{l}\text { Flodida } \\
\text { Lake Whath } \\
\text { Chy of } \\
\text { September } 30\end{array}$ & $\begin{array}{l}\text { Florita } \\
\text { Lakeland } \\
\text { Cily of } \\
\text { Sepleniber } 30\end{array}$ & 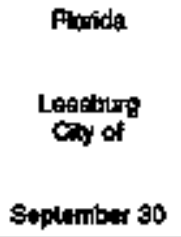 & 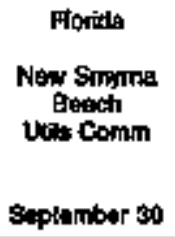 & $\begin{array}{l}\text { Foprida } \\
\text { Ocila } \\
\text { Sty of } \\
\text { Saptember } 30\end{array}$ \\
\hline 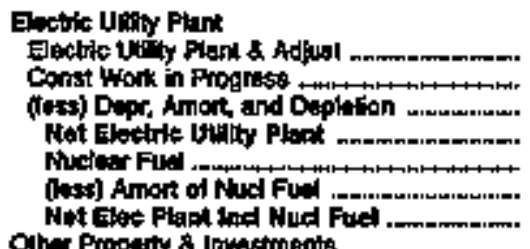 & $\begin{array}{r}142,498 \\
64,912 \\
56,695 \\
180,711 \\
2,566 \\
2,113 \\
+61,184\end{array}$ & $\begin{array}{r}77,747 \\
1,016 \\
3 \$ 0,008 \\
30,756 \\
0 \\
0 \\
39,756\end{array}$ & $\begin{array}{r}667,165 \\
17,419 \\
170,020 \\
404,560 \\
0 \\
0 \\
404,560\end{array}$ & $\begin{array}{r}46,337 \\
1,997 \\
16,178 \\
32,156 \\
977 \\
519 \\
32,617\end{array}$ & 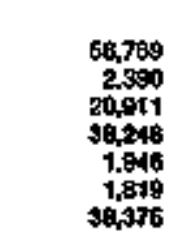 & $\begin{array}{r}06,290 \\
11,381 \\
0,440 \\
67,210 \\
2,905 \\
1,748 \\
69,073\end{array}$ \\
\hline 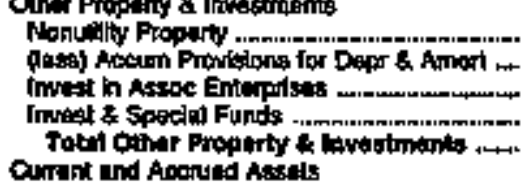 & $\begin{array}{r}0 \\
0 \\
0 \\
198,383 \\
196,383\end{array}$ & $\begin{array}{r}0 \\
0 \\
14,736 \\
14,798\end{array}$ & $\begin{array}{r}59,985 \\
19,0686 \\
0 \\
144,635 \\
195,398\end{array}$ & $\begin{array}{r}0 \\
0 \\
0 \\
12,534 \\
12,594\end{array}$ & $\begin{array}{r}54,442 \\
14,800 \\
16,000 \\
58,169\end{array}$ & $\begin{array}{r}0 \\
0 \\
36989 \\
38,519\end{array}$ \\
\hline 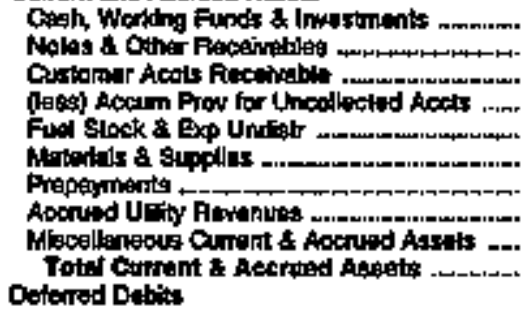 & $\begin{array}{r}13,950 \\
4,82 \\
7,685 \\
138 \\
502 \\
4,094 \\
10 \\
0 \\
48 \\
25,973\end{array}$ & $\begin{array}{r}6,160 \\
468 \\
2,294 \\
0 \\
0 \\
1,890 \\
58 \\
0 \\
0 \\
10,817\end{array}$ & $\begin{array}{r}16,413 \\
1,600 \\
13,157 \\
1,66 \\
4,979 \\
17,724 \\
4 \\
2,011 \\
1,234 \\
56,402\end{array}$ & $\begin{array}{r}6,120 \\
1,774 \\
2,0034 \\
410 \\
0 \\
600 \\
1 \\
0 \\
0 \\
10,127\end{array}$ & $\begin{array}{r}1,285 \\
249 \\
1,075 \\
46 \\
0 \\
802 \\
168 \\
2,064 \\
0 \\
6,086\end{array}$ & $\begin{array}{r}2 \\
154 \\
6,157 \\
268 \\
0 \\
2,058 \\
1,56 \\
4,354 \\
240 \\
12,659\end{array}$ \\
\hline 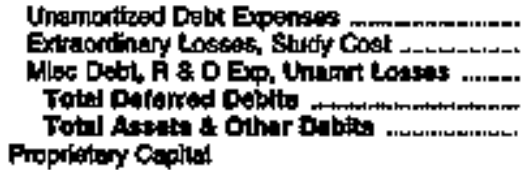 & $\begin{array}{r}2,787 \\
0 \\
52,209 \\
64,090 \\
\text { sal, } 361\end{array}$ & $\begin{array}{r}609 \\
0 \\
0 \\
069 \\
095\end{array}$ & $\begin{array}{r}1,644 \\
0 \\
0 \\
1,544 \\
54,637\end{array}$ & $\begin{array}{r}137 \\
0 \\
0 \\
137 \\
55,414\end{array}$ & $\begin{array}{r}697 \\
0 \\
0 \\
097 \\
100,942\end{array}$ & $\begin{array}{r}254 \\
0 \\
0 \\
204 \\
117,07\end{array}$ \\
\hline 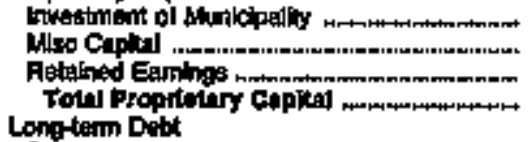 & $\begin{array}{r}0 \\
0 \\
102,108 \\
102,108\end{array}$ & $\begin{array}{r}0 \\
0 \\
22,067 \\
22,667\end{array}$ & $\begin{array}{r}0 \\
0 \\
208,890 \\
204,900\end{array}$ & $\begin{array}{r}0 \\
39,0002 \\
33,002\end{array}$ & $\begin{array}{r}24,249 \\
4,84 t \\
30,090\end{array}$ & $\begin{array}{r}0 \\
71,000 \\
71,009\end{array}$ \\
\hline 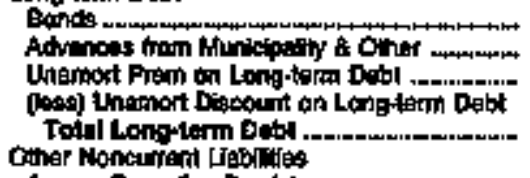 & $\begin{array}{r}242,410 \\
0 \\
0 \\
5,105 \\
207,245\end{array}$ & $\begin{array}{r}37,674 \\
0 \\
0 \\
0 \\
37,974\end{array}$ & $\begin{array}{r}401,009 \\
31,488 \\
0 \\
24,421 \\
405,13\end{array}$ & $\begin{array}{r}14,173 \\
1,459 \\
0 \\
119 \\
15,812\end{array}$ & $\begin{array}{r}65,640 \\
0 \\
0 \\
1,5,47 \\
64,0093\end{array}$ & $\begin{array}{r}27,972 \\
0 \\
0 \\
0 \\
20,072\end{array}$ \\
\hline 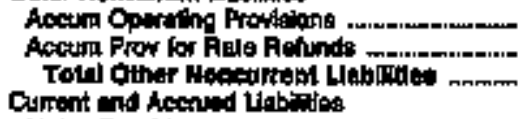 & $\begin{array}{r}129 \\
0 \\
129\end{array}$ & $\begin{array}{l}0 \\
0 \\
0\end{array}$ & $\begin{array}{l}0 \\
0 \\
0\end{array}$ & $\begin{array}{l}0 \\
0 \\
0\end{array}$ & $\begin{array}{r}1,591 \\
0 \\
1,6091\end{array}$ & $\begin{array}{r}1,248 \\
0 \\
1,218\end{array}$ \\
\hline 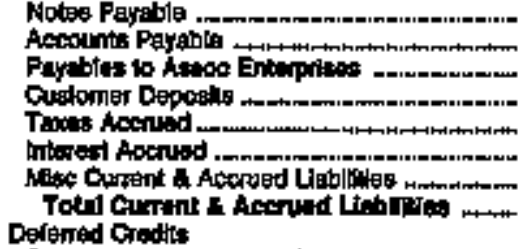 & $\begin{array}{r}0 \\
7,174 \\
1,073 \\
\mathrm{~g}, 832 \\
484 \\
6,881 \\
0,907 \\
26,301\end{array}$ & $\begin{array}{r}0 \\
t, 781 \\
1,852 \\
0 \\
141 \\
0 \\
2,500 \\
0,254\end{array}$ & $\begin{array}{r}0 \\
9,068 \\
0 \\
9,406 \\
4,401 \\
12,751 \\
1,840 \\
32,400\end{array}$ & $\begin{array}{r}1,212 \\
0 \\
0 \\
1,218 \\
0 \\
694 \\
1,139 \\
1,048\end{array}$ & $\begin{array}{r}0 \\
1,051 \\
495 \\
071 \\
0 \\
1,050 \\
001 \\
6,170\end{array}$ & $\begin{array}{r}0 \\
4,301 \\
2,691 \\
3,034 \\
0 \\
642 \\
11,150\end{array}$ \\
\hline 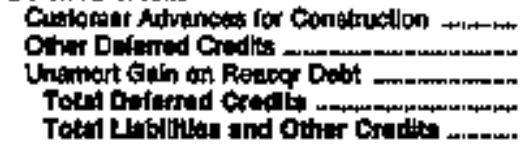 & $\begin{array}{r}560 \\
0 \\
0 \\
580 \\
30,36-1\end{array}$ & $\begin{array}{r}0 \\
0 \\
0 \\
0 \\
6596\end{array}$ & 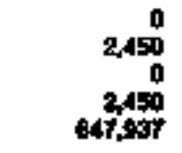 & $\begin{array}{r}105 \\
2,728 \\
0 \\
2,931 \\
55,414\end{array}$ & $\begin{array}{r}0 \\
0 \\
0 \\
0 \\
0\end{array}$ & $\begin{array}{r}4,144 \\
1,200 \\
0 \\
117,698\end{array}$ \\
\hline
\end{tabular}

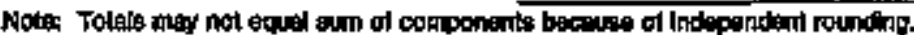

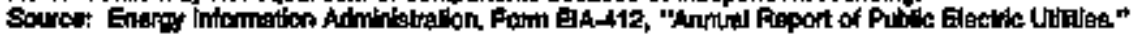


Table 22. Balance Sheat by Major U.S. Publlely Owned Electric Utility Within State at End of Period, 1994

(Thousand Dollars)

\begin{tabular}{|c|c|c|c|c|c|c|}
\hline hem & 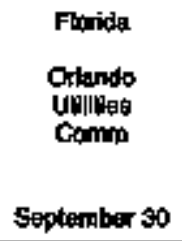 & 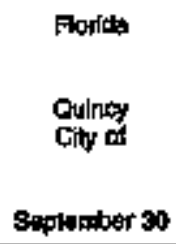 & 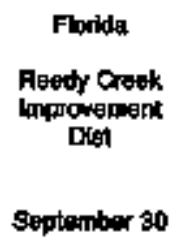 & $\begin{array}{l}\text { Forita } \\
\text { Silckourd } \\
\text { Septentor } 30\end{array}$ & 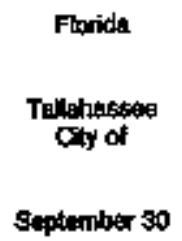 & 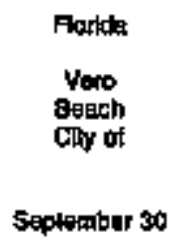 \\
\hline 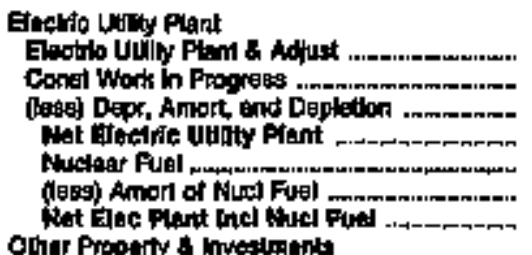 & $\begin{array}{r}1,268,005 \\
213,950 \\
345,602 \\
1,137,033 \\
20,549 \\
20,720 \\
1,13,6,602\end{array}$ & $\begin{array}{r}6,160 \\
0 \\
2,860 \\
3,203 \\
0 \\
0 \\
5,288\end{array}$ & $\begin{array}{r}117,901 \\
9,019 \\
17,009 \\
109,971 \\
0 \\
0 \\
109,971\end{array}$ & $\begin{array}{r}70,854 \\
72 \\
20,640 \\
50,0 \% 8 \\
0 \\
0 \\
50,068\end{array}$ & $\begin{array}{r}398,088 \\
37,794 \\
161,139 \\
268,743 \\
0 \\
0 \\
260,743\end{array}$ & $\begin{array}{r}t 64,409 \\
764 \\
40,991 \\
109,181 \\
0 \\
0 \\
108,161\end{array}$ \\
\hline 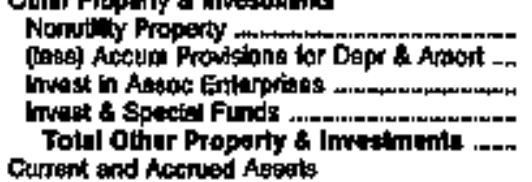 & $\begin{array}{r}401 \\
7 \\
0 \\
422,041 \\
422,435\end{array}$ & $\begin{array}{r}0 \\
0 \\
0 \\
029 \\
\theta 29\end{array}$ & $\begin{array}{l}0 \\
0 \\
0 \\
0 \\
0\end{array}$ & $\begin{array}{l}0 \\
6 \\
0 \\
0 \\
0\end{array}$ & $\begin{array}{r}7,542 \\
4,248 \\
0 \\
101,016 \\
104,339\end{array}$ & $\begin{array}{r}0 \\
0 \\
0 \\
12700 \\
12700\end{array}$ \\
\hline 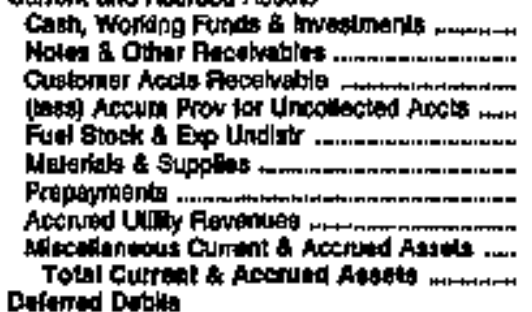 & $\begin{array}{r}95,108 \\
1,805 \\
27,609 \\
681 \\
8,078 \\
25,895 \\
715 \\
14,008 \\
19,397 \\
196,209\end{array}$ & $\begin{array}{r}937 \\
110 \\
757 \\
200 \\
0 \\
00 \\
39 \\
0 \\
0 \\
1,430\end{array}$ & $\begin{array}{r}35,0,08 \\
1,39 \\
1,99 \\
0 \\
60 \\
t, 220 \\
124 \\
2,490 \\
0 \\
41,149\end{array}$ & $\begin{array}{r}2,760 \\
203 \\
1,512 \\
117 \\
0 \\
1,276 \\
44 \\
1,200 \\
0 \\
6,904\end{array}$ & $\begin{array}{r}17,968 \\
494 \\
12,094 \\
1,297 \\
2,644 \\
0 \\
0 \\
0 \\
0 \\
32,508\end{array}$ & 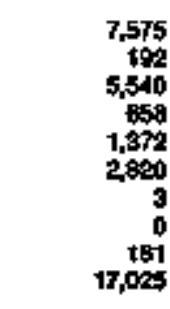 \\
\hline 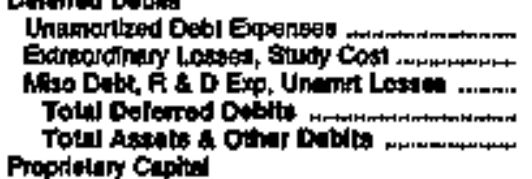 & $\begin{array}{r}89,771 \\
0 \\
12,700 \\
99,477 \\
1,841,976\end{array}$ & $\begin{array}{r}0 \\
0 \\
0 \\
0 \\
5,60\end{array}$ & $\begin{array}{r}2,409 \\
0 \\
0 \\
2,498 \\
163,604\end{array}$ & $\begin{array}{r}5+0 \\
0 \\
3,700 \\
4219 \\
61 ; 005\end{array}$ & $\begin{array}{r}401 \\
0 \\
0 \\
401 \\
40,498\end{array}$ & $\begin{array}{r}1,100 \\
0 \\
0 \\
1,101 \\
130,011\end{array}$ \\
\hline 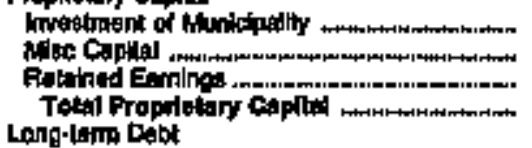 & $\begin{array}{r}0 \\
000,803 \\
302,000\end{array}$ & $\begin{array}{r}0 \\
190 \\
4,243 \\
4,438\end{array}$ & $\begin{array}{r}9 \\
9 \\
5,001 \\
5,901\end{array}$ & $\begin{array}{r}3,409 \\
20,800 \\
39,100\end{array}$ & $\begin{array}{r}0 \\
0 \\
208,248 \\
20,248\end{array}$ & $\begin{array}{r}0 \\
0 \\
44,434 \\
44,434\end{array}$ \\
\hline 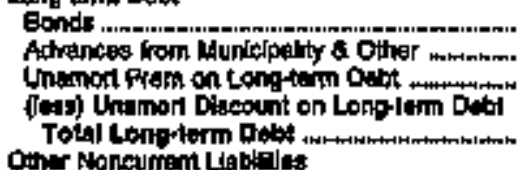 & $\begin{array}{r}1,432,600 \\
0 \\
0 \\
71,723 \\
1,360,675\end{array}$ & $\begin{array}{r}160 \\
0 \\
0 \\
190\end{array}$ & $\begin{array}{r}141,040 \\
0 \\
0 \\
9,318 \\
132,522\end{array}$ & $\begin{array}{r}25,100 \\
0 \\
0 \\
24 \pi \\
321\end{array}$ & $\begin{array}{r}114,988 \\
0 \\
1,247 \\
+13,094\end{array}$ & $\begin{array}{r}80,058 \\
316 \\
0 \\
1,848 \\
67,505\end{array}$ \\
\hline 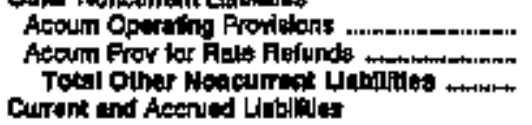 & $\begin{array}{l}0 \\
0 \\
0\end{array}$ & $\begin{array}{l}0 \\
0 \\
0\end{array}$ & $\begin{array}{l}0 \\
0 \\
0\end{array}$ & $\begin{array}{l}0 \\
0 \\
0 \\
0\end{array}$ & $\begin{array}{l}0 \\
0 \\
0\end{array}$ & $\begin{array}{l}0 \\
0 \\
0\end{array}$ \\
\hline 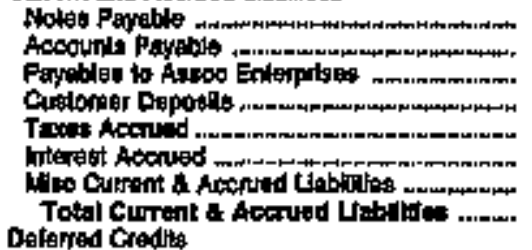 & $\begin{array}{r}17,609 \\
32,768 \\
860 \\
12,471 \\
505 \\
35,245 \\
9,204 \\
109,001\end{array}$ & $\begin{array}{r}0 \\
608 \\
0 \\
337 \\
0 \\
2 \\
108 \\
1,040\end{array}$ & $\begin{array}{r}0 \\
10,468 \\
0 \\
0 \\
207 \\
0 \\
0 \\
10,673\end{array}$ & $\begin{array}{r}665 \\
t, 240 \\
0 \\
481 \\
0 \\
292 \\
979 \\
2969\end{array}$ & $\begin{array}{r}0 \\
17,600 \\
0 \\
7,158 \\
0 \\
0 \\
0 \\
24,660\end{array}$ & $\begin{array}{r}1,265 \\
2,998 \\
0 \\
1,597 \\
0 \\
1,578 \\
278 \\
7,052\end{array}$ \\
\hline 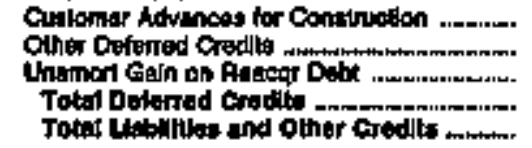 & $\begin{array}{r}25,516 \\
43,729 \\
0 \\
60,246 \\
1,041,476\end{array}$ & $\begin{array}{r}0 \\
0 \\
0 \\
0\end{array}$ & $\begin{array}{r}0 \\
4,579 \\
0 \\
4,570 \\
1+3,604\end{array}$ & $\begin{array}{r}325 \\
0 \\
325 \\
61,205\end{array}$ & $\begin{array}{r}0 \\
089 \\
0 \\
408,986\end{array}$ & $\begin{array}{r}0 \\
0 \\
0 \\
0 \\
130,0+1\end{array}$ \\
\hline
\end{tabular}

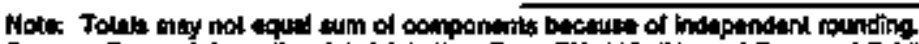

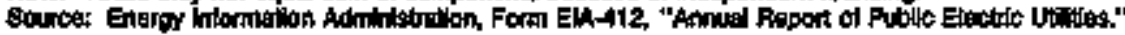


Table 22. Balance Sheet by Major U.S. Publicly Owned Electric Utility Within State at End of Perlod, 1994 (Thousand Dollars)

\begin{tabular}{|c|c|c|c|c|c|c|}
\hline ILER & 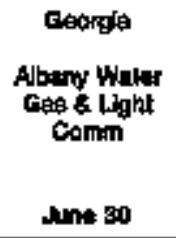 & 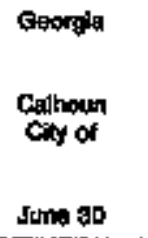 & 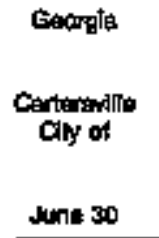 & $\begin{array}{l}\text { Goporga } \\
\text { College } \\
\text { Park Ciny of } \\
\text { Jun so }\end{array}$ & $\begin{array}{l}\text { Ceorgat } \\
\text { Gonfiglan } \\
\text { Oly of } \\
\text { Decomber as }\end{array}$ & 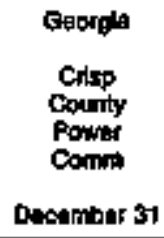 \\
\hline 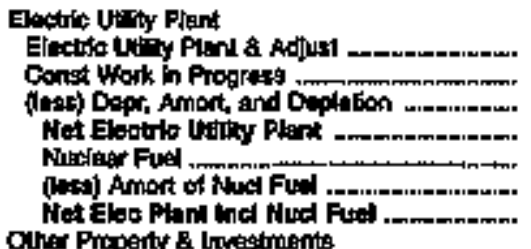 & $\begin{array}{r}29,934 \\
0 \\
19,501 \\
0,743 \\
0 \\
0 \\
0,745\end{array}$ & $\begin{array}{r}63,536 \\
617 \\
15,117 \\
50,637 \\
0 \\
0 \\
60,037\end{array}$ & $\begin{array}{r}1,502 \\
0 \\
3,948 \\
8,167 \\
0 \\
0 \\
0,167\end{array}$ & $\begin{array}{r}8, B 41 \\
0 \\
3,619 \\
5,2,20 \\
0 \\
0,00\end{array}$ & $\begin{array}{r}6,640 \\
0 \\
3,947 \\
3,2,46 \\
0 \\
0 \\
8,208\end{array}$ & $\begin{array}{r}39,+130 \\
215 \\
2 n, 460 \\
16,900 \\
0 \\
0 \\
16,903\end{array}$ \\
\hline 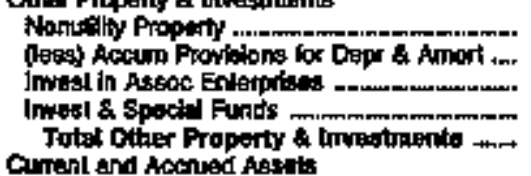 & $\begin{array}{r}40,151 \\
26,50.2 \\
0 \\
19,506 \\
31,107\end{array}$ & $\begin{array}{l}\mathbf{0} \\
\mathbf{0} \\
\mathbf{0} \\
\mathbf{0} \\
\mathbf{0}\end{array}$ & $\begin{array}{l}0 \\
0 \\
0 \\
0 \\
0\end{array}$ & $\begin{array}{l}0 \\
0 \\
\mathbf{0} \\
\mathbf{0} \\
0\end{array}$ & $\begin{array}{l}0 \\
0 \\
0 \\
0 \\
0\end{array}$ & $\begin{array}{r}1,611 \\
0 \\
0 \\
0 \\
1,511\end{array}$ \\
\hline 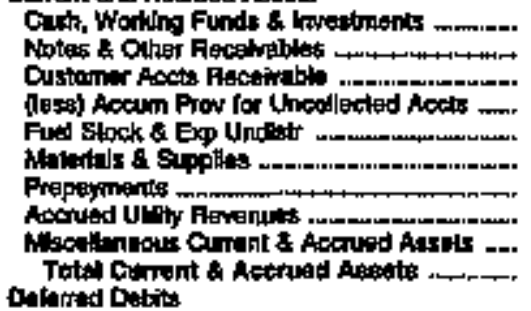 & $\begin{array}{r}41: \\
0 \\
10,699 \\
126 \\
0 \\
3,498 \\
250 \\
0 \\
60 \\
14,731\end{array}$ & $\begin{array}{r}7,054 \\
0 \\
2,739 \\
0 \\
0 \\
200 \\
07 \\
0 \\
40 \\
10,629\end{array}$ & $\begin{array}{r}8,090 \\
24 \\
3,585 \\
314 \\
0 \\
713 \\
0 \\
0 \\
0 \\
7,098\end{array}$ & $\begin{array}{r}4,697 \\
0 \\
2,459 \\
299 \\
0 \\
0 \\
65 \\
0 \\
297 \\
7,300\end{array}$ & $\begin{array}{r}62 \\
0 \\
2007 \\
11 \\
1 \\
282 \\
18 \\
159 \\
0 \\
2,496\end{array}$ & $\begin{array}{r}1,874 \\
2,94 \\
1,980 \\
46 \\
187 \\
476 \\
86 \\
6 \\
0 \\
4,929\end{array}$ \\
\hline 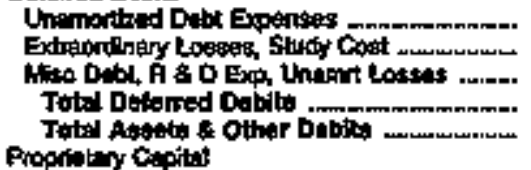 & $\begin{array}{r}0 \\
0 \\
790 \\
790\end{array}$ & $\begin{array}{r}501 \\
0 \\
0 \\
601\end{array}$ & $\begin{array}{r}0 \\
0 \\
0 \\
0 \\
15,104\end{array}$ & $\begin{array}{r}0 \\
0 \\
0 \\
17,0094\end{array}$ & $\begin{array}{r}0 \\
0 \\
0 \\
0 \\
5,708\end{array}$ & 22,640 \\
\hline 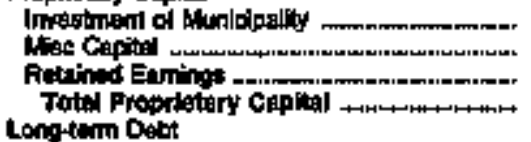 & $\begin{array}{r}0 \\
265 \\
47,109 \\
\$ 7,374\end{array}$ & $\begin{array}{r}5,729 \\
0 \\
39,874 \\
39,102\end{array}$ & $\begin{array}{r}100 \\
12,124 \\
12,324\end{array}$ & $\begin{array}{r}1,295 \\
0 \\
9,278 \\
10,067\end{array}$ & $\begin{array}{r}16 \\
0 \\
4,182 \\
4,196\end{array}$ & $\begin{array}{r}0 \\
0 \\
20,763 \\
20,763\end{array}$ \\
\hline 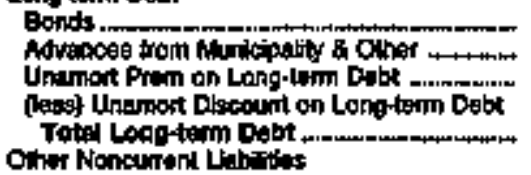 & $\begin{array}{r}769 \\
0 \\
0 \\
0 \\
759\end{array}$ & $\begin{array}{r}6,840 \\
13,185 \\
0 \\
0 \\
10825\end{array}$ & $\begin{array}{r}0 \\
253 \\
0 \\
0 \\
203\end{array}$ & $\begin{array}{r}0 \\
13 \% \\
0 \\
10 \\
10\end{array}$ & $\begin{array}{r}310 \\
0 \\
0 \\
0 \\
910\end{array}$ & $\begin{array}{l}0 \\
0 \\
0 \\
0 \\
0\end{array}$ \\
\hline 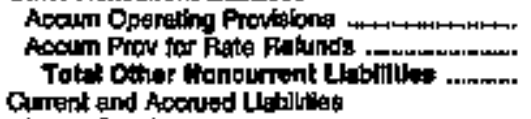 & $\begin{array}{l}0 \\
0 \\
0\end{array}$ & $\begin{array}{l}0 \\
0 \\
0\end{array}$ & $\begin{array}{l}0 \\
0 \\
0\end{array}$ & $\begin{array}{l}0 \\
0 \\
0\end{array}$ & $\begin{array}{l}0 \\
0 \\
0\end{array}$ & $\begin{array}{l}0 \\
0 \\
0\end{array}$ \\
\hline 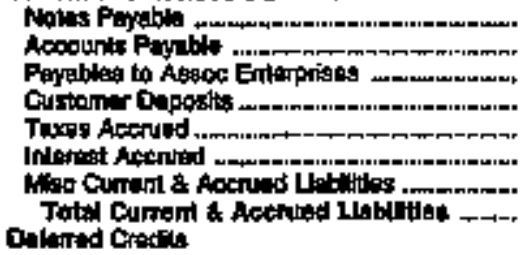 & $\begin{array}{r}0 \\
3,808 \\
1,750 \\
2,7 \\
1,450 \\
0 \\
160 \\
7,600\end{array}$ & $\begin{array}{r}979 \\
1,800 \\
110 \\
903 \\
9 \\
109 \\
90 \\
4,000\end{array}$ & $\begin{array}{r}0 \\
1,990 \\
0 \\
478 \\
0 \\
0 \\
131 \\
2,657\end{array}$ & $\begin{array}{r}0 \\
1, \sin \\
0 \\
0 \\
0 \\
0 \\
0 \\
1,809\end{array}$ & $\begin{array}{r}0 \\
894 \\
0 \\
327 \\
0 \\
2 \\
61 \\
1,214\end{array}$ & $\begin{array}{r}0 \\
1.240 \\
0 \\
967 \\
77 \\
0 \\
177 \\
1,461\end{array}$ \\
\hline 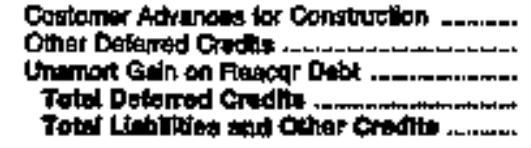 & $\begin{array}{r}0 \\
790 \\
0 \\
790 \\
0,431\end{array}$ & $\begin{array}{r}0 \\
0 \\
0 \\
0 \\
0 \\
0,2,57\end{array}$ & $\begin{array}{r}0 \\
0 \\
0 \\
0 \\
16,184\end{array}$ & $\begin{array}{r}0 \\
0 \\
0 \\
0 \\
0 \\
12+204\end{array}$ & $\begin{array}{r}20 \\
0 \\
0 \\
8,79\end{array}$ & $\begin{array}{r}0 \\
0 \\
0 \\
22,844\end{array}$ \\
\hline
\end{tabular}

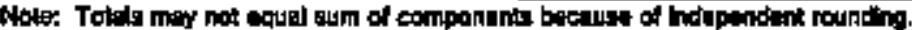

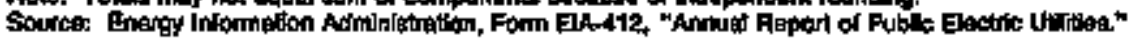


Table 22 Balance Sheet by Major U.S. Publlcly Owned Electric Utilty Within state at End of Poriod, 1994

(Thousand Doltars)

\begin{tabular}{|c|c|c|c|c|c|c|}
\hline I10m & $\begin{array}{l}\text { Goxgta } \\
\text { Oadion } \\
\text { Chy of } \\
\text { Noworiber } 30\end{array}$ & $\begin{array}{l}\text { Ceorgla } \\
\text { Douglag } \\
\text { Ciny of } \\
\text { Junn } 30\end{array}$ & 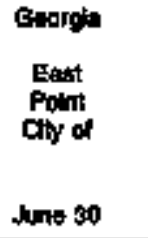 & 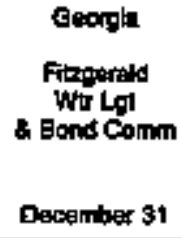 & 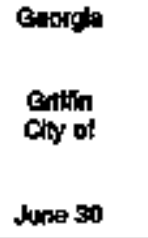 & $\begin{array}{l}\text { Cecorga } \\
\text { La Granga } \\
\text { Ciny of } \\
\text { Juno } 30\end{array}$ \\
\hline 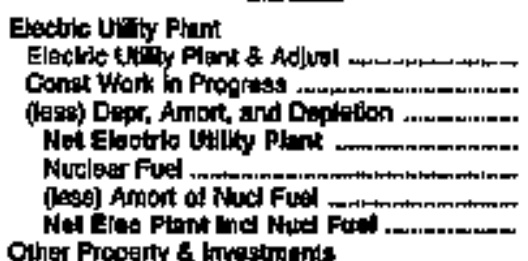 & 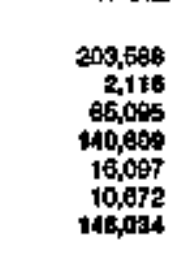 & $\begin{array}{r}4,119 \\
0 \\
2,290 \\
1,600 \\
0 \\
0 \\
1,060\end{array}$ & $\begin{array}{r}6,250 \\
0 \\
5,898 \\
2,412 \\
0 \\
0 \\
2,412\end{array}$ & $\begin{array}{r}6,730 \\
0 \\
3,027 \\
3,713 \\
0 \\
0 \\
3,713\end{array}$ & $\begin{array}{r}11,260 \\
0 \\
330 \\
10,989 \\
0 \\
0 \\
10,928\end{array}$ & $\begin{array}{r}7,6086 \\
0 \\
2,071 \\
5,62,5 \\
0 \\
0 \\
5,6025\end{array}$ \\
\hline 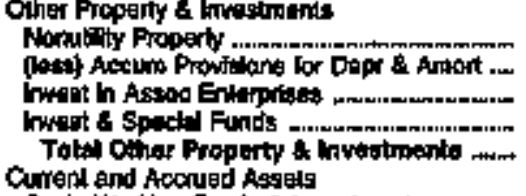 & $\begin{array}{r}3,346 \\
760 \\
12,498 \\
230,576 \\
246,644\end{array}$ & $\begin{array}{r}551 \\
307 \\
0 \\
1,4,43 \\
1,307\end{array}$ & $\begin{array}{l}0 \\
0 \\
0 \\
0 \\
0 \\
0\end{array}$ & $\begin{array}{r}18,009 \\
4,677 \\
6 \\
1,419 \\
14,750\end{array}$ & $\begin{array}{r}28,4 B B \\
4,411 \\
0 \\
0 \\
09,007\end{array}$ & $\begin{array}{l}0 \\
0 \\
0 \\
0 \\
0\end{array}$ \\
\hline 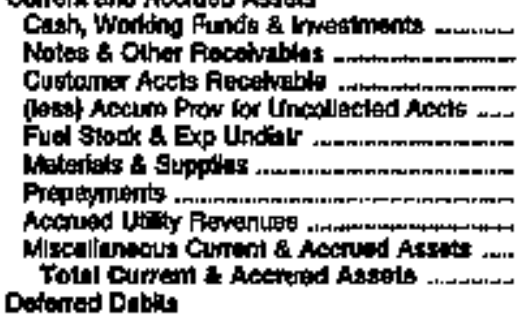 & $\begin{array}{r}80 \\
616 \\
2,402 \\
62 \\
2,098 \\
4,549 \\
65 \\
1,790 \\
11,308\end{array}$ & $\begin{array}{r}279 \\
7 \\
1+751 \\
70 \\
0 \\
650 \\
0 \\
0 \\
0 \\
2,500\end{array}$ & $\begin{array}{r}0 \\
0 \\
4,218 \\
107 \\
0 \\
704 \\
240 \\
0 \\
5,068\end{array}$ & $\begin{array}{r}1.179 \\
11 \\
393 \\
114 \\
1 \\
675 \\
0 \\
0 \\
0 \\
2,095\end{array}$ & $\begin{array}{r}941 \\
3731 \\
0 \\
0 \\
0 \\
597 \\
68 \\
0 \\
0 \\
5,350\end{array}$ & $\begin{array}{l}0 \\
0 \\
0 \\
0 \\
0 \\
0 \\
0 \\
0 \\
0 \\
0\end{array}$ \\
\hline 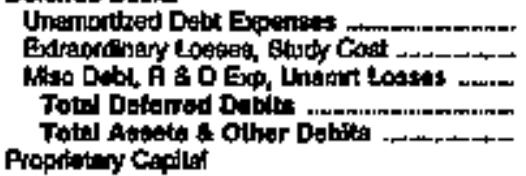 & $\begin{array}{r}814 \\
0 \\
5,042 \\
1,858 \\
404,969\end{array}$ & $\begin{array}{r}0 \\
0 \\
0 \\
0 \\
\mathbf{0}, 686\end{array}$ & $\begin{array}{r}0 \\
0 \\
0 \\
0 \\
0 \\
0 \\
0\end{array}$ & $\begin{array}{r}0 \\
0 \\
0 \\
20\end{array}$ & $\begin{array}{r}0 \\
0 \\
0 \\
0 \\
11,354\end{array}$ & $\begin{array}{r}0 \\
0 \\
0 \\
0 \\
5,625\end{array}$ \\
\hline 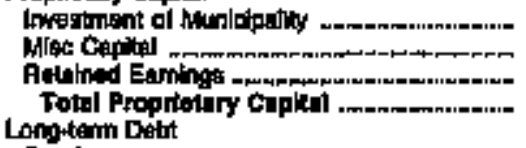 & $\begin{array}{r}0 \\
0 \\
294,979 \\
294,973\end{array}$ & $\begin{array}{l}280 \\
1,290 \\
3,749 \\
6,815\end{array}$ & $\begin{array}{r}0 \\
3,656 \\
3,666\end{array}$ & $\begin{array}{r}0 \\
0 \\
13,944 \\
13,944\end{array}$ & $\begin{array}{r}0 \\
0 \\
26,072 \\
26,072\end{array}$ & $\begin{array}{r}0 \\
0 \\
5,825 \\
5,650\end{array}$ \\
\hline 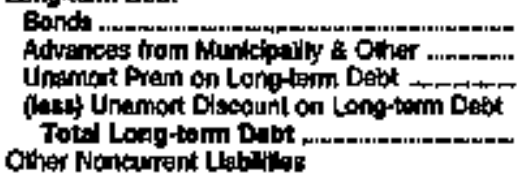 & $\begin{array}{r}68,695 \\
0 \\
0 \\
197 \\
99,558\end{array}$ & $\begin{array}{l}0 \\
0 \\
0 \\
0 \\
0\end{array}$ & $\begin{array}{l}0 \\
0 \\
0 \\
0 \\
0 \\
0\end{array}$ & $\begin{array}{r}4,390 \\
0 \\
7217 \\
704 \\
5,815\end{array}$ & $\begin{array}{r}13,162 \\
0 \\
0 \\
0 \\
19,180\end{array}$ & $\begin{array}{l}0 \\
0 \\
0 \\
0 \\
0\end{array}$ \\
\hline 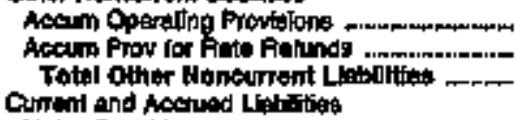 & $\begin{array}{r}984 \\
90\end{array}$ & $\begin{array}{l}0 \\
0 \\
0\end{array}$ & $\begin{array}{l}\text { D } \\
\text { D } \\
\text { D }\end{array}$ & $\begin{array}{l}0 \\
0 \\
0\end{array}$ & $\begin{array}{l}0 \\
0 \\
0\end{array}$ & $\begin{array}{l}0 \\
0 \\
0\end{array}$ \\
\hline 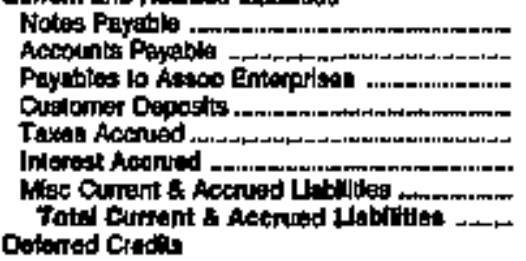 & $\begin{array}{r}2,005 \\
255 \\
020 \\
0 \\
2,400 \\
4,040 \\
70,900\end{array}$ & $\begin{array}{r}0 \\
0 \\
0 \\
265 \\
0 \\
0 \\
87 \\
877\end{array}$ & $\begin{array}{r}0 \\
3,417 \\
0 \\
309 \\
0 \\
0 \\
6 \\
3814\end{array}$ & $\begin{array}{r}0 \\
382 \\
0 \\
249 \\
0 \\
60 \\
80 \\
768\end{array}$ & $\begin{array}{r}0 \\
17 \\
0 \\
995 \\
0 \\
0 \\
1,169 \\
2120\end{array}$ & $\begin{array}{l}0 \\
0 \\
0 \\
0 \\
0 \\
0 \\
0 \\
0\end{array}$ \\
\hline 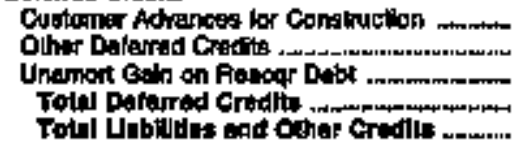 & $\begin{array}{r}2,213 \\
6,681 \\
0 \\
0,094 \\
404,659\end{array}$ & $\begin{array}{r}0 \\
0 \\
0 \\
0 \\
0,686\end{array}$ & $\begin{array}{r}0 \\
0 \\
0 \\
0 \\
7,409\end{array}$ & 20,840 & $\begin{array}{r}0 \\
0 \\
0 \\
0 \\
41,354\end{array}$ & $\begin{array}{r}0 \\
0 \\
0 \\
0 \\
0,928\end{array}$ \\
\hline
\end{tabular}

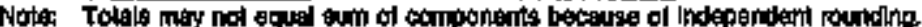

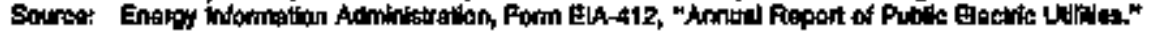


Table 22. Balance Shoot by Major U.S. Publioly Owned Electric Utility Whith'n State at End of Pertod, 1994

(Thousand Dollars)

\begin{tabular}{|c|c|c|c|c|c|c|}
\hline Iem & 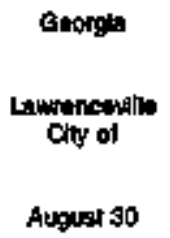 & 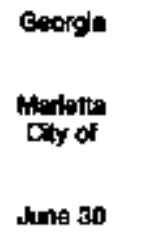 & 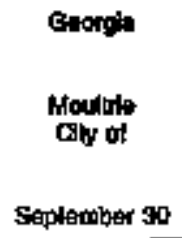 & 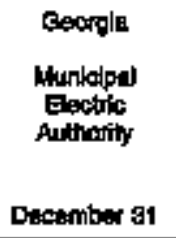 & 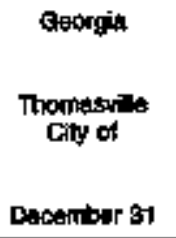 & $\begin{array}{l}\text { Iidabo } \\
\text { Idatso } \\
\text { Ciny of } \\
\text { September } 30\end{array}$ \\
\hline 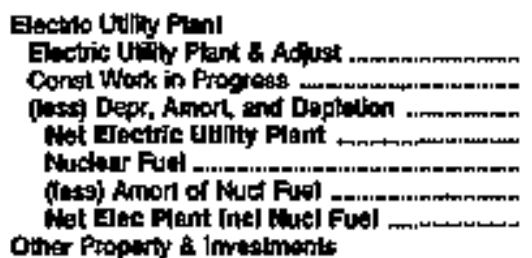 & $\begin{array}{r}13,209 \\
0 \\
3,370 \\
9,500 \\
0 \\
0 \\
0,500\end{array}$ & $\begin{array}{r}40,613 \\
0 \\
14,642 \\
18,971 \\
0 \\
0 \\
13,971\end{array}$ & $\begin{array}{r}5,832 \\
141 \\
3,747 \\
2,320 \\
0 \\
0 \\
2,328\end{array}$ & $\begin{array}{r}3,042,958 \\
17,402 \\
043,416 \\
2,217,094 \\
346,145 \\
312,292 \\
2,270,967\end{array}$ & $\begin{array}{r}14,909 \\
7 \\
4,736 \\
10,207 \\
0 \\
0 \\
10,267\end{array}$ & 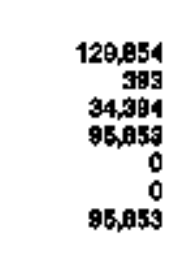 \\
\hline 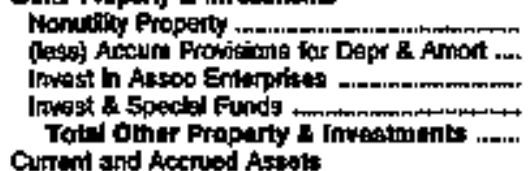 & $\begin{array}{l}0 \\
0 \\
0 \\
0 \\
0\end{array}$ & $\begin{array}{r}45,955 \\
18,852 \\
0 \\
0 \\
27,208\end{array}$ & $\begin{array}{r}714 \\
490 \\
0 \\
0 \\
220\end{array}$ & $\begin{array}{r}0 \\
0 \\
0 \\
1,892,273 \\
1,022,273\end{array}$ & $\begin{array}{l}0 \\
0 \\
0 \\
0 \\
0\end{array}$ & $\begin{array}{r}0 \\
0 \\
0 \\
28,081 \\
28,051\end{array}$ \\
\hline 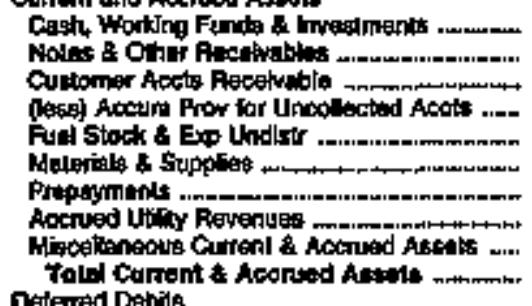 & $\begin{array}{r}0 \\
0 \\
2,507 \\
518 \\
0 \\
0 \\
0 \\
0 \\
0 \\
\text { 2,011 }\end{array}$ & $\begin{array}{r}28,786 \\
186 \\
12,258 \\
811 \\
0 \\
2,188 \\
0 \\
0 \\
2 \\
2,566\end{array}$ & $\begin{array}{r}1,296 \\
0 \\
1,290 \\
395 \\
0 \\
241 \\
14 \\
0 \\
0 \\
2,10\end{array}$ & $\begin{array}{r}149,632 \\
11,065 \\
25,054 \\
0 \\
15,244 \\
40,633 \\
2,077 \\
0 \\
0 \\
244,628\end{array}$ & $\begin{array}{r}1,148 \\
385 \\
1,730 \\
75 \\
0 \\
1,468 \\
4 \\
1,394 \\
6 \\
6,044\end{array}$ & $\begin{array}{r}2,998 \\
407 \\
2,498 \\
395 \\
0 \\
2,055 \\
0 \\
21 \\
0 \\
7,562\end{array}$ \\
\hline 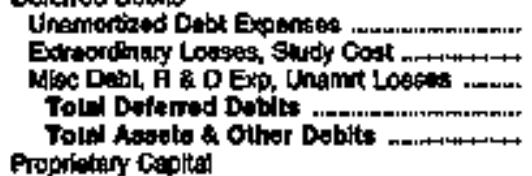 & $\begin{array}{r}0 \\
0 \\
0 \\
0 \\
1+, 919\end{array}$ & $\begin{array}{r}160 \\
0 \\
3,765 \\
3,015 \\
9,5=4\end{array}$ & $\begin{array}{r}0 \\
0 \\
0 \\
0 \\
4,9+2\end{array}$ & $\begin{array}{r}369,304 \\
607,405 \\
56,769 \\
6,204,774\end{array}$ & $\begin{array}{r}0 \\
0 \\
0 \\
0\end{array}$ & $\begin{array}{r}2,180 \\
1,702 \\
0 \\
3,980 \\
13,4,46\end{array}$ \\
\hline 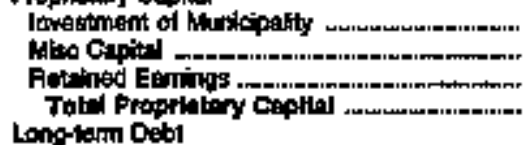 & $\begin{array}{r}0 \\
10,002 \\
10,02\end{array}$ & $\begin{array}{r}1,206 \\
49 \\
76,989 \\
79,249\end{array}$ & $\begin{array}{r}12 \\
0 \\
4,608 \\
+, 620\end{array}$ & $\begin{array}{l}0 \\
0 \\
0 \\
0\end{array}$ & $\begin{array}{r}0 \\
208 \\
12,800 \\
12,068\end{array}$ & $\begin{array}{r}0 \\
0 \\
30,571 \\
30,571\end{array}$ \\
\hline 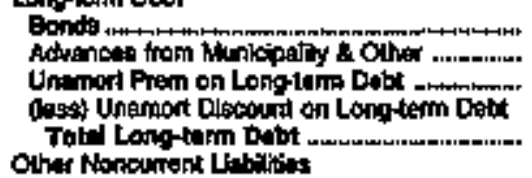 & $\begin{array}{l}0 \\
0 \\
0 \\
0 \\
0\end{array}$ & $\begin{array}{r}7,865 \\
35 \\
0 \\
0 \\
7,900\end{array}$ & $\begin{array}{l}0 \\
0 \\
0 \\
0 \\
0\end{array}$ & $\begin{array}{r}4,3,29,564 \\
544,726 \\
3,9,924 \\
70,292 \\
4,696,9027\end{array}$ & $\begin{array}{l}0 \\
0 \\
0 \\
0 \\
0 \\
0\end{array}$ & $\begin{array}{r}0,359 \\
0 \\
3,526 \\
1,579 \\
0,300\end{array}$ \\
\hline 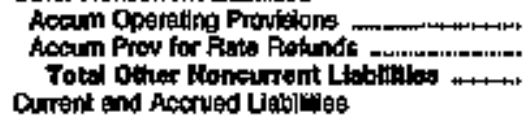 & $\begin{array}{l}0 \\
0 \\
0\end{array}$ & $\begin{array}{l}0 \\
0 \\
0\end{array}$ & $\begin{array}{l}0 \\
0 \\
0\end{array}$ & $\begin{array}{r}6,165 \\
6 \\
5,168\end{array}$ & $\begin{array}{l}0 \\
0 \\
0\end{array}$ & $\begin{array}{l}0 \\
0 \\
0\end{array}$ \\
\hline 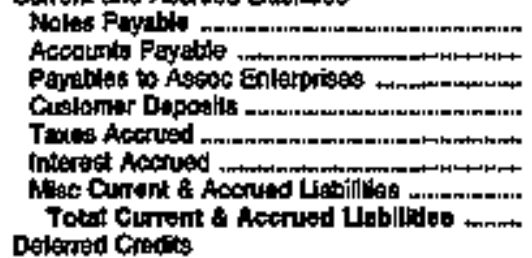 & $\begin{array}{r}0 \\
1,117 \\
0 \\
0 \\
0 \\
0 \\
0 \\
1,117\end{array}$ & $\begin{array}{r}6,25 \\
5,200 \\
0 \\
2,121 \\
5 \% 5 \\
112 \\
2,659 \\
11,409\end{array}$ & $\begin{array}{r}0 \\
355 \\
0 \\
0 \\
0 \\
0 \\
0 \\
395\end{array}$ & $\begin{array}{r}27,000 \\
18,671 \\
0 \\
0 \\
28 \\
114,578 \\
738 \\
161,015\end{array}$ & $\begin{array}{r}49 \\
1,673 \\
0 \\
642 \\
78 \\
0 \\
1,787 \\
4,218\end{array}$ & $\begin{array}{r}0 \\
1,965 \\
142 \\
1 \\
0 \\
13,158 \\
2,581 \\
17,665\end{array}$ \\
\hline 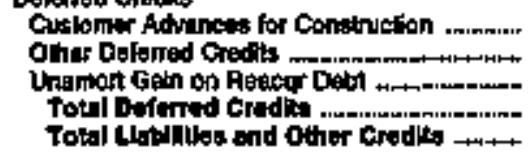 & $\begin{array}{r}0 \\
0 \\
0 \\
0 \\
11,919\end{array}$ & $\begin{array}{r}0 \\
0 \\
0 \\
0 \\
97,5,54\end{array}$ & $\begin{array}{r}0 \\
7 \\
0 \\
7 \\
4962\end{array}$ & $\begin{array}{r}0 \\
300,672 \\
0 \\
305,6572 \\
\text { s,304,774 }\end{array}$ & $\begin{array}{r}0 \\
0 \\
0 \\
0 \\
16,911\end{array}$ & $\begin{array}{r}0 \\
0 \\
0 \\
0 \\
193,456\end{array}$ \\
\hline
\end{tabular}

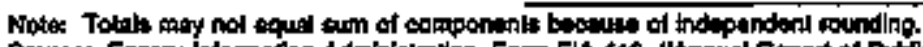

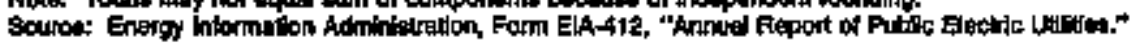


Table 22. Balance Stheet by Malor U.S. Publicly Owned Electrle Uthlty Within state at End of Perlod, 1994 (Thousand Dollars)

\begin{tabular}{|c|c|c|c|c|c|c|}
\hline Hem & $\begin{array}{l}\text { Illincis } \\
\text { Balavia } \\
\text { Ciny of } \\
\text { Decariber } \$ 1\end{array}$ & $\begin{array}{l}\text { Whoie } \\
\text { Canowa } \\
\text { Cly of } \\
\text { April so }\end{array}$ & 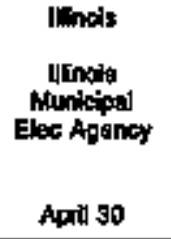 & $\begin{array}{l}\text { Mlnots } \\
\text { Nupenith of } \\
\text { Apro so }\end{array}$ & 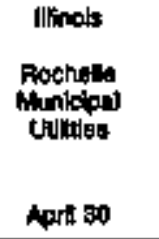 & $\begin{array}{l}\text { Nitinota } \\
\text { Sprinotiold } \\
\text { Ciny of } \\
\text { Fetruary } 28\end{array}$ \\
\hline 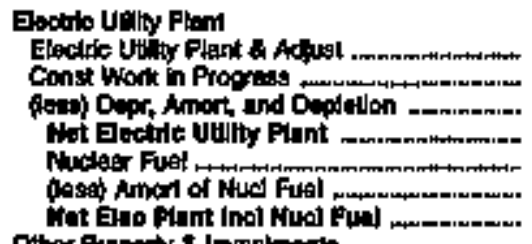 & $\begin{array}{r}10,293 \\
0 \\
0,102 \\
9,031 \\
0 \\
0 \\
0 \\
901\end{array}$ & $\begin{array}{r}21,652 \\
50 \\
9,12 t \\
12,480 \\
0 \\
0 \\
12,4: 0\end{array}$ & $\begin{array}{r}90,540 \\
3,64 \\
0,605 \\
97,390 \\
0 \\
0 \\
97,395\end{array}$ & $\begin{array}{r}107,680 \\
90939 \\
20,017 \\
6,000 \\
0 \\
0 \\
0,002\end{array}$ & $\begin{array}{r}29,066 \\
14 \\
16,605 \\
14,057 \\
0 \\
0 \\
14,0.57\end{array}$ & $\begin{array}{r}357,278 \\
18,480 \\
170,758 \\
198,660 \\
0 \\
0 \\
196,980\end{array}$ \\
\hline 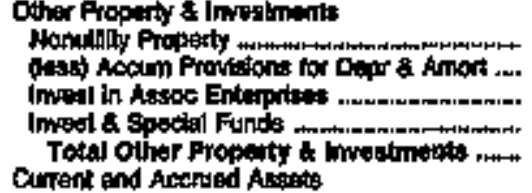 & $\begin{array}{l}0 \\
0 \\
0 \\
0 \\
0\end{array}$ & $\begin{array}{r}0 \\
0 \\
0 \\
443 \\
449\end{array}$ & $\begin{array}{l}0 \\
0 \\
0 \\
0 \\
0\end{array}$ & $\begin{array}{r}0 \\
0 \\
0 \\
7,519 \\
7,519\end{array}$ & $\begin{array}{r}0 \\
0 \\
0 \\
2,597 \\
2,597\end{array}$ & $\begin{array}{r}4,887 \\
0 \\
0 \\
71,815 \\
76,600\end{array}$ \\
\hline 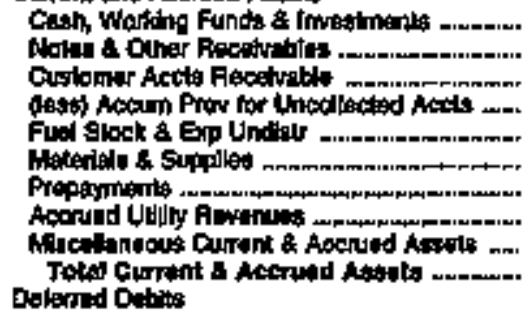 & $\begin{array}{r}2,749 \\
7,304 \\
0 \\
0 \\
0 \\
0 \\
1,040 \\
1 \\
0 \\
0 \\
0 \\
11,700\end{array}$ & $\begin{array}{r}1,557 \\
150 \\
1,254 \\
58 \\
0 \\
470 \\
0 \\
0 \\
0 \\
3,972\end{array}$ & $\begin{array}{r}29,604 \\
0 \\
4,471 \\
0 \\
0 \\
0 \\
4 \\
0 \\
0 \\
0 \\
0,118\end{array}$ & $\begin{array}{r}36,741 \\
0 \\
5,457 \\
309 \\
0 \\
4,801 \\
112 \\
00 \\
7869 \\
47,100\end{array}$ & $\begin{array}{r}2,017 \\
0 \\
1,044 \\
65 \\
258 \\
408 \\
49 \\
201 \\
111 \\
4,107\end{array}$ & $\begin{array}{r}1,797 \\
832 \\
7,472 \\
5723 \\
1,448 \\
6,278 \\
1,227 \\
4,390 \\
31 \\
29,980\end{array}$ \\
\hline 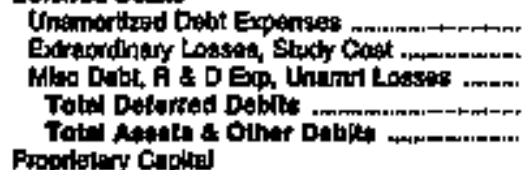 & $\begin{array}{r}0 \\
0 \\
0 \\
0 \\
0 \\
21000\end{array}$ & $\begin{array}{r}36 \\
0 \\
0 \\
38 \\
15,301\end{array}$ & $\begin{array}{r}3,270 \\
0 \\
2,871 \\
6,129 \\
126,050\end{array}$ & $\begin{array}{r}0 \\
0 \\
0 \\
0 \\
149,7+11\end{array}$ & $\begin{array}{r}7 \\
35 \\
0 \\
01,106\end{array}$ & $\begin{array}{r}258 \\
0 \\
0 \\
259 \\
200,061\end{array}$ \\
\hline 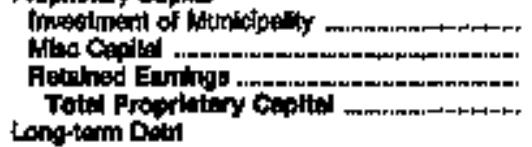 & $\begin{array}{r}0 \\
0 \\
14,387 \\
14,317\end{array}$ & $\begin{array}{r}0 \\
0 \\
14,421 \\
14,421\end{array}$ & $\begin{array}{r}0 \\
0 \\
4,902 \\
4040\end{array}$ & $\begin{array}{r}0 \\
20,779 \\
106,117 \\
126,916\end{array}$ & $\begin{array}{r}0 \\
0 \\
10,579 \\
10,579\end{array}$ & $\begin{array}{r}10,025 \\
140,029 \\
160,954\end{array}$ \\
\hline 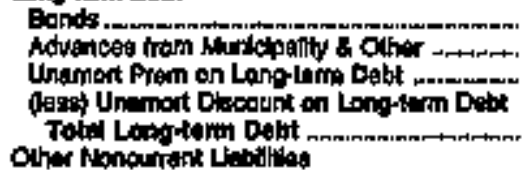 & $\begin{array}{l}0 \\
0 \\
0 \\
0 \\
0\end{array}$ & $\begin{array}{r}305 \\
601 \\
0 \\
0 \\
1,138\end{array}$ & $\begin{array}{r}12,980 \\
0 \\
0 \\
6,6 \times 9 \\
115,664\end{array}$ & $\begin{array}{r}16 \beta 15 \\
0 \\
0 \\
0 \\
17,210\end{array}$ & $\begin{array}{r}7,8689 \\
0 \\
0 \\
0 \\
7,989\end{array}$ & $\begin{array}{r}12,005 \\
0 \\
0 \\
1,094 \\
120,974\end{array}$ \\
\hline 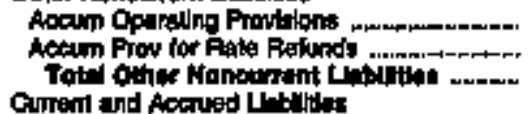 & $\begin{array}{l}0 \\
0 \\
0\end{array}$ & $\begin{array}{l}20 \\
0\end{array}$ & $\begin{array}{l}0 \\
0 \\
0\end{array}$ & $\begin{array}{l}0 \\
0 \\
0\end{array}$ & $\begin{array}{l}0 \\
0 \\
0\end{array}$ & $\begin{array}{l}0 \\
0 \\
0\end{array}$ \\
\hline 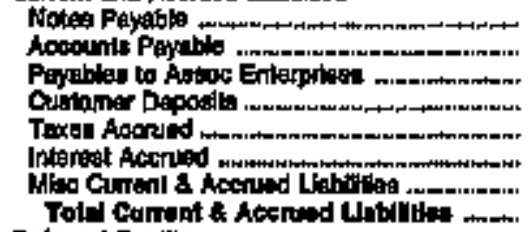 & $\begin{array}{r}0 \\
6,509 \\
0 \\
104 \\
0 \\
0 \\
0 \\
0,698\end{array}$ & $\begin{array}{r}0 \\
749 \\
0 \\
0 \\
0 \\
0 \\
2 \\
740\end{array}$ & $\begin{array}{r}0 \\
3,024 \\
0 \\
0 \\
0 \\
1,780 \\
80 \\
6,7 \% 0\end{array}$ & $\begin{array}{r}0 \\
2,569 \\
1,692 \\
0 \\
0 \\
0 \\
2,280 \\
0,417\end{array}$ & $\begin{array}{r}300 \\
1,600 \\
0 \\
0 \\
0 \\
280 \\
240 \\
2,440\end{array}$ & $\begin{array}{r}5,945 \\
10,019 \\
0 \\
609 \\
2 \\
4,610 \\
01,109\end{array}$ \\
\hline 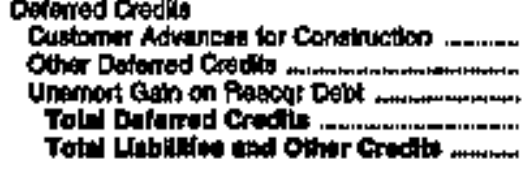 & $\begin{array}{r}0 \\
0 \\
0 \\
0 \\
\operatorname{210} 0\end{array}$ & $\begin{array}{r}0 \\
0 \\
0 \\
0 \\
10,31\end{array}$ & $\begin{array}{r}0 \\
46 \\
0 \\
40 \\
40468\end{array}$ & $\begin{array}{r}180 \\
0 \\
0 \\
180 \\
109711\end{array}$ & $\begin{array}{r}0 \\
201 \\
0 \\
201 \\
21,4010\end{array}$ & $\begin{array}{r}874 \\
0 \\
10,070 \\
10,644 \\
\sin 00101\end{array}$ \\
\hline
\end{tabular}

Noter Totpla may not equal aum of componanda because of independent reunding.

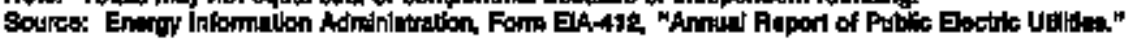


Toble 22. Baknoe Sheot by Major U.\$. Publicly Owned Electrle Uillity Within State at End of Period, 1894

(Thousand Dollars)

\begin{tabular}{|c|c|c|c|c|c|c|}
\hline Ham & $\begin{array}{l}\text { Inots } \\
\text { St Cheries } \\
\text { Chy of } \\
\text { Apdil on }\end{array}$ & $\begin{array}{l}\text { Indian: } \\
\text { Andereon } \\
\text { Civy of } \\
\text { Oenomber } 31\end{array}$ & $\begin{array}{l}\text { Inting } \\
\text { Autum } \\
\text { Chy of } \\
\text { Deoenter } 31\end{array}$ & $\begin{array}{l}\text { Inditan: } \\
\text { Ehfiton } \\
\text { City of } \\
\text { Docosinber } 3\end{array}$ & 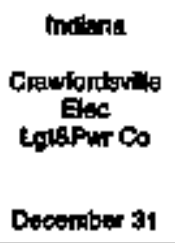 & $\begin{array}{l}\text { molans } \\
\text { Ftankioxt } \\
\text { Cly of } \\
\text { Decomber } 31\end{array}$ \\
\hline 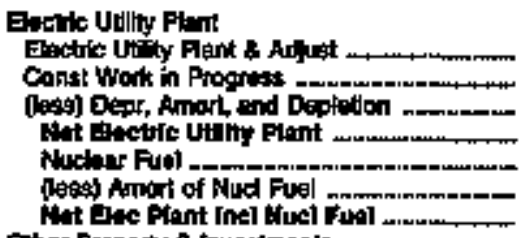 & $\begin{array}{r}20,760 \\
0 \\
0,444 \\
20,386 \\
0 \\
0 \\
20,896\end{array}$ & $\begin{array}{r}53,196 \\
1,117 \\
2,024 \\
32,220 \\
0 \\
0 \\
32,229\end{array}$ & $\begin{array}{r}13,800 \\
24 \\
4,268 \\
9,673 \\
0 \\
0 \\
9,67 \%\end{array}$ & $\begin{array}{r}8,022 \\
0 \\
4,4 t 6 \\
4,207 \\
0 \\
0 \\
4,207\end{array}$ & $\begin{array}{r}31,697 \\
117 \\
16,682 \\
15,992 \\
0 \\
15,802\end{array}$ & $\begin{array}{r}18,498 \\
493 \\
6,593 \\
12,278 \\
0 \\
0 \\
12,276\end{array}$ \\
\hline 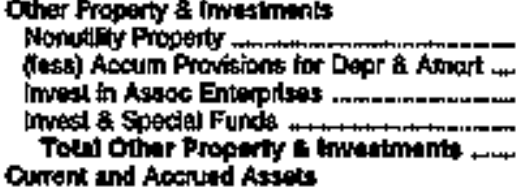 & $\begin{array}{l}0 \\
0 \\
0 \\
0 \\
0\end{array}$ & $\begin{array}{l}0 \\
0 \\
0 \\
0 \\
0\end{array}$ & $\begin{array}{l}0 \\
0 \\
0 \\
0\end{array}$ & $\begin{array}{r}0 \\
0 \\
0 \\
976 \\
976\end{array}$ & $\begin{array}{l}0 \\
0 \\
0 \\
0 \\
0\end{array}$ & $\begin{array}{l}0 \\
0 \\
0 \\
0 \\
0\end{array}$ \\
\hline 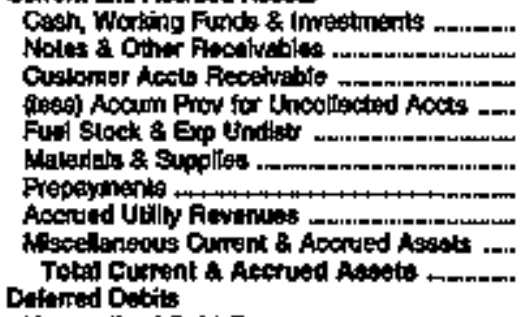 & $\begin{array}{r}10,679 \\
876 \\
1,414 \\
4 \\
0 \\
2 \\
14 \\
0 \\
16 \\
12,696\end{array}$ & $\begin{array}{r}1,399 \\
202 \\
1,749 \\
527 \\
0 \\
063 \\
0 \\
0 \\
0 \\
3,676\end{array}$ & $\begin{array}{r}11,617 \\
540 \\
250 \\
0 \\
0 \\
401 \\
43 \\
0 \\
0 \\
12,609\end{array}$ & $\begin{array}{r}1,049 \\
9 \\
456 \\
39 \\
0 \\
704 \\
21 \\
0 \\
0 \\
2,200\end{array}$ & $\begin{array}{r}6,027 \\
0 \\
701 \\
0 \\
101 \\
600 \\
150 \\
0 \\
609\end{array}$ & $\begin{array}{r}7,638 \\
153 \\
1,004 \\
0 \\
0 \\
582 \\
35 \\
0 \\
8 \\
8 \\
0,44\end{array}$ \\
\hline 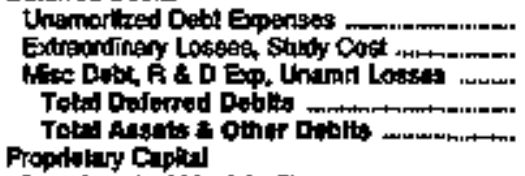 & $\begin{array}{r}0 \\
0 \\
0 \\
0 \\
\sin , 2 \pi 2\end{array}$ & $\begin{array}{r}13 \\
0 \\
552 \\
696 \\
39,471\end{array}$ & $\begin{array}{r}0 \\
0 \\
0 \\
0 \\
22,411\end{array}$ & $\begin{array}{r}0 \\
0 \\
0 \\
0 \\
0 \\
7,202\end{array}$ & $\begin{array}{r}172 \\
0 \\
67 \\
620 \\
29,616\end{array}$ & $\begin{array}{r}0 \\
0 \\
0 \\
21,6928\end{array}$ \\
\hline 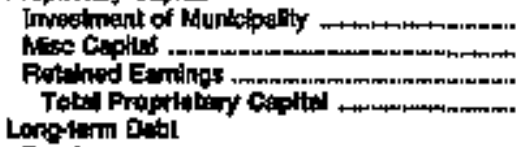 & $\begin{array}{r}0 \\
0 \\
20,720 \\
20,720\end{array}$ & $\begin{array}{r}0 \\
0 \\
27,079 \\
27,070\end{array}$ & $\begin{array}{r}0 \\
0 \\
20,257 \\
20,2=07\end{array}$ & $\begin{array}{r}0 \\
0 \\
6,350 \\
6,359\end{array}$ & $\begin{array}{r}0 \\
13,809 \\
13,690\end{array}$ & $\begin{array}{r}0 \\
0 \\
17,316 \\
17,316\end{array}$ \\
\hline 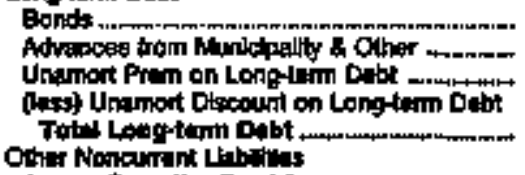 & $\begin{array}{l}0 \\
0 \\
0 \\
0 \\
0\end{array}$ & $\begin{array}{r}\mathbf{3} 00 \\
0 \\
0 \\
0 \\
610\end{array}$ & $\begin{array}{r}540 \\
0 \\
0 \\
0 \\
540\end{array}$ & $\begin{array}{l}0 \\
0 \\
0 \\
0 \\
0\end{array}$ & $\begin{array}{r}4,060 \\
0 \\
0 \\
0 \\
6,9010\end{array}$ & $\begin{array}{l}0 \\
6 \\
0 \\
0 \\
6\end{array}$ \\
\hline 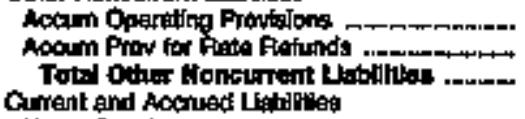 & $\begin{array}{l}0 \\
0 \\
0\end{array}$ & $\begin{array}{r}66 \\
0 \\
58\end{array}$ & $\begin{array}{l}0 \\
0 \\
0\end{array}$ & $\begin{array}{l}0 \\
0\end{array}$ & $\begin{array}{l}0 \\
0 \\
0\end{array}$ & $\begin{array}{l}0 \\
\text { D } \\
0\end{array}$ \\
\hline 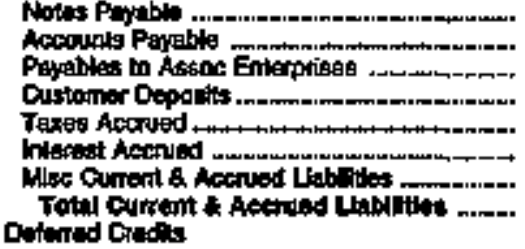 & $\begin{array}{r}0 \\
7,309 \\
200 \\
165 \\
0 \\
0 \\
1,840 \\
3,497\end{array}$ & $\begin{array}{r}0 \\
4,487 \\
0 \\
387 \\
113 \\
0 \\
0 \\
4,080\end{array}$ & $\begin{array}{r}390 \\
1,139 \\
0 \\
13 \\
20 \\
53 \\
0 \\
1,614\end{array}$ & $\begin{array}{r}0 \\
742 \\
0 \\
102 \\
2 \\
0 \\
0 \\
640\end{array}$ & $\begin{array}{r}305 \\
1925 \\
0 \\
99 \\
4 \\
0 \\
170 \\
2407\end{array}$ & $\begin{array}{r}0 \\
008 \\
0 \\
260 \\
250 \\
0 \\
010 \\
1,500\end{array}$ \\
\hline 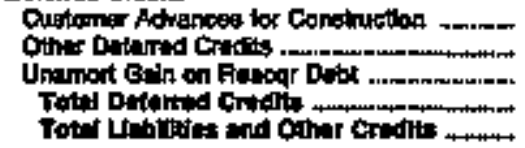 & $\begin{array}{r}0 \\
0 \\
05 \\
25,292\end{array}$ & $\begin{array}{r}3,804 \\
0 \\
0 \\
3,804 \\
30,47 t\end{array}$ & $\begin{array}{r}0 \\
0 \\
0 \\
0 \\
22,411\end{array}$ & $\begin{array}{r}189 \\
-112 \\
0 \\
77 \\
7,202\end{array}$ & $\begin{array}{r}40 \\
0 \\
0 \\
25,016\end{array}$ & $\begin{array}{r}0 \\
2,081 \\
0 \\
21,051 \\
21, a t 2\end{array}$ \\
\hline
\end{tabular}

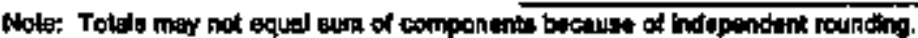

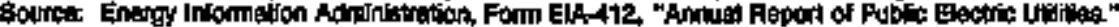


Table 22. Balance Sheet by Major US. Publisly Owned Electric Utilly Whin state at End of Perlod, 1994

(Thousand Dollars)

\begin{tabular}{|c|c|c|c|c|c|c|}
\hline |lem & 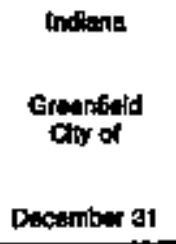 & 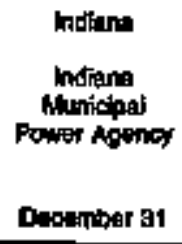 & $\begin{array}{l}\text { tollarin } \\
\text { Jespar } \\
\text { Cty of } \\
\text { Decomber at }\end{array}$ & $\begin{array}{l}\text { Indiand } \\
\text { Lonemsport } \\
\text { Chy of } \\
\text { Dooember } 91\end{array}$ & 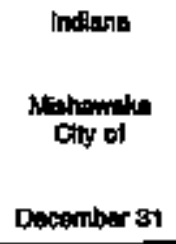 & 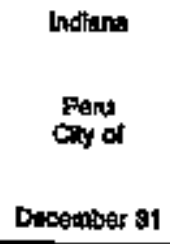 \\
\hline 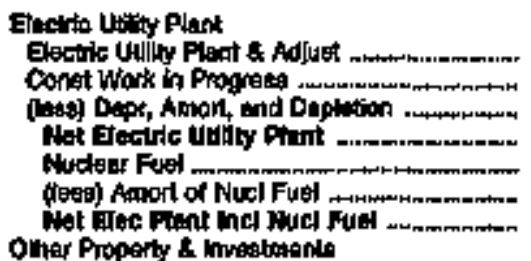 & $\begin{array}{r}6,226 \\
0 \\
2,185 \\
6,043 \\
0 \\
0 \\
6,0,03\end{array}$ & $\begin{array}{r}314,607 \\
3,414 \\
0 \times, 9395 \\
251,678 \\
0 \\
0 \\
251,676\end{array}$ & $\begin{array}{r}13,970 \\
7,159 \\
7,699 \\
13,428 \\
0 \\
0 \\
13,428\end{array}$ & $\begin{array}{r}68,216 \\
2,04 \\
27,709 \\
30,792 \\
0 \\
0 \\
30,792\end{array}$ & $\begin{array}{r}32,135 \\
0 \\
15, a 17 \\
16,398 \\
0 \\
0 \\
16,318\end{array}$ & $\begin{array}{r}30,085 \\
0 \\
16,310 \\
111,75 \\
0 \\
0 \\
13,775\end{array}$ \\
\hline 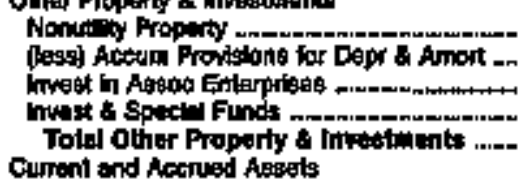 & $\begin{array}{r}0 \\
0 \\
0 \\
1,055 \\
1,055\end{array}$ & $\begin{array}{l}0 \\
0 \\
0 \\
0 \\
0\end{array}$ & $\begin{array}{r}0 \\
0 \\
2798 \\
2,798\end{array}$ & $\begin{array}{r}0 \\
0 \\
0 \\
7,742 \\
7,742\end{array}$ & $\begin{array}{r}18 \\
0 \\
0 \\
1,594 \\
1,812\end{array}$ & $\begin{array}{r}22 \\
0 \\
0 \\
0 \\
2\end{array}$ \\
\hline 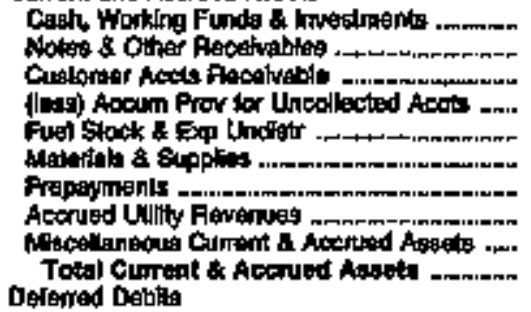 & $\begin{array}{r}1,806 \\
310 \\
488 \\
0 \\
0 \\
0 \\
080 \\
0 \\
0 \\
0 \\
3,471\end{array}$ & $\begin{array}{r}08,659 \\
1+9 \\
10,921 \\
0 \\
4,808 \\
1,000 \\
3,344 \\
0 \\
1,705 \\
124,050\end{array}$ & $\begin{array}{r}2,168 \\
0 \\
1,147 \\
28 \\
10 \\
1,511 \\
110 \\
0 \\
0 \\
4,918\end{array}$ & $\begin{array}{r}758 \\
719 \\
1,325 \\
2 \\
0 \\
2,004 \\
419 \\
17 \\
0 \\
6,2030\end{array}$ & $\begin{array}{r}3,309 \\
20 \\
3,158 \\
6,57 \\
0 \\
1,077 \\
41 \\
0 \\
0 \\
0,947\end{array}$ & $\begin{array}{r}2,760 \\
24 \\
497 \\
76 \\
36 \\
87 \\
0 \\
0 \\
255 \\
3,600\end{array}$ \\
\hline 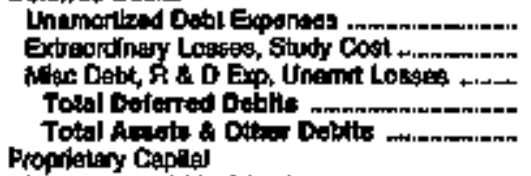 & $\begin{array}{r}46 \\
0 \\
0 \\
10 \\
10,614\end{array}$ & $\begin{array}{r}5,825 \\
52,001 \\
839 \\
86,764 \\
435,274\end{array}$ & 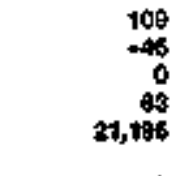 & $\begin{array}{r}0 \\
0 \\
0 \\
0 \\
0,764\end{array}$ & $\begin{array}{r}2 \\
0 \\
-3 \\
-1 \\
2497\end{array}$ & $\begin{array}{r}24 \\
0 \\
0 \\
24 \\
17,496\end{array}$ \\
\hline 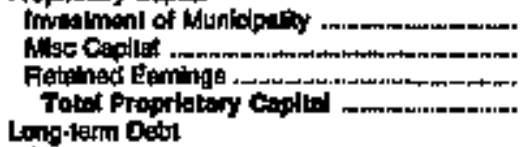 & $\begin{array}{r}0 \\
0,030 \\
0,00\end{array}$ & $\begin{array}{r}0 \\
0 \\
42,722 \\
4,722\end{array}$ & $\begin{array}{r}0 \\
146 \\
11,114 \\
11,2 \% 0\end{array}$ & $\begin{array}{r}0 \\
25,705 \\
2575\end{array}$ & $\begin{array}{r}0 \\
21,200 \\
2 t, 203\end{array}$ & $\begin{array}{r}109 \\
0 \\
14,009 \\
14,2010\end{array}$ \\
\hline 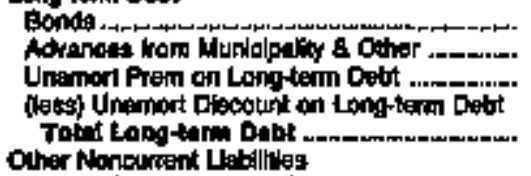 & $\begin{array}{r}1,540 \\
0 \\
0 \\
0 \\
1,040\end{array}$ & $\begin{array}{r}411,535 \\
-42,399 \\
14,025 \\
455,174\end{array}$ & $\begin{array}{r}6,000 \\
0 \\
0 \\
0 \\
0,050\end{array}$ & $\begin{array}{r}74,580 \\
0 \\
0 \\
0 \\
14,50\end{array}$ & $\begin{array}{r}401 \\
010 \\
3 \\
3\end{array}$ & $\begin{array}{r}1,955 \\
0 \\
0 \\
10 \\
1,955\end{array}$ \\
\hline 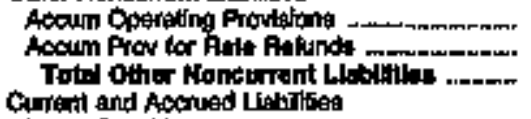 & $\begin{array}{l}0 \\
0 \\
0\end{array}$ & $\begin{array}{l}0 \\
0 \\
0\end{array}$ & $\begin{array}{l}0 \\
0 \\
0\end{array}$ & $\begin{array}{r}109 \\
0 \\
103\end{array}$ & $\begin{array}{l}0 \\
0 \\
0\end{array}$ & $\begin{array}{r}67 \\
07\end{array}$ \\
\hline 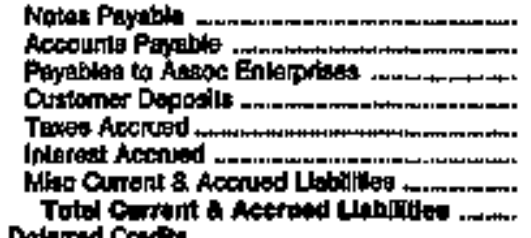 & $\begin{array}{r}0 \\
1,070 \\
0 \\
100 \\
48 \\
0 \\
20 \\
1,239\end{array}$ & $\begin{array}{r}9,675 \\
13,418 \\
0 \\
0 \\
1034 \\
11,740 \\
1,100 \\
36,600\end{array}$ & $\begin{array}{r}0 \\
851 \\
0 \\
200 \\
0 \\
0 \\
35 \\
1,199\end{array}$ & $\begin{array}{r}0 \\
769 \\
0 \\
97 \\
0 \\
405 \\
1,925 \\
3,275\end{array}$ & $\begin{array}{r}0 \\
1,0 \pi 7 \\
0 \\
640 \\
170 \\
41 \\
3 \\
2,791\end{array}$ & $\begin{array}{r}0 \\
529 \\
0 \\
159 \\
0 \\
29 \\
50 \\
750\end{array}$ \\
\hline 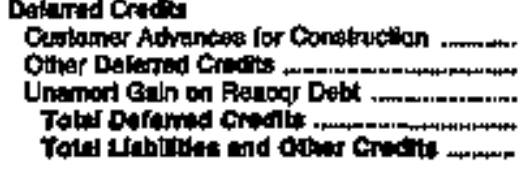 & $\begin{array}{r}0 \\
0 \\
0 \\
010 \\
010\end{array}$ & 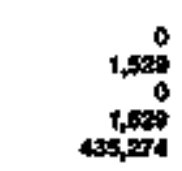 & 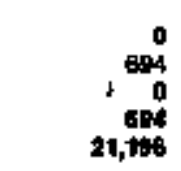 & $\begin{array}{r}0 \\
0 \\
0 \\
0 \\
0\end{array}$ & $\begin{array}{r}284 \\
0 \\
24 \\
2407\end{array}$ & $\begin{array}{r}40 \\
0 \\
0 \\
1740 \\
190\end{array}$ \\
\hline
\end{tabular}

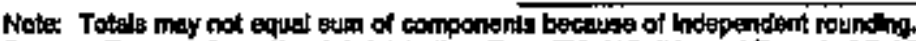

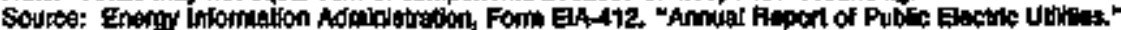


Table 22. Bakance sheet by Major U.S. Publicly Owned Electric Utility , Within state at End of Perlod, 1994

(Thousand Dollars)

\begin{tabular}{|c|c|c|c|c|c|c|}
\hline them & 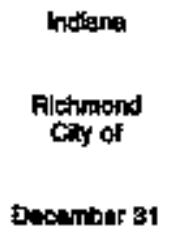 & $\begin{array}{l}\text { Intignta } \\
\text { Waghington } \\
\text { Cily of } \\
\text { Dectember } 31\end{array}$ & $\begin{array}{l}\text { lowi } \\
\text { Antal } \\
\text { Sty of } \\
\text { Jung so }\end{array}$ & $\begin{array}{l}\text { Contre } \\
\text { Cadtar } \\
\text { Falla } \\
\text { City of } \\
\text { Cocimber } \$ 1\end{array}$ & $\begin{array}{l}\text { lown } \\
\text { Muscation } \\
\text { Cty of } \\
\text { Decentoer } 31\end{array}$ & $\begin{array}{l}\text { Poule } \\
\text { City of } \\
\text { Otcomborm } 31\end{array}$ \\
\hline 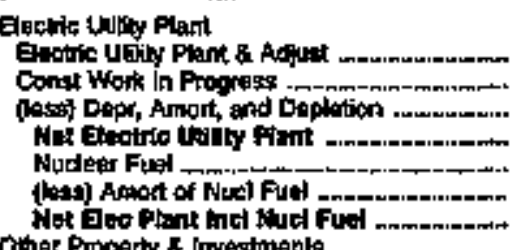 & $\begin{array}{r}39,435 \\
4,05 B \\
41,521 \\
61,052 \\
6 \\
61,062\end{array}$ & $\begin{array}{r}10,796 \\
0 \\
4,921 \\
6,474 \\
0 \\
0 \\
6,474\end{array}$ & $\begin{array}{r}100,350 \\
64,790 \\
45,540 \\
0 \\
0 \\
45,50\end{array}$ & 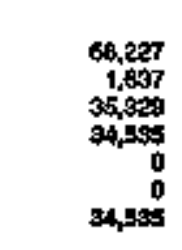 & $\begin{array}{r}2 \% 2,170 \\
1,152 \\
192,698 \\
170,419 \\
0 \\
0 \\
170,425\end{array}$ & $\begin{array}{l}0 \\
0 \\
0 \\
0 \\
0 \\
0 \\
0\end{array}$ \\
\hline 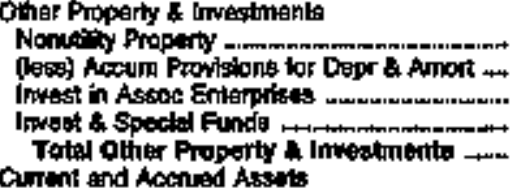 & $\begin{array}{r}470 \\
0 \\
0 \\
13,210 \\
12,696\end{array}$ & $\begin{array}{r}0 \\
0 \\
0 \\
254 \\
254\end{array}$ & $\begin{array}{r}0 \\
0 \\
0 \\
7,6 a 7 \\
7,547\end{array}$ & $\begin{array}{r}0 \\
0 \\
0 \\
1,001 \\
1,001\end{array}$ & $\begin{array}{r}0 \\
0 \\
0 \\
119,854 \\
112,054\end{array}$ & $\begin{array}{r}0 \\
0 \\
0 \\
589 \\
809\end{array}$ \\
\hline 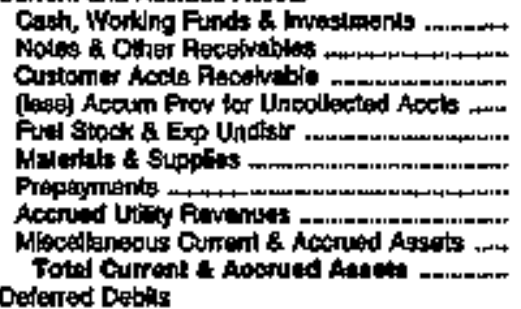 & $\begin{array}{r}3,970 \\
2,500 \\
3,712 \\
5 \\
2,70 \% \\
2,414 \\
305 \\
6 \\
658 \\
16,172\end{array}$ & $\begin{array}{r}766 \\
14 \\
536 \\
76 \\
0 \\
214 \\
0 \\
0 \\
0 \\
1,448\end{array}$ & $\begin{array}{r}8,651 \\
403 \\
2,646 \\
17 \\
534 \\
669 \\
10 \\
0 \\
0 \\
14,005\end{array}$ & $\begin{array}{r}11,761 \\
0 \\
1,540 \\
0 \\
1,435 \\
3 \times 4 \\
21 \\
320 \\
167 \\
16,661\end{array}$ & 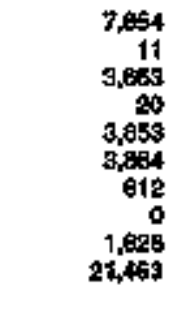 & $\begin{array}{r}11,482 \\
0 \\
713 \\
0 \\
60 \\
250 \\
0 \\
0 \\
187 \\
12,780\end{array}$ \\
\hline 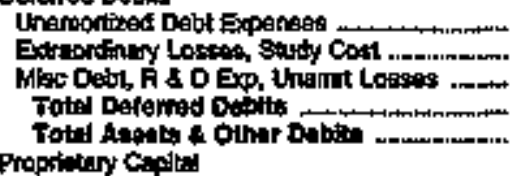 & $\begin{array}{r}0 \\
713 \\
730 \\
7130\end{array}$ & $\begin{array}{r}0 \\
0 \\
0 \\
0 \\
0,173\end{array}$ & $\begin{array}{r}138 \\
0 \\
0 \\
135 \\
97,267\end{array}$ & $\begin{array}{r}0 \\
0 \\
1,570 \\
\mathbf{1 , 6 7 0} \\
62,789\end{array}$ & $\begin{array}{r}2,027 \\
11,027 \\
2,147 \\
16,004 \\
326,536\end{array}$ & $\begin{array}{r}26 \\
0 \\
0 \\
26 \\
13,824\end{array}$ \\
\hline 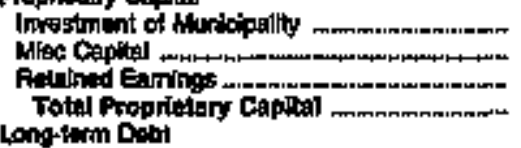 & $\begin{array}{r}0 \\
0 \\
73,460\end{array}$ & $\begin{array}{r}480 \\
0 \\
8,690 \\
7,146\end{array}$ & $\begin{array}{r}0 \\
0 \\
36,985 \\
35,981\end{array}$ & $\begin{array}{r}6 \\
49,434 \\
69,194\end{array}$ & $\begin{array}{r}0 \\
0 \\
12 \theta, 202 \\
12 \% 282\end{array}$ & $\begin{array}{r}0 \\
0 \\
7,169 \\
7,163\end{array}$ \\
\hline 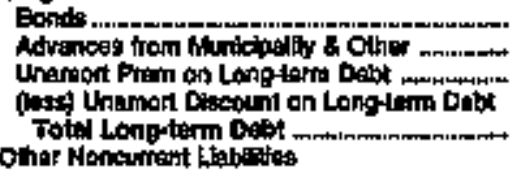 & $\begin{array}{l}0 \\
0 \\
0 \\
0 \\
0\end{array}$ & $\begin{array}{l}0 \\
0 \\
0 \\
0 \\
0\end{array}$ & $\begin{array}{r}24,408 \\
0 \\
0 \\
0 \\
24,408\end{array}$ & $\begin{array}{l}0 \\
0 \\
0 \\
0 \\
0\end{array}$ & $\begin{array}{r}184,400 \\
0 \\
0 \\
7,607 \\
178,798\end{array}$ & $\begin{array}{r}5,125 \\
0 \\
0 \\
5 \\
5,010\end{array}$ \\
\hline 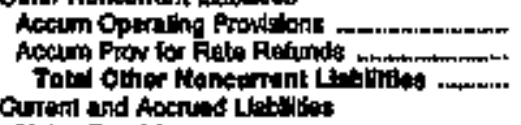 & $\begin{array}{l}0 \\
0 \\
0\end{array}$ & $\begin{array}{l}0 \\
0 \\
0\end{array}$ & $\begin{array}{r}302 \\
0 \\
352\end{array}$ & $\begin{array}{l}0 \\
0 \\
0\end{array}$ & $\begin{array}{l}0 \\
0 \\
0\end{array}$ & $\begin{array}{l}0 \\
0 \\
0\end{array}$ \\
\hline 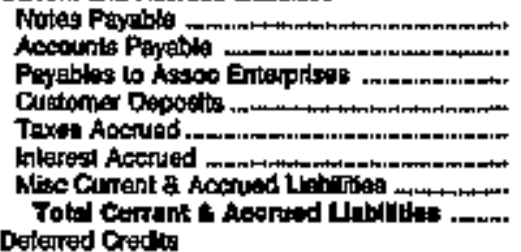 & $\begin{array}{r}2,609 \\
1,757 \\
2,112 \\
137 \\
211 \\
3 \\
488 \\
7,678\end{array}$ & $\begin{array}{r}0 \\
0 \\
0 \\
05 \\
35 \\
0 \\
20 \\
0\end{array}$ & $\begin{array}{r}2909 \\
677 \\
0 \\
308 \\
0 \\
747 \\
1,574 \\
6,646\end{array}$ & $\begin{array}{r}0 \\
1,005 \\
3 \\
71 \\
411 \\
12 \\
974 \\
1,060\end{array}$ & $\begin{array}{r}0 \\
1,181 \\
0 \\
115 \\
100 \\
5,757 \\
8,398 \\
10,494\end{array}$ & $\begin{array}{r}300 \\
704 \\
0 \\
0 \\
0 \\
08 \\
102 \\
1,1132\end{array}$ \\
\hline 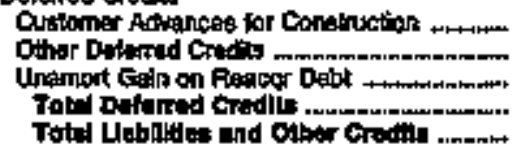 & $\begin{array}{r}0 \\
184 \\
1,338 \\
1,581 \\
02,680\end{array}$ & $\begin{array}{r}152 \\
0 \\
0 \\
152 \\
0,973\end{array}$ & $\begin{array}{r}0 \\
0 \\
0 \\
0\end{array}$ & $\begin{array}{r}0 \\
1,670 \\
0 \\
1,870 \\
5,766\end{array}$ & $\begin{array}{r}0 \\
11,927 \\
0 \\
11,007 \\
320,0 \% 5\end{array}$ & $\begin{array}{r}0 \\
0 \\
0 \\
0 \\
13,+20\end{array}$ \\
\hline
\end{tabular}

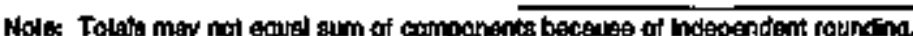

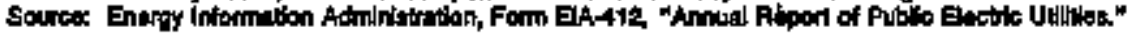


Table 22. Balance sheet by Major U.S. Publicly Owned Electrle Utirty Within state at End of Poriod, 1994

(Thousand Dollars)

\begin{tabular}{|c|c|c|c|c|c|c|}
\hline INDI & $\begin{array}{l}\text { Kongas } \\
\text { Gianuta } \\
\text { Onty of } \\
\text { ancember } 31\end{array}$ & 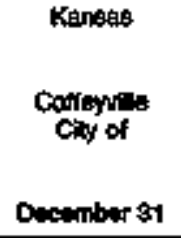 & $\begin{array}{l}\text { Kangag } \\
\text { Cianditin } \\
\text { Dacumber of } 31\end{array}$ & $\begin{array}{c}\text { Kensiga } \\
\text { Kanses } \\
\text { Cly City of } \\
\text { Decomber at }\end{array}$ & 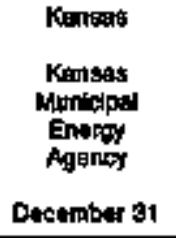 & $\begin{array}{l}\text { Kanasg } \\
\text { Nepperson } \\
\text { Cly of } \\
\text { December } 3 t\end{array}$ \\
\hline 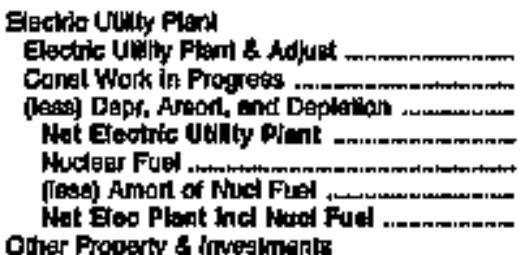 & $\begin{array}{r}25,970 \\
0 \\
26,070 \\
0 \\
0 \\
25,870\end{array}$ & $\begin{array}{r}36,+67 \\
0 \\
03,538 \\
12,691 \\
0 \\
0 \\
12,601\end{array}$ & $\begin{array}{r}16,274 \\
0 \\
9,110 \\
7,160 \\
0 \\
0 \\
7,+60\end{array}$ & $\begin{array}{r}560,270 \\
34,921 \\
240,1067 \\
375,130 \\
0 \\
0 \\
375,130\end{array}$ & $\begin{array}{r}4,882 \\
9 \\
2,000 \\
2,8692 \\
0 \\
0 \\
2,869\end{array}$ & $\begin{array}{r}47,712 \\
0 \\
26,694 \\
20,619 \\
0 \\
0 \\
20,819\end{array}$ \\
\hline 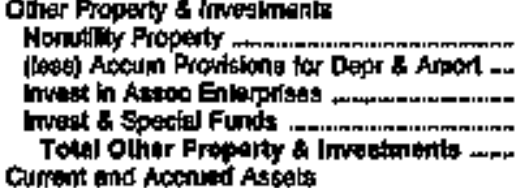 & $\begin{array}{r}50 \\
5,496 \\
0 \\
-5,493\end{array}$ & $\begin{array}{l}0 \\
0 \\
0 \\
0 \\
0\end{array}$ & $\begin{array}{r}27 \\
27 \\
0 \\
0 \\
1\end{array}$ & $\begin{array}{r}0 \\
0 \\
0 \\
20,419 \\
29,419\end{array}$ & $\begin{array}{r}0 \\
0 \\
0 \\
5,822 \\
5,922\end{array}$ & $\begin{array}{r}202 \\
0 \\
0 \\
19,150 \\
19,954\end{array}$ \\
\hline 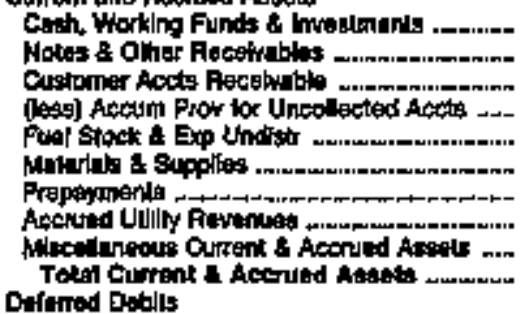 & $\begin{array}{r}2,009 \\
0 \\
297 \\
0 \\
0 \\
0 \\
0 \\
0 \\
0 \\
2,35\end{array}$ & $\begin{array}{r}7,330 \\
0 \\
405 \\
0 \\
069 \\
570 \\
0 \\
0 \\
0 \\
0,200\end{array}$ & $\begin{array}{r}2,149 \\
0 \\
501 \\
0 \\
0 \\
0 \\
0 \\
0 \\
0 \\
2,7 \% 0\end{array}$ & $\begin{array}{r}25,004 \\
24,659 \\
11,034 \\
1,897 \\
5,296 \\
13,840 \\
1,273 \\
5,413 \\
0 \\
64,498\end{array}$ & $\begin{array}{r}895 \\
1,429 \\
0 \\
0 \\
0 \\
0 \\
567 \\
0 \\
0 \\
2,990\end{array}$ & $\begin{array}{r}4,337 \\
0 \\
1,800 \\
0 \\
19 \\
820 \\
21 \\
0 \\
339 \\
7,837\end{array}$ \\
\hline 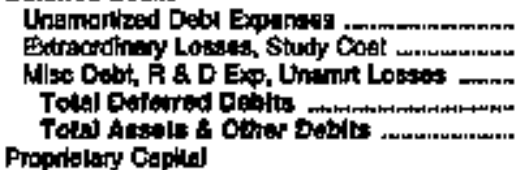 & $\begin{array}{r}0 \\
0 \\
0 \\
0 \\
0\end{array}$ & $\begin{array}{r}0 \\
0 \\
0 \\
0 \\
21,9 \% 0\end{array}$ & $\begin{array}{r}0 \\
0 \\
0 \\
0 \\
0,971\end{array}$ & $\begin{array}{r}5,354 \\
1,509 \\
6,693 \\
495,682\end{array}$ & $\begin{array}{r}\$ 94 \\
0 \\
5,081 \\
5,9678 \\
19,310\end{array}$ & $\begin{array}{r}1,579 \\
0 \\
0 \\
1,979 \\
99,209\end{array}$ \\
\hline 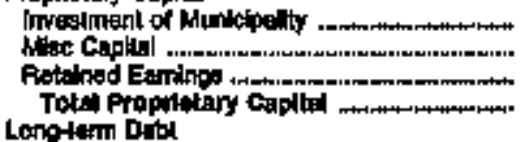 & $\begin{array}{r}0 \\
0 \\
6,349 \\
6,348\end{array}$ & $\begin{array}{r}8,159 \\
0 \\
8,298 \\
17,459\end{array}$ & $\begin{array}{r}0 \\
0 \\
9,150 \\
9,150\end{array}$ & $\begin{array}{r}0 \\
0 \\
268,549 \\
2037,599\end{array}$ & $\begin{array}{r}0 \\
0 \\
2,252 \\
2,232\end{array}$ & $\begin{array}{r}0 \\
0 \\
29,981 \\
29,951\end{array}$ \\
\hline 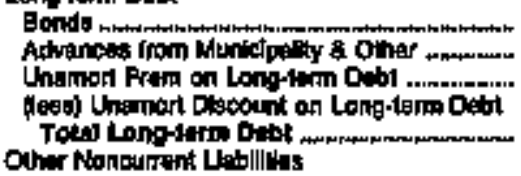 & $\begin{array}{r}10,450 \\
0 \\
0 \\
0 \\
15,450\end{array}$ & $\begin{array}{l}0 \\
0 \\
0 \\
0 \\
0\end{array}$ & $\begin{array}{l}0 \\
0 \\
0 \\
0 \\
0\end{array}$ & $\begin{array}{r}t 65,960 \\
0 \\
0 \\
0 \\
103,900\end{array}$ & $\begin{array}{r}0 \\
0 \\
17,200 \\
17,010\end{array}$ & $\begin{array}{r}17,397 \\
0 \\
0 \\
0 \\
17,397\end{array}$ \\
\hline 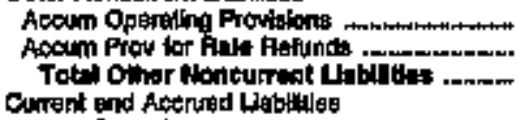 & $\begin{array}{l}0 \\
0 \\
0\end{array}$ & $\begin{array}{l}0 \\
0 \\
0\end{array}$ & $\begin{array}{l}0 \\
0 \\
0\end{array}$ & $\begin{array}{r}1,608 \\
0 \\
1,608\end{array}$ & $\begin{array}{l}0 \\
0 \\
0\end{array}$ & $\begin{array}{l}0 \\
0 \\
0\end{array}$ \\
\hline 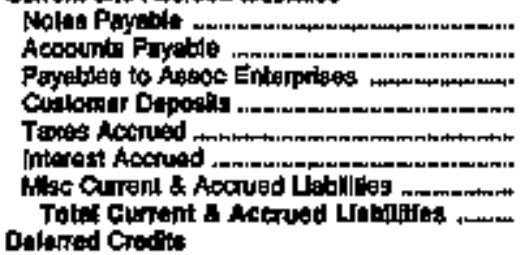 & $\begin{array}{r}0 \\
0 \\
0 \\
0 \\
0 \\
0 \\
0 \\
0\end{array}$ & $\begin{array}{r}0 \\
2,250 \\
9 \\
247 \\
1,585 \\
9 \\
426 \\
4,055\end{array}$ & $\begin{array}{r}684 \\
0 \\
0 \\
60 \\
0 \\
0 \\
0 \\
721\end{array}$ & $\begin{array}{r}0 \\
10,356 \\
0 \\
1,891 \\
390 \\
3,088 \\
\$, 240 \\
24,710\end{array}$ & $\begin{array}{r}0 \\
71 \\
0 \\
0 \\
0 \\
71 \\
190 \\
1,340\end{array}$ & $\begin{array}{r}0 \\
1,158 \\
0 \\
101 \\
0 \\
00 \\
553 \\
1,910\end{array}$ \\
\hline 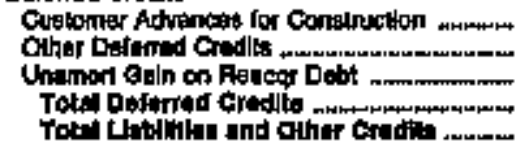 & $\begin{array}{r}0 \\
0 \\
0 \\
0 \\
0\end{array}$ & $\begin{array}{r}0 \\
0 \\
0 \\
0 \\
\mathbf{2 1 , 9 2 0}\end{array}$ & $\begin{array}{r}0 \\
0 \\
0 \\
0 \\
0,87 t\end{array}$ & $\begin{array}{r}0 \\
0 \\
0 \\
0 \\
496,882\end{array}$ & $\begin{array}{r}0 \\
2,688 \\
0 \\
19,849 \\
19,849\end{array}$ & $\begin{array}{r}0 \\
0 \\
0 \\
0 \\
49,298\end{array}$ \\
\hline
\end{tabular}

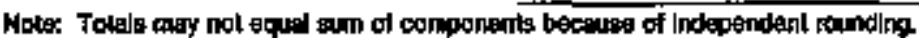

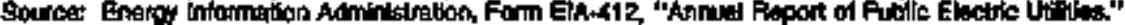


Table 22. Balance Sheet by Major U.S. Publiely Owned Electric Utility Within State at End of Perlod, 1994

(Thousand Dollars)

\begin{tabular}{|c|c|c|c|c|c|c|}
\hline llent & $\begin{array}{l}\text { Kansas } \\
\text { Winifald } \\
\text { City of } \\
\text { Dexember ay }\end{array}$ & $\begin{array}{l}\text { Kerituck } \\
\text { Bonting } \\
\text { Evegn } \\
\text { Coly of } \\
\text { Juna so }\end{array}$ & $\begin{array}{l}\text { Kentucity } \\
\text { Frankiont } \\
\text { Cily of } \\
\text { wune on }\end{array}$ & 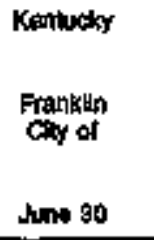 & 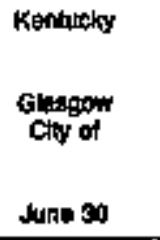 & 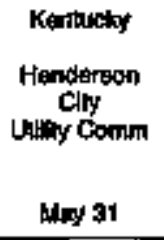 \\
\hline 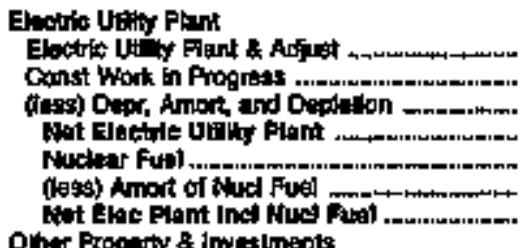 & $\begin{array}{r}31,001 \\
345 \\
16,076 \\
17,070 \\
0 \\
0 \\
17,670\end{array}$ & $\begin{array}{r}39,129 \\
670 \\
12,547 \\
27,498 \\
0 \\
0 \\
27,440\end{array}$ & $\begin{array}{r}22,852 \\
0 \\
12,205 \\
10,80 \% \\
0 \\
10,587\end{array}$ & $\begin{array}{r}5,890 \\
38 \\
1,644 \\
4,094 \\
0 \\
0 \\
4,094\end{array}$ & $\begin{array}{r}16,038 \\
120 \\
6,928 \\
9,698 \\
0 \\
0 \\
9,696\end{array}$ & $\begin{array}{r}102,092 \\
10,185 \\
62,192 \\
03,028 \\
0 \\
0 \\
50,028\end{array}$ \\
\hline 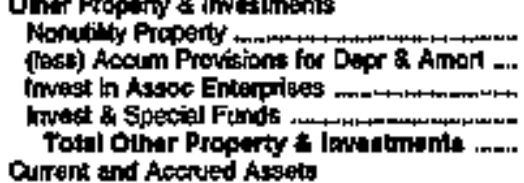 & $\begin{array}{r}0 \\
0 \\
0 \\
879\end{array}$ & $\begin{array}{r}0 \\
0 \\
0 \\
3,596 \\
3,598\end{array}$ & $\begin{array}{r}27,185 \\
9,540 \\
0 \\
6,509 \\
2,197\end{array}$ & $\begin{array}{r}0 \\
0 \\
0 \\
420 \\
420\end{array}$ & $\begin{array}{r}0 \\
0 \\
0 \\
609\end{array}$ & $\begin{array}{r}0 \\
0 \\
0 \\
27,0052 \\
27,052\end{array}$ \\
\hline 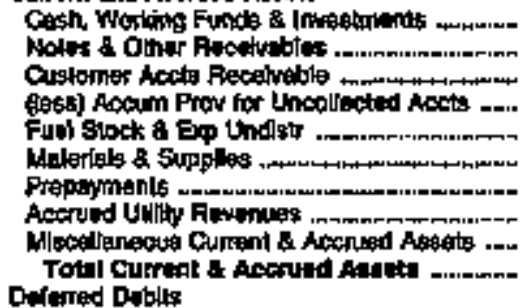 & $\begin{array}{r}1,289 \\
1,407 \\
91 \\
0 \\
29 \\
0 \\
0 \\
0 \\
0 \\
2,765\end{array}$ & $\begin{array}{r}4,475 \\
2,909 \\
0 \\
0 \\
0 \\
678 \\
149 \\
0 \\
38 \\
8,239\end{array}$ & 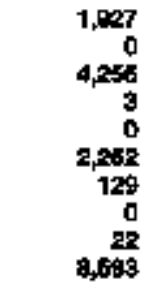 & $\begin{array}{r}787 \\
927 \\
0 \\
0 \\
0 \\
102 \\
43 \\
0 \\
0 \\
1,060\end{array}$ & $\begin{array}{r}309 \\
0 \\
1,492 \\
0 \\
0 \\
312 \\
114 \\
0 \\
0 \\
2,307\end{array}$ & $\begin{array}{r}8,920 \\
214 \\
167 \\
3 \\
3,097 \\
2,465 \\
318 \\
7,46 \\
0 \\
14,151\end{array}$ \\
\hline 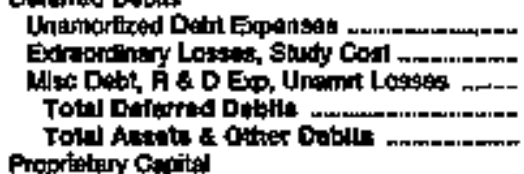 & $\begin{array}{r}0 \\
0 \\
0 \\
0 \\
20,714\end{array}$ & $\begin{array}{r}50 \\
0 \\
806 \\
306 \\
40,06\end{array}$ & $\begin{array}{r}0 \\
0 \\
0 \\
0 \\
42,340\end{array}$ & $\begin{array}{r}0 \\
0 \\
159 \\
169 \\
6,589\end{array}$ & $\begin{array}{r}46 \\
0 \\
128 \\
1297\end{array}$ & $\begin{array}{r}522 \\
0 \\
0 \\
592 \\
94,770\end{array}$ \\
\hline 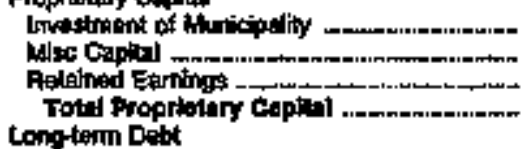 & $\begin{array}{r}0 \\
0 \\
15,200 \\
16,202\end{array}$ & $\begin{array}{r}0 \\
0 \\
22,406 \\
2,106\end{array}$ & $\begin{array}{r}0 \\
0 \\
32,628 \\
32,928\end{array}$ & $\begin{array}{r}\text { i } \\
0 \\
5,374 \\
5,379\end{array}$ & $\begin{array}{r}7,102 \\
0 \\
151 \\
7,258\end{array}$ & $\begin{array}{r}0 \\
0 \\
29,889 \\
29,969\end{array}$ \\
\hline 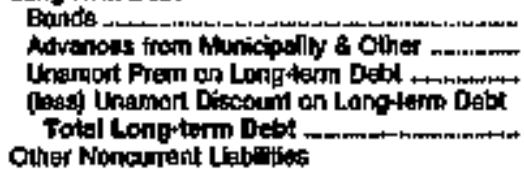 & $\begin{array}{r}4,820 \\
0 \\
0 \\
0 \\
4,620\end{array}$ & $\begin{array}{r}9.925 \\
8000 \\
-+151 \\
10,500\end{array}$ & $\begin{array}{r}4,494 \\
0 \\
0 \\
0 \\
4,494\end{array}$ & $\begin{array}{r}0 \\
149 \\
0 \\
0 \\
140\end{array}$ & $\begin{array}{r}3,662 \\
114 \\
0 \\
62 \\
9,615\end{array}$ & $\begin{array}{r}37,205 \\
0 \\
0 \\
0 \\
37,206\end{array}$ \\
\hline 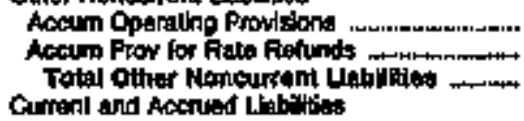 & $\begin{array}{l}0 \\
0 \\
0\end{array}$ & $\begin{array}{l}0 \\
0 \\
0\end{array}$ & $\begin{array}{l}0 \\
0 \\
0\end{array}$ & $\begin{array}{l}0 \\
0 \\
0\end{array}$ & $\begin{array}{r}80 \\
0 \\
28\end{array}$ & $\begin{array}{l}0 \\
0 \\
0\end{array}$ \\
\hline 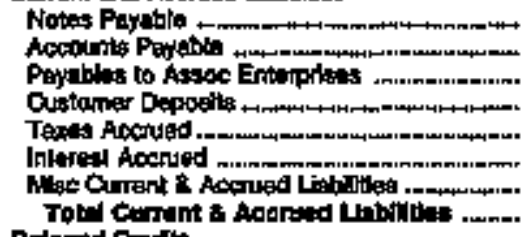 & $\begin{array}{r}300 \\
121 \\
6 \\
0 \\
0 \\
90 \\
112 \\
602\end{array}$ & $\begin{array}{r}0 \\
3,710 \\
0 \\
2,491 \\
151 \\
480 \\
357 \\
7,180\end{array}$ & $\begin{array}{r}0 \\
3698 \\
0 \\
583 \\
250 \\
193 \\
401 \\
4,998\end{array}$ & $\begin{array}{r}0 \\
714 \\
0 \\
200 \\
22 \\
0 \\
6 \\
051\end{array}$ & $\begin{array}{r}345 \\
1,205 \\
0 \\
217 \\
70 \\
29 \\
140 \\
2,048\end{array}$ & $\begin{array}{r}3,766 \\
5,741 \\
0 \\
300 \\
0 \\
586 \\
12,419 \\
24,511\end{array}$ \\
\hline 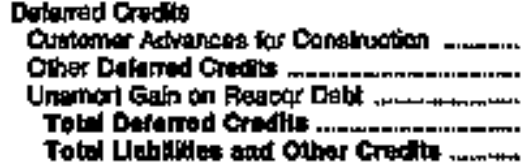 & $\begin{array}{r}0 \\
0 \\
0 \\
0 \\
20,74\end{array}$ & $\begin{array}{r}7 \\
0 \\
0 \\
7 \\
10,1099\end{array}$ & $\begin{array}{r}307 \\
0 \\
307 \\
4946\end{array}$ & $\begin{array}{r}0 \\
50 \\
0 \\
60 \\
609\end{array}$ & $\begin{array}{r}0 \\
10 \\
10\end{array}$ & $\begin{array}{r}0 \\
4,760 \\
0 \\
4,765 \\
84,770\end{array}$ \\
\hline
\end{tabular}

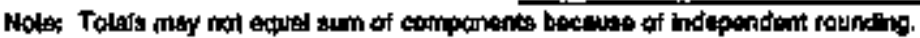

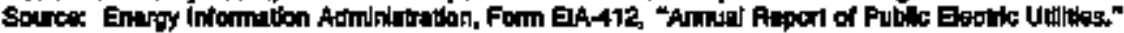


Table 22. Balance Sheet by Major U.S. Publity Owned Electric Utlity Whin state at End of Perfod, 1994

(Thousand Dollars)

\begin{tabular}{|c|c|c|c|c|c|c|}
\hline Ilispip & $\begin{array}{l}\text { Kentucky } \\
\text { Hapkinguife } \\
\text { City of } \\
\text { Wure } 30\end{array}$ & 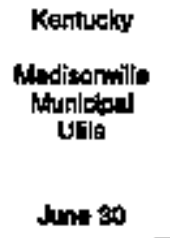 & $\begin{array}{l}\text { Kentucky } \\
\text { Mayileld } \\
\text { Oily of } \\
\text { June } 30\end{array}$ & $\begin{array}{l}\text { Karthucky } \\
\text { Mungy } \\
\text { Chy of } \\
\text { Junt } 30\end{array}$ & $\begin{array}{l}\text { Kentuchy } \\
\text { Owensbore } \\
\text { Ciny o! } \\
\text { Hay } 31\end{array}$ & 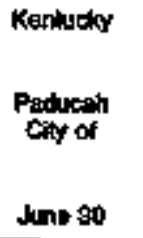 \\
\hline 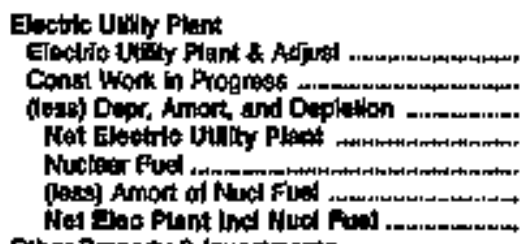 & $\begin{array}{r}15,447 \\
150 \\
6,600 \\
8,910 \\
0 \\
0 \\
0,910\end{array}$ & $\begin{array}{r}4,325 \\
0 \\
0 \\
4,320 \\
0 \\
0 \\
4,325\end{array}$ & $\begin{array}{r}5,867 \\
60 \\
2,669 \\
3,3590 \\
0 \\
0 \\
0,350\end{array}$ & $\begin{array}{r}0,454 \\
35 \\
4,006 \\
4,406 \\
0 \\
0 \\
4,491\end{array}$ & $\begin{array}{r}137,292 \\
113,598 \\
76,609 \\
175,268 \\
0 \\
0 \\
175,288\end{array}$ & $\begin{array}{r}43,467 \\
2,375 \\
13,4+0 \\
32,402 \\
0 \\
0 \\
32,402\end{array}$ \\
\hline 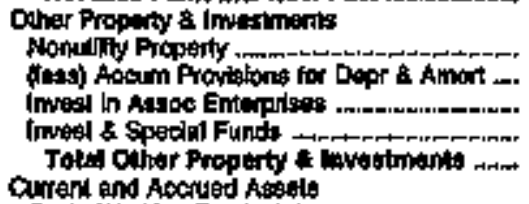 & $\begin{array}{r}1 B 7 \\
0 \\
0 \\
268 B \\
2,975\end{array}$ & $\begin{array}{l}0 \\
0 \\
0 \\
0 \\
0\end{array}$ & $\begin{array}{l}0 \\
0 \\
0 \\
4 \\
4\end{array}$ & $\begin{array}{r}0 \\
0 \\
0 \\
739 \\
739\end{array}$ & $\begin{array}{r}0 \\
0 \\
0 \\
+304,167 \\
136,167\end{array}$ & $\begin{array}{r}0 \\
0 \\
0 \\
1,394 \\
1,394\end{array}$ \\
\hline 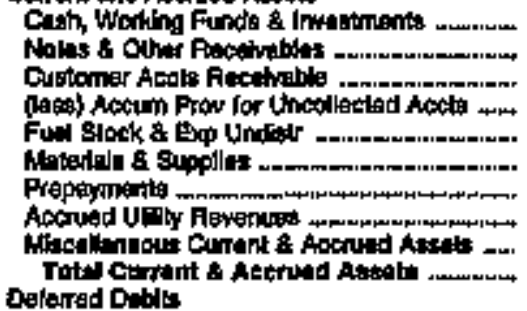 & $\begin{array}{r}5,587 \\
2,061 \\
0 \\
0 \\
0 \\
186 \\
67 \\
0 \\
97 \\
3,989\end{array}$ & $\begin{array}{r}721 \\
1,000 \\
1,310 \\
0 \\
0 \\
303 \\
22 \\
0 \\
458 \\
3,908\end{array}$ & $\begin{array}{r}68 \\
1,160 \\
0 \\
0 \\
0 \\
110 \\
10 \\
0 \\
6 \\
1,341\end{array}$ & $\begin{array}{r}808 \\
1,109 \\
0 \\
0 \\
0 \\
183 \\
0 \\
0 \\
22 \\
2,197\end{array}$ & $\begin{array}{r}11,604 \\
2,912 \\
1,912 \\
457 \\
0 \\
000 \\
10 \\
0 \\
0 \\
14,361\end{array}$ & $\begin{array}{r}2,895 \\
1,911 \\
0 \\
0 \\
0 \\
912 \\
30 \\
0 \\
62 \\
5,000\end{array}$ \\
\hline 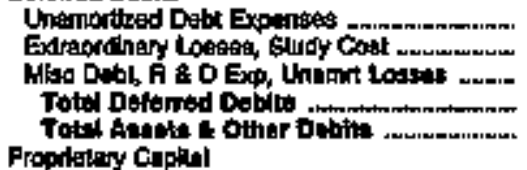 & $\begin{array}{r}16 \\
0 \\
297 \\
242 \\
t 0,046\end{array}$ & $\begin{array}{r}0 \\
0 \\
0 \\
0 \\
0,20\end{array}$ & $\begin{array}{r}0 \\
0 \\
3 \\
3 \\
4005\end{array}$ & $\begin{array}{r}0 \\
0 \\
8 \\
3 \\
7,382\end{array}$ & $\begin{array}{r}1,644 \\
0 \\
256 \\
1,000 \\
3,7,736\end{array}$ & $\begin{array}{r}96 \\
0 \\
492 \\
579 \\
4,113\end{array}$ \\
\hline 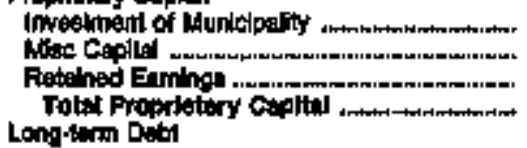 & $\begin{array}{r}0 \\
0 \\
11,000 \\
11,602\end{array}$ & $\begin{array}{r}0 \\
130 \\
6,657 \\
0.798\end{array}$ & $\begin{array}{r}0 \\
0 \\
3,600 \\
3,506\end{array}$ & $\begin{array}{r}0 \\
0 \\
5,902 \\
5,902\end{array}$ & $\begin{array}{l}1,779 \\
60,302 \\
60,075\end{array}$ & $\begin{array}{r}0 \\
0 \\
31,028 \\
31,025\end{array}$ \\
\hline 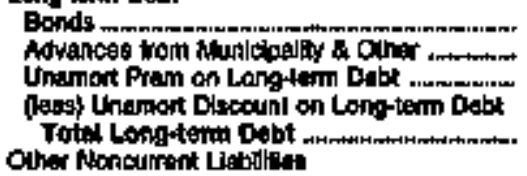 & $\begin{array}{r}1,890 \\
204 \\
305 \\
0 \\
2,150\end{array}$ & $\begin{array}{l}0 \\
0 \\
0 \\
0 \\
0\end{array}$ & $\begin{array}{l}0 \\
a \\
0 \\
0 \\
0\end{array}$ & $\begin{array}{l}0 \\
2 \\
0 \\
0 \\
2\end{array}$ & $\begin{array}{r}251,807 \\
5849 \\
0 \\
0 \\
757,549\end{array}$ & $\begin{array}{r}4,330 \\
397 \\
-73 \\
0 \\
4,843\end{array}$ \\
\hline 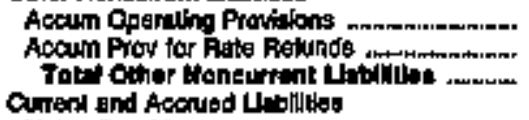 & $\begin{array}{l}0 \\
0 \\
0\end{array}$ & $\begin{array}{l}0 \\
0 \\
0\end{array}$ & $\begin{array}{l}0 \\
0 \\
0\end{array}$ & $\begin{array}{l}0 \\
0 \\
0\end{array}$ & $\begin{array}{l}0 \\
0 \\
0\end{array}$ & $\begin{array}{l}0 \\
0 \\
0\end{array}$ \\
\hline 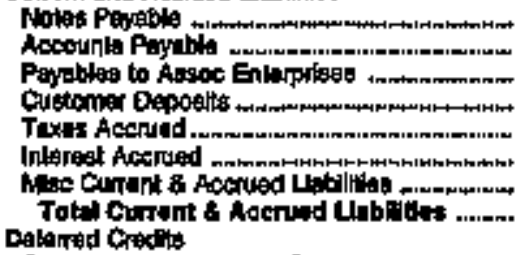 & $\begin{array}{r}0 \\
1,658 \\
0 \\
900 \\
104 \\
45 \\
68 \\
2,100\end{array}$ & $\begin{array}{r}0 \\
1,181 \\
0 \\
216 \\
0 \\
70 \\
0 \\
1,440\end{array}$ & $\begin{array}{r}0 \\
740 \\
0 \\
200 \\
68 \\
0 \\
97 \\
1,006\end{array}$ & $\begin{array}{r}972 \\
374 \\
0 \\
68 \\
0 \\
0 \\
44 \\
1,458\end{array}$ & $\begin{array}{r}0 \\
4,107 \\
0 \\
0 \\
0 \\
3,204 \\
1,004 \\
9,312\end{array}$ & $\begin{array}{r}0 \\
2,808 \\
0 \\
459 \\
770 \\
138 \\
401 \\
3,495\end{array}$ \\
\hline 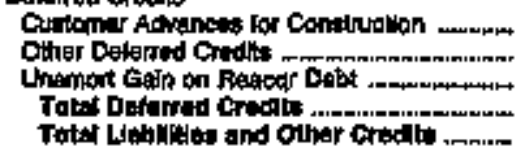 & $\begin{array}{r}0 \\
14 \\
0 \\
14\end{array}$ & $\begin{array}{r}0 \\
0 \\
0 \\
0 \\
0\end{array}$ & $\begin{array}{r}0 \\
0 \\
0 \\
4,705\end{array}$ & $\begin{array}{r}0 \\
0 \\
0 \\
0 \\
7,362\end{array}$ & $\begin{array}{r}1,700 \\
0 \\
1,700 \\
327,736\end{array}$ & $\begin{array}{r}9 \\
147 \\
0 \\
147 \\
140,118\end{array}$ \\
\hline
\end{tabular}

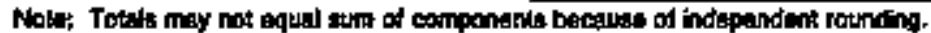

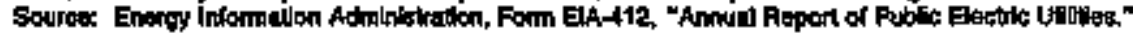


Table 22. Bafance Sheet by Bajor U.8. Publiely Owned Electric Utility Within State at End of Petlod, 1994

(Thousand Dollars)

\begin{tabular}{|c|c|c|c|c|c|c|}
\hline Nem & 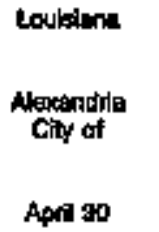 & 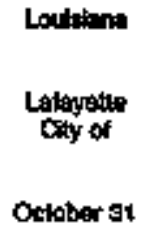 & 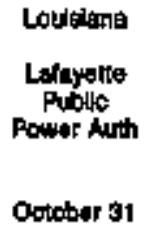 & $\begin{array}{l}\text { Loulsiang } \\
\text { Lovistang } \\
\text { Engrgy } \\
\text { Power Auth } \\
\text { December } 01\end{array}$ & $\begin{array}{l}\text { Louletiana } \\
\text { Norgan } \\
\text { Chy Cily of } \\
\text { Dacombar } 31\end{array}$ & 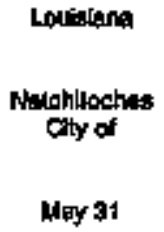 \\
\hline 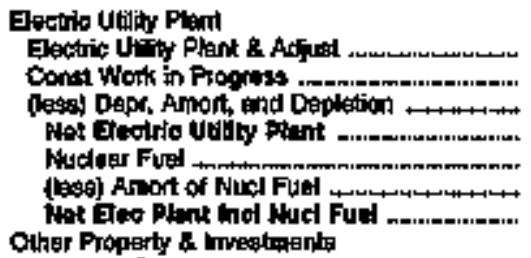 & $\begin{array}{r}141,071 \\
165 \\
60,3928 \\
01,614 \\
0 \\
0 \\
0+, 814\end{array}$ & $\begin{array}{r}289,145 \\
0 \\
91,021 \\
132,125 \\
0 \\
132,125\end{array}$ & $\begin{array}{r}160,447 \\
1,327 \\
68,108 \\
93,606 \\
0 \\
0 \\
93,600\end{array}$ & $\begin{array}{r}87,288 \\
247 \\
19,740 \\
67,769 \\
0 \\
0 \\
07,769\end{array}$ & $\begin{array}{r}28,391 \\
47 \\
19,614 \\
8,065 \\
0 \\
0 \\
9,665\end{array}$ & $\begin{array}{r}5,032 \\
0 \\
14,416 \\
38,617 \\
0 \\
0 \\
38,617\end{array}$ \\
\hline 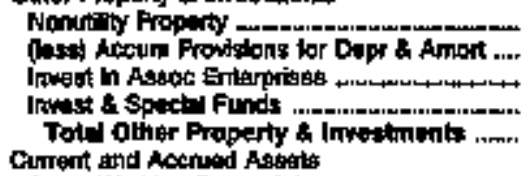 & $\begin{array}{r}2,835 \\
0 \\
0 \\
40,084 \\
42,919\end{array}$ & $\begin{array}{r}0 \\
0 \\
0 \\
78,167 \\
78,107\end{array}$ & $\begin{array}{r}0 \\
0 \\
0 \\
17,916 \\
17,910\end{array}$ & $\begin{array}{r}1,169 \\
78 \\
0 \\
17,657 \\
18,976\end{array}$ & $\begin{array}{l}0 \\
0 \\
0 \\
0 \\
0\end{array}$ & $\begin{array}{l}0 \\
0 \\
0 \\
0\end{array}$ \\
\hline 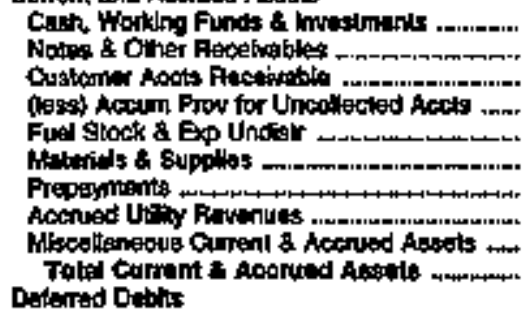 & $\begin{array}{r}5,441 \\
7,005 \\
0 \\
607 \\
0 \\
1,776 \\
0 \\
0 \\
3,191 \\
19,024\end{array}$ & $\begin{array}{r}3,702 \\
1,034 \\
16,101 \\
491 \\
1,707 \\
1,347 \\
16 \\
0 \\
-277 \\
2,700\end{array}$ & $\begin{array}{r}27,0393 \\
30 \\
104 \\
0 \\
2098 \\
37 \\
3 \\
200 \\
90 \\
30,946\end{array}$ & $\begin{array}{r}12,056 \\
110 \\
6,000 \\
0 \\
2,258 \\
0 \\
119 \\
0 \\
0 \\
20,167\end{array}$ & $\begin{array}{r}3,085 \\
65 \\
1,018 \\
0 \\
0 \\
234 \\
242 \\
590 \\
840 \\
8494\end{array}$ & $\begin{array}{r}1,835 \\
46 \\
1,749 \\
0 \\
0 \\
804 \\
0 \\
0 \\
0 \\
4,350\end{array}$ \\
\hline 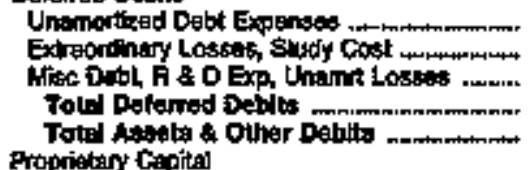 & $\begin{array}{r}0 \\
0 \\
0 \\
0 \\
141,00\end{array}$ & $\begin{array}{r}641 \\
0 \\
3,400 \\
4,189 \\
397,160\end{array}$ & $\begin{array}{r}395 \\
18,765 \\
19,510 \\
38,595 \\
181,030\end{array}$ & $\begin{array}{r}39,441 \\
0 \\
826 \\
34,296 \\
141,169\end{array}$ & $\begin{array}{r}0 \\
0 \\
538 \\
595 \\
10,986\end{array}$ & $\begin{array}{r}0 \\
0 \\
0 \\
0 \\
42,06 ?\end{array}$ \\
\hline 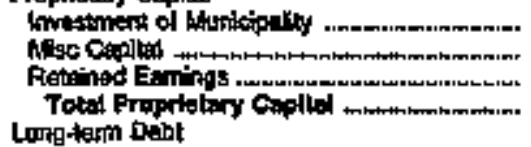 & $\begin{array}{r}37,181 \\
98,094 \\
73,215\end{array}$ & $\begin{array}{r}6,210 \\
0 \\
130,769 \\
130,100\end{array}$ & $\begin{array}{r}0 \\
0 \\
226 \\
206\end{array}$ & $\begin{array}{r}0 \\
0 \\
0,351 \\
9,351\end{array}$ & $\begin{array}{r}4 \pi 28 \\
0 \\
205 A \\
7,206\end{array}$ & $\begin{array}{r}20,986 \\
0,132 \\
35,120\end{array}$ \\
\hline 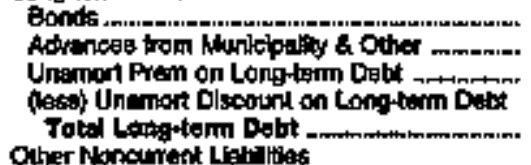 & $\begin{array}{r}58,400 \\
256 \\
0 \\
0 \\
59,6046\end{array}$ & $\begin{array}{r}59,195 \\
0 \\
0 \\
0 \\
69,105\end{array}$ & $\begin{array}{r}178,200 \\
0 \\
0 \\
2,086 \\
179,514\end{array}$ & $\begin{array}{r}124,090 \\
0 \\
0 \\
5,648 \\
1+147\end{array}$ & $\begin{array}{r}6,257 \\
1,2020 \\
0 \\
0 \\
7,100\end{array}$ & $\begin{array}{r}4,619 \\
0 \\
0 \\
0 \\
4,613\end{array}$ \\
\hline 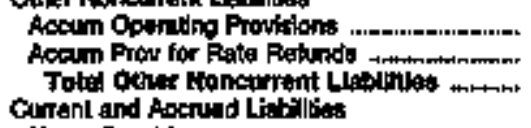 & $\begin{array}{l}0 \\
0 \\
0\end{array}$ & $\begin{array}{l}0 \\
0 \\
0 \\
0\end{array}$ & $\begin{array}{l}0 \\
0 \\
0\end{array}$ & $\begin{array}{l}0 \\
0 \\
0\end{array}$ & $\begin{array}{l}0 \\
0 \\
0\end{array}$ & $\begin{array}{r}0 \\
0 \\
0\end{array}$ \\
\hline 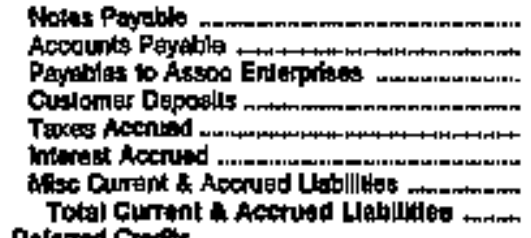 & $\begin{array}{r}140 \\
1,102 \\
381 \\
4,040 \\
0 \\
1,618 \\
1,272 \\
9,4,4\end{array}$ & $\begin{array}{r}0 \\
4,228 \\
0 \\
3,676 \\
0 \\
1,250 \\
965 \\
10,109\end{array}$ & $\begin{array}{r}0 \\
2,171 \\
182 \\
0 \\
0 \\
4,087 \\
0 \\
7,2=0\end{array}$ & $\begin{array}{r}0 \\
4,633 \\
0 \\
0 \\
0 \\
4,045 \\
4,001 \\
\mathbf{2 , 6 7 7}\end{array}$ & $\begin{array}{r}913 \\
92 \\
0 \\
717 \\
0 \\
203 \\
403 \\
2791\end{array}$ & $\begin{array}{r}549 \\
1,200 \\
890 \\
474 \\
0 \\
0 \\
121 \\
3,294\end{array}$ \\
\hline 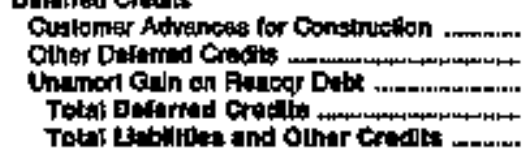 & $\begin{array}{r}0 \\
0 \\
0 \\
0 \\
141,300\end{array}$ & $\begin{array}{r}31, \pi 7 \\
0 \\
0 \\
21,771 \\
291,100\end{array}$ & $\begin{array}{r}0 \\
0 \\
0 \\
0 \\
0\end{array}$ & $\begin{array}{r}0 \\
0 \\
0 \\
0 \\
141,109\end{array}$ & $\begin{array}{r}0 \\
0 \\
0 \\
0 \\
\text { It, }\end{array}$ & $\begin{array}{r}0 \\
0 \\
0 \\
0 \\
42,907\end{array}$ \\
\hline
\end{tabular}

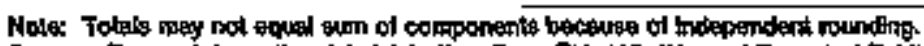

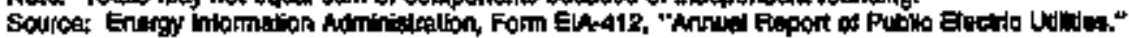


Table 22 Balance sheet by Major U.S. Publichy Owned Electric Utility Within State at End of Perjod, 1994 (Thousand Dollars)

\begin{tabular}{|c|c|c|c|c|c|c|}
\hline hant & 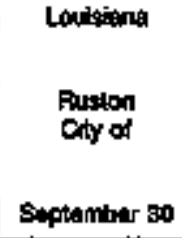 & 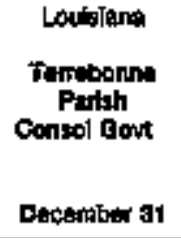 & $\begin{array}{l}\text { Mundand } \\
\text { Easton } \\
\text { Ubitios } \\
\text { Coman } \\
\text { Juna to }\end{array}$ & 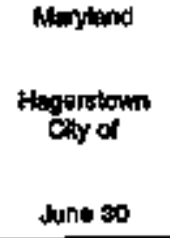 & 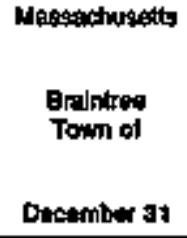 & 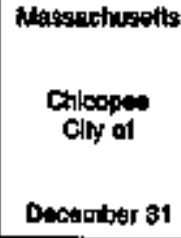 \\
\hline 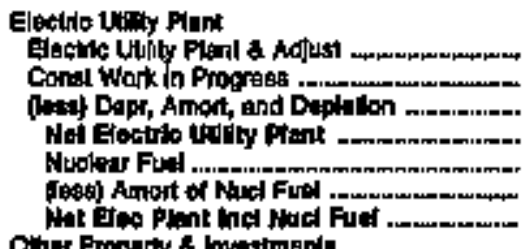 & $\begin{array}{r}30,086 \\
0 \\
18,618 \\
11,472 \\
0 \\
0 \\
11,972\end{array}$ & $\begin{array}{r}4,6,160 \\
3,162 \\
34,698 \\
77,739 \\
0 \\
0 \\
17,739\end{array}$ & $\begin{array}{r}40,012 \\
701 \\
17,134 \\
23,570 \\
0 \\
0 \\
23,579\end{array}$ & $\begin{array}{r}24,107 \\
3300 \\
10,284 \\
14,263 \\
0 \\
0 \\
14,208\end{array}$ & 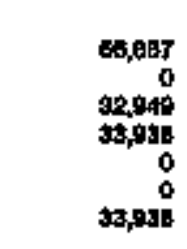 & $\begin{array}{r}67,754 \\
554 \\
25,309 \\
4,320 \\
4,214 \\
3,149 \\
4,092\end{array}$ \\
\hline 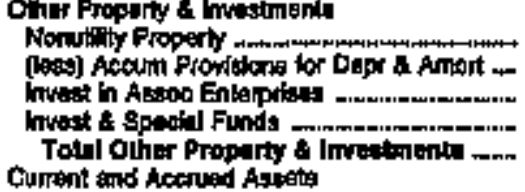 & $\begin{array}{r}0 \\
0 \\
3,658 \\
3658\end{array}$ & $\begin{array}{r}10,036 \\
\$, 217 \\
0 \\
0,548 \\
13,360\end{array}$ & $\begin{array}{r}454 \\
59 \\
0 \\
0 \\
205\end{array}$ & $\begin{array}{l}0 \\
0 \\
0 \\
0 \\
0\end{array}$ & $\begin{array}{r}0 \\
0 \\
3,066 \\
3,066\end{array}$ & $\begin{array}{r}0 \\
0 \\
0 \\
28,0003 \\
28,1083\end{array}$ \\
\hline 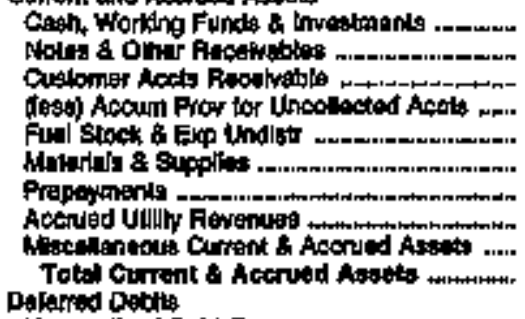 & $\begin{array}{r}1,245 \\
452 \\
1094 \\
0 \\
0 \\
417 \\
50 \\
1,091 \\
0 \\
3,951\end{array}$ & 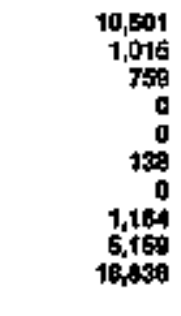 & $\begin{array}{r}3,441 \\
807 \\
1,241 \\
0 \\
355 \\
694 \\
37 \\
7,130 \\
0 \\
7,205\end{array}$ & $\begin{array}{r}1,168 \\
297 \\
1,859 \\
708 \\
0 \\
201 \\
16 \\
0 \\
0 \\
5,976\end{array}$ & $\begin{array}{r}3,1998 \\
30 \\
2,199 \\
29 \\
129 \\
209 \\
131 \\
292 \\
12 \\
0,769\end{array}$ & $\begin{array}{r}4,018 \\
728 \\
2,151 \\
100 \\
39 \\
2,298 \\
1,137 \\
0 \\
10 \\
10,281\end{array}$ \\
\hline 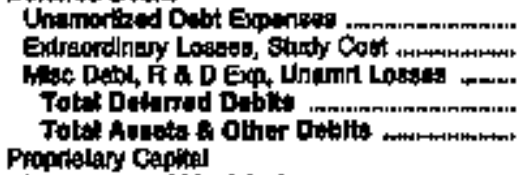 & $\begin{array}{r}0 \\
0 \\
0 \\
0 \\
18,9 r 9\end{array}$ & $\begin{array}{r}0 \\
0 \\
0 \\
0 \\
0 \\
40,942\end{array}$ & $\begin{array}{r}132 \\
51 \\
70 \\
253 \\
31,432\end{array}$ & 20,193 & $\begin{array}{r}47 \\
295 \\
342 \\
14904\end{array}$ & $\begin{array}{r}280 \\
25 \\
1,112 \\
1,425 \\
02,891\end{array}$ \\
\hline 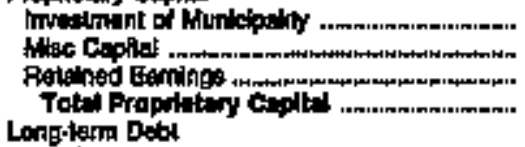 & $\begin{array}{r}0 \\
12,725 \\
12725\end{array}$ & $\begin{array}{r}3,414 \\
0 \\
24,413 \\
27,047\end{array}$ & $\begin{array}{r}1,245 \\
0 \\
7,195 \\
10,151\end{array}$ & $\begin{array}{r}0 \\
569 \\
16 \% 39 \\
10,958\end{array}$ & $\begin{array}{r}42,729 \\
0 \\
0 \\
42,729\end{array}$ & $\begin{array}{r}40,400 \\
0 \\
0 \\
49,409\end{array}$ \\
\hline 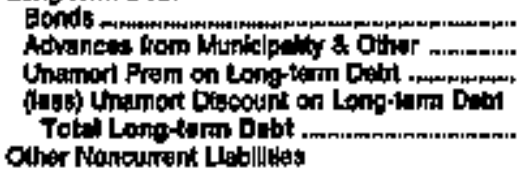 & $\begin{array}{r}2,1975 \\
144 \\
0 \\
0 \\
3,119\end{array}$ & $\begin{array}{r}17,159 \\
0 \\
0 \\
0 \\
17,165\end{array}$ & $\begin{array}{r}10,2,89 \\
172 \\
0 \\
0 \\
10,498\end{array}$ & $\begin{array}{r}\text { 日12 } \\
0 \\
0 \\
0 \\
\text { ote }\end{array}$ & $\begin{array}{r}250 \\
6 \\
1 \\
0 \\
251\end{array}$ & $\begin{array}{r}28,005 \\
64 \\
0 \\
0 \\
23,080\end{array}$ \\
\hline 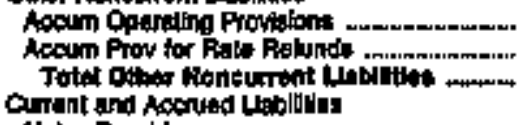 & $\begin{array}{l}0 \\
0 \\
0\end{array}$ & $\begin{array}{l}0 \\
0 \\
4\end{array}$ & $\begin{array}{l}0 \\
0 \\
0\end{array}$ & $\begin{array}{l}0 \\
0 \\
0\end{array}$ & $\begin{array}{l}0 \\
0 \\
0\end{array}$ & $\begin{array}{l}0 \\
0 \\
0\end{array}$ \\
\hline 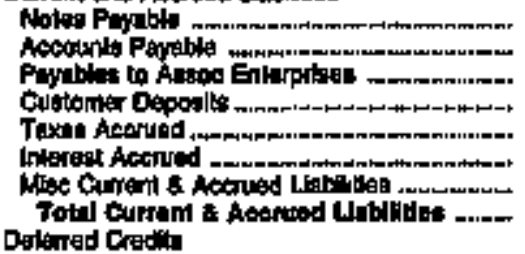 & 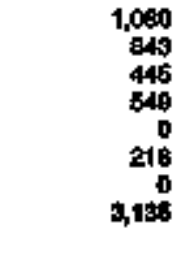 & $\begin{array}{r}665 \\
2009 \\
0 \\
807 \\
0 \\
0 \\
508 \\
4000\end{array}$ & $\begin{array}{r}401 \\
702 \\
0 \\
68 \\
0 \\
160 \\
1,7151 \\
2,471\end{array}$ & $\begin{array}{r}76 \\
1,300 \\
0 \\
286 \\
41 \\
43 \\
648 \\
0,346\end{array}$ & $\begin{array}{r}0 \\
1,710 \\
0 \\
147 \\
0 \\
5 \\
0 \\
1,080\end{array}$ & $\begin{array}{r}0 \\
3,102 \\
0 \\
720 \\
203 \\
1,+64 \\
6,100\end{array}$ \\
\hline 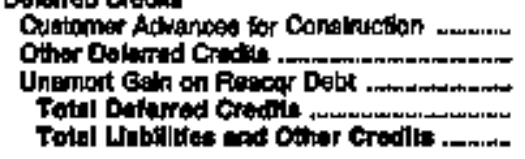 & $\begin{array}{r}0 \\
0 \\
0 \\
\operatorname{tash} 0\end{array}$ & 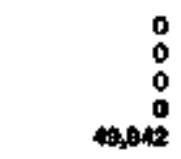 & $\begin{array}{r}173 \\
0 \\
0 \\
173 \\
31,402\end{array}$ & $\begin{array}{r}0 \\
0 \\
0 \\
0 \\
0\end{array}$ & $\begin{array}{r}0 \\
56 \\
0 \\
500\end{array}$ & $\begin{array}{r}2,030 \\
2,112 \\
727 \\
4,470 \\
4,481\end{array}$ \\
\hline
\end{tabular}

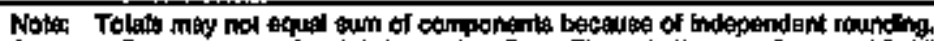

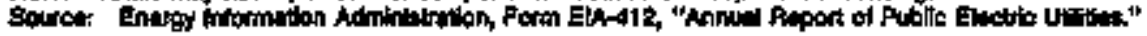


Table 22 Bakance Sheet by Major U.S. Publloly Owned Electric Utilly Within State at End of Period, t994

\begin{tabular}{|c|c|c|c|c|c|c|}
\hline Hornt & $\begin{array}{l}\text { Mascuolitutifs } \\
\text { Concord } \\
\text { Tomm of } \\
\text { Deceruber } 31\end{array}$ & $\begin{array}{l}\text { Messachusatts } \\
\text { Dowran } \\
\text { Downt of } \\
\text { Decenter } 31\end{array}$ & 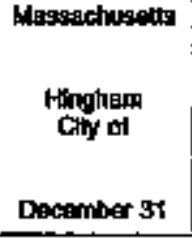 & 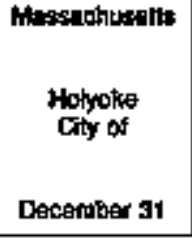 & 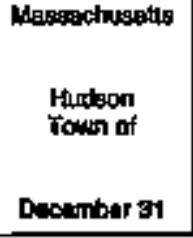 & $\begin{array}{l}\text { Massachuselts } \\
\text { Litiviton } \\
\text { Tom of } \\
\text { December a1 }\end{array}$ \\
\hline 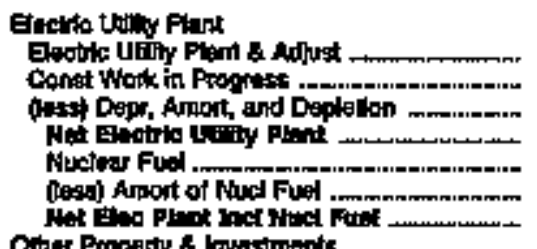 & 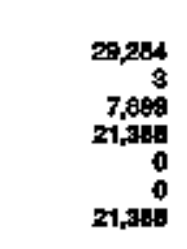 & 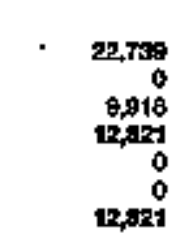 & $\begin{array}{r}21,816 \\
0 \\
6,113 \\
15,705 \\
0 \\
0 \\
15,709\end{array}$ & 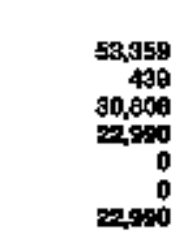 & $\begin{array}{r}18,615 \\
0 \\
12,552 \\
6,008 \\
200 \\
148 \\
6,114\end{array}$ & $\begin{array}{r}15,358 \\
170 \\
8,175 \\
0,300 \\
0 \\
0 \\
0,390\end{array}$ \\
\hline 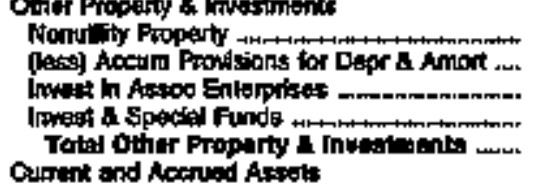 & $\begin{array}{r}0 \\
0 \\
0 \\
4,052 \\
4,042\end{array}$ & $\begin{array}{r}0 \\
0 \\
0 \\
9,148 \\
9,148\end{array}$ & $\begin{array}{r}0 \\
0 \\
0 \\
1,349 \\
1,306\end{array}$ & $\begin{array}{r}19,5+6 \\
10,963 \\
00 \\
2,595 \\
11,100\end{array}$ & $\begin{array}{r}9 \\
0 \\
146 \\
11,603 \\
11,710\end{array}$ & $\begin{array}{r}0 \\
0 \\
0 \\
7,151 \\
7,251\end{array}$ \\
\hline 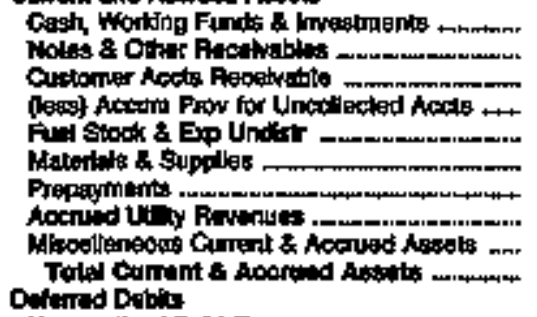 & $\begin{array}{r}6,599 \\
8 \\
1,397 \\
30 \\
579 \\
0 \\
67 \\
502 \\
0 \\
0.085\end{array}$ & $\begin{array}{r}5,409 \\
285 \\
3,708 \\
115 \\
0 \\
709 \\
141 \\
0 \\
405 \\
10,675\end{array}$ & $\begin{array}{r}790 \\
10 \\
1,298 \\
0 \\
0 \\
172 \\
605 \\
0 \\
0 \\
2,00\end{array}$ & $\begin{array}{r}6,324 \\
645 \\
6,258 \\
500 \\
1,217 \\
1,202 \\
872 \\
0 \\
1,104 \\
17,106\end{array}$ & $\begin{array}{r}3607 \\
43 \\
2,602 \\
0 \\
171 \\
800 \\
401 \\
0 \\
180 \\
7,904\end{array}$ & $\begin{array}{r}82 \\
92 \\
1,443 \\
20 \\
0 \\
426 \\
2,165 \\
0 \\
0 \\
4,108\end{array}$ \\
\hline 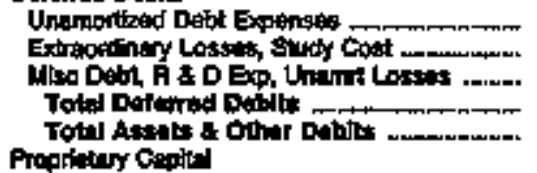 & $\begin{array}{r}59 \\
0 \\
0 \\
\text { 15,341 }\end{array}$ & $\begin{array}{r}0 \\
0 \\
12 \\
12 \\
12,0.5\end{array}$ & $\begin{array}{r}70 \\
0 \\
00 \\
160\end{array}$ & $\begin{array}{r}220 \\
0 \\
1,687 \\
1,161 \\
8,1,146\end{array}$ & $\begin{array}{r}0 \\
0 \\
309 \\
303096\end{array}$ & $\begin{array}{r}0 \\
0 \\
0 \\
0 \\
0 \\
20,737\end{array}$ \\
\hline 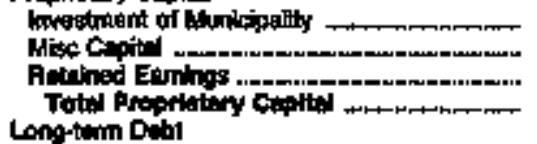 & $\begin{array}{r}3,328 \\
0 \\
10,777 \\
28,704\end{array}$ & $\begin{array}{r}1,034 \\
0 \\
26,264 \\
23,104\end{array}$ & $\begin{array}{r}0 \\
0 \\
13,007 \\
13,067\end{array}$ & $\begin{array}{r}0 \\
30,600 \\
50,600\end{array}$ & $\begin{array}{r}90 \\
0 \\
23,989 \\
24,000\end{array}$ & $\begin{array}{r}18,580 \\
0 \\
0 \\
10,580\end{array}$ \\
\hline 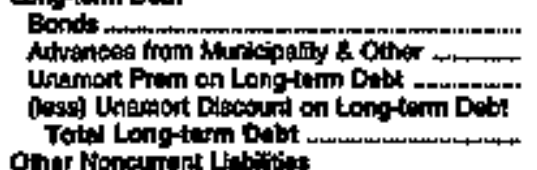 & $\begin{array}{r}8,920 \\
0 \\
0 \\
0 \\
0\end{array}$ & $\begin{array}{r}400 \\
0 \\
0 \\
0 \\
400\end{array}$ & $\begin{array}{r}3,430 \\
0 \\
0 \\
0 \\
3,450\end{array}$ & $\begin{array}{r}4,75 \% \\
0 \\
0 \\
0 \\
4,755\end{array}$ & $\begin{array}{l}0 \\
0 \\
0 \\
0 \\
0\end{array}$ & $\begin{array}{r}50 \\
0 \\
0 \\
0 \\
50\end{array}$ \\
\hline 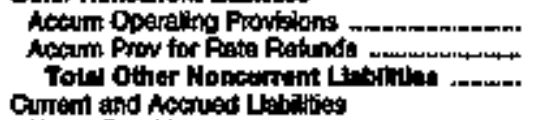 & $\begin{array}{r}113 \\
54 \\
147\end{array}$ & $\begin{array}{l}0 \\
0 \\
0\end{array}$ & $\begin{array}{l}0 \\
0 \\
0\end{array}$ & $\begin{array}{l}0 \\
0 \\
0\end{array}$ & $\begin{array}{r}605 \\
0 \\
005\end{array}$ & $\begin{array}{r}0 \\
1,045 \\
1,045\end{array}$ \\
\hline 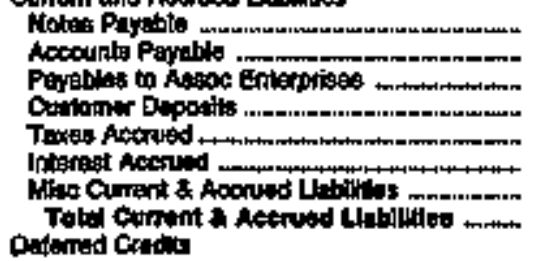 & $\begin{array}{r}0 \\
2,424 \\
0 \\
113 \\
11 \\
180 \\
2,700\end{array}$ & $\begin{array}{r}0 \\
1,070 \\
0 \\
481 \\
0 \\
4 \\
89 \\
1,59\end{array}$ & $\begin{array}{r}0 \\
1,028 \\
315 \\
395 \\
16 \\
79 \\
120 \\
1,897\end{array}$ & $\begin{array}{r}0 \\
7,685 \\
0 \\
959 \\
0 \\
00 \\
0 \\
0 \\
0,580\end{array}$ & $\begin{array}{r}0 \\
535 \\
0 \\
358 \\
16 \\
0 \\
0 \\
011\end{array}$ & $\begin{array}{r}0 \\
-20 \\
0 \\
50 \\
0 \\
0 \\
0 \\
0\end{array}$ \\
\hline 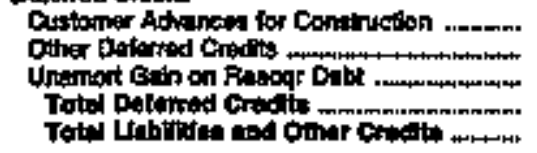 & $\begin{array}{r}84 \\
959 \\
0 \\
449\end{array}$ & $\begin{array}{r}0 \\
3,484 \\
0 \\
3,494\end{array}$ & $\begin{array}{r}462 \\
678 \\
0 \\
1,100 \\
20,034\end{array}$ & $\begin{array}{r}0 \\
1,200 \\
0 \\
1,700 \\
63,146\end{array}$ & $\begin{array}{r}6 \\
619 \\
50 \\
521 \\
20009\end{array}$ & $\begin{array}{r}0 \\
84 \\
0 \\
80,737\end{array}$ \\
\hline
\end{tabular}

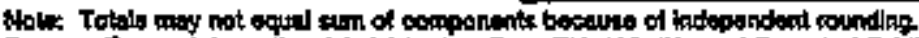

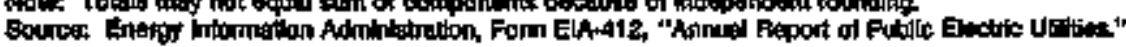


Table 22. Galance Sheet by Major U.S. Publlely Owned Electrie Utility Within State at End of Period, 1994

(Thousand Dollars)

\begin{tabular}{|c|c|c|c|c|c|c|}
\hline Item & 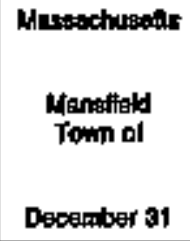 & 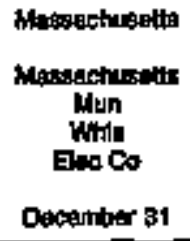 & 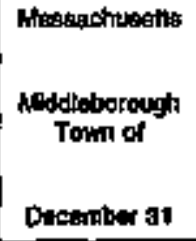 & 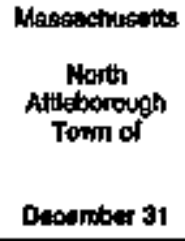 & $\begin{array}{l}\text { Mastichusetts } \\
\text { Nonmad } \\
\text { Ciby of } \\
\text { June } 30\end{array}$ & 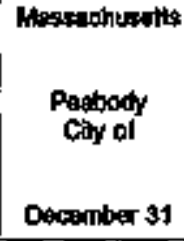 \\
\hline 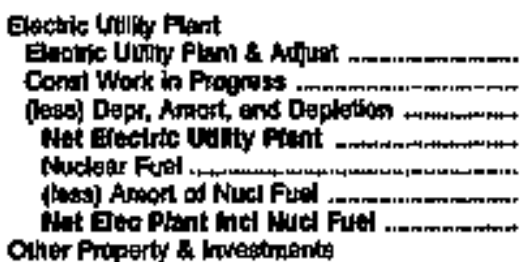 & $\begin{array}{r}0,754 \\
0 \\
3,008 \\
3,948 \\
0 \\
0 \\
3,940\end{array}$ & 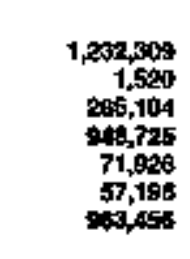 & $\begin{array}{r}15,846 \\
0 \\
6,673 \\
8,973 \\
0 \\
0 \\
0,073\end{array}$ & $\begin{array}{r}20,004 \\
1,32 \\
6,400 \\
18,727 \\
0 \\
0 \\
18,727\end{array}$ & $\begin{array}{r}21,789 \\
0 \\
15,003 \\
4,793 \\
0 \\
0 \\
6,793\end{array}$ & $\begin{array}{r}12,103 \\
0 \\
23,599 \\
3.514 \\
0 \\
0 \\
39,514\end{array}$ \\
\hline 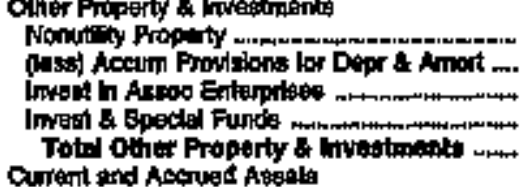 & $\begin{array}{r}0 \\
0 \\
0 \\
1,2030 \\
1,200\end{array}$ & $\begin{array}{l}0 \\
0 \\
0 \\
0 \\
0\end{array}$ & $\begin{array}{r}0 \\
0 \\
100 \\
1,051 \\
1,157\end{array}$ & $\begin{array}{r}0 \\
0 \\
0 \\
4,070 \\
4,070\end{array}$ & $\begin{array}{r}0 \\
0 \\
0 \\
3,973 \\
3,979\end{array}$ & $\begin{array}{r}0 \\
0 \\
0 \\
0,74 \\
0,74\end{array}$ \\
\hline 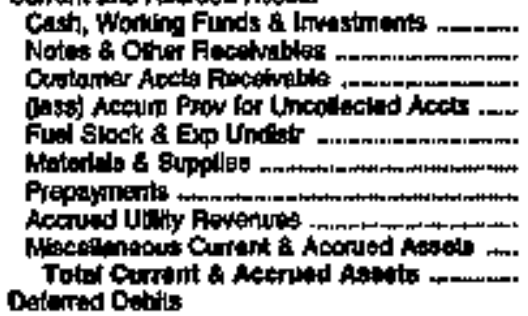 & 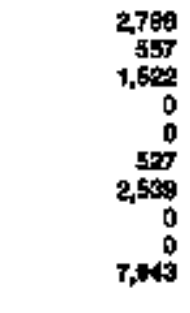 & $\begin{array}{r}193,019 \\
4,491 \\
606 \\
0 \\
5,151 \\
10,448 \\
7,413 \\
5,104 \\
0 \\
20,961\end{array}$ & 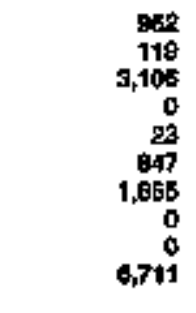 & $\begin{array}{r}5,294 \\
14 \\
1,025 \\
3+4 \\
0 \\
904 \\
179 \\
0 \\
0 \\
7,192\end{array}$ & $\begin{array}{r}1,129 \\
0 \\
1,627 \\
610 \\
0 \\
0 \\
0 \\
0 \\
0 \\
2,2,5\end{array}$ & $\begin{array}{r}5,449 \\
122 \\
3,680 \\
100 \\
180 \\
905 \\
921 \\
0 \\
0 \\
11,00.8\end{array}$ \\
\hline 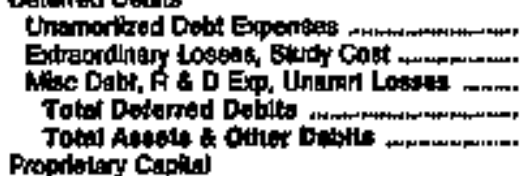 & $\begin{array}{r}0 \\
0 \\
3 \\
3 \\
13,060\end{array}$ & $\begin{array}{r}35,817 \\
1,808 \\
220,677 \\
2,0,806 \\
1,440,813\end{array}$ & $\begin{array}{r}0 \\
0 \\
485 \\
496 \\
17,927\end{array}$ & $\begin{array}{r}294 \\
0 \\
294 \\
25,294\end{array}$ & $\begin{array}{r}0 \\
0 \\
0 \\
0 \\
12,401\end{array}$ & $\begin{array}{r}195 \\
0 \\
0 \\
\text { sagsis }\end{array}$ \\
\hline 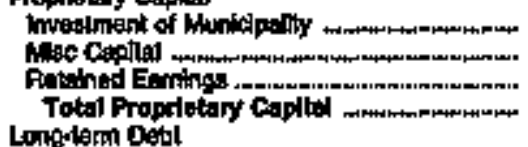 & $\begin{array}{r}0 \\
13 \\
12,050 \\
12,000\end{array}$ & $\begin{array}{l}0 \\
0 \\
0 \\
0\end{array}$ & $\begin{array}{r}2,407 \\
11,424 \\
73,452\end{array}$ & $\begin{array}{r}0 \\
19,469 \\
19,148\end{array}$ & $\begin{array}{r}9,867 \\
0 \\
1,250 \\
0,000\end{array}$ & $\begin{array}{r}4,800 \\
28,804 \\
28,904\end{array}$ \\
\hline 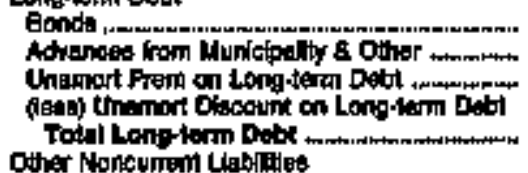 & $\begin{array}{l}0 \\
0 \\
0 \\
0 \\
0\end{array}$ & $\begin{array}{r}1,341,215 \\
0 \\
0 \\
0 \\
1,341,21 \%\end{array}$ & $\begin{array}{r}1,265 \\
915 \\
0 \\
0 \\
1,000\end{array}$ & $\begin{array}{r}3,919 \\
0 \\
0 \\
0 \\
3,4,40\end{array}$ & $\begin{array}{l}0 \\
0 \\
0 \\
0 \\
0 \\
0\end{array}$ & $\begin{array}{r}19,535 \\
0 \\
0 \\
0 \\
10,35 \%\end{array}$ \\
\hline 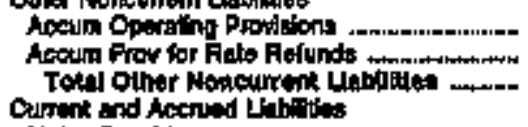 & $\begin{array}{r}6 \\
0 \\
6\end{array}$ & $\begin{array}{r}2,306 \\
2700\end{array}$ & $\begin{array}{r}540 \\
0 \\
540\end{array}$ & $\begin{array}{l}0 \\
0 \\
0\end{array}$ & $\begin{array}{l}0 \\
0 \\
0\end{array}$ & $\begin{array}{r}7,427 \\
7,427\end{array}$ \\
\hline 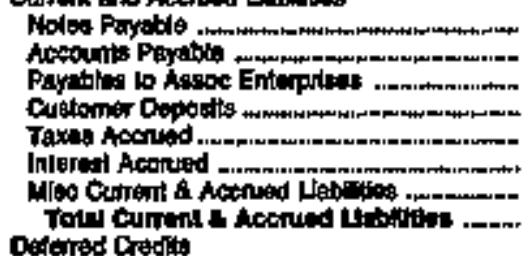 & $\begin{array}{r}0 \\
309 \\
305 \\
10 \\
0 \\
0\end{array}$ & $\begin{array}{r}0 \\
29,049 \\
0 \\
0 \\
32 \\
344 \\
47,009 \\
79,853\end{array}$ & $\begin{array}{r}0 \\
790 \\
0 \\
17 \\
5 \\
110 \\
0 \\
992\end{array}$ & $\begin{array}{r}0 \\
t, 399 \\
0 \\
209 \\
8 \\
198 \\
295 \\
2980\end{array}$ & 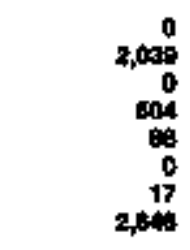 & $\begin{array}{r}0 \\
1,000 \\
189 \\
1,570 \\
0 \\
498 \\
0 \\
3,246\end{array}$ \\
\hline 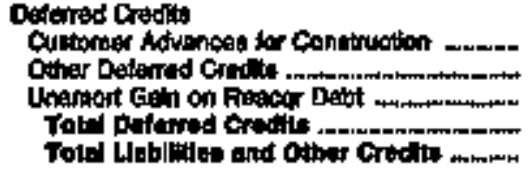 & $\begin{array}{r}0 \\
0 \\
0 \\
0 \\
0\end{array}$ & $\begin{array}{r}-18 \\
20,357 \\
0 \\
20,389 \\
1,40,613\end{array}$ & $\begin{array}{r}0 \\
49 \\
0 \\
143 \\
1439\end{array}$ & $\begin{array}{r}0 \\
0 \\
0 \\
0 \\
28,248\end{array}$ & $\begin{array}{r}135 \\
0 \\
0 \\
135 \\
12,401\end{array}$ & $\begin{array}{r}0 \\
0 \\
0 \\
0 \\
50,511\end{array}$ \\
\hline
\end{tabular}

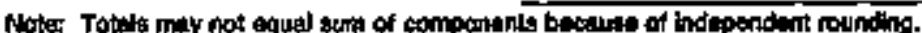

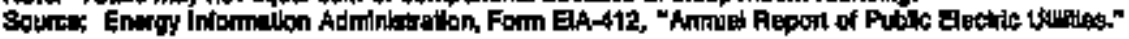


Table 22. Balance Sheet by Mhajor U.S. Publchy Omed Electric Utility Whthln State at End of Poriod, 1994 (Thousand Dollars)

\begin{tabular}{|c|c|c|c|c|c|c|}
\hline IWDI & 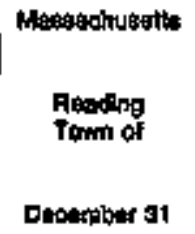 & 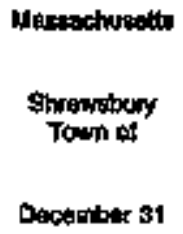 & 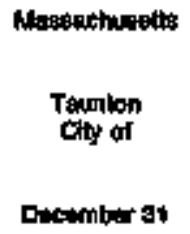 & 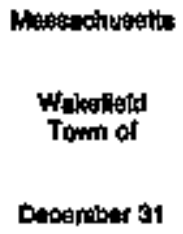 & 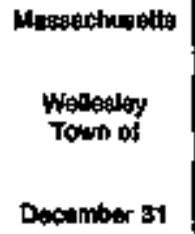 & 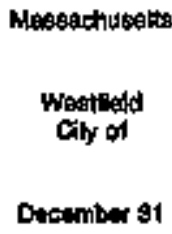 \\
\hline 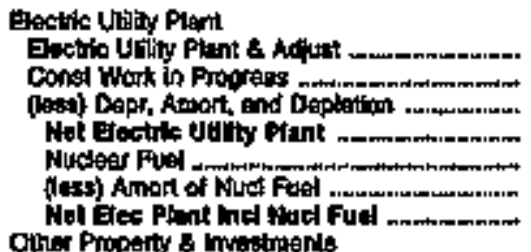 & $\begin{array}{r}48,658 \\
0 \\
20,471 \\
20,394 \\
0 \\
0 \\
29,894\end{array}$ & $\begin{array}{r}24,250 \\
0 \\
11,576 \\
12,60 \% \\
0 \\
12,467\end{array}$ & 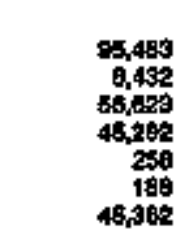 & $\begin{array}{r}14,6=4 \\
0 \\
11,313 \\
2,7401 \\
0 \\
0 \\
2,741\end{array}$ & $\begin{array}{r}29,989 \\
1,697 \\
12,369 \\
18,310 \\
0 \\
0 \\
16,310\end{array}$ & $\begin{array}{r}24,005 \\
619 \\
1,454 \\
25,904 \\
0 \\
0 \\
28,904\end{array}$ \\
\hline 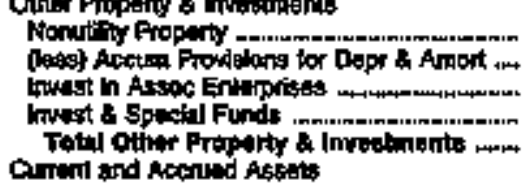 & $\begin{array}{r}0 \\
0 \\
2,309 \\
2,3909\end{array}$ & $\begin{array}{r}0 \\
0 \\
160 \\
4933 \\
4,409\end{array}$ & $\begin{array}{r}0 \\
9 \\
12,595 \\
12,515\end{array}$ & $\begin{array}{r}0 \\
0 \\
0 \\
1,000 \\
+, 096\end{array}$ & $\begin{array}{r}0 \\
0 \\
0 \\
2073 \\
2,079\end{array}$ & $\begin{array}{r}0 \\
0 \\
1,561 \\
1,51\end{array}$ \\
\hline 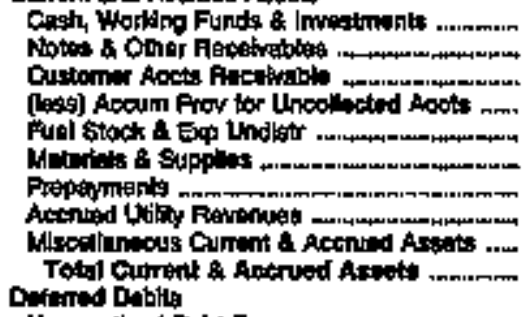 & $\begin{array}{r}12,559 \\
499 \\
5,135 \\
300 \\
0 \\
800 \\
807 \\
0 \\
0 \\
17,680\end{array}$ & $\begin{array}{r}4,470 \\
16 \\
1,276 \\
9 \\
0 \\
157 \\
1,396 \\
4 \\
0 \\
7,368\end{array}$ & $\begin{array}{r}3,901 \\
3591 \\
3,350 \\
0 \\
9024 \\
1,024 \\
1,248 \\
0 \\
258 \\
1,090\end{array}$ & $\begin{array}{r}1,630 \\
193 \\
2,008 \\
145 \\
0 \\
400 \\
270 \\
0 \\
0 \\
4,644\end{array}$ & $\begin{array}{r}1,513 \\
0 \\
1,591 \\
133 \\
0 \\
658 \\
75 \\
0 \\
52 \\
\$, 749\end{array}$ & $\begin{array}{r}7,105 \\
307 \\
4,9037 \\
1,158 \\
0 \\
1,250 \\
0 \\
0 \\
13,373\end{array}$ \\
\hline 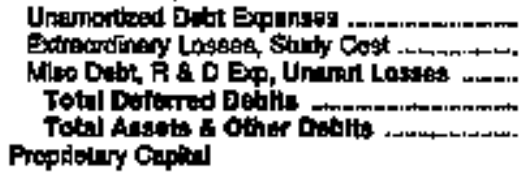 & $\begin{array}{r}0 \\
0 \\
28 \\
28 \\
28,436\end{array}$ & $\begin{array}{r}0 \\
0 \\
1 \\
1 \\
24,96\end{array}$ & $\begin{array}{r}0 \\
0 \\
208 \\
246 \\
20,292\end{array}$ & $\begin{array}{r}0 \\
0 \\
34 \\
34 \\
34\end{array}$ & $\begin{array}{r}0 \\
0 \\
0 \\
0 \\
2,+133\end{array}$ & 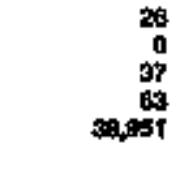 \\
\hline 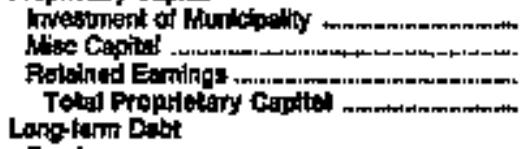 & 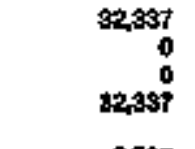 & $\begin{array}{r}0 \\
0 \\
22,355 \\
22,366\end{array}$ & $\begin{array}{r}44,197 \\
0 \\
0 \\
44,197\end{array}$ & $\begin{array}{r}0 \\
6,185 \\
0,125\end{array}$ & $\begin{array}{r}1,820 \\
0 \\
17,710 \\
10,630\end{array}$ & $\begin{array}{r}24,084 \\
0 \\
0 \\
24,084\end{array}$ \\
\hline 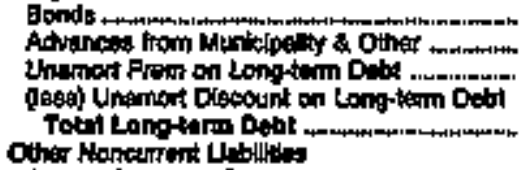 & $\begin{array}{r}6,787 \\
0 \\
0 \\
0 \\
6,707\end{array}$ & $\begin{array}{r}75 \\
70 \\
0 \\
0 \\
115\end{array}$ & $\begin{array}{r}16,200 \\
0 \\
0 \\
0 \\
10,200\end{array}$ & $\begin{array}{l}0 \\
0 \\
0 \\
0 \\
0\end{array}$ & $\begin{array}{r}400 \\
0 \\
0 \\
0 \\
000\end{array}$ & $\begin{array}{r}3.840 \\
0 \\
0 \\
0 \\
0 \\
0.940\end{array}$ \\
\hline 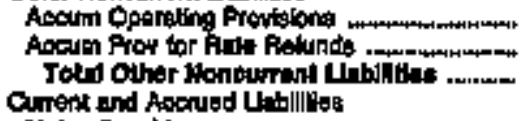 & $\begin{array}{l}0 \\
0 \\
0\end{array}$ & $\begin{array}{l}0 \\
0 \\
0\end{array}$ & $\begin{array}{l}0 \\
0 \\
0\end{array}$ & $\begin{array}{l}0 \\
0 \\
0\end{array}$ & $\begin{array}{l}0 \\
0 \\
0\end{array}$ & $\begin{array}{l}0 \\
0 \\
0\end{array}$ \\
\hline 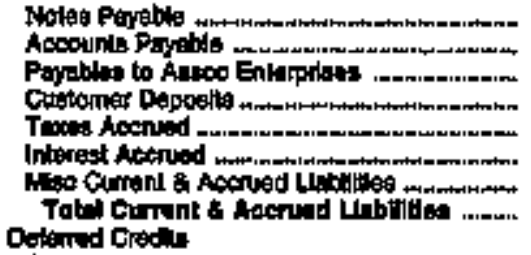 & 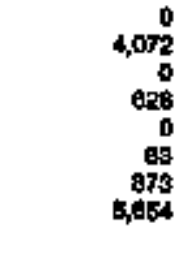 & $\begin{array}{r}0 \\
1,427 \\
0 \\
378 \\
14 \\
2 \\
0 \\
1,020\end{array}$ & $\begin{array}{r}0 \\
2,568 \\
0 \\
384 \\
0 \\
598 \\
307 \\
3,710\end{array}$ & $\begin{array}{r}0 \\
1,089 \\
0 \\
685 \\
0 \\
0 \\
200 \\
2430\end{array}$ & $\begin{array}{r}0 \\
1, \mathrm{AB} \\
0 \\
0 \\
390 \\
0 \\
0 \\
0 \\
109 \\
2,149\end{array}$ & $\begin{array}{r}1,000 \\
2,800 \\
259 \\
30 \\
3 \\
114 \\
3,772 \\
8,078\end{array}$ \\
\hline 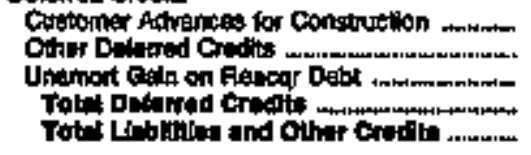 & $\begin{array}{r}\$, 445 \\
1,206 \\
0 \\
4,076 \\
4,4456\end{array}$ & $\begin{array}{r}196 \\
0 \\
195 \\
19,005\end{array}$ & $\begin{array}{r}37 \\
4,301 \\
767 \\
6,108 \\
09,290\end{array}$ & $\begin{array}{r}0 \\
0 \\
0 \\
0 \\
0\end{array}$ & $\begin{array}{r}67 \\
0 \\
0 \\
67 \\
2,130\end{array}$ & $\begin{array}{r}0 \\
0 \\
0 \\
0 \\
\text { ats, } 981\end{array}$ \\
\hline
\end{tabular}

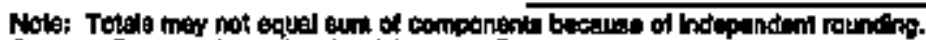

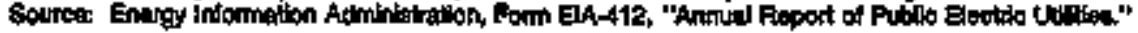


Table 22. Balance Sheet by Major U.S. Pubnlly Owned Electrie Utility Within State at End of Pertod, 1994

(Thousand Dollars)

\begin{tabular}{|c|c|c|c|c|c|c|}
\hline Item & Ulotigan & 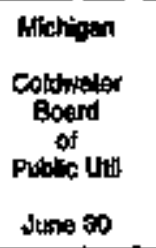 & $\begin{array}{l}\text { Mlohlogn } \\
\text { Detrotit } \\
\text { Chy of }\end{array}$ & $\begin{array}{l}\text { Minchiogn } \\
\text { Bnand Haven } \\
\text { Clay of } \\
\text { June ao }\end{array}$ & 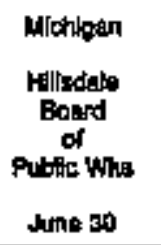 & 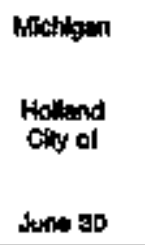 \\
\hline 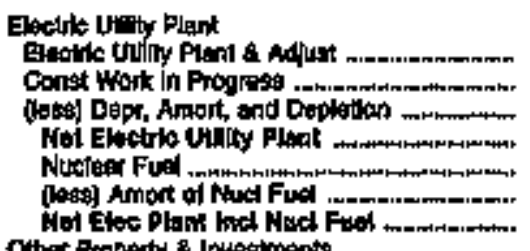 & $\begin{array}{r}41,070 \\
0 \\
13,085 \\
30,934 \\
0 \\
0 \\
34,934\end{array}$ & $\begin{array}{r}14,719 \\
0 \\
0,359 \\
0,409 \\
0 \\
0 \\
0,350\end{array}$ & 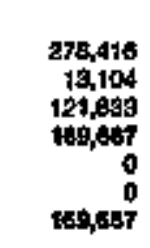 & $\begin{array}{r}102,771 \\
6 \times 1 \\
4,360 \\
00,040 \\
0 \\
0 \\
60,045\end{array}$ & $\begin{array}{r}10,667 \\
5653 \\
7,278 \\
3,001 \\
0 \\
0 \\
5,801\end{array}$ & $\begin{array}{r}03,081 \\
1,974 \\
41,420 \\
50,095 \\
0 \\
0 \\
50,036\end{array}$ \\
\hline 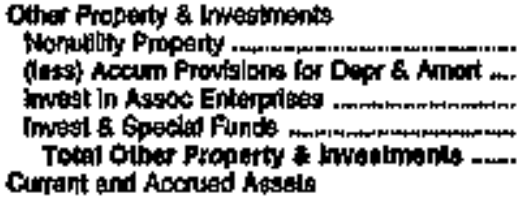 & $\begin{array}{r}0 \\
0 \\
0 \\
6,485 \\
6,491\end{array}$ & $\begin{array}{r}0 \\
2,000 \\
2,008\end{array}$ & $\begin{array}{l}0 \\
0 \\
0 \\
0 \\
0\end{array}$ & $\begin{array}{r}0 \\
0 \\
0 \\
315 \\
315\end{array}$ & $\begin{array}{r}0 \\
0 \\
078 \\
3,+11 \\
4,009\end{array}$ & \\
\hline 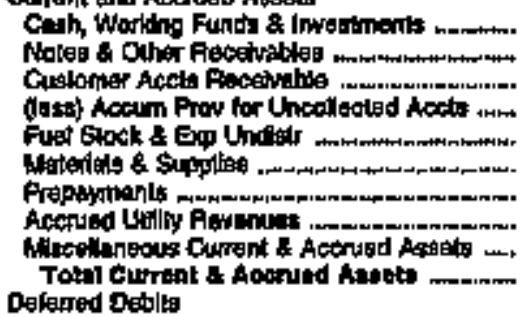 & 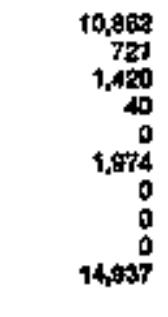 & $\begin{array}{r}54 \\
1,584 \\
1,206 \\
0 \\
0 \\
344 \\
24 \\
0 \\
0 \\
3,227\end{array}$ & $\begin{array}{r}79,647 \\
16,306 \\
20,450 \\
2,107 \\
1,226 \\
7,702 \\
0 \\
0 \\
0 \\
129,97\end{array}$ & $\begin{array}{r}12,694 \\
544 \\
t, 591 \\
0 \\
2,294 \\
0 \\
167 \\
9 \\
40 \\
24,800\end{array}$ & $\begin{array}{r}1,242 \\
303 \\
1,098 \\
120 \\
0 \\
763 \\
13 \\
0 \\
39 \\
3,34\end{array}$ & $\begin{array}{r}97,377 \\
572 \\
1,897 \\
10 \\
2,606 \\
2,471 \\
0 \\
1,825 \\
0 \\
96,638\end{array}$ \\
\hline 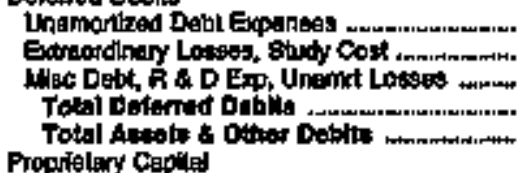 & 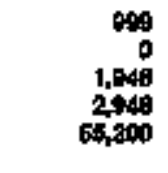 & $\begin{array}{r}0 \\
0 \\
0 \\
0 \\
12,40\end{array}$ & $\begin{array}{r}0 \\
0 \\
2,512 \\
2,512 \\
205,578\end{array}$ & $\begin{array}{r}14,458 \\
0 \\
0 \\
14,459 \\
0,900\end{array}$ & $\begin{array}{r}0 \\
0 \\
0 \\
0 \\
+1,421\end{array}$ & $\begin{array}{r}0 \\
0 \\
0 \\
0 \\
102670\end{array}$ \\
\hline 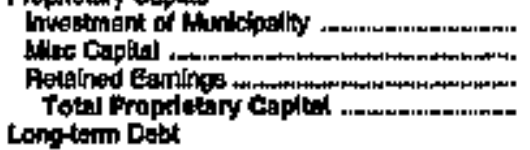 & $\begin{array}{r}0 \\
0 \\
27,027 \\
27, A 25\end{array}$ & $\begin{array}{r}8,884 \\
9 \\
0 \\
8,984\end{array}$ & $\begin{array}{r}26,477 \\
-207,508 \\
158,135 \\
214,104\end{array}$ & $\begin{array}{r}0 \\
0 \\
483 \\
4183\end{array}$ & $\begin{array}{r}0 \\
0 \\
10,433 \\
10,423\end{array}$ & $\begin{array}{r}0 \\
0 \\
65,356 \\
65,358\end{array}$ \\
\hline 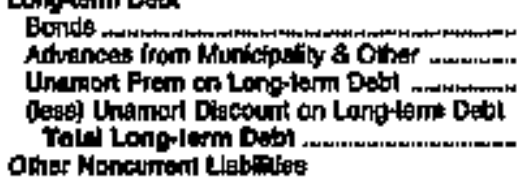 & $\begin{array}{r}25,165 \\
91 \\
0 \\
0 \\
25,276\end{array}$ & $\begin{array}{r}780 \\
901 \\
0 \\
0 \\
1,781\end{array}$ & $\begin{array}{r}73,005 \\
0 \\
0 \\
0 \\
73,005\end{array}$ & $\begin{array}{r}98,006 \\
0 \\
0 \\
3,426 \\
92,609\end{array}$ & $\begin{array}{l}0 \\
0 \\
0 \\
0 \\
0\end{array}$ & $\begin{array}{r}34,315 \\
0 \\
0 \\
1,750 \\
32,985\end{array}$ \\
\hline 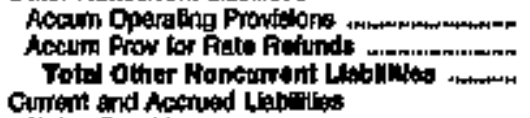 & $\begin{array}{l}0 \\
0 \\
0\end{array}$ & $\begin{array}{l}0 \\
0 \\
0\end{array}$ & $\begin{array}{l}0 \\
0 \\
0\end{array}$ & $\begin{array}{l}0 \\
0 \\
0\end{array}$ & $\begin{array}{l}0 \\
0 \\
0\end{array}$ & \\
\hline 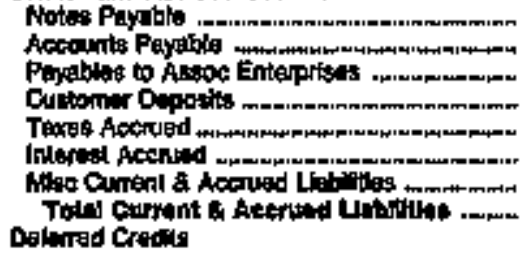 & $\begin{array}{r}1,180 \\
113 \\
649 \\
64 \\
0 \\
6 \\
152 \\
2,051\end{array}$ & $\begin{array}{r}0 \\
8+5 \\
69 \\
0 \\
0 \\
34 \\
351 \\
1,100\end{array}$ & $\begin{array}{r}0 \\
2,550 \\
0 \\
357 \\
0 \\
0 \\
5,558 \\
0,486\end{array}$ & $\begin{array}{r}0 \\
1,048 \\
0 \\
158 \\
78 \\
2,580 \\
1,804 \\
6,050\end{array}$ & $\begin{array}{r}0 \\
742 \\
0 \\
19 \\
0 \\
0 \\
198 \\
608\end{array}$ & $\begin{array}{r}0 \\
3,981 \\
89 \\
0 \\
0 \\
1,012 \\
294 \\
4,749\end{array}$ \\
\hline 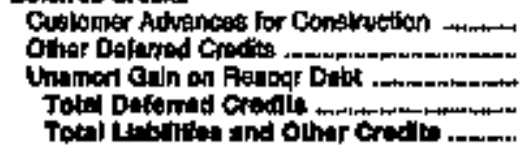 & $\begin{array}{r}48 \\
0 \\
0 \\
48 \\
40,800\end{array}$ & $\begin{array}{r}0 \\
0 \\
0 \\
0 \\
12,405\end{array}$ & $\begin{array}{r}0 \\
0 \\
0 \\
0 \\
205676\end{array}$ & $\begin{array}{r}0 \\
0 \\
0 \\
0 \\
0\end{array}$ & $\begin{array}{r}0 \\
0 \\
0 \\
0 \\
11,221\end{array}$ & $\begin{array}{r}0 \\
0 \\
0 \\
0 \\
102,070\end{array}$ \\
\hline
\end{tabular}

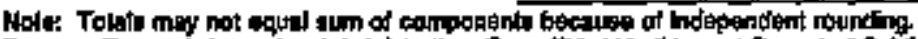

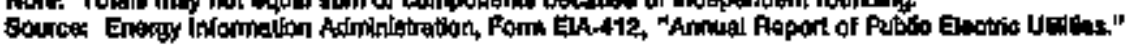


Table 22. Balance Sheet by Major U.S. Publty Owned Eleotric Utilly Within State at End of Porlod, 1994

(Thousend Doliers)

\begin{tabular}{|c|c|c|c|c|c|c|}
\hline tuem & $\begin{array}{l}\text { Wientigen } \\
\text { Laroging } \\
\text { Chy of } \\
\text { June } 30\end{array}$ & 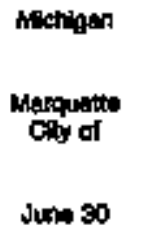 & 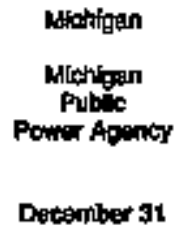 & 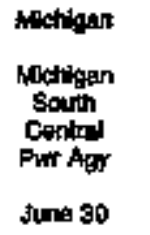 & 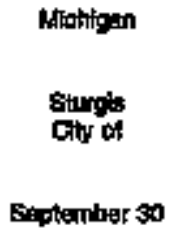 & 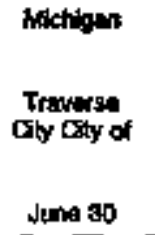 \\
\hline 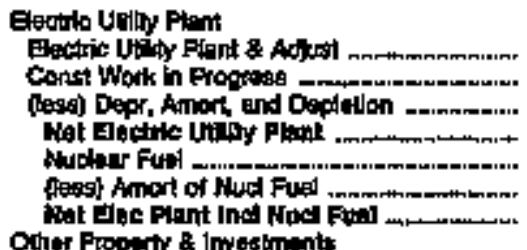 & $\begin{array}{r}374,329 \\
24,478 \\
224,108 \\
174,699 \\
0 \\
0 \\
174,69\end{array}$ & $\begin{array}{r}05,427 \\
816 \\
42,107 \\
54,436 \\
0 \\
0 \\
5,985\end{array}$ & $\begin{array}{r}409,488 \\
0 \\
137,436 \\
332,050 \\
0 \\
0 \\
332,050\end{array}$ & $\begin{array}{r}7,288 \\
560 \\
25,982 \\
4,668 \\
0 \\
0 \\
97,608\end{array}$ & $\begin{array}{r}28,607 \\
0 \\
14,083 \\
19,924 \\
0 \\
0 \\
13,924\end{array}$ & $\begin{array}{r}30,059 \\
312 \\
12,479 \\
18,086 \\
0 \\
18,88\end{array}$ \\
\hline 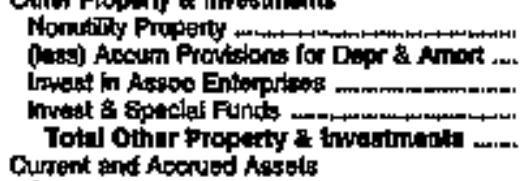 & $\begin{array}{r}0 \\
0 \\
0 \\
19,08 \\
\operatorname{mos}\end{array}$ & $\begin{array}{r}0 \\
0 \\
0 \\
14,104 \\
14,104\end{array}$ & $\begin{array}{r}6 a \% \\
50 \\
0 \\
118,110 \\
173,742\end{array}$ & $\begin{array}{r}0 \\
0 \\
0 \\
20,063 \\
0030\end{array}$ & $\begin{array}{r}0 \\
0 \\
0 \\
7,942 \\
7,9,42\end{array}$ & $\begin{array}{r}0 \\
0 \\
0 \\
654 \\
654\end{array}$ \\
\hline 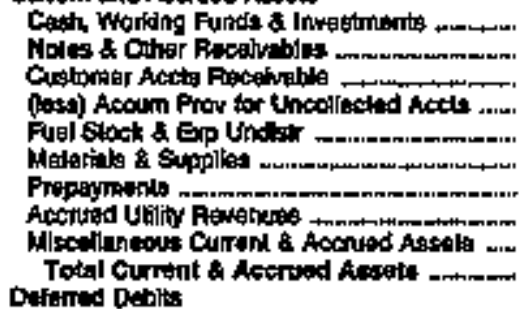 & $\begin{array}{r}5,945 \\
0 \\
9,797 \\
5,04 \\
5,600 \\
3,597 \\
2,70 \\
0 \\
3,206 \\
70,050\end{array}$ & $\begin{array}{r}7,738 \\
1 \\
1,081 \\
167 \\
2,278 \\
258 \\
105 \\
0 \\
4 \\
11,395\end{array}$ & $\begin{array}{r}15,0097 \\
0 \\
0,300 \\
0 \\
0,970 \\
2,027 \\
0 \\
0 \\
182 \\
30,336\end{array}$ & $\begin{array}{r}49 \\
509 \\
1,673 \\
0 \\
1,276 \\
205 \\
38 \\
0 \\
412 \\
4,549\end{array}$ & $\begin{array}{r}191 \\
272 \\
1,510 \\
0 \\
0 \\
411 \\
0 \\
0 \\
1,004 \\
3,927\end{array}$ & $\begin{array}{r}5,234 \\
173 \\
1,367 \\
29 \\
0 \\
1,380 \\
1,42 \\
0 \\
5 \\
0,208\end{array}$ \\
\hline 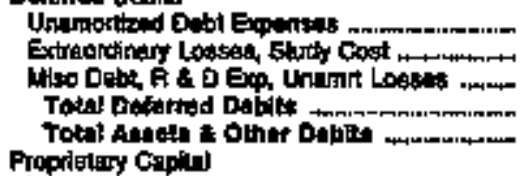 & $\begin{array}{r}0 \\
0,295 \\
3,205 \\
276,010\end{array}$ & $\begin{array}{r}119 \\
0 \\
0 \\
90948\end{array}$ & $\begin{array}{r}4,176 \\
0 \\
0 \\
4,173 \\
460,312\end{array}$ & $\begin{array}{r}2,509 \\
62 \\
22,870 \\
25,240 \\
206,241\end{array}$ & 26,696 & $\begin{array}{r}108 \\
0 \\
0 \\
406 \\
26,041\end{array}$ \\
\hline 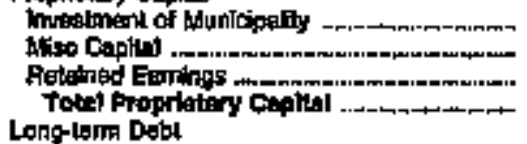 & $\begin{array}{r}0 \\
-37,059 \\
297,299 \\
219,941\end{array}$ & $\begin{array}{r}0 \\
0 \\
30,624 \\
30,624\end{array}$ & $\begin{array}{r}0 \\
250 \\
05\end{array}$ & $\begin{array}{r}0 \\
0 \\
3,894 \\
3,034\end{array}$ & $\begin{array}{r}0 \\
19 \\
19,148 \\
19,146\end{array}$ & $\begin{array}{r}56 \\
0 \\
23,757 \\
23,757\end{array}$ \\
\hline 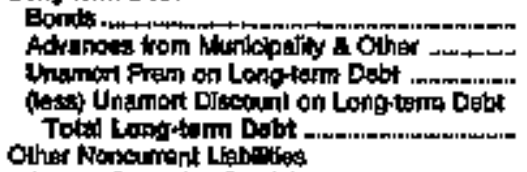 & $\begin{array}{r}22,450 \\
2,240 \\
0 \\
0 \\
24,7 / 2\end{array}$ & $\begin{array}{r}41,390 \\
0 \\
0 \\
474 \\
40,918\end{array}$ & $\begin{array}{r}426,1000 \\
0 \\
0 \\
0 \\
429,909\end{array}$ & $\begin{array}{r}102,015 \\
0 \\
0 \\
2,79 \\
0,269\end{array}$ & $\begin{array}{r}3,675 \\
0 \\
0 \\
0 \\
3,675\end{array}$ & $\begin{array}{r}2,795 \\
0 \\
0 \\
2,735\end{array}$ \\
\hline 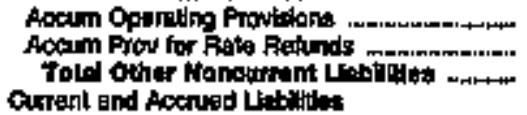 & $\begin{array}{r}19,860 \\
19,980\end{array}$ & $\begin{array}{r}708 \\
0 \\
705\end{array}$ & $\begin{array}{l}0 \\
0 \\
0\end{array}$ & $\begin{array}{l}0 \\
0 \\
0\end{array}$ & $\begin{array}{r}1,200 \\
0 \\
1,2 \geq 20\end{array}$ & $\begin{array}{r}319 \\
0 \\
316\end{array}$ \\
\hline 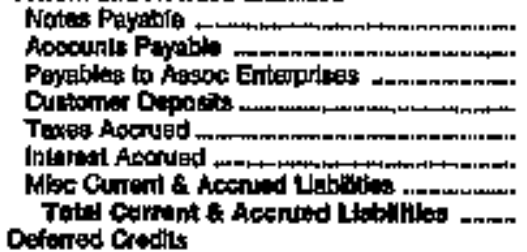 & 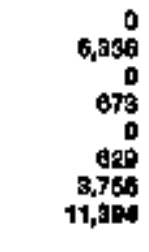 & $\begin{array}{r}4,450 \\
1,462 \\
0 \\
94 \\
146 \\
1,090 \\
0 \\
9,101\end{array}$ & $\begin{array}{r}7.587 \\
3,209 \\
0 \\
0 \\
0 \\
11,951 \\
589 \\
29,284\end{array}$ & $\begin{array}{r}0 \\
1,959 \\
0 \\
0 \\
0 \\
802 \\
217 \\
3,120\end{array}$ & $\begin{array}{r}0 \\
1,949 \\
0 \\
2 \\
0 \\
0 \\
0 \\
1,362\end{array}$ & $\begin{array}{r}105 \\
000 \\
0 \\
51 \\
0 \\
09 \\
65 \\
1000\end{array}$ \\
\hline 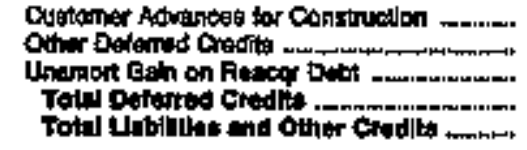 & $\begin{array}{r}214 \\
0 \\
0 \\
214 \\
276,010\end{array}$ & $\begin{array}{r}494 \\
0 \\
0 \\
\text { ongen }\end{array}$ & $\begin{array}{r}0 \\
\$ 5,242 \\
55 \\
\$ 5,242 \\
415,312\end{array}$ & $\begin{array}{r}0 \\
0 \\
0 \\
0 \\
106,241\end{array}$ & $\begin{array}{r}300 \\
0 \\
9 \\
300 \\
25,000\end{array}$ & $\begin{array}{r}0 \\
0 \\
0 \\
0 \\
2941\end{array}$ \\
\hline
\end{tabular}

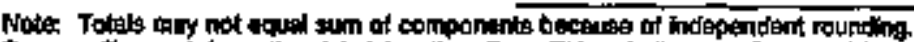

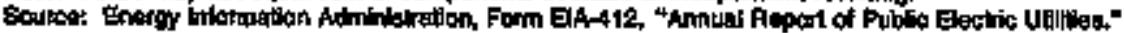


Table 22. Balance Sheet by Major U.S. Publlely Owned Electric Utility Within State at End of Period, 1994

(Thousind Dollaus)

\begin{tabular}{|c|c|c|c|c|c|c|}
\hline hem & $\begin{array}{l}\text { Mochigun } \\
\text { Whandona } \\
\text { Sunicipal } \\
\text { Serv Comm } \\
\text { September so }\end{array}$ & $\begin{array}{l}\text { Mothipin } \\
\text { Zouland } \\
\text { Cily of } \\
\text { Jung sot }\end{array}$ & 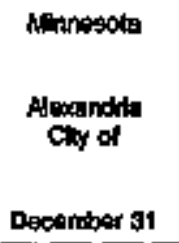 & $\begin{array}{l}\text { Hinmesald } \\
\text { Anoke } \\
\text { Ciny of } \\
\text { Decombet } 31\end{array}$ & 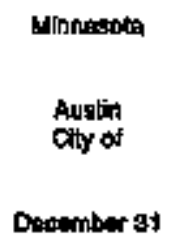 & $\begin{array}{l}\text { Mimesola } \\
\text { Bralnerd } \\
\text { Chy of } \\
\text { Decariber } 31\end{array}$ \\
\hline 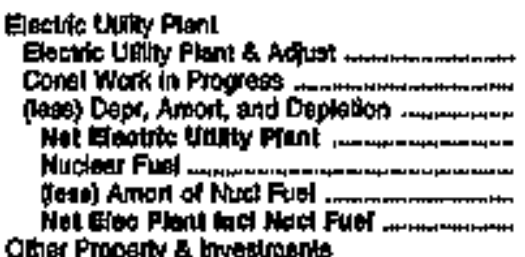 & $\begin{array}{r}69,710 \\
37,600 \\
34,500 \\
72,012 \\
0 \\
0 \\
72,017\end{array}$ & $\begin{array}{r}17,421 \\
1,050 \\
7,000 \\
11,170 \\
0 \\
11,170\end{array}$ & $\begin{array}{r}18,928 \\
17 \\
8,898 \\
6,646 \\
0 \\
0 \\
6,848\end{array}$ & $\begin{array}{r}13,609 \\
0 \\
0,605 \\
7,0020 \\
0 \\
0 \\
7,0028\end{array}$ & $\begin{array}{r}34,195 \\
48 \\
20,881 \\
18,981 \\
0 \\
0 \\
19,361\end{array}$ & $\begin{array}{r}6,301 \\
365 \\
3,138 \\
3,529 \\
0 \\
0 \\
0,528\end{array}$ \\
\hline 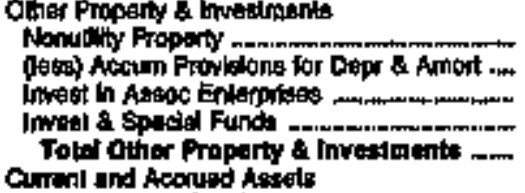 & $\begin{array}{r}0 \\
0 \\
0 \\
11,370 \\
11,370\end{array}$ & $\begin{array}{r}0 \\
0 \\
0 \\
10,427 \\
10,427\end{array}$ & $\begin{array}{r}5,221 \\
2,550 \\
0 \\
6,580 \\
6,781\end{array}$ & $\begin{array}{l}0 \\
0 \\
0 \\
0 \\
0\end{array}$ & $\begin{array}{r}14,689 \\
0,686 \\
0 \\
9,790 \\
17,806\end{array}$ & $\begin{array}{r}1,206 \\
852 \\
614 \\
1,945 \\
9,034\end{array}$ \\
\hline 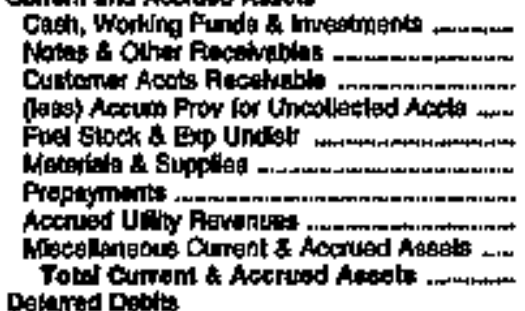 & $\begin{array}{r}5,178 \\
3,299 \\
0 \\
40 \\
0 \\
1,089 \\
10 \\
0 \\
121 \\
10,591\end{array}$ & $\begin{array}{r}1,002 \\
0 \\
887 \\
0 \\
0 \\
201 \\
18 \\
0 \\
0 \\
2,187\end{array}$ & $\begin{array}{r}210 \\
49 \\
298 \\
10 \\
4 \\
467 \\
89 \\
0 \\
0 \\
1,106\end{array}$ & $\begin{array}{r}5,013 \\
0 \\
1,782 \\
0 \\
0 \\
201 \\
0 \\
0 \\
67 \\
7,127\end{array}$ & 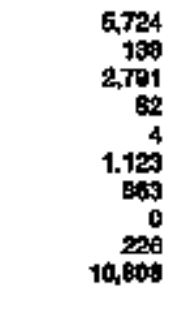 & $\begin{array}{r}14 \\
96 \\
659 \\
0 \\
0 \\
595 \\
4 \\
0 \\
0 \\
1,319\end{array}$ \\
\hline 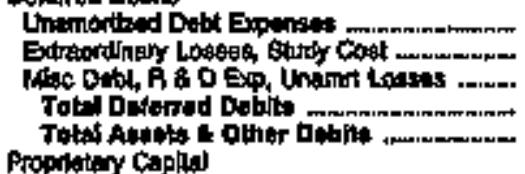 & $\begin{array}{r}0 \\
0 \\
0 \\
0 \\
2,013\end{array}$ & $\begin{array}{r}0 \\
0 \\
0 \\
0 \\
23,7\end{array}$ & $\begin{array}{r}0 \\
0 \\
651 \\
17,135\end{array}$ & $\begin{array}{r}0 \\
0 \\
0 \\
0 \\
14,549\end{array}$ & $\begin{array}{r}655 \\
0 \\
6 \\
659\end{array}$ & $\begin{array}{r}0 \\
0 \\
0 \\
0 \\
+0,473\end{array}$ \\
\hline 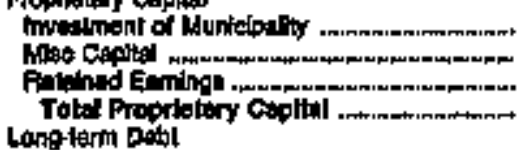 & $\begin{array}{r}0 \\
2,789 \\
2,735 \\
24,004\end{array}$ & $\begin{array}{r}0 \\
13,392 \\
13,7 a d\end{array}$ & $\begin{array}{r}0 \\
24,146 \\
12,876 \\
1,5,070\end{array}$ & $\begin{array}{r}0 \\
0 \\
12,183 \\
12,133\end{array}$ & $\begin{array}{r}0 \\
32,640 \\
32,640\end{array}$ & $\begin{array}{r}879 \\
18 \\
8,573 \\
0.494\end{array}$ \\
\hline 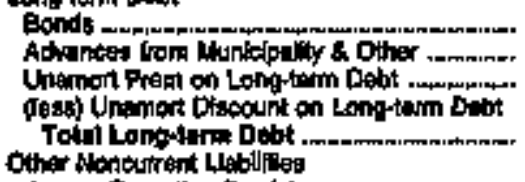 & $\begin{array}{r}8 x, 185 \\
47 \\
0 \\
0 \\
81,232\end{array}$ & $\begin{array}{r}8,916 \\
0 \\
0 \\
0 \\
8,916\end{array}$ & $\begin{array}{l}0 \\
0 \\
0 \\
0 \\
0\end{array}$ & $\begin{array}{l}0 \\
0 \\
0 \\
0 \\
0\end{array}$ & $\begin{array}{l}0 \\
0 \\
0 \\
0 \\
0\end{array}$ & \\
\hline 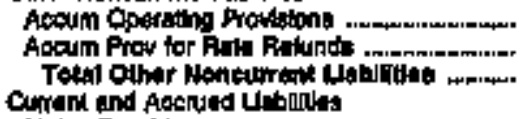 & $\begin{array}{r}4,070 \\
0 \\
4,70\end{array}$ & $\begin{array}{l}0 \\
0 \\
0\end{array}$ & $\begin{array}{l}0 \\
0 \\
0\end{array}$ & $\begin{array}{l}0 \\
0 \\
0\end{array}$ & $\begin{array}{r}3,973 \\
0 \\
3,078\end{array}$ & $\begin{array}{r}171 \\
0 \\
171\end{array}$ \\
\hline 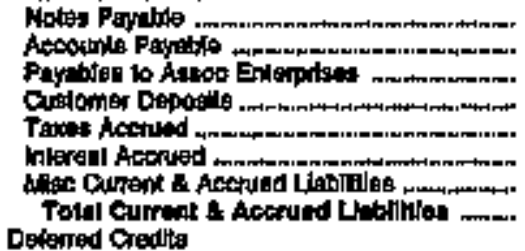 & $\begin{array}{r}0 \\
0 \\
0 \\
153 \\
0 \\
29 \\
3,516 \\
3,709\end{array}$ & $\begin{array}{r}0 \\
916 \\
0 \\
0 \\
0 \\
122 \\
28 \\
1,081\end{array}$ & $\begin{array}{r}0 \\
606 \\
809 \\
88 \\
0 \\
0 \\
162 \\
t, 461\end{array}$ & $\begin{array}{r}0 \\
778 \\
0 \\
1,048 \\
0 \\
80 \\
141 \\
2,017\end{array}$ & $\begin{array}{r}2,290 \\
120 \\
137 \\
9 \\
901 \\
3,134\end{array}$ & $\begin{array}{r}0 \\
710 \\
0 \\
98 \\
28 \\
0 \\
12 \\
930\end{array}$ \\
\hline 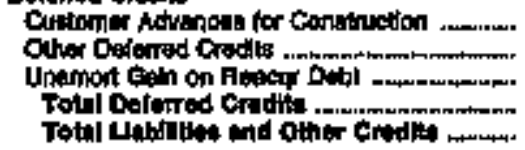 & $\begin{array}{r}0 \\
0 \\
0 \\
0 \\
2,1013\end{array}$ & $\begin{array}{r}0 \\
0 \\
0 \\
0 \\
25,7+4\end{array}$ & $\begin{array}{r}0 \\
051 \\
0 \\
051 \\
17,135\end{array}$ & $\begin{array}{r}0 \\
0 \\
0 \\
0 \\
14,+140\end{array}$ & $\begin{array}{r}0 \\
2,006 \\
0 \\
2,900 \\
42,74 t\end{array}$ & $\begin{array}{r}0 \\
0 \\
0 \\
0 \\
12,473\end{array}$ \\
\hline
\end{tabular}

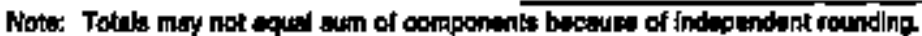

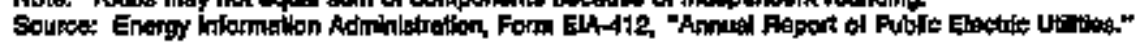


Table 22. Balance Sheet by Major U.S. Publicly Owned Electric Utilty Whitin State at End of Period, 1994 (Thousand Dollars)

\begin{tabular}{|c|c|c|c|c|c|c|}
\hline I1em & $\begin{array}{l}\text { Molnnesota } \\
\text { Chaske } \\
\text { City of } \\
\text { Deceniber } 31\end{array}$ & 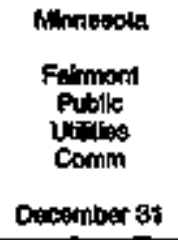 & 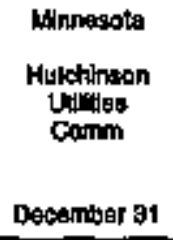 & $\begin{array}{l}\text { Alinisede } \\
\text { Marihall } \\
\text { Ciay of } \\
\text { Decambor } 31\end{array}$ & $\begin{array}{l}\text { Mlinnegate } \\
\text { Moonteand } \\
\text { City of } \\
\text { Dacember } 31\end{array}$ & 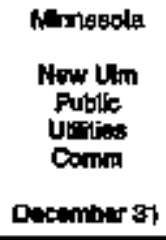 \\
\hline 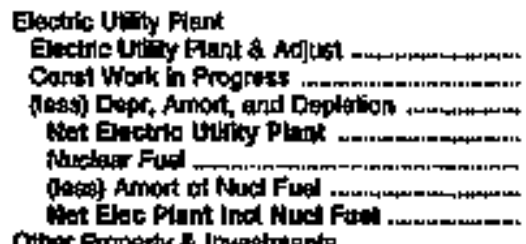 & $\begin{array}{r}8,932 \\
0 \\
1,579 \\
5,394 \\
0 \\
0 \\
5,354\end{array}$ & $\begin{array}{r}7,8,890 \\
20 \\
17,9,44 \\
7,374 \\
0 \\
7,374\end{array}$ & $\begin{array}{r}48,908 \\
0 \\
14,544 \\
34,393 \\
0 \\
0 \\
34,393\end{array}$ & $\begin{array}{r}2,451 \\
116 \\
6,697 \\
16,689 \\
0 \\
0 \\
16,1869\end{array}$ & $\begin{array}{r}30,038 \\
15,205 \\
15,650 \\
0 \\
0 \\
15,050\end{array}$ & $\begin{array}{r}25,0,002 \\
200 \\
13,000 \\
12,005 \\
0 \\
0 \\
12,005\end{array}$ \\
\hline 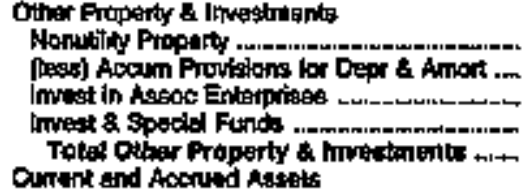 & $\begin{array}{l}0 \\
0 \\
0 \\
0 \\
0\end{array}$ & $\begin{array}{l}0 \\
0 \\
0 \\
0 \\
0\end{array}$ & $\begin{array}{r}0 \\
0 \\
0 \\
1,388 \\
1,399\end{array}$ & $\begin{array}{r}0 \\
0 \\
2,094 \\
1,476 \\
3,570\end{array}$ & $\begin{array}{r}0 \\
0 \\
0 \\
5,18 \% \\
5,191\end{array}$ & $\begin{array}{r}0 \\
0 \\
0 \\
1,900 \\
1,900\end{array}$ \\
\hline 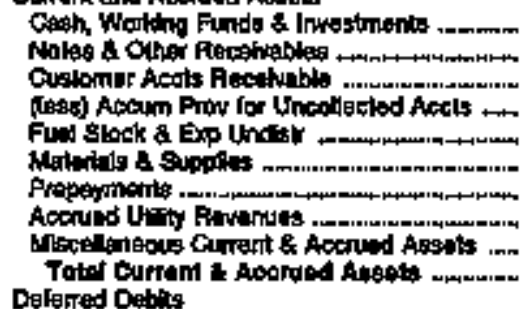 & $\begin{array}{r}4,357 \\
669 \\
897 \\
8 \\
0 \\
69 \\
0 \\
658 \\
0 \\
6,944\end{array}$ & $\begin{array}{r}456 \\
7,313 \\
2,072 \\
30 \\
29 \\
251 \\
0 \\
0 \\
0 \\
0,008\end{array}$ & $\begin{array}{r}1,492 \\
0 \\
1,283 \\
25 \\
0 \\
571 \\
0 \\
0 \\
31 \\
3929\end{array}$ & $\begin{array}{r}7,6900 \\
0 \\
1,205 \\
0 \\
0 \\
542 \\
52 \\
0 \\
0 \\
0,419\end{array}$ & $\begin{array}{r}213 \\
65 \\
013 \\
0 \\
0 \\
293 \\
09 \\
0 \\
0 \\
1,407\end{array}$ & $\begin{array}{r}5,176 \\
191 \\
-129 \\
0 \\
130 \\
688 \\
0 \\
685 \\
219 \\
7,179\end{array}$ \\
\hline 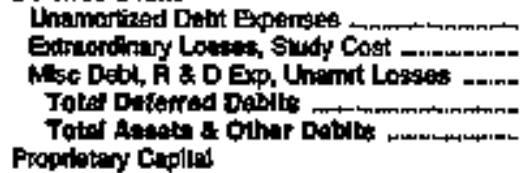 & $\begin{array}{r}24 \\
0 \\
0 \\
24 \\
12,342\end{array}$ & $\begin{array}{r}30 \\
0 \\
0 \\
30 \\
17,491\end{array}$ & $\begin{array}{r}194 \\
0 \\
184 \\
5999\end{array}$ & $\begin{array}{r}241 \\
123 \\
-63 \\
300 \\
20,206\end{array}$ & $\begin{array}{r}0 \\
0 \\
0 \\
0 \\
27,279\end{array}$ & 21,031 \\
\hline 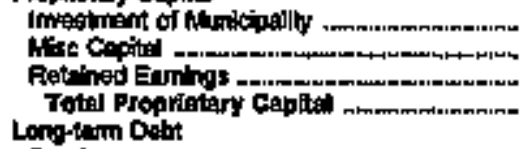 & $\begin{array}{r}0 \\
1,136 \\
0,758 \\
0,891\end{array}$ & $\begin{array}{r}320 \\
0 \\
14,000 \\
14305\end{array}$ & $\begin{array}{r}22,068 \\
0 \\
200 \\
2081\end{array}$ & $\begin{array}{r}0 \\
10,193 \\
15,188\end{array}$ & $\begin{array}{r}0 \\
0 \\
17,305 \\
17,065\end{array}$ & $\begin{array}{r}0 \\
0 \\
16,757 \\
16,767\end{array}$ \\
\hline 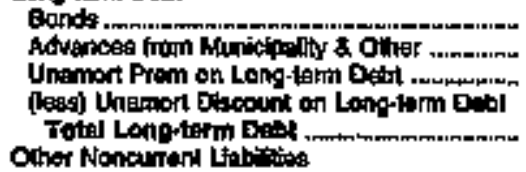 & $\begin{array}{r}1,600 \\
40 \\
0 \\
9 \\
1,642\end{array}$ & $\begin{array}{r}2,250 \\
0 \\
0 \\
0 \\
2,2,0\end{array}$ & $\begin{array}{r}13,725 \\
0 \\
0 \\
0 \\
13,725\end{array}$ & $\begin{array}{r}8,242 \\
0 \\
0 \\
9 \\
0,212\end{array}$ & $\begin{array}{r}3,374 \\
0 \\
0 \\
0 \\
3,375\end{array}$ & $\begin{array}{r}3,209 \\
0 \\
0 \\
37 \\
3,291\end{array}$ \\
\hline 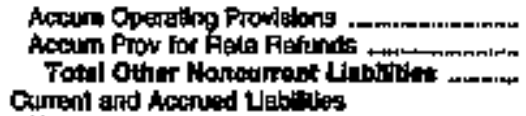 & $\begin{array}{l}0 \\
0 \\
0\end{array}$ & $\begin{array}{l}0 \\
0 \\
0\end{array}$ & $\begin{array}{l}0 \\
0 \\
0\end{array}$ & $\begin{array}{l}0 \\
0 \\
0\end{array}$ & $\begin{array}{l}0 \\
0 \\
0\end{array}$ & 0 \\
\hline 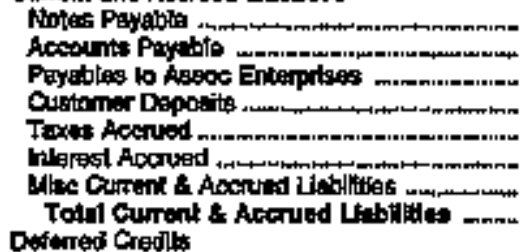 & $\begin{array}{r}0 \\
723 \\
0 \\
76 \\
0 \\
0 \\
0 \\
79\end{array}$ & $\begin{array}{r}0 \\
732 \\
25 \\
28 \\
0 \\
07 \\
0 \\
0 \\
04\end{array}$ & $\begin{array}{r}455 \\
960 \\
0 \\
85 \\
0 \\
57 \\
194 \\
1,710\end{array}$ & $\begin{array}{r}292 \\
1,202 \\
0 \\
45 \\
0 \\
219 \\
59 \\
1,759\end{array}$ & $\begin{array}{r}273 \\
809 \\
25 \\
126 \\
40 \\
37 \\
119 \\
1,519\end{array}$ & $\begin{array}{r}150 \\
742 \\
0 \\
0 \\
0 \\
10 \\
174 \\
1,077\end{array}$ \\
\hline 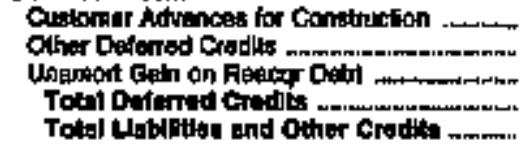 & $\begin{array}{r}0 \\
0 \\
0 \\
0 \\
12,352\end{array}$ & $\begin{array}{r}0 \\
0 \\
0 \\
0 \\
17,491\end{array}$ & $\begin{array}{r}0 \\
0 \\
0 \\
0 \\
0\end{array}$ & $\begin{array}{r}0 \\
0 \\
0 \\
0 \\
0\end{array}$ & $\begin{array}{r}0 \\
0 \\
0 \\
0 \\
2,775\end{array}$ & $\begin{array}{r}0 \\
0 \\
21,001\end{array}$ \\
\hline
\end{tabular}

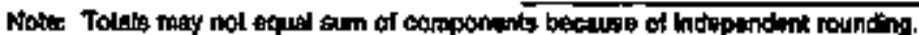

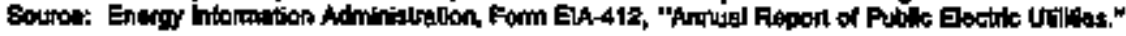


Table 22. Balance Sheet by Major U.S. Publicly Owned Electric Utility Within State at End of Period, 1994

(Thousand Dollars)

\begin{tabular}{|c|c|c|c|c|c|c|}
\hline $\mathrm{Itam}$ & 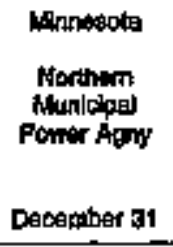 & $\begin{array}{l}\text { Minesols } \\
\text { Omatonis } \\
\text { Chy of } \\
\text { Deccember } 31\end{array}$ & 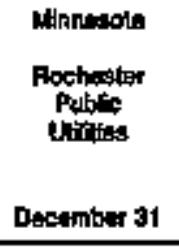 & 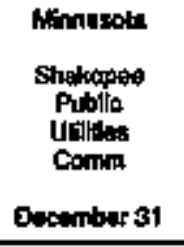 & 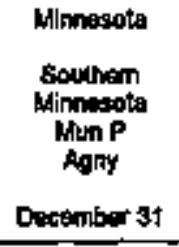 & 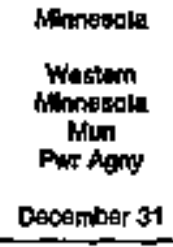 \\
\hline 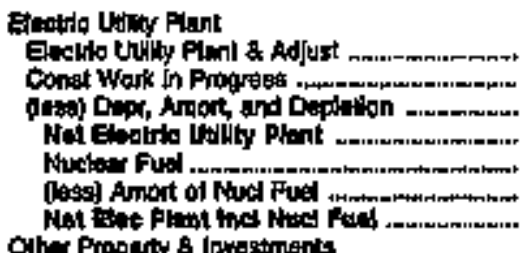 & $\begin{array}{r}322,000 \\
0 \\
18,280 \\
303,039 \\
0 \\
0 \\
003,630\end{array}$ & 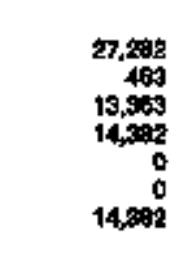 & $\begin{array}{r}105,018 \\
4,902 \\
62897 \\
5 r, 061 \\
0 \\
0 \\
67,061\end{array}$ & $\begin{array}{r}6,433 \\
6,00 \\
2,398 \\
4,911 \\
0 \\
0 \\
1,971\end{array}$ & $\begin{array}{r}521.526 \\
8,282 \\
115,287 \\
413,651 \\
0 \\
0 \\
413,651\end{array}$ & $\begin{array}{r}240,493 \\
1051 \\
52,160 \\
180,293 \\
0 \\
0 \\
195,200\end{array}$ \\
\hline 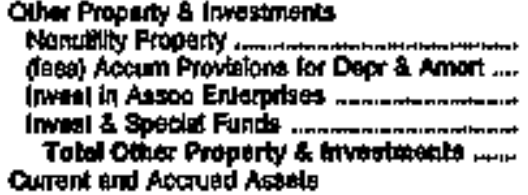 & $\begin{array}{r}0 \\
0 \\
0 \\
68,925 \\
85,075\end{array}$ & $\begin{array}{r}0 \\
0 \\
0 \\
909\end{array}$ & $\begin{array}{r}0 \\
0 \\
0 \\
2803\end{array}$ & $\begin{array}{r}0 \\
0 \\
0 \\
1,050 \\
1,990\end{array}$ & $\begin{array}{r}49 \\
0 \\
0 \\
73,100 \\
73,196\end{array}$ & $\begin{array}{r}0 \\
0 \\
0 \\
30,094 \\
30,094\end{array}$ \\
\hline 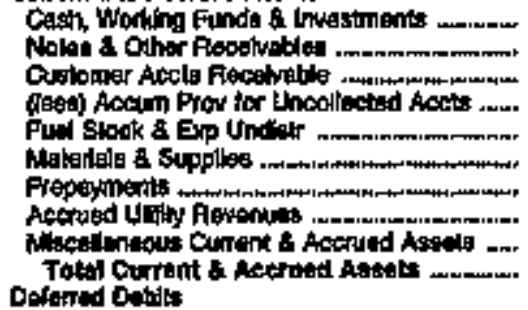 & $\begin{array}{r}98 \\
1,164 \\
0 \\
0 \\
0 \\
0 \\
0 \\
0 \\
0 \\
1,262\end{array}$ & $\begin{array}{r}0,500 \\
92 \\
1,2077 \\
64 \\
0 \\
477 \\
65 \\
978 \\
900 \\
9,672\end{array}$ & $\begin{array}{r}8,162 \\
817 \\
3,862 \\
300 \\
1,1770 \\
2,870 \\
200 \\
3,270 \\
119 \\
20,700\end{array}$ & $\begin{array}{r}3,677 \\
115 \\
091 \\
0 \\
0 \\
090 \\
25 \\
0 \\
4,970 \\
40\end{array}$ & 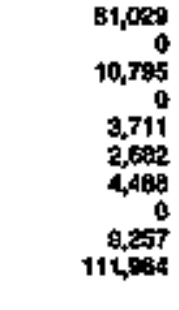 & $\begin{array}{r}14,121 \\
0 \\
5,555 \\
0 \\
1,974 \\
3,298 \\
59 \\
0 \\
4,911 \\
29,918\end{array}$ \\
\hline 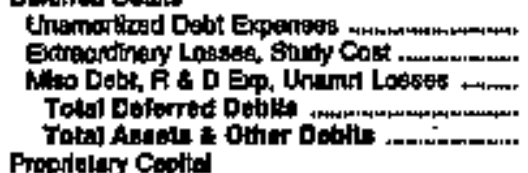 & 381,026 & $\begin{array}{r}648 \\
0 \\
3 \\
651 \\
25,613\end{array}$ & 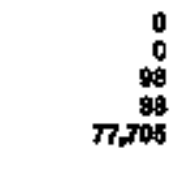 & $\begin{array}{r}84 \\
0 \\
0 \\
11,194\end{array}$ & $\begin{array}{r}175,444 \\
741 \\
09,591 \\
265,777 \\
884,78 .\end{array}$ & $\begin{array}{r}7,014 \\
0 \\
6,918 \\
1 ; 032 \\
271,060\end{array}$ \\
\hline 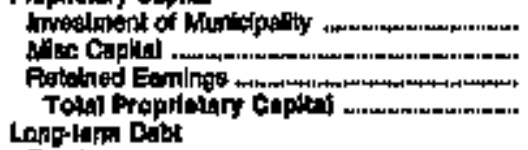 & $\begin{array}{l}0 \\
0 \\
0 \\
0\end{array}$ & $\begin{array}{c}0 \\
16,507 \\
16,027\end{array}$ & $\begin{array}{r}0 \\
0 \\
02,844 \\
02,844\end{array}$ & $\begin{array}{r}0 \\
0 \\
7,979 \\
7,379\end{array}$ & $\begin{array}{r}\text { a } \\
0 \\
23,702 \\
23,702\end{array}$ & $\begin{array}{l}0 \\
0 \\
0 \\
0\end{array}$ \\
\hline 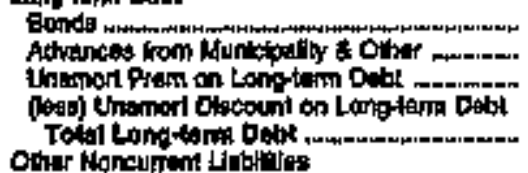 & $\begin{array}{r}250,050 \\
0 \\
0 \\
0 \\
050,005\end{array}$ & $\begin{array}{r}6,915 \\
0 \\
0 \\
1+2 \\
6,775\end{array}$ & $\begin{array}{r}1,800 \\
0 \\
1,6000\end{array}$ & $\begin{array}{r}2,650 \\
741 \\
0 \\
0 \\
3,201\end{array}$ & $\begin{array}{r}1,290,680 \\
0 \\
6 \\
479,185 \\
747,495\end{array}$ & $\begin{array}{r}259,485 \\
0 \\
0 \\
10,212 \\
249,063\end{array}$ \\
\hline 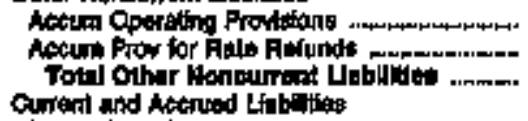 & $\begin{array}{l}0 \\
0 \\
0\end{array}$ & $\begin{array}{r}10 ? \\
07\end{array}$ & 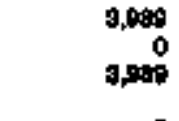 & $\begin{array}{l}0 \\
0 \\
0\end{array}$ & $\begin{array}{l}0 \\
0 \\
0\end{array}$ & $\begin{array}{r}0,446 \\
0 \\
0,448\end{array}$ \\
\hline 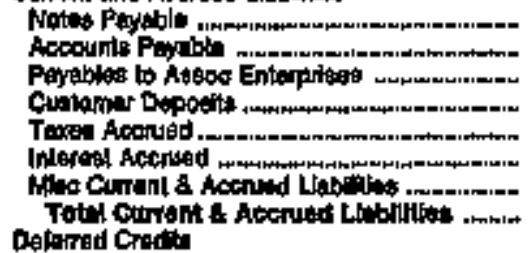 & $\begin{array}{r}0 \\
485 \\
0 \\
0 \\
0 \\
10,405 \\
10,97\end{array}$ & $\begin{array}{r}0 \\
1,428 \\
0 \\
15 \\
0 \\
190 \\
485 \\
2,118\end{array}$ & $\begin{array}{r}0 \\
4,598 \\
559 \\
559 \\
419 \\
0 \\
1,502 \\
7,092\end{array}$ & $\begin{array}{r}0 \\
740 \\
276 \\
97 \\
0 \\
70 \\
0 \\
1,216\end{array}$ & $\begin{array}{r}14,000 \\
5,122 \\
902 \\
0 \\
7,900 \\
19,785 \\
99,757 \\
70,616\end{array}$ & $\begin{array}{r}0 \\
30 \$ 0 \\
0 \\
0 \\
854 \\
0,088 \\
0 \\
19,508\end{array}$ \\
\hline 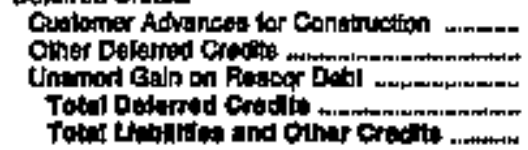 & 36,0 & $\begin{array}{r}0 \\
0 \\
0 \\
0 \\
0 \\
0\end{array}$ & $\begin{array}{r}0 \\
1,310 \\
0 \\
1,310 \\
7,705\end{array}$ & $\begin{array}{r}0 \\
0 \\
0 \\
0 \\
11,090\end{array}$ & $\begin{array}{r}0 \\
27,974 \\
0 \\
27,974 \\
04,740\end{array}$ & $\begin{array}{r}0 \\
0 \\
0 \\
0 \\
271,869\end{array}$ \\
\hline
\end{tabular}

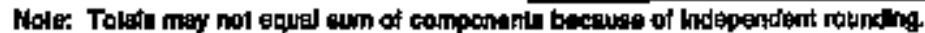

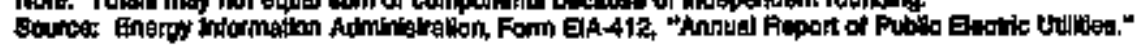


Table 22. Batance Sheet by Major U,S. Publldy Owned Electrio Utily Within state at End of Pertod, 1994 (Thousand Dollars)

\begin{tabular}{|c|c|c|c|c|c|c|}
\hline inen & 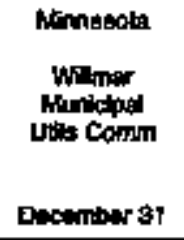 & 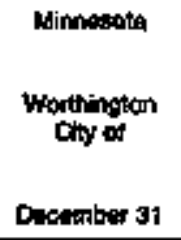 & 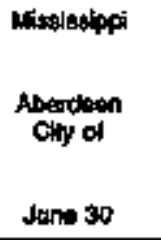 & 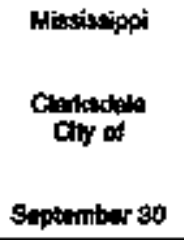 & 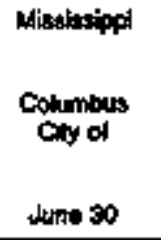 & 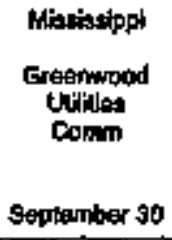 \\
\hline 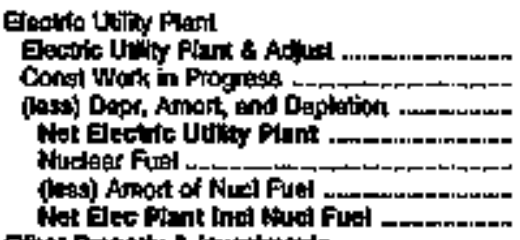 & $\begin{array}{r}29,3869 \\
85 \\
15,867 \\
13,651 \\
0 \\
0 \\
13,661\end{array}$ & $\begin{array}{r}12,091 \\
0 \\
5,105 \\
0,105 \\
0 \\
0 \\
0,0,50\end{array}$ & $\begin{array}{r}4,600 \\
13 \\
2,065 \\
2,460 \\
0 \\
0 \\
0,460\end{array}$ & $\begin{array}{r}28,967 \\
0 \\
18,5,57 \\
3 ; 299 \\
0 \\
0 \\
8,291\end{array}$ & $\begin{array}{r}16,340 \\
14 \\
6,6802 \\
7,691 \\
0 \\
0 \\
7,691\end{array}$ & $\begin{array}{r}26,638 \\
2,157 \\
15,742 \\
13,053 \\
0 \\
0 \\
13,050\end{array}$ \\
\hline 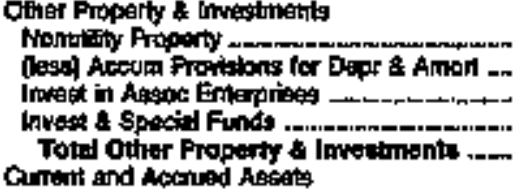 & $\begin{array}{r}31,7860 \\
3,444 \\
0 \\
7,776 \\
16,318\end{array}$ & $\begin{array}{l}0 \\
0 \\
0 \\
0 \\
0\end{array}$ & $\begin{array}{l}0 \\
0 \\
0 \\
7 \\
7\end{array}$ & $\begin{array}{r}0 \\
0 \\
0 \\
1,044 \\
4,044\end{array}$ & $\begin{array}{l}0 \\
0 \\
0 \\
0 \\
0 \\
0\end{array}$ & $\begin{array}{r}0 \\
0 \\
0 \\
10,937 \\
10,937\end{array}$ \\
\hline 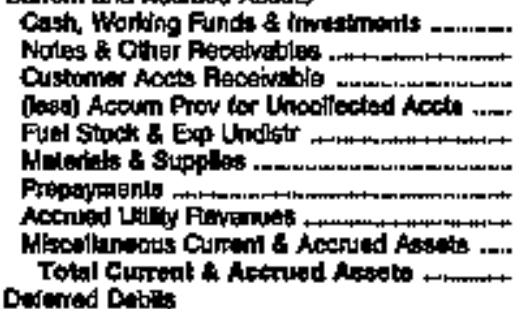 & $\begin{array}{r}4,148 \\
0 \\
1,405 \\
0 \\
190 \\
933 \\
161 \\
0 \\
0 \\
0,256\end{array}$ & $\begin{array}{r}3,762 \\
6.2 \\
2 \\
0 \\
0 \\
70 \\
16 \\
0 \\
0 \\
4721\end{array}$ & $\begin{array}{r}106 \\
909 \\
0 \\
0 \\
0 \\
113 \\
16 \\
0 \\
25 \\
1,257\end{array}$ & $\begin{array}{r}2,160 \\
656 \\
2,139 \\
0 \\
161 \\
178 \\
197 \\
0 \\
2,580 \\
0,050\end{array}$ & $\begin{array}{r}4,682 \\
1,825 \\
0 \\
0 \\
0 \\
416 \\
34 \\
0 \\
70 \\
7,416\end{array}$ & $\begin{array}{r}4,610 \\
395 \\
1,535 \\
76 \\
729 \\
313 \\
113 \\
344 \\
0 \\
0,2005\end{array}$ \\
\hline 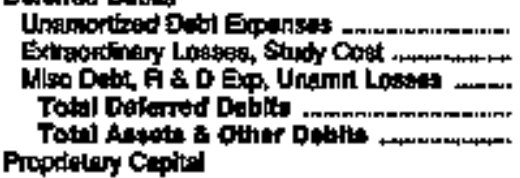 & $\begin{array}{r}20 \% \\
0 \\
182 \\
394 \\
30,-40\end{array}$ & $\begin{array}{r}0 \\
0 \\
0 \\
0 \\
11,706\end{array}$ & $\begin{array}{r}0 \\
5 \\
590 \\
500 \\
4,259\end{array}$ & $\begin{array}{r}0 \\
0 \\
0 \\
0 \\
20390\end{array}$ & $\begin{array}{r}0 \\
0 \\
9 \\
0 \\
15,196\end{array}$ & $\begin{array}{r}0 \\
0 \\
0 \\
0 \\
0 \\
3 \rightarrow, 195\end{array}$ \\
\hline 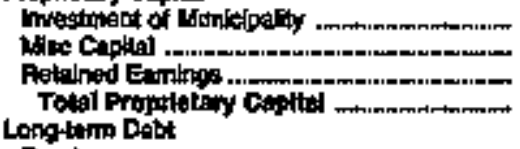 & $\begin{array}{r}0 \\
0 \\
21,612 \\
21,612\end{array}$ & $\begin{array}{r}0 \\
0 \\
11,159 \\
11,150\end{array}$ & $\begin{array}{r}0 \\
9 \\
2,7734 \\
2,732\end{array}$ & $\begin{array}{r}2,059 \\
167 \\
14,158 \\
16,394\end{array}$ & $\begin{array}{r}0 \\
11,051 \\
11,091\end{array}$ & $\begin{array}{r}0 \\
0 \\
29,0,29 \\
29,029\end{array}$ \\
\hline 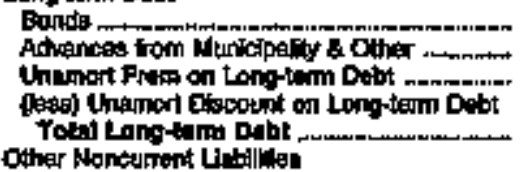 & $\begin{array}{r}11,671 \\
0 \\
0 \\
0 \\
+1,57\end{array}$ & $\begin{array}{l}0 \\
0 \\
0 \\
0 \\
0\end{array}$ & $\begin{array}{r}0 \\
537 \\
0 \\
0 \\
507\end{array}$ & $\begin{array}{r}1,940 \\
108 \\
0 \\
0 \\
2,046\end{array}$ & $\begin{array}{r}0 \\
12 \\
0 \\
0 \\
12\end{array}$ & $\begin{array}{r}16 \\
16 \\
0 \\
0 \\
171\end{array}$ \\
\hline 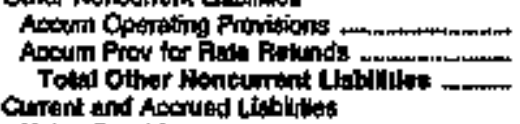 & $\begin{array}{l}0 \\
0 \\
0\end{array}$ & $\begin{array}{l}0 \\
0 \\
0\end{array}$ & $\begin{array}{l}0 \\
0 \\
0\end{array}$ & $\begin{array}{l}0 \\
0 \\
0\end{array}$ & $\begin{array}{l}0 \\
0 \\
0\end{array}$ & $\begin{array}{l}0 \\
0 \\
0\end{array}$ \\
\hline 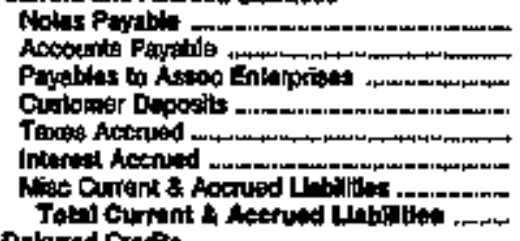 & $\begin{array}{r}1,465 \\
608 \\
138 \\
118 \\
46 \\
392 \\
792 \\
7,427\end{array}$ & $\begin{array}{r}0 \\
466 \\
22 \\
54 \\
0 \\
0 \\
11 \\
560\end{array}$ & $\begin{array}{r}0 \\
771 \\
0 \\
181 \\
1 \\
0 \\
\mathbf{3 t} \\
914\end{array}$ & $\begin{array}{r}65 \\
1,028 \\
0 \\
098 \\
38 \\
3 \\
281 \\
1,464\end{array}$ & $\begin{array}{r}13 \\
2086 \\
0 \\
955 \\
0 \\
0 \\
650 \\
4020\end{array}$ & $\begin{array}{r}0 \\
1,065 \\
772 \\
450 \\
01 \\
1 \\
76 \\
2096\end{array}$ \\
\hline 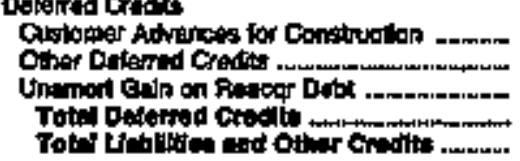 & $\begin{array}{r}0 \\
0 \\
0 \\
0 \\
0\end{array}$ & $\begin{array}{r}0 \\
0 \\
0 \\
0 \\
11,706\end{array}$ & $\begin{array}{r}0 \\
0 \\
0 \\
0 \\
4,253\end{array}$ & $\begin{array}{r}0 \\
0 \\
0 \\
0 \\
20,500\end{array}$ & $\begin{array}{r}0 \\
2 \\
0 \\
2 \\
+5,10\end{array}$ & $\begin{array}{r}27 \\
20 \\
0 \\
60 \\
\text { s2, } 105\end{array}$ \\
\hline
\end{tabular}

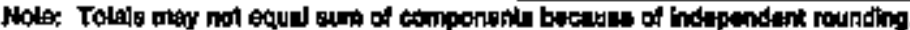

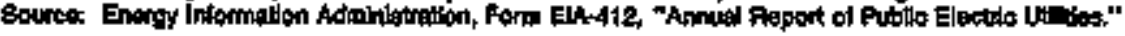


Table 22. Balance Shaet by Major U.S. Publiely Owned Electrle Utilty Within State at End of Period, 1994

(Thousand Dollars)

\begin{tabular}{|c|c|c|c|c|c|c|}
\hline ltert & 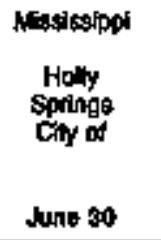 & 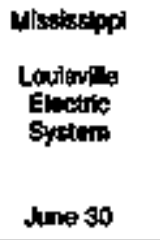 & 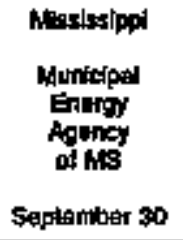 & $\begin{array}{l}\text { Mhestastipi } \\
\text { Now Albany } \\
\text { Oty of } \\
\text { June } 30\end{array}$ & 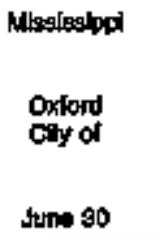 & 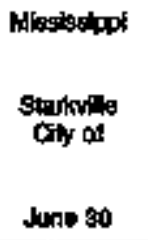 \\
\hline 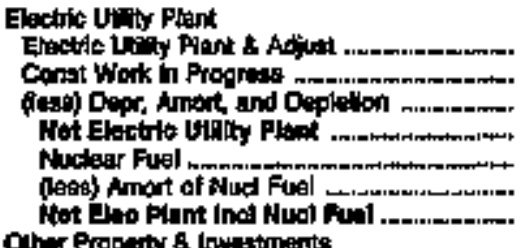 & $\begin{array}{r}13,546 \\
209 \\
5,250 \\
6,600 \\
0 \\
0 \\
0,600\end{array}$ & $\begin{array}{r}7,000 \\
112 \\
2,498 \\
5,518 \\
0 \\
0 \\
5,525\end{array}$ & $\begin{array}{r}735 \\
4,457 \\
180 \\
5,014 \\
0 \\
0 \\
5,011\end{array}$ & $\begin{array}{r}1,721 \\
557 \\
4,040 \\
8,287 \\
0 \\
0 \\
8,287\end{array}$ & $\begin{array}{r}5,871 \\
1,717 \\
2,190 \\
6,393 \\
0 \\
0 \\
0,903\end{array}$ & $\begin{array}{r}11,474 \\
107 \\
3,702 \\
7,960 \\
0 \\
0 \\
7,400\end{array}$ \\
\hline 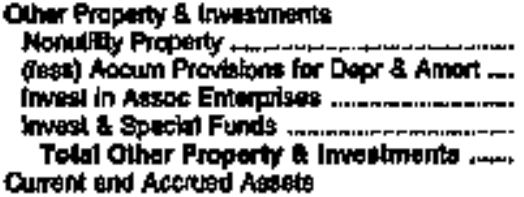 & $\begin{array}{r}0 \\
9 \\
1,285 \\
1,258\end{array}$ & $\begin{array}{l}0 \\
0 \\
0 \\
8 \\
0\end{array}$ & $\begin{array}{l}0 \\
0 \\
0 \\
0 \\
0\end{array}$ & $\begin{array}{r}0 \\
0 \\
0 \\
140 \\
140\end{array}$ & $\begin{array}{r}0 \\
0 \\
0 \\
11 \\
11\end{array}$ & $\begin{array}{r}n \\
0 \\
6.695 \\
6.506\end{array}$ \\
\hline 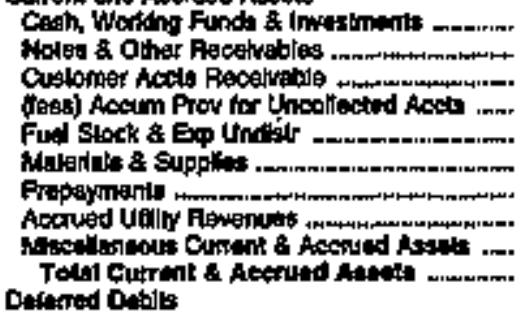 & $\begin{array}{r}601 \\
754 \\
956 \\
9 \\
0 \\
294 \\
15 \\
0 \\
46 \\
2,265\end{array}$ & $\begin{array}{r}1,543 \\
1,451 \\
0 \\
0 \\
0 \\
121 \\
3 \\
0 \\
20 \\
3,146\end{array}$ & $\begin{array}{r}9,757 \\
0 \\
2,731 \\
0 \\
0 \\
0 \\
0 \\
0 \\
40 \\
12,608\end{array}$ & $\begin{array}{r}2,555 \\
2,020 \\
0 \\
0 \\
0 \\
200 \\
17 \\
0 \\
51 \\
4,700\end{array}$ & $\begin{array}{r}1,294 \\
1,350 \\
0 \\
0 \\
0 \\
170 \\
10 \\
0 \\
11 \\
2,962\end{array}$ & 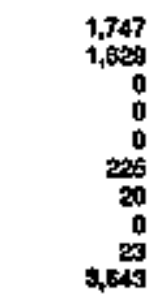 \\
\hline 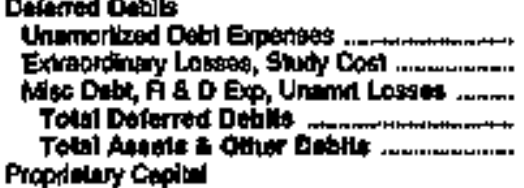 & $\begin{array}{r}0 \\
29 \\
20 \\
109 \\
10\end{array}$ & $\begin{array}{r}0 \\
0 \\
106 \\
196 \\
8,795\end{array}$ & $\begin{array}{r}0 \\
0 \\
0 \\
0 \\
7,580\end{array}$ & $\begin{array}{r}1 \\
0 \\
50 \\
51 \\
13,199\end{array}$ & $\begin{array}{r}0 \\
7 \\
98 \\
96 \\
\text { 8,951 }\end{array}$ & $\begin{array}{r}60 \\
0 \\
24 \\
112 \\
10,159\end{array}$ \\
\hline 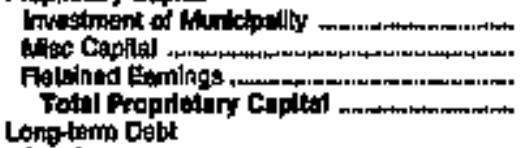 & $\begin{array}{r}0 \\
0 \\
t 0,676 \\
10,579\end{array}$ & $\begin{array}{r}0 \\
0 \\
7,690 \\
7,690\end{array}$ & $\begin{array}{r}6058 \\
0 \\
0 \\
0068\end{array}$ & $\begin{array}{r}0 \\
0 \\
70,696 \\
10,005\end{array}$ & $\begin{array}{r}0 \\
0 \\
5,758 \\
6,758\end{array}$ & $\begin{array}{r}0 \\
0 \\
0,389 \\
2,896\end{array}$ \\
\hline 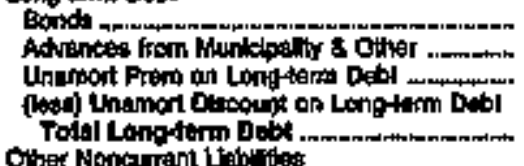 & $\begin{array}{r}0 \\
20 \\
0 \\
0 \\
20\end{array}$ & $\begin{array}{r}0 \\
15 \\
0 \\
0 \\
15\end{array}$ & $\begin{array}{r}5,000 \\
0 \\
0 \\
0 \\
0\end{array}$ & $\begin{array}{r}127 \\
60 \\
0 \\
0 \\
100\end{array}$ & $\begin{array}{r}0 \\
0 \\
0 \\
0\end{array}$ & $\begin{array}{r}6,000 \\
10 \\
0 \\
0 \\
0,018\end{array}$ \\
\hline 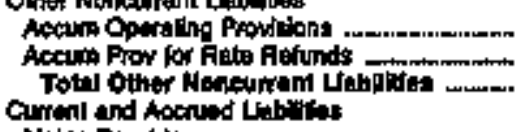 & $\begin{array}{l}0 \\
0 \\
0\end{array}$ & $\begin{array}{l}0 \\
0 \\
0 \\
0\end{array}$ & $\begin{array}{r}40 \\
0 \\
0\end{array}$ & $\begin{array}{l}0 \\
0 \\
0\end{array}$ & $\begin{array}{l}0 \\
0 \\
0\end{array}$ & $\begin{array}{l}0 \\
0 \\
0\end{array}$ \\
\hline 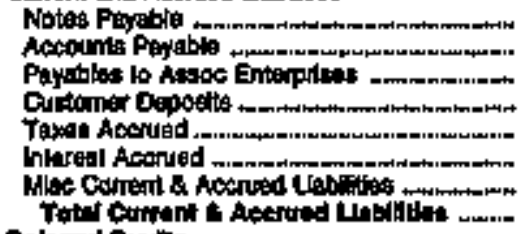 & $\begin{array}{r}0 \\
97 \\
0 \\
469 \\
48 \\
0 \\
35 \\
1,58\end{array}$ & $\begin{array}{r}0 \\
819 \\
0 \\
195 \\
10 \\
0 \\
47 \\
1,070\end{array}$ & $\begin{array}{r}9 \\
5,470 \\
0 \\
0 \\
0 \\
1 \% 9 \\
5 \\
5,986\end{array}$ & $\begin{array}{r}0 \\
1,371 \\
0 \\
509 \\
0 \\
10 \\
2,2787\end{array}$ & $\begin{array}{r}0 \\
1,737 \\
0 \\
686 \\
1 \\
0 \\
104 \\
2,507\end{array}$ & $\begin{array}{r}224 \\
2,345 \\
0 \\
1,007 \\
2 \\
26 \\
97 \\
9,701\end{array}$ \\
\hline 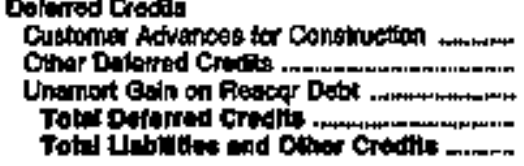 & $\begin{array}{r}0 \\
-7 \\
0 \\
-7 \\
13,140\end{array}$ & $\begin{array}{r}0 \\
1 \\
0 \\
1 \\
1 \\
9786\end{array}$ & $\begin{array}{r}0 \\
0 \\
0 \\
0 \\
\pi, 590\end{array}$ & $\begin{array}{r}0 \\
5 \\
0 \\
5 \\
12,19\end{array}$ & $\begin{array}{r}0 \\
5 \\
0 \\
5 \\
0401\end{array}$ & $\begin{array}{r}0 \\
51 \\
0 \\
51 \\
18,16\end{array}$ \\
\hline
\end{tabular}

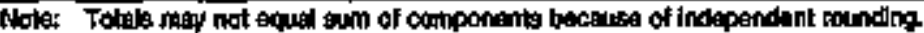

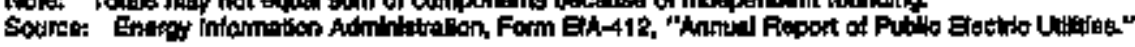


Table 22. Batance Sheet by Major U.S. Publichy Owmed Electrie Utilly Within State at End of Parlod, 1994

(Thousand Dollers)

\begin{tabular}{|c|c|c|c|c|c|c|}
\hline tom & $\begin{array}{l}\text { Mopiosipot } \\
\text { Tupaty } \\
\text { Ciny of } \\
\text { Jure } 30\end{array}$ & 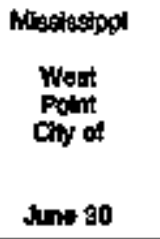 & 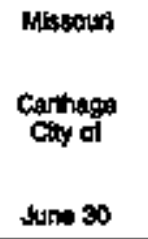 & Septembers so & $\begin{array}{l}\text { Misount } \\
\text { Hannod } \\
\text { Chy of } \\
\text { June } 30\end{array}$ & 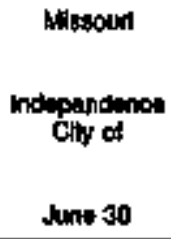 \\
\hline 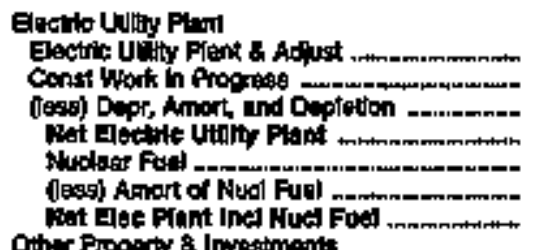 & $\begin{array}{r}23,491 \\
7,44 \\
7,3,37 \\
16,210 \\
0 \\
0 \\
16,216\end{array}$ & $\begin{array}{r}6,914 \\
2,25 \\
2,698 \\
4,605 \\
0 \\
0 \\
4,000\end{array}$ & $\begin{array}{r}18,210 \\
720 \\
13,655 \\
6,276 \\
0 \\
0 \\
6,276\end{array}$ & $\begin{array}{r}78,962 \\
4,678 \\
35,708 \\
4,921 \\
0 \\
0 \\
97,921\end{array}$ & $\begin{array}{r}10,474 \\
77 \\
7,0 \times 0 \\
3,510 \\
0 \\
0 \\
3,518\end{array}$ & $\begin{array}{r}159,079 \\
6,400 \\
88,024 \\
76,646 \\
0 \\
79,646\end{array}$ \\
\hline 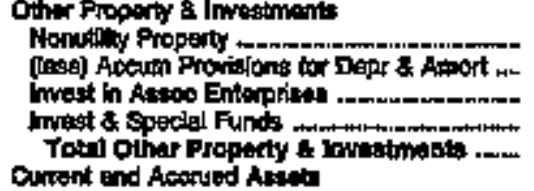 & $\begin{array}{l}0 \\
0 \\
0 \\
23 \\
2\end{array}$ & $\begin{array}{r}0 \\
0 \\
0 \\
93 \\
93\end{array}$ & $\begin{array}{r}0 \\
0 \\
0 \\
\$ 116 \\
116\end{array}$ & $\begin{array}{r}40,121 \\
10,187 \\
03,002 \\
53,795\end{array}$ & $\begin{array}{r}0 \\
507 \\
5,777 \\
679\end{array}$ & $\begin{array}{r}0 \\
0 \\
34,0 \rightarrow 0 \\
0\end{array}$ \\
\hline 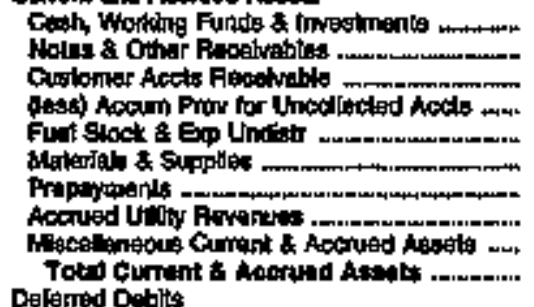 & $\begin{array}{r}4,839 \\
3,629 \\
0 \\
0 \\
0 \\
917 \\
93 \\
0 \\
90 \\
90\end{array}$ & $\begin{array}{r}354 \\
1,192 \\
0 \\
0 \\
0 \\
216 \\
20 \\
0 \\
2 \\
2,7=2\end{array}$ & $\begin{array}{r}4,409 \\
22 \\
846 \\
20 \\
0 \\
209 \\
5 \\
0 \\
17 \\
5,461\end{array}$ & $\begin{array}{r}13,648 \\
913 \\
6,019 \\
61 \\
298 \\
2,076 \\
45 \\
2,008 \\
6000 \\
0,170\end{array}$ & $\begin{array}{r}3,126 \\
101 \\
839 \\
20 \\
0 \\
206 \\
62 \\
0 \\
0 \\
4,104\end{array}$ & 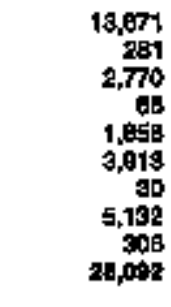 \\
\hline 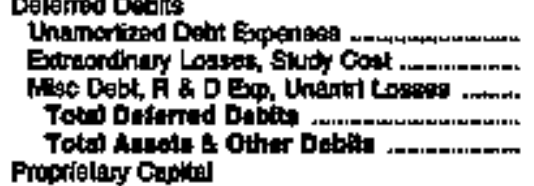 & $\begin{array}{r}9 \\
200 \\
28+4 \\
28+2\end{array}$ & $\begin{array}{r}4 \\
0 \\
47 \\
51 \\
6,040\end{array}$ & $\begin{array}{r}69 \\
0 \\
0 \\
11,095\end{array}$ & $\begin{array}{r}397 \\
0 \\
0 \\
397 \\
127,297\end{array}$ & $\begin{array}{r}0 \\
0 \\
0 \\
0 \\
1600\end{array}$ & $\begin{array}{r}7,965 \\
0 \\
2,247 \\
5,167 \\
+44,770\end{array}$ \\
\hline 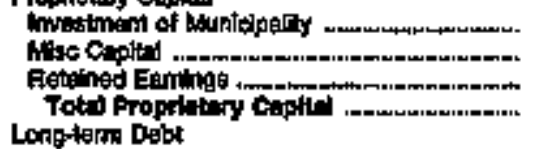 & $\begin{array}{r}0 \\
0 \\
20006 \\
20,50\end{array}$ & $\begin{array}{r}0 \\
0 \\
4,731 \\
4,711\end{array}$ & $\begin{array}{r}696 \\
7,044 \\
7,200\end{array}$ & $\begin{array}{r}1,216 \\
0 \\
64,129 \\
05,945\end{array}$ & $\begin{array}{r}0 \\
0 \\
13,248 \\
13,240\end{array}$ & $\begin{array}{r}0 \\
0 \\
101,011 \\
101,911\end{array}$ \\
\hline 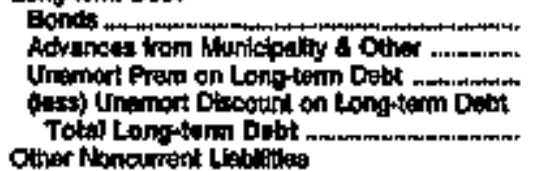 & $\begin{array}{r}0 \\
228 \\
0 \\
0 \\
220\end{array}$ & $\begin{array}{r}200 \\
0 \\
0 \\
0\end{array}$ & $\begin{array}{r}0 \\
2,857 \\
0 \\
0 \\
2,8 \% ?\end{array}$ & $\begin{array}{r}52,195 \\
0 \\
0 \\
414 \\
51,771\end{array}$ & $\begin{array}{l}0 \\
0 \\
0 \\
0 \\
0\end{array}$ & $\begin{array}{r}34,105 \\
0 \\
0 \\
0 \\
36,105\end{array}$ \\
\hline 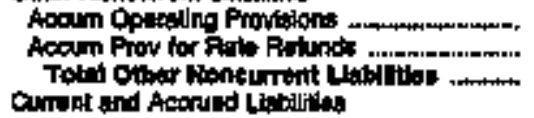 & $\begin{array}{l}0 \\
0 \\
0\end{array}$ & $\begin{array}{l}0 \\
0 \\
0\end{array}$ & $\begin{array}{l}0 \\
0 \\
0\end{array}$ & $\begin{array}{l}0 \\
0 \\
0\end{array}$ & $\begin{array}{r}229 \\
220\end{array}$ & $\begin{array}{r}1,8 \times 0 \\
1,6050\end{array}$ \\
\hline 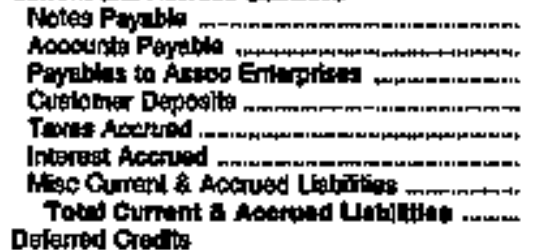 & $\begin{array}{r}0 \\
3,475 \\
0 \\
054 \\
0 \\
0 \\
215 \\
4,544\end{array}$ & $\begin{array}{r}0 \\
1,080 \\
0 \\
272 \\
0 \\
20 \\
13 \\
1,850\end{array}$ & $\begin{array}{r}0 \\
988 \\
0 \\
111 \\
0 \\
0 \\
920 \\
1,718\end{array}$ & $\begin{array}{r}0 \\
2,005 \\
0 \\
1,696 \\
019 \\
1,769 \\
3,600 \\
10,170\end{array}$ & $\begin{array}{r}0 \\
1,048 \\
0 \\
105 \\
0 \\
0 \\
4 \\
1,105\end{array}$ & 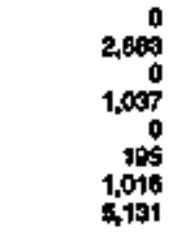 \\
\hline 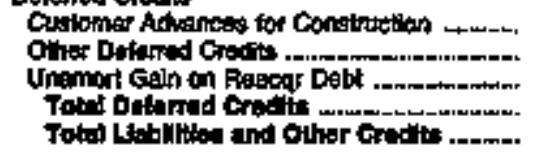 & $\begin{array}{r}0 \\
13 \\
0 \\
13 \\
25,202\end{array}$ & $\begin{array}{r}0 \\
0 \\
0 \\
0 \\
0\end{array}$ & $\begin{array}{r}0 \\
0 \\
0 \\
0 \\
11,035\end{array}$ & $\begin{array}{r}0 \\
0 \\
0 \\
0 \\
0 \\
127,297\end{array}$ & $\begin{array}{r}0 \\
0 \\
0 \\
0 \\
14,408\end{array}$ & $\begin{array}{r}003 \\
0 \\
0 \\
144770 \\
140\end{array}$ \\
\hline
\end{tabular}

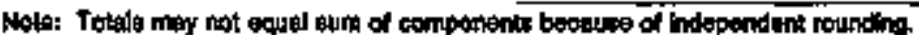

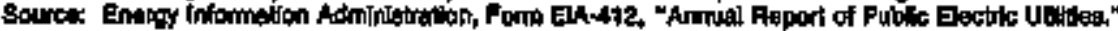


Table 22. Batance Sheet by Major U.S. Publioly Owned Electrle Utility Within Stale at End of Perlod, 1994

(Thoussand Dollars)

\begin{tabular}{|c|c|c|c|c|c|c|}
\hline llens & 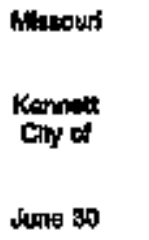 & $\begin{array}{l}\text { Howpoud } \\
\text { Kolinood } \\
\text { Chy of } \\
\text { Maren 3y }\end{array}$ & $\begin{array}{l}\text { Magoun } \\
\text { Lobinop } \\
\text { Chy of } \\
\text { Oclober } 31\end{array}$ & 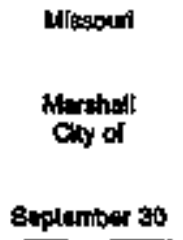 & $\begin{array}{l}\text { Miseouti } \\
\text { Moneh } \\
\text { Ciny of } \\
\text { Warth } 31\end{array}$ & 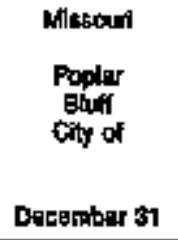 \\
\hline 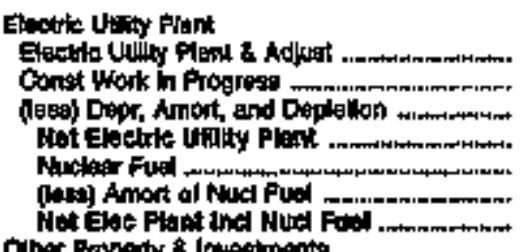 & $\begin{array}{r}14,116 \\
10,040 \\
3,779 \\
0 \\
0 \\
3,579\end{array}$ & $\begin{array}{r}4,640 \\
0 \\
2,576 \\
2,054 \\
0 \\
0 \\
2,004\end{array}$ & $\begin{array}{l}0 \\
0 \\
0 \\
0 \\
0 \\
0 \\
0\end{array}$ & $\begin{array}{r}35,817 \\
3,690 \\
17,696 \\
21,970 \\
0 \\
0 \\
21,970\end{array}$ & $\begin{array}{r}3,906 \\
0 \\
0,690 \\
1,816 \\
0 \\
0 \\
1,318\end{array}$ & $\begin{array}{r}21,444 \\
0 \\
8,045 \\
12,599 \\
0 \\
0 \\
12,599\end{array}$ \\
\hline 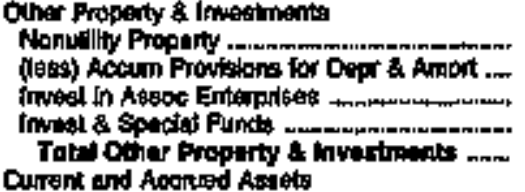 & $\begin{array}{l}0 \\
0 \\
0 \\
0 \\
0\end{array}$ & $\begin{array}{l}0 \\
0 \\
0 \\
0 \\
0\end{array}$ & $\begin{array}{l}0 \\
0 \\
0 \\
0 \\
0\end{array}$ & $\begin{array}{l}0 \\
0 \\
0 \\
0 \\
0\end{array}$ & $\begin{array}{l}0 \\
0 \\
0 \\
0 \\
0\end{array}$ & $\begin{array}{r}0 \\
0 \\
0 \\
10,934 \\
10,931\end{array}$ \\
\hline 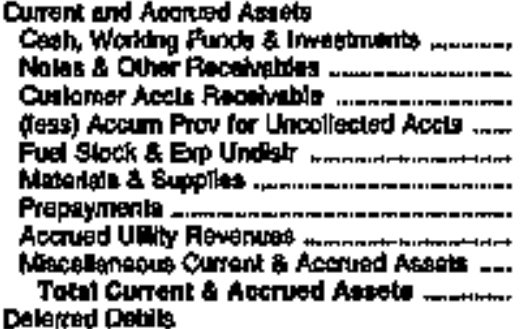 & $\begin{array}{r}2383 \\
0 \\
173 \\
1 \\
105 \\
0 \\
329 \\
0 \\
0 \\
2,008\end{array}$ & $\begin{array}{r}6,390 \\
0 \\
340 \\
0 \\
0 \\
70 \\
0 \\
979 \\
0 \\
0,490\end{array}$ & $\begin{array}{l}0 \\
0 \\
0 \\
0 \\
0 \\
0 \\
0 \\
0 \\
0 \\
0 \\
0\end{array}$ & $\begin{array}{r}6,958 \\
180 \\
821 \\
0 \\
28 \\
764 \\
112 \\
204 \\
0 \\
9,058\end{array}$ & $\begin{array}{r}18,103 \\
680 \\
0 \\
0 \\
0 \\
0 \\
0 \\
0 \\
0 \\
16,706\end{array}$ & $\begin{array}{r}1,793 \\
23 \\
518 \\
140 \\
9 t \\
254 \\
116 \\
696 \\
3.180 \\
5,470\end{array}$ \\
\hline 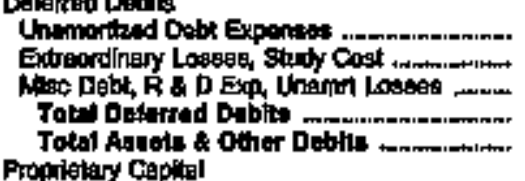 & $\begin{array}{r}0 \\
0 \\
0 \\
0 \\
0,271\end{array}$ & $\begin{array}{r}105 \\
0 \\
-0 \\
105 \\
5,600\end{array}$ & $\begin{array}{l}0 \\
0 \\
0 \\
0 \\
0 \\
0\end{array}$ & $\begin{array}{r}0 \\
0 \\
0 \\
0 \\
31,020\end{array}$ & $\begin{array}{r}0 \\
0 \\
0 \\
0 \\
10,104\end{array}$ & $\begin{array}{r}0 \\
0 \\
0 \\
0 \\
30,000\end{array}$ \\
\hline 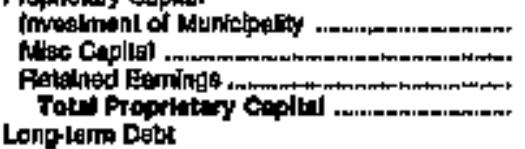 & $\begin{array}{r}19 t \\
12 \\
5,920 \\
5,628\end{array}$ & $\begin{array}{r}0 \\
266 \\
7,285 \\
7,569\end{array}$ & $\begin{array}{l}0 \\
0 \\
0 \\
0\end{array}$ & $\begin{array}{r}190 \\
0 \\
28, f 15 \\
26,695\end{array}$ & $\begin{array}{r}0 \\
0 \\
17,497 \\
17,497\end{array}$ & $\begin{array}{r}0 \\
20,204 \\
20,284\end{array}$ \\
\hline 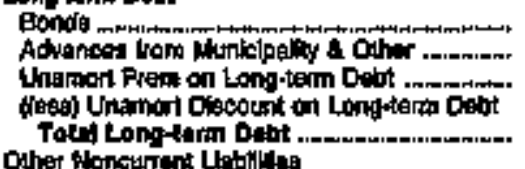 & $\begin{array}{l}0 \\
0 \\
0 \\
0 \\
0\end{array}$ & $\begin{array}{r}0 \\
0 \\
0 \\
9\end{array}$ & $\begin{array}{l}0 \\
0 \\
0 \\
0 \\
0\end{array}$ & $\begin{array}{r}1,460 \\
0 \\
0 \\
0 \\
1,450\end{array}$ & $\begin{array}{l}0 \\
0 \\
0 \\
0 \\
0\end{array}$ & $\begin{array}{l}0 \\
0 \\
0 \\
0 \\
0\end{array}$ \\
\hline 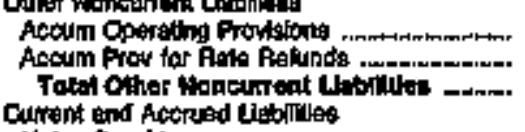 & $\begin{array}{l}0 \\
0 \\
0\end{array}$ & $\begin{array}{l}0 \\
0 \\
0\end{array}$ & $\begin{array}{l}0 \\
0 \\
0\end{array}$ & $\begin{array}{l}0 \\
0 \\
0\end{array}$ & $\begin{array}{l}0 \\
0 \\
0\end{array}$ & $\begin{array}{l}0 \\
0 \\
0\end{array}$ \\
\hline 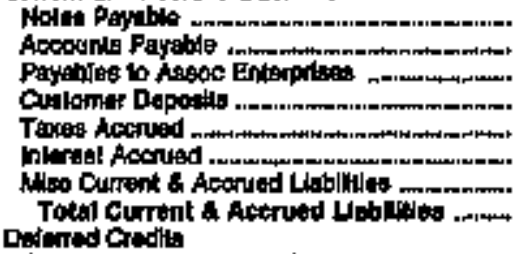 & $\begin{array}{r}0 \\
391 \\
0 \\
288 \\
0 \\
0 \\
91 \\
748\end{array}$ & $\begin{array}{r}15 \\
486 \\
345 \\
78 \\
0 \\
27 \\
55 \\
956\end{array}$ & $\begin{array}{l}0 \\
0 \\
0 \\
0 \\
0 \\
0 \\
0 \\
0\end{array}$ & $\begin{array}{r}0 \\
2,301 \\
0 \\
177 \\
028 \\
23 \\
131 \\
2,075\end{array}$ & $\begin{array}{r}0 \\
474 \\
0 \\
139 \\
0 \\
0 \\
0 \\
007\end{array}$ & $\begin{array}{r}0 \\
464 \\
0 \\
168 \\
29 \\
0 \\
0 \\
058\end{array}$ \\
\hline 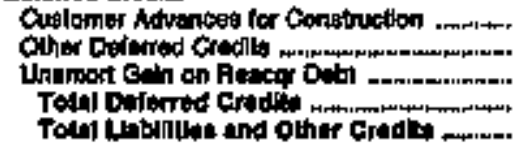 & $\begin{array}{r}0 \\
0 \\
0 \\
0 \\
0,271\end{array}$ & $\begin{array}{r}9 \\
0 \\
0 \\
0 \\
0,000\end{array}$ & $\begin{array}{l}0 \\
0 \\
0 \\
0 \\
0 \\
0\end{array}$ & $\begin{array}{r}0 \\
0 \\
0 \\
0 \\
31,000\end{array}$ & $\begin{array}{r}0 \\
0 \\
0 \\
0 \\
18,104\end{array}$ & $\begin{array}{r}08 \\
0 \\
0 \\
03000\end{array}$ \\
\hline
\end{tabular}

Note: Totale muy not oqual oun of componenis becauso of independent counchno

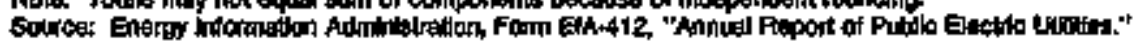


Table 22. Bakance Sheat by Major U.S. Publioly Owned Eleotric Utilty Within state at End of Period, 1994

(Thousand Dollars)

\begin{tabular}{|c|c|c|c|c|c|c|}
\hline Hevn & $\begin{array}{l}\text { Mlassourt } \\
\text { Roild } \\
\text { Chy of } \\
\text { Septomber so }\end{array}$ & $\begin{array}{l}\text { Mascouri } \\
\text { Slkuston } \\
\text { Coty of } \\
\text { Map } 31\end{array}$ & 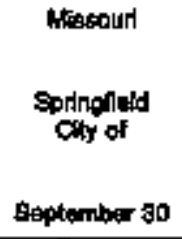 & $\begin{array}{l}\text { Nebratkn } \\
\text { Oeatice } \\
\text { Clty of } \\
\text { July st }\end{array}$ & 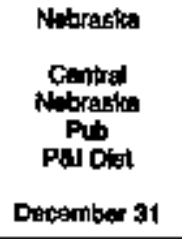 & $\begin{array}{l}\text { Mabratian } \\
\text { Comminesker } \\
\text { Publio } \\
\text { Power Oigl } \\
\text { December 31 }\end{array}$ \\
\hline 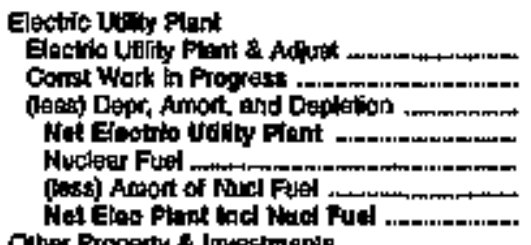 & $\begin{array}{r}8,913 \\
0 \\
6,149 \\
3,765 \\
0 \\
0 \\
2,765\end{array}$ & 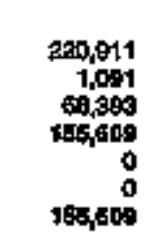 & $\begin{array}{r}399,092 \\
14,589 \\
127,594 \\
29,070 \\
0 \\
0 \\
295,075\end{array}$ & 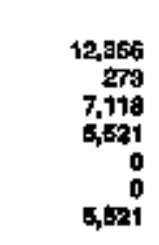 & $\begin{array}{r}138,371 \\
138 \\
56,912 \\
61,897 \\
0 \\
0 \\
\text { a1,\$07 }\end{array}$ & $\begin{array}{r}32,055 \\
861 \\
10.442 \\
22,505 \\
0 \\
0 \\
22,505\end{array}$ \\
\hline 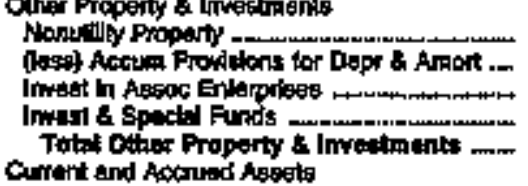 & $\begin{array}{r}5,702 \\
2,007 \\
0 \\
4,701 \\
7,496\end{array}$ & $\begin{array}{r}0 \\
0 \\
0 \\
33,914 \\
83,314\end{array}$ & $\begin{array}{r}\stackrel{0}{0} \\
0 \\
142,600 \\
142,003\end{array}$ & $\begin{array}{r}0 \\
0 \\
0 \\
205 \\
205\end{array}$ & $\begin{array}{r}68 \\
0 \\
0 \\
0,989 \\
10,026\end{array}$ & $\begin{array}{r}0 \\
0 \\
776 \\
1,681 \\
2,467\end{array}$ \\
\hline 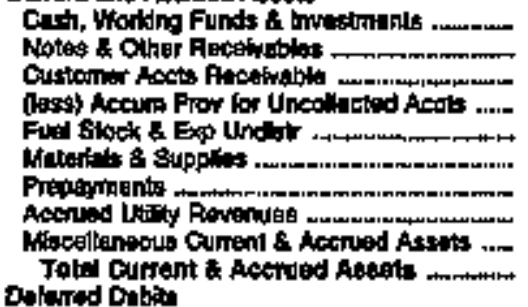 & $\begin{array}{r}1,143 \\
0 \\
727 \\
10 \\
0 \\
379 \\
20 \\
0 \\
70 \\
70601\end{array}$ & $\begin{array}{r}13,353 \\
170 \\
4,717 \\
128 \\
9,896 \\
1,916 \\
371 \\
0 \\
695 \\
31,006\end{array}$ & $\begin{array}{r}10,2277 \\
1,146 \\
10,009 \\
91 \\
4,090 \\
7,500 \\
300 \\
0 \\
0 \\
34,240\end{array}$ & $\begin{array}{r}1,457 \\
27 \\
457 \\
74 \\
07 \\
293 \\
14 \\
379 \\
4 \\
2,514\end{array}$ & $\begin{array}{r}589 \\
1,378 \\
0 \\
4 \\
1,130 \\
1,150 \\
141 \\
0 \\
2,169 \\
6,630\end{array}$ & 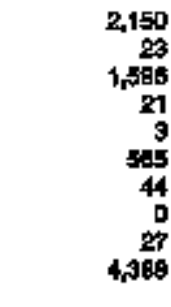 \\
\hline 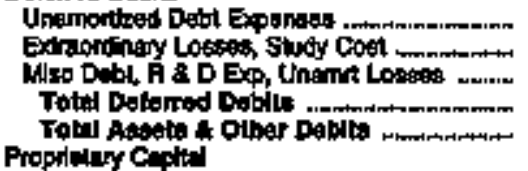 & $\begin{array}{r}0 \\
0 \\
0 \\
0 \\
12,592\end{array}$ & $\begin{array}{r}16,290 \\
0 \\
0 \\
15,230 \\
28 B, 760\end{array}$ & $\begin{array}{r}462 \\
0 \\
0,4 a z \\
3,404 \\
77,093\end{array}$ & $\begin{array}{r}4 \\
0 \\
-1 \\
3 \\
0,263\end{array}$ & $\begin{array}{r}39 \\
130 \\
157 \\
93,393\end{array}$ & $\begin{array}{r}584 \\
0 \\
1,048 \\
s 0,374\end{array}$ \\
\hline 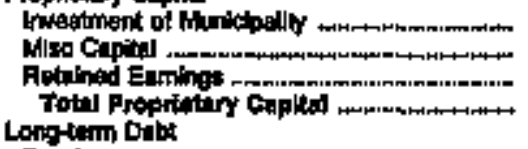 & $\begin{array}{r}52 \\
0 \\
11,104 \\
11,157\end{array}$ & $\begin{array}{r}0 \\
0 \\
-1,702 \\
-1,702\end{array}$ & $\begin{array}{r}0 \\
0 \\
327,600 \\
327,900\end{array}$ & $\begin{array}{r}-52 \\
576 \\
6,811 \\
7,129\end{array}$ & $\begin{array}{r}0 \\
0 \\
20,735\end{array}$ & $\begin{array}{r}0 \\
0 \\
15,178 \\
16,176\end{array}$ \\
\hline 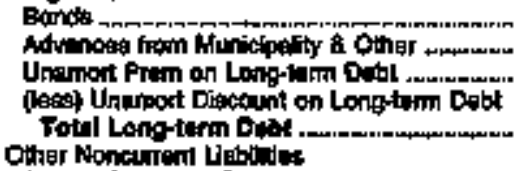 & $\begin{array}{l}0 \\
0 \\
0 \\
6 \\
0\end{array}$ & $\begin{array}{r}205,680 \\
0 \\
0 \\
1,409 \\
2 \pi+257\end{array}$ & $\begin{array}{r}93,729 \\
16,290 \\
0 \\
752 \\
109,275\end{array}$ & $\begin{array}{r}71 \\
0 \\
0 \\
0 \\
71\end{array}$ & $\begin{array}{r}250 \\
0 \\
0 \\
0 \\
250\end{array}$ & $\begin{array}{r}10,700 \\
0 \\
0 \\
0 \\
19,790\end{array}$ \\
\hline 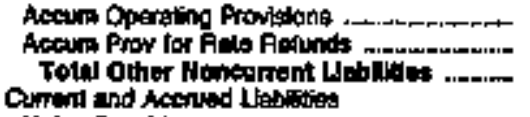 & $\begin{array}{l}0 \\
0 \\
0\end{array}$ & $\begin{array}{l}0 \\
0 \\
0\end{array}$ & $\begin{array}{r}8,805 \\
0 \\
a, 605\end{array}$ & $\begin{array}{l}0 \\
0 \\
0\end{array}$ & $\begin{array}{r}1,122 \\
0 \\
1,128\end{array}$ & $\begin{array}{l}0 \\
0 \\
0\end{array}$ \\
\hline 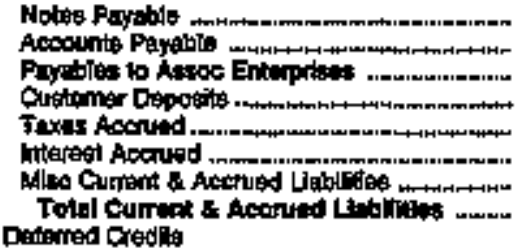 & $\begin{array}{r}0 \\
805 \\
184 \\
292 \\
0 \\
0 \\
1,45\end{array}$ & $\begin{array}{r}0 \\
440 \\
0 \\
345 \\
0 \\
6,842 \\
1,497 \\
8,139\end{array}$ & $\begin{array}{r}0 \\
7,072 \\
1,151 \\
688 \\
0 \\
1,798 \\
6,960 \\
17,700\end{array}$ & $\begin{array}{r}0 \\
694 \\
287 \\
72 \\
48 \\
0 \\
98 \\
1,030\end{array}$ & $\begin{array}{r}0 \\
3,377 \\
0 \\
0 \\
0 \\
0 \\
386 \\
3, \pi 71\end{array}$ & $\begin{array}{r}0 \\
604 \\
0 \\
70 \\
52 \\
197 \\
174 \\
1,107\end{array}$ \\
\hline 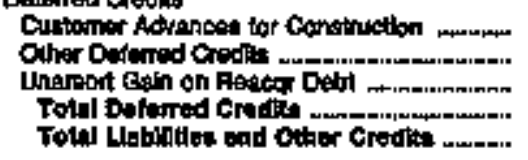 & $\begin{array}{r}0 \\
0 \\
0 \\
0 \\
12,692\end{array}$ & $\begin{array}{r}0 \\
7,5 \% 4 \\
7,50 \\
2015,109\end{array}$ & $\begin{array}{r}1 \\
7,099 \\
0 \\
7,009 \\
471,000\end{array}$ & $\begin{array}{r}0 \\
0 \\
0 \\
0 \\
0\end{array}$ & $\begin{array}{r}0 \\
60,454 \\
03,464 \\
60,359\end{array}$ & $\begin{array}{r}0 \\
13 \\
3,200 \\
3,20 \\
30,374\end{array}$ \\
\hline
\end{tabular}

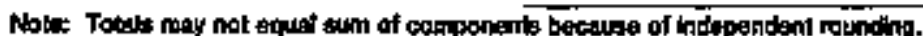

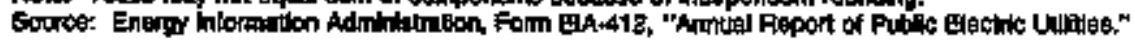


Table 22. Balance Sheat by Major U.S. Publlcly Owned Electric Utility Within State at End of Period, 1994

(Thousanut Dollars)

\begin{tabular}{|c|c|c|c|c|c|c|}
\hline Ilem & 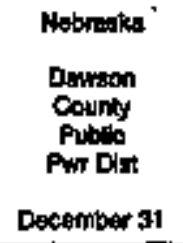 & $\begin{array}{l}\text { Nebrouph } \\
\text { Franont } \\
\text { Cyy of } \\
\text { July ot }\end{array}$ & 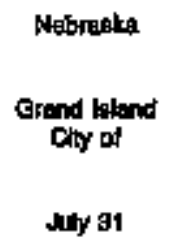 & $\begin{array}{l}\text { Nebraska } \\
\text { Hotrings } \\
\text { Ciky of } \\
\text { Denenter } 31\end{array}$ & $\begin{array}{l}\text { Nebreske } \\
\text { Lncolt } \\
\text { Electite } \\
\text { Syoten } \\
\text { Decumber } 31\end{array}$ & 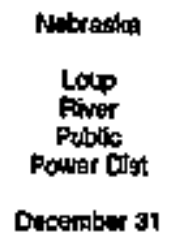 \\
\hline 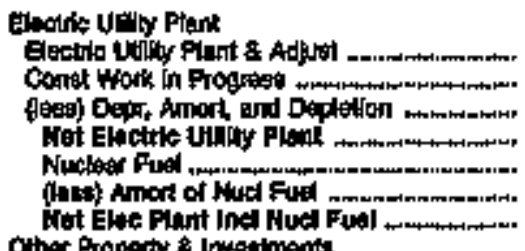 & $\begin{array}{r}46,395 \\
1,900 \\
20,149 \\
20,288 \\
0 \\
0 \\
20,280\end{array}$ & $\begin{array}{r}6,997 \\
1,105 \\
47,004 \\
6,79 \\
0 \\
0 \\
7,790\end{array}$ & $\begin{array}{r}16,204 \\
580 \\
0,312 \\
96,431 \\
0 \\
0 \\
00,431\end{array}$ & $\begin{array}{r}108,395 \\
2,912 \\
37,598 \\
68,911 \\
0 \\
06 \\
06,911\end{array}$ & $\begin{array}{r}141,705 \\
26,460 \\
140,600 \\
327,555 \\
0 \\
0 \\
327,655\end{array}$ & $\begin{array}{r}63,116 \\
3,650 \\
24,496 \\
32,270 \\
0 \\
0 \\
32,270\end{array}$ \\
\hline 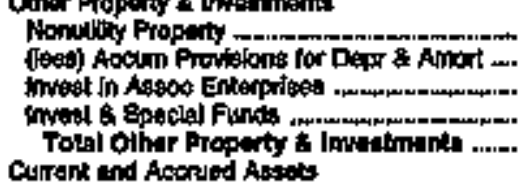 & $\begin{array}{r}0 \\
0 \\
41 \\
270 \\
261\end{array}$ & $\begin{array}{r}0 \\
0 \\
0 \\
28,539 \\
28,59\end{array}$ & $\begin{array}{r}470 \\
0 \\
0 \\
0,570 \\
10,090\end{array}$ & $\begin{array}{r}0 \\
0 \\
0 \\
10,400 \\
10,460\end{array}$ & $\begin{array}{r}0 \\
0 \\
15,624 \\
15,624\end{array}$ & $\begin{array}{r}501 \\
0 \\
0 \\
12372 \\
12,674\end{array}$ \\
\hline 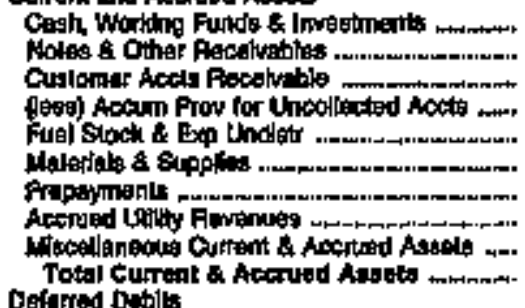 & $\begin{array}{r}6,692 \\
6,340 \\
1,769 \\
89 \\
0 \\
1,456 \\
05 \\
0 \\
104 \\
1,217\end{array}$ & $\begin{array}{r}10 \\
1,487 \\
528 \\
44 \\
128 \\
1,881 \\
169 \\
1,050 \\
0 \\
0,000\end{array}$ & $\begin{array}{r}12,365 \\
1,357 \\
1,060 \\
110 \\
1,342 \\
2,050 \\
126 \\
0 \\
0 \\
19,102\end{array}$ & $\begin{array}{r}7,51 \\
0 \\
1,445 \\
0 \\
873 \\
602 \\
0 \\
0 \\
209 \\
10,520\end{array}$ & 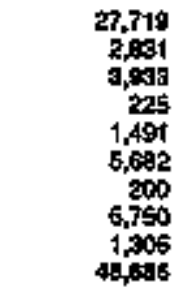 & $\begin{array}{r}6,087 \\
716 \\
2, a x s \\
4 \\
0 \\
9 \pi \\
109 \\
0 \\
10,104\end{array}$ \\
\hline 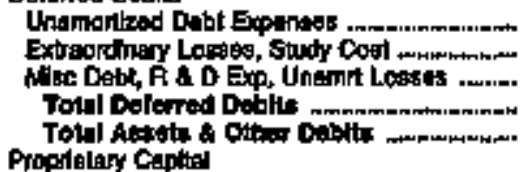 & $\begin{array}{r}50 \\
0 \\
265 \\
265 \\
46,960\end{array}$ & $\begin{array}{r}151 \\
0 \\
1,676 \\
2,096 \\
49,308\end{array}$ & $\begin{array}{r}402 \\
1,795 \\
7250 \\
127,031\end{array}$ & $\begin{array}{r}0 \\
0 \\
41 \\
41 \\
49,032\end{array}$ & $\begin{array}{r}38,115 \\
1,658 \\
8,090 \\
49,392 \\
41,27 \%\end{array}$ & $\begin{array}{r}0 \\
890 \\
890 \\
69,2015\end{array}$ \\
\hline 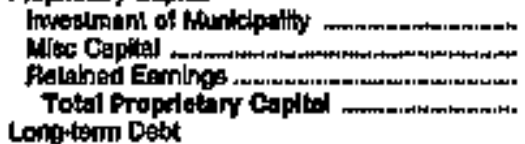 & $\begin{array}{r}0 \\
0 \\
39,600 \\
38,600\end{array}$ & $\begin{array}{r}0 \\
0 \\
35,828 \\
35,628\end{array}$ & $\begin{array}{r}0 \\
04,988 \\
64,690\end{array}$ & $\begin{array}{r}0 \\
24,400 \\
24,409\end{array}$ & $\begin{array}{r}0 \\
0 \\
121,800 \\
121,060\end{array}$ & $\begin{array}{r}0 \\
0 \\
\operatorname{sen} 922 \\
00,-22\end{array}$ \\
\hline 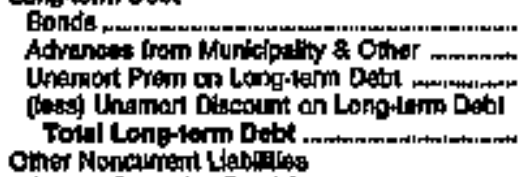 & $\begin{array}{r}0 \\
11,338 \\
0 \\
0 \\
11,203\end{array}$ & $\begin{array}{r}0,850 \\
0 \\
0 \\
0 \\
0,650\end{array}$ & $\begin{array}{r}3,495 \\
055 \\
0 \\
0 \\
40,959\end{array}$ & $\begin{array}{r}64,065 \\
0 \\
0 \\
1,509 \\
92,460\end{array}$ & $\begin{array}{r}270,510 \\
0 \\
0 \\
0 \\
270,510\end{array}$ & $\begin{array}{l}0 \\
0 \\
0 \\
0 \\
0\end{array}$ \\
\hline 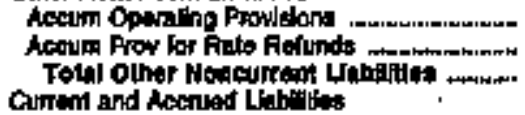 & $\begin{array}{l}0 \\
0 \\
0\end{array}$ & $\begin{array}{r}167 \\
0 \\
157\end{array}$ & $\begin{array}{l}0 \\
0 \\
0\end{array}$ & $\begin{array}{l}0 \\
0 \\
0\end{array}$ & $\begin{array}{l}0 \\
0 \\
0\end{array}$ & $\begin{array}{l}0 \\
0 \\
0\end{array}$ \\
\hline 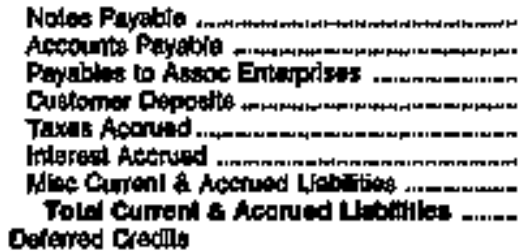 & $\begin{array}{r}0 \\
1,016 \\
0 \\
154 \\
60 \\
0 \\
720 \\
1,00\end{array}$ & $\begin{array}{r}0 \\
500 \\
0 \\
46 \\
68 \\
73 \\
344 \\
1,060\end{array}$ & $\begin{array}{r}0 \\
615 \\
0 \\
90 \\
735 \\
957 \\
320 \\
2,640\end{array}$ & $\begin{array}{r}0 \\
277 \\
395 \\
50 \\
0 \\
1,781 \\
0 \\
2,494\end{array}$ & $\begin{array}{r}7,850 \\
13,006 \\
0 \\
10 \\
5,723 \\
4,760 \\
3,466 \\
34,693\end{array}$ & $\begin{array}{r}0 \\
2720 \\
0 \\
145 \\
1,644 \\
0 \\
239 \\
4,749\end{array}$ \\
\hline 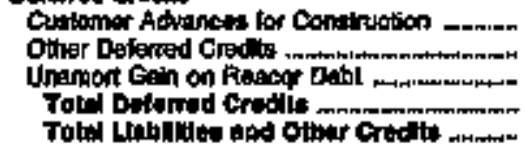 & $\begin{array}{r}0 \\
150 \\
0 \\
150 \\
49,998\end{array}$ & $\begin{array}{r}0 \\
0 \\
2,003 \\
2,000 \\
49,983\end{array}$ & $\begin{array}{r}0 \\
0 \\
0 \\
0 \\
137,0101\end{array}$ & $\begin{array}{r}0 \\
479 \\
0 \\
479 \\
49098\end{array}$ & $\begin{array}{r}0 \\
\operatorname{s,024} 0 \\
0 \\
\sin , 044\end{array}$ & $\begin{array}{r}0 \\
08 \\
0 \\
6005\end{array}$ \\
\hline
\end{tabular}

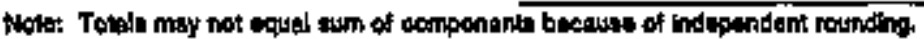

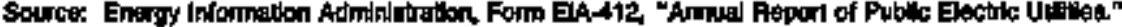


Table 22. Balance Sheet by Mejor U.S. Pubildy Owned Electric Utility Within State at End of Perlod, 1994

(Thousand Dollars)

\begin{tabular}{|c|c|c|c|c|c|c|}
\hline man & 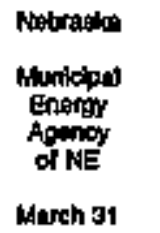 & 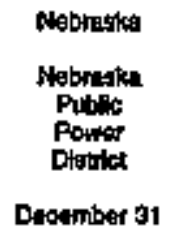 & $\begin{array}{l}\text { Nobraske } \\
\text { Nonia } \\
\text { Publit } \\
\text { Power } \\
\text { Dialket } \\
\text { Decomber 31 }\end{array}$ & $\begin{array}{l}\text { Nobreska } \\
\text { North } \\
\text { Flelle } \\
\text { Ciny of } \\
\text { Why a1 }\end{array}$ & 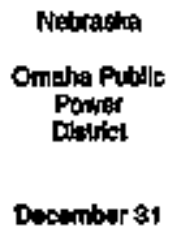 & 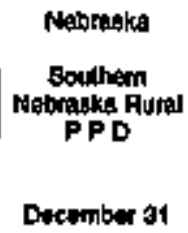 \\
\hline 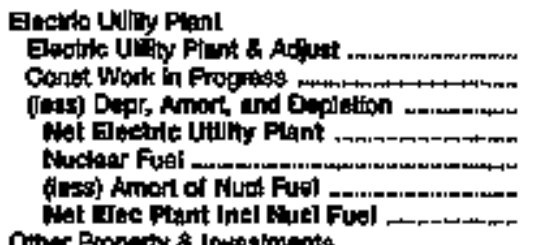 & $\begin{array}{r}34,725 \\
0 \\
1,968 \\
32,760 \\
0 \\
0 \\
32,760\end{array}$ & $\begin{array}{r}1,910,407 \\
185,436 \\
840,202 \\
1,247,142 \\
428,169 \\
391,870 \\
1,344,432\end{array}$ & $\begin{array}{r}60,614 \\
439 \\
19,215 \\
4 t, 689 \\
0 \\
0 \\
41,089\end{array}$ & $\begin{array}{r}19,160 \\
3,15 \\
8,177 \\
5,328 \\
0 \\
0 \\
5,320\end{array}$ & 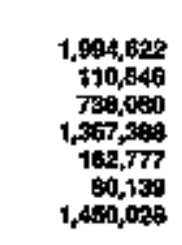 & $\begin{array}{r}73,218 \\
9 \mathrm{~B} \\
32,185 \\
40,151 \\
0 \\
0 \\
10,161\end{array}$ \\
\hline 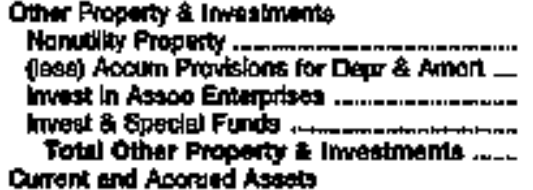 & $\begin{array}{r}2588 \\
589 \\
0 \\
5040 \\
0.915\end{array}$ & $\begin{array}{r}0 \\
0 \\
140,258 \\
14,258\end{array}$ & $\begin{array}{r}0 \\
0 \\
0 \\
3,734 \\
3,734\end{array}$ & $\begin{array}{l}0 \\
0 \\
0 \\
0 \\
0\end{array}$ & $\begin{array}{r}0 \\
0 \\
0 \\
342,867 \\
34,2607\end{array}$ & $\begin{array}{r}0 \\
0 \\
0 \\
t, 577 \\
1,577\end{array}$ \\
\hline 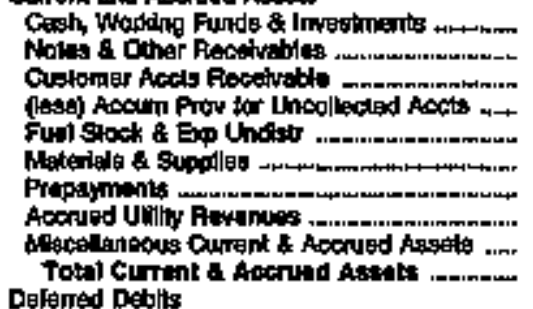 & $\begin{array}{r}60 \\
0 \\
6,281 \\
0 \\
0 \\
0 \\
169 \\
0 \\
1,111 \\
6,602\end{array}$ & 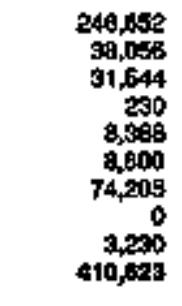 & $\begin{array}{r}6,063 \\
23 \\
1,972 \\
44 \\
0 \\
1,229 \\
113 \\
827 \\
0 \\
10,703\end{array}$ & $\begin{array}{r}3,606 \\
0 \\
098 \\
48 \\
0 \\
477 \\
9 \\
0 \\
35 \\
4,773\end{array}$ & $\begin{array}{r}42,471 \\
51,923 \\
29,535 \\
674 \\
9,462 \\
37,190 \\
1,179 \\
16,514 \\
5,045 \\
190,641\end{array}$ & $\begin{array}{r}11,685 \\
0 \\
1,683 \\
0 \\
0 \\
1,696 \\
55 \\
0 \\
140 \\
10,090\end{array}$ \\
\hline 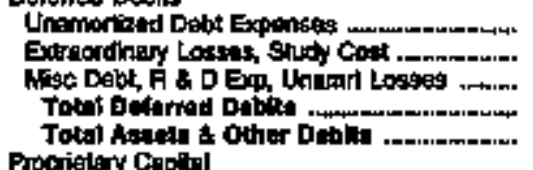 & $\begin{array}{r}3,727 \\
10,474 \\
1,391 \\
62,478\end{array}$ & $\begin{array}{r}2060 \\
549 \\
94,614 \\
97,225 \\
1,004,5544\end{array}$ & $\begin{array}{r}871 \\
0 \\
112 \\
503 \\
57,358\end{array}$ & $\begin{array}{r}0 \\
0 \\
0 \\
0 \\
0,016\end{array}$ & $\begin{array}{r}2,122 \\
0 \\
101,816 \\
103,489 \\
2,067,872\end{array}$ & $\begin{array}{r}0 \\
250 \\
256 \\
515\end{array}$ \\
\hline 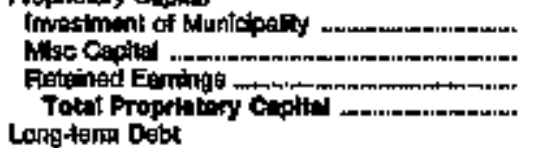 & $\begin{array}{r}0 \\
0 \\
3,129 \\
3,49\end{array}$ & $\begin{array}{r}0 \\
0 \\
230,6937 \\
200,057\end{array}$ & $\begin{array}{r}0 \\
31,736 \\
31,736\end{array}$ & $\begin{array}{r}0 \\
0 \\
8,926 \\
9,025\end{array}$ & $\begin{array}{r}0 \\
0 \\
783,296 \\
765,260\end{array}$ & $\begin{array}{r}0 \\
54356 \\
54993\end{array}$ \\
\hline 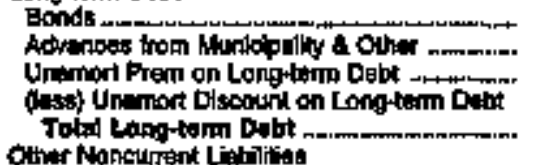 & $\begin{array}{r}49,560 \\
0 \\
0 \\
0 \\
49,500\end{array}$ & $\begin{array}{r}1,305,675 \\
1,779 \\
\text { an } \\
11,141 \\
t, 30,5,753\end{array}$ & $\begin{array}{r}21,007 \\
0 \\
0 \\
0 \\
21,00 \%\end{array}$ & $\begin{array}{l}0 \\
0 \\
0 \\
0 \\
0\end{array}$ & $\begin{array}{r}847,990 \\
84,251 \\
0 \\
11,914 \\
1,020,927\end{array}$ & $\begin{array}{l}0 \\
0 \\
0 \\
0 \\
0\end{array}$ \\
\hline 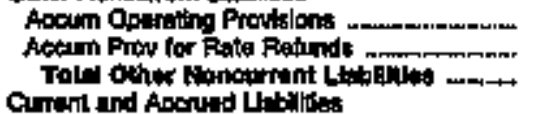 & $\begin{array}{r}5, \mathrm{dyt} \\
0 \\
\text { B,at7 }\end{array}$ & $\begin{array}{l}0 \\
0 \\
0\end{array}$ & $\begin{array}{l}0 \\
0 \\
0\end{array}$ & $\begin{array}{l}0 \\
0 \\
0\end{array}$ & $\begin{array}{r}4,0 B S \\
0 \\
4,986\end{array}$ & $\begin{array}{l}0 \\
0 \\
0\end{array}$ \\
\hline 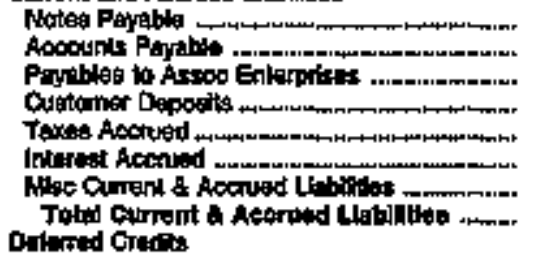 & $\begin{array}{r}0 \\
2,275 \\
0 \\
0 \\
96 \\
1,2,98 \\
209 \\
3,970\end{array}$ & 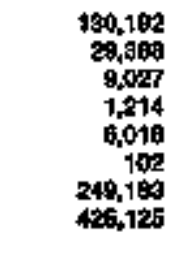 & $\begin{array}{r}0 \\
3,056 \\
0 \\
57 \\
154 \\
220 \\
607 \\
4,696\end{array}$ & $\begin{array}{r}0 \\
1,148 \\
0 \\
129 \\
0 \\
0 \\
0 \\
1,270\end{array}$ & $\begin{array}{r}27,206 \\
34,351 \\
0 \\
5,598 \\
14,570 \\
29,368 \\
34,051 \\
190,096\end{array}$ & $\begin{array}{r}0 \\
2,459 \\
0 \\
54 \\
0 \\
0 \\
476 \\
2,409\end{array}$ \\
\hline 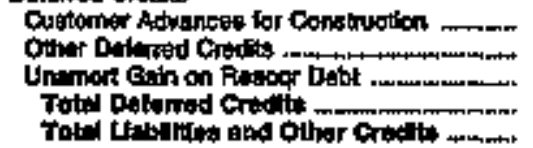 & $\begin{array}{r}0 \\
0 \\
0 \\
0 \\
62,46\end{array}$ & $\begin{array}{r}0 \\
16,039 \\
0 \\
10,050 \\
1,006,534\end{array}$ & $\begin{array}{r}0 \\
0 \\
0 \\
0 \\
57398\end{array}$ & $\begin{array}{r}0 \\
0 \\
0 \\
0 \\
10,006\end{array}$ & $\begin{array}{r}374 \\
159,607 \\
4 \\
160,001 \\
2,097,672\end{array}$ & $\begin{array}{r}0 \\
0 \\
0 \\
0 \\
-7,392\end{array}$ \\
\hline
\end{tabular}

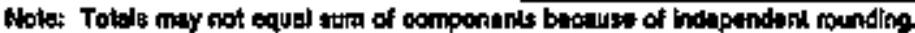

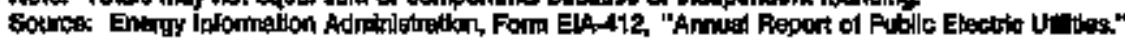


Table 22. Ealance Sheet by Mejor U.S. Publicty Owned Electito Utillty Within State at End of Period, 1994

(Thousand Dolkars)

\begin{tabular}{|c|c|c|c|c|c|c|}
\hline nem & 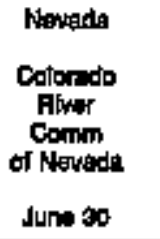 & $\begin{array}{l}\text { New Jersey } \\
\text { Vinelend } \\
\text { Oty of } \\
\text { June } 30\end{array}$ & 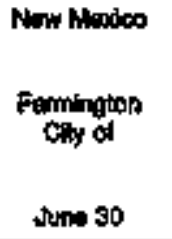 & 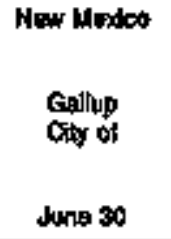 & 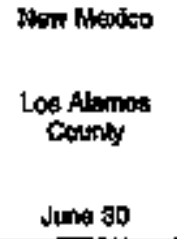 & $\begin{array}{l}\text { Mow York } \\
\text { Foipont } \\
\text { Mideys of }\end{array}$ \\
\hline 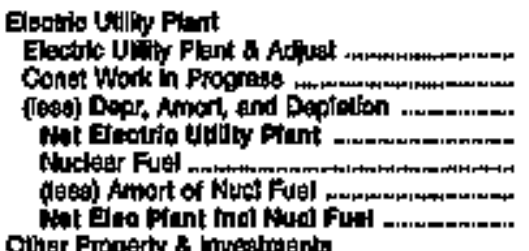 & $\begin{array}{l}0 \\
0 \\
0 \\
0 \\
0 \\
0 \\
0\end{array}$ & $\begin{array}{r}69,410 \\
3,451 \\
34,796 \\
38,074 \\
0 \\
0 \\
36,074\end{array}$ & $\begin{array}{r}172,756 \\
11,946 \\
6,965 \\
196,768 \\
0 \\
0 \\
136,764\end{array}$ & $\begin{array}{r}11,460 \\
0 \\
5,425 \\
5,050 \\
0 \\
0 \\
5,055\end{array}$ & $\begin{array}{r}112,555 \\
362 \\
29,985 \\
29,935 \\
0 \\
0 \\
02,935\end{array}$ & $\begin{array}{r}16,620 \\
5 \\
0,070 \\
0,705 \\
0 \\
0 \\
0,70\end{array}$ \\
\hline 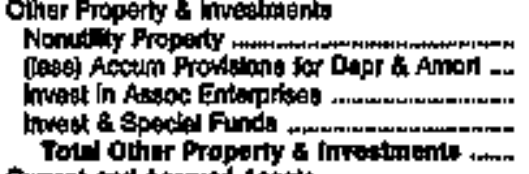 & $\begin{array}{r}268,690 \\
76,705 \\
0 \\
45,150 \\
2 \times 7,234\end{array}$ & $\begin{array}{r}0 \\
0 \\
0 \\
4,714 \\
4,714\end{array}$ & $\begin{array}{l}0 \\
0 \\
0 \\
0 \\
0\end{array}$ & $\begin{array}{r}20,084 \\
11,025 \\
0 \\
0 \\
12,000\end{array}$ & $\begin{array}{r}0 \\
0 \\
0 \\
12,05 s \\
12,058\end{array}$ & $\begin{array}{r}0 \\
0 \\
1,876 \\
1,076\end{array}$ \\
\hline 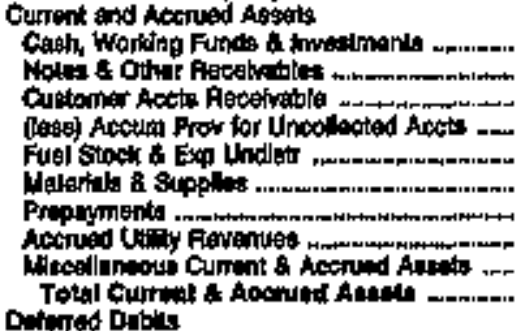 & $\begin{array}{r}4,006 \\
640 \\
7,151 \\
0 \\
0 \\
115 \\
7,110 \\
0 \\
0 \\
19,002\end{array}$ & $\begin{array}{r}26,451 \\
2 \\
3,980 \\
0 \\
0 \\
1,229 \\
0 \\
0 \\
0 \\
30,041\end{array}$ & $\begin{array}{r}040 \\
0 \\
8,127 \\
340 \\
400 \\
2,317 \\
0 \\
2,170 \\
28,242 \\
36,757\end{array}$ & $\begin{array}{r}3,240 \\
0 \\
2,076 \\
215 \\
0 \\
1,009 \\
0 \\
0 \\
3,300 \\
9,430\end{array}$ & $\begin{array}{r}4,251 \\
107 \\
3,049 \\
89 \\
340 \\
400 \\
0 \\
390 \\
1,00 \\
5,201\end{array}$ & $\begin{array}{r}712 \\
0 \\
432 \\
8 \\
0 \\
491 \\
972 \\
0 \\
7 \\
206\end{array}$ \\
\hline 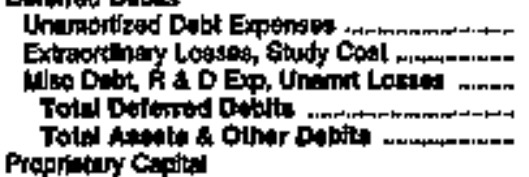 & 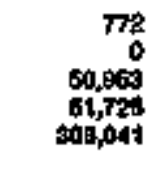 & $\begin{array}{r}\mathbf{0} \\
\mathbf{0} \\
\mathbf{0} \\
\mathbf{0} \\
72,6=2\end{array}$ & $\begin{array}{r}3,806 \\
0 \\
9 \\
3,605 \\
177,126\end{array}$ & $\begin{array}{r}88 \\
0 \\
0 \\
68 \\
27,621\end{array}$ & $\begin{array}{r}3,0602 \\
5,572 \\
15 \\
114,4046\end{array}$ & $\begin{array}{r}0 \\
0 \\
0 \\
0 \\
13,295\end{array}$ \\
\hline 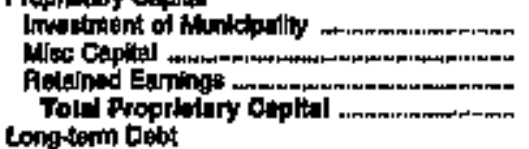 & $\begin{array}{r}1,405 \\
0 \\
-61,688 \\
-40,342\end{array}$ & $\begin{array}{r}0 \\
0 \\
00,+191 \\
60,191\end{array}$ & $\begin{array}{r}0 \\
13,464 \\
7,310 \\
20,774\end{array}$ & $\begin{array}{r}13,970 \\
7,400 \\
20,773\end{array}$ & $\begin{array}{r}0 \\
0 \\
0,0,808 \\
0,060\end{array}$ & $\begin{array}{r}-4,607 \\
494 \\
16,685 \\
1,3,302\end{array}$ \\
\hline 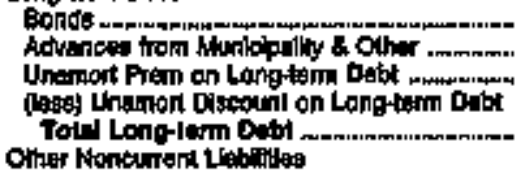 & $\begin{array}{r}162,691 \\
182,181 \\
2 \\
0 \\
334,635\end{array}$ & $\begin{array}{r}3,485 \\
0 \\
0 \\
3,485\end{array}$ & $\begin{array}{r}160,847 \\
0 \\
0 \\
2,683 \\
48,114\end{array}$ & $\begin{array}{r}4,698 \\
68 \\
0 \\
0 \\
4,7,485\end{array}$ & $\begin{array}{r}80,990 \\
100 \\
0 \\
1,092 \\
0+000\end{array}$ & $\begin{array}{r}1,180 \\
0 \\
0 \\
0 \\
1,180\end{array}$ \\
\hline 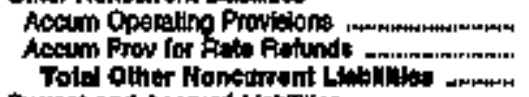 & $\begin{array}{l}0 \\
0 \\
0\end{array}$ & $\begin{array}{r}4,714 \\
0 \\
4,714\end{array}$ & $\begin{array}{l}0 \\
0 \\
0\end{array}$ & $\begin{array}{l}0 \\
0 \\
0\end{array}$ & $\begin{array}{l}0 \\
0 \\
0\end{array}$ & 0 \\
\hline 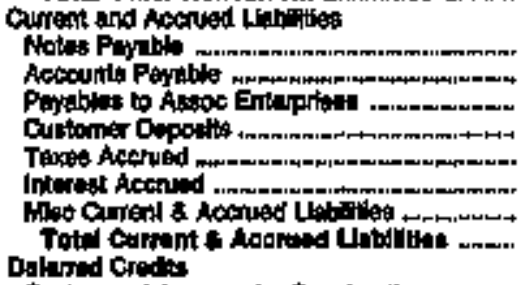 & $\begin{array}{r}0 \\
5,054 \\
0 \\
0 \\
0 \\
5,404 \\
8,177 \\
7,952\end{array}$ & $\begin{array}{r}0 \\
3,27 \\
0 \\
525 \\
0 \\
316 \\
4,405\end{array}$ & $\begin{array}{r}0 \\
1,087 \\
0 \\
445 \\
500 \\
1,1 \% 0 \\
640 \\
2,706\end{array}$ & $\begin{array}{r}0 \\
326 \\
0 \\
791 \\
72 \\
0 \\
166 \\
1,295\end{array}$ & $\begin{array}{r}0 \\
898 \\
597 \\
37 \\
38 \\
3,760 \\
270 \\
5,591\end{array}$ & $\begin{array}{r}0 \\
597 \\
91 \\
171 \\
14 \\
16 \\
79 \\
760\end{array}$ \\
\hline 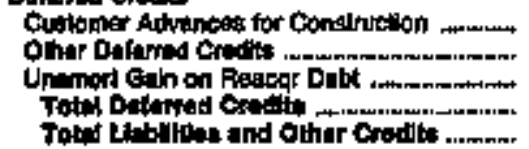 & $\begin{array}{r}0 \\
3,097 \\
0 \\
3,077 \\
300,041\end{array}$ & $\begin{array}{r}58 \\
0 \\
0 \\
58 \\
72,699\end{array}$ & $\begin{array}{r}3,084 \\
1,300 \\
0 \\
4,1304\end{array}$ & $\begin{array}{r}0 \\
701 \\
0 \\
701 \\
27,501\end{array}$ & $\begin{array}{r}0 \\
2,950 \\
0 \\
2,3500 \\
114,650\end{array}$ & $\begin{array}{r}0 \\
0 \\
0 \\
0\end{array}$ \\
\hline
\end{tabular}

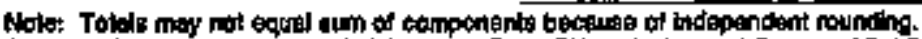

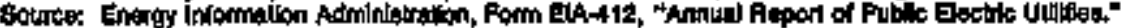


Table 22. Balance Sheet by Major U.S. Publicly Owned Electrlc Utility Whin State at End of Perlod, 1994 (Thousand Dollars)

\begin{tabular}{|c|c|c|c|c|c|c|}
\hline Ilem & $\begin{array}{l}\text { Wew York } \\
\text { Freapont } \\
\text { Villoge of } \\
\text { Int } \\
\text { Fubruery } 20\end{array}$ & $\begin{array}{l}\text { Now York } \\
\text { Jemealown } \\
\text { Ciny of } \\
\text { Decomber } 31\end{array}$ & $\begin{array}{l}\text { Now York } \\
\text { Lato Plactd } \\
\text { Vingog ho } \\
\text { Juty } 31\end{array}$ & $\begin{array}{l}\text { thew York } \\
\text { Town of } \\
\text { Decembur } 31\end{array}$ & $\begin{array}{l}\text { New York } \\
\text { Puatusurgh } \\
\text { Ciny of } \\
\text { Deoember } 31\end{array}$ & $\begin{array}{l}\text { Now York } \\
\text { Power } \\
\text { Authority } \\
\text { of Sile of } \mathrm{NY} \\
\text { Deconber } 31\end{array}$ \\
\hline 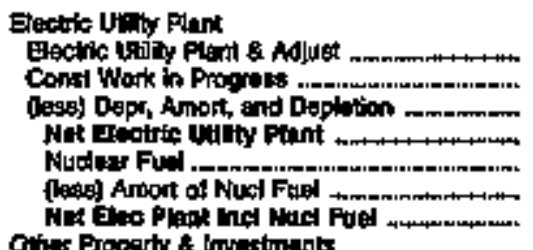 & $\begin{array}{r}30,435 \\
2,464 \\
19,024 \\
13,676 \\
0 \\
0 \\
13,076\end{array}$ & $\begin{array}{r}61,769 \\
2,503 \\
27,514 \\
56,728 \\
0 \\
0 \\
50,729\end{array}$ & $\begin{array}{r}11,918 \\
0 \\
2,092 \\
9026 \\
0 \\
0 \\
9,026\end{array}$ & $\begin{array}{r}22,459 \\
40 \\
7,092 \\
14,615 \\
0 \\
0 \\
14,515\end{array}$ & $\begin{array}{r}26,790 \\
945 \\
11,212 \\
10,502 \\
0 \\
0 \\
16,502\end{array}$ & 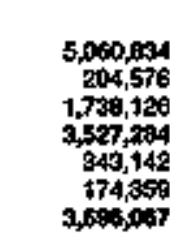 \\
\hline 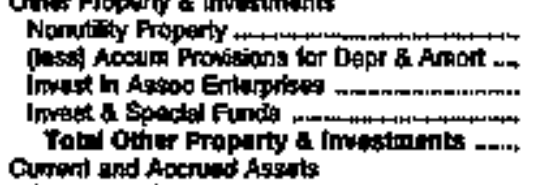 & $\begin{array}{l}0 \\
0 \\
0 \\
0 \\
0\end{array}$ & $\begin{array}{r}10 \\
0 \\
0 \\
000 \\
710\end{array}$ & $\begin{array}{c}0 \\
0 \\
0 \\
0 \\
0\end{array}$ & $\begin{array}{r}0 \\
0 \\
0 \\
0,313 \\
2,319\end{array}$ & $\begin{array}{r}0 \\
0 \\
0 \\
2,358 \\
2,345\end{array}$ & $\begin{array}{r}0 \\
0 \\
0 \\
256,148 \\
256,149\end{array}$ \\
\hline 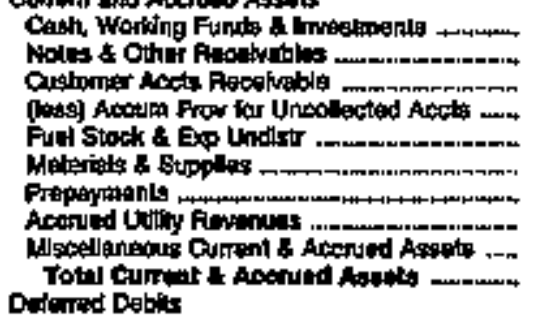 & $\begin{array}{r}5,0057 \\
0 \\
1,484 \\
100 \\
0 \\
1,244 \\
11 \\
0 \\
0 \\
7,076\end{array}$ & $\begin{array}{r}167 \\
0 \\
2,076 \\
117 \\
0 \\
731 \\
62 \\
0 \\
1 \\
2,403\end{array}$ & $\begin{array}{r}740 \\
95 \\
685 \\
118 \\
0 \\
343 \\
318 \\
0 \\
0 \\
1,004\end{array}$ & $\begin{array}{r}1,231 \\
0 \\
600 \\
32 \\
0 \\
710 \\
116 \\
0 \\
0 \\
2,549\end{array}$ & $\begin{array}{r}503 \\
1,404 \\
0 \\
92 \\
618 \\
10 \\
0 \\
0 \\
0 \\
2,058\end{array}$ & $\begin{array}{r}1,353,374 \\
27,439 \\
130,359 \\
0 \\
9,881 \\
79,244 \\
4,9019 \\
0 \\
28,071 \\
1,695,049\end{array}$ \\
\hline 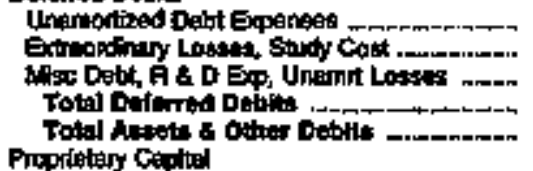 & $\begin{array}{r}0 \\
0 \\
0 \\
0 \\
21,852\end{array}$ & $\begin{array}{r}0 \\
0 \\
75 \\
75 \\
50938\end{array}$ & $\begin{array}{r}0 \\
0 \\
0 \\
0 \\
11,011\end{array}$ & $\begin{array}{r}0 \\
0 \\
0 \\
0 \\
12,371\end{array}$ & $\begin{array}{r}24 \\
0 \\
0 \\
24 \\
24,51\end{array}$ & $\begin{array}{r}20,731 \\
0 \\
185,307 \\
212,048 \\
5,789,351\end{array}$ \\
\hline 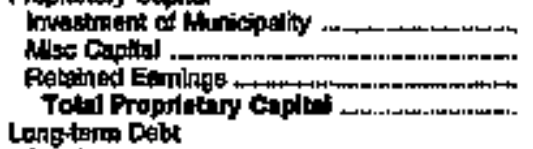 & $\begin{array}{r}0 \\
0 \\
15,987 \\
15,1067\end{array}$ & $\begin{array}{r}67,369 \\
-24,479 \\
0 \\
42,996\end{array}$ & $\begin{array}{r}0 \\
0 \\
0,470 \\
0,470\end{array}$ & $\begin{array}{r}0 \\
11, \pi / 2 \\
11,7 \pi 2\end{array}$ & $\begin{array}{r}-10,454 \\
0 \\
27,4,26 \\
16,572\end{array}$ & $\begin{array}{r}0 \\
0 \\
1,443,941 \\
1,448,941\end{array}$ \\
\hline 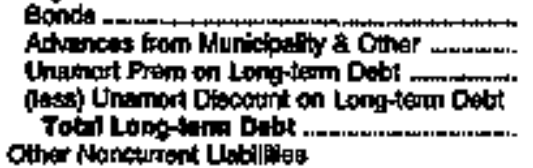 & $\begin{array}{r}740 \\
0 \\
0 \\
0 \\
740\end{array}$ & $\begin{array}{r}14,678 \\
0 \\
0 \\
14,678\end{array}$ & $\begin{array}{r}1,100 \\
2000 \\
0 \\
0 \\
1,900\end{array}$ & $\begin{array}{r}6,760 \\
0 \\
0 \\
0 \\
6,750\end{array}$ & $\begin{array}{r}4,672 \\
519 \\
8 \\
0 \\
5,198\end{array}$ & $\begin{array}{r}3,291,015 \\
200,0000 \\
0 \\
62,473 \\
3,34,5,542\end{array}$ \\
\hline 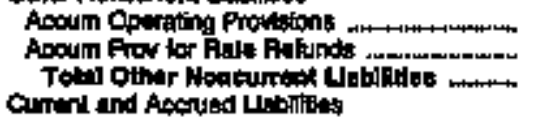 & $\begin{array}{r}2,507 \\
0 \\
2,6 \theta 7\end{array}$ & $\begin{array}{l}0 \\
0 \\
0\end{array}$ & $\begin{array}{l}0 \\
0 \\
0\end{array}$ & $\begin{array}{l}0 \\
0 \\
0\end{array}$ & $\begin{array}{l}0 \\
0 \\
0\end{array}$ & $\begin{array}{r}17,028 \\
0 \\
17,028\end{array}$ \\
\hline 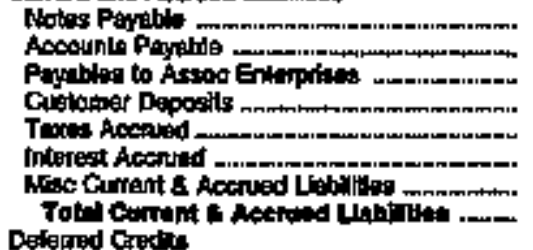 & $\begin{array}{r}0 \\
306 \\
160 \\
1,300 \\
200 \\
200 \\
2,076\end{array}$ & $\begin{array}{r}0 \\
1,349 \\
11 \\
78 \\
0 \\
302 \\
460 \\
2,169\end{array}$ & $\begin{array}{r}100 \\
1+16 \\
0 \\
36 \\
0 \\
05 \\
51 \\
54 \\
042\end{array}$ & $\begin{array}{r}0 \\
30 \\
0 \\
108 \\
0 \\
140 \\
0 \\
670\end{array}$ & $\begin{array}{r}0 \\
610 \\
0 \\
08 \\
101 \\
145 \\
856 \\
1,761\end{array}$ & $\begin{array}{r}160,315 \\
21,291 \\
0 \\
0 \\
0 \\
3,397 \\
169,414 \\
364,417\end{array}$ \\
\hline 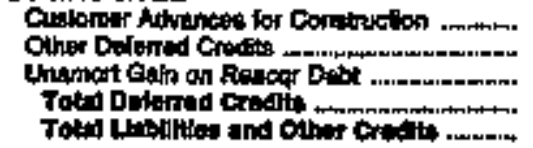 & $\begin{array}{r}100 \\
0 \\
0 \\
109 \\
21,562\end{array}$ & $\begin{array}{r}200 \\
0 \\
0 \\
200 \\
0\end{array}$ & $\begin{array}{r}0 \\
0 \\
0 \\
0 \\
11,011\end{array}$ & $\begin{array}{r}271 \\
0 \\
0 \\
271 \\
19871\end{array}$ & $\begin{array}{r}0 \\
0 \\
0 \\
0 \\
23,581\end{array}$ & $\begin{array}{r}0 \\
614,028 \\
0 \\
614,023 \\
5,70,051\end{array}$ \\
\hline
\end{tabular}

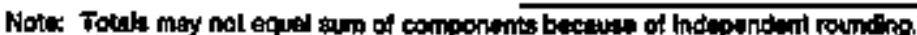

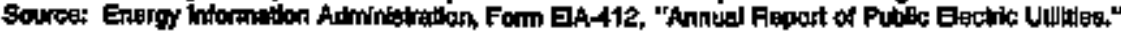


Table 22. Balance Sheet by Major U.S. Publicly Owned Electric Utilly Within State at End of Perlod, 1994

(Thousand Dollars)

\begin{tabular}{|c|c|c|c|c|c|c|}
\hline Ilam & $\begin{array}{l}\text { How York } \\
\text { Pockille } \\
\text { Contre } \\
\text { Whay of } \\
\text { Mey at }\end{array}$ & $\begin{array}{l}\text { Now York } \\
\text { Solvay } \\
\text { Villinge of } \\
\text { May } 31\end{array}$ & 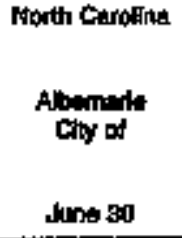 & $\begin{array}{l}\text { Noth Carolin } \\
\text { Concond } \\
\text { Ciny of } \\
\text { tunn } 30\end{array}$ & 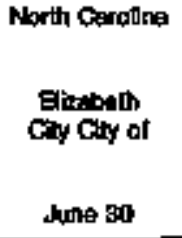 & 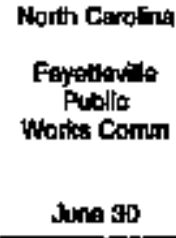 \\
\hline 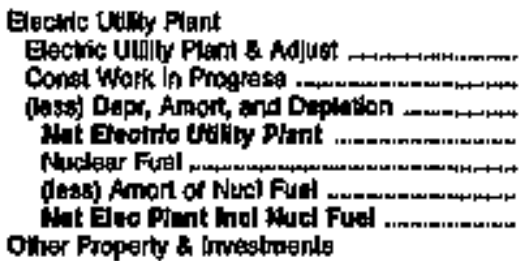 & $\begin{array}{r}28,166 \\
6,961 \\
13,592 \\
21,444 \\
0 \\
0 \\
21,444\end{array}$ & $\begin{array}{r}10,460 \\
0 \\
4,058 \\
0,370 \\
0 \\
0 \\
0,376\end{array}$ & $\begin{array}{r}18,792 \\
0 \\
10,2099 \\
8,502 \\
0 \\
0 \\
8,502\end{array}$ & $\begin{array}{r}35,678 \\
0 \\
10,395 \\
19,3+5 \\
0 \\
0 \\
10,313\end{array}$ & $\begin{array}{r}24,659 \\
0 \\
0,097 \\
16,912 \\
0 \\
0 \\
10,512\end{array}$ & $\begin{array}{r}218,262 \\
13,128 \\
65,447 \\
165,907 \\
0 \\
0 \\
165,063\end{array}$ \\
\hline 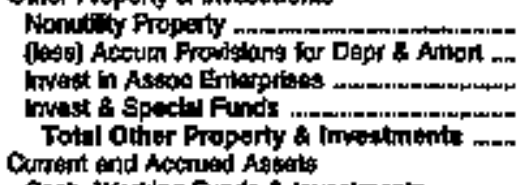 & $\begin{array}{r}0 \\
0 \\
0 \\
-349 \\
2 \$ 48\end{array}$ & $\begin{array}{l}0 \\
0 \\
0 \\
1 \\
1\end{array}$ & $\begin{array}{l}0 \\
0 \\
0 \\
0 \\
0\end{array}$ & $\begin{array}{l}0 \\
0 \\
0 \\
0 \\
0\end{array}$ & $\begin{array}{r}0 \\
143 \\
0 \\
148\end{array}$ & $\begin{array}{l}0 \\
0 \\
0 \\
0 \\
0\end{array}$ \\
\hline 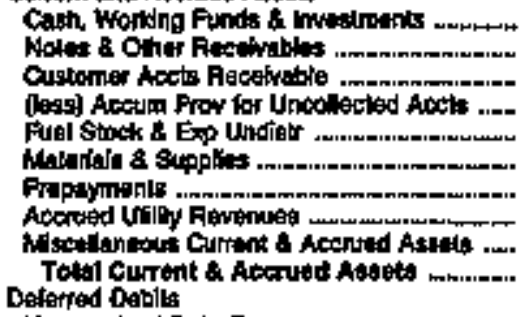 & $\begin{array}{r}1,675 \\
1,120 \\
979 \\
169 \\
0 \\
1,461 \\
127 \\
597 \\
1,509 \\
7,209\end{array}$ & $\begin{array}{r}571 \\
13 \\
1,057 \\
699 \\
0 \\
361 \\
0 \\
0 \\
38 \\
1,328\end{array}$ & $\begin{array}{r}2,752 \\
0 \\
1,958 \\
0 \\
0 \\
1,144 \\
5 \\
0 \\
0 \\
5,057\end{array}$ & $\begin{array}{r}9,028 \\
672 \\
3,017 \\
0 \\
0 \\
2,660 \\
0 \\
0 \\
0 \\
14,772\end{array}$ & $\begin{array}{r}3,455 \\
1,000 \\
2,657 \\
106 \\
0 \\
1,305 \\
0 \\
0 \\
9 \\
0,214\end{array}$ & $\begin{array}{r}27,190 \\
2,365 \\
14,149 \\
45 \\
1,595 \\
6,376 \\
64 \\
0 \\
604 \\
02,200\end{array}$ \\
\hline 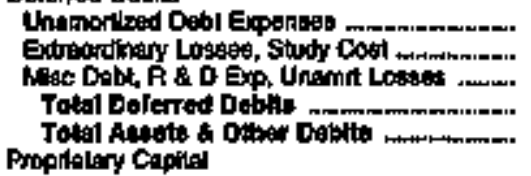 & $\begin{array}{r}240 \\
0 \\
0 \\
247 \\
20,642\end{array}$ & $\begin{array}{r}0 \\
0 \\
50 \\
50 \\
7,760\end{array}$ & $\begin{array}{r}0 \\
0 \\
0 \\
0 \\
0 \\
4,350\end{array}$ & $\begin{array}{r}364 \\
0 \\
0 \\
364 \\
91,49\end{array}$ & $\begin{array}{r}\stackrel{0}{0} \\
\stackrel{0}{0} \\
24,899\end{array}$ & $\begin{array}{r}0 \\
0 \\
3,060 \\
3,060 \\
224211\end{array}$ \\
\hline 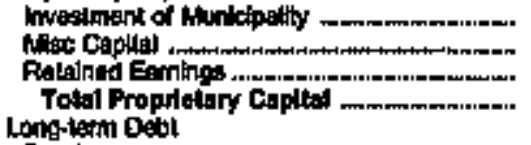 & $\begin{array}{r}-0,801 \\
0 \\
17,700 \\
10,978\end{array}$ & $\begin{array}{r}0 \\
0 \\
4,582 \\
4,582\end{array}$ & $\begin{array}{r}6,315 \\
0 \\
7,175 \\
t, 400\end{array}$ & $\begin{array}{r}0 \\
0 \\
16,371 \\
10,871\end{array}$ & $\begin{array}{r}157 \\
0 \\
22,506 \\
21,760\end{array}$ & $\begin{array}{r}0 \\
0 \\
197,554 \\
137,554\end{array}$ \\
\hline 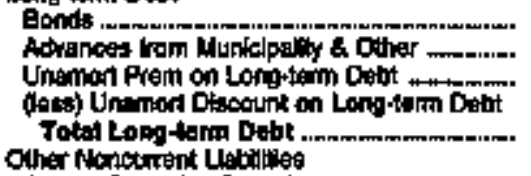 & $\begin{array}{r}12,57 \\
0 \\
0 \\
0 \\
12,571\end{array}$ & $\begin{array}{r}1,555 \\
28 \\
0 \\
1,670\end{array}$ & $\begin{array}{l}0 \\
0 \\
0 \\
0 \\
0\end{array}$ & $\begin{array}{r}11,409 \\
047 \\
0 \\
0 \\
11,716\end{array}$ & $\begin{array}{l}0 \\
0 \\
0 \\
0 \\
0\end{array}$ & $\begin{array}{r}70,881 \\
0 \\
0 \\
0 \\
70,001\end{array}$ \\
\hline 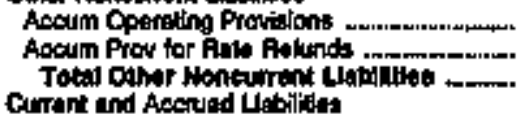 & $\begin{array}{r}1,410 \\
0 \\
1,410\end{array}$ & 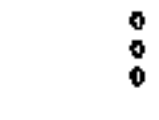 & $\begin{array}{l}0 \\
0 \\
0\end{array}$ & $\begin{array}{l}0 \\
0 \\
0\end{array}$ & $\begin{array}{l}0 \\
0 \\
0\end{array}$ & $\begin{array}{l}0 \\
0 \\
0\end{array}$ \\
\hline 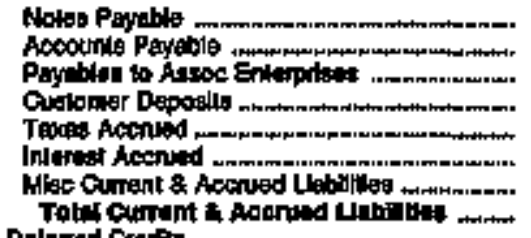 & $\begin{array}{r}1,600 \\
1,001 \\
0 \\
369 \\
0 \\
208 \\
258 \\
20,350\end{array}$ & $\begin{array}{r}125 \\
215 \\
433 \\
39 \\
16 \\
40 \\
12 \\
100\end{array}$ & $\begin{array}{r}0 \\
1,671 \\
0 \\
109 \\
0 \\
0 \\
0 \\
1,967\end{array}$ & $\begin{array}{r}0 \\
2770 \\
209 \\
286 \\
0 \\
55 \\
85 \\
3958\end{array}$ & $\begin{array}{r}0 \\
1,745 \\
0 \\
291 \\
0 \\
0 \\
09 \\
2,119\end{array}$ & $\begin{array}{r}0 \\
10,088 \\
0 \\
1,45 \\
1,258 \\
0 \\
12,78\end{array}$ \\
\hline 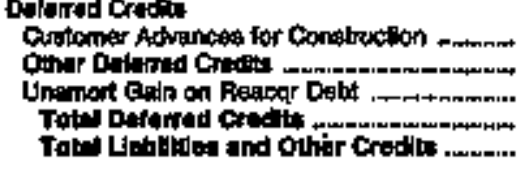 & $\begin{array}{r}0 \\
\operatorname{ang} \\
0 \\
927 \\
25,942\end{array}$ & $\begin{array}{r}75 \\
0 \\
0 \\
7,76\end{array}$ & $\begin{array}{r}0 \\
3 \\
0 \\
\mathbf{3} \\
10,360\end{array}$ & $\begin{array}{r}0 \\
0 \\
0 \\
0 \\
31,49\end{array}$ & $\begin{array}{r}0 \\
0 \\
0 \\
0 \\
24,860\end{array}$ & $\begin{array}{r}0 \\
0 \\
0 \\
0 \\
2212+1\end{array}$ \\
\hline
\end{tabular}

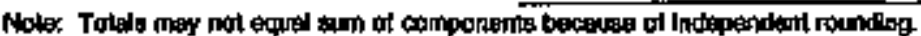

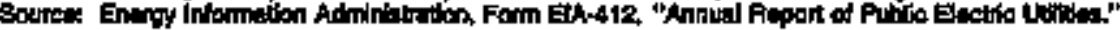


Table 22. Balance Sheet by Major US. Publlely Owned Electric Utllity Whithin State at End of Perlod, 1994 (Thousand Dollars)

\begin{tabular}{|c|c|c|c|c|c|c|}
\hline then & $\begin{array}{l}\text { North Ceroling } \\
\text { Foneat Chy } \\
\text { Town of } \\
\text { June } 30\end{array}$ & $\begin{array}{l}\text { North Caralling } \\
\text { Gexionif } \\
\text { Caty of } \\
\text { June } 30\end{array}$ & 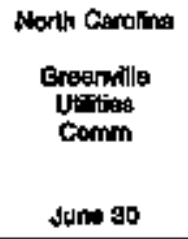 & $\begin{array}{l}\text { North Corosina } \\
\text { High } \\
\text { Point } \\
\text { Toim } \\
\text { of } \\
\text { June } 30\end{array}$ & $\begin{array}{l}\text { North Cerolinim } \\
\text { Kinston } \\
\text { Ciny of } \\
\text { June } 30\end{array}$ & $\begin{array}{l}\text { North Guroling } \\
\text { Lenthotion } \\
\text { Chy of } \\
\text { Jing } 30\end{array}$ \\
\hline 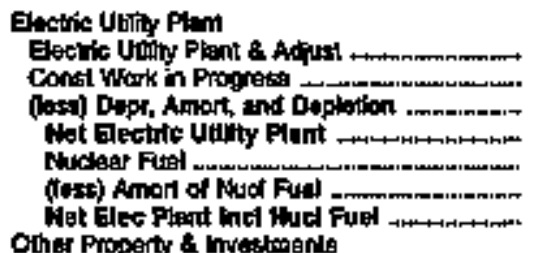 & $\begin{array}{r}6,300 \\
0 \\
2,498 \\
3,904 \\
0 \\
0 \\
2,604\end{array}$ & $\begin{array}{r}38,981 \\
0 \\
19,871 \\
10,060 \\
0 \\
0 \\
19,680\end{array}$ & $\begin{array}{r}67,430 \\
0 \\
49,401 \\
41,015 \\
0 \\
0 \\
44,025\end{array}$ & $\begin{array}{r}67,810 \\
5 \% \\
23,810 \\
\$ 4,847 \\
0 \\
0 \\
84,347\end{array}$ & $\begin{array}{r}19,679 \\
77 \\
7,951 \\
11,909 \\
0 \\
0 \\
11,909\end{array}$ & $\begin{array}{r}28,599 \\
375 \\
0,655 \\
1,310 \\
0 \\
0 \\
19,519\end{array}$ \\
\hline 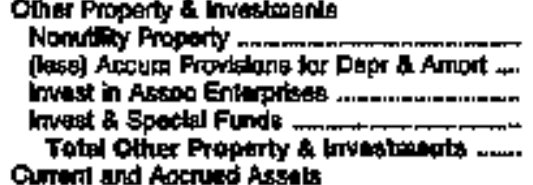 & $\begin{array}{r}0 \\
0 \\
0 \\
1,745 \\
1,748\end{array}$ & $\begin{array}{l}0 \\
0 \\
0 \\
0 \\
0 \\
0\end{array}$ & $\begin{array}{l}0 \\
0 \\
0 \\
0 \\
0\end{array}$ & $\begin{array}{l}0 \\
0 \\
0 \\
0 \\
0\end{array}$ & $\begin{array}{l}0 \\
0 \\
0 \\
0 \\
0\end{array}$ & $\begin{array}{l}0 \\
0 \\
0 \\
0 \\
0\end{array}$ \\
\hline 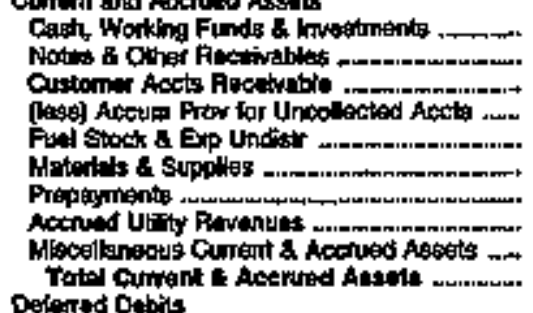 & $\begin{array}{r}4,197 \\
0 \\
440 \\
0 \\
0 \\
0 \\
0 \\
0 \\
0 \\
4,643\end{array}$ & $\begin{array}{r}4,462 \\
0 \\
4,359 \\
2,496 \\
0 \\
419 \\
0 \\
0 \\
3,676 \\
10,462\end{array}$ & $\begin{array}{r}14,241 \\
83 \\
11,117 \\
0 \\
0 \\
1,908 \\
225 \\
0 \\
365 \\
27,944\end{array}$ & $\begin{array}{r}16,160 \\
0 \\
3,052 \\
0 \\
0 \\
0 \\
0 \\
0 \\
112 \\
19,304\end{array}$ & $\begin{array}{r}5,737 \\
278 \\
4,113 \\
262 \\
0 \\
018 \\
0 \\
0 \\
0 \\
11,675\end{array}$ & $\begin{array}{r}347 \\
2,409 \\
0 \\
0 \\
0 \\
380 \\
944 \\
500 \\
1,587 \\
\mathbf{8 , 1 7 6}\end{array}$ \\
\hline 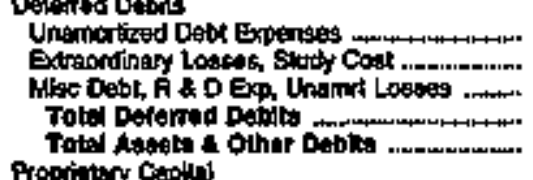 & $\begin{array}{r}0 \\
0 \\
0 \\
0 \\
9,102\end{array}$ & $\begin{array}{r}\mathbf{0} \\
\mathbf{0} \\
0 \\
\mathbf{0} \\
29,722\end{array}$ & $\begin{array}{r}0 \\
0 \\
0 \\
0 \\
71,9 \pi 4\end{array}$ & $\begin{array}{r}0 \\
0 \\
0 \\
0 \\
03,0000\end{array}$ & $\begin{array}{r}17 \\
0 \\
0 \\
17 \\
20,5 \% 8\end{array}$ & $\begin{array}{r}0 \\
0 \\
0 \\
0 \\
0 \\
0\end{array}$ \\
\hline 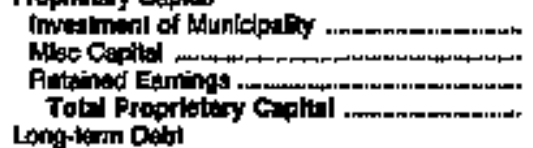 & $\begin{array}{r}2,308 \\
0 \\
8,084 \\
8,372\end{array}$ & $\begin{array}{r}4,109 \\
21,628 \\
25,980\end{array}$ & $\begin{array}{r}0 \\
0 \\
59,167 \\
59,167\end{array}$ & $\begin{array}{r}0 \\
158 \\
47,951 \\
48,190\end{array}$ & $\begin{array}{r}0 \\
0 \\
16,379 \\
16,379\end{array}$ & $\begin{array}{r}4,197 \\
0 \\
8,917 \\
13,055\end{array}$ \\
\hline 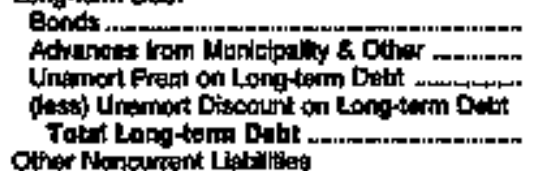 & $\begin{array}{l}0 \\
0 \\
0 \\
0 \\
0 \\
0\end{array}$ & $\begin{array}{l}0 \\
0 \\
0 \\
0\end{array}$ & $\begin{array}{r}2,0019 \\
0 \\
0 \\
0 \\
2,015\end{array}$ & $\begin{array}{r}150 \\
365 \\
360 \\
0 \\
595\end{array}$ & $\begin{array}{r}2,371 \\
1,163 \\
0 \\
0 \\
3,654\end{array}$ & $\begin{array}{r}210 \\
8,15 \\
0 \\
0 \\
0,967\end{array}$ \\
\hline 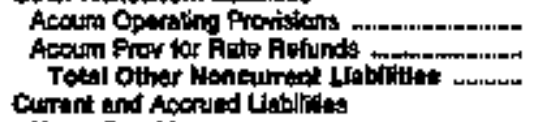 & $\begin{array}{l}0 \\
0 \\
0\end{array}$ & 9 & $\begin{array}{l}0 \\
0 \\
0\end{array}$ & $\begin{array}{l}0 \\
0 \\
0\end{array}$ & $\begin{array}{l}0 \\
0 \\
0\end{array}$ & $\begin{array}{l}0 \\
0 \\
0\end{array}$ \\
\hline 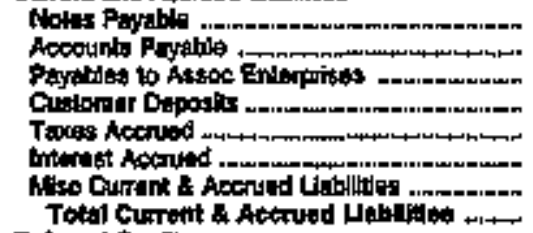 & $\begin{array}{r}0 \\
604 \\
0 \\
206 \\
0 \\
0 \\
9 \\
819\end{array}$ & $\begin{array}{r}0 \\
3,492 \\
0 \\
194 \\
0 \\
0 \\
107 \\
9,747\end{array}$ & $\begin{array}{r}0 \\
0,671 \\
0 \\
5 \% 0 \\
0 \\
49 \\
1,316 \\
10,608\end{array}$ & $\begin{array}{r}0 \\
4,578 \\
58 \\
215 \\
0 \\
7 \\
188 \\
5,048\end{array}$ & $\begin{array}{r}0 \\
3,071 \\
68 \\
460 \\
6 \\
0 \\
76 \\
3,0962\end{array}$ & $\begin{array}{r}1,000 \\
2,523 \\
0 \\
0 \\
0 \\
0 \\
0 \\
41 \\
4074\end{array}$ \\
\hline 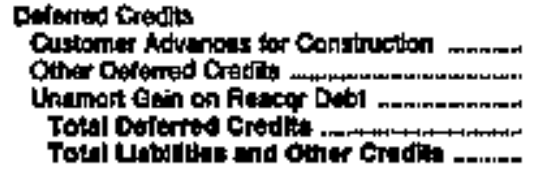 & $\begin{array}{r}0 \\
0 \\
0 \\
0 \\
0,192\end{array}$ & $29,72 \frac{0}{0}$ & $\begin{array}{r}177 \\
0 \\
0 \\
17 \\
71,974\end{array}$ & $\begin{array}{r}0 \\
0 \\
0 \\
0 \\
0,8,0\end{array}$ & $\begin{array}{r}0 \\
6 \\
6 \\
0 \\
20,509\end{array}$ & $\begin{array}{r}0 \\
0 \\
0 \\
0 \\
25,40+5\end{array}$ \\
\hline
\end{tabular}

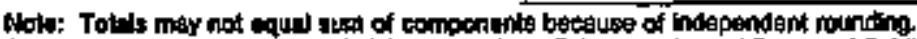

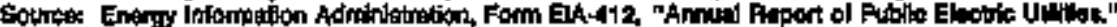


Table 22. Balance Sheet by Major US. Publicly Owned Electric Utility Withiti State at End of Period, 1994

(Thousand Dollars)

\begin{tabular}{|c|c|c|c|c|c|c|}
\hline bem & $\begin{array}{l}\text { North Caroling } \\
\text { Lumbertum } \\
\text { Chy of } \\
\text { June so }\end{array}$ & $\begin{array}{l}\text { North Garolina } \\
\text { Chinget } \\
\text { June on }\end{array}$ & 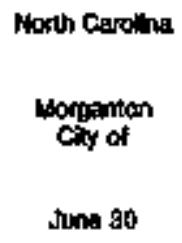 & $\begin{array}{l}\text { North Cerolne } \\
\text { Wungly of } \\
\text { June so }\end{array}$ & $\begin{array}{l}\text { North Caroling } \\
\text { Nont Eam } \\
\text { Chy of } \\
\text { June } 30\end{array}$ & $\begin{array}{l}\text { Norith Gercilna } \\
\text { Now Pher } \\
\text { Light } \\
\text { Porrer Co } \\
\text { Docomber } 31\end{array}$ \\
\hline 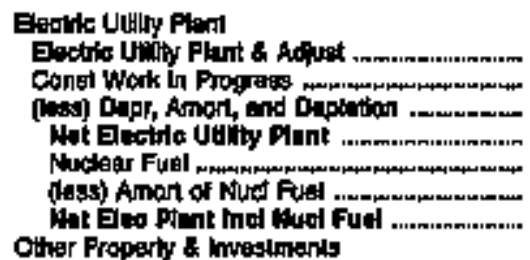 & $\begin{array}{r}11,340 \\
2 \\
6,198 \\
6,157 \\
0 \\
0 \\
0,157\end{array}$ & $\begin{array}{r}22,470 \\
3,522 \\
7,248 \\
18,762 \\
0 \\
0 \\
10,792\end{array}$ & $\begin{array}{r}11,288 \\
1,247 \\
4,968 \\
7,597 \\
0 \\
7,537\end{array}$ & $\begin{array}{r}7,500 \\
174 \\
2,252 \\
5,423 \\
0 \\
0 \\
5,420\end{array}$ & $\begin{array}{r}21,990 \\
137 \\
9,730 \\
12,408 \\
0 \\
12,40\end{array}$ & $\begin{array}{r}11,111 \\
1 \\
3,834 \\
6,270 \\
0 \\
0 \\
0,270\end{array}$ \\
\hline 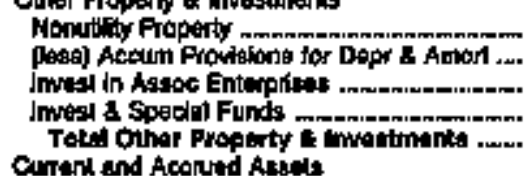 & $\begin{array}{l}0 \\
0 \\
0 \\
0 \\
0\end{array}$ & $\begin{array}{r}0 \\
0 \\
0 \\
4,771 \\
4,71\end{array}$ & $\begin{array}{l}0 \\
0 \\
0 \\
0 \\
0\end{array}$ & $\begin{array}{r}0 \\
0 \\
0 \\
1,861 \\
1,951\end{array}$ & $\begin{array}{l}0 \\
0 \\
0 \\
0 \\
0\end{array}$ & $\begin{array}{r}0 \\
0 \\
6,618 \\
2,200 \\
7,0015\end{array}$ \\
\hline 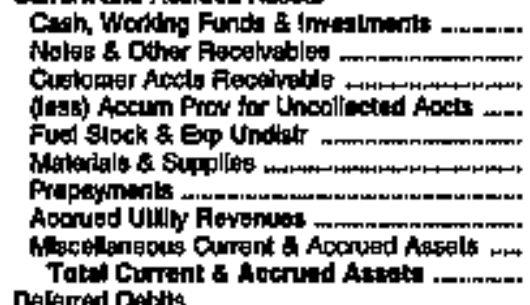 & $\begin{array}{r}3,319 \\
42 \\
1,235 \\
0 \\
0 \\
376 \\
0 \\
0 \\
0 \\
4,870\end{array}$ & $\begin{array}{r}18,093 \\
0 \\
1,946 \\
0 \\
0 \\
1,143 \\
0 \\
0 \\
0 \\
21,055\end{array}$ & $\begin{array}{r}5,859 \\
677 \\
1,697 \\
0 \\
0 \\
0 \\
0 \\
0 \\
61 \\
9627\end{array}$ & $\begin{array}{r}699 \\
642 \\
0 \\
0 \\
0 \\
135 \\
118 \\
0 \\
1,404\end{array}$ & $\begin{array}{r}4,978 \\
0 \\
4,006 \\
0 \\
0 \\
1,040 \\
0 \\
0 \\
0 \\
10 ; 013\end{array}$ & $\begin{array}{r}38 \\
1,113 \\
33 \\
30 \\
0 \\
394 \\
17 \\
0 \\
0 \\
1,508\end{array}$ \\
\hline 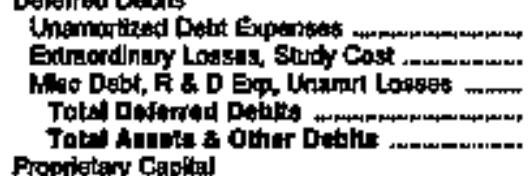 & $\begin{array}{r}0 \\
0 \\
0 \\
0 \\
10,12 \%\end{array}$ & $\begin{array}{r}0 \\
177 \\
177 \\
44,745\end{array}$ & $\begin{array}{r}0 \\
0 \\
0 \\
0 \\
16,164\end{array}$ & $\begin{array}{r}0 \\
56 \\
50 \\
504\end{array}$ & $\begin{array}{r}0 \\
0 \\
0 \\
0 \\
0 \\
0\end{array}$ & $\begin{array}{r}0 \\
0 \\
0 \\
0 \\
17,6 \Delta 0\end{array}$ \\
\hline 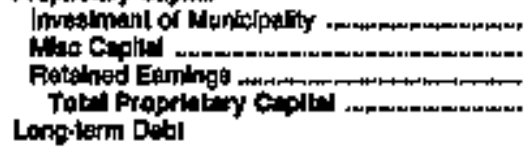 & $\begin{array}{r}857 \\
0 \\
6,606 \\
7,550\end{array}$ & $\begin{array}{r}0 \\
997 \\
39270 \\
37,267\end{array}$ & $\begin{array}{r}3,172 \\
0 \\
11,369 \\
14,000\end{array}$ & $\begin{array}{r}0 \\
0 \\
8,103 \\
8,10 \%\end{array}$ & $\begin{array}{r}4,511 \\
0 \\
13,319 \\
17,1890\end{array}$ & $\begin{array}{r}0 \\
0 \\
15,975 \\
15,975\end{array}$ \\
\hline 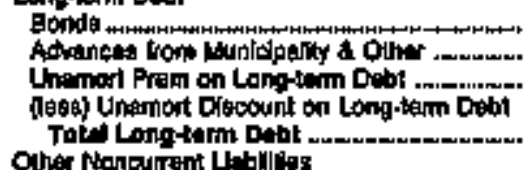 & $\begin{array}{l}0 \\
0 \\
0 \\
0 \\
0\end{array}$ & $\begin{array}{l}0 \\
0 \\
0 \\
0 \\
0\end{array}$ & $\begin{array}{l}0 \\
0 \\
0 \\
0 \\
0\end{array}$ & $\begin{array}{r}0 \\
4 \\
0 \\
4\end{array}$ & $\begin{array}{r}0 \\
526 \\
0 \\
0 \\
526\end{array}$ & $\begin{array}{r}0 \\
460 \\
0 \\
450\end{array}$ \\
\hline 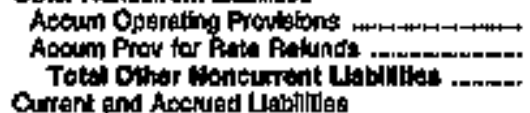 & $\begin{array}{r}58 \\
\mathbf{0} \\
\mathbf{B 8}\end{array}$ & $\begin{array}{l}0 \\
0 \\
0\end{array}$ & $\begin{array}{l}0 \\
0 \\
0\end{array}$ & $\begin{array}{l}0 \\
0 \\
0\end{array}$ & $\begin{array}{l}0 \\
0 \\
0\end{array}$ & $\begin{array}{l}0 \\
0 \\
0\end{array}$ \\
\hline 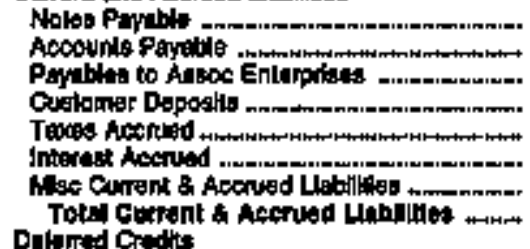 & $\begin{array}{r}0 \\
2,517 \\
0 \\
0 \\
0 \\
0 \\
0 \\
2,547\end{array}$ & $\begin{array}{r}4,952 \\
2,125 \\
0 \\
398 \\
0 \\
0 \\
29 \\
7,490\end{array}$ & $\begin{array}{r}0 \\
1,417 \\
0 \\
211 \\
0 \\
0 \\
0 \\
1,05 \%\end{array}$ & $\begin{array}{r}0 \\
492 \\
0 \\
216 \\
0 \\
0 \\
0 \\
0\end{array}$ & $\begin{array}{r}400 \\
2679 \\
0 \\
817 \\
0 \\
0 \\
77 \\
4090\end{array}$ & $\begin{array}{r}190 \\
921 \\
0 \\
206 \\
0 \\
14 \\
1,175\end{array}$ \\
\hline 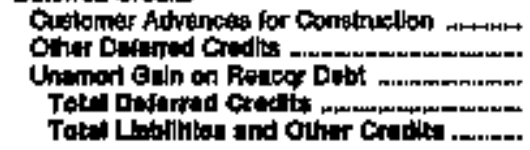 & $\begin{array}{r}0 \\
0 \\
0 \\
+0 \\
10,12 \pi\end{array}$ & $\begin{array}{r}0 \\
0 \\
0 \\
0 \\
44,758\end{array}$ & $\begin{array}{r}0 \\
0 \\
0 \\
0 \\
18, \mathbf{r a d}\end{array}$ & $\begin{array}{r}0 \\
0 \\
0 \\
0\end{array}$ & $\begin{array}{r}0 \\
0 \\
0 \\
0 \\
02410\end{array}$ & $\begin{array}{r}0 \\
0 \\
0 \\
17,000\end{array}$ \\
\hline
\end{tabular}

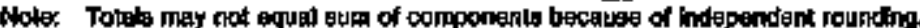

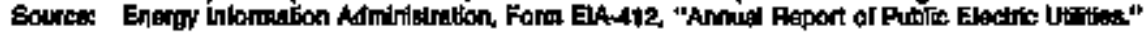


Table 22. Balance Sheet by Major U.S. Publicly Owned Electric Utility Whthin state at End of Period, 1994

(Thousand Dollers)

\begin{tabular}{|c|c|c|c|c|c|c|}
\hline lem & 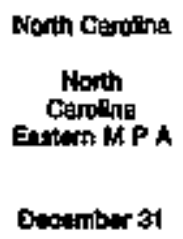 & 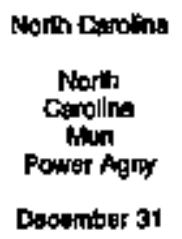 & 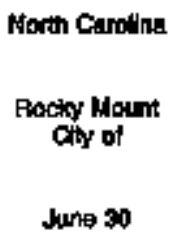 & $\begin{array}{l}\text { North Coring } \\
\text { Shatry } \\
\text { City of } \\
\text { June so }\end{array}$ & $\begin{array}{l}\text { North Caroina } \\
\text { Statesville } \\
\text { City of } \\
\text { June a0 }\end{array}$ & $\begin{array}{l}\text { Horth Cerolisa } \\
\text { Torborto } \\
\text { Town of } \\
\text { June } 30\end{array}$ \\
\hline 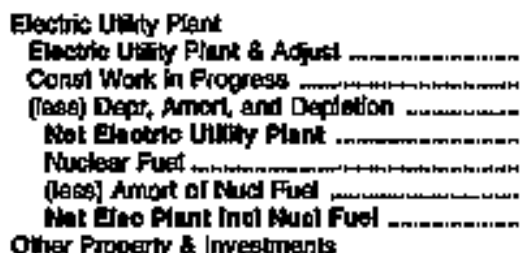 & $\begin{array}{r}1,410,129 \\
29,741 \\
404,200 \\
1,086,070 \\
74,090 \\
47,002 \\
1,062,069\end{array}$ & $\begin{array}{r}1,409,624 \\
18,948 \\
391,412 \\
1,099,168 \\
129,091 \\
73,276 \\
1,138,016\end{array}$ & 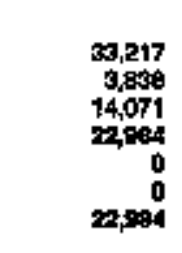 & $\begin{array}{r}8,2,29 \\
2,090 \\
4,617 \\
3,791 \\
0 \\
0 \\
3,711\end{array}$ & $\begin{array}{r}15,5 \% 0 \\
357 \\
6,527 \\
0,419 \\
0 \\
0 \\
0,419\end{array}$ & $\begin{array}{r}17,046 \\
0,052 \\
11,797 \\
0 \\
0 \\
01,797\end{array}$ \\
\hline 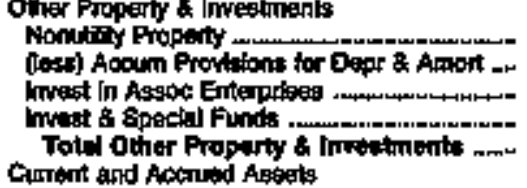 & $\begin{array}{r}2,370 \\
982 \\
0 \\
679,251 \\
691,240\end{array}$ & $\begin{array}{r}3,168 \\
1,215 \\
0 \\
364,590 \\
376,-151\end{array}$ & $\begin{array}{l}0 \\
0 \\
0 \\
0 \\
0 \\
0\end{array}$ & $\begin{array}{r}9 \\
0 \\
0 \\
109 \\
100\end{array}$ & $\begin{array}{r}970 \\
480 \\
0 \\
0 \\
496\end{array}$ & $\begin{array}{l}0 \\
0 \\
0 \\
0 \\
0\end{array}$ \\
\hline 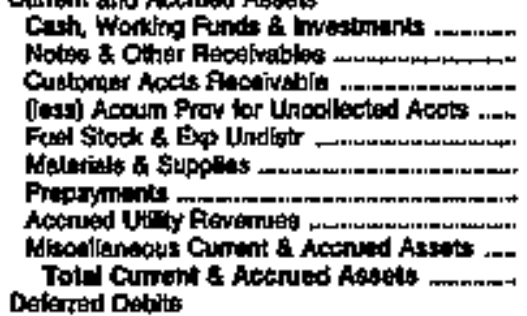 & $\begin{array}{r}210,010 \\
0 \\
31,052 \\
0 \\
6,006 \\
8,402 \\
098 \\
0 \\
0 \\
207,50 \%\end{array}$ & $\begin{array}{r}2,24,5 \\
13,342 \\
16,509 \\
0 \\
0 \\
0 \\
15,1+2 \\
10 \\
0 \\
576,361 \\
648,848\end{array}$ & $\begin{array}{r}1,914 \\
215 \\
6,790 \\
0 \\
0 \\
577 \\
0 \\
0 \\
0 \\
9,494\end{array}$ & $\begin{array}{r}3,155 \\
33 \\
053 \\
0 \\
0 \\
272 \\
0 \\
0 \\
0 \\
4,314\end{array}$ & $\begin{array}{r}6,767 \\
29 \\
3,097 \\
307 \\
0 \\
1,089 \\
16 \\
0 \\
0 \\
11,200\end{array}$ & $\begin{array}{r}6.9391 \\
2,328 \\
0 \\
31 \\
0 \\
640 \\
4 \\
0 \\
4\end{array}$ \\
\hline 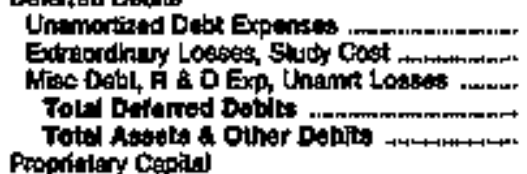 & $\begin{array}{r}39,677 \\
1,728,372 \\
1,790,890 \\
3,606,912\end{array}$ & $\begin{array}{r}34,540 \\
350,554 \\
90 \\
365,094 \\
2,927,128\end{array}$ & $\begin{array}{r}0 \\
0 \\
0 \\
0 \\
32,48\end{array}$ & $\begin{array}{r}8 \\
0 \\
6 \\
8 \\
8 \\
0,187\end{array}$ & $\begin{array}{r}0 \\
0 \\
0 \\
0 \\
21,163\end{array}$ & $\begin{array}{r}0 \\
0 \\
0 \\
0 \\
21,069\end{array}$ \\
\hline 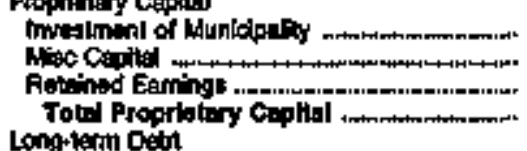 & $\begin{array}{r}0 \\
28,000 \\
20,000\end{array}$ & $\begin{array}{r}0 \\
0 \\
7,100 \\
7,100\end{array}$ & $\begin{array}{r}0 \\
811 \\
23,089 \\
23,950\end{array}$ & $\begin{array}{r}0 \\
4,000 \\
4,160\end{array}$ & $\begin{array}{r}35 \\
165 \\
18,150 \\
18,348\end{array}$ & $\begin{array}{r}008 \\
18,480 \\
19,986\end{array}$ \\
\hline 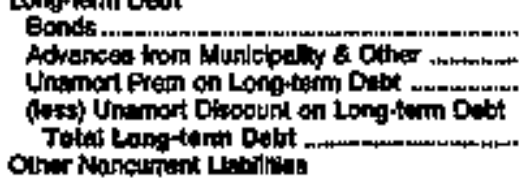 & $\begin{array}{r}3,472,275 \\
28,002 \\
10,017 \\
160,772 \\
5,990,976\end{array}$ & $\begin{array}{r}2,305,707 \\
249,744 \\
11,600 \\
191,139 \\
2,420,919\end{array}$ & $\begin{array}{r}1,057 \\
180 \\
0 \\
0 \\
1,896\end{array}$ & $\begin{array}{r}2,588 \\
0 \\
0 \\
0 \\
2,696\end{array}$ & $\begin{array}{r}394 \\
0 \\
0 \\
0 \\
0\end{array}$ & $\begin{array}{l}0 \\
0 \\
0 \\
0 \\
0\end{array}$ \\
\hline 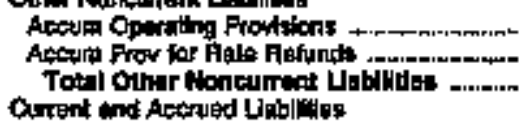 & $\begin{array}{l}0 \\
0 \\
0\end{array}$ & $\begin{array}{l}0 \\
0 \\
0\end{array}$ & $\begin{array}{l}0 \\
0 \\
0\end{array}$ & $\begin{array}{l}0 \\
0 \\
0\end{array}$ & $\begin{array}{r}6 \\
0 \\
0\end{array}$ & $\begin{array}{l}0 \\
0 \\
0\end{array}$ \\
\hline 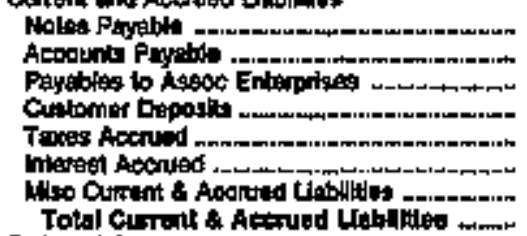 & $\begin{array}{r}139,605 \\
18,101 \\
0 \\
0 \\
5090 \\
107,850 \\
0 \\
971,598\end{array}$ & $\begin{array}{r}0 \\
3 \neq 7 \\
0 \\
0 \\
13,400 \\
67,253 \\
0 \\
07,073\end{array}$ & $\begin{array}{r}0 \\
5,03 \\
0 \\
0 \\
0 \\
72 \\
703 \\
7,112\end{array}$ & $\begin{array}{r}70 \\
950 \\
0 \\
364 \\
0 \\
14 \\
71 \\
790\end{array}$ & $\begin{array}{r}0 \\
2,260 \\
0 \\
60 \\
0 \\
4 \\
0 \\
2,859\end{array}$ & $\begin{array}{r}0 \\
2,040 \\
0 \\
198 \\
0 \\
0 \\
36 \\
2,273\end{array}$ \\
\hline 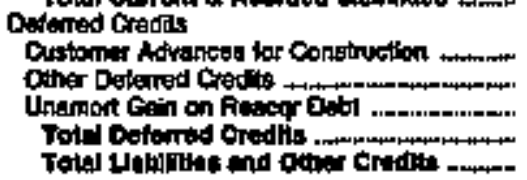 & $\begin{array}{r}0 \\
0 \\
0 \\
0 \\
0\end{array}$ & $\begin{array}{r}0 \\
8,740^{0} \\
5 \\
2,790^{5} \\
2,627,428\end{array}$ & 2,470 & $\begin{array}{r}0 \\
0 \\
0 \\
0 \\
0,167\end{array}$ & $\begin{array}{r}0 \\
0 \\
0 \\
0 \\
0 \\
21,163\end{array}$ & $21, \begin{array}{r}0 \\
0 \\
0 \\
0\end{array}$ \\
\hline
\end{tabular}

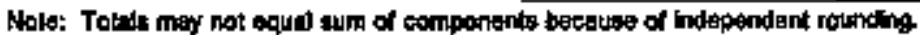

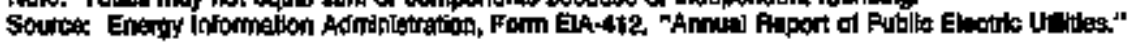


Table 22. Balance Sheet by Major U.S. Publicly Owned Electric Uttlity Within state at End of Perlod, 1994

(Thousand Dollars)

\begin{tabular}{|c|c|c|c|c|c|c|}
\hline ttem & $\begin{array}{l}\text { North Gurolina } \\
\text { Washingtan } \\
\text { Coly or } \\
\text { Jung so }\end{array}$ & 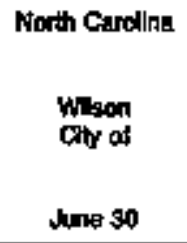 & 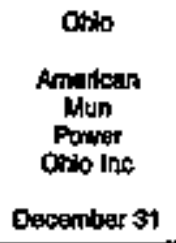 & 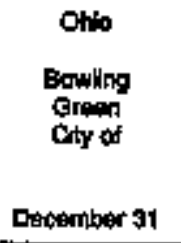 & $\begin{array}{l}\text { Crib } \\
\text { Byrin } \\
\text { Cryy of } \\
\text { Decepiber } 31\end{array}$ & $\begin{array}{l}\text { Ohio } \\
\text { Coxity of } \\
\text { Comber } 31\end{array}$ \\
\hline 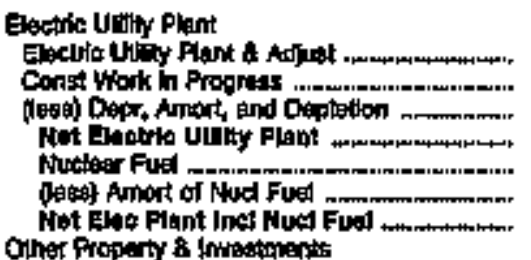 & $\begin{array}{r}26,215 \\
16 \\
11,763 \\
14,469 \\
0 \\
0 \\
14,480\end{array}$ & $\begin{array}{r}51,775 \\
0 \\
28,380 \\
25,455 \\
0 \\
0 \\
25,455\end{array}$ & $\begin{array}{r}0,910 \\
4,445 \\
19,109 \\
40,246 \\
0 \\
0 \\
49,246\end{array}$ & 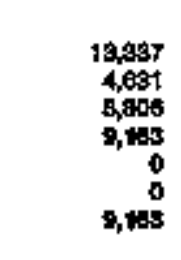 & $\begin{array}{r}14,862 \\
0 \\
11,221 \\
3,462 \\
0 \\
0 \\
3,460\end{array}$ & $\begin{array}{r}18,480 \\
0 \\
0 \\
15,400 \\
0 \\
0 \\
0 \\
10,400\end{array}$ \\
\hline 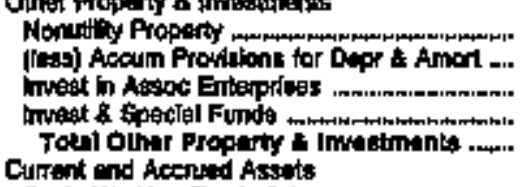 & $\begin{array}{l}0 \\
0 \\
0 \\
0 \\
0\end{array}$ & $\begin{array}{l}0 \\
0 \\
0 \\
0 \\
0\end{array}$ & $\begin{array}{r}1,995 \\
974 \\
0 \\
12,677 \\
13,694\end{array}$ & $\begin{array}{r}0 \\
0 \\
0 \\
2,483 \\
2,463\end{array}$ & $\begin{array}{l}0 \\
0 \\
0 \\
0 \\
0\end{array}$ & $\begin{array}{l}0 \\
0 \\
0 \\
0 \\
0\end{array}$ \\
\hline 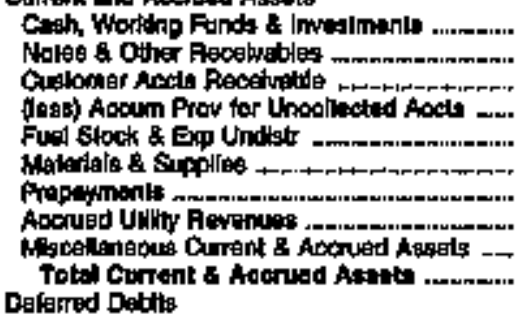 & $\begin{array}{r}6,840 \\
0 \\
2,322 \\
0 \\
0 \\
557 \\
0 \\
0 \\
0 \\
11,720\end{array}$ & $\begin{array}{r}22,960 \\
3: 2 \\
2,472 \\
192 \\
0 \\
1,254 \\
97 \\
6,000 \\
0 \\
32,909\end{array}$ & $\begin{array}{r}10,094 \\
132 \\
16,314 \\
0 \\
213 \\
5,157 \\
218 \\
0 \\
564 \\
32,600\end{array}$ & $\begin{array}{r}1,428 \\
0 \\
605 \\
0 \\
0 \\
1,007 \\
106 \\
890 \\
0 \\
5,941\end{array}$ & $\begin{array}{r}3,217 \\
14 \\
1,019 \\
0 \\
0 \\
394 \\
30 \\
0 \\
0 \\
4,673\end{array}$ & $\begin{array}{r}1,606 \\
0 \\
310 \\
267 \\
0 \\
609 \\
11 \\
601 \\
0 \\
7,890\end{array}$ \\
\hline 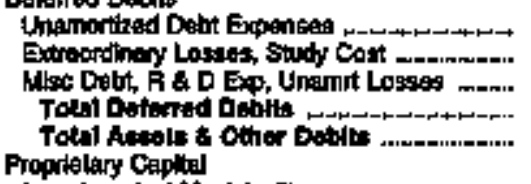 & $\begin{array}{r}0 \\
0 \\
0 \\
0 \\
26,187\end{array}$ & $\begin{array}{r}0 \\
0 \\
0 \\
0 \\
\text { se,jes }\end{array}$ & $\begin{array}{r}0 \\
0 \\
0 \\
0 \\
0\end{array}$ & $\begin{array}{r}0 \\
0 \\
0 \\
0 \\
16,686\end{array}$ & $\begin{array}{r}0 \\
0 \\
0 \\
0 \\
0\end{array}$ & $\begin{array}{r}0 \\
0 \\
0 \\
0 \\
21,20\end{array}$ \\
\hline 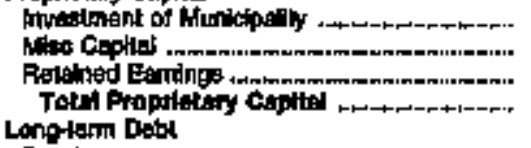 & $\begin{array}{r}810 \\
0 \\
18,252 \\
18,-50\end{array}$ & $\begin{array}{r}78 \\
10 \\
50,161 \\
50,240\end{array}$ & $\begin{array}{r}565 \\
0 \\
3,054 \\
4,520\end{array}$ & $\begin{array}{r}11,56 ? \\
0 \\
1,481 \\
13,647\end{array}$ & $\begin{array}{r}0 \\
0 \\
6,094 \\
6,040\end{array}$ & $\begin{array}{r}10,059 \\
9 \\
1,605 \\
20,687\end{array}$ \\
\hline 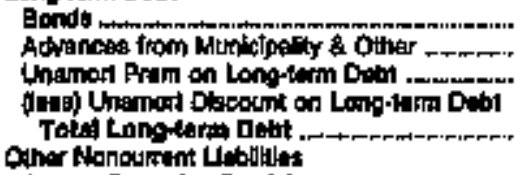 & $\begin{array}{r}4,647 \\
002 \\
0 \\
50 \\
5,449\end{array}$ & $\begin{array}{r}60 \\
0 \\
0 \\
0 \\
50\end{array}$ & $\begin{array}{r}0,000 \\
0 \\
0 \\
0 \\
0,000\end{array}$ & $\begin{array}{l}0 \\
0 \\
0 \\
0 \\
0\end{array}$ & $\begin{array}{l}0 \\
0 \\
0 \\
0 \\
0\end{array}$ & $\begin{array}{l}0 \\
0 \\
0 \\
0 \\
0\end{array}$ \\
\hline 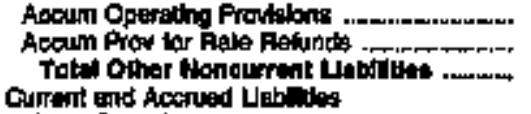 & $\begin{array}{l}0 \\
0 \\
0\end{array}$ & $\begin{array}{l}0 \\
0 \\
0\end{array}$ & $\begin{array}{l}0 \\
0 \\
0\end{array}$ & $\begin{array}{l}0 \\
0 \\
0\end{array}$ & $\begin{array}{l}0 \\
0 \\
0\end{array}$ & $\begin{array}{r}60 \\
0 \\
0\end{array}$ \\
\hline 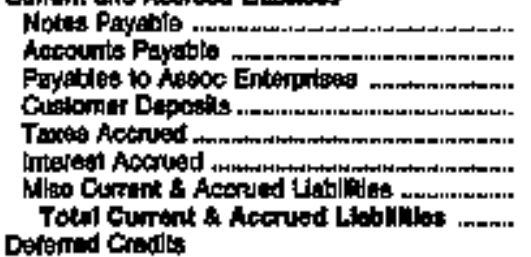 & $\begin{array}{r}0 \\
1,601 \\
0 \\
157 \\
0 \\
0 \\
131 \\
2,169\end{array}$ & $\begin{array}{r}5 \\
8,928 \\
9 \\
584 \\
0 \\
7 \\
1,197 \\
8,016\end{array}$ & $\begin{array}{r}0 \\
13,608 \\
141 \\
6 \\
6,025 \\
1,794 \\
3,200 \\
23,600\end{array}$ & $\begin{array}{r}8: 5 \\
1,328 \\
0 \\
0 \\
0 \\
11 \\
130 \\
2,294\end{array}$ & $\begin{array}{r}080 \\
150 \\
0 \\
0 \\
0 \\
0 \\
110 \\
1051\end{array}$ & $\begin{array}{r}0 \\
404 \\
0 \\
109 \\
0 \\
0 \\
0 \\
03\end{array}$ \\
\hline 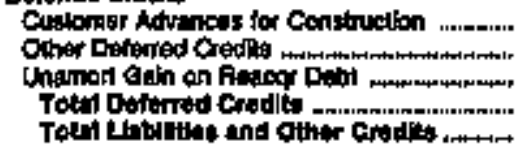 & $\begin{array}{r}0 \\
0 \\
0 \\
0 \\
26,187\end{array}$ & $\begin{array}{r}0 \\
0 \\
0 \\
0 \\
50,354\end{array}$ & $\begin{array}{r}0 \\
0,527 \\
0 \\
3,627 \\
0,1007\end{array}$ & $\begin{array}{r}256 \\
0 \\
0 \\
2.5 \\
25,400\end{array}$ & $\begin{array}{r}0 \\
0 \\
0 \\
0 \\
0,150\end{array}$ & $\begin{array}{r}0 \\
0 \\
0 \\
0 \\
21,320\end{array}$ \\
\hline
\end{tabular}

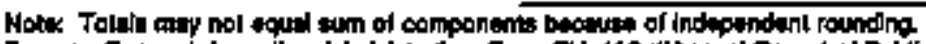

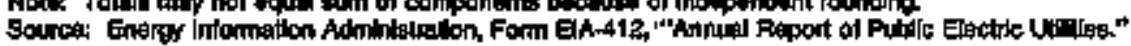


Tabłe 22. Balance Sheet by Major U.S. Publicly Owned Electric Utility Within State at End of Period, 1904

(Thousand Dollars)

\begin{tabular}{|c|c|c|c|c|c|c|}
\hline Itarn & $\begin{array}{l}\text { Onio } \\
\text { Cimidand } \\
\text { Othy of } \\
\text { Decentioer } 31\end{array}$ & $\begin{array}{l}\text { Otio } \\
\text { Cydt } \\
\text { Oly of } \\
\text { Decenniber } \$ 1\end{array}$ & $\begin{array}{l}\text { Onts } \\
\text { Columbus } \\
\text { Cly of } \\
\text { Doosmiter } 31\end{array}$ & 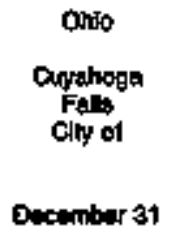 & $\begin{array}{l}\text { Onis } \\
\text { Dower } \\
\text { Chy of } \\
\text { Doomber } 31\end{array}$ & 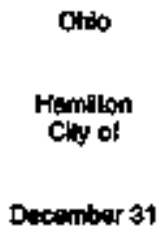 \\
\hline 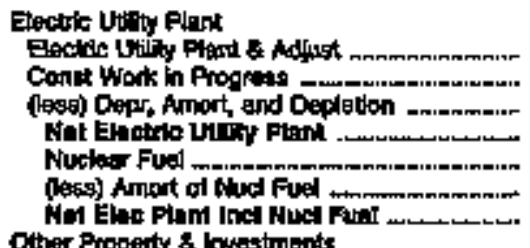 & 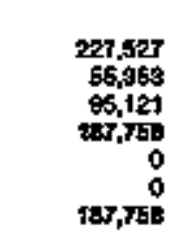 & $\begin{array}{r}10,765 \\
6 \\
6 \\
10,765 \\
0 \\
0 \\
10,765\end{array}$ & $\begin{array}{r}80,159 \\
0 \\
32,466 \\
47,671 \\
0 \\
0 \\
47,671\end{array}$ & $\begin{array}{r}20,728 \\
0 \\
10,907 \\
8,801 \\
0 \\
0 \\
0,891\end{array}$ & $\begin{array}{r}0,841 \\
0 \\
0 \\
8,141 \\
0 \\
0 \\
8,141\end{array}$ & $\begin{array}{r}232,558 \\
9,759 \\
79,206 \\
163,161 \\
0 \\
0 \\
163,161\end{array}$ \\
\hline 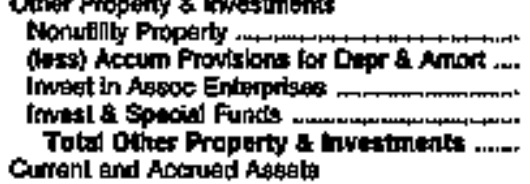 & $\begin{array}{r}0 \\
0 \\
0 \\
114,767 \\
114,707\end{array}$ & $\begin{array}{r}0 \\
0 \\
0 \\
1,254 \\
1,264\end{array}$ & $\begin{array}{r}0 \\
0 \\
11,0.06 \\
6,9=3 \\
18,029\end{array}$ & $\begin{array}{l}0 \\
0 \\
0 \\
0 \\
0\end{array}$ & $\begin{array}{l}0 \\
0 \\
0 \\
0 \\
0\end{array}$ & $\begin{array}{r}0 \\
0 \\
0 \\
27,020 \\
27,025\end{array}$ \\
\hline 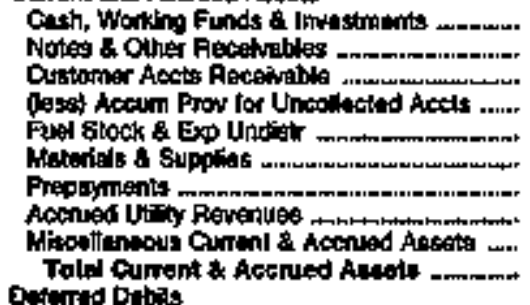 & $\begin{array}{r}8,258 \\
0 \\
1,016 \\
240 \\
0 \\
7,018 \\
16 \\
1,093 \\
28 \\
25,940\end{array}$ & $\begin{array}{r}1,841 \\
0 \\
695 \\
0 \\
0 \\
192 \\
1 \\
0 \\
11 \\
2,780\end{array}$ & $\begin{array}{r}4,049 \\
604 \\
4,205 \\
0 \\
0 \\
1,342 \\
0 \\
0 \\
0 \\
10,096\end{array}$ & $\begin{array}{r}7,010 \\
873 \\
2,400 \\
0 \\
0 \\
2,711 \\
40 \\
0 \\
0 \\
13,404\end{array}$ & $\begin{array}{r}1 \\
0 \\
1,067 \\
0 \\
0 \\
682 \\
95 \\
808 \\
2,941 \\
0,086\end{array}$ & $\begin{array}{r}5,858 \\
5,384 \\
0 \\
0 \\
0 \\
2,026 \\
240 \\
0 \\
5,500 \\
10,026\end{array}$ \\
\hline 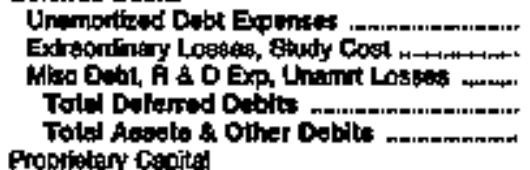 & $\begin{array}{r}3,041 \\
0 \\
0 \\
3,041 \\
301,500\end{array}$ & $\begin{array}{r}1,209 \\
0 \\
0 \\
1,200 \\
18,046\end{array}$ & $\begin{array}{r}0 \\
0 \\
590 \\
590 \\
76,57\end{array}$ & $\begin{array}{r}0 \\
0 \\
0 \\
0 \\
0\end{array}$ & $\begin{array}{r}0 \\
0 \\
0 \\
0\end{array}$ & $\begin{array}{r}2784 \\
0 \\
2784 \\
212,976\end{array}$ \\
\hline 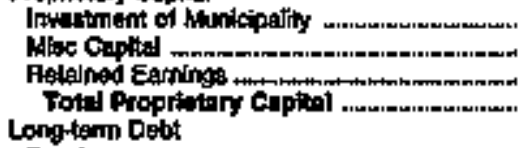 & $\begin{array}{r}12,+60 \\
0 \\
59,606 \\
71,042\end{array}$ & $\begin{array}{r}0 \\
4,186 \\
4,256\end{array}$ & $\begin{array}{r}16,519 \\
0 \\
-30,514 \\
-13,928\end{array}$ & $\begin{array}{r}0 \\
0 \\
17,290 \\
17,206\end{array}$ & $\begin{array}{r}135 \\
0 \\
0,200 \\
1,34\end{array}$ & $\begin{array}{r}0 \\
0 \\
-5,988 \\
-5,986\end{array}$ \\
\hline 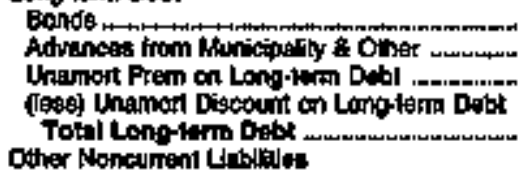 & 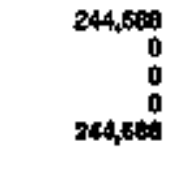 & $\begin{array}{r}10,905 \\
0 \\
0 \\
0 \\
10,005\end{array}$ & $\begin{array}{r}08,186 \\
0 \\
0 \\
0 \\
0 \%, 196\end{array}$ & $\begin{array}{r}3,5+5 \\
0 \\
0 \\
0 \\
3,5,55\end{array}$ & $\begin{array}{r}1,340 \\
300 \\
0 \\
0 \\
1,606\end{array}$ & $\begin{array}{r}206,621 \\
0 \\
0 \\
0 \\
208,621\end{array}$ \\
\hline 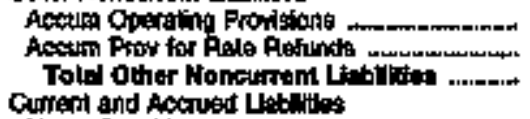 & $\begin{array}{r}2,002 \\
2,002\end{array}$ & $\begin{array}{l}0 \\
0 \\
0\end{array}$ & $\begin{array}{l}0 \\
0 \\
0\end{array}$ & $\begin{array}{l}0 \\
0 \\
0\end{array}$ & $\begin{array}{l}0 \\
0 \\
0\end{array}$ & $\begin{array}{r}085 \\
0 \\
946\end{array}$ \\
\hline 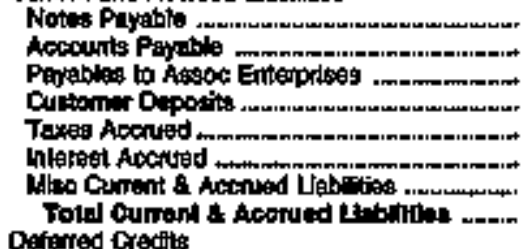 & $\begin{array}{r}0 \\
4,2024 \\
0 \\
0 \\
0 \\
2,407 \\
5,749 \\
12,574\end{array}$ & $\begin{array}{r}0 \\
902 \\
0 \\
0 \\
0 \\
101 \\
354 \\
827\end{array}$ & $\begin{array}{r}545 \\
2,294 \\
201 \\
475 \\
0 \\
608 \\
1,179 \\
0,262\end{array}$ & $\begin{array}{r}0 \\
1,260 \\
101 \\
169 \\
0 \\
21 \\
984 \\
2,414\end{array}$ & $\begin{array}{r}4,915 \\
347 \\
68 \\
61 \\
0 \\
00 \\
375 \\
5,67\end{array}$ & $\begin{array}{r}2,775 \\
2934 \\
0 \\
427 \\
0 \\
2,794 \\
497 \\
0,457\end{array}$ \\
\hline 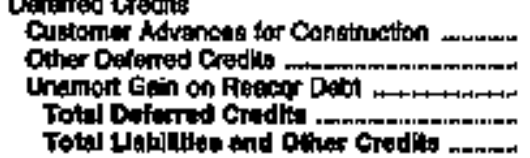 & $\begin{array}{r}\mathbf{0} \\
0 \\
0 \\
0 \\
0\end{array}$ & $\begin{array}{r}0 \\
0 \\
0 \\
0\end{array}$ & $\begin{array}{r}0 \\
67 \\
5 \\
57 \\
70,5 / 7\end{array}$ & $\begin{array}{r}0 \\
0 \\
0 \\
0 \\
0\end{array}$ & $\begin{array}{r}0 \\
0 \\
0 \\
0 \\
0 \\
15,696\end{array}$ & $\begin{array}{r}0 \\
0 \\
0 \\
0 \\
217,978\end{array}$ \\
\hline
\end{tabular}

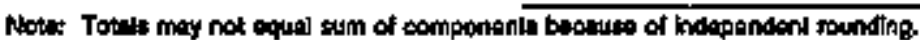

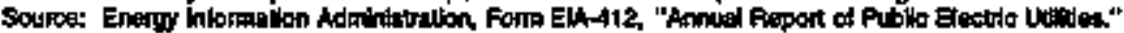


Table 22. Balance Sheet by Major U.S. Publtoly Owned Electrie Uillity Within state at End of Poriod, 1994

(Thousand Dollars)

\begin{tabular}{|c|c|c|c|c|c|c|}
\hline Item & $\begin{array}{l}\text { Olia } \\
\text { Nupoleon } \\
\text { City of } \\
\text { December } 31\end{array}$ & $\begin{array}{l}\text { Onio } \\
\text { Cily of } \\
\text { December } 31\end{array}$ & $\begin{array}{l}\text { Ohing } \\
\text { Orvile } \\
\text { Cily of } \\
\text { Decomber } 31\end{array}$ & 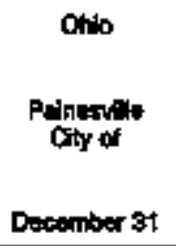 & $\begin{array}{l}\text { Othin } \\
\text { Figu: } \\
\text { Ority of } \\
\text { Documber } 31\end{array}$ & 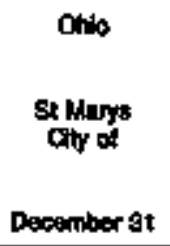 \\
\hline 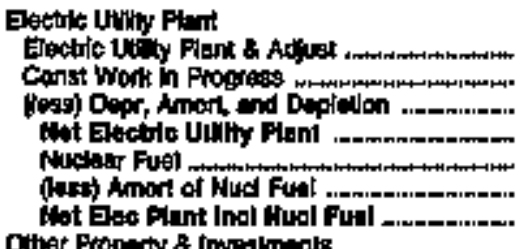 & $\begin{array}{r}2,344 \\
0 \\
0 \\
2,34 \\
0 \\
0 \\
0 \\
0,344\end{array}$ & $\begin{array}{r}12,013 \\
7,001 \\
6,012 \\
0 \\
0 \\
5,012\end{array}$ & $\begin{array}{r}\$ 1,410 \\
981 \\
27,050 \\
25,371 \\
0 \\
0 \\
25,371\end{array}$ & $\begin{array}{r}86,5 \% 9 \\
0 \\
20,772 \\
15,707 \\
0 \\
16,707\end{array}$ & $\begin{array}{r}4,273 \\
599 \\
20,372 \\
24,491 \\
0 \\
0 \\
24,4101\end{array}$ & 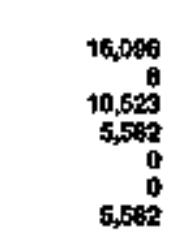 \\
\hline 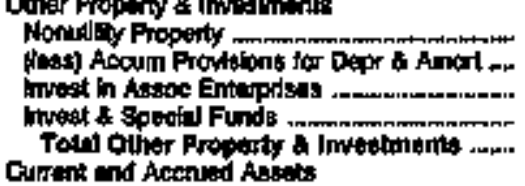 & $\begin{array}{l}\mathbf{0} \\
\mathbf{0} \\
\mathbf{0} \\
\mathbf{0} \\
\mathbf{0}\end{array}$ & $\begin{array}{l}0 \\
0 \\
0 \\
0 \\
0\end{array}$ & $\begin{array}{l}0 \\
0 \\
0 \\
0 \\
0\end{array}$ & $\begin{array}{r}0 \\
0 \\
0 \\
6,512 \\
6 ; 512\end{array}$ & $\begin{array}{r}0 \\
0 \\
0 \\
1,074 \\
1,074\end{array}$ & $\begin{array}{r}0 \\
0 \\
2,405 \\
2,405\end{array}$ \\
\hline 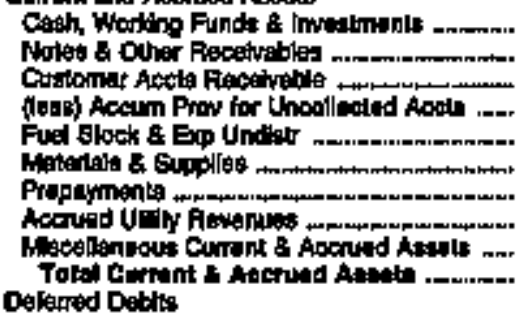 & $\begin{array}{l}0 \\
0 \\
0 \\
0 \\
0 \\
0 \\
10 \\
10 \\
0 \\
0\end{array}$ & $\begin{array}{r}5,900 \\
0 \\
1,517 \\
0 \\
0 \\
0 \\
0 \\
0 \\
0 \\
7,425\end{array}$ & $\begin{array}{r}8,365 \\
3 \% \\
1,244 \\
109 \\
0 \\
2,065 \\
20 \\
0 \\
100 \\
12,065\end{array}$ & $\begin{array}{r}450 \\
0 \\
1,553 \\
0 \\
0 \\
684 \\
28 \\
0 \\
0 \\
2,642\end{array}$ & $\begin{array}{r}1,67 \\
50 \\
1,010 \\
76 \\
0 \\
0 \\
004 \\
712 \\
113 \\
1,224\end{array}$ & $\begin{array}{r}2604 \\
0 \\
555 \\
0 \\
0 \\
255 \\
58 \\
18 \\
4 \\
3,358\end{array}$ \\
\hline 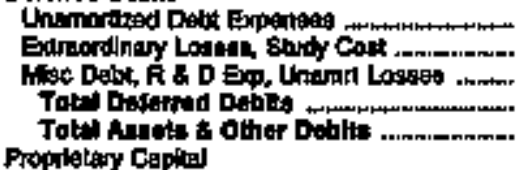 & $\begin{array}{r}0 \\
0 \\
0 \\
0 \\
2,84\end{array}$ & $\begin{array}{r}0 \\
0 \\
0 \\
0\end{array}$ & $\begin{array}{r}497 \\
0 \\
0 \\
407 \\
30,405\end{array}$ & $\begin{array}{r}0 \\
0 \\
0 \\
0 \\
24,671\end{array}$ & $\begin{array}{r}0 \\
0 \\
0 \\
2\end{array}$ & $\begin{array}{r}182 \\
0 \\
0 \\
102 \\
11,657\end{array}$ \\
\hline 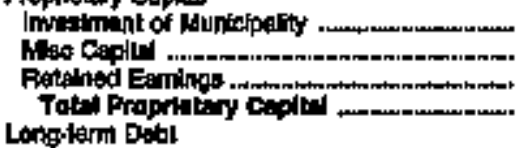 & $\begin{array}{r}0 \\
0 \\
2,344 \\
2,344\end{array}$ & $\begin{array}{r}0 \\
0 \\
9,797 \\
9,797\end{array}$ & $\begin{array}{r}0 \\
18,254 \\
19,254\end{array}$ & $\begin{array}{r}47 \\
0 \\
10,87 \\
16,+26\end{array}$ & $\begin{array}{r}0 \\
19,424 \\
19,42\end{array}$ & $\begin{array}{r}0 \\
57 \\
5,469 \\
5,400\end{array}$ \\
\hline 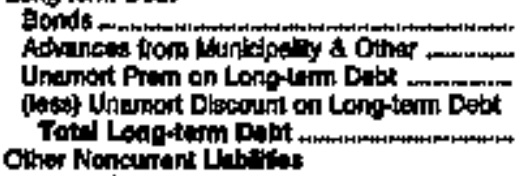 & $\begin{array}{l}0 \\
0 \\
0 \\
0 \\
0\end{array}$ & $\begin{array}{l}0 \\
0 \\
0 \\
0 \\
0\end{array}$ & $\begin{array}{r}17,695 \\
6 \\
0 \\
0 \\
17,90\end{array}$ & $\begin{array}{r}6,540 \\
0 \\
0 \\
0 \\
0,50\end{array}$ & $\begin{array}{r}8,006 \\
0 \\
0 \\
0 \\
0,600\end{array}$ & $\begin{array}{r}5,165 \\
0 \\
0 \\
0 \\
5,165\end{array}$ \\
\hline 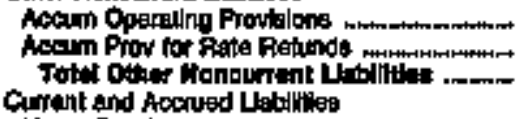 & $\begin{array}{l}0 \\
0 \\
0\end{array}$ & $\begin{array}{l}0 \\
0 \\
0\end{array}$ & $\begin{array}{l}0 \\
0 \\
0\end{array}$ & $\begin{array}{r}218 \\
0 \\
218\end{array}$ & $\begin{array}{r}420 \\
0 \\
420\end{array}$ & \\
\hline 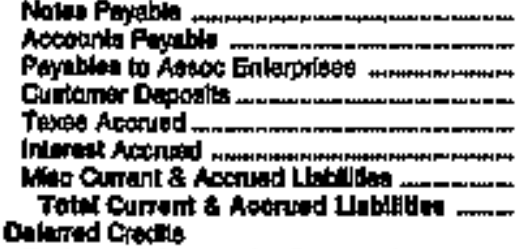 & $\begin{array}{l}0 \\
0 \\
0 \\
0 \\
0 \\
0 \\
0 \\
0\end{array}$ & $\begin{array}{r}0 \\
0 \\
0 \\
0 \\
0 \\
0 \\
2,540 \\
2040\end{array}$ & $\begin{array}{r}540 \\
747 \\
0 \\
0 \\
0 \\
127 \\
641 \\
2168\end{array}$ & $\begin{array}{r}0 \\
1,008 \\
0 \\
259 \\
0 \\
0 \\
0 \\
1,000\end{array}$ & $\begin{array}{r}0 \\
762 \\
0 \\
0 \\
0 \\
0 \\
287 \\
1,960\end{array}$ & $\begin{array}{r}0 \\
400 \\
0 \\
219 \\
0 \\
20 \\
193 \\
942\end{array}$ \\
\hline 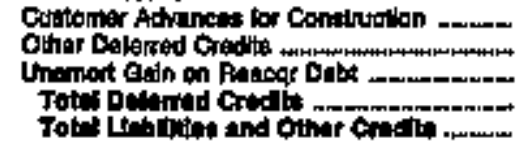 & $\begin{array}{r}0 \\
0 \\
0 \\
0 \\
2,34\end{array}$ & $\begin{array}{r}0 \\
0 \\
0 \\
12, \pi 7\end{array}$ & $\begin{array}{r}0 \\
0 \\
0 \\
0 \\
0\end{array}$ & $\begin{array}{r}0 \\
0 \\
0 \\
0 \\
24,97\end{array}$ & $\begin{array}{r}0 \\
0 \\
0 \\
0 \\
200\end{array}$ & $\begin{array}{r}0 \\
0 \\
0 \\
0 \\
+15 \% ?\end{array}$ \\
\hline
\end{tabular}

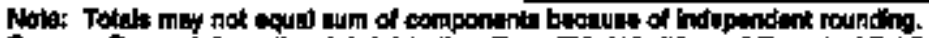

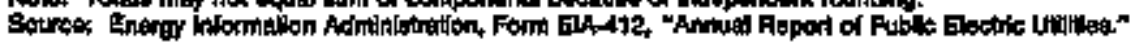


Table 22. Balance Sheet by Major U.S. Publiely Owned Electric Utilty Within state at End of Period, 1994

(Thousand Dollars)

\begin{tabular}{|c|c|c|c|c|c|c|}
\hline Iform & $\begin{array}{l}\text { Onio } \\
\text { Wartionoth } \\
\text { Ciny of } \\
\text { Deosmber } 31\end{array}$ & $\begin{array}{l}\text { Onio } \\
\text { Weakeneth } \\
\text { Cony of } \\
\text { Decenber } 31\end{array}$ & 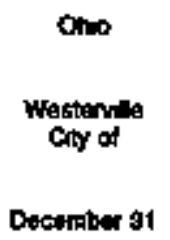 & $\begin{array}{l}\text { Oit:homa } \\
\text { Altus } \\
\text { Cing of } \\
\text { Juns so }\end{array}$ & $\begin{array}{l}\text { Olidunom: } \\
\text { Clesemora } \\
\text { City of } \\
\text { June } 30\end{array}$ & $\begin{array}{l}\text { Ottahors. } \\
\text { Duncen } \\
\text { Oiy of } \\
\text { Juno } 30\end{array}$ \\
\hline 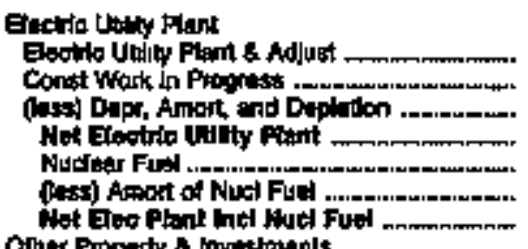 & $\begin{array}{r}11,008 \\
0 \\
1,178 \\
1,028 \\
0 \\
0 \\
6,609\end{array}$ & $\begin{array}{l}0 \\
0 \\
0 \\
0 \\
0 \\
0 \\
0\end{array}$ & $\begin{array}{r}23,381 \\
60 \\
9,398 \\
14,052 \\
0 \\
0 \\
0,052\end{array}$ & $\begin{array}{r}7,673 \\
0 \\
5,309 \\
2,604 \\
0 \\
0 \\
2,604\end{array}$ & $\begin{array}{l}0 \\
0 \\
0 \\
0 \\
0 \\
0 \\
0\end{array}$ & $\begin{array}{r}19,742 \\
0 \\
0,060 \\
10,069 \\
0 \\
0 \\
10,002\end{array}$ \\
\hline 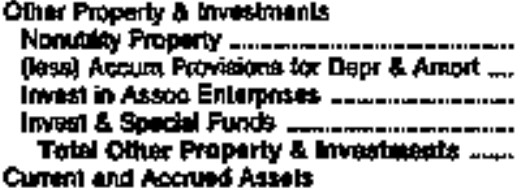 & $\begin{array}{l}0 \\
0 \\
0 \\
0 \\
0\end{array}$ & $\begin{array}{l}0 \\
0 \\
0 \\
0 \\
0\end{array}$ & $\begin{array}{l}0 \\
0 \\
0 \\
0 \\
0\end{array}$ & $\begin{array}{l}0 \\
0 \\
0 \\
0 \\
0\end{array}$ & $\begin{array}{l}0 \\
0 \\
0 \\
0 \\
0\end{array}$ & $\begin{array}{l}0 \\
0 \\
0 \\
0 \\
0\end{array}$ \\
\hline 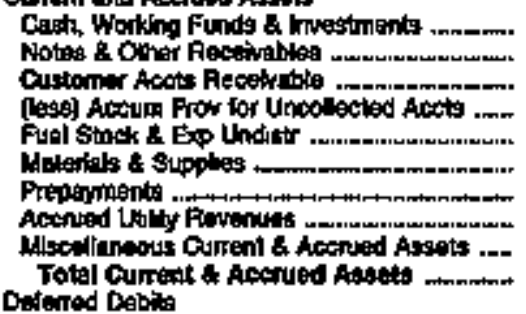 & $\begin{array}{r}1,509 \\
0 \\
1,610 \\
0 \\
0 \\
0 \\
15 \\
0 \\
2,300 \\
6,001\end{array}$ & $\begin{array}{r}2,122 \\
0 \\
0 \\
0 \\
0 \\
0 \\
0 \\
0 \\
0 \\
2,120\end{array}$ & $\begin{array}{r}29,028 \\
0 \\
2,481 \\
67 \\
0 \\
1,014 \\
0 \\
0 \\
44 \\
32,496\end{array}$ & $\begin{array}{r}6,411 \\
0 \\
1,070 \\
200 \\
0 \\
0 \\
0 \\
0 \\
79 \\
6,040\end{array}$ & $\begin{array}{r}363 \\
0 \\
1,280 \\
0 \\
0 \\
0 \\
0 \\
0 \\
0 \\
1,593\end{array}$ & $\begin{array}{r}3,340 \\
1,470 \\
31 \\
0 \\
0 \\
0 \\
0 \\
35 \\
4,928\end{array}$ \\
\hline 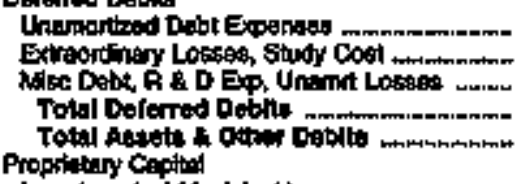 & $\begin{array}{r}0 \\
0 \\
0 \\
12,600\end{array}$ & $\begin{array}{r}0 \\
0 \\
0 \\
0 \\
2,+20\end{array}$ & $\begin{array}{r}0 \\
0 \\
0 \\
0 \\
40,546\end{array}$ & $\begin{array}{r}0 \\
0 \\
0 \\
0 \\
10,04\end{array}$ & $\begin{array}{r}0 \\
0 \\
0 \\
0 \\
i, 993\end{array}$ & $\begin{array}{r}0 \\
0 \\
0 \\
0 \\
14,9095\end{array}$ \\
\hline 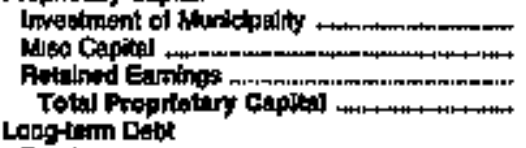 & $\begin{array}{r}0 \\
11,9 \operatorname{sen}^{4} \\
11,629\end{array}$ & $\begin{array}{r}27 \\
0 \\
2,005 \\
2,12\end{array}$ & $\begin{array}{r}0 \\
235 \\
44,947 \\
45,77\end{array}$ & $\begin{array}{r}3,504 \\
0 \\
6,807 \\
9,8 \geq 2\end{array}$ & $\begin{array}{r}9 \\
760 \\
768\end{array}$ & $\begin{array}{r}13,324 \\
1 \% 3 \\
441 \\
19,919\end{array}$ \\
\hline 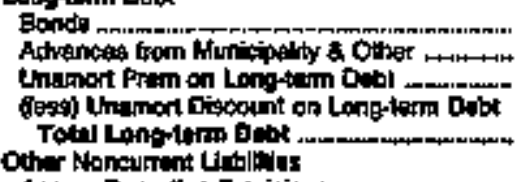 & $\begin{array}{l}0 \\
0 \\
0 \\
0 \\
0\end{array}$ & $\begin{array}{l}0 \\
0 \\
0 \\
0 \\
0\end{array}$ & $\begin{array}{l}0 \\
0 \\
0 \\
0 \\
0\end{array}$ & $\begin{array}{l}0 \\
0 \\
0 \\
0 \\
0 \\
0\end{array}$ & $\begin{array}{l}0 \\
0 \\
0 \\
0\end{array}$ & $\begin{array}{l}0 \\
0 \\
0 \\
0 \\
0\end{array}$ \\
\hline 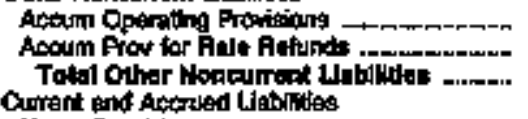 & $\begin{array}{l}0 \\
0 \\
0\end{array}$ & $\begin{array}{l}0 \\
0 \\
0\end{array}$ & $\begin{array}{r}305 \\
0 \\
305\end{array}$ & $\begin{array}{l}\text { a } \\
\text { D } \\
\text { D }\end{array}$ & $\begin{array}{l}0 \\
0 \\
0\end{array}$ & $\begin{array}{l}0 \\
0 \\
0\end{array}$ \\
\hline 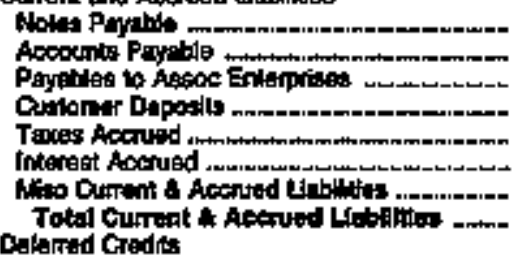 & $\begin{array}{r}0 \\
700 \\
0 \\
0 \\
0 \\
0 \\
10201\end{array}$ & $\begin{array}{l}0 \\
0 \\
0 \\
0 \\
0 \\
0 \\
0 \\
0\end{array}$ & $\begin{array}{r}0 \\
809 \\
0 \\
37 \\
0 \\
0 \\
121 \\
1,050\end{array}$ & $\begin{array}{r}0 \\
223 \\
0 \\
0 \\
0 \\
0 \\
0 \\
020\end{array}$ & $\begin{array}{r}0 \\
601 \\
0 \\
0 \\
0 \\
0 \\
0 \\
01\end{array}$ & $\begin{array}{r}0 \\
69 \\
690 \\
0 \\
0 \\
94\end{array}$ \\
\hline 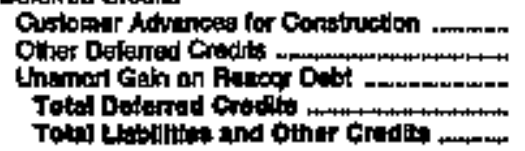 & $\begin{array}{r}0 \\
0 \\
0 \\
0 \\
12000\end{array}$ & $\begin{array}{r}0 \\
0 \\
0 \\
0 \\
0\end{array}$ & $\begin{array}{r}10 \\
11 \\
0 \\
11 \\
46,50\end{array}$ & $\begin{array}{r}0 \\
0 \\
0 \\
0 \\
10,4\end{array}$ & $\begin{array}{r}0 \\
0 \\
0 \\
0 \\
1,000\end{array}$ & $\begin{array}{r}0 \\
0 \\
0 \\
14005\end{array}$ \\
\hline
\end{tabular}

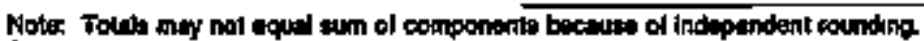

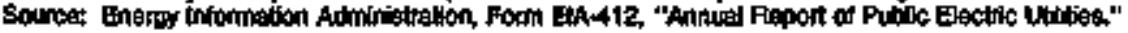


Table 22. Balance Sheet by Major U.S. Publlofy Owned Electrio Utility Whin State at End of Period, 1994 (Thousand Dollars)

\begin{tabular}{|c|c|c|c|c|c|c|}
\hline Itam & $\begin{array}{l}\text { Olumborma } \\
\text { Edmond } \\
\text { Ciny of } \\
\text { Juna so }\end{array}$ & $\begin{array}{l}\text { Oldahoma } \\
\text { Grand Fiver } \\
\text { Degat } \\
\text { Authority } \\
\text { Decomber at }\end{array}$ & 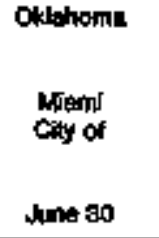 & 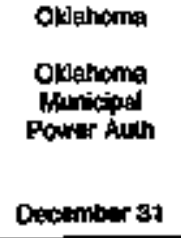 & 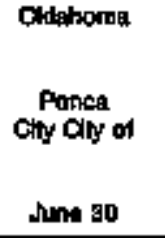 & 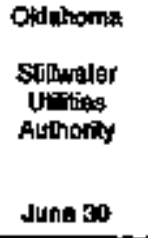 \\
\hline 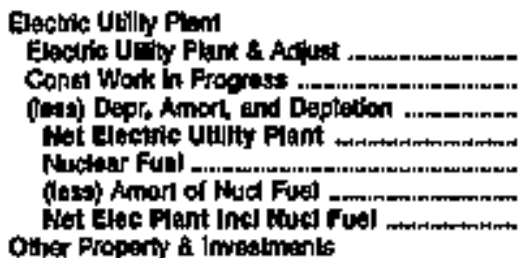 & $\begin{array}{r}37,5,40 \\
16,00 \\
16,504 \\
20,98 \\
0 \\
0 \\
20,988\end{array}$ & 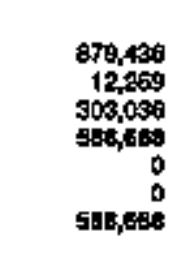 & $\begin{array}{r}3,060 \\
0 \\
2,197 \\
0,99 \\
0 \\
0 \\
0 \% 9\end{array}$ & $\begin{array}{r}162,860 \\
27,174 \\
34,790 \\
155,240 \\
0 \\
0 \\
155,248\end{array}$ & $\begin{array}{r}35,080 \\
0 \\
15,608 \\
19,471 \\
0 \\
0 \\
19,471\end{array}$ & $\begin{array}{r}34,681 \\
28 \\
14,089 \\
24,5009 \\
0 \\
0 \\
24,880\end{array}$ \\
\hline 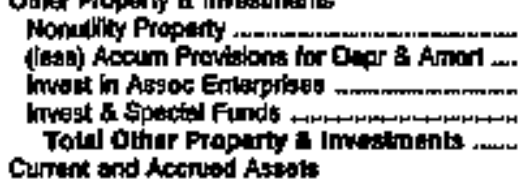 & $\begin{array}{r}0 \\
0 \\
0 \\
2,442 \\
2,442\end{array}$ & $\begin{array}{r}33 \\
0 \\
0 \\
90,99 \\
100,091\end{array}$ & $\begin{array}{r}11,099 \\
4,394 \\
0 \\
0 \\
7,5015\end{array}$ & $\begin{array}{r}0 \\
0 \\
0 \\
70,290 \\
70,290\end{array}$ & $\begin{array}{r}0 \\
0 \\
0 \\
4,198 \\
4,196\end{array}$ & $\begin{array}{l}0 \\
0 \\
0 \\
0 \\
0\end{array}$ \\
\hline 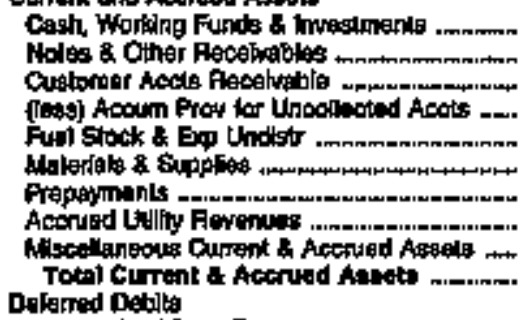 & $\begin{array}{r}2,948 \\
0 \\
1,841 \\
5 \\
0 \\
0 \\
0 \\
0 \\
64 \\
4,600 \\
404\end{array}$ & $\begin{array}{r}126,460 \\
28,129 \\
13,830 \\
200 \\
4,653 \\
10,492 \\
700 \\
0 \\
2,000 \\
19,776\end{array}$ & $\begin{array}{r}5,748 \\
90 \\
775 \\
174 \\
0 \\
675 \\
0 \\
0 \\
0 \\
7,048\end{array}$ & $\begin{array}{r}28,821 \\
4,97 \\
0 \\
0 \\
0 \\
0 \\
0 \\
0 \\
0 \\
1,527 \\
25,324\end{array}$ & $\begin{array}{r}8 \\
240 \\
200 \\
0 \\
0 \\
0 \\
0 \\
0 \\
0 \\
2,445\end{array}$ & $\begin{array}{r}13,974 \\
29 \\
0,881 \\
6 \\
0 \\
479 \\
0 \\
0 \\
0 \\
19,954\end{array}$ \\
\hline 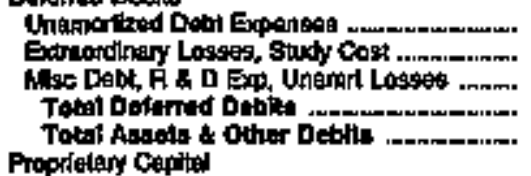 & $\begin{array}{r}\mathbf{0} \\
\mathbf{0} \\
\mathbf{0} \\
\mathbf{0} \\
20, \mathbf{1 7}\end{array}$ & $\begin{array}{r}0,007 \\
40 \\
194,712 \\
145,700 \\
1,025,606\end{array}$ & $\begin{array}{r}0 \\
0 \\
0 \\
0 \\
15,422\end{array}$ & $\begin{array}{r}04,004 \\
0 \\
5,005 \\
147,989 \\
116,791\end{array}$ & $\begin{array}{r}0 \\
0 \\
0 \\
26,115\end{array}$ & $\begin{array}{r}0 \\
0 \\
0 \\
0 \\
42928\end{array}$ \\
\hline 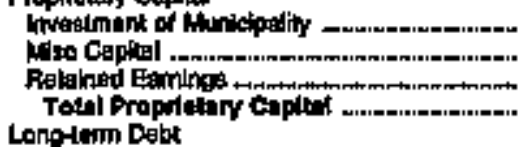 & $\begin{array}{r}106 \\
12008 \\
20,568\end{array}$ & $\begin{array}{r}0 \\
0 \\
28,255 \\
28,216\end{array}$ & $\begin{array}{r}0 \\
14,135 \\
14,130\end{array}$ & $\begin{array}{r}0 \\
0 \\
11,073 \\
11,079\end{array}$ & $\begin{array}{r}0 \\
0 \\
21,572 \\
21,672\end{array}$ & $\begin{array}{r}11,817 \\
0 \\
29,637 \\
10,453\end{array}$ \\
\hline 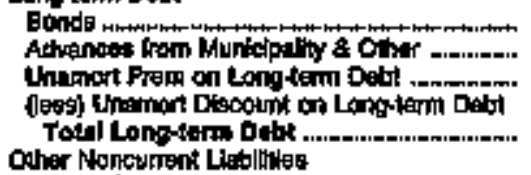 & $\begin{array}{r}3,116 \\
0 \\
0 \\
0 \\
3,119\end{array}$ & $\begin{array}{r}1,101,840 \\
1,727 \\
0 \\
144,635 \\
968,932\end{array}$ & $\begin{array}{l}0 \\
0 \\
0 \\
0 \\
0\end{array}$ & $\begin{array}{r}\$ 94,675 \\
0 \\
15,780 \\
976,907\end{array}$ & $\begin{array}{r}3,405 \\
0 \\
0 \\
3,405\end{array}$ & $\begin{array}{l}0 \\
0 \\
0 \\
0 \\
0\end{array}$ \\
\hline 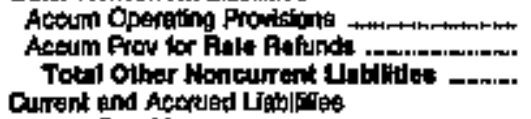 & $\begin{array}{l}\text { D } \\
\text { a } \\
\mathbf{0}\end{array}$ & $\begin{array}{l}0 \\
0 \\
0\end{array}$ & $\begin{array}{l}0 \\
0 \\
0\end{array}$ & $\begin{array}{l}0 \\
0 \\
0\end{array}$ & $\begin{array}{l}0 \\
0 \\
0\end{array}$ & $\begin{array}{l}0 \\
9 \\
0\end{array}$ \\
\hline 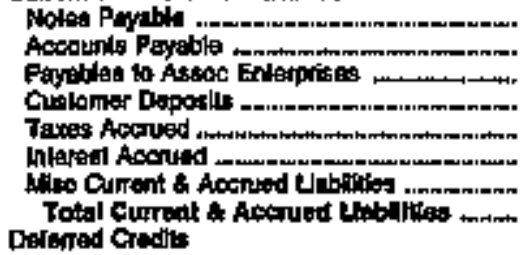 & $\begin{array}{r}0 \\
2,50 ; \\
0 \\
1,609 \\
90 \\
69 \\
177 \\
4,510\end{array}$ & $\begin{array}{r}0 \\
7,399 \\
0 \\
0 \\
0 \\
5,072 \\
5,121 \\
17,942\end{array}$ & $\begin{array}{r}0 \\
1,012 \\
0 \\
200 \\
0 \\
0 \\
0 \\
1,201\end{array}$ & $\begin{array}{r}0 \\
0 \\
4,185 \\
0 \\
0 \\
10,825 \\
1,085 \\
10,106\end{array}$ & $\begin{array}{r}0 \\
289 \\
0 \\
714 \\
0 \\
00 \\
62 \\
1,199\end{array}$ & $\begin{array}{r}0 \\
2,3004 \\
24 \\
0 \\
0 \\
0 \\
142 \\
2,470\end{array}$ \\
\hline 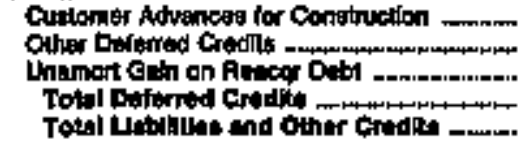 & $\begin{array}{r}0 \\
0 \\
0 \\
0 \\
\mathbf{0} \\
\mathbf{0}\end{array}$ & $\begin{array}{r}0 \\
22,988 \\
0 \\
27,936 \\
1,026,068\end{array}$ & $\begin{array}{r}0 \\
10 \\
10,428 \\
0 \\
0\end{array}$ & $\begin{array}{r}7,370 \\
276 \\
0 \\
7,948 \\
418,791\end{array}$ & $\begin{array}{r}0 \\
0 \\
0 \\
0 \\
0 \\
26,115\end{array}$ & $\begin{array}{r}0 \\
0 \\
0 \\
0 \\
4,923\end{array}$ \\
\hline
\end{tabular}

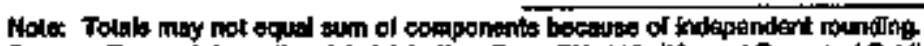

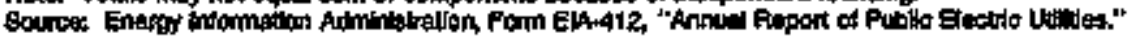


Table 22. Belence Street by Major U.S. Publkly Owned Eloctrle Utilty, Within State at End of Perlod, 1994 (Thousand Dollars)

\begin{tabular}{|c|c|c|c|c|c|c|}
\hline Ilom & $\begin{array}{l}\text { Oreogon } \\
\text { Aphliand } \\
\text { City of } \\
\text { June ao }\end{array}$ & 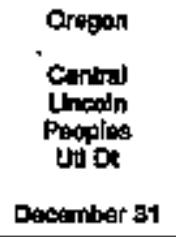 & 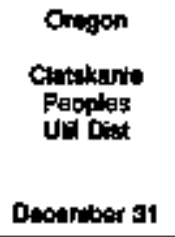 & 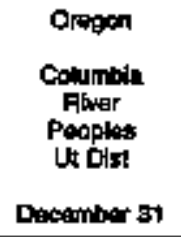 & $\begin{array}{l}\text { Oragon } \\
\text { Emerald } \\
\text { Pecples } \\
\text { Utiliy Dist } \\
\text { Docentuber } 31\end{array}$ & 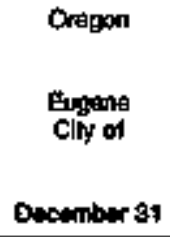 \\
\hline 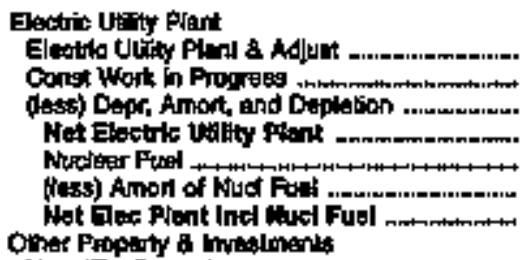 & 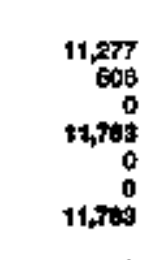 & $\begin{array}{r}82,889 \\
7,284 \\
34,856 \\
8,319 \\
0 \\
0 \\
66,310\end{array}$ & $\begin{array}{r}6,752 \\
40 \\
9,504 \\
3,294 \\
0 \\
0 \\
3,204\end{array}$ & $\begin{array}{r}23,417 \\
1030 \\
4,415 \\
19,165 \\
0 \\
0 \\
10,766\end{array}$ & $\begin{array}{r}72,347 \\
1,546 \\
27,152 \\
45,741 \\
0 \\
0 \\
48,741\end{array}$ & $\begin{array}{r}901,069 \\
4,477 \\
129,640 \\
162,180 \\
0 \\
192,196\end{array}$ \\
\hline 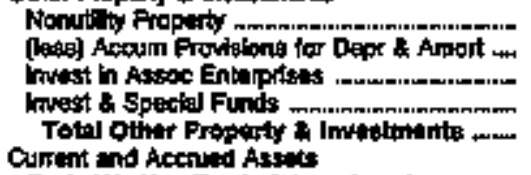 & $\begin{array}{l}0 \\
0 \\
0 \\
0 \\
0\end{array}$ & $\begin{array}{r}0 \\
0 \\
0 \\
7,110 \\
7,110\end{array}$ & $\begin{array}{l}0 \\
0 \\
0 \\
0 \\
0\end{array}$ & $\begin{array}{r}509 \\
148 \\
0 \\
3,139 \\
3,500\end{array}$ & $\begin{array}{r}0 \\
0 \\
10,202 \\
10,202\end{array}$ & $\begin{array}{r}0 \\
0 \\
0 \\
2,940 \\
\times, 946\end{array}$ \\
\hline 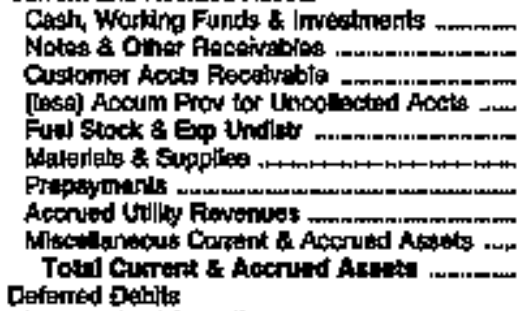 & $\begin{array}{r}494 \\
120 \\
458 \\
0 \\
0 \\
0 \\
0 \\
0 \\
476 \\
1,540\end{array}$ & $\begin{array}{r}t, 831 \\
0 \\
4,517 \\
147 \\
0 \\
1,996 \\
1,102 \\
0 \\
9,105\end{array}$ & $\begin{array}{r}4,127 \\
0 \\
2,478 \\
7 \\
0 \\
178 \\
04 \\
0 \\
0 \\
6,050\end{array}$ & $\begin{array}{r}968 \\
27 \\
1,305 \\
25 \\
0 \\
280 \\
26 \\
0 \\
61 \\
2,610\end{array}$ & $\begin{array}{r}4,074 \\
1,250 \\
1,694 \\
36 \\
0 \\
550 \\
160 \\
880 \\
0 \\
0,401\end{array}$ & $\begin{array}{r}14,488 \\
0 \\
12,407 \\
216 \\
0 \\
2,414 \\
4,53 \\
6,112 \\
8,080 \\
43,951\end{array}$ \\
\hline 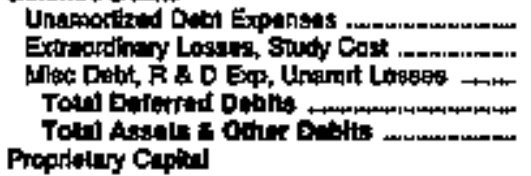 & $\begin{array}{r}527 \\
0 \\
0 \\
527 \\
13,659\end{array}$ & $\begin{array}{r}258 \\
0 \\
5298 \\
5,494 \\
77,+05\end{array}$ & $\begin{array}{r}0 \\
281 \\
0 \\
291 \\
10,493\end{array}$ & $\begin{array}{r}2,781 \\
0 \\
0 \\
2,781 \\
28,081\end{array}$ & $\begin{array}{r}1,105 \\
0 \\
0,278 \\
10,440 \\
7,7,786\end{array}$ & $\begin{array}{r}459 \\
1,725 \\
10,272 \\
21,456 \\
280,491\end{array}$ \\
\hline 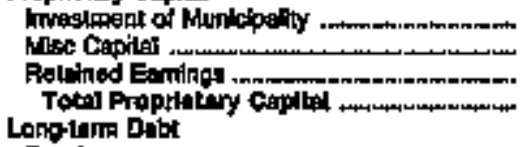 & $\begin{array}{r}2,287 \\
0,516 \\
782 \\
12,680\end{array}$ & $\begin{array}{r}0 \\
0 \\
58,5,46 \\
5,646\end{array}$ & $\begin{array}{r}0 \\
0 \\
7,656 \\
7,668\end{array}$ & $\begin{array}{r}0 \\
0 \\
0,756 \\
\mathbf{B}, 766\end{array}$ & $\begin{array}{r}0 \\
0 \\
1,397 \\
1,397\end{array}$ & $\begin{array}{r}0 \\
0 \\
127,488 \\
197,496\end{array}$ \\
\hline 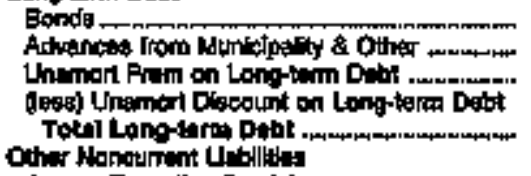 & $\begin{array}{r}605 \\
2 \\
0 \\
0 \\
627\end{array}$ & $\begin{array}{r}13,715 \\
0 \\
0 \\
0 \\
13,716\end{array}$ & $\begin{array}{l}0 \\
0 \\
0 \\
0 \\
0\end{array}$ & $\begin{array}{r}16,765 \\
0 \\
0 \\
0 \\
16,766\end{array}$ & $\begin{array}{r}60,849 \\
2,420 \\
0 \\
710 \\
60,864\end{array}$ & $\begin{array}{r}98,027 \\
0 \\
0 \\
2,095 \\
95,048\end{array}$ \\
\hline 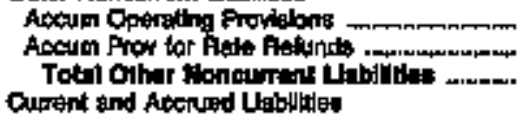 & $\begin{array}{l}0 \\
0 \\
0\end{array}$ & $\begin{array}{r}1,917 \\
0 \\
1,917\end{array}$ & $\begin{array}{l}05 \\
0\end{array}$ & $\begin{array}{l}0 \\
0 \\
0\end{array}$ & $\begin{array}{l}0 \\
0 \\
0\end{array}$ & $\begin{array}{l}0 \\
0 \\
0\end{array}$ \\
\hline 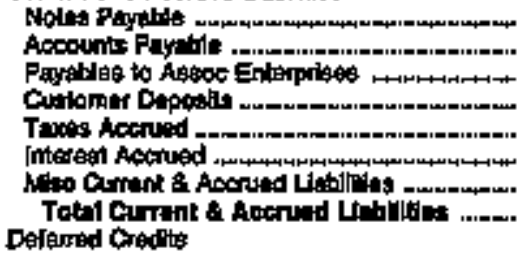 & $\begin{array}{r}0 \\
05 \\
0 \\
108 \\
0 \\
0 \\
89 \\
97\end{array}$ & $\begin{array}{r}0 \\
4,595 \\
0 \\
208 \\
0 \\
16 \\
0 \\
4,915\end{array}$ & $\begin{array}{r}0 \\
2,317 \\
0 \\
19 \\
0 \\
0 \\
0 \\
0 \\
2,305\end{array}$ & $\begin{array}{r}0 \\
1,292 \\
0 \\
41 \\
75 \\
165 \\
216 \\
1,74\end{array}$ & $\begin{array}{r}0 \\
1,813 \\
0 \\
14 \\
9 \\
701 \\
3,469 \\
5,000\end{array}$ & $\begin{array}{r}0 \\
10,205 \\
0 \\
108 \\
659 \\
3,700 \\
10,145 \\
15,305\end{array}$ \\
\hline 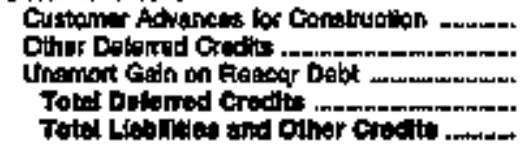 & 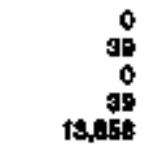 & $\begin{array}{r}2 \\
3,110 \\
0 \\
3,112 \\
\pi, 105\end{array}$ & $\begin{array}{r}445 \\
0 \\
0 \\
445 \\
1045\end{array}$ & $\begin{array}{r}160 \\
647 \\
0 \\
012 \\
20,001\end{array}$ & $\begin{array}{r}0 \\
5 \\
95 \\
95,796\end{array}$ & $\begin{array}{r}54 \\
756 \\
1,897 \\
94,480 \\
250,441\end{array}$ \\
\hline
\end{tabular}

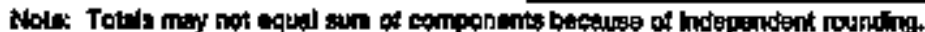

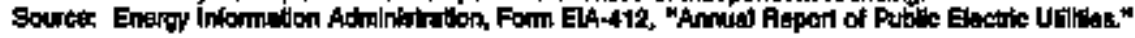


Table 22. Balance sheet by Major U.S. Publicly Owned Electric Utillty Within State at End of Period, 1994 (Thousand Dollars)

\begin{tabular}{|c|c|c|c|c|c|c|}
\hline lbom & $\begin{array}{l}\text { Oregan } \\
\text { Fonist Ginow } \\
\text { ofty of } \\
\text { dunte } 30\end{array}$ & $\begin{array}{l}\text { Oragon } \\
\text { Metenndila } \\
\text { Ciny of } \\
\text { Jurio ad }\end{array}$ & 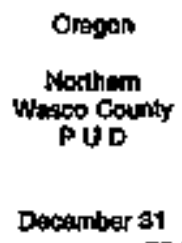 & $\begin{array}{l}\text { Oregon } \\
\text { Springifield } \\
\text { Gity of } \\
\text { Detcomber } \$ 1\end{array}$ & 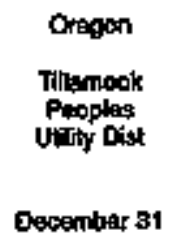 & 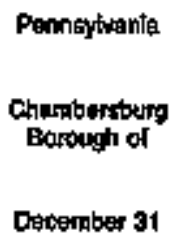 \\
\hline 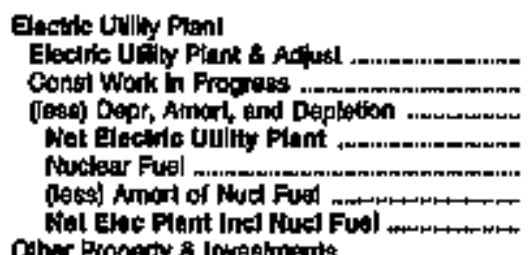 & $\begin{array}{r}11,600 \\
100 \\
3,656 \\
7,000 \\
0 \\
0 \\
7,006\end{array}$ & $\begin{array}{r}27,403 \\
100 \\
5,723 \\
15,025 \\
0 \\
0 \\
15,025\end{array}$ & $\begin{array}{r}34,971 \\
7,2,57 \\
9,759 \\
32,379 \\
0 \\
0 \\
30,969\end{array}$ & $\begin{array}{r}44,010 \\
1,443 \\
13,707 \\
31,746 \\
0 \\
9 \\
31,746\end{array}$ & $\begin{array}{r}36,300 \\
1,544 \\
9,792 \\
27,060 \\
0 \\
0 \\
27,000\end{array}$ & $\begin{array}{r}28,051 \\
8,90 \\
14,110 \\
12,152 \\
0 \\
0 \\
12,952\end{array}$ \\
\hline 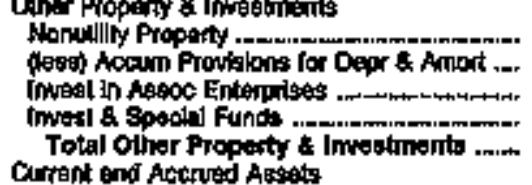 & $\begin{array}{l}0 \\
0 \\
0 \\
0 \\
0\end{array}$ & $\begin{array}{l}0 \\
0 \\
0 \\
0 \\
0\end{array}$ & $\begin{array}{r}0 \\
0 \\
0 \\
1,607 \\
1,607\end{array}$ & $\begin{array}{r}0 \\
0 \\
0 \\
4,149 \\
4,143\end{array}$ & $\begin{array}{r}0 \\
0 \\
4,360 \\
4,361\end{array}$ & $\begin{array}{r}0 \\
0 \\
202 \\
1,098 \\
1,482\end{array}$ \\
\hline 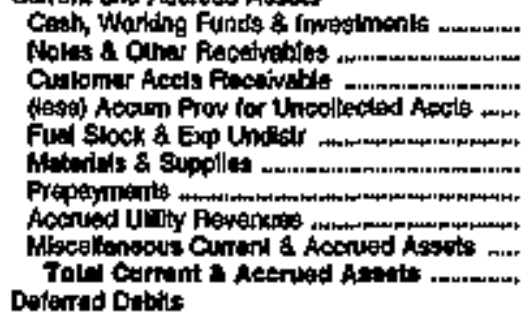 & $\begin{array}{r}1,317 \\
3 \\
489 \\
140 \\
4 \\
277 \\
0 \\
9 \\
98 \\
2,076\end{array}$ & $\begin{array}{r}3,600 \\
124 \\
1,440 \\
12 \\
0 \\
200 \\
0 \\
0 \\
0 \\
0 \\
0\end{array}$ & 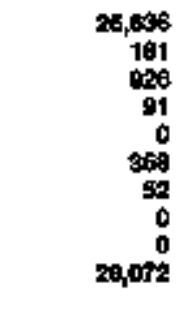 & $\begin{array}{r}5,959 \\
7,03 \\
4,042 \\
64 \\
0 \\
1,193 \\
0 \\
0 \\
23 \\
11,6=1\end{array}$ & $\begin{array}{r}4,465 \\
327 \\
1,682 \\
92 \\
0 \\
617 \\
221 \\
0 \\
57 \\
7,176\end{array}$ & $\begin{array}{r}2,098 \\
9 \\
918 \\
3 \\
49 \\
0 \\
10 \\
6 \times 2 \\
32 \\
3,677\end{array}$ \\
\hline 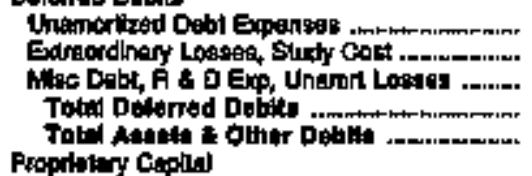 & $\begin{array}{r}0 \\
0 \\
0 \\
0 \\
2,011\end{array}$ & $\begin{array}{r}0 \\
0 \\
606 \\
695 \\
21,058\end{array}$ & $\begin{array}{r}967 \\
54 \\
0 \\
1001 \\
60,000\end{array}$ & $\begin{array}{r}73 \\
0 \\
961 \\
1,024 \\
48,110\end{array}$ & $\begin{array}{r}1,92 \\
7,020 \\
1,219 \\
39,010\end{array}$ & $\begin{array}{r}0 \\
0 \\
0 \\
0 \\
17,000\end{array}$ \\
\hline 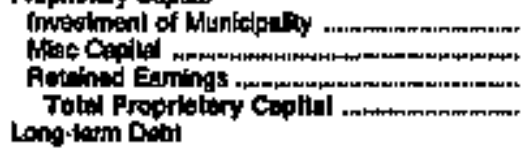 & $\begin{array}{r}8,607 \\
0 \\
9,45 \\
9,040\end{array}$ & $\begin{array}{r}440 \\
2,685 \\
18,649 \\
18,629\end{array}$ & $\begin{array}{r}76 \\
73 \\
9,577 \\
0,57\end{array}$ & $\begin{array}{r}0 \\
2208 \\
32,894 \\
35,172\end{array}$ & $\begin{array}{r}0 \\
0 \\
2,574 \\
2,574\end{array}$ & $\begin{array}{r}697 \\
0 \\
16,617 \\
16,64\end{array}$ \\
\hline 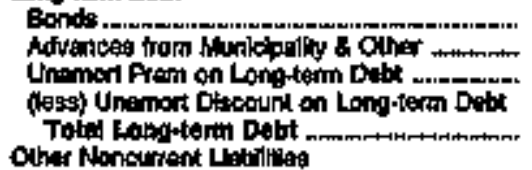 & $\begin{array}{l}0 \\
0 \\
0 \\
0 \\
0\end{array}$ & $\begin{array}{r}0 \\
0 \\
0 \\
0\end{array}$ & $\begin{array}{r}49,389 \\
0 \\
0 \\
0 \\
40,399\end{array}$ & $\begin{array}{r}3,092 \\
0 \\
0 \\
0 \\
3012\end{array}$ & $\begin{array}{r}14,05 \\
0 \\
0 \\
0 \\
14,05\end{array}$ & $\begin{array}{l}0 \\
0 \\
0 \\
0\end{array}$ \\
\hline 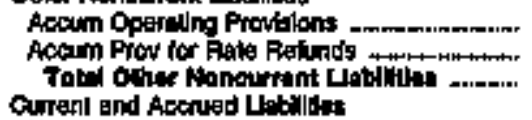 & $\begin{array}{l}0 \\
0 \\
0\end{array}$ & $\begin{array}{l}0 \\
0 \\
0\end{array}$ & $\begin{array}{l}0 \\
0 \\
0\end{array}$ & $\begin{array}{l}0 \\
0 \\
0\end{array}$ & $\begin{array}{l}0 \\
0 \\
0\end{array}$ & $\begin{array}{l}0 \\
0 \\
0\end{array}$ \\
\hline 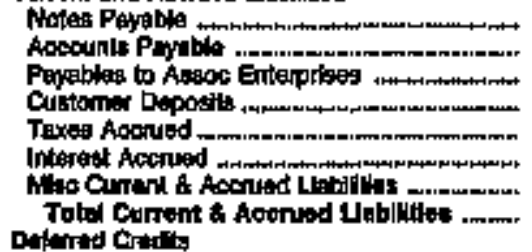 & $\begin{array}{r}187 \\
373 \\
0 \\
0 \\
0 \\
0 \\
0 \\
564\end{array}$ & $\begin{array}{r}0 \\
1,489 \\
0 \\
4 \\
0 \\
0 \\
158 \\
1,690\end{array}$ & $\begin{array}{r}0 \\
2557 \\
0 \\
85 \\
48 \\
690 \\
297 \\
3,576\end{array}$ & $\begin{array}{r}0 \\
7,77 \\
0 \\
514 \\
16 \\
113 \\
808 \\
9,027\end{array}$ & $\begin{array}{r}0 \\
1,475 \\
0 \\
68 \\
0 \\
305 \\
345 \\
2,439\end{array}$ & $\begin{array}{r}0 \\
002 \\
0 \\
0 \\
0 \\
0 \\
121 \\
1059\end{array}$ \\
\hline 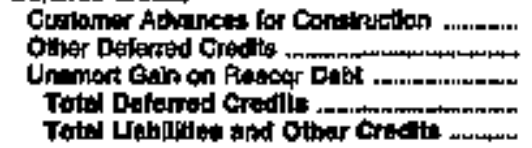 & $\begin{array}{r}248 \\
43 \\
295 \\
295\end{array}$ & $\begin{array}{r}0 \\
0 \\
0 \\
0 \\
0 \\
21,4=8\end{array}$ & $\begin{array}{r}t 6 \\
491 \\
+\quad 0 \\
609 \\
2,99\end{array}$ & $\begin{array}{r}45 \\
76 x \\
6 \\
679 \\
40,110\end{array}$ & $\begin{array}{r}0 \\
78 \% \\
0 \\
782 \\
39,496\end{array}$ & $\begin{array}{r}309 \\
0 \\
0 \\
309 \\
17,900\end{array}$ \\
\hline
\end{tabular}

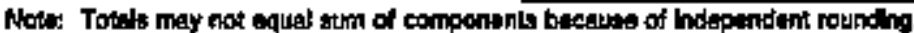

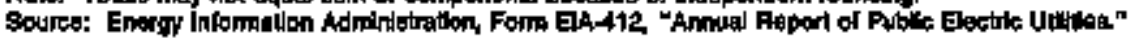


Table 22. Balance Shoet by Major U.S. Publlchy Owned Electric Utilly Whithin State at End of Perlod, 1994

(Thousand Dollars)

\begin{tabular}{|c|c|c|c|c|c|c|}
\hline item & $\begin{array}{l}\text { Pennosmanta } \\
\text { Lenodale } \\
\text { Borough of } \\
\text { December } 31\end{array}$ & $\begin{array}{l}\text { South Curolina } \\
\text { Cundon } \\
\text { ciny of } \\
\text { Nhe so }\end{array}$ & 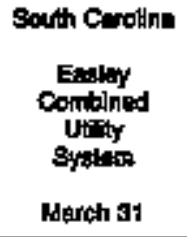 & $\begin{array}{l}\text { South Curoing } \\
\text { Cithoy } \\
\text { Oty of } \\
\text { Slarch } 31\end{array}$ & 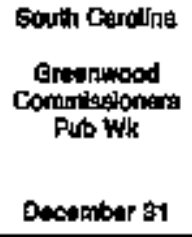 & 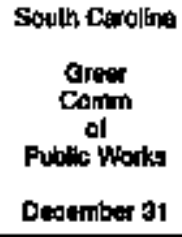 \\
\hline 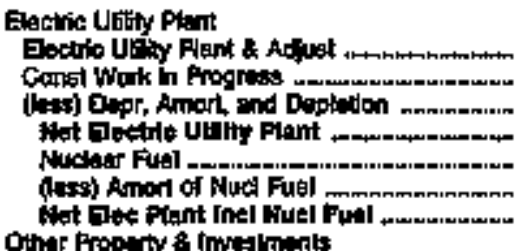 & 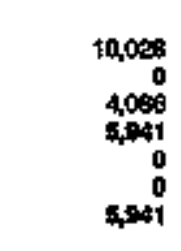 & $\begin{array}{r}11,059 \\
0 \\
8,644 \\
2,414 \\
0 \\
0 \\
2,414\end{array}$ & $\begin{array}{r}15,371 \\
5 \times 37 \\
5,6907 \\
10,079 \\
0 \\
0 \\
10,079\end{array}$ & $\begin{array}{r}2,102 \\
0 \\
919 \\
1,2182 \\
0 \\
0 \\
1,282\end{array}$ & $\begin{array}{r}9,260 \\
0 \\
4,146 \\
6,122 \\
0 \\
0,120\end{array}$ & $\begin{array}{r}83,364 \\
2,224 \\
24,091 \\
94,615 \\
0 \\
0 \\
04,515\end{array}$ \\
\hline 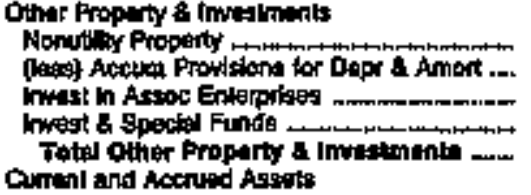 & $\begin{array}{l}0 \\
0 \\
0 \\
0 \\
0\end{array}$ & $\begin{array}{r}12,991 \\
2,600 \\
0 \\
1,170 \\
11,497\end{array}$ & $\begin{array}{r}32,050 \\
11,360 \\
0 \\
8,274 \\
27,974\end{array}$ & $\begin{array}{r}15,743 \\
5,017 \\
0 \\
0 \\
10,729\end{array}$ & $\begin{array}{r}64,084 \\
10,722 \\
0,97 \\
62,779\end{array}$ & $\begin{array}{r}0 \\
0 \\
0 \\
1,134 \\
1,134\end{array}$ \\
\hline 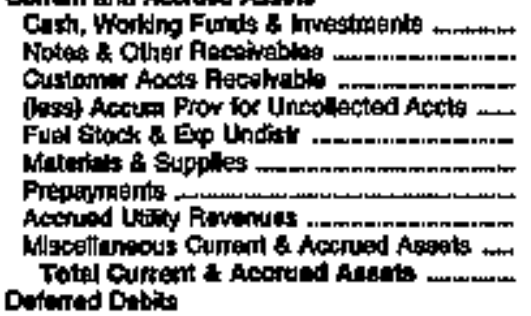 & $\begin{array}{r}17,601 \\
251 \\
604 \\
39 \\
0 \\
389 \\
0 \\
0 \\
0 \\
1906\end{array}$ & $\begin{array}{r}2785 \\
0 \\
890 \\
0 \\
0 \\
5+6 \\
44 \\
0 \\
0 \\
4,260\end{array}$ & $\begin{array}{r}759 \\
203 \\
1,809 \\
0 \\
0 \\
498 \\
0 \\
0 \\
0 \\
\mathbf{3} 998\end{array}$ & $\begin{array}{r}3,154 \\
0 \\
970 \\
58 \\
0 \\
65 \\
9 \\
942 \\
0 \\
4001\end{array}$ & $\begin{array}{r}7,917 \\
0 \\
0 \\
0 \\
0 \\
1,341 \\
70 \\
0 \\
9 \\
9326\end{array}$ & $\begin{array}{r}2020 \\
4 \\
1,1100 \\
0 \\
2 \\
285 \\
0 \\
0 \\
0 \\
3,060\end{array}$ \\
\hline 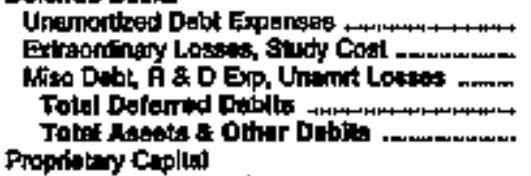 & $\begin{array}{r}167 \\
0 \\
0 \\
167 \\
24,254\end{array}$ & $\begin{array}{r}0 \\
0 \\
0 \\
0 \\
18,184\end{array}$ & $\begin{array}{r}28 \\
0 \\
0 \\
23 \\
21, * 43\end{array}$ & $\begin{array}{r}0 \\
0 \\
0 \\
0\end{array}$ & $\begin{array}{r}530 \\
0 \\
\gamma, 001 \\
1,531 \\
70,721\end{array}$ & $\begin{array}{r}21 \\
0 \\
0 \\
21 \\
09000\end{array}$ \\
\hline 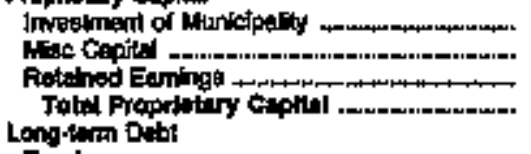 & $\begin{array}{r}0 \\
5,580 \\
14,406 \\
15,0403\end{array}$ & $\begin{array}{r}0 \\
13,249 \\
13,240\end{array}$ & $\begin{array}{r}179 \\
18,162 \\
15,352 \\
26,462\end{array}$ & $\begin{array}{r}0 \\
15,2 a 8 \\
t, 2010\end{array}$ & $\begin{array}{r}0 \\
6,949 \\
49,876 \\
50,944\end{array}$ & $\begin{array}{r}0 \\
13,698 \\
49,691 \\
62,207\end{array}$ \\
\hline 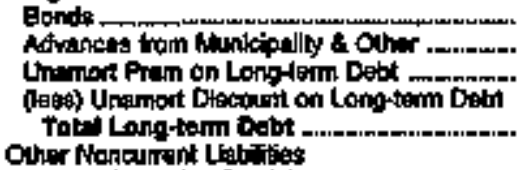 & $\begin{array}{r}7,980 \\
0 \\
0 \\
7,90\end{array}$ & $\begin{array}{r}3,300 \\
0 \\
0 \\
0 \\
0,500\end{array}$ & $\begin{array}{r}5,135 \\
21 \\
0 \\
0 \\
6,160\end{array}$ & $\begin{array}{r}2,510 \\
0 \\
0 \\
0 \\
2,510\end{array}$ & $\begin{array}{r}22,200 \\
0 \\
0 \\
0 \\
2,2,200\end{array}$ & $\begin{array}{r}3,809 \\
0 \\
0 \\
0 \\
3,000\end{array}$ \\
\hline 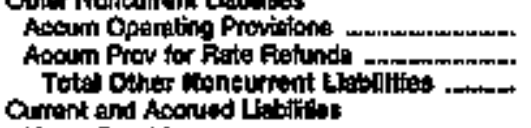 & $\begin{array}{l}0 \\
0 \\
0\end{array}$ & $\begin{array}{r}50 \\
0 \\
4\end{array}$ & $\begin{array}{l}0 \\
0 \\
0\end{array}$ & $\begin{array}{l}0 \\
0 \\
0\end{array}$ & $\begin{array}{r}1,525 \\
0 \\
1,626\end{array}$ & \\
\hline 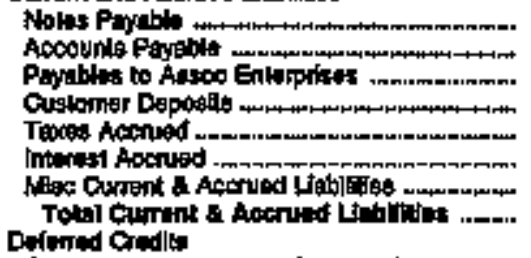 & $\begin{array}{r}0 \\
57 \\
0 \\
201 \\
0 \\
90 \\
74 \\
900\end{array}$ & $\begin{array}{r}0 \\
091 \\
0 \\
297 \\
0 \\
75 \\
\operatorname{sog} \\
1600\end{array}$ & $\begin{array}{r}516 \\
580 \\
0 \\
368 \\
0 \\
6 \\
1,241 \\
2,500\end{array}$ & $\begin{array}{r}0 \\
114 \\
0 \\
29 \\
66 \\
0 \\
724 \\
1,101\end{array}$ & $\begin{array}{r}1,145 \\
3,135 \\
0 \\
217 \\
0 \\
00 \\
4,761\end{array}$ & $\begin{array}{r}0 \\
2,697 \\
0 \\
306 \\
0 \\
0 \\
2,22 \\
3,524\end{array}$ \\
\hline 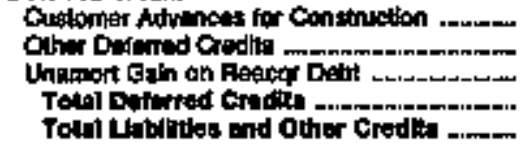 & $\begin{array}{r}0 \\
0 \\
0 \\
0 \\
24,864\end{array}$ & $\begin{array}{r}\stackrel{0}{0} \\
0 \\
0 \\
0\end{array}$ & $\begin{array}{r}4,767 \\
4,04 \\
41,449\end{array}$ & $\begin{array}{r}0 \\
0 \\
0 \\
0\end{array}$ & $\begin{array}{r}0 \\
0 \\
0 \\
0 \\
70,721\end{array}$ & $\begin{array}{r}0 \\
0 \\
0 \\
0 \\
09,600\end{array}$ \\
\hline
\end{tabular}

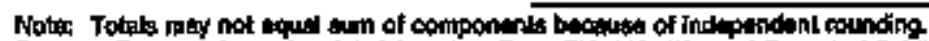

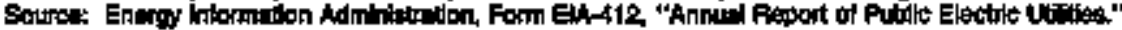


Table 22. Balance Stheet by Major U.S. Publely Owned Electric Utilly Whin State at End of Period, 1994

(Thousand Dollars)

\begin{tabular}{|c|c|c|c|c|c|c|}
\hline Inen & 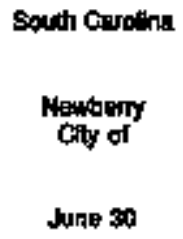 & 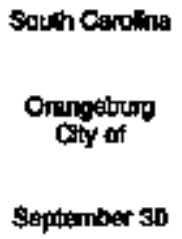 & 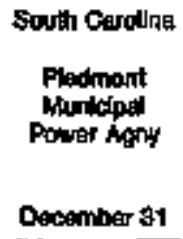 & $\begin{array}{l}\text { South Cenoling } \\
\text { Ploth Hull } \\
\text { Cocember of }\end{array}$ & $\begin{array}{l}\text { South Cantina } \\
\text { Sentea } \\
\text { Cay oI } \\
\text { Wune } 30\end{array}$ & 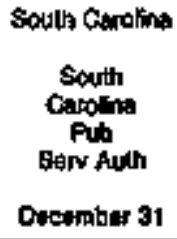 \\
\hline 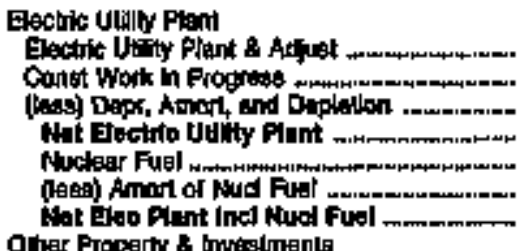 & $\begin{array}{r}7,920 \\
0 \\
4,3020 \\
3,601 \\
0 \\
0 \\
3,600\end{array}$ & $\begin{array}{r}54,696 \\
12,616 \\
42,016 \\
0 \\
0 \\
42,084\end{array}$ & $\begin{array}{r}542,300 \\
7,600 \\
152,201 \\
309,094 \\
44,7,77 \\
27,507 \\
415,204\end{array}$ & $\begin{array}{r}30,083 \\
1,090 \\
12095 \\
19,940 \\
0 \\
0 \\
19,948\end{array}$ & $\begin{array}{r}20,027 \\
5,00 \\
10,059 \\
16,550 \\
0 \\
0 \\
16,658\end{array}$ & 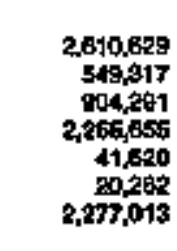 \\
\hline 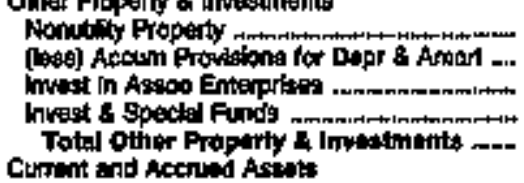 & $\begin{array}{r}24,195 \\
9,6 \% 9 \\
0 \\
5,023 \\
2,0 ; 71\end{array}$ & $\begin{array}{r}4,604 \\
2,037 \\
12,007 \\
14,574\end{array}$ & $\begin{array}{r}0 \\
0 \\
177,487 \\
177,497\end{array}$ & $\begin{array}{r}109,600 \\
28,684 \\
0 \\
0 \\
06,005\end{array}$ & $\begin{array}{r}2,324 \\
079 \\
0 \\
0 \\
1,448\end{array}$ & $\begin{array}{r}7,909 \\
189 \\
0 \\
290,527 \\
202,247\end{array}$ \\
\hline 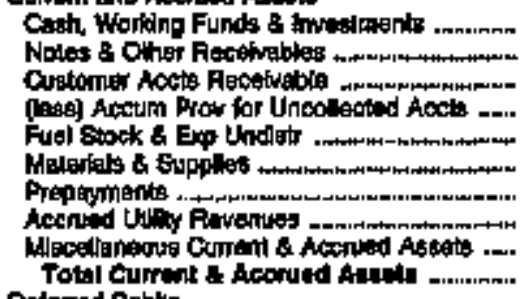 & $\begin{array}{r}1,758 \\
0 \\
1,042 \\
02 \\
0 \\
598 \\
0 \\
0 \\
314 \\
3,693\end{array}$ & $\begin{array}{r}1,586 \\
120 \\
2,000 \\
30 \\
06 \\
2,486 \\
190 \\
6 \\
65,907 \\
62,456\end{array}$ & $\begin{array}{r}3 \times, 451 \\
2,940 \\
6,996 \\
0 \\
0 \\
4,930 \\
0 \\
0 \\
0 \\
380,159\end{array}$ & $\begin{array}{r}14,07 \\
2,767 \\
6,721 \\
0 \\
0 \\
1,207 \\
0 \\
0 \\
0 \\
04,672\end{array}$ & $\begin{array}{r}4,969 \\
1 \\
1,294 \\
2 \\
0 \\
209 \\
11 \\
0 \\
45 \\
0,581\end{array}$ & $\begin{array}{r}157,102 \\
0 \\
55,6003 \\
887 \\
13,944 \\
33,019 \\
1,011 \\
0 \\
2908 \\
297813\end{array}$ \\
\hline 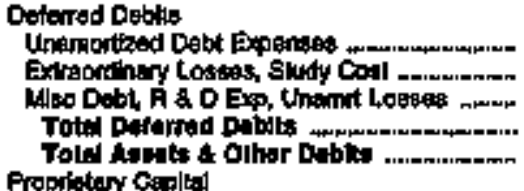 & $\begin{array}{r}0 \\
0 \\
0 \\
0 \\
27,505\end{array}$ & 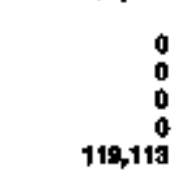 & $\begin{array}{r}2+219 \\
0 \\
416,978 \\
4 \$, 807 \\
1,300,427\end{array}$ & $\begin{array}{r}5,560 \\
0 \\
0 \\
5,503 \\
139,385\end{array}$ & $\begin{array}{r}0 \\
0 \\
0 \\
0 \\
24,567\end{array}$ & $\begin{array}{r}24,142 \\
0 \\
704,216 \\
724,98 \% \\
3,590,261\end{array}$ \\
\hline 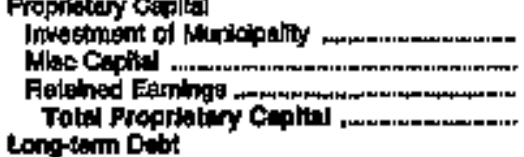 & $\begin{array}{r}320 \\
14,777 \\
15,0.0 \% 7\end{array}$ & $\begin{array}{r}0 \\
100,200 \\
100,200\end{array}$ & $\begin{array}{r}9 \\
0 \\
0,351 \\
0,351\end{array}$ & $\begin{array}{r}0 \\
39,573 \\
24,914 \\
64,398\end{array}$ & $\begin{array}{r}4,078 \\
0 \\
19,555 \\
23,415\end{array}$ & $\begin{array}{r}34,496 \\
0 \\
849,601 \\
602,059\end{array}$ \\
\hline 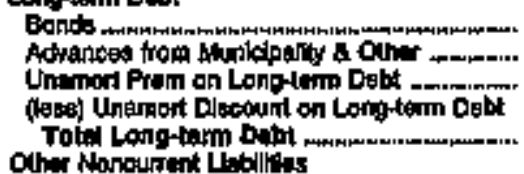 & $\begin{array}{r}10,770 \\
50 \\
0 \\
0 \\
1,1,37 \%\end{array}$ & $\begin{array}{r}6,2,5 \\
0 \\
0 \\
0 \\
0,225\end{array}$ & $\begin{array}{r}1,398,890 \\
0 \\
0 \\
67,217 \\
1,290,099\end{array}$ & $\begin{array}{r}67,065 \\
0 \\
0 \\
67,005\end{array}$ & $\begin{array}{l}0 \\
0 \\
0 \\
0 \\
0\end{array}$ & $\begin{array}{r}2,456,1600 \\
49,440 \\
0 \\
54,005 \\
2,451,600\end{array}$ \\
\hline 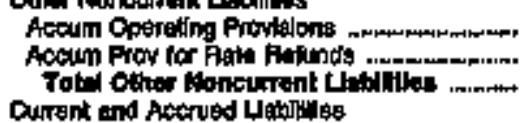 & $\begin{array}{l}0 \\
0 \\
0\end{array}$ & $\begin{array}{r}4 \% 1 \\
\text { t,12f }\end{array}$ & $\begin{array}{r}12,834 \\
0 \\
12,034\end{array}$ & $\begin{array}{l}0 \\
0 \\
0\end{array}$ & $\begin{array}{l}0 \\
0 \\
0\end{array}$ & $\begin{array}{l}0 \\
0 \\
0\end{array}$ \\
\hline 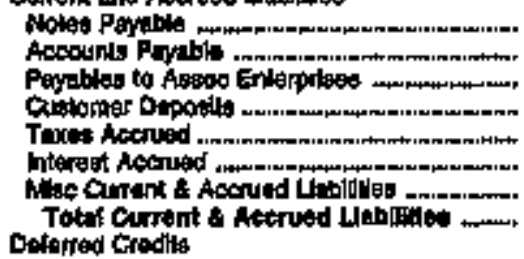 & $\begin{array}{r}0 \\
870 \\
0 \\
0 \\
0 \\
106 \\
02 \\
1,141\end{array}$ & $\begin{array}{r}0 \\
0,100 \\
0 \\
724 \\
0 \\
0 \\
928 \\
5587\end{array}$ & 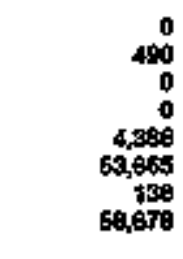 & $\begin{array}{r}0 \\
2,510 \\
0 \\
1,328 \\
0 \\
0 \\
1,079 \\
4,913\end{array}$ & $\begin{array}{r}0 \\
654 \\
0 \\
418 \\
35 \\
0 \\
67 \\
1,174\end{array}$ & $\begin{array}{r}270,071 \\
60,978 \\
0 \\
5,491 \\
1,958 \\
71,972 \\
42,394 \\
45,, 234\end{array}$ \\
\hline 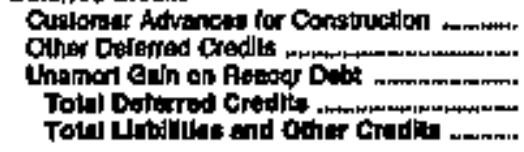 & $\begin{array}{r}0 \\
0 \\
0 \\
0 \\
07,566\end{array}$ & $\begin{array}{r}0 \\
0 \\
0 \\
0 \\
\text { ite, 1ts }\end{array}$ & $\begin{array}{r}0 \\
0 \\
1 \quad 0 \\
0 \\
0\end{array}$ & $\begin{array}{r}0 \\
0 \\
0 \\
0 \\
0\end{array}$ & $\begin{array}{r}0 \\
0 \\
0 \\
0 \\
24,607\end{array}$ & $\begin{array}{r}0 \\
1,061 \\
324 \\
2,296 \\
3,590,251\end{array}$ \\
\hline
\end{tabular}

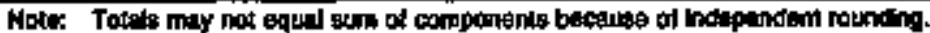

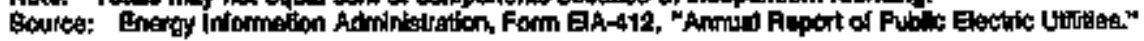


Table 22. Balance sheet by Major U.S. Publicly Owned Electric Utilty Within State at End of Period, 1994 (Thousand Dollars)

\begin{tabular}{|c|c|c|c|c|c|c|}
\hline tien & 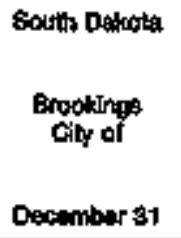 & 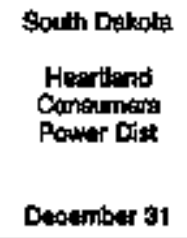 & 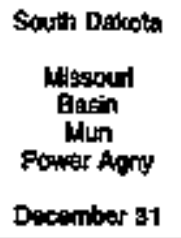 & $\begin{array}{l}\text { South Dakolp } \\
\text { Pienre } \\
\text { City of } \\
\text { Daceraber } 31\end{array}$ & 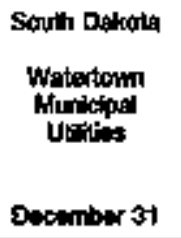 & 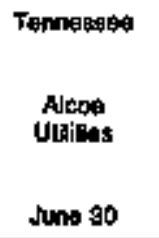 \\
\hline 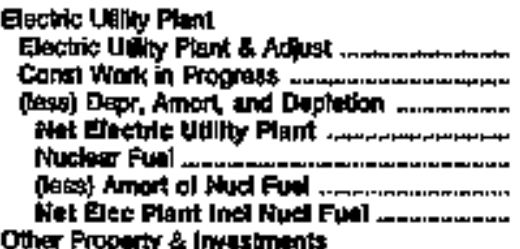 & $\begin{array}{r}18,807 \\
1,60 \\
5,881 \\
13,13,2 \\
0 \\
0 \\
18,1,92\end{array}$ & $\begin{array}{r}57,438 \\
169 \\
8,081 \\
40,524 \\
6 \\
0 \\
40,502\end{array}$ & $\begin{array}{r}2,734 \\
0 \\
795 \\
1,090 \\
0 \\
0 \\
1,909\end{array}$ & $\begin{array}{r}8,070 \\
0 \\
2,644 \\
5,427 \\
0 \\
0 \\
5,227\end{array}$ & $\begin{array}{r}17,3110 \\
59 \\
11,002 \\
0,200 \\
0 \\
0 \\
6,209\end{array}$ & $\begin{array}{r}19,144 \\
290 \\
6,443 \\
12,991 \\
0 \\
0 \\
12,981\end{array}$ \\
\hline 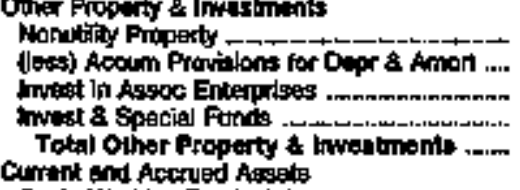 & $\begin{array}{l}0 \\
0 \\
0 \\
0 \\
0\end{array}$ & $\begin{array}{r}0 \\
0 \\
0 \\
9,208 \\
9,200\end{array}$ & $\begin{array}{r}0 \\
0 \\
12,026 \\
12,426\end{array}$ & $\begin{array}{r}0 \\
0 \\
0 \\
575 \\
573\end{array}$ & $\begin{array}{l}0 \\
0 \\
0 \\
0 \\
0\end{array}$ & $\begin{array}{r}0 \\
0 \\
0 \\
1,009 \\
1,050\end{array}$ \\
\hline 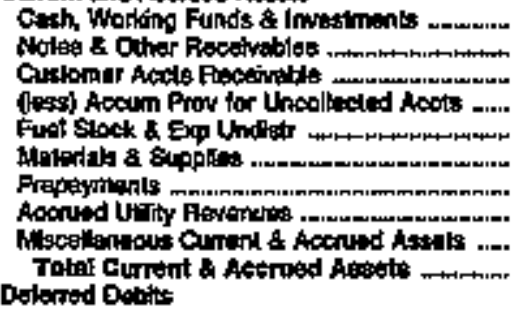 & $\begin{array}{r}2,272 \\
0 \\
1,135 \\
0 \\
0 \\
2,5 \\
4 \\
0 \\
45 \\
3,075\end{array}$ & $\begin{array}{r}5,767 \\
308 \\
947 \\
0 \\
18 \\
8,187 \\
17 \\
398 \\
119 \\
9,660\end{array}$ & $\begin{array}{r}3,847 \\
0 \\
6,009 \\
0 \\
61 \\
0 \\
1,590 \\
0 \\
093 \\
12,877\end{array}$ & $\begin{array}{r}1,325 \\
0 \\
600 \\
57 \\
0 \\
651 \\
0 \\
1,428 \\
10 \\
3,993\end{array}$ & $\begin{array}{r}2,557 \\
0 \\
1,246 \\
5 \\
0 \\
329 \\
0 \\
0 \\
5 \\
4,130\end{array}$ & $\begin{array}{r}2,837 \\
1,690 \\
0 \\
0 \\
0 \\
900 \\
7 \\
0 \\
1,088\end{array}$ \\
\hline 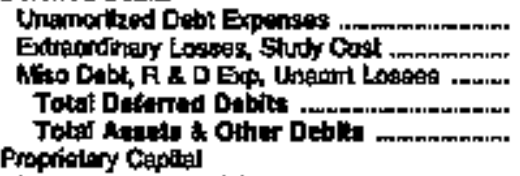 & $\begin{array}{r}0 \\
0 \\
0 \\
0 \\
0\end{array}$ & 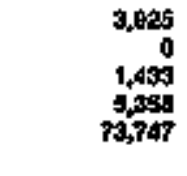 & $\begin{array}{r}0 \\
0 \\
0 \\
0 \\
26,902\end{array}$ & $\begin{array}{r}0 \\
0 \\
0 \\
0 \\
9,768\end{array}$ & $\begin{array}{r}0 \\
0 \\
0 \\
0 \\
10,413\end{array}$ & $\begin{array}{r}27 \\
0 \\
1,156 \\
1,184 \\
20,151\end{array}$ \\
\hline 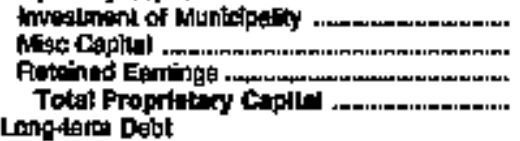 & $\begin{array}{r}9 \\
15,946 \\
15,946\end{array}$ & $\begin{array}{r}0 \\
2,000 \\
2,004\end{array}$ & $\begin{array}{r}0 \\
0 \\
20,069 \\
20,058\end{array}$ & $\begin{array}{r}62 \\
8,092 \\
8,744\end{array}$ & $\begin{array}{r}0 \\
101 \\
6,813 \\
0,006\end{array}$ & $\begin{array}{r}0 \\
12,0 e 9 \\
12,020\end{array}$ \\
\hline 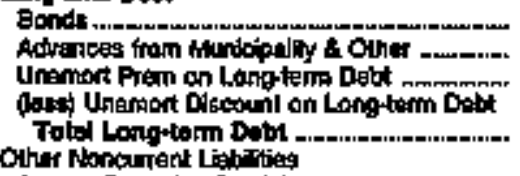 & $\begin{array}{l}0 \\
0 \\
0 \\
0 \\
0\end{array}$ & $\begin{array}{r}04,165 \\
0 \\
0 \\
0 \\
64,169\end{array}$ & $\begin{array}{l}0 \\
0 \\
0 \\
0 \\
0\end{array}$ & $\begin{array}{l}0 \\
0 \\
0 \\
0 \\
0\end{array}$ & $\begin{array}{l}0 \\
0 \\
0 \\
0 \\
0\end{array}$ & $\begin{array}{r}2,982 \\
974 \\
-27 \\
0 \\
3,358\end{array}$ \\
\hline 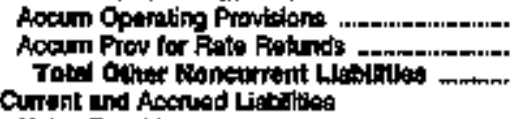 & $\begin{array}{l}0 \\
0 \\
0\end{array}$ & $\begin{array}{l}0 \\
0 \\
0\end{array}$ & $\begin{array}{l}9 \\
0 \\
0\end{array}$ & $\begin{array}{c}0 \\
0 \\
60\end{array}$ & $\begin{array}{l}0 \\
0 \\
0\end{array}$ & $\begin{array}{l}0 \\
0 \\
0\end{array}$ \\
\hline 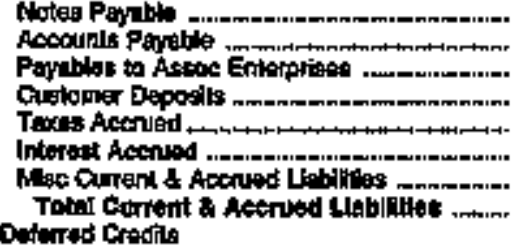 & $\begin{array}{r}0 \\
734 \\
0 \\
0 \\
31 \\
0 \\
95 \\
81\end{array}$ & $\begin{array}{r}0 \\
779 \\
0 \\
0 \\
170 \\
1,867 \\
1,472 \\
4,309\end{array}$ & $\begin{array}{r}0 \\
6,025 \\
9 \\
0 \\
24 \\
0 \\
0 \\
6,050\end{array}$ & $\begin{array}{r}0 \\
700 \\
0 \\
227 \\
20 \\
0 \\
0 \\
968\end{array}$ & $\begin{array}{r}640 \\
0 \\
10 \\
168 \\
05 \\
0 \\
728 \\
1,600\end{array}$ & $\begin{array}{r}0 \\
2,114 \\
0 \\
1,650 \\
0 \\
28 \\
280 \\
3,918\end{array}$ \\
\hline 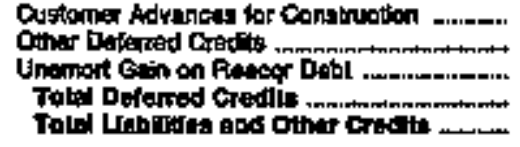 & $\begin{array}{r}0 \\
0 \\
0 \\
+6,600\end{array}$ & $\begin{array}{r}0 \\
712 \\
2,476 \\
3,160 \\
73,747\end{array}$ & $\begin{array}{r}0 \\
0 \\
0 \\
20,002\end{array}$ & $\begin{array}{r}3 \\
0 \\
0 \\
3 \\
3\end{array}$ & $\begin{array}{r}0 \\
0 \\
0 \\
0 \\
0 \\
10,4+3\end{array}$ & $\begin{array}{r}206 \\
0 \\
0 \\
296 \\
20,151\end{array}$ \\
\hline
\end{tabular}

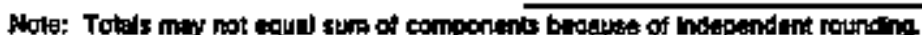

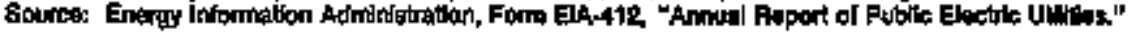


Table 22. Balance Sheet by Major U.S. Publicly Owned Electric Utitity Within state at End of Period, 1994

(Thousand Dollars)

\begin{tabular}{|c|c|c|c|c|c|c|}
\hline Itom & 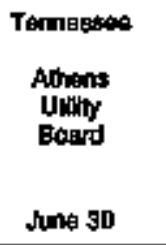 & 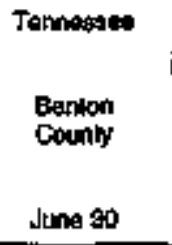 & $\begin{array}{l}\text { Tennususes } \\
\text { Bolivar } \\
\text { Ciby of } \\
\text { June } 30\end{array}$ & 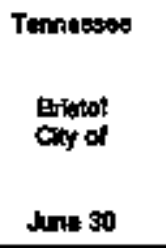 & $\begin{array}{l}\text { Tonnogespa } \\
\text { Bnownosillo } \\
\text { City of } \\
\text { June } 30\end{array}$ & 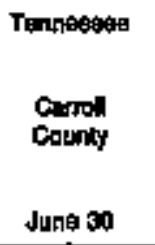 \\
\hline 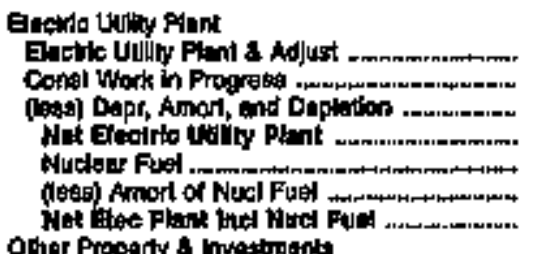 & $\begin{array}{r}17.718 \\
286 \\
6,074 \\
11,328 \\
0 \\
0 \\
11,320\end{array}$ & $\begin{array}{r}14,609 \\
10 \\
5,022 \\
0,997 \\
0 \\
0 \\
0,997\end{array}$ & $\begin{array}{r}16,211 \\
170 \\
5,224 \\
10,457 \\
0 \\
10,407\end{array}$ & $\begin{array}{r}40,009 \\
4,054 \\
32,200 \\
21,000 \\
0 \\
0 \\
21,100\end{array}$ & $\begin{array}{r}6,508 \\
794 \\
2,3992 \\
4,506 \\
0 \\
0 \\
4,005\end{array}$ & $\begin{array}{r}19,694 \\
0 \\
7,9062 \\
11,671 \\
0 \\
0 \\
11,679\end{array}$ \\
\hline 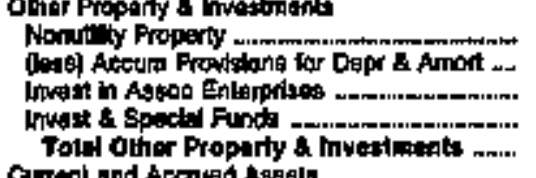 & $\begin{array}{l}\text { D } \\
0 \\
0 \\
0 \\
\text { D }\end{array}$ & $\begin{array}{r}0 \\
0 \\
0 \\
1,103 \\
1,163\end{array}$ & $\begin{array}{r}0 \\
0 \\
0 \\
140 \\
140\end{array}$ & $\begin{array}{r}190 \\
9 \\
0 \\
10,200 \\
10,390\end{array}$ & $\begin{array}{r}0 \\
0 \\
0 \\
m \\
m\end{array}$ & $\begin{array}{r}0 \\
0 \\
0 \\
1,107 \\
t, 107\end{array}$ \\
\hline 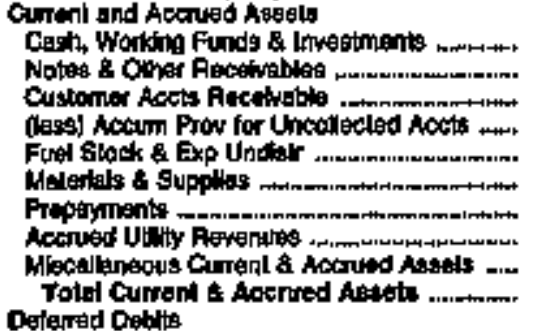 & $\begin{array}{r}519 \\
2,176 \\
0 \\
0 \\
0 \\
2+0 \\
3 \\
0 \\
60 \\
2,970\end{array}$ & $\begin{array}{r}38 \\
1,028 \\
0 \\
0 \\
0 \\
128 \\
77 \\
0 \\
10 \\
1,281\end{array}$ & $\begin{array}{r}325 \\
1,500 \\
0 \\
0 \\
0 \\
301 \\
16 \\
0 \\
28 \\
2,209\end{array}$ & $\begin{array}{r}2,707 \\
2,541 \\
0 \\
0 \\
0 \\
605 \\
107 \\
0 \\
158 \\
6,0081\end{array}$ & $\begin{array}{r}505 \\
674 \\
0 \\
0 \\
0 \\
148 \\
52 \\
0 \\
8 \\
1 \text { A75 }\end{array}$ & 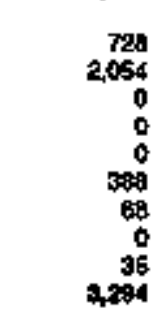 \\
\hline 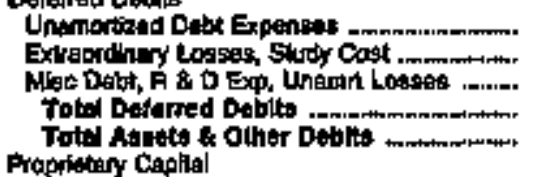 & $\begin{array}{r}0 \\
0 \\
859 \\
15,159\end{array}$ & $\begin{array}{r}3 \\
0 \\
289 \\
205 \\
11,728\end{array}$ & $\begin{array}{r}55 \\
0 \\
1,125 \\
1,170 \\
14008\end{array}$ & $\begin{array}{r}0 \\
5,205 \\
5,235 \\
4,4,40\end{array}$ & $\begin{array}{r}3 \\
0 \\
24 \\
7,190\end{array}$ & $\begin{array}{r}16 \\
0 \\
130 \\
145 \\
10,219\end{array}$ \\
\hline 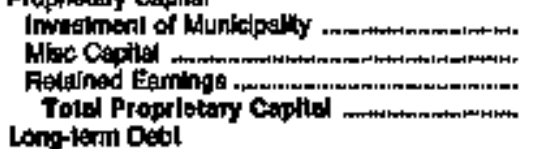 & $\begin{array}{r}0 \\
0 \\
13,764 \\
13,754\end{array}$ & $\begin{array}{r}0 \\
0,854 \\
6,954\end{array}$ & $\begin{array}{r}0 \\
8,107 \\
8,107\end{array}$ & $\begin{array}{r}0 \\
0 \\
39,947 \\
39047\end{array}$ & $\begin{array}{r}0 \\
0 \\
6,288 \\
6,286\end{array}$ & $\begin{array}{r}0 \\
0 \\
12,281 \\
12,261\end{array}$ \\
\hline 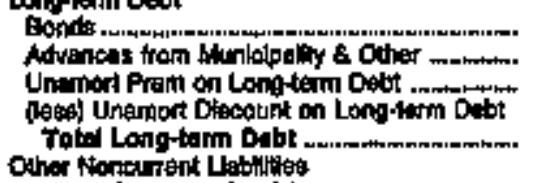 & $\begin{array}{r}0 \\
09 \\
0 \\
0 \\
109\end{array}$ & $\begin{array}{r}606 \\
280 \\
0 \\
9 \\
985\end{array}$ & $\begin{array}{r}1,2200 \\
2,702 \\
0 \\
0 \\
3,912\end{array}$ & $\begin{array}{l}0 \\
0 \\
0 \\
0 \\
0\end{array}$ & $\begin{array}{r}585 \\
2 \\
0 \\
0 \\
667\end{array}$ & $\begin{array}{r}045 \\
122 \\
-11 \\
0 \\
1,058\end{array}$ \\
\hline 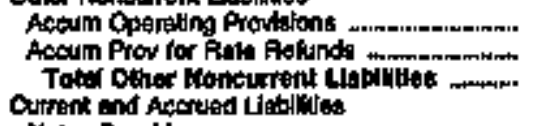 & $\begin{array}{l}\mathbf{0} \\
\mathbf{0} \\
\mathbf{0}\end{array}$ & $\begin{array}{l}0 \\
0 \\
0\end{array}$ & $\begin{array}{l}0 \\
0 \\
0\end{array}$ & $\begin{array}{l}0 \\
0 \\
0\end{array}$ & $\begin{array}{l}0 \\
0 \\
0\end{array}$ & 0 \\
\hline 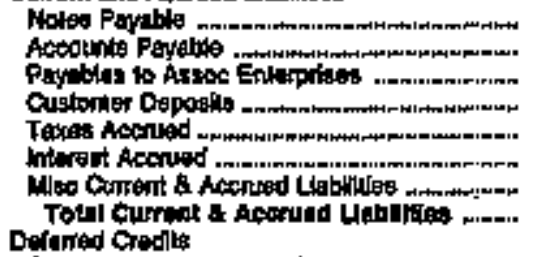 & $\begin{array}{r}0 \\
303 \\
0 \\
0 \\
0 \\
0 \\
191 \\
627\end{array}$ & $\begin{array}{r}0 \\
800 \\
0 \\
400 \\
0 \\
12 \\
600 \\
1,076\end{array}$ & $\begin{array}{r}0 \\
1,27 \\
0 \\
461 \\
0 \\
8 \\
841 \\
1,977\end{array}$ & $\begin{array}{r}0 \\
1,888 \\
0 \\
608 \\
188 \\
0 \\
790 \\
5,400\end{array}$ & $\begin{array}{r}0 \\
082 \\
0 \\
207 \\
0 . \\
3 \\
21 \\
1,213\end{array}$ & $\begin{array}{r}0 \\
1,537 \\
0 \\
415 \\
291 \\
0 \\
651 \\
2904\end{array}$ \\
\hline 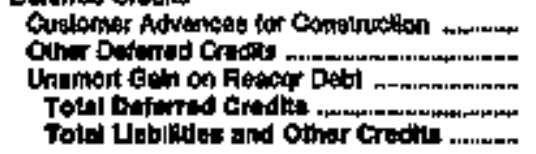 & $\begin{array}{r}0 \\
7 \\
0 \\
7 \\
15,187\end{array}$ & $\begin{array}{r}0 \\
1 \\
0 \\
1 \\
11,725\end{array}$ & $\begin{array}{r}9 \\
0 \\
10 \\
14,006\end{array}$ & $\begin{array}{r}0 \\
23 \\
0 \\
23 \\
4 \$ 40\end{array}$ & $\begin{array}{r}0 \\
+20 \\
0 \\
120 \\
7,190\end{array}$ & $\begin{array}{r}7 \\
0 \\
0 \\
7 \\
18,219\end{array}$ \\
\hline
\end{tabular}

Motex Totels migy not equal oum of componants beceupe of independent rounding.

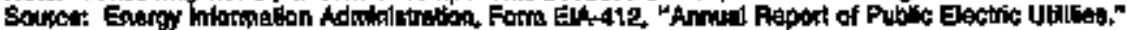


Table 22. Balance Shent by Major U.S. Publicly Owned Electric Utility Whithin State at End of Perlod, 1994

(Thousand Dollars)

\begin{tabular}{|c|c|c|c|c|c|c|}
\hline kem & $\begin{array}{l}\text { Tennegonos } \\
\text { Chattenoogs } \\
\text { City of } \\
\text { Juna } 30\end{array}$ & $\begin{array}{l}\text { Tennossere } \\
\text { Cleitewillo } \\
\text { City of } \\
\text { June } 30\end{array}$ & $\begin{array}{l}\text { Teranessop } \\
\text { Clowelond } \\
\text { Gty of } \\
\text { Jume 30 }\end{array}$ & $\begin{array}{l}\text { Tennosses } \\
\text { Clindon } \\
\text { Oty of } \\
\text { Jume so }\end{array}$ & $\begin{array}{l}\text { Tomnesset } \\
\text { Columbla } \\
\text { Coty oil } \\
\text { Jume } 30\end{array}$ & 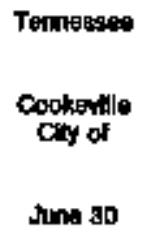 \\
\hline 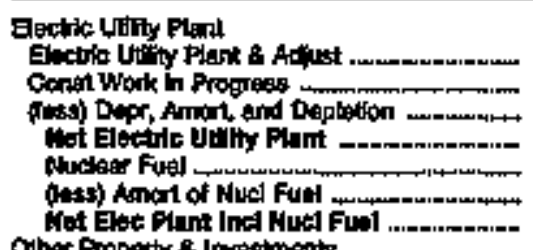 & $\begin{array}{r}250,215 \\
7,697 \\
100,390 \\
167,531 \\
0 \\
1670 \\
167,531\end{array}$ & 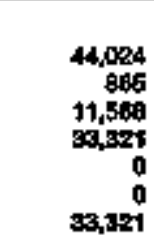 & $\begin{array}{r}45,773 \\
1,233 \\
16,406 \\
33,606 \\
0 \\
0 \\
33,004\end{array}$ & $\begin{array}{r}37,779 \\
405 \\
12,602 \\
25,391 \\
0 \\
0 \\
25,01\end{array}$ & $\begin{array}{r}Z, 160 \\
400 \\
9,809 \\
17,890 \\
0 \\
0 \\
7,800\end{array}$ & $\begin{array}{r}19,009 \\
218 \\
\$, 013 \\
14,200 \\
0 \\
0 \\
14,200\end{array}$ \\
\hline 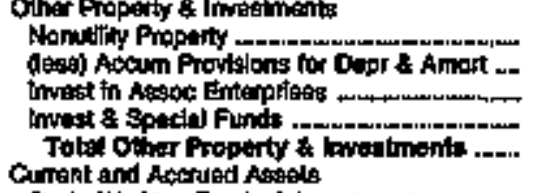 & $\begin{array}{r}0 \\
0 \\
0 \\
12000 \\
12000\end{array}$ & $\begin{array}{r}56 \\
0 \\
0 \\
9.277 \\
0.912\end{array}$ & $\begin{array}{r}0 \\
0 \\
0 \\
\mathbf{3 8} \\
\mathbf{3 8}\end{array}$ & $\begin{array}{r}0 \\
0 \\
0 \\
370 \\
370\end{array}$ & $\begin{array}{r}0 \\
0 \\
0 \\
3,351 \\
8,351\end{array}$ & $\begin{array}{r}0 \\
0 \\
216 \\
218\end{array}$ \\
\hline 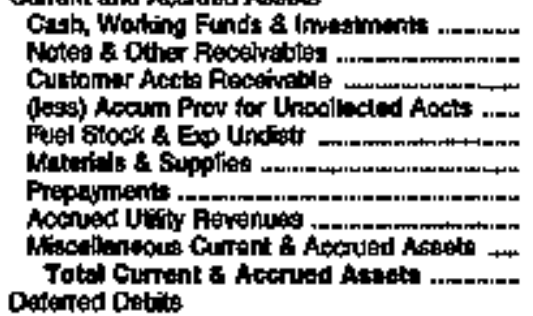 & $\begin{array}{r}31,707 \\
49,000 \\
0 \\
0 \\
0 \\
3,816 \\
1,106 \\
0 \\
17,169 \\
69,407\end{array}$ & $\begin{array}{r}1,4,9 \\
3,421 \\
0 \\
0 \\
0 \\
505 \\
3 \\
0 \\
101 \\
100\end{array}$ & $\begin{array}{r}2,778 \\
4,681 \\
0 \\
0 \\
0 \\
652 \\
128 \\
0 \\
55 \\
5 \\
142\end{array}$ & $\begin{array}{r}2,113 \\
3,099 \\
0 \\
0 \\
0 \\
676 \\
274 \\
0 \\
110 \\
6,700\end{array}$ & $\begin{array}{r}514 \\
1,505 \\
0 \\
0 \\
0 \\
610 \\
41 \\
0 \\
51 \\
900\end{array}$ & $\begin{array}{r}1,200 \\
1,792 \\
0 \\
0 \\
0 \\
191 \\
7 \\
0 \\
31 \\
3,527\end{array}$ \\
\hline 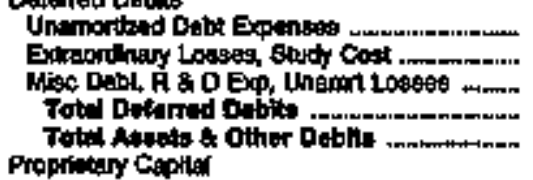 & $\begin{array}{r}0 \\
0 \\
13,081 \\
13,031 \\
262,110\end{array}$ & $\begin{array}{r}132 \\
0 \\
5,267 \\
5,379 \\
54,012\end{array}$ & $\begin{array}{r}0 \\
0 \\
2,205 \\
2,295 \\
4,070\end{array}$ & $\begin{array}{r}0 \\
2,806 \\
2,906 \\
340,077\end{array}$ & $\begin{array}{r}54 \\
0 \\
1,302 \\
1,356 \\
25,146\end{array}$ & $\begin{array}{r}6 \\
0 \\
370 \\
370 \\
10,000\end{array}$ \\
\hline 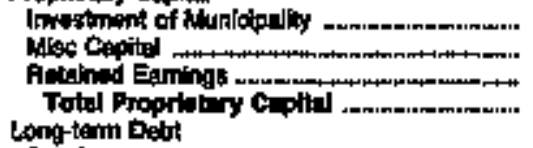 & $\begin{array}{r}0 \\
132,136 \\
172,136\end{array}$ & $\begin{array}{r}0 \\
0 \\
27,396 \\
27,395\end{array}$ & $\begin{array}{r}0 \\
0 \\
34,258 \\
34,2,15\end{array}$ & $\begin{array}{r}0 \\
0 \\
25,719 \\
20,710\end{array}$ & $\begin{array}{r}0 \\
0 \\
18,201 \\
10,201\end{array}$ & $\begin{array}{r}0 \\
10,800 \\
13,408\end{array}$ \\
\hline 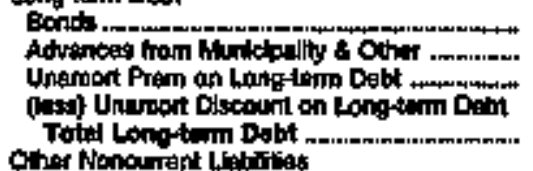 & $\begin{array}{r}11,158 \\
14,7 / 1 \\
0 \\
4 \\
25,424\end{array}$ & $\begin{array}{r}10,005 \\
4,005 \\
-116 \\
0 \\
13,0 \times 6\end{array}$ & $\begin{array}{r}0 \\
2,171 \\
0 \\
0 \\
2,171\end{array}$ & $\begin{array}{r}1,995 \\
2,780 \\
0 \\
0 \\
4,764\end{array}$ & $\begin{array}{r}2,0,95 \\
1,171 \\
-41 \\
0 \\
4,228\end{array}$ & $\begin{array}{r}1,115 \\
388 \\
0 \\
0 \\
1,601\end{array}$ \\
\hline 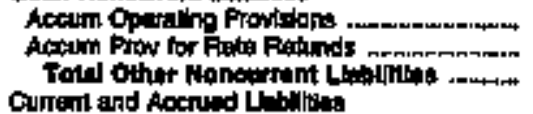 & $\begin{array}{l}0 \\
0 \\
0\end{array}$ & $\begin{array}{l}0 \\
0 \\
0\end{array}$ & $\begin{array}{l}0 \\
0 \\
0\end{array}$ & $\begin{array}{l}0 \\
0 \\
0\end{array}$ & $\begin{array}{l}0 \\
0 \\
0\end{array}$ & $\begin{array}{l}0 \\
0 \\
0\end{array}$ \\
\hline 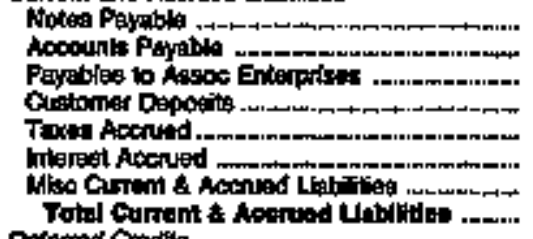 & $\begin{array}{r}0 \\
38,025 \\
5,290 \\
5,614 \\
1,176 \\
7,587 \\
81,040\end{array}$ & $\begin{array}{r}0 \\
5,7 \% 0 \\
0 \\
1,600 \\
0 \\
158 \\
1,168 \\
9,592\end{array}$ & $\begin{array}{r}0 \\
4,3510 \\
0 \\
071 \\
0 \\
0 \\
291 \\
5,001\end{array}$ & $\begin{array}{r}0 \\
2,749 \\
0 \\
925 \\
1 \\
33 \\
727 \\
4,4 * 5\end{array}$ & $\begin{array}{r}0 \\
1,083 \\
0 \\
601 \\
0 \\
47 \\
619 \\
2,720\end{array}$ & $\begin{array}{r}0 \\
2,051 \\
0 \\
403 \\
0 \\
28 \\
0 \\
0.600\end{array}$ \\
\hline 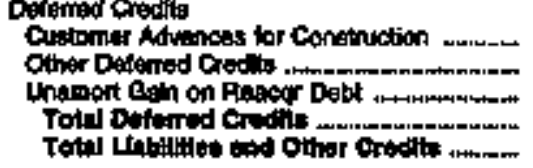 & $\begin{array}{r}0 \\
2,200 \\
2,209 \\
2,110\end{array}$ & $\begin{array}{r}6 \\
6,1008 \\
0 \\
6,108 \\
64,012\end{array}$ & $\begin{array}{r}0 \\
2049 \\
0 \\
2,040 \\
4,079\end{array}$ & $\begin{array}{r}0 \\
0 \\
20 \\
+4097\end{array}$ & $\begin{array}{r}0 \\
0 \\
0 \\
0 \\
0 \\
25,146\end{array}$ & $\begin{array}{r}285 \\
0 \\
285 \\
10,330\end{array}$ \\
\hline
\end{tabular}

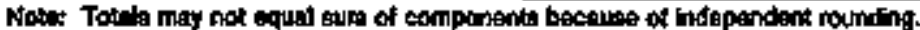

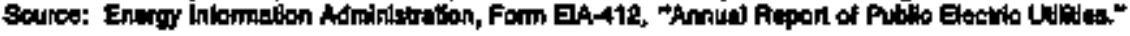


Table 22. Balance Sheet by Major U.S. Publicly Owned Electric Utility Whith State at End of Perlod, 1994

(Thousand Dollars)

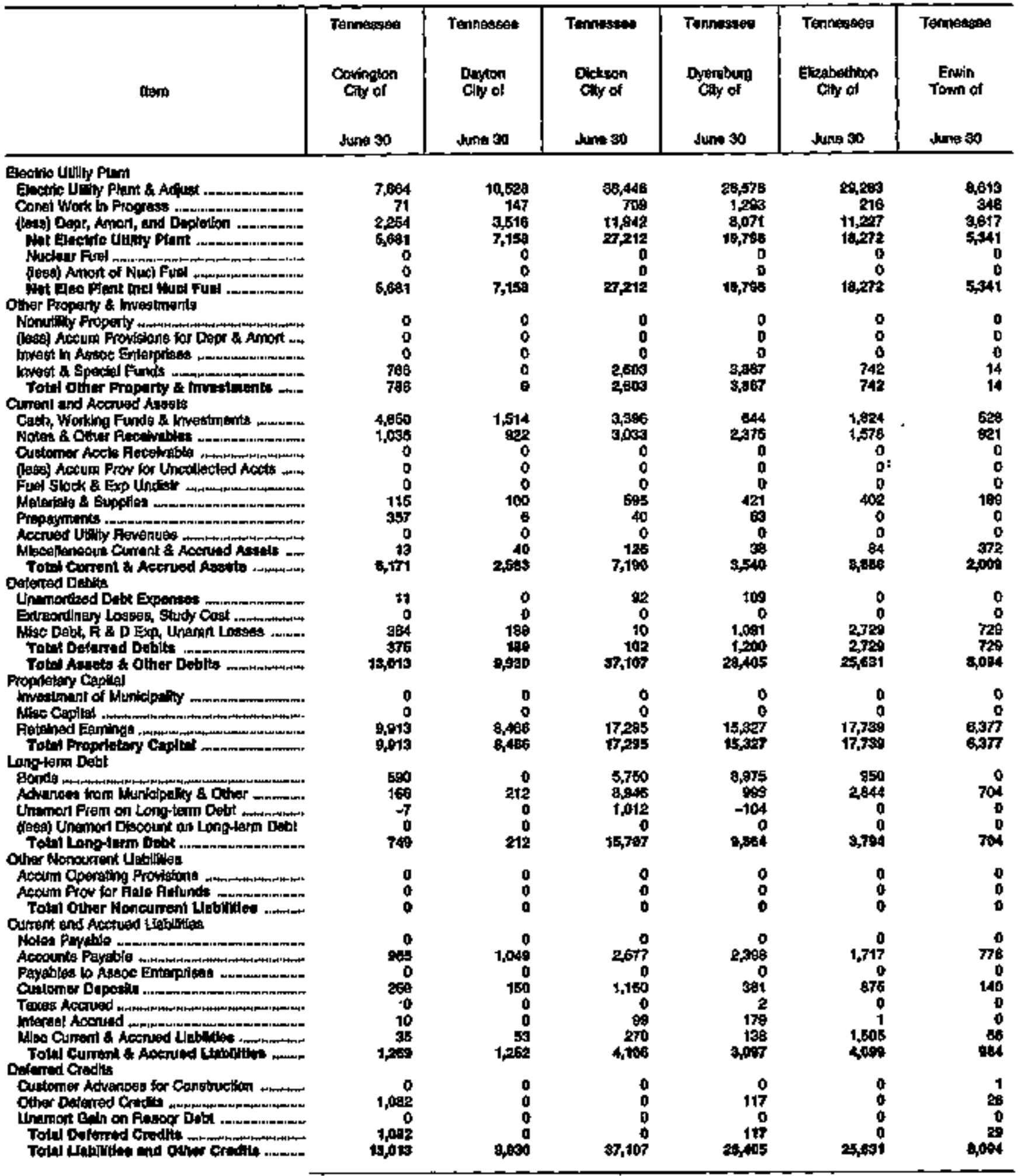

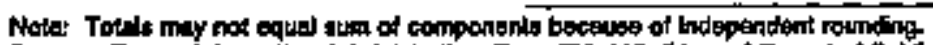

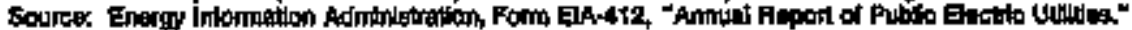


Tabie 22. Badance \$heet by Major U.8. Publicly Owned Electric Utility Whin state at End of Perlod, 1994 (Thousand Dodlars)

\begin{tabular}{|c|c|c|c|c|c|c|}
\hline IAm & $\begin{array}{l}\text { Temnacesea } \\
\text { Eteming ol } \\
\text { June } 30\end{array}$ & 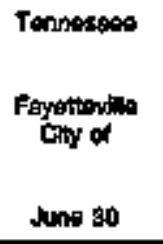 & $\begin{array}{l}\text { Tonnostos } \\
\text { Gellebih } \\
\text { Giny of } \\
\text { tuno so }\end{array}$ & 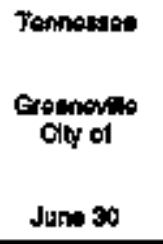 & $\begin{array}{l}\text { Torneases } \\
\text { Herimaty } \\
\text { Cty of } \\
\text { tom so }\end{array}$ & $\begin{array}{l}\text { Temosios } \\
\text { Hunbold: } \\
\text { Ciny of } \\
\text { June } 30\end{array}$ \\
\hline 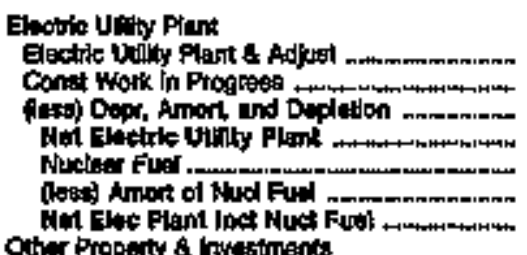 & $\begin{array}{r}5,851 \\
74 \\
2,400 \\
3,455 \\
0 \\
0,485\end{array}$ & $\begin{array}{r}28,674 \\
1,780 \\
0,006 \\
10,167 \\
0 \\
0 \\
10,157\end{array}$ & $\begin{array}{r}11,402 \\
27 \\
6,429 \\
0,000 \\
0 \\
0 \\
0,000\end{array}$ & 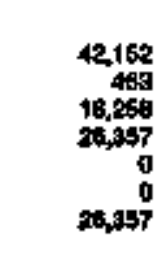 & $\begin{array}{r}18,287 \\
461 \\
8,057 \\
10,7+0 \\
0 \\
0 \\
10,7+0\end{array}$ & $\begin{array}{r}7,020 \\
05 \\
2,697 \\
5,096 \\
0 \\
0 \\
5,036\end{array}$ \\
\hline 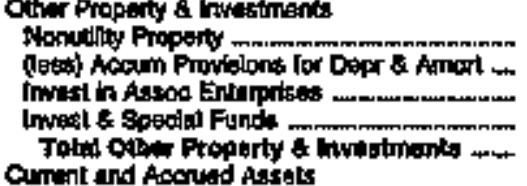 & $\begin{array}{r}0 \\
0 \\
0 \\
980 \\
989\end{array}$ & $\begin{array}{r}0 \\
0 \\
0 \\
5,625 \\
5,585\end{array}$ & $\begin{array}{r}0 \\
0 \\
0 \\
2,467 \\
2,467\end{array}$ & $\begin{array}{r}0 \\
0 \\
7,577 \\
7,577\end{array}$ & $\begin{array}{r}0 \\
0 \\
0 \\
182 \\
192\end{array}$ & $\begin{array}{r}0 \\
0 \\
0 \\
316 \\
316\end{array}$ \\
\hline 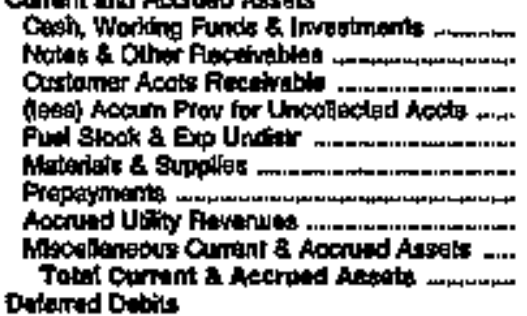 & $\begin{array}{r}149 \\
60 \\
0 \\
0 \\
0 \\
105 \\
13 \\
0 \\
15 \\
035\end{array}$ & $\begin{array}{r}1,398 \\
1,290 \\
0 \\
0 \\
0 \\
395 \\
41 \\
0 \\
6 \\
3,145\end{array}$ & $\begin{array}{r}3,377 \\
1,300 \\
0 \\
0 \\
0 \\
220 \\
197 \\
0 \\
23 \\
1,0997\end{array}$ & $\begin{array}{r}5,956 \\
3,010 \\
0 \\
0 \\
0 \\
908 \\
115 \\
0 \\
124 \\
10,100\end{array}$ & $\begin{array}{r}2,260 \\
1,408 \\
0 \\
0 \\
0 \\
140 \\
3 \\
0 \\
049 \\
1,755\end{array}$ & $\begin{array}{r}1,728 \\
1,427 \\
0 \\
0 \\
0 \\
250 \\
27 \\
0 \\
12 \\
3,444\end{array}$ \\
\hline 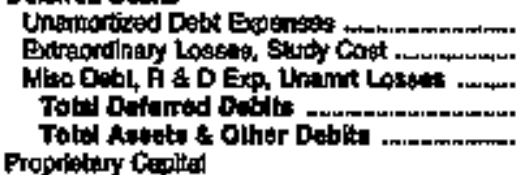 & $\begin{array}{r}0 \\
0 \\
494 \\
594 \\
5520\end{array}$ & $\begin{array}{r}126 \\
50 \\
692 \\
7969 \\
796\end{array}$ & $\begin{array}{r}0 \\
0 \\
380 \\
359 \\
13,881\end{array}$ & $\begin{array}{r}0 \\
0 \\
8,905 \\
8,905 \\
60,990\end{array}$ & $\begin{array}{r}3 \\
1,060 \\
1,072 \\
16,720\end{array}$ & $\begin{array}{r}0 \\
400 \\
400 \\
4,256\end{array}$ \\
\hline 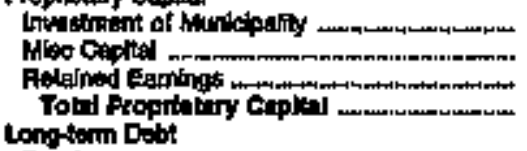 & $\begin{array}{r}0 \\
0 \\
3,211 \\
3,211\end{array}$ & $\begin{array}{r}0 \\
0 \\
+2,800 \\
19,600\end{array}$ & $\begin{array}{r}0 \\
11,240 \\
11,910\end{array}$ & $\begin{array}{r}0 \\
0 \\
43,200 \\
48,240\end{array}$ & $\begin{array}{r}0 \\
12,620 \\
12,420\end{array}$ & $\begin{array}{r}0 \\
0 \\
6,908 \\
8,963\end{array}$ \\
\hline 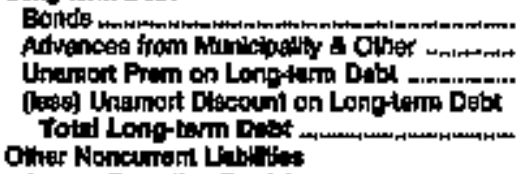 & $\begin{array}{r}40 \\
415 \\
498 \\
0\end{array}$ & $\begin{array}{r}0,935 \\
2,206 \\
-67 \\
0 \\
11,527\end{array}$ & $\begin{array}{r}0 \\
370 \\
0 \\
0 \\
5 \pi 0\end{array}$ & $\begin{array}{r}0 \\
6,798 \\
0 \\
0 \\
6,798\end{array}$ & $\begin{array}{r}479 \\
90 \\
468 \\
0 \\
+, 005\end{array}$ & $\begin{array}{r}200 \\
452 \\
0 \\
0 \\
0.5\end{array}$ \\
\hline 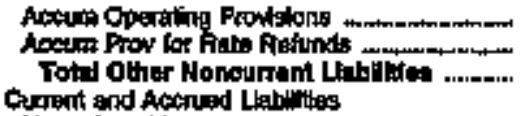 & $\begin{array}{l}0 \\
0 \\
0\end{array}$ & $\begin{array}{l}0 \\
0 \\
0\end{array}$ & $\begin{array}{l}0 \\
0 \\
0\end{array}$ & $\begin{array}{l}0 \\
0 \\
0\end{array}$ & $\begin{array}{l}0 \\
0 \\
0\end{array}$ & \\
\hline 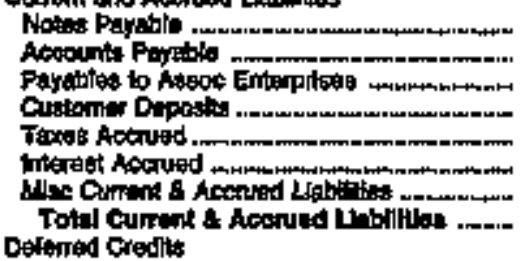 & $\begin{array}{r}0 \\
07 \\
0 \\
0 \\
3 \\
204 \\
1,27\end{array}$ & $\begin{array}{r}0 \\
1,0.58 \\
0 \\
508 \\
0 \\
141 \\
702 \\
2,785\end{array}$ & $\begin{array}{r}0 \\
1,725 \\
0 \\
352 \\
0 \\
0 \\
100 \\
2,297\end{array}$ & $\begin{array}{r}0 \\
448 \\
0 \\
146 \\
0 \\
0 \\
216 \\
010\end{array}$ & $\begin{array}{r}0 \\
1,849 \\
0 \\
301 \\
0 \\
7 \\
2,131\end{array}$ & $\begin{array}{r}0 \\
1,307 \\
0 \\
40 \\
0 \\
2 \\
28 \\
1,37\end{array}$ \\
\hline 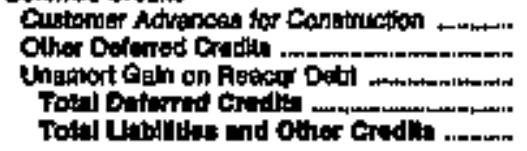 & $\begin{array}{r}0 \\
0 \\
0 \\
0 \\
0\end{array}$ & $\begin{array}{r}0 \\
0 \\
0 \\
00,5072\end{array}$ & 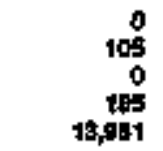 & $\begin{array}{r}0 \\
31 \\
0 \\
31 \\
30\end{array}$ & $\begin{array}{r}0 \\
984 \\
0 \\
984 \\
96,720\end{array}$ & $\begin{array}{r}0 \\
204 \\
0 \\
234 \\
0,250\end{array}$ \\
\hline
\end{tabular}

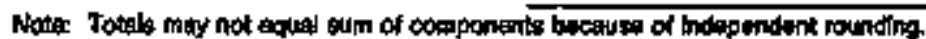

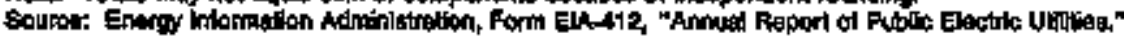


Table 22. Balance Sheet by Major U.S. Publicly Owned Electric Utility Within State at End of Prrlod, 1994

(Thousand Dollars)

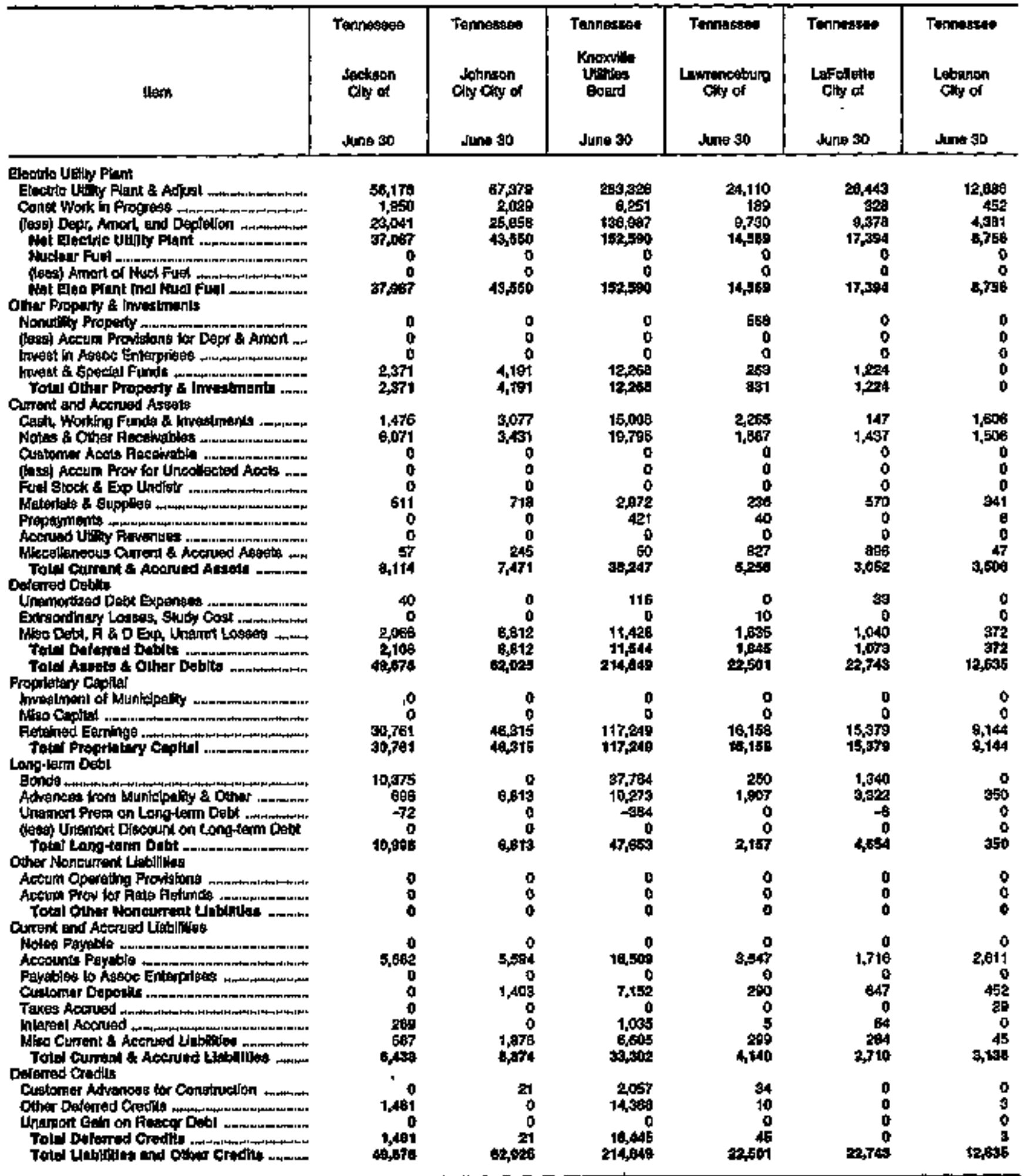

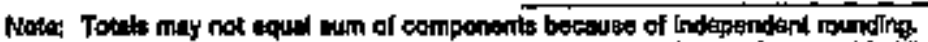

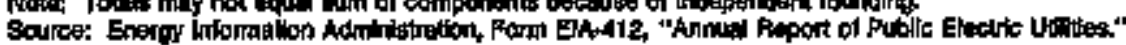


Table 22. Balance theet by Major U.8. Publicly Owned Eloctric Utilty Within State at End of Period, 1994

(Thousand Dollars)

\begin{tabular}{|c|c|c|c|c|c|c|}
\hline flom & $\begin{array}{l}\text { Temmosice } \\
\text { Lenoly } \\
\text { City Cly of } \\
\text { June so }\end{array}$ & $\begin{array}{l}\text { Tenkicsere } \\
\text { Lewisturg } \\
\text { Oty of } \\
\text { June } 30\end{array}$ & 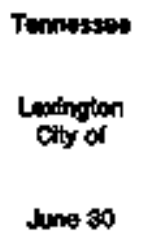 & 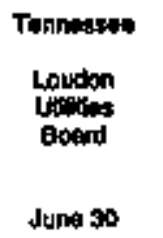 & Tomnopsiag & 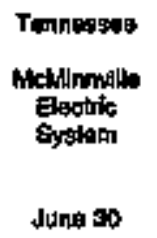 \\
\hline 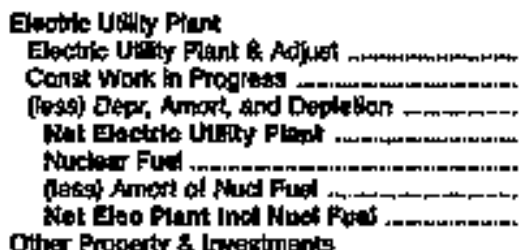 & $\begin{array}{r}63,427 \\
435 \\
15,921 \\
47,941 \\
0 \\
0 \\
47,941\end{array}$ & $\begin{array}{r}70,750 \\
4,570 \\
7,400 \\
0 \\
7,410\end{array}$ & $\begin{array}{r}22,489 \\
201 \\
0,190 \\
14,404 \\
0 \\
0 \\
14,404\end{array}$ & 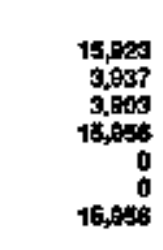 & $\begin{array}{r}25,269 \\
131 \\
7,973 \\
7,421 \\
0 \\
0 \\
77,401\end{array}$ & $\begin{array}{r}12,430 \\
74 \\
5,712 \\
7,390 \\
0 \\
0 \\
7,308\end{array}$ \\
\hline 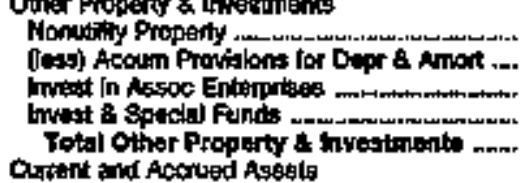 & $\begin{array}{r}0 \\
0 \\
5 \\
5,0028 \\
6,002\end{array}$ & $\begin{array}{r}0 \\
0 \\
0 \\
154 \\
164\end{array}$ & $\begin{array}{r}0 \\
0 \\
0 \\
2,307 \\
2,397\end{array}$ & $\begin{array}{r}0 \\
0 \\
0 \\
1,523 \\
1,523\end{array}$ & $\begin{array}{r}100 \\
0 \\
0 \\
694 \\
694\end{array}$ & $\begin{array}{r}0 \\
0 \\
9 \\
456 \\
416\end{array}$ \\
\hline 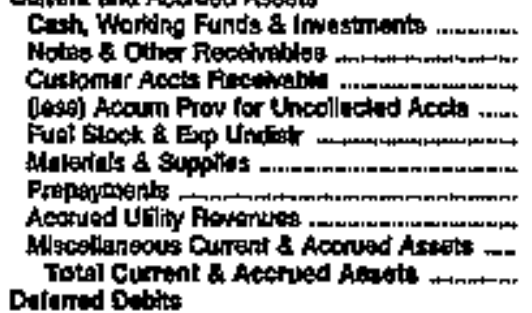 & $\begin{array}{r}544 \\
5,175 \\
0 \\
0 \\
0 \\
900 \\
118 \\
0 \\
1,700 \\
8,900\end{array}$ & 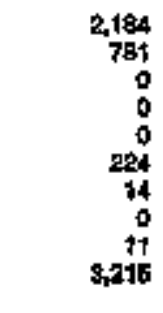 & $\begin{array}{r}1,135 \\
1,645 \\
0 \\
0 \\
0 \\
369 \\
39 \\
0 \\
70 \\
7,260\end{array}$ & $\begin{array}{r}309 \\
2027 \\
0 \\
0 \\
0 \\
208 \\
-0 \\
0 \\
17 \\
17 \\
2,962\end{array}$ & $\begin{array}{r}1,128 \\
1,433 \\
0 \\
0 \\
0 \\
375 \\
23 \\
0 \\
78 \\
3,035\end{array}$ & $\begin{array}{r}684 \\
716 \\
0 \\
0 \\
9 \\
148 \\
14 \\
0 \\
10 \\
1,567\end{array}$ \\
\hline 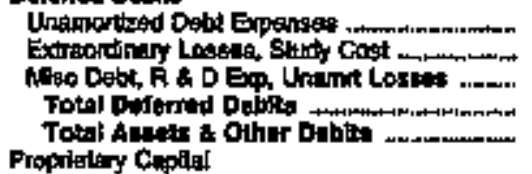 & $\begin{array}{r}425 \\
0 \\
2,000 \\
2,494 \\
0,9,967\end{array}$ & $\begin{array}{r}0 \\
0 \\
298 \\
260 \\
11,076\end{array}$ & 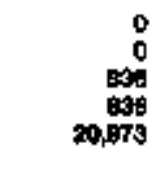 & $\begin{array}{r}03 \\
0 \\
658 \\
701 \\
20,942\end{array}$ & 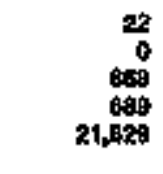 & $\begin{array}{r}0 \\
519 \\
613 \\
6,978\end{array}$ \\
\hline 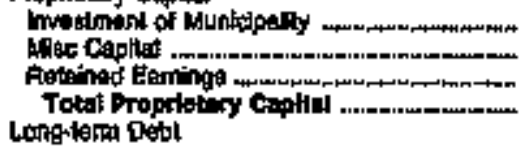 & $\begin{array}{r}0 \\
0 \\
30,488 \\
90,498\end{array}$ & $\begin{array}{r}0 \\
0 \\
8,576 \\
6,976\end{array}$ & $\begin{array}{r}0 \\
0 \\
17,402 \\
17,402\end{array}$ & $\begin{array}{r}0 \\
8,048 \\
8,048\end{array}$ & $\begin{array}{r}0 \\
0 \\
10,042 \\
10,042\end{array}$ & $\begin{array}{r}0 \\
8,398 \\
6,326\end{array}$ \\
\hline 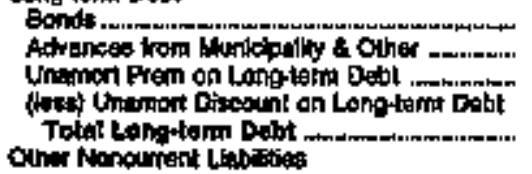 & $\begin{array}{r}22,686 \\
2,160 \\
0 \\
0 \\
24,7 \pi\end{array}$ & $\begin{array}{r}602 \\
211 \\
0 \\
0\end{array}$ & $\begin{array}{r}0 \\
070 \\
0 \\
0 \\
0 \times 0\end{array}$ & $\begin{array}{r}7,485 \\
4 \\
1,312 \\
0 \\
4,901\end{array}$ & $\begin{array}{r}2,005 \\
509 \\
-10 \\
0 \\
2,509\end{array}$ & $\begin{array}{r}0 \\
524 \\
0 \\
0 \\
524\end{array}$ \\
\hline 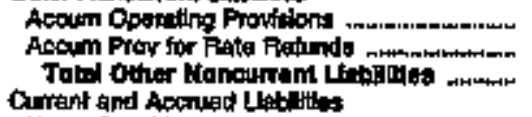 & $\begin{array}{l}0 \\
0 \\
0\end{array}$ & $\begin{array}{l}0 \\
0 \\
0\end{array}$ & $\begin{array}{l}0 \\
0 \\
0\end{array}$ & $\begin{array}{l}0 \\
0 \\
0\end{array}$ & $\begin{array}{l}0 \\
0 \\
0\end{array}$ & $\begin{array}{l}0 \\
0 \\
0\end{array}$ \\
\hline 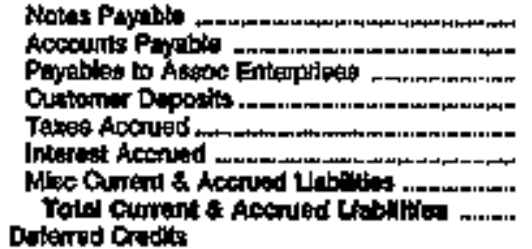 & $\begin{array}{r}0 \\
4,787 \\
0 \\
1,650 \\
0 \\
1,100 \\
1,021 \\
3,089\end{array}$ & $\begin{array}{r}0 \\
1,119 \\
0 \\
2016 \\
0 \\
0 \\
68 \\
1,413\end{array}$ & $\begin{array}{r}0 \\
1,718 \\
0 \\
102 \\
0 \\
0 \\
2,700\end{array}$ & $\begin{array}{r}600 \\
2,740 \\
0 \\
3 \\
0 \\
17 \\
405 \\
3.969\end{array}$ & $\begin{array}{r}0 \\
2,672 \\
0 \\
281 \\
0 \\
22 \\
284 \\
3,250\end{array}$ & $\begin{array}{r}0 \\
142 \\
0 \\
474 \\
0 \\
0 \\
140 \\
708\end{array}$ \\
\hline 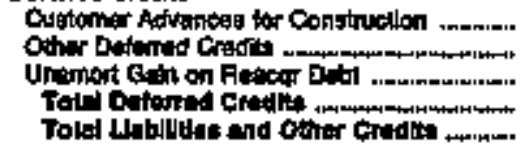 & $\begin{array}{r}508 \\
89 \\
0 \\
640\end{array}$ & $\begin{array}{r}0 \\
298 \\
1+078\end{array}$ & $\begin{array}{r}0 \\
0 \\
0 \\
0 \\
20,0 \% 9\end{array}$ & $\begin{array}{r}27 \\
0 \\
0 \\
27 \\
20,002\end{array}$ & $\begin{array}{r}0 \\
0 \\
0 \\
0 \\
21,020\end{array}$ & $\begin{array}{r}0 \\
284 \\
0 \\
764 \\
9878\end{array}$ \\
\hline
\end{tabular}

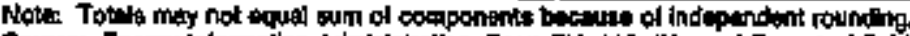

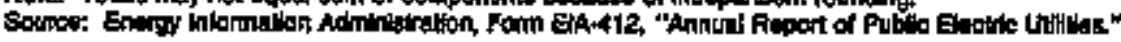


Table 22. Balance Sheet by Major U.S. Publely Owned Electric Utulty Within State at End of Period, 1994 (Thousand Dollars)

\begin{tabular}{|c|c|c|c|c|c|c|}
\hline $\operatorname{ltam}$ & $\begin{array}{l}\text { Tornessege } \\
\text { Mlamphilg } \\
\text { Chy of } \\
\text { stuin } 30\end{array}$ & 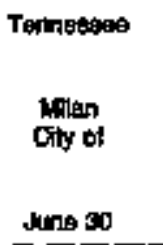 & 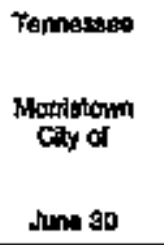 & 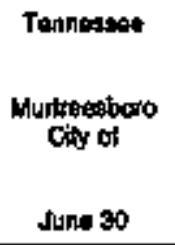 & 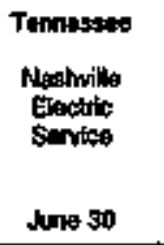 & 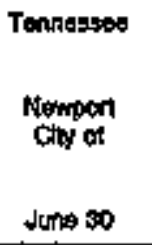 \\
\hline 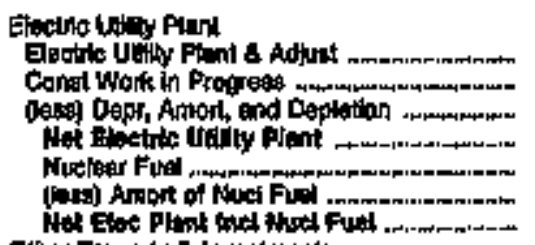 & 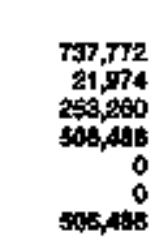 & $\begin{array}{r}10,060 \\
209 \\
4,150 \\
6,113 \\
0 \\
0 \\
6,113\end{array}$ & $\begin{array}{r}20,798 \\
170 \\
10,276 \\
10,209 \\
0 \\
0 \\
10,260\end{array}$ & $\begin{array}{r}35,045 \\
3,530 \\
10,030 \\
27,742 \\
0 \\
0 \\
27,742\end{array}$ & $\begin{array}{r}545,816 \\
17,915 \\
20 t, 845 \\
381,665 \\
0 \\
0 \\
381,695\end{array}$ & $\begin{array}{r}26,414 \\
4 \\
9,707 \\
17,792 \\
0 \\
6 \\
17,712\end{array}$ \\
\hline 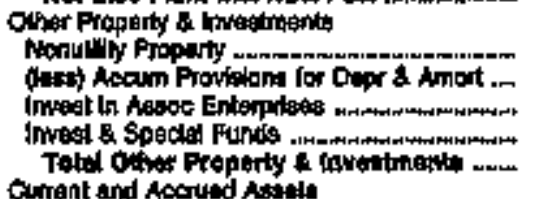 & $\begin{array}{r}0 \\
0 \\
0 \\
79,799\end{array}$ & $\begin{array}{l}0 \\
0 \\
0 \\
0 \\
0\end{array}$ & $\begin{array}{r}0 \\
0 \\
0 \\
14 \\
14\end{array}$ & $\begin{array}{r}0 \\
0 \\
0 \\
3,002 \\
3,002\end{array}$ & $\begin{array}{r}0 \\
0 \\
70,496 \\
70,400\end{array}$ & $\begin{array}{r}0 \\
0 \\
1,713 \\
1,713\end{array}$ \\
\hline 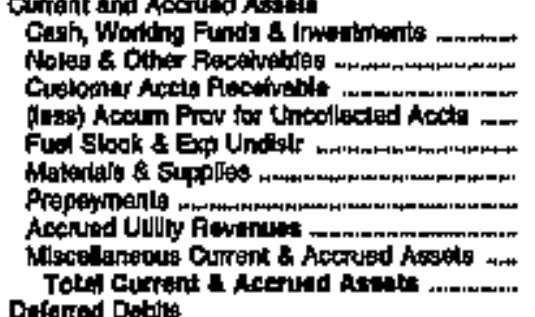 & $\begin{array}{r}33,739 \\
56,028 \\
0 \\
0 \\
0 \\
10,184 \\
0 \\
0 \\
4,670 \\
04027\end{array}$ & $\begin{array}{r}599 \\
1,174 \\
0 \\
0 \\
0 \\
234 \\
84 \\
0 \\
31 \\
2,052\end{array}$ & $\begin{array}{r}5,614 \\
3,416 \\
0 \\
0 \\
0 \\
509 \\
2 \\
0 \\
0 \\
10,209\end{array}$ & $\begin{array}{r}2,593 \\
2,217 \\
0 \\
0 \\
0 \\
547 \\
40 \\
0 \\
34 \\
5300\end{array}$ & $\begin{array}{r}47,200 \\
39,198 \\
0 \\
0 \\
6 \\
7,521 \\
398 \\
0 \\
17,958 \\
112,204\end{array}$ & $\begin{array}{r}1,199 \\
896 \\
0 \\
0 \\
0 \\
345 \\
11 \\
0 \\
1,350 \\
3,904\end{array}$ \\
\hline 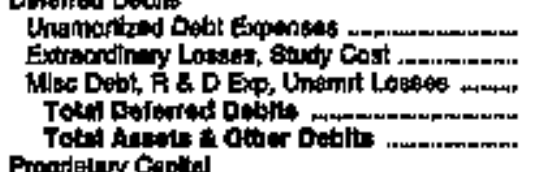 & $\begin{array}{r}3,659 \\
0 \\
15,198 \\
16,751 \\
700,668\end{array}$ & $\begin{array}{r}0 \\
0 \\
906 \\
9050 \\
0000\end{array}$ & $\begin{array}{r}0 \\
0 \\
1,797 \\
1,727 \\
3+, 969\end{array}$ & $\begin{array}{r}25 \\
0 \\
1,866 \\
1,481 \\
30,406\end{array}$ & $\begin{array}{r}1,500 \\
0 \\
22,016 \\
23,516 \\
667,905\end{array}$ & $\begin{array}{r}0 \\
4,101 \\
4,200 \\
27,519\end{array}$ \\
\hline 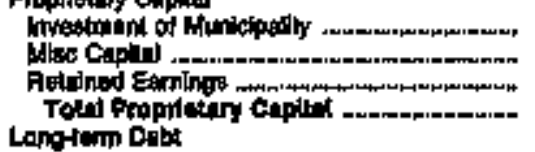 & $\begin{array}{r}0 \\
0 \\
300,020 \\
360,000\end{array}$ & $\begin{array}{r}0 \\
8 \\
8,754 \\
6,764\end{array}$ & $\begin{array}{r}0 \\
0 \\
22,403 \\
22,493\end{array}$ & $\begin{array}{r}0 \\
30,513 \\
30,113\end{array}$ & $\begin{array}{r}0 \\
0 \\
258,159 \\
2 \$ 8,159\end{array}$ & $\begin{array}{r}0 \\
0 \\
18,601 \\
18,601\end{array}$ \\
\hline 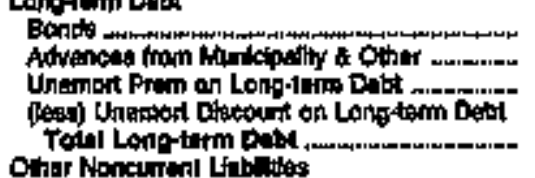 & $\begin{array}{r}246,150 \\
4,730 \\
0 \\
0 \\
0 \\
262,6000\end{array}$ & $\begin{array}{r}0 \\
800 \\
0 \\
0 \\
900\end{array}$ & $\begin{array}{r}10 \\
1,756 \\
0 \\
0 \\
1,706\end{array}$ & $\begin{array}{r}3,665 \\
1,5 \% 0 \\
0 \\
5 \\
5,215\end{array}$ & $\begin{array}{r}205,605 \\
10947 \\
-2812 \\
0 \\
200910\end{array}$ & $\begin{array}{r}4,705 \\
1,378 \\
-57 \\
0 \\
6,004\end{array}$ \\
\hline 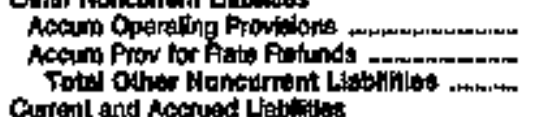 & $\begin{array}{l}0 \\
0 \\
0\end{array}$ & $\begin{array}{l}0 \\
0 \\
0\end{array}$ & $\begin{array}{l}0 \\
0 \\
0\end{array}$ & $\begin{array}{l}0 \\
0 \\
0\end{array}$ & $\begin{array}{l}0 \\
0 \\
0\end{array}$ & $\begin{array}{l}0 \\
0 \\
0\end{array}$ \\
\hline 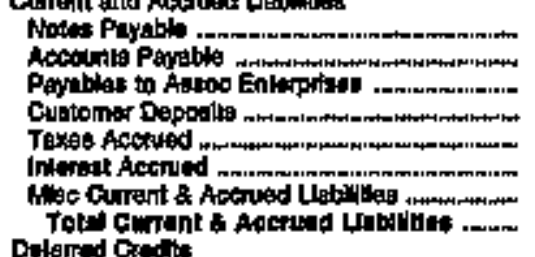 & $\begin{array}{r}0 \\
60,851 \\
0 \\
0 \\
1,694 \\
0 \\
4,955 \\
67,481\end{array}$ & $\begin{array}{r}0 \\
1,189 \\
0 \\
167 \\
0 \\
0 \\
76 \\
7,411\end{array}$ & $\begin{array}{r}3,457 \\
0 \\
1,200 \\
0 \\
0 \\
840 \\
\mathbf{5 , 6 0 5}\end{array}$ & $\begin{array}{r}0 \\
483 \\
1358 \\
0 \\
18 \\
409 \\
2,200\end{array}$ & $\begin{array}{r}0 \\
65,701 \\
0 \\
12,016 \\
0 \\
2,314 \\
2,105 \\
8,137\end{array}$ & $\begin{array}{r}0 \\
2,070 \\
0 \\
05 \\
0 \\
4 \\
1,77 \\
2,060\end{array}$ \\
\hline 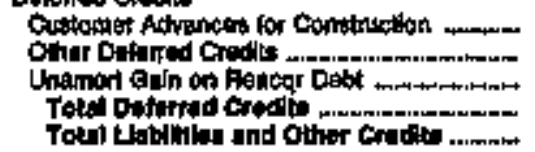 & $\begin{array}{r}1,643 \\
37,691 \\
0 \\
30,274 \\
7090,063\end{array}$ & $\begin{array}{r}6 \\
0 \\
0 \\
8 \\
2,000\end{array}$ & $\begin{array}{r}0 \\
1,001 \\
0 \\
1,601 \\
31,200\end{array}$ & 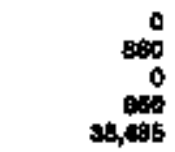 & $\begin{array}{r}121 \\
4,876 \\
0 \\
567,500\end{array}$ & $\begin{array}{r}29 \\
0 \\
0 \\
28 \\
27,519\end{array}$ \\
\hline
\end{tabular}

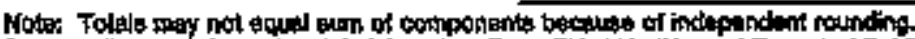

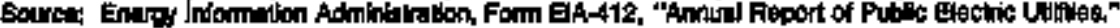


Table 22. Balance Sheet by Major U.S. Publlohy Owned Electric Utlity Whthln State at End of Period, 1994

(Thousand Dollars)

\begin{tabular}{|c|c|c|c|c|c|c|}
\hline them & $\begin{array}{l}\text { Tounosopo } \\
\text { Oak Riogige } \\
\text { City of } \\
\text { June so }\end{array}$ & $\begin{array}{l}\text { Tennostang } \\
\text { Puris } \\
\text { Chy of } \\
\text { June } 90\end{array}$ & 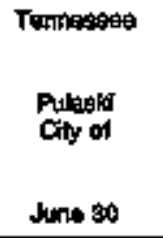 & 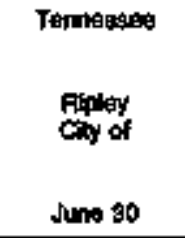 & $\begin{array}{l}\text { Tennessegs } \\
\text { Rockinood } \\
\text { Ciny ol } \\
\text { June so }\end{array}$ & 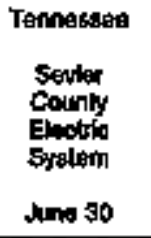 \\
\hline 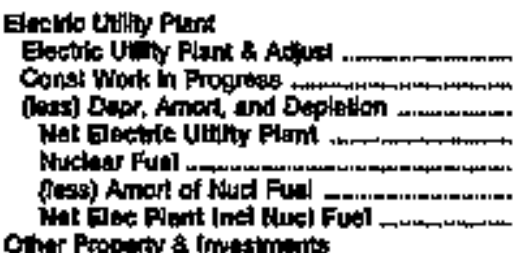 & $\begin{array}{r}24,690 \\
2,017 \\
17,928 \\
17,210 \\
0 \\
7,29\end{array}$ & $\begin{array}{r}20,652 \\
544 \\
11,059 \\
16,509 \\
0 \\
15,959\end{array}$ & $\begin{array}{r}24,376 \\
1,092 \\
0,020 \\
16,456 \\
0 \\
0 \\
16,495\end{array}$ & $\begin{array}{r}8,872 \\
10 \\
2,649 \\
9,394 \\
0 \\
6 \\
6,3014\end{array}$ & $\begin{array}{r}17,169 \\
1,090 \\
5,617 \\
12,081 \\
0 \\
0 \\
12,081\end{array}$ & $\begin{array}{r}64,000 \\
1,573 \\
17,905 \\
7,678 \\
0 \\
0 \\
97,678\end{array}$ \\
\hline 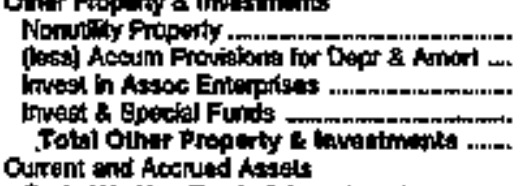 & $\begin{array}{r}0 \\
0 \\
0 \\
023 \\
503\end{array}$ & $\begin{array}{r}0 \\
0 \\
0 \\
1,520 \\
1,000\end{array}$ & $\begin{array}{r}0 \\
0 \\
0 \\
984 \\
984\end{array}$ & $\begin{array}{r}0 \\
0 \\
0 \\
5,404 \\
5,404\end{array}$ & $\begin{array}{r}0 \\
0 \\
0 \\
10 \\
10\end{array}$ & $\begin{array}{r}0 \\
0 \\
1,155 \\
1,155\end{array}$ \\
\hline 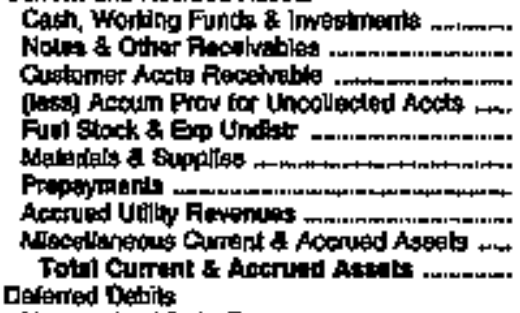 & $\begin{array}{r}121 \\
2,610 \\
0 \\
0 \\
0 \\
355 \\
0 \\
0 \\
25 \\
3,311\end{array}$ & $\begin{array}{r}1,250 \\
1,125 \\
0 \\
0 \\
0 \\
307 \\
9 \\
0 \\
4 \\
2,74\end{array}$ & $\begin{array}{r}739 \\
1,494 \\
0 \\
0 \\
0 \\
189 \\
67 \\
0 \\
1,019 \\
3,909\end{array}$ & $\begin{array}{r}116 \\
1,121 \\
0 \\
0 \\
0 \\
+194 \\
69 \\
0 \\
22 \\
1,929\end{array}$ & $\begin{array}{r}206 \\
720 \\
0 \\
0 \\
0 \\
184 \\
0 \\
0 \\
942 \\
2,064\end{array}$ & $\begin{array}{r}3,791 \\
2,8009 \\
0 \\
0 \\
0 \\
695 \\
77 \\
0 \\
1,069 \\
9,504\end{array}$ \\
\hline 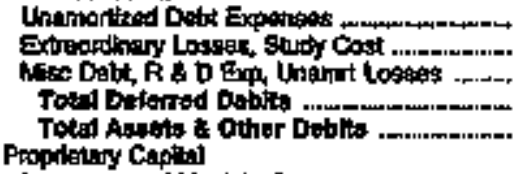 & $\begin{array}{r}45 \\
0 \\
309 \\
354 \\
24,47\end{array}$ & $\begin{array}{r}49 \\
0 \\
1,849 \\
1,8 \% 2 \\
21,697\end{array}$ & $\begin{array}{r}19 \\
0 \\
600 \\
607 \\
21,918\end{array}$ & $\begin{array}{r}0 \\
0 \\
1,017 \\
1,017 \\
14,279\end{array}$ & $\begin{array}{r}0 \\
0 \\
1 \\
1 \\
14,70 t\end{array}$ & $\begin{array}{r}0 \\
0 \\
1,800 \\
1,500 \\
00,320\end{array}$ \\
\hline 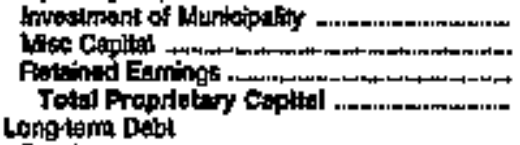 & $\begin{array}{r}0 \\
12,049 \\
12,043\end{array}$ & $\begin{array}{r}0 \\
0 \\
14,798 \\
14,799\end{array}$ & $\begin{array}{r}0 \\
0 \\
15,071 \\
15,071\end{array}$ & $\begin{array}{r}0 \\
0 \\
10,360 \\
10,3=2\end{array}$ & $\begin{array}{r}a \\
0 \\
12,181 \\
12,181\end{array}$ & $\begin{array}{r}0 \\
0 \\
46,586 \\
46,186\end{array}$ \\
\hline 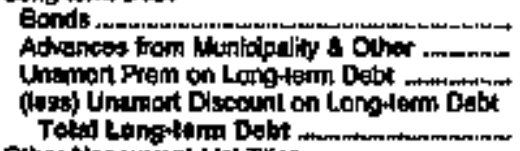 & $\begin{array}{r}6,150 \\
318 \\
-74 \\
0 \\
6008\end{array}$ & $\begin{array}{r}2,655 \\
1,785 \\
0 \\
9 \\
4,440\end{array}$ & $\begin{array}{r}3,207 \\
605 \\
0 \\
0 \\
0,902\end{array}$ & $\begin{array}{r}0 \\
1,019 \\
0 \\
0 \\
1,019\end{array}$ & $\begin{array}{r}825 \\
2 \\
0 \\
0 \\
677\end{array}$ & $\begin{array}{r}3,398 \\
1,709 \\
0 \\
0 \\
5,107\end{array}$ \\
\hline 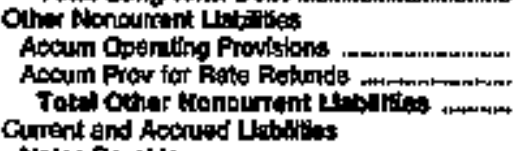 & $\begin{array}{l}0 \\
0 \\
0\end{array}$ & $\begin{array}{l}0 \\
0 \\
0\end{array}$ & 0 & $\begin{array}{l}0 \\
0 \\
0\end{array}$ & $\begin{array}{l}0 \\
0 \\
0\end{array}$ & $\begin{array}{l}0 \\
0 \\
0\end{array}$ \\
\hline 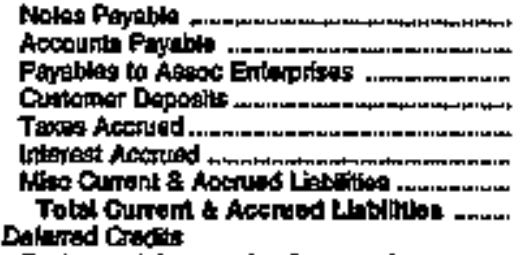 & $\begin{array}{r}0 \\
2,494 \\
0 \\
366 \\
0 \\
107 \\
2,879\end{array}$ & $\begin{array}{r}0 \\
1,049 \\
0 \\
470 \\
0 \\
12 \\
161 \\
2,291\end{array}$ & $\begin{array}{r}0 \\
2,060 \\
0 \\
309 \\
48 \\
16 \\
191 \\
2,097\end{array}$ & $\begin{array}{r}0 \\
1,271 \\
0 \\
370 \\
0 \\
0 \\
220 \\
1,0159\end{array}$ & $\begin{array}{r}0 \\
1,141 \\
0 \\
398 \\
0 \\
5 \\
290 \\
1,924\end{array}$ & $\begin{array}{r}0 \\
1,240 \\
0 \\
3,648 \\
0 \\
58 \\
617 \\
8,542\end{array}$ \\
\hline 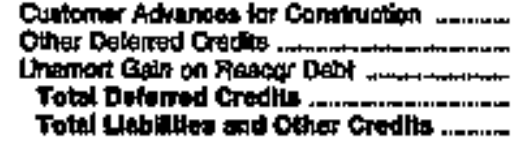 & $21, \begin{array}{r}0 \\
0 \\
0 \\
0 \\
0\end{array}$ & $\begin{array}{r}0 \\
0 \\
01,498\end{array}$ & $\begin{array}{r}0 \\
14 \\
0 \\
14 \\
21,619\end{array}$ & $\begin{array}{r}0 \\
1,036 \\
0 \\
1,058 \\
14,276\end{array}$ & $\begin{array}{r}0 \\
73 \\
0 \\
74 \\
14,707\end{array}$ & $\begin{array}{r}9 \\
32 \\
0 \\
92 \\
00,38\end{array}$ \\
\hline
\end{tabular}

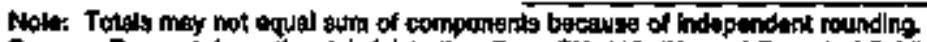

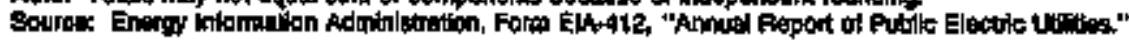


Table 22. Balance Sheet by Major U.S. Publidy Owned Electric Utility Within State at End of Perlod, 1994

(Thousand Dollars)

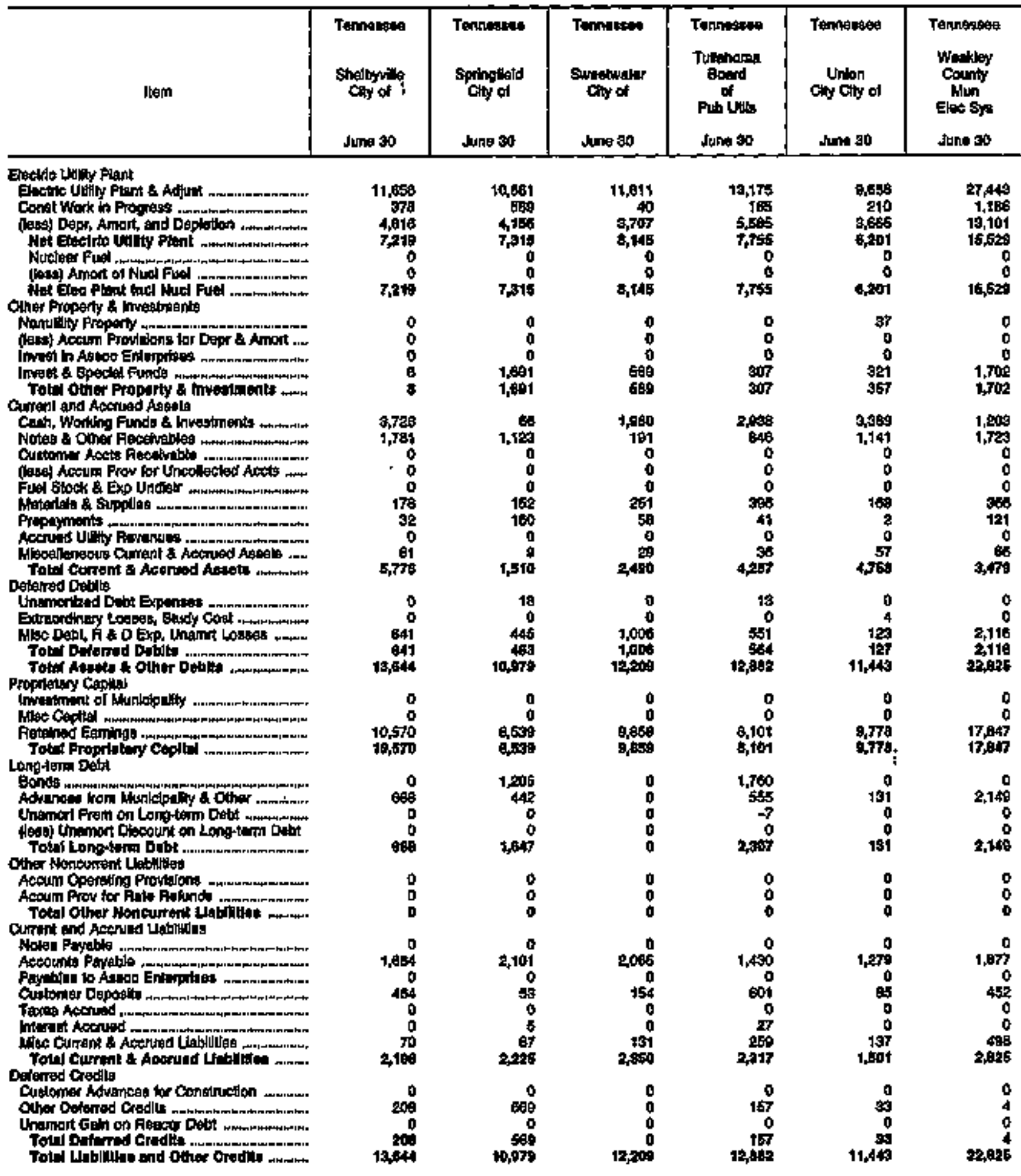

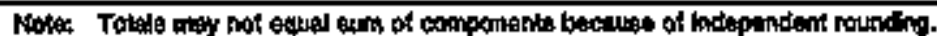

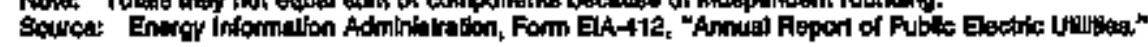


Table 22. Balance Sheet by Major U.S. Publicly Owned Electric Utilty Within stote at End of Period, 1994

(Thousand Dọllars)

\begin{tabular}{|c|c|c|c|c|c|c|}
\hline Iteth & $\begin{array}{l}\text { Texted } \\
\text { Angtin } \\
\text { Chy of } \\
\text { September } 00\end{array}$ & 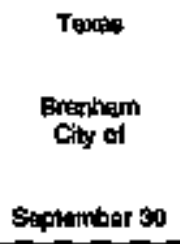 & 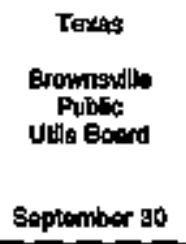 & $\begin{array}{l}\text { Texpes } \\
\text { Byyen } \\
\text { Chty of } \\
\text { Seplentery } 30\end{array}$ & $\begin{array}{l}\text { Tekas } \\
\text { Colkegs } \\
\text { Elapon } \\
\text { Chy of } \\
\text { September } 30\end{array}$ & $\begin{array}{l}\text { Teocts } \\
\text { Denion } \\
\text { Chy ol } \\
\text { Septentor } 30\end{array}$ \\
\hline 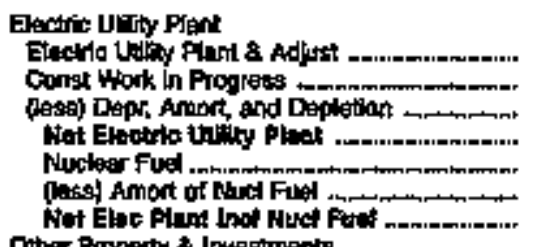 & $\begin{array}{r}2,150,783 \\
127,8087 \\
618,910 \\
1,093,000 \\
93,996 \\
48,167 \\
1,711,696\end{array}$ & $\begin{array}{r}8,760 \\
0 \\
3,240 \\
5,563 \\
0 \\
0 \\
5,6 \times 3\end{array}$ & $\begin{array}{r}255,496 \\
39,740 \\
8+, 0650 \\
275,386 \\
0 \\
0 \\
273,386\end{array}$ & $\begin{array}{r}197,041 \\
4,112 \\
59,795 \\
77,059 \\
0 \\
0 \\
77,659\end{array}$ & $\begin{array}{r}27,701 \\
9,922 \\
9,477 \\
22,152 \\
0 \\
0 \\
22,15 \%\end{array}$ & $\begin{array}{r}01,870 \\
5,5 \\
52,489 \\
39,916 \\
0 \\
0 \\
39,018\end{array}$ \\
\hline 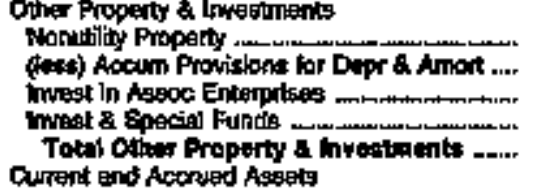 & $\begin{array}{r}0 \\
0 \\
0 \\
23 a, 018 \\
203,018\end{array}$ & $\begin{array}{r}0 \\
0 \\
0 \\
2,970 \\
2,970\end{array}$ & $\begin{array}{r}0 \\
0 \\
0 \\
40,090\end{array}$ & $\begin{array}{r}0 \\
542 \\
13,500 \\
12,931\end{array}$ & $\begin{array}{r}171 \\
60 \\
0 \\
0 \\
103\end{array}$ & $\begin{array}{r}0 \\
0 \\
042 \\
0 \\
0.432\end{array}$ \\
\hline 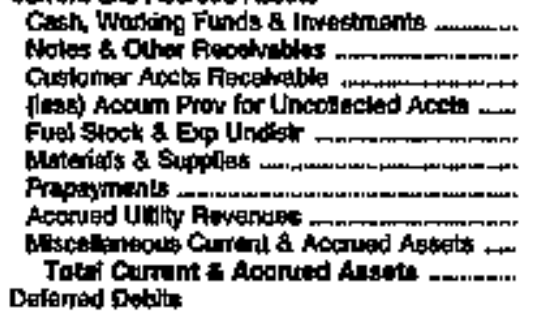 & $\begin{array}{r}20,049 \\
28 \\
49,139 \\
9,754 \\
19,596 \\
30,142 \\
659 \\
0 \\
0 \\
117,050\end{array}$ & $\begin{array}{r}1,804 \\
0 \\
1,069 \\
91 \\
0 \\
79 \\
0 \\
0 \\
0 \\
2,390\end{array}$ & 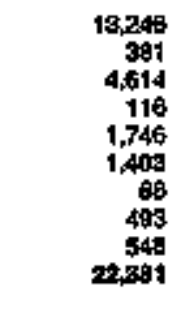 & $\begin{array}{r}4,346 \\
3,777 \\
7,676 \\
202 \\
0 \\
2,879 \\
31 \\
0 \\
0 \\
17,843\end{array}$ & $\begin{array}{r}0,658 \\
1,004 \\
3,005 \\
659 \\
0 \\
01 \\
2 \\
1,008 \\
1,003 \\
16,607\end{array}$ & $\begin{array}{r}37,744 \\
1,082 \\
+2,762 \\
0,072 \\
1,293 \\
0 \\
0 \\
3,287 \\
5: 35 \\
60,629\end{array}$ \\
\hline 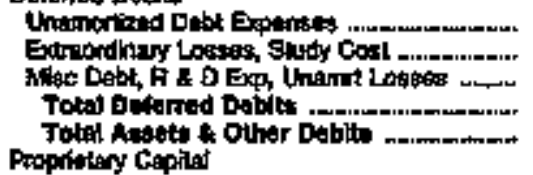 & $\begin{array}{r}0,460 \\
0 \\
250,726 \\
272,156 \\
2,534,620\end{array}$ & $\begin{array}{r}5 \\
0 \\
0 \\
5 \\
0,931\end{array}$ & $\begin{array}{r}5,609 \\
0 \\
2,655 \\
0,5,48 \\
285,193\end{array}$ & $\begin{array}{r}302 \\
0 \\
1,096 \\
1,396 \\
111,130\end{array}$ & $\begin{array}{r}55 \\
0 \\
6 \\
69 \\
39.960\end{array}$ & $\begin{array}{r}0 \\
0 \\
0 \\
0 \\
06,977\end{array}$ \\
\hline 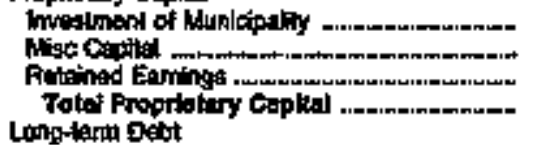 & $\begin{array}{r}678 \\
49,778 \\
419,719 \\
470,275\end{array}$ & $\begin{array}{r}0 \\
0 \\
8,252 \\
0,252\end{array}$ & $\begin{array}{r}0 \\
41,146 \\
\$ 9,764 \\
94,9010\end{array}$ & $\begin{array}{r}0 \\
0 \\
83,154 \\
8,164\end{array}$ & $\begin{array}{r}3,48 B \\
24,55 \\
20,057\end{array}$ & $\begin{array}{r}509 \\
58,109 \\
0 ., 748\end{array}$ \\
\hline 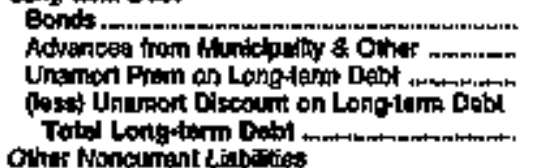 & $\begin{array}{r}1,849,520 \\
109,339 \\
15,507 \\
54,810 \\
1,719,260\end{array}$ & $\begin{array}{r}60 \\
0 \\
0 \\
0 \\
\cos 8\end{array}$ & $\begin{array}{r}160,446 \\
1 \\
0 \\
3,391 \\
17,058\end{array}$ & $\begin{array}{r}21,210 \\
0 \\
0 \\
0 \\
21,219\end{array}$ & $\begin{array}{r}5,619 \\
69 \\
2 \\
0 \\
6,609\end{array}$ & $\begin{array}{r}23,915 \\
0 \\
0 \\
144 \\
2 \$, 771\end{array}$ \\
\hline 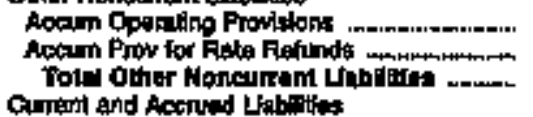 & $\begin{array}{r}18,400 \\
18,404\end{array}$ & $\begin{array}{l}0 \\
0 \\
0\end{array}$ & $\begin{array}{l}0 \\
0 \\
0\end{array}$ & $\begin{array}{l}0 \\
0 \\
0\end{array}$ & $\begin{array}{l}0 \\
0 \\
0\end{array}$ & 0 \\
\hline 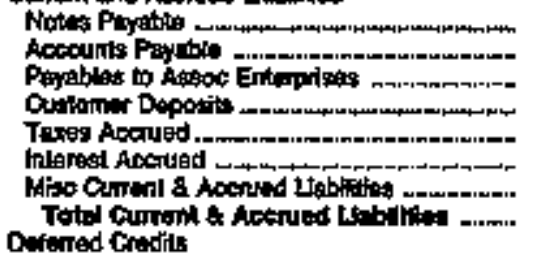 & $\begin{array}{r}0 \\
18,772 \\
0 \\
4,754 \\
1,011 \\
85,690 \\
70,127 \\
116,286\end{array}$ & $\begin{array}{r}0 \\
1,103 \\
0 \\
006 \\
0 \\
4 \\
90 \\
1,940\end{array}$ & $\begin{array}{r}\$ 4 \\
3,897 \\
0 \\
1,658 \\
31 \\
1,049 \\
6,370 \\
12,982\end{array}$ & 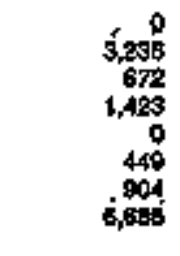 & $\begin{array}{r}0 \\
2,859 \\
0 \\
0 \\
1,801 \\
0 \\
80 \\
463 \\
5,218\end{array}$ & $\begin{array}{r}0 \\
2,492 \\
0 \\
1,249 \\
0 \\
460 \\
311 \\
4,450\end{array}$ \\
\hline 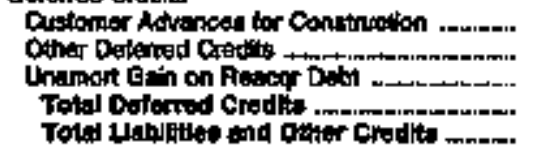 & $\begin{array}{r}0 \\
0,380 \\
0 \\
0,340000\end{array}$ & $\begin{array}{r}0 \\
0 \\
0 \\
0\end{array}$ & $\begin{array}{r}11 \\
214 \\
0 \\
206 \\
205,783\end{array}$ & $\begin{array}{r}0 \\
72 \\
0 \\
72 \\
712,150\end{array}$ & $\begin{array}{r}24 \\
3 \\
0 \\
27 \\
28,960\end{array}$ & $\begin{array}{r}0 \\
0 \\
0 \\
0\end{array}$ \\
\hline
\end{tabular}

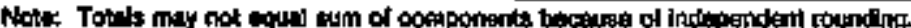

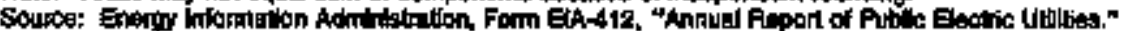


Table 22. Balance Sheet by Mijor U.S. Publicly Owned Electric Utility Within state at End of Petiod, 1994

(Thousand Dollars)

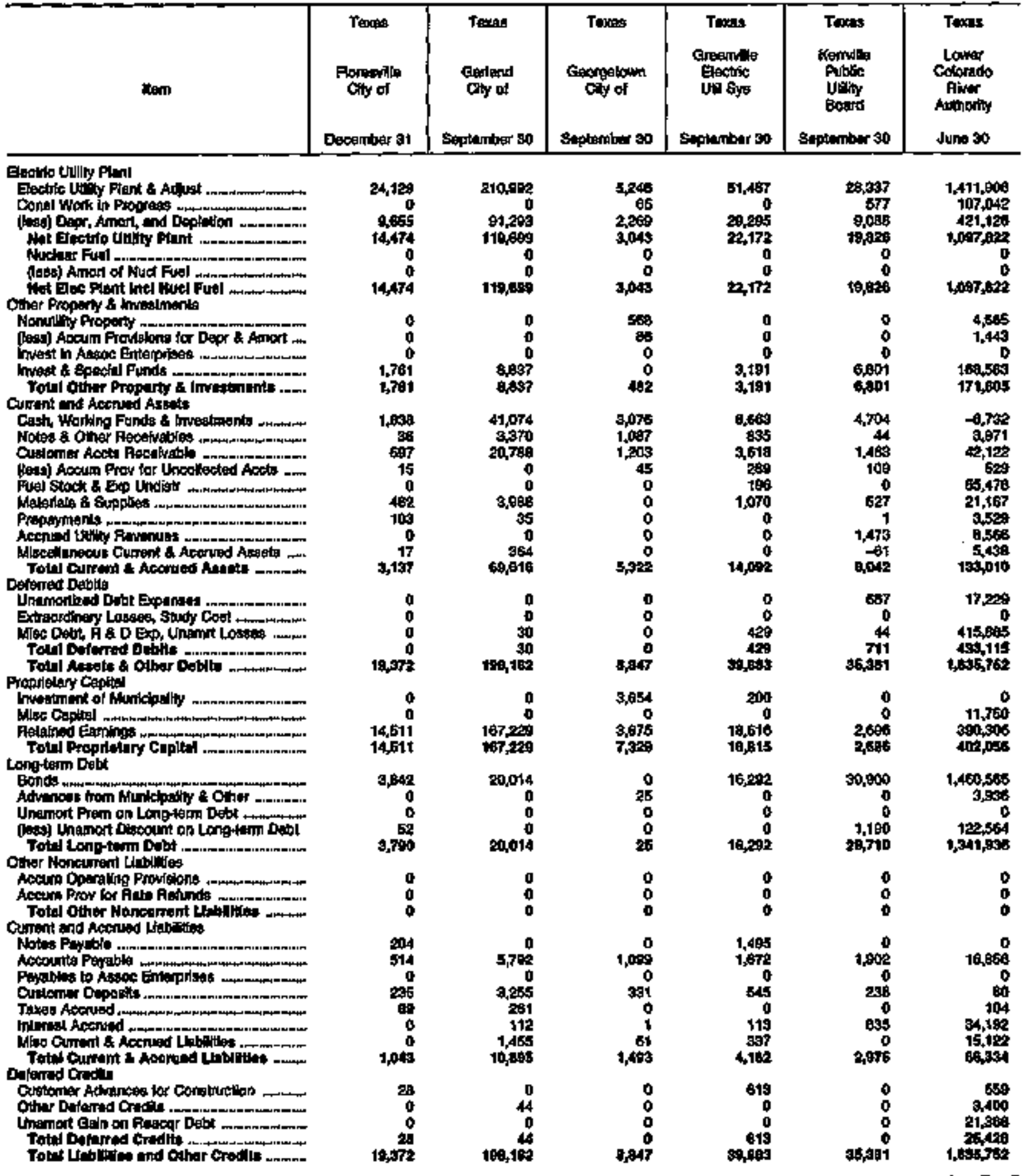

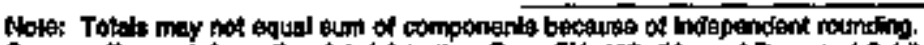

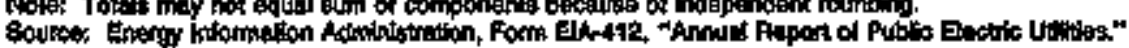


Table 22. Eakance Sheet by Major U.S. PubHedy Owned Eectric Utilty Within State at End of Foriod, 1094

(Thousand Dollars)

\begin{tabular}{|c|c|c|c|c|c|c|}
\hline leem & 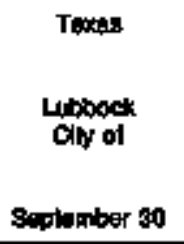 & $\begin{array}{l}\text { Texass } \\
\text { Now Enounteds } \\
\text { Cun of }\end{array}$ & 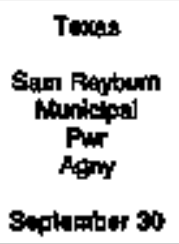 & 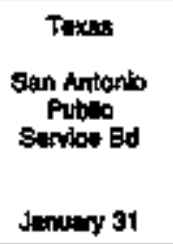 & $\begin{array}{l}\text { Teoss } \\
\text { San Hincos } \\
\text { Clty of } \\
\text { Saptomber } 30\end{array}$ & $\begin{array}{l}\text { Theos } \\
\text { Seguln } \\
\text { Sopy of } \\
\text { September so }\end{array}$ \\
\hline 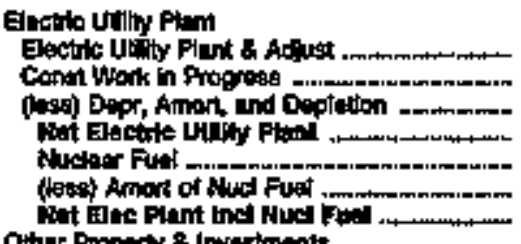 & $\begin{array}{r}127,664 \\
8,700 \\
47,870 \\
8,7,700 \\
0 \\
0 \\
88,7,00\end{array}$ & $\begin{array}{r}54,605 \\
100 \\
20,651 \\
34,123 \\
0 \\
0 \\
34,123\end{array}$ & $\begin{array}{r}141,029 \\
672 \\
14,389 \\
07,314 \\
0 \\
07,314\end{array}$ & $\begin{array}{r}4,753,678 \\
180,693 \\
1,169,569 \\
3,775,110 \\
172,074 \\
83,703 \\
3,053,471\end{array}$ & $\begin{array}{r}16,585 \\
1,057 \\
5,800 \\
12,509 \\
0 \\
12,509\end{array}$ & $\begin{array}{r}6,443 \\
0 \\
3,890 \\
2,614 \\
0 \\
0 \\
2,614\end{array}$ \\
\hline 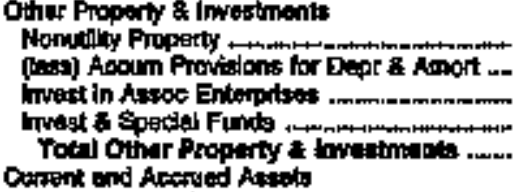 & $\begin{array}{l}0 \\
0 \\
0 \\
0 \\
0\end{array}$ & 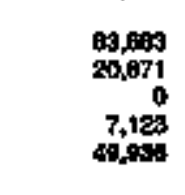 & $\begin{array}{r}0 \\
0 \\
0 \\
45,914 \\
45,914\end{array}$ & $\begin{array}{r}0 \\
0 \\
0 \\
25,4 a B 7 \\
258,947\end{array}$ & $\begin{array}{l}0 \\
0 \\
0 \\
0 \\
0 \\
0\end{array}$ & $\begin{array}{r}0 \\
1,228 \\
1,296\end{array}$ \\
\hline 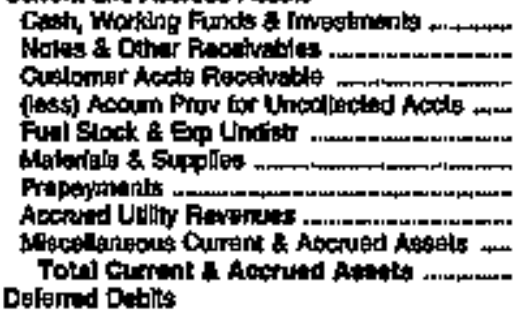 & $\begin{array}{r}7,820 \\
1,527 \\
0 \\
0 \\
0 \\
0 \\
0 \\
0 \\
198 \\
12,045\end{array}$ & $\begin{array}{r}7,498 \\
1,419 \\
3,600 \\
0 \\
0 \\
708 \\
134 \\
0 \\
0 \\
13,050\end{array}$ & $\begin{array}{r}20,720 \\
0,49 \\
2,025 \\
0 \\
1,421 \\
8,56 \\
04 \\
0 \\
06 \\
25,109\end{array}$ & 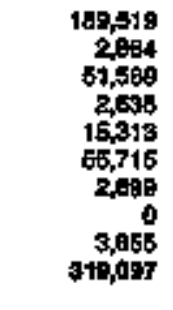 & $\begin{array}{r}13,677 \\
340 \\
4,272 \\
901 \\
0 \\
440 \\
20 \\
0 \\
64 \\
17,697\end{array}$ & 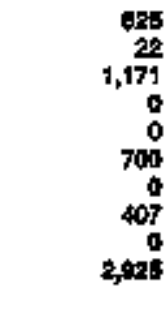 \\
\hline 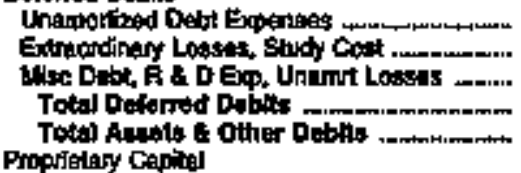 & 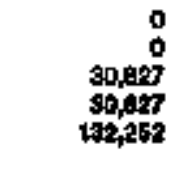 & $\begin{array}{r}0 \\
0 \\
0 \\
0 \\
97,698\end{array}$ & $\begin{array}{r}0, \pi 72 \\
0 \\
100,692 \\
112,404 \\
201,791\end{array}$ & $\begin{array}{r}5,072 \\
0 \\
22,985 \\
20,057 \\
4,459,998\end{array}$ & $\begin{array}{r}294 \\
0 \\
-50 \\
20,400\end{array}$ & $\begin{array}{r}34 \\
0 \\
0 \\
34 \\
6,79\end{array}$ \\
\hline 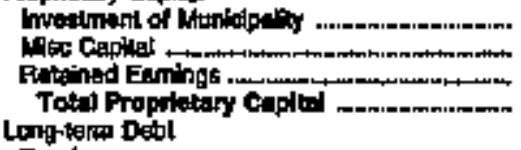 & $\begin{array}{r}8,108 \\
0 \\
07,148 \\
65,286\end{array}$ & $\begin{array}{r}2,458 \\
0 \\
394,570\end{array}$ & $\begin{array}{r}0 \\
0 \\
89,696 \\
0,616\end{array}$ & $\begin{array}{r}0 \\
0 \\
1,746,004 \\
1,740,004\end{array}$ & $\begin{array}{r}0 \\
769 \\
9,72\end{array}$ & $\begin{array}{r}0 \\
0,000 \\
2,849 \\
5,702\end{array}$ \\
\hline 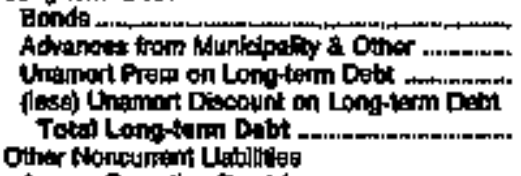 & $\begin{array}{r}28,008 \\
7,208 \\
0 \\
0 \\
20,248\end{array}$ & $\begin{array}{r}26,510 \\
14,697 \\
0 \\
128 \\
11,270\end{array}$ & $\begin{array}{r}280959 \\
0 \\
0 \\
0 \\
23,159\end{array}$ & $\begin{array}{r}2,751,618 \\
284,600 \\
0 \\
560,698 \\
2,465,728\end{array}$ & $\begin{array}{r}16,217 \\
0 \\
0 \\
0 \\
16,217\end{array}$ & $\begin{array}{l}0 \\
0 \\
0 \\
0\end{array}$ \\
\hline 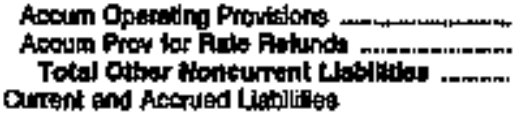 & $\begin{array}{l}0 \\
0 \\
0\end{array}$ & $\begin{array}{l}0 \\
0 \\
0\end{array}$ & $\begin{array}{l}0 \\
0 \\
0\end{array}$ & $\begin{array}{r}31,698 \\
0 \\
31,698\end{array}$ & $\begin{array}{c}68 \\
60\end{array}$ & \\
\hline 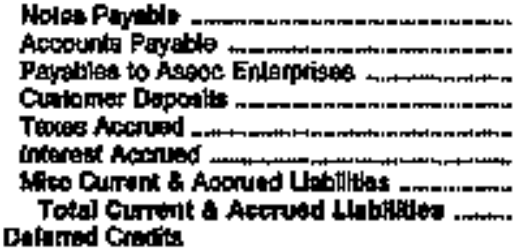 & $\begin{array}{r}0 \\
0,472 \\
0 \\
30 \\
48 \\
t, 041 \\
2,93 \\
7,763\end{array}$ & $\begin{array}{r}1,516 \\
3, \mathrm{Bg} 7 \\
0 \\
568 \\
0 \\
172 \\
1,740 \\
7,202\end{array}$ & $\begin{array}{r}0 \\
1,209 \\
0 \\
0 \\
0 \\
7,617 \\
0 \\
0,816\end{array}$ & $\begin{array}{r}0 \\
09,309 \\
98,510 \\
25,569 \\
6,5 \\
1,356 \\
2,054 \\
197,008\end{array}$ & 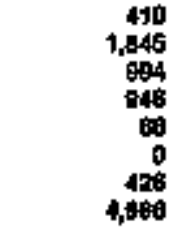 & $\begin{array}{r}0 \\
625 \\
0 \\
202 \\
0 \\
0 \\
69 \\
090\end{array}$ \\
\hline 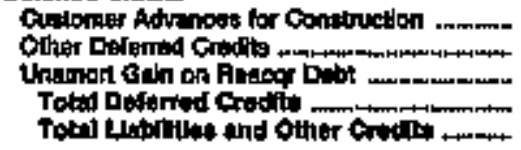 & $\begin{array}{r}0 \\
0 \\
0 \\
0 \\
02,28\end{array}$ & $\begin{array}{r}7,775 \\
0 \\
0 \\
7,776\end{array}$ & at1,701 & $\begin{array}{r}10,712 \\
6,0096 \\
0 \\
10,791 \\
4,40,603\end{array}$ & $\begin{array}{r}0 \\
0 \\
0 \\
0 \\
30,990\end{array}$ & $\begin{array}{r}0 \\
0 \\
0 \\
0 \\
0,790\end{array}$ \\
\hline
\end{tabular}

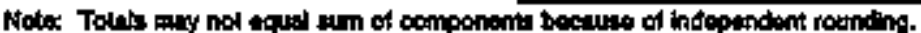

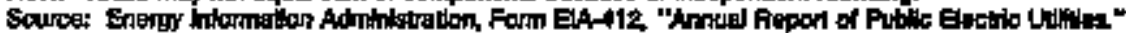


Table 22. Balance Sheet by Major U.S. Publicly Owmed Electric Utility Within State at End of Period, 1994

(Thousand Dollars)

\begin{tabular}{|c|c|c|c|c|c|c|}
\hline Ham & 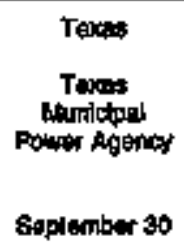 & $\begin{array}{l}\text { Tours } \\
\text { Tolode Bend } \\
\text { Prolect } \\
\text { Jotint } \\
\text { Oper } \\
\text { Atrong } 90\end{array}$ & 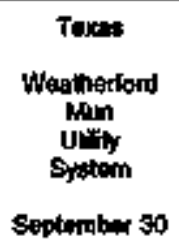 & $\begin{array}{l}\text { Uiah } \\
\text { Gountiful } \\
\text { Gity Chy of } \\
\text { June } 30\end{array}$ & $\begin{array}{l}\text { Utibh } \\
\text { Power Agency } \\
\text { Jume so }\end{array}$ & $\begin{array}{l}\text { Utah } \\
\text { Logan } \\
\text { Cly of } \\
\text { Juno ao }\end{array}$ \\
\hline 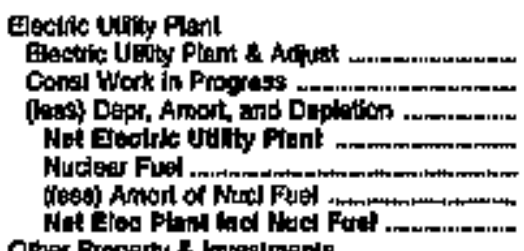 & $\begin{array}{r}76,612 \\
25,795 \\
273,209 \\
630,200 \\
0 \\
0 \\
034,208\end{array}$ & $\begin{array}{r}72,563 \\
0 \\
0 \\
72,559 \\
0 \\
0 \\
72,650\end{array}$ & $\begin{array}{r}12,165 \\
0 \\
7,018 \\
5,147 \\
0 \\
0 \\
5,+47\end{array}$ & $\begin{array}{r}36,773 \\
7,393 \\
11,598 \\
25,7000 \\
0 \\
0 \\
25,009\end{array}$ & 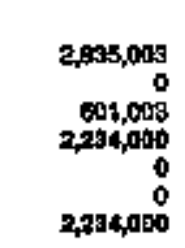 & $\begin{array}{r}28,128 \\
0 \\
9,506 \\
10,602 \\
0 \\
0 \\
10,002\end{array}$ \\
\hline 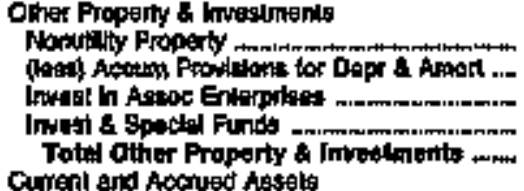 & $\begin{array}{r}0 \\
0 \\
170,758 \\
170,758\end{array}$ & $\begin{array}{l}0 \\
0 \\
0 \\
0 \\
0\end{array}$ & $\begin{array}{r}37,776 \\
4,364 \\
0 \\
14,799 \\
48,040\end{array}$ & $\begin{array}{l}0 \\
0 \\
0 \\
0 \\
0\end{array}$ & $\begin{array}{r}28,400 \\
0 \\
0 \\
2,518,881 \\
2,5 \text {, } 12,001\end{array}$ & $\begin{array}{r}334 \\
+34 \\
0 \\
0 \\
200\end{array}$ \\
\hline 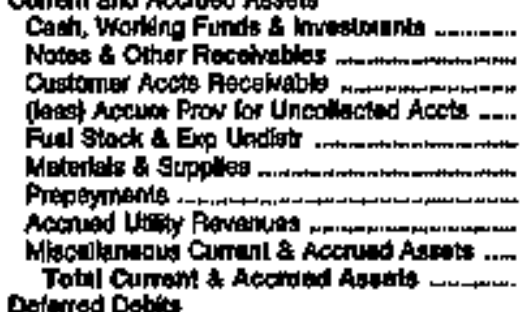 & $\begin{array}{r}51,012 \\
0,782 \\
0 \\
6 \\
4,205 \\
4,018 \\
0 \\
0 \\
1,008 \\
70,089\end{array}$ & $\begin{array}{r}15 \\
0 \\
0 \\
0 \\
0 \\
0 \\
0 \\
0 \\
3 \\
10\end{array}$ & $\begin{array}{r}5,168 \\
1,010 \\
1,708 \\
71 \\
0 \\
1,728 \\
0 \\
0 \\
194 \\
0,177\end{array}$ & $\begin{array}{r}4,090 \\
8 \\
1,611 \\
14 \\
0 \\
1,209 \\
71 \\
0 \\
0 \\
6,878\end{array}$ & $\begin{array}{r}105,587 \\
28,876 \\
0 \\
0 \\
61,516 \\
14,869 \\
0 \\
0 \\
1,005 \\
202,733\end{array}$ & $\begin{array}{r}5,576 \\
105 \\
1,879 \\
50 \\
0 \\
1,008 \\
0 \\
0 \\
0 \\
0,611\end{array}$ \\
\hline 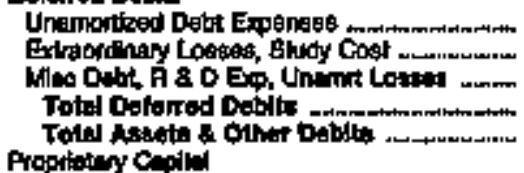 & $\begin{array}{r}19,622 \\
9,08 \\
640,402 \\
661,013 \\
1,430,000\end{array}$ & $\begin{array}{r}0 \\
0 \\
0 \\
0 \\
0\end{array}$ & $\begin{array}{r}503 \\
0 \\
0 \\
900 \\
90,807\end{array}$ & $\begin{array}{r}0 \\
0 \\
0 \\
0 \\
32,789\end{array}$ & $\begin{array}{r}924,375 \\
1,032,185 \\
1,088,006 \\
8,942,390\end{array}$ & $\begin{array}{r}102 \\
0 \\
0 \\
102 \\
27,517\end{array}$ \\
\hline 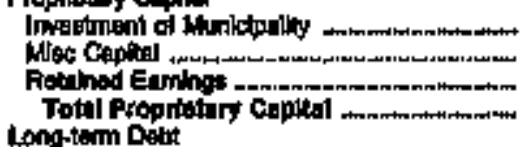 & $\begin{array}{r}0 \\
0 \\
30,0927 \\
34,927\end{array}$ & $\begin{array}{r}72,509 \\
0 \\
-5 \\
72,540\end{array}$ & $\begin{array}{r}7,298 \\
0 \\
29,915 \\
\$ 7,17 \%\end{array}$ & $\begin{array}{r}60 \\
30,505 \\
31,435\end{array}$ & $\begin{array}{l}0 \\
0 \\
0 \\
0\end{array}$ & $\begin{array}{r}674 \\
14,048 \\
15,603\end{array}$ \\
\hline 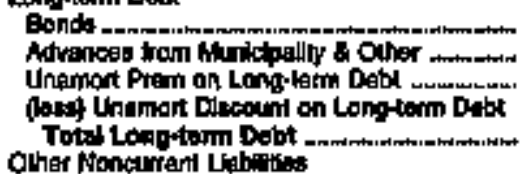 & $\begin{array}{r}1,146,007 \\
195,9386 \\
0 \\
0 \\
90,468 \\
1,322,367\end{array}$ & $\begin{array}{l}0 \\
0 \\
0 \\
0 \\
0\end{array}$ & $\begin{array}{r}21,585 \\
0 \\
0 \\
21,341\end{array}$ & $\begin{array}{l}0 \\
0 \\
0 \\
0 \\
0\end{array}$ & $\begin{array}{r}5,348,702 \\
10,650 \\
214,704 \\
6,6188,606\end{array}$ & $\begin{array}{r}0,760 \\
146 \\
0 \\
0 \\
2,920\end{array}$ \\
\hline 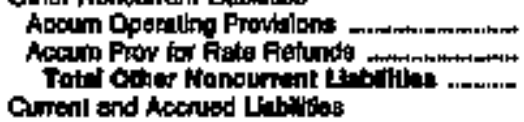 & $\stackrel{0}{0}$ & $\begin{array}{l}0 \\
0 \\
0\end{array}$ & $\begin{array}{l}0 \\
0 \\
0\end{array}$ & $\begin{array}{l}0 \\
0 \\
0\end{array}$ & $\begin{array}{l}0 \\
0 \\
0\end{array}$ & \\
\hline 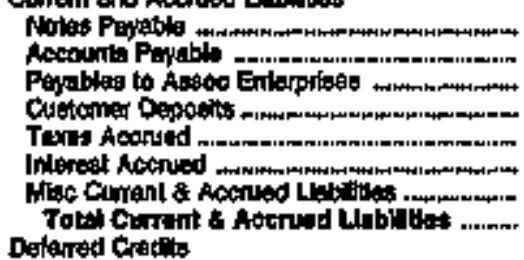 & $\begin{array}{r}38,000 \\
19,602 \\
1,301 \\
0 \\
0 \\
28,750 \\
70,076\end{array}$ & $\begin{array}{r}0 \\
23 \\
0 \\
0 \\
0 \\
0 \\
0 \\
20\end{array}$ & $\begin{array}{r}0 \\
1,277 \\
0 \\
65 \\
149 \\
111 \\
345 \\
1,986\end{array}$ & $\begin{array}{r}0 \\
001 \\
0 \\
209 \\
0 \\
0 \\
2040\end{array}$ & $\begin{array}{r}0 \\
37,053 \\
37,031 \\
0 \\
0 \\
98,645 \\
1,024,045 \\
1,740,772\end{array}$ & $\begin{array}{r}147 \\
1,849 \\
0 \\
500 \\
0 \\
\$ 12 \\
261 \\
2,668\end{array}$ \\
\hline 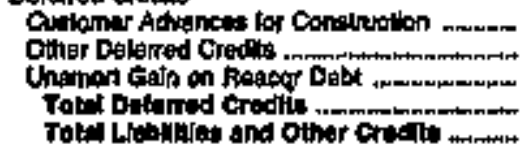 & $\begin{array}{r}0 \\
0 \\
0 \\
0 \\
0\end{array}$ & $\begin{array}{r}0 \\
0 \\
0 \\
0 \\
\text { ratit }\end{array}$ & $\begin{array}{r}414 \\
0 \\
44\end{array}$ & $\begin{array}{r}0 \\
0 \\
0 \\
0 \\
32,786\end{array}$ & $\begin{array}{r}0 \\
0 \\
0 \\
0 \\
0\end{array}$ & $\begin{array}{r}0 \\
0 \\
0 \\
0 \\
27,517\end{array}$ \\
\hline
\end{tabular}

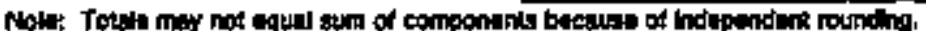

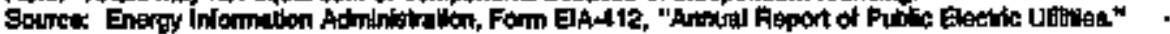


Table 22. Balance Sheet by Major U.S. Publicly Owned Electric Utility Within State at End of Period, 1994 (Thousand Dollars)

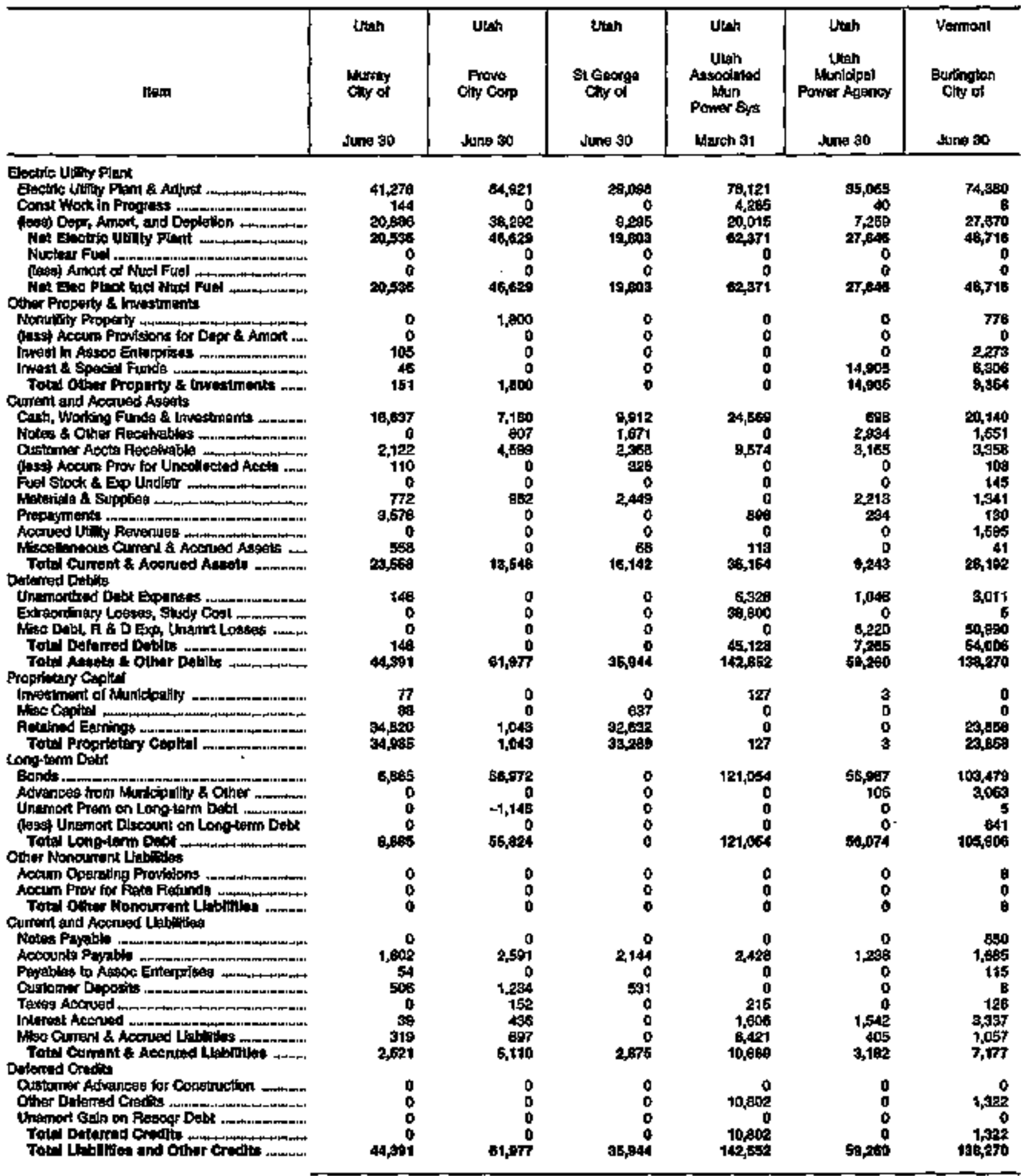

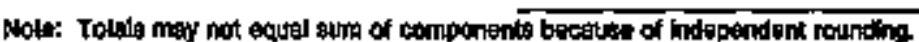

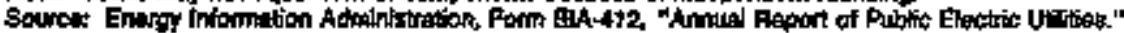


Table 22. Ealance Sheet by Major U.S. Publicly Owned Electic Utllty Within State at End of Pestod, 1994

(Thousand Dollars)

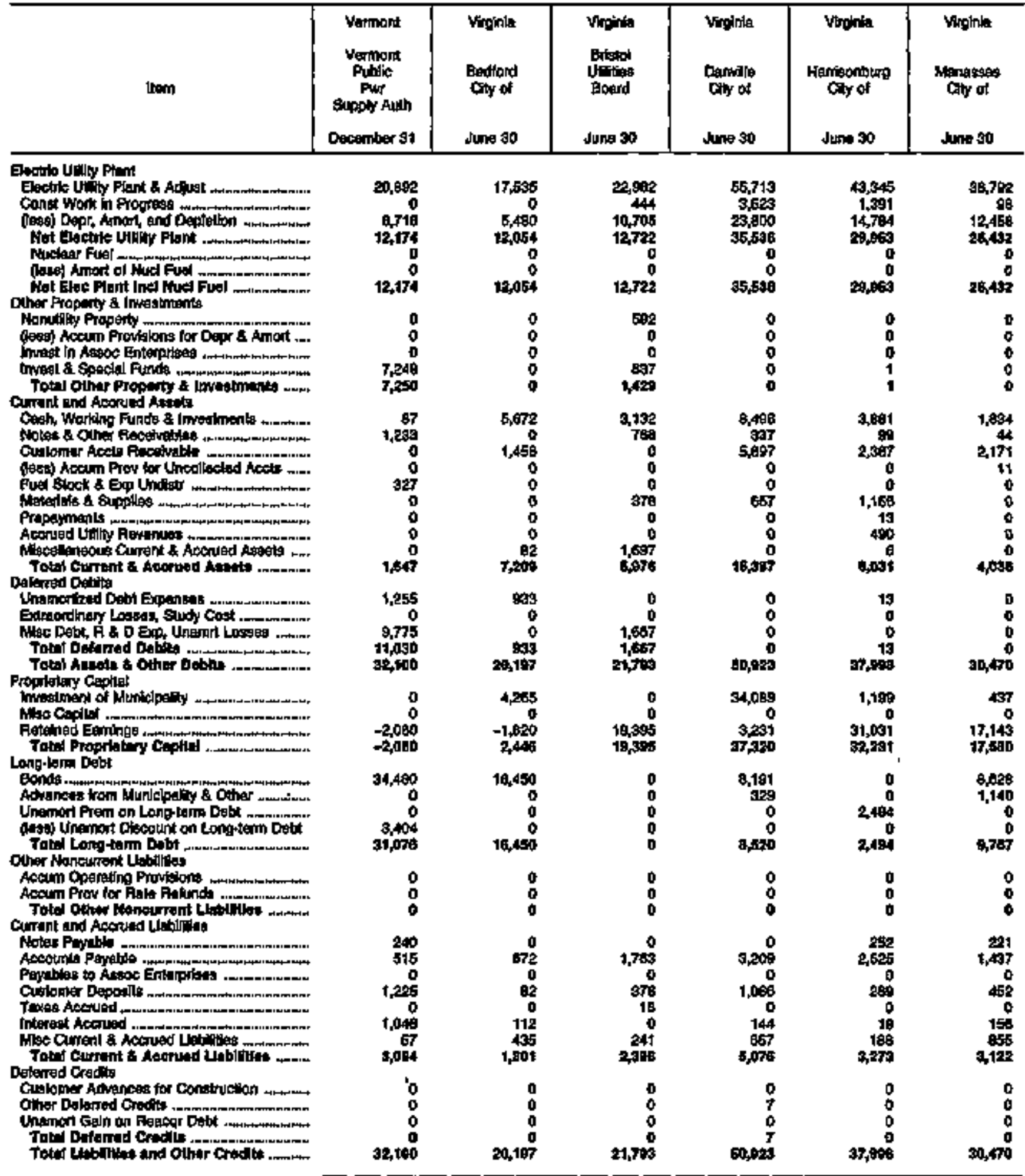

Note: Tolata may nol equal sum of camponenta becturse of thdependent rounding.

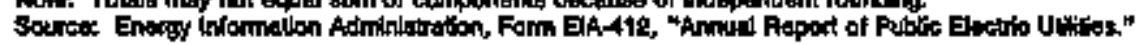


Table 22. Babance Sheet by Major U.S. Publlely Owned Electric Utilly Within State at End of Period, 1994

(Thousand Dollers)

\begin{tabular}{|c|c|c|c|c|c|c|}
\hline n & 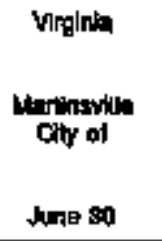 & 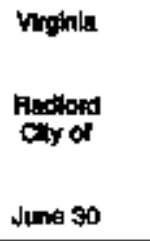 & $\begin{array}{l}\text { Wroint: } \\
\text { Sulem } \\
\text { Coty of } \\
\text { June } \mathbf{3 0}\end{array}$ & 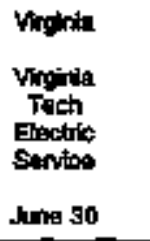 & $\begin{array}{l}\text { Woshington } \\
\text { Centrolla } \\
\text { City iol } \\
\text { Dacosinher ot }\end{array}$ & $\begin{array}{l}\text { Wraghingion } \\
\text { Ellengburg } \\
\text { Gity of } \\
\text { Decumber } 31\end{array}$ \\
\hline 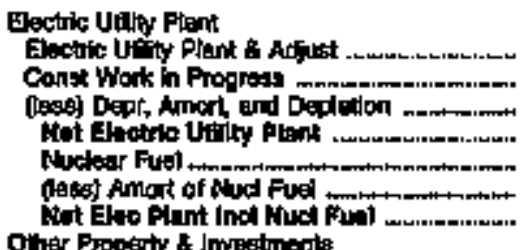 & $\begin{array}{r}17,105 \\
0 \\
6,765 \\
10,35 \% \\
0 \\
0 \\
10,350\end{array}$ & 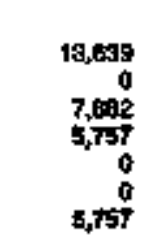 & $\begin{array}{r}20,658 \\
0 \\
10,172 \\
10,484 \\
0 \\
0 \\
10,404\end{array}$ & $\begin{array}{l}0 \\
0 \\
0 \\
0 \\
0 \\
0 \\
0\end{array}$ & 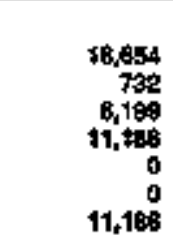 & $\begin{array}{r}13,240 \\
0 \\
5,049 \\
7,309 \\
0 \\
7,397\end{array}$ \\
\hline 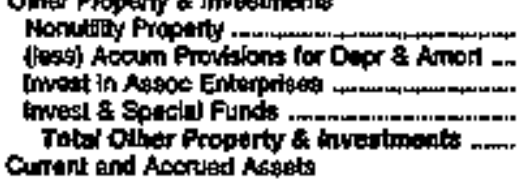 & $\begin{array}{l}0 \\
0 \\
0 \\
0 \\
0\end{array}$ & $\begin{array}{l}0 \\
0 \\
0 \\
0 \\
0\end{array}$ & $\begin{array}{r}0 \\
0 \\
0 \\
700 \\
708\end{array}$ & $\begin{array}{l}0 \\
0 \\
0 \\
0 \\
0\end{array}$ & $\begin{array}{r}69 \\
0 \\
0 \\
485 \\
534\end{array}$ & $\begin{array}{r}291 \\
111 \\
0 \\
0 \\
160\end{array}$ \\
\hline 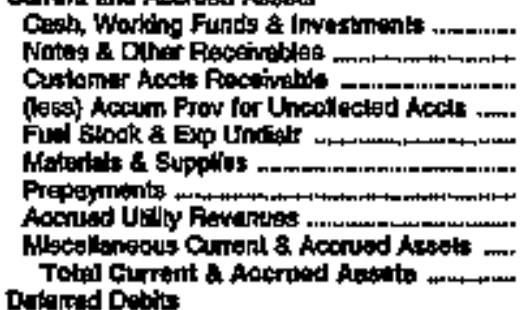 & $\begin{array}{r}1,000 \\
0 \\
1,48 \\
23 \\
0 \\
0 \\
0 \\
0 \\
0 \\
3,040\end{array}$ & $\begin{array}{r}3,600 \\
4,395 \\
1,300 \\
69 \\
0 \\
219 \\
10 \\
0 \\
0 \\
8,500\end{array}$ & $\begin{array}{r}3000 \\
9 \\
944 \\
47 \\
0 \\
628 \\
0 \\
1,203 \\
0 \\
6,206\end{array}$ & $\begin{array}{r}2,129 \\
150 \\
454 \\
0 \\
0 \\
324 \\
0 \\
0 \\
0 \\
3,000\end{array}$ & $\begin{array}{r}170 \\
102 \\
1,011 \\
14 \\
0 \\
147 \\
0 \\
0 \\
7 \\
1,372\end{array}$ & $\begin{array}{r}1,020 \\
0 \\
696 \\
9 \\
0 \\
400 \\
0 \\
0 \\
0 \\
2,110\end{array}$ \\
\hline 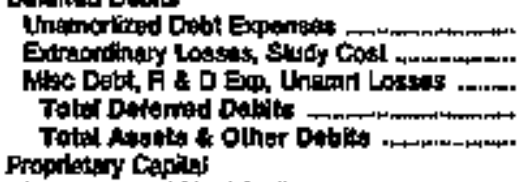 & $\begin{array}{r}0 \\
0 \\
0 \\
0 \\
13,70 \%\end{array}$ & $\begin{array}{r}0 \\
0 \\
0 \\
0 \\
15,277\end{array}$ & $\begin{array}{r}0 \\
0 \\
0 \\
0 \\
17, A 50\end{array}$ & $\begin{array}{r}2,075 \\
0 \\
0 \\
2,076 \\
5,095\end{array}$ & $\begin{array}{r}0 \\
0 \\
0 \\
13,09\end{array}$ & $\begin{array}{r}0 \\
0 \\
0 \\
0 \\
0,907\end{array}$ \\
\hline 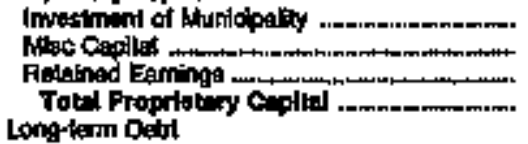 & $\begin{array}{r}0 \\
0 \\
12,498 \\
12,498\end{array}$ & $\begin{array}{r}0 \\
10,518 \\
10,819\end{array}$ & $\begin{array}{r}0 \\
0 \\
6517 \\
6,817\end{array}$ & $\begin{array}{r}0 \\
0 \\
2,155 \\
2,150\end{array}$ & $\begin{array}{r}672 \\
0 \\
B, 202 \\
B, 06\end{array}$ & $\begin{array}{r}0 \\
0 \\
0,489 \\
0,489\end{array}$ \\
\hline 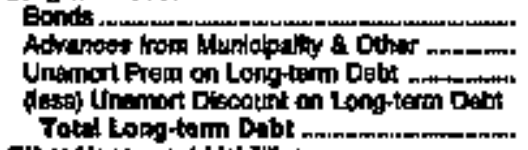 & $\begin{array}{l}0 \\
0 \\
0 \\
0 \\
0\end{array}$ & $\begin{array}{r}3,800 \\
0 \\
0 \\
0 \\
3,000\end{array}$ & $\begin{array}{r}9,085 \\
32 \\
0 \\
73 \\
9,024\end{array}$ & $\begin{array}{r}2,575 \\
0 \\
0 \\
0 \\
2,57\end{array}$ & $\begin{array}{r}385 \\
0 \\
0 \\
16 \\
706\end{array}$ & $\begin{array}{r}0 \\
460 \\
0 \\
0 \\
180\end{array}$ \\
\hline 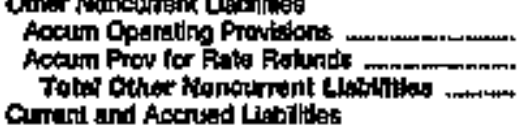 & $\begin{array}{l}0 \\
0 \\
0\end{array}$ & $\begin{array}{l}0 \\
0 \\
0\end{array}$ & $\begin{array}{l}0 \\
0 \\
0\end{array}$ & $\begin{array}{l}0 \\
0 \\
0\end{array}$ & $\begin{array}{r}295 \\
0 \\
235\end{array}$ & $\begin{array}{l}0 \\
0 \\
0\end{array}$ \\
\hline 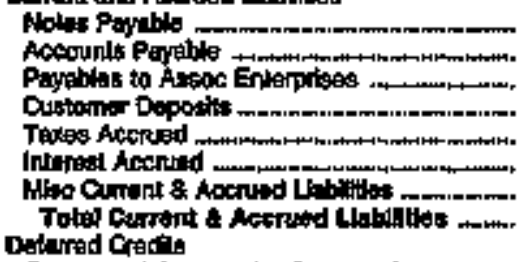 & $\begin{array}{r}0 \\
758 \\
0 \\
242 \\
0 \\
0 \\
207 \\
1,208\end{array}$ & $\begin{array}{r}0 \\
881 \\
0 \\
\$ 80 \\
0 \\
0 \\
247 \\
1, \$ 50\end{array}$ & $\begin{array}{r}0 \\
1,808 \\
0 \\
245 \\
0 \\
96 \\
250 \\
1,908\end{array}$ & $\begin{array}{r}0 \\
740 \\
0 \\
0 \\
0 \\
15 \\
150 \\
904\end{array}$ & $\begin{array}{r}0 \\
2,001 \\
0 \\
208 \\
0 \\
5 \\
0 \\
8,04\end{array}$ & $\begin{array}{r}0 \\
625 \\
0 \\
0 \\
0 \\
2 \\
113 \\
740\end{array}$ \\
\hline 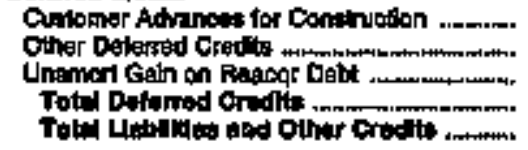 & $\begin{array}{r}0 \\
0 \\
0 \\
0 \\
\text { ta,708 }\end{array}$ & $\begin{array}{r}0 \\
0 \\
0 \\
0 \\
16,2 \pi 7\end{array}$ & $\begin{array}{r}0 \\
0 \\
0 \\
0 \\
17,460\end{array}$ & $\begin{array}{r}0 \\
0 \\
0 \\
0 \\
50.036\end{array}$ & $\begin{array}{r}20 \\
10 \\
6 \\
50 \\
19,093\end{array}$ & $\begin{array}{r}0 \\
0 \\
0 \\
0 \\
0.607\end{array}$ \\
\hline
\end{tabular}

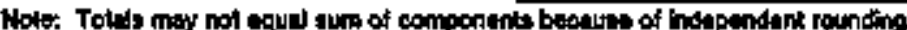

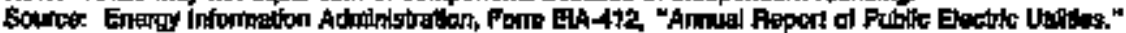


Teble 22. Balence sheet by Major U.8. Publicly Owned Electric Villty Whthln State at End of Pertod, 1994

(Thousand Dollars)

\begin{tabular}{|c|c|c|c|c|c|c|}
\hline Lem & 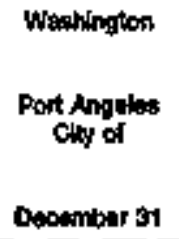 & $\begin{array}{l}\text { Woentinglon } \\
\text { Puo No } 1 \\
\text { of } \\
\text { Benton } \\
\text { County } \\
\text { Decomber } 3\end{array}$ & $\begin{array}{l}\text { Wisghington } \\
\text { Puo No } 1 \\
\text { of } \\
\text { Chelan } \\
\text { County } \\
\text { Decamber } 31\end{array}$ & 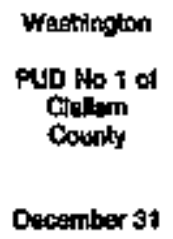 & 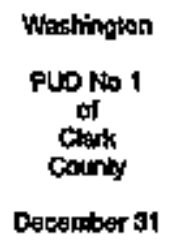 & 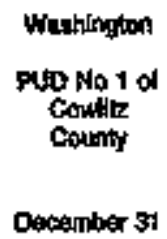 \\
\hline 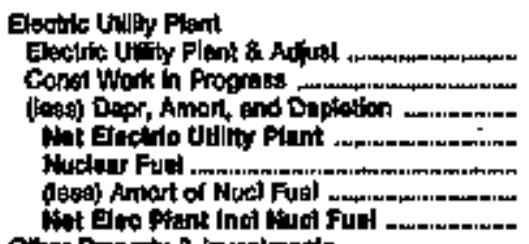 & $\begin{array}{r}22,275 \\
8,15 \\
9,203 \\
13,668 \\
0 \\
0 \\
13,058\end{array}$ & $\begin{array}{r}80,163 \\
2,011 \\
36,103 \\
66,671 \\
0 \\
0 \\
66,071\end{array}$ & $\begin{array}{r}004,716 \\
10,0006 \\
174,027 \\
747,502 \\
0 \\
747,500\end{array}$ & $\begin{array}{r}69,813 \\
3,882 \\
31,777 \\
\$ 1,619 \\
0 \\
0 \\
01,319\end{array}$ & $\begin{array}{r}226,268 \\
5,407 \\
60,508 \\
145,225 \\
0 \\
0 \\
142,208\end{array}$ & $\begin{array}{r}516,552 \\
521 \\
51,817 \\
6,1296 \\
0 \\
0 \\
65,2,86\end{array}$ \\
\hline 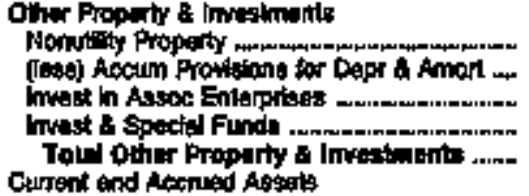 & $\begin{array}{l}0 \\
0 \\
0 \\
0 \\
0\end{array}$ & $\begin{array}{r}0 \\
0 \\
13,100 \\
13,100\end{array}$ & $\begin{array}{r}0 \\
6 \\
6,965 \\
137,9006 \\
144,958\end{array}$ & $\begin{array}{r}0 \\
0 \\
0 \\
3,572 \\
3,372\end{array}$ & $\begin{array}{r}118 \\
8 \\
0 \\
7,911 \\
\text { 4,015 }\end{array}$ & $\begin{array}{r}1 \\
0 \\
1,212 \\
1,734 \\
2,968\end{array}$ \\
\hline 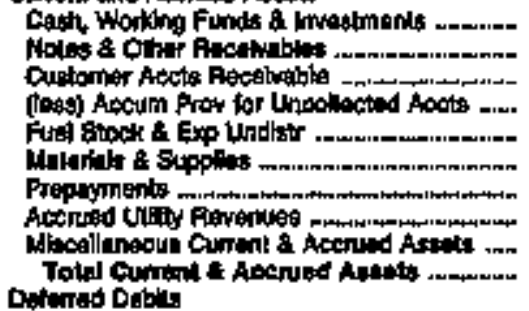 & $\begin{array}{r}3,000 \\
806 \\
2,950 \\
0 \\
0 \\
749 \\
0 \\
0 \\
0 \\
7,468\end{array}$ & $\begin{array}{r}0,120 \\
811 \\
4,685 \\
11 \\
0 \\
0.574 \\
60 \\
0 \\
413 \\
10,742\end{array}$ & $\begin{array}{r}28,450 \\
21,369 \\
7,416 \\
0 \\
0 \\
4,792 \\
557 \\
0 \\
989 \\
93,619\end{array}$ & $\begin{array}{r}3,389 \\
2,49 \\
1,724 \\
34 \\
0 \\
1,454 \\
184 \\
0 \\
34 \\
7,491\end{array}$ & $\begin{array}{r}11,359 \\
3,108 \\
16,697 \\
4,600 \\
0 \\
2,875 \\
108 \\
2,640 \\
34,030\end{array}$ & $\begin{array}{r}13,+101 \\
1,978 \\
12,096 \\
159 \\
0 \\
1,614 \\
616 \\
0 \\
\text { 8f } \\
29,207\end{array}$ \\
\hline 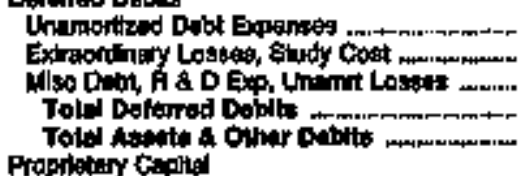 & $\begin{array}{r}0 \\
0 \\
0 \\
0 \\
25,025\end{array}$ & $\begin{array}{r}1,135 \\
0 \\
7 \\
1,140 \\
06,060\end{array}$ & $\begin{array}{r}18,765 \\
1,677 \\
28,890 \\
47,331 \\
1,000,240\end{array}$ & $\begin{array}{r}100 \\
0 \\
0 \\
180 \\
12,620\end{array}$ & $\begin{array}{r}3,298 \\
0 \\
2,335 \\
5,604 \\
100,468\end{array}$ & $\begin{array}{r}2 \\
0 \\
67 \\
69 \\
67,609\end{array}$ \\
\hline 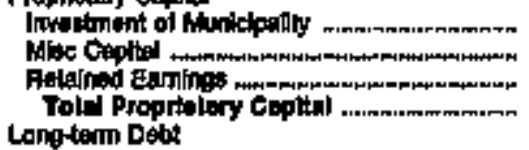 & $\begin{array}{r}897 \\
0 \\
12,003 \\
10,640\end{array}$ & $\begin{array}{r}0 \\
0 \\
33,200 \\
39,2 i n\end{array}$ & $\begin{array}{r}10,358 \\
0 \\
20,0,356 \\
230,714\end{array}$ & $\begin{array}{r}0 \\
27,3,27\end{array}$ & $\begin{array}{r}0 \\
0 \\
74,297 \\
74,267\end{array}$ & $\begin{array}{r}0 \\
0 \\
00,004\end{array}$ \\
\hline 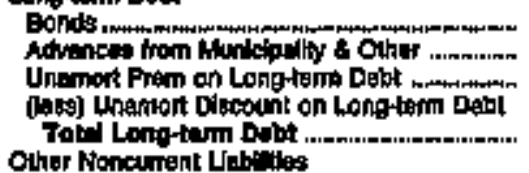 & $\begin{array}{r}2,795 \\
0 \\
0 \\
0 \\
2,795\end{array}$ & $\begin{array}{r}37,840 \\
1,385 \\
0 \\
0 \\
30,028\end{array}$ & $\begin{array}{r}510,149 \\
178,987 \\
2,05 \\
209651\end{array}$ & $\begin{array}{r}0,028 \\
50 \\
0 \\
0,074\end{array}$ & $\begin{array}{r}72,010 \\
0 \\
0 \\
72,004\end{array}$ & $\begin{array}{r}2,406 \\
4,300 \\
0 \\
2 \\
6,723\end{array}$ \\
\hline 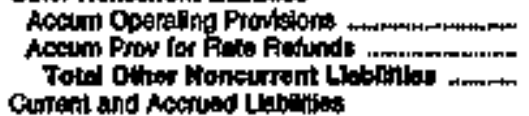 & $\begin{array}{r}15 t \\
0 \\
151\end{array}$ & $\begin{array}{l}0 \\
0 \\
0\end{array}$ & $\begin{array}{l}0 \\
0 \\
0\end{array}$ & $\begin{array}{l}0 \\
0 \\
0\end{array}$ & $\begin{array}{r}2000 \\
2500\end{array}$ & $\begin{array}{r}1,506 \\
0 \\
1,600\end{array}$ \\
\hline 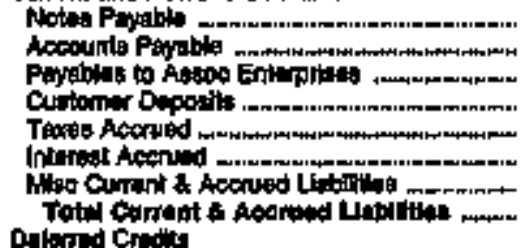 & $\begin{array}{r}0 \\
2,398 \\
58 \\
0 \\
0 \\
108 \\
222 \\
2,619\end{array}$ & $\begin{array}{r}691 \\
3,891 \\
0 \\
669 \\
1,751 \\
1,40 \\
1,047 \\
0,397\end{array}$ & $\begin{array}{r}0 \\
27,452 \\
21,849 \\
186 \\
2,055 \\
2,037 \\
15,359 \\
69,018\end{array}$ & $\begin{array}{r}0 \\
4,079 \\
0 \\
249 \\
097 \\
170 \\
417 \\
0,605\end{array}$ & $\begin{array}{r}12,389 \\
13,806 \\
0 \\
1 \\
3,807 \\
2,209 \\
0,989 \\
41,354\end{array}$ & $\begin{array}{r}1,300 \\
12,760 \\
44 \\
3009 \\
2,599 \\
51 \\
495 \\
19,500\end{array}$ \\
\hline 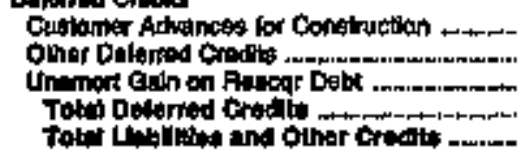 & $\begin{array}{r}1,071 \\
0 \\
0 \\
1,871 \\
21,325\end{array}$ & $\begin{array}{r}5,349 \\
21 \\
0 \\
5,370 \\
0,000\end{array}$ & $\begin{array}{r}0,02 \% \\
0 \\
0,003,240\end{array}$ & 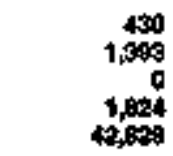 & $\begin{array}{r}225 \\
206 \\
200,408\end{array}$ & $\begin{array}{r}10,523 \\
40 \\
10,093 \\
97,509\end{array}$ \\
\hline
\end{tabular}

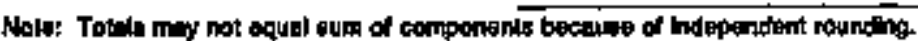

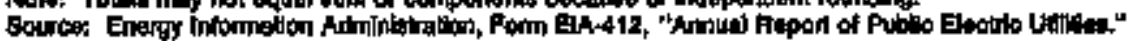


Table 22. Balance Sheet by Major U.S. Publicly Owned Etectrle Cullty Within state at End of Period, 1994

(Thousarnd Dollars)

\begin{tabular}{|c|c|c|c|c|c|c|}
\hline Itom & 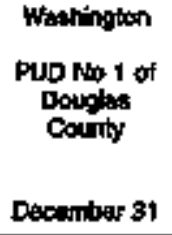 & $\begin{array}{l}\text { Washitiolon } \\
\text { Pup No } 1 \text { of } \\
\text { Prantlth } \\
\text { Casenty } \\
\text { Decomber } 31\end{array}$ & 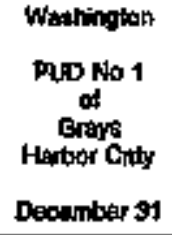 & $\begin{array}{l}\text { Wastinglon } \\
\text { Pub No } 1 \text { of } \\
\text { Klickitut } \\
\text { County } \\
\text { December } 31\end{array}$ & $\begin{array}{l}\text { Wathinglon } \\
\text { PUD Ho } 1 \\
\text { of } \\
\text { Lewis } \\
\text { Dounty } \\
\text { Decuntor } 31\end{array}$ & 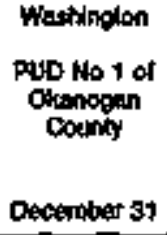 \\
\hline 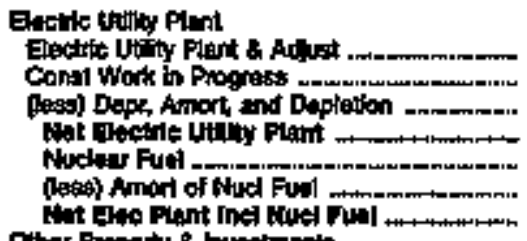 & $\begin{array}{r}270,935 \\
1,658 \\
60,391 \\
281,397 \\
0 \\
0 \\
2 \$ 1,307\end{array}$ & $\begin{array}{r}41,657 \\
1,547 \\
16,448 \\
26,667 \\
0 \\
0 \\
30,6.57\end{array}$ & $\begin{array}{r}107,445 \\
1,469 \\
40,739 \\
69,169 \\
0 \\
0 \\
49,169\end{array}$ & $\begin{array}{r}32,937 \\
9,474 \\
13,977 \\
36,424 \\
0 \\
0 \\
34,424\end{array}$ & $\begin{array}{r}56,940 \\
13,122 \\
15,460 \\
54,602 \\
0 \\
54,000\end{array}$ & $\begin{array}{r}35,310 \\
2,562 \\
25,049 \\
3,015 \\
0 \\
0 \\
27,815\end{array}$ \\
\hline 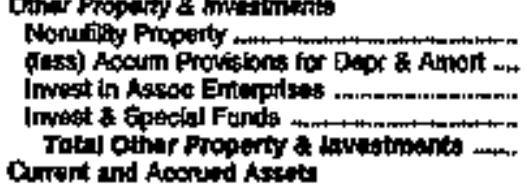 & $\begin{array}{r}0 \\
0 \\
0 \\
27,061 \\
27,651\end{array}$ & $\begin{array}{r}0 \\
0 \\
0 \\
5,218 \\
5,2+\$\end{array}$ & $\begin{array}{r}t 21 \\
0 \\
0 \\
0,022 \\
4,0,2\end{array}$ & $\begin{array}{r}0 \\
0 \\
0 \\
2,732 \\
2,732\end{array}$ & $\begin{array}{r}0 \\
0 \\
0 \\
1,649 \\
1,649\end{array}$ & $\begin{array}{r}0 \\
0 \\
0 \\
39900 \\
3,9950\end{array}$ \\
\hline 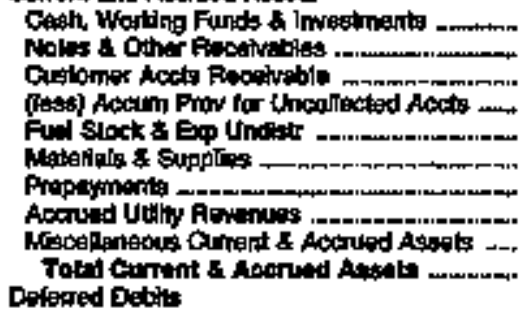 & $\begin{array}{r}16,069 \\
575 \\
523 \\
33 \\
0 \\
1,789 \\
725 \\
0 \\
1,082 \\
19,904\end{array}$ & $\begin{array}{r}0,371 \\
0 \\
3,404 \\
8 \\
0 \\
1,798 \\
45 \\
1,129 \\
15,724\end{array}$ & $\begin{array}{r}14,269 \\
827 \\
4,760 \\
50 \\
150 \\
2,613 \\
74 \\
0 \\
35 \\
2,701\end{array}$ & $\begin{array}{r}2,027 \\
0 \\
1,156 \\
\$ 0 \\
0 \\
817 \\
3 \\
300 \\
0 \\
1,072\end{array}$ & $\begin{array}{r}13,000 \\
0 \\
4,917 \\
0 \\
0 \\
1,684 \\
12 \\
0 \\
0 \\
19,904\end{array}$ & $\begin{array}{r}12,006 \\
148 \\
934 \\
14 \\
0 \\
1,524 \\
26 \\
0 \\
0 \\
15,415\end{array}$ \\
\hline 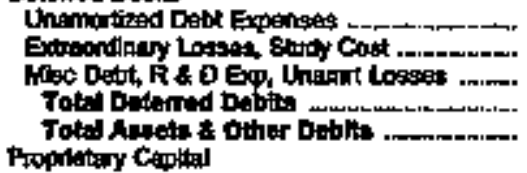 & $\begin{array}{r}2,307 \\
187 \\
29,693 \\
32,367 \\
311,1,99\end{array}$ & $\begin{array}{r}431 \\
104 \\
61 \\
586 \\
48,1 \% 6\end{array}$ & 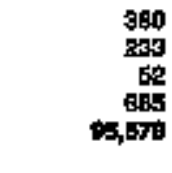 & $\begin{array}{r}297 \\
17 \\
6 \\
350 \\
38,957\end{array}$ & $\begin{array}{r}0 \\
0 \\
0 \\
7 \\
76,044\end{array}$ & $\begin{array}{r}0 \\
78 \\
175 \\
170 \\
4 \rightarrow 30\end{array}$ \\
\hline 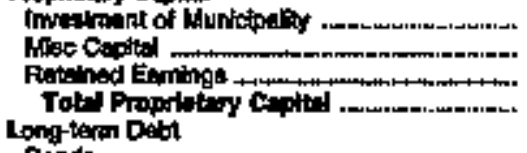 & $\begin{array}{r}0 \\
9 \\
99,278 \\
98,278\end{array}$ & $\begin{array}{r}854 \\
0 \\
13,606 \\
14,499\end{array}$ & $\begin{array}{r}0 \\
0 \\
60,690 \\
60,6 \% 9\end{array}$ & $\begin{array}{r}4,940 \\
15,280 \\
20,167\end{array}$ & $\begin{array}{r}0 \\
1,310 \\
66,402 \\
69,02\end{array}$ & 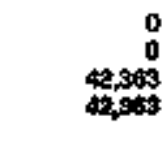 \\
\hline 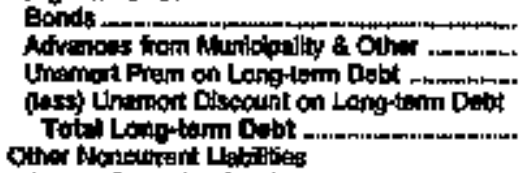 & $\begin{array}{r}195,810 \\
4,344 \\
0 \\
0 \\
200,144\end{array}$ & $\begin{array}{r}27,175 \\
0 \\
0 \\
0 \\
0 \\
0\end{array}$ & $\begin{array}{r}11,676 \\
1,614 \\
0 \\
0 \\
13,509\end{array}$ & $\begin{array}{r}3,010 \\
10,680 \\
0 \\
0 \\
13,670\end{array}$ & $\begin{array}{r}0 \\
549 \\
0 \\
0 \\
548\end{array}$ & $\begin{array}{r}0 \\
819 \\
0 \\
0 \\
010\end{array}$ \\
\hline 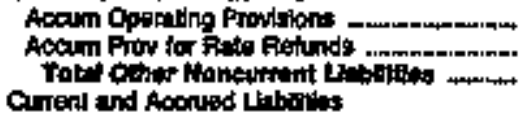 & $\begin{array}{l}0 \\
0 \\
0\end{array}$ & $\begin{array}{r}645 \\
045\end{array}$ & $\begin{array}{r}182 \\
0 \\
182\end{array}$ & $\begin{array}{l}0 \\
0 \\
0\end{array}$ & $\begin{array}{l}0 \\
0 \\
0\end{array}$ & $\begin{array}{l}0 \\
0 \\
0\end{array}$ \\
\hline 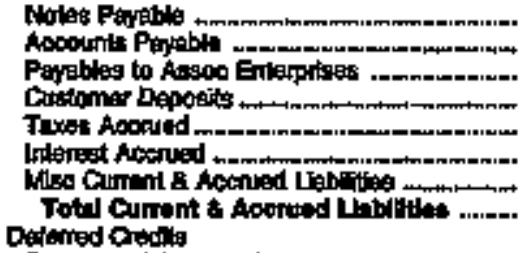 & 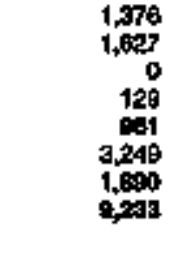 & $\begin{array}{r}2,262 \\
134 \\
0 \\
361 \\
876 \\
584 \\
2105 \\
6,312\end{array}$ & $\begin{array}{r}4,281 \\
4,691 \\
0 \\
628 \\
1,302 \\
0 \\
3,108 \\
7,924\end{array}$ & $\begin{array}{r}0 \\
1,041 \\
0 \\
100 \\
346 \\
150 \\
280 \\
1,096\end{array}$ & $\begin{array}{r}0 \\
22 \\
394 \\
348 \\
0 \\
0 \\
4,048 \\
4,781\end{array}$ & $\begin{array}{r}868 \\
2,397 \\
0 \\
173 \\
4,7 \\
0 \\
520 \\
4,3=4\end{array}$ \\
\hline 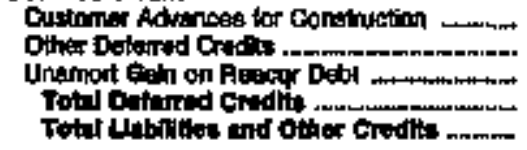 & $\begin{array}{r}0 \\
3,469 \\
0 \\
\mathbf{3 , 4 6 3} \\
\mathbf{8 1 1 , 1 1 9}\end{array}$ & $\begin{array}{r}130 \\
0 \\
130 \\
450\end{array}$ & $\begin{array}{r}31 \\
1,54 \\
0 \\
1,505 \\
0,570\end{array}$ & 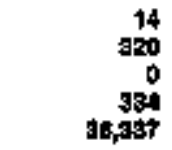 & $\begin{array}{r}0 \\
919 \\
0 \\
8+3 \\
70,040\end{array}$ & $\begin{array}{r}0 \\
-1 \\
0 \\
-1 \\
47,3 \mathrm{a}=\end{array}$ \\
\hline
\end{tabular}

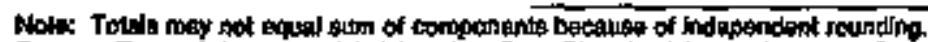

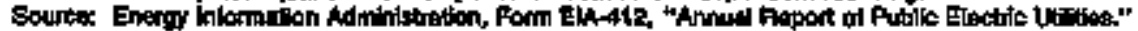


Table 22. Balance Sheet by Major U.S. Publicly Owned Electric Utility Within State at End of Porlod, t994

(Thousuand Dollars)

\begin{tabular}{|c|c|c|c|c|c|c|}
\hline Irear & $\begin{array}{l}\text { Weatingtion } \\
\text { Pub No } 1 \text { of } \\
\text { Pand Oretle } \\
\text { Ciny } \\
\text { December } 31\end{array}$ & $\begin{array}{l}\text { Wattingion } \\
\text { PuO No } 1 \text { of } \\
\text { Snghompligh } \\
\text { County } \\
\text { Deooniber } 31\end{array}$ & 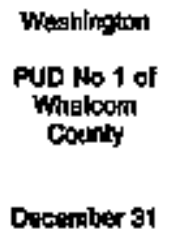 & $\begin{array}{l}\text { Wathingion } \\
\text { Puo kito } 2 \\
\text { of } \\
\text { Conint } \\
\text { Decentiber al }\end{array}$ & 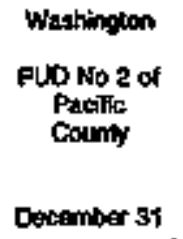 & 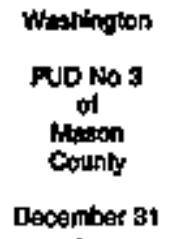 \\
\hline 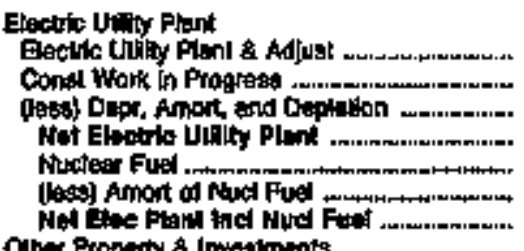 & $\begin{array}{r}48,271 \\
494 \\
15,756 \\
31,007 \\
0 \\
0 \\
31,007\end{array}$ & $\begin{array}{r}786,941 \\
114,394 \\
200,066 \\
694,399 \\
0 \\
694,399\end{array}$ & $\begin{array}{r}2,707 \\
0 \\
576 \\
2,131 \\
0 \\
0 \\
2,181\end{array}$ & $\begin{array}{r}67,491 \\
41,731 \\
223,197 \\
443,026 \\
0 \\
0 \\
44,054\end{array}$ & $\begin{array}{r}27,643 \\
6,097 \\
14,951 \\
14,729 \\
0 \\
0 \\
18,729\end{array}$ & $\begin{array}{r}67,642 \\
2,640 \\
17,419 \\
58,040 \\
0 \\
52,00\end{array}$ \\
\hline 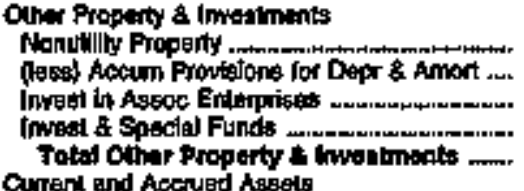 & $\begin{array}{r}38 \\
0 \\
0 \\
2098 \\
294\end{array}$ & $\begin{array}{r}0 \\
0 \\
48,036 \\
200,300 \\
240,935\end{array}$ & $\begin{array}{r}0 \\
0 \\
0 \\
1, B 90 \\
1,850\end{array}$ & $\begin{array}{r}0 \\
0 \\
0 \\
138,055 \\
t 38,055\end{array}$ & $\begin{array}{r}0 \\
0 \\
0 \\
4,084 \\
4,064\end{array}$ & $\begin{array}{r}0 \\
0 \\
5,008 \\
5,000\end{array}$ \\
\hline 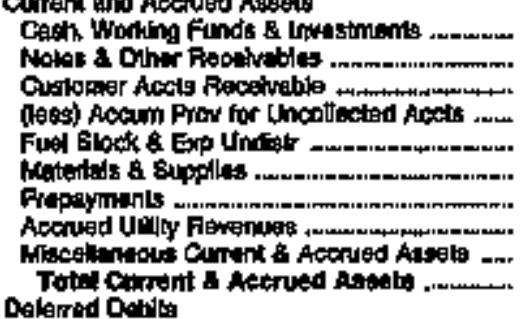 & $\begin{array}{r}8969 \\
728 \\
947 \\
7 \\
0 \\
481 \\
145 \\
130 \\
0 \\
10,752\end{array}$ & $\begin{array}{r}46,770 \\
3,041 \\
45,399 \\
+, 523 \\
520 \\
5,405 \\
206 \\
0 \\
2,289 \\
102,070\end{array}$ & $\begin{array}{r}210 \\
37 \\
424 \\
0 \\
0 \\
0 \\
8 \\
0 \\
324 \\
1,000\end{array}$ & $\begin{array}{r}108,689 \\
\$ 6,060 \\
9,800 \\
279 \\
0 \\
5,957 \\
809 \\
0 \\
1,861 \\
137,063\end{array}$ & $\begin{array}{r}2,489 \\
2,06 \\
1,146 \\
59 \\
0 \\
1,809 \\
51 \\
0 \\
5 \\
5,434\end{array}$ & $\begin{array}{r}958 \mathrm{a} \\
314 \\
3,385 \\
38 \\
0 \\
2009 \\
21 \\
90 \\
30\end{array}$ \\
\hline 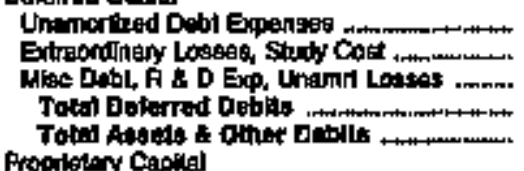 & $\begin{array}{r}47 \\
7,190 \\
1,909 \\
16,007\end{array}$ & $\begin{array}{r}5,208 \\
169,076 \\
169,054 \\
1,214,457\end{array}$ & $\begin{array}{r}0 \\
0 \\
0 \\
0 \\
1,989\end{array}$ & $\begin{array}{r}3,649 \\
166 \\
+, 109 \\
709,069\end{array}$ & $\begin{array}{r}171 \\
0 \\
73 \\
244 \\
2147\end{array}$ & $\begin{array}{r}316 \\
256 \\
34 \\
618 \\
74,453\end{array}$ \\
\hline 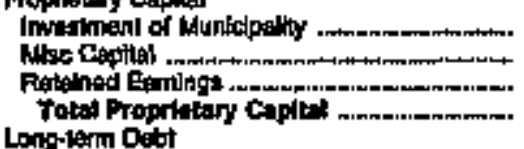 & $\begin{array}{r}0 \\
0 \\
38,843 \\
30,049\end{array}$ & $\begin{array}{r}0 \\
0 \\
200,504 \\
209,594\end{array}$ & $\begin{array}{r}0 \\
1,547 \\
2,915 \\
4,408\end{array}$ & 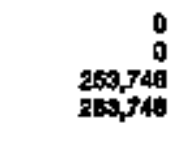 & $\begin{array}{r}0 \\
3,140 \\
15,967 \\
26,107\end{array}$ & $\begin{array}{r}0 \\
4 \\
41,443 \\
41,443\end{array}$ \\
\hline 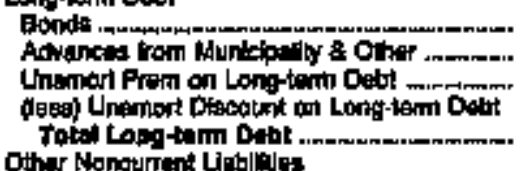 & $\begin{array}{r}3,172 \\
1,180 \\
0 \\
0 \\
4,006\end{array}$ & $\begin{array}{r}678,300 \\
17,671 \\
727 \\
14,550 \\
692,196\end{array}$ & $\begin{array}{l}0 \\
0 \\
0 \\
0 \\
0\end{array}$ & $\begin{array}{r}56,, 570 \\
0 \\
200 \\
21,810 \\
341,300\end{array}$ & $\begin{array}{r}5,200 \\
465 \\
0 \\
0 \\
0\end{array}$ & $\begin{array}{r}16,976 \\
0 \\
0 \\
0 \\
16,976\end{array}$ \\
\hline 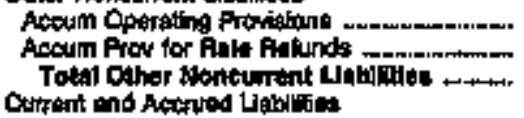 & $\begin{array}{l}0 \\
0 \\
0\end{array}$ & $\begin{array}{r}2,130 \\
0 \\
2,199\end{array}$ & $\begin{array}{l}0 \\
0 \\
0\end{array}$ & $\begin{array}{l}0 \\
0 \\
0\end{array}$ & $\begin{array}{l}0 \\
0 \\
0\end{array}$ & $\begin{array}{l}0 \\
0 \\
0\end{array}$ \\
\hline 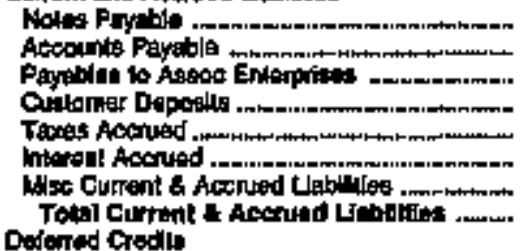 & 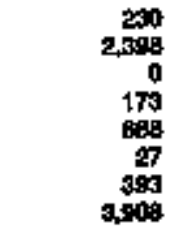 & $\begin{array}{r}5,166 \\
54,398 \\
0 \\
546 \\
7,586 \\
21,506 \\
9,787 \\
98,900\end{array}$ & $\begin{array}{r}0 \\
428 \\
0 \\
0 \\
104 \\
0 \\
0 \\
627\end{array}$ & $\begin{array}{r}518 \\
12,600 \\
15,7 \% 3 \\
5003 \\
3,0,02 \\
9,745 \\
74,704 \\
116,094\end{array}$ & $\begin{array}{r}119 \\
1,85 \\
0 \\
095 \\
302 \\
35 \\
177 \\
2806\end{array}$ & $\begin{array}{r}210 \\
3,600 \\
0 \\
t 60 \\
685 \\
607 \\
8090 \\
6,044\end{array}$ \\
\hline 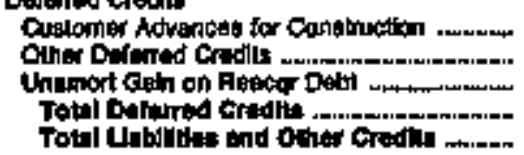 & $\begin{array}{r}55 \\
020 \\
0 \\
001 \\
06,097\end{array}$ & $\begin{array}{r}0 \\
221,646 \\
0 \\
221,648 \\
1,214,457\end{array}$ & $\begin{array}{r}0 \\
0 \\
0 \\
0 \\
4,000\end{array}$ & $\begin{array}{r}730 \\
524 \\
0 \\
1,795 \\
720,069\end{array}$ & $\begin{array}{r}390 \\
4 \\
0 \\
394\end{array}$ & $\begin{array}{r}1,989 \\
103 \\
498 \\
0,972 \\
74,465\end{array}$ \\
\hline
\end{tabular}

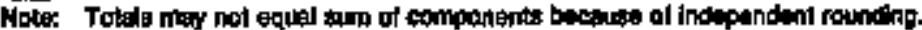

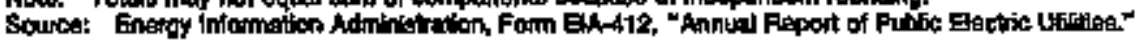


Table 22. Balance Sheet by Major U.S. Publich Owned Electrio Utilty Within State at End of Perlod, 1994

(Thoussand Dollars)

\begin{tabular}{|c|c|c|c|c|c|c|}
\hline Itern & $\begin{array}{l}\text { Weshingion } \\
\text { Pichiand } \\
\text { City of } \\
\text { Decentiber } 31\end{array}$ & 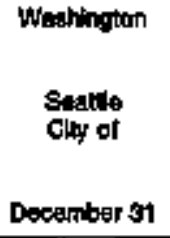 & $\begin{array}{l}\text { Wastibgton } \\
\text { Tacoma } \\
\text { Cly of } \\
\text { Decomber } 31\end{array}$ & 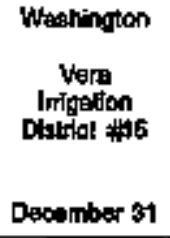 & $\begin{array}{l}\text { Wastinglon } \\
\text { Waghington } \\
\text { Pub } \\
\text { Sumb } 30\end{array}$ & 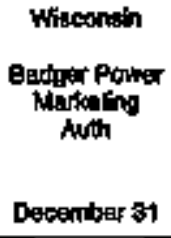 \\
\hline 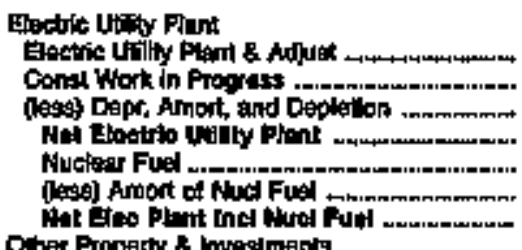 & $\begin{array}{r}44,223 \\
4,496 \\
16,014 \\
31,909 \\
0 \\
0 \\
31,000\end{array}$ & $\begin{array}{r}1,244,250 \\
100,462 \\
340,563 \\
107,349 \\
0 \\
0 \\
007,34,5\end{array}$ & $\begin{array}{r}700,758 \\
18,508 \\
244,700 \\
47,5,555 \\
0 \\
0 \\
475,495\end{array}$ & $\begin{array}{r}13,425 \\
252 \\
4,359 \\
9,919 \\
0 \\
0 \\
9,818\end{array}$ & $\begin{array}{r}3,315,025 \\
116,677 \\
1,010,534 \\
2,412,170 \\
212,778 \\
93,973 \\
2,590,973\end{array}$ & $\begin{array}{r}5,785 \\
1,251 \\
4,184 \\
0 \\
0 \\
4,604\end{array}$ \\
\hline 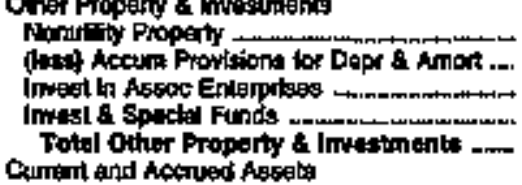 & $\begin{array}{r}0 \\
0 \\
1,754 \\
1,764\end{array}$ & $\begin{array}{r}5,822 \\
2,204 \\
1,620 \\
140,306 \\
163,3=6\end{array}$ & $\begin{array}{r}178 \\
8 \\
0 \\
52,110 \\
52,78\end{array}$ & $\begin{array}{r}0 \\
0 \\
0 \\
206 \\
200\end{array}$ & $\begin{array}{r}0 \\
0 \\
0 \\
212,597 \\
212,597\end{array}$ & $\begin{array}{r}0 \\
0 \\
0 \\
1,772 \\
1,7 / 2\end{array}$ \\
\hline 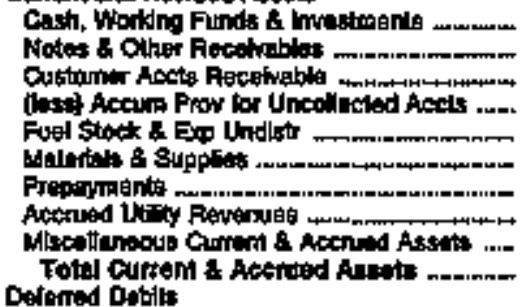 & $\begin{array}{r}2,856 \\
346 \\
3,956 \\
138 \\
0 \\
1,009 \\
11 \\
0 \\
21 \\
2,148\end{array}$ & 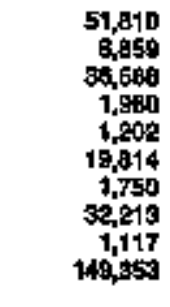 & $\begin{array}{r}95,081 \\
9,120 \\
16,226 \\
671 \\
1,867 \\
9,408 \\
3,05 \\
19,627 \\
1,171 \\
10,776\end{array}$ & $\begin{array}{r}394 \\
130 \\
690 \\
0 \\
0 \\
940 \\
76 \\
0 \\
0 \\
1,678\end{array}$ & $\begin{array}{r}35,398 \\
64,998 \\
0 \\
0 \\
0 \\
54,758 \\
1,608 \\
0 \\
0 \\
178,924\end{array}$ & $\begin{array}{r}4 \\
868 \\
0 \\
0 \\
0 \\
0 \\
18 \\
0 \\
12 \\
800\end{array}$ \\
\hline 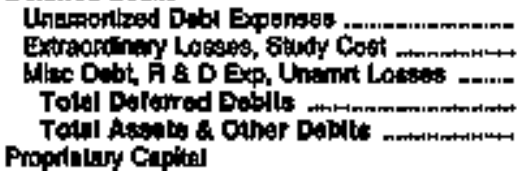 & 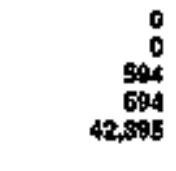 & $\begin{array}{r}1,504 \\
0 \\
111,014 \\
119,410 \\
1,228,372\end{array}$ & $\begin{array}{r}5,170 \\
0 \\
4,362 \\
6,541 \\
977,150\end{array}$ & $\begin{array}{r}87 \\
0 \\
0 \\
11,069\end{array}$ & $\begin{array}{r}19,171 \\
16,736 \\
3,579 \\
39,479 \\
2,958,978\end{array}$ & $\begin{array}{r}240 \\
000 \\
0 \\
1,080 \\
6,985\end{array}$ \\
\hline 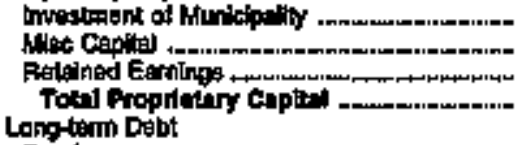 & $\begin{array}{r}0 \\
0 \\
11,346 \\
11,945\end{array}$ & $\begin{array}{r}0 \\
0 \\
270,024 \\
270,024\end{array}$ & $\begin{array}{r}0 \\
216,007 \\
210,007\end{array}$ & $\begin{array}{r}0 \\
0 \\
0,351 \\
0 ; 1\end{array}$ & $\begin{array}{l}0 \\
0 \\
0 \\
0\end{array}$ & $\begin{array}{r}0 \\
0 \\
020 \\
0\end{array}$ \\
\hline 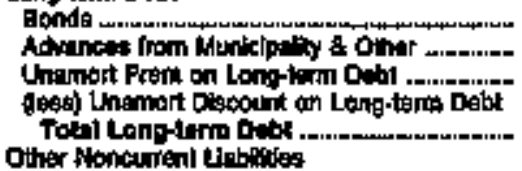 & $\begin{array}{r}16,5,56 \\
0 \\
0 \\
659 \\
15,507\end{array}$ & $\begin{array}{r}798,600 \\
0 \\
0 \\
10,676 \\
785,194\end{array}$ & $\begin{array}{r}431,024 \\
0 \\
184 \\
11,292 \\
410,915\end{array}$ & $\begin{array}{r}1,810 \\
0 \\
0 \\
0 \\
1,810\end{array}$ & $\begin{array}{r}2,700,546 \\
0 \\
2,178 \\
113,602 \\
2,902,121\end{array}$ & $\begin{array}{r}6,795 \\
0 \\
0 \\
0 \\
6,795\end{array}$ \\
\hline 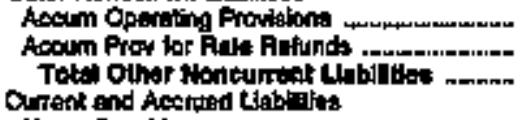 & $\begin{array}{l}0 \\
0 \\
0\end{array}$ & $\begin{array}{r}3,055 \\
109,508 \\
107,498\end{array}$ & $\begin{array}{l}0 \\
0 \\
0\end{array}$ & $\begin{array}{l}0 \\
0 \\
0\end{array}$ & $\begin{array}{r}2,590 \\
0 \\
0,590\end{array}$ & $\begin{array}{l}0 \\
0 \\
0\end{array}$ \\
\hline 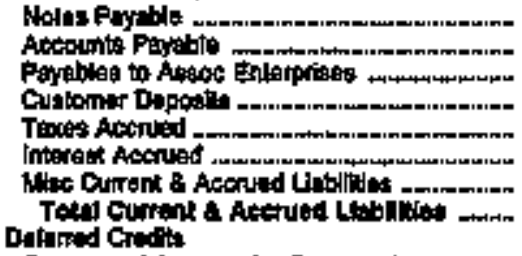 & $\begin{array}{r}0 \\
3,317 \\
0 \\
0 \\
0 \\
131 \\
0 \\
3,469\end{array}$ & $\begin{array}{r}0 \\
29,174 \\
3,625 \\
03 \\
7,848 \\
8,418 \\
9,053 \\
58,977\end{array}$ & $\begin{array}{r}0 \\
15,349 \\
581 \\
1,409 \\
3,997 \\
11,821 \\
8,190 \\
89,731\end{array}$ & $\begin{array}{r}0 \\
834 \\
477 \\
0 \\
0 \\
68 \\
94 \\
1,426\end{array}$ & $\begin{array}{r}0 \\
84,650 \\
751 \\
0 \\
1,065 \\
58 \\
47,611 \\
135,076\end{array}$ & $\begin{array}{r}0 \\
838 \\
0 \\
0 \\
0 \\
90 \\
0 \\
910\end{array}$ \\
\hline 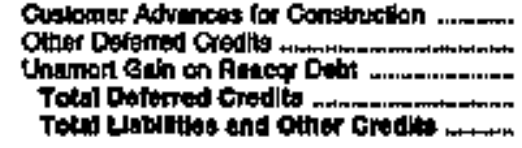 & $\begin{array}{r}11,607 \\
0 \\
11,807 \\
42,366\end{array}$ & $\begin{array}{r}0 \\
725 \\
0 \\
725 \\
1,223,372\end{array}$ & $\begin{array}{r}1,585 \\
912 \\
0 \\
2,497 \\
67,160\end{array}$ & $\begin{array}{r}0 \\
0 \\
0 \\
0 \\
11008\end{array}$ & $\begin{array}{r}227,312 \\
67 \\
227,360 \\
2,69879\end{array}$ & $\begin{array}{r}2 \\
54 \\
6 \\
6,595\end{array}$ \\
\hline
\end{tabular}

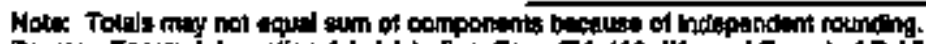

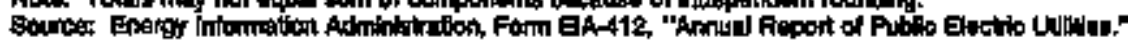


Table 22. Balance Sheet by Major U.S. Publleby Owned Electrlc Utility Within State at End of Period, 1994 (Thousand Dollars)

\begin{tabular}{|c|c|c|c|c|c|c|}
\hline Item & 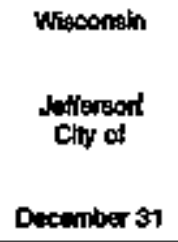 & 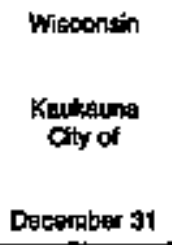 & 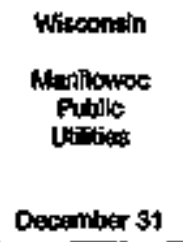 & 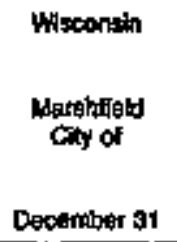 & $\begin{array}{l}\text { Whoonsin } \\
\text { Chyogha } \\
\text { Daxtember } 31\end{array}$ & 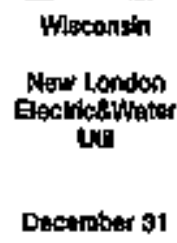 \\
\hline 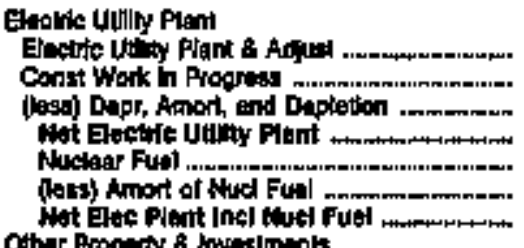 & $\begin{array}{r}7,867 \\
115 \\
2,247 \\
5,795 \\
0 \\
0 \\
5,795\end{array}$ & $\begin{array}{r}40,725 \\
978 \\
15,048 \\
25,692 \\
0 \\
0 \\
25,958\end{array}$ & $\begin{array}{r}6,576 \\
5,569 \\
29,361 \\
47,5002 \\
0 \\
0 \\
6,8002\end{array}$ & $\begin{array}{r}26,520 \\
280 \\
5,950 \\
21,047 \\
0 \\
0 \\
21,047\end{array}$ & $\begin{array}{r}23,770 \\
496 \\
11,674 \\
12,502 \\
6 \\
12,609\end{array}$ & $\begin{array}{r}8,219 \\
0 \\
2,258 \\
6,989 \\
0 \\
0 \\
6,969\end{array}$ \\
\hline 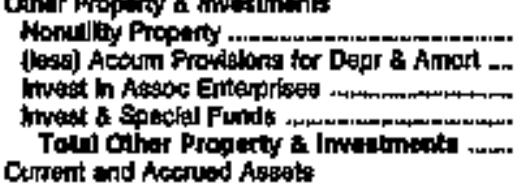 & $\begin{array}{l}0 \\
0 \\
0 \\
0 \\
0 \\
0\end{array}$ & $\begin{array}{r}657 \\
166 \\
0 \\
4670 \\
5,942\end{array}$ & $\begin{array}{r}173 \\
0 \\
0,856\end{array}$ & $\begin{array}{r}7,067 \\
5,031 \\
0 \\
1,647 \\
2,604\end{array}$ & $\begin{array}{r}201 \\
0 \\
0 \\
3,514 \\
3,715\end{array}$ & $\begin{array}{r}6,050 \\
2,027 \\
0 \\
2,509 \\
0,942\end{array}$ \\
\hline 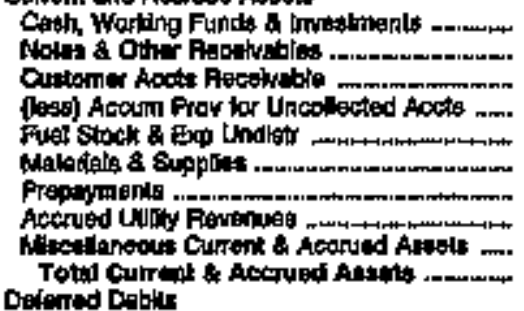 & 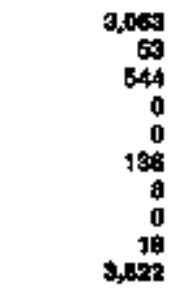 & $\begin{array}{r}898 \\
502 \\
2,368 \\
30 \\
0 \\
670 \\
375 \\
0 \\
-96 \\
4,764\end{array}$ & $\begin{array}{r}1,040 \\
607 \\
1,345 \\
0 \\
097 \\
401 \\
80 \\
0 \\
08 \\
4,603\end{array}$ & $\begin{array}{r}2060 \\
41 \\
1,189 \\
0 \\
0 \\
953 \\
15 \\
0 \\
20 \\
4250\end{array}$ & $\begin{array}{r}38 \\
109 \\
1,915 \\
3 \\
0 \\
17 \% \\
31 \\
0 \\
28 \\
2,204\end{array}$ & $\begin{array}{r}60 \\
124 \\
881 \\
0 \\
9 \\
268 \\
35 \\
229 \\
14 \\
1.596\end{array}$ \\
\hline 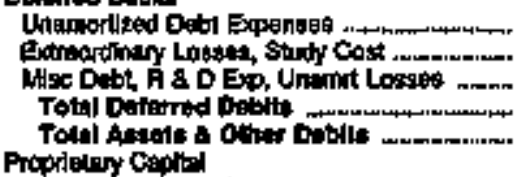 & $\begin{array}{r}840 \\
0 \\
0 \\
10,507\end{array}$ & $\begin{array}{r}1,379 \\
0 \\
0 \\
1,379 \\
37,076\end{array}$ & $\begin{array}{r}270 \\
-101 \\
1,190 \\
60,591\end{array}$ & $\begin{array}{r}195 \\
0 \\
275 \\
471 \\
20,957\end{array}$ & $\begin{array}{r}176 \\
0 \\
519 \\
19,295\end{array}$ & $\begin{array}{r}202 \\
0 \\
1943 \\
1,145 \\
17,040\end{array}$ \\
\hline 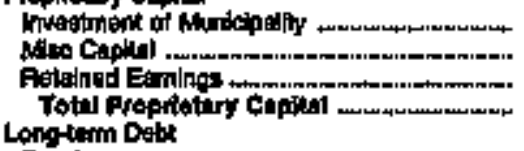 & $\begin{array}{r}158 \\
208 \\
3,711 \\
4,107\end{array}$ & $\begin{array}{r}0 \\
0 \\
14,592 \\
14,692\end{array}$ & $\begin{array}{r}0 \\
0 \\
32,445 \\
32,445\end{array}$ & $\begin{array}{r}0 \\
0 \\
17,392 \\
17,302\end{array}$ & $\begin{array}{r}405 \\
7,0,059 \\
2,75 \\
7,706\end{array}$ & $\begin{array}{r}166 \\
1,585 \\
4,984 \\
7,086\end{array}$ \\
\hline 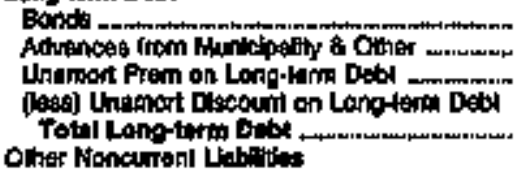 & $\begin{array}{l}0 \\
0 \\
0 \\
0 \\
0\end{array}$ & $\begin{array}{r}17,225 \\
0 \\
0 \\
0 \\
17,225\end{array}$ & $\begin{array}{r}21,905 \\
0 \\
0 \\
0 \\
24,505\end{array}$ & $\begin{array}{r}B, 685 \\
0 \\
0 \\
0 \\
B, 685\end{array}$ & $\begin{array}{r}6,200 \\
0 \\
0,200\end{array}$ & $\begin{array}{r}3,025 \\
0 \\
0 \\
0 \\
0\end{array}$ \\
\hline 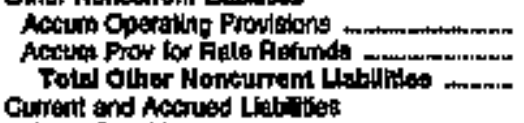 & $\begin{array}{l}0 \\
0 \\
0\end{array}$ & $\begin{array}{l}0 \\
0 \\
0\end{array}$ & $\begin{array}{r}729 \\
0 \\
70\end{array}$ & $\begin{array}{l}0 \\
0 \\
0\end{array}$ & $\begin{array}{l}0 \\
0 \\
0\end{array}$ & $\begin{array}{r}140 \\
148 \\
148\end{array}$ \\
\hline 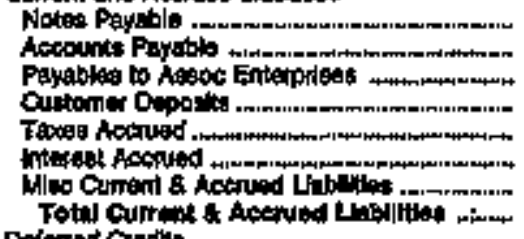 & $\begin{array}{r}5,605 \\
403 \\
184 \\
3 \\
0 \\
0 \\
20 \\
5,204\end{array}$ & $\begin{array}{r}0 \\
1,906 \\
0 \\
-20 \\
506 \\
48 \\
77 \\
2,858\end{array}$ & $\begin{array}{r}0 \\
1,391 \\
0 \\
59 \\
1,458 \\
599 \\
71 \\
3,678\end{array}$ & 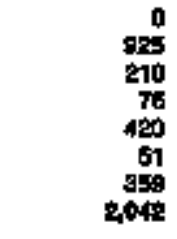 & $\begin{array}{r}0 \\
1, \operatorname{teg} 4 \\
15 \\
0 \\
000 \\
160 \\
0 \\
2,014\end{array}$ & $\begin{array}{r}0 \\
849 \\
111 \\
19 \\
861 \\
129 \\
29 \\
1,814\end{array}$ \\
\hline 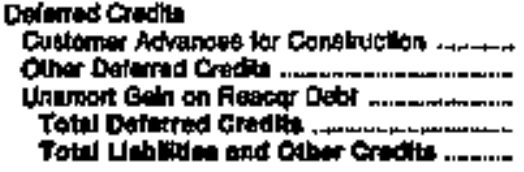 & $\begin{array}{r}5 \\
0 \\
6 \\
6\end{array}$ & $\begin{array}{r}2,402 \\
100 \\
0 \\
20 \\
37,070\end{array}$ & $\begin{array}{r}1,252 \\
4 \\
0 \\
1,55 \\
0,501\end{array}$ & $\begin{array}{r}1,260 \\
0 \\
0 \\
1,250 \\
20,907\end{array}$ & $\begin{array}{r}367 \\
403 \\
08 \\
708 \\
19285\end{array}$ & $\begin{array}{r}6 \\
202 \\
0 \\
207 \\
17,049\end{array}$ \\
\hline
\end{tabular}

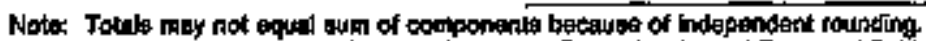

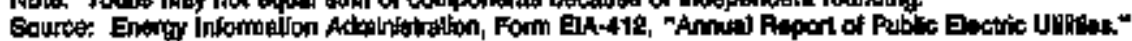


Table 22. Balance Sheet by Major U.S. Publicly Owned Electric Utilly Whthin State at End of Perlod, 1994

(Thousand Dollars)

\begin{tabular}{|c|c|c|c|c|c|c|}
\hline Itafe & 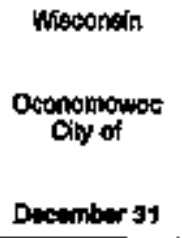 & 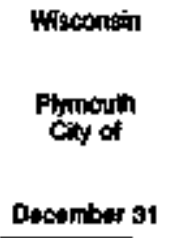 & 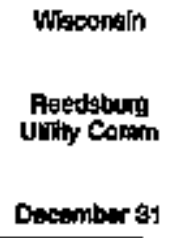 & 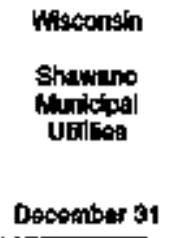 & 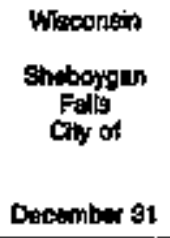 & 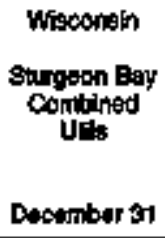 \\
\hline 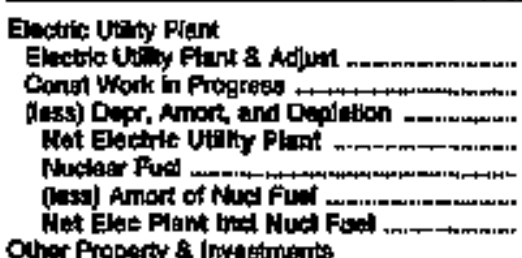 & $\begin{array}{r}16,152 \\
41 \\
5,614 \\
10,519 \\
0 \\
0 \\
+0,670\end{array}$ & $\begin{array}{r}14,297 \\
20 \\
5,006 \\
9,411 \\
0 \\
0 \\
0,411\end{array}$ & $\begin{array}{r}0,185 \\
0 \\
2,483 \\
6,712 \\
0 \\
0 \\
6,712\end{array}$ & $\begin{array}{r}6,797 \\
241 \\
2,907 \\
6,112 \\
0 \\
0 \\
0,112\end{array}$ & $\begin{array}{r}7,708 \\
340 \\
3,259 \\
4,966 \\
0 \\
9 \\
4,905\end{array}$ & $\begin{array}{r}18,184 \\
40 \\
5,096 \\
11,129 \\
0 \\
0 \\
11,128\end{array}$ \\
\hline 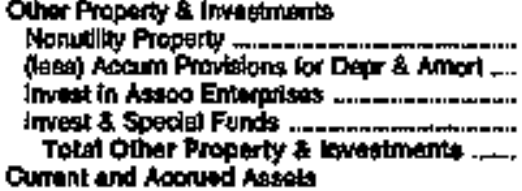 & $\begin{array}{r}0 \\
0 \\
0 \\
676 \\
676\end{array}$ & $\begin{array}{r}0 \\
0 \\
1,004 \\
1,004\end{array}$ & $\begin{array}{r}4,139 \\
681 \\
0 \\
1,423 \\
4,186\end{array}$ & $\begin{array}{r}6,6 \infty 2 \\
0 \\
0 \\
7,608\end{array}$ & $\begin{array}{r}5290 \\
888 \\
4 \\
4 \\
4,316\end{array}$ & $\begin{array}{r}0 \\
0 \\
0 \\
1, \$ 00 \\
1,600\end{array}$ \\
\hline 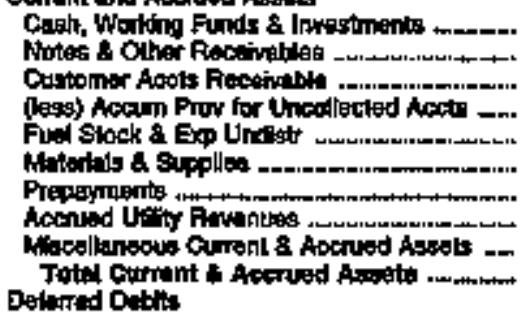 & $\begin{array}{r}2,895 \\
50 \\
707 \\
0 \\
0 \\
28 \\
14 \\
0 \\
0 \\
3 \\
3,944\end{array}$ & $\begin{array}{r}0 \\
671 \\
041 \\
0 \\
0 \\
240 \\
14 \\
0 \\
0 \\
672\end{array}$ & $\begin{array}{r}730 \\
0 \\
770 \\
0 \\
0 \\
980 \\
0 \\
0 \\
440 \\
2,300\end{array}$ & $\begin{array}{r}1,772 \\
277 \\
067 \\
0 \\
0 \\
398 \\
117 \\
0 \\
0 \\
3,400\end{array}$ & $\begin{array}{r}683 \\
198 \\
624 \\
0 \\
0 \\
305 \\
0 \\
0 \\
0 \\
2,100\end{array}$ & $\begin{array}{r}255 \\
81 \\
771 \\
15 \\
0 \\
100 \\
52 \\
0 \\
30 \\
1,607\end{array}$ \\
\hline 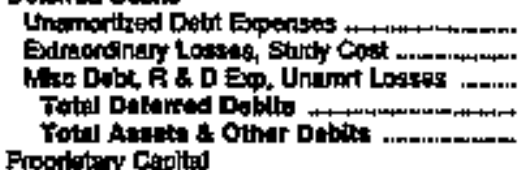 & $\begin{array}{r}38 \\
6 \\
240 \\
276 \\
15,474\end{array}$ & $\begin{array}{r}10 \\
0 \\
4 \\
13 \\
10,300\end{array}$ & $\begin{array}{r}116 \\
0 \\
160 \\
201 \\
14,101\end{array}$ & $\begin{array}{r}31 \\
186 \\
0 \\
216 \\
17,497\end{array}$ & $\begin{array}{r}10 \\
276 \\
0 \\
2 \% \\
11,567\end{array}$ & $\begin{array}{r}794 \\
270 \\
1,401 \\
16,482\end{array}$ \\
\hline 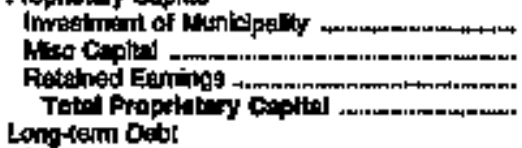 & $\begin{array}{r}271 \\
2398 \\
10,042 \\
12,049\end{array}$ & $\begin{array}{r}1,870 \\
7,50 \\
9,500\end{array}$ & $\begin{array}{l}1,030 \\
2,305 \\
4,413 \\
7,776\end{array}$ & $\begin{array}{r}1,475 \\
0 \\
8,494 \\
9,0.40\end{array}$ & $\begin{array}{r}405 \\
2371 \\
5,609 \\
0,460\end{array}$ & $\begin{array}{r}28 \\
0 \\
5,549 \\
6,669\end{array}$ \\
\hline 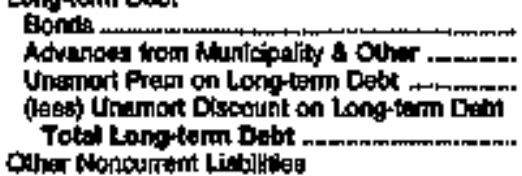 & $\begin{array}{r}1,014 \\
0 \\
0 \\
0 \\
1,041\end{array}$ & $\begin{array}{r}301 \\
305 \\
0 \\
0\end{array}$ & $\begin{array}{r}5,205 \\
12 \\
0 \\
0 \\
6,2,75\end{array}$ & $\begin{array}{r}2,090 \\
1,200 \\
0 \\
0 \\
3,310\end{array}$ & $\begin{array}{r}0 \\
t, 085 \\
0 \\
0 \\
1,005\end{array}$ & $\begin{array}{r}7,102 \\
0 \\
0 \\
0 \\
7,102\end{array}$ \\
\hline 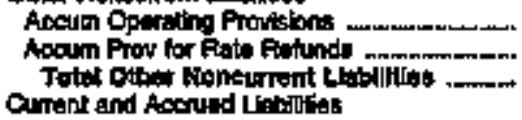 & $\begin{array}{l}0 \\
0 \\
0\end{array}$ & $\begin{array}{l}0 \\
0 \\
0\end{array}$ & $\begin{array}{l}0 \\
0 \\
0\end{array}$ & $\begin{array}{l}0 \\
0 \\
0\end{array}$ & $\begin{array}{l}0 \\
0 \\
0\end{array}$ & $\begin{array}{l}0 \\
0 \\
0\end{array}$ \\
\hline 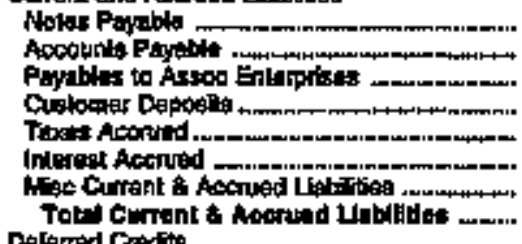 & $\begin{array}{r}0 \\
0 \\
0 \\
33 \\
941 \\
40 \\
0 \\
1,015\end{array}$ & $\begin{array}{r}0 \\
491 \\
0 \\
6 \\
148 \\
7 \\
17 \\
089\end{array}$ & $\begin{array}{r}0 \\
543 \\
128 \\
10 \\
305 \\
95 \\
35 \\
1,054\end{array}$ & $\begin{array}{r}0 \\
02 \\
0 \\
42 \\
250 \\
32 \\
20 \\
1,101\end{array}$ & $\begin{array}{r}0 \\
534 \\
114 \\
4 \\
206 \\
4 \\
140 \\
1,022\end{array}$ & $\begin{array}{r}0 \\
188 \\
0 \\
44 \\
924 \\
212 \\
60 \\
1,115\end{array}$ \\
\hline 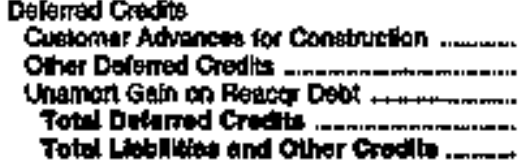 & $\begin{array}{r}0 \\
0 \\
0 \\
0 \\
15,471\end{array}$ & $\begin{array}{r}0 \\
0 \\
0 \\
0 \\
0\end{array}$ & $\begin{array}{r}0 \\
187 \\
0 \\
137 \\
14,181\end{array}$ & $\begin{array}{r}2670 \\
301 \\
0 \\
17,407\end{array}$ & $\begin{array}{r}25 \\
9 \\
11,5107\end{array}$ & 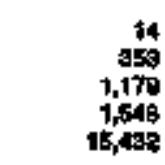 \\
\hline
\end{tabular}

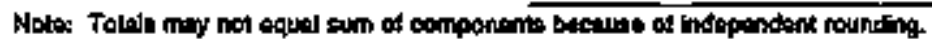

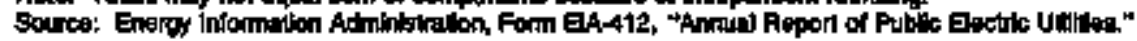


Table 22. Balance Sheet by Major U.S. Publicly Owned Electrle Utilty Whthin State at End of Perlod, 1994 (Thotund Dosllars)

\begin{tabular}{|c|c|c|c|c|c|}
\hline llem & $\begin{array}{l}\text { Whoonin } \\
\text { Sun Pialfis } \\
\text { Waler } 8 \text { Light } \\
\text { Comm } \\
\text { Decenter } 31\end{array}$ & 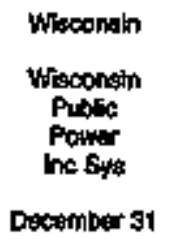 & 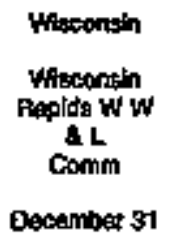 & $\begin{array}{l}\text { Wyoring } \\
\text { Ctilette } \\
\text { Ciby of } \\
\text { une } 30\end{array}$ & 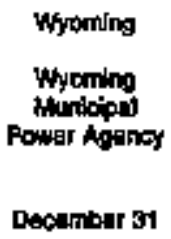 \\
\hline 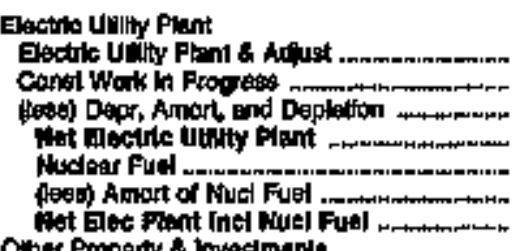 & $\begin{array}{r}13,618 \\
219 \\
5,609 \\
10,103 \\
0 \\
0 \\
10,102\end{array}$ & 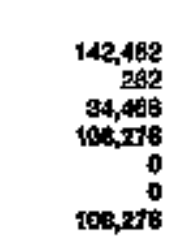 & $\begin{array}{r}17,904 \\
57 \\
5,500 \\
12,49 t \\
0 \\
0 \\
12,491\end{array}$ & $\begin{array}{r}18.859 \\
0 \\
8.982 \\
9.9180 \\
0 \\
0 \\
0.980\end{array}$ & $\begin{array}{r}92,414 \\
1 \\
7,345 \\
15,070 \\
0 \\
0 \\
15,070\end{array}$ \\
\hline 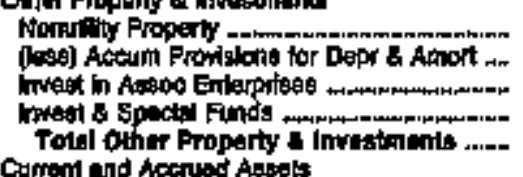 & $\begin{array}{r}45 \\
29 \\
0 \\
1,134 \\
1,138\end{array}$ & $\begin{array}{r}0 \\
0 \\
0 \\
20,976 \\
28,976\end{array}$ & $\begin{array}{r}0 \\
0 \\
0 \\
1,013 \\
1,8113\end{array}$ & $\begin{array}{l}0 \\
0 \\
0 \\
0 \\
0\end{array}$ & $\begin{array}{r}0 \\
0 \\
0 \\
\mathbf{5}, 351 \\
6,351\end{array}$ \\
\hline 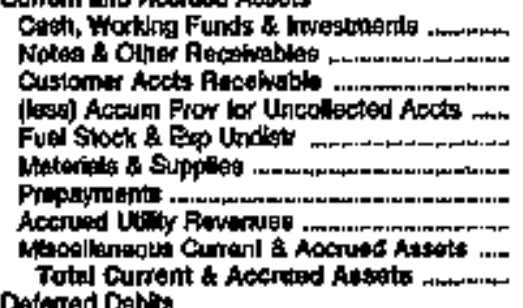 & $\begin{array}{r}130 \\
202 \\
749 \\
0 \\
0 \\
158 \\
12 \\
0 \\
0 \\
1292\end{array}$ & 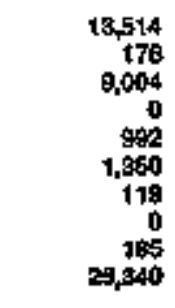 & $\begin{array}{r}1,130 \\
254 \\
478 \\
0 \\
0 \\
325 \\
50 \\
0 \\
12 \\
2,248\end{array}$ & $\begin{array}{r}2,299 \\
6 \\
85 \\
81 \\
0 \\
0 \\
0 \\
0 \\
0 \\
3,100\end{array}$ & $\begin{array}{r}300 \\
47 \\
358 \\
0 \\
144 \\
608 \\
7 \\
542 \\
74 \\
6,620\end{array}$ \\
\hline 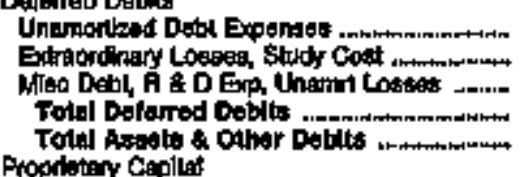 & $\begin{array}{r}60 \\
0 \\
250 \\
310 \\
12,890\end{array}$ & $\begin{array}{r}2,096 \\
0 \\
2,800 \\
91,094 \\
\text { tis, } 400\end{array}$ & $\begin{array}{r}4 \\
0 \\
33 \\
37 \\
78,59\end{array}$ & $\begin{array}{r}100 \\
0 \\
0 \\
103 \\
13,171\end{array}$ & $\begin{array}{r}1,248 \\
541 \\
0 \\
1,79 \\
27,920\end{array}$ \\
\hline 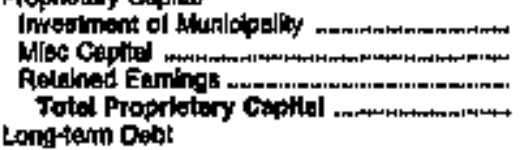 & $\begin{array}{r}010 \\
0 \\
4,758 \\
6,558\end{array}$ & $\begin{array}{r}0 \\
0 \\
9,518 \\
9,518\end{array}$ & $\begin{array}{r}579 \\
0 \\
10,687 \\
11,205\end{array}$ & $\begin{array}{r}0 \\
9,0,2 \\
\sin 2\end{array}$ & $\begin{array}{r}0 \\
0 \\
7,396 \\
7,850\end{array}$ \\
\hline 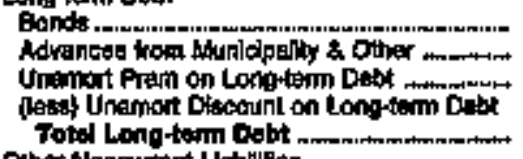 & $\begin{array}{r}4,065 \\
647 \\
0 \\
0 \\
4712\end{array}$ & $\begin{array}{r}165,750 \\
0 \\
0 \\
3,614 \\
169,239\end{array}$ & $\begin{array}{r}0 \\
752 \\
0 \\
0 \\
7 \% 2\end{array}$ & $\begin{array}{r}3,100 \\
0 \\
0 \\
0 \\
3,104\end{array}$ & $\begin{array}{r}18,730 \\
0 \\
0 \\
0 \\
1 * ; 790\end{array}$ \\
\hline 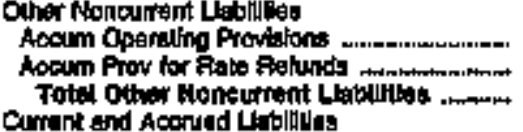 & $\begin{array}{l}0 \\
0 \\
0\end{array}$ & $\begin{array}{r}3,2,77 \\
0,2,7\end{array}$ & $\begin{array}{l}0 \\
0 \\
0\end{array}$ & $\begin{array}{l}0 \\
0 \\
0\end{array}$ & $\begin{array}{l}0 \\
0 \\
0\end{array}$ \\
\hline 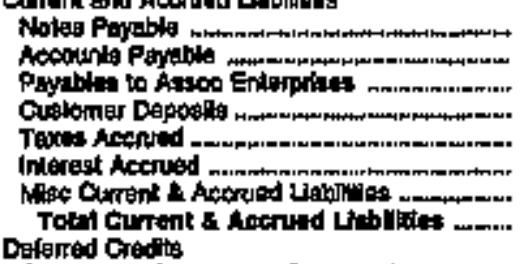 & 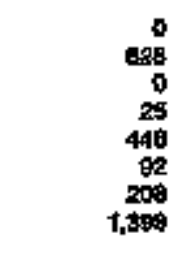 & $\begin{array}{r}0 \\
0,858 \\
0 \\
0 \\
1,811 \\
3,710 \\
2,007 \\
7,377\end{array}$ & $\begin{array}{r}0 \\
697 \\
64 \\
18 \\
307 \\
6 \\
310 \\
1,500\end{array}$ & 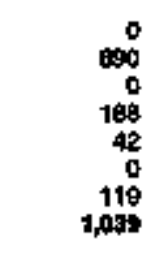 & $\begin{array}{r}0 \\
470 \\
0 \\
0 \\
0 \\
581 \\
719 \\
1,702\end{array}$ \\
\hline 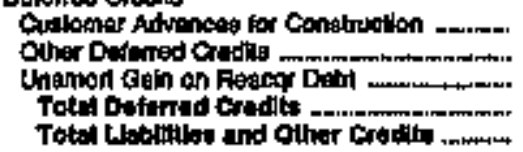 & $\begin{array}{r}1,151 \\
0 \\
0 \\
1,961 \\
12,990\end{array}$ & $\begin{array}{r}0 \\
2,125 \\
0 \\
2,125 \\
194,485\end{array}$ & $\begin{array}{r}36 \\
3,065 \\
0 \\
3,071 \\
16,008\end{array}$ & $\begin{array}{r}0 \\
0 \\
0 \\
0 \\
13,17\end{array}$ & $\begin{array}{r}0 \\
0 \\
0 \\
0 \\
2020\end{array}$ \\
\hline
\end{tabular}

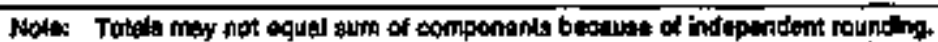

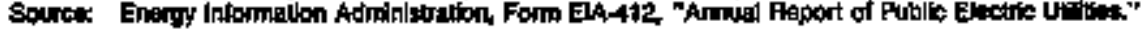


Table 20. Electro Operation and Maintonance Expenees by Major U.S. Publicly Owned Electric Utilly Within State, 1994 (Thousand Dollars)

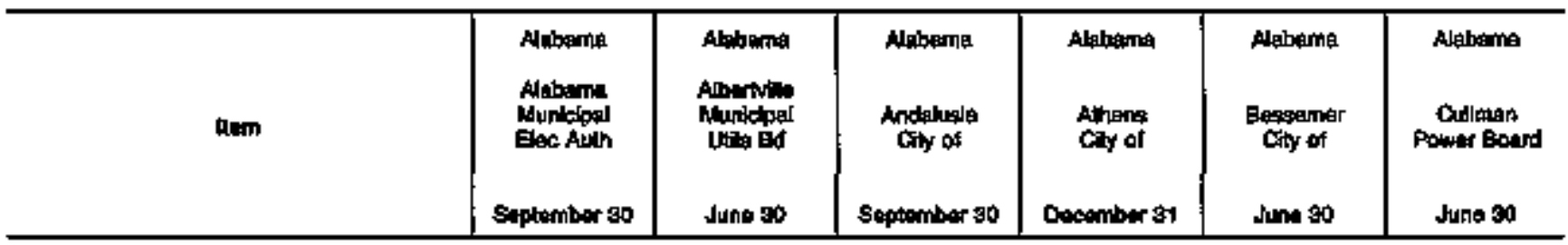

Production Expontes.

giean Power Emagration

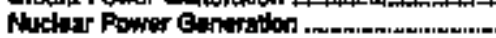

Hydeder Power Generation

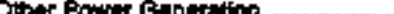

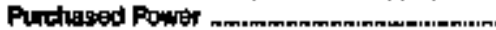

Othet Pipduction Expligits

Toted Prodtition Exponsen

Trengmleglar Exphis:

Diatritoution Expertsas

Cutcomer Acoount Gipenses

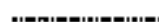

Custangar Sarvice and toficrmation

Expentoves

B-los Exoness

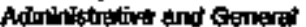

Expin:s:

Tolve Enotrie Opinrition and

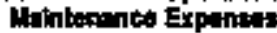

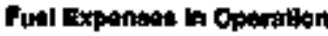

Sten Powrer Genwalon

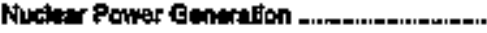

Oun Powar CEmeration

0
0
0
0
76,442
0

0
0
0
0
10,405
0

0
0
0
0
$11+00$
0

70,442

18,465

11,939

268
1271

6넌

0
0
0
0
31,800
0

0
0
0
0
14,605
0

t4655

158

814

1,140

解

25

ega

447

84

ristor

zupes

12,772

se707

Number of Eloc Dapt Employwes

Fingyer Futhdma

6

53

12

67

49

ar

Fart-ina 8 Tomporary

0

0

0

D

o

b

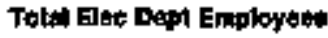

$\theta$

38

12

67

4

22

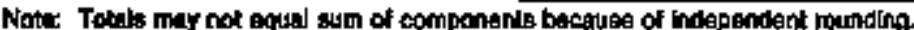

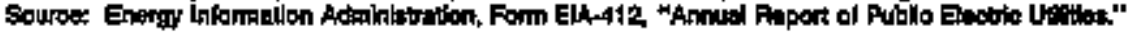


Tabje 23. Electric Operalion and Malntenance Expanses by Mejor U.S. Publcly Owned Electrite Utillty Whin State, 1994 (Continued) (Thousand Dolitars)

\begin{tabular}{|c|c|c|c|c|c|c|}
\hline $\operatorname{tam}$ & $\begin{array}{l}\text { Alabsing } \\
\text { Decolur } \\
\text { Cty of } \\
\text { Jtene } 30\end{array}$ & $\begin{array}{l}\text { Alobeing } \\
\text { Dothan } \\
\text { Chy of } \\
\text { Septamber } 30\end{array}$ & $\begin{array}{l}\text { Alahania } \\
\text { Fonence } \\
\text { Chy of } \\
\text { tuns so }\end{array}$ & 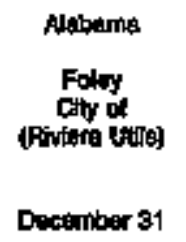 & 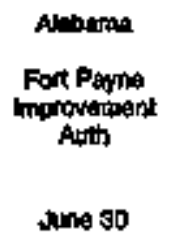 & $\begin{array}{l}\text { Antame } \\
\text { Eumtersinla } \\
\text { Eoctic } \\
\text { Boand } \\
\text { uns } 30\end{array}$ \\
\hline 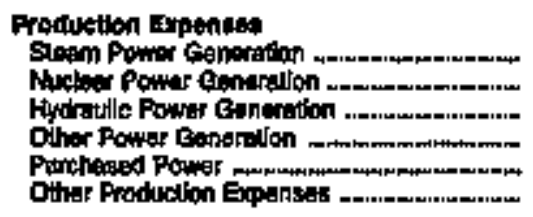 & $\begin{array}{r}0 \\
0 \\
0 \\
0 \\
060 \\
0\end{array}$ & $\begin{array}{r}0 \\
0 \\
0 \\
0 \\
300\end{array}$ & $\begin{array}{r}0 \\
0 \\
0 \\
0 \\
48,126 \\
0\end{array}$ & $\begin{array}{r}0 \\
0 \\
0 \\
0 \\
0 \\
23,442 \\
0\end{array}$ & $\begin{array}{r}0 \\
0 \\
0 \\
0 \\
14,308 \\
0\end{array}$ & $\begin{array}{r}0 \\
0 \\
0 \\
0 \\
10,312 \\
0\end{array}$ \\
\hline Total Production Exponted & 5,2015 & 40,267 & 48,125 & 20,442 & 24,306 & 10,312 \\
\hline 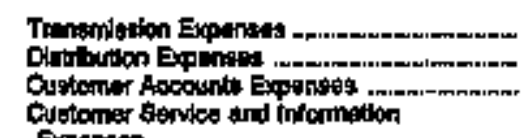 & $\begin{array}{r}0 \\
1,608 \\
462\end{array}$ & 1,0 & $\begin{array}{r}397 \\
5,113 \\
984\end{array}$ & $\begin{array}{r}240 \\
1,293 \\
481\end{array}$ & $\frac{0}{20 t}$ & $\begin{array}{r}0 \\
504\end{array}$ \\
\hline 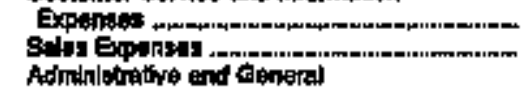 & $\begin{array}{l}32 \\
24\end{array}$ & $\begin{array}{l}0 \\
0\end{array}$ & $\begin{array}{r}1 \pm 6 \\
81\end{array}$ & $\underset{58}{22}$ & $\begin{array}{l}30 \\
20\end{array}$ & 8 \\
\hline 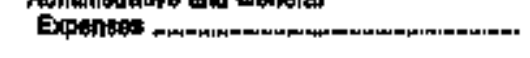 & 741 & 940 & 2,125 & 1,405 & $3 \% 2$ & 30 \\
\hline 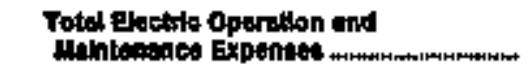 & 59,113 & 4 , & GApsit & 26,939 & 15,000 & 11,971 \\
\hline \multicolumn{7}{|l|}{ Fut Expantios In Operation } \\
\hline Stann Powrer Generakon , & 0 & 0 & $\mathbf{0}$ & 0 & $\mathbf{0}$ & 0 \\
\hline Puclaar Fowat Centration & 0 & 0 & $\mathbf{0}$ & 0 & 0 & 0 \\
\hline 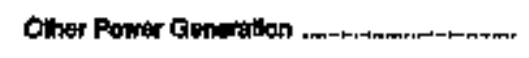 & $\mathbf{0}$ & 0 & D & 0 & 0 & t \\
\hline \multicolumn{7}{|l|}{ 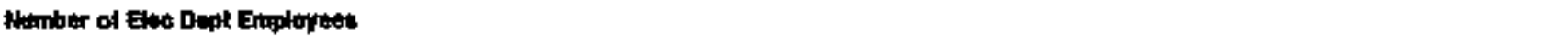 } \\
\hline 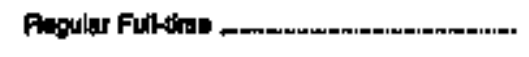 & $\theta 2$ & 73 & 159 & 120 & $\mathbf{2}$ & 29 \\
\hline Pathing 4 Teqfiporay & 0 & i & 0 & a & 0 & 0 \\
\hline 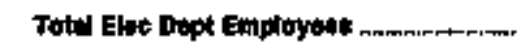 & 6 & 74 & $15 s$ & 120 & $\mathbf{2 3}$ & 2 \\
\hline
\end{tabular}

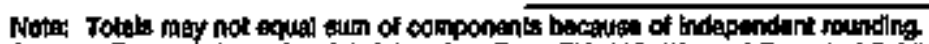

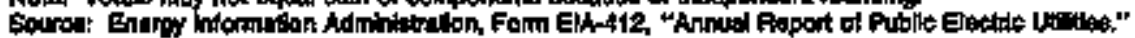


Table 23. Electrto Operation and Maintenanoe Expenses by Mafor U.S. Publicly Owned Electric Utillty Within State, 1994 (Continued) (Thousend Dollers)

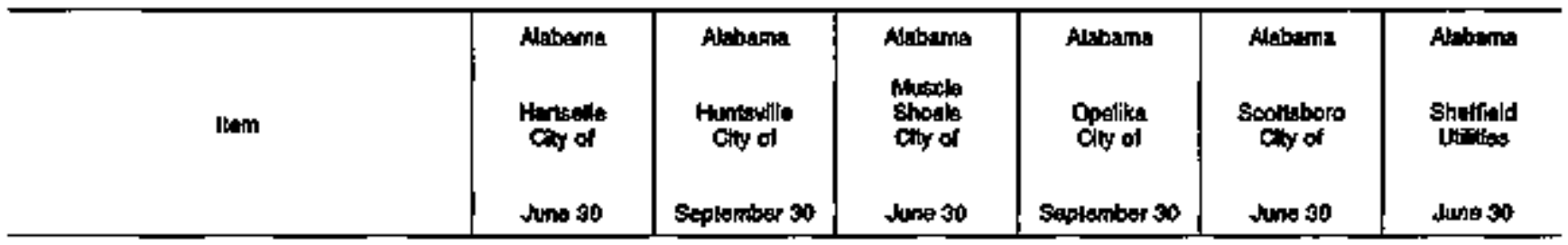

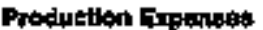

Stean Penuer Benutabon

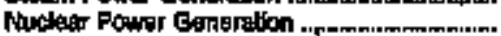
Fydratic Power tanertion

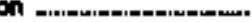

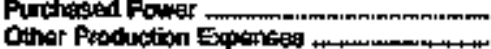

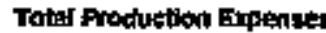

Transtiogion Exarseg

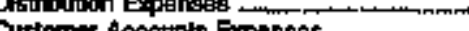

Customin Berko and information

Exporsiss

STlas Exonts

Administralive and Cengral

Epansis

Total dectrit Optation and

Molokenanos Expentea

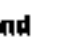

-

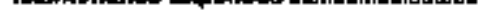

Fened Expented it opertition

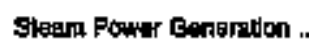

Nucles Powte Goneration .

Other Power Centiation

$\begin{array}{rr}0 & \\ 0 & \\ 0 & \\ 0 & \\ 6,184 & 173,08 \\ 0 & \end{array}$

0
0
0
0
7,051
0

$\mathbf{9 . 4 8}$

0
0
0
0
0,428
0

6,184 178,051

341 5,124

$\begin{array}{ll}341 & 5,124 \\ 121 & 1,209\end{array}$

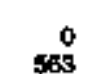

$\begin{array}{rr}9 & 192 \\ 15 & 68\end{array}$

250255

6,918 1.2984

172

41

392

10,585

0
0
0
0
13.998
0

0
0
0
0
14,902
0

0
0
0
0
10,354
0

13,992

t4,85e

10354

$\underset{60}{0}$

$\begin{array}{rr}0 & 176 \\ 941 & 1.029 \\ 287 & 587\end{array}$

0 287

19

3rt

20

$674 \quad 377 \quad 1,160$

15,289

18.00r

27.9면

Number of Elac tept Eanproyeat

Plaguriar Furbinte

t)

240
0

2

29

31

60

Fart-ting \& Temporery

0

b

0

o

q

Total Elos Dept Enployeds

11

2

2

31

93

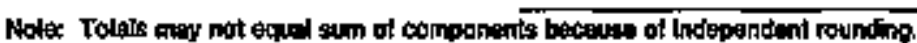

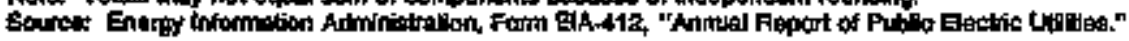


Table 23. Electric Operation and Haintenance Exponses by Malor U.S. Publich Owned Electric Uttlity Withln State, 1994 (Continued) (Thousand Dollars)

\begin{tabular}{|c|c|c|c|c|c|c|}
\hline Hem & 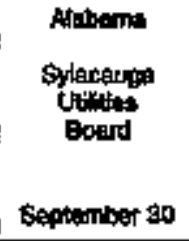 & 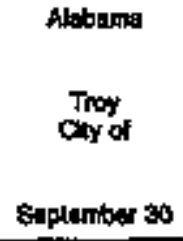 & $\begin{array}{l}\text { Alabamia } \\
\text { Tuakegge } \\
\text { City of } \\
\text { September } 30\end{array}$ & 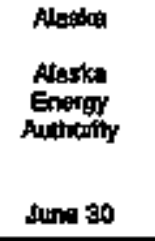 & 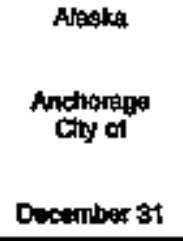 & 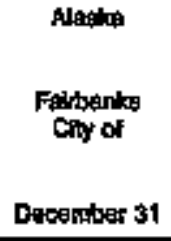 \\
\hline 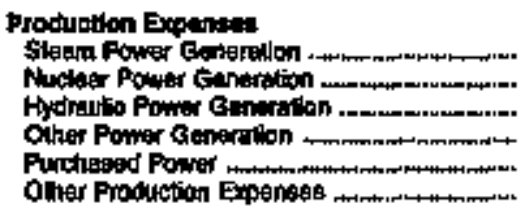 & $\begin{array}{r}0 \\
0 \\
0 \\
0 \\
5,904 \\
0\end{array}$ & $\begin{array}{r}0 \\
0 \\
0 \\
0 \\
7,909 \\
0\end{array}$ & $\begin{array}{r}0 \\
0 \\
0 \\
0 \\
0,219 \\
0\end{array}$ & $\begin{array}{r}0 \\
0 \\
1,732 \\
0 \\
0 \\
498\end{array}$ & $\begin{array}{r}1,678 \\
0 \\
0 \\
19,608 \\
4,800 \\
813\end{array}$ & $\begin{array}{r}8,250 \\
0 \\
0 \\
0 \\
1,301 \\
0\end{array}$ \\
\hline Totel Produetion Expentit: & 6,pou & 7,935 & 6,219 & 2930 & 27,273 & 8,500 \\
\hline 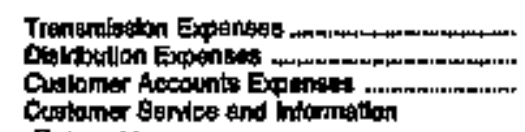 & $\stackrel{0}{138}$ & $\begin{array}{r}0 \\
270 \\
0\end{array}$ & $\begin{array}{l}0 \\
0 \\
0\end{array}$ & $\begin{array}{r}1,072 \\
0 \\
0\end{array}$ & $\begin{array}{r}160 \\
5,967\end{array}$ & $\begin{array}{r}0 \\
1,005 \\
0\end{array}$ \\
\hline 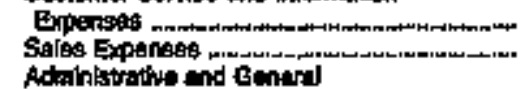 & $\stackrel{t \theta}{0}$ & 428 & $\stackrel{0}{0}$ & 0 & 120 & $\stackrel{0}{0}$ \\
\hline 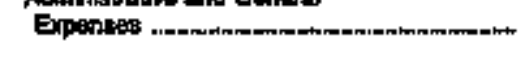 & 675 & 355 & 1,575 & 2,372 & 3,609 & ees \\
\hline $\begin{array}{l}\text { Totet Elooblo Operation and } \\
\text { Mnhtoontence Expenises }\end{array}$ & 6,974 & 9.803 & t,red & 5,624 & 40,252 & 11,613 \\
\hline \multicolumn{7}{|l|}{ Futst Expentesa in Oparation } \\
\hline Stean Pöner Generalion & 0 & 0 & 0 & 0 & so1 & 0 \\
\hline Nuclear Power Beneration and & 0 & 0 & - & $\mathbf{0}$ & o & 0 \\
\hline Other Powar Genaralion & 0 & 0 & 0 & $\mathbf{0}$ & 16,050 & 0 \\
\hline \multicolumn{7}{|l|}{ Mumber of Etec Dapt Employees } \\
\hline Feguler Fodkthe & 23 & 15 & 25 & 4 & 200 & 43 \\
\hline Partimo \& Temporary n.m. & 1 & o & a & 1 & $\mathbf{2}$ & 0 \\
\hline 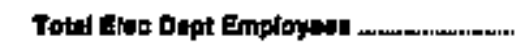 & 76 & 16 & 25 & $\mathbf{5}$ & 20 & 4 \\
\hline
\end{tabular}

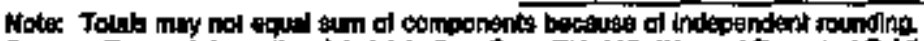

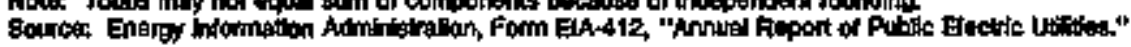


Tabie 23. Electric Operstion and Maintenance Expences by Miajor U.S.,Publichy Owned Electric Utilly Within State, 1994 (Continued) (Thousand Dohtars)

\begin{tabular}{|c|c|c|c|c|c|c|}
\hline lesth & 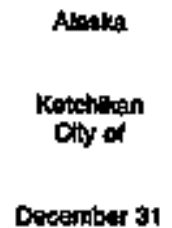 & 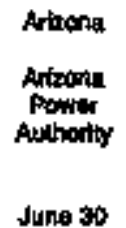 & 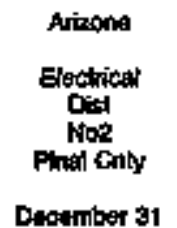 & 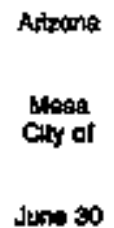 & $\begin{array}{l}\text { Arizonti } \\
\text { Ninvafo } \\
\text { Tibel } \\
\text { Urilly } \\
\text { Authi } \\
\text { Decardoer } 31\end{array}$ & $\begin{array}{l}\text { Atzena } \\
\text { Salt Rher } \\
\text { Prod Ag } \\
\text { I\& P Dist } \\
\text { Apd } 30\end{array}$ \\
\hline
\end{tabular}

Produrtion Equanow

Stum Powar temerabon

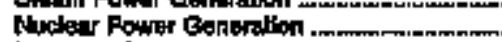

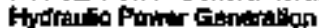

Other Poaver Ganeredon

Purtughed Pow

Other Production Expandes

Totat Production Expanters

Trangmasion Equentes

Distibution Expen:5es

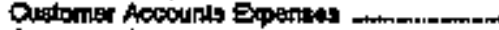

Customer senvica and informalion

Equn:as:

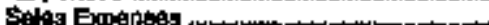

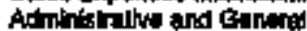

Exqunas

Totrl Elortric Opurban and

trantenance Eipointores

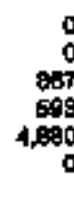

0
0
897
698
080
0

0
0
0
0
14,564
0

4,35:

1,135

159

1,177

a.t:4

14,584

0
0
0
0
6.584
0

5, 694

$3,0 \%$

i

$\mathbf{0}$

solo

18.688

0
0
0
0
12,371
0

0
0
0
0
10,491

10,401
0

tomat

13.871

20

421

070

17,248

$\mathrm{r}, \mathbf{B}+\mathbf{8}$

3,

24521

279745

0.840

9.405

16,40

04,352

3.840

457,419

14,109

37,155

so64

- 6,871

0,354

4067

67719

Fued Ixponser in Operation

Skam Power Ganeration

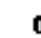

Auclegar Pyings Geneation

Othes Pewar Connalon

$\begin{array}{rr}0 & 0 \\ 0 & 0 \\ 345 & 0\end{array}$

0

0

211,507

20,040

topos

Number of Eleo Dept Employent

Aegutar Fution

42

Farkting 8 Tempor:y

4

20

65

4,250

4

o

64

20

65

0

4314

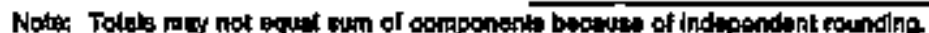

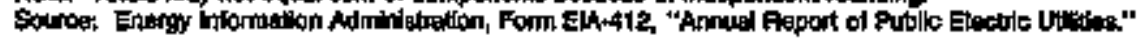


Table 23. Electric Operation and Maintentance Expenges by Major U.S. Publicly Owned Electric Utility Within State, 1994 (Continued)

(Thoustand Dallars)

\begin{tabular}{|c|c|c|c|c|c|c|}
\hline Ilem & $\begin{array}{l}\text { Altzona } \\
\text { Tohono } \\
\text { Codthen } \\
\text { Utity Auth } \\
\text { Detconber ot }\end{array}$ & $\begin{array}{l}\text { Artarapes } \\
\text { Banden } \\
\text { Cing of } \\
\text { Deourater } 31\end{array}$ & 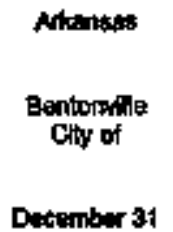 & 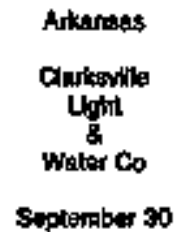 & 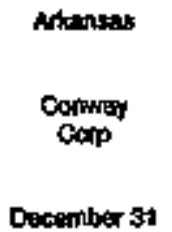 & $\begin{array}{l}\text { Alkanstas } \\
\text { Hope } \\
\text { Cily of } \\
\text { Decentuer } 31\end{array}$ \\
\hline
\end{tabular}

Production Erpenses

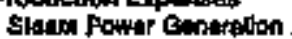

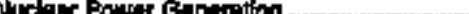

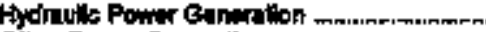

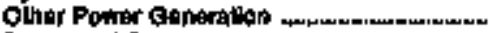

Puchoped Rowr

Cha PTotution Expangers

Totel Production Expanowe

Trengmiastoun Expena6s

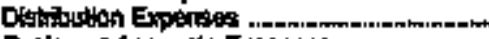

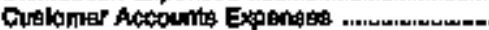

Culomer Sontes and htormation

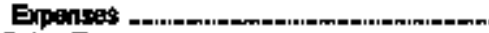

Sglos Expengos

Mdininistriliwe and Gentral

Exponting --2ure-cusenn-

Tobat Elopitic Oparpilion and

Uaphananca tipenasts

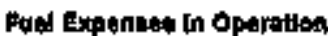

0
0
0
0
5010
0

6.013

8
482

402

1

368

0
0
0
$7, \operatorname{seg}$
0

0
0
0
0
6,786
0

0
0
0
0
505

6.706

0

0

1,203

0

69.5

0

105

$\$ 78$

9,697

7,676

6,684

19596

$\begin{array}{rr}7,045 & 0 \\ 0 & 0 \\ 0 & 0 \\ 0 & 0 \\ 6,505 & 0.015 \\ 0 & 0\end{array}$

15,670

6.615

1,597

1,574

37

o

479

140

701
0

0

728

1394
Stean Power Cenamilon

Mucleder Rouner Comeredion

Obrer Power Ganeration

$\mathbf{0}$

0

0

Number of Eleo Dapt Employean

Regutar Forlitis:

Puthine \& Temporary

25

0

Tot:l Ees Dept Employect

0
0
0

o

20

0

20
0

0

$\mathbf{0}$

14

o

14
155

$\mathbf{0}$

$\mathbf{0}$

$\mathbf{0}$

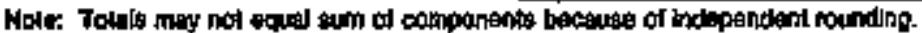

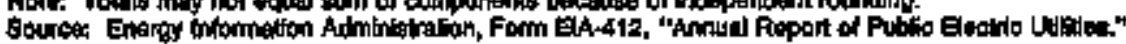


Table 23. Electric Operation and Maintenanoe Expenses by Malor U.S. Publloly Owned Electric Utilty Withn State, 1994 (Continued) (Thousand Dollars)

\begin{tabular}{|c|c|c|c|c|c|c|}
\hline Han & $\begin{array}{l}\text { Allowis:s } \\
\text { Jonouboro } \\
\text { Gity of } \\
\text { Decenilyer } 91\end{array}$ & 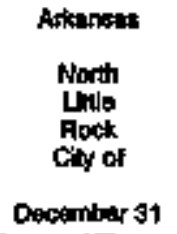 & 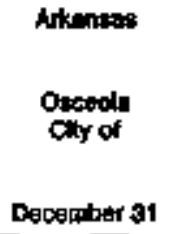 & 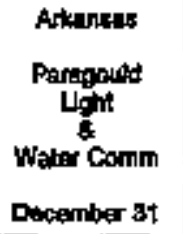 & $\begin{array}{l}\text { Avkuna:s } \\
\text { Slean } \\
\text { Spring: } \\
\text { City of } \\
\text { December } 31\end{array}$ & 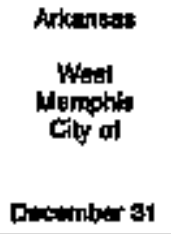 \\
\hline 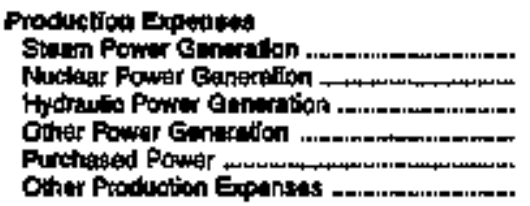 & $\begin{array}{r}9,658 \\
0 \\
0 \\
0 \\
10,740 \\
0\end{array}$ & 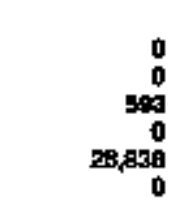 & $\begin{array}{r}0 \\
0 \\
0 \\
0 \\
5,685 \\
5\end{array}$ & $\begin{array}{c}0 \\
0 \\
0 \\
0 \\
0 \\
0 \\
0 \\
0\end{array}$ & $\begin{array}{r}0 \\
0 \\
0 \\
0 \\
7,1=0 \\
0\end{array}$ & $\begin{array}{r}451 \\
0 \\
0 \\
0 \\
11,887 \\
0\end{array}$ \\
\hline 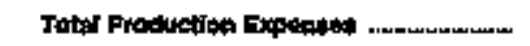 & 20,898 & 20,4st & 9,720 & Q,012 & 7,100 & 12,350 \\
\hline 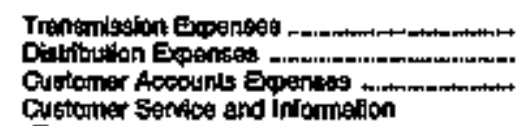 & $\begin{array}{r}0 \\
1,024 \\
1,132\end{array}$ & $\begin{array}{r}0 \\
2,583 \\
\$ 2,284\end{array}$ & $\begin{array}{r}0 \\
682 \\
0\end{array}$ & $\begin{array}{l}839 \\
687 \\
291\end{array}$ & $\begin{array}{l}0 \\
0 \\
0\end{array}$ & 8 \\
\hline 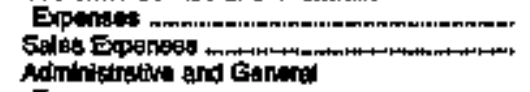 & $\stackrel{0}{11}$ & $\begin{array}{l}0 \\
0\end{array}$ & $\begin{array}{l}0 \\
0\end{array}$ & $\begin{array}{l}0 \\
0\end{array}$ & $\begin{array}{l}0 \\
0\end{array}$ & $\stackrel{0}{0}$ \\
\hline 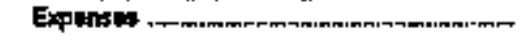 & 1,130 & apsi & 1,004 & 430 & 0 & 53 \\
\hline 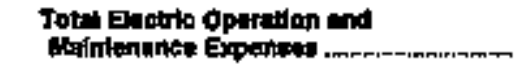 & 24,800 & 38,270 & 7,408 & 10,247 & 7,150 & 13,028 \\
\hline \multicolumn{7}{|l|}{ Fut expantas h Oparation } \\
\hline Statm Pomer Genarditation & 4,696 & 0 & 0 & a & 0 & 981 \\
\hline 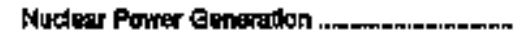 & 0 & 0 & 0 & $\mathbf{0}$ & 0 & 0 \\
\hline 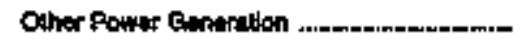 & 0 & $\mathbf{0}$ & 0 & 9 & 0 & a \\
\hline \multicolumn{7}{|l|}{ Number of Elet Dept Employesos } \\
\hline Regular Full-4tma & 99 & 97 & so & 68 & 21 & 16 \\
\hline 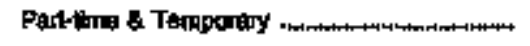 & $\mathbf{5}$ & 0 & $\mathbf{0}$ & g & 0 & 0 \\
\hline 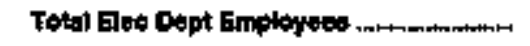 & 104 & or & 36 & 的 & 21 & 18 \\
\hline
\end{tabular}

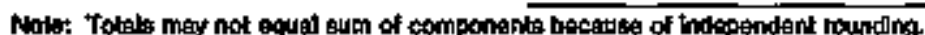

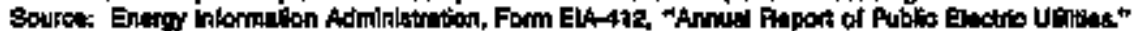


Tabie 28. Electric Operation and Meintenance Expenses by Major U.S. Pubildy Owned Electric Utility Withis State, 1994 (Continued) (Thousand Dollars)

\begin{tabular}{|c|c|c|c|c|c|c|}
\hline Item & 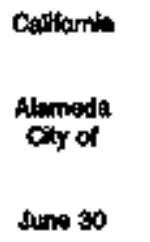 & $\begin{array}{l}\text { Calfornla } \\
\text { Anothelf } \\
\text { Coity of } \\
\text { June } 30\end{array}$ & $\begin{array}{l}\text { Cultomin } \\
\text { Azuse } \\
\text { City of } \\
\text { Jume } 30\end{array}$ & $\begin{array}{l}\text { Cullomis } \\
\text { Butbents } \\
\text { Chy of } \\
\text { Juno so }\end{array}$ & 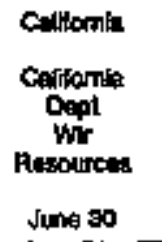 & $\begin{array}{l}\text { Callomin } \\
\text { Cothon } \\
\text { Clity on! } \\
\text { Juns } \$ 00\end{array}$ \\
\hline 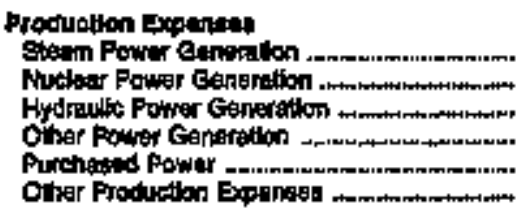 & $\begin{array}{r}0 \\
0 \\
0 \\
0 \\
29,790 \\
0\end{array}$ & $\begin{array}{r}0 \\
13,650 \\
0 \\
0 \\
1396,602 \\
390\end{array}$ & $\begin{array}{r}0 \\
0 \\
0 \\
0 \\
10,877 \\
1990\end{array}$ & $\begin{array}{r}15,675 \\
0 \\
0 \\
0 \\
49,136 \\
566\end{array}$ & $\begin{array}{r}25,697 \\
0 \\
5,273 \\
0 \\
37,008 \\
0\end{array}$ & $\begin{array}{r}0 \\
0 \\
0 \\
0 \\
21,000 \\
0\end{array}$ \\
\hline Totw Produciton Expentes . & 30,700 & 190,1002 & 12,317 & $64,5 t$ & $a t ;, 368$ & 12,000 \\
\hline 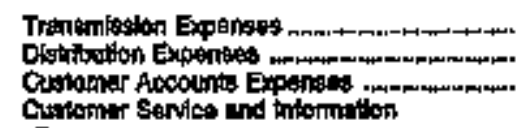 & $\begin{array}{r}1,348 \\
280\end{array}$ & $\begin{array}{r}14,272 \\
8,169 \\
5,634\end{array}$ & $\begin{array}{r}0 \\
1,491 \\
1,031\end{array}$ & $\begin{array}{r}0 \\
6,703 \\
1,0 \% 5\end{array}$ & $\begin{array}{l}0 \\
0 \\
0\end{array}$ & $\begin{array}{r}0 \\
1,614 \\
0\end{array}$ \\
\hline 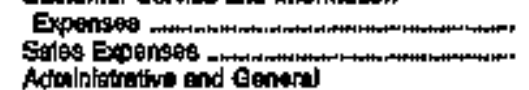 & $\begin{array}{r}188 \\
18 B\end{array}$ & 0 & 0 & $\begin{array}{l}0 \\
0\end{array}$ & 0 & 0 \\
\hline Epensos ........ & 4,345 & 1,069 & 1,005 & 6,086 & a & 3,304 \\
\hline 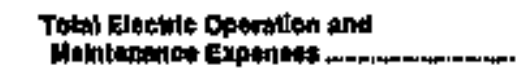 & 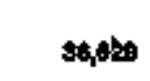 & $10 \% 110$ & 10,375 & 70,273 & 66,166 & 15,027 \\
\hline \multicolumn{7}{|l|}{ Fues Exponace in Operation } \\
\hline 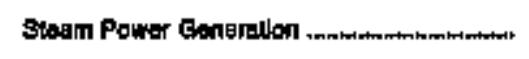 & D & 0 & 0 & 8,840 & 24,265 & 0 \\
\hline Muclear Powrer Goneration .....-.....-nn.-m-...... & a & 2957 & 0 & 0 & o & 0 \\
\hline 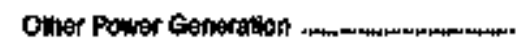 & $\mathbf{0}$ & 0 & 0 & 0 & 0 & 0 \\
\hline \multicolumn{7}{|l|}{ Hombew of Elec Deps Enplopese } \\
\hline 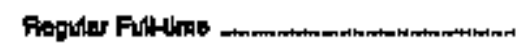 & 97 & 256 & 15 & $28 \%$ & $\theta$ & 37 \\
\hline 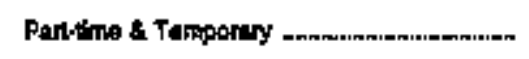 & 2 & 48 & 0 & 0 & o & 0 \\
\hline 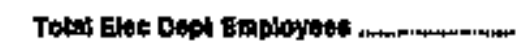 & s & 306 & w6 & 262 & 9 & ד \\
\hline
\end{tabular}

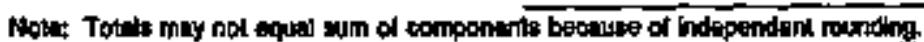

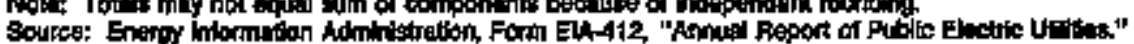


Table 23. Electrio Operation and Meintenance Expenses by Major US. Publely Owned Electric Utillty Within State, 1994 (Conthued)

(Thousand Dollars)

\begin{tabular}{|c|c|c|c|c|c|c|}
\hline Ilem & $\begin{array}{l}\text { Celfonmla } \\
\text { Cisendeds } \\
\text { Ciny of } \\
\text { June } 30\end{array}$ & 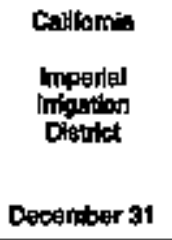 & 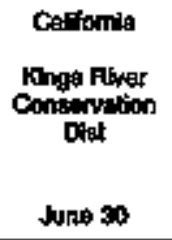 & 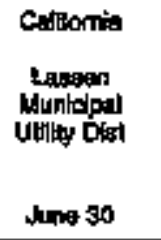 & $\begin{array}{l}\text { Calfomia } \\
\text { Lodi } \\
\text { City of } \\
\text { Nurs } 300\end{array}$ & $\begin{array}{l}\text { Corfitemin } \\
\text { Los Angoles } \\
\text { Cxyy or } \\
\text { Jume so }\end{array}$ \\
\hline 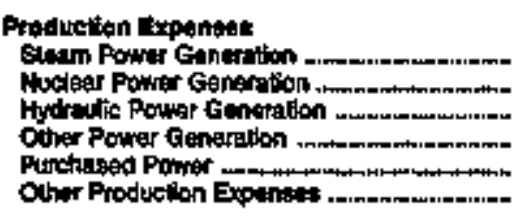 & $\begin{array}{r}0,000 \\
0 \\
0 \\
2,840 \\
50,054 \\
6,582\end{array}$ & $\begin{array}{r}18,003 \\
5,15 \% \\
6 \% \\
04,200 \\
770\end{array}$ & $\begin{array}{r}0 \\
0 \\
4,837 \\
0 \\
0 \\
0\end{array}$ & $\begin{array}{r}0 \\
0 \\
0 \\
0 \\
0,397 \\
0\end{array}$ & $\begin{array}{r}0 \\
0 \\
0 \\
0 \\
26,590 \\
980\end{array}$ & $\begin{array}{r}390,168 \\
28,769 \\
17,759 \\
296 \\
09969\end{array}$ \\
\hline Total Proditurifon Expansis & B5,59: & 119,919 & 4037 & 0,287 & 265000 & $\operatorname{ses}, 329$ \\
\hline 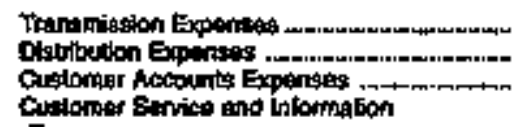 & $\begin{array}{l}1,147 \\
6,084 \\
3,131\end{array}$ & $\begin{array}{l}2,511 \\
8,709 \\
3,677\end{array}$ & $\begin{array}{l}0 \\
0 \\
0\end{array}$ & $\begin{array}{r}31 \\
298\end{array}$ & $\begin{array}{r}0 \\
1,410 \\
1,276\end{array}$ & $\begin{array}{r}28,658 \\
140,609 \\
50,6 \geqslant 1\end{array}$ \\
\hline 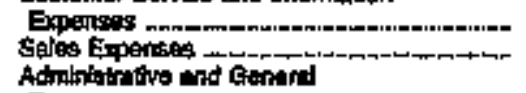 & 0 & $:$ & $\begin{array}{l}0 \\
0\end{array}$ & $\begin{array}{r}109 \\
0\end{array}$ & $\stackrel{0}{0}$ & 25,6000 \\
\hline Expengeg & 10,000 & 13,020 & o & 1,418 & 1,611 & 20.010 \\
\hline 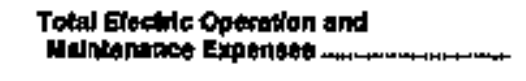 & 74946 & 146,642 & 4037 & 10920 & 30,965 & $1,470,611$ \\
\hline \multicolumn{7}{|l|}{ Futl Expernes in Optratlon } \\
\hline Shap Fower Emaration . & 7,494 & 11,951 & 0 & 0 & D & 254,446 \\
\hline 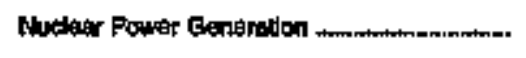 & $\mathbf{0}$ & o & 0 & 0 & 0 & $7,2,2$ \\
\hline Ohe Pown Ganeratos & 1,627 & 202 & $\mathbf{0}$ & $\mathbf{0}$ & o & 20 \\
\hline \multicolumn{7}{|l|}{ Number of Eleo Dept Employeul } \\
\hline 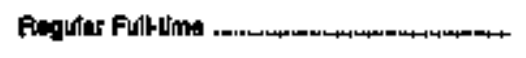 & 272 & 480 & 18 & 16 & 99 & 7,735 \\
\hline 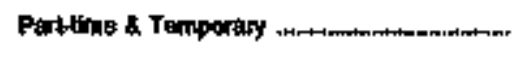 & $\mathbf{0}$ & 0 & 0 & 0 & 2 & 499 \\
\hline Toter Eloc Dopt Employeos ...........-... & 272 & 459 & It & 1a & 40 & 0,176 \\
\hline
\end{tabular}

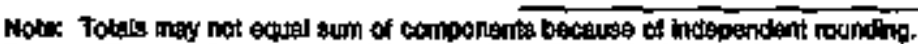

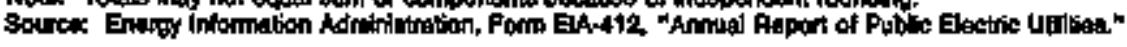


Tabje 28. Electric Operation and Waintenance Expanses by Major U.S. Publichy Owned Eloctrlo Utility Within State, 1994 (Continued) (Thousand Dollars)

\begin{tabular}{|c|c|c|c|c|c|c|}
\hline tiem & 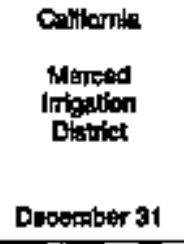 & 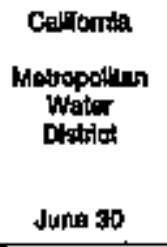 & 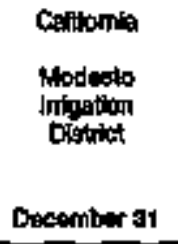 & 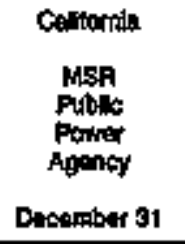 & 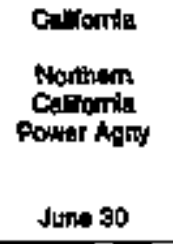 & 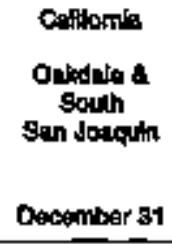 \\
\hline 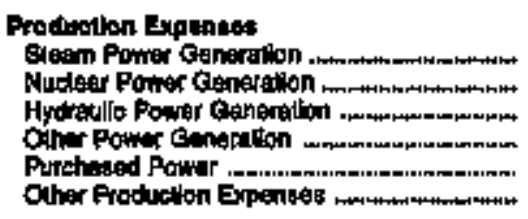 & $\begin{array}{r}0 \\
0 \\
2,087 \\
0 \\
0 \\
0\end{array}$ & $\begin{array}{r}0 \\
0 \\
1,291 \\
0 \\
0 \\
0\end{array}$ & $\begin{array}{r}0 \\
0 \\
791 \\
0,208 \\
70,794 \\
1,700\end{array}$ & $\begin{array}{r}8 T, 703 \\
0 \\
0 \\
0 \\
21,290 \\
58\end{array}$ & $\begin{array}{r}61,251 \\
0 \\
2,076 \\
1,658 \\
24,040 \\
1,917\end{array}$ & $\begin{array}{r}0 \\
016 \\
0 \\
0 \\
0\end{array}$ \\
\hline 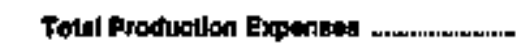 & 2,067 & 1,281 & $B 0,007$ & 45,060 & 91,042 & a16 \\
\hline 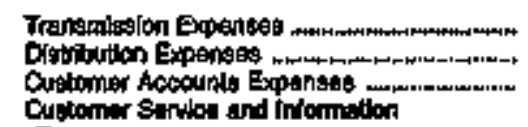 & $\begin{array}{l}0 \\
0 \\
0\end{array}$ & $\begin{array}{l}0 \\
0 \\
0\end{array}$ & $\begin{array}{r}245 \\
0,070 \\
3,849\end{array}$ & $\begin{array}{r}048 \\
0 \\
0\end{array}$ & $\begin{array}{r}9,919 \\
0 \\
0\end{array}$ & $\begin{array}{l}0 \\
0 \\
0\end{array}$ \\
\hline Epenats .... & $\begin{array}{l}0 \\
0\end{array}$ & $\stackrel{0}{0}$ & 1,20 & $\begin{array}{l}0 \\
0\end{array}$ & $\stackrel{9}{0}$ & o \\
\hline 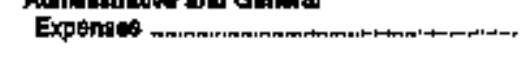 & 285 & 0 & 9,104 & 1,809 & 223 & 1,171 \\
\hline 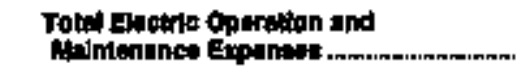 & 2,349 & $1,2: 1$ & 100, & $\mathbf{4 5 , 5 1 7}$ & 102,078 & 1,097 \\
\hline \multicolumn{7}{|l|}{ Fuol Exponena in oparation } \\
\hline 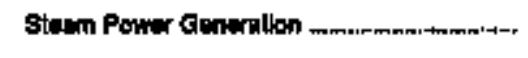 & 0 & 0 & 0 & 17,070 & 47,783 & 0 \\
\hline 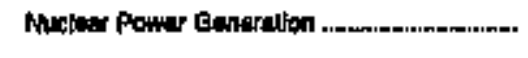 & 0 & 9 & 0 & $\mathbf{0}$ & 0 & 0 \\
\hline 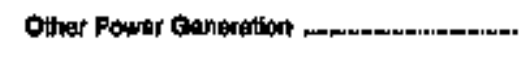 & $\mathbf{0}$ & 0 & 9,6959 & 0 & 20 & 0 \\
\hline \multicolumn{7}{|l|}{ 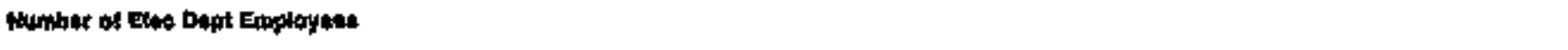 } \\
\hline 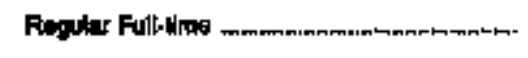 & 10 & 57 & 290 & 17 & 174 & 22 \\
\hline 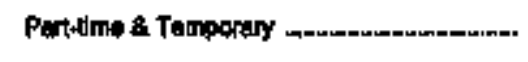 & 0 & 0 & 8 & $\mathbf{0}$ & t1 & 0 \\
\hline Told Eloc Dept Employinet & 10 & 67 & 296 & 17 & 1:8 & 2 \\
\hline
\end{tabular}

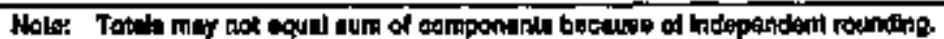

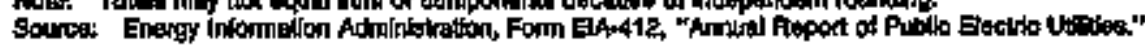


Table 23. Electric Operation and Maintenance Expenses by Mafor US. Publichy Owned Electrlc Utility Within State, 1994 (Continuted) (Thousand Dollars)

\begin{tabular}{|c|c|c|c|c|c|c|}
\hline Itom & 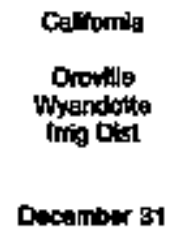 & $\begin{array}{l}\text { Gallorita } \\
\text { Palo Nto } \\
\text { City of } \\
\text { Jume } 30\end{array}$ & 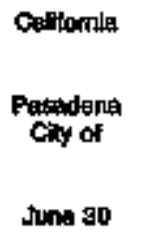 & 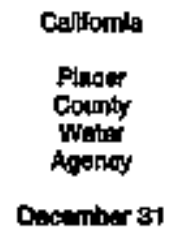 & 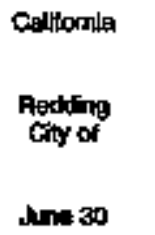 & $\begin{array}{l}\text { Cellomia } \\
\text { Pthintidy } \\
\text { Ciny of } \\
\text { June } 30\end{array}$ \\
\hline 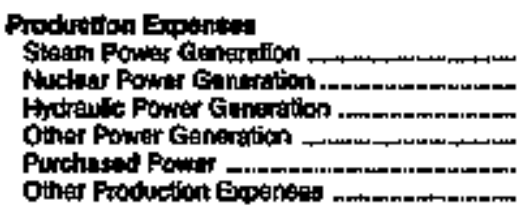 & $\begin{array}{r}0 \\
0 \\
2330 \\
0 \\
0 \\
0\end{array}$ & $\begin{array}{r}0 \\
0 \\
0 \\
0 \\
0,620 \\
0\end{array}$ & $\begin{array}{r}15,202 \\
0 \\
68 \\
74 \\
50,198 \\
698\end{array}$ & $\begin{array}{r}0 \\
0 \\
229 \\
0 \\
0 \\
1\end{array}$ & $\begin{array}{r}1,554 \\
0 \\
0 \\
0 \\
20,991 \\
0\end{array}$ & $\begin{array}{r}0 \\
0,476 \\
4 \\
0 \\
00,554 \\
764\end{array}$ \\
\hline Total Production Expensas . & 2,358 & $30,6 \times 0$ & 71,240 & 2,250 & 30501 & $80,7 t 6$ \\
\hline 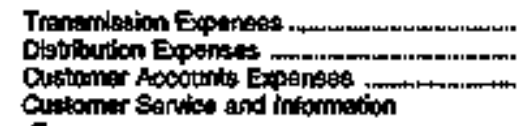 & $\begin{array}{l}0 \\
0 \\
0\end{array}$ & $\begin{array}{r}0 \\
6,198 \\
0\end{array}$ & $\begin{array}{r}1,128 \\
4,021 \\
917\end{array}$ & $\begin{array}{r}89 \\
0 \\
0\end{array}$ & $\begin{array}{r}0 \\
3,936 \\
t, 052\end{array}$ & $\begin{array}{r}13, \mathrm{gig} 7 \\
8,007 \\
2,032\end{array}$ \\
\hline 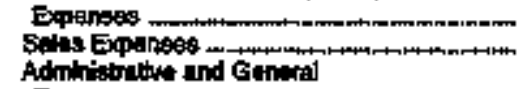 & $\begin{array}{l}0 \\
0\end{array}$ & $\begin{array}{r}0 \\
1,419\end{array}$ & $\frac{0}{176}$ & $\stackrel{0}{0}$ & $\stackrel{0}{0}$ & 1,004 \\
\hline Expenses nom & 0 & 1,558 & 7900 & 1,017 & 10,055 & 19,889 \\
\hline \multirow[t]{2}{*}{ Total Elestrlo Opuration and } & 2,358 & 39028 & 00,291 & 3,836 & 46,398 & 125,479 \\
\hline & & & & & & . \\
\hline \multicolumn{7}{|l|}{ Fud Expanate in Gperation } \\
\hline 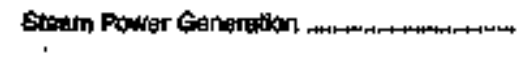 & 0 & 0 & 10,560 & 0 & 271 & 0 \\
\hline 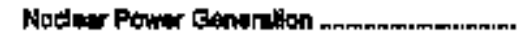 & 0 & 0 & 0 & 0 & 0 & 5,139 \\
\hline Oaher Power Gerreradon & 0 & o & 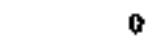 & 0 & 0 & 0 \\
\hline \multicolumn{7}{|l|}{ Kuribar of Ene Dept Emplopias } \\
\hline 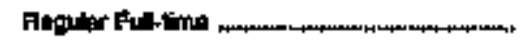 & 16 & 102 & 225 & 10 & 108 & ald \\
\hline 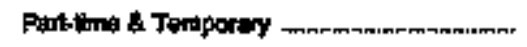 & 2 & 0 & $\mathbf{6}$ & 3 & 6 & 10 \\
\hline Totat Evo Dopt Employen: & w & 102 & 230 & 10 & 112 & 290 \\
\hline
\end{tabular}

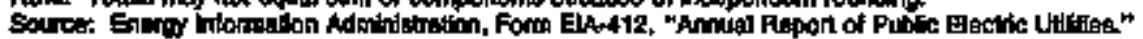


Table 23. Electric Operation and Maintenanee Expenges by Major U.S. Publlchy Owned Electric Uthlisy Withln State, 1994 (Continued) (Thousand Dollars)

\begin{tabular}{|c|c|c|c|c|c|c|}
\hline Ham & 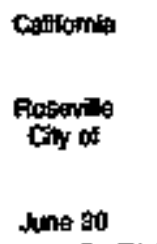 & 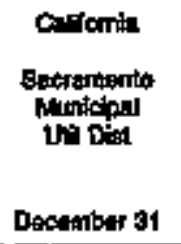 & 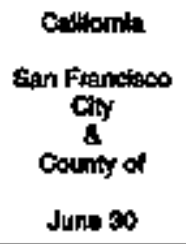 & $\begin{array}{l}\text { canlomia } \\
\text { Sarin } \\
\text { Clora } \\
\text { chy of } \\
\text { Jump 30 }\end{array}$ & $\begin{array}{l}\text { Cefforita } \\
\text { Southem } \\
\text { Corfornle } \\
P P \\
\text { Jime sD }\end{array}$ & 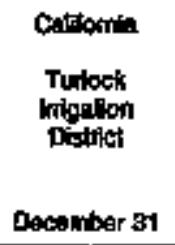 \\
\hline 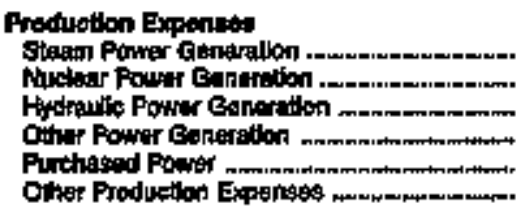 & $\begin{array}{r}0 \\
0 \\
0 \\
0 \\
28,400 \\
1,240\end{array}$ & $\begin{array}{r}13,917 \\
0 \\
8,0,07 \\
200,844 \\
4,851\end{array}$ & $\begin{array}{r}0 \\
0 \\
47,020 \\
0 \\
37,018 \\
0\end{array}$ & $\begin{array}{r}0 \\
0 \\
69 \\
+19,070 \\
672\end{array}$ & $\begin{array}{r}37,684 \\
26,635 \\
0 \\
0 \\
2342 \\
252\end{array}$ & $\begin{array}{r}0 \\
0 \\
3,010 \\
1,727 \\
00,024 \\
005\end{array}$ \\
\hline 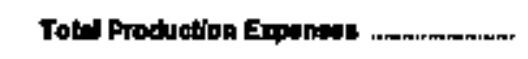 & 29,680 & ans,5as & 41,041 & 126,200 & 66098 & $\cos 050$ \\
\hline 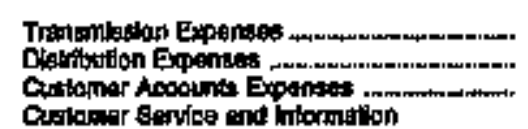 & $\begin{array}{r}0 \\
0,592 \\
1,025\end{array}$ & $\begin{array}{l}22,571 \\
24,655 \\
25,951\end{array}$ & $\begin{array}{r}1, \text { Bas } \\
0 \\
0\end{array}$ & $\begin{array}{r}174 \\
\text { a.t77 }\end{array}$ & $\begin{array}{r}14345 \\
0 \\
0\end{array}$ & $\begin{array}{r}301 \\
0,955\end{array}$ \\
\hline 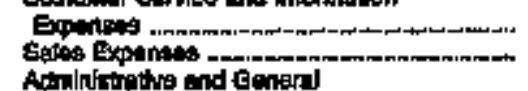 & 0 & 7,347 & $\begin{array}{l}0 \\
0\end{array}$ & $\stackrel{0}{98}$ & $\begin{array}{l}0 \\
0\end{array}$ & $\begin{array}{l}0 \\
0\end{array}$ \\
\hline Epensen & 1,259 & 28,587 & 14,183 & 23,018 & 16,017 & 10,153 \\
\hline 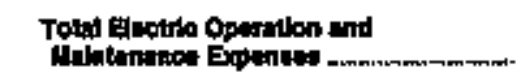 & $\operatorname{sen} 50$ & 428,450 & 67,047 & 151,695 & 07ses & 82604 \\
\hline \multicolumn{7}{|l|}{ 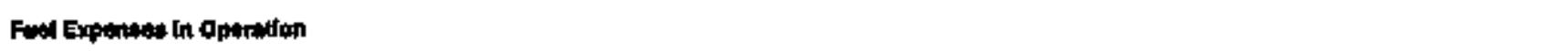 } \\
\hline 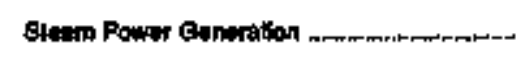 & 0 & o & 0 & 0 & 29712 & 0 \\
\hline 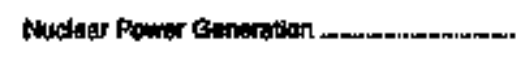 & : & o & 0 & 0 & 7,7 ted & 0 \\
\hline Other Power eloneration & 0 & 199 & o & 1,074 & $\bullet$ & 25 \\
\hline \multicolumn{7}{|l|}{ 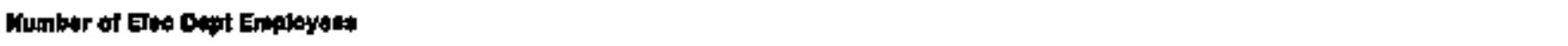 } \\
\hline 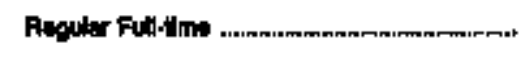 & 67 & 2,369 & 30 & 102 & 16 & 100 \\
\hline Pattinn 8 Temporary & 10 & 68 & o & 7 & 0 & 1 \\
\hline 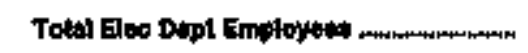 & $\pi$ & 2,45 & 3 & $1 \infty$ & to & 164 \\
\hline
\end{tabular}

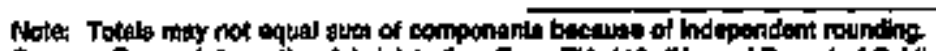

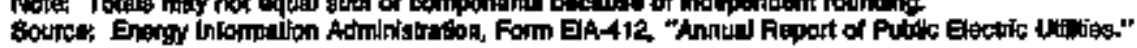


Table 23. Electric Operation and Maintenance Exponees by Major U.S. Publicly Owned Eleotric Utilty Within Stote, 1994 (Contlnued) (Thousand Dollers)

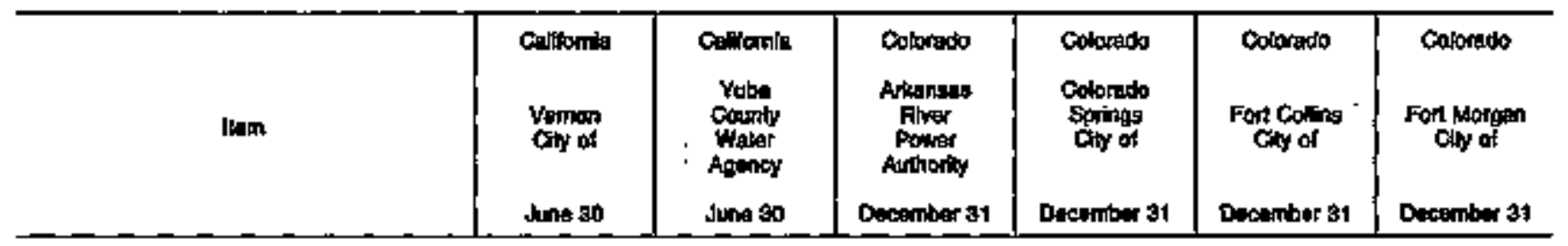

\section{Produstion Expentes}

Stoon Power Genaralion

Nucluat Poivier eneriention

Hidratic Rower Cancration

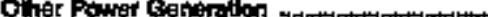

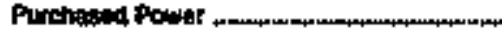

Durer Froducton Epinsas

Tol Produetion Exparian:

Than:mintesion Expenose

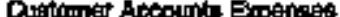

Duttomer sonica and information

Expenses:

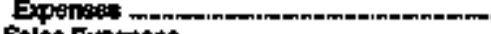

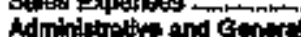

Expenses

Totet Ematrito Dpartion end

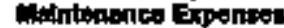

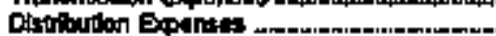

0
0
0
2,962
3,029
0

0
0
1,804
0
0
0

ged

aptond

1,ass

4,086

378
0

$3,44 t$

45,750$$
\text { 1,8004 }
$$

0
0
0

0

o

$1,20 ?$

$\mathbf{3 , 0 4 0}$

10,269
$6 \quad 60,120$

60,120
0

365

14,705

$6 t$

75,262

$1.99 \%$

12,740

4,759

381
0

11,407

108,306 $\begin{array}{rr}0 & 0 \\ 0 & 0 \\ 0 & 0 \\ 0 & 0 \\ 32,809 & 4012 \\ 0 & 0\end{array}$

32,809

4,012

4,056

1,370

423
0

2100

40.679

Epors

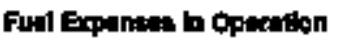

Stom Pamb Gombation

Nuthar Poner Genention

Otho Pow t Earation

0
0
$\cos$

0
0
0

0

43,386

$\mathbf{0}$

$\mathbf{0}$

อ

$\begin{array}{ll}\text { at } & \text { t5 } \\ 3 & 36 \\ \text { at } & 58\end{array}$

s.

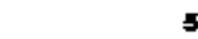

25

$6 \times 8$ 
Table 23. Electrio Operallon and Hajntenance Expenses by Major U.S. Publichy Owned Electrio Ut!lty Wthtn State, 1994 (Continuad) (Thousand Dollars)

\begin{tabular}{|c|c|c|c|c|c|c|}
\hline them & $\begin{array}{l}\text { Colutado } \\
\text { Longmont } \\
\text { Chy of } \\
\text { Decomber } 31\end{array}$ & $\begin{array}{l}\text { Caloxado } \\
\text { loneland } \\
\text { Chy of } \\
\text { Dexomber sy }\end{array}$ & 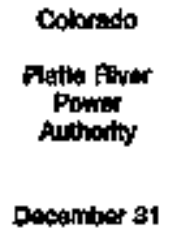 & 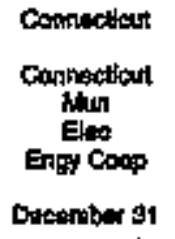 & $\begin{array}{l}\text { Connectiout } \\
\text { Croten } \\
\text { Chy of } \\
\text { June } 30\end{array}$ & $\begin{array}{l}\text { Conmuctout } \\
\text { Nonich } \\
\text { City of } \\
\text { Jume of }\end{array}$ \\
\hline 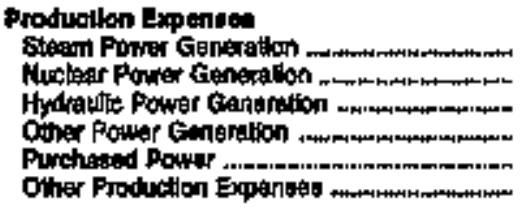 & $\begin{array}{r}0 \\
0 \\
17,079 \\
0 \\
0\end{array}$ & $\begin{array}{r}0 \\
0 \\
58 \\
0 \\
13,46 \\
0\end{array}$ & $\begin{array}{r}47,217 \\
0 \\
0 \\
0 \\
12,050 \\
689\end{array}$ & $\begin{array}{r}0 \\
1,442 \\
0 \\
0 \\
46,408 \\
651\end{array}$ & $\begin{array}{r}0 \\
0 \\
0 \\
0 \\
0 \\
0\end{array}$ & $\begin{array}{r}0 \\
0 \\
286 \\
0 \\
16,619 \\
0\end{array}$ \\
\hline Toled Produgtion Expentaq ...mmummm & 17,413 & 13,482 & $6 \mathbf{n}, 727$ & 40,390 & 50,050 & 16,ast \\
\hline 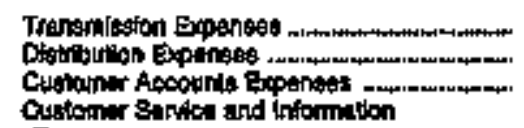 & $\begin{array}{r}0 \\
1,688 \\
0\end{array}$ & $\underset{1,300}{1,80}$ & $\begin{array}{r}2908 \\
0 \\
0\end{array}$ & $\begin{array}{r}2.537 \\
0 \\
0\end{array}$ & $\begin{array}{l}184 \\
290\end{array}$ & $\begin{array}{l}211 \\
894 \\
856\end{array}$ \\
\hline 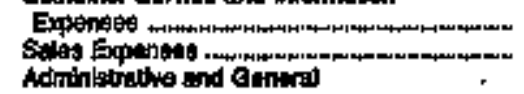 & 1,208 & 158 & $\stackrel{0}{0}$ & 0 & 16. & 0 \\
\hline Expens & $1, \mathrm{Nat}$ & 391 & 8,004 & 2,167 & 2,111 & 5,054 \\
\hline 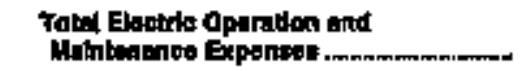 & 21,03s & 16,469 & 6B,940 & $\mathbf{2 0 , 1 0 3}$ & 35,074 & 23,600 \\
\hline \multicolumn{7}{|l|}{ Fue: Expenines In Oparation. } \\
\hline Stean Poner Generalion & 0 & 0 & 27,202 & 0 & 0 & 0 \\
\hline 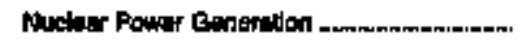 & 0 & 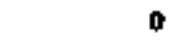 & 0 & 498 & D & $\mathbf{0}$ \\
\hline Oher Powler Certortition & 0 & $\mathbf{0}$ & o & 0 & 0 & a \\
\hline \multicolumn{7}{|l|}{ Number of telog Dipt Employend } \\
\hline 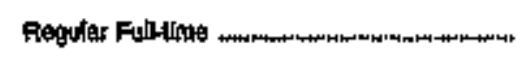 & $8 \mathbf{s}$ & 5 & 10 & 18 & 42 & 62 \\
\hline Partime \& Tanporay nen & 1 & 4 & 2 & t & 4 & a \\
\hline 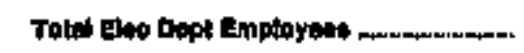 & 8 & 68. & 201 & $\mathbf{7}$ & 49 & 68 \\
\hline
\end{tabular}

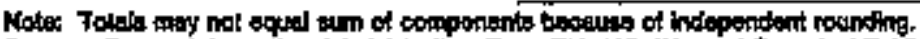

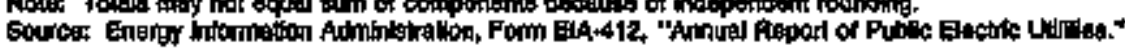


Table 23. Electrle Operation and Malntenance Expenses by hajor Us. Publichy Owned Electric Utulty Whin State, 1994 (Continued) (Thousand Dollars)

\begin{tabular}{|c|c|c|c|c|c|c|}
\hline Nem & $\begin{array}{l}\text { Conmectiest } \\
\text { Wotingtord } \\
\text { Town of } \\
\text { turia } 30\end{array}$ & $\begin{array}{l}\text { Dalawne } \\
\text { Dower } \\
\text { Ciky of } \\
\text { Jung so }\end{array}$ & $\begin{array}{l}\text { Deinmere } \\
\text { Millord } \\
\text { City of } \\
\text { Septeminer on }\end{array}$ & 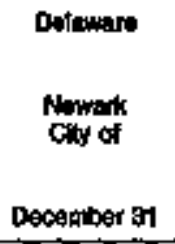 & $\begin{array}{l}\text { Flodde } \\
\text { Butow } \\
\text { City of } \\
\text { september } 30\end{array}$ & $\begin{array}{c}\text { Ftorida } \\
\text { Fiorida } \\
\text { Munilodpal } \\
\text { Pown Agency } \\
\text { Beplember so }\end{array}$ \\
\hline 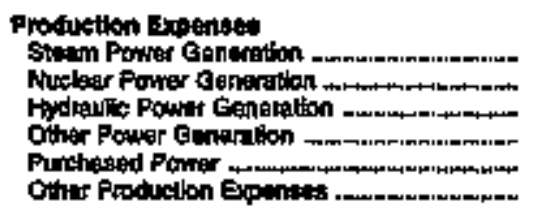 & $\begin{array}{r}67 \\
0 \\
0 \\
0 \\
30,959 \\
0\end{array}$ & $\begin{array}{r}16,300 \\
0 \\
0 \\
0 \\
6,605 \\
\text { B.48 }\end{array}$ & $\begin{array}{r}0 \\
0 \\
0 \\
0 \\
609 \\
0\end{array}$ & $\begin{array}{r}0 \\
0 \\
0 \\
0 \\
14,375 \\
0\end{array}$ & $\begin{array}{r}0 \\
0 \\
0 \\
0 \\
12,190 \\
0\end{array}$ & $\begin{array}{r}16,641 \\
10,607 \\
0 \\
1,379 \\
09,261 \\
471\end{array}$ \\
\hline Totel Produotion Expenses: & 31,595 & 25,962 & 6,935 & 14,578 & $1 \%, 190$ & 46,356 \\
\hline 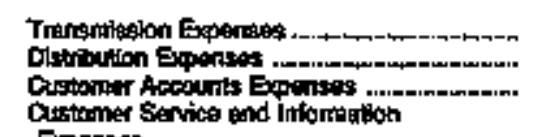 & $\begin{array}{r}15 \\
1,87 t \\
849\end{array}$ & $\begin{array}{r}2,592 \\
0 \\
0\end{array}$ & 1,684 & $\begin{array}{r}0 \\
1,181 \\
0\end{array}$ & $\begin{array}{r}0 \\
418 \\
200\end{array}$ & $\begin{array}{r}12,734 \\
0 \\
0\end{array}$ \\
\hline 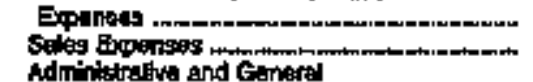 & $\begin{array}{r}65 \\
0\end{array}$ & : & 0 & 0 & 0 & 0 \\
\hline Expenseg ... & 3,016 & 2,776 & $\mathbf{4 2}$ & 0 & $3,5 \times 2$ & a,gra \\
\hline 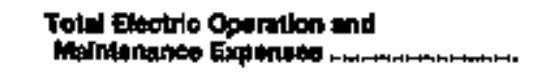 & 37,980 & $\mathbf{3 1} \mathbf{5 7}$ & 6 495 & 16,634 & 4,143 & 120,762 \\
\hline \multicolumn{7}{|l|}{ Fuel Expenases in Operadion } \\
\hline Stuem Powar Gonemofiton & $\infty$ & 10,318 & 0 & $\theta$ & 0 & 11,600 \\
\hline 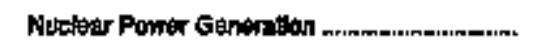 & 0 & 0 & 0 & 0 & 0 & 2,224 \\
\hline OUner Porwer Generation & 0 & 0 & 0 & a & 0 & 842 \\
\hline \multicolumn{7}{|l|}{ Hunber of Elec Dept Enployece } \\
\hline 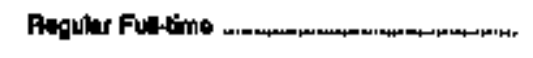 & 76 & 106 & 13 & 21 & 25 & 28 \\
\hline 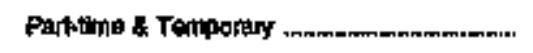 & 1 & 0 & d & o & 0 & 2 \\
\hline Totat Eles Dept Employed & $\pi$ & $\mathbf{x}$ & to & 21 & as & 30 \\
\hline
\end{tabular}

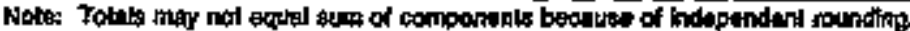

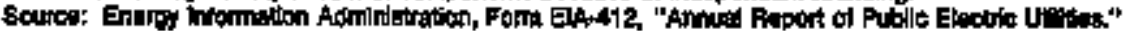


Table 23. Electrlc Operation and Maintenance Expenses by Major U.S. Publichy Owned Eleotric Utility Within State, 1994 (Continued) (Thousand Dollar's)

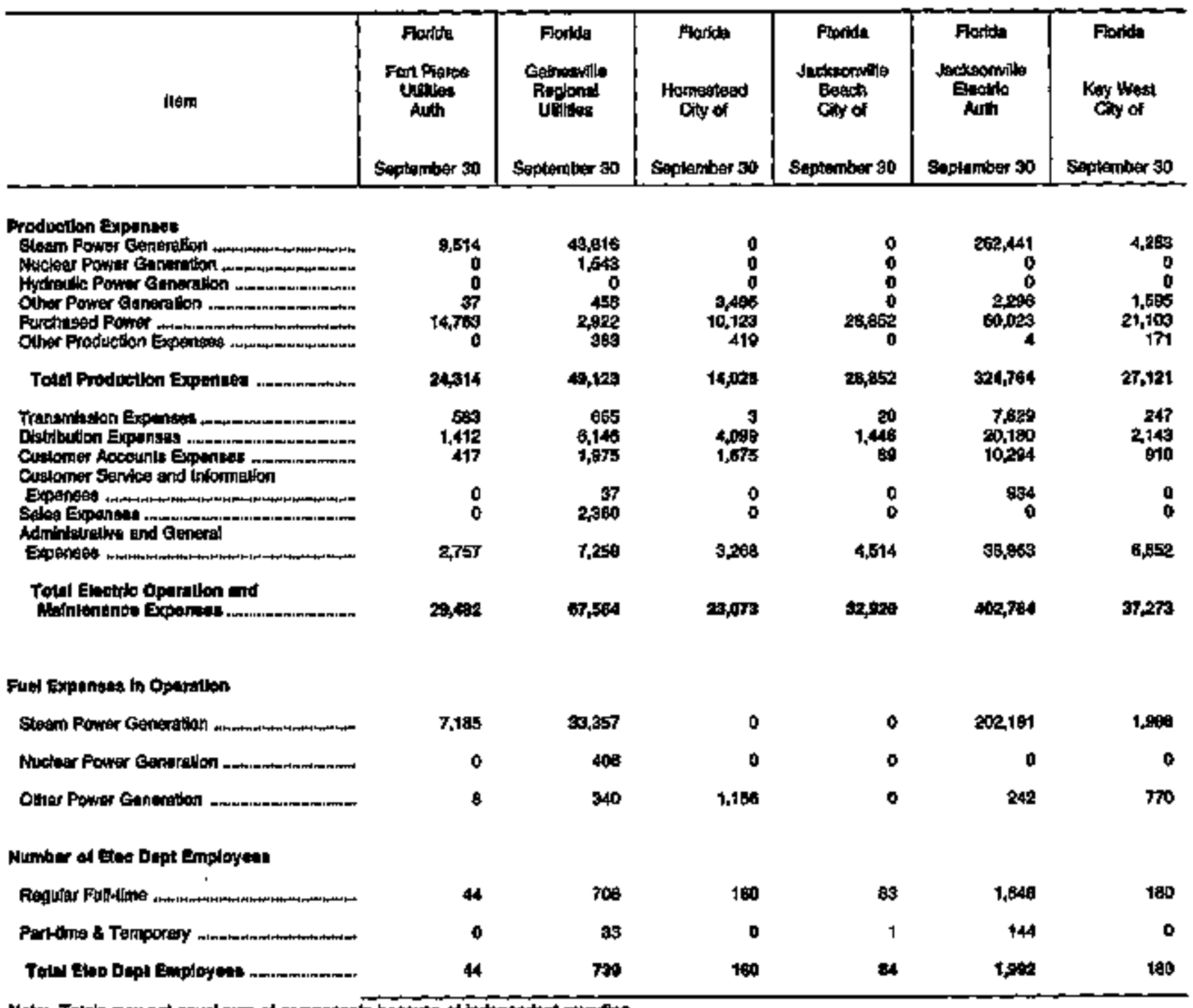

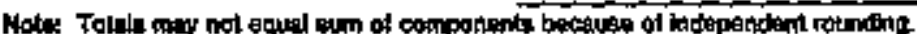

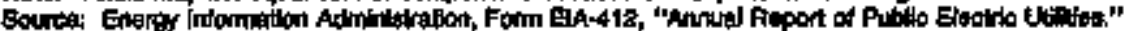


Table 23. Electric Operation and Malntenance Expenses by Major U.S. Publlely Owned Electrlc Utilty Within State, 1994 (Continued) (Thousand Dollars)

\begin{tabular}{|c|c|c|c|c|c|c|}
\hline INom & 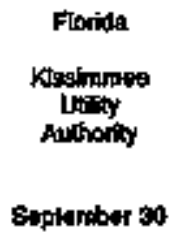 & $\begin{array}{l}\text { Phoride } \\
\text { Laloe Woth } \\
\text { Cily of } \\
\text { September } 30\end{array}$ & $\begin{array}{l}\text { Forida } \\
\text { Lalkeland } \\
\text { City of } \\
\text { Sepunter } 30\end{array}$ & 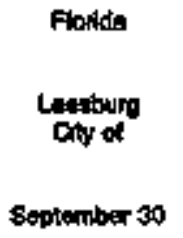 & 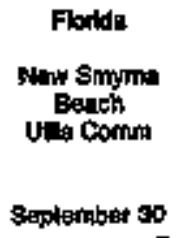 & $\begin{array}{l}\text { Fonide } \\
\text { Oanle } \\
\text { Cily of } \\
\text { Seprombet ad }\end{array}$ \\
\hline 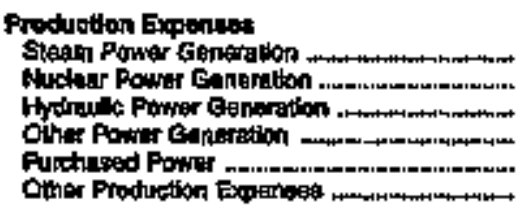 & 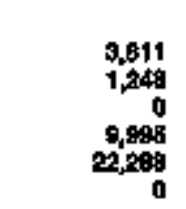 & $\begin{array}{r}7,909 \\
0 \\
0 \\
11,496 \\
0\end{array}$ & $\begin{array}{r}4,910 \\
0 \\
0 \\
9,8090 \\
4,847 \\
0\end{array}$ & $\begin{array}{r}1,269 \\
0 \\
0 \\
15,348 \\
0\end{array}$ & $\begin{array}{r}0 \\
60 \\
0 \\
397 \\
13,047 \\
360\end{array}$ & $\begin{array}{r}0 \\
2,006 \\
0 \\
0 \\
41,370 \\
0\end{array}$ \\
\hline 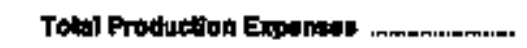 & 37,344 & $+9,946$ & $0 \times, 400$ & 16,614 & 14,6,0 & 43,45 \\
\hline 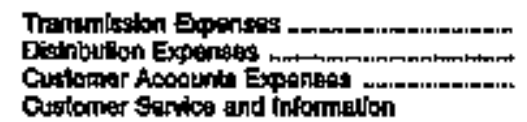 & ${ }_{1,760}^{206}$ & $\begin{array}{r}716 \\
1,342 \\
645\end{array}$ & $\begin{array}{l}1,5968 \\
7,801 \\
2,848\end{array}$ & $\begin{array}{r}0 \\
2778 \\
764\end{array}$ & $\begin{array}{r}\sin \\
1,0894 \\
490\end{array}$ & 4.283 \\
\hline - Expentest & 704 & 0 & $\begin{array}{r}740 \\
0\end{array}$ & $\begin{array}{l}0 \\
0\end{array}$ & 0 & $\begin{array}{l}206 \\
624\end{array}$ \\
\hline 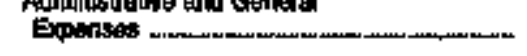 & 2719 & 411 & 17,418 & 592 & 2,428 & 2,183 \\
\hline 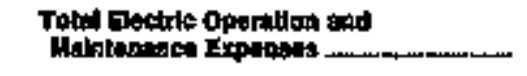 & 40,000 & $2 \$, 220$ & 94,164 & 24,75 & 18958 & 51,280 \\
\hline \multicolumn{7}{|l|}{ Fud Expontew In Oporalken } \\
\hline 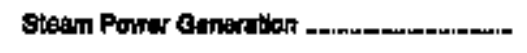 & 244 & 5,000 & 32,005 & 0 & 0 & 0 \\
\hline Nuclear Power Genertiton & 421 & 0 & 0 & 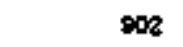 & $\infty$ & 193 \\
\hline 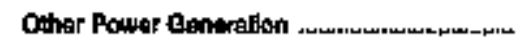 & 0,160 & 183 & 7,720 & 0 & 15 & 0 \\
\hline \multicolumn{7}{|l|}{ thember of Eteo Dapl Emptoyes: } \\
\hline 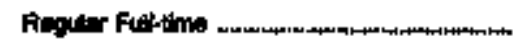 & 247 & 103 & 737 & 5 & 92 & 143 \\
\hline Pertitione \& Tomporary, & 0 & 2 & 28 & 0 & 0 & $\mathbf{0}$ \\
\hline Totpl Epe Dept Emplowow & $\mathbf{2 4 7}$ & ws & tos & $\mathbf{5 1}$ & 92 & $M S$ \\
\hline
\end{tabular}

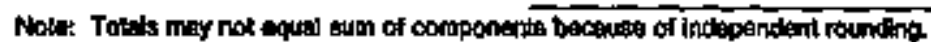

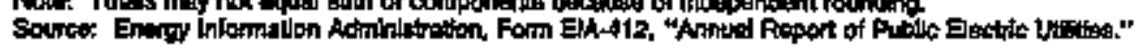


Table 23. Electric Operation and Maintenance Expenses by Major U.S. Publcly Owned Electrio Utility Within State, 1994 (Continued) (Thousand Dollars)

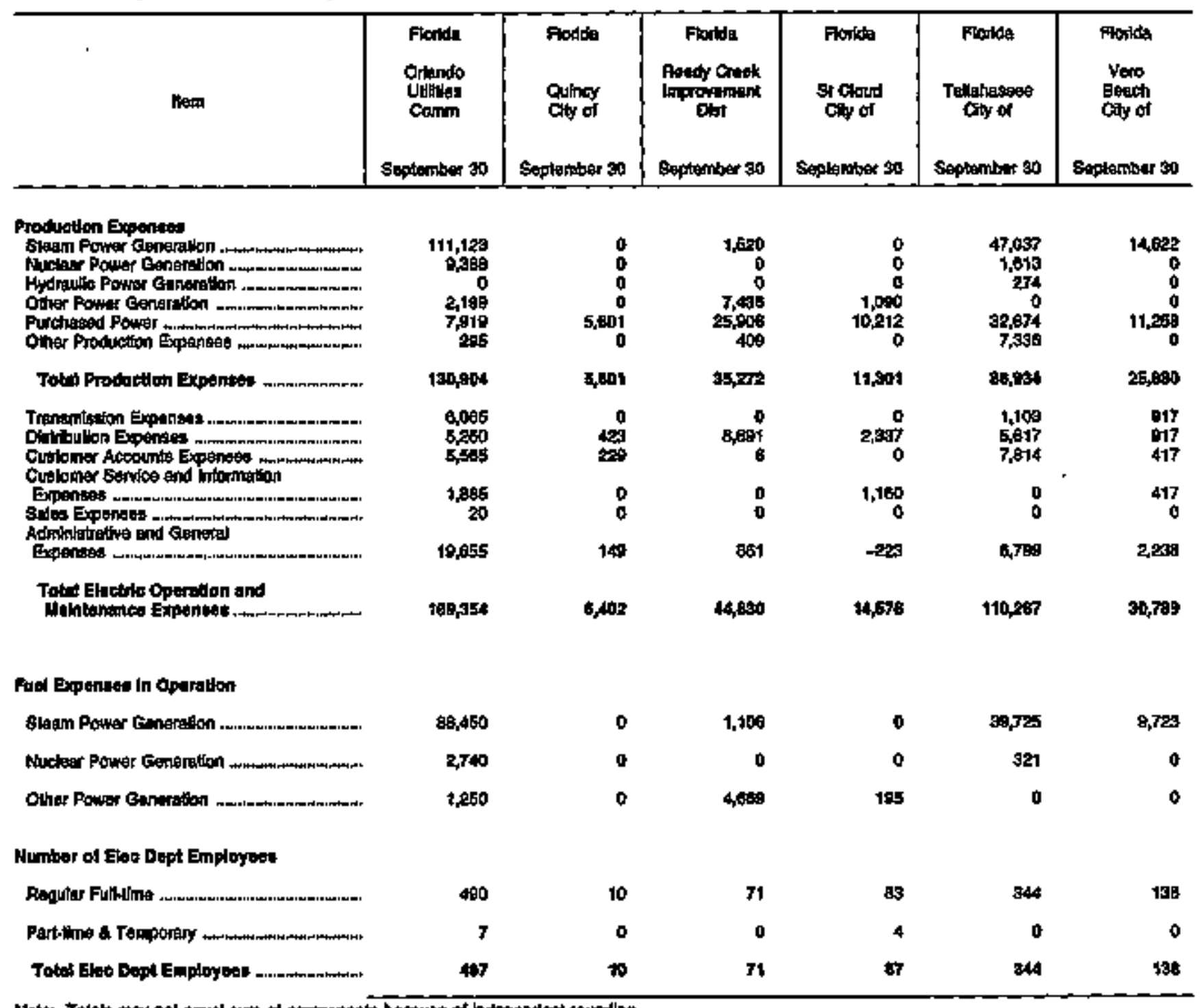

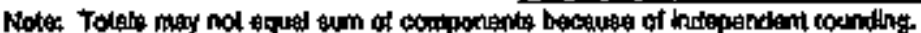

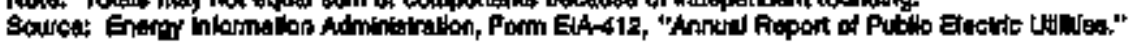


Table 23. Etectric Operation and Meintenance Expenses by Major U.S. Publicly Owned Electric Utility Within State, 1994 (Continued) (Thousand Dollars)

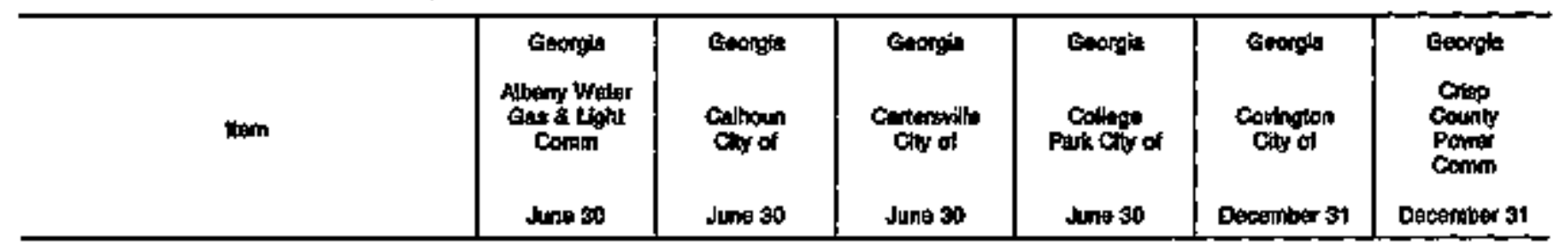

Production Expons:

Steem Power Ganerition

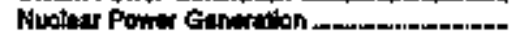

Hydrudio Fower Eengration

Other Pounar Gertitition

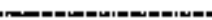

Other Production Expenses m-monnm

Total Production Erpenes:s

Traraniston Expansas

Cistutution Epirtis .-

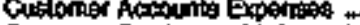

custores Sarvice and inforration

Expenages

Sele: Expmiog

Administralke and Conana

Expenoses

Total Exotrio Dpwation and

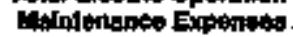

0
0
0
0
46,837
0
45,457
$3,9850,600$
0
0
0
0
8,475

59,675

16,202

0
0
0
0
16.256
0

15,25

201040

0
87
80

.

$\mathbf{0}$

894

20149

0
0
0
0
0,921
0

10,821

1,554

1.554
128

$$
18
$$$$
\begin{aligned}
& \mathbf{0} \\
& \mathbf{0}
\end{aligned}
$$

127

12,730

328
0
316
0
11,389
0

1 thean

13

762
205

0

1,144

14,195

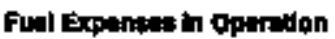

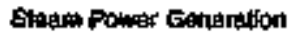

$$
\text { o }
$$

Murdeger Powis Canometh

o

0

Othe Pow Coneriton

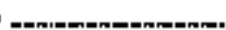

Aunbar of Eloc Dept Enployea:

Reguter Ful':rime

Pattima 8 Tereportary

207

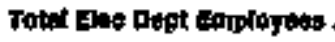

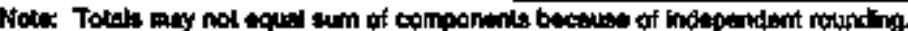

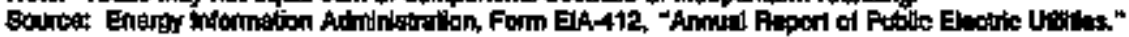


Table 23. Electric Operation and Maintenance Expenses by Major U.S. Publicly Ommed Electric Utility Whithin State, 1994 (Continued)

(Thousand Dollars)

\begin{tabular}{|c|c|c|c|c|c|c|}
\hline $\operatorname{ltm}$ & $\begin{array}{l}\text { Ceorgia } \\
\text { Dalion } \\
\text { Cisy of } \\
\text { Novernber } 30\end{array}$ & $\begin{array}{l}\text { Beongla } \\
\text { Doughas } \\
\text { Chy of } \\
\text { Jun } 30\end{array}$ & 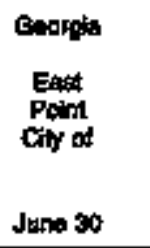 & $\begin{array}{c}\text { Georgin } \\
\text { Fitrgind } \\
\text { Wirkgt } \\
\text { a Bond Comm } \\
\text { December } 31\end{array}$ & 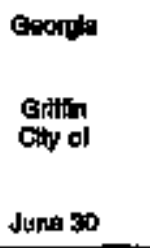 & $\begin{array}{l}\text { Georgle } \\
\text { La Ginge } \\
\text { Aty of } \\
\text { tune as }\end{array}$ \\
\hline 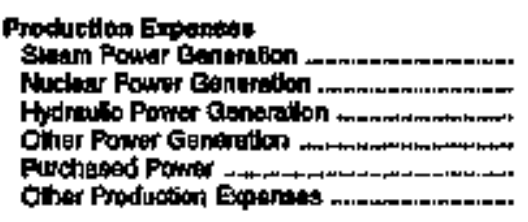 & $\begin{array}{r}5,496 \\
10,775 \\
0 \\
0 \\
14,742 \\
0\end{array}$ & $\begin{array}{r}0 \\
0 \\
0 \\
0 \\
11,050 \\
0\end{array}$ & $\begin{array}{r}0 \\
0 \\
0 \\
0 \\
16,671 \\
0\end{array}$ & $\begin{array}{r}0 \\
0 \\
0 \\
0 \\
8,6,8 \\
2\end{array}$ & $\begin{array}{r}0 \\
0 \\
0 \\
0 \\
12,045 \\
0\end{array}$ & $\begin{array}{r}0 \\
0 \\
0 \\
0 \\
2158 \\
0\end{array}$ \\
\hline 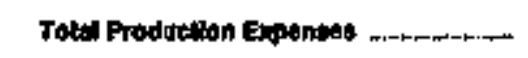 & $31, \mathrm{Crab}$ & 11,050 & 15,671 & 6,830 & 18,045 & 21,536 \\
\hline 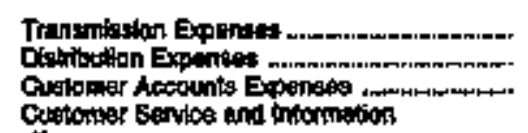 & $\begin{array}{r}480 \\
2005 \\
0\end{array}$ & $\begin{array}{r}0 \\
242 \\
0\end{array}$ & $\begin{array}{r}0 \\
1,797 \\
0\end{array}$ & $\begin{array}{r}0 \\
0\end{array}$ & $\begin{array}{r}0 \\
140 \\
0\end{array}$ & $\begin{array}{l}0 \\
0\end{array}$ \\
\hline 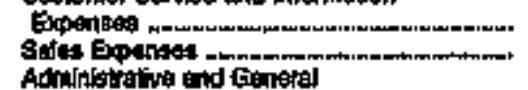 & $\stackrel{0}{0}$ & $\stackrel{0}{0}$ & 0 & 0 & 0 & $\stackrel{0}{0}$ \\
\hline Expentses & 717 & 645 & 6 & 395 & 82 & 953 \\
\hline 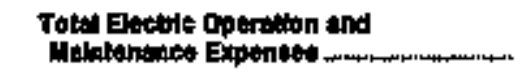 & 34, ats & 11,937 & 17,058 & 9,900 & 19,267 & 22,4:9 \\
\hline \multicolumn{7}{|l|}{ Pud Exponsen in Optration } \\
\hline Stegin Power Gertoretion & 4,690 & 0 & o & 0 & 0 & 0 \\
\hline Nucken Power Ganeration . & 3,182 & 9 & o & 0 & 0 & a \\
\hline Other Power Genatation .... & o & 4) & 0 & $\mathbf{0}$ & 0 & 0 \\
\hline \multicolumn{7}{|l|}{ Number of Elec bepk Enporyes: } \\
\hline Fogtiper Fuldithat & 19 & 16 & 34 & 17 & 25 & to \\
\hline 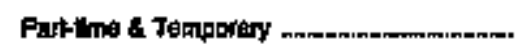 & 0 & 0 & 0 & o & 0 & 0 \\
\hline Tatat Eleo bept Eaptayeat - & 19 & 16 & 34 & 17 & 28 & 13 \\
\hline
\end{tabular}

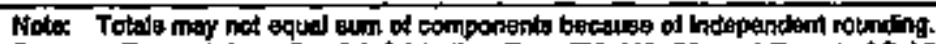

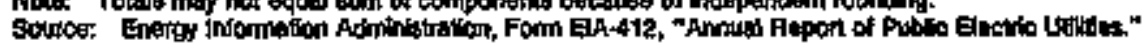


Table 23. Electric Opention and Mintenance Expensets by Major U.S. Publity Owred Electrlo Utillty Wihln State, 1994 (Continued) (Thousand Dollars)

\begin{tabular}{|c|c|c|c|c|c|c|}
\hline ftem & $\begin{array}{l}\text { Coorga } \\
\text { Lemencenilla } \\
\text { City of } \\
\text { Mugues aso }\end{array}$ & 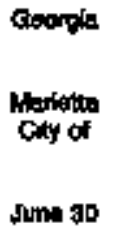 & 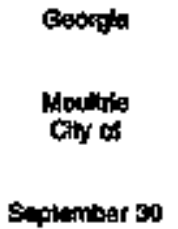 & 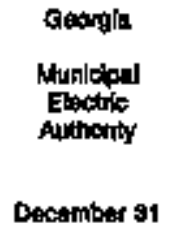 & $\begin{array}{l}\text { Coporyta } \\
\text { Thomasule } \\
\text { Chty of } \\
\text { Oncumbar } 31\end{array}$ & $\begin{array}{l}\text { bdaho } \\
\text { daho } \\
\text { Pats } \\
\text { Chy of } \\
\text { Suptumber } 30\end{array}$ \\
\hline
\end{tabular}

Moduction Exponist:

Blogrn Fonr Benorition

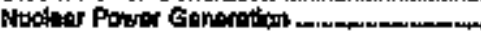

Hudreu is Ponrer Ganiralon

Olver Pint: Gentatiol

Archased Pourer

Othar Production Expenssis

Total Produdion Expen:as:

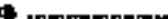

Transmistin Epansas

Olatibution Expontas

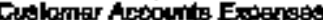

Cultomer SerAou and infarmetitan

Expengags

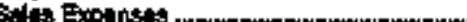

Adminlstrothe ond eeneral

Exponsos

0
0
0
0
$11,40 \%$
0

0
0
0
0
46,000
0

0
0
0
0
8,742
0

03505

tthas

16.tis

$+742$

$\begin{array}{rr}0 & 0 \\ 7 & 4,070\end{array}$

651

0

1,818

3ats

119

0

2,245

$14, \mathrm{pad}$

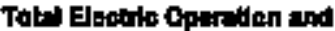

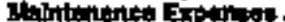

13,252

51,173

$\begin{array}{rr}0 & 0 \\ 0 & 0 \\ 0 & 1,050 \\ 0 & 0 \\ 20,818 & 16,000 \\ 0 & 0\end{array}$

20,810

17,809

974

114

1,770

262$$
1,025
$$

1

o

1,160

1,767

Fud Expences In Operation

Stom Pawer Generaton

0

70,728

o

Nuclat Fower Eonerabon

0

34,059

o

Other Rouns Ceratiodon

a

0

0

0

21,961

Hunber of Eloc Dept Empłoyseat

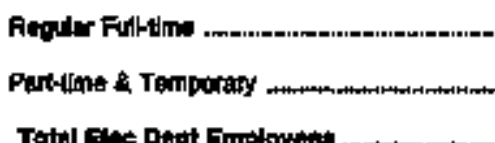

1 ส

0

15 t1

0

at
14

0

14

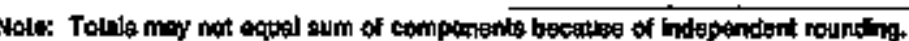

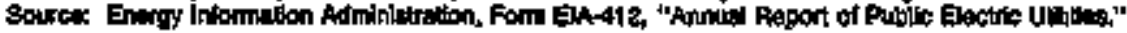


Table z2. Electric Oparation and Maintenence Expenses by Major U.S. Publioly Owned Electric (tillty Witin State, 1994 (Continued) (Thousand Dollars)

\begin{tabular}{|c|c|c|c|c|c|c|}
\hline Whit; & 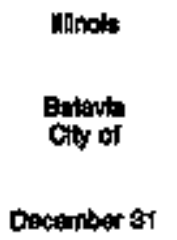 & 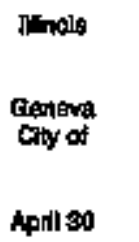 & 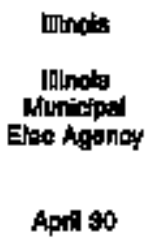 & 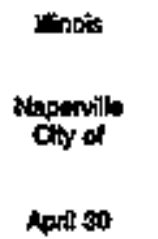 & 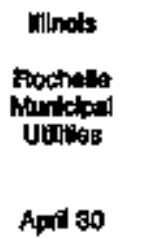 & $\begin{array}{l}\text { Whingly } \\
\text { Soingfeld } \\
\text { Cily od } \\
\text { Februany } 28\end{array}$ \\
\hline 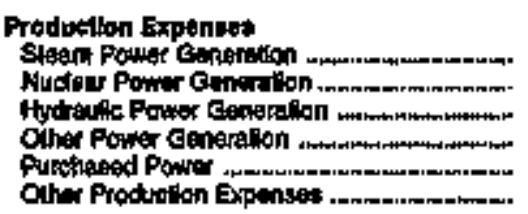 & $\begin{array}{r}0 \\
0 \\
0 \\
0 \\
0 \\
0\end{array}$ & $\begin{array}{r}0 \\
0 \\
0 \\
0 \\
0 \\
0 \\
0\end{array}$ & $\begin{array}{r}7,409 \\
0 \\
0 \\
0 \\
7,589 \\
7.028\end{array}$ & $\begin{array}{r}0 \\
0 \\
0 \\
0 \\
0,140 \\
0\end{array}$ & $\begin{array}{r}2,019 \\
0 \\
0 \\
512 \\
4,172 \\
0\end{array}$ & $\begin{array}{r}14,034 \\
0 \\
0 \\
5 \\
040 \\
0 \\
0\end{array}$ \\
\hline 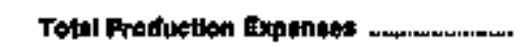 & $10,-80$ & 6,706 & 7869 & 34,140 & 7,000 & 14:40 \\
\hline 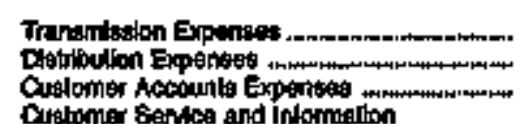 & $\begin{array}{l}0 \\
751 \\
455\end{array}$ & $\begin{array}{r}0 \\
1,40\end{array}$ & $\begin{array}{r}4,420 \\
0 \\
0\end{array}$ & $\begin{array}{r}0 \\
4,831 \\
401\end{array}$ & $\begin{array}{l}15 \\
194\end{array}$ & $\begin{array}{l}1,071 \\
\text { t.,81 } \\
0,892\end{array}$ \\
\hline Expontea . & 0 & $\begin{array}{r}\mathbf{5 2} \\
\mathbf{0}\end{array}$ & 0 & 780 & 0 & 189 \\
\hline 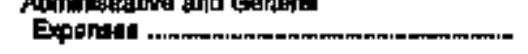 & 400 & $\mathbf{3 7 9}$ & 1,701 & 2,660 & 1,843 & Q:,720 \\
\hline 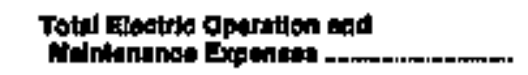 & 12315 & P.54 & 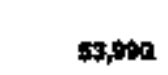 & $4,5,5$ & 9,494 & 66470 \\
\hline \multicolumn{7}{|l|}{ Fugl Expenses in Opertiton } \\
\hline 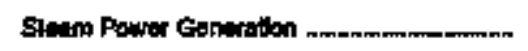 & $\mathbf{0}$ & 0 & 4,548 & o & 1,723 & 25000 \\
\hline 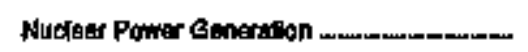 & 0 & $\mathbf{0}$ & $\mathbf{0}$ & 0 & $\mathbf{0}$ & $\mathbf{0}$ \\
\hline 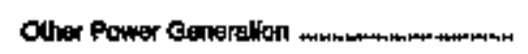 & 0 & $\mathbf{0}$ & 0 & 0 & 113 & 29 \\
\hline \multicolumn{7}{|l|}{ Ruaber of Gec Dept Employetie } \\
\hline 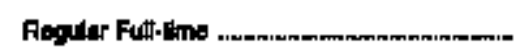 & 18 & 14 & 19 & 101 & 48 & 580 \\
\hline Peottifipe \& Temparary & 1 & 0 & $\mathbf{0}$ & $\mathbf{0}$ & 3 & $\mathbf{0}$ \\
\hline Total Eles Dept Enplopees & tis & 14 & 15 & 101 & 51 & $\operatorname{sen}$ \\
\hline
\end{tabular}

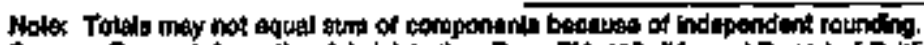

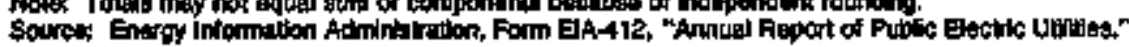


Table 23. Electrlc Operation and Maintenance Expenses by Major U.S. Publlely Owned Eloctric Utility Wittin State, 1994 (Continuod) (Thousand Dollars)

\begin{tabular}{|c|c|c|c|c|c|c|}
\hline hom & $\begin{array}{l}\text { Ifolp } \\
\text { ot Chanles } \\
\text { Chy of }\end{array}$ & $\begin{array}{l}\text { Indlana } \\
\text { Andarion } \\
\text { City of }\end{array}$ & $\begin{array}{l}\text { Injland } \\
\text { Aplonm } \\
\text { Chy of }\end{array}$ & $\begin{array}{l}\text { Indlan: } \\
\text { Elyfipon } \\
\text { Cly of }\end{array}$ & 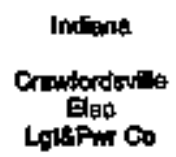 & $\begin{array}{l}\text { Indlant } \\
\text { Pranitort } \\
\text { Chty of }\end{array}$ \\
\hline & Apt 30 & Decomber 37 & tecambar st & Decenter 31 & busonber 31 & Decentber 31 \\
\hline
\end{tabular}

Productop Equanta

Sleam Power Generation

Nuclear Powirer Gentabion

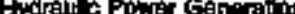

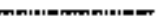

Other Poun Cartshation

Purchased Power

Oiner Production Expenser

Totil Produrtion Expenises

Trunamiston Exprass

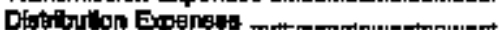

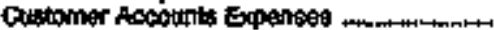

Customer Sorkicy and information

Expengegs

Sals Expensets

Adrumistrative und Generd

Expondas

Tottel Eletchlo Operallion mith

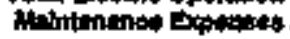

0
0
0
0
17,100
0

0
0
0
0
0
$2=-216$
0

0
0
0
0
13,005

17,104

2*t:216

4,909

$$
7
$$$$
\begin{array}{r}
2665 \\
524
\end{array}
$$

0

0

a

Q

0

13,5:5

0

30

0

595

20109

98,781 $\begin{array}{rr}1,974 & 0 \\ 0 & 0 \\ 0 & 0 \\ 0 & 0 \\ 14,544 & 17,961 \\ 0 & 0\end{array}$

to.517 11,451

$\underbrace{12}_{720} 0$

541

182

0

749

412

t,025

$13,4 \% 3$

Fued stpenese In Opecallon

Stoam Power Guneration

Nuctear Power Generation

$\mathbf{0}$

0

0

0

a

Other Foulat Ganarelion

o

0
0
0

0
0
0

50.8

o

0

0

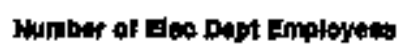

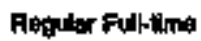

24

80

5

0

29

5

14

28

53

29

t.

1

8

0

Totol Elec bopt Employens

$-$

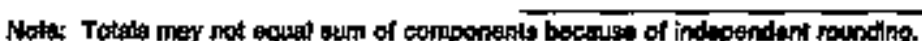

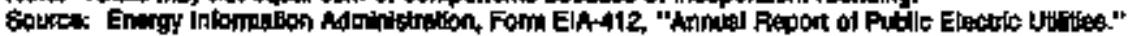


Table 23. Electrte Operation and Maintenance Expenses by Major U.S. Pubitchy Owned Electric Utility Whthin State, 1894 (Continued) (Thousand Dollars)

\begin{tabular}{|c|c|c|c|c|c|c|}
\hline ther & $\begin{array}{l}\text { Indland } \\
\text { Creenfiold } \\
\text { City of }\end{array}$ & 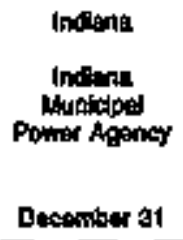 & $\begin{array}{l}\text { holponat } \\
\text { Lapper } \\
\text { Cty of } \\
\text { Docombur } 31\end{array}$ & $\begin{array}{l}\text { Indeane } \\
\text { Logentoport } \\
\text { City of } \\
\text { Dooumber } 31\end{array}$ & 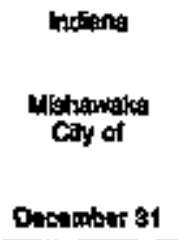 & $\begin{array}{l}\text { molang } \\
\text { Peru } \\
\text { Decty of }\end{array}$ \\
\hline 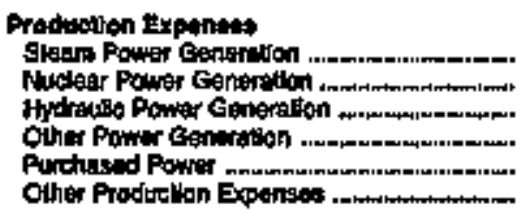 & $\begin{array}{r}0 \\
0 \\
0 \\
0 \\
0 \\
0\end{array}$ & $\begin{array}{r}27,409 \\
0 \\
0 \\
1,095 \\
84,002 \\
347\end{array}$ & $\begin{array}{r}2,368 \\
0 \\
0 \\
0 \\
0,045 \\
0\end{array}$ & $\begin{array}{r}8.289 \\
0 \\
0 \\
5,300 \\
0\end{array}$ & $\begin{array}{r}0 \\
0 \\
0 \\
0 \\
0.485 \\
0\end{array}$ & $\begin{array}{r}584 \\
0 \\
0 \\
0 \\
5,790 \\
0\end{array}$ \\
\hline Tobil Prodtsetion Expunwes --...--....-... & E,t11 & istaps & 11,414 & 11,602 & 20,455 & 4.314 \\
\hline 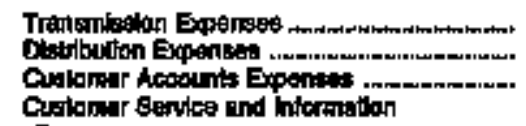 & $\begin{array}{l}0 \\
671 \\
138\end{array}$ & $\begin{array}{r}5,495 \\
0\end{array}$ & $\underset{60}{0}$ & $\begin{array}{r}0 \\
1,209 \\
111\end{array}$ & $\underset{602}{1,59}$ & $\begin{array}{r}15 \\
686 \\
166\end{array}$ \\
\hline 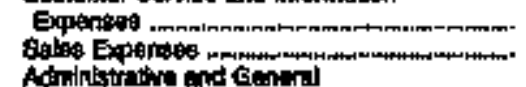 & $\begin{array}{l}0 \\
0\end{array}$ & 0 & $\stackrel{0}{0}$ & 24 & 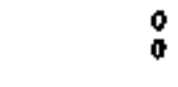 & 0 \\
\hline Expentios ..mom & $\$ \$$ & 2,201 & 764 & 972 & 911 & 1,010 \\
\hline 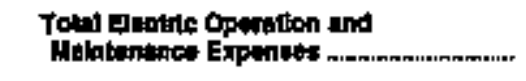 & 0,011 & 121,798 & 12,009 & 14,067 & $23,6+7$ & 8,196 \\
\hline \multicolumn{7}{|l|}{ Fut tripenesin In Oparotion } \\
\hline Steapl Power Genterallon . & 0 & 19,715 & 1,319 & 3,955 & a & 126 \\
\hline 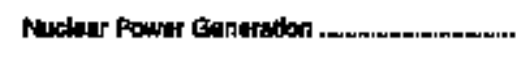 & 0 & 0 & $\mathbf{0}$ & 0 & 0 & $\mathbf{0}$ \\
\hline 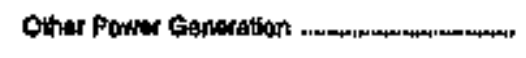 & 0 & 751 & 0 & 6 & 0 & 0 \\
\hline \multicolumn{7}{|l|}{ 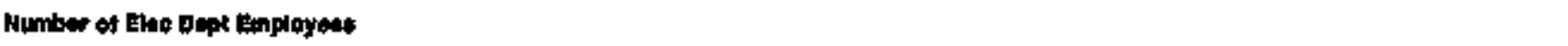 } \\
\hline 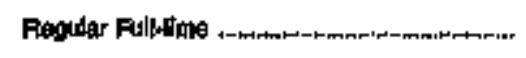 & sp & 20 & 46 & 71 & 80 & 43 \\
\hline Partitine \& Tamporay n n & 7 & 0 & 0 & t & a & 11 \\
\hline Totel Elog Despt Employseat & $\mathbf{s z}$ & 23 & 49 & $\boldsymbol{7 z}$ & 69 & 54 \\
\hline
\end{tabular}

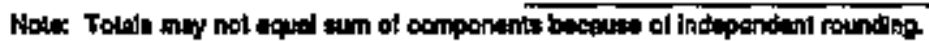

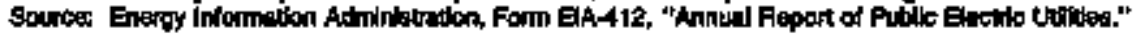


Table 23. Electro Operation and Maintenance Expenses by Major U.S. Publlory Owned Electric Utility Within State, 1994 (Continuted) (Thousand Dolars)

\begin{tabular}{|c|c|c|c|c|c|c|}
\hline IHem & $\begin{array}{l}\text { Inditure } \\
\text { Pichmond } \\
\text { City of } \\
\text { Destember } 34\end{array}$ & $\begin{array}{l}\text { Inditure } \\
\text { Wushington } \\
\text { Chy of } \\
\text { Decentiver } 31\end{array}$ & $\begin{array}{l}\text { lonis } \\
\text { Ante: } \\
\text { City of } \\
\text { June on }\end{array}$ & 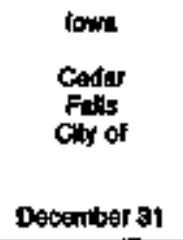 & $\begin{array}{l}\text { kowa } \\
\text { Huecattine } \\
\text { Clity of } \\
\text { Docember } 3 y\end{array}$ & $\begin{array}{c}\text { lowe } \\
\text { Delle } \\
\text { Decanter or } 31\end{array}$ \\
\hline 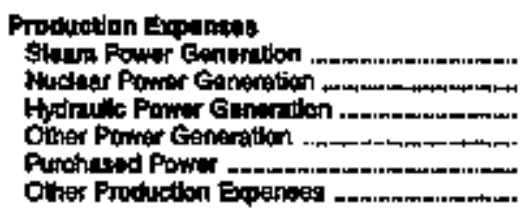 & $\begin{array}{r}13,918 \\
0 \\
0 \\
0 \\
13,494 \\
7\end{array}$ & $\begin{array}{r}0 \\
0 \\
0 \\
0 \\
0 \\
0 \\
0\end{array}$ & $\begin{array}{r}0,179 \\
0 \\
0 \\
0 \\
1,020 \\
484\end{array}$ & $\begin{array}{r}4,422 \\
0 \\
0 \\
1,301 \\
00\end{array}$ & $\begin{array}{r}22,280 \\
0 \\
0 \\
0 \\
738 \\
968\end{array}$ & $\begin{array}{r}4,240 \\
0 \\
0 \\
0 \\
1,1000 \\
42\end{array}$ \\
\hline 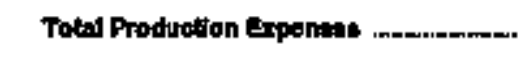 & $27,24:$ & 6475 & 10,903 & $5,0,92$ & $2,0,0$ & 6,212 \\
\hline 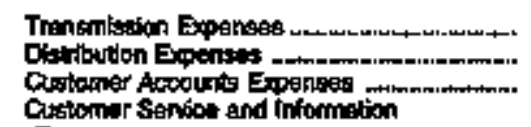 & $\begin{array}{r}28 \\
1,849 \\
584\end{array}$ & $\begin{array}{r}0 \\
614 \\
174\end{array}$ & $\begin{array}{r}0 \\
2728 \\
292\end{array}$ & $\begin{array}{r}424 \\
1,908 \\
340\end{array}$ & $\begin{array}{r}306 \\
1,496 \\
252\end{array}$ & 1,609 \\
\hline 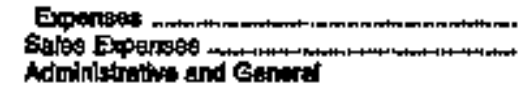 & 76 & $\begin{array}{l}0 \\
0\end{array}$ & 帛 & 20 & $\begin{array}{r}106 \\
0\end{array}$ & a \\
\hline Expons & 4,310 & 240 & 670 & 1,300 & 6,413 & $1,8.17$ \\
\hline 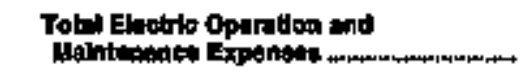 & 94,139 & 7,608 & 14,917 & 9,400 & 31,549 & $9 \pi 79$ \\
\hline \multicolumn{7}{|l|}{ Fuel Expenses: In Oparaulon } \\
\hline 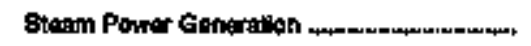 & 11,570 & o & 8,592 & 2,5s: & 18,est & $\mathbf{2}, \mathbf{5 7 2}$ \\
\hline 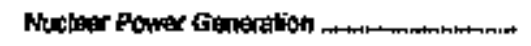 & 0 & 0 & 0 & 0 & 0 & 0 \\
\hline 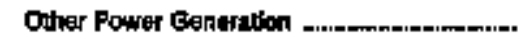 & 6 & 0 & 0 & 71 & 0 & 0 \\
\hline \multicolumn{7}{|l|}{ Namber of Elec Dept Employeses } \\
\hline Fegpler Fuil-ting .... & 186 & 28 & 83 & 的 & 240 & 29 \\
\hline Partime \& Temparay & 24 & $\mathbf{0}$ & t & 4 & $\mathbf{2}$ & 0 \\
\hline 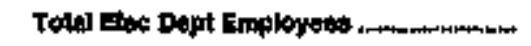 & 189 & 28 & 94 & 6 & 242 & 29 \\
\hline
\end{tabular}

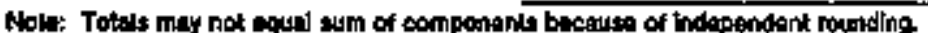

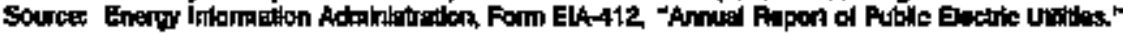


Table 23. Electrio Operation and Maintenance Expenses by Major U.S. Publlchy Owned Electric Utilly Within State, 1994 (Continued)

(Thousand Dollars)

\begin{tabular}{|c|c|c|c|c|c|c|}
\hline Inom & $\begin{array}{l}\text { Kangas } \\
\text { Chanute } \\
\text { City of } \\
\text { Decemibas \$s }\end{array}$ & 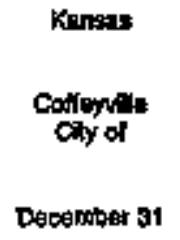 & 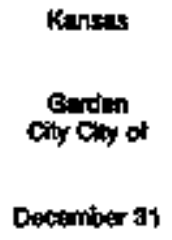 & $\begin{array}{l}\text { Konsas } \\
\text { Kansal } \\
\text { Clty Clay ol } \\
\text { Decomber } 31\end{array}$ & 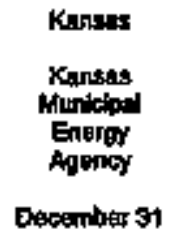 & $\begin{array}{l}\text { Kanses: } \\
\text { Wofherson } \\
\text { City of } \\
\text { Decentiber } 31\end{array}$ \\
\hline 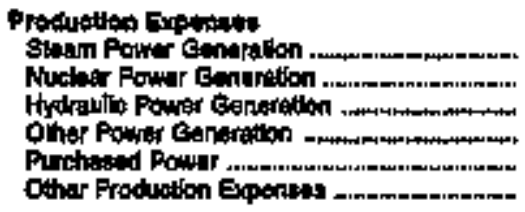 & $\begin{array}{r}0 \\
0 \\
0 \\
1,290 \\
3,615 \\
145\end{array}$ & $\begin{array}{r}3,578 \\
0 \\
0 \\
0 \\
4,407 \\
0\end{array}$ & $\begin{array}{r}0 \\
0 \\
0 \\
0 \\
8,94 t \\
102\end{array}$ & $\begin{array}{r}75,488 \\
0 \\
0 \\
404 \\
6,492 \\
1,034\end{array}$ & $\begin{array}{r}0 \\
0 \\
0 \\
0 \\
B, 743 \\
0\end{array}$ & $\begin{array}{r}327 \\
0 \\
0 \\
756 \\
12,586 \\
67 \%\end{array}$ \\
\hline 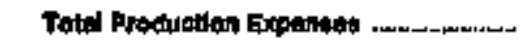 & s,ops & 7,693 & s,out & 69,018 & 6,749 & 14,191 \\
\hline 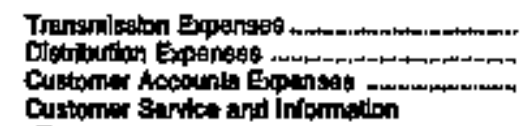 & $\begin{array}{l}709 \\
208 \\
198\end{array}$ & 896 & 60 & $\begin{array}{r}448 \\
10,248 \\
2,1068\end{array}$ & $\begin{array}{r}150 \\
0\end{array}$ & $\begin{array}{r}40 \\
1279\end{array}$ \\
\hline 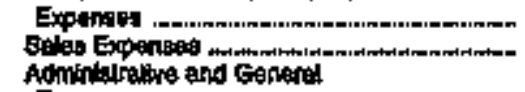 & $\stackrel{0}{0}$ & $\begin{aligned} 191 \\
0\end{aligned}$ & 69 & $\stackrel{0}{0}$ & $\stackrel{0}{0}$ & 2 \\
\hline 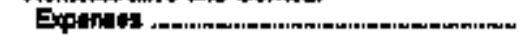 & 419 & 564 & 650 & 13,948 & $\mathbf{s o s}$ & 593 \\
\hline 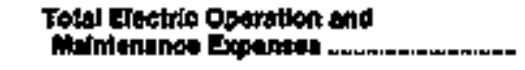 & 5,561 & $9,-67$ & $6, a 95$ & 91,009 & 9,59 & 14:549 \\
\hline \multicolumn{7}{|l|}{ Fud Exponess it Opertion } \\
\hline 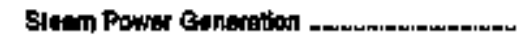 & $\mathbf{0}$ & 1,200 & 0 & 35,51a & o & 40 \\
\hline 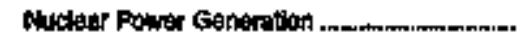 & 0 & 0 & 0 & $\mathbf{0}$ & 0 & 0 \\
\hline 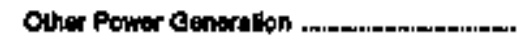 & 20 & 0 & 0 & o & 0 & 205 \\
\hline \multicolumn{7}{|l|}{ Hunbor of Enc Dept Enptoyes: } \\
\hline 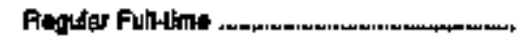 & 25 & 40 & 19 & 800 & $\theta$ & 60 \\
\hline 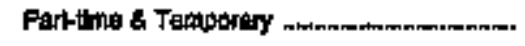 & 0 & $\mathbf{B}$ & 0 & 0 & 1 & 1 \\
\hline 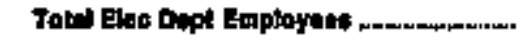 & $m$ & 46 & ts & 500 & 10 & 6t \\
\hline
\end{tabular}

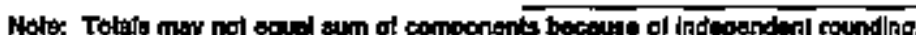

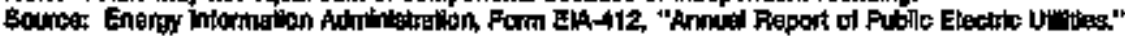


Tahle 23. Electric Oparation and Maintenance Expentea by Major U.S. Publlaty Owned Electric Utlity Within State, 1994 (Continued) (Thousand Dollars)

\begin{tabular}{|c|c|c|c|c|c|c|}
\hline $\lim$ & $\begin{array}{l}\text { Keneges } \\
\text { Whilidd } \\
\text { Ciny of } \\
\text { Dacomber } 31\end{array}$ & $\begin{array}{l}\text { Komtucky } \\
\text { Bowing } \\
\text { Grean } \\
\text { Oty of } \\
\text { duns } 30\end{array}$ & $\begin{array}{l}\text { Kendukty } \\
\text { Frendfort } \\
\text { City of } \\
\text { June } 30\end{array}$ & $\begin{array}{l}\text { Konturity } \\
\text { Franidn } \\
\text { Cily of } \\
\text { June sor }\end{array}$ & $\begin{array}{l}\text { Kartidiay } \\
\text { Clapgow } \\
\text { Cty of } \\
\text { tine ad }\end{array}$ & 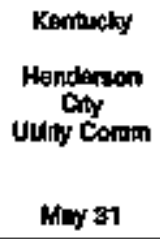 \\
\hline 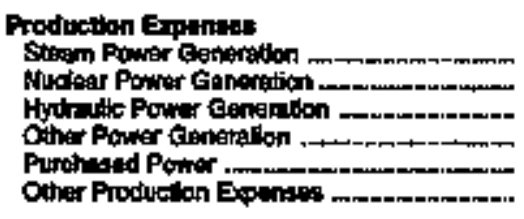 & $\begin{array}{r}2,443 \\
0 \\
0 \\
0 \\
0,979 \\
0\end{array}$ & $\begin{array}{r}0 \\
0 \\
0 \\
0 \\
30,130 \\
0\end{array}$ & $\begin{array}{r}0 \\
0 \\
0 \\
0 \\
19,414 \\
0\end{array}$ & $\begin{array}{r}0 \\
0 \\
0 \\
7,849 \\
0\end{array}$ & $\begin{array}{r}0 \\
0 \\
0 \\
0 \\
19,479 \\
0\end{array}$ & $\begin{array}{r}12,370 \\
0 \\
0 \\
0 \\
1,201\end{array}$ \\
\hline 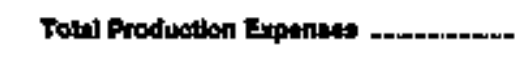 & tale & 3n, 14:2 & $19,4 t 4$ & 7,949 & 19,479 & 14,000 \\
\hline 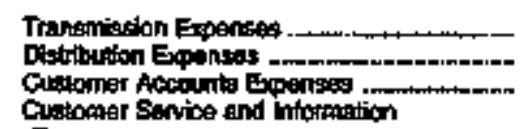 & $\begin{array}{l}0 \\
704 \\
t 95\end{array}$ & $\begin{array}{r}0 \\
\mathbf{2 , 1 3 0} \\
\mathbf{4 1 0}\end{array}$ & $\underset{\mathbf{3 0 6}}{2}$ & $\frac{0}{124}$ & $\begin{aligned} 0 \\
151 \\
151\end{aligned}$ & $\begin{array}{r}2018 \\
222\end{array}$ \\
\hline 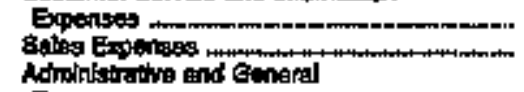 & $\stackrel{0}{0}$ & $\begin{aligned} 162 \\
34\end{aligned}$ & $\begin{array}{l}0 \\
0\end{array}$ & 39 & 210 & $\begin{array}{l}0 \\
\theta\end{array}$ \\
\hline Expenses & 1,002 & $1,0,2$ & 1,888 & sts & 440 & 2,028 \\
\hline Tobal Eitutic Oporation and & to.4t: & 34,000 & 2,668 & seot: & 148+18 & to,194 \\
\hline \multicolumn{7}{|l|}{ Fuel Erpease:; in Oparation } \\
\hline Bteation PGor Contetalion & 1,684 & 0 & 0 & 0 & 0 & 4,491 \\
\hline 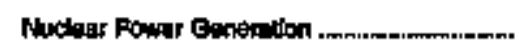 & 0 & 0 & 0 & 0 & 0 & 0 \\
\hline 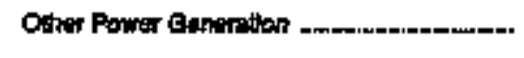 & $a$ & 0 & 0 & $a$ & o & 0 \\
\hline \multicolumn{7}{|l|}{ Hunter of Elec Dept Employeals } \\
\hline 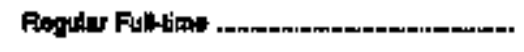 & 31 & $\mathbf{7 z}$ & 59 & 18 & 34 & $5 \%$ \\
\hline Pertime \& Tamporay & 1 & 0 & 0 & 0 & a & 0 \\
\hline Totel Ese Dept Fnplopess & $\mathbf{3 2}$ & $\mathbf{7 2}$ & B & $\mathbf{w}$ & 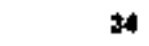 & 68 \\
\hline
\end{tabular}

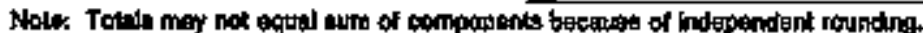

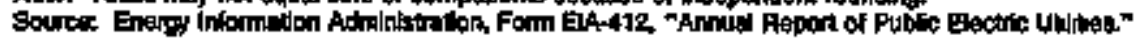


Table 28. Electric Operation and Maintenence Expenses by Major U.S. Publiely Owned Electric Utilly Within \$tate, 1994 (Conilmued) (Thousand Dollars)

\begin{tabular}{|c|c|c|c|c|c|c|}
\hline Uem & $\begin{array}{l}\text { Kentuchs } \\
\text { Hopkinswillo } \\
\text { City of } \\
\text { June Bo }\end{array}$ & 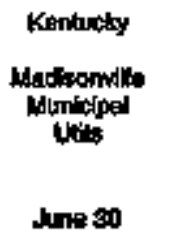 & $\begin{array}{l}\text { Kentucky } \\
\text { Magyifid } \\
\text { Ety of } \\
\text { Jung } 30\end{array}$ & $\begin{array}{l}\text { Kentusty } \\
\text { Minity } \\
\text { Chy of } \\
\text { Jurte } 30\end{array}$ & $\begin{array}{l}\text { Kentuchy } \\
\text { Omensbons } \\
\text { Chy of } \\
\text { Mlay } 31\end{array}$ & $\begin{array}{l}\text { Kantucky } \\
\text { Paducilo } \\
\text { City of } \\
\text { Jurte } 30\end{array}$ \\
\hline 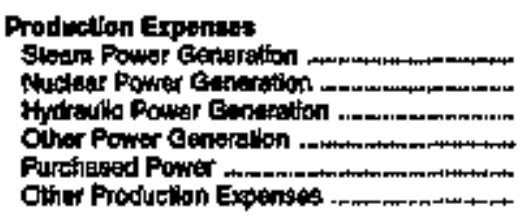 & $\begin{array}{r}0 \\
0 \\
0 \\
0 \\
10,701 \\
0\end{array}$ & $\begin{array}{r}0 \\
0 \\
0 \\
0 \\
8,747 \\
0\end{array}$ & $\begin{array}{r}0 \\
0 \\
0 \\
0 \\
0,920 \\
0\end{array}$ & $\begin{array}{r}0 \\
0 \\
0 \\
0 \\
90,644 \\
0\end{array}$ & $\begin{array}{r}29,497 \\
0 \\
0 \\
0 \\
352 \\
0\end{array}$ & $\begin{array}{r}0 \\
0 \\
0 \\
0 \\
2511 \\
0\end{array}$ \\
\hline 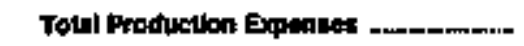 & 18,101 & 9.747 & 6,980 & 10,444 & 2s;asp & 25,311 \\
\hline 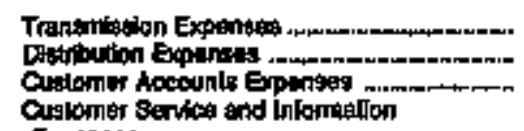 & 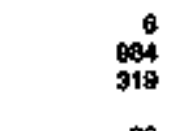 & $\begin{array}{r}0 \\
279\end{array}$ & $\begin{array}{r}0 \\
618 \\
185\end{array}$ & $\begin{array}{r}0 \\
\text { BA1 } \\
105\end{array}$ & $\begin{array}{r}187 \\
6700\end{array}$ & $\begin{array}{r}48 \\
1,874 \\
604\end{array}$ \\
\hline 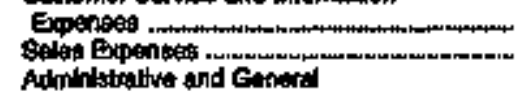 & 37 & 0 & 52 & $\mathbf{1 3}$ & 0 & 241 \\
\hline Expensil ... & 716 & 0 & 489 & 415 & s,as & 1,6087 \\
\hline 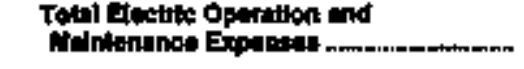 & 20,194 & 9006 & B,240 & 11,688 & 36,206 & 20091 \\
\hline \multicolumn{7}{|l|}{ Futl Expantat: la Opestion } \\
\hline Sin:an Pown Generition . & 0 & $\mathbf{0}$ & $\mathbf{0}$ & 0 & 20,083 & 0 \\
\hline 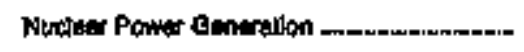 & 0 & 0 & n & 0 & o & 0 \\
\hline 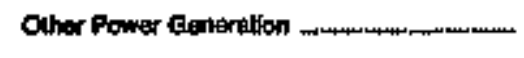 & 0 & $\mathbf{0}$ & a & $\mathbf{0}$ & 0 & o \\
\hline \multicolumn{7}{|l|}{ 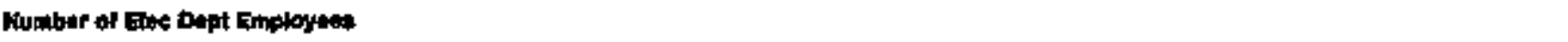 } \\
\hline 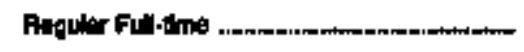 & 33 & $2 a$ & 28 & 23 & 214 & 70 \\
\hline Partolion \& Tamporay & 0 & 1 & 0 & 0 & 6 & 0 \\
\hline 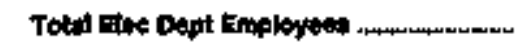 & $\mathbf{s}$ & 2 & 20 & $\mathbf{2 3}$ & 20 & 70 \\
\hline
\end{tabular}

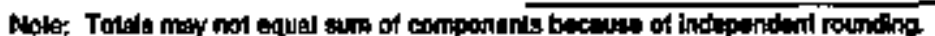

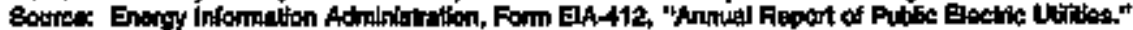


Table 23. Electric Operation and Maintenence Expenses by Major U.S. Publefy Owned Electrio Utulty Wihln State, 1994 (Continued)

(Thousand Dollars)

\begin{tabular}{|c|c|c|c|c|c|c|}
\hline Iteng & $\begin{array}{l}\text { Lothstane } \\
\text { Alunendita } \\
\text { Cly of } \\
\text { Apor } 30\end{array}$ & 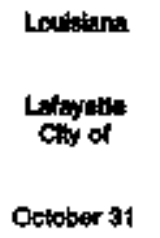 & $\begin{array}{l}\text { Loulydarl } \\
\text { Lafeyette } \\
\text { Publd } \\
\text { Power Auth } \\
\text { Oetober } 31\end{array}$ & 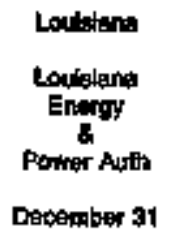 & $\begin{array}{l}\text { Loursiana } \\
\text { Morgan } \\
\text { city Ciny od } \\
\text { Decemiber \$1 }\end{array}$ & 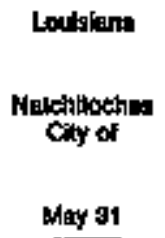 \\
\hline 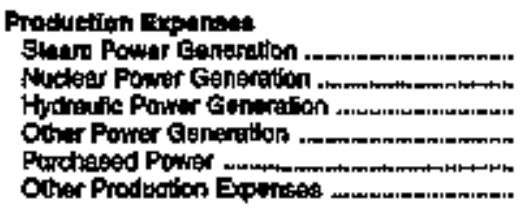 & $\begin{array}{r}1,824 \\
0 \\
0 \\
0 \\
2,987 \\
0\end{array}$ & $\begin{array}{r}12,528 \\
0 \\
0 \\
0 \\
54,416 \\
0\end{array}$ & $\begin{array}{r}3,485 \\
0 \\
0 \\
0 \\
0 \\
0\end{array}$ & $\begin{array}{r}19, \frac{902}{0} \\
0 \\
0 \\
28,005 \\
0\end{array}$ & $\begin{array}{r}64 \\
0 \\
0 \\
0 \\
0 \\
0 \\
10 \\
12\end{array}$ & $\begin{array}{r}0 \\
0 \\
0 \\
0 \\
7,510 \\
1,524\end{array}$ \\
\hline 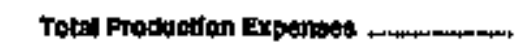 & 24,251 & 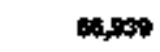 & 38,445 & 45,2ar & 7,131 & 2,004 \\
\hline 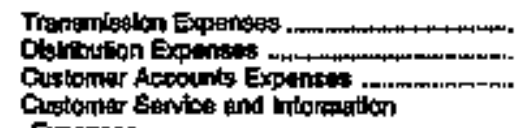 & 209 & $\begin{array}{l}3,766 \\
2,772 \\
1,721\end{array}$ & $\begin{array}{l}0 \\
0 \\
0\end{array}$ & $\begin{array}{r}5,092 \\
0 \\
0\end{array}$ & $\begin{array}{r}725 \\
0 \\
0\end{array}$ & $\begin{array}{r}1,009 \\
1,401 \\
412\end{array}$ \\
\hline 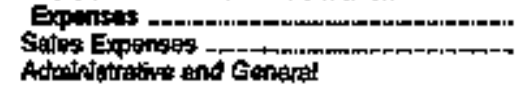 & 0 & 80 & $\begin{array}{l}\mathbf{0} \\
\mathbf{0}\end{array}$ & 0 & o & o \\
\hline Expenses - & 7,358 & 4,054 & 1,906 & 2,528 & 362 & 632 \\
\hline 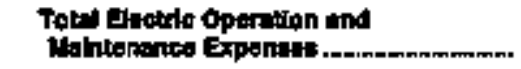 & 2:568 & 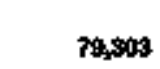 & 86,800 & 52002 & 1.,200 & 1t:ob \\
\hline \multicolumn{7}{|l|}{ Pud trpeasea in Oparation } \\
\hline 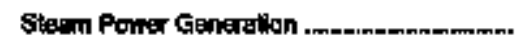 & 603 & 9,819 & 30,425 & 16,092 & $\mathbf{0}$ & 0 \\
\hline 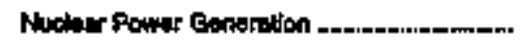 & 0 & 0 & 0 & 0 & $\mathbf{0}$ & 0 \\
\hline Other Pawer Ganeration & 0 & 0 & 0 & 0 & $\mathbf{0}$ & o \\
\hline \multicolumn{7}{|l|}{ Muraber of Eeo Dept Employued } \\
\hline 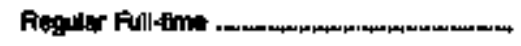 & 2 & 175 & 172 & 6 & 9 & $\mathbf{3 7}$ \\
\hline 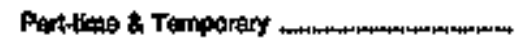 & 0 & 11 & 20 & 0 & 1 & $\mathbf{1}$ \\
\hline Toted Exo Dept Employnen ...-. & $\mathbf{2 4}$ & 188 & 105 & 90 & 10 & 38 \\
\hline
\end{tabular}

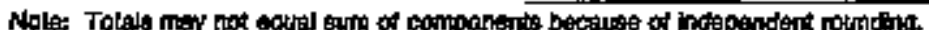

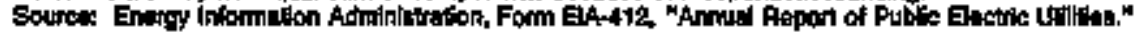


Table 23. Electric Operatton and Maintentance Expanses by Major U.S. Publichy Owned Electric Uility Within State, 1994 (Continued) (Thousand Dollars)

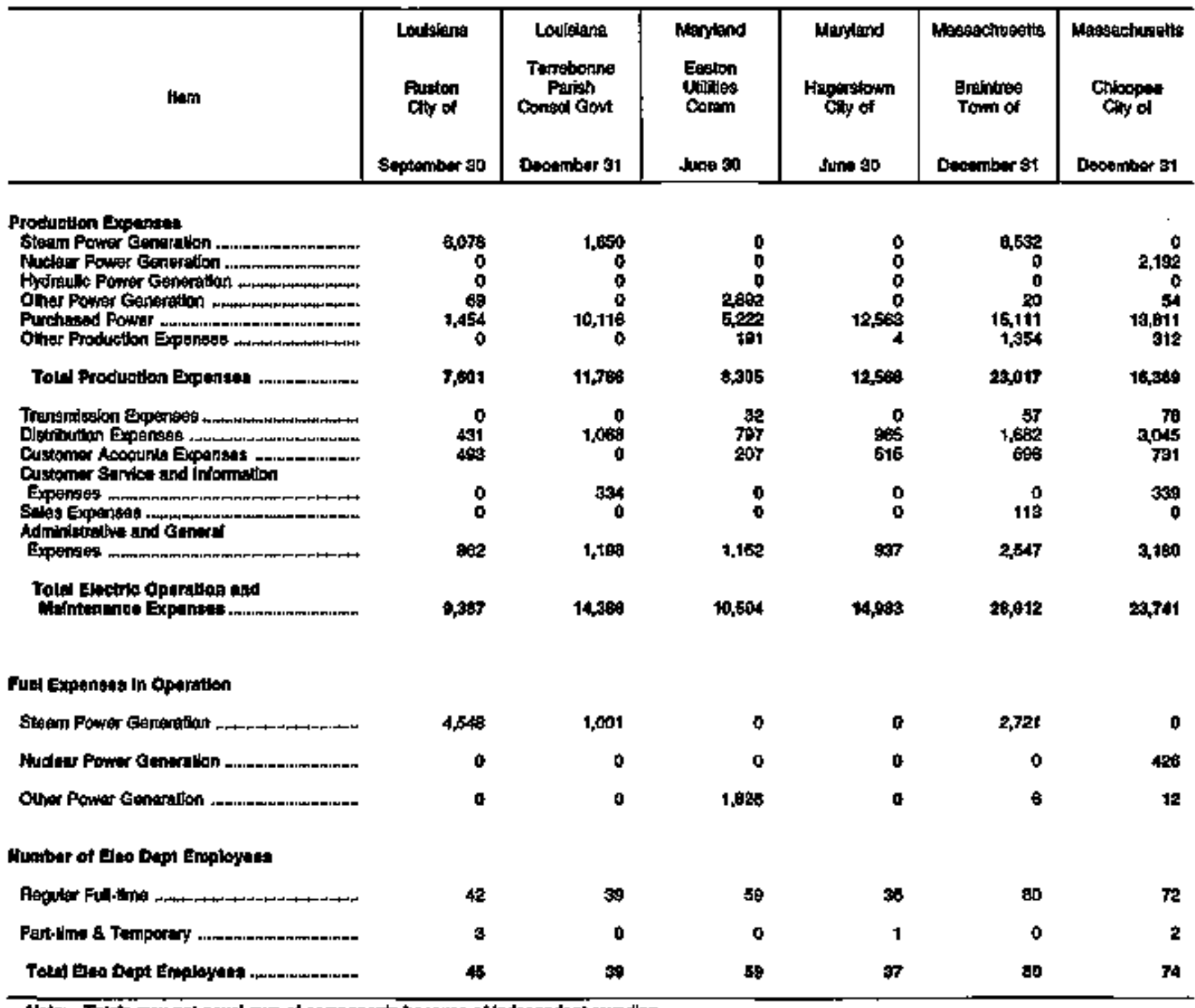

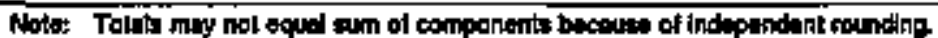

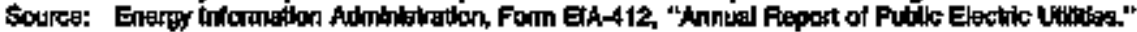


Table 23. Electrio Operation and Malntenance Expenses by Mejor U.S. Publioly Owned Electric Utlity Within State, 1994 (Continued)

(Thousand Dollars)

\begin{tabular}{|c|c|c|c|c|c|c|}
\hline & 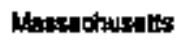 & Mnssucturesets & Musposchuselta & Masscachutatifs & Mascohusolt: & Mrogechusetit. \\
\hline $\mathrm{m}: \mathbf{m}$ & $\begin{array}{l}\text { Conoond } \\
\text { Townt of }\end{array}$ & $\begin{array}{l}\text { Darisen } \\
\text { Town of }\end{array}$ & $\begin{array}{c}\text { Hirghtem } \\
\text { Cily of }\end{array}$ & $\begin{array}{l}\text { Hohrite } \\
\text { Cty of }\end{array}$ & $\begin{array}{l}\text { Hudpoph } \\
\text { Townt if }\end{array}$ & $\begin{array}{l}\text { Litisteth } \\
\text { Town of }\end{array}$ \\
\hline & Dopember 31 & Docenter a1 & Decomber $3 t$ & Dedember 31 & Dacomber 31 & Decamber 31 \\
\hline
\end{tabular}

Production Expenter.

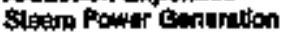

Nueder Power Generation

Hidraute Fowe Genereafion

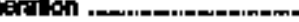

Olher Production Expentses

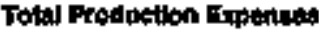

Trartimbsion Expenses

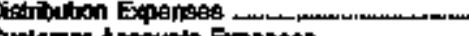

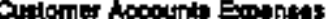

Customer Sarkes and informallion

Expensa.

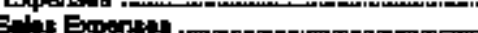

Adm'hlstrathe and Generat

Expen:es:

0
0
0
0
2,187
600
a,605

0
0
0
0
2.713
498
2711

$\mathbf{0}$

0

1

9,611

a,605

211

181

1,383

9.597

406

734

325

0

49
6

1,104

toras

20,275

11,766 $\begin{array}{rl}447 & 1,435\end{array}$

0
119
0
21,705
602

27,56

900

421

18

1,310

2,168

24, 2ath

26,498

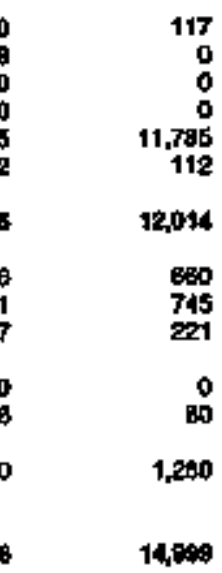

Fued Exptnose In Operalloo

Steam Power Cennaton .

$\mathbf{0}$

Nuctem Pow Certatho

D

$\mathbf{0}$

203

0

$\mathbf{0}$

0

0

0

0

o

$\mathbf{0}$

a2

102

0

Number of Eno Oept Enployers

Fipgular Fatutions

28

40

25

78

tos

30.

9

$\mathbf{z}$

2

a

한

tas

42

25

10

35

at

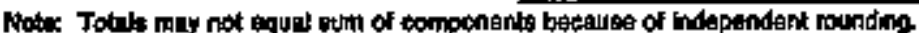

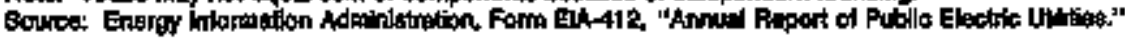


Table 23. Electric Operation and Maintenance Experises by Major U.S. Publicly Owned Electric Utllty Within State, 1994 (Continued) (Thousand Dollars)

\begin{tabular}{|c|c|c|c|c|c|c|}
\hline Hen & $\begin{array}{l}\text { Masonctuselts } \\
\text { Town of } \\
\text { December } 31\end{array}$ & 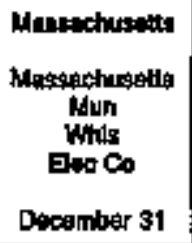 & $\begin{array}{l}\text { Masuachusents } \\
\text { Neddiborouph } \\
\text { Towm of } \\
\text { Deceriater } 31\end{array}$ & $\begin{array}{l}\text { Massachuselis } \\
\text { Nath } \\
\text { Atuborough } \\
\text { Tawn of } \\
\text { December } 31\end{array}$ & $\begin{array}{l}\text { Magandhuselts } \\
\text { Morwood } \\
\text { Chy of } \\
\text { Lne } 30\end{array}$ & $\begin{array}{l}\text { Massachusott. } \\
\text { Poabady } \\
\text { Ciny of } \\
\text { Decenaber \$1 }\end{array}$ \\
\hline 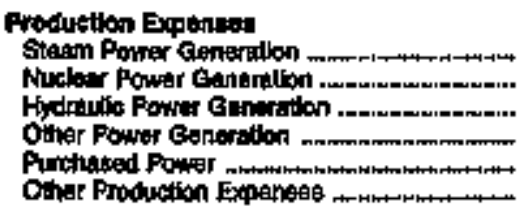 & $\begin{array}{r}0 \\
0 \\
0 \\
0 \\
15,120 \\
0\end{array}$ & $\begin{array}{r}601 \\
31,600 \\
12,009 \\
59,6000 \\
17\end{array}$ & $\begin{array}{r}0 \\
0 \\
0 \\
0 \\
72,472 \\
0\end{array}$ & $\begin{array}{r}218 \\
0 \\
0 \\
0 \\
10,775 \\
0\end{array}$ & $\begin{array}{r}0 \\
0 \\
0 \\
0 \\
21,320 \\
0\end{array}$ & $\begin{array}{r}0 \\
0 \\
0 \\
351 \\
2090 \\
0\end{array}$ \\
\hline 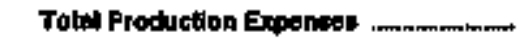 & 15,160 & 103,501 & 12,472 & nogat & 21,320 & 20,541 \\
\hline 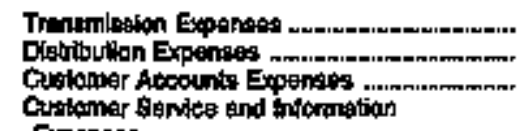 & $\frac{0}{\pi}$ & $\begin{array}{r}4,004 \\
0 \\
0\end{array}$ & $\begin{array}{r}76 B \\
1,266 \\
682\end{array}$ & $\begin{array}{l}600 \\
790 \\
497\end{array}$ & $\begin{array}{r}0 \\
1,209 \\
402\end{array}$ & $\begin{array}{r}170 \\
1,280 \\
600\end{array}$ \\
\hline 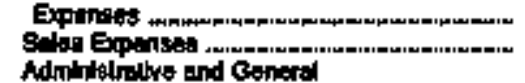 & 0 & 0 & $\stackrel{0}{32}$ & $\begin{array}{r}79 \\
0\end{array}$ & $\mathbf{0}$ & 0 \\
\hline 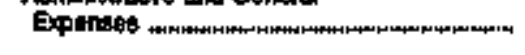 & 798 & taxegs & 1,288 & 1,142 & 1,253 & 3,332 \\
\hline $\begin{array}{l}\text { Totol Elestro Oparstion and } \\
\text { Maintenante Expeniest }\end{array}$ & t6,a59 & 121,247 & 16,346 & 14,295 & 24,585 & 9to003 \\
\hline \multicolumn{7}{|l|}{ Fund Expenese in cpartion } \\
\hline Stem Pomer Generalion & 0 & 39 & 0 & 140 & 0 & - \\
\hline 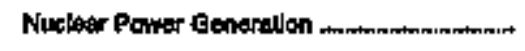 & 0 & 7,6000 & 0 & 0 & D & 0 \\
\hline Other Powar Genenation & 0 & 1.429 & 0 & 0 & 0 & 114 \\
\hline \multicolumn{7}{|l|}{ Nomber of tace Dept Employseas } \\
\hline 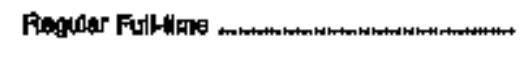 & 21 & 126 & 40 & 25 & $\mathbf{5 0}$ & $\mathbf{E}$ \\
\hline 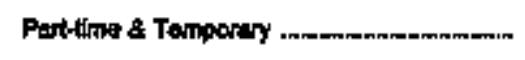 & $\mathbf{t}$ & 1 & a & 2 & 0 & 14 \\
\hline 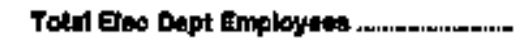 & 20 & 130 & 12 & $\mathbf{3 0}$ & 50 & 由1 \\
\hline
\end{tabular}

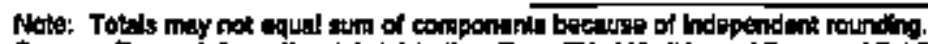

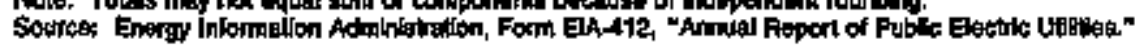


Table 29. Electrle Operation and Malntenance Expenses by Major U.S. Publlely Owned Electrlc Utilly Within State, 1994 (Continued) (Thousanand Dollars)

\begin{tabular}{|c|c|c|c|c|c|c|}
\hline & Hesenchusitits & Ltassachustedi: & Mresechreatts & Alagsarduratitg & 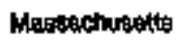 & Mascoctwatits \\
\hline Ilem & $\begin{array}{l}\text { Reading } \\
\text { Town ol }\end{array}$ & $\begin{array}{l}\text { Strrewribury } \\
\text { Town of }\end{array}$ & $\begin{array}{l}\text { Texmitul } \\
\text { Ety of }\end{array}$ & $\begin{array}{l}\text { Wekeffind } \\
\text { Town of }\end{array}$ & $\begin{array}{l}\text { Weiletily } \\
\text { Town of }\end{array}$ & $\begin{array}{l}\text { Whattigld } \\
\text { City of }\end{array}$ \\
\hline & Destmber 31 & Decelntar 31 & Decendber 31 & Dacember $\$ 1$ & Deosmber 31 & Dacentber 31 \\
\hline
\end{tabular}

\section{Producton Expan:er:}

sian Fowar Cerdition

Nuplear Power Eenuration . .

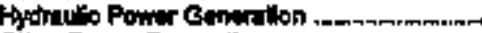

Othor Power Generation

Punchlowd Powror

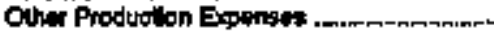

Total Grodudion Expente:

Trtentidiston Hxpentis:

Oletibution Expongeg

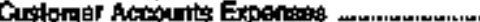

Cualoner senvise and inlometion

Expenses

Salat Exponsots

Adminithretwe and Conora

Bxpan17tat

Total Glectric Oporallom and

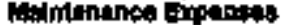

Fund Exponse In Operalon

Steam Power Benmator

Phuclace Power cenaration

Dthor Fower Cenaralion

Nomber of Elate Dopt Employsopa

Regulor Fadlitime

Purting \& Tenporary

80

0

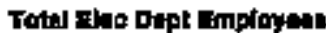

0
0
0
0
39,200

0
0
0
1469
14,867
180

39,200

2403

1,604

280

2270

45,76

$15,1+5$

512

$\cos$

345

0

121

1,362

18,309
7,136

0

713

190

301

200672
246

2474

$1,36:$

6

4,694

아와서

14tatst

0
1,000

345

$\begin{array}{rr}0 & 0 \\ 0 & 0 \\ 0 & 0 \\ 0 & 0 \\ 10,570 & 21,284 \\ 0 & 28\end{array}$

I1)

10576

216:51

209
1,420

$1,2 \pi 4$

2,130

1,179

12

20

2,551

TWT

13,46t.

2895

\begin{tabular}{|c|c|c|c|c|c|}
\hline 0 & $\mathbf{0}$ & 2,348 & 0 & 0 & 0 \\
\hline & 0 & 0 & 0 & 0 & 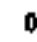 \\
\hline & 24 & 218 & 0 & 0 & \\
\hline
\end{tabular}

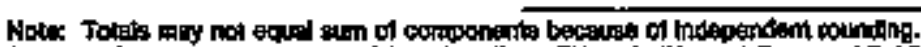

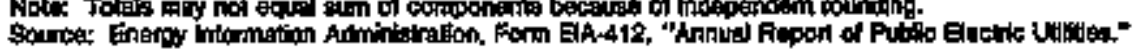


Table 23. Elactrlc Operation end Maintenance Expensed by Major U.S. Publicly Owned Electric titily Within State, 1994 (Continued)

(Thousand Dollers)

\begin{tabular}{|c|c|c|c|c|c|c|}
\hline Hem & 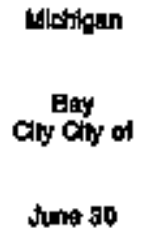 & 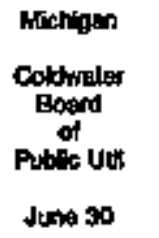 & 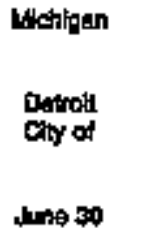 & $\begin{array}{l}\text { Mrigigan } \\
\text { Cingd Havert } \\
\text { Chy of } \\
\text { Jung so }\end{array}$ & 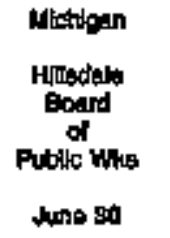 & $\begin{array}{l}\text { Mrenigan } \\
\text { Holand } \\
\text { Chy od } \\
\text { Jima sD }\end{array}$ \\
\hline 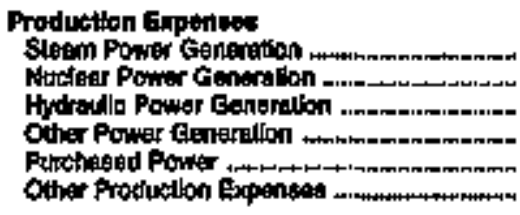 & $\begin{array}{r}0 \\
0 \\
0 \\
0 \\
10,19 \frac{9}{2} \\
0\end{array}$ & $\begin{array}{r}120 \\
0 \\
0 \\
146 \\
6,2-16 \\
0\end{array}$ & $\begin{array}{r}17,259 \\
0 \\
0 \\
0 \\
14,113 \\
0\end{array}$ & $\begin{array}{r}2514 \\
0 \\
0 \\
145 \\
122 \\
1 \leq 0\end{array}$ & $\begin{array}{r}0 \\
0 \\
0 \\
6 \pi, 37 \\
0\end{array}$ & $\begin{array}{r}10,560 \\
0 \\
0 \\
302 \\
14,509 \\
0\end{array}$ \\
\hline 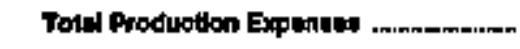 & 0,192 & exter & 31,342 & 5030 & 7,048 & 25,467 \\
\hline 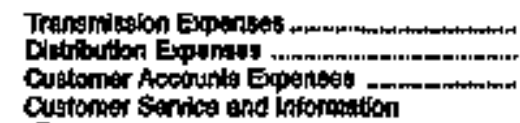 & $\begin{array}{r}0 \\
2,07 t \\
0\end{array}$ & $\begin{aligned} 0 \\
430 \\
430\end{aligned}$ & $\frac{1,008}{9,308}$ & $\begin{array}{r}0 \\
654 \\
276\end{array}$ & $\begin{array}{r}9 \\
385 \\
-12\end{array}$ & $\begin{array}{r}0 \\
1,647 \\
309\end{array}$ \\
\hline 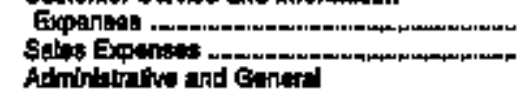 & o & $\stackrel{0}{0}$ & $\stackrel{0}{0}$ & 兽 & 2 & $\$$ \\
\hline 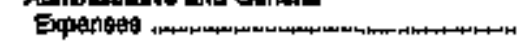 & 1,624 & 68 & 18,185 & 1,120 & $\mathbf{3 4 4}$ & 1,506 \\
\hline 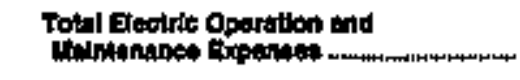 & 14,0089 & B,745 & spestas & 11,994 & $7,7 t-1$ & 29,117 \\
\hline \multicolumn{7}{|l|}{ Fuel Expenses h Operditan } \\
\hline Blegm Power Gonerations & 0 & $\mathbf{0}$ & 10.590 & 7,795 & o & $7,5 \times$ \\
\hline 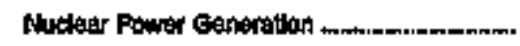 & $\mathbf{0}$ & 0 & 0 & 0 & 0 & 0 \\
\hline OVher Power Genoraten & $\mathbf{0}$ & 81 & 0 & 27 & 67 & 390 \\
\hline \multicolumn{7}{|l|}{ Humbor of Erec Dapd Employest: } \\
\hline 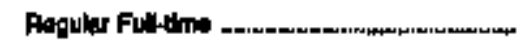 & 42 & 17 & 110 & 64 & 28 & $m$ \\
\hline Fart-tine \& Temporany & 0 & o & 0 & 1 & 0 & o \\
\hline Toted Elec Depl Enployaes . & 42 & 17 & 110 & 65 & 20 & $\mathbf{7 1}$ \\
\hline
\end{tabular}

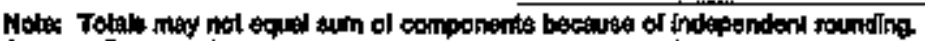

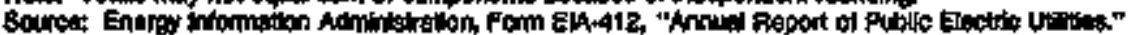


Tabie 23. Electrio Oporation and Maintenance Expenses by Mejor U.S. Publicly Owned Electrio Utility Withln State, 1994 (Continued)

(Thousand Dollers)

\begin{tabular}{|c|c|c|c|c|c|c|}
\hline \multirow{3}{*}{ nem } & allinging & Alchigen & A & Whyight & Mithigan & Mliariogen \\
\hline & Latho & Mancyolip & $\begin{array}{c}\text { Mochion } \\
\text { Publitio } \\
\text { Powner Adoney }\end{array}$ & 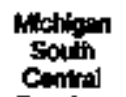 & shomos of & $\begin{array}{l}\text { Tranerse } \\
\text { Cry City of }\end{array}$ \\
\hline & Junna as & Whe 30 & Decomperer 51 & June 30 & September 30 & Jung 30 \\
\hline
\end{tabular}

Prodution sipuntum

Stem Point te

Nucker Rower Congrition

Hydraylic Power Genoration

Other Pownt Coratration

Purchated Fowar

Other Foduction Exphingeg

Total Produrtiont Expentro:

Transiotsition Eponsis:

Ditstionton Experises

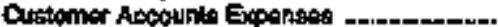

Customer sartes and information

Eipenoses

Selas Exombos _-

Adainatopitive end Generai

Exponses:

41,703

0

0

97, 817

Ta,64

1,300

5,548

2807

246

23,705

114,101

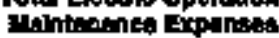

Fued Expentes In Oporition

Shosm Ponver Gendation

Nucteser Powar chenaration

Orher Power Eoneration

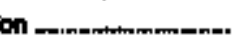

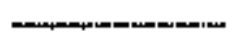

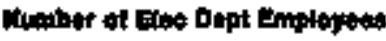

Pogite Futhome

695

Pattine \& Temporiny

31,504

6.701

$\$ 1,001$

8,474

0

$\mathbf{a}$

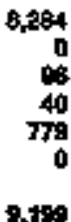

$\$ 7,106$

0
0
0
25503
0

apole

0
0

6,380

6reas

14 -ise

7,959

4

0

4,869

69.486

0

13

0

b

0

162
0
0

0

1,219

19.345

0
706
700
7

1,000

0

12

6.874.

0

490

83

607

243

1,279

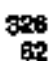

1,047

1,011

11, ats

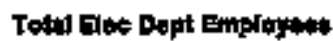

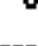

B5

to

50

29

48

d.

o

1

0

cas

6

10

51

o

20

4

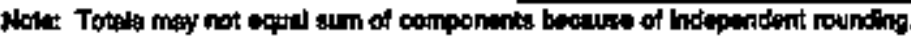

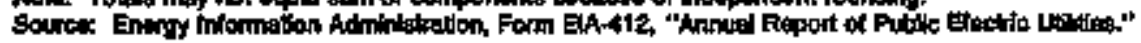


Table 23. Electric Operation and Maintenance Expenses by Major U.S. Publicly Owned Electric Usility Within State, 1994 (Continued) (Thoussand Dollars)

\begin{tabular}{|c|c|c|c|c|c|c|}
\hline Imom & 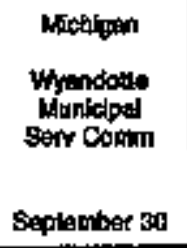 & $\begin{array}{l}\text { Bsibigan } \\
\text { Zeelend } \\
\text { City of } \\
\text { June } 30\end{array}$ & $\begin{array}{l}\text { Monnespot } \\
\text { Alepondita } \\
\text { Cha of } \\
\text { Dacamber } 31\end{array}$ & $\begin{array}{l}\text { Minnesolt } \\
\text { Anoke } \\
\text { City of } \\
\text { Decenter 3t }\end{array}$ & $\begin{array}{l}\text { Mimnosoln } \\
\text { Austin } \\
\text { City of } \\
\text { Deoumbor } 31\end{array}$ & $\begin{array}{l}\text { Minnusole } \\
\text { Antiniad } \\
\text { Ony of } \\
\text { Decomber } 31\end{array}$ \\
\hline 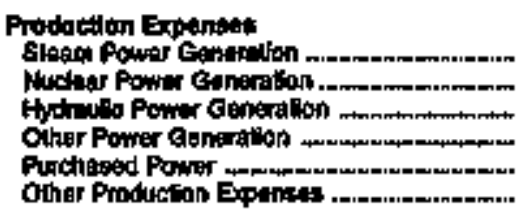 & $\begin{array}{r}11,480 \\
0 \\
0 \\
0 \\
0 \\
0 \\
0\end{array}$ & $\begin{array}{r}0 \\
0 \\
0 \\
7 \leq 3 \\
4,728 \\
0\end{array}$ & $\begin{array}{r}0 \\
0 \\
0 \\
72 \\
4,042 \\
\mathbf{9}\end{array}$ & $\begin{array}{r}0 \\
0 \\
0 \\
0 \\
6,895 \\
0\end{array}$ & $\begin{array}{r}4,405 \\
0 \\
0 \\
0 \\
14,597 \\
50\end{array}$ & $\begin{array}{r}0 \\
0 \\
0 \\
0 \\
5,222 \\
194\end{array}$ \\
\hline 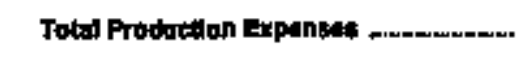 & $11,4: 8$ & 5,461 & 5,023 & 6,945 & 18,998 & 6417 \\
\hline 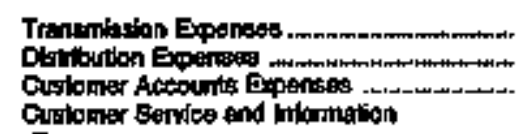 & $\begin{array}{l}714 \\
116 \\
111\end{array}$ & $\begin{array}{r}413 \\
185 \\
0\end{array}$ & $\begin{array}{r}1,007 \\
673 \\
274\end{array}$ & 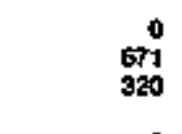 & $\begin{array}{r}0 \\
760\end{array}$ & 604 \\
\hline 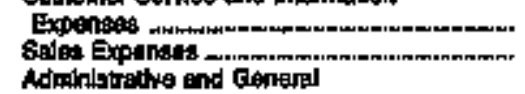 & $\begin{array}{l}317 \\
105\end{array}$ & 78 & $\mathbf{5}$ & 0 & 71 & 0 \\
\hline 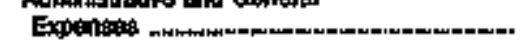 & 2,480 & 472 & 472 & 531 & 697 & 560 \\
\hline 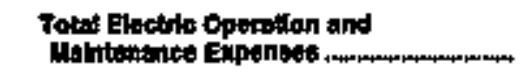 & 15,389 & 9,628 & 7860 & 70,317 & $20 ; 0,03$ & 6581 \\
\hline \multicolumn{7}{|l|}{ Pacl texpenece in Oparation } \\
\hline 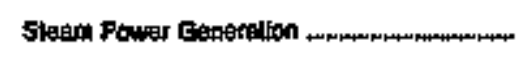 & 7,875 & D & 0 & 0 & 2,002 & 0 \\
\hline Auclew Powis Ganeration & 0 & 0 & o & 0 & o & o \\
\hline Oliner Pomar Generaton .....-................. & 0 & 38 & 37 & $\mathbf{0}$ & o & 0 \\
\hline \multicolumn{7}{|l|}{ 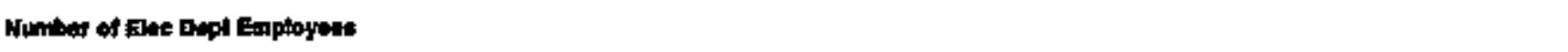 } \\
\hline 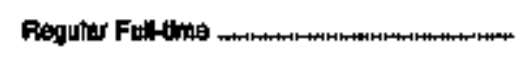 & 74 & 21 & 24 & 19 & 54 & 10 \\
\hline Partume $\&$ Taporery - & a & 4 & a & 6 & 皇 & 4 \\
\hline 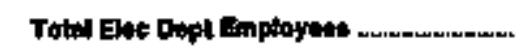 & 74 & st & 24 & 26 & 6if & 14 \\
\hline
\end{tabular}

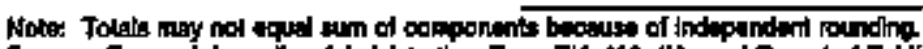

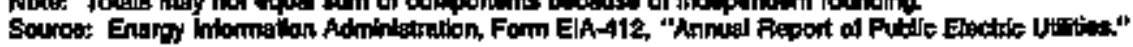


Table 23. Electrlo Operation and Malntenance Expenses by Malor U.S.,Publlciy Owned Electric Utility Within State, 1994 (Continued)

(Thousand Dollars)

\begin{tabular}{|c|c|c|c|c|c|c|}
\hline how & $\begin{array}{l}\text { Miniresote } \\
\text { Chosk } \\
\text { Ciy of } \\
\text { Dacambar } 31\end{array}$ & 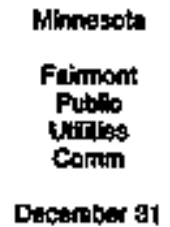 & 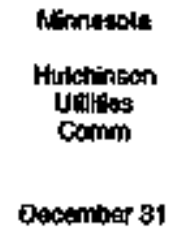 & $\begin{array}{l}\text { Minnosola } \\
\text { Marbinal } \\
\text { Chto of }\end{array}$ & $\begin{array}{l}\text { Whnesols } \\
\text { Noomead } \\
\text { City of } \\
\text { December } 31\end{array}$ & 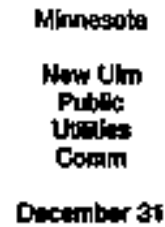 \\
\hline
\end{tabular}

Produntion Experion:

Stom Powion Genwition.

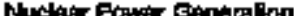

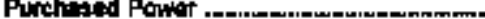

Dther Production Explises

n--2m-mommon

Total Produston Epentea

Tranamiastion Expontses

Dlgtribution Equnges

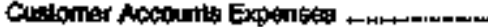

Customer Sorvike and inlomiton

Expenthé

Sula Explatis

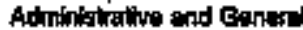

Exparseco

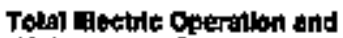

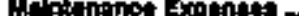

Foel Fipenos in Operntop

Sigum Power Clenaraton

Nudar Fowir Canereftion

Other Powt Gontationt

0
0
0
0
6,734
0

1,260

0

0
8,50

0

4.794

bous

0

490

10

10
501
0

o

0

375

0

ap

7,000

1.,

0

0
0
0
2,700

4,707

7,400

10

109

104

$1 \%$

0

9우웅

apes

o

0
0
0
0
0,743

84

84
0
0
84
7,894
0

3,090

0

0

29

357

B, $6: 9$

a,tos

0,253

806

get

0

000

at

390

75

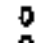

126

18

112

752

798

7,085

11,729

10,075

Nember of Etos Oept Employeat

Ranutar Fulptime

18

24

46

10

20

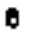

40

Partima 8 Temporty

0

$\mathbf{0}$

0

0

20

1,213

o

$\mathbf{0}$

$\mathbf{1 5}$

24

45

10

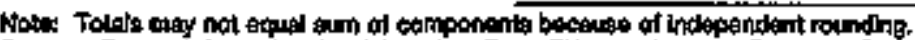

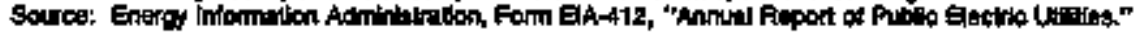


Table 23. Eectrio Operation and Malntenanoe Expenses by Major U.S. Publicly Owned Electrk Utlity Within State, 1994 (Continued)

(Thousand Dollars)

\begin{tabular}{|c|c|c|c|c|c|c|}
\hline ltem & 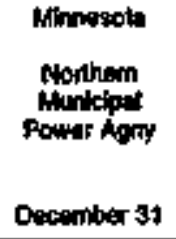 & 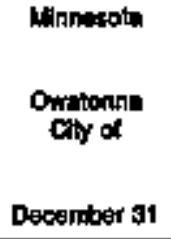 & 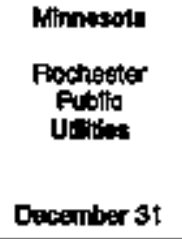 & 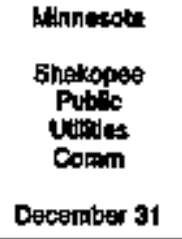 & 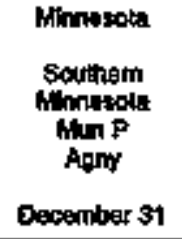 & 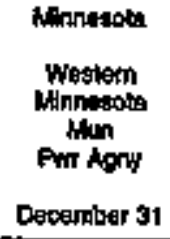 \\
\hline 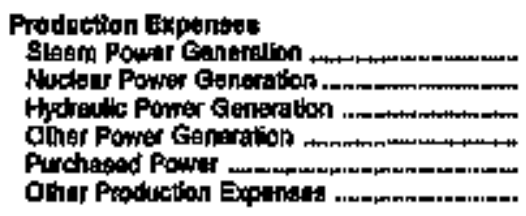 & $\begin{array}{r}13,579 \\
0 \\
0 \\
0 \\
0 \\
0\end{array}$ & $\begin{array}{r}0 \\
0 \\
0 \\
677 \\
14,479 \\
0\end{array}$ & $\begin{array}{r}7,584 \\
0 \\
791 \\
131 \\
19,697 \\
269\end{array}$ & $\begin{array}{r}0 \\
0 \\
0 \\
0 \\
8,028 \\
0\end{array}$ & $\begin{array}{r}33,274 \\
0 \\
0 \\
0 \\
14,003 \\
870\end{array}$ & $\begin{array}{r}19.415 \\
0 \\
0 \\
0 \\
0 \\
0\end{array}$ \\
\hline Tolol Production Expantest & $12, \mathbf{5 7 9}$ & $\mathbf{t} 6,368$ & 87,800 & 6,an: & s2,15t & to,4ts \\
\hline 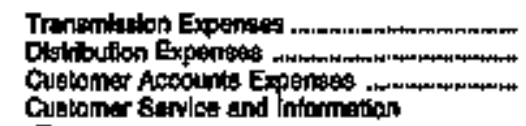 & $\begin{array}{r}731 \\
0 \\
0\end{array}$ & $\begin{array}{r}0 \\
1,044 \\
390\end{array}$ & $\begin{array}{r}229 \\
1,809 \\
009\end{array}$ & $\begin{array}{r}0 \\
\$ 9318 \\
143\end{array}$ & $\begin{array}{r}\sin \\
0 \\
0\end{array}$ & $\begin{array}{r}\infty 6 \\
0 \\
0\end{array}$ \\
\hline 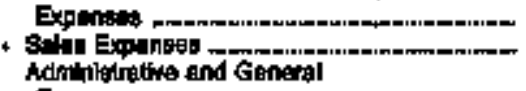 & $\stackrel{0}{0}$ & 49 & 80 & $\stackrel{0}{0}$ & $\begin{array}{l}0 \\
0\end{array}$ & $\begin{array}{l}\mathbf{0} \\
\mathbf{0}\end{array}$ \\
\hline Erpenses & 236 & 40 & 3,160 & 206 & 4,214 & 2,768 \\
\hline 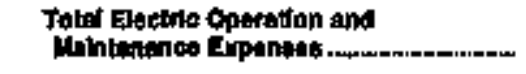 & 14,615 & 17,057 & 04,148 & 7,0 tot & 68,02 & 22,70 \\
\hline \multicolumn{7}{|l|}{ Fue Expeniass la Oparation } \\
\hline Stawn Power Conoralion ................... & 7298 & 0 & 4,717 & 0 & 25,020 & 10,900 \\
\hline 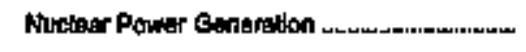 & 0 & 0 & 0 & 0 & 0 & 0 \\
\hline 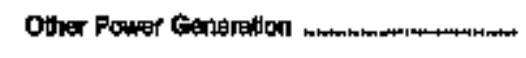 & 0 & 6 & 89 & 0 & D & 0 \\
\hline \multicolumn{7}{|l|}{ Wumber of Eec Dopt Employeet } \\
\hline Feguler Fulbllne . . & 0 & $\$ 7$ & 169 & 13 & 37 & 0 \\
\hline 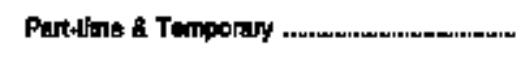 & 0 & 0 & 0 & 7 & 0 & 0 \\
\hline Total Elec Dapt Employeate & $\mathbf{0}$ & $\mathbf{3 7}$ & 156 & 20 & 37 & a \\
\hline
\end{tabular}

Nolf; Totus mey not equal sum of componala beceuse of indopurdient rounding.

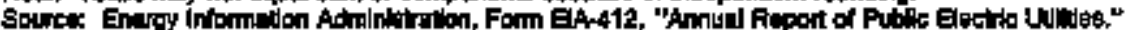


Table 23. Electric Operation and MaIntenance Expensets by Major U.S. Publiely Owned Electric Utalky Whin State, 1994 (Continued)

(Thousand Dollars)

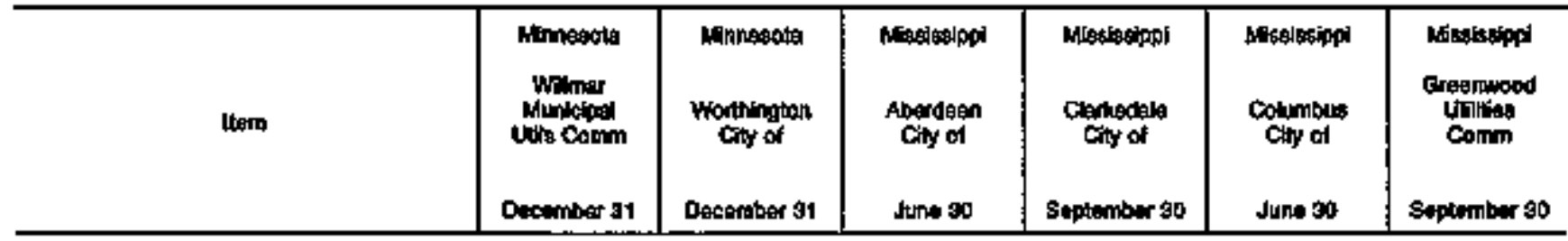

Produxtlon Expunas:

Sta:m Pows Gentention

Mudrar Power Grneration...._...............

Hydrad le Powner Genaralion

Other Power Ganoration --

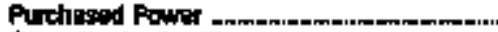

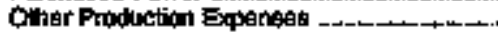

Total Prodocton Expenses

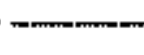

Transmiasion Expanase

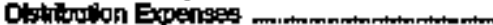

Cistomer Aceocints Expenses ..................

Guaboner Sonves and information

Expensags

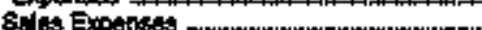

Adiminiotrative and General

Expintses

Totol Giectite 0peration and

Hainiapanco exponstos
1,890

0
0
0
4,584

4.594

6,444

44

695

185

0

1,006

8.406

0
0
0
0
7205
0

7,206

27

10

40

7

246

7,066
7986

0

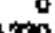

8,500

10,291

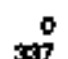

184

0

792

10,004

20,010

220

4

552
1,087

0

948

407

11,394

0

191

1,0 s

19,244

Fued Expenses In Oparabion

Sinam Powe Bonmation

1,213

0

3945

○

o

n

0

781

0

0

Oither Power Generetion

0

0

0

0

37

3

73

0

37

8

Total Zise Dept Emplaysed

45

11

14

o

0

7

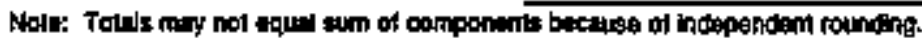

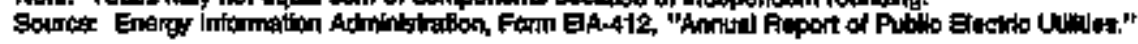


Table 23. Etectric Operation and Meintenance Expenses by Major U.s. Publloly Owned Electric Utility Within State, 1994 (Continued) (Thousand Dollars)

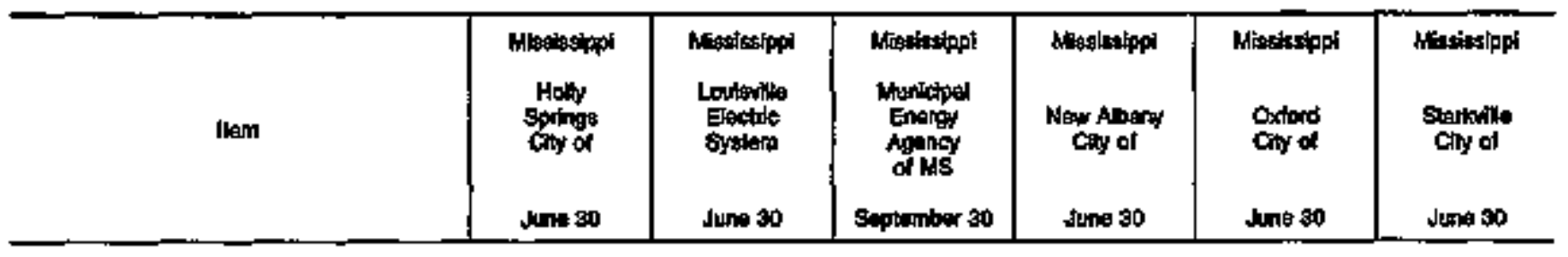

Prodution Exomes

Skan Power Geniration

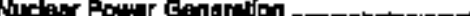

Hydraul's Power Gentarith

Othit Powter Ganeratich

Puchaised Foint

Tohd Production Expantite

Trangration Expenser

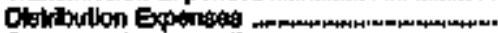

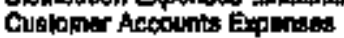

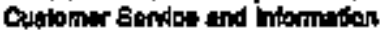

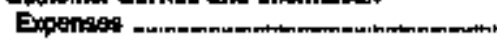

Sales Expentas

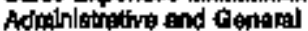

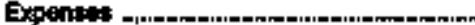

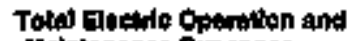

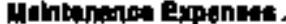

0
0
0
0
$0,7+9$
0

P.7.69

0
0.49

290

10

206

0,951

0
0
0
0
7,000
0

7,0

0

350

09

9

28

296

7,797

0
0
0
0
27,095
0

27,658

2,75t

0

0

48

40683

0
0
0
0
11,390
0

t1, 300

0

的3

222

4

12

297

12556

$\begin{array}{rr}0 & 0 \\ 0 & 0 \\ 0 & 0 \\ 0 & 0 \\ 7,111 & 14,511 \\ 0 & 0\end{array}$

$7.11 t$

14,5tt

0

359

137

20

30

180

$7,60 \%$

1.

Fud Exptrines In Oparitiom

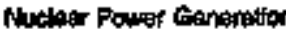

t

o

o

$$
0
$$

n

$\mathbf{0}$

$\begin{array}{rr}4 & 13 \\ 0 & 0 \\ 40 & 13\end{array}$

4
1
5

39

20

32

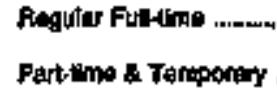

Tobl Elat Dopt Employset

49

5

D

4

D

o

20

52

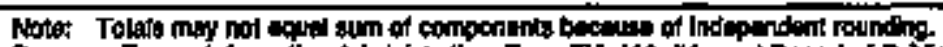

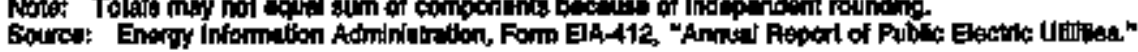


Table 23. Eloctric Operation and Maintenance Expenees by Major US. Publicly Omned Electrlo Utilly Within \$tate, 1994 (Continued) (Thousand Dollars)

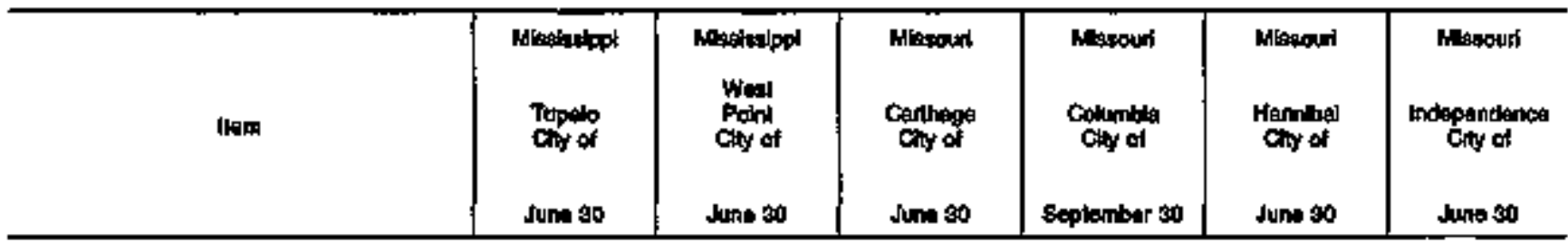

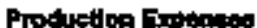

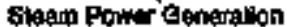

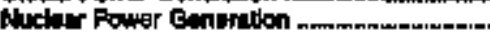

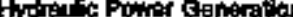

Opher Power Cenrabetion

Purchased Fow

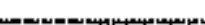

Other Production Expinteges

Tohid Produtiton Exponter

Tronsmasion Expmsat

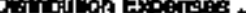

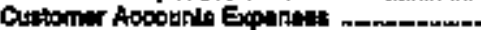

Customer servico and informetton

Impentas

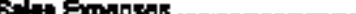

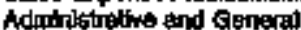

Expina:s

Tolle Elotile Oporalkat fid

Maintenaroe Expenatit

\section{.}

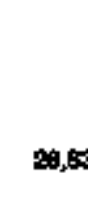

0
0
0
0

0
0
0
0
0
0

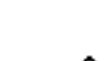

28,001

ges

2.01

0
0
0
418
6,671
70

4.500
0
0
0
25,773
11

0
0
0
7,605
0

30,910

7.635

0,077
1,258

0
467
130

6,053
0
0
642
10,523
476

422

67

sases

\section{Fapio Txponate in Oparation}

Sten Porm Gineralon

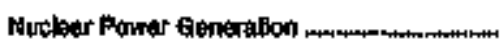

Dther Rouror Clenturidon

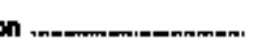

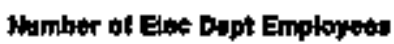

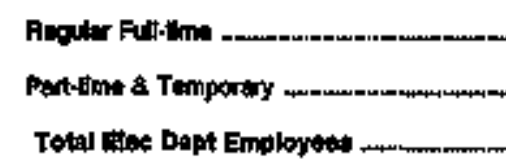

0
0
0

0

0
0
208

2050
0

$\begin{array}{lr}0 & 2201 \\ 0 & 0 \\ 0 & 358\end{array}$

\begin{tabular}{rrrrrr}
52 & 12 & 36 & 202 & 33 & 206 \\
0 & 0 & 0 & 0 & 0 & 0 \\
62 & 12 & 96 & 210 & 33 & 206 \\
\hline
\end{tabular}

Note: Totals may not equal sum of somponenis becisuse of thdependent rounding

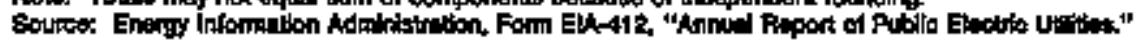


Table 23. Electrio Operation and Maintenance Expenses by Mejor U.S. Pubilcly Owned Eloctrio Villty Withlo State, 1994 (Continured)

(Thousand Dollars)

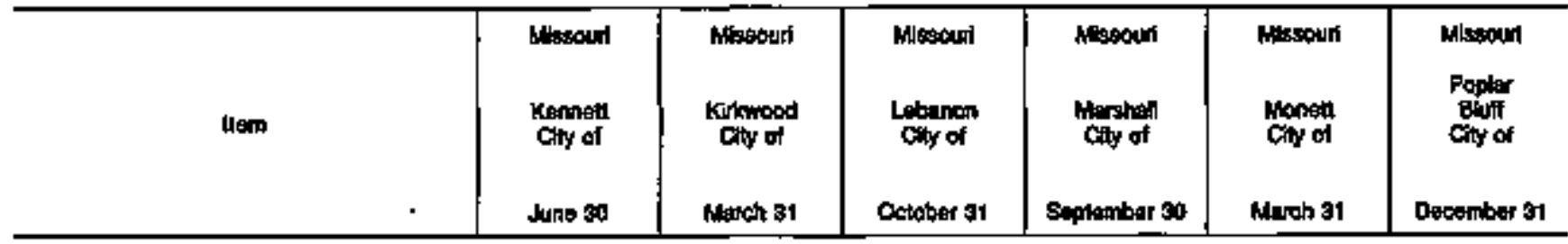

\section{Produed an Exponas.}

Stegm Powar Gentridion

Nuchaar Row Ger Generation.

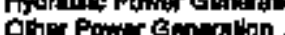

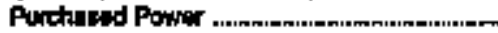

Olher Produetion Expenses

Tolut Produtiton Expanass

Traitinkstan Expenses.

Cralifurtion Expentes

Culomar rocolnts Expentiss ...mmm.n.m.

Drtomar service end hitormation

Expentios

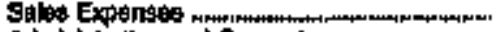

Administratrog and Ganemal

Expentes:

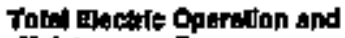

Mulatinanos Exponues -

\section{Fut Explantode In Oparation}

Sigun Fows Gentertion

Nuclear Power Gmwabion

2010

Other Pawer Generation

Numbe of Eac bept Employase

Regutiar Fultorio

Fartünd 8 Temporry

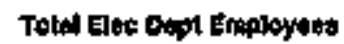

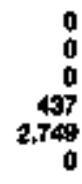

0
0
0
0
7,98
25

3,197

7,568

654

100

1,006
166

o

407

4,240

0

379
3,000

0

1,791

4021

6,958

1,495

0

207

to,sso

t,379

o

o

0

0

5

2t

0
0
0
0
6,309
0

9

21

6,114
129

4:2014

0

0

0

1,491

8887

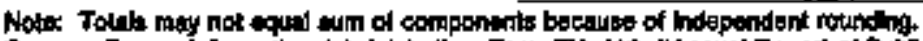

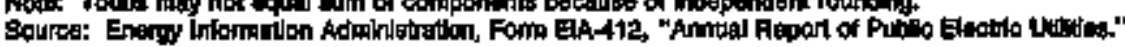


Table 23. Electric Operation and Meintenance Expenses by Major U.S. Publicly Owned Electric Utillity Whin State, 1994 (Continued) (Thousand Dollars)

\begin{tabular}{|c|c|c|c|c|c|c|}
\hline tem & 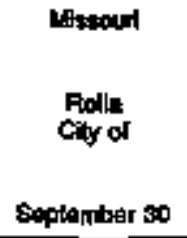 & $\begin{array}{l}\text { Nispoud } \\
\text { sulpotorn } \\
\text { Chy of } \\
\text { Mey } 31\end{array}$ & $\begin{array}{l}\text { Mhoout } \\
\text { Spingield } \\
\text { City of } \\
\text { Soptominer ao }\end{array}$ & $\begin{array}{l}\text { Nebraskn } \\
\text { Epatices } \\
\text { City ol } \\
\text { July \$1 }\end{array}$ & 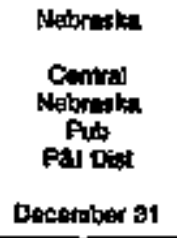 & 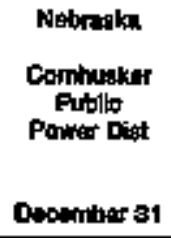 \\
\hline 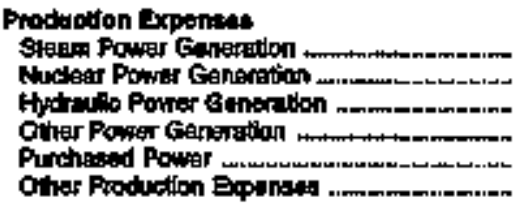 & $\begin{array}{r}0 \\
0 \\
0 \\
0 \\
0 \\
0 \\
0 \\
0\end{array}$ & $\begin{array}{r}28,675 \\
0 \\
0 \\
0 \\
3,205 \\
0\end{array}$ & $\begin{array}{r}41,849 \\
0 \\
0 \\
1,429 \\
13,967 \\
0\end{array}$ & $\begin{array}{r}0 \\
0 \\
0 \\
0 \\
4.913 \\
0\end{array}$ & $\begin{array}{r}2902 \\
0 \\
2714 \\
0 \\
0 \\
0\end{array}$ & $\begin{array}{r}0 \\
0 \\
0 \\
0 \\
0.49 \\
0\end{array}$ \\
\hline Toty Production Expans:s & 6,90: & $29, a 81$ & 57,045 & 4913 & 5,706 & 6,491 \\
\hline 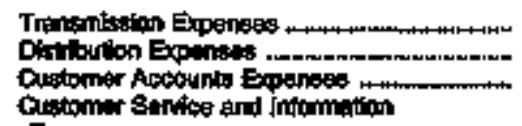 & $\begin{array}{r}0 \\
354 \\
148\end{array}$ & $\begin{array}{r}0 \\
\mathbf{2} 89\end{array}$ & $\begin{array}{r}188 \\
8,727 \\
1,648\end{array}$ & $\begin{aligned} 0 \\
559 \\
t 00\end{aligned}$ & $\begin{array}{r}26 \\
0 \\
0\end{array}$ & $\begin{array}{r}17 \\
610 \\
249\end{array}$ \\
\hline 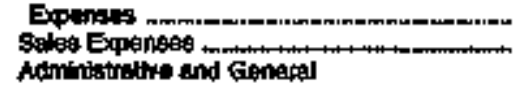 & 0 & $\begin{array}{l}0 \\
0\end{array}$ & $\stackrel{0}{0}$ & 115 & $\stackrel{0}{0}$ & $\begin{array}{l}\text { 97 } \\
19\end{array}$ \\
\hline Expents - & 413 & 8,045 & 8,516 & 394 & 20184 & $\mathbf{B 1 2}$ \\
\hline 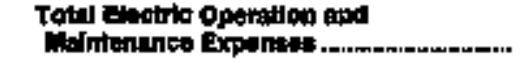 & 9,400 & 34,298 & 76,0* & 5,006 & 8,596 & o,pes \\
\hline \multicolumn{7}{|l|}{ Ful Eypanases In Oporation } \\
\hline 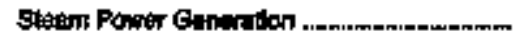 & 0 & 20,277 & 27,348 & $\mathbf{0}$ & 2,404 & 0 \\
\hline Mxdear Poww Genabibion & 0 & 0 & $\bullet$ & $\mathbf{0}$ & 0 & $\mathbf{0}$ \\
\hline Othar Power Genterition & 0 & 0 & 1,200 & 0 & 0 & $\mathbf{0}$ \\
\hline \multicolumn{7}{|l|}{ 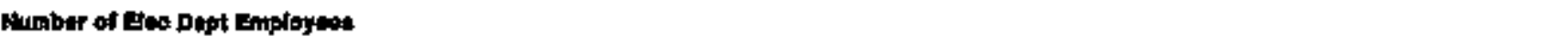 } \\
\hline 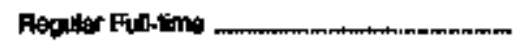 & 23 & 144 & 142 & 81 & 74 & 48 \\
\hline Put-tme \& Temporay ....- & 1 & 0 & 5 & $\mathbf{6}$ & 5 & 4 \\
\hline Tola1 Eoo Dopt Employses: & 24 & 144 & 147 & 69 & 7 & $\mathbf{5}$ \\
\hline
\end{tabular}

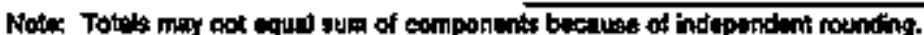

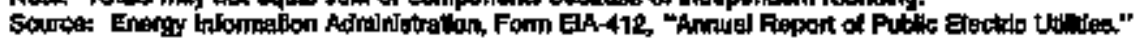


Table 29. Electrio Operation and Malntenance Expenises by Mejor U.S. Publlcty Owned Electris Util'ty Whin State, 1994 (Continuted)

(Thousand Dollars)

\begin{tabular}{|c|c|c|c|c|c|c|}
\hline Item & $\begin{array}{l}\text { Nebratke } \\
\text { Damins } \\
\text { County } \\
\text { Pubtic } \\
\text { Pur Dist } \\
\text { Oecember \$1 }\end{array}$ & $\begin{array}{l}\text { Hobresiad } \\
\text { Fromont } \\
\text { Chy of } \\
\text { Juty } 31\end{array}$ & $\begin{array}{l}\text { Nebraska } \\
\text { Grand Inind } \\
\text { Gity of } \\
\text { suly } 31\end{array}$ & $\begin{array}{l}\text { Nebragkp } \\
\text { Hastings } \\
\text { City of } \\
\text { Dagainder } 31\end{array}$ & 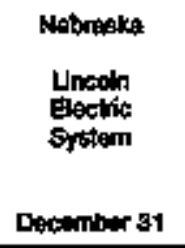 & 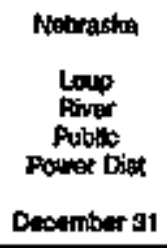 \\
\hline 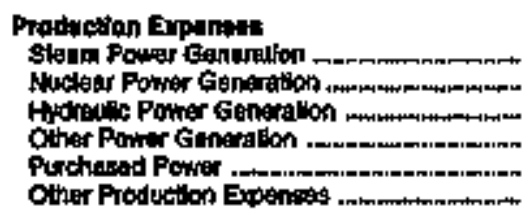 & $\begin{array}{r}0 \\
0 \\
0 \\
0 \\
0,599 \\
0\end{array}$ & $\begin{array}{r}5,578 \\
0 \\
0 \\
0 \\
3,095 \\
4\end{array}$ & $\begin{array}{r}7,762 \\
0 \\
0 \\
0 \\
788 \\
0\end{array}$ & $\begin{array}{r}0,327 \\
0 \\
0 \\
2,000 \\
0\end{array}$ & $\begin{array}{r}13,702 \\
0 \\
0 \\
08,5 \\
57,713 \\
1,060\end{array}$ & $\begin{array}{r}0 \\
0 \\
1,294 \\
0 \\
0 \\
0 \\
0\end{array}$ \\
\hline Toten Producilen Expenies & 0,699 & 6,616 & 0,550 & 7,005 & 73,161 & 29,85: \\
\hline 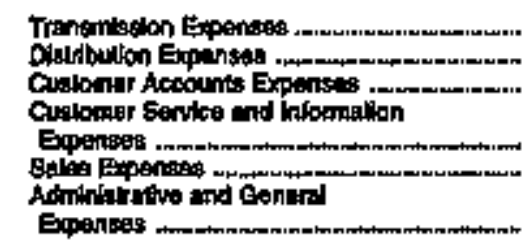 & $\begin{array}{r}19 \\
1,191 \\
412 \\
199 \\
54 \\
1,222\end{array}$ & $\begin{array}{r}0 \\
1,113 \\
220 \\
0 \\
0 \\
1,709\end{array}$ & $\begin{array}{r}129 \\
8020 \\
0 \\
0 \\
0 \\
2,400\end{array}$ & $\begin{array}{r}101 \\
403 \\
200 \\
41 \\
0 \\
1,305\end{array}$ & $\begin{array}{r}2,391 \\
5,806 \\
2,217 \\
1,881 \\
0 \\
5,818\end{array}$ & $\begin{array}{r}285 \\
859 \\
503 \\
112 \\
86 \\
\\
2128\end{array}$ \\
\hline Toun Eteotrio Oportilon and & 11,660 & 90600 & 12,492 & 6,765 & 21,4t1 & \$9,515 \\
\hline \multicolumn{7}{|l|}{ Fuel Expones it Optration } \\
\hline 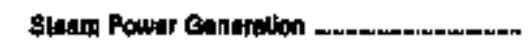 & 0 & 2634 & 4,818 & 4,198 & 0,254 & D \\
\hline 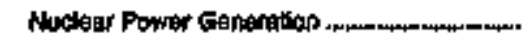 & 0 & 0 & 0 & 0 & 0 & o \\
\hline 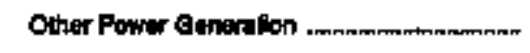 & 0 & n & D & 16 & 305 & o \\
\hline \multicolumn{7}{|l|}{ Number of Eet Dupt Employets } \\
\hline 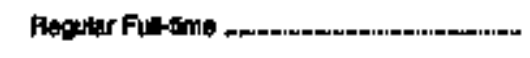 & 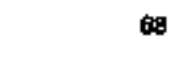 & t11 & 100 & 84 & 997 & \pm 07 \\
\hline 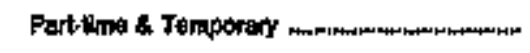 & 0 & 7 & 0 & 1 & 17 & 17 \\
\hline Totet Eho Dept Enploytes: ....nmmnn....... & e9 & 118 & 106 & 8 & 604 & 124 \\
\hline
\end{tabular}

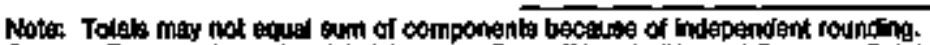

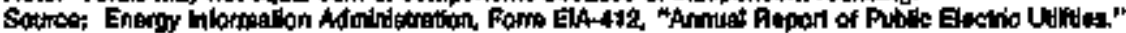


Table 23. Electric Operation and Maintename Expenses by Major U.S. Publioly Ownad Electric Gitily Within State, 1994 (Continued)

(Thousand Dollars)

\begin{tabular}{|c|c|c|c|c|c|c|}
\hline Item & 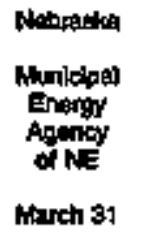 & 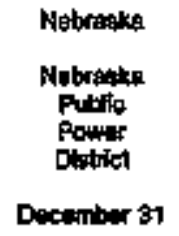 & 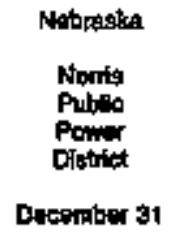 & 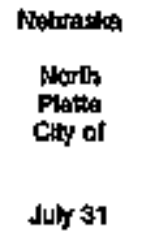 & $\begin{array}{l}\text { Nobraske } \\
\text { Oniphe Fubse } \\
\text { Poenter } \\
\text { Distict } \\
\text { December } 31\end{array}$ & 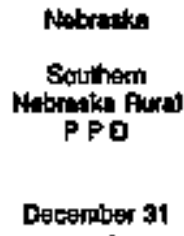 \\
\hline 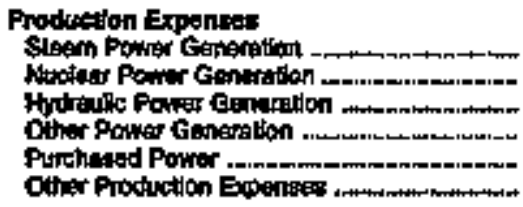 & $\begin{array}{r}2,102 \\
0 \\
0 \\
0 \\
10,8 \times 7 \\
0\end{array}$ & $\begin{array}{r}113,858 \\
01,287 \\
2,130 \\
650 \\
17,741 \\
1,810\end{array}$ & $\begin{array}{r}0 \\
0 \\
0 \\
0 \\
13,408 \\
0\end{array}$ & $\begin{array}{r}0 \\
0 \\
0 \\
0 \\
7,692 \\
0\end{array}$ & $\begin{array}{r}57,551 \\
107,735 \\
0 \\
793 \\
-14,471 \\
10,671\end{array}$ & $\begin{array}{r}0 \\
0 \\
0 \\
0 \\
14,690 \\
0\end{array}$ \\
\hline 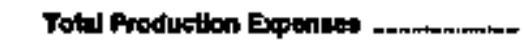 & 20,035 & 267,471 & 18,408 & 7,692 & 172,267 & 14,609 \\
\hline 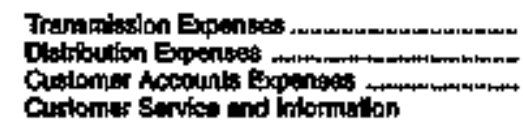 & $\begin{array}{r}3,309 \\
0 \\
0\end{array}$ & $\begin{array}{l}13,642 \\
18,241 \\
10,901\end{array}$ & $\begin{array}{r}5 \% \\
1,971 \\
405\end{array}$ & $\begin{array}{r}30 \\
317\end{array}$ & $\begin{array}{r}3,798 \\
28,090 \\
10,794\end{array}$ & $\begin{array}{r}1 \\
1,390 \\
300\end{array}$ \\
\hline 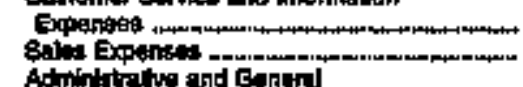 & $\begin{array}{l}0 \\
0 \\
0\end{array}$ & 2,535 & 2003 & $\begin{array}{r}76 \\
0\end{array}$ & $\begin{array}{r}3,675 \\
185\end{array}$ & $\begin{array}{r}114 \\
0\end{array}$ \\
\hline Expentios & 4,169 & 20,483 & Bod & 128 & 18,097 & $1,0 \cos$ \\
\hline Totel Exthe Qperzidion and & 28,110 & arz,gat & 16,958 & 9,106 & 2as;,-66 & 16760 \\
\hline \multicolumn{7}{|l|}{ Fud Expopeses in Optredion } \\
\hline Shum Rower Benuration .................... & $\mathbf{s m}$ & $79, \mathrm{ros}$ & 0 & $\mathbf{0}$ & 38,518 & 0 \\
\hline Nuclagr Powrar Generetion & 0 & 11,067 & 0 & 0 & 38,075 & o \\
\hline Other Power Cenartion .... & 0 & 347 & 0 & 0 & 645 & 0 \\
\hline \multicolumn{7}{|l|}{ 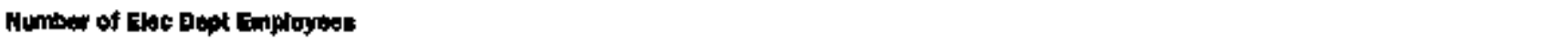 } \\
\hline 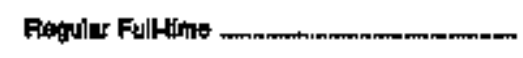 & 38 & 2,252 & 70 & 34 & 2,008 & $n$ \\
\hline Pertimb \& Tempopayy & 6 & 160 & 8 & 0 & 60 & D \\
\hline Totul Elor Dept Employses: & $\mu$ & 2,412 & To & $\$ 4$ & 2,;0s: & 7 \\
\hline
\end{tabular}

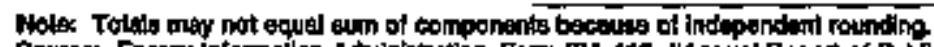

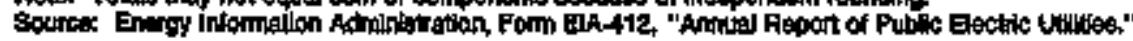


Table 23. Eleotrle Operation and Maintenance Expanses by Major U.S. Publlcly Owned Electric Utillty Withln State, 1994 (Continued) (Thousand Dollars)

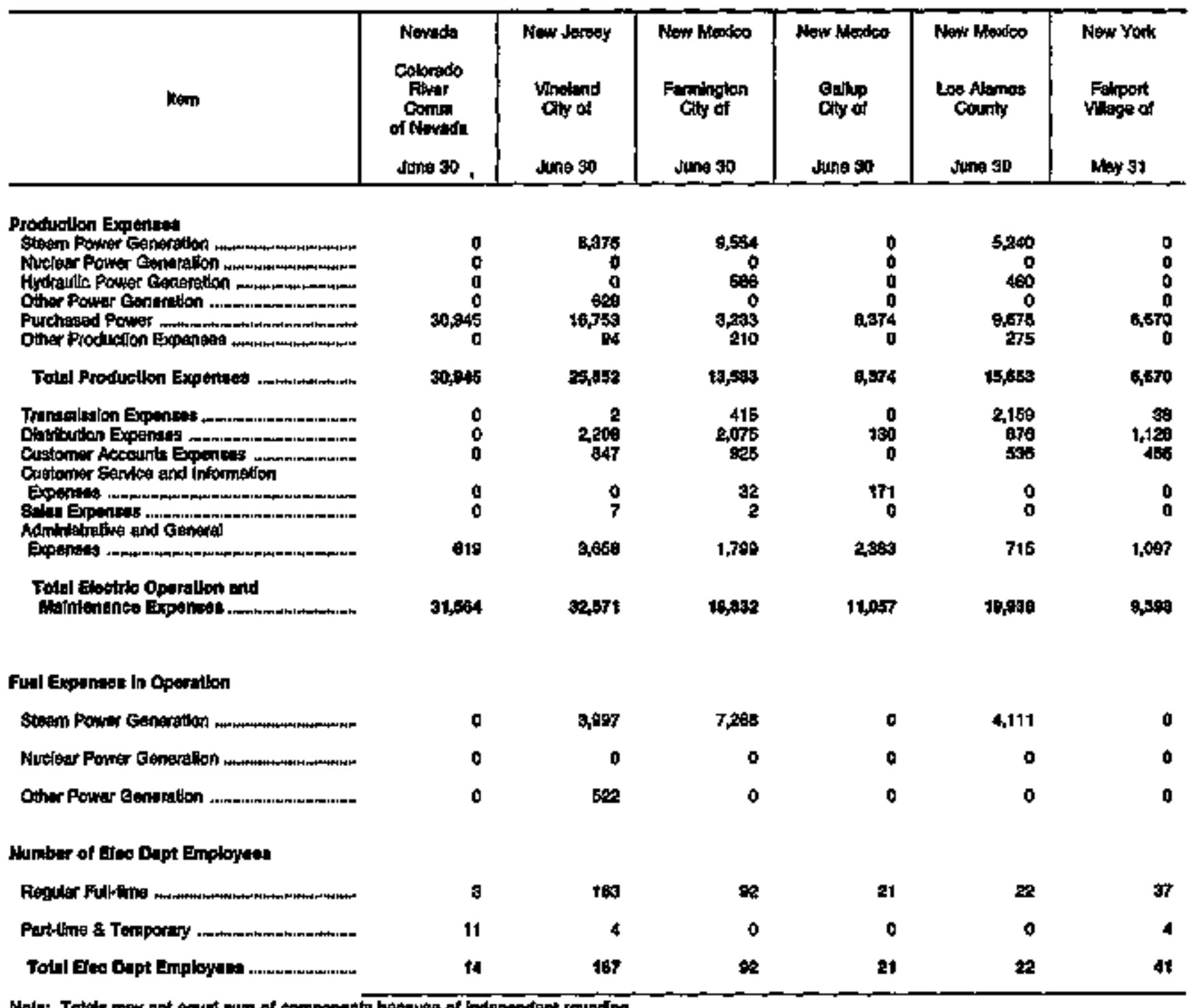

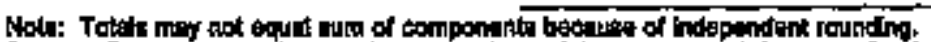

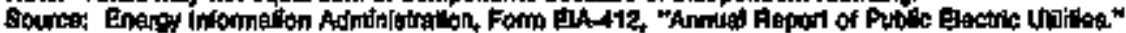


Table 28. Electric Operation and Maintentence Expensess by Major U.S. Publioly Owned Electric Utility Within State, 1994 (Continued)

(Thousand Dollars)

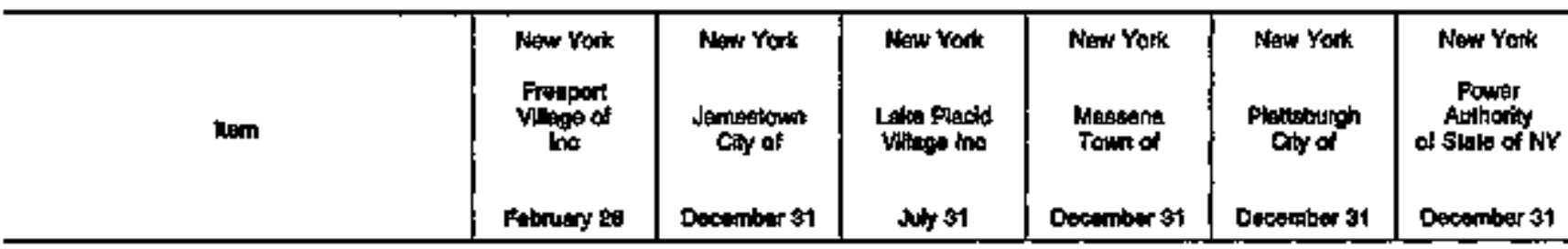

Production Lipensas

Gisem Powar Genariolon

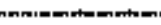

Hydrasto Power Gentidion

Othat Poiver Gingation

Totul Productlon Expanact

Trunsmisxion Expences.

(1)

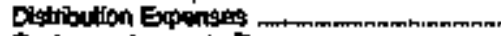

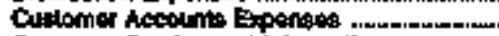

Customer Service and hilcmition

Expenaes

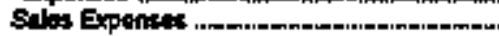

Adminktalve end Cianaral

Empanse:

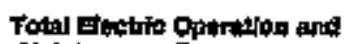

Melintenance Erpaniti:

Fad Exporise in Oparation

sieam Power Gerteration

Shulagr Fowgr Cangrulon

Other Power Conterilon

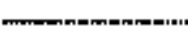

olone

Refoler Fin|Him

Pattume \& Temporisy

92

2

Fotal Elag Dopt Employeas

0
0
0
2,681
4,977

5,772

0

0

5,572

0

7,657

11,343

573

573

\section{0}

91

274 A

11,55

106

t,08:

sot

5

$-8$

1,489

14.98:
0
0
0
0
2,298

2,20.

3,000

c

to

101

0

101

609

201

o

170

3,311
0
0
0
0
0
0
0

14A9

15

437

1, t50,73:

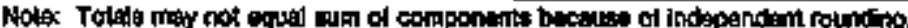

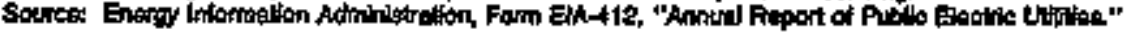


Table 23. Electric Operation and Maintenance Expenses by Major U.S. Publicly Owned Eloctric Utility Within State, 1994 (Continued) (Thousand Dollars)

\begin{tabular}{|c|c|c|c|c|c|c|}
\hline llem & $\begin{array}{l}\text { Man York } \\
\text { Rookvile } \\
\text { Contre } \\
\text { viloge of } \\
\text { Mays }\end{array}$ & $\begin{array}{l}\text { Nene York } \\
\text { Solray } \\
\text { Vilegg of } \\
\text { Mny } 31\end{array}$ & 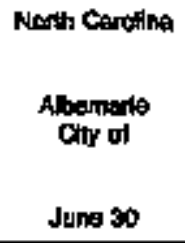 & $\begin{array}{l}\text { Harth Conotina } \\
\text { Conteord } \\
\text { City of } \\
\text { Jure } 30\end{array}$ & 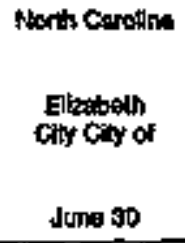 & 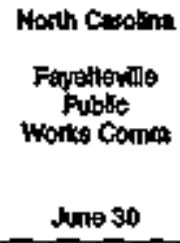 \\
\hline 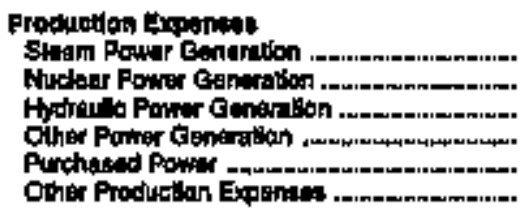 & $\begin{array}{r}0 \\
0 \\
0 \\
2,585 \\
3,741 \\
0\end{array}$ & $\begin{array}{r}0 \\
0 \\
0 \\
0 \\
2,000 \\
0\end{array}$ & 15,404 & $\begin{array}{r}0 \\
0 \\
0 \\
0 \\
10,283 \\
0\end{array}$ & $\begin{array}{r}0 \\
0 \\
0 \\
0 \\
0\end{array}$ & $\begin{array}{r}0 \\
0 \\
0 \\
13,500 \\
73,555 \\
2\end{array}$ \\
\hline 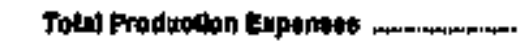 & 5,068 & 2,008 & 16,484 & 10,208 & 18,190 & 87,060 \\
\hline 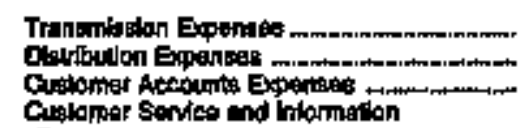 & $\begin{array}{r}49 \\
671 \\
607\end{array}$ & $\begin{array}{r}0 \\
657 \\
187\end{array}$ & $\begin{array}{r}0 \\
1,0054 \\
0\end{array}$ & 8,480 & 2,405 & $\begin{array}{r}147 \\
5,001 \\
1,485\end{array}$ \\
\hline 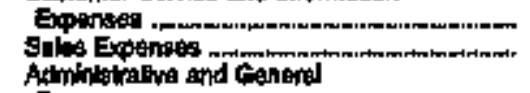 & 0 & $\begin{array}{l}0 \\
0\end{array}$ & : & $\mathbf{0}$ & 217 & 100 \\
\hline 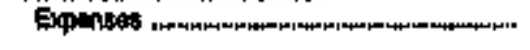 & 90 & 414 & 691 & $\mathbf{7 . 1 1 6}$ & 30 & 4,029 \\
\hline 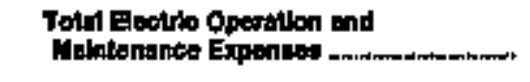 & 7,861 & 3,271 & 17,119 & 29,000 & 20,092 & $\operatorname{mans}$ \\
\hline \multicolumn{7}{|l|}{ Pus Exponsos in Oparation } \\
\hline 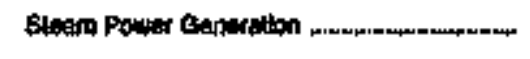 & $\mathbf{0}$ & 0 & 0 & 0 & 0 & 0 \\
\hline Nudder POmer Generation & $\mathbf{0}$ & 0 & 0 & 0 & 0 & $\mathbf{0}$ \\
\hline 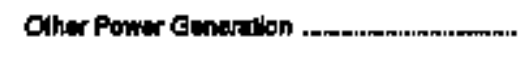 & 96* & $\mathbf{0}$ & o & a & 0 & 1.240 \\
\hline \multicolumn{7}{|l|}{ Wumber of Enc Dap Employot } \\
\hline 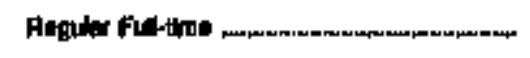 & 43 & 22 & 22 & 47 & 20 & क्षा \\
\hline 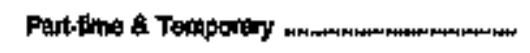 & 1 & 3 & t & o & 0 & 6 \\
\hline 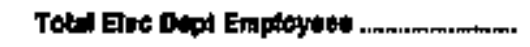 & 4 & $\mathbf{2 6}$ & 23 & $\mathbf{A T}$ & 20 & 202 \\
\hline
\end{tabular}

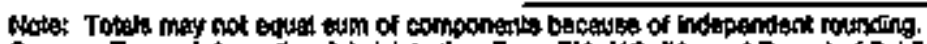

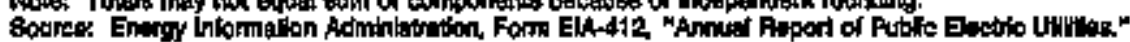


Table 23. Electrlc Operation and Maintenance Expenses by Mojor U.S. Publicly Omned Electric (tility Within 8tate, 1994 (Continued) (Thousand Dollars)

\begin{tabular}{|c|c|c|c|c|c|c|}
\hline $\operatorname{lom}$ & 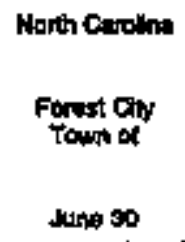 & 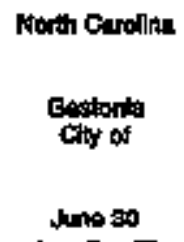 & 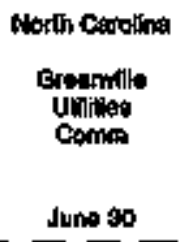 & $\begin{array}{l}\text { North Ceroura } \\
\text { High } \\
\text { Pown } \\
\text { of } \\
\text { June } 30\end{array}$ & 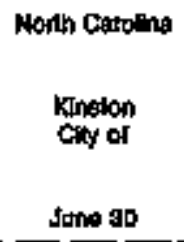 & $\begin{array}{l}\text { North Garcline } \\
\text { Lesdinglon } \\
\text { Cily of } \\
\text { Juno } 30\end{array}$ \\
\hline 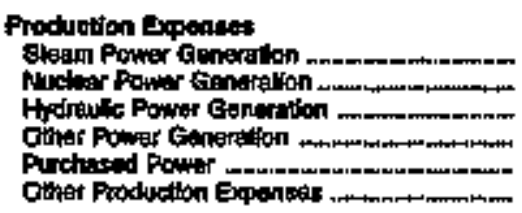 & $\begin{array}{r}0 \\
0 \\
0 \\
0 \\
6,189 \\
0\end{array}$ & $\begin{array}{r}0 \\
0 \\
0 \\
0 \\
\operatorname{sid}, \operatorname{coss} \\
0\end{array}$ & $\begin{array}{r}0 \\
0 \\
0 \\
0 \\
80,802 \\
0\end{array}$ & $\begin{array}{r}0 \\
0 \\
0 \\
0 \\
47009\end{array}$ & $\begin{array}{r}0 \\
0 \\
0 \\
0 \\
0,511 \\
0\end{array}$ & $\begin{array}{r}0 \\
0 \\
0 \\
0 \\
2 B, 2 a p 1 \\
0\end{array}$ \\
\hline Tote Production Experses - & 0,189 & s1,035s & 60,800 & 47 ads & 30,61t & 20,321 \\
\hline 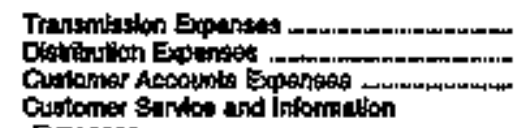 & $\begin{aligned} 0 \\
5+9 \\
0\end{aligned}$ & 1,25 & 2720 & $\begin{array}{r}3,853 \\
774\end{array}$ & 914 & $\begin{array}{r}0 \\
2,542 \\
0\end{array}$ \\
\hline 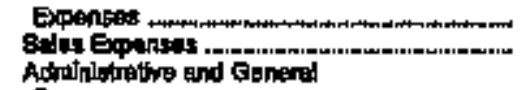 & $\begin{array}{l}0 \\
0\end{array}$ & $\begin{array}{l}0 \\
0\end{array}$ & 105 & 60 & $\begin{array}{l}0 \\
0\end{array}$ & $\stackrel{0}{0}$ \\
\hline Eptensts & 128 & 1,392 & 9,516 & $\$ 60$ & 1,429 & 0 \\
\hline 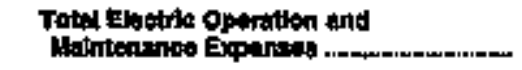 & B, & \$3, $\mathrm{Ba2}$ & 1937 & 54,354 & 52,656 & ansos \\
\hline \multicolumn{7}{|l|}{ Mutef Erpenges in Optaratition } \\
\hline 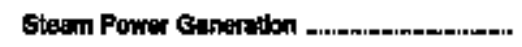 & $\mathbf{0}$ & $\mathbf{0}$ & $\mathbf{0}$ & 0 & 0 & $\mathbf{0}$ \\
\hline 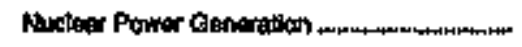 & 0 & 0 & 0 & 0 & 0 & 0 \\
\hline Other Fowar Congralon ...... & 0 & - & 0 & 0 & o & 0 \\
\hline \multicolumn{7}{|l|}{ 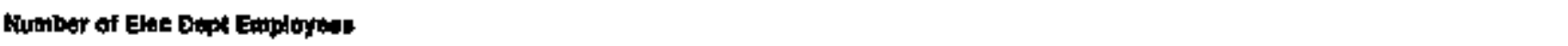 } \\
\hline 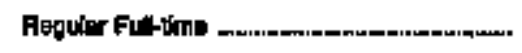 & $\mathbf{6}$ & 30 & 110 & 100 & 43 & \% \\
\hline Parting A Tarpocery & 0 & $\mathbf{0}$ & 1 & 6 & 0 & 3 \\
\hline 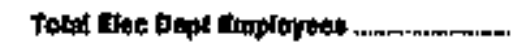 & e & sit & 119 & 109 & 43 & so \\
\hline
\end{tabular}

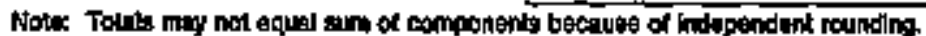

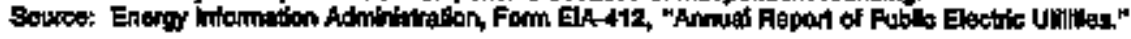


Table 23. Electic Operation and Malntenance Expenses by Major U.S. Publicly Owned Electric Utlity Within Stato, 1994 (Continued) (Thousand Dollars)

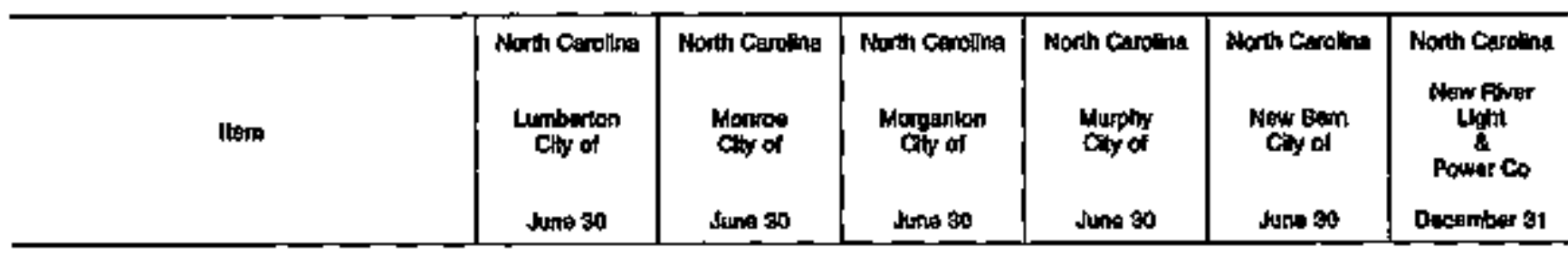

Production Expinters

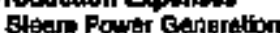

Muclagr Pouren Renteration

Hydran to Perver Genaraton

Other Power Ganitation

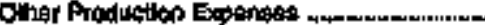

Taks Pratuction Expartise

Trembinison Expones

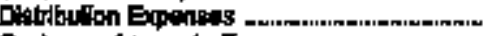

Cudomer Accounts Exporisges term

Gislaner senvice tond lutoritation

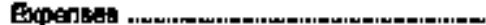

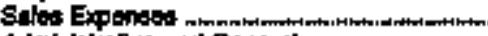

Adminiblalwa and Eartert

Expanse

Total Eactils Cportan ant

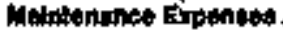

Fad Exponeden in Oparalion

Rleam Powar Genemilon

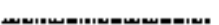

Kuclegr Rower Generation

Oher Power Generalion

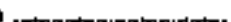

Nunber of tho Bopt Employes

Resular Pultima

Put-ing \& Temporay

0
0
0
0
10,475
0

0
0
0
0
21,991
698

tipas

21:8as

694

956

170

0

234

218

0

588

4

134

$21,7 \cdot 2$

23, 574

0
0
0
0
14,772
0

0
0
0
0
5584

0
0
0
0
27,245

0
0
0
0
8,203
0

14ritit

55:4

27,684

a,200:

0

Bad

178

0

2460

1.401

19.172

31,204

$\begin{array}{ll}0 & 0 \\ 0 & 0 \\ 0 & 0\end{array}$

o

$\mathbf{0}$

a

00

0

0

0

o

0

$\theta$

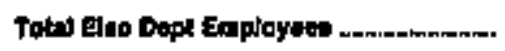

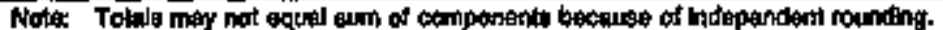

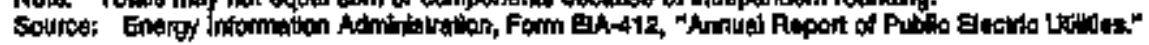


Table 29. Eectric Operation and Maintenance Expenses by Major U.S. Publiely Owned Eloctric Utalty Whiln State, 1994 (Continuted)

(Thousand Dollars)

\begin{tabular}{|c|c|c|c|c|c|c|}
\hline tham & 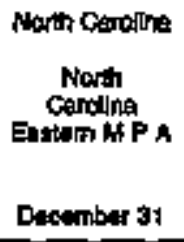 & 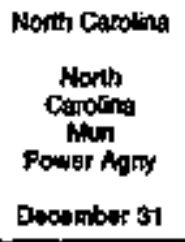 & 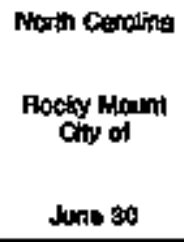 & $\begin{array}{l}\text { North Carolina } \\
\text { shelly } \\
\text { Chy of } \\
\text { Jum } 30\end{array}$ & 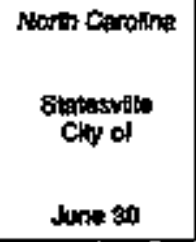 & $\begin{array}{l}\text { North Caraing } \\
\text { Turtore } \\
\text { Town of } \\
\text { Juno } 30\end{array}$ \\
\hline 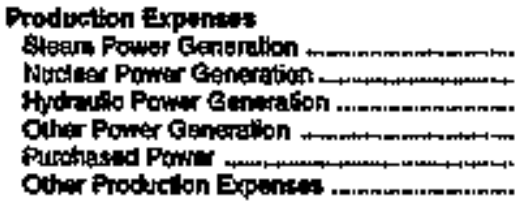 & $\begin{array}{r}21,040 \\
51,275 \\
0 \\
0 \\
120,219 \\
3,110\end{array}$ & $\begin{array}{r}0 \\
94,100 \\
0 \\
0 \\
117,820 \\
13,620\end{array}$ & $\begin{array}{r}0 \\
0 \\
0 \\
0 \\
5208 \\
0\end{array}$ & $\begin{array}{r}0 \\
0 \\
0 \\
9 \\
0 \\
0\end{array}$ & $\begin{array}{r}0 \\
0 \\
0 \\
0 \\
20,754 \\
0\end{array}$ & $\begin{array}{r}0 \\
0 \\
0 \\
0 \\
10,423 \\
0\end{array}$ \\
\hline Total Prodpetion Expentests & 205,644 & 225,442 & 32,152 & $9,19,77$ & 20,754 & 18,428 \\
\hline 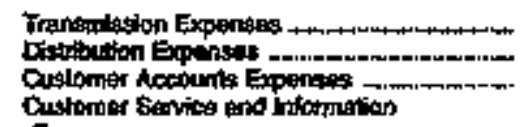 & $\begin{array}{r}14,726 \\
2,214 \\
0\end{array}$ & $\begin{array}{r}11,249 \\
2,773 \\
0\end{array}$ & $\begin{array}{r}0 \\
4,397 \\
0\end{array}$ & $\begin{array}{r}0 \\
1,297 \\
0\end{array}$ & $\begin{array}{l}0 \\
0\end{array}$ & $\begin{array}{l}0 \\
0 \\
0\end{array}$ \\
\hline 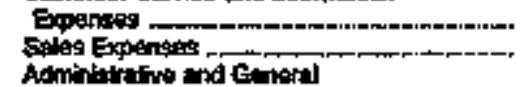 & $\stackrel{0}{0}$ & $\begin{array}{l}0 \\
0\end{array}$ & $\stackrel{0}{0}$ & $\stackrel{6}{0}$ & $\stackrel{0}{0}$ & $\begin{array}{l}0 \\
0\end{array}$ \\
\hline Expenses .... & 27,760 & 25,064 & 504 & 438 & 2,210 & 1,441 \\
\hline 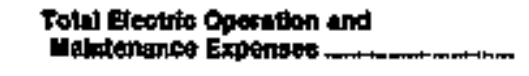 & 250,342 & abs,910 & 57 aes & 10,672 & 22,994 & 19,864 \\
\hline \multicolumn{7}{|l|}{ Fuel Expenses In Oparallon } \\
\hline Shan Polwar Gonmation & 17,450 & $\mathbf{0}$ & 0 & 0 & 0 & $\mathbf{0}$ \\
\hline Nucthar Powar Generation & 14,336 & steps & 0 & a & 0 & 0 \\
\hline Other Power Gontration & o & 0 & 0 & o & 0 & 0 \\
\hline \multicolumn{7}{|l|}{ Number of Eloc Dept Employeen } \\
\hline 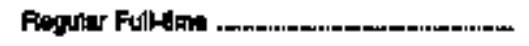 & 0 & 0 & 49 & 17 & 29 & 21 \\
\hline Purtime \& Tempotary :- & 0 & 0 & 0 & $\mathbf{0}$ & 0 & 0 \\
\hline Total Eac Dapt Employede & 0 & $\mathbf{0}$ & $\$$ & 17 & 25 & 21 \\
\hline
\end{tabular}

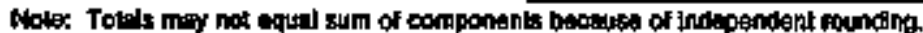

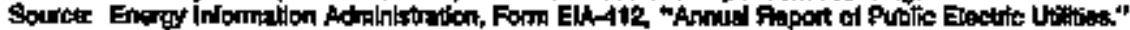


Table 23. Electrlo Operation and Maintenance Expences by Major U.s. Publloby Owned Electric Utility Within state, 1994 (Continued)

(Thousand Dollars)

\begin{tabular}{|c|c|c|c|c|c|c|}
\hline Item & 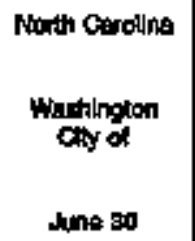 & $\begin{array}{l}\text { North Cenoting } \\
\text { Whon } \\
\text { Cly of } \\
\text { Juns } 90\end{array}$ & 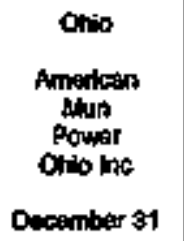 & $\begin{array}{l}\text { Otio } \\
\text { Bonfint } \\
\text { Citsy of } \\
\text { Decombor } 31\end{array}$ & $\begin{array}{l}\text { Oplo } \\
\text { Enyen } \\
\text { City of } \\
\text { Decenter } 31\end{array}$ & 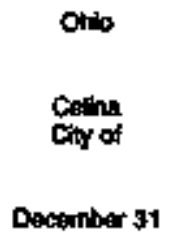 \\
\hline 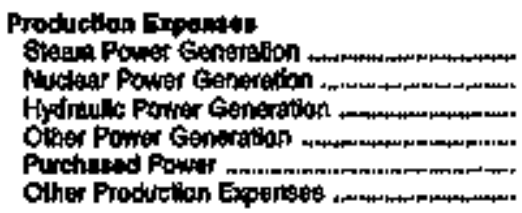 & $\begin{array}{r}0 \\
0 \\
0 \\
0 \\
17,483 \\
0\end{array}$ & $\begin{array}{r}0 \\
0 \\
0 \\
0 \\
68,678 \\
0\end{array}$ & $\begin{array}{r}21,950 \\
0 \\
0 \\
0 \\
107,005 \\
0\end{array}$ & $\begin{array}{r}0 \\
0 \\
0 \\
0 \\
13,770 \\
0\end{array}$ & $\begin{array}{r}0 \\
0 \\
0 \\
300 \\
0,703 \\
0\end{array}$ & $\begin{array}{r}0 \\
0 \\
0 \\
0 \\
6,101 \\
78\end{array}$ \\
\hline 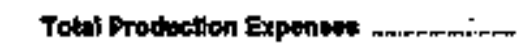 & 17,400 & 68,678 & $12 \% 968$ & 13,770 & 7,114 & $6,1 \pi$ \\
\hline 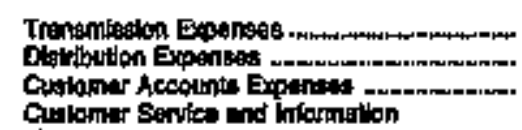 & $\begin{array}{r}0 \\
0\end{array}$ & $\begin{array}{r}0 \\
2,913 \\
2,3915\end{array}$ & $\begin{array}{r}0 \\
446\end{array}$ & $\begin{array}{r}209 \\
1,066 \\
361\end{array}$ & $\underset{0}{781}$ & $\begin{array}{r}0 \\
642 \\
146\end{array}$ \\
\hline 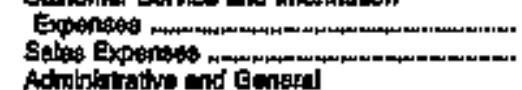 & $\stackrel{a}{a}$ & $\begin{array}{r}\mathbf{0} \\
\mathbf{5 8}\end{array}$ & : & $\begin{array}{c}0 \\
\text { B }\end{array}$ & 0 & $\underset{\mathbf{B}}{\mathbf{0}}$ \\
\hline 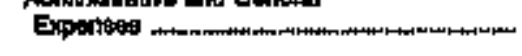 & 1,220 & 1,370 & 4,995 & 780 & 1,195 & 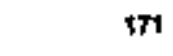 \\
\hline 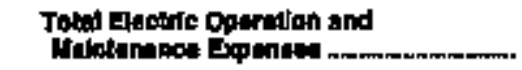 & 20,301 & 76,349 & 135045 & 16,206 & 0,070 & 7,205 \\
\hline \multicolumn{7}{|l|}{ Fod Exponate in Operation } \\
\hline 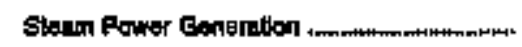 & D & 0 & $\mathbf{9 , 7 6 0}$ & $\mathbf{0}$ & 0 & o \\
\hline 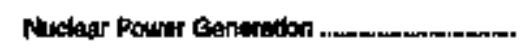 & o & 0 & 0 & 0 & 0 & 0 \\
\hline Other Pomer Gengatiban & 0 & 0 & 0 & 0 & 0 & $\mathbf{0}$ \\
\hline \multicolumn{7}{|l|}{ 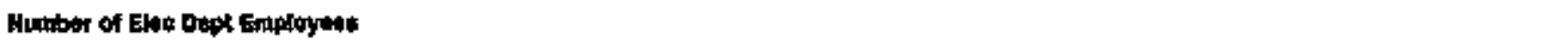 } \\
\hline 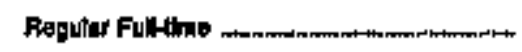 & 39 & 74 & 116 & 30 & 28 & 17 \\
\hline 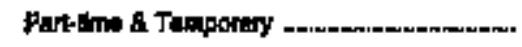 & 0 & o & 0 & $\mathbf{0}$ & 0 & 0 \\
\hline 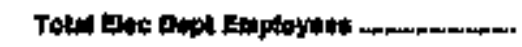 & $*$ & 74 & 116 & 30 & 26 & $\boldsymbol{\eta t}$ \\
\hline
\end{tabular}

Notw: Totals may not equad eum of componeris beatuses of hodependent rounding

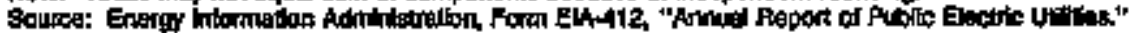


Table 29. Electrtic Operation and Maintenance Expenses by Majar U.S. Publloly Owned Electio Utlity Whin State, 1994 (Contmued) (Thousand Dollers)

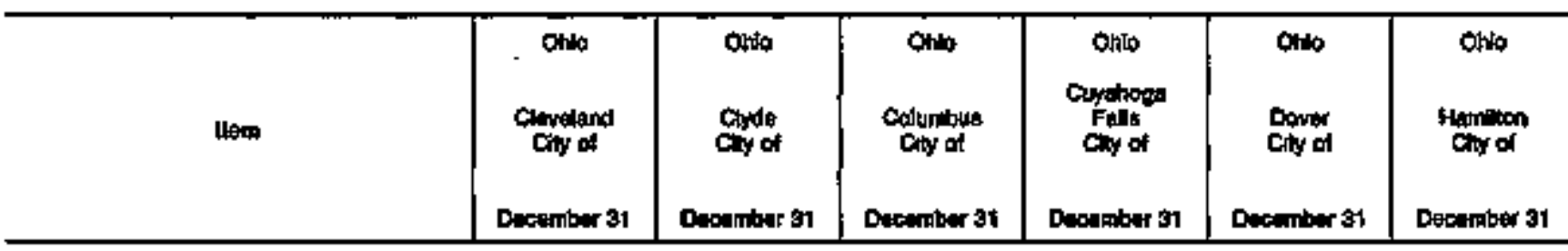

Proctutalon Expanios

Slean Powmer timeration

Murclarir Pound Canantion

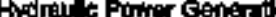

Oblef Pawir Canefation

Purchasied Fowar rmmemas

Totol Production Exponstis:

Thismissbon Equases

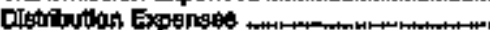

Customar Acoctinis Erpenses

Customin sonios and informitton

Expenges

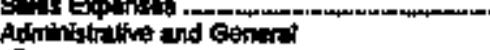

expanses

Total Elaptito Oporaliont tad

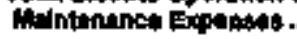

Fuel Expanses la Oporiton

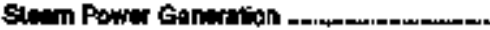

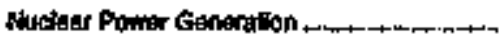

Other Powre cenoriton

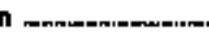

Luraber of Eloc Dept Erployrea

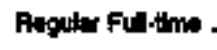

Partime \& Temporary

$\$ 49$

a

34

Totel rifo Dopt Enpleyeto

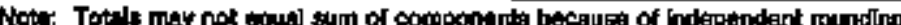

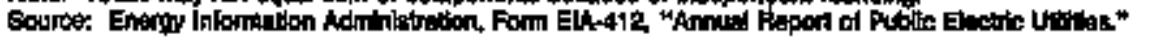

\begin{tabular}{|c|c|c|c|}
\hline $\begin{array}{r}0 \\
0 \\
172 \\
0 \\
10940 \\
200\end{array}$ & $\begin{array}{r}0 \\
0 \\
0 \\
0 \\
19,64 \% \\
0\end{array}$ & $\begin{array}{r}0 \\
0 \\
0 \\
0 \\
3,096 \\
1,749\end{array}$ & $\begin{array}{r}10,231 \\
0 \\
1,228 \\
577 \\
0,618 \\
0\end{array}$ \\
\hline 20,316 & $13, \mathbf{B}^{4}$ & 6,744 & 18,477 \\
\hline $\begin{array}{r}7,208^{\circ} \\
0\end{array}$ & $\underset{402}{0}$ & 2,0 & $\begin{array}{r}775 \\
1,560 \\
177\end{array}$ \\
\hline $\begin{array}{r}482 \\
0\end{array}$ & $\begin{array}{l}0 \\
0\end{array}$ & $\begin{array}{l}0 \\
0\end{array}$ & $\begin{array}{r}510 \\
60\end{array}$ \\
\hline 3,465 & 2,468 & 54 & 4,702 \\
\hline $31, \pi 1$ & 14,708 & B,ES4 & 25,667 \\
\hline
\end{tabular}

0
0
0

0

6,584

0

341

$\mathbf{0}$

109

2

111 
Table 23. Electric Operation and Maintenence Expenses by Major U.S. Publlely Ownod Electric Utility Within state, 1994 (Continued)

(Thousand Dollars)

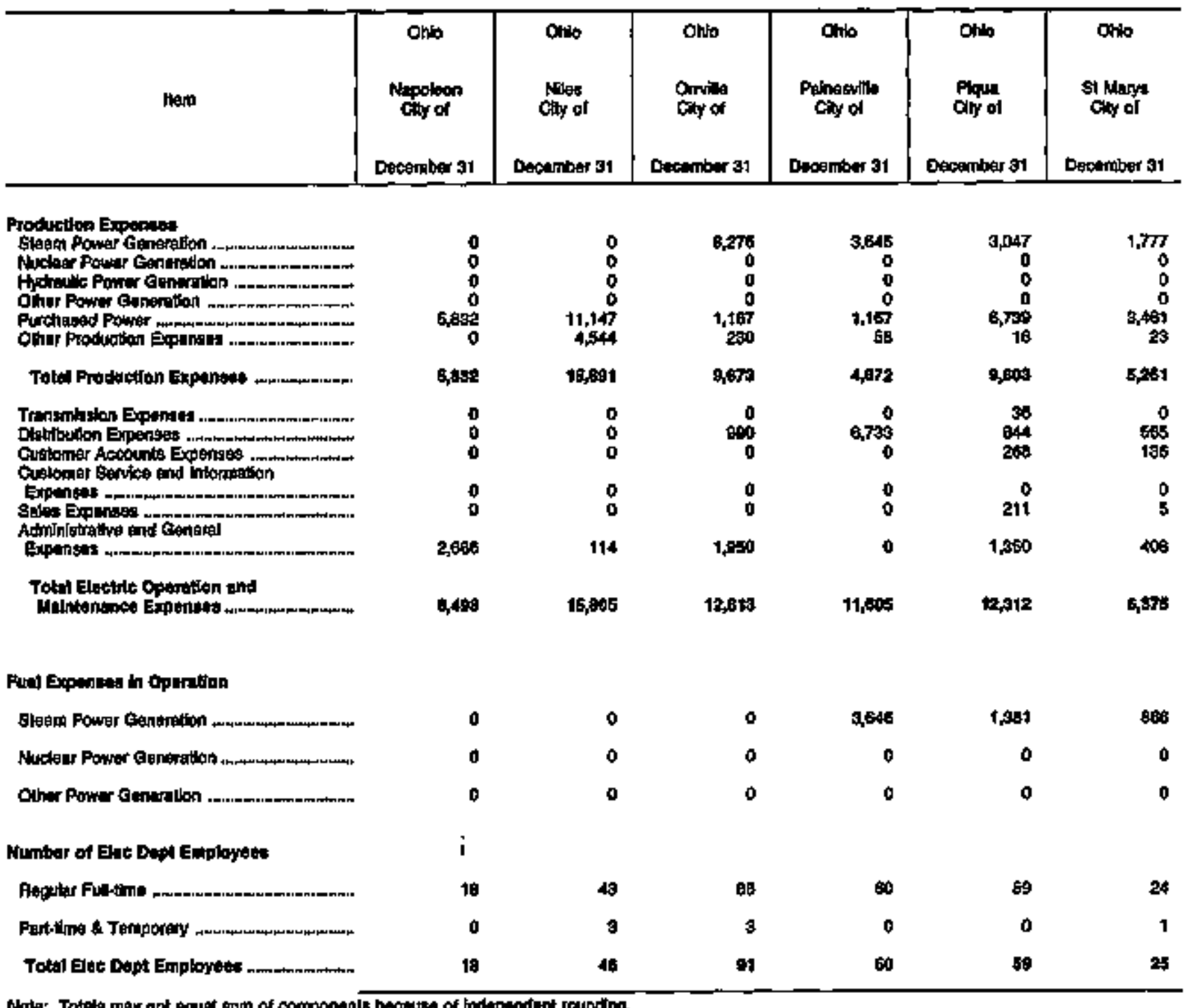

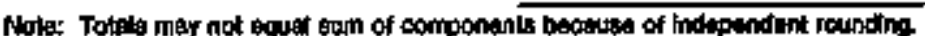

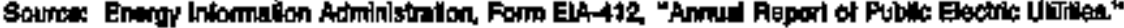


Table 23. Electric Operation and Maintenance Expenses by Major U.S. Publichy Owned Electric Utilly Within State, 1994 (Continued)

(Thousand Dollars)

\begin{tabular}{|c|c|c|c|c|c|c|}
\hline \multirow{3}{*}{$1 \mathrm{bmm}$} & Ohio & otion & Ono & Oklahome & OtJinhand & Oktahong \\
\hline & $\begin{array}{l}\text { Widsuorth } \\
\text { Chty of }\end{array}$ & $\begin{array}{l}\text { Wupatonoty } \\
\text { Chy of }\end{array}$ & Haturnity & $\begin{array}{l}\text { arous } \\
\text { Chy of }\end{array}$ & $\begin{array}{l}\text { Clurembre } \\
\text { Cily of }\end{array}$ & $\begin{array}{l}\text { Ouncenn } \\
\text { Cry of }\end{array}$ \\
\hline & Deterinber \$5 & Decenter 31 & Decomber 31 & Jueso & June 30 & June as \\
\hline
\end{tabular}

Prodditifion Expantaer.

Sianm Powt Genoriton

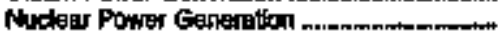

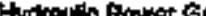

Olsw Ponm Bencraton

Puchigad Pawir

Other Production Eqpenses

Tekal Prodaction ritomoses

Transmigelan Expenses

Dishibution Exyentsas

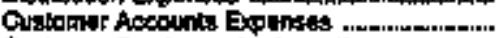

Customar Senvioe and inlumation

Gophits

S-log 5

Moletintetrative and flenekal

Expontes

totat Enotile tparation and

Mahteanarice Expances

Fied Equagea in Operaliap

titagra Powar clemeraton

Nucloar Power Coneretion

0

Ofter Power Gentortion

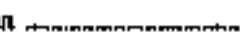

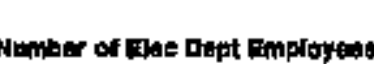

Riganter Fuiftime

Partine \& Tomponery

Tata Etere Dept timpleryes.

0
0
0
0
8585
0

0
0
0
0
0

0
0
0
10,780

6,515

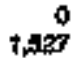

238

$$
0
$$

787

11,116

$$
5,400
$$

torsis

1,825

0

2,109

48

0

680

te?

7,265

13,081 $\begin{array}{rr}0 & 0 \\ 0 & 0 \\ 0 & 0 \\ 0 & 0 \\ 7,419 & 4,709 \\ 0 & 0\end{array}$

6.

7.419

4700

0

270

1.003

1,003
989

0

1,108
0

118

0

t

108

Bods

9.516

5,819

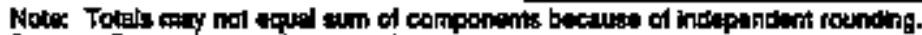

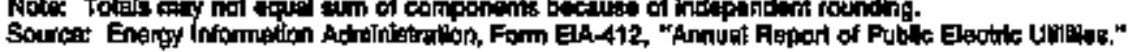


Table 29. Electric Operaltion and Ilaintenance Expenses by Major U.S. Publicly Owned Electric Utilly Within State, 1894 (Conthued)

(Thousand Dollers)

\begin{tabular}{|c|c|c|c|c|c|c|}
\hline $\tan$ & $\begin{array}{l}\text { Oddrome } \\
\text { Edmond } \\
\text { Cliy of } \\
\text { June } 30\end{array}$ & 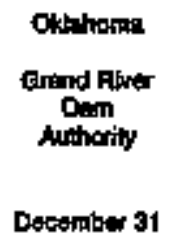 & $\begin{array}{l}\text { Oldahome } \\
\text { City of } \\
\text { June } 30\end{array}$ & 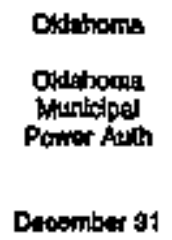 & $\begin{array}{l}\text { Olithema } \\
\text { Poncty } \\
\text { City of } \\
\text { Jine so }\end{array}$ & 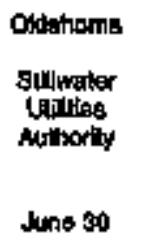 \\
\hline 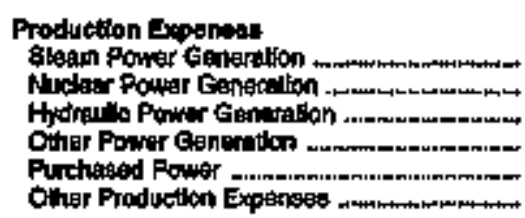 & $\begin{array}{r}0 \\
0 \\
0 \\
0 \\
2+, 082 \\
0\end{array}$ & $\begin{array}{r}6,548 \\
0 \\
2,092 \\
6,006 \\
0\end{array}$ & $\begin{array}{r}0 \\
0 \\
0 \\
0 \\
4,850 \\
0\end{array}$ & $\begin{array}{r}14,273 \\
0 \\
28 \% \\
0 \\
36,264 \\
0\end{array}$ & $\begin{array}{r}56 \\
0 \\
0 \\
61,800 \\
0\end{array}$ & $\begin{array}{r}511 \\
0 \\
0 \\
0 \\
12,002 \\
0\end{array}$ \\
\hline Totat Produttion Exponats .........nnmen & $21, \$ \%$ & 67,620 & 4,050 & 40,009 & 10,038 & 12 ; 13 \\
\hline 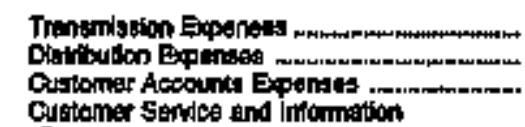 & 2,000 & $\begin{array}{r}6,995 \\
094\end{array}$ & S42 & $\begin{array}{r}8,049 \\
0 \\
0\end{array}$ & 2,0 & 1,949 \\
\hline 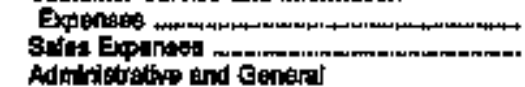 & 193 & ${ }_{0}^{7}$ & $\begin{aligned} 40 \\
0\end{aligned}$ & $\stackrel{0}{0}$ & 127 & 398 \\
\hline Explonst & 95 & 0,445 & 256 & 2,112 & 465 & 582 \\
\hline 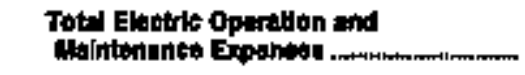 & 24,411 & $B, 500$ & 5,740 & 52,091 & 16,816 & 15,704 \\
\hline \multicolumn{7}{|l|}{ Fued Expennes In Oparation } \\
\hline Stapin Power Generatian & 0 & 49,726 & $\mathbf{D}$ & $11,0<2$ & 6 & 421 \\
\hline 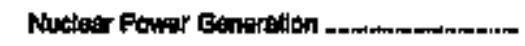 & 0 & 0 & 0 & 0 & $\mathbf{0}$ & $\mathbf{0}$ \\
\hline OThar fower Gentration .................... & 0 & 0 & 0 & 0 & 100 & 0 \\
\hline \multicolumn{7}{|l|}{ Number of Elec Dept Employeen } \\
\hline 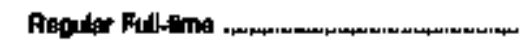 & 41 & 46: & 77 & 24 & 5 & 6 \\
\hline 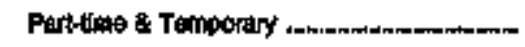 & 0 & $\theta$ & 0 & 0 & $\mathbf{0}$ & 8 \\
\hline Total Gec Dopt Emplopeos .............. & 44 & 470 & $\mathbf{y}$ & 24 & 60 & to \\
\hline
\end{tabular}

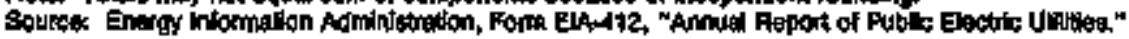


Table 23. Electric Operation and Maintenance Expenses by Major U.S. Publicly Owned Eloctric Utility Within State, 1994 (Continued) (Thousand Dollars)

\begin{tabular}{|c|c|c|c|c|c|c|}
\hline \multirow{3}{*}{ Hem } & Ohoghan & Orefon & Ongon & Oregon & Oregon & oragn \\
\hline & $\begin{array}{l}\text { Aptiand } \\
\text { Cisy of }\end{array}$ & 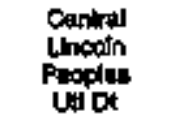 & 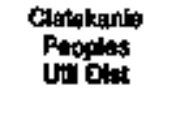 & 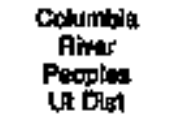 & $\begin{array}{l}\text { Emeraid } \\
\text { Puoptes } \\
\text { Uetlity Dlst }\end{array}$ & $\begin{array}{l}\text { Eugerse } \\
\text { Chy of }\end{array}$ \\
\hline & Jum 30 & Decamber $\$ 1$ & De⿻0mber 31 & Decembar & Decomber 31 & Deconber 31 \\
\hline
\end{tabular}

Produstion Fipemited

Sivim Power Genoration

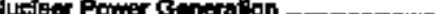

Othar Rowiar Conaralion

Puthaged Fower

Other Frodiction Exponges

Tatal Prodution Enptintaso

Trensmilstion Expungs:

Dithipution Exhanog

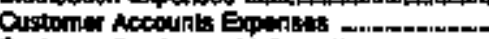

Onstomiar servica and infomation

Expentates - .

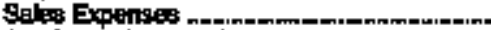

Adminitralive and Gerisen:

Epansis:

Total fiteotric Opamilon and

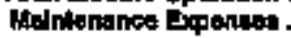

rul Expenpese in operation

0
0
0
0
4,596
11

0
0
0
0
87,531
8

0
0
0
0
23245

0
0
0
0
0

4,607

47, 589

23,245

7,295

690 3,18

06007,182

1,110

348

son

2712

8.roto

2712

44908

0

1,124

316

105

2 的定

1,093

164

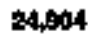

10,251

$\begin{array}{rr}0 & 5,690 \\ 0 & 0 \\ 0 & 3,000 \\ 4,7 & 0 \\ 10,253 & 54,277 \\ 0 & 1,453\end{array}$

10,679

44935

$0 \quad 2,197$

1,0

B41 3,062

113459

$1,082 \quad 12100$

13, tat?

42,913

Fham Powrar Conowation

Nudour Power Conaration

Ohw Powe cencralton

0

0

o

Number of Elc topt Enptoyen:

Rogutio Fultime

Farting \& Tectporay

19

0

19

Tolat Elec Dapl Enployest:

\section{o}

$\mathbf{0}$

0

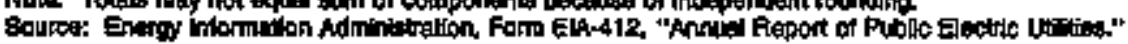


Table 23. Electric Operation and Maintenence Expenses by Major U.S. Publicty Owned Electrlo Utilly Withan State, 1994 (Continued)

(Thousand Dollars)

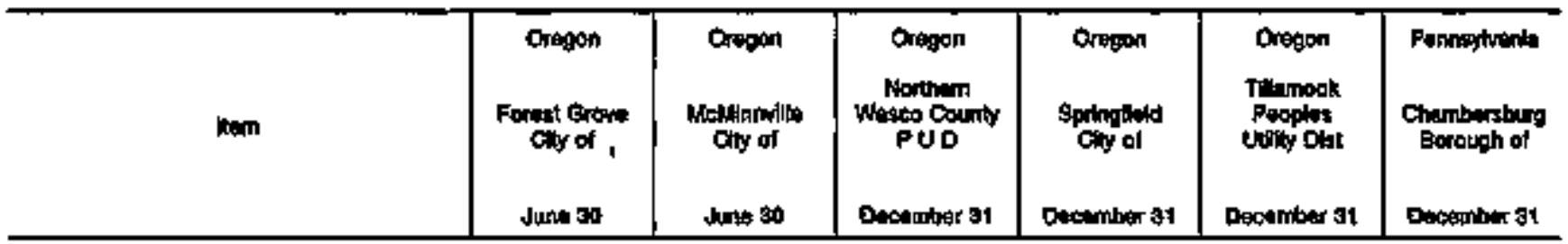

Prodyction Fypencis

siatin Fowir Cacheriton

Nuledour Pown Genorition

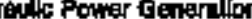

Cint Ponte Ganation

Putchasad Paver .

Other Production Expenses:

Toth Prapketion Eipancit

Trationtikiton Expentes

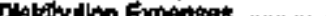

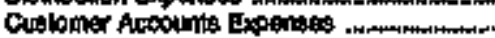

Cusidarior sentes end intormatipn

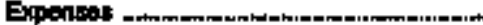

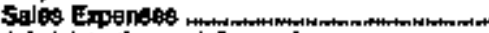

Adrinlatrative and Genaral

Expentas:

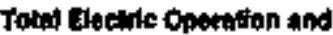

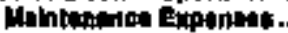

$\begin{array}{rr}0 & 0 \\ 0 & 0 \\ 0 & 0 \\ 0 & 0 \\ 6,+27 & 17,544 \\ 0 & 0 \\ 5,187 & 17,544 \\ 0 & 0 \\ 387 & 954 \\ 75 & 18 t \\ 0 & 0 \\ 0 & 0 \\ 1,210 & 007\end{array}$

to, st:
0
0
200
7
7,804
0

7,05

14

68

200

164

$\theta 8$

94)
0
0
0
0
2760

o

27.790

1

1,443

808

986

1558

20.5\%

$\begin{array}{rr}0 & 0 \\ 0 & 0 \\ 0 & 0 \\ 0 & 183 \\ 10,258 & 0,284 \\ 63 & 354\end{array}$

thats

9014

028

2,076

470 2112

ato 0

940 sts

t5, 194

11,14

Fued Expences In Operation

Shan Power Conmiton

Nurlagr Powar Generation

0

$\mathbf{0}$

0

o

0

o

D

4

\$.

4

Other Rower Ganeration

0

0

o

$\mathbf{0}$

80

Nubber of Eac Dapt Employeat

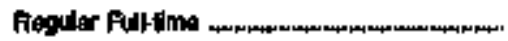

Putfints \& Tomporiny

23

Totrl Ereo Dept Employen:

28

s.

$\mathbf{3 0}$

84

6.

29

$\mathbf{0}$

18

o

61

4

84

2.

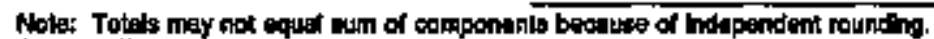

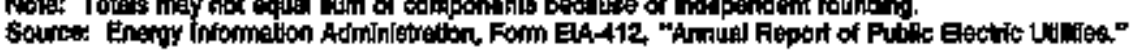


Table 23. Eleotrtc Operation and Maintenance Expenses by Major U.S. Publohy Owned Eloctute Utalty Within State, 1994 (Contisued) (Thousand Dollars)

\begin{tabular}{|c|c|c|c|c|c|c|}
\hline Hen & 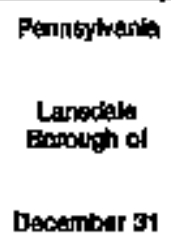 & $\begin{array}{l}\text { South Coroling } \\
\text { Camden } \\
\text { City of } \\
\text { Junt } 30\end{array}$ & $\begin{array}{l}\text { south Caroina } \\
\text { Endoy } \\
\text { Combinot } \\
\text { Unilyy } \\
\text { Syrtem } \\
\text { much 31 }\end{array}$ & $\begin{array}{l}\text { Sourih Canding } \\
\text { Gefiteg } \\
\text { Ciny of } \\
\text { Warch a1 }\end{array}$ & 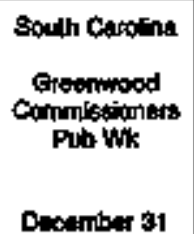 & 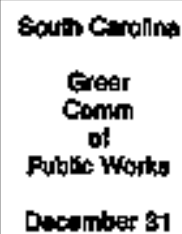 \\
\hline
\end{tabular}

Produration Erquatra

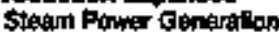

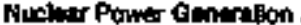

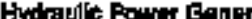

Other Powis tentetition

Purchiand Powar

Other Production Exinarass

Tole' Produrton Expenter.

Tranarisalon Exporasa

Disutiovilan Exponsas .

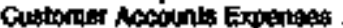

Customer Surice and intomution

Expenses.

Seras Expences

Adminlatistwe and Baneral

Expariagen

Total Eeotito Oparition and

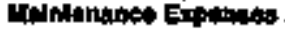

Fud Exposes in Opereston

Sirem Power Goreration

Muclear Pown ctomprition

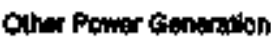

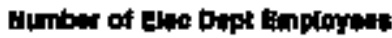

Regular Pulltith

19

Parthe \& Tempondy

D

Totat Euct anpt Enploreat

0
0
0
0
9,947
0

0
0
0
0
0,515
0

A.tot

21
744

744
242

$$
0
$$

300

7,761
0
0
0
0
$1+290$

11)하웅

0

698

0

acs

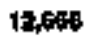

$\begin{array}{r}0 \\ 0 \\ 0 \\ 7,748 \\ \hline 0\end{array}$

7구우

6

867

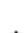

o

1,137

977
0
0
0
0
0
025
0

a,ess

oto

287

$$
0
$$

140

9000

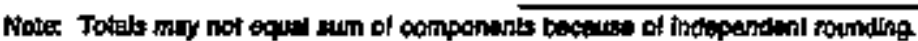

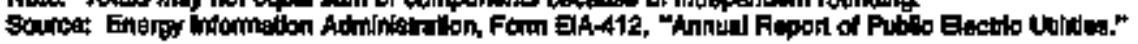


Table 23. Electrle Operation and Meintenance Expenses by Major U.S. Publicly Owned Electrio Utility Within State, 1994 (Continued) (Thousand Dotlers)

\begin{tabular}{|c|c|c|c|c|c|c|}
\hline Ilem & $\begin{array}{l}\text { South Cerotina } \\
\text { Nowberry } \\
\text { City of } \\
\text { June } 30\end{array}$ & $\begin{array}{l}\text { South Cantina } \\
\text { Orargoburg } \\
\text { Coty of }\end{array}$ & 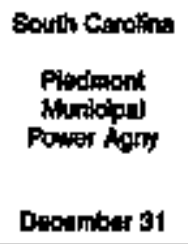 & $\begin{array}{l}\text { South Caroina } \\
\text { Rooth in } \\
\text { City of } \\
\text { Decumber } 31\end{array}$ & $\begin{array}{l}\text { Soth Curolina } \\
\text { Sanata } \\
\text { Ghy of } \\
\text { hine } 30\end{array}$ & 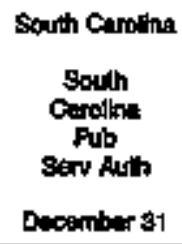 \\
\hline 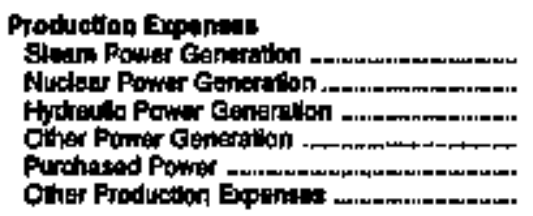 & $\begin{array}{r}\mathbf{0} \\
\mathbf{0} \\
\mathbf{0} \\
0 \\
7,675 \\
0\end{array}$ & $\begin{array}{r}0 \\
0 \\
0 \\
049 \\
28,200 \\
0\end{array}$ & $\begin{array}{r}0 \\
32,022 \\
0 \\
0 \\
4,646 \\
0\end{array}$ & $\begin{array}{r}0 \\
0 \\
0 \\
0 \\
25770 \\
0\end{array}$ & $\begin{array}{r}0 \\
0 \\
0 \\
0 \\
8,519 \\
0\end{array}$ & $\begin{array}{r}231,657 \\
39,393 \\
5,006 \\
1,091 \\
29,274 \\
637\end{array}$ \\
\hline 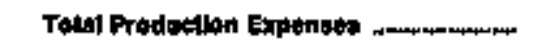 & 7,675 & 29940 & $7 \% 57$ & $25, \pi T 9$ & 6,519 & 304,874 \\
\hline 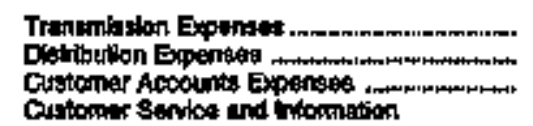 & $\begin{array}{r}0 \\
452 \\
70\end{array}$ & 1,09 & $\begin{array}{r}3,602 \\
2,600 \\
1,83\end{array}$ & 2,95 & $\begin{array}{r}0 \\
2,518 \\
0\end{array}$ & $\begin{array}{l}0,061 \\
5,055 \\
1,701\end{array}$ \\
\hline 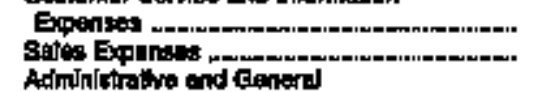 & $\stackrel{0}{183}$ & 0 & $\begin{array}{l}0 \\
0\end{array}$ & $\begin{array}{l}0 \\
0\end{array}$ & $\stackrel{0}{0}$ & $\begin{array}{r}776 \\
1,610\end{array}$ \\
\hline 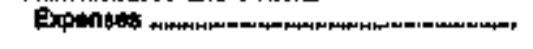 & 1804 & 6 & 11,208 & 1,125 & 460 & 81,800 \\
\hline 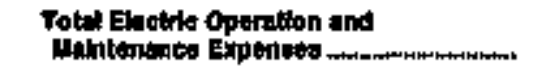 & 0,900 & 31,A38 & $97 / 49$ & 20800 & $\sin$ & SMABT \\
\hline \multicolumn{7}{|l|}{ Fuel ETpences in Oparalon } \\
\hline 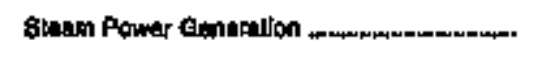 & 0 & 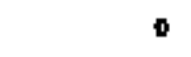 & 0 & $\mathbf{0}$ & 0 & 180, tot \\
\hline 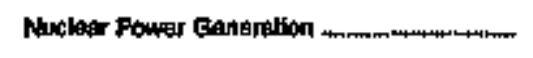 & 0 & 0 & 9.991 & 0 & 0 & Boy \\
\hline 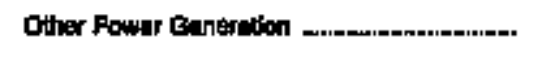 & 0 & 314 & 0 & 0 & 0 & 807 \\
\hline \multicolumn{7}{|l|}{ Whmbtr of Eloc Dept Employses: } \\
\hline 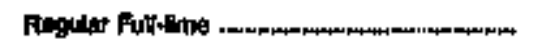 & 12 & 39 & 10 & 29 & 7 & t, des \\
\hline Part-lume \& Templary & 0 & 0 & 2 & 0 & 0 & 37 \\
\hline Tolvl Elor Dept Employs:as & $\mathbf{1 2}$ & 39 & 12 & 20 & 7 & 1,900 \\
\hline
\end{tabular}

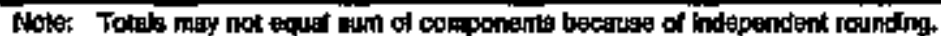

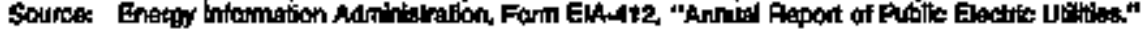


Table 28. Electrito Operatlon and likintenance Expenses by Major U.S. Publloly Owned Electrto Utilly Within State, 1994 (Continued) (Thousand Dollars)

\begin{tabular}{|c|c|c|c|c|c|c|}
\hline IIem & $\begin{array}{l}\text { south Dodrota } \\
\text { Brookings } \\
\text { City of }\end{array}$ & 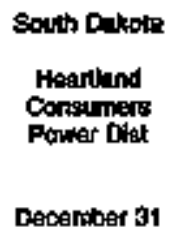 & 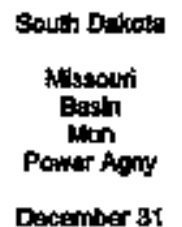 & $\begin{array}{c}\text { South Dokote } \\
\text { Ping } \\
\text { city of } \\
\text { Decemiter } 01\end{array}$ & 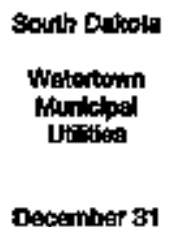 & 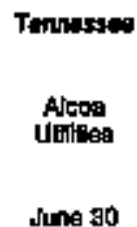 \\
\hline
\end{tabular}

\section{Production Emprosicto}

Siluna Power ceneration

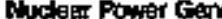

Hothate Power Generation

Pimctiaged Prow

Othet Production Expented

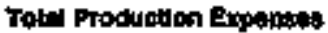

Trangomigepon Expenese

Orotoner Accounts Erpenters

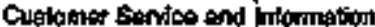

Exinst:

Silog Sxpanges ,

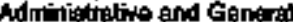

Expentas

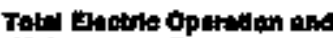

Uahtenance Expanses:

\section{0}

0

10

4.872
25

4,09

66

00

148

o

462

6,362
3,736

0
0
0

1,060

70

5,674

1,823

0

(1)

a

895

7. ketra

2,367

d

o

a

24

6

29

0

0

0
0
0
0
44,874
64

44,45:

10,98\%

$\mathbf{0}$

0

1,801

67,227

4,40

$\begin{array}{rr}0 & 0 \\ 0 & 0 \\ 0 & 0 \\ 0 & 0 \\ 0,090 & 20,000 \\ 10 & 0\end{array}$

6010

20,60

0

840

16

1,469

cos

0
42

0

2ro

ota

7,530

20,755

Furs cipenate in Coination

Nuclear Fower Cangrablon

6

中

a

b

$\mathbf{0}$

Other Rowar cennalton

0

o

d

d

Hurber of Eloc Dopt Employen:

Reguler Fultime

Partidme \& Temporary

Totad Gere Dopt Empleyetu.

24
1
26

ed

61

$\mathbf{3}$

$\mathbf{0}$

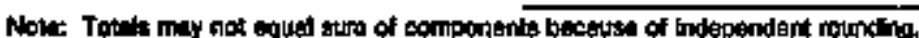

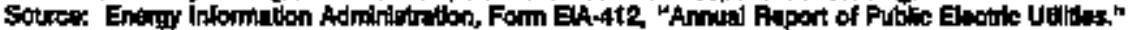


Table 23. Electric Operation and Maintenance Expenses by Major U.S. Publicty Owned Electric Utitity Within Statt, 1994 (Continued) (Thoustand Dollars)

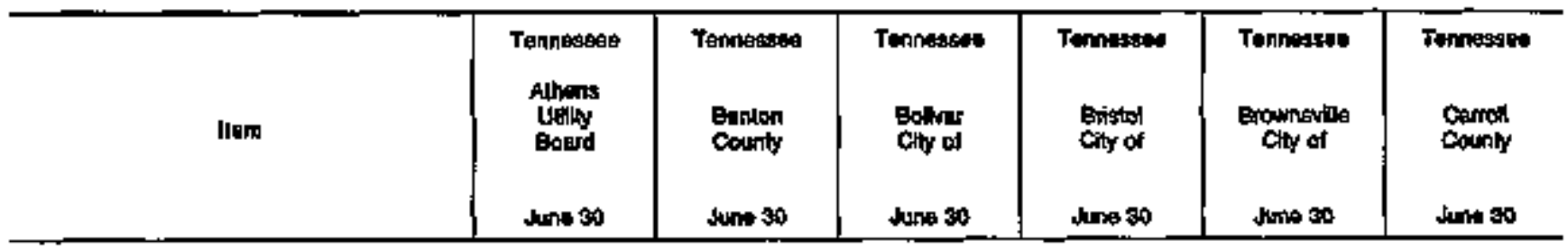

Production Expunas

Siém Power Eentertion

Thelear Powis Generation. ...

Hycteor somer Oenor lion

Obar Pawn Gantro

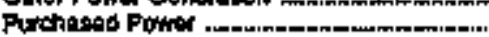

Other Produatos Exponsas

Tok:al Prodututon Expantes .

Tramamladon Expenates.

Olalibution Expontos

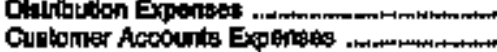

Cuslonar Senvise and inlormal'an

Exponser.

(1)

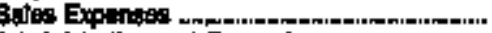

Adinin[otrative and Conoril

Exparsat .

0
0
0
0
21,985
0

0
0
0
0
9,902
0

0
0
0
0
$\operatorname{tas} 5$
0

21,965

10,813

1,879

0

ass

1,007
296

b.

781

240

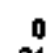

5

34

30

714

489

27

12

50

11,705

1 t.978.

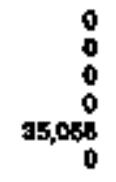

0
0
0
0
0,605
0

0

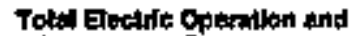

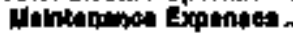

2479
210
1570

502

B

80

714

9.6003

0

988

0

127

0

564

8

19

14

216

Ass

Fod Exparean in Oparatot

Sinam Powtr Banantion

0

0

(

0

Nuclaar Ponnar Genumation

o

0

0

จ

Other Porrar Genaralion

Q

$\mathbf{0}$

0

0

Q

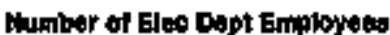

Regeler Ful-

41

48

95

65

14

49

0

p

D

0

ง

0

Total Gee Dopt rmployeta

41

4

36

as

14

4

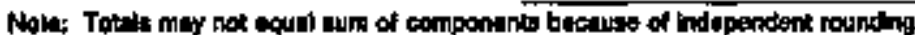

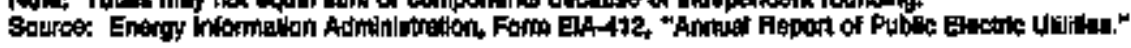


Tabte 23. Electrie Oporation and Malntenance Expenses by Major U.S. Pubiciy Owned Etectrle Utility Withln state, 1984 (Continued) (Thoutaand Dollars)

\begin{tabular}{|c|c|c|c|c|c|c|}
\hline \multirow{3}{*}{$\operatorname{lnem}$} & Teinnessed & Tanneseges & Tẹnnesses & Terhipgog & Totmetseg & 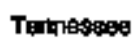 \\
\hline & $\begin{array}{c}\text { Chatianooge } \\
\text { Chy of }\end{array}$ & $\begin{array}{c}\text { Chingsilia } \\
\text { Chy of }\end{array}$ & $\begin{array}{l}\text { Gheniland } \\
\text { City of }\end{array}$ & $\begin{array}{l}\text { Colinton } \\
\text { Clty of }\end{array}$ & $\begin{array}{c}\text { Cobstmbla } \\
\text { chy of }\end{array}$ & $\begin{array}{c}\text { Cookew ol } \\
\text { Cany of }\end{array}$ \\
\hline & Jum 30 & Juis so & ل8 & June 80 & Jun so & June 30 \\
\hline
\end{tabular}

\section{Produstion Expantes}

Stecin Pinwi Gontratog

Nuclare Pownor Censation

Hydroulit Powit Eaperation

Othar Powor Gonertition

Purchend Ponis

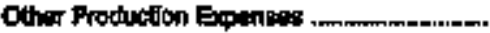

Tot: Produriton Expenset:

Tranaribision Epancos

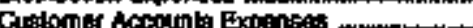

Customer Servks and Infomartion

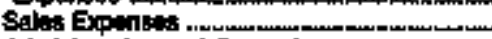

Adminintratwe and Gererd

Expenstas

Total Eloptin Oporalion and

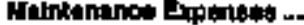

Expang98

0
0
0
0
245,069
0

20,005

1,20

16, $8: 7 ?$

5.904

1.507

a.204

275509

0
0
0
0
39,478
0

32,45

221

2470

8s:

186

28

1,235

44,458
0
0
0
0
40,024

40,024
0

4ipst

1. 12

58

74

115

1,112

4.9.9.9.

$\begin{array}{rrr}0 & 0 & 0 \\ 0 & 0 & 0 \\ 0 & 0 & 0 \\ 0 & 0 & 0 \\ 20,301 & 23,092 & 23,931 \\ 0 & 0 & 0\end{array}$

2apsi

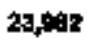

$21,4 x$

105

1,607

810

$\begin{array}{rr}0 & 0 \\ 1,596 & 1,+69 \\ 795 & \end{array}$

(⿻)

14

$90 \%$

5029

$20, \div 2$

28,002

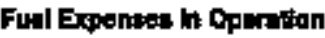

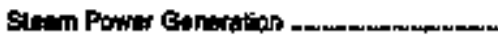

Muchar Powor Cenoralion o

$\mathbf{0}$

$\mathbf{0}$

494
0
494

70

0

79 $\mathbf{0}$

0

$\mathbf{0}$
6

a

$\mathbf{n}$
0

9

0
Numbar of Eno Ropt Enployat:

Reguler Fullifits

48

70

61

\$7

45

fot.ting 4 Tomponery

0

d

0

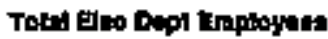

70

日1

5

43

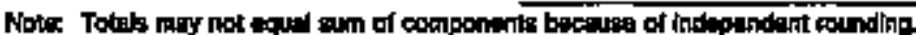

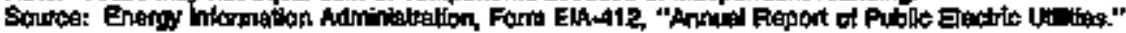


Table 23. Electric Oporation and Malntenance Expenses by Major U.S. Publicly Owned Eleotric Utility Within State, 1994 (Continued)

(Thousand Dollars)

\begin{tabular}{|c|c|c|c|c|c|c|}
\hline Nem & $\begin{array}{l}\text { Tennosges } \\
\text { Conington } \\
\text { Chy of } \\
\text { June so }\end{array}$ & 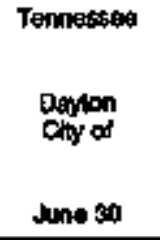 & $\begin{array}{l}\text { Tannopeses } \\
\text { Diekson } \\
\text { Chy of } \\
\text { Jing } 30\end{array}$ & $\begin{array}{l}\text { Tennegse } \\
\text { Dywhug } \\
\text { City of } \\
\text { Jump } 30\end{array}$ & 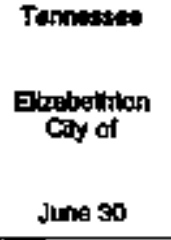 & $\begin{array}{l}\text { Temnesses } \\
\text { Enwin } \\
\text { Town of } \\
\text { June so }\end{array}$ \\
\hline 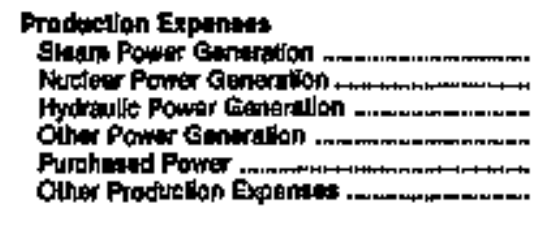 & $\begin{array}{r}0 \\
0 \\
0 \\
0 \\
0,186 \\
0\end{array}$ & $\begin{array}{r}0 \\
0 \\
0 \\
0 \\
2,149 \\
0\end{array}$ & $\begin{array}{r}0 \\
0 \\
0 \\
0 \\
27,598 \\
0\end{array}$ & $\begin{array}{r}0 \\
0 \\
0 \\
0 \\
24,412 \\
0\end{array}$ & $\begin{array}{r}0 \\
0 \\
0 \\
0 \\
22,611 \\
0\end{array}$ & $\begin{array}{r}0 \\
0 \\
0 \\
0 \\
0,138 \\
0\end{array}$ \\
\hline Total Praduotion Eypente: ................. & $\$, 108$ & 2,149 & 27,528 & 24412 & 22,611 & 9,138 \\
\hline 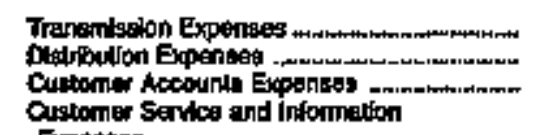 & $\begin{array}{r}3 \\
190 \\
790\end{array}$ & 306 & $\begin{array}{r}0 \\
1,801 \\
780\end{array}$ & $\frac{4}{368}$ & $\begin{array}{r}47 \\
1,698 \\
669\end{array}$ & 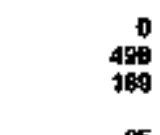 \\
\hline 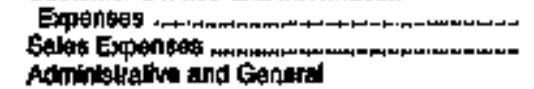 & $\begin{array}{l}7 \\
\mathbf{g}\end{array}$ & $\begin{array}{r}0 \\
47\end{array}$ & $\begin{array}{l}15 \\
15\end{array}$ & $\begin{array}{l}40 \\
46\end{array}$ & $\begin{array}{r}0 \\
\mathbf{8}\end{array}$ & $\begin{array}{r}\mathbf{2 5} \\
0\end{array}$ \\
\hline 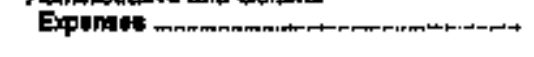 & 281 & 249 & $5 \% 8$ & 784 & 828 & 200 \\
\hline 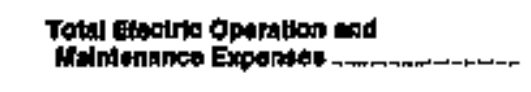 & 8,941 & $\mathbf{2 , 4 8 0}$ & $30,7 \mathrm{~s}$ & $20,8+5$ & 26,935 & 10,111 \\
\hline \multicolumn{7}{|l|}{ Fuol Expentese in Opattillon } \\
\hline 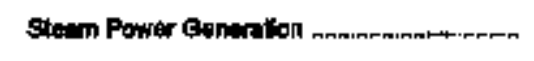 & 0 & $\mathbf{0}$ & 0 & 0 & 0 & $\mathbf{0}$ \\
\hline 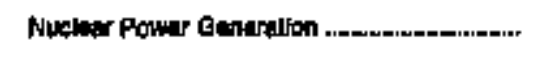 & 0 & a & 0 & $\mathbf{0}$ & $\mathbf{0}$ & 0 \\
\hline Other Powar Gantinatton & 0 & $\mathbf{0}$ & $\mathbf{0}$ & 0 & 0 & 0 \\
\hline \multicolumn{7}{|l|}{ 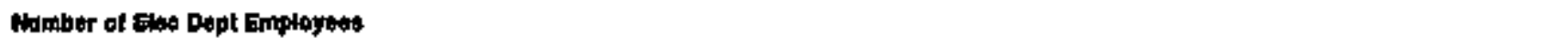 } \\
\hline 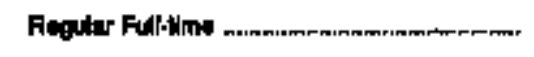 & 17 & 21 & $\mathbf{6 1}$ & 52 & $\mathbf{5 9}$ & 18 \\
\hline 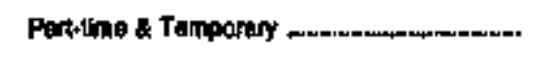 & 0 & 0 & 0 & 0 & $\mathbf{0}^{+}$ & 0 \\
\hline Total Eloc Dopt Employsalt & 17 & 21 & $\mathbf{6 1}$ & $\boldsymbol{n}$ & $\infty$ & t: \\
\hline
\end{tabular}

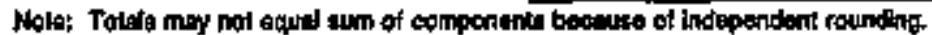

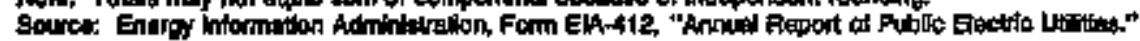


Table 23. Electric Operation and Maintentince Exponoes by Major U.S. Publicly Owned Electrle Utillty Within State, 1994 (Continued) (Thousand Dollars)

\begin{tabular}{|c|c|c|c|c|c|c|}
\hline \multirow{3}{*}{ Harn } & Tennipeser & Tenknosese & Tannéles:os & Tenne:89op & Termigesee & Tomp \\
\hline & $\begin{array}{l}\text { Elowah } \\
\text { Chy ot }\end{array}$ & $\begin{array}{l}\text { Fayelterilas } \\
\text { City of }\end{array}$ & $\begin{array}{l}\text { Gallath } \\
\text { Gry of }\end{array}$ & $\begin{array}{l}\text { Croenerial } \\
\text { cily of }\end{array}$ & $\begin{array}{c}\text { Hemlman } \\
\text { Gity of }\end{array}$ & $\begin{array}{c}\text { Hounbatet } \\
\text { Ciny of }\end{array}$ \\
\hline & Jun 30 & June so & tune so & Mure 300 & ס & $\operatorname{Jun} 30$ \\
\hline
\end{tabular}

Pootugtion Exponne:

Steotm Ponver Gintration

Nuclar Power Benertion

Bydraulic Powior Gerpiation

Purchated Pows

Othar Production Expenses

Tolel Produstion Expengots

Trantatsalon Exponsts.

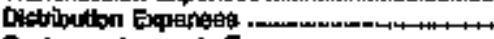

Custome Mocounts Exponats

Gustomer Sorvica and inlomation

Epenses.

Belos Experists .

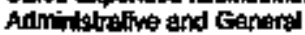

Exponases.

Totel Eactric oparatien and

IHalnimanos Expendes

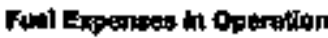

Stom Power Coneration

Nhrofesr Power Genmeton

Ouhr Pouat Ginition

Numbar of Ehe Dept Enptayest

Regular Furtime

16

Partime \& Teatporary

Total Eoc Dopt Employed:

0
0
0
0
0,25
0

0
0
0
0
18,746

0
0
0
0
20,599
0

a,gen

14746

124

124

6

20.9

7,140

s,14:

20,589

0
0
0
0
09.484
0

0
0
0
0
19,188
0

4
0
0
9
9,949
0

30,464

13,169

oges

$1 \quad 165$

2,812

781

102

120

1,005

44,260

2tos.s.5

15:5t

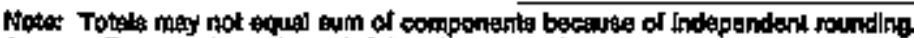

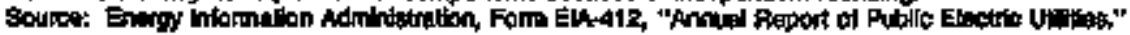


Table 23. Electric Operation and Malntenance Expenses by Malor U.S. Publicly Ownod Electrie Utilty Within State, 1994 (Continued) (Thousand Dollars)

\begin{tabular}{|c|c|c|c|c|c|c|}
\hline Hen & 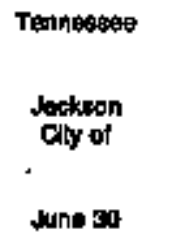 & 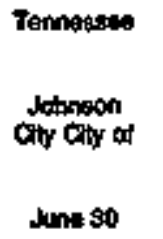 & 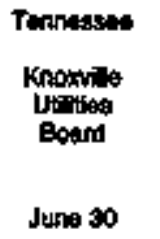 & 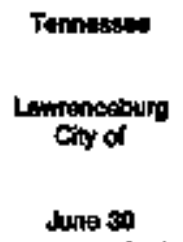 & 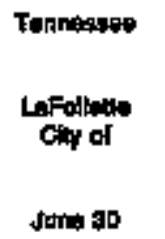 & $\begin{array}{l}\text { Tennessoe } \\
\text { Lebinoit } \\
\text { Chy of } \\
\text { Juns so }\end{array}$ \\
\hline 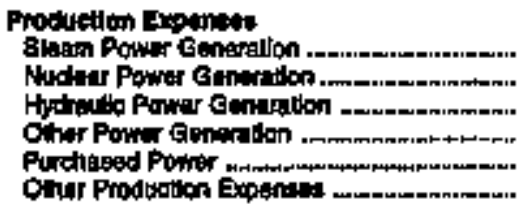 & $\begin{array}{r}0 \\
0 \\
0 \\
0 \\
0 \\
0\end{array}$ & $\begin{array}{r}0 \\
0 \\
0 \\
0 \\
71,043 \\
0\end{array}$ & $\begin{array}{r}0 \\
0 \\
0 \\
0 \\
0 \\
0\end{array}$ & $\begin{array}{r}0 \\
0 \\
0 \\
0 \\
20,778 \\
0\end{array}$ & $\begin{array}{r}0 \\
0 \\
0 \\
0 \\
16,200 \\
0\end{array}$ & $\begin{array}{r}0 \\
0 \\
0 \\
0 \\
15 \\
0 \\
0 \\
0\end{array}$ \\
\hline 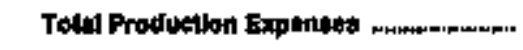 & 6479 & 71,843 & 217,697 & $20 r r a$ & to;as & 15,100 \\
\hline 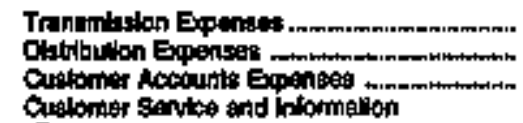 & $\begin{array}{r}734 \\
2,726 \\
727\end{array}$ & $\begin{array}{r}385 \\
8,760 \\
1,811\end{array}$ & $\begin{array}{r}0 \\
12,800 \\
5,588\end{array}$ & $\begin{array}{r}64 \\
1,124 \\
404\end{array}$ & $\begin{array}{r}24 \\
1,698 \\
533\end{array}$ & $\begin{array}{r}0 \\
2759\end{array}$ \\
\hline 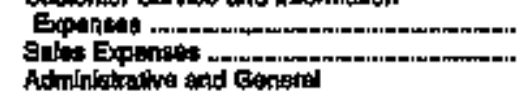 & $\begin{array}{r}190 \\
26\end{array}$ & $\begin{array}{r}61 \\
138\end{array}$ & $\operatorname{ses}$ & 39 & $\begin{array}{l}11 \\
\text { ES }\end{array}$ & $\begin{array}{r}14 \\
0\end{array}$ \\
\hline 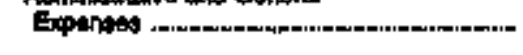 & 1,577 & B70 & s,as & os & 898 & $\sin$ \\
\hline 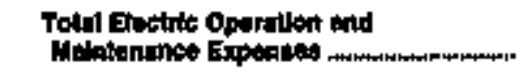 & 57,005 & 70,574 & 246,342 & 23,390 & Th831 & 17042 \\
\hline \multicolumn{7}{|l|}{ Fued Exponase it Cperation } \\
\hline Sleam Power Gateration ...-. & 0 & 0 & 0 & 0 & 0 & n \\
\hline Notiegr Powror Genaralion & 0 & 0 & 0 & 0 & 0 & 0 \\
\hline 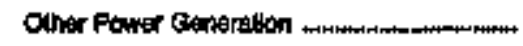 & 0 & o & 0 & 0 & 0 & 0 \\
\hline \multicolumn{7}{|l|}{ 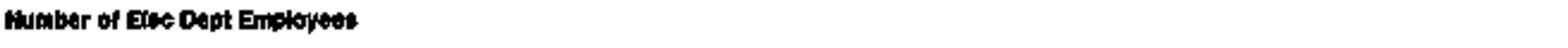 } \\
\hline Aequle Ful-tmo . . & B4 & 122 & 54 & es & 67 & $\$ 2$ \\
\hline Partitime st Temporary , & 0 & 0 & 0 & 0 & a & 0 \\
\hline Toilal Eloc Dept Employeas & a4 & 128 & B:A & es & 7 & 42 \\
\hline
\end{tabular}

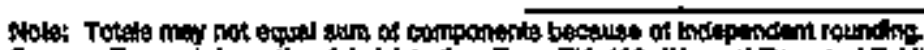

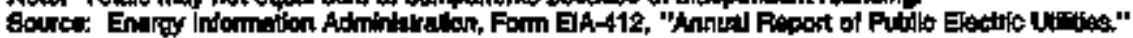


Tabte 23. Elsctrio Operation and Maintenanee Expenses by Major U.S. Publioly Owned Electric Utility Within state, 1994 (Continued) (Thousand Dollars)

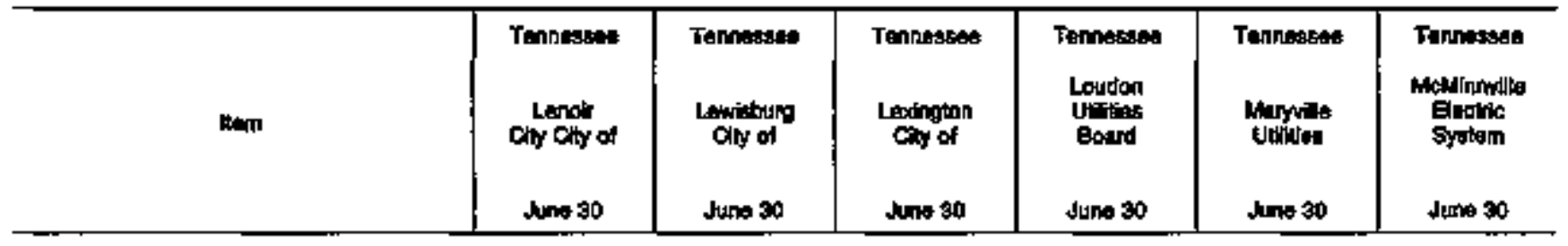

Producton Sompinte:

Gtatim Powter Generition.

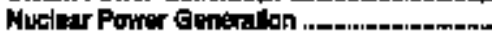

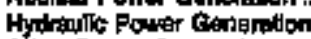

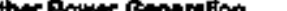

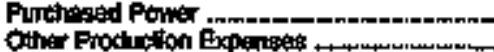

Total Produstion foptingts

Tringisun Expenges

Distiloution Expenses

Customer hecount: Expensest

Guslomer Benve and intormalon

Eqpersea

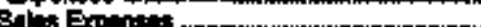

Adrolinglotative and Cancrol

Expenseg

Total Ioptint OFtation and

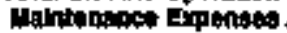

0
0
0
0
0
0

0
0
0
0
0
0

0
0
0
0
18,257
0

48,660

$$
12324
$$

18,207

2, E7t?

1,300

0

47
137

1,563

418

0
24

30

1,609

416

13,900

Fupto:

0
0
0
0
11,500
0

0
0
0
0
23,308
0

11,500

20.869

$\begin{array}{rr}1 & 64\end{array}$

t38

1,100

18

719

28,705

12,736

\section{Fod Expanpan in Operation}

sta.m Pown Centrifion

Nuclarer Pow Caneration

Other Puwer Eonoration

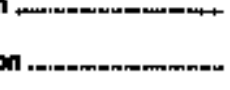

0

0

0

0
0
0

0.

o

b

104

114 $\mathbf{0}$

10426

0

2

$\begin{array}{rr}70 & 18 \\ 0 & 0 \\ 70 & 18\end{array}$

70
0
0
0
0
0,054
0

10.054

600

104

$\underset{\infty}{\infty}$

492

11,478

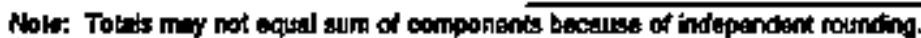

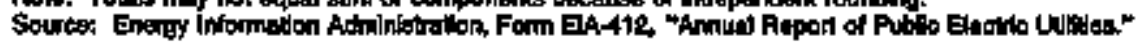


Tablo 23. Electric Operation and Maintenence Expenses by Major U.S. Publiefy Owned Electrio Utility Within 8tate, 1994 (Continued)

(Thousand Dollars)

\begin{tabular}{|c|c|c|c|c|c|c|}
\hline Inm & $\begin{array}{l}\text { Tannopsese } \\
\text { Coty of } \\
\text { Jurese } 30\end{array}$ & $\begin{array}{l}\text { Tennisse: } \\
\text { Mity of } \\
\text { Jung so }\end{array}$ & $\begin{array}{l}\text { Tennesses } \\
\text { Monistown } \\
\text { City of } \\
\text { wure } 30\end{array}$ & $\begin{array}{l}\text { Tennussea } \\
\text { Mufinestboen } \\
\text { Gity of } \\
\text { June 34 }\end{array}$ & $\begin{array}{l}\text { Tennowses } \\
\text { Naglanilie } \\
\text { Eectic } \\
\text { Service } \\
\text { June } 30\end{array}$ & $\begin{array}{l}\text { Tennusses } \\
\text { Nowport } \\
\text { Chy of } \\
\text { Jung } 90\end{array}$ \\
\hline 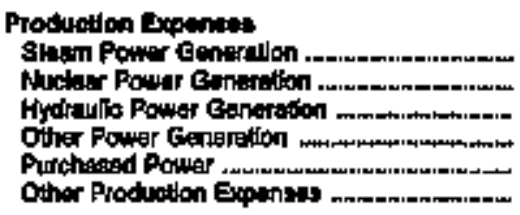 & $\begin{array}{r}0 \\
0 \\
0 \\
0 \\
0\end{array}$ & $\begin{array}{r}0 \\
0 \\
0 \\
0 \\
10,303 \\
0\end{array}$ & $\begin{array}{r}0 \\
0 \\
0 \\
0 \\
29050 \\
0\end{array}$ & $\begin{array}{r}0 \\
0 \\
0 \\
0 \\
30341 \\
0\end{array}$ & $\begin{array}{r}0 \\
0 \\
0 \\
0 \\
0\end{array}$ & $\begin{array}{r}0 \\
0 \\
0 \\
0 \\
18,497 \\
0\end{array}$ \\
\hline 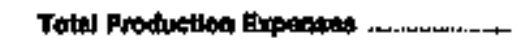 & 530,221 & 10,003 & 29,059 & 35,341 & Aba, & $18, \Delta$ a 7 \\
\hline 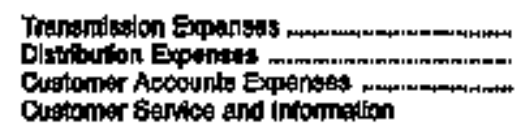 & $\begin{array}{r}3,491 \\
52,967 \\
8,438\end{array}$ & $\begin{array}{r}11 \\
509 \\
174\end{array}$ & $\begin{array}{r}18 \\
1,694 \\
2,88\end{array}$ & $\begin{array}{r}0 \\
1,287 \\
819\end{array}$ & $\begin{aligned} 0 \\
20,886 \\
12,915\end{aligned}$ & $\begin{array}{r}0 \\
1,611 \\
578\end{array}$ \\
\hline 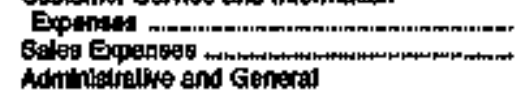 & 74t & $\begin{array}{l}21 \\
50\end{array}$ & $\begin{array}{r}0 \\
147\end{array}$ & $\begin{array}{l}69 \\
13\end{array}$ & 1,549 & $\begin{array}{l}13 \\
21\end{array}$ \\
\hline 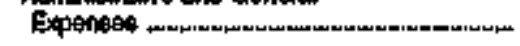 & 35,489 & 361 & 724 & 帛57 & 19,494 & 713 \\
\hline Tolnl Giectita Oparrallon and & $0 \$ 5,205$ & $11,5 \mathrm{gsa}$ & $31, a b s$ & 42,178 & 50 , 160 & 21,425 \\
\hline
\end{tabular}

Fual Expunsas is Operetion

Sham Powtr Generation.

Phudpur Power Generatox

$\mathbf{0}$

0

Oliw Powar Censralon

0

0

0

0

0

o

o

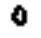

o

a

0

0

0

0

6

Nunbar of Eto Dapt Employees

Reguier Fullitime

$\begin{array}{rr}1,750 & 24 \\ 0 & 0 \\ 1700 & 2\end{array}$

63
0
$6 *$

0
0
6

ors

$6 r$

Partine 4 Tenotity

1,700

2

6s

6

0
875

$\mathbf{0}$

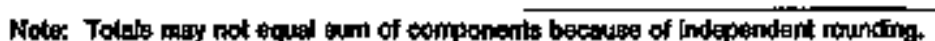

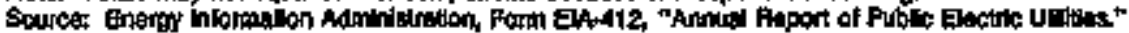


Table 23. Eleptrio Operation and Malntonance Expenges by Major U.S. Publichy Owned Electutic Utillty Within State, 1994 (Continued)

(Thousand Dolkars)

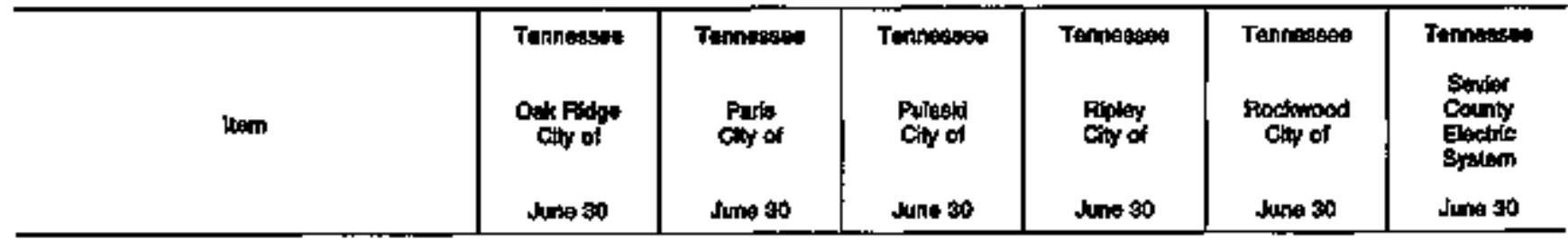

Proiduallon Empontors

Steam Prows Eaneriotion

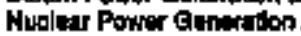

Hydranlle Power feneration

Ohit Panter Genman "on

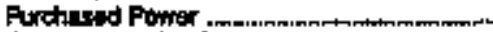

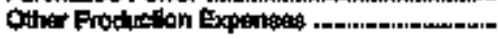

Toinl Production Faptinges

0
0
0
0
0
0
0

21,340

Trangmission Expenses

Cuelomer Aocounts Ementeg:

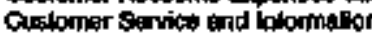

Exprass

Frlag Evons

Almint:

Equnis:

Tod시 Eswotitc Oparalion end

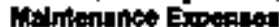$$
1,160
$$

$1, \mathrm{t} 68$

$\$ 92$

5

48

607

20

0
0
0
0
0,128
0

20,tes

0
0
0
0
17,878
0

0
0
0
0
0
0

17.879

0
0
9
0
$10,74 ?$
0
10,749

1,009

98

65

485

178

50

11

37

40

$5 \times 0$

810

2AdTr

mpro

porat

12,12

$\begin{array}{rr}0 & 0 \\ 0 & 0 \\ 0 & 0 \\ 0 & 0 \\ 13,027 & 42,691 \\ 0 & 0\end{array}$

13,027

42,6하

bo:

305

ga

2,044

1,037

4

10

1,139

597

4714

Ful expanase In Opection

Stagm Promor Gengratian

Nocelear Power Gennaraton

n.

Other Fown cenontion

6

$\mathbf{0}$

0

0

a

67

69

0

60

6

4

27

a

$\infty$

Purtime \& Temposary

0

0

E4

Q

D

0

Total tife Dapt Employsea

28

52

et

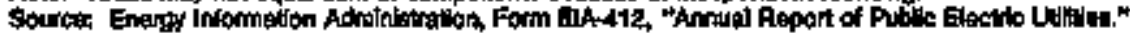


Table 29. Electrlo Operation and Maintenanoe Expeneses by Major U.S. Pubitety Owned Electric Utilly Whin State, 1994 (Continued) (Thousand Dollers)

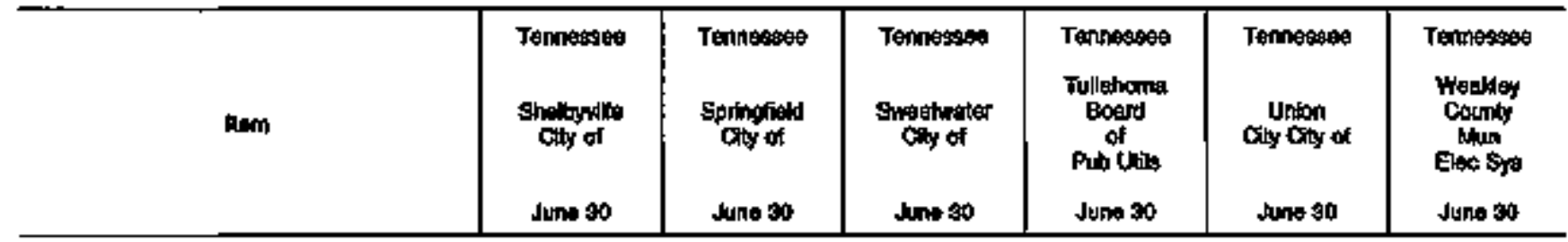

\section{Production Eypontis:}

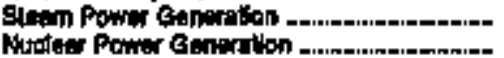

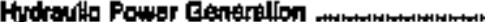

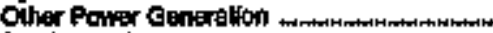

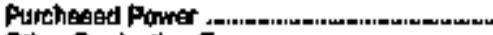

Odher Produditon Expenises

Total Preduetion Expence:

Tranemlaston Experises

Otaldistion Emong

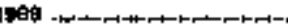

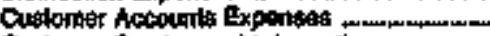

Cuslomes Senite exd inlormalion

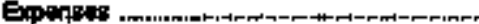

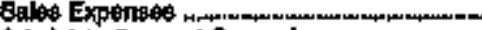

Admirialrative and Corrorl

Exporets.

Total Eectitit Opantion and

Malabanance tapenates

0
0
0
0
0
0

$14,0+2$

0

20

17

432

18.205

0
0
0
0
0.91
0

0,881

451

203

t5

$\$ 13$

p.054

$\begin{array}{rr}0 & 0 \\ 0 & 0 \\ 0 & 0 \\ 0 & 0 \\ 8,647 & 12409 \\ 0 & 0\end{array}$

12.489

Apr

0

164

13

12

304

t5on

0
0
0
0
13,600
0

0
0
0
0
21,875
0

t).60\%

21,675

60

$3 \mathrm{SB}$

168

23

47

417

t4.647

24200

Fod Expostost in Operation

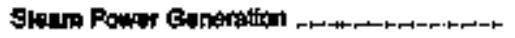

Auclagr Pown Generdon

Chor PGomer Gengraton

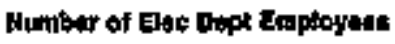

Reguler Fullinito

Fovitme T Taporary

Total EMat Dopk finptayese

$\mathbf{0}$
$\mathbf{0}$
$\mathbf{0}$

0

9

0

27

$\mathbf{0}$

27

\begin{tabular}{rrrrrr}
28 & 20 & 27 & 20 & 17 & 65 \\
0 & 0 & 0 & 0 & 0 & 0 \\
20 & 20 & 27 & 29 & -17 & 65 \\
\hline
\end{tabular}

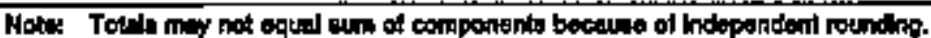

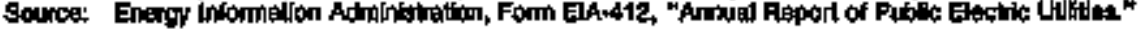


Table 23. Electric Oporation and Maintenance Expentes by Major U.S. Publlely Ownod Eloctrio Utilty Within State, 1994 (Continued)

(Thousand Dollars)

\begin{tabular}{|c|c|c|c|c|c|c|}
\hline Itom & 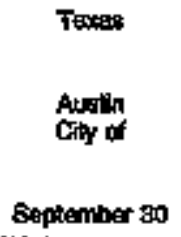 & $\begin{array}{l}\text { Twass } \\
\text { Bronhan } \\
\text { Chy of } \\
\text { Seplember so }\end{array}$ & 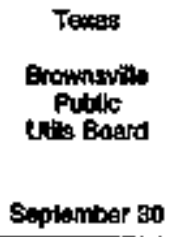 & $\begin{array}{l}\text { Tores } \\
\text { Byon } \\
\text { Ciy of } \\
\text { Seplember so }\end{array}$ & $\begin{array}{l}\text { Toxns } \\
\text { Collego } \\
\text { Stotion } \\
\text { Ciny of } \\
\text { Septeminer so }\end{array}$ & $\begin{array}{l}\text { Texkes } \\
\text { Denton } \\
\text { Ciny of } \\
\text { Sepientuen } 30\end{array}$ \\
\hline 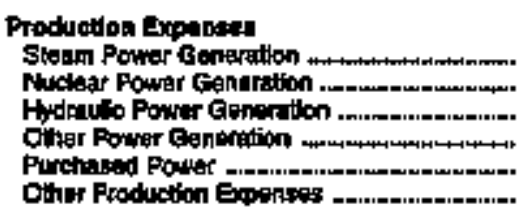 & $\begin{array}{r}143,707 \\
49,019 \\
0 \\
0 \\
19,077 \\
4,097\end{array}$ & $\begin{array}{r}0 \\
0 \\
0 \\
0 \\
0 \\
0\end{array}$ & $\begin{array}{r}17,172 \\
0 \\
0 \\
0 \\
5,097 \\
929\end{array}$ & $\begin{array}{r}18,697 \\
0 \\
0 \\
39,104 \\
69\end{array}$ & $\begin{array}{r}0 \\
0 \\
0 \\
0 \\
22,689 \\
0\end{array}$ & $\begin{array}{r}9,842 \\
0 \\
268 \\
0 \\
9,151 \\
4\end{array}$ \\
\hline 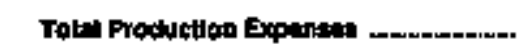 & 217,900 & 9,900 & 23,992 & 50,171 & 22,008 & 45,209 \\
\hline 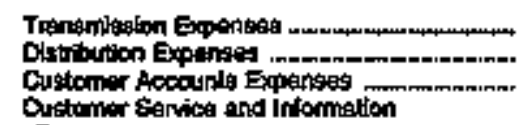 & $\begin{array}{r}1,619 \\
21,028 \\
12,991\end{array}$ & 0 & $\begin{array}{r}1,614 \\
908 \\
623\end{array}$ & $\begin{array}{r}0 \\
3,959 \\
1,340\end{array}$ & $\begin{array}{r}140 \\
1,97 t \\
1,41 \uparrow\end{array}$ & $\begin{array}{r}156 \\
3,142 \\
1,286\end{array}$ \\
\hline 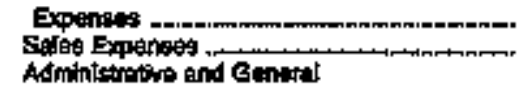 & $\begin{array}{r}13,445 \\
0\end{array}$ & $\stackrel{0}{0}$ & 0 & $\stackrel{0}{0}$ & 0 & $\begin{array}{r}410 \\
0\end{array}$ \\
\hline 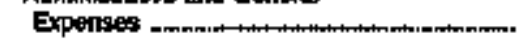 & 36,296 & 390 & 2,829 & 2,621 & 1,080 & 1,710 \\
\hline 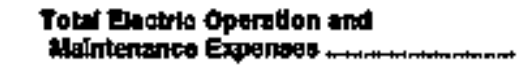 & $297,07 \%$ & 11,070 & 29,960 & $\theta 0,2,8 s$ & 26,436 & 61, 866 \\
\hline \multicolumn{7}{|l|}{ Fund Expensas b Oparmilon } \\
\hline 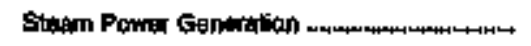 & 108,701 & o & 10,932 & 15,588 & 0 & 7,77 \\
\hline 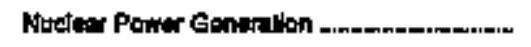 & 7,195 & 0 & 0 & - & 0 & o \\
\hline 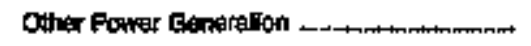 & 0 & a & $\mathbf{0}$ & 0 & 0 & 0 \\
\hline \multicolumn{7}{|l|}{ Nububar of Eec Dept Employases } \\
\hline Roguber Futthe & 1,209 & 10 & 118 & $1 B 4$ & 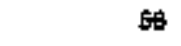 & so \\
\hline Purtime \& Temporary ..mmenten & 9 & $\mathbf{0}$ & 60 & 3 & 2 & o \\
\hline 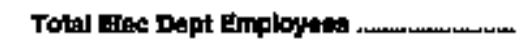 & 1,397 & 10 & 178 & 109 & 58 & \$a \\
\hline
\end{tabular}

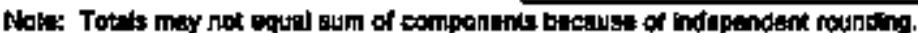

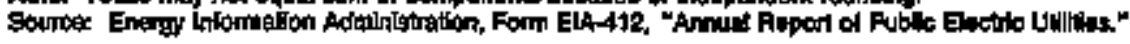


Table 23. Electro Operation and Maintenanes Expenses by Major U.S. Publicly Owned Elactric Utility Withla State, 1994 (Continuod)

(Thousand Dollers)

\begin{tabular}{|c|c|c|c|c|c|c|}
\hline in & 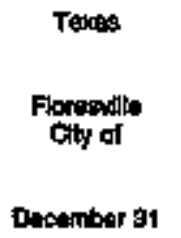 & 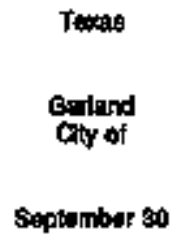 & $\begin{array}{l}\text { Tences } \\
\text { Georgitown } \\
\text { Ciy oI } \\
\text { Soptember } 90\end{array}$ & 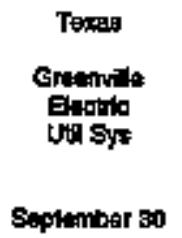 & 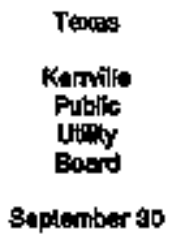 & 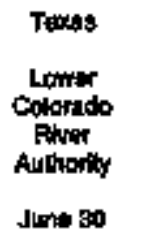 \\
\hline 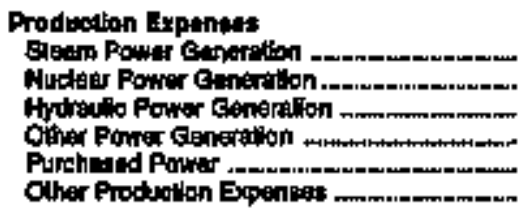 & $\begin{array}{r}0 \\
0 \\
0 \\
0 \\
0,268 \\
0\end{array}$ & $\begin{array}{r}30,025 \\
0 \\
0 \\
0 \\
1,1+5 \\
0\end{array}$ & $\begin{array}{r}0 \\
0 \\
0 \\
0 \\
0.018 \\
0\end{array}$ & $\begin{array}{r}3,188 \\
0 \\
0 \\
170 \\
17,309 \\
0\end{array}$ & $\begin{array}{r}0 \\
0 \\
0 \\
0 \\
15,787 \\
0\end{array}$ & $\begin{array}{r}194,571 \\
0 \\
5,903 \\
0 \\
1,814 \\
5,021\end{array}$ \\
\hline 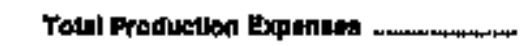 & 6,206 & 170,170 & a,do & $\mathbf{2 1 , 4 5 1}$ & 1:7678 & 207,799 \\
\hline 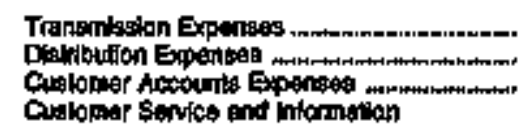 & $\underset{513}{50}$ & $\begin{array}{r}968 \\
8.468 \\
5,297\end{array}$ & $\begin{array}{r}0 \\
1,450 \\
0\end{array}$ & $\begin{array}{r}0 \\
0,8+3 \\
0\end{array}$ & 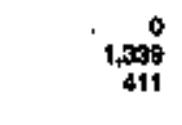 & $\begin{array}{r}27,404 \\
5\end{array}$ \\
\hline 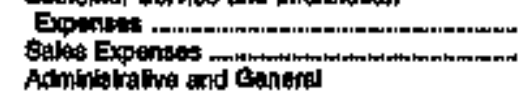 & 0 & $\begin{array}{l}25 t \\
482\end{array}$ & 0 & $\stackrel{0}{a}$ & 0 & 909 \\
\hline 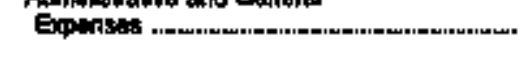 & 678 & $\$, 528$ & o & 1,740 & 1,0 , & 6,280 \\
\hline 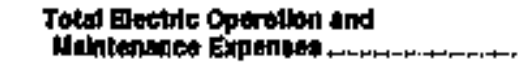 & 0,361 & 12t: 14: & 8,467 & 25,017 & 16,474 & 245;,03B \\
\hline \multicolumn{7}{|l|}{ 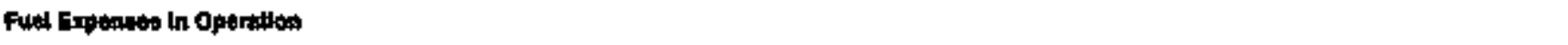 } \\
\hline Stonm Roun Gentralion .......................... & 0 & 33,424 & 0 & 2,010 & 0 & 148.584 \\
\hline 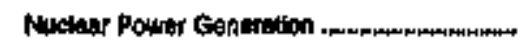 & 0 & 0 & 0 & 0 & 0 & $\mathbf{0}$ \\
\hline Other Rower Generattion & 0 & 0 & 0 & 7 & 0 & 0 \\
\hline \multicolumn{7}{|l|}{ 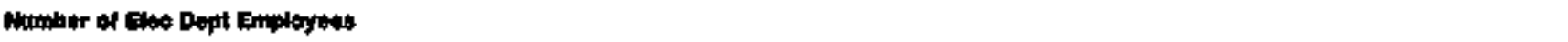 } \\
\hline 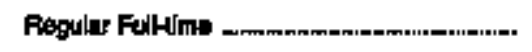 & ES & 220 & 11 & 73 & 67 & 914 \\
\hline Partime \& Tampory & 4 & 2 & $\mathbf{0}$ & $\mathbf{1}$ & 1 & $\mathbf{0}$ \\
\hline 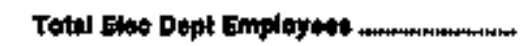 & 62 & 291 & $1 t$ & 74 & 69 & 914 \\
\hline
\end{tabular}

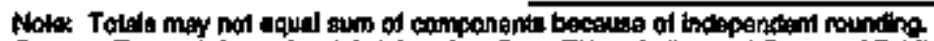

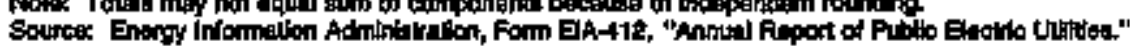


Table 23. Etectric Operation and Maintenanee Expenses by Major U.S. Publlcly Owned Electric Utility Within State, 1994 (Continued) (Thousand Dollars)

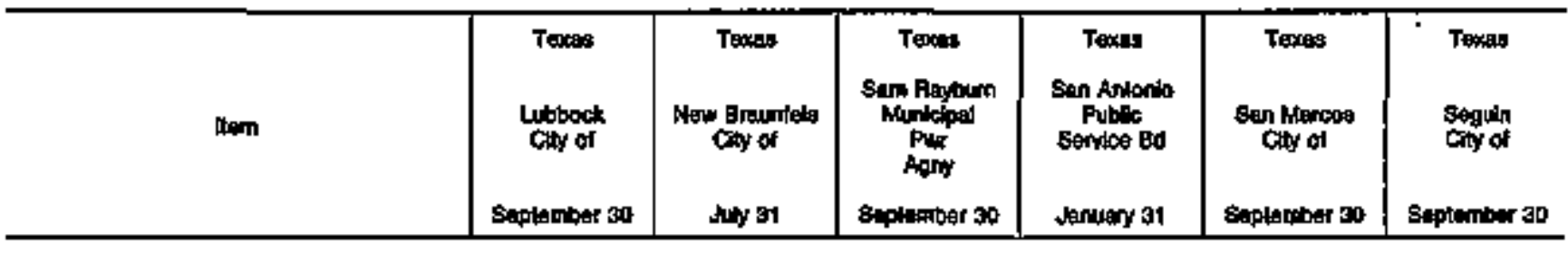

Produrblon Expen:as:

Sleam Power Ganemation +

Murctear Pomer Gonarofop

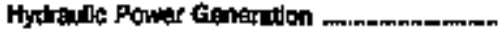

Otim Pown Omnetion

Furéraged Pomer

Olhw Production Exporseg

Total Ptodpetion Enpenses:

Trangmisalox) Expentoses.

Odrtribution Expernasa

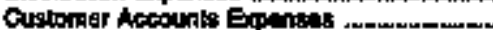

Gustomer Servica end infomation

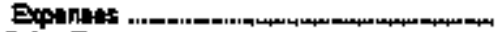

Sples Epentises.

Admin stralive and Canori

Exponsta

Toln Jistrio Cpuration and

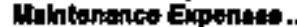

Fed Expenesa in Operation

\$leam Fower censeration

theter Rourar Gonerition

11,504

130011

0
5,94

14,290

3004

a.501

3,497

0

cor

301

41,726

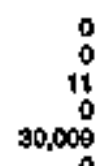

13,50?

160,165

0
0
0

다요

$5 \mathrm{gs}$

$-00$

17,ant

2)18018

30000

87

1379

305

o

0

1,244

32,92:

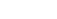

0

2924

50.587

$\mathbf{7 , 4 1 1}$

2,171
0

64,585

1,019

14,219

ato, a6t

17,250

\$,044

Ohar Porrer Ganaraton
4,145

0

10,342

128,188

28955

o

0

0

2716

41

0

0

0

2+15:

4

0

0

o

200

6

3

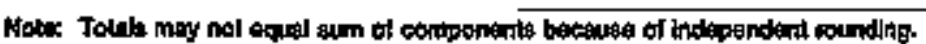

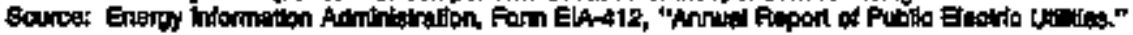


Tablo 23. Electivic Operation ard Maintenance Expenses by Major U.S. Publicly Owned Electrio Wility Within state, 1994 (Continued)

(Thousand Dollars)

\begin{tabular}{|c|c|c|c|c|c|c|}
\hline Vtem & 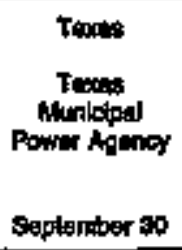 & 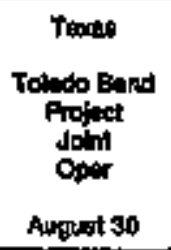 & 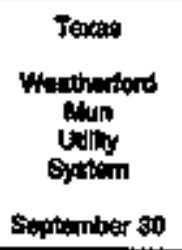 & 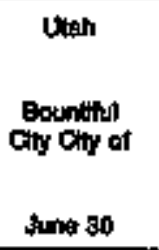 & 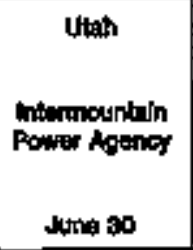 & $\begin{array}{l}\text { Uan } \\
\text { Logen } \\
\text { Cing of } \\
\text { Jupg } 300\end{array}$ \\
\hline 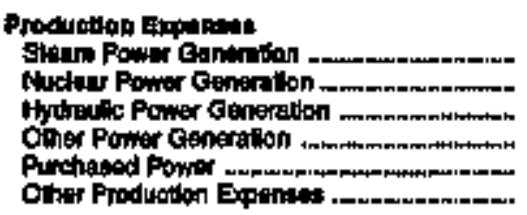 & $\begin{array}{r}078 \\
0 \\
0 \\
0 \\
0\end{array}$ & $\begin{array}{r}0 \\
0 \\
100 \\
0 \\
0 \\
0\end{array}$ & $\begin{array}{r}0 \\
0 \\
0 \\
127 \\
7,950 \\
0\end{array}$ & $\begin{array}{r}0 \\
0 \\
184 \\
004 \\
400\end{array}$ & $\begin{array}{r}213,761 \\
0 \\
0 \\
0 \\
0,760 \\
0\end{array}$ & $\begin{array}{r}0 \\
0 \\
192 \\
702 \\
8+5+7 \\
0\end{array}$ \\
\hline 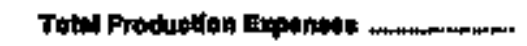 & 69,065 & 100 & sans & 5,695 & 200181 & B,?11 \\
\hline 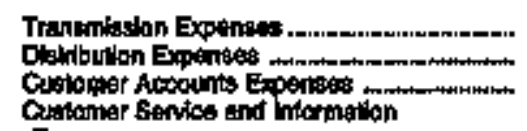 & $\begin{array}{r}3,300 \\
0 \\
0\end{array}$ & $\begin{array}{l}0 \\
0 \\
0\end{array}$ & $\begin{array}{r}0 \\
764 \\
274\end{array}$ & 1,024 & $\begin{array}{r}10,611 \\
0 \\
0\end{array}$ & $\begin{array}{r}205 \\
001\end{array}$ \\
\hline 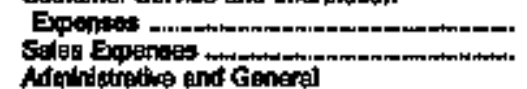 & 0 & 0 & 0 & $\begin{array}{l}0 \\
0\end{array}$ & 0 & 166 \\
\hline Eepenatet & $\$ 1,370$ & 8,008 & e日e & 1,147 & 6,915 & 1,478 \\
\hline 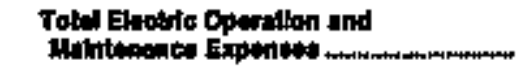 & 609769 & Q.162 & 9042 & 8,27 & $\sin 247$ & 11,721 \\
\hline \multicolumn{7}{|l|}{ Fual Expenses in Oparrilon } \\
\hline Stan Poner Gennintion . & 49,800 & 0 & 0 & 0 & $\$ 76,2028$ & 0 \\
\hline 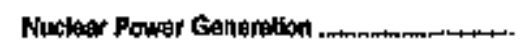 & o & 0 & 0 & 0 & 0 & 0 \\
\hline Other Power Cerrerition ... & $\mathbf{0}$ & 0 & 127 & ats & 0 & 0 \\
\hline \multicolumn{7}{|l|}{ Humber of Eloc Dept Emplojeas: } \\
\hline 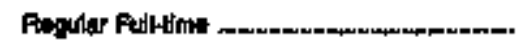 & $\mathbf{3 1 0}$ & 14 & $\mathbf{3 7}$ & 34 & 612 & 26 \\
\hline 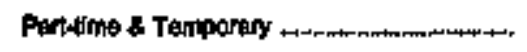 & 30 & 0 & 3 & 5 & $\mathbf{0}$ & 8 \\
\hline Totri Eloc Dapt Enptopwes & 340 & 16 & 4 & $\infty$ & 612 & 32 \\
\hline
\end{tabular}

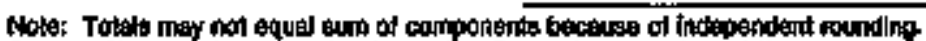

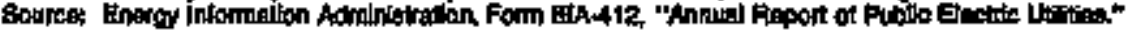


Table 23. Electric Operetion and Maintenance Exponsed by Major U.S. Publicly

Owned Electrte Utility Withln Stale, 1994 (Continued)

(Thousand Dollars)

\begin{tabular}{|c|c|c|c|c|c|c|}
\hline $\ln m$ & $\begin{array}{l}\text { Ulah } \\
\text { Nurry } \\
\text { City of } \\
\text { Juns } 30\end{array}$ & $\begin{array}{l}\text { Utah } \\
\text { Prowo } \\
\text { Crty Colp } \\
\text { June } 30\end{array}$ & $\begin{array}{l}\text { Utah } \\
\text { si esoope } \\
\text { City of } \\
\text { Jine go }\end{array}$ & $\begin{array}{l}\text { Uinh } \\
\text { Ulah } \\
\text { Asoociniod } \\
\text { Mun } \\
\text { Powre Sya } \\
\text { Matren } 31\end{array}$ & 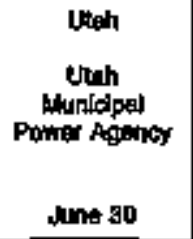 & $\begin{array}{l}\text { Verpiont } \\
\text { Euningion } \\
\text { City od } \\
\text { Juna } 30\end{array}$ \\
\hline 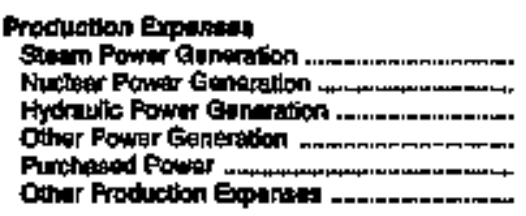 & $\begin{array}{r}0 \\
0 \\
91 \\
92 \\
9,592 \\
0\end{array}$ & $\begin{array}{r}0 \\
0 \\
0 \\
0 \\
02,718 \\
0\end{array}$ & $\begin{array}{r}0 \\
0 \\
0 \\
390 \\
12,146 \\
0\end{array}$ & $\begin{array}{r}7,000 \\
0 \\
0 \\
0 \\
12,60,04 \\
0\end{array}$ & $\begin{array}{r}7,050 \\
0 \\
0 \\
0,208 \\
3,422 \\
0\end{array}$ & $\begin{array}{r}2,060 \\
0 \\
0 \\
146 \\
14,716 \\
574\end{array}$ \\
\hline 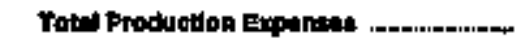 & 975 & $23,7+9$ & 12,508 & 19499 & 24,5at & 18,410 \\
\hline 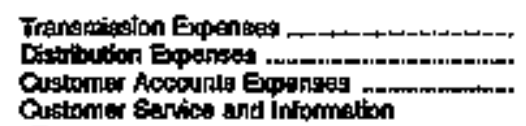 & $\begin{array}{r}8 t \\
1,409 \\
377\end{array}$ & $\begin{array}{r}347 \\
1,470\end{array}$ & $\begin{array}{l}0 \\
0 \\
0\end{array}$ & $\begin{array}{r}4,469 \\
0 \\
0\end{array}$ & 1,503 & $\begin{array}{r}4,89 \\
1,700 \\
1,201\end{array}$ \\
\hline 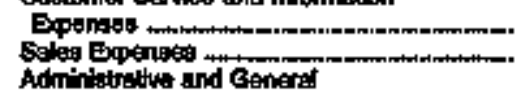 & $\begin{array}{r}189 \\
0\end{array}$ & $\underset{0}{E s}$ & $\stackrel{0}{0}$ & 0 & $\stackrel{0}{0}$ & 284 \\
\hline 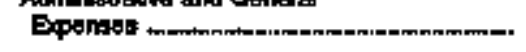 & 1,881 & 347 & 2,105 & 3,285 & 675 & 3,369 \\
\hline 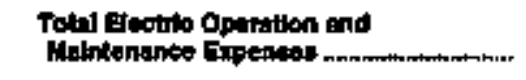 & $\$, 394$ & 25,204 & 14,630 & 27,400 & 20,676 & 26,410 \\
\hline \multicolumn{7}{|l|}{ Fual Expansate in operition } \\
\hline Susem Powror Gonerditon . & 0 & 0 & 0 & 5,474 & 0 & 1,960 \\
\hline 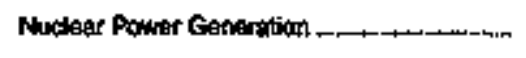 & 0 & a & 0 & 0 & 0 & $\mathbf{0}$ \\
\hline 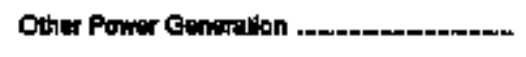 & 1 & 0 & 44 & D & 5,069 & 95 \\
\hline \multicolumn{7}{|l|}{ Number of Elec Depl Employea } \\
\hline יمبس & 50 & al & 48 & 19 & 25 & 161 \\
\hline Partiong \& Tauponery - & 1 & 17 & 6 & 0 & 0 & 4 \\
\hline Toted Elec Dopt Eaptoyeas & $\mathbf{5 1}$ & 105 & 47 & to & 25 & 106 \\
\hline
\end{tabular}

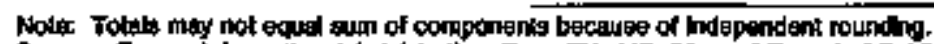

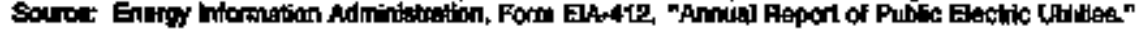


Table 23. Electric Operation and Waintenance Expenses by Major U.3. Publicly Owned Electric Utilty Within State, 1994 (Continued) (Thousiand Dollars)

\begin{tabular}{|c|c|c|c|c|c|c|}
\hline Than & $\begin{array}{l}\text { Vemomt } \\
\text { Vemont } \\
\text { Putble } \\
\text { supidy Auth } \\
\text { December } 31\end{array}$ & $\begin{array}{l}\text { Writila } \\
\text { Bedtord } \\
\text { City of } \\
\text { Jina go }\end{array}$ & 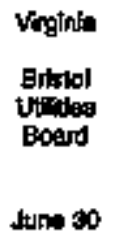 & $\begin{array}{l}\text { Virginil } \\
\text { Denmilis } \\
\text { City of } \\
\text { Jung is }\end{array}$ & 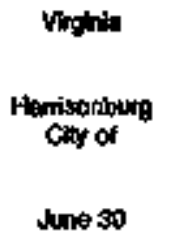 & 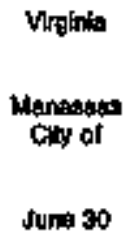 \\
\hline
\end{tabular}

Productlon Expenues

Gtesm Pomer Conoratom

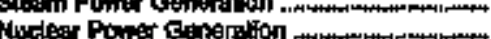

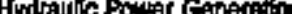

1214

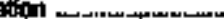

Othin Fowat Ganteretion

Purch hed Pow1

Ohar Froduction Emolisen

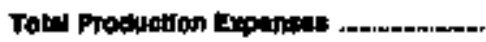

Trangmingion Expenses.

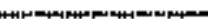

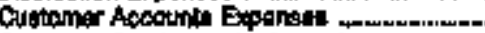

Customer Sarkica and informalion

Extensine

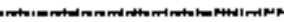

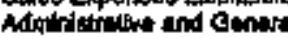

Expenings

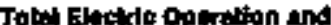

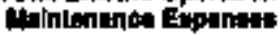

$\begin{array}{rr}1,214 & \\ 0 & \\ 0 & 10 \\ 0 & \\ 3,048 & 7,0,50 \\ 5 & \\ 4,287 & 7,74 \\ 28 & 39 \\ 0 & 207 \\ 0 & 8 \\ 0 & \\ 0 & \\ 1008 & \end{array}$

$\begin{array}{rr}0 & 0 \\ 0 & 0 \\ 108 & 0 \\ 0 & 0 \\ 4006 & 22.297 \\ 4 & \end{array}$

0
0
600
0
0.489
347

0
0
9
0
20,096
0

o

$748 \quad 2920$

29:7

31,40.

2a,ts

$2 \mathrm{~g}$

207

1,9

ง69

1,4t1

$-2$

95

280

1,154

2,288

012

12
28

1,836

48

704

o

39

13

685

6.5S1

5025

24,5t

49

1,544

Futl Expontes in Opartion

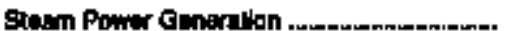

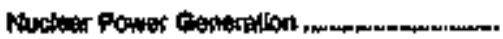

Cthur Power Generation

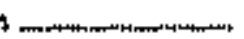

78

0

0

0

0

Q

\section{a}

t

o

Q

b

$\mathbf{0}$

$\mathbf{0}$

o

$\mathbf{0}$

0

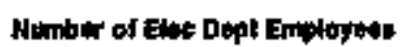

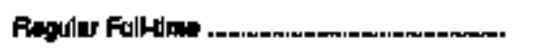

Parlative to Temporany

$\begin{array}{rr}10 & 16 \\ 0 & 0 \\ 10 & 15\end{array}$

\begin{tabular}{rrrr}
44 & 74 & 47 & 42 \\
0 & 1 & 4 & 0 \\
4 & 75 & 51 & 42 \\
\hline
\end{tabular}

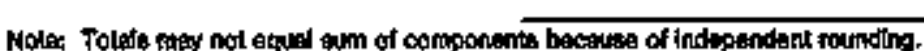

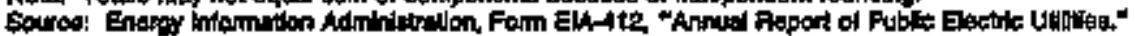


Table 23. Electric Oparation and Mairatenance Expenses by Mujor U.S. Publicty Owmod Eloctric Utility Within State, 1994 (Continuted) (Thousand Dollars)

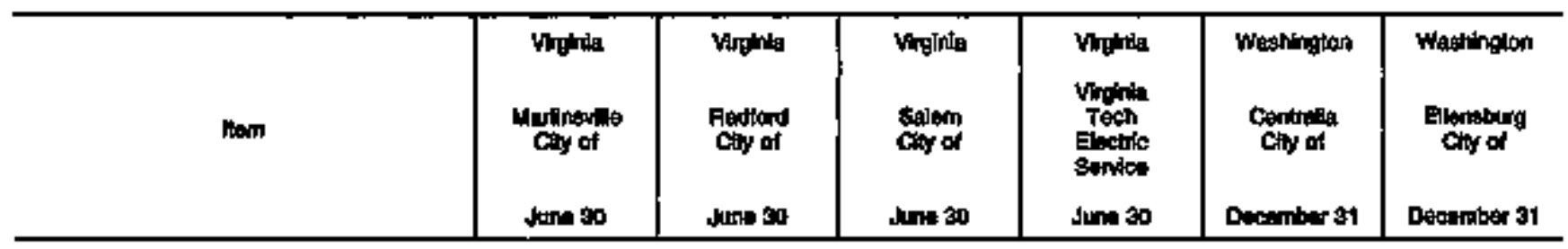

Production Expman:

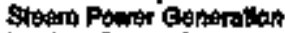

Nucle:1r Popter Gencition

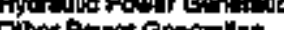

Purthesed Ponter

Other Prod Poner

Tolll Prodinotion Expencei

Thanemlaston Expenseas

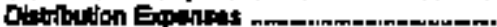

Custoner Accounts Explansos

Cuatomer service and intomarton

Experans .

Salas Expantang

Adniniatrative and Conimel

Exparag

Totid Eleotite Qperatlon and

Melphentance Expearos

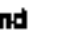

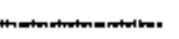

0
0
100
0
7975
0

0
0
20
0
0.072
20

7 toin

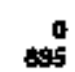

tos

116

o

\$28

4784
0
0
0
12,09

19

1patst

T $\mathrm{P}$

웅

0

146

464

19,7ia

214

610

1474
142
0
0
0
7,675
0

rot

10

34

631

1t.

0
0
597
0
6,25
0

0
0
0
0
4,728
0

bㅎ1

4,72:

125

ot1

645

0

221

2

458

432

7,428

5 ,76s

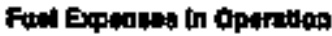

steram Poner timartion

Nuclear Rower Contrition

0

0

Other Ponwer Genmalion

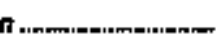

0

$\mathbf{0}$

19

aㅗ

25

30

28

10

1

o

20

22

1

4

13

3

29

2

11

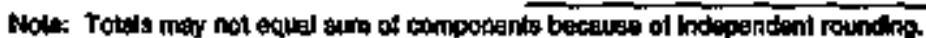

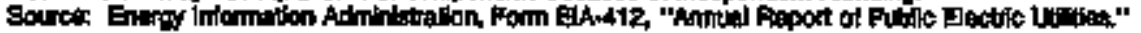


Table 23. Electrtc Operation and Malintenanee Expenses by Major US. Publichy Owned Eleptric Utllity Within State, 1994 (Continued)

(Thousand Dollars)

\begin{tabular}{|c|c|c|c|c|c|c|}
\hline ltem & $\begin{array}{l}\text { Whahingtor } \\
\text { Port Angules } \\
\text { Ciny of } \\
\text { Docombar sy }\end{array}$ & $\begin{array}{l}\text { Washintion } \\
\text { Pyo No } 1 \\
\text { of } \\
\text { Eenton } \\
\text { Coynty } \\
\text { Desember } 91\end{array}$ & 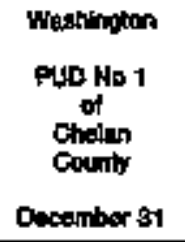 & $\begin{array}{l}\text { Washingen } \\
\text { Pud No } 1 \text { of } \\
\text { Coblim } \\
\text { Coenty } \\
\text { Denember at }\end{array}$ & $\begin{array}{l}\text { Wearinglon } \\
\text { PUD No } 1 \\
\text { of } \\
\text { Clark } \\
\text { Decanty }\end{array}$ & 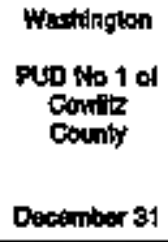 \\
\hline 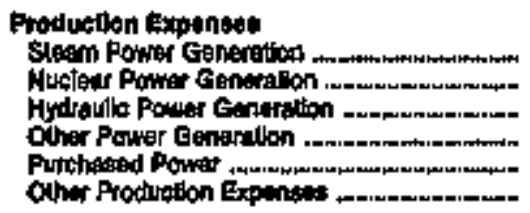 & $\begin{array}{r}0 \\
0 \\
14 \\
0 \\
17,569 \\
39\end{array}$ & $\begin{array}{r}0 \\
0 \\
0 \\
0 \\
9 \\
0\end{array}$ & $\begin{array}{r}0 \\
25,004 \\
0 \\
24,378 \\
140\end{array}$ & $\begin{array}{r}0 \\
0 \\
0 \\
0 \\
13,980 \\
0\end{array}$ & $\begin{array}{r}0 \\
0 \\
0 \\
0 \\
108,277 \\
0\end{array}$ & $\begin{array}{r}0 \\
195 \\
19 \\
114,477 \\
2,089\end{array}$ \\
\hline Told Production Expthuse & 17, toga & antate & 4,552 & 11,000 & 108,277 & 118,765 \\
\hline 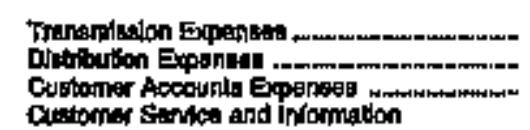 & $\begin{array}{r}10 \\
1,192 \\
401\end{array}$ & $\begin{array}{r}17 \\
3,377 \\
1,179\end{array}$ & $\begin{array}{l}2,407 \\
5,277 \\
605\end{array}$ & $\begin{array}{l}120 \\
2001 \\
1,061\end{array}$ & $\begin{array}{r}19 \\
5,284 \\
6,390\end{array}$ & $\begin{array}{r}159 \\
3,102 \\
1,666\end{array}$ \\
\hline 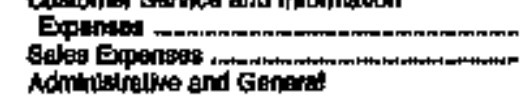 & 408 & $\begin{array}{r}374 \\
0\end{array}$ & 1,302 & 6 & Spg & 340 \\
\hline 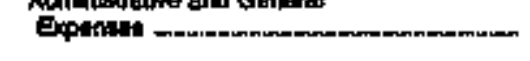 & 790 & s,221 & 15,491 & 2,469 & $6,9,8$ & 3,565 \\
\hline 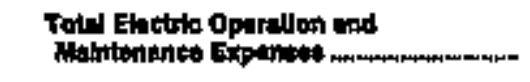 & 20,403 & 47082 & 74,747 & 19,740 & 21,373 & 125,600 \\
\hline \multicolumn{7}{|l|}{ Fued Expenises In Optration } \\
\hline 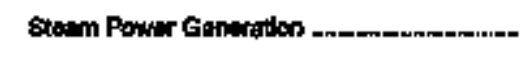 & 0 & 0 & 0 & 0 & 4 & o \\
\hline 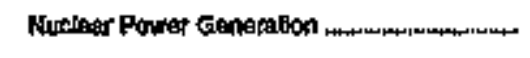 & $\mathbf{0}$ & $\mathbf{0}$ & 0 & 0 & 0 & 0 \\
\hline Other Pows Gangndon & 0 & 0 & v & 0 & 0 & 0 \\
\hline \multicolumn{7}{|l|}{ Hamber of Eleo Dept Employesos } \\
\hline 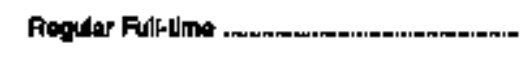 & 37 & 132 & 426 & 100 & soe & 189 \\
\hline Partilins \& Tampopayy & $\mathbf{I}$ & $\mathbf{5}$ & t8 & 10 & 21 & 4 \\
\hline Totel Eles Dept Enployeses & a) & 197 & 44 & 118 & ats & 143 \\
\hline
\end{tabular}

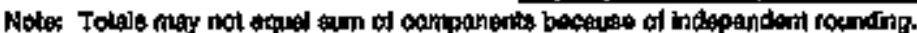

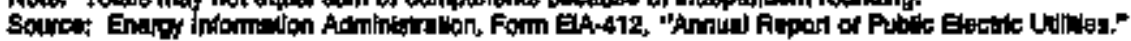


Table 23. Electric Operation and Maintenance Expenses by Major U.S. Pubilety Owned Electric Utility Within State, 1984 (Continued)

(Thousand Dollars)

\begin{tabular}{|c|c|c|c|c|c|c|}
\hline then & 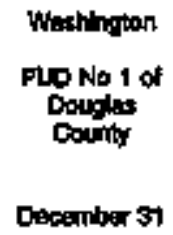 & 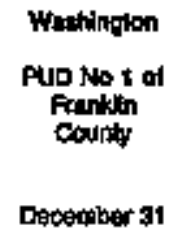 & 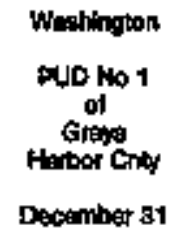 & 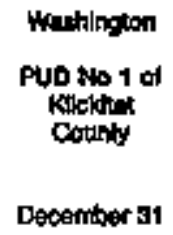 & $\begin{array}{c}\text { Woshington } \\
\text { mol ko } 1 \\
\text { of } \\
\text { Conis } \\
\text { Deceminges } 31\end{array}$ & $\begin{array}{l}\text { Waabingion } \\
\text { PUD No } 1 \text { of } \\
\text { Ohenogan } \\
\text { Counly }\end{array}$ \\
\hline
\end{tabular}

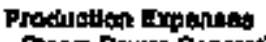

Staten Power Ganeration

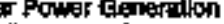

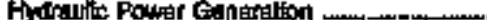

Oithr Pown Genaration

Funchuased Fowar

Tata Produstion Explangets

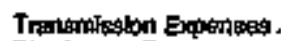

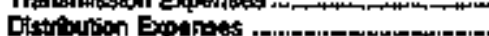

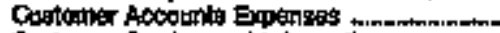

Duteomer sarvice and intormation

Expensess +ric.

Sales Expentes

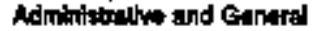

Exporises

\section{ral}

Total Elothio Oporation and

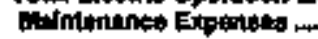

Fued Ifpenses in Operdition

Stan Power Ganatation

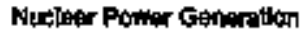

Other Fower Gonnaton

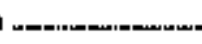

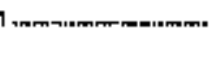

ippoyen:

Regule Fultime

Part-ima \& Teaponary

125

Tatar Gof Oept Enjplojpes

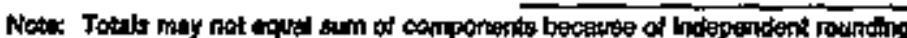

$\begin{array}{rr}0 & 0 \\ 0 & 0 \\ 6,250 & 0 \\ 1,300 & 17,681\end{array}$

295

7,799

842

2,406

369

60

4,690

19.258
B.717

0

2905

.

t다장

509

coto

1,744

10

$3,6+4$

1.62:

21-197

4 A69

0
0
0
0
$7,0 \%$
0

0
0
805
0
10.761
02

189-2?

451

2,000

1,474

0

1,018

24695
0
0
17
0
$10,67 t$
01

10,84

25

$1,65$.

476

30

1,400

14,240

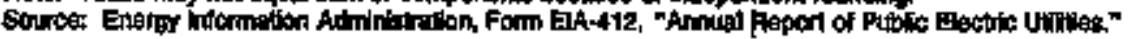


Tabie 23. Electric Operation and Malntenance Expenses by Major US. Publloly Owned Electrite Utully whin State, 1994 (Continued) (Thousand Dollars)

\begin{tabular}{|c|c|c|c|c|c|c|}
\hline Minn & 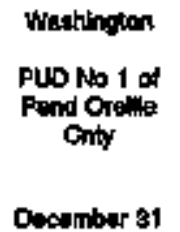 & 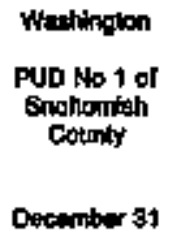 & 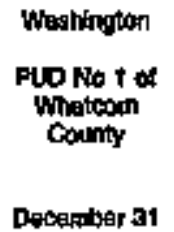 & 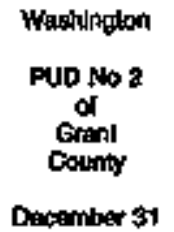 & 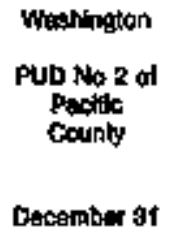 & $\begin{array}{l}\text { Wasthingtom } \\
\text { PUD itos } \\
\text { of } \\
\text { Wason } \\
\text { County } \\
\text { Decumber } 31\end{array}$ \\
\hline
\end{tabular}

Arotiuction Expentes:

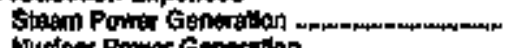

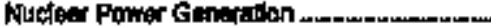

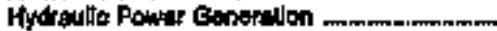

Othar Powar Cimerallon

Potficheded Powis

Othe Producliton Expensas ...............m.

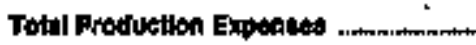

Tremarnigation Bupanses

Distribution Expentest

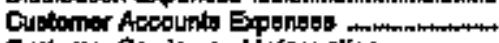

Costomer serwice end infarinaling

Expan:ses

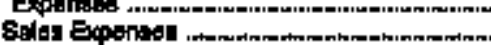

Admintatrathrs and General

Expentes?

Tobil Elaosts Gporston and

Nintiontion Eypenoset

\section{Fut Expenas in Operndon}

Sivam Powar Genaralion

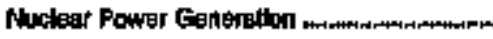

Other Fower Coneration

$\begin{array}{rr}0 & 13,000 \\ 0 & 0 \\ 1,279 & 1,073 \\ 0 & 0 \\ 12,193 & 130,326 \\ 1,439 & 32,060\end{array}$

14,055 184034

3
1,390
370

20.5

20417

9.402

2,514

11

$1, \operatorname{esc}$

15,769

1:0018

23090

11,497

0

0
0
0
25,178
0
12,684
-6

27,033

$12 \mathrm{aB}$

6,598

1,070

309

8,005

57,05 $\begin{array}{rr}0 & 0 \\ 0 & 0 \\ 0 & 0 \\ 0 & 0 \\ 8,141 & 15,432 \\ 0 & 0\end{array}$

9,141 15,492

6

459

200

808

675

1 5at

029

20,605

thmber of Elec Bopt Emplorete

Raguler Fu'dine

50 8

b

0

$\mathbf{0}$

0

o

0

a

0

0

Payllita a Tentrontary

40

o12

912
0
912

1
0
1

450
27
477

48
2
50

109

39

197

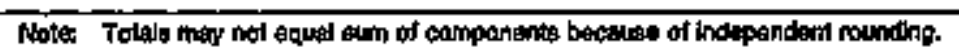

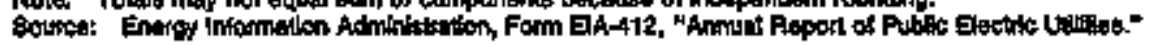


Table 23. Flectric Operation and Maintenance Expenses by Major U.S. Pubicly Owned Electric Utilly Within State, 1094 (Continued) (Thousand Dollars)

\begin{tabular}{|c|c|c|c|c|c|c|}
\hline I10m & $\begin{array}{l}\text { Washingien } \\
\text { Alstiend } \\
\text { Chy of } \\
\text { December or }\end{array}$ & $\begin{array}{l}\text { Whatringlon } \\
\text { Seatila } \\
\text { City of } \\
\text { Oecomber 3t }\end{array}$ & $\begin{array}{l}\text { Wo:chingion } \\
\text { Tocom } \\
\text { Chy of } \\
\text { Decomber } 91\end{array}$ & 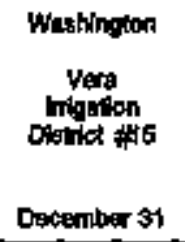 & $\begin{array}{l}\text { Wathingion } \\
\text { Washingion } \\
\text { Pub } \\
\text { Eur } \\
\text { supty syt } \\
\text { June so }\end{array}$ & 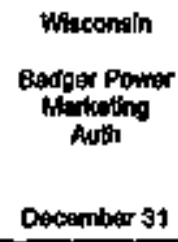 \\
\hline 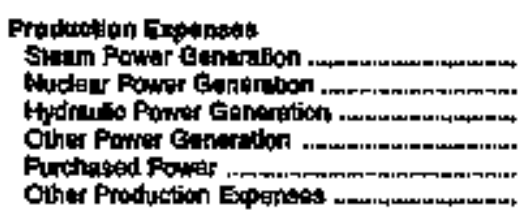 & $\begin{array}{r}0 \\
0 \\
0 \\
0 \\
18,309 \\
0\end{array}$ & $\begin{array}{r}13,104 \\
14,917 \\
0 \\
92,94 \\
2,906\end{array}$ & $\begin{array}{r}01,000 \\
0 \\
6,148 \\
0 \\
69,550 \\
65\end{array}$ & $\begin{array}{r}0 \\
0 \\
0 \\
0 \\
5,0 B 4 \\
0\end{array}$ & $\begin{array}{r}0 \\
156,017 \\
491 \\
0 \\
0 \\
0\end{array}$ & $\begin{array}{r}0 \\
0 \\
0 \\
0 \\
0,374 \\
0\end{array}$ \\
\hline Total Pratutetion Fipenats . & 1aspas & 102,206 & 60,563 & $5,0 \mathrm{~B} 4$ & 130,451 & 2,374 \\
\hline 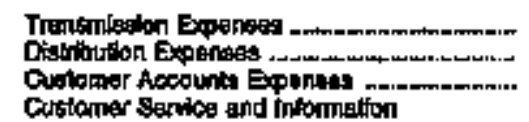 & $\begin{array}{r}0 \\
1,844 \\
414\end{array}$ & $\begin{array}{l}15,184 \\
38,3,68 \\
14,006\end{array}$ & $\begin{array}{r}3,950 \\
1,9,47 \\
3,060\end{array}$ & $\begin{array}{c}0 \\
380 \\
381\end{array}$ & $\begin{array}{r}411 \\
0 \\
0\end{array}$ & $\begin{array}{r}48 \\
0 \\
1\end{array}$ \\
\hline 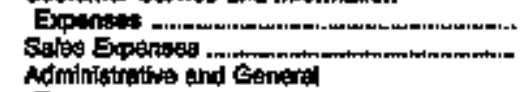 & 854 & 7.648 & $\begin{array}{r}2,360 \\
264\end{array}$ & 24 & 0 & $\stackrel{0}{0}$ \\
\hline 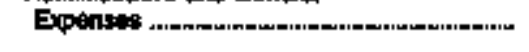 & 1,028 & 37,176 & 19,000 & 981 & 58,584 & 112 \\
\hline 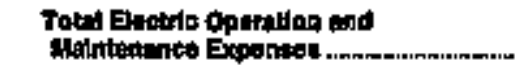 & 21,84:46 & 291,546 & 142,650 & 4,42 & 210,403 & 0,595 \\
\hline \multicolumn{7}{|l|}{ Fuet Expunas: la operition } \\
\hline 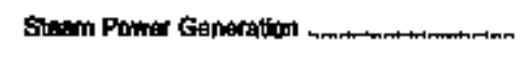 & 0 & 10,057 & 13,060 & 0 & 0 & 0 \\
\hline 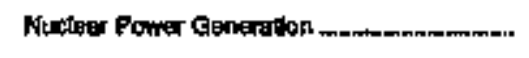 & 0 & 0 & 0 & 0 & $30,5,21$ & 0 \\
\hline 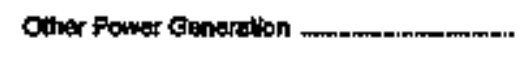 & 0 & 0 & 0 & 0 & 0 & 0 \\
\hline \multicolumn{7}{|l|}{ 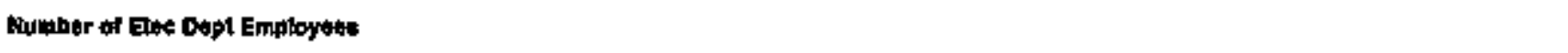 } \\
\hline 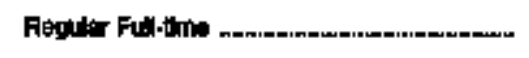 & 52 & 1,749 & 700 & 29 & 1,359 & 0 \\
\hline Patt-line 8 Temporty & $\mathbf{s}$ & 190 & 60 & $\mathbf{t}$ & 187 & 0 \\
\hline 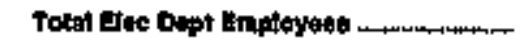 & 57 & 1,0099 & 76 & 90 & 1,528 & 0 \\
\hline
\end{tabular}

Note: Tokals may not equal sum of components beceuse of independian minfing.

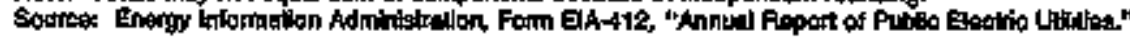


Table 2x. Electric Operatlon and Malntenano Exponess by Major Us. Publichy Owned Electric Utilly Withln State, 1994 (Conthued) (Thousand Doliars)

\begin{tabular}{|c|c|c|c|c|c|c|}
\hline llam & $\begin{array}{l}\text { Wioconaln } \\
\text { Jefingon } \\
\text { Cily of } \\
\text { December } 31\end{array}$ & 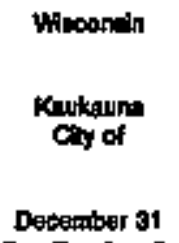 & 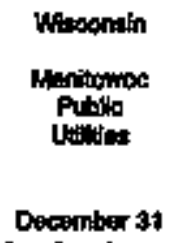 & 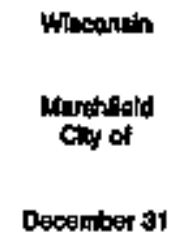 & 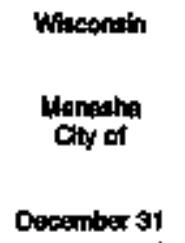 & 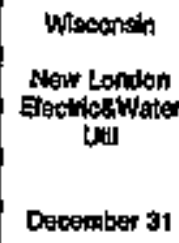 \\
\hline 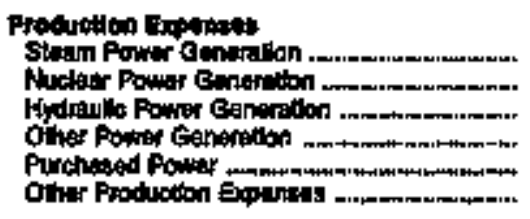 & $\begin{array}{r}0 \\
0 \\
0 \\
0 \\
5,184 \\
0\end{array}$ & $\begin{array}{r}0 \\
0 \\
696 \\
54 \\
17,669 \\
184\end{array}$ & $\begin{array}{r}10,128 \\
0 \\
0 \\
250 \\
5,693 \\
0\end{array}$ & $\begin{array}{r}146 \\
0 \\
0 \\
94 \\
9.979 \\
0\end{array}$ & $\begin{array}{r}674 \\
0 \\
0 \\
0 \\
+6,646 \\
0\end{array}$ & $\begin{array}{r}0 \\
0 \\
0 \\
0 \\
0 \\
0\end{array}$ \\
\hline 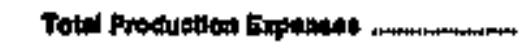 & $5,+34$ & 19,5MF & 16,044 & 9:918 & 10,420 & 4,87r \\
\hline 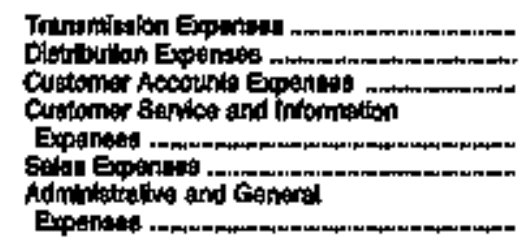 & $\begin{array}{r}007 \\
88 \\
01 \\
101\end{array}$ & $\begin{array}{r}10 \\
600 \\
100 \\
0 \\
6 \\
5\end{array}$ & $\begin{array}{r}582 \\
580 \\
298 \\
328 \\
1.075\end{array}$ & $\begin{array}{r}34 \\
690 \\
164 \\
0 \\
179 \\
528\end{array}$ & $\begin{array}{r}28 \\
347 \\
147 \\
0 \\
200 \\
786\end{array}$ & $\begin{array}{r}0 \\
190 \\
81 \\
0 \\
70 \\
700\end{array}$ \\
\hline 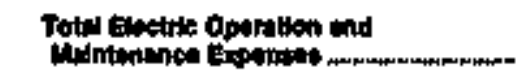 & sest & 20191 & 14958 & 11,106 & 200130 & 0,044 \\
\hline \multicolumn{7}{|l|}{ Fual Expensas in Operinon } \\
\hline 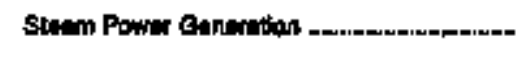 & - & 0 & 6,018 & - & 17 & o \\
\hline 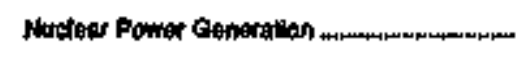 & 0 & 0 & 0 & 0 & 0 & 0 \\
\hline Other POmit Gentation & 0 & 0 & 176 & 0 & 0 & 0 \\
\hline \multicolumn{7}{|l|}{ Linber of Dec Dept Enpleyet } \\
\hline 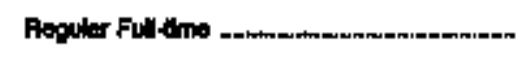 & $\mathbf{T}$ & 4 & 84 & 24 & as & 19 \\
\hline Partisno $\$$ Temporary & 0 & 4 & s & 1 & 1 & 0 \\
\hline 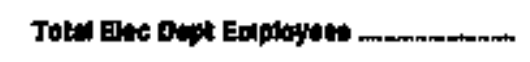 & $\mathbf{7}$ & 47 & ot & $\mathbf{6}$ & 39 & 19 \\
\hline
\end{tabular}

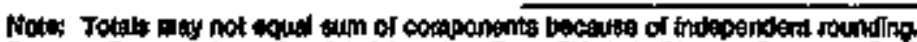

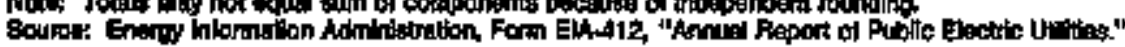


Table 23. Electrlc Operation and Malntenance Expenses by Major U.S. Publlety Owned Electric Utility Within State, 1994 (Continued) (Thousand Doltars)

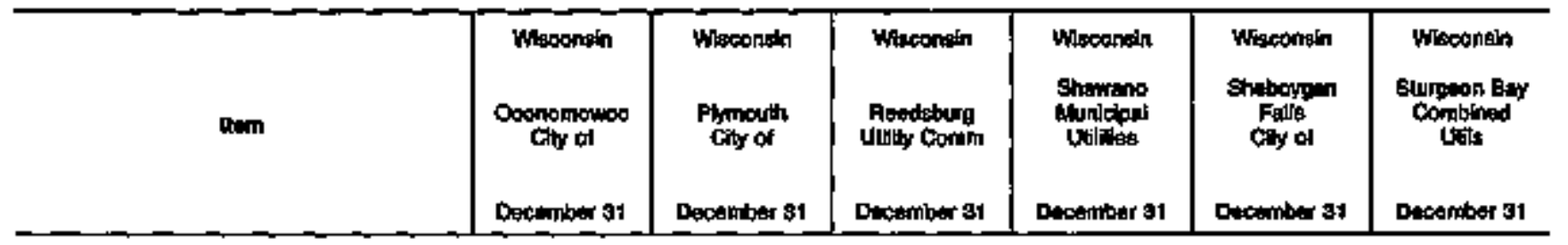

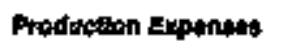

Skan Fowr Earorition

Nutroar Pount Cencaration

Hydraulio Ponter tenaracion

Outer Power Cennotiton

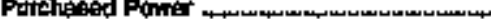

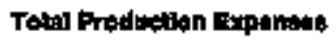

Trangindon Expenses

Cuslomer hccounts Expenses .........-.-.

Customer seovita rid inloringion

Sales Expenses roministraliva and Generel

Emines:

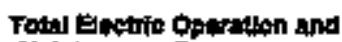

Mintenino Exponis:
OWh Produotion Epentas

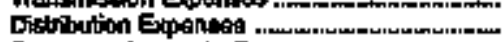

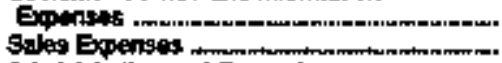

0
0
0
0
5,515
0

0
0
0
0
6,303
0

Expr

20

203

(1)

6

378

5,513

0

4

(1)

10

271

0,301

6, 305

71

180

t

97

24

6,977 $\begin{array}{rr}0 & 0 \\ 0 & 0 \\ 0 & 0 \\ 0 & 0 \\ 5,294 & 5,102 \\ 0 & 0\end{array}$

$5,2: 44 \quad 5,102$

9

Bos

0

4

100

\$.640

5,977

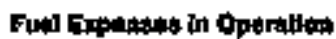

Slean Power Cenoration.

Nurdur Power Cennerotion.

o

o

a

0

D

D

o

o

0

7,679

Ouner Pown Gennation

0

$\mathbf{0}$

o

0 mpilnyees

Hunber of Eles Dept Emolnyees

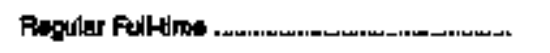

Parting The Tempocary

Tated Elat Dopk Finplopios:
18

18

sto
16

a

10
10

0

10

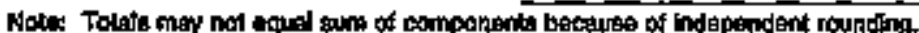

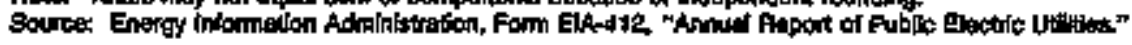


Table 23. Electric Operation and Maintenance Expenses by Mejor U.8. Publcly Owned Electric Utitity Within State, 1994 (Continued) (Thousand Dollars)

\begin{tabular}{|c|c|c|c|c|c|}
\hline Han & 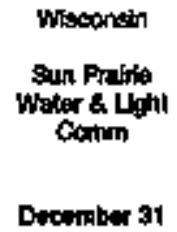 & $\begin{array}{l}\text { Witsconsin } \\
\text { Wistonsin } \\
\text { Puble } \\
\text { Powter } \\
\text { Inch Sirt } \\
\text { Decambor } 31\end{array}$ & $\begin{array}{l}\text { Woconsis } \\
\text { Wrocoungin } \\
\text { Papists W W } \\
\text { Comm } \\
\text { Dotember } 31\end{array}$ & $\begin{array}{l}\text { Wroming } \\
\text { Cotuctis } \\
\text { Cry of } \\
\text { June so }\end{array}$ & 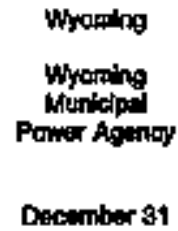 \\
\hline
\end{tabular}

\section{Production tepentivet}

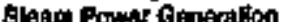

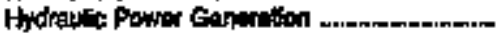

Oher Pown Cleneration

Purchased Ponter

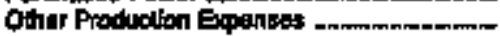

Tot:a Production Expanses

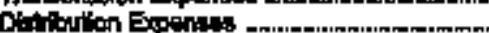

Ovetarner Avoodnts Expenses

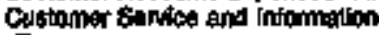

Exponses

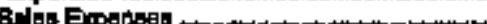

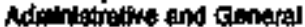

Expentas

Totel Eletult Operaton and

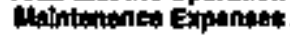

Fud Expences In Opurabon

Stan Ponder Genertifion

Nucka: Pourer Cangrallon

Other Power Genmatas

(20)

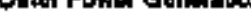

Number at eloo Dept Employede

Aegular Futhins

Padting \& Temporary

Y

Toled Elao Dept Employed
Tranationton Equrses

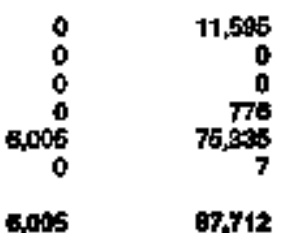

sis

a.6\%5

217

217

0

8

164

4,487

$$
\begin{array}{r}
0.65 \\
0
\end{array}
$$$$
\text { o }
$$

3,450

or 808

0
0
0
0
6.840
0

0
0
0
0
8,007

1519

0

as

4

6.840

8087

8000

40

29.8

146

682

208

0

181
0

a

59

52

416

376

250

best

2456

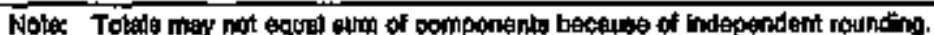

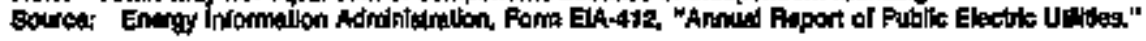


Table 24. Electrie Utilty Ptant by Major U.S. Publloly Owned Eleotrie Utity Within State at End of Period, 1994 (Thousand Dollars)

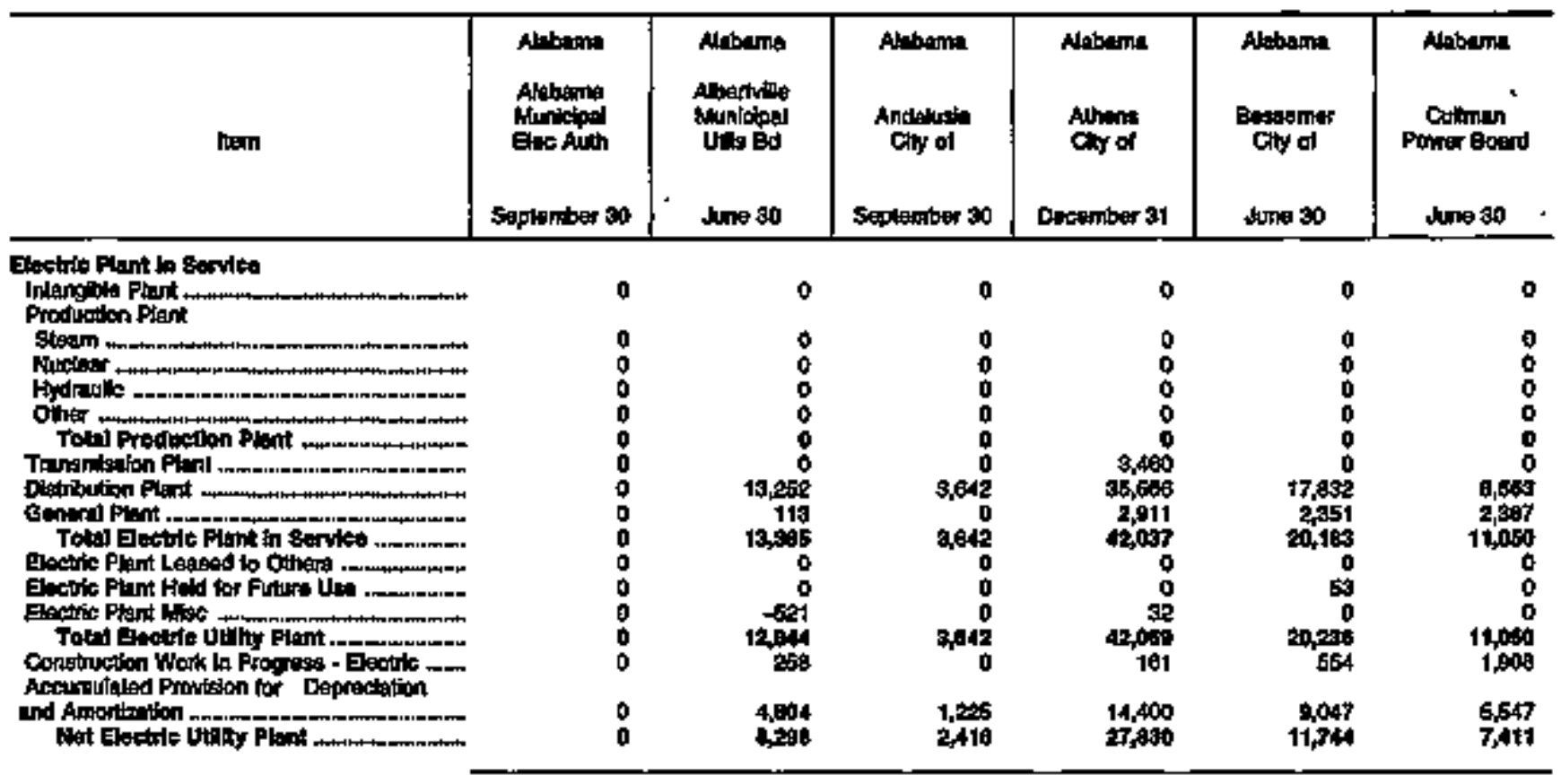

\begin{tabular}{|c|c|c|c|c|c|c|}
\hline lints & $\begin{array}{l}\text { Alpharte } \\
\text { Docethr } \\
\text { Cty of } \\
\text { Jima so }\end{array}$ & 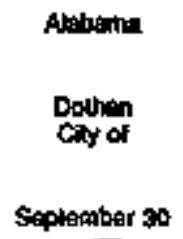 & 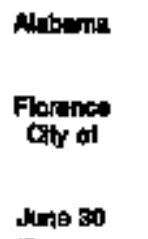 & 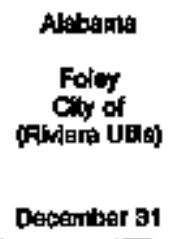 & 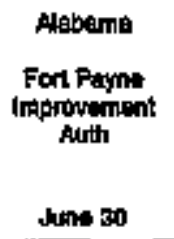 & 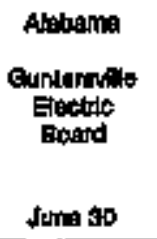 \\
\hline 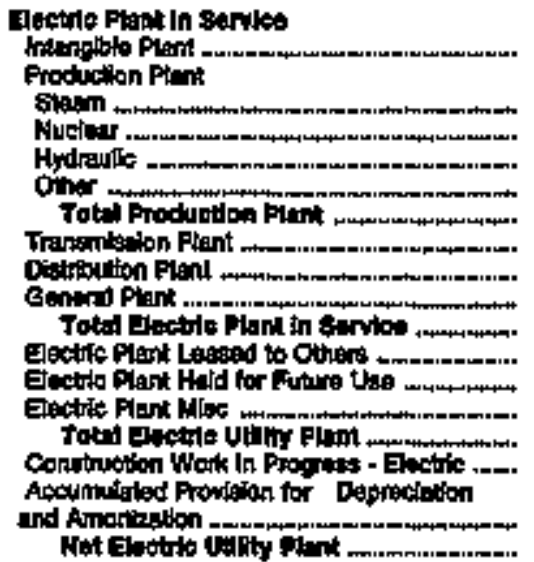 & 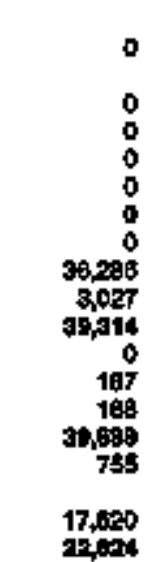 & $\begin{array}{r}0 \\
0 \\
0 \\
0 \\
0 \\
0 \\
0 \\
0 \\
58973 \\
64979 \\
0 \\
0 \\
0,673 \\
0\end{array}$ & $\begin{array}{r}0 \\
0 \\
0 \\
0 \\
0 \\
14,188 \\
68,299 \\
6,760 \\
74,105 \\
0 \\
0 \\
119 \\
74,244 \\
1,344\end{array}$ & 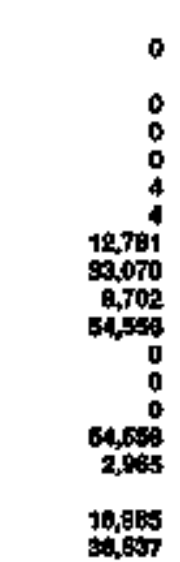 & $\begin{array}{r}0 \\
0 \\
0 \\
0 \\
0 \\
0 \\
11,192 \\
7,500 \\
12,700 \\
0 \\
0 \\
12,794 \\
598 \\
4,994 \\
840\end{array}$ & $\begin{array}{r}0 \\
0 \\
0 \\
0 \\
0 \\
0 \\
0 \\
0,287 \\
8,00 \\
0,067 \\
0 \\
0 \\
0 \\
0,067 \\
873 \\
4,128 \\
5,817\end{array}$ \\
\hline
\end{tabular}

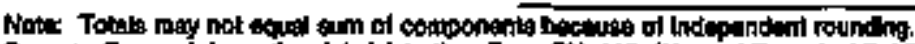

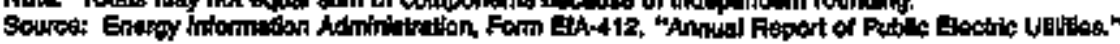


Table 24. Electric Utility Plant by Major U.S. Publety Owned Electric Utilty Within State at End of Perlod, 1994 (Continued) (Thousand Dollars)

\begin{tabular}{|c|c|c|c|c|c|c|}
\hline kem & 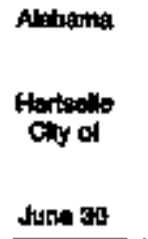 & 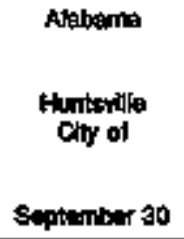 & 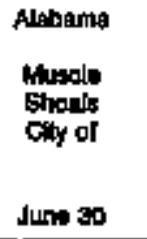 & $\begin{array}{l}\text { Alebeme } \\
\text { Opolikn } \\
\text { Cly of } \\
\text { September 30 }\end{array}$ & $\begin{array}{l}\text { Alabama } \\
\text { Sooltsboro } \\
\text { fity of } \\
\text { tuns } 30\end{array}$ & 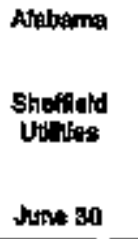 \\
\hline 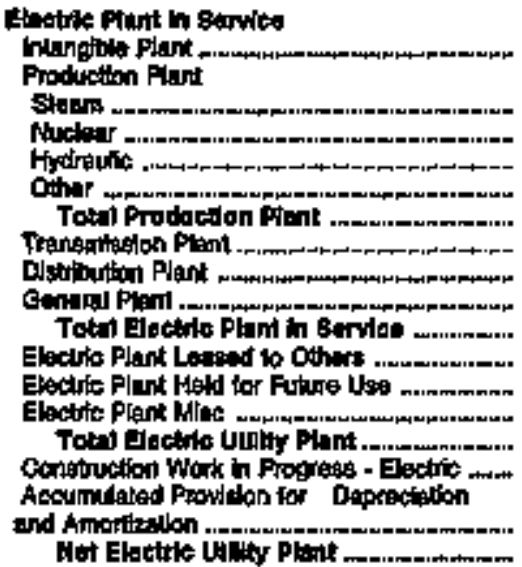 & $\begin{array}{r}0 \\
0 \\
0 \\
0 \\
0 \\
0 \\
0 \\
4,877 \\
324 \\
6,202 \\
0 \\
10 \\
0 \\
0,214 \\
6\end{array}$ & $\begin{array}{r}0 \\
0 \\
0 \\
0 \\
0 \\
0 \\
14,928 \\
134,750 \\
10,592 \\
199,771 \\
0 \\
0 \\
0 \\
199,771 \\
5,302 \\
109,371 \\
101,783\end{array}$ & $\begin{array}{r}0 \\
0 \\
0 \\
0 \\
0 \\
0 \\
0 \\
0 \\
0 \\
11,359 \\
2,381 \\
13,740 \\
0 \\
0 \\
0 \\
13,740 \\
619 \\
4,600 \\
10,060\end{array}$ & $\begin{array}{r}0 \\
0 \\
0 \\
0 \\
0 \\
0 \\
0 \\
18,950 \\
0 \\
0 \\
13,990 \\
0 \\
0 \\
0 \\
10,900 \\
378 \\
10,447 \\
6,950\end{array}$ & $\begin{array}{r}0 \\
0 \\
0 \\
0 \\
0 \\
0 \\
13,403 \\
1,541 \\
14,944 \\
0 \\
0 \\
0 \\
14,944 \\
1383 \\
5,508 \\
9,627\end{array}$ & $\begin{array}{r}0 \\
0 \\
0 \\
0 \\
0 \\
1,273 \\
27,040 \\
4,144 \\
33,269 \\
0 \\
0 \\
140 \\
35,359 \\
1,334 \\
14,004 \\
10,029\end{array}$ \\
\hline
\end{tabular}

\begin{tabular}{|c|c|c|c|c|c|c|}
\hline Iken & $\begin{array}{l}\text { Alabama } \\
\text { Sylacang } \\
\text { Utivlea } \\
\text { Board } \\
\text { saplomber so }\end{array}$ & $\begin{array}{l}\text { Alabanta } \\
\text { Thoy } \\
\text { Clty of } \\
\text { Seplembar io }\end{array}$ & $\begin{array}{l}\text { Alabeme } \\
\text { Tutkegen } \\
\text { Chy of } \\
\text { Steptimber } 30\end{array}$ & 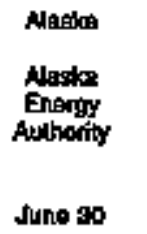 & $\begin{array}{l}\text { Alaska } \\
\text { Anthorege } \\
\text { City of } \\
\text { Dacember is }\end{array}$ & 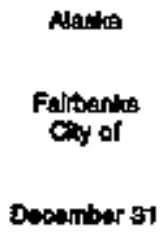 \\
\hline 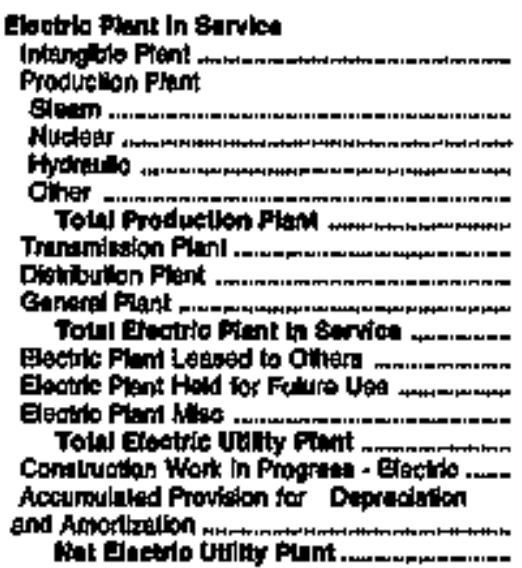 & $\begin{array}{r}0 \\
0 \\
0 \\
0 \\
0 \\
0 \\
0 \\
0,316 \\
1,118 \\
10,484 \\
0 \\
0 \\
0 \\
10,484 \\
0 \\
6,279 \\
4,155\end{array}$ & $\begin{array}{r}0 \\
0 \\
0 \\
0 \\
0 \\
0 \\
0 \\
0 \\
0,461 \\
1,159 \\
9400 \\
0 \\
0 \\
0 \\
9,920 \\
0\end{array}$ & $\begin{array}{r}0 \\
0 \\
0 \\
0 \\
0 \\
0 \\
0 \\
0 \\
7,031 \\
0 \\
7,051 \\
0 \\
0 \\
0 \\
7,001 \\
0\end{array}$ & 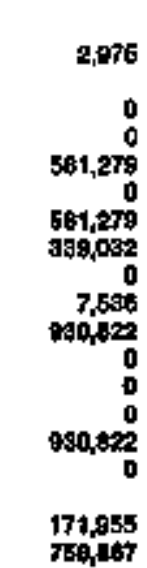 & $\begin{array}{r}13,013 \\
17,642 \\
0 \\
9 \\
00,405 \\
100,307 \\
18,521 \\
87,172 \\
37,967 \\
293,179 \\
0 \\
0 \\
0,254 \\
262,473 \\
5,441 \\
117,544 \\
150,074\end{array}$ & 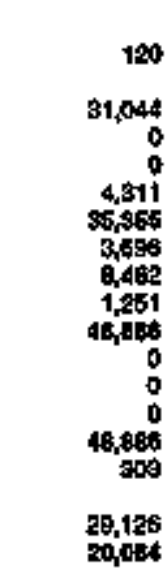 \\
\hline
\end{tabular}

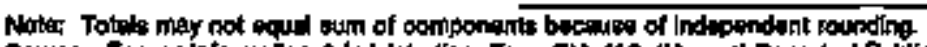

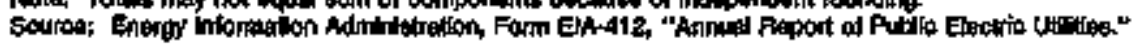


Table 24. Electric Ltility Plant by Major U.S. Publicly Owned Electrlc Utility Within State at End of Period, 1994 (Continued) (Thousand Dollars)

\begin{tabular}{|c|c|c|c|c|c|c|}
\hline nom & 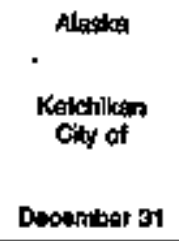 & $\begin{array}{l}\text { Afizoni } \\
\text { Affong } \\
\text { Power } \\
\text { Authorily } \\
\text { June } 30\end{array}$ & 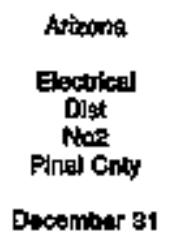 & 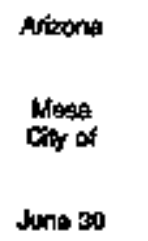 & 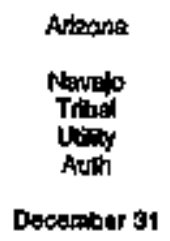 & 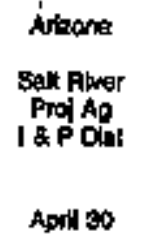 \\
\hline 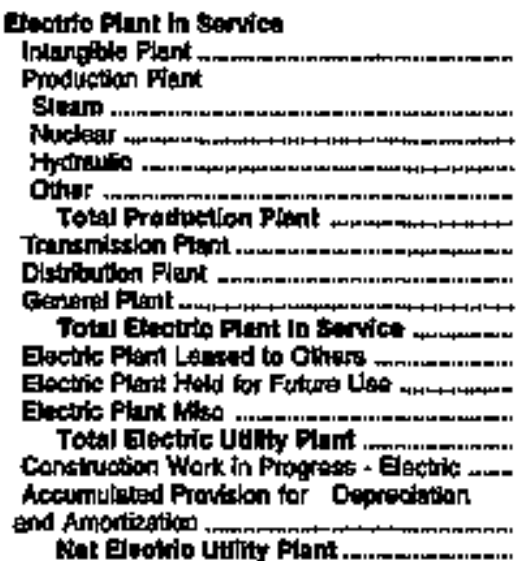 & 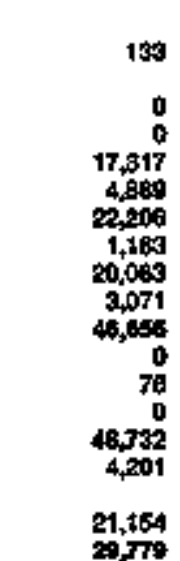 & $\begin{array}{r}0 \\
0 \\
0 \\
0 \\
0 \\
20 \\
208 \\
198 \\
972 \\
1,158 \\
0 \\
0 \\
0 \\
1,158 \\
0 \\
718 \\
740\end{array}$ & $\begin{array}{r}0 \\
0 \\
0 \\
0 \\
0 \\
0 \\
13,691 \\
2,571 \\
16,16 ! \\
0 \\
0 \\
0 \\
18,181 \\
0 \\
0,610 \\
0 \\
0.5 \%\end{array}$ & $\begin{array}{r}0 \\
0 \\
0 \\
0 \\
0 \\
0 \\
0 \\
51,029 \\
51,029 \\
0 \\
0 \\
51,029 \\
4,128 \\
13,104 \\
42,050\end{array}$ & 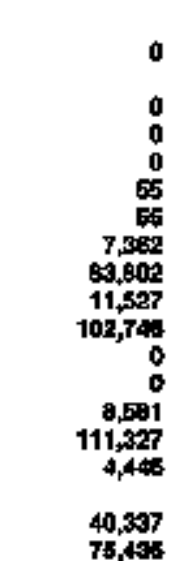 & 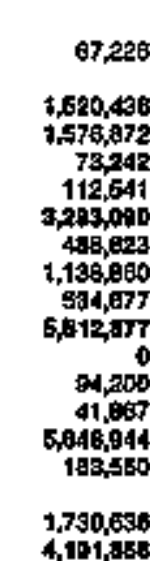 \\
\hline
\end{tabular}

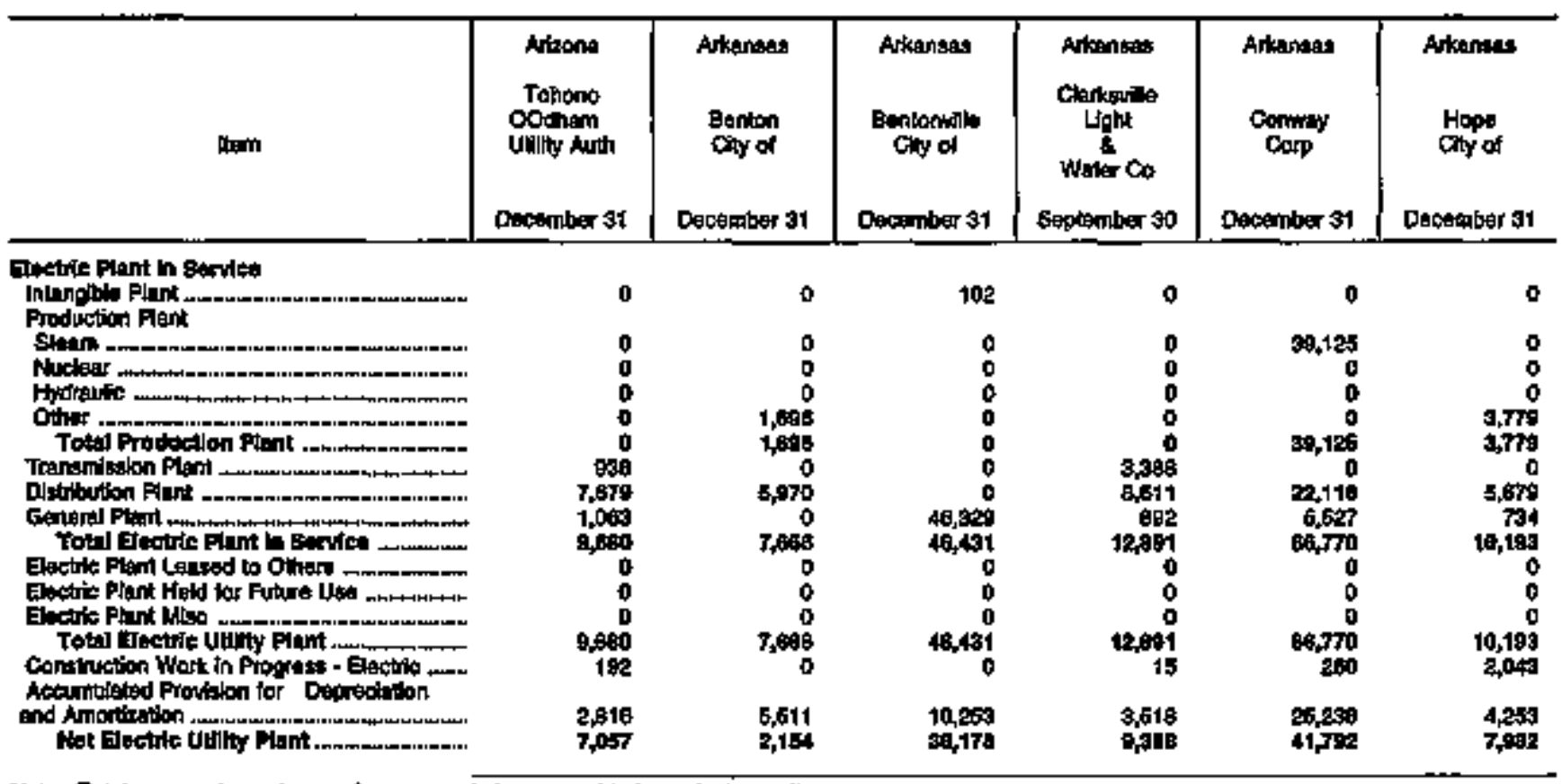

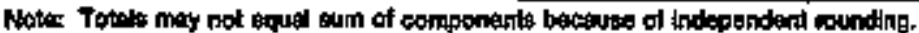

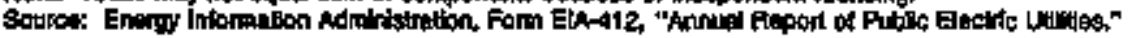


Table 24. Electric Utilly Plant by Major U.S. Publlofy Owned Eectrle Utillity Within State at End of Perlod, 1994 (Continued)

(Thousand Dollars)

\begin{tabular}{|c|c|c|c|c|c|c|}
\hline Jlem & 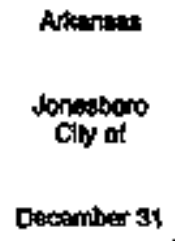 & 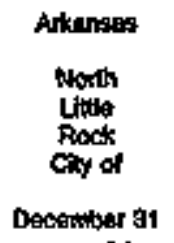 & $\begin{array}{l}\text { Artorist: } \\
\text { Oscoolis } \\
\text { Cily of }\end{array}$ & 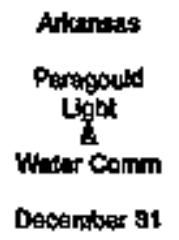 & 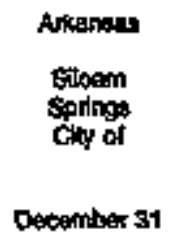 & 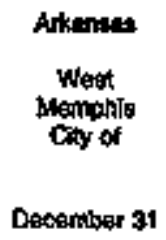 \\
\hline 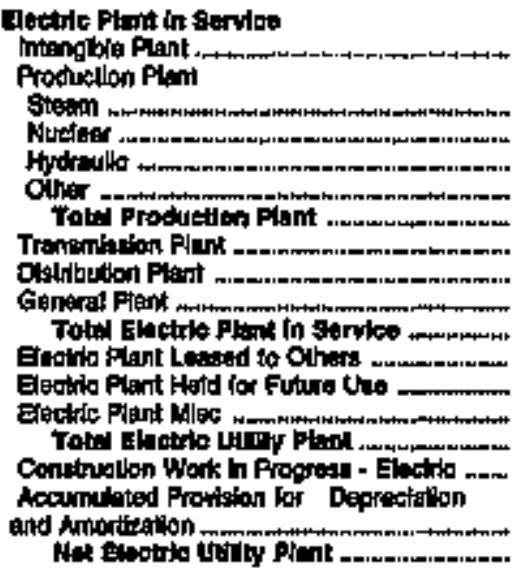 & 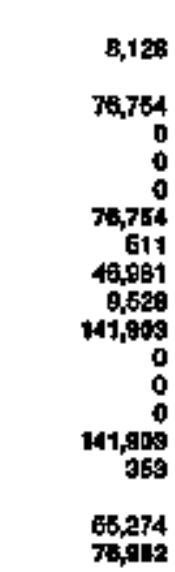 & 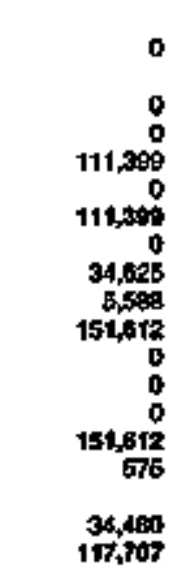 & $\begin{array}{r}0 \\
0 \\
0 \\
0 \\
0 \\
0 \\
0 \\
11,501 \\
3,431 \\
19,080 \\
0 \\
0 \\
0 \\
19,904 \\
0 \\
8,562 \\
11,401\end{array}$ & 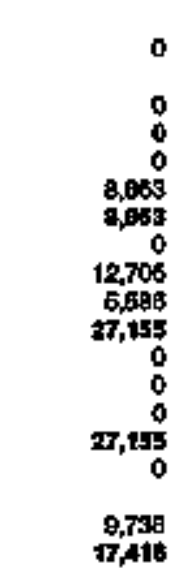 & $\begin{array}{r}0 \\
0 \\
0 \\
0 \\
0 \\
0 \\
0 \\
6,702 \\
6,102 \\
0 \\
0 \\
0 \\
6,102 \\
1,620 \\
3,209 \\
4,416\end{array}$ & $\begin{array}{r}10,695 \\
18,708 \\
0 \\
0 \\
0 \\
10,705 \\
0 \\
0 \\
0 \\
29,405 \\
0 \\
0 \\
0 \\
29,05 \\
0 \\
13,391 \\
18,010\end{array}$ \\
\hline
\end{tabular}

\begin{tabular}{|c|c|c|c|c|c|c|}
\hline hem & 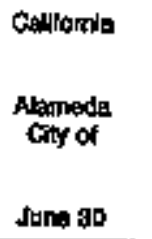 & 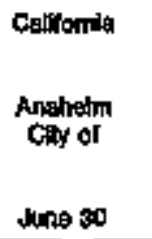 & $\begin{array}{l}\text { Callomina } \\
\text { Aarsa } \\
\text { Chy of } \\
\text { Jume an }\end{array}$ & 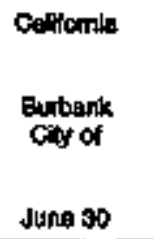 & 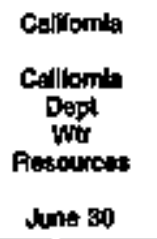 & 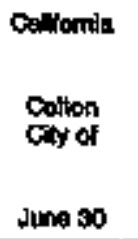 \\
\hline 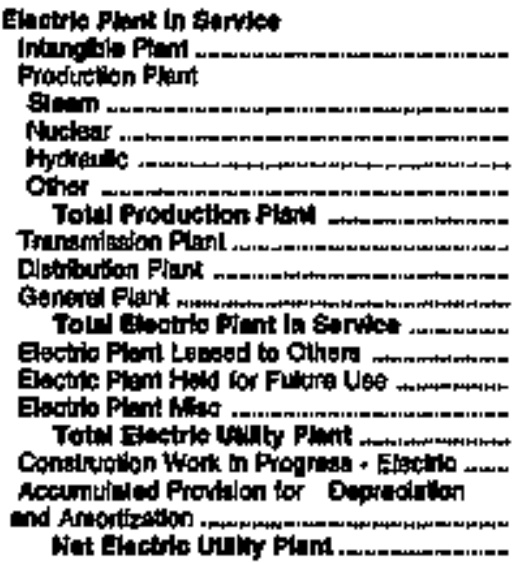 & $\begin{array}{r}0 \\
0 \\
0 \\
0 \\
0 \\
0 \\
3,5,4 \\
35,764 \\
8,191 \\
97,510 \\
0 \\
0 \\
0 \\
47,600 \\
0 \\
13,970 \\
34,140\end{array}$ & 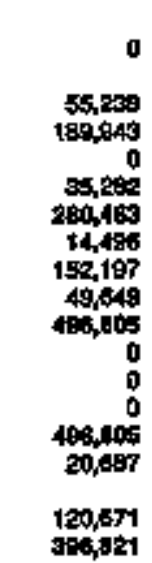 & $\begin{array}{r}0 \\
0 \\
0 \\
0 \\
0 \\
0 \\
0 \\
14,798 \\
0 \\
14,795 \\
0 \\
0 \\
0 \\
14,736 \\
0 \\
4,955 \\
9009\end{array}$ & 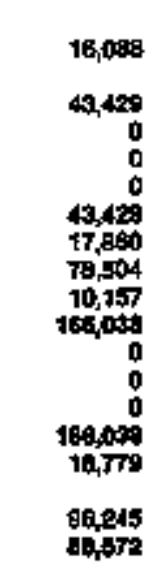 & 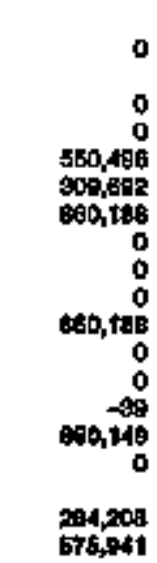 & $\begin{array}{r}0 \\
0 \\
0 \\
0 \\
0 \\
0 \\
0 \\
0 \\
13,605 \\
13,505 \\
0 \\
0 \\
0 \\
13,505 \\
0 \\
5,551 \\
7,054\end{array}$ \\
\hline
\end{tabular}

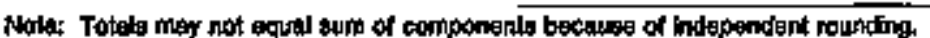

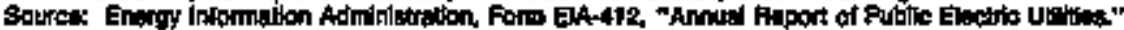


Table 24. Electrle Utility Plent by Major U.S. Publkly Owned Electric Utility Within State at End of Perlod, 1994 (Continuod) (Thousand Dolars)

\begin{tabular}{|c|c|c|c|c|c|c|}
\hline anm & $\begin{array}{l}\text { Oalomia } \\
\text { Giendele } \\
\text { Cly of } \\
\text { Juns } 30\end{array}$ & 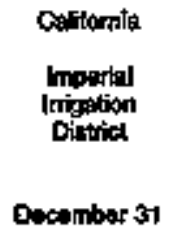 & 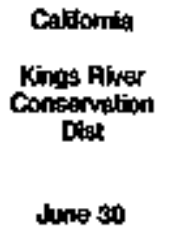 & 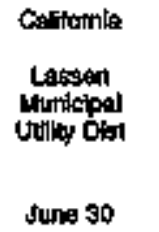 & $\begin{array}{l}\text { Cealfomiala } \\
\text { Lodl } \\
\text { Cily of } \\
\text { Junto } 30\end{array}$ & $\begin{array}{l}\text { Calfiomila } \\
\text { Los Anowlos } \\
\text { Chy of } \\
\text { Jente aD }\end{array}$ \\
\hline 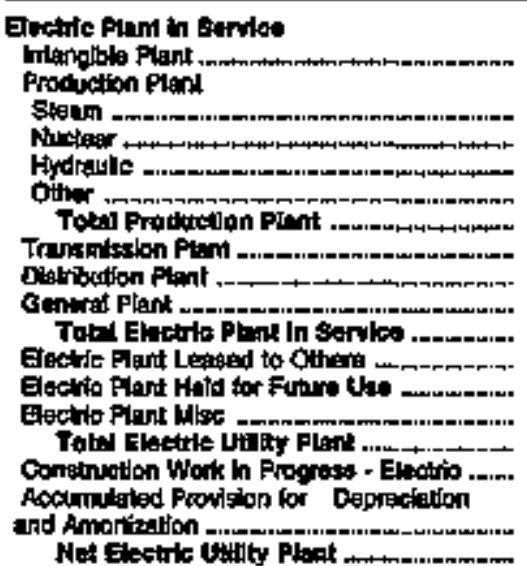 & $\begin{array}{r}0 \\
48,671 \\
0 \\
0 \\
0 \\
46,671 \\
10,2652 \\
108,242 \\
38,974 \\
237,539 \\
0 \\
0 \\
0 \\
235,539 \\
10,764 \\
110,410 \\
137,980\end{array}$ & 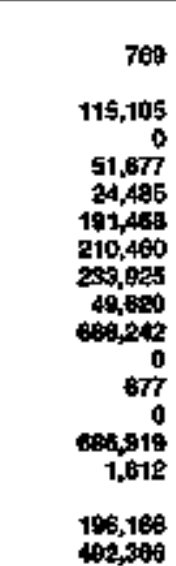 & $\begin{array}{r}0 \\
0 \\
0 \\
45,47 \\
0 \\
65,47 \\
0 \\
0 \\
0 \\
16,47 \\
0 \\
0 \\
65,47 \\
0 \\
15,934 \\
50,143\end{array}$ & $\begin{array}{r}0 \\
0 \\
0 \\
0 \\
0 \\
5,108 \\
16,545 \\
1,935 \\
23,492 \\
0 \\
0 \\
0 \\
23,492 \\
0 \\
4,190 \\
19,303\end{array}$ & $\begin{array}{r}0 \\
0 \\
0 \\
0 \\
0 \\
0 \\
18,0+5 \\
0 \\
18,015 \\
0 \\
0 \\
0 \\
0 \\
13,115 \\
0 \\
3,965 \\
10,480\end{array}$ & 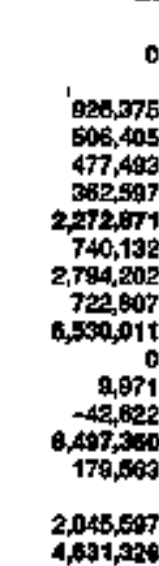 \\
\hline
\end{tabular}

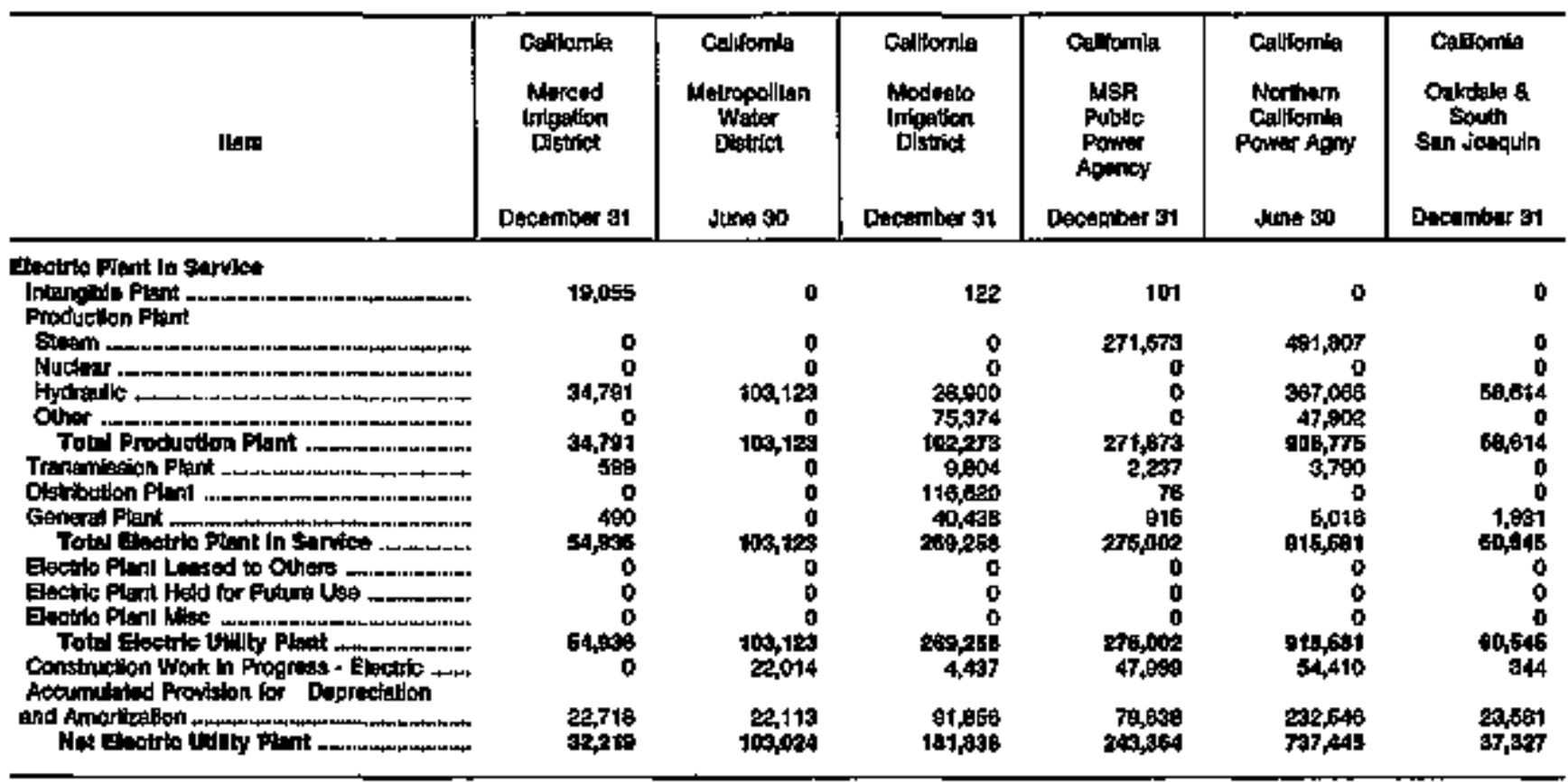

Notex. Totals may not equal eum of components because of holopendank rounding

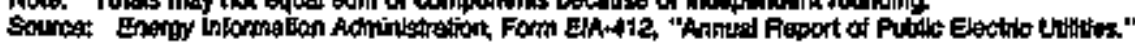


Table 24. Electric Utilly Plant by Major U.S. Pubitoly Owned Electric Utilly Within State at End of Poriod, 1994

(Thoustand Dollars)

\begin{tabular}{|c|c|c|c|c|c|c|}
\hline im & 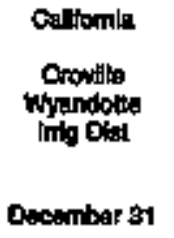 & $\begin{array}{l}\text { Caliomba } \\
\text { Palo Alo } \\
\text { Cily of } \\
\text { Jum } 80\end{array}$ & 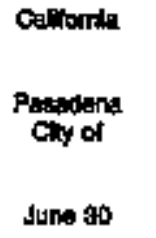 & $\begin{array}{l}\text { Cadiloxn'a } \\
\text { Placear } \\
\text { Counky } \\
\text { Wubr } \\
\text { Agancy } \\
\text { Decomber si }\end{array}$ & $\begin{array}{l}\text { Gellorala } \\
\text { Andeling } \\
\text { Chy of } \\
\text { June so }\end{array}$ & 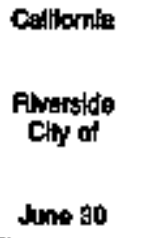 \\
\hline 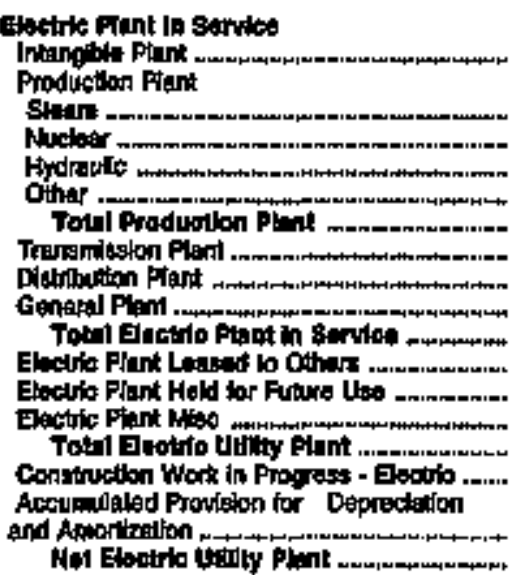 & $\begin{array}{r}0 \\
0 \\
0 \\
0 \\
0 \\
0 \\
1,736 \\
79,826 \\
3,415 \\
04,477 \\
0 \\
0 \\
0 \\
04,477 \\
7692 \\
37,705 \\
47,524\end{array}$ & $\begin{array}{r}0 \\
0 \\
0 \\
0 \\
0 \\
0 \\
115,034 \\
0 \\
115,094 \\
0 \\
0 \\
0 \\
115,034 \\
10,047 \\
45,010 \\
40,071\end{array}$ & 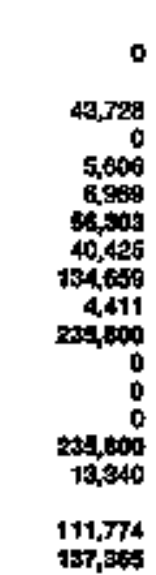 & $\begin{array}{r}149 \\
0 \\
0 \\
111,089 \\
8 \\
111,058 \\
499 \\
0 \\
5,941 \\
117,455 \\
0 \\
0 \\
0 \\
117,455 \\
189 \\
42,970 \\
74,674\end{array}$ & 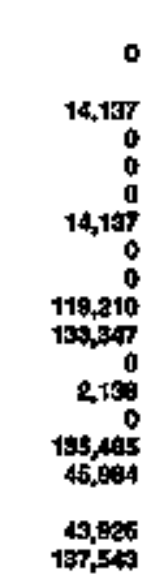 & 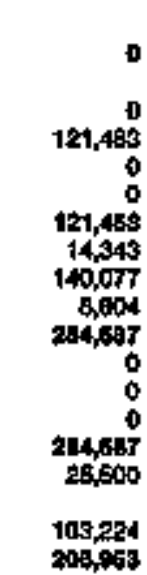 \\
\hline
\end{tabular}

\begin{tabular}{|c|c|c|c|c|c|c|}
\hline ilend & 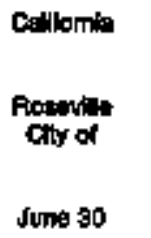 & 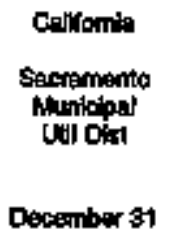 & 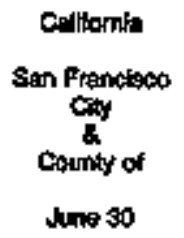 & $\begin{array}{l}\text { Goriomin } \\
\text { Stinla } \\
\text { Clara } \\
\text { Gity of } \\
\text { Juno } 30\end{array}$ & $\begin{array}{l}\text { Calfomlo } \\
\text { Southem } \\
\text { Caltomia } \\
\text { P P } \\
\text { A } \\
\text { Ju } 30\end{array}$ & 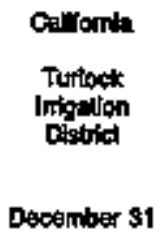 \\
\hline 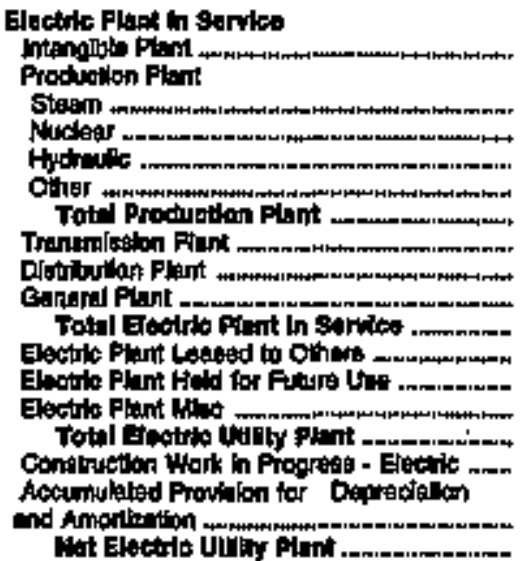 & $\begin{array}{r}0 \\
0 \\
0 \\
0 \\
0 \\
0 \\
0 \\
00,442 \\
058 \\
01,305 \\
0 \\
0 \\
0 \\
01,305 \\
600 \\
15,368 \\
09,645\end{array}$ & 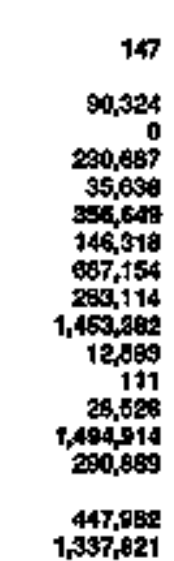 & $\begin{array}{r}7,058 \\
0 \\
0 \\
94,095 \\
0 \\
94,005 \\
14,040 \\
78,104 \\
3,695 \\
197,670 \\
0 \\
0 \\
249,167 \\
445,745 \\
8,606 \\
198,341 \\
261,017\end{array}$ & 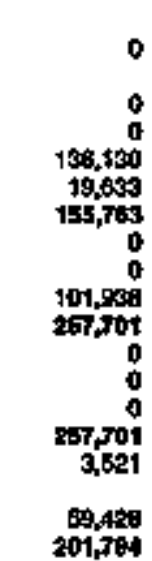 & 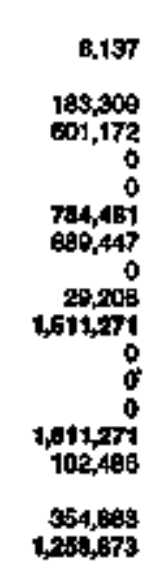 & 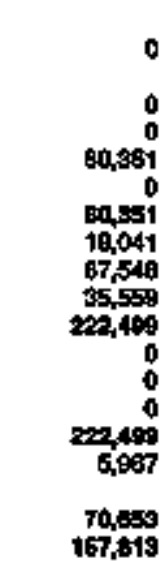 \\
\hline
\end{tabular}

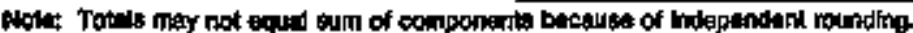

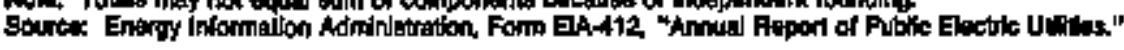


Table 24. Electric Utilty Plent by Major U.S. Publloly Owad Eleotric Utilty Whitin State at End of Period, 1994 (Comtinued) (Thousand Dollers)

\begin{tabular}{|c|c|c|c|c|c|c|}
\hline Itan & $\begin{array}{l}\text { custarta } \\
\text { Vemon } \\
\text { Gity of } \\
\text { Jema so }\end{array}$ & $\begin{array}{l}\text { Contonts } \\
\text { Yube } \\
\text { Counly } \\
\text { Waler } \\
\text { Agangy } \\
\text { June od }\end{array}$ & 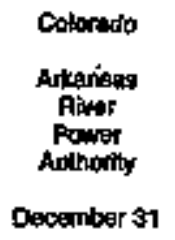 & $\begin{array}{l}\text { Colorado } \\
\text { Colorato } \\
\text { Spring: } \\
\text { City of } \\
\text { Decemiber } 31\end{array}$ & $\begin{array}{l}\text { Colorado } \\
\text { Fort collint } \\
\text { City of } \\
\text { Dacember \$1 }\end{array}$ & $\begin{array}{l}\text { Calorado } \\
\text { Fort Mlongun } \\
\text { City of } \\
\text { - } \\
\text { Detember } 31\end{array}$ \\
\hline 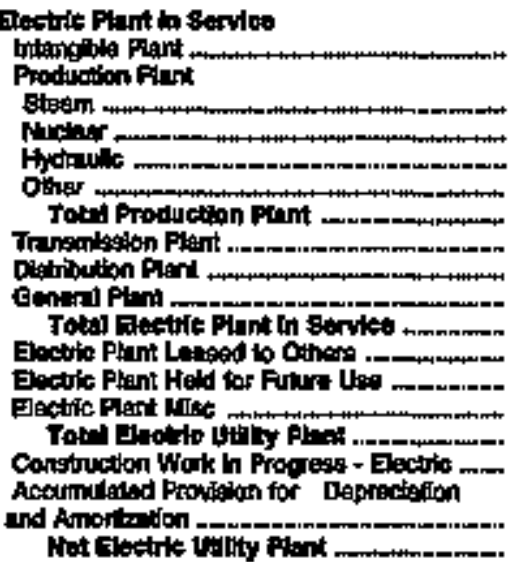 & $\begin{array}{r}0 \\
0 \\
0 \\
0 \\
4,330 \\
4,3340 \\
48,920 \\
10,273 \\
2,054 \\
71,000 \\
0 \\
0 \\
0 \\
71,904 \\
8,963 \\
05,342 \\
54,500\end{array}$ & 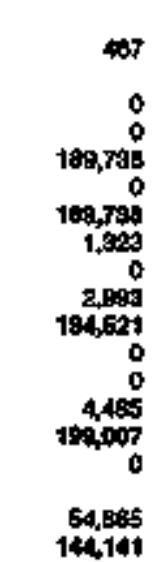 & $\begin{array}{r}0 \\
0 \\
0 \\
0 \\
0 \\
2710 \\
0 \\
0 \\
2,710 \\
0 \\
0 \\
0 \\
2,740 \\
0\end{array}$ & 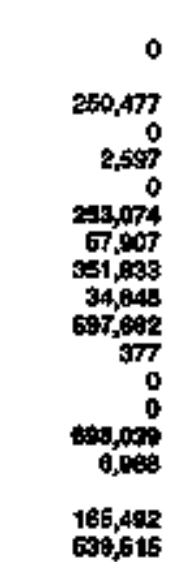 & 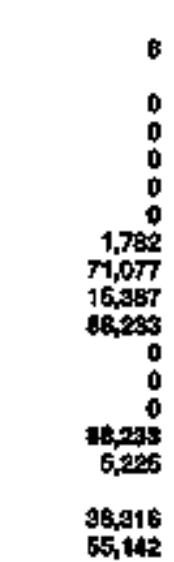 & $\begin{array}{r}0 \\
0 \\
0 \\
0 \\
0 \\
0 \\
0 \\
0,063 \\
1,0020 \\
10,005 \\
0 \\
0 \\
0 \\
10,000 \\
484 \\
4,019 \\
0,472\end{array}$ \\
\hline
\end{tabular}

\begin{tabular}{|c|c|c|c|c|c|c|}
\hline Hem & $\begin{array}{l}\text { Colarato } \\
\text { Lonitingent } \\
\text { City of } \\
\text { trocimber } 31\end{array}$ & $\begin{array}{l}\text { Coloreds } \\
\text { Lovbland } \\
\text { Cty tht } \\
\text { Decemberst }\end{array}$ & 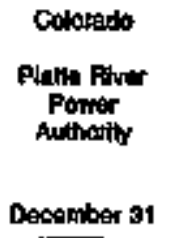 & 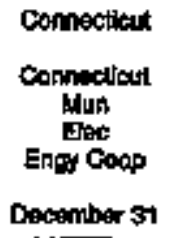 & $\begin{array}{l}\text { Cennectieul } \\
\text { Crotar } \\
\text { City of } \\
\text { Jin } \$ 0\end{array}$ & $\begin{array}{l}\text { Connactitut } \\
\text { Monuich } \\
\text { Cry of } \\
\text { June } 30\end{array}$ \\
\hline 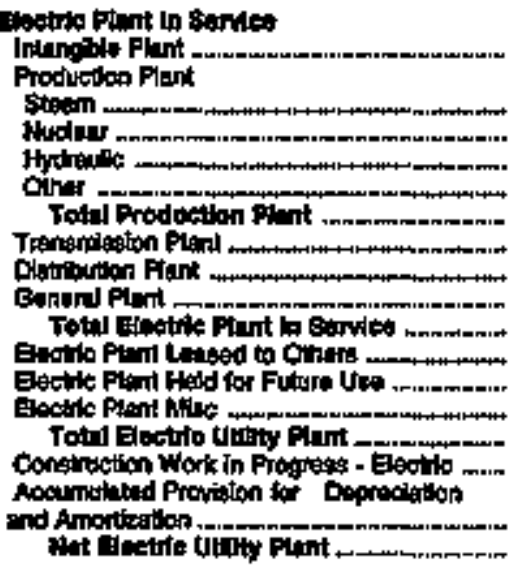 & 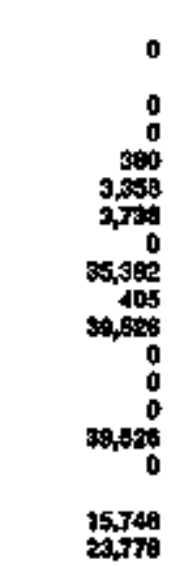 & $\begin{array}{r}0 \\
0 \\
0 \\
1,500 \\
0 \\
1,500 \\
3,098 \\
35,065 \\
5,454 \\
45,098 \\
0 \\
0 \\
0 \\
45,952 \\
605 \\
11,052 \\
35,534\end{array}$ & $\begin{array}{r}61,029 \\
0 \\
0 \\
0 \\
651,028 \\
104,050 \\
0 \\
12,087 \\
74,570 \\
0 \\
0 \\
14,035 \\
76,511 \\
6,156\end{array}$ & $\begin{array}{r}942 \\
0 \\
00,481 \\
0 \\
0 \\
90,41 \\
1,188 \\
0 \\
1,900 \\
54,411 \\
0 \\
0 \\
0 \\
14,511 \\
150 \\
14,200 \\
40,400\end{array}$ & $\begin{array}{r}0 \\
0 \\
0 \\
0 \\
0 \\
5,210 \\
15,85 \\
3,057 \\
20,705 \\
0 \\
0 \\
2,369 \\
25,154 \\
0 \\
15,659 \\
10,645\end{array}$ & 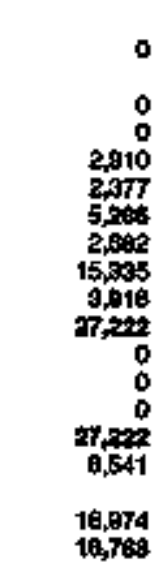 \\
\hline
\end{tabular}

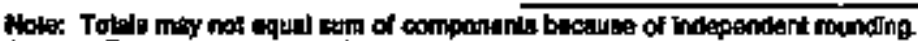

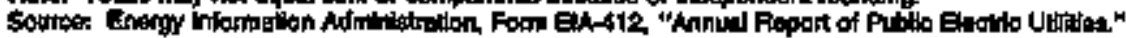


Table 24. Electric Utilty Plant by Major U.8. Publody Owned Eleotrio Utility Within state at End of Period, 1994 (Continued) (Thousand Dollars)

\begin{tabular}{|c|c|c|c|c|c|c|}
\hline Ilem & 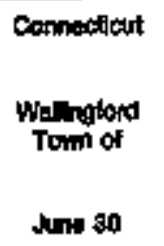 & $\begin{array}{l}\text { Delangere } \\
\text { Donver } \\
\text { Cint of } \\
\text { Jump } 30\end{array}$ & 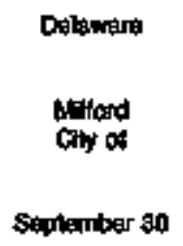 & $\begin{array}{l}\text { Dalenvare } \\
\text { Nown of } \\
\text { Doommat } 31\end{array}$ & $\begin{array}{l}\text { Finstes } \\
\text { Burlow } \\
\text { Chy of } \\
\text { September } 30\end{array}$ & 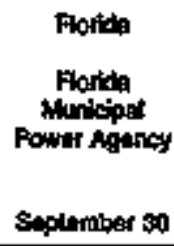 \\
\hline 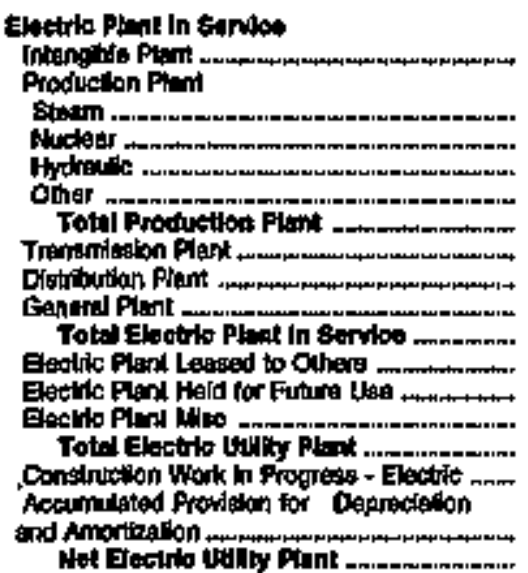 & $\begin{array}{r}6,595 \\
0 \\
0 \\
0 \\
6,505 \\
1,280 \\
31,011 \\
4,488 \\
44,276 \\
0 \\
0 \\
0 \\
44,476 \\
3,205 \\
25,570 \\
24,902\end{array}$ & $\begin{array}{r}01,377 \\
0 \\
0 \\
0 \\
61,977 \\
15,756 \\
17,770 \\
1,657 \\
99,604 \\
0 \\
0 \\
0 \\
94,500 \\
0 \\
32,008 \\
0,904\end{array}$ & $\begin{array}{r}0 \\
0 \\
0 \\
0 \\
0 \\
0 \\
0 \\
7,008 \\
0 \\
7049 \\
0 \\
0 \\
0 \\
7040 \\
0 \\
4,109 \\
29915\end{array}$ & $\begin{array}{l}0 \\
0 \\
0 \\
0 \\
0 \\
0 \\
0 \\
0 \\
0 \\
0 \\
0 \\
0 \\
0 \\
0\end{array}$ & $\begin{array}{r}0 \\
0 \\
0 \\
0 \\
0 \\
0 \\
11,059 \\
0 \\
11,650 \\
0 \\
0 \\
0 \\
11,650 \\
0 \\
6,2039 \\
5,435\end{array}$ & 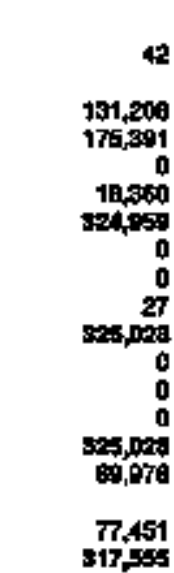 \\
\hline
\end{tabular}

\begin{tabular}{|c|c|c|c|c|c|c|}
\hline Inent & 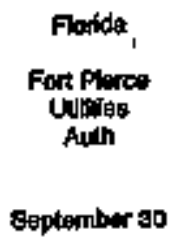 & 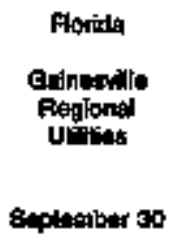 & 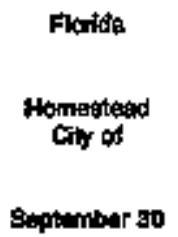 & 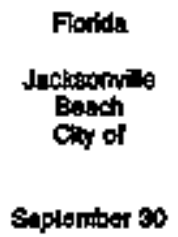 & 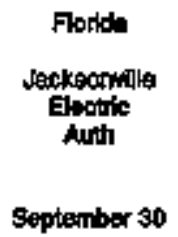 & 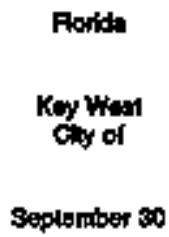 \\
\hline 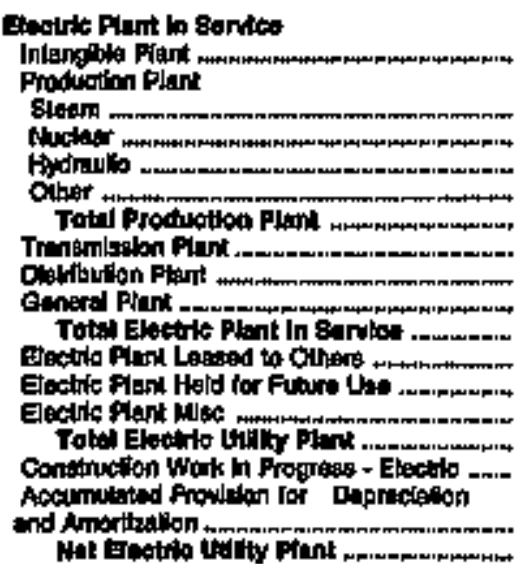 & 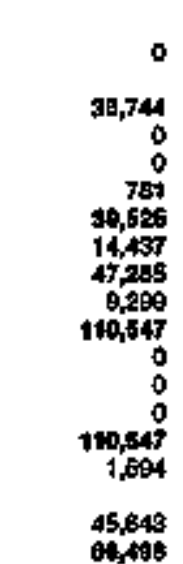 & $\begin{array}{r}247,755 \\
0 \\
0 \\
0 \\
247,755 \\
140,460 \\
0 \\
34,108 \\
431,005 \\
0 \\
0 \\
0 \\
421,402 \\
34,035 \\
144,654 \\
310,693\end{array}$ & $\begin{array}{r}0 \\
0 \\
0 \\
0 \\
0 \\
0 \\
0 \\
43,160 \\
49,140 \\
0 \\
0 \\
0 \\
49,160 \\
0 \\
79,296 \\
2994\end{array}$ & $\begin{array}{r}0 \\
0 \\
0 \\
0 \\
0 \\
0 \\
74,562 \\
0 \\
74,6,5 \\
0 \\
0 \\
0 \\
74,50 \% \\
2,408 \\
21,6047 \\
65,0 \% 2\end{array}$ & 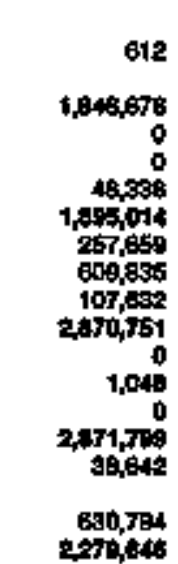 & 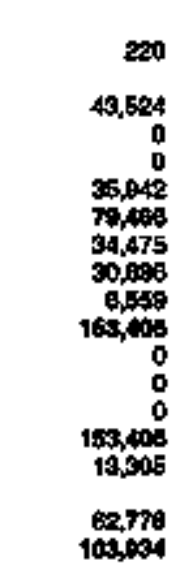 \\
\hline
\end{tabular}

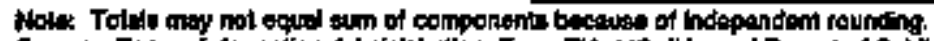

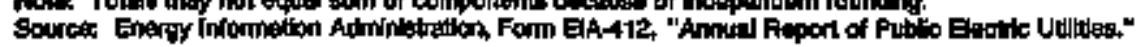


Tabte 24. Electric Utility Plant by Major U.S. Publicly Owned Eloctrle Utility Within State at End of Period, 1994 (Continuad)

(Thousand Dollars)

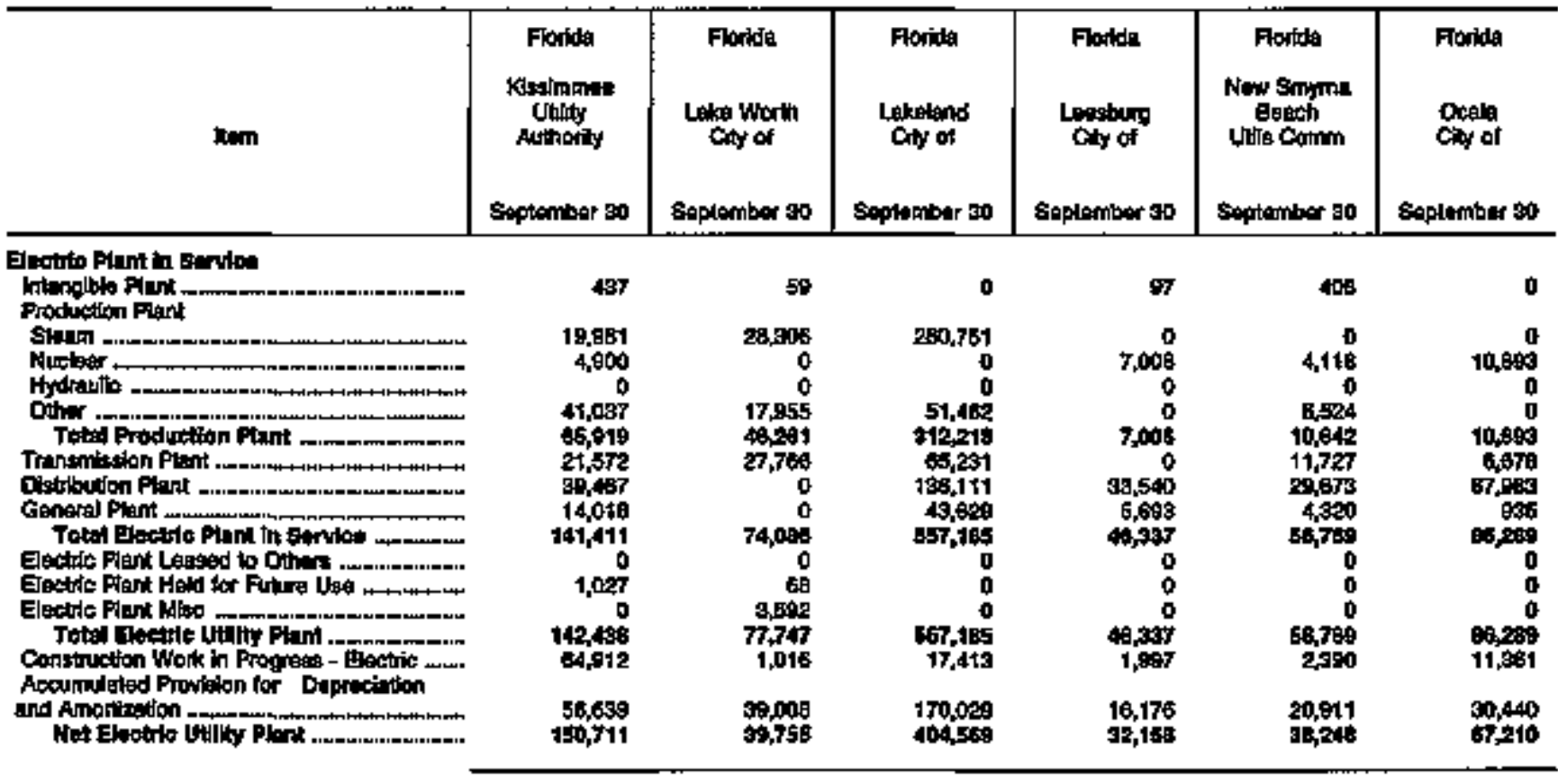

\begin{tabular}{|c|c|c|c|c|c|c|}
\hline llam & $\begin{array}{l}\text { Florida } \\
\text { Ortando } \\
\text { Stbitat } \\
\text { Comm } \\
\text { Beptember } 30\end{array}$ & $\begin{array}{l}\text { Fortita } \\
\text { Culney } \\
\text { Ciny of } \\
\text { seplember } \$ 0\end{array}$ & $\begin{array}{l}\text { Flotida } \\
\text { Peody Crack } \\
\text { Improvement } \\
\text { Oija } \\
\text { Eeptember sa }\end{array}$ & $\begin{array}{l}\text { Fortal } \\
\text { st Goud } \\
\text { City of } \\
\text { Sapleatuer } 30\end{array}$ & 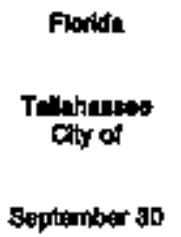 & $\begin{array}{l}\text { Fordds } \\
\text { Voro } \\
\text { Botech } \\
\text { City of } \\
\text { Stpiambar so }\end{array}$ \\
\hline 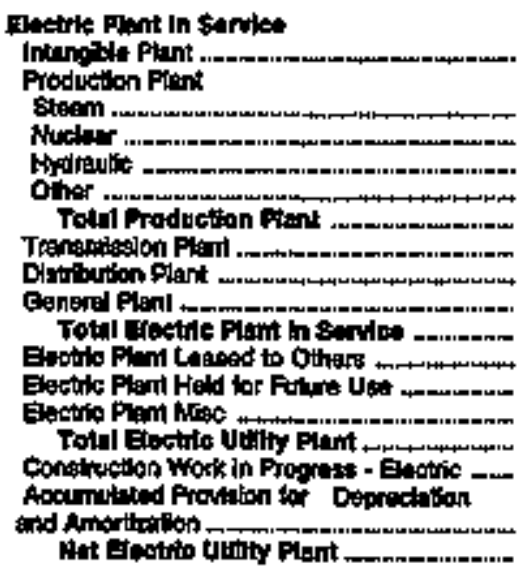 & $\begin{array}{r}3,675 \\
690,154 \\
102,540 \\
0 \\
55,830 \\
754,525 \\
171,394 \\
269,104 \\
70,2009 \\
1,259,005 \\
0 \\
0 \\
0 \\
1,268,005 \\
213,050\end{array}$ & $\begin{array}{r}0 \\
0 \\
0 \\
0 \\
0 \\
0 \\
0 \\
5,551 \\
690 \\
6,150 \\
0 \\
0 \\
0 \\
0 \\
0,110 \\
0\end{array}$ & 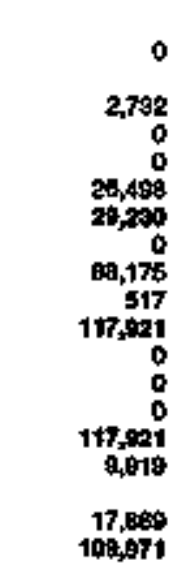 & $\begin{array}{r}0 \\
0 \\
0 \\
25,447 \\
35,447 \\
12,6,12 \\
32,805 \\
0 \\
70,850 \\
0 \\
0 \\
0 \\
70,004 \\
72\end{array}$ & 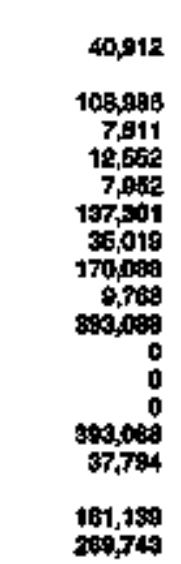 & $\begin{array}{r}2,604 \\
74,2,60 \\
0 \\
0 \\
3,558 \\
77,015 \\
31,708 \\
39,600 \\
3,718 \\
154,400 \\
0 \\
0 \\
151,400 \\
704\end{array}$ \\
\hline
\end{tabular}

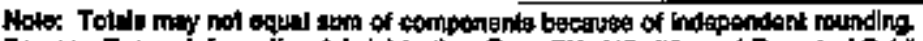

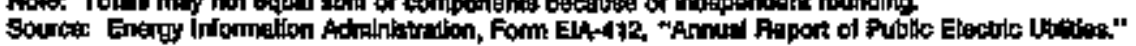


Table 24. Electric Utility Plant by Major U.S. Publlely Owned Electric Utillty Within State at End of Period, 1994 (Continued)

(Thoussand Dollars)

\begin{tabular}{|c|c|c|c|c|c|c|}
\hline I|⿴囗十 & 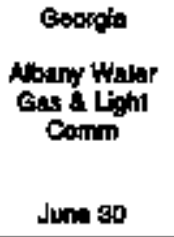 & $\begin{array}{l}\text { Ceongla } \\
\text { canow } \\
\text { City of } \\
\text { June 3n }\end{array}$ & $\begin{array}{l}\text { coorgla } \\
\text { Carlenstit. } \\
\text { Any of } \\
\text { Jum } 80\end{array}$ & 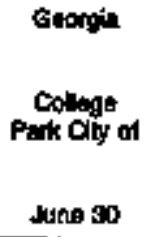 & 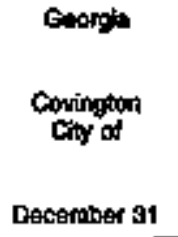 & $\begin{array}{l}\text { Georip } \\
\text { Cilep } \\
\text { Coumty } \\
\text { Powar } \\
\text { Comm } \\
\text { Docember } 31\end{array}$ \\
\hline 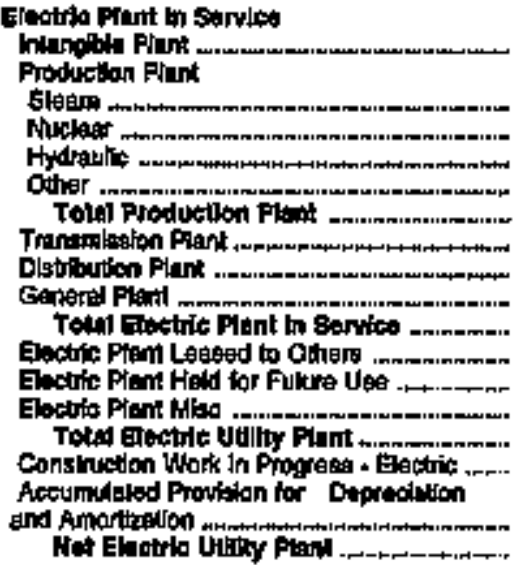 & $\begin{array}{r}0 \\
0 \\
0 \\
0 \\
0 \\
0 \\
29,354 \\
0 \\
0 \\
29,234 \\
0 \\
0 \\
0 \\
29,504 \\
0 \\
19,591 \\
9,740\end{array}$ & $\begin{array}{r}0 \\
0 \\
0 \\
0 \\
0 \\
0 \\
0 \\
0 \\
65,330 \\
66,336 \\
0 \\
0 \\
0 \\
66,350 \\
617 \\
15,117 \\
50,937\end{array}$ & $\begin{array}{r}0 \\
0 \\
0 \\
0 \\
0 \\
0 \\
0 \\
11,502 \\
0 \\
11,502 \\
0 \\
0 \\
0 \\
11,500 \\
0 \\
0 \\
3,340 \\
0,15 \%\end{array}$ & $\begin{array}{r}0 \\
0 \\
0 \\
0 \\
0 \\
0 \\
0 \\
0 \\
0,841 \\
0 \\
0,841 \\
0 \\
0 \\
0 \\
8,441 \\
0 \\
3,613 \\
5,2243\end{array}$ & $\begin{array}{r}0 \\
0 \\
0 \\
0 \\
0 \\
0 \\
0 \\
9,648 \\
0 \\
0,848 \\
0 \\
0 \\
0 \\
6,843 \\
0 \\
3,347 \\
3,208\end{array}$ & $\begin{array}{r}105 \\
5,127 \\
0 \\
6,459 \\
0 \\
10,575 \\
1,080 \\
29,557 \\
3,971 \\
39,138 \\
0 \\
0 \\
0 \\
39,138 \\
215 \\
22,450 \\
16,903\end{array}$ \\
\hline
\end{tabular}

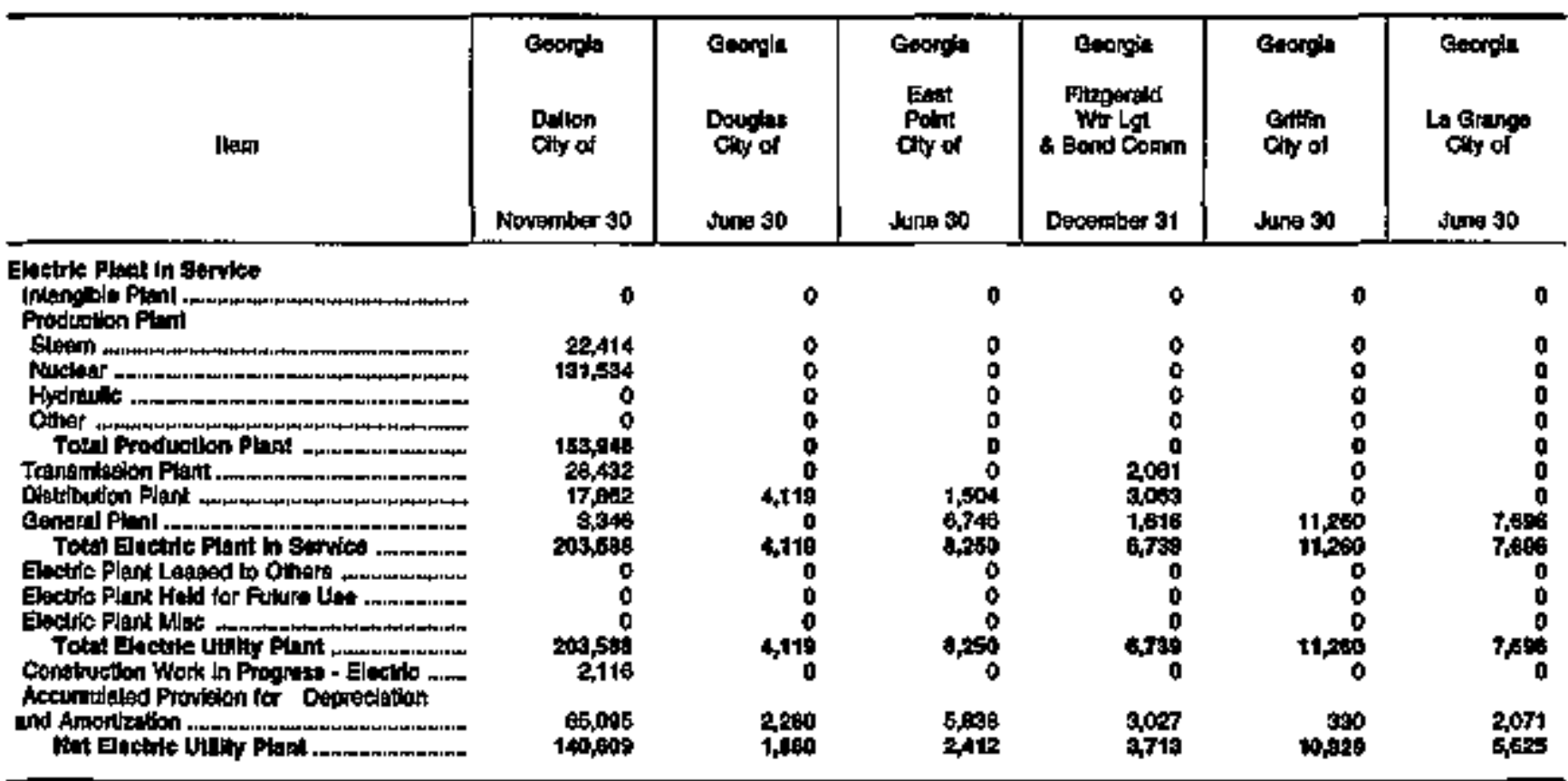

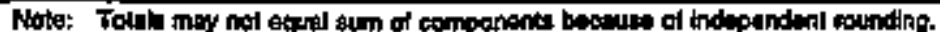

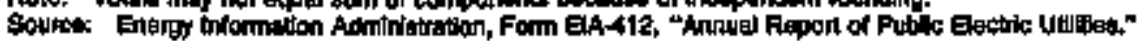


Table 24. Electrit Utilly P1ant by Major U.S. Publlcly Owned Electric Utility Whin State at End of Perlod, 1994

(Thousand Dollars)

\begin{tabular}{|c|c|c|c|c|c|c|}
\hline Ihan & 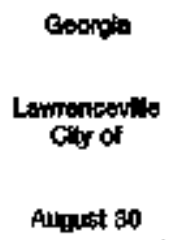 & 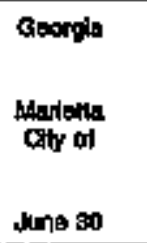 & 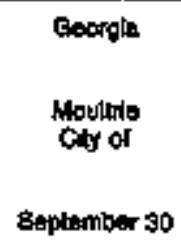 & 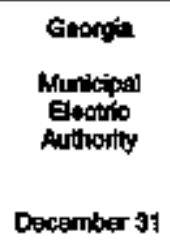 & $\begin{array}{c}\text { Beorola } \\
\text { Thomassilis } \\
\text { Ciny of }\end{array}$ & 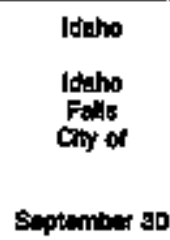 \\
\hline 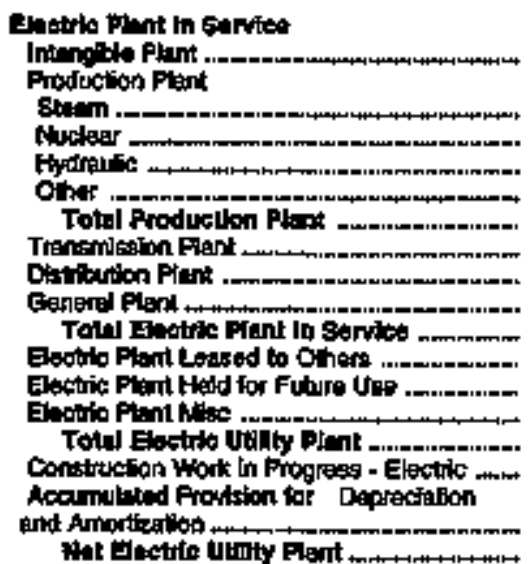 & $\begin{array}{r}0 \\
0 \\
0 \\
0 \\
0 \\
0 \\
0 \\
13,209 \\
0 \\
13,209 \\
0 \\
0 \\
0 \\
13,000 \\
0 \\
3,370 \\
8,900\end{array}$ & $\begin{array}{r}0 \\
0 \\
0 \\
0 \\
0 \\
0 \\
40,819 \\
0 \\
40,613 \\
0 \\
0 \\
0 \\
40,813 \\
0 \\
0 \\
18,042 \\
20971\end{array}$ & $\begin{array}{r}0 \\
0 \\
0 \\
0 \\
0 \\
0 \\
0 \\
5,982 \\
0 \\
5,932 \\
0 \\
0 \\
0 \\
5,982 \\
141 \\
3,747 \\
3,326\end{array}$ & 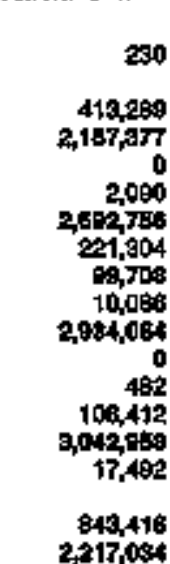 & $\begin{array}{r}0 \\
0 \\
0 \\
0 \\
0 \\
0 \\
0 \\
12,911 \\
2,195 \\
14,999 \\
0 \\
0 \\
0 \\
14,90 \% \\
7 \\
4,795 \\
10,267\end{array}$ & 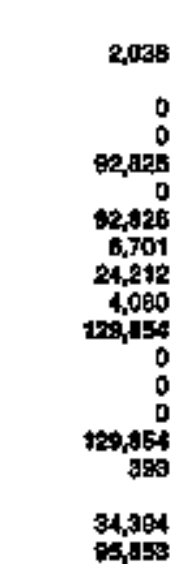 \\
\hline
\end{tabular}

\begin{tabular}{|c|c|c|c|c|c|c|}
\hline inm & 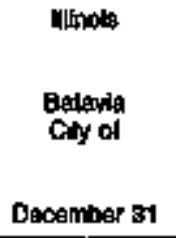 & $\begin{array}{l}\text { Enole } \\
\text { Eenteng } \\
\text { Giy of } \\
\text { Aptil so }\end{array}$ & 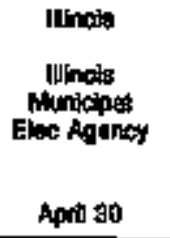 & $\begin{array}{l}\text { Altrols } \\
\text { Nepervile } \\
\text { Cty of } \\
\text { April so }\end{array}$ & 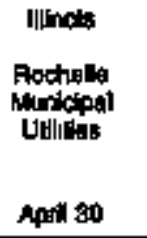 & $\begin{array}{l}\text { Sinota } \\
\text { Springilend } \\
\text { City of } \\
\text { February } 29\end{array}$ \\
\hline 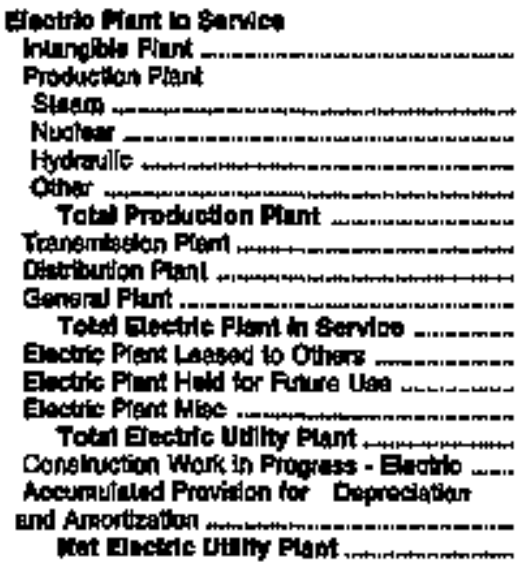 & 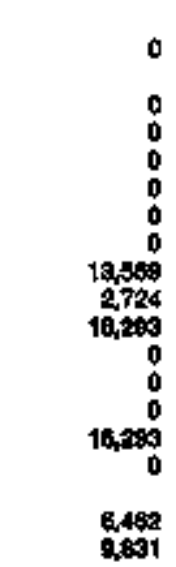 & $\begin{array}{r}0 \\
0 \\
0 \\
0 \\
0 \\
0 \\
0 \\
14,197 \\
7,395 \\
21,652 \\
0 \\
0 \\
0 \\
21,002 \\
50\end{array}$ & 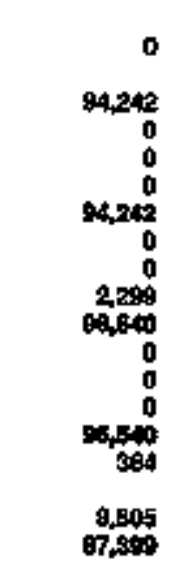 & $\begin{array}{r}0 \\
0 \\
0 \\
0 \\
0 \\
0 \\
6,471 \\
90,047 \\
10,978 \\
107,998 \\
0 \\
0 \\
0 \\
w, 598 \\
0,398\end{array}$ & $\begin{array}{r}0 \\
10,890 \\
0 \\
0 \\
5,757 \\
16,746 \\
1,667 \\
0,560 \\
1,707 \\
28,946 \\
0 \\
0 \\
0 \\
2,060 \\
14\end{array}$ & 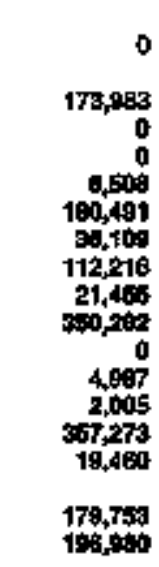 \\
\hline
\end{tabular}

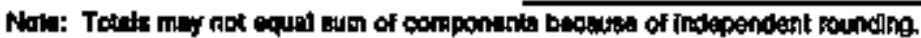

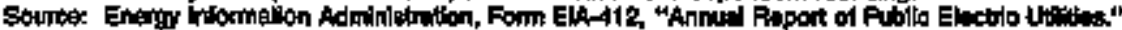


Table 24. Electrto Utilty Plant by Major U.S. Publlcly Owned Electric Utility Whthin State at End of Perlod, 1994 (Continued)

(Thousand Dollers)

\begin{tabular}{|c|c|c|c|c|c|c|}
\hline liem & 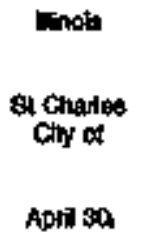 & $\begin{array}{l}\text { Indluna } \\
\text { Anderson } \\
\text { Chy of } \\
\text { Decomber } 91\end{array}$ & $\begin{array}{l}\text { Indina } \\
\text { Cily on } \\
\text { December S1 }\end{array}$ & $\begin{array}{l}\text { Irolana } \\
\text { Bithition } \\
\text { City of } \\
\text { Depentiber } 31\end{array}$ & 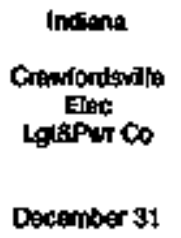 & $\begin{array}{l}\text { mollantid } \\
\text { Franidort } \\
\text { Ciny of } \\
\text { Deceniber \$1 }\end{array}$ \\
\hline 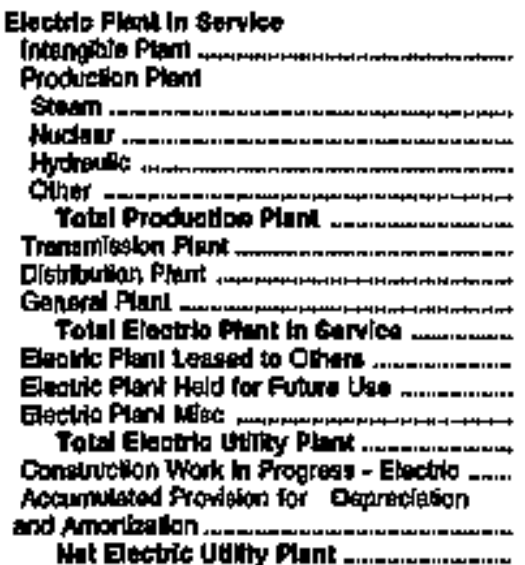 & $\begin{array}{r}0 \\
0 \\
0 \\
0 \\
0 \\
0 \\
0 \\
29,718 \\
60 \\
21,790 \\
0 \\
0 \\
0 \\
20,790 \\
0 \\
0,444 \\
20,336\end{array}$ & $\begin{array}{r}0 \\
0 \\
0 \\
0 \\
0 \\
1,176 \\
44,597 \\
7,391 \\
58,196 \\
0 \\
0 \\
5,135 \\
1,117\end{array}$ & 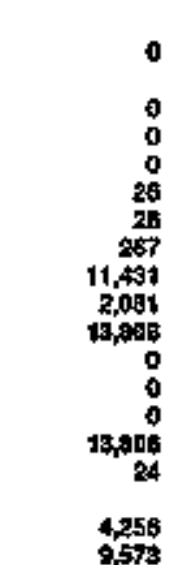 & $\begin{array}{r}0 \\
0 \\
0 \\
1,259 \\
1,230 \\
260 \\
0,147 \\
970 \\
0,422 \\
0 \\
0 \\
0 \\
0,692 \\
0 \\
4,418 \\
4,207\end{array}$ & 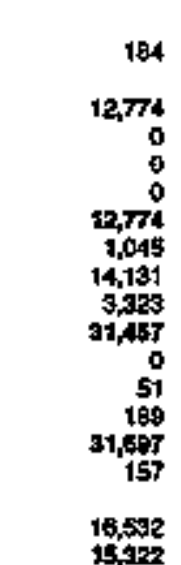 & 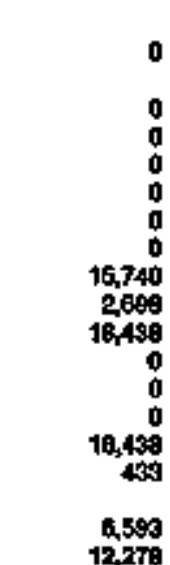 \\
\hline
\end{tabular}

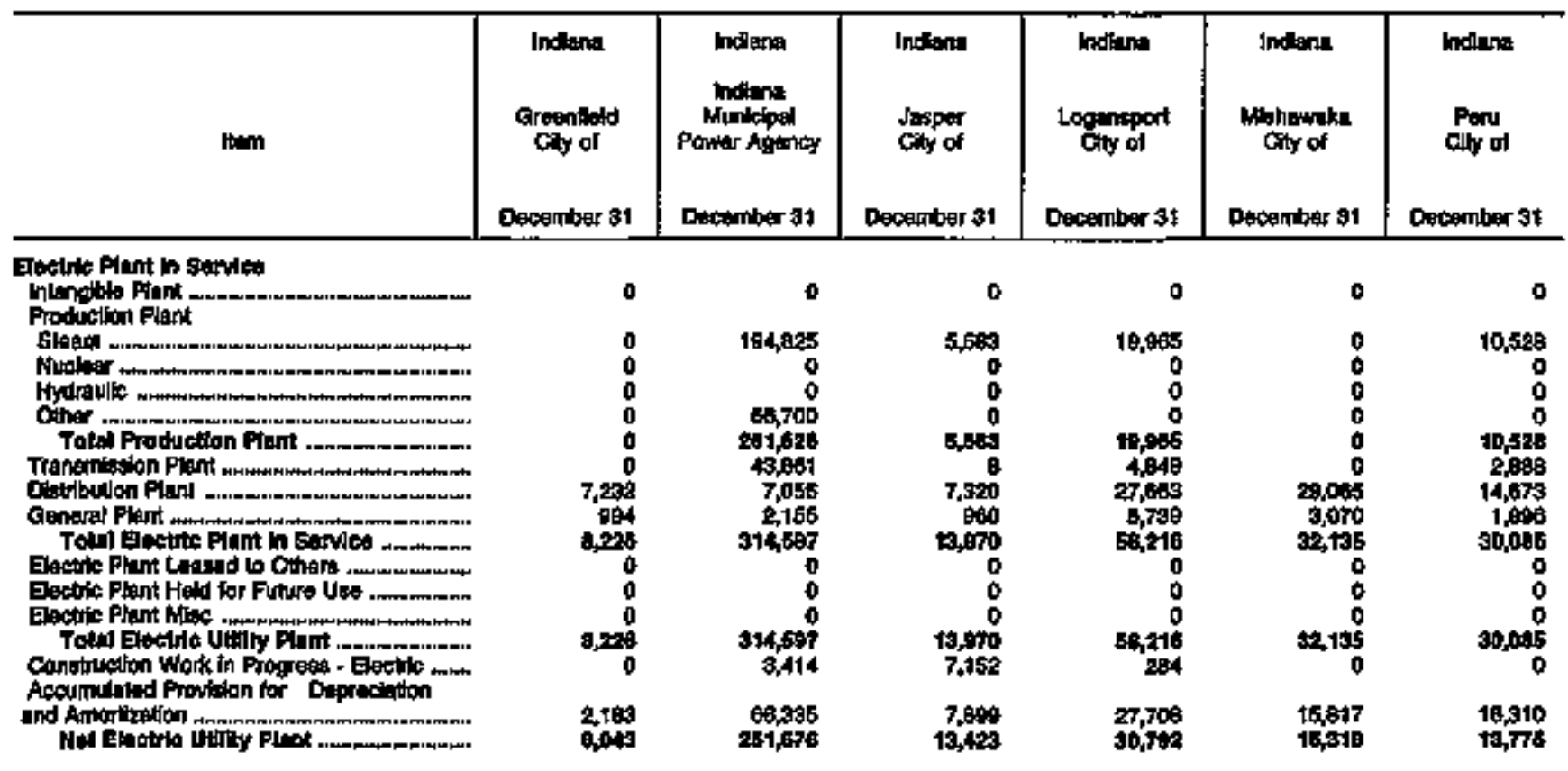

Nole: Toutu ary not equal wim ol conponents bectuls of independent counding

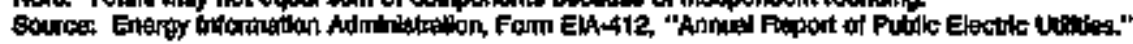


Table 24. Electric Utilty Plant by Major U.S. Publtely Owned Electric Utilty Wthin State at End of Period, 1994 (Continued) (Thousand Dollars)

\begin{tabular}{|c|c|c|c|c|c|c|}
\hline Iham & $\begin{array}{l}\text { Indianda } \\
\text { Alohnond } \\
\text { Gity of } \\
\text { December } 31\end{array}$ & 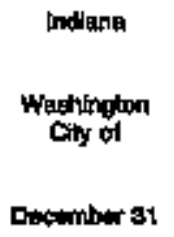 & 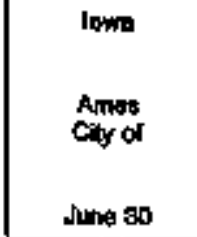 & 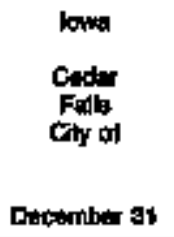 & $\begin{array}{l}\text { lowa } \\
\text { chy ol } \\
\text { Donoumber } 31\end{array}$ & Doma \\
\hline 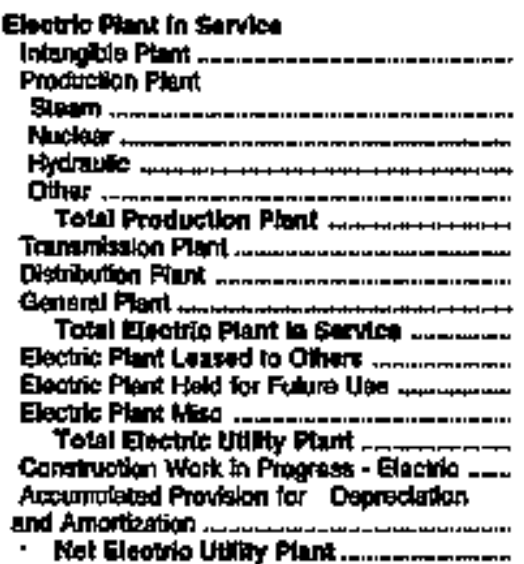 & 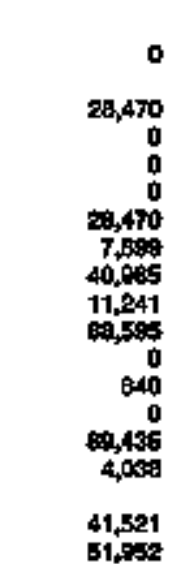 & $\begin{array}{r}0 \\
0 \\
0 \\
0 \\
0 \\
0 \\
500 \\
9,898 \\
809 \\
10,798 \\
0 \\
0 \\
0 \\
10,795 \\
0 \\
4,479 \\
6,474\end{array}$ & $\begin{array}{r}0 \\
0 \\
0 \\
0 \\
0 \\
0 \\
0 \\
100,359 \\
100,859 \\
0 \\
0 \\
100,850 \\
0 \\
54,790 \\
45,54\end{array}$ & 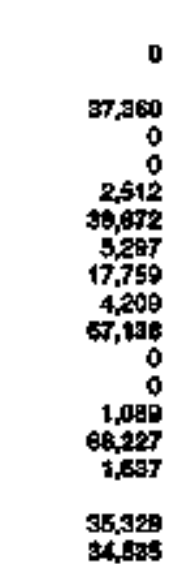 & 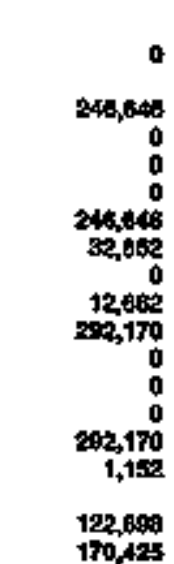 & $\begin{array}{l}0 \\
0 \\
0 \\
0 \\
0 \\
0 \\
0 \\
0 \\
0 \\
0 \\
0 \\
0 \\
0 \\
0\end{array}$ \\
\hline
\end{tabular}

\begin{tabular}{|c|c|c|c|c|c|c|}
\hline 伷界 & $\begin{array}{l}\text { Kanses } \\
\text { Chrnute } \\
\text { City of } \\
\text { Decomber \$1 }\end{array}$ & $\begin{array}{c}\text { Kanise } \\
\text { Coifenille } \\
\text { Ciny of } \\
\text { Dacember } 91\end{array}$ & $\begin{array}{c}\text { Karsas } \\
\text { Cardien } \\
\text { City City of } \\
\text { Decormber } 31\end{array}$ & $\begin{array}{l}\text { Kunsts } \\
\text { Kunsers } \\
\text { Citr Ciby of } \\
\text { Decamber } 91\end{array}$ & 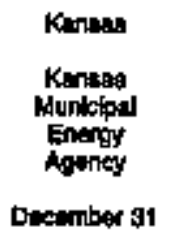 & 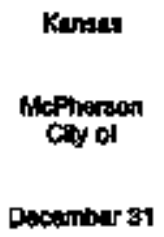 \\
\hline 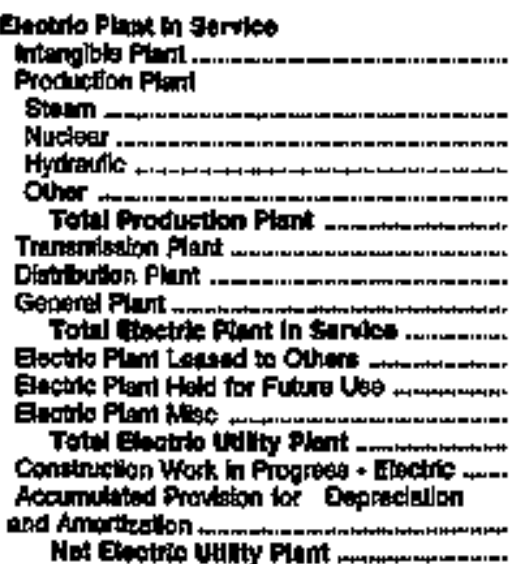 & $\begin{array}{r}0 \\
0 \\
0 \\
0 \\
21,870 \\
21,970 \\
3,000 \\
1,000 \\
0 \\
25,970 \\
0 \\
0 \\
0 \\
28,079 \\
0 \\
0 \\
29,979\end{array}$ & 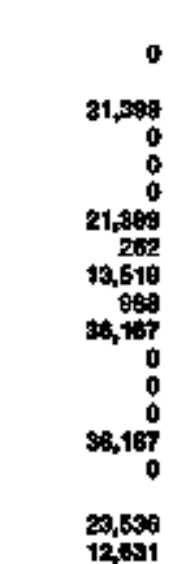 & $\begin{array}{r}0 \\
0 \\
0 \\
0 \\
0 \\
0 \\
0 \\
18,274 \\
0 \\
10 \% 7 \\
0 \\
0 \\
0 \\
4051 \\
0\end{array}$ & 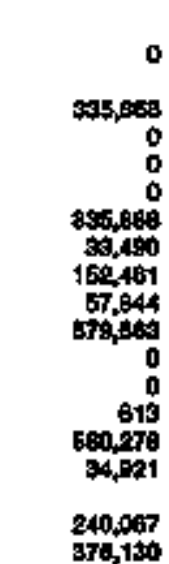 & $\begin{array}{r}0 \\
0 \\
0 \\
0 \\
0 \\
4,723 \\
0 \\
189 \\
4,68 \\
0 \\
0 \\
0 \\
4698 \\
8\end{array}$ & 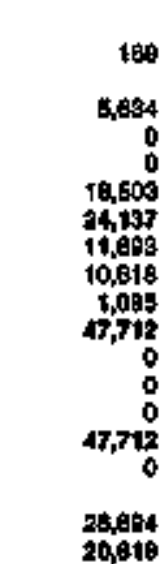 \\
\hline
\end{tabular}

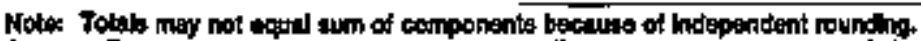

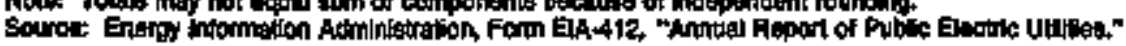


Tabfe 24. Electric Utilty Plant by Major U.S. Publicly Omned Electrio Utilly Within State at End of Period, 1994 (Continued)

(Thousand Dollers)

\begin{tabular}{|c|c|c|c|c|c|c|}
\hline Ilean & 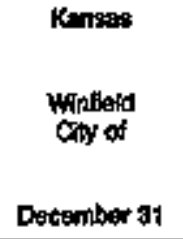 & 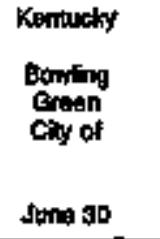 & 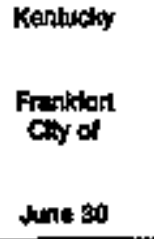 & $\begin{array}{l}\text { Kentuaky } \\
\text { Franidis } \\
\text { Ciny of } \\
\text { June so }\end{array}$ & 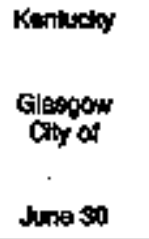 & 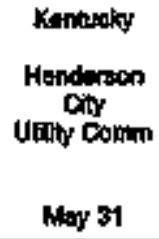 \\
\hline 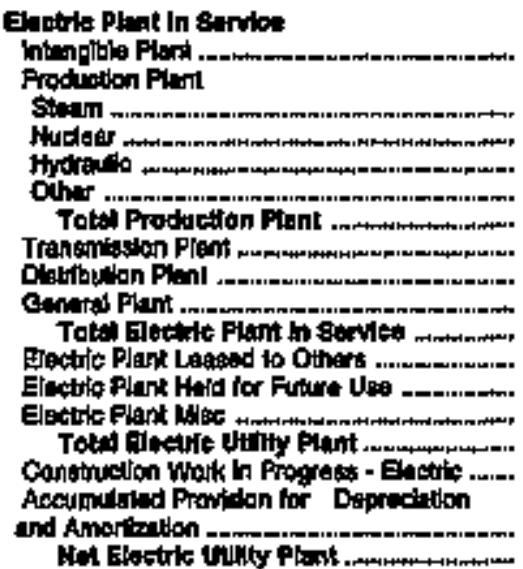 & $\begin{array}{r}18,369 \\
0 \\
0 \\
1,711 \\
19,500 \\
0 \\
10,770 \\
1,620 \\
31,401 \\
0 \\
0 \\
0 \\
31,801 \\
3446 \\
16,070 \\
17,070\end{array}$ & 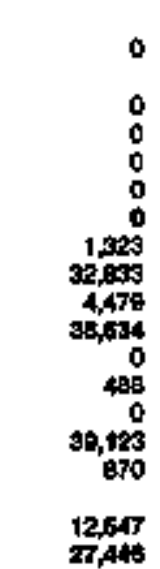 & $\begin{array}{r}0 \\
0 \\
0 \\
0 \\
0 \\
0 \\
7,652 \\
14,890 \\
0 \\
02,660 \\
0 \\
0 \\
0 \\
22,652 \\
0\end{array}$ & $\begin{array}{r}0 \\
0 \\
0 \\
0 \\
0 \\
0 \\
4,078 \\
1,014 \\
5990 \\
0 \\
0 \\
0 \\
5900 \\
36\end{array}$ & 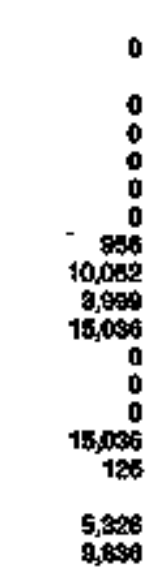 & 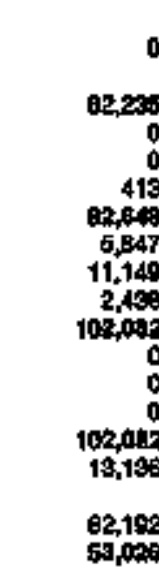 \\
\hline
\end{tabular}

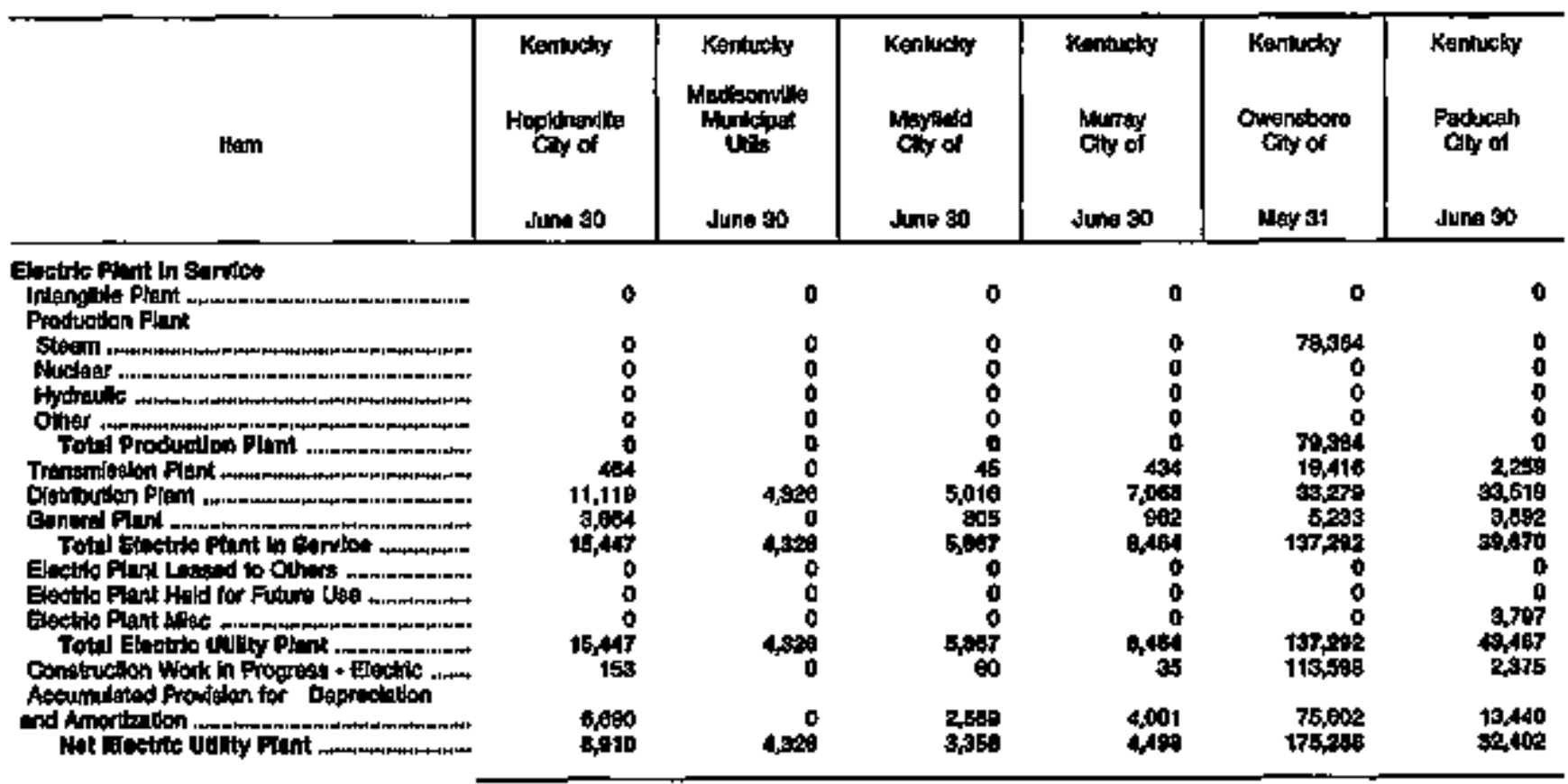

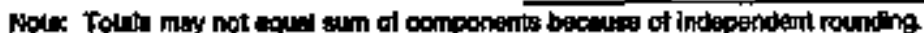

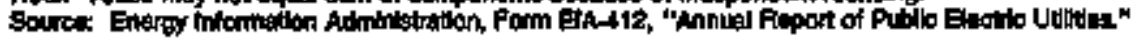


Table 24. Elactric Utilty Plant by Major U.S. Publicly Owned Electric Uttlly Within State at End of Poriod, 1984 (Continued)

(Thousand Dollars)

\begin{tabular}{|c|c|c|c|c|c|c|}
\hline |10नI & 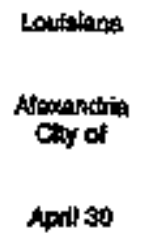 & $\begin{array}{l}\text { Loubitara } \\
\text { Lafoyetted } \\
\text { Chy of } \\
\text { October } 31\end{array}$ & 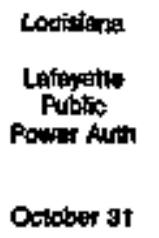 & 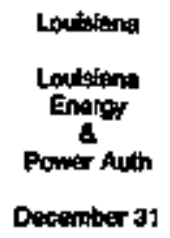 & 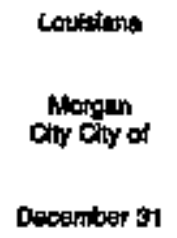 & 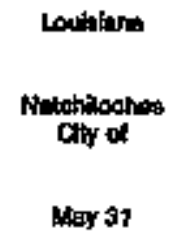 \\
\hline 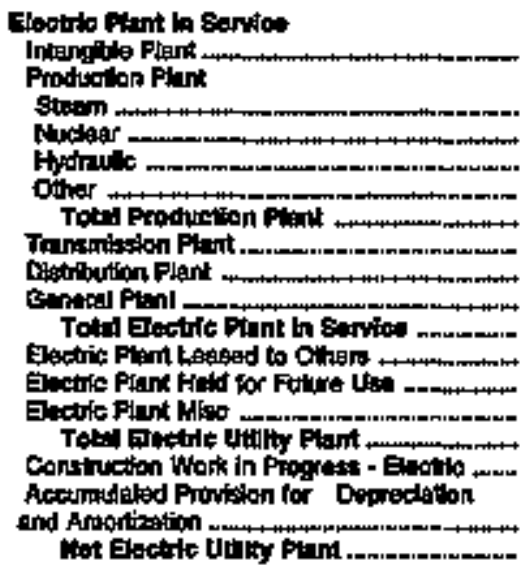 & 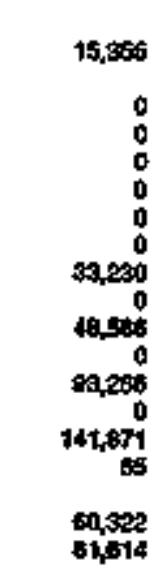 & 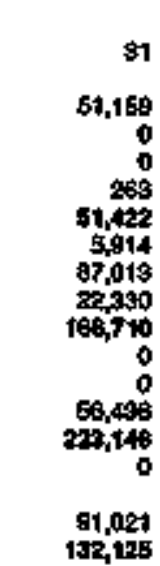 & 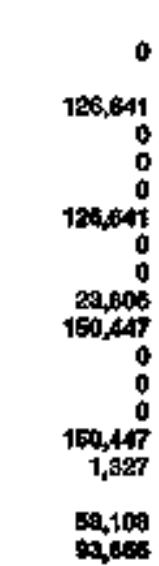 & $\begin{array}{r}8676 \\
67,87 \% \\
0 \\
0 \\
0 \\
57,972 \\
410 \\
16 \\
4,674 \\
71,549 \\
0 \\
0 \\
15,728 \\
97,298 \\
241 \\
19,740 \\
67,780\end{array}$ & 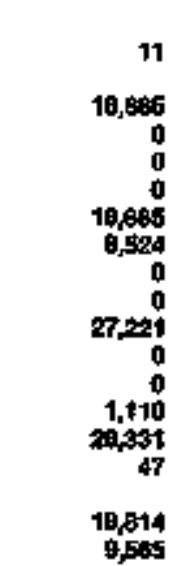 & $\begin{array}{r}0 \\
0 \\
0 \\
0 \\
0 \\
0 \\
0 \\
59,082 \\
0 \\
63,032 \\
0 \\
0 \\
0 \\
53,082 \\
0 \\
14,415 \\
39,67 \%\end{array}$ \\
\hline
\end{tabular}

\begin{tabular}{|c|c|c|c|c|c|c|}
\hline Ilam & 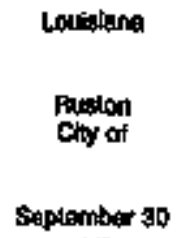 & 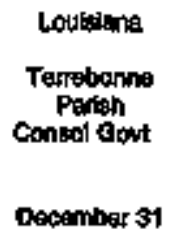 & $\begin{array}{l}\text { Manylund } \\
\text { Easton } \\
\text { Utimitios } \\
\text { Cormm } \\
\text { Jume } 50\end{array}$ & $\begin{array}{l}\text { Maryand } \\
\text { Hegarstom } \\
\text { chy of } \\
\text { Itra sp }\end{array}$ & 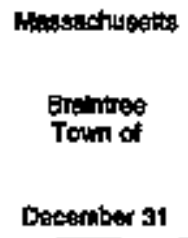 & 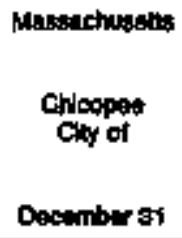 \\
\hline 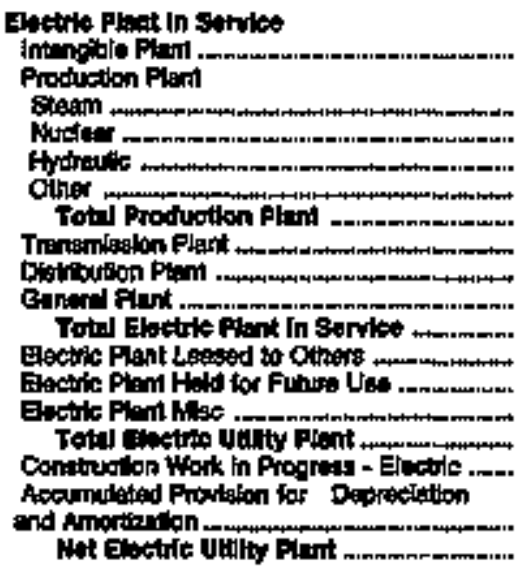 & 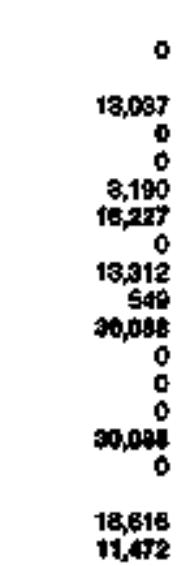 & 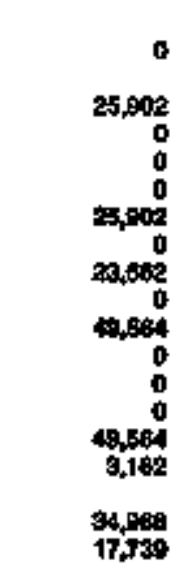 & $\begin{array}{r}0 \\
0 \\
0 \\
20,483 \\
20,403 \\
0 \\
17,127 \\
2,402 \\
40,0112 \\
0 \\
0 \\
0 \\
4,012 \\
701 \\
17,194 \\
28,570\end{array}$ & 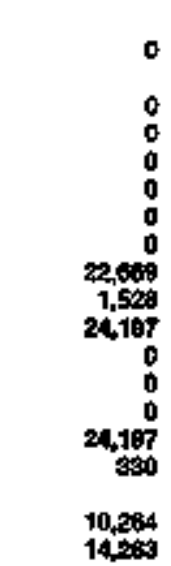 & 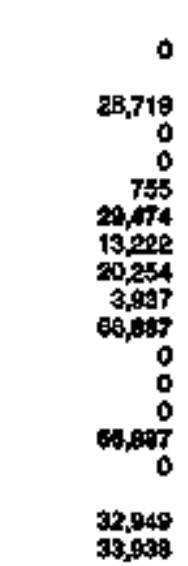 & 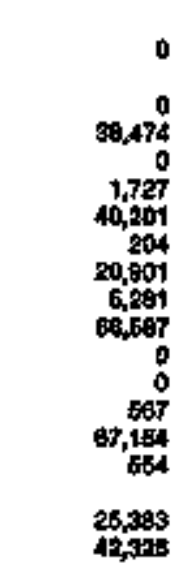 \\
\hline
\end{tabular}

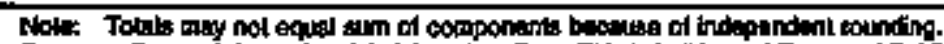

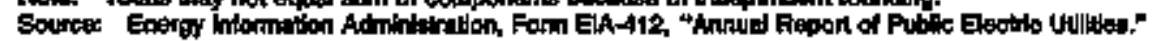


Table 24. Electric Utitity Plant by Major U\$. Publlaly Owned Electric Utility Within State at End of Period, 1994 (Thousand Dollars)

\begin{tabular}{|c|c|c|c|c|c|c|}
\hline Item & $\begin{array}{l}\text { Masmachuselts } \\
\text { Concond } \\
\text { Town of } \\
\text { Dacentiber i1 }\end{array}$ & 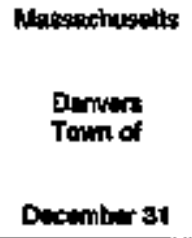 & $\begin{array}{l}\text { Masachusutts } \\
\text { Hingham } \\
\text { Chy of }\end{array}$ & 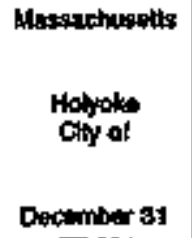 & 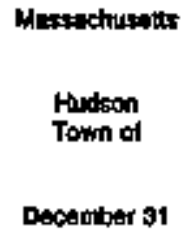 & 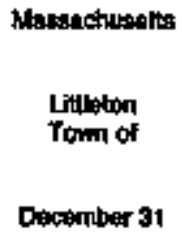 \\
\hline 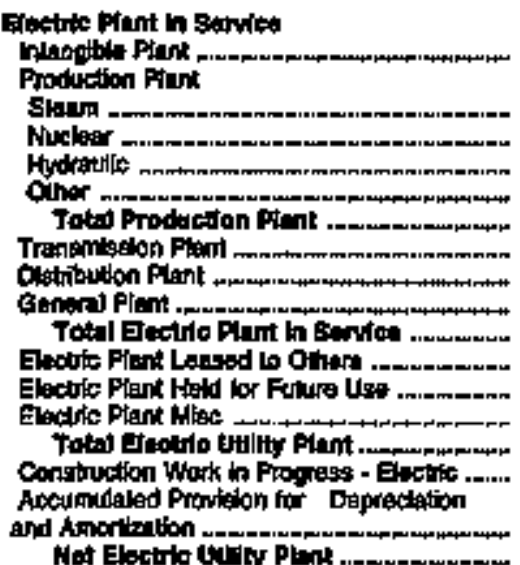 & $\begin{array}{r}2,009 \\
0 \\
0 \\
0 \\
0 \\
0 \\
0 \\
72,697 \\
+2,095 \\
2,408 \\
29,204 \\
0 \\
0 \\
0 \\
20,200 \\
3\end{array}$ & $\begin{array}{r}0 \\
0 \\
0 \\
0 \\
0 \\
0 \\
19,600 \\
3,130 \\
2,790 \\
0 \\
0 \\
0 \\
22,799 \\
0\end{array}$ & $\begin{array}{r}0 \\
0 \\
0 \\
0 \\
0 \\
0 \\
1,489 \\
1,649 \\
1,729 \\
24,045 \\
0 \\
0 \\
0 \\
21,616 \\
0 \\
6,513 \\
15,703\end{array}$ & 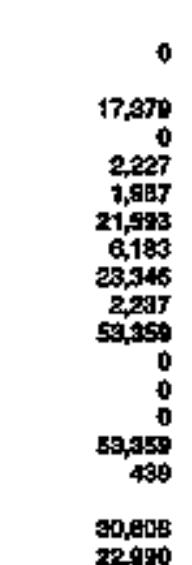 & 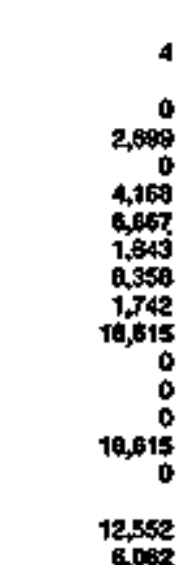 & $\begin{array}{r}342 \\
0 \\
0 \\
0 \\
342 \\
15 \\
10,798 \\
4,198 \\
15,353 \\
0 \\
0 \\
0 \\
15,353 \\
170 \\
0,125 \\
9,399\end{array}$ \\
\hline
\end{tabular}

\begin{tabular}{|c|c|c|c|c|c|c|}
\hline Hean & 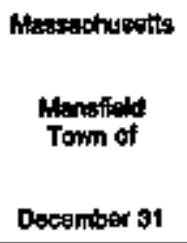 & 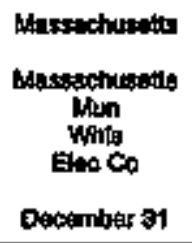 & $\begin{array}{l}\text { Masuachuzets } \\
\text { Mlofinbonough } \\
\text { Tom of } \\
\text { Devember } 31\end{array}$ & $\begin{array}{l}\text { Messechusetts } \\
\text { Morth } \\
\text { Artoborough } \\
\text { Town of } \\
\text { Dectomber } 31\end{array}$ & 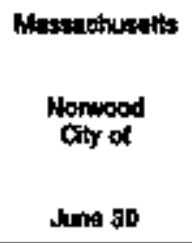 & $\begin{array}{l}\text { Mnsatchuasts } \\
\text { Pubody } \\
\text { cly of }\end{array}$ \\
\hline 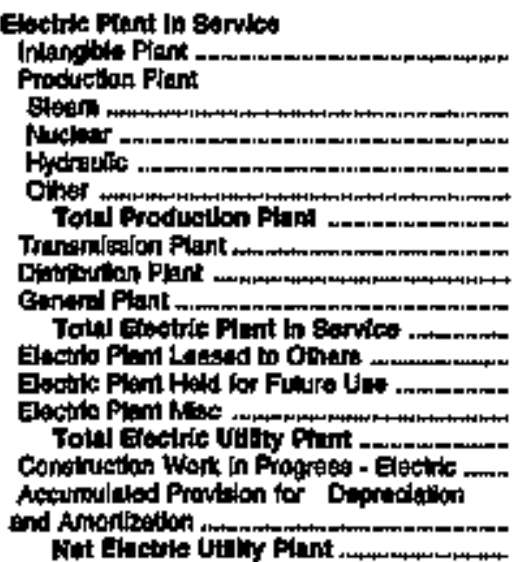 & $\begin{array}{r}0 \\
0 \\
0 \\
0 \\
0 \\
0 \\
8,744 \\
1,014 \\
9,744 \\
0 \\
0 \\
0 \\
9,754 \\
0\end{array}$ & 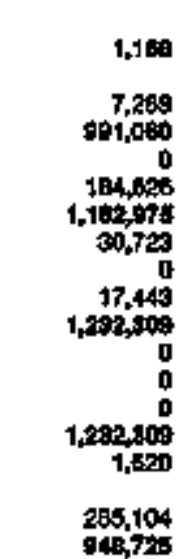 & $\begin{array}{r}0 \\
0 \\
0 \\
0 \\
0 \\
2,797 \\
10,360 \\
2,498 \\
15,048 \\
0 \\
0 \\
0 \\
+5,649 \\
0\end{array}$ & $\begin{array}{r}0 \\
785 \\
0 \\
0 \\
0 \\
705 \\
1,774 \\
12,898 \\
4,557 \\
20,004 \\
0 \\
0 \\
0 \\
20,094 \\
192\end{array}$ & $\begin{array}{r}0 \\
0 \\
0 \\
0 \\
0 \\
509 \\
19,539 \\
1,737 \\
21,790 \\
0 \\
0 \\
0 \\
21,796 \\
0 \\
15,000 \\
8,769\end{array}$ & 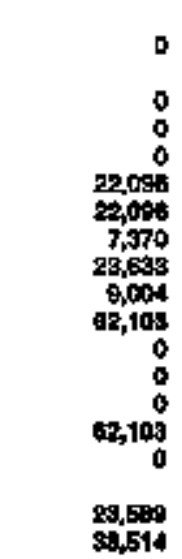 \\
\hline
\end{tabular}

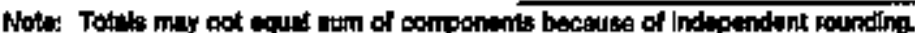

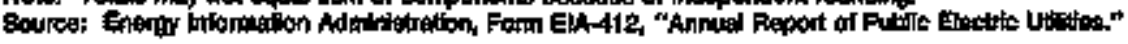


Table 24. Eeotric Utilly Plant by Major U.S. Publtely Owned Electric Utility Whin State at End of Period, 1994 (Contimued) (Thotusand Dollars)

\begin{tabular}{|c|c|c|c|c|c|c|}
\hline ILAM & 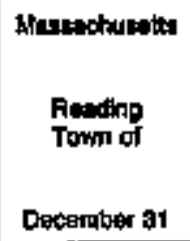 & 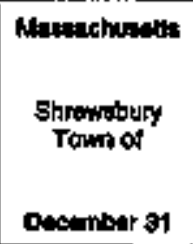 & 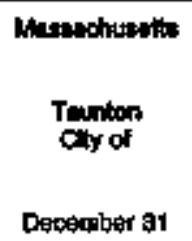 & 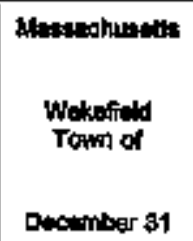 & 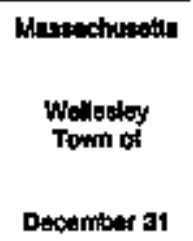 & 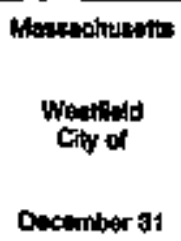 \\
\hline 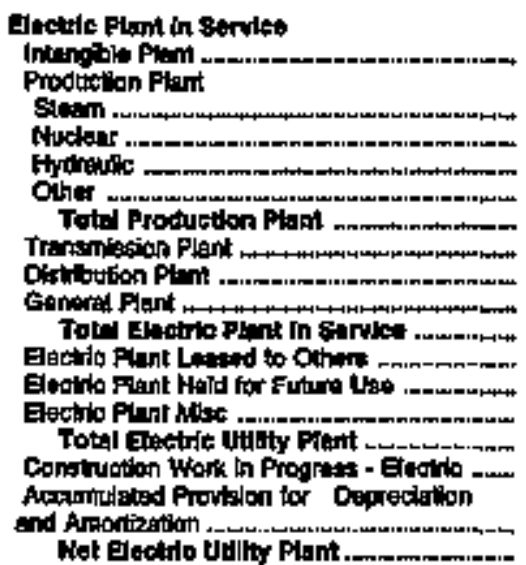 & 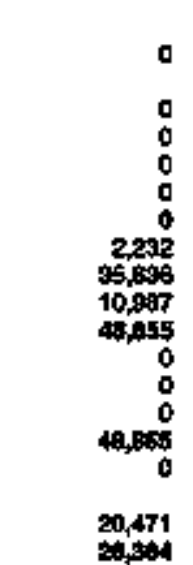 & 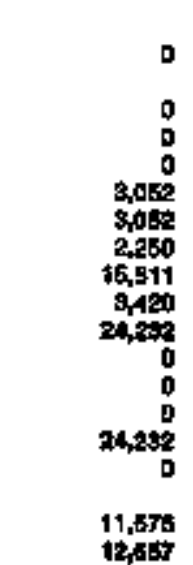 & 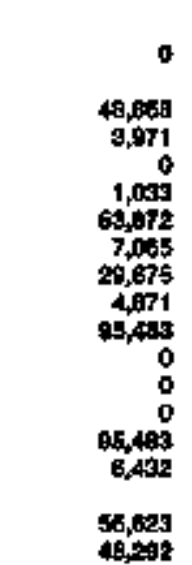 & $\begin{array}{r}0 \\
0 \\
0 \\
0 \\
0 \\
0 \\
0 \\
19,597 \\
507 \\
14,094 \\
0 \\
0 \\
14,004 \\
0 \\
11,319 \\
2,751\end{array}$ & $\begin{array}{r}0 \\
0 \\
0 \\
0 \\
0 \\
5,469 \\
19,451 \\
1,502 \\
28,902 \\
0 \\
0 \\
0 \\
29,962 \\
1,607 \\
12,3609 \\
16,510\end{array}$ & $\begin{array}{r}0 \\
0 \\
0 \\
0 \\
0 \\
0 \\
0 \\
18,655 \\
5,950 \\
24,405 \\
0 \\
0 \\
0 \\
24,605 \\
813 \\
1,454 \\
23,944\end{array}$ \\
\hline
\end{tabular}

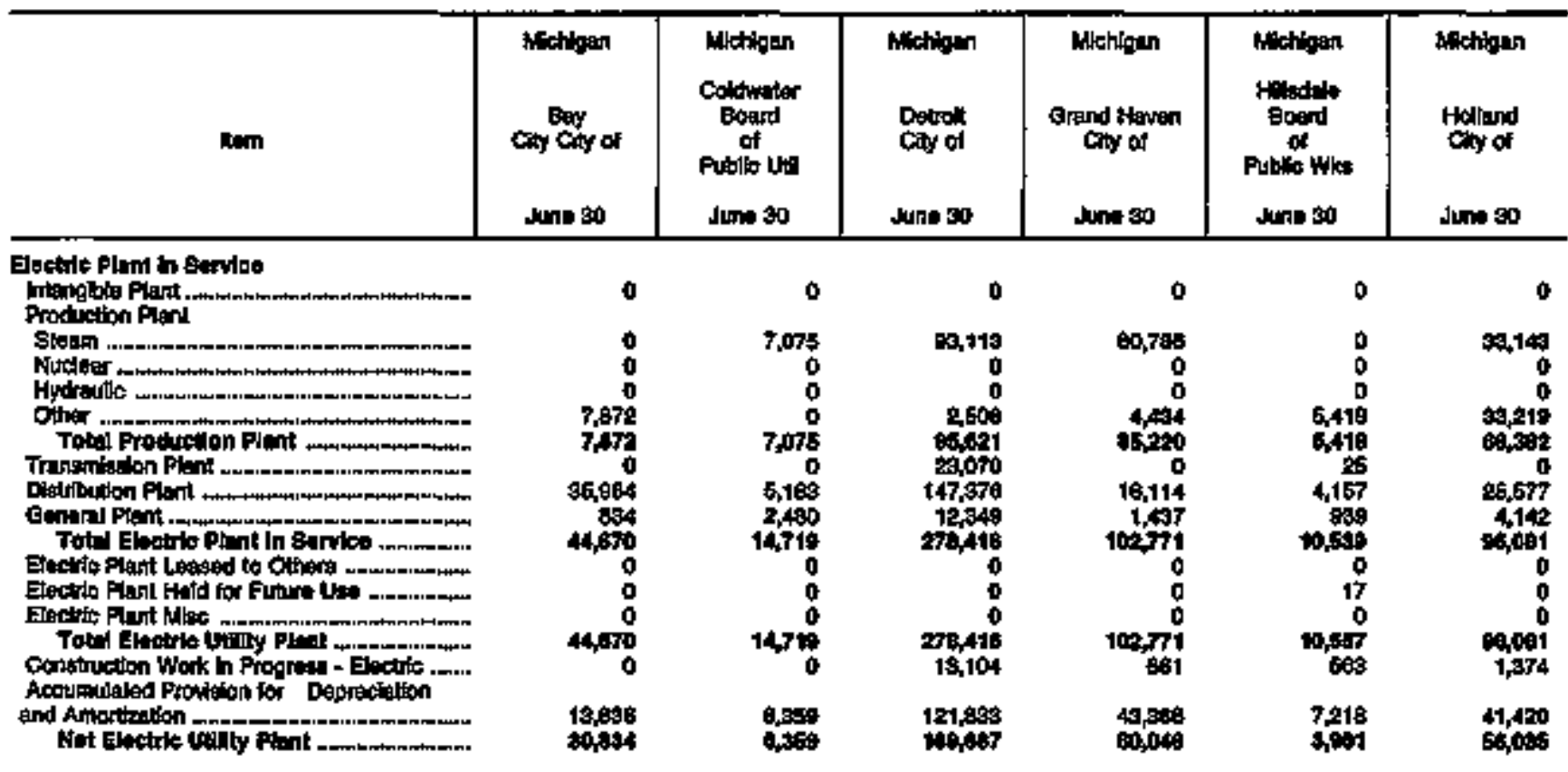

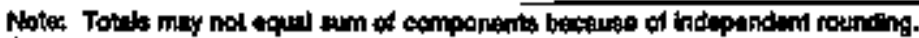

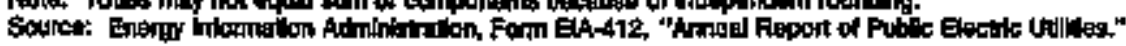


Table 24. Electrto Utilty Plant by. Major U.S. Publicly Owned Electric Utility Whithlin State at End of Perfod, 1994 (Continued)

(Thousand Dollars)

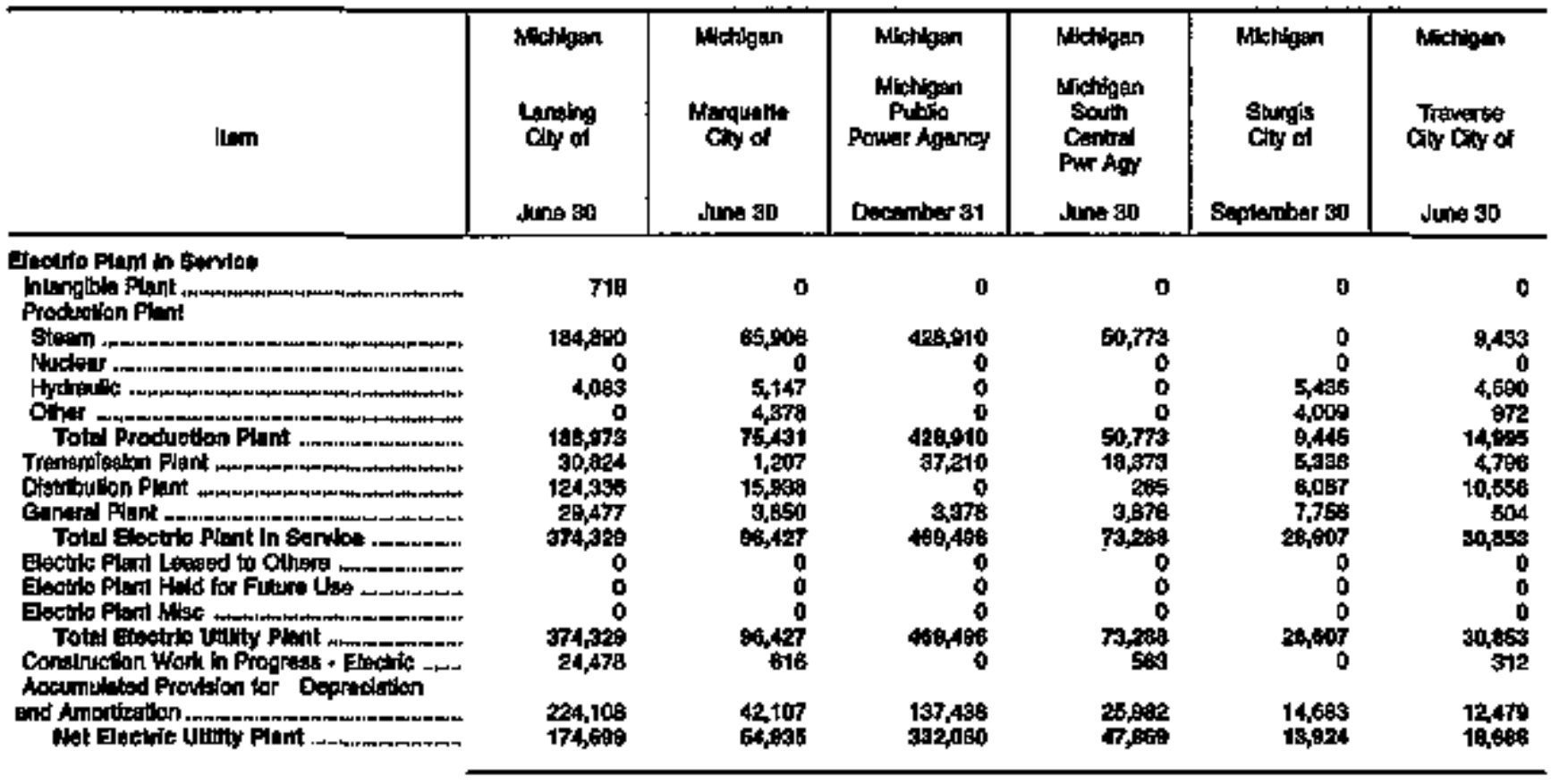

\begin{tabular}{|c|c|c|c|c|c|c|}
\hline Htem & 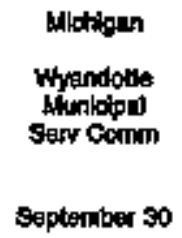 & $\begin{array}{l}\text { Mlohigan } \\
\text { Zeoland } \\
\text { City of } \\
\text { Junte so }\end{array}$ & 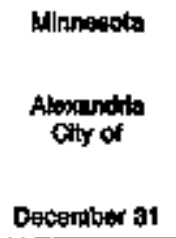 & $\begin{array}{l}\text { Mhingeola } \\
\text { Anoica } \\
\text { Cly of } \\
\text { Dowembar } 31\end{array}$ & $\begin{array}{l}\text { Munnegota } \\
\text { Austin } \\
\text { Cof of } \\
\text { Decomber } 31\end{array}$ & $\begin{array}{l}\text { Minnesoln } \\
\text { Gruinerd } \\
\text { Glyy of } \\
\text { Dacember \$1 }\end{array}$ \\
\hline 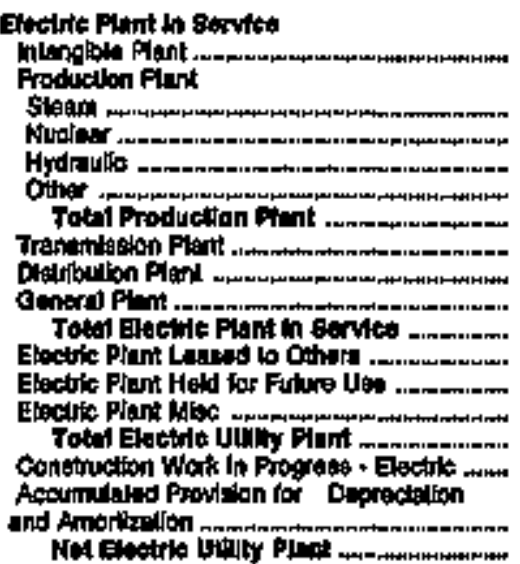 & 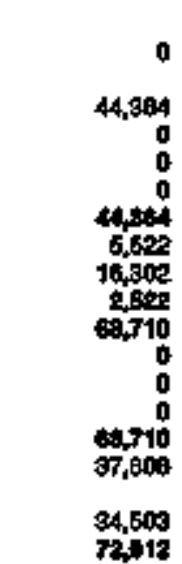 & $\begin{array}{r}0 \\
0 \\
0 \\
0 \\
10,728 \\
1,720 \\
0 \\
5,457 \\
1,298 \\
17,421 \\
0 \\
0 \\
0 \\
17,41 \\
1,1558\end{array}$ & $\begin{array}{r}0 \\
494 \\
0 \\
0 \\
2070 \\
2,684 \\
901 \\
9,91 \\
1,800 \\
15,800 \\
+\quad 0 \\
16,802 \\
17\end{array}$ & 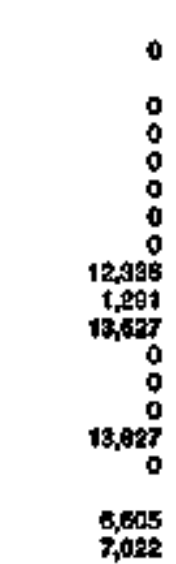 & $\begin{array}{r}0 \\
14,982 \\
0 \\
0 \\
0 \\
14,092 \\
1,175 \\
14,017 \\
2,047 \\
3,190 \\
1,009 \\
0 \\
0 \\
34,189 \\
40 \\
10,831 \\
18,401\end{array}$ & 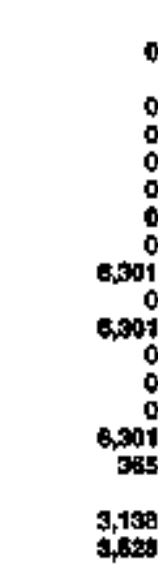 \\
\hline
\end{tabular}

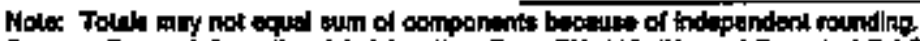

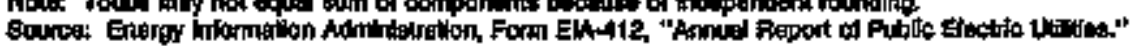


Table 24. Electrlo Utilty Plent by Major U.S. Publely Owned Electric Utlity Within state at End of Period, 1994 (Conkinued)

(Thousand Dollars)

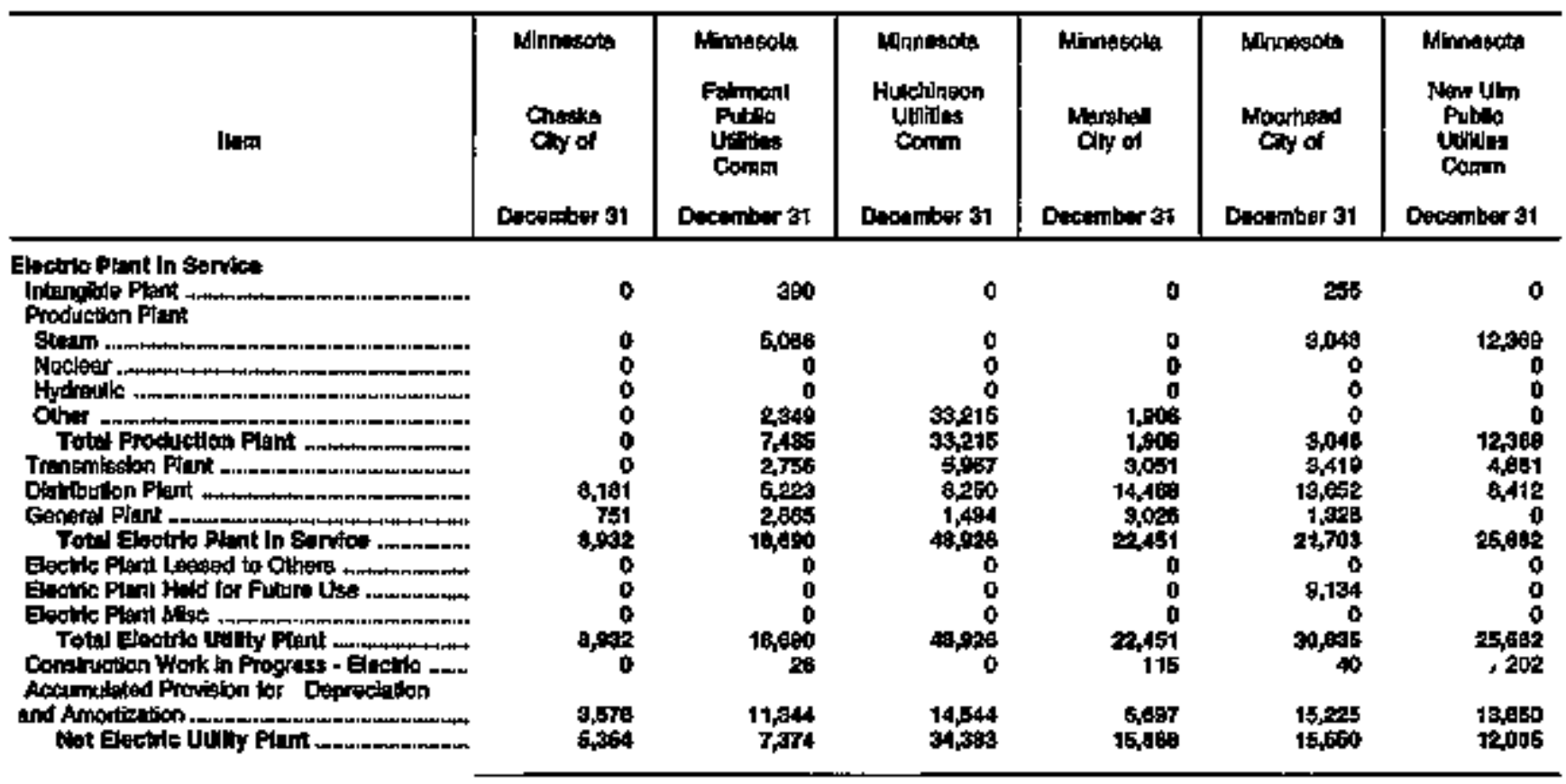

\begin{tabular}{|c|c|c|c|c|c|c|}
\hline Itoen & 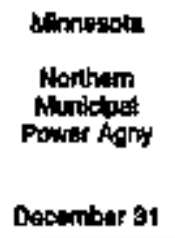 & $\begin{array}{l}\text { Minmisole } \\
\text { Omationne } \\
\text { City of } \\
\text { December } 31\end{array}$ & 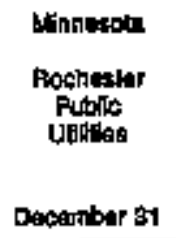 & 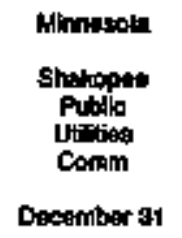 & 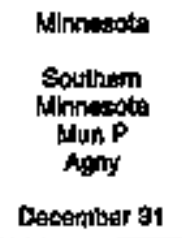 & 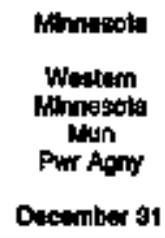 \\
\hline 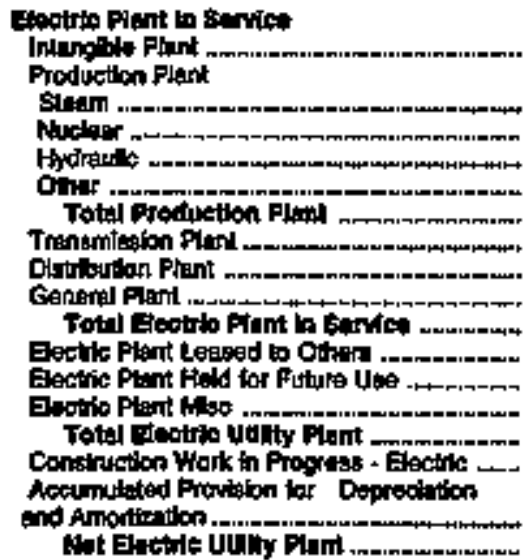 & 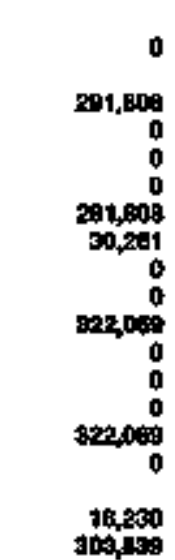 & 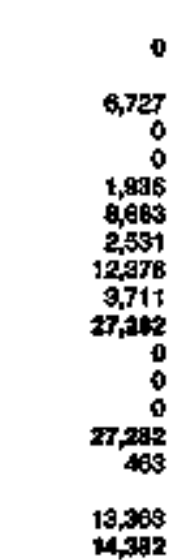 & $\begin{array}{r}2,153 \\
25,701 \\
0 \\
2,407 \\
2,554 \\
30,722 \\
10,328 \\
44,194 \\
17,029 \\
105,016 \\
0 \\
0 \\
0 \\
105,016 \\
4,8088\end{array}$ & $\begin{array}{r}0 \\
0 \\
0 \\
0 \\
0 \\
0 \\
0 \\
5,852 \\
580 \\
6,499 \\
0 \\
0 \\
0 \\
0.43 \\
800\end{array}$ & 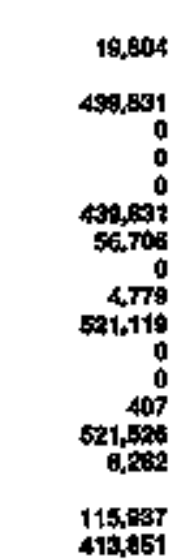 & 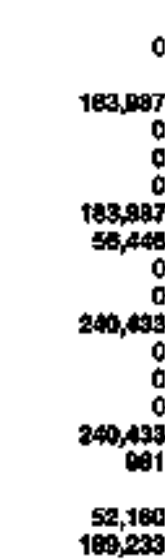 \\
\hline
\end{tabular}

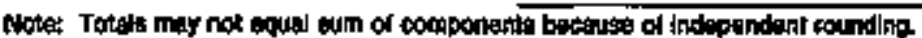

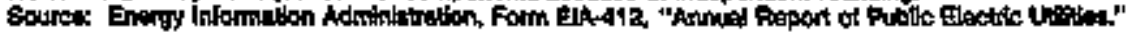


Table 24. Electric Utility Fiant by Major U.S. Publicly Owned Eectric Utlity Within State at End of Period, 1994 (Continued)

(Thousand Dollars)

\begin{tabular}{|c|c|c|c|c|c|c|}
\hline Ilom & 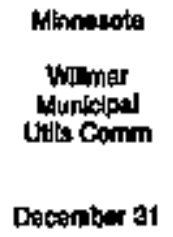 & 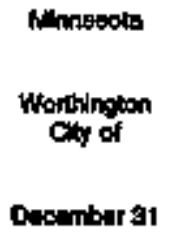 & 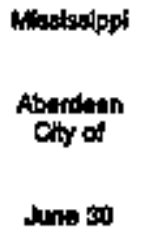 & 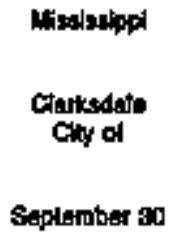 & 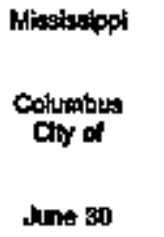 & 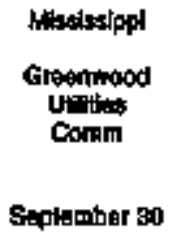 \\
\hline 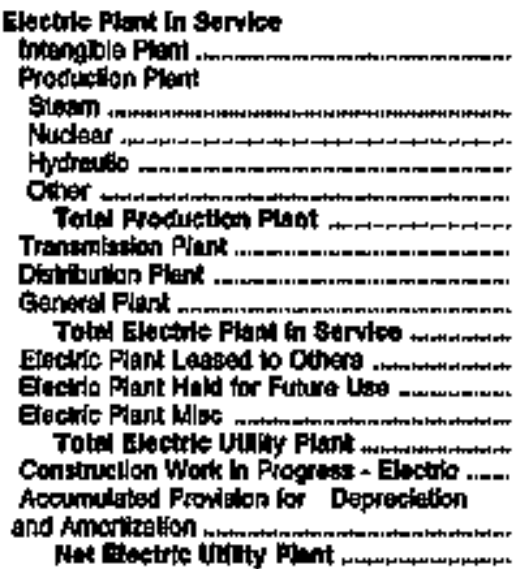 & 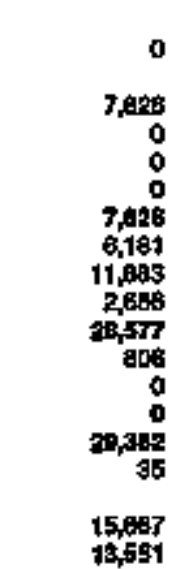 & $\begin{array}{r}0 \\
0 \\
0 \\
0 \\
0 \\
0 \\
0 \\
11,415 \\
675 \\
12,091 \\
0 \\
0 \\
0 \\
7,091 \\
0 \\
5,103 \\
3,005\end{array}$ & $\begin{array}{r}0 \\
0 \\
0 \\
0 \\
0 \\
0 \\
5,615 \\
916 \\
4,500 \\
0 \\
0 \\
0 \\
4,580 \\
13 \\
2,085 \\
2,450\end{array}$ & $\begin{array}{r}15,1991 \\
0 \\
0 \\
0 \\
15,011 \\
1,086 \\
0,671 \\
1,110 \\
28,957 \\
0 \\
0 \\
0 \\
28,057 \\
0 \\
18,567 \\
0,251\end{array}$ & $\begin{array}{r}0 \\
0 \\
0 \\
0 \\
0 \\
10 \\
14,360 \\
+, 450 \\
16,940 \\
0 \\
0 \\
0 \\
16,340 \\
14 \\
0,462 \\
7,501\end{array}$ & 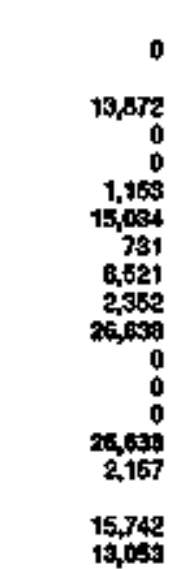 \\
\hline
\end{tabular}

\begin{tabular}{|c|c|c|c|c|c|c|}
\hline$t: m$ & 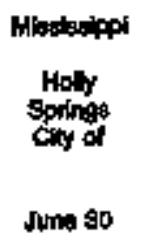 & 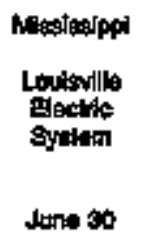 & 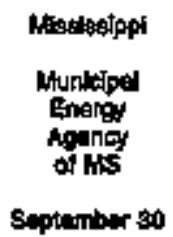 & 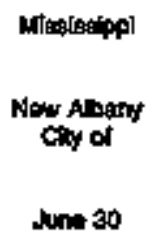 & $\begin{array}{l}\text { heselastpor } \\
\text { Oxterd } \\
\text { Cly of } \\
\text { June } 30\end{array}$ & 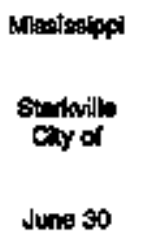 \\
\hline 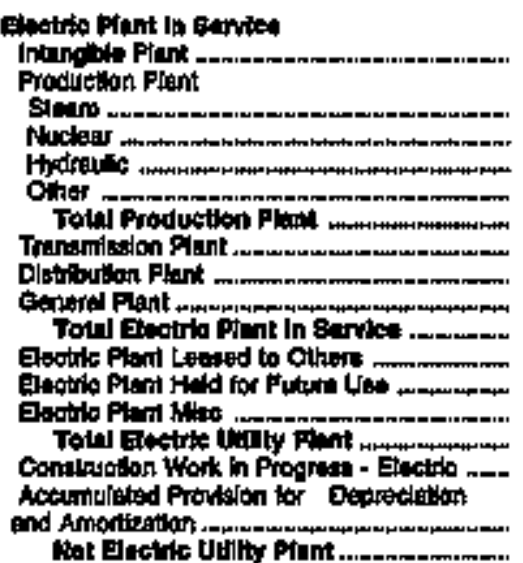 & $\begin{array}{r}0 \\
0 \\
0 \\
10 \\
0 \\
0 \\
0 \\
11,409 \\
2,138 \\
13,548 \\
0 \\
0 \\
0 \\
+2,545 \\
293 \\
5,290 \\
5,600\end{array}$ & 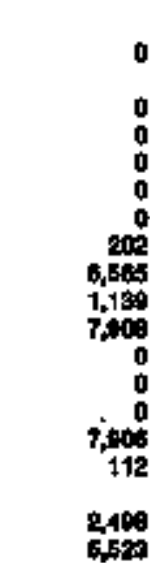 & $\begin{array}{r}2 t \theta \\
0 \\
0 \\
0 \\
252 \\
2.5 \\
0 \\
0 \\
980 \\
735 \\
0 \\
0 \\
0 \\
75 \\
4,457 \\
100 \\
5011\end{array}$ & $\begin{array}{r}0 \\
0 \\
0 \\
0 \\
0 \\
0 \\
0 \\
0 \\
10,531 \\
1,148 \\
11,675 \\
0 \\
0 \\
400 \\
11,721 \\
557 \\
4,040 \\
0,437\end{array}$ & $\begin{array}{r}0 \\
0 \\
0 \\
0 \\
0 \\
0 \\
4,910 \\
46 \\
4,967 \\
0 \\
0 \\
914 \\
5,071 \\
1,717 \\
\\
2,194 \\
5,304\end{array}$ & $\begin{array}{r}0 \\
0 \\
0 \\
0 \\
0 \\
308 \\
0,440 \\
1,700 \\
11,445 \\
0 \\
0 \\
37 \\
11,474 \\
127 \\
3,792 \\
7,645\end{array}$ \\
\hline
\end{tabular}

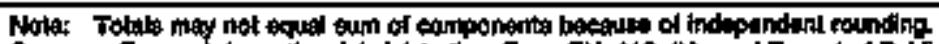

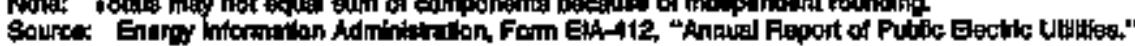


Table 24. Electric Utilty Plant by Major US. Publicly Owned Electric Utibty Within State at End of Period, 1994

(Thousand Dollars)

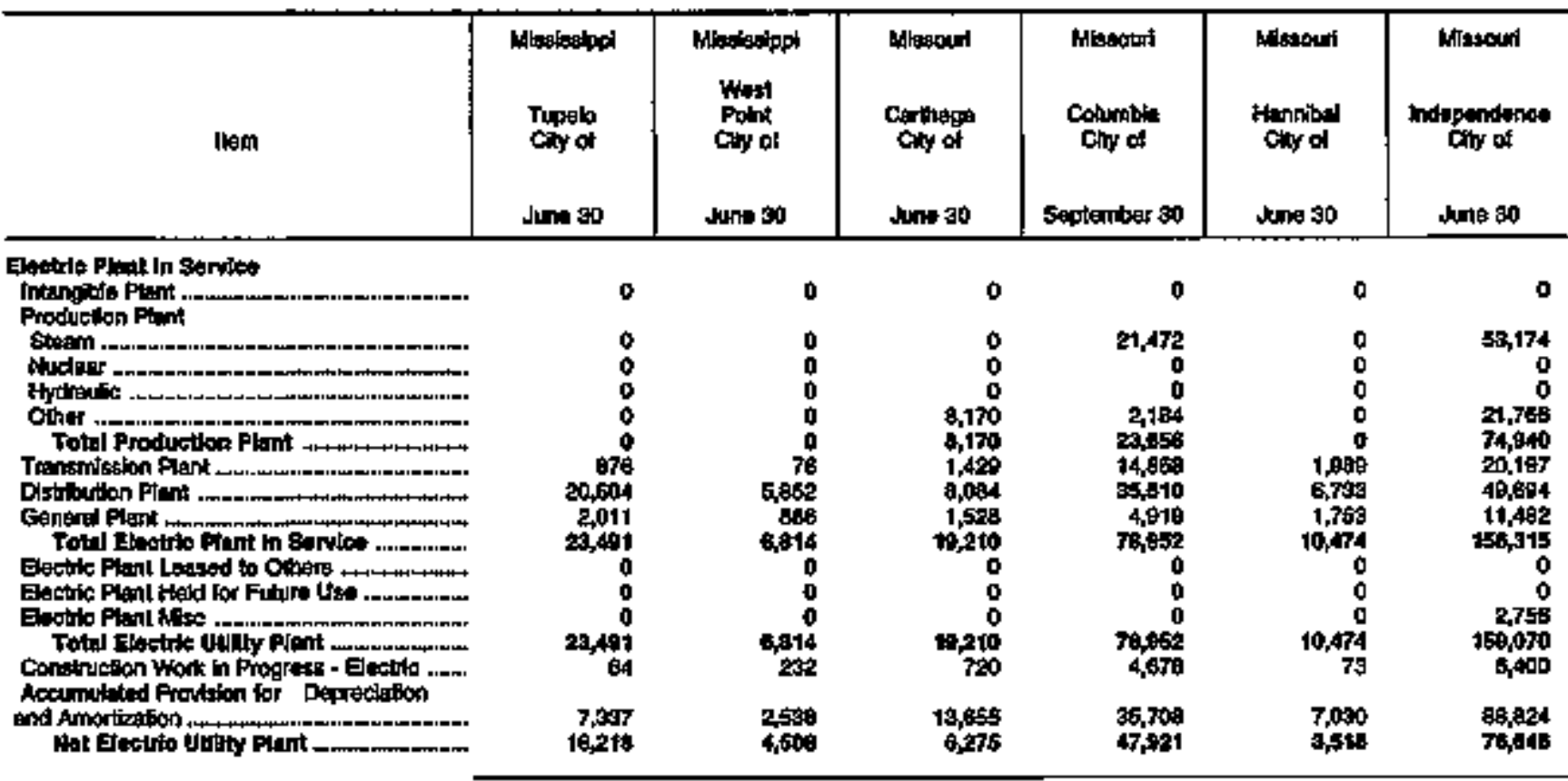

\begin{tabular}{|c|c|c|c|c|c|c|}
\hline Iann & $\begin{array}{l}\text { Mhosouad } \\
\text { Kenneit } \\
\text { Chy of } \\
\text { June so }\end{array}$ & 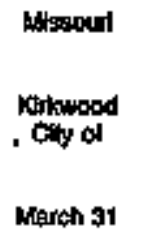 & 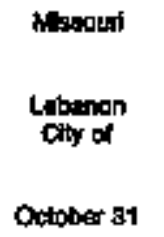 & 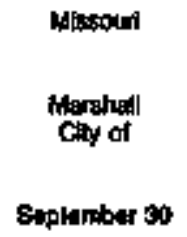 & $\begin{array}{l}\text { Meouti } \\
\text { Monet } \\
\text { Cay of } \\
\text { Mardin } 31\end{array}$ & $\begin{array}{c}\text { Missout } \\
\text { Poptar } \\
\text { Bltwif } \\
\text { Clyy of } \\
\text { Oecenmber } 31\end{array}$ \\
\hline 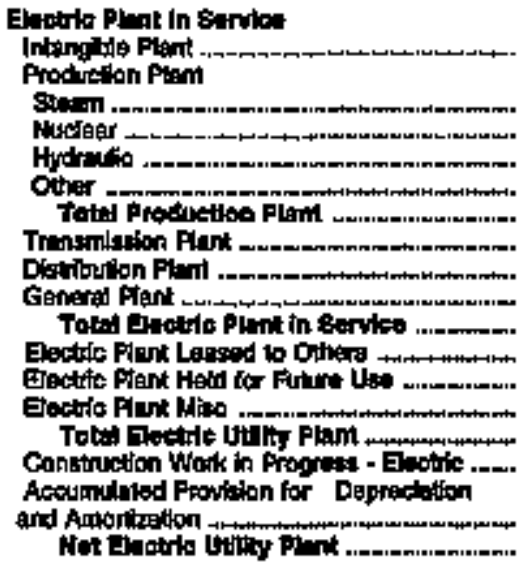 & $\begin{array}{r}0 \\
0 \\
0 \\
8,218 \\
0,215 \\
700 \\
5,111 \\
0 \\
14,118 \\
0 \\
0 \\
0 \\
14,1118 \\
0\end{array}$ & $\begin{array}{r}0 \\
0 \\
0 \\
0 \\
0 \\
0 \\
0 \\
3,583 \\
0 \\
3,688 \\
0 \\
0 \\
1,108 \\
4,400 \\
0\end{array}$ & $\begin{array}{l}0 \\
0 \\
0 \\
0 \\
0 \\
0 \\
0 \\
0 \\
0 \\
0 \\
0 \\
0 \\
0 \\
0\end{array}$ & 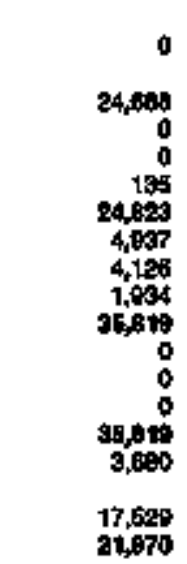 & $\begin{array}{r}0 \\
0 \\
0 \\
0 \\
0 \\
0 \\
0 \\
0 \\
3,908 \\
3,900 \\
0 \\
0 \\
0 \\
2,000 \\
0 \\
2,890 \\
1,310\end{array}$ & $\begin{array}{r}0 \\
0 \\
0 \\
0 \\
3,129 \\
3,126 \\
0 \\
15,441 \\
2,879 \\
21,449 \\
0 \\
0 \\
0 \\
21,444 \\
0 \\
0,845 \\
12,000\end{array}$ \\
\hline
\end{tabular}

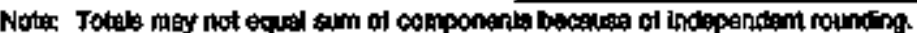

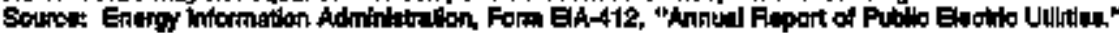


Table 24. Electric Utillty Plant by Major U.S. Publicly Owned Electric Utility Whin State at End of Period, 1994 (Continued)

(Thousand Dollers)

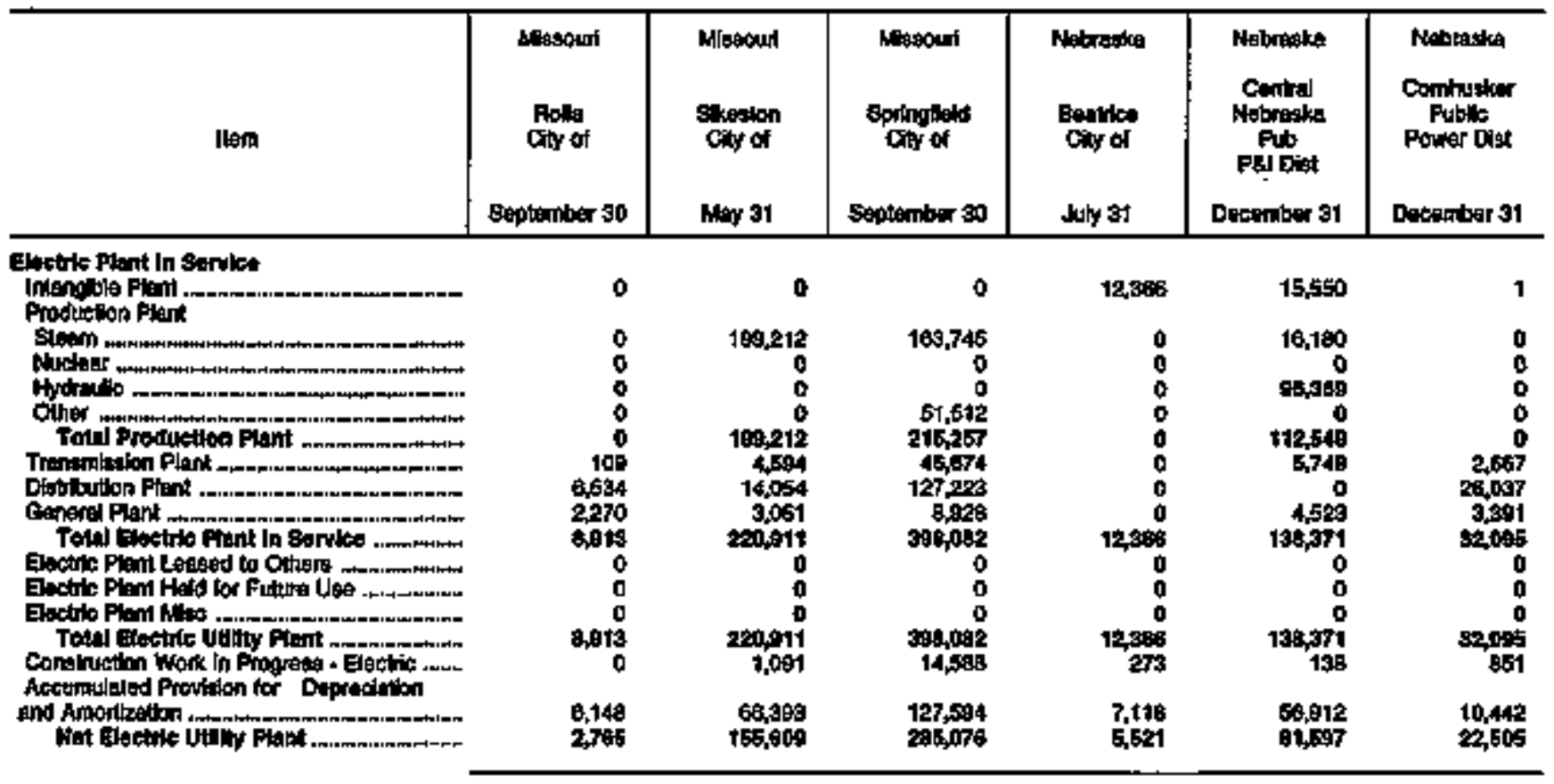

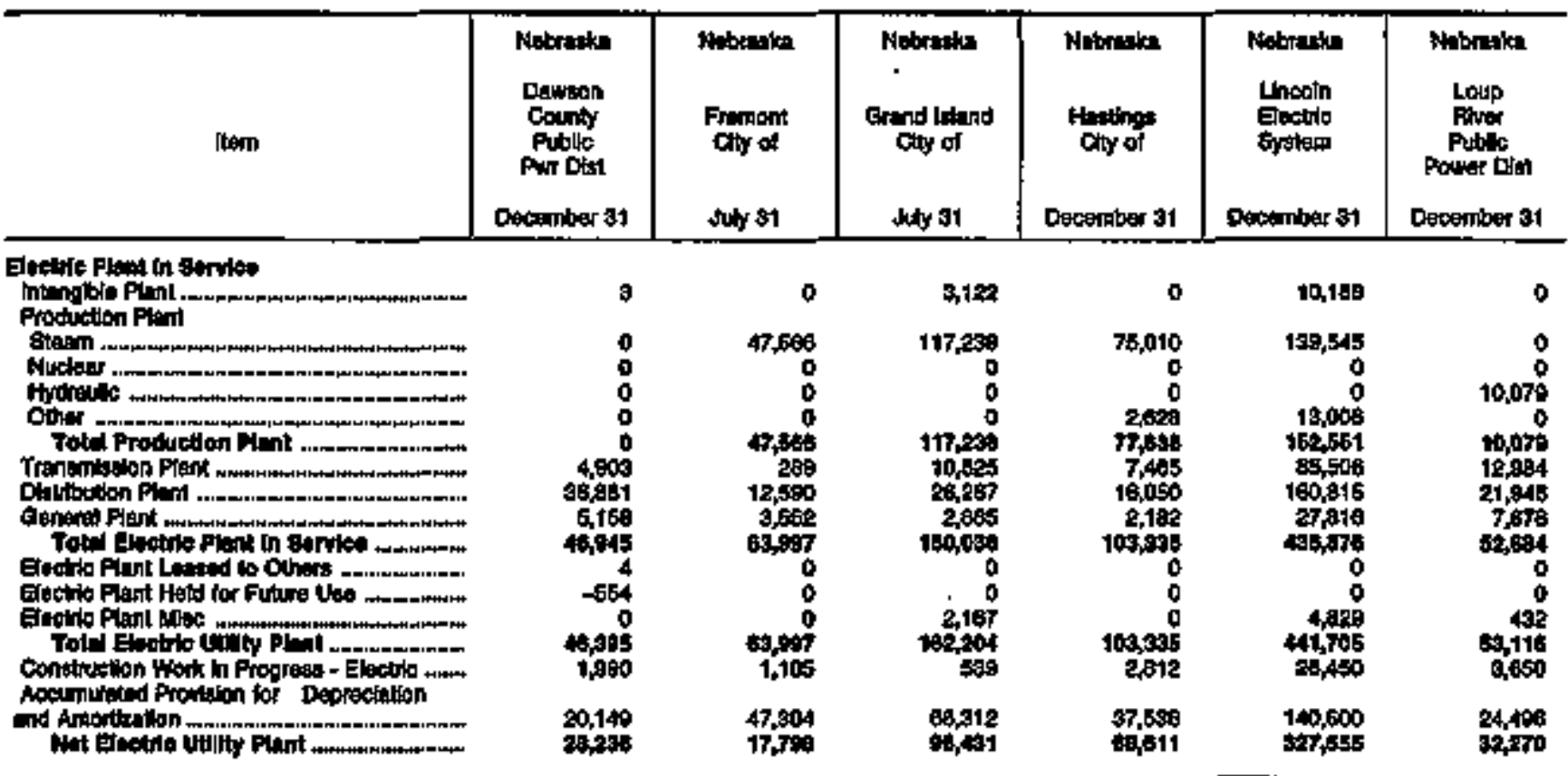

Now: Totete may not equal eum of componend beciune of hidupendent rounding

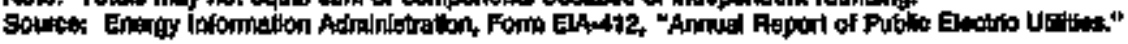


Table 24. Etectric Uaility Plant by Major U.S. Publicly Owned Electric Utility Within State at End of Poriod, 1994 (Continuod)

(Thousand Doliars)

\begin{tabular}{|c|c|c|c|c|c|c|}
\hline Liem & 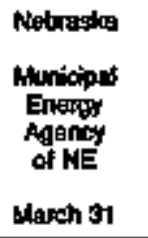 & 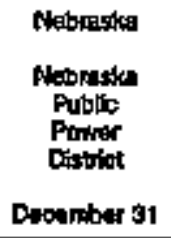 & 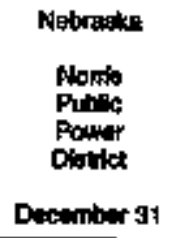 & $\begin{array}{l}\text { Nebragtia } \\
\text { North } \\
\text { Plakig } \\
\text { City of } \\
\text { Juy } 31\end{array}$ & $\begin{array}{l}\text { Mebraske } \\
\text { Onnind Publo } \\
\text { Porre } \\
\text { District } \\
\text { Decomber at }\end{array}$ & 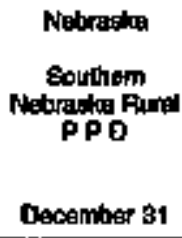 \\
\hline 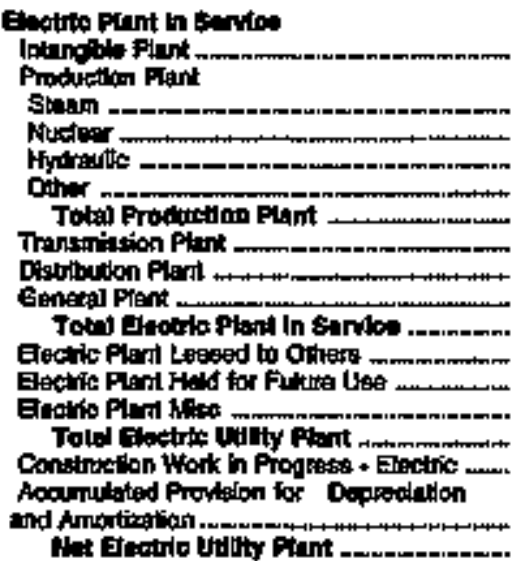 & $\begin{array}{r}28,677 \\
0 \\
0 \\
0 \\
25,677 \\
0 \\
0 \\
0 \\
25,677 \\
0 \\
0 \\
6,048 \\
34,725 \\
0 \\
1,969 \\
32,760\end{array}$ & 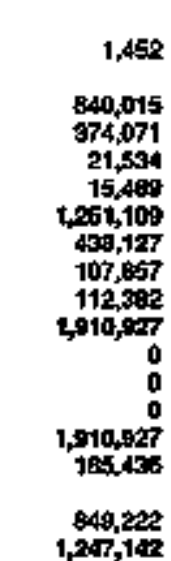 & $\begin{array}{r}0 \\
0 \\
0 \\
0 \\
0 \\
7,722 \\
46,4+2 \\
7,020 \\
60,156 \\
0 \\
0 \\
459 \\
40,914 \\
439 \\
10,216 \\
41,436\end{array}$ & $\begin{array}{r}0 \\
0 \\
0 \\
0 \\
0 \\
591 \\
0,742 \\
2,928 \\
13,158 \\
0 \\
0 \\
0 \\
13,169 \\
345\end{array}$ & 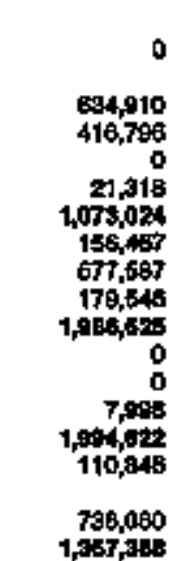 & $\begin{array}{r}0 \\
0 \\
0 \\
0 \\
0 \\
0 \\
3,178 \\
63,970 \\
6,069 \\
79,210 \\
0 \\
0 \\
0 \\
0 \\
73,218 \\
83 \\
30,165 \\
40,151\end{array}$ \\
\hline
\end{tabular}

\begin{tabular}{|c|c|c|c|c|c|c|}
\hline Item & $\begin{array}{l}\text { Newarta } \\
\text { Colorado } \\
\text { Finer } \\
\text { Comm } \\
\text { of Novrada } \\
\text { June } 30\end{array}$ & $\begin{array}{l}\text { Now Jersidy } \\
\text { VInekand } \\
\text { Coty of } \\
\text { June so }\end{array}$ & $\begin{array}{l}\text { New Mendipo } \\
\text { Famington } \\
\text { Ciny of } \\
\text { June as }\end{array}$ & 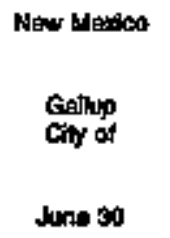 & $\begin{array}{l}\text { Nent Medico } \\
\text { Los Alamis } \\
\text { County } \\
\text { Jun } 30\end{array}$ & $\begin{array}{l}\text { New York } \\
\text { Faiport } \\
\text { Villuge of } \\
\text { Wry } 31\end{array}$ \\
\hline 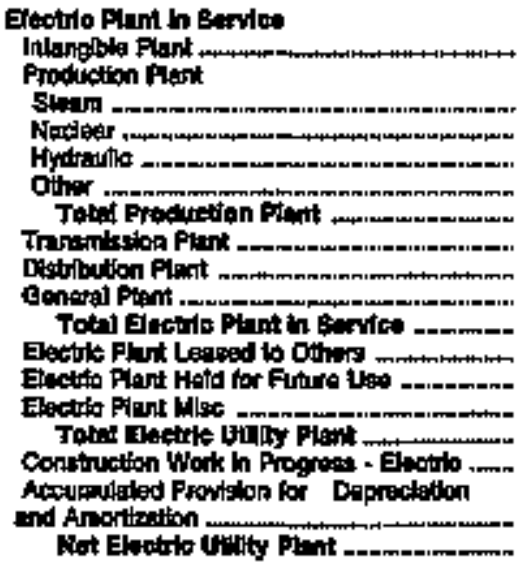 & $\begin{array}{l}0 \\
0 \\
0 \\
0 \\
0 \\
0 \\
0 \\
0 \\
0 \\
0 \\
0 \\
0 \\
0 \\
0\end{array}$ & 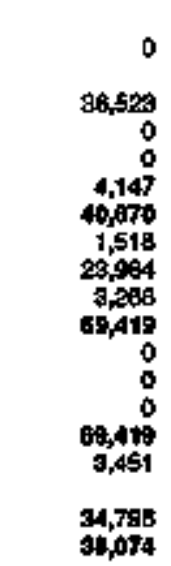 & 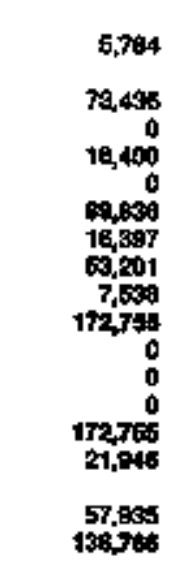 & $\begin{array}{r}0 \\
0 \\
0 \\
0 \\
0 \\
0 \\
0 \\
10,074 \\
1,3=5 \\
11,400 \\
0 \\
0 \\
0 \\
11,400 \\
0 \\
6,4025 \\
5,035\end{array}$ & 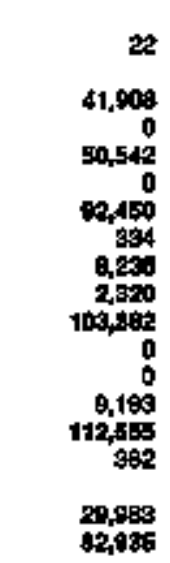 & $\begin{array}{r}0 \\
0 \\
0 \\
0 \\
0 \\
0 \\
3,003 \\
11,470 \\
1,549 \\
10,000 \\
0 \\
0 \\
0 \\
16,000 \\
6 \\
0,070 \\
8,760\end{array}$ \\
\hline
\end{tabular}

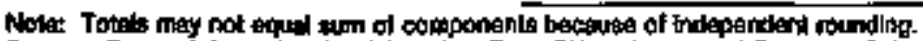

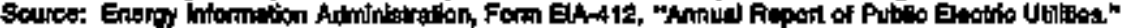


Teble 24. Electric Utility Plant by Uafor U.S. Publlcly Owned Electric Uillity Whith Stabe at End of Perlod, 1994 (Continued) (Thousand Dollars)

\begin{tabular}{|c|c|c|c|c|c|c|}
\hline nam & 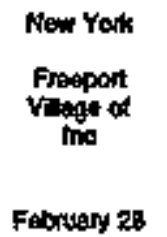 & $\begin{array}{c}\text { May Kodr } \\
\text { Jemestown } \\
\text { Chy of } \\
\text { Decanber a1 }\end{array}$ & 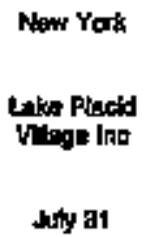 & 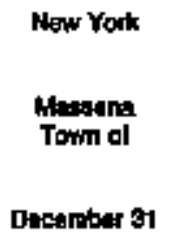 & 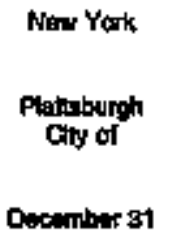 & 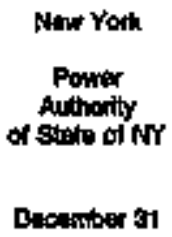 \\
\hline 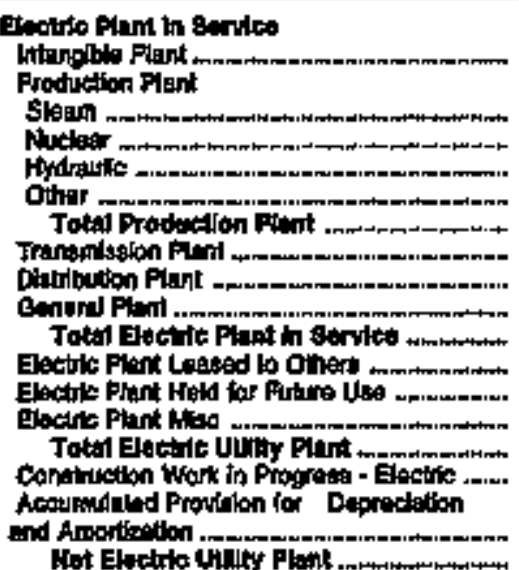 & 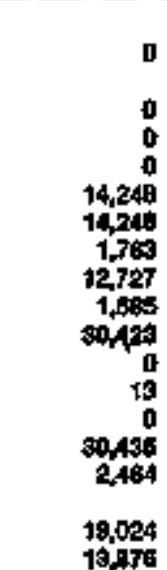 & $\begin{array}{r}43,419 \\
0 \\
0 \\
0 \\
4,419 \\
7,028 \\
22,425 \\
5,086 \\
91,769 \\
0 \\
0 \\
0 \\
01,769 \\
2,503\end{array}$ & $\begin{array}{r}1 \\
0 \\
0 \\
0 \\
0 \\
0 \\
105 \\
11,090 \\
760 \\
11,910 \\
0 \\
0 \\
0 \\
1+910 \\
0\end{array}$ & $\begin{array}{r}2,163 \\
0 \\
0 \\
0 \\
0 \\
0 \\
4,785 \\
8,541 \\
1,581 \\
14,040 \\
0 \\
0 \\
4,490 \\
20,469 \\
48\end{array}$ & $\begin{array}{r}0 \\
0 \\
0 \\
0 \\
0 \\
7,940 \\
17,077 \\
3,767 \\
29,709 \\
0 \\
0 \\
0 \\
29,709 \\
845 \\
11,212 \\
18,602\end{array}$ & 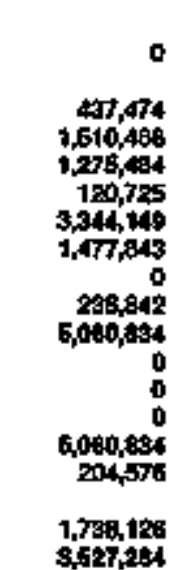 \\
\hline
\end{tabular}

\begin{tabular}{|c|c|c|c|c|c|c|}
\hline Dem & 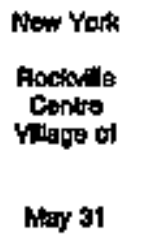 & $\begin{array}{l}\text { Mew York } \\
\text { Sohry } \\
\text { Wlage of } \\
\text { Mey } 31\end{array}$ & 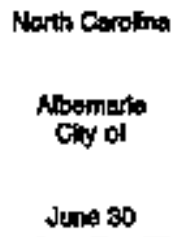 & 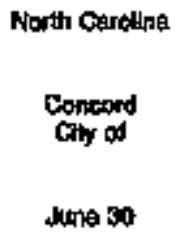 & 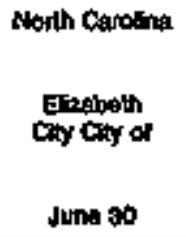 & 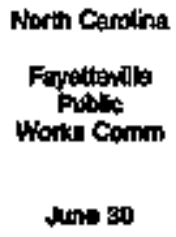 \\
\hline 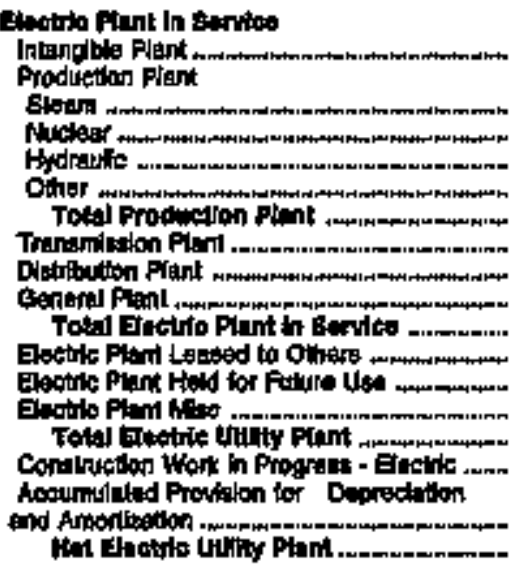 & 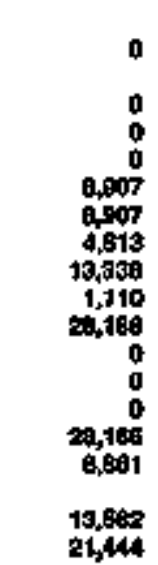 & $\begin{array}{r}0 \\
0 \\
0 \\
0 \\
0 \\
0 \\
0 \\
10,450 \\
0 \\
0,400 \\
0 \\
0 \\
0,00 \\
0 \\
0\end{array}$ & $\begin{array}{r}0 \\
0 \\
0 \\
0 \\
0 \\
0 \\
17,580 \\
18,790 \\
00 \\
0 \\
0 \\
16,7 \% \frac{2}{0} \\
0\end{array}$ & $\begin{array}{r}0 \\
0 \\
0 \\
0 \\
0 \\
0 \\
0 \\
35,670 \\
35,679 \\
0 \\
0 \\
0 \\
35,675 \\
0\end{array}$ & 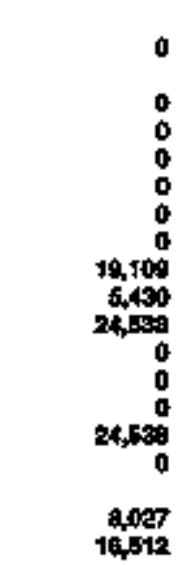 & 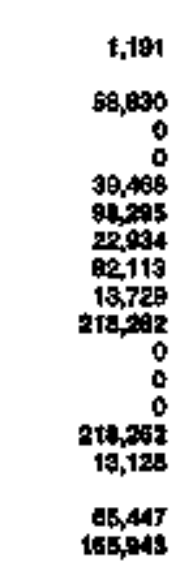 \\
\hline
\end{tabular}

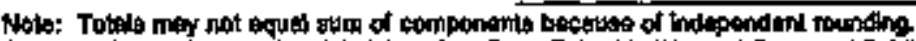

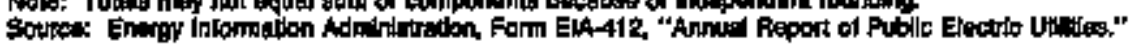


Tabje 24. Electric Utllty Fiant by Major U.S. Publicly Owned Electric Utility Within Stote at End of Perlod, 1994 (Continued) (Thousand Dollars)

\begin{tabular}{|c|c|c|c|c|c|c|}
\hline Item & 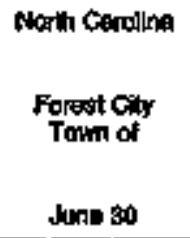 & $\begin{array}{l}\text { North Corsling } \\
\text { Cagtonfa } \\
\text { Cuy of } \\
\text { June } 90\end{array}$ & 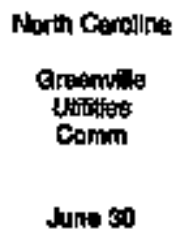 & $\begin{array}{l}\text { North Comolna } \\
\text { Fogh } \\
\text { Tount } \\
\text { of } \\
\text { Juna so }\end{array}$ & $\begin{array}{l}\text { Nurth Canding } \\
\text { Kanston } \\
\text { Cly of } \\
\text { Juse } 30\end{array}$ & $\begin{array}{l}\text { North carolina } \\
\text { Lendington } \\
\text { City of } \\
\text { June } 30\end{array}$ \\
\hline 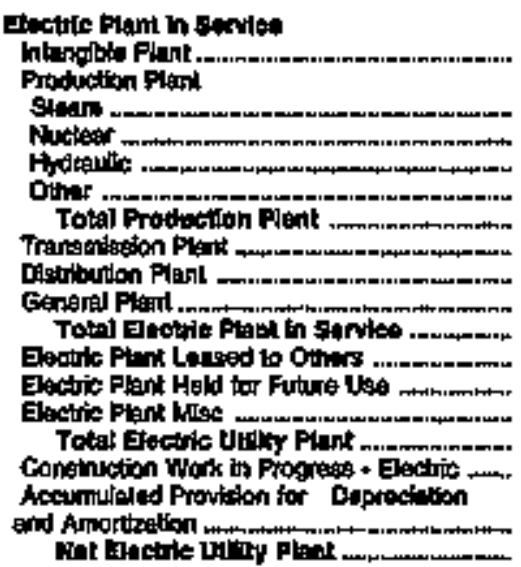 & $\begin{array}{r}0 \\
0 \\
0 \\
0 \\
0 \\
0 \\
0 \\
4,993 \\
307 \\
5,390 \\
0 \\
0 \\
0 \\
5,300 \\
0 \\
2,490 \\
2,004\end{array}$ & 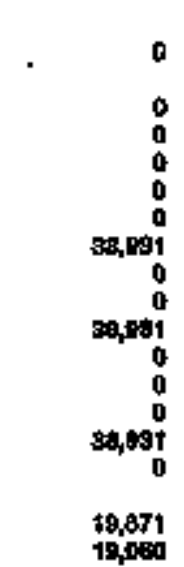 & 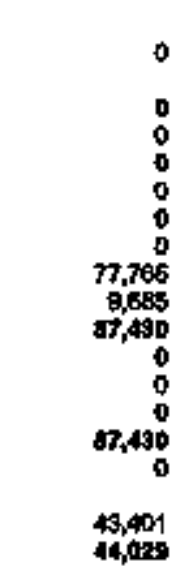 & 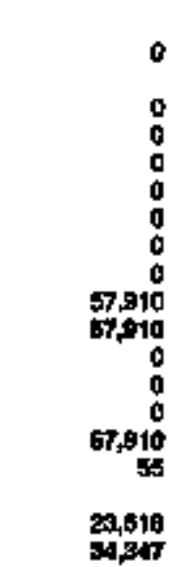 & $\begin{array}{r}0 \\
0 \\
0 \\
0 \\
0 \\
0 \\
0 \\
14,249 \\
5,405 \\
1,670 \\
0 \\
0 \\
0 \\
10,078 \\
77 \\
7,051 \\
11,005\end{array}$ & 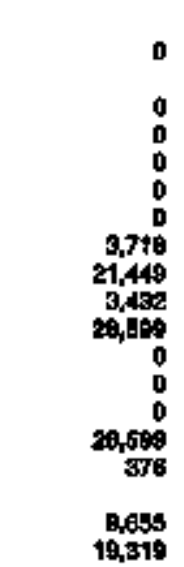 \\
\hline
\end{tabular}

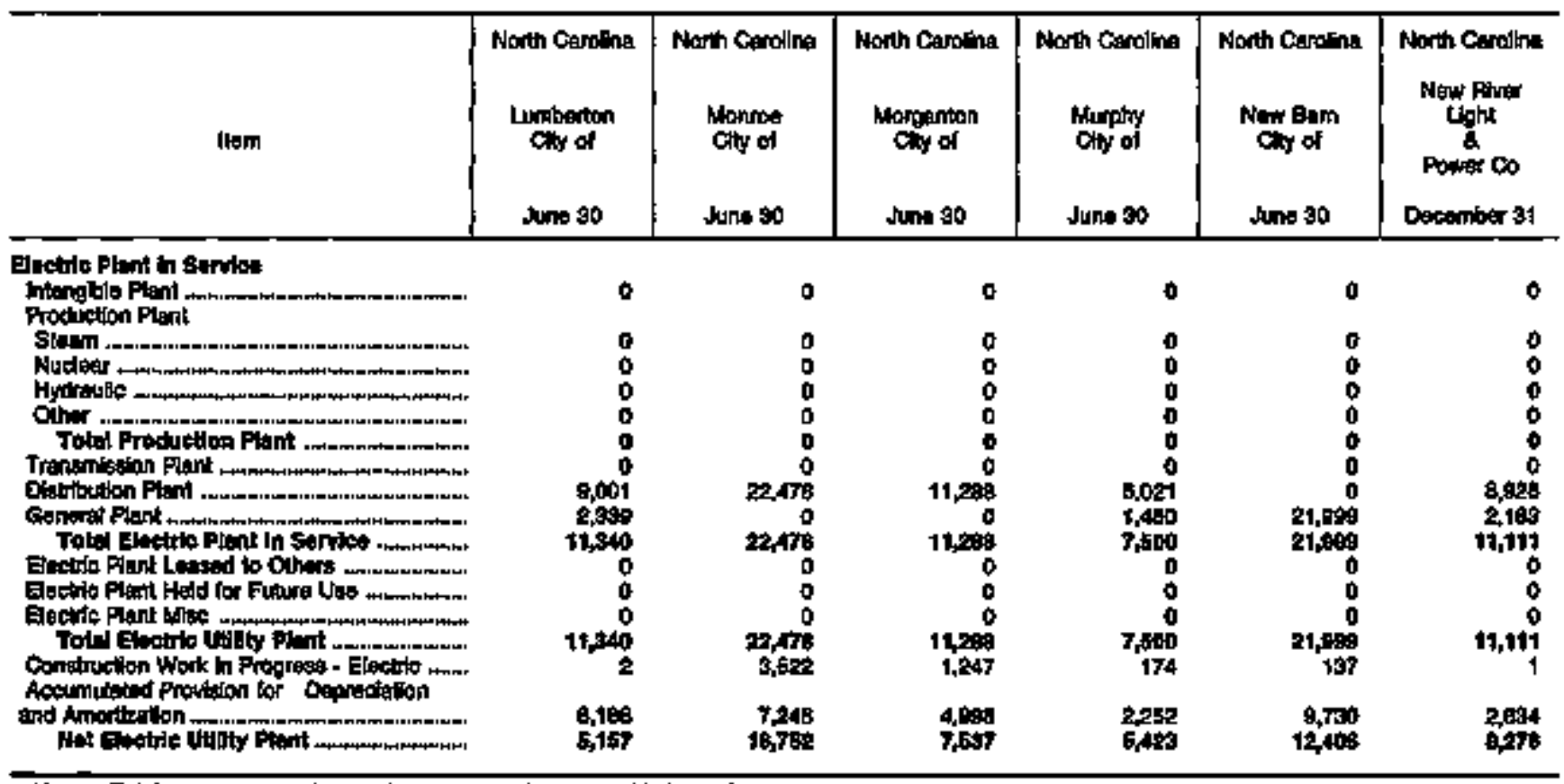

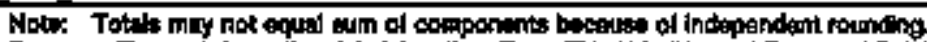

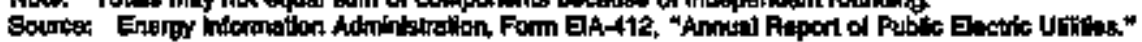


Table 24. Electric Utility Pant by Major U.S. Publichy Ownod Elactric Utilly Within State at End of Period, 1994

(Thousand Dollars)

\begin{tabular}{|c|c|c|c|c|c|c|}
\hline them & 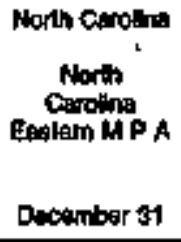 & 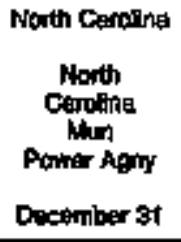 & $\begin{array}{l}\text { Nouth Carofing } \\
\text { Pocky Nornt } \\
\text { City of } \\
\text { Jund } 30\end{array}$ & $\begin{array}{l}\text { North ceanolna } \\
\text { Shelby } \\
\text { Chy of } \\
\text { June } 30\end{array}$ & 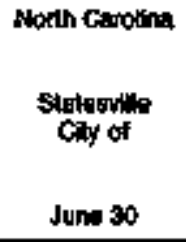 & $\begin{array}{l}\text { Nepth Caralnat } \\
\text { Toboro } \\
\text { Town of } \\
\text { Jun } 30\end{array}$ \\
\hline 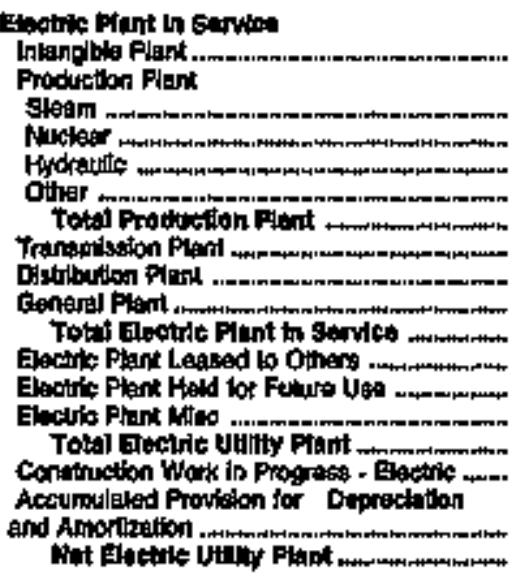 & $\begin{array}{r}129,214 \\
1,546,800 \\
0 \\
0 \\
1,276,417 \\
0 \\
0 \\
0 \\
1,276,517 \\
0 \\
0 \\
134,112 \\
1,410,129 \\
74,741 \\
404,290 \\
1,485,870\end{array}$ & 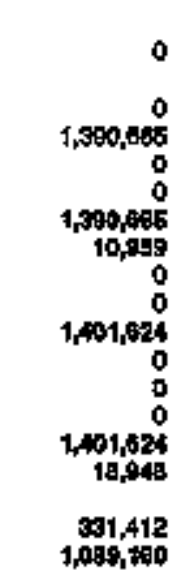 & $\begin{array}{r}0 \\
0 \\
0 \\
0 \\
0 \\
0 \\
0 \\
33,217 \\
0 \\
39,217 \\
0 \\
0 \\
0 \\
35,217 \\
3,85=9 \\
14,071 \\
20,094\end{array}$ & $\begin{array}{r}0 \\
0 \\
0 \\
0 \\
0 \\
0 \\
6,290 \\
0 \\
0,229 \\
0 \\
0 \\
0 \\
6,200 \\
2,095 \\
4,617 \\
8,711\end{array}$ & $\begin{array}{r}0 \\
0 \\
0 \\
0 \\
0 \\
0 \\
16,506 \\
0 \\
15,500 \\
0 \\
0 \\
0 \\
15,690 \\
357 \\
0,5 \% 7 \\
0,419\end{array}$ & $\begin{array}{r}0 \\
0 \\
0 \\
0 \\
0 \\
0 \\
17,747 \\
0 \\
17,849 \\
0 \\
0 \\
0 \\
17,049 \\
0 \\
6,052 \\
11,797\end{array}$ \\
\hline
\end{tabular}

\begin{tabular}{|c|c|c|c|c|c|c|}
\hline llem & $\begin{array}{l}\text { Nonth Grothe } \\
\text { Watington } \\
\text { City of } \\
\text { Jieso } 30\end{array}$ & 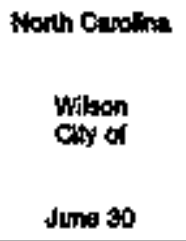 & $\begin{array}{l}\text { Ohis } \\
\text { Amariean } \\
\text { Fower } \\
\text { Onio ine } \\
\text { December } 3 t\end{array}$ & $\begin{array}{l}\text { Otis } \\
\text { Bowing } \\
\text { Brien } \\
\text { City of } \\
\text { Decomber } 31\end{array}$ & $\begin{array}{l}\text { Othio } \\
\text { Byan } \\
\text { City of } \\
\text { Onember } 34\end{array}$ & 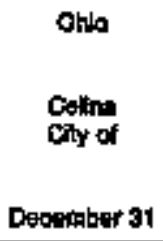 \\
\hline 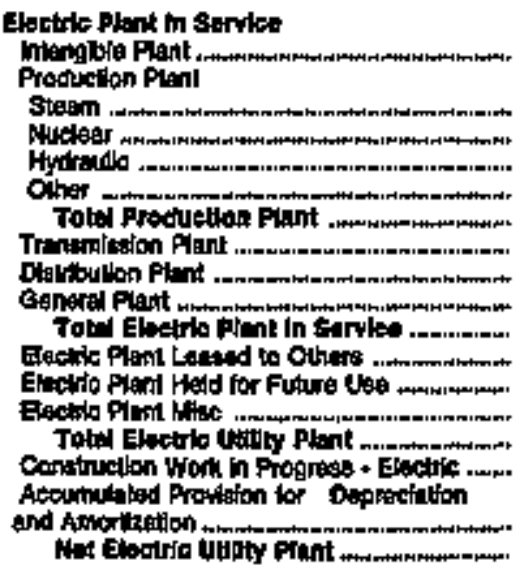 & $\begin{array}{r}0 \\
0 \\
0 \\
0 \\
0 \\
0 \\
28,093 \\
0 \\
3,124 \\
24,215 \\
0 \\
0 \\
0 \\
46,015 \\
18 \\
14,769 \\
14,400\end{array}$ & $\begin{array}{r}0 \\
0 \\
0 \\
0 \\
0 \\
0 \\
0 \\
46,211 \\
5,564 \\
51,775 \\
0 \\
0 \\
0 \\
5+, 775 \\
0 \\
25,320 \\
05,455\end{array}$ & $\begin{array}{r}7,710 \\
64,709 \\
0 \\
0 \\
0 \\
4,789 \\
688 \\
0 \\
727 \\
40,40 \\
0 \\
0 \\
0 \\
43,410 \\
4,445 \\
10,109 \\
40,248\end{array}$ & 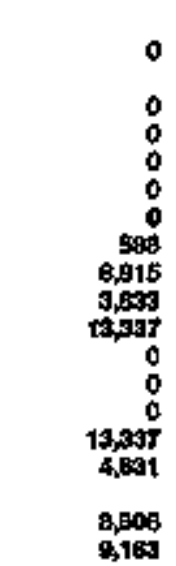 & $\begin{array}{r}0 \\
0 \\
0 \\
0 \\
0 \\
0 \\
0 \\
14,692 \\
14,6102 \\
0 \\
0 \\
0 \\
14,692 \\
0 \\
11,2,21 \\
3,482\end{array}$ & 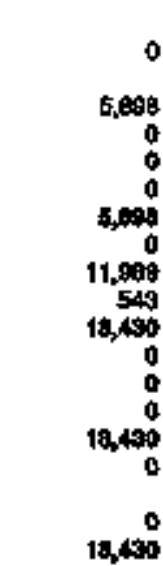 \\
\hline
\end{tabular}

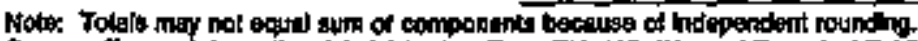

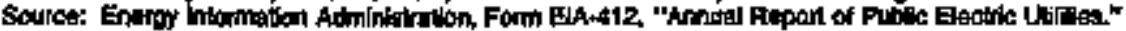


Table 24. Eloctric Utility Plent by Major U.S. Publohy Owned Electric Utility Within state at End of Period, 1994 (Continued)

(Thousand Dollars)

\begin{tabular}{|c|c|c|c|c|c|c|}
\hline Item & 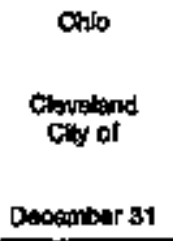 & $\begin{array}{l}\text { Onim } \\
\text { Ctyte } \\
\text { City of } \\
\text { Decomber } 31\end{array}$ & $\begin{array}{c}\text { onis } \\
\text { Columbers } \\
\text { Clity of } \\
\text { December } 31\end{array}$ & $\begin{array}{l}\text { Ohto } \\
\text { Gopaltoga } \\
\text { Fedilo } \\
\text { Chy of } \\
\text { Dooumber } 31\end{array}$ & $\begin{array}{l}\text { Orilo } \\
\text { Dover } \\
\text { Cfty of } \\
\text { Decomber } 31\end{array}$ & $\begin{array}{l}\text { Ohio } \\
\text { Henilion } \\
\text { ory of } \\
\text { Decomber } 31\end{array}$ \\
\hline 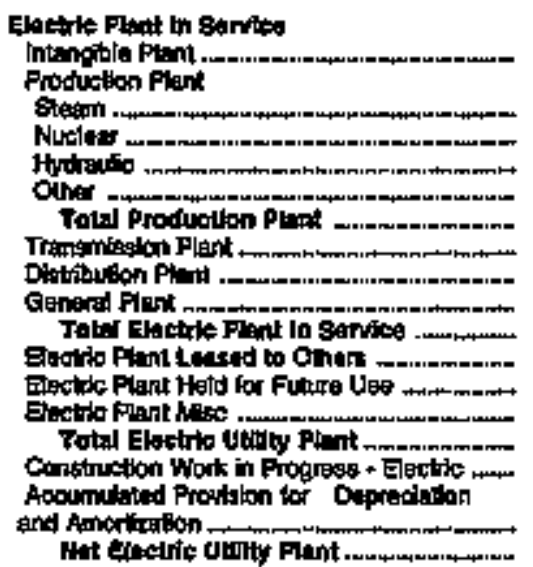 & 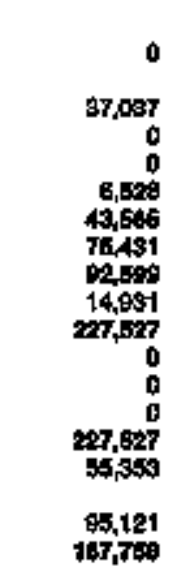 & $\begin{array}{r}0 \\
0 \\
0 \\
0 \\
0 \\
0 \\
10,7 e 5 \\
0 \\
0,785 \\
0 \\
0 \\
0 \\
0,785 \\
0 \\
0 \\
0,765\end{array}$ & $\begin{array}{r}0 \\
3,327 \\
0 \\
0 \\
0 \\
3,427 \\
42,321 \\
0,650 \\
25,651 \\
60,159 \\
0 \\
0 \\
0 \\
60,169 \\
0\end{array}$ & $\begin{array}{r}0 \\
0 \\
0 \\
0 \\
0 \\
711 \\
18,044 \\
1,972 \\
30,725 \\
0 \\
0 \\
0 \\
20,726 \\
0\end{array}$ & $\begin{array}{r}0 \\
0 \\
0 \\
0 \\
0 \\
0 \\
0 \\
0 \\
9,841 \\
9,841 \\
0 \\
0 \\
0 \\
0,041 \\
0 \\
0 \\
0 \\
0,841\end{array}$ & 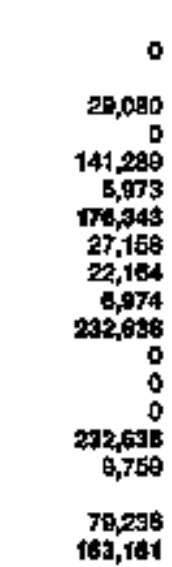 \\
\hline
\end{tabular}

\begin{tabular}{|c|c|c|c|c|c|c|}
\hline heon & $\begin{array}{l}\text { Ohis } \\
\text { Nopolion } \\
\text { Cyby of } \\
\text { Ducumber a3 }\end{array}$ & $\begin{array}{l}\text { Ohlo } \\
\text { Decemper } 31\end{array}$ & $\begin{array}{l}\text { Onlo } \\
\text { Orvilim } \\
\text { Chy of } \\
\text { Dectumber } 31\end{array}$ & $\begin{array}{l}\text { Chloto } \\
\text { Painowilis } \\
\text { Clty of } \\
\text { Decentiber } 31\end{array}$ & $\begin{array}{l}\text { Ohio } \\
\text { Pipun } \\
\text { City of } \\
\text { Decanter } 31\end{array}$ & $\begin{array}{l}\text { Otho } \\
\text { S1 Mlarys } \\
\text { Cty of } \\
\text { Dotember } 31\end{array}$ \\
\hline 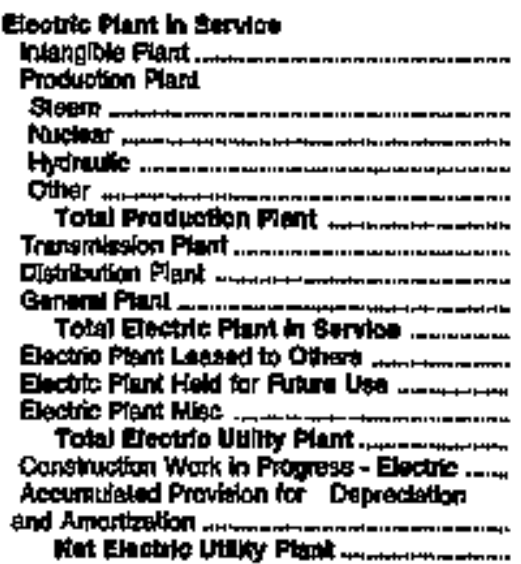 & 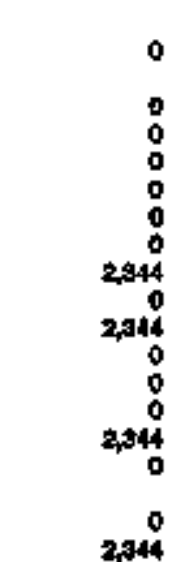 & $\begin{array}{r}0 \\
0 \\
0 \\
0 \\
0 \\
0 \\
0 \\
0 \\
12,013 \\
12,013 \\
0 \\
0 \\
0 \\
0 \\
12,013 \\
0\end{array}$ & 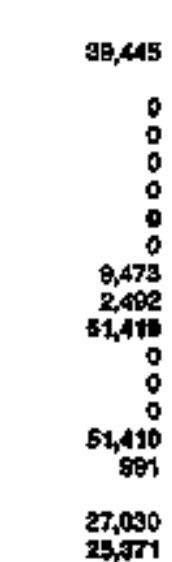 & 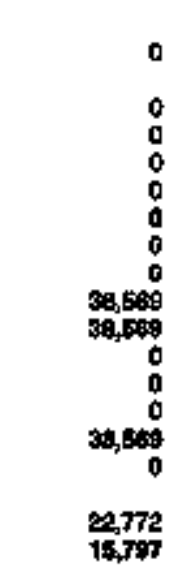 & $\begin{array}{r}780 \\
20,169 \\
0 \\
0 \\
123 \\
20,292 \\
2,572 \\
18,212 \\
2,417 \\
4,373 \\
0 \\
0 \\
0 \\
44,975 \\
590 \\
20,572 \\
24,491\end{array}$ & $\begin{array}{r}0 \\
0 \\
0 \\
0 \\
0 \\
0 \\
0 \\
0 \\
0 \\
18,090 \\
18,000 \\
0 \\
0 \\
0 \\
10,000 \\
B\end{array}$ \\
\hline
\end{tabular}

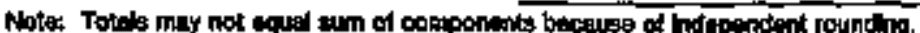

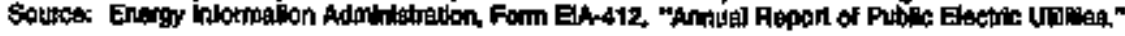


Table 24. Electuic Ut:lity Piant by Major U.S. Publicly Owned Electric Utility Within State at End of Perlod, 1994 (Continued)

(Thousand Dollars)

\begin{tabular}{|c|c|c|c|c|c|c|}
\hline intm & $\begin{array}{c}\text { Ohlo } \\
\text { Wedsurith } \\
\text { Cily of } \\
\text { Decembien at }\end{array}$ & 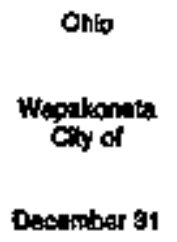 & $\begin{array}{c}\text { Onis } \\
\text { Wastenila } \\
\text { City of } \\
\text { December at }\end{array}$ & $\begin{array}{l}\text { Chlingona } \\
\text { Alus } \\
\text { Chy of } \\
\text { tung } 30\end{array}$ & $\begin{array}{l}\text { Dlaphama } \\
\text { Clarimare } \\
\text { City of } \\
\text { June st }\end{array}$ & $\begin{array}{l}\text { Otlahoma } \\
\text { Durnatn } \\
\text { Chy of } \\
\text { June so }\end{array}$ \\
\hline 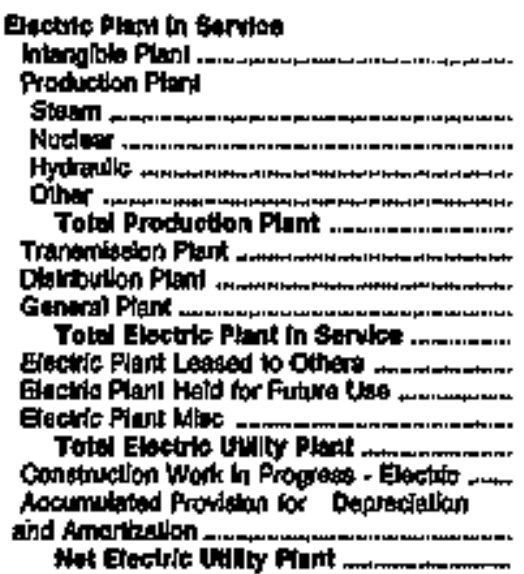 & $\begin{array}{r}0 \\
0 \\
0 \\
0 \\
0 \\
0 \\
0 \\
10,056 \\
550 \\
11,005 \\
0 \\
0 \\
0 \\
11,008 \\
0 \\
4,178 \\
6,928\end{array}$ & $\begin{array}{l}0 \\
0 \\
0 \\
0 \\
0 \\
0 \\
0 \\
0 \\
0 \\
0 \\
0 \\
0 \\
0 \\
0\end{array}$ & $\begin{array}{r}0 \\
0 \\
0 \\
0 \\
0 \\
0 \\
1,497 \\
17,810 \\
4,054 \\
24,381 \\
0 \\
0 \\
0 \\
29,381 \\
500 \\
1,988 \\
14,052\end{array}$ & $\begin{array}{r}0 \\
0 \\
0 \\
0 \\
0 \\
0 \\
7973 \\
0 \\
0 \\
7,975 \\
0 \\
0 \\
0 \\
7,973 \\
0 \\
5,960 \\
2,904\end{array}$ & $\begin{array}{l}0 \\
0 \\
0 \\
0 \\
0 \\
0 \\
0 \\
0 \\
0 \\
0 \\
0 \\
0 \\
0 \\
0\end{array}$ & $\begin{array}{r}0 \\
0 \\
0 \\
0 \\
0 \\
0 \\
0 \\
19,742 \\
0 \\
19,742 \\
0 \\
0 \\
0 \\
14,742 \\
8 \\
9,688 \\
10,092\end{array}$ \\
\hline
\end{tabular}

\begin{tabular}{|c|c|c|c|c|c|c|}
\hline $\mathrm{kem}$ & $\begin{array}{l}\text { Ohdmoina } \\
\text { Edmond } \\
\text { chy of } \\
\text { Juns so }\end{array}$ & 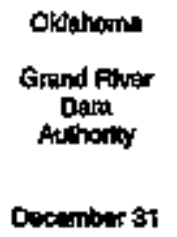 & 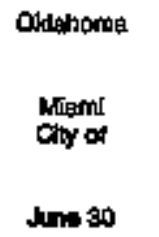 & 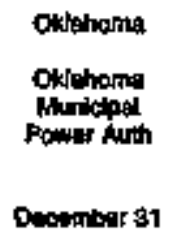 & 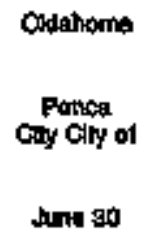 & 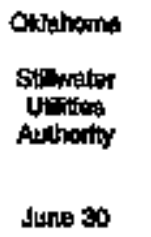 \\
\hline 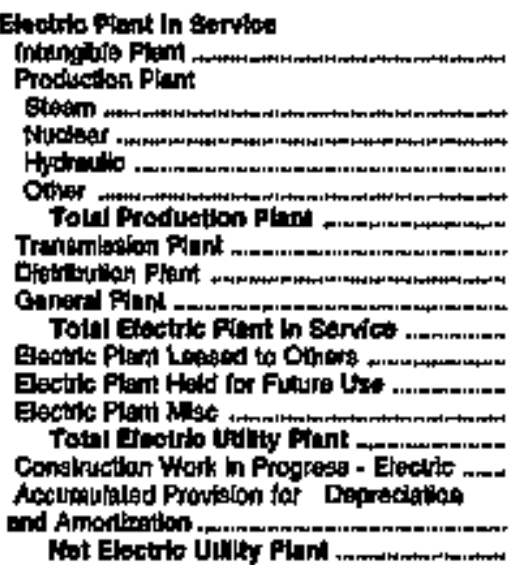 & $\begin{array}{r}0 \\
0 \\
0 \\
0 \\
0 \\
0 \\
0 \\
37,540 \\
0 \\
37,640 \\
0 \\
0 \\
0 \\
37,580 \\
0 \\
18,604 \\
20,030\end{array}$ & 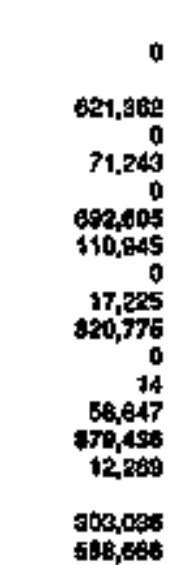 & $\begin{array}{r}0 \\
0 \\
0 \\
0 \\
0 \\
0 \\
1,630 \\
1598 \\
3,060 \\
0 \\
0 \\
0 \\
7,000 \\
1 \quad 0 \\
2,197 \\
049\end{array}$ & $\begin{array}{r}116,319 \\
0 \\
35,621 \\
0 \\
151,984 \\
3,657 \\
1,200 \\
2,474 \\
15,664 \\
0 \\
3,270 \\
0 \\
18,4663 \\
27,974\end{array}$ & $\begin{array}{r}18,588 \\
0 \\
0 \\
8,070 \\
22,108 \\
1,986 \\
10,047 \\
357 \\
35,040 \\
0 \\
0 \\
0 \\
35,060 \\
0 \\
16,8099 \\
18,471\end{array}$ & 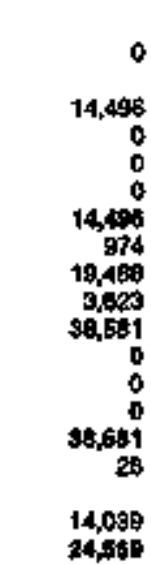 \\
\hline
\end{tabular}

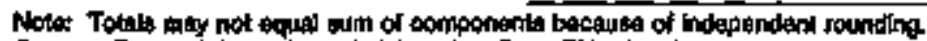

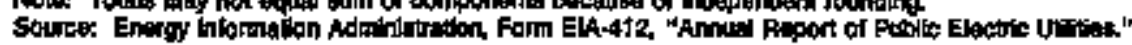


Table 24. Eloctric Utlity Plant by Major U.S. Publicly Owhed Electric Utilty Wihin state at End of Period, 1994 (Continued)

(Thossand Dollars)

\begin{tabular}{|c|c|c|c|c|c|c|}
\hline Itam & $\begin{array}{l}\text { Oregon } \\
\text { Agdidund } \\
\text { Cly of } \\
\text { June so }\end{array}$ & 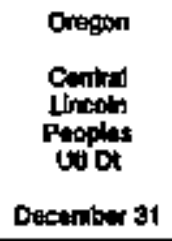 & 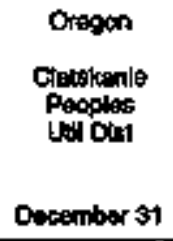 & $\begin{array}{l}\text { Oregon } \\
\text { Columbin } \\
\text { Priver } \\
\text { Proples } \\
\text { Ut Dist } \\
\text { December } 31\end{array}$ & 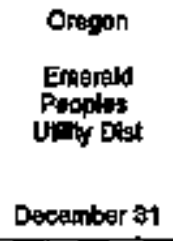 & $\begin{array}{l}\text { Oregon } \\
\text { Eugomen } \\
\text { Otry of } \\
\text { Decentumer } 31\end{array}$ \\
\hline 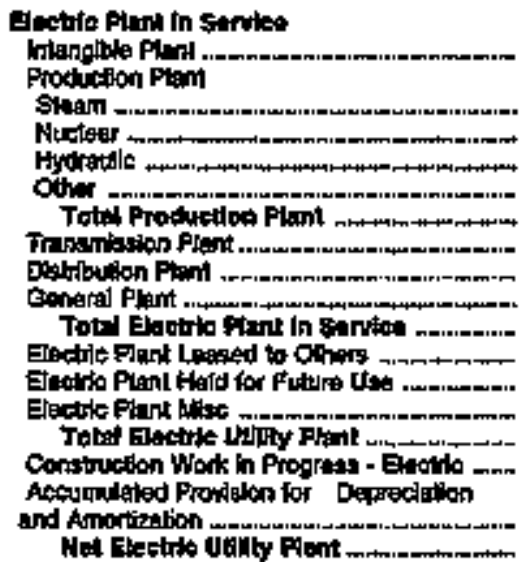 & 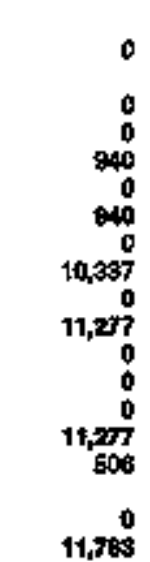 & 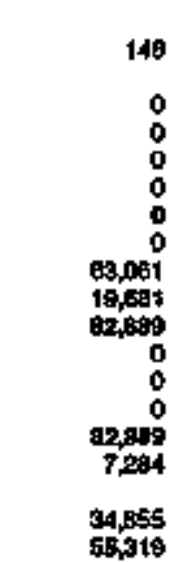 & $\begin{array}{r}0 \\
0 \\
0 \\
0 \\
0 \\
0 \\
6,195 \\
1,640 \\
6,762 \\
0 \\
0 \\
0 \\
6,752 \\
40 \\
3,504 \\
3,200\end{array}$ & $\begin{array}{r}0 \\
0 \\
0 \\
0 \\
0 \\
008 \\
10,055 \\
4015 \\
16,648 \\
0 \\
0 \\
7,074 \\
25,417 \\
109 \\
4,415 \\
19,105\end{array}$ & $\begin{array}{r}142 \\
0 \\
0 \\
0 \\
2,801 \\
2,001 \\
096 \\
42,816 \\
6,818 \\
65,570 \\
0 \\
16,777 \\
72,347 \\
1,540 \\
27,162 \\
48,74 t\end{array}$ & 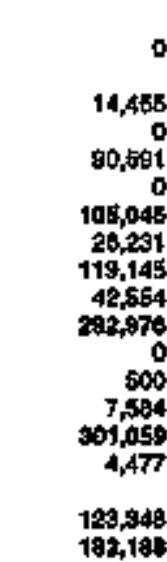 \\
\hline
\end{tabular}

\begin{tabular}{|c|c|c|c|c|c|c|}
\hline item & $\begin{array}{l}\text { Oreagon } \\
\text { Forfogt Growl } \\
\text { City of } \\
\text { Juro to }\end{array}$ & 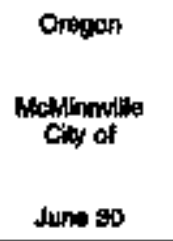 & $\begin{array}{l}\text { Dregon } \\
\text { Northem } \\
\text { Wasce Counly } \\
\text { P U D } \\
\text { Decemaber gi }\end{array}$ & $\begin{array}{l}\text { Oregon } \\
\text { Springliold } \\
\text { Chy or }\end{array}$ & 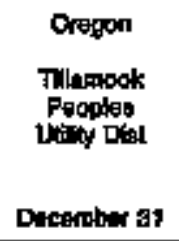 & 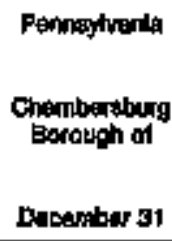 \\
\hline 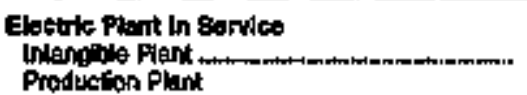 & 0 & 0 & 71 & 0 & 1 & 5 \\
\hline 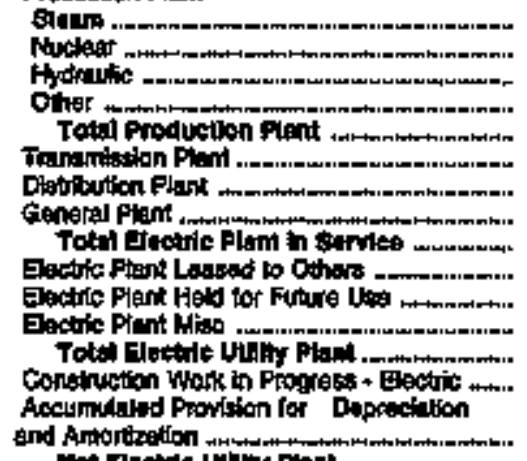 & $\begin{array}{r}0 \\
0 \\
0 \\
0 \\
0 \\
25 \\
0.44 \\
1,804 \\
11,60 \\
0 \\
0 \\
11,500 \\
100\end{array}$ & $\begin{array}{r}0 \\
0 \\
0 \\
0 \\
0 \\
1,630 \\
16,230 \\
3,684 \\
21,400 \\
0 \\
0 \\
0 \\
21,490 \\
460\end{array}$ & $\begin{array}{r}0 \\
0 \\
14,580 \\
0 \\
14,508 \\
1,600 \\
14,053 \\
2,3,40 \\
32,090 \\
0 \\
0 \\
1,390 \\
34,771 \\
7,697\end{array}$ & $\begin{array}{r}0 \\
0 \\
0 \\
0 \\
0 \\
0,062 \\
29,544 \\
4,350 \\
55,456 \\
0 \\
527 \\
7,427 \\
44,010 \\
1,449\end{array}$ & $\begin{array}{r}0 \\
0 \\
0 \\
0 \\
0 \\
1,032 \\
25,318 \\
8,945 \\
33,000 \\
0 \\
0 \\
1,008 \\
35,300 \\
1,544\end{array}$ & $\begin{array}{r}4,297 \\
0 \\
0 \\
1,985 \\
6,483 \\
3,984 \\
75,524 \\
908 \\
26,001 \\
0 \\
0 \\
0 \\
26,091 \\
880\end{array}$ \\
\hline
\end{tabular}

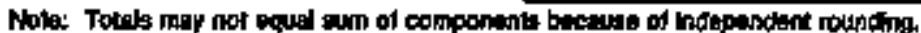

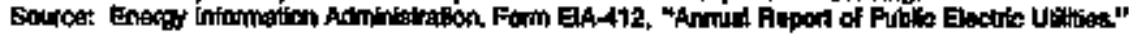


Table 24, Electric Uility Plant by Major US. Publicly Omed Electric Utluty Within State at End of Poriod, 1994 (Continued) (Thousand Dollars)

\begin{tabular}{|c|c|c|c|c|c|c|}
\hline IIIn & 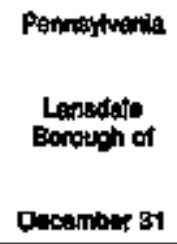 & 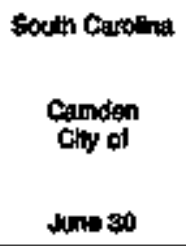 & Shuth tandina & 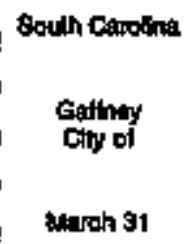 & 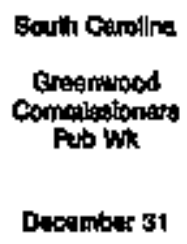 & 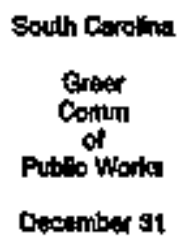 \\
\hline 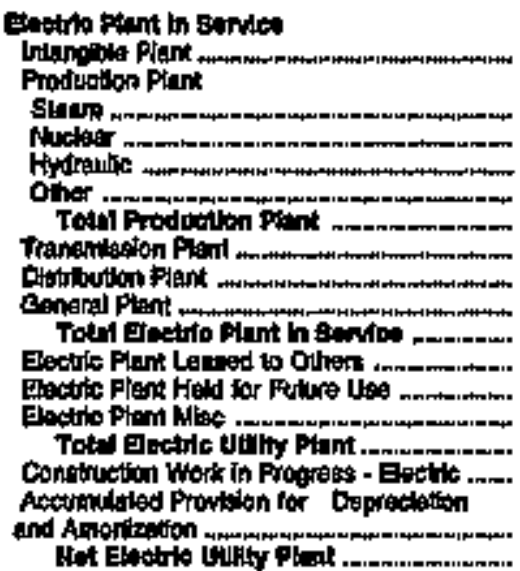 & $\begin{array}{r}0 \\
0 \\
0 \\
0 \\
0 \\
2,800 \\
5,659 \\
1,280 \\
10,023 \\
0 \\
0 \\
0 \\
10,020 \\
0 \\
4,086 \\
6,441\end{array}$ & $\begin{array}{r}0 \\
0 \\
0 \\
0 \\
0 \\
0 \\
0 \\
11,059 \\
11,080 \\
0 \\
0 \\
0 \\
0 \\
0 \\
0\end{array}$ & $\begin{array}{r}0 \\
0 \\
0 \\
0 \\
0 \\
0 \\
0 \\
15,971 \\
0 \\
+5,71 \\
0 \\
0 \\
0 \\
18,471 \\
087\end{array}$ & 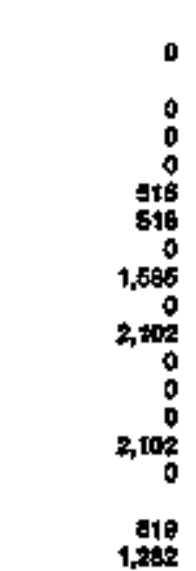 & $\begin{array}{r}0 \\
0 \\
0 \\
0 \\
0 \\
0 \\
0 \\
9,289 \\
0 \\
0,200 \\
0 \\
0 \\
0 \\
0 \\
0 \\
0200 \\
0\end{array}$ & $\begin{array}{r}0 \\
0 \\
0 \\
0 \\
0 \\
0 \\
11,567 \\
0 \\
7,795 \\
0,351 \\
0 \\
0 \\
0 \\
43,51 \\
2,204 \\
21,06 t \\
04,515\end{array}$ \\
\hline
\end{tabular}

\begin{tabular}{|c|c|c|c|c|c|c|}
\hline Ilem & $\begin{array}{l}\text { South cavoling } \\
\text { Nhintery } \\
\text { Chy of } \\
\text { Jin } 20\end{array}$ & 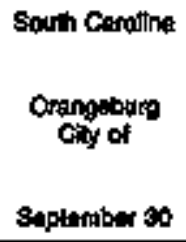 & 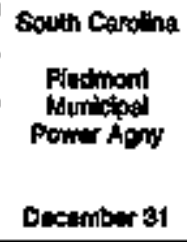 & 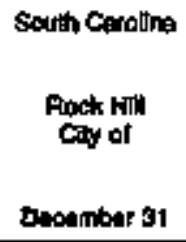 & $\begin{array}{l}\text { South Carstha } \\
\text { Senecta } \\
\text { Cty of } \\
\text { tere to }\end{array}$ & 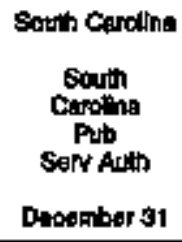 \\
\hline 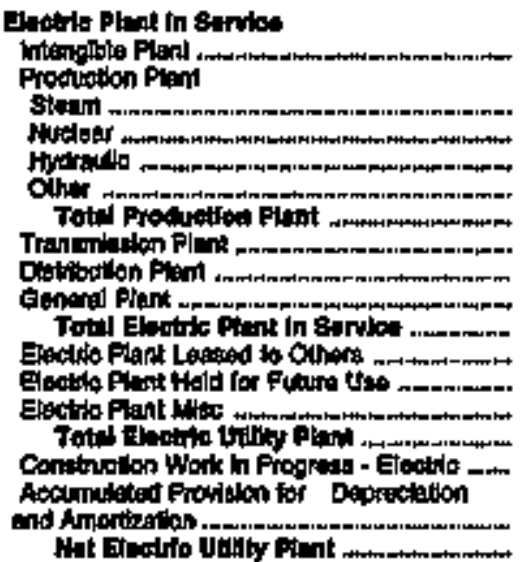 & 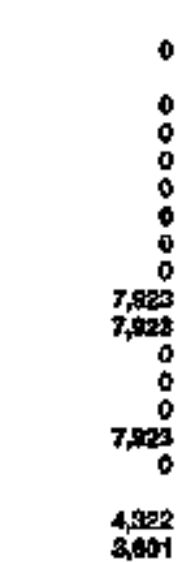 & 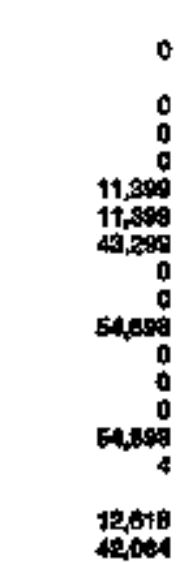 & 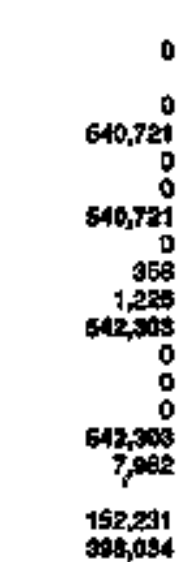 & $\begin{array}{r}0 \\
0 \\
0 \\
0 \\
0 \\
0 \\
30,000 \\
0 \\
80,004 \\
0 \\
0 \\
30,090 \\
1,600\end{array}$ & 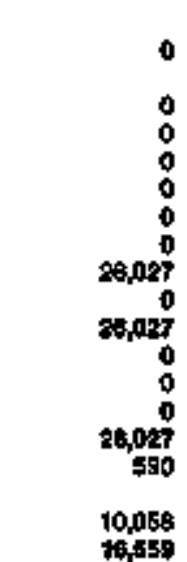 & 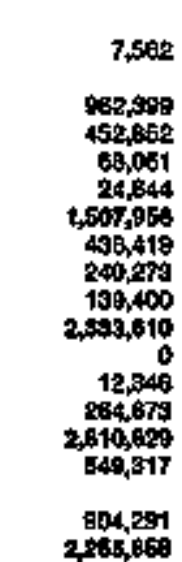 \\
\hline
\end{tabular}

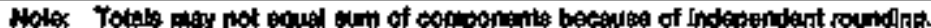

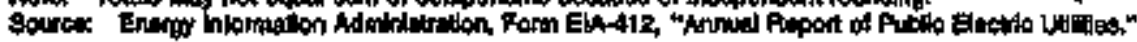


Table 24. Electric Uthly Plant by Hajor U.S. Publdely Owned Electric Uthliy Whin State at End of Period, 1994

(Thousend Dollars)

\begin{tabular}{|c|c|c|c|c|c|c|}
\hline Hom & $\begin{array}{c}\text { South Dolkote } \\
\text { Eroding: } \\
\text { Ghy of } \\
\text { December a1 }\end{array}$ & $\begin{array}{l}\text { South Oakota } \\
\text { Hagrtiand } \\
\text { Consumas: } \\
\text { Power Diot } \\
\text { Docamber } 34\end{array}$ & $\begin{array}{l}\text { Bouth Daikoln } \\
\text { MLssouti } \\
\text { Batin } \\
\text { Mun } \\
\text { Powitit Miny } \\
\text { Dacember } 31\end{array}$ & $\begin{array}{l}\text { South Dascota } \\
\text { Pown } \\
\text { City of } \\
\text { Decemiber at }\end{array}$ & 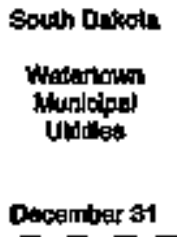 & 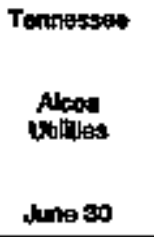 \\
\hline 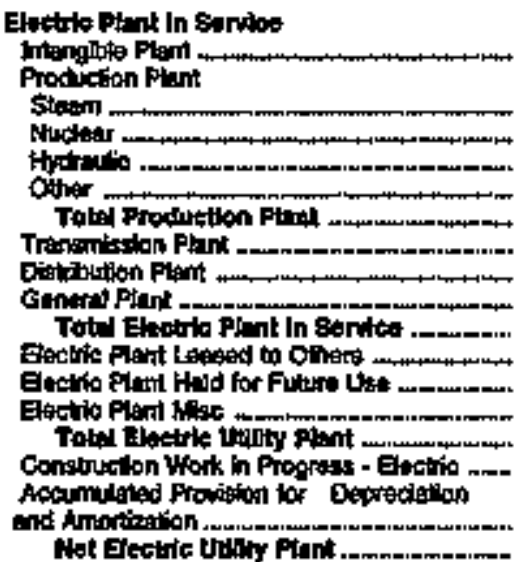 & $\begin{array}{r}0 \\
0 \\
0 \\
0 \\
0 \\
0 \\
0 \\
3,801 \\
11,300 \\
3,450 \\
18,607 \\
0 \\
0 \\
0 \\
18,607 \\
180 \\
5,601 \\
10,182\end{array}$ & $\begin{array}{r}0 \\
48,268 \\
0 \\
0 \\
0 \\
48,25 \\
8,401 \\
0 \\
774 \\
57,438 \\
0 \\
0 \\
0 \\
4,485 \\
169 \\
8,081 \\
48,624\end{array}$ & $\begin{array}{r}0 \\
0 \\
0 \\
0 \\
0 \\
0 \\
0 \\
0 \\
2734 \\
2,734 \\
0 \\
0 \\
0 \\
2,74 \\
0 \\
735 \\
7,969\end{array}$ & $\begin{array}{r}0 \\
9 \\
0 \\
0 \\
0 \\
0 \\
7,005 \\
7,055 \\
0,070 \\
0 \\
0 \\
0 \\
0,070 \\
0 \\
2,044 \\
5,27\end{array}$ & $\begin{array}{r}13 \\
0 \\
0 \\
0 \\
209 \\
209 \\
304 \\
15,720 \\
1,005 \\
17,816 \\
0 \\
0 \\
0 \\
17,516 \\
69 \\
11,002 \\
0,200\end{array}$ & 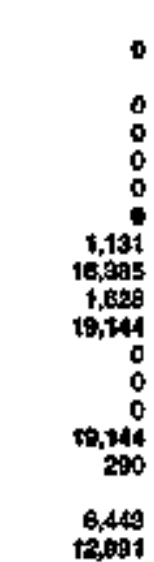 \\
\hline
\end{tabular}

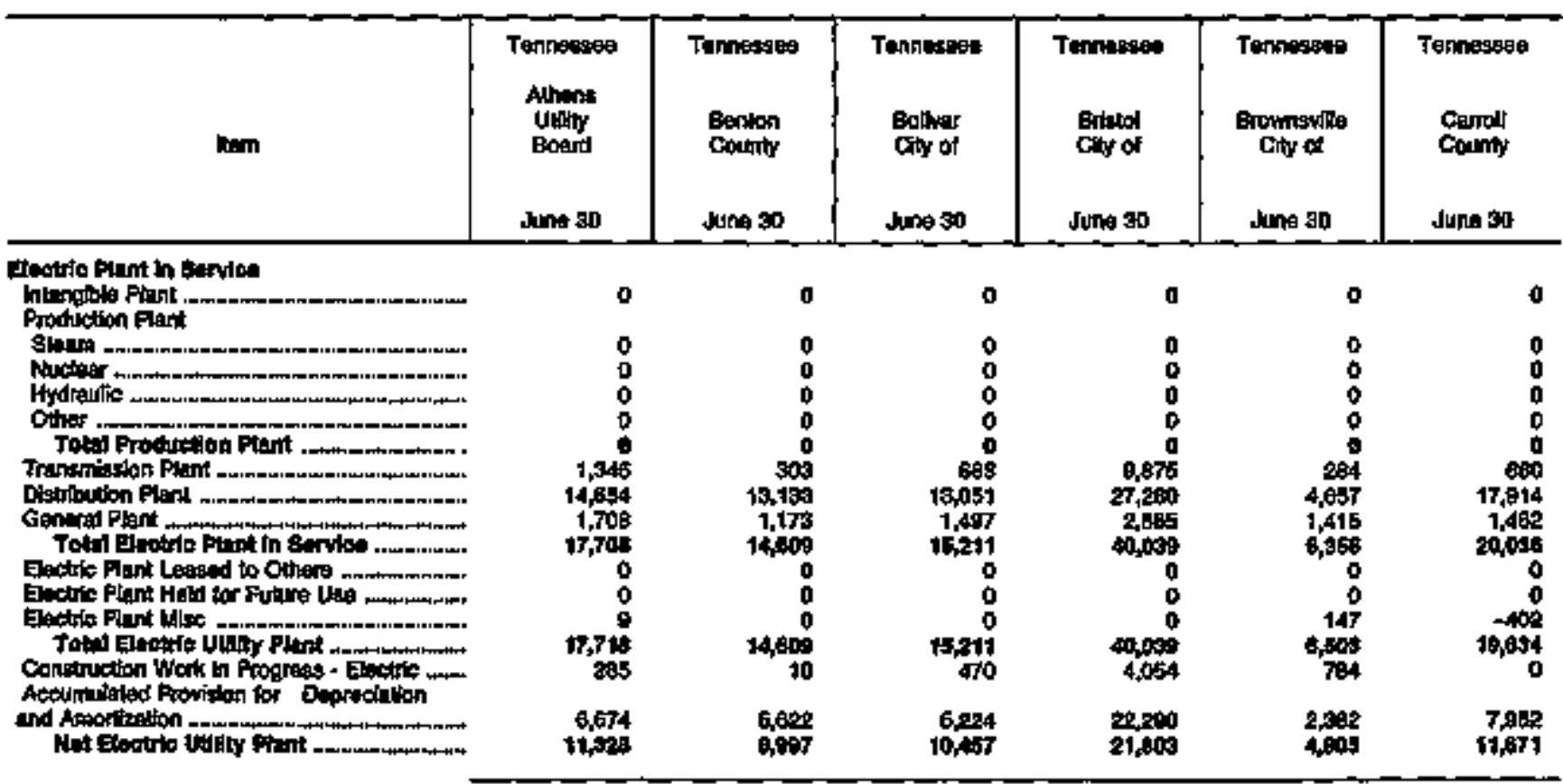

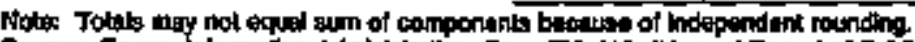

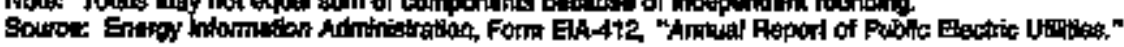


Table 24. Electric Utilty Plant by Major U.S. Publlcly Owned Electitc Uthlity Whin State at End of Period, 1994 (Continued) (Thousand Dollars)

\begin{tabular}{|c|c|c|c|c|c|c|}
\hline Iles & $\begin{array}{l}\text { Tannesese } \\
\text { Chati:roega } \\
\text { City of } \\
\text { June } 30\end{array}$ & 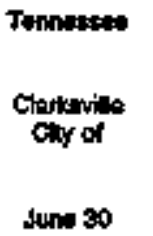 & 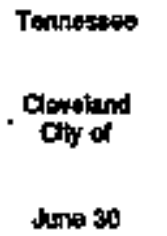 & $\begin{array}{l}\text { Tennmespos } \\
\text { Cintor } \\
\text { Gity or } \\
\text { Juns } 80\end{array}$ & 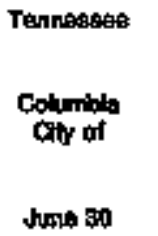 & 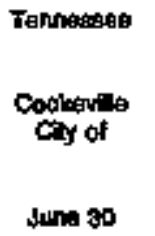 \\
\hline 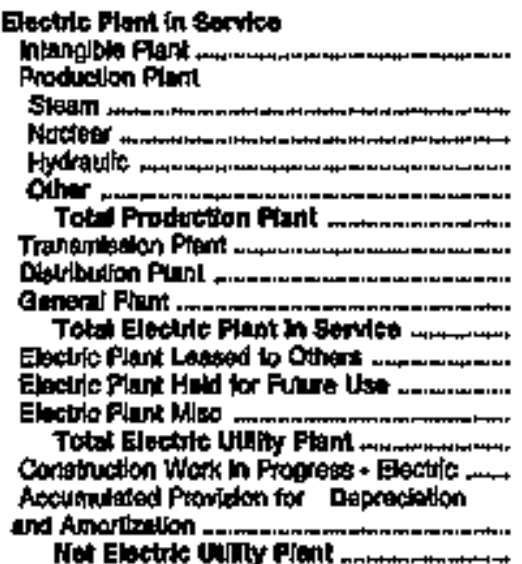 & $\begin{array}{r}0 \\
0 \\
0 \\
0 \\
0 \\
0 \\
29,907 \\
100,098 \\
27,220 \\
250,215 \\
0 \\
0 \\
0 \\
250,215 \\
7,637 \\
100,350 \\
157,511\end{array}$ & $\begin{array}{r}0 \\
0 \\
0 \\
0 \\
0 \\
0 \\
1,916 \\
20,920 \\
4,790 \\
38,58 \\
0 \\
0 \\
7,498 \\
44,024 \\
695\end{array}$ & $\begin{array}{r}0 \\
0 \\
0 \\
0 \\
0 \\
0 \\
4,201 \\
97,609 \\
3,973 \\
40,000 \\
0 \\
0 \\
2,609 \\
40,776 \\
1,230\end{array}$ & $\begin{array}{r}0 \\
0 \\
0 \\
0 \\
0 \\
0 \\
7,126 \\
28,975 \\
9,677 \\
37,778 \\
0 \\
0 \\
0 \\
37,778 \\
406\end{array}$ & $\begin{array}{r}0 \\
0 \\
0 \\
0 \\
0 \\
0 \\
0,669 \\
20,579 \\
2,814 \\
27,150 \\
0 \\
0 \\
4 \\
27,100 \\
400 \\
0,020 \\
17,830\end{array}$ & 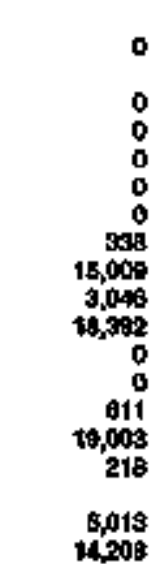 \\
\hline
\end{tabular}

\begin{tabular}{|c|c|c|c|c|c|c|}
\hline then & $\begin{array}{l}\text { Tennessese } \\
\text { Coningion } \\
\text { Ciby of } \\
\text { Jum } 30\end{array}$ & $\begin{array}{l}\text { Temresite } \\
\text { Datylon } \\
\text { Chy of } \\
\text { tune so }\end{array}$ & $\begin{array}{l}\text { Tannosise } \\
\text { Oistion } \\
\text { Gily of } \\
\text { Jine } 30\end{array}$ & 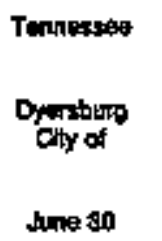 & 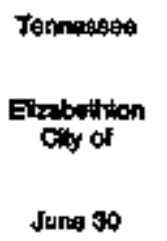 & 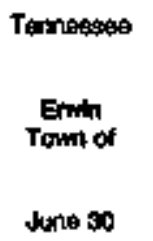 \\
\hline 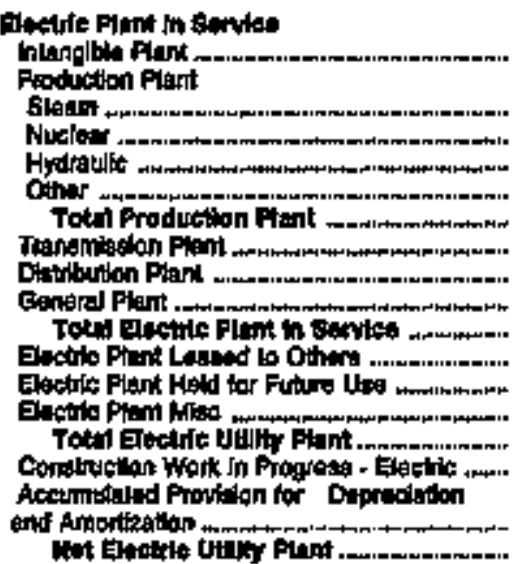 & 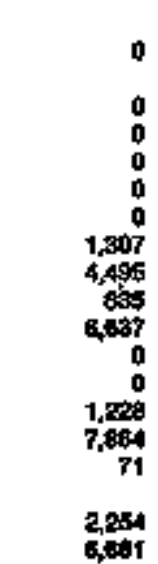 & $\begin{array}{r}0 \\
0 \\
0 \\
0 \\
0 \\
0 \\
0 \\
0,253 \\
1,775 \\
10525 \\
0 \\
0 \\
0 \\
0,578 \\
147 \\
3,518 \\
7,458\end{array}$ & 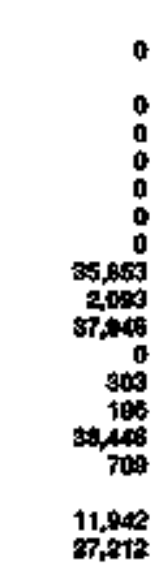 & $\begin{array}{r}0 \\
0 \\
0 \\
0 \\
0 \\
0 \\
2,107 \\
19,731 \\
4,798 \\
26,676 \\
0 \\
0 \\
0 \\
20,578 \\
1,293 \\
8,071 \\
10,798\end{array}$ & $\begin{array}{r}0 \\
0 \\
0 \\
0 \\
0 \\
0 \\
4,682 \\
21,240 \\
3,512 \\
29,283 \\
0 \\
0 \\
0 \\
20,53 \\
218 \\
11,297 \\
10,072\end{array}$ & 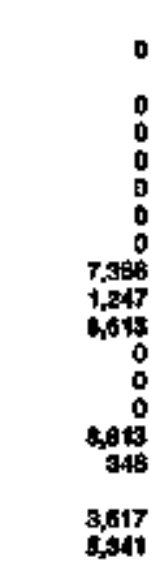 \\
\hline
\end{tabular}

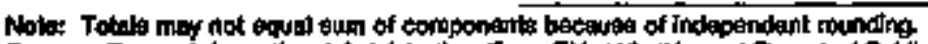

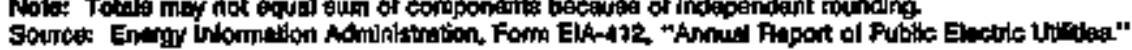


Table 24. Electric Utilly Plant by Mejor U.S. Publicty Owned Electric Utilly Whin State at End of Perlod, 1994 (Contiousd) (Thousand Dollars)

\begin{tabular}{|c|c|c|c|c|c|c|}
\hline Hem & 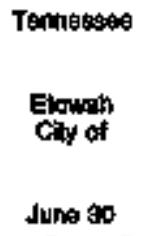 & 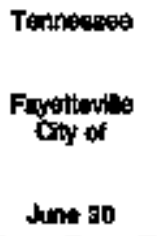 & 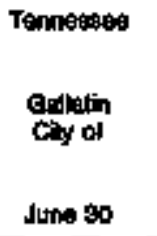 & $\begin{array}{c}\text { Tennesese } \\
\text { cremowle } \\
\text { une } 30\end{array}$ & 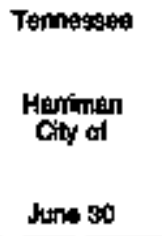 & 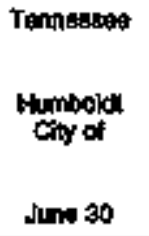 \\
\hline 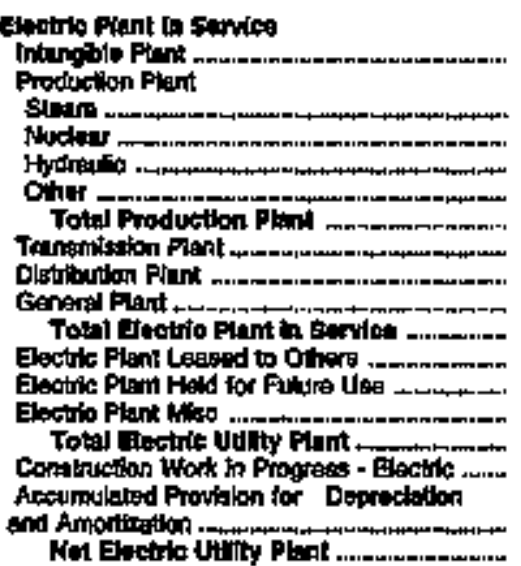 & $\begin{array}{r}0 \\
0 \\
0 \\
0 \\
0 \\
0 \\
0 \\
5,375 \\
476 \\
5,051 \\
0 \\
0 \\
0 \\
5,651 \\
74 \\
2,490 \\
3,455\end{array}$ & $\begin{array}{r}0 \\
0 \\
0 \\
0 \\
0 \\
0 \\
010 \\
21,500 \\
4,755 \\
28,974 \\
0 \\
0 \\
0 \\
26,974 \\
1,789 \\
9,005 \\
19,15 \%\end{array}$ & $\begin{array}{r}0 \\
0 \\
0 \\
0 \\
0 \\
0 \\
501 \\
9,570 \\
1,294 \\
11,370 \\
0 \\
0 \\
89 \\
11,402 \\
27 \\
5,420 \\
8,000\end{array}$ & 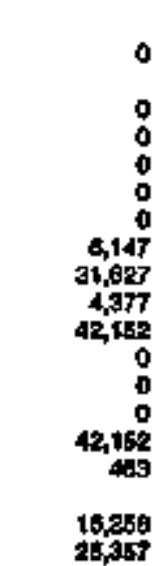 & 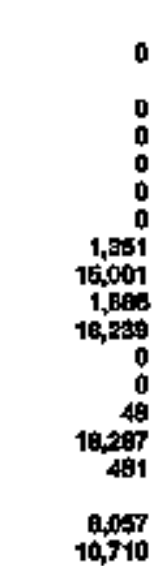 & 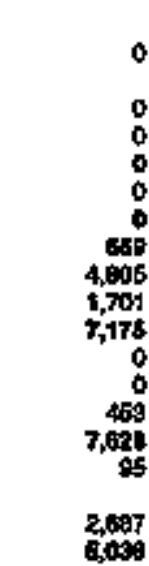 \\
\hline
\end{tabular}

\begin{tabular}{|c|c|c|c|c|c|c|}
\hline ltem & 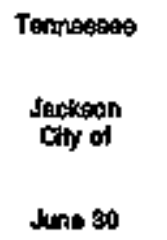 & $\begin{array}{l}\text { Tennegsea } \\
\text { Jahmeon } \\
\text { Chy City of } \\
\text { Juna so }\end{array}$ & 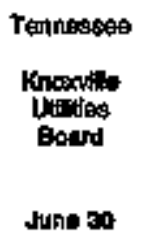 & 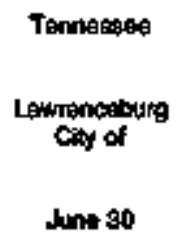 & $\begin{array}{l}\text { Tannesaes } \\
\text { Leforetia } \\
\text { Gity of } \\
\text { whe } \$ 0\end{array}$ & $\begin{array}{l}\text { Termusase } \\
\text { Lebanon } \\
\text { Chy of } \\
\text { Jung ao }\end{array}$ \\
\hline 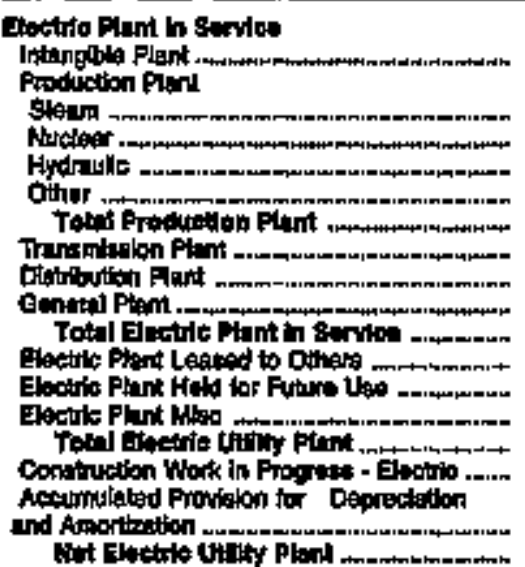 & 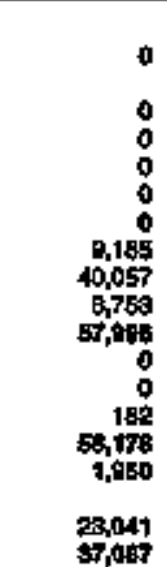 & 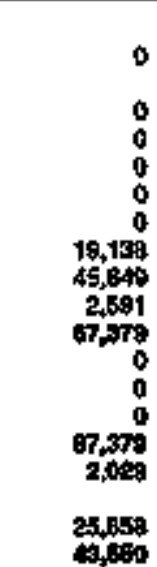 & 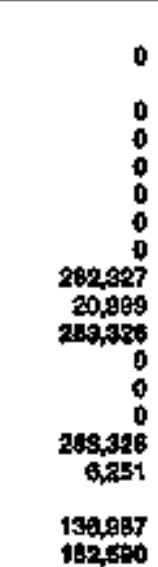 & $\begin{array}{r}0 \\
0 \\
0 \\
0 \\
0 \\
0 \\
3,975 \\
17,690 \\
2,274 \\
24,110 \\
0 \\
0 \\
0 \\
24,110 \\
169 \\
9,730 \\
140 \%\end{array}$ & 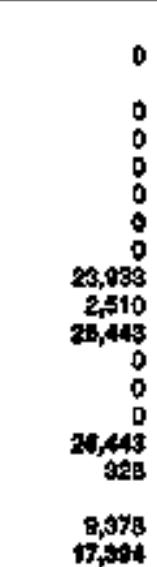 & 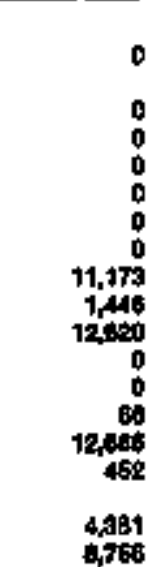 \\
\hline
\end{tabular}

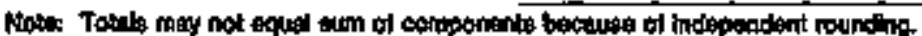

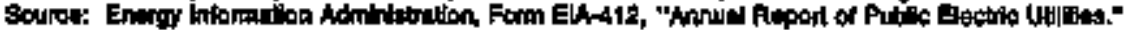


Table 24. Electrtc Utllity Plant by Mejor U.S. Publioly Owned Electric Utility Whin state at End of Perlod, 1994 (Continued)

(Thousand Dollars)

\begin{tabular}{|c|c|c|c|c|c|c|}
\hline lim & 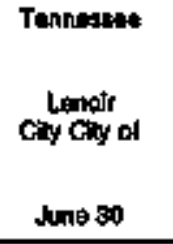 & 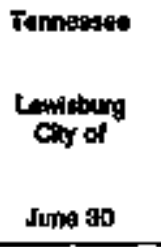 & $\begin{array}{l}\text { Tenribeses } \\
\text { Lenington } \\
\text { City of } \\
\text { June } 50\end{array}$ & $\begin{array}{l}\text { Tenneosese } \\
\text { Loudon } \\
\text { Uithida } \\
\text { Bodid } \\
\text { Junn } 30\end{array}$ & 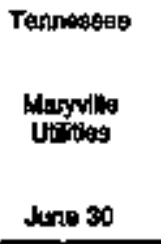 & 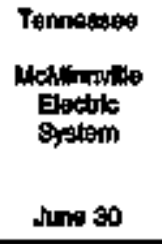 \\
\hline 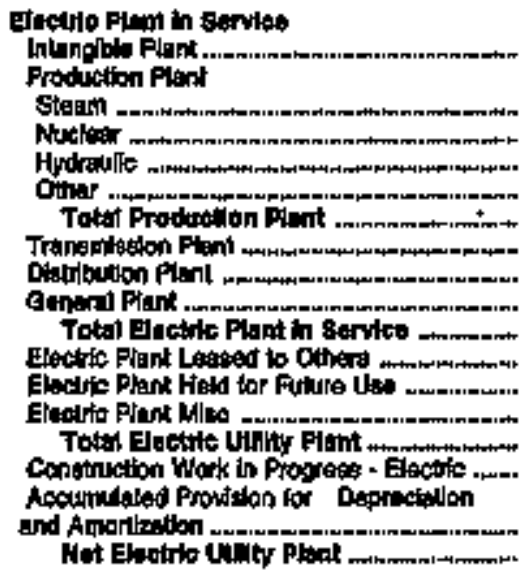 & 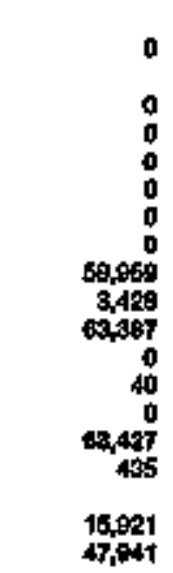 & 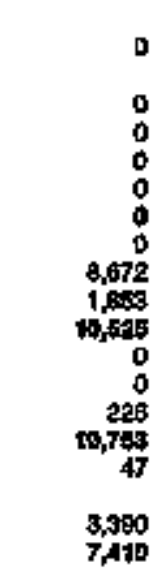 & 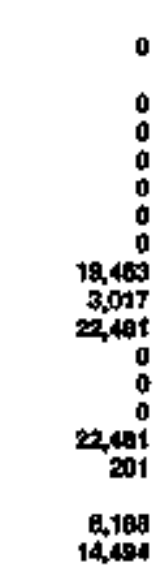 & 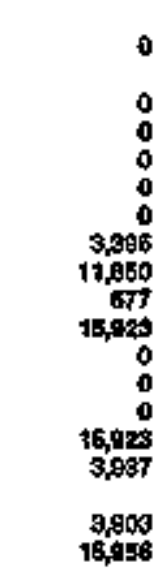 & $\begin{array}{r}0 \\
0 \\
0 \\
0 \\
0 \\
2,301 \\
19,374 \\
4,570 \\
28,245 \\
0 \\
0 \\
18 \\
25,263 \\
131 \\
7,978 \\
17,421\end{array}$ & $\begin{array}{r}0 \\
0 \\
0 \\
0 \\
0 \\
0 \\
10,454 \\
1,650 \\
12,054 \\
0 \\
0 \\
348 \\
12,490 \\
74 \\
5,112 \\
7,908\end{array}$ \\
\hline
\end{tabular}

\begin{tabular}{|c|c|c|c|c|c|c|}
\hline Item & $\begin{array}{l}\text { Tennesses } \\
\text { Momphis } \\
\text { City of } \\
\text { June } 30\end{array}$ & 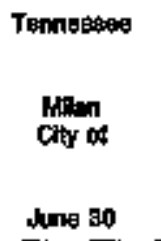 & 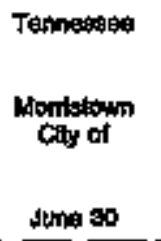 & 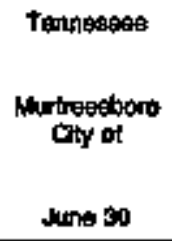 & 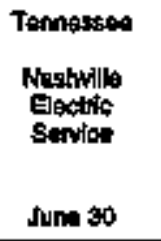 & 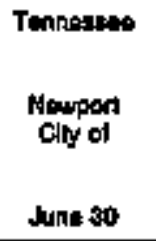 \\
\hline 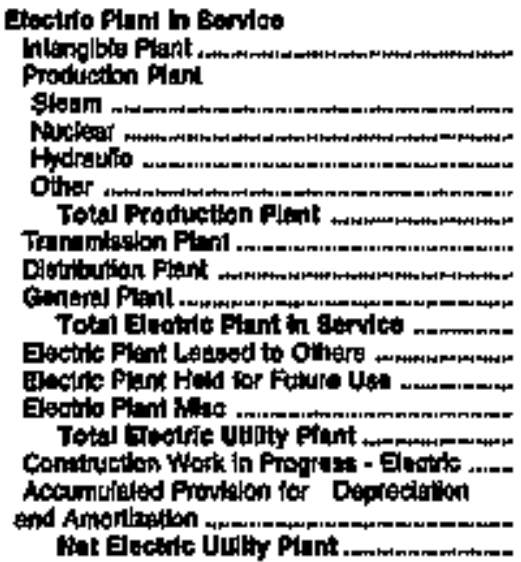 & 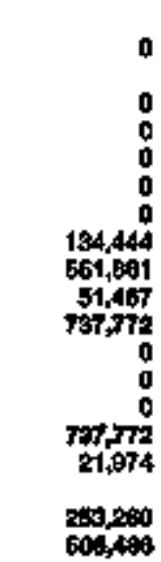 & 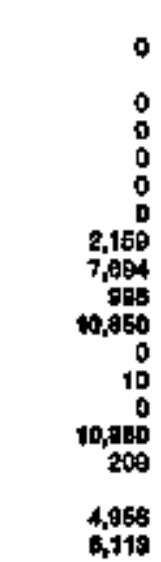 & $\begin{array}{r}0 \\
0 \\
0 \\
0 \\
0 \\
4,750 \\
19,201 \\
4,448 \\
27,425 \\
0 \\
0 \\
1,971 \\
20,390 \\
179 \\
10,276 \\
10,299\end{array}$ & $\begin{array}{r}0 \\
0 \\
0 \\
0 \\
0 \\
0 \\
20,895 \\
4,444 \\
34,340 \\
0 \\
0 \\
744 \\
95,045 \\
3,530 \\
10,895 \\
27,742\end{array}$ & $\begin{array}{r}0 \\
0 \\
0 \\
0 \\
0 \\
0 \\
491,765 \\
64,050 \\
54,516 \\
0 \\
0 \\
0 \\
648,015 \\
17,615 \\
201,945 \\
291,6015\end{array}$ & $\begin{array}{r}0 \\
0 \\
0 \\
0 \\
0 \\
0 \\
0 \\
22,314 \\
4,101 \\
26,414 \\
0 \\
0 \\
0 \\
26,414 \\
4 \\
8,707 \\
17,712\end{array}$ \\
\hline
\end{tabular}

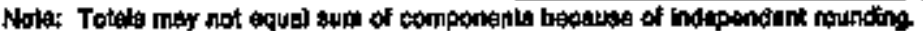

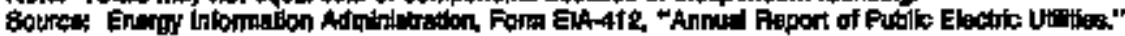


Table 24. Electric Utllly Plant by Mejor U.S. Publlcly Owned Electric Utulity Whthln State at End of Perlod, 1994 (Continutd) (Thousand Dollars)

\begin{tabular}{|c|c|c|c|c|c|c|}
\hline toma & 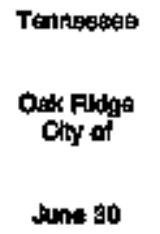 & $\begin{array}{l}\text { Tonnogsep } \\
\text { Pagta } \\
\text { Chy of } \\
\text { June to }\end{array}$ & $\begin{array}{l}\text { Tennegsee } \\
\text { Putagid } \\
\text { Coty of } \\
\text { June } 30\end{array}$ & $\begin{array}{l}\text { Tonnesea } \\
\text { Fipky ol } \\
\text { Cany ol } \\
\text { June so }\end{array}$ & 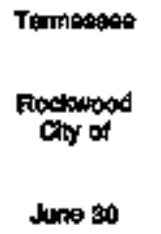 & $\begin{array}{l}\text { Tonnussec } \\
\text { Senviter } \\
\text { County } \\
\text { Electitc } \\
\text { Syromem } \\
\text { June } 30\end{array}$ \\
\hline 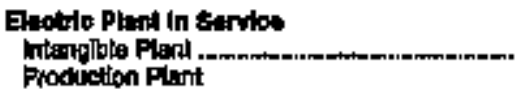 & 0 & 0 & 0 & 6 & 0 & 0 \\
\hline 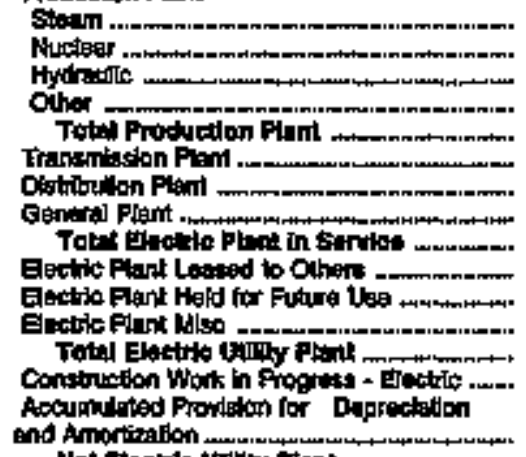 & $\begin{array}{r}0 \\
0 \\
0 \\
0 \\
0 \\
618 \\
20,294 \\
1,277 \\
24,498 \\
0 \\
0 \\
111 \\
24,690 \\
2,817\end{array}$ & $\begin{array}{r}0 \\
0 \\
0 \\
0 \\
0 \\
1,005 \\
28,000 \\
1,049 \\
28,58 \\
0 \\
0 \\
0 \\
26,662 \\
544\end{array}$ & $\begin{array}{r}0 \\
0 \\
0 \\
0 \\
0 \\
0 \\
24,468 \\
2,915 \\
24,379 \\
0 \\
0 \\
0 \\
24,379 \\
1,078\end{array}$ & $\begin{array}{r}0 \\
0 \\
0 \\
0 \\
0 \\
589 \\
5,446 \\
1,505 \\
7,025 \\
0 \\
0 \\
1,0448 \\
0,872 \\
10\end{array}$ & 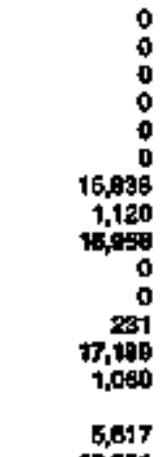 & 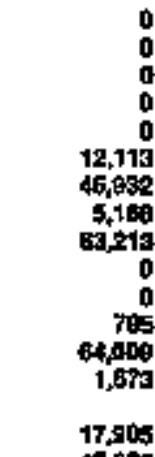 \\
\hline
\end{tabular}

\begin{tabular}{|c|c|c|c|c|c|c|}
\hline Hawn & $\begin{array}{l}\text { Tennesses } \\
\text { Shelbyille } \\
\text { Cty of } \\
\text { Jume so }\end{array}$ & $\begin{array}{l}\text { Tannessos } \\
\text { Springiend } \\
\text { Cily of } \\
\text { Whine ao }\end{array}$ & $\begin{array}{l}\text { Tenthaseo } \\
\text { Singeturiter } \\
\text { Chy of } \\
\text { June ao }\end{array}$ & 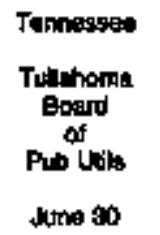 & $\begin{array}{l}\text { Tenungeses } \\
\text { Undon } \\
\text { cty Chy of } \\
\text { Junt so }\end{array}$ & $\begin{array}{l}\text { Ternosige } \\
\text { Wouldey } \\
\text { Counily } \\
\text { Mun } \\
\text { Eluc 8ys } \\
\text { June 30 }\end{array}$ \\
\hline 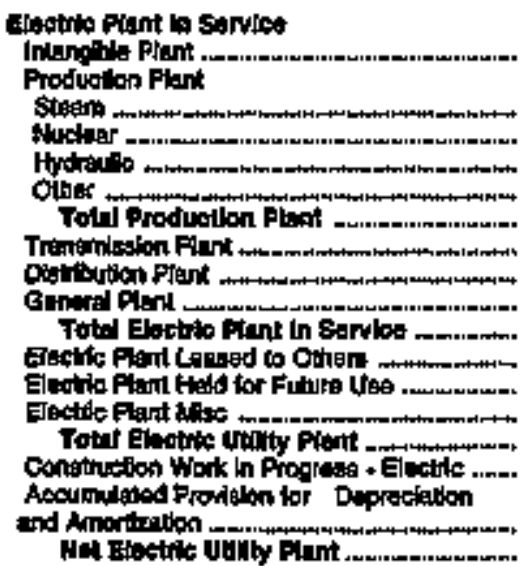 & $\begin{array}{r}0 \\
0 \\
0 \\
0 \\
0 \\
0 \\
8,996 \\
1,421 \\
+1,4 \% \\
0 \\
0 \\
241 \\
+1,640 \\
378 \\
4,016 \\
7,216\end{array}$ & $\begin{array}{r}0 \\
0 \\
0 \\
0 \\
0 \\
0 \\
8,776 \\
1,407 \\
10,906 \\
0 \\
0 \\
10,980 \\
580 \\
4,158 \\
7,816\end{array}$ & $\begin{array}{r}0 \\
0 \\
0 \\
0 \\
0 \\
0 \\
10,793 \\
1,008 \\
11,911 \\
0 \\
0 \\
0 \\
11,611 \\
40 \\
3,707 \\
8,145\end{array}$ & 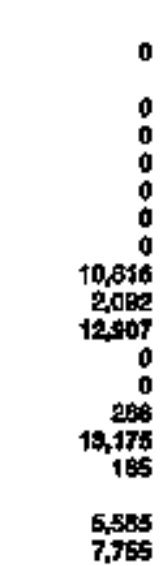 & $\begin{array}{r}0 \\
0 \\
0 \\
0 \\
0 \\
1,158 \\
6,077 \\
1,512 \\
8,646 \\
0 \\
104 \\
6 \\
965 \\
210 \\
0,685 \\
8,201\end{array}$ & $\begin{array}{r}0 \\
0 \\
0 \\
0 \\
0 \\
0 \\
2,985 \\
2+, 918 \\
2,645 \\
27,449 \\
0 \\
0 \\
0 \\
27,443 \\
1,188 \\
23,100 \\
15,420\end{array}$ \\
\hline
\end{tabular}

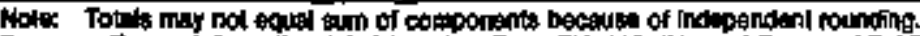

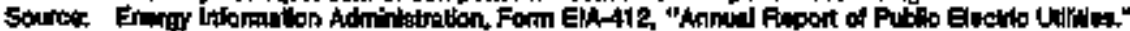


Tabte 24. Electric Utalty Plant by Major U.S. Publaby Owned Electric Utilly Wilkin State at End of Period, 1994

(Thousand Dollars)

\begin{tabular}{|c|c|c|c|c|c|c|}
\hline$k=n$ & 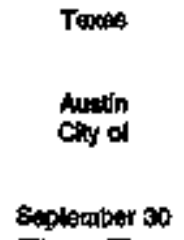 & $\begin{array}{l}\text { Texpla } \\
\text { Bronthyol } \\
\text { Gity of } \\
\text { September an }\end{array}$ & 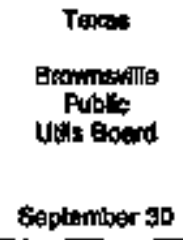 & $\begin{array}{l}\text { Texis } \\
\text { Bryan } \\
\text { Civy of } \\
\text { Septenibor on }\end{array}$ & $\begin{array}{l}\text { Tocas } \\
\text { Corega } \\
\text { Slation } \\
\text { Sity ot } \\
\text { September on }\end{array}$ & 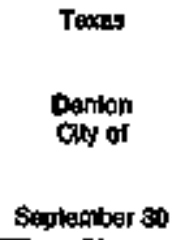 \\
\hline 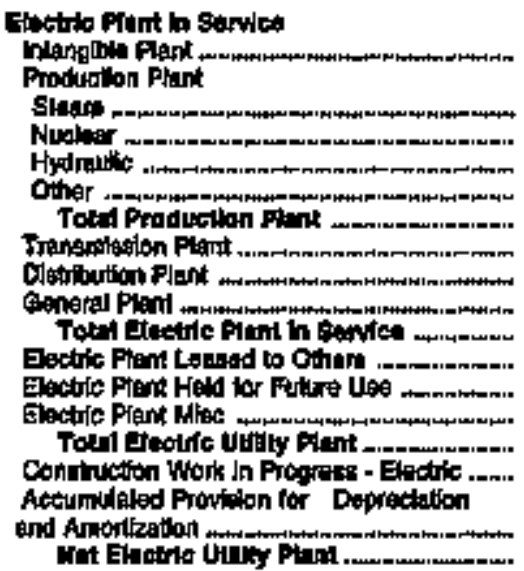 & 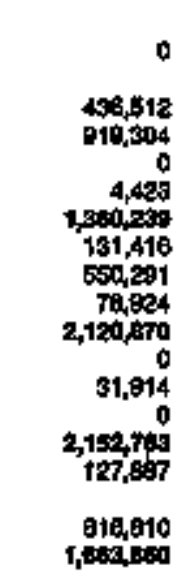 & $\begin{array}{r}0 \\
0 \\
0 \\
0 \\
0 \\
0 \\
0 \\
0 \\
8,703 \\
0 \\
0,70 \\
0 \\
0 \\
0 \\
0,708 \\
0\end{array}$ & $\begin{array}{r}18,488 \\
0 \\
0 \\
268 \\
15,757 \\
65,850 \\
49,217 \\
120,061 \\
275,495 \\
0 \\
0 \\
0 \\
20,495 \\
39,740\end{array}$ & 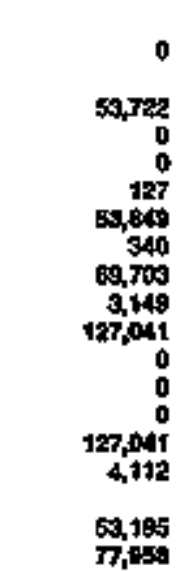 & $\begin{array}{r}0 \\
0 \\
0 \\
0 \\
0 \\
0 \\
9,086 \\
14,208 \\
4,349 \\
27,701 \\
0 \\
0 \\
0 \\
37,701 \\
3,020 \\
9,471 \\
22,152\end{array}$ & 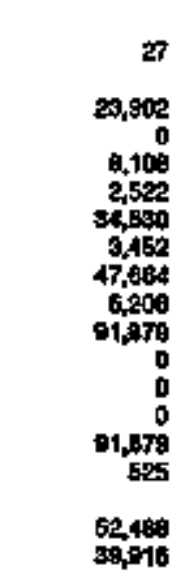 \\
\hline
\end{tabular}

\begin{tabular}{|c|c|c|c|c|c|c|}
\hline ILA & $\begin{array}{l}\text { Texins } \\
\text { Foremilo } \\
\text { Drty of } \\
\text { Deteraben at }\end{array}$ & 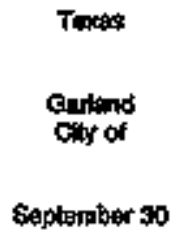 & $\begin{array}{l}\text { Teang } \\
\text { Ceorgotom } \\
\text { City of } \\
\text { seplember } 30\end{array}$ & 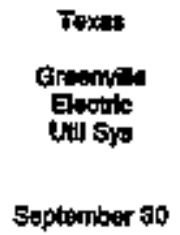 & 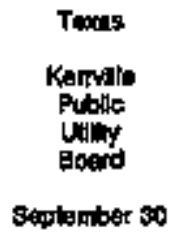 & 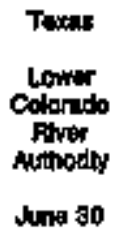 \\
\hline 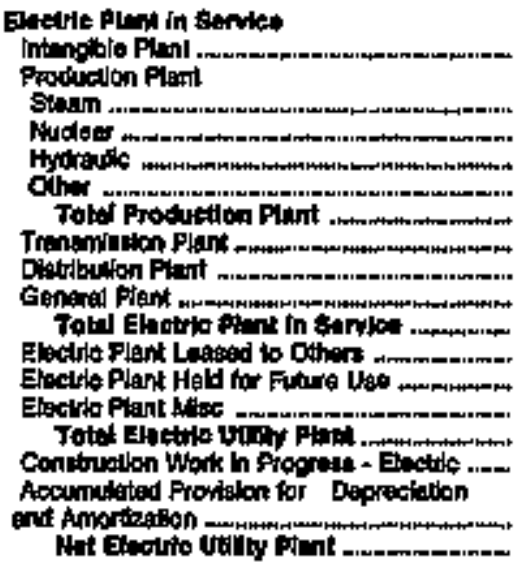 & $\begin{array}{r}0 \\
0 \\
0 \\
0 \\
0 \\
0 \\
1,497 \\
20,024 \\
2,608 \\
24,179 \\
0 \\
0 \\
0 \\
24,129 \\
0 \\
9,655 \\
14,494\end{array}$ & $\begin{array}{r}390 \\
76,408 \\
0 \\
0 \\
0 \\
79,400 \\
19,967 \\
93,768 \\
20,741 \\
210,90 \% \\
0 \\
0 \\
0 \\
210,992 \\
0\end{array}$ & $\begin{array}{r}0 \\
0 \\
0 \\
0 \\
0 \\
0 \\
0 \\
0 \\
6,248 \\
5,240 \\
0 \\
0 \\
5,240 \\
65\end{array}$ & $\begin{array}{r}18,295 \\
0 \\
0 \\
4,962 \\
28,498 \\
1,497 \\
22,141 \\
4,641 \\
51,467 \\
0 \\
0 \\
0 \\
54,467 \\
0\end{array}$ & $\begin{array}{r}209 \\
0 \\
0 \\
0 \\
0 \\
0 \\
0 \\
29,798 \\
4,967 \\
24,974 \\
0 \\
0 \\
-637 \\
20,337 \\
577 \\
0,059 \\
10,949\end{array}$ & 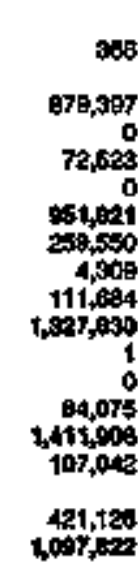 \\
\hline
\end{tabular}

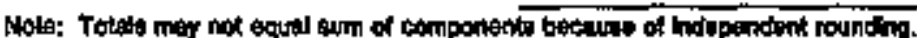

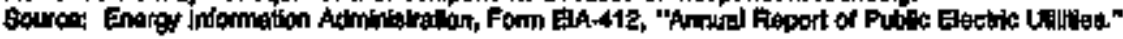


Table 24. Electric Udilty Piant by Major U.S. Publicly Owned Electric Uullty Within State at End of Period, 1994 (Contiousd)

(Thousand Dollars)

\begin{tabular}{|c|c|c|c|c|c|c|}
\hline Hem & $\begin{array}{l}\text { Tences } \\
\text { ubbork } \\
\text { Civy of } \\
\text { soplember so }\end{array}$ & 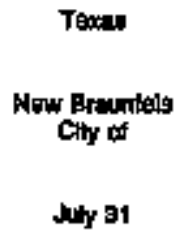 & 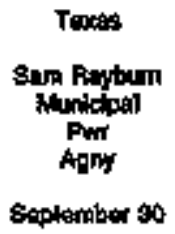 & 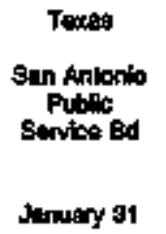 & $\begin{array}{l}\text { Texas } \\
\text { San hivoo: } \\
\text { Chy of } \\
\text { seplomber } 30\end{array}$ & 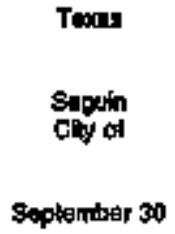 \\
\hline 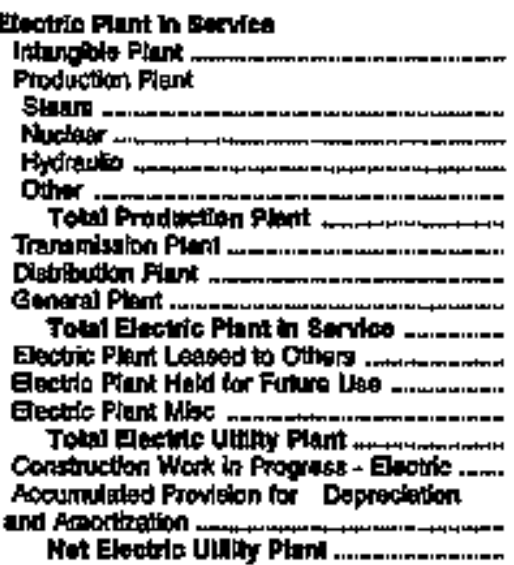 & $\begin{array}{r}127,884 \\
0 \\
0 \\
0 \\
127,484 \\
0 \\
0 \\
0 \\
127,504 \\
0 \\
0 \\
0 \\
127,064 \\
0,700 \\
47,675 \\
0,700\end{array}$ & $\begin{array}{r}0 \\
0 \\
14,757 \\
0 \\
14,7,57 \\
5,069 \\
23,004 \\
6,055 \\
94,045 \\
0 \\
0 \\
0 \\
54,658 \\
100 \\
20,051 \\
34,126\end{array}$ & 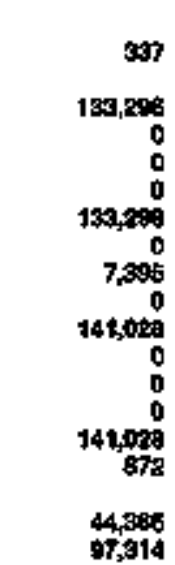 & 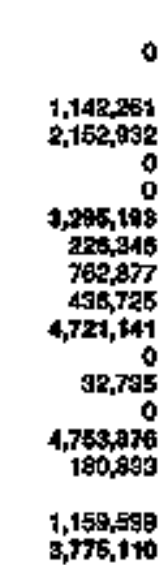 & $\begin{array}{r}0 \\
0 \\
0 \\
0 \\
0 \\
0 \\
10,658 \\
2,910 \\
12,975 \\
0 \\
0 \\
2,659 \\
16,595 \\
1,057 \\
5,599 \\
12,900\end{array}$ & $\begin{array}{r}0 \\
0 \\
0 \\
608 \\
0 \\
572 \\
808 \\
4,049 \\
1,050 \\
6,443 \\
0 \\
0 \\
0 \\
6,448 \\
0 \\
3,990 \\
2,814\end{array}$ \\
\hline
\end{tabular}

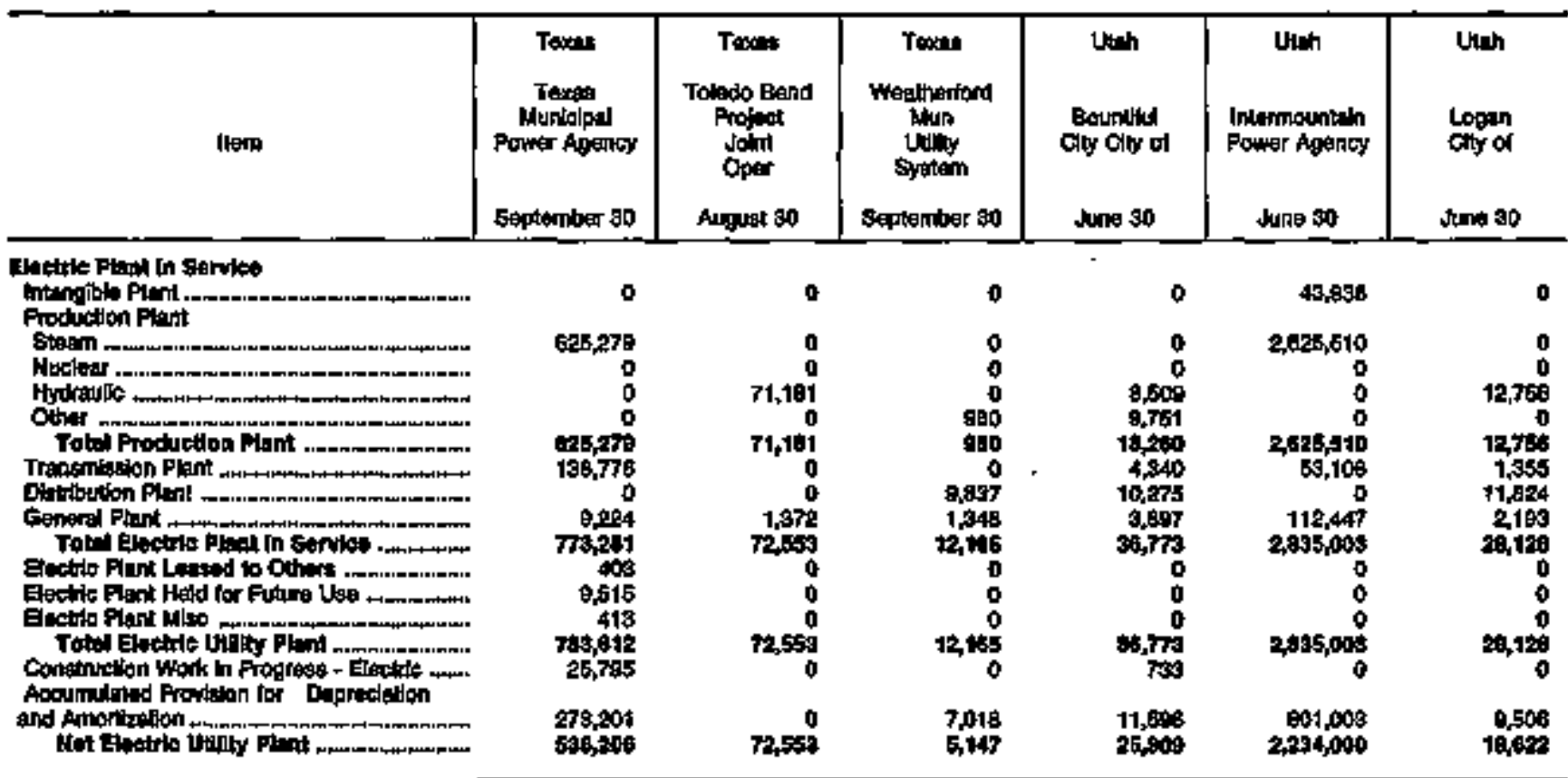

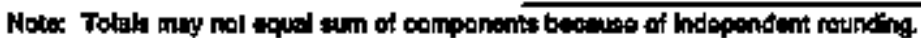

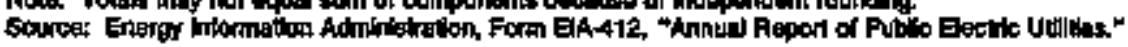


Table 24. Electric Utllity Plant by Major U.S. Publicly Owned Electric Utulity Within State at End of Pertod, 1994 (Continued) (Thousand Dollars)

\begin{tabular}{|c|c|c|c|c|c|c|}
\hline Jism & 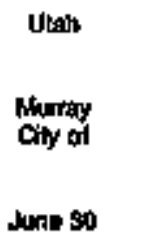 & $\begin{array}{l}\text { Wtan } \\
\text { Ftomin Cosp } \\
\text { Juns so }\end{array}$ & 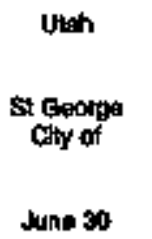 & 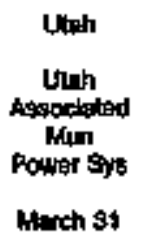 & 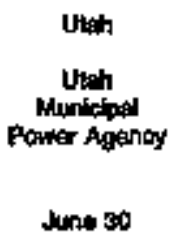 & $\begin{array}{l}\text { Vermont } \\
\text { Arisiglon } \\
\text { Ciny of } \\
\text { June so }\end{array}$ \\
\hline 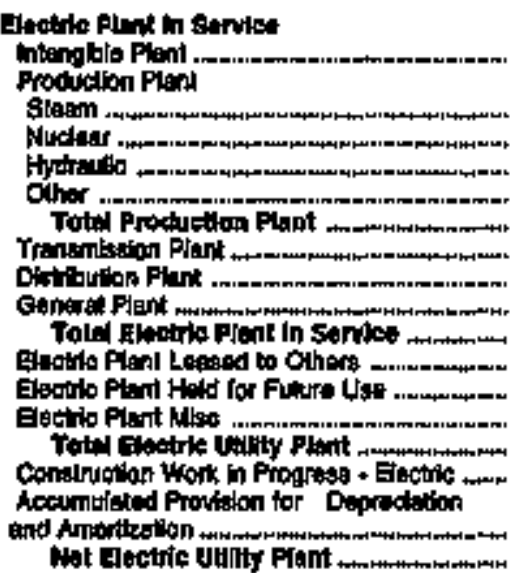 & $\begin{array}{r}0 \\
0 \\
0 \\
8,453 \\
1,840 \\
10,192 \\
4,913 \\
20,298 \\
6,406 \\
41,278 \\
0 \\
0 \\
0 \\
41,278 \\
144 \\
20,096 \\
20,5 \times 3\end{array}$ & $\begin{array}{r}44,500 \\
0 \\
0 \\
9,000 \\
5,500 \\
9,591 \\
38,785 \\
4,045 \\
84,821 \\
0 \\
0 \\
0 \\
04,01 \\
0\end{array}$ & $\begin{array}{r}0 \\
0 \\
0 \\
619 \\
8,610 \\
7,136 \\
9,715 \\
9,658 \\
2,566 \\
29,098 \\
0 \\
0 \\
0 \\
20,098 \\
0 \\
9,295 \\
10,003\end{array}$ & 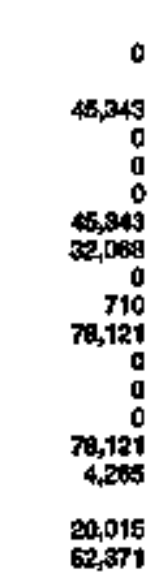 & 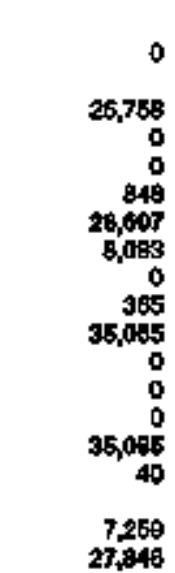 & $\begin{array}{r}488 \\
39,610 \\
0 \\
0 \\
4,044 \\
43,465 \\
3,675 \\
20,090 \\
5,609 \\
74,291 \\
0 \\
85 \\
0 \\
74,390 \\
0 \\
27,670 \\
46,716\end{array}$ \\
\hline
\end{tabular}

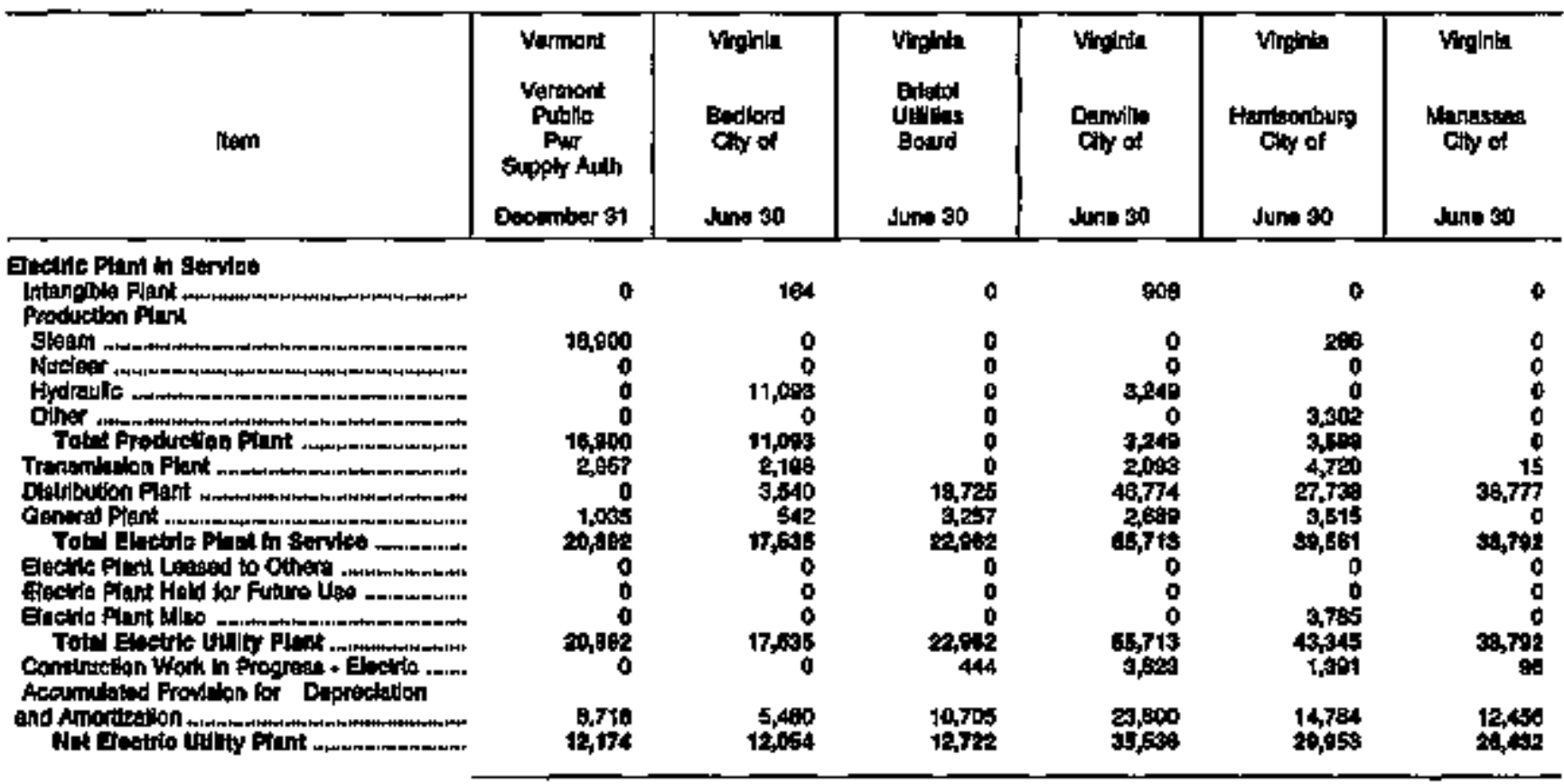

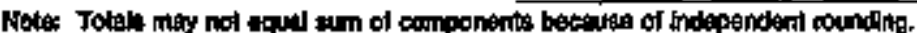

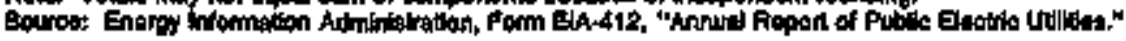


Table 24. Electrle Utilly Plant by Major L:S. Publely Omned Electrlo Uthly Within State at End of Period, 1994 (Continued)

(Thousand Dollars)

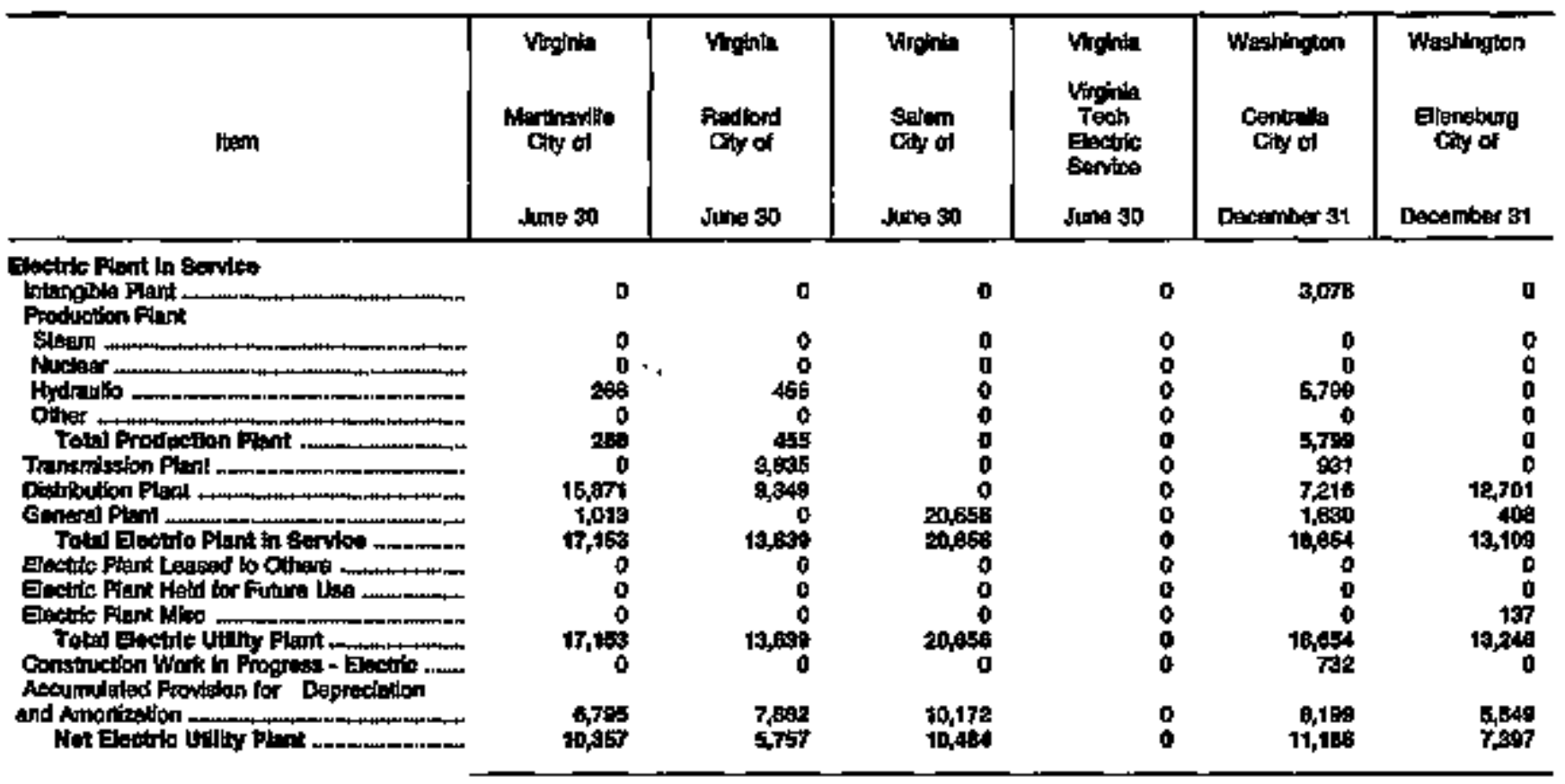

\begin{tabular}{|c|c|c|c|c|c|c|}
\hline Hogm & $\begin{array}{l}\text { Washington } \\
\text { Port Angelos } \\
\text { City of } \\
\text { Oecennber } 31\end{array}$ & $\begin{array}{l}\text { Washinglon } \\
\text { PUD blo } t \\
\text { of } \\
\text { Bentor } \\
\text { County } \\
\text { December } 34\end{array}$ & 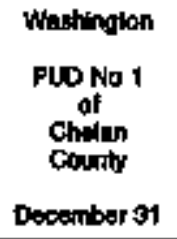 & $\begin{array}{l}\text { Wastington } \\
\text { PUO No } 1 \text { of } \\
\text { Cieinam } \\
\text { Counky }\end{array}$ & 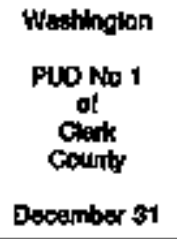 & 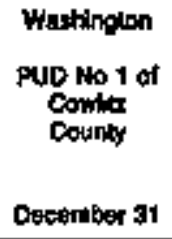 \\
\hline 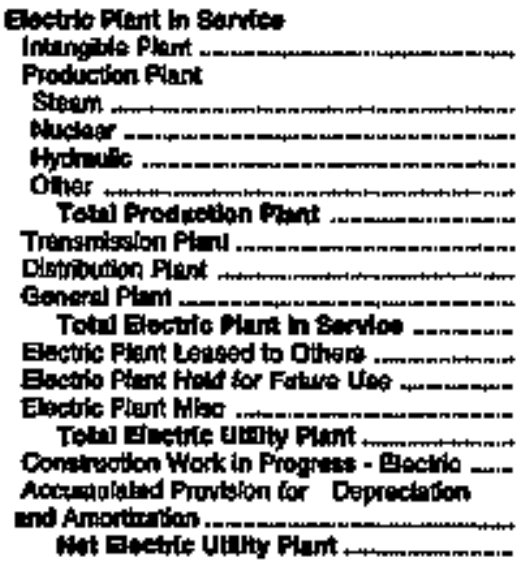 & 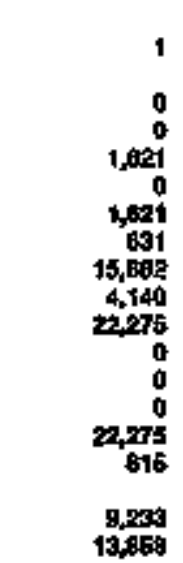 & 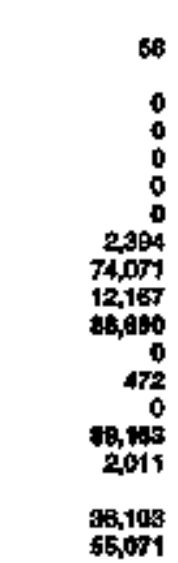 & 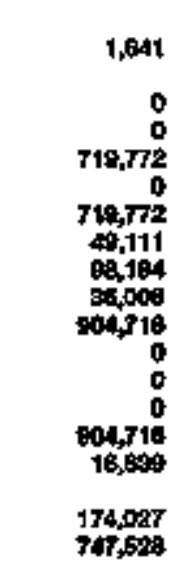 & $\begin{array}{r}17 \\
0 \\
0 \\
0 \\
0 \\
0 \\
5,005 \\
45,985 \\
5,111 \\
5,720 \\
0 \\
85 \\
0 \\
50,913 \\
3,582 \\
31,777 \\
31,918\end{array}$ & 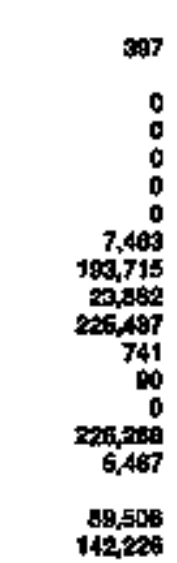 & 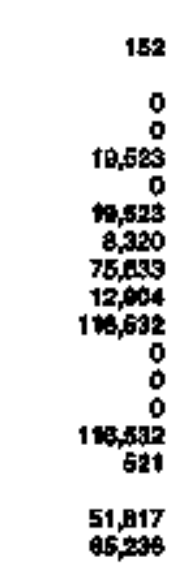 \\
\hline
\end{tabular}

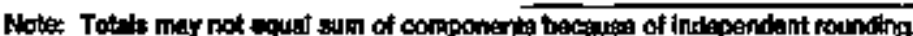

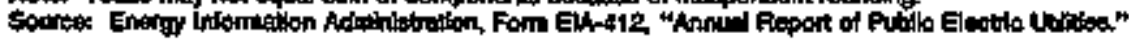


Tabie 24. Electrle Ua'lty Plant by Major U.\$. Publchy Owned Electrle Utility Within State at End of Period, 1994 (Continued)

(Thousand Dollars)

\begin{tabular}{|c|c|c|c|c|c|c|}
\hline Jtram & 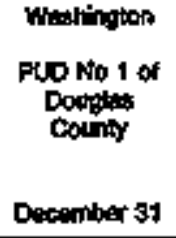 & $\begin{array}{l}\text { Wastington } \\
\text { Pud plo } 1 \text { of } \\
\text { Frainlfin } \\
\text { County } \\
\text { Decentior } 31\end{array}$ & 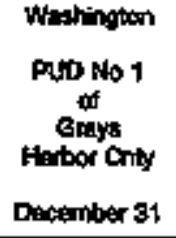 & 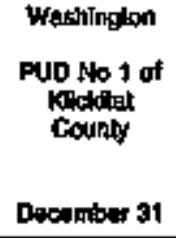 & 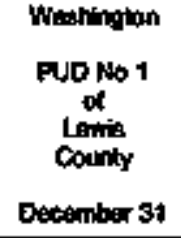 & 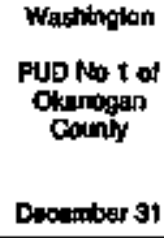 \\
\hline 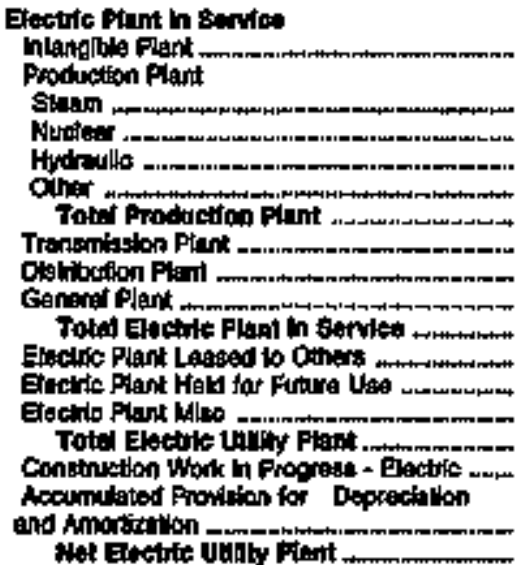 & 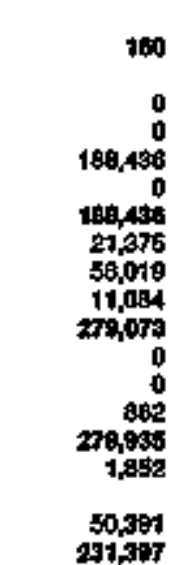 & 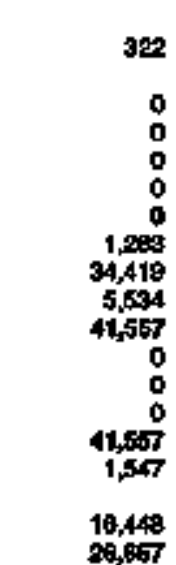 & 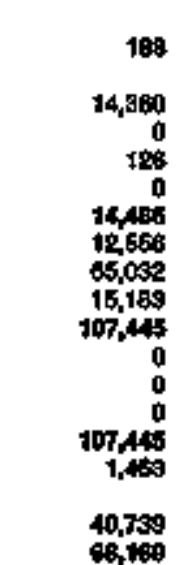 & $\begin{array}{r}218 \\
0 \\
0 \\
0 \\
0 \\
0 \\
2,091 \\
26,398 \\
4,041 \\
32,428 \\
0 \\
0 \\
5003 \\
32,931 \\
9,671 \\
13,077 \\
20,424\end{array}$ & $\begin{array}{r}121 \\
0 \\
0 \\
1,421 \\
0 \\
1,421 \\
4,340 \\
48,797 \\
4,251 \\
59,910 \\
0 \\
0 \\
0 \\
56,940 \\
13,172 \\
15,400 \\
54,002\end{array}$ & 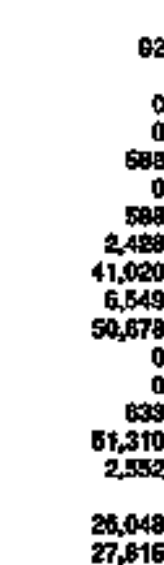 \\
\hline
\end{tabular}

\begin{tabular}{|c|c|c|c|c|c|c|}
\hline $\lim$ & 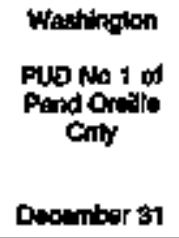 & $\begin{array}{l}\text { Whatingtun } \\
\text { Fut No } 1 \text { of } \\
\text { Sinohomish } \\
\text { Coumb } \\
\text { December } 31\end{array}$ & $\begin{array}{l}\text { Wartington } \\
\text { PUD Not it } \\
\text { Whatown } \\
\text { County } \\
\text { Oeountur is }\end{array}$ & $\begin{array}{l}\text { Wealingtor } \\
\text { Pulo No } 2 \\
\text { of } \\
\text { Countly } \\
\text { Decumber at }\end{array}$ & 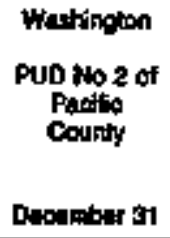 & $\begin{array}{l}\text { Whahington } \\
\text { puo klo } 3 \\
\text { of } \\
\text { wisos } \\
\text { Cotinty } \\
\text { December } 31\end{array}$ \\
\hline 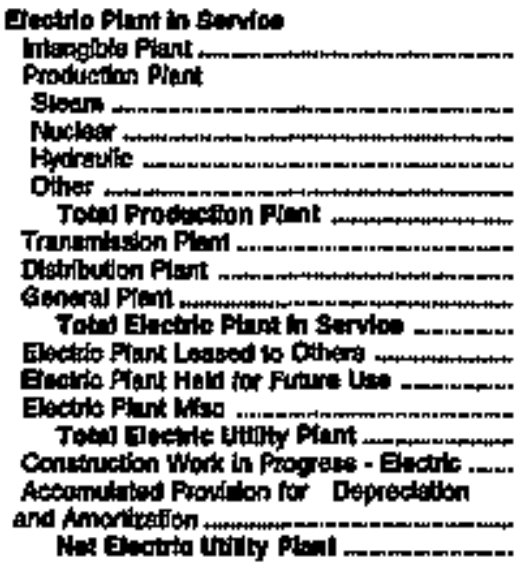 & 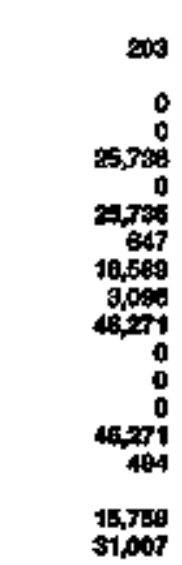 & 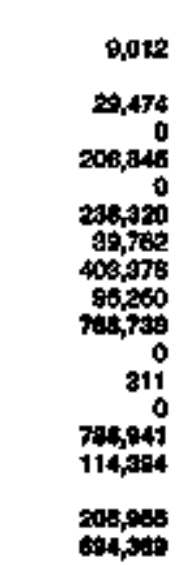 & $\begin{array}{r}0 \\
0 \\
0 \\
0 \\
0 \\
0 \\
2,640 \\
0 \\
007 \\
2, \pi 07 \\
0 \\
0 \\
0 \\
2,707 \\
0 \\
2,191\end{array}$ & 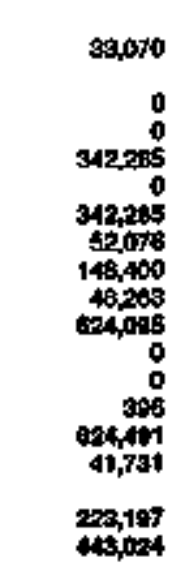 & 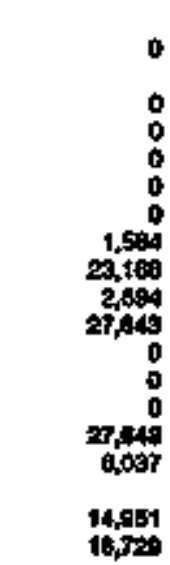 & $\begin{array}{r}12 \\
0 \\
0 \\
0 \\
0 \\
1,000 \\
60,044 \\
4,903 \\
07,042 \\
0 \\
0 \\
0 \\
07,049 \\
2,648 \\
17,419 \\
62,000\end{array}$ \\
\hline
\end{tabular}

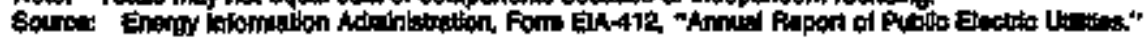


Table 24. Electric Uility Plant by Major US. Publiely Owned Electrito Vitlty Within State at End of Perlod, 1994 (Thousand Dollars)

\begin{tabular}{|c|c|c|c|c|c|c|}
\hline Ithen & 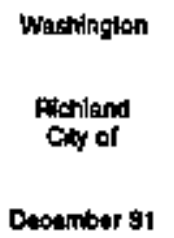 & $\begin{array}{l}\text { Wabitingten } \\
\text { Seatib } \\
\text { Caby of } \\
\text { December } 31\end{array}$ & $\begin{array}{l}\text { Wastirgon } \\
\text { Thooma } \\
\text { Givy of } \\
\text { Decenter } 31\end{array}$ & $\begin{array}{c}\text { Wastington } \\
\text { Yera } \\
\text { Migation } \\
\text { Ointex \#15 } \\
\text { Desember } 34\end{array}$ & $\begin{array}{l}\text { Washingion } \\
\text { Washinglon } \\
\text { Pub } \\
\text { Pur } \\
\text { Groph Sya } \\
\text { June } 30\end{array}$ & 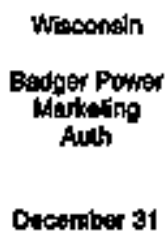 \\
\hline 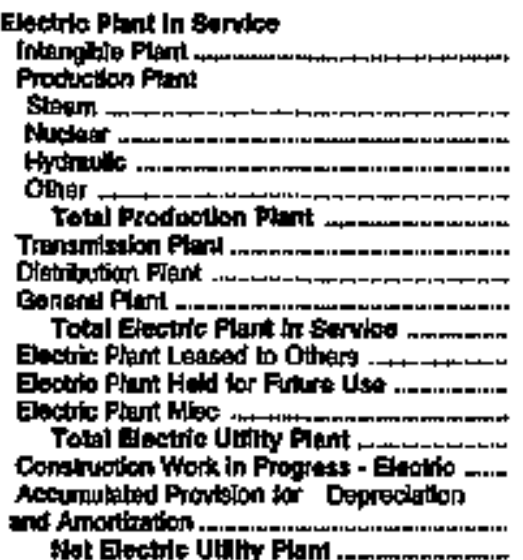 & $\begin{array}{r}0 \\
0 \\
0 \\
0 \\
0 \\
0 \\
659 \\
41,840 \\
1,724 \\
44,280 \\
0 \\
0 \\
0 \\
44,270 \\
4,403 \\
16,814 \\
16,403\end{array}$ & $\begin{array}{r}34,371 \\
27,133 \\
0 \\
395,791 \\
0 \\
472,994 \\
77,134 \\
579,466 \\
197,052 \\
1,241,728 \\
0 \\
2,498 \\
0 \\
1,244,226 \\
103,682\end{array}$ & 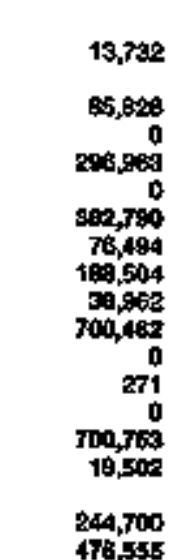 & $\begin{array}{r}0 \\
0 \\
0 \\
0 \\
0 \\
0 \\
10,050 \\
2,787 \\
13,425 \\
0 \\
0 \\
0 \\
13,405 \\
258\end{array}$ & 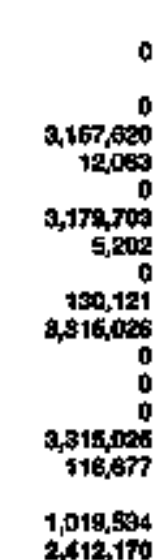 & $\begin{array}{r}0 \\
0 \\
0 \\
0 \\
0 \\
5,992 \\
0 \\
193 \\
6,560 \\
0 \\
0 \\
549 \\
5,965 \\
0 \\
1,251 \\
4604\end{array}$ \\
\hline
\end{tabular}

\begin{tabular}{|c|c|c|c|c|c|c|}
\hline II!n & $\begin{array}{c}\text { Wiaconali } \\
\text { Joflerson } \\
\text { Cty of } \\
\text { Dacember of }\end{array}$ & 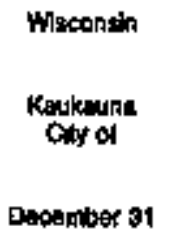 & 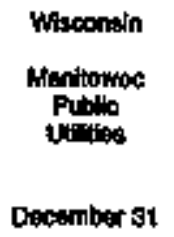 & $\begin{array}{c}\text { Wheconsin } \\
\text { Marahleyd } \\
\text { Giy of } \\
\text { Decention } 31\end{array}$ & 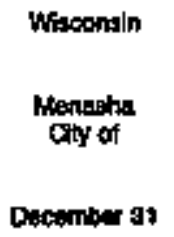 & $\begin{array}{l}\text { Wipconsin } \\
\text { Now tondon } \\
\text { Electriesthaler } \\
\text { Uil }\end{array}$ \\
\hline 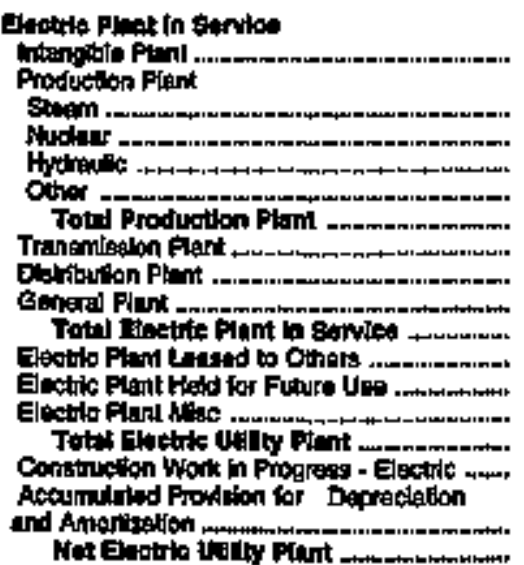 & $\begin{array}{r}0 \\
0 \\
0 \\
0 \\
0 \\
0 \\
0 \\
7020 \\
647 \\
7,607 \\
0 \\
0 \\
0 \\
7,807 \\
115 \\
2,247 \\
5,735\end{array}$ & 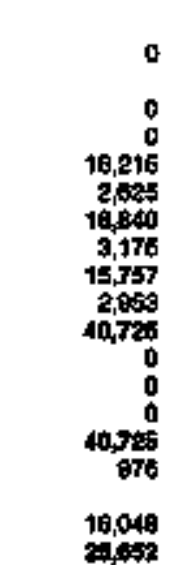 & 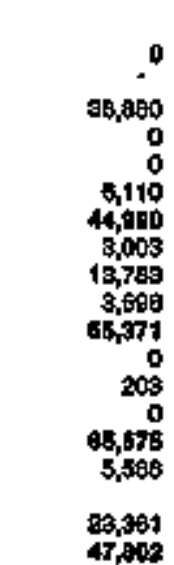 & 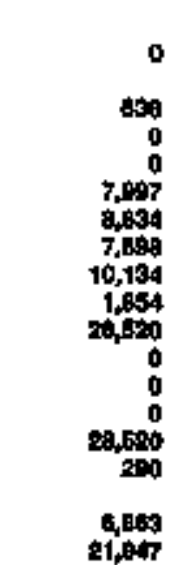 & 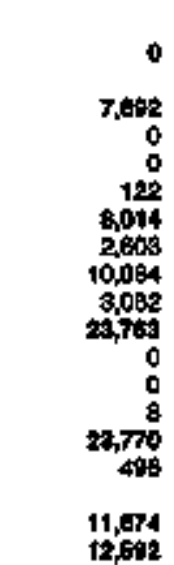 & 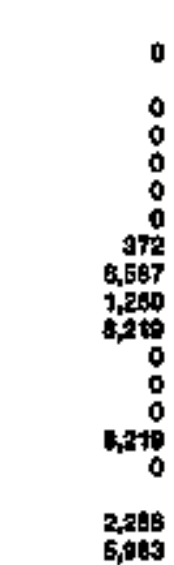 \\
\hline
\end{tabular}

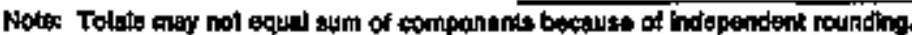

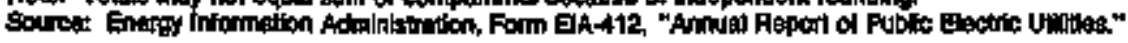


Table 24. Electric Utilty Plant by Major U.S. Publicly Owned Electric Utility Within state at End of Period, 1994 (Continued) (Thousand Dollars)

\begin{tabular}{|c|c|c|c|c|c|c|}
\hline Item & 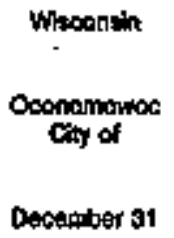 & $\begin{array}{l}\text { Mincontin } \\
\text { Plymouth } \\
\text { City of } \\
\text { Ductinber } 31\end{array}$ & 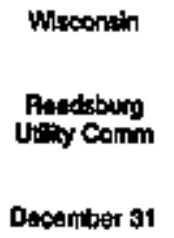 & 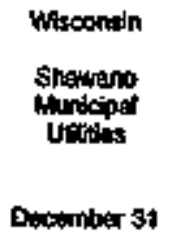 & 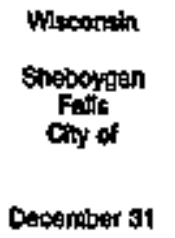 & 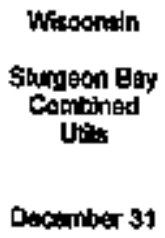 \\
\hline 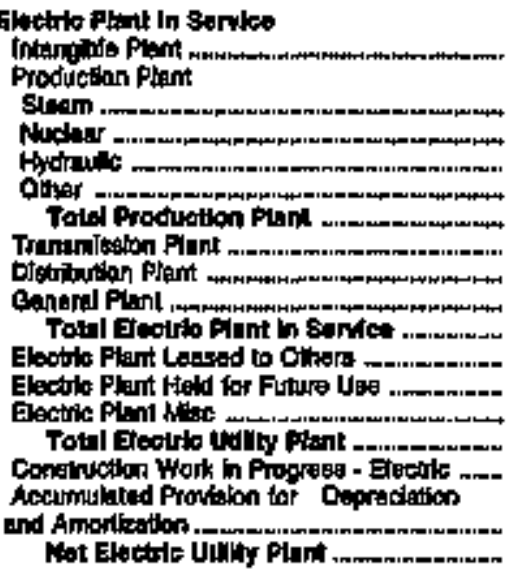 & $\begin{array}{r}0 \\
0 \\
0 \\
0 \\
0 \\
0 \\
0 \\
14,678 \\
975 \\
19,585 \\
0 \\
0 \\
589 \\
18,182 \\
41 \\
5,614 \\
10,679\end{array}$ & $\begin{array}{r}0 \\
0 \\
0 \\
0 \\
0 \\
0 \\
218 \\
27,04 \\
1,154 \\
14,297 \\
0 \\
0 \\
0 \\
14,497 \\
20\end{array}$ & $\begin{array}{r}0 \\
0 \\
0 \\
0 \\
0 \\
0 \\
648 \\
7,978 \\
640 \\
5,157 \\
0 \\
0 \\
38 \\
0,405 \\
0\end{array}$ & $\begin{array}{r}0 \\
0 \\
0 \\
0 \\
0 \\
377 \\
7,306 \\
1,115 \\
0757 \\
0 \\
0 \\
0 \\
079 \\
241\end{array}$ & $\begin{array}{r}0 \\
0 \\
0 \\
0 \\
0 \\
513 \\
6,552 \\
731 \\
7,795 \\
0 \\
0 \\
0 \\
7,795 \\
342 \\
3,253 \\
4,996\end{array}$ & $\begin{array}{r}0 \\
0 \\
0 \\
0 \\
0 \\
2,286 \\
11,507 \\
2,152 \\
16,184 \\
0 \\
0 \\
0 \\
16,184 \\
40 \\
5,006 \\
11,128\end{array}$ \\
\hline
\end{tabular}

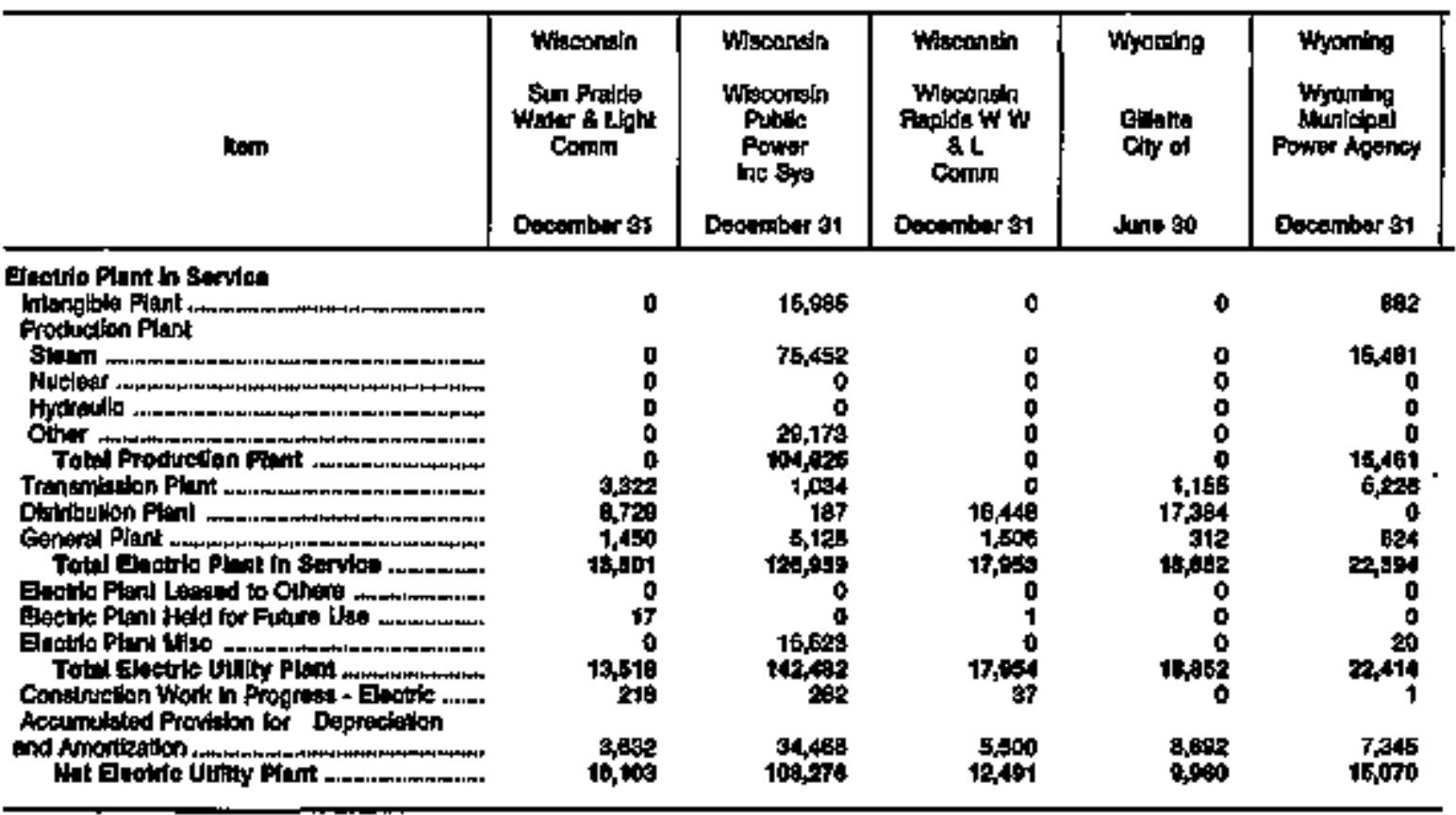

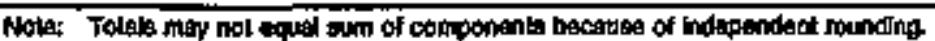

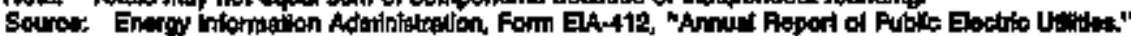


Tabje 25. Mumber of Consumers, Sales, and Operating Revenue by Major U.S. Publiely Owned Electric Utility Within state, 1994

\begin{tabular}{|c|c|c|c|c|c|c|}
\hline Dert & 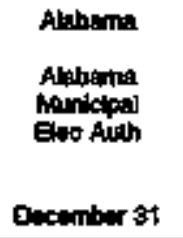 & 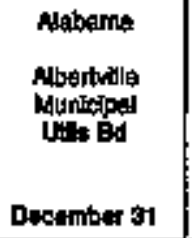 & 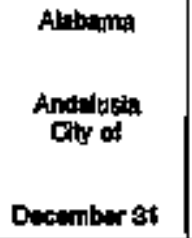 & 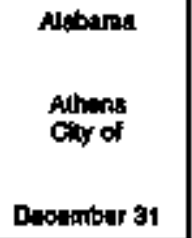 & $\begin{array}{l}\text { Alebama } \\
\text { Basosmer } \\
\text { City of } \\
\text { Decomber औ }\end{array}$ & $\begin{array}{l}\text { Allowana } \\
\text { Calman } \\
\text { Powr Boud } \\
\text { Doovmbor } 31\end{array}$ \\
\hline 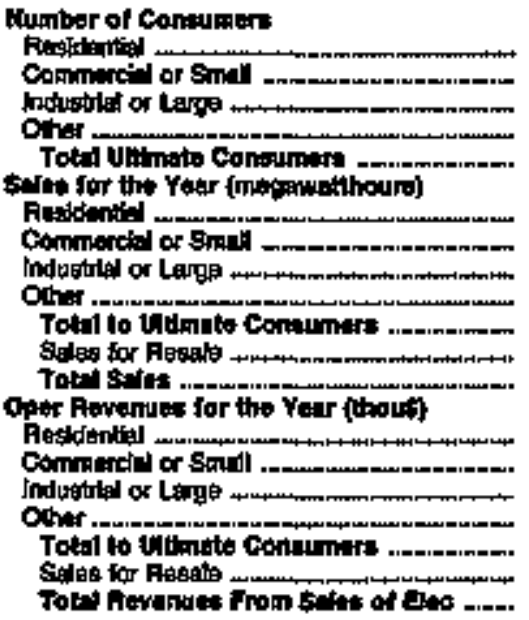 & 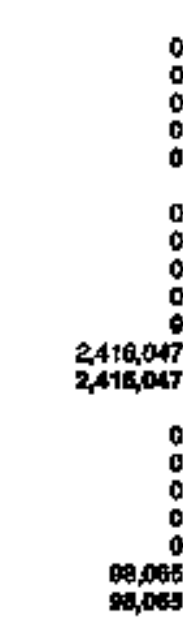 & 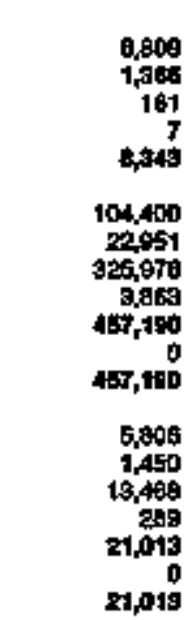 & 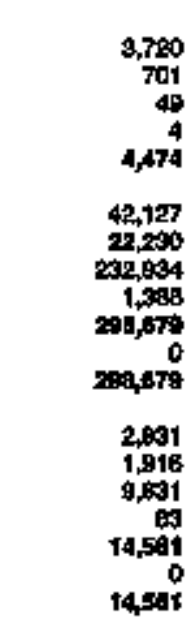 & 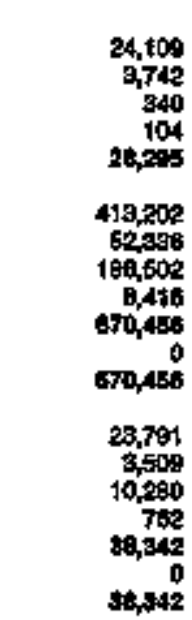 & $\begin{array}{r}11,015 \\
1,258 \\
258 \\
21 \\
12,589 \\
124,599 \\
31,0,04 \\
164,151 \\
5,981 \\
328,704 \\
0 \\
30,704 \\
7,799 \\
2,091 \\
7,910 \\
497 \\
18,251 \\
0 \\
10,241\end{array}$ & 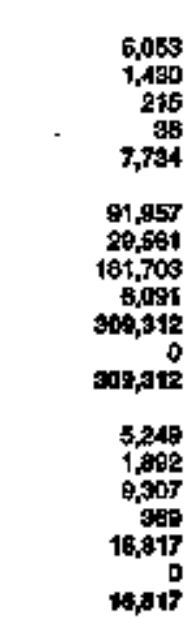 \\
\hline
\end{tabular}

\begin{tabular}{|c|c|c|c|c|c|c|}
\hline Hัตอ & 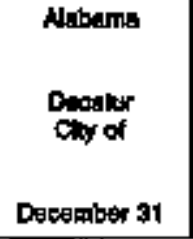 & 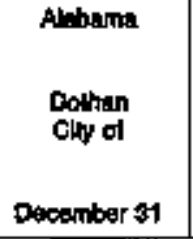 & $\begin{array}{l}\text { Nribeme } \\
\text { Florance } \\
\text { Cty of } \\
\text { Dextember } 31\end{array}$ & 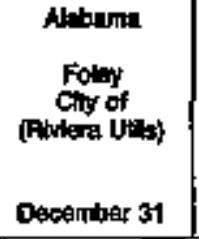 & 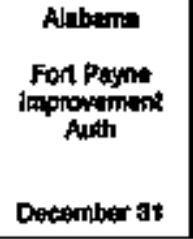 & 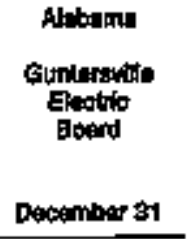 \\
\hline 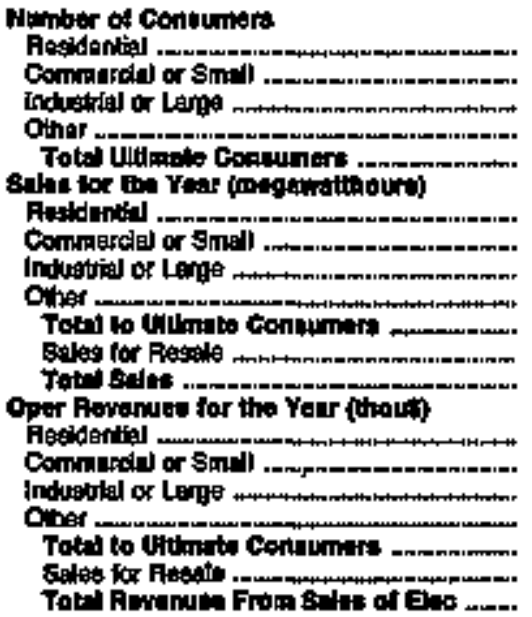 & 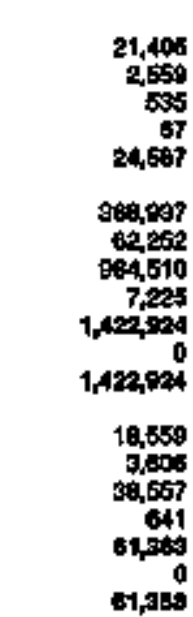 & 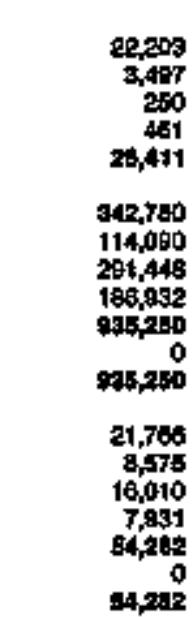 & 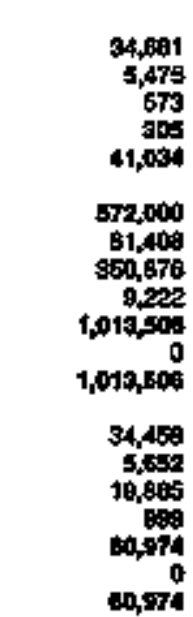 & 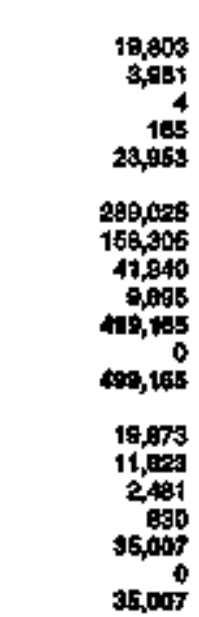 & 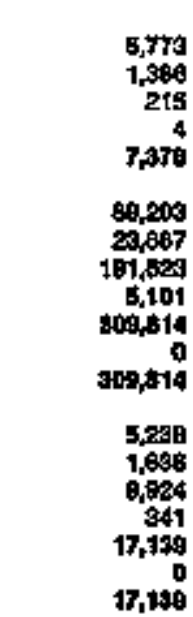 & 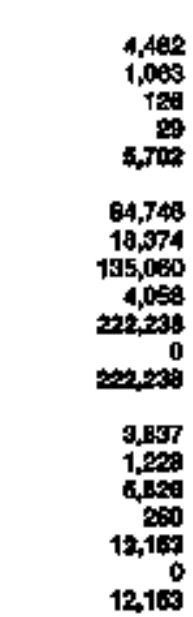 \\
\hline
\end{tabular}

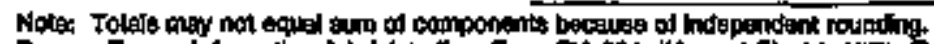

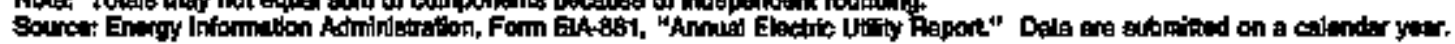


Table 25. Number of Conamers, Sales, and Operating Revenue by Major U.S. Publicly Owned Electric Utility Within State, 1994 (Continued)

\begin{tabular}{|c|c|c|c|c|c|c|}
\hline liem & $\begin{array}{l}\text { Alabama } \\
\text { City al } \\
\text { Decomber } 31\end{array}$ & $\begin{array}{c}\text { Alobame } \\
\text { Cly of } \\
\text { December at }\end{array}$ & 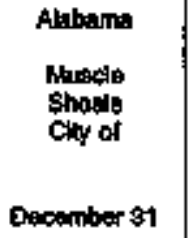 & $\begin{array}{l}\text { Albarng } \\
\text { Opeipa } \\
\text { Oby of } \\
\text { Dosember } 31\end{array}$ & 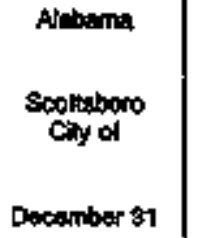 & 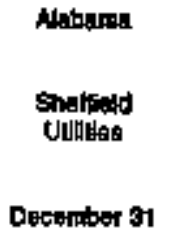 \\
\hline 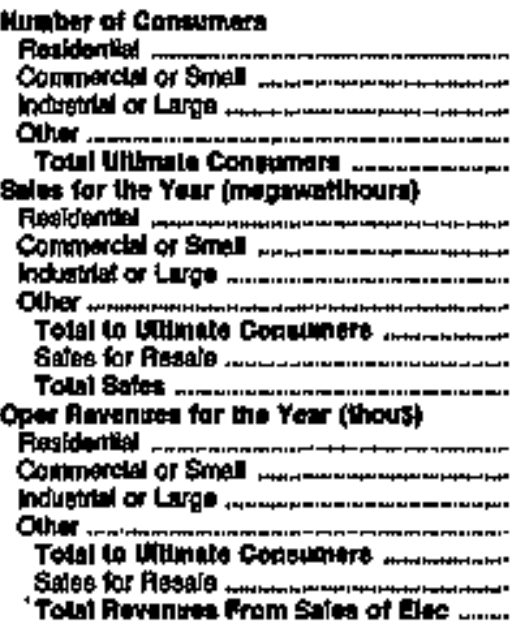 & 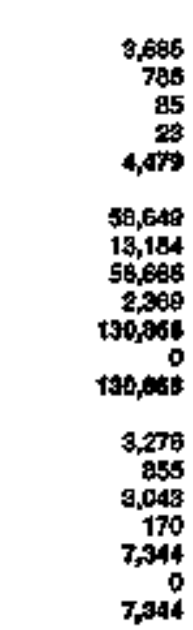 & 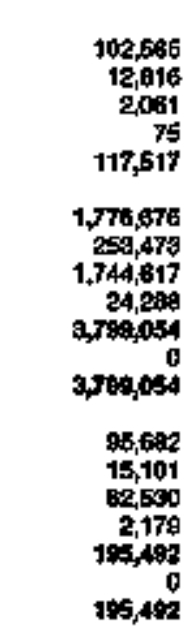 & 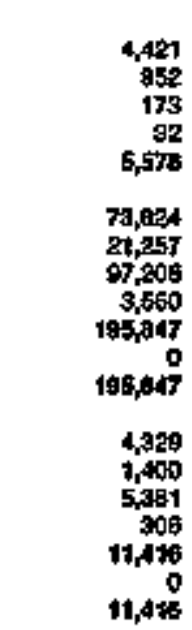 & 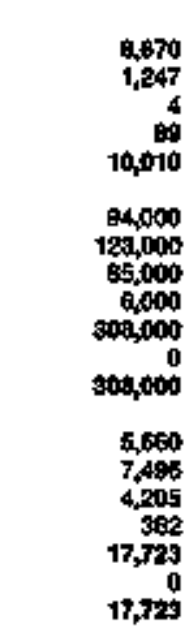 & $\begin{array}{r}6,000 \\
1,240 \\
167 \\
3 \\
7,440 \\
97,319 \\
2,771 \\
290,606 \\
3,551 \\
350,741 \\
0 \\
350,241 \\
1,724 \\
1,580 \\
10,316 \\
310 \\
17,970 \\
4 \\
17,470\end{array}$ & 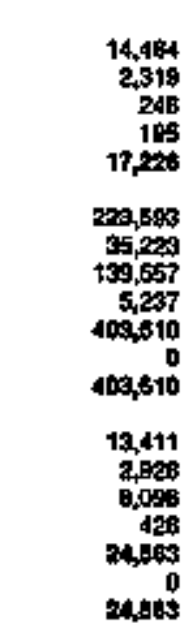 \\
\hline
\end{tabular}

\begin{tabular}{|c|c|c|c|c|c|c|}
\hline them & 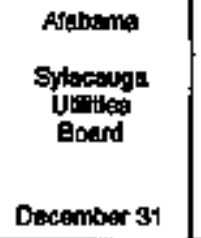 & $\begin{array}{c}\text { Nubame } \\
\text { Thioy of } \\
\text { Decty of }\end{array}$ & 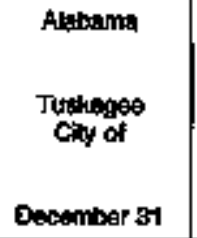 & 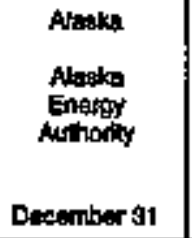 & $\begin{array}{l}\text { Alakta } \\
\text { Anchoregs } \\
\text { Chy of } \\
\text { Decomber } 31\end{array}$ & 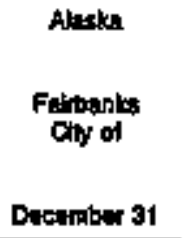 \\
\hline 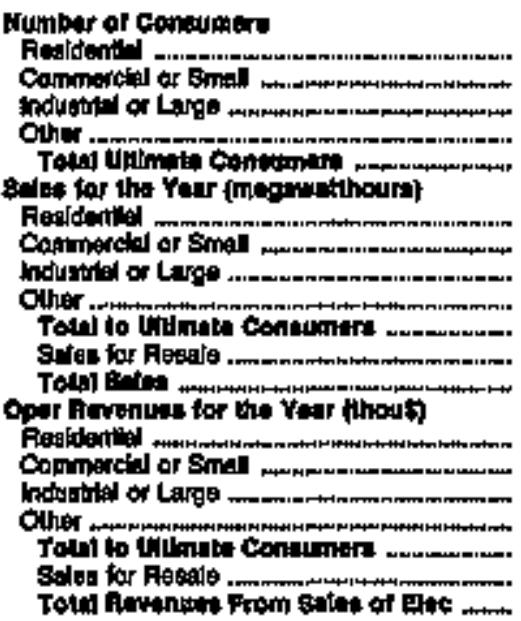 & 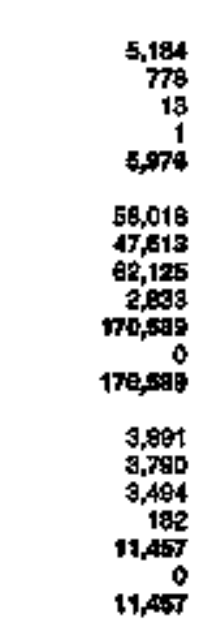 & $\begin{array}{r}5,119 \\
907 \\
94 \\
57 \\
6,241 \\
74,232 \\
21,139 \\
124,543 \\
1,370 \\
221,200 \\
0 \\
21,7600 \\
4,205 \\
1,309 \\
7,972 \\
13,360 \\
19,300\end{array}$ & 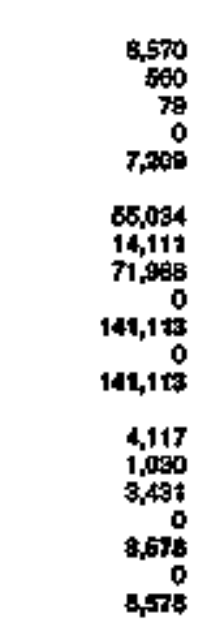 & $\begin{array}{r}0 \\
0 \\
0 \\
0 \\
0 \\
7+1,980 \\
7+1,980\end{array}$ & 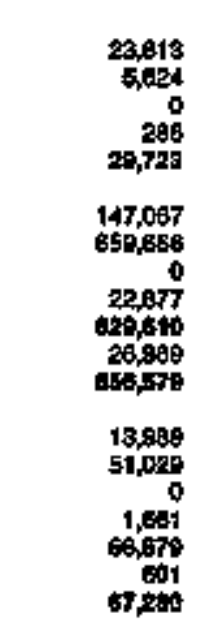 & 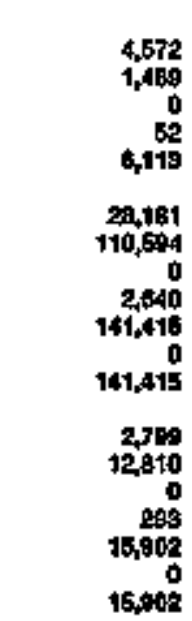 \\
\hline
\end{tabular}

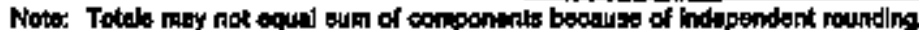

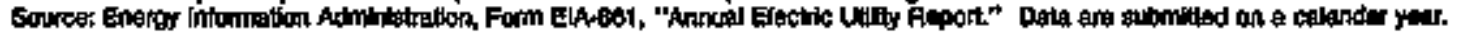


Table 26. Number of Consumers, Sales, and Operating Aovenuo by Major U.S. Publlchy Owned Etectrle Utility With'n State, 1994 (Continued)

\begin{tabular}{|c|c|c|c|c|c|c|}
\hline them & $\begin{array}{l}\text { Alaska } \\
\text { Kelchilcan } \\
\text { Cily of } \\
\text { Oecember a1 }\end{array}$ & 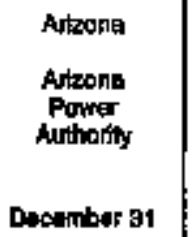 & 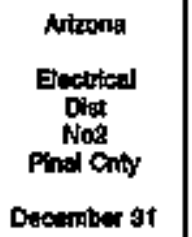 & $\begin{array}{l}\text { Arkong } \\
\text { Hose } \\
\text { City of } \\
\text { Decomber o1 }\end{array}$ & 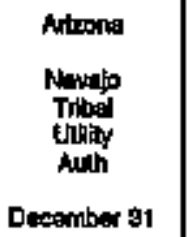 & 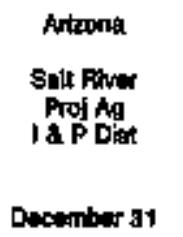 \\
\hline 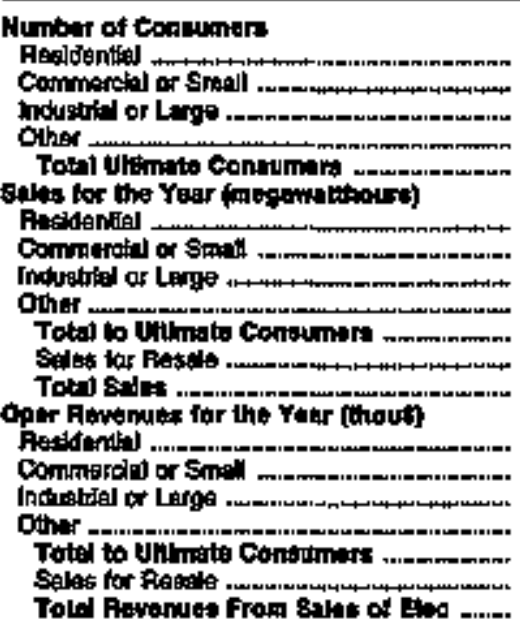 & 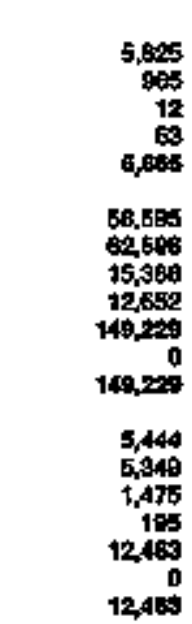 & $\begin{array}{r}0 \\
0 \\
0 \\
0 \\
0 \\
750,397 \\
758,5 \% \\
0 \\
0 \\
0 \\
0 \\
18,254 \\
10,281\end{array}$ & 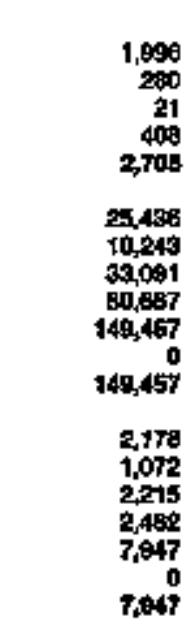 & $\begin{array}{r}12,938 \\
2,102 \\
0 \\
190 \\
15,158 \\
137,491 \\
144,579 \\
0 \\
49,308 \\
328,378 \\
701 \\
323,079 \\
11,949 \\
11,631 \\
0 \\
3,129 \\
28,609 \\
17 \\
28,625\end{array}$ & 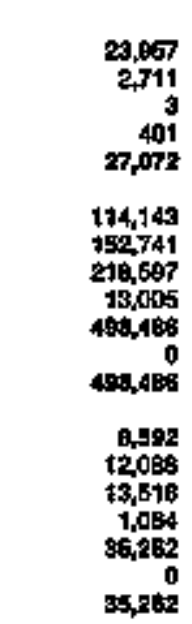 & 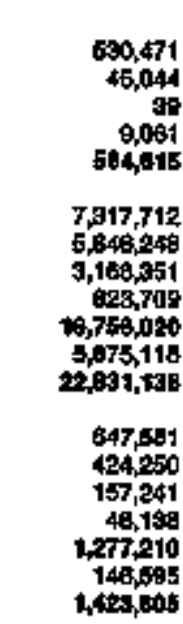 \\
\hline
\end{tabular}

\begin{tabular}{|c|c|c|c|c|c|c|}
\hline Han & 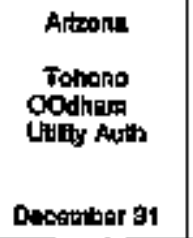 & 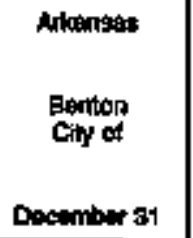 & $\begin{array}{l}\text { Aukromids } \\
\text { Bentomilia } \\
\text { City or } \\
\text { Dacomber } 31\end{array}$ & 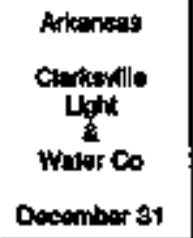 & 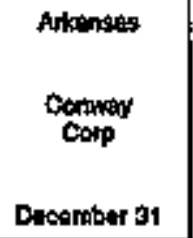 & 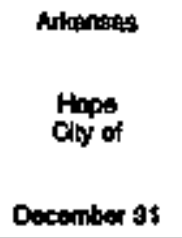 \\
\hline 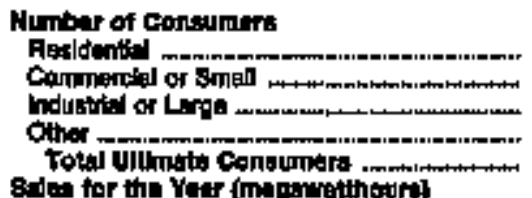 & $\begin{array}{r}2,484 \\
392 \\
1 \\
20 \\
2,967\end{array}$ & $\begin{array}{r}7,005 \\
1,001 \\
21 \\
0 \\
0,007\end{array}$ & $\begin{array}{r}6,002 \\
705 \\
170 \\
0 \\
6,477\end{array}$ & $\begin{array}{r}2,865 \\
510 \\
58 \\
0 \\
3,488\end{array}$ & $\begin{array}{r}12,848 \\
1,050 \\
68 \\
3 \\
14,572\end{array}$ & $\begin{array}{r}5,690 \\
89 \\
56 \\
0 \\
6,991\end{array}$ \\
\hline 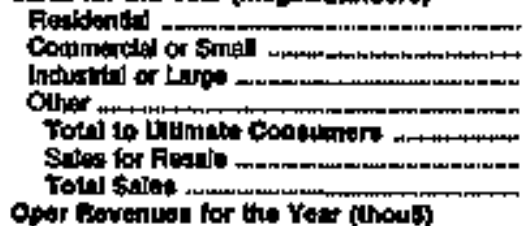 & $\begin{array}{r}17,048 \\
18,327 \\
48,033 \\
4,604 \\
90,007 \\
00 \\
00,007\end{array}$ & $\begin{array}{r}71,6 \% 8 \\
\$ 1,141 \\
34,971 \\
0 \\
197,169 \\
197,109\end{array}$ & $\begin{array}{r}38,686 \\
13,694 \\
179,513 \\
0 \\
220,058 \\
0 \\
209,035\end{array}$ & $\begin{array}{r}29,474 \\
15,096 \\
149,370 \\
0 \\
192,94 \\
102,940\end{array}$ & $\begin{array}{r}137,726 \\
7,009 \\
200,247 \\
7,896 \\
509,037 \\
0 \\
609,997\end{array}$ & 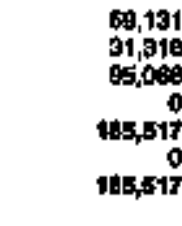 \\
\hline 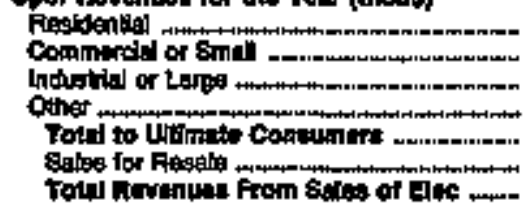 & $\begin{array}{r}1,462 \\
1,501 \\
1,420 \\
4,23 \\
7,700 \\
7,700\end{array}$ & $\begin{array}{r}7,609 \\
4,605 \\
2,281 \\
14,514 \\
14,514\end{array}$ & $\begin{array}{r}2780 \\
700 \\
6,361 \\
0 \\
0,040 \\
0 \\
0901\end{array}$ & $\begin{array}{r}1,660 \\
1,160 \\
7,350 \\
0 \\
10,008 \\
10,060\end{array}$ & $\begin{array}{r}8,256 \\
1,638 \\
13,255 \\
510 \\
28,658 \\
0 \\
28,859\end{array}$ & 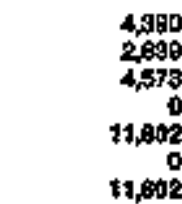 \\
\hline
\end{tabular}

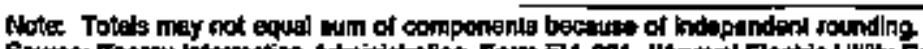

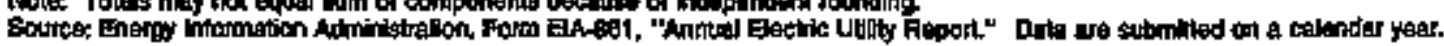


Table 25. Number of Consumers, Sales, and Oporating Revenue by Major U.S. Publledy Owmed Electric Utilly Within State, 1994 (Continued)

\begin{tabular}{|c|c|c|c|c|c|c|}
\hline ILAm & 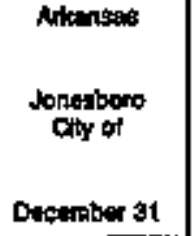 & 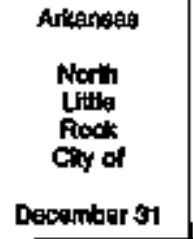 & $\begin{array}{l}\text { Alquapes } \\
\text { Oscende } \\
\text { Eijy of }\end{array}$ & $\begin{array}{c}\text { Attansas } \\
\text { Pantentid } \\
\text { Water Comm } \\
\text { Dacember \$1 }\end{array}$ & 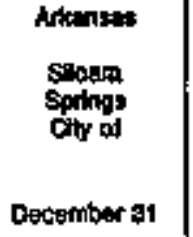 & 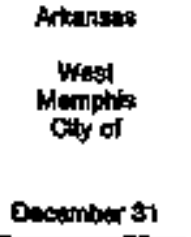 \\
\hline 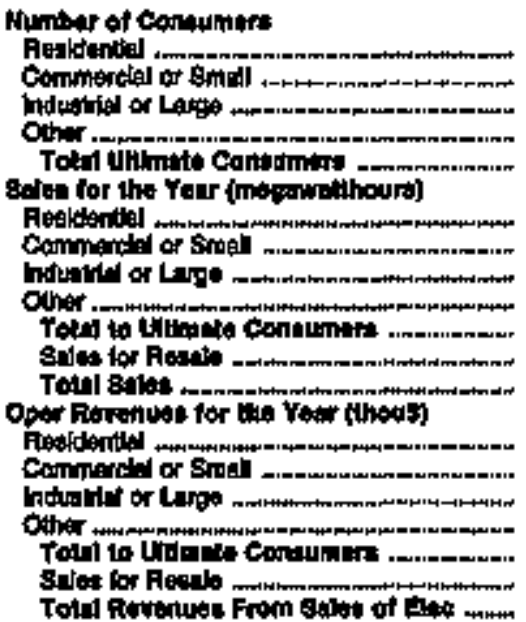 & 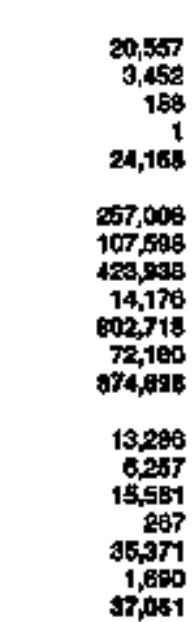 & 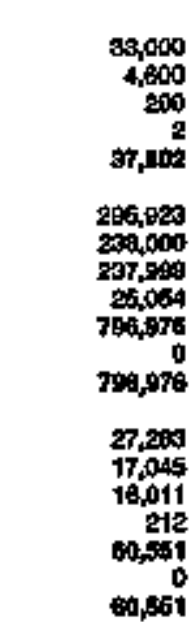 & 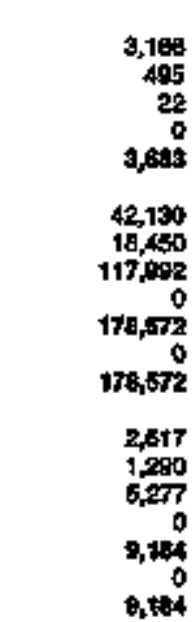 & 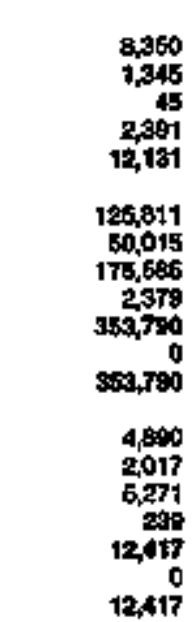 & 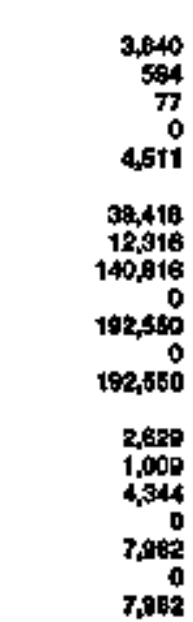 & 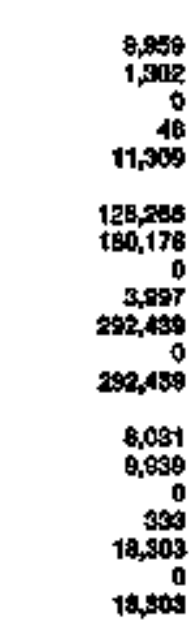 \\
\hline
\end{tabular}

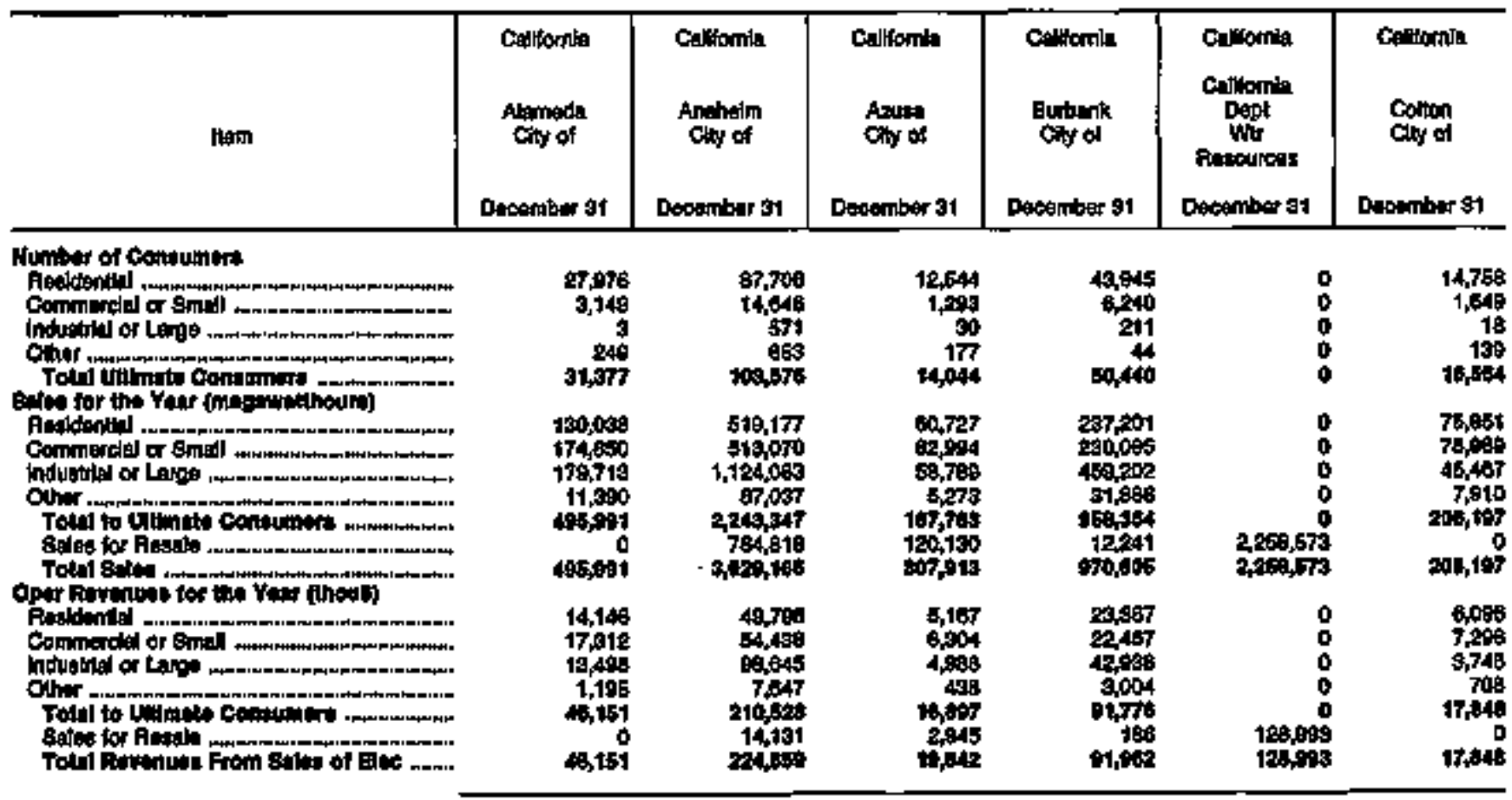

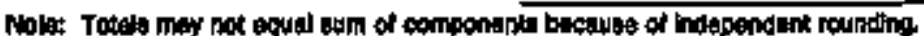

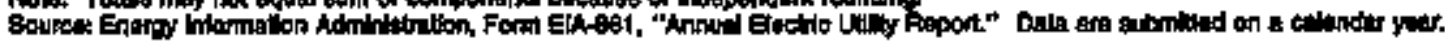


Table 25. Number of Constmers, Sales, and Operating Aevenue by Major U\$. Publioly Owned Electrit Utility Within State, 1994 (Continued)

\begin{tabular}{|c|c|c|c|c|c|c|}
\hline tem & $\begin{array}{l}\text { Ceifomid } \\
\text { Cily of } \\
\text { December } 34\end{array}$ & 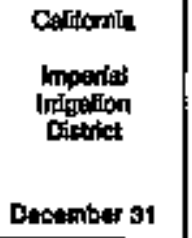 & 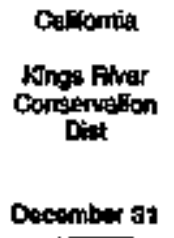 & 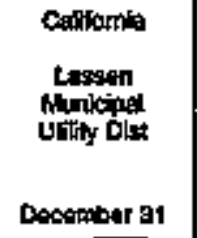 & Calomia & $\begin{array}{l}\text { Oafomia } \\
\text { Los ingelas } \\
\text { Cin of } \\
\text { Documber s1 }\end{array}$ \\
\hline 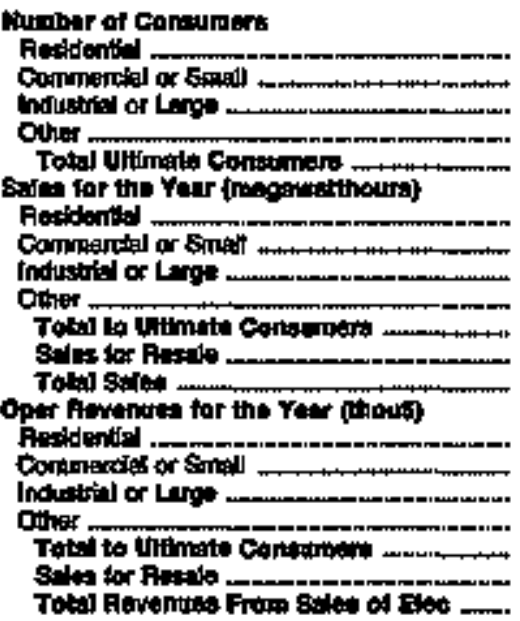 & 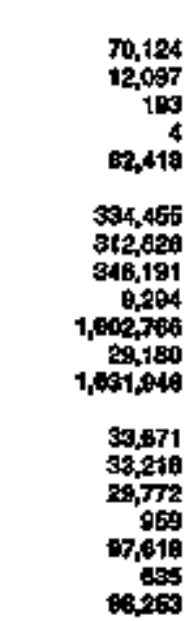 & 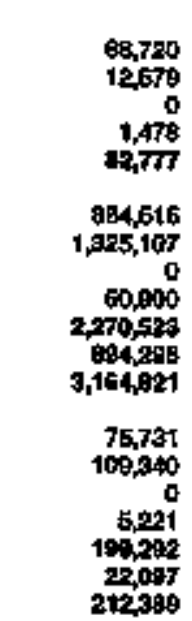 & $\begin{array}{l}46,57 \\
44,57\end{array}$ & $\begin{array}{r}9,291 \\
1,198 \\
3 \\
1,498 \\
10,920 \\
68,174 \\
41,408 \\
19,617 \\
5,616 \\
132,711 \\
132,711 \\
0 \\
6,319 \\
4,698 \\
2,195 \\
679 \\
13,993 \\
0 \\
19,093\end{array}$ & 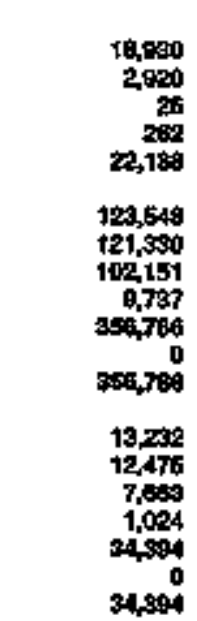 & 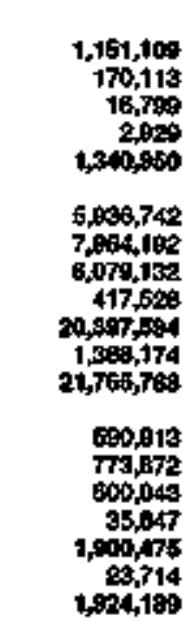 \\
\hline
\end{tabular}

\begin{tabular}{|c|c|c|c|c|c|c|}
\hline trem & 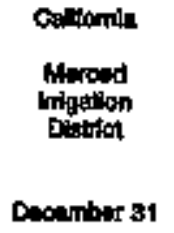 & 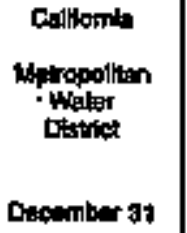 & 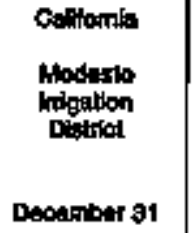 & 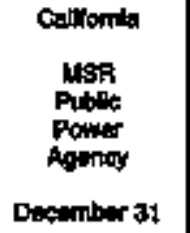 & 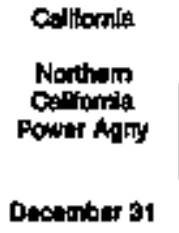 & 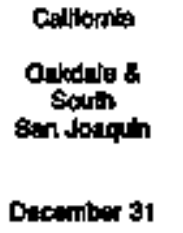 \\
\hline 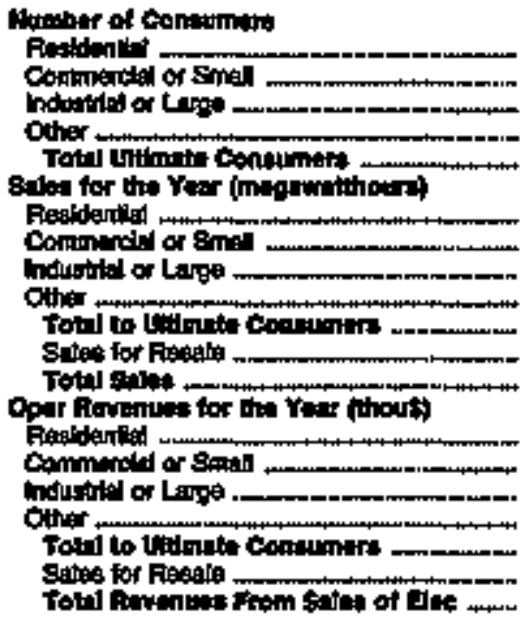 & & $\begin{array}{r}0 \\
0 \\
0 \\
0 \\
0 \\
261,724 \\
30+, 724 \\
0 \\
0 \\
0 \\
0 \\
0 \\
12055 \\
12,056\end{array}$ & 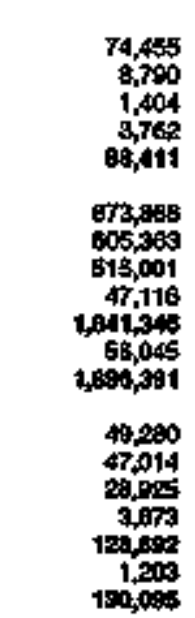 & $\begin{array}{r}0 \\
0 \\
0 \\
0 \\
0 \\
1,411,686 \\
1,411,506\end{array}$ & $\begin{array}{r}0 \\
0 \\
0 \\
0 \\
0 \\
2,397,969 \\
2857969\end{array}$ & $\begin{array}{r}0 \\
0 \\
0 \\
0 \\
0 \\
310,386 \\
510,125\end{array}$ \\
\hline
\end{tabular}

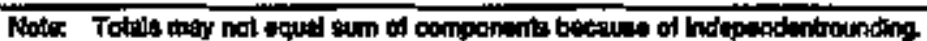

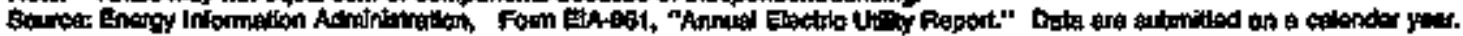


Table 25. Number of Consumers, Sales, and Operating Revenue by Major US. Publicly Owned Electric Ut\#ty Within State, 1994 (Contlimede)

\begin{tabular}{|c|c|c|c|c|c|c|}
\hline Inem & 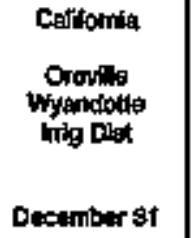 & 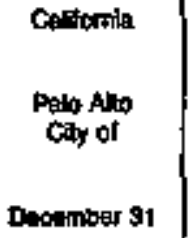 & $\begin{array}{c}\text { Callomba } \\
\text { Papadera } \\
\text { City of } \\
\text { Decanber 3t }\end{array}$ & $\begin{array}{l}\text { Celifarila } \\
\text { Flacer } \\
\text { Courty } \\
\text { Wheter } \\
\text { Apency } \\
\text { Docomber } 31\end{array}$ & 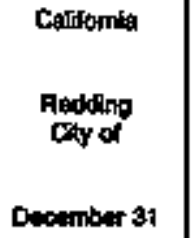 & 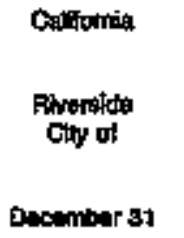 \\
\hline 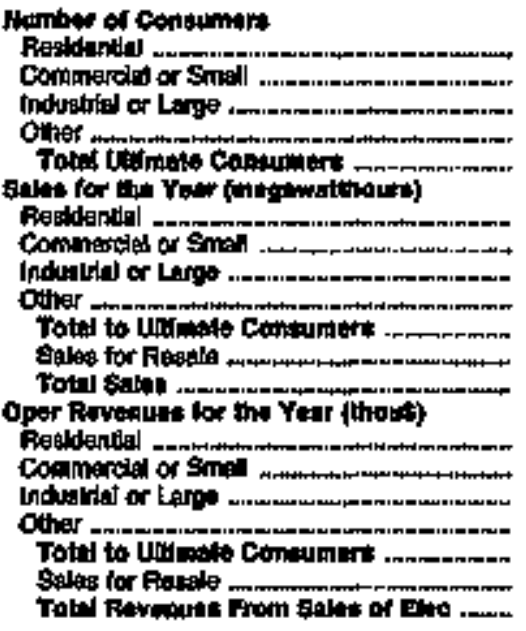 & $\begin{array}{r}0 \\
0 \\
0 \\
0 \\
0 \\
0 \\
0 \\
0 \\
0 \\
0 \\
035,927 \\
205,928\end{array}$ & 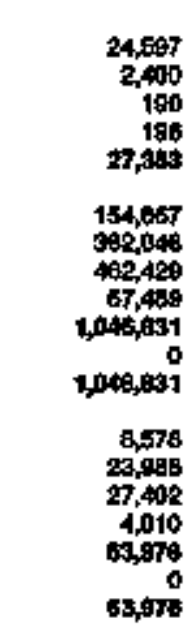 & 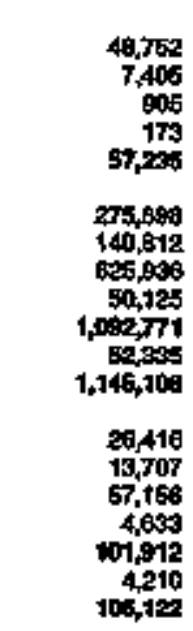 & $\begin{array}{r}0 \\
0 \\
0 \\
0 \\
0 \\
45 t, 680 \\
451,6=0\end{array}$ & 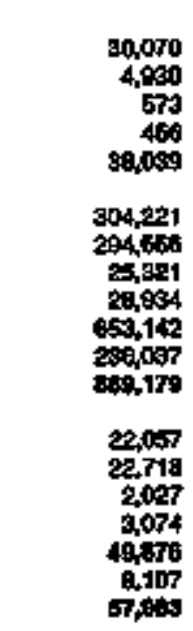 & 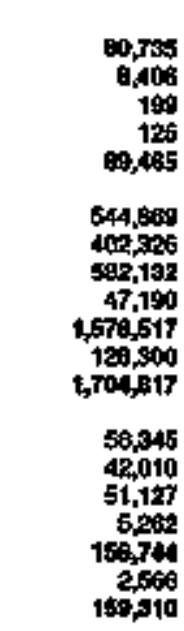 \\
\hline
\end{tabular}

\begin{tabular}{|c|c|c|c|c|c|c|}
\hline mom & 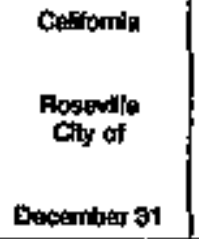 & 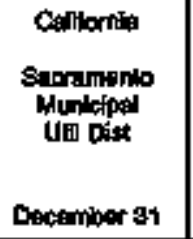 & 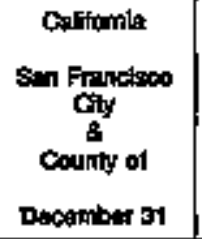 & 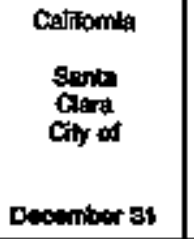 & 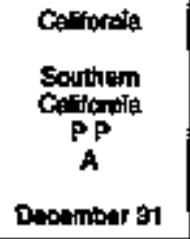 & 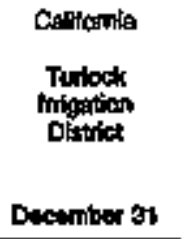 \\
\hline 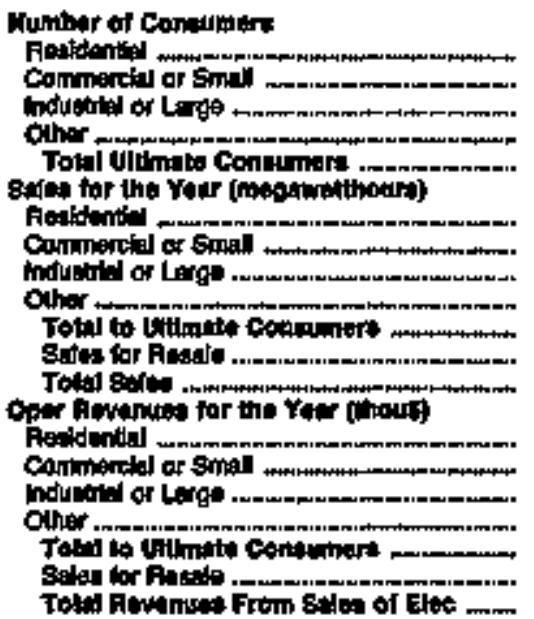 & 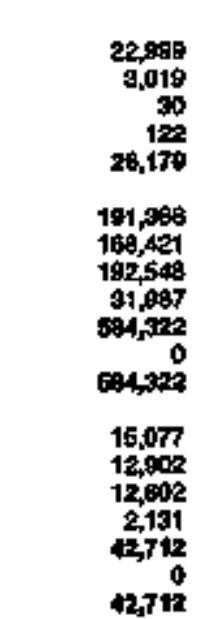 & 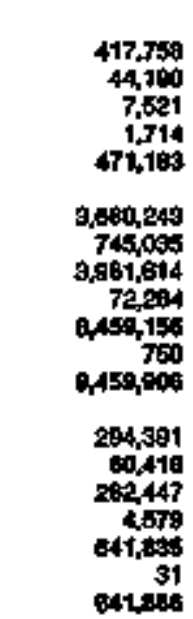 & 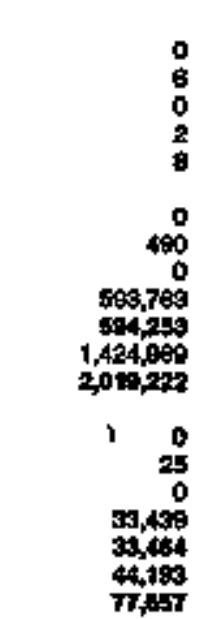 & 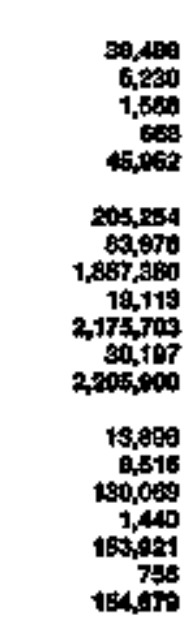 & 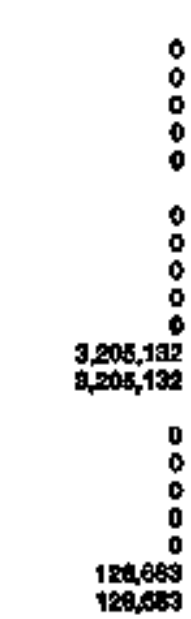 & 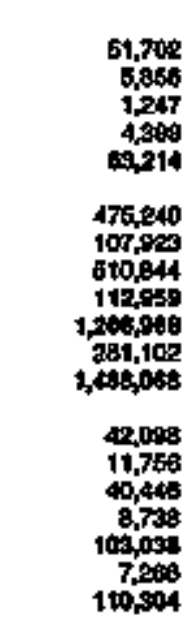 \\
\hline
\end{tabular}

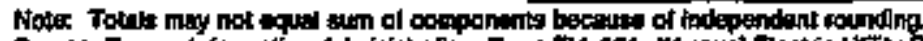

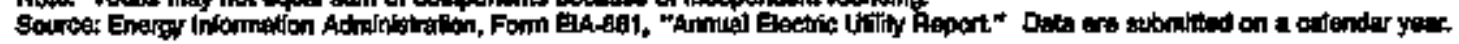


Table 25. Number of Contumers, Sales, and Operating Revenue by Major U.S. Publicly Owhed Eloctric Utidty Within State, 1994 (Continued)

\begin{tabular}{|c|c|c|c|c|c|c|}
\hline Itean & $\begin{array}{l}\text { Cetitomita } \\
\text { Vomon } \\
\text { City of } \\
\text { Decentuer } 31\end{array}$ & 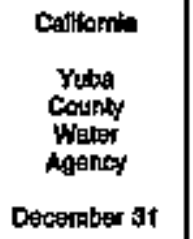 & 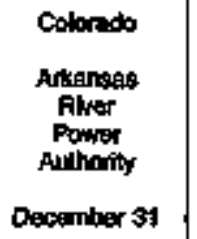 & $\begin{array}{l}\text { Colorado } \\
\text { Crlomedo } \\
\text { Sping: } \\
\text { Chy of } \\
\text { Decamper \$1 }\end{array}$ & $\begin{array}{l}\text { Colonado } \\
\text { Fort Collin: } \\
\text { Cyy of } \\
\text { Degrmber } 31\end{array}$ & $\begin{array}{l}\text { Colorido } \\
\text { Fort Horgur } \\
\text { Glyy of }\end{array}$ \\
\hline 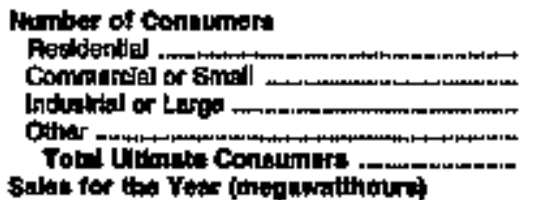 & $\begin{array}{r}27 \\
1,000 \\
000 \\
105 \\
2,071\end{array}$ & $\begin{array}{l}0 \\
0 \\
0 \\
0 \\
0\end{array}$ & $\begin{array}{l}0 \\
0 \\
0 \\
0 \\
0\end{array}$ & $\begin{array}{r}\$ 34,502 \\
17,045 \\
344 \\
300 \\
15,751\end{array}$ & $\begin{array}{r}35,932 \\
5,272 \\
11 \\
1 \\
41,216\end{array}$ & $\begin{array}{r}5,171 \\
395 \\
0 \\
78 \\
5,609\end{array}$ \\
\hline 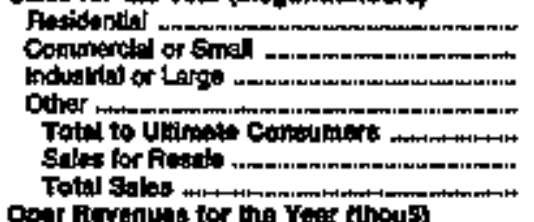 & $\begin{array}{r}123 \\
220,112 \\
790,745 \\
9,440 \\
1,092,400 \\
0 \\
1,0032,420\end{array}$ & $\begin{array}{r}0 \\
0 \\
0 \\
0 \\
0 \\
090,458 \\
090,450\end{array}$ & $\begin{array}{r}0 \\
0 \\
0 \\
0 \\
0 \\
208,009 \\
202,030\end{array}$ & $\begin{array}{r}779,800 \\
785,485 \\
1,315,7 \% 9 \\
84,347 \\
3,159,401 \\
781,044 \\
3,340,446\end{array}$ & $\begin{array}{r}202,349 \\
304,042 \\
360,907 \\
2,050 \\
900,320 \\
000,329\end{array}$ & $\begin{array}{r}87,525 \\
91,286 \\
0 \\
6,084 \\
+1,776 \\
151,776\end{array}$ \\
\hline 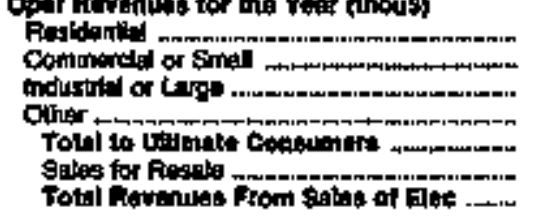 & $\begin{array}{r}3 \\
13,293 \\
39, \mathrm{BSO} \\
6006 \\
59,045 \\
63,045\end{array}$ & $\begin{array}{r}0 \\
0 \\
0 \\
0 \\
0 \\
10,864 \\
10,854\end{array}$ & $\begin{array}{r}0 \\
0 \\
0 \\
0 \\
0 \\
10,124 \\
\mathbf{1 0 , 1 2 4}\end{array}$ & $\begin{array}{r}5,109 \\
12,814 \\
54,913 \\
6,148 \\
102,964 \\
5,854 \\
180,1839\end{array}$ & 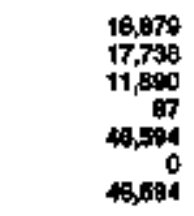 & $\begin{array}{r}2,425 \\
3,905 \\
0 \\
205 \\
8,505 \\
0 \\
6,5065\end{array}$ \\
\hline
\end{tabular}

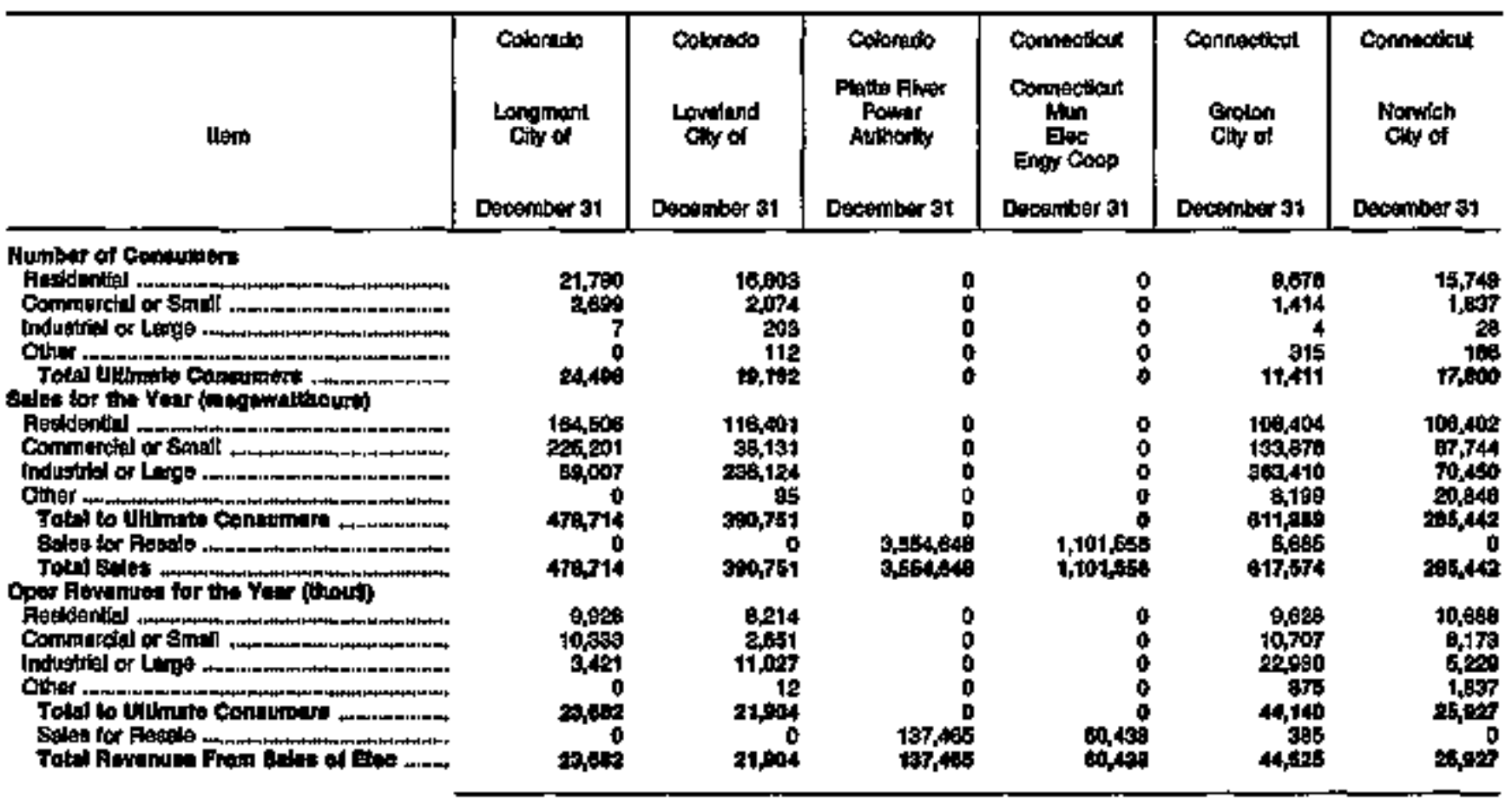

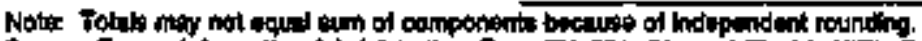

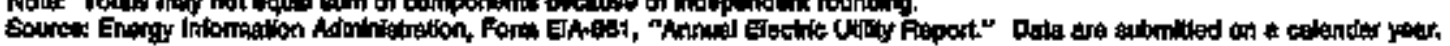


Table 25. Number of Consumers, Sales, and Operating Revenue by Malor U.S. Publicly Owned Electirfo Utalty Within State, 1994 (Continued)

\begin{tabular}{|c|c|c|c|c|c|c|}
\hline "tem & 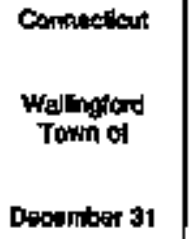 & $\begin{array}{l}\text { Delanest } \\
\text { Dover } \\
\text { Cty 여 } \\
\text { Decomber } 31\end{array}$ & 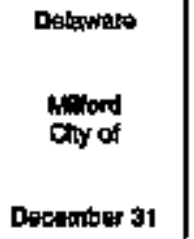 & $\begin{array}{l}\text { Oalanise } \\
\text { Newulk } \\
\text { City of } \\
\text { Decamber } 31\end{array}$ & $\begin{array}{l}\text { Florids } \\
\text { Berton } \\
\text { Etry of } \\
\text { Denember } 31\end{array}$ & 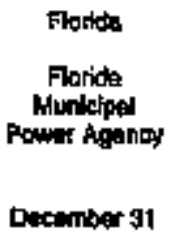 \\
\hline 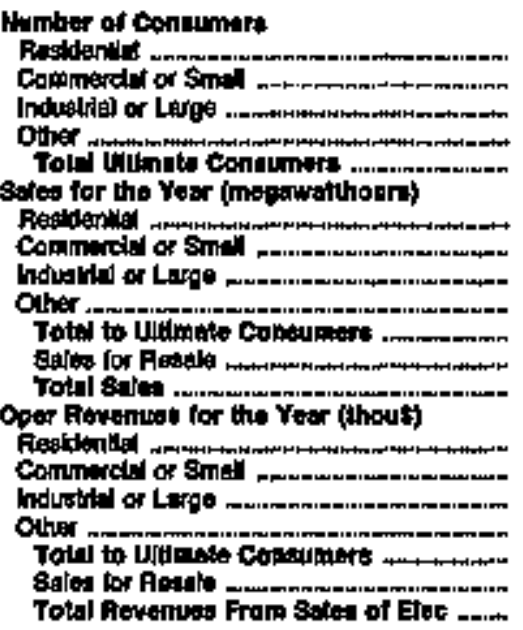 & $\begin{array}{r}18,786 \\
2,777 \\
30 \\
124 \\
21,717 \\
167,701 \\
143,053 \\
208,972 \\
10,195 \\
580,011 \\
0 \\
652,011 \\
13,655 \\
11,900 \\
13,058 \\
1,059 \\
40,353 \\
0 \\
40,365\end{array}$ & 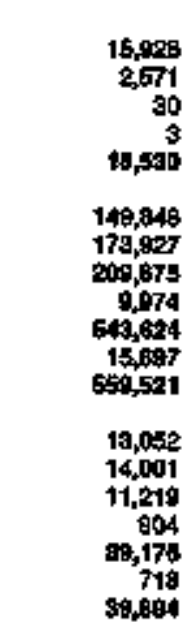 & 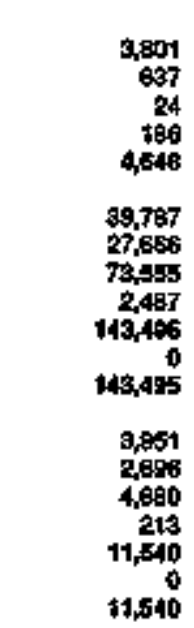 & $\begin{array}{r}8,428 \\
1,047 \\
30 \\
0 \\
9,500 \\
72,0,08 \\
52,441 \\
158,000 \\
0 \\
292,029 \\
0 \\
292,025 \\
0,036 \\
9,986 \\
10,135 \\
0 \\
21,157 \\
0 \\
21,167\end{array}$ & 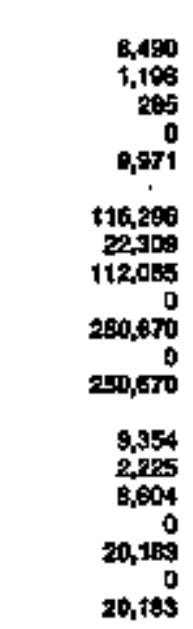 & $\begin{array}{r}0 \\
0 \\
0 \\
0 \\
0 \\
155,517 \\
169,517\end{array}$ \\
\hline
\end{tabular}

\begin{tabular}{|c|c|c|c|c|c|c|}
\hline Ilan & $\begin{array}{c}\text { Elortete } \\
\text { Fort Floces } \\
\text { Oitios } \\
\text { Auth } \\
\text { Doximber at }\end{array}$ & 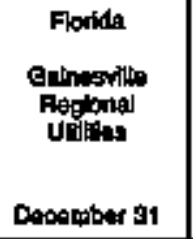 & $\begin{array}{l}\text { Florida } \\
\text { Homeglead } \\
\text { Ciny of }\end{array}$ & 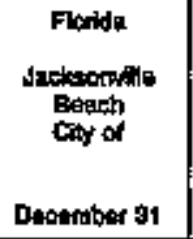 & 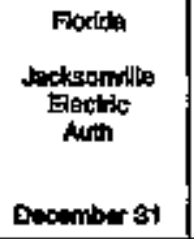 & $\begin{array}{l}\text { Flatida } \\
\text { Kay Wool } \\
\text { City of } \\
\text { Doonmber } 91\end{array}$ \\
\hline 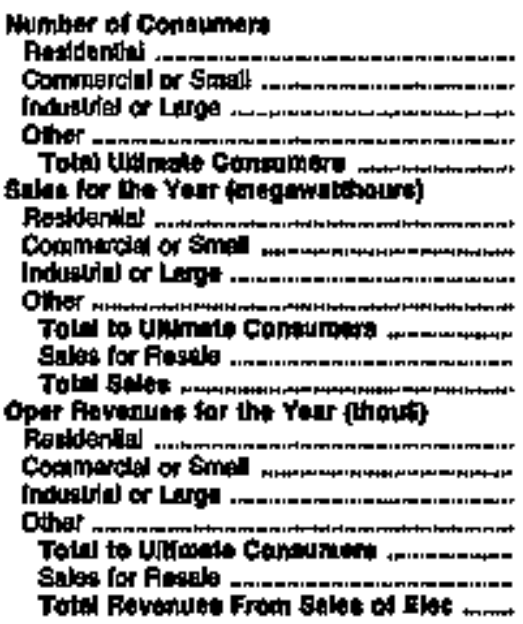 & 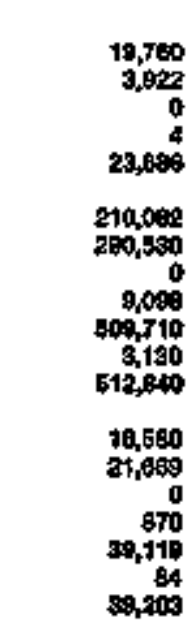 & 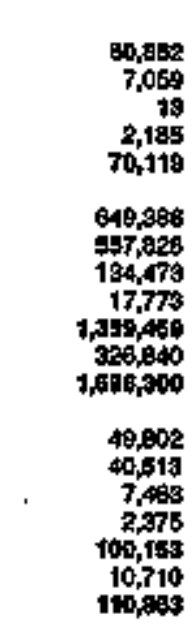 & 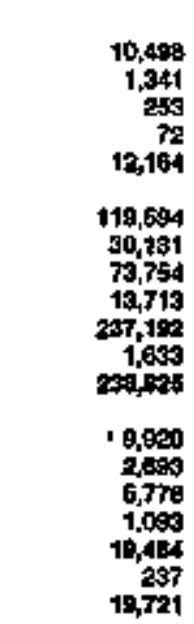 & $\begin{array}{r}24,445 \\
3,616 \\
0 \\
499 \\
25,550 \\
324,783 \\
193,177 \\
0 \\
4,475 \\
51,455 \\
0 \\
512,455 \\
24,164 \\
15,667 \\
0 \\
458 \\
4,16 \\
0 \\
40,195\end{array}$ & 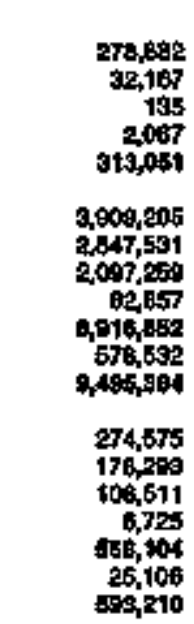 & 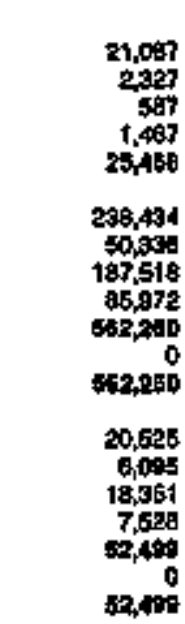 \\
\hline
\end{tabular}

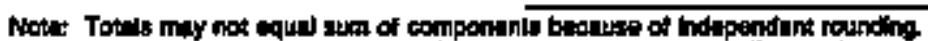

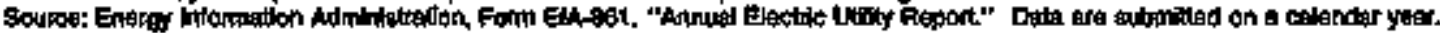


Table 25. Number of Conaumers, Sales, and Operating Revenue by Major U.S. Pubilcy Owned Electric Utllity Whin state, 1994 (Continued)

\begin{tabular}{|c|c|c|c|c|c|c|}
\hline Ilam & 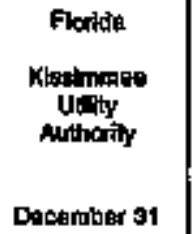 & $\begin{array}{l}\text { Foxita } \\
\text { Loke Horth } \\
\text { Chy of }\end{array}$ & 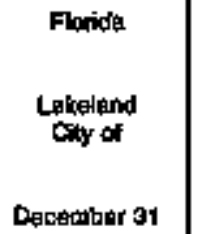 & 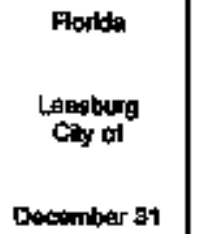 & 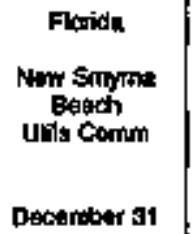 & $\begin{array}{l}\text { Flosfla } \\
\text { Cosaly } \\
\text { City of } \\
\text { Decenter } 31\end{array}$ \\
\hline 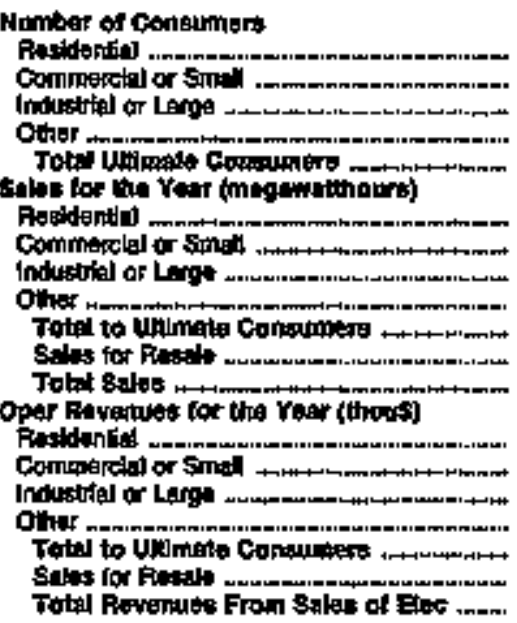 & 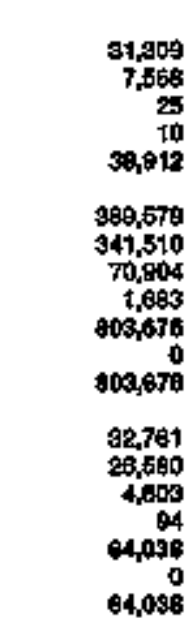 & 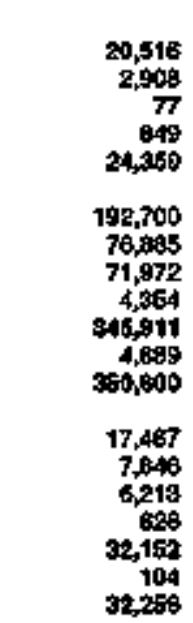 & 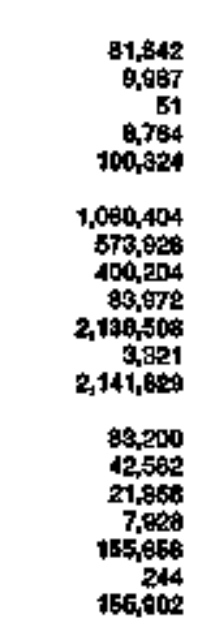 & $\begin{array}{r}14,302 \\
2,722 \\
0 \\
t \\
77,025 \\
165,301 \\
204,215 \\
0 \\
1,869 \\
371,394 \\
0 \\
371,394 \\
12,605 \\
14,745 \\
0 \\
181 \\
27,659 \\
0 \\
27,509\end{array}$ & 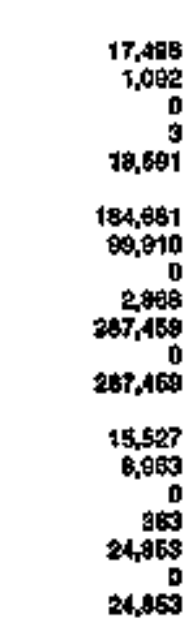 & 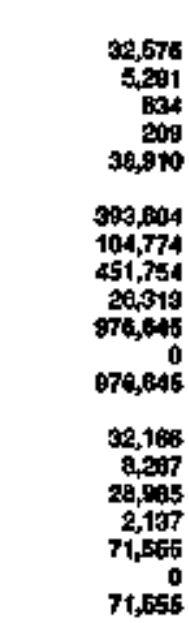 \\
\hline
\end{tabular}

\begin{tabular}{|c|c|c|c|c|c|c|}
\hline men & 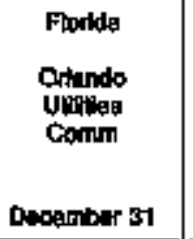 & $\begin{array}{l}\text { Elopida } \\
\text { Oulnoy } \\
\text { Chy of } \\
\text { Desambar } 31\end{array}$ & 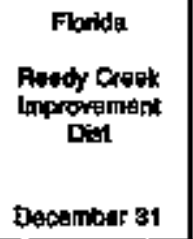 & $\begin{array}{l}\text { Forida } \\
\text { es cloud } \\
\text { Ciy of } \\
\text { December } 91\end{array}$ & 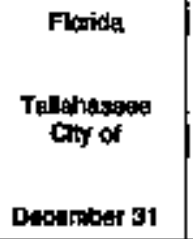 & $\begin{array}{l}\text { Fiorids } \\
\text { Vorg } \\
\text { Esach } \\
\text { City of } \\
\text { Detentom } 31\end{array}$ \\
\hline 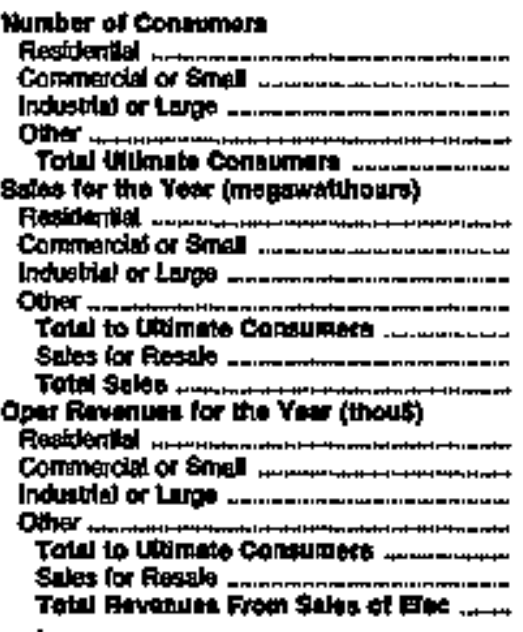 & 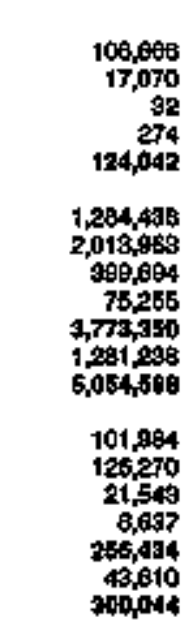 & 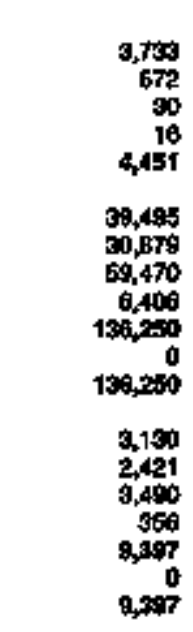 & 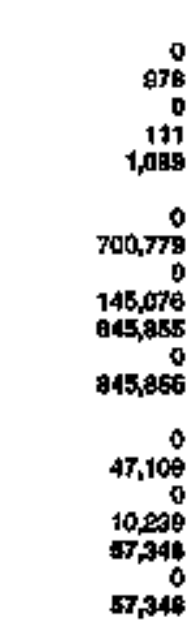 & $\begin{array}{r}13,561 \\
1,300 \\
119 \\
0 \\
14,979 \\
169,127 \\
16,705 \\
64,013 \\
0 \\
240,825 \\
240,025 \\
14,979 \\
1,814 \\
4,887 \\
0 \\
21,400 \\
0 \\
21,400\end{array}$ & 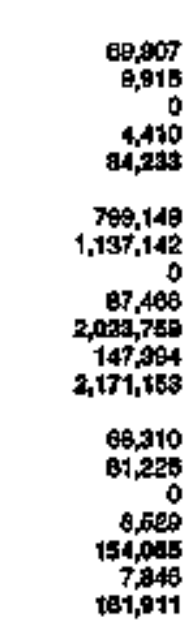 & 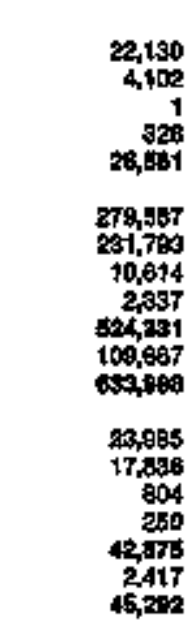 \\
\hline
\end{tabular}

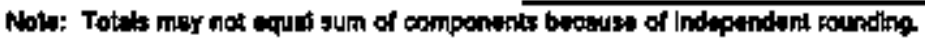

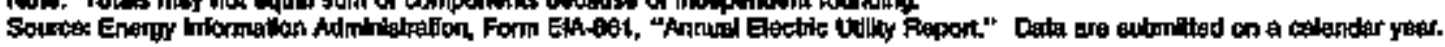


Table 25. Number of Consumera, Sales, and Operating Revenue by Mejor U.S.

Publiefy Owned Eleotrio Utilly Wittin State, 1994 (Contimued)

\begin{tabular}{|c|c|c|c|c|c|c|}
\hline Ilem & 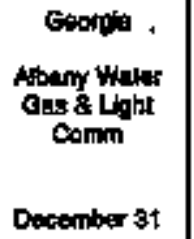 & 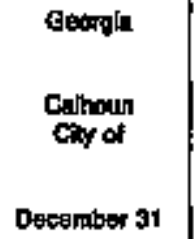 & 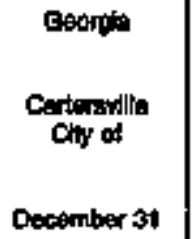 & 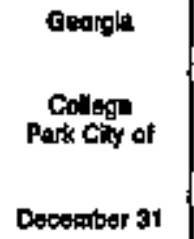 & 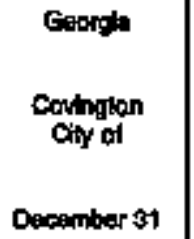 & 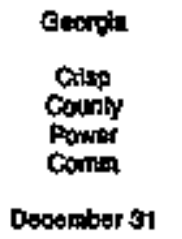 \\
\hline 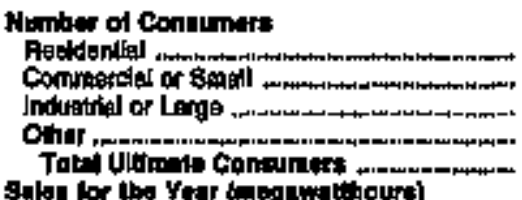 & $\begin{array}{r}31,000 \\
4,000 \\
35 \\
3,805 \\
40,800\end{array}$ & $\begin{array}{r}2780 \\
671 \\
55 \\
107 \\
3,819\end{array}$ & $\begin{array}{r}4,11090 \\
1,0020 \\
300 \\
1 \\
5,200\end{array}$ & $\begin{array}{r}9300 \\
757 \\
0 \\
0 \\
74,057\end{array}$ & $\begin{array}{r}8,409 \\
1,702 \\
7 \\
7,6007\end{array}$ & $\begin{array}{r}9,405 \\
1,605 \\
71 \\
118 \\
6,454\end{array}$ \\
\hline 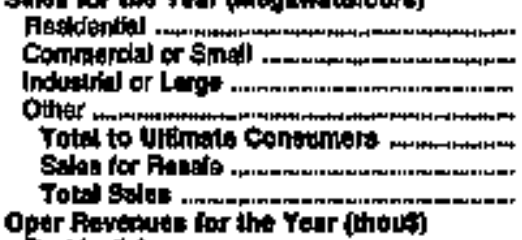 & $\begin{array}{r}308,292 \\
470,319 \\
0,509 \\
17,899 \\
107,102 \\
087,102\end{array}$ & $\begin{array}{r}27,200 \\
48,535 \\
2002,719 \\
24,045 \\
321,095 \\
321,006\end{array}$ & 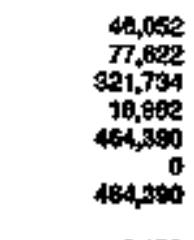 & $\begin{array}{r}95,495 \\
142,184 \\
0 \\
0 \\
234,509 \\
0 \\
244,609\end{array}$ & $\begin{array}{r}73,406 \\
61,030 \\
67,497 \\
0 \\
211,679 \\
211,073\end{array}$ & 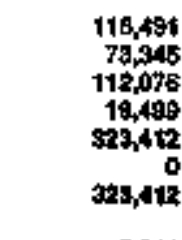 \\
\hline 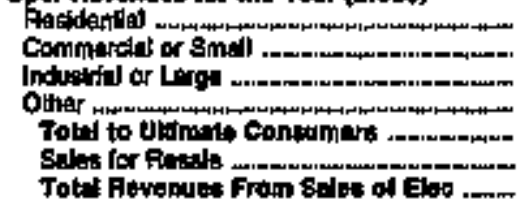 & 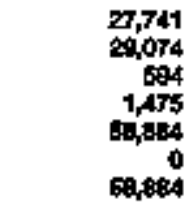 & $\begin{array}{r}1,651 \\
3,509 \\
11,761 \\
1,658 \\
1,600 \\
00 \\
18,909\end{array}$ & $\begin{array}{r}3,1 \mathrm{Bg} \\
8,107 \\
16,050 \\
1,891 \\
25,701 \\
0 \\
25,731\end{array}$ & $\begin{array}{r}6,369 \\
10,190 \\
0 \\
0 \\
10,000 \\
16,530\end{array}$ & $\begin{array}{r}5,350 \\
7,170 \\
2,310 \\
0 \\
15,050 \\
15,0 \\
150\end{array}$ & $\begin{array}{r}6,644 \\
1,042 \\
6,001 \\
1,197 \\
17,764 \\
17,794\end{array}$ \\
\hline
\end{tabular}

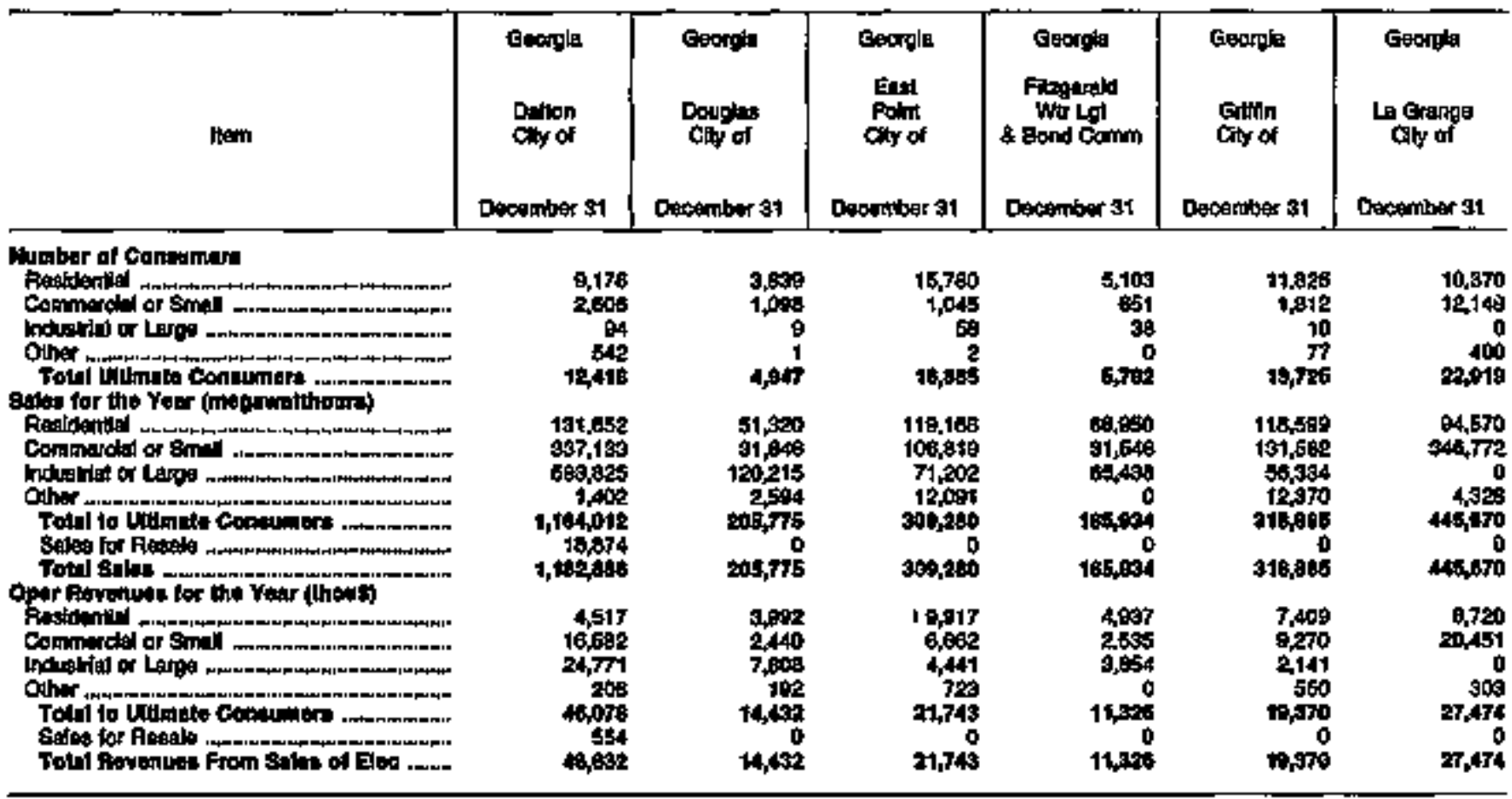

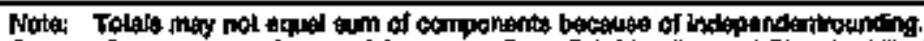

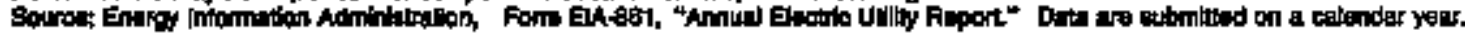


Table 25. Mumber of Consumera, Sales, and Operating Fevenue by Major U.S. Publkly Ownod Electric Utilly Whtin State, 1994 (Continued)

\begin{tabular}{|c|c|c|c|c|c|c|}
\hline them & 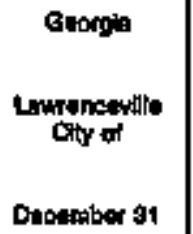 & $\begin{array}{l}\text { Georgle } \\
\text { Mejotta } \\
\text { City of } \\
\text { Decombar } 31\end{array}$ & $\begin{array}{l}\text { Geonga } \\
\text { Moultilo } \\
\text { City of } \\
\text { December } 31\end{array}$ & $\begin{array}{l}\text { Eergla } \\
\text { Munichpigl } \\
\text { Elvetris } \\
\text { Authority } \\
\text { Dosember a1 }\end{array}$ & 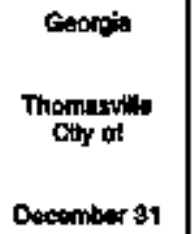 & 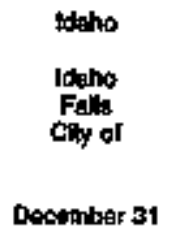 \\
\hline 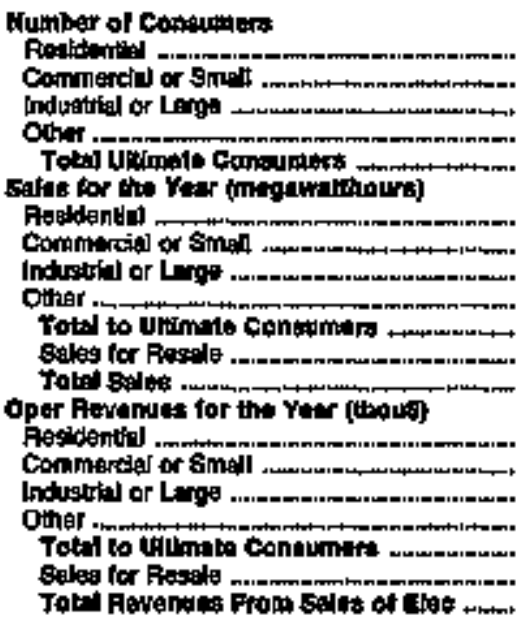 & $\begin{array}{r}6,687 \\
1,067 \\
0 \\
0 \\
7,724 \\
70,311 \\
125,160 \\
0 \\
0 \\
19,4,497 \\
0 \\
196,497 \\
6,209 \\
0,037 \\
0 \\
0 \\
14,245 \\
14,245\end{array}$ & 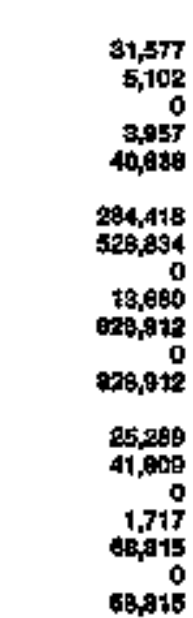 & 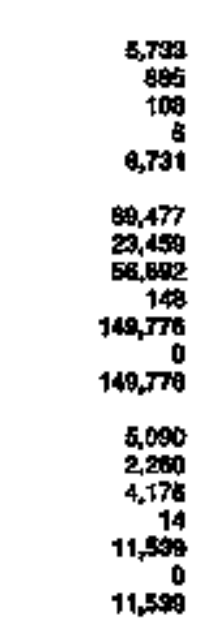 & 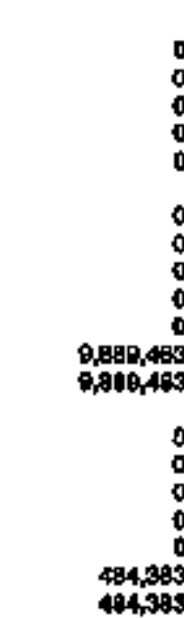 & 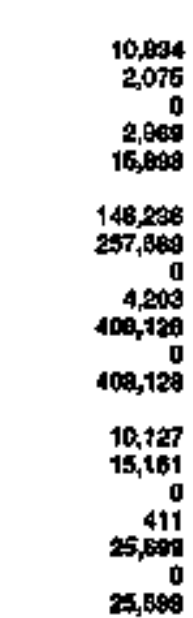 & 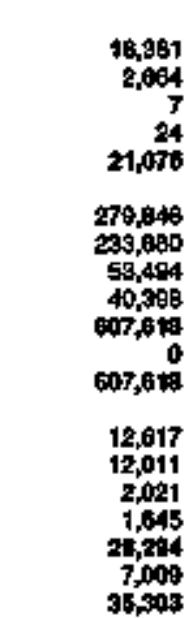 \\
\hline
\end{tabular}

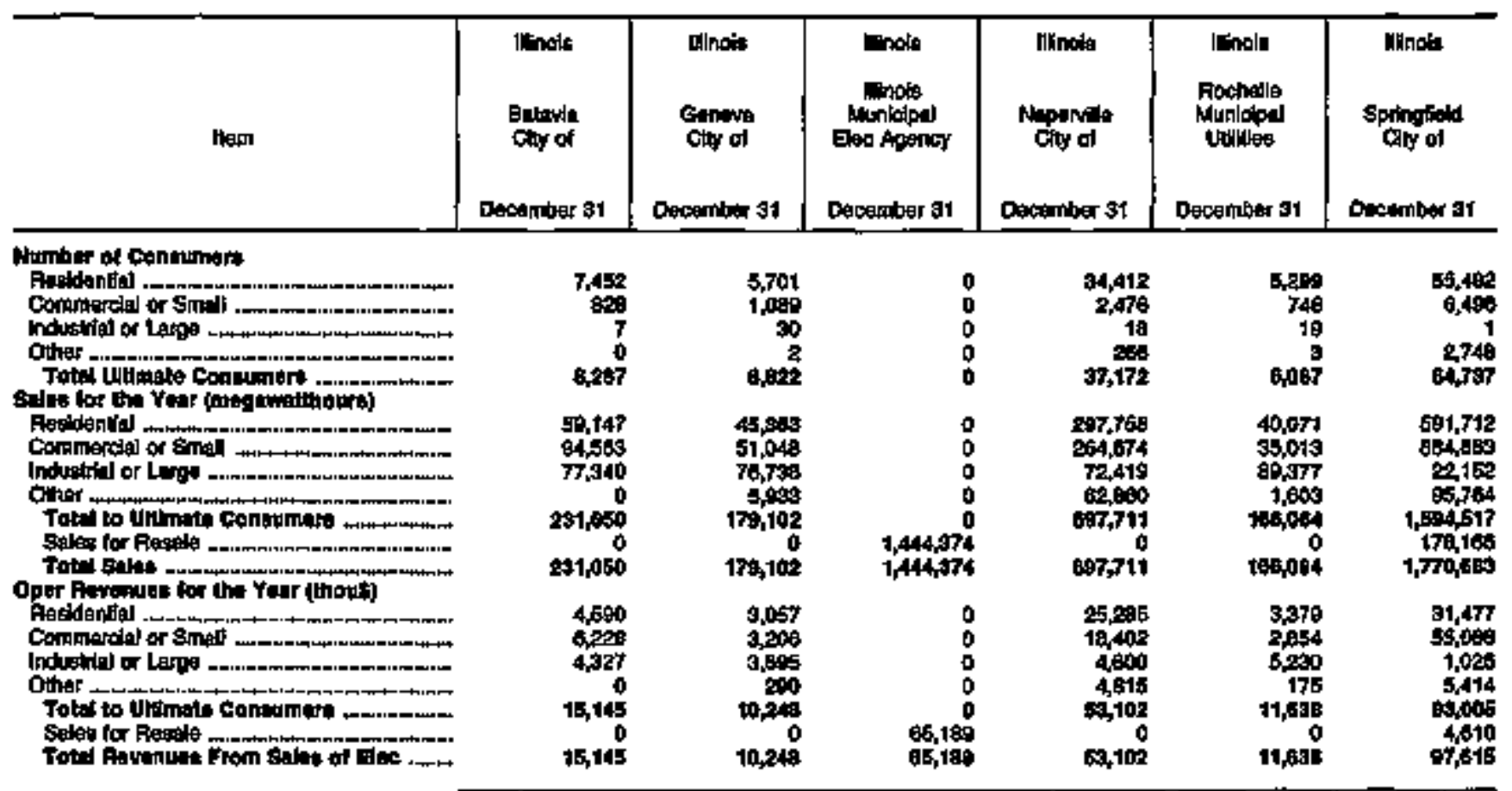

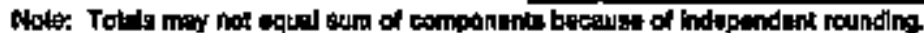

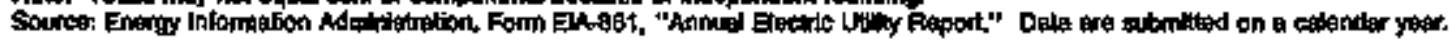


Table 25. Number of Consumers, Sales, and Operating Reverue by Major US.

Publicly Owned Electric (tillity Within State, 1994 (Continued)

\begin{tabular}{|c|c|c|c|c|c|c|}
\hline Hem & 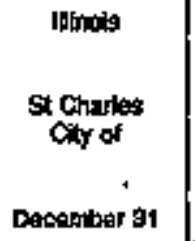 & $\begin{array}{l}\text { Indiane } \\
\text { Anderson } \\
\text { City of } \\
\text { Ducember is }\end{array}$ & 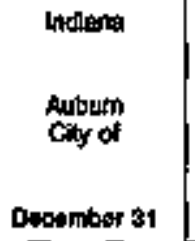 & 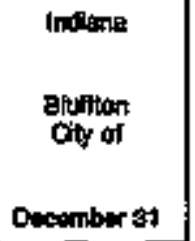 & 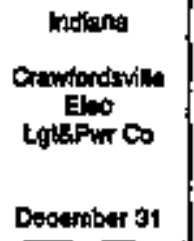 & 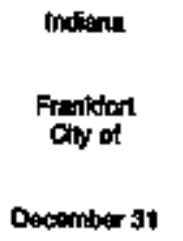 \\
\hline 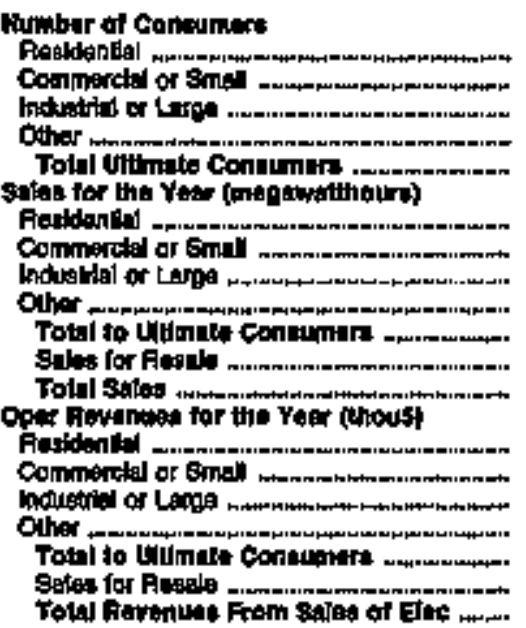 & 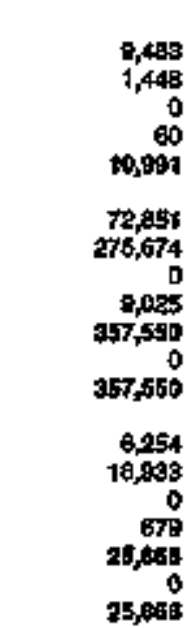 & 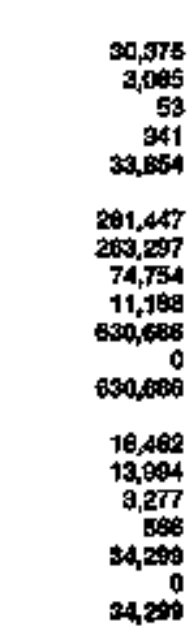 & 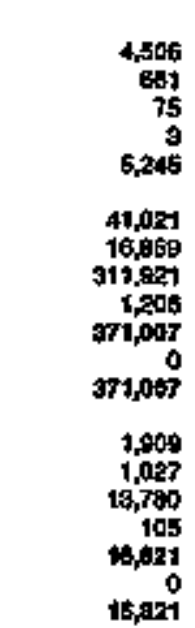 & 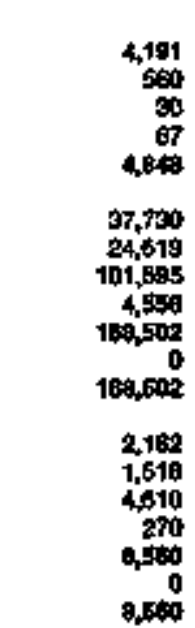 & 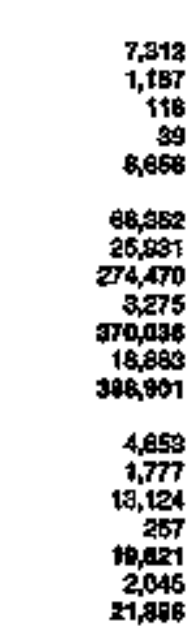 & 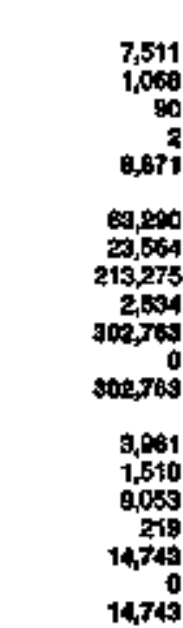 \\
\hline
\end{tabular}

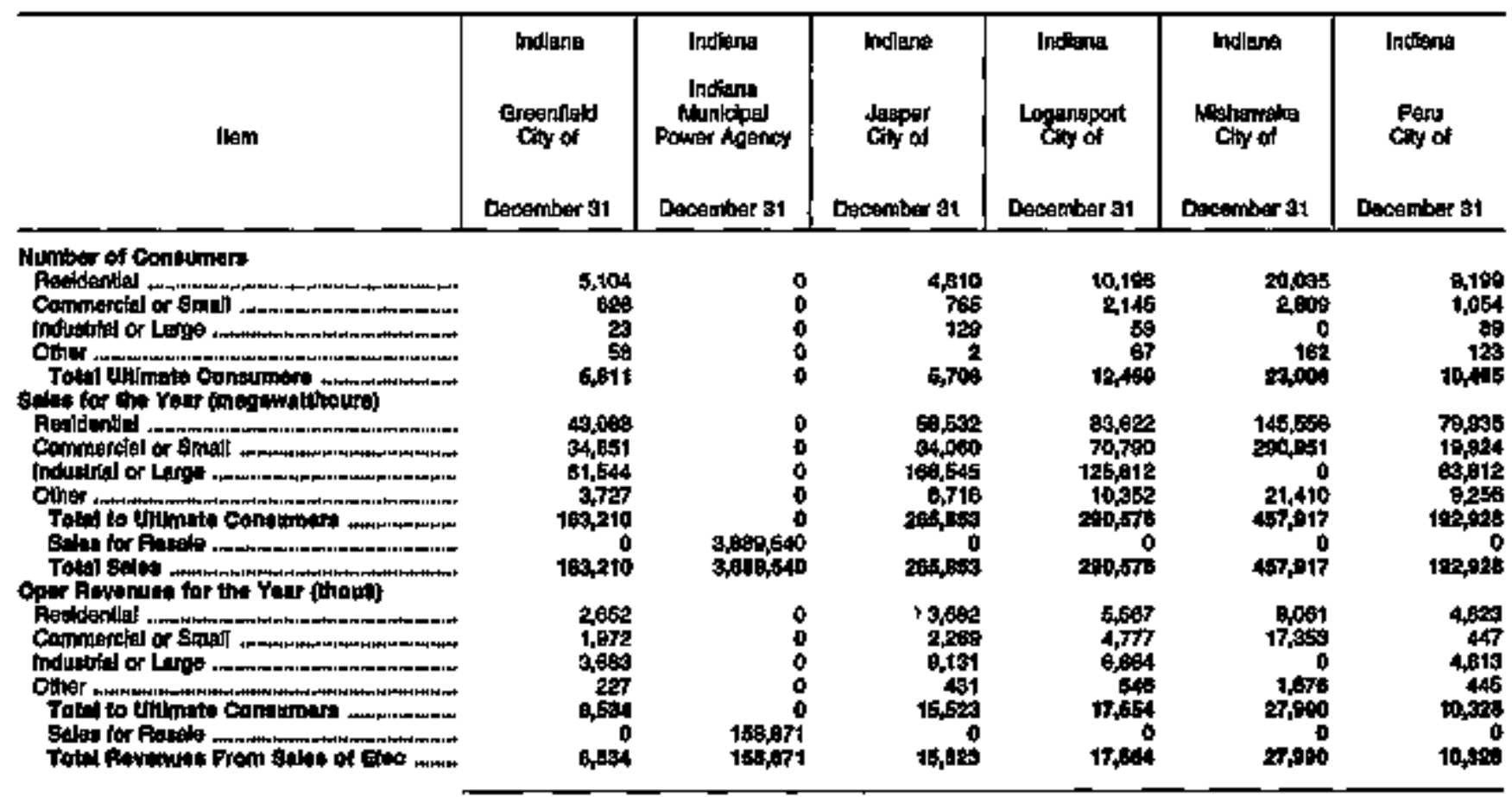

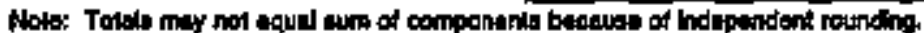

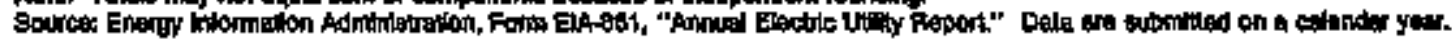


Table 25. Nunber of Consumers, Sales, and Operating Rovenue by Major U.S. Publlcly Owned Electric Utility Within state, 1994 (Continued)

\begin{tabular}{|c|c|c|c|c|c|c|}
\hline them & 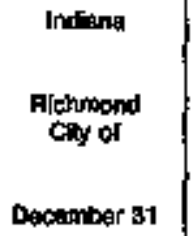 & $\begin{array}{l}\text { todiang } \\
\text { Cecember } 31 \\
\text { Cily of }\end{array}$ & $\begin{array}{l}\text { tows } \\
\text { Amas } \\
\text { Cily of } \\
\text { Dectinbur } 31\end{array}$ & 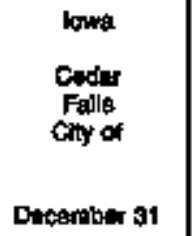 & 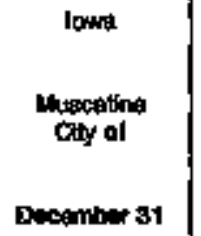 & 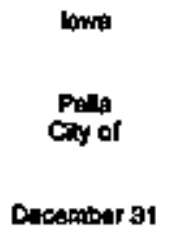 \\
\hline 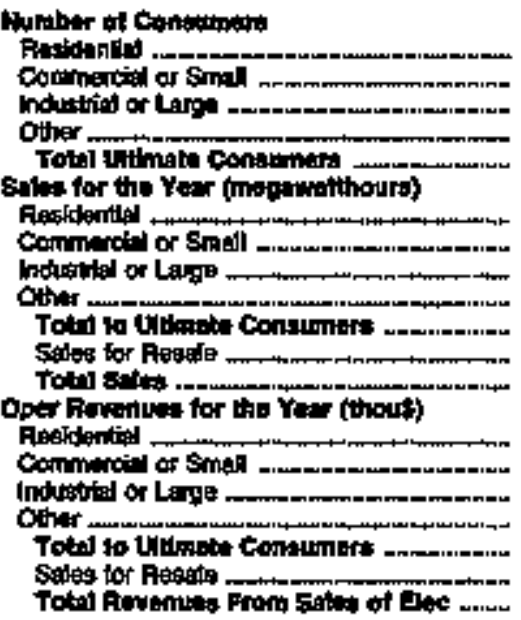 & 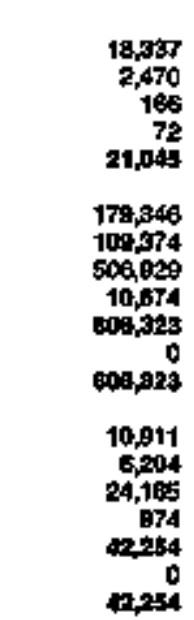 & 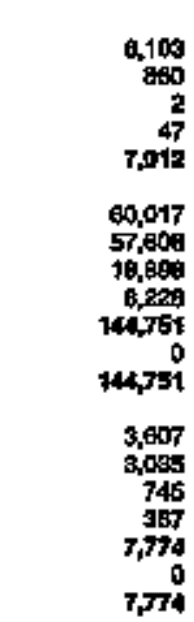 & 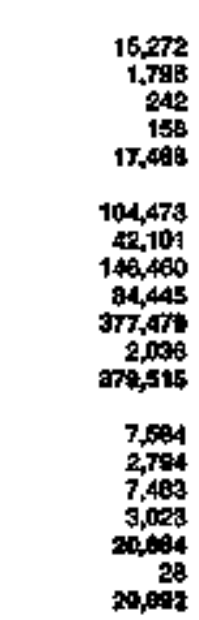 & 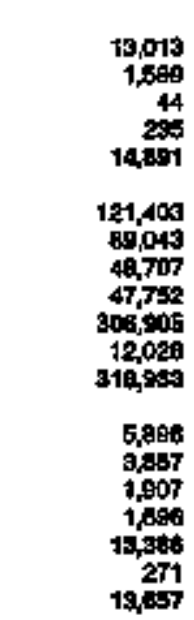 & 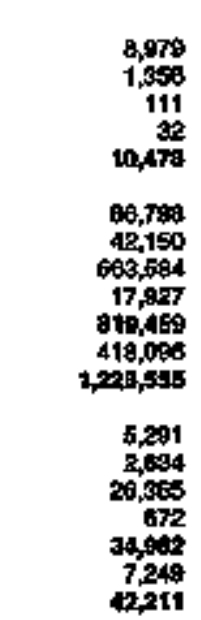 & 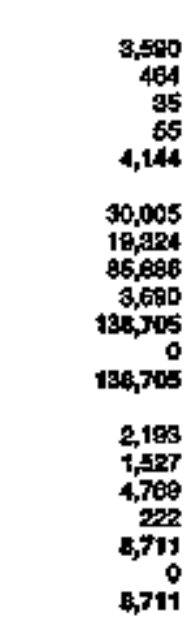 \\
\hline
\end{tabular}

\begin{tabular}{|c|c|c|c|c|c|c|}
\hline Hang & 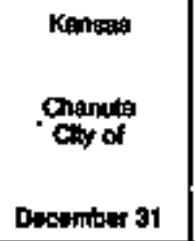 & 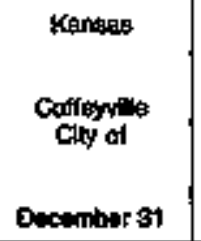 & $\begin{array}{l}\text { Kankeg } \\
\text { Gindten } \\
\text { Cony City of } \\
\text { Decenmber } 31\end{array}$ & $\begin{array}{l}\text { Kentises } \\
\text { Kertses } \\
\text { Cry Chy of } \\
\text { Decomber } 31\end{array}$ & 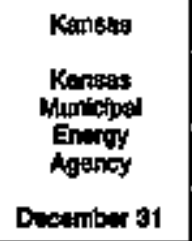 & $\begin{array}{l}\text { Kansas } \\
\text { Muphorson } \\
\text { City of } \\
\text { Decumber } 31\end{array}$ \\
\hline 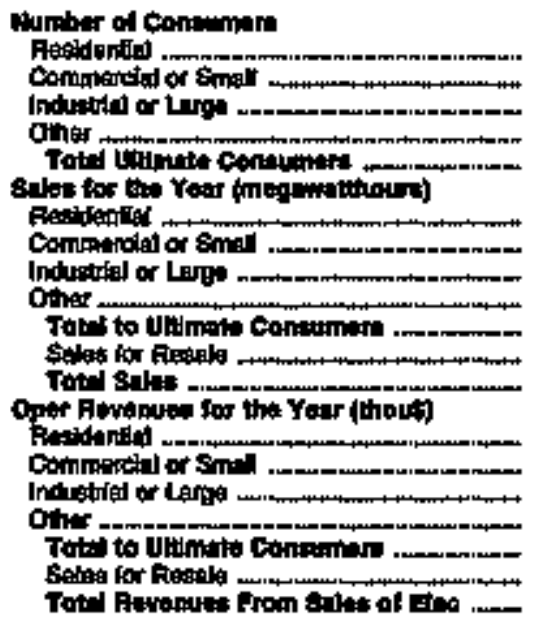 & 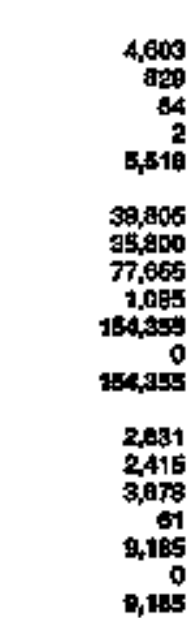 & 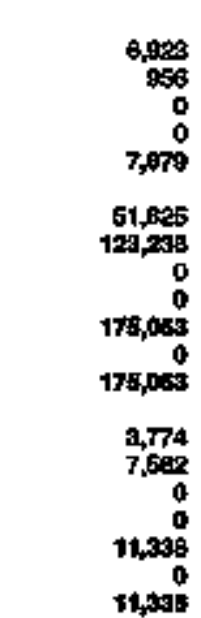 & 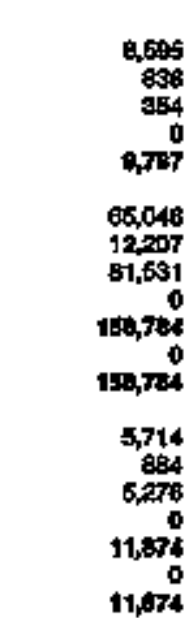 & 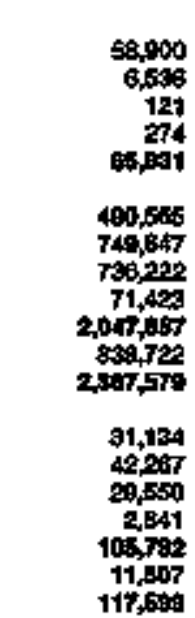 & $\begin{array}{r}0 \\
0 \\
0 \\
0 \\
0 \\
204240 \\
234,240 \\
0 \\
0 \\
0 \\
0 \\
0 \\
0,798 \\
7,735\end{array}$ & 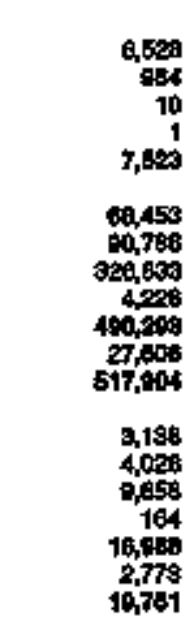 \\
\hline
\end{tabular}

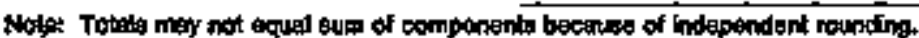

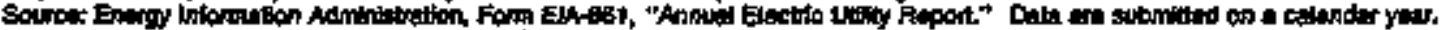


Tabte 25. Number of Constmers, Sales, and Operating Aevenue by Major U.S. Publiely Owned Electric Utilly Within State, 1994 (Contlnued)

\begin{tabular}{|c|c|c|c|c|c|c|}
\hline IterR & $\begin{array}{l}\text { Kangas } \\
\text { Winfied } \\
\text { Ctiy od } \\
\text { Doctimber } 3 y\end{array}$ & 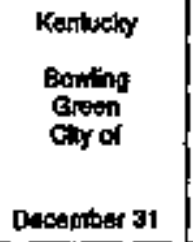 & $\begin{array}{l}\text { Kentuciky } \\
\text { Frankfort } \\
\text { Cily of } \\
\text { Doctombar \$t }\end{array}$ & $\begin{array}{l}\text { Kenluchy } \\
\text { Franlath } \\
\text { Ciny of } \\
\text { Decenuber a1 }\end{array}$ & $\begin{array}{l}\text { Kontuciny } \\
\text { Clipy of } \\
\text { Decomber } 31\end{array}$ & $\begin{array}{c}\text { Kerintrly } \\
\text { Henderton } \\
\text { Cly } \\
\text { Decenty Comm }\end{array}$ \\
\hline 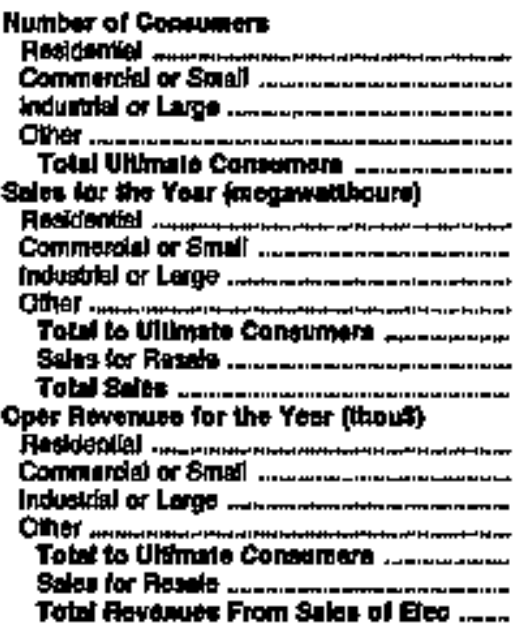 & 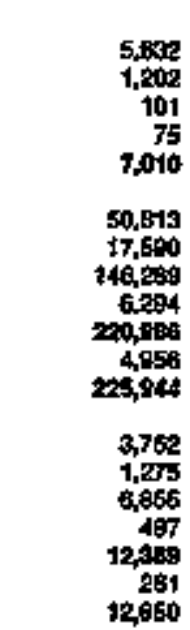 & 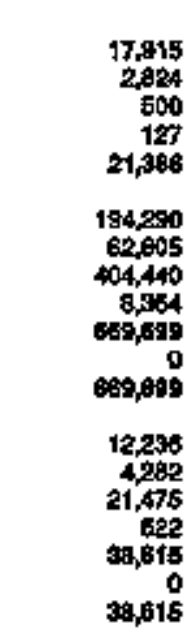 & 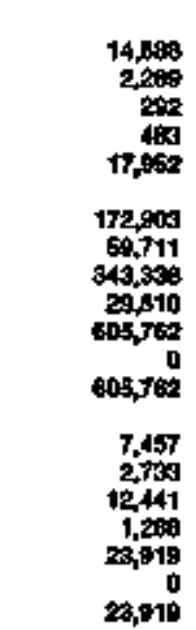 & 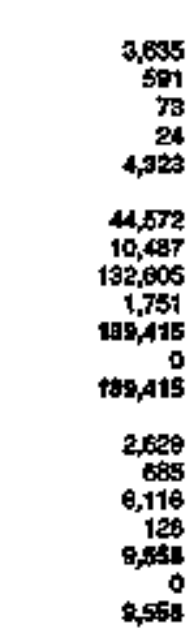 & $\begin{array}{r}4,985 \\
1,101 \\
169 \\
47 \\
4,292 \\
58,194 \\
19,051 \\
228,455 \\
2,970 \\
30,470 \\
0 \\
30,4,40 \\
3,400 \\
1,350 \\
10,900 \\
240 \\
16,041 \\
0 \\
16,041\end{array}$ & 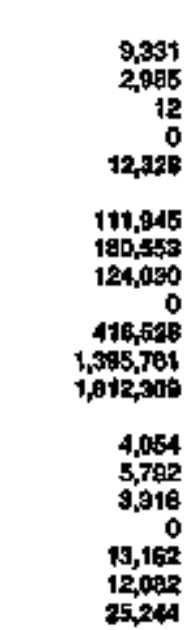 \\
\hline
\end{tabular}

\begin{tabular}{|c|c|c|c|c|c|c|}
\hline then & $\begin{array}{l}\text { Kentuchy } \\
\text { Hopkingille } \\
\text { Cly of } \\
\text { December \$t }\end{array}$ & $\begin{array}{c}\text { Kontuoky } \\
\text { Madititomila } \\
\text { Municlpil } \\
\text { Uills }\end{array}$ & $\begin{array}{l}\text { Kentucky } \\
\text { Mnyifid } \\
\text { Cly of } \\
\text { Decamber } 37\end{array}$ & 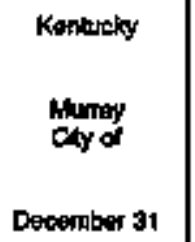 & 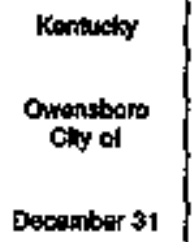 & $\begin{array}{l}\text { Kantuctoy } \\
\text { Paducals } \\
\text { Ctis of } \\
\text { Decamber } 31\end{array}$ \\
\hline \multicolumn{7}{|l|}{ Mumbor of conaunes: } \\
\hline 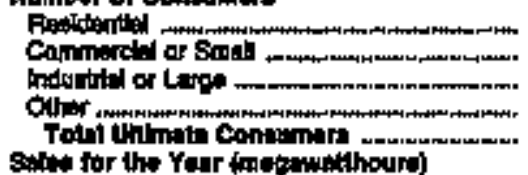 & $\begin{array}{r}11,3 \% 06 \\
1,657 \\
254 \\
13,505\end{array}$ & $\begin{array}{r}7,040 \\
1,293 \\
0 \\
0 \\
0,300\end{array}$ & $\begin{array}{r}4,910 \\
722 \\
122 \\
45 \\
3,790\end{array}$ & $\begin{array}{r}6,369 \\
026 \\
138 \\
13 \\
5,456\end{array}$ & 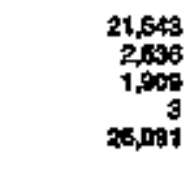 & 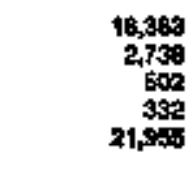 \\
\hline 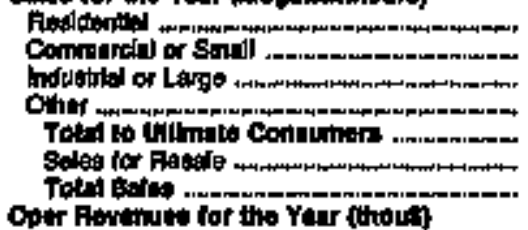 & $\begin{array}{r}13,6,600 \\
35,706 \\
200,690 \\
5,709 \\
417,904 \\
017,904\end{array}$ & $\begin{array}{r}99,461 \\
195,860 \\
0 \\
0 \\
294,381 \\
0 \\
0,4,3 \% 1\end{array}$ & $\begin{array}{r}50,558 \\
14,149 \\
73,204 \\
2,489 \\
148,408 \\
146,409\end{array}$ & $\begin{array}{r}76,644 \\
20,751 \\
139,306 \\
2,272 \\
233,052 \\
0 \\
233,098\end{array}$ & 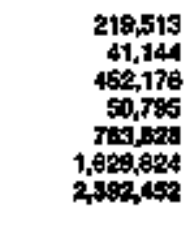 & 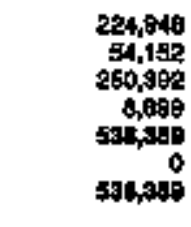 \\
\hline 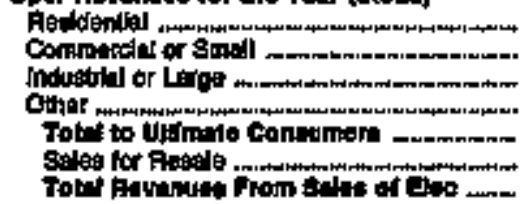 & $\begin{array}{r}7,764 \\
2,280 \\
20,802 \\
490 \\
21,300 \\
21,30\end{array}$ & $\begin{array}{r}4,164 \\
7,002 \\
0 \\
0 \\
12,045 \\
0 \\
12045\end{array}$ & $\begin{array}{r}3,667 \\
0,99 \\
4,780 \\
4,157 \\
4,07 \\
0 \\
0,057\end{array}$ & $\begin{array}{r}4,410 \\
1,311 \\
6,058 \\
167 \\
12,458 \\
0 \\
1254\end{array}$ & $\begin{array}{r}10,373 \\
1,474 \\
13,979 \\
1,196 \\
27,450 \\
21,720 \\
40,102\end{array}$ & $\begin{array}{r}19,612 \\
3,72 \\
14,008 \\
775 \\
5,121 \\
0 \\
12,121\end{array}$ \\
\hline
\end{tabular}

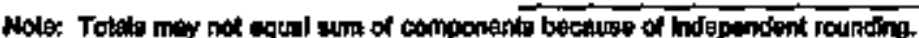

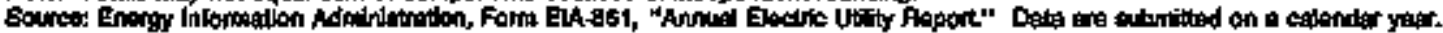


Table 26. Number of Congumers, Salos, and Operating Revenue by Major U.S. Punfloly Owned Electrio Utilty Whin State, 1994 (Continued)

\begin{tabular}{|c|c|c|c|c|c|c|}
\hline 1lem & 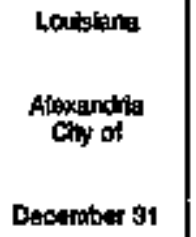 & 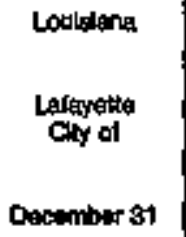 & 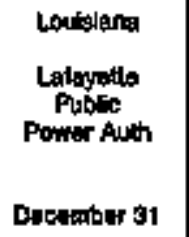 & 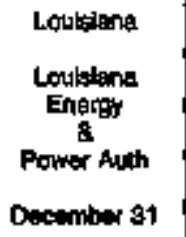 & 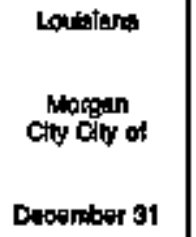 & 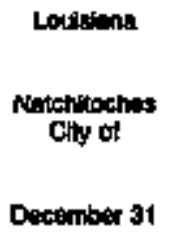 \\
\hline 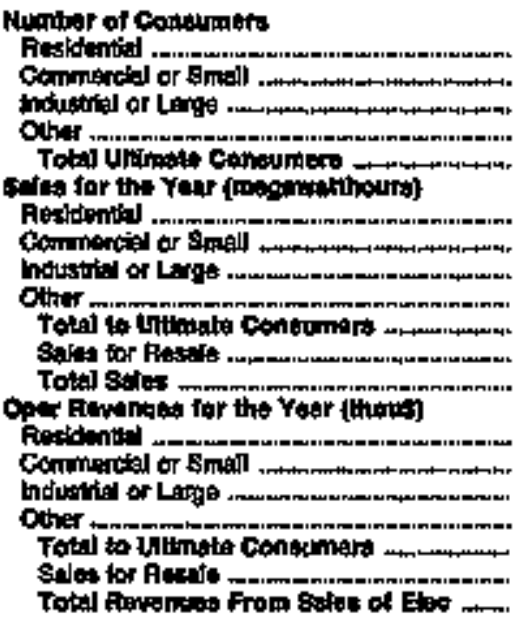 & 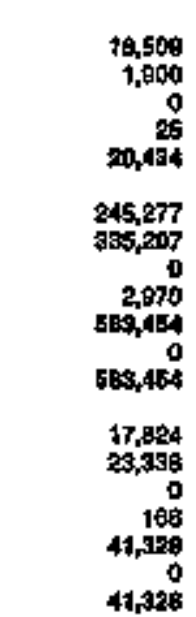 & 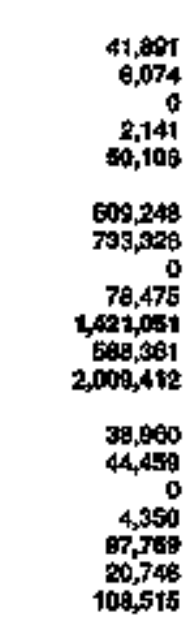 & $\begin{array}{r}0 \\
0 \\
0 \\
0 \\
0 \\
1,474,736 \\
1,414,736 \\
0 \\
0 \\
0 \\
0 \\
0 \\
48,547 \\
48,547\end{array}$ & $\begin{array}{r}0 \\
0 \\
0 \\
0 \\
0 \\
1,602,624 \\
+, 502,924\end{array}$ & $\begin{array}{r}1,280 \\
4,073 \\
0 \\
0 \\
6,296 \\
80,714 \\
75,767 \\
0 \\
0 \\
156,471 \\
0 \\
156,471 \\
5,470 \\
5,142 \\
0 \\
0 \\
10,679 \\
0 \\
10,621\end{array}$ & 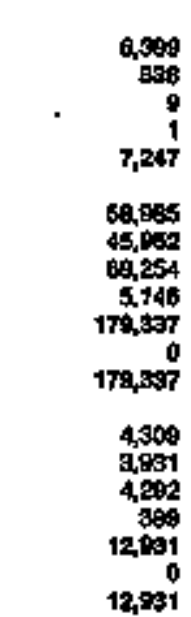 \\
\hline
\end{tabular}

\begin{tabular}{|c|c|c|c|c|c|c|}
\hline Herpo & $\begin{array}{l}\text { Lotifiania } \\
\text { Puston } \\
\text { ciny of } \\
\text { Oecomber } \$ 1\end{array}$ & $\begin{array}{l}\text { Loutstanas } \\
\text { Temibonno } \\
\text { Patial } \\
\text { Consol Eork } \\
\text { Dooumber } 31\end{array}$ & $\begin{array}{l}\text { Morydand } \\
\text { Enoton } \\
\text { UFiliga } \\
\text { Comm } \\
\text { Docomber } 31\end{array}$ & 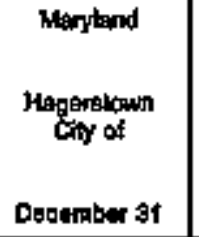 & 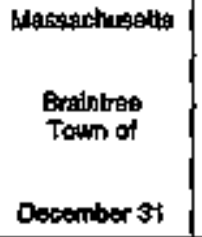 & 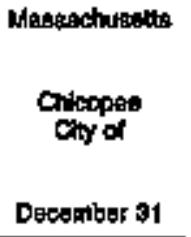 \\
\hline 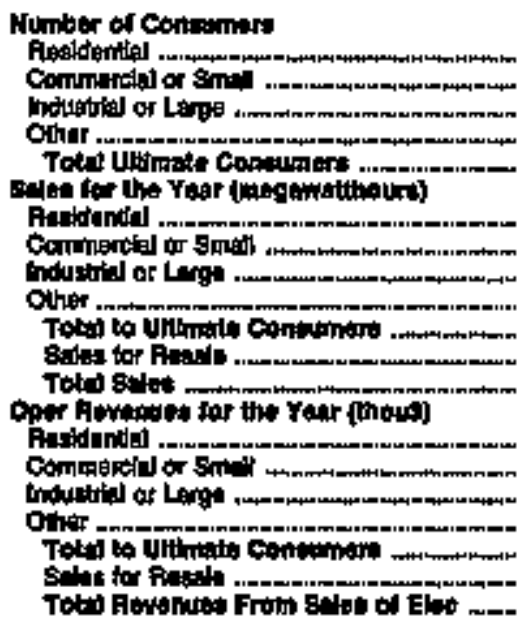 & 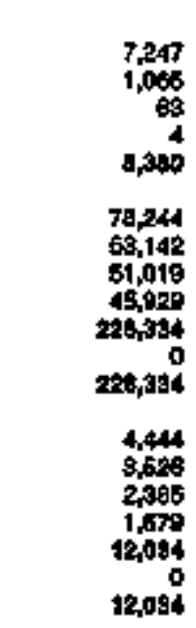 & 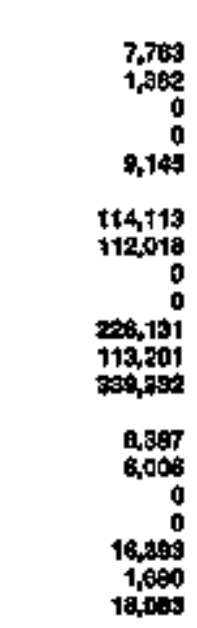 & $\begin{array}{r}6,070 \\
1,591 \\
0 \\
112 \\
7,778 \\
76,041 \\
197,023 \\
0 \\
10,140 \\
203,504 \\
0 \\
203,004\end{array}$ & $\begin{array}{r}25,694 \\
1,6499 \\
525 \\
65 \\
27,453 \\
123,170 \\
59,132 \\
117,671 \\
0,606 \\
306,741 \\
0 \\
300,741\end{array}$ & $\begin{array}{r}11,568 \\
1,847 \\
11 \\
290 \\
13,701 \\
92,104 \\
209,554 \\
47,689 \\
13,452 \\
304,793 \\
44,155 \\
400,949 \\
7,317 \\
10,369 \\
3,402 \\
1,077 \\
28,194 \\
2,424 \\
30,509\end{array}$ & 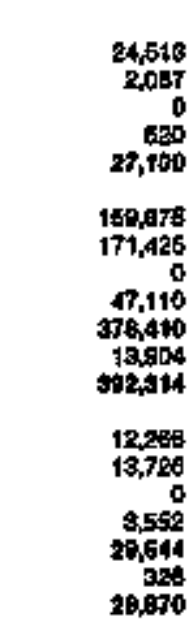 \\
\hline
\end{tabular}

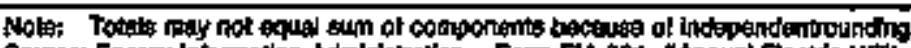

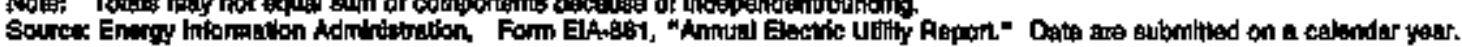


Table 25. Number of Consumers, sales, and Operating Revenue by Major t.s. Publicly Owned Electrio Utility Whithin State, t994 (Continued)

\begin{tabular}{|c|c|c|c|c|c|c|}
\hline |ten| & 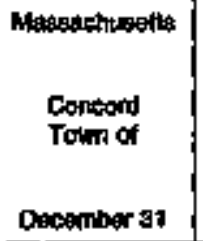 & 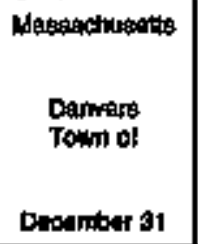 & $\begin{array}{l}\text { Masseachuselt: } \\
\text { Hinghan } \\
\text { Cty of } \\
\text { December 3t }\end{array}$ & 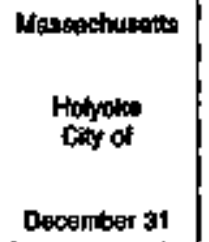 & 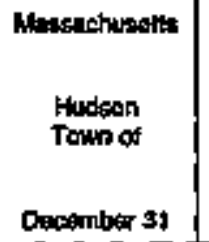 & 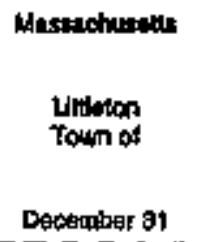 \\
\hline 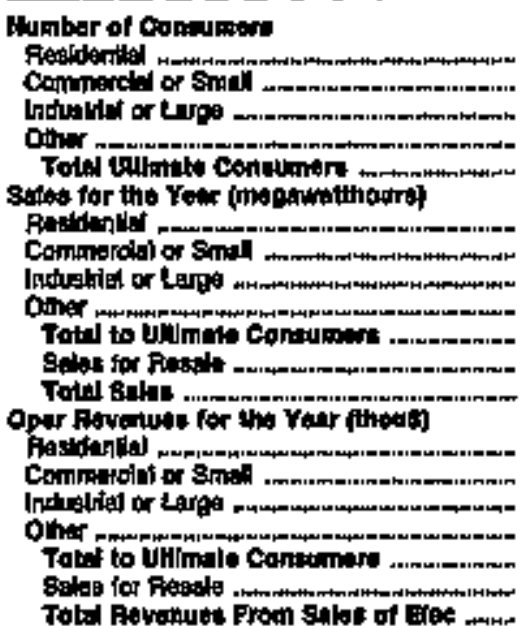 & 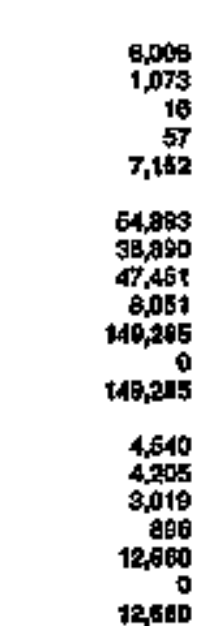 & 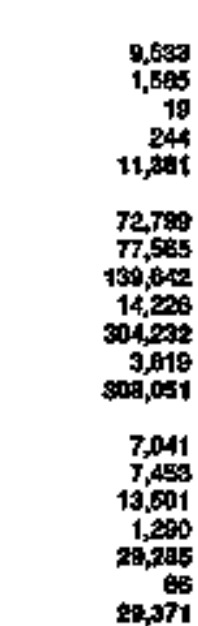 & 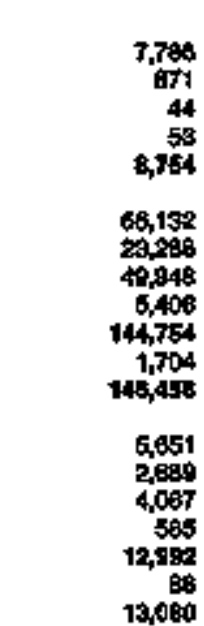 & 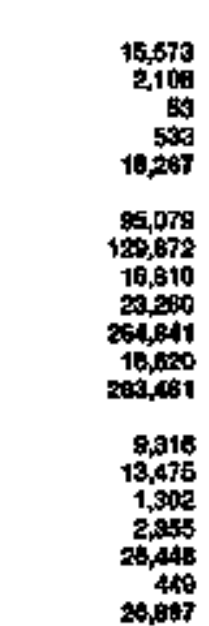 & 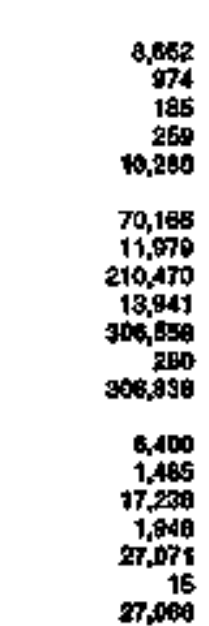 & 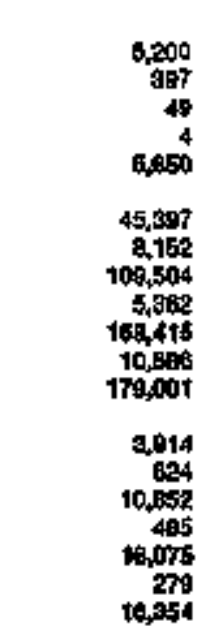 \\
\hline
\end{tabular}

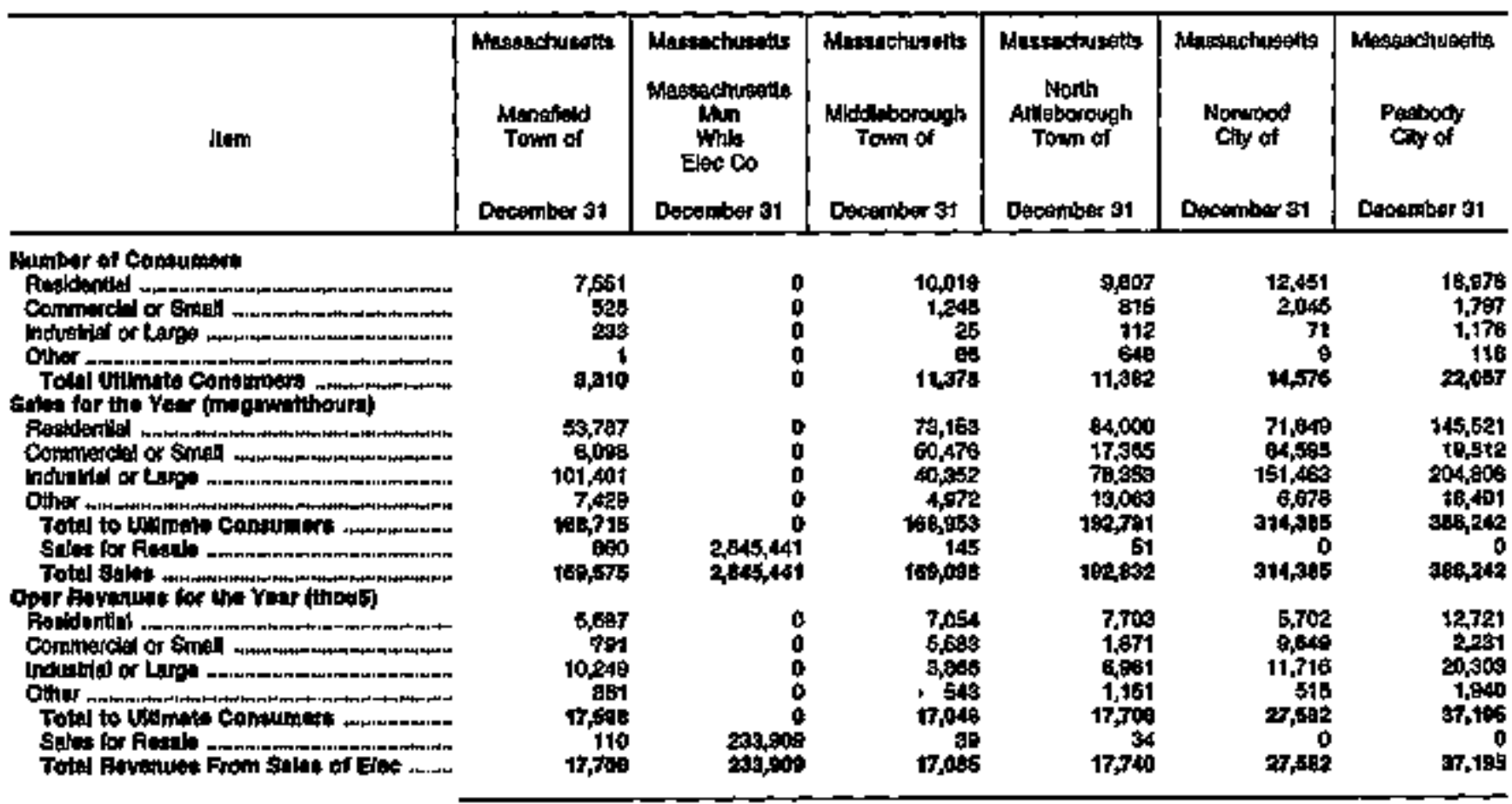

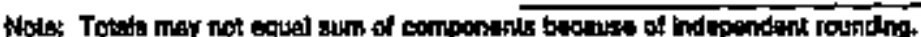

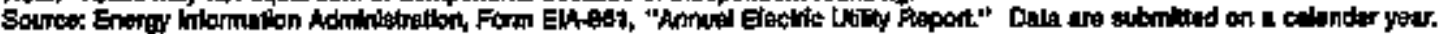


Table 25. Number of Consumers, Sales, and Operating Revenue by Mejor U.S. PubHcly Owned Electric Utilty Within State, 1994 (Continued)

\begin{tabular}{|c|c|c|c|c|c|c|}
\hline Han & 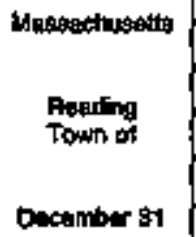 & 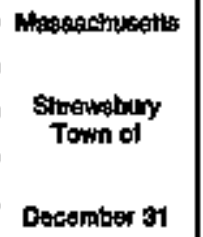 & 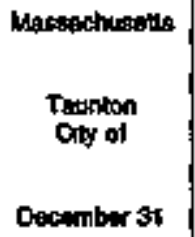 & 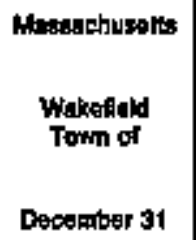 & 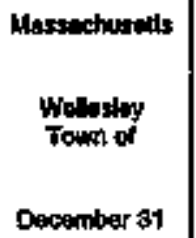 & 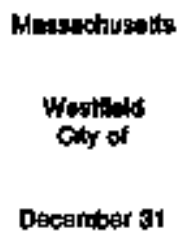 \\
\hline 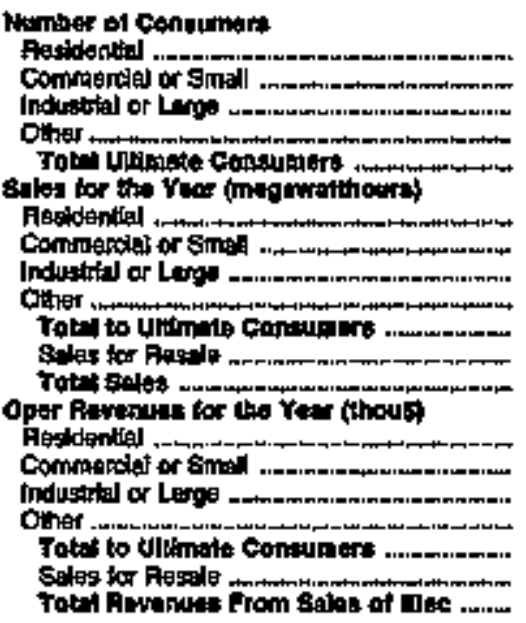 & 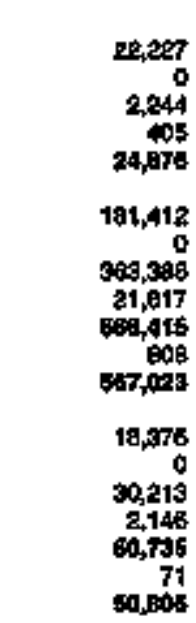 & 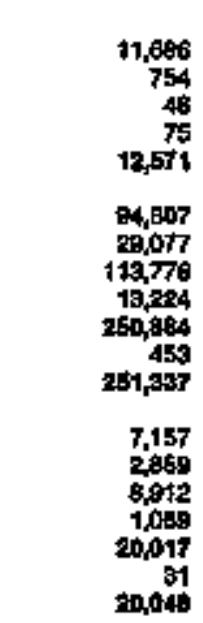 & 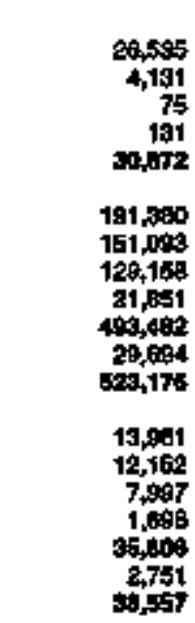 & 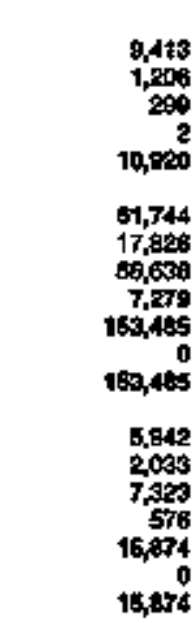 & 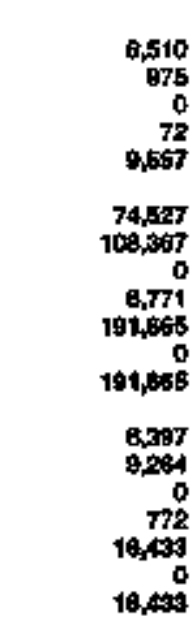 & 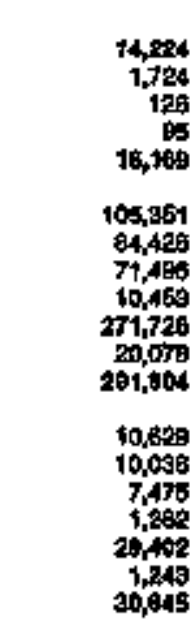 \\
\hline
\end{tabular}

\begin{tabular}{|c|c|c|c|c|c|c|}
\hline ham & 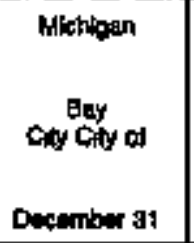 & 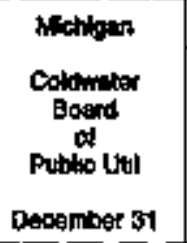 & $\begin{array}{l}\text { Mlobilgen } \\
\text { Dotrolt } \\
\text { Chy of } \\
\text { Dacomber } 31\end{array}$ & $\begin{array}{l}\text { Alchions } \\
\text { Crand Hewon } \\
\text { Caty of } \\
\text { Decenter } 91\end{array}$ & 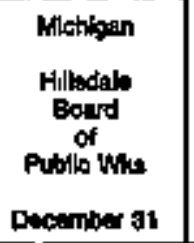 & 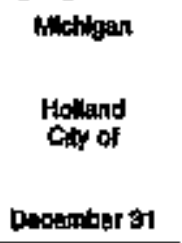 \\
\hline 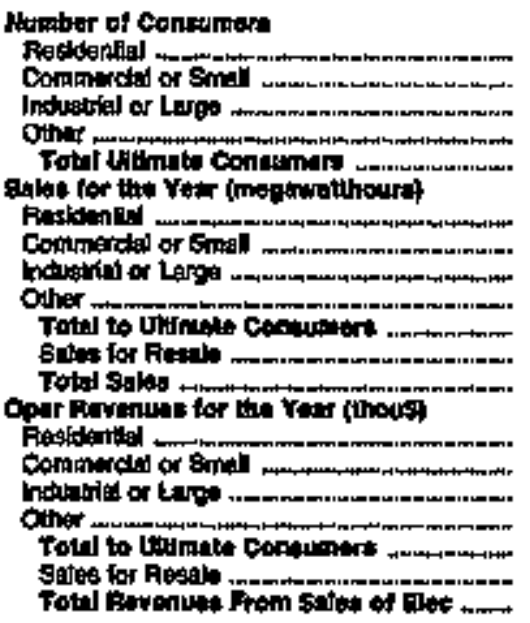 & 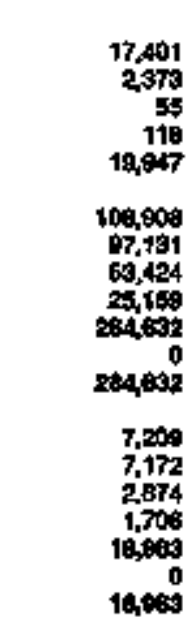 & 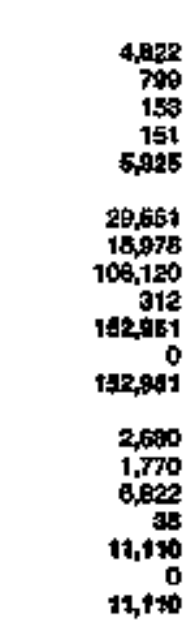 & 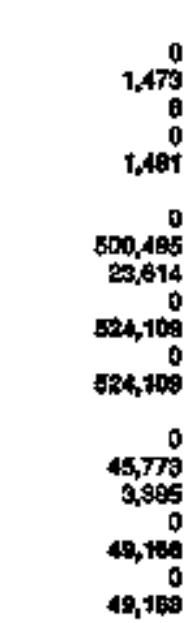 & 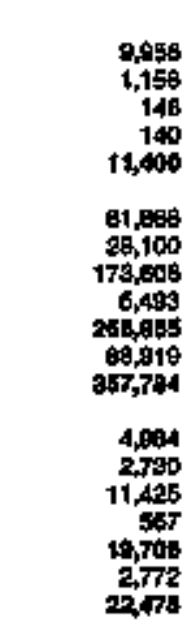 & 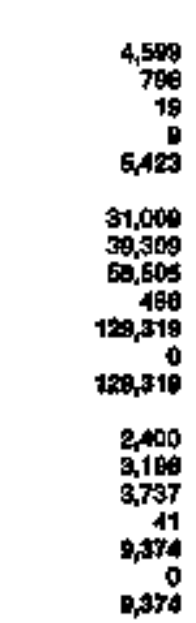 & 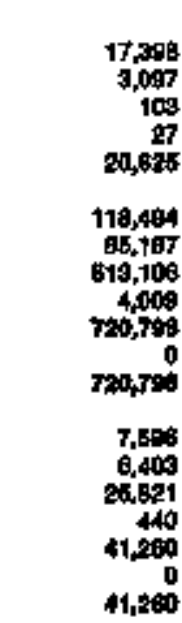 \\
\hline
\end{tabular}

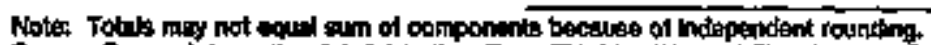

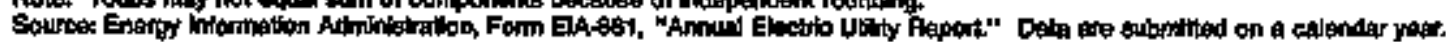


Table 25. Number of Consumers, Sales, and Operating Rovenue by Major U.S. Publicly Owned Electric Utility Within State, 1994 (Continued)

\begin{tabular}{|c|c|c|c|c|c|c|}
\hline INAM & 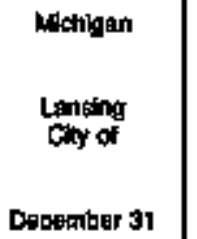 & 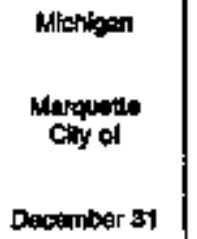 & 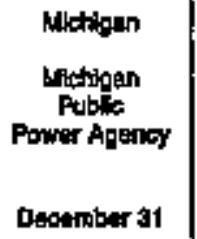 & $\begin{array}{l}\text { Mlehigan } \\
\text { Michion } \\
\text { South } \\
\text { Centrel } \\
\text { Pur Aqy } \\
\text { Docembor a1 }\end{array}$ & $\begin{array}{l}\text { Mocitgan } \\
\text { Shity of } \\
\text { Cecamber } 31\end{array}$ & 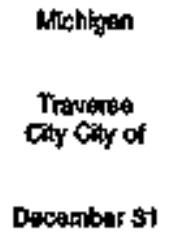 \\
\hline 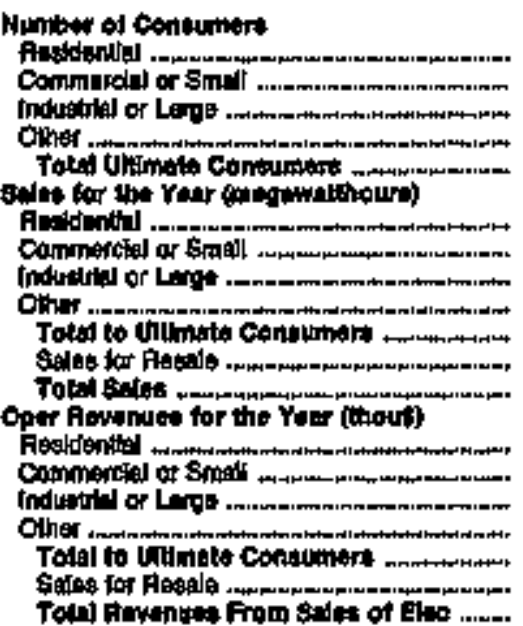 & 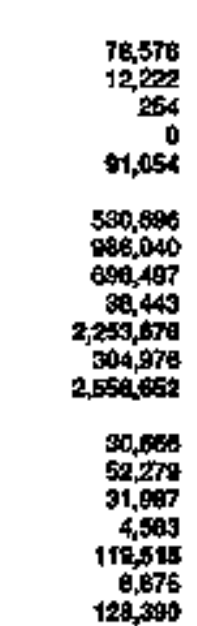 & $\begin{array}{r}12,771 \\
1,486 \\
4 \\
434 \\
14,686 \\
85,112 \\
113,180 \\
0 \\
48,170 \\
241,444 \\
14,386 \\
265,830 \\
6,397 \\
7,189 \\
0 \\
2,841 \\
16,427 \\
704 \\
17,221\end{array}$ & $\begin{array}{r}0 \\
0 \\
0 \\
0 \\
0 \\
2,458,042 \\
2,469,042 \\
0 \\
0 \\
0 \\
102,686 \\
108,696\end{array}$ & 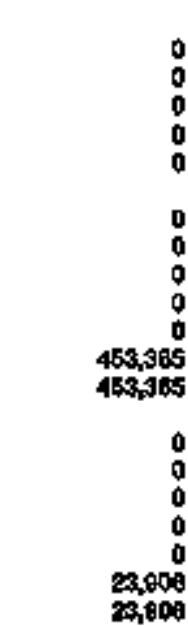 & $\begin{array}{r}6,697 \\
618 \\
70 \\
0 \\
6,475 \\
43,208 \\
53,109 \\
108,149 \\
0 \\
204,481 \\
0 \\
204,441 \\
3,014 \\
4,0,08 \\
6,194 \\
0 \\
13,234 \\
0 \\
13,294\end{array}$ & 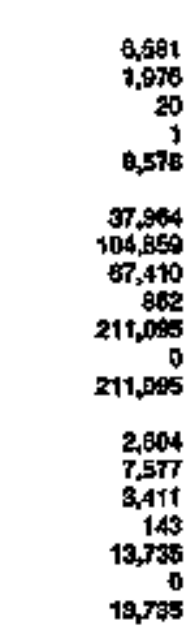 \\
\hline
\end{tabular}

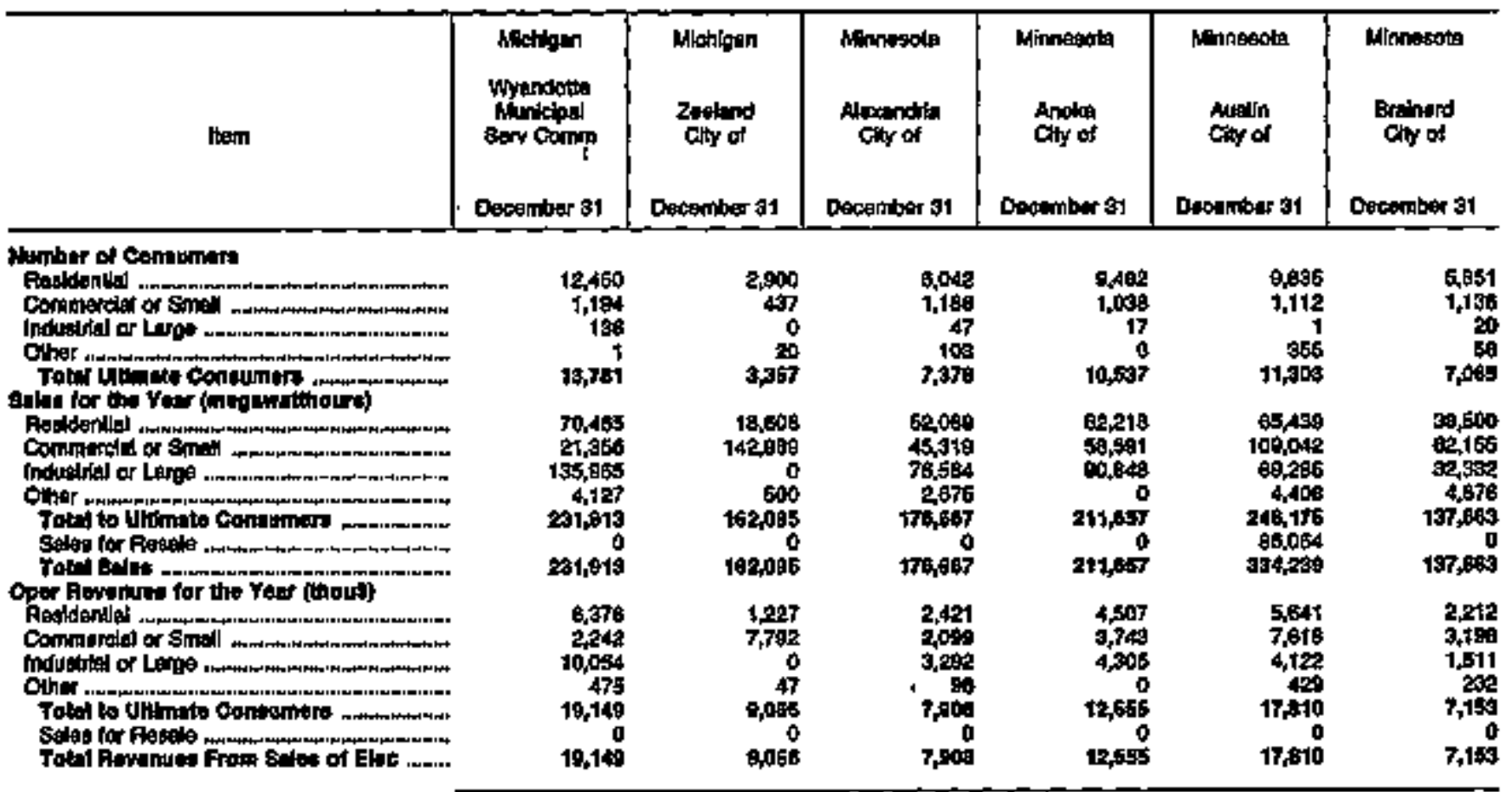

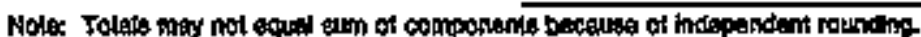

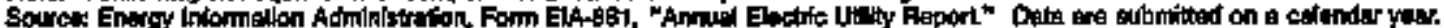


Table 25. Number of Consumere, Sales, and Operating Revenue by Major U.S. Publichy Owned Etectric Ut'lly Withln State, 1994 (Continued)

\begin{tabular}{|c|c|c|c|c|c|c|}
\hline livm & $\begin{array}{l}\text { Minnescta } \\
\text { Chasita } \\
\text { Ciny of } \\
\text { Cercentom } 31\end{array}$ & 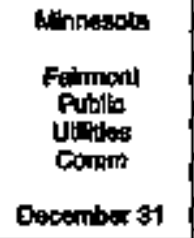 & 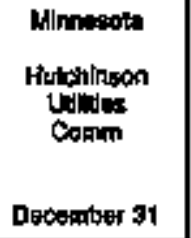 & 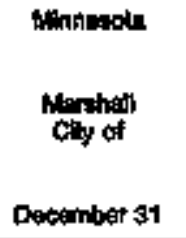 & 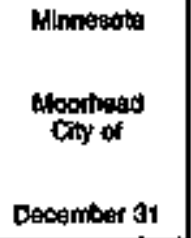 & $\begin{array}{l}\text { Minmesota } \\
\text { Mow Uim } \\
\text { Cocomber ar }\end{array}$ \\
\hline 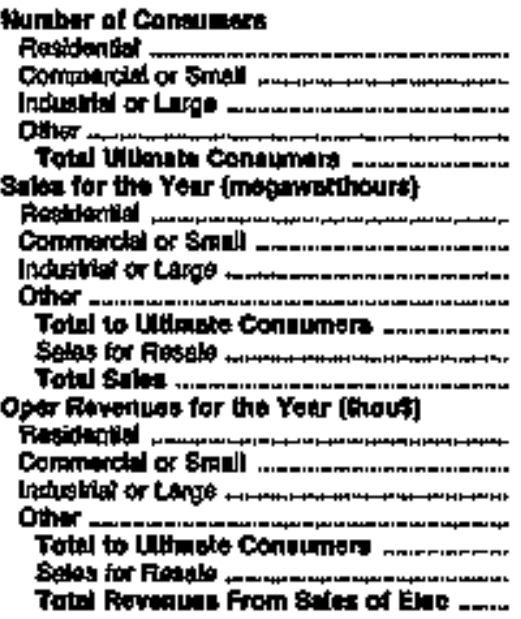 & 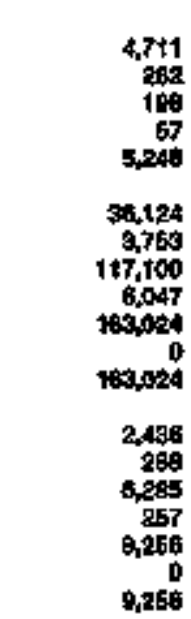 & 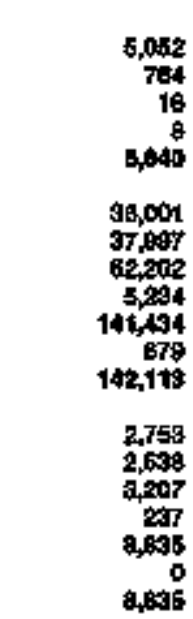 & 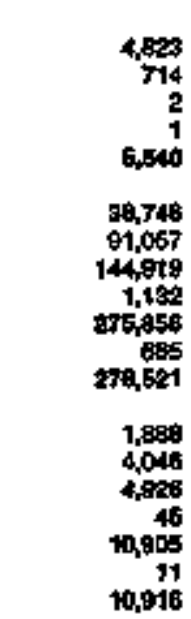 & 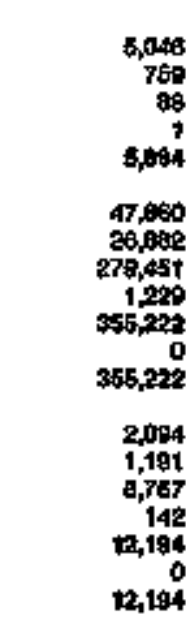 & 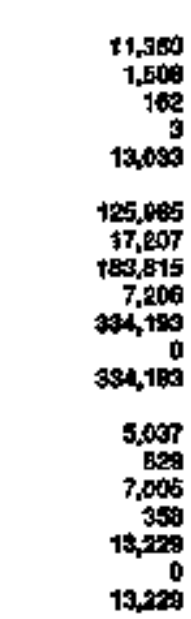 & 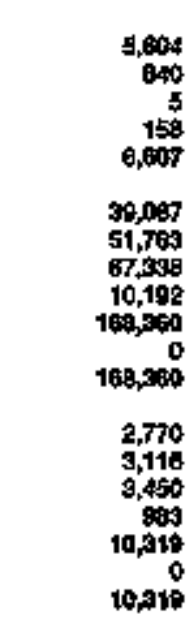 \\
\hline
\end{tabular}

\begin{tabular}{|c|c|c|c|c|c|c|}
\hline item & 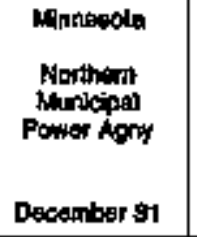 & 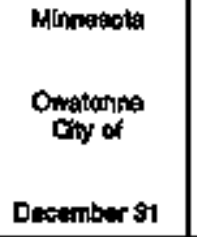 & 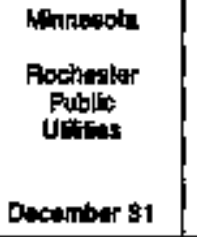 & 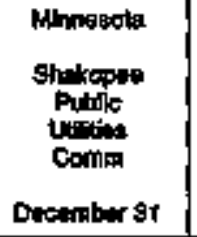 & 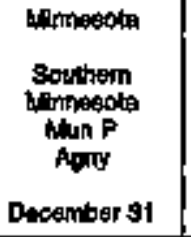 & 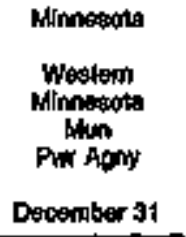 \\
\hline 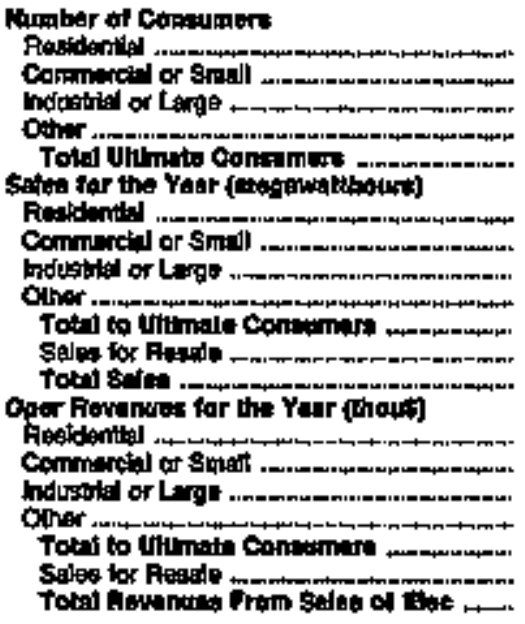 & $\begin{array}{r}0 \\
0 \\
0 \\
0 \\
0 \\
762,010 \\
792,086 \\
0 \\
0 \\
0 \\
0 \\
0 \\
38,598 \\
38,636\end{array}$ & 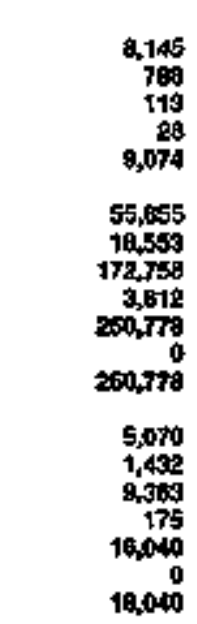 & 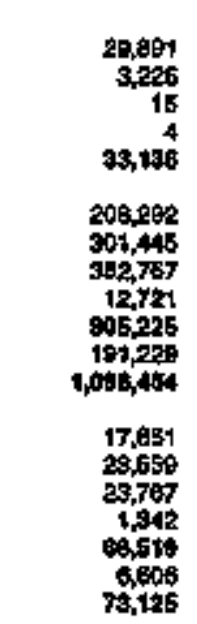 & $\begin{array}{r}5,806 \\
716 \\
0 \\
1 \\
6,390 \\
44,441 \\
63,407 \\
0 \\
1,449 \\
139,200 \\
0 \\
1309,200 \\
9,170 \\
4,061 \\
0 \\
41 \\
6,102 \\
0 \\
0,192\end{array}$ & $\begin{array}{r}0 \\
0 \\
0 \\
0 \\
0 \\
2505,60 \\
2,653,620 \\
0 \\
0 \\
0 \\
0 \\
0 \\
0 \\
115,005 \\
155,05\end{array}$ & 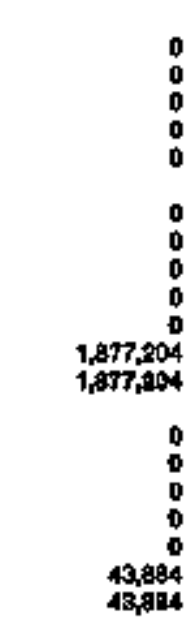 \\
\hline
\end{tabular}

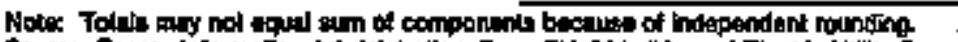

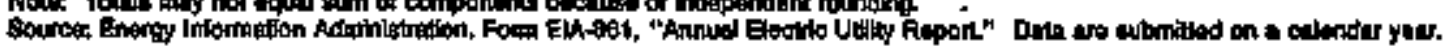


Table 25. Number of Censumers, Sales, and Operating Revenus by Major U.S. Publiely Owned Electrie Utilty Whin State, 1994 (Continued)

\begin{tabular}{|c|c|c|c|c|c|c|}
\hline Ilem & 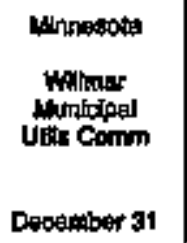 & 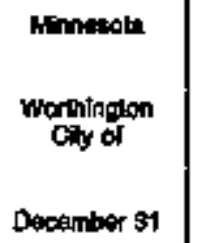 & 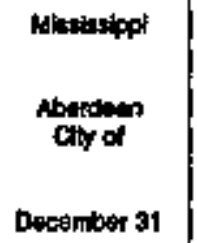 & 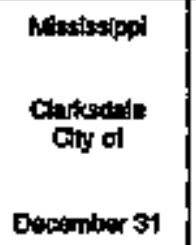 & $\begin{array}{l}\text { Mflastastppi } \\
\text { Columbus } \\
\text { Cry of } \\
\text { Docembor } 31\end{array}$ & 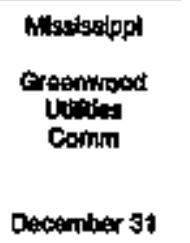 \\
\hline 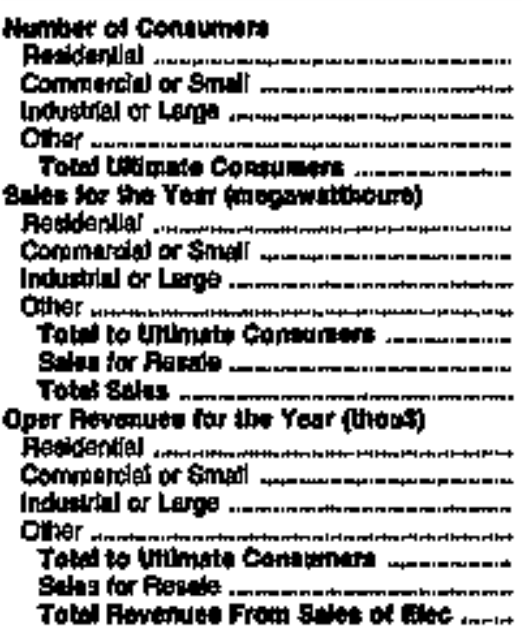 & 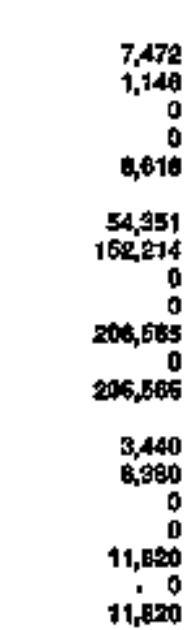 & $\begin{array}{r}4,320 \\
670 \\
5 \\
64 \\
5,068 \\
29,294 \\
42,971 \\
48,704 \\
3,047 \\
134,096 \\
3,187 \\
197,248\end{array}$ & 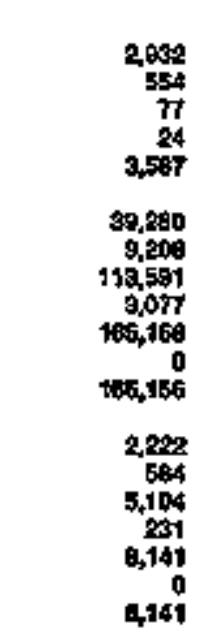 & 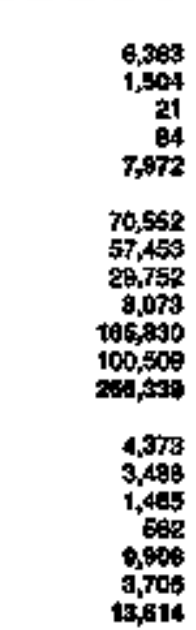 & 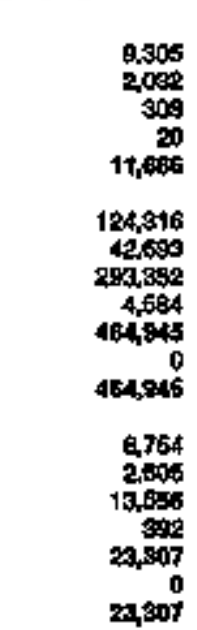 & 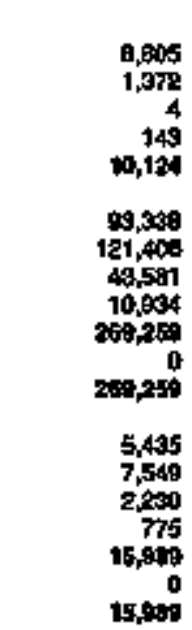 \\
\hline
\end{tabular}

\begin{tabular}{|c|c|c|c|c|c|c|}
\hline Inen & 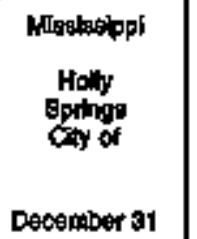 & 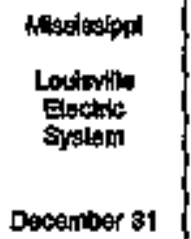 & 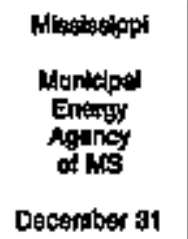 & 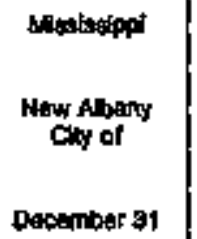 & $\begin{array}{l}\text { Mnstasippi . } \\
\text { Ondord } \\
\text { Ctty of } \\
\text { Deccmber s1 }\end{array}$ & 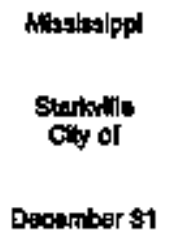 \\
\hline 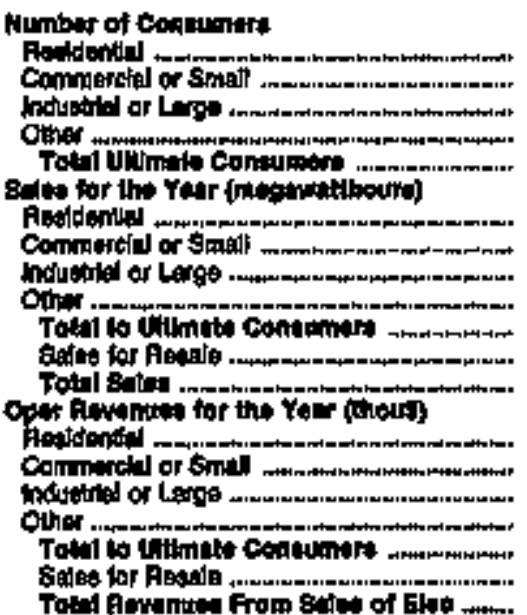 & 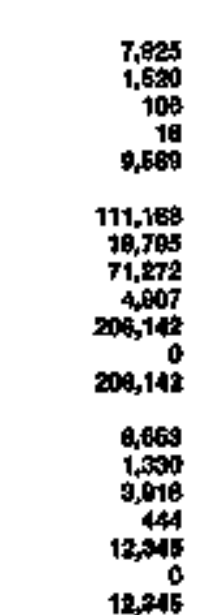 & 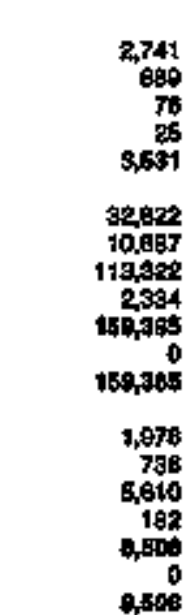 & $\begin{array}{r}0 \\
0 \\
0 \\
0 \\
0 \\
847,201 \\
0 \times 7,201\end{array}$ & 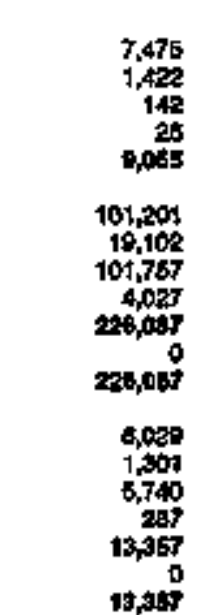 & 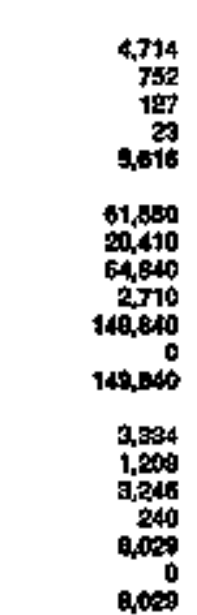 & 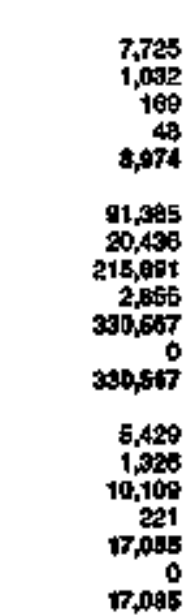 \\
\hline
\end{tabular}

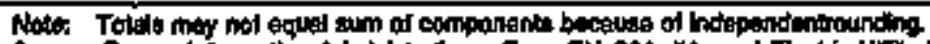

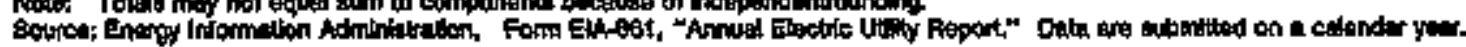


Table 25. Number of Consumers, Sales, and Operating Revenue by Major U.S. Publdely Owned Electric Litity Withan State, 1994 (Continued)

\begin{tabular}{|c|c|c|c|c|c|c|}
\hline ltam & $\begin{array}{l}\text { Inlostspipp } \\
\text { Tupelo } \\
\text { City of } \\
\text { Dactember } 31\end{array}$ & $\begin{array}{l}\text { Mlisolissingt } \\
\text { Whet } \\
\text { Point } \\
\text { Gity of } \\
\text { December } 31\end{array}$ & $\begin{array}{l}\text { Ansout } \\
\text { Curtuge } \\
\text { City of } \\
\text { Dacember } 91\end{array}$ & 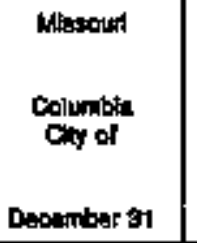 & $\begin{array}{l}\text { Atserour } \\
\text { Aentibed } \\
\text { Clty of } \\
\text { Docember } 31\end{array}$ & $\begin{array}{l}\text { Mlesoud } \\
\text { hrdependenca } \\
\text { Gly or } \\
\text { Decenber } 31\end{array}$ \\
\hline 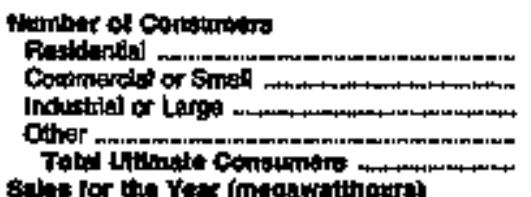 & $\begin{array}{r}10,551 \\
4,091 \\
478 \\
15 \\
4,85\end{array}$ & $\begin{array}{r}3962 \\
555 \\
00 \\
8 \\
4055\end{array}$ & $\begin{array}{r}5,843 \\
0,7 \\
20 \\
2 \\
6,002\end{array}$ & $\begin{array}{r}26,852 \\
3,786 \\
427 \\
5 \\
30,056\end{array}$ & $\begin{array}{r}7,497 \\
1,060 \\
119 \\
19 \\
9,844\end{array}$ & $\begin{array}{r}46,258 \\
1,404 \\
16 \\
55 \\
50,933\end{array}$ \\
\hline 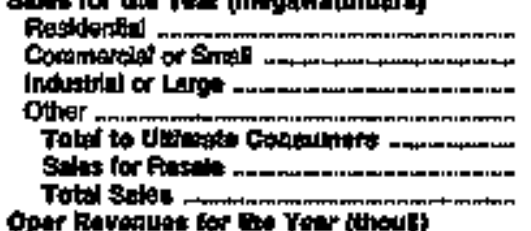 & 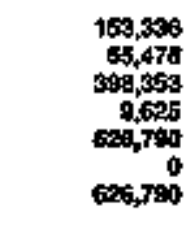 & 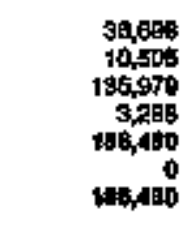 & $\begin{array}{r}40,040 \\
3,010 \\
00,800 \\
10,568 \\
10+, 200 \\
191,270\end{array}$ & 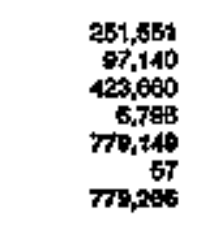 & 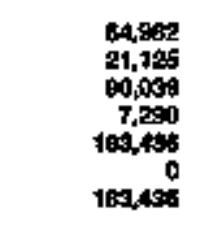 & $\begin{array}{r}391,608 \\
377,586 \\
47,022 \\
8,674 \\
925,090 \\
6,725 \\
0 \times 1,704\end{array}$ \\
\hline 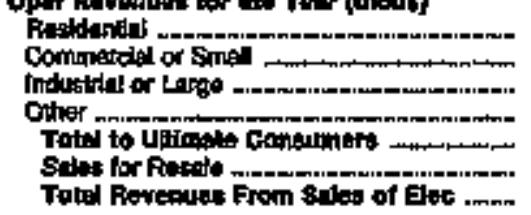 & 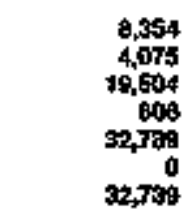 & $\begin{array}{r}2,257 \\
719 \\
6,672 \\
241 \\
9,098 \\
0 \\
9,990\end{array}$ & $\begin{array}{r}2,900 \\
2,544 \\
3,790 \\
440 \\
9,744 \\
9,240\end{array}$ & $\begin{array}{r}17,760 \\
6,300 \\
24,099 \\
1,064 \\
49,213 \\
4 \\
49,217\end{array}$ & $\begin{array}{r}4,572 \\
1,459 \\
4,500 \\
20,94 \\
10,449 \\
10,449\end{array}$ & $\begin{array}{r}28,949 \\
22,148 \\
2,014 \\
648 \\
94,754 \\
\$, 197 \\
55,941\end{array}$ \\
\hline
\end{tabular}

\begin{tabular}{|c|c|c|c|c|c|c|}
\hline Qems & $\begin{array}{l}\text { Mtascint } \\
\text { Keronelt } \\
\text { Coy of } \\
\text { Decompor } 31\end{array}$ & $\begin{array}{l}\text { Mtesouti } \\
\text { Kothwood } \\
\text { Ghy of } \\
\text { Oecember i1 }\end{array}$ & 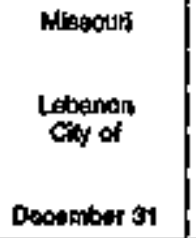 & 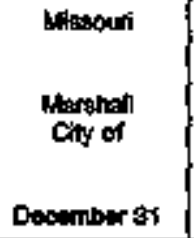 & $\begin{array}{l}\text { Missoptad } \\
\text { Monet } \\
\text { City of } \\
\text { Deosuber } 31\end{array}$ & 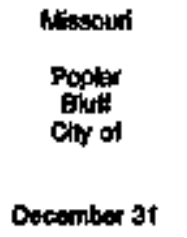 \\
\hline 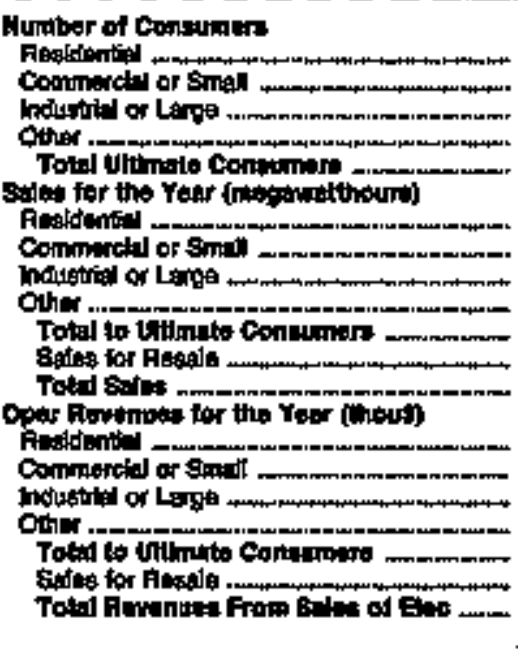 & 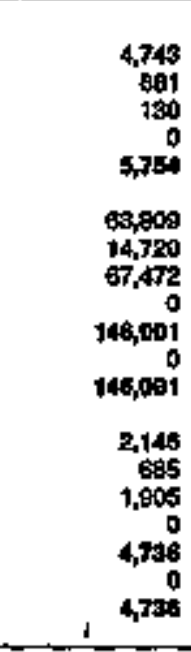 & 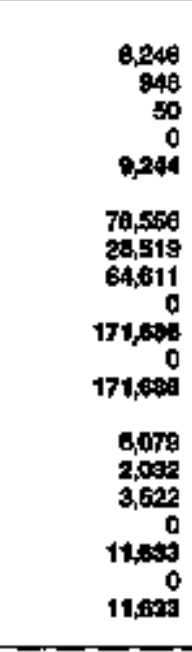 & 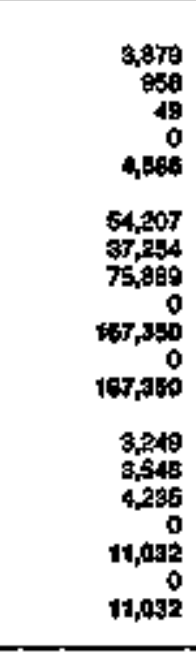 & $\begin{array}{r}4,703 \\
418 \\
3 \\
1 \\
4,2018 \\
40,091 \\
64,813 \\
45,690 \\
1,549 \\
15 \%, 547 \\
0 \\
15,947 \\
2,802 \\
4,584 \\
2,479 \\
117 \\
9,741 \\
0 \\
9,741\end{array}$ & 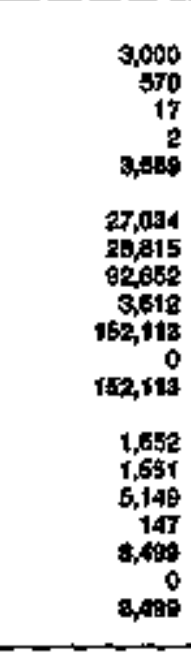 & 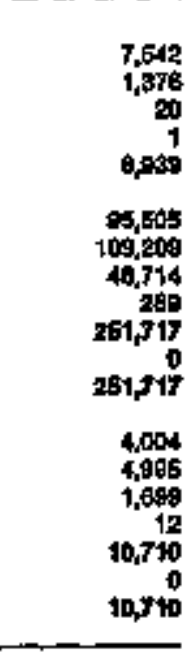 \\
\hline
\end{tabular}

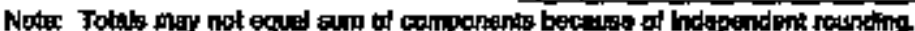

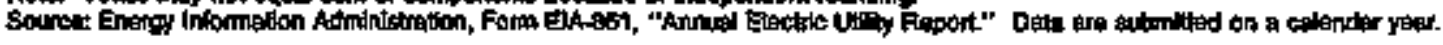


Table 25. Number of Consumers, Sales, and Operating Revenue by Major U.S.

Publlety Owned Electric Utility Within State, 1894 (Cont/nued)

\begin{tabular}{|c|c|c|c|c|c|c|}
\hline $\mathrm{kmn}$ & $\begin{array}{l}\text { Adisoutit } \\
\text { Finle } \\
\text { Chy of } \\
\text { Documber } 31\end{array}$ & 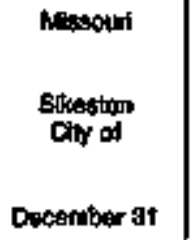 & 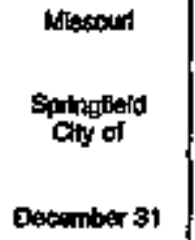 & 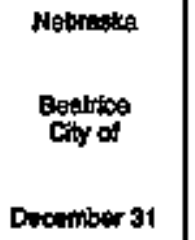 & 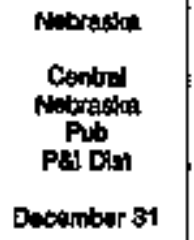 & 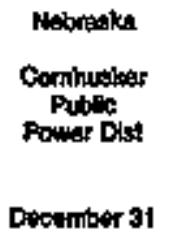 \\
\hline 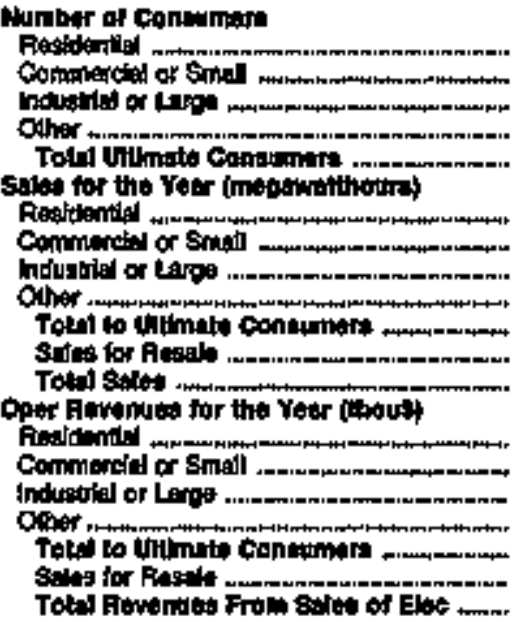 & 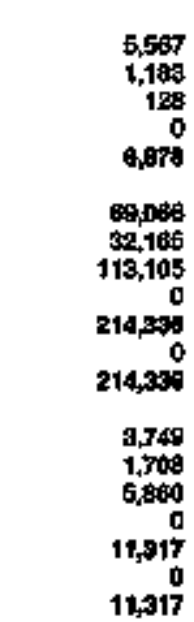 & 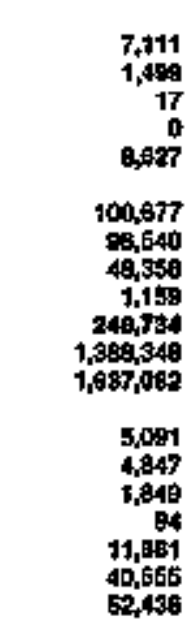 & 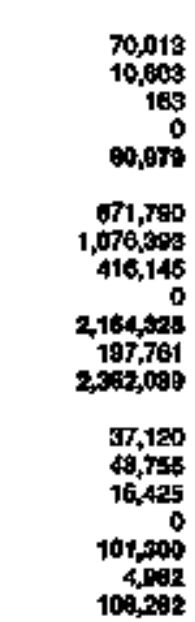 & 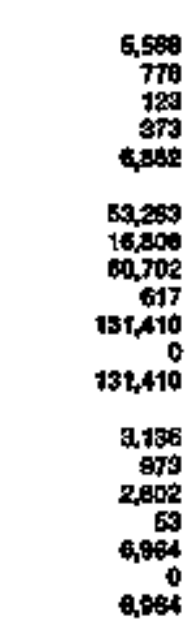 & $\begin{array}{r}0 \\
0 \\
0 \\
0 \\
0 \\
388,189 \\
308,110 \\
0 \\
0 \\
0 \\
0 \\
0 \\
0 \\
10,071 \\
0,071\end{array}$ & 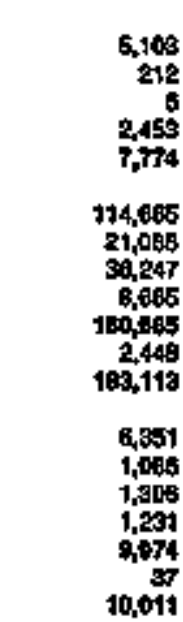 \\
\hline
\end{tabular}

\begin{tabular}{|c|c|c|c|c|c|c|}
\hline กอต & 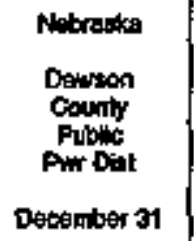 & $\begin{array}{l}\text { Habreake } \\
\text { Fremom } \\
\text { Ctht of } \\
\text { Dectinber 31 }\end{array}$ & 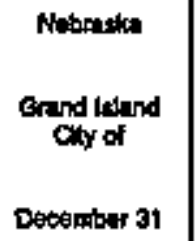 & $\begin{array}{l}\text { Nebraske } \\
\text { Hastings } \\
\text { Cint of } \\
\text { Decumber } 31\end{array}$ & 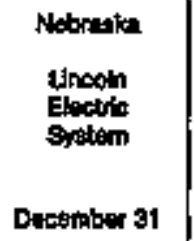 & 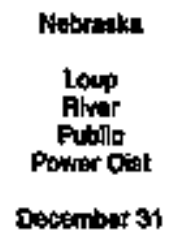 \\
\hline 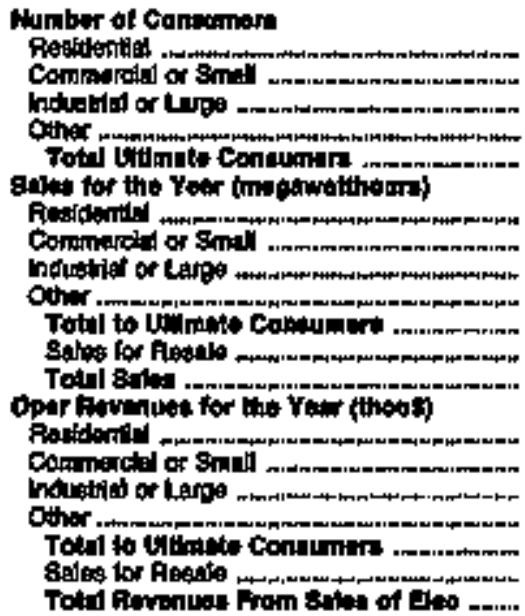 & 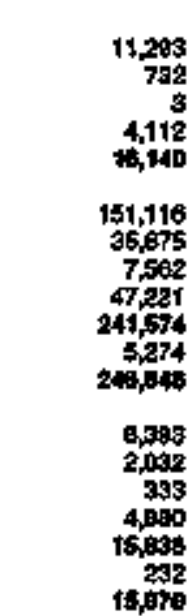 & 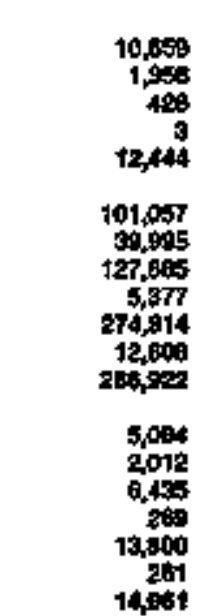 & 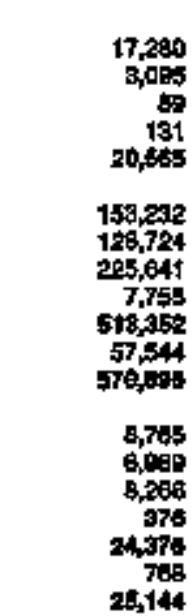 & 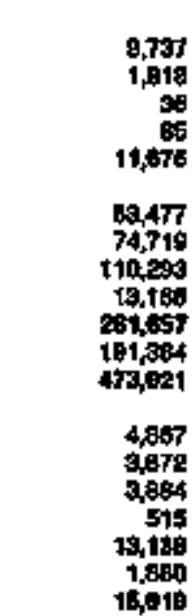 & 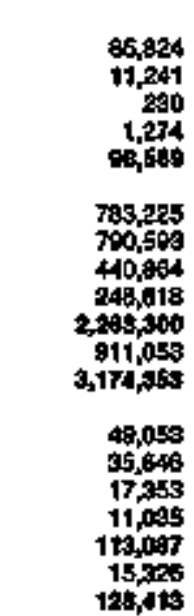 & 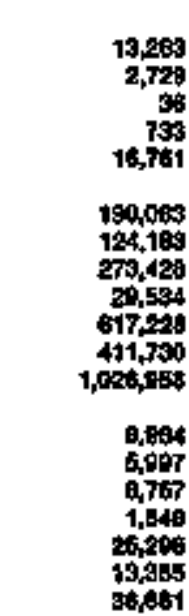 \\
\hline
\end{tabular}

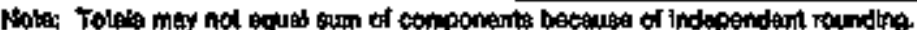

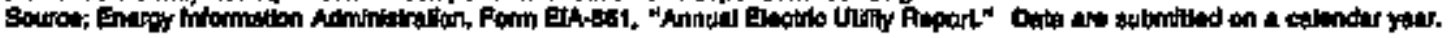


Table 25. Number of Consumers, Sales, and Operating Revenue by Major U.S. Publtely Owned Eleotrlo Utility Within State, 1994 (Continued)

\begin{tabular}{|c|c|c|c|c|c|c|}
\hline Hen & $\begin{array}{l}\text { Muprasich } \\
\text { Munloted } \\
\text { Erorger } \\
\text { Agonsy } \\
\text { of ME } \\
\text { Deoumber } 31\end{array}$ & 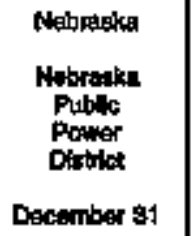 & 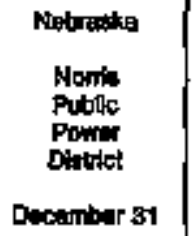 & $\begin{array}{l}\text { Alebregika } \\
\text { North } \\
\text { Plitila } \\
\text { Ciny of } \\
\text { December a1 }\end{array}$ & 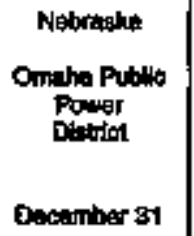 & 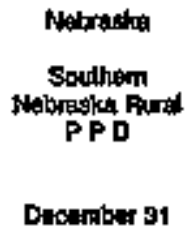 \\
\hline 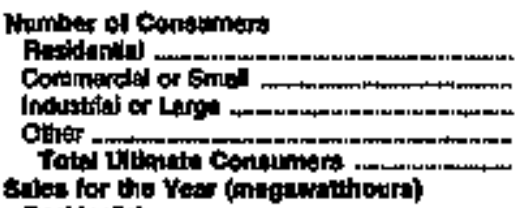 & $\begin{array}{l}0 \\
0 \\
0 \\
0 \\
0\end{array}$ & $\begin{array}{r}15,476 \\
10,357 \\
68 \\
4,174 \\
108,106\end{array}$ & $\begin{array}{r}10,088 \\
2,700 \\
68 \\
58 \\
12,+88\end{array}$ & $\begin{array}{r}11,581 \\
1,988 \\
0 \\
2 \\
14,681\end{array}$ & $\begin{array}{r}29,391 \\
32,430 \\
95 \\
616 \\
249,49\end{array}$ & $\begin{array}{r}10,894 \\
031 \\
131 \\
0,968 \\
18,727\end{array}$ \\
\hline 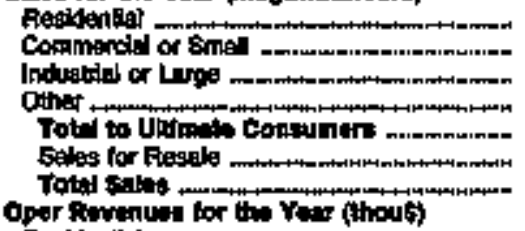 & $\begin{array}{r}0 \\
0 \\
0 \\
0 \\
0 \\
1,021,058 \\
1,021,800\end{array}$ & $\begin{array}{r}909,837 \\
776,292 \\
008,540 \\
180,656 \\
17,0,287 \\
0,311,130 \\
1,018,417\end{array}$ & 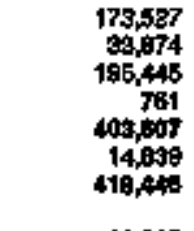 & 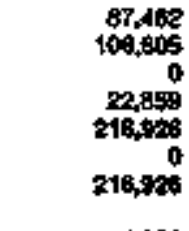 & 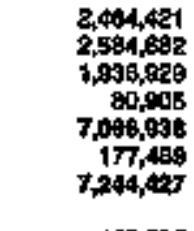 & $\begin{array}{r}176,613 \\
14,855 \\
130,557 \\
30,510 \\
304,374 \\
0 \\
304374\end{array}$ \\
\hline 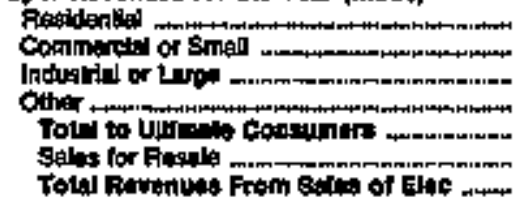 & $\begin{array}{r}0 \\
0 \\
0 \\
0 \\
0 \\
29000 \\
2000\end{array}$ & $\begin{array}{r}6,411 \\
47,382 \\
31,280 \\
11,035 \\
132,056 \\
332,054 \\
4,4,700\end{array}$ & $\begin{array}{r}10,993 \\
3,049 \\
7,416 \\
75 \\
21,512 \\
627 \\
20,049\end{array}$ & $\begin{array}{r}4,001 \\
5,377 \\
0 \\
589 \\
10,980 \\
0 \\
10,990\end{array}$ & $\begin{array}{r}165,5 a 5 \\
148,507 \\
76,798 \\
10,626 \\
09,511 \\
4,211 \\
403,598\end{array}$ & 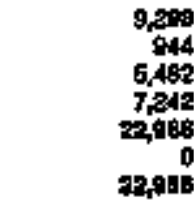 \\
\hline
\end{tabular}

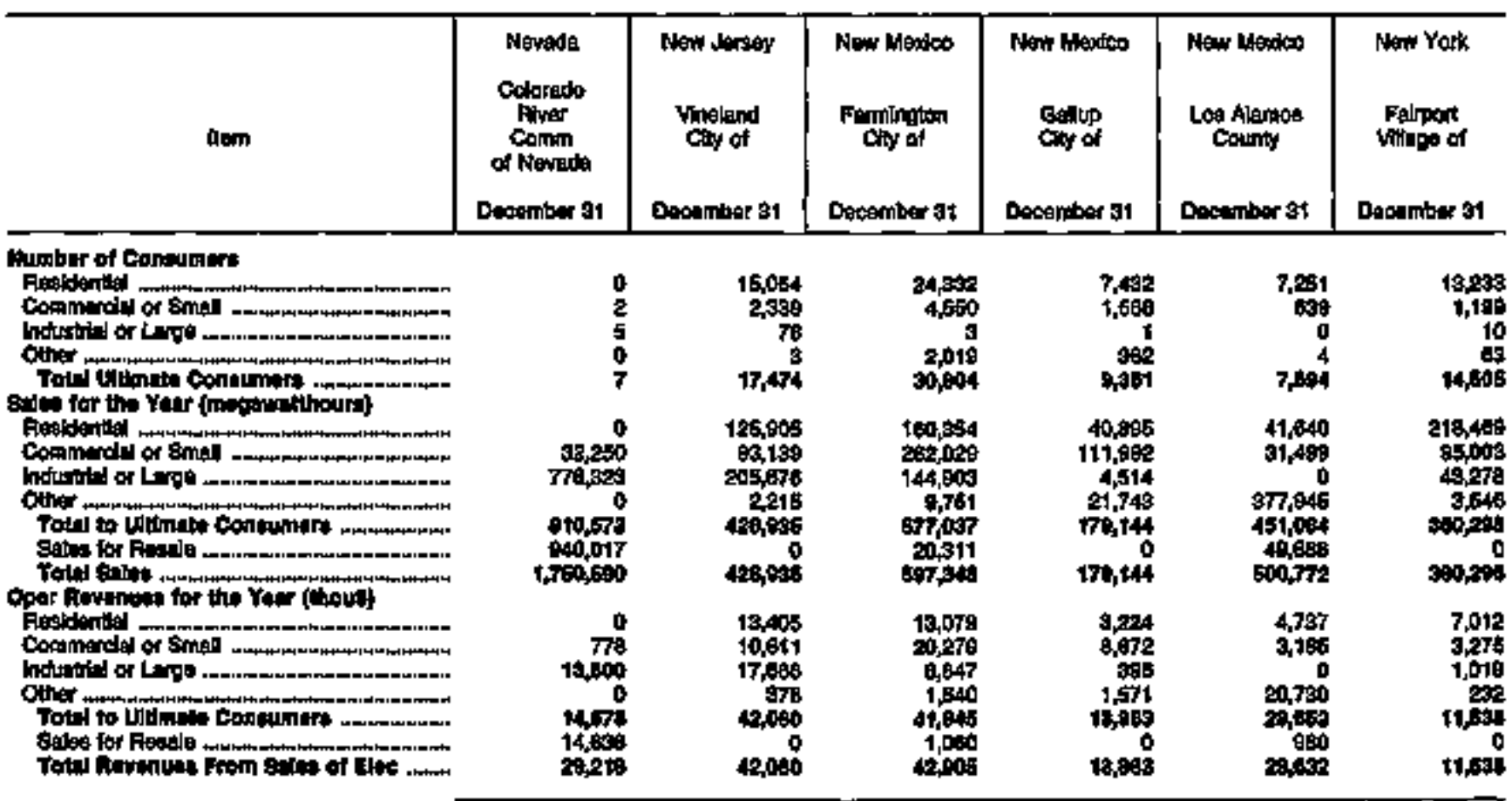

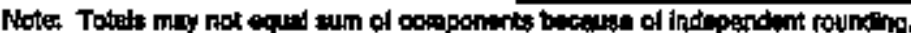

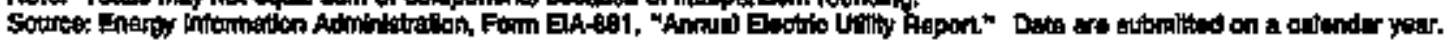


Table 25. Number of Consunters, Sales, and Operating Revenue by Major U.S. Publicly Owned Electric Utilty Whith State, 1994 (Contlnued)

\begin{tabular}{|c|c|c|c|c|c|c|}
\hline Hann & $\begin{array}{l}\text { How Yoik } \\
\text { Freeport } \\
\text { Vlloge of } \\
\text { lne }\end{array}$ & 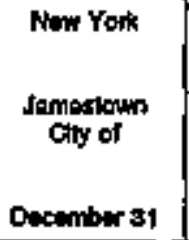 & $\begin{array}{l}\text { Now Yoik } \\
\text { Lolie Plack } \\
\text { Viltege inc } \\
\text { Decomber a1 }\end{array}$ & $\begin{array}{l}\text { Now York } \\
\text { Mossene } \\
\text { Town of } \\
\text { Oecoimber } 31\end{array}$ & $\begin{array}{l}\text { Now York } \\
\text { Platisturnh } \\
\text { Cthy of } \\
\text { Decomber } 31\end{array}$ & 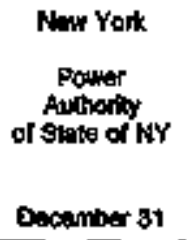 \\
\hline 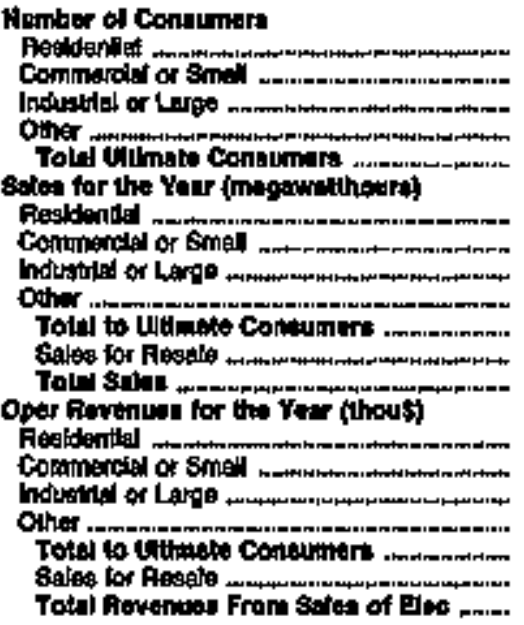 & 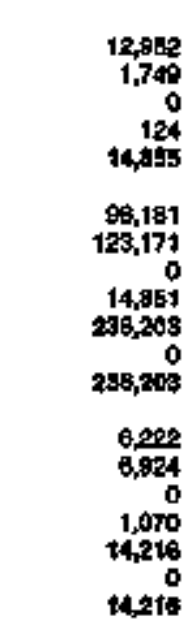 & 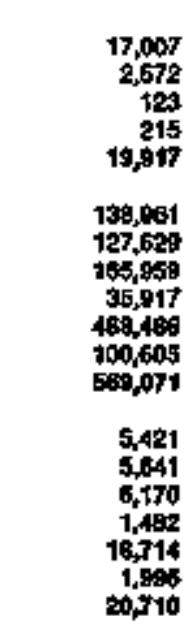 & 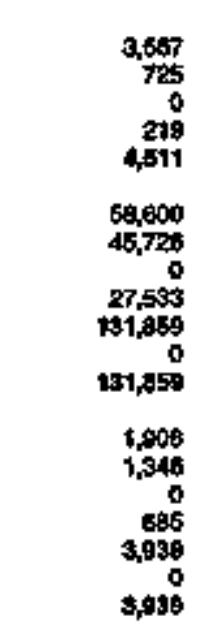 & 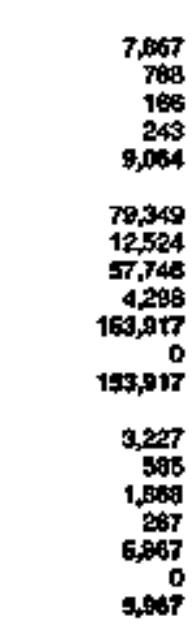 & $\begin{array}{r}7,535 \\
1,293 \\
4 \\
109 \\
9,081 \\
102,021 \\
164,180 \\
101,720 \\
6,069 \\
520,190 \\
0 \\
503,194 \\
4,264 \\
0,706 \\
2,752 \\
307 \\
11,016 \\
0 \\
11,010\end{array}$ & 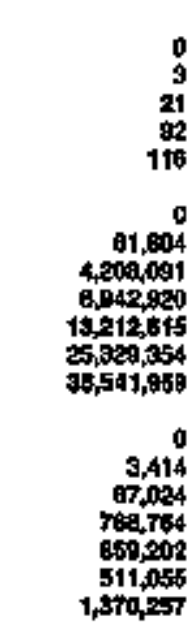 \\
\hline
\end{tabular}

\begin{tabular}{|c|c|c|c|c|c|c|}
\hline llem & 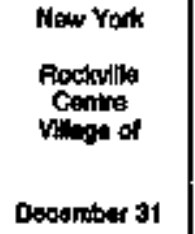 & $\begin{array}{c}\text { Neri York } \\
\text { solway } \\
\text { Villige of } \\
\text { Decoumber o1 }\end{array}$ & 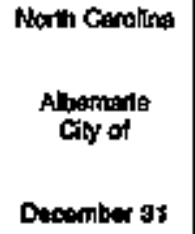 & $\begin{array}{l}\text { North Cangina } \\
\text { Concond } \\
\text { Chy of } \\
\text { Docomber } 31\end{array}$ & $\begin{array}{l}\text { Noth Ceoling } \\
\text { Eleabelh } \\
\text { Chy Chy of } \\
\text { December 31 }\end{array}$ & 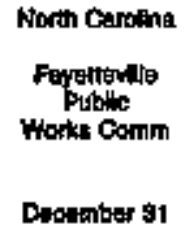 \\
\hline 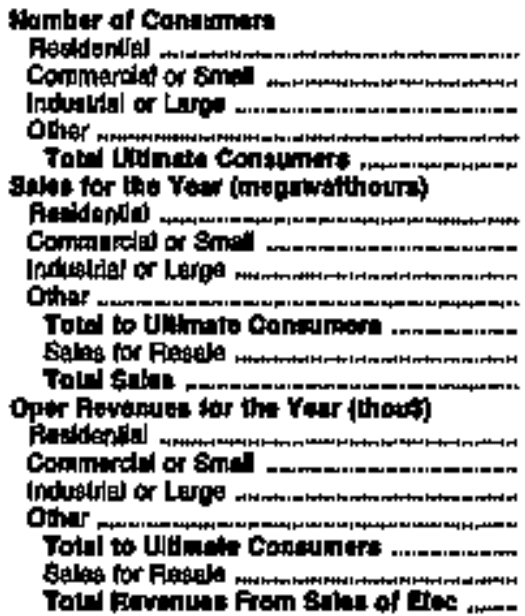 & 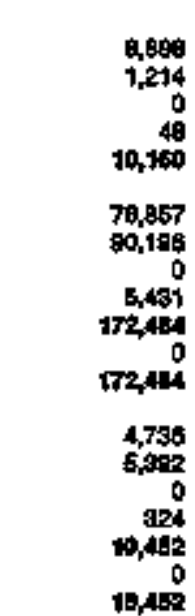 & 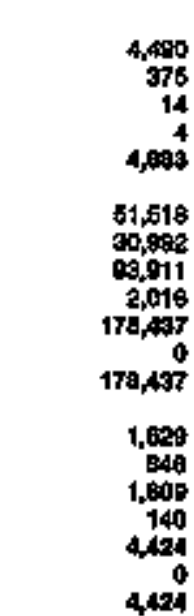 & 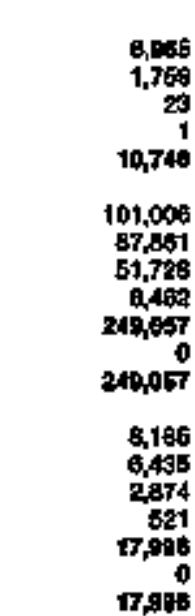 & 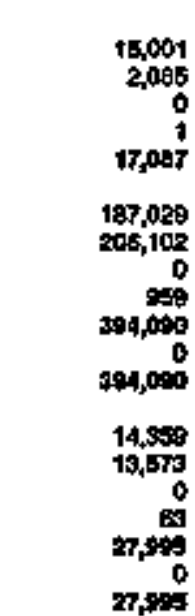 & 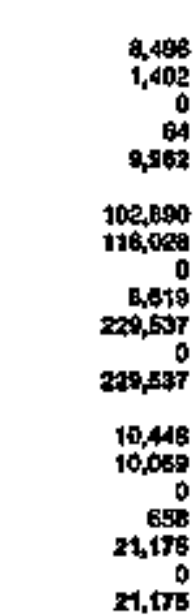 & 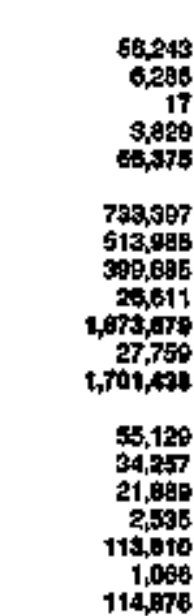 \\
\hline
\end{tabular}

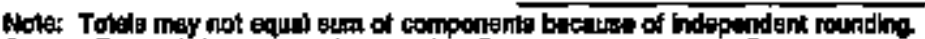

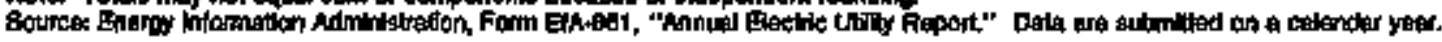


Tabte 25. Number of Consumers, Sales, and Operating Revenue by Major U.S. Publicly Owned Electrte Ut|lly Within State, 1994 (Contriced)

\begin{tabular}{|c|c|c|c|c|c|c|}
\hline Ilam & 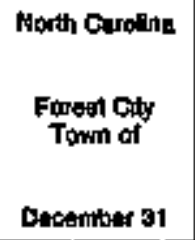 & 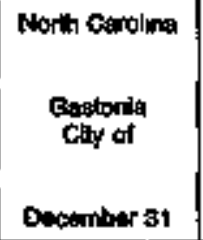 & 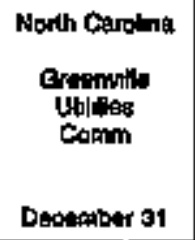 & 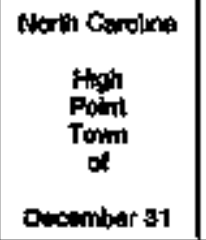 & $\begin{array}{l}\text { North Cerasina } \\
\text { Kontlon } \\
\text { City of } \\
\text { Denomber } 31\end{array}$ & $\begin{array}{l}\text { North cerothe } \\
\text { Couingion } \\
\text { Chy of } \\
\text { Decamber } 34\end{array}$ \\
\hline 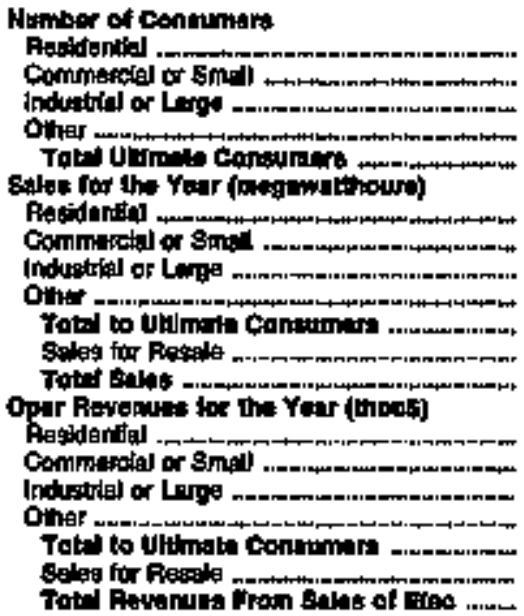 & 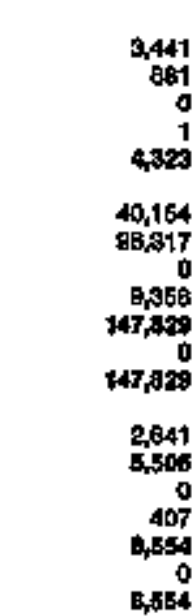 & 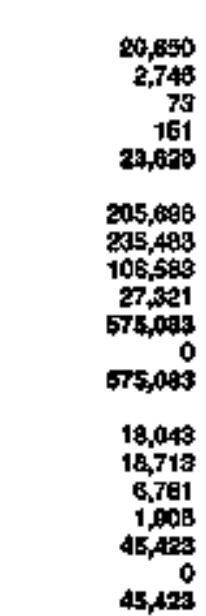 & 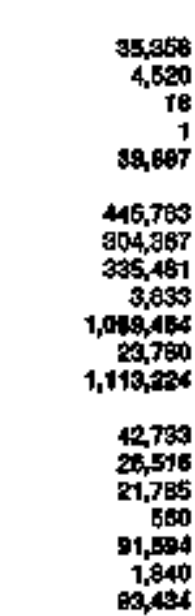 & 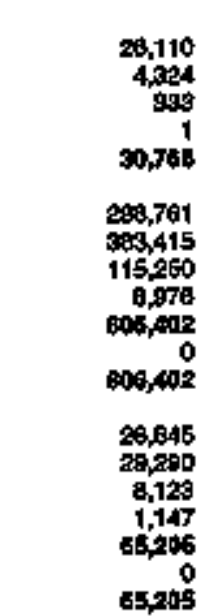 & 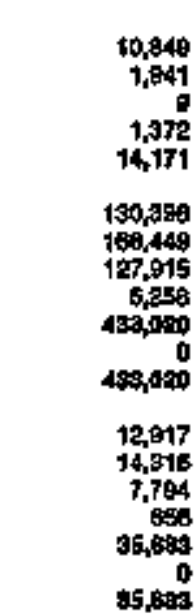 & 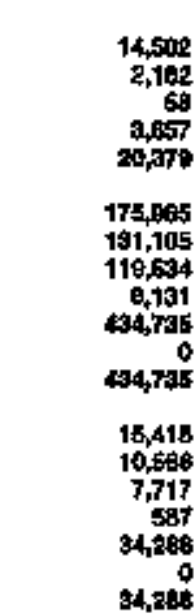 \\
\hline
\end{tabular}

\begin{tabular}{|c|c|c|c|c|c|c|}
\hline nem & 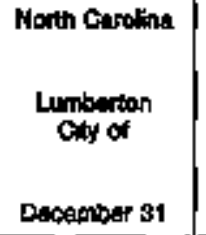 & $\begin{array}{l}\text { North Corolint } \\
\text { Monros } \\
\text { City of } \\
\text { Deamber } 37\end{array}$ & $\begin{array}{c}\text { North Curtint } \\
\text { Wompunton } \\
\text { City of } \\
\text { Docember } 31\end{array}$ & $\begin{array}{l}\text { Morth Comolina } \\
\text { Cunphy of } \\
\text { Decomber at }\end{array}$ & $\begin{array}{l}\text { North Curchn: } \\
\text { How Bem } \\
\text { City of }\end{array}$ & 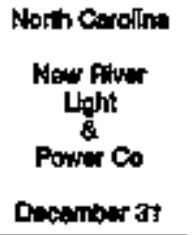 \\
\hline 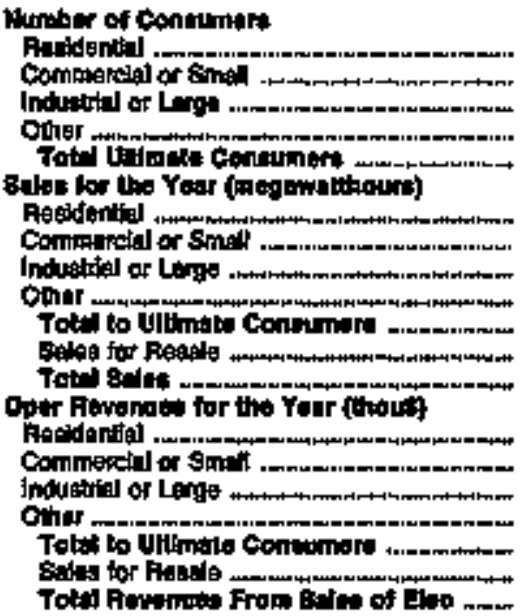 & 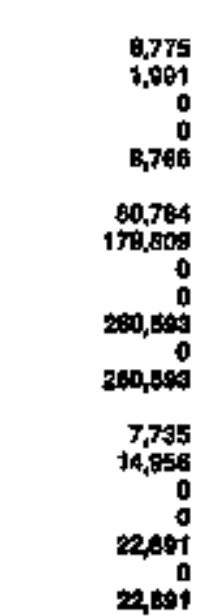 & 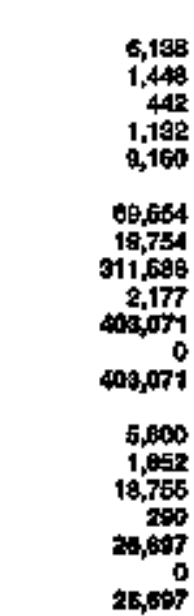 & 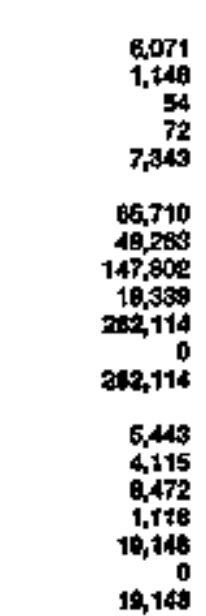 & 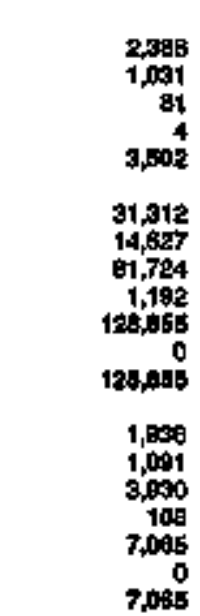 & 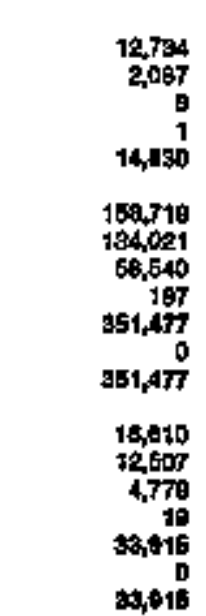 & 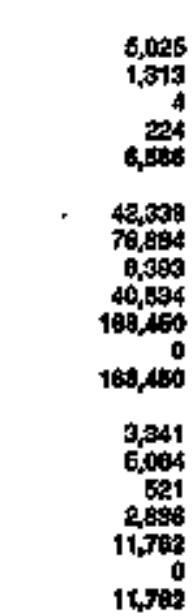 \\
\hline
\end{tabular}

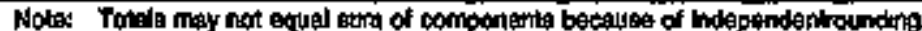

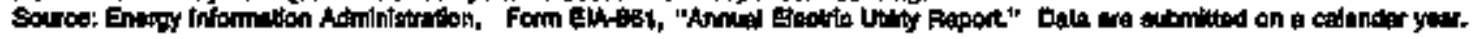


Table 25. Number of Consumers, 8ales, and Operating Revenue by Major U.s. Publicty Owmed Electric Utllity Whth Stake, to94 (Continued)

\begin{tabular}{|c|c|c|c|c|c|c|}
\hline Ilem & 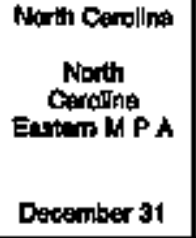 & 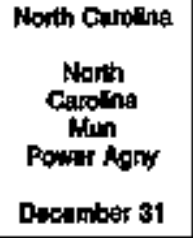 & 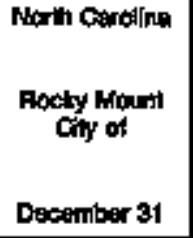 & 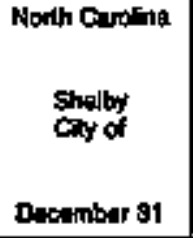 & 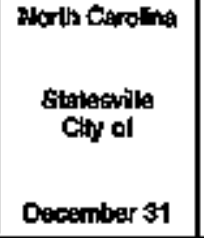 & $\begin{array}{l}\text { North Gurcilise } \\
\text { Tountors } \\
\text { Town of } \\
\text { Deramber } 31\end{array}$ \\
\hline 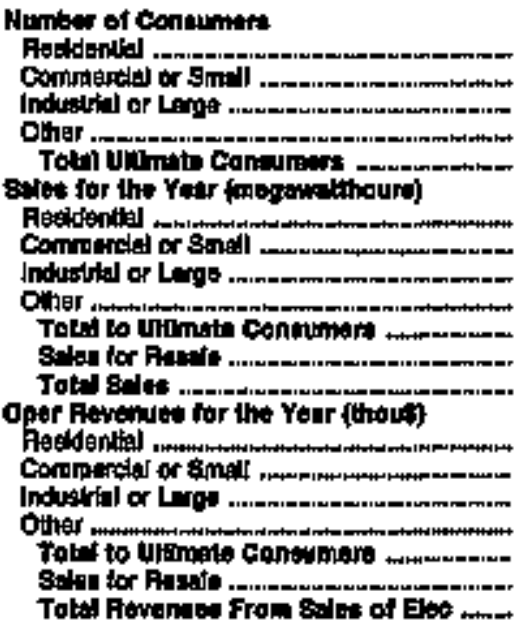 & $\begin{array}{r}0 \\
0 \\
0 \\
0 \\
0 \\
0,960,075 \\
0,300,086\end{array}$ & $\begin{array}{r}0 \\
0 \\
0 \\
0 \\
0 \\
0 \\
+838,759 \\
\quad, 036,75 \%\end{array}$ & 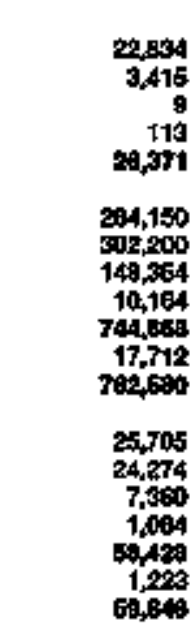 & 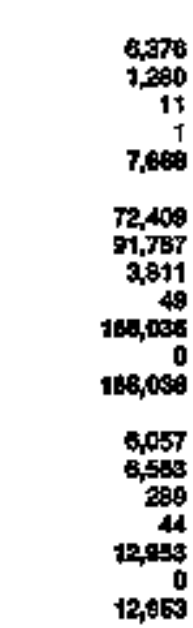 & 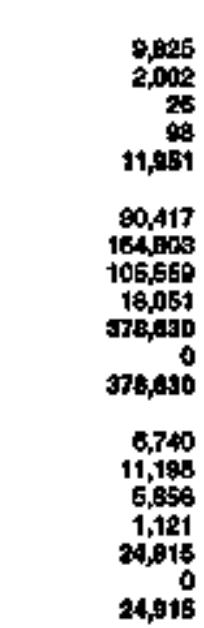 & 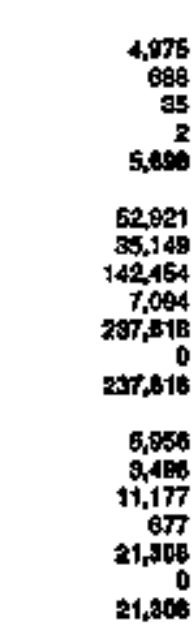 \\
\hline
\end{tabular}

\begin{tabular}{|c|c|c|c|c|c|c|}
\hline Hant & $\begin{array}{l}\text { North Canthe } \\
\text { Whatioglon } \\
\text { Chy of } \\
\text { Decentor } 31\end{array}$ & $\begin{array}{l}\text { Norts Carolnt } \\
\text { Wilson } \\
\text { Ciky of } \\
\text { Oecember } 81\end{array}$ & 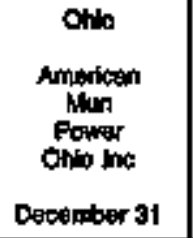 & $\begin{array}{l}\text { Ohlo } \\
\text { Bowing } \\
\text { Gieen } \\
\text { Gity of } \\
\text { Decomber } 31\end{array}$ & $\begin{array}{l}\text { Ohio } \\
\text { Enyan } \\
\text { City of } \\
\text { Desember } 31\end{array}$ & $\begin{array}{l}\text { Otitin } \\
\text { Coltin } \\
\text { chy of } \\
\text { Doounter } 31\end{array}$ \\
\hline 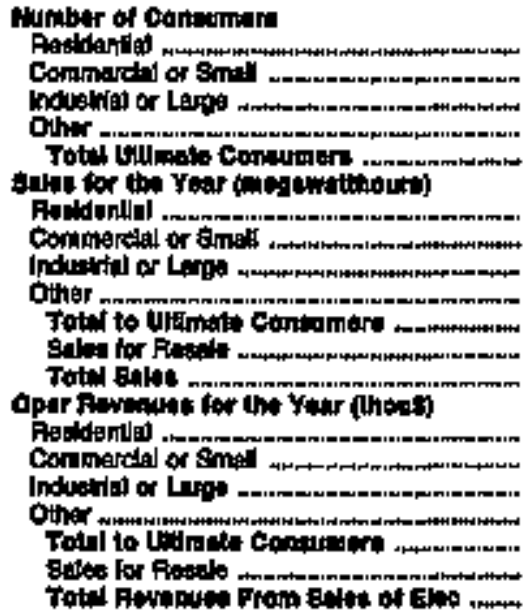 & 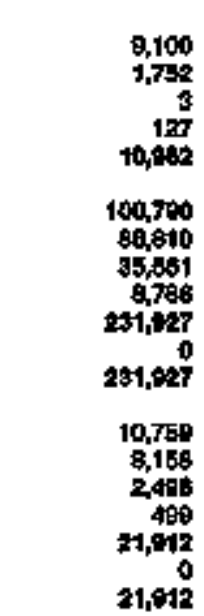 & 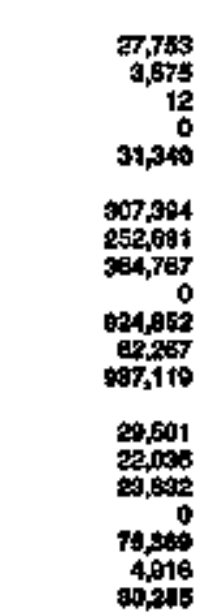 & $\begin{array}{r}0 \\
0 \\
737,497 \\
0 \\
787,497 \\
4,183,029 \\
4,131,365 \\
0 \\
0 \\
15,057 \\
0 \\
15,054 \\
194,631 \\
149,502\end{array}$ & 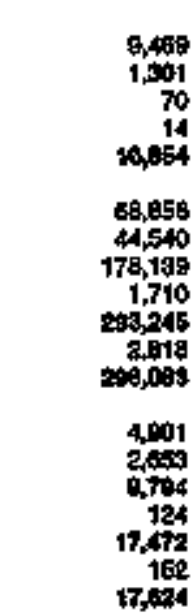 & 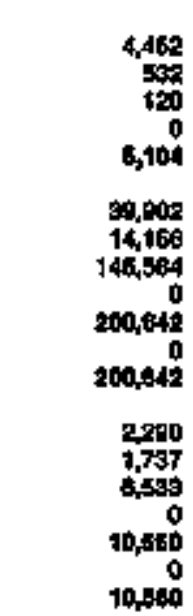 & 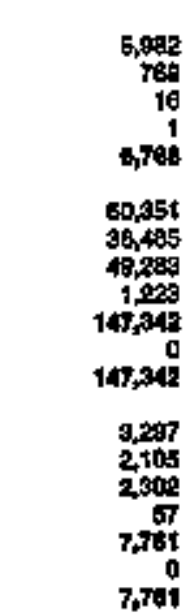 \\
\hline
\end{tabular}

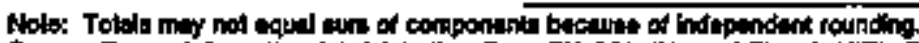

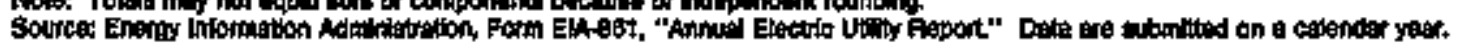


Table 25. Number of Consumers, Sales, and Operating Revenue by Major U.S.

Publicly Owned Electrio Utilty within state, 1994 (Continued)

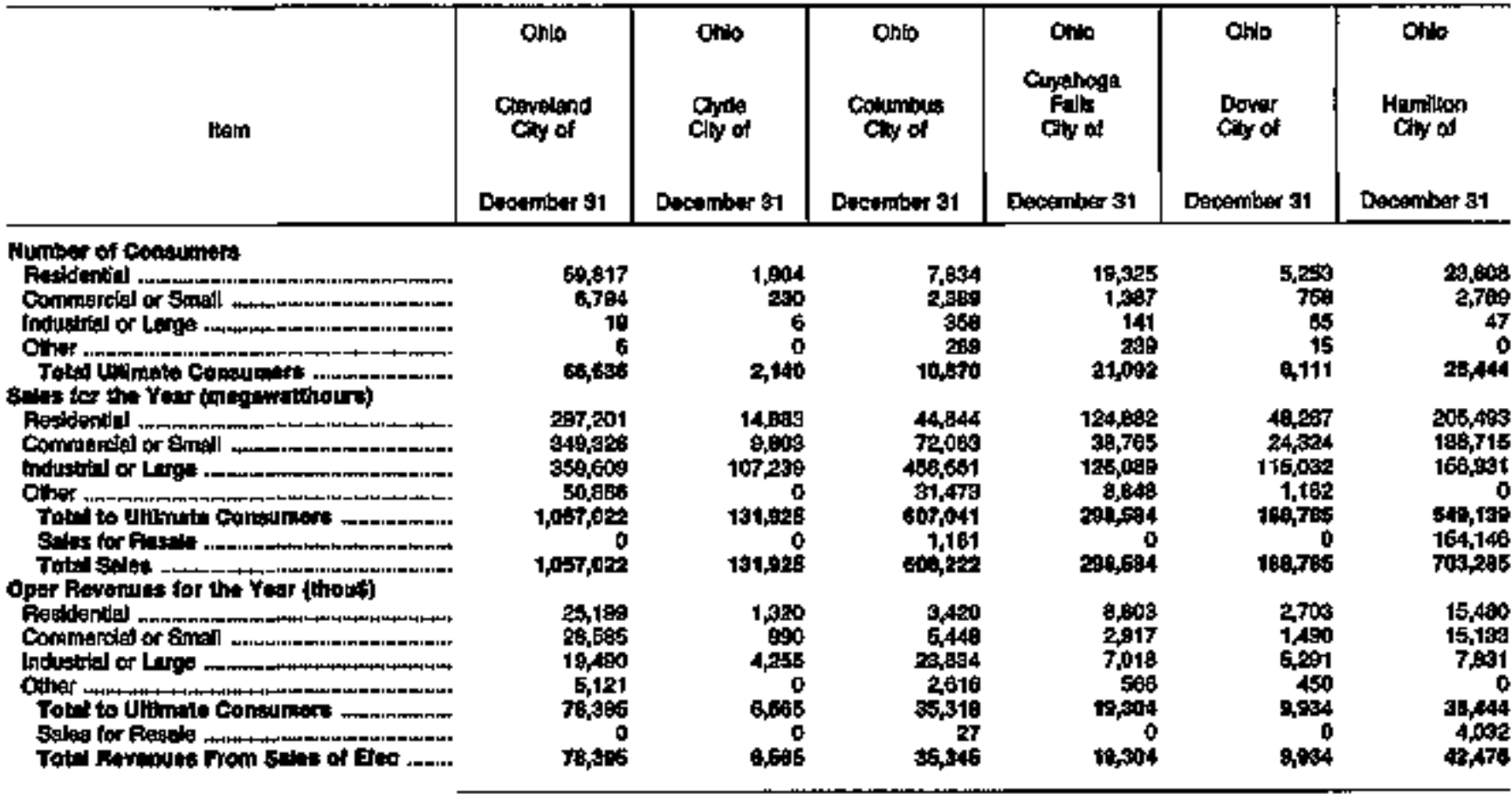

\begin{tabular}{|c|c|c|c|c|c|c|}
\hline liem & $\begin{array}{l}\text { Otio } \\
\text { Nopolion } \\
\text { Othy of } \\
\text { Doonmber } 31\end{array}$ & Decomber 31 & $\begin{array}{l}\text { Onb } \\
\text { Orvilo } \\
\text { City of } \\
\text { Docerdiber a1 }\end{array}$ & $\begin{array}{l}\text { Ohito } \\
\text { Paineswile } \\
\text { Ciny of } \\
\text { Deomber } 1\end{array}$ & $\begin{array}{l}\text { Onis } \\
\text { Pfipis } \\
\text { Dety of } \\
\text { December } 31\end{array}$ & $\begin{array}{l}\text { Obilo } \\
\text { St Harys ol } \\
\text { Decaniber } 31\end{array}$ \\
\hline 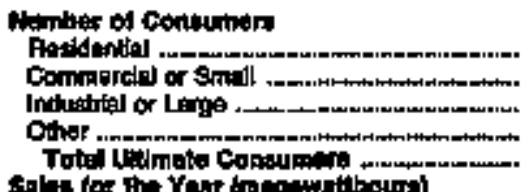 & $\begin{array}{r}4,717 \\
669 \\
59 \\
6896 \\
6,506\end{array}$ & $\begin{array}{r}10,411 \\
1,034 \\
40 \\
470 \\
12,005\end{array}$ & $\begin{array}{r}6,278 \\
665 \\
13 \\
90 \\
5,196\end{array}$ & $\begin{array}{r}8,458 \\
1,685 \\
1 \\
9 \\
0,114\end{array}$ & $\begin{array}{r}0,556 \\
1,032 \\
20 \\
0 \\
0,610\end{array}$ & $\begin{array}{r}3,3989 \\
487 \\
15 \\
14 \\
3,694\end{array}$ \\
\hline 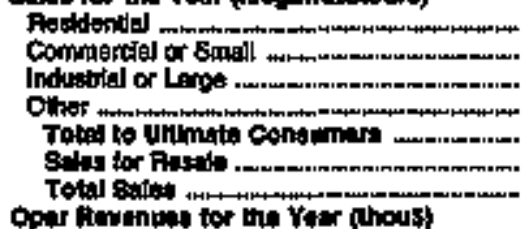 & 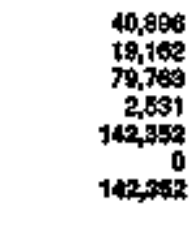 & $\begin{array}{r}76,603 \\
91,457 \\
95,611 \\
1,147 \\
241,716 \\
94,718\end{array}$ & $\begin{array}{r}60,340 \\
50,105 \\
130,200 \\
0,060 \\
20,709 \\
97,990 \\
300,093\end{array}$ & $\begin{array}{r}58,698 \\
98,349 \\
32,764 \\
0 \\
190,7 \% 7 \\
0 \\
10,7 \% 7\end{array}$ & $\begin{array}{r}71,730 \\
01,215 \\
02,070 \\
0 \\
266,0024 \\
0 \\
250,020\end{array}$ & $\begin{array}{r}30,600 \\
40,052 \\
02,414 \\
1,760 \\
164,649 \\
5,159 \\
180,000\end{array}$ \\
\hline 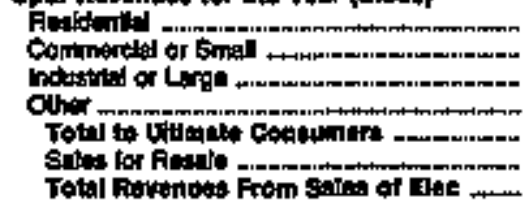 & $\begin{array}{r}2,603 \\
1,3012 \\
4,485 \\
28 \\
2,449 \\
9,40\end{array}$ & 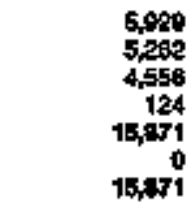 & $\begin{array}{r}3,707 \\
3,186 \\
6,796 \\
258 \\
19,967 \\
1,912 \\
15,649\end{array}$ & $\begin{array}{r}4,045 \\
7,425 \\
1,440 \\
0 \\
15,011 \\
0 \\
15, a 11\end{array}$ & $\begin{array}{r}4,625 \\
5,758 \\
5,009 \\
16,570 \\
0 \\
15,870\end{array}$ & $\begin{array}{r}1,849 \\
2,021 \\
3,140 \\
64 \\
7,090 \\
164 \\
r, 293\end{array}$ \\
\hline
\end{tabular}

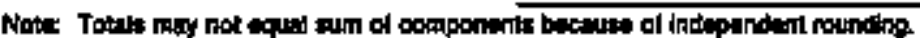

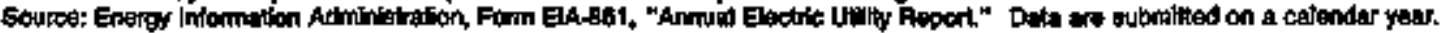


Table 25. Number of Consumers, Seles, and Operating Revenue by Major U.S. Publlely Owmed Electric Utilty Within State, 1994 (Continued)

\begin{tabular}{|c|c|c|c|c|c|c|}
\hline $\mathrm{kem}$ & $\begin{array}{l}\text { Otho } \\
\text { Wactomariti } \\
\text { Cry of } \\
\text { Deoumber } 31\end{array}$ & $\begin{array}{l}\text { Ohio } \\
\text { Weptakonota } \\
\text { Ciny of } \\
\text { December } 3 t\end{array}$ & 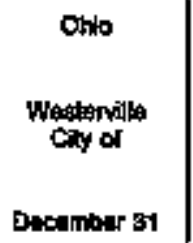 & $\begin{array}{l}\text { Oldshome } \\
\text { Altog } \\
\text { City of } \\
\text { December at }\end{array}$ & $\begin{array}{l}\text { Didehoma } \\
\text { Ctaramore } \\
\text { Cry of } \\
\text { Duonmber } 31\end{array}$ & 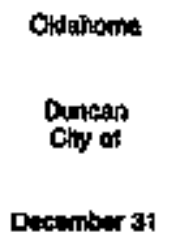 \\
\hline 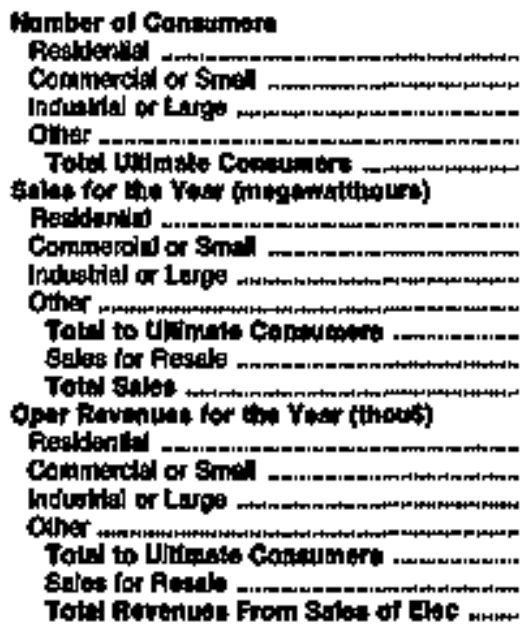 & 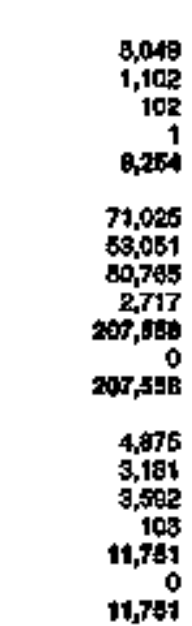 & 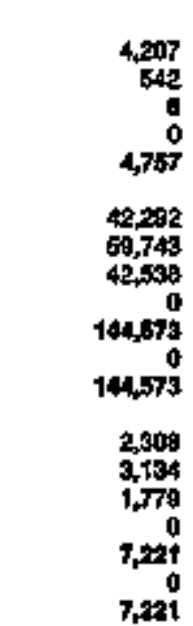 & 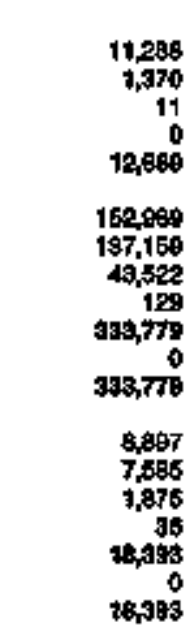 & $\begin{array}{r}7,855 \\
1,267 \\
40 \\
1 \\
9,163 \\
70,848 \\
70,433 \\
6,9077 \\
1659 \\
149,707 \\
0 \\
149,707 \\
5,216 \\
4,739 \\
172 \\
48 \\
10,174 \\
0 \\
10,174\end{array}$ & 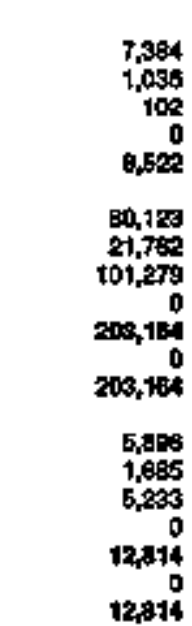 & 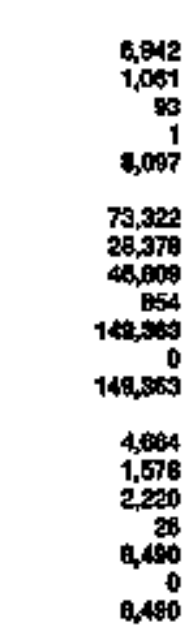 \\
\hline
\end{tabular}

\begin{tabular}{|c|c|c|c|c|c|c|}
\hline IFam & $\begin{array}{l}\text { Oddaltoma } \\
\text { Edmond } \\
\text { City of } \\
\text { December } 31\end{array}$ & $\begin{array}{l}\text { Oklahomi } \\
\text { Grend Ftrer } \\
\text { Oum } \\
\text { Authoitly } \\
\text { Deconter } 91\end{array}$ & $\begin{array}{l}\text { Oldriome } \\
\text { City of } \\
\text { Decomber at }\end{array}$ & 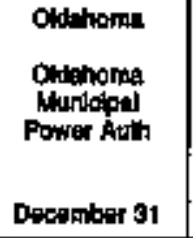 & $\begin{array}{l}\text { Oklnheine } \\
\text { Ponct } \\
\text { Givy Ciky of } \\
\text { Decomber } 31\end{array}$ & 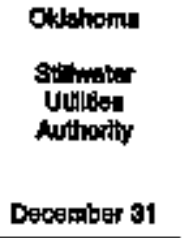 \\
\hline 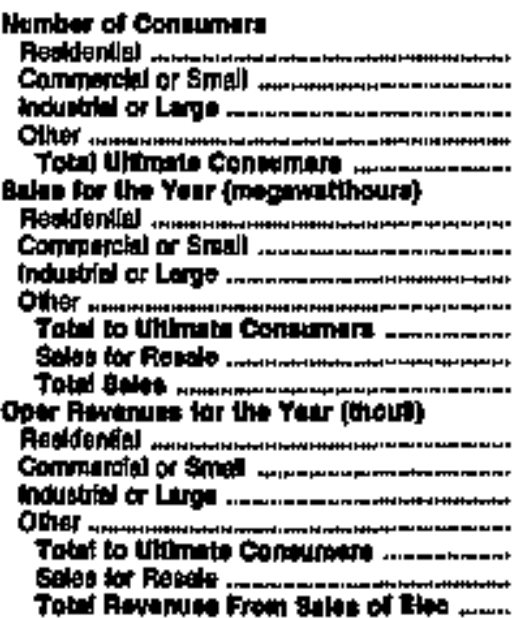 & 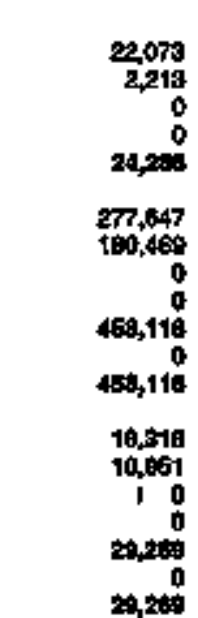 & 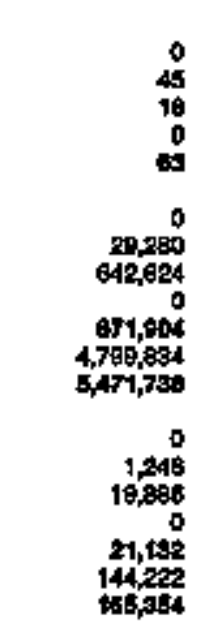 & 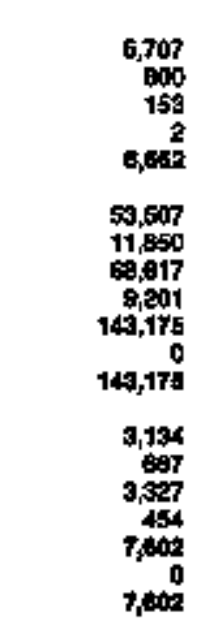 & $\begin{array}{r}0 \\
0 \\
0 \\
0 \\
0 \\
1,680,084 \\
1,500,040 \\
0 \\
0 \\
0 \\
0 \\
0 \\
71,020 \\
71,020\end{array}$ & 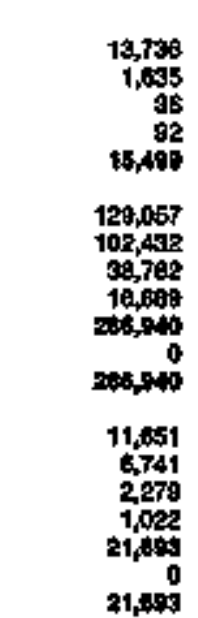 & 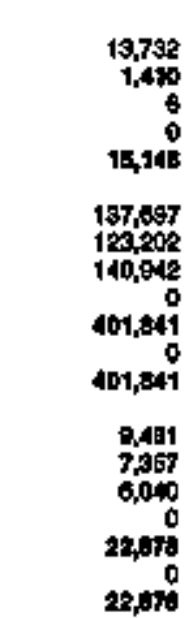 \\
\hline
\end{tabular}

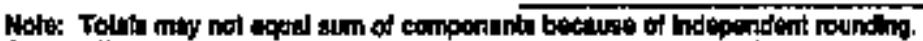

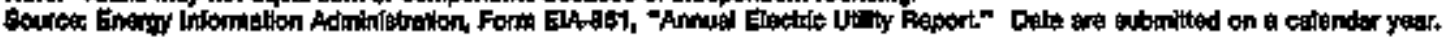


Table 25. Number of Consumert, Sales, and Operating Revenue by Malor U.S. Publdy Owned Electric Litily with'n state, 1994 (Continued)

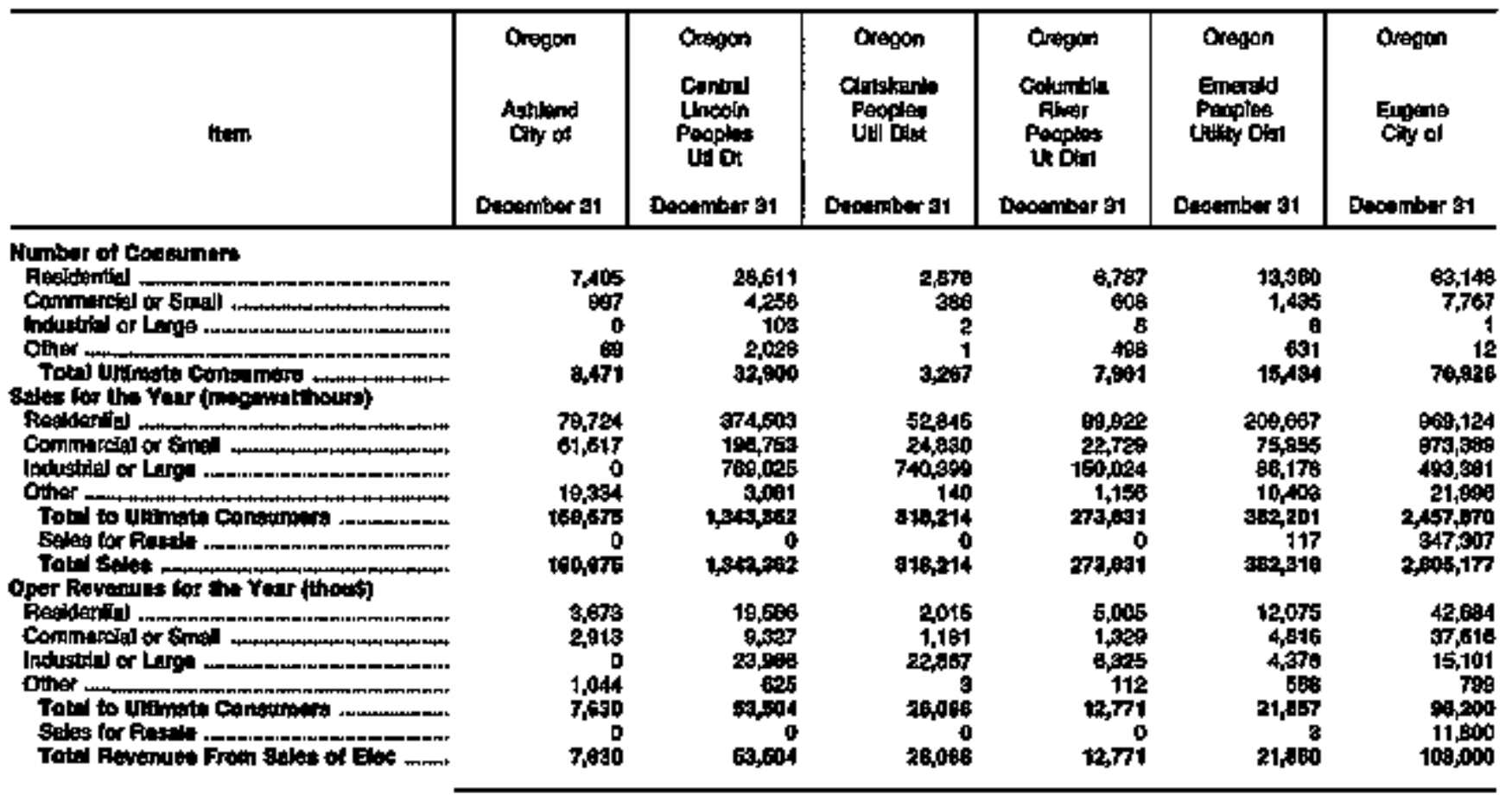

\begin{tabular}{|c|c|c|c|c|c|c|}
\hline tim & $\begin{array}{c}\text { Oregon } \\
\text { Forest timing } \\
\text { Clty of } \\
\text { December } 31\end{array}$ & 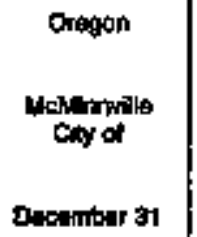 & $\begin{array}{l}\text { Oretion } \\
\text { Northom } \\
\text { whoco Coenty } \\
\text { PU D } \\
\text { Decomber at }\end{array}$ & 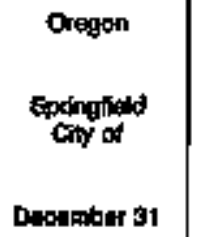 & 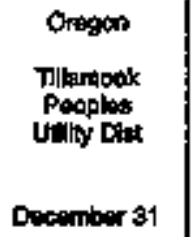 & 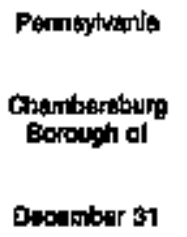 \\
\hline 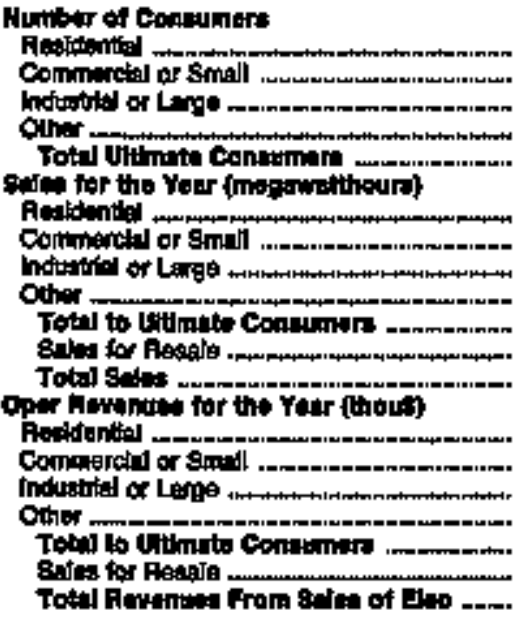 & 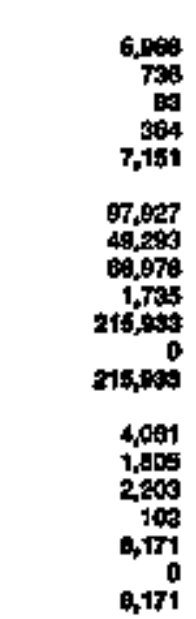 & 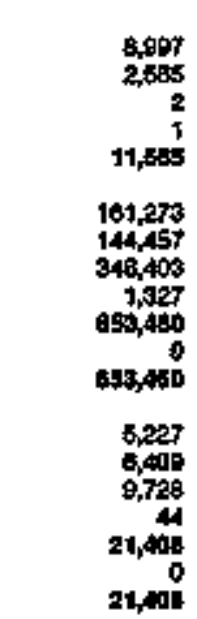 & 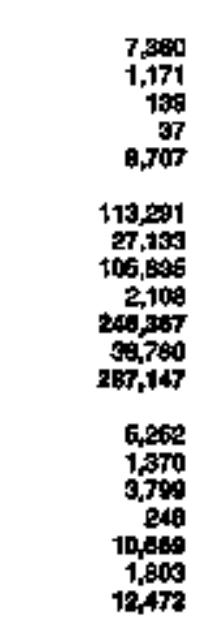 & 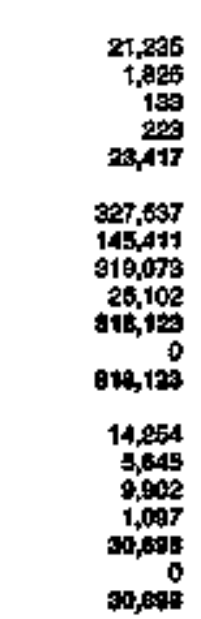 & 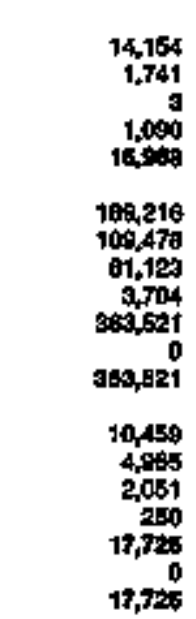 & 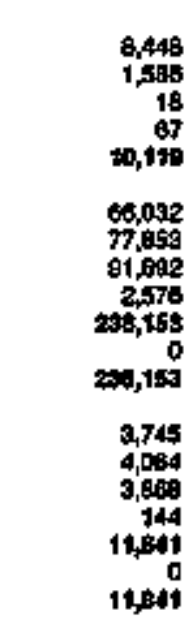 \\
\hline
\end{tabular}

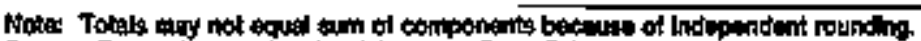

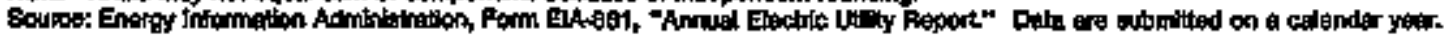


Table 25. Nurnber of Conwumers, Sales, and Operating Revemu by Major U.S. Publicly Owned Electric Utilty Whin State, 1994 (Continuted)

\begin{tabular}{|c|c|c|c|c|c|c|}
\hline Item & 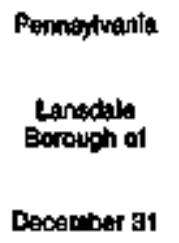 & $\begin{array}{c}\text { Bouth Caroning } \\
\text { Comply of } \\
\text { Dactimber } 31\end{array}$ & 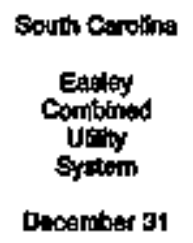 & $\begin{array}{l}\text { South Carolna } \\
\text { Gelfity } \\
\text { Ciny of } \\
\text { Dactomber } 31\end{array}$ & 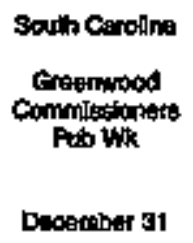 & 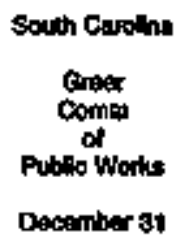 \\
\hline 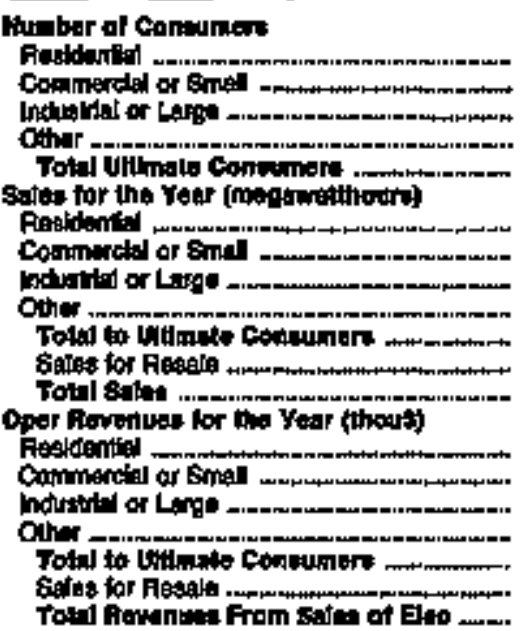 & 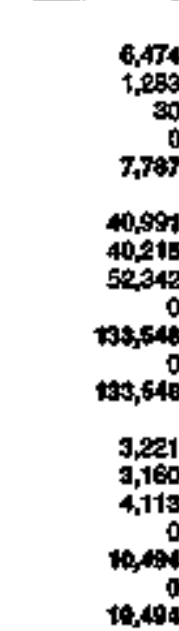 & 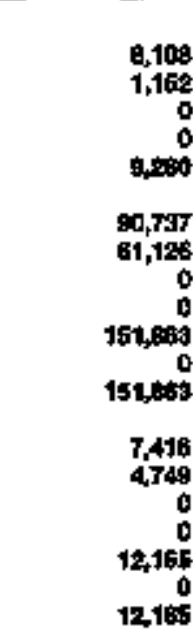 & 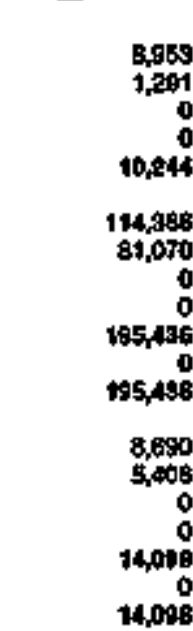 & 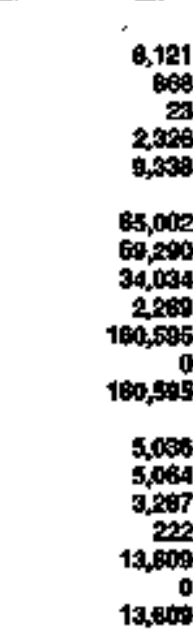 & 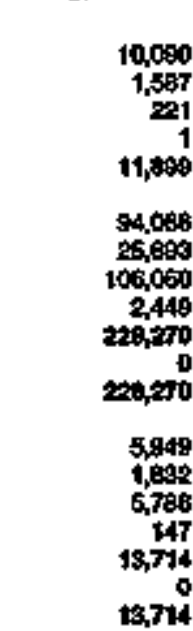 & 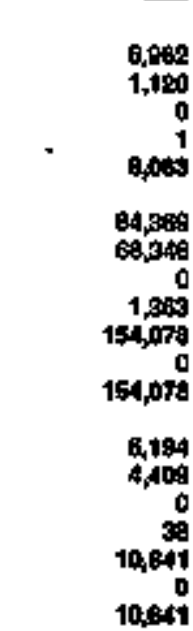 \\
\hline
\end{tabular}

\begin{tabular}{|c|c|c|c|c|c|c|}
\hline $\mathrm{Ilam}$ & 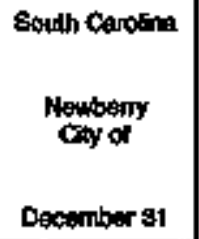 & 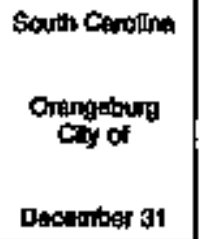 & 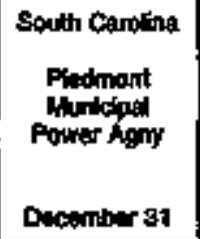 & $\begin{array}{l}\text { Shath Ceroing } \\
\text { Rock rip } \\
\text { Cny of } \\
\text { Deounber } \$ 1\end{array}$ & $\begin{array}{l}\text { South caroine } \\
\text { Dectinber } 31\end{array}$ & 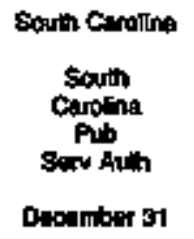 \\
\hline 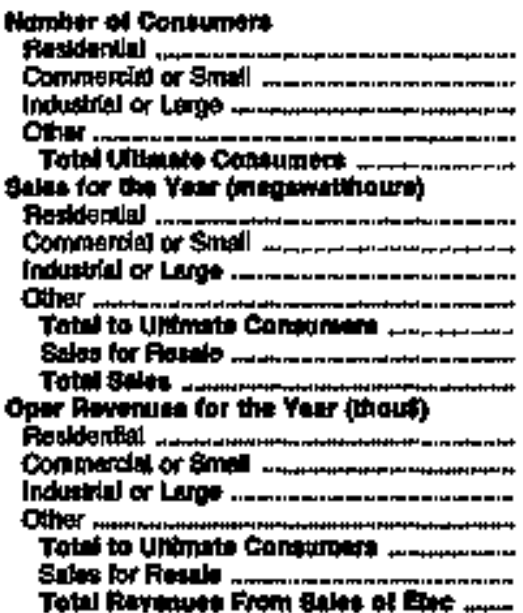 & 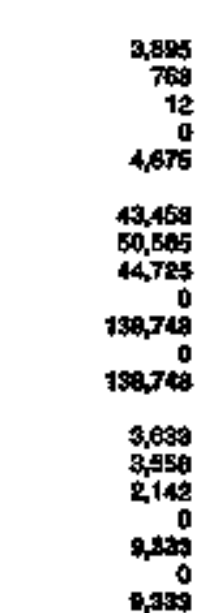 & 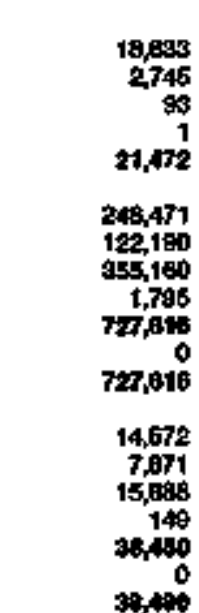 & 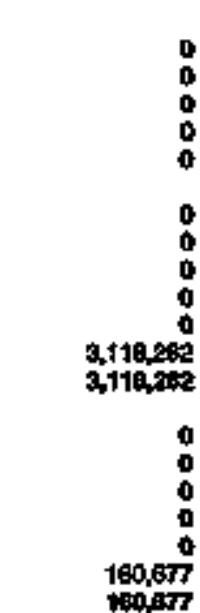 & 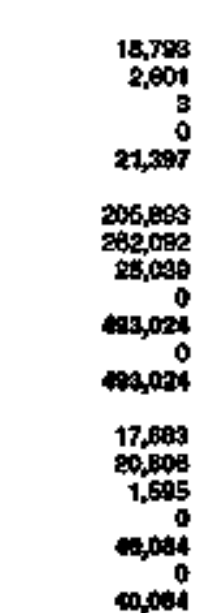 & 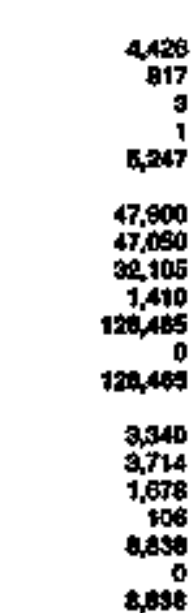 & 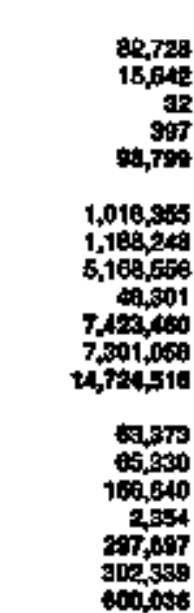 \\
\hline
\end{tabular}

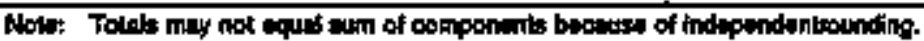

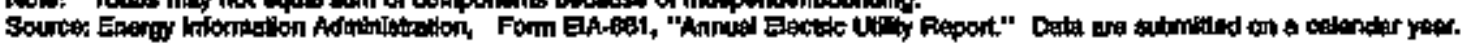


Tabte 25. Number of Constumers, Sales, and Operating Pevenue by Major U.S. Publlely Owned Electric Utilty Within State, 1994 (Continued)

\begin{tabular}{|c|c|c|c|c|c|c|}
\hline Henl & $\begin{array}{l}\text { Bowth Dakola } \\
\text { Broolings } \\
\text { oly of } \\
\text { Docember } 31\end{array}$ & 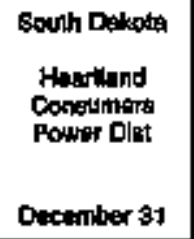 & 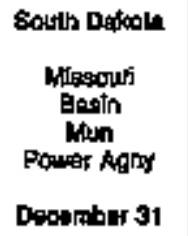 & 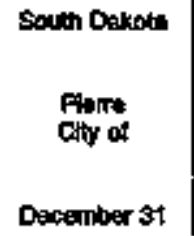 & 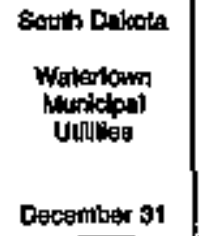 & $\begin{array}{c}\text { Tennesses } \\
\text { Aleos } \\
\text { Utllites } \\
\text { Dexember } 31\end{array}$ \\
\hline 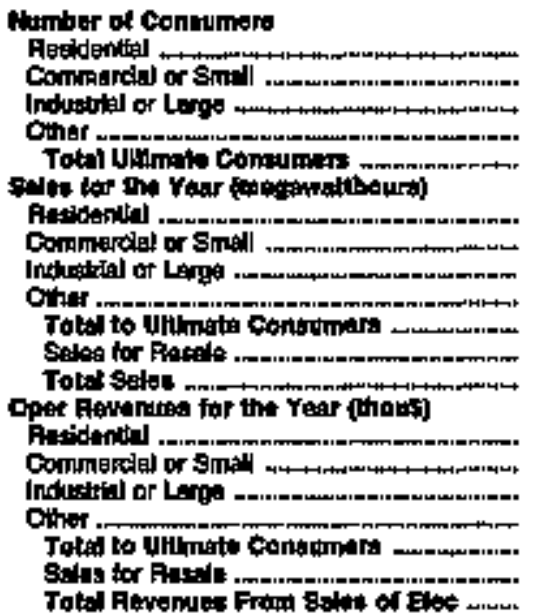 & $\begin{array}{r}8,052 \\
918 \\
35 \\
102 \\
7,705 \\
61,052 \\
97,301 \\
68,975 \\
14,782 \\
181,410 \\
0 \\
111,418 \\
2,485 \\
1,705 \\
2,754 \\
731 \\
7,748 \\
7,745\end{array}$ & $\begin{array}{r}0 \\
0 \\
0 \\
183 \\
193 \\
438,158 \\
433,941 \\
0 \\
0 \\
0 \\
3 \\
5 \\
11,498 \\
11,441\end{array}$ & $\begin{array}{r}0 \\
0 \\
0 \\
0 \\
0 \\
1,806,129 \\
1,490,120 \\
0 \\
0 \\
0 \\
0 \\
0 \\
59,020 \\
5,402\end{array}$ & 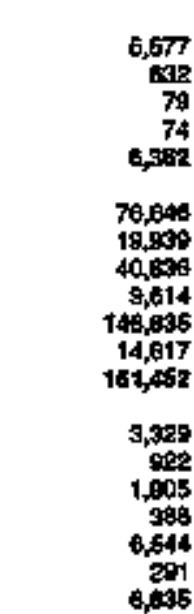 & 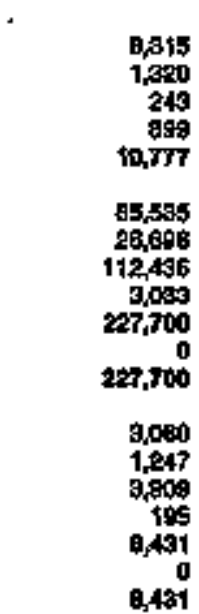 & 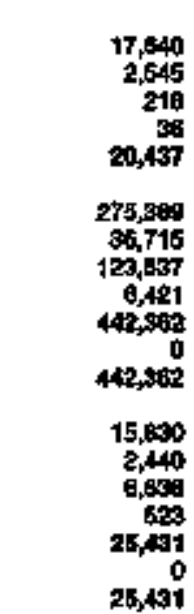 \\
\hline
\end{tabular}

\begin{tabular}{|c|c|c|c|c|c|c|}
\hline Hem & $\begin{array}{l}\text { Tennessine } \\
\text { Alhena } \\
\text { Utily } \\
\text { Boend } \\
\text { December 31 }\end{array}$ & $\begin{array}{l}\text { Temnesses } \\
\text { Bankon } \\
\text { Counly } \\
\text { Decenter } 31\end{array}$ & $\begin{array}{l}\text { Tennorege } \\
\text { Boing } \\
\text { Gly ol } \\
\text { Decomber } 91\end{array}$ & 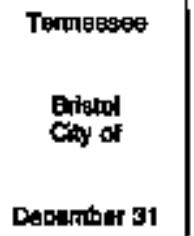 & 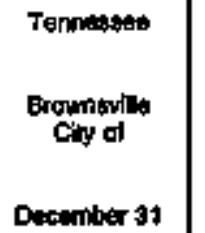 & 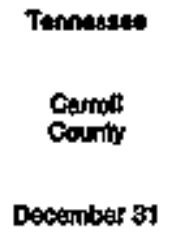 \\
\hline 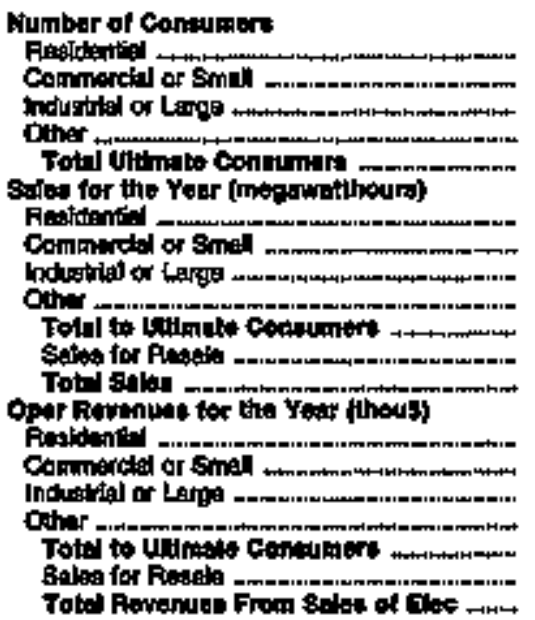 & 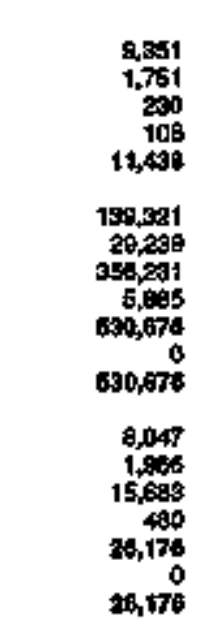 & 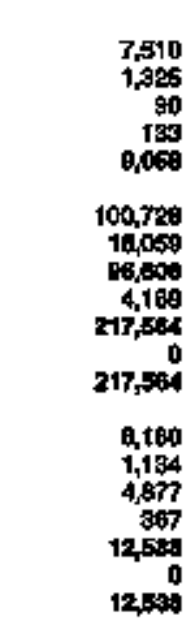 & 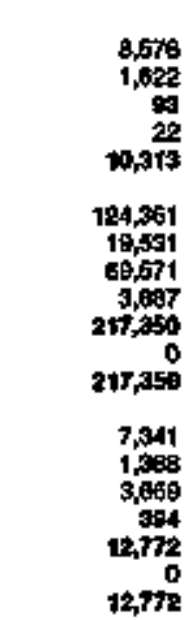 & 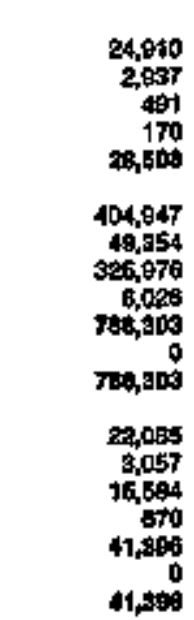 & 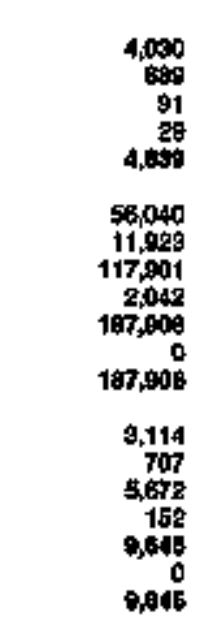 & 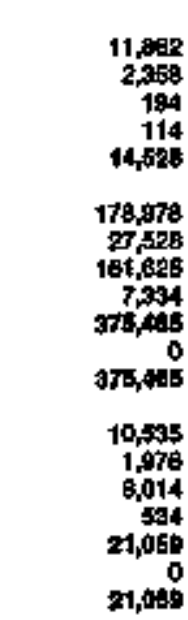 \\
\hline
\end{tabular}

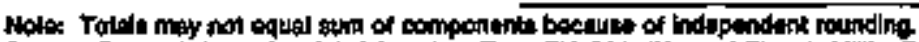

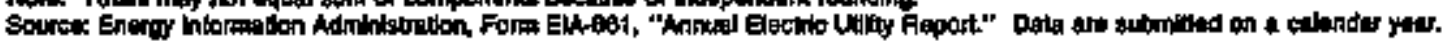


Table 25. Number of Consumers, Sales, and Operating Revenue by Malor U.S. Publleły Owned Eiectrle Utlity Within state, 1994 (Continued)

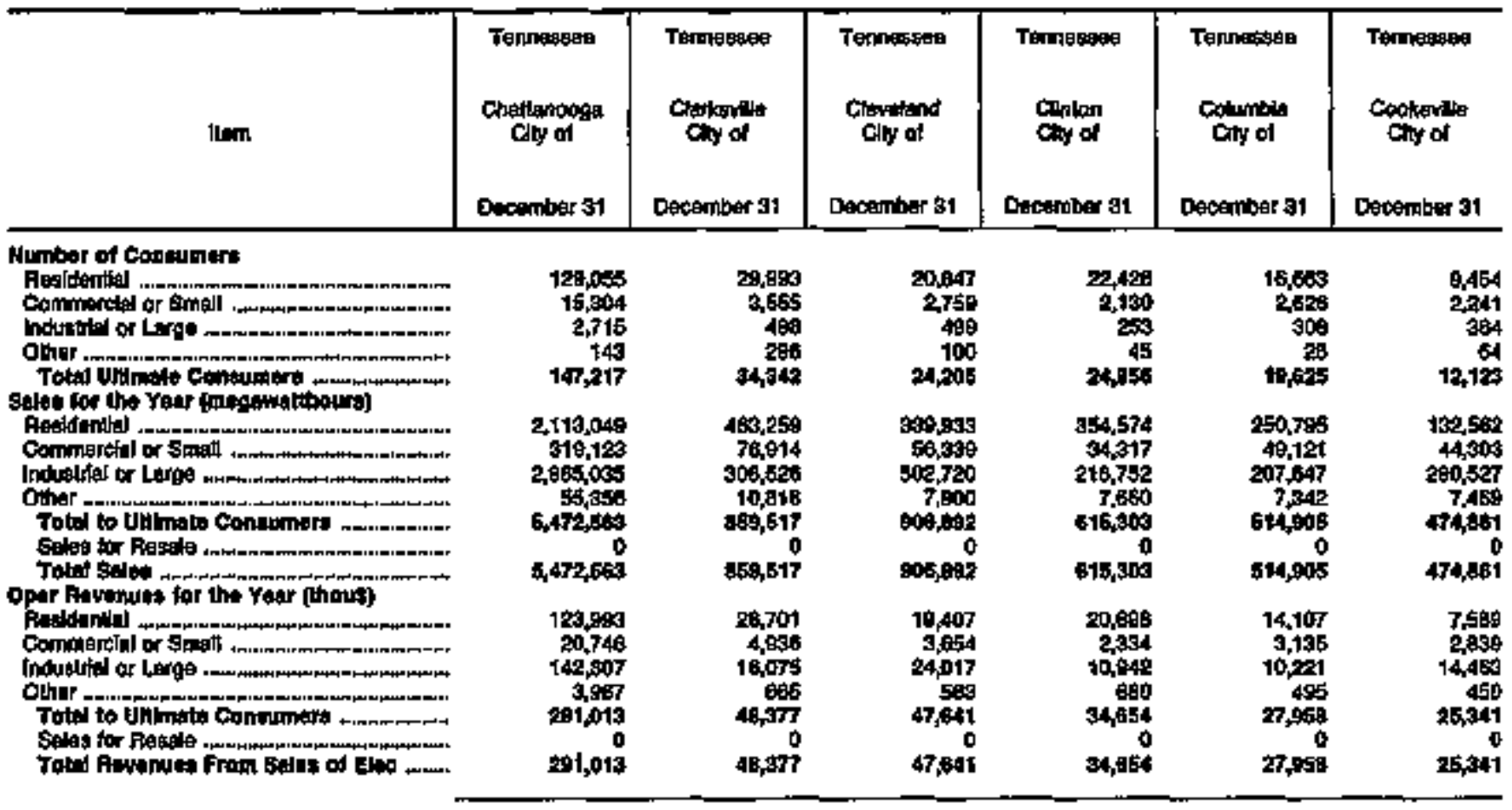

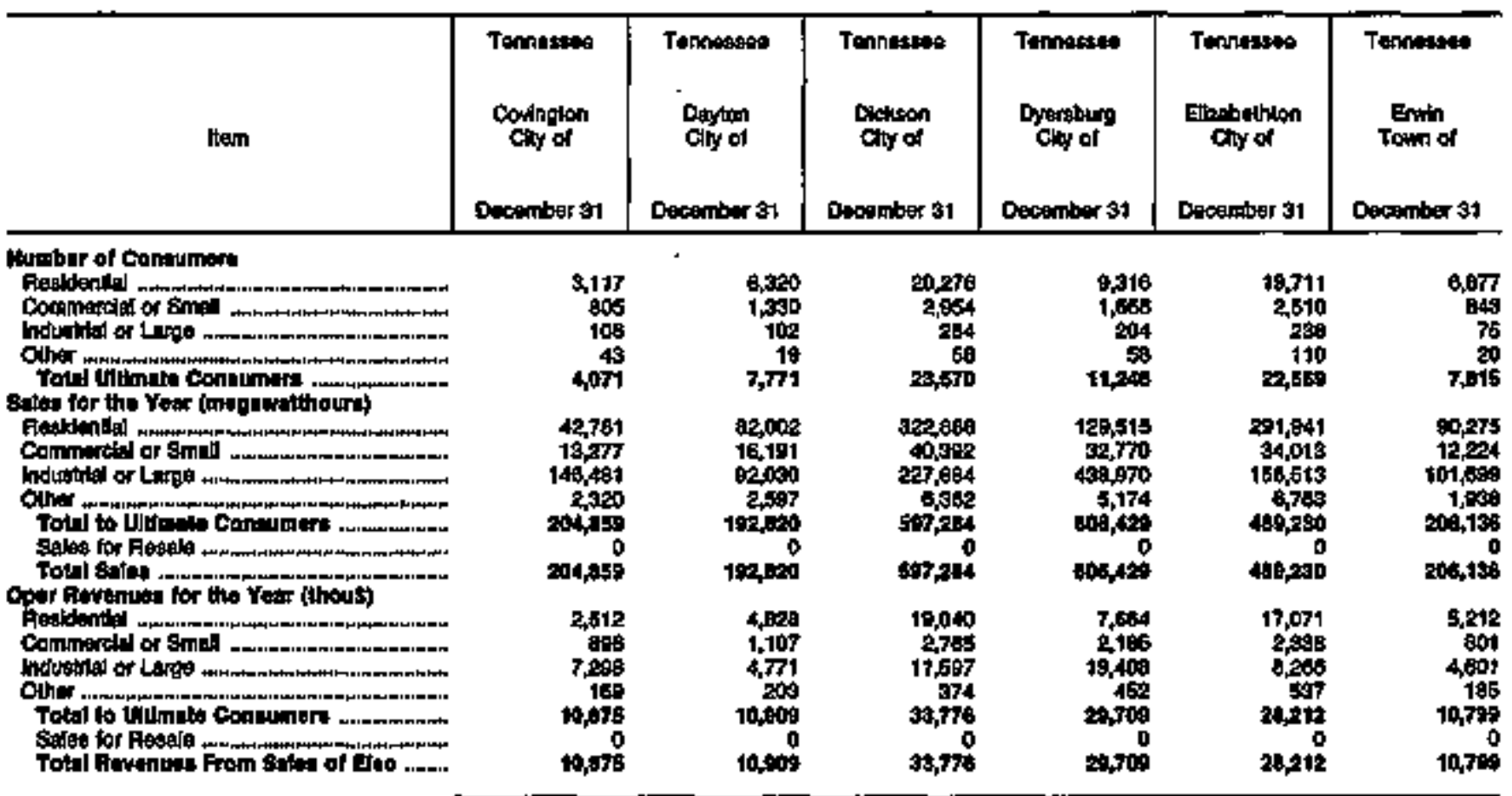

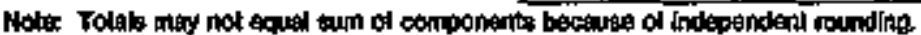

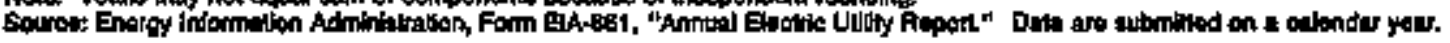


Table 25. Mumber of Conoumera, Sales, and Operating Revenue by Major U.8. Publicly Owned Electric Ut:ilty Within State, 1994 (Continued)

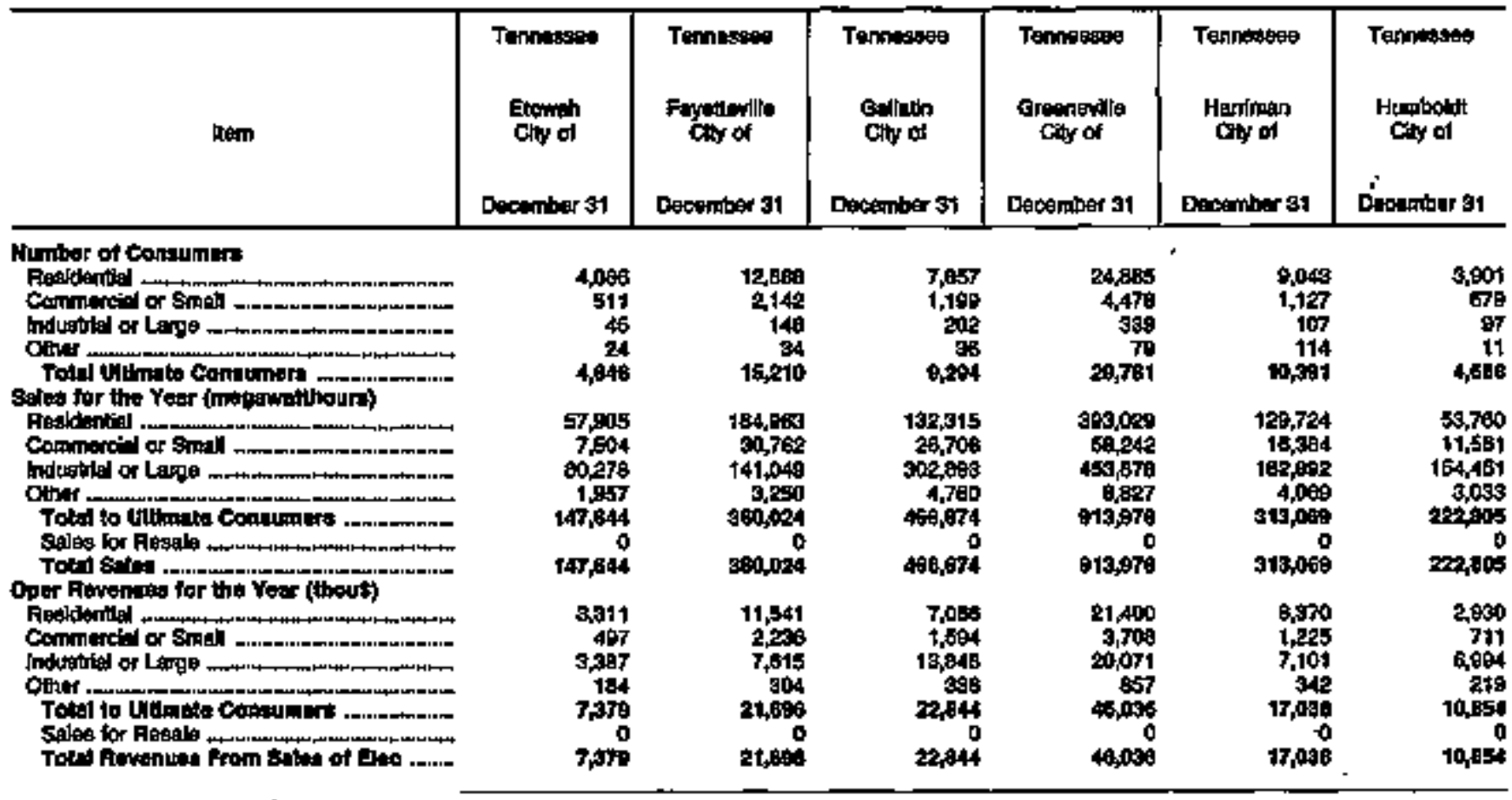

\begin{tabular}{|c|c|c|c|c|c|c|}
\hline Hem & 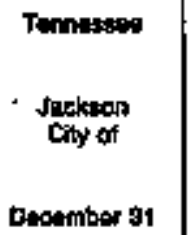 & 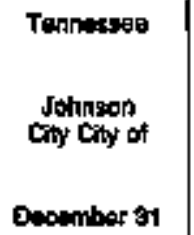 & 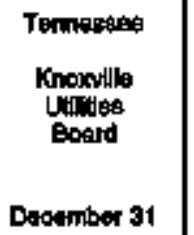 & 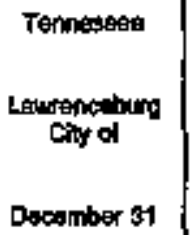 & 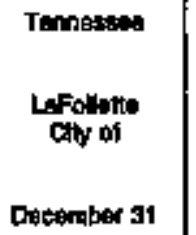 & 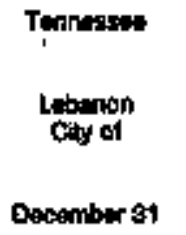 \\
\hline 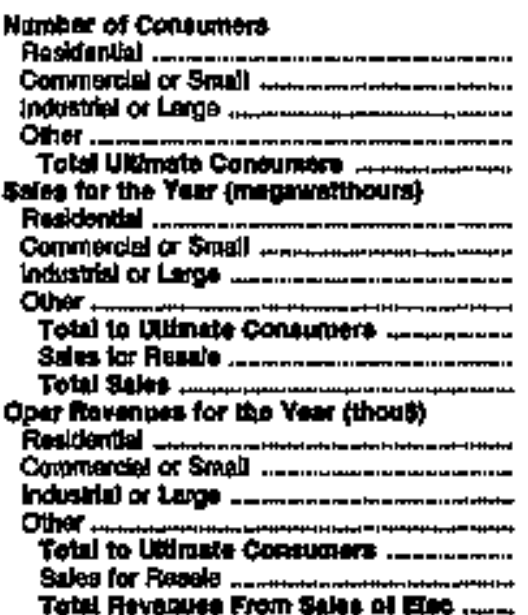 & 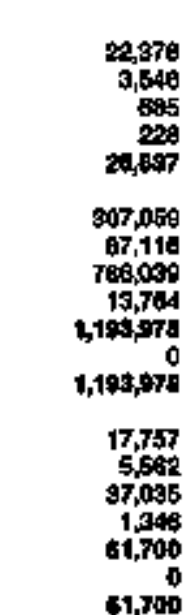 & 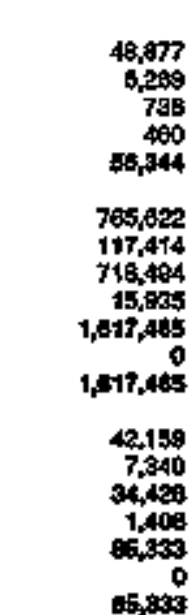 & 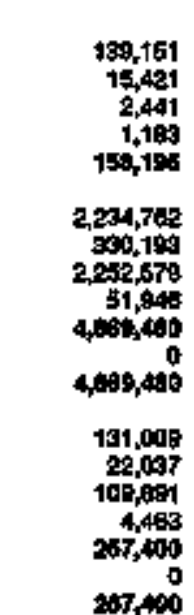 & 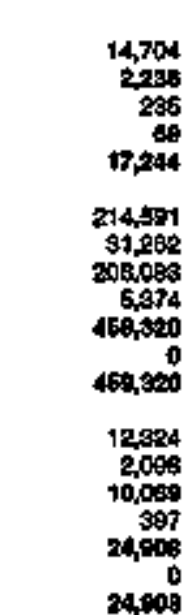 & $\begin{array}{r}15,245 \\
1,946 \\
268 \\
54 \\
17,462 \\
207,498 \\
25,463 \\
03,841 \\
4,271 \\
39,091 \\
034,031 \\
12,203 \\
1,765 \\
5,627 \\
303 \\
20,021 \\
0 \\
20,021\end{array}$ & 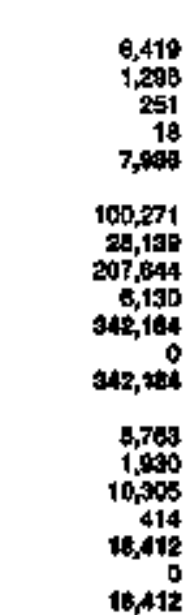 \\
\hline
\end{tabular}

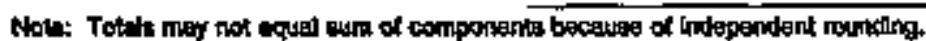

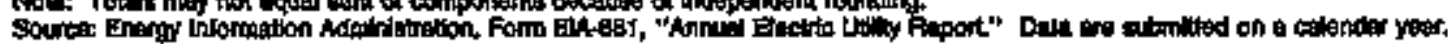


Table 25. Mumber of Conoumers, Sales, and Operating Fevenue by Major U.S. Publichy Owned Electric Utilty Wthin State, 1994 (Continued)

\begin{tabular}{|c|c|c|c|c|c|c|}
\hline Itom & 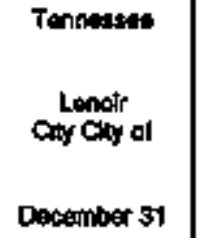 & 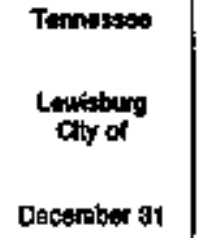 & $\begin{array}{c}\text { Tennosise } \\
\text { Leinglon } \\
\text { Oty of } \\
\text { December } 81\end{array}$ & $\begin{array}{l}\text { Tennessed } \\
\text { Loudon } \\
\text { Utitios } \\
\text { Bours } \\
\text { December } 31\end{array}$ & $\begin{array}{l}\text { Tonneasut } \\
\text { December } 31\end{array}$ & 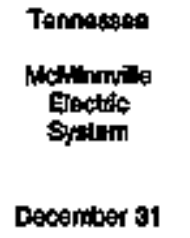 \\
\hline 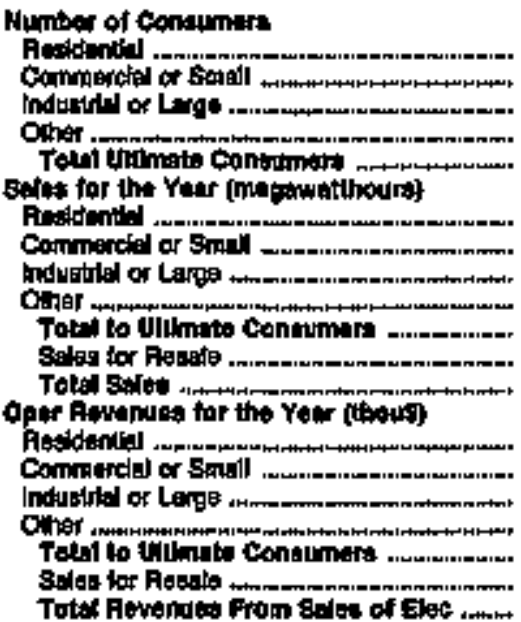 & 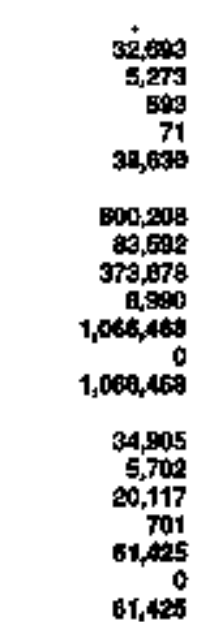 & 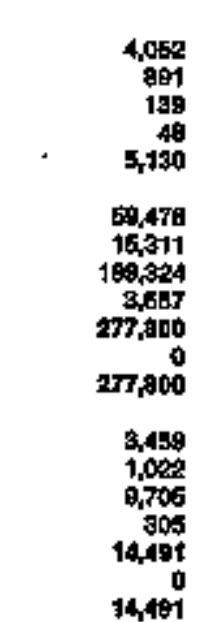 & $\begin{array}{r}15,004 \\
2,775 \\
208 \\
00 \\
0,075 \\
198,421 \\
30,428 \\
100,197 \\
7,421 \\
309,407 \\
0 \\
398,407 \\
11,404 \\
2,178 \\
8,745 \\
628 \\
22,950 \\
0 \\
22,960\end{array}$ & 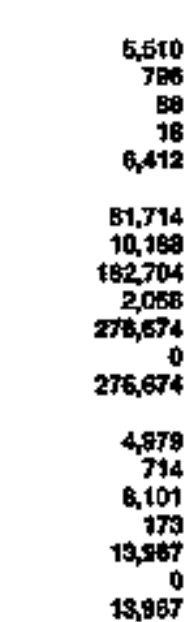 & 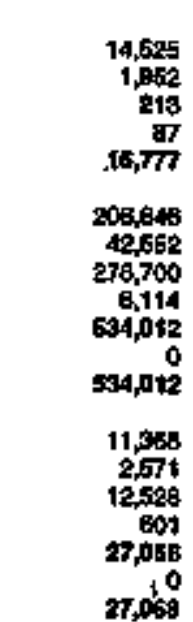 & 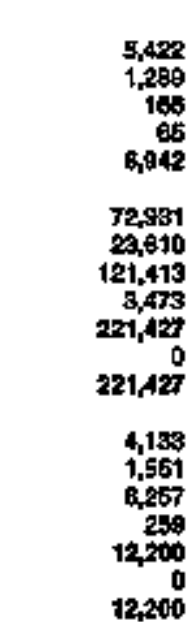 \\
\hline
\end{tabular}

\begin{tabular}{|c|c|c|c|c|c|c|}
\hline Ihm & $\begin{array}{l}\text { Tenresses } \\
\text { Aortyinle } \\
\text { Caty of } \\
\text { December ay }\end{array}$ & 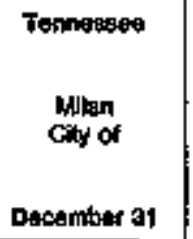 & $\begin{array}{l}\text { Tennowses } \\
\text { Montalown } \\
\text { Coly of }\end{array}$ & 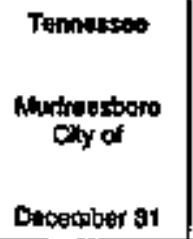 & 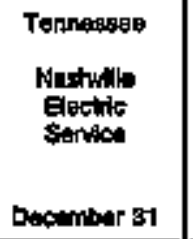 & 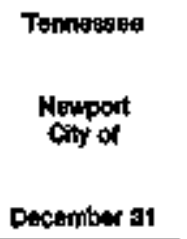 \\
\hline 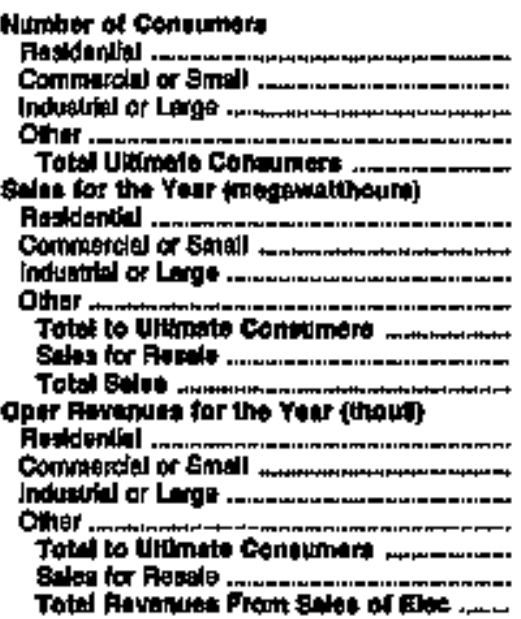 & 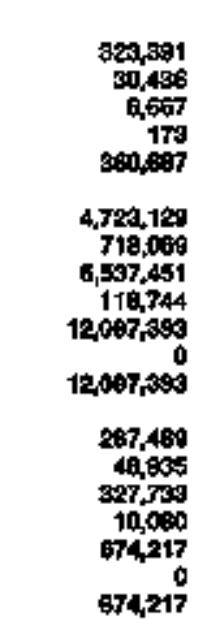 & 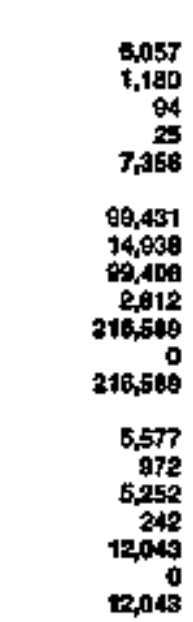 & 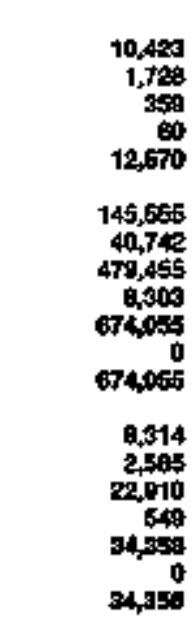 & 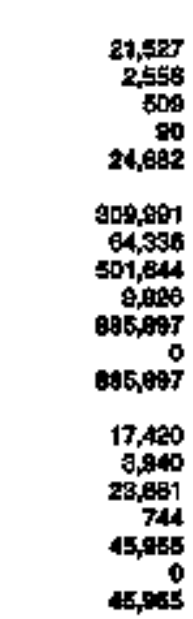 & 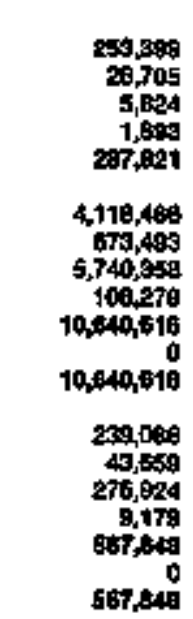 & 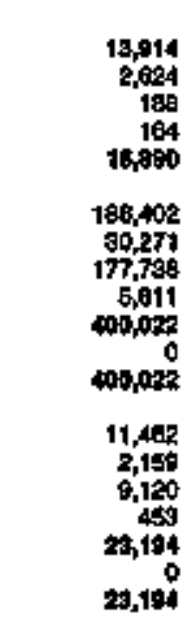 \\
\hline
\end{tabular}

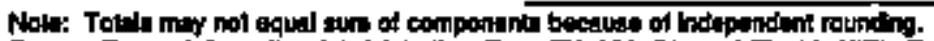

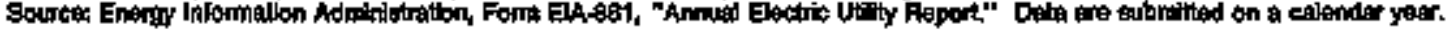


Teble 25. Number of Consumere, Sales, and Operating Revenue by Major U.S. Publicly Ownod Electric Utility Withis State, 1994 (Continued)

\begin{tabular}{|c|c|c|c|c|c|c|}
\hline |kep & 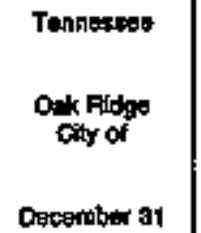 & 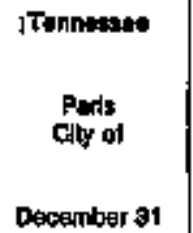 & 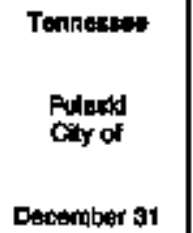 & $\begin{array}{l}\text { Temosseo } \\
\text { Alploy } \\
\text { Cily ot } \\
\text { Dectinber } 31\end{array}$ & $\begin{array}{c}\text { Tennessed } \\
\text { Pockwrod } \\
\text { Gly of }\end{array}$ & 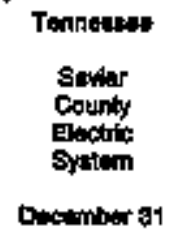 \\
\hline 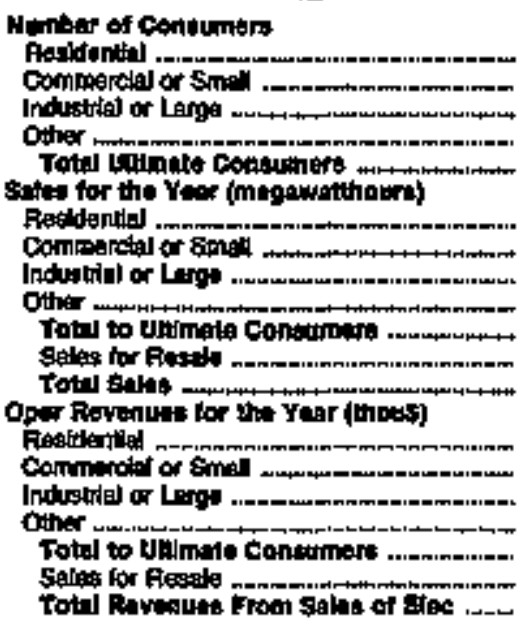 & 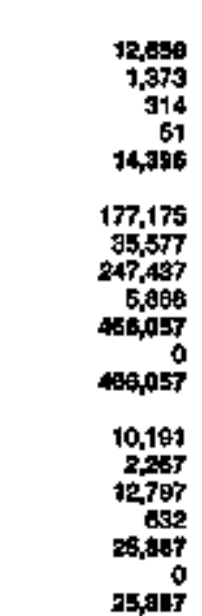 & 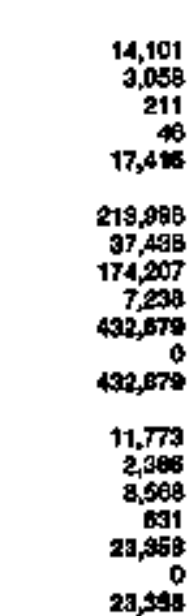 & 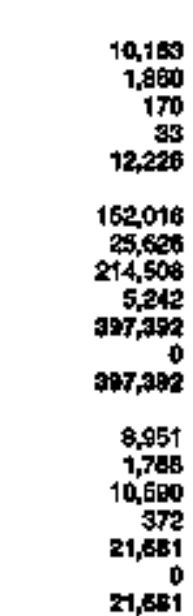 & 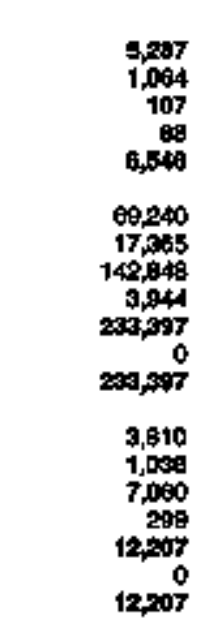 & 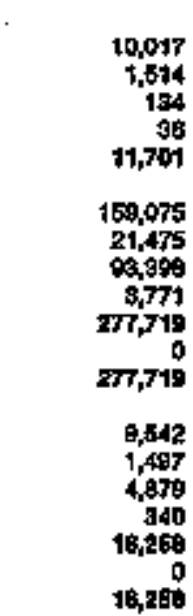 & 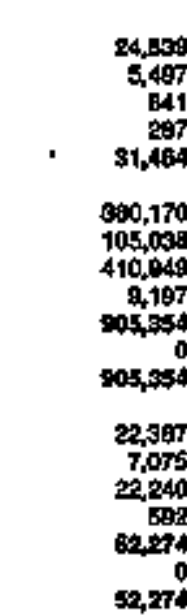 \\
\hline
\end{tabular}

\begin{tabular}{|c|c|c|c|c|c|c|}
\hline ltem & $\begin{array}{l}\text { Thannoseses } \\
\text { Sheloyille } \\
\text { City of } \\
\text { Decernber of }\end{array}$ & $\begin{array}{l}\text { Tennostet } \\
\text { Sprinofield } \\
\text { City of } \\
\text { December } 31\end{array}$ & 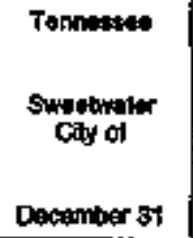 & 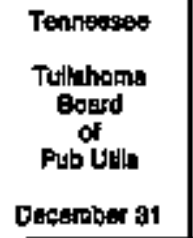 & 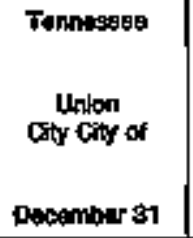 & 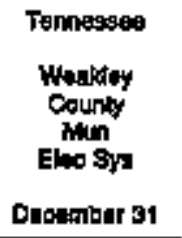 \\
\hline 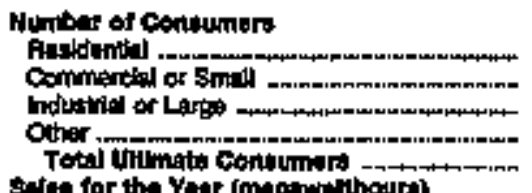 & $\begin{array}{r}6,390 \\
912 \\
195 \\
28 \\
7,455\end{array}$ & $\begin{array}{r}4,859 \\
758 \\
146 \\
13 \\
5,478\end{array}$ & $\begin{array}{r}5,379 \\
106 \\
106 \\
2,806\end{array}$ & $\begin{array}{r}7,503 \\
1,250 \\
165 \\
37 \\
0,061\end{array}$ & $\begin{array}{r}4,008 \\
709 \\
138 \\
11 \\
5,64 ?\end{array}$ & $\begin{array}{r}15,164 \\
2,771 \\
298 \\
66 \\
18,506\end{array}$ \\
\hline 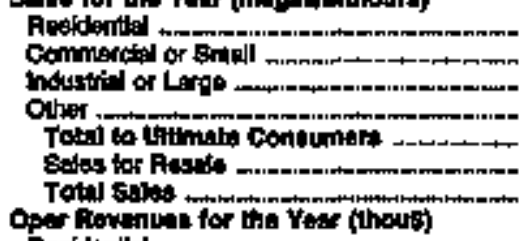 & 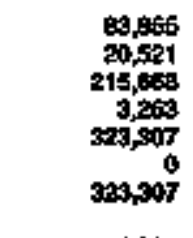 & 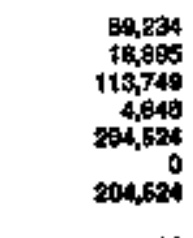 & $\begin{array}{r}1,254 \\
15,000 \\
69,702 \\
4,118 \\
169,948 \\
190,94\end{array}$ & 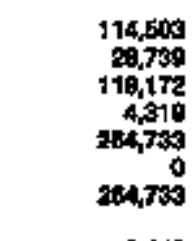 & 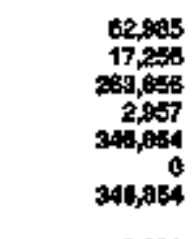 & $\begin{array}{r}258,401 \\
34,619 \\
167,648 \\
6,990 \\
462,650 \\
4=2,005\end{array}$ \\
\hline 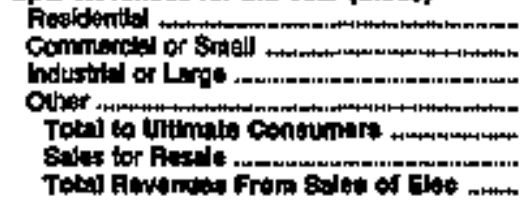 & $\begin{array}{r}4,894 \\
1,912 \\
10,594 \\
271 \\
17,011 \\
17,011\end{array}$ & 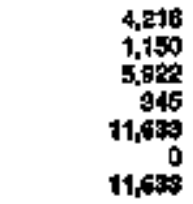 & $\begin{array}{r}4,0,50 \\
1,041 \\
4,604 \\
300 \\
10,610 \\
10,010\end{array}$ & $\begin{array}{r}6,442 \\
1,676 \\
8,100 \\
787 \\
14,614 \\
0 \\
14,614\end{array}$ & $\begin{array}{r}3,301 \\
1,000 \\
10,360 \\
241 \\
14,560 \\
14,04\end{array}$ & 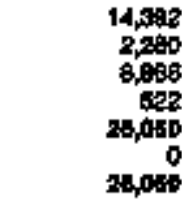 \\
\hline
\end{tabular}

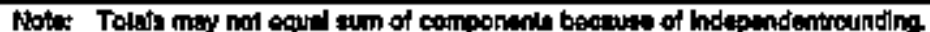

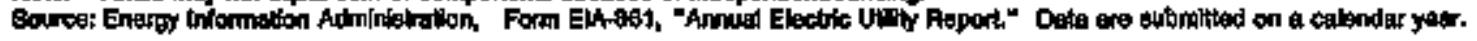


Table 25. Number of Consumers, Sales, and Operating Aevenue by Major U.S. Publcly Owned Electric Utiolity Within State, 1994 (Continued)

\begin{tabular}{|c|c|c|c|c|c|c|}
\hline $110 \mathrm{~m}$ & $\begin{array}{l}\text { Toxas } \\
\text { Aurd } \\
\text { Cily of } \\
\text { December of }\end{array}$ & 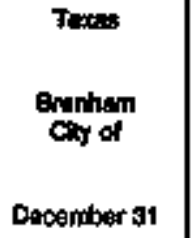 & 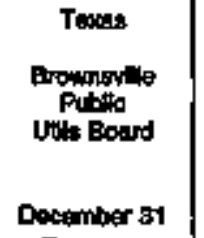 & 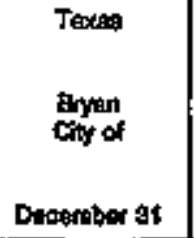 & 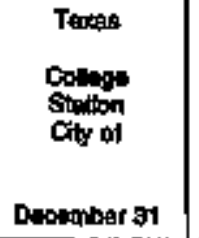 & $\begin{array}{l}\text { Taxps } \\
\text { Denton } \\
\text { cly of } \\
\text { Decouper } 91\end{array}$ \\
\hline 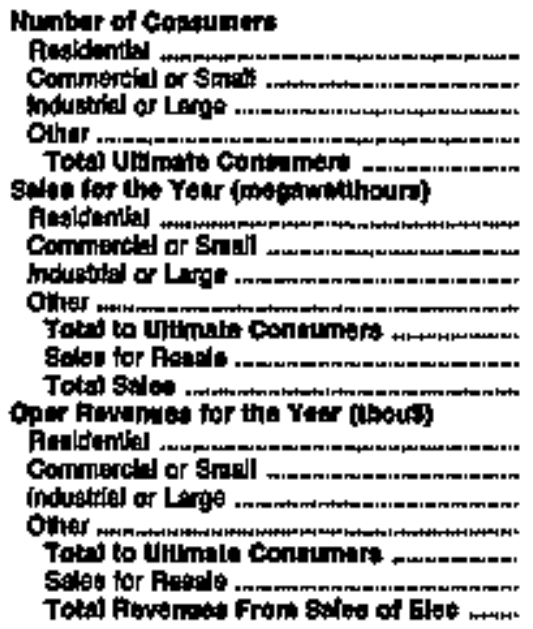 & 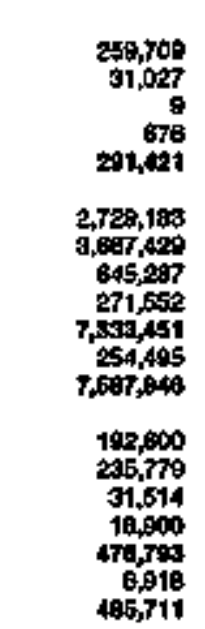 & 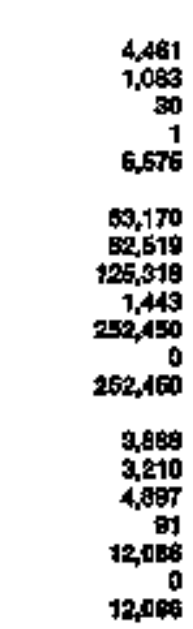 & 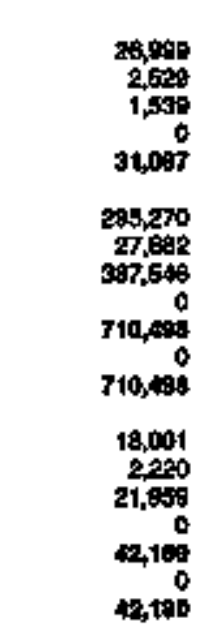 & 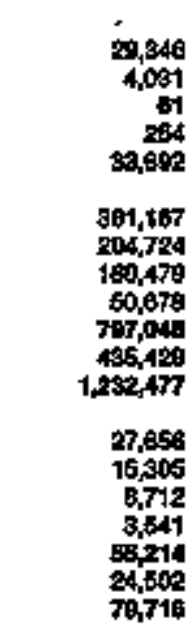 & $\begin{array}{r}21,215 \\
1,692 \\
0 \\
0 \\
0 \\
25,107 \\
23,097 \\
29,097 \\
22,178 \\
0 \\
0 \\
463,275 \\
0 \\
493,275 \\
17,612 \\
16,134 \\
0 \\
0 \\
32,748 \\
0 \\
32,748\end{array}$ & 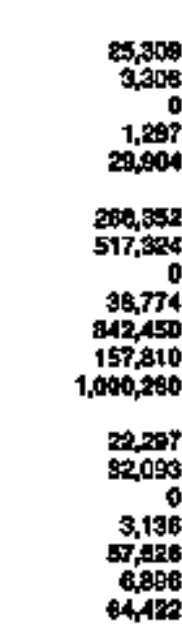 \\
\hline
\end{tabular}

\begin{tabular}{|c|c|c|c|c|c|c|}
\hline llam & 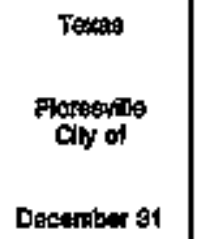 & $\begin{array}{l}\text { Texpes } \\
\text { Gertind } \\
\text { Cyy of } \\
\text { Dacombar } 91\end{array}$ & $\begin{array}{l}\text { Texas } \\
\text { Coompotom } \\
\text { City of } \\
\text { December } 31\end{array}$ & 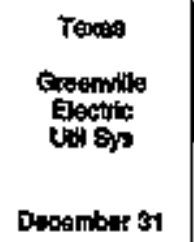 & 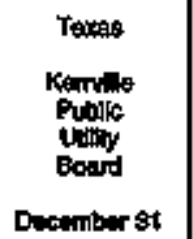 & 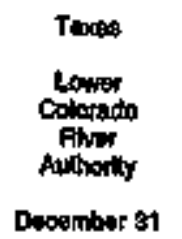 \\
\hline 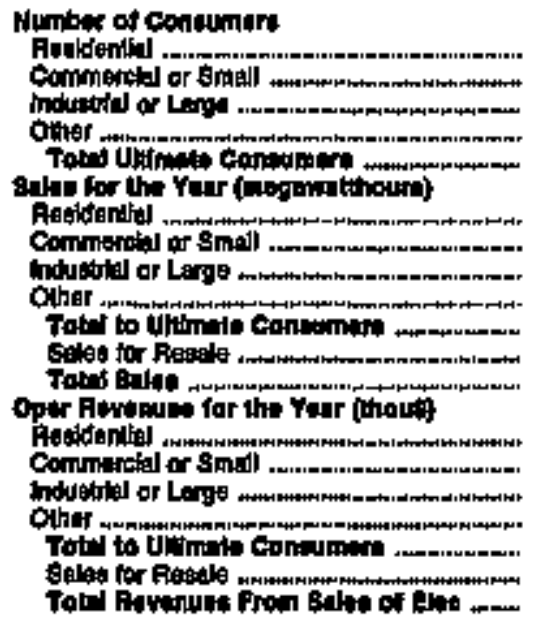 & 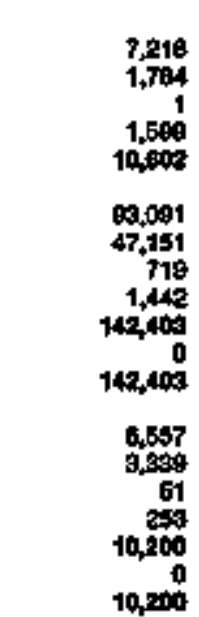 & 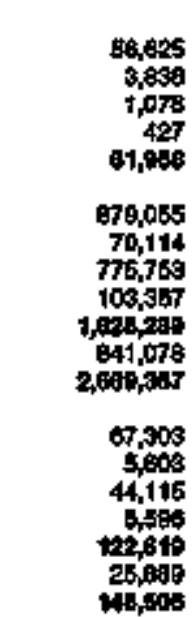 & 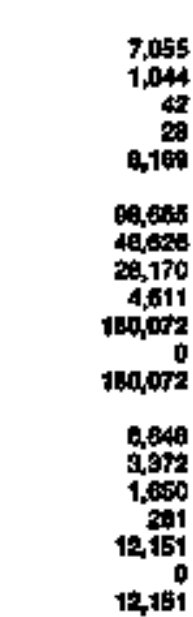 & 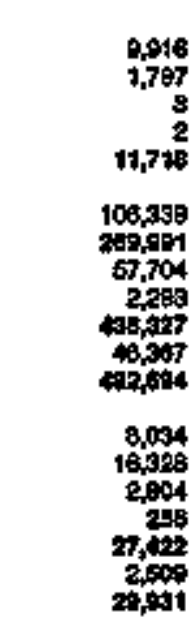 & 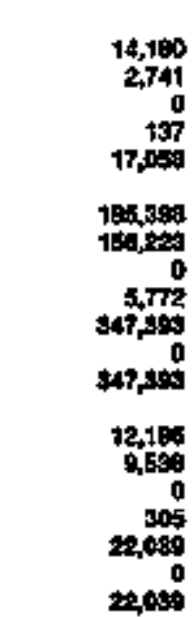 & 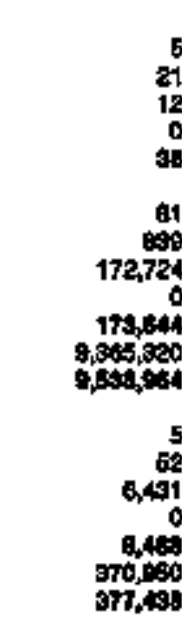 \\
\hline
\end{tabular}

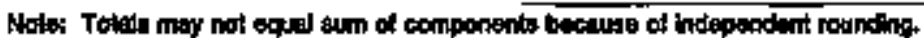

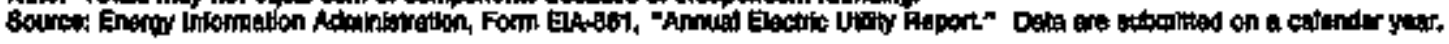


Table 25. Number of Consumers, selee, and Operathg Revenus by Malor U.S. Publicly Owned Electrio Uallty Within State, 1994 (Continuted)

\begin{tabular}{|c|c|c|c|c|c|c|}
\hline trem & $\begin{array}{l}\text { Thes: } \\
\text { Lalbbock } \\
\text { Cty of } \\
\text { Deconter is }\end{array}$ & $\begin{array}{c}\text { Texes } \\
\text { Now Erainlels } \\
\text { City of } \\
\text { Oecomber } 31\end{array}$ & 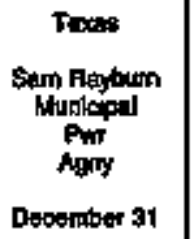 & $\begin{array}{c}\text { Texts } \\
\text { Sant Anionto } \\
\text { Publo } \\
\text { Servite Bd } \\
\text { Decomber } 31\end{array}$ & 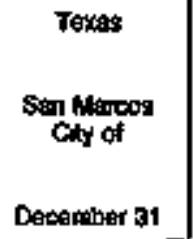 & $\begin{array}{l}\text { Texas } \\
\text { Seguin } \\
\text { Chy of } \\
\text { December at }\end{array}$ \\
\hline 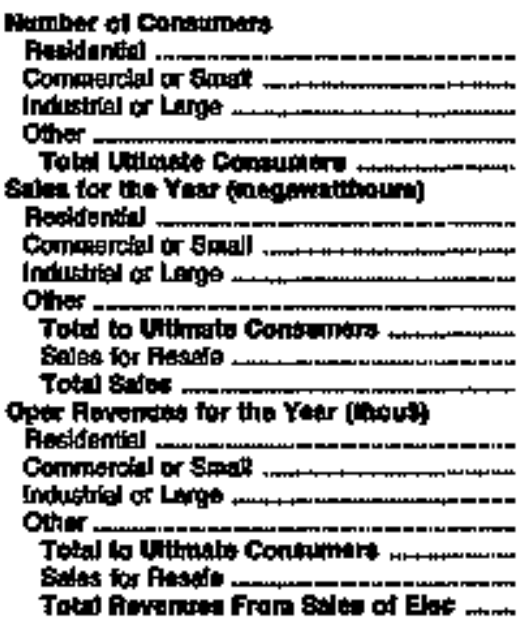 & 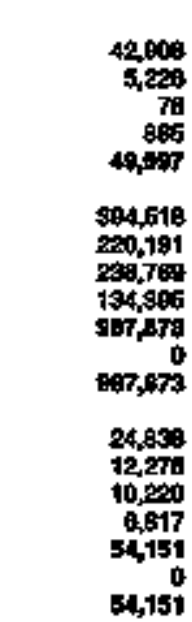 & 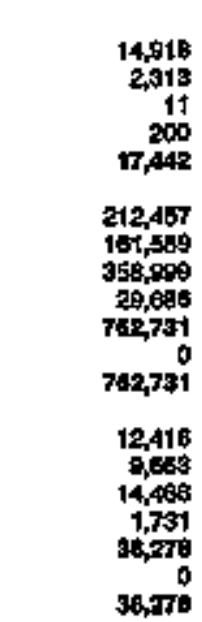 & 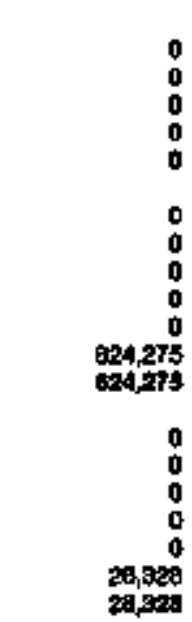 & 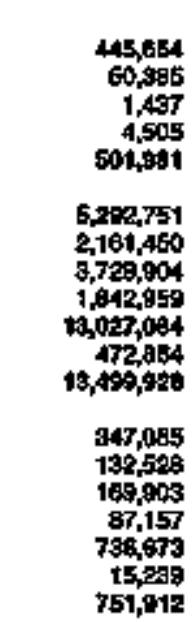 & 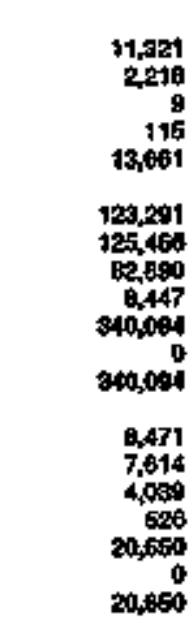 & 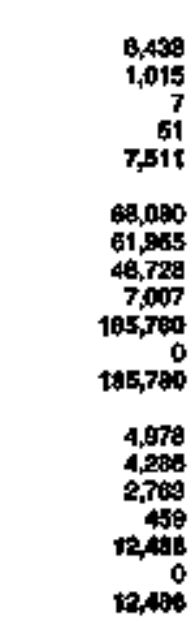 \\
\hline
\end{tabular}

\begin{tabular}{|c|c|c|c|c|c|c|}
\hline 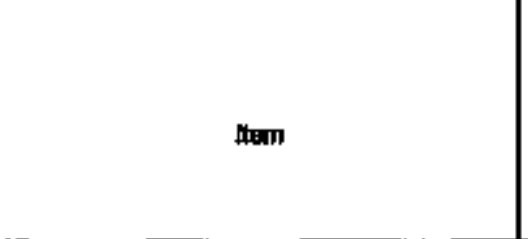 & 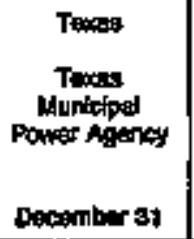 & $\begin{array}{l}\text { Texees } \\
\text { Tolodo Bend } \\
\text { Frokert } \\
\text { Joind } \\
\text { Opert } \\
\text { Deounter } 31\end{array}$ & Decomos & 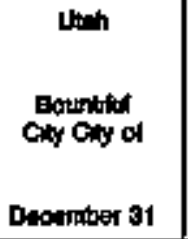 & 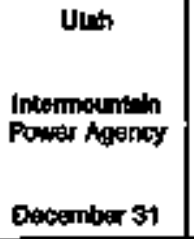 & $\begin{array}{l}\text { Uteh } \\
\text { Login } \\
\text { City of } \\
\text { Deccutiber } 51\end{array}$ \\
\hline 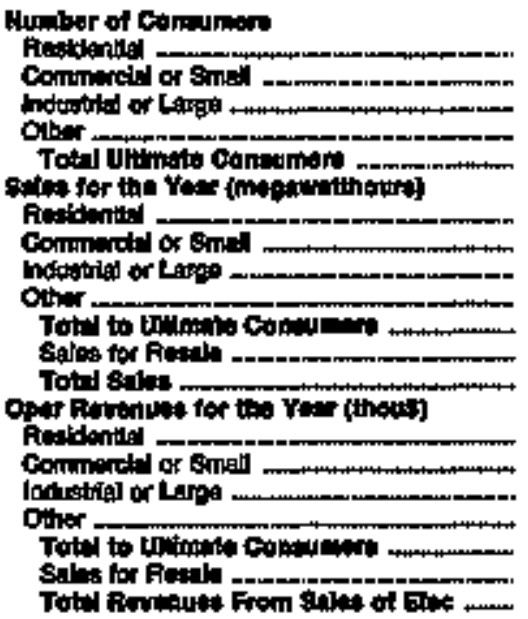 & $\begin{array}{r}0 \\
0 \\
0 \\
0 \\
0 \\
2,078,784 \\
2979,744 \\
0 \\
0 \\
0 \\
0 \\
145,095 \\
145,045\end{array}$ & $\begin{array}{r}0 \\
0 \\
0 \\
0 \\
0 \\
005,009 \\
20500 \\
0 \\
0 \\
0 \\
0 \\
0 \\
5,912 \\
5,012\end{array}$ & 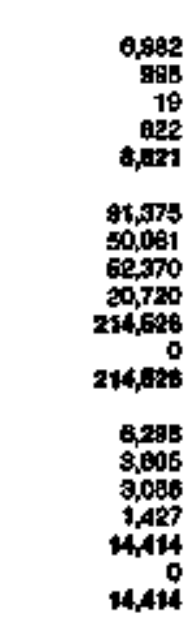 & 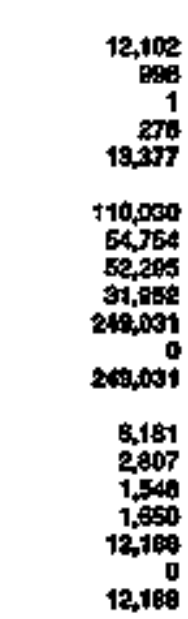 & 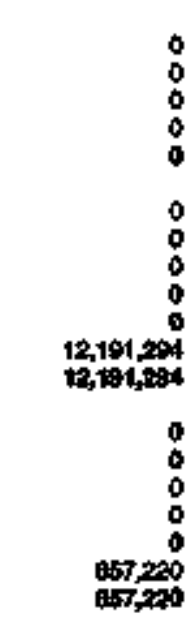 & 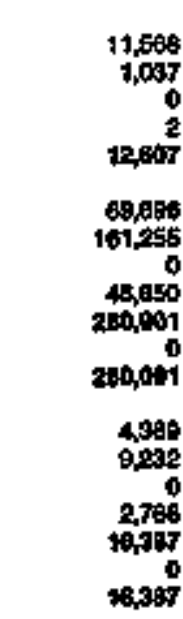 \\
\hline
\end{tabular}

Nolex Tobata may not equal surn of components becture of hdipendont rounding.

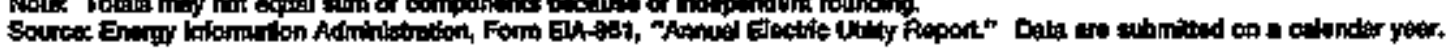


Tabje 25. Mumber of Consumers, Sales, and Operating Revenue by Mafor U.S. Publicly Owned Electric Utillty Within State, 1994 (Continued)

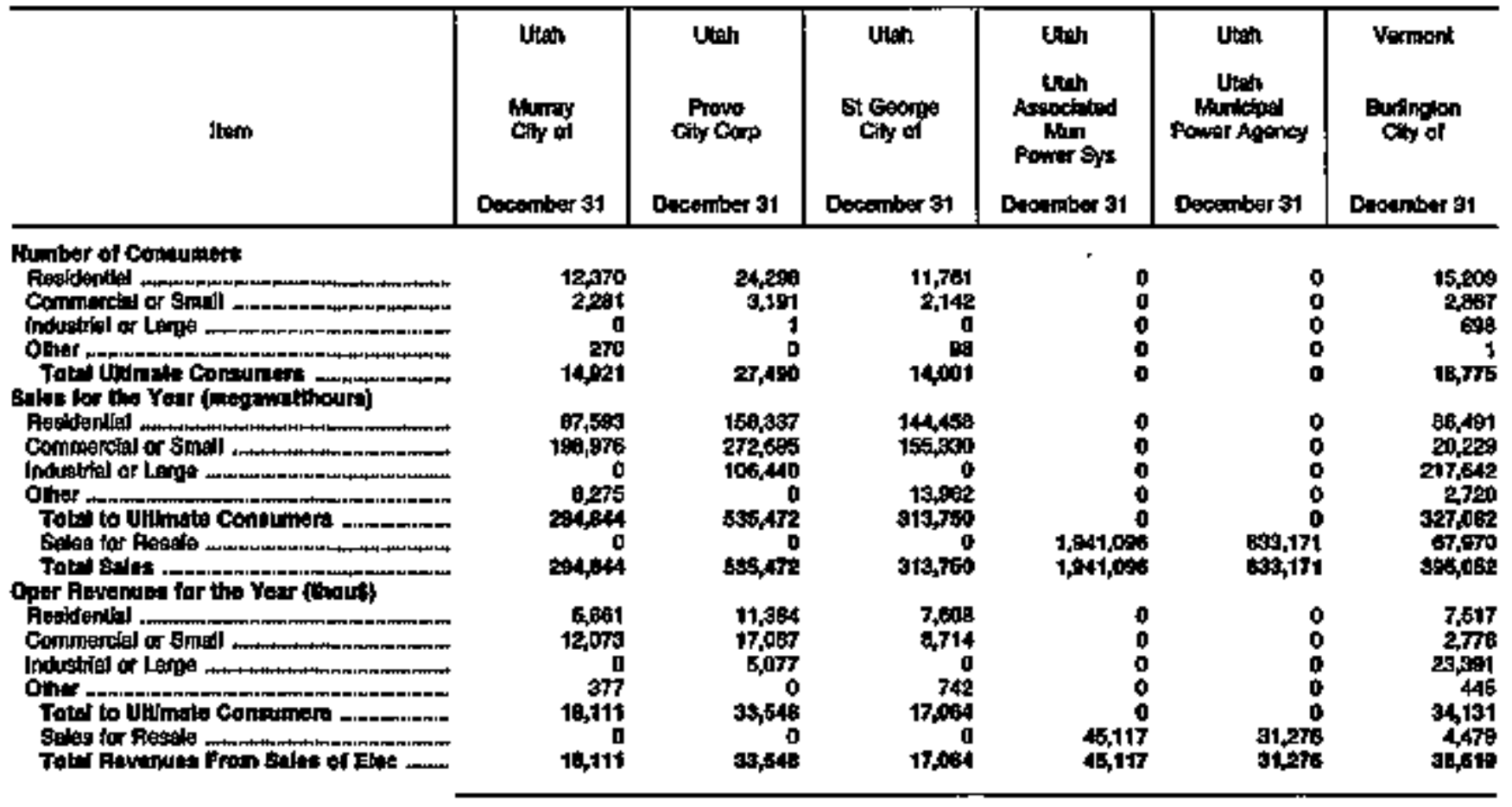

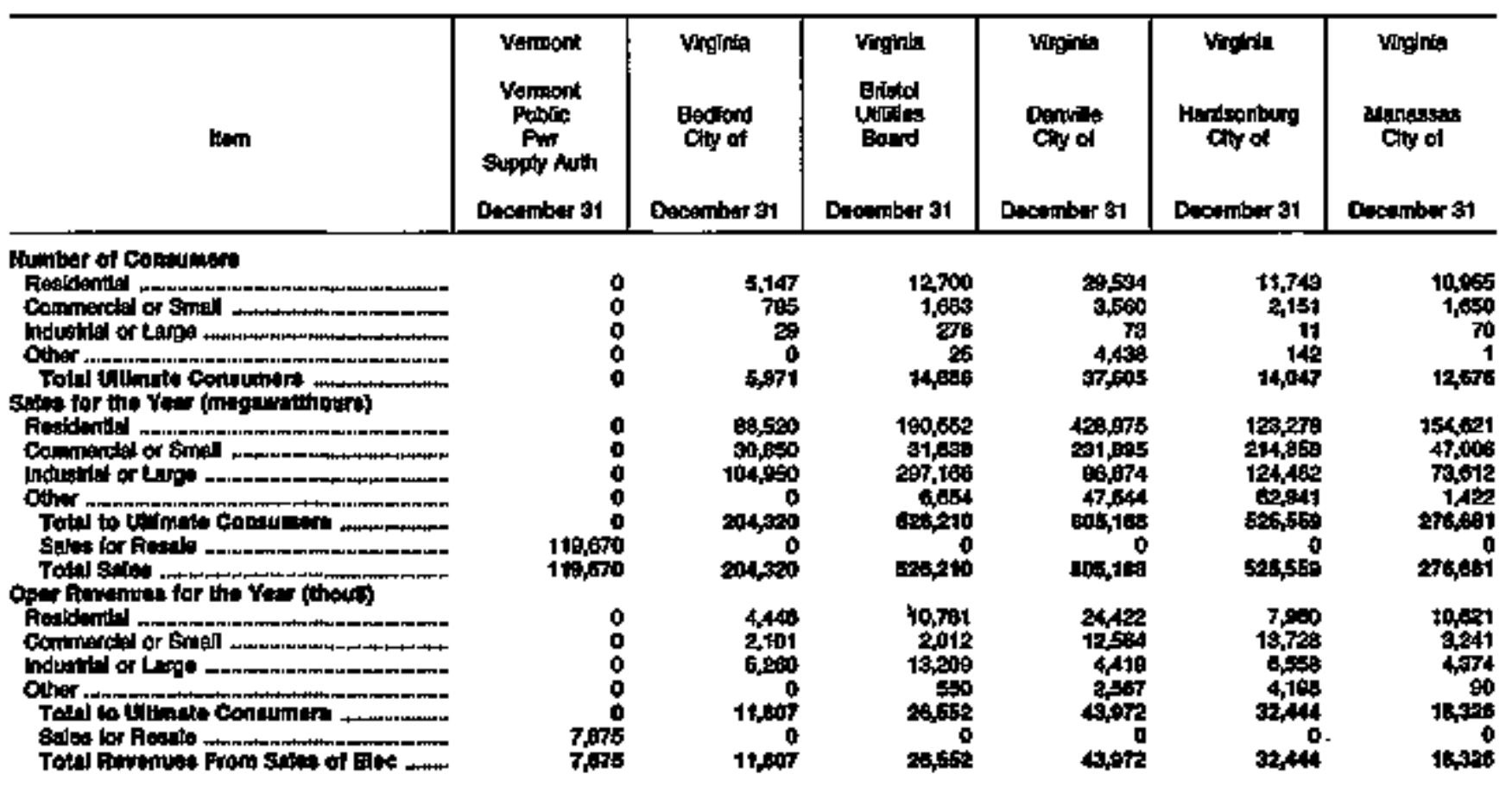

Notex Totels may not equat susp of components becasuse of independent rounding.

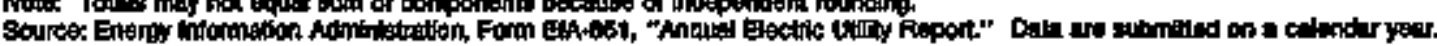


Table 26. Number of Consumers, Sales, and Operating Revenue by Major U.S. Publichy Owned Electric Utillty Whin State, 1994 (Continued)

\begin{tabular}{|c|c|c|c|c|c|c|}
\hline tent & $\begin{array}{l}\text { Ninginia } \\
\text { Martinesine } \\
\text { Cily of }\end{array}$ & 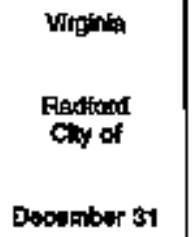 & $\begin{array}{l}\text { Vintrita } \\
\text { Satem } \\
\text { City of } \\
\text { Docember } \$ 1\end{array}$ & 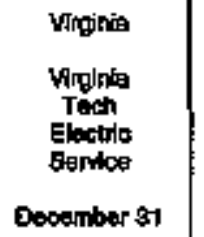 & $\begin{array}{l}\text { Washinglon } \\
\text { Cactcalia } \\
\text { Chty of } \\
\text { Dectriber } 31\end{array}$ & $\begin{array}{c}\text { Washinglen } \\
\text { Ellansture } \\
\text { Ciy of } \\
\text { Decembar } \$ 1\end{array}$ \\
\hline 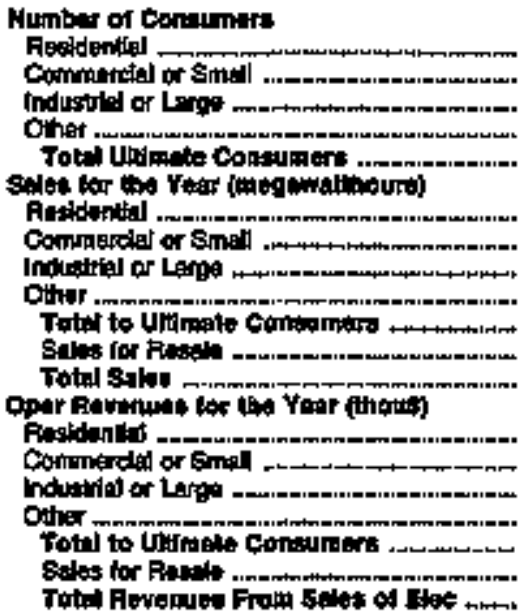 & 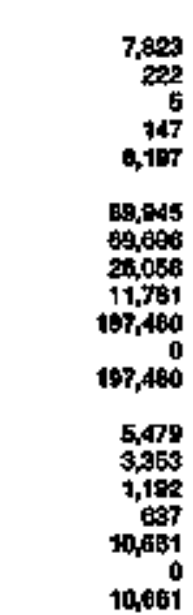 & 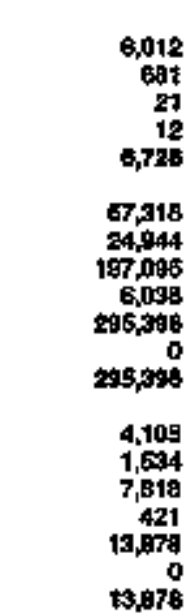 & 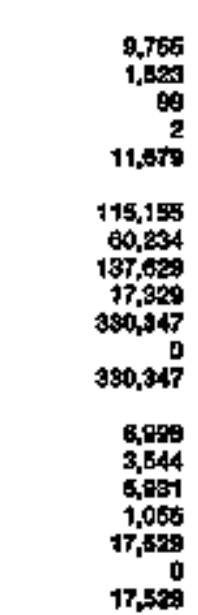 & 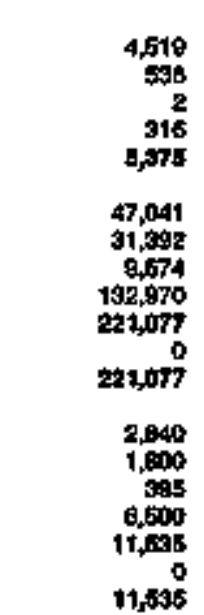 & 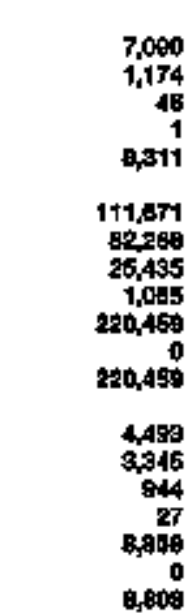 & 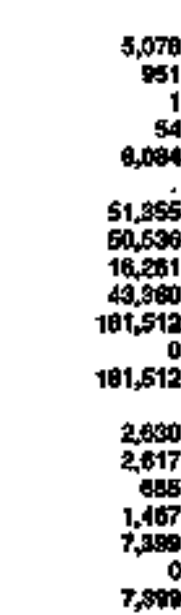 \\
\hline
\end{tabular}

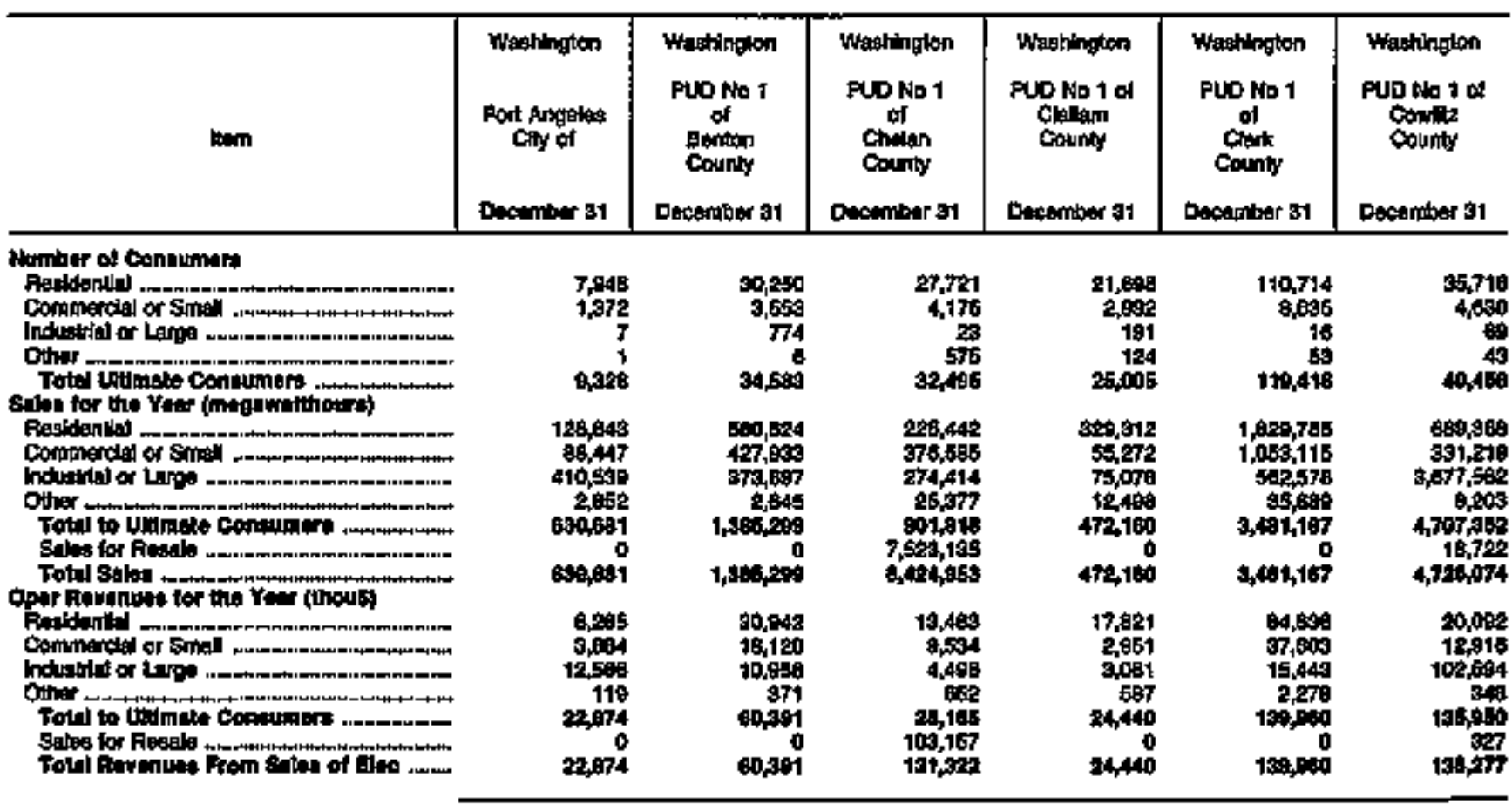

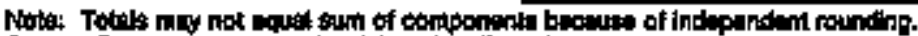

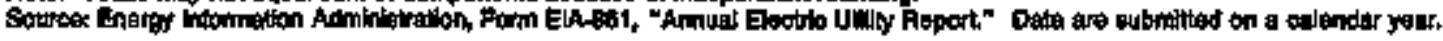


Tabfe 25. Number of Consumers, Salea, and Operating Revenue by Major U.S. Publicly Owned Electric Utilty Within State, 1994 (Continued)

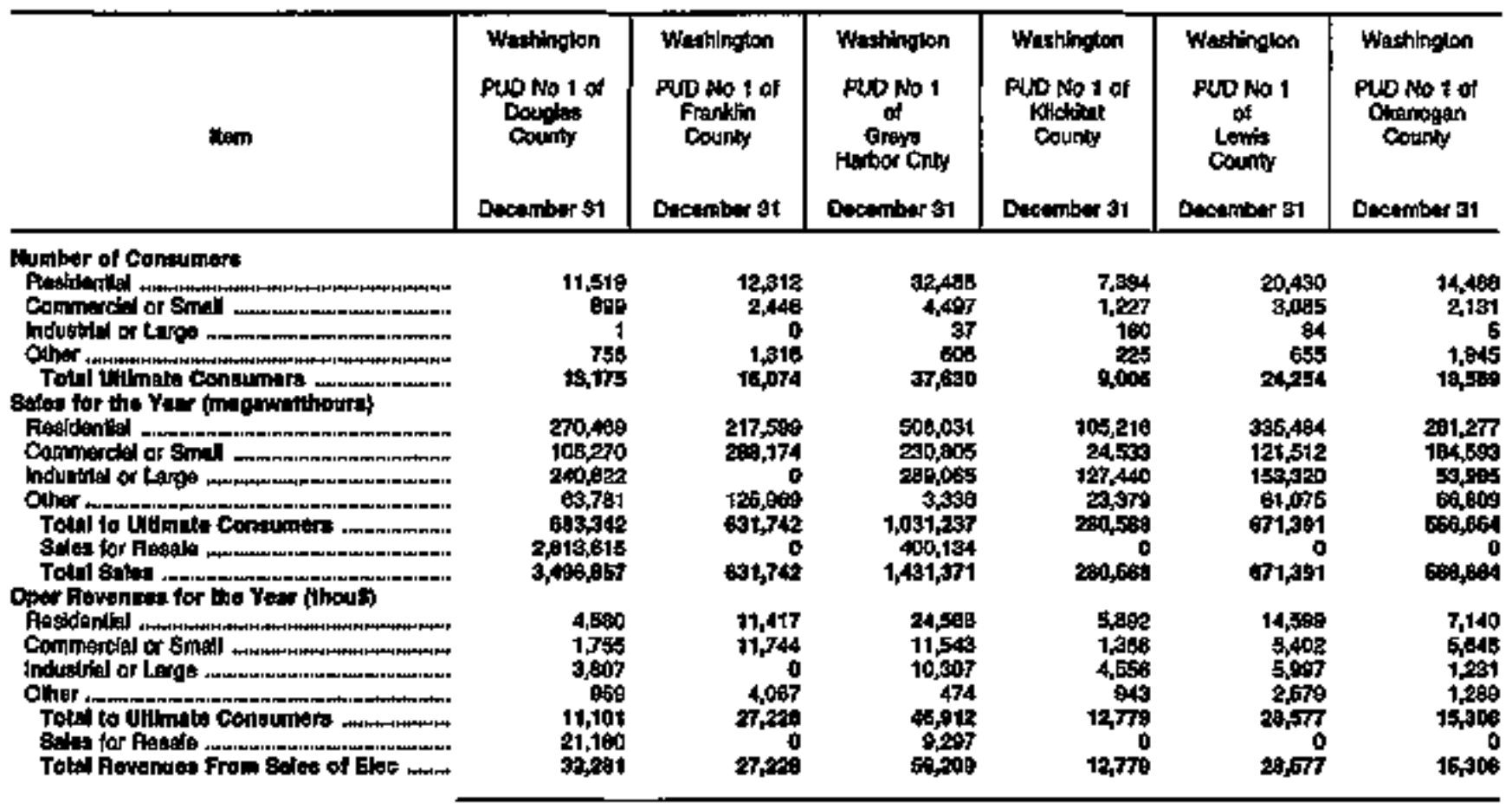

\begin{tabular}{|c|c|c|c|c|c|c|}
\hline Hearn & 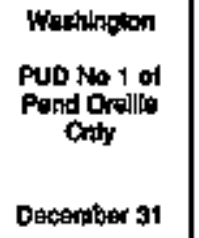 & 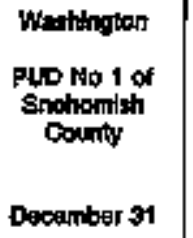 & 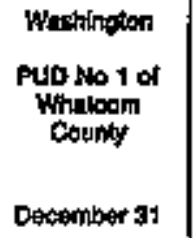 & $\begin{array}{l}\text { Wastiniton } \\
\text { PuD No } 2 \\
\text { of } \\
\text { Giant } \\
\text { County } \\
\text { Dacember } 31\end{array}$ & 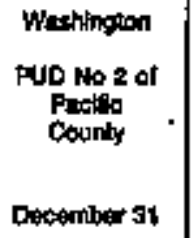 & 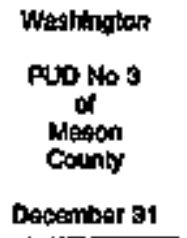 \\
\hline 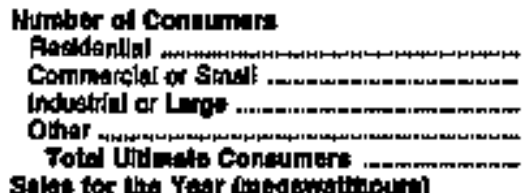 & $\begin{array}{r}6039 \\
620 \\
10 \\
30 \\
0.600\end{array}$ & $\begin{array}{r}204,702 \\
10,0,58 \\
90 \\
1,007 \\
228,967\end{array}$ & $\begin{array}{l}0 \\
0 \\
1 \\
0 \\
1\end{array}$ & $\begin{array}{r}24,090 \\
2,707 \\
1,008 \\
58 \\
20,460\end{array}$ & $\begin{array}{r}12,817 \\
1,406 \\
2 \\
534 \\
14,759\end{array}$ & $\begin{array}{r}22,675 \\
1,604 \\
1 \\
71 \\
24,341\end{array}$ \\
\hline 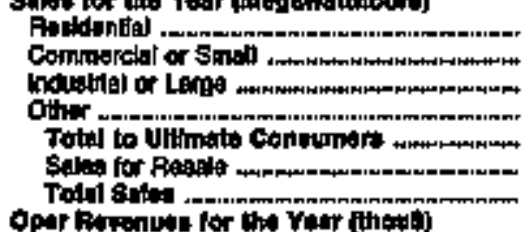 & 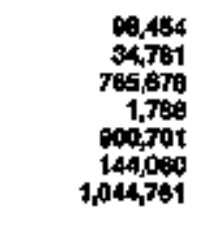 & 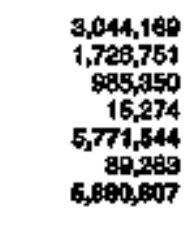 & $\begin{array}{r}0 \\
0 \\
171,659 \\
0 \\
171,659 \\
171,959\end{array}$ & $\begin{array}{r}574,996 \\
495,706 \\
1,77,145 \\
4,472 \\
2,9,49,290 \\
8,019,043 \\
9,40 \%, 003\end{array}$ & $\begin{array}{r}165,967 \\
50,915 \\
23,409 \\
20,592 \\
20,002 \\
259,902\end{array}$ & $\begin{array}{r}305,641 \\
127,600 \\
62,002 \\
1,010 \\
4,0100 \\
3,200 \\
50,000\end{array}$ \\
\hline 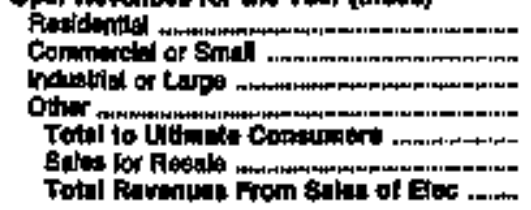 & 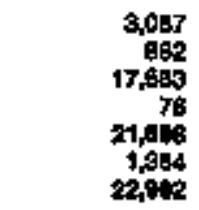 & $\begin{array}{r}165,060 \\
76,778 \\
39,208 \\
1,420 \\
207,058 \\
2,306 \\
200,301\end{array}$ & $\begin{array}{r}0 \\
4,089 \\
4,00 \\
4,060\end{array}$ & 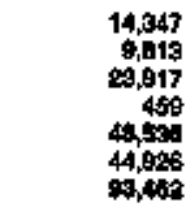 & $\begin{array}{r}8,198 \\
3,501 \\
849 \\
1,401 \\
13,657 \\
0 \\
13,697\end{array}$ & $\begin{array}{r}15,047 \\
6,941 \\
2143 \\
7,92 \\
24,609 \\
110 \\
24,040\end{array}$ \\
\hline
\end{tabular}

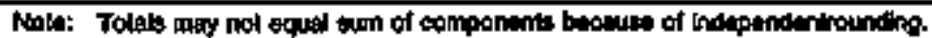

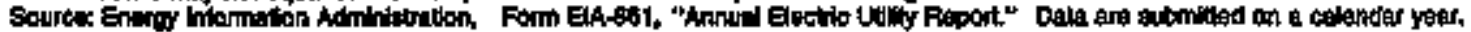


Table 25. Number of Constumers, \$ales, and Operating Fevenue by Major U.S. Publicly Owned Electrio Utility Within State, 1994 (Continued)

\begin{tabular}{|c|c|c|c|c|c|c|}
\hline ltbem & $\begin{array}{l}\text { Weshington } \\
\text { Fichlond } \\
\text { City of } \\
\text { Dosember as }\end{array}$ & 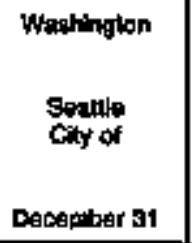 & 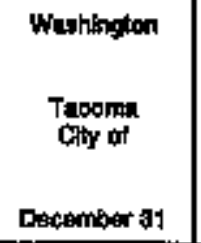 & 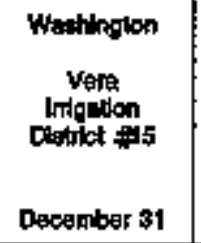 & $\begin{array}{l}\text { Wuatington } \\
\text { Weatington } \\
\text { Ruts } \\
\text { Supply sys } \\
\text { December a1 }\end{array}$ & 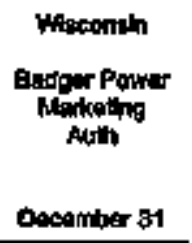 \\
\hline 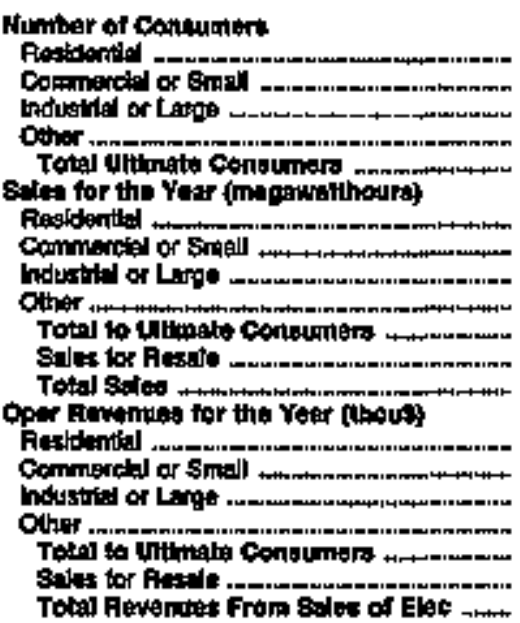 & 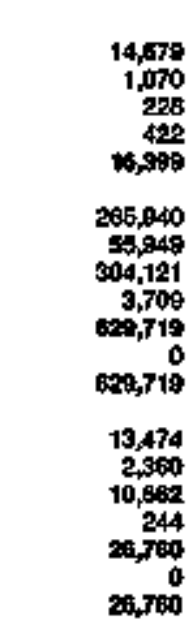 & 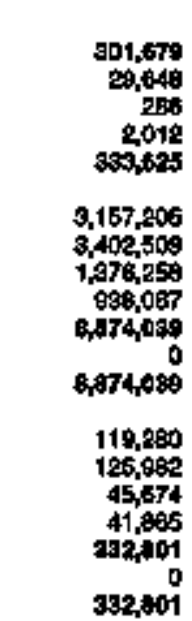 & 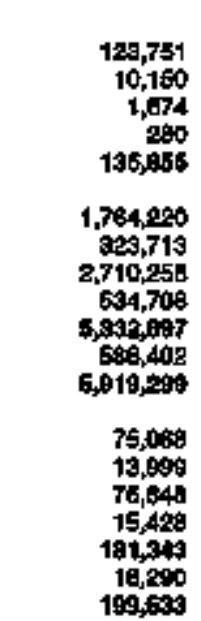 & 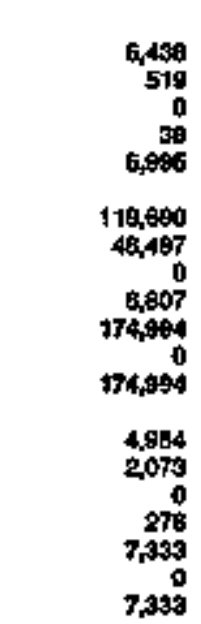 & $\begin{array}{r}0 \\
0 \\
0 \\
0 \\
0 \\
6,796,193 \\
6,709,193 \\
0 \\
0 \\
0 \\
0 \\
0 \\
075,745 \\
575,745\end{array}$ & $\begin{array}{r}0 \\
0 \\
0 \\
0 \\
0 \\
297,800 \\
207,900 \\
0 \\
0 \\
0 \\
0 \\
0 \\
10,365 \\
70,396\end{array}$ \\
\hline
\end{tabular}

\begin{tabular}{|c|c|c|c|c|c|c|}
\hline Ihm & 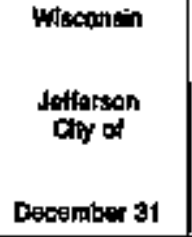 & 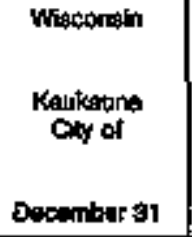 & 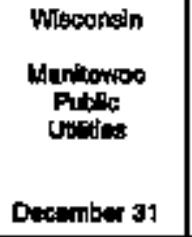 & 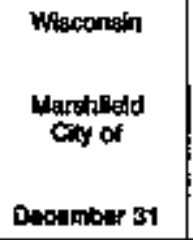 & $\begin{array}{l}\text { Wecongln } \\
\text { Steraghin } \\
\text { Oty of } \\
\text { December } 31\end{array}$ & 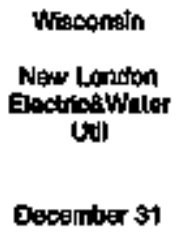 \\
\hline 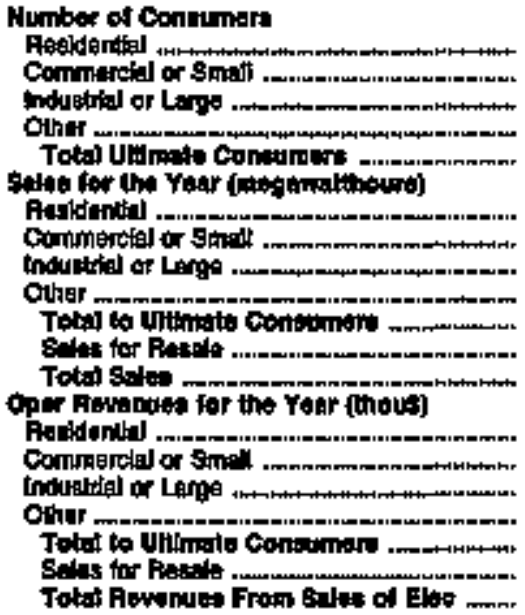 & 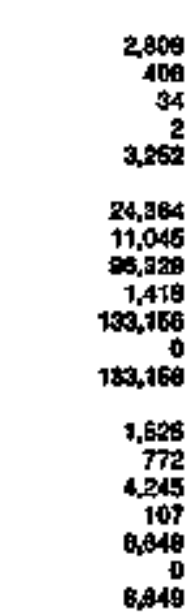 & $\begin{array}{r}97,409 \\
44,741 \\
514,025 \\
7,928 \\
658,192 \\
0 \\
050,102 \\
4,298 \\
2,082 \\
17,331 \\
169 \\
23,075 \\
0 \\
29,078\end{array}$ & 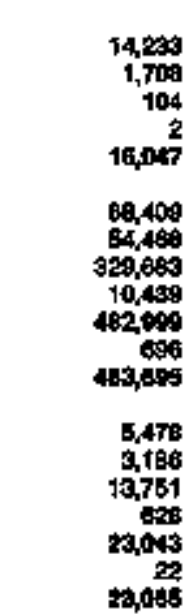 & 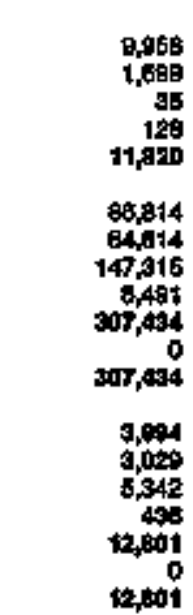 & 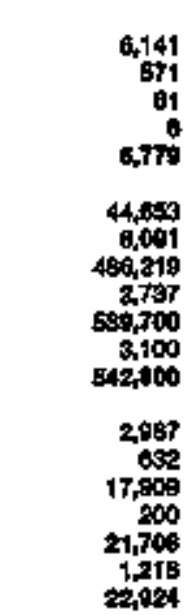 & 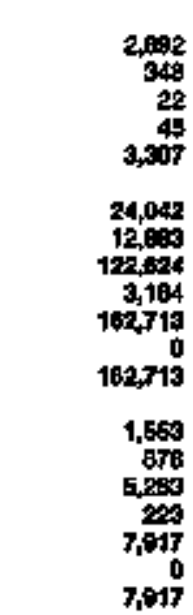 \\
\hline
\end{tabular}

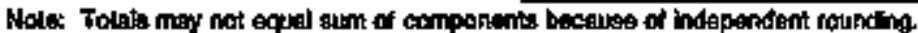

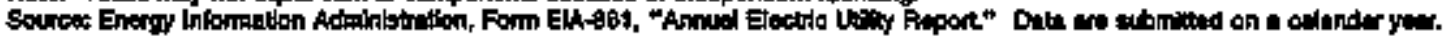


Table 25. Number of Consumare, Sales, and Operating Revenue by Malor U.8. Pubichy Owned Eeetrio Utility Within State, 1994 (Continued)

\begin{tabular}{|c|c|c|c|c|c|c|}
\hline Item & 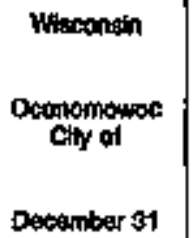 & 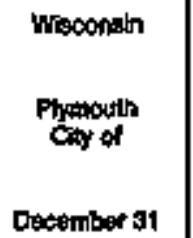 & $\begin{array}{l}\text { mocontin } \\
\text { Apedshum } \\
\text { Uflly Conm } \\
\text { Deceninger } 31\end{array}$ & $\begin{array}{l}\text { Wioconein } \\
\text { Shamino } \\
\text { Municeal } \\
\text { Utiltios }\end{array}$ & 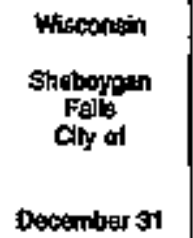 & 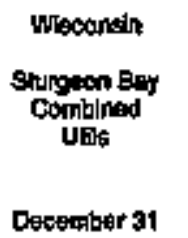 \\
\hline 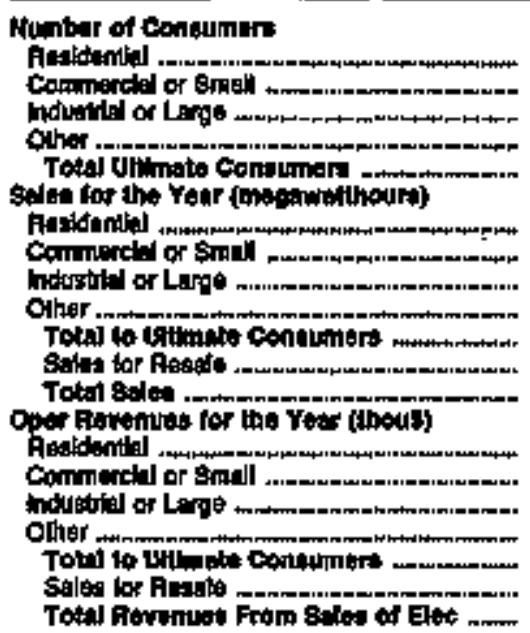 & 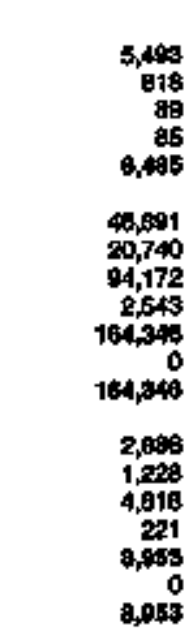 & 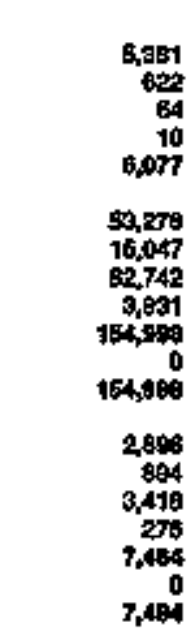 & 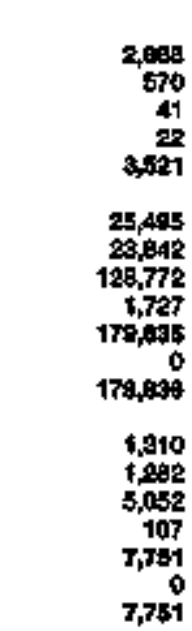 & 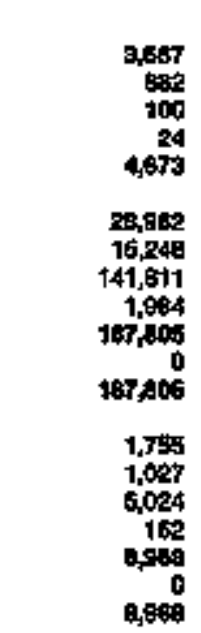 & 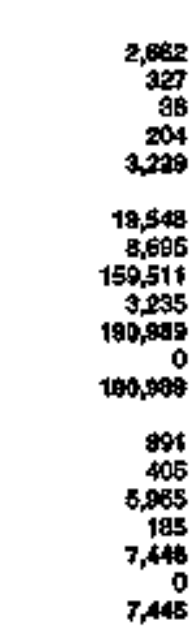 & 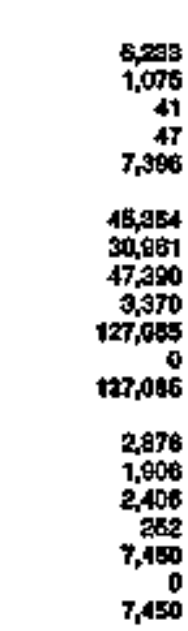 \\
\hline
\end{tabular}

\begin{tabular}{|c|c|c|c|c|c|}
\hline Deต & $\begin{array}{l}\text { Wisconth } \\
\text { sun Pralie } \\
\text { Walar \& Ught } \\
\text { Canm } \\
\text { Dacember } 31\end{array}$ & 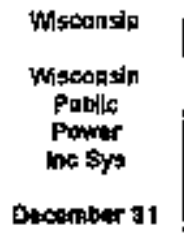 & 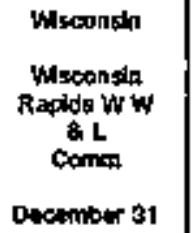 & $\begin{array}{l}\text { Myomilag } \\
\text { Ginute } \\
\text { City of } \\
\text { Decomber } 51\end{array}$ & 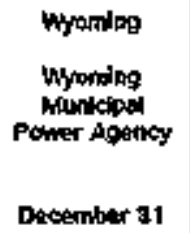 \\
\hline 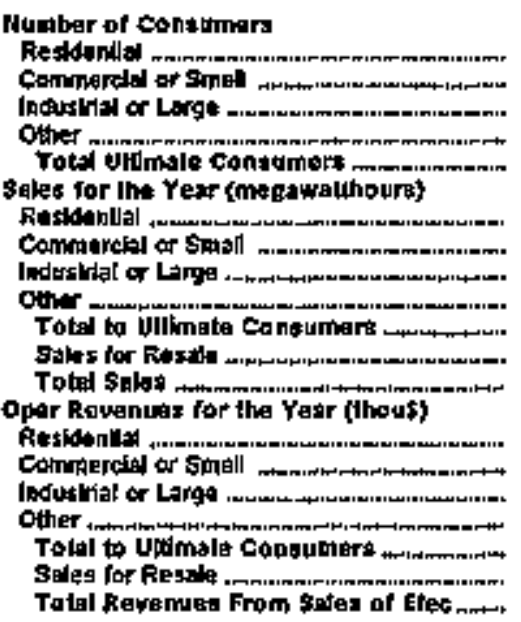 & 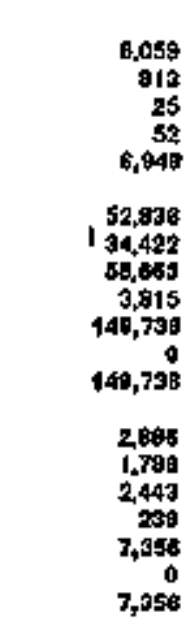 & $\begin{array}{r}0 \\
0 \\
0 \\
0 \\
0 \\
3,035,560 \\
3,009,650 \\
0 \\
0 \\
0 \\
0 \\
0 \\
113,245 \\
113,245\end{array}$ & $\begin{array}{r}10,108 \\
1,348 \\
28 \\
12 \\
14,409 \\
89,001 \\
65,153 \\
49,564 \\
4,989 \\
135,607 \\
0 \\
195,607 \\
4,231 \\
3,052 \\
2,259 \\
395 \\
0,946 \\
0 \\
9,046\end{array}$ & $\begin{array}{r}7,400 \\
216 \\
0 \\
1 \\
0,197 \\
40,162 \\
98,637 \\
0 \\
9,325 \\
169,124 \\
0 \\
169,124 \\
4,529 \\
5,597 \\
0 \\
60 \\
10,206 \\
0 \\
10,290\end{array}$ & $\begin{array}{r}0 \\
0 \\
0 \\
0 \\
0 \\
200,419 \\
209,416 \\
0 \\
0 \\
0 \\
0 \\
0 \\
5,751 \\
5,751\end{array}$ \\
\hline
\end{tabular}


Table 26. Eleotrle Energy Acoount by Major U.8. Publledy Owned Electric Utifly Within Stato, 1994

(Megawathours)

\begin{tabular}{|c|c|c|c|c|c|c|}
\hline Item & $\begin{array}{l}\text { Alabuma } \\
\text { Alabaing } \\
\text { Hunteipg: } \\
\text { Elec Auth } \\
\text { Septembar } 30\end{array}$ & 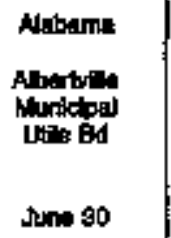 & 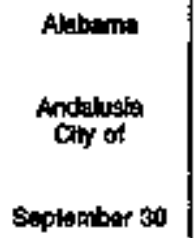 & $\begin{array}{l}\text { Alaburil } \\
\text { Anhong } \\
\text { Cly of } \\
\text { Decenturar } 91\end{array}$ & $\begin{array}{l}\text { Alabema } \\
\text { Besgoner } \\
\text { Caty of } \\
\text { Junte } 300\end{array}$ & 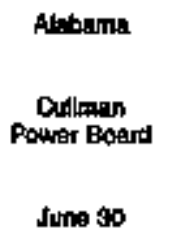 \\
\hline 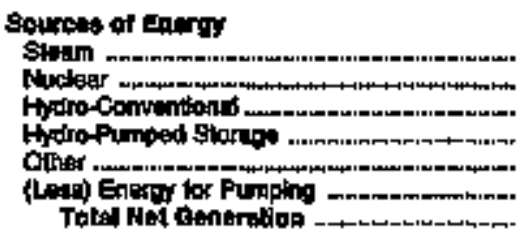 & $\begin{array}{l}0 \\
0 \\
0 \\
0 \\
0 \\
0 \\
0\end{array}$ & $\begin{array}{l}0 \\
0 \\
0 \\
0 \\
0 \\
0 \\
0\end{array}$ & $\begin{array}{l}0 \\
0 \\
0 \\
0 \\
0 \\
0 \\
0\end{array}$ & $\begin{array}{l}0 \\
0 \\
0 \\
0 \\
0 \\
0 \\
0 \\
0\end{array}$ & $\begin{array}{l}0 \\
0 \\
0 \\
0 \\
0 \\
0 \\
0 \\
0\end{array}$ & $\begin{array}{l}0 \\
0 \\
0 \\
0 \\
0 \\
0 \\
0\end{array}$ \\
\hline 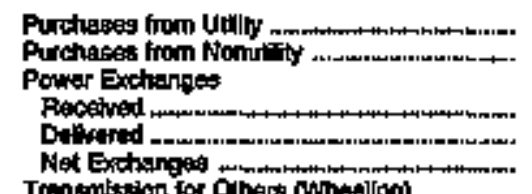 & $\begin{array}{r}2,416,058 \\
0\end{array}$ & $\begin{array}{r}460,074 \\
0 \\
0 \\
0 \\
0\end{array}$ & $\begin{array}{r}329.184 \\
0 \\
0 \\
0 \\
0\end{array}$ & $\begin{array}{r}729,892 \\
0 \\
0 \\
0 \\
0\end{array}$ & $\begin{array}{r}343,413 \\
0 \\
0 \\
0 \\
0\end{array}$ & $\begin{array}{r}324,324 \\
0 \\
0 \\
0 \\
0\end{array}$ \\
\hline 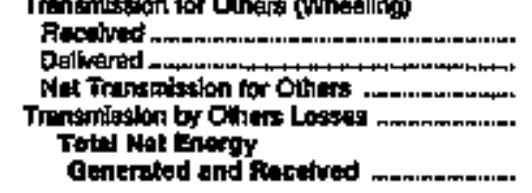 & $\begin{array}{r}0 \\
0 \\
0 \\
0 \\
, 418,060\end{array}$ & $\begin{array}{r}0 \\
0 \\
0 \\
0 \\
0=071\end{array}$ & $\begin{array}{r}0 \\
0 \\
0 \\
0 \\
302,184\end{array}$ & $\begin{array}{r}0 \\
0 \\
0 \\
0 \\
72,042\end{array}$ & $\begin{array}{r}0 \\
0 \\
0 \\
0 \\
343,413\end{array}$ & $\begin{array}{r}0 \\
0 \\
0 \\
0 \\
324,324\end{array}$ \\
\hline 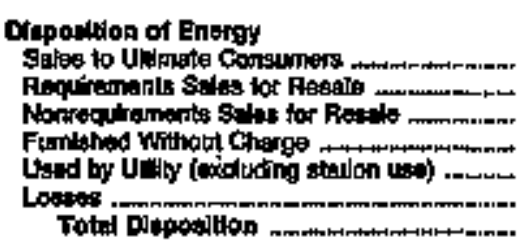 & $\begin{array}{r}2,415,056 \\
0 \\
0 \\
0 \\
0 \\
2,416,058\end{array}$ & $\begin{array}{r}467,191 \\
0 \\
0 \\
0 \\
0 \\
12,790 \\
409,971\end{array}$ & $\begin{array}{r}29,679 \\
0 \\
0 \\
0 \\
0 \\
30,606 \\
320,184\end{array}$ & $\begin{array}{r}670,456 \\
0 \\
0 \\
0 \\
0 \\
58,588 \\
728,982\end{array}$ & $\begin{array}{r}326,704 \\
0 \\
0 \\
0 \\
480 \\
77,200 \\
34,413\end{array}$ & $\begin{array}{r}300,312 \\
0 \\
0 \\
0 \\
60 \\
14,051 \\
324,324\end{array}$ \\
\hline
\end{tabular}

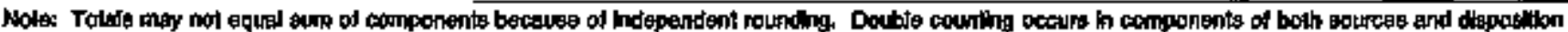

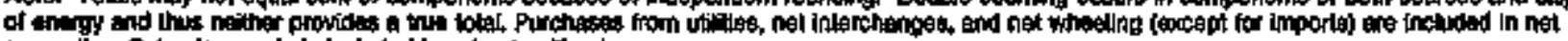

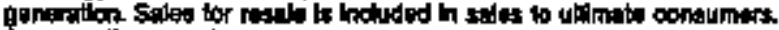

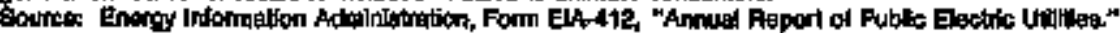


Table 26. Electric Energy Acoount by Najor U.S. Publicly Owned Electric Utilly Whin State, 1994 (Conthuod) (Megawatthours)

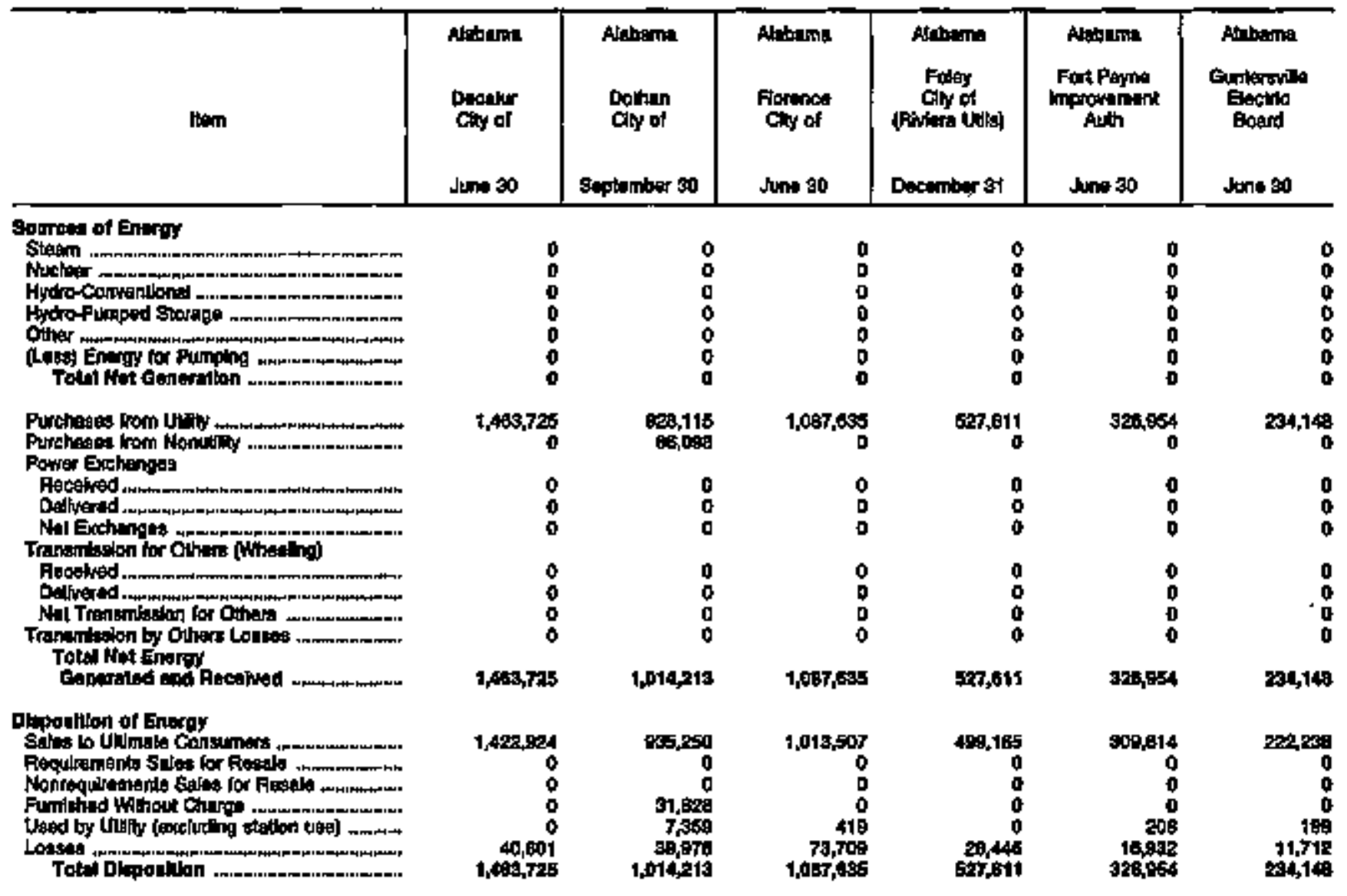

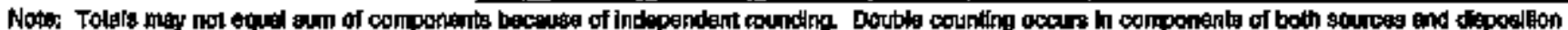

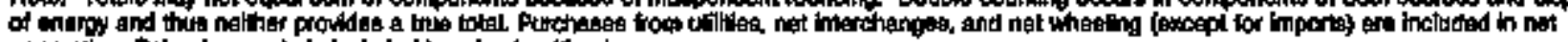

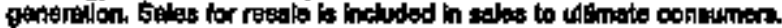

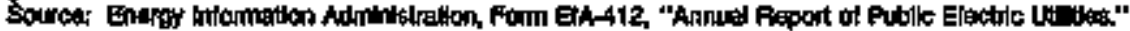


Toble 28. Electric Energy Acoount by Major U.S. Publlely Owned Eleotrio Vitity Withln \$tate, 1994 (Continued)

(Megawatthours)

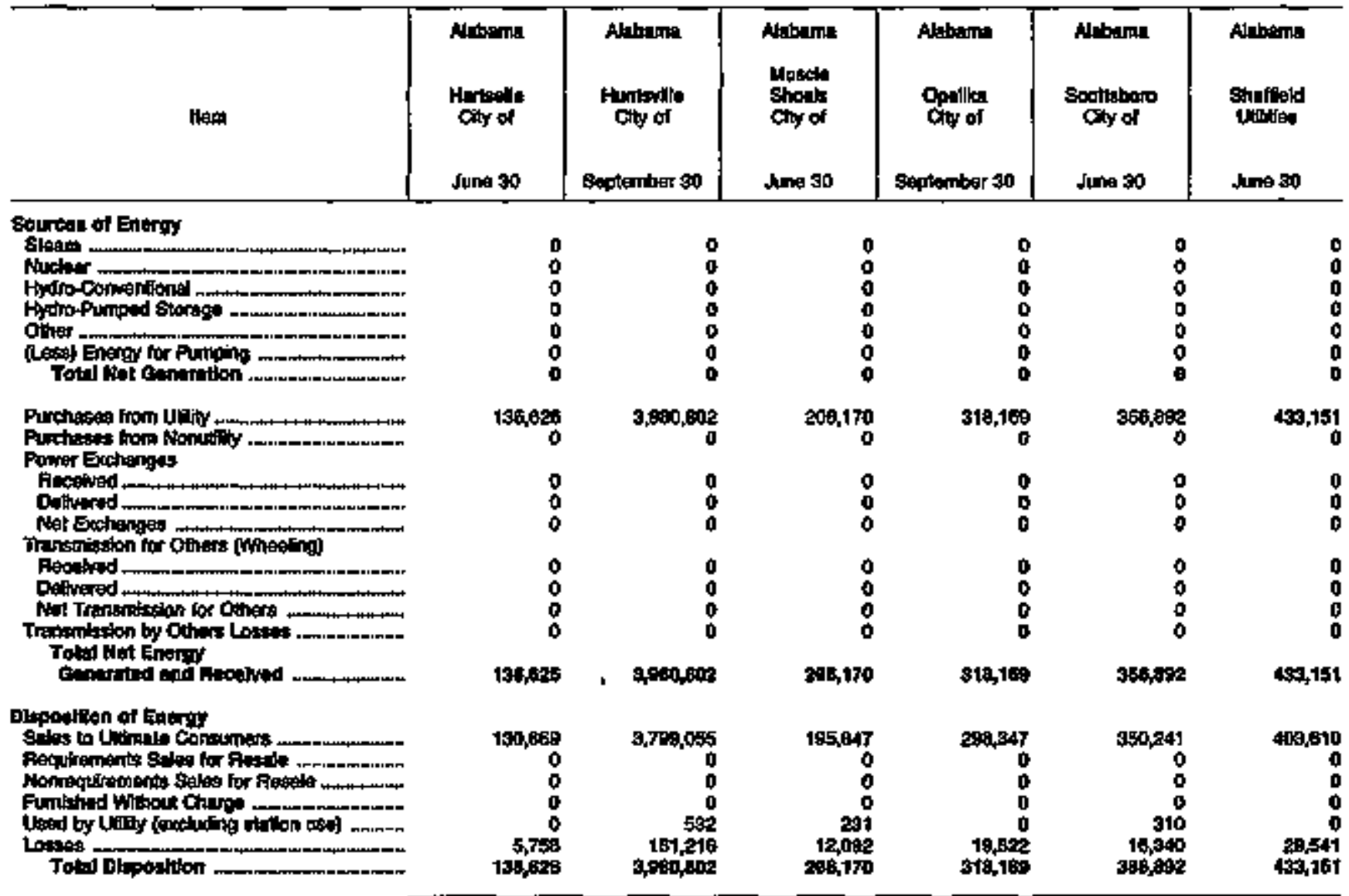

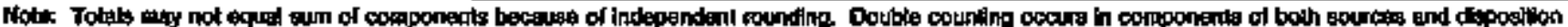

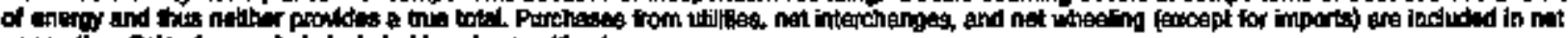

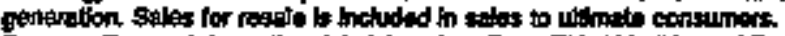

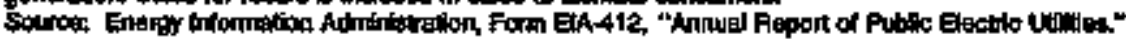


Table 26. Eleetric Energy Account by Major U.S. Publlcly Owned Electric Utility Within State, 1994 (Continued)

(Megawathours)

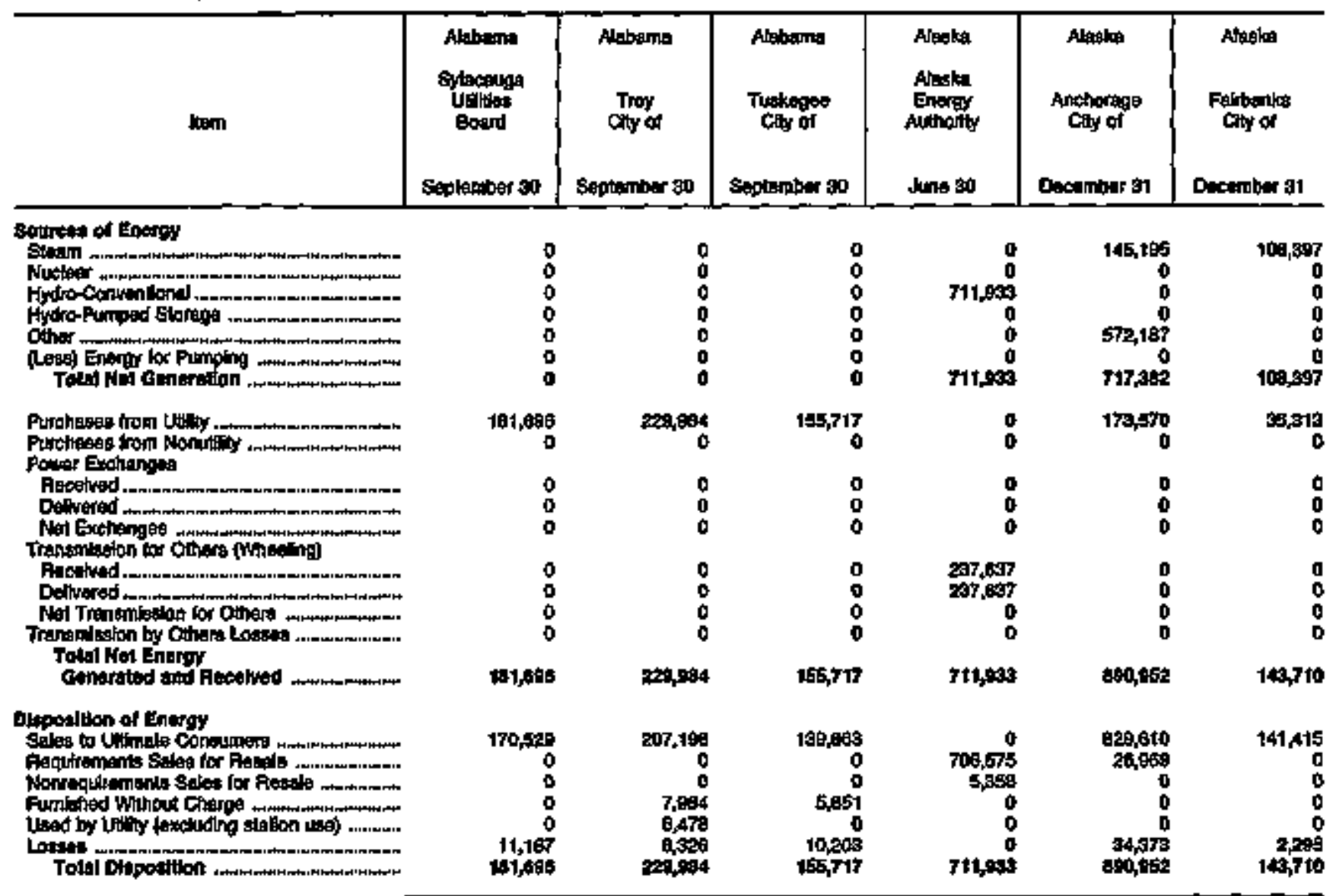

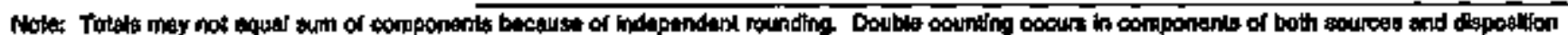

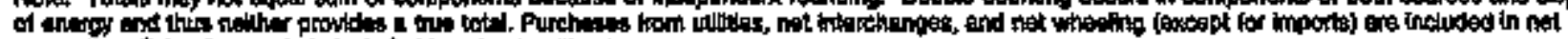

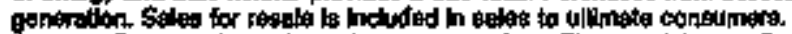

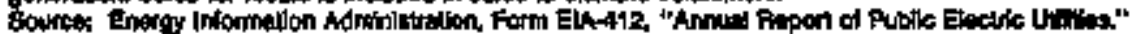


Table 26. Electric Energy Account by Major U.S. Publicly Owned Electric Utility Whthln State, 1994 (Continued) (Megawatthours)

\begin{tabular}{|c|c|c|c|c|c|c|}
\hline Rem & $\begin{array}{l}\text { Alagki } \\
\text { Ketchtlkan } \\
\text { Cily of } \\
\text { Deoamber 91 }\end{array}$ & $\begin{array}{l}\text { Artiong } \\
\text { Atwone } \\
\text { Fower } \\
\text { Authoity } \\
\text { Jume } 30\end{array}$ & 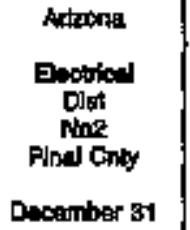 & $\begin{array}{l}\text { Arizona } \\
\text { Mloga } \\
\text { City of } \\
\text { Juns so }\end{array}$ & 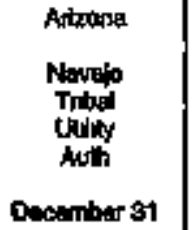 & 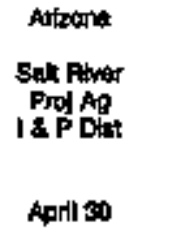 \\
\hline 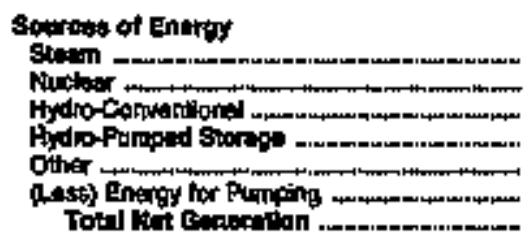 & $\begin{array}{r}0 \\
0 \\
74,512 \\
0 \\
1,674 \\
0 \\
79,89\end{array}$ & $\begin{array}{l}0 \\
0 \\
0 \\
0 \\
0 \\
0 \\
0\end{array}$ & $\begin{array}{l}0 \\
0 \\
0 \\
0 \\
0 \\
0 \\
0\end{array}$ & $\begin{array}{l}0 \\
0 \\
0 \\
0 \\
0 \\
0 \\
0\end{array}$ & $\begin{array}{l}0 \\
0 \\
0 \\
0 \\
0 \\
0 \\
0\end{array}$ & 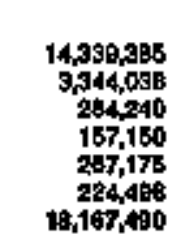 \\
\hline 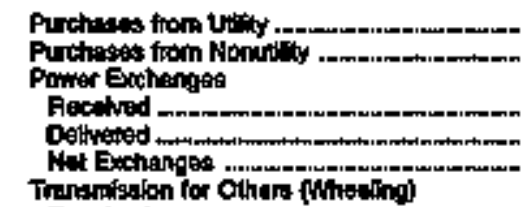 & $\begin{array}{r}76,915 \\
49 \\
0 \\
0 \\
0\end{array}$ & $\begin{array}{r}656,926 \\
0 \\
0 \\
0 \\
0\end{array}$ & $\begin{array}{r}967,730 \\
0 \\
0 \\
0 \\
0\end{array}$ & $\begin{array}{r}342,080 \\
0 \\
0 \\
0 \\
0\end{array}$ & $\begin{array}{r}\text { E48,8xg } \\
0 \\
0 \\
0 \\
0\end{array}$ & $\begin{array}{r}2,414,799 \\
155 \\
200,964 \\
148,340 \\
102,604\end{array}$ \\
\hline 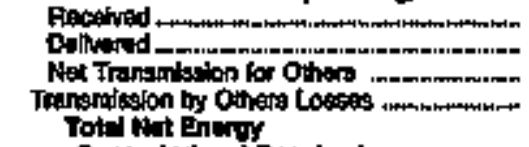 & $\begin{array}{l}0 \\
0 \\
0 \\
0\end{array}$ & $\begin{array}{l}0 \\
0 \\
0 \\
0\end{array}$ & $\begin{array}{l}0 \\
0 \\
0 \\
0\end{array}$ & $\begin{array}{l}0 \\
0 \\
0 \\
0\end{array}$ & $\begin{array}{l}0 \\
0 \\
0 \\
0\end{array}$ & $\begin{array}{r}119,10 y \\
114,470 \\
4,682 \\
0\end{array}$ \\
\hline 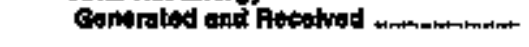 & 163,350 & 955,428 & 167,790 & $\$ 42,060$ & 549.982 & 20699,684 \\
\hline 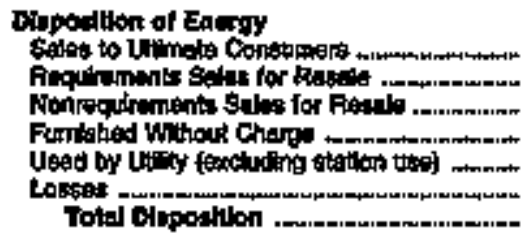 & 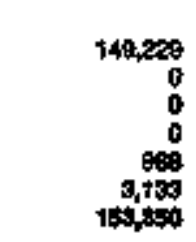 & 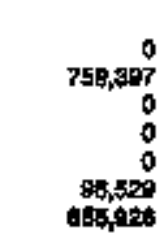 & $\begin{array}{r}140,457 \\
0 \\
0 \\
0 \\
309 \\
17,010 \\
167,790\end{array}$ & $\begin{array}{r}328,376 \\
701 \\
0 \\
0 \\
0 \\
75,009 \\
342,040\end{array}$ & $\begin{array}{r}49,467 \\
0 \\
0 \\
0 \\
0 \\
50,445 \\
540,982\end{array}$ & $\begin{array}{r}16,056,298 \\
3,668,478 \\
0 \\
0 \\
0 \\
908,607 \\
20,6 a t, 694\end{array}$ \\
\hline
\end{tabular}

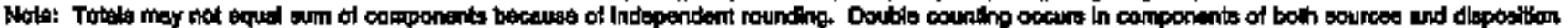

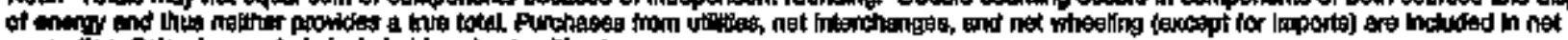

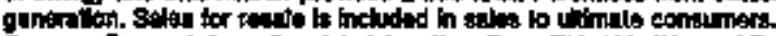

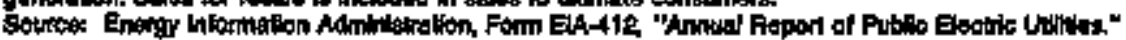


Tabte 26. Eleckric Energy Account by Major U.S. Publtcly Owned Etectric Utilly Within State, 1994 (Continued)

(Megawatthours)

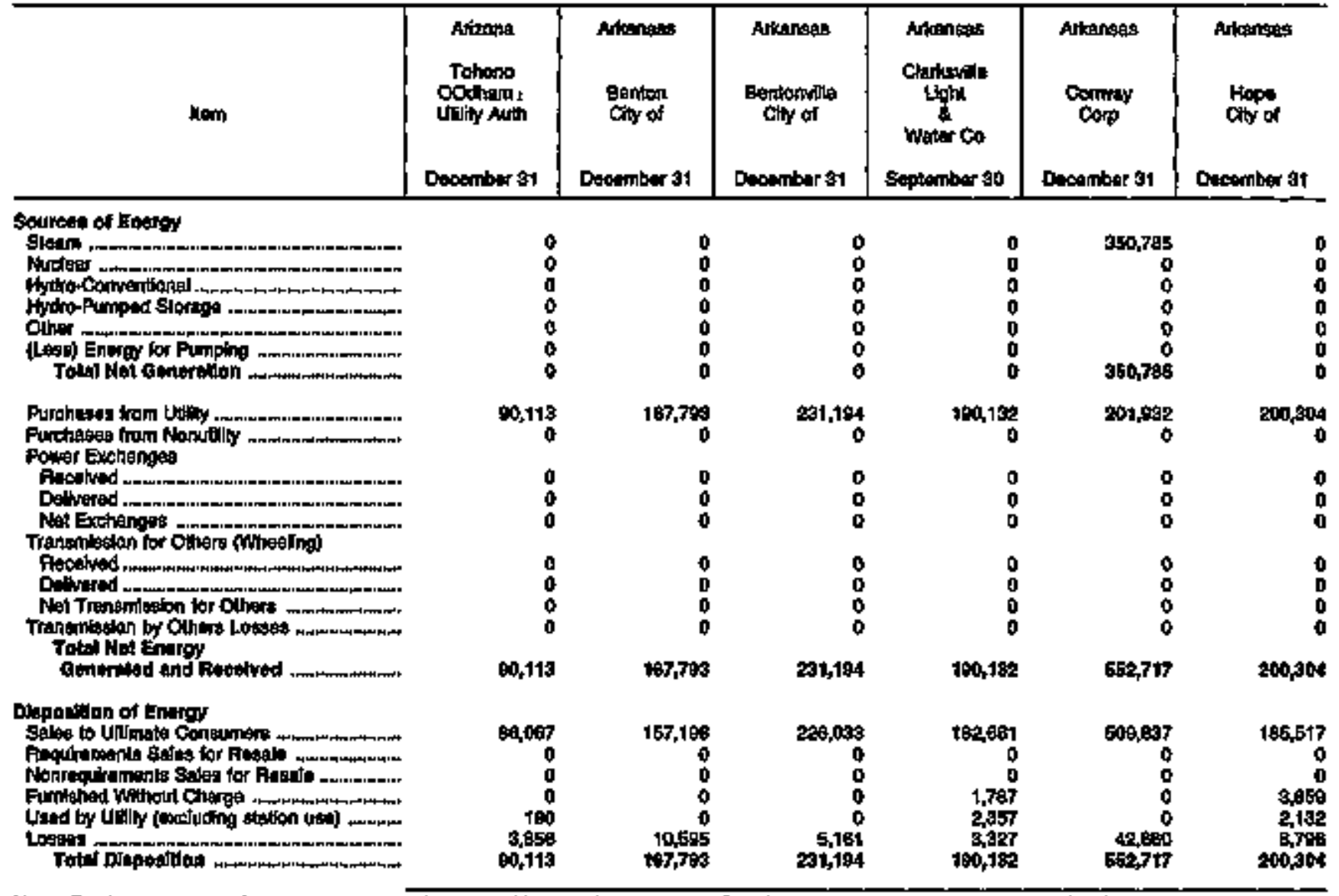

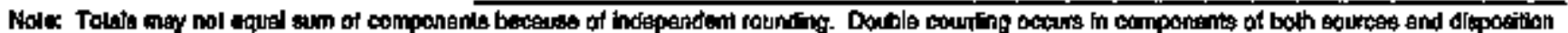

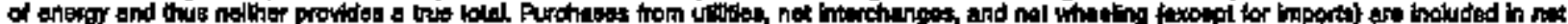

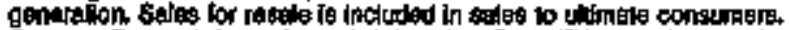

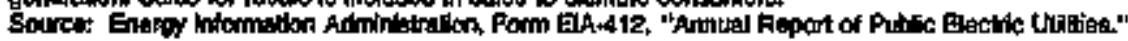


Table 26. Electric Energy Acoount by Mejor U.S. Publicly Owned Electric Utility Within state, 1994 (Continued)

(Megawatthours)

\begin{tabular}{|c|c|c|c|c|c|c|}
\hline Heat & 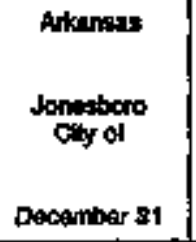 & 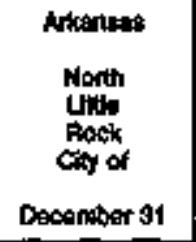 & 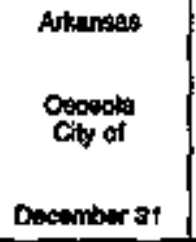 & 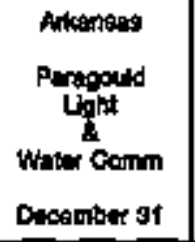 & 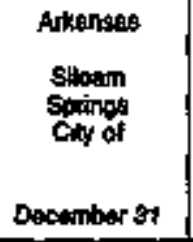 & 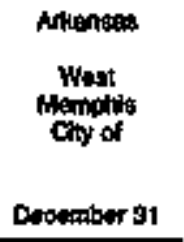 \\
\hline 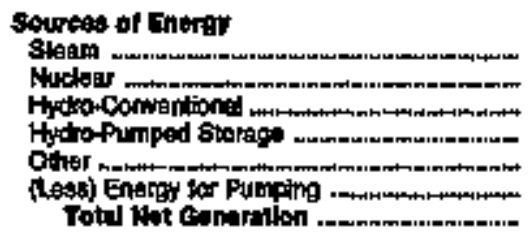 & $\begin{array}{r}274,358 \\
0 \\
0 \\
0 \\
0 \\
0 \\
274,353\end{array}$ & $\begin{array}{r}0 \\
134,620 \\
0 \\
0 \\
0 \\
156,020\end{array}$ & $\begin{array}{r}0 \\
0 \\
0 \\
0 \\
467 \\
0 \\
497\end{array}$ & $\begin{array}{r}0 \\
0 \\
0 \\
0 \\
129 \\
0 \\
120\end{array}$ & $\begin{array}{l}0 \\
0 \\
0 \\
0 \\
0 \\
0 \\
0\end{array}$ & $\begin{array}{r}175,908 \\
0 \\
0 \\
0 \\
0 \\
0 \\
176,306\end{array}$ \\
\hline 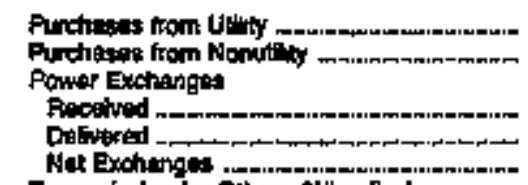 & $\begin{array}{r}688,138 \\
0 \\
70,451 \\
0 \\
70,461\end{array}$ & $\begin{array}{r}708,2909 \\
0\end{array}$ & $\begin{array}{r}161,295 \\
0 \\
0 \\
0 \\
0\end{array}$ & $\begin{array}{r}375,626 \\
0 \\
0 \\
0 \\
0\end{array}$ & $\begin{array}{r}107,619 \\
0\end{array}$ & $\begin{array}{r}162,372 \\
0 \\
0 \\
0 \\
0\end{array}$ \\
\hline 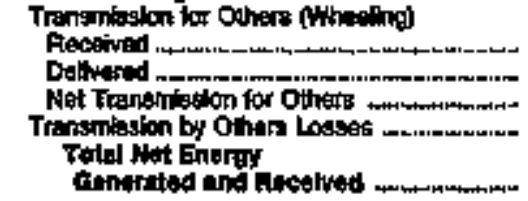 & $\begin{array}{r}0 \\
0 \\
0 \\
0 \\
912940\end{array}$ & $\begin{array}{r}0 \\
0 \\
0 \\
0 \\
0\end{array}$ & $\begin{array}{r}0 \\
0 \\
0 \\
0\end{array}$ & $\begin{array}{r}0 \\
0 \\
0 \\
0 \\
375,5050\end{array}$ & $\begin{array}{r}0 \\
0 \\
0 \\
0 \\
197,919\end{array}$ & $\begin{array}{r}0 \\
0 \\
0 \\
0 \\
3 \times 7,705\end{array}$ \\
\hline 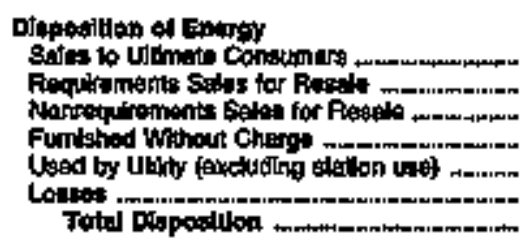 & $\begin{array}{r}\cos , 718 \\
40,310 \\
31,970 \\
7,3100 \\
00 \\
30,844 \\
912,940\end{array}$ & $\begin{array}{r}796,975 \\
0 \\
0 \\
0 \\
0 \\
0 \\
48,948 \\
44,016\end{array}$ & $\begin{array}{r}170,572 \\
0 \\
0 \\
2,500 \\
600 \\
0 \\
18 x, 702\end{array}$ & $\begin{array}{r}359,790 \\
0 \\
0 \\
20 \\
2,140 \\
0 \\
18,725 \\
375,450\end{array}$ & $\begin{array}{r}198,500 \\
0 \\
0 \\
0 \\
0 \\
5,209 \\
157,010\end{array}$ & $\begin{array}{r}29,439 \\
0 \\
0 \\
1,548 \\
4,973 \\
21,607 \\
327,706\end{array}$ \\
\hline
\end{tabular}

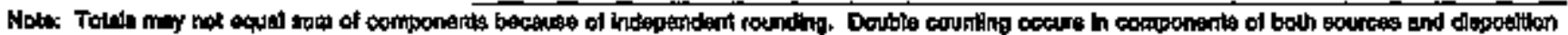

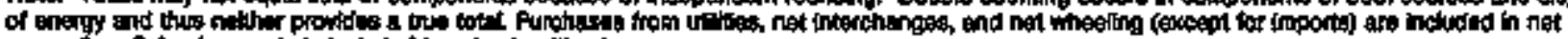

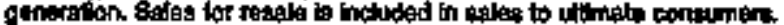

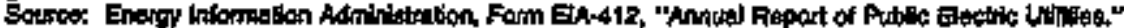


Table 26. Electrte Energy Account by Major U.S. Publlely Owned Electic Uttlity Within State, 1994 (Continued)

(Megawatthours)

\begin{tabular}{|c|c|c|c|c|c|c|}
\hline 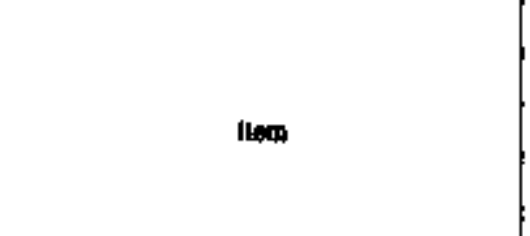 & 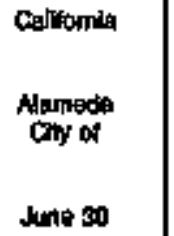 & 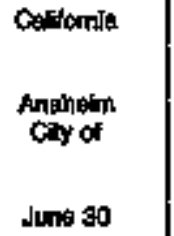 & $\begin{array}{l}\text { Cariomia } \\
\text { Crity of } \\
\text { Junte } 30\end{array}$ & 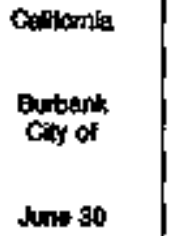 & 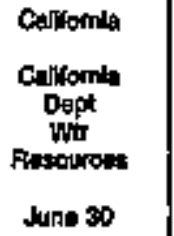 & 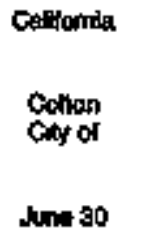 \\
\hline 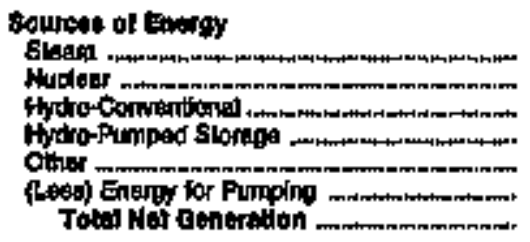 & $\begin{array}{l}0 \\
0 \\
0 \\
0 \\
0 \\
0 \\
0 \\
0\end{array}$ & $\begin{array}{r}787,60 \% \\
0 \\
0 \\
0 \\
4,169 \\
0 \\
791,800\end{array}$ & $\begin{array}{l}0 \\
0 \\
0 \\
0 \\
0 \\
0 \\
0\end{array}$ & $\begin{array}{r}185,195 \\
0 \\
0 \\
0 \\
4,687 \\
0 \\
199,720\end{array}$ & 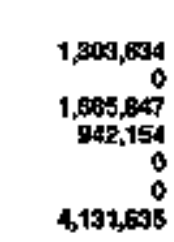 & $\begin{array}{l}0 \\
0 \\
0 \\
0 \\
0 \\
0\end{array}$ \\
\hline 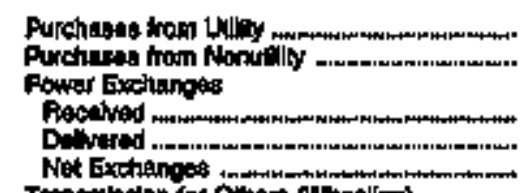 & $\begin{array}{r}495,457 \\
0 \\
0 \\
0 \\
0\end{array}$ & $\begin{array}{r}2,459,510 \\
0 \\
500 \\
28,558 \\
-28,068\end{array}$ & $\begin{array}{r}\sec , 005 \\
0 \\
0 \\
0\end{array}$ & $\begin{array}{r}840,397 \\
4,606 \\
7,490 \\
10,237 \\
-2742\end{array}$ & 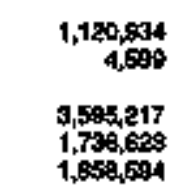 & $\begin{array}{r}2+9,687 \\
0 \\
0 \\
0 \\
0\end{array}$ \\
\hline 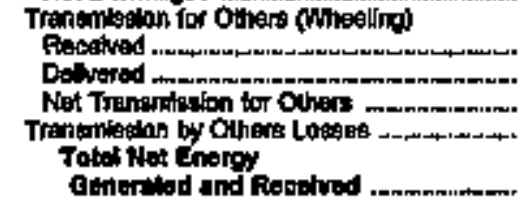 & $\begin{array}{r}0 \\
0 \\
0 \\
0 \\
495,467\end{array}$ & $\begin{array}{r}0 \\
0 \\
0 \\
-156,121 \\
3,057,130\end{array}$ & $\begin{array}{r}0 \\
0 \\
0 \\
0 \\
\$ 2 \pi, 005\end{array}$ & $\begin{array}{r}0 \\
0 \\
0 \\
-39,450 \\
1,002,816\end{array}$ & $\begin{array}{r}0 \\
0 \\
0 \\
0 \\
7,115,762\end{array}$ & $\begin{array}{r}0 \\
0 \\
0 \\
0 \\
210887\end{array}$ \\
\hline 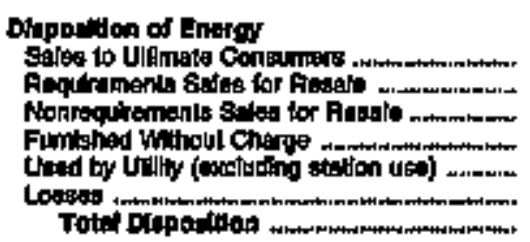 & $\begin{array}{r}476,703 \\
0 \\
0 \\
0 \\
0 \\
26,751 \\
40,457\end{array}$ & $\begin{array}{r}2,200,798 \\
0 \\
793,294 \\
0 \\
0 \\
114,052 \\
3,057,139\end{array}$ & $\begin{array}{r}197,793 \\
120,130 \\
0 \\
2,194 \\
0 \\
16,009 \\
\$ 77,005\end{array}$ & $\begin{array}{r}859,097 \\
4,044 \\
815 \\
0 \\
0 \\
0,690 \\
1,000,615\end{array}$ & $\begin{array}{r}9 \\
2,256,579 \\
0 \\
0 \\
4,649,246 \\
215,949 \\
7,11+, 74\end{array}$ & $\begin{array}{r}209,197 \\
0 \\
0 \\
0 \\
0 \\
11,490 \\
319,667\end{array}$ \\
\hline
\end{tabular}

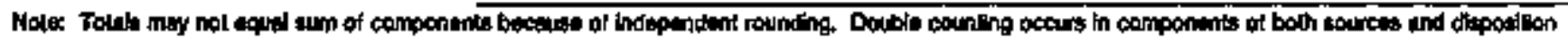

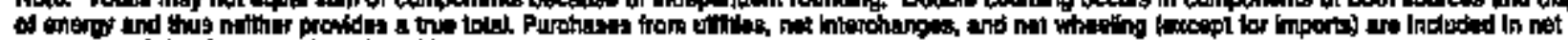

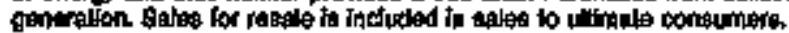

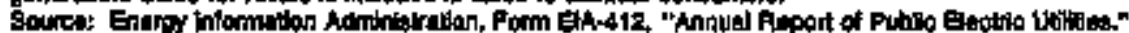


Table 26. Electrle Energy Account by Mejor U.S. Publicly Owned Efectric Utility Within State, 1994 (Continued)

(Megawatthours)

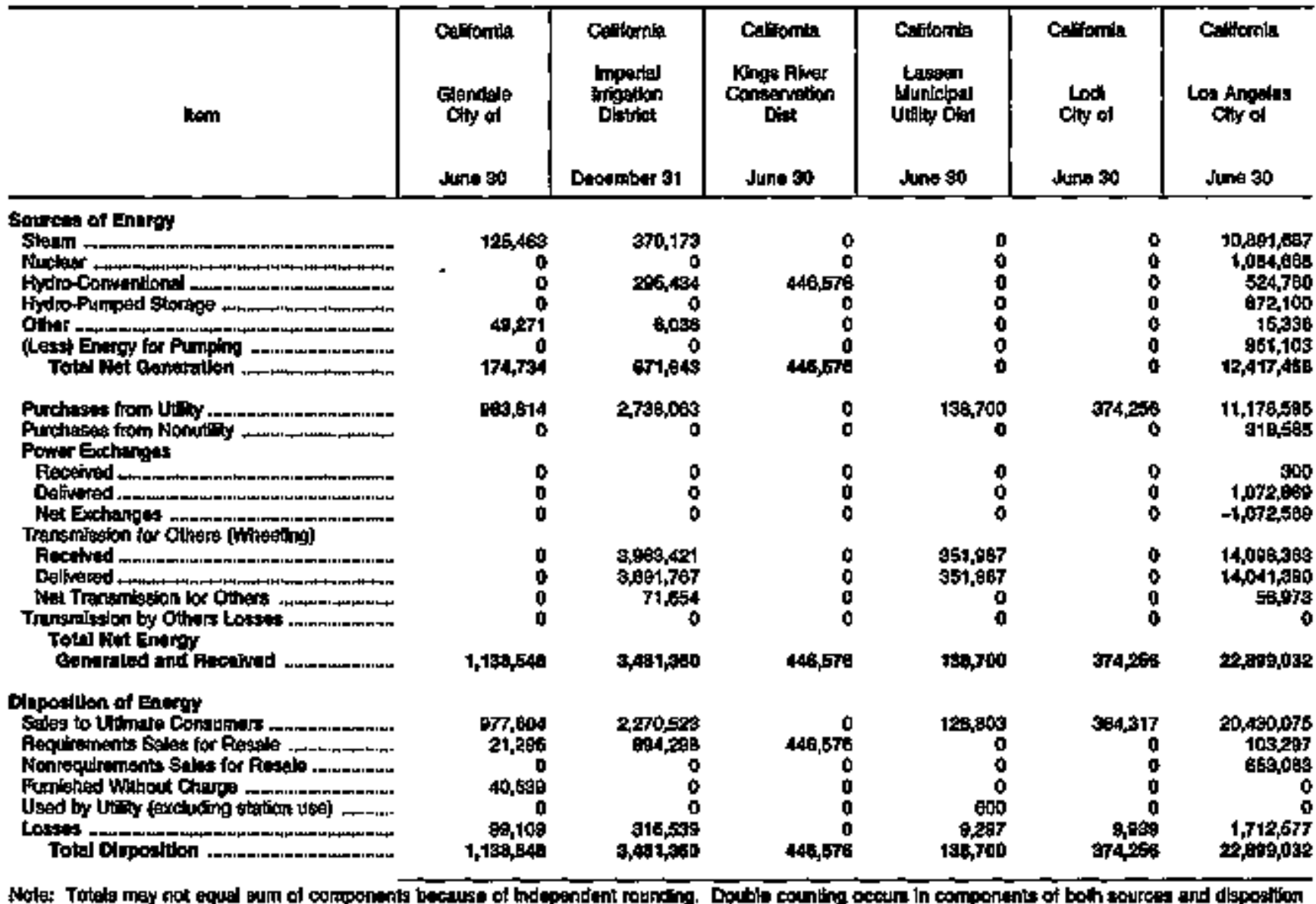

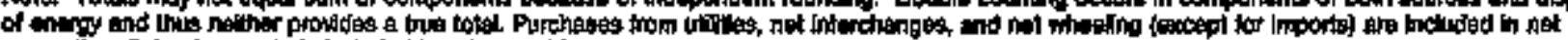

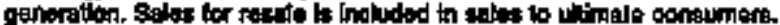

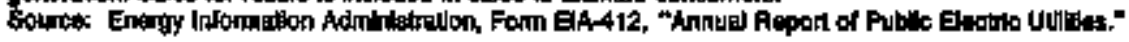


Teble 26. Electric Energy Account by Major U.S. Publidy Owned Electric Utisty Wimin state, 1994 (Continued)

(Megawatthours)

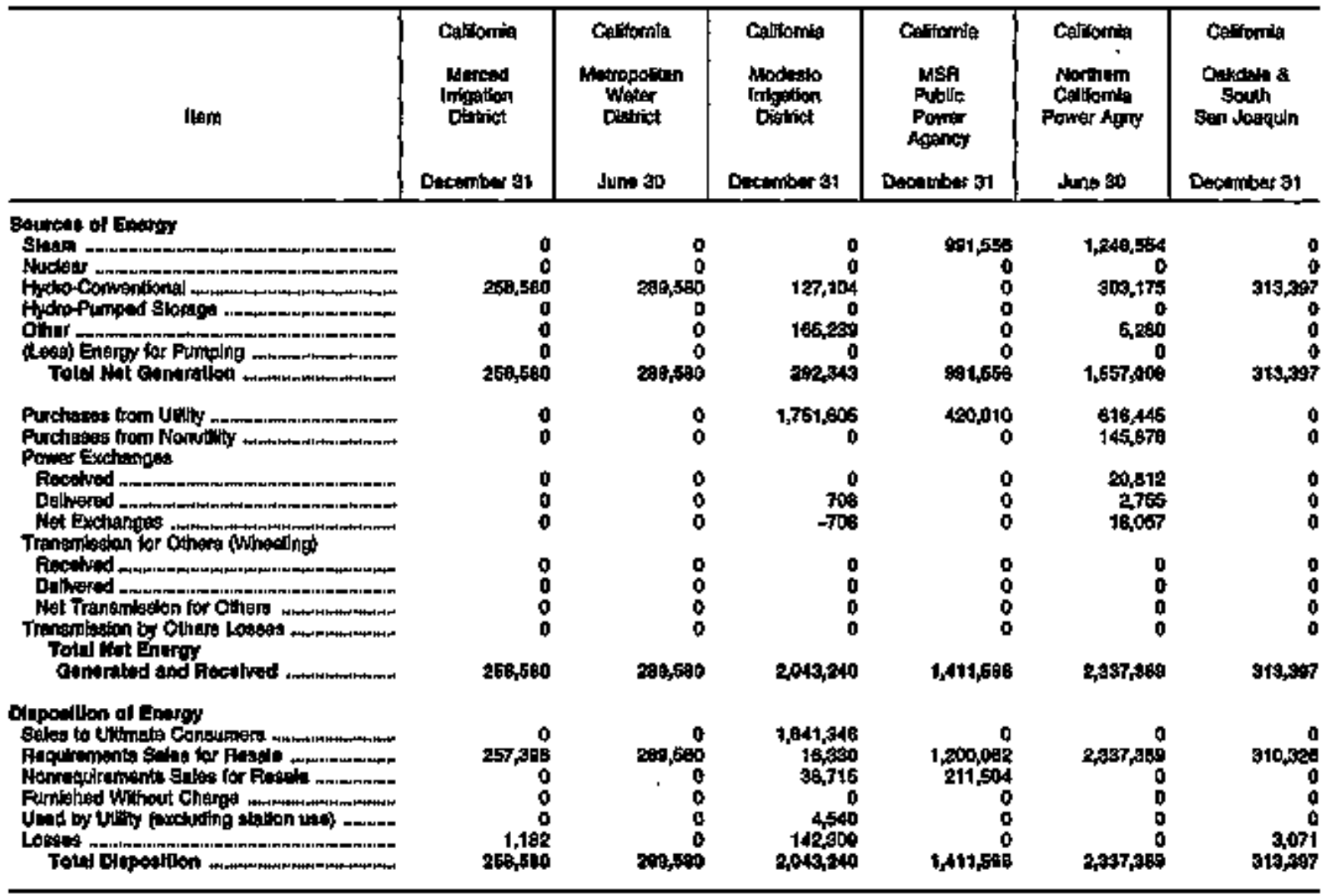

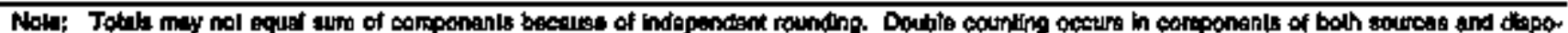

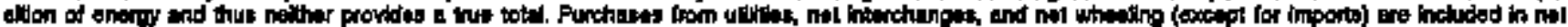

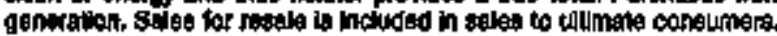

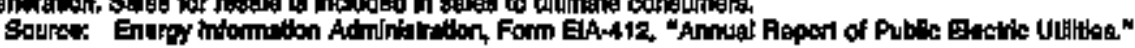


Table 26. Eleotrio Energy Account by Malor U.S. Publiely Owned Eleotric Utility Within state, 1994 (Continued)

(Megewatihours)

\begin{tabular}{|c|c|c|c|c|c|c|}
\hline Heen & 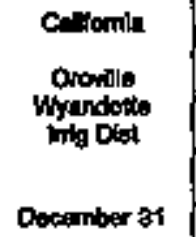 & $\begin{array}{l}\text { Callomia } \\
\text { Pato Alio } \\
\text { City of } \\
\text { Jum so }\end{array}$ & 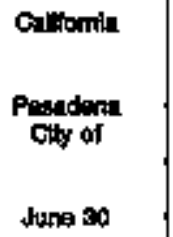 & 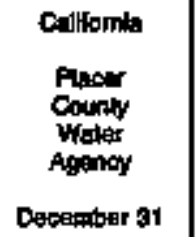 & $\begin{array}{l}\text { Calfonda } \\
\text { Rooding } \\
\text { Ohy of } \\
\text { thing } 30\end{array}$ & 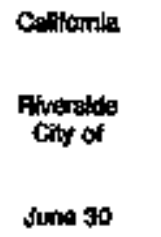 \\
\hline 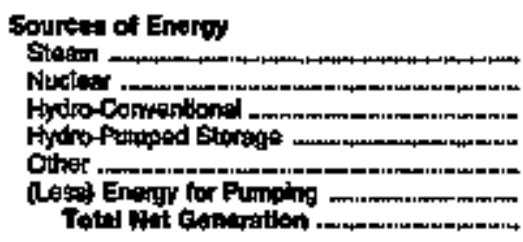 & $\begin{array}{r}0 \\
0 \\
295,927 \\
0 \\
0 \\
0 \\
290,027\end{array}$ & $\begin{array}{l}0 \\
0 \\
0 \\
0 \\
0 \\
0 \\
0\end{array}$ & $\begin{array}{r}257,671 \\
0 \\
7,615 \\
0 \\
0 \\
0 \\
265,298\end{array}$ & $\begin{array}{r}0 \\
454,029 \\
0 \\
0 \\
0 \\
144,028\end{array}$ & $\begin{array}{r}10,250 \\
0 \\
0 \\
0 \\
0 \\
0 \\
10,250\end{array}$ & $\begin{array}{r}276,015 \\
0 \\
0 \\
0 \\
77,05\end{array}$ \\
\hline 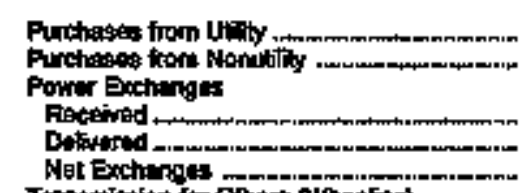 & $\begin{array}{l}0 \\
0 \\
0\end{array}$ & $\begin{array}{r}1,072,805 \\
0 \\
0 \\
0 \\
0\end{array}$ & $\begin{array}{r}509,165 \\
691\end{array}$ & $\begin{array}{l}0 \\
0 \\
0\end{array}$ & $\begin{array}{r}7,5,298 \\
0 \\
0 \\
0\end{array}$ & $\begin{array}{r}1,511,040 \\
1,692 \\
29,280 \\
-27,00 d\end{array}$ \\
\hline 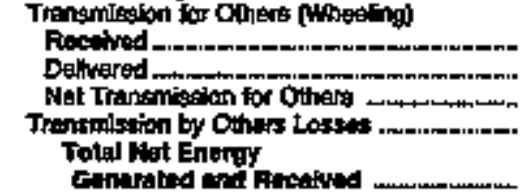 & $\begin{array}{l}0 \\
0 \\
0 \\
0\end{array}$ & $\begin{array}{r}0 \\
0 \\
0 \\
0 \\
1,07 r a g 5\end{array}$ & $1,102,142$ & $\begin{array}{r}0 \\
0 \\
0 \\
0 \\
454,006\end{array}$ & $\begin{array}{r}0 \\
0 \\
0 \\
0 \\
785,590\end{array}$ & 1,750,07 \\
\hline 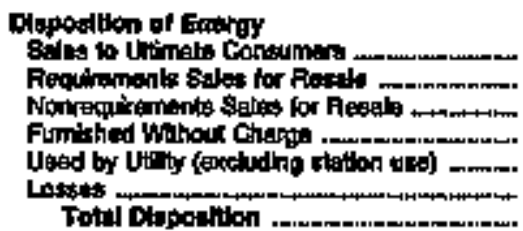 & $\begin{array}{r}0 \\
285,027 \\
0 \\
0 \\
0 \\
0 \\
265,977\end{array}$ & 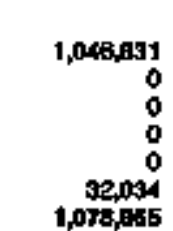 & $\begin{array}{r}1,076,202 \\
34,600 \\
0 \\
0 \\
0 \\
0 \\
118,489 \\
1,202,148\end{array}$ & $\begin{array}{r}0 \\
0 \\
451,600 \\
0 \\
0 \\
2,340 \\
454,025\end{array}$ & $\begin{array}{r}841,562 \\
84,524 \\
0 \\
0 \\
0 \\
39,452 \\
765,506\end{array}$ & $\begin{array}{r}1,5 \times 3,000 \\
107,394 \\
0 \\
0 \\
0 \\
128,128 \\
1,759,567\end{array}$ \\
\hline
\end{tabular}

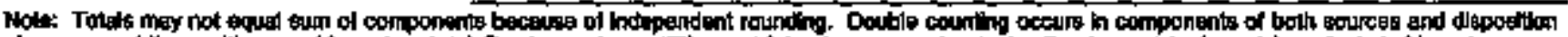

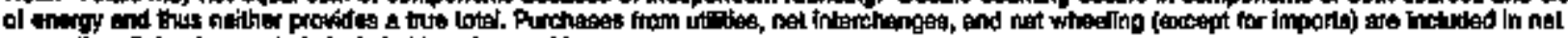

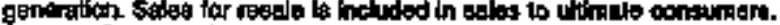

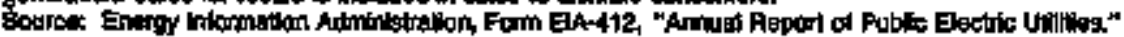


Table 26. Electrlc Eneryy Account by Major U.S. Publicly Omned Electric Utillty Within state, 1994 (Continued)

(Megawatthours)

\begin{tabular}{|c|c|c|c|c|c|c|}
\hline Hean & $\begin{array}{l}\text { Gaciomis } \\
\text { Focenilla } \\
\text { Ciny of } \\
\text { Juno } 30\end{array}$ & 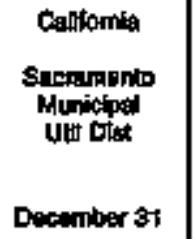 & 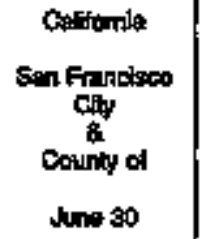 & $\begin{array}{l}\text { Cationita } \\
\text { Sinto } \\
\text { Cing ati } \\
\text { Jano } 30\end{array}$ & 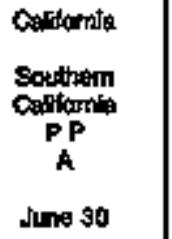 & 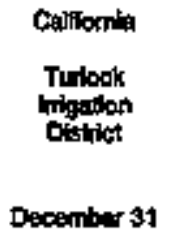 \\
\hline 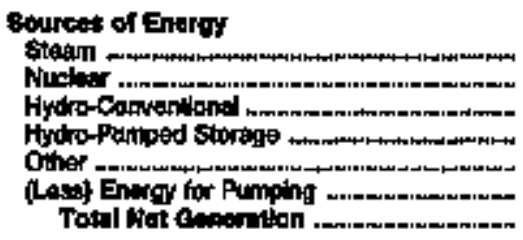 & $\begin{array}{l}0 \\
0 \\
0 \\
0 \\
0 \\
0 \\
0\end{array}$ & $\begin{array}{r}332,370 \\
0 \\
739,740 \\
0 \\
19,760 \\
1,004,676\end{array}$ & $\begin{array}{r}0 \\
0 \\
t, 373,673 \\
0 \\
0 \\
0 \\
0 \\
1,37 \%, 678\end{array}$ & $\begin{array}{r}0 \\
0 \\
101,573 \\
0 \\
48,944 \\
107,917\end{array}$ & $\begin{array}{r}1,51,002 \\
1,1+1,683 \\
0 \\
0 \\
0 \\
0 \\
3,102,866\end{array}$ & $\begin{array}{r}0 \\
0 \\
297,735 \\
0 \\
-115 \\
0 \\
207,6200\end{array}$ \\
\hline 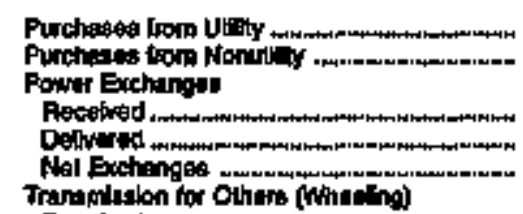 & $\begin{array}{r}77,348 \\
0 \\
0 \\
0 \\
0\end{array}$ & $\begin{array}{r}7,974,40 \\
0 \\
0 \\
11,809 \\
-11,009\end{array}$ & $\begin{array}{r}634,274 \\
0 \\
0 \\
0 \\
0\end{array}$ & $\begin{array}{r}2,211,308 \\
0 \\
0 \\
0 \\
0\end{array}$ & $\begin{array}{r}102,447 \\
0 \\
0 \\
0 \\
0\end{array}$ & $\begin{array}{r}1,36 e, 671 \\
0 \\
1,207 \\
1,144 \\
6 \times 1\end{array}$ \\
\hline 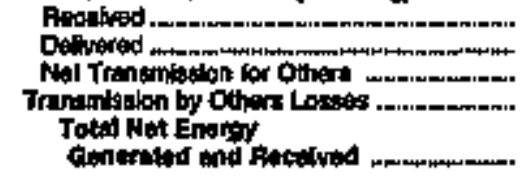 & $\begin{array}{r}0 \\
0 \\
0 \\
0 \\
T 6,9019\end{array}$ & $\begin{array}{r}0 \\
0 \\
0 \\
2,002 \\
4,400,327\end{array}$ & $\begin{array}{r}0 \\
0 \\
0 \\
0 \\
2,007+047\end{array}$ & $\begin{array}{r}210,769 \\
214,965 \\
-4,213 \\
0 \\
2,355,004\end{array}$ & $\begin{array}{r}0 \\
0 \\
0 \\
0 \\
3,2,050,132\end{array}$ & $\begin{array}{r}814 \\
5,852 \\
-3,078 \\
-25,250 \\
1,584,024\end{array}$ \\
\hline 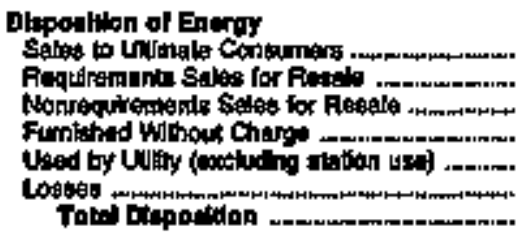 & $\begin{array}{r}50,103 \\
0 \\
0 \\
0 \\
0 \\
20,215 \\
\text { Brs,518 }\end{array}$ & $\begin{array}{r}0,4=0,758 \\
0 \\
7500 \\
0 \\
20,057 \\
470,394 \\
8,980,327\end{array}$ & $\begin{array}{r}573,075 \\
1,034,051 \\
300,547 \\
2,484 \\
11,057 \\
154,022 \\
2,000,047\end{array}$ & $\begin{array}{r}2+79,194 \\
27,0,00 \\
7,190 \\
6,019 \\
0 \\
139,596 \\
2,185,004\end{array}$ & $\begin{array}{r}3,205,132 \\
0 \\
0 \\
0 \\
0 \\
3,205,152\end{array}$ & $\begin{array}{r}1,206,968 \\
275,860 \\
5,240 \\
0 \\
10,750 \\
81,217 \\
1,010,024\end{array}$ \\
\hline
\end{tabular}

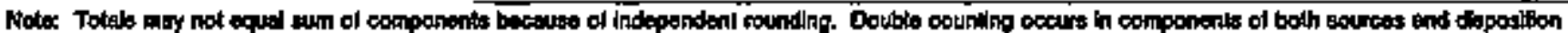

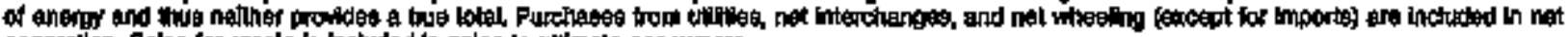

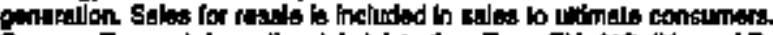

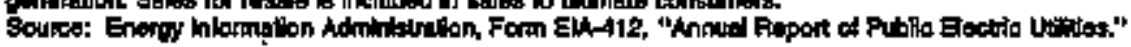


Table 28. Electrile Energy Account by Major U.s. Pub"loly Owned Electric Uknky Whthin stote, 1994 (Continued)

(Megawatthours)

\begin{tabular}{|c|c|c|c|c|c|c|}
\hline hem & 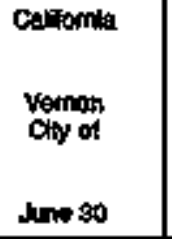 & 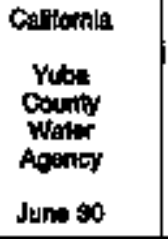 & 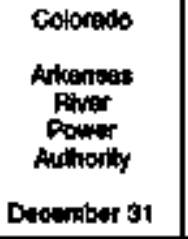 & $\begin{array}{l}\text { Colorado } \\
\text { Colorodo } \\
\text { spings } \\
\text { cony of } \\
\text { Deomber \$1 }\end{array}$ & 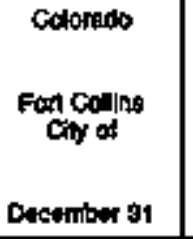 & $\begin{array}{l}\text { Colonado } \\
\text { Fort Moman } \\
\text { City of } \\
\text { Decomber } 3 t\end{array}$ \\
\hline 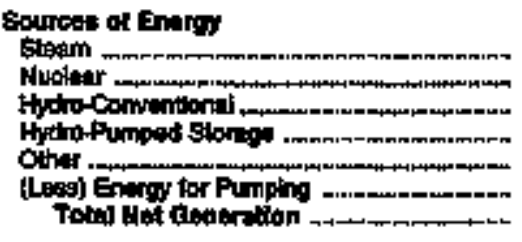 & $\begin{array}{r}0 \\
0 \\
0 \\
0 \\
0.005 \\
0 \\
0.000\end{array}$ & 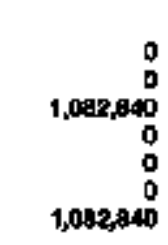 & $\begin{array}{l}0 \\
0 \\
0 \\
0 \\
0 \\
0 \\
0 \\
0\end{array}$ & $\begin{array}{r}2,814,082 \\
0 \\
21,202 \\
0 \\
0 \\
0 \\
2,989,184\end{array}$ & $\begin{array}{l}0 \\
0 \\
0 \\
0 \\
0 \\
0 \\
0 \\
0\end{array}$ & $\begin{array}{l}0 \\
0 \\
0 \\
0 \\
0 \\
0 \\
0\end{array}$ \\
\hline 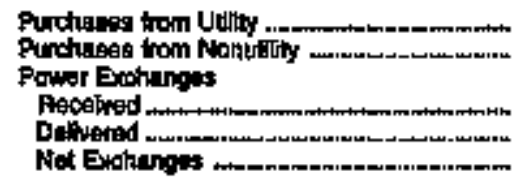 & $\begin{array}{r}1,060,200 \\
0 \\
0 \\
0 \\
0\end{array}$ & $\begin{array}{l}0 \\
0\end{array}$ & 307,769 & $\begin{array}{r}648,448 \\
0 \\
1,978 \\
687 \\
1,311\end{array}$ & $\begin{array}{r}\theta 89,001 \\
0 \\
0 \\
0 \\
0\end{array}$ & $\begin{array}{r}167016 \\
0 \\
0 \\
0 \\
0\end{array}$ \\
\hline 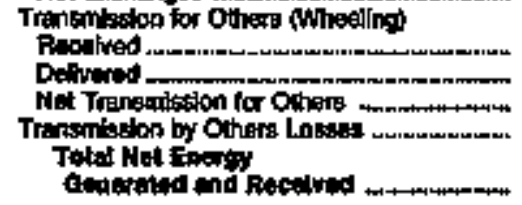 & 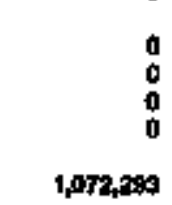 & $1,092,940$ & 307,759 & $\begin{array}{r}35,074 \\
31,074 \\
0 \\
0\end{array}$ & $\begin{array}{r}0 \\
0 \\
0 \\
0 \\
090001\end{array}$ & $\begin{array}{r}0 \\
0 \\
0 \\
0 \\
t 67,606\end{array}$ \\
\hline 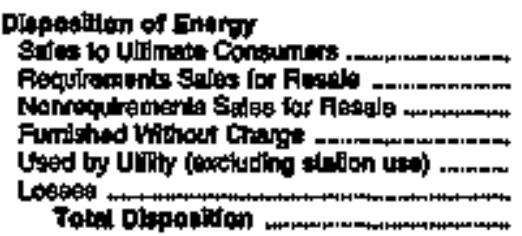 & $\begin{array}{r}1,031,703 \\
0 \\
0 \\
0 \\
0 \\
40,600 \\
1,072,709\end{array}$ & $\begin{array}{r}0 \\
1,000,084 \\
0 \\
0 \\
0 \\
1,908 \\
1,092,040\end{array}$ & $\begin{array}{r}282,030 \\
0 \\
0 \\
0 \\
0 \\
25,720 \\
307,750\end{array}$ & $\begin{array}{r}3,159,401 \\
138,080 \\
44,084 \\
0 \\
0 \\
146,443 \\
3445,904\end{array}$ & $\begin{array}{r}709,329 \\
0 \\
0 \\
6,448 \\
0 \\
20,280 \\
\$ 09061\end{array}$ & $\begin{array}{r}134,778 \\
0 \\
0 \\
0 \\
0 \\
12,040 \\
167,640\end{array}$ \\
\hline
\end{tabular}

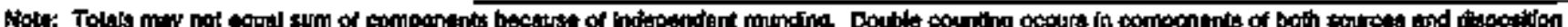

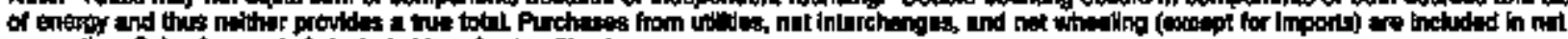

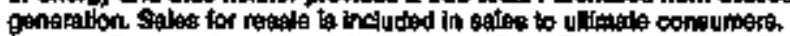

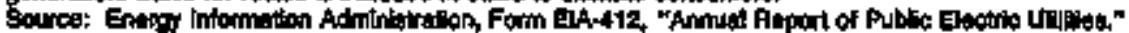


Table 26. Electric Energy Account by Major U.S. Publlety Ownad Eloctrte Utilty Whinin State, 1994 (Continued)

(Megawatthours)

\begin{tabular}{|c|c|c|c|c|c|c|}
\hline Intw & 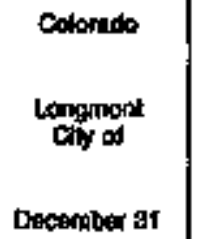 & $\begin{array}{l}\text { Colorado } \\
\text { Loveland } \\
\text { Cisy of } \\
\text { December a1 }\end{array}$ & 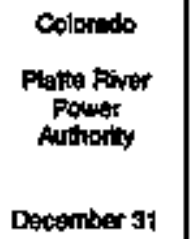 & 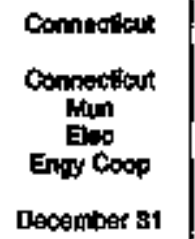 & $\begin{array}{l}\text { Conneoticul } \\
\text { Grotion } \\
\text { Oty of } \\
\text { Wha so }\end{array}$ & 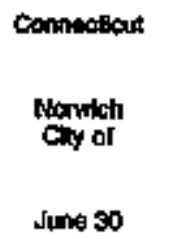 \\
\hline 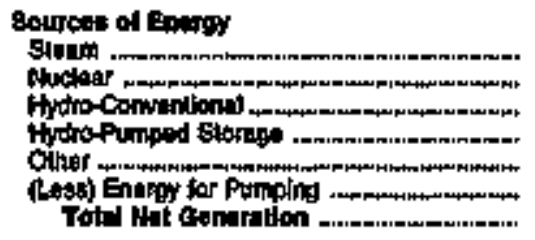 & $\begin{array}{r}0 \\
0 \\
3,567 \\
0 \\
0 \\
0 \\
0,587\end{array}$ & $\begin{array}{r}0 \\
0 \\
03 \\
0 \\
0 \\
0 \\
03\end{array}$ & $\begin{array}{r}2,895,349 \\
0 \\
0 \\
0 \\
0 \\
0 \\
0,000,048\end{array}$ & $\begin{array}{r}0 \\
102,41 \\
0 \\
0 \\
0 \\
9 \\
102,441\end{array}$ & $\begin{array}{l}0 \\
0 \\
0 \\
0 \\
0 \\
0 \\
0\end{array}$ & $\begin{array}{r}0 \\
0 \\
9,450 \\
0 \\
0 \\
0 \\
0,454\end{array}$ \\
\hline 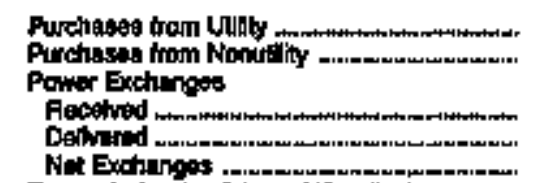 & $\begin{array}{r}194,217 \\
0 \\
0 \\
0 \\
0\end{array}$ & $\begin{array}{r}400,852 \\
0 \\
0 \\
0 \\
0\end{array}$ & $\begin{array}{r}797,029 \\
0 \\
12,477 \\
12,47 \\
0\end{array}$ & $\begin{array}{r}704,354 \\
0 \\
312,989 \\
15,450 \\
209,5,29\end{array}$ & $\begin{array}{r}041+602 \\
0 \\
0 \\
0\end{array}$ & $\begin{array}{r}297290 \\
0 \\
0 \\
0 \\
0\end{array}$ \\
\hline 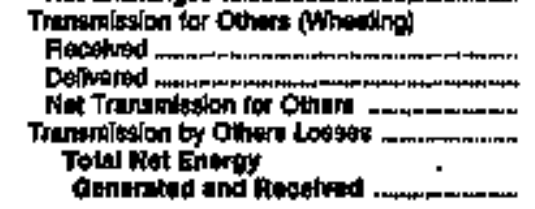 & 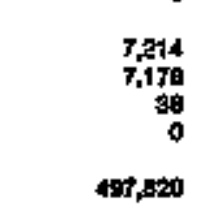 & $\begin{array}{r}0 \\
0 \\
0 \\
0 \\
40 B, 996\end{array}$ & 3 3) & $\begin{array}{r}0 \\
0 \\
0 \\
0 \\
1,+10,3820\end{array}$ & $\begin{array}{r}0 \\
0 \\
0 \\
0 \\
04 \cos 2\end{array}$ & $\begin{array}{r}0 \\
0 \\
0 \\
0 \\
\mathbf{3} 14,714\end{array}$ \\
\hline 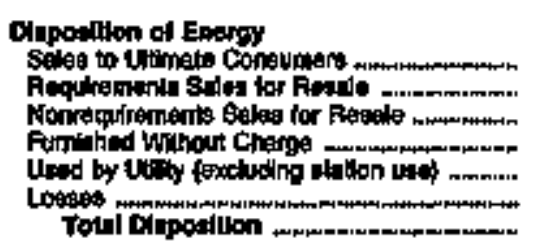 & $\begin{array}{r}478,714 \\
0 \\
0 \\
8,475 \\
0 \\
12,651 \\
407,4,00\end{array}$ & $\begin{array}{r}390,751 \\
0 \\
0 \\
5,177 \\
0 \\
10,907 \\
0015\end{array}$ & $\begin{array}{r}0 \\
2,055,4340 \\
599,209 \\
0 \\
0 \\
67,724 \\
3,890,972\end{array}$ & $\begin{array}{r}0 \\
1,107,568 \\
0 \\
0 \\
0 \\
1,767 \\
1,103,329\end{array}$ & $\begin{array}{r}616,771 \\
5,605 \\
0 \\
669 \\
877 \\
15,731 \\
641,672\end{array}$ & $\begin{array}{r}205,442 \\
0 \\
0 \\
0 \\
0 \\
21,272 \\
\sin , 714\end{array}$ \\
\hline
\end{tabular}

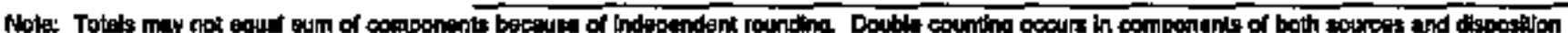

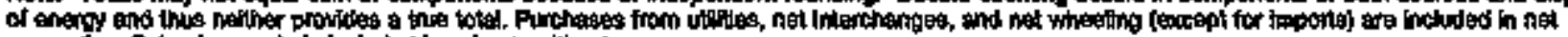

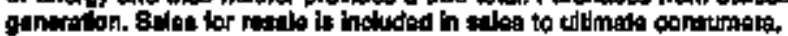

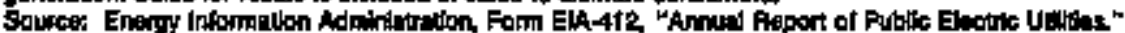


Tabłe 26. Electrlc Energy Aocount by Major US. Publlch Owned Electrlo Utility Within State, 1994 (Continued)

(Megawatthours)

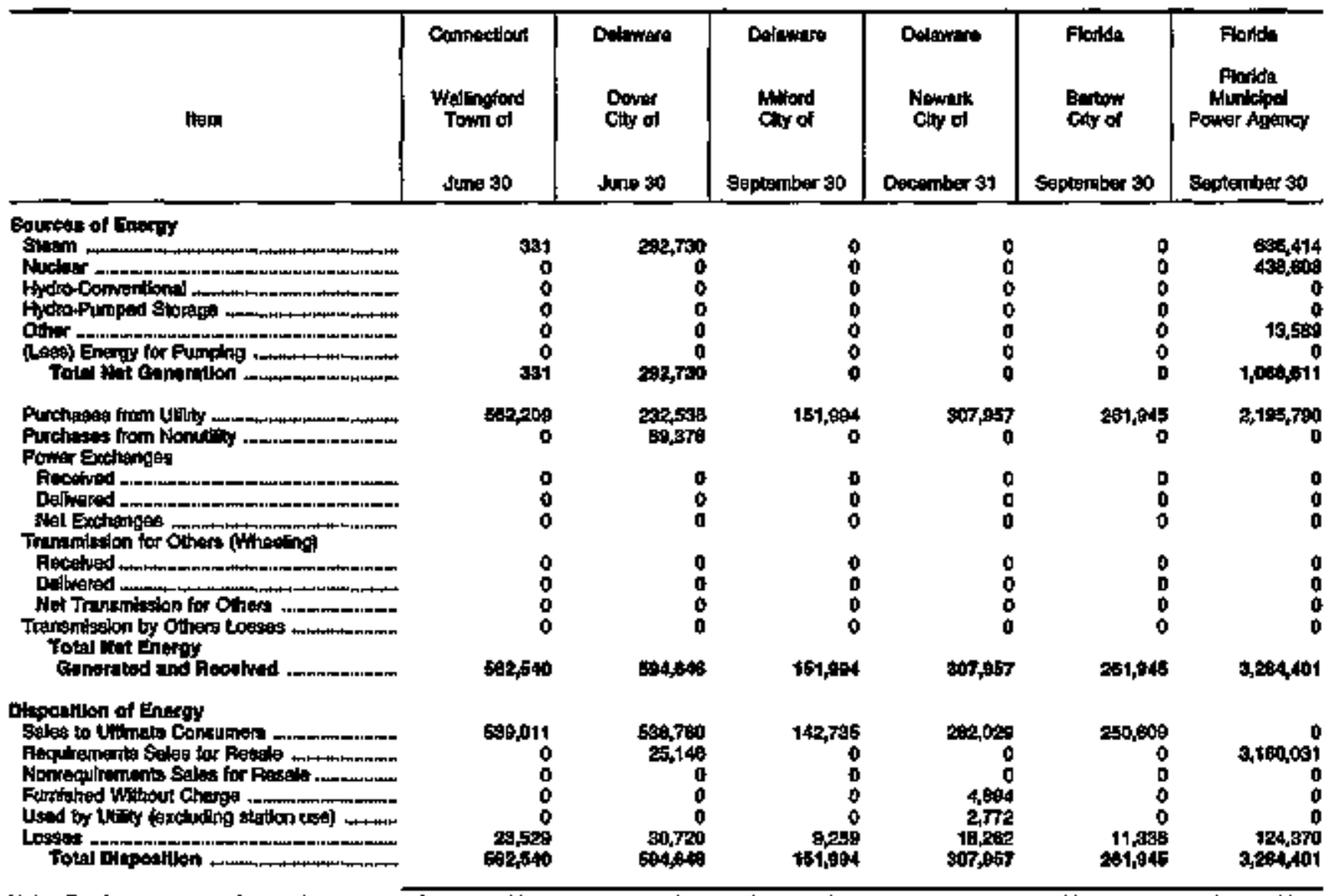

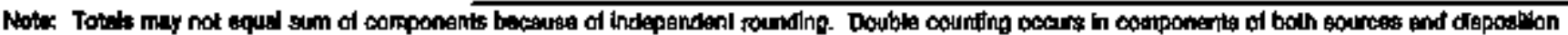

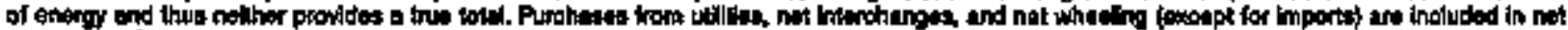

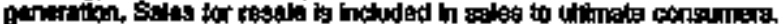

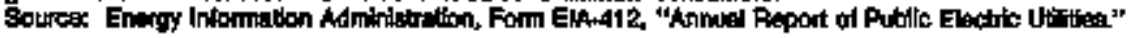


Table 28. Electric Energy Account by Major U.S. Publlely Omed Electrio Utillty Withle state, 1994 (Continued)

(Megawatthours)

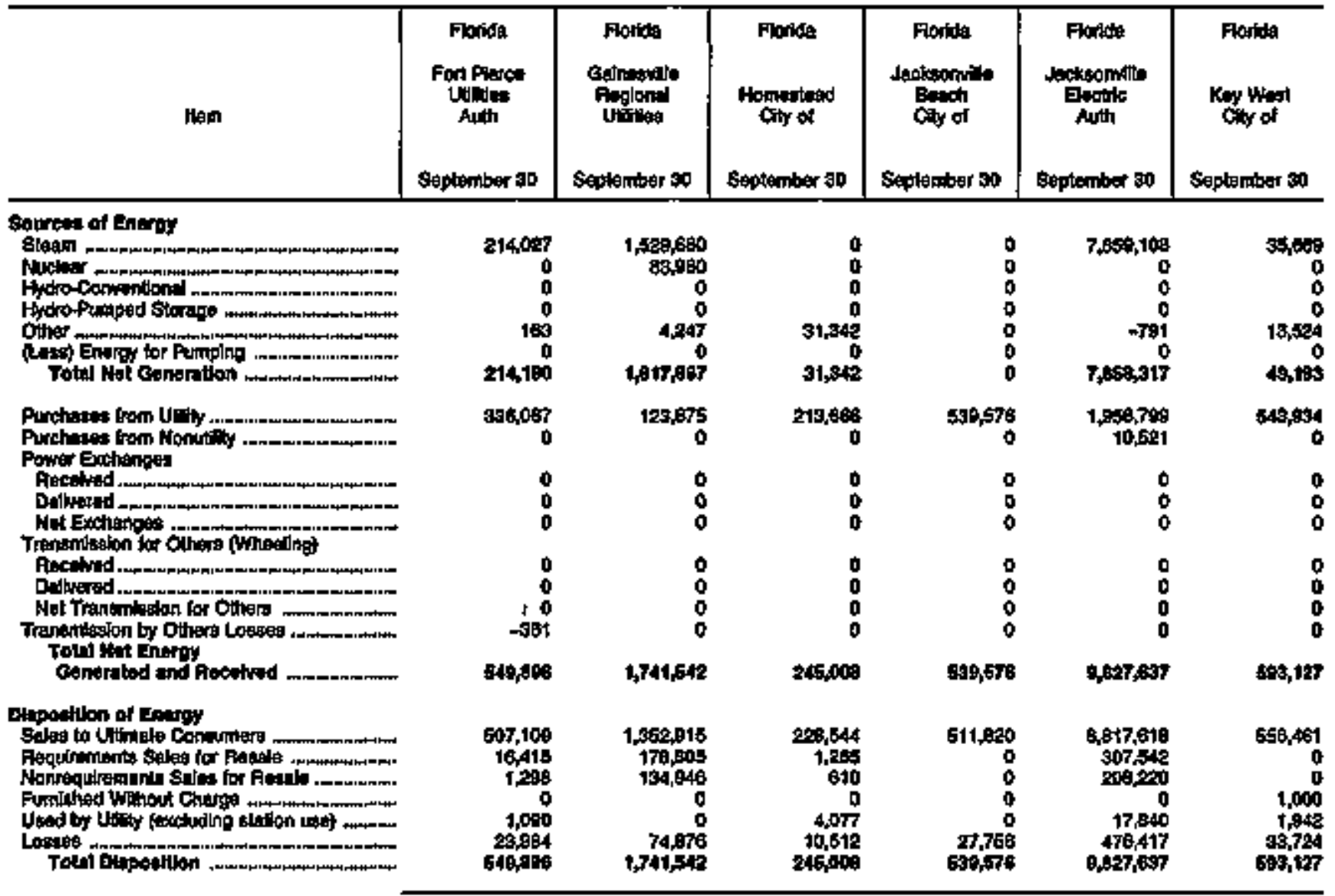

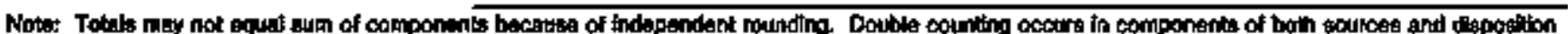

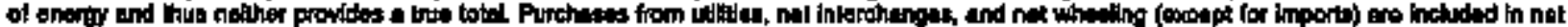

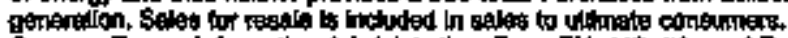

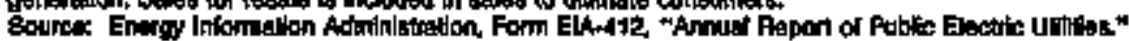


Table 26. Electric Energy Account by Aajor U.S. Publicly Owned Eectric Uitity Within State, 1994 (Continued) (Megawatthours)

\begin{tabular}{|c|c|c|c|c|c|c|}
\hline $\mathrm{HEm}$ & 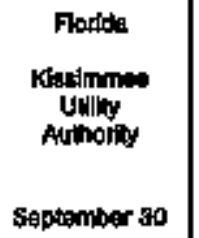 & 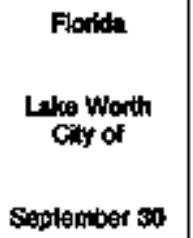 & $\begin{array}{l}\text { Foride } \\
\text { Lekglund } \\
\text { Ciny of } \\
\text { September on }\end{array}$ & $\begin{array}{l}\text { Fionida } \\
\text { Leesturg } \\
\text { Coty of } \\
\text { Seplemiter so }\end{array}$ & $\begin{array}{l}\text { Forida } \\
\text { New Snyma } \\
\text { Beach } \\
\text { Utils Cotm } \\
\text { September so }\end{array}$ & 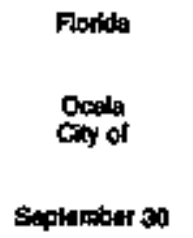 \\
\hline 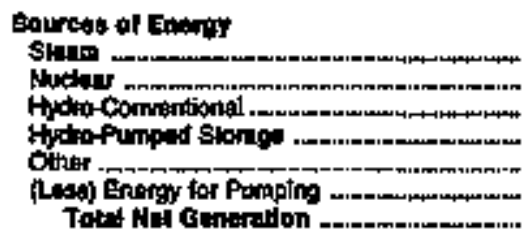 & 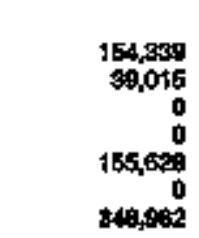 & $\begin{array}{r}157,055 \\
0 \\
0 \\
0 \\
147 \\
0 \\
158,002\end{array}$ & $\begin{array}{r}1,791,311 \\
0 \\
0 \\
0 \\
272,897 \\
0 \\
2,084,148\end{array}$ & $\begin{array}{r}40,000 \\
0 \\
0 \\
0 \\
0 \\
40,000\end{array}$ & $\begin{array}{r}0 \\
32,201 \\
0 \\
0 \\
-180 \\
0 \\
32,000\end{array}$ & $\begin{array}{r}0 \\
92,294 \\
0 \\
0 \\
0 \\
0 \\
92,234\end{array}$ \\
\hline 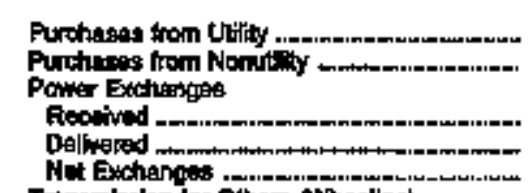 & 488,24 & $\begin{array}{r}167,104 \\
0 \\
39,408 \\
0 \\
99,408\end{array}$ & $\begin{array}{r}213,107 \\
0\end{array}$ & aes,oro & $\begin{array}{r}272,508 \\
0\end{array}$ & $\begin{array}{r}050,55 \\
0 \\
0\end{array}$ \\
\hline 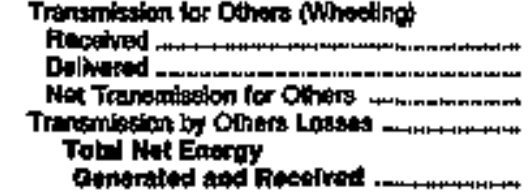 & $\begin{array}{l}0 \\
0 \\
0 \\
0\end{array}$ & $\begin{array}{l}0 \\
0 \\
0 \\
0\end{array}$ & $\begin{array}{r}134,275 \\
139,820 \\
4650 \\
0 \\
2,47,710\end{array}$ & $\begin{array}{l}0 \\
0 \\
0 \\
0\end{array}$ & $\begin{array}{r}0 \\
0 \\
0 \\
-2,720 \\
301,698\end{array}$ & $\begin{array}{r}31,310 \\
31,210 \\
0 \\
0 \\
1,094,79 \%\end{array}$ \\
\hline 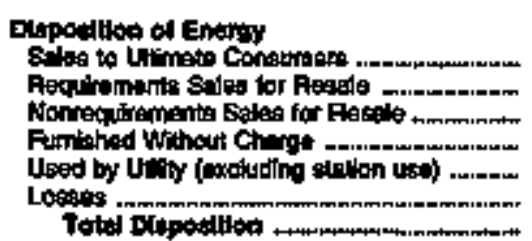 & $\begin{array}{r}7 r, 6=5 \\
0 \\
0 \\
0 \\
0 \\
37,340 \\
956,200\end{array}$ & $\begin{array}{r}345,911 \\
1,228 \\
4,6606 \\
0 \\
11,005 \\
596 \\
594,600\end{array}$ & $\begin{array}{r}2,111,1227 \\
7,005 \\
702 \\
0 \\
0 \\
157,146 \\
2,297,710\end{array}$ & $\begin{array}{r}35,935 \\
0 \\
0 \\
0 \\
0 \\
17,085 \\
374,000\end{array}$ & $\begin{array}{r}287,459 \\
0 \\
0 \\
0 \\
0 \\
14,120 \\
201,602\end{array}$ & $\begin{array}{r}\text { Dra,67? } \\
0 \\
0 \\
0 \\
0 \\
5,05,009 \\
1,034,709\end{array}$ \\
\hline
\end{tabular}

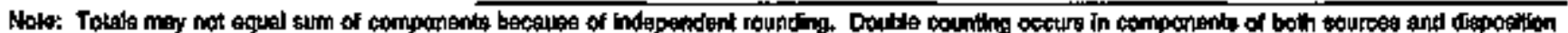

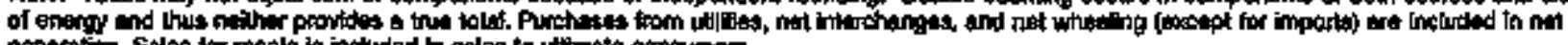

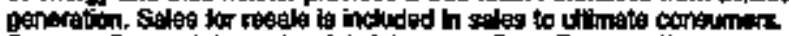

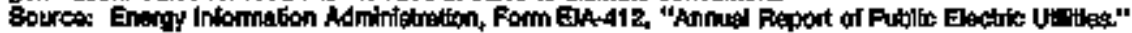


Table 26. Electric Energy Account by Major U.S. Publicly Owned Electrle Utilly Within State, 1894 (Continued)

(Megawathours)

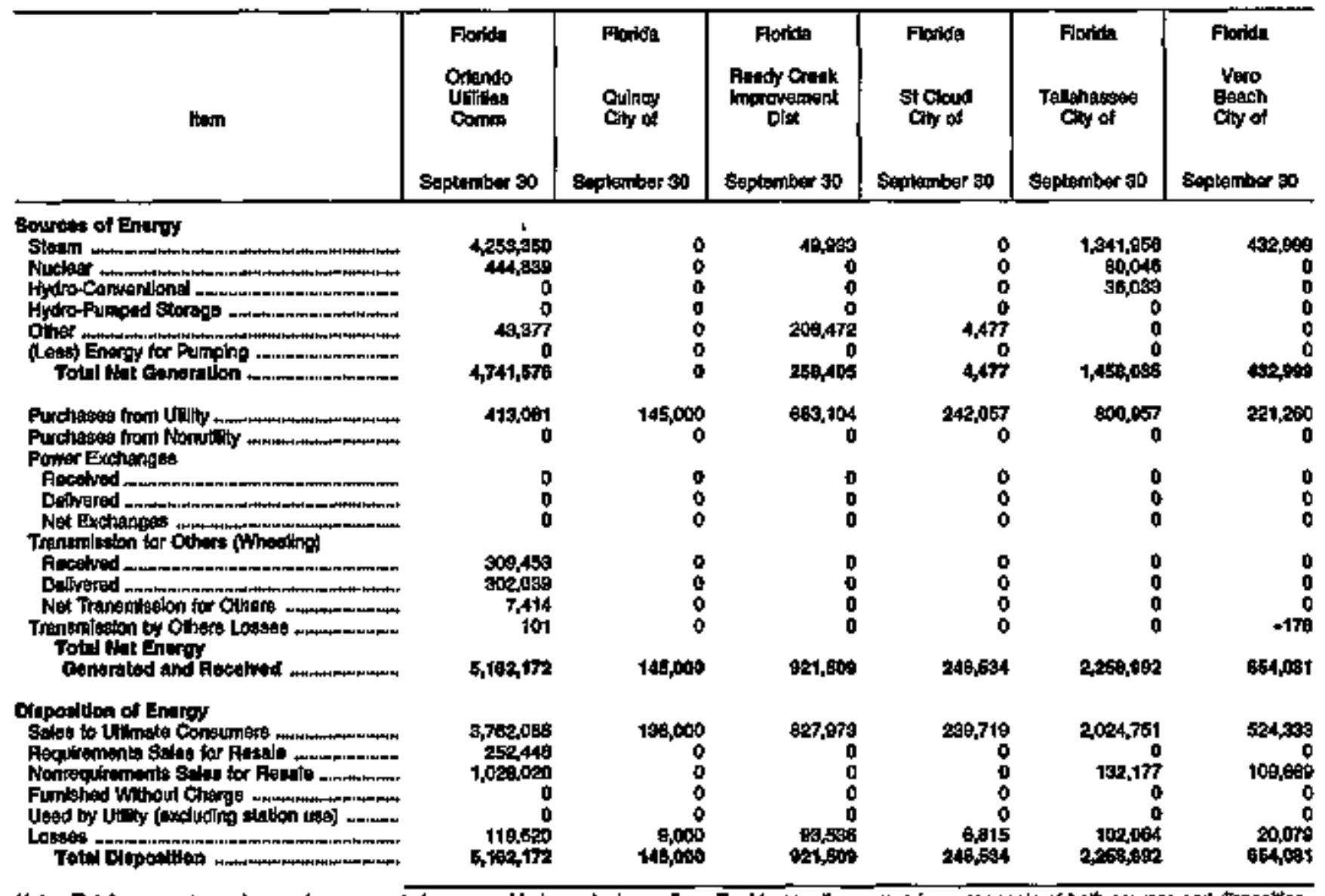

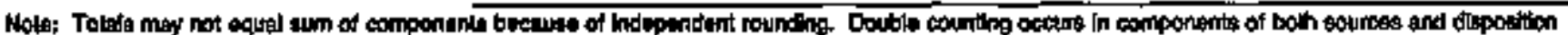

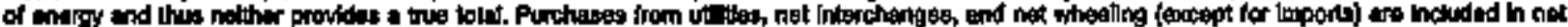

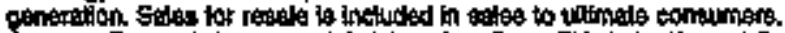

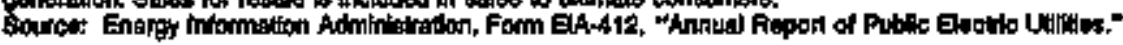


Table 26. Electric Eneroy Account by Major U.8. Publichy Owned Electric Utily Whin state, 1994 (Contmued)

(Megawatthours)

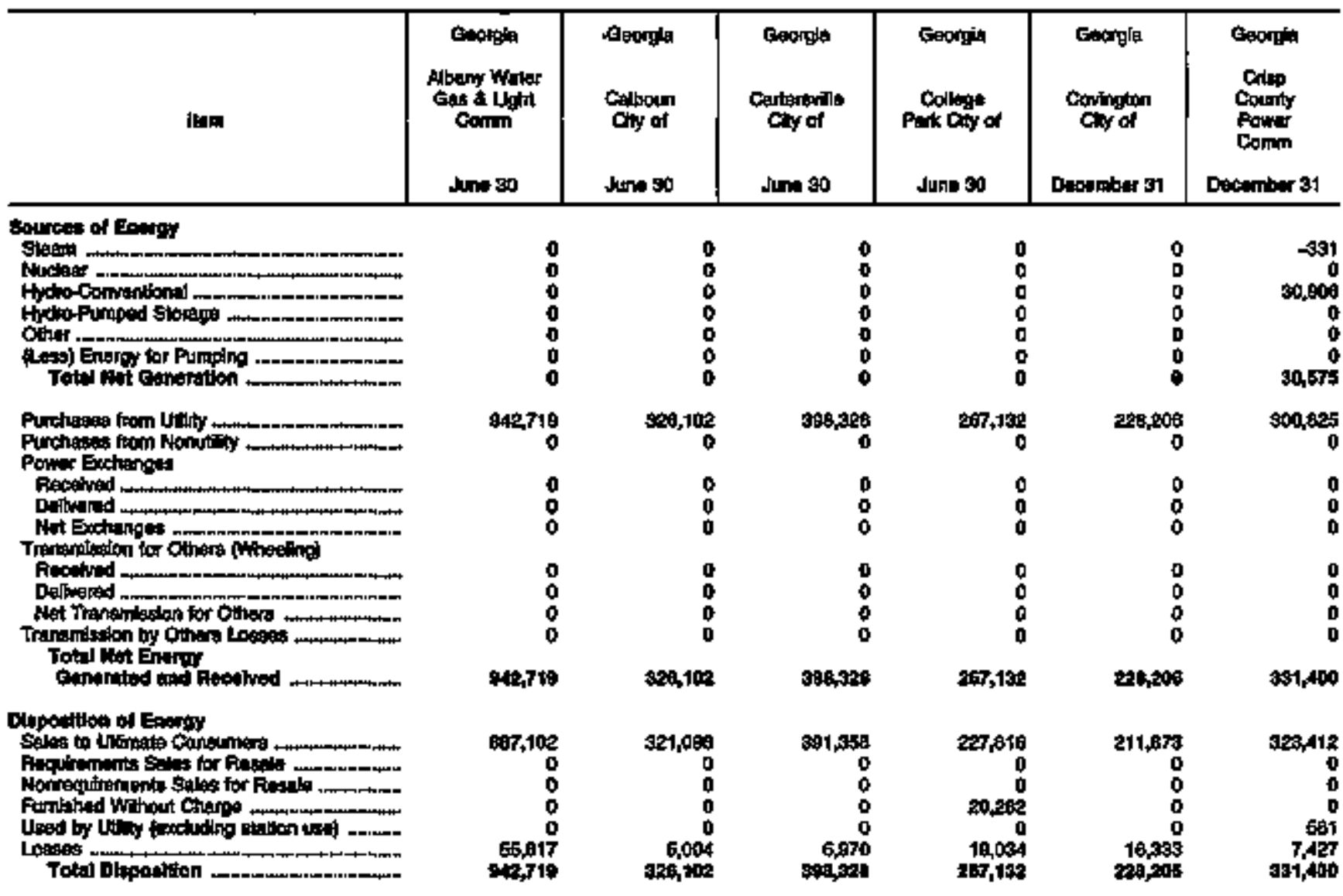

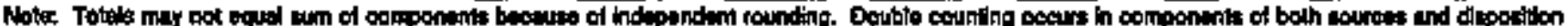

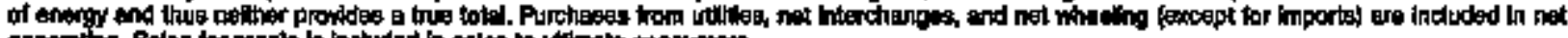

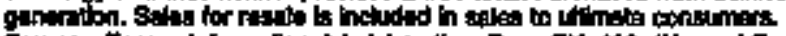

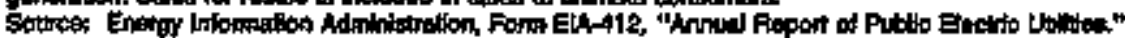


Table 26. Electric Energy Account by Mejor U.S. Publicly Owned Eectric Gillty Whin State, 1994 (Continued)

(Megawatthours)

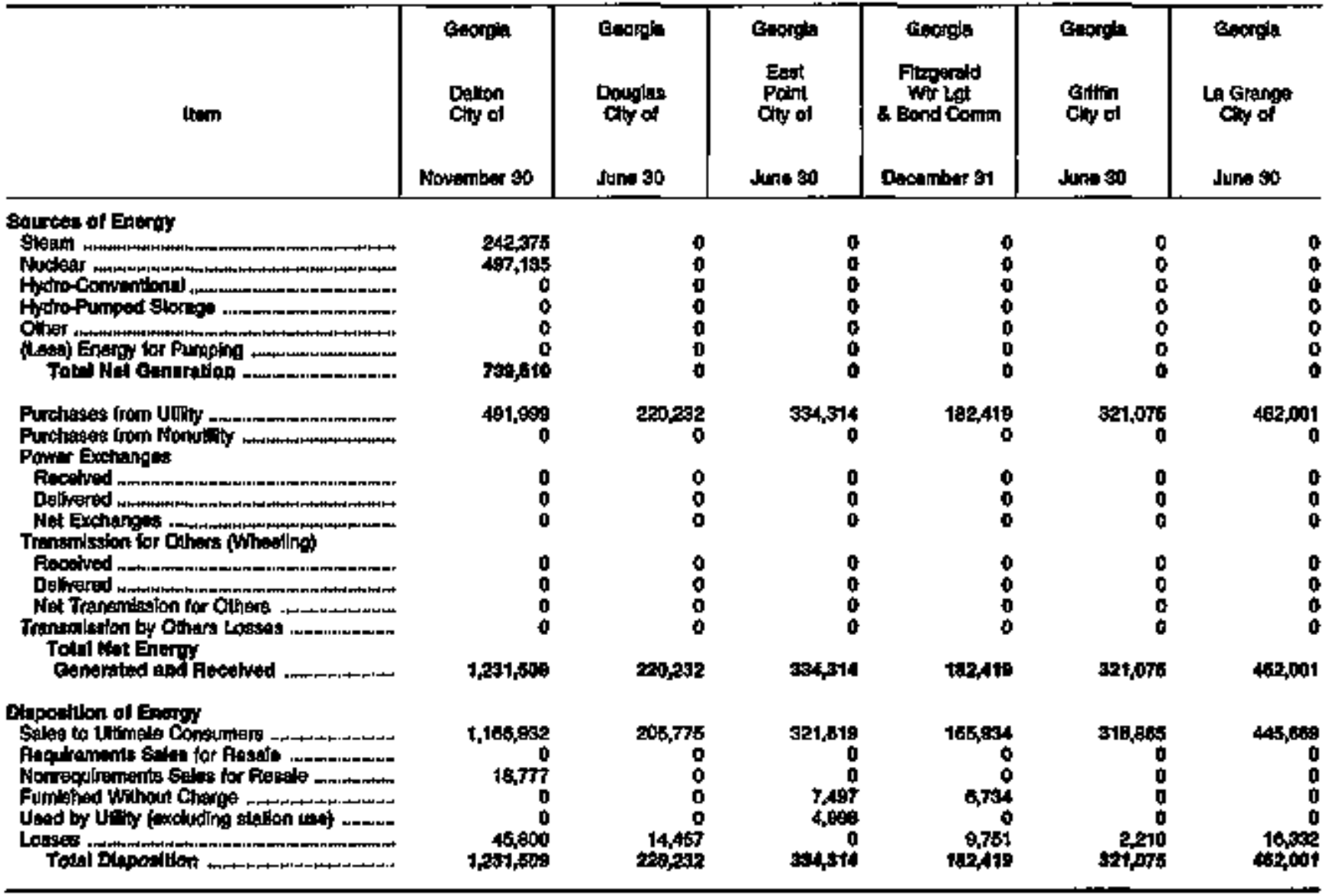

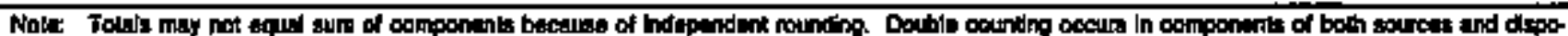

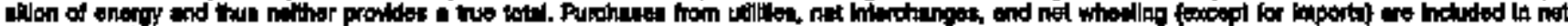

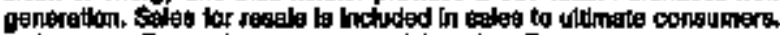

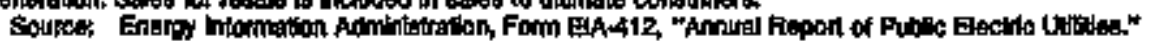


Table 26. Electric Enorgy Accoumt by Malor U.S. Pubilcly Owned Electric Utillty Within State, 1994 (Continued)

(Megawatthours)

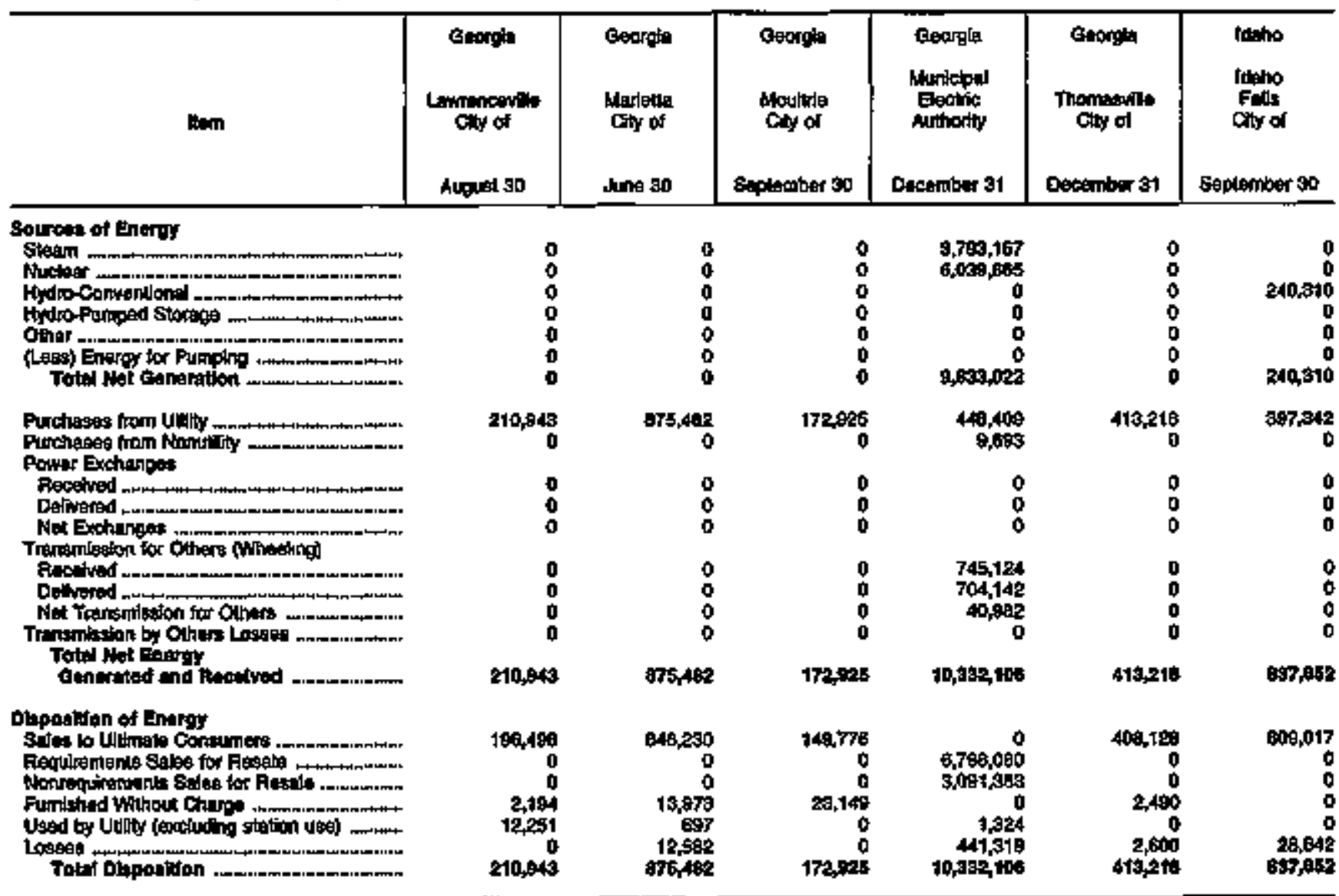

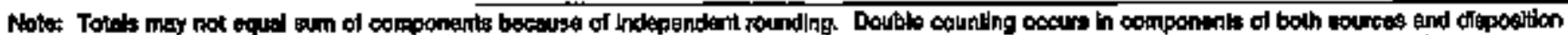

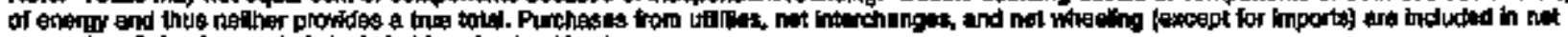

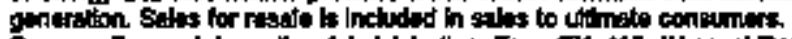

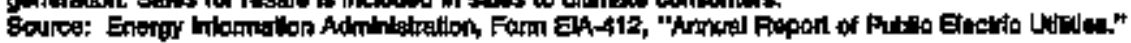


Table 26. Electrle Energy Aceotunt by Major U.S. Publiely Owned Electric Utility Withln State, 1994 (Continued) (Megawatthours)

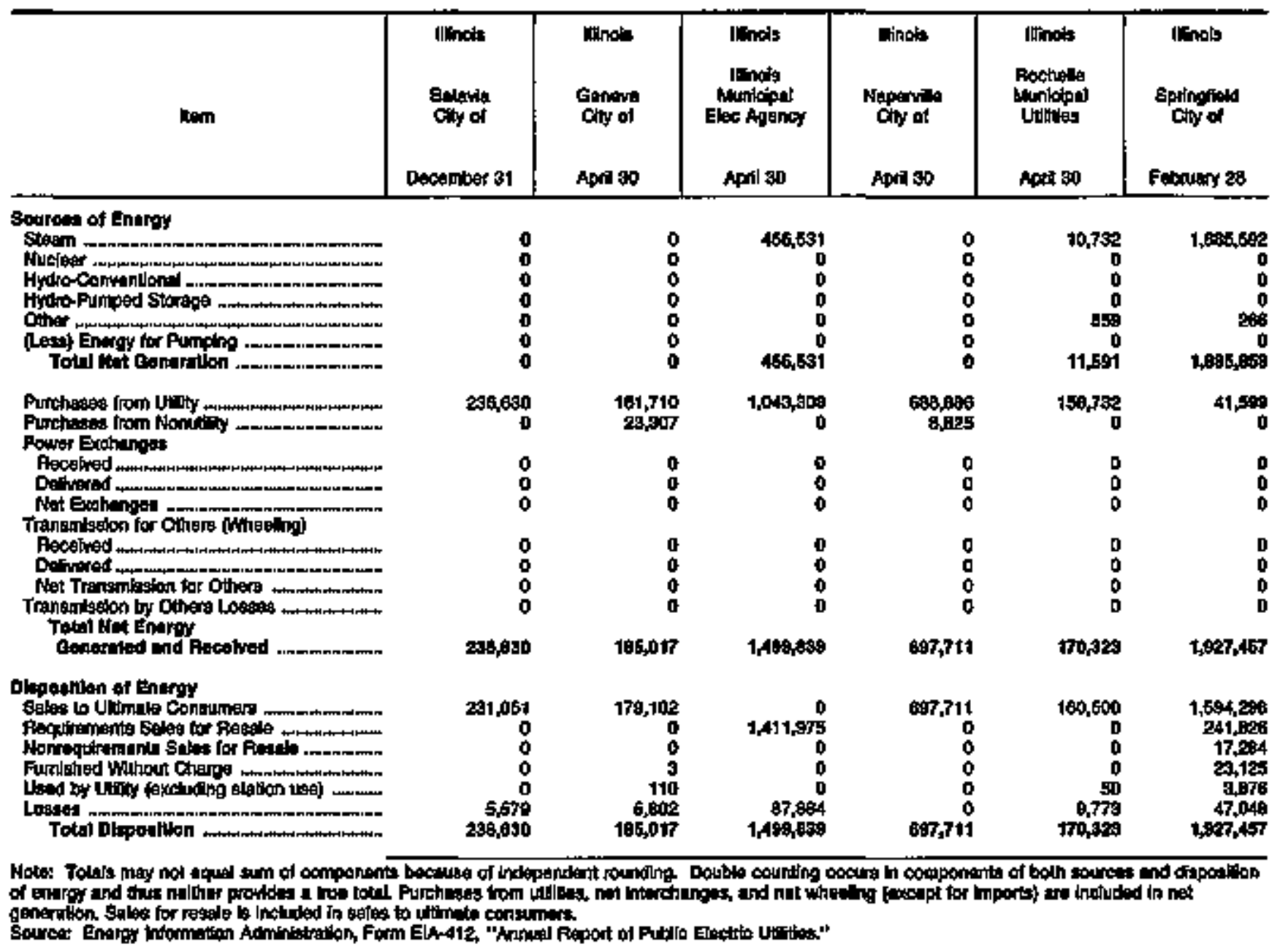


Table 26. Eloctric Energy Account by Major U.S. Publlely Owned Electric Utilty Withln State, 1994 (Continued)

(Megawatthours)

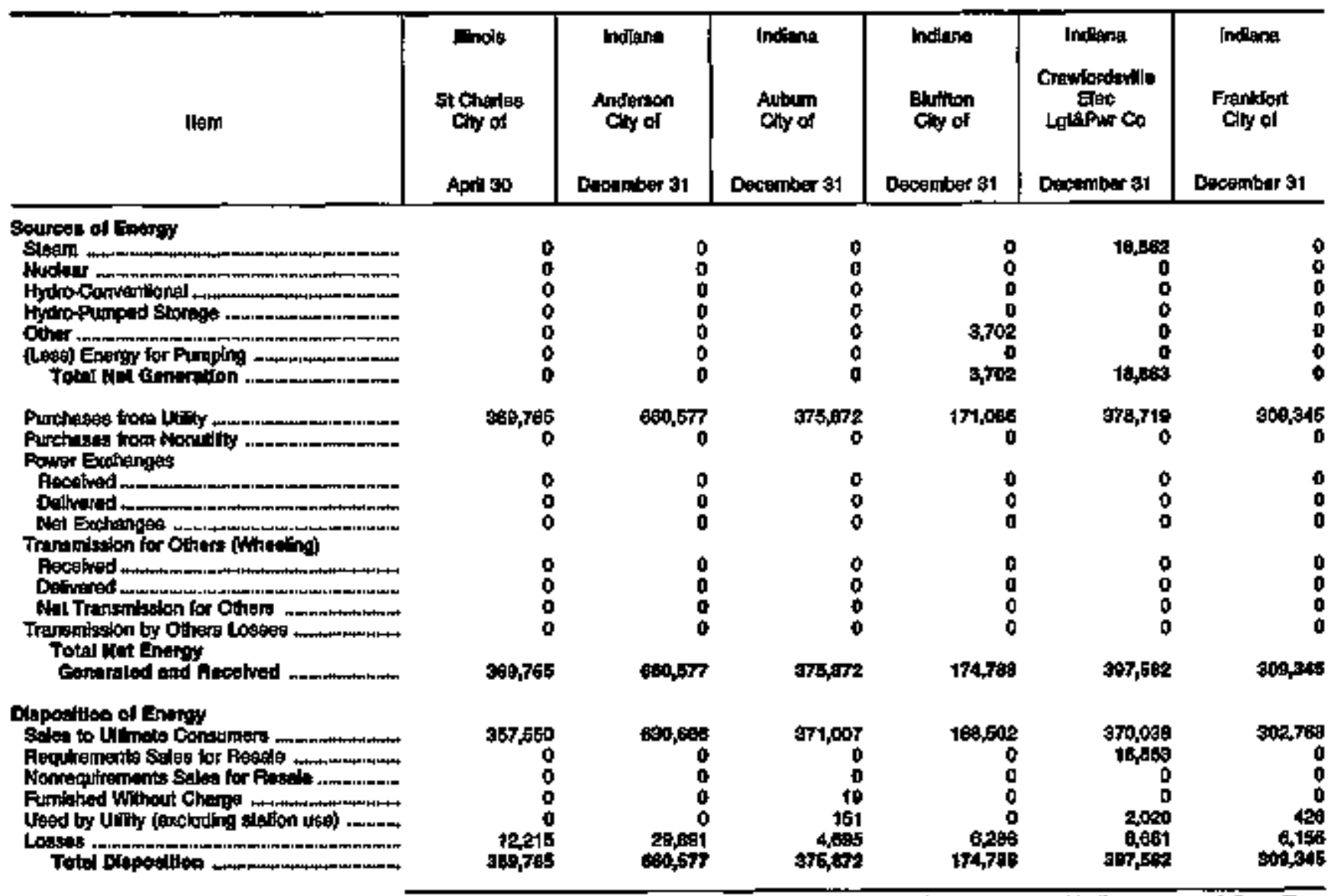

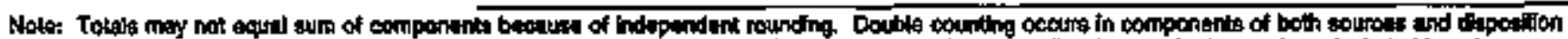

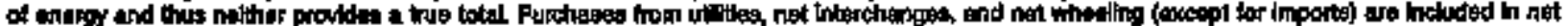

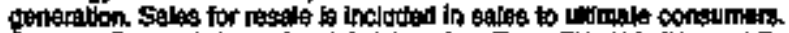

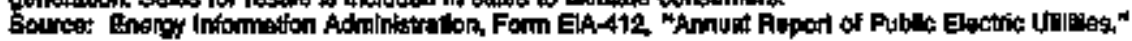


Table 26. Electric Energy Account by Major U.S. Publicly Owned Electric Utility Within State, 1994 (Continued)

(Megawatthours)

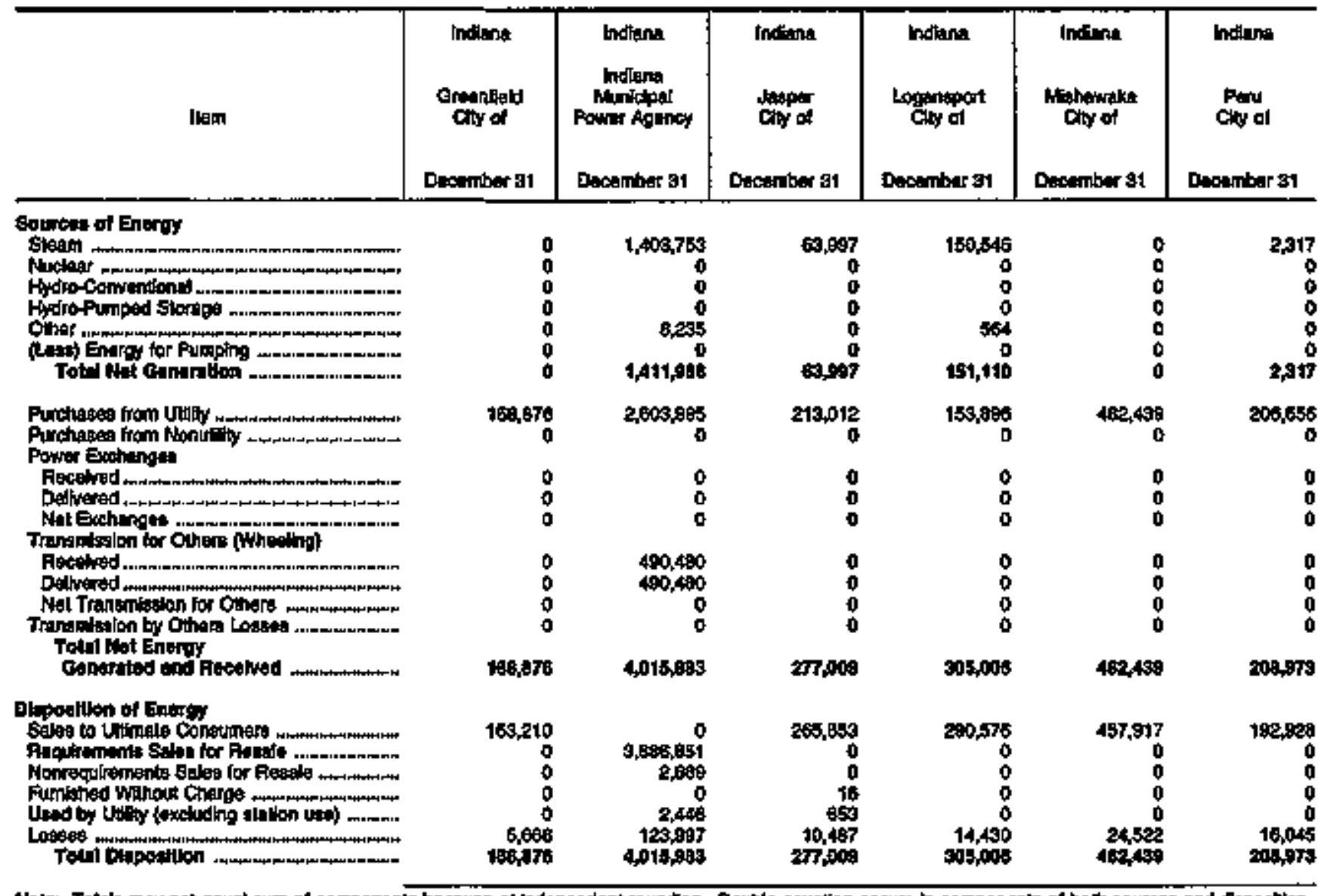

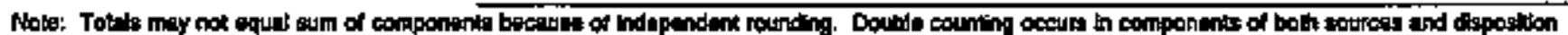

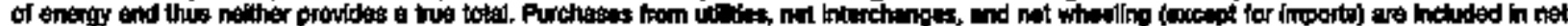

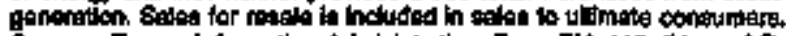

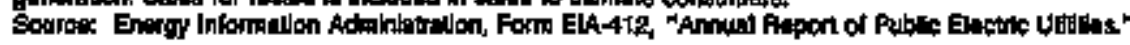


Table 26. Electric Entergy Account by Major U.S. Publicly Owned Electric Uttlity Within State, 1994 (Continued)

(Megawatthours)

\begin{tabular}{|c|c|c|c|c|c|c|}
\hline nen & 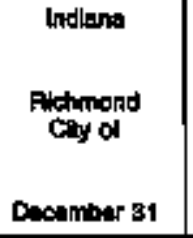 & $\begin{array}{l}\text { Indians } \\
\text { Washinglon } \\
\text { Cotty of } \\
\text { Decounher a1 }\end{array}$ & $\begin{array}{l}\text { lown } \\
\text { Amos } \\
\text { Ging of } \\
\text { Jung an }\end{array}$ & $\begin{array}{l}\text { Compo } \\
\text { Cadar } \\
\text { Coty of } \\
\text { Desember } 31\end{array}$ & $\begin{array}{l}\text { lowid } \\
\text { Wuscating } \\
\text { Clyy of } \\
\text { Dacoumber } 31\end{array}$ & $\begin{array}{l}\text { Jowe } \\
\text { Polla of } \\
\text { Destymber } 31\end{array}$ \\
\hline 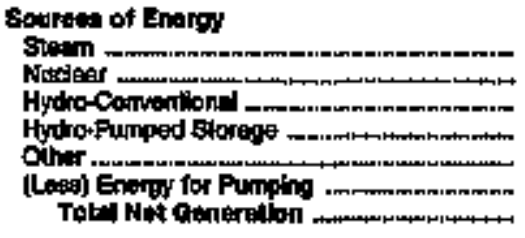 & $\begin{array}{r}021,492 \\
0 \\
0 \\
0 \\
0 \\
0 \\
0 \\
\text { 691, } 492\end{array}$ & $\begin{array}{c}0 \\
0 \\
0 \\
0 \\
0 \\
0 \\
0\end{array}$ & $\begin{array}{r}391,227 \\
0 \\
0 \\
0 \\
0 \\
0 \\
391,27\end{array}$ & $\begin{array}{r}240,675 \\
0 \\
0 \\
0 \\
2,054 \\
0 \\
250,720\end{array}$ & $\begin{array}{r}1,208,673 \\
0 \\
0 \\
0 \\
0 \\
0 \\
1,200,073\end{array}$ & $\begin{array}{r}83,744 \\
0 \\
0 \\
0 \\
0 \\
0 \\
84,744\end{array}$ \\
\hline 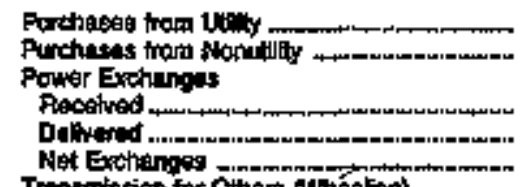 & $\begin{array}{r}200,104 \\
0 \\
0 \\
0 \\
0\end{array}$ & $\begin{array}{r}160.250 \\
0\end{array}$ & $\begin{array}{r}6,416 \\
0 \\
125 \\
195 \\
-70\end{array}$ & $\begin{array}{r}\theta 8,781 \\
0 \\
0 \\
0\end{array}$ & $\begin{array}{r}40,465 \\
0 \\
0 \\
0 \\
0\end{array}$ & $\begin{array}{r}60,998 \\
0 \\
6,217 \\
6,905 \\
-708\end{array}$ \\
\hline 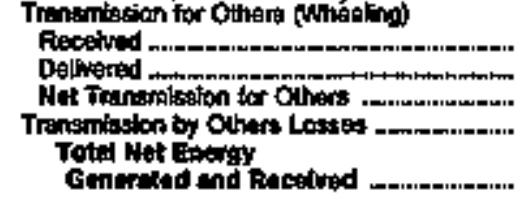 & $\begin{array}{r}0 \\
0 \\
0 \\
0 \\
0\end{array}$ & 162,4v5 & $\begin{array}{r}0 \\
0 \\
0 \\
0 \\
401,57 \%\end{array}$ & $\begin{array}{r}0 \\
0 \\
0 \\
0\end{array}$ & $\begin{array}{r}6,279 \\
6,058 \\
6 \\
1,264,188\end{array}$ & $\begin{array}{r}0 \\
0 \\
0 \\
0 \\
\end{array}$ \\
\hline 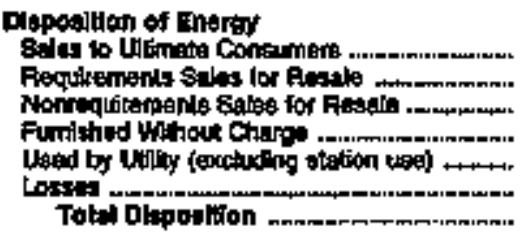 & $\begin{array}{r}806,323 \\
0 \\
0 \\
5 \\
5,753 \\
22,595 \\
231,586\end{array}$ & $\begin{array}{r}144,751 \\
0 \\
0 \\
0 \\
0 \\
15,074 \\
102,0108\end{array}$ & $\begin{array}{r}37,479 \\
2,038 \\
0 \\
0 \\
471 \\
21,597 \\
401,579\end{array}$ & $\begin{array}{r}300,905 \\
0 \\
12,028 \\
0 \\
2,401 \\
34,4 \% 9\end{array}$ & $\begin{array}{r}810,459 \\
63 \\
419,006 \\
5,024 \\
2,596 \\
20,014 \\
1,284,16 \%\end{array}$ & $\begin{array}{r}134,765 \\
0 \\
0 \\
0 \\
0 \\
5,284 \\
14,460\end{array}$ \\
\hline
\end{tabular}

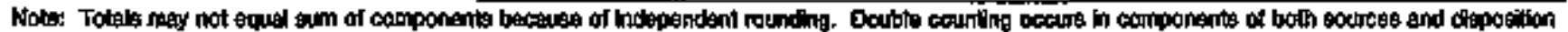

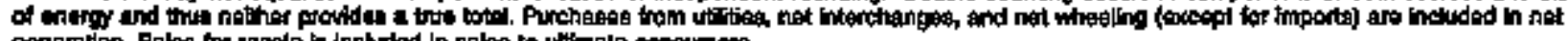

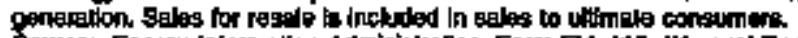

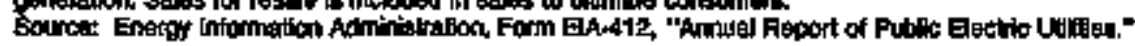


Table 26. Eleotrlo Energy Account by Major U.S. Publioly Owned Electric Utilly Within state, 1994 (Continued)

(Megawatthours)

\begin{tabular}{|c|c|c|c|c|c|c|}
\hline nim & 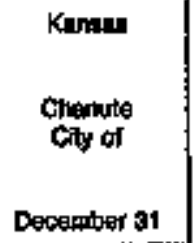 & 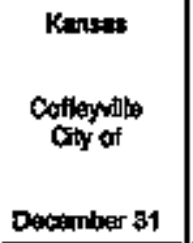 & 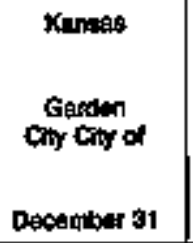 & $\begin{array}{l}\text { Kontoss } \\
\text { Ciny City of } \\
\text { Decimber } 31\end{array}$ & 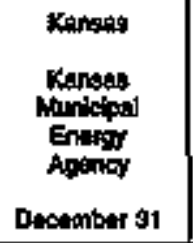 & $\begin{array}{l}\text { Konses } \\
\text { Wepmerean } \\
\text { Ciny of } \\
\text { Ducumbur a1 }\end{array}$ \\
\hline 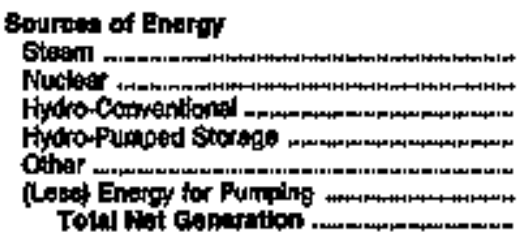 & $\begin{array}{r}0 \\
0 \\
0 \\
0 \\
0,130 \\
2,4 t 6 \\
B, 712\end{array}$ & $\begin{array}{r}37,340 \\
0 \\
0 \\
0 \\
0 \\
0 \\
0\end{array}$ & $\begin{array}{l}0 \\
0 \\
0 \\
0 \\
0 \\
0 \\
0\end{array}$ & $\begin{array}{r}2,250,600 \\
0 \\
0 \\
0 \\
019 \\
0 \\
2,200,69\end{array}$ & 0 & $\begin{array}{r}1,495 \\
0 \\
0 \\
0 \\
4,072 \\
0 \\
6,587\end{array}$ \\
\hline 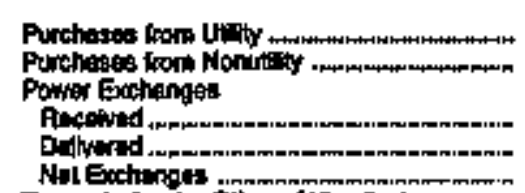 & $\begin{array}{r}182,740 \\
0\end{array}$ & $\begin{array}{r}140,504 \\
0 \\
149,302 \\
149,6,24 \\
-222\end{array}$ & $\begin{array}{r}178,174 \\
0 \\
0 \\
0 \\
0\end{array}$ & $\begin{array}{r}325,021 \\
0 \\
0 \\
11,070 \\
-11,070\end{array}$ & $\begin{array}{r}254,240 \\
0\end{array}$ & 590,850 \\
\hline 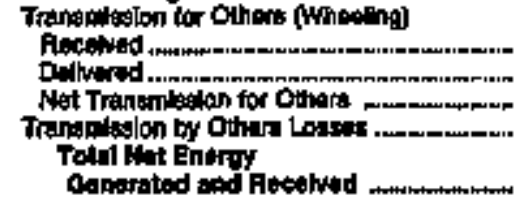 & $\begin{array}{l}0 \\
0 \\
0 \\
0\end{array}$ & 1898,51 & $\begin{array}{l}0 \\
0 \\
0 \\
0\end{array}$ & $2,57,5000$ & 264,240 & 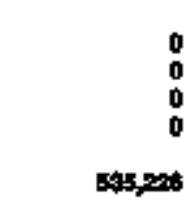 \\
\hline 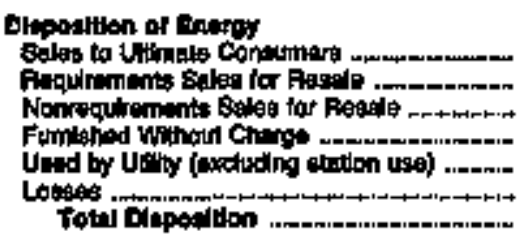 & $\begin{array}{r}154,055 \\
0 \\
0 \\
0 \\
2,418 \\
2,685 \\
109,480\end{array}$ & $\begin{array}{r}175,069 \\
0 \\
0 \\
4,651 \\
087 \\
6,070 \\
10,684\end{array}$ & $\begin{array}{r}188,784 \\
0 \\
0 \\
6,418 \\
0,279 \\
0,839 \\
178,114\end{array}$ & $\begin{array}{r}2,047,169 \\
360,722 \\
0 \\
111,729 \\
75,192 \\
9,574,500\end{array}$ & $\begin{array}{r}0 \\
254,240 \\
0 \\
0 \\
0 \\
0 \\
064240\end{array}$ & $\begin{array}{r}40,290 \\
27,506 \\
0 \\
117 \\
0 \\
17,205 \\
535220\end{array}$ \\
\hline
\end{tabular}

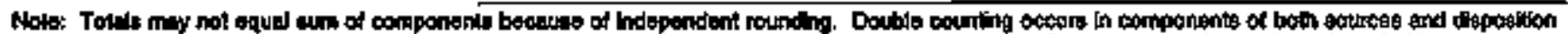

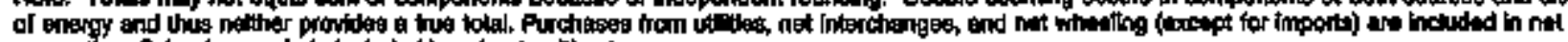

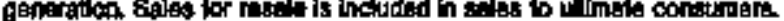

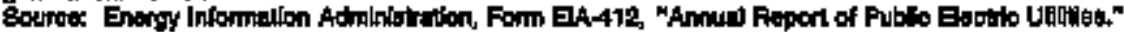


Table 26. Electric Energy Account by Major U.S. Publichy Owned Electric Utility Withln State, 1994 (Conthued)

(Megawathours)

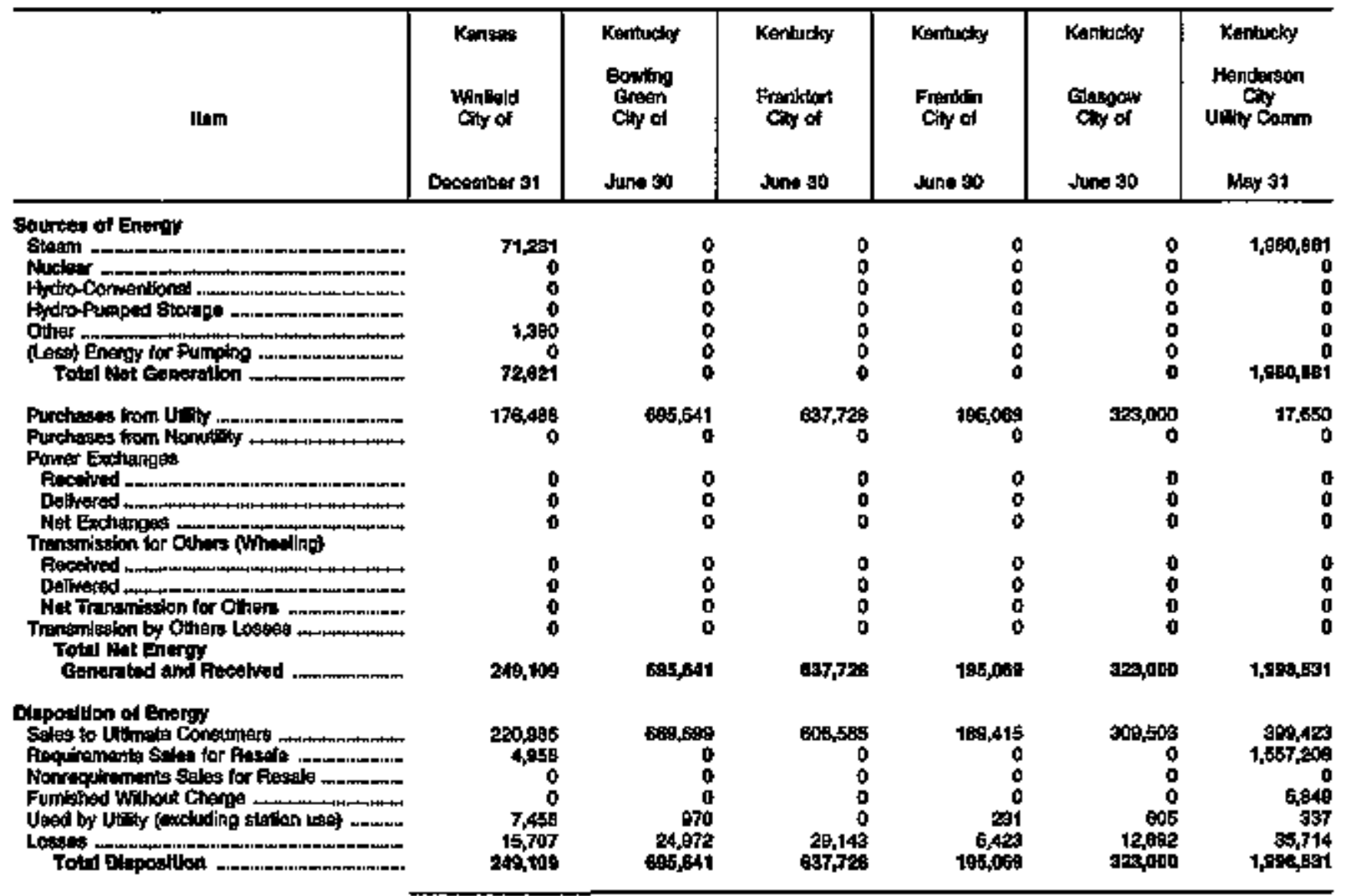

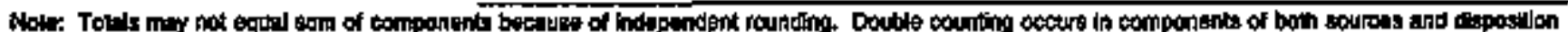

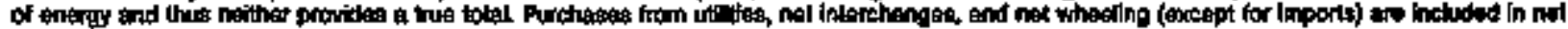

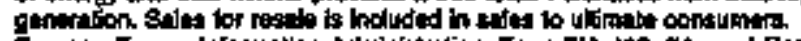

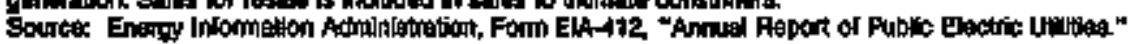


Teble 26. Electrle Energy Account by Major U.S. Publicly Omed Electric Uility Within state, 1994 (Continued)

(Megawatthours)

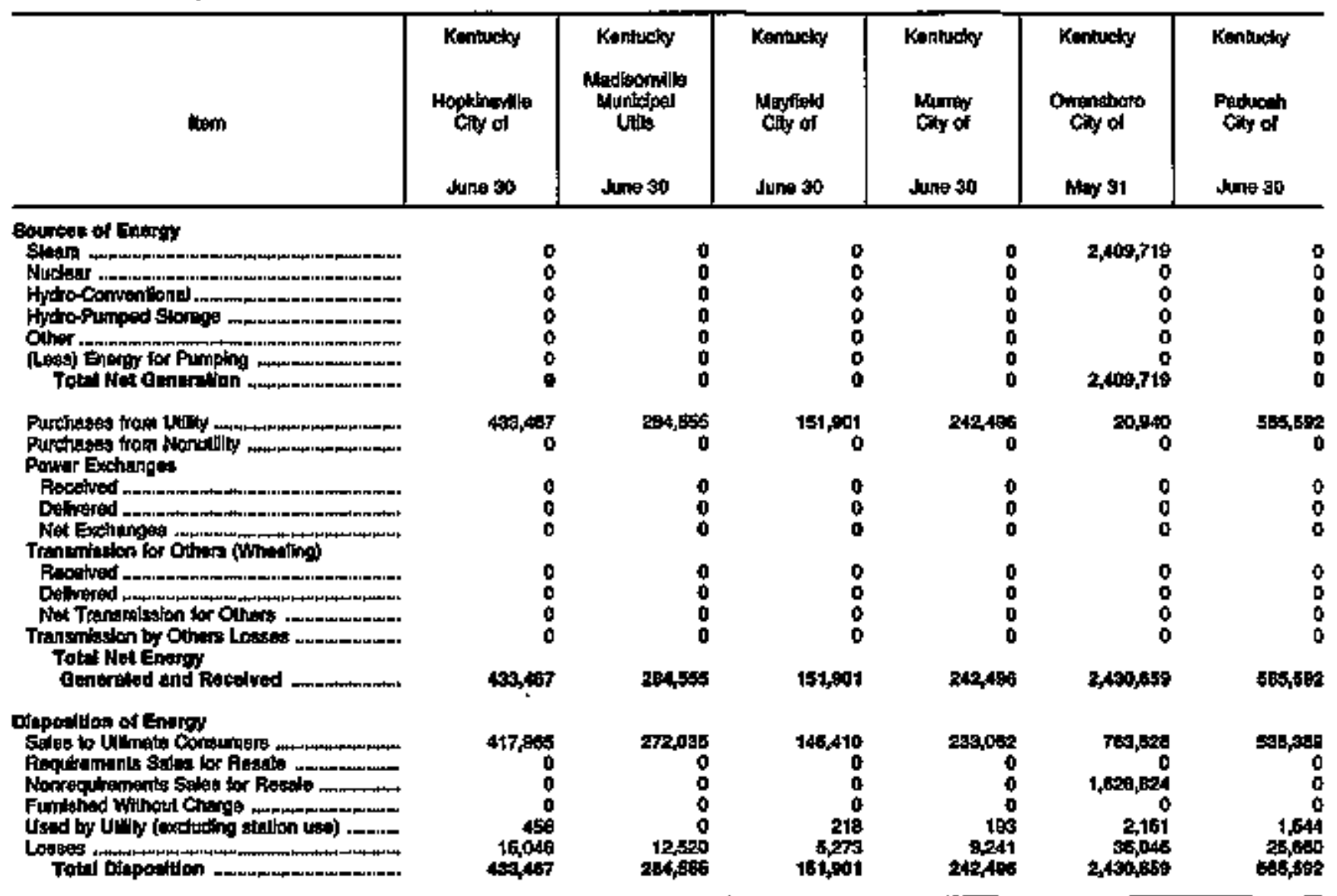

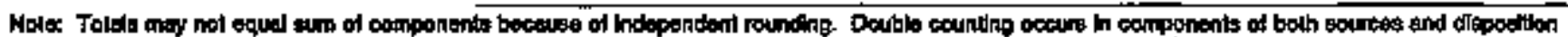

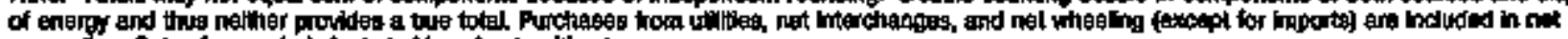

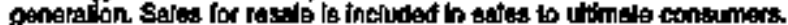

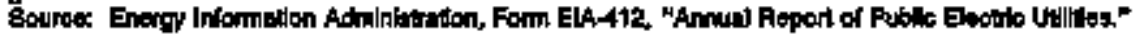


Tabje 26. Electric Energy Account by Major US. Publldy Owned Electric Utilly Within State, 1894 (Contimuod)

(Megawatthours)

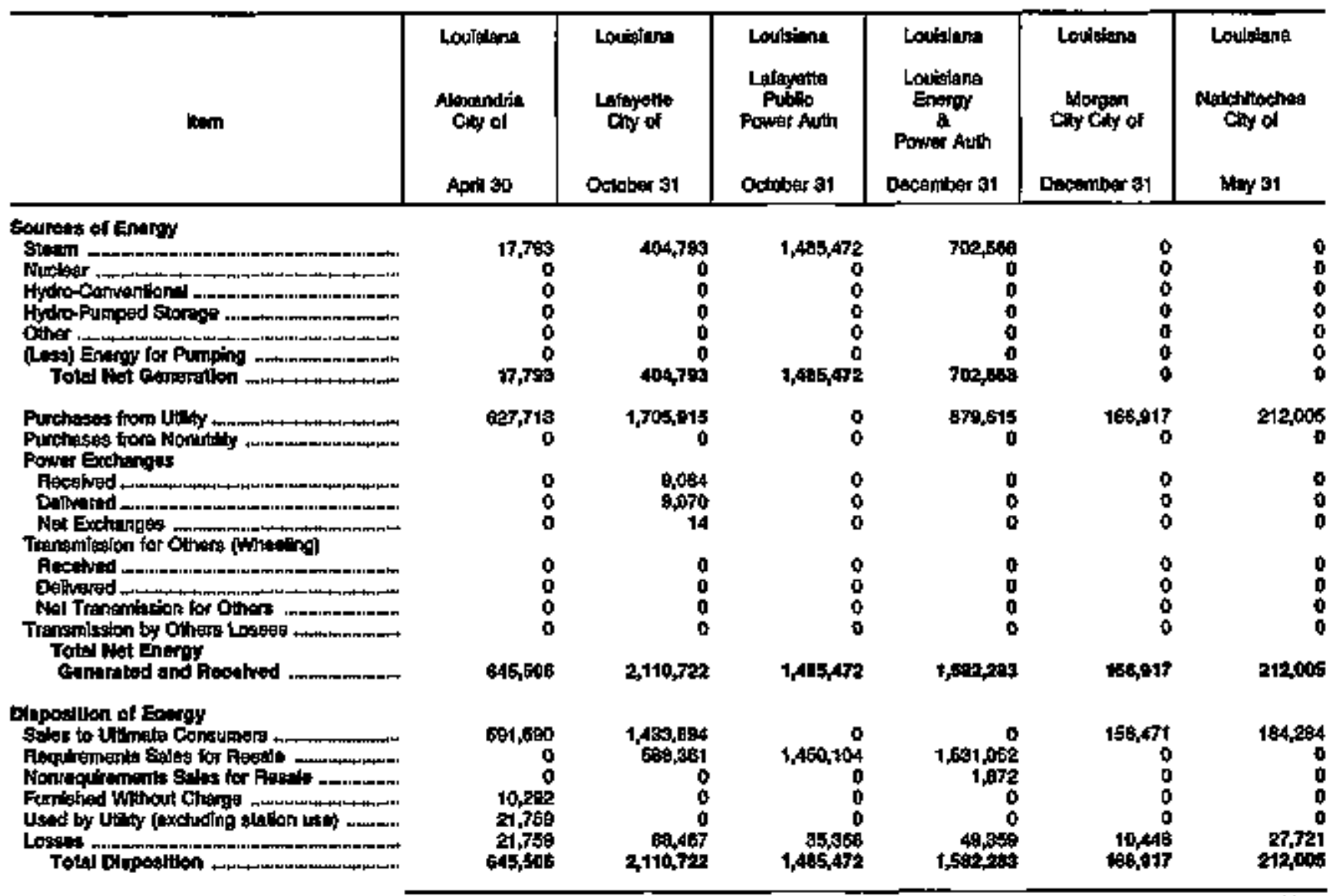

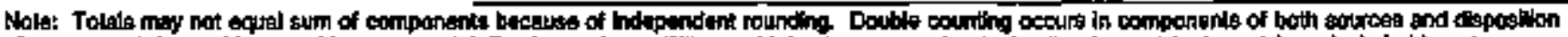

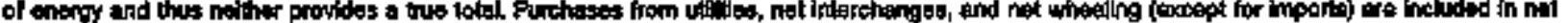

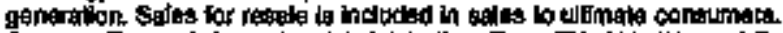

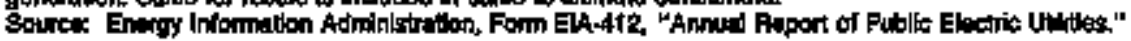


Table 26. Electric Energy Aocount by Major U.S. Publicly Owned Electric Utility Within State, 1994 (Continued) (Megawatthotrs)

\begin{tabular}{|c|c|c|c|c|c|c|}
\hline llom & 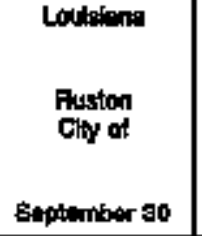 & 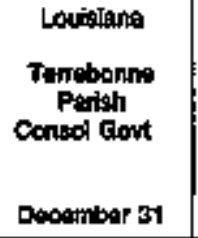 & 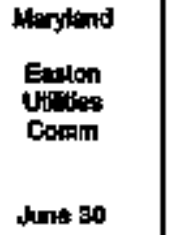 & 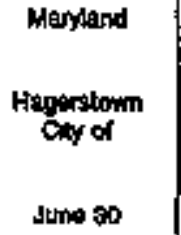 & 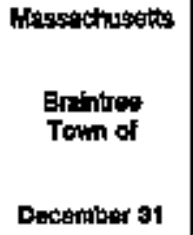 & $\begin{array}{l}\text { Bassachusetts } \\
\text { Chicoper } \\
\text { Civy of } \\
\text { Daceanber ot }\end{array}$ \\
\hline 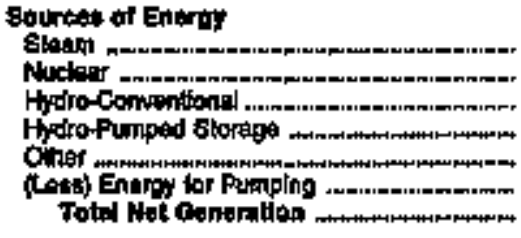 & $\begin{array}{r}175,258 \\
0 \\
0 \\
0 \\
0 \\
0 \\
0 \\
175,280\end{array}$ & $\begin{array}{r}113,244 \\
0 \\
0 \\
0 \\
0 \\
0 \\
0 \\
119294\end{array}$ & $\begin{array}{r}0 \\
0 \\
0 \\
0 \\
46,01011 \\
0 \\
40,011\end{array}$ & $\begin{array}{l}0 \\
0 \\
0 \\
0 \\
0 \\
0 \\
0\end{array}$ & $\begin{array}{r}02389 \\
0 \\
0 \\
0 \\
128 \\
0 \\
0 \\
0\end{array}$ & $\begin{array}{r}127,221 \\
0 \\
0 \\
528 \\
0 \\
137,750\end{array}$ \\
\hline 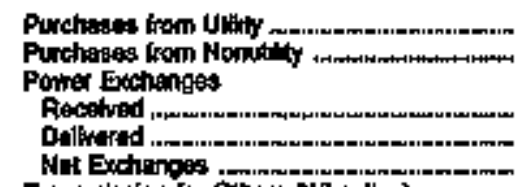 & $\begin{array}{r}e s p+0 \\
0 \\
0 \\
0\end{array}$ & $\begin{array}{r}242,387 \\
0 \\
0 \\
0 \\
0\end{array}$ & $\begin{array}{r}176,045 \\
1,774 \\
174,271\end{array}$ & $\begin{array}{r}324,384 \\
0 \\
0 \\
0 \\
0\end{array}$ & $\begin{array}{r}284,774 \\
0 \\
108,627 \\
51,269 \\
65,336\end{array}$ & $\begin{array}{r}205,200 \\
0 \\
2,006 \\
2,601 \\
-731\end{array}$ \\
\hline 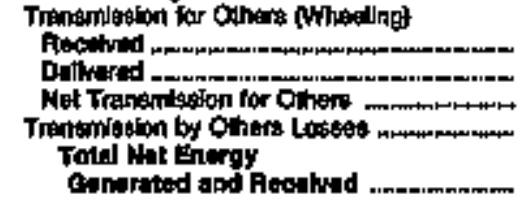 & $\begin{array}{r}0 \\
0 \\
0 \\
0 \\
241,406\end{array}$ & $\begin{array}{r}0 \\
0 \\
0 \\
0 \\
345,691\end{array}$ & $\begin{array}{l}\mathbf{0} \\
0 \\
0 \\
0\end{array}$ & $\begin{array}{r}0 \\
0 \\
0 \\
0 \\
324,594\end{array}$ & $\begin{array}{r}0 \\
0 \\
0 \\
0 \\
119902\end{array}$ & $\begin{array}{r}0 \\
0 \\
0 \\
0 \\
413,5+5\end{array}$ \\
\hline 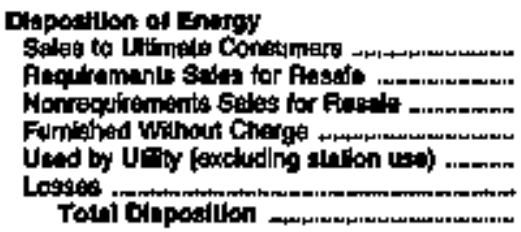 & $\begin{array}{r}210,060 \\
0 \\
0 \\
0 \\
0 \\
31,009 \\
241,105\end{array}$ & $\begin{array}{r}206,174 \\
113,201 \\
0 \\
0 \\
0 \\
16,258 \\
19,631\end{array}$ & $\begin{array}{r}255, a 17 \\
0 \\
0 \\
22 \\
280 \\
4,567 \\
200,202\end{array}$ & $\begin{array}{r}300,754 \\
0 \\
0 \\
0 \\
472 \\
15,161 \\
324,314\end{array}$ & 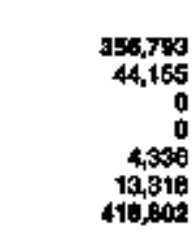 & $\begin{array}{r}37 a, 410 \\
13,604 \\
0 \\
0 \\
1,509 \\
19,492 \\
415,315\end{array}$ \\
\hline
\end{tabular}

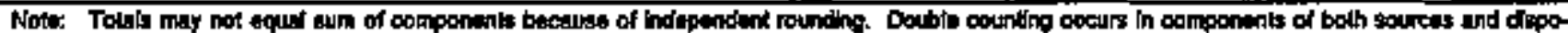

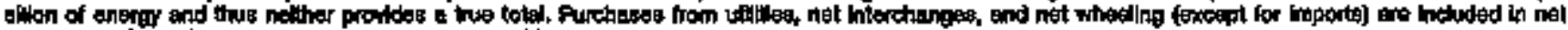

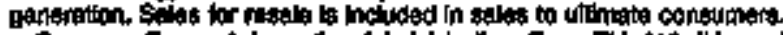

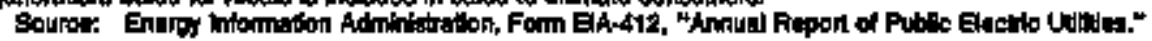


Table 26. Electric Energy Account by Major U.S. Publlely Owned Electric Vtilly within state, 1994 (Continued)

(Megawatihours)

\begin{tabular}{|c|c|c|c|c|c|c|}
\hline kem & $\begin{array}{l}\text { Mrsuchuseht: } \\
\text { Conowd } \\
\text { Town of } \\
\text { Decentor } 31\end{array}$ & 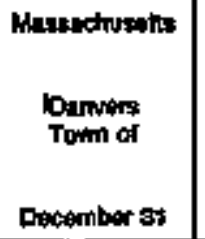 & 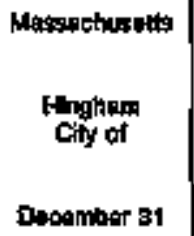 & $\begin{array}{l}\text { Magsenchupetts } \\
\text { Holyoke } \\
\text { City of } \\
\text { Ducamber 3t }\end{array}$ & 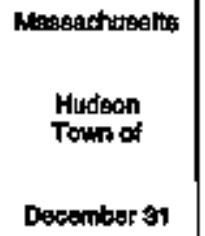 & 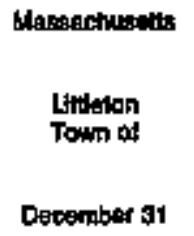 \\
\hline 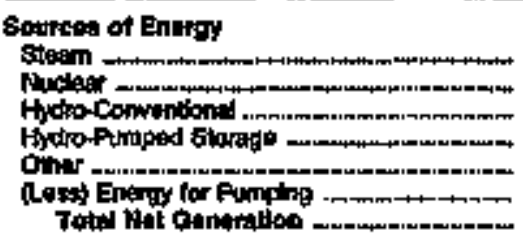 & $\begin{array}{l}0 \\
0 \\
0 \\
0 \\
0 \\
0 \\
0\end{array}$ & $\begin{array}{l}0 \\
0 \\
0 \\
0 \\
0 \\
0 \\
0\end{array}$ & $\begin{array}{l}0 \\
0 \\
0 \\
0 \\
0 \\
0 \\
0 \\
0\end{array}$ & $\begin{array}{r}-1,8 \% 7 \\
0 \\
12,720 \\
0 \\
0 \\
0 \\
10,905\end{array}$ & $\begin{array}{r}0 \\
4,170 \\
0 \\
0 \\
4,259 \\
0 \\
0,000\end{array}$ & $\begin{array}{r}2,784 \\
0 \\
0 \\
0 \\
0 \\
0 \\
2,784\end{array}$ \\
\hline 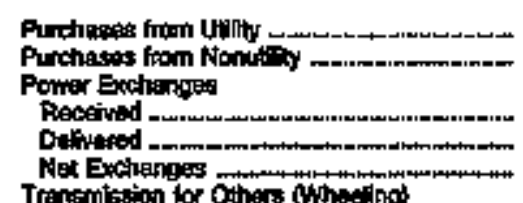 & $\begin{array}{r}157.589 \\
0 \\
0 \\
0 \\
0\end{array}$ & $\begin{array}{r}298,0058 \\
0 \\
125,918 \\
28,245 \\
98,679\end{array}$ & $\begin{array}{r}102,828 \\
0 \\
67,985 \\
+4,869 \\
6 \times 3,470\end{array}$ & $\begin{array}{r}320,194 \\
0 \\
18,6,69 \\
57,175 \\
\$ 813\end{array}$ & $\begin{array}{r}742,007 \\
2,1 \pm 8 \\
81,730 \\
5,000 \\
70,727\end{array}$ & $\begin{array}{r}77,419 \\
\text { o } \\
17,311 \\
7,370 \\
9,791\end{array}$ \\
\hline 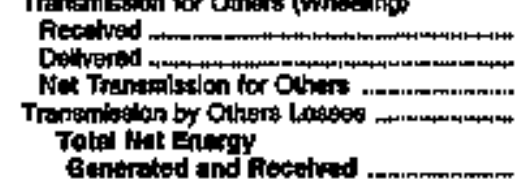 & $\begin{array}{l}0 \\
0 \\
0 \\
0\end{array}$ & $\begin{array}{l}0 \\
0 \\
0 \\
0\end{array}$ & 106,762 & $\begin{array}{r}0 \\
24,5,8 B\end{array}$ & $\begin{array}{r}0 \\
0 \\
0 \\
-11,671 \\
317,050\end{array}$ & 180,784 \\
\hline 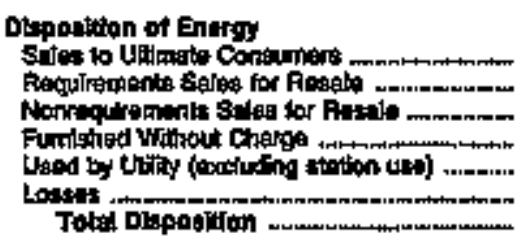 & $\begin{array}{r}140,285 \\
0 \\
0 \\
6 \\
416 \\
7,660 \\
15,500\end{array}$ & $\begin{array}{r}304,234 \\
3,919 \\
0 \\
175 \\
696 \\
13,047 \\
982,772\end{array}$ & $\begin{array}{r}144,759 \\
1,704 \\
0 \\
0 \\
346 \\
0,946 \\
155,746\end{array}$ & $\begin{array}{r}294,841 \\
18,680 \\
0 \\
0 \\
526 \\
10,570 \\
284,586\end{array}$ & $\begin{array}{r}290,051 \\
279 \\
0 \\
0 \\
915 \\
21,014 \\
317,600\end{array}$ & $\begin{array}{r}108,416 \\
10,506 \\
109 \\
7,598 \\
70,794\end{array}$ \\
\hline
\end{tabular}

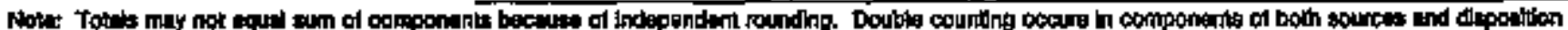

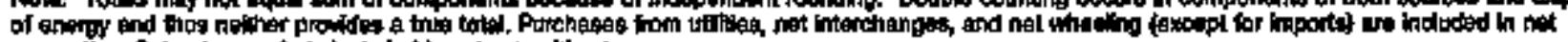

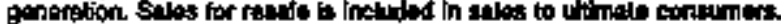

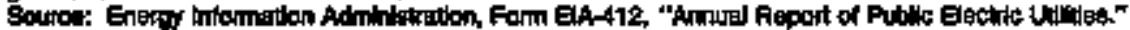


Tabie 26. Electric Energy Account by Major U.S. Publloly Owned plectric Utilty Whin State, 1994 (Continued)

(Megawalthours)

\begin{tabular}{|c|c|c|c|c|c|c|}
\hline $\mathrm{mem}$ & 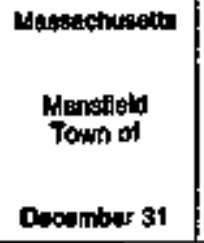 & 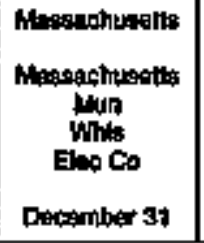 & 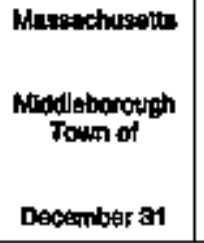 & 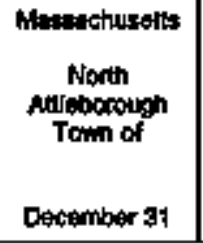 & 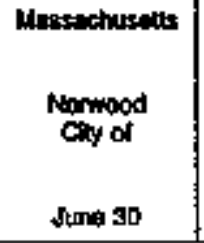 & $\begin{array}{l}\text { Mesclachusats } \\
\text { Pagbody } \\
\text { Cing of } \\
\text { Dopember } 31\end{array}$ \\
\hline 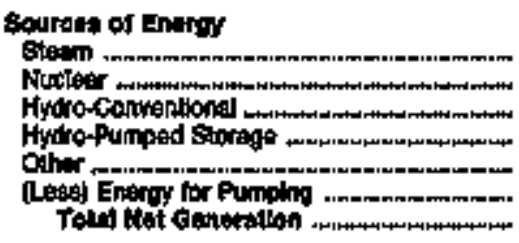 & $\begin{array}{l}0 \\
0 \\
0 \\
0 \\
0 \\
0 \\
0\end{array}$ & $\begin{array}{r}294,720 \\
1,050,468 \\
0 \\
0 \\
121,000 \\
1,486,100\end{array}$ & $\begin{array}{l}0 \\
0 \\
0 \\
0 \\
0 \\
0 \\
0\end{array}$ & $\begin{array}{r}5,590 \\
0 \\
0 \\
0 \\
0 \\
0 \\
0 \\
5,50\end{array}$ & $\begin{array}{l}0 \\
0 \\
0 \\
0 \\
0 \\
0 \\
0\end{array}$ & $\begin{array}{r}0 \\
0 \\
0 \\
0 \\
3,000 \\
0 \\
0,000\end{array}$ \\
\hline 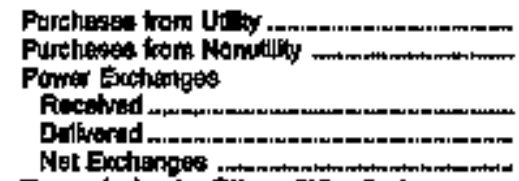 & $\begin{array}{r}139,550 \\
0 \\
71,050 \\
18,670 \\
52,400\end{array}$ & $\begin{array}{r}761,871 \\
60,369 \\
781,299 \\
204,294 \\
516,905\end{array}$ & $\begin{array}{r}165,972 \\
0 \\
29,219 \\
9,169 \\
10,051\end{array}$ & $\begin{array}{r}105,701 \\
0 \\
105,306 \\
12,067 \\
22,978\end{array}$ & $\begin{array}{r}325,482 \\
0\end{array}$ & $\begin{array}{r}\text { 206,693 } \\
\text { Tra } \\
182,072 \\
49,0,54 \\
134,017\end{array}$ \\
\hline 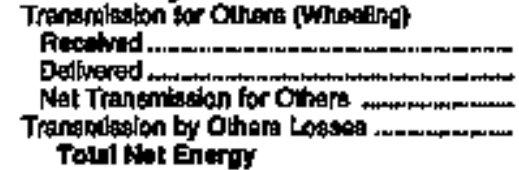 & $\begin{array}{l}0 \\
0 \\
0 \\
0\end{array}$ & $\begin{array}{l}0 \\
0 \\
0 \\
0\end{array}$ & $\begin{array}{l}\text { D } \\
\text { D } \\
0 \\
\text { o }\end{array}$ & $\begin{array}{l}0 \\
0 \\
0 \\
0\end{array}$ & $\begin{array}{l}0 \\
0 \\
0 \\
0\end{array}$ & $\begin{array}{l}0 \\
0 \\
0 \\
0\end{array}$ \\
\hline 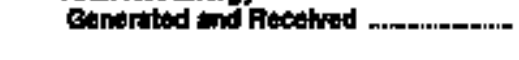 & W1,030 & 2,845,411 & Tr5/34 & 2013,740 & 376,492 & 405,114 \\
\hline 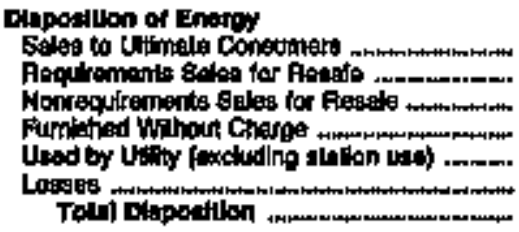 & $\begin{array}{r}168,720 \\
880 \\
0 \\
0 \\
50 \\
32,890 \\
1+1,090\end{array}$ & $\begin{array}{r}2,846,441 \\
0 \\
0 \\
0 \\
0 \\
0,845,411\end{array}$ & $\begin{array}{r}168,458 \\
145 \\
0 \\
0 \\
0 \\
6,396 \\
176,434\end{array}$ & $\begin{array}{r}192,781 \\
61 \\
0 \\
0 \\
316 \\
10,002 \\
203,760\end{array}$ & $\begin{array}{r}316,0 \pi 2 \\
0 \\
0 \\
0 \\
0 \\
0 \\
10,490 \\
326,402\end{array}$ & $\begin{array}{r}360,249 \\
0 \\
0 \\
18 \\
1,538 \\
18,380 \\
405,114\end{array}$ \\
\hline
\end{tabular}

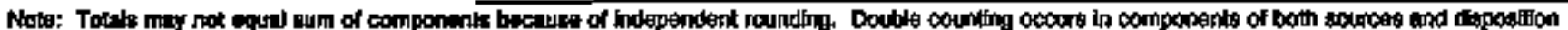

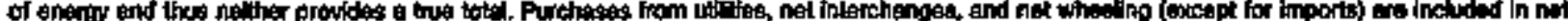

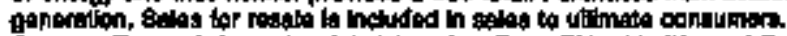

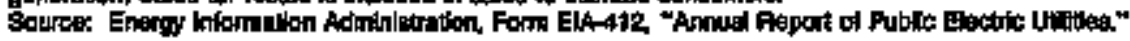


Tabje 26. Electric Energy Account by Mejor U.S. Publlely Owned Electric Utllky whin State, 1994 (Continued)

(Megawatthours)

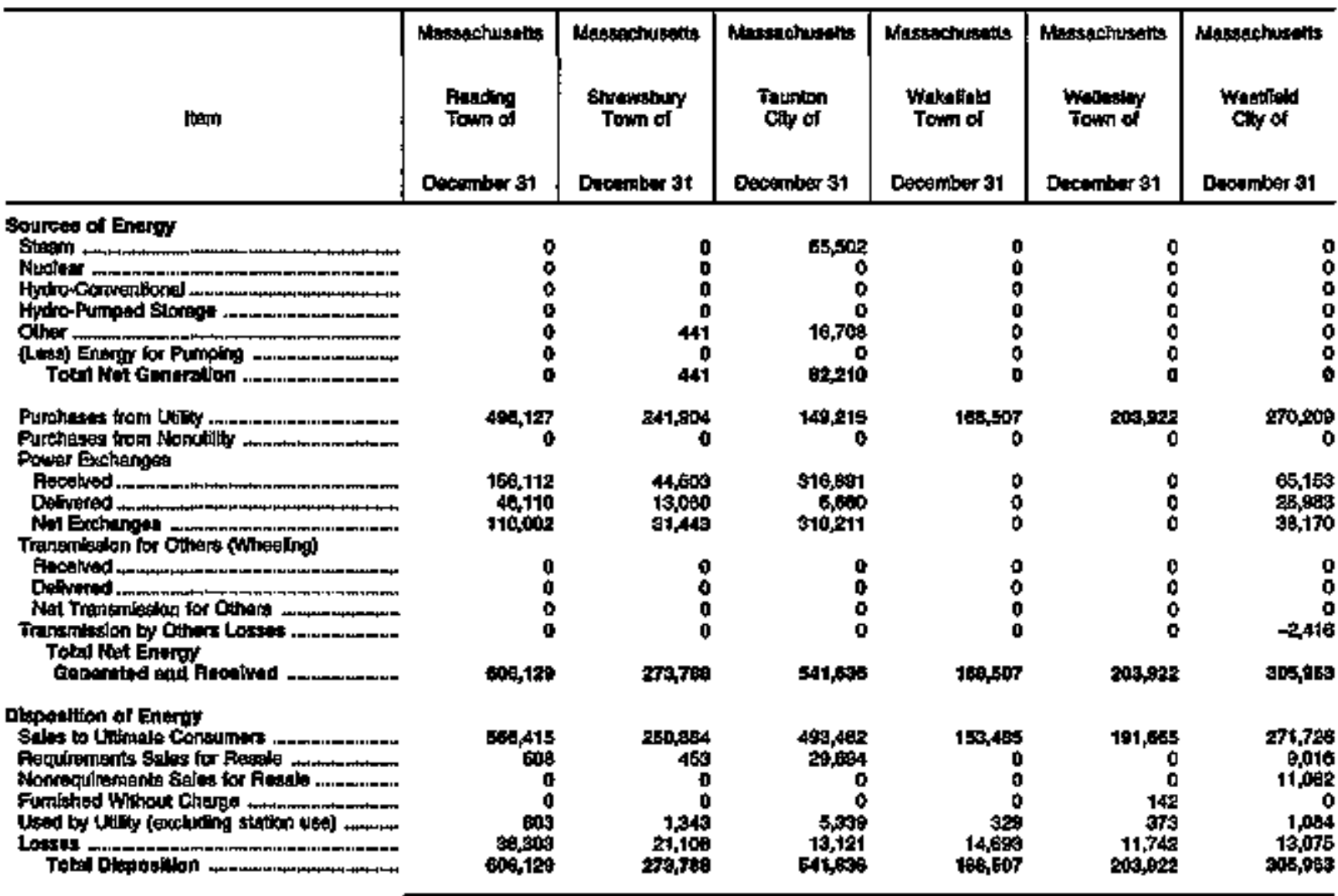

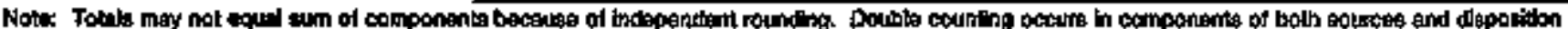

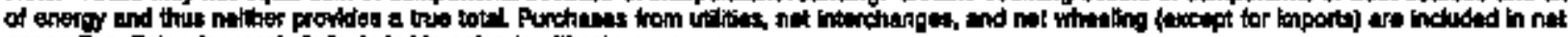

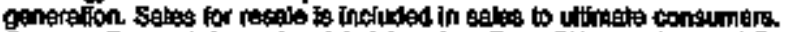

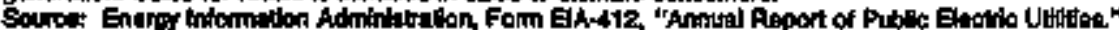


Table 26. Electric Ënergy Account, by Major U.S. Publloly Owned Electric Utility Within Stake, 1994 (Continued)

(Megawatthours)

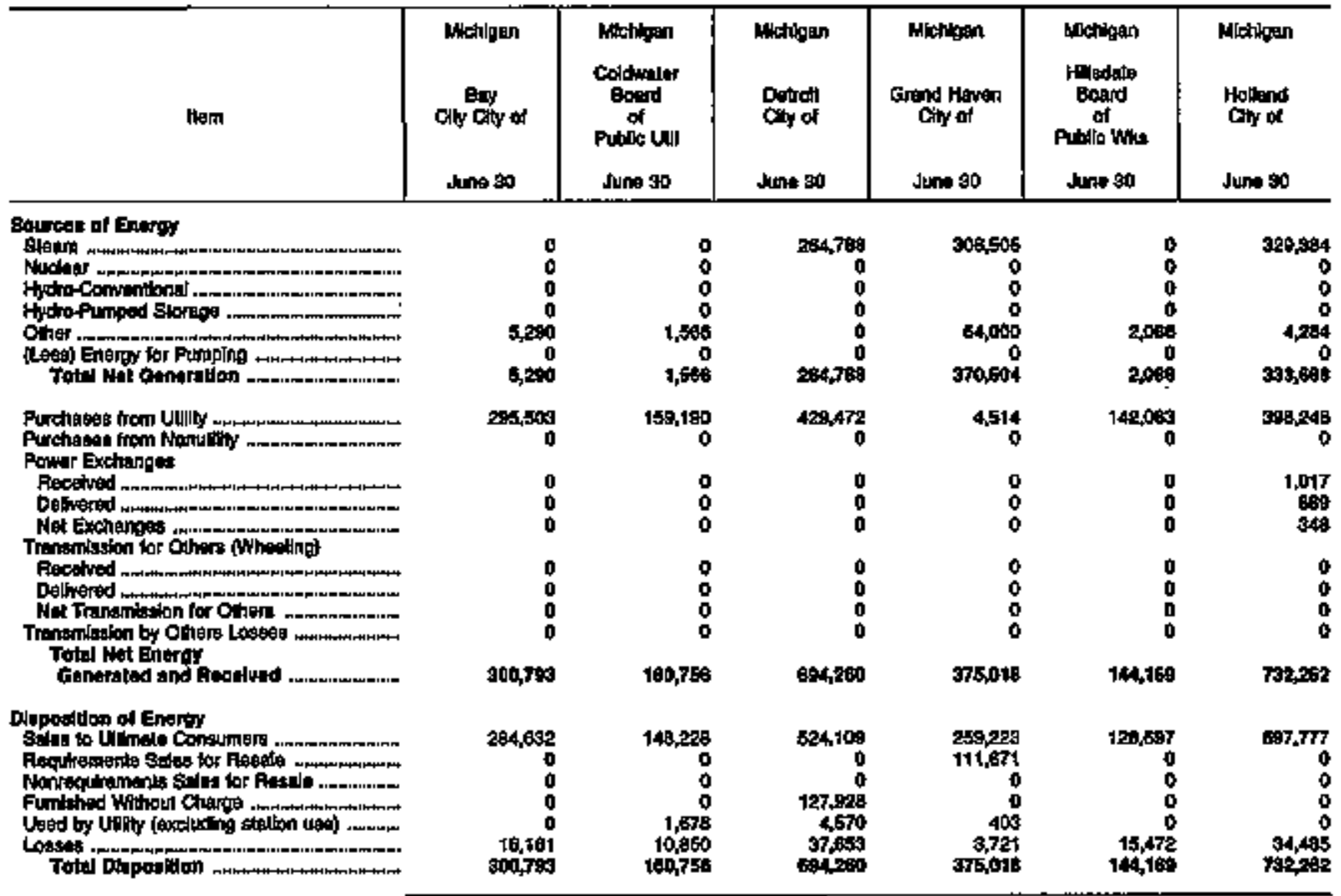

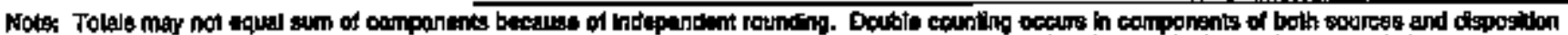

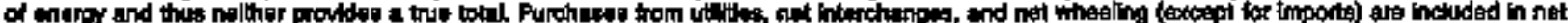

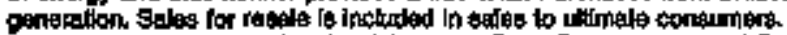

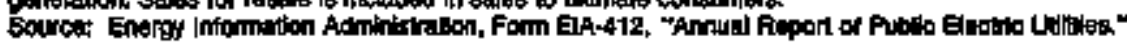


Table 26. Eleetrto Energy Aceount by Major Us. Publicly Owned Electric Utility Within State, 1994 (Continuted) (Magawatthours)

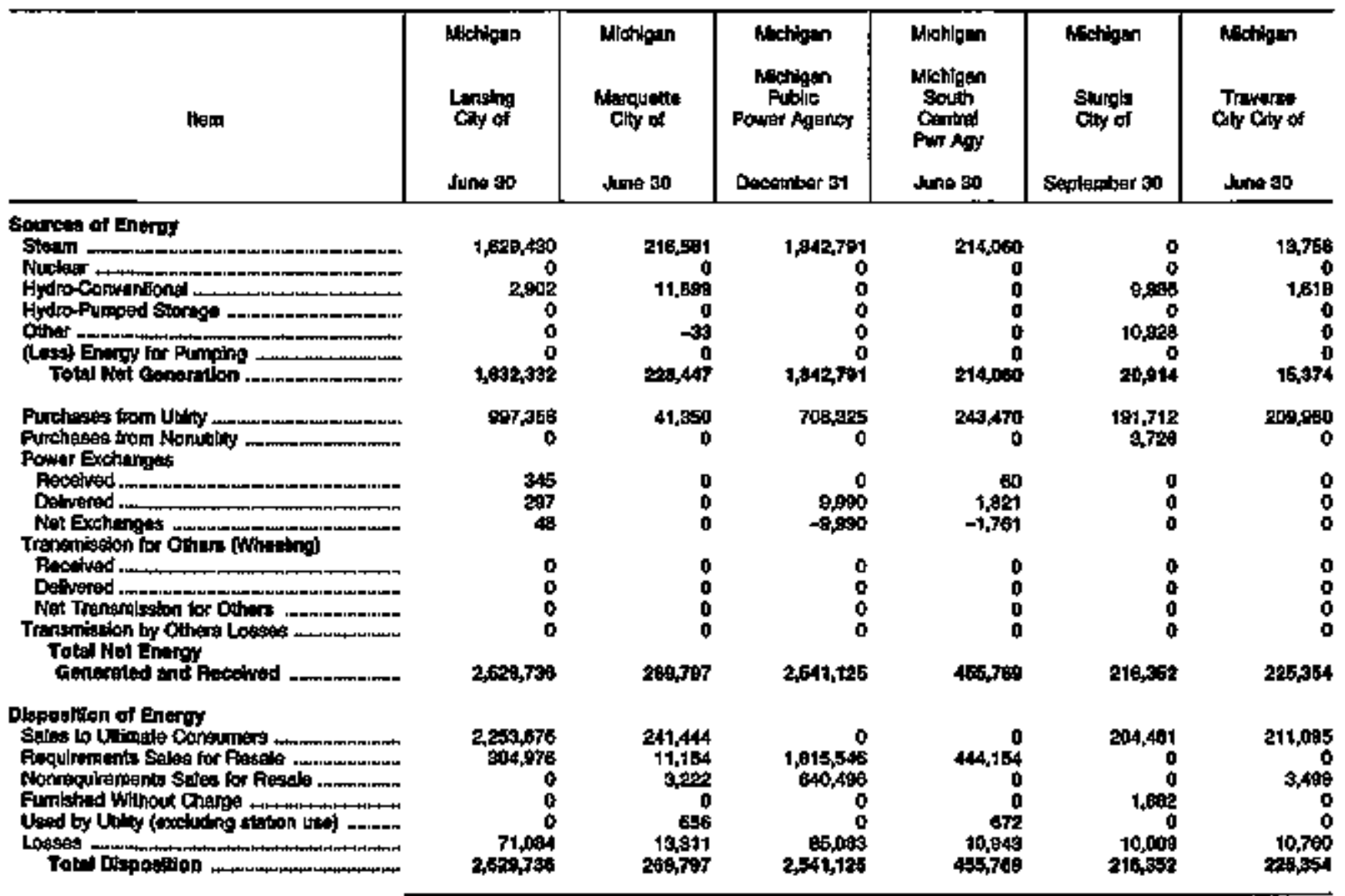

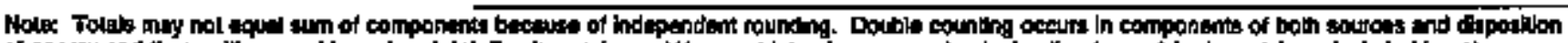

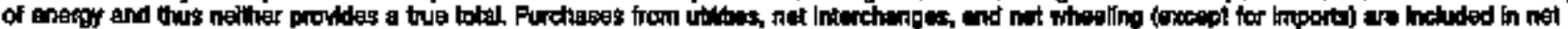

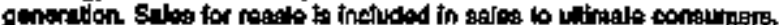

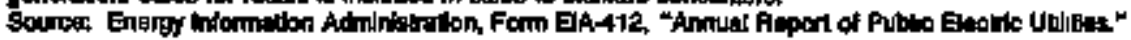


Table 26. Electric Entergy Account by Naijor U.S. Publicly Owhed Electric Uility Within State, 1994 (Continued)

(Megawatthours)

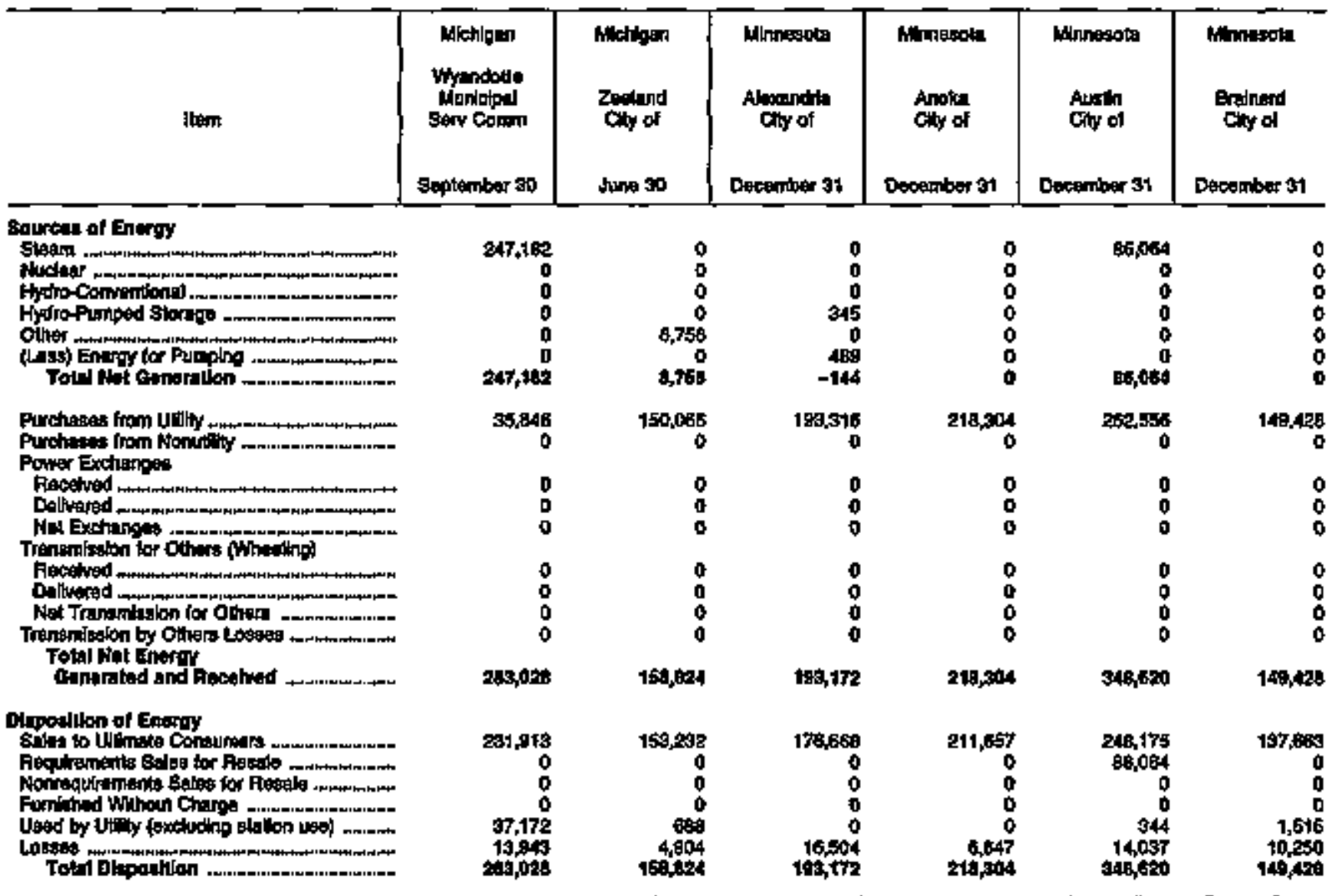

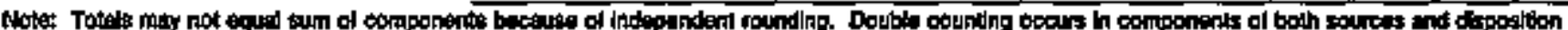

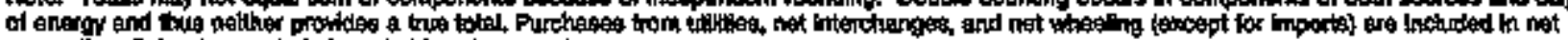

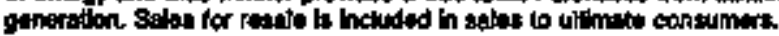

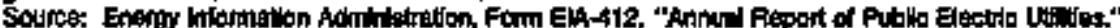


Table 26. Electric Energy Account by Major US. Publicly Owned Electric Utulity Within State, 1994 (Conthuod)

(Megawatthours)

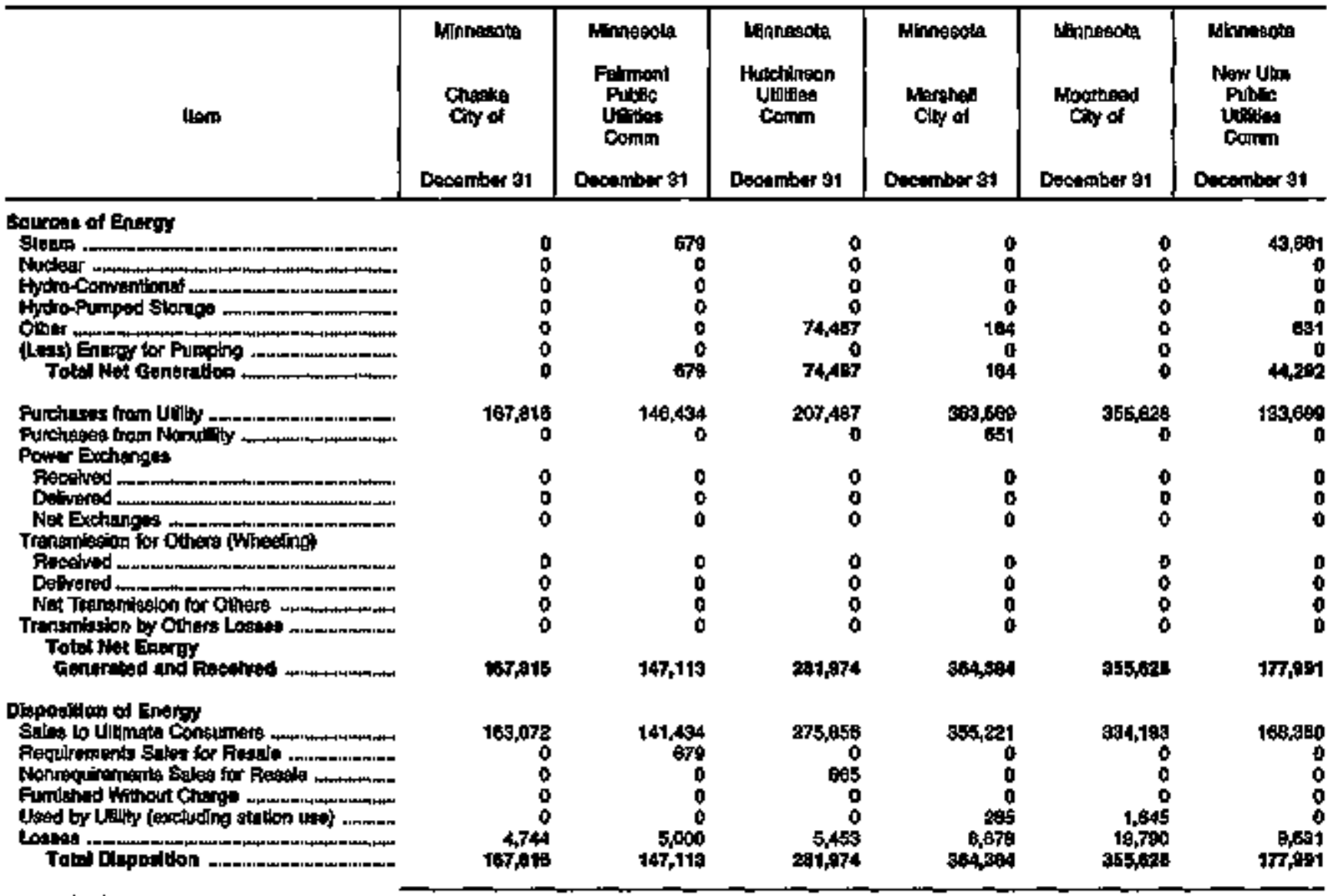

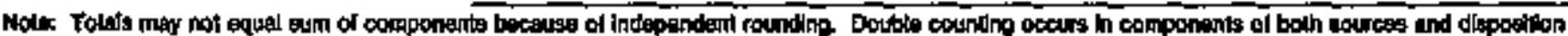

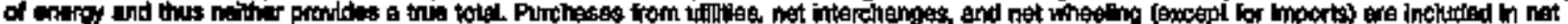

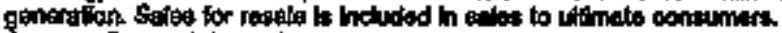

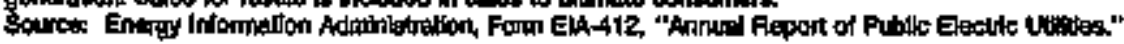


Table 26. Electrle Energy Account by Major U.8. Publicly Owned Electric Utilty Whin State, 1994 (Continued)

(Megewatthours)

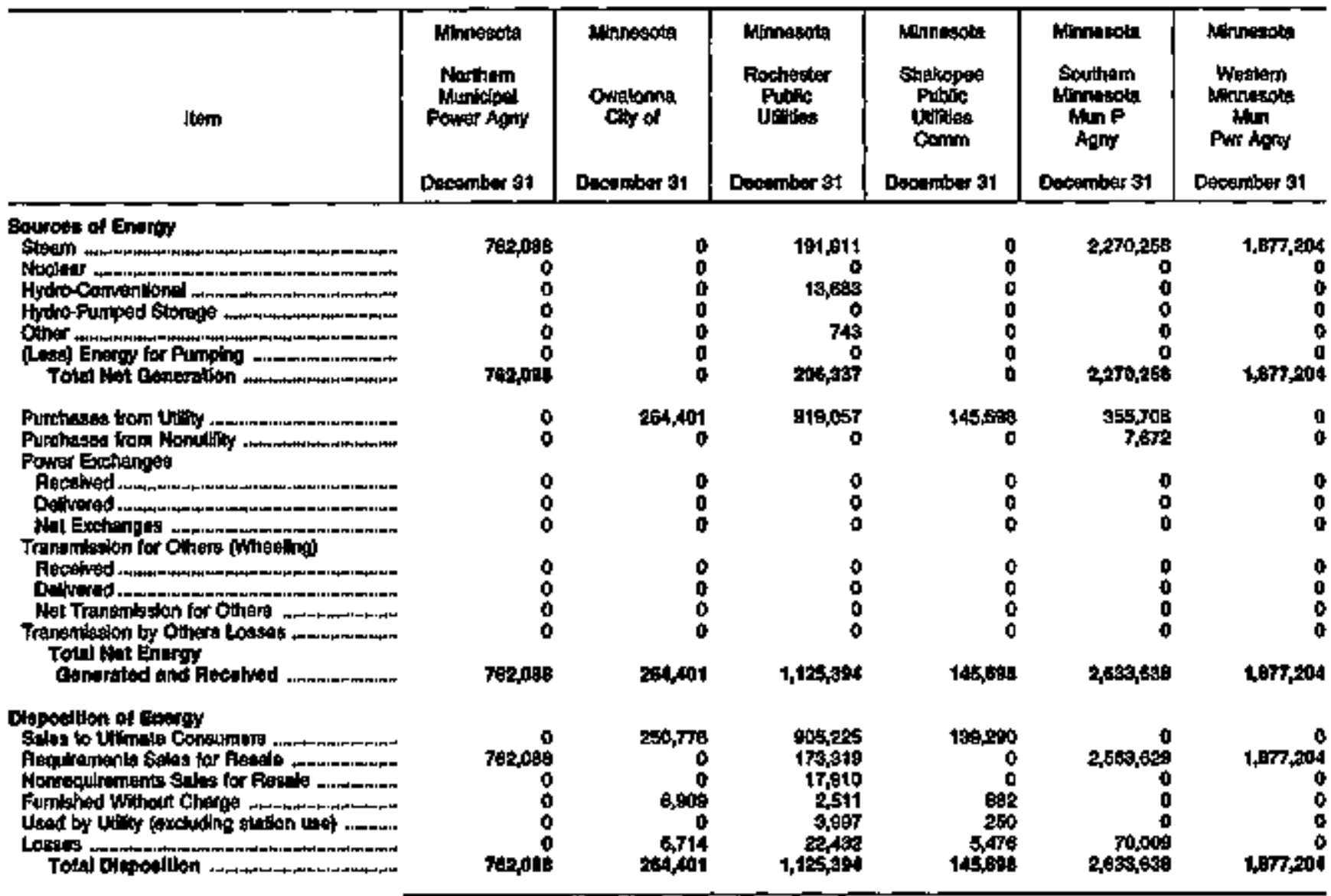

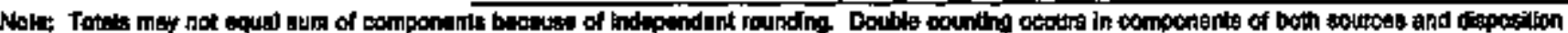

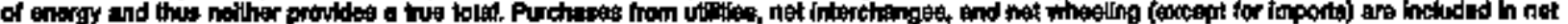

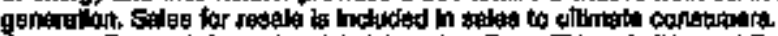

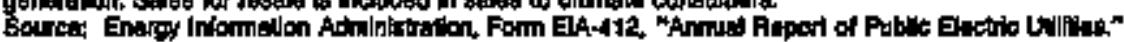


Table 26. Electric Energy Account by Major U.S. Publichy Owned Electric Utility Within State, 1994 (Continued) (Megawatthours)

\begin{tabular}{|c|c|c|c|c|c|c|}
\hline lemp & 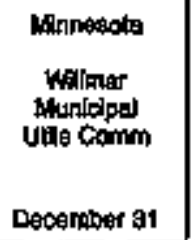 & 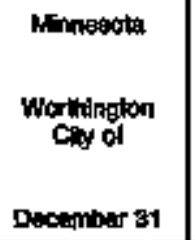 & 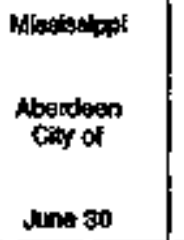 & 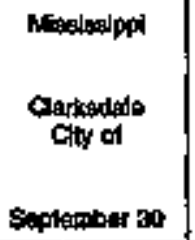 & 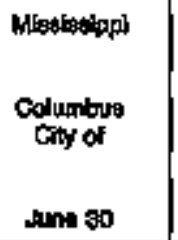 & 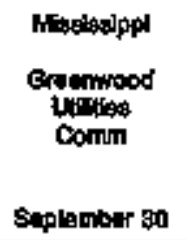 \\
\hline 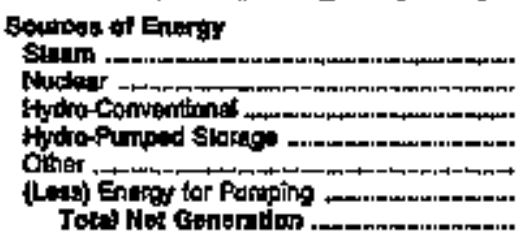 & $\begin{array}{r}34,183 \\
0 \\
0 \\
0 \\
0 \\
0 \\
34,108\end{array}$ & $\begin{array}{l}0 \\
0 \\
0 \\
0 \\
0 \\
0 \\
0\end{array}$ & $\begin{array}{l}0 \\
0 \\
0 \\
0 \\
0 \\
0 \\
0\end{array}$ & $\begin{array}{r}100,554 \\
0 \\
0 \\
0 \\
0 \\
0 \\
104,654\end{array}$ & $\begin{array}{l}0 \\
0 \\
0 \\
0 \\
0 \\
0 \\
0\end{array}$ & $\begin{array}{r}20,47 \\
0 \\
0 \\
0 \\
0 \\
0 \\
0 \\
0,47\end{array}$ \\
\hline 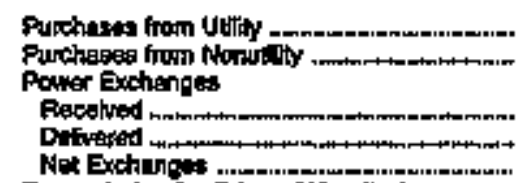 & $\begin{array}{r}188,616 \\
0 \\
0 \\
0 \\
0\end{array}$ & $\begin{array}{r}149,600 \\
0 \\
0 \\
0 \\
0\end{array}$ & $\begin{array}{r}172,190 \\
0 \\
0 \\
0 \\
0\end{array}$ & $\begin{array}{r}181,074 \\
0 \\
0 \\
0 \\
0\end{array}$ & $\begin{array}{r}405,831 \\
0 \\
0 \\
0 \\
0\end{array}$ & $\begin{array}{r}209,970 \\
0 \\
0 \\
0 \\
0\end{array}$ \\
\hline 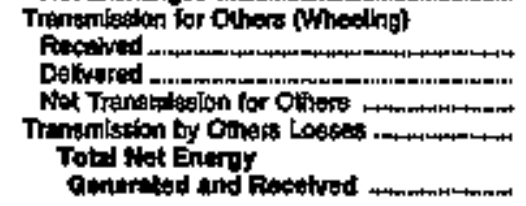 & $\begin{array}{r}0 \\
0 \\
9 \\
4\end{array}$ & $\begin{array}{r}0 \\
0 \\
0 \\
0 \\
143,690\end{array}$ & $\begin{array}{r}0 \\
0 \\
0 \\
0 \\
172,+109\end{array}$ & 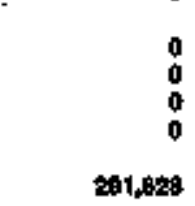 & $\begin{array}{r}0 \\
0 \\
0 \\
0\end{array}$ & $\begin{array}{r}0 \\
0 \\
0 \\
0 \\
269,647\end{array}$ \\
\hline 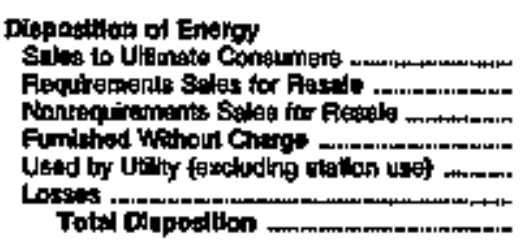 & $\begin{array}{r}206,665 \\
0 \\
0 \\
2,461 \\
2,024 \\
8,729 \\
2,67\end{array}$ & $\begin{array}{r}184,086 \\
3,137 \\
0 \\
0 \\
76 \\
7,392 \\
149,000\end{array}$ & $\begin{array}{r}165,157 \\
0 \\
0 \\
0 \\
78 \\
6,907 \\
172,039\end{array}$ & $\begin{array}{r}169,659 \\
100,954 \\
0 \\
0 \\
0 \\
21,416 \\
291,429\end{array}$ & $\begin{array}{r}484,945 \\
0 \\
0 \\
0 \\
189 \\
20,498 \\
496,641\end{array}$ & $\begin{array}{r}240,299 \\
20,477 \\
0 \\
0 \\
3,548 \\
18,523 \\
208,947\end{array}$ \\
\hline
\end{tabular}

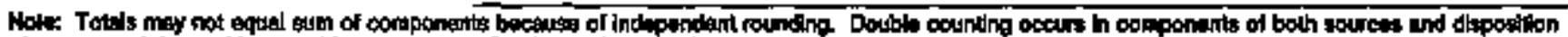

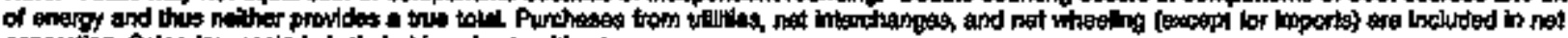

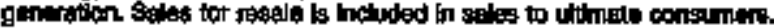

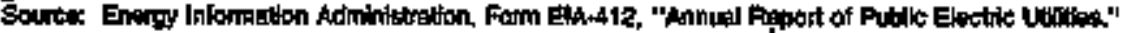


Table 26. Electric Energy Account by Major U.S. Publicly Owned Electric Uillity Whith State, 1994 (Continued)

(Megawathours)

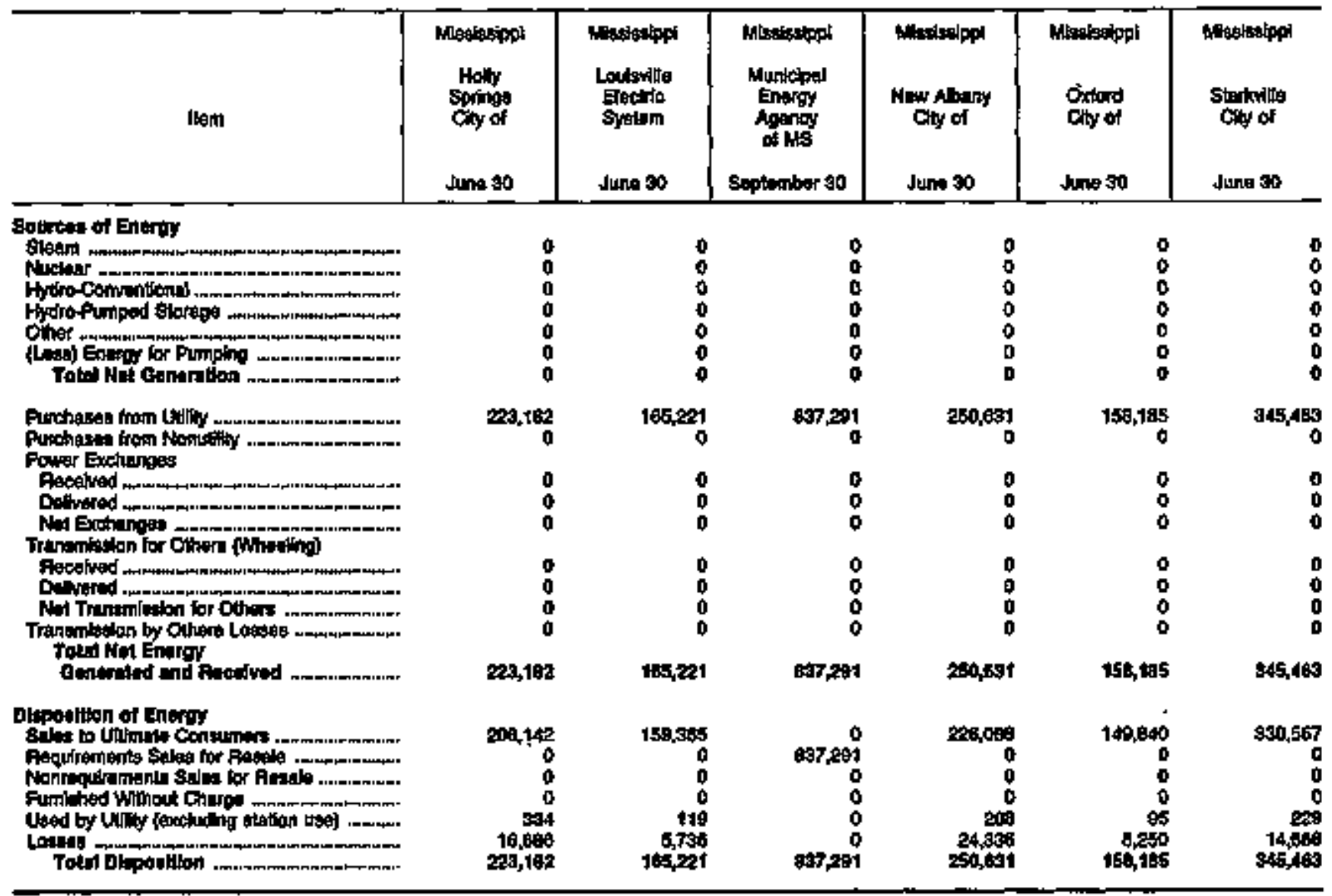

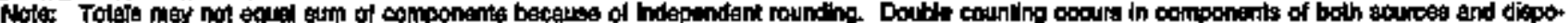

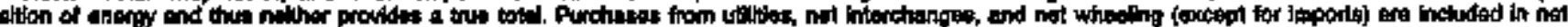

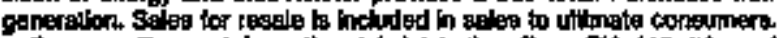

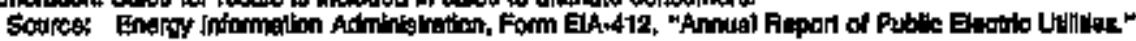


Table 26. Electric Energy Account by Major U.S. Publicly Owned Electric Utility Within State, 1994 (Continued) (Megawatthours)

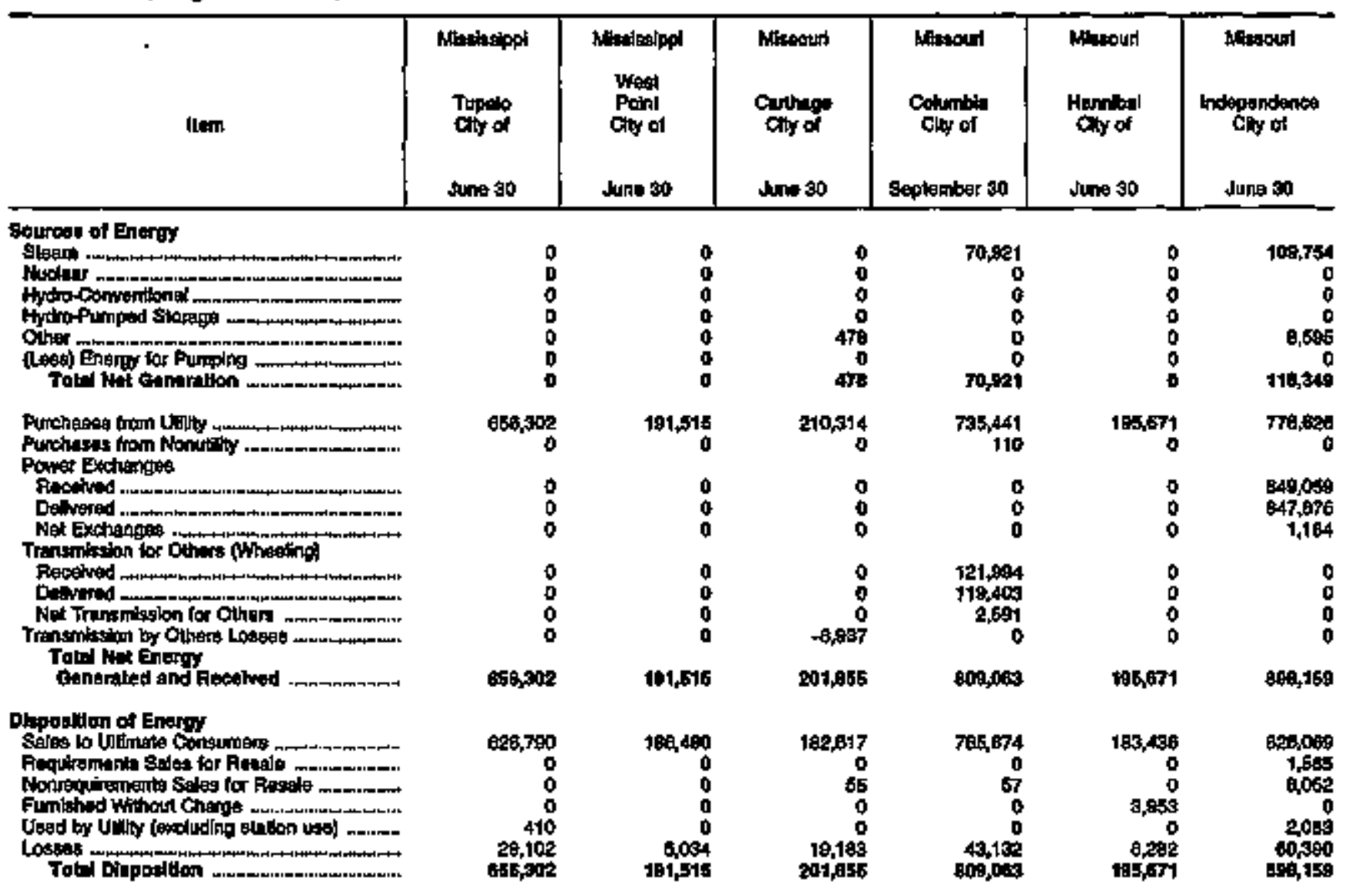

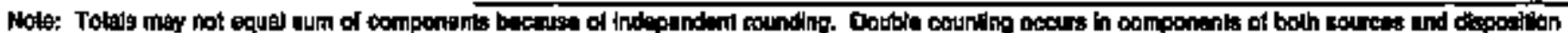

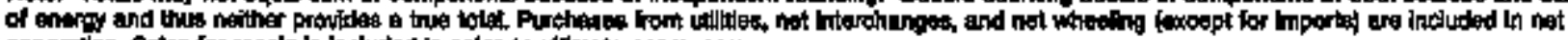

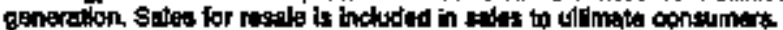

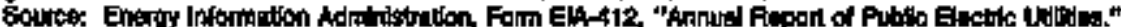


Tabie 26. Electric Energy Aocount by Major U.S. Publidy Owned Electrto Utillity Within State, 1994 (Conthused)

(Megawatthours)

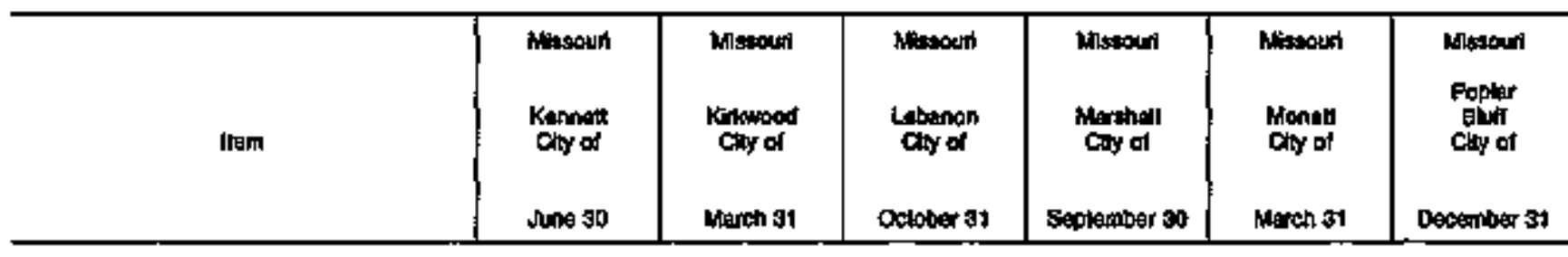

Sarreas of Earor

8lean

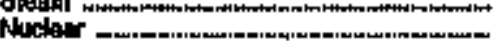

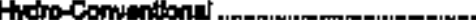

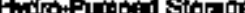

Othe

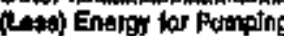

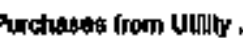

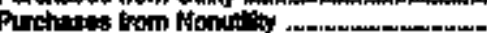

Ponver Exchange:

Ferothod

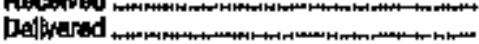

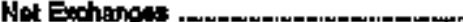

Trenambsalon for Others (Wheallnal

Focoinod

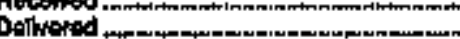

Wat Tranimigson tor Othm.

Thantureston by Other Longen

Toill thit Enory

eanurited and Peonhed

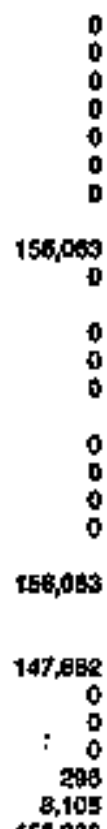

0
0
0
0
0
0
0

0

0

0

0

2ind

0
0
0
0
0
0
0

163,145

t63,050

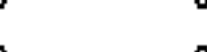

$\begin{array}{ll}0 & 0 \\ 0 & 0\end{array}$

0

$\begin{array}{ll}0 & 0 \\ 0 & 0\end{array}$

8,018

164,145

15s, thoto

5,400
0
0
0
0
0
58,000

105358

15,510

D

20,791

0

0

0
0
0

0

0

0

popostion of enory

selas to Lismele Conewners

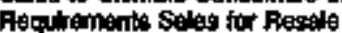

Fintiod thingut chas

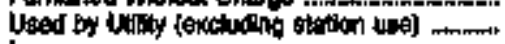

Total Dinonilon

t58098

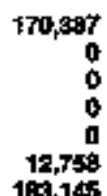

183,145

$\begin{array}{rr}170,397 & 150,080 \\ 0 & 0 \\ 0 & 0 \\ 0 & 10,980 \\ 0 & 29,800 \\ 12,758 & 0 \\ 180,145 & 14+090\end{array}$

totsonso
16,752

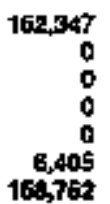

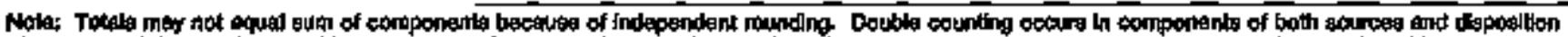

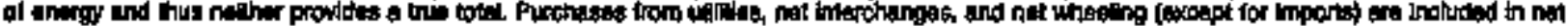

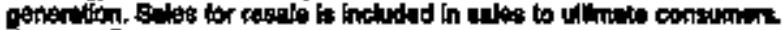

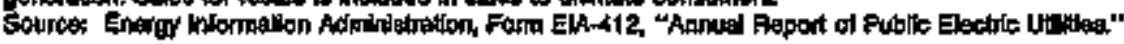


Table 26. Eloctric Eneray Account by Major U.S. Publlch Owned Electrlo Utilty Within State, 1994 (Continued)

(Mogawatthous)

\begin{tabular}{|c|c|c|c|c|c|c|}
\hline ||tor| & $\begin{array}{l}\text { Mitsount } \\
\text { Poill } \\
\text { Chy of } \\
\text { Septomber } 30\end{array}$ & 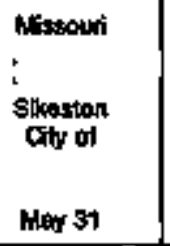 & $\begin{array}{l}\text { Mlswout } \\
\text { Springfield } \\
\text { Chy of } \\
\text { Septomber } 30\end{array}$ & $\begin{array}{l}\text { Nobrasken } \\
\text { Oedebioe } \\
\text { City of } \\
\text { Juty } 31\end{array}$ & 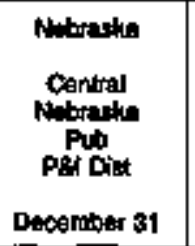 & 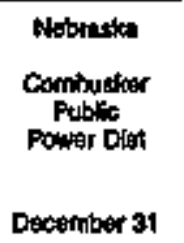 \\
\hline 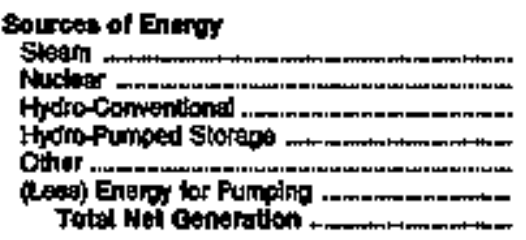 & $\begin{array}{l}0 \\
0 \\
0 \\
0 \\
0 \\
0 \\
0\end{array}$ & $\begin{array}{r}1,369,542 \\
0 \\
0 \\
0 \\
0 \\
0 \\
1,3090408\end{array}$ & $\begin{array}{r}1,744,489 \\
0 \\
0 \\
0 \\
53,281 \\
0 \\
1,767,749\end{array}$ & $\begin{array}{l}0 \\
0 \\
0 \\
0 \\
0 \\
0 \\
0\end{array}$ & $\begin{array}{r}0 \\
0 \\
109,829 \\
0 \\
278,988 \\
9 \\
9146,199\end{array}$ & $\begin{array}{l}0 \\
0 \\
0 \\
0 \\
0 \\
0 \\
0\end{array}$ \\
\hline 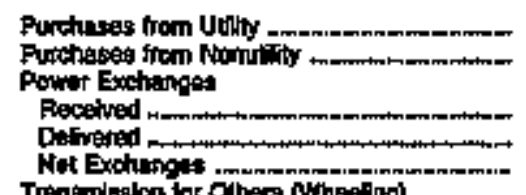 & $\begin{array}{r}292,164 \\
0 \\
0 \\
0\end{array}$ & $\begin{array}{r}119,572 \\
0 \\
207,290 \\
15,007 \\
142,201\end{array}$ & $\begin{array}{r}721,638 \\
0 \\
176,910 \\
113,998 \\
62,514\end{array}$ & $\begin{array}{r}141,400 \\
0 \\
0 \\
0 \\
0\end{array}$ & $\begin{array}{l}0 \\
0 \\
0\end{array}$ & $\begin{array}{r}200,005 \\
0 \\
0 \\
0 \\
0\end{array}$ \\
\hline 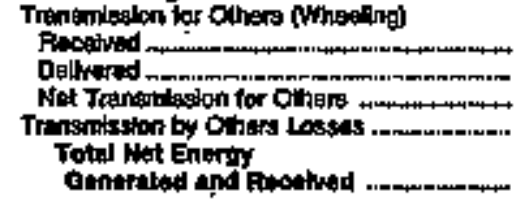 & $\begin{array}{r}0 \\
0 \\
0 \\
0 \\
202,164\end{array}$ & $\begin{array}{r}0 \\
0 \\
0 \\
0 \\
1,651,406\end{array}$ & $\begin{array}{r}0 \\
0 \\
0 \\
-2,195 \\
2,5 \text { ra, } 704\end{array}$ & $\begin{array}{r}0 \\
0 \\
0 \\
0 \\
0 \\
144090\end{array}$ & 340, 109 & $\begin{array}{r}0 \\
0 \\
0 \\
0 \\
20,005\end{array}$ \\
\hline 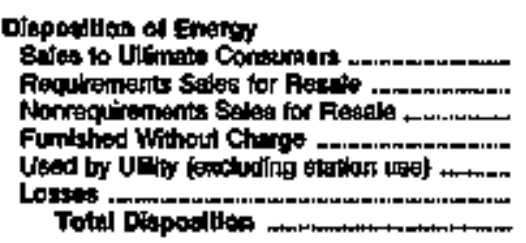 & $\begin{array}{r}215,258 \\
0 \\
0 \\
4,300 \\
310 \\
12,316 \\
292,194\end{array}$ & $\begin{array}{r}240,734 \\
725,207 \\
650,040 \\
3,604 \\
0 \\
10,672 \\
1,061,406\end{array}$ & $\begin{array}{r}2,153,335 \\
100,068 \\
128,163 \\
69,619 \\
28,000 \\
70,504 \\
2,646,701\end{array}$ & $\begin{array}{r}130,799 \\
0 \\
0 \\
0,491 \\
617 \\
7,769 \\
111,6000\end{array}$ & $\begin{array}{r}38,189 \\
0 \\
0 \\
0 \\
0 \\
348,199\end{array}$ & $\begin{array}{r}10,465 \\
2,448 \\
0 \\
0 \\
\$ 60 \\
16,412 \\
200,066\end{array}$ \\
\hline
\end{tabular}

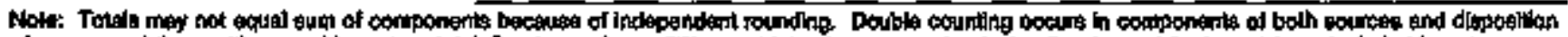

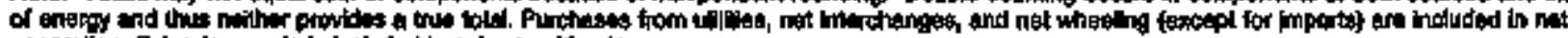

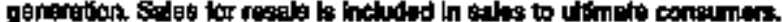

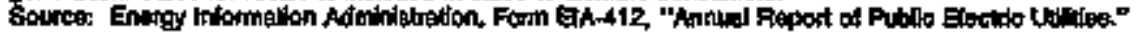


Tebie 26. Electric Energy Account by Major US. Publicly Owned Elective Utility Whiln state, 1994 (Conkirued)

(Megewathours)

\begin{tabular}{|c|c|c|c|c|c|c|}
\hline $\min$ & 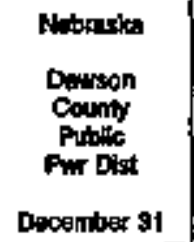 & $\begin{array}{l}\text { Mobroske } \\
\text { Fomom of } \\
\text { Juy a1 }\end{array}$ & 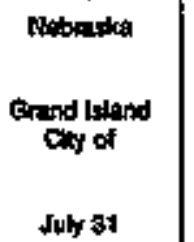 & 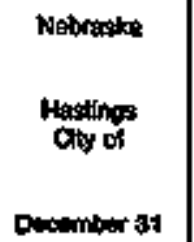 & 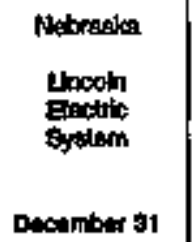 & Nobreater \\
\hline 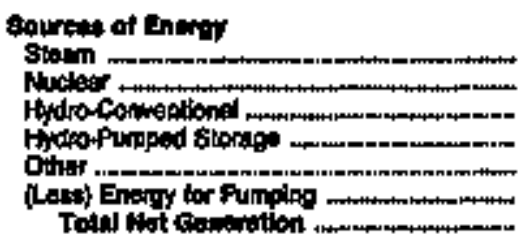 & $\begin{array}{l}0 \\
0 \\
0 \\
0 \\
0 \\
0 \\
0\end{array}$ & 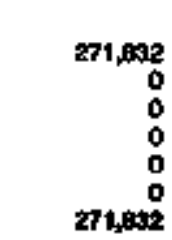 & 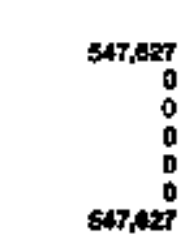 & $\begin{array}{r}427,402 \\
0 \\
0 \\
0 \\
108 \\
0 \\
027,600\end{array}$ & $\begin{array}{r}1,343,067 \\
0 \\
0 \\
0 \\
0,981 \\
0 \\
1,352,010\end{array}$ & $\begin{array}{r}0 \\
128,205 \\
0 \\
0 \\
0 \\
12,2,05\end{array}$ \\
\hline 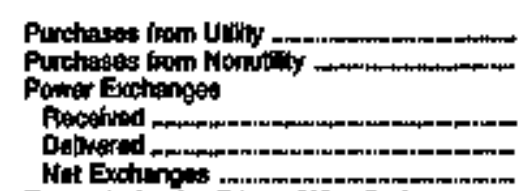 & 269,611 & 68,694 & $\begin{array}{r}65,208 \\
0 \\
569 \\
596 \\
96\end{array}$ & $\begin{array}{r}5, \pi / 5 \\
0\end{array}$ & 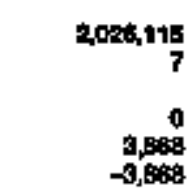 & 2028 \\
\hline 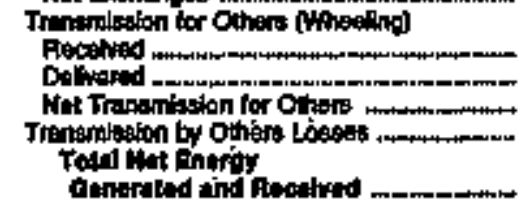 & 269,611 & $\begin{array}{l}0 \\
0 \\
0 \\
0\end{array}$ & $\begin{array}{l}0 \\
0 \\
0 \\
0\end{array}$ & $\begin{array}{r}5,5 \% 4 \\
5,504 \\
0 \\
0\end{array}$ & $\begin{array}{r}709,471 \\
900,471 \\
0 \\
0\end{array}$ & $1,055,068$ \\
\hline 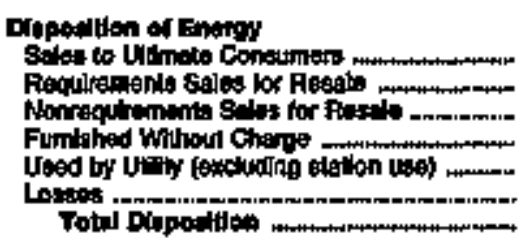 & $\begin{array}{r}24,574 \\
5274 \\
0 \\
0 \\
187 \\
22696 \\
299611\end{array}$ & $\begin{array}{r}274,314 \\
0 \\
12,608 \\
5,530 \\
39000 \\
8,1,5 \\
340,54\end{array}$ & $\begin{array}{r}50,774 \\
0 \\
76,379 \\
0 \\
0 \\
03,587 \\
20,404\end{array}$ & $\begin{array}{r}235,657 \\
161,304 \\
0 \\
0 \\
0 \\
13,682 \\
40,08\end{array}$ & 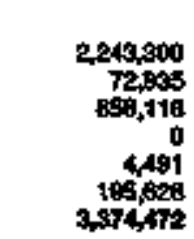 & $\begin{array}{r}617,208 \\
41,730 \\
0 \\
0 \\
1,517 \\
24,5 e 2 \\
1,055,506\end{array}$ \\
\hline
\end{tabular}

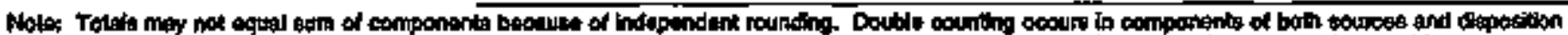

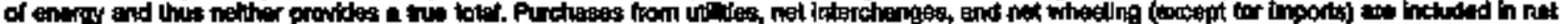

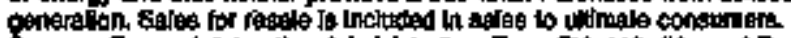

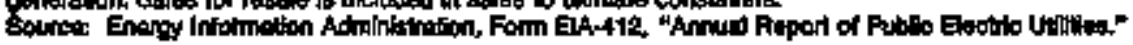


Table 26. Electric Energy Account by Major U.3. Publicty Owned Electric Utality Within State, 1994 (Continued) (Megawatthours)

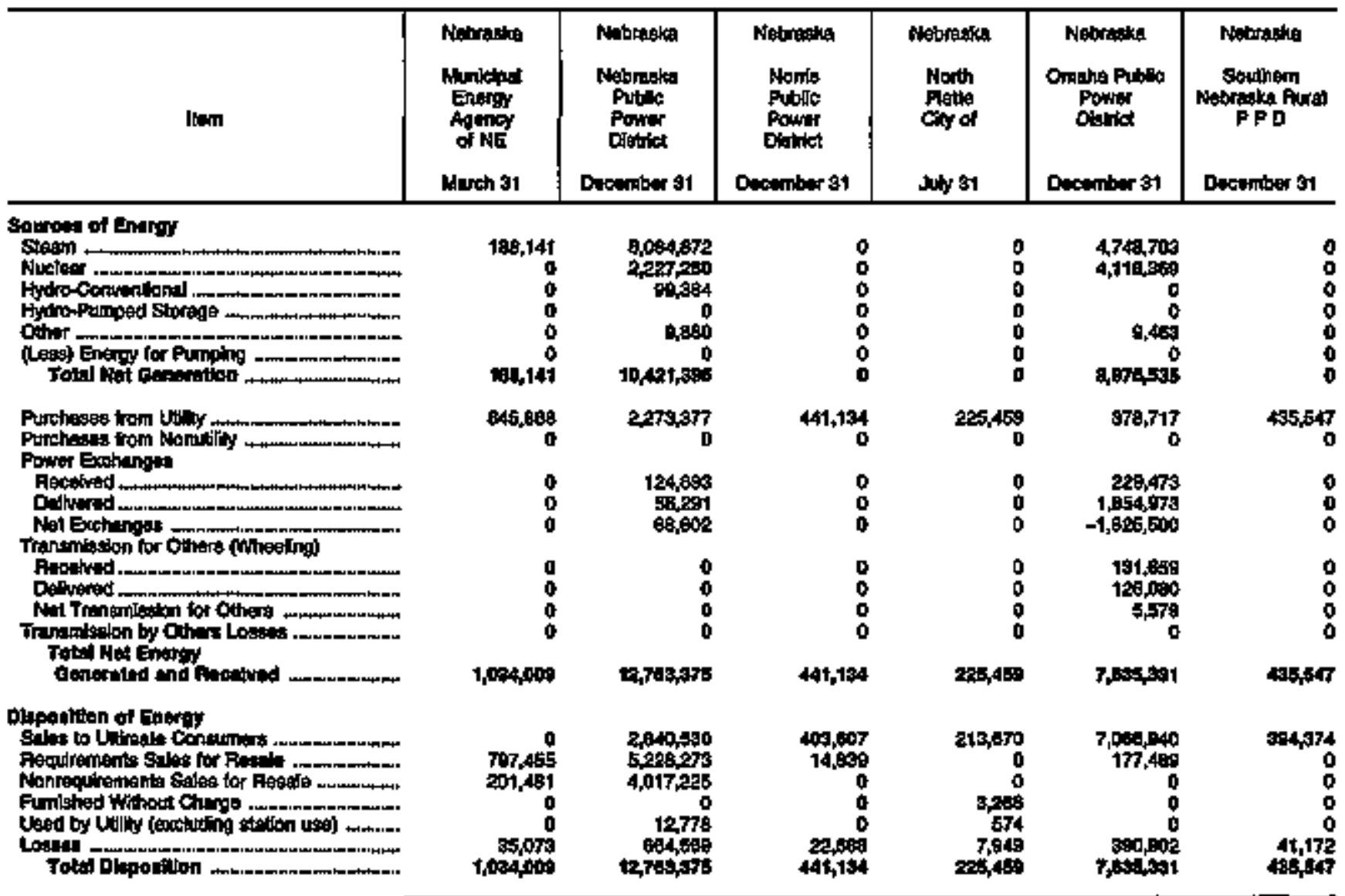

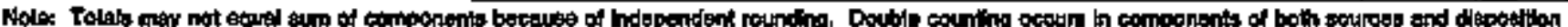

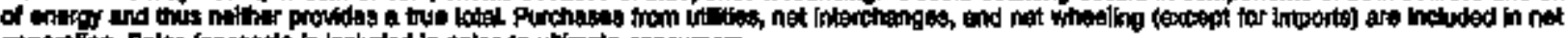

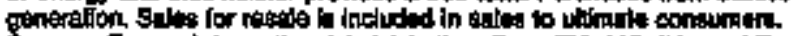

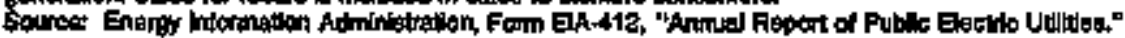


Tabje 26. Electric Energy Account by Usjor U.S. Publicly Owned Electric Utility Within State, 1994 (Conthued)

(Megawatthours)

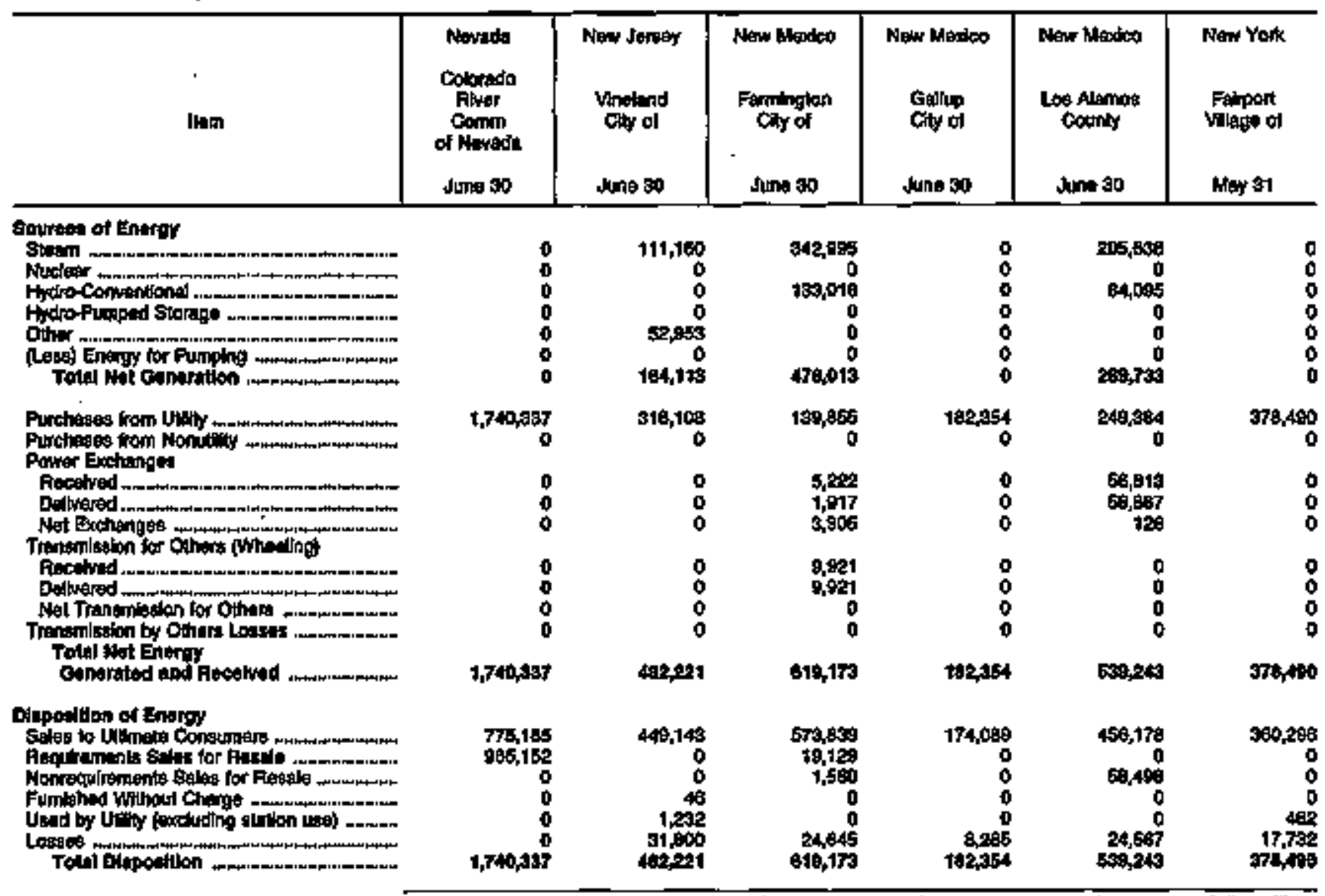

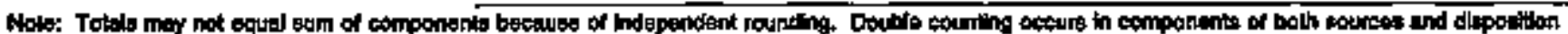

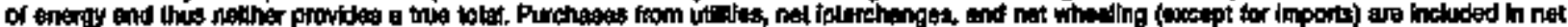

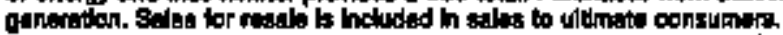

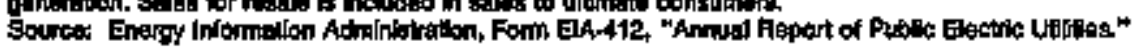


Table 26. Electric Energy Account by Major U.S. Publichy Owned Electrlc Wtility Within State, 1994 (Conthured)

(Megawatthours)

\begin{tabular}{|c|c|c|c|c|c|c|}
\hline llem & 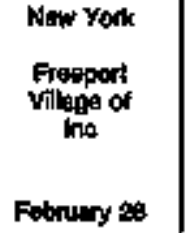 & 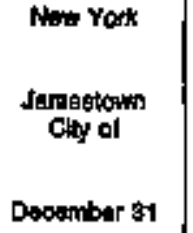 & 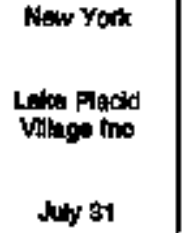 & $\begin{array}{l}\text { Now Youk } \\
\text { Massene } \\
\text { Town of } \\
\text { Docomber } 31\end{array}$ & 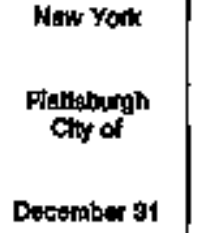 & $\begin{array}{l}\text { New York } \\
\text { Fower } \\
\text { of Sitatily of WY } \\
\text { Oecember } 39\end{array}$ \\
\hline 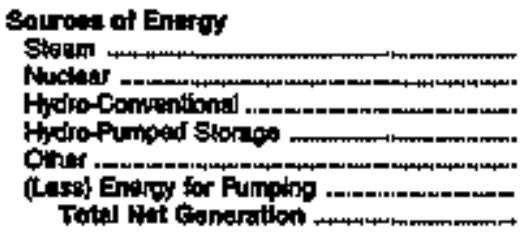 & $\begin{array}{r}0 \\
0 \\
0 \\
0 \\
15,984 \\
0 \\
16,994\end{array}$ & $\begin{array}{r}169,800 \\
0 \\
0 \\
0 \\
0 \\
0 \\
169,600\end{array}$ & $\begin{array}{l}0 \\
0 \\
0 \\
0 \\
0\end{array}$ & $\begin{array}{l}0 \\
0 \\
0 \\
0 \\
0\end{array}$ & $\begin{array}{l}0 \\
0 \\
0 \\
0 \\
0 \\
0 \\
0\end{array}$ & 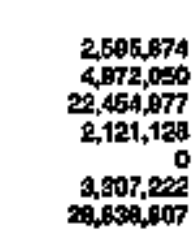 \\
\hline 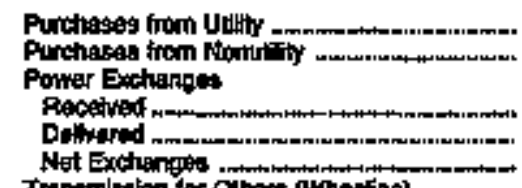 & $\begin{array}{r}228,646 \\
0 \\
0\end{array}$ & $\begin{array}{r}461,76 ? \\
0 \\
0\end{array}$ & $\begin{array}{r}139,3602 \\
0\end{array}$ & $\begin{array}{r}164,313 \\
0\end{array}$ & $\begin{array}{r}639,400 \\
0\end{array}$ & $\begin{array}{r}10,423,430 \\
0 \\
321,605 \\
322,191 \\
-305\end{array}$ \\
\hline 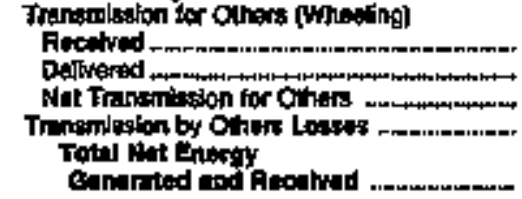 & $\begin{array}{l}0 \\
0 \\
0 \\
0\end{array}$ & $\begin{array}{r}0 \\
0 \\
0 \\
-29,460 \\
-91,118\end{array}$ & $\begin{array}{r}149,160 \\
147,680 \\
1,492 \\
0\end{array}$ & 154,943 & $\begin{array}{l}0 \\
0 \\
0 \\
0\end{array}$ & $\begin{array}{r}6,070,208 \\
5,007,405 \\
102,601 \\
0 \\
39,36,713\end{array}$ \\
\hline 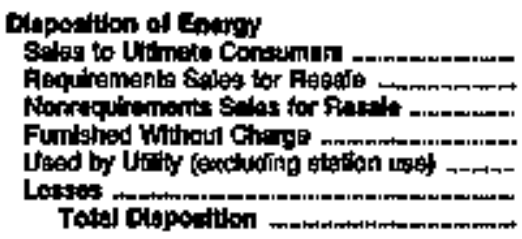 & $\begin{array}{r}292,134 \\
4 \\
0 \\
0 \\
4,060 \\
6,005 \\
242,200\end{array}$ & 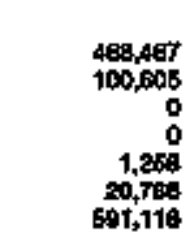 & $\begin{array}{r}128,200 \\
0 \\
0 \\
1,600 \\
276 \\
15,789 \\
140,454\end{array}$ & $\begin{array}{r}159,917 \\
0 \\
0 \\
0 \\
396 \\
0 \\
154,313\end{array}$ & $\begin{array}{r}529.1109 \\
0 \\
0 \\
0 \\
0 \\
1,131 \\
+5,000 \\
599,409\end{array}$ & $\begin{array}{r}19,212,615 \\
4,200,240 \\
21,003,109 \\
7,677 \\
15,747 \\
797,320 \\
39,362,713\end{array}$ \\
\hline
\end{tabular}

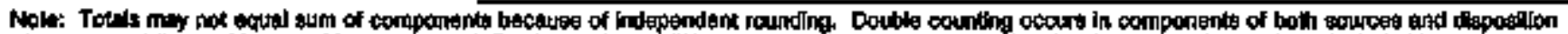

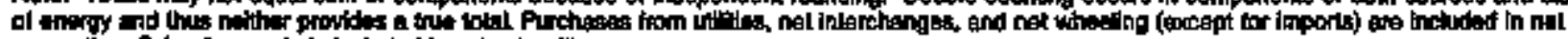

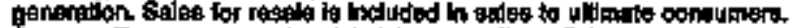

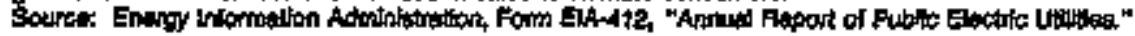


Table 26. Eiectric Eneroy Acootint by Major UA Publicly Owned Electric Utilly Whth'n State, 1994 (Continued) (Meganatthours)

\begin{tabular}{|c|c|c|c|c|c|c|}
\hline Hern & 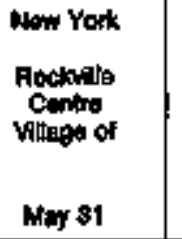 & 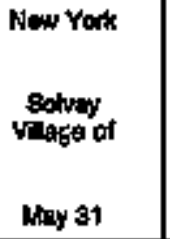 & $\begin{array}{l}\text { North Ousolina } \\
\text { Atbomile } \\
\text { Gity of } \\
\text { Jum } 30\end{array}$ & $\begin{array}{l}\text { North Curelta } \\
\text { Conoond } \\
\text { City of } \\
\text { June oo }\end{array}$ & 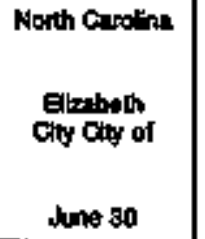 & 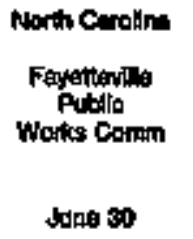 \\
\hline 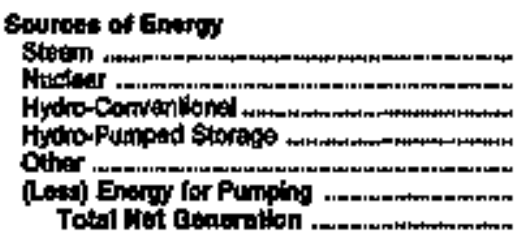 & $\begin{array}{r}0 \\
0 \\
0 \\
0 \\
20,850 \\
0 \\
20,600\end{array}$ & $\begin{array}{l}0 \\
0 \\
0 \\
0 \\
0 \\
0 \\
0\end{array}$ & $\begin{array}{l}0 \\
0 \\
0 \\
0 \\
0 \\
0 \\
0\end{array}$ & $\begin{array}{l}0 \\
0 \\
0 \\
0 \\
0 \\
0 \\
0\end{array}$ & $\begin{array}{l}0 \\
0 \\
0 \\
0 \\
0 \\
0 \\
0\end{array}$ & $\begin{array}{r}0 \\
0 \\
0 \\
0 \\
1002 \pi 5 \\
0 \\
+0,215\end{array}$ \\
\hline 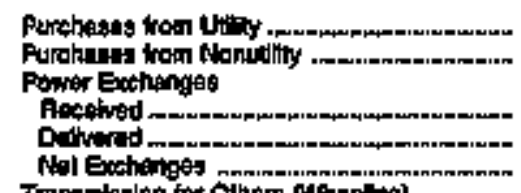 & $\begin{array}{r}168,003 \\
0 \\
0 \\
0 \\
0\end{array}$ & $\begin{array}{r}159,874 \\
0 \\
0 \\
0 \\
0\end{array}$ & $\begin{array}{r}277,113 \\
0 \\
0 \\
0 \\
0\end{array}$ & $\begin{array}{r}42,068 \\
0 \\
0 \\
0 \\
0\end{array}$ & $\begin{array}{r}258,0 \\
0 \\
0 \\
0 \\
0\end{array}$ & $\begin{array}{r}1,45,180 \\
0 \\
240,152 \\
240,152\end{array}$ \\
\hline 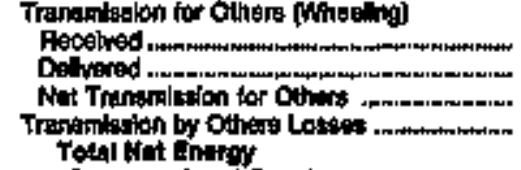 & $\begin{array}{l}0 \\
0 \\
0 \\
0\end{array}$ & $\begin{array}{l}0 \\
0 \\
0 \\
0\end{array}$ & $\begin{array}{l}0 \\
0 \\
0 \\
0\end{array}$ & $\begin{array}{l}0 \\
0 \\
0 \\
0\end{array}$ & $\begin{array}{l}0 \\
0 \\
0 \\
0 \\
0\end{array}$ & $\begin{array}{l}0 \\
0 \\
0 \\
0\end{array}$ \\
\hline 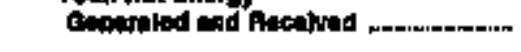 & 104,565 & 159,674 & 277,115 & 425,062 & 208,900 & 1970,5s \\
\hline 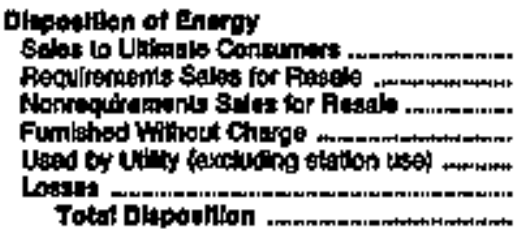 & $\begin{array}{r}172,486 \\
0 \\
0 \\
0 \\
2,294 \\
8,774 \\
104,563\end{array}$ & $\begin{array}{r}137,350 \\
0 \\
0 \\
0 \\
0 \\
0 \\
16,604 \\
163,674\end{array}$ & $\begin{array}{r}248,990 \\
0 \\
0 \\
3,688 \\
125 \\
24,781 \\
977,118\end{array}$ & $\begin{array}{r}394,090 \\
0 \\
0 \\
0 \\
3,570 \\
27,402 \\
405,002\end{array}$ & 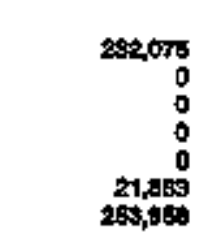 & $\begin{array}{r}1,716,300 \\
20,907 \\
0 \\
39,407 \\
94,250 \\
1,679,680\end{array}$ \\
\hline
\end{tabular}

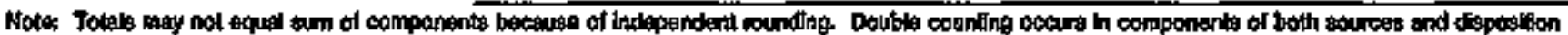

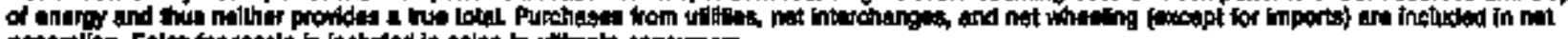

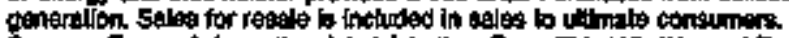

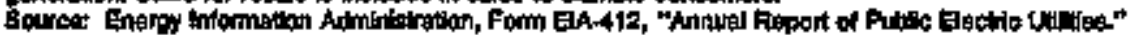


Table 26. Electric Energy Account by Mejor U.S. Publicly Owned Electric Uttllty Whiln State, 1984 (Continued)

(Megawatthours)

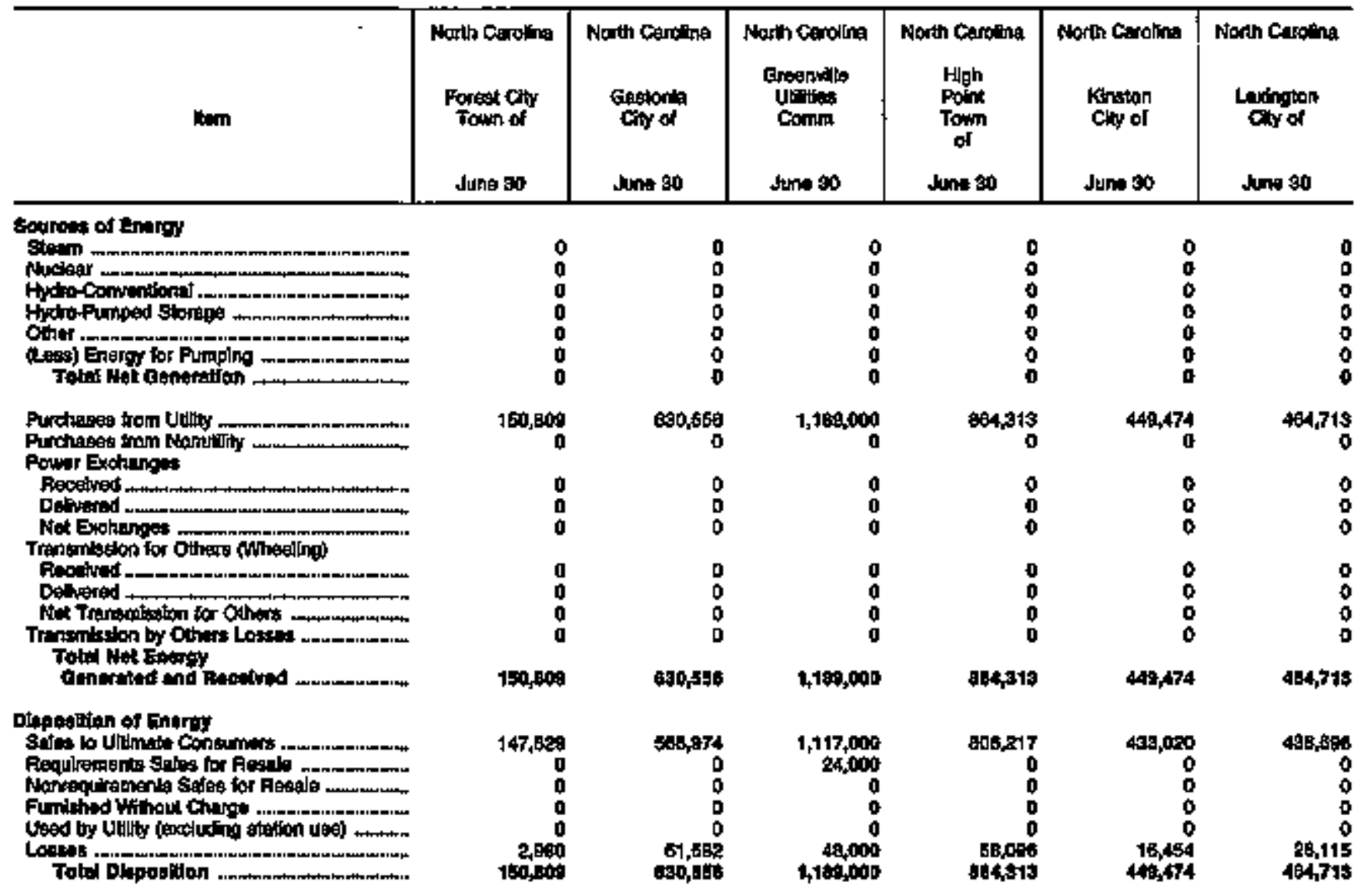

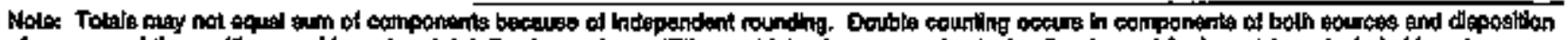

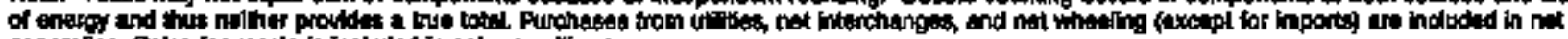

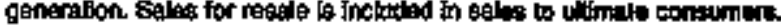

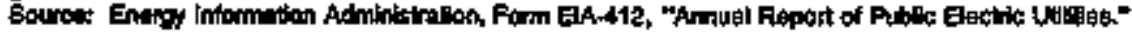


Table 26. Electric Eneroy Account by Major U.S. Publicly Owned Eloctric Utility Withln State, 1994 (Continued)

(Megawatthours)

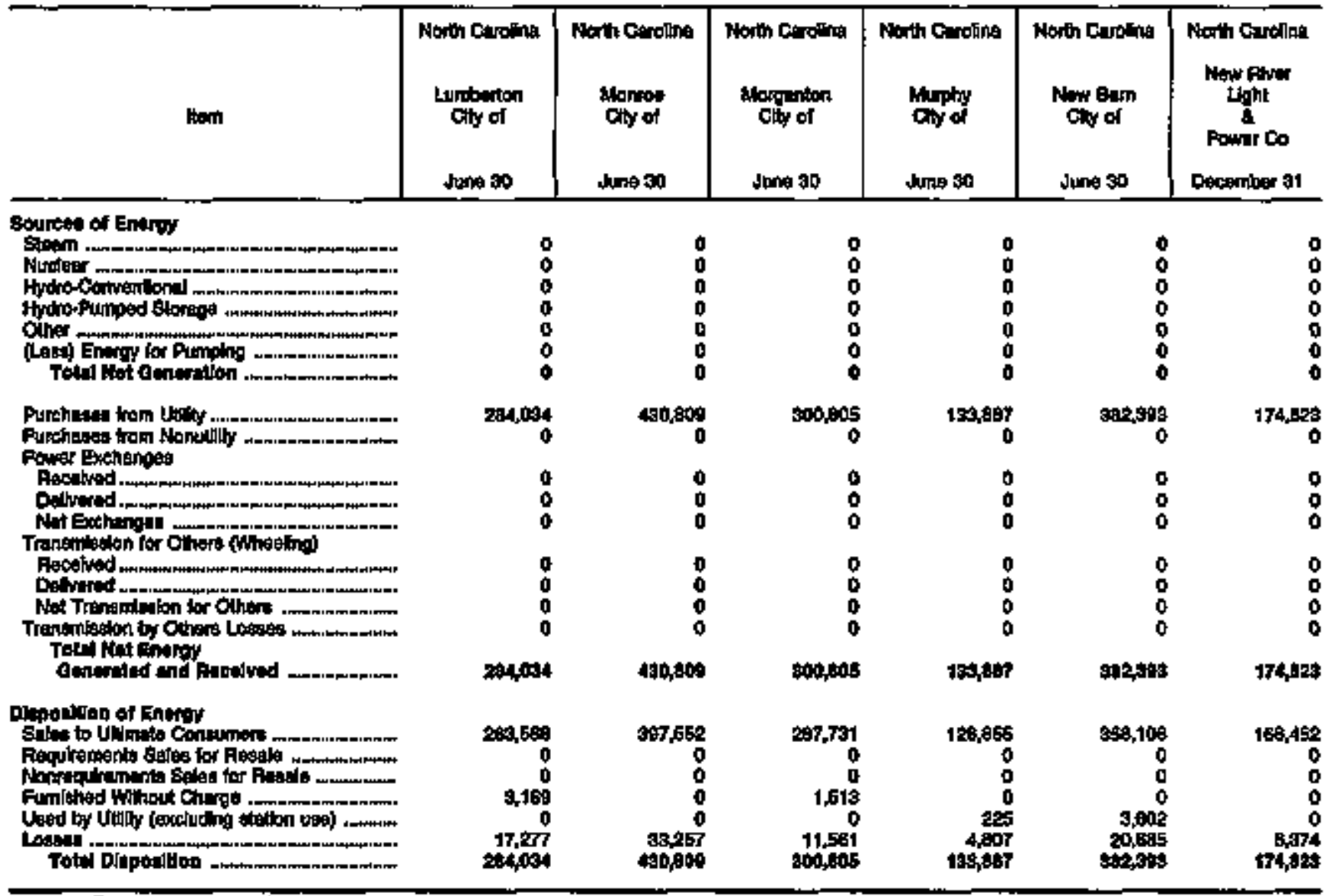

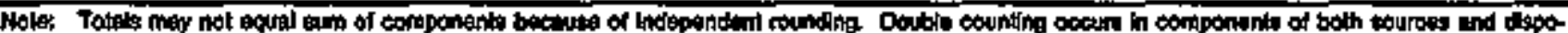

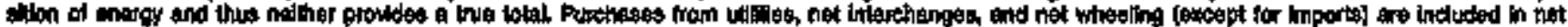

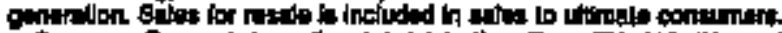

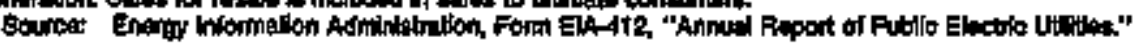


Table 26. Electric Energy Aocount by Major U.S. Publicly Owned Electric Utilty Within Stote, 1894 (Continued)

(Megawatthours)

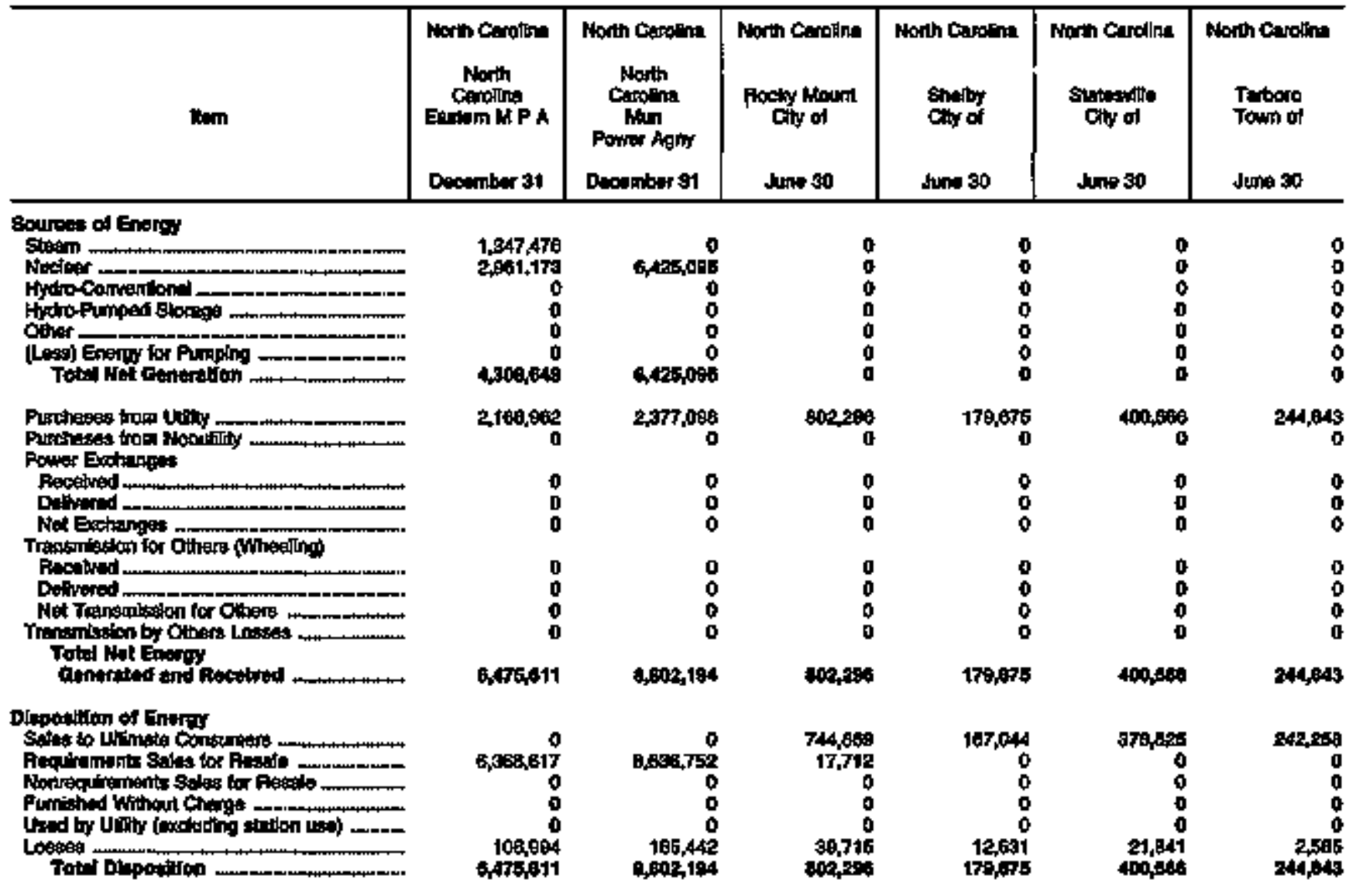

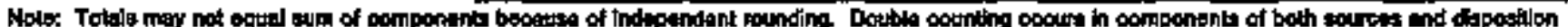

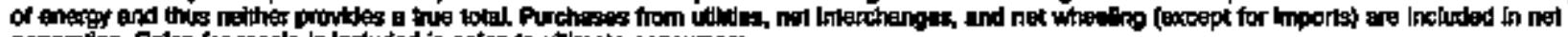

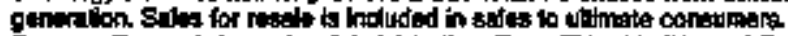

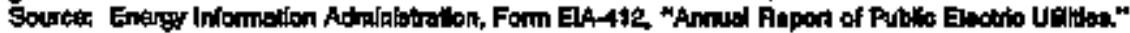


Tabie 26. Eiectric Energy Acoount by Major U.S. Publicly Owned Electric Utilty Within State, 1994 (Continued)

(Megawatthours)

\begin{tabular}{|c|c|c|c|c|c|c|}
\hline ham & $\begin{array}{l}\text { Morth Carotin } \\
\text { Whathington } \\
\text { City of } \\
\text { Jung so }\end{array}$ & $\begin{array}{l}\text { North Cardilna } \\
\text { Whityon of } \\
\text { June } 3: 0\end{array}$ & 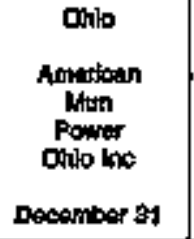 & 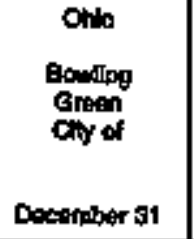 & 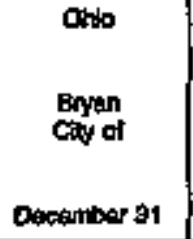 & $\begin{array}{l}\text { Onis } \\
\text { Citing } \\
\text { Cony of } \\
\text { Docomber } 31\end{array}$ \\
\hline 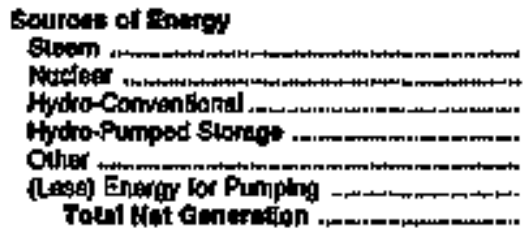 & $\begin{array}{l}0 \\
0 \\
0 \\
0 \\
0 \\
0 \\
0\end{array}$ & $\begin{array}{l}0 \\
0 \\
0 \\
0 \\
0 \\
0 \\
0 \\
0\end{array}$ & $\begin{array}{r}1,215,060 \\
0 \\
0 \\
0 \\
0 \\
0 \\
1,215,015\end{array}$ & $\begin{array}{l}0 \\
0 \\
0 \\
0 \\
0 \\
0 \\
0 \\
0\end{array}$ & 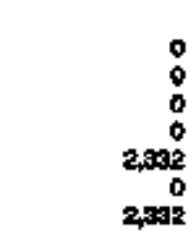 & $\begin{array}{l}0 \\
0 \\
0 \\
0\end{array}$ \\
\hline 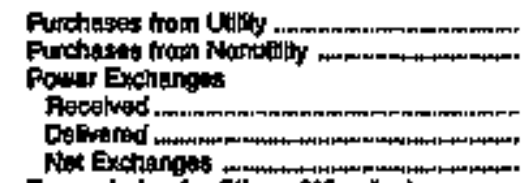 & $\begin{array}{r}252,470 \\
0 \\
0 \\
0 \\
0\end{array}$ & $\begin{array}{r}1,034,904 \\
0 \\
0 \\
0 \\
0\end{array}$ & $\begin{array}{r}3,6,7,168 \\
0 \\
0 \\
0 \\
0\end{array}$ & $\begin{array}{r}311,652 \\
0 \\
0 \\
0 \\
0\end{array}$ & $\begin{array}{r}209,700 \\
0 \\
0 \\
0\end{array}$ & $\begin{array}{r}157,750 \\
0\end{array}$ \\
\hline 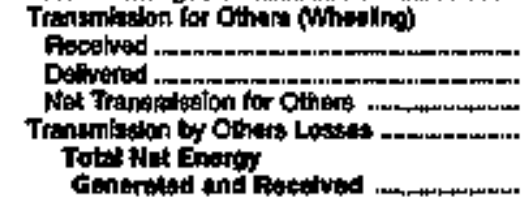 & $\begin{array}{r}0 \\
0 \\
0 \\
0 \\
252,470\end{array}$ & $\begin{array}{r}0 \\
0 \\
0 \\
0 \\
1004,0404\end{array}$ & $\begin{array}{r}39,079 \\
39,679 \\
0 \\
0 \\
5,072,204\end{array}$ & $\begin{array}{r}0 \\
0 \\
0 \\
0 \\
311,452\end{array}$ & $\begin{array}{r}0 \\
0 \\
0 \\
0 \\
212,02\end{array}$ & $\begin{array}{r}0 \\
0 \\
0 \\
0 \\
\$ \$ 7,750\end{array}$ \\
\hline 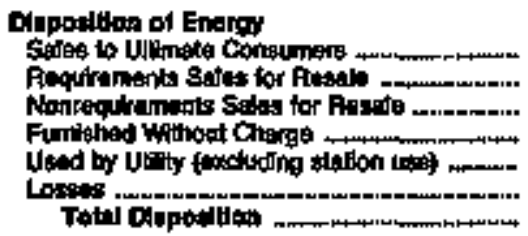 & $\begin{array}{r}235,623 \\
0 \\
0 \\
0 \\
0 \\
+69,47 \\
202,470\end{array}$ & $\begin{array}{r}913777 \\
62,89 ? \\
0 \\
0 \\
0 \\
58,240 \\
1,034,904\end{array}$ & $\begin{array}{r}737,137 \\
4,163,028 \\
0 \\
0 \\
0 \\
140,858 \\
5,072,224\end{array}$ & $\begin{array}{r}208,245 \\
2,818 \\
0 \\
3,591 \\
125 \\
11,878 \\
311,1,82\end{array}$ & $\begin{array}{r}200,642 \\
0 \\
0 \\
3,210 \\
1,306 \\
8,880 \\
212,120\end{array}$ & $\begin{array}{r}147,342 \\
0 \\
0 \\
2,210 \\
309 \\
7,800 \\
t=7,750\end{array}$ \\
\hline
\end{tabular}

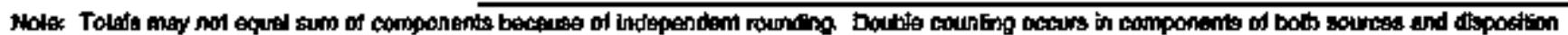

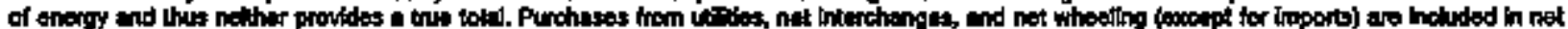

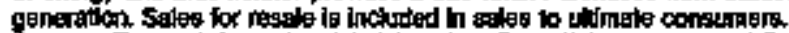

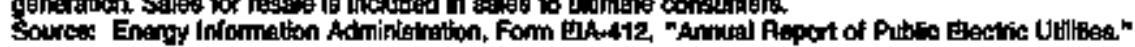


Table 25. Eleotrlo Energy Account by Major U.S. Publichy Owned Electric Utibity With State, 1994 (Continued)

(Megawatthours)

\begin{tabular}{|c|c|c|c|c|c|c|}
\hline ltert & 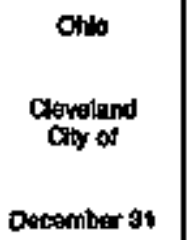 & $\begin{array}{l}\text { Onlo } \\
\text { Cinde } \\
\text { City ef } \\
\text { Docomber os }\end{array}$ & $\begin{array}{l}\text { Oniw } \\
\text { Columbits } \\
\text { Ony of } \\
\text { Deownber } 31\end{array}$ & $\begin{array}{c}\text { Onio } \\
\text { Oyshosen } \\
\text { Fallo } \\
\text { Ciny ol } \\
\text { Dewomber } 31\end{array}$ & $\begin{array}{l}\text { Otio } \\
\text { Dower } \\
\text { Cofy of } \\
\text { Deomber } 31\end{array}$ & $\begin{array}{l}\text { Onio } \\
\text { Hivilion of } \\
\text { Dencimber } 31\end{array}$ \\
\hline 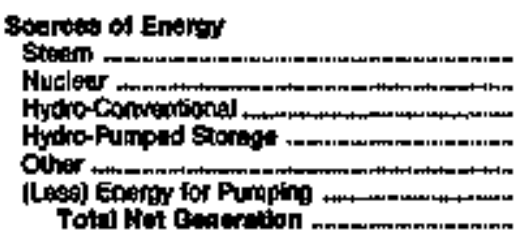 & $\begin{array}{r}0 \\
0 \\
0 \\
0 \\
10,976 \\
10,978\end{array}$ & $\begin{array}{l}0 \\
0 \\
0 \\
0 \\
0 \\
0 \\
0 \\
0\end{array}$ & $\begin{array}{r}0 \\
0 \\
10,032 \\
0 \\
0 \\
0 \\
10,1002\end{array}$ & $\begin{array}{l}0 \\
0 \\
0 \\
0 \\
0 \\
0 \\
0\end{array}$ & $\begin{array}{r}75,67 \\
0 \\
0 \\
0 \\
0 \\
0 \\
75,67\end{array}$ & 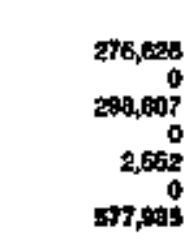 \\
\hline 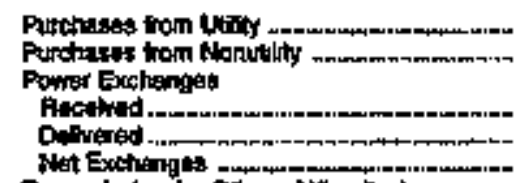 & 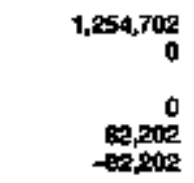 & $\begin{array}{r}138,059 \\
0 \\
0 \\
0 \\
0\end{array}$ & $\begin{array}{r}08,00 \% \\
0 \\
0 \\
0 \\
0\end{array}$ & $\begin{array}{r}392,286 \\
0 \\
0 \\
0 \\
0\end{array}$ & $\begin{array}{r}T 17,492 \\
0 \\
0 \\
0 \\
0\end{array}$ & $\begin{array}{r}191,594 \\
0 \\
3,498 \\
23,016 \\
-15,177\end{array}$ \\
\hline 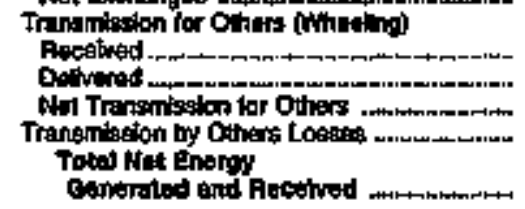 & $\begin{array}{r}0 \\
0 \\
0 \\
-17,150 \\
1,160,09\end{array}$ & $\begin{array}{l}0 \\
0 \\
0 \\
0\end{array}$ & $\begin{array}{r}401,304 \\
401,304 \\
0 \\
0 \\
67,4,059\end{array}$ & 3512,206 & 198,35 & $\begin{array}{r}0 \\
0 \\
0 \\
0 \\
740,392\end{array}$ \\
\hline 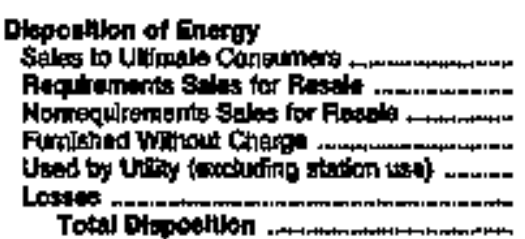 & $\begin{array}{r}1,097,027 \\
0 \\
0 \\
0 \\
1,791 \\
107,615 \\
1,160,92,\end{array}$ & $\begin{array}{r}131,+25 \\
0 \\
0 \\
0 \\
0 \\
4,104 \\
13+40\end{array}$ & 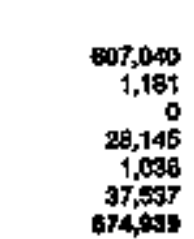 & $\begin{array}{r}200,693 \\
0 \\
0 \\
10,429 \\
132 \\
20,142 \\
2,280\end{array}$ & $\begin{array}{r}169,705 \\
0 \\
0 \\
0 \\
10 \\
10 \\
198,984\end{array}$ & $\begin{array}{r}549,139 \\
135,555 \\
18,190 \\
10,986 \\
0 \\
26,109 \\
740,492\end{array}$ \\
\hline
\end{tabular}

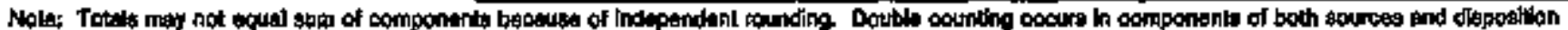

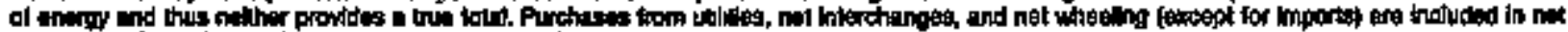

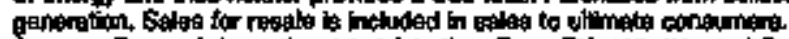

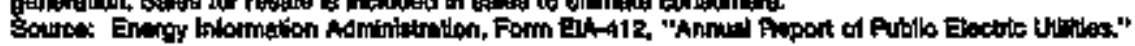


Table 26. Electric Energy Account by Major U.S. Publioly Owned Electric Utilly Within State, 1994 (Continued)

(Megawatthours)

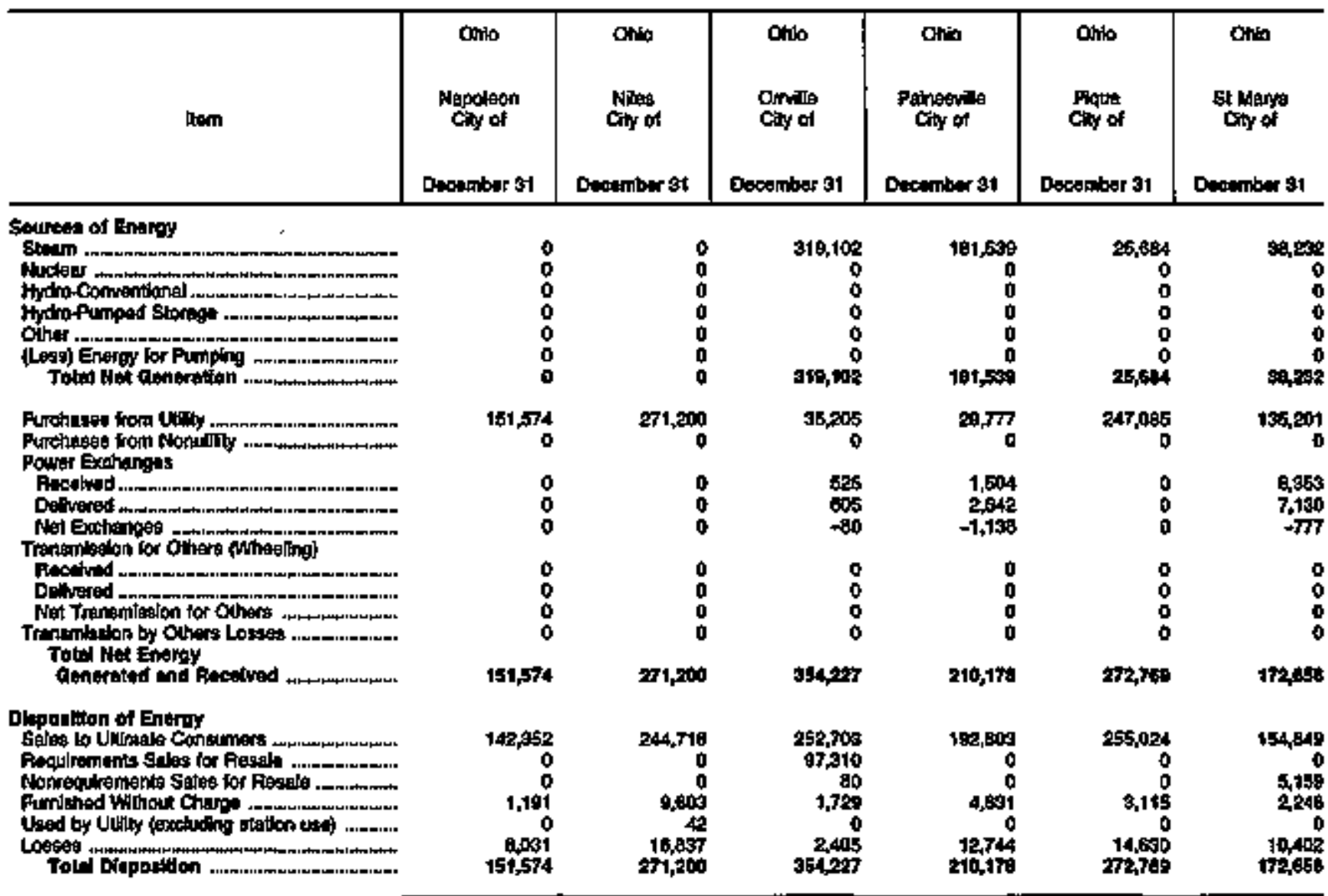

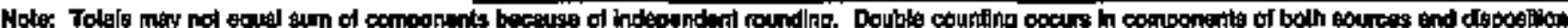

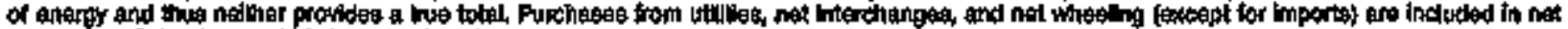

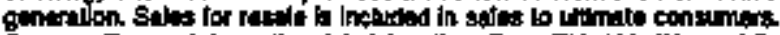

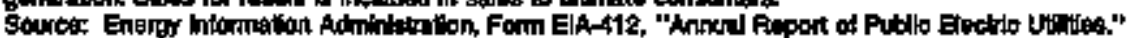


Table 26. Electric Energy Account by Major U.8. Publidy Omed Elootrtc Utilly Withlin state, 1994 (Continued)

(Megawatthours)

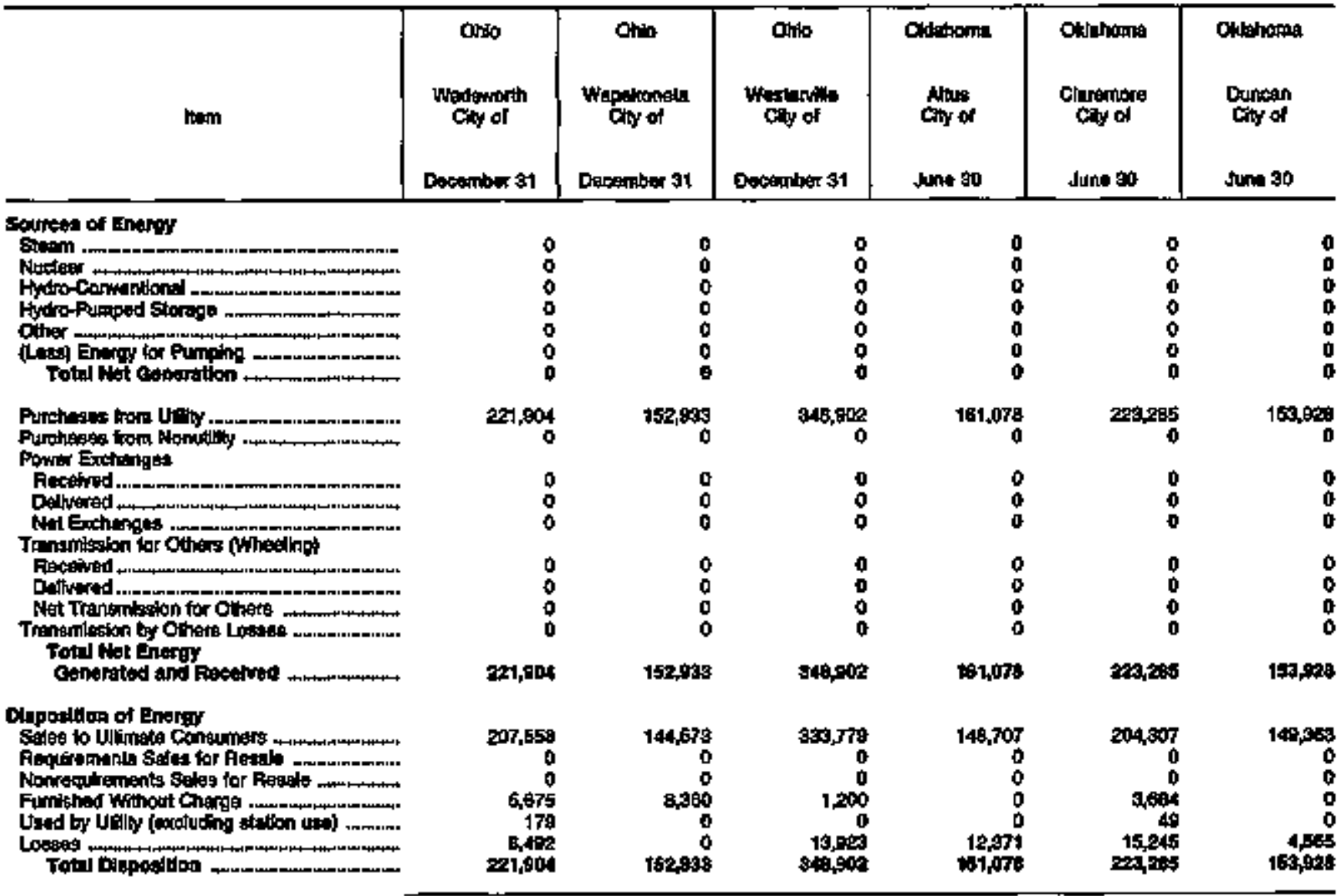

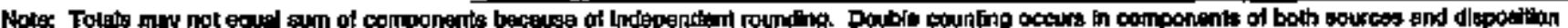

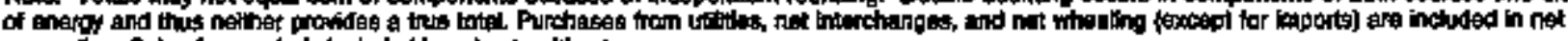

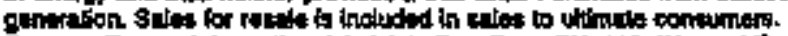

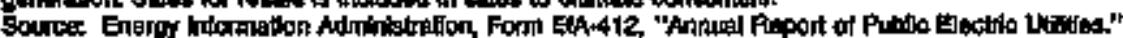


Table 26. Electric Energy Account by Major U.S. Pubilely Owned Electrlc Utllty Writhin State, 1994 (ContInured)

(Megawatthours)

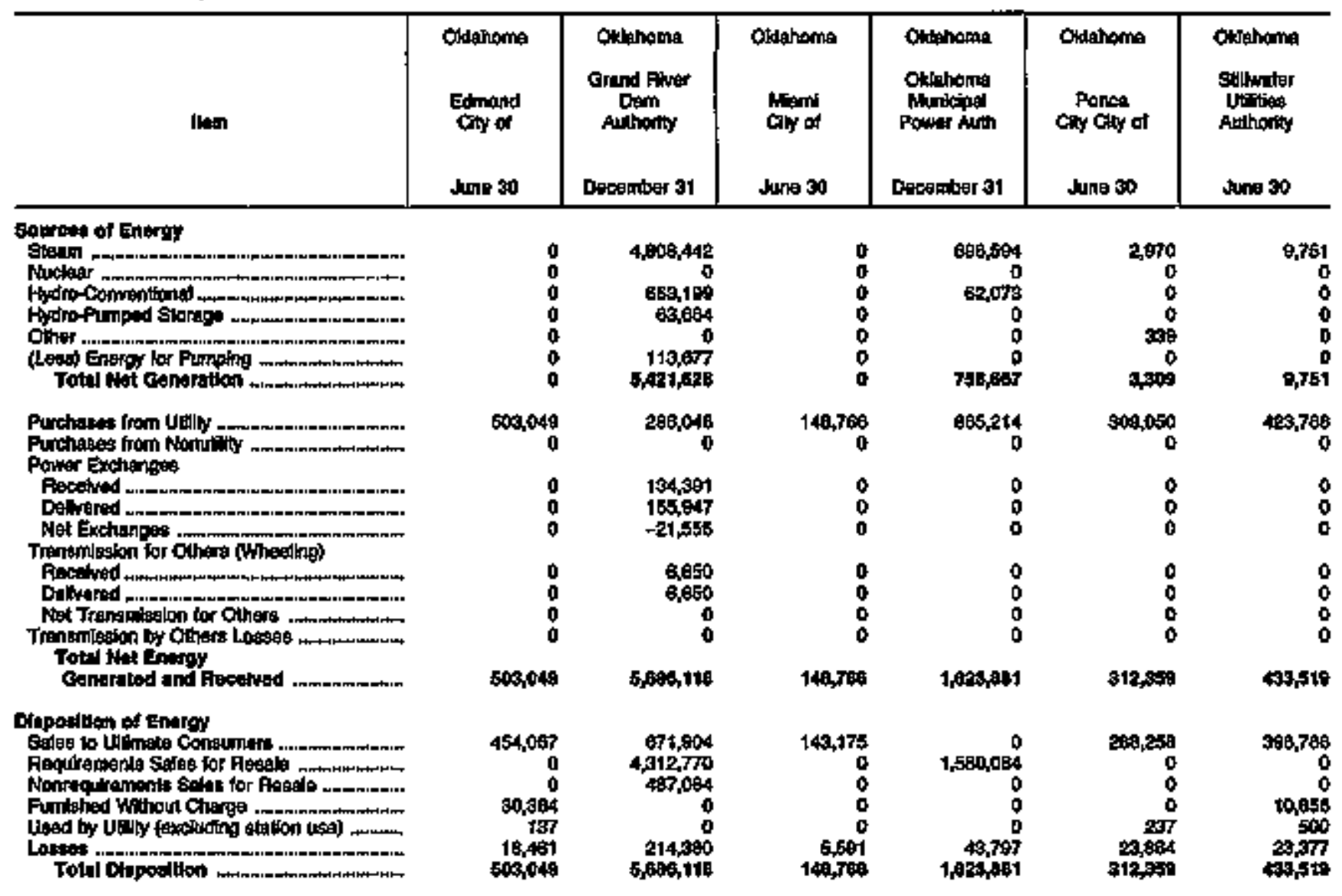

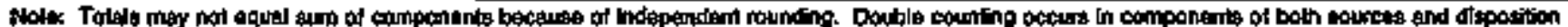

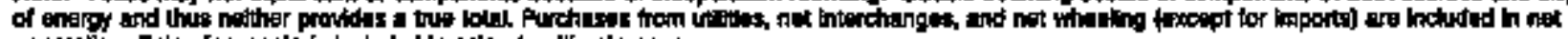

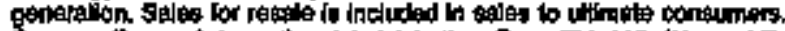

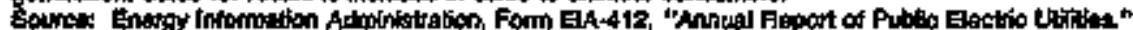


Table 26. Electrle Energy Account by Major U.S. Publkbly Omined Electric Utility Within State, 1994 (Continued) (Megawatthours)

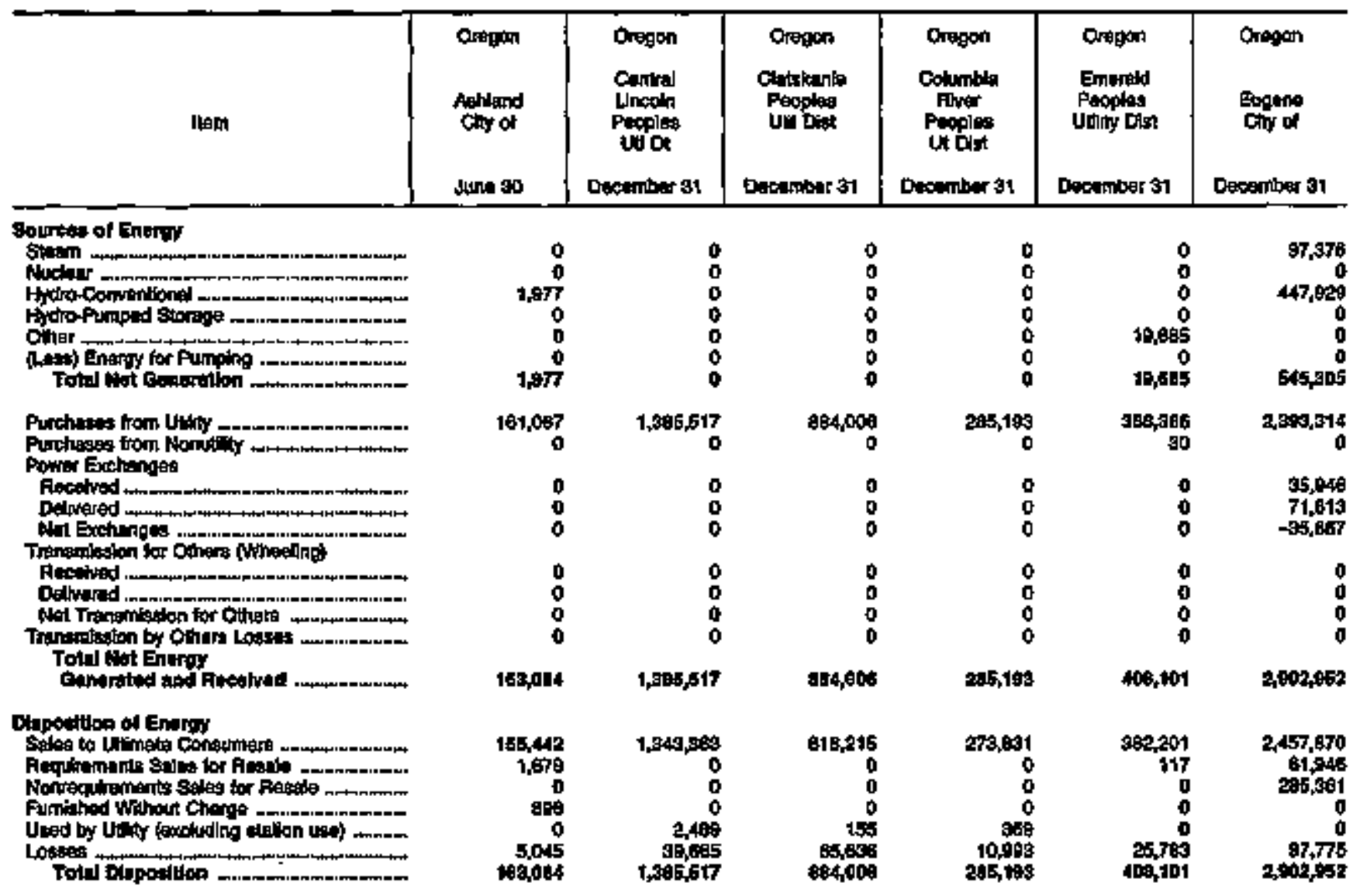

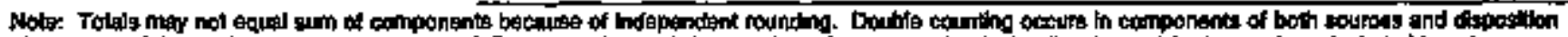

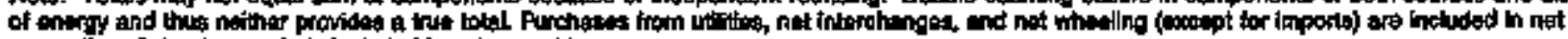

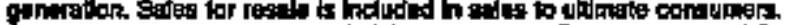

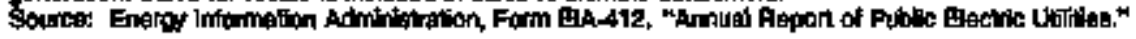


Table 26. Electrk Energy Account by Major U.S. Pubilely Owned Electrc Uticty Within State, 1994 (Continued)

(Megawatthours)

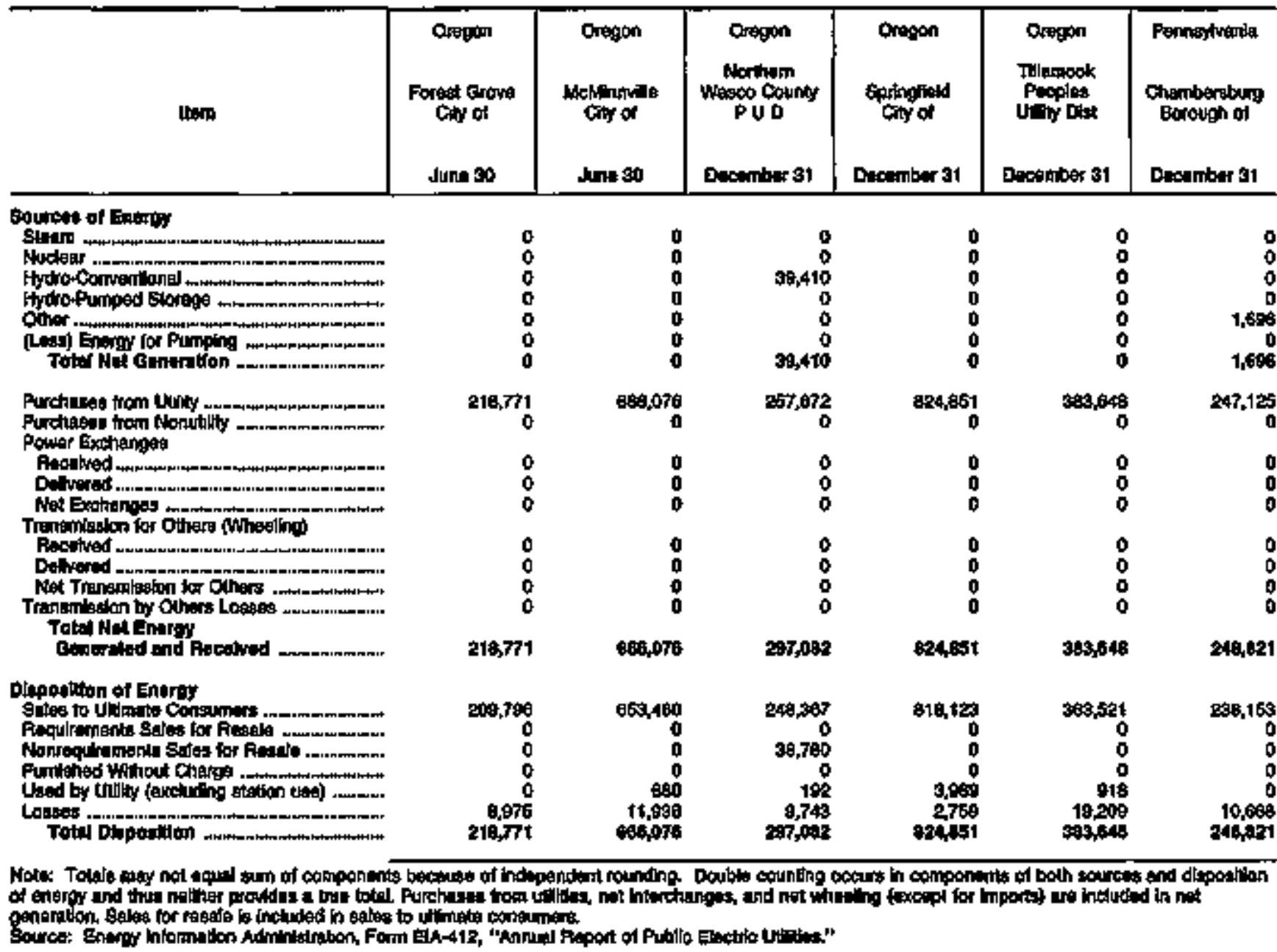


Tabje 26. Etectrlc Energy Account by Mejor US. Publicly Owned Electrle Utility within Stake, 1994 (Continued)

(Megawatthours)

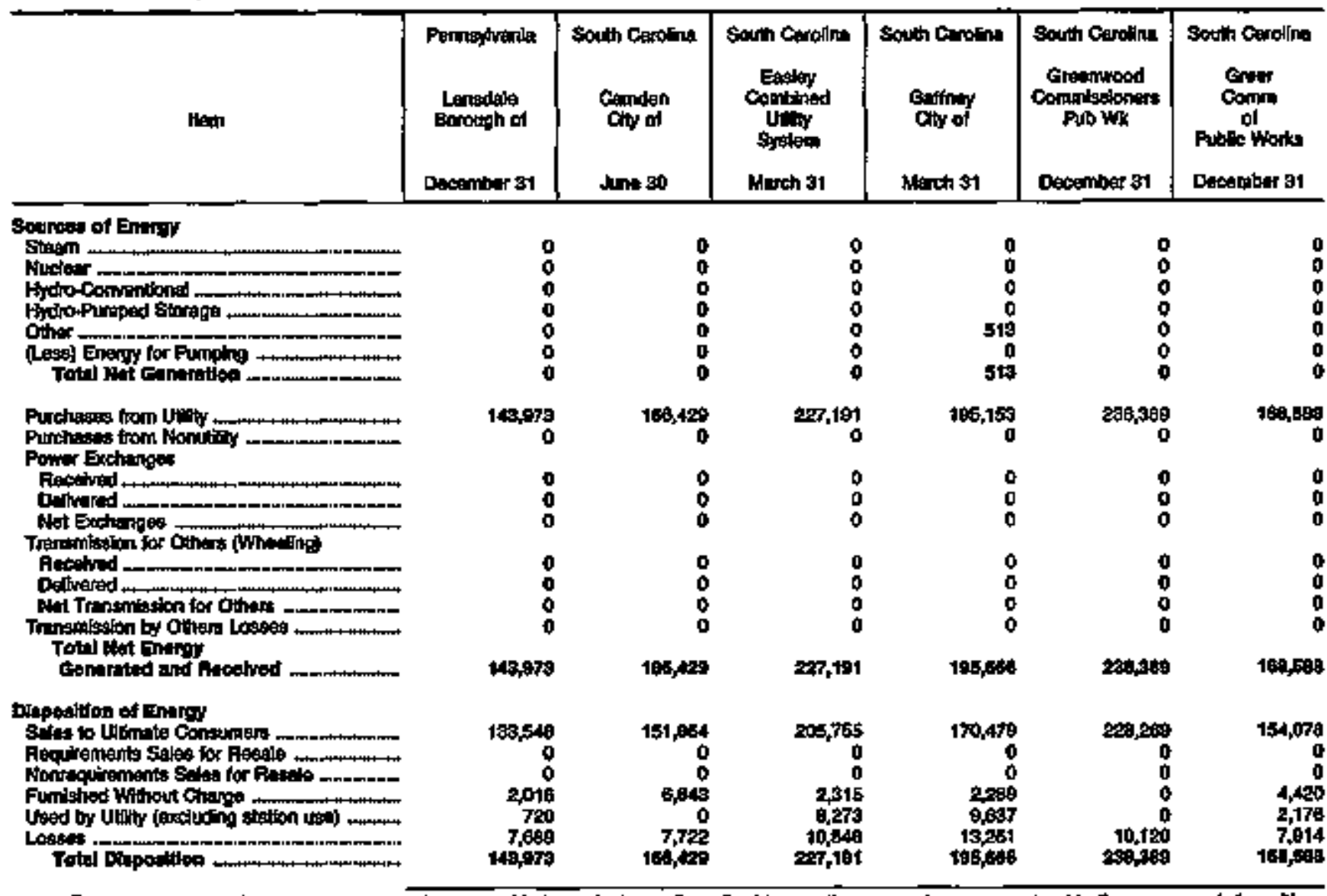

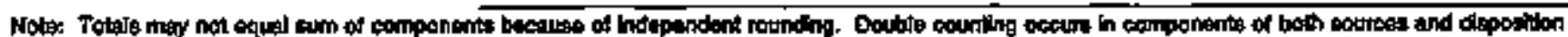

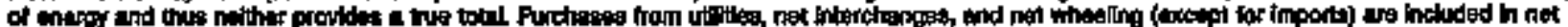

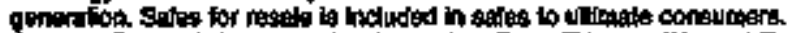

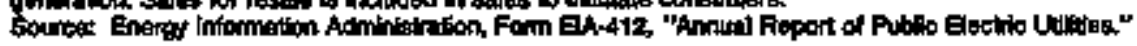


Table 26. Electric Energy Account by Mejor U.S. Publkly Owned Electric Utinity Within State, 1994 (Corlinued)

(Megawatthours)

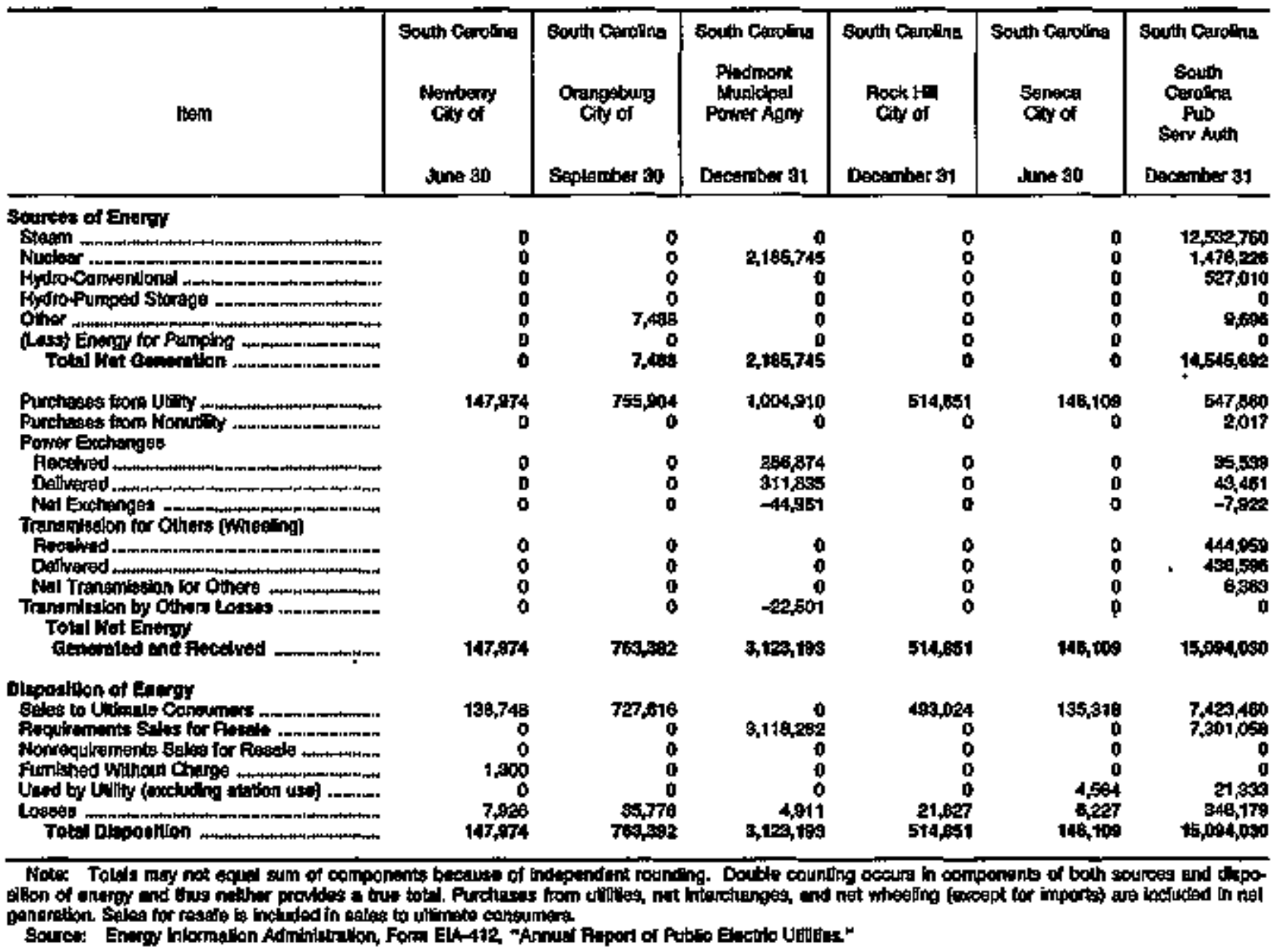


Table 26. Electrto Enorgy Account by Major U.S. Publicly Owned Electrlc Utifity Within State, 1994 (Contlnued)

(Megawatthours)

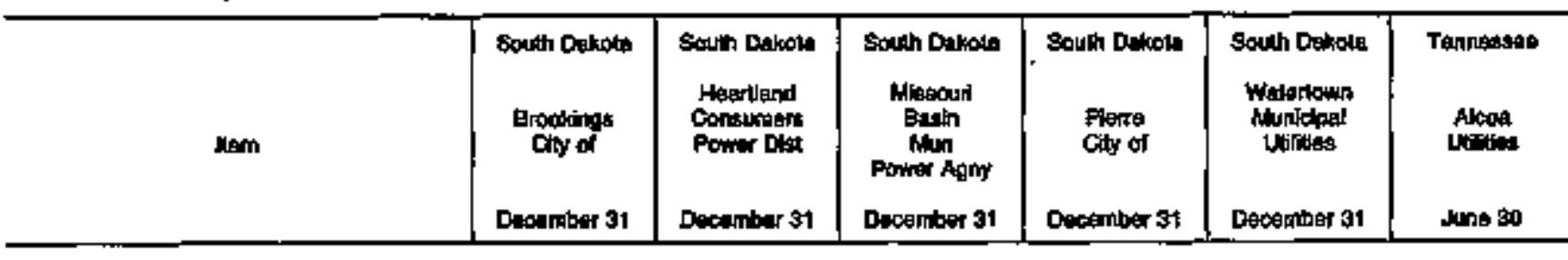

\section{Bources of Fonery}

Steem

Mudolor

Hudrocomrontinal .

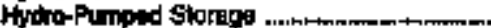

Qihner

(List) Eraroy for Pumping -

Takal No contrith

Pumbareg trom Ualiny

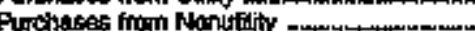

Powitr Exola unows

Rocelved

Dolitifed

Nats Exuloninges

Transinistion for Onters Mines:ingl

fincentured.

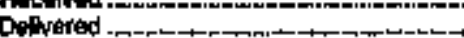

Mas Tiandint

Tranesulgalon by Dohars Looges . Total Hat Energy

toneratod end fincolved

0
0
0
0
0
0
0

305,470
0
0
0
0
0
369,470

191,106

100.150

0

$1,90,102$

0

12091
2024

10257

$$
19,210
$$$$
-10,573
$$

0
0
0
0
0
0
0

0
0
0
0
0

o

o

$\begin{array}{ll}\mathbf{0} & \mathbf{0} \\ \mathbf{0} & \mathbf{0} \\ 0 & 0\end{array}$

0

$19+, 029$

$473+197$

blepotition of Emergy

Slas to Unirale Contumers

Requlrimantis Saleg for Rogele

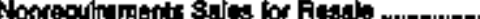

Funtalied Whout Charge

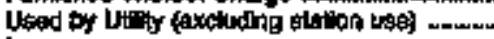

Losses

Totel Dipodition

163
290,007
193,091
0
0
40,046
479,607

146.697

ग4,617

$\begin{array}{rr}1,051,197 & 74,617 \\ 646,997 & 0 \\ 0 & 0 \\ 0 & 2,000 \\ 40,300 & 7,501\end{array}$

297,700

0

6.217

233,917
42,389

0

20

27.198

4.pista

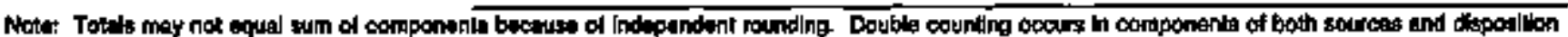

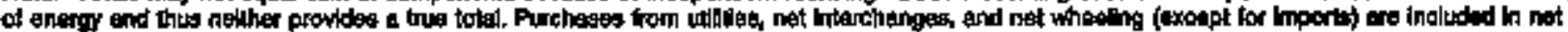

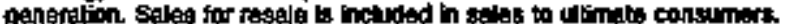

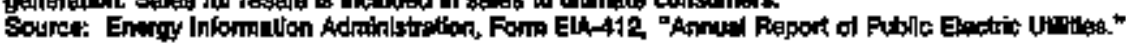


Table 26. Electric Energy Aocount by Major U.S. Publicly Owned Electric Utilly Withln State, 1994 (Continued)

(Megawatthours)

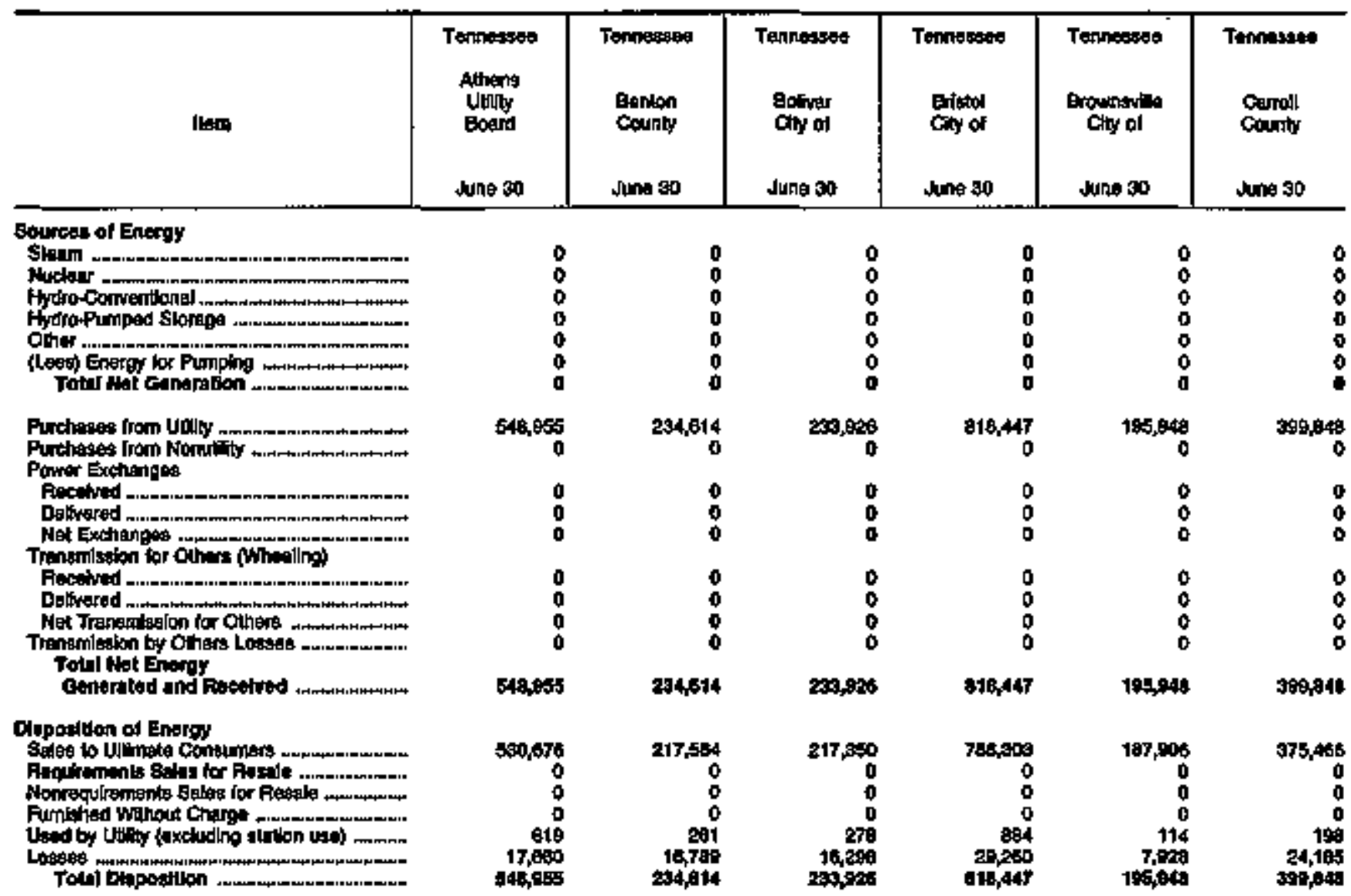

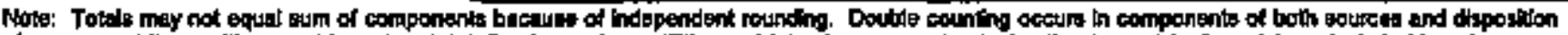

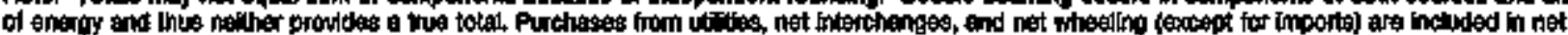

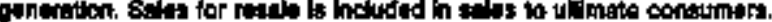

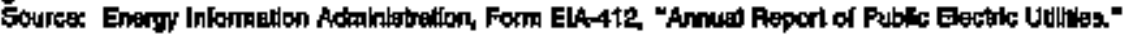


Table 26. Electrio Energy Account by Malor U.S. Publicly Owned Electrlc Utilty Wthin State, 1994 (Continued)

(Megawatthours)

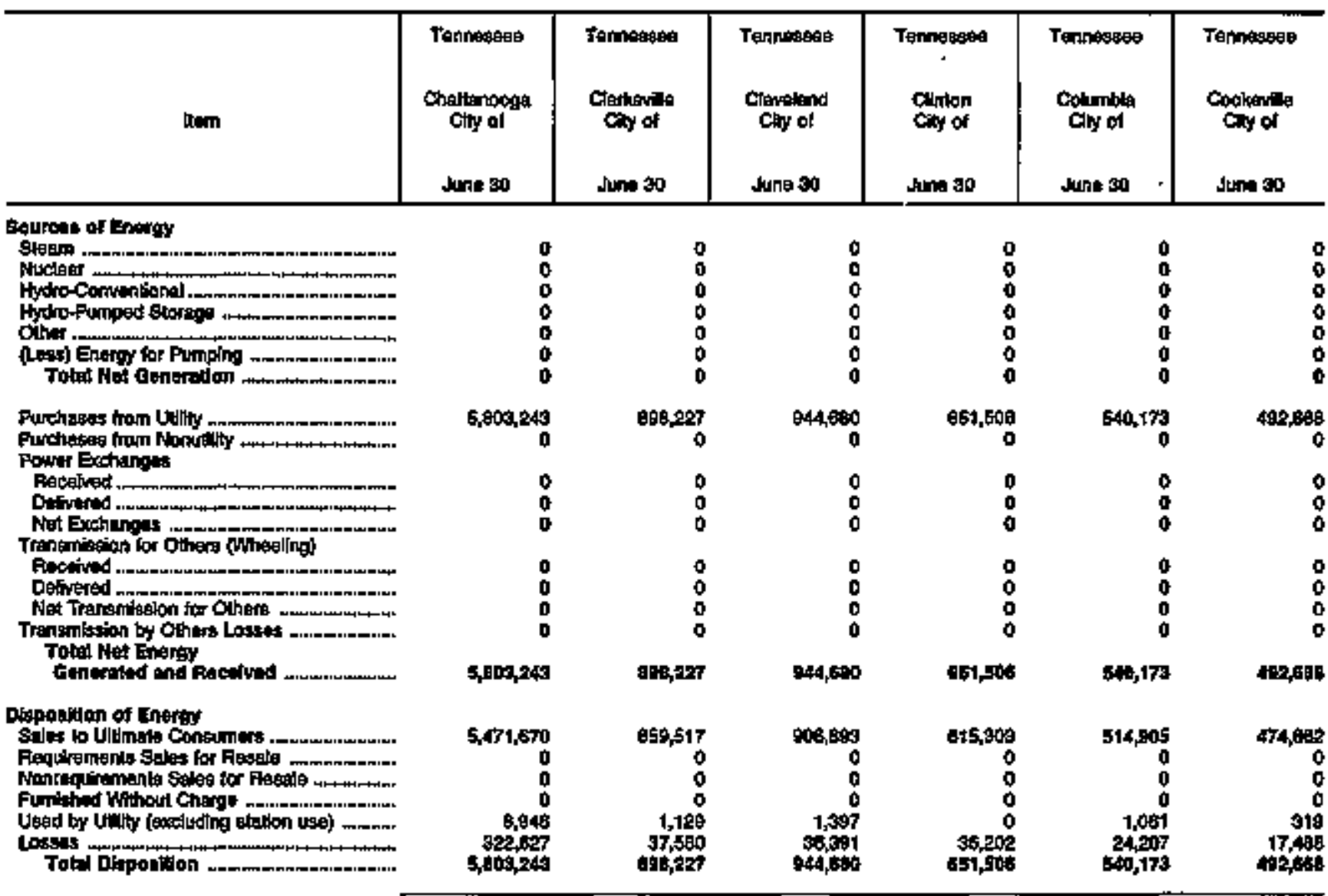

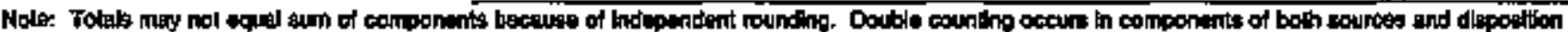

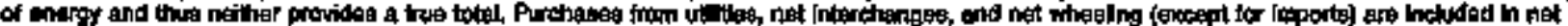

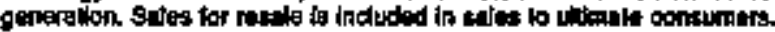

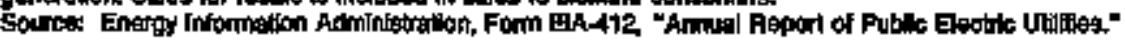


Table 26. Electric Energy Account by Major U.S. Publiely Owned Electric Utilly Withln State, 1994 (Contimuad)

(Megawatthours)

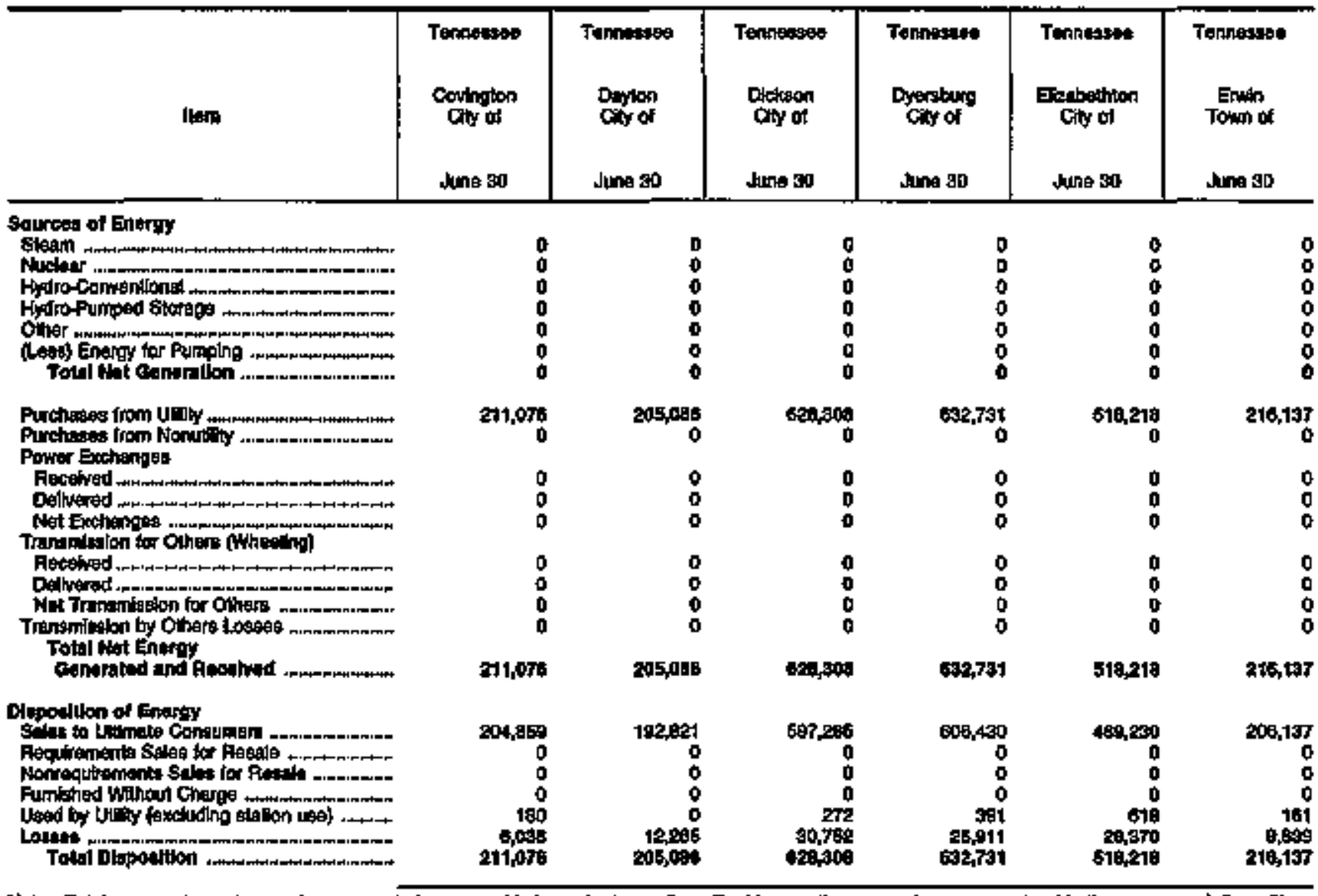

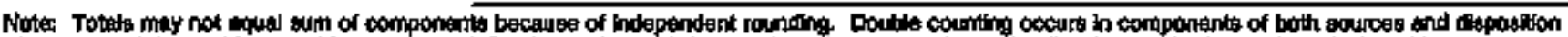

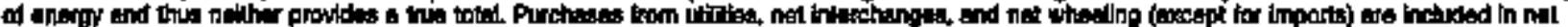

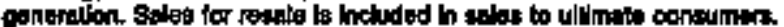

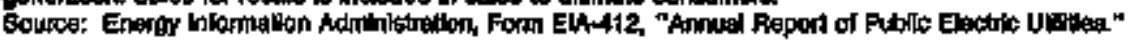


Table 26. Electrle Energy Account by Major U.S. Publoty Owned Electric Utilty Within State, 1994 (Continued)

(Megawatthours)

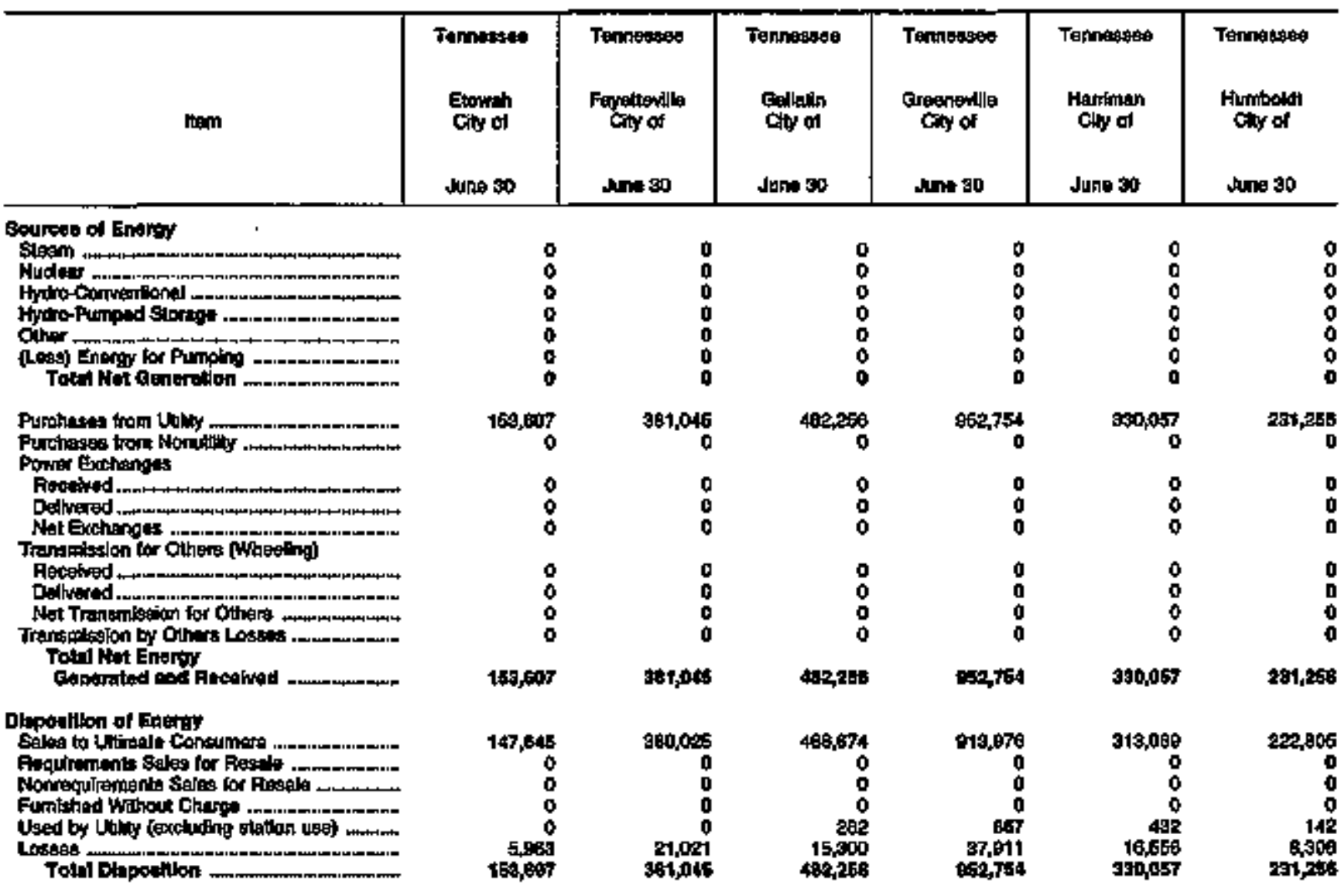

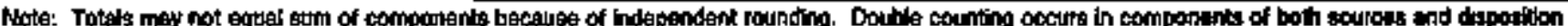

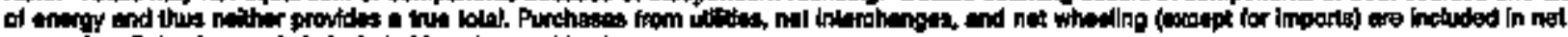

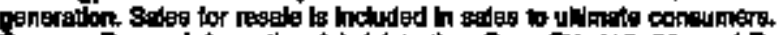

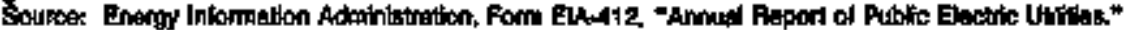


Table 26. Electric Energy Account by Mejor U.S. Pubilich Owned Electric Utillyy Withla State, 1994 (Continued)

(Megawatthours)

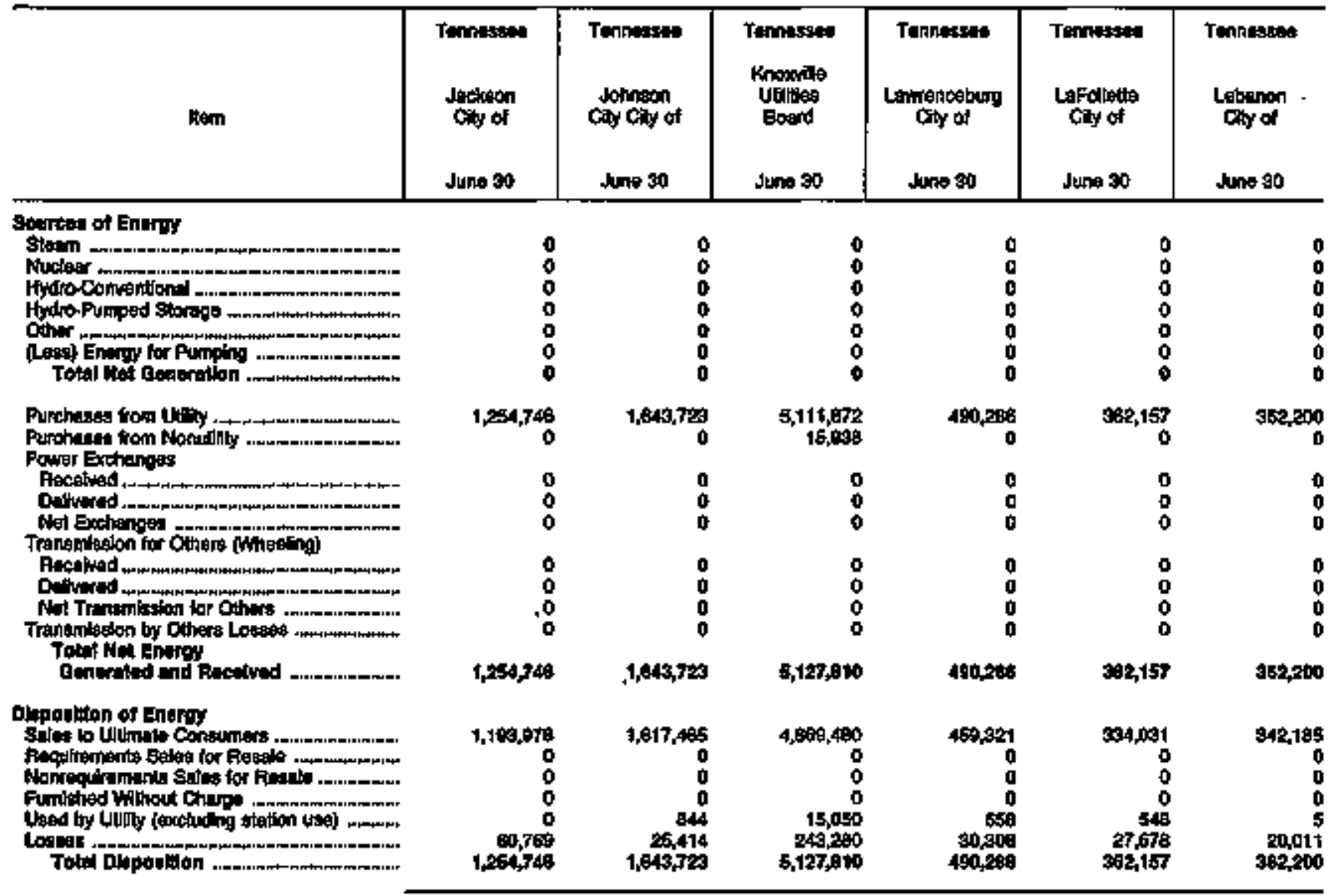

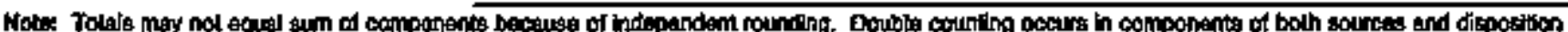

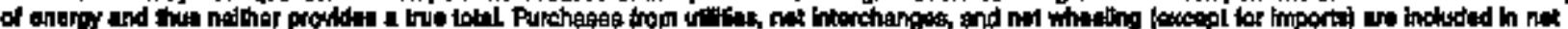

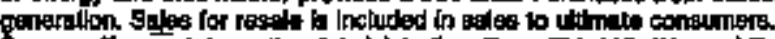

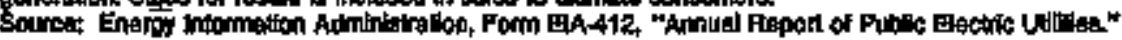


Table 26. Electrio Energy Account by Major U.S. Publleby Omned Eloctrio Wtility Within State, 1994 (Conlinued) (Megawatthours)

\begin{tabular}{|c|c|c|c|c|c|c|}
\hline Aem & $\begin{array}{l}\text { Tennesses } \\
\text { Lenoit } \\
\text { Ciy Chy of } \\
\text { June } 30\end{array}$ & $\begin{array}{l}\text { Tenrebsen } \\
\text { Lewloburg } \\
\text { City of } \\
\text { Jume } 30\end{array}$ & $\begin{array}{l}\text { Tannesses } \\
\text { Lodingten } \\
\text { Cing of } \\
\text { Juno } 30\end{array}$ & $\begin{array}{l}\text { Tennessas: } \\
\text { Loudon } \\
\text { Ubitides } \\
\text { Bourd } \\
\text { Jurre sal }\end{array}$ & $\begin{array}{l}\text { Thinossese } \\
\text { Muryilio } \\
\text { Jifitiss } \\
\text { June bo }\end{array}$ & 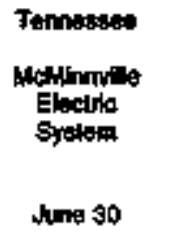 \\
\hline 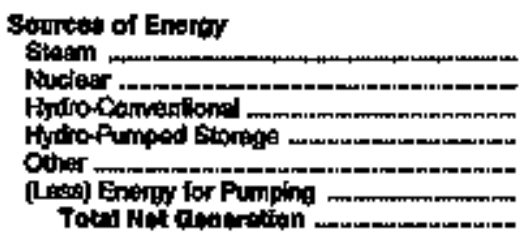 & $\begin{array}{l}0 \\
0 \\
0 \\
0 \\
0 \\
0 \\
0\end{array}$ & $\begin{array}{l}0 \\
0 \\
0 \\
0 \\
0 \\
0 \\
0\end{array}$ & $\begin{array}{l}0 \\
0 \\
0 \\
0 \\
0 \\
0 \\
0\end{array}$ & $\begin{array}{l}0 \\
0 \\
0 \\
0 \\
0 \\
0 \\
0\end{array}$ & $\begin{array}{l}0 \\
0 \\
0 \\
0 \\
0 \\
0 \\
0\end{array}$ & $\begin{array}{l}0 \\
0 \\
0 \\
0 \\
0 \\
0 \\
0\end{array}$ \\
\hline 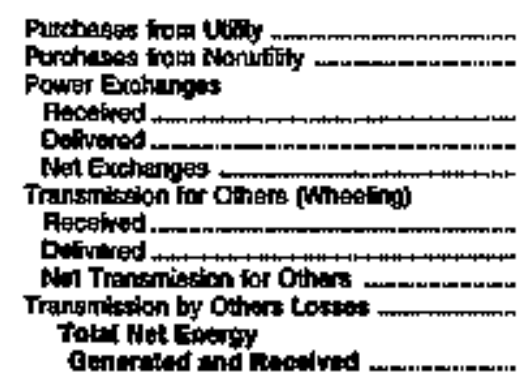 & $\begin{array}{r}1,100,012 \\
0 \\
0 \\
0\end{array}$ & $\begin{array}{r}290,141 \\
0 \\
0 \\
0 \\
0\end{array}$ & $\begin{array}{r}416,025 \\
0 \\
0 \\
0 \\
0\end{array}$ & $\begin{array}{r}285,981 \\
0 \\
0 \\
0 \\
0\end{array}$ & $\begin{array}{r}665,476 \\
0 \\
0 \\
0 \\
0\end{array}$ & $\begin{array}{r}0 \\
0 \\
0 \\
0 \\
2 \times 15 \times 3\end{array}$ \\
\hline 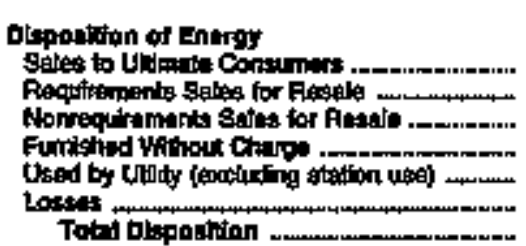 & $\begin{array}{r}1,068,488 \\
0 \\
0 \\
0 \\
570 \\
41,874 \\
1,109,012\end{array}$ & $\begin{array}{r}2 \pi, 800 \\
0 \\
0 \\
0 \\
457 \\
10,004 \\
20,141\end{array}$ & $\begin{array}{r}389,409 \\
0 \\
0 \\
0 \\
601 \\
28,800 \\
415,005\end{array}$ & $\begin{array}{r}278,675 \\
0 \\
0 \\
0 \\
0 \\
19,256 \\
278,031\end{array}$ & $\begin{array}{r}596,012 \\
0 \\
0 \\
0 \\
0 \\
0 \\
31,404 \\
506,4,45\end{array}$ & 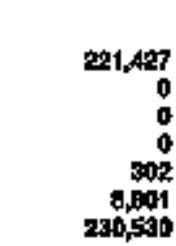 \\
\hline
\end{tabular}

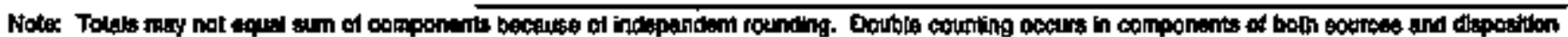

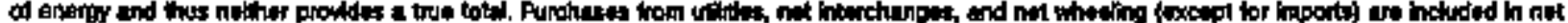

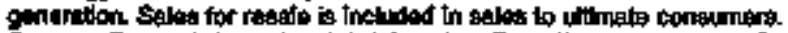

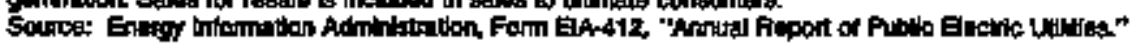


Table 26. Electric Energy Acoount by Major U.S. Publichy Owned Elactric Uility Within State, 1994 (Contrued)

(Megawatthours)

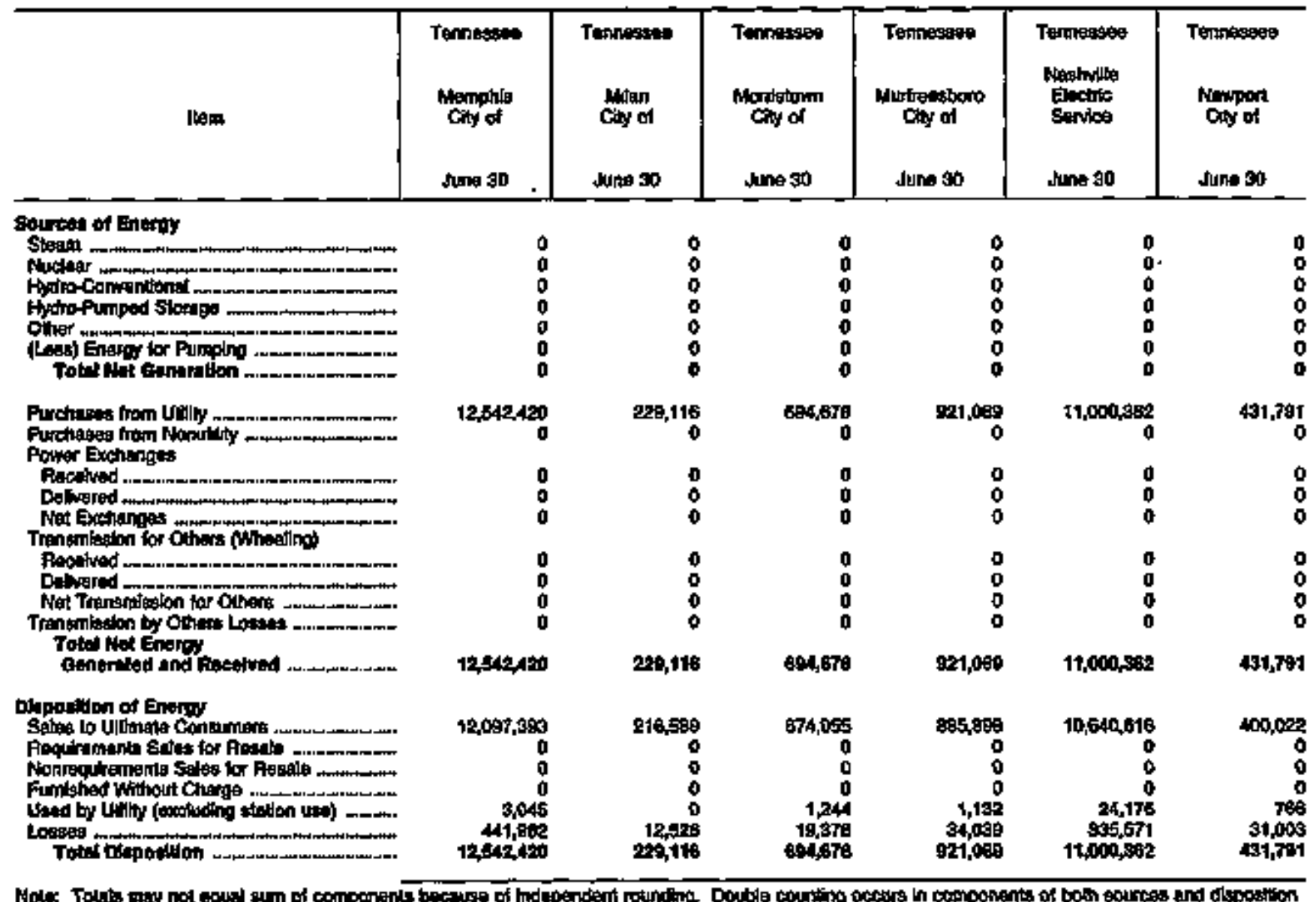

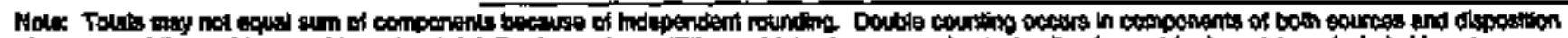

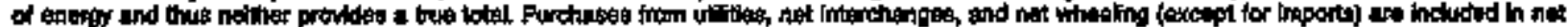

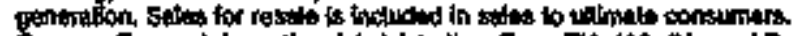

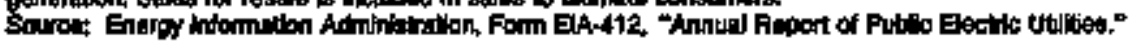


Table 26. Elactrit Enorgy Account by Major U.S. Publicly Owned Eloctric Utilly Withis State, 1994 (Continued) (Megawatthours)

\begin{tabular}{|c|c|c|c|c|c|c|}
\hline lom & 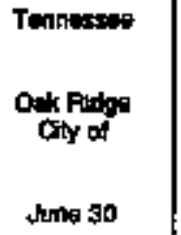 & $\begin{array}{l}\text { Tannossino } \\
\text { Paris } \\
\text { Chy of } \\
\text { Jeune } 30\end{array}$ & 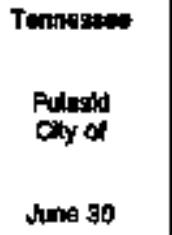 & 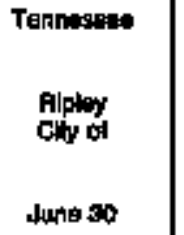 & $\begin{array}{l}\text { Tennossed } \\
\text { Pockwoud } \\
\text { Cty of } \\
\text { him so }\end{array}$ & $\begin{array}{l}\text { Tennewes } \\
\text { Sorviar } \\
\text { County } \\
\text { Glectric } \\
\text { Syution } \\
\text { June so }\end{array}$ \\
\hline 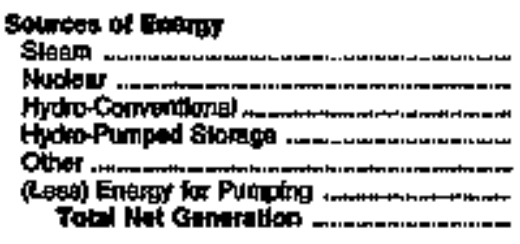 & $\begin{array}{l}0 \\
0 \\
0 \\
0 \\
0 \\
0 \\
0\end{array}$ & $\begin{array}{l}0 \\
0 \\
0 \\
0 \\
0 \\
0 \\
0\end{array}$ & $\begin{array}{l}0 \\
0 \\
0 \\
0 \\
0 \\
0 \\
0\end{array}$ & $\begin{array}{l}0 \\
0 \\
0 \\
0 \\
0 \\
0 \\
0 \\
0\end{array}$ & $\begin{array}{l}0 \\
0 \\
0 \\
0 \\
0 \\
0 \\
0\end{array}$ & $\begin{array}{l}0 \\
0 \\
0 \\
0 \\
0 \\
0 \\
0\end{array}$ \\
\hline 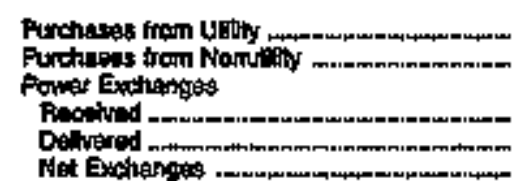 & $\begin{array}{r}495855 \\
0 \\
0 \\
0 \\
0\end{array}$ & $\begin{array}{r}460,257 \\
0 \\
0 \\
0 \\
0\end{array}$ & $\begin{array}{r}424,275 \\
0 \\
0 \\
0 \\
0\end{array}$ & $\begin{array}{r}245,305 \\
0 \\
0 \\
0 \\
0\end{array}$ & $\begin{array}{r}203,000 \\
0 \\
0 \\
0 \\
0\end{array}$ & $\begin{array}{r}858,8085 \\
275 \\
0 \\
0 \\
0\end{array}$ \\
\hline 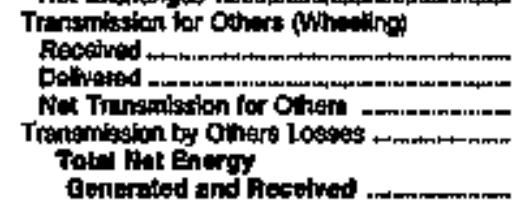 & $\begin{array}{r}0 \\
0 \\
0 \\
0 \\
0\end{array}$ & $\begin{array}{r}0 \\
0 \\
0 \\
0\end{array}$ & $\begin{array}{r}0 \\
0 \\
0 \\
0 \\
424,273\end{array}$ & $\begin{array}{r}0 \\
0 \\
0 \\
0 \\
245,808\end{array}$ & $\begin{array}{r}0 \\
0 \\
0 \\
0 \\
2000000\end{array}$ & $\begin{array}{r}0 \\
0 \\
0 \\
0 \\
067,2 \times 10\end{array}$ \\
\hline 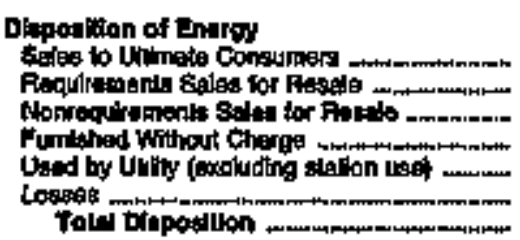 & $\begin{array}{r}480,067 \\
0 \\
0 \\
0 \\
0 \\
52,598 \\
498,055\end{array}$ & $\begin{array}{r}432,870 \\
0 \\
0 \\
0 \\
249 \\
27,120 \\
460,267\end{array}$ & $\begin{array}{r}897,392 \\
0 \\
0 \\
0 \\
698 \\
28,169 \\
424,278\end{array}$ & $\begin{array}{r}233,397 \\
0 \\
0 \\
0 \\
200 \\
21,706 \\
246,305\end{array}$ & $\begin{array}{r}277,719 \\
0 \\
0 \\
0 \\
228 \\
10,146 \\
299,090\end{array}$ & $\begin{array}{r}905,363 \\
0 \\
0 \\
0 \\
54 \\
51,450 \\
907,90\end{array}$ \\
\hline
\end{tabular}

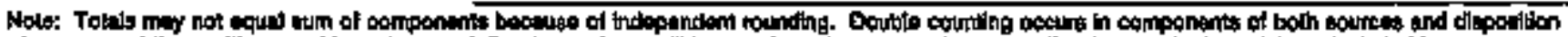

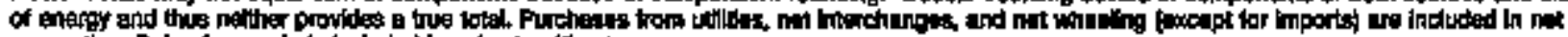

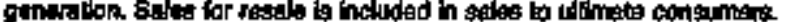

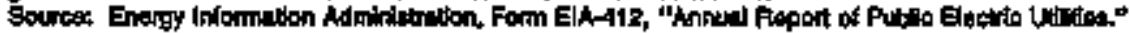


Table 26. Electic Energy Account by Major U.S. Publiely Owned Electrle Uti:ty Within State, 1994 (Continued) (Megawatthours)

\begin{tabular}{|c|c|c|c|c|c|c|}
\hline ther & 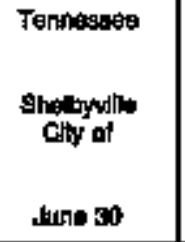 & $\begin{array}{l}\text { Tenniegene } \\
\text { Springifidd } \\
\text { chy of } \\
\text { Jne } 30\end{array}$ & 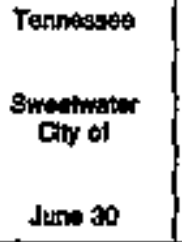 & 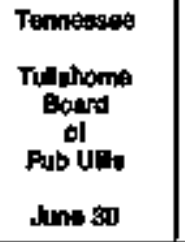 & $\begin{array}{l}\text { Uennosegen } \\
\text { Union Gity of } \\
\text { Juna } 30\end{array}$ & 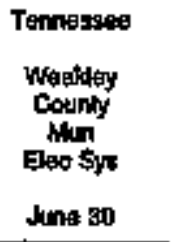 \\
\hline 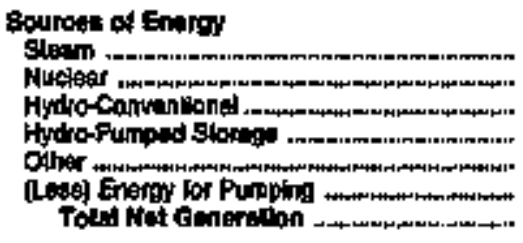 & $\begin{array}{l}0 \\
0 \\
0 \\
0 \\
0 \\
0 \\
0\end{array}$ & $\begin{array}{l}0 \\
0 \\
0 \\
0 \\
0 \\
0 \\
0\end{array}$ & $\begin{array}{l}0 \\
0 \\
0 \\
0 \\
0 \\
0 \\
0\end{array}$ & $\begin{array}{l}0 \\
0 \\
0 \\
0 \\
0 \\
0 \\
0 \\
0\end{array}$ & $\begin{array}{l}0 \\
0 \\
0 \\
0 \\
0 \\
0 \\
0\end{array}$ & $\begin{array}{l}0 \\
0 \\
0 \\
0 \\
0\end{array}$ \\
\hline 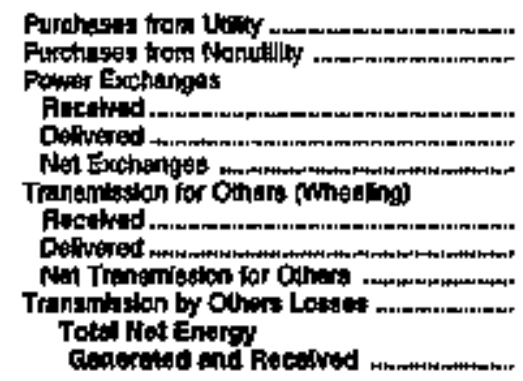 & $\begin{array}{r}395,768 \\
0 \\
0 \\
0 \\
0 \\
0 \\
0 \\
0 \\
0 \\
356,768\end{array}$ & $\begin{array}{r}211,+06 \\
0 \\
0 \\
0 \\
0 \\
0 \\
0 \\
0 \\
0 \\
211,106\end{array}$ & $\begin{array}{r}198,469 \\
0 \\
0 \\
0 \\
0\end{array}$ & $\begin{array}{r}280,0629 \\
0 \\
0 \\
0 \\
0 \\
0 \\
0 \\
0 \\
0 \\
200,020\end{array}$ & $\begin{array}{r}358,799 \\
0 \\
0 \\
0 \\
0 \\
0 \\
0 \\
0 \\
0 \\
305,733\end{array}$ & $\begin{array}{r}495,602 \\
0 \\
0 \\
0 \\
0 \\
0 \\
0 \\
0 \\
0 \\
485,662\end{array}$ \\
\hline 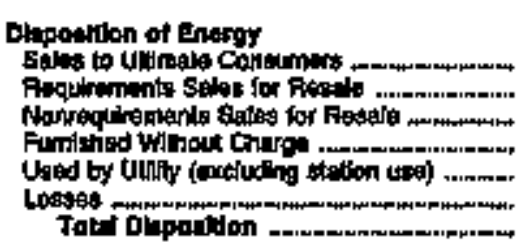 & $\begin{array}{r}32,307 \\
0 \\
0 \\
0 \\
275 \\
12,196 \\
305,760\end{array}$ & $\begin{array}{r}204,524 \\
0 \\
0 \\
0 \\
0 \\
0 \\
0,562 \\
211,106\end{array}$ & $\begin{array}{r}169,943 \\
0 \\
0 \\
0 \\
0 \\
8,589 \\
190,49 .\end{array}$ & $\begin{array}{r}284,789 \\
0 \\
0 \\
0 \\
989 \\
15,250 \\
200,00\end{array}$ & $\begin{array}{r}348,654 \\
0 \\
0 \\
0 \\
208 \\
71,671 \\
35,733\end{array}$ & $\begin{array}{r}4 B 2,658 \\
0 \\
0 \\
0 \\
963 \\
32,349 \\
405,462\end{array}$ \\
\hline
\end{tabular}

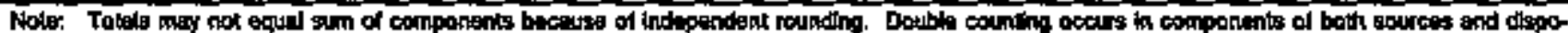

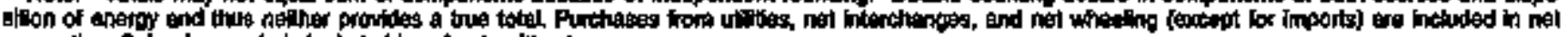

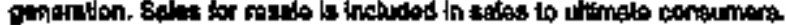

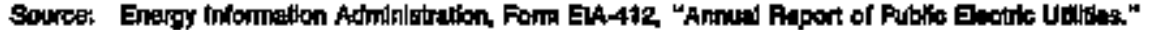


Table 26. Electric Encrgy Account by Major U.S. Publichy Owned Eloctric Utillty Within State, 1994 (Continued)

(Mepawathouss)

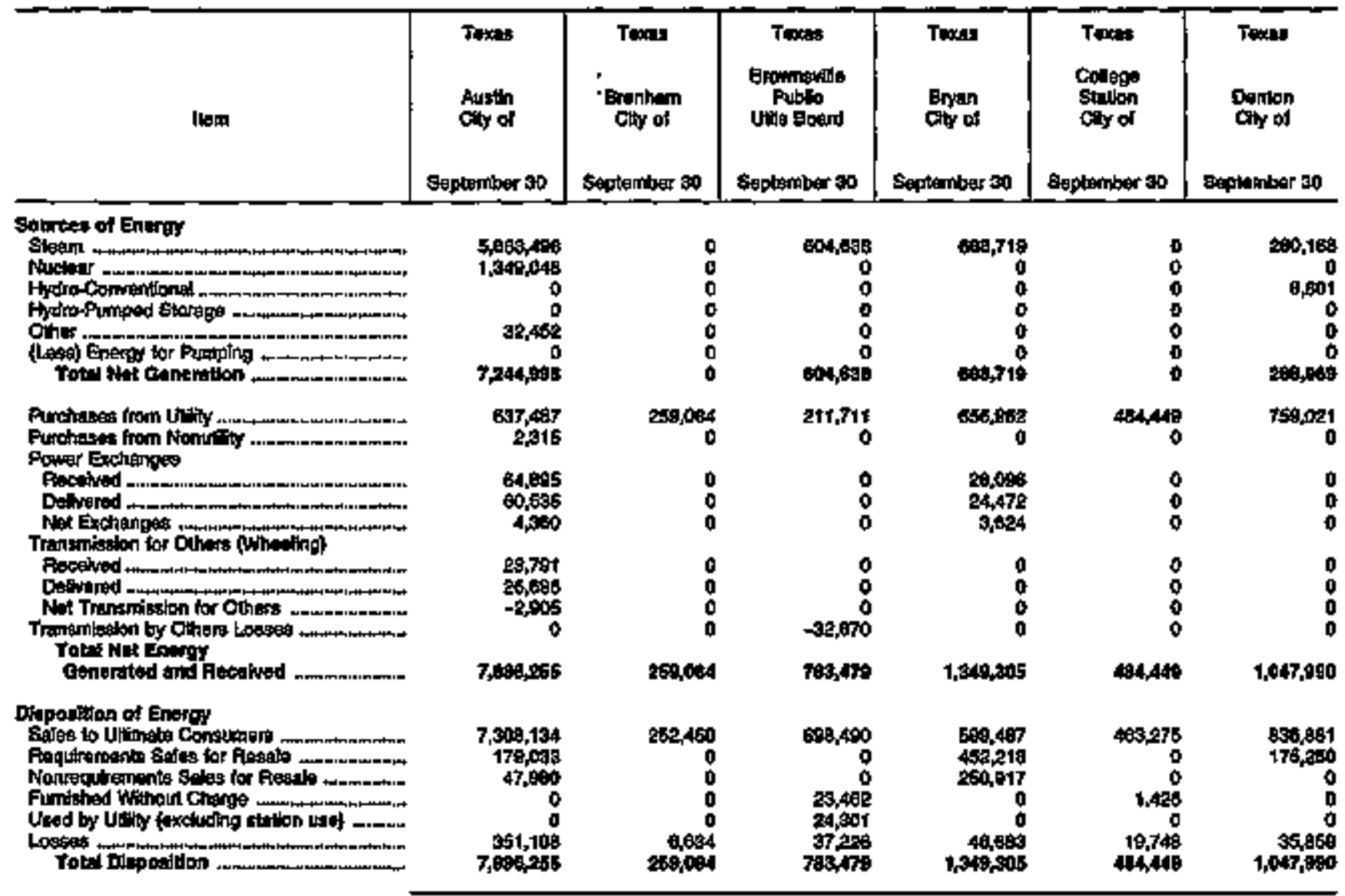

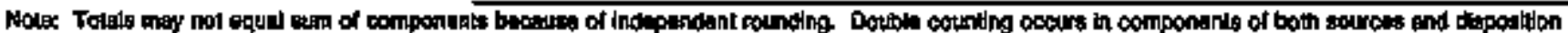

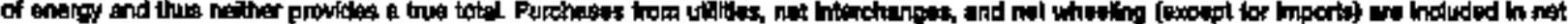

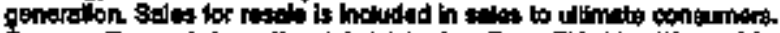

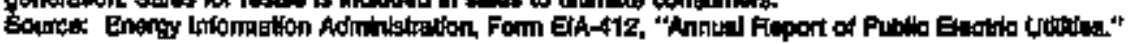


Table 26. Electric Energy Account by Major U.8. Publicly Owmed Electric Uk:lthy Whithin State, 1994 (Continued) (Megawalthours)

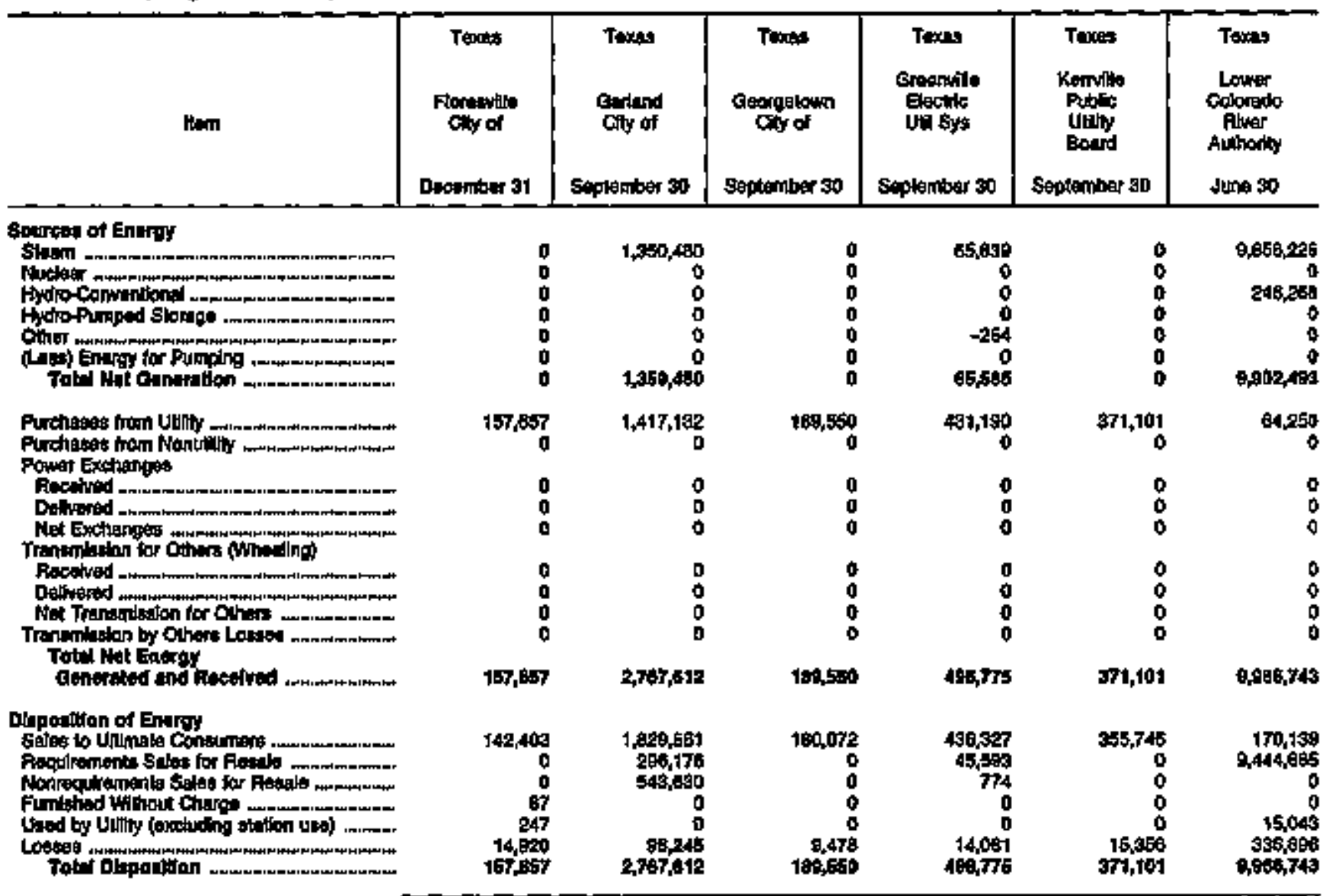

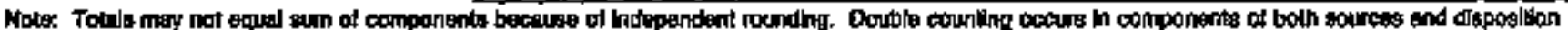

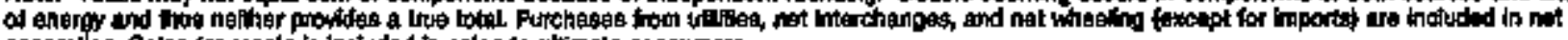

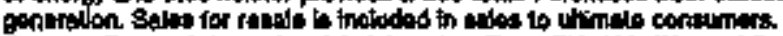

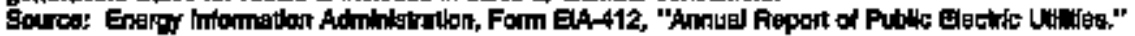


Table 26. Eleotrlo Energy Aceount by Major U.8. Publioly Owned Eloetrie Utility Within State, 1994 (Continued) (Megawatthours)

\begin{tabular}{|c|c|c|c|c|c|c|}
\hline hom & $\begin{array}{c}\text { Tauss } \\
\text { Lubbock } \\
\text { Chy of } \\
\text { Seplentor } 30\end{array}$ & Naw Bnomida & 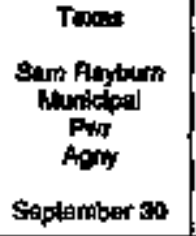 & 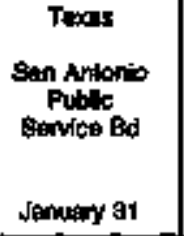 & 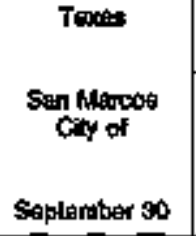 & $\begin{array}{l}\text { Texas } \\
\text { Seguln } \\
\text { Cily ot } \\
\text { September so }\end{array}$ \\
\hline 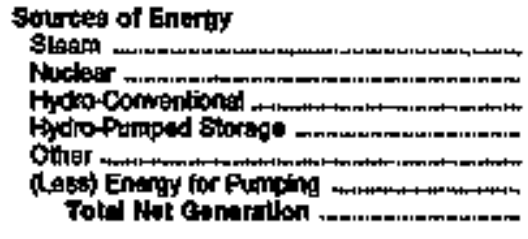 & $\begin{array}{r}403,721 \\
0 \\
0 \\
0 \\
155,213 \\
0 \\
598,934\end{array}$ & $\begin{array}{l}0 \\
0 \\
0 \\
0 \\
0 \\
0 \\
0 \\
0\end{array}$ & $\begin{array}{r}\operatorname{ses}, 40 \\
0 \\
0 \\
0 \\
0 \\
0 \\
5 * 3,449\end{array}$ & $\begin{array}{r}9,520,567 \\
4,42,049 \\
0 \\
0 \\
0 \\
0 \\
0 \\
13,94,5,510\end{array}$ & $\begin{array}{l}0 \\
0 \\
0 \\
0 \\
0 \\
0 \\
0\end{array}$ & $\begin{array}{r}0 \\
3,159 \\
0 \\
0 \\
0 \\
3,150\end{array}$ \\
\hline 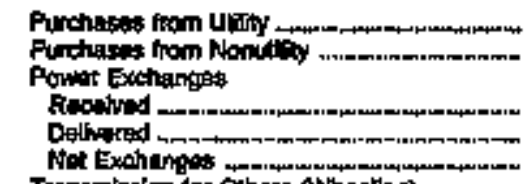 & $\begin{array}{r}497,792 \\
0 \\
0 \\
0 \\
0\end{array}$ & $7 B 7_{4} 189$ & $\begin{array}{r}68035 \\
0 \\
0 \\
0 \\
0\end{array}$ & $\begin{array}{r}967,794 \\
6,269 \\
1,397,439 \\
1,391,667 \\
5,442\end{array}$ & $\begin{array}{r}\text { wes,gro } \\
0\end{array}$ & 206,732 \\
\hline 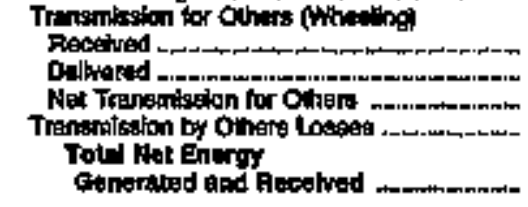 & $\begin{array}{r}0 \\
0 \\
0 \\
0\end{array}$ & 787,186 & $\begin{array}{r}0 \\
0 \\
0 \\
0 \\
\operatorname{tog} 44\end{array}$ & $\begin{array}{r}0 \\
0 \\
0 \\
0 \\
14,270,040\end{array}$ & $\begin{array}{r}0 \\
0 \\
0 \\
0 \\
364070\end{array}$ & $\begin{array}{r}0 \\
0 \\
0 \\
206,065\end{array}$ \\
\hline 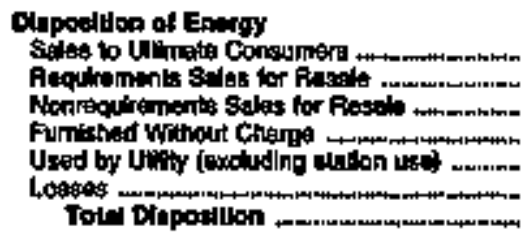 & 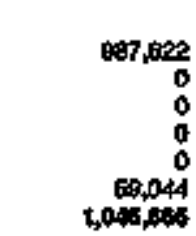 & $\begin{array}{r}763,360 \\
0 \\
0 \\
2,019 \\
0 \\
21,600 \\
787,1100\end{array}$ & $\begin{array}{r}0 \\
342,089 \\
202,177 \\
0 \\
6 \\
6,139 \\
694,414\end{array}$ & 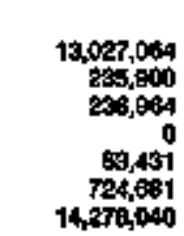 & $\begin{array}{r}335,029 \\
0 \\
0 \\
0 \\
0 \\
31,64 t \\
361,670\end{array}$ & $\begin{array}{r}201,420 \\
0 \\
0 \\
7,459 \\
0 \\
0 \\
20,0,085\end{array}$ \\
\hline
\end{tabular}

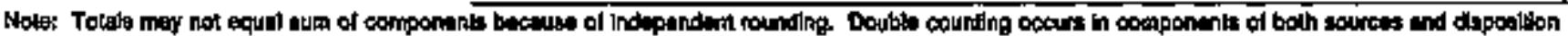

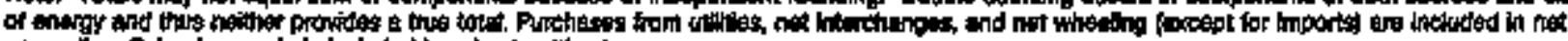

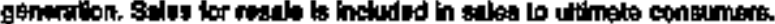

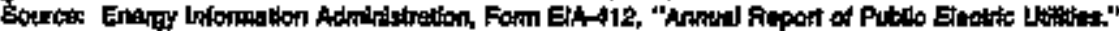


Table 26. Electric Energy Account by Major U.S. Publichy Owned Electric Utillity Within State, 1994 (Continued) (Megawatthours)

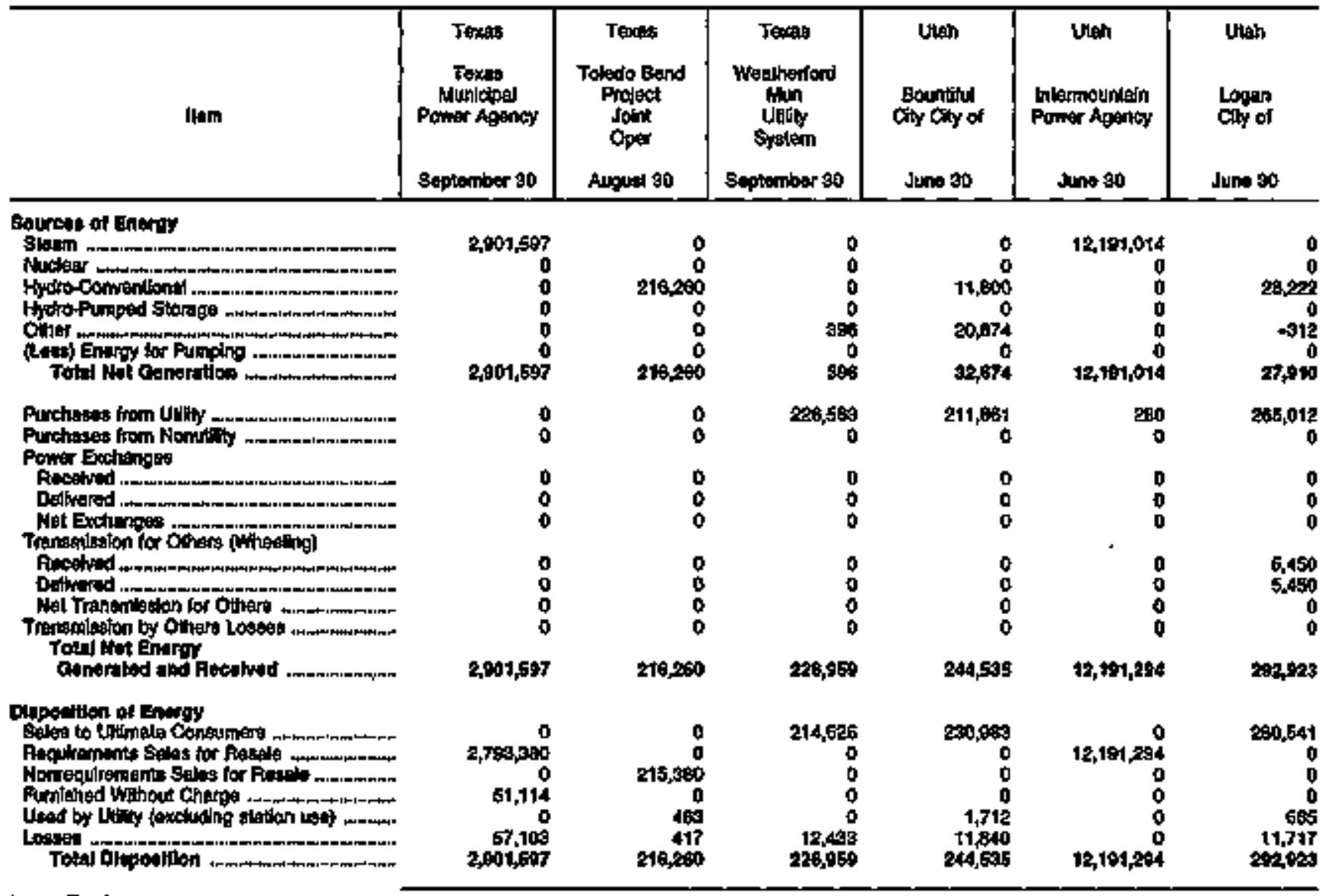

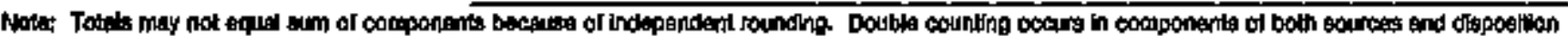

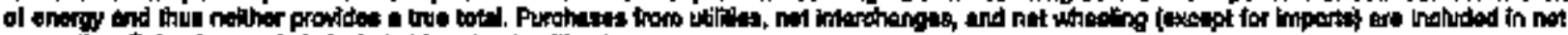

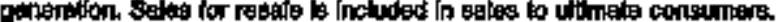

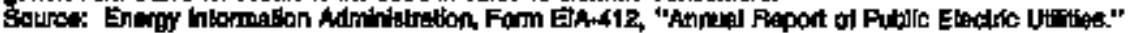


Table 26. Electric Energy Account by Major U.S. Publicly Owned Electric Utitity Withit State, 1994 (Continuted) (Megawatthours)

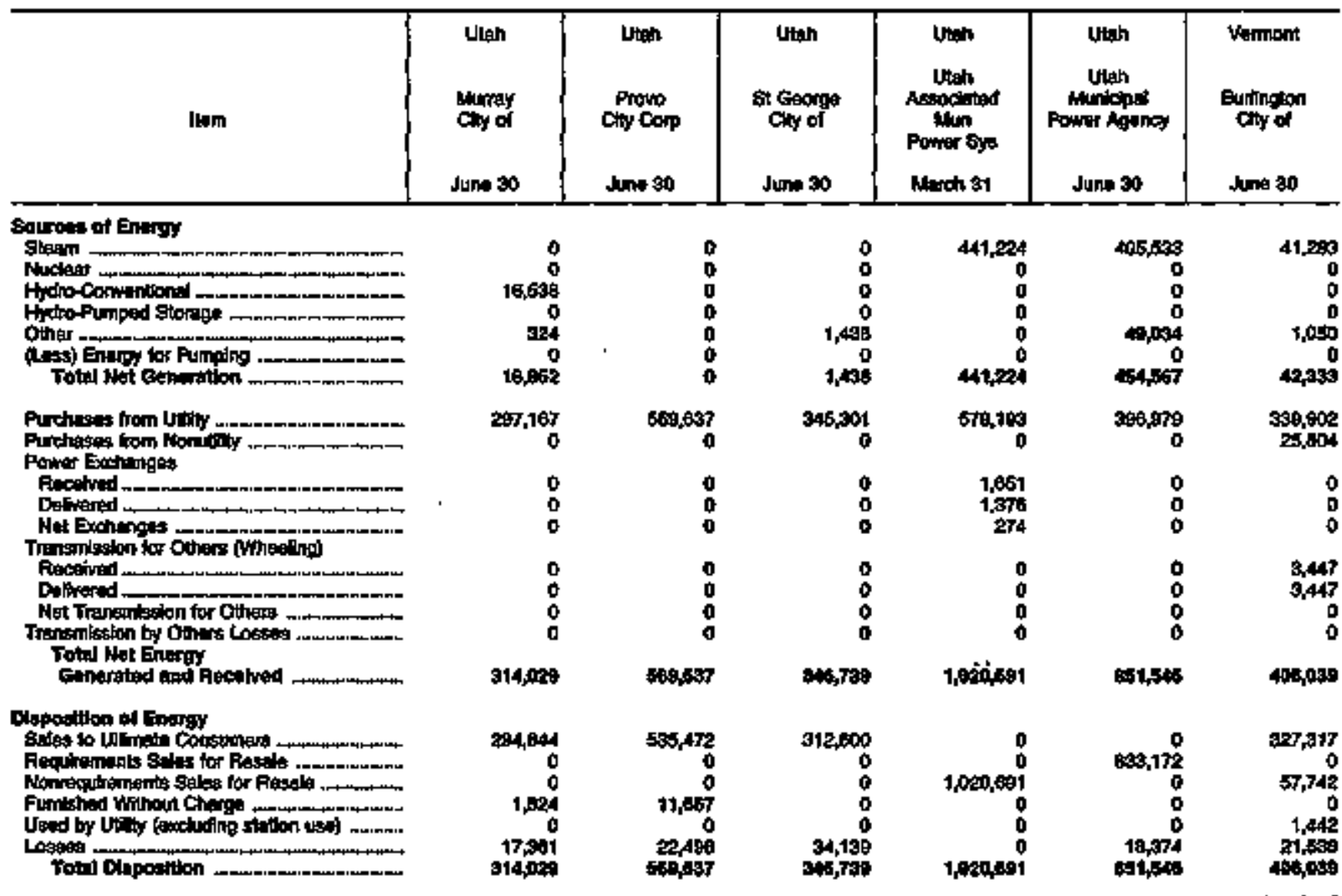

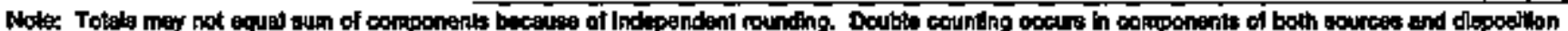

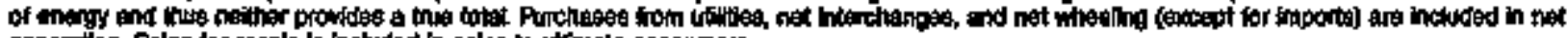

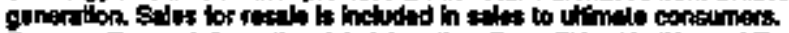

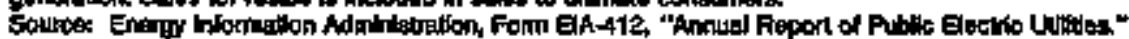


Table 26. Eleptric Energy Acoount by Lejor U.S. Publicly Owned Electric Utilty Whin State, 1994 (Continued) (Megawatthours)

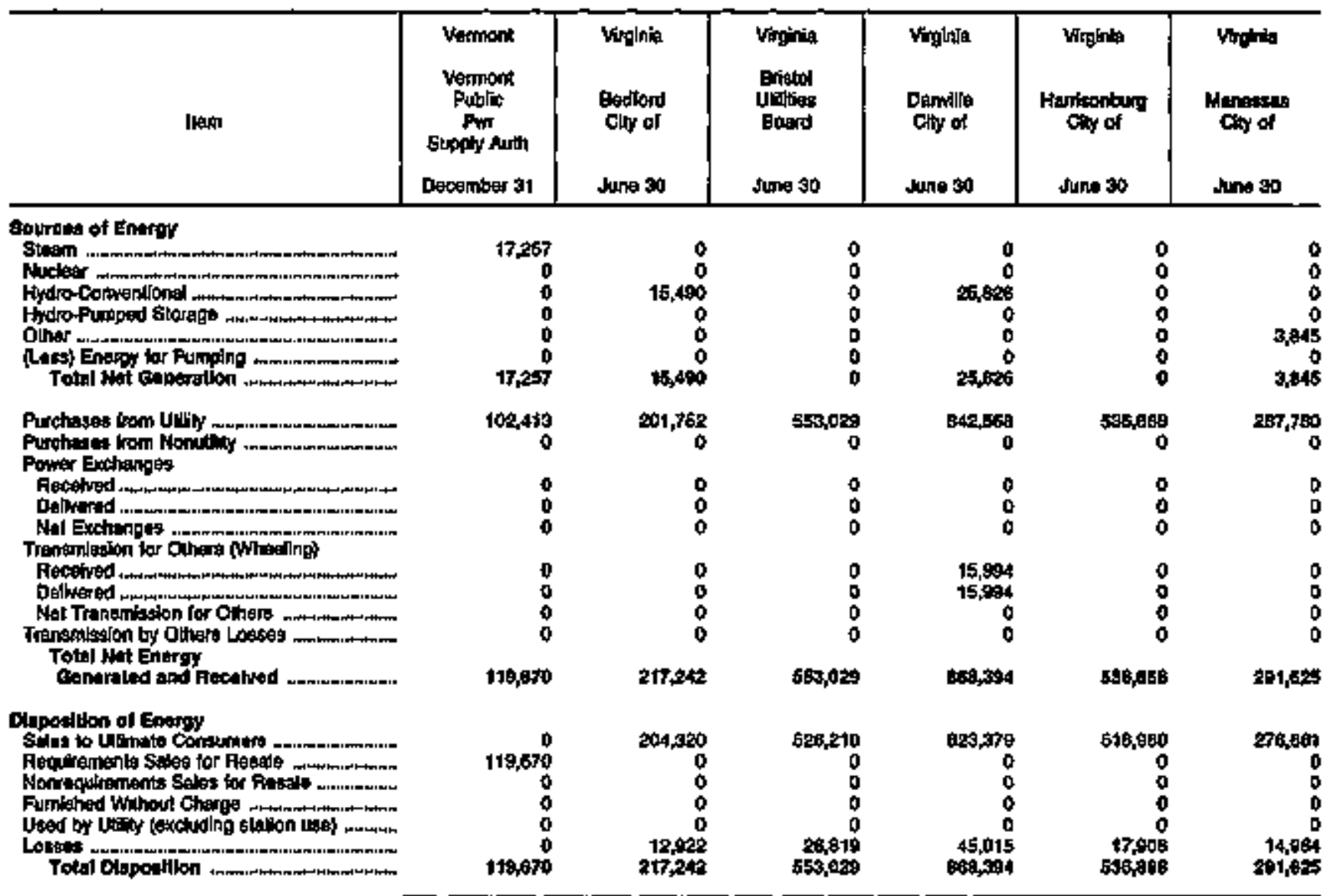

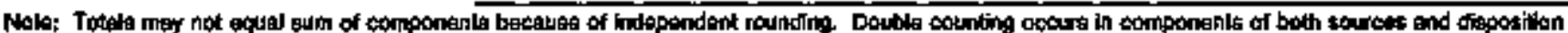

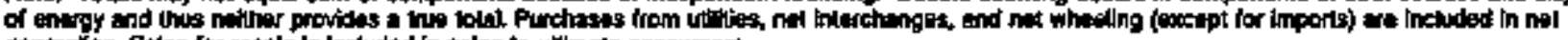

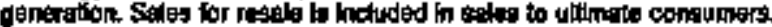

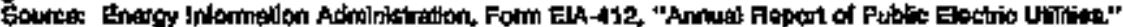


Table 26. Electrlc Energy Aocount by Major U.S. Publlely Owned Electric Utility Whin State, 1994 (Continued)

(Megawatthours)

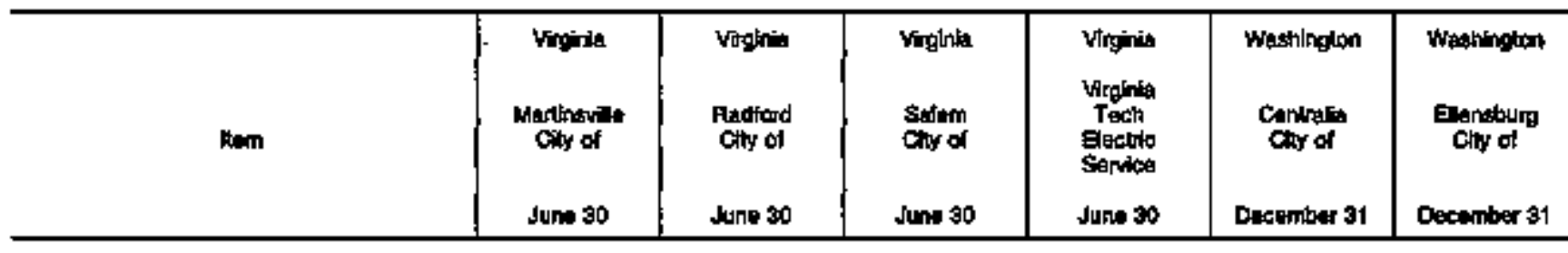

\section{Sourote of Energy}

Stexim

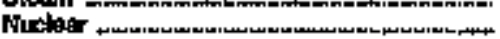

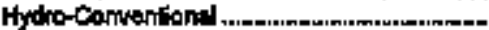

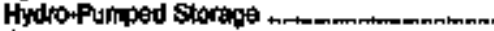

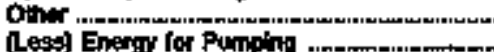

Total mot chanartion

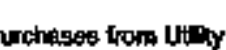

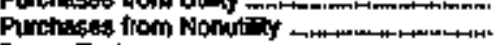

Power Exinanges

Ficketrad .

Dellwared

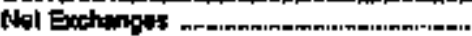

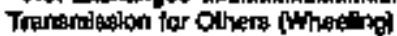

Roosind.

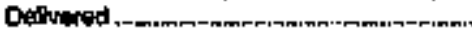

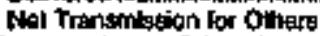

Trangenterton wy Oathers Loses:

Total A能 Enwgy

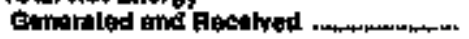

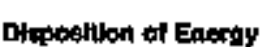

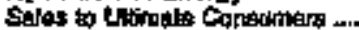

Rirquinements Salss for Rasals ...

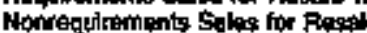

Funished whout Chamo

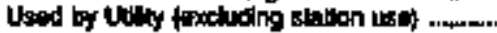

Lo\$ses

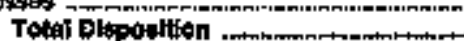

$\begin{array}{rr}0 & 0 \\ 0 & 0 \\ 10,235 & 0 \\ 0 & 5,450 \\ 0 & 0 \\ 0 & 0 \\ 10,855 & 5,400\end{array}$

214,344

0

0

0

0

0

0

274,5is

206,390

0
0
165

180

16,004

234,
300,101

0

0

0

0

0

300,551

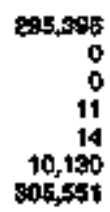

15,027

0

0

0

15,627

215,474

350,490
0

$\begin{array}{rr}0 & 0 \\ 0 & 0 \\ 59714 & 0 \\ 0 & 0 \\ 0 & 0 \\ 0 & 0 \\ 59,714 & 0\end{array}$

$\$ 72020$

107,402

$$
\text { o }
$$

0

0

0

0
0
0

0

231, 101

197,als

350,400

271,157
0
0
0
0
0,944

2at,101

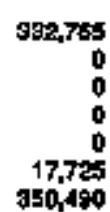

20,499

$$
\begin{array}{r}
0 \\
0 \\
0 \\
11.746
\end{array}
$$

$23 r^{3} 540$
161,512

0
0
0

5,950

197,407

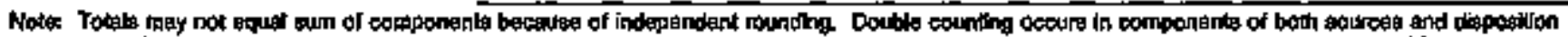

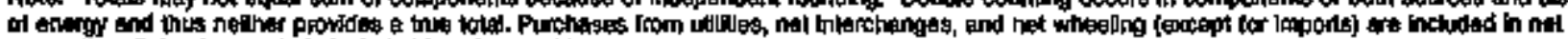

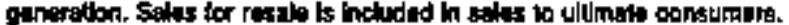

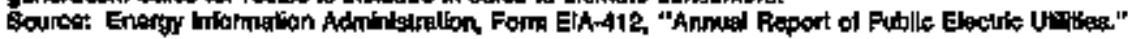


Table 26. Eleckilc Energy Account by Major U.S. Publley Owned Etectrle Utily whth State, 1994 (Conttnued)

(Negawatthours)

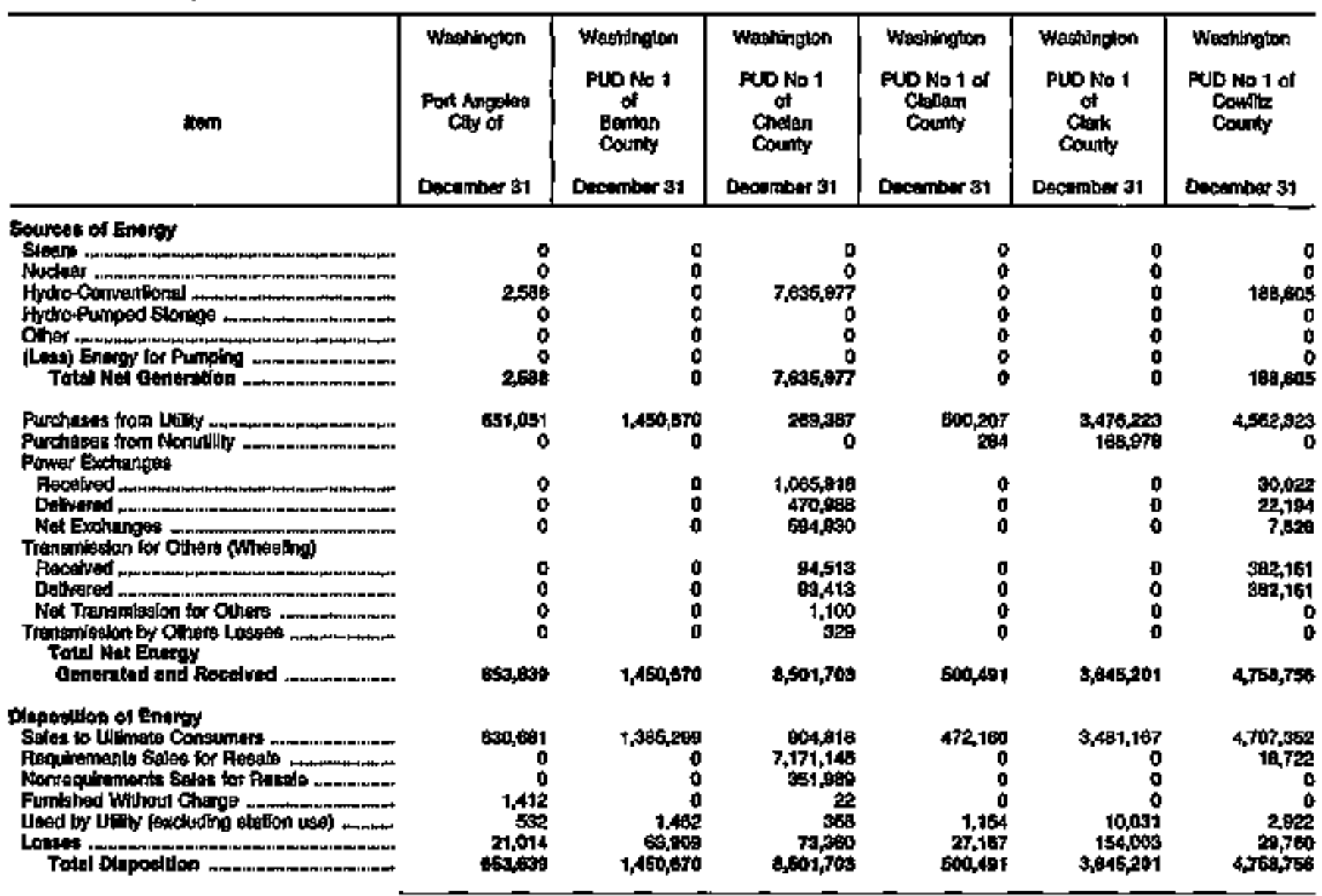

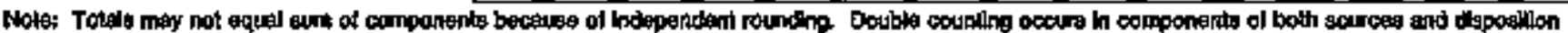

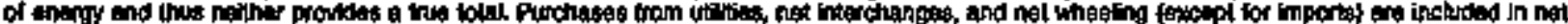

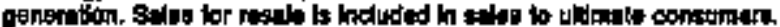

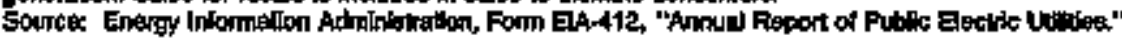


Tabie 26. Electric Entergy Account by Major U.S. Pubilchy Owned Eloctric Utility Within state, 1994 (Continued)

(Megawatthours)

\begin{tabular}{|c|c|c|c|c|c|c|}
\hline 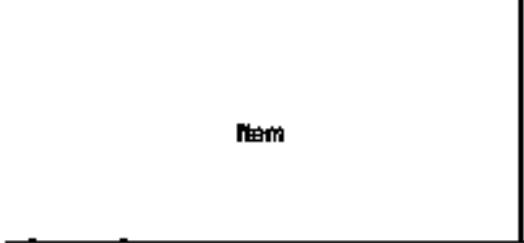 & $\begin{array}{l}\text { Wushington } \\
\text { PUo No } 1 \text { of } \\
\text { Dougleg } \\
\text { County } \\
\text { Deceaniner } 31\end{array}$ & $\begin{array}{l}\text { Wratingion } \\
\text { Pub ko } x \text { of } \\
\text { Frenklin } \\
\text { cotinty } \\
\text { Docember } \$ 1\end{array}$ & $\begin{array}{l}\text { Washinglon } \\
\text { FuD No } 1 \\
\text { of } \\
\text { Hatbor Cint } \\
\text { Decomber } 31\end{array}$ & 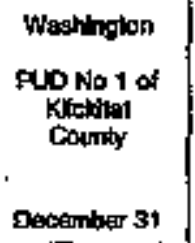 & 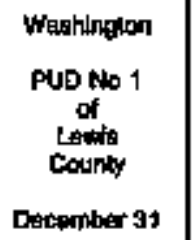 & $\begin{array}{l}\text { Washingion } \\
\text { Puo wo } 1 \text { of } \\
\text { Otangign } \\
\text { County } \\
\text { December } 31\end{array}$ \\
\hline 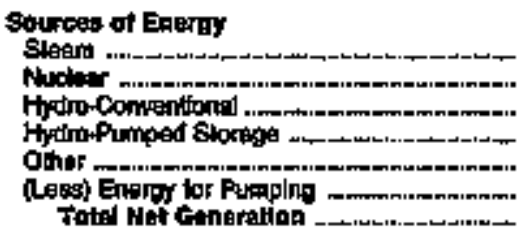 & $\begin{array}{r}0 \\
3,630,071 \\
0 \\
0 \\
0 \\
0,1,630,071\end{array}$ & $\begin{array}{l}0 \\
0 \\
0 \\
0\end{array}$ & $\begin{array}{r}400,195 \\
0 \\
0 \\
0 \\
0 \\
0 \\
40,125\end{array}$ & $\begin{array}{l}0 \\
0 \\
0 \\
0 \\
0 \\
0 \\
0\end{array}$ & $\begin{array}{r}0 \\
0 \\
76 \\
0 \\
0 \\
0 \\
m 6\end{array}$ & $\begin{array}{l}0 \\
0 \\
0 \\
0 \\
0 \\
0 \\
0\end{array}$ \\
\hline 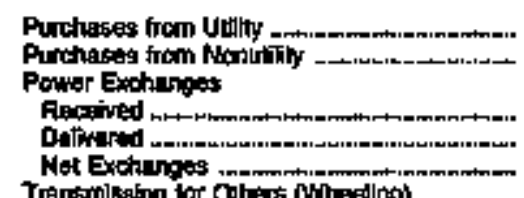 & $\begin{array}{r}148,011 \\
0 \\
391,058 \\
420,979 \\
-29,016\end{array}$ & $\begin{array}{r}670,417 \\
0 \\
0 \\
0\end{array}$ & $1,078,067$ & $\begin{array}{r}298,807 \\
28 B\end{array}$ & $\begin{array}{r}7+0,771 \\
0 \\
0 \\
0 \\
0\end{array}$ & $\begin{array}{r}001,237 \\
8,450\end{array}$ \\
\hline 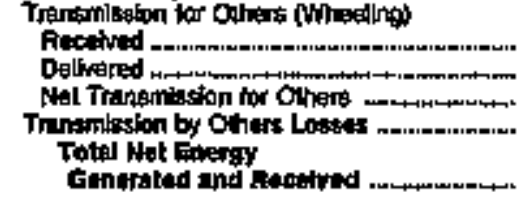 & $3,949,067$ & 870,417 & $1,470,202$ & 208,975 & $\begin{array}{r}0 \\
0 \\
0 \\
0 \\
711587\end{array}$ & $\begin{array}{r}0 \\
0 \\
0 \\
0 \\
607,607\end{array}$ \\
\hline 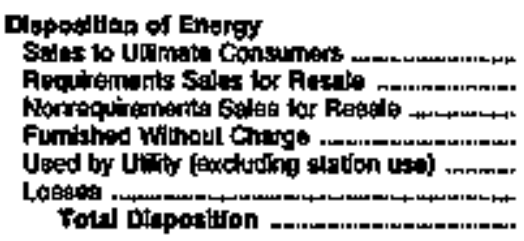 & $\begin{array}{r}899,3442 \\
2041,071 \\
172,644 \\
37,6,07 \\
2,413 \\
74,690 \\
3,949,067\end{array}$ & $\begin{array}{r}691,742 \\
0 \\
0 \\
0 \\
1,201 \\
37,474 \\
670,417\end{array}$ & $\begin{array}{r}1,031,5977 \\
400,135 \\
0 \\
3,275 \\
0 \\
43,255 \\
1,476,202\end{array}$ & $\begin{array}{r}280,568 \\
0 \\
0 \\
0 \\
618 \\
17,508 \\
298,975\end{array}$ & $\begin{array}{r}871,380 \\
0 \\
0 \\
0 \\
873 \\
39,769 \\
711,567\end{array}$ & $\begin{array}{r}585,694 \\
0 \\
0 \\
0 \\
1,450 \\
38,573 \\
600,460\end{array}$ \\
\hline
\end{tabular}

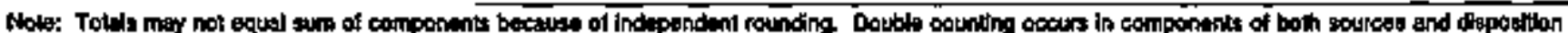

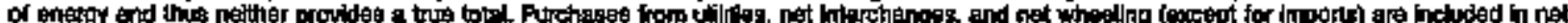

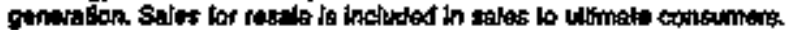

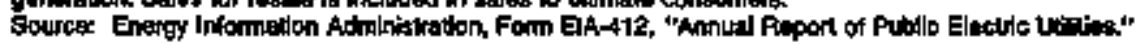


Table 26. Electric Energy Account by Major U.S. Publlety Owned Electic Utilly Within State, 1994 (Continued)

(Megawatthours)

\begin{tabular}{|c|c|c|c|c|c|c|}
\hline inem & 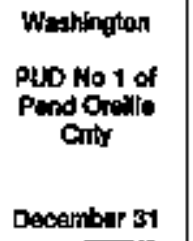 & $\begin{array}{l}\text { Washinglon } \\
\text { Pun No t of } \\
\text { Snohamish } \\
\text { County } \\
\text { Daxambarat }\end{array}$ & $\begin{array}{l}\text { Washingtion } \\
\text { Pub vio } 1 \text { of } \\
\text { Whatcom } \\
\text { Courily } \\
\text { December } 31\end{array}$ & $\begin{array}{l}\text { Washinglon } \\
\text { PuD Na } 2 \\
\text { of } \\
\text { Count } \\
\text { Deceanber } 31\end{array}$ & $\begin{array}{l}\text { Wustington } \\
\text { Mud ka } 2 \text { of } \\
\text { Pacific } \\
\text { Courly } \\
\text { December al }\end{array}$ & 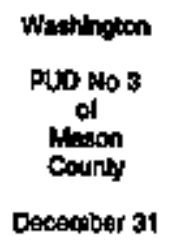 \\
\hline 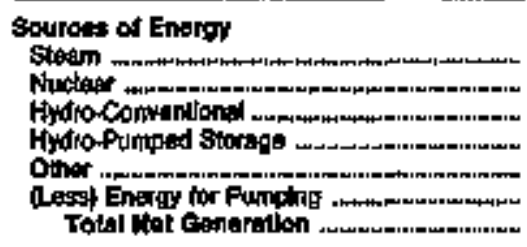 & $\begin{array}{r}0 \\
0 \\
414,165 \\
0 \\
0 \\
0 \\
414,165\end{array}$ & 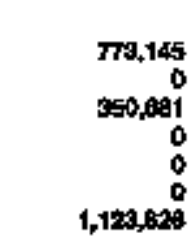 & $\begin{array}{l}0 \\
0 \\
0 \\
0 \\
0 \\
0 \\
0\end{array}$ & $\begin{array}{r}0 \\
0,7 \in 0,759 \\
0 \\
0 \\
0 \\
0 \\
0,700,759\end{array}$ & $\begin{array}{l}0 \\
0 \\
0 \\
0\end{array}$ & $\begin{array}{l}0 \\
0 \\
0 \\
0 \\
0\end{array}$ \\
\hline 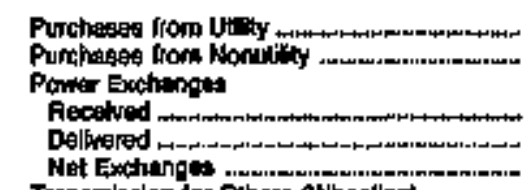 & $\begin{array}{r}697,109 \\
0 \\
50,473 \\
20,215 \\
8,260\end{array}$ & $\begin{array}{r}5,098,0077 \\
677 \\
128,995 \\
169,311 \\
-90,316\end{array}$ & 171,659 & $\begin{array}{r}5 e 6,761 \\
0 \\
390,410 \\
976,218 \\
23,191\end{array}$ & 276,a9y & $=20,509$ \\
\hline 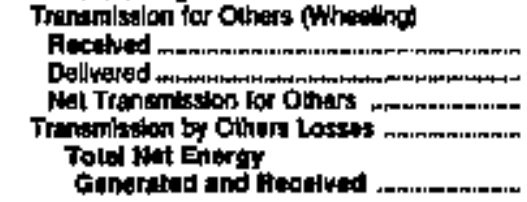 & $1,069,592$ & $6,122,184$ & 171,600 & $\begin{array}{l}0 \\
0 \\
0 \\
0\end{array}$ & $270,60 t$ & 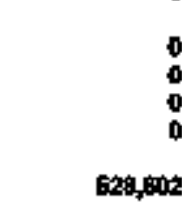 \\
\hline 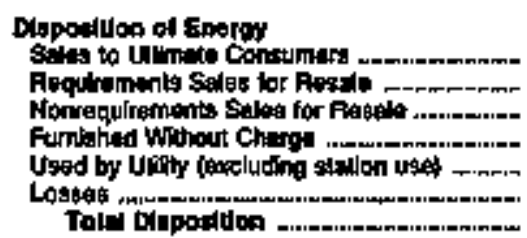 & $\begin{array}{r}900,701 \\
134,0606 \\
0,094 \\
0 \\
077 \\
14,084 \\
1,069,5022\end{array}$ & $\begin{array}{r}6,771,543 \\
2,025 \\
67,238 \\
0 \\
13,783 \\
247,685 \\
6,122,184\end{array}$ & $\begin{array}{r}171,669 \\
0 \\
0 \\
0 \\
0 \\
0 \\
171,650\end{array}$ & $\begin{array}{r}2,943,280 \\
5,619,045 . \\
0 \\
706,944 \\
8,760 \\
181,109 \\
0,339,106\end{array}$ & $\begin{array}{r}269,902 \\
0 \\
0 \\
0 \\
500 \\
18,397 \\
276,891\end{array}$ & $\begin{array}{r}49,060 \\
3,206 \\
0 \\
0 \\
606 \\
27,424 \\
520,002\end{array}$ \\
\hline
\end{tabular}

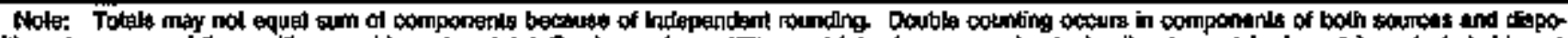

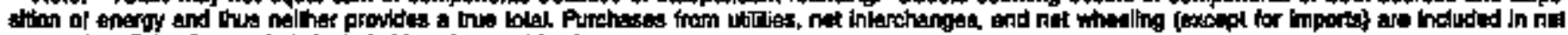

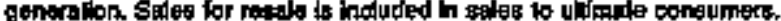

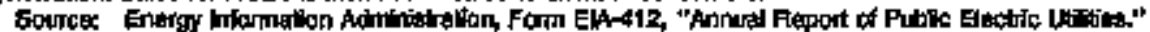


Table 26. Electric Energy Account by Major U.S. Publicly Owmed Electric Utility Within State, 1994 (Continued) (Megawatthours)

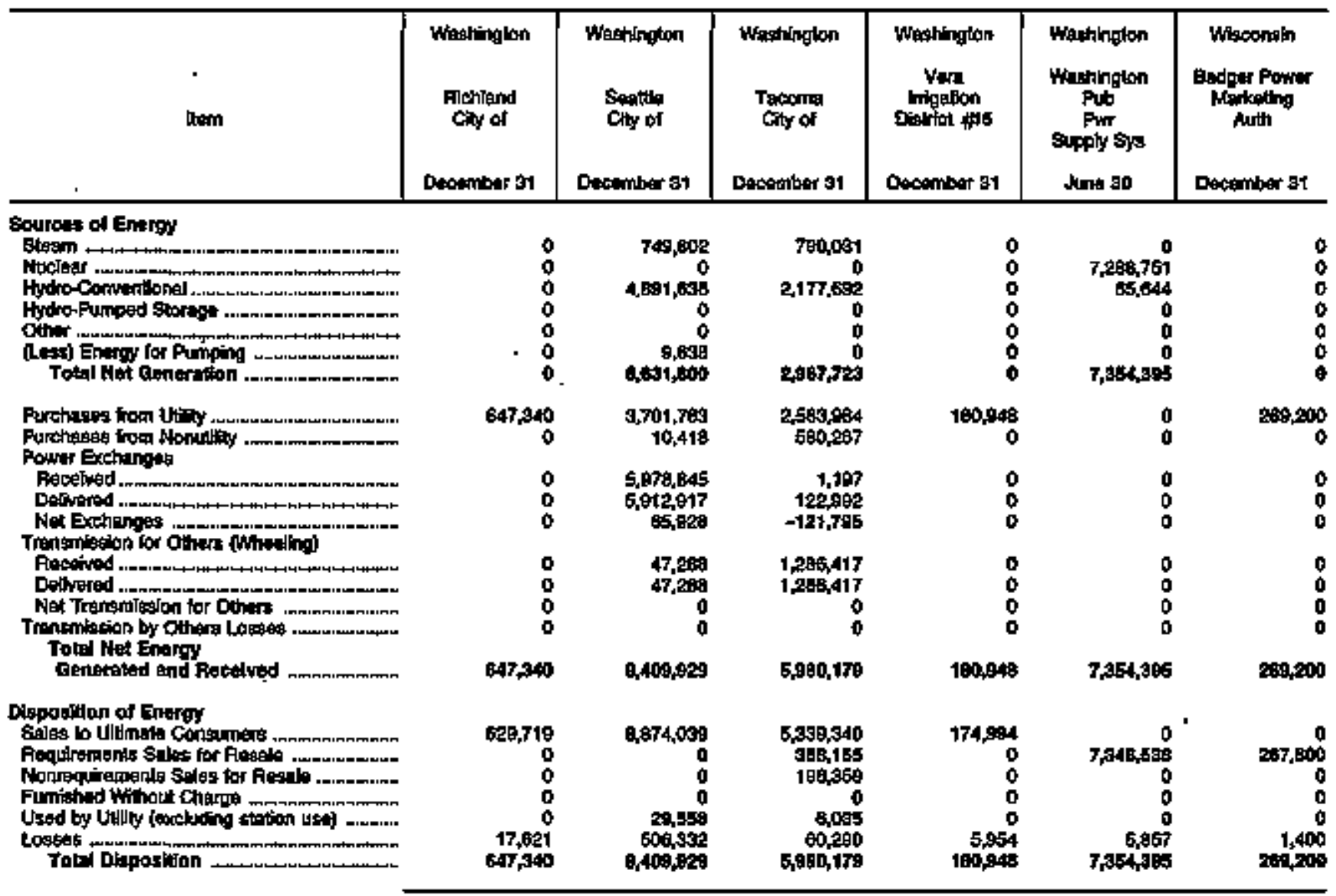

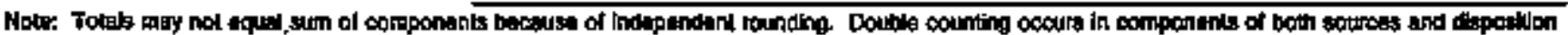

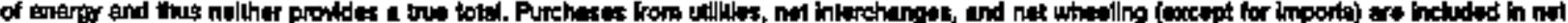

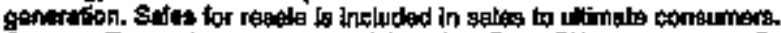

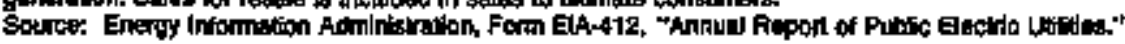


Teble 26, Electric Energy Account by Major U.S. Publloby Owned Electrlc Utlily Within State, 1994 (Continued)

(Megawatthours)

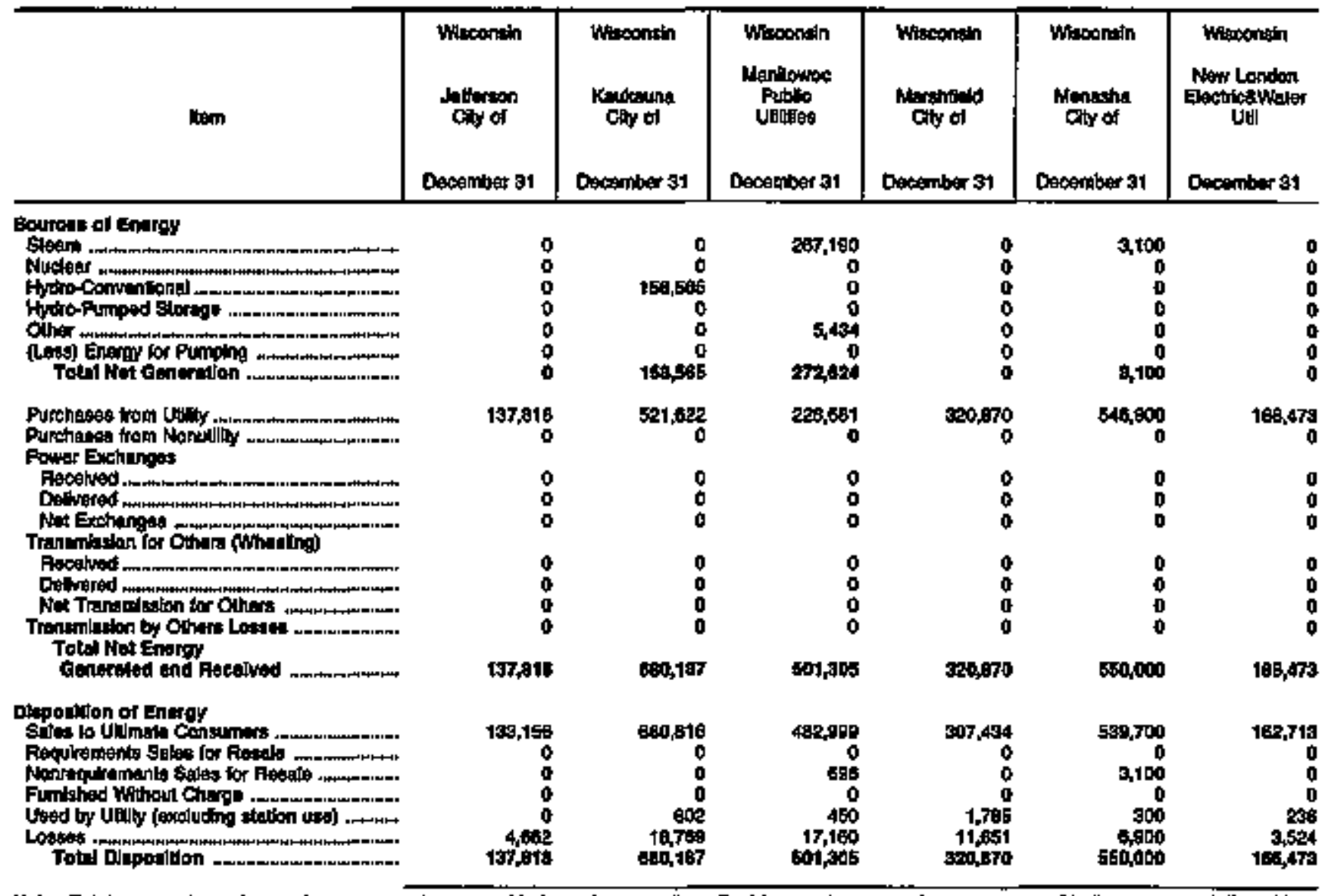

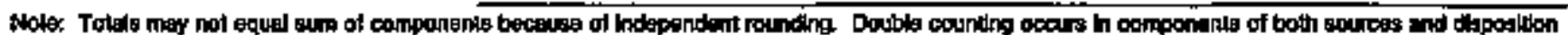

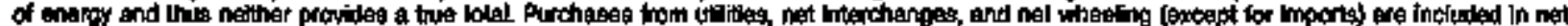

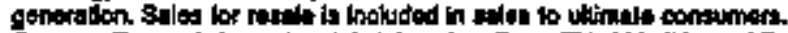

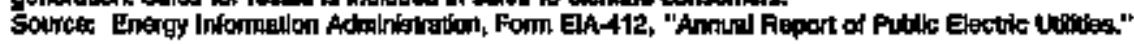


Table 26. Electrlc Energy Acoount by Major U.S. Publicly Owned Electrlo Utilily Within State, 1994 (Continued)

(Megkwatthours)

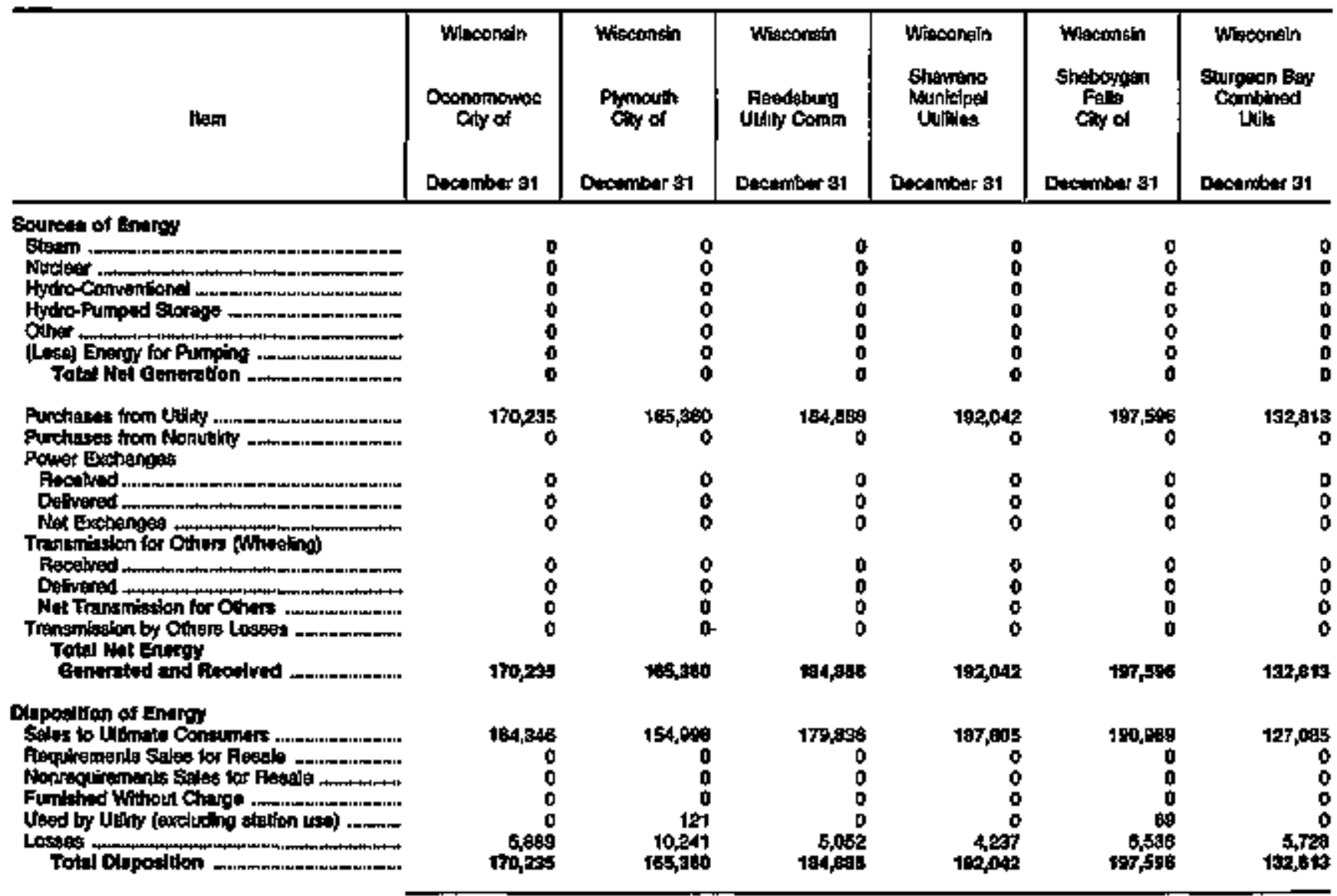

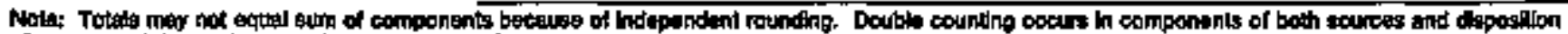

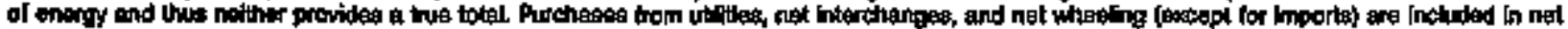

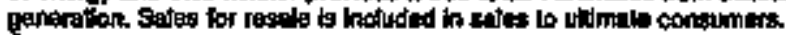

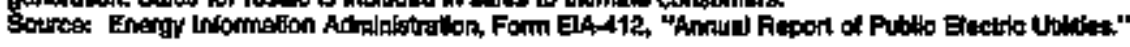


Table 26. Electrto Energy Account by Major U.S. Publlety Owned Electrtc Utility Within State, 1984 (Continued) (Megawatthours)

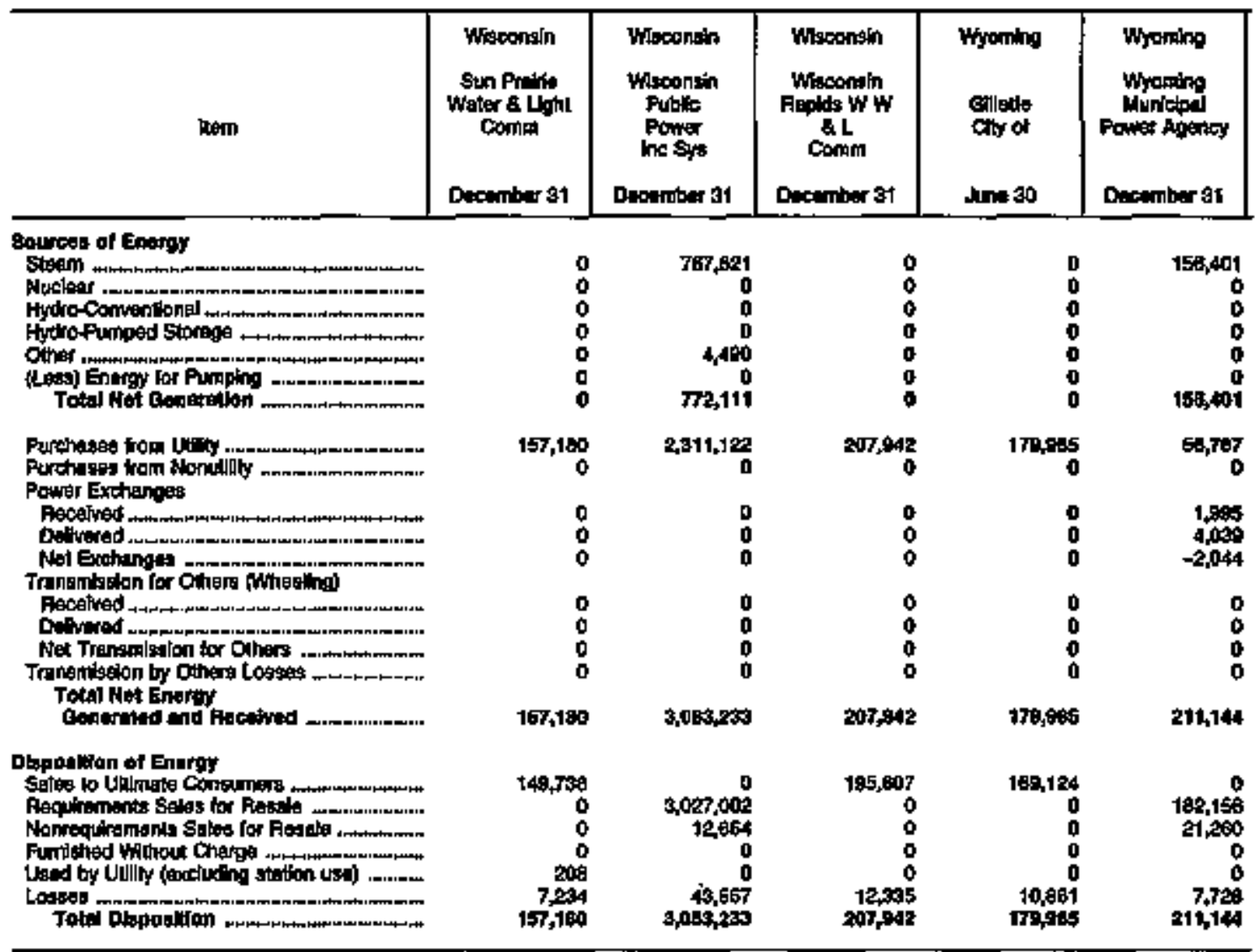

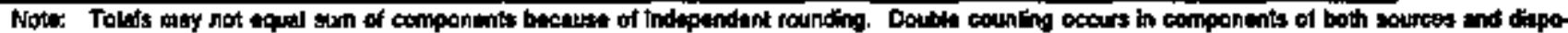

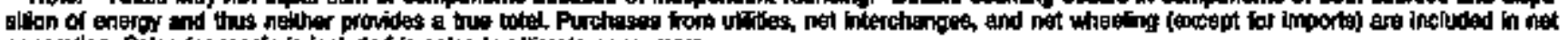

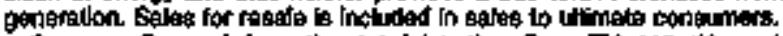

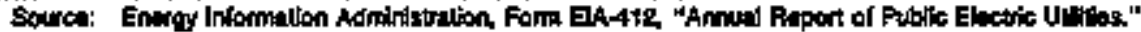




\section{Summary Statlstics of U.S. Federal Electric Utilities}




\section{Financial Performance}

\section{Background}

There are 10 Fedieral electric utilities in the United States. They are the Department of Defense's U.S. Army Corps of Engineers; the Department of Energy's five power marketing administrations, Alaska, Bonneville, Southeastern, Southwestern, and Western Area Power Administrations; the Department of Interior's U.S. Bureal of Indian Affairs and the U.S. Bureau of Reclamation; the Department of State's Intemational Water and Boundary Commission; and, the Ternessee Valley Anthority.

The Federal electric utilities are primarily generators and wholesalers of electricity rather than distributors to ultimate consumers. Federal electric utilities operate over 150 power plapts and produce approximately 8 percent of the electricity generated in the United States. Most of the power plants are Federal hydroelectric projects intially designed for flood control and irrigation purposes. Federal power is sold at cost. This cost includes production expenses and the repayment of the federally provided financing. Most Federal generation is sold for resale to municipals, cooperative electric atilities, and other nonprofit preference customers, as required by law.

There are three major producers of electricity: the Tennessee Valley Authority (TVA), the largest Federal producer; the U.S. Army Corps of Engineers (USCE); and the U.S. Bureau of Reclamation (USSRR). The TVA markets its own power while generation by the USCE, except for the North Central Division (Saint Mary's Falls at Sault St. Marie, Michipan), and the USBR is marketed by four of the Federal power marketing admintstrations - Bonneville, Southeastem, Southwestern, and Westem Area. These four power marketing administrations also purchase energy for resale from other electric utilities in the United States and Canada. Alaska, the fifth power marketing administration, operates its own power plamts and distributes power to ultimate consumers.

\section{Income Statement}

As of the end of the fiscal year (September 31, 1994), operating revenues for the federal electric utilities totaled \$8,552.3 million. Total electric utility operating expetises were $\$ 6,309.3$ million in 1994. A major portion of these total electric utility operating expenses inciude production expenses that totaled \$4,463.6 million. Production expenses for the Federal electric utilities were 70.8 percent of total electric utility operating expenses. Total electric operation and maintenance expenses were \$5,253.1 million, 83.3 percent of total electric ntiltty operating expenses for the Federal electric atlities.

Total electric ntility income for the Federal electric utilities was $\$ 2,140.7$ million. Ircome deductions totaled $\$ 2,1500$ million. Of the income deductions, $\$ 1,840,4$ million came from interest on long-teren debt, which represented 86.0 percent of total income deductions. Net income for the Federal electric ntij:ties as of the end of September 1994 was $\$ 309.6$ million compared with $\$ 1,486.7$ million in 1993 .

\section{Baknce Sheet}

As of September 30, 1994, net fnvestment in electric utility plant for the Federal electric utilities was $\$ 34,115.9$ million, including construction work in progress, which increased to $516,626.4$ million, compared with $\$ 15,660.1$ million in 1993.

Total proprietary capital was $\$ 10,089.3$ mitlion in 1994, a slight increase from $\$ 11,128.8$ million in 1993 , 20.8 percent of total lisbilities and other eredits. The amount of longeterm debt and current and accrued

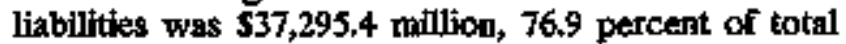
liabilities and other credits of the Federal electric utiitios.

\section{Sales of Electric Power}

In 1994, the Federal electric utilttes had sales of elec. tric energy to ultimate consumers of 46.8 million megawatthours and electricity sold for resale of 199.0 million megawathours. Total disposition of energy was 262.7 mitlion megawatthours of which the Federal electric utilities had a net generation of 249.3 million knegawatthours (Table 32), 


\section{Historitod Synopsis of Tennessee Valley Authority}

The Tennesse Volley Authority (TVA) was the first of the wholesale marketing organizations to be formed. It was authorized nnder the Tennessee Valley Authority Act in 1933 "for the purposes of main. tatning and operating the properties now owned by the United States in the vicinity of Muscle Shoals, Alnbama, in the interest of national defense and for Agricultural and industrial development, and to improve navigation in the Tennessee River and to control the destructive flood waters in the Tennessee River and Mississippi River Basins." It was given the authority to both own and operate damk, transmission lines, and power plents along the Tennessee River and its tributaries. By the beginning of World War II, the TVA had developed most of its water resources, but growing war demands and domestic needs required new capacity. In 1949, Congress approved cor: struction of a steam plart, opening the way for construction of other nophydroelectrtic facilities. The TVA's fossil-fueled capacity and nuclear capacity now each exceed its hydroelectric capacity (run of river and pumped storage).

\section{Tennessee Valley Authorlty 1994 Summary}

In 1994, Tennessee Valley Authority (TVA) remained one of America's largest producers of electric power. Through 160 municipal and cooperative power distributors, TVA serves more than 7 million people in an 80,000 square-mile region. The four largest mumicipalities are the Temnessee cities of Memphis, Nashville, Chattanooga, and Knoxville. Of the 130.1 million megawatthours of electricity generated in 1994 by TVA, the four largest municipals distributed 33.1 million inegawatthours or 25.4 percent of TVA's total generation to their customers. For this repouting period, the power system consisted of three nuclear generating units, 11 coal-fired plants, and 29 hydro. electric dams, and as of Septeriber 30, 1994, TVA had 19,027 employees.

In 1994, TVA experienced a $\$ 845$ million increase in construction work in progress, a $\$ 1.3$ billion decrease in nuclear fuel assets, and a $\$ 1.3$ billion increase in long-term debt (Figure 2). Reclassification of a portion of the capitalized interest component of nuckear plant to other assets resulted in a reduction in nuclear fuel. Long-term debr was increased to finance the completion of one nuclear fuel unit under construction, improvements at existing facilities, trustswisston lines, and environmental compliance. Future earnisgs, which will cover these debs, are depeadent upon energy sales that are subject to factors such as weather, economic conditions, growth, competition, and open transmission access and TVA's ability to manage within existing rates or to raise rates to cover these cost.

Figure 2 Long-Térm Debt, Construotion Work In Process, and Nuclear Fuel for TVA, 1990-1994

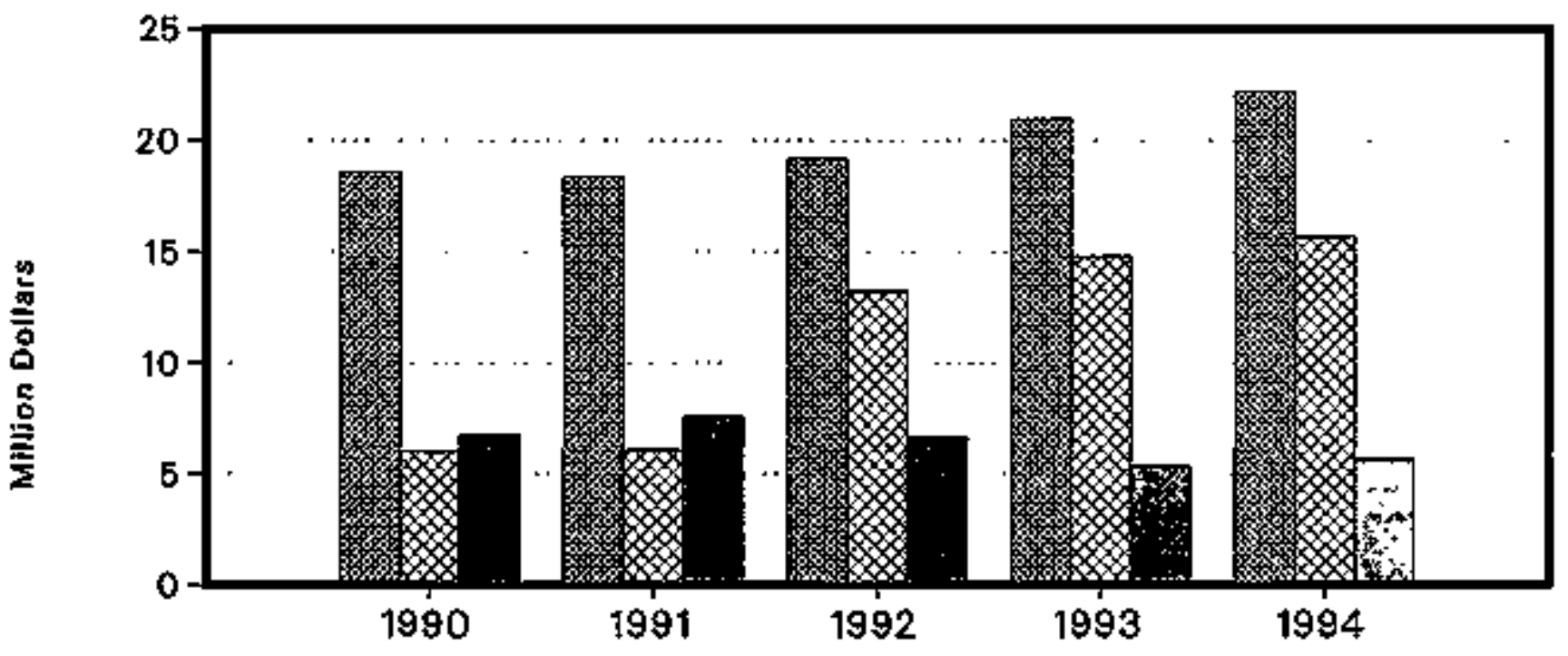

EX Lono-Term Debt
EX Construction Work in Progress
Nuclear Fuel

Source: Tenne\$see Valley Authortty. '1994 Annual feport,' (Knoxville, TN, 1996). 
Operating revenues were $\mathbf{5 . 4}$ billion for $1994,55.3$ billion in 1993, and 55.1 billion in 1992. These increases occurred in spite of steady power rates since 1987. Total kilowatthour sales were 123 billion in 1994, 119 billion in 1993, and $112 \mathrm{kWh}$ billion in 1992. The impact on sales of mild summer temperatures in 1994 was offiset by overall sales growth of 5.0 percent in 1994 and 2.5 percent in 1993. A winter peak demand record of 24,723 megawatts was set January 18, 1994, while temperatures were in the single digita. Operating expenses remained unchanged at $\$ 2.3$ billion for 1993 and 1994 Maintenance expenses decreased slightly which reflected continuing efforts to reduce cost and maintain competitive rates.

\section{TVA's Energy Future}

Besides taking cost cutting measures today, TVA has begun a two-year Integrated Resource Planning Process. During these two years, TVA will evaluate ways to produce and conserve power, enhance eftir ciency, and develop a 25-year plan - called Energy Viston 2020 - to meet future needs. Energy Vision
2020 focuses on demand-side management techniques, ovaluating existing facilities for future demand needs, and exploring innovative technologies that may hold the key to future energy supply. Although TVA bas used energy planning in the past, Energy Vision 2020 represents the first time the agency has agked the public to participate on 2 large scalt through con docting public meetings and interviews.

TVA's primary competitors in the utillity industry are the natural ges industry and other electric atilities hoping to expand their consumer base in the Tennessex Valley. In 1994, with the support of their distributors, TVA began new marketing initiatives. These new marketing initiatives promote the agency, the power distributors, and electricity, as well as emphasize the wise use of energy.6 


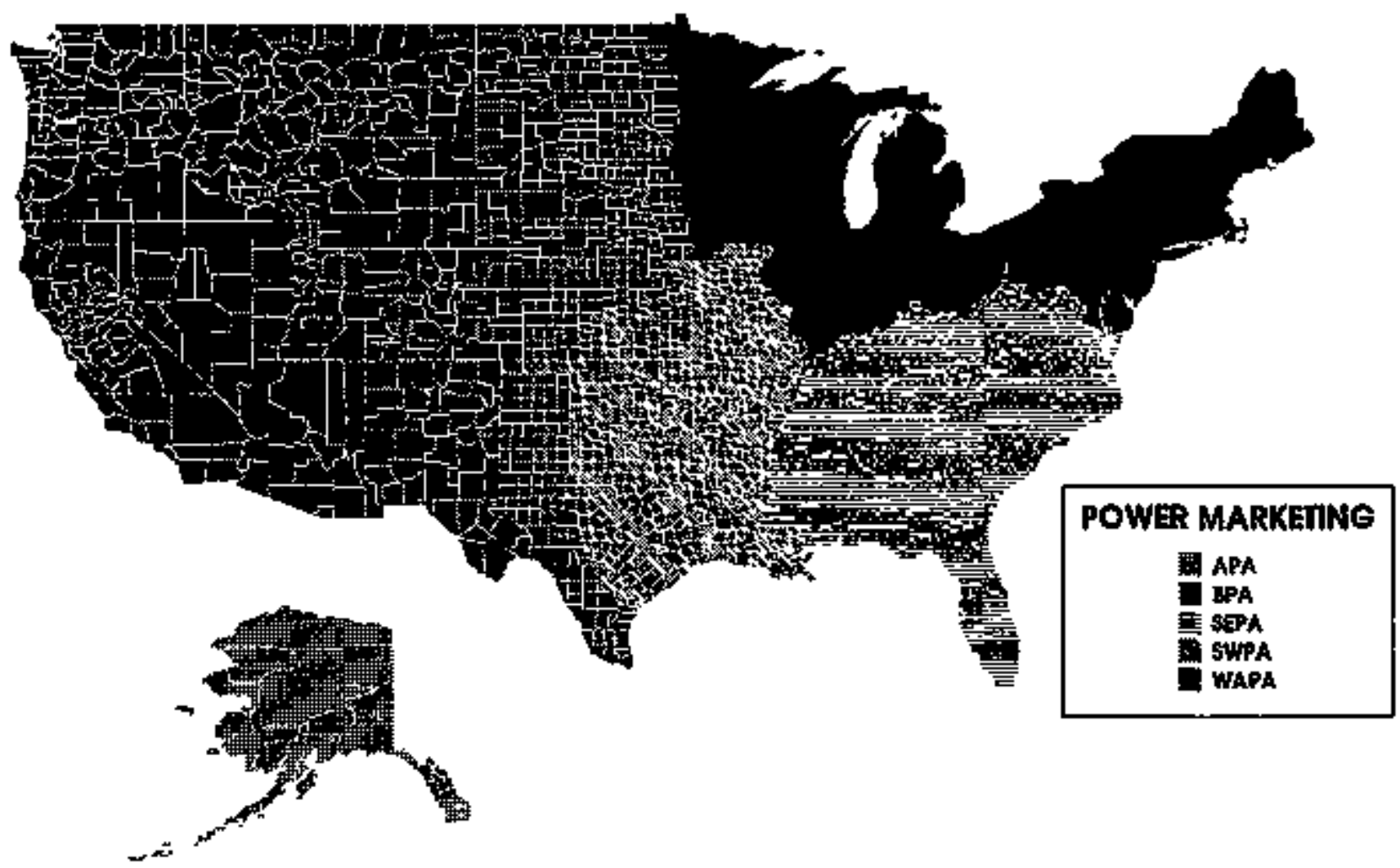

Source: Energy Information Admtnistration, Form EIA-412, 'Annual Report of Public Eloctric Utilities.' 


\section{Historical Synopsls of Akaska Power Adminlstration}

The Alskka Power Marketing Administration (APA) was formed in 1967 under the Floot Comtrol Act of 1944 to both operate and market power from two hydroelectric plants in Alaska: the Ekluma Project (30 nlegawatts) and the Snettisham Project (78 megawatts). The TVA and the APA are the only two Federal marketing orgenizations to operate their own plants.

\section{Alaska Power Admh/stration 1994 Summsy}

In 1994, the Alaska Power Admintstration (APA) bad sales and revenues totaling $\mathbf{4 0 2 . 9}$ million kilowatthours and $\$ 10.2$ million, respectively. This was APA's second highest revenue year on record. Recejpts exceedied outlays for a net return of $\$ 5.7$ million to the U.S. Treasury, and the total repayment made now stands at 18.3 percent. In fascal year 1994, the Spettisham Project generated 236 million kilowatthours, which produced revenues of $\$ 7.4$ million, and the Elkutna Project sales million kilowatthours that yielded $\$ 2.8$ million in revennes.

\section{APA's Energy Future}

Due to budget cuts and ongoing Congressional debates concerning the sale of APA, a Congressional Bill to authorize the sale of APA's assets passed the UJ.S. House of Representatives in the first half of the last Congressional session and the U.S. Senate version cleared committer. A new bill was fintroduced in the 104th Congress that transfers ownership of the facilities to the state and local utilities, which if passed, would eliminate the Alaska Power Administration.

Untilke the ofber power marketing administrattons, APA owns hydoelectric projects; operates the projects for the sole purpose of producing power; operates entirely in one state, and was never intended to remain under government control indefinitely. After taking these potnts into consideration for more than six years, the Congress is seeking to divest APA, ${ }^{10}$

Figure 4. Rovenue Applled Chart for APA, 1990-1994

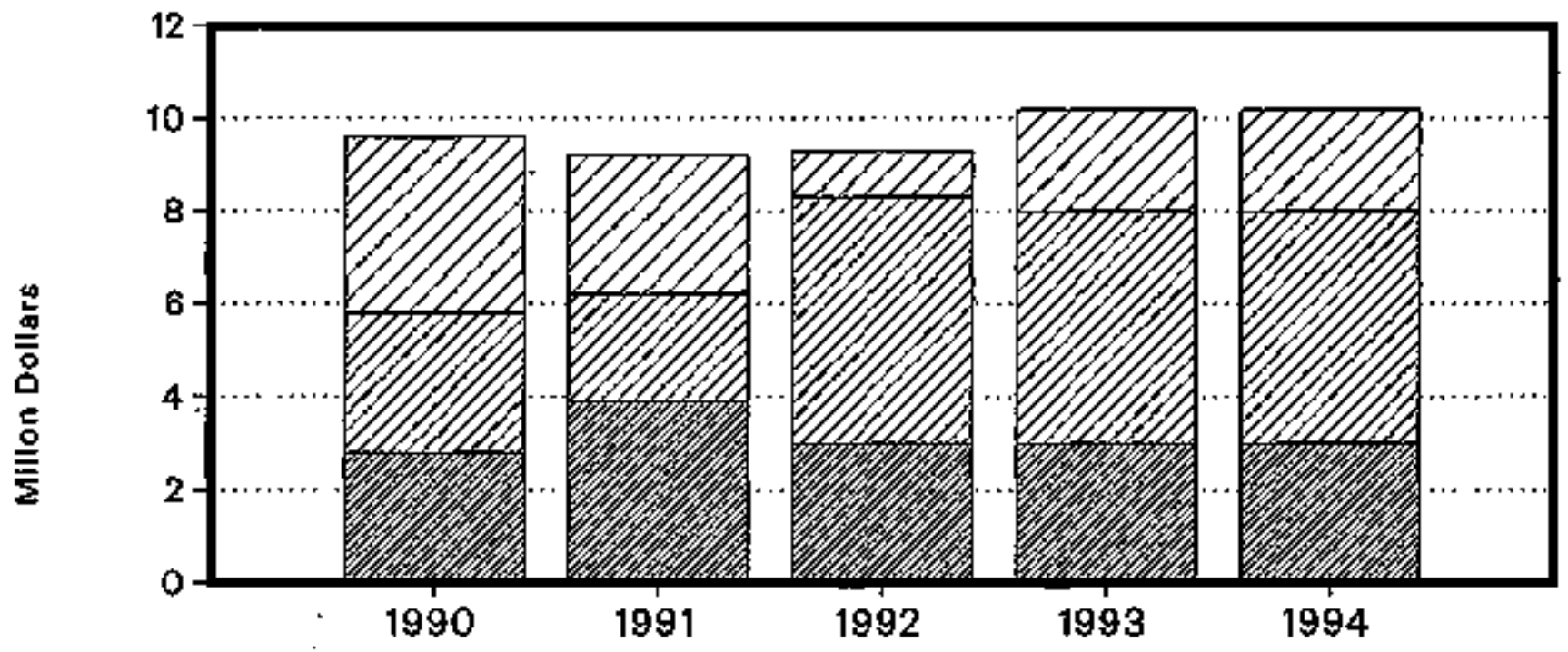

Soturce: Alaska Power Administration, '1994 Annual Report, DOE/APA' [Juneau, AK, 1996).

10 Alnska Power Administration, 1994 Annad Report DOE/APA (Junesh, AR, 1995). 


\section{Hitorical Synopets of Bonnoville Power Administrailon}

During the depression in the early 1930's, New Deal legislation was passed that authorized construction of a number of Federal dams, inciuding Grand Coulee and Bonneville dams in the Pecific Northwest. In 1937, the Government decided that the U.S. Bureau of Reclamation would be responsible for butlding and cparating the dams in the Northwest, and a new marketing administration, the Bonneville Power Admitststration (BPA), was created by the Bonneville Project Act of 1937 to build and operate transmission facilities and to martet the power. The BPA grew, but in the late $1960^{\circ}$, like the TVA, the BPA faced a potential shortage of hydroelectric capacity to meet their bad. In 1980, the Pacific Narthwest Electric Power Planning and Conservation Act gave the BPA the authority to plan for and acquire additional power to mest' its growing load requirements. The BPA's responsibilíties were also extended from only marketing Federal power to supplying the power. Its authority to snpply power, however, was restricted to obtaining it from plants built by others BPA cammot baild its own power pilants. Oily the BPA and TVA are responsible for meeting their consumers loads. Under the 1980 Act, the BPA also must protect and enbance the fish and wildife of the Columbia River and its tributaries.

\section{Bonneville Power Admin/stration 1994 Summary}

Beginning fiscal year 1994, Bonneville Power Administration (BPA) raised wholesale power rates an gverage 15.0 percent. The new rates were designed to generate total operating revenues of $\$ 2,313$ million in 1994; however, dry weather, power system adjust ments for fish, and a protracted slump in sluminum prices combined to depress revenues. Actual revenues fell \$124 million short of the projection. The volume of megawathour sales did not change dramatically in any consumer category; however, expenses increased due to the corresponding need to import replacement power. Total expeases exceeded total revenues by $\$ 61$ million in 1994, and for the third straight year reveares have failed to cover expenses (Fignre 4).

Figure 5. Total Revenute and Expenses for BPA, 1990-1994

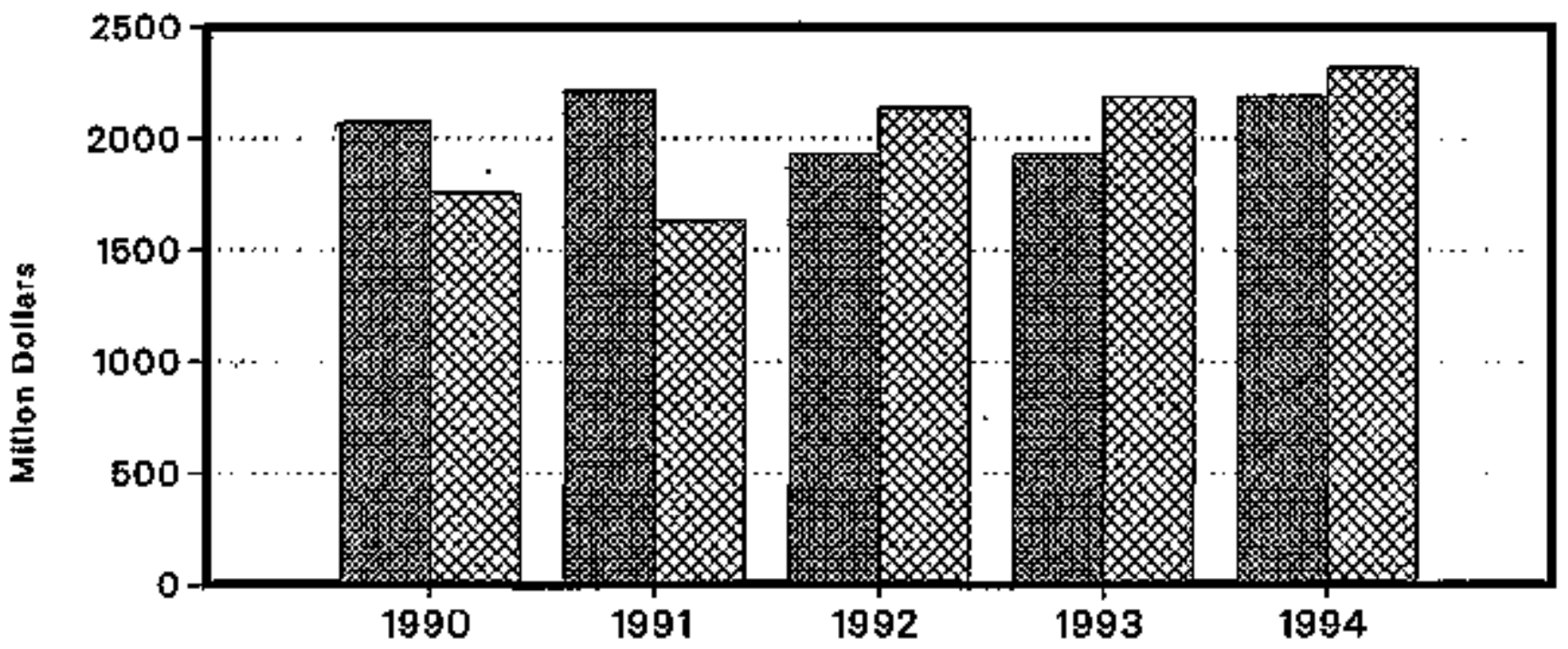

婜 Revenue

Sourca: Bannavilia Powar Administration, '1994 Annual Ragort, DoE/BP-2621' \{Portland, OR, Jan, 1996\} 
Revenues from power sales to pablicly owned and cooperative electric utilities rose $\$ 173$ million to $\$ 1,204$ million in 1994. These utilities are BPA's largest and fartest growing consumer base in revenues and number of seles. Included in this category are 28 public utility districts, 41 mundcipals, and 56 cooperatives.

Revenues froth the eight glominum companies that buy power from BPA were \$391 million in 1994. Normally, sales to aluminum smelters make up weil over onc-Fourth of BPA total revenues; however, in the past three years aluminuma's share of total revenues has fallen to 21.2 in 1992 to 18.1 percent in 1993, and in 1994, to 17.8 percent. The drop was due primarily to a depressed global market for aluminum. This resulted in aluminam sales representing a lower portion of total sales.

Revenute from seven investor-owned electric utilities were stable at $\$ 303$ million in 1994. However, these electric utilities own generating power resources and BPA only supplements their power resources.

Revenues from seven Federal agencies and eight nonaluminum industries dropped to $\$ 54$ million. While demand from Federal agencies held steady, energy sales to nonaluminum industries decreased.

\section{BPA's Energy Future}

The Competitive Project began in 1993 with a top-tobottom and function by function review of everything BPA does. BPA huddled with customers and interest groups and came out with a new strategrio mission. As fiscd year 1994 came to a close, the transformation was basically complete. BPA is now organtzed by the types of customers it serves. There are six segment managers, each watching the special needs of a customer group. BPA is repositioning itself to operate more as a business that sells and delivers electricity in an environmentally resporasible way and creates enough revenne to carry out acher mandates such as protecting fish and wildiffe. Instead of offering generic packages, products and services will be unbundled and rebundled to fit discrete market segments. The unbundled product line makes possible different $00 \mathrm{~m}$ binations of power, transmission, loadshaping, wheeling, and environmental services.

BPA repayed $\$ 696$ million to the U.S. Treasury while committing additional linance to cleaning up residues, hazardous wastes, and preventing future contaminations of trassmission and other' sites. This annulal obligation was met on time for the sleventh consec. utive year? 


\section{Mrtorical Synopsts of Southeastern Power Administration}

The thitd power marketing administration, Southeastern Power Administration (SEPA), was established in 1950 under the authority of the Flood Contral Act of 1944 to sell power produced by the U.S. Army Corps of Engineers in the Southeast. The SEPA currently markets power in West Virginita, Virginia, North Carolina, South Carolina, Georgia, Florida, Alabiana, Mississippi, Tennessee, and Kentucky. The SEPA is unique from the othet marketing authorities in that it owns no transmission lines. It musk rely on private firms to transmit the power it sells. In its role to market energy penerated by the Southeastem Federal teservoir projects, it participated in the establishment of the Southeastern Pederal Power Alliance, which consist. of SEPA, the South Atlantic Division of the U.S. Anmy Corps of Engineers, and SEPA's preference customers. The purpose of this organization is to improve communication and establish a strategy by which the three groups can better implement the Federal Power Program in the southeast.

\section{Southeasterm Power Administration 1994 Summary}

In 1994, the Sontheastern Power Administration (SEPA) marketed wholesale power to 293 wholessle customers in 11 southern stales. The sale of 7.9 billion kilowatthours of energy and approximately 3.0 mitlion
Wlowatts of capacity penerated revenues of $\$ 156$ million produced revenues totaling \$158 million.

In 1994, SEPA opened a temporary Operations Center which enabled scheduling hourly geineration of hydroelectric projects in the marketing area. The facility also serves as an emergency center in the advent of a disaster.

The Stonewall Jackson Project, located in West Virginia, was operated and evergized in 1994 and became SEPA'B 23 rd project. The 300 kilowatt generator was added to the existing dam and commercial operation began in September. Energy geverated in excess of project use-is marketed to the Monongahela Power Company. During fiscal year 1994, 63,306 kilowatthours were generated. Annisal average generation is expected to be 1,420,000 kilowatthours.

SEPA's rates and repayments are sond and sufficient to cover all costs assoctated with power production and transmission costs. SEPA has maintained an average debt service ratio of 1.1. for 5 yegrs, and a ratio of 1.0 indicates enough cash flow to make principal and interest payments on outstanding debts, as well as meeting all other cash expenses (Figure 6 ).

Cumulative principal payment as a percent of total investment indicates profitability. SEPA's tepayment of investment funds advanced bave increased over the past 5 years from 22 percent to 31 percent of the total Federal investment.

Figure 6. Debt Service Coverage Ratio for SEPA, 1990-1994

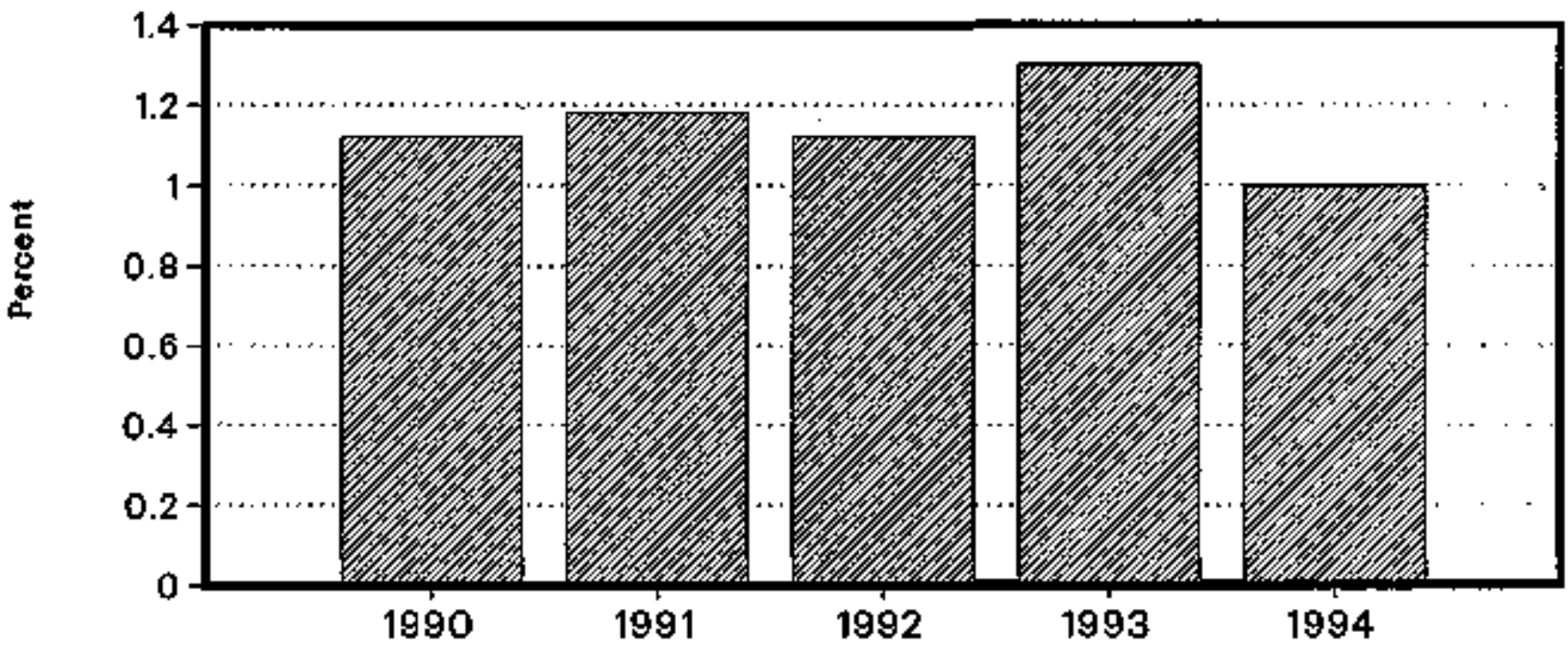

Source: Southeostern Power AdmInlstration, '1994 Annual Fepart, DOE/SEPA' (Elbarton, GA, I995). 


\section{SEPA's Energy Fufure}

Manufactured housing accounts for a signifficant portion of SEPA's residential consumer load. There fore, SEPA, in conjunction with some other entities, has funded a research project that will result in a significent inpcovement in the energy efinciency of manufactured housing. In 1994, the Resource Planning Guide was available to SEPA's customers who found it a good tool for developing an Integrated Resource Plan.'

- Southestem Power Administralion, IS94 Amourl Report, DOE/SEPA (Elberton, GA, 1995). 


\section{Southwestern Power Adminlstration 1994 Summary}

In 1943, the Southwestern Power Administration (SWPA) was created using the Executive Branch's emergency war powers authority to meet the growing power demands from weapons developminet and domestic needs. Later, the SWPA's authority to continue to operate after World War II came from the Flond Control Act of 1944. Initially, the SWPA was assigned to market power from dams in Arkansas, Oklahoma, and Texas that were operated by the U.S. Department of Army to serve munitions plants. In 1945, the SWPA was designated as the agent for markettog power generated by the U.S. Army Corps of Engineers in the States of Atikansas, Kansas, Louisiana, Missouri, Oklahoma, and Texas. Today, SWPA sells power from 24 hydroelectric facilities in these States that total 2,158 megawatts of installed capacity.
At the end of 1994, Sonthwestern Power Admidistration (SWPA) marketed power to 11 cooperatives, 3 military imstallations, 41 municipal utilities, and three municipal utility joint action agencies. SWPA experienced another above average year in hydropower generation with 6,939 gigawatthours of energy produced. SWRA collected revenues totaling \$109.4 million, which allowed $\$ 32.2$ million to be repatd on Federal investment, raising the total cumulative payment to $\$ 329.9$ million. million. Durtus 1994, two SWPA customers received rate increases.

In order to maintain a postive debt ratio and cashi flow, SWPA has developed four financial performance measures as management tools to help monitor specific area of interest. These tools include SWPA debt coverage ratio, cumulative principat payments as a percent of total Federal investment, percent variance of actusl from planned and annusl paywents, and net cash flow to the U.S. Treasary (Figure 5).

Figure 7. Financial Performance for SWPA, 1990-1994

\begin{tabular}{|c|c|c|c|c|c|c|}
\hline Item & $1+4$ & $1 \% 91$ & $1+2$ & 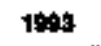 & $1 \%$ a & Analyate \\
\hline \multicolumn{7}{|l|}{ Cobt bervite corrarege rato } \\
\hline & 1.495 & 1.124 & 1.142 & 1.400 & 1.265 & 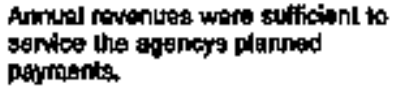 \\
\hline \multicolumn{7}{|l|}{ 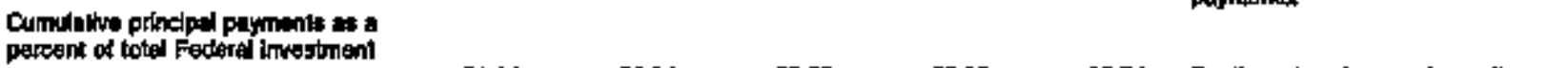 } \\
\hline & 2t.14 & 22.84 & $25 x$ & 28,80 & ap.74 & 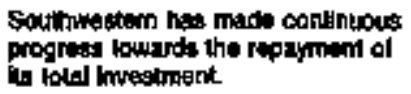 \\
\hline 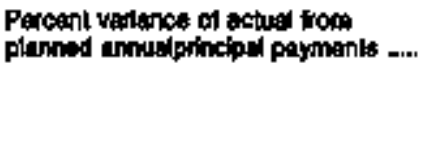 & 69.74 & -5 & 18.08 & 68.16 & 35: & 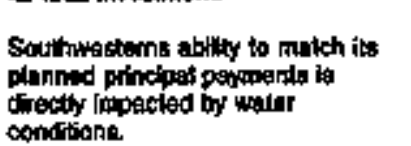 \\
\hline 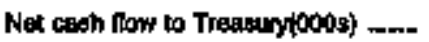 & 25,0e7 & 17,604 & $32,3,24$ & 80,169 & 25.679 & Provitied posthe eagh tow. \\
\hline
\end{tabular}

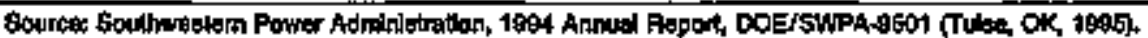

\section{SWPA's Energy Future}

The effective use of energy banks htas produced a net deposít of 104,569,000 kilowatthours which offset hydrologic conditions and allow the reduction of energy purchases. The use of energy benks has helped maintain low rates to customers and continues to be a priority. Fiscal year 1994 brought favorable water conditions which allowed SWPA to make a net deposit of 105 gigawatthours into its energy banks.
Thus ending the year with 1,759 gigawatthours of banked energy.

To serve as a more customer focused utility, SWPA drafted a customer survey in 1994 to be distributed in 1995. The purpose is two-fold: to determine customer expectations and to identify areas for process and service improvements. SWPA has also flattened the organization and standardized equipment to reduce overall maintenance and support costs." 


\section{Historical Synopsls of Westem Area} Power Administration

The last Federal marketing administration to be created was the Western Area Power Administration (WAPA), which was formed in 1977 when the Conpress created the U.S. Department of Energy and assipned the other Federal marketing administrations to be a part of the new energy department. The territory served by WAPA covers the 15 Central and Western States of Arizona, California, Colorado, Iowa, Kansas, Minresota, Montana, Nebraska, Nevada, New Mexico, North Dakota, South Dakota, Texas, Utah, and Wyouming. Its mission is to merket Federally-owned bydroelectrtic resources " +..in such a manner as to encourage the most widespread use there of at the lowest possible rates to consumers consistent with sound business piunciples ..." The WAPA's authority was extended through the Hoover Power Plant Act of 1984 to require customer utilities to undertake certair conservation activities and to withhold a part of customers' power allocations if they did aot comply. The WAPA markets hydroelectric power from 51 plants operated by the U.S. Bureau of Reclamation, the U.S. Aniny Corps of Engineers, and the International Boundary and Water Commis. sion. In addition, the WAPA markets the Federal Govertiment's 547 megswatt entitlement from the coal-fired Navajo Generating Station in Arizona.
Westem Area Power Administration 1994 Summary

In 1994, Western Area Power Administrution (WAPA) marketed hydroelectric power to 697 curtomers, operated and maintained 16,727 miles of transmission tire (inoluding 257 substations), sold more than 36 billion kilowatthours of energy which resulted in $\$ 658$ million net operating eeventes (Figure 8). These revenues were earned though the lingering effects of drought years limited hydroelectric generation to about 90 percent of a average year and operational constratints increased expenses.

In 1994, declining resources continued to be a problem around WAPA's river basin because of envin. ronmental and recreationgl concerns. WAPA's cost to replace power resulting from aew operating requirements was approximately $\$ 21$ mrillion from August 1991 to September 1994. In 1994, the U.S. Corps of Engineers published a draft environmental impact statement that would resnlt in lost revenue for the hydropower system of an estimated $\$ 3$ million annually.

As of Septeruber 1994, the investment to be repaid by WAPA's power systems totaled about $\$ 5.9$ billion, of which $\$ 2.2$ billion (38.0) percent has been repaid.

Figure 8. Electric Sales and Revenue for Western Area Power Administration

\begin{tabular}{|c|c|c|c|}
\hline Cunloner growp & Numbar & Soles whiplator & Gewents $\$(000)$ \\
\hline 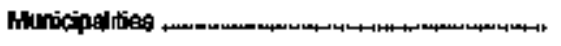 & 267 & $9,592,520$ & 103,491 \\
\hline 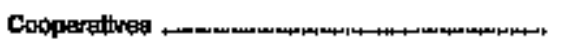 & 40 & $7,814,4009$ & $127,7,74$ \\
\hline Federnal agoncios & G9 & $2,140,001$ & 54,764 \\
\hline State sgencies .......-- & 51 & $6,271,745$ & 100,397 \\
\hline Pubio utity distiota .. & 22 & $4,12 a, 48,9$ & 105,174 \\
\hline Irefgetion doftrilets & B⿺ & $2,209,610$ & 29,20 \\
\hline 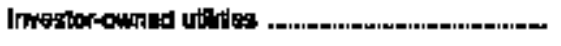 & 27 & $2,614,081$ & 49.539 \\
\hline Inderdeperimental ......-- & 7 & 16,677 & 0 \\
\hline 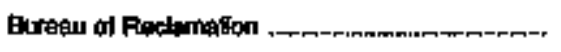 & 79 & $1,279,224$ & $7,0,92$ \\
\hline Intereran ciles nm-...- & B & $B 1,905$ & 1,524 \\
\hline 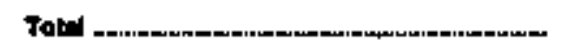 & 687 & $30,057,596$ & $\$ 59,165$ \\
\hline
\end{tabular}

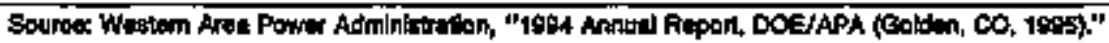




\section{WAPA's Energy Future}

WAPA continues developing the Energy Planning and Management Prograni to ensure long-teem planning and efficient energy tse by customert In addition, WAPA continues to provide technical, assistance to meet customer needs through the Energy Services program.

The Mead-Phoenix and Mead-Adelanto Projects are prime exarsples of WAPA's joint participation with others in the industry to provide the needed transmission capacity and to offer the most efincient utlizsm. tion of existing energy resources. These projects link the Phoenix, Arizona, area with Southern California and create regional marketing opportunities for electricity and efficient application of WAPA's power resources through interregional power transfers and seasonal diversity exchanges. WAPA is participating with other electric ntilities in a project that will provide a positive rate impact to WAPA's customers." 
Table 27. Statement of Income by U.S. Federal Electric Utalty, 1994 (Thousand Dollars)

\begin{tabular}{|c|c|c|c|c|c|}
\hline Item & 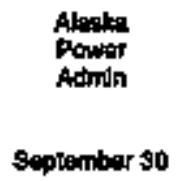 & 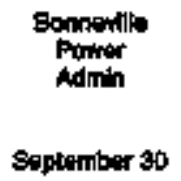 & $\begin{array}{l}\text { Southunitien } \\
\text { Powion } \\
\text { Adintn } \\
\text { Septomber } 30\end{array}$ & 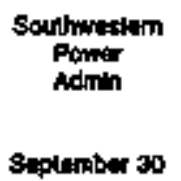 & $\begin{array}{l}\text { Westom Aros } \\
\text { Fowner } \\
\text { Astinla } \\
\text { September go }\end{array}$ \\
\hline 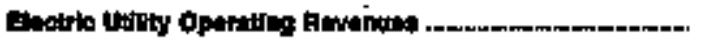 & wasts & 2,10:,002 & 155,002 & 109,193 & $482,50 B$ \\
\hline 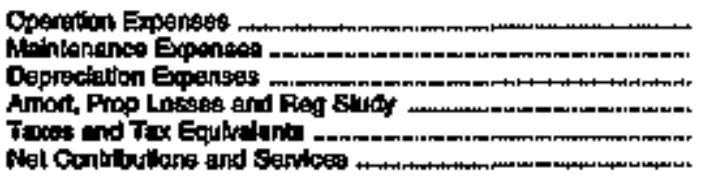 & $\begin{array}{r}3,679 \\
696 \\
2,607 \\
0 \\
0 \\
0\end{array}$ & $\begin{array}{r}1,85,6001 \\
94,734 \\
10,6,16 \\
55,698 \\
0 \\
0\end{array}$ & $\begin{array}{r}33,091 \\
0 \\
0 \\
0 \\
0\end{array}$ & $\begin{array}{r}62,277 \\
10,591 \\
2,418 \\
515 \\
0 \\
0\end{array}$ & $\begin{array}{r}\text { G0,367 } \\
0 \\
0 \\
0 \\
0\end{array}$ \\
\hline Totol Eoctift Utilly Opordiling & 6,532 & 3,0or,0at & 19,169 & 95,901 & 570,357 \\
\hline 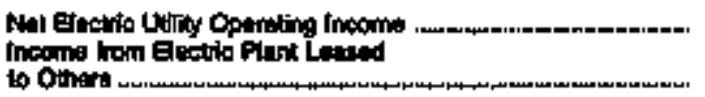 & $\begin{array}{r}3.674 \\
0\end{array}$ & $\begin{array}{r}\text { Be,7a1 } \\
208\end{array}$ & $\begin{array}{r}122,743 \\
0\end{array}$ & $\begin{array}{r}13,393 \\
0\end{array}$ & $\begin{array}{r}78,149 \\
0\end{array}$ \\
\hline 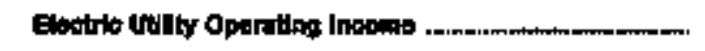 & 3,674 & 69,909 & 102743 & 13,393 & 73,249 \\
\hline Oiner Electric hoome .... & 6 & 709 & 12 & 0 & 136,108 \\
\hline 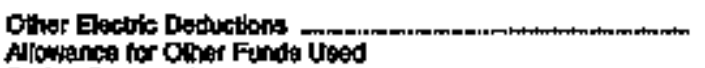 & $\mathbf{0}$ & o & o & 0 & 0 \\
\hline 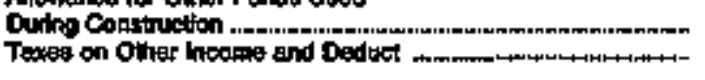 & $\stackrel{0}{\circ}$ & o & $\stackrel{0}{0}$ & 0 & $-164,561$ \\
\hline Eectric Udity theome mmm & 3,890 & 9,60 & 122,195 & $13,3: 30$ & 23,005: \\
\hline 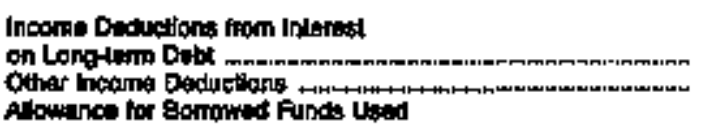 & 4,850 & $\begin{array}{r}227,620 \\
5,624\end{array}$ & $\begin{array}{r}57 \\
122,088\end{array}$ & 501 & 79,847 \\
\hline During Construction nom & o & $-16,450$ & 0 & o & 0 \\
\hline 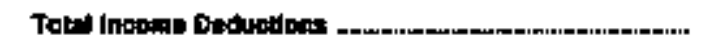 & 4059 & 248,085 & 127,753 & 501 & 73,647 \\
\hline 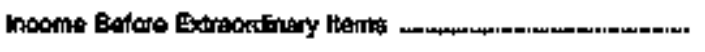 & $-1,178$ & $-127,987$ & 0 & 12,662 & $-50,151$ \\
\hline 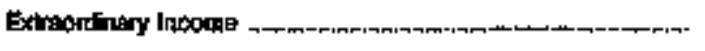 & o & 0 & 0 & a & 317,202 \\
\hline 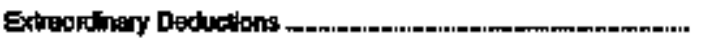 & o & 0 & 0 & $\mathbf{0}$ & o \\
\hline Not heome & $-1,170$ & $-107,383$ & o & 12,982 & 207001 \\
\hline
\end{tabular}

Ste andhales at and of fitts tablis. 

(Thousand Dollars)

\begin{tabular}{|c|c|c|c|c|c|}
\hline \multirow[b]{2}{*}{ Itern } & \multirow[b]{2}{*}{ 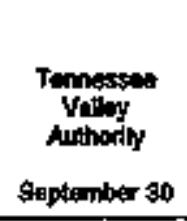 } & \multicolumn{2}{|c|}{ 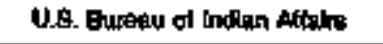 } & \multirow[b]{2}{*}{ 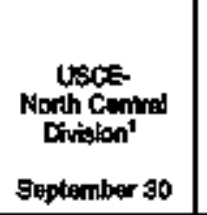 } & \multirow[b]{2}{*}{ Toptal } \\
\hline & & 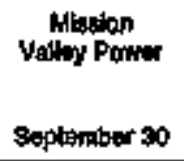 & 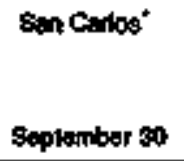 & & \\
\hline 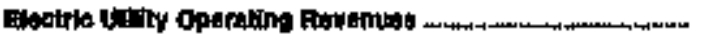 & 5,001,7935 & 14,450 & - & 1,9:91 & B,55,2,308 \\
\hline 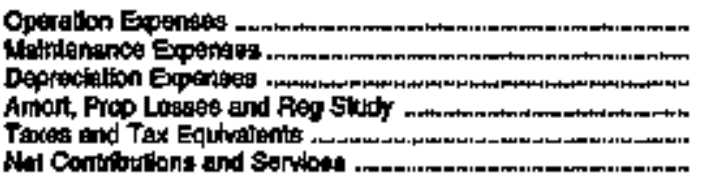 & $\begin{array}{r}2,296,503 \\
278,139 \\
636,757 \\
0 \\
247,540 \\
0\end{array}$ & 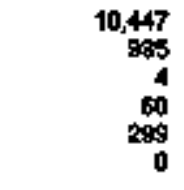 & $\begin{array}{l}= \\
\overline{-} \\
\bar{z}\end{array}$ & $\begin{array}{r}749 \\
623 \\
147 \\
19 \\
0 \\
0\end{array}$ & $\begin{array}{r}4,870,600 \\
376,564 \\
745,841 \\
68,492 \\
247,004 \\
0\end{array}$ \\
\hline Total Eectrit Utilty Oparation & a,ast,ps & 11,744 & - & $1,0,099^{-}$ & $6,908,310$ \\
\hline 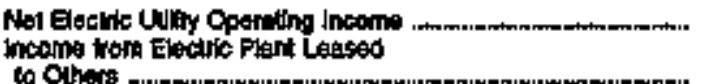 & $1,942,897$ & 2600 & - & 169 & $2,048,900$ \\
\hline 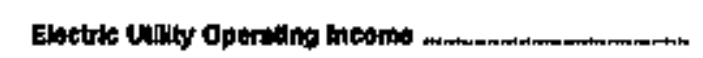 & $1,089,736$ & 2,660 & - & 143 & $2,216,605$ \\
\hline 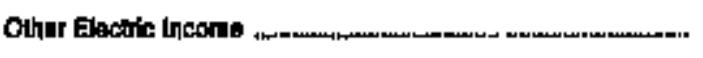 & 659 & 65 & - & 0 & 197,732 \\
\hline 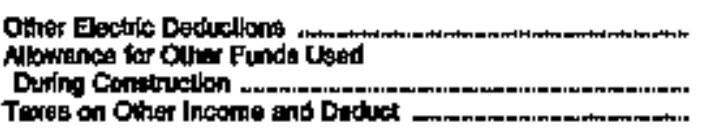 & $\begin{array}{r}59, \$ 17 \\
0 \\
0\end{array}$ & 0 & $\begin{array}{l}- \\
-\end{array}$ & 0 & $\begin{array}{r}59,147 \\
-184,581 \\
0\end{array}$ \\
\hline 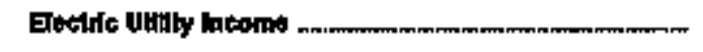 & $1,981,270$ & . $\$, 340$ & - & 149 & $2,140,650$ \\
\hline 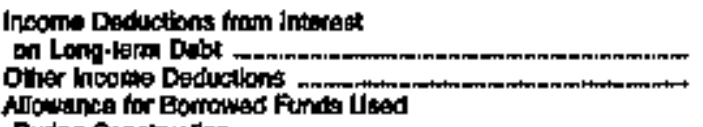 & $1,607,340$ & $\stackrel{0}{0}$ & 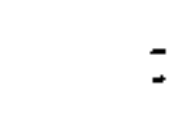 & $\stackrel{0}{0}$ & $\begin{array}{r}1,9 \$ 0,394 \\
417,718\end{array}$ \\
\hline 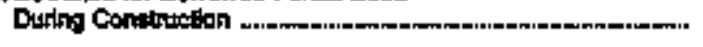 & $-122,635$ & 0 & - & 0 & $-138,494$ \\
\hline 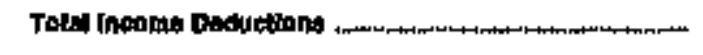 & $1,729,062$ & 0 & $=$ & 0 & 2,150,009 \\
\hline Income Bafore Exaraordinay Jtem! _- & 151,370 & 3,340 & - & 143 & $-0,350$ \\
\hline 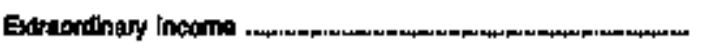 & 0 & a & - & o & 318,928 \\
\hline 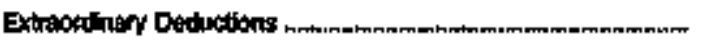 & 0 & 0 & $=$ & o & 0 \\
\hline 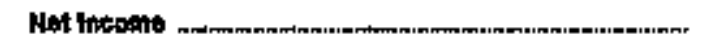 & $\$ 51,316$ & 3,340 & - & 143 & stoposs \\
\hline
\end{tabular}

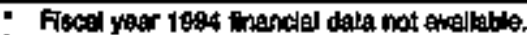

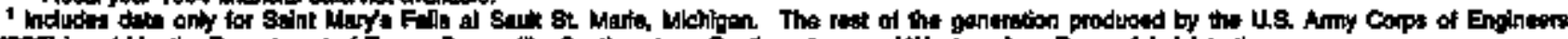

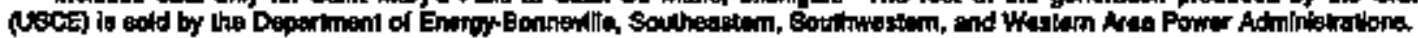

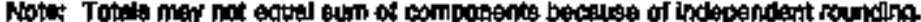

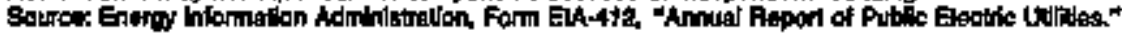


Table 28. Balance Sheet by U.S. Federal Electric Utitity

on September 30,1994

(Thousand Dollars)

\begin{tabular}{|c|c|c|c|c|c|}
\hline Item & $\begin{array}{c}\text { Alesica } \\
\text { Potwer } \\
\text { Admin }\end{array}$ & $\begin{array}{l}\text { Bonnerilite } \\
\text { Powar } \\
\text { Athith }\end{array}$ & $\begin{array}{c}\text { Bouthoostem } \\
\text { Pomer } \\
\text { ndmin }\end{array}$ & 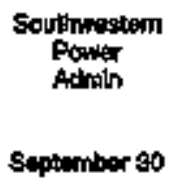 & $\begin{array}{l}\text { Westem Aras } \\
\text { Power } \\
\text { Admin } \\
\text { septombur } 30\end{array}$ \\
\hline 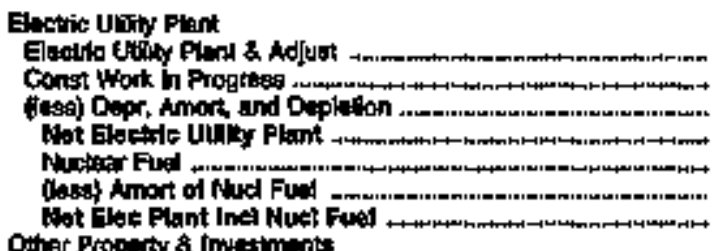 & $\begin{array}{r}107,067 \\
1090 \\
39,119 \\
151,758 \\
0 \\
0 \\
151,758\end{array}$ & $\begin{array}{r}4,167,659 \\
351,423 \\
1,322,514 \\
3,166,139 \\
0 \\
0 \\
0,160,49\end{array}$ & $\begin{array}{r}672 \\
0 \\
186 \\
096 \\
0 \\
0 \\
098\end{array}$ & $\begin{array}{r}120,110 \\
25,155 \\
20,348 \\
116,190 \\
0 \\
0 \\
115,419\end{array}$ & $\begin{array}{r}4,560,021 \\
5,20,047 \\
1,511,480 \\
3,659,289 \\
0 \\
0 \\
3,650,489\end{array}$ \\
\hline 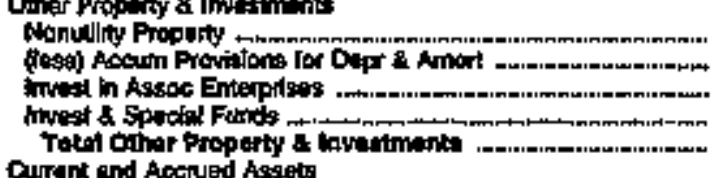 & $\begin{array}{l}0 \\
0 \\
0 \\
0 \\
0\end{array}$ & $\begin{array}{r}39 \\
0 \\
0 \\
0 \\
39\end{array}$ & $\begin{array}{l}0 \\
0 \\
0 \\
0 \\
0\end{array}$ & $\begin{array}{l}0 \\
0 \\
0 \\
0 \\
0\end{array}$ & $\begin{array}{l}0 \\
0 \\
0 \\
0 \\
0\end{array}$ \\
\hline 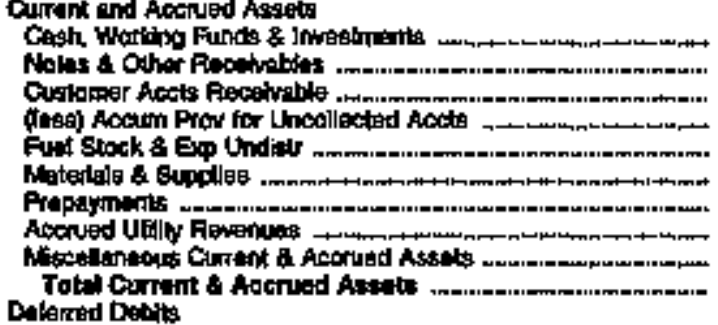 & $\begin{array}{r}1,894 \\
7 \\
305 \\
0 \\
0 \\
0 \\
0 \\
0 \\
0 \\
2,207\end{array}$ & $\begin{array}{r}369,869 \\
16,762 \\
7,172 \\
388 \\
0 \\
75,284 \\
293,057 \\
7,377 \\
762,244\end{array}$ & $\begin{array}{r}20,6023 \\
3 \\
3,036 \\
0 \\
0 \\
0 \\
0 \\
0,403 \\
0 \\
30,197\end{array}$ & $\begin{array}{r}32,989 \\
0 \\
26,416 \\
0 \\
0 \\
5,540 \\
0 \\
0 \\
10 \\
64,186\end{array}$ & $\begin{array}{r}451,819 \\
0 \\
1+4,661 \\
0 \\
0 \\
0 \\
0 \\
0 \\
114,312 \\
600,482\end{array}$ \\
\hline 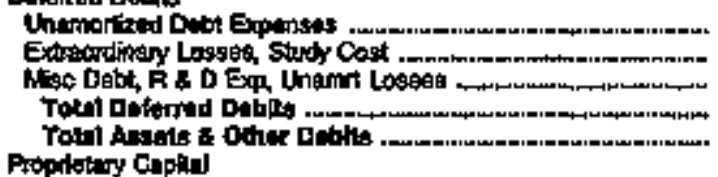 & $\begin{array}{r}17,561 \\
0 \\
0 \\
17,51 \\
171,52 B\end{array}$ & $\begin{array}{r}0 \\
0 \\
0,001,002 \\
0,001,032 \\
11,930,769\end{array}$ & $\begin{array}{r}0 \\
0 \\
0 \\
0 \\
039803\end{array}$ & $\begin{array}{r}0 \\
0 \\
0 \\
0 \\
180,085\end{array}$ & $\begin{array}{r}0 \\
0 \\
0 \\
0 \\
4,290,730\end{array}$ \\
\hline 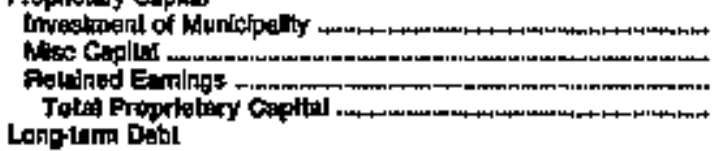 & $\begin{array}{r}160,005 \\
0 \\
3,231 \\
171, \pi 96\end{array}$ & $\begin{array}{r}1,466,591 \\
0 \\
218,608 \\
1,086,2,27\end{array}$ & $\begin{array}{r}31,475 \\
0 \\
0 \\
31,475\end{array}$ & $\begin{array}{r}67,162 \\
0 \\
71,0022 \\
189,204\end{array}$ & $\begin{array}{r}11,050,717 \\
-7,401,053 \\
297,091 \\
3,081,965\end{array}$ \\
\hline 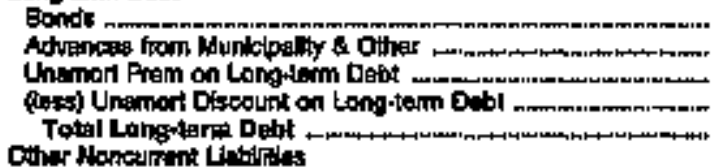 & $\begin{array}{l}0 \\
0 \\
0 \\
0 \\
0\end{array}$ & $\begin{array}{r}2,816,600 \\
7,200,200 \\
0 \\
0 \\
0,679,700\end{array}$ & $\begin{array}{l}0 \\
0 \\
0 \\
0 \\
0\end{array}$ & $\begin{array}{l}0 \\
0 \\
0 \\
0 \\
0\end{array}$ & $\begin{array}{l}0 \\
0 \\
0 \\
0 \\
0\end{array}$ \\
\hline 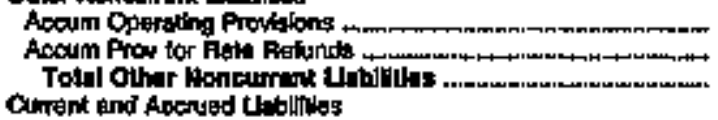 & $\begin{array}{l}0 \\
0 \\
0\end{array}$ & $\begin{array}{l}0 \\
0 \\
0\end{array}$ & $\begin{array}{l}0 \\
0 \\
0\end{array}$ & $\begin{array}{l}0 \\
0 \\
0\end{array}$ & $\begin{array}{l}0 \\
0 \\
0\end{array}$ \\
\hline 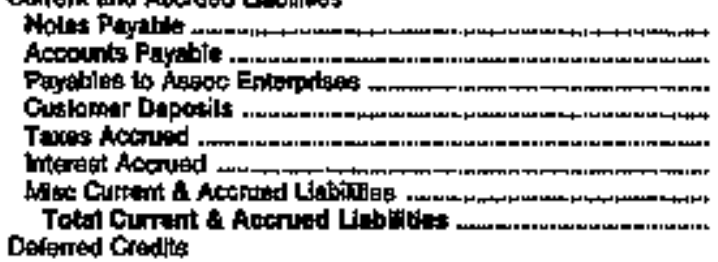 & $\begin{array}{r}0 \\
0 \\
0 \\
0 \\
0 \\
0 \\
290 \\
230\end{array}$ & $\begin{array}{r}0 \\
B 4,074 \\
0 \\
0 \\
0 \\
43,310 \\
227,472 \\
354,856\end{array}$ & $\begin{array}{r}0 \\
2,098 \\
117 \\
0 \\
0 \\
0 \\
173 \\
2,328\end{array}$ & $\begin{array}{r}0 \\
4,689 \\
0 \\
0 \\
0 \\
0 \\
2,779 \\
6,770\end{array}$ & $\begin{array}{r}0 \\
69,609 \\
0 \\
0 \\
0 \\
0 \\
249,177 \\
317,765\end{array}$ \\
\hline 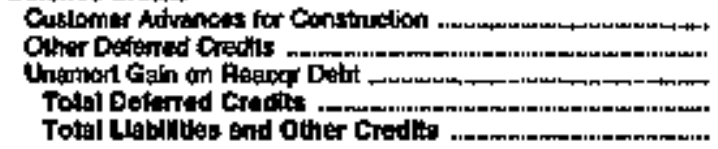 & $\begin{array}{r}0 \\
0 \\
0 \\
0 \\
171,628\end{array}$ & $\begin{array}{r}11,079 \\
8,891 \\
0 \\
19,970 \\
14939,763\end{array}$ & $\begin{array}{r}0 \\
0 \\
0 \\
0 \\
98,900\end{array}$ & $\begin{array}{r}0 \\
35,011 \\
0 \\
35,911 \\
100,685\end{array}$ & $\begin{array}{r}0 \\
0 \\
0 \\
0 \\
0,239,730\end{array}$ \\
\hline
\end{tabular}

See anduates et and od tile titto. 
Table 28. Balance Sheat by U.S. Fedoral Eloctrle Utinty on September 30, 1994 (Continued)

(Thousend Dollars)

\begin{tabular}{|c|c|c|c|c|c|}
\hline \multirow[b]{2}{*}{ Iten| } & \multirow[b]{2}{*}{$\begin{array}{c}\text { Tempesser } \\
\text { Velloy } \\
\text { Aurthorty } \\
\text { September so }\end{array}$} & \multicolumn{2}{|c|}{ U.S. Buratul ot hofan Affelin } & \multirow[b]{2}{*}{$\begin{array}{l}\text { USCE. } \\
\text { North Gentirl } \\
\text { Dinlinen' } \\
\text { September } 30\end{array}$} & \multirow[b]{2}{*}{$\begin{array}{c}\text { Total } \\
\text { Septomber so }\end{array}$} \\
\hline & & $\begin{array}{c}\text { Mtasion } \\
\text { Velley Powner } \\
\text { Septentber } 30\end{array}$ & $\begin{array}{l}\text { Sen Calos' } \\
\text { September so }\end{array}$ & & \\
\hline 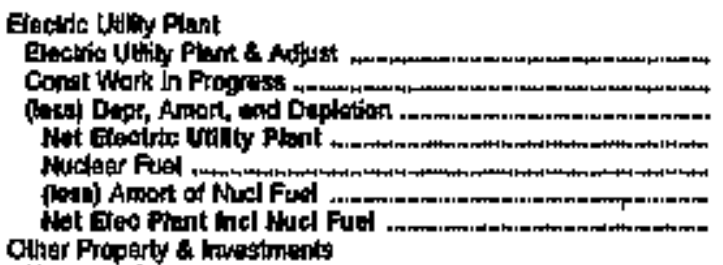 & $\begin{array}{r}15,910,756 \\
15,725,723 \\
6,580,993 \\
27,056,946 \\
2,517,497 \\
1,503,426 \\
29,076,048\end{array}$ & $\begin{array}{r}2,2,20 \\
2,50,6 \\
0,300 \\
22,600 \\
0 \\
0 \\
2,, 502\end{array}$ & $\begin{array}{l}\bar{z} \\
\bar{z} \\
\bar{z}\end{array}$ & $\begin{array}{r}12,343 \\
0 \\
3,524 \\
8,060 \\
0 \\
0 \\
8,619\end{array}$ & 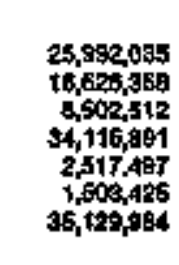 \\
\hline 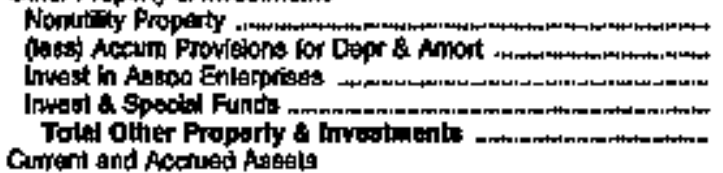 & $\begin{array}{r}4,059 \\
2,959 \\
0 \\
150,049 \\
151,140\end{array}$ & $\begin{array}{l}0 \\
0 \\
0 \\
0 \\
0\end{array}$ & $\begin{array}{l}z \\
z \\
z\end{array}$ & $\begin{array}{l}0 \\
0 \\
0 \\
0 \\
0\end{array}$ & $\begin{array}{r}4,158 \\
2,989 \\
0 \\
150,049 \\
181,186\end{array}$ \\
\hline 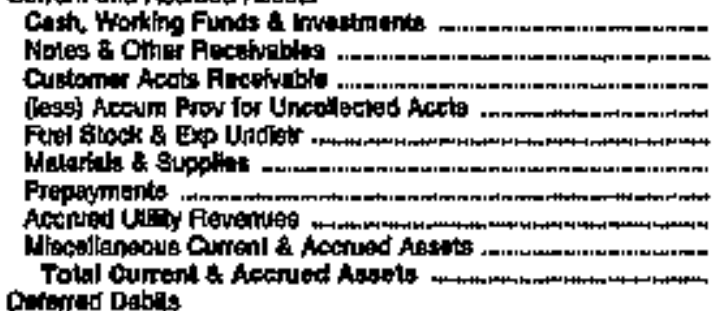 & $\begin{array}{r}6,858 \\
40,197 \\
635,508 \\
0 \\
104,978 \\
249,097 \\
0 \\
0 \\
0 \\
1,025,+17\end{array}$ & 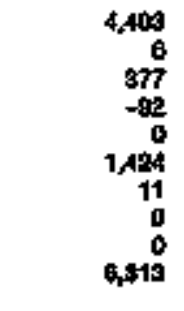 & $\begin{array}{l}\bar{z} \\
\bar{z} \\
\bar{z} \\
\bar{z} \\
\bar{z}\end{array}$ & $\begin{array}{l}45 \\
0 \\
0 \\
0 \\
0 \\
0 \\
0 \\
0 \\
0 \\
45\end{array}$ & $\begin{array}{r}884,723 \\
58,449 \\
789,785 \\
487 \\
104,378 \\
327,284 \\
208,068 \\
17,263 \\
116,400 \\
2,590,958\end{array}$ \\
\hline 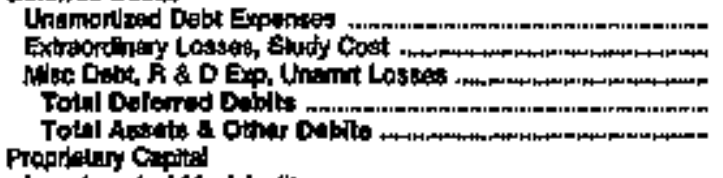 & 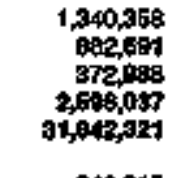 & $\begin{array}{r}0 \\
0 \\
0 \\
0 \\
20,676\end{array}$ & $\begin{array}{l}\bar{z} \\
\bar{z} \\
\bar{z}\end{array}$ & $\begin{array}{r}0 \\
0 \\
0 \\
0 \\
0\end{array}$ & $\begin{array}{r}1,357,919 \\
802,691 \\
8,374,020 \\
10,614,620 \\
18,186,698\end{array}$ \\
\hline 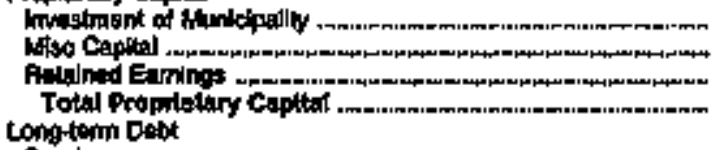 & $\begin{array}{r}048,315 \\
0 \\
3,494,153 \\
4,092,468\end{array}$ & $\begin{array}{r}0 \\
0 \\
21,350 \\
21,350\end{array}$ & $\begin{array}{l}\bar{z} \\
\overline{-}\end{array}$ & $\begin{array}{r}0 \\
0 \\
8,864\end{array}$ & $\begin{array}{r}13,438,346 \\
-7,405,053 \\
4,050,804 \\
10,049,206\end{array}$ \\
\hline 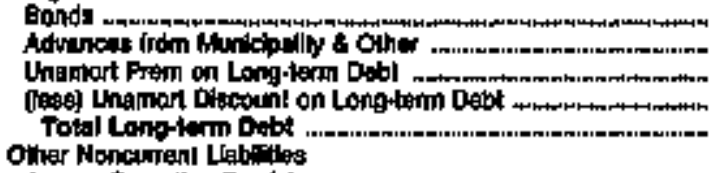 & $\begin{array}{r}22,546,100 \\
0 \\
48,198 \\
388,620 \\
22,205,678\end{array}$ & $\begin{array}{r}0 \\
6,140 \\
0 \\
0 \\
6,140\end{array}$ & $\begin{array}{l}\bar{z} \\
\bar{z} \\
\bar{z}\end{array}$ & $\begin{array}{l}0 \\
0 \\
0 \\
0 \\
0\end{array}$ & $\begin{array}{r}25,169,600 \\
7,277,420 \\
48,198 \\
388,620 \\
32,099,600\end{array}$ \\
\hline 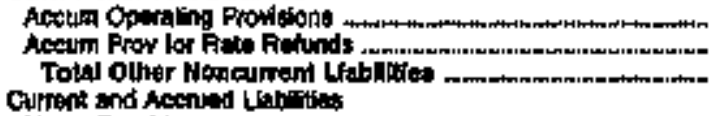 & $\begin{array}{l}210,608 \\
264,548 \\
478,408\end{array}$ & $\begin{array}{l}0 \\
0 \\
0\end{array}$ & $\ddot{z}$ & $\begin{array}{l}0 \\
0 \\
0\end{array}$ & $\begin{array}{l}21 t, 154 \\
104,591 \\
475,744\end{array}$ \\
\hline 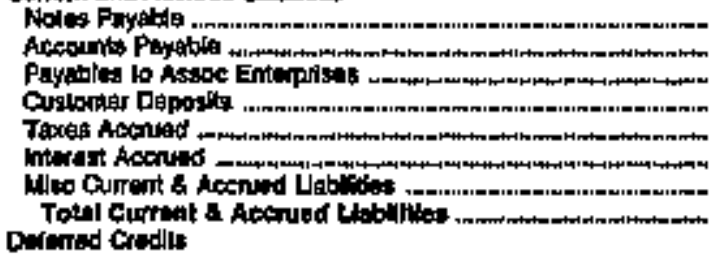 & $\begin{array}{r}2,600,170 \\
756,292 \\
0 \\
0 \\
0 \\
423,902 \\
719,000 \\
4,509,704\end{array}$ & $\begin{array}{r}0 \\
861 \\
0 \\
108 \\
-10 \\
0 \\
-\infty \\
-040\end{array}$ & $\begin{array}{l}\bar{z} \\
\bar{z} \\
\bar{z} \\
\bar{z}\end{array}$ & $\begin{array}{l}0 \\
0 \\
0 \\
0 \\
0 \\
0 \\
0 \\
0\end{array}$ & $\begin{array}{r}2,609,658 \\
94,4,43 \\
117 \\
1,405 \\
-19 \\
406,612 \\
1,190,627 \\
8,195,947\end{array}$ \\
\hline 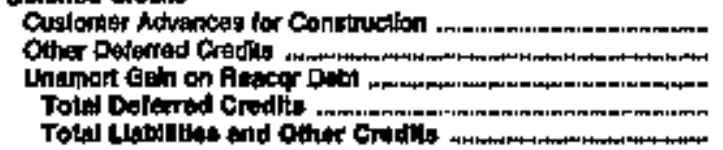 & 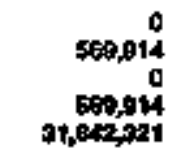 & $\begin{array}{r}365 \\
0 \\
0 \\
385 \\
20,976\end{array}$ & $\begin{array}{l}\overline{-} \\
\bar{z} \\
\bar{z}\end{array}$ & $\begin{array}{r}0 \\
0 \\
0 \\
0 \\
0,100\end{array}$ & $\begin{array}{r}11,435 \\
614,715 \\
0 \\
625,151 \\
41,494,658\end{array}$ \\
\hline
\end{tabular}

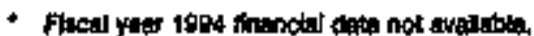

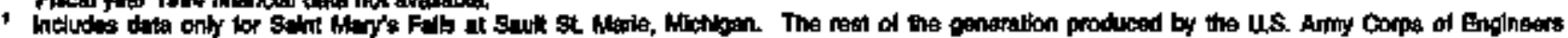

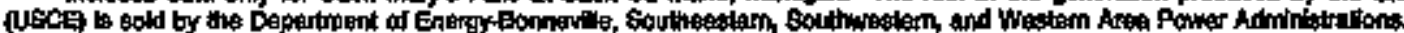

Noter Toth's mey nat equal sum of comporrants becalus od indepandem rounding.

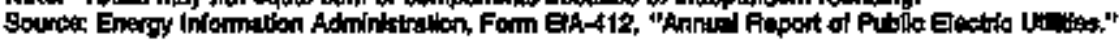


Table 29. Electric Oporation and Malintenance Expenses by U.S. Federal Electric Utllity, 1994 (Thousand Dollars)

\begin{tabular}{|c|c|c|c|c|c|}
\hline Itan & Soplember 30 & 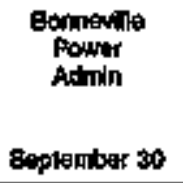 & $\begin{array}{l}\text { Southeastion } \\
\text { Powre } \\
\text { Adinils } \\
\text { September } 30\end{array}$ & $\begin{array}{l}\text { Souldivestatis } \\
\text { Pown } \\
\text { Admin } \\
\text { Septendon } 30\end{array}$ & $\begin{array}{l}\text { Wegtem Area } \\
\text { Poiter } \\
\text { Septemin } \\
\text { Septem } 30\end{array}$ \\
\hline 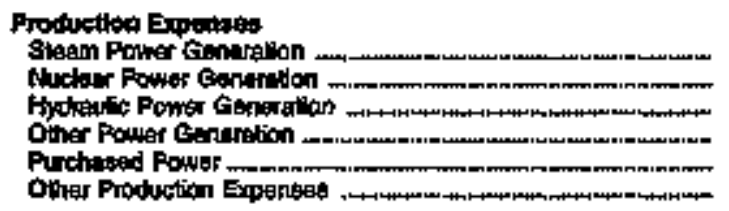 & $\begin{array}{r}0 \\
79 \\
0 \\
0 \\
0\end{array}$ & $\begin{array}{r}0 \\
0 \\
1,+161 \\
0 \\
215,469 \\
1,487,506\end{array}$ & $\begin{array}{r}0 \\
0 \\
2,395 \\
0 \\
0,765 \\
0\end{array}$ & $\begin{array}{r}0 \\
0 \\
04,001 \\
0 \\
7,762 \\
2,645\end{array}$ & $\begin{array}{r}0 \\
0 \\
204,902 \\
0 \\
217,044 \\
84,580\end{array}$ \\
\hline 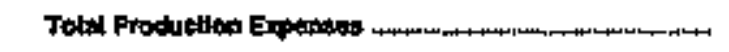 & 79 & $1,704,206$ & 7,109 & 70,997 & 500,626 \\
\hline 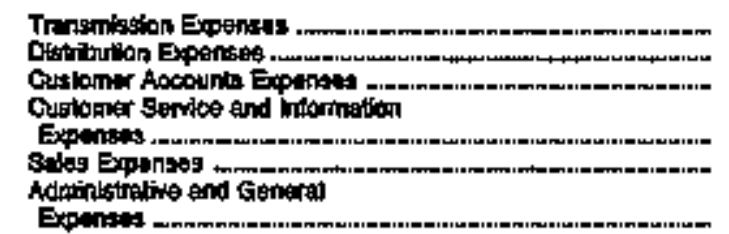 & $\begin{array}{r}037 \\
0 \\
0 \\
0 \\
0 \\
7,940\end{array}$ & $\begin{array}{r}170,408 \\
0 \\
2,200 \\
0 \\
0 \\
60.580\end{array}$ & $\begin{array}{r}20,076 \\
0 \\
41 \\
0 \\
0 \\
2,978\end{array}$ & $\begin{array}{r}10,601 \\
0 \\
0 \\
5,2000 \\
0\end{array}$ & $\begin{array}{r}25,109 \\
0 \\
0 \\
0 \\
0 \\
47,722\end{array}$ \\
\hline 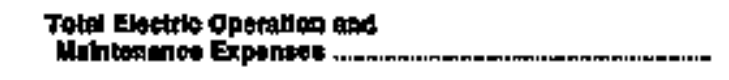 & 3,695 & $1,9+0,565$ & 33,091 & 92,606: & 57,357 \\
\hline \multicolumn{6}{|l|}{ Whmber of Eleo Dept Employves } \\
\hline 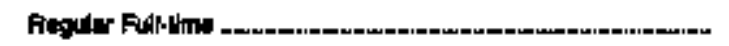 & 29 & 3,821 & 40 & 200 & 1,400 \\
\hline 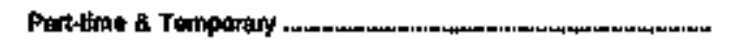 & 4 & 120 & 4 & o & 68 \\
\hline Total Etec Dept țmpleyes: & 39 & 8,444 & 44 & 200 & 1,465 \\
\hline
\end{tabular}

Ser endroles at and of this table. 
Table 29. Electric Operation and Malntenance Expenses by U.S. Federal Electric Utility, 1994 (Continued) (Thousand Dollars)

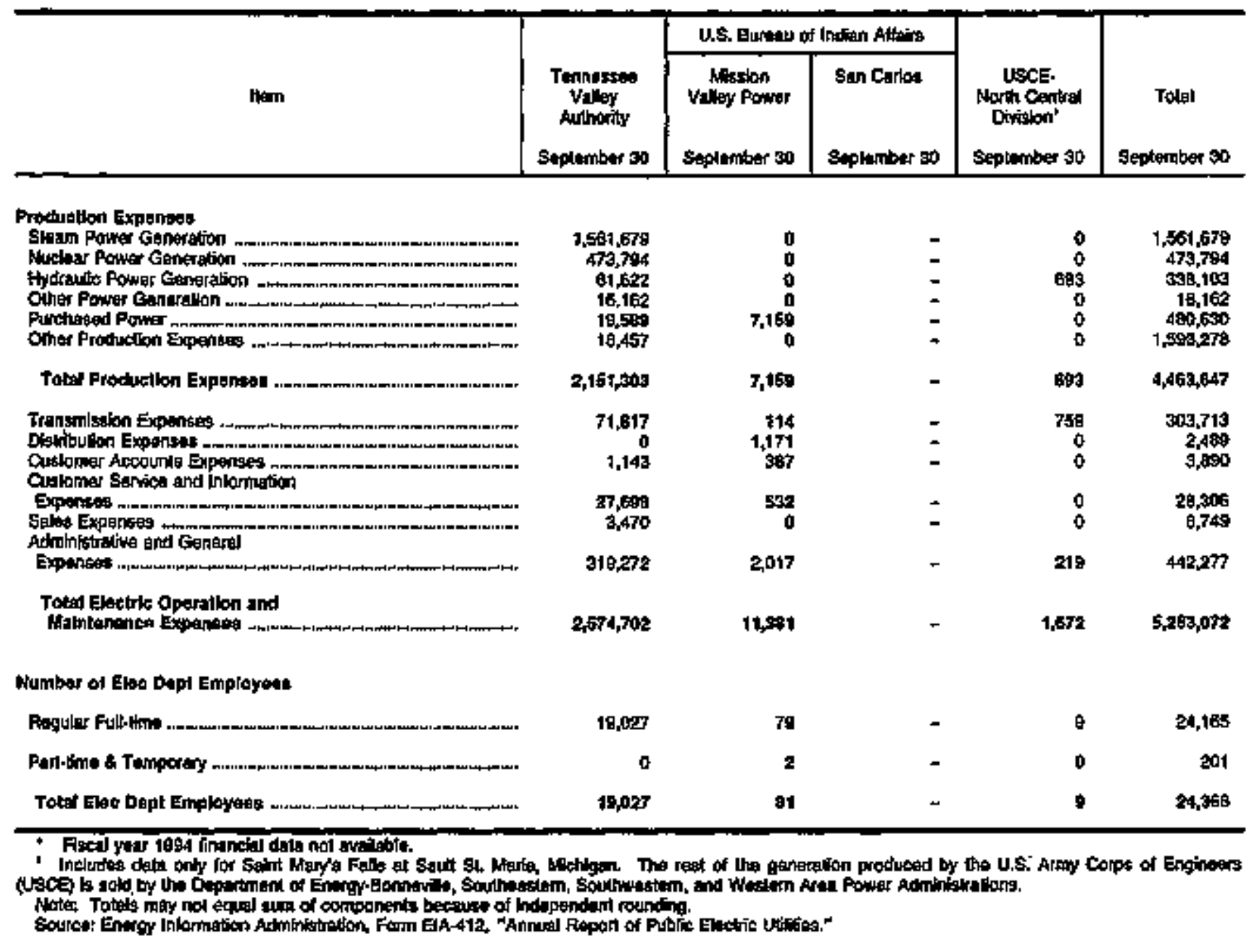


Table 30. Electric Utility Plant by U.S. Federal Electric Utility on September 30, 1994

(Thousand Dollars)

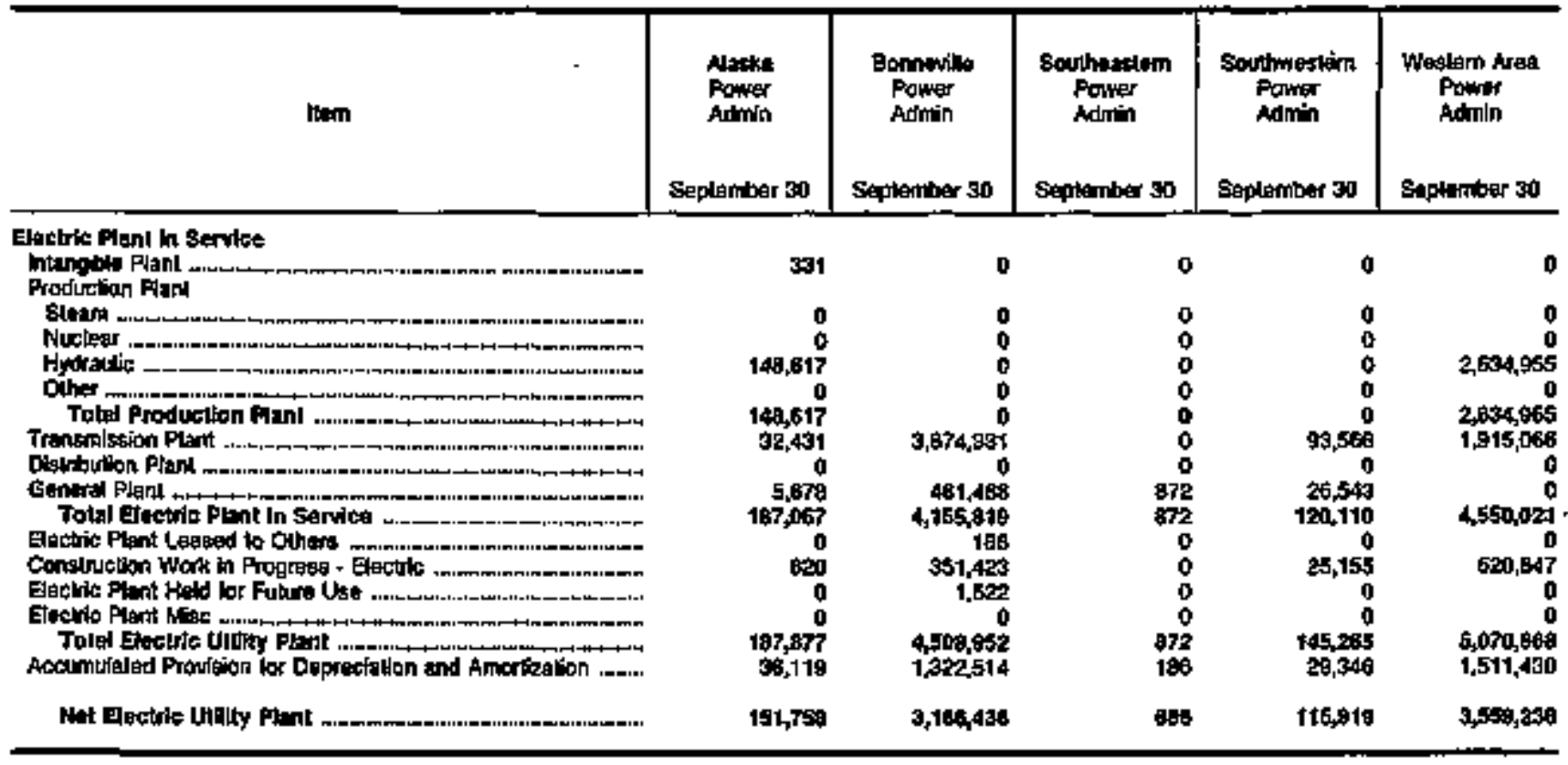

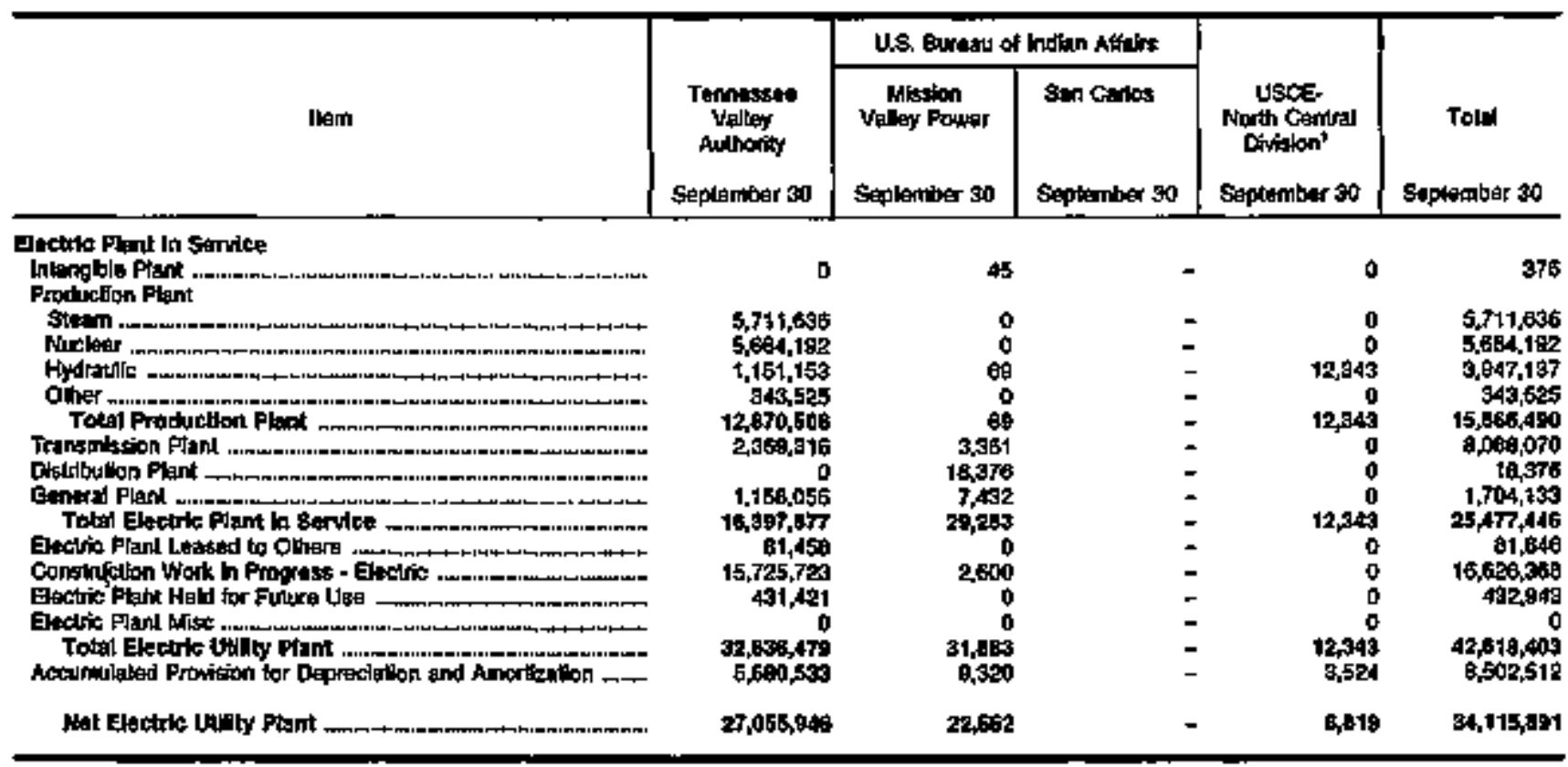

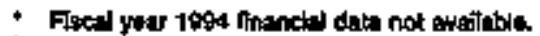

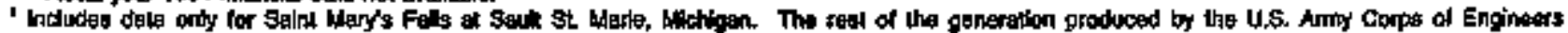

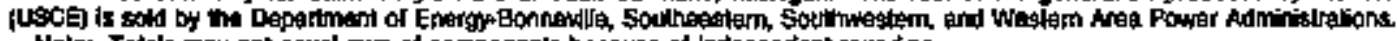

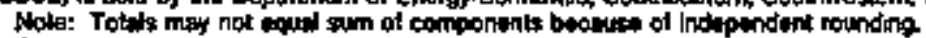

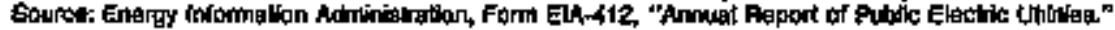


Table 31. Number of Consumera, Sales, and Operating Revenue by U.S. Federal Electric Utility, 1994

\begin{tabular}{|c|c|c|c|c|c|}
\hline $\operatorname{licm}$ & $\begin{array}{l}\text { Alaskike } \\
\text { Pouner } \\
\text { Aulinth }\end{array}$ & $\begin{array}{c}\text { Bonnesille } \\
\text { Power } \\
\text { Adetiry } \\
\text { Decunber } 31\end{array}$ & $\begin{array}{l}\text { Southeaglert } \\
\text { Ponner } \\
\text { Adrin } \\
\text { Dooumber } 31\end{array}$ & $\begin{array}{l}\text { Sorlywagtem } \\
\text { Pongr } \\
\text { Admin }\end{array}$ & 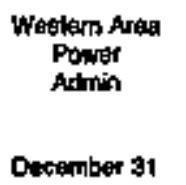 \\
\hline 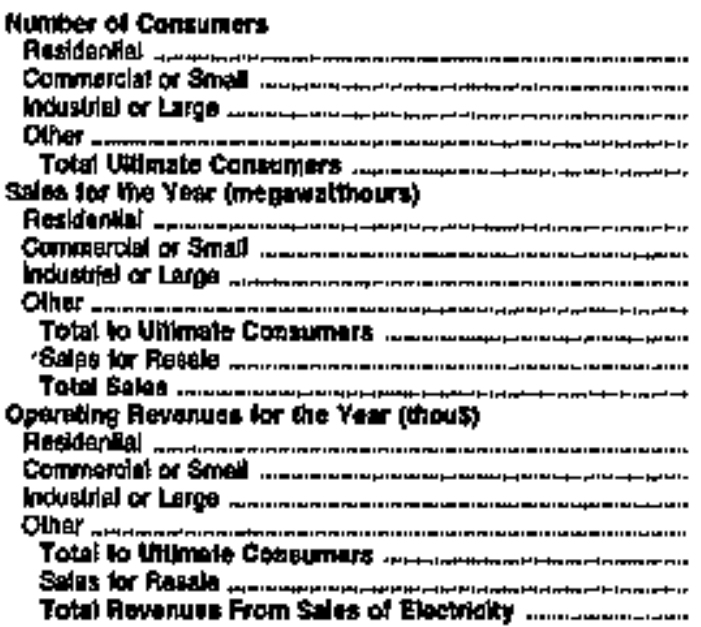 & $\begin{array}{r}0 \\
0 \\
0 \\
4,095 \\
4,098 \\
990,758 \\
394,794\end{array}$ & 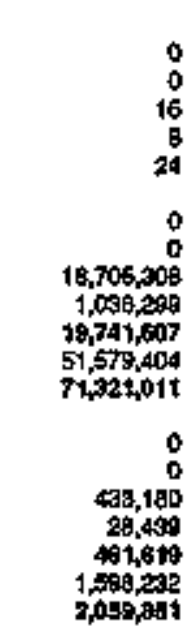 & $\begin{array}{r}0 \\
0 \\
0 \\
0 \\
0 \\
8,230,000 \\
0,0094028\end{array}$ & $\begin{array}{r}0 \\
0 \\
0 \\
0 \\
0 \\
6,273,797 \\
6,873,767\end{array}$ & $\begin{array}{r}0 \\
1 \\
0 \\
2,13 \\
241 \\
0 \\
37 \\
0 \\
5,590,250 \\
5,500,301 \\
30,458,090 \\
36,149,000\end{array}$ \\
\hline
\end{tabular}

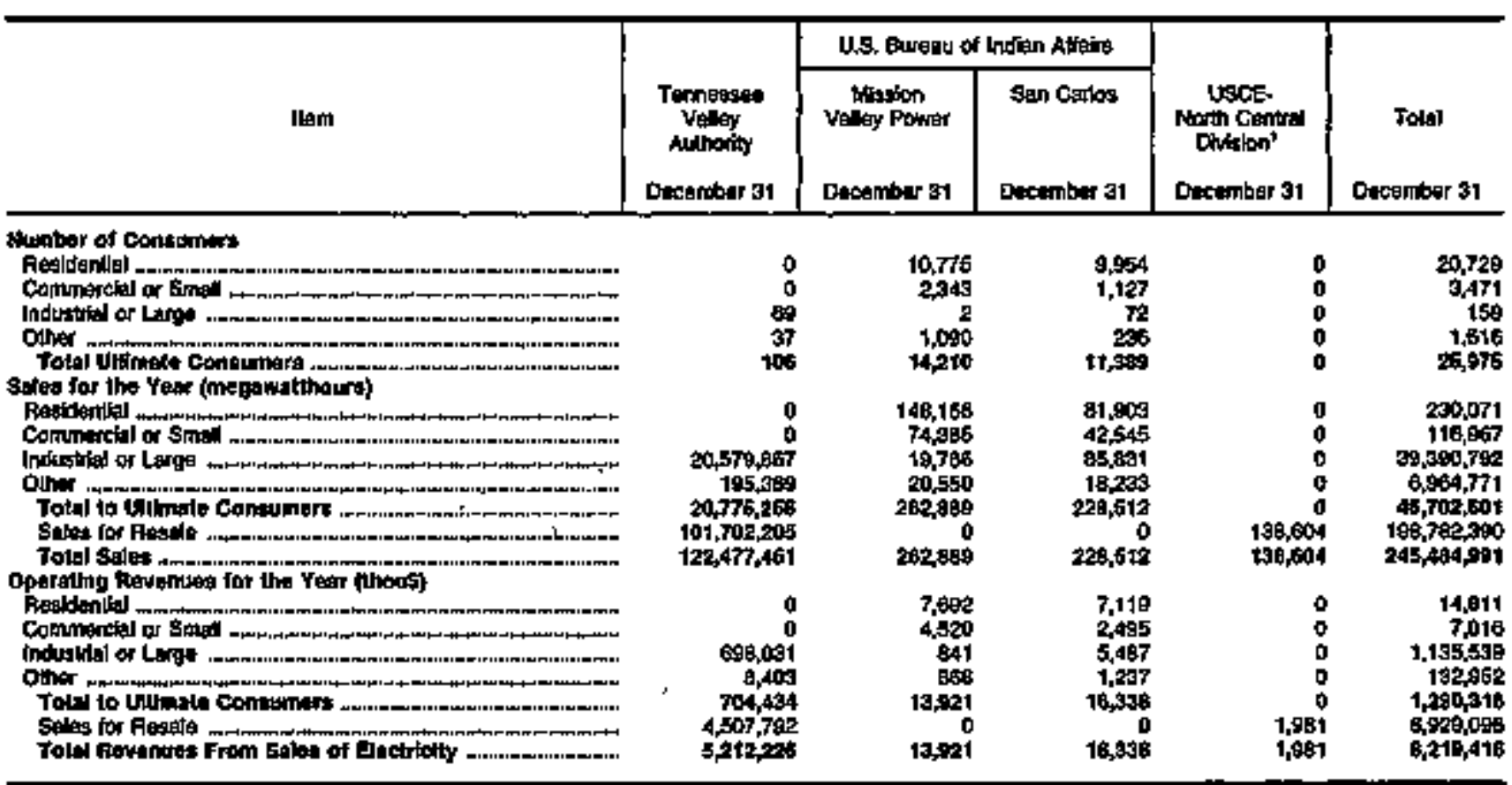

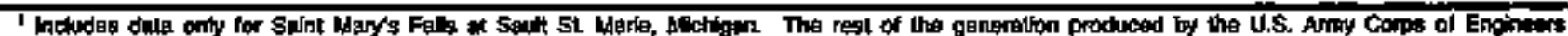

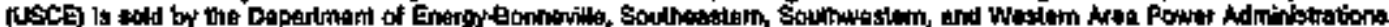

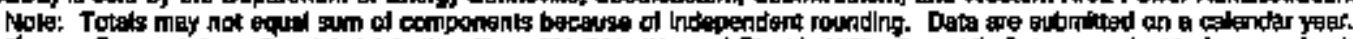

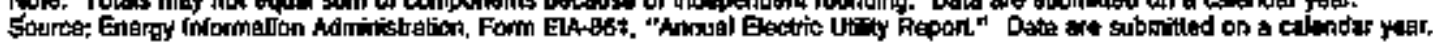




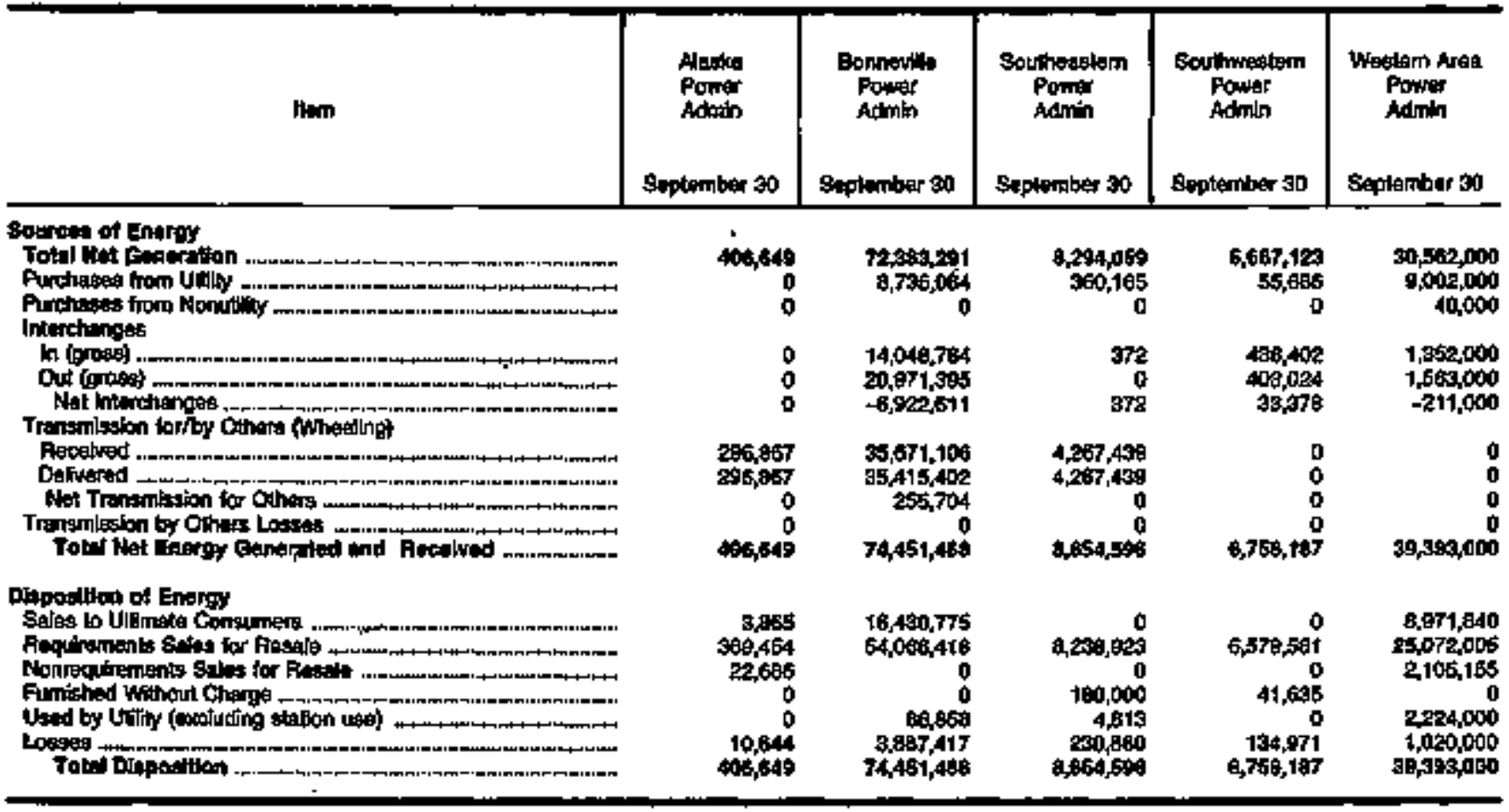

\begin{tabular}{|c|c|c|c|c|c|}
\hline \multirow[b]{2}{*}{ Ilam } & \multirow[b]{2}{*}{$\begin{array}{l}\text { Temestegé } \\
\text { Veloy } \\
\text { Authorily } \\
\text { Septumber jo }\end{array}$} & \multicolumn{2}{|c|}{ 1.S. Burean of Indran Atfits } & \multirow[b]{2}{*}{$\begin{array}{l}\text { USCE. } \\
\text { North Central } \\
\text { Divieion' } \\
\text { September } \$ 0\end{array}$} & \multirow[b]{2}{*}{ Totel } \\
\hline & & $\begin{array}{l}\text { Miastion } \\
\text { Valley Powes } \\
\text { Enplombor } 30\end{array}$ & $\begin{array}{l}\text { San Carips" } \\
\text { Soptemibụ } 30\end{array}$ & & \\
\hline 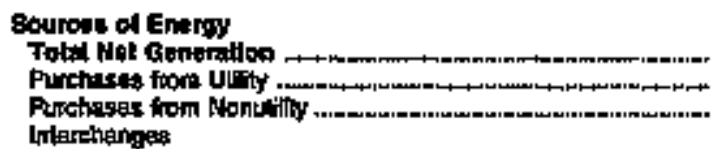 & $\begin{array}{r}130,640,760 \\
75,200\end{array}$ & $\begin{array}{r}4,609 \\
295,464 \\
1,041\end{array}$ & - & $\begin{array}{r}166,5008 \\
0 \\
0\end{array}$ & $\begin{array}{r}249,319,315 \\
18,721,726 \\
116,244\end{array}$ \\
\hline 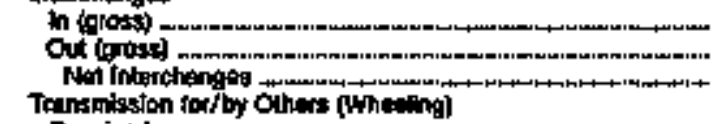 & $\begin{array}{r}25,046,600 \\
24,603,358 \\
1,303,245\end{array}$ & $\begin{array}{l}0 \\
0 \\
0\end{array}$ & - & $\begin{array}{l}0 \\
0 \\
0\end{array}$ & $\begin{array}{l}41,004,161 \\
47,620,777 \\
-5,736,610\end{array}$ \\
\hline 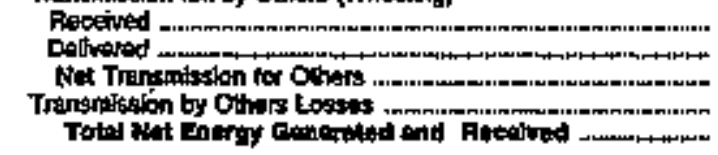 & $\begin{array}{r}1,562,607 \\
1,504,306 \\
38,501 \\
0 \\
192,395,747\end{array}$ & $\begin{array}{r}0 \\
0 \\
0 \\
0 \\
2089\end{array}$ & 2 & $\begin{array}{r}0 \\
0 \\
0 \\
0 \\
155,508\end{array}$ & $\begin{array}{r}11,798,219 \\
11,604,014 \\
204,205 \\
262,714,074\end{array}$ \\
\hline 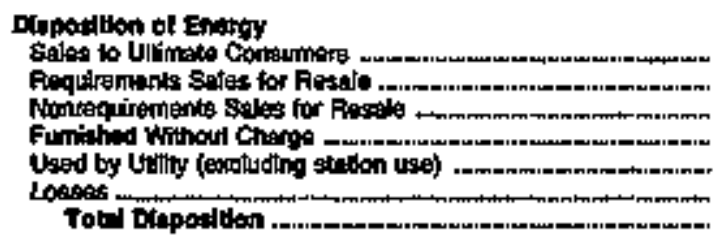 & $\begin{array}{r}20,922,905 \\
102,375,347 \\
0 \\
100,542 \\
8,633 \\
0,828,417 \\
132,455,447\end{array}$ & 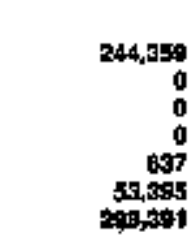 & 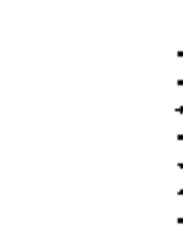 & $\begin{array}{r}0 \\
149,459 \\
0 \\
3,617 \\
9892 \\
1,739 \\
166,506\end{array}$ & $\begin{array}{r}46,837,610 \\
196,1851,467 \\
2,127,841 \\
416,794 \\
2,305,593 \\
14,177,009 \\
26,, 714,674\end{array}$ \\
\hline
\end{tabular}

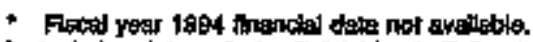

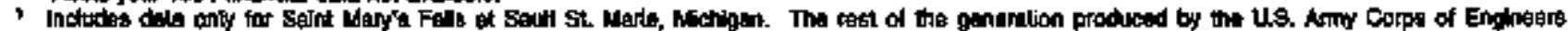

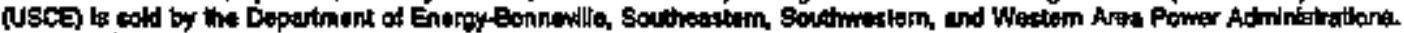

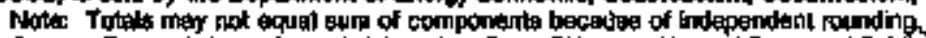

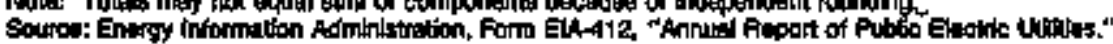




\title{
Appendix A
}

\author{
Summary \\ Statistics of \\ U.S. Rural \\ Electric \\ Cooperative \\ Borrowers
}





\section{Summary Statistics of U.S. Rural Electric Cooperative Borrowers}

\section{Background}

The Rural Utilities Service (RUS), U.S. Depatment. of Agriculture, previously The Rural Electrification Administration (REA), was established under the Rural Electrification Act of 1936. The purpose was to extend electrto service to small rural communities (usually under 1,500 customers) and farms where it was more expensive to provide service. Through the REA, electrtc cooperatives (customer-owned, nonproit entities) were formed and provided with low interest rate, goverminent-guaranteed loans to allow them to build power lines to transmit and distribute wholesale electricity purchased from other electric utilities By the early 1960's, the REA began to malke large loans to cooperatives for the construction of generating plants and transmission facilities to "protect the secority and effectiveness of REA-financed systeras."

The latest statistics taken from the 1994 Statistical Repon, Rural Electic Borrowers' 12 publication show that 808 of 855 cooperative borrowers were distrib. ution borrowers. The remainting 47 were power supply borrowers. By the end of 1994, the RUS-financed electric utilities wets serving more than 11 million consumers in 46 States. When the REA was formed, less than 10 percent of mral areas in the Untted States hed electric service Today, about 99 percent of U.S. farmers have electric power.

\section{Composite income Account}

Operating revenues for cooperative borrowers were $\$ 23.8$ bition in 1994, compared with $\$ 24.9$ billion in 1993 , and $\$ 23.3$ billion in 1992.

Total electric utilty operattog expenses for the cooperative borrowers were \$21.0 bitlion in 1994. Opera. tion and maintenance expenses represented $\$ 12.6$ billion or 89.0 percent of the total operating expenses. Purchased power, a majos portion of operation and mainternance expenses, was $\$ 12.5$ billion. Taxes were 50.6 billion or 2.8 percent of total electric operating experses.

Utility operating income for cooperative borrowers was $\$ 2.8$ billion in 1994 . Utility operating income, as a proportion of net utility plant, was 6.5 percent. Net moome was $\$ 0.8$ billion.

Interest expense on long-term debt was $\$ \mathbf{2 . 4}$ billion in 1994, a decrease from $\$ 2.7$ million in 1993. Interest expenses as i percentage of long-term debt was 6.1 percent in 1994, compared with 6.3 percent in 1993 .

\section{Balance Sheot}

The net invesiment in electric utility plant for cooperative borrowers was $\$ 43.0$ billion at the end of 1994 , which includes $\$ 1.8$ billion for construction work in progress (CWIP). The CWIP was \$1.7 billion in 1993. As a percentage of net investment in electric utitity plant, CWIP was about 8.9 percent higher in 1994, compared with 1990. The investment and funds accounts were $\$ \$ .2$ billton and lonte-term debt was $\$ 40.1$ billion at the end of 1994.

\section{Electric Uthty Operating Revenues}

The number of residential consumers served by cooperative borrowers was 10.2 million in 1994, down slightly from 10.5 million in 1993. Revenues from residential consumers were $\$ 9.5$ billion or 64.5 percent of total revenues from all ultimate consumers. In 1994, consumption of electricity by each residential customer averaged 12.1 megawattsours at an average annual cost of $\$ 933.61$, a deerease from 1993 when each residential customer averaged 11.3 megawatthours at an average ennual cost of $\$ 946,42$. 
Table A1. Composite Stalement of Income for the U.S. Cooperative Bomowers, 1990-1994

(Thousard Doilars)

\begin{tabular}{|c|c|c|c|c|c|}
\hline Hem & 1904 & 访的 & 1902 & 1891 & 1000 \\
\hline 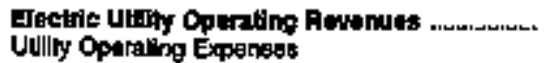 & $28,774,648$ & 24972684 & $23,325,191$ & $23,794,208$ & $22,208,000$ \\
\hline 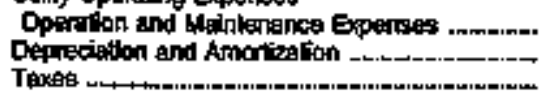 & $\begin{array}{r}18,649,598 \\
1,741,638 \\
601,250\end{array}$ & $\begin{array}{r}19,291,776 \\
1,767,525 \\
615,090\end{array}$ & $\begin{array}{r}18,038,115 \\
1,709,203 \\
1005,275\end{array}$ & $\begin{array}{r}17,654,790 \\
1,630,148 \\
592,050\end{array}$ & $\begin{array}{r}17,034,673 \\
1,616,945 \\
516,409\end{array}$ \\
\hline 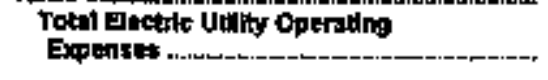 & $20,952,625$ & $21,675,194$ & $20,352,603$ & 19,838,754 & $19,100,304$ \\
\hline 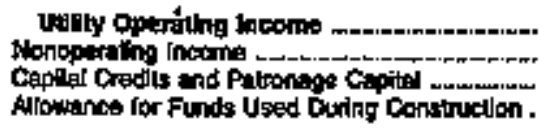 & $\begin{array}{r}2,794,093 \\
293,164 \\
279,622 \\
49,009\end{array}$ & $\begin{array}{r}3,197,493 \\
399,378 \\
320,345 \\
50,906\end{array}$ & $\begin{array}{r}2,973,007 \\
433,518 \\
249,096 \\
54,440\end{array}$ & $\begin{array}{r}2,807,454 \\
506,059 \\
244,737 \\
52,481\end{array}$ & $\begin{array}{r}3,066,704 \\
53: 9,204 \\
478,600 \\
69,056\end{array}$ \\
\hline 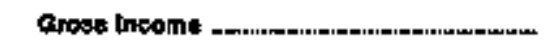 & $8,404,917$ & $3,971,122$ & $3,710,161$ & $3,690,691$ & $3,043,184$ \\
\hline 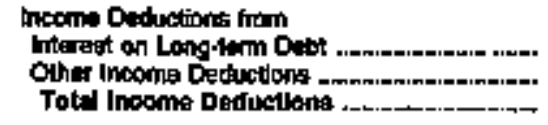 & $\begin{array}{r}2,416,973 \\
164,995 \\
2,583,668\end{array}$ & $\begin{array}{r}2,719,249 \\
218,024 \\
2,989,273\end{array}$ & $\begin{array}{r}2,693,659 \\
165,921 \\
2,099,674\end{array}$ & $\begin{array}{r}2,869,859 \\
67,847 \\
2,1661,699\end{array}$ & $\begin{array}{r}2,876,060 \\
354,197 \\
3,130,260\end{array}$ \\
\hline Bet Incorae and Patrongog Cuplut .-.-... & enapasts & 1,003, Eesp & Tro, & 730,232 & 704,204 \\
\hline
\end{tabular}

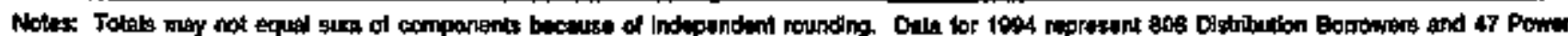

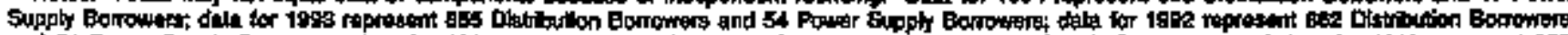

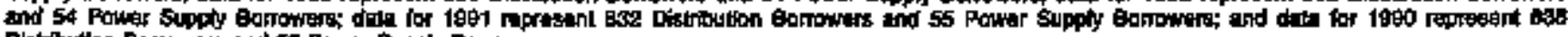

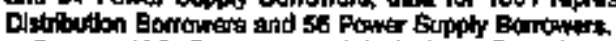

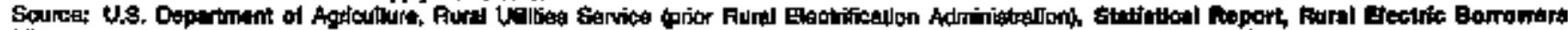

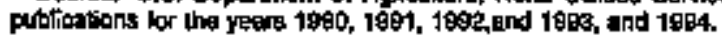

Table A2. Composite Balince Sheet for the U.S. Cooperative Borrowers on December 31, 1990-1994

(Thousand Dollars)

\begin{tabular}{|c|c|c|c|c|c|}
\hline llam & . 1904 & 1695 & to9e & 1901 & 1040 \\
\hline \\
\hline 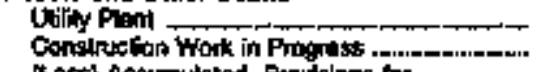 & $\begin{array}{l}60,612,615 \\
1,760,475\end{array}$ & $\begin{array}{l}60,945,128 \\
1,708,186\end{array}$ & $\begin{array}{r}60,040,411 \\
1,0,26,5=2\end{array}$ & $\begin{array}{r}58,7 \$ 2,584 \\
1, \$ 11,459\end{array}$ & $\begin{array}{l}58,211,868 \\
1,826,46,9\end{array}$ \\
\hline 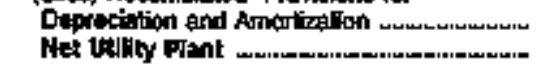 & $\begin{array}{l}18,266,320 \\
43,004,767\end{array}$ & $\begin{array}{l}17,007.989 \\
44746,351\end{array}$ & $\begin{array}{l}16,504,355 \\
44,075,605\end{array}$ & $\begin{array}{l}15,003,904 \\
43,134,6.8\end{array}$ & $\begin{array}{l}14,109,095 \\
13,40,275\end{array}$ \\
\hline 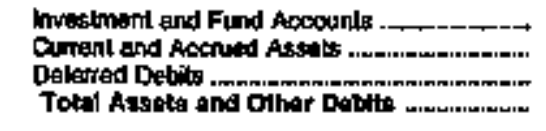 & $\begin{array}{r}5,607,609 \\
7,108,509 \\
3,911,087 \\
5,689,947\end{array}$ & $\begin{array}{r}5,379,256 \\
7,068,340 \\
3,970,858 \\
6,430,398\end{array}$ & $\begin{array}{r}5,579,400 \\
7,860,050 \\
2,287,018 \\
5,952,018\end{array}$ & $\begin{array}{r}5,647,772 \\
6,002,973 \\
1,811,064 \\
60,002,497\end{array}$ & $\begin{array}{r}1,676,202 \\
7,065,085 \\
2,028,780 \\
68,101,121\end{array}$ \\
\hline 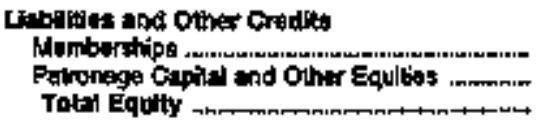 & $\begin{array}{r}104,652 \\
12,277,054 \\
12,394,706\end{array}$ & $\begin{array}{r}97,031 \\
12,280,419 \\
12,377,500\end{array}$ & $\begin{array}{r}1,372,465 \\
11,469,611\end{array}$ & $\begin{array}{r}01,684 \\
10,470,186 \\
10,961,634\end{array}$ & $\begin{array}{r}84,192 \\
8,94,270 \\
10,065,412\end{array}$ \\
\hline 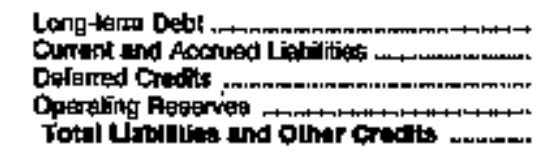 & $\begin{array}{r}40,129,573 \\
3,660,0155 \\
1,581,958 \\
1,961,552 \\
96,634,347\end{array}$ & $\begin{array}{r}4,718,109 \\
3,052,009 \\
1,556,059 \\
1,975,746 \\
8,490,305\end{array}$ & 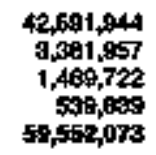 & 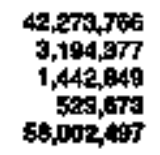 & $\begin{array}{r}42,887,350 \\
3,281,216 \\
1,546,174 \\
410,971 \\
54,104,121\end{array}$ \\
\hline
\end{tabular}

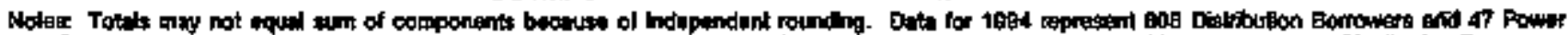

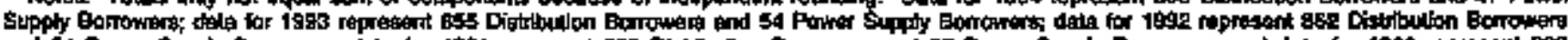

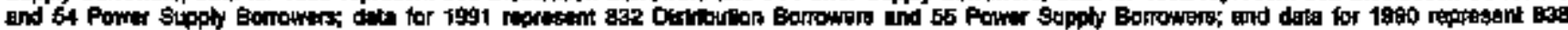

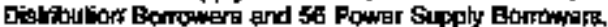

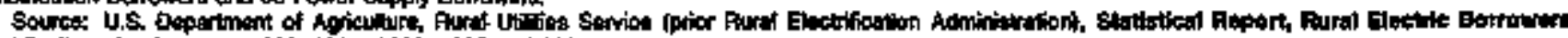
publialions for the years 1980, $1901,1992,1993$ and 1994 . 
Table A3. Electrtc Operatlon and Melntenance Expenete for the U.S. Cooperatlve Bonowert, 1990-1994

(Thousand Dollars)

\begin{tabular}{|c|c|c|c|c|c|}
\hline Itane & 1904 & 1098 & $19 \% 2$ & 1021 & 1000 \\
\hline 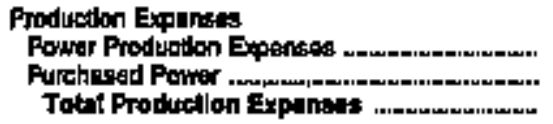 & $\begin{array}{r}2,072,458 \\
12,190,459 \\
15,470,914\end{array}$ & $\begin{array}{r}3,098,578 \\
13,017,485 \\
18,10+008\end{array}$ & 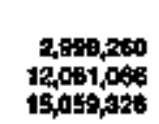 & $\begin{array}{r}2,87 a, 362 \\
11,807,785 \\
14,056,127\end{array}$ & $\begin{array}{r}3,100,258 \\
11,245,600 \\
14,40,600\end{array}$ \\
\hline 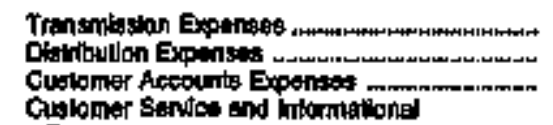 & 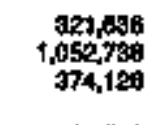 & $\begin{array}{r}35,401 \\
1,044,359 \\
300,310\end{array}$ & $\begin{array}{l}323527 \\
900,017 \\
388,650\end{array}$ & $\begin{array}{l}312,802 \\
916,509 \\
340,406\end{array}$ & $\begin{array}{l}318,117 \\
877,1947 \\
34,200\end{array}$ \\
\hline 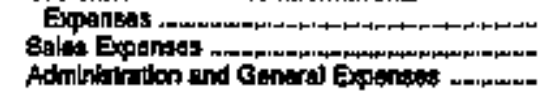 & $\begin{array}{r}104,509 \\
60,584 \\
1,285,122\end{array}$ & $\begin{array}{r}100,991 \\
57,498 \\
1,265,214\end{array}$ & $\begin{array}{r}94,907 \\
52,235 \\
t, 159,540\end{array}$ & $\begin{array}{r}89,029 \\
47,150 \\
1,104,291\end{array}$ & $\begin{array}{r}60,714 \\
41,519 \\
1,039,919\end{array}$ \\
\hline 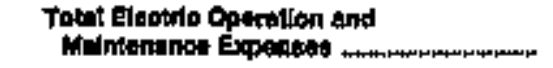 & $18,648,524$ & $19,2: 1,7 \mathrm{~B}$ & $18,08 B, 115$ & $17,45,7 \div 6$ & Th:5iry \\
\hline
\end{tabular}

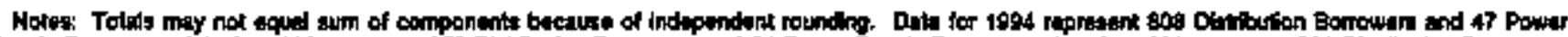

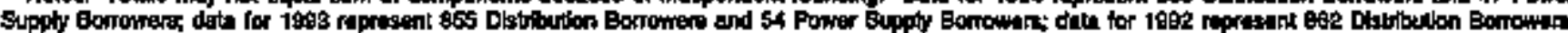

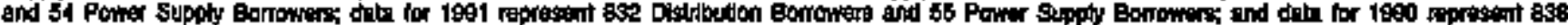

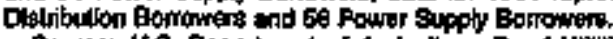

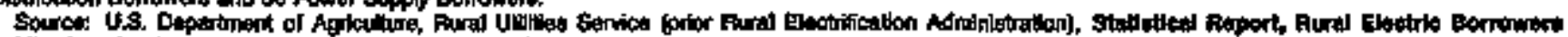
publeatong for tho yeare 1990,1991 , 1992, 1993 and 1994.

Table A4. Number of Consumars, Sales, and Operating Revenue for the U.S. Cooperattve Distributor Borrowers, 1990-1994

\begin{tabular}{|c|c|c|c|c|c|}
\hline $\mathrm{kmm}$ & $\operatorname{logn}$ & $19 x$ & 192 & 1981 & ote \\
\hline 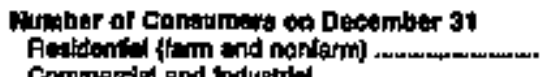 & $16,184,657$ & $10,500,502$ & $10,3 \times 0,348$ & 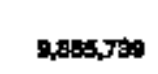 & $9,72,404$ \\
\hline 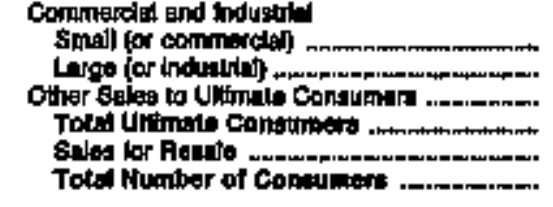 & $\begin{array}{r}970,796 \\
7,944 \\
192,367 \\
11,345,914 \\
11,348,518\end{array}$ & 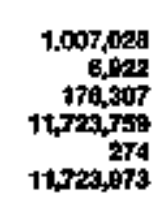 & $\begin{array}{r}997,281 \\
6,499 \\
172,905 \\
11,407,193 \\
11,467,354\end{array}$ & $\begin{array}{r}820,435 \\
6,280 \\
167,600 \\
10,807,669 \\
107 \\
10,067,765\end{array}$ & $\begin{array}{r}809,111 \\
6,292 \\
165,924 \\
10,501,354 \\
10,001,604\end{array}$ \\
\hline 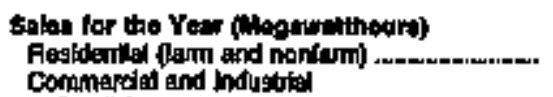 & $124,877,676$ & $120,030,270$ & 118,602,0:82 & $175,076,510$ & $111,776,628$ \\
\hline 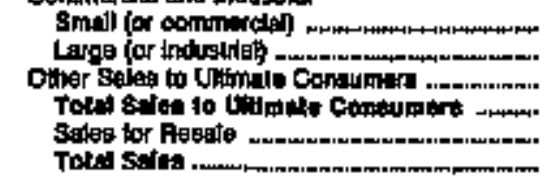 & $\begin{array}{r}37,058,413 \\
3=, 237,790 \\
6,717,250 \\
207,27,900 \\
2,375,590 \\
209,602,400\end{array}$ & $\begin{array}{r}39,747,491 \\
39,297,790 \\
5,591,171 \\
212,969,722 \\
2645,739 \\
215,242,460\end{array}$ & $\begin{array}{r}37,109,079 \\
93,952,497 \\
5,033,0 \% 6 \\
106,267,544 \\
2,741,089 \\
201,020,497\end{array}$ & $\begin{array}{r}34,602,307 \\
30,619,491 \\
5,608,651 \\
10,090,968 \\
1,034,117 \\
101,906,002\end{array}$ & 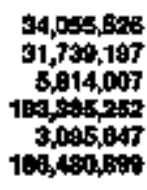 \\
\hline \multicolumn{6}{|l|}{ 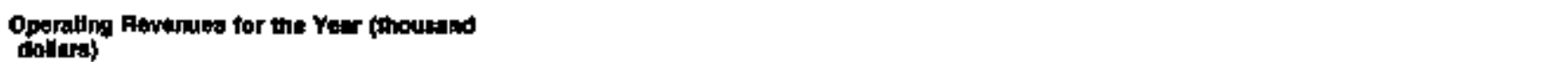 } \\
\hline 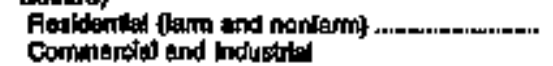 & P,508,739 & $9,0.09,111$ & $0,172,348$ & $0,806,001$ & $0,403,275$ \\
\hline 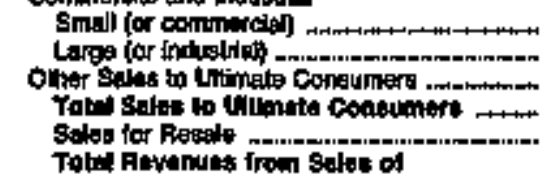 & $\begin{array}{r}2,735,01 \mathrm{~B} \\
9,740,572 \\
445,800 \\
14,450,135 \\
\text { es,78t }\end{array}$ & $\begin{array}{r}2,828,108 \\
1,717,304 \\
394,028 \\
14,004,239 \\
66,797\end{array}$ & 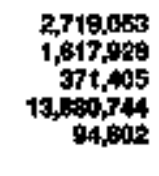 & $\begin{array}{r}2,545,472 \\
1,602,140 \\
36 ;, 007 \\
10,215,750 \\
64,548\end{array}$ & $\begin{array}{r}2,467,090 \\
1,438,974 \\
974,504 \\
12,04,4,4 \\
121,006\end{array}$ \\
\hline 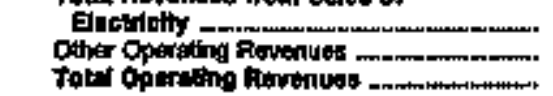 & $\begin{array}{r}t 4,51,916 \\
210,772 \\
t 4,720,606\end{array}$ & $\begin{array}{l}14,990,976 \\
210,031 \\
15,20,007\end{array}$ & $\begin{array}{l}13,4,5,540 \\
21,504 \\
14,10,5000\end{array}$ & $\begin{array}{r}15,301,283 \\
198,943 \\
10,40,290\end{array}$ & 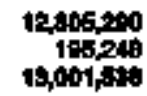 \\
\hline
\end{tabular}

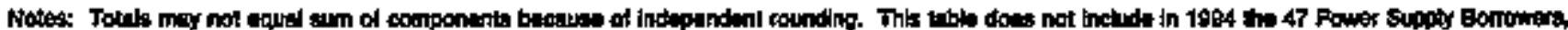

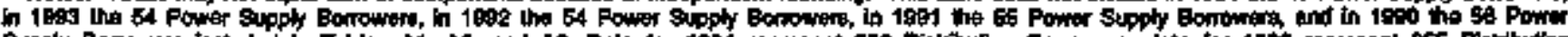

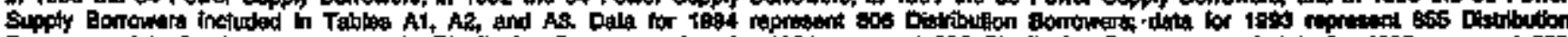

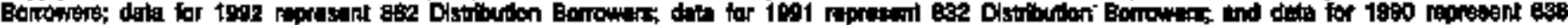

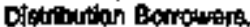

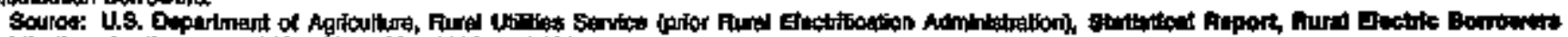

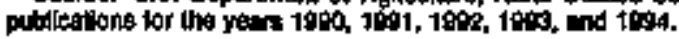





\section{Appendix B}

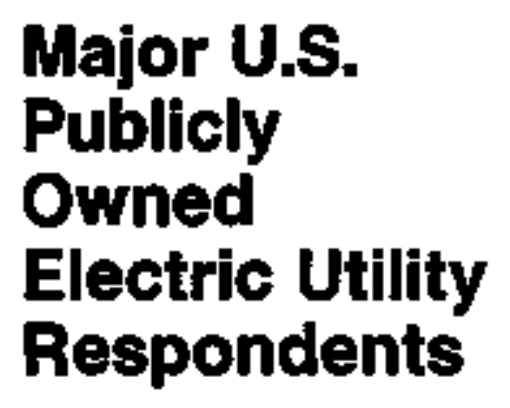




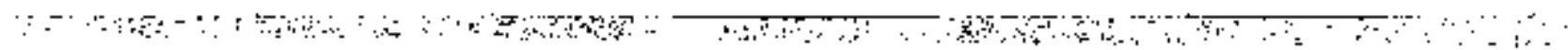




\section{Major U.S. Publicly Owned Electric Utility Respondents}


Table B4. Publicly Owned Electric Utidtes Added to and Deloted from the Form ElA-412, 1990-1994

\begin{tabular}{|c|c|c|c|c|c|}
\hline \multirow{2}{*}{ Year } & \multicolumn{2}{|r|}{ Added } & \multicolumn{2}{|r|}{ Dateted } & \multirow{2}{*}{$\begin{array}{l}\text { Totol Nhmber } \\
\text { Avatiolo' }\end{array}$} \\
\hline & Na. & Nems & Na. & Nham & \\
\hline 1990 & 13 & 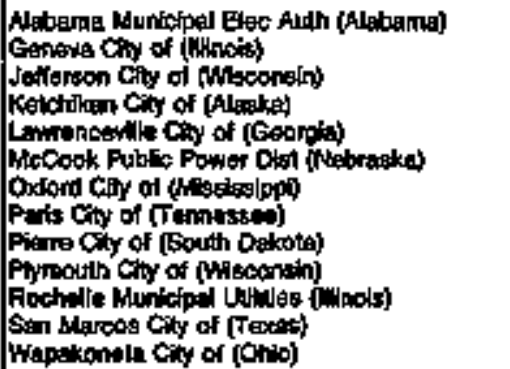 & & & 467 \\
\hline I991 & 06 & 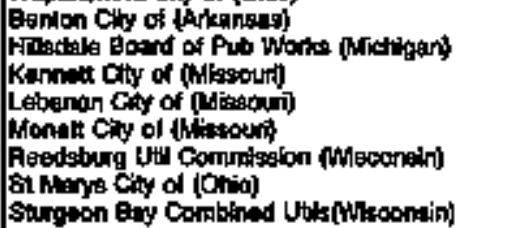 & 06 & 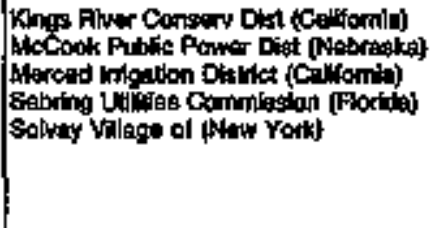 & 470 \\
\hline 1902 & 14 & 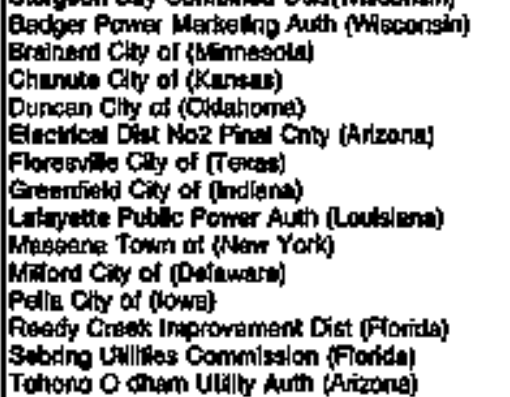 & 01 & Brian Chy of (Tenmegsea) & 403 \\
\hline $1900 . .$. & ts & 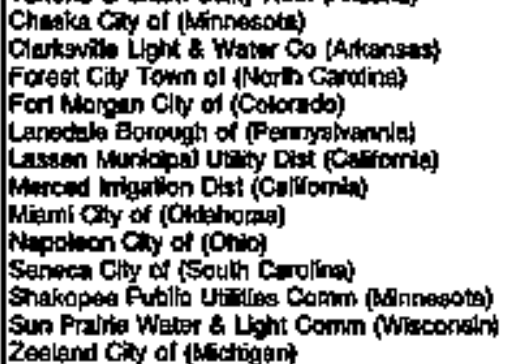 & 01 & Sabring Utalas Commiseion (Florida) & 495 \\
\hline $1904 \mathrm{mo}$ & $\mathbf{0 6}$ & 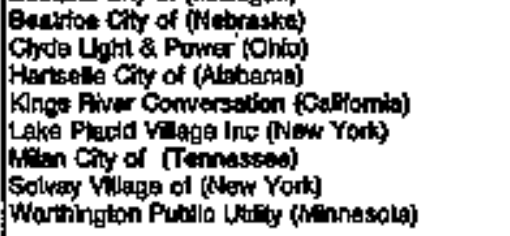 & & & 503 \\
\hline
\end{tabular}

1 Excuded ane the Foderal alectio ullilles.

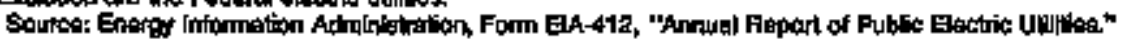


Table E2. Major US. Publlely Owned Electric Utilities by Flscel Year and Generator/Nongenerator Status from the Form EAA-412, 1994

\begin{tabular}{|c|c|c|c|}
\hline Fincost Year & An Raspondenta & denterstor Feapontienta & Nontpenerator Heupondionth \\
\hline JUne 30 , & 201 & 57 & 144 \\
\hline Deoember 31 .......-rm & 207 & 112 & 96 \\
\hline 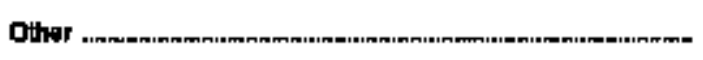 & $\infty$ & 58 & 97 \\
\hline 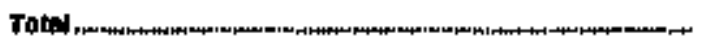 & 500 & 207 & 278 \\
\hline
\end{tabular}

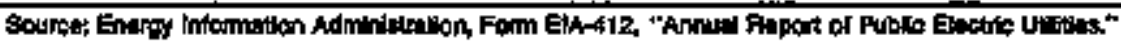


Teble B3. Major U.S. Publicly Owned Electric Utilites by State and Gentrator/Nongenterator Skatus, 1994

\begin{tabular}{|c|c|c|c|}
\hline stute & Fo:pondents & $\begin{array}{l}\text { Gapentip } \\
\text { fouponsionts }\end{array}$ & $\begin{array}{l}\text { fiongenoratitr } \\
\text { fespondenth }\end{array}$ \\
\hline 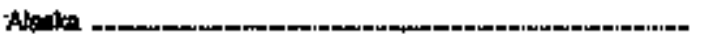 & 4 & 4 & 0 \\
\hline ATabema & 21 & 0 & 21 \\
\hline 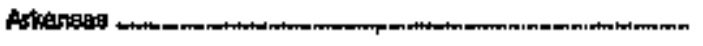 & $\mathbf{1 1}$ & 6 & $\mathbf{5}$ \\
\hline 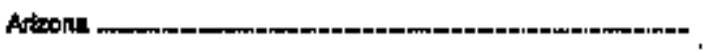 & $\mathbf{8}$ & 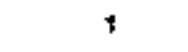 & $\mathbf{s}$ \\
\hline Calfomill & $\mathbf{a z}$ & 25 & $\mathbf{7}$ \\
\hline Collordo & 7 & 4 & 3 \\
\hline 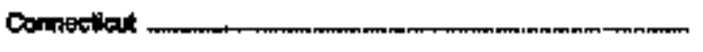 & 4 & 3 & 1 \\
\hline 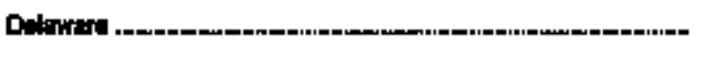 & 3 & $\tau$ & 2 \\
\hline Plotidn ....-.-. & $\mathbf{2 0}$ & 17 & $\mathbf{3}$ \\
\hline 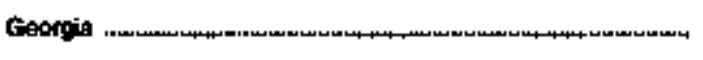 & 17 & 3 & 14 \\
\hline Hantion & 0 & 0 & 0 \\
\hline kowat ----r- & 4 & 4 & 0 \\
\hline 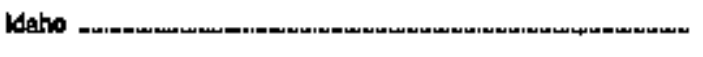 & $\mathbf{1}$ & 1 & $\mathbf{0}$ \\
\hline 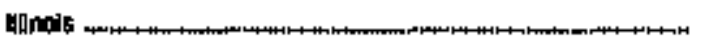 & 7 & 3 & 4 \\
\hline Indiang & 13 & 7 & 6 \\
\hline Ken\$s & 7 & 6 & 2 \\
\hline 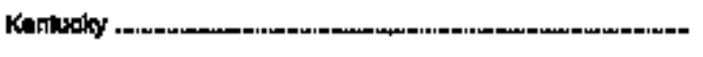 & 11 & $\mathbf{2}$ & $\theta$ \\
\hline 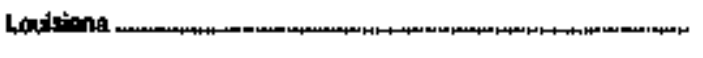 & 8 & 6 & $\mathbf{2}$ \\
\hline 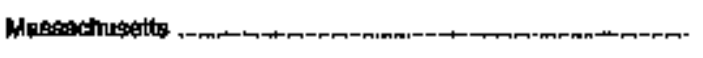 & 30 & 14 & 10 \\
\hline Mtarytend m.m. & 2 & 1 & 1 \\
\hline - & 0 & $\mathbf{0}$ & 0 \\
\hline 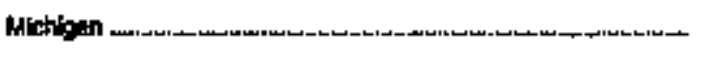 & 14 & 14 & $\mathbf{0}$ \\
\hline Mlnuespita & 18 & 11 & 7 \\
\hline 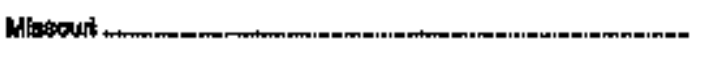 & 13 & 7 & 6 \\
\hline 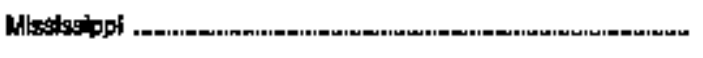 & 12 & $\mathbf{2}$ & 10 \\
\hline Montentat & 0 & 4 & 0 \\
\hline Ninth Certing & 24 & 3 & 2* \\
\hline North Detwote ...mmm & 0 & $\mathbf{0}$ & 0 \\
\hline Nebra:ke --w.- & 15 & 9 & B \\
\hline Nim Hardpehire & 0 & D & 0 \\
\hline 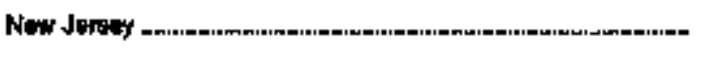 & 1 & $t$ & 0 \\
\hline 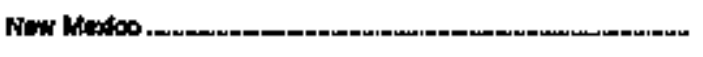 & $\mathbf{s}$ & 2 & $\mathbf{t}$ \\
\hline Nowada & 1 & 0 & 1 \\
\hline 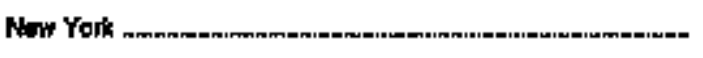 & 中 & 4 & $\mathbf{5}$ \\
\hline 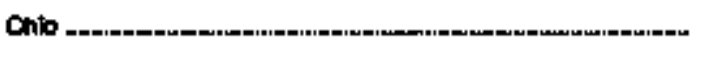 & 18 & 10 & $\theta$ \\
\hline 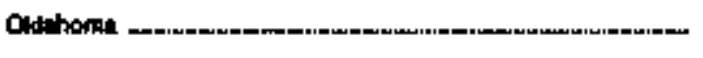 & 8 & 4 & 5 \\
\hline Oregen & i1 & 4 & 3 \\
\hline
\end{tabular}

Sest endroties at end of this inblo. 
Table B3. Major U.S. Publicly Owned Electrte Utlities by State and Generator/Nongenerator Status, 1994 Continued

\begin{tabular}{|c|c|c|c|}
\hline state & All & $\begin{array}{l}\text { Generator } \\
\text { Raupondeats }\end{array}$ & $\begin{array}{l}\text { Nonganerator } \\
\text { Reipordents: }\end{array}$ \\
\hline 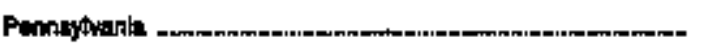 & 2 & 1 & 1 \\
\hline 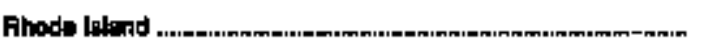 & a & 0 & 0 \\
\hline 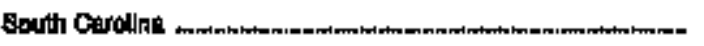 & 11 & 4 & 7 \\
\hline 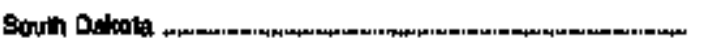 & 6 & 1 & 4 \\
\hline Tennegses & $\mathbf{s 5}$ & $\mathbf{0}$ & 65 \\
\hline Texag & 21 & 14 & 7 \\
\hline 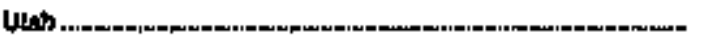 & 帛 & 7 & $\mathbf{1}$ \\
\hline 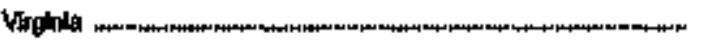 & 9 & 6 & 3 \\
\hline 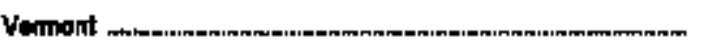 & 2 & 2 & 0 \\
\hline Washinglon & 25 & 13 & 12 \\
\hline 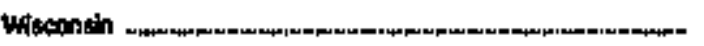 & 16 & 4 & 12 \\
\hline 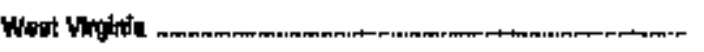 & 0 & 0 & 0 \\
\hline Wyoming & 2 & 1 & 1 \\
\hline 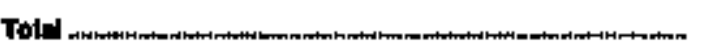 & 503 & 207 & 276 \\
\hline
\end{tabular}

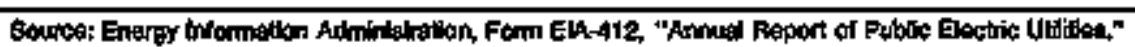




\begin{tabular}{|c|c|c|c|}
\hline 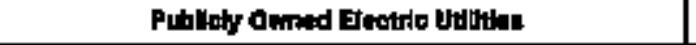 & sint & Feporting Dote & Benerating Stabua \\
\hline 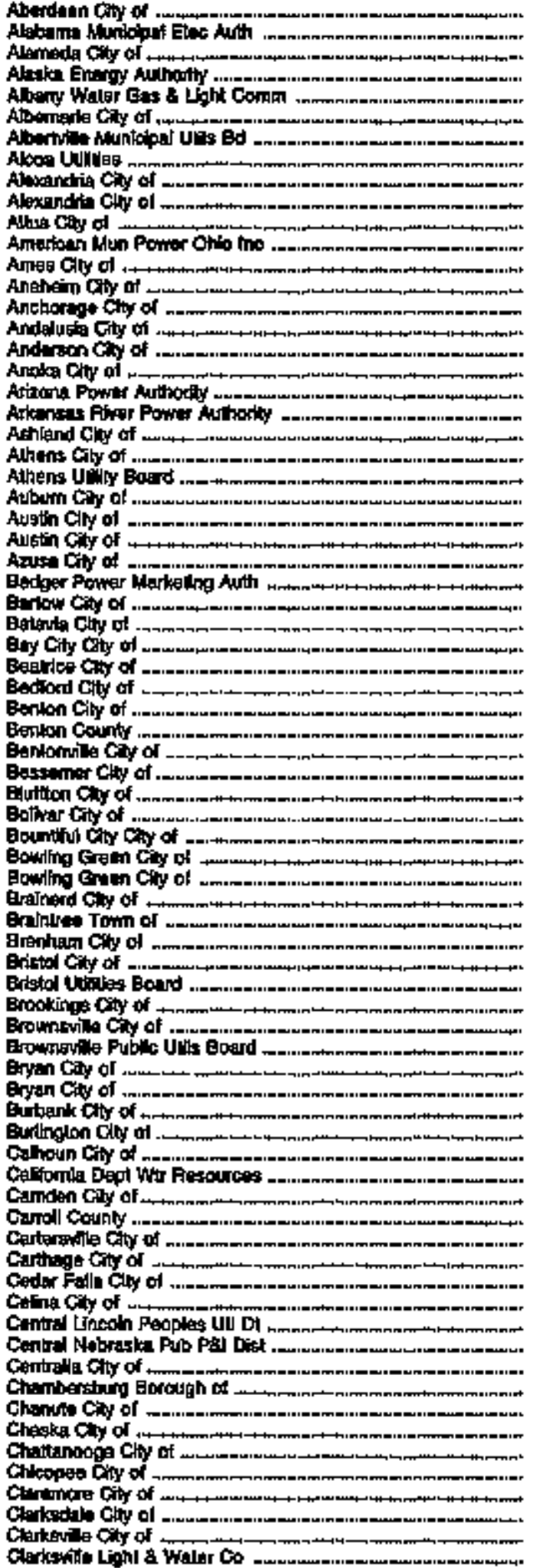 & 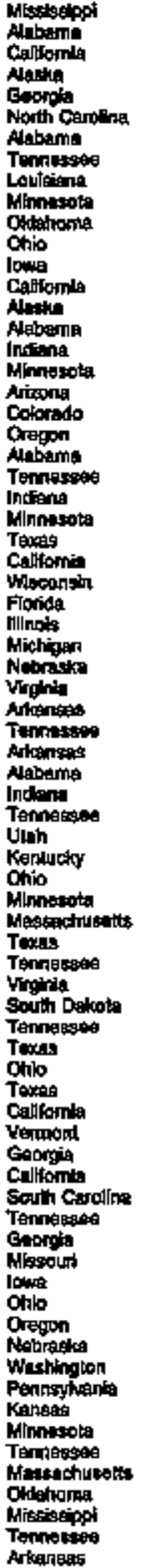 & 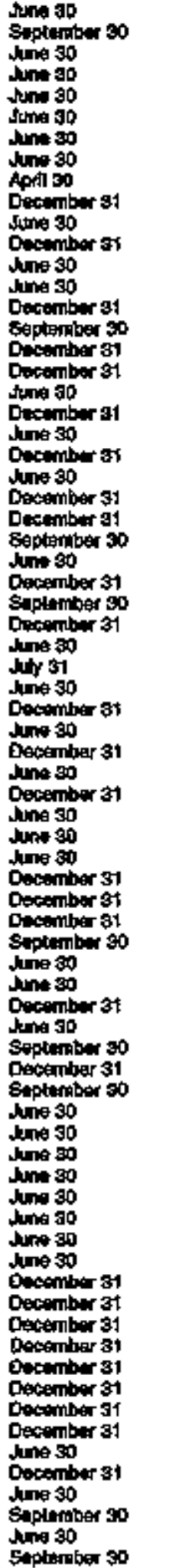 & 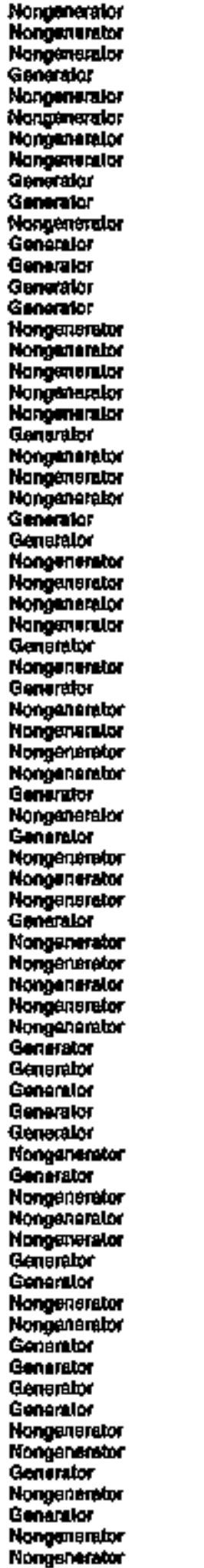 \\
\hline
\end{tabular}

Bise encholes at end ol thla tabte. 


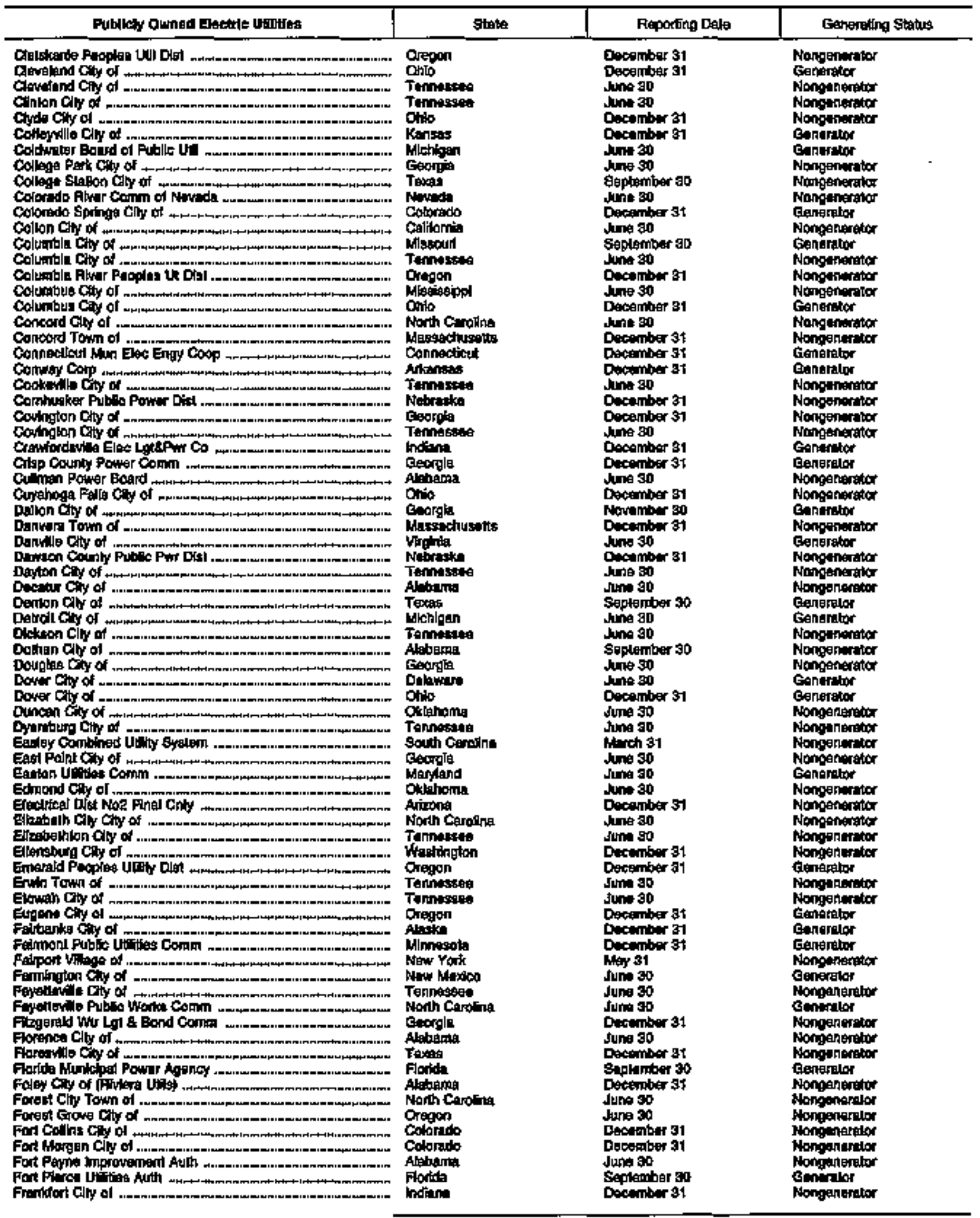

Seg endinates at end ol this tablo. 

Form ElA-412, 1994 (Continued)

\begin{tabular}{|c|c|c|c|}
\hline 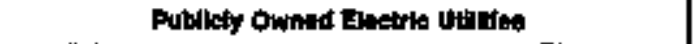 & stato & Reporting Date & Generaing Statug \\
\hline 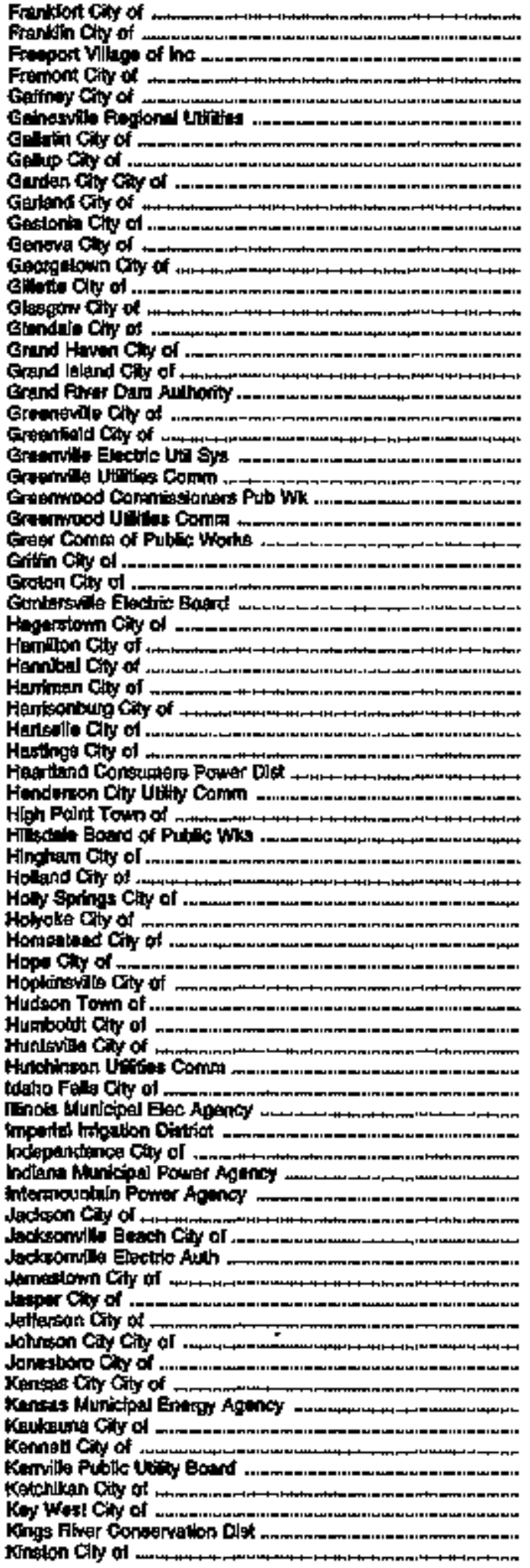 & 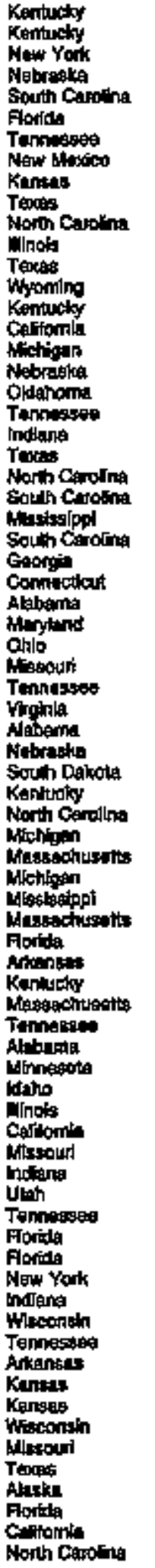 & 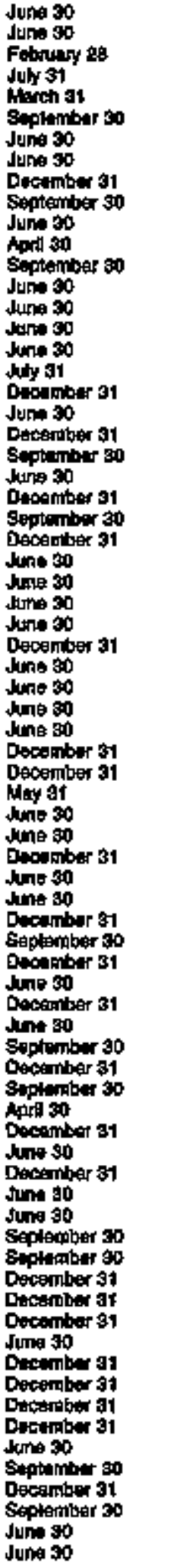 & 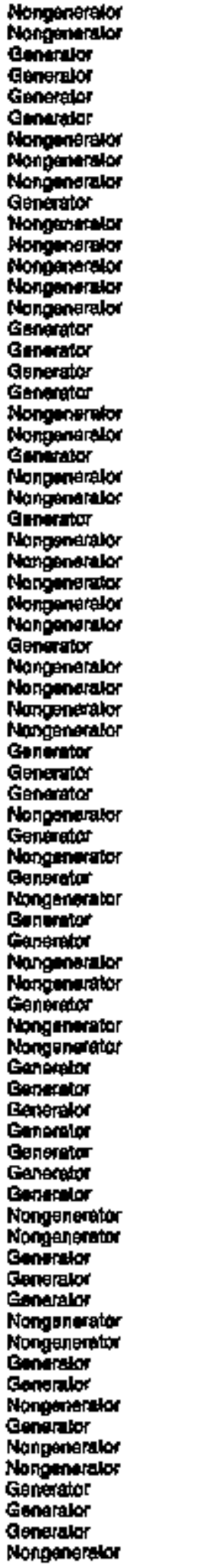 \\
\hline
\end{tabular}

See andnoleg al end of thls lable. 
Table B4. Publledy Owned Electric Utlities That Submitted the Form ElA-412, 1994 (Continited)

\begin{tabular}{|c|c|c|c|}
\hline 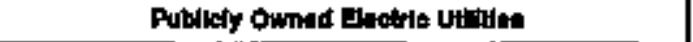 & Staks & Feporting Dats & Gonerating Stelds \\
\hline 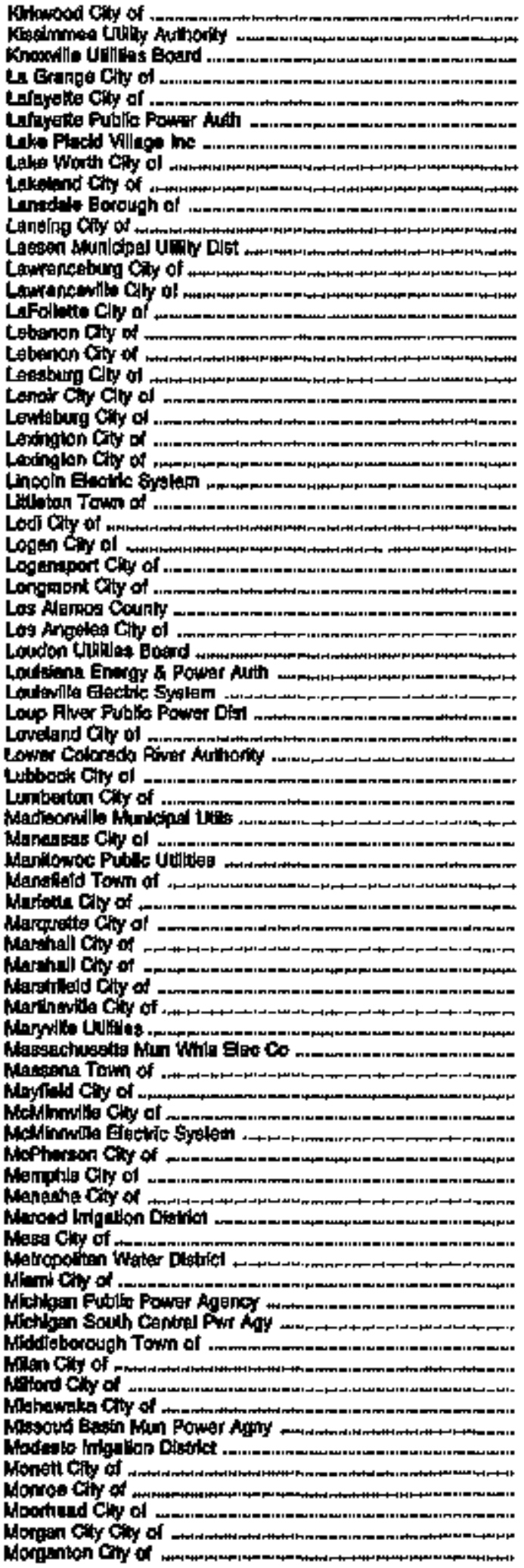 & 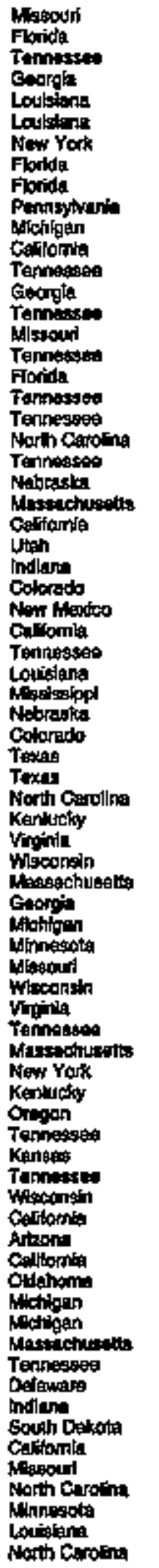 & 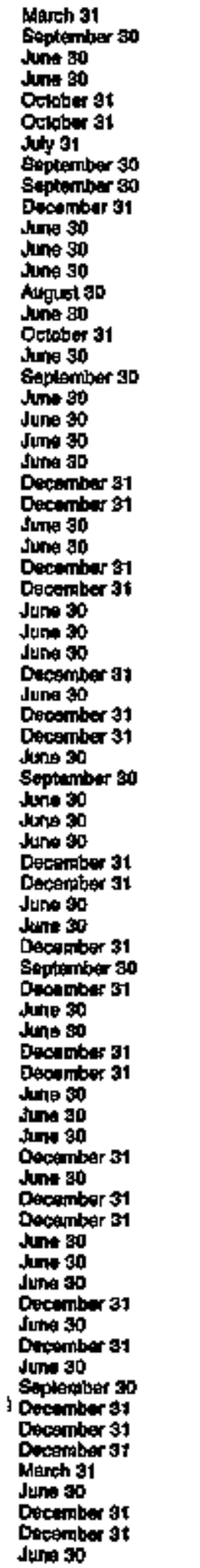 & 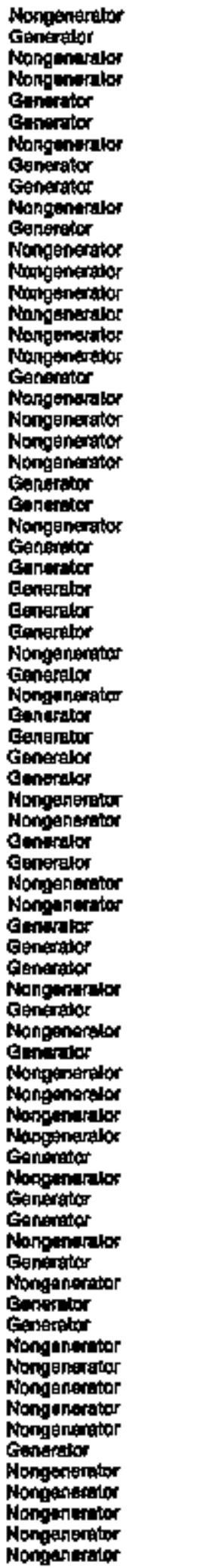 \\
\hline
\end{tabular}

Soo endnotes at end of thls tuble. 
Table BA. Publicly Owned Electric Uthlites That Submitted the Form ElA-412, 1994 (Continued)

\begin{tabular}{|c|c|c|c|}
\hline 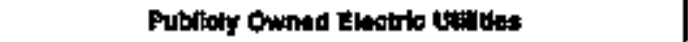 & etris & Picporiag Doth & 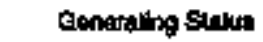 \\
\hline 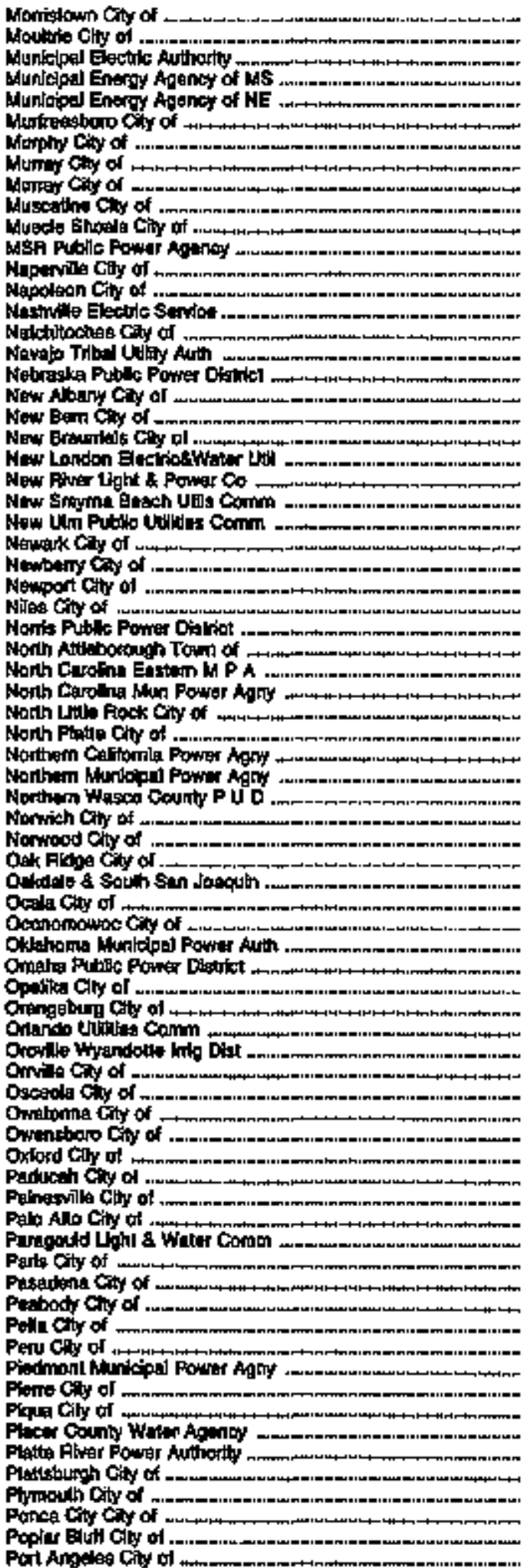 & 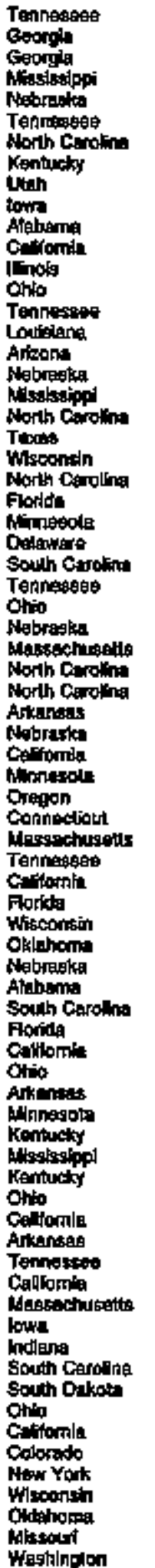 & 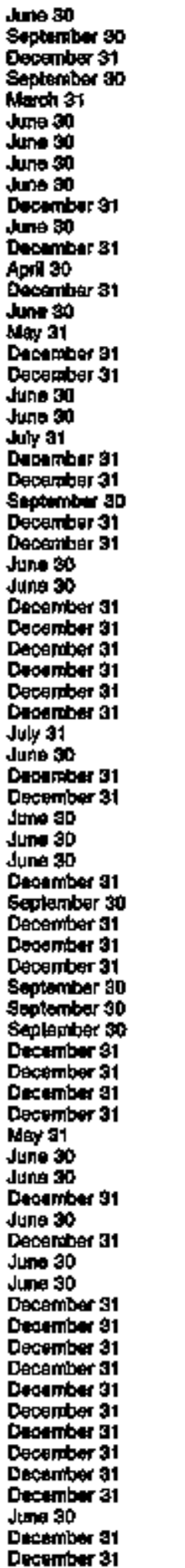 & 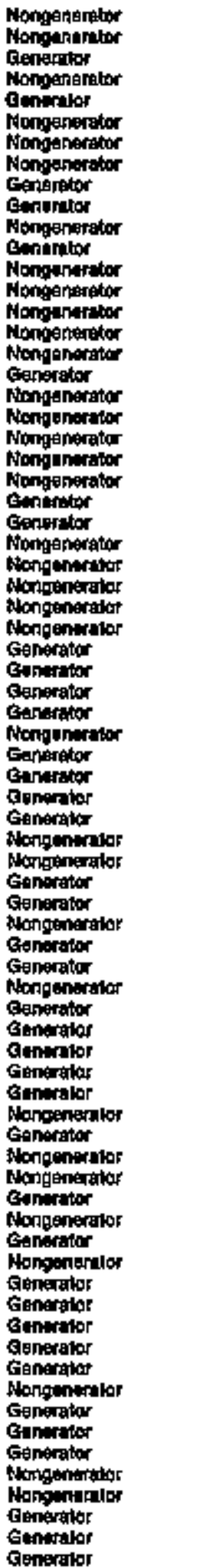 \\
\hline
\end{tabular}

Sue endinotes at ond of this lable. 


\begin{tabular}{|c|c|c|c|}
\hline 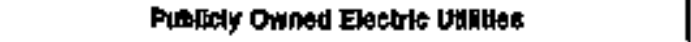 & Stave & Pieporting Dale & Eonerating Status \\
\hline 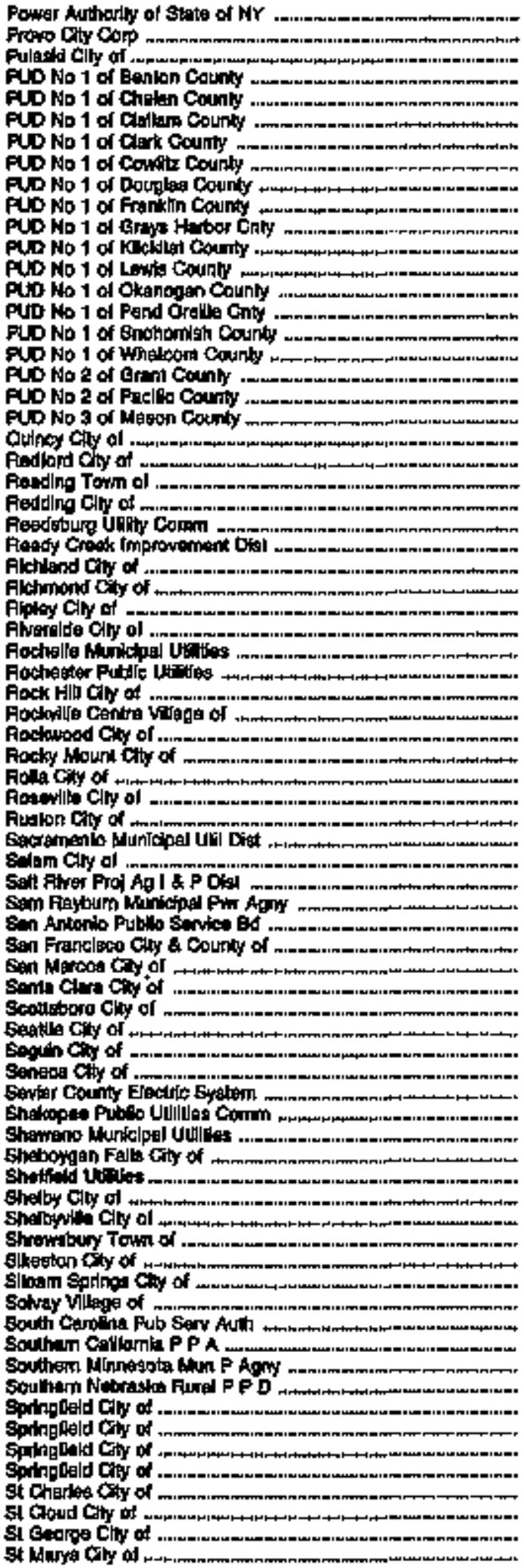 & 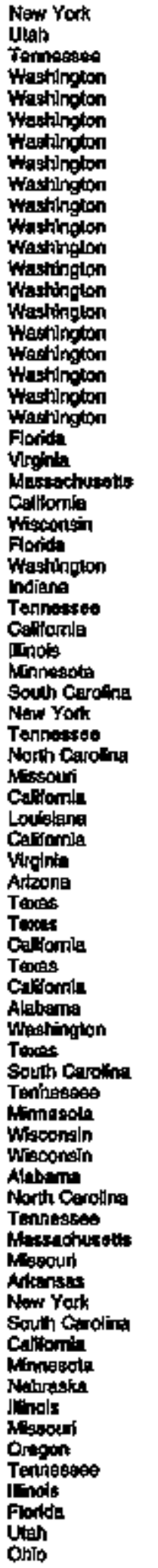 & 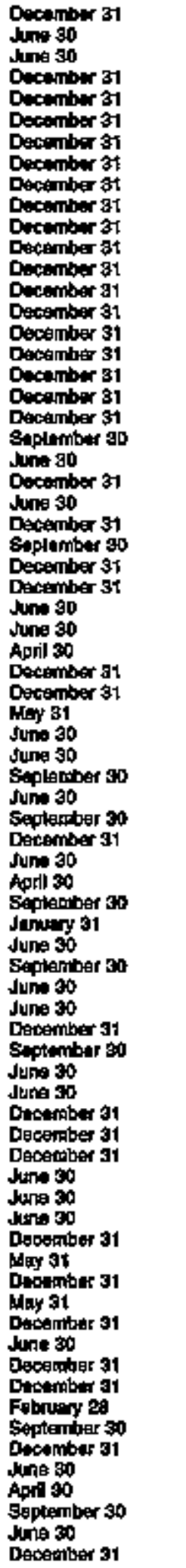 & 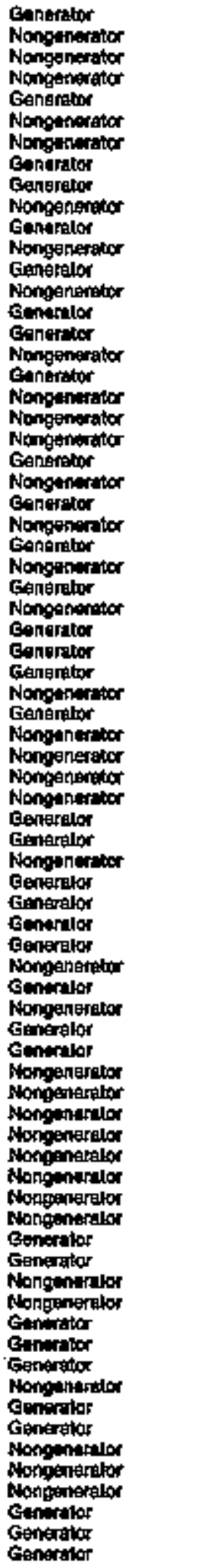 \\
\hline
\end{tabular}

Sea endnotes al end of this tabla 
Table B4, Publicly Owned Electric Utilities That Submitted the Form EIA-412, 1994 (Continued)

\begin{tabular}{|c|c|c|c|}
\hline 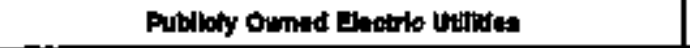 & gato & Peporthy Dala & Genarnthe Statro \\
\hline 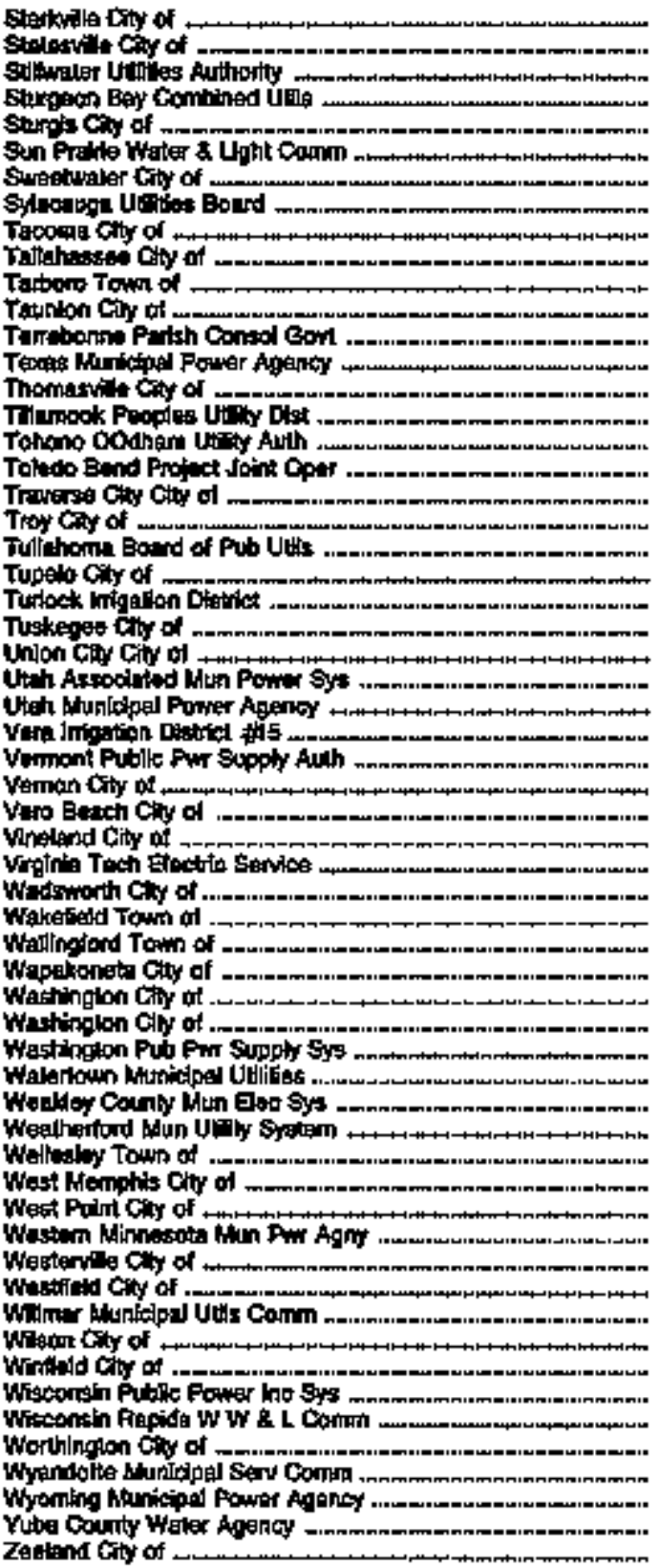 & 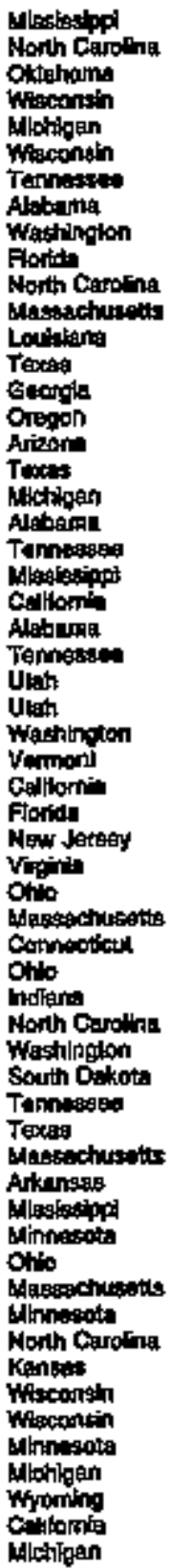 & 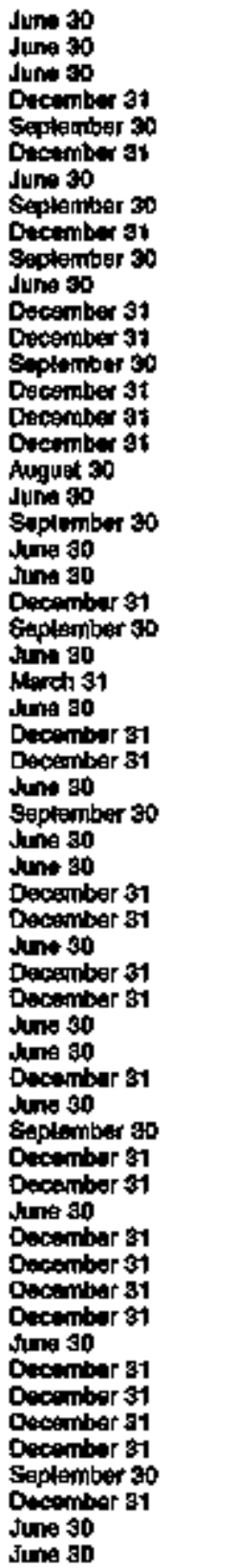 & 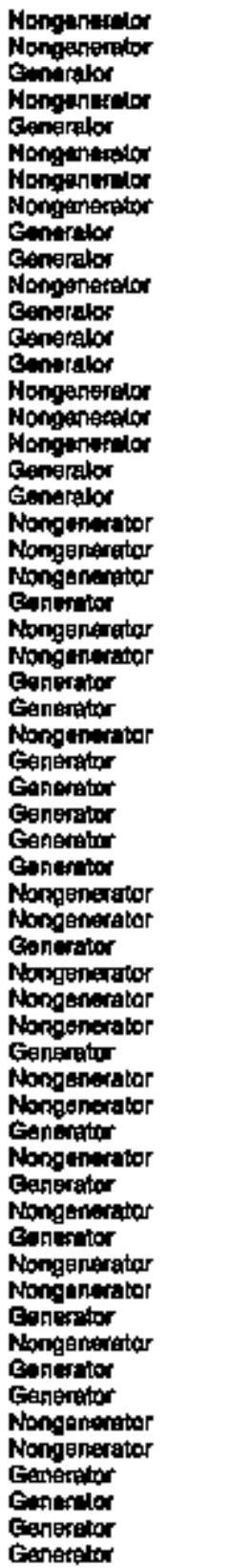 \\
\hline
\end{tabular}

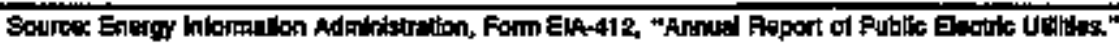


Flgure B1. Principal Business OFfice of the Major U.S. Publicly Owned Electric Utilities, 1994

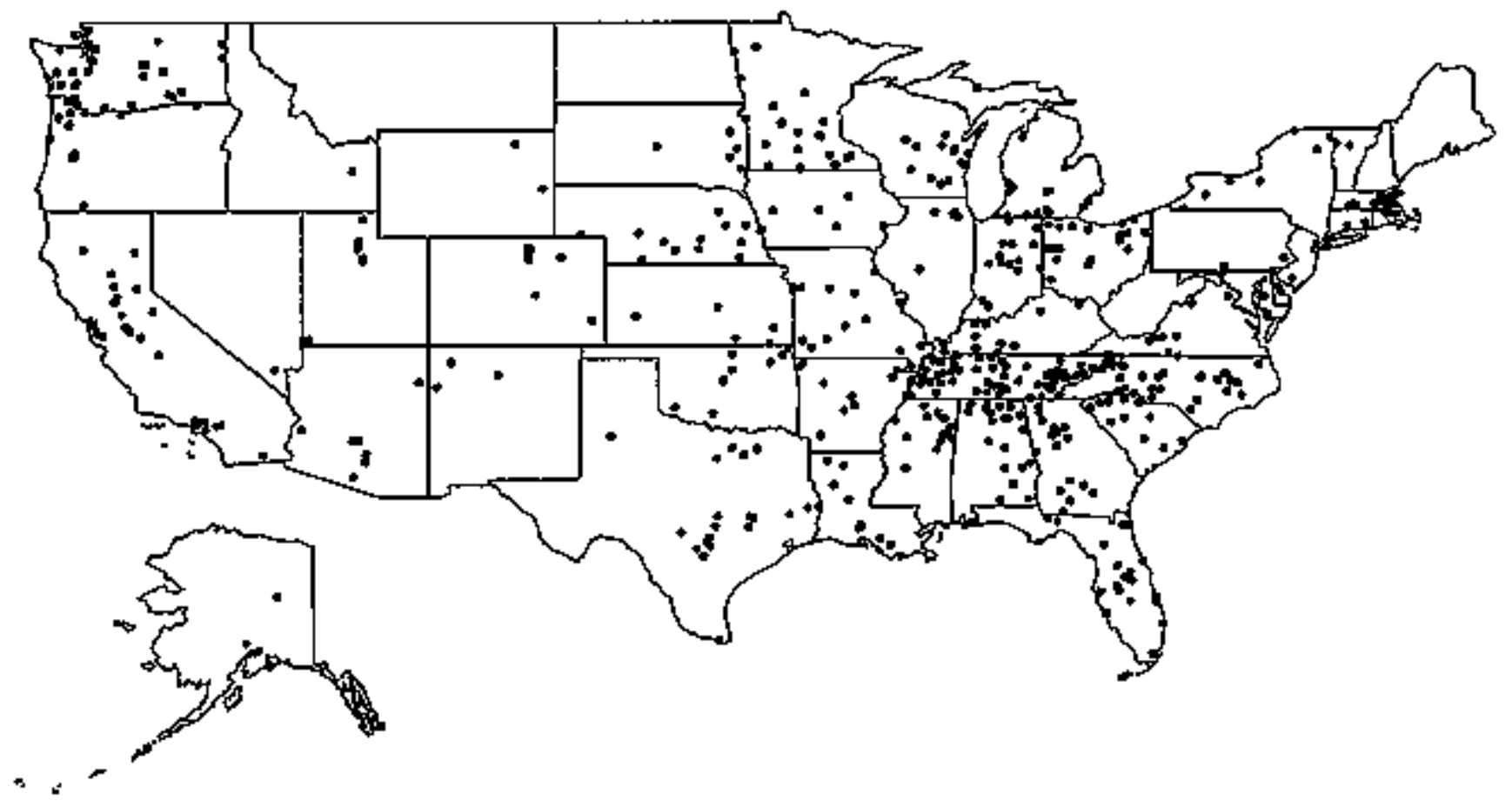

Source: Energy Information Administration, Form EtA-412, 'Annual Report af Public Eleqtrio Utilities.' 


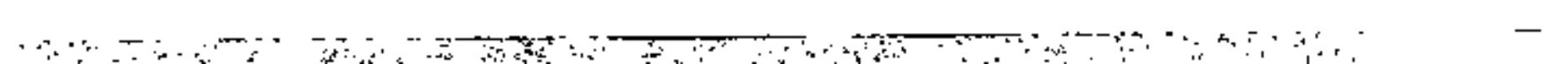




\section{Appendix C}

Major U.S. Generator/ Nongenerator Respondents by June 30 and December 31 Fiscal Years and by All Respondents, 1990-1994 



\section{Appendix C}

\section{Major U.S. Generator/Nongenerator Respondents by June $\mathbf{3 0}$ and December $\mathbf{3 1}$ Fiscal Years and by All Respondents, 1990-1994}


Table C1. Ten Largest U.S. Publicly Owned Cenerator Electric Utilties Ranked by Megawatthour Sales to UAtinate Consumers with Financial Year Ending on dune 30,1994

\begin{tabular}{|c|c|c|c|c|}
\hline 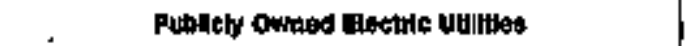 & State & Antorit & Porcont & \\
\hline Los Ningles Chy of n-m. & Cantorrile & $20,430,076$ & 43.38 & \\
\hline 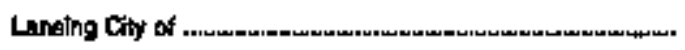 & nethidom & $2,258,675$ & 4.78 & \\
\hline Anshelph City of & Cosiforala & $2,200,798$ & 4,49 & \\
\hline 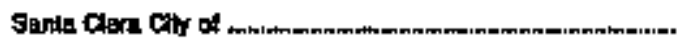 & Gelloomin & $2,178,184$ & 4.68 & \\
\hline Fayounthe Publo Worke Comm & North Cerolina & $1,710,000$ & 3.85 & \\
\hline Fiversidie Ciny of we... & Cerforite & $1,590,000$ & 3.24 & . \\
\hline 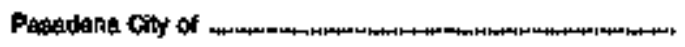 & Cantornita & $\$, 076,202$ & 2.26 & \\
\hline Verron City of - & Guthomia & $t, 099,708$ & 210 & \\
\hline Giendedp Cay of ... & Cestonita & काT,804 & 207 & \\
\hline Bubtenk Cty of & Califinata & $95,0,087$ & 202 & \\
\hline Subtotes & & $34,350,098$ & 7287 & \\
\hline
\end{tabular}

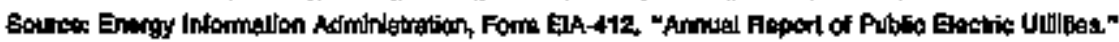

Table C2 Ten Largest US. Publlcly Owned Generator Electrlc Utintles Ranked by Megawatthour Salos for Resale with Financial Year Ending on June 30, 1994

\begin{tabular}{|c|c|c|c|}
\hline Puthofy Owned Eleotrio urevis: & state & Amodnt & Peroent \\
\hline 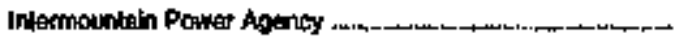 & Ulah & $12,18+, 294$ & at.4B \\
\hline 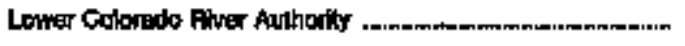 & Twarts & $0,444,066$ & 21.29 \\
\hline Wastington PUb PWr Suppoy Sys ... & Washinutan & $7,348,598$ & ts.st \\
\hline Southem Calitomia PPA A & 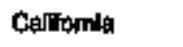 & $3,200,132$ & 122 \\
\hline 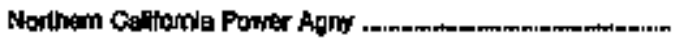 & Calfomba & $2,397,390$ & 5.27 \\
\hline 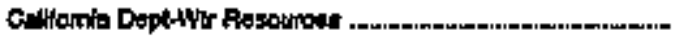 & Calfomia & 2,055,5rs & 6.00 \\
\hline Sen Frandibes Chy a County of . & Ceallitamid & 90,507 & .76 \\
\hline Yuba County Waver Agency .....m. & Calfomba & $1,000,904$ & 2.44 \\
\hline 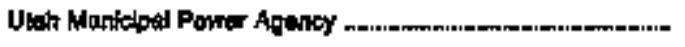 & Unah & exs,172 & 189 \\
\hline Los Angules Chy of ............ & Calfomia & 658,069 & 6.47 \\
\hline 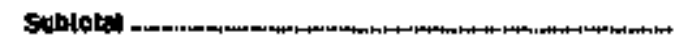 & & $40,918,27 \%$ & $\$ 201$ \\
\hline
\end{tabular}

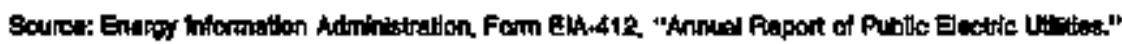


Table C3. Composite Statement of Income for Ustor U.S. Publichy Owned Generator Electric Uthilea with Financlel Year Ending on June 30, 1990-1994

(Thousand Dollars)

\begin{tabular}{|c|c|c|c|c|c|}
\hline |חell & topd & $10 \%$ & $19 \% 2$ & 1991 & 1900 \\
\hline 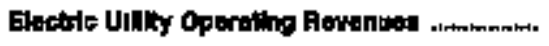 & $0,8+2,194$ & $6,056,818$ & $5,675,621$ & EREST,9BS & $6,622,510$ \\
\hline 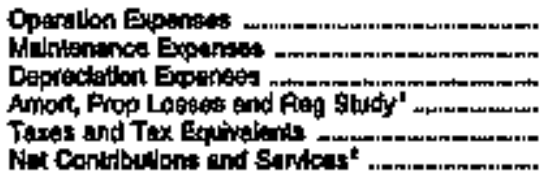 & $\begin{array}{r}3,750,460 \\
400,442 \\
730,717 \\
4,989 \\
125,721 \\
-\end{array}$ & $\begin{array}{r}3,607,050 \\
376,051 \\
605,941 \\
4,572 \\
126,376 \\
=\end{array}$ & $\begin{array}{r}3,505,008 \\
309,050 \\
007,770 \\
36,028 \\
100,703 \\
-\end{array}$ & $\begin{array}{r}3,989,558 \\
350,968 \\
620,160 \\
-107,916 \\
66,809\end{array}$ & $\begin{array}{r}3,249,479 \\
404,302 \\
602,904 \\
101,26 \\
72,042\end{array}$ \\
\hline 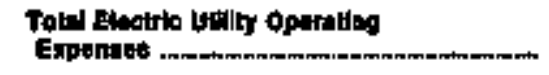 & $6,015,307$ & 4922,660 & $4,669,469$ & $4,638,407$ & $4,590,357$ \\
\hline 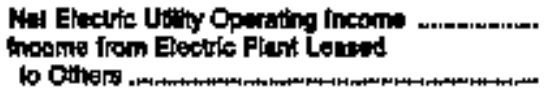 & $\begin{array}{r}1,305,650 \\
725\end{array}$ & $\begin{array}{r}1,234,086 \\
791\end{array}$ & $\begin{array}{r}1,205,152 \\
2,474\end{array}$ & $\begin{array}{r}1,045,578 \\
719\end{array}$ & $\begin{array}{r}1,139,179 \\
440\end{array}$ \\
\hline 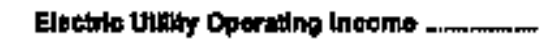 & $1,307,692$ & $1,234,827$ & $1,07,07,027$ & $1,046,205$ & $1,13+, 001$ \\
\hline 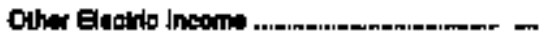 & $320,+37$ & $398,6 \pi$ & 391,118 & 995,740 & 349,547 \\
\hline 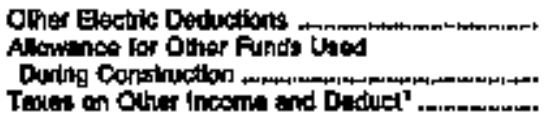 & $\begin{array}{l}91.770 \\
2,678\end{array}$ & $\begin{array}{r}109.128 \\
84\end{array}$ & $\begin{array}{r}123,354 \\
685\end{array}$ & $\begin{array}{r}1, \mathrm{a} 24 \\
6,149 \\
-\end{array}$ & $\begin{array}{r}= \\
\mathbf{3 , 1 8 a} \\
-\end{array}$ \\
\hline 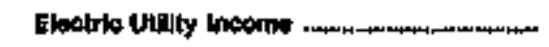 & $1,899,279$ & $1,4,2,347$ & $t, 475,581$ & 1,436,554 & t,49tast \\
\hline 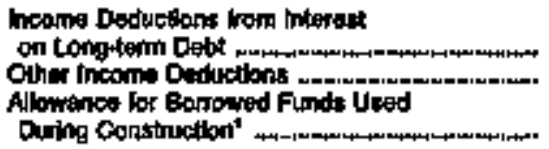 & $\begin{array}{r}1,286,4100 \\
151 \\
-7,350\end{array}$ & $\begin{array}{r}1,219,759 \\
-73,744 \\
-15,152\end{array}$ & $\begin{array}{r}1,290,247 \\
-12,878 \\
-10,592\end{array}$ & $\begin{array}{r}1,182,755 \\
-87,038\end{array}$ & $\begin{array}{r}1,+72,797 \\
57,629 \\
-\end{array}$ \\
\hline 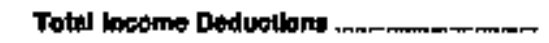 & $1,259,181$ & $1,130,898$ & $t, 274,778$ & $1,006,248$ & $1,2,00,409$ \\
\hline 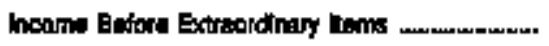 & 270,091 & $\mathbf{3 a 1 , 4 5 8}$ & 200,744 & a11,2]2 & $\mathbf{2 8 0 , 9 4 7}$ \\
\hline 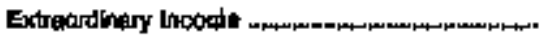 & 5,075 & 7,174 & e.5\%3 & 5,750 & 02,159 \\
\hline 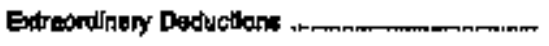 & 177,428 & 112,481 & 73,027 & 192,671 & 120,517 \\
\hline 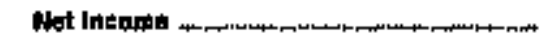 & 104,698 & 220,144 & 134310 & $19 \mathrm{~d}, 4 \mathrm{~s}$ & 216,569 \\
\hline
\end{tabular}

* Dota reportico in'ilaled in 1992.

2 Deata

- Oatis nol avaliabia.

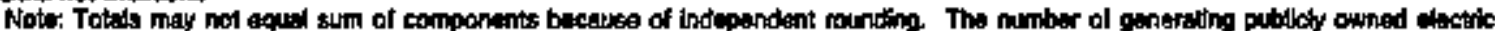

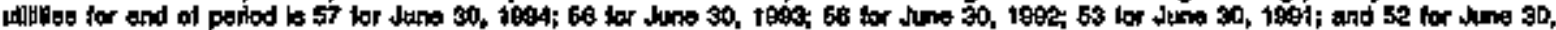

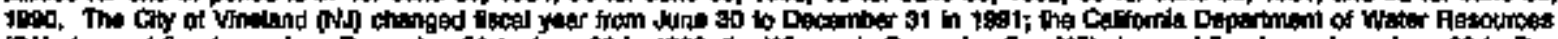

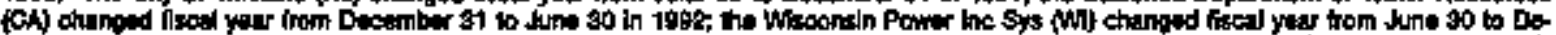

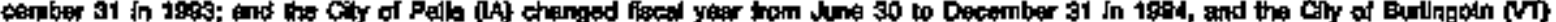

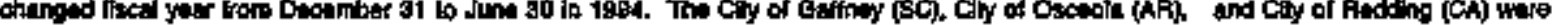

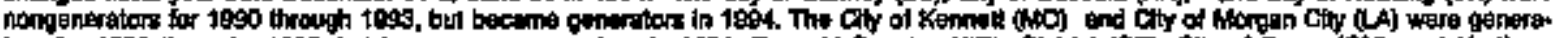

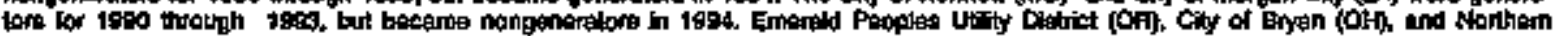

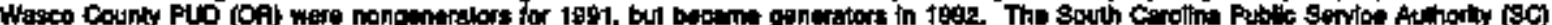

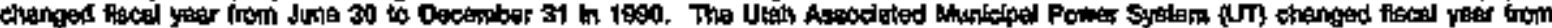

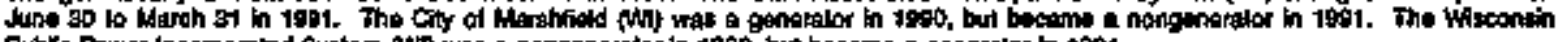

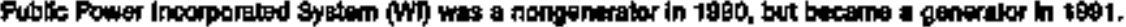

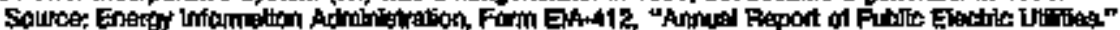


Table C4. Composite Balance shet for Major U.S. Pubncly Owned Generator Electric Utikties with Finantial Year Ending on June 30 at End of Perlod, 1990-1994 (Thousand Dollars)

\begin{tabular}{|c|c|c|c|c|c|}
\hline Item & 1894 & 1993 & 1892 & $199 x$ & 1000 \\
\hline 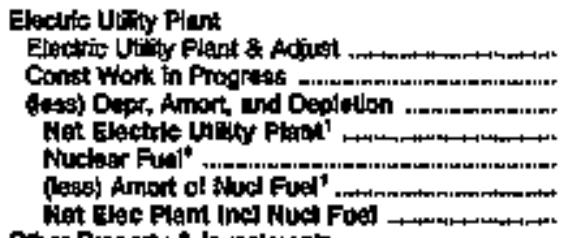 & $\begin{array}{r}23,649,149 \\
843,150 \\
7,247,601 \\
17,244,790 \\
394,060 \\
201,865 \\
17,396,994\end{array}$ & $\begin{array}{r}22,456,024 \\
079,759 \\
6,605,704 \\
15,012,072 \\
309,198 \\
197,695 \\
15,977,396\end{array}$ & 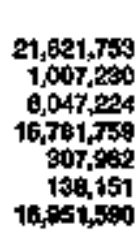 & $\begin{array}{r}21,287,167 \\
6,313,940 \\
= \\
= \\
15,973,296\end{array}$ & $\begin{array}{r}20,522,021 \\
4,722,91 \overline{5} \\
= \\
= \\
15,799,108\end{array}$ \\
\hline 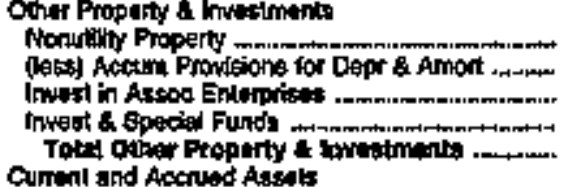 & $\begin{array}{r}6,280,581 \\
1,643,704 \\
34,984 \\
5,976,184 \\
9,648,438\end{array}$ & 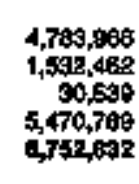 & $\begin{array}{r}4,390,194 \\
1,426,040 \\
39,099 \\
3,859,741 \\
0,564,605\end{array}$ & $\begin{array}{r}4,083,541 \\
1,729,745 \\
2,751 \\
4,046,793 \\
5,910,940\end{array}$ & $\begin{array}{r}3,609,750 \\
1,212,730 \\
4,216 \\
4,151,242 \\
6,612,46\end{array}$ \\
\hline 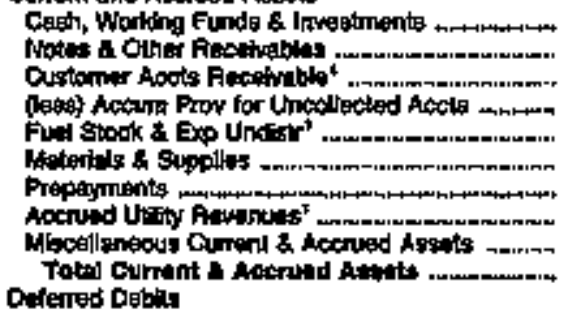 & 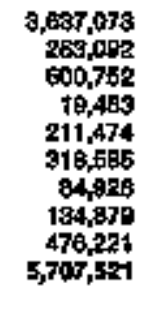 & $\begin{array}{r}3,042,190 \\
251,049 \\
650,561 \\
10,691 \\
219,279 \\
30,697 \\
73,367 \\
130,552 \\
917,390 \\
8,677,308\end{array}$ & 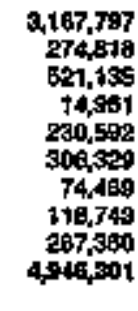 & 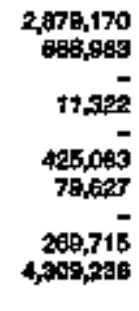 & 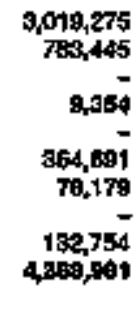 \\
\hline 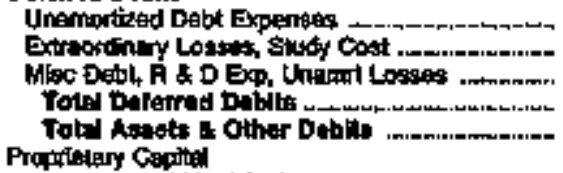 & $\begin{array}{r}1,515,843 \\
78,485 \\
2,409,460 \\
4,007,720 \\
35,761,967\end{array}$ & 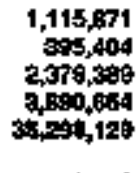 & $\begin{array}{r}\cos , 381 \\
12,500 \\
2,590,210 \\
3,531,511 \\
3,2,391,297\end{array}$ & $\begin{array}{r}954,622 \\
2,399,612 \\
3,351,435 \\
38,444,637\end{array}$ & $\begin{array}{r}8 B \times, 190 \\
2,135,192 \\
3,121,3 \mathrm{Bt} \\
29,901,460\end{array}$ \\
\hline 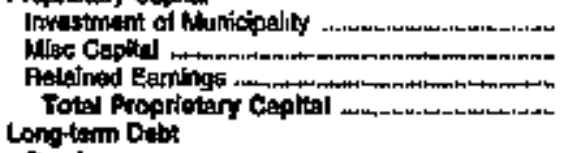 & $\begin{array}{r}1,010,703 \\
118,978 \\
7,489,964 \\
8,619,570\end{array}$ & $\begin{array}{r}890,695 \\
97,240 \\
7,165,700 \\
6,249,040\end{array}$ & $\begin{array}{r}1,020,557 \\
-14,376 \\
6,911,454 \\
7,917,044\end{array}$ & $\begin{array}{r}1,171,715 \\
-261,794 \\
6,795,165 \\
7,715,085\end{array}$ & $\begin{array}{r}1,033,649 \\
-80,260 \\
6,462,752 \\
7,434,040\end{array}$ \\
\hline 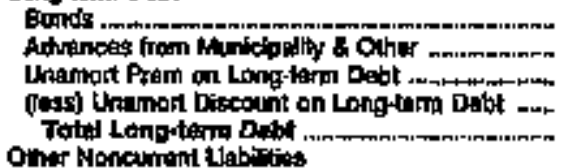 & $\begin{array}{r}22,970,6985 \\
1,677,910 \\
8,674 \\
94,600 \\
20,8+4,978\end{array}$ & 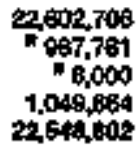 & $\begin{array}{r}20,377,974 \\
550,413 \\
5,743 \\
1,072,455 \\
10,8,2,718\end{array}$ & $\begin{array}{r}19,695,964 \\
594,617 \\
689 \\
988,782 \\
10,444,4048\end{array}$ & $\begin{array}{r}58,600,618 \\
521,812 \\
748 \\
944,680 \\
18,179,869\end{array}$ \\
\hline 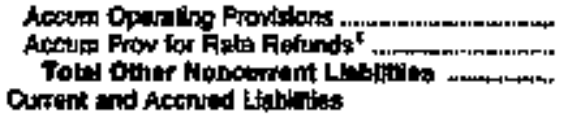 & $\begin{array}{r}119,568 \\
119,509\end{array}$ & $\begin{array}{r}\mathrm{B9}, 777 \\
09,777\end{array}$ & $\begin{array}{l}89,277 \\
69,277\end{array}$ & $\begin{array}{r}32,515 \\
30,5,5\end{array}$ & $\begin{array}{r}30,369 \\
39,362\end{array}$ \\
\hline 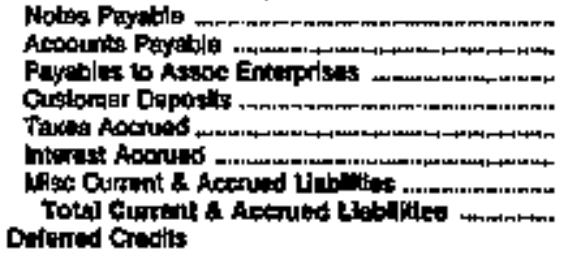 & $\begin{array}{r}112,648 \\
914,732 \\
195,708 \\
19,0,701 \\
14,141 \\
44,461 \\
1,669,441 \\
3,690,113\end{array}$ & $\begin{array}{r}515,218 \\
836,092 \\
150,227 \\
70,007 \\
16,696 \\
492,509 \\
1,012,747 \\
\$, 544,709\end{array}$ & $\begin{array}{r}124,980 \\
636,494 \\
145,023 \\
93,197 \\
21,683 \\
392,500 \\
1,940,650 \\
3,944,497\end{array}$ & $\begin{array}{r}100,601 \\
740,541 \\
149,697 \\
75,121 \\
21,529 \\
410,700 \\
1,627,133 \\
3,391,299\end{array}$ & $\begin{array}{r}117,025 \\
684,029 \\
139,980 \\
41,682 \\
14,020 \\
342,985 \\
1,924,751 \\
3,145,494\end{array}$ \\
\hline 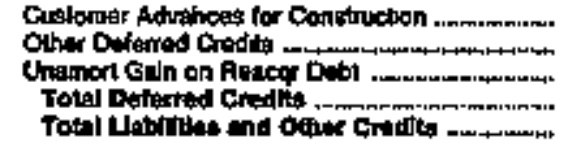 & $\begin{array}{r}45,438 \\
651,766 \\
21,434 \\
717,738 \\
36,761,667\end{array}$ & $\begin{array}{r}45,188 \\
74,739 \\
105,182 \\
901,200 \\
95,496,499\end{array}$ & $\begin{array}{r}42,340 \\
01 t, 973 \\
142,572 \\
98,845 \\
90, \$ 91,297\end{array}$ & $\begin{array}{r}61,062 \\
695,1689 \\
174,185 \\
020,455 \\
30,464,157\end{array}$ & $\begin{array}{r}34,180 \\
928,499 \\
147,404 \\
1,110,043 \\
29,901,959\end{array}$ \\
\hline
\end{tabular}

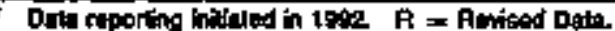

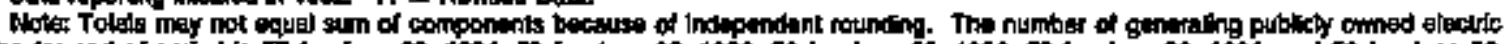

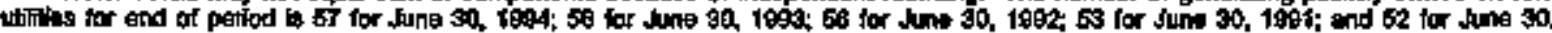

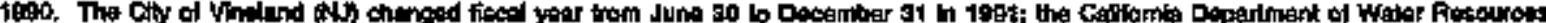

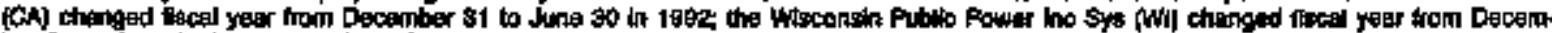

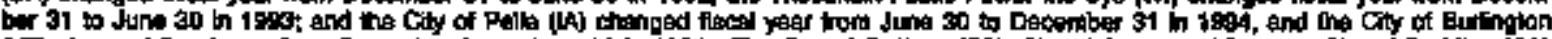

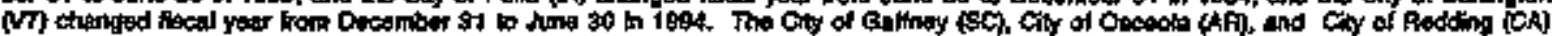

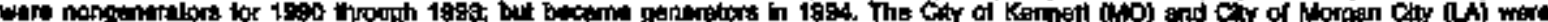

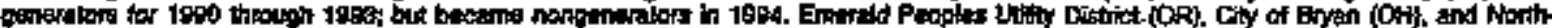

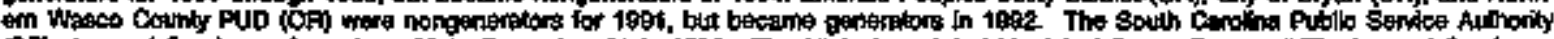

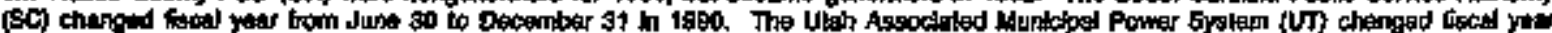

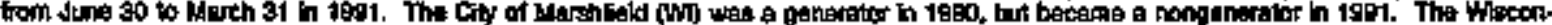

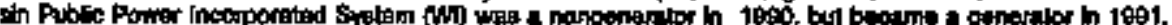

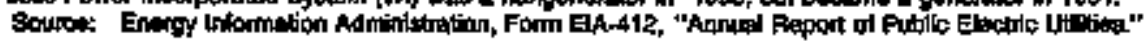


Table C5. Composite Financlal Indleatore tor Major U.S. Publichy Owned Generator Electric Utilities With Financial Year Einding on June 30, 1990-1994

\begin{tabular}{|c|c|c|c|c|c|}
\hline Heam & 1994 & 1599 & 1992 & 1691 & $\operatorname{teg}$ \\
\hline 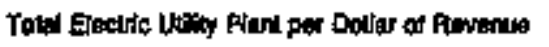 & 9,9 & 3.8 & 9,9 & $\mathbf{3 0}$ & 9.7 \\
\hline Cument Assuts lo Cturenl Libillisat & 1.5 & $\$ .6$ & 1,4 & t. 3 & 1,4 \\
\hline 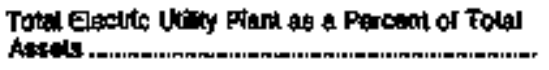 & 67.0 & 87.1 & $7 t .4$ & $\theta$ & 69.8 \\
\hline 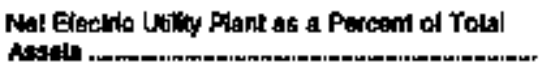 & 47.3 & 48. & 62.3 & ses & 528 \\
\hline Dabt as a Percant of Tolal thatrotios & 743 & 79,9 & 729 & 71.5 & $\mathbf{7 1 , 5}$ \\
\hline 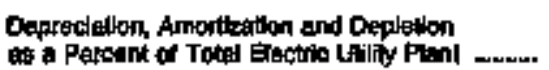 & 3000 & 20.4 & 28.7 & 25.0 & 23.0 \\
\hline 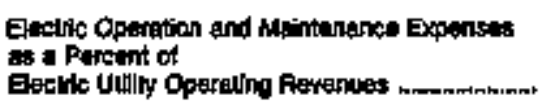 & 65.7 & 6.6 & 68.3 & 67.0 & 60.1 \\
\hline 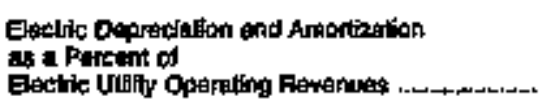 & 11.6 & 11.0 & 90.7 & 112 & 102 \\
\hline 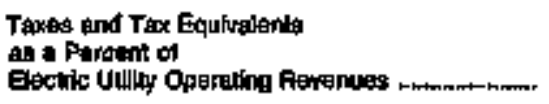 & 2.0 & 2.1 & 1.8 & 1.9 & 1.a \\
\hline 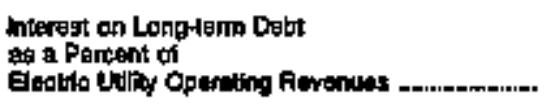 & 200 & 80.1 & axs & 21.2 & t2t? \\
\hline 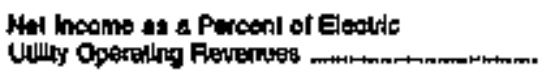 & 1.7 & $\mathbf{3 . 7}$ & 23 & 3.3 & 89 \\
\hline 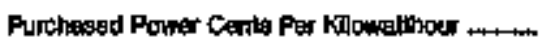 & 4.6 & 4,3 & 4.3 & $\mathbf{4 . 5}$ & 4.7 \\
\hline 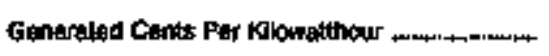 & 2.3 & 2.3 & 23 & 2.3 & 23 \\
\hline $\begin{array}{l}\text { Total Power Suppy Per } \\
\text { tellownow Solt }\end{array}$ & 3.4 & 3,4 & 35 & $\mathbf{3 . 5}$ & S.S \\
\hline
\end{tabular}

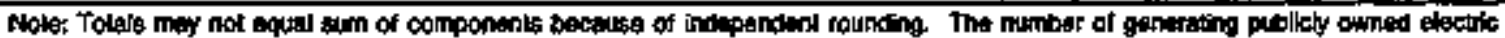

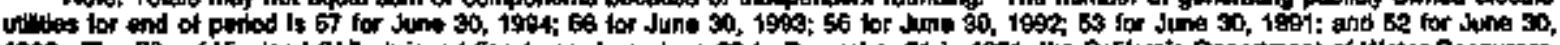

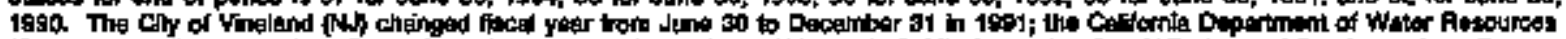

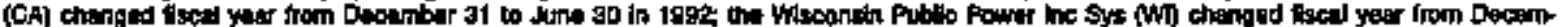

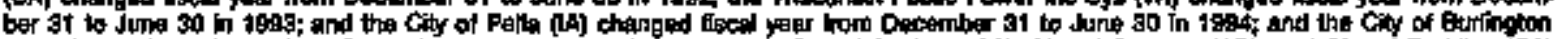

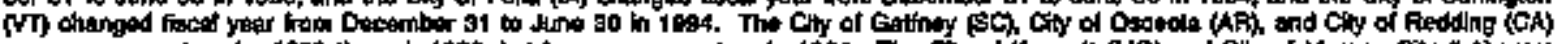

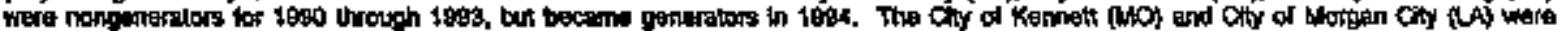

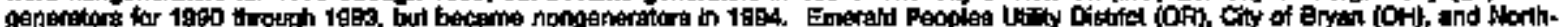

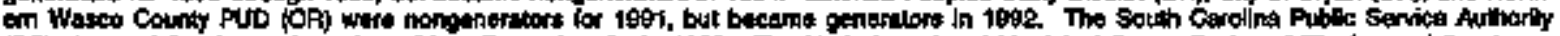

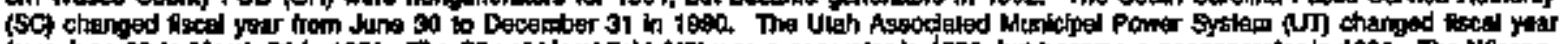

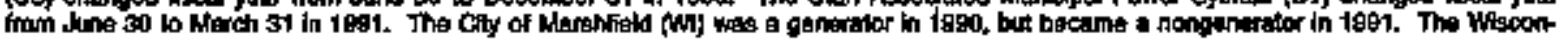

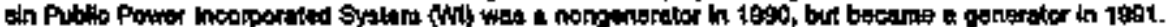

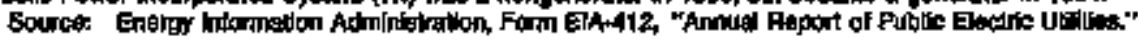


Table C6. Electrle Operation and Maintenance Expenses for Major U.S.

Publicly Owned Generator Electric Utilities with Financial

Year Ending on June 30, t990-1994

(Thousand Dollars)

\begin{tabular}{|c|c|c|c|c|c|}
\hline Itom & 1984 & 1080 & 1982 & 1691 & 1900 \\
\hline \multicolumn{6}{|l|}{ Produtolton Expontise } \\
\hline 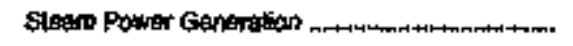 & $1,090,342$ & $2,078,045$ & 252,198 & 920,777 & $991+189$ \\
\hline Meder Power Generalion ...n. & 234,047 & 211,994 & 195,820 & 200,0404 & 197,714 \\
\hline 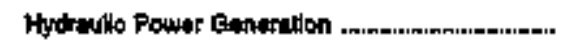 & 48,678 & 61,177 & 51,216 & 49,211 & 45,352 \\
\hline 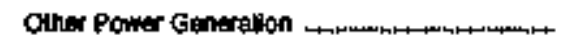 & 46,908 & 41,629 & 39,213 & $24, A 79$ & 94, B99 \\
\hline Fuxchegod Powner tinn & $1,723,450$ & $1,618,260$ & $1,696,102$ & $1,684,203$ & $1,542,275$ \\
\hline 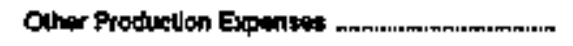 & 20,092 & 16,763 & 25,393 & 20,376 & 12,417 \\
\hline 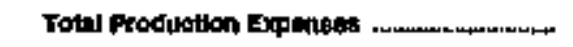 & 3,158,691 & 9,016,050 & $2,05,9,932$ & 2,E83,145 & 2,023,0998 \\
\hline 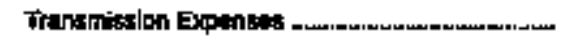 & 141,292 & 129886 & 122,955 & 114,691 & 113,463 \\
\hline Dostibullon Expenseg & 250,442 & 287,820 & 249,276 & 230,297 & 212,305 \\
\hline 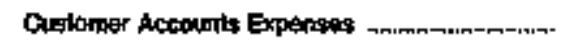 & 84,475 & 02,470 & a5,956 & $\pi, 4 \% ?$ & 75,973 \\
\hline 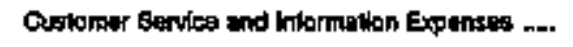 & 31,73 & 28,378 & 20,898 & 10,760 & 14,472 \\
\hline 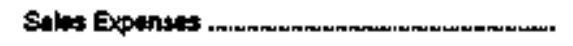 & $\mathbf{B 1 2}$ & 8xa & 1,508 & 3.128 & 4,156 \\
\hline Adrministralive and Genteral Expangeng & 469,764 & 447,484 & 452,973 & 430,027 & 409,548 \\
\hline $\begin{array}{l}\text { Total Electic Operation } \\
\text { end Walutentance Expentsea }\end{array}$ & $4,160,611$ & $3,509,691$ & $3,894,915$ & $2,740,513$ & $3,647,775$ \\
\hline \multicolumn{6}{|l|}{ Folel Experasea tn Operadon } \\
\hline 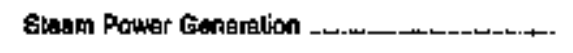 & 812,127 & 790,613 & 702,009 & 651.050 & 729,084 \\
\hline 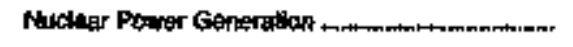 & 69,000 & 54,436 & se,sed & 56,309 & 42,094 \\
\hline 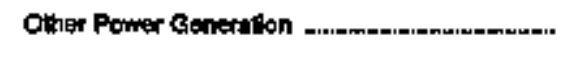 & 21,917 & 10,689 & 17,092 & 16,002 & 11,670 \\
\hline \multicolumn{6}{|l|}{ Number of Eloc Dept Employest } \\
\hline 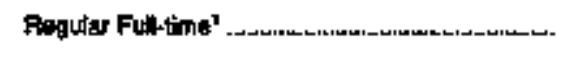 & 15,653 & 15,442 & 16,6994 & - & - \\
\hline 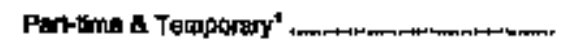 & 815 & 967 & 1,217 & - & - \\
\hline 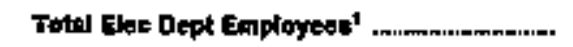 & 16,4603 & $+4,400$ & 10,111 & - & - \\
\hline
\end{tabular}

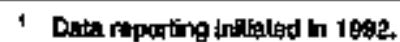

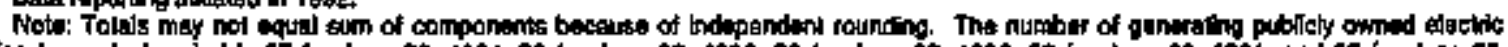

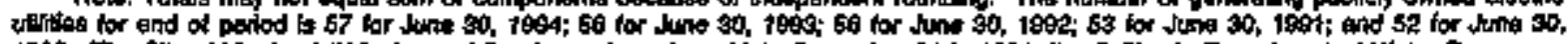

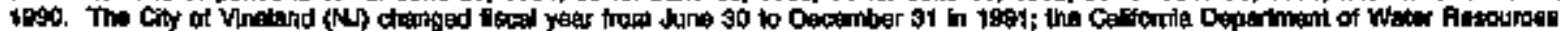

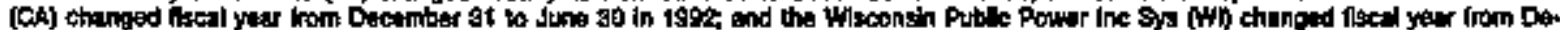

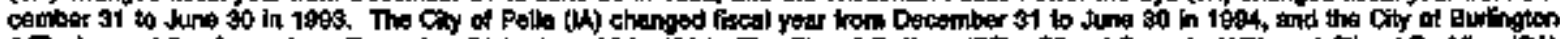

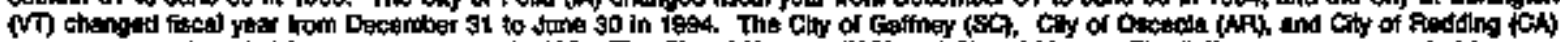

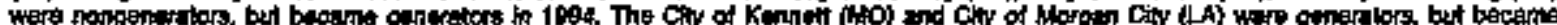

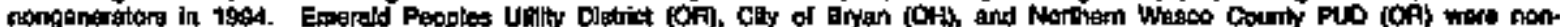

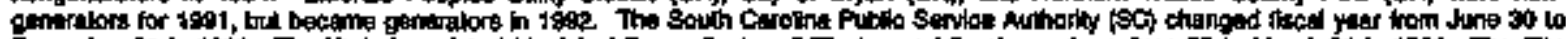

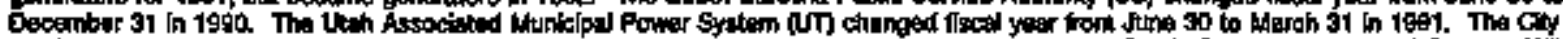

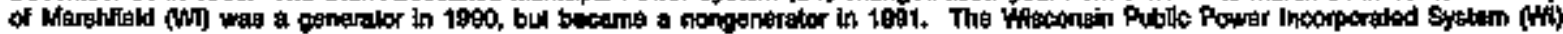

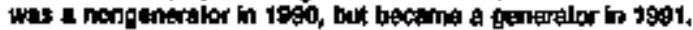

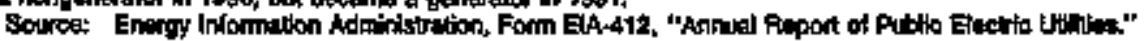


Table C7. Electrk Utility Plent for Mejor U.S. Publicly Owned Generator Electric Uttlities with FInanclal Year Ending on June 30 at End of Perlod, 1990-1994

(Thousand Dollars)

\begin{tabular}{|c|c|c|c|c|c|}
\hline $\operatorname{lem}$ & 1904 & 1000 & 1992 & 1991 & 1890 \\
\hline \multicolumn{6}{|l|}{ Eluotrle Plank in serviles } \\
\hline Iintanglble Prani ..... & 88,900 & 的,231 & 108,370 & $141,4 \$ 8$ & 83,134 \\
\hline \multicolumn{6}{|l|}{ Production Plapi } \\
\hline 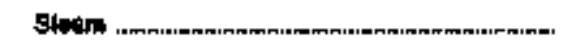 & $9,294,970$ & $0,391,047$ & 0,074,987 & $5,040,504$ & $6,789,000$ \\
\hline 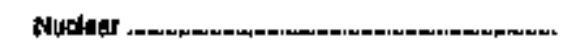 & $4,588,800$ & $4,500,480$ & $4,684,312$ & 4,059,075 & $4,857,227$ \\
\hline 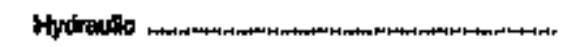 & $2,705,014$ & $2,002,692$ & 2810,855 & $1,794,146$ & $1,709,620$ \\
\hline Otow ... & 9si,62t & 435,125 & sea,er & 249,842 & 297,512 \\
\hline Told Predustion Plant, & $t 4,618,215$ & $14,004,504$ & 33,9018,205 & $12,762,197$ & $12,857,249$ \\
\hline Trunarisalon Plant .. & $2,488,078$ & $2,443,364$ & $2,372,536$ & $2,257_{2}, 038$ & $2,211,441$ \\
\hline 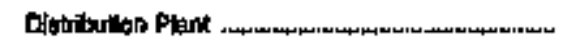 & $4,453,002$ & $4,287,154$ & $4,056,844$ & $3,757,918$ & $5,448,680$ \\
\hline Gonered flant & $1,701,054$ & $1,373,609$ & $1,189,867$ & $1,122,472$ & $1,087,843$ \\
\hline 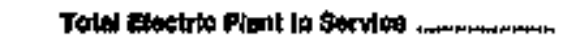 & $23,909,917$ & $22,167,272$ & $21,590,702$ & $20,032,658$ & $10,4 S 8,997$ \\
\hline 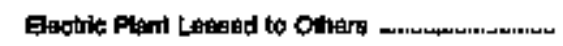 & 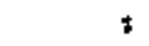 & 1 & 1 & sts: & 1,920 \\
\hline 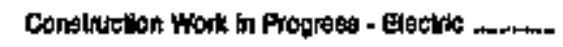 & 040,150 & 679.750 & $1,007,280$ & $1,002,842$ & 840,947 \\
\hline 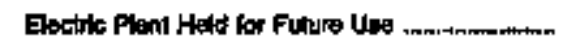 & 12,216 & 9,407 & $\$ 7$ & $\mathbf{2 6 4 , 2 9 5}$ & 20,278 \\
\hline 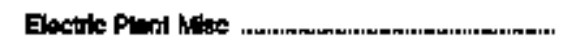 & 307,018 & 281,284 & 231,030 & $-13,099$ & $-2,2,522$ \\
\hline Totad Eactrte UtIIy Plant & $24,492,290$ & $23,897,7^{6}$ & 22928,963 & $24,297,167$ & $20,620,021$ \\
\hline 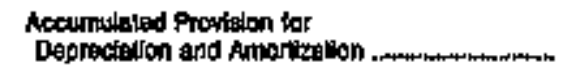 & $7,247,501$ & $6,625,704$ & $6,047,224$ & $5,313,940$ & $4,722,915$ \\
\hline Wht Electirc Utilny Plant & $17,244,76 s$ & $18,6-12,07 z$ & $t 6,781,760$ & $15,973,229$ & $16,7 \in 9,40:$ \\
\hline
\end{tabular}

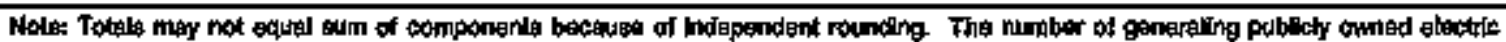

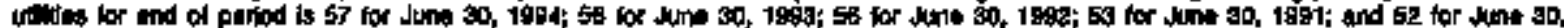

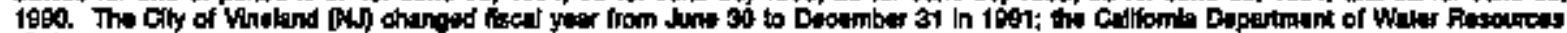

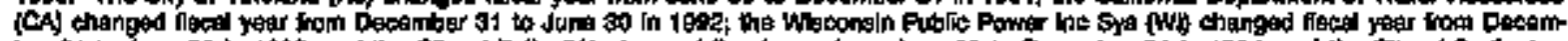

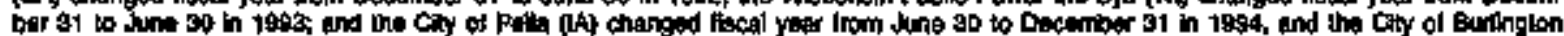

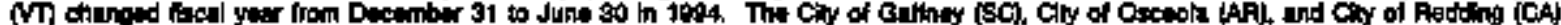
wore nongenergedors for 19Bo tox J

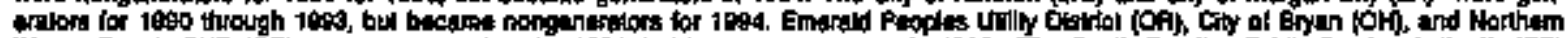

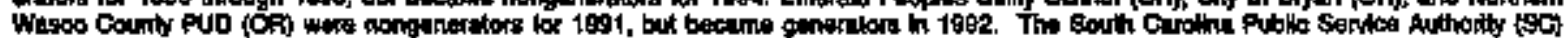

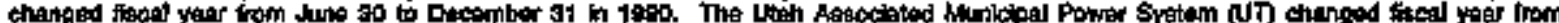

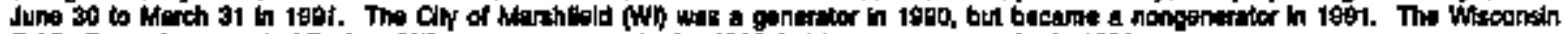

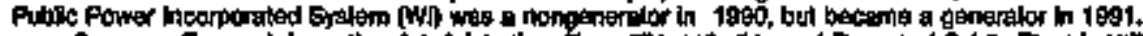

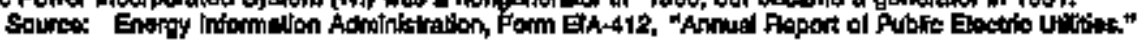


Table C8. Number of Consumers, Sales, and Operating Revenue for Mejor U.S. Publicly Owmed Benerator Eleotrio Utilties with Financlal Year Ending on June 30, 1990-1994

\begin{tabular}{|c|c|c|c|c|c|}
\hline Ilem & 1994 & 1023 & 1982 & 1991 & 1980 \\
\hline \multicolumn{6}{|l|}{ Number of Consoumpers } \\
\hline Rosidential _me...rem & $2,0093,440$ & $2,088,964$ & $2,051,700$ & $2,00 \%, 780$ & $2,004,891$ \\
\hline Commintill oc Small & 300,505 & 289,6002 & 298,150 & 234,039 & 237.605 \\
\hline hoduttal or Laye - & 24,124 & 23,482 & 29,792 & 20,205 & 28,732 \\
\hline 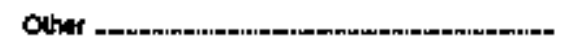 & 19,298 & $\$ 8,039$ & 10es: & 20,058 & 24,402 \\
\hline Total Ultimata car & $2,40,975$ & $2,407,747$ & $2,398,470$ & $2,374,142$ & 2,290,680 \\
\hline
\end{tabular}

Sedes for the Yarr (mogowathoura)

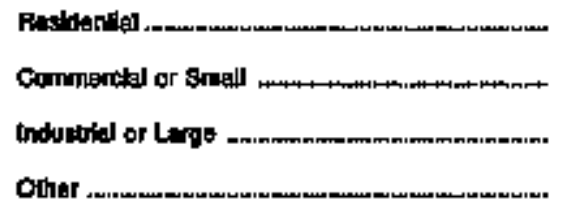

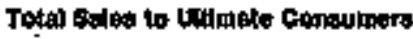

Salos tor Rande

Totil 8ele:

\begin{tabular}{|c|c|c|c|c|}
\hline $19,1 \mathrm{~B} 6,582$ & $12,646,3986$ & $12,802,964$ & $12,2 \times 2,289$ & $12,293,575$ \\
\hline$\$ 5,495,318$ & $18,091,042$ & $18,772,290$ & $18,643,257$ & $18,525,053$ \\
\hline$t 8,201,280$ & $12,437,301$ & $12,741,765$ & $12,461,063$ & $11,067,126$ \\
\hline $2,334,719$ & 2,180,702 & $2,008,594$ & $2,209,17$ & $2,234,449$ \\
\hline $47,277,690$ & $48,395,381$ & $49,945,003$ & 45,40,572 & $45,711,003$ \\
\hline $44,154,100$ & $44,312,290$ & $39,009,950$ & $33,631,354$ & $36,638,050$ \\
\hline 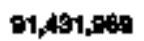 & $90,68\}, 650$ & B6,D14,562 & $79,467,128$ & as,347,053 \\
\hline
\end{tabular}

Opereling Amenowe for the Year (thoutend dallaris]

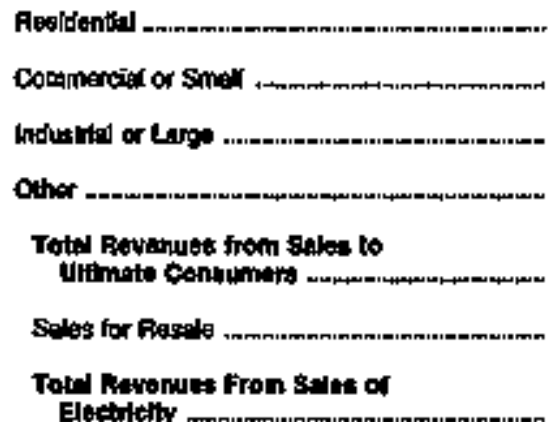

\begin{tabular}{|c|c|c|c|c|}
\hline $1,160,463$ & $1,109,163$ & $1,073,326$ & $1,002,074$ & 909,394 \\
\hline $1,342,650$ & $1,618,563$ & $1,685,038$ & $1,469,595$ & $1,576,3394$ \\
\hline $1,193,294$ & 005,778 & 801,541 & 238,380 & 775,832 \\
\hline 150,079 & $149,7 \$ 1$ & 177005 & 145,970 & 182,520 \\
\hline $3,955,46$ & $3,777,275$ & $3,606,900$ & $3,455,000$ & $3,513,130$ \\
\hline $2,272,654$ & $2,131,533$ & $2,005,351$ & $1,058,972$ & $1,045,602$ \\
\hline $0,128,1 t)$ & 5,908,768 & $6,722,260$ & $5,314,990$ & $6,459,082$ \\
\hline
\end{tabular}

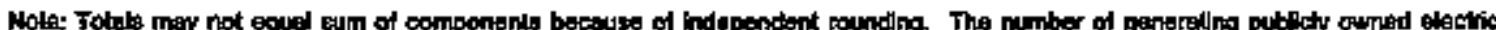

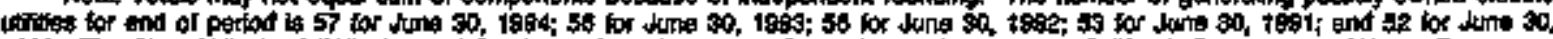

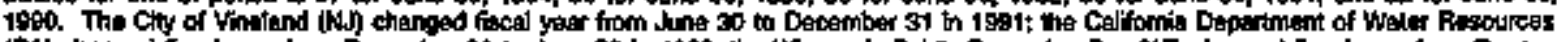

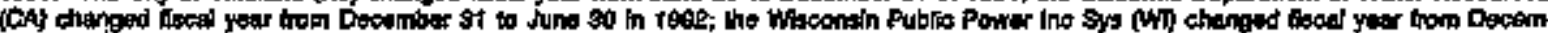

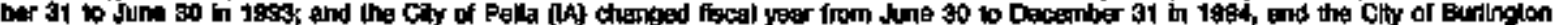

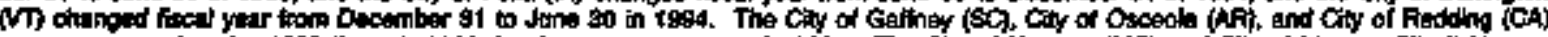

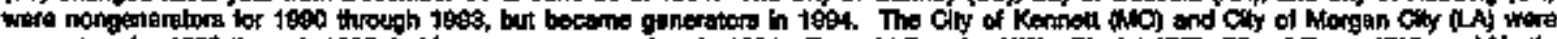

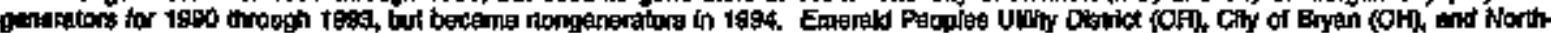

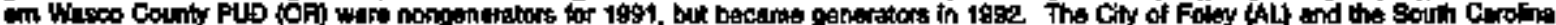

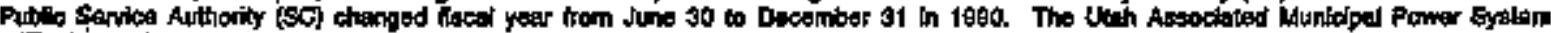

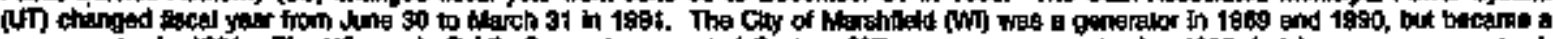

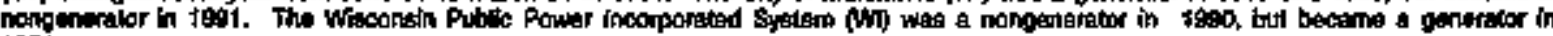
199. stons.

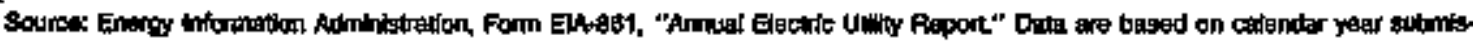


Table C9. Electric Energy Aocount for Wejor U.S. Publicly Owned Generator Electric Utilites with Flnanclal Year Ending on vine $80,1990 \cdot 1994$ (Megenwatthours)

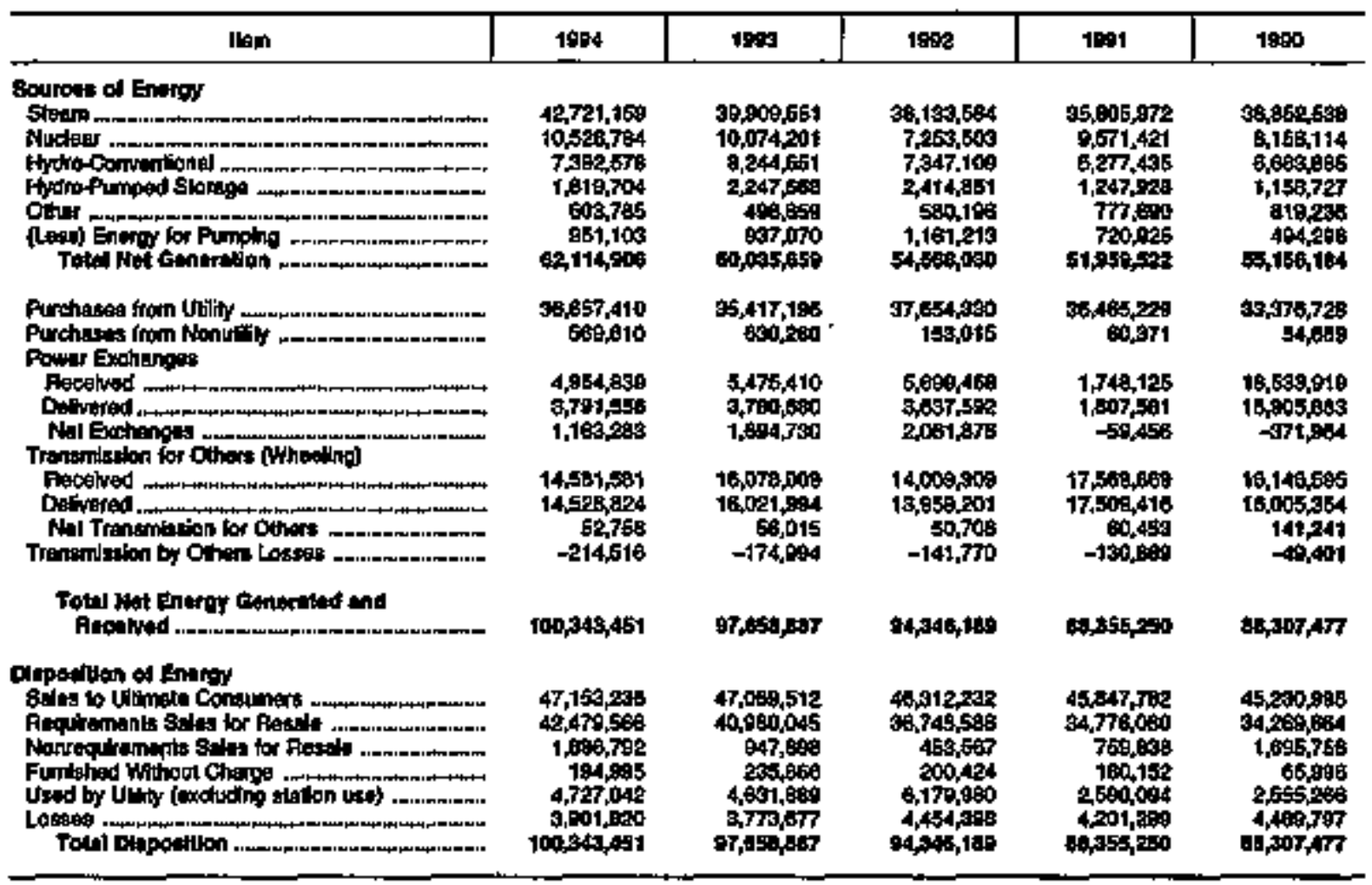

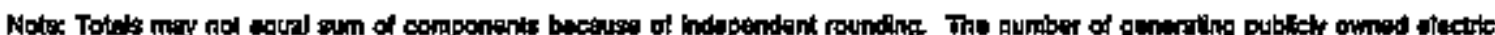

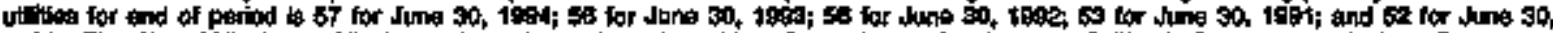

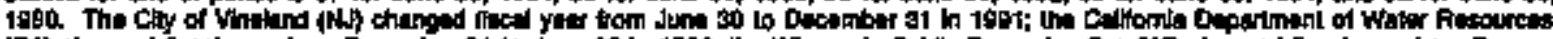

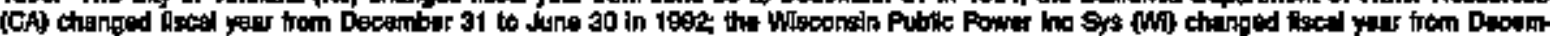

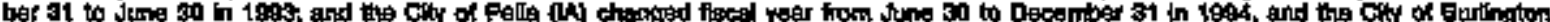

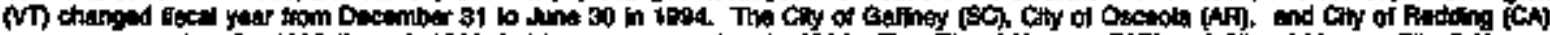

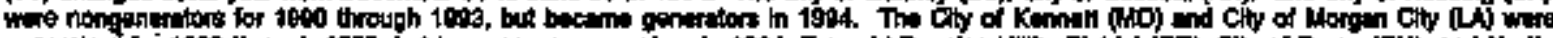

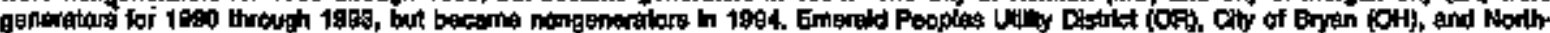

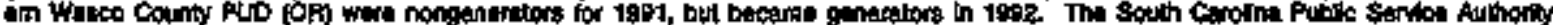

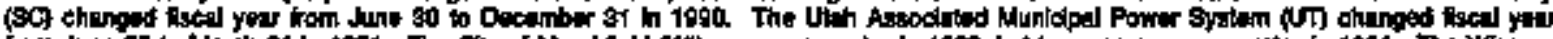

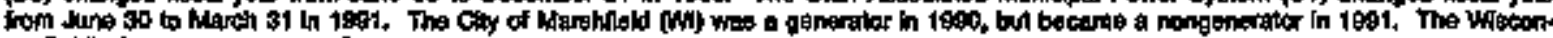

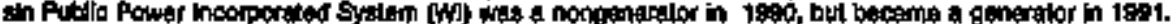

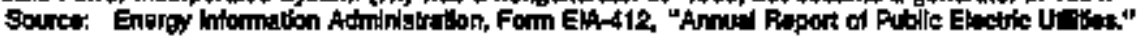


Table C10. Ten Largest U.S. Publacly Omed Generator Electric Utilities Ranked by Megawatthour Sales to Utimate Consumers with Finanetal Year Ending on December 31, 1994

\begin{tabular}{|c|c|c|c|}
\hline 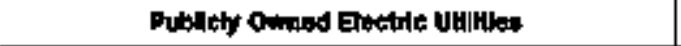 & State & Ambent & Poreat \\
\hline 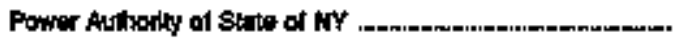 & Shan York & $13,212,815$ & 11.91 \\
\hline 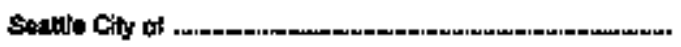 & Weshingten & $8,074,038$ & 8.00 \\
\hline 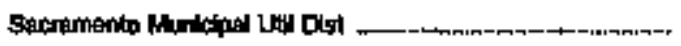 & Contomin & $8,450,168$ & 7.62 \\
\hline South Cerotirat Pub Senv Auth = & South Cerohing & $7,423,480$ & 8.69 \\
\hline 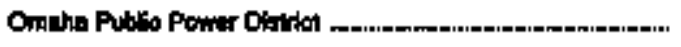 & Nobralka & $7,068,940$ & 697 \\
\hline DUD No 1 of Snchoritsh County & Wabingtor & 4771,543 & E.90 \\
\hline Tacoria Cidy of & Weshondtar & $\$, 338,340$ & 4.81 \\
\hline PUD No 1 of Confitz Courdy -- & Wushingtan & $4,707,602$ & 4.24 \\
\hline 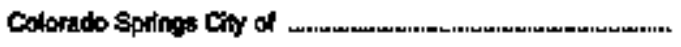 & Colmerato & $3,158,401$ & 285 \\
\hline PUD No 2 of Grant County & Waginglon & $2,843,260$ & 2.56 \\
\hline Subtated I & & $66,657,106$ & 60.24 \\
\hline
\end{tabular}

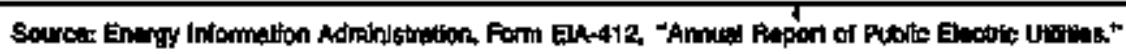

Table C11. Ten Largest U.S. Publicly Owned Generator Electric Utullies Ranked by Mogawatthour Sales for Resale with Financlal Year Ending on December 31, 1994

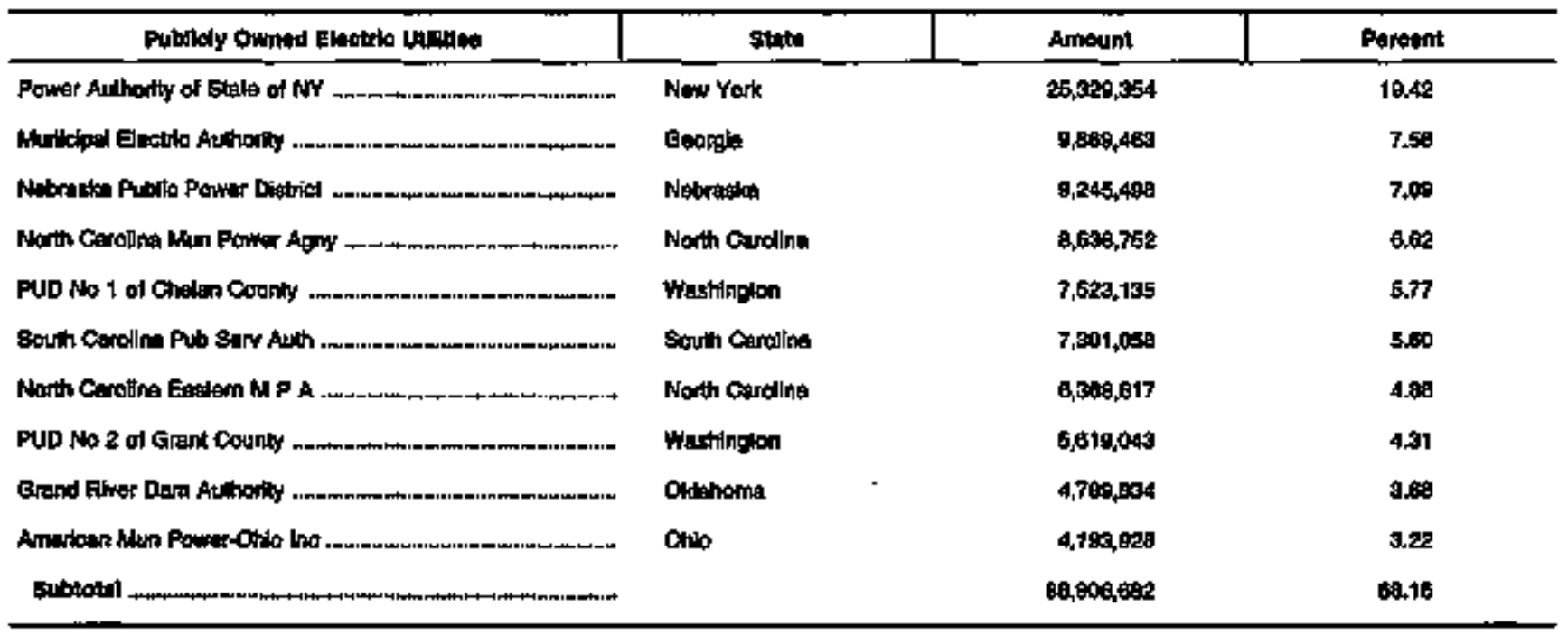

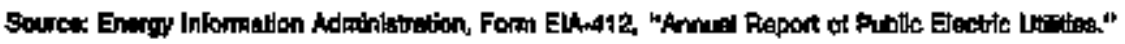


Table C12. Composite Statement of Income for Major U.S. Publcly Owmed Generator Electric Utilites with Financial Year Ending on December 31, 1990-1994 (Thousand Dollars)

\begin{tabular}{|c|c|c|c|c|c|}
\hline nem & 1984 & 1898 & 1992 & tert & 1990 \\
\hline 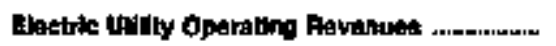 & $10,035,041$ & $10,265,144$ & $9,975,72 \pi$ & $9,846,735$ & $5,65,60 B$ \\
\hline 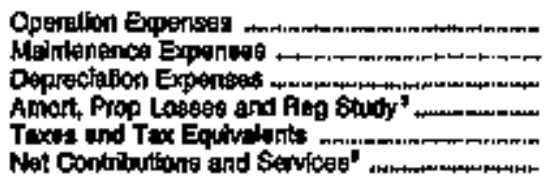 & $\begin{array}{r}6,449,328 \\
735,679 \\
1,159,118 \\
112,749 \\
200,967 \\
=\end{array}$ & $\begin{array}{r}6,271,030 \\
726, \sin \\
1,1092,908 \\
189,467 \\
281,135 \\
=\end{array}$ & $\begin{array}{r}5,929,895 \\
785,906 \\
1,042,218 \\
98,504 \\
298,234 \\
-\end{array}$ & $\begin{array}{r}5,834,690 \\
691,105 \\
1,096,958 \\
237,000 \\
3,2,207\end{array}$ & $\begin{array}{r}5,60,117 \\
650,581 \\
804,508 \\
20,400 \\
34,021\end{array}$ \\
\hline Tothi Elecilit Utiling Opernting & $8,7 \pi, 931$ & 8,44t,404 & $8,098,989$ & $7,692,200$ & $7,710,248$ \\
\hline 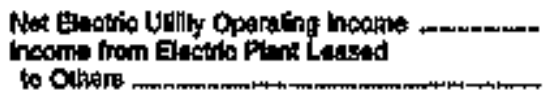 & $\begin{array}{r}1,918,910 \\
18,756\end{array}$ & $\begin{array}{r}1,823,740 \\
10,131\end{array}$ & $\begin{array}{r}1, \text { Hat, } 0 \text {, } \\
1,685\end{array}$ & $2,0,270$ & $\begin{array}{r}1,023,451 \\
1,605\end{array}$ \\
\hline Eroolrto dully oparating lneome _........- & 1,969685 & 1,833,871 & $1,0942,953$ & 2,102807 & $1,925,057$ \\
\hline Other Elestift lincopne & 521,466 & 720,647 & $1,021,072$ & 047.124 & $\operatorname{seg}, \sqrt{662}$ \\
\hline 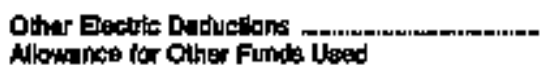 & $-1,290$ & S4,ABA & 31,702 & 24,236 & - \\
\hline 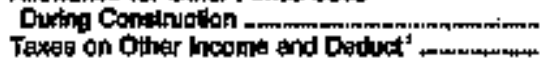 & $\begin{array}{l}6,8989 \\
3,059\end{array}$ & $\begin{array}{l}6,721 \\
2,952\end{array}$ & $\begin{array}{l}\text { 6,16: } \\
2,755\end{array}$ & 15,842 & 84,305 \\
\hline Electro Utalty Inoiden & $2,48,4,260$ & $2,520,000$ & $2,699,61$ & $2,904,5 \$ 9$ & $2,000,203$ \\
\hline 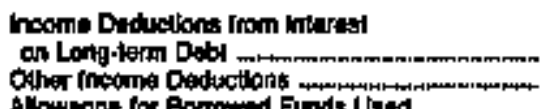 & $2,020,119$ & $\begin{array}{r}2,086,098 \\
173,302\end{array}$ & $\begin{array}{r}2,258,140 \\
130,097\end{array}$ & $\begin{array}{r}2,406,347 \\
1+9,052\end{array}$ & $2,200,235$ \\
\hline 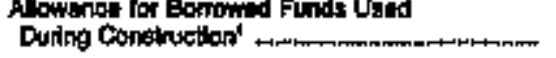 & $-12,812$ & $-10,057$ & $-10,843$ & $=$ & $=$ \\
\hline 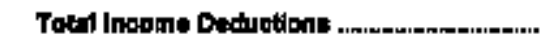 & $2,165,503$ & $2,251,202$ & $2,300,309$ & $2,5,24,399$ & $2,403,649$ \\
\hline 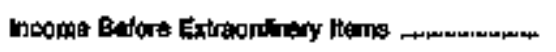 & 270,499 & 271,527 & 500,106 & 470,139 & 325,874 \\
\hline 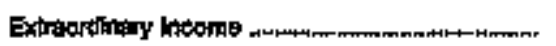 & 67,060 & 64,910 & 72800 & 84,000 & 31,678 \\
\hline 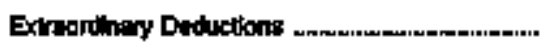 & 18,200 & 137,912 & 128,379 & 28.113 & 900,814 \\
\hline Hea heome .............. & $\operatorname{san}, \sec$ & 1at,oze & 449,449 & 5FE, 125 & 250,439 \\
\hline
\end{tabular}

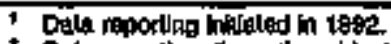

- Date reportino ditacominted in 198\%.

- Data not avaliable.

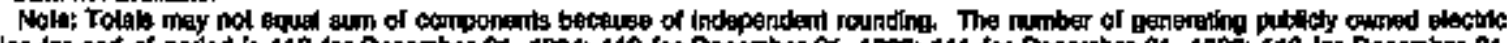

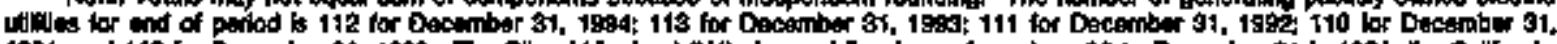

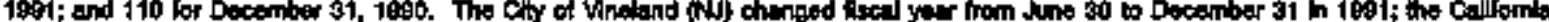

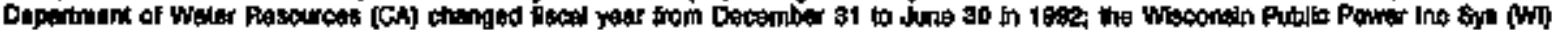

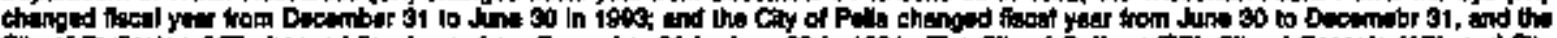

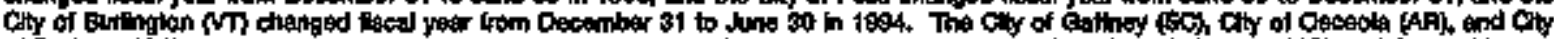

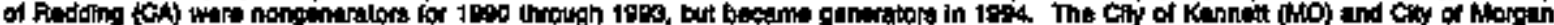

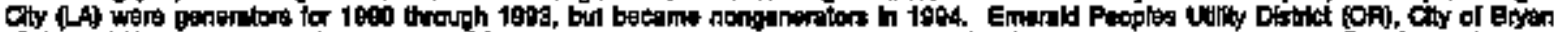

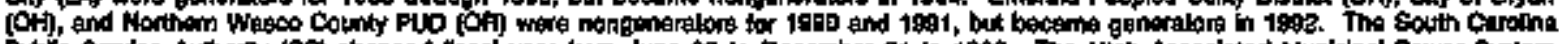

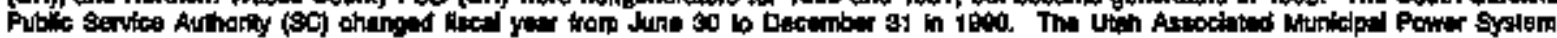

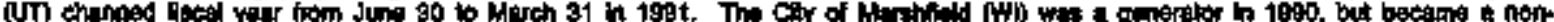

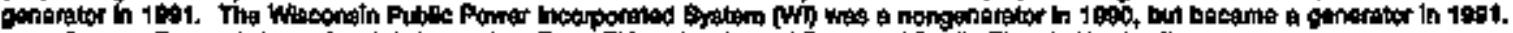

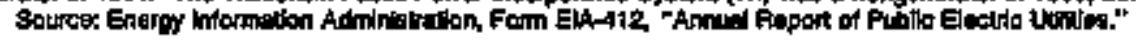


Table C13. Composite Balance Sheet for Major U.S. Publidy Owned Generator Electric Utilities with Financial Year Ending on December 31 at End of Period, 1990-1994 (Thousand Dolkars)

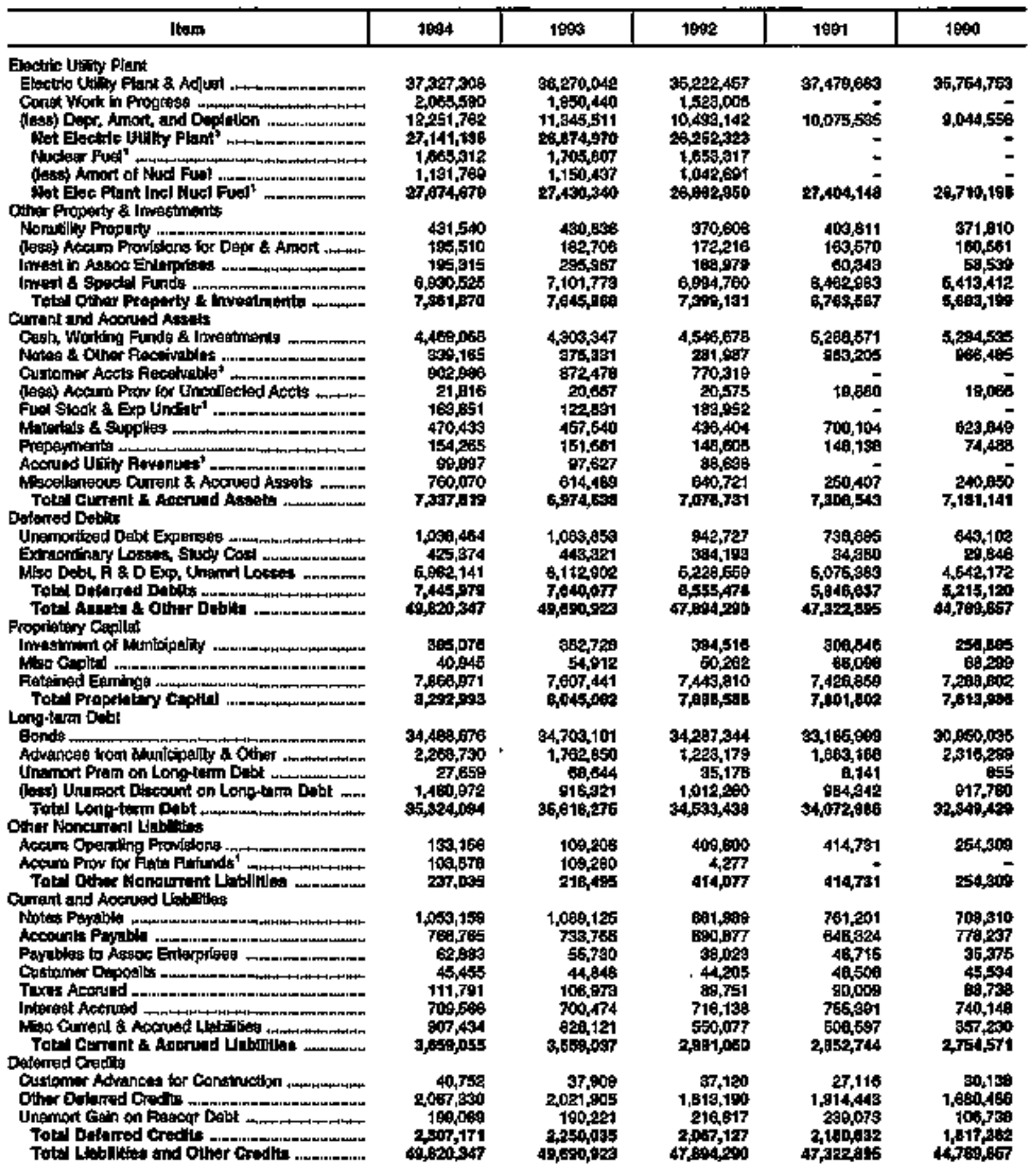

1 Dath reporting intilated in 1992.

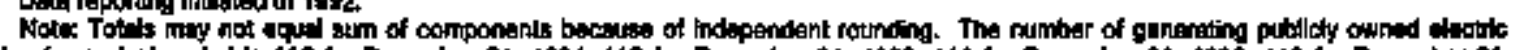

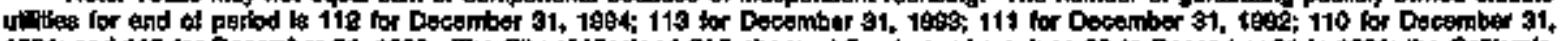

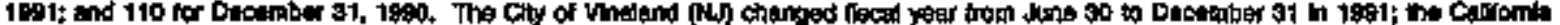

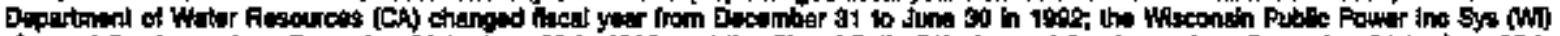

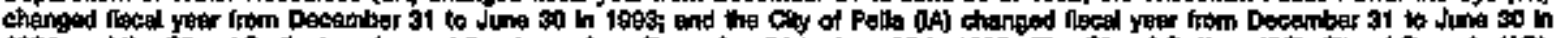

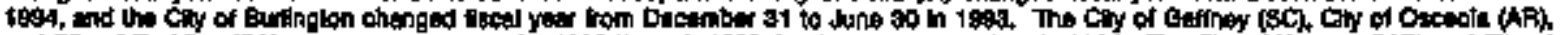

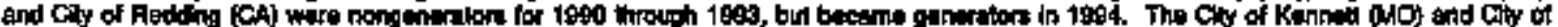

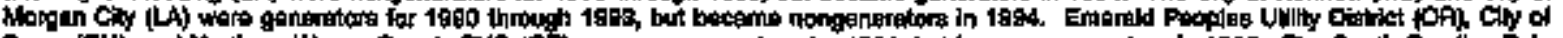

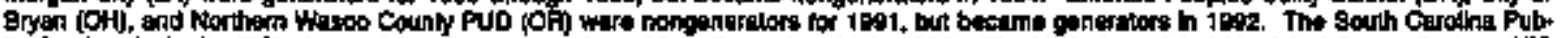

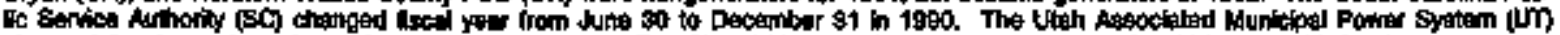

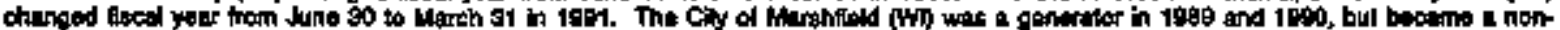

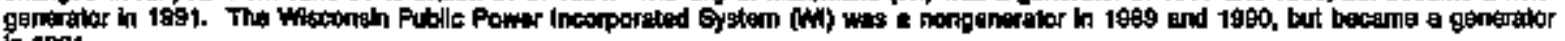
in 1901 .

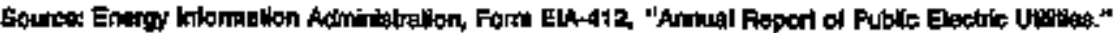


Table C14. Composite Finencla: Indicators for Major U.S. Publicly Owned Generator Electric Utilities with Financlal Year Ending on December 31, 1990-1994

\begin{tabular}{|c|c|c|c|c|c|}
\hline Dem & 1994 & 1893 & 1992 & 1891 & 1090 \\
\hline 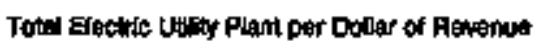 & $\mathbf{3 . 8}$ & 29 & $\mathbf{3 . 6}$ & 3.8 & $\mathbf{3 . 7}$ \\
\hline Current Assols o Ourenh Llahrites & 2.0 & 20 & 2.4 & 28 & 26 \\
\hline Total Electife thiny Plan as a Pencent al Total & 624 & 80.3 & 60.2 & 72 & ro \\
\hline 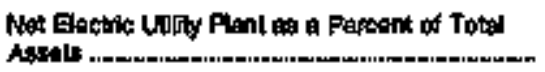 & 565 & 562 & ES.1 & 57.8 & $\$ 0,6$ \\
\hline 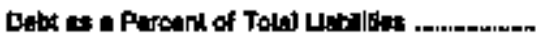 & 70.2 & 78.8 & 79.3 & $7: 0$ & $\operatorname{7ta4}$ \\
\hline 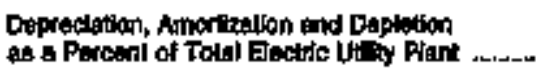 & 326 & $3 t 3$ & 30.0 & 200.9 & 25,3 \\
\hline 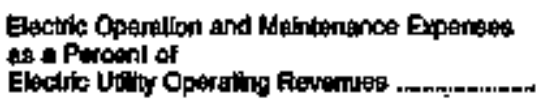 & 67.6 & 68.2 & 67.3 & 65.6 & 的.1 \\
\hline 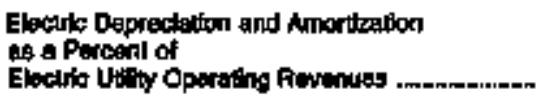 & 10.9 & 10.5 & 10.4 & 11.0 & 10.1 \\
\hline 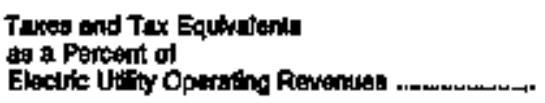 & 25 & 25 & 2.4 & 24 & 24 \\
\hline 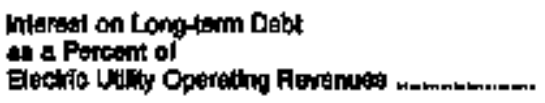 & 190 & 20.3 & 2026 & 242 & 240 \\
\hline 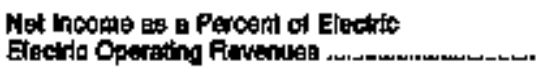 & 3.1 & 1.0 & 4.5 & 5.3 & 25 \\
\hline 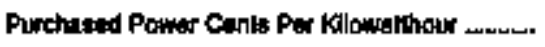 & 32 & 32 & 3.4 & s.4 & $\mathbf{3}, \mathbf{5}$ \\
\hline Centralod Cents Fur Klowatidhour ..................... & 1.5 & 1.5 & 1.6 & 1.4 & 1.3 \\
\hline 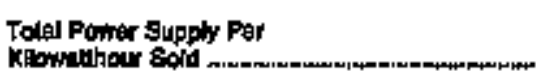 & 22 & $2 \pi$ & 20 & 21 & 22 \\
\hline
\end{tabular}

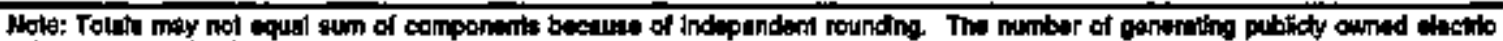

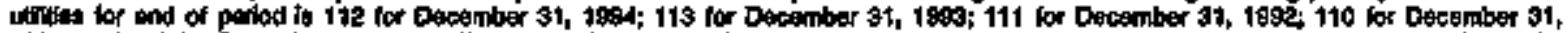

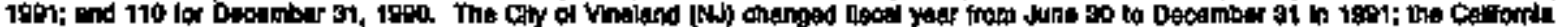

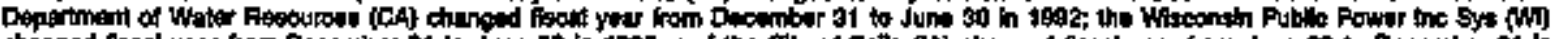

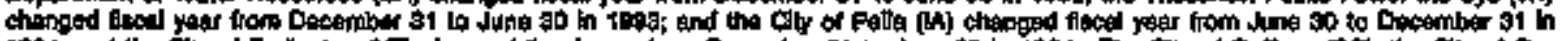

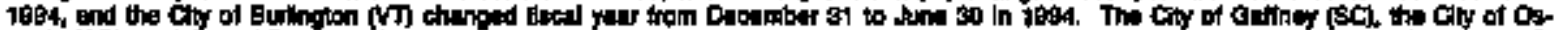

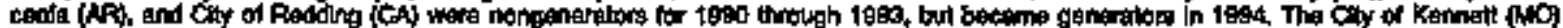

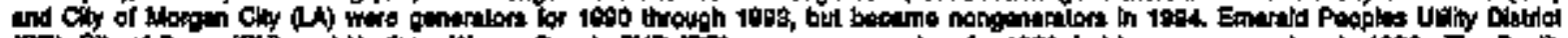

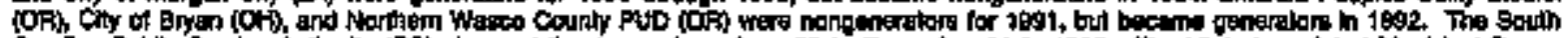

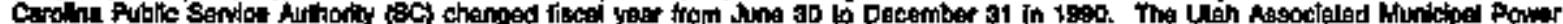

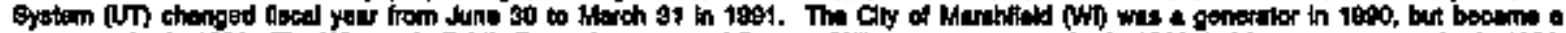

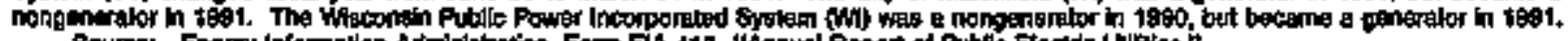

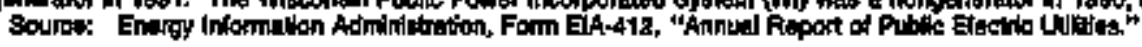


Table C15. Electric Operation and Maintenance Expenses for Major U.S.

Publicly Owned Cenerator Electric Utilties with Financlal

Yoar Ending on December 31, 1990-1994

(Thousend Dollars)

\begin{tabular}{|c|c|c|c|c|c|}
\hline item & 1004 & 1908 & the & 1901 & 1000 \\
\hline \multicolumn{6}{|l|}{ Froduction Expenuses } \\
\hline Steann Power Generalon .mm & 1,350,8006 & $5,338,640$ & $1,202,034$ & $1,300,701$ & $1,281,277$ \\
\hline 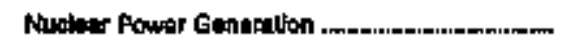 & $800,749^{\circ}$ & gasost & 874,098 & 776,240 & $722,8=29$ \\
\hline 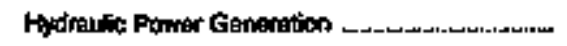 & 188,959 & 176.149 & 170,079 & 169,004 & 146,008 \\
\hline Other Fowler Gegrefatton & 59729 & 56,429 & $73,9 e 7$ & 93,359 & 6,$0 ; 040$ \\
\hline Punchased fouver mint & $2,985,692$ & $2,704,807$ & $2,1,00,016$ & $2,589,397$ & $2,770,250$ \\
\hline Other Froduction Express ........................ & 91,720 & 84,807 & 31,450 & 46,277 & 73,468 \\
\hline Total Produdtion Expantale & $5,425,549$ & $5,294,603$ & $5,100,351$ & $4,943,929$ & $5,058,518$ \\
\hline Trungmistion Expmuss .......- & 498,491 & 498984 & 439,035 & 429,842 & $397, m$ \\
\hline 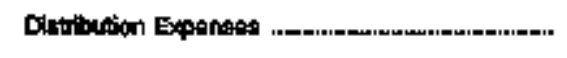 & 344,372 & 390,158 & 308,300 & 296,500 & 261,485 \\
\hline 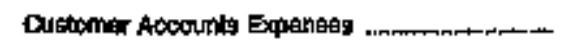 & $\$ 27.227$ & 124.587 & 116,460 & 116,785 & 107,500 \\
\hline Dustomer Sander and Information Expenieg ... & 42508 & $\$ 8,145$ & 40,765 & $30,6 \mathbf{a}_{4}$ & 31,340 \\
\hline 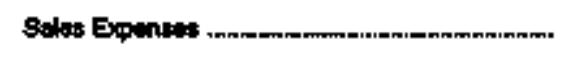 & 10,697 & 7,960 & 9,274 & 7,617 & 7,067 \\
\hline 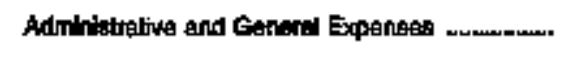 & $742.9 B 5$ & T1B,S4B & To1,500 & 705,486 & BAH,707 \\
\hline 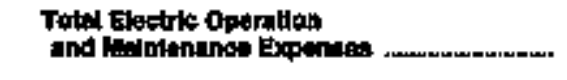 & $7,1886,697$ & $8,887,844$ & $6,713,681$ & $5,528,004$ & 6,516,667 \\
\hline \multicolumn{6}{|l|}{ Funl Expansess in Operollan } \\
\hline Stoem Powe Ganeritan .............................. & S48,085 & $95 t, 80 \mathrm{Bg}$ & Bg9,205 & 898,197 & 6837385 \\
\hline 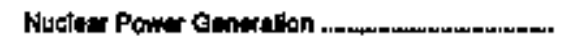 & 192,505 & 205,282 & to93,280 & 215;ass & 195,738 \\
\hline 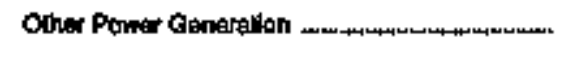 & 37,290 & 32,606 & 32,709 & 42,798 & A6, $48 B$ \\
\hline \multicolumn{6}{|l|}{ Number of the bapt Employnen } \\
\hline Peguar Fullime' & 25,020 & 26,313 & 20.370 & $=$ & 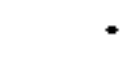 \\
\hline 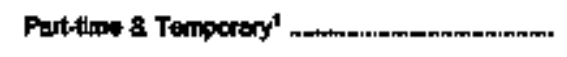 & 1,101 & ofs & 1,127 & - & $=$ \\
\hline Total Eno Dept Employeas' ........mmenen...... & 27,119 & 27,209 & $27,5+\infty$ & - & - \\
\hline
\end{tabular}

1 Dath reporfing hittated in toge.

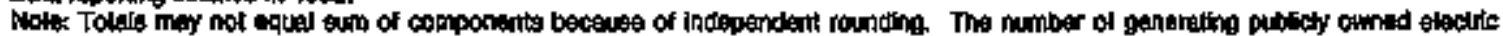

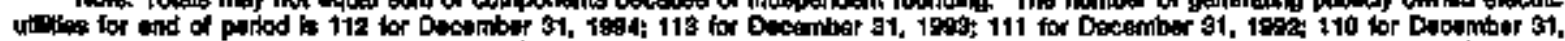

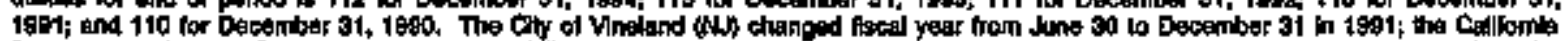

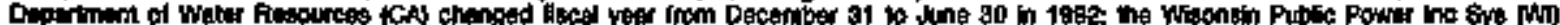

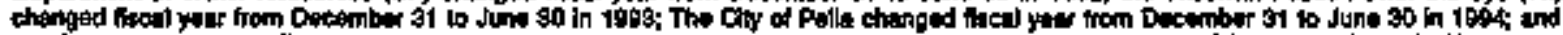

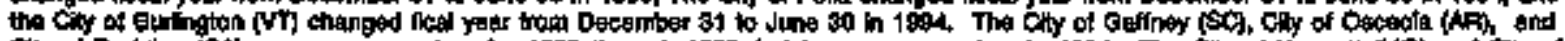

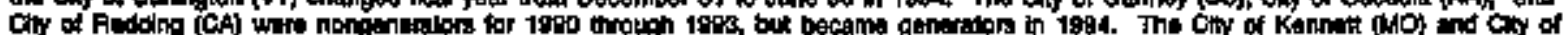

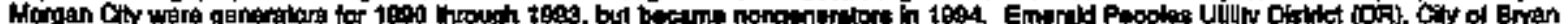

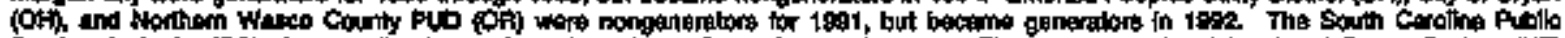

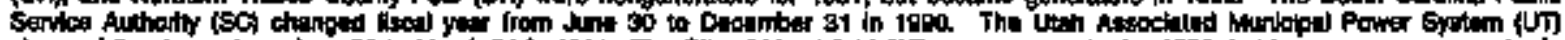

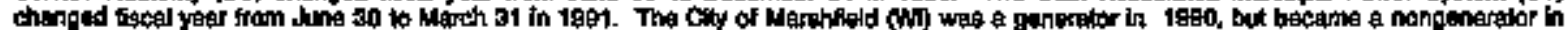

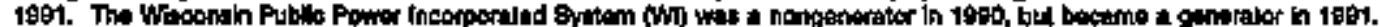

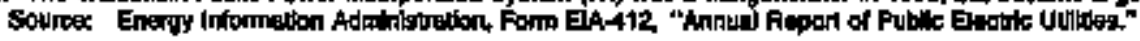


Table C16. Electric Utiility Plant for Major U.S. Publlcly Owned Generator

Etactric Uthlites whin Finandal Year Ending on

December 31 at End of Period, 1990-1994

(Thousand Dollars)

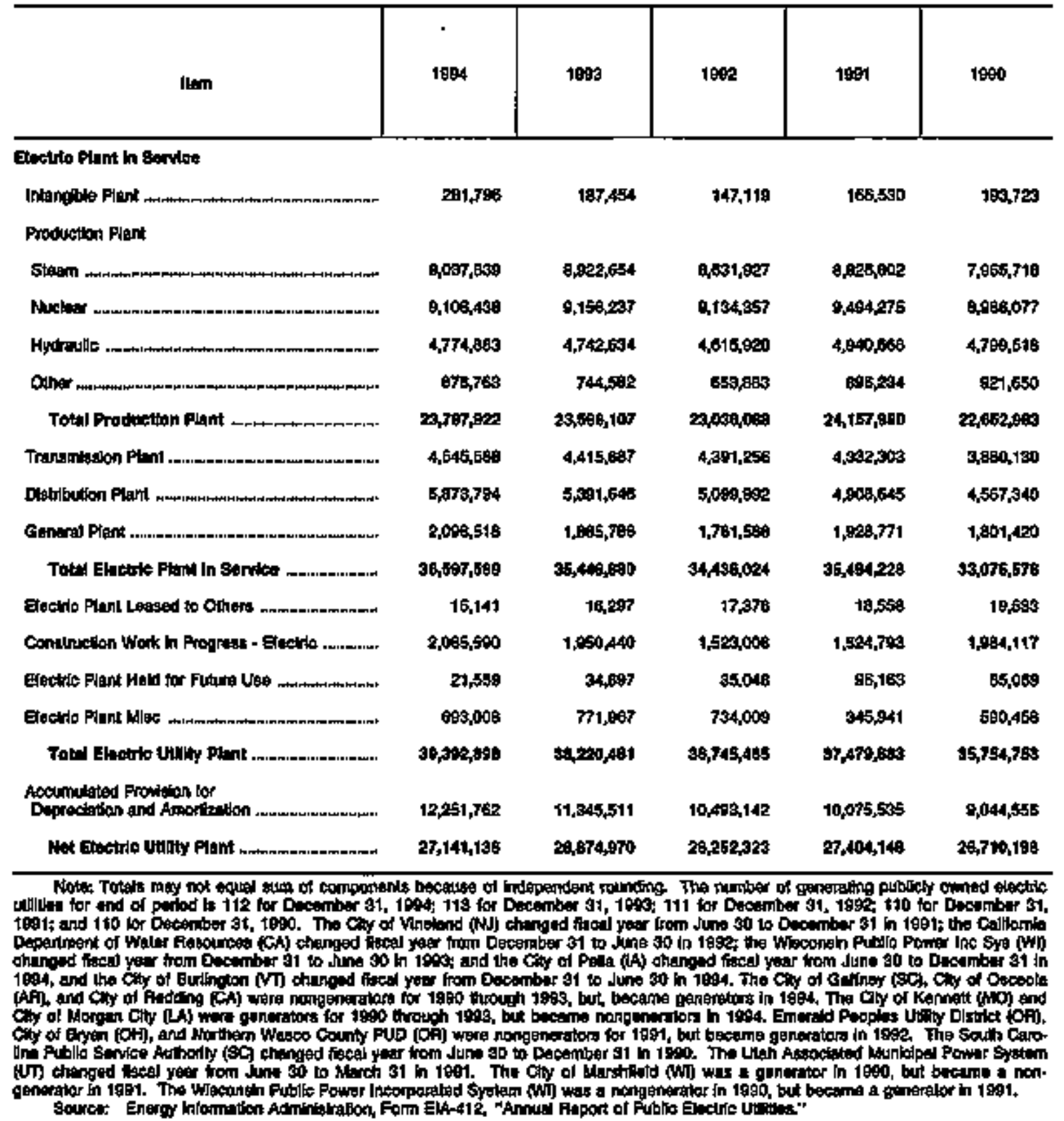


Table C17. Mumber of Consumera, Sales, and Oporating Revenue tor Major U.S. Publlcly Omned Cenerator Eectric Utilities with Financlal Year Ending on December 31, 1990-1894

\begin{tabular}{|c|c|c|c|c|c|}
\hline Item & 1904 & 1003 & 19002 & 1991 & 1990 \\
\hline \multicolumn{6}{|l|}{ Hubur of Consumers } \\
\hline 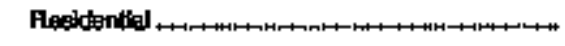 & $2,877,171$ & $2,697,306$ & $2,614,249$ & $2,704,621$ & $2,715,134$ \\
\hline 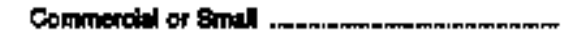 & 367,325 & 373,282 & 374,138 & 364,247 & 350,950 \\
\hline Indusbutd or Lape - - & 29,129 & 19,018 & 17.308 & 17,000 & TB, 6 esc \\
\hline Othor - & 34,181 & 32,448 & $3 t, 7 t 5$ & 39,909 & $35,4=9$ \\
\hline 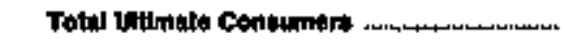 & $8,296,816$ & $3,262,034$ & $9,297,410$ & $3,18,5,007$ & $9,129,2 \pm 2$ \\
\hline \multicolumn{6}{|l|}{ Soles for the Yaer (megrwitinoura) } \\
\hline Retidenlied & $30,425,165$ & $*$, 50,7JB,4es & $28,973,698$ & $30,265,250$ & $29,000,284$ \\
\hline 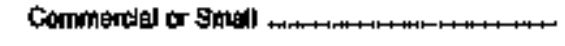 & $23,075,138$ & ${ }^{*} 23,277,716$ & $22,590,007$ & $20,300,283$ & $21,694,020$ \\
\hline Industrial of Lange.... & $44,348,397$ & $* 43,240,136$ & $43,005,294$ & $41,800,834$ & $41,714,090$ \\
\hline 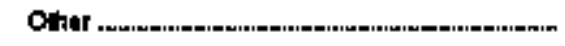 & $12,2000,400$ & * 1r,gesagas & $11,578,048$ & $11,574,340$ & $11,358,778$ \\
\hline 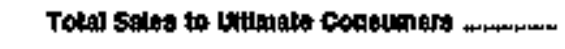 & $170,993,691$ & - w00007,440 & $108, t+0,932$ & $106,120,740$ & $104,009,965$ \\
\hline Sales lor Rougte & $130,489,161$ & 126,756,a76 & $110,996,792$ & $127,000,000$ & $129,453,278$ \\
\hline Total Soles ...mm....n & $241,402,292$ & " 237,868,610 & $20,107,564$ & $238,213,8 * 3$ & $202,401,2,44$ \\
\hline
\end{tabular}

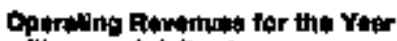
(theusind dolinre)

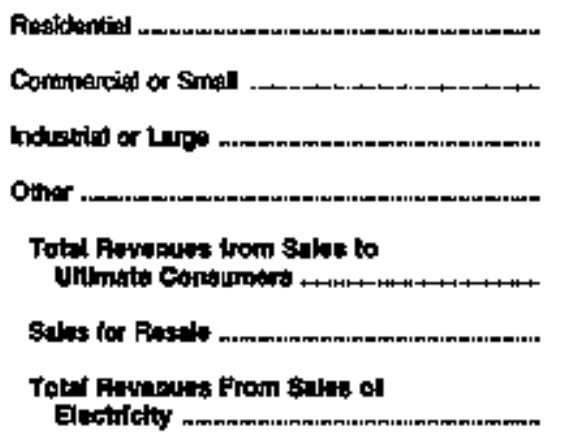

\begin{tabular}{|c|c|c|c|c|}
\hline $1,810,+59$ & $1,791,802$ & $1,648,002$ & $1,062,381$ & $1,585,476$ \\
\hline $1,327,064$ & $1,205,184$ & $1,207,356$ & $1,182,190$ & $1,134,745$ \\
\hline $1,8 B 4, D 29$ & 1 1,605,752 & 1,B08,698 & $1,571,144$ & $1,650,861$ \\
\hline 944,539 & $\cos 1,771$ & Exta,977 & 799,890 & 745,745 \\
\hline $6,767,577$ & 6,526,606 & 5,297,203 & $6,166,503$ & 502a,619 \\
\hline $4,870,772$ & 1,554,809 & $4,286,18 d$ & $4,317,857$ & $4,374,767$ \\
\hline $10,450,300$ & re,0rs,sts & $\$, 55 \mathrm{x}, 491$ & $9,473,480$ & $9,402,608$ \\
\hline
\end{tabular}

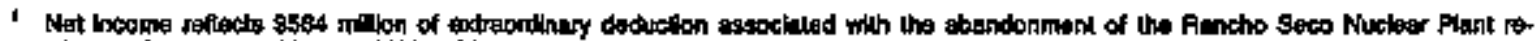

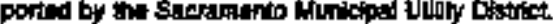

A - Rovisod Dote

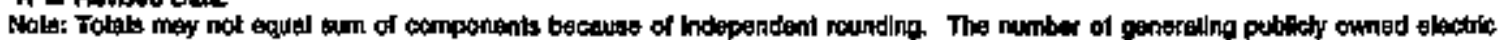

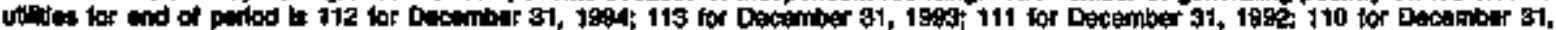

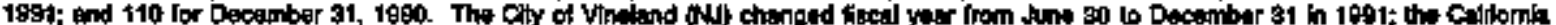

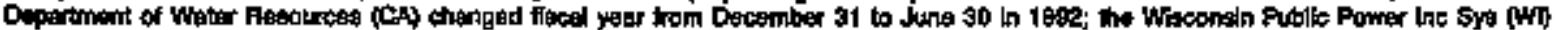

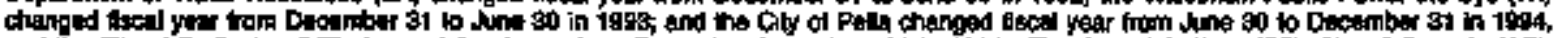

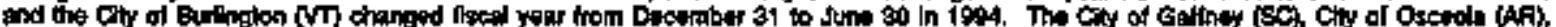

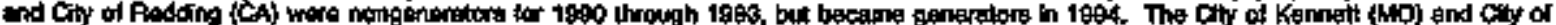

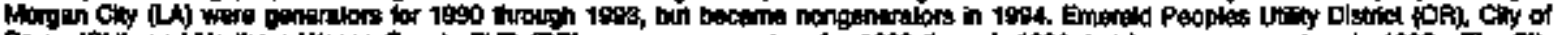

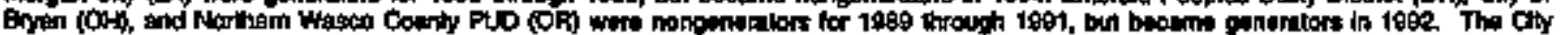

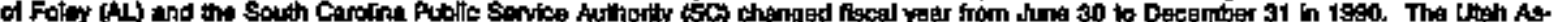

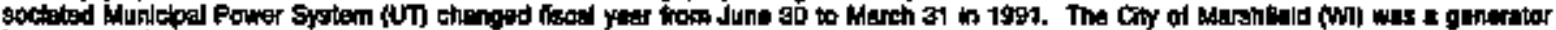

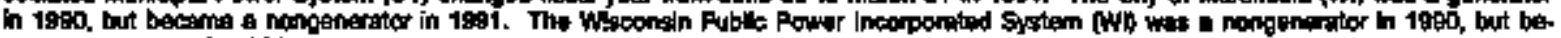
came a gentalor in 190 . gion:

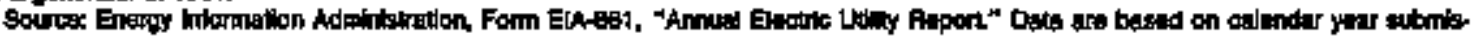


Table C18. Electric Energy Account for Mejor US. Publicty Owned Cenerator Electrle Utilites with Financial Year

Ending on December 31, 1980-1994

(Megawatthours)

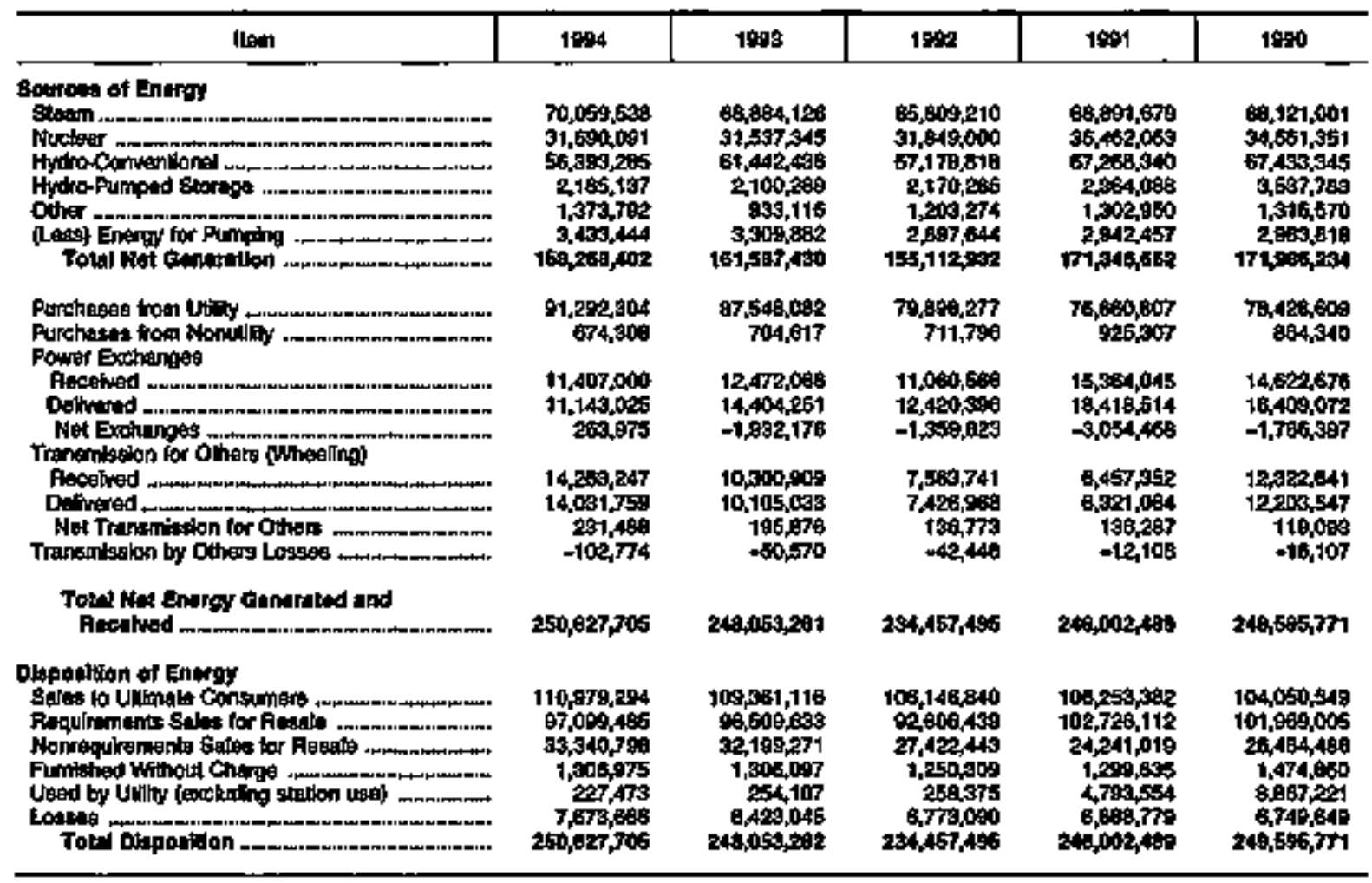

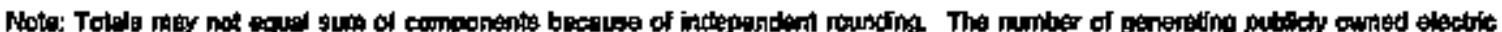

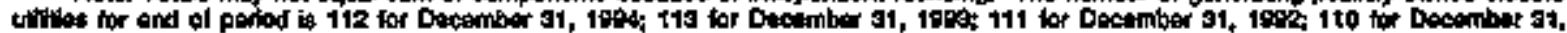

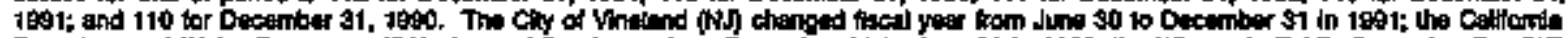

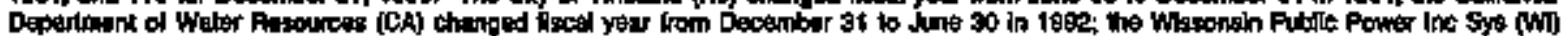

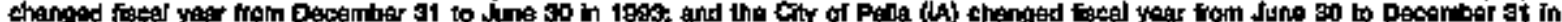

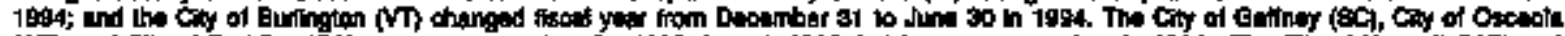

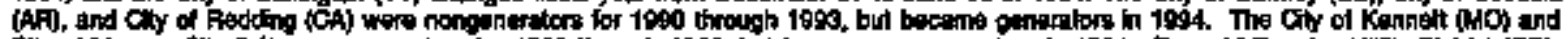

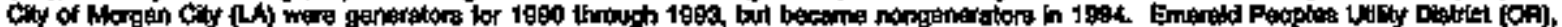

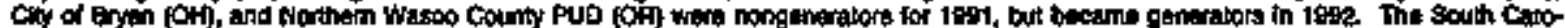

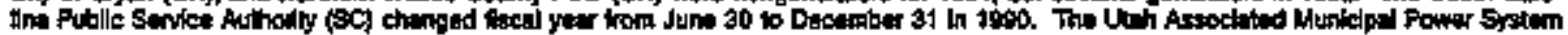

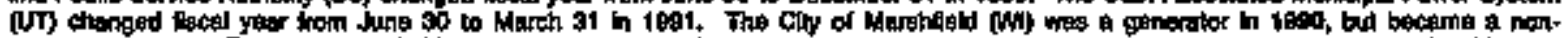

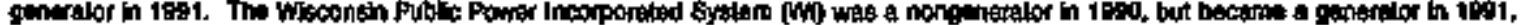

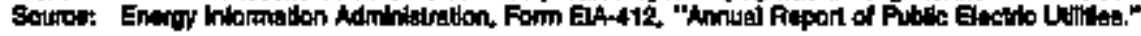


Table C19. Ton Largest U.S. Publlcly Owned Mongenerator Electrie Utilites

Ranked by Megawatthour Sales to Litimate Consumers with

Financlal Year Ending on June 30, 1994

\begin{tabular}{|c|c|c|c|}
\hline Publlchy Onowd Electito vululas & state & Ambint & Parowit \\
\hline 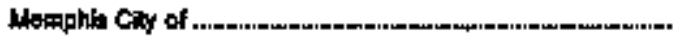 & Tonnousese & $12,099,3993$ & 1327 \\
\hline Nastrile Electic Strvice & Tonnesees & $10,640,616$ & 11.68 \\
\hline 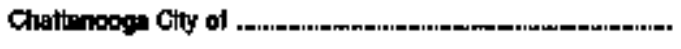 & Tenneasent & $5,471,670$ & Bon \\
\hline 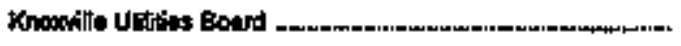 & Totriensen & $4,6,89,490$ & $\$ 34$ \\
\hline Johneon Cily Caty of . . & Téningenes & $1,617,465$ & 1.77 \\
\hline 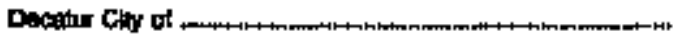 & Alnome & $1,422,924$ & 1.50 \\
\hline Jackson Caly of t... & Temosises & 1.109,97e & 131 \\
\hline 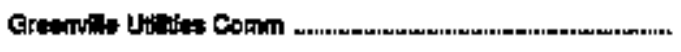 & Nom Comitina & $1,117,000$ & 1.23 \\
\hline Linoir Cly Cly of ......... & 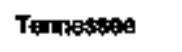 & $1,000,460$ & 1.17 \\
\hline 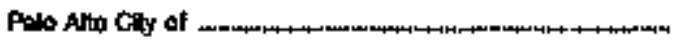 & Callomba & $1,046,831$ & $1+16$ \\
\hline Subtotal & & $40,549,625$ & 44.49 \\
\hline
\end{tabular}

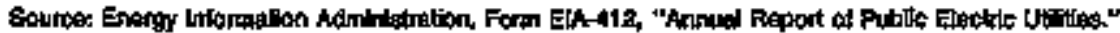

Table C20. Us. Publiply Owned Nongenerator Electric Utilltes

Ranked by Mogawatthour Saies for Resale with Financlal Year

Ending on June 30, 1994

\begin{tabular}{|c|c|c|c|}
\hline Publkly Omnad Elnotrio Utitedes & thaka & Amount & Pareent \\
\hline Colorado Flves Comm of thevada & Menda & 865,152 & 19.35 \\
\hline Mitzonita Powar Authiontly & Arizona & 760,397 & 38.83 \\
\hline Azusal City of mmmonnm. & Calfomba & 120,190 & 6.14 \\
\hline 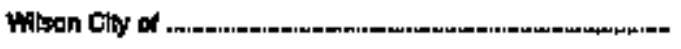 & Morth Camine & 6zon? & 3.28 \\
\hline 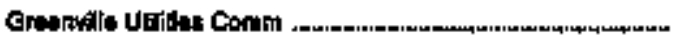 & Nonth Caraling & $24 ; 000$ & 1,23 \\
\hline focky Matrit CXy of . & North Cuollin & 17,712 & .91 \\
\hline Groton Chty of & Connowivar & 5,605 & 29 \\
\hline 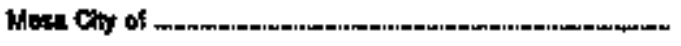 & Artzoni & 701 & .04 \\
\hline Subtolal 1. & & $1,505,694$ & 100.00 \\
\hline
\end{tabular}

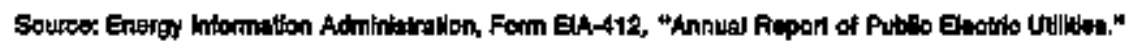


Table C2t. Composite Statement of Ineome for Mejor U.S. Publicly Owned Nongenerator Electric Utilities with Finenclal Year Ending on June \$0, 1990-1994

(Thousand Dolars)

\begin{tabular}{|c|c|c|c|c|c|}
\hline Item & 1904 & 2003 & 1982 & 1091 & 1990 \\
\hline 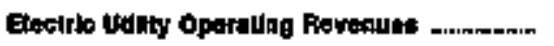 & $6,348,031$ & $6,040,609$ & $4,205,030$ & $4,187,470$ & 4,$143 ; 051$ \\
\hline 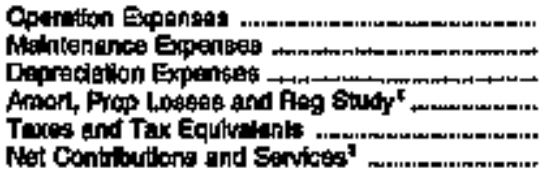 & $\begin{array}{r}4,692,620 \\
165,878 \\
158,075 \\
1,689 \\
124,898 \\
-\end{array}$ & $\begin{array}{r}4,390,415 \\
143,849 \\
159,296 \\
1,492 \\
109,434 \\
-\end{array}$ & $\begin{array}{r}3,735,749 \\
100,346 \\
135,218 \\
478 \\
05,310 \\
-\end{array}$ & $\begin{array}{r}3,646,908 \\
104,662 \\
121,975 \\
- \\
69,509 \\
108,005\end{array}$ & $\begin{array}{r}3,645,672 \\
111,773 \\
116,221 \\
64,410 \\
88,261\end{array}$ \\
\hline 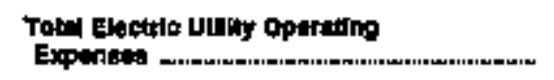 & $5,133,611$ & $4,797,546$ & $4,057,164$ & $4,040,350$ & $4,028,050$ \\
\hline 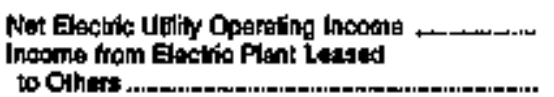 & $\begin{array}{r}215,3200 \\
2200\end{array}$ & 249062 & $\begin{array}{r}\text { 20B,65B } \\
81\end{array}$ & $\begin{array}{r}11 a, 154 \\
1,160\end{array}$ & $\begin{array}{r}116,204 \\
696\end{array}$ \\
\hline Eteotrio utity Oparming mooms . . & 215,550 & 248,0002 & 20B,740 & 110,203 & 1t5,ags \\
\hline Other thoth in Inecm & 124,914 & 117,200 & 90,578 & 79,710 & 78,072 \\
\hline 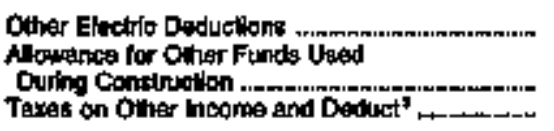 & 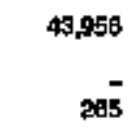 & 14,856 & 14,944 & $\begin{array}{r}0,200 \\
1,209 \\
=\end{array}$ & $\begin{array}{r}- \\
130 \\
-\end{array}$ \\
\hline 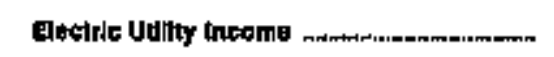 & 296,243 & 321,400 & 244329 & 180,012 & 193,096 \\
\hline 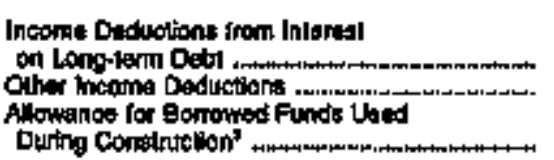 & $\begin{array}{r}59,397 \\
26,461 \\
-\end{array}$ & $\begin{array}{r}60,902 \\
92,697 \\
-\end{array}$ & $\begin{array}{r}42,612 \\
19,618 \\
+\end{array}$ & $\begin{array}{r}49,191 \\
16,867 \\
.\end{array}$ & $\begin{array}{r}41,711 \\
14,092 \\
-\end{array}$ \\
\hline 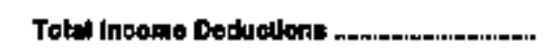 & e1,658 & thes & 61,250 & 60,167 & sapos \\
\hline 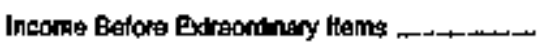 & 214,395 & 208,4868 & 189,089 & 125,65 & 139,496 \\
\hline Extraordinary Incoma & 12,648 & 16,006 & 18,338 & 21,330 & 2591 \\
\hline Extraordinary Deductions n. & $31 / 400$ & 29,190 & $11, \mathrm{ere}$ & 10,747 & 13,004 \\
\hline Hot lneoms & 105,804 & 216,064 & 109,459 & 127,450 & 1220,012 \\
\hline
\end{tabular}

I Dule reporing irtitated in 1992

1 Oela repording discontinued in 1952

- Daía not evilkable.

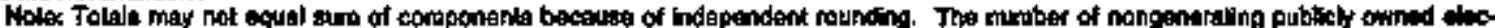

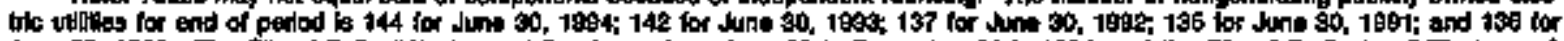

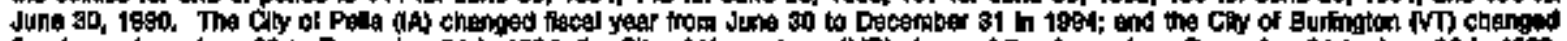

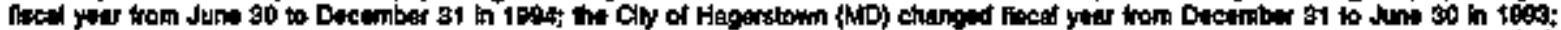

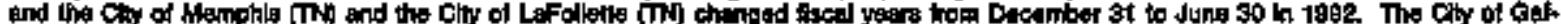

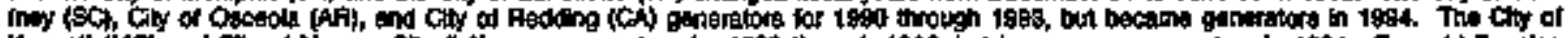

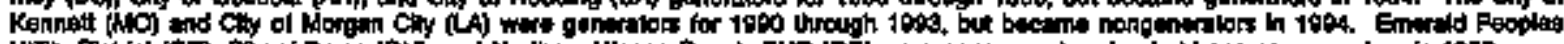

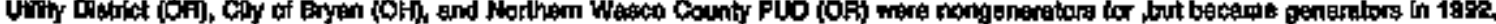

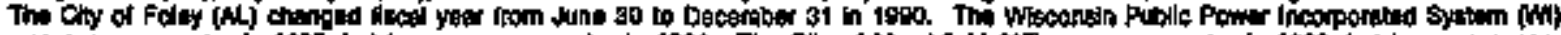

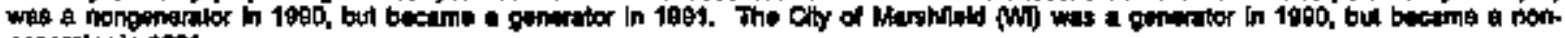
penandorit t:991.

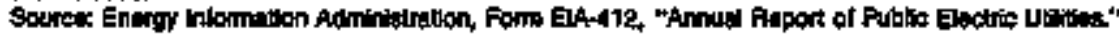


Table C22. Composite Balance Sheot for Major U.S. Publlcly Owned Nongenorator Electrlo Vtilites with Financfal Year Ending on June 30 at End of Period, 1980-1994

(Thousand Dollars)

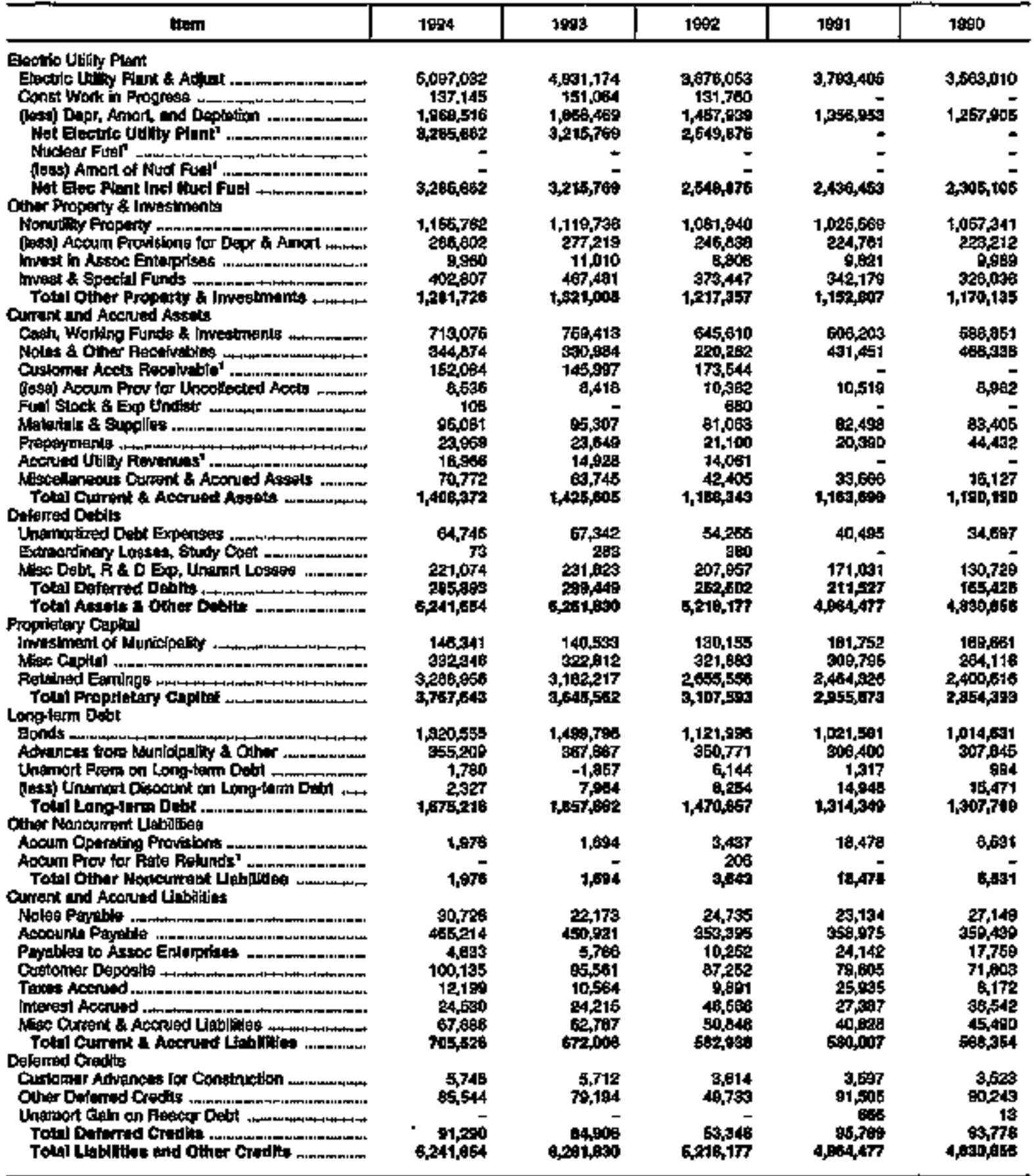

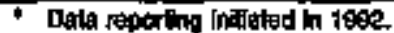

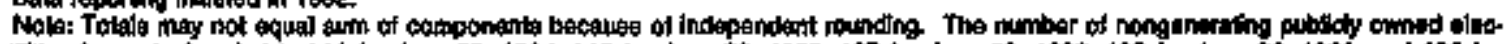

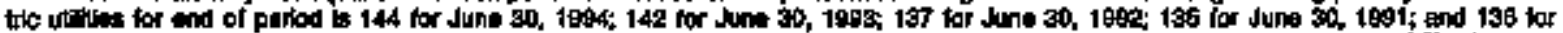

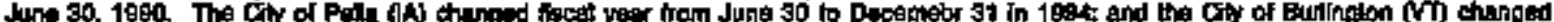

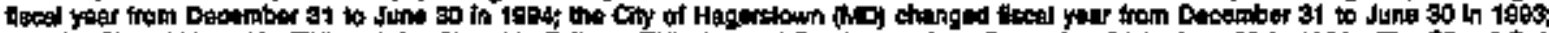

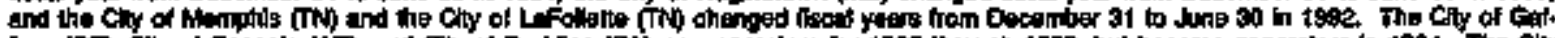

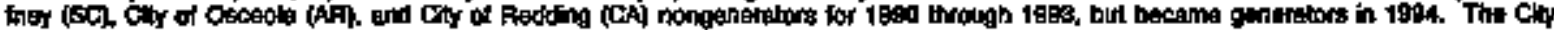

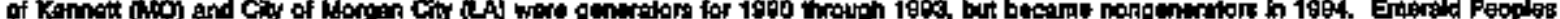

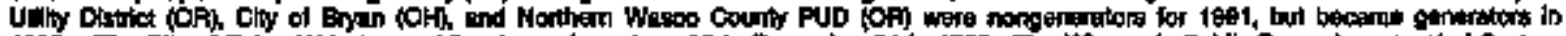

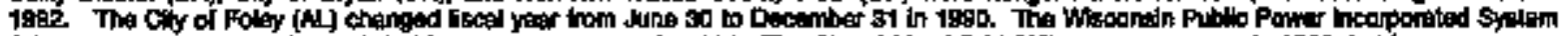

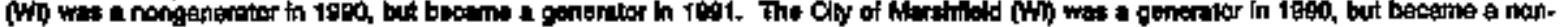
Deretelor in 1 的1.

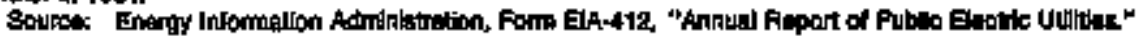


Table C28. Composite Financial Indicators for Major U.S. Publicly Owned Nonganerator Electric Utilitios with Financlial Vear Ending on June 30, 1990-1994

\begin{tabular}{|c|c|c|c|c|c|}
\hline IIem & 1694 & 1908 & 1002 & 1891 & 1090 \\
\hline 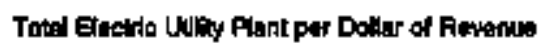 & 1.0 & $\$ .0$ & 0.9 & 0.8 & 0.0 \\
\hline 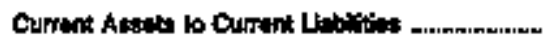 & 20 & 21 & 20 & 20 & 2.1 \\
\hline 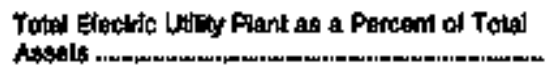 & 629 & 812 & 78.0 & 76.4 & 73.8 \\
\hline 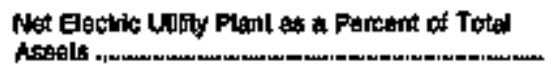 & $\mathbf{5 2 3}$ & 51.4 & 48.9 & 19.1 & 47.7 \\
\hline 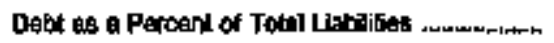 & ant & 40.4 & 39,4 & IB.2 & 98.8 \\
\hline 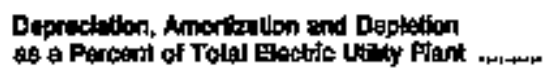 & 375 & as.7 & 30,4 & 359 & 35.3 \\
\hline 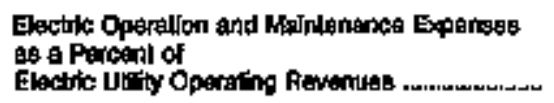 & $\mathbf{g} 0 \mathrm{~B}$ & 898 & 90.1 & san & 0.7 \\
\hline 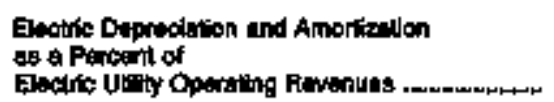 & 30 & 3.0 & $\mathbf{3 , 0}$ & 29 & 2.5 \\
\hline 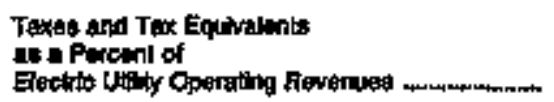 & 23 & 2.1 & 20 & t.7 & 1,6 \\
\hline 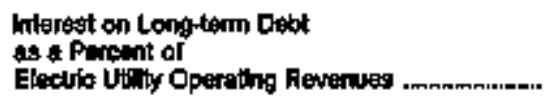 & 1.0 & 12 & 1.0 & 1.0 & 1.1 \\
\hline 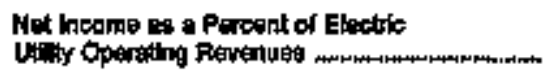 & 37 & 43 & 4.4 & 3,1 & 3,0 \\
\hline Furchased Power Cenls Per Kallowathour ..... & 4.4 & 43 & 4.4 & 4,4 & 4,4 \\
\hline
\end{tabular}

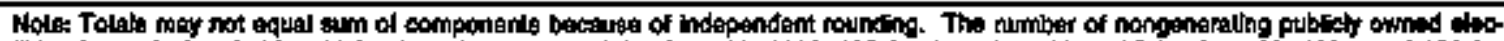

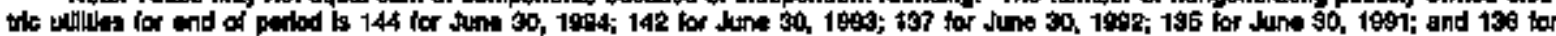

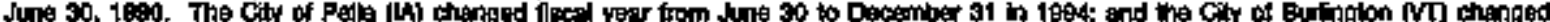

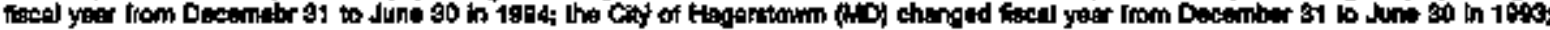

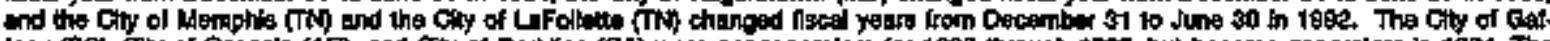

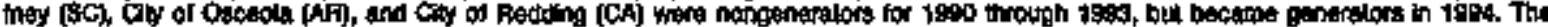

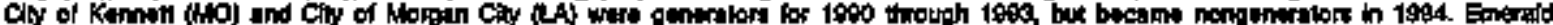

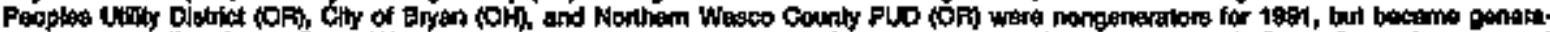

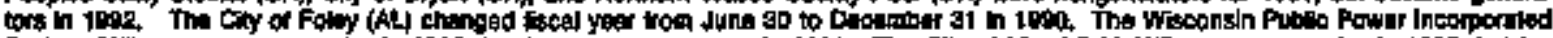

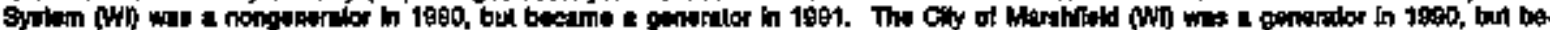
cems a nongenorator in 1991.

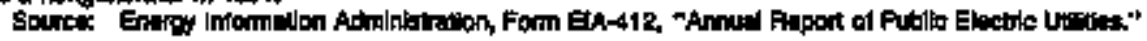


Table C24. Electric Operation and Maintenance Expenses for Wajor US. Publicly Owned Nongenerator Electrle Utilities with Financial Year Ending on June 30, 1990-1994 (Thousand Dollars)

\begin{tabular}{|c|c|c|c|c|c|}
\hline llem & 1894 & 1989 & 1982 & to91 & 1980 \\
\hline \multicolumn{6}{|l|}{ Praduetton ETpunsus: } \\
\hline Stram Fown Gantration & - & - & - & - & - \\
\hline 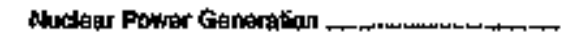 & - & - & - & - & - \\
\hline 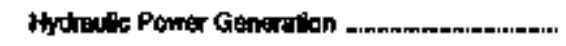 & - & - & - & $=$ & - \\
\hline 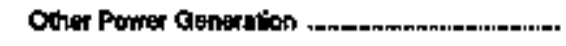 & 437 & - & $=$ & - & - \\
\hline 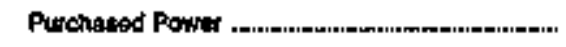 & $4,271,410$ & $3,001,725$ & $3,410,285$ & $3,359,710$ & $3,352,355$ \\
\hline 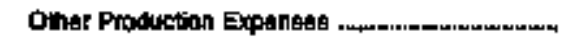 & 5,858 & 2,769 & 2.585 & 6,949 & 12,358 \\
\hline Tolat Frodudtin Expenses & $4,277,709$ & $3,494,514$ & $\$, 412,929$ & $3,340,859$ & 3394,711 \\
\hline Transmberion Expentes & 1B,0RP & 10,335 & 17,158 & 13,300 & 11,290 \\
\hline 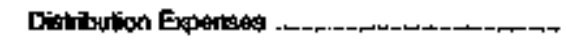 & 276,734 & 253,320 & 184,782 & 167 , Bos & 150,615 \\
\hline 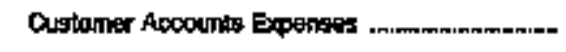 & 76,473 & 77,485 & 64,164 & 60,355 & 59,192 \\
\hline Dustomer Sertces and informetion Expenses ... & 9,417 & 0,659 & 7,703 & 9,0006 & 8,049 \\
\hline Sales Explnate & 7,124 & 6,308 & 8.557 & 9,731 & 8,635 \\
\hline 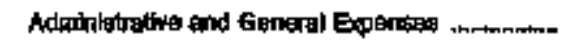 & 192,115 & 164,764 & 139,857 & 145 ,Des & 144,759 \\
\hline 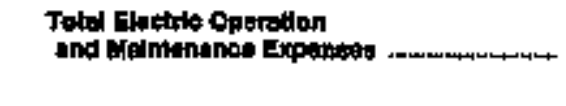 & 4049,490 & $4,594,969$ & 3945,0199 & $3,761,767$ & $3,757,449$ \\
\hline \multicolumn{6}{|l|}{ Fut Expendot In Operation } \\
\hline 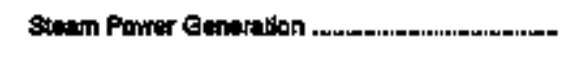 & - & - & - & - & - \\
\hline Nurcloer Power Genepalion & - & - & - & - & $\cdot$ \\
\hline 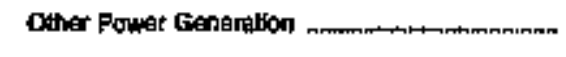 & 13 . & - & - & $=$ & - \\
\hline \multicolumn{6}{|l|}{ Wunbet ol Eias Dept Implopeosa } \\
\hline 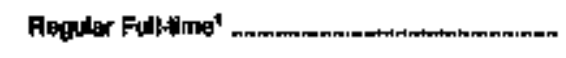 & 9,716 & 0,749 & 7,772 & - & - \\
\hline Put-Haw \& Temponay' .......- & 67 & $10 x$ & 165 & - & - \\
\hline Tolat שe Dapt Employets' & 8,709 & $8, a 50$ & 7,807 & - & - \\
\hline
\end{tabular}

1 Date ragorting Lutilakos in 1992

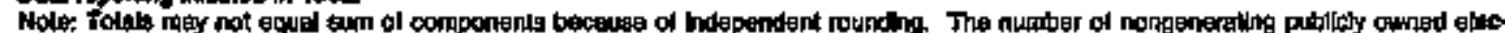

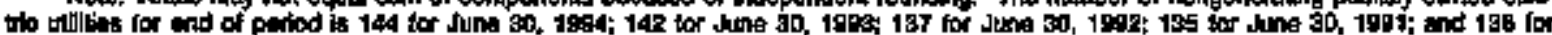

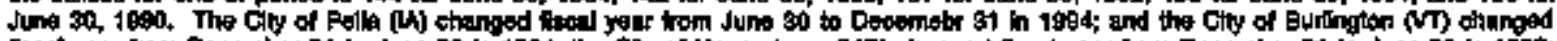

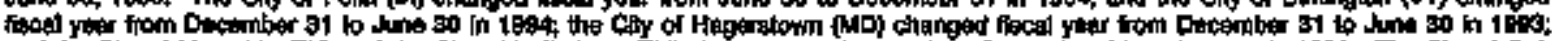

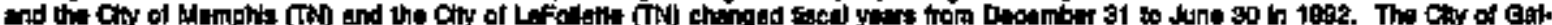

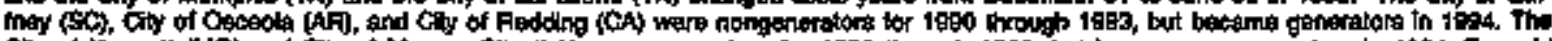

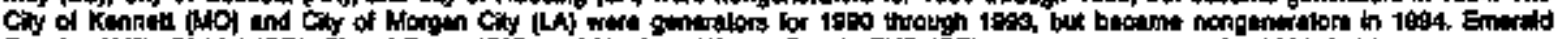

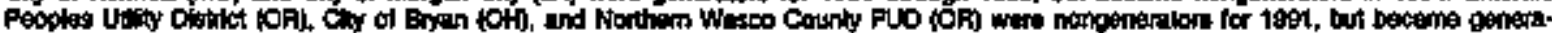

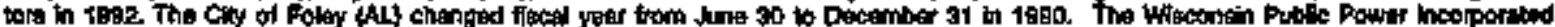

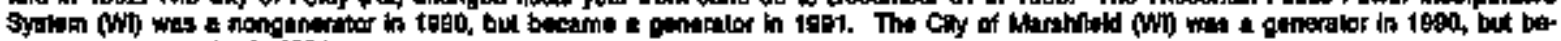
cama a nordenearatot in 1891.

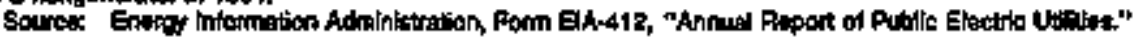


Table C25. Electric Utility Plant for Major U.S. Publlely Owned Nongenerator Electrle Utillites with Financlal Yoar Ending on June 30 at End of Period, 1990-1994 (Thoustand Dollars)

\begin{tabular}{|c|c|c|c|c|c|}
\hline han & 1904 & $1 \mathrm{bog}$ & $1 \mathrm{sen}$ & 1991 & 1890 \\
\hline \multicolumn{6}{|l|}{ Deositio Plant in Butwick } \\
\hline Intengible Planl & 102 & 102 & 102 & 1 & $\mathbf{t}$ \\
\hline \multicolumn{6}{|l|}{ Produclion Plart } \\
\hline 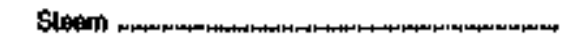 & 44,766 & $59,4 \infty$ & 41,649 & 40,412 & 289 \\
\hline 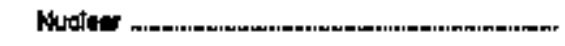 & - & - & - & - & - \\
\hline 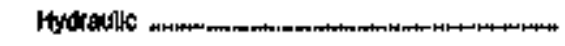 & + & $=$ & - & - & $=$ \\
\hline 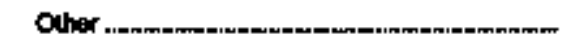 & 10,649 & 13,151 & 12,615 & $12,6,2$ & 46,446 \\
\hline Total Production Fithid & 64,9396 & 66,613 & $51,20 \%$ & 5,034 & 46,731 \\
\hline Trantmiatin Plant , & 445383 & 409,020 & 284,002 & 303,770 & 225,995 \\
\hline 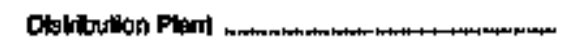 & $3,028,981$ & $9,995,1 \div 8$ & $2,796,842$ & $2,905,391$ & $2,5084,5,20$ \\
\hline Generad Fint & 726,408 & $813,5 e 0$ & 710,789 & $6,67,670$ & $624,4+4$ \\
\hline 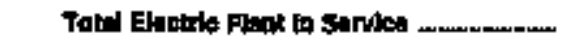 & 5,058, tes & 4684,618 & $3,158,099$ & $3,680,067$ & $3,431,647$ \\
\hline 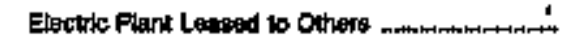 & $=$ & 0 & $=$ & - & - \\
\hline Contstruction Work in Frogrous - Electrle & 137,145 & 151,004 & 131,760 & 91,741 & 107,001 \\
\hline Eactile Plonl Hald for Future Uar .-. & 1,198 & $14,97 \mathrm{e}$ & 14,796 & 3,207 & 1,195 \\
\hline - & so,es & 91,762 & 27,189 & 18,391 & 23,178 \\
\hline 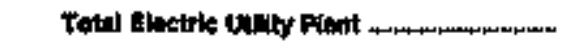 & $5,234,776$ & $5,092,207$ & 4007,914 & $5,59,405$ & $3,5033,010$ \\
\hline 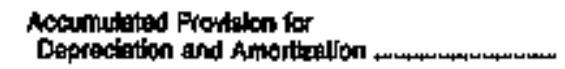 & $1,968,514$ & 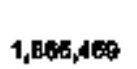 & $7,457,839$ & $1,30,050$ & $1,257,905$ \\
\hline Met Electile Uubly Pant .... & $3,205,942$ & $3,215,76$ & $2,549,875$ & $2,439,450$ & $2,300,105$ \\
\hline
\end{tabular}

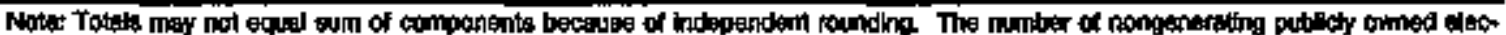

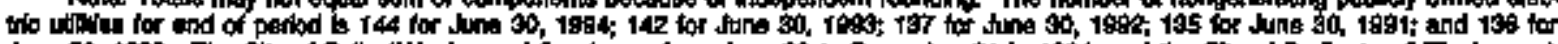

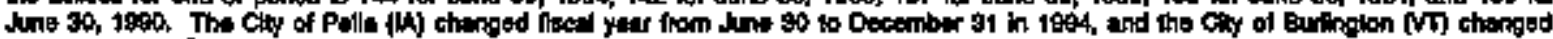

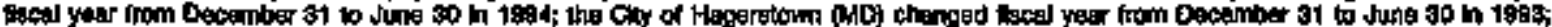

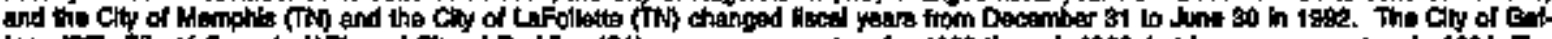

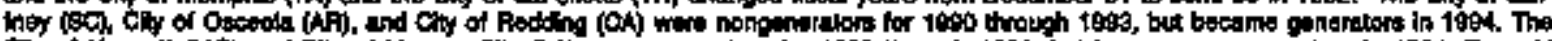

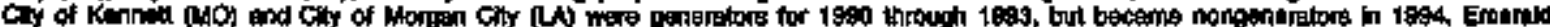

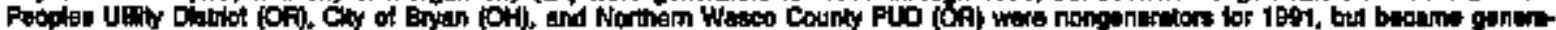

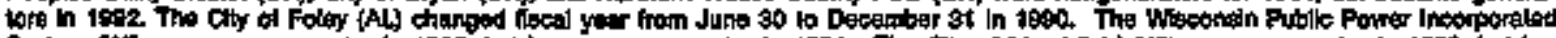

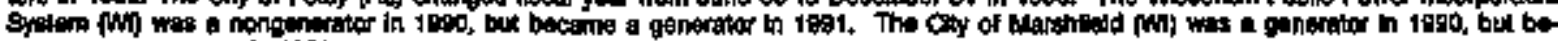
etipe a nongenterator h 1091.

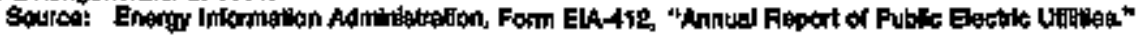


Table C26. Number of Consumors, Sates, and Operating Revenus for Major

U.S. Publely Owned Nongenerator Electrio Utilities with

Financial Year Ending on June 30, 1990-1994

\begin{tabular}{|c|c|c|c|c|c|}
\hline Hem & 1994 & 1983 & 1892 & 1094 & 1990 \\
\hline \multicolumn{6}{|l|}{ Atumber of Contunes: } \\
\hline 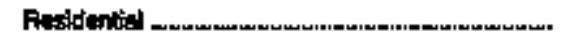 & $2,516,576$ & $2,501,498$ & 2076.559 & $2,049,351$ & $2,014,320$ \\
\hline Commental or Simal & 357,545 & 346,544 & 302,956 & 304,003 & 290,570 \\
\hline 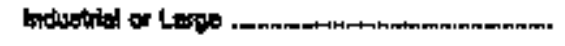 & 39,825 & 36,048 & 28,125 & 21,272 & 22,680 \\
\hline 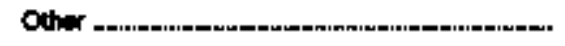 & 28,489 & 28,718 & 29744 & 37,397 & 39,918 \\
\hline Total tilimate conoumers ..... & $2,942,432$ & $2,913,704$ & $2,497,369$ & 2,406,923 & $2,375,9 a:$ \\
\hline \multicolumn{6}{|l|}{ gales for the Yaur (nepmidthoum) } \\
\hline . & $34,215,606$ & $32,294,944$ & $28,477,707$ & $28,467,624$ & $25,874,710$ \\
\hline 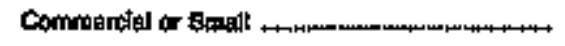 & $12,77, a 58$ & $12,44,9689$ & $11,851,242$ & $12,826,602$ & 12,2a4,8a1 \\
\hline hodugoital or Lege n.. & $42,056,730$ & $40,318,790$ & $\$ 1,079,721$ & $30,010,647$ & $29,8 \times 8,480$ \\
\hline Other =-n & $1,386,100$ & $1,501,485$ & $1,304,309$ & $1,335,162$ & $1,310,707$ \\
\hline 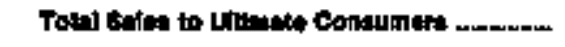 & $91,212,370$ & Bs, swoss & $71,503,069$ & $74,700,225$ & ep,jtapats \\
\hline 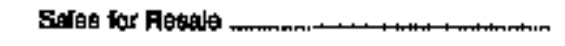 & $1,928,669$ & $1,611,743$ & 1,600t,017 & $1,729,660$ & 4,488,08B \\
\hline 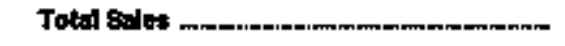 & $93,142,034$ & $0,170,000$ & $7,194,068$ & $72,469,701$ & 73,05ese:4 \\
\hline \multicolumn{6}{|l|}{ 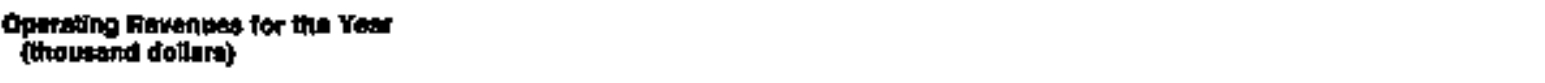 } \\
\hline 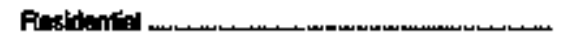 & $2,159,567$ & 2,008,00as & $1,638,729$ & $1,607,450$ & $1,568,0800$ \\
\hline 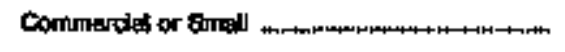 & $0000,47 ?$ & 896,361 & 290,365 & 674,690 & 825,248 \\
\hline Indugtald or Lorge . & $2,110,100$ & $2,084,644$ & $1,094,958$ & $1,680,691$ & $1,532,602$ \\
\hline 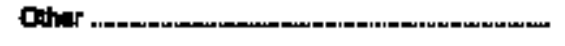 & 100,027 & 113894 & 98,564 & 100,996 & 90,640 \\
\hline Tolve Ravinute from salat to & $5,273,491$ & $5,040,902$ & $4,250,6 \times 0$ & $4,2,500$ & $4,025,602$ \\
\hline 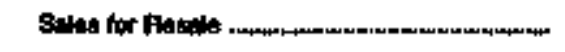 & 44,215 & 49,755 & $37,6 a 2$ & $\$ 4,291$ & 128,218 \\
\hline 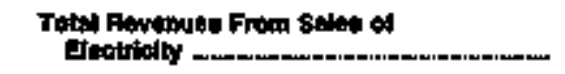 & $5,817,678$ & $5,0184,67$ & $4,240,442$ & $4,1=6,551$ & $4,40,050$ \\
\hline
\end{tabular}

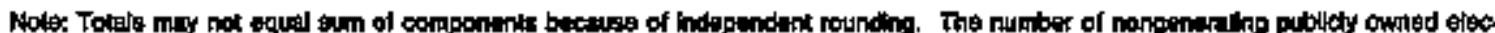

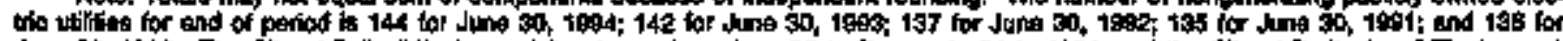

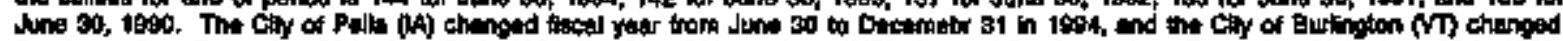

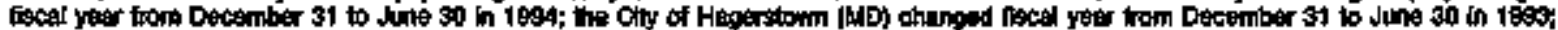

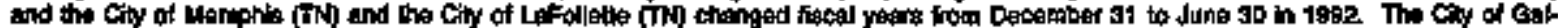

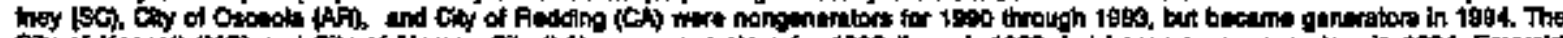

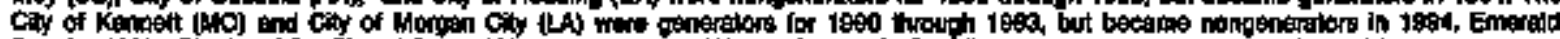

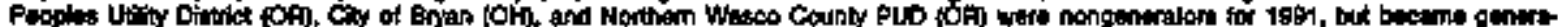

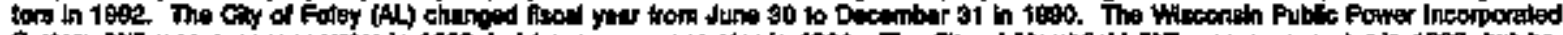

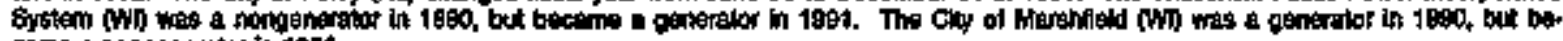
camo a nongenoratcer th 1969 . oions.

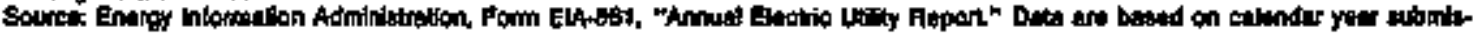


Table C27. Eleotric Energy Account for Major US. Publicly Owned Nongenerator Electric Uthlites with Financial Year Ending on June 30, 1990-1994

(Megawatthours)

\begin{tabular}{|c|c|c|c|c|c|}
\hline Itant & 1994 & 1998 & $19: 92$ & 1991 & $\operatorname{lag} 0$ \\
\hline \multicolumn{6}{|l|}{ sodrew of Enerisy } \\
\hline 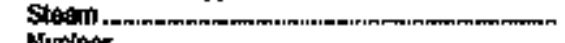 & - & - & - & - & - \\
\hline 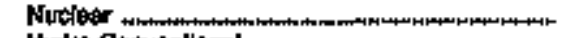 & $=$ & - & - & - & $=$ \\
\hline 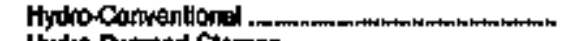 & $=$ & * & - & - & - \\
\hline 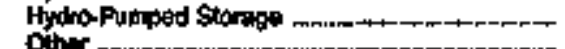 & $=$ & $=$ & $=$ & $\overline{-}$ & - \\
\hline 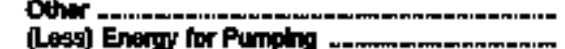 & - & $\overline{-}$ & $\overline{-}$ & $\overline{-}$ & $\begin{array}{l}- \\
\end{array}$ \\
\hline 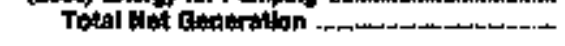 & $=$ & $=$ & $=$ & $=$ & - \\
\hline 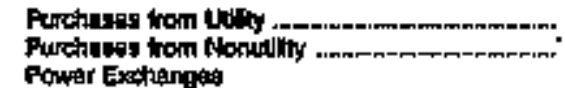 & $\begin{array}{r}97,458,860 \\
10,213\end{array}$ & $91,640,505$ & $7,780,784$ & $\begin{array}{r}75,437,318 \\
2,040\end{array}$ & $\begin{array}{r}76,601,651 \\
2,000\end{array}$ \\
\hline 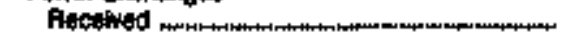 & $\pi$ & Bast4 & $=$ & 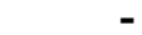 & 17 \\
\hline 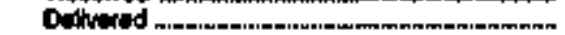 & - & 11,649 & - & - & $m$ \\
\hline Net Exchiangeg a & $=$ & $-8,355$ & $=$ & - & 17 \\
\hline \multicolumn{6}{|l|}{ Transmibeion for Othere (Whoeling] } \\
\hline Rectived _- & 351,907 & 304,378 & - & - & - \\
\hline Oebleres , & 351,867 & 300,4013 & $=$ & $=$ & $=$ \\
\hline 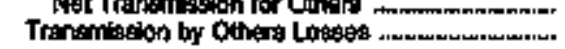 & $\overline{-}$ & $-3,020$ & $\overline{-}$ & 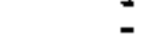 & - \\
\hline \multicolumn{5}{|l|}{ Tobit Hel Enary cenarated and } & Thamenos \\
\hline \multirow{2}{*}{\multicolumn{6}{|c|}{ Bopontran of Enargy }} \\
\hline & & & & & \\
\hline 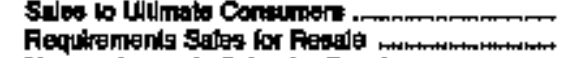 & $\begin{array}{l}91,130,429 \\
1,855,584\end{array}$ & $\begin{aligned} 05,534,702 \\
1,517,540\end{aligned}$ & $\begin{array}{r}71,571,297 \\
1,669,176\end{array}$ & $\begin{array}{r}70,082,792 \\
1,660,195\end{array}$ & $\begin{array}{r}49,036,009 \\
4,226,700\end{array}$ \\
\hline 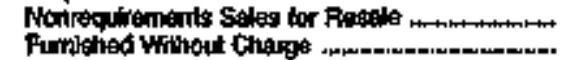 & $190,9 \overline{-}$ & 78054 & $\begin{array}{r}\mathbf{6 , 6 4 2} \\
51,491\end{array}$ & 6020 & $44, \mathrm{abs}$ \\
\hline Uaed by Ulity (weriveng siation use) & 100,835 & 128,406 & 11276 & 128,49 & 129,009 \\
\hline 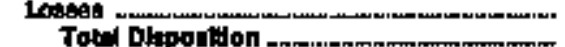 & $\begin{array}{r}4,177,289 \\
07,476,102\end{array}$ & $\begin{array}{r}4,390,140 \\
91,638,172\end{array}$ & $\begin{array}{r}3,378,459 \\
78,769,768\end{array}$ & $\begin{aligned} 3,350,848 \\
76,439,358\end{aligned}$ & $\begin{array}{r}3,4 B 6,319 \\
78,600,560\end{array}$ \\
\hline
\end{tabular}

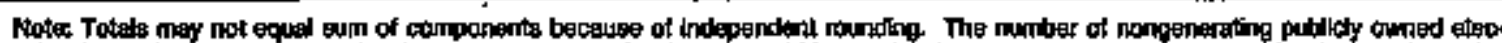

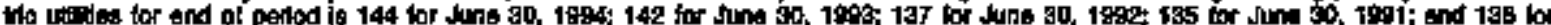

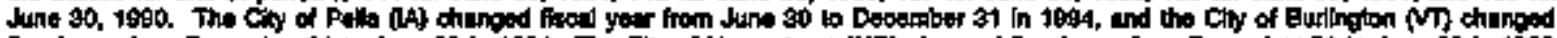

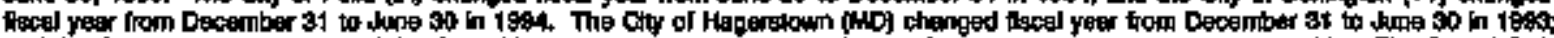

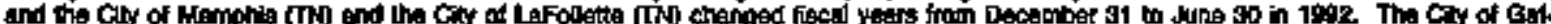

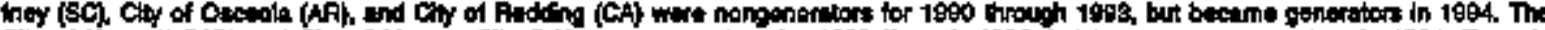

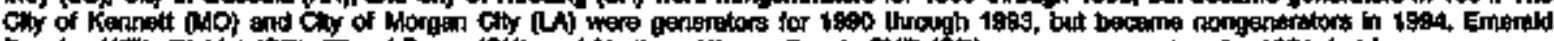

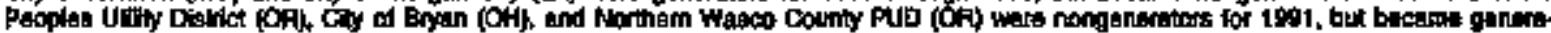

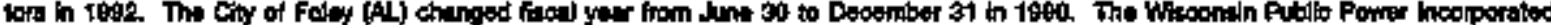

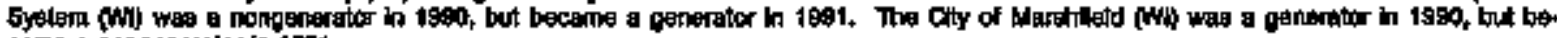
came a nongenetralor in 189 .

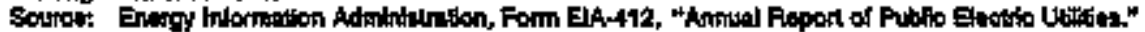


Table C28. Ten Largest U.S. Publloty Owned Nongenerator Electric Utilltios Fanked by Megawatthour Sales to Ultimate Consumers with Financial Year Ending on December 31, 1994

\begin{tabular}{|c|c|c|c|}
\hline 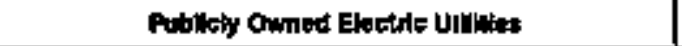 & State & Amownt & Percent \\
\hline PUD No 1 of Gurk Coumy - & Whathnoten & $3,481,167$ & 11.31 \\
\hline FLD Fa 1 of Benton Costunty ......... & Washington & $1,965,298$ & 4.50 \\
\hline Gentral Lineoln Peopleg Ud Dt & Oregon & $1,343,360$ & 4.37 \\
\hline Fort Colling City of ...... & Colorado & 000,909 & 206 \\
\hline Ctelshania Peoplest Ual Dist ........... & Oregon & 818,215 & 263 \\
\hline Spoling fild City of & Ongon & atB,1zo & 265 \\
\hline Athens Coty of مسع & Alabaria & 670,456 & 2,16 \\
\hline FUD tho it of Franidin County nnmm & Wushingron & 631,742 & 2.06 \\
\hline 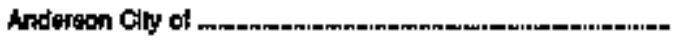 & indiens & 600,680 & 206 \\
\hline Plochland Chy of . . & Weshinglon & 620,719 & 205 \\
\hline Seblotat & & $11,918,099$ & \$2.7 \\
\hline
\end{tabular}

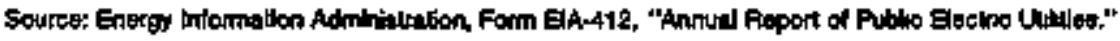

Table C29. Ten Largest U.S. Publlaly Owned Nongenerator Electrle Utilitles Renked by Megawatthour Sales for Resale with Financlal Year Ending on December 31, 1994

\begin{tabular}{|c|c|c|c|}
\hline 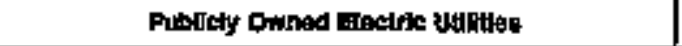 & state & Ambuin & Pertenil \\
\hline Mlsapar Basin Nun Power Agno & Sourh Oakota & $1,898,120$ & 14 \\
\hline 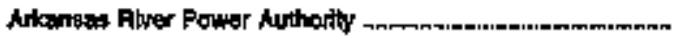 & Cotorado & 292,030 & 10.12 \\
\hline Badger Power Mtarketing Aulh ......-. & Whementin & 287,600 & 9.61 \\
\hline Kantes Murdidpal Enmegy Agency & Kenrsals & 264,240 & 949 \\
\hline Weatifiatd Cay of of & 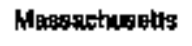 & 20,079 & .72 \\
\hline 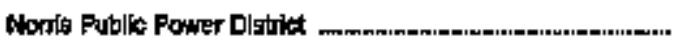 & Nabraska & 14,839 & .53 \\
\hline 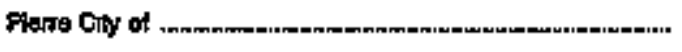 & Sould Dakols & 14,817 & 쇼 \\
\hline Dawon Counly Pubte Pwer Dist n....... & Nabrateka & 5.274 & .18 \\
\hline Dankars Torm of of & Massactivasteg & 3,819 & .14 \\
\hline PLD No 3 of Mdesion County & Washinglon & 3,206 & .12 \\
\hline Subtotial _-... & & 2774,043 & 4058 \\
\hline
\end{tabular}

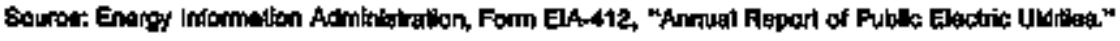


Table C30. Composite Statement of Income for Major U.S. Publicly Owned Nongenerator Electric Utilities with Financial Year Ending on December 31, 1990-1994 (Thoustand Dollars)

\begin{tabular}{|c|c|c|c|c|c|}
\hline Han & 1994 & 1090 & 1902 & 1991 & 1000 \\
\hline 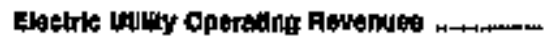 & $1,735,083$ & 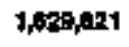 & $2,169,597$ & 2,251, ta1 & $2,126,674$ \\
\hline 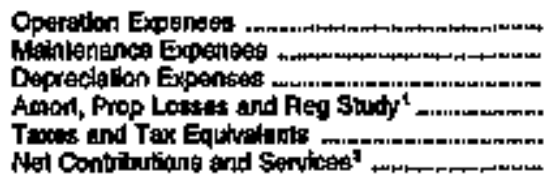 & $\begin{array}{r}1,428,489 \\
48,814 \\
5,897 \\
3,097 \\
6,2911 \\
-\end{array}$ & $\begin{array}{r}1,34,9,021 \\
48,241 \\
74,479 \\
2,168 \\
48,502 \\
-\end{array}$ & $\begin{array}{r}1,833,150 \\
68,759 \\
87,395 \\
2,340 \\
56,344 \\
2\end{array}$ & $\begin{array}{r}1,894,463 \\
60,240 \\
94,169 \\
54,151 \\
35,714\end{array}$ & $\begin{array}{r}1,704,946 \\
63,287 \\
89,019 \\
6,000 \\
\$ 5,098\end{array}$ \\
\hline 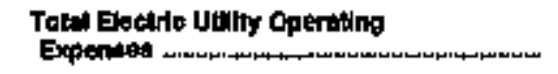 & $1,615,551$ & $1,515,501$ & $2,047,091$ & $2,140,790$ & $2,035,548$ \\
\hline 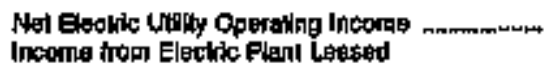 & 120,452 & 114,500 & $1 \pm 0,707$ & 110,401 & 08,131 \\
\hline 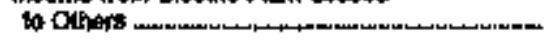 & 94t & 1,440 & 750 & $\operatorname{seg}$ & 424 \\
\hline Electic Utity Operaling Inoome - & 121,973 & $115, \sin$ & 111,456 & 110,701 & 88,556 \\
\hline 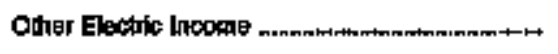 & ง2,159 & 34,50 & 85,967 & $\$ 1,653$ & 34,380 \\
\hline 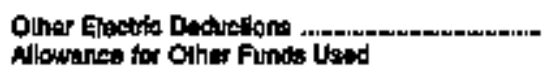 & 14,718 & 0,165 & 20,910 & 4,879 & $=$ \\
\hline 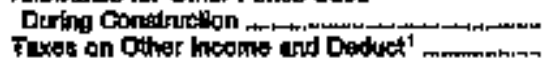 & 2,516 & $18 \%$ & 1,374 & 351 & 5 \\
\hline 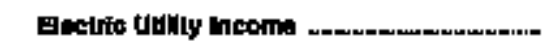 & 135,299 & 140,810 & $152 / 71$ & 157,002 & 14t5sas \\
\hline 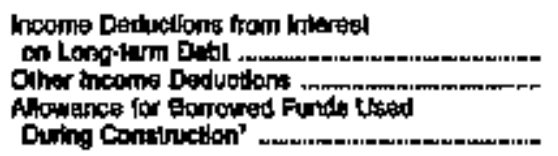 & $\begin{array}{r}30,434 \\
6,394 \\
-176\end{array}$ & $\begin{array}{r}30,060 \\
14,211 \\
-270\end{array}$ & $\begin{array}{r}40,377 \\
4,172 \\
-75\end{array}$ & $\begin{array}{r}61,140 \\
4,724 \\
-\end{array}$ & $\begin{array}{r}57.95 \\
5958 \\
-\end{array}$ \\
\hline 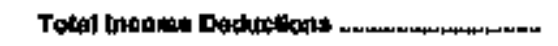 & 34653 & 48,002 & $50,4=5$ & $6 \leq, 864$ & 63,a7s \\
\hline keome Beplore Extraondinary liants ..momm & 00,616 & 96,609 & 102,005 & ga,08:8 & 94,608 \\
\hline 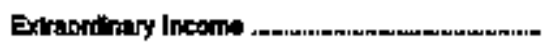 & 18,254 & 1,284 & 13,567 & 1,973 & 2,508 \\
\hline 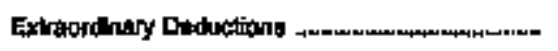 & 43: & 1,000 & 11,209 & 6,428 & 240 \\
\hline 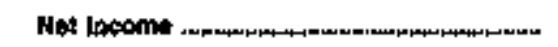 & 117,045 & osing & 101,354 & atertas & etritr \\
\hline
\end{tabular}

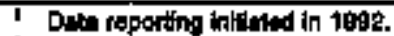

- Date reporting dlecorthued h 189e.

- Dala not avaliatida.

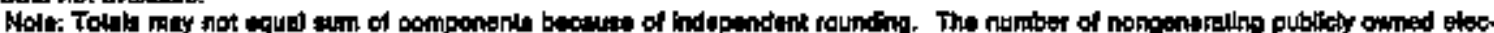

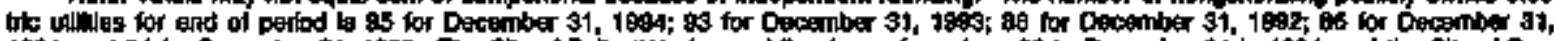

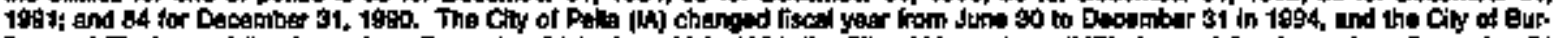

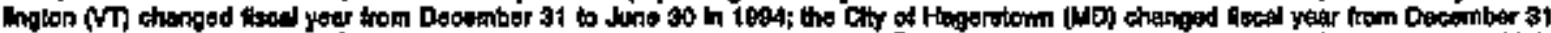

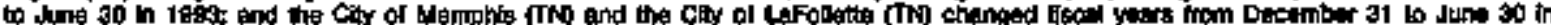

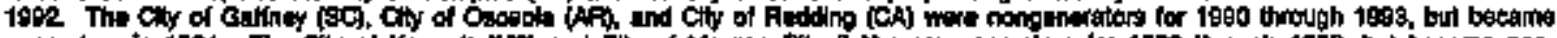

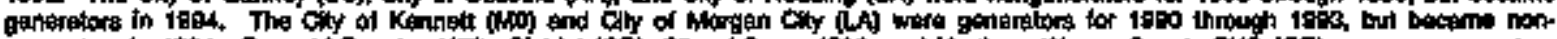

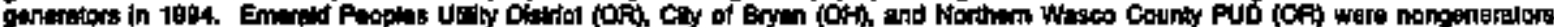

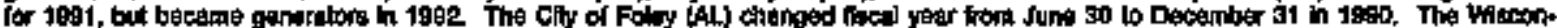

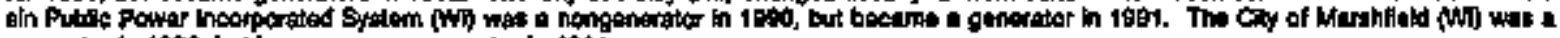

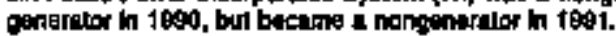

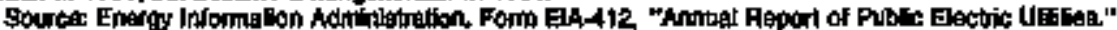


Table C31. Composite Balance Sheet for Major U.S. Publicly Owned Nongenerator Electric Utilties with Financlal Year Ending on December 31 at End of Period, 1990-1994 (Thousand Dollars)

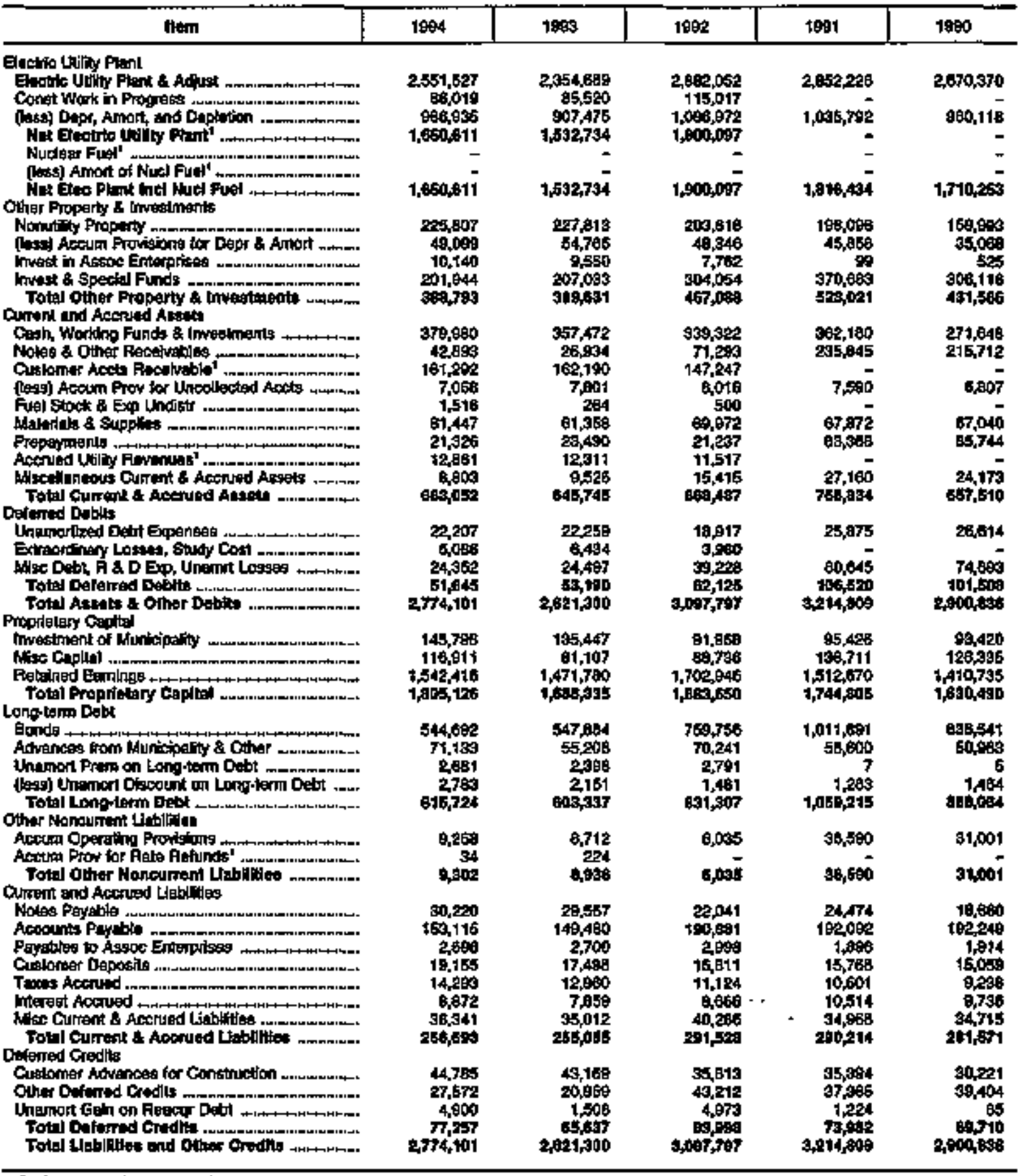

Dale reporfing intiated in 7982.

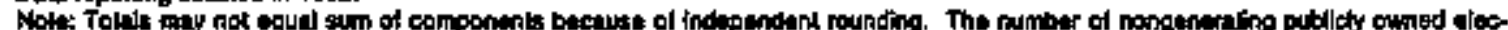

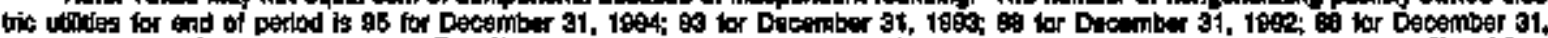

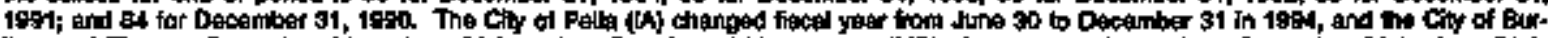

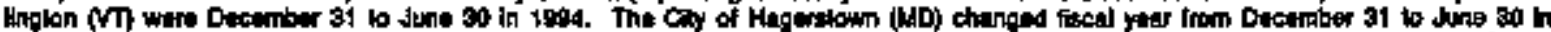

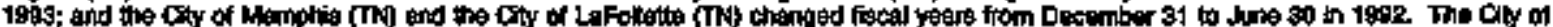

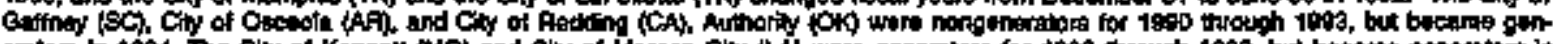

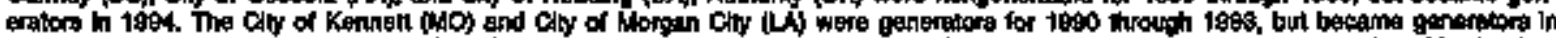

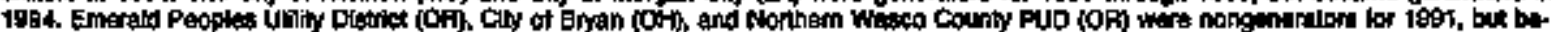

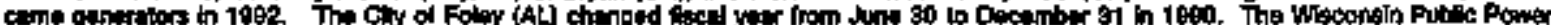

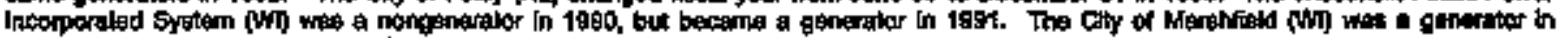
1980, but became a nongunerater th 1901.

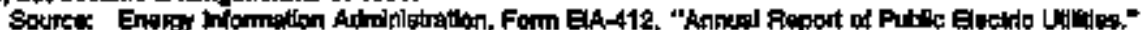


Table C32. Composite Financlal Indleators for Malor U.S. Publicly Owned Nongenerator Electric Utnlities with Flnancial Year Ending on December 31, 1990-1994

\begin{tabular}{|c|c|c|c|c|c|}
\hline Ilem & 1999 & $\operatorname{mos}$ & 1902 & 1991 & 1990 \\
\hline 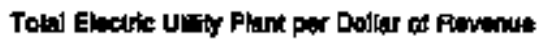 & 1.5 & 1.5 & 1.4 & 1.3 & 1.3 \\
\hline 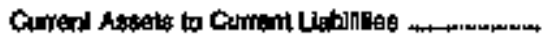 & 26 & 25 & 20 & 26 & 23 \\
\hline 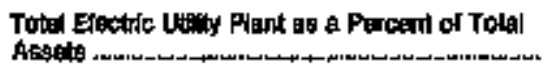 & 85.1 & $\mathbf{9 3 . 1}$ & 85.7 & anj & 82.1 \\
\hline 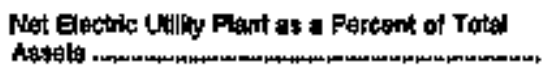 & 95 & 58.5 & 61.3 & $5 \$ 5$ & 59.0 \\
\hline 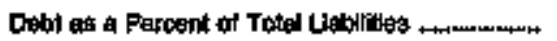 & 31,8 & 327 & 36.2 & 123 & 40.3 \\
\hline 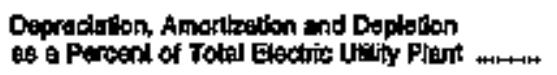 & 374 & 372 & $\mathbf{3 6 . 6}$ & 365 & 380 \\
\hline 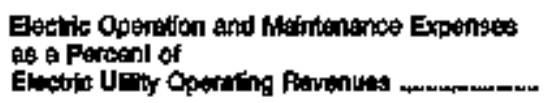 & Bs.t & 88.3 & 0.1 & 97.0 & 87.3 \\
\hline 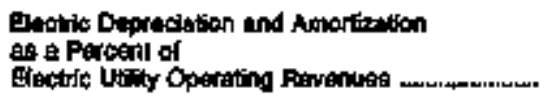 & 4.7 & 4.8 & 40 & 4.1 & 4.2 \\
\hline 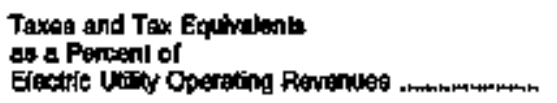 & 3.0 & $\mathbf{a . 0}$ & 2.8 & 24 & 25 \\
\hline 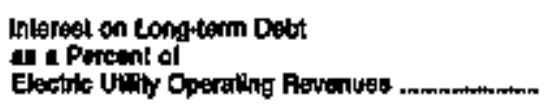 & 1.8 & 1.8 & 2.1 & 2.7 & 2.7 \\
\hline 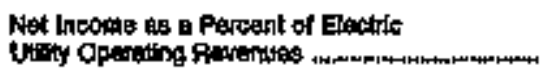 & 6.8 & 5.9 & 4.7 & $\mathbf{3 9}$ & 4.4 \\
\hline 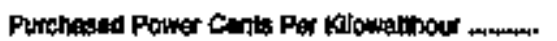 & 3,5 & $\mathbf{3 . 3}$ & $9 B$ & $\mathbf{3 . 6}$ & 3.5 \\
\hline
\end{tabular}

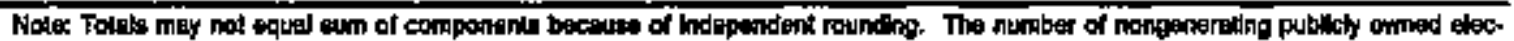

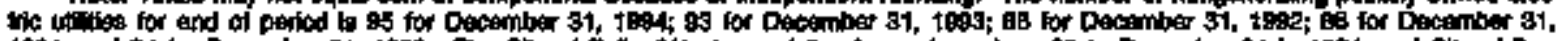

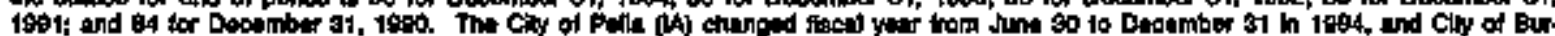

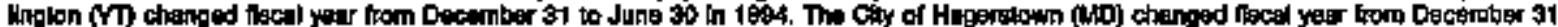

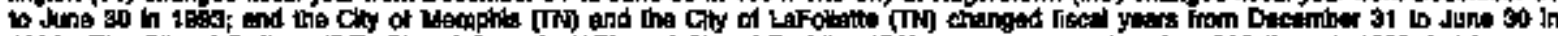

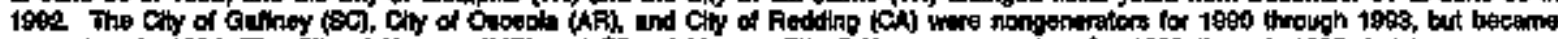

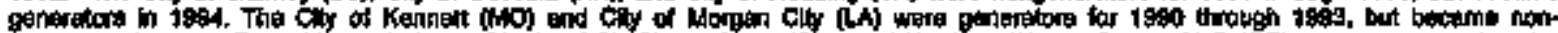

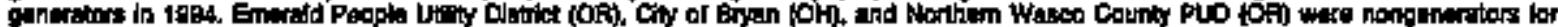

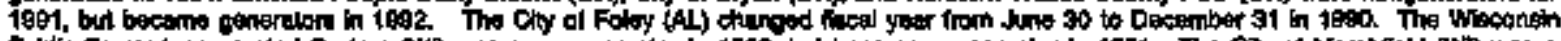

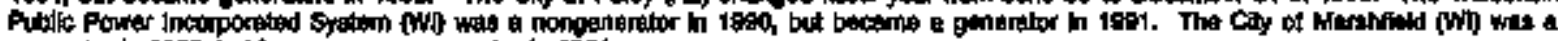

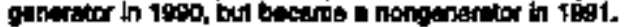

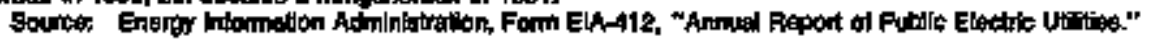


Table Ca3. Electric Operation and Malintenance Expenses for Mojor U.8.

Publicly Owned Nongenerator Electric Utilities with

Financial Year Ending on December 31, 1990-1994

(Thousend Dollars)

\begin{tabular}{|c|c|c|c|c|c|}
\hline Ilent & 1904 & 19903 & 1002 & 1991 & 1000 \\
\hline \multicolumn{6}{|l|}{ Production Expenves: } \\
\hline Stem Powren Gonerditan & 294 & 386 & 416 & 644 & 230 \\
\hline 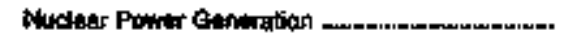 & - & - & - & - & - \\
\hline 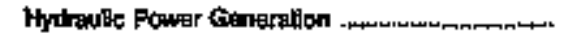 & 11 & 8 & 1 & - & - \\
\hline Olhar Powar Genterallon . . & 1,000 & $\$$ \$240 & 622 & $\theta 7$ & 105 \\
\hline Purohesed Power , & 1, apes, 673 & $1,140,781$ & 1,570,889 & $1,649,190$ & $1,638,238$ \\
\hline 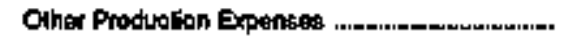 & 6,605 & 8,112 & 4,976 & 7,388 & 36,240 \\
\hline Trotel Production Expente日ed & $1,230,536$ & $1,150,514$ & $1,565,505$ & $5,656,155$ & $1,574,011$ \\
\hline 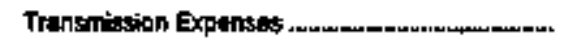 & 21,087 & 19,145 & 2ags7 & 20,321 & 22,877 \\
\hline 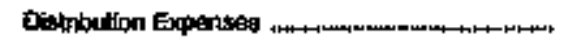 & 6.9.982 & 97,151 & 134,614 & 125,755 & 114,903 \\
\hline 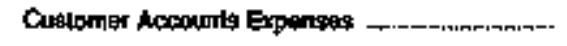 & 33,849 & 33,444 & 39.822 & 37,058 & 30,105 \\
\hline 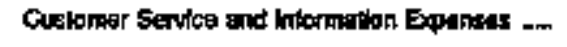 & 5,090 & 6,763 & 6,173 & 6,200 & 4,670 \\
\hline Sales Expenses .mmn & 2,649 & 2,187 & 2,416 & 1,562 & 7,493 \\
\hline Administralive and Bernartal Expentess & B7.aBs & a1,, 07 : & 111,537 & 111,572 & 108,a74 \\
\hline 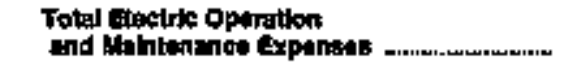 & $1,477,246$ & $1,390,042$ & $1,-101,872$ & 1,957,728 & $1,05: 231$ \\
\hline \multicolumn{6}{|l|}{ 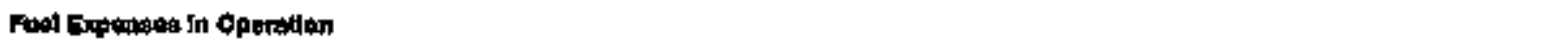 } \\
\hline 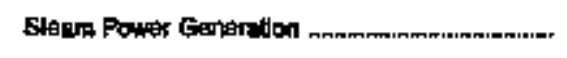 & - & 2 & 13 & 2 & -3 \\
\hline Auchar Rowrer Generation , & - & - & - & - & - \\
\hline 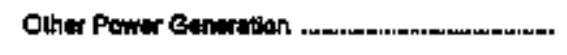 & - & 19 & $\mathbf{5}$ & 2 & 3 \\
\hline \multicolumn{6}{|l|}{ Humber of Eloc Dept Emptoyes: } \\
\hline 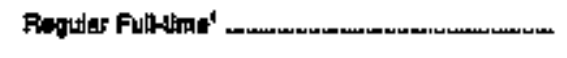 & 8,704 & $\mathbf{3 , 7 1 4}$ & 5,493 & - & - \\
\hline Paytima 8 Tertiporary" & 260 & 911 & 870 & - & - \\
\hline 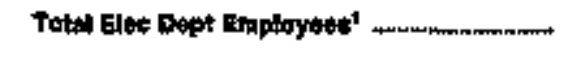 & 4,020 & 4,626 & 6,866 & 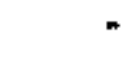 & - \\
\hline
\end{tabular}

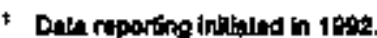

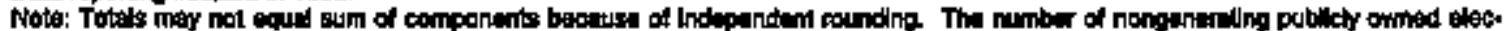

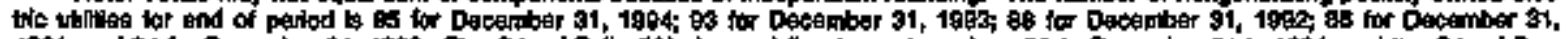

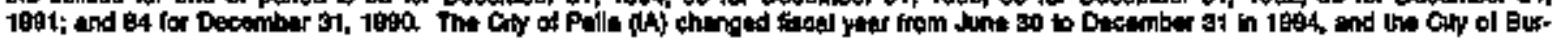

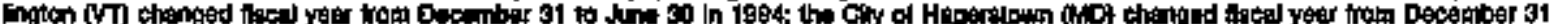

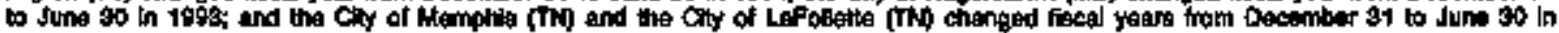

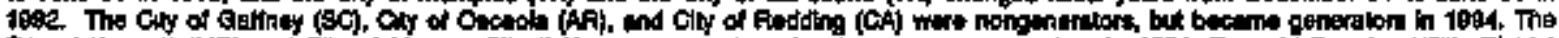

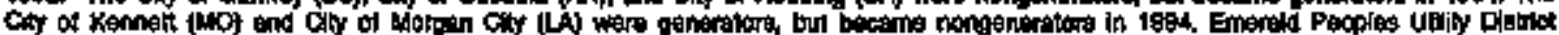

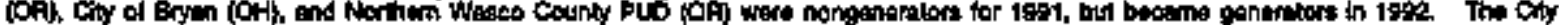

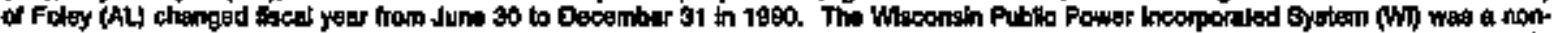

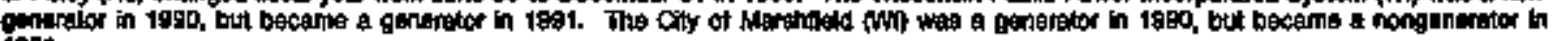
1981.

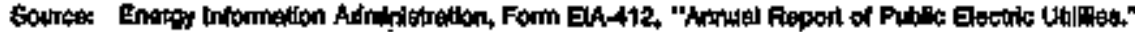


Table C34. Electric Utility Plant for Major U.S. Publichy Owned Nongenerator Eectric Utilties with Financial Year Ending on

December 31 at End of Pertod, 1990-1994

(Thousand Dollars)

\begin{tabular}{|c|c|c|c|c|c|}
\hline Itom & 1004 & t9os & 1902 & 1091 & 19800 \\
\hline \multicolumn{6}{|l|}{ Electede Pland in Eervioe } \\
\hline 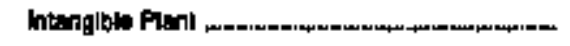 & 5,909 & 10,101 & 10,091 & 7,860 & 7,015 \\
\hline \multicolumn{6}{|l|}{ Production Ptant } \\
\hline 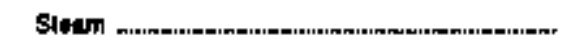 & 34,995 & 18,209 & 25,078 & 27,051 & 25,928 \\
\hline 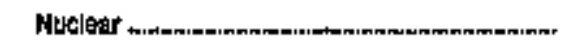 & $=$ & - & - & - & - \\
\hline 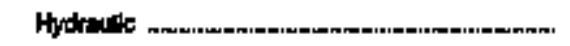 & 598 & 582 & 582 & $5 B 2$ & 592 \\
\hline Oather & $15,70 \mathrm{r}$ & 15,991 & 6,369 & 6,541 & 2,162 \\
\hline Total Production Plank ... & 51,293 & 30,811 & 35,029 & 34,774 & 29679 \\
\hline 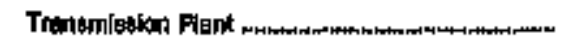 & 194,372 & 157,091 & 207,707 & 251,486 & 242,341 \\
\hline Dletibuston Fiant -n. & $1,848,697$ & $1,762,874$ & $2,129,096$ & 2010,843 & $1,024,058$ \\
\hline 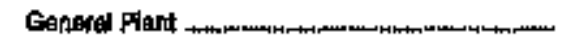 & 416,677 & 959,139 & 376,397 & 346,682 & 302,205 \\
\hline Toted Eloctric Pont In Sorvice . . & $2,506,998$ & $2,310,095$ & $2,289,210$ & $2,701,650$ & $2,650,190$ \\
\hline Esolito Plan! Liased to Othan .... & 745 & 704 & $\mathbf{6 1 6}$ & 68 & 700 \\
\hline Conelnuetion Work in Progress - Esoctio ........ & 88,019 & 85,520 & 115,017 & 200,298 & $28, B 70$ \\
\hline 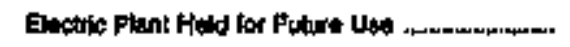 & 8,871 & 1,292 & 1,3008 & 10,608 & 10,197 \\
\hline 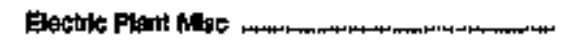 & 34013 & 12,699 & 40,900 & 36,950 & 39,407 \\
\hline 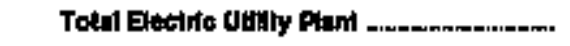 & $2,487,549$ & $2,400,209$ & $2,00 \%, 000$ & $2,952,228$ & 2,870,370 \\
\hline $\begin{array}{l}\text { Accumblatied Provition tor } \\
\text { Depreciation and Amorthrion ....-. }\end{array}$ & 906,005 & 907,476 & $1,008,972$ & $1,096,792$ & $060, t+6$ \\
\hline 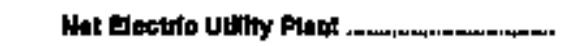 & $1,0,50,6 t 1$ & $1,052,746$ & $1,000,007$ & $1,816,454$ & $1,710,265$ \\
\hline
\end{tabular}

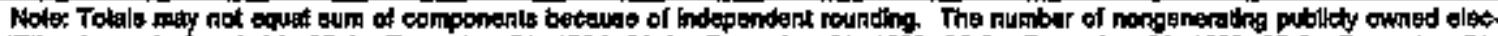

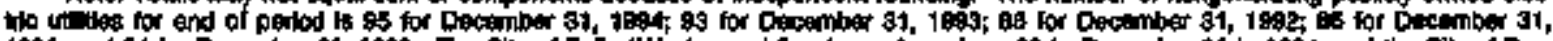

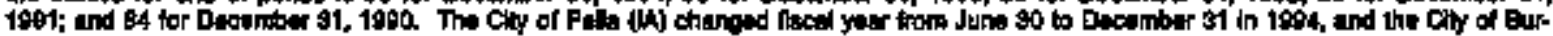

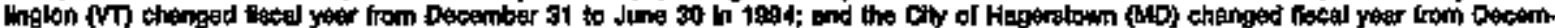

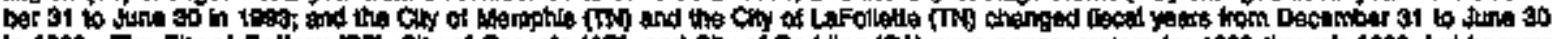

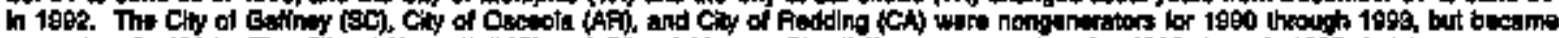

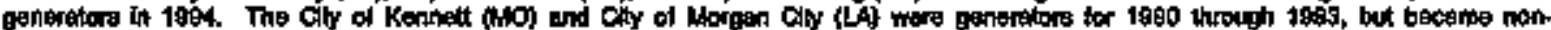

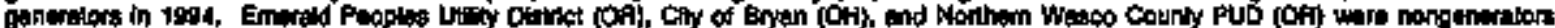

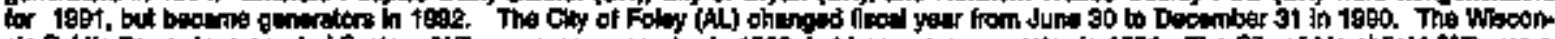

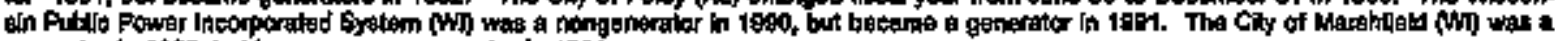

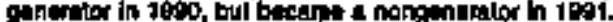

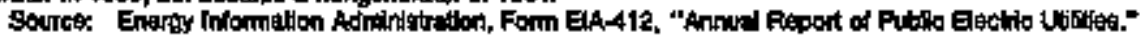


Table Ca5. Number of Consumers, Sales, and Operating Revenue for Major U.S. Publicly Owned Nongenerator Electric Utilitios with Financtal Year Ending on December 31, 1990-1994

\begin{tabular}{|c|c|c|c|c|c|}
\hline inem & 1999 & 1908 & 1992 & 1951 & 1890 \\
\hline \multicolumn{6}{|l|}{ Nuthber of Cotteumers } \\
\hline 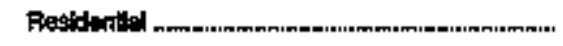 & $\$ 1,878$ & 972,174 & $1,252,707$ & $1,215,874$ & $1,187,500$ \\
\hline 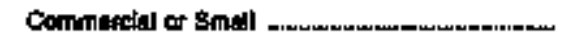 & 127,688 & 121,118 & 143,672 & 148,187 & 149/A35 \\
\hline 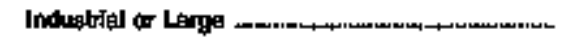 & a,sas & 6,702 & $14,3: 00$ & 6,913 & 6, 1024 \\
\hline 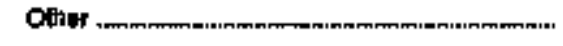 & 33,200 & 35,169 & 49,800 & 58,258 & 54,050 \\
\hline Tot"I Uwrmik Consume & $1,16 t, 260$ & $1,137,761$ & $t, 460,496$ & $1,407,232$ & $1,392,101$ \\
\hline
\end{tabular}

Salas for the Yer fmegawstifindres

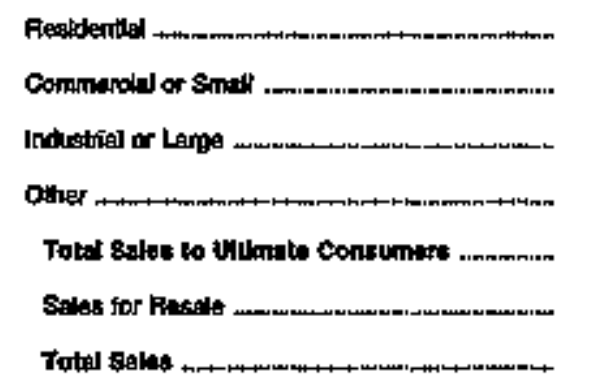

\begin{tabular}{|c|c|c|c|c|}
\hline $11,779,0906$ & $11,880,290$ & $15,000,540$ & 15,659,505 & $14,897,373$ \\
\hline $7,449,714$ & $7,048,676$ & $7,256,665$ & $1+, 392,825$ & $t 0,808,838$ \\
\hline $10,510,208$ & 19,347.973 & $15,865,347$ & $11,090,887$ & $10,624,838$ \\
\hline 089,474 & 783,029 & $1,250,996$ & $5,492,510$ & $1,400,768$ \\
\hline $20,772,035$ & $30,088,576$ & $3,200,440$ & $30,615,70 ?$ & $37,501,607$ \\
\hline $2,765,813$ & $2,725, \sqrt{35}$ & 2,895,020 & $4,788,485$ & $4,517,100$ \\
\hline $39,5,7,949^{\circ}$ & $32,799,051$ & $42,167,469$ & 44,362,192 & $42,306,907$ \\
\hline
\end{tabular}

Operaling Revanus: for the Year (thougund dollant)

Regidnndal 68g,0\% 687.634 851,389 059,173 614,217

Copummoled or small 415,137 393,543 300,B07 605575 5963as

indiofitis of Larige 469,267 452,305

720,419 464,741 44,373

Other 58,402 49,644

71,459

70,256

76,567

Totol Ravmune from Satus to

Uninate Conturmers

1,67:4,45

1,583,128

2,045,119

$2,028,745$

$1,530,410$

Selus for Ficall

ax, 250

79.291

164,73;

158,081

Total Rowenual From salat of Unctulathy

$1,716,498$

1,097,395

$2,129,409$

3,193,401

2,092,46:

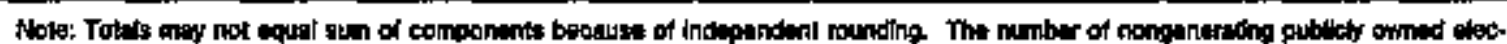

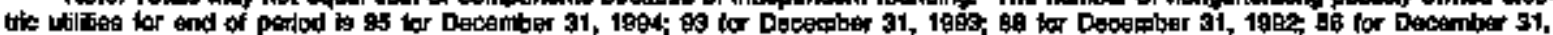

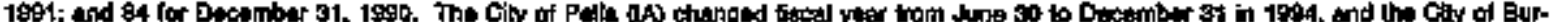

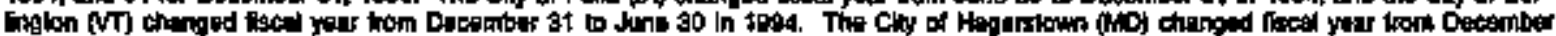

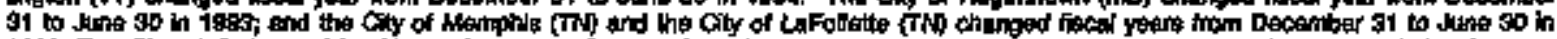

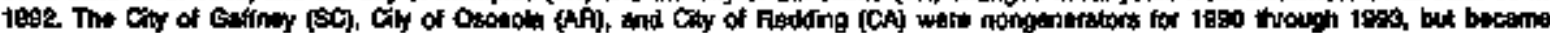

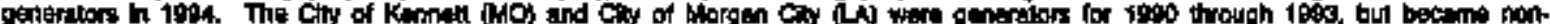

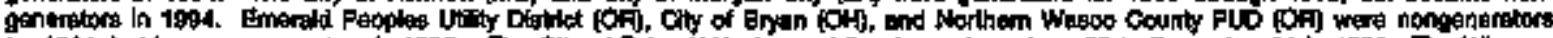

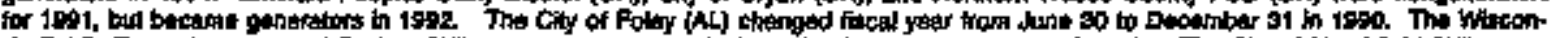

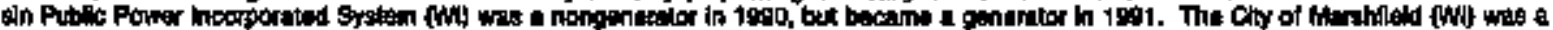

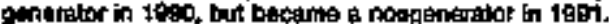

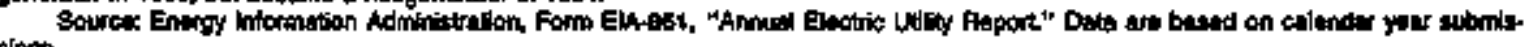


Table Ca6. Electric Energy Account for Major U.S. Publichy Owned

Nongenerator Electric Utilities with Financial Year

Ending on December 31, 1990-1994

(Megawatthours)

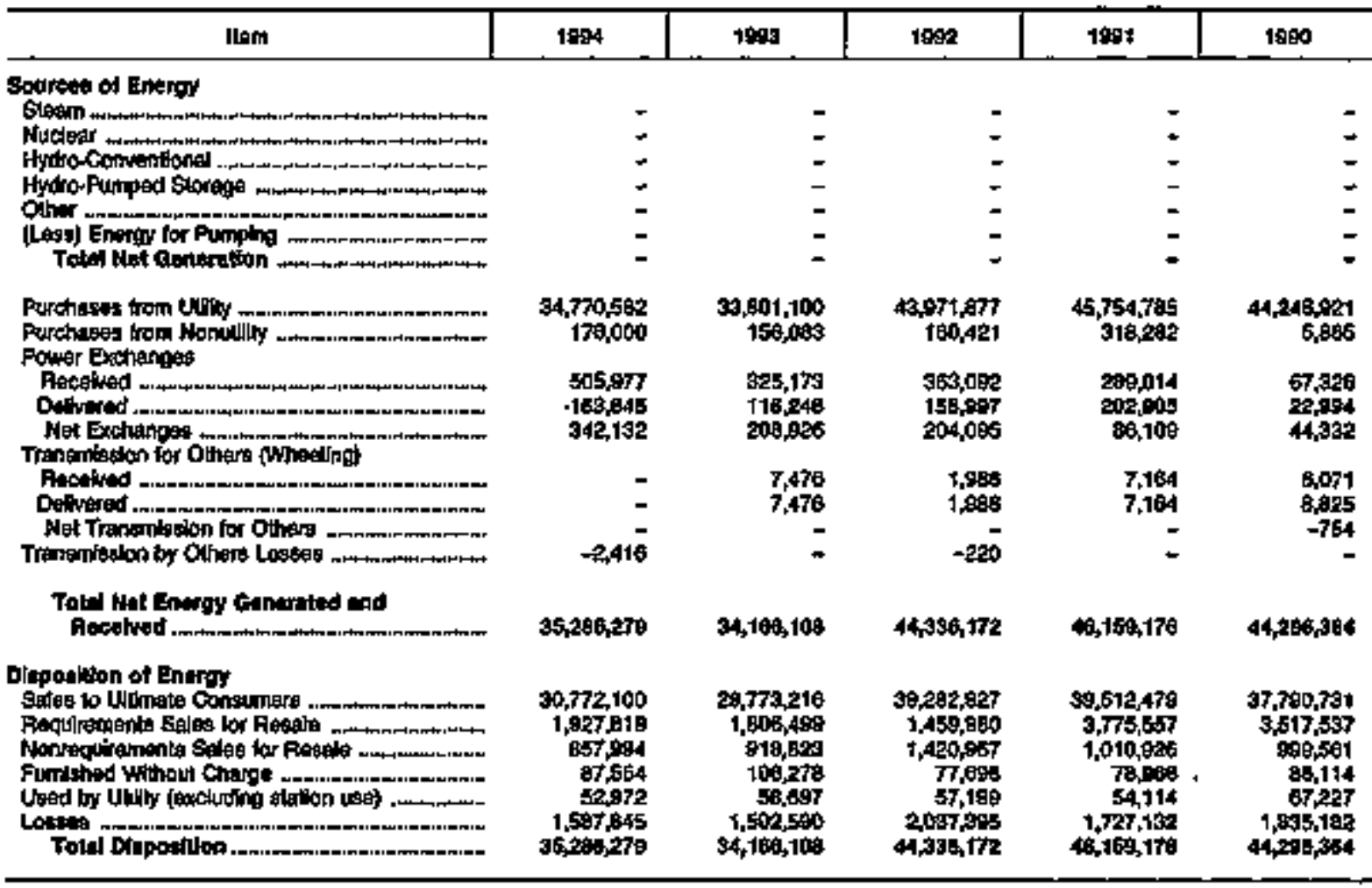

- Dola not evalibtio.

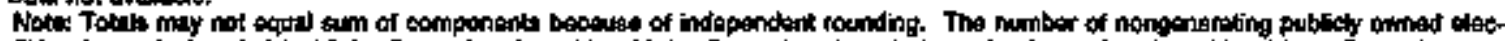

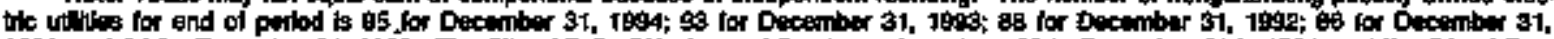

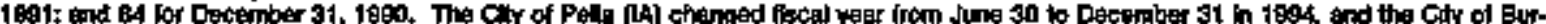

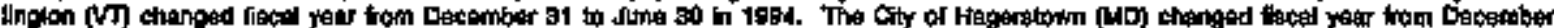

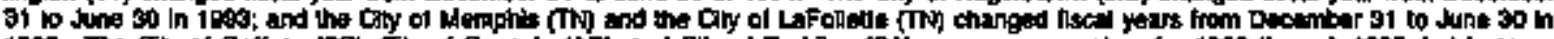

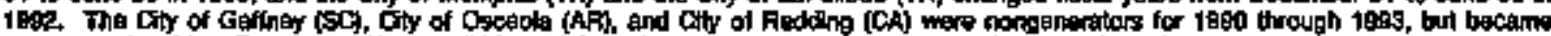

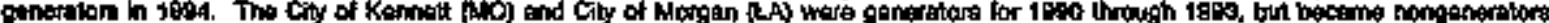

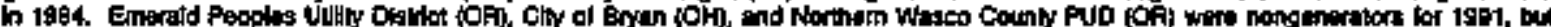

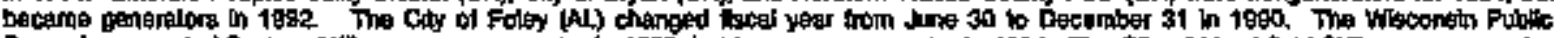

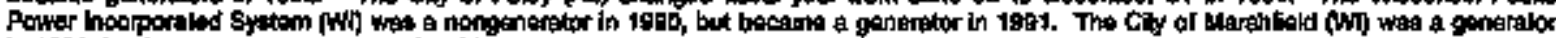
In toge, but beceme a nonguretalor in 1901.

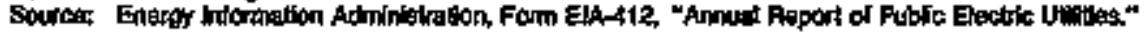


Tabje C37. Twenty Largest U.S. Publloly Owned Ekectrlc Utilties Ranked by Megawatthour Sales to UHtmate Consumers for All Respondents, 1994

\begin{tabular}{|c|c|c|c|}
\hline Pubteby Owred Jectuic Utilibe & sinte & Amount & Reporting Dato \\
\hline 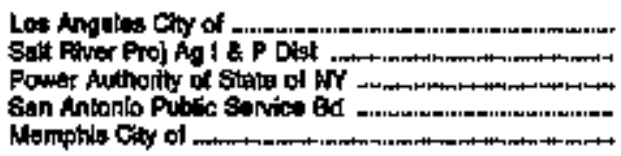 & 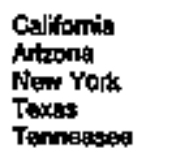 & $\begin{array}{l}20,480,075 \\
16,009,289 \\
13,212,613 \\
13,0,7,064 \\
12,097,340\end{array}$ & 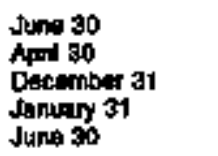 \\
\hline 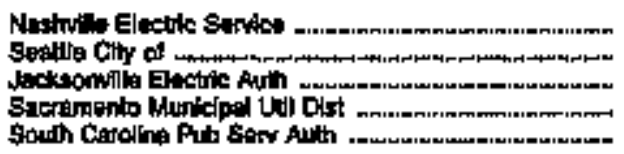 & 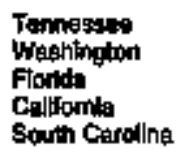 & $\begin{array}{r}10,640,616 \\
6,674,059 \\
6,817,610 \\
6,40,169 \\
7,423,4=0\end{array}$ & $\begin{array}{l}\text { June 30 } \\
\text { Decomber } 31 \\
\text { September } 30 \\
\text { December } 31 \\
\text { Decomber } 31\end{array}$ \\
\hline 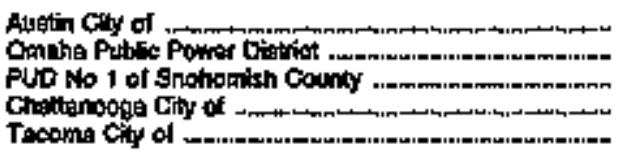 & 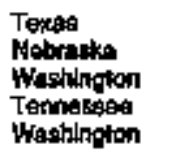 & $\begin{array}{l}7,306,134 \\
7,068,040 \\
5,771,6403 \\
5,471,870 \\
6,889,340\end{array}$ & $\begin{array}{l}\text { September } 30 \\
\text { Deoenaber } 31 \\
\text { December } \$ 1 \\
\text { Juns 30 } \\
\text { Deoember } 31\end{array}$ \\
\hline 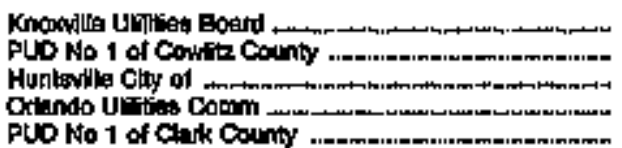 & 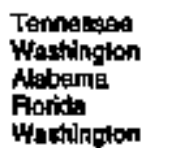 & $\begin{array}{l}4,8 B 9,4 B 0 \\
4,707,362 \\
3,799,487 \\
3,782,088 \\
3,481,167\end{array}$ & $\begin{array}{l}\text { Juna sb } \\
\text { Deboriber } 31 \\
\text { Sepleanber } 30 \\
\text { September } 30 \\
\text { Docember } 31\end{array}$ \\
\hline
\end{tabular}

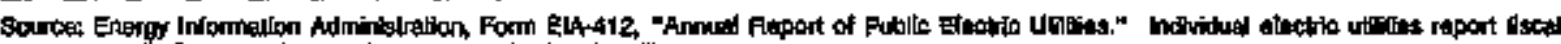

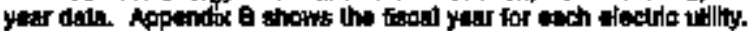

Table C38. Twenty Largest U.S. Publiely Owned Electric Utillites Ranked by Megawatthour Seles for Resele for All Respondento, 1994

\begin{tabular}{|c|c|c|c|}
\hline 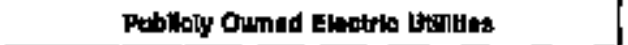 & Stete & Apount & Reporting Date \\
\hline 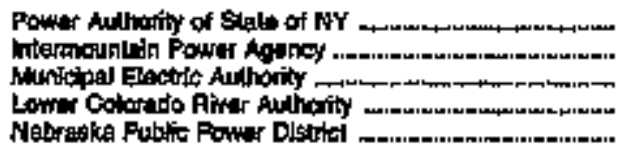 & 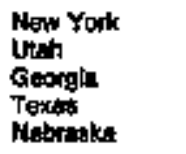 & 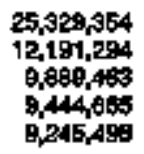 & 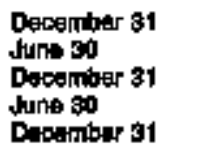 \\
\hline 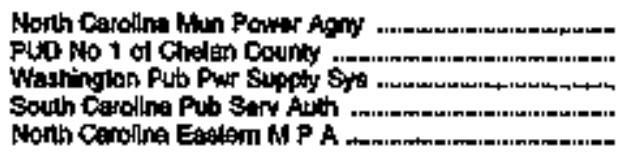 & 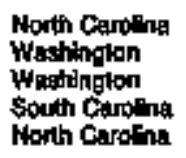 & $\begin{array}{l}6,636,752 \\
7,593,185 \\
7,346,698 \\
7,401,056 \\
3,388,617\end{array}$ & 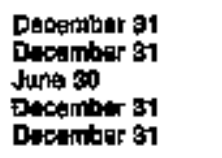 \\
\hline 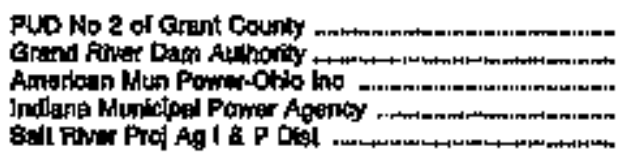 & 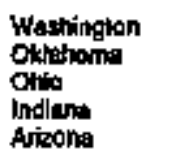 & $\begin{array}{l}5,910,043 \\
4,790,884 \\
4,193,926 \\
3,899,540 \\
3,662,470\end{array}$ & $\begin{array}{l}\text { Dacambar } 31 \\
\text { Decomber } 31 \\
\text { Dacember } 31 \\
\text { Decenber } 31 \\
\text { Apil } 30\end{array}$ \\
\hline 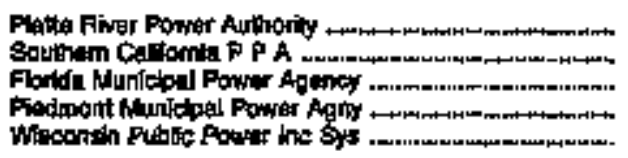 & 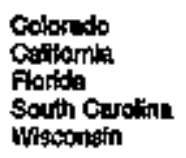 & $\begin{array}{l}3,664,648 \\
3,205,132 \\
3,180,054 \\
3,118,2802 \\
3,089,668\end{array}$ & 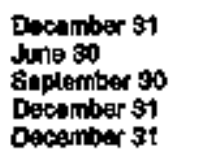 \\
\hline
\end{tabular}

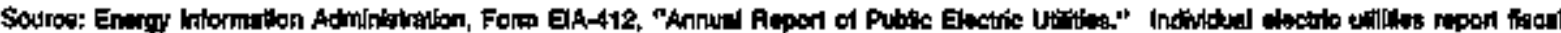

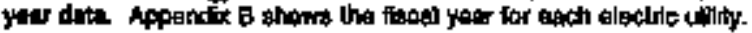


Tanle C39. Twenty Largest U.S. Publlcty Owned Electric Utilites Ranked by Electric Utility Ravenues for All Respondents, 1994 (Thousand Dollars)

\begin{tabular}{|c|c|c|c|}
\hline Publlely Owned Electrk Ualluter & Statio & Amounk & Reportag Dato \\
\hline 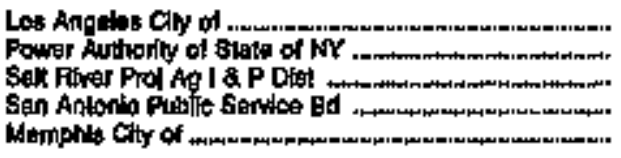 & 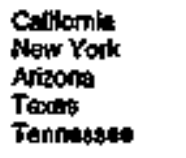 & 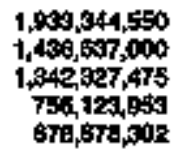 & 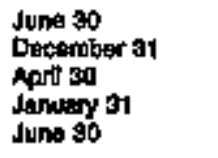 \\
\hline 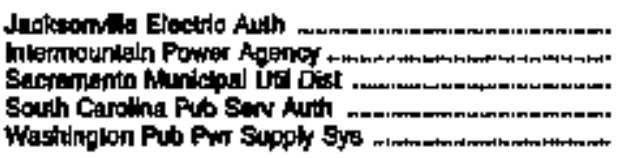 & $\begin{array}{l}\text { Forida } \\
\text { Wtah } \\
\text { Catitomia } \\
\text { South Caroning } \\
\text { Waghinglon }\end{array}$ & $\begin{array}{l}68,201,090 \\
697,240,000 \\
644,342,102 \\
60,200,000 \\
504,770,350\end{array}$ & $\begin{array}{l}\text { Sepkentber } 30 \\
\text { Jung } 30 \\
\text { December at } \\
\text { Decomber } 31 \\
\text { June } 30\end{array}$ \\
\hline 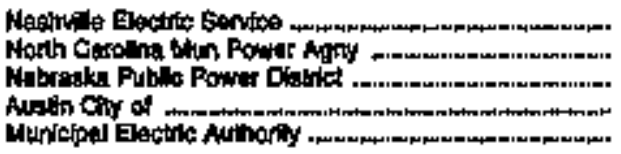 & 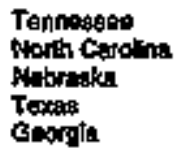 & $\begin{array}{l}571,508,177 \\
640,805,010 \\
610,207,441 \\
49,510,273 \\
494,771,000\end{array}$ & 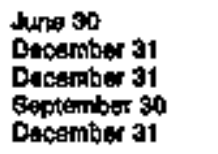 \\
\hline 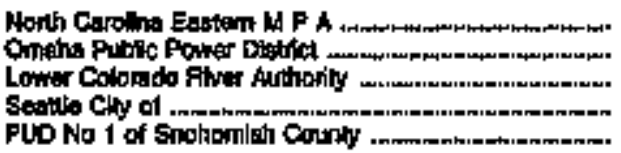 & 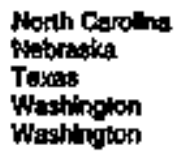 & 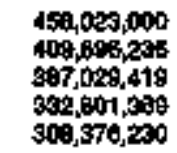 & 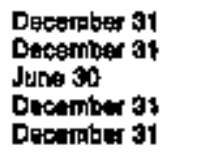 \\
\hline
\end{tabular}

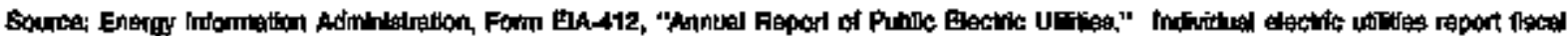

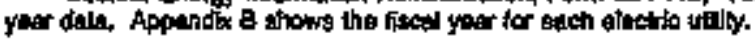

Table CA0. Twenty Largest US. Publicty Owned Eleotrio Utilties Ranked by Purchase Power Expenses for All Bespondents, 1994 (Thousand Dollars)

\begin{tabular}{|c|c|c|c|}
\hline 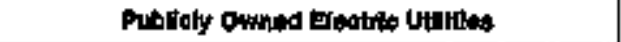 & Ethth & Antount & Eeporting Doth \\
\hline 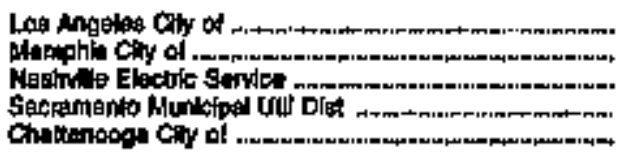 & 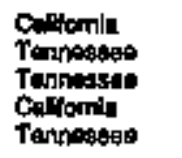 & 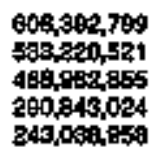 & $\begin{array}{l}\operatorname{lung} 30 \\
\ln 30 \\
\text { June so } \\
\text { Decopolber } 31 \\
\text { June } 30\end{array}$ \\
\hline 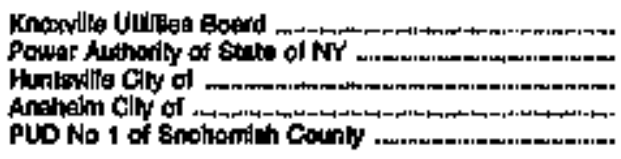 & 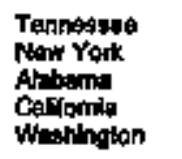 & $\begin{array}{l}217,687,259 \\
209,946,000 \\
13,080,640 \\
136,602,000 \\
138,920,025\end{array}$ & 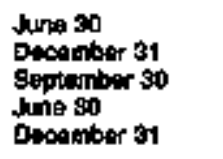 \\
\hline 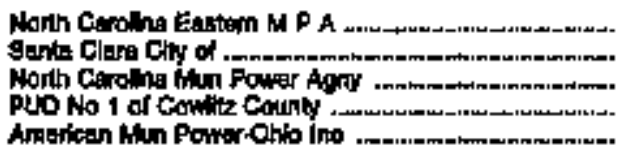 & 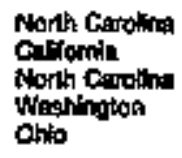 & 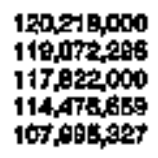 & 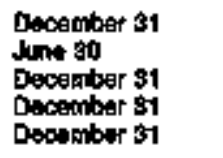 \\
\hline 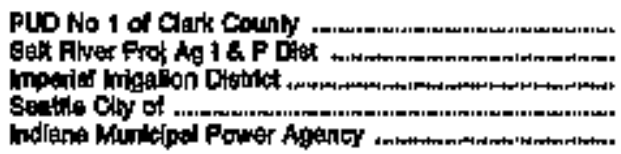 & 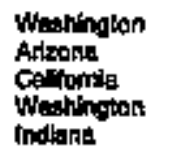 & 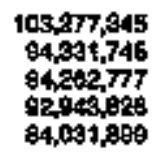 & $\begin{array}{l}\text { Docomber } 31 \\
\text { Aprit } 30 \\
\text { Decomber } \$ 1 \\
\text { Decombar } 31 \\
\text { Dencember } \$ 1\end{array}$ \\
\hline
\end{tabular}

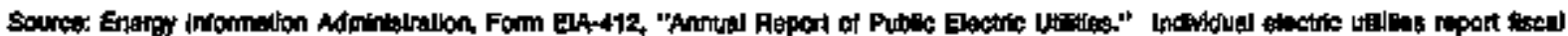

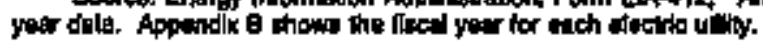


Table C41. Twenty Langest U.S. Publicly Owned Electric Utatiles Ranked by Electric Utility Piant for All Respondients, 1984

(Thousand Dollars)

\begin{tabular}{|c|c|c|c|}
\hline Publely Ounnd Elatrio tolibus & Stoto & Ampount & Atporting Dale \\
\hline 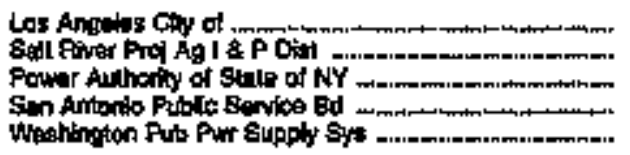 & 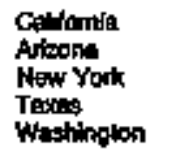 & 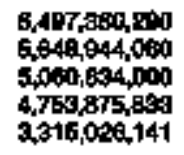 & 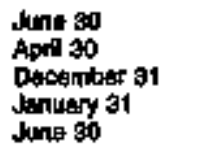 \\
\hline 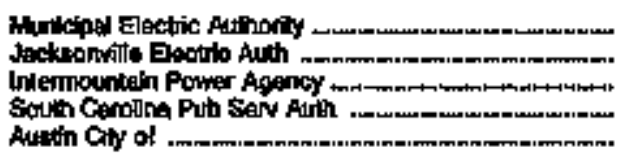 & 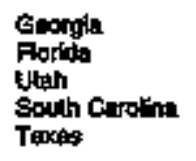 & $\begin{array}{l}3,042,950,000 \\
2,871,709,001 \\
2,84,000,000 \\
2,6+0,850,000 \\
2,152,789,451\end{array}$ & $\begin{array}{l}\text { gecomber } 31 \\
\text { september \$D } \\
\text { Jum } 30 \\
\text { gecamber } \$ 1 \\
\text { \$eptember \$0 }\end{array}$ \\
\hline 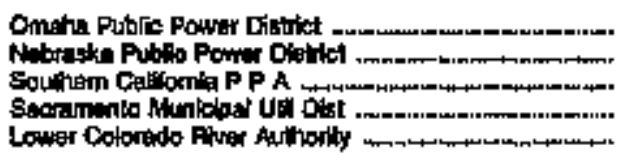 & 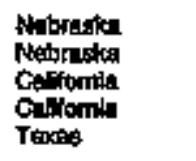 & 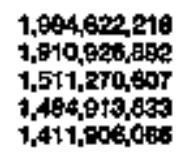 & $\begin{array}{l}\text { Decamber } 81 \\
\text { Dectimber } 31 \\
\text { June } 30 \\
\text { Decomber } 31 \\
\text { Junt } 30\end{array}$ \\
\hline 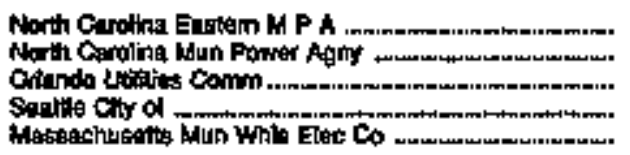 & 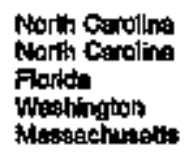 & $\begin{array}{l}1,410,129,000 \\
1,401,624,000 \\
1,260,004,069 \\
1,244,225,500 \\
1,232,300,040\end{array}$ & $\begin{array}{l}\text { December } 31 \\
\text { Docember } 31 \\
\text { September } 30 \\
\text { December } 31 \\
\text { Decamber } 31\end{array}$ \\
\hline
\end{tabular}

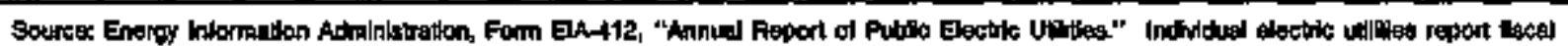

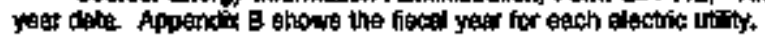

Table C42. Twenty Largest U.S. Publkly Omned Electrito Utities Ranked by Construction Work in Progress for All Reapondento, 1994 (Thousand Dollars)

\begin{tabular}{|c|c|c|c|}
\hline Publaly Onened Electric tullon & stote & Amownt & Raporting Deto \\
\hline 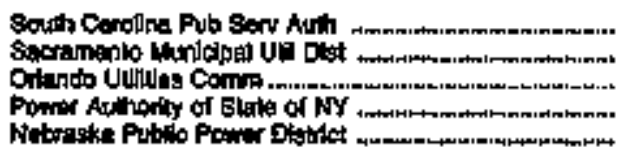 & 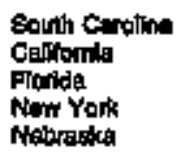 & 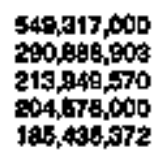 & $\begin{array}{l}\text { Decomber } 31 \\
\text { Decomber } 31 \\
\text { September } 30 \\
\text { December } 31 \\
\text { Decamber } 37\end{array}$ \\
\hline 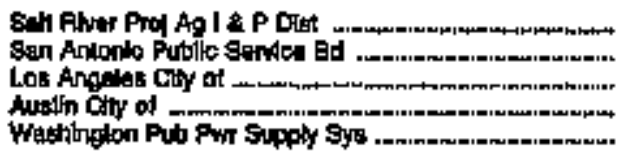 & 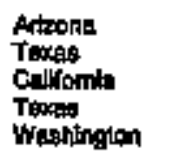 & $\begin{array}{l}193,669,784 \\
190,632,773 \\
179,689,140 \\
127,8969727 \\
116,677,029\end{array}$ & 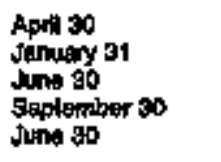 \\
\hline 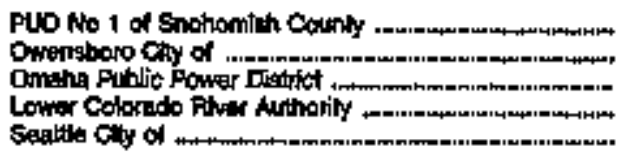 & 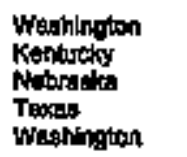 & $\begin{array}{l}114,390,698 \\
113,597,7,78 \\
110,845,798 \\
107,042,009 \\
10,6,692,349\end{array}$ & 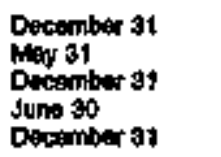 \\
\hline 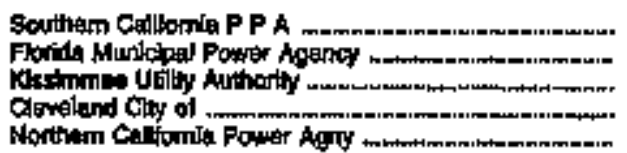 & 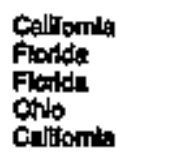 & $\begin{array}{l}102,496,8,96 \\
69,97,600 \\
84,912,141 \\
56,352,681 \\
\$ 4,410,000\end{array}$ & 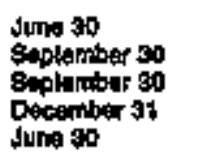 \\
\hline
\end{tabular}

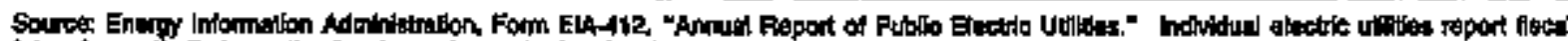

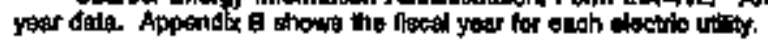


Table C43. Compostte Statement of Income for Major U.S. Publicly Owned Electric Uttutles for All Respondents, 1990-1994 (Thousand Dollars)

\begin{tabular}{|c|c|c|c|c|c|}
\hline nem & 1094 & 1983 & tsoe & 1991 & istop \\
\hline 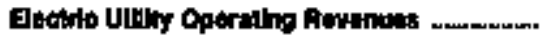 & $31,262,318$ & 30,0 : 5,300 & $2: 435,7=5$ & $20,792,745$ & $27,449,120$ \\
\hline 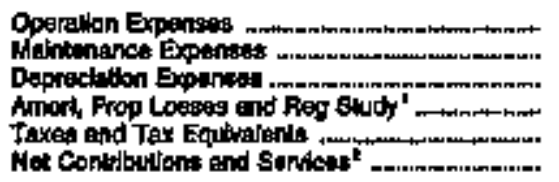 & $\begin{array}{r}20,435,545 \\
1,818,411 \\
2,880,213 \\
134,117 \\
8 B 7,106 \\
=\end{array}$ & $\begin{array}{r}19,008,305 \\
1,772,339 \\
2,094,777 \\
158,059 \\
995,695 \\
-\end{array}$ & $\begin{array}{r}18,772,260 \\
1,757,427 \\
2,639,847 \\
134,511 \\
866,134 \\
-\end{array}$ & $\begin{array}{r}18,274,460 \\
1,632,589 \\
2,547,148 \\
734,709 \\
558,189\end{array}$ & $\begin{array}{r}17,979,112 \\
1,847,407 \\
2,308,702 \\
683,187 \\
688,149\end{array}$ \\
\hline 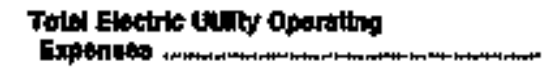 & $28,415,492$ & $25,226,425$ & $24,084,169$ & $23,748,541$ & $20,301,623$ \\
\hline Nel Elocule U:Hy Oporating incomp & $6,046,1065$ & $4,819,876$ & $4,899,671$ & $4,456,804$ & $4,247,497$ \\
\hline 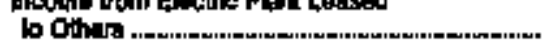 & 32,426 & 25,081 & 16,912 & 9.207 & 13,452 \\
\hline 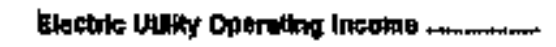 & $5,079,312$ & $4,045,958$ & $4,916 / 73$ & $1,465,411$ & $4,260,949$ \\
\hline 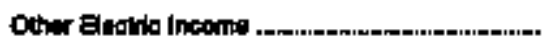 & $T, 425,68 \mathrm{Bg}$ & $1,028,682$ & $2,012,42,2$ & $2,0037,255$ & $1,889,347$ \\
\hline 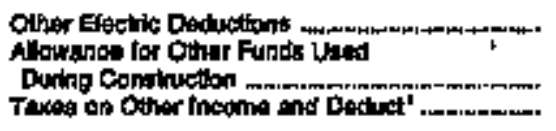 & $\begin{array}{r}2+5,181 \\
7,820 \\
40,184\end{array}$ & $\begin{array}{l}33,659 \\
28,692 \\
27,965\end{array}$ & $\begin{array}{l}324,310 \\
24,222 \\
25,807\end{array}$ & $\begin{array}{r}137,294 \\
72,602 \\
-\end{array}$ & $\begin{array}{r}= \\
t 20,090\end{array}$ \\
\hline 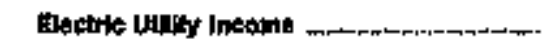 & $6,249,471$ & $6,136,407$ & $6,800,007$ & 4,438,000 & $6,273,365$ \\
\hline 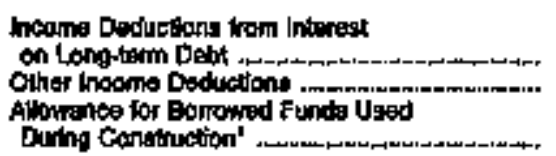 & $\begin{array}{r}4,40,043 \\
485,469 \\
-46,827\end{array}$ & $\begin{array}{r}4,547,594 \\
360,500 \\
.40,270\end{array}$ & $\begin{array}{r}4,668,961 \\
345,454 \\
+45,797\end{array}$ & $\begin{array}{r}4,697,654 \\
468,570\end{array}$ & $\begin{array}{r}4,773,006 \\
40,181 \\
-\end{array}$ \\
\hline 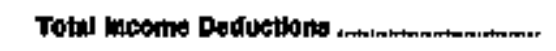 & $1,937,674$ & 4,054,ats & $5,766,618$ & $5,345,605$ & $5,202,247$ \\
\hline 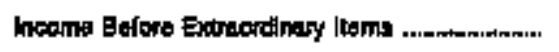 & $1,406,988$ & $1,209,692$ & $1,436,3802$ & $1,092,009$ & $1,071,1 \mathrm{ts}$ \\
\hline Extracidinary thoome & 117,547 & 67,78 & 146,747 & 128,504 & 141,888 \\
\hline 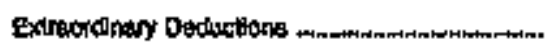 & 241,670 & 327,605 & 264,178 & 188,300 & 252,239 \\
\hline Hat theolita . . & $1,277,966$ & $1,043,768$ & $1,318,861$ & $t, 017,603$ & 860,845 \\
\hline 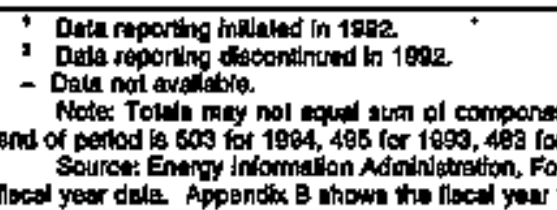 & & 4 & נ. & 4 & 1 \\
\hline
\end{tabular}


Table C44. Composite Balance Sheet for Major U.S. Publiely Owned Electrle Utilities for All Respondents at End of Period, 1990-1994

(Thousand Dollars)

\begin{tabular}{|c|c|c|c|c|c|}
\hline Rem & 1994 & $19 x$ & $19 \mathrm{sp}$ & 1891 & 1900 \\
\hline 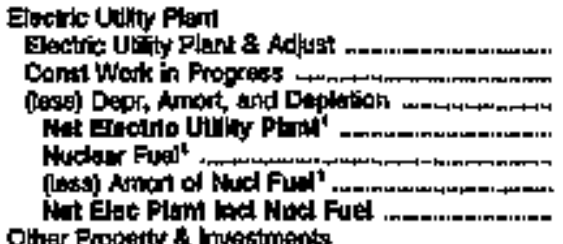 & 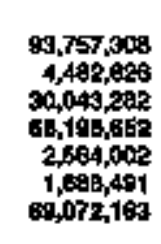 & $\begin{array}{r}10,051,059 \\
4,089,619 \\
27,273,464 \\
76,816,911 \\
2,680,170 \\
1,680,775 \\
67,746,614\end{array}$ & 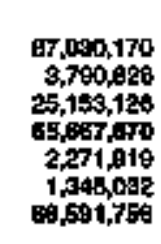 & $\begin{array}{r}38,854,281 \\
23,454,3044 \\
= \\
= \\
66,399,837\end{array}$ & $\begin{array}{r}65,108,007 \\
21,101,995 \\
54,004,0032\end{array}$ \\
\hline 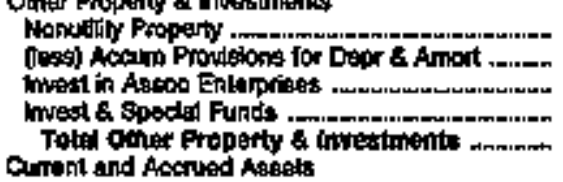 & $\begin{array}{r}7,541,303 \\
2,201,902 \\
202,296 \\
17,393,494 \\
-20,679,191\end{array}$ & $\begin{array}{r}6987,700 \\
2,136,049 \\
374,792 \\
17,207,623 \\
22,398,120\end{array}$ & $\begin{array}{r}6,467,698 \\
1,977,104 \\
255,281 \\
16,416,346 \\
20,119,399\end{array}$ & $\begin{array}{r}6,089,837 \\
1,840,691 \\
87,717 \\
14,855,266 \\
19,162,166\end{array}$ & $\begin{array}{r}5,870,256 \\
1,712,103 \\
101,471 \\
13,02,271 \\
17,671,694\end{array}$ \\
\hline 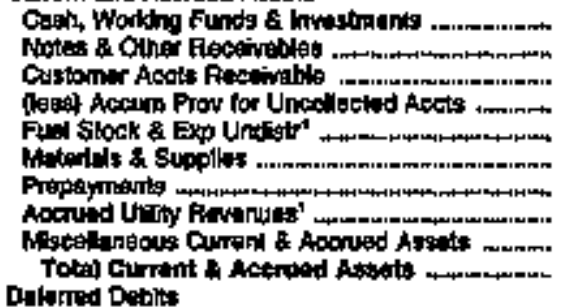 & 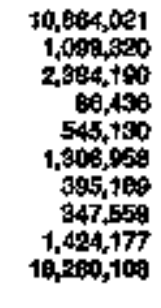 & $\begin{array}{r}10,890,868 \\
1,102,641 \\
2,374,004 \\
125,066 \\
498,473 \\
1,293,844 \\
\$ 93,297 \\
1,94,841 \\
1,102,481 \\
17,9,2,972\end{array}$ & $\begin{array}{r}10,521,161 \\
1,047,990 \\
8,141,085 \\
121,394 \\
545,911 \\
1,391,030 \\
405,001 \\
297,478 \\
1,058,908 \\
17,217,790\end{array}$ & $\begin{array}{r}10,485,643 \\
3,055,407 \\
154,245 \\
1,706,964 \\
377,684 \\
692,469 \\
16,246,162\end{array}$ & $\begin{array}{r}10,316,691 \\
3,254,072 \\
104,320 \\
1,620,700 \\
321,670 \\
15,903,141\end{array}$ \\
\hline 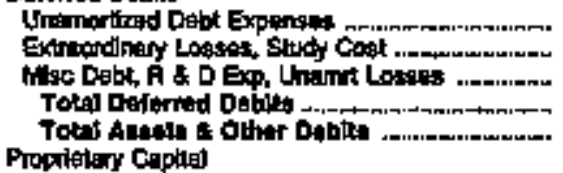 & $\begin{array}{r}2,989,439 \\
822,306 \\
10,902,367 \\
14,314,201 \\
124,144,606\end{array}$ & $\begin{array}{r}2,598,132 \\
\$ 18,432 \\
10,958,687 \\
14,411,220 \\
120,418,042\end{array}$ & $\begin{array}{r}2,291,314 \\
469,651 \\
9,842,349 \\
12,403,304 \\
116,335,289\end{array}$ & $\begin{array}{r}1,000,169 \\
34,350 \\
9,271,082 \\
11,214,901 \\
112,043,449\end{array}$ & $\begin{array}{r}1,830,959 \\
31,911 \\
0,335,276 \\
10,109,147 \\
107,705,166\end{array}$ \\
\hline 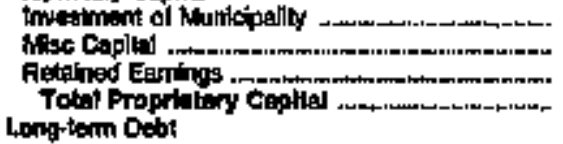 & $\begin{array}{r}1,897,267 \\
772,032 \\
26,131,109 \\
80,100,498\end{array}$ & $\begin{array}{r}1,001,224 \\
658,509 \\
28,983,181 \\
20,510,873\end{array}$ & $\begin{array}{r}1,865,550 \\
524,110 \\
20,057,700 \\
29,345,498\end{array}$ & 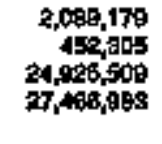 & $\begin{array}{r}1,901,842 \\
145,205 \\
24,368,102 \\
20,574,251\end{array}$ \\
\hline 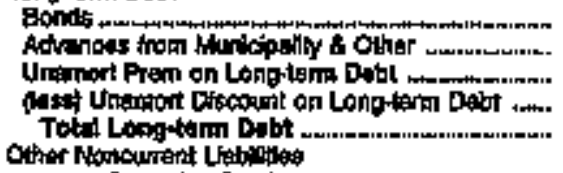 & $\begin{array}{r}77,480,291 \\
5,376,899 \\
80,062 \\
8,381,207 \\
78,1590,616\end{array}$ & $\begin{array}{r}77,624,677 \\
4,180,027 \\
47,445 \\
2,044,060 \\
70,067,600\end{array}$ & $\begin{array}{r}74,050,100 \\
2,972,520 \\
70,350 \\
2,076,041 \\
74,719,112\end{array}$ & $\begin{array}{r}70,415,938 \\
3,581,423 \\
16,960 \\
2,699,469 \\
71,413,451\end{array}$ & $\begin{array}{r}67,435,694 \\
3,679,676 \\
1,469 \\
2,465,742 \\
60,459,400\end{array}$ \\
\hline 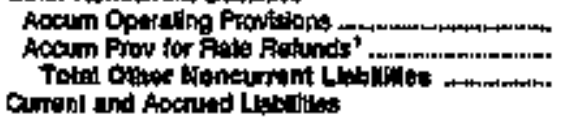 & $\begin{array}{l}608,270 \\
104,542 \\
712,020\end{array}$ & $\begin{array}{l}496,149 \\
115,389 \\
601,638\end{array}$ & $\begin{array}{r}70,751 \\
4,498 \\
700,4035\end{array}$ & $\begin{array}{r}677,995 \\
677,966\end{array}$ & $\begin{array}{l}473027 \\
473,427\end{array}$ \\
\hline 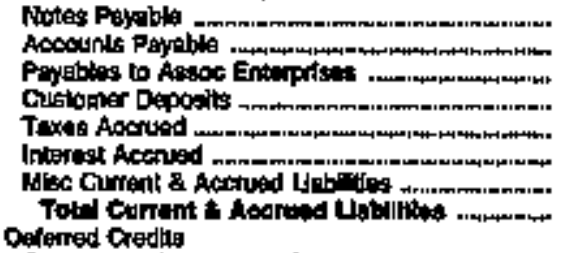 & $\begin{array}{r}1,344,467 \\
2,839,353 \\
325,697 \\
195,025 \\
346,280 \\
1,545,141 \\
3,284,750 \\
10,012,006\end{array}$ & 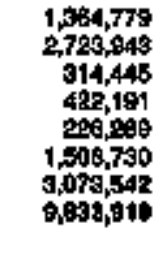 & 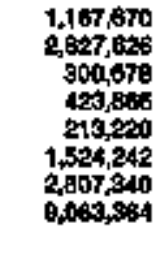 & $\begin{array}{r}1,294,298 \\
2,437,691 \\
269,323 \\
364,587 \\
295,651 \\
1,549,977 \\
2,642,284 \\
0,918,694\end{array}$ & 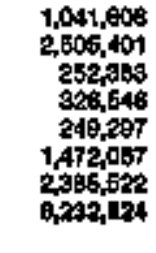 \\
\hline 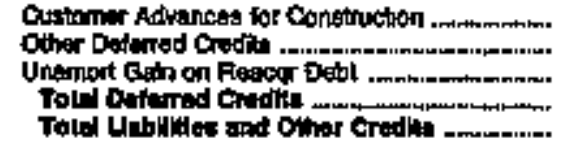 & $\begin{array}{r}231,470 \\
3,010,570 \\
238,916 \\
3,400,486 \\
124,544,469\end{array}$ & $\begin{array}{r}209,307 \\
3,905,314 \\
311,3012 \\
3,695,012 \\
129,409,042\end{array}$ & $\begin{array}{r}218,047 \\
2,889,706 \\
369,640 \\
3,495,309 \\
110,392,289\end{array}$ & $\begin{array}{r}189,399 \\
2,912,504 \\
568,040 \\
3,670,916 \\
11,049,40\end{array}$ & $\begin{array}{r}171,257 \\
2,6,69,551 \\
424,657 \\
3,464,365 \\
107,705,506\end{array}$ \\
\hline
\end{tabular}

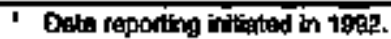

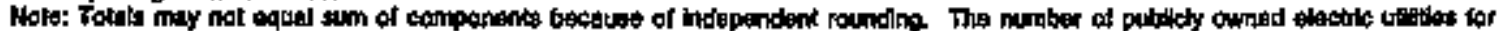

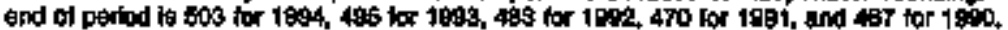

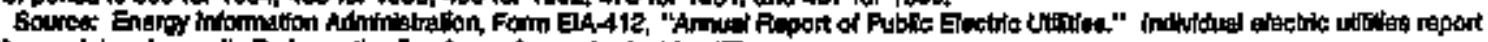

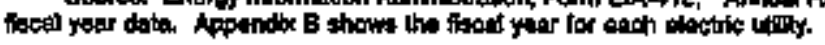


Table C45. Composite Financlal Indlcators for Major U,S. Publicly Owned Electric Utilities for All Rispontents, 1990-1994

\begin{tabular}{|c|c|c|c|c|c|}
\hline hentir & 1894 & 1989 & 1002 & 1591 & 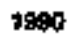 \\
\hline 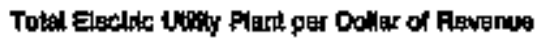 & 9,2 & 3.2 & 3.2 & 32 & 3.1 \\
\hline 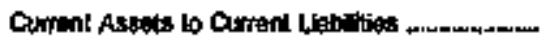 & 1.8 & $1 . s$ & 1,9 & 1.0 & 1,5 \\
\hline 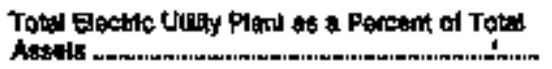 & 80.9 & 700 & $\cos 0$ & 79.3 & 790 \\
\hline 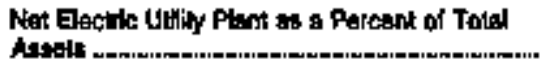 & 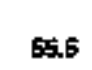 & 65s & 67.2 & 58.4 & 59,1 \\
\hline Dobl as a Pertent of Tota Linbliba & 71.0 & $72 S$ & 720 & 71.8 & $\mathrm{M}, \mathrm{B}$ \\
\hline 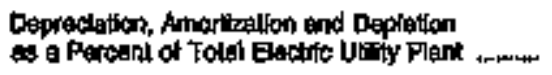 & 91.5 & 29.9 & 295 & 26.4 & 24.6 \\
\hline 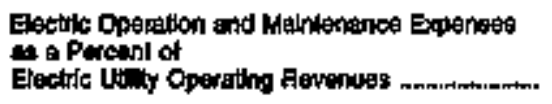 & 72 & 71.4 & 71.0 & 700 & 71.6 \\
\hline 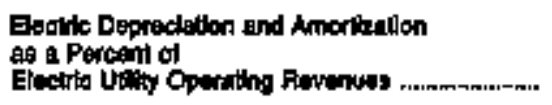 & 9.1 & $\theta .0$ & A.8 & 8.0 & B.4 \\
\hline 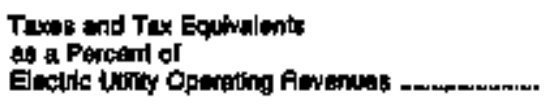 & 3.1 & 3.1 & ag & $\mathbf{2 . 8}$ & 2.5 \\
\hline 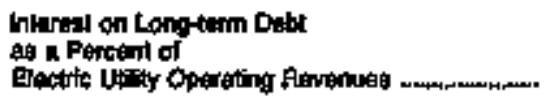 & 148 & 15,1 & 16.8 & 17,3 & 17.4 \\
\hline 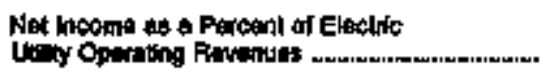 & 4.1 & 3.5 & 4.6 & $3 . \dot{\theta}$ & 3.5 \\
\hline Purahnewd Power Conss Per kllownathour ........ & 3.9 & $\mathbf{3 . B}$ & 3.9 & 3.9 & ss \\
\hline Genurated Cents Per Kolowathour ................ & f.g & 1.9 & 1.9 & 1.8 & 1.8 \\
\hline 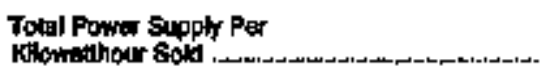 & 3.0 & 3,0 & $\mathbf{3 . 1}$ & 3.0 & 3.0 \\
\hline
\end{tabular}


Table C46. Electric Operation and Haintenance Expenses for Najor U.S.

Publichy Owmed Electrio Utillites for All Respondents, 1990-1994

(Thousand Dollars)

\begin{tabular}{|c|c|c|c|c|c|}
\hline Itan & 1004 & $10 \mathrm{ses}$ & 100 & 1901 & 1000 \\
\hline \multicolumn{6}{|l|}{ Produotlon Expennes: } \\
\hline 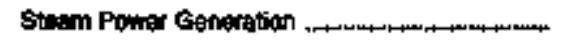 & 4,037848 & $n_{4,105,002}$ & 3.750 .989 & $3,889,672$ & $3,741,589$ \\
\hline 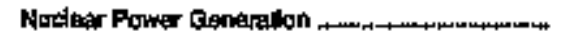 & $7,251,=92$ & $1,304,604$ & $1,378,449$ & $1,217,567$ & $1,133,495$ \\
\hline 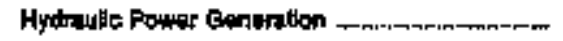 & 243817 & 241,549 & 244,160 & 225,099 & 204,512 \\
\hline 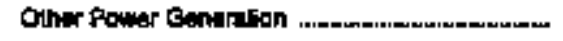 & 178,982 & 179,738 & $175,8 \pi$ & 167,280 & 198,419 \\
\hline 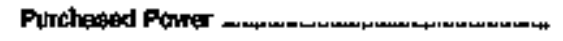 & $11.808,960$ & $11,007,002$ & 10,894, and & $10,571,167$ & $10,541,975$ \\
\hline OTher froducton Expensess & 154,633 & 140,868 & 80,582 & $102, \pi / 2$ & 164,970 \\
\hline Total Produrilon Explenes: .. & $17,7 \times 18,230$ & n 17,06s, osta & *6,416,200 & $15,978,107$ & 15,$972 ; 241$ \\
\hline 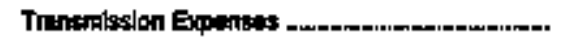 & 766,010 & 724,745 & 67,711 & 045,169 & 604,017 \\
\hline Dtstribution Exponats. & $1,240,104$ & $1,1009,411$ & $1,126,391$ & $1,027,678$ & 950,27 \\
\hline 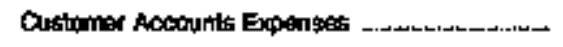 & 455,813 & 432,343 & 408,405 & Sess,468 & 374,729 \\
\hline Cuntomex Servica and hloxmelon Expenses a- & 121,042 & 111,205 & 06,350 & 80,056 & 74,710 \\
\hline 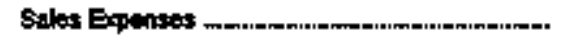 & 9epsis & es,014 & 29,191 & 20,605 & 29,900 \\
\hline Administratwo and Generel Expentes & $1,954,998$ & $1,671,156$ & $1,774,365$ & $1,740,28$ & $1,610,500$ \\
\hline 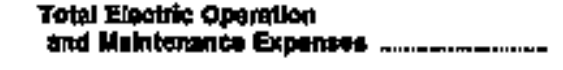 & 22,256,408 & $21,430,603$ & $20,520,095$ & 19,007,020 & $19,625,5 t$ \\
\hline \multicolumn{6}{|l|}{ 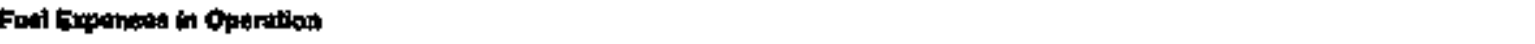 } \\
\hline 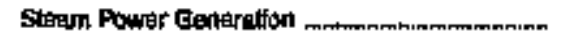 & $2,970,628$ & $3,036,077$ & $2,733,48 t$ & $2,604,848$ & $2,394,668$ \\
\hline 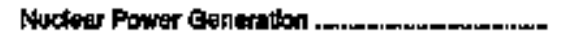 & $\mathbf{s 1 s , 8 0 0 3}$ & 289,445 & $\mathbf{5 n g}, 04 \mathrm{~A}$ & 845,206 & 242,283 \\
\hline 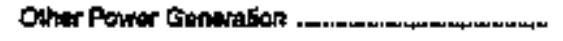 & 101,302 & 102,414 & ac,acs & 9et19 & 113,041 \\
\hline \multicolumn{6}{|l|}{ Numiter of Eloo Depk Employene. } \\
\hline Reglar Fuldims' & 73,923 & 78,315 & 74,695 & - & $=$ \\
\hline 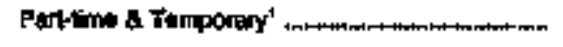 & 2,834 & 3,041 & 3,006 & - & $=$ \\
\hline Tohal Eloc Deph Employeen' & 78,044 & $76,48 *$ & $r t, 7 t: t$ & - & - \\
\hline
\end{tabular}

1 Dake teporing infitalod in 1902

R = Rivitat data.

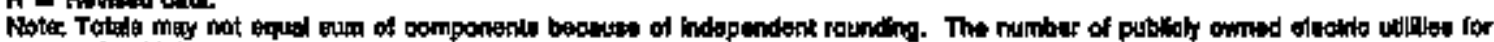

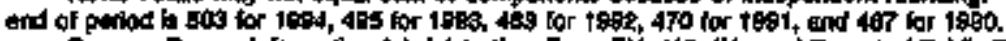

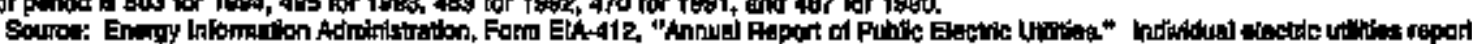

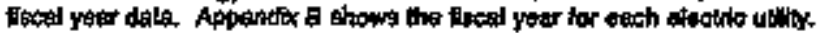


Tabje C47. Electic Utilty Plant for Major U.S. Publichy Owned Electric

Utilties for All Respondents at End of Period, 1990-1994

(Thousand Dollars)

\begin{tabular}{|c|c|c|c|c|c|}
\hline Hem & 1004 & 1893 & 1992 & 1901 & 1000 \\
\hline \multicolumn{6}{|l|}{ Eloctide ptant In 8arike } \\
\hline Iflangito Ptank & $5: 7,021$ & $95 \tau, 052$ & 294,715 & 373,272 & 3es, ses \\
\hline \multicolumn{6}{|l|}{ Production Plant } \\
\hline 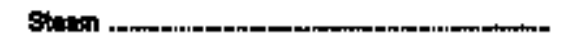 & $24,334,200$ & $24,239,169$ & $20,415,620$ & $12,550,413$ & $21,246,648$ \\
\hline 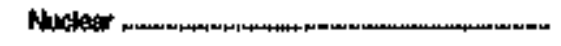 & $18,706,140$ & 18,914,sto & $18,740,460$ & $10,440,482$ & $16,992,607$ \\
\hline 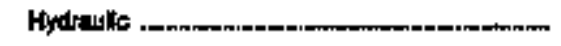 & $7,830,107$ & $7,648,270$ & $7,500,768$ & $6,991,010$ & $0,862,874$ \\
\hline 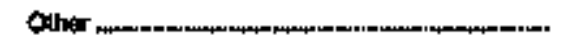 & $2,471,586$ & $1, \mathrm{~B} 40,331$ & $1,887,000$ & $1,578,289$ & 1,639,497 \\
\hline 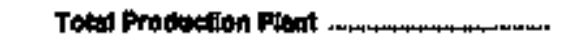 & $\$, 4,31,049$ & $52,545,619$ & $51,565,142$ & $50,584,209$ & $49,790+, 005$ \\
\hline Tranemlesion Pland .-. & $0,920,860$ & $9,548,897$ & $9,345,9095$ & $0,070,912$ & $0,340,819$ \\
\hline 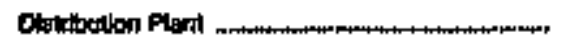 & $2+, 506,957$ & $20,14=, 751$ & to,846,975 & $17,779,290$ & $16,579,615$ \\
\hline Gentral Ptant . .m. & $6,768,564$ & $5,660,450$ & $6,455,979$ & $6,22 t, 083$ & $4,697,428$ \\
\hline 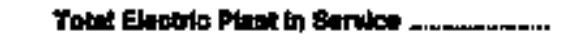 & $12,245,1200$ & $89,452,709$ & $85,499,746$ & asotr, $6 \mathrm{sr}$ & $70,854,54$ \\
\hline Eectic Plant Leased to Others & 16,880 & 17,404 & 69,189 & 566,610 & $4 B 3,654$ \\
\hline 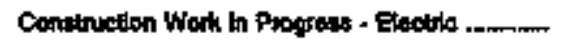 & $4,482,628$ & $4,050,613$ & $3,790,898$ & $4,118,184$ & $4,161,170$ \\
\hline 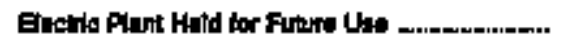 & 313,685 & 397,976 & 321,639 & 040,603 & 830,390 \\
\hline 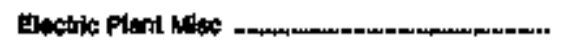 & $1,181,288$ & $1,242,970$ & $1,143,590$ & 610,128 & 787200 \\
\hline Total Eactric Uaily Prant & $90,230,934$ & $04,089,672$ & $90,920,906$ & 69,854,201 & $15,106,027$ \\
\hline 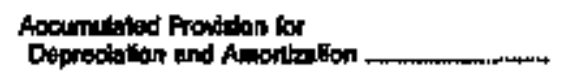 & $30,049,282$ & $27,273,454$ & $26,183,125$ & $22,454,394$ & $21,101,909$ \\
\hline Nat שechitc villty Pint ... & $0: 19+5652$ & $60,616,219$ & $65,667,970$ & $65,309,637$ & 54004032 \\
\hline
\end{tabular}

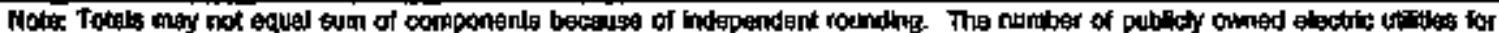

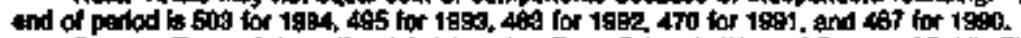

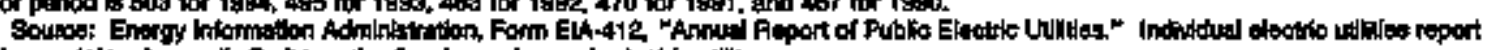

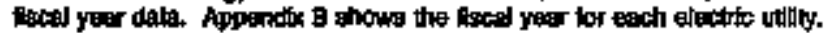


Table C48. Number of Consumers, Sales, and Operating Revenue tor Major U.S. Publicly Owned Electric Utilities

for All Respondents, 1990-1994

\begin{tabular}{|c|c|c|c|c|c|}
\hline Hem & 1994 & 1993 & 1892 & 1991 & 1980 \\
\hline Kunber of Conauner: & & & & & \\
\hline 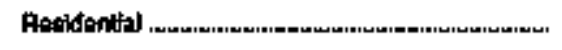 & $11,528,503$ & $n+1,319,389$ & $17,105,178$ & $10,944,058$ & $10,712,154$ \\
\hline 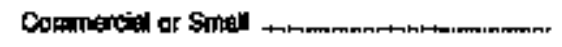 & $1,534,040$ & $=1,502,760$ & $1,477,033$ & $1,396,521$ & $1,386,959$ \\
\hline hondustal or Lepe & 106,152 & 100.639 & 08,002 & 7,691 & 82,683 \\
\hline Other nmmirianm.... & 164,008 & 160,034 & 246,135 & 206,248 & 264,000 \\
\hline Total thimate Consumars. & $13,392,849$ & "13,005;,671 & $12,924,348$ & $12,864,658$ & $12,445,798$ \\
\hline \multicolumn{6}{|l|}{ Solpa for the Year (me-pinwithoura) } \\
\hline 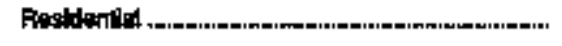 & $127,267,239$ & $123,066,334$ & $117,820,115$ & $118,476,942$ & $116,428,617$ \\
\hline 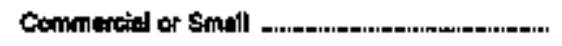 & $\mathrm{gB}, 727,484$ & * $80,830,265$ & $88,817,000$ & $92,271,349$ & $01,071,107$ \\
\hline 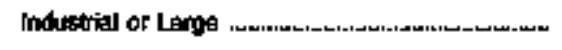 & $135,277,6069$ & - 125,952,830 & $122.151,652$ & $\{13,244,276$ & $111,325,058$ \\
\hline Datrar + & $21,491,742$ & ${ }^{R} 20,474,342$ & $20,914,175$ & $20,790,016$ & $30,493,764$ \\
\hline 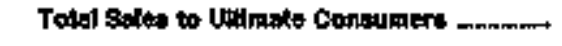 & $372,744,324$ & " $360,003,871$ & $340,388,142$ & $344,732,670$ & $336,266,546$ \\
\hline Sdes for Rasale & $211,395,561$ & $208,07 \mathrm{~s}, 207$ & $191,760,731$ & $100,707,300$ & $195,603,628$ \\
\hline 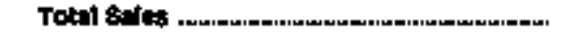 & sab,135,875 & Es6, 102,070 & $541,069,073$ & $595,579,679$ & $533,000,072$ \\
\hline \multicolumn{6}{|l|}{ 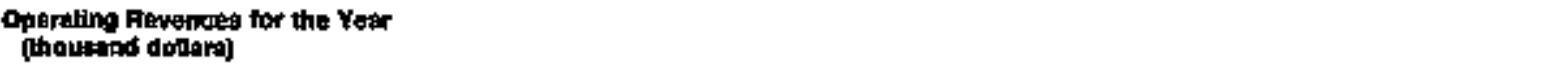 } \\
\hline 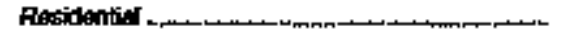 & a, 538, 126 & "8.125.274 & $7,67 t, 058$ & 7.512 .582 & $7,335,329$ \\
\hline 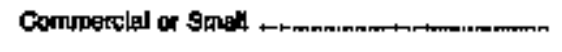 & $5,909,051$ & $* 0,107,260$ & $6,648,417$ & 5,924,645 & 5, ,eas, 278 \\
\hline 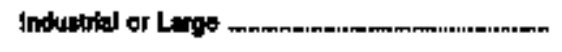 & $8,510,710$ & $n_{B, 040,473}$ & $5,707,886$ & $6,305,256$ & $6,106,253$ \\
\hline 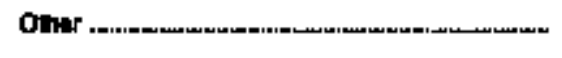 & $1,5389,894$ & ${ }^{*} 1,452,014$ & $1,494,609$ & $1,909,801$ & $1,333,960$ \\
\hline 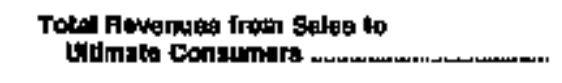 & $22,570,790$ & n 21,735,090 & $\mathbf{x 0 , 7 4 7 , 1 4 5}$ & $20,045,204$ & (5,725,8t: \\
\hline Stales for Retale & 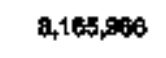 & $7,898,849$ & $7,478,049$ & $7,221,545$ & $7,397,549$ \\
\hline 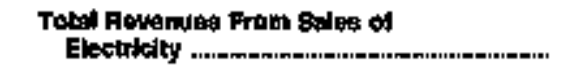 & 3a,735,75s & " 29,-75, 900 & $28,225,+74$ & $27,267,520$ & $27,123,3918$ \\
\hline
\end{tabular}

$R=$ Foviged Data

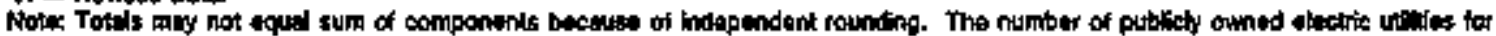
end of period is 503 lor 1994, 4651989,463 for 1992,470 for 1901 , and 467 lor 1990 . slons.

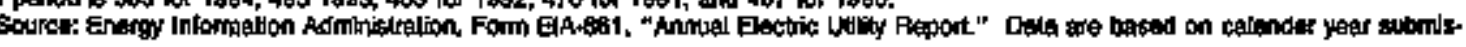


Table C49. Electric Energy Account for Major U.S. Publlcly Owned Electric Utilities for All Respondents, 1990-1994

(Megawatthours)

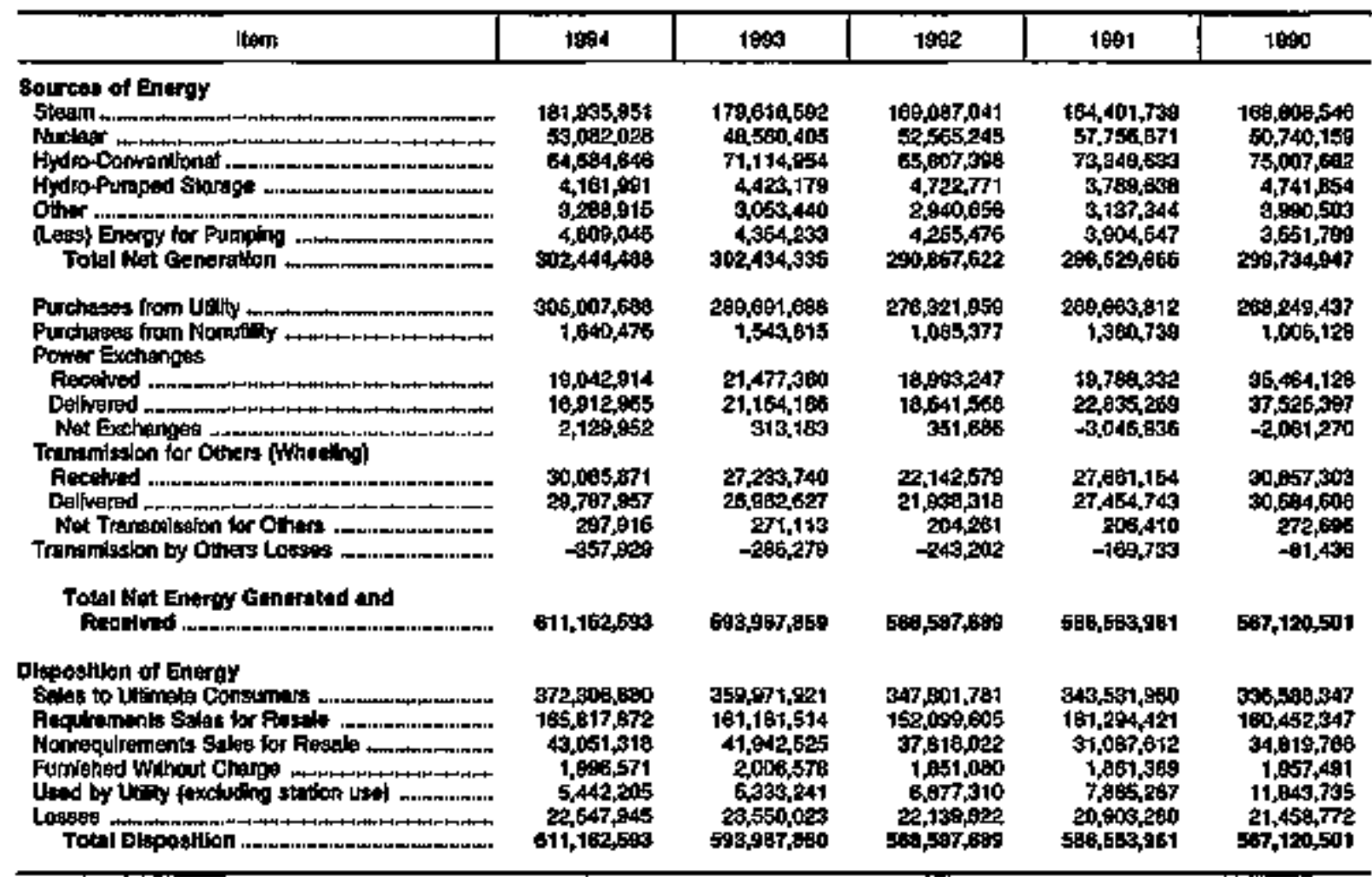

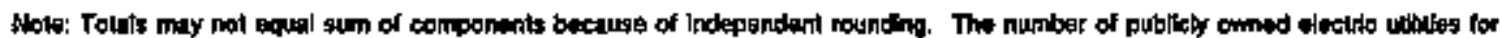

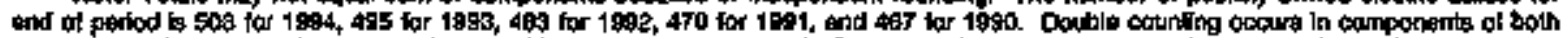

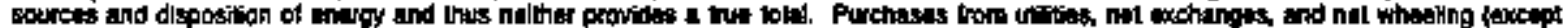

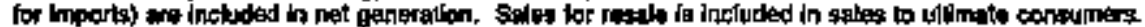

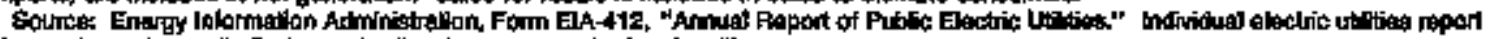

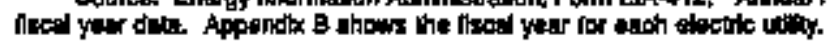


Table C50. Comparison of the Eneroy Account for Najor U.\$. Publicly Owned Electric Utllties for All Respondents, 1990-1994

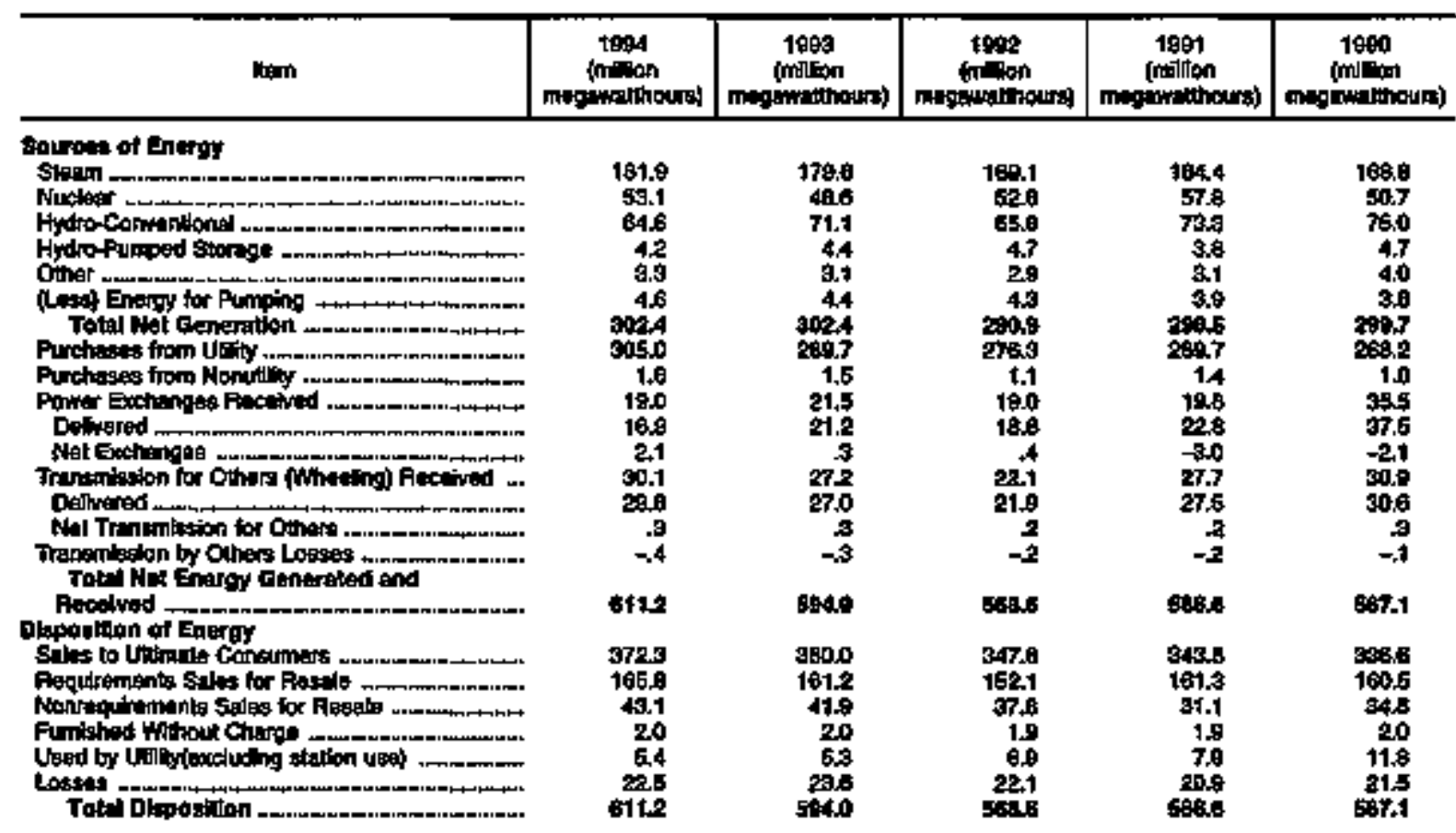

\begin{tabular}{|c|c|c|c|c|}
\hline llom & $\begin{array}{l}\text { Faront } \\
\text { Change } \\
\text { 19gond }\end{array}$ & 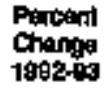 & $\begin{array}{l}\text { Portort } \\
\text { Chring: } \\
\text { 19a1-92 }\end{array}$ & 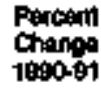 \\
\hline 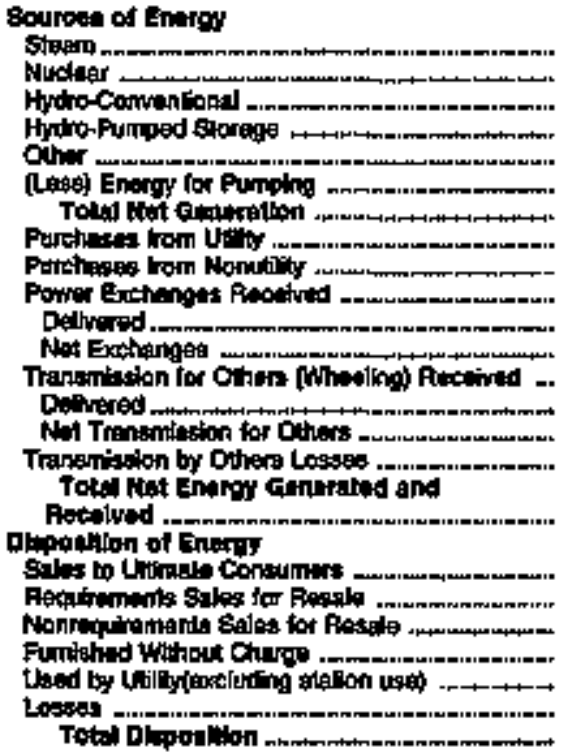 & 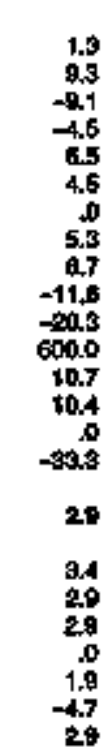 & 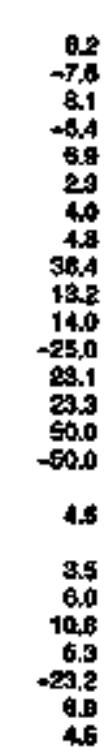 & $\begin{array}{r}2.9 \\
-9.0 \\
-10.2 \\
24.7 \\
-4.5 \\
10.9 \\
-2.5 \\
2.4 \\
-21.4 \\
-4.0 \\
-12.4 \\
112.5 \\
-20.2 \\
-20.4 \\
.0 \\
4 \\
4 \\
1.3 \\
-4.7 \\
21.8 \\
.0 \\
-12.7 \\
6.7 \\
4\end{array}$ & 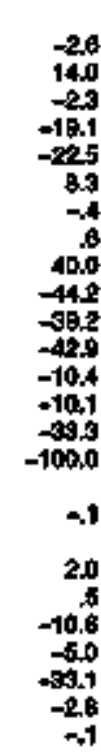 \\
\hline
\end{tabular}

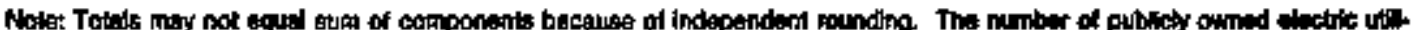

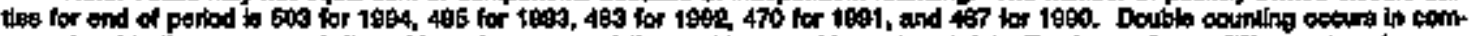

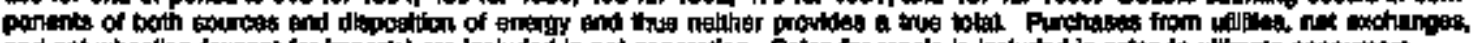

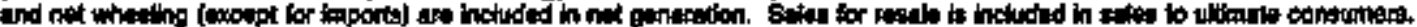

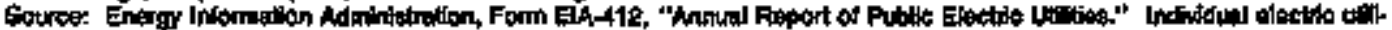

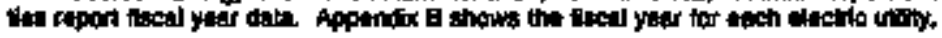




\section{Appendix D}

Regulation of

U.S. Publicly

Owned

Electric

Utilities 



\section{Regulation of U.S. Publicly Owned Electric Utillties}

Table D1. State Agency Authorlyy to Regulate Rates of Public Owned Electric Utlities, 1994

\begin{tabular}{|c|c|c|c|c|c|c|}
\hline \multirow[b]{2}{*}{ Elate } & \multirow[b]{2}{*}{ State Agency Aultionity } & \multirow{2}{*}{$\begin{array}{l}\text { Authority } \\
\text { To Fequilate } \\
\text { Pintas }\end{array}$} & \multirow[b]{2}{*}{ Bounderies } & \multicolumn{3}{|c|}{ Sales Pegulated } \\
\hline & & & & $\begin{array}{l}\text { Whimate } \\
\text { Consumer }\end{array}$ & $\begin{array}{l}\text { Pubtio } \\
\text { Autharty }\end{array}$ & $\begin{array}{l}\text { Sales for } \\
\text { Resalle }\end{array}$ \\
\hline AL & Alabama Public findee Commlisation & Mo & & & & \\
\hline AK & Alakikg Fubic Un'ities Conmission & YES & Inosda soudside & $x$ & $x$ & $x$ \\
\hline $\mathbf{N}$ & Arluons Copporation Comantasion & 10 & & & & \\
\hline AR & 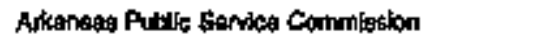 & mo & & & & \\
\hline CA & 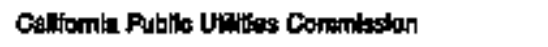 & No & & & & \\
\hline$\infty$ & Coloredo Publia triviss Commlasion & eto & oudinds & & & \\
\hline Cा & 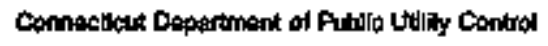 & LTO & & & & $x$ \\
\hline DE & Detantere Public Senvite Comunketion & No & & & & \\
\hline $\mathbf{F L}$ & Forida Pubits Sentar Compdision & tTo & iaglde \& qutalde' & $x$ & $x$ & \\
\hline ex & Goorda Putallo Sonto Commlition & No & oultide hame oty & & & \\
\hline HI & Hawn: Pubile Urentas Commikstion & mo & & & & \\
\hline 10 & 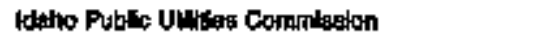 & NO & & & & \\
\hline H. & 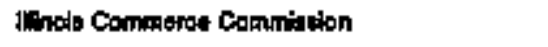 & NO & imtide 8 oultido & & & \\
\hline $\mathbf{N}$ & Indine Utith Repulatory Commislan & LTD & intibe \& oultide" & $x$ & $\mathbf{x}$ & $x$ \\
\hline IA & 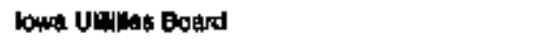 & No & holde \& ouls dde & $x$ & $x$ & \\
\hline KS & Kathease State Corparalion Commilesen & YES & outalde & $x$ & $x$ & $x$ \\
\hline $\mathbf{K r}$ & Kanlueiky Public Service Comnisalon & No & & & & \\
\hline LA & Loublant Fublic Senties Conmlation & No & & & & \\
\hline ME & Malna Pubilic Utrisus Commmation & YES & ottsidita & $x$ & $x$ & \\
\hline$M D$ & Maryland Puble Sersice cammison & YES & intinte \& otstoide & $x$ & $\mathbf{x}$ & \\
\hline MA & 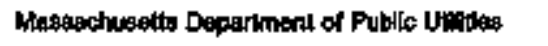 & YES & haidg 8 cutsida & $x$ & $\mathbf{x}$ & $x$ \\
\hline 셰 & Wentign Publo Sondes Commlsalon & No & & & & \\
\hline WN & Minnesola Putbil's Senvol Commistion & No & & & & \\
\hline As & 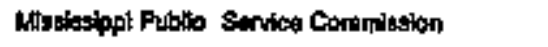 & LTO & 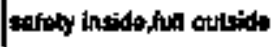 & $x$ & $x$ & \\
\hline No & Mttesourd Pubire Service Commiselon & No & & & & \\
\hline MT & 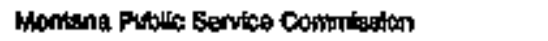 & 10 & 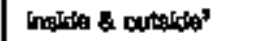 & & & \\
\hline
\end{tabular}

Bane endroles at and of thit lotien. 
Tabie D1. State Agency Authorly to Regulate Rates of Public Owned Electric Utilities, 1994

\begin{tabular}{|c|c|c|c|c|c|c|}
\hline \multirow[b]{2}{*}{ Etata } & \multirow[b]{2}{*}{ State Agentey Authotiky } & \multirow{2}{*}{$\begin{array}{l}\text { Muthority } \\
\text { To preptiate } \\
\text { Ratus }\end{array}$} & \multirow[b]{2}{*}{ Boundtales } & \multicolumn{3}{|c|}{ Salas fiodulated } \\
\hline & & & & Consusto & $\begin{array}{l}\text { Publot } \\
\text { Authority }\end{array}$ & $\begin{array}{l}\text { Sales for } \\
\text { Preatur }\end{array}$ \\
\hline ME & 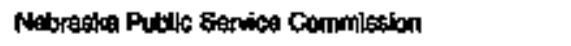 & 96 & instide \& ountala & & & \\
\hline $\mathbf{N}$ & Nevada Pusibe Servica Conumbseion & No & & & & \\
\hline MH & 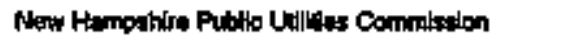 & YES & outopids & $x$ & $x$ & $\mathbf{x}$ \\
\hline inj & 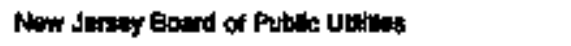 & YES & outiolds & $x$ & & \\
\hline NM & 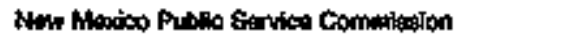 & 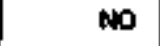 & & & & \\
\hline NH & 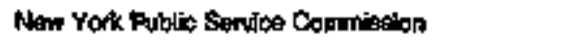 & YES & motide ountate & $x$ & $\mathbf{x}$ & $\mathbf{x}$ \\
\hline NG & 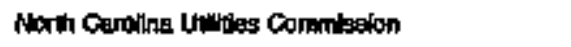 & NO & & & & \\
\hline NO & North Datcota Putilo Sentos Commilselon & NO & & & & \\
\hline OH & Ofilo Publo Ltellites Comrilsoston & No & & & & \\
\hline OK & Odathon: Copporation Commtsalor & no & & & & \\
\hline Oq & 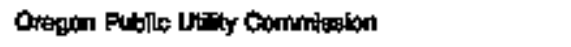 & no & & & & \\
\hline PA & 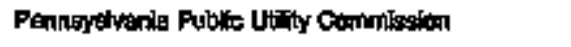 & YES & autsoldo & $x$ & & \\
\hline AI & Finode Island Publio Utilles Commisstion & YES & Malde 8 autabide & $x$ & $x$ & \\
\hline so & Soth Crrotin Putso Service Commitsion & LT & halde a curstido & & & \\
\hline sb & 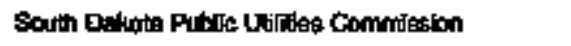 & LTO & cartibita & & & \\
\hline TN & 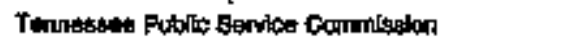 & mo & putistda & & & \\
\hline $\mathbf{T x}$ & 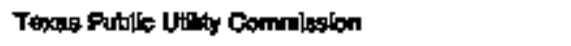 & Yes & outsida & $x$ & $\mathbf{x}$ & $\mathbf{x}$ \\
\hline UT & Ulun Fublic Service Commlaston & ס & & & & \\
\hline $\boldsymbol{r}$ & Vemont Publie Sentoe Baurs & YES & 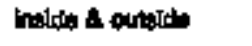 & $x$ & $\mathbf{x}$ & $\mathbf{x}$ \\
\hline VA & 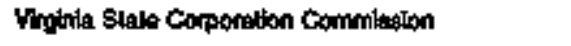 & 10 & & & & \\
\hline WA & 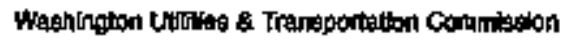 & NO & intide 8 outaldo & & & \\
\hline$w$ & 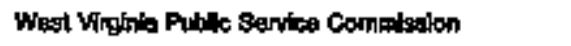 & LTD & & & & \\
\hline M & 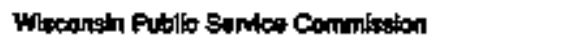 & VES & ineide $\mathbf{3}$ coutside & $\mathbf{x}$ & $\mathbf{x}$ & $\mathbf{x}$ \\
\hline$w r$ & Myaning Putitie Sendes Commission & YES & ontsible & $\mathbf{x}$ & & \\
\hline
\end{tabular}

Tate Schidida.

Pates Orly.

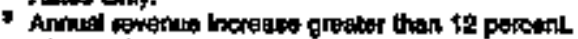

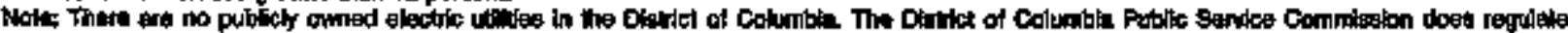

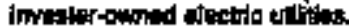

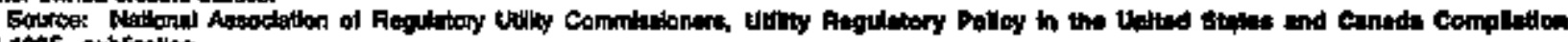
1904-1965, pubitication. 
Appendix E

\section{Technical Notes}





\section{Technical Notes}

\section{Sources of Data}

The Financial Statistics of Mojor U.S. Publicly Owned Electric Utilities (FSMPO) publication is prepered by the Coal and Electric Data and Renewables Division; Office of Cosl, Nuclear, Electric and Altemate Fuels; Energy Information Administration (EIA); U.S. Department of Energy (DOE). Detailed fingncial data published in this publication are from the Form EIA-412, "Arnual Report of Public Electric Utilities. "Other sumunary data are provided from the Form EIA-861, "Annual Electric Utility Report," and the Rural Utitities Service statistics taken from the Statis. tical Report, Rural Electric Bornowers publication for the yeers 1990 throngh 1994. A brief summary of surveys used in this publication is presented below.

\section{Form E/A-412}

The Form EIA.412 is used annually to collect accounting, financial, and operating date from major pablicly owned electric atilitises in the United States. For the fiscal or calendar year that eaded December 31. 1994, the criteria used to seleet the respondents for this survey resulted in submissions by 503 publicly owned and B Federal electric utilities. Those publicly owned electric utilities engaged in the generation, trankmission, or distribution of electricity which had 120,000 megawatthours of sales to ultimate consumers and/or 120,000 megawatthours of sales for resale for the 2 previous years, as reported on the Form EIA-861, "Annual Electric Utility Report," must submit the Form EIA-4t2. Strmary data Bre also pablished in the Electric Power Annual, Volume $I$.

Federally owned electric utilities are reculired to file the Form EIA-412. The financial data for the U.S. Army Corps of Engineers (except for Saint Mary's Falls at Sault St. Marie, Michigan), the U.S. Internatoonal Boundary end Water Commission, and the U.S. Department of Interior Burean of Reclamation were collected on the Form EIA-412 from the Federal power marketing adiministrations.

Instruntent and Deeign History. The FPC ereated the Form 1M in 1961 as a mandatory survey. It became the responsibility of the ELA in October 1977 when the FPC was merged with DOE. Since 1979, the FPC Form $1 M$ has been superseded by the Econoritc Rers- ulatory Administration (ERA) Form ERA-412, and in January 1980 by the Form EIA.412.

Data Processing The processing of data reported on this survey is the responsibitity of the Cosl and Electric Data and Renweables Division' Office of Coal, Nuclear, Electric and Alternote Fuels. The completed surveys are due on April 30 or before the last day of the third month following the close of the fiscal year. Nonresponse follow-up procedures are useff to attain 100 percent response. Antomated systems are used to edit data from the sarveys using deterministic and sta tistical checks. When all data have passed the edit process, the data are aggregated into a master file used as input to the publication.

\section{Form EIA-861}

The Form ELA-861 is a mandatory census of clectric utilities in the United States, its tetritories, and Puerto Rico. The survey is used to collect information on power production and sales data from approximately 3,200 electric utilities in the United States and its territories. These data collected are used to maintain and update the electric utility frame data base for the EIA. This data base supports queries from the Executive Branch, Congress, other public agencies, and the general pubtic. Summary data from the Form ELA-861 are also contsined in Electric Power Monthly, Elactric Power Annutal, Electric Sales and Reventue, Annual Outlook for U.S. Electric Power, Finaneial Sta. thatios of Major U.S. Investor-Onened Electric Utitities and Financial Statistios of Major U.S. Publicly Owned Electric Utilles These reports present aggregate totals for electric utilities on the national and State level by and by ownership type.

Instrmment and Destign History. The Form EIA-B61 was implemented in Joluary 1985 to collect data as of year-end 1984. The Federal Administration Act of 1974 (Public Law 93-275) defines the lepislative authority to collect these data.

Datr Procesaing. The Form EIA-861 is majled to the respondents at year end to collect data for the calendar year. The completed surveys are due to the EIA by April 30. These data are manually edited before being entered into an unteractive on-line system. Internal edit check are performed to verify that current data total across and between schedules and are comparable to data reported the previous year. Edit checks are also performed to compare data 
reported on the Form EIA-861 with strillar data reported on the Form EIA-826, Monthly Electric Utility Sales and Reventue Report with State Distributions," the FERC Form 1, "Annual Report of Major Electric Utitities, Licensees and Others," and the Form EIA-412, "Annual Report of Public Electric Utilities." These are utility-level checks. Respondents are called to clarify reported data and to obtain missing data

\section{Rural Uththtes Service}

The Rural Utilities Service (RUS), prior the The Raral Electrification Administration (REA), in the U.S. Department of Agriculture is authorized to provide long-term financing and gurantee long-term loans for utilities supplying power to rural America. Borrowing electric utilities file the RUS Form 7. "Financial and Statistical Report" and the RUS Form 12a throngh 12i, "Electric Power Supply Borrowers" or the RUS Form 12c through 12g, "Electric Distribution Borrowers with Generating Facilities." Data are provided on a yearly basis. Other revente and expense statistics show the year's financial operations. For 1994, borrowess' operations data are based on the financial and operabing statements of 855 active borrowers, of which 808 wefe distribation borrowers and 47 were power supply borrowers. Operations of cooperative borrowers systems are based on reports submitted by borrowers. The reports are subject to possible revisions from audits and adjustments. No attempt has been made to consolidate (in the techritcal accounting sense) the borrowers' accounts in the summary statement appearing in this publication. The combined totais represent the sum of all acconnts as reponted by the individual borrowers.

\section{Quality of Data}

The Office of Coal, Nuclear, Electric and Alternate Fuels (CNEAF) is responsible for routine data improvement and quality assurance. All operations at CNEAF are done in accordance with formal standards established by ELA. Data mprovement efforts include verification of data-keyed input by computerized methods, editing by sabject matter specialists, and follow-np on nonrespondents. CNEAF reviews the structure of information requirements and proposed desigans for new and revised data collection surveys and systems. Once started, the performance of working data collection systems is also validated. Computerized respondent data files are checked to identify those respondents which fail to respond to the survey. EIA tries to obtain required information by encouraging the cooperation of nomrespondents. By law, nonrespondents may be fined or penalized for not fling a mandatory EIA data survey.

CNEAF screens subutitted surveys for completeness and keys the data onto computer opes for storage. These data are transferred to randon access databases for computer processing. The information coded on the computet tapes is manuatly spot-checked against the sorveys to certify accuracy of the tapes. To ensure EIA quality standards, formulas using the past history of data values in the data base have been desigred and implemented to automatically check data imput for errors. Data values falling outside the ranges prescribed in the formulas are verifed by telephoning respondents to resolve any discrepancies.

Conceptual problems affecting the quality of data are discussed in the report, $A n$ Assessment of the Quality of Selected EIA Dota Series: Electric Potrer Dats. This report is published by the Office of Statistical Standards in EIA.

\section{Data Entry System}

Mantal editing of the reported data is completed prior to data entry. Additional edit checks of the data are performed through computer progtams. The program edits include both deterministic eltecks, in which records are checked for the presence of data in required fields, and statistical checks, in which data are checked against a range of values based on historical data values and for logical or mathematical consistency with data elements reported in the survey. Discrepancies found in the data, as a result of these checks, are resolved either by the procesting office or by further information obtained from a telephone call to the respondent.

\section{Conffdentlally of the Data}

Data collected on the surveys for this publication are not confidental.

\section{Rounding fules for Data}

Given a number with $r$ digits to the left of the decimal and $d+t$ digits in the fraction part, with $d$ being the place to which the number is to be rounded and $t$ being the remaining digits which will be truncated. This number is then rounded to $r+d$ digits by adding five to the $(r+d+1)$ th digit when the nuraber is positive or by subtracting five when the number is negative. The $t$ digits are then truneated at the $(r+d+1)$ th digit. The symbol for a rounded number truncated to zero is (*).

\section{Data Corroction and Revlston Procedures}

The CNEAF has adopted the followitg policy with respect to the revision and correction of recurrent data in energy pablications :

- Annual survey data collected by this office are published either as preliminary or foral when first appearing in a data report. Data initially released as preliminary will be so noted in the report. These data will be revised, if necessary, and declared finel is the next publication of the data.

- All montbly and quarterty survey data collected by this office are poblished as pretiminary. These dats are revised only after the completion of the 12-month cycle of the data. No revisions are made to the published data before this. 
- The magnitudes of changes due to revisions experienced in the past will be included in the data reports, so that the reader can assess the accuracy of the data.

- After data are published es ffugl, corrections will be made only in the event of a greater than one percent difference at the antional level. Corrections for differences that are less than the before-mentioned threshold are left to the discretion of the Office Director.

\section{Formulas and Calculations}

\section{Composte Fhandal Indlcators for Selected Publich Owned Electric Utilites}

Total Electrtc Utilty Plant per Dollar of Revenue =

$$
\frac{\sum\left(T E U P_{i}\right)}{\sum_{i}\left(E U O R_{j}\right)}
$$

where TEUP is the Total Electric Utility Plant for the $i^{\text {th }}$ public utility; and, EUOR is the Electric Utility Operating Reventue for the ith public ntility.

Current Assets to Current Liablities =

$$
\frac{\sum(C A)}{\sum_{I}(C L)}
$$

where $C A_{1}$ are the Current and Accrued Assets for the its public utisity, and, $C L_{2}$ are the Current and Accrued Libbilities for the $i^{\text {th }}$ public atility.

Total Electric Utility PIant as a Percent of Total Assets $=$

$$
\frac{\sum_{l}\left(T E U P_{D}\right)}{\sum_{i}\left(T A_{j}\right)} \times 100
$$

where TEUP, is the Total Electric Utility Plant for the I $^{\text {th }}$ public utility; and, $T A$, are the Total Assets for

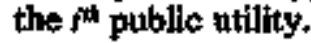

\section{Net Electric Utility Plant as a Percent of} Total Assets -

$$
\frac{\sum_{i}(N E U P)}{\sum_{i}\left(T A_{j}\right)} \times 100
$$

where NEUP, is the Net Electric Utility Plant for the $I^{\text {sk }}$ public utility; and, $T A_{3}$ ts the Total Assets for the in public utility.

Debt as a percent of Total Liabilities =

$$
\frac{\sum_{i}\left(D_{i}\right)}{\sum\left(T L_{\bar{\lambda}}\right)} \times 100,
$$

where $D_{\text {i }}$ is the Debt for the $i^{\text {th }}$ public ntility; and, $T L_{r}$ is the Total Liabilities for the its public utitity.

Depreciation, Amortization and Depletion as a Pexcent of Total Electric Uttity Plant =

$$
\frac{\sum_{f}\left(D A D_{i}\right)}{\sum_{i}\left(T E U P_{j}\right)} \times 100,
$$

where $D A D$, is the Depreciation, Amortization and Depletion for the $F^{\text {ah }}$ public utility; and, TEUP, is the Total Electric Plant for the $i^{\text {th }}$ public utility.

Wectric Operation and Maintenance Expenses as a Percent of Electric Utllity Operatiog Revenues =

$$
\frac{\sum_{l}\left(E O M E_{j}\right)}{\sum_{I}\left(E U O R_{1}\right)} \times 100
$$

where EOME is the Electric Operation and Maintenance Expenses for the $i^{\text {th }}$ pablic utility; and, EUOR, is the Electric Utility Operating Revenues for the $i^{\text {in }}$ pablic utitity.

Electric Depreciation and Amortization as a Percent of Flectric Utility Operafing Reverues =

$$
\frac{\sum_{i}\left(E D A_{i}\right)}{\sum_{i}\left(E U O R_{j}\right)} \times 100
$$

where $E D A$, is Electric Depreciation and Amortization for the public utility; and, EVOR, is the Electric Utility Operating Revenues for the $i^{i t h}$ public utility.

Taxes and Tax Equifalents as a Percent of Electric Utility Operoting Revennes =

$$
\frac{\sum_{i}(T T E)}{\sum_{i}(E U O R)} \times 100
$$


where $T T E_{\mathrm{f}}$ are the Taxes and Tax Equivalents for the it public utility; aud, EUOR, is the Electric Utillty Operationg Revenues for the it public utility.

Interest on Lang-term Debt as a Percent of Electric Utility Operating Rerenues =

$$
\frac{\sum\left(I L T D_{D}\right)}{\sum_{i}\left(E U O R_{D}\right)} \times 100,
$$

where $I L T D_{i}$ is the Interest on Longoterm Debt for the $l^{\text {th }}$ public utility; and, $E U O R_{i}$ is the Blectrle Utilty Operating Revenues for the $i^{\text {th }}$ public atility.

Not Ineome as a Pereent of Electric Utillty Operating Revenues =

$\frac{\left.\sum_{l}(N)_{j}\right)}{\sum_{I}\left(E \cup O R_{j}\right)} \times 100$,

where $N I_{i}$ is the Net Income for the $I^{\text {th }}$ publitc utility; and, $E U O R$, is the Electric Utility Operating Revenues for the $i^{\text {tot }}$ public utility.

Parchase Power Cents Pex Kilowatthour =

$$
\frac{\sum_{i}\left(P P C_{i}\right)}{\sum_{i}\left(P P K_{i}\right)} \times 10
$$

where $P P C$, is the Purchase Power Costs (in cents) for the public utility; and, $P P K_{1}$ is the Purchsed Power Kilowatthours for the $I^{\text {th }}$ public utility.

Gemerated Centa Per Kilowatthour =

$$
\frac{\sum_{i}\left(T G C_{j}\right)}{\sum_{i}\left(T G K_{j}\right)} \times 10,
$$

where $T G C_{\text {r }}$ is the Total Generation Costs (in cents) for the I $^{\text {th }}$ public utility; and, TGK is the Total Generated Killowatthours for the it public utility.

Total Power Supply Per Kilowatthour Sold =

$$
\frac{\sum_{i}\left(T P C_{j}\right)}{\sum\left(T P K_{j}\right)} \times 10
$$

whore TPC is the Total Generation and Purchase Power Cost for the $i^{\text {th }}$ public utility; and, TPK, is the Total Generated and Purchased Power Kilowatthours Sold for the fth public ntility.

\section{General Information}

\section{Use of the Clossary}

The terms in the glossary have been defined for general use. Restrictions on the definitions, as used in these data collection systems, are included in each definition when necessary to define the terms as they are used in this report.

\section{Obtaining Coples of Data}

Upon EIA approval of the Finonctal Stativites of Major U.S. Publlely Owned Electric Uthlities, these date are available for public use.

Computer listings are obtained by submirting a written request to :

Energy Information Administration

Coral and Electric Data and Renewables, EI-\$23

U. S. Department of Energy

1000 Independence Avenne, S.W.

Washington, DC 20585

(202) 426-1160

FAX (202) 426-1308

Maguetic tapes may be purchased by using Visa, Master Card, or American Express cardk, as well as money orders or checks payable to the National Technical Information Service (NTIS). Purchasets may also use NTIS and Govemment Printing Office deposit acoounts. To place an order, contact :

National Technical Information Service (NTIS)

Office of Data Base Services

U.S. Department of Commerce

5285 Port Royal Roud

Springfield, Virginia 22161

(703) $487-4650$

FAX (703) 321-8547

Personal computer diskettes (9 $1 / 2^{*}$ or $51 / 4^{\star}$ ) may be purchased by using Visa or Master Card, as well al money orders or checks payable to the U.S. Depart. ment of Energy. To place an order, contact:

Office of Scientific and Technical Information

U.S. Department of Energy

Request Services

P.O. Pkx 62

Oak Ridge, Tennessee 37831

(615) 576-8401 of Fax (615) 576-2865 
Accounting System. A method of recorting accounting data for a utility or company or a method of supplying accounting information for controlling evaluating, planning and decisionmaking.

Administrative and General Expenses. Expenses of an electrite utility relating to the overall directions of its corporats ofilces and administrative affairs, as contrasted with expenses incurred for specialized functions. Examples include office salaries, office supplies, advertising, and other general expenses.

Allowince for Funds Used During Canstruction (AFUDC). A noncash item representing the estimated composite interest costs of debt and a return on equity funds used to fmance construction. The allowance is capitalized in the property accounts and included in moome.

Anortization. The gradual write-off of an amount in an account by distributing such amount over a fixed periad, over the life of the asset or liability to which it applies, or over the period during which it is antic. ipated the benefit will be realized.

Antet. An economic resource, tangible or intangible, which is expected to provide benefits to a basiness.

Average Stream Flow. The rate, usually expressed in cubic foet per second, at which water passes 8 given point in a stream over a set period of time.

Cappeity: The amount of electric power delivered or required for which a generator, turtion, transformer, trangmission circuit, station, or system is rated by the manufacturer.

Cipacity (Porehesed). The amount of energy and capacity available for purchase fron outside the system.

Capltal. The equity interest of the owners consisting of common stock, preferred stook, and retained earmings in the entity, that is the difference between asets and liabilities.

Capital (Binancial). The line iteans on the right side of a balance sheet, that inclade debt, preferred stock, and common equity. $A$ net incresse in assets must be financed by en trerease in one or more forms of capital.

Capital Intensive. A condition in which investment in plant and equipment is relatively large compared to labor and to operation and maintenance expenses.

Capitalization. The long-term sources of funis com" prising an entity's total capitalization; that is, the long- term debt, preferred stock, and common equity. The short-term sources of capital are not included.

Capilalliration Ratio. The percentage of debt, or preferred stock, or common stock, or other equity to the total capital structure of an entity.

Cincuit. A conductor or a system of conductors through which electric current flows.

Circuit-Mile. The total length in miles of separate circuits regardless of the number of conductors used per circuit.

Classes of Strvice. Consumers groupsd by similar characteristics in order to be identified for the purpose of setting a common rate for electric service. Usually classified into groups identiffed as residential, com* mercial, industrial and other.

Commerefal. The commercial sector is geverally defined as nonmanutacturing business establishments, including hotels, motels, sestaurants, wholeste bosinesses, retail stores, and health, socisl, and educational institutions. The ntility may classify commercial service as all consumers whose demand or annugl use exceeds some specified limit. The limit may be set by the utillty bised on the tate schedule of the utility.

Commercial and Industrial. Classes of service sup. ptied to a sinillar protsping of consumers. These customer groupings are uzually subdivided into smaller segments by classifying such consumers as comsonercial or industrial using the Federal Govermment's Office Of Management and Budget's Standard Industrial Classification Gride and/or a scale of energy usage as yardsticks; other consumers are reclassified as commercial or industrial when their demands or annual use exceeds some spectifed timit. These limits are generally based on a utifity's rate schedules, except for those constumers who are supplied under special contracts or agreements calling for particular services.

Cammon Equlty (Bonk Valme). The retained earnings and common stoek extrings plus the balances in common equity reserves and all other common stock accounts. This atso incledes the capital surplus, the paid-in suphus, the premium on common stocks, except those balances specifically related to preferred or preference stocks; less any common stocks held in the treasury.

Condensar Cooling Water. A source of water external to a boiler's feed system is passed through the steam leaving the turbine in order to cool and condense the steam. This reduces the steam's exit pressure and recaptures its heat, which is then used to prebeat fluid entering the boiler, thereby inereasing the plant's thermodynamic efficiency. 
Conilitionally Effective Rates. An electric rate schedule that has been put into effect by the FERC subject to refund pending final disposition or refiling.

Construction Costs (of the electric pomer lminustry). AI direct and indirect costs incured in scguiring and constructing electric atility plant and equipment and proportionate shares of comimon utility plant. Included are the cost of land and improvements, nuclear fuel and spare parts, allowance for funds used during construction, general overheads capitalized, less the cost of acquiring plant and equipment previously operated in utility service.

Construction Expenditures (af the electric power indistiry). The gross expenditures for construction costs, including the cost of replacing worn-out plants, and electric construction costs and land held for future use.

Construction Work In Progress (CWIP). The balance shown on a ntilfty's balance sheet for construction work not yet completed but in process. This balence line item may or may not be included in the rate base.

Conrentional Hydroelectric Plant. A plant in which all of the power is produced from natural streamflow as regulated by available storage.

Cooperative Electric Utility. An electric utility legally established to be owned by and operated for the benefit of those using its service. The utility company will generate, transmit, and/or distribute supplites of electric energy to a specified area not being serviced by another utility. Such ventures are generally exempt from Federal income tar laws. Most clecticic cooperattives have been initially funanced by the Rural Electrification Administration, U.S. Department of Agriculture.

Cost. The amount paid to acquire resources, such as plant and equipment, fnel, or labour services.

Cost of Capital. The rate of return a tutlity must offer to obtain additional funds. The cost of capital varies with the leverage ratio, the effective income tax rate, conditions in the bond and stock markets, growth rate of the utility, its dividend strategy, stability of net income, the amount of new capital required, and other factors dealing with bustuess and financial risks. It is a composite of the cost for debt interest, preferred stock dividends, and common stockholders' earnings that provide the facilities ased in supplying utility servios.

Cost of Dobt. The interest rate paid on new increments of debt capital multiplied by 1 minus the tax rate.

Cost of Preferred Stock The preferred dividend divided by the net price of preferted stock.

Cost of Retained Earnings. The residual of a utility's earnings over expenditures, including taxes and dividends, that are reinvested in its business. The cost of these funds is always lower than the cost of new equity capital, due to taxes and transactions costs. Therefore, the cost of refained extrings is the yield that retained earnings accrue upon reinvestment.

Cost of Service. A ratemaking concept used for the design and development of rate schednles to ensure that the filed rate schedules recover only the cost of providing the electric service at issue. These costs include operating and matntentance expentses, depreciation and amortization expenses, and income and other taxes found just and reasonable by the regula. tory agency for ratemaking purposes plus, in the cast of privately owned electric utilitates, an allowance for a keturn on capital (usually computed by applying a rate of return to the rate base). This concept attempts to equate the cost incurred by the utility to the revenue received for the service provided to each of the consumer elasses.

Curreat Assets. Cash and other assets that afe expected to be turned into cash, sold, or exchanged within the normal operating cycle of the utility. usually one year. Current assets include cash, marketable securities, receivables, inventory and current prepayments.

Correat Labilites. A debt or other obligation that must be discharged withtim one yeur or the normal operating cycle of the utility by expending a current asset or the fictarrence of another short-term obligation. Current liabilities included account payable, short-term notes payable, and accrued expenses payable such as taxes and salaries payable.

Current Ratio. The ratio of current assets divided by current labilities that shows the ability of a utility to pay its current obligations from its current ansets. A measire of liquidity, the higher the current ratio, the more assurance that current liabilities can be peid.

Debt. Money or services owed through a tegal obligation to an outside party. Debt may be classified short-term whth is one year or less or long-term which is more than one year.

Deferred Cost. An expenditure not recognized as a cost of operation of the period in which incucred, bat cartied forward to be written off in future periods.

Deferred Furil Costs. An expenditure for fiel that is not recognized for bookkeoping prictices as a cost in the operating period incurred, but carried forward to be written off in future periods.

Deferred Income Tax (Liability). A tability in the balance sheet representing the additional Federal income taxes that would have been due if a utility had not been allowed to compute tax expenses diffierently for income tax reporting purposes than for ratemaking ptaposes.

Depreciation. Charges made against income for distributing the cost of a tangible asset, so as to allocate it systematically across the period in which the asset is used. 
Desiga Head. The achieved river, pondage, or reser. voir surface beight (forebay elevation) that provides the water kevel to produce the full flow at the gate of the turbine in order to attain the manufacturer's installed nameplate rating for generation capacity.

Diesel-Glectric Plant. A generating station that uses diesel engines to drive fits electric generators.

Distribution System. The portion of an electric system that is dedicated to delivering electric energy to an end werer.

Dacket A formal record of a Federal Energy Regulatory Commission proceeding. These records ane available for inspection and copying by the public. Each individual case proceeding is identified by an assigned number.

Econorny of Scale. The principle that larger production facilities have lower unt costs than smaller facilities.

Electric Expenses. The cost of labor, material, and expenses incurred in operating a facility's prime movers, generators, auxiliary apparatus, switching gear, and other electric equipment for each of the points where electricity enters the transmisston or distribution grid.

Electric Optrating Expenses. Summation of electric operation-related expenses, such ss operation expenses, maintentance expenses, depreciation expenses, amortization, taxes other than imcome taxes, Federal tincome taxes, other licome taxes, provision for deferred income taxes, provision for deferred income-credit, and tovestment tax credit adjustment.

Electric Plant (Financial). Assets comprising land, building, and equipment permanently employed.

Flectric Power Induatry. The privately, publicly, federally and cooperatively owned electric utilities of the United States taken as a whole. This includes all electric systems serving the public regulated investorowned electric utility companies; Federal power projects; State mumicipal, and other povernmentowued systems, including electric public utility districts; electric cooperatives, including seneration and transmission entities. Excluded from this defintition are the special purpose electric facilities or systems that do not offer service to the public.

Electric Power Systew. An individual electric power entity - a company, an electric cooperative, a public electric supply corporation as the Tennessee Valley Authority, i similar Federal department or apency as the Bonneville Power Administration, the Bureau of Reclamation or the Corps of Engineers, a municipally owned, slectric department ofrering service to the publis, or an electrie pablic utility district (a "PUD "), also a jointly owned electric supply project such as the Keystone.

Electric Rate Schedule. A statement of the eleetric rate and the terms and conditions governing its appli- cation, including attendant contract terms and conditions that have been accepted by a regulatory body with appropriate oversite authority.

Blectric Uttlity. A corporation, person, agency, anthority, or other legal entity or instromentality that owns and/or operates facilities within the United States, its territories, or Puerto Rico for the gener. ation, transmission, distribution, or sale of electric entergy primarily for use by the public and files forms listed in the Code of Federal Regulations, Title 18, Part 141. Facilities that qualify as cogenerators or small power producers under the Public Utility Regulatory Policies Act (PURPA) are not considered electric ufilities.

Electrical System Bnergy Losses. The amount of energy lost during generation, transmission, and distribution of electricity, including plant ind unaccounted for use.

Fnd Uster. The final consumer of electricity.

Eneray. The capacity for doing work as measured by the capability of doing work (potential energy) of the conversion of this capability to motion (kinetic energy). Energy has several forms, some of which are easily convertible and can be changed to another form useful for work. Most of the world's convertible eneray comes from fossil fuels that are burned to produce heat that is then used as a transfer medinm to mechanical or other means in order to accomplish tasks. Electrical energy is uspally measured in kilowatthours, while heat energy is usually measured in British thermal units.

Energy Deliweries. Energy generated by one electric utility system and delivered to anotber system through one or more transmission lines.

Enarge Information Administration (FIA). An inde. pendent agency within the U.S. Department of Energy that develops surveys, collects energy dats, and does analytical and modeling analyses of energy issues. The Agency must satisfy the requests of Congress, other elements within the Department of Energy, Federal Energy Regulatory Commisston, the Executive Branch, its own independent needs, and assist the genersl pubtic, or other interest groups, without taking a policy position.

Bnergy Loss. The difference between energy input and output as a result of transfer of energy between two points.

Bnergy Recelpts. Energy generated by one electric utility system and received by another system through one or more transmisston lines.

Equity (Fimancial). Ownership of sharehotders in a corporation represented by stock.

Equity Capital. The sum of capital from retnined earnings and the issuance of stocks. 
Exchange Energy. Exchange energy refers to specific electricity transactions between electric utilities where electricity received is returned in kind at a later ime or accumulated as energy balances unti the end of the stated period, after which settlement may be by monetary payment.

Expenditure. The incurrence of a leability to obtain an asset or service.

Federal Electric Utility. A utility that is either owned or financed by the Federal Government.

Federal Enericy Rexulatary Commission (PERC). A quasi-independent regulatory agency within the Department of Energy having jurissitiction over interstate electricity sales, wholesale electric rates, hytroelectric licensing, natural gas pricing, oil pipeline rates, and gas pipeline certification.

Federal Power Act. Endeted in 1920, and amended in 1935, the Act consists of three parts. The first part incocporated the Federal Water Power Act administered by the former Federal Power Commission, whose activities were confined almost entirely to licensing non-Federal hydroelectro projects. Parts II and II were added with the passage of the Pnblic Utility Act. These parts extended the Act's jutisdic. tion to include regalating the interstate trannmission of electrical energy and rates for its sale as wholessle in interstste commerce. The Federal Enesgy Regulatory Commigsion is now charged with the administration of this law.

Federal Power Commission. The predecessor agency of the Feteral Energy Regulatory Commission. The Federal Power Commission (FPC) was created by an Act of Congress under the Federal Water Power Act. on Jume 10, 1920. It was charged originally with regukatigs the electric power and natural gas industries. The FPC was abolished on September 20, 1977, when the Department of Energy was created. The functions of the FPC were divided between the Department of Energy and the Federal Energy Regulatory Commission.

\section{FERC. The Federal Energy Regulatory Commission.}

FERC Guidelines. A compilation of the Federal Energy Rerulatory Commission's enabling statutes, procedural and program regulations, and orders, opinions and decisions.

Financial Accounting Standards Boand (FASB). An independent board responsible, since 1973, for estabtishing tentrally accepted accounting principles. Its officiel pronouncement are called "Statements of Financial Accounting Standards" and "Interpretations of Financilal Accounting Standards."

Fiscel Year. A inancial year based on a predetermined starting date. The Federal Government's linancial year suns fromt October I through September 30.
Fired Asset Turnover. A ratio of revenue to fixed assets which is a measure of the prodnctivity and efficiency of property, plant, and equipment in generating revenue. A higher turnover reflects positively on the entity's abiltty to utilize properly its fixed assets in buginess operations.

Fixed Assets. Tangible property used in the operstions of an entity, but not expected to be consumed or converted into cash in the ordinary course of events. With a life is excess of one year, not intended for resale to customers, and subject to depreciation (with the exception of land), they are usually referred to as property, plant, and equipment.

Fured Charge Corerage. The ratio of earnings available to pay so-called fixed charges to stch fixed charges. Fixed charges include interest on funded debt, inchuding leases, plus the related amortization of debt discount, premium and expense. Earnings available for fixed charges may be computed before or after deducting income taxes. Oxcasionally credits for the "allowance for fund used during construction" are excluded from the earnings figures. The precise procedures followed in calculating fixed charge or interest coverages vary widely.

Fixed Cast (expense). An expenditure or expense that does not vary with volume level of activity.

Fixed Operating Costs. Costs other than those associated with capital investment that do not vary with the operation, such as maintenance and payroll.

Fossil Fuel. Any naturally occurring organic fuel, such as petrolenm, coal, and natural gas.

Fossil-Fuel Plant. A plant using coal, petroleum, or gas as its source of energy.

Fuel Expenses. These costs include the fuel used in the production of steam or diting inother prime mover for the generation of electricity. Other associated expenses include unloading the shipped fuel and alf handling of the fuel up to the point where it enters the first bumker, hopper, bucket, tank, or holder in the boiler-house structure.

Ges Turbine Flant. A plant in which the poime mover is a gas turtine. A gas turbine consists typically of an axial-fiow air compressor, one or more combustion chambers, where liquid or gaseons fuel is burned and the hot gases are passed to the turbine and where the hot gases expand to drive the generator and are then used to run the compressor.

Generrilly Accepted Accounting Princtples (GAAP). Defined by the FASB as the conventions, rules, and procedures necessary to define accepted accounting practice at a particular time; includes both broad guidelines and relatively detaiked practices and procedures.

Geterating Unit. Any comblnation of physically connected generator(s), reactor(s), boiler(s), combustion 
turbine(s), or other prime mover(s) operated together to produce electric power.

Generator Nameplate Capaclity. The full-load contin. wous rating of a generator, prime mover, or other electric power production equipment under specific conditions as designated by the manufacturer. Instalted generator nameplate rating is usually indicated on a nameplate physically attached to the generator.

Gentherwal Plent. A plant in which the prime mover is a stean turbine. The turbine is driven either by steam produced from hot water or by natural steam that derives its energy from heat found in rocks or fluids at various depths beneath the surface of the earth. The entergy is extracted by dritling and/or pumping.

Grld. The layout of an electrical distribution system.

Gross Generation. The total amount of electric energy produced by a generating facility, as measured at the genterator terminals.

Head. The product of the water's weight and a usable difference in elevation gives a measurement of the potential energy possessed by water.

Historical Plant Cost of Equipment. The charges for equipment assigned to power production inciude: the net purchased price thereof; sales taxes; investigration and inspection expenses necessary for such purchases, any expenses of transportation when borne by the utility; Jabor employed charges; materials and supplies consumed; and expenses incurred by the utilty in unloading and placing the equipment in readiness to operate.

Historieal Plant Cost of Land and Land Riohts. The cost of land purchased or the fees paid by the utility for rights, interests, and privileges to be held by the utility in land owned by others. The types of rights acguired include leaseholds, easements, water and water power rights, rights-of-way, and other like interests.

Histarieal Plant Cost of Structurea and Improvements (Expenses). The cost of all buildings and facilities to house, support, or safeguard property or persons, including all fixtures permanently attached to and made a part of building. Also includes the cost incurred in connection with the first clearing and grading of land and rightson-ways.

Holding Company. A company that confines its activities to owning stock in, and supervising management of, other companies. The Securities and Exchange Commission, as administrator of the Public Utility Holding Company Act of 1935, defines a holding company as a company which directly or indirectly owns, controls or holds 10 percent or more of the outstanding voting securities of a holding compeny" (15 USC 79b, par. a (7)).
Hydrostectric Energy. The production of electricity from kinetic energy in flowing water.

Hydroelectric Plant. A plant in which the turbioe generators are driven by falling water.

Hydroelectric Plant Capacity. This capacity figure is a function of flukd flow losses, hydraulic turbines, head, and water flow. The minimum net head limits the firm capacity of the plant.

Hydroelectric Power. The harnessing of flowing water to produce mechanical or electrical energy.

Independent Power Producer. A corporation, person, sgency, authority, or other legal entity or instrumentality that owns electric generating capacity and is a wholesale electric prodmcer without a desiguated franchised service area. The entity is not a qualifying facility as defined in the Public Utility Reguilatory Policies Act of 1978.

Industrial. The incustrial sector is generality defined as mannfacturing, construction, mining, agriculture, fishing and forestry establishments Standard Indurtrial Classification (SIC) codes 01-39. The utility may classify industrial service using the SIC codes, or based on demand or annual usage exceeding some specified limit. The limit may be sef by the otility based on the rate schedule of the utility.

Ingtantaneous Peak Demand. The maximum demand at the instant of greatest Ioad.

Interchange Energy. Kilowatthours detivered to or received by one electric utility or pooling system from another. Settlement may be by payment, returned in kind at a later time or accomulated as energy balances until the end of the stated period.

Interconnection. Two or more electric systems having a common transmission lins that permits a flow of eresgy between them. The physical connection of the electric power transmission facilities allows for the saje or exchange of energy.

Interdepartmantol Service (Eleetric). Interdepartmental servics includes amoumts charged by the electric department at tariff or other specified rates for electricity supplied by it to other utility departments.

Interest Coverage Ratio. The number of tiosos that fixed interest charges were earned. It indicates the margin of safety of toterest on fixed debt. The timesinterest-earned ratio is calculated using net income before and after income taxes; and the oredits of interest charged to construction being treated as other income. The interest charges include interest on lon 5 term debt, interest on debt of assoctated companies, and other interest expense.

Interlocking Direetorates. The holding of a significant position in management or a position on the corporate board of a utillty, while simultaneously holding a comparable position with another utility, or with a firm doing business with the utility. 
Internal Combustion Ptant. A plant in which the prime nover is an interual combustion engine. An internal combustion eggine has one ar more cylinders in which the process of combustion takes place, converting energy released from the rapid burning of a fuel-air mixture into mechanical energy. Diesel or gasfired engines are the principal types wed in electric plants. The plant is usually operated durting pertods of high demand for electricity.

Investor-Orned Flectric Utility. A class of utility that is investor owned and organized as a tax paying bosiness, usually financed by the sales of securities in the captital market.

Kilowatt (

Knowathour (kWh). One thousand watthours.

Leperage Ratio. A measure that indicates the financial ability to meet debt service requirements and increase the value of the inyestment to the stockholders. (i.e the ratio of total debt to total assets).

Liability. An amount payable in dollars or by future services to be cendered.

Ifcensees. Entity that has been granted permission to engage in an activity otherwise unlawiul (t.e. hydropower project).

Line Lass. Euercy kilowatthours lost in transmission and distribution lines.

Load (Electric). The amount of electric power delivered or required at any specific point or points on a system. The requilrement originates at the energy. consuming equipment of the consumers.

Longterm Debt. Debt securities or borrowings having a maturity of more than one year.

Maintenance Fixpenses. That portion of operating expenses consisting of labor, matertals, and other direct and indirect expenses incurred for preserving the operating efficiency and/or phystcal condttion of utility plants used for power production, transmission, and distribution of energy.

Maximam Demsand. The greatest of all demands of the load that has occurred withth a specified period of time.

Mot. One thonsand cubtc feet.

Meghwatt (MW). One million watts.

Megawatthour (MWh). One million watthours.

Mill. A monetary cost and billing nnit used by utilities; it is equal to $1 / 1000$ of the U.S. dollar (equtivalent to $1 / 10$ of 1 cent).

Multiple Purpose Reserroir. Stored water and tts usage governed by advanced water resource conservation practices to achieve more than one water control objective Some of the objectives include flood control, hydro- electrto power development, irrigation, recreation usige, and wilderness protection.

Municipality. (As defined in section 3, paragraph (7) of the Federal Power Act, P.L. 66-280 as amended) A city, coonty, irrigation district, drainage district, or other political subdivision or agency of a State competent under the laws thereof to carry on the basiness of developing, transmitting, utilizing, or distributing power (41 Stat. 1064; 49 Stat. 838; 16 U.S.C. $796(7)$ ).

Net Generation. Gross generation minus plant use from sll electric ntility owned plants. The energy required for pumping at a pumped-storage plant is regarded as plant use and must be deducted from the gross generation.

Net Inconte. The excess of all reventues and gains for a period over all expenses and losses of the period.

Nenntilfty Power Producer. A corporation, person, agency, authority, or other legal entity or instrumentality that owns electric generating capacity and is not an electric utility. Nonntility power pro. ducers include qualifying cogenerators, qualifying small power producers, and other nonutility genergtors (including independent power producers) without a designated franchised service area, and which do not file forms listed in the Code of Federal Regulations, Title 18, Part 141.

Nuclear Fuel. Fissionable materials that have been enriched to such a composition that, when placed in a nuclear reactor, will support a self-sustairing fission chain reaction, producing heat in a controlled manner for process use.

Nuclear Power Ptant. A facility in which heat produced in a reactor by the fissionizg of nuclear inel is used to drive a steam turbine.

Nuclear Reactor. An apparatus in which the nuclear fission clain can be isutiated, maintained, and controlled so that energy is released at a specific rate. The reactor includes fissionable material (iuel), such as arsniusn or plutonium; fertile material; moderating material (unless it is a fast reactor); a beavy-walled pressure vessel; shielding to protect personnel; provision for heat removal; and control elements and instrumentation.

Ohm. The unit of mensurement of electrical resistance. The resistance of a circuit in which a potential ilifference of 1 volt produces a current of 1 ampere.

Operating Bxperses. Expenses related to utility operations, which include operation and maintenance expenses, provisions for depreciation and amortization, taxes otjee than income trxes, income taxes, provision for deferred income taxes, income taxes deferred in prior years- credit and investment tax credit adjustments-net.

Operotiog Incoune. Operafing revenues less operating expenses. 
Operation Erpenses. The components of power production expenses that incor cost for operations that are directly related to producing electricity. The major item is almost always fuel that has to be burned to generate the electricity.

Operation Supervision and Eugincering (Expenses). These expenses friclude the cost of labor and expenses incurred in the general supervision and direction of the operation of power generation stations. The supervision and engineering costs consist of the pay and expenses of staff and consultants engaged in supervising and directing the operation of each utility function. Direct supervision and engineering of activitiex, such as fuel handling, boiler room operations, and generator operations, are charged to the appropriate accounts.

Otigimal Cost. The intial amount of money spent to acquire an asset. It is equal to the price paid, or present value of the liability incurned, or fair value of stock issued, phus notmal incidental costs aecessary to put the assget into its initial use.

Other Generation. Electricity originating from these sonrces: biomass, fuel cells, geothermal heat, solar power, waste, wind, and wood.

Owner's Equity. Interest of the owners in the assets of the business represented by capital contributions and retained earnings.

Pareat Company. Company owning more then 50 percent of the voting shares of another company, called the subsidiary.

Plant. A facility at which are located prime movers, electric generators, and amxiliary equipment for converting mechanical, chemical, and/or nuclear energy into electric energy. A plant may contain more than one type of prime mover. Electric utility plants exclude facilities that satisfy the definition of a qualifying facility under the Public Utility Regulatory: Pol. icies Act of 1978 .

Flant-Use Electricity. The electric energy used in the operation of a plant. This energy total is snbtracted from the gross energy production of the plant; for reporting purposes the plant energy production is then reported as a net figure. The energy required for pumping at pumped-storage plants is, by definition, subtracted, and the energy production for these plants is then reported as a net figure.

Pole-Mile. A unit of measuring the simple Ienoth of a transintssion line carrying electric conductors, without regard to the number of conductors carried.

Power. The rate at which energy is transferred. Electrical energy is usually measured in watts. Alsò used for a measurement of capacity.

Power (Flectrical). An electric measurement unit of power calted a voltampere is equal to the product of 1 volt and 1 ampere. This is equivelent to 1 Watt for a dírect current system and a unit of apparent power is separated into real and reactive power. Real power is the work- producing part of apparent power that measures the rate of supply of energy and is denoted as Kilowatts (KW). Reactive power is the portion of apparent power that does no work and is referred to as kilovars; this type of potwer must be supplied to most types of magnetie equipment, such as motors, and is supplied by gentrator or by electrostatic equipment. Voltamperes are usually divided by 1,000 and called kilowoltamperes (kVA). Energy is denoted by the product of real power and the length of time uti. lized; this product is expressed as kilowatthours.

Power Production Plant. All the land and land rights, structures and improvements, boiler or reactor vesset equipment, engines and engine-driven generator, turbogenerator units, accessory electric equipment, and miscellaneous power plant equipment are grouped together for each individual facility.

Preferred Stock. Ownership interests in a corporation which have been granted a preference, usually in the distribution of dividends before payment of dividends to conmon stockholders and assets in dissolution. It is usually nonvoting.

Price. The amount of money or consideration-in-kind for which a service is bought, sold, or offered for sale.

Prime Morex. The motive force that drives an electric generator ( $e_{-} \xi_{+}$steam emgton, turbite, or water wheel).

Production (Electric). Act or process of producing electric energy from other forms of energy; also, the amount of electric energy expressed in watthonrs (Wh).

Production Expenses. Costs incurred in the production of electric power that conform to the accounting requitements of the Operation and Maintenance Expense Accounts of the FERC Uniform System of Accoumts.

Profit. The income remaining after all business expentses are paid.

Public Authority Service to Public Authorities. Public authority service includes electricity supplied and services rendered to municipalities or divisions or agencies of State or Federal governments, under special contracts or agreements or service classifications applicable only to public authorities.

Public Street and Fighway Lighting, Public strect and highway lighting includes electricity supplied and services rendered for the purposes of lighting streets, highways, parks, and other public places; or for traffic or other signal system service, for municipalities, or ofher divisions or agencies of State or Federal governments.

Pablic Utility. Enterprise providing essential palbic services as electric, gas, telephons, water, and sewer, under legally established monopoly conditions 
Public Utility Dietrict. Municipal corporations organized to provide electric service to both incorporated cities and towns and unincorporated rural areas. Public utility districts, sometimes callet "People's Utility Districts" or "Public Power Districts," operate in six States.

Publicly Owend Flectric Utillty. A class of ownership found in the electric power industry. This group includes those utilities operated by municipalities, and State and Federal power agencies.

Pumped-Stocage Fyudroelectric Plant. A plant that usually generates electric energy during peal-logd pertods by using water previously pumper into an elevated storage reservoir during off-peak periods when excess generating capacity is available to do so. When additional generatiog capacity is needed, the water can be released from the reservoir through a conduit to turbine generators located in a power plant at a lower level.

Purchased Power. Power purchased or available for purchase from a source outside the system.

Railroad and Raftway Serrices. Railroad and railway services include electricity supplited and services rendered to railroads and interurban and street railways, for gentral railtoad use, fucluding the propulsion of cars or locomotives, where such electricity is supplied under separate and distinct rate schedules.

Rate Hase. The value of property upon which a utlity is permitted to earn a specified rate of retum as established by a regulatory atuthorty. The rate base generally repeesents the value of property used by the utility in providing service and may be calculated by any one or a combination of the following accounting methods: fair value, prudent inveatment, reproduction cost, or original cost. Deppeading on which method is used, the tate base includes cash, working capital, materials and supplies, and deductions for acoumulated provisions for depreciation, contributions in aid of coristruction, customer advances for construction, accumulated deferred income taxes, and accumulated deferred investment tax credits.

Ratemaking Authority. A utility commission's leggl authority to fix, modify, approve, or disapprove rates, as determined by the powers given the commission by a State or Federal leglslature.

Rate of Return. The ratio of tuet operating income earmed by a utility is calculated as a percentage of its rate base.

Rate of Return on Rote Base. The ratio of net operating income carned by a utility calculated as a percentsge of its rate base.

Refimiting. Retirement of one security isspe with proceeds aceived from selling another. Refunding pro. vides for retiring maturing debt by taking advantage of favorable money market conditions.
Regelation. The governmental function of controlling or directing economic entities through the process of rulemaking and adjudication.

Resale (Wholesale) Sales. Resale or wholesile sales are electrciity sold (except under exchange agreements) to other electric utilities or to the public authorities for resale distribution.

Residential. The residential sector is defined as private household establishments which cansume energy primarily for space beating, water heating, air conditioning lighting, refrigeration, cooking and clothes drying. The classification of an individual consumer's account, where the ust is both residential and commercial, is based on principal use. For the residential class, do not duplicate consumer sccounts due to Iulutiple metering for special services (water, heating. etc.). Apartment houses are also included.

Retail, Sales covering electrical energy supplied for residential, commercial, and industrial end-use purposes. Other stall classes, such agriculture and street lighting, also are included in this category.

Retril Wheeling, An arrangement in which a utility transmits electricity from outside its service territory to a reteil customer within its customer service territory.

Retained Earninga. The balance, either debit or credit, of appropriated or unappropriated exraings of an entity that are retained in the business.

Return on Common Equify. The net income less pre ferred stock dividends divided by the average common stock equity.

Return on Common Stack Equity. An entity's earnirgs availsble for common stockholders calculated as a percentage of its common equity capital.

Reverue. The total anount of money recetved by a firm from sales of its proctuets and/or services, gains from the sales or exchange of assets, interest and divi dends earned on investments, and other increases in the owner's equity except those arising from capital adjistments.

Revenure Requirement. The total revenue that the utility is anthorized an opportunity to recover, which includes operating expenses and a reasonable return on rate baste.

Rural Flectrification Admintstration (REA). A lending asency of the U.S. Department of Agriculture, the REA makes self-liquidatton loans to qualified torrowers to finance electric and telephone service to rural areas. The REA also finances the construction and operation of generating plants, electric transmisston and otstribution lines, or systems for the furnishing of initial and continued adequate electric services to persons in mral areas not receiving central stationt service. 
Sales. The amount of kilowatthours sold in a given period of time; usually grouped by classes of service, such as residential, conmercial, industrial, and other. Other sales include publis street and highway lighting, other sales to public authorities and railways, and interdepartmental seles.

Sales far Resele. Energy supplied to other electric utilities, cooperatives, municipalíties, and Federal and State electric agencles for resale to altimate consumers.

Short-term Debt or Bortowings. Debt securities or borrowings having a maturity of less than one year.

Solar Energy. Energy produced from the sun's radiation.

Steam-Electric Plant (Conventiomal). A plant in which the prime mover is a steam turbine. The steam used to drive the turbine is produced in a boiler where fossil fuels are burned.

Steam Expenses. The cost of labor, materials, fuel, and other expenses incurred in production of steam for electric generation.

Stenu from other Sources. Steam purchased, transferred from anather department of the utility, or acculired from others under a joint-facility operating agreement.

Steam Transferred-Credit The expenses of producing steam charged to others or to other utility departments under a joint operating arrangement.

Substation. Facitity equipment that switches, changes, or regulates electric voltage.

Switchiog Station, Facility equipment used to tie together two or more electric circuits through switches. The switches are selectively arranged to permit a circuit to be disconsected, or to change the electric connection between the circuits.

System (Electric). Physically connected generation. transmission, and distribution facilities operated as an integrated unit under one central management, or operating supervision.
Transformer. An electrical device for changing the voltage of alternating current.

Tranamaission. The movement or transfer of electic energy over an interconnected group of lines and associated equipment befween points of supply and points at which it is transformed for delivery to consumers, or is delivered to other electric systems. Transmission is considered to end when the energy is transformed for distribution to the consumer.

Transmission System (Electric). An interconnected group of electric transmission lines and associated equipment for moving or transferring electric energy in bulk between points of supply and points at which it is transformed for delivery over the distribution system lines to consumers, or is delivered to other electric systems.

Turhine. A machine for generating rotary mechanical power from the energy of a stream of find (such as water, stean, or hot gas). Turbines convert the kinetic eaergy of fluids to mechanical energy through the principles of impulse and reaction, or a mixture of the two.

Ultimate Consumer. A consumer that purchases electriolty for its own use and not for resale.

Uniform System of Accomats. Prescribed financial rules and ragulations established by the Federal Energy Regulatory Commission for utilities subject to its jurisdiction under the authority granted by the Federal Power Act.

Utility Generation. Generation by electric systems engaged in selling electric energy to the public.

Watt. The eleotrical unit of power. The rate of energy transfer equivalent to 1 ampere flowing under a pressure of 1 volt at untty power factor.

Watthour (Wh). An electrical energy anit of measure oqual to 1 watt of power supplied to, or taken from, an electric circnit steadily for 1 hour.

Wheeling service. The movement of electricity from one system to another over transmission facilites of intervening systems. Wheeling service contracts ean be established between two or more systems. 